CALENDAR FOR WATER YEAR 1991

\begin{tabular}{|c|c|c|c|c|c|c|c|c|c|c|c|c|c|c|c|c|c|c|c|}
\hline \multicolumn{20}{|c|}{1990} \\
\hline \multicolumn{7}{|c|}{ OCTOBER } & \multicolumn{7}{|c|}{ NOVEMBER } & \multicolumn{6}{|c|}{ DECEMBER } \\
\hline$S$ & $M$ & $T \quad W$ & W T & $\mathrm{T}$ & $F$ & $S$ & $S$ & $M$ & $\mathrm{~T}$ & $W$ & $\mathrm{~T}$ & $\mathrm{~F}$ & $S$ & $S$ & $M$ & $T W$ & $\mathrm{~T}$ & $F$ & $S$ \\
\hline $\begin{array}{rr}7 \\
74 \\
14 \\
21 & 2 \\
28 & 2\end{array}$ & $\begin{array}{rr}1 \\
8 \\
15 & 1 \\
22 & 2 \\
29 & 3\end{array}$ & $\begin{array}{rr}2 & 3 \\
9 & 10 \\
16 & 17 \\
23 & 24 \\
30 & 31\end{array}$ & $\begin{array}{rr}3 & 4 \\
0 & 11 \\
7 & 18 \\
4 & 25 \\
1 & \end{array}$ & $\begin{array}{ll}4 & \\
1 & 12 \\
8 & 19 \\
5 & 26\end{array}$ & $\begin{array}{ll}5 & \\
2 & 1 \\
19 & 20 \\
26 & 2\end{array}$ & $\begin{array}{l}6 \\
13 \\
20 \\
27\end{array}$ & $\begin{array}{r}4 \\
11 \\
18 \\
25\end{array}$ & $\begin{array}{cc}5 & \\
12 & 1 \\
19 & 2 \\
26 & 2\end{array}$ & $\begin{array}{rr}6 & \\
13 & 1 \\
20 & 2 \\
27 & 2\end{array}$ & $\begin{array}{ll}7 & \\
14 & 1 \\
21 & 2 \\
28 & 2\end{array}$ & 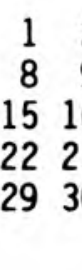 & $\begin{array}{rr}2 & \\
9 & 1 \\
16 & 1 \\
23 & 2 \\
30 & \end{array}$ & $\begin{array}{r}3 \\
10 \\
17 \\
24\end{array}$ & $\begin{array}{r}2 \\
9 \\
16 \\
23 \\
30\end{array}$ & $\begin{array}{r}3 \\
10 \\
17 \\
24 \\
31\end{array}$ & $\begin{array}{rr}4 & 5 \\
11 & 12 \\
18 & 19 \\
25 & 26\end{array}$ & $\begin{array}{r}6 \\
13 \\
20 \\
27\end{array}$ & $\begin{array}{r}7 \\
14 \\
21 \\
28\end{array}$ & $\begin{array}{r}1 \\
8 \\
15 \\
22 \\
29\end{array}$ \\
\hline \multicolumn{20}{|c|}{1991} \\
\hline \multicolumn{7}{|c|}{ JANUARY } & \multicolumn{7}{|c|}{ FEBRUARY } & \multicolumn{6}{|c|}{ MARCH } \\
\hline$S$ & $M$ & $T h$ & W T & $\mathrm{T}$ & F & $S$ & $S$ & $M$ & $T$ & $W$ & $T$ & $F$ & $S$ & $S$ & $M$ & $T \quad W$ & $T$ & $F$ & $S$ \\
\hline $\begin{array}{r}6 \\
13 \\
20 \\
27\end{array}$ & $\begin{array}{rr}7 & \\
14 & 1 \\
21 & 2 \\
28 & 2\end{array}$ & $\begin{array}{rr}1 & 2 \\
8 & 9 \\
15 & 16 \\
22 & 23 \\
29 & 30\end{array}$ & $\begin{array}{ll}2 & 3 \\
9 & 10 \\
6 & 17 \\
3 & 24 \\
30 & 31\end{array}$ & $\begin{array}{ll}3 & \\
0 & 1 \\
7 & 1 \\
4 & 2 \\
1 & \end{array}$ & $\begin{array}{ll}4 & \\
1 & 1 \\
18 & 1 \\
25 & 2\end{array}$ & $\begin{array}{r}5 \\
12 \\
19 \\
26\end{array}$ & $\begin{array}{r}3 \\
10 \\
17 \\
24\end{array}$ & $\begin{array}{cc}4 \\
11 & 1 \\
18 & 1 \\
25 & 2\end{array}$ & $\begin{array}{cc}5 & \\
12 & 1 \\
19 & 2 \\
26 & 2\end{array}$ & $\begin{array}{ll}6 & \\
13 & 1 \\
20 & 2 \\
27 & 2\end{array}$ & $\begin{array}{rl}7 & \\
14 & 1 \\
21 & 2 \\
28 & \end{array}$ & $\begin{array}{rl}1 \\
8 \\
15 & 1 \\
22 & 2\end{array}$ & $\begin{array}{r}2 \\
9 \\
16 \\
23\end{array}$ & $\begin{array}{r}5 \\
10 \\
17 \\
24 \\
31\end{array}$ & $\begin{array}{cc}4 & \\
11 & 1 \\
18 & 1 \\
25 & 2\end{array}$ & $\begin{array}{rr}5 & 6 \\
12 & 13 \\
19 & 20 \\
26 & 27\end{array}$ & $\begin{array}{r}7 \\
14 \\
21 \\
28\end{array}$ & $\begin{array}{r}1 \\
8 \\
15 \\
22 \\
29\end{array}$ & $\begin{array}{r}2 \\
9 \\
16 \\
23 \\
30\end{array}$ \\
\hline \multicolumn{7}{|c|}{ APRIL } & \multicolumn{7}{|c|}{ MAY } & \multicolumn{6}{|c|}{ JUNE } \\
\hline$S$ & $M$ & $\mathrm{~T} \quad \mathrm{~V}$ & W & $\mathrm{T}$ & $F$ & $S$ & $S$ & $M$ & $T$ & $W$ & $\mathrm{~T}$ & $F$ & $S$ & $S$ & $M$ & $T \quad W$ & $\mathrm{~T}$ & $F$ & $S$ \\
\hline $\begin{array}{r}7 \\
14 \\
21 \\
28\end{array}$ & $\begin{array}{r}1 \\
8 \\
15 \\
22 \\
29\end{array}$ & $\begin{array}{rr}2 & 3 \\
9 & 10 \\
16 & 17 \\
23 & 24 \\
30 & \end{array}$ & $\begin{array}{rr}3 & 4 \\
10 & 11 \\
17 & 18 \\
24 & 25\end{array}$ & $\begin{array}{ll}4 & \\
1 & 1 \\
8 & 1 \\
5 & 2\end{array}$ & $\begin{array}{rr}5 & \\
12 & 1 \\
19 & 2 \\
26 & 2\end{array}$ & $\begin{array}{r}6 \\
13 \\
20 \\
27\end{array}$ & $\begin{array}{r}5 \\
12 \\
19 \\
26\end{array}$ & $\begin{array}{cc}6 & \\
13 & 1 \\
20 & 2 \\
27 & 2\end{array}$ & $\begin{array}{rr}7 & \\
14 & 1 \\
21 & 2 \\
28 & 2\end{array}$ & $\begin{array}{rl}1 \\
8 \\
15 & 1 \\
22 & 2 \\
29 & 3\end{array}$ & $\begin{array}{rr}2 & \\
9 & 1 \\
16 & 1 \\
23 & 2 \\
30 & 3\end{array}$ & $\begin{array}{ll}3 & \\
10 & 1 \\
17 & 1 \\
24 & 2 \\
31 & \end{array}$ & $\begin{array}{r}4 \\
11 \\
18 \\
25\end{array}$ & $\begin{array}{r}2 \\
9 \\
16 \\
23 \\
30\end{array}$ & $\begin{array}{cc}3 & \\
10 & 1 \\
17 & 1 \\
24 & 2\end{array}$ & $\begin{array}{rr}4 & 5 \\
11 & 12 \\
18 & 19 \\
25 & 26\end{array}$ & $\begin{array}{r}6 \\
13 \\
20 \\
27\end{array}$ & $\begin{array}{r}7 \\
14 \\
21 \\
28\end{array}$ & $\begin{array}{r}1 \\
8 \\
15 \\
22 \\
29\end{array}$ \\
\hline \multicolumn{7}{|c|}{ JULY } & \multicolumn{7}{|c|}{ AUGUST } & \multicolumn{6}{|c|}{ SEPTEMBER } \\
\hline$S$ & $M$ & $\mathrm{~T} \quad \mathrm{~V}$ & W & $\mathrm{T}$ & $\mathrm{F}$ & $S$ & $S$ & $M$ & $\mathrm{~T}$ & $W$ & $\mathrm{~T}$ & $F$ & $S$ & $S$ & $M$ & $T \quad W$ & $\mathrm{~T}$ & $F$ & $S$ \\
\hline $\begin{array}{r}7 \\
14 \\
21 \\
28\end{array}$ & $\begin{array}{r}1 \\
8 \\
15 \\
22 \\
29\end{array}$ & $\begin{array}{rr}2 & \\
9 & 10 \\
16 & 1 \\
23 & 2 \\
30 & 3\end{array}$ & $\begin{array}{ll}3 & \\
10 & 1 \\
17 & 1 \\
24 & 2 \\
31 & \end{array}$ & $\begin{array}{ll}4 & \\
1 & 1 \\
8 & 1 \\
25 & 2\end{array}$ & $\begin{array}{rr}5 & \\
12 & 1 \\
19 & 2 \\
26 & 2\end{array}$ & $\begin{array}{r}6 \\
13 \\
20 \\
27\end{array}$ & $\begin{array}{r}4 \\
11 \\
18 \\
25\end{array}$ & $\begin{array}{r}5 \\
12 \\
19 \\
26\end{array}$ & $\begin{array}{cc}6 & \\
13 & 1 \\
20 & 2 \\
27 & 2\end{array}$ & $\begin{array}{r}7 \\
14 \\
21 \\
28\end{array}$ & $\begin{array}{rl}1 \\
8 \\
15 & 1 \\
22 & 2 \\
29 & 3\end{array}$ & $\begin{array}{rr}2 & \\
9 & 1 \\
16 & 1 \\
23 & 2 \\
30 & 3\end{array}$ & $\begin{array}{r}3 \\
10 \\
17 \\
24 \\
31\end{array}$ & $\begin{array}{r}1 \\
8 \\
15 \\
22 \\
29\end{array}$ & $\begin{array}{rr}2 & \\
9 & 1 \\
16 & 1 \\
23 & 2 \\
30 & \end{array}$ & $\begin{array}{rr}3 & 4 \\
10 & 11 \\
17 & 18 \\
24 & 25\end{array}$ & $\begin{array}{r}5 \\
12 \\
19 \\
26\end{array}$ & $\begin{array}{r}6 \\
13 \\
20 \\
27\end{array}$ & $\begin{array}{r}7 \\
14 \\
21 \\
28\end{array}$ \\
\hline
\end{tabular}


Water Resources Data Indiana

Water Year 1991

by James A. Stewart and Clyde E. Deiwert

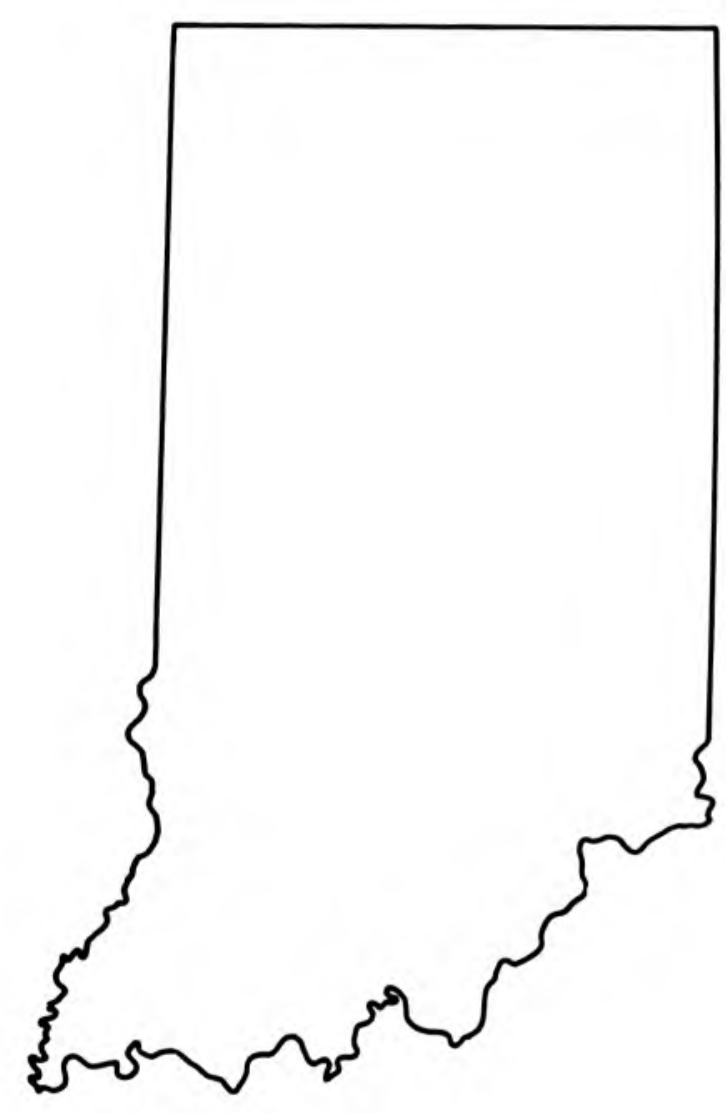

U.S. GEOLOGICAL SURVEY WATER-DATA REPORT IN-91-1

Prepared in cooperation with the State of Indiana and with other agencies 


\section{U. S. DEPARTMENT OF THE INTERIOR}

MANUEL LUJAN, JR., Secretary

\section{U.S. GEOLOGICAL SURVEY}

Dallas L. Peck, Director

For additional information, write to District Chief, Water Resources Division U.S. Geological Survey 5957 Lakeside Boulevard Indianapolis, Indiana 46278 


\section{PREFACE}

This volume of the annual hydrologic data report of Indiana is one of a series of annual reports that document hydrologic data gathered from the U.S. Geological Survey's surface- and ground-water datacollection networks in each State, Puerto Rico, and the Trust Territories. These records of streamflow, stage, lake levels, ground-water levels, and water quality provide the hydrologic information needed by State, local, and Federal agencies, and the private sector for developing and managing our Nation's land and water resources.

This report is the culmination of a concerted effort by dedicated personnel of the U.S. Geological Survey who collected, compiled, analyzed, verified, and organized the data, and who typed, edited, and assembled the report. In addition to the authors, who had primary responsibility for assuring that the information contained herein is accurate, complete, and adheres to Geological Survey policy and established guidelines, the following individuals contributed significantly to the collection, processing, and tabulation of the data:
D.V. Arvin
C.R. Keeton
B.L. Benedict
M.T. Kelly
H.R. Christensen
R.G. Knapp
J. R. Davis
P.H. Laird
C.E. Deiwert
R.J. Lewins
T.J. Eaton
D.K. Majors
L. E. Hammil
S. E. Morlock
G.A. Hodgkins
H.T. Nguyen
R.E. Hoggatt
R.R. Ondrish
J. H. Ibsen
L. R. Watson

The following individuals contributed significantly to the typing, drafting, and assembling of the report:
J. R. Davis
L. M. Huff
D. K. Majors

This report was prepared in cooperation with the State of Indiana and with other agencies under the general supervision of J. A. Macy, District Chief, Indiana, and S. P. Sauer, Regional Hydrologist, Northeastern Region 


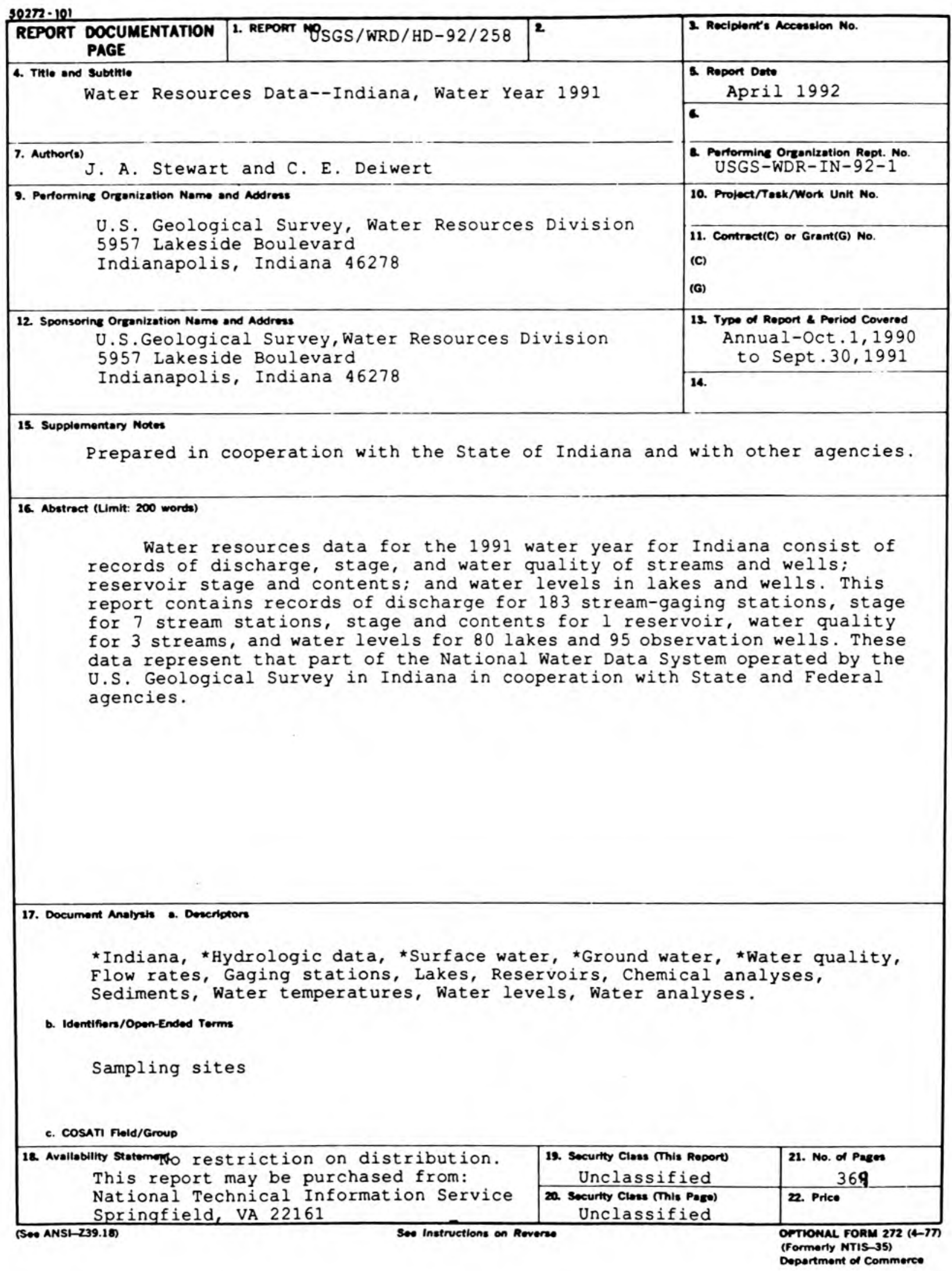




\section{CONTENTS}

Page

Preface

List of stream and reservoir gaging stations, in downstream order for which records are published in this volume

List of lake gaging stations, in alphabetical order, for which records are published in this volume

List of ground-water wells, in alphanumeric order by county, for which records are published in this volume

List of discontinued surface-water discharge or stage-only stations

List of discontinued surface-water-quality stations.

Introduction

Cooperation

Summary of hydrologic conditions

Special networks and programs

Explanation of the records

Station identification numbers

Downstream order system.

Latitude-longitude system

Data collection and computation.

Data presentation

Station manuscript

Data table of daily mean values

Statistics of monthly mean data....

Summary statistics.

Identifying estimated daily discharge

Accuracy of the records.

Other records available

vii

xii

xiv

xvii

xix

1

2

3

8

9

9

9

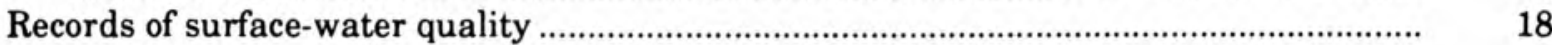

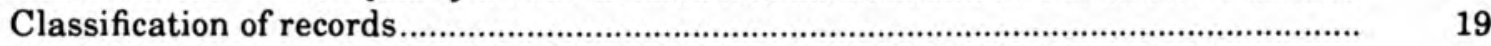

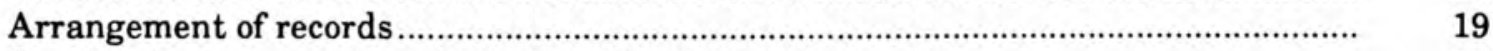

On-site measurements and sample collection ............................................................ 19

Laboratory measurements ......................................................................................... 20

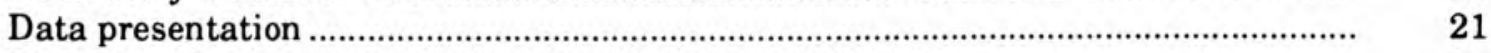

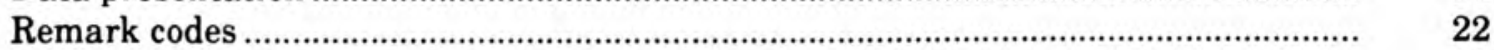

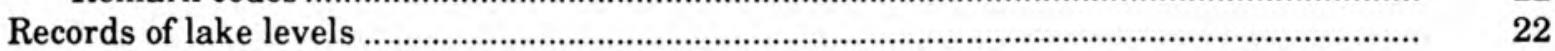

Data collection and computation.................................................................................... 23

Data presentation ........................................................................................................

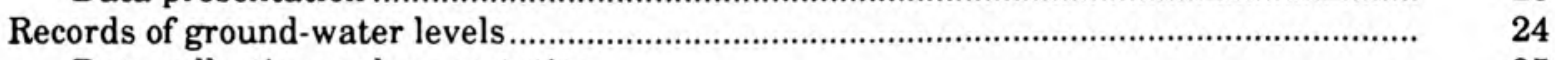

Data collection and computation............................................................................ 25

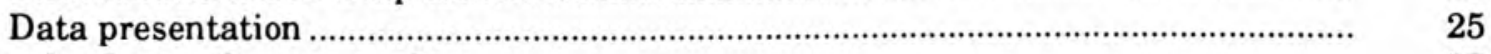

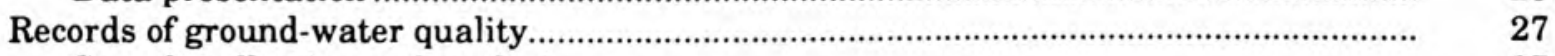

Sample collection and analysis .............................................................................. 27

Data presentation .................................................................................................. 27

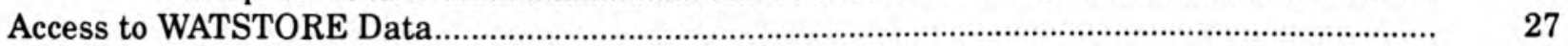

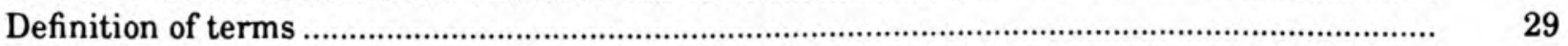

Publications on techniques of water-resources investigations ................................................. 40

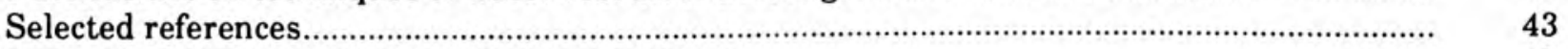

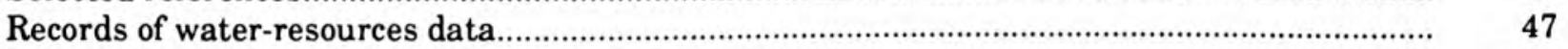

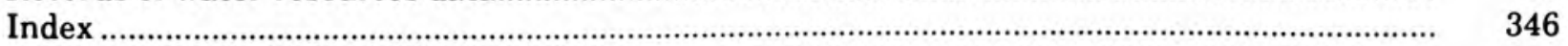




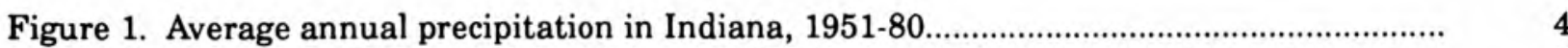

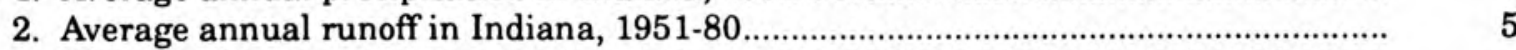

3. Mean discharges at Indiana index stations during 1991 water year and median discharges for period 1951-80.

4. Location of streamflow and water-quality gaging stations in Indiana ....................... 44

5. Location of streamflow and water-quality gaging stations in Marion County, IN..... $\quad 46$

6. Number of lakes by county having 1991 water-level records..................................... $\quad 249$

7. Number of ground-water wells by county having 1991 water-level records................. 295

\section{TABLES}

Table 1. Factors for conversion of chemical constituents in milligrams or micrograms per liter to milliequivalents per liter.

2. Factors for conversion of sediment concentrations in milligrams per liter to parts per million. 
S'TREAM AND RESERVOIR GAGING STATIONS, IN DOWNSTREAM ORDER, vii FOR WHICH RECORDS ARE PUBLISHED IN THIS VOLUME

(d-discharge, e-gage heights, c-chemical, t-temperature, s-sediment, v-contents)

\section{OHIO RIVER BASIN}

GREAT MIAMI RIVER BASIN

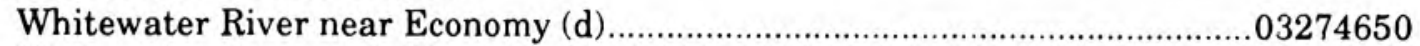

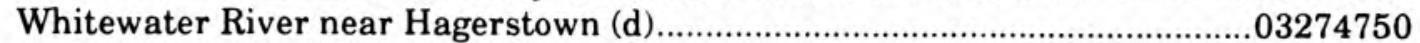

Little Williams Creek at Connersville (d) .................................................03274950

Whitewater River near Alpine (d,c,t,s)....

03275000

49

East Fork Whitewater River at Abington (d).

03275600

East Fork Whitewater River at Brookville (d) ..........................................03276000

Whitewater River at Brookville (d).

03276500

HOGAN CREEK BASIN

South Hogan Creek near Dillsboro (d,c,t,s)

INDIAN-KENTUCK CREEK BASIN

Indian-Kentuck Creek near Canaan (d)

03276700

SILVER CREEK BASIN

Silver Creek near Sellersburg (d)

03291780

BUCK CREEK BASIN

03294000

Buck Creek near New Middletown (d)

03302220

INDIAN CREEK BASIN

Indian Creek:

Little Indian Creek near Galena (d).

03302300

Indian Creek near Corydon (d).

BLUE RIVER BASIN

Blue River:

West Fork Blue River at Salem (d)

.03302680

Blue River at Fredericksburg (d)

Whiskey Run at Marengo (d)

Blue River near White Cloud (d)

ANDERSON RIVER BASIN

Anderson River:

Middle Fork Anderson River at Bristow (d)

CROOKED CREEK BASIN

Crooked Creek near Santa Claus (d)

PIGEON CREEK BASIN

Pigeon Creek near Fort Branch (d)

WABASH RIVER BASIN

Wabash River at Linn Grove (d)

Wabash River at Bluffton (e).

Wabash River at Huntington (d)

Little River near Huntington (d)

Salamonie River at Portland (d)...

Salamonie River near Warren (d)

Salamonie River at Dora (d).

Wabash River at Wabash (d)

Mississinewa River:

Little Mississinewa River at Union City (d) 
OHIO RIVER BASIN--Continued

WABASH RIVER BASIN--Continued

Mississinewa River--Continued

Big Lick Creek near Hartford City (d)...................................................03326070

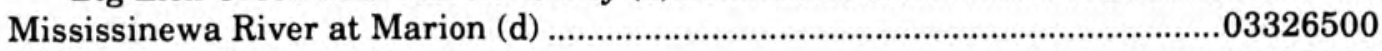

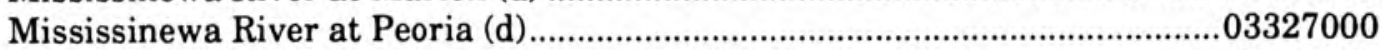

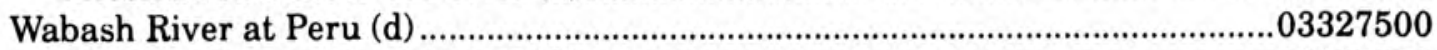

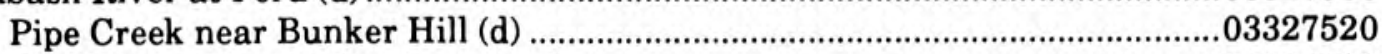

Eel River at North Manchester (d).

03328000

Weesau Creek near Deedsville (d) .........................................................03328430

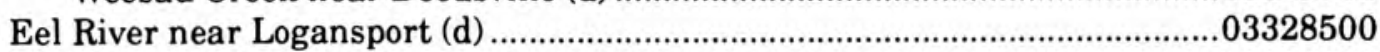

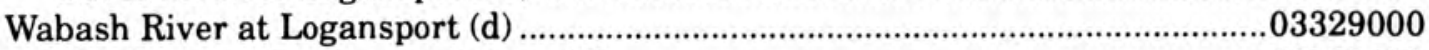

Rattlesnake Creek near Patton (d) .................................................................03329400

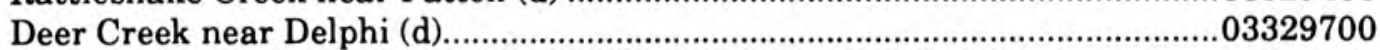

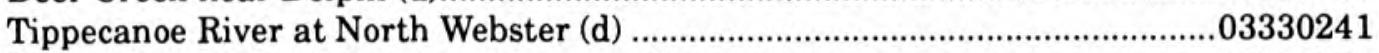

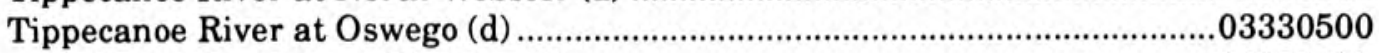

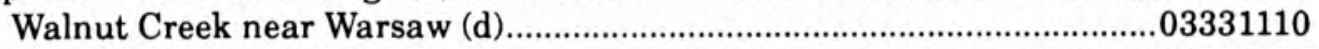

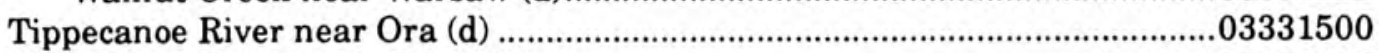

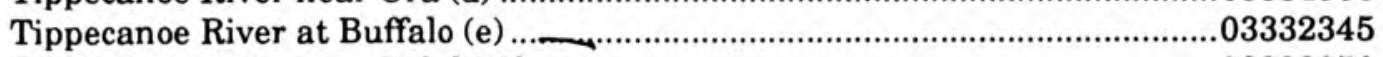

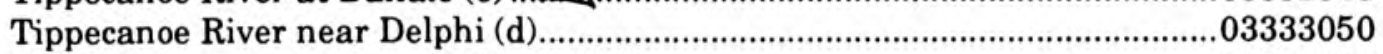

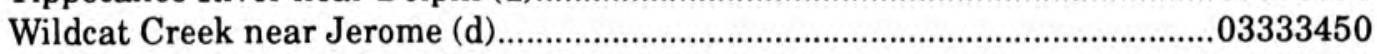

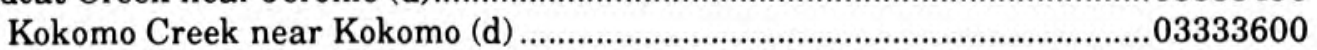

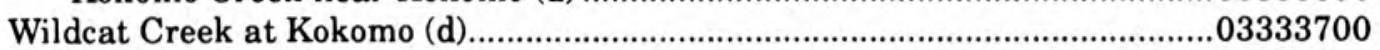

Wildcat Creek at Owasco (d) .........................................................................03334000

South Fork Wildcat Creek near Lafayette (d).........................................03334500

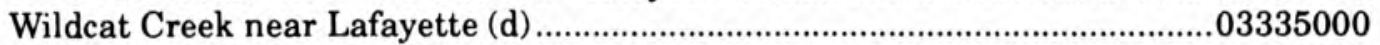

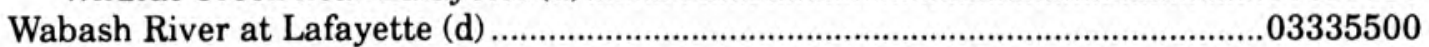

Little Pine Creek:

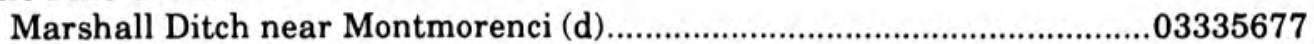

Indian Creek near Montmorenci (d).

Little Pine Creek at Green Hill (d)

Big Pine Creek:

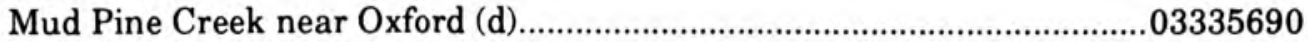

Wabash River at Covington (d).

Coal Creek:

East Fork Coal Creek near Hillsboro (d).

Sugar Creek at Crawfordsville (d)

Big Raccoon Creek near Fincastle (d)

Big Raccoon Creek at Ferndale (d).

Big Raccoon Creek at Coxville (e)

Big Raccoon Creek near Mecca (d).

Wabash River at Terre Haute (d). 


\section{OHIO RIVER BASIN--Continued}

WABASH RIVER BASIN--Continued

Busseron Creek near Carlisle (d)

Wabash River at Vincennes (d)

03342500

122

White River at Muncie (d)

.03343000

Buck Creek near Muncie (d)

.03347000

123

124

White River at Anderson (d

.03347500

125

Killbuck Creek near Gaston (d) ........ 03348020

126

Pipe Creek at Frankton (d) ..................................................................03348350

127

128

White River at Noblesville (d)

.03349000

129

Cicero Creek at Noblesville (d)

03350500

130

Stony Creek near Noblesville (d)

03350700

131

White River near Nora (d)

03351000

132

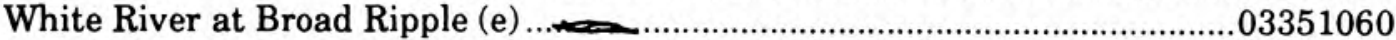

Crooked Creek at Indianapolis (d).

03351310

Fall Creek:

Fall Creek near Fortville (d)

.03351500

Fall Creek at Millersville (d)

03352500

Fall Creek at 16th Street at Indianapolis (d)

03352875

03353000

133

134

White River at Indianapolis (d)

03353120

03353180

135

136

137

138

Pleasant Run at Arlington Avenue at Indianapolis (d)

139

Bean Creek at Indianapolis (d)

Eagle Creek at Zionsville (d)

03353200

141

Eagle Creek Reservoir near Indianapolis (v)

03353450

142

Eagle Creek at Indianapolis (d)

03353500

Little Eagle Creek at 52nd St. at Indianapolis (d)

03353551

Guion Creek at 52nd St. at Indianapolis (d)

03353560

Falcon Creek at 30th St. at Indianapolis (d)

03353583

Little Eagle Creek at Speedway (d)

03353600

03353620

Lick Creek at Indianapolis (d).

Little Buck Creek near Southport (d)

03353635

Derbyshire Creek at Southport (d)

03353636

Little Buck Creek at Southport (d)

White Lick Creek:

West Fork White Lick Creek at Danville (d) ........................................03353700

143

144

145

146

147

148

149

150

151

152

White Lick Creek at Mooresville (d)

Beanblossom Creek at Beanblossom (d)

White River at Spencer (e). 03357000

Big Walnut Creek (head of Eel River):

Plum Creek near Bainbridge (d)

Big Walnut Creek near Reelsville (d) .....................................................03357500

Mill Creek near Cataract (d)

03358000

Mill Creek near Manhattan (d)

03359000

03360000

03360500

.03361000

03361500 


\section{OHIO RIVER BASIN--Continued}

WABASH RIVER BASIN--Continued

White River--Continued

Big Blue River--Continued

Sugar Creek at New Palestine (d).

03361650

168

Buck Creek at Acton (d)

03361850

Youngs Creek near Edinburgh (d)

03362000

169

Sugar Creek near Edinburgh (d).

03362500

170

Driftwood River (continuation of Big Blue River)

near Edinburgh $(\mathrm{d})$

03363000

171

Flatrock River at St. Paul (d)

03363500

Flatrock River at Columbus (d)

03363900

East Fork White River (continuation of Driftwood River)

at Columbus (d).

03364000

03364200

Haw Creek near Clifford (d)

03364500

Clifty Creek at Hartsville (d)

03365500

East Fork White River at Seymour (d)

172

173

174

Graham Creek (head of Muscatatuck River):

Big Creek:

Harberts Creek near Madison (d)

03366200

Muscatatuck River near Deputy (d)

03368000

03369000

03369500

03371500

East Fork White River near Bedford (d)

03371520

175

176

177

178

Guthrie Creek:

Back Creek at Leesville (d)

179

180

181

182

183

185

Salt Creek:

Middle Fork Salt Creek:

Stephens Creek near Bloomington (d) ....................................03372300

Salt Creek near Harrodsburg (d)

East Fork White River at Shoals (d)

Lost River near West Baden Springs (d)

.03373700

White River above Petersburg (d)

03373980

White River at Petersburg (d)

.03374000

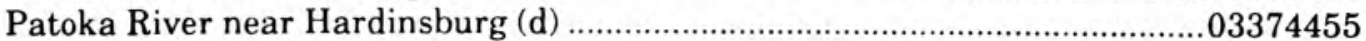

Patoka River near Cuzco (d)

03374500

Patoka River at Jasper (d)

.03375500

Straight River:

Hall Creek (head of Straight River) near St. Anthony (d) ..................03375800

Patoka River at Winslow (d).

Patoka River near Princeton (d)

03376500

186

187

188

189

190

191

192

193

194

195

196

197

.03377500

198

Wabash River at Mount Carmel, IL (d)

03378500

199

Wabash River at New Harmony (e).

03378550

200

Big Creek near Wadesville (d)

201 


\section{STREAMS TRIBUTARY TO LAKE MICHIGAN}

BURNS WATERWAY

Deep River (head of Burns Waterway) at Lake George outlet at Hobart (d). .04093000

Little Calumet River at Gary (e) .04093200

Burns ditch (continuation of Deep River) at Gary (d) .04093500 Little Calumet River at Porter (d). .04094000 Salt Creek near McCool (d) .04094500 TRAIL CREEK BASIN

Trail Creek at Michigan City (d, s) 04095300

GALIEN RIVER BASIN

South Branch Galien River: Galena River near LaPorte (d) 04096100 ST. JOSEPH RIVER BASIN

Pigeon Creek near Angola (d) .04099510

Pigeon River near Scott (d) .04099750

Little Elkhart River at Middlebury (d) 04099808

Pine Creek near Elkhart (d) 04099850

North Branch Elkhart River (head of Elkhart River) at Cosperville (d) .04100222 South Branch Elkhart River:

Forker Creek near Burr Oak (d) 04100252

Rimmell Branch (head of Craft ditch) near Albion (d). 04100295

Solomon Creek near Syracuse (d) 04100377

Elkhart River at Goshen (d) 04100500 202 203 204 205 206

\section{STREAMS TRIBUTARY TO LAKE ERIE}

\section{MAUMEE RIVER BASIN}

St. Joseph River (head of Maumee River):

Fish Creek at Hamilton (d) 04177720

St. Joseph River near Newville (d) 04178000

St. Joseph River near Fort Wayne (d) 04180500

St. Marys River near Fort Wayne (d) 04182000

\section{UPPER MISSISSIPPI RIVER BASIN}

\section{ILLINOIS RIVER BASIN}

Kankakee River (head of Illinois River) near North Liberty (d) ...........................05515000

Kankakee River at Davis (d). 


\section{UPPER MISSISSIPPI RIVER BASIN--Continued}

ILLINOIS RIVER BASIN--Continued

Kankakee River--Continued

Kankakee River at Shelby (d)

.05518000

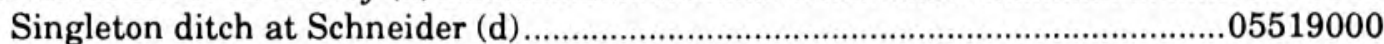

Iroquois River at Rosebud (d)

.05521000

Iroquois River near North Marion (d).

.05522000

Iroquois River at Rensselaer (d) .05522500

Slough Creek:

Bice ditch near South Marion (d)

Iroquois River near Foresman (d)

DES PLAINES RIVER BASIN

Chicago Sanitary and Ship Canal

Little Calumet River (western portion):

Hart ditch at Dyer(d)

\section{LAKE GAGING STATIONS, IN ALPHABETICAL ORDER, FOR WHICH RECORDS} ARE PUBLISHED IN THIS VOLUME

$$
\text { (e - gage heights) }
$$

Adams Lake near Wolcottville (e)

Ball Lake near Hamilton (e)

Bass Lake at Bass Lake (e)

Bear Lake near Wolflake (e)

Big Chapman Lake near Warsaw (e)

Big Lake near Wolflake (e)

Big Long Lake near Stroh (e).

Bixler Lake at Kendallville (e)

Blue Lake near Churubusco (e)

Bower Lake near Pleasant Lake (e)

Cass Lake near Shipshewana (e).

Cedar Lake at Cedar Lake (e).

Center Lake at Warsaw (e)

Clear Lake at Clear Lake (e).

Clear Lake at LaPorte (e).

Crooked Lake at Crooked Lake (e)

Dewart Lake near Leesburg (e)

Diamond Lake near Silver Lake (e)

Diamond Lake near Wawaka (e).

Engle Lake near Ligonier (e)

Fish Lake near Plato (e)

Fish Lake near Scott (e) 


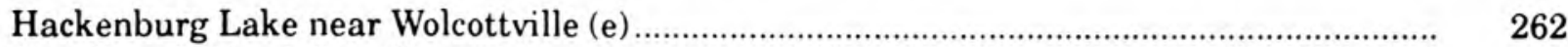

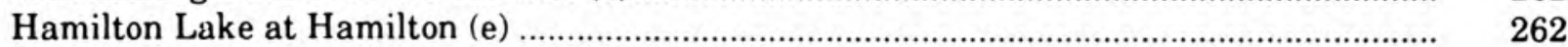

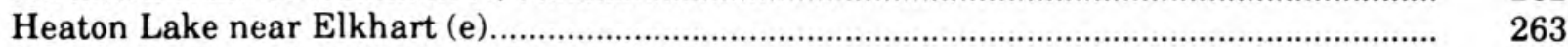

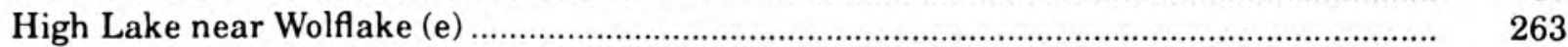

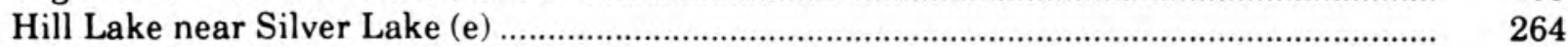

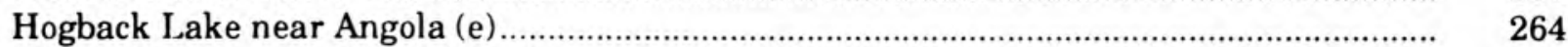

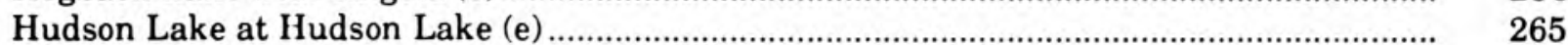

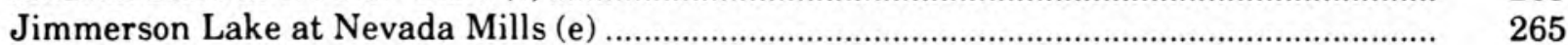

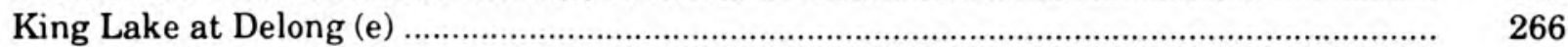

Knapp Lake near Washington Center (e) (........................................................................... 266

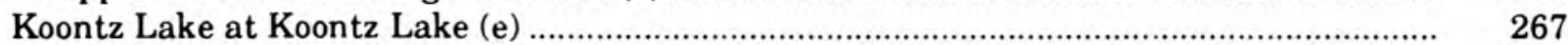

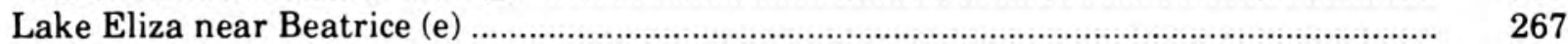

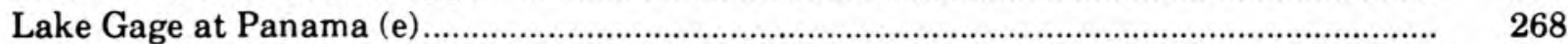

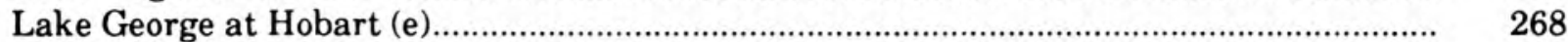

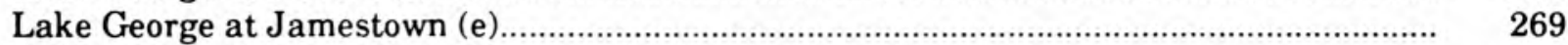

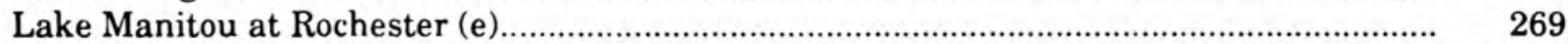

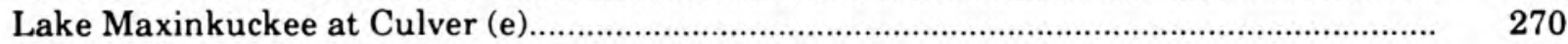

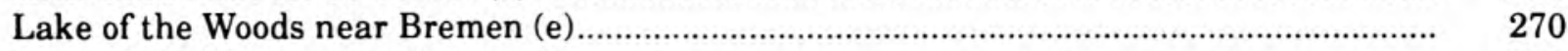

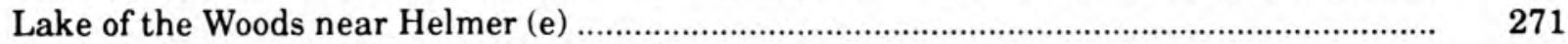

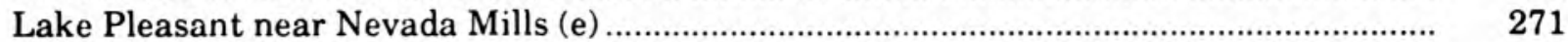

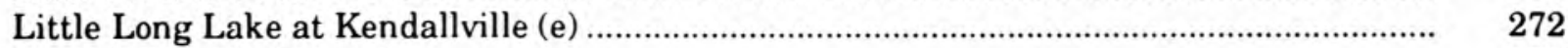

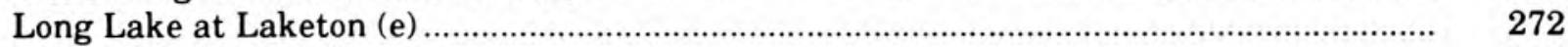

Long Lake at Moonlight (e) ............................................................................................ 273

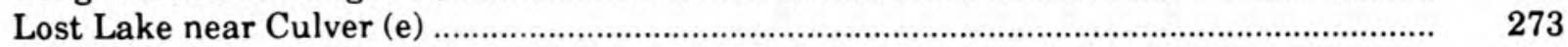

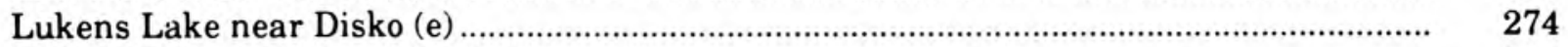

Muncie Lake near Burr Oak (e)..................................................................................... 274

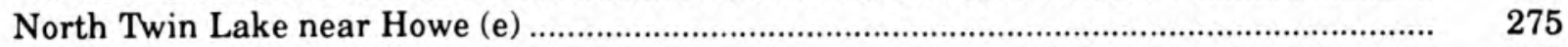

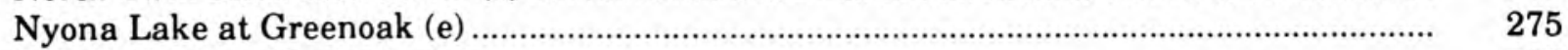

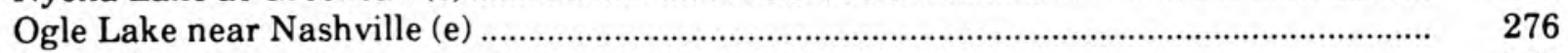

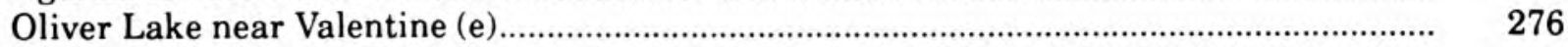

Palestine Lake at Palestine (e) .................................................................................. 277

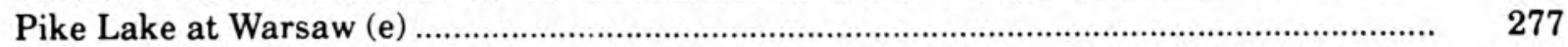

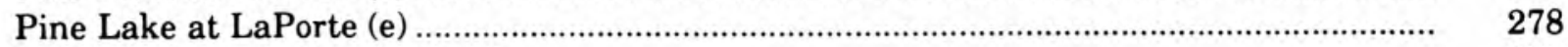

Pretty Lake near Plymouth (e) ..................................................................................... 278

Riddles Lake near Lakeville (e) ..................................................................................... 279

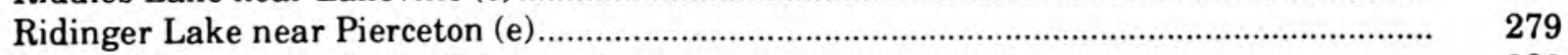

Sawmill Lake near North Webster (e) ............................................................................ 280

Sherburn Lake near Pierceton (e) ...................................................................................... 280

Shipshewana Lake near Shipshewana (e) ….................................................................. 281

Shoe Lake near Oswego (e) ............................................................................................. 281

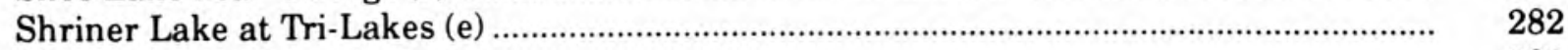

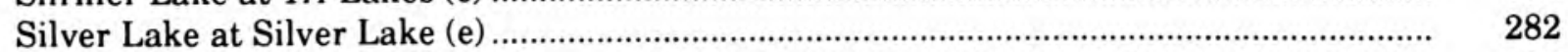

Simonton Lake near Elkhart (e) ................................................................................... 283

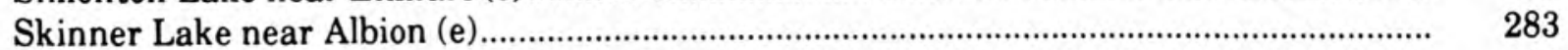

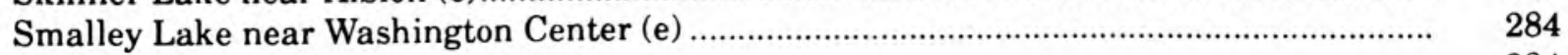

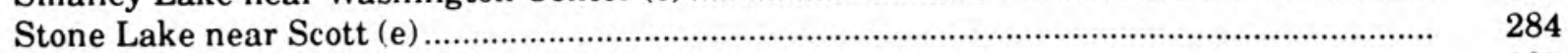

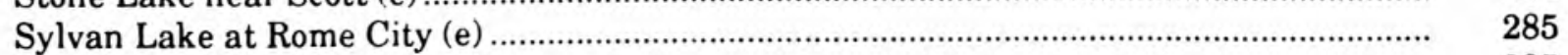

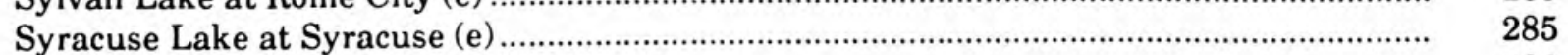

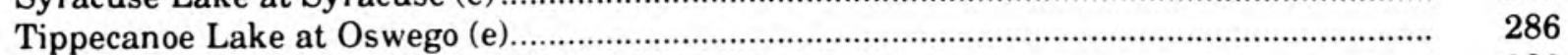

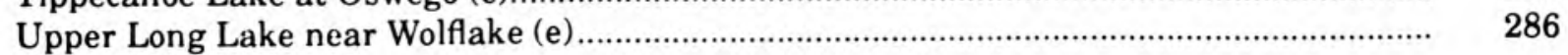


Versailles Lake near Versailles (e).

Waldron Lake near Cosperville (e)

Wauhob Lake near Valparaiso (e).

Webster Lake at North Webster (e)

Wharton Lake near South Bend (e)

Winona Lake at Warsaw (e)

Records available on lakes

\section{GROUND-WATER WELLS, IN ALPHANUMERIC ORDER BY COUNTY, FOR WHICH RECORDS ARE PUBLISHED IN THIS VOLUME}

$$
\text { (e - gage heights, c - chemical, } \mathrm{t} \text { - temperature) }
$$

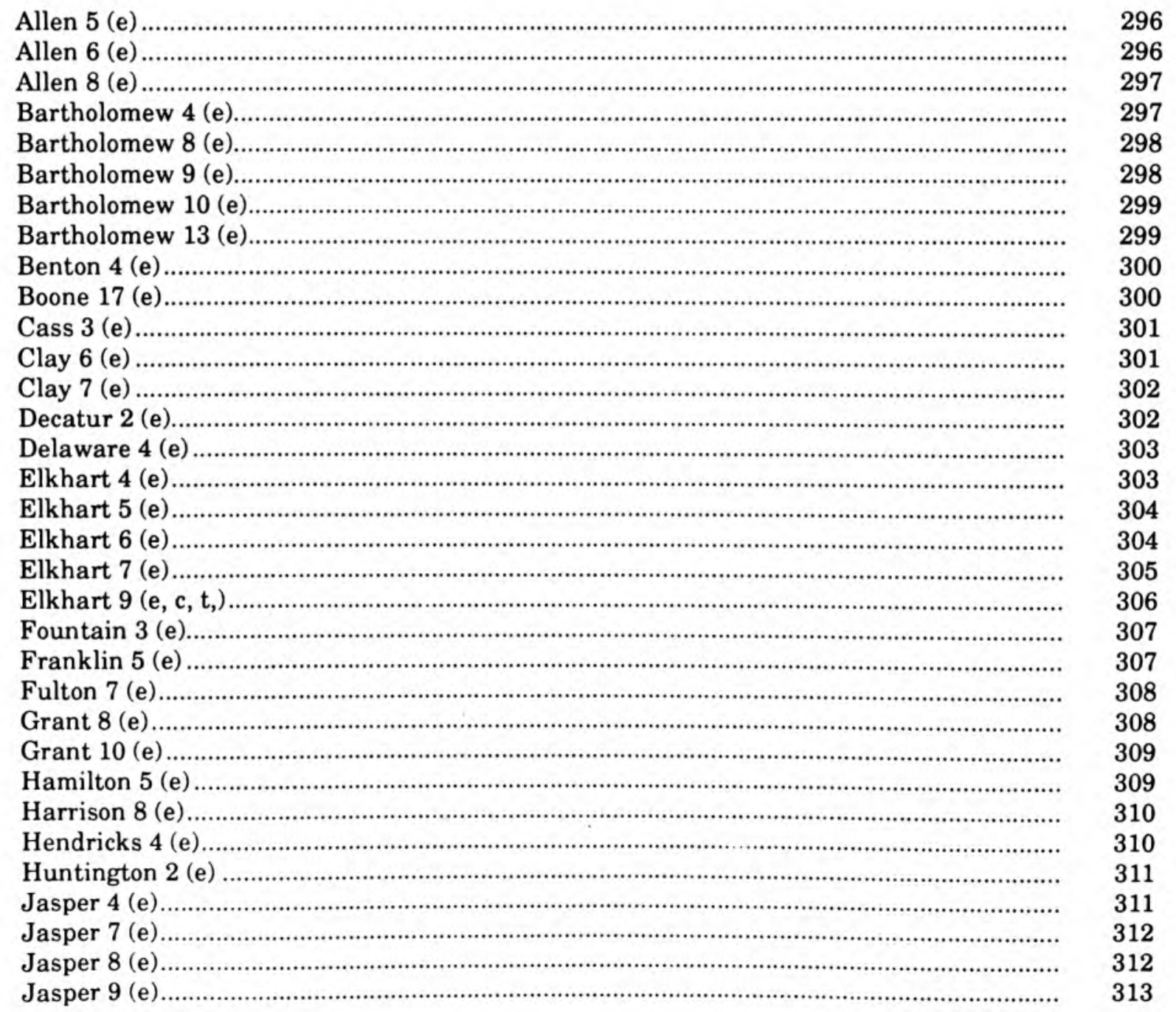




\begin{tabular}{|c|c|}
\hline & \\
\hline & \\
\hline & \\
\hline & 315 \\
\hline (e).. & 315 \\
\hline & 316 \\
\hline (1) & 316 \\
\hline . & 317 \\
\hline $06(\mathrm{e})$. & 317 \\
\hline .............. & 318 \\
\hline ................ & 318 \\
\hline ................. & 19 \\
\hline$\ldots \ldots . . . . . .$. & 19 \\
\hline & 20 \\
\hline & 320 \\
\hline (1) & 321 \\
\hline (1) & 321 \\
\hline (e)... & 322 \\
\hline (e) & 322 \\
\hline ......... & 323 \\
\hline .................. & 323 \\
\hline & 324 \\
\hline & 324 \\
\hline & 325 \\
\hline & 325 \\
\hline . & 326 \\
\hline (1) & 326 \\
\hline (1) & 327 \\
\hline (1) & 327 \\
\hline 8 (e) & 328 \\
\hline 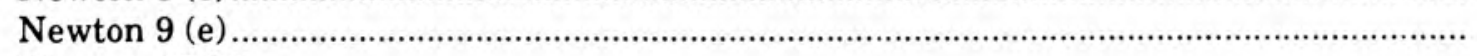 & 328 \\
\hline ................. & 329 \\
\hline .............. & 329 \\
\hline 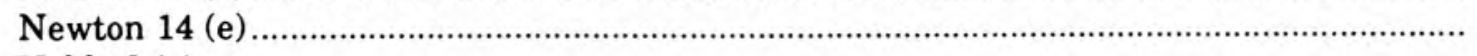 & 330 \\
\hline (1) & 330 \\
\hline 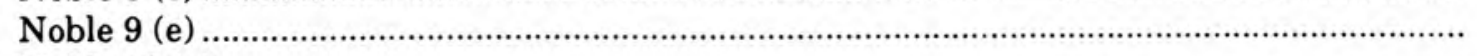 & 331 \\
\hline 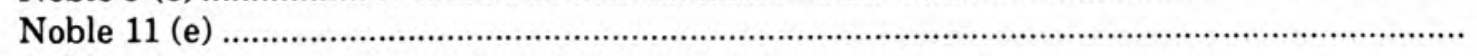 & 331 \\
\hline (1) & 332 \\
\hline . & 33 \\
\hline (1) & 3 \\
\hline . & 3 \\
\hline . & 334 \\
\hline . & 334 \\
\hline . & 335 \\
\hline . & 335 \\
\hline 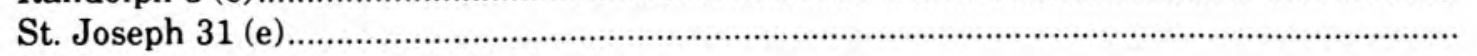 & 336 \\
\hline (1) & 33 \\
\hline (1) & 33 \\
\hline & 338 \\
\hline
\end{tabular}


Tippecanoe 17 (e)

Tippecanoe 18 (e)

Vanderburgh 6 (e)

Vanderburgh 7 (e)

Vigo 7 (e)

Wabash 3 (e)

Wabash 4 (e)

Warrick 4 (e).

Washington 2 (e)

Wayne 6 (e)

Wells 4 (e)

White 4 (e)

Whitley 3 (e). 
The following continuous-record surface-water discharge or stage-only stations (gaging stations) in Indiana have been discontinued. Daily streamflow or stage records were collected and published for the period of record, expressed in water years, shown for each station. Discontinued short-term project stations have not been included. Information regarding these stations may be obtained from the District Office at the address given on the back side of the title page of this report.

(Most stations are surface-water discharge, exceptions are designated with footnotes)

Station name

Station

number

\section{Drainage \\ $\underset{\left(\mathrm{mi}^{2}\right)}{\operatorname{area}}$}

Period of record
East Fork Whitewater River at Richmond Laughery Creek near Farmers lwtreat (a)

Friday Branch tribulary near Saint Meinrad (b)

Little Pigeon Creek near Tennyson

Pigeon Creek at Evansville

Wabash River near New Corydon

Mississinewa River near Eaton (b)

Wabash River at Delphi

Tippecanoe River near Warsaw

Tippecanoe River at Pulaski

Little Indian Creek near Royal Center (a)

Big Monon Creek near Francesville (a)

Tippecanoe River near Monticello (c)

Wildcat Creek at Greentown

Big Pine Creek near Williams port

Coal Creek at Coal Creek

Little Vermilion River near Newport

Sugar Creek tributary near Deer Mill (b)

Sugar Creek near Byron (b)

Big Raccoon Creek at Mansfield (d)

Little Raccoon Creek near Catlin (d,g)

Brouilletts Creek near L'niversal (b)

North Coal Creek near Terre Haute

Honey Creek near Riley (b)

West Fork Busseron Creek near Hymera

Mud Creek near Dugger

Busseron Creek near Sullivan

Buttermilk Creek near Paxton

Buttermilk Creek near Sullivan

South Fork Smalls Creek at Bruceville $(b, g)$

Killbuck Creek near Anderson

White River near Noblesville

Cicero Creek near Arcadia (a)

Little Cicero Creek near Arcadia (a)

Ciceru Creek near Cicero

Hinkle Creek near Cicero (a)

Sugar Creek near Middletown

Lawrence Creek at Fort Benjamin Harrison

Mud Creek at Indianapolis (a)

Pleasant Run at Brookville Road at Indpls.

White River at Waverly

Bear Creek near Trevlac (a)

Beanblussom Creek at Dolan

Beanblossom Creek near Bloomington

Big Walnut Creek at Greencastle

Deer Creek near Putnamville

Jordan Creek near Jordan (b)

Sand Creek near Brewersville

Grahan Creek near Vernon

Muscatatuck River near Austin

Stucker Creek near Austin

Vernon Fork near Crothersville

Muscatatuck River near Tampico

Muscatatuck River near Vallonia

South Fork Salt Creek at Kurtz

\section{WABASH RIVER BASIN}

\begin{tabular}{|c|c|c|}
\hline $\begin{array}{l}03275500 \\
03277000 \\
03303276 \\
03304000 \\
03322100\end{array}$ & $\begin{array}{l}121 \\
248 \\
187 \\
323\end{array} .096$ & $\begin{array}{l}1949-78 \\
1941-73 \\
1981 \\
1944-47 \\
1960-85\end{array}$ \\
\hline $\begin{array}{l}03322500 \\
03326000 \\
03329500 \\
03331000 \\
03332000\end{array}$ & $\begin{array}{r}262 \\
310 \\
4,072 \\
126 \\
1,089\end{array}$ & $\begin{array}{l}1951-88 \\
1952-71 \\
1940-71 \\
1943-49 \\
1928-31\end{array}$ \\
\hline $\begin{array}{l}03332300 \\
03332400 \\
03332500 \\
03333500 \\
03335700\end{array}$ & $\begin{array}{r}35.0 \\
152 \\
1,732 \\
168 \\
323\end{array}$ & $\begin{array}{l}1959-73 \\
1959-73 \\
1932-81 \\
1945-61 \\
1955-87\end{array}$ \\
\hline $\begin{array}{l}03339120 \\
03339150 \\
03339855 \\
03340000 \\
03341000\end{array}$ & $\begin{array}{l}214 \\
237 \\
670 \\
248\end{array}$ & $\begin{array}{l}1965-72 \\
1965-72 \\
1981 \\
1941-71 \\
1939-58\end{array}$ \\
\hline $\begin{array}{l}03341200 \\
03341420 \\
03341470 \\
03341570 \\
03342150\end{array}$ & $\begin{array}{c}134 \\
321 \\
1.91 \\
5.79 \\
14.4\end{array}$ & $\begin{array}{l}1957-71 \\
1966-71 \\
1974-76 \\
1981 \\
1966-86\end{array}$ \\
\hline $\begin{array}{l}03342250 \\
03342300 \\
03342350 \\
03342360 \\
03342800\end{array}$ & $\begin{array}{c}11.9 \\
138 \\
16.5 \\
17.6 \\
4.94\end{array}$ & $\begin{array}{l}1966-81 \\
1966-86 \\
1966-73 \\
1975-78 \\
1972-75\end{array}$ \\
\hline $\begin{array}{l}03348100 \\
03348500\end{array}$ & $\begin{array}{l}97.8 \\
828\end{array}$ & $\begin{array}{l}1964-68 \\
1915-26 \\
1929-74\end{array}$ \\
\hline $\begin{array}{l}03349500 \\
03349700 \\
03350000\end{array}$ & $\begin{array}{l}131 \\
40.4 \\
196\end{array}$ & $\begin{array}{l}1955-76 \\
1956-76 \\
1946-54\end{array}$ \\
\hline $\begin{array}{l}03350100 \\
03351400 \\
03352000\end{array}$ & $\begin{array}{r}18.5 \\
5.80 \\
2.74\end{array}$ & \multirow{2}{*}{$\begin{array}{l}1956-76 \\
1969-89 \\
1952-56, \\
1958-69 \\
1958-76 \\
1960-81\end{array}$} \\
\hline $\begin{array}{l}03352200 \\
03353160\end{array}$ & $\begin{array}{l}42.4 \\
10.1\end{array}$ & \\
\hline $\begin{array}{l}03353660 \\
03355000 \\
03356000 \\
03356500 \\
03357420\end{array}$ & $\begin{array}{c}2,026 \\
6.94 \\
100 \\
112 \\
216\end{array}$ & $\begin{array}{l}1986-88 \\
1952-73 \\
1946-78 \\
1931-33 \\
1975-1982\end{array}$ \\
\hline 03359500 & 59.0 & \multirow{2}{*}{$\begin{array}{l}1955-65 \\
1968-72 \\
1981 \\
1948-86 \\
1955-73 \\
1932-43 \text {, } 194-71 \text { (n) }\end{array}$} \\
\hline $\begin{array}{l}03359980 \\
03365000 \\
03366000 \\
03367000\end{array}$ & $\begin{array}{c}25.9 \\
155 \\
77.2 \\
359\end{array}$ & \\
\hline $\begin{array}{l}03367500 \\
03370000 \\
03370500 \\
03371000 \\
03371600\end{array}$ & $\begin{array}{c}127 \\
391 \\
960 \\
1,134 \\
38.2\end{array}$ & $\begin{array}{l}1932-33 \\
1932-33 \\
1939 \\
1932-33 \\
1961-71 \\
1972-75\end{array}$ \\
\hline
\end{tabular}


Station name

North Fork Salt Creek at Nashville (a) Nurth Fork Salt Creck near Belmont

Clear Creek near Harrodsburg

Salt Creek near Peerless

Indian Creek near Springville (a)

White River at Hazleton (h)

Patoka River near Jasper (g)

Flat Creek near Otwell

Little Flat Creek near Otwell (b)

Suuth Fork Patoka River near Spurgeon
Station

number

\section{Drainage \\ $\underset{\left(\mathrm{mi}^{2}\right)}{\operatorname{area}}$}

WABASH RIVER BASIN--Continued

$\begin{array}{ccl}03371650 & 76.1 & 1962-76 \\ 03372000 & 120 & 1946-71 \\ 03372700 & 55.2 & 1960-71 \\ 03373000 & 573 & 1939-50 \\ & & 1957-71(\mathrm{~d}) \\ 03373200 & 60.7 & 1961-73 \\ & & \\ 03374100 & 11,305 & 1928-38 \\ 03376000 & 348 & 1944-47 \\ 03376260 & 21.3 & 1965-1982 \\ 03376279 & 6.56 & 1981 \\ 03376350 & 42.8 & 1964-86\end{array}$

Period

of record

Dunes Creek at Porter

Derby ditch at Beverly Shores

Lime Lake outlet at Panama

Fawn River at Orland

Pigeon Creek and Hogback Lake near Angola

Pretty Lake Inlet near Stroh

Christiana Creek at Elkhart

North Branch Elkhart River near Cosperville

Turkey Creek at Syracuse

STREAMS TRIBUTARY TO LAKE MICHIGAN

04090500

04095100

04097970

04098000

04099500

04099610

04100000

04100220

04100465

3.40
4.64
17.5
86.4
103

1979-1982

1980

1969-86

1943-47

1946-74

1.96

1963-80

1947-52

$1951-71$

1969-87

\section{STREAMS TRIBUTARY TO LAKE ERIE}

St. Joseph River at Hursh

St. Joseph River at Cedarville

04178500

734

1950-54

$04179000 \div 763$

1931-32,

04179500

87.3

04182700

810

1956-81

1943-73

1905-06

\section{UPPER MISSISSIPPI RIVER BASIN}

Kingsbury Creek near LaPorte

Yellow River near Bremen (a)

Singleton ditch near Hebron

West Creek near Schneider

05515400

05516000

05518500

05519500

05520000

Singleton ditch at Illinoi, IL

05521500

05523500

05524000

7.08
135
34.2
54.7

1970-86

1955-73

1949-51

1948-52,

1954-72

1945-77

79.6

83.7

44.8

1948-51

1948-52,

1953-82'

1948-52,

1953-82'

a Continued as a crest-stage and low-flow partial-record station through 1984

b Some quality of water data available.

c Records of daily discharges furnished by Northern Indiana Public Service Company.

d Continued as a stage only station through 1984 .

e Stage only station.

f High-water records only.

g Some record fragmentary.
h Some quality of water data available after station discontinued for stream-gaging records. 
The following stations were discontinued as surface-water-quality stations. Records of temperature, specific conductance, $\mathrm{pH}$, dissolved oxygen or sediment were collected and published for the record shown for each station. Discontinued short-term project stations have not been included. Information regarding these stations may be obtained from the District Office at the address given on the back side of the title page of this report.

Station name

Friday Branch tributary near S

Sugar Creek tributary near Deer Mill

Sugar Creek near Byron

Brouilletts Creek near Universal

Honey Creek near Riley

South Furk Smalls Creek at Bruceville (a)

White River near Noblesville

Jordan Creek near Jordan

Little Flat Creek near Otwell

White River at Hazleton (b)

$\begin{array}{lc}\text { Station } & \begin{array}{c}\text { Drainage } \\ \text { area } \\ \text { number }\end{array} \\ \left(\mathrm{mi}^{2}\right)\end{array}$

WABASH RIVER BASIN

03303276

03326000

03339855

03340000

03341420

310

$670^{.45}$

321

03341570

03342800

03348500

03359980

03376279

03374100
Type
of

Period

of

record

a Sume record fragmentary.

b Some quality of water data available after station discontinued for stream-gaging records.

1981

1952.7

1981

$1941-71$

1966-71

1981

$1972-75$

$1929-74$

1981

1981

1928-38 



\section{WATER RESOURCES DATA - INDIANA, 1991}

\section{INTRODUCTION}

The Water Resources Division of the U.S. Geological Survey, in cooperation with State and Federal agencies, obtains a large amount of data pertaining to the water resources of Indiana each water year. These data, accumulated during many water years, constitute a valuable data base for developing an improved understanding of the water resources of the State. To make these data readily available to interested parties outside the U.S. Geological Survey, the data are published annually in this report series entitled "Water Resources Data - Indiana."

Water-resources data for the 1991 water year for Indiana consist of records of discharge, stage, and water quality of streams, and water levels of lakes and ground-water wells. This volume contains records for water discharge at 183 gaging stations, stage at 7 gaging stations, stage and contents at 1 reservoir, water quality at 3 stream sites, sediment discharge at 1 gaging station, water levels at 80 lakes, and water levels at 95 observation wells. Locations of the streamflow and water-quality sites, and ground-water observation wells are shown on figures 4,5 , and 7 . The number of lakes by county having 1991 water-level records are shown on figure 6. A systematic collection of stages on selected lakes was begun in 1943 in cooperation with the State of Indiana, Department of Natural Resources. The data collected since the beginning of record have not been published previously in the annual water data reports for Indiana. They are available from the Indiana District Office. A selected amount of lake data was published in Water-Supply Paper 1363, "Hydrology of Indiana Lakes," by J. I. Perrey and D. M. Corbett (1956). Additional lake data were published in Open-File Report 88-331, "Annual maximum and minimum lake levels for Indiana, water years 1942-85," by Kathleen K. Fowler (1988). These data represent that part of the National Water Data System collected by the U.S. Geological Survey and cooperating State and Federal agencies in Indiana.

This series of annual reports for Indiana began with the 1961 water year with a report that contained only data relating to the quantities of surface water. For the 1964 water year, a similar report was introduced that contained only data relating to water quality. Beginning with the 1975 water year, the report format was changed to present, in one volume, data on quantity and quality of surface and ground water.

Prior to introduction of this series and for several water years concurrent with it, waterresources data for Indiana were published in U.S. Geological Survey Water-Supply Papers. Data on stream discharge and stage; and on lake or reservoir contents and stage, through September 1960, were published annually under the title "Surface-Water Supply of the United States." Stream discharge and stage data were published in four compilation reports (through the 1950, 1951-60, 1961-65, and 1966-70 water years). Data on water quality, temperature, and suspended sediment for the 1941 through 1970 water years were published annually under the title "Quality of Surface Waters of the United States," and water levels for the 1935 through 1974 water years were published under the 
title "Ground-Water Levels in the United States." The above mentioned Water-Supply Papers may be consulted in the libraries of the principal cities of the United States and may be purchased from U.S. Geological Survey, Books and Open-File Reports, Federal Center, Building 41, Box 25425, Denver, CO 80225 .

Publications similar to this report are published annually by the U.S. Geological Survey for all States. These official U.S. Geological Survey reports have an identification number consisting of the two-letter State abbreviation, the last two digits of the water year, and the volume number. For example, this volume is identified as "U.S. Geological Survey Water-Data Report IN-91-1." For archiving and general distribution, the reports for 1971-74 water years also are identified as water-data reports. These water-data reports are for sale in paper copy or in microfiche by the National Technical Information Service, U.S. Department of Commerce, Springfield, VA 22161. Beginning with the 1990 water year, all water-data reports will also be available on Compact Disc - Read Only Memory (CD-ROM). All data reports published for the current water year for the entire Nation, including Puerto Rico and the Trust Territories, will be reproduced on a single CD-ROM disc.

Every five years since 1950 the Geological Survey has compiled data on water use in the United States. During 1987, this effort was completed again for 1985 use in Indiana primarily through the auspices of the Water Management Branch, Division of Water, Indiana Department of Natural Resources. The Water Management Branch found that in 1985 more than 8 billion gallons per day were withdrawn from the surface- and ground-water resources of Indiana to meet the needs of its citizens. Approximately 92 percent of this withdrawal was from surface-water sources. The largest single source was Lake Michigan, which accounted for about 40 percent of the water withdrawn.

Additional information, including current prices, for ordering specific reports may be obtained from the District Chief at the address given on the back of the title page or by telephone (317) 290-3333. A limited number of CD-ROM discs will be available for sale by the Books and Open-File Reports SecAis , U.S. Geological Survey, Federal Center, Box 25425, Denver, Colorado 80225.

\section{COOPERATION}

The U.S. Geological Survey and agencies of the State of Indiana have had cooperative agreements for the systematic collection of streamflow records since 1930, for ground-water levels since 1940 , for lake stages since 1943, and for water-quality records since 1951. Organizations that supplied data are acknowledged in station manuscripts. Organizations that assisted in collecting data in this report through cooperative agreement with the U.S. Geological Survey are:

State of Indiana, Department of Natural Resources, Patrick R. Ralston, Director, through the Bureau of Water and Mineral Resources, Gary N. Doxtater, Deputy Director 
State of Indiana, Department of Environmental Management, Kathy Prosser, Commissioner, Corinne Wellish, Assistant Commissioner

State of Indiana, Department of Highways, John Dillion, Director

Assistance in the form of funds or services was given by the U.S. Army Corps of Engineers in collecting records for surface-water gaging stations published in this report.

The following organizations aided in collecting records: The cities of Carmel, Columbus, Elkhart, Fort Wayne, Indianapolis, and Syracuse; Hoosier Energy, Indianapolis Water Co.; Indianapolis Power and Light Co.; Public Service Company of Indiana; Container Corporation of America; Prudential Insurance Co.; Northern Indiana Public Service Co.; Sheller-Globe Corp.

\section{SUMMARY OF HYDROLOGIC CONDITIONS}

Precipitation patterns in Indiana differ seasonally and geographically. Although some precipitation falls each month, the greatest amounts usually fall during February, March, and April. Average annual amounts (fig. 1) range from about 34 inches in the northeastern part of the State to about 46 inches in the south-central part. Evapotranspiration consumption is relatively uniform and averages 26 inches per year (Clark, 1980).

Runoff generally follows the precipitation patterns. Average annual amounts (fig. 2) range from about 12 inches in northern and central parts of the State to about 18 inches in the extreme southern part.

Precipitation and runoff amounts in Indiana during the 1991 water year departed significantly from normal. Precipitation ranged from over 2 inches below normal in the southwestern part of the State to over 4 inches above normal in the northeastern part. Runoff ranged from almost 3 inches above normal to slightly greater than 15 inches above normal.

The effects of greater-than-normal precipitation on discharges are shown on figure 3, which compares 1991 water year monthly and annual means at the three Indiana index stations to monthly and annual medians for the period 1951-80. Monthly means were higher than monthly medians at all three index stations for 7 out of 12 months. The 1991 annual means at the three index stations were significantly greater than the medians, reflecting the generally wet year; the annual means ranged from 136 to 138 percent of their respective medians. 


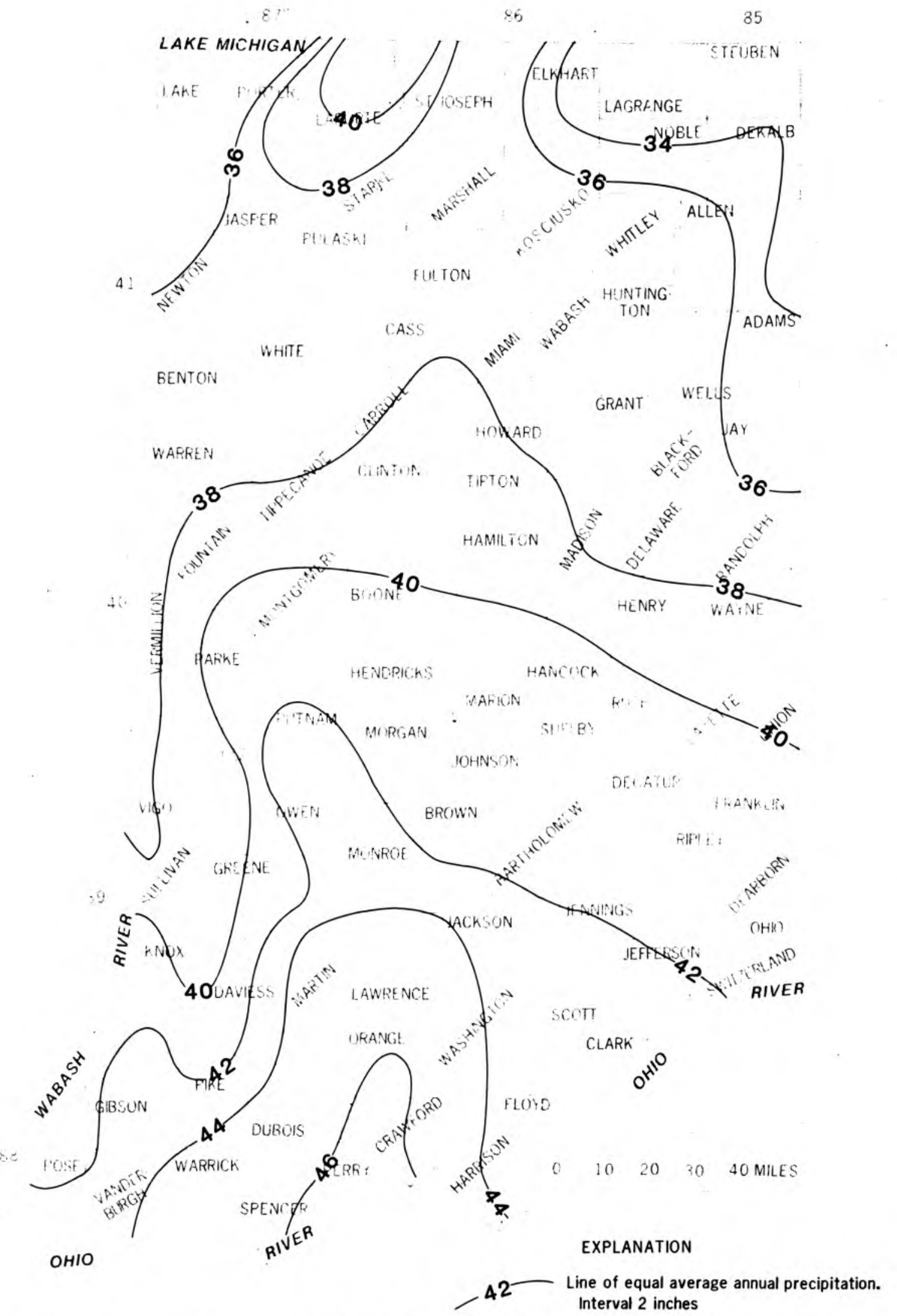

Figure 1.-- Average annual precipitation in Indiana, 1951-80.

(Data from National Oceanic and Atmospheric Administration, 1983.) 
$\therefore$ ४र सrots

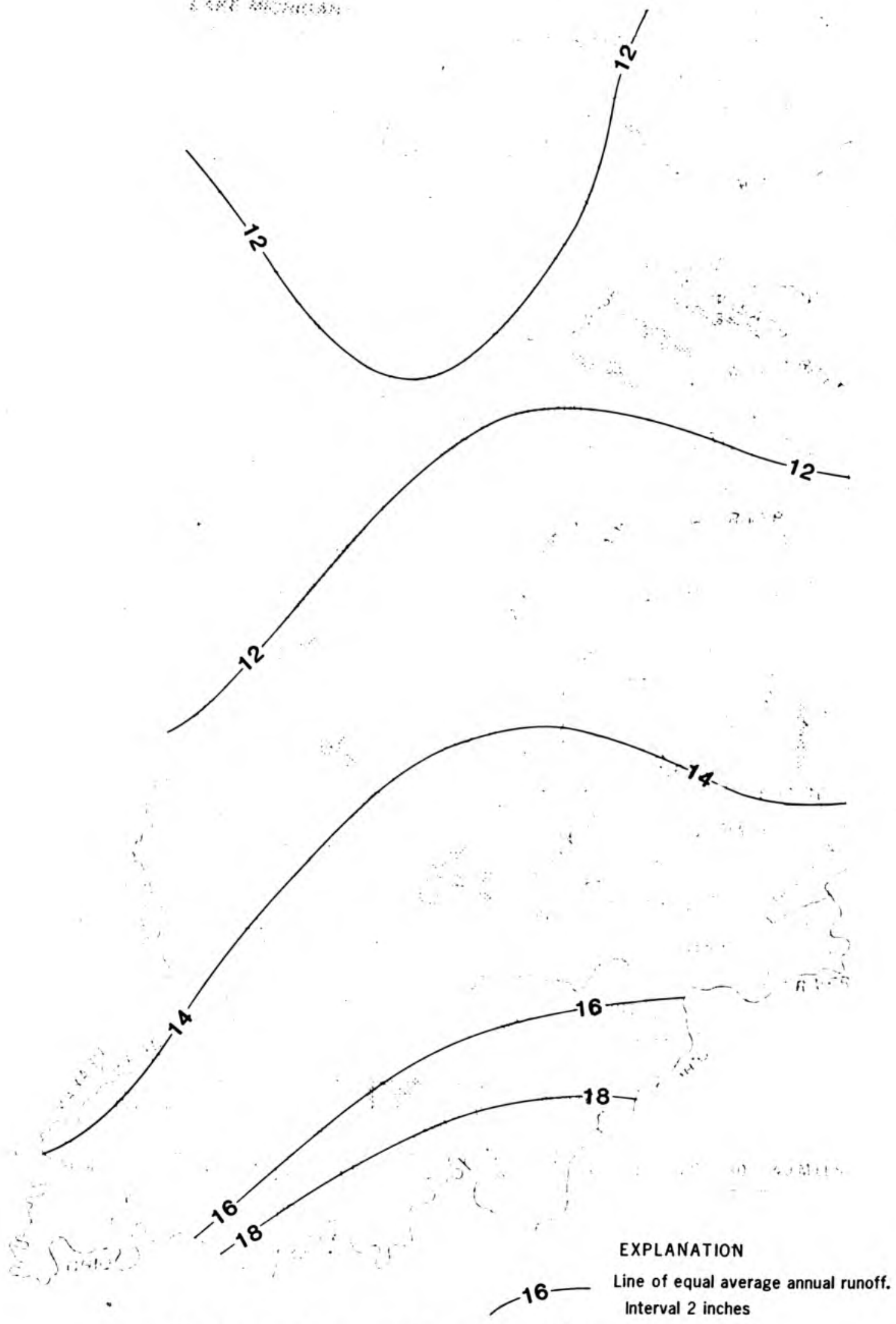

Figure 2.-- Average annual runoff in Indiana, 1951-80.

(Data from Gebert, Graczyk, and Krug, 1985) 

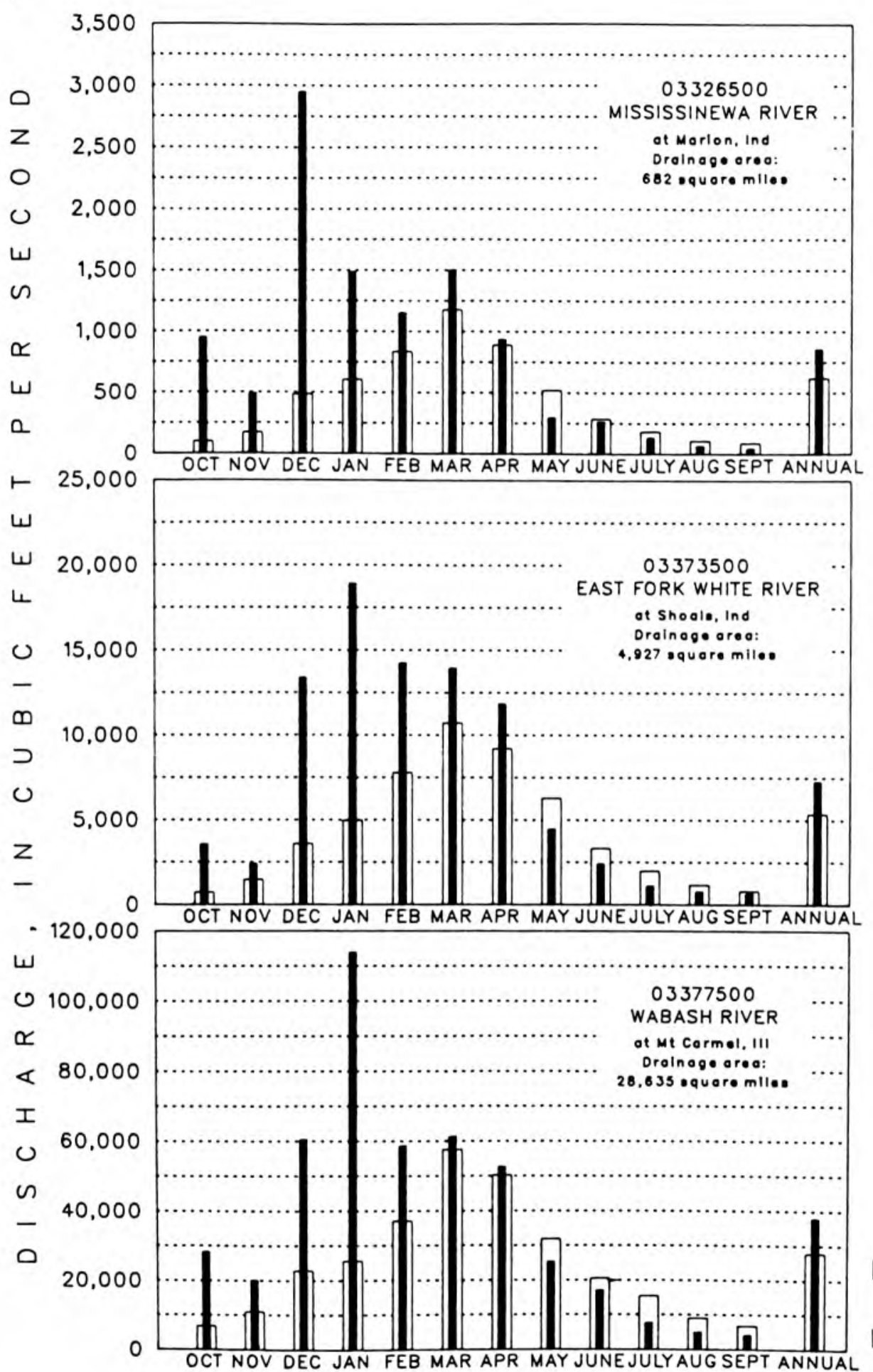

EXPLANATION

Means of monthly and yearly discharges,

1991 woter year

Medians of monthly and yearly mean discharges. 1951-80 woter years

Figure 3. -- Mean discharges ot Indiano index stations during 1991 water year and median discharges for period 1951-80. 
October 1990 precipitation amounts were all above normal, ranging from slightly less than 2 inches above normal in the east-central portion of Indiana to greater than 3 inches above normal in the west-central portion. Monthly mean discharges at the three index stations ranged from 408 to 950 percent of the monthly medians.

During November, precipitation ranged from slightly less than 1 inch below normal in the southeastern portion of the State to greater than 3 inches above normal in the northwestern portion. Monthly mean discharges at the three index stations ranged from 162 to 280 percent of the monthly medians.

December 1990 precipitation amounts were all above normal, ranging from more than 3 inches above normal in the northwestern part of the State to greater than 5 inches above normal in the eastcentral portion. Monthly mean discharges at the three index stations ranged from 263 to 605 percent of the monthly medians.

During January 1991, precipitation amounts were all below normal, ranging from slightly below normal in the southwestern part of the State to nearly 1 inch below normal in the central portion. Monthly mean discharges at the three index stations ranged from 243 to 442 percent of the monthly medians.

February precipitation ranged from greater than 1 inch below normal in the west-central portion of the State to less than 1 inch above normal in the southeastern portion. Monthly mean discharges at the three ndex stations ranged from 135 to 182 percent of the monthly medians.

During March, precipitation ranged from slightly below normal in the northeastern portion of the State to slightly greater than 2 inches above normal in the central portion. Monthly mean discharges at the three index stations ranged from 106 to 130 percent of the monthly medians.

April precipitation ranged from slightly more than 1 inch below normal in the south-central portion of the State to slightly less than 1 inch above normal in the northeastern portion. Monthly mean discharges at the three index stations ranged from 104 to 128 percent of the monthly medians.

During May, precipitation ranged from slightly less than 2 inches below normal in the southwestern portion of the Sate to slightly less than 3 inches above normal in the northeastern portion. Monthly mean discharges at the three index stations ranged from 57 to 79 percent of the monthly medians.

June precipitation amounts were all below normal, ranging from more than 2 inches below normal in the southeastern and northeastern portions of the State to greater than 3 inches below normal in the west-central portion. Monthly mean discharges at the three index stations ranged from 72 to 95 percent of the monthly medians. 
During July, precipitation amounts were all below normal, ranging from slightly greater than 1 inch in the east-central portion of the State to nearly 3 inches below normal in the northwestern portion. Monthly mean discharges at the three index stations ranged from 49 to 74 percent of the monthly medians.

August precipitation ranged from greater than 1 inch below normal in the southwestern portion of the State to slightly less than 2 inches above normal in the southeastern portion. Monthly mean discharges at the three index stations ranged from 53 to 64 percent of the monthly medians.

During September, precipitation amounts were all below normal, ranging from slightly below normal in the south-central portion of the State to greater than 1 inch below normal in the west-central portion. Monthly mean discharges at the three index stations ranged from 48 to 83 percent of the monthly medians.

\section{SPECIAL NETWORKS AND PROGRAMS}

Hydrologic Bench-Mark Network is a nationwide network of 57 sites in small drainage basins around the country whose purposes are to provide consistent data on the hydrology, water quality, and related factors in undeveloped watersheds, and to provide analyses on a continuing basis to compare and contrast conditions observed in basins more obviously affected by the activities of man.

National Stream Quality Accounting Network (NASQAN) is a nationwide data-collection network of approximately 500 sites designed by the U.S. Geological Survey to meet many of the information needs of government agencies and other groups involved in natural or regional water-quality planning and management. NASQAN sites generally are located at the downstream ends of hydrologic accounting units designated by the U.S. Geological Survey Office of Water Data Coordination in consultation with the Water Resources Council. The objectives of NASQAN are to: (1) Obtain information on the quality and quantity of water moving within and from the United States through a systematic and uniform process of data collection, summarization, analysis, and reporting; (2) describe the areal variability of water quality in the Nation's rivers through analysis of data from this and other programs; (3) detect changes or trends with time in the pattern of occurrence of water-quality characteristics; and (4) provide a nationally consistent data base useful for water-quality assessment and hydrologic research. 


\section{EXPLANATION OF THE RECORDS}

The surface-water and ground-water records published in this report are for the 1991 water year that began October 1, 1990, and ended September 30,1991. A calendar of the water year is provided on the inside of the front cover. The records contain streamflow and stage data, stage and content data for a reservoir, water-quality data for surface water, and ground-water, lake-level data, peak-flow data, and ground-water-level data. The following sections of the introductory text are presented to provide users with a more detailed explanation of how the hydrologic data published in this report were collected, analyzed, computed, and arranged for presentation.

\section{$\underline{\text { Station Identification Numbers }}$}

Each data station, whether streamsite or well, in this report is assigned a unique identification number. This number is unique in that it applies specifically to a given station and to no other. The number usually is assigned when a station is first established and is retained for that station indefinitely. The systems used by the U.S. Geological Survey to assign identification numbers for surfacewater stations and for ground-water well sites differ, but both are based on geographic location. The "downstream order" system is used for regular surface-water stations and for surface-water stations where only miscellaneous measurements are made; the "latitude-longitude" system is used for wells.

\section{Downstream Order System}

Since October 1, 1950, the order of listing hydrologic-station records in U.S. Geological Survey reports is in a downstream direction along the main stream. All stations on a tributary entering upstream from a mainstream station are listed before that station. A station on a tributary that enters between two mainstream stations is listed between them. A similar order is followed in listing stations on first rank, second rank, and other ranks of tributaries. The rank of any tributary with respect to the stream to which it is immediately tributary is indicated by an indention in the "List of Stations" in the front of this report. Each indention represents one rank. This downstream order and system of indention show which stations are on tributaries between any two stations and the rank of the tributary on which each station is situated. 
The station-identification number is assigned according to downstream order. In assigning station numbers, no distinction is made between partial-record stations and other stations; therefore, the station number for a partial-record station indicates downstream-order position in a list made up of both types of stations. Gaps are left in the series of numbers to allow for new stations that may be established; hence, the numbers are not consecutive. The complete 8-digit number for each station, such as 03335500 , which appears just to the left of the station name, includes the 2-digit Part number "03" plus the 6-digit downstream-order number "335500." The Part number designates the major river basin; for example, Part "03" is the Ohio River basin.

Records in this report are in Part 03 (Ohio River basin), Part 04 (St. Lawrence River basin), and Part 05 (Upper Mississippi River basin). All records for a drainage basin encompassing more than one State can be arranged in downstream order by assembling pages from the various State reports by station number to include all records in the basin.

\section{Latitude-Longitude System}

The identification numbers for wells are assigned according to the grid system of latitude and longitude. The number consists of 15 digits. The first six digits denote the degrees, minutes, and seconds of latitude, the next seven digits denote degrees, minutes, and seconds of longitude, and the last two digits (assigned sequentially) identify the wells or other sites within a 1-second grid. This siteidentification number, once assigned, is a pure number and has no locational significance. In the rare instance where the initial determination of latitude and longitude are found to be in error, the station will retain its initial identification number; however, its true latitude and longitude will be listed in the LOCATION paragraph of the station description.

In addition, each well in Indiana carries dual-identification numbers. The second system is by county name with a sequential number of the well; that is, number one is the first well in that county for which records were obtained. 


\author{
Data Collection and Computation
}

The data obtained at a complete-record gaging station on a stream or canal consist of a continuous record of stage, individual measurements of discharge throughout a range of stages, and notations regarding factors that may affect the relations between stage and discharge. These data, together with supplemental information, such as weather records, are used to compute daily discharges.

Continuous records of stage are obtained with analog recorders that trace continuous graphs of stage, with digital recorders that punch stage values on paper tapes at selected time intervals, or with data collection platforms that store stage data electronically. Measurements of discharge are made with current meters using methods adopted by the U.S. Geological Survey as a result of experience accumulated since 1880. These methods are described in standard textbooks, in Water-Supply Paper 2175, and in U.S. Geological Survey Techniques of Water-Resources Investigations (TWRI), Book 3, Chap. A6.

In computing discharge records, results of individual measurements are plotted against the corresponding stages, and stage-discharge relation curves are then constructed. From these curves, rating tables indicating the approximate discharge for any stage within the range of the measurements are prepared. If it is necessary to define extremes of discharge outside the range of the current-meter measurements, the curves are extended using: (1) Logarithmic plotting; (2) velocity-area studies; (3) results of indirect measurments of peak discharge, such as slope-area or contracted-opening measurements, and computations of flow over dams or weirs; or (4) step-backwater techniques.

Daily mean discharges are computed by applying the instantaneous stages (gage heights) to the stage-discharge curves or tables and then assigning the arithmetic mean. If the stage-discharge relation is subject to change because of frequent or continual change in the physical features that form the control, the daily mean discharge is determined by the shifting-control method, in which correction factors based on the individual discharge measurements and notes of the personnel making the measurements are applied to the gage heights before the discharges are determined from the curves or tables. This shifting-control method also is used if the stage-discharge relation is changed temporarily because of aquatic growth or debris on the control. For some stations, formation of ice in the winter may so obscure the stage-discharge relations that daily mean discharges must be estimated from other information such as temperature and precipitation records, notes of observations, and records for other stations in the same or nearby basins for comparable periods.

At some stream-gaging stations, the stage-discharge relation is affected by the backwater from reservoirs, tributary streams, or other sources. This necessitates the use of the slope method in which the slope or fall in a reach of the stream is a actor in computing discharge. The slope or fall is 
obtained by means of an auxiliary gage set at some distance from the base gage. At some stations, the stage-discharge relation is affected by changing stage; at these stations the rate of change in stage is used as a factor in computing discharge.

For some gaging stations, there are periods when no gage-height record is obtained, or the recorded gage height is so faulty that it cannot be used to compute daily discharge or contents. This happens when the recorder stops or otherwise fails to operate properly, intakes are plugged, the float is frozen in the well, or for various other reasons. For such periods, the daily discharges are estimated from the recorded range in stage, previous or following record, discharge measurements, weather records, and comparison with other station records from the same or nearby basins. Information explaining how estimated daily-discharge values are identified in station records is included in the next two sections, "Data Presentation" (REMARKS paragraph) and "Identifying Estimated Daily Discharge."

\section{Data Presentation}

Streamflow data in this report are presented in a new format that is considerably different from the format in data reports prior to the 1991 water year. The major changes are that statistical characteristics of discharge now appear in tabular summaries following the water-year data table and less information is provided in the text or station manuscript above the table. These changes represent the results of a pilot program to reformat the annual water-data report to meet current user needs and data preferences.

The records published for each continuous-record surface-water discharge station (gaging station) now consist of four parts: the manuscript or station description; the data table of daily mean values of discharge for the current water year with summary data; a tabular statistical summary of monthly mean flow data for a designated period, by water year; and a summary statistics table that includes statistical data of annual, daily, and instantaneous flows as well as data pertaining to annual runoff, 7-day low-flow minimums, and flow duration.

\section{Station manuscript}

The manuscript provides, under various headings, descriptive information, such as station location; period of record; historical extremes outside the period of record; record accuracy; and other remarks pertinent to station operation and regulation. The following information, as appropriate, is provided with each continuous record of discharge or lake content. Comments to follow clarify information presented under the various headings of the station description. 
LOCATION.--Information on locations is obtained from the most accurate maps available. The location of the gage with respect to the cultural and physical features in the vicinity and with respect to the reference place mentioned in the station name is given. River mileages were determined by methods given in "River Mileage Measurement," Bulletin 14, revision of October 1968, prepared by the Water Resources Council or were provided by the U.S. Army Corps of Engineers.

DRAINAGE AREA.--Drainage areas are measured using the most accurate maps available.

PERIOD OF RECORD.--This indicates the period for which there are published records for the station or for an equivalent station. An equivalent station is one that was in operation at a time that the present station was not, and whose location was such that records from it can reasonably be considered equivalent with records from the present station.

REVISED RECORDS.--Because of new information, published records, occasionally are found to be incorrect, and revisions are printed in later reports. Listed under this heading are all the reports in which revisions have been published for the station and the water years to which the revisions apply. If a revision did not include daily, monthly, or annual figures of discharge, that fact is noted after the year dates as follows: "(M)" means that only the instantaneous maximum discharge was revised; "(m)" that only the instantaneous minimum was revised; and " $(\mathrm{P})$ " that only peak discharges were revised. If the drainage area has been revised, the report in which the most recently revised figure was first published is given.

GAGE.--The type of gage in current use, the datum of the current gage referred to National Geodetic Vertical Datum of 1929 (see glossary), and a condensed history of the types, locations, and datums of previous gages are given under this heading.

REMARKS.--All periods of estimated daily-discharge record will either be identified by date in this paragraph of the station description for water-discharge stations or flagged in the daily-discharge table. (See next section, "Identifying Estimated Daily Discharge.") If a remarks statement is used to identify estimated record, the paragraph will begin with this information presented as the first entry. The paragraph is also used to present information relative to the accuracy of the records, to special methods of computation, to conditions that affect natural flow at the station and, possibly, to other pertinent items. For reservoir stations, information is given on the dam forming the reservoir, the capacity, outlet works and spillway, and purpose and use of the reservoir.

COOPERATION.--Records provided by a cooperating organization or obtained for the U.S. Geological Survey by a cooperating organization are identified here.

EXTREMES OUTSIDE PERIOD OF RECORD.--Included here is information concerning major floods or unusually low flows that occurred outside the stated period of record. The information may or may not have been obtained by the U.S. Geological Survey. 
REVISIONS.--If a critical error in published records is discovered, a revision is included in the first report published following discovery of the error.

Although rare, occasionally the records of a discontinued gaging station may need revision. Because for these stations there would be no current or, possibly, future station manuscript published to document the revision in a "Revised Records" entry, users of data for these stations who obtained the record from previously published data reports may wish to contact the offices whose addresses are given on the back of the title page of this report to determine if the published records were ever revised after the station was discontinued. Of course, if the data were obtained by computer retrieval, the data would be current and there would be no need to check because any published revision of data is always accompanied by revision of the corresponding data in computer storage.

Manuscript information for lake or reservoir stations differs from that for stream stations in the nature of the "Remarks" and in the inclusion of a skeleton stage-capacity table when daily contents are given.

Headings for AVERAGE DISCHARGE, EXTREMES FOR PERIOD OF RECORD, AND EXTREMES FOR CURRENT YEAR have been deleted and the information contained in these paragraphs, except for the listing of secondary instantaneous peak discharges in the EXTREMES FOR CURRENT YEAR paragraph, is now presented in the tabular summaries following the discharge table or in the REMARKS paragraph, as appropriate. No changes have been made to the data presentations of lake contents.

\section{Data table of daily mean values}

The daily table for stream-gaging stations gives mean discharge for each day of the water year. In the monthly summary for the table, the line headed "TOTAL" gives the sum of the daily figures for each month. the line headed "MEAN" gives the average flow in cubic feet per second for the month; and the lines headed "MAX" and "MIN" give the maximum and minimum daily discharges, respectively, for each month. Discharge for the month also is usually expressed in cubic feet per second per square mile (line headed "CFSM"); or in inches (line headed "IN."); or in acre-feet (line headed "ACFT"). Figures for cubic feet per second per square mile and runoff in inches or in acre-feet may be omitted if there is extensive regulation or diversion or if the drainage area includes large noncontributing areas. At some stations monthly and (or) yearly observed discharges are adjusted for reservoir storage or diversion, or diversion data or reservoir contents are gives. These figures are identified by a symbol and corresponding footnote.

\section{Statistics of monthly mean data}

A tabular summary of the mean (line headed "MEAN"), maximum (line headed "MAX"), and minimum (line headed "MIN") of monthly mean flows for each month for a designated period is provided below the mean values table. The water years of the first occurrence of the maximum and minium 
monthly flows are provided immediately below those figures. The designated period of will be expressed as "FOR WATER YEARS BY WATER YEAR (WY)," and will list the first and last water years of the range of years selected from the PERIOD OF RECORD paragraph in the station manuscript. It will consist of all of the station record within the specified water years, inclusive, including complete months of record for partial water years, if any, and may coincide with the period of record for the station. The water years for which the statistics are computed will be consecutive, unless a break in the station record is indicated in the manuscript.

\section{Summary statistics}

A table titled "SUMMARY STATISTICS" follows the statistics of monthly mean data tabulation. This table consists of four columns, with the first column containing the line headings of the statistics being reported. The table provides a statistical summary of yearly, daily, and instantaneous flows, not only for the current water year but also for the previous calendar year and for a designated period, as appropriate. The designated period selected, "WATER YEARS " will consist of all of the station record within the specified water years, inclusive, including complete months of record for partial water years, if any, and may coincide with the period of record for the station. The water year for which the statistics are computed will be consecutive, unless a break in the station record is indicated in the manuscript. All of the calculations for the statistical characteristics designated ANNUAL (See line headings below.), except for the "ANNUAL" 7-DAY MINIMUM" statistic, are calculated for the designated period using complete water years. The other statistical characteristics may be calculated using partial water years.

The date or water year, as appropriate, of the first occurrence of each statistic reporting extreme values of discharge is provided adjacent to the statistic. Repeated occurrences may be noted in the REMARKS paragraph of the manuscript or in footnotes. Because the designated period may not be the same as the station period of record published in the manuscript, occasionally the dates of occurrence listed for the daily and instantaneous extremes in the designated-period column may not be within the selected water years listed in the handing. When this occurs, it will be noted in the REMARKS paragraph or in footnotes. Selected streamflow duration curve statistics and runoff data are also given. Runoff data may be omitted if there is extensive regulation or diversion of flow in the drainage basin.

The following summary statistics data, as appropriate, are provided with each continuous record of discharge. Comments to follow clarify information presented under the various line headings of the summary statistics table. ANNUAL TOTAL.--The sum of the daily mean values of discharge for the year. At some stations the annual total discharge is adjusted for reservoir storage or diversion. The adjusted figures are identified by a symbol and corresponding footnotes.

ANNUAL TOTAL.--The sum of the daily mean values of discharge for the year. At some stations the annual total discharge is adjusted for reservoir storage or diversion. The adjusted figures are identified by a symbol and corresponding footnotes. 
ANNUAL MEAN.--The arithmetic mean of the individual daily mean discharges for the year noted or for the designated period. At some stations the yearly mean discharge is adjusted for reservoir storage or diversion. The adjusted figures are identified by a symbol and corresponding footnotes. At least five complete years of record must be available before this statistic is published for the designated period.

HIGHEST ANNUAL MEAN.--The maximum annual mean discharge occurring for the designated period.

LOWEST ANNUAL MEAN.--The minimum annual mean discharge occurring for the designated period.

HIGHEST DAILY MEAN.--The maximum daily mean discharge for the year or for the designated period.

LOWEST DAILY MEAN.--The minimum daily mean discharge for the year or for the designated period.

ANNUAL 7-DAY MINIMUM.--The lowest mean discharge for seven consecutive days for a calendar year or a water year. Note that most low-flow frequency analyses of annual 7-day minimum flows use a climatic year (April 1-March 31). The date shown in the summary statistics table is the initial date of the 7-day period. (This value should not be confused with the 7day 10-year low-flow statistic.)

INSTANTANEOUS PEAK FLOW.--The maximum instantaneous discharge occurring for the water year or for the designated period. Note that secondary instantaneous peak discharges above a selected base discharge are stored in District computer files for stations meeting certain criteria. Those discharge values may be obtained by writing to the District Office. (See address on back of title page of this report.)

INSTANTANEOUS PEAK STAGE.--The maximum instantaneous stage occurring for the water year or for the designated period. If the dates of occurrence for the instantaneous peak flow and instantaneous peak stage differ, the REMARKS paragraph in the manuscript or a footnote may be used to provide further information.

INSTANTANEOUS LOW FLOW.--The minimum instantaneous discharge occurring for the water year or for the designated period.

ANNUAL RUNOFF (AC-FT).--Indicates the depth, in acre-feet, to which the drainage area would be covered if all the runoff for the year were uniformly distributed on it. 
ANNUAL RUNOFF (CFSM).--Indicates the average number or cubic feet of water flowing per second from each square mile of area drained, assuming that the runoff is distributed uniformly in time and area for the year.

ANNUAL RUNOFF (INCHES).--Indicates the depth to which the drainage area would be covered if all the runoff for the year were uniformly distributed on it.

10 PERCENT EXCEEDS.--The discharge that is exceeded by 10 percent of the flow for the designated period.

50 PERCENT EXCEEDS.--The discharge that is exceeded by 50 percent of the flow for the designated period.

90 PERCENT EXCEEDS.--The discharge that is exceeded by 90 percent of the flow for the designated period.

Identifying Estimated Daily Discharge

Estimated daily-discharge values published in the water-discharge tables of annual State data reports are identified either by flagging individual daily values with the letter symbol " $\mathrm{e}$ " and printing a table footnote, "Estimated," or by listing the dates of the estimated record in the "REMARKS" paragraph of the station description.

Accuracy of the Records

The accuracy of streamflow records depends primarily on: (1) The stability of the stage-discharge relation or, if the control is unstable, the frequency of discharge measurements; and (2) the accuracy of measurements of stage, measurements of discharge, and interpretation of records.

The accuracy attributed to the records is indicated under "REMARKS." "Excellent" means that about 95 percent of the daily discharges are within 5 percent of their true values; "good," within 10 percent; and "fair," within 15 percent. Records that do not meet the criteria mentioned are rated "poor." Different accuracies may be attributed to different parts of a given record. 
Daily mean discharges in this report are given to the nearest hundredth of a cubic foot per second for values less than $1 \mathrm{ft}^{3} / \mathrm{s}$; to the nearest tenth between 1.0 and $10 \mathrm{ft}^{3} / \mathrm{s}$; to whole numbers between 10 and $1,000 \mathrm{ft}^{3} / \mathrm{s}$; and to 3 significant figures for more than $1,000 \mathrm{ft}^{3} / \mathrm{s}$. The number of significant figures used is based solely on the magnitude of the discharge value. The same rounding rules apply to discharges listed for partial-record stations and miscellaneous sites.

Discharge at many stations, as indicated by the monthly mean, may not reflect natural runoff due to the effects of diversion, consumption, regulation by storage, increase or decrease in evaporation due to artificial causes, or to other factors. For such stations, figures of cubic feet per second per square mile and of runoff, in inches, are not published unless satisfactory adjustments can be made for diversions, for changes in contents of reservoirs, or for other changes incident to use and control. Evaporation from a reservoir is not included in the adjustments for changes in reservoir contents, unless it is so stated. Even at those stations where adjustments are made, large errors in computed runoff may occur if adjustments or losses are large in comparison with the observed discharge.

Other Records Available

Information used in the preparation of the records in this publication, such as discharge-measurement notes gage-height records, temperature measurements, and rating tables is on file in the Indiana District Office. Also, most of the daily mean discharges are in computer-readable form and have been analyzed statistically. Information on the availability of the unpublished information or on the results of statistical analyses of the published records may be obtained from the Indiana District Office.

\section{Records of Surface-Water Quality}

Records of surface-water quality ordinarily are obtained at or near stream-gaging stations because interpretation of records of surface-water quality nearly always requires corresponding discharge data. 


\section{Classification of Records}

Water-quality data for surface-water sites are grouped into one of three classifications. A continuing-record station is a site where data are collected on a regularly scheduled basis. Frequency may be one or more times daily, weekly, monthly, or quarterly. A partial-record station is a site where limited water-quality data are collected systematically over a period of years. Frequency of sampling usually is less than quarterly. A miscellaneous sampling site is a location other than a continuing or partial-record station where random samples are collected to give better areal coverage to define waterquality conditions in the river basin.

A careful distinction needs to be made between "continuing records," as used in this report, and "continuous recordings," which refers to a continuous graph or a series of discrete values punched at short intervals on a paper tape. Some records of water quality, such as temperature and specific conductance, may be obtained through continuous recordings; however, because of cost, most data are obtained monthly or less frequently.

Records of surface-water quality in this report are for continuing-record stations only. These stations are part of the Hydrologic Bench-Mark Network or the National Stream Quality Accounting Network (NASQAN). Locations of stations for which records on the quality of surface water appear in this report are shown on figures 4 and 5.

Arrangement of Records

Water-quality records collected at a surface-water daily record station are published immediately following that record, regardless of the frequency of sample collection. Station number and name are the same for both records.

On-site Measurements and Sample Collection

The major concern in obtaining water-quality data is assuring that the data represent the in situ quality of the water. To assure this, certain measurements, such as water temperature, $\mathrm{pH}$, specific conductance, alkalinity, and dissolved oxygen, are made on-site when the samples are taken. To assure 
that measurements made in the laboratory also represent the in situ water, carefully prescribed procedures need to be followed in collecting the samples, in treating the samples to prevent changes in quality pending analysis, and in shipping the samples to the laboratory. Procedures for on-site measurements and for collecting, treating, and shipping samples are given in publications on "Techniques of Water-Resources Investigations," Book 1, Chap. D2; Book 3, Chap. C2; Book 5, Chap. A1, A3, and A4. All of these references are listed under "PUBLICATIONS ON TECHNIQUES OF WATERRESOURCES INVESTIGATIONS" which appears at the end of the introductory text. Detailed information on collecting, treating, and shipping samples also may be obtained from the U.S. Geological Survey, Indiana District Office.

One sample can define adequately the water quality at a given time only if the mixture of solutes and sediment throughout the stream cross section is homogeneous. However, the concentration of solutes and sediment at different locations in the cross section can vary widely with different rates of water discharge, depending on the sources of the solutes and sediment, the turbulence and mixing of the stream, and other factors. Most streams must be sampled through several vertical sections using a depth-integrating sampler to obtain a representative sample. All samples obtained for the National Stream Quality Accounting Network and the Hydrologic Bench-Mark Network are obtained from at least several verticals.

NOTE: Traditionally, dissolved trace-element concentrations have been reported at the microgram per liter $(\mu \mathrm{g} / \mathrm{L})$ level. Recent evidence, mostly from large rivers, indicates that actual dissolvedphase concentrations for a number of trace elements are with the range of 10's to 100's of nanograms per liter (ng/L). Present data above the $\mu \mathrm{g} / \mathrm{L}$ level should be viewed with caution. Such data may actually represent elevated environmental concentrations from natural or human causes; however, these data could reflect contamination introduced during sampling, processing, or analysis. To confidently produce dissolved trace-element data with insignificant contamination, the U.S. Geological Survey will begin using new trace-element protocols in the near future.

\section{Laboratory Measurements}

Specific conductance, $\mathrm{pH}$, air and water temperatures, dissolved oxygen, barometric pressure, and alkalinity are measured on-site. Fecal coliform and fecal streptococci bacteria are analyzed in the Indiana District laboratory. Suspended sediment and particle-size distribution are analyzed in the U.S. Geological Survey laboratory in Louisville, Kentucky. All other samples are analyzed in the U.S. Geological Survey National Water-Quality Laboratory in Arvada, Colorado. Methods used in analyzing sediment samples are given in TWRI, Book 5, Chap. C1. Methods used by the National WaterQuality Laboratory are given in TWRI, Book 5, Chap. A1, A4, and A5. 


\author{
Data Presentation
}

For continuing-record stations, information pertinent to the history of station operation is provided in descriptive headings preceding the tabular data. These descriptive headings give details regarding location, drainage area, period of record, and type of data available.

In the descriptive headings, if the location is identical to that of the discharge gaging station, neither the LOCATION nor the DRAINAGE AREA statements are repeated. The following information, as appropriate, is provided with each continuous-record station. Comments that follow clarify information presented under the various headings of the station description.

LOCATION.--See "Data Presentation" under "Records of Stage and Water Discharge."

DRAINAGE AREA.--See "Data Presentation" under "Records of Stage and Water Discharge."

PERIOD OF RECORD.--This indicates the periods for which there are published water-quality records for the station

REMARKS.--Remarks provide added information pertinent to the collection, analysis, or computation of the records.

REVISIONS.--If errors in published water-quality records are discovered after publication, appropriate updates are made to the Water-Quality File in the U.S. Geological Survey's computerized data system, WATSTORE, and subsequently by monthly transfer of update transactions to the U.S. Environmental Protection Agency's STORET system. Because the usual volume of updates makes it impractical to document individual changes in the State data-report series or elsewhere, potential users of U.S. Geological Survey water-quality data are encouraged to obtain all required data from the appropriate computer file to ensure the most recent updates. 


\author{
Remark Codes
}

The following remark codes may appear with the water-quality data in this report:

PRINTED OUTPUT

E

$>$

$<$

K

L

D

$\&$

\section{REMARK}

Estimated value

Actual value is known to be greater than the value shown

Actual value is known to be less than the value shown

Results based on colony count outside the acceptance range (nonideal colony count)

Biological organism count less than 0.5 percent (organism may be observed rather than counted.)

Biological organism count equal to or greater than 15 percent (dominant).

Biological organism estimated as dominant.

NOTE: In March 1989 the National Water-Quality Laboratory discovered a bias in the turbidimetric method for sulfate analysis, indicating that values below $75 \mathrm{mg} / \mathrm{L}$ have a median positive bias of $2 \mathrm{mg} / \mathrm{L}$ above the true value for the period between 1982 and 1989. Correct sulfate values have been made by the laboratory and published in this report since April 17, 1989.

\title{
Records of Lake Levels
}

Water-level data from a network of lake gaging stations are given in this report. These data are intended to provide a historical record of water-level changes in lakes where established average legal levels have been designated by the State. Numbers of lakes by county having current water-level records are shown on figure 6. 


\section{Data Collection and Computation}

Measurements of water levels are made under varying conditions, but the methods are standardized to the extent possible. The equipment and measuring techniques used at each lake gage will ensure that the measurements are of consistent accuracy and reliability.

Tables of water-level data are presented by lake names arranged in alphabetical order. The prime identification number for a given lake is the "downstream-order" number previously discussed in this report and appears to the left of the lake name.

Lake-level records are obtained from direct measurement with a steel tape, from observation of steel staff gages, or from punched tape in a water-stage recorder. The water-level measurements in this report are given in feet above gage datum. Gage datum is a datum plane above the National Geodetic Vertical Datum of 1929 . Water levels are reported to one-hundredth of a foot.

\section{Data Presentation}

Each lake record consists of two parts, the station description, and the data table of water levels observed during the year. The description of the lake gage is presented first through use of descriptive headings preceding the tabular data. Comments that follow clarify information presented under the various headings.

LOCATION.--See "Data Presentation" under "Records of Stage and Water Discharge."

SURFACE AREA.--This entry specifies the surface area of the lake at it's established legal level.

DRAINAGE AREA.--See "Data Presentation" under "Records of Stage and Water Discharge."

PERIOD OF RECORD.--This entry indicates the periods for which lake-level records at the site have been collected.

DATUM OF GAGE.--This entry indicates the datum of the current gage referred to the National Geodetic Vertical Datum of 1929 (see glossary).

GAGE.--The type of gage in current use and a condensed history of the types, locations, and datums of previous gages are given under this heading. 
ESTABLISHED LEGAL LEVEL.--This entry indicates the average level in feet above gage datum and National Geodetic Vertical Datum of 1929 at which the lake is to be maintained, the data of decree, and court specifying the decreed level.

LAKE-LEVEL CONTROL.--This entry indicates the type of structure used to maintain the lake level.

INLET AND OUTLET.--This entry, if appropriate, describes where surface inflow comes into the lake and where outflow departs. Some lakes may have neither inlets, outlets, nor both; in such cases parts or all of this heading may not appear.

EXTREMES FOR PERIOD OF RECORD.--Extremes include maximum and minimum levels and the dates of occurrence.

REVISIONS.--If a critical error in published records is discovered, a revision is included in the first report published following discovery of the error.

A table of water levels follows the station description for each lake gage. Water levels are reported in feet above gage datum. Only abbreviated tables are published; water-levels at midnight (2400) are listed for every fifth day and at the end of the month (EOM). The highest and lowest 2400 levels with dates of occurrence and mean of the water year are shown on a line below the abbreviated table. Because all values are not published, the extremes may be values not listed in the table. Missing records are indicated by dashes in place of the water level.

\section{Records of Ground-Water Levels}

Only water-level data from a representative network of observation wells are given in this report. These data are intended to provide a sampling and historical record of water-level changes in the State's most important aquifers. Locations of the observation wells in this network in Indiana are shown on figure 7 . 
Data Collection and Computation

Measurements of water levels are made in many types of wells under varying conditions, but the methods of measurement are standardized to the extent possible. The equipment and measuring techniques used at each observation well ensure that measurements at each well are of consistent accuracy and reliability.

Tables of water-level data are presented by counties arranged in alphabetical order. The prime identification number for a given well is the 15-digit number that appears in the upper left corner of the table. The secondary identification number is the local well number.

Water-level records are obtained from direct measurements with a steel tape or punched tape of a water-stage recorder. The water-level measurements in this report are given in feet with reference to land-surface datum (lsd). Land-surface datum is a datum plane that is approximately at land surface at each well. If known, the elevation of the land-surface datum is given in the well description. The height of the measuring point (MP) above or below land-surface datum is given in each well descrition.

Water levels are reported to as many significant figures as can be justified by the local conditions. For example, in a measurement of a depth to water of several hundred feet, the error of determining the absolute value of the total depth to water may be a few tenths of a foot, whereas the error in determining the net change of water level between successive measurements may be only one-hundredth or a few hundredths of a foot. For lesser depths to water, the accuracy is greater. Accordingly, most measurements are reported to one-hundredth of a foot, but some are given to one-tenth of a foot or a larger unit.

\section{Data Presentation}

Each well record consists of two parts, the station description and the data table of water levels observed during the water year. The description of the well is presented first through use of descriptive headings preceding the tabular data. The comments that follow clarify information presented under the various headings.

LOCATION.--This paragraph follows the well-identification number and reports the latitude and longitude (given in degrees, minutes, and seconds), a landline location designation, the hydrologicunit number, the distance and direction from a geographic point of reference, and the owner's name. 
AQUIFER.--This entry designates by name (if a name exists) and geologic age the aquifer(s) open to the well.

WELL CHARACTERISTICS.--This entry describes the well in terms of depth, diameter, casing depth and/or screened interval, method of construction, use, and additional information such as casing breaks, collapsed screen, and other changes since construction.

INSTRUMENTATION.--This paragraph provides information on both the frequency of measurement and the collection method used, allowing the user to better evaluate the reported water-level extremes by knowing whether they are based on weekly, monthly, or some other frequency of measurement.

DATUM.--This entry describes both the measuring point and the land-surface elevation at the well. The measuring point is described physically (such as top of collar, notch in top of casing, plug in pump base and so forth), and in relation to land surface (such as $1.3 \mathrm{ft}$ above land-surface datum). The elevation of the land-surface datum is described in feet above (or below) National Geodetic Vertical Datum of 1929 (NGVD of 1929); it is reported with a precision depending on the method of determination.

REMARKS.--This entry describes factors that may influence the water level in a well or the measurement of the water level. It should identify wells that also are water-quality observation wells and may be used to acknowledge the assistance of local (non-U.S. Geological Survey) observers.

PERIOD OF RECORD.--This entry indicates the period for which there are published records for the well. It reports the month and year of the start of publication of water-level records by the U.S. Geological Survey and the words "to current year" if the records are to be continued into the following year. Periods for which water-level records are available but are not published by the U.S. Geological Survey may be noted.

EXTREMES FOR PERIOD OF RECORD.--This entry contains the highest and lowest water levels of the period of published record, with respect to land-surface datum, and the dates of their occurrence.

Tables of water levels follow the station description for each well. Water levels are reported in feet below land-surface datum. Only abbreviated tables are published; water-level highs and lows are listed for every fifth day and at the end of the month (EOM). The highest and lowest water levels of the water year and their dates of occurrence are shown on a line below the abbreviated tables. Because all values are not published, the extremes may be values that are not listed in the tables. Missing records are indicated by dashes in place of the water level. 


\author{
Records of Ground-Water Quality
}

Records of ground-water quality in this report differ from other types of records in that they consist of only one set of measurements for the water year. Ground-water quality is sampled immediately after installation and development of a new observation well. As new observation wells are usually installed late in the water year, records of ground-water quality are typically published in the first water year with complete records for ground-water levels.

Sample Collection and Analysis

Measurements of specific conductance, $\mathrm{pH}$, water temperature, dissolved oxygen, and alkalinity are measured on-site. Other constituents and properties are analyzed in the U.S. Geological Survey National Water-Quality Laboratory in Arvada, Colorado. Methods used in collecting and analyzing ground-water-quality samples are given in TWRI, Book 1, Chap. D2, and Book 5, Chap. A1.

Data Presentation

Records of ground-water quality immediately follow records of ground-water levels.

\title{
ACCESS TO WATSTORE DATA
}

The U.S. Geological Survey is the principal Federal water-data agency and, as such, collects and disseminates about 70 percent of the water data currently being used by numerous State, local, private, and other Federal agencies to develop and manage our water resources. As part of the GeologicalSurvey's program of releasing water data to the public, a large-scale computerized system has been developed for the storage and retrieval of water data collected through its activities. The

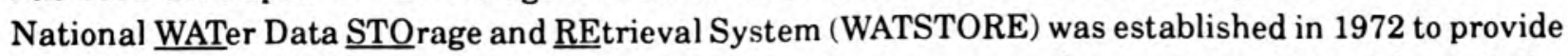
an effective and efficient means for the processing and maintenance of water data collected through the 
the activities of the U.S. Geological Survey and to facilitate release of the data to the public. A variety of useful products, ranging from data tables to complex statistical analyses such as Log Pearson Type III, can be produced using WATSTORE. The system resides on the central computer facilities of the U.S. Geological Survey at its National Center in Reston, Virginia and consists of related filed and data bases.

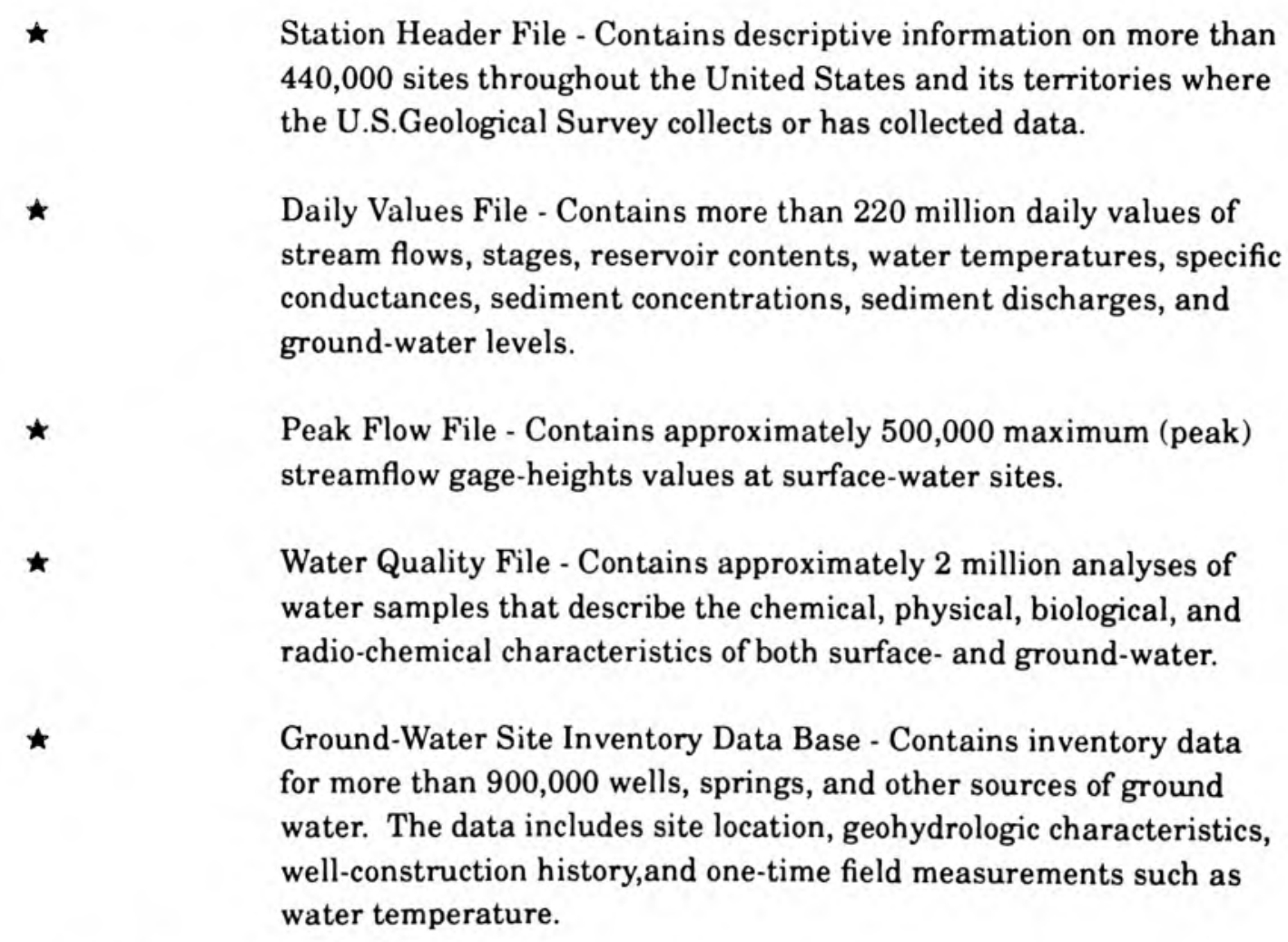

In 1976, the U.S. Geological Survey opened WATSTORE to the public for direct access. The signing of a Memorandum of Agreement with the Survey is required to obtain direct access to WATSTORE. The system can be accessed either synchronously or asynchronously. The requestor will be expected to pay all computer costs he/she incurs. Direct access may be obtained by contacting:

\author{
U.S. Geological Survey \\ National Water Data Exchange \\ 421 USGS National Center \\ Reston, Virginia 22092
}


In addition to providing direct access to WATSTORE, data can be provided in various machinereadable formats on magnetic tape or 5-1/4 inch floppy disk; and, as noted in the introduction, on CDROM discs. Beginning with the 1990 water year, all water-data reports will also be available on Compact Disc - Read Only Memory (CD-ROM). All data reports published for the current water year for the entire Nation, including Puerto Rico and the Trust Territories, will be reproduced on a single CDROM disc. Information about the availability of specific types of data or products, and user charges, can be obtained locally from each of the Water Resources Divisions's District offices. (See address on the back of the title page.) A limited number of CD-ROM discs will be available for sale by the Books and Open-File Reports Section, U.S. Geological Survey, Federal Center, Box 25425, Denver, Colorado 80225 .

\section{DEFINITION OF TERMS}

Terms related to streamflow, water-quality, and other hydrologic data, as used in this report, are defined below. Also, see table for converting English units to International System (SI) units on the inside of the back cover.

Acre-foot (AC-FT, ac-ft) is the quantity of water required to cover 1 acre to a depth of 1 foot and is equal to 43,560 cubic feet or about 326,000 gallons or 1,233 cubic meters.

Aquifer is a geologic formation, group of formations, or part of a formation that contains sufficient saturated permeable material to yield significant quantities of water to wells and springs.

Artesian means confined and is used to describe a well in which the water level stands above the top of the aquifer tapped by the well. A flowing artesian well is one in which the water level is above the land surface.

Bacteria are microscopic unicellular organisms, typically spherical, rodlike, or spiral and threadlike in shape, often clumped into colonies. Some bacteria cause disease, while others perform an essential role in nature in the recycling of materials; for example, by decomposing organic matter into a form available for reuse by plants.

Fecal coliform bacteria are bacteria that are present in the intestine or feces of warmblooded animals. They are often used as indicators of the sanitary quality of the water. In the laboratory, they are defined as all organisms that produce blue colonies within 24 hours when incubated at $44.5^{\circ} \mathrm{C} \pm 0.2^{\circ} \mathrm{C}$ on M-FC medium (nutrient medium for bacterial growth). Their concentrations are expressed as number of colonies per $100 \mathrm{~mL}$ of sample. 
Fecal streptococcal bacteria are bacteria found also in the intestine of warm-blooded animals. Their presence in water is considered to verify fecal pollution. They are characterized as Gram-positive, cocci bacteria which are capable of growth in brain-heart infusion broth. In the laboratory, they are defined as all the organisms which produce red or pink colonies within 48 hours at $35^{\circ} \mathrm{C} \pm 1.0^{\circ} \mathrm{C}$ on $\mathrm{KF}$-streptococcus medium (nutrient medium for bacterial growth). Their concentrations are expressed as number of colonies per $100 \mathrm{~mL}$ of sample.

Bed material is the sediment mixture of which a streambed, lake, pond, reservoir, or estuary bottom is composed.

\section{Bottom material: See Bed material.}

Color unit is produced by 1 milligram per liter of platinum in the form of the chloro-platinate ion. Color is expressed in units of the platinum-cobalt scale.

Contents is the volume of water in a reservoir or lake. Unless otherwise indicated, volume is computed on the basis of a level pool and does not include bank storage.

Control designates a feature downstream from the gage that determines the stage-discharge relation at the gage. This feature may be a natural constriction of the channel, an artificial structure, or a uniform cross section over a long reach of the channel.

Control structure as used in this report is a structure on a stream, canal, or lake that is used to regulate the flow or stage or to prevent the intrusion of salt water.

Cubic foot per second $\left(\mathrm{ft}^{3} / \mathrm{s}\right)$ is the rate of discharge representing a volume of 1 cubic foot passing a given point during 1 second and is equivalent to 7.48 gallons per second or 448.8 gallons per minute or 0.02832 cubic meters per second.

Cubic foot per second-day is the volume of water represented by a flow of 1 cubic foot per second for 24 hours. It is equivalent to 86,400 cubic feet, approximately 1.9835 acre-feet, about 646,000 gallons, or 2,445 cubic meters.

Cubic feet per second per square mile $\left[\left(\mathrm{ft}^{3} / \mathrm{s}\right) / \mathrm{mi}^{2}\right]$ is the average number of cubic feet of water flowing per second from each square mile of area drained, assuming that the runoff is distributed uniformly in time and area.

Discharge is the volume of water (or more broadly, volume of fluid plus suspended sediment) that passes a given point within a given period of time.

Mean discharge (MEAN) is the arithmetic mean of individual daily mean discharges during a specific period. 
Instantaneous discharge is the discharge at a particular instant of time.

Annual 7-day minimum is the lowest mean discharge for 7 consecutive days for a calender year or a water year. Note that most low-flow frequency analyses of annual 7-day minimum flows use a climatic year (April 1 - March 31). The date shown in the summary statistics table is the initial date of the 7-day period. (This value should not be confused with the 7-day 10-year low-flow statistic.)

Dissolved refers to that material in a representative water sample which passes through a 0.45 micron $(\mu \mathrm{m})$ membrane filter. This is a convenient operational definition used by Federal agencies that collect water data. Determinations of "dissolved" constituents are made on subsamples of the filtrate.

Dissolved-solids concentration of water is determined either analytically by the "residue-onevaporation" method, or mathematically by totaling the concentrations of individual constituents reported in a comprehensive chemical analysis. During the analytical determination of dissolved solids, the bicarbonate (generally a major dissolved component of water) is converted to carbonate. Therefore, in the mathematical calculation of dissolved-solids concentration, the bicarbonate value, in milligrams per liter, is multiplied by 0.492 to reflect the change.

Drainage area of a stream at a specified location is that area, measured in a horizontal plane, enclosed by a topographic divide from which direct surface runoff from precipitation normally drains by gravity into the stream above the specified point. Figures of drainage area given herein include all closed basins, or noncontributing areas, within the area unless otherwise specified.

Drainage basin is a part of the surface of the earth that is occupied by a drainage system, which consists of a surface stream or a body of impounded surface water together with all tributary surface streams and bodies of impounded surface water.

Gage height (G.H.) is the water-surface elevation referred to some arbitrary gage datum. Gage height is often used interchangeably with the more general term "stage," although gage height is more appropriate when used with a reading on a gage.

Gaging station is a particular site on a stream, canal, lake, or reservoir where systematic observations of hydrologic data are obtained.

Hardness of water is a physical-chemical characteristic that commonly is recognized by the increased quantity of soap required to produce lather. It is computed as the sum of equivalents of polyvalent cations and is expressed as the equivalent concentration of calcium carbonate $\left(\mathrm{CaCO}_{3}\right)$.

Hydrologic unit is a geographic area representing part or all of a surface drainage basin or distinct hydrologic feature as delineated by the Office of Water Data Coordination on the State Hydrologic Unit Maps; each hydrologic unit is identified by an 8-digit number. 


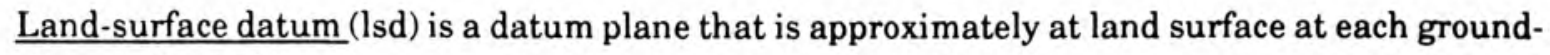
water observation well.

Measuring point (MP) is an arbitrary permanent reference point from which the distance to the water surface in a well is measured to obtain the water level.

Micrograms per gram $(\mu \mathrm{g} / \mathrm{g})$ is a unit expressing the concentration of a chemical constituent as the mass (micrograms) of the element per unit mass (gram) of material analyzed.

Micrograms per liter (UG/L, $\mu \mathrm{g} / \mathrm{L}$ ) is a unit expressing the concentration of chemical constituents in solution as mass (micrograms) of solute per unit volume (liter) of water. One thousand micrograms per liter is equivalent to one milligram per liter.

Milligrams per liter $(\mathrm{MG} / \mathrm{L}, \mathrm{mg} / \mathrm{L})$ is a unit for expressing the concentration of chemical constituents in solution. Milligrams per liter represents the mass of solute per unit volume (liter) of water. Concentration of suspended sediment also is expressed in $\mathrm{mg} / \mathrm{L}$ and is based on the mass of dry sediment per liter of water-sediment mixture.

National Geodetic Vertical Datum of 1929 (NGVD of 1929) is a geodetic datum derived from a general adjustment of the first order level nets of both the United States and Canada. It was formerly called "Sea Level Datum of 1929" or "mean sea level" in this series of reports. Although the datum was derived from the average sea level over a period of many years at 26 tide stations along the Atlantic, Gulf of Mexico, and Pacific coasts, it does not necessarily represent local mean sea level at any particular place.

Organism count/volume refers to the number of organisms collected and enumerated in a sample and adjusted to the number per sample volume, usually milliliter $(\mathrm{mL})$ or liter $(\mathrm{L})$. Numbers of planktonic organisms can be expressed in these terms.

Total organism count is the total number of organisms collected and enumerated in any particular sample.

Parameter code is a 5-digit number used in the U.S. Geological Survey computerized data system, WATSTORE, to uniquely identify a specific constituent. The codes used in WATSTORE are the same as those used in the U.S. Environmental Protection Agency data system, STORET. The U.S. Environmental Protection Agency assigns and approves all requests for new codes.

Partial-record station is a particular site where limited streamflow and/or water-quality data are collected systematically over a period of years for use in hydrologic analyses. 
Particle size is the diameter, in millimeters $(\mathrm{mm})$, of a particle determined by either sieve or sedimentation methods. Sedimentation methods (pipet, bottom-withdrawal tube, visual-accumulation tube) determine fall diameter of particles in either distilled water (chemically dispersed) or in native water (the river water at the time and point of sampling).

Particle-size classification used in this report agrees with the recommendation made by the American Geophysical Union Subcommittee on Sediment Terminology. The classification is as follows:

\begin{tabular}{lccc} 
Classification & \multicolumn{2}{c}{$\underline{\text { Size }(\mathrm{mm})}$} & Method of analysis \\
\hline Clay............... & $0.00024-0.004$ & Sedimentation \\
Slit.......... & .004 & -062 & Sedimentation \\
Sand.......... & .062 & -2.0 & Sedimentation or sieve \\
Gravel........ & 2.0 & -64.0 & Sieve
\end{tabular}

The particle-size distributions given in this report are not necessarily representative of all particles in transport in the stream. Most of the organic matter is removed, and the sample is subjected to mechanical and chemical dispersion before analysis in distilled water. Chemical dispersion is not used for native-water analysis.

Picocurie $(\mathrm{PC}, \mathrm{pCi})$ is one-trillionth $\left(1 \times 10^{-12}\right)$ of the amount of radioactivity represented by a curie (Ci). A curie is the amount of radioactivity that yields $3.7 \times 1010$ radioactive disintegrations per second (dpm). A picocurie yields $2.22 \mathrm{dpm}$.

Return period is the average time interval between occurrences of a hydrological event of a given or greater magnitude, usually expressed in years. May also be called recurrence interval.

Runoff in inches (IN., in) shows the depth to which the drainage area would be covered if all the runoff for a given time period were uniformly distributed on it.

Sediment is solid material that originates mostly from disintegrated rocks and is transported by, suspended in, or deposited from water; it includes chemical and biochemical precipitates and decomposed organic material, such as humus. The quantity, characteristics, and cause of the occurrence of sediment in streams are influenced by environmental factors. Some major factors are degree of slope, length of slope, soil characteristics, land usage, and quantity and intensity of precipitation.

Bed load is the sediment that is transported in a stream by rolling, sliding, or skipping along the bed and very close to it. In this report, bed load is considered to consist of particles in transit within $0.25 \mathrm{ft}$ of the streambed.

Bed load discharge (tons per day) is the quantity of bed load measured by dry weight that moves past a section as bed load in a given time. 
Suspended sediment is the sediment that at any given time is maintained in suspension by the upward components of turbulent currents or that exists in suspension as a colloid.

Suspended-sediment concentration is the velocity-weighted concentration of suspended sediment in the sampled zone (from the water surface to a point approximately $0.3 \mathrm{ft}$ above the bed) expressed as milligrams of dry sediment per liter of water-sediment mixture $(\mathrm{mg} / \mathrm{L})$.

Mean concentration is the time-weighted concentration of suspended sediment passing a stream section during a 24 -hour day.

Suspended-sediment discharge (tons/day) is the rate at which dry mass of sediment passes a section of a stream or is the quantity of sediment, as measured by dry mass or volume, that passes a section in a given time. It is calculated in units of tons per day as follows: Concentration $(\mathrm{mg} / \mathrm{L}) \mathrm{x}$ discharge $\left(\mathrm{ft}^{3} / \mathrm{s}\right) \times 0.0027$.

Suspended-sediment load is a general term that refers to material in suspension. It is not synonymous with either discharge or concentration.

Total-sediment discharge (tons/day) is the sum of the suspended-sediment discharge and the bed-load discharge. It is the total quantity of sediment, as measured by dry mass or volume, that passes a section during a given time.

Total-sediment load or total load is a term which refers to the total sediment (bed load plus suspended-sediment load) that is in transport. It is not synonymous with totalsediment discharge.

7-day 10-year low flow $\left(7 \mathrm{Q}^{10}\right)$ is the discharge at the 10 -year recurrence interval taken from a frequency curve of annual values of the lowest mean discharge for 7 consecutive days (the 7-day low flow).

Sodium-adsorption-ratio (SAR) is the expression of relative activity of sodium ions in exchange reactions within soil and is an index of sodium or alh ali hazard to the soil. Waters range in respect to sodium hazard from those which can be used for irrigation on almost all soils to those which are generally unsatisfactory for irrigation.

Solute is any substance that is dissolved in water.

Specific conductance is a measure of the ability of a water to conduct an electrical current. It is expressed in microsiemens per centimeter at $25^{\circ} \mathrm{C}$. Specific conductance is related to the type and concentration of ions in solution and can be used for approximating the dissolved-solids content of the water. Commonly, the concentration of dissolved solids (in milligrams per liter) is about 65 percent of the specific conductance (in microsiemens). This relation is not constant from stream to stream, and it may vary in the same source with changes in the composition of the water. 
Stage-discharge relation is the relation between gage height (stage) and volume of water, per unit of time, flowing in a channel.

Streamflow is the discharge that occurs in a natural channel. Although the term "discharge" can be applied to the flow of a canal, the word "streamflow" uniquely describes the discharge in a surface stream course. The term "streamflow" is more general than "runoff," as streamflow may be applied to discharge whether or not it is affected by diversion or regulation.

Surface area of a lake is that area outlined on the latest U.S. Geological Survey topographic map as the boundary of the lake and measured by a planimeter in acres. In localities not covered by topographic maps, the areas are computed from the best maps available at the time planimetered. All areas shown are those for the stage when the planimetered map was made.

Surficial bed material is the part ( 0.1 to $0.2 \mathrm{ft}$ ) of the bed material that is sampled using U.S. Series Bed-Material Samplers.

Suspended (as used in tables of chemical analyses) refers to the amount (concentration) of undissolved material in a water-sediment mixture. It is associated with the material retained on a $0.45-\mu \mathrm{m}$ filter.

Suspended, recoverable is the amount of a given constituent that is in solution after the part of a representative water-suspended sediment sample that is retained on a $0.45-\mu \mathrm{m}$ membrane filter has been digested by a method (usually using a dilute acid solution) that results in dissolution of only readily soluble substances. Complete dissolution of all the particulate matter is not achieved by the digestion treatment and thus the determination represents something less than the "total" amount (that is, less than 95 percent) of the constituent present in the sample. To achieve comparability of analytical data, equivalent digestion procedures are required of all laboratories performing such analyses because different digestion procedures are likely to produce different analytical results.

Determinations of "suspended, recoverable" constituents are made either by analyzing portions of the material collected on the filter or, more commonly, by difference, based on determinations of: (1) Dissolved; and (2) total recoverable concentrations of the constituent.

Suspended, total is the total amount of a given constituent in the part of a representative watersuspended sediment sample that is retained on a $0.45-\mu \mathrm{m}$ membrane filter. This term is used only when the analytical procedure assures measurement of at least 95 percent of the constituent determined. A knowledge of the expected form of the constituent in the sample, as well as the analytical methodology used, is required to determine when the results should be reported as "suspended, total."

Determinations of "suspended, total" constituents are made either by analyzing portions of the material collected on the filter or, more commonly, by difference, based on determinations of: (1) Dissolved; and (2) total concentrations of the constituent. 
Time-weighted average is computed by multiplying the number of days in the sampling period by the concentrations of individual constituents for the corresponding period and dividing the sum of the products by the total number of days. A time-weighted average represents the composition of water that would be contained in a vessel or reservoir that had received equal quantities of water from the stream each day for the year.

Tons per acre-foot indicates the dry mass of dissolved solids in 1 acre-foot of water. It is computed by multiplying the concentration of the constituent, in milligrams per liter, by 0.00136 .

Tons per day (T/DAY) is the quantity of a substance in solution or suspension that passes a stream section during a 24-hour period.

Total is the total amount of a given constituent in a representative water-suspended sediment sample, regardless of the constituent's physical or chemical form. This term is used only when the analytical procedure assures measurement of at least 95 percent of the constituent present in both the dissolved and suspended phases of the sample. A knowledge of the expected form of the constituent in the sample, as well as the analytical methodology used, is required to judge when the results should be reported as "total." (Note that the word "total" does double duty here, indicating both that the sample consists of a water-suspended sediment mixture and that the analytical method determined all of the constituent in the sample.)

Total discharge is the total quantity of any individual constituent, as measured by dry mass or volume, that passes through a stream cross section per unit of time. This term needs to be qualified, such as "total sediment discharge," "total chloride discharge," and so on.

Total, recoverable is the amount of a given constituent that is in solution after a representative water-suspended sediment sample has been digested by a method (usually using a dilute acid solution) that results in dissolution of only readily soluble substances. Complete dissolution of all particulate matter is not achieved by the digestion treatment, and thus the determination represents something less than the "total" amount (that is, less than 95 percent) of the constituent present in the dissolved and suspended phases of the sample. To achieve comparability of analytical data, equivalent digestion procedures are required of all laboratories performing such analyses because different digestion procedures are likely to produce different analytical results.

Water year in U.S. Geological Survey reports dealing with surface-water supply is the 12-month period October 1 through September 30 . The water year is designated by the calendar year in which it ends and which includes 9 of the 12 months. Thus, the year ending September 30,1985 , is called the "1985 water year."

WDR is used as an abbreviation for "Water-Data Report" in the REVISED RECORDS paragraph to refer to State annual hydrologic-data reports (WRD was used as an abbreviation for "WaterResources Data" in reports published prior to 1976). 
Weighted average is used in this report to indicate discharge-weighted average. It is computed by multiplying the discharge for a sampling period by the concentrations of individual constituents for the corresponding period and dividing the sum of the products by the sum of the discharges. A discharge-weighted average approximates the composition of water that would be found in a reservoir containing all the water passing a given location during the water year after thorough mixing in the reservoir.

WSP is used as an abbreviation for "Water-Supply Paper" in reference to previously published reports. 
Table 1.--Factors for conversion of chemical constituents in milligrams or micrograms per liter to milliequivalents per liter

\begin{tabular}{llll}
\hline \multicolumn{1}{c}{ Ion } & $\begin{array}{c}\text { Multiply } \\
\text { by }\end{array}$ & \multicolumn{1}{c}{ lon } & $\begin{array}{c}\text { Multiply } \\
\text { by }\end{array}$ \\
\hline Aluminum $\left(\mathrm{Al}^{+3}\right)$ & 0.11119 & Iodide $\left(\mathrm{I}^{1}{ }^{1}\right)$ & 0.00788 \\
Ammonia as $\mathrm{NH}_{4}{ }^{+}$ & .05544 & Iron $\left(\mathrm{Fe}+{ }^{3}\right)^{*}$ & .05372 \\
Barium $\left(\mathrm{Ba}^{2}\right)$ & .01456 & Lead $\left(\mathrm{Pb}+^{2}\right)^{*}$ & .00965 \\
Bicarbonate $\left(\mathrm{HCO}_{3}{ }^{-1}\right.$ & .01639 & Lithium $\left(\mathrm{Li}+{ }^{1}\right)^{*}$ & .14411 \\
Bromide $\left(\mathrm{Br}^{-1}\right)$ & .01251 & Magnesium $\left(\mathrm{Mg}+^{2}\right)$ & .08226 \\
Calcium $\left(\mathrm{Ca}^{2}\right)$ & .04990 & Manganese $\left(\mathrm{Mn}^{2}{ }^{2}\right)^{*}$ & .03640 \\
Carbonate $\left(\mathrm{CO}_{3}{ }^{-2}\right)$ & .03333 & Nickel $\left(\mathrm{Ni}^{2}\right)^{2}$ & .03406 \\
Chloride $\left(\mathrm{C1}^{-1}\right)$ & .02821 & Nitrate $\left(\mathrm{NO}_{3}{ }^{-1}\right)$ & .01613 \\
Chromium $\left(\mathrm{Cr}^{+6}\right)^{*}$ & .11539 & Nitrite $\left(\mathrm{NO}_{2}{ }^{-1}\right)$ & .02174 \\
Cobalt $\left(\mathrm{Co}^{+2}\right)^{*}$ & .03394 & Phosphate $\left(\mathrm{PO}_{4}{ }^{-3}\right)$ & .03159 \\
Copper $\left(\mathrm{Cu}^{+2}\right)^{*}$ & .03148 & Potassium $\left(\mathrm{K}^{+1}\right)$ & .02557 \\
Cyanide $\left(\mathrm{CN}^{-1}\right)$ & .03844 & Sodium $\left(\mathrm{Na}^{+1}\right)$ & .04350 \\
Fluoride $\left(\mathrm{F}^{-1}\right)$ & .05264 & Strontium $\left(\mathrm{Sr}^{+2}\right)^{*}$ & .02283 \\
Hydrogen $\left(\mathrm{H}^{+1}\right)$ & .99209 & Sulfate $\left(\mathrm{SO}_{4}{ }^{-2}\right)$ & .02082 \\
Hydroxide $\left(\mathrm{OH}^{-1}\right)$ & .05880 & Zinc $\left(\mathrm{Zn}^{+2}\right)^{*}$ & .03060 \\
\hline
\end{tabular}

*Constituent reported in micrograms per liter; multiply by factor and divide results by 1,000 . 
Table 2.--Factors for conversion of sediment concentrations in milligrams per liter to parts per million*

(All values calculated to three significant figures)

\begin{tabular}{|c|c|c|c|c|c|c|c|}
\hline $\begin{array}{l}\text { Range of } \\
\text { concen- } \\
\text { tration } \\
\text { in } 1,000 \\
\mathrm{mg} / \mathrm{L}\end{array}$ & $\begin{array}{l}\text { Divide } \\
\text { by }\end{array}$ & $\begin{array}{c}\text { Range of } \\
\text { concen- } \\
\text { tration } \\
\text { in } 1,000 \\
\mathrm{mg} / \mathrm{L}\end{array}$ & $\begin{array}{c}\text { Divide } \\
\text { by }\end{array}$ & $\begin{array}{l}\text { Range of } \\
\text { concen- } \\
\text { tration } \\
\text { in } 1,000 \\
\mathrm{mg} / \mathrm{L}\end{array}$ & $\begin{array}{c}\text { Divide } \\
\text { by }\end{array}$ & $\begin{array}{c}\text { Range of } \\
\text { concen- } \\
\text { tration } \\
\text { in } 1,000 \\
\mathrm{mg} / \mathrm{L}\end{array}$ & $\begin{array}{c}\text { Divide } \\
\text { by }\end{array}$ \\
\hline $0-8$ & 1.00 & $201-217$ & 1.13 & $411-424$ & 1.26 & $619-634$ & 1.39 \\
\hline $8.05-24$ & 1.01 & $218-232$ & 1.14 & $427-440$ & 1.27 & $636-650$ & 1.40 \\
\hline $24.2-40$ & 1.02 & $234-248$ & 1.15 & $443-457$ & 1.28 & $652-666$ & 1.41 \\
\hline $40.5-56$ & 1.03 & $250-264$ & 1.16 & $460-473$ & 1.29 & $668-682$ & 1.42 \\
\hline $56.5-72$ & 1.04 & $266-280$ & 1.17 & $476-489$ & 1.30 & $684-698$ & 1.43 \\
\hline $72.5-88$ & 1.05 & $282-297$ & 1.18 & $492-508$ & 1.31 & $700-715$ & 1.44 \\
\hline $88.5-104$ & 1.06 & $299-313$ & 1.19 & $508-522$ & 1.32 & $717-730$ & 1.45 \\
\hline $105-120$ & 1.07 & $315-329$ & 1.20 & $524-538$ & 1.33 & $732-747$ & 1.46 \\
\hline $121-136$ & 1.08 & $331-345$ & 1.21 & $540-554$ & 1.34 & $749-762$ & 1.47 \\
\hline $137-152$ & 1.09 & $347-361$ & 1.22 & $556-570$ & 1.35 & $765-780$ & 1.48 \\
\hline $153-169$ & 1.10 & $363-378$ & 1.23 & $572-585$ & 1.36 & $782-796$ & 1.49 \\
\hline $170-185$ & 1.11 & $380-393$ & 1.24 & $587-602$ & 1.37 & $798-810$ & 1.50 \\
\hline $186-200$ & 1.12 & $395-409$ & 1.25 & $604-617$ & 1.38 & & \\
\hline
\end{tabular}

*Based on water density of $1.000 \mathrm{mg} / \mathrm{L}$ and a specific gravity of sediment of 2.65 . 


\section{PUBLICATIONS ON TECHNIQUES OF WATER-RESOURCES INVESTIGATIONS}

The U.S. Geological Survey publishes a series of manuals describing procedures for planning and conducting specialized work in water-resources investigations. The material is grouped under major subject headings called books and is further divided into sections and chapters. For example, Section A of Book 3 (Applications of Hydraulics) pertains to surface water. The chapter, the unit of publication, is limited to a narrow field of subject matter. This format permits flexibility in revision and publication as the need arises

The reports listed below are for sale by the U.S. Geological Survey, Books and Open-File Reports Section, Federal Center, Box 25425, Denver, Colorado 80225 (authorized agent of the Superintendent of Documents, Government Printing Office). Prepayment is required. Remittance should be sent by check or money order payable to the U.S. Geological Survey. Prices are not included because they are subject to change. Current prices can be obtained by writing to the above address. When ordering or inquiring about prices for any of these publications, please give the title, book number, chapter number, and "U.S. Geological Survey Techniques of Water-Resources Investigations."

1-D1. Water temperature--influential factors, field measurement, and data presentation, by H. H. Stevens, Jr., J. F. Ficke, and G. F. Smoot: USGS-TWRI Book 1, Chapter D1. 1975. 65 pages.

1-D2. Guidelines for collection and field analysis of ground-water samples for selected unstable constituents, by W. W. Wood: USGS-TWRI Book 1, Chapter D2. 1976. 24 pages.

2-D1. Application of surface geophysics to ground-water investigations, by A. A. R. Zohdy, G. P. Eaton, and D. R. Mabey: USGS-TWRI Book 2, Chapter D1. 1974. 116 pages.

2-D2. Application of seismic-refraction techniques to hydrologic studies, by F. P. Haeni: USGS--TWRI Book 2, Chapter D2. 1988.86 pages.

2-E1. Application of borehole geophysics to water-resources investigations, by W. S. Keys and L. M. McCary: USGS--TWRI Book 2, Chapter E1. 1971, 126 pages.

2-E2. Borehole geophysics applied to ground-water investigations, by W. Scott Keys: USGS--TWRI Book 2, Chapter E2. 1990. 150 pages.

2-F1. Application of drilling, coring, and sampling techniques to test holes and wells, by Eugene Shuter and Warren E. Teasdale: USGS--TWRI Book 2, Chapter F1. 1989. 97 pages.

3-A1. General field and office procedures for indirect discharge measurements, by M. A. Benson and Tate Dalrymple: USGS--TWRI Book 3, Chapter A1. 1967. 30 pages.

3-A2. Measurement of peak discharge by the slope-area method, by Tate Dalrymple and M. A. Benson: USGS-- TWRI Book 3, Chapter A2. 1967. 12 pages.

3-A3. Measurement of peak discharge at culverts by indirect methods, by G. L. Bodhaine: USGS--TWRI Book 3, Chapter A3. 1968. 60 pages.

3-A4. Measurement of peak discharge at width contractions by idirect methods, by H. F. Matthai: USGS-TWRI Book 3, Chapter A4. 1967. 44 pages.

3-A5. Measurement of peak discharge at dams by indirect methods, by Harry Hulsing: USGS--TWRI Book 3, Chapter A5. 1967. 29 pages.

3-A6. General procedure for gaging streams, by R. W. Carter and Jacob Davidian: USGS--TWRI Book 3, Chapter A6. 1968. 13 pages.

3-A7. Stage measurements at gaging stations, by T. J. Buchanan and W. P. Somers: USGS--TWRI Book 3. Chapter A7. 1968. 28 pages.

3-A8. Discharge measurements at gaging stations, by T. J. Buchanan and W. P. Somers: USGS--TWRI Book 3, Chapter A8. 1969. 65 pages.

3-A9. Measurement of time of travel in streams by dye tracing, by F. A. Kilpatrick and J. F. Wilson, Jr.: USGS--TWRI Book 3, Chapter A9. 1989.27 pages.

3-A10. Discharge ratings at gaging stations, by E. J. Kennedy: USGS--TWRI Book 3, Chapter A 10. 1984. 59 pages. 


\section{PUBLICATIONS ON TECHNIQUES OF WATER-RESOURCES INVESTIGATIONS--Continued}

3-A11. Measurement of discharge by moving-boat method, by G. F. Smoot and C. E. Novak: USGS--TWRI Book 3, Chapter A11. 1969. 22 pages.

3-A12. Fluorometric procedures for dye tracing, by J. F. Wilson, Jr., E. D. Cobb, and F. A. Kilpatrick: USGS- -TWRI Book 3, Chapter A12. 1986. 41 pages.

3-A13. Computation of continuous records of streamflow, by E. J. Kennedy: USGS--TWRI Book 3, Chapter A13. 1983. 53 pages.

3-A14. Use of flumes in measuring discharge, by F. A. Kilpatrick and V. R. Schneider: USGS--TWRI Book 3, Chapter A14. 1983. 46 pages.

3-A15. Computation of water-surface profiles in open channels, by Jacob Davidian: USGS--TWRI Book 3, Chapter A15. 1984. 48 pages.

3-A16. Measurement of discharge using tracers, by F. A. Kilpatrick and E. D. Cobb: USGS--TWRI Book 3, Chapter A16. 1985. 52 pages.

3-A17. Acoustic velocity meter systems, by Antonius Laenen: USGS--TWRI Book 3, Chapter A17. 1985. 38 pages.

3-A18. Determination of stream reaeration coefficients by use of tracers, by F. A. Kilpatrick, R. E. Rathburn, N. Yotsukura, G. W. Parker, and L. L. DeLong: USGS--TWRI Book 3, Chapter A18. 1989. 52 pages.

3-A19. Levels of streamflow gaging stations, by E.J. Kennedy: USGS--TWRI Book 3, Chapter A 19. 1990. 27 pages.

3-B1. Aquifer-test design, observation, and data analysis, by R. W. Stallman: USGS--TWRI Book 3, Chapter B1. 1971. 26 pages.

3-B2. Introduction to ground-water hydraulics, a programmed text for self-instruction, by G. D. Bennett: USGS-- TWRI Book 3, Chapter B2. 1976. 172 pages.

3-B3. Type curves for selected problems of flow to wells in confined aquifers, by J. E. Reed: USGS--TWRI Book 3, Chapter B3. 1980. 106 pages.

3-B4. Regression modeling of ground-water flow, by Richard L. Cooley and Richard L. Naft: USGS--TWRI Book 3, Chapter B4. 1990. 232 pages.

3-B5. Definition of boundary and initial conditions in the analysis of saturated ground-water flow systems--An introduction, by O. L. Franke, T. E. Reilly, and G. D. Bennett: USGS--TWRI Book 3, Chapter B5. 1987. 15 pages.

3-B6. The principle of superposition and its application in ground-water hydraulics, by T. E. Reilly, O. L. Franke, and G. D. Bennett: USGS--TWRI Book 3, Chapter B6. 1987. 28 pages.

3-C1. Fluvial sediment concepts, by H. P. Guy: USGS--TWRI Book 3, Chapter C1. 1970. 55 pages.

3-C2. Field methods for measurement of fluvial sediment, by H. P. Guy and V. W. Norman: USGS--TWRI Book 3, Chapter C2. 1970. 59 pages.

3-C3. Computation of fluvial-sediment discharge, by George Porterfield: USGS--TWRI Book 3, Chapter C3. 1972. 66 pages.

4-A1. Some statistical tools in hydrology, by H. C. Riggs: USGS--TWRI Book 4, Chapter A1. 1968. 39 pages.

4-A2. Frequency curves, by H. C. Riggs: USGS--TWRI Book 4, Chapter A2. 1968. 15 pages.

4-B1. Low-flow investigations, by H. C. Riggs: USGS--TWRI Book 4, Chapter B1. 1972. 18 pages.

4-B2. Storage analyses for water supply, by H. C. Riggs and C. H. Hardison: USGS--TWRI Book 4, Chapter B2. 1973.20 pages.

4-B3. Regional analyses of streamflow characteristics, by H. C. Riggs: USGS--TWRI Book 4, Chapter B3. 1973.15 pages.

4-D1. Computation of rate and volume of stream depletion by wells, by C. T. Jenkins: USGS--TWRI Book 4, Chapter D1. 1970. 17 pages.

5-A1. Methods for determination of inorganic substances in water and fluvial sediments, by M. J. Fishman and L. C. Friedman : USGS--TWRI Book 5, Chapter A1. 1989. 545 pages. 


\section{PUBLICATIONS ON TECHNIQUES OF WATER-RESOURCES INVESTIGATIONS--Continued}

5-A2. Determination of minor elements in water by emission spectroscopy, by P. R. Barnett and E. C. Mallory, Jr.: USGS--TWRI Book 5. Chapter A2. 1971. 31 pages.

5-A3. Methods for the determination of organic substances in water and fluvial sediments, edited by R. L. Wershaw, M. J. Fishman, R. R. Grabbe, and L. E. Lowe: USGS--TWRI Book 5, Chapter A3. 1987. 80 pages.

5-A4. Methods for collection and analysis of aquatic biological and microbiological samples, by L. J. Britton and P. E. Greeson, editors: USGS--TWRI Book 5, Chapter A4. 1989. 363 pages.

5-A5. Methods for determination of radioactive substances in water and fluvial sediments, by L. L. Thatcher, V. J. Janzer, and K. W. Edwards: USGS--TWRI Book 5, Chapter A5. 1977. 95 pages.

5-A6. Quality assurance practices for the chemical and biological analyses of water and fluvial sediments, by L. C. Friedman and D. E. Erdmann: USGS--TWRI Book 5, Chapter A6. 1982. 181 pages.

5-C1. Laboratory theory and methods for sediment analysis, by H. P. Guy: USGS-TWRI Book 5, Chapter C1. 1969. 58 pages.

6-A1. A modular three-dimensional finite-difference ground-water flow model, by M. G. McDonald and A. W. Harbaugh: USGS--TWRI Book 6, Chapter A1. 1988. 586 pages.

7-C1. Finite difference model for aquifer simulation in two dimensions with results of numerical experiments, by P. C. Trescott, G. F. Pinder, and S. P. Larson: USGS--TWRI Book 7, Chapter C1. 1976. 116 pages.

7-C2. Computer model of two-dimensional solute transport and dispersion in ground water, by L. F. Konikow and J. D. Bredehoeft: USGS--TWRI Book 7, Chapter C2. 1978. 90 pages.

7-C3. A model for simulation of flow in singular and interconnected channels, by R. W. Schaffrannek, R. A. Baltzer, and D. E. Goldberg: USGS--TWRI Book 7, Chapter C3. 1981. 110 pages.

8-A1. Methods of measuring water levels in deep wells, by M. S. Garber and F. C. Koopman: USGS--TWRI Book 8, Chapter A1. 1968. 23 pages.

8-A2. Installation and service manual for U.S. Geological Survey manometers, by J. D. Craig: USGS--TWRI Book 8, Chapter A2. 1983. 57 pages.

8-B2. Calibration and maintenance of vertical-axis type current meters, by G. F. Smoot and C. E. Novak: USGS--TWRI Book 8, Chapter B2. 1968. 15 pages. 


\section{SELECTED REFERENCES}

Clark, G. D., ed., 1980, The Indiana water resource: Availability, uses, and needs: Indianapolis, Indiana Department of Natural Resources, 1508 p.

Fowler, K. K, 1988, Annual maximum and minimum lake levels for Indiana, water years 1942-85: U.S. Geological Survey Open-File Report 88-331, 363 p.

Gebert, W. A., Graczyk, D. J., and Krug, W. R., 1985, Average annual runoff in the United States, 195180: U.S. Geological Survey Open-File Report 85-627.

Glatfelter, D. R., 1984, Techniques for estimating magnitude and frequency of floods on streams in Indiana: U.S. Geological Survey Water-Resources Investigations Report 84-4134, 110 p.

Indiana Department of Natural Resources, 1986, Coordinated discharges of selected streams in Indiana: Indiana Department of Natural Resources, Division of Water.

National Oceanic and Atmospheric Administration, 1983, Monthly normals of temperature, precipitation, and heating and cooling days, 1951-80: no. 81 .

National Oceanic and Atmospheric Administration, 1986-87, Climatological data, Indiana: Asheville, N.C., National Climatic Center, v. 90, nos. 10-12, and v. 91, nos. 1-9.

Perrey, J. I., and Corbett, D. M., 1956, Hydrology of Indiana lakes: U.S. Geological Survey Water-Supply Paper 1363,347 p.

Rantz, S. E., and others, 1982, Volume 1, Measurement of stage and discharge: U.S. Geological Survey Water-Supply Paper 2175, 284 p.

Rantz, S. E., and others, 1982, Volume 2, Computation of discharge: U.S. Geological Survey Water-Supply Paper $2175,631 \mathrm{p}$.

Stewart, J. A., 1983, Low-flow characteristics of Indiana streams: U.S. Geological Survey Open-File Report 82-1007, 277 p.

Stewart, J. A., Miller, R. L., and Butch, G. K., 1986, Cost-effectiveness of the U.S. Geological Survey stream-gaging program in Indiana: U.S. Geological Survey Water-Resources Investigations Report 85-4343, 92 p. 


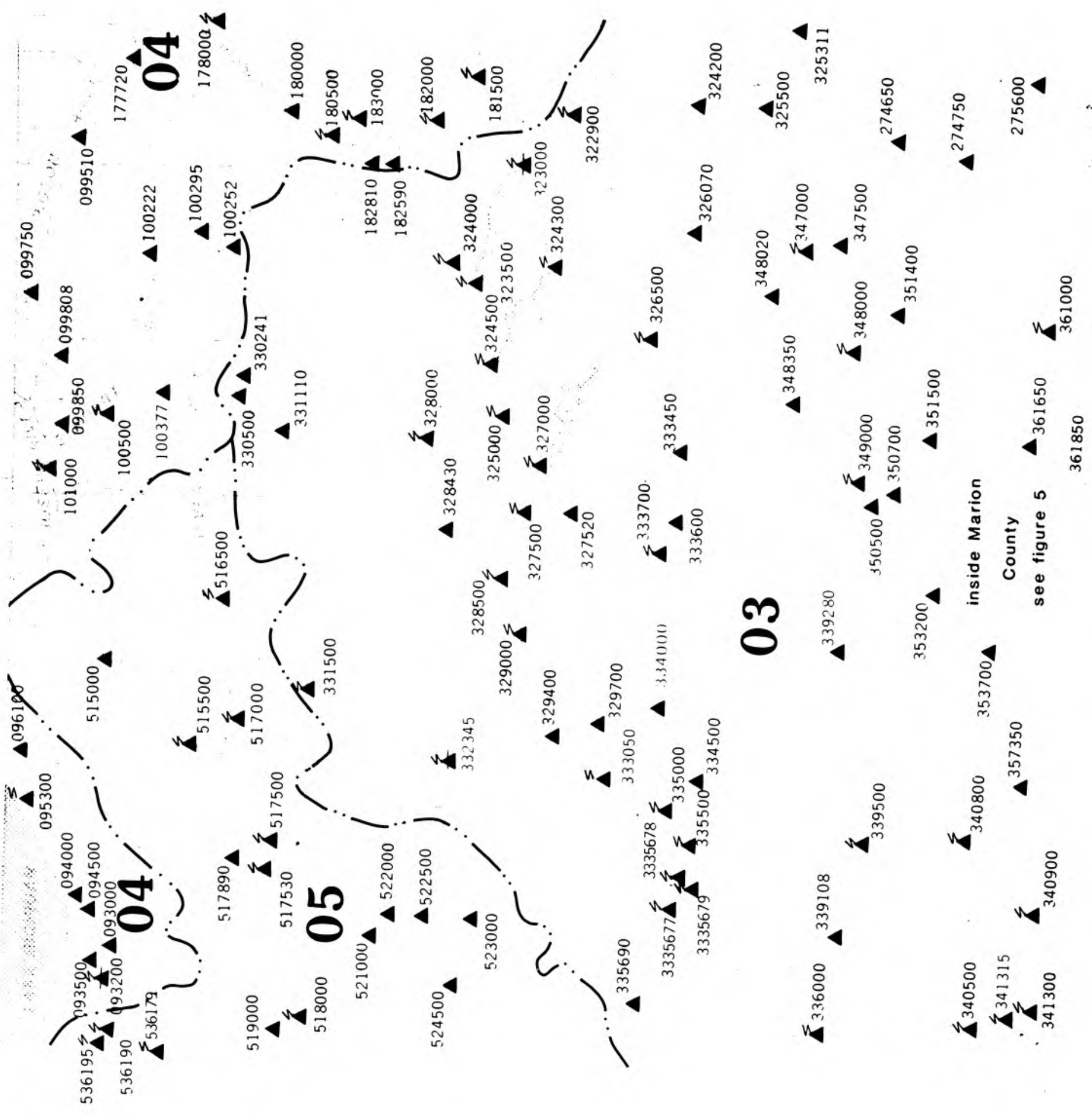



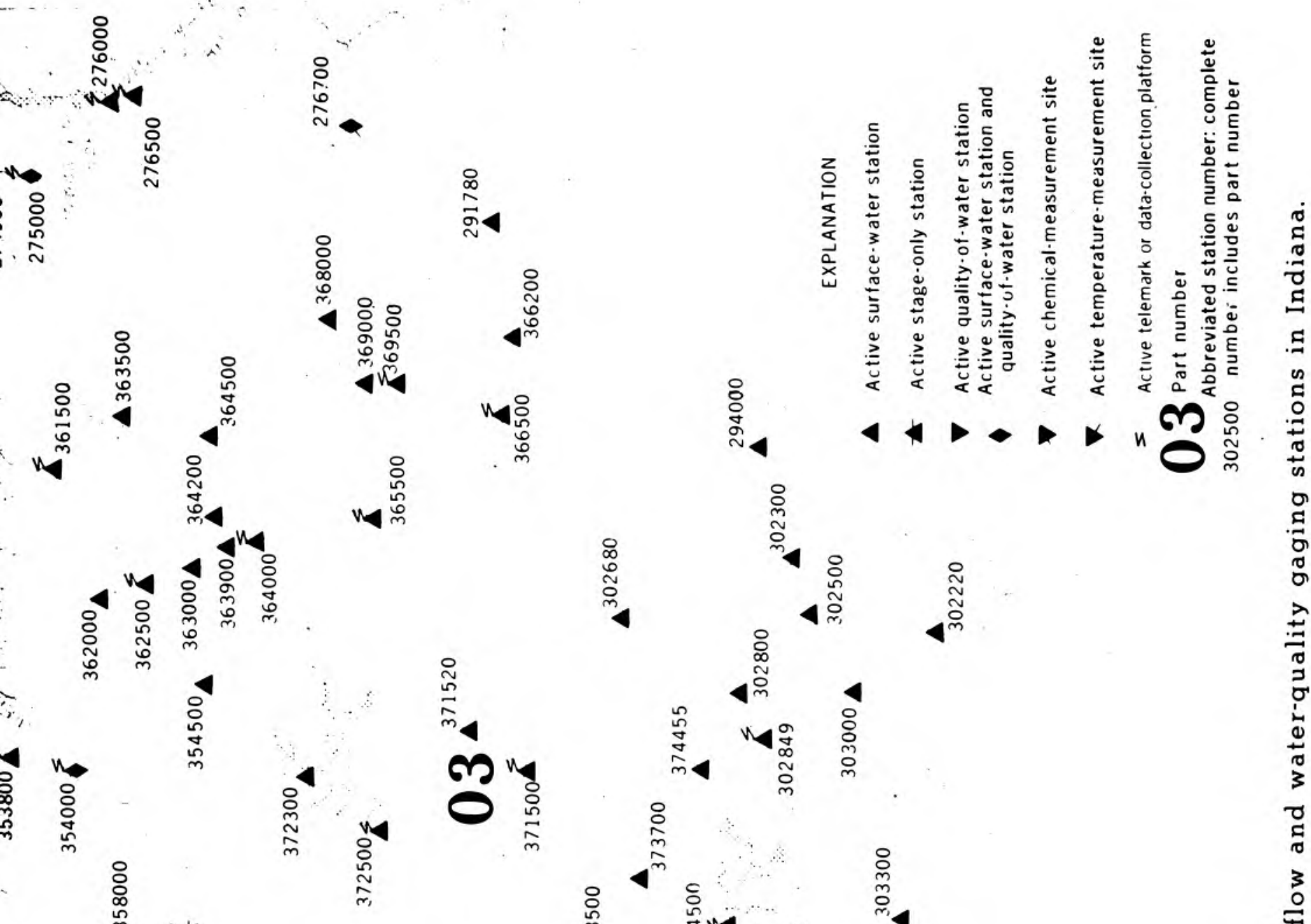

in
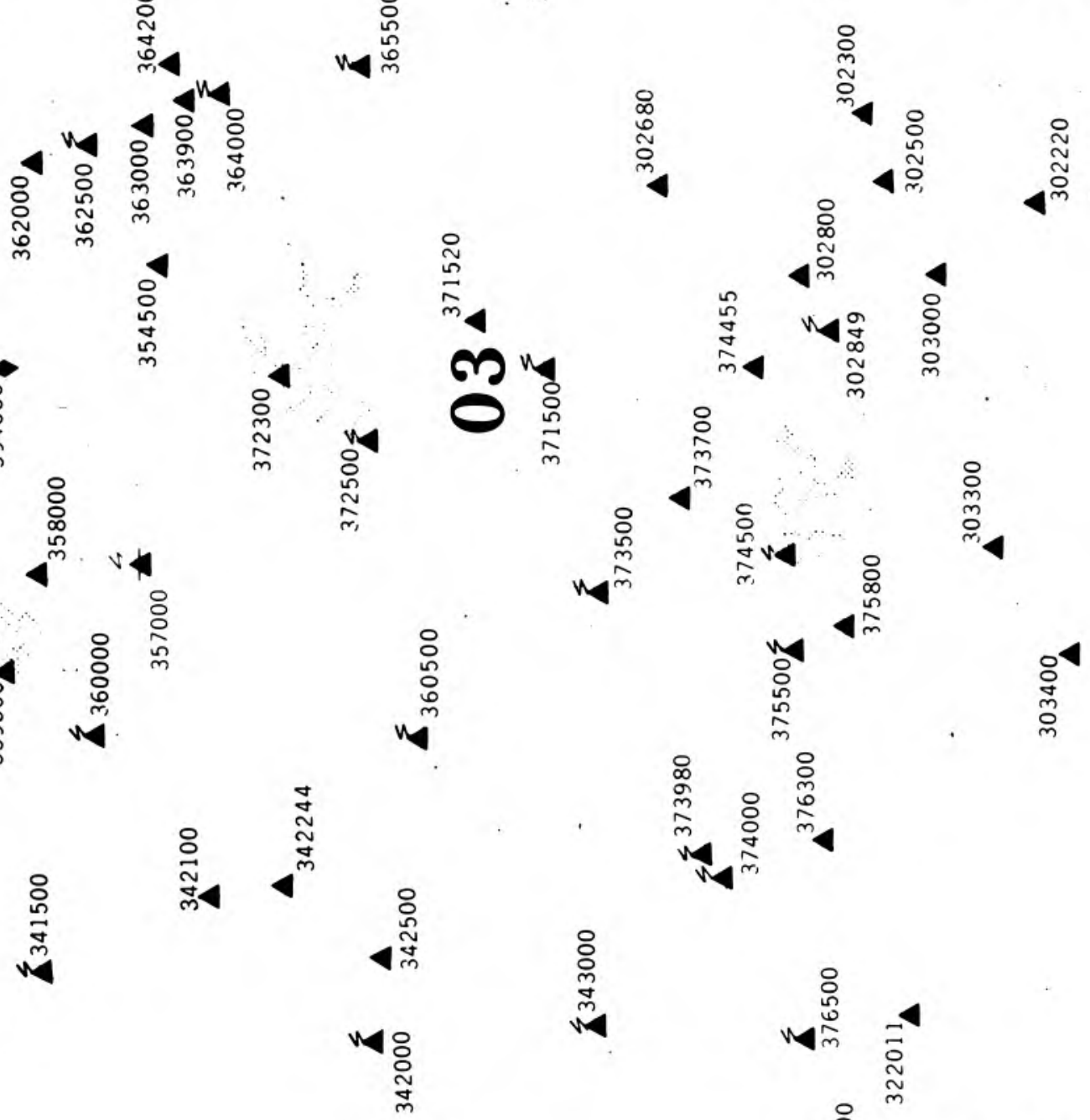

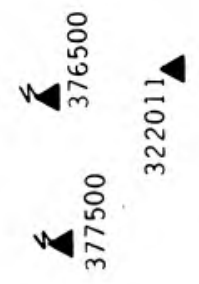

疍 


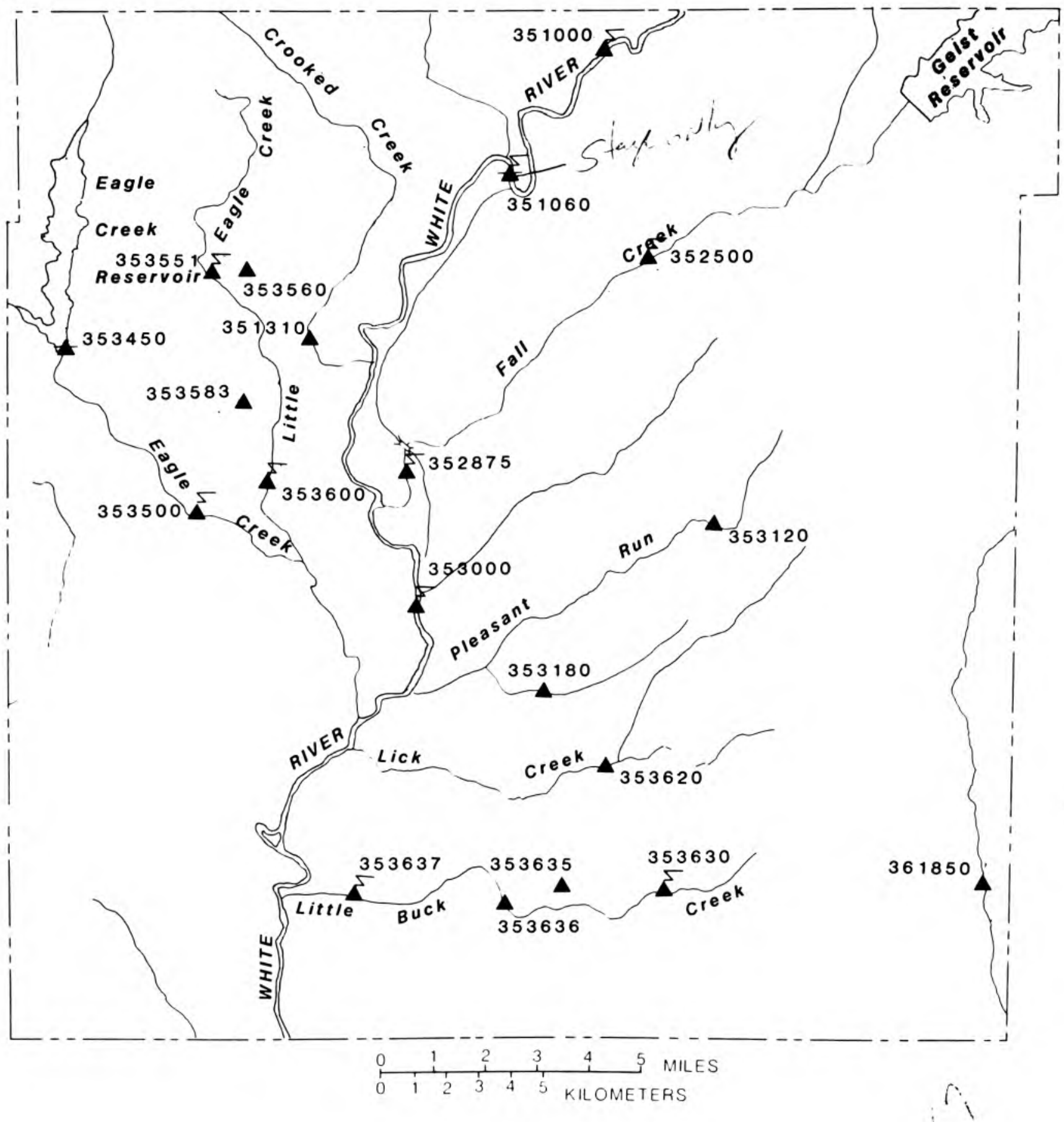

Figure 5.-- Location of streamflow and water-quality gaging stations in Marion County. 


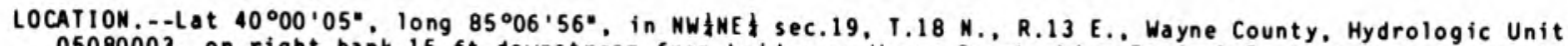

05080003 , on right bank $15 \mathrm{ft}$ downstrea froe bridge on Wayne County Line Road, 1.7 apstrean froe Little Creek. 2 northwest of Econosy, and at aile 91.9

PERIOD OF RECORD.--O October 1970 to current year.

REVISED RECORDS...-WRD IN 83-1: 1982.

GAGE.--Water-stage recorder. Datue of gage is $1,066.00 \mathrm{ft}$ above National Geodetic Vertical Datue of 1929.

REMARKS. - Records good except for estieated daily discharges, which are poor.

DISCHARGE, CUBIC FEET PER SECOND, WATER YEAR OCTOBER 1990 TO SEPTEMBER 1991 DAILY MEAM VALUES

\begin{tabular}{|c|c|c|c|c|c|c|c|c|c|c|c|c|}
\hline DAY & $O C T$ & MOV & DEC & JAN & FE B & MAR & APR & MAY & JUN & JUL & AUG & SEP \\
\hline $\begin{array}{l}1 \\
2 \\
3 \\
4 \\
5\end{array}$ & $\begin{array}{l}\text { e3.0 } \\
\text { e2.9 } \\
2.9 \\
21 \\
11\end{array}$ & $\begin{array}{l}3.9 \\
3.7 \\
3.6 \\
3.6 \\
6.9\end{array}$ & $\begin{array}{r}\text { e7.0 } \\
e 5.4 \\
\text { e52 } \\
\text { e25 } \\
\text { e11 }\end{array}$ & $\begin{array}{l}\text { e } 45 \\
e 36 \\
\text { e } 30 \\
\text { e } 24 \\
\text { e20 }\end{array}$ & $\begin{aligned} e 1.8 \\
e 9.5 \\
\text { e13 } \\
\text { e12 } \\
\text { e20 }\end{aligned}$ & $\begin{array}{l}\text { e7.3 } \\
\text { e9.0 } \\
\text { e } 8.0 \\
\text { e7.5 } \\
\text { e7.0 }\end{array}$ & $\begin{array}{l}\text { ell } \\
\text { el } \\
\text { el } 2 \\
\text { ell } \\
\text { el } 1\end{array}$ & $\begin{array}{l}6.1 \\
5.6 \\
5.2 \\
5.7 \\
7.1\end{array}$ & $\begin{array}{l}31 \\
12 \\
7.1 \\
5.1 \\
4.2\end{array}$ & $\begin{array}{l}1.7 \\
1.7 \\
1.6 \\
1.6 \\
1.5\end{array}$ & $\begin{array}{r}.89 \\
.86 \\
.86 \\
1.2 \\
.94\end{array}$ & $\begin{array}{r}.76 \\
.73 \\
.86 \\
1.1 \\
1.0\end{array}$ \\
\hline $\begin{array}{r}6 \\
7 \\
8 \\
9 \\
10\end{array}$ & $\begin{array}{l}6.8 \\
5.5 \\
4.8 \\
19 \\
52\end{array}$ & $\begin{array}{l}7.5 \\
4.9 \\
4.2 \\
4.4 \\
5.6\end{array}$ & $\begin{array}{l}\text { e } 8.5 \\
\text { e7.7 } \\
\text { e6.9 } \\
\text { e6.6 } \\
\text { e6.5 }\end{array}$ & $\begin{array}{l}\text { e11 } \\
\text { e14 } \\
\text { e13 } \\
\text { e12 } \\
\text { e11 }\end{array}$ & $\begin{array}{l}\text { e60 } \\
\text { e32 } \\
\text { el } 8 \\
\text { e1 } 4 \\
\text { el } 2\end{array}$ & $\begin{array}{l}\text { e6.8 } \\
\text { e6.8 } \\
\text { e6.8 } \\
\text { e6.6 } \\
\text { e6.5 }\end{array}$ & $\begin{array}{l}\text { e11 } \\
\text { e11 } \\
\text { e10 } \\
\text { e } 9.8 \\
\text { e9.6 }\end{array}$ & $\begin{array}{r}13 \\
8.4 \\
6.6 \\
6.0 \\
5.6\end{array}$ & $\begin{array}{l}3.7 \\
3.3 \\
3.2 \\
3.1 \\
2.9\end{array}$ & $\begin{array}{l}1.5 \\
1.4 \\
2.0 \\
1.7 \\
1.6\end{array}$ & $\begin{array}{r}1.0 \\
.98 \\
.98 \\
.96 \\
.90\end{array}$ & $\begin{array}{l}.83 \\
.70 \\
.65 \\
.64 \\
.60\end{array}$ \\
\hline $\begin{array}{l}11 \\
12 \\
13 \\
14 \\
15\end{array}$ & $\begin{array}{c}22 \\
13 \\
9.4 \\
7.6 \\
6.1\end{array}$ & $\begin{array}{r}4.6 \\
4.0 \\
\mathrm{e} 3.6 \\
\mathrm{e} 3.5 \\
\mathrm{e} 3.5\end{array}$ & $\begin{array}{l}\text { e6.3 } \\
\text { e6.1 } \\
\text { e5.9 } \\
\text { e5.7 } \\
\text { e30 }\end{array}$ & $\begin{array}{l}\text { e } 35 \\
\text { e24 } \\
\text { e13 } \\
\text { e11 } \\
\text { e10 }\end{array}$ & $\begin{array}{l}\text { ell } \\
\text { el } 0 \\
\text { el } 0 \\
\text { el1 } \\
\text { ell }\end{array}$ & $\begin{array}{l}\text { e6.4 } \\
\text { e } 7.0 \\
\text { e52 } \\
\text { e } 52 \\
\text { e } 52\end{array}$ & $\begin{array}{l}\text { e9.3 } \\
\text { e9.1 } \\
\text { e } 50 \\
\text { e25 } \\
\text { e1 } 8\end{array}$ & $\begin{array}{l}5.3 \\
5.2 \\
5.0 \\
4.8 \\
4.6\end{array}$ & $\begin{array}{l}2.9 \\
2.9 \\
2.8 \\
2.8 \\
2.8\end{array}$ & $\begin{array}{l}1.5 \\
1.5 \\
1.4 \\
1.3 \\
1.3\end{array}$ & $\begin{array}{l}.82 \\
.81 \\
.77 \\
.78 \\
.71\end{array}$ & $\begin{array}{l}.61 \\
.61 \\
.58 \\
.57 \\
.58\end{array}$ \\
\hline $\begin{array}{l}16 \\
17 \\
18 \\
19 \\
20\end{array}$ & $\begin{array}{r}5.2 \\
4.9 \\
14 \\
9.1 \\
7.0\end{array}$ & $\begin{array}{l}\mathrm{e} 3 \cdot 5 \\
\mathrm{e} 3 \cdot 3 \\
\mathrm{e} 3 \cdot 3 \\
\mathrm{e} 3 \cdot 3 \\
\mathrm{e} 3 \cdot 3\end{array}$ & $\begin{array}{c}e 10 \\
e 8.6 \\
e 100 \\
e 35 \\
e 14\end{array}$ & $\begin{array}{l}\text { e26 } \\
\text { e16 } \\
\text { e12 } \\
\text { e11 } \\
\text { e11 }\end{array}$ & $\begin{array}{rl} & e 8.6 \\
\mathrm{e} 8.6 \\
\mathrm{e} 20 \\
\mathrm{e} & 42 \\
\mathrm{e} 22\end{array}$ & $\begin{array}{l}\text { e27 } \\
\text { e22 } \\
\text { e } 50 \\
\text { e16 } \\
\text { e13 }\end{array}$ & $\begin{array}{r}\text { e1 } \\
\text { el } \\
\text { e1 } \\
\text { e40 } \\
22\end{array}$ & $\begin{array}{r}4.4 \\
6.4 \\
17 \\
9.7 \\
6.5\end{array}$ & $\begin{array}{l}3.2 \\
2.9 \\
2.6 \\
2.6 \\
2.6\end{array}$ & $\begin{array}{l}1.3 \\
1.3 \\
1.3 \\
1.3 \\
1.2\end{array}$ & $\begin{array}{l}.71 \\
.97 \\
1.9 \\
1.8 \\
1.6\end{array}$ & $\begin{array}{l}.73 \\
.70 \\
.75 \\
.79 \\
.70\end{array}$ \\
\hline $\begin{array}{l}21 \\
22 \\
23 \\
24 \\
25\end{array}$ & $\begin{array}{l}5.9 \\
8.3 \\
8.2 \\
6.6 \\
5.5\end{array}$ & $\begin{array}{l}\mathrm{e} 3.2 \\
\mathrm{e} 6.0 \\
\mathrm{e} 5.2 \\
\mathrm{e} 4.6 \\
\mathrm{e} 4.3\end{array}$ & $\begin{array}{l}\text { e60 } \\
\text { e35 } \\
\text { e23 } \\
\text { e16 } \\
\text { e13 }\end{array}$ & $\begin{array}{r}\text { e10 } \\
\text { e9.7 } \\
\text { e9.2 } \\
\text { e } 8.5 \\
\text { e } 8.0\end{array}$ & $\begin{array}{l}\text { e13 } \\
\text { e11 } \\
\text { e10 } \\
\text { e9.4 } \\
\text { e9.0 }\end{array}$ & $\begin{array}{r}\text { e12 } \\
\text { e110 } \\
\text { e } 45 \\
\text { e22 } \\
\text { e19 }\end{array}$ & $\begin{array}{c}15 \\
13 \\
12 \\
12 \\
9.6\end{array}$ & $\begin{array}{l}5.4 \\
5.9 \\
7.0 \\
5.1 \\
4.4\end{array}$ & $\begin{array}{l}2.6 \\
2.7 \\
2.7 \\
2.4 \\
2.4\end{array}$ & $\begin{array}{l}1.1 \\
1.1 \\
1.1 \\
1.0 \\
.99\end{array}$ & $\begin{array}{l}1.5 \\
1.4 \\
1.3 \\
1.4 \\
1.4\end{array}$ & $\begin{array}{l}.66 \\
.61 \\
.61 \\
.54 \\
.53\end{array}$ \\
\hline $\begin{array}{l}26 \\
27 \\
28 \\
29 \\
30 \\
31\end{array}$ & $\begin{array}{l}5.0 \\
4.8 \\
4.5 \\
4.1 \\
4.1 \\
4.0\end{array}$ & $\begin{array}{r}\mathrm{e} 4.0 \\
\mathrm{e} 5.6 \\
\mathrm{e} 29 \\
\mathrm{e} 20 \\
\mathrm{e} 8.6 \\
-\cdots\end{array}$ & $\begin{array}{l}\text { e12 } \\
\text { el1 } \\
\text { e10 } \\
\text { e150 } \\
\text { e300 } \\
\text { e100 }\end{array}$ & $\begin{array}{r}\text { e } 7.6 \\
\text { e } 7.3 \\
\text { e } 7.0 \\
\text { e7.5 } \\
\text { e1 } 1 \\
\text { e } 9.0\end{array}$ & $\begin{array}{r}\text { e } 8.5 \\
\text { e8.0 } \\
\text { e7.7 } \\
\ldots . . \\
\ldots . .\end{array}$ & $\begin{array}{l}\text { e } 28 \\
\text { e21 } \\
\text { e24 } \\
\text { e } 18 \\
\text { e15 } \\
\text { e14 }\end{array}$ & $\begin{array}{l}9.0 \\
8.5 \\
7.8 \\
7.6 \\
6.6 \\
-\ldots\end{array}$ & $\begin{array}{r}6.6 \\
5.7 \\
4.4 \\
8.0 \\
17 \\
8.7\end{array}$ & $\begin{array}{l}2.4 \\
2.2 \\
2.0 \\
1.9 \\
1.8 \\
\cdots-.\end{array}$ & $\begin{array}{l}.98 \\
.98 \\
.93 \\
.97 \\
.96 \\
.90\end{array}$ & $\begin{array}{l}1.3 \\
1.2 \\
1.3 \\
.93 \\
.85 \\
.93\end{array}$ & $\begin{array}{l}.51 \\
.45 \\
.46 \\
.48 \\
.51 \\
. . .\end{array}$ \\
\hline $\begin{array}{l}\text { TOTAL } \\
\text { MEAN } \\
\text { MAX } \\
\text { MIN } \\
\text { CF SM } \\
\text { IN. }\end{array}$ & $\begin{array}{r}288.2 \\
9.30 \\
52 \\
2.9 \\
.89 \\
1.03\end{array}$ & $\begin{array}{r}174.7 \\
5.82 \\
29 \\
3.2 \\
.56 \\
.62\end{array}$ & $\begin{array}{r}1088.2 \\
35.1 \\
300 \\
5.4 \\
3.38 \\
3.89\end{array}$ & $\begin{array}{r}485.8 \\
15.7 \\
45 \\
7.0 \\
1.51 \\
1.74\end{array}$ & $\begin{array}{r}428.1 \\
15.3 \\
60 \\
7.7 \\
1.47 \\
1.53\end{array}$ & $\begin{array}{r}697.7 \\
22.5 \\
110 \\
6.4 \\
2.16 \\
2.50\end{array}$ & $\begin{array}{r}420.9 \\
14.0 \\
50 \\
6.6 \\
1.35 \\
1.51\end{array}$ & $\begin{array}{r}216.4 \\
6.98 \\
17 \\
4.4 \\
.67 \\
.77\end{array}$ & $\begin{array}{c}126.8 \\
4.23 \\
31 \\
1.8 \\
.41 \\
.45\end{array}$ & $\begin{array}{c}40.71 \\
1.31 \\
2.0 \\
.90 \\
.13 \\
.15\end{array}$ & $\begin{array}{c}33.95 \\
1.10 \\
1.9 \\
.71 \\
.11 \\
.12\end{array}$ & $\begin{array}{c}19.85 \\
.66 \\
1.1 \\
.45 \\
.06 \\
.07\end{array}$ \\
\hline
\end{tabular}

STATISTICS OF MONTHLY MEAN DATA FOR WATER YEARS 1971 - 1991, BY WATER YEAR (WN)

\begin{tabular}{|c|c|c|c|c|c|c|c|c|c|c|c|c|}
\hline $\begin{array}{l}\text { MEAN } \\
\text { MAX } \\
\text { (WY) } \\
\text { MI } \\
\text { (WY) }\end{array}$ & $\begin{array}{r}4.19 \\
39.9 \\
1987 \\
.56 \\
1972\end{array}$ & $\begin{array}{r}9.10 \\
53.0 \\
1973 \\
195 \\
1972\end{array}$ & $\begin{array}{r}14.4 \\
39.7 \\
1978 \\
.51 \\
1977\end{array}$ & $\begin{array}{r}12.2 \\
33.0 \\
1975 \\
.33 \\
1977\end{array}$ & $\begin{array}{l}20.9 \\
56.0 \\
1985 \\
3.31 \\
1978\end{array}$ & $\begin{array}{l}22.1 \\
41.6 \\
1978 \\
2.58 \\
1981\end{array}$ & $\begin{array}{l}17.6 \\
38.0 \\
1989 \\
2.96 \\
1971\end{array}$ & $\begin{array}{l}12.3 \\
42.6 \\
1989 \\
1.47 \\
1988\end{array}$ & $\begin{array}{l}8.12 \\
22.4 \\
1973 \\
1.03 \\
1977\end{array}$ & $\begin{array}{r}6.15 \\
27.5 \\
1979 \\
157 \\
1977\end{array}$ & $\begin{array}{r}5.37 \\
61.5 \\
1979 \\
191 \\
1988\end{array}$ & $\begin{array}{r}3.69 \\
32.2 \\
1989 \\
.40 \\
1988\end{array}$ \\
\hline
\end{tabular}

SUMMARY STATISTICS

ANMUAL TOTAL

ANMUAL MEAN

HIGHEST ANNUAL MEAN

LOWEST ANNUAL MEAN

HIGHEST DAILY MEAN

LOWEST DAILY MEAN

ANNUAL SEVEN-DAY MINIMUM

INSTANTANEOUS PEAK FLOW

INSTANTANEOUS PEAK STAGE

ANMUAL RUNOFF (CFSM)

ANMUAL RUNOFF (INCHES)

10 PERCENT EXCEEDS

50 PERCENT EXCEEDS

90 PERCENT EXCEEDS
FOR 1990 CALENDAR YEAR

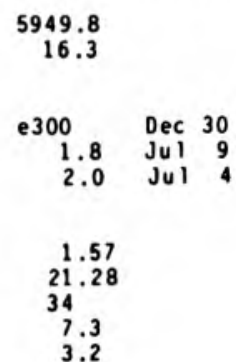

FOR 1991 WATER YEAR

4021.31
11.0

e 300 Dec 30

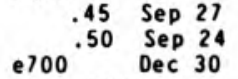

unknown

1.06

22.38

6.3

.86
WATER YEARS 1971 - 1991

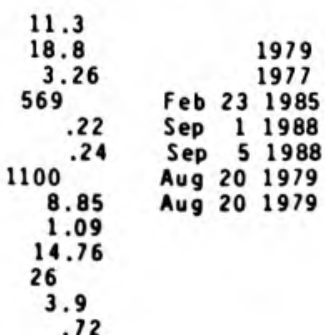




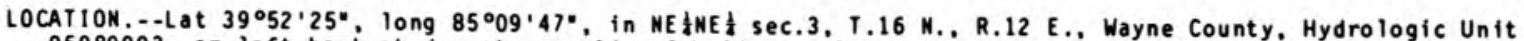

05080003 , on left bank at downstreas side of bridge on Jerry Meyers Road, 1.0 i upstrea frou Pronghorn Run. $1.5 \mathrm{~m}$ i north of Interstate $70,2.0$ i downstrea fro Nettle Creek. 2.6 i south of Hagerstown, and at eile 84.9.

DRAI NAGE AREA. $-58.7 \cdot 1^{2}$

PERIOD OF RECORD.--0 ctober 1970 to current year.

GAGE - Water-stage recorder. Datue of gage is $950.00 \mathrm{ft}$ above National Geodetic Vertical Datue of 1929 (Indiana Flood Control and Water Resources Conaission bench nark).

REMARKS. - - Records good except est inated daily discharges, which are poor.

DISCHARGE, CUBIC FEET PER SECOND, WATER YEAR OCTOBER 1990 TO SEPTEMBER 1991 DAI IY MEAN VALUES

\begin{tabular}{|c|c|c|c|c|c|c|c|c|c|c|c|c|}
\hline DAY & $\mathrm{OCT}$ & NOV & $\mathrm{DEC}$ & JAN & FEB & MAR & APR & MAY & JUN & JUL & AUG & SEP \\
\hline $\begin{array}{l}1 \\
2 \\
3 \\
4 \\
5\end{array}$ & $\begin{array}{l}29 \\
28 \\
29 \\
57 \\
41\end{array}$ & $\begin{array}{l}33 \\
33 \\
32 \\
32 \\
36\end{array}$ & $\begin{array}{r}47 \\
43 \\
291 \\
119 \\
75\end{array}$ & $\begin{array}{l}249 \\
203 \\
167 \\
141 \\
129\end{array}$ & $\begin{array}{r}64 \\
83 \\
107 \\
109 \\
171\end{array}$ & $\begin{array}{l}69 \\
76 \\
69 \\
67 \\
65\end{array}$ & $\begin{array}{r}116 \\
107 \\
101 \\
99 \\
103\end{array}$ & $\begin{array}{l}74 \\
71 \\
69 \\
73 \\
79\end{array}$ & $\begin{array}{r}184 \\
85 \\
72 \\
59 \\
53\end{array}$ & $\begin{array}{l}27 \\
27 \\
27 \\
26 \\
25\end{array}$ & $\begin{array}{l}17 \\
16 \\
16 \\
17 \\
16\end{array}$ & $\begin{array}{r}\text { e13 } \\
e 12 \\
25 \\
21 \\
19\end{array}$ \\
\hline $\begin{array}{r}6 \\
7 \\
8 \\
9 \\
10\end{array}$ & $\begin{array}{r}35 \\
33 \\
32 \\
52 \\
161\end{array}$ & $\begin{array}{l}40 \\
35 \\
33 \\
34 \\
35\end{array}$ & $\begin{array}{l}64 \\
58 \\
55 \\
52 \\
51\end{array}$ & $\begin{array}{r}121 \\
111 \\
102 \\
95 \\
89\end{array}$ & $\begin{array}{l}308 \\
260 \\
140 \\
115 \\
101\end{array}$ & $\begin{array}{l}67 \\
66 \\
64 \\
63 \\
63\end{array}$ & $\begin{array}{l}98 \\
94 \\
94 \\
92 \\
87\end{array}$ & $\begin{array}{r}108 \\
80 \\
72 \\
69 \\
67\end{array}$ & $\begin{array}{l}48 \\
46 \\
44 \\
44 \\
43\end{array}$ & $\begin{array}{l}24 \\
23 \\
36 \\
27 \\
32\end{array}$ & $\begin{array}{l}19 \\
19 \\
19 \\
19 \\
18\end{array}$ & $\begin{array}{l}\text { e17 } \\
\text { e15 } \\
\text { e14 } \\
\text { e13 } \\
\text { e12 }\end{array}$ \\
\hline $\begin{array}{l}11 \\
12 \\
13 \\
14 \\
15\end{array}$ & $\begin{array}{l}76 \\
53 \\
46 \\
43 \\
40\end{array}$ & $\begin{array}{l}34 \\
33 \\
32 \\
32 \\
31\end{array}$ & $\begin{array}{r}49 \\
48 \\
47 \\
46 \\
169\end{array}$ & $\begin{array}{r}195 \\
169 \\
111 \\
97 \\
95\end{array}$ & $\begin{array}{l}90 \\
83 \\
84 \\
91 \\
78\end{array}$ & $\begin{array}{r}62 \\
63 \\
294 \\
296 \\
297\end{array}$ & $\begin{array}{r}83 \\
80 \\
204 \\
220 \\
165\end{array}$ & $\begin{array}{l}65 \\
61 \\
60 \\
58 \\
56\end{array}$ & $\begin{array}{l}42 \\
44 \\
41 \\
40 \\
39\end{array}$ & $\begin{array}{l}27 \\
28 \\
26 \\
24 \\
23\end{array}$ & $\begin{array}{l}17 \\
17 \\
17 \\
17 \\
17\end{array}$ & $\begin{array}{l}\text { e12 } \\
\text { e12 } \\
\text { e17 } \\
\text { e15 } \\
\text { e14 }\end{array}$ \\
\hline $\begin{array}{l}16 \\
17 \\
18 \\
19 \\
20\end{array}$ & $\begin{array}{l}38 \\
36 \\
62 \\
47 \\
42\end{array}$ & $\begin{array}{l}31 \\
31 \\
31 \\
31 \\
31\end{array}$ & $\begin{array}{r}83 \\
73 \\
521 \\
238 \\
116\end{array}$ & $\begin{array}{r}150 \\
130 \\
101 \\
93 \\
93\end{array}$ & $\begin{array}{r}72 \\
71 \\
165 \\
241 \\
178\end{array}$ & $\begin{array}{l}240 \\
193 \\
281 \\
142 \\
116\end{array}$ & $\begin{array}{r}122 \\
103 \\
95 \\
141 \\
142\end{array}$ & $\begin{array}{l}55 \\
54 \\
96 \\
65 \\
55\end{array}$ & $\begin{array}{l}41 \\
39 \\
38 \\
36 \\
35\end{array}$ & $\begin{array}{l}23 \\
22 \\
21 \\
21 \\
21\end{array}$ & $\begin{array}{r}16 \\
20 \\
21 \\
\mathrm{e} 20 \\
18\end{array}$ & $\begin{array}{l}\text { e13 } \\
\text { e13 } \\
\text { e12 } \\
\text { e12 } \\
\text { e12 }\end{array}$ \\
\hline $\begin{array}{l}21 \\
22 \\
23 \\
24 \\
25\end{array}$ & $\begin{array}{l}39 \\
42 \\
43 \\
40 \\
38\end{array}$ & $\begin{array}{l}31 \\
42 \\
43 \\
37 \\
35\end{array}$ & $\begin{array}{r}278 \\
247 \\
178 \\
111 \\
87\end{array}$ & $\begin{array}{r}88 \\
\text { e } 78 \\
\text { e72 } \\
\text { e67 } \\
\text { e63 }\end{array}$ & $\begin{array}{r}116 \\
97 \\
86 \\
83 \\
77\end{array}$ & $\begin{array}{l}104 \\
553 \\
455 \\
203 \\
168\end{array}$ & $\begin{array}{r}110 \\
100 \\
95 \\
102 \\
89\end{array}$ & $\begin{array}{l}49 \\
99 \\
83 \\
59 \\
52\end{array}$ & $\begin{array}{l}32 \\
31 \\
31 \\
30 \\
31\end{array}$ & $\begin{array}{l}20 \\
20 \\
20 \\
19 \\
19\end{array}$ & $\begin{array}{l}17 \\
e 16 \\
e 15 \\
e 14 \\
e 13\end{array}$ & $\begin{array}{l}\text { e12 } \\
\text { e12 } \\
\text { e14 } \\
\text { 13 } \\
\text { e12 }\end{array}$ \\
\hline $\begin{array}{l}26 \\
27 \\
28 \\
29 \\
30 \\
31\end{array}$ & $\begin{array}{l}37 \\
36 \\
35 \\
34 \\
34 \\
34\end{array}$ & $\begin{array}{r}34 \\
45 \\
165 \\
75 \\
52 \\
---\end{array}$ & $\begin{array}{r}76 \\
71 \\
70 \\
697 \\
1700 \\
446\end{array}$ & $\begin{array}{l}\text { e61 } \\
\text { e58 } \\
\text { e56 } \\
\text { e60 } \\
89 \\
70\end{array}$ & $\begin{array}{r}73 \\
70 \\
68 \\
\ldots- \\
\ldots \\
\ldots\end{array}$ & $\begin{array}{l}250 \\
203 \\
216 \\
151 \\
130 \\
122\end{array}$ & $\begin{array}{r}93 \\
88 \\
84 \\
82 \\
77 \\
\ldots\end{array}$ & $\begin{array}{r}63 \\
59 \\
50 \\
92 \\
173 \\
76\end{array}$ & $\begin{array}{l}31 \\
29 \\
29 \\
28 \\
28 \\
\cdots\end{array}$ & $\begin{array}{l}18 \\
17 \\
17 \\
19 \\
19 \\
17\end{array}$ & $\begin{array}{l}\text { e13 } \\
\text { e13 } \\
\text { e13 } \\
\text { e14 } \\
\text { e16 } \\
\text { e14 }\end{array}$ & $\begin{array}{l}\text { e12 } \\
\text { e12 } \\
\text { e11 } \\
\text { e11 } \\
\text { e11 } \\
\ldots . .\end{array}$ \\
\hline $\begin{array}{l}\text { TOTAL } \\
\text { MEAN } \\
\text { MAX } \\
\text { MIN } \\
\text { CF SM } \\
\text { IN. }\end{array}$ & $\begin{array}{r}1392 \\
44.9 \\
161 \\
28 \\
.76 \\
.88\end{array}$ & $\begin{array}{r}1219 \\
40.6 \\
165 \\
31 \\
.69 \\
.77\end{array}$ & $\begin{array}{r}6206 \\
200 \\
1700 \\
43 \\
3.41 \\
3.93\end{array}$ & $\begin{array}{r}3403 \\
110 \\
249 \\
56 \\
1.87 \\
2.16\end{array}$ & $\begin{array}{r}3281 \\
117 \\
308 \\
64 \\
2.00 \\
2.08\end{array}$ & $\begin{array}{r}5208 \\
168 \\
553 \\
62 \\
2.86 \\
3.30\end{array}$ & $\begin{array}{r}3266 \\
109 \\
220 \\
77 \\
1.85 \\
2.07\end{array}$ & $\begin{array}{r}2242 \\
72.3 \\
173 \\
49 \\
1.23 \\
1.42\end{array}$ & $\begin{array}{c}1373 \\
45.8 \\
184 \\
28 \\
.78 \\
.87\end{array}$ & $\begin{array}{r}715 \\
23.1 \\
36 \\
17 \\
.39 \\
.45\end{array}$ & $\begin{array}{r}514 \\
16.6 \\
21 \\
13 \\
.28 \\
.33\end{array}$ & $\begin{array}{c}413 \\
13.8 \\
25 \\
11 \\
.23 \\
.26\end{array}$ \\
\hline
\end{tabular}

STATISTICS OF MONTHLY MEAN DATA FOR WATER YEARS 1971 - 1991. BY WATER YEAR (WY)

\begin{tabular}{|c|c|c|c|c|c|c|c|c|c|c|}
\hline $\begin{array}{l}\text { MEAN } \\
\text { MAX } \\
\text { (WY) } \\
\text { MI } N \\
\text { (WY) }\end{array}$ & $\begin{array}{r}30.6 \\
188 \\
1987 \\
11.6 \\
1977\end{array}$ & $\begin{array}{r}50.4 \\
230 \\
1973 \\
12.1 \\
1977\end{array}$ & $\begin{array}{r}79.3 \\
205 \\
1978 \\
12.0\end{array}$ & $\begin{array}{r}71.1 \\
170 \\
1975 \\
8.48\end{array}$ & $\begin{array}{r}110 \\
233 \\
1975 \\
29.4\end{array}$ & $\begin{array}{r}121 \\
224 \\
1973 \\
25.6\end{array}$ & $\begin{array}{r}107 \\
189 \\
1972 \\
28.0 \\
1971\end{array}$ & $\begin{array}{r}81.7 \\
196 \\
1990 \\
23.0 \\
1988\end{array}$ & $\begin{array}{r}54.9 \\
114 \\
1980 \\
14.6 \\
1977\end{array}$ & \\
\hline
\end{tabular}

SUMMARY STATISTICS

ANNUAL TOTAL

ANNUAL MEAN

HI GHEST ANNUAL MEAM

LOWEST ANNUAL MEAM

HIGHEST DAILY MEAM

LOWEST DAILY MEAN

ANNUAL SEVEN-DAY MI NIMUM

INSTANTANEOUS PEAK FLOW

INSTANTANEOUS PEAK STAGE

ANNUAL RUNOFF (CFSM)

ANNUAL RUNOFF (INCHES)

10 PERCENT EXCEEDS

50 PERCENT EXCEEDS

90 PERCENT EXCEEDS
FOR 1990 CALENDAR YEAR

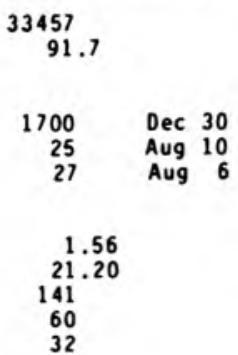

FOR 1991 WATER YEAR

29232

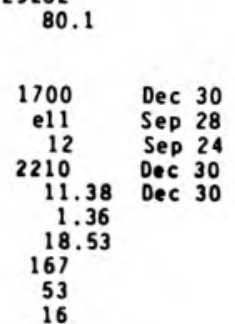

WATER YEARS 1971 - 1991

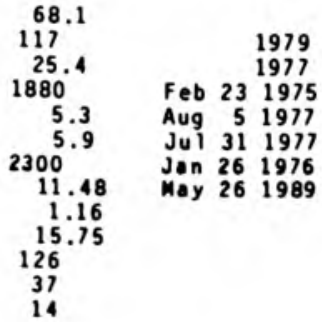




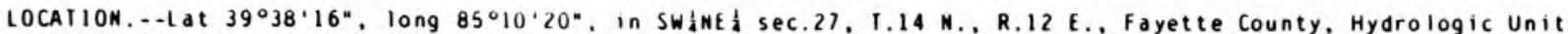
05080003 , On downstrea left bank wingwall of bridge on State Highway 44 , 1 i west of Connersville. and 2.6 ei upstrean frov outh.

DRAI NAGE AREA. .-9.16 $i^{2}$

PERIOD OF RECORD.--Septenber 1968 to current year.

GAGE. - Water-stage recorder. Datuo of gage is $842.00 \mathrm{ft}$ above National Geodetic Vertical Datua of 1929.

REMARKS. - Records fair except for estiaded daily discharges. which are poor. Peak flows affected by ponding at abandoned railroad culvert 0.5 i upstrean.

DISCHARGE, CUBIC FEET PER SECONO, WAIER YEAR OCTOBER 1990 TO SEPIEMBER 1991 DAII MEAN VALUES

\begin{tabular}{|c|c|c|c|c|c|c|c|c|c|c|c|c|}
\hline DAY & $O C \mathrm{~T}$ & NOV & DEC & JAN & FE B & MAR & APR & MAY & JUN & JUL & AUG & SEP \\
\hline $\begin{array}{l}1 \\
2 \\
3 \\
4 \\
5\end{array}$ & $\begin{array}{r}\mathrm{e} 3.0 \\
\mathrm{e} 2.8 \\
\mathrm{e} 2.7 \\
7.2 \\
4.0\end{array}$ & $\begin{array}{l}\text { e } 4.8 \\
\text { e } 4.8 \\
\text { e } 4.8 \\
\text { e } 4.7 \\
\text { e6.0 }\end{array}$ & $\begin{array}{r}4.5 \\
4.4 \\
22 \\
9.8 \\
7.7\end{array}$ & $\begin{array}{l}24 \\
20 \\
17 \\
15 \\
15\end{array}$ & $\begin{array}{l}\text { e9.0 } \\
10 \\
10 \\
10 \\
12\end{array}$ & $\begin{array}{l}10 \\
11 \\
9.7 \\
9.5 \\
9.2\end{array}$ & $\begin{array}{l}12 \\
12 \\
11 \\
11 \\
12\end{array}$ & $\begin{array}{l}8.5 \\
8.1 \\
7.7 \\
7.8 \\
8.3\end{array}$ & $\begin{array}{l}6.4 \\
5.9 \\
5.7 \\
5.2 \\
4.9\end{array}$ & $\begin{array}{l}1.8 \\
1.5 \\
1.6 \\
2.0 \\
1.8\end{array}$ & $\begin{array}{l}.64 \\
.59 \\
.59 \\
.89 \\
.61\end{array}$ & $\begin{array}{l}1.0 \\
.85 \\
2.5 \\
2.9 \\
1.0\end{array}$ \\
\hline $\begin{array}{r}6 \\
7 \\
8 \\
9 \\
10\end{array}$ & $\begin{array}{l}3.4 \\
3.3 \\
3.3 \\
33 \\
26\end{array}$ & $\begin{array}{l}\text { e5.6 } \\
\text { e5.2 } \\
\text { e4.8 } \\
\text { e5.0 } \\
\text { e5.6 }\end{array}$ & $\begin{array}{l}6.9 \\
6.1 \\
5.6 \\
5.3 \\
5.2\end{array}$ & $\begin{array}{l}16 \\
15 \\
14 \\
13 \\
13\end{array}$ & $\begin{array}{l}45 \\
28 \\
17 \\
14 \\
13\end{array}$ & $\begin{array}{l}9.9 \\
9.4 \\
9.1 \\
9.0 \\
8.9\end{array}$ & $\begin{array}{l}11 \\
11 \\
11 \\
13 \\
12\end{array}$ & $\begin{array}{l}8.3 \\
7.4 \\
6.9 \\
6.9 \\
6.6\end{array}$ & $\begin{array}{l}4.8 \\
4.6 \\
4.4 \\
4.0 \\
3.6\end{array}$ & $\begin{array}{l}1.7 \\
1.6 \\
8.9 \\
2.6 \\
2.5\end{array}$ & $\begin{array}{l}1.2 \\
1.2 \\
.96 \\
1.3 \\
1.2\end{array}$ & $\begin{array}{l}.77 \\
.67 \\
.53 \\
.50 \\
.55\end{array}$ \\
\hline $\begin{array}{l}11 \\
12 \\
13 \\
14 \\
15\end{array}$ & $\begin{array}{r}9.6 \\
7.6 \\
6.8 \\
\mathrm{e} 6.2 \\
\mathrm{e} 5.8\end{array}$ & $\begin{array}{r}\text { e4.9 } \\
\text { e4.8 } \\
\text { e4.7 } \\
\text { e4.6 } \\
4.4\end{array}$ & $\begin{array}{r}5.0 \\
4.9 \\
4.8 \\
4.6 \\
21\end{array}$ & $\begin{array}{l}36 \\
22 \\
15 \\
14 \\
14\end{array}$ & $\begin{array}{l}11 \\
11 \\
12 \\
13 \\
11\end{array}$ & $\begin{array}{c}8.8 \\
11 \\
119 \\
38 \\
21\end{array}$ & $\begin{array}{l}11 \\
11 \\
39 \\
38 \\
17\end{array}$ & $\begin{array}{l}6.4 \\
6.2 \\
6.1 \\
6.6 \\
6.1\end{array}$ & $\begin{array}{l}3.9 \\
4.3 \\
3.6 \\
3.3 \\
3.2\end{array}$ & $\begin{array}{l}1.9 \\
2.4 \\
2.0 \\
1.6 \\
1.4\end{array}$ & $\begin{array}{l}.95 \\
.73 \\
.64 \\
.65 \\
.60\end{array}$ & $\begin{array}{l}.48 \\
.44 \\
1.2 \\
1.3 \\
.78\end{array}$ \\
\hline $\begin{array}{l}16 \\
17 \\
18 \\
19 \\
20\end{array}$ & $\begin{array}{r}\text { e5. } 5 \\
\text { e5.2 } \\
11 \\
6.9 \\
\text { e6.2 }\end{array}$ & $\begin{array}{l}4.4 \\
4.4 \\
4.4 \\
4.4 \\
4.3\end{array}$ & $\begin{array}{c}8.3 \\
21 \\
159 \\
27 \\
16\end{array}$ & $\begin{array}{l}18 \\
16 \\
14 \\
13 \\
13\end{array}$ & $\begin{array}{l}10 \\
10 \\
19 \\
23 \\
18\end{array}$ & $\begin{array}{l}16 \\
21 \\
31 \\
17 \\
14\end{array}$ & $\begin{array}{l}14 \\
12 \\
12 \\
14 \\
13\end{array}$ & $\begin{array}{r}6.5 \\
6.3 \\
132 \\
18 \\
14\end{array}$ & $\begin{array}{l}3.8 \\
3.3 \\
3.0 \\
2.6 \\
2.6\end{array}$ & $\begin{array}{l}1.2 \\
1.1 \\
1.1 \\
1.1 \\
1.0\end{array}$ & $\begin{array}{r}.50 \\
.79 \\
1.4 \\
1.8 \\
1.6\end{array}$ & $\begin{array}{l}.75 \\
.75 \\
.77 \\
.18 \\
.71\end{array}$ \\
\hline $\begin{array}{l}21 \\
22 \\
23 \\
24 \\
25\end{array}$ & $\begin{array}{l}\text { e5.6 } \\
\text { e6.4 } \\
\text { e6.1 } \\
\text { e5.8 } \\
\text { e5.6 }\end{array}$ & $\begin{array}{l}4.3 \\
6.6 \\
5.0 \\
4.4 \\
4.3\end{array}$ & $\begin{array}{l}48 \\
31 \\
50 \\
17 \\
14\end{array}$ & $\begin{array}{r}12 \\
11 \\
\mathrm{e} 10 \\
\mathrm{e} 9.5 \\
\mathrm{e} 9.0\end{array}$ & $\begin{array}{l}15 \\
13 \\
12 \\
11 \\
11\end{array}$ & $\begin{array}{r}13 \\
124 \\
49 \\
19 \\
16\end{array}$ & $\begin{array}{l}12 \\
11 \\
11 \\
10 \\
9.8\end{array}$ & $\begin{array}{l}12 \\
11 \\
10 \\
9.5 \\
9.2\end{array}$ & $\begin{array}{l}2.4 \\
2.4 \\
2.4 \\
2.2 \\
2.0\end{array}$ & $\begin{array}{l}.98 \\
.98 \\
.94 \\
.92 \\
.93\end{array}$ & $\begin{array}{l}1.1 \\
.85 \\
.64 \\
.66 \\
.62\end{array}$ & $\begin{array}{l}.68 \\
.73 \\
.82 \\
.72 \\
.70\end{array}$ \\
\hline $\begin{array}{l}26 \\
27 \\
28 \\
29 \\
30 \\
31\end{array}$ & $\begin{array}{l}\text { e5. } \\
\text { e5. } \\
\text { e5.2 } \\
\text { e5.1 } \\
\text { e5.0 } \\
\text { e } 4.9\end{array}$ & $\begin{array}{l}4.2 \\
4.2 \\
7.7 \\
5.4 \\
4.7 \\
\ldots . .\end{array}$ & $\begin{array}{r}12 \\
11 \\
\mathrm{e} 10 \\
96 \\
410 \\
38\end{array}$ & $\begin{array}{c}e 8.5 \\
e 8.2 \\
e 7.8 \\
e 8.4 \\
13 \\
9.5\end{array}$ & $\begin{array}{c}10 \\
9.9 \\
9.8 \\
\ldots . \\
\ldots . \\
\ldots\end{array}$ & $\begin{array}{l}38 \\
22 \\
16 \\
14 \\
13 \\
13\end{array}$ & $\begin{array}{l}9.9 \\
9.6 \\
9.4 \\
9.2 \\
8.8 \\
\ldots . .\end{array}$ & $\begin{array}{r}32 \\
11 \\
8.8 \\
8.3 \\
8.2 \\
7.1\end{array}$ & $\begin{array}{l}2.0 \\
1.9 \\
1.7 \\
1.8 \\
1.7 \\
\cdots\end{array}$ & $\begin{array}{l}.86 \\
.90 \\
.88 \\
.79 \\
.81 \\
.71\end{array}$ & $\begin{array}{l}.56 \\
.52 \\
.85 \\
.78 \\
2.5 \\
1.5\end{array}$ & $\begin{array}{l}.61 \\
.57 \\
.52 \\
.54 \\
.50 \\
. . .\end{array}$ \\
\hline $\begin{array}{l}\text { IOIAL } \\
\text { MEAN } \\
\text { MAX } \\
\text { MIN } \\
\text { CF SM } \\
\text { IN. }\end{array}$ & $\begin{array}{r}219.9 \\
7.09 \\
33 \\
2.7 \\
.77 \\
.89\end{array}$ & $\begin{array}{r}147.4 \\
4.91 \\
i .7 \\
4.2 \\
.54 \\
.60\end{array}$ & $\begin{array}{r}1086.1 \\
35.0 \\
410 \\
4.4 \\
3.82 \\
4.41\end{array}$ & $\begin{array}{r}443.9 \\
14.3 \\
36 \\
1.8 \\
1.56 \\
1.80\end{array}$ & $\begin{array}{r}391.7 \\
14.2 \\
45 \\
9.0 \\
1.55 \\
1.62\end{array}$ & $\begin{array}{r}729.5 \\
23.5 \\
124 \\
8.8 \\
2.57 \\
2.96\end{array}$ & $\begin{array}{r}391.1 \\
13.3 \\
39 \\
8.8 \\
1.45 \\
1.62\end{array}$ & $\begin{array}{r}412.4 \\
13.3 \\
132 \\
6.1 \\
1.45 \\
1.67\end{array}$ & $\begin{array}{c}103.6 \\
3.45 \\
6.4 \\
1.7 \\
.38 \\
.42\end{array}$ & $\begin{array}{c}50.50 \\
1.63 \\
8.9 \\
.71 \\
.18 \\
.21\end{array}$ & $\begin{array}{c}29.42 \\
.95 \\
2.5 \\
.50 \\
.10 \\
.12\end{array}$ & $\begin{array}{r}25.62 \\
.85 \\
2.9 \\
.44 \\
.09 \\
.10\end{array}$ \\
\hline
\end{tabular}

e Estinated

STATISTICS OF MONTHIY MEAN DATA FOR WAIER YEARS 1969 - 1991, BY WAIER YEAR (WY)

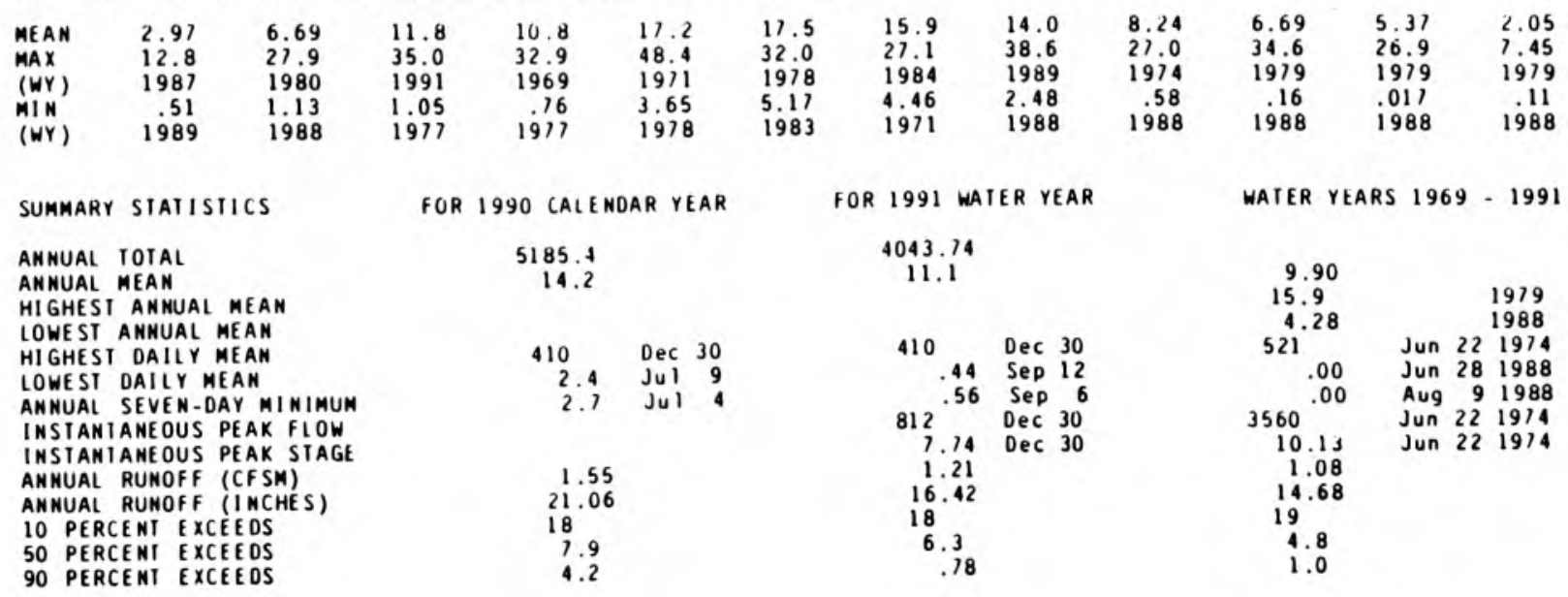


03275000 WHIIEWATER RIVER NEAR ALPINE, IN

(National stream-quality accounting network station)

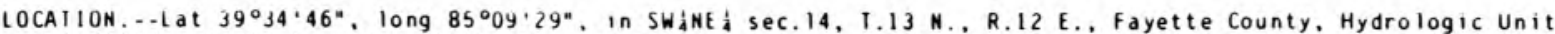

05080003 , on right bank at Nulltown. $400 \mathrm{ft}$ upstrea fro Wilson Creek, 0.4 i upstrea from bridge on County Road 480 South, $2.0 \mathrm{i}$ northedst of Alpine, $5.1 \mathrm{mi}$ upstrea from Bear Creek, and at aile 54.8 .

DRAINAGE AREA. $--522 \mathrm{mi}^{2}$

\section{WAIER-DISCHARGE RECORDS}

PERIOD OF RECORD.--0ctober 1928 to current yedr. Prior to October 1936, published as West Fork Whitewater River near Alpine.

REVISED RECORDS.--WSP 1143: 1943-44(M), 1947 (M). WSP 1335: 1929-30, 1932(M), 1938, 1946-47(m), 1949-50. WSP 1505: 1942(P). WSP 1908: 1937(M), 1944, 1949(M), drainage area. WDR IN-79-1: ig75 (P).

GAGE. - Water-stage recorder and crest-stage gage. Datum of gage is $750.19 \mathrm{ft}$ above National Geodetic Vertical Datum of 1929. Prior to Nov. 9, 1928, nonrecording gage and Nov. 10, 1928, to Sept. 30, 1982, at site 0.5 i downstrean at same datum.

REMARKS. - Records good.

DISCHARGE, CUBIC FEET PER SECOND, WAIER YEAR OCTOBER 1990 TO SEPIEMBER 1991 DAI IY MEAN VALUES

\begin{tabular}{|c|c|c|c|c|c|c|c|c|c|c|c|c|}
\hline DAY & $O C \mathrm{~T}$ & NOV & DE $C$ & JAN & $F E B$ & MAR & $A P R$ & MAY & JUN & JUL & AUG & SEP \\
\hline $\begin{array}{l}1 \\
2 \\
3 \\
4 \\
5\end{array}$ & $\begin{array}{l}243 \\
234 \\
232 \\
429 \\
526\end{array}$ & $\begin{array}{l}318 \\
307 \\
299 \\
298 \\
315\end{array}$ & $\begin{array}{r}547 \\
479 \\
1490 \\
2450 \\
1080\end{array}$ & $\begin{array}{l}3870 \\
2580 \\
1990 \\
1590 \\
1390\end{array}$ & $\begin{array}{r}653 \\
676 \\
842 \\
885 \\
1040\end{array}$ & $\begin{array}{l}596 \\
622 \\
593 \\
561 \\
543\end{array}$ & $\begin{array}{l}969 \\
892 \\
842 \\
825 \\
832\end{array}$ & $\begin{array}{l}558 \\
532 \\
518 \\
521 \\
544\end{array}$ & $\begin{array}{l}728 \\
598 \\
543 \\
454 \\
400\end{array}$ & $\begin{array}{l}222 \\
212 \\
207 \\
203 \\
203\end{array}$ & $\begin{array}{l}129 \\
127 \\
123 \\
126 \\
122\end{array}$ & $\begin{array}{l}109 \\
104 \\
110 \\
323 \\
179\end{array}$ \\
\hline $\begin{array}{r}6 \\
7 \\
8 \\
9 \\
10\end{array}$ & $\begin{array}{r}392 \\
330 \\
308 \\
791 \\
2000\end{array}$ & $\begin{array}{l}349 \\
340 \\
307 \\
305 \\
334\end{array}$ & $\begin{array}{l}811 \\
665 \\
585 \\
532 \\
496\end{array}$ & $\begin{array}{r}1290 \\
1150 \\
1030 \\
959 \\
903\end{array}$ & $\begin{array}{r}2530 \\
3560 \\
1800 \\
1240 \\
985\end{array}$ & $\begin{array}{l}542 \\
544 \\
513 \\
497 \\
490\end{array}$ & $\begin{array}{l}792 \\
752 \\
764 \\
853 \\
799\end{array}$ & $\begin{array}{l}686 \\
650 \\
557 \\
523 \\
500\end{array}$ & $\begin{array}{l}376 \\
350 \\
342 \\
339 \\
323\end{array}$ & $\begin{array}{l}199 \\
193 \\
277 \\
268 \\
242\end{array}$ & $\begin{array}{l}137 \\
138 \\
133 \\
144 \\
137\end{array}$ & $\begin{array}{l}149 \\
134 \\
124 \\
119 \\
119\end{array}$ \\
\hline $\begin{array}{l}11 \\
12 \\
13 \\
14 \\
15\end{array}$ & $\begin{array}{r}1700 \\
972 \\
736 \\
606 \\
523\end{array}$ & $\begin{array}{l}328 \\
308 \\
294 \\
288 \\
275\end{array}$ & $\begin{array}{r}465 \\
447 \\
422 \\
390 \\
1060\end{array}$ & $\begin{array}{l}1430 \\
2780 \\
1590 \\
1220 \\
1100\end{array}$ & $\begin{array}{l}851 \\
759 \\
742 \\
816 \\
740\end{array}$ & $\begin{array}{r}471 \\
500 \\
3360 \\
3820 \\
3150\end{array}$ & $\begin{array}{r}701 \\
663 \\
1690 \\
2510 \\
1830\end{array}$ & $\begin{array}{l}481 \\
465 \\
446 \\
457 \\
488\end{array}$ & $\begin{array}{l}319 \\
340 \\
314 \\
306 \\
298\end{array}$ & $\begin{array}{l}234 \\
232 \\
232 \\
212 \\
203\end{array}$ & $\begin{array}{l}134 \\
129 \\
117 \\
120 \\
124\end{array}$ & $\begin{array}{l}114 \\
114 \\
127 \\
134 \\
114\end{array}$ \\
\hline $\begin{array}{l}16 \\
17 \\
18 \\
19 \\
20\end{array}$ & $\begin{array}{l}463 \\
423 \\
635 \\
194 \\
595\end{array}$ & $\begin{array}{l}269 \\
263 \\
262 \\
262 \\
260\end{array}$ & $\begin{array}{r}1400 \\
993 \\
4960 \\
6600 \\
2260\end{array}$ & $\begin{array}{r}1460 \\
1710 \\
1300 \\
1060 \\
980\end{array}$ & $\begin{array}{r}628 \\
651 \\
813 \\
2510 \\
2260\end{array}$ & $\begin{array}{l}2580 \\
2000 \\
3270 \\
1960 \\
1350\end{array}$ & $\begin{array}{r}1340 \\
1020 \\
864 \\
949 \\
1350\end{array}$ & $\begin{array}{r}444 \\
505 \\
2940 \\
1230 \\
765\end{array}$ & $\begin{array}{l}306 \\
303 \\
283 \\
276 \\
273\end{array}$ & $\begin{array}{l}187 \\
178 \\
167 \\
161 \\
160\end{array}$ & $\begin{array}{l}119 \\
124 \\
178 \\
166 \\
156\end{array}$ & $\begin{array}{l}112 \\
107 \\
106 \\
106 \\
106\end{array}$ \\
\hline $\begin{array}{l}21 \\
22 \\
23 \\
24 \\
25\end{array}$ & $\begin{array}{l}518 \\
514 \\
542 \\
505 \\
451\end{array}$ & $\begin{array}{l}249 \\
332 \\
498 \\
440 \\
379\end{array}$ & $\begin{array}{l}2200 \\
4440 \\
3380 \\
2040 \\
1300\end{array}$ & $\begin{array}{l}940 \\
838 \\
804 \\
761 \\
683\end{array}$ & $\begin{array}{r}1380 \\
1010 \\
843 \\
771 \\
710\end{array}$ & $\begin{array}{l}1110 \\
4760 \\
7430 \\
2770 \\
1740\end{array}$ & $\begin{array}{r}1050 \\
896 \\
799 \\
779 \\
729\end{array}$ & $\begin{array}{l}603 \\
609 \\
902 \\
600 \\
517\end{array}$ & $\begin{array}{l}262 \\
265 \\
293 \\
293 \\
270\end{array}$ & $\begin{array}{l}155 \\
152 \\
146 \\
142 \\
142\end{array}$ & $\begin{array}{l}139 \\
133 \\
127 \\
117 \\
113\end{array}$ & $\begin{array}{l}102 \\
104 \\
114 \\
111 \\
109\end{array}$ \\
\hline $\begin{array}{l}26 \\
27 \\
28 \\
29 \\
30 \\
31\end{array}$ & $\begin{array}{l}415 \\
391 \\
374 \\
353 \\
336 \\
332\end{array}$ & $\begin{array}{r}344 \\
337 \\
694 \\
1040 \\
662 \\
\ldots\end{array}$ & $\begin{array}{r}1020 \\
846 \\
801 \\
3500 \\
15400 \\
15400\end{array}$ & $\begin{array}{l}676 \\
649 \\
651 \\
623 \\
778 \\
735\end{array}$ & $\begin{array}{l}659 \\
633 \\
612 \\
\cdots \\
\cdots \\
\cdots\end{array}$ & $\begin{array}{l}2270 \\
2580 \\
1900 \\
1440 \\
1170 \\
1030\end{array}$ & $\begin{array}{l}698 \\
686 \\
649 \\
626 \\
592 \\
\ldots\end{array}$ & $\begin{array}{l}722 \\
787 \\
572 \\
503 \\
726 \\
550\end{array}$ & $\begin{array}{l}262 \\
249 \\
238 \\
232 \\
229 \\
\cdots-\end{array}$ & $\begin{array}{l}138 \\
136 \\
136 \\
133 \\
134 \\
132\end{array}$ & $\begin{array}{l}111 \\
109 \\
111 \\
109 \\
126 \\
113\end{array}$ & $\begin{array}{r}104 \\
102 \\
98 \\
97 \\
99 \\
-\cdots\end{array}$ \\
\hline $\begin{array}{l}\text { IOIAL } \\
\text { MEAN } \\
\text { MAX } \\
\text { MIN } \\
\text { CF SM } \\
\text { IN. }\end{array}$ & $\begin{array}{r}17663 \\
570 \\
2000 \\
232 \\
1.09 \\
1.26\end{array}$ & $\begin{array}{r}10956 \\
365 \\
1040 \\
249 \\
.70 \\
.78\end{array}$ & $\begin{array}{r}78459 \\
2531 \\
15400 \\
390 \\
4.85 \\
5.59\end{array}$ & $\begin{array}{r}39520 \\
1275 \\
3870 \\
623 \\
2.44 \\
2.82\end{array}$ & $\begin{array}{r}31599 \\
1129 \\
3560 \\
612 \\
2.16 \\
2.25\end{array}$ & $\begin{array}{r}56162 \\
1812 \\
7430 \\
471 \\
3.47 \\
4.00\end{array}$ & $\begin{array}{r}28741 \\
958 \\
2510 \\
592 \\
1.84 \\
2.05\end{array}$ & $\begin{array}{r}20901 \\
674 \\
2940 \\
444 \\
1.29 \\
1.49\end{array}$ & $\begin{array}{c}10064 \\
335 \\
728 \\
229 \\
.64 \\
.72\end{array}$ & $\begin{array}{l}5738 \\
185 \\
277 \\
132 \\
.35 \\
.41\end{array}$ & $\begin{array}{l}3991 \\
129 \\
178 \\
109 \\
.25 \\
.28\end{array}$ & $\begin{array}{l}3650 \\
122 \\
323 \\
97 \\
.23 \\
.26\end{array}$ \\
\hline
\end{tabular}

SIATISIICS OF MONIHLY MEAN DATA FOR WAIER YEARS 1929 - 1991, BY WATER YEAR (WY)

\begin{tabular}{|c|c|c|c|c|c|c|c|c|c|c|c|c|}
\hline $\begin{array}{l}\text { MEAN } \\
\text { MAX } \\
\text { (WY) } \\
\text { MIN } \\
(W Y)\end{array}$ & $\begin{array}{r}189 \\
1685 \\
1987 \\
47.1 \\
1935\end{array}$ & $\begin{array}{r}332 \\
1536 \\
1973 \\
49.8 \\
1935\end{array}$ & $\begin{array}{r}555 \\
2531 \\
1991 \\
50.6 \\
1935\end{array}$ & $\begin{array}{r}813 \\
4409 \\
1937 \\
58.9 \\
1935\end{array}$ & $\begin{array}{r}893 \\
2639 \\
1950 \\
56.9 \\
1935\end{array}$ & $\begin{array}{r}1023 \\
2522 \\
1963 \\
120 \\
1935\end{array}$ & $\begin{array}{r}964 \\
2359 \\
1964 \\
122 \\
1941\end{array}$ & $\begin{array}{l}722 \\
2253 \\
1933 \\
70.0 \\
1941\end{array}$ & $\begin{array}{r}485 \\
2314 \\
1958 \\
68.9 \\
1934\end{array}$ & $\begin{array}{l}352 \\
1777 \\
1979 \\
61.1 \\
1934\end{array}$ & $\begin{array}{l}245 \\
2342 \\
1979 \\
61.3 \\
1988\end{array}$ & $\begin{array}{r}178 \\
920 \\
1989 \\
50.3 \\
1934\end{array}$ \\
\hline
\end{tabular}

SUMMARY SIATISTICS

ANMUAL TOTAL

ANMUAL MEAN

HIGHESI ANNUAL MEAM

LOWESI ANNUAL MEAN

HIGHESI DAILY MEAN

LOWEST DAILY MEAN

ANNUAL SEVEN-DAY MINIMUM

INSIANIANEOUS PEAK FIOW

INSIANTANEOUS PEAK SIAGE

ANNUAL RUNOFF (CFSM)

ANNUAL RUNOFF (I NCHES)

10 PERCENT EXCEEDS

50 PERCENT EXCEEDS

90 PERCENT EXCEEDS
FOR 1990 CAIENDAR YEAR

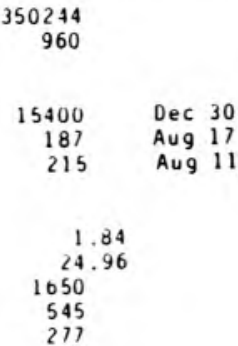

FOR 1991 WAIER YEAR

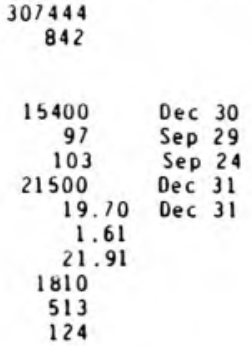

WAIER YEARS $1929-1991$

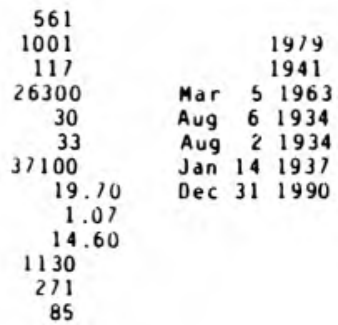


PERIOD OF RE CORO.-

CHEMICAL ANALYSIS: OCtober 1980 to current year.

SEDIMENT DISCHARGE: July 1968 to SEDtenber 1976. October 1986 to current year (partial-record station).

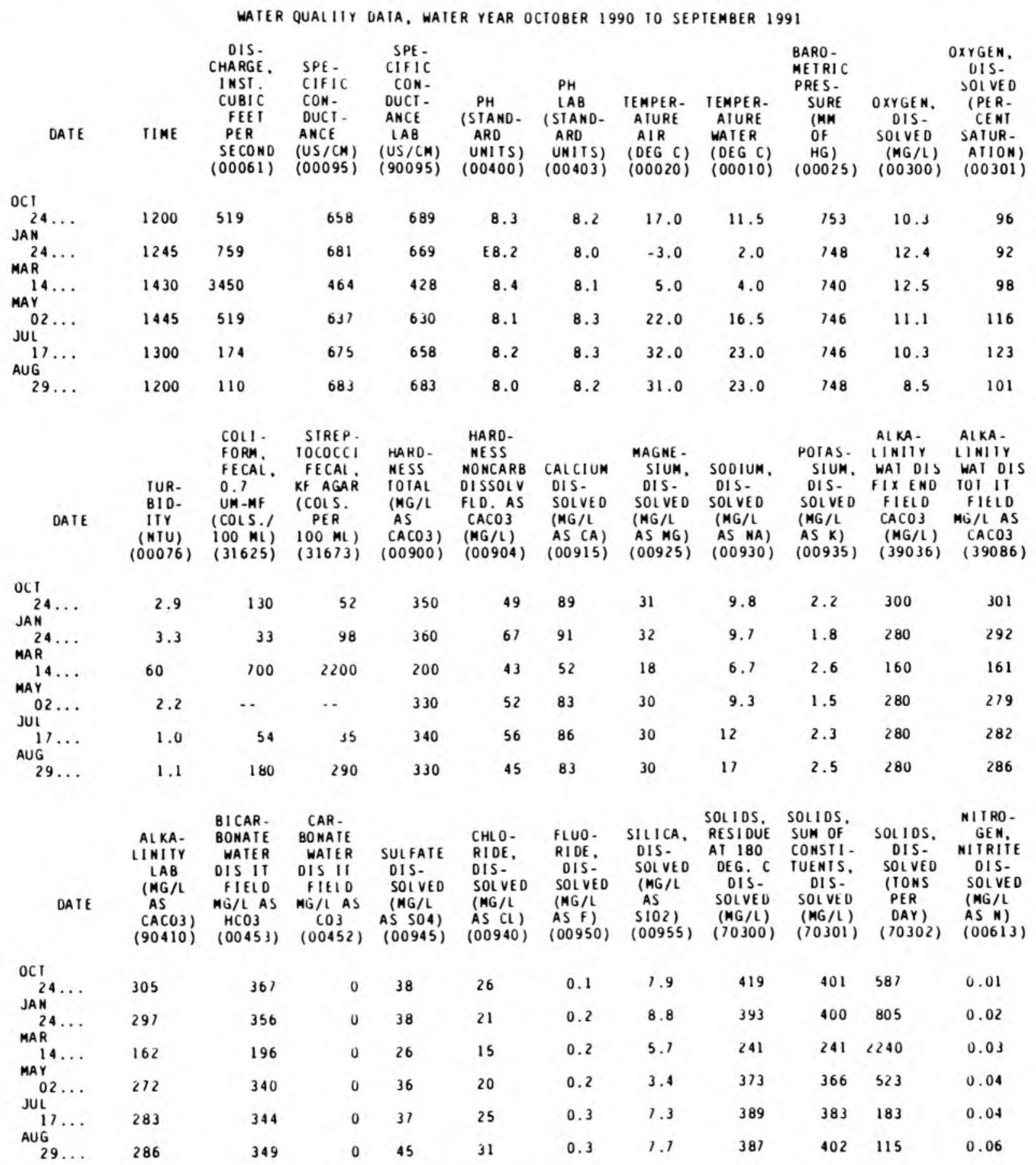


03275000 WHIIEWAIER RIVER NEAR ALPINE, IN -- Cont inued

(National strea-quality accounting network station)

WAIER QUALITY DATA, WATER YEAR OCTOBER 1990 TO SEPTEMBER 1991

NITRO- NITRO-

GEN, NITRO- GEN, GEN,AM-

GEN, NITRO- GEN, GEN,AM-
NO2+NO3 GEN, AMMONIA MONIA + PHOS- PHORUS PHORUS

AMMONIA DIS- ORGANIC PHORUS PHORUS ORTHO, INUM, ARSENIC BARIUM, DIS-

SOLVED TOTAL SOLVED TOIAL TOTAL SOLVED SOLVED SOLVED SOLVED SOLVED

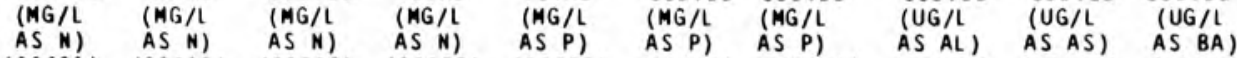

$\begin{array}{lllllllllllll}(00631) & (00610) & (00608) & (00625) & (00665) & (00666) & (00671) & (01106) & (01000) & (01005)\end{array}$

$O C$

\begin{tabular}{|c|c|c|c|c|c|c|c|c|c|c|}
\hline${ }_{\text {JAN }}^{24} \cdots$ & 3.5 & 0.02 & 0.03 & 0.3 & 0.06 & 0.06 & 0.05 & $<10$ & 3 & 19 \\
\hline${ }_{M A R}^{24} \ldots$ & 4.9 & 0.27 & 0.27 & 0.9 & 0.03 & 0.04 & 0.04 & -. & -. & $\cdots$ \\
\hline${ }_{\text {MAY }}^{14 \ldots}$ & 3.9 & 0.19 & 0.15 & 1.0 & 0.25 & 0.10 & 0.10 & $<10$ & $<1$ & 41 \\
\hline${ }_{\text {JuL }} 02 \ldots$ & 3.4 & 0.06 & 0.07 & 0.5 & 0.04 & 0.02 & $<0.01$ & 10 & $\cdot 1$ & 72 \\
\hline${ }_{A \cup G}^{17} \ldots$ & 3.2 & 0.03 & 0.04 & 0.6 & 0.07 & 0.06 & 0.05 & -. & $\cdots$ & $\cdots$ \\
\hline $29 \ldots$ & 3.0 & 0.08 & 0.09 & 0.5 & 0.17 & 0.15 & 0.11 & 10 & $<1$ & 81 \\
\hline DAIE & $\begin{array}{l}\text { BERYL - } \\
\text { LIUM, } \\
\text { DIS- } \\
\text { SOLVED } \\
\text { (UG/L } \\
\text { AS BE) } \\
(01010)\end{array}$ & $\begin{array}{l}\text { CAOMIUM } \\
\text { OIS- } \\
\text { SOI VED } \\
\text { (UG/L } \\
\text { AS CD) } \\
(01025)\end{array}$ & $\begin{array}{l}\text { CHRO- } \\
\text { MIUM, } \\
\text { DIS- } \\
\text { SOIVED } \\
\text { (UG/L } \\
\text { AS CR) } \\
(01030)\end{array}$ & $\begin{array}{l}\text { COBALT, } \\
\text { DIS- } \\
\text { SOLVED } \\
\text { (UG/L } \\
\text { AS CO) } \\
(01035)\end{array}$ & $\begin{array}{l}\text { COPPER, } \\
\text { DIS- } \\
\text { SOLVED } \\
\text { (UG/L } \\
\text { AS CU) } \\
(01040)\end{array}$ & $\begin{array}{l}\text { IRON, } \\
\text { OIS- } \\
\text { SOLVED } \\
\text { (UG/L } \\
\text { AS FE) } \\
(01046)\end{array}$ & $\begin{array}{l}\text { LEAD, } \\
\text { DIS- } \\
\text { SOLVED } \\
\text { (UG/L } \\
\text { AS PB) } \\
(01049)\end{array}$ & $\begin{array}{l}\text { LITHIUM } \\
\text { OIS- } \\
\text { SOLVED } \\
\text { (UG/L } \\
\text { AS LI) } \\
(01130)\end{array}$ & $\begin{array}{l}\text { MANGA- } \\
\text { NESE. } \\
\text { DIS: } \\
\text { SOLVED } \\
\text { (UG/L } \\
\text { AS MN) } \\
(01056)\end{array}$ & $\begin{array}{l}\text { MERCURY } \\
\text { DIS- } \\
\text { SOLVED } \\
\text { (UG/L } \\
\text { AS HG) } \\
(71890)\end{array}$ \\
\hline
\end{tabular}

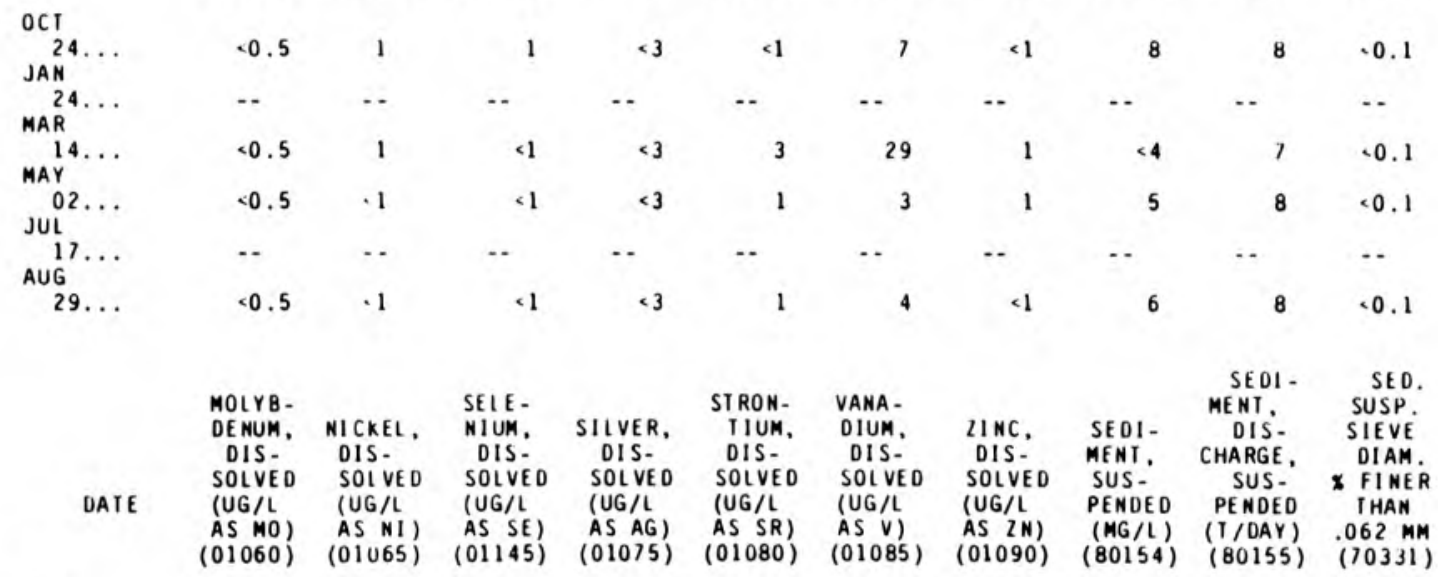

\begin{tabular}{|c|c|c|c|c|c|c|c|c|c|}
\hline 10 & 1 & $<1$ & $<1$ & 360 & .6 & 6 & 93 & 130 & 19 \\
\hline$\cdots$ & - & - & $\cdots$ & - & $\cdots$ & - & 43 & 88 & 20 \\
\hline$<10$ & 1 & $=1$ & $<1$ & 150 & $<6$ & 9 & 295 & 2750 & 60 \\
\hline$<10$ & 1 & 1 & $<1$ & 330 & -6 & 8 & 6 & 8.4 & 65 \\
\hline$\cdots$ & $\cdots$ & $\cdots$ & - & $\cdots$ & $\cdots$ & - & 13 & 6.1 & 45 \\
\hline 20 & 1 & $<1$ & $<1$ & 310 & $<6$ & 13 & 9 & 2.6 & 54 \\
\hline
\end{tabular}




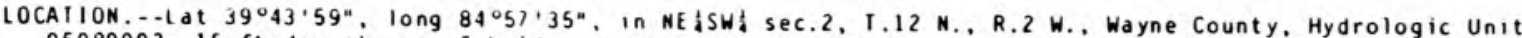
$05080003,15 \mathrm{ft}$ downstrean of bridge on county road at Abington, 3 a downstrea fro Elkhorn Creek. 8 a southwest of Richmond, and at ile 26.7 DRAINAGE AREA. . .200

PERIOU OF RECORD..-OCtober 1965 to current year. REVISED RECORDS,-WWP 2108: Oraindge ared. WDR IN-90-1: 1966(M), 1967-75(P), 1976-77(M), 1978-19(P), 1982(P),

GAGE.--Water-stage recorder. Datua of gage is $791.00 \mathrm{ft}$ above Mational Geodetic Vertical Datua of 1929 . Prior to Aug. 2. 1991 at site $250 \mathrm{ft}$ downstream at same datua.

REMARKS.--Records fair.

OISCHARGE, CUBIC FEET PER SECONO, WAIER YEAR OCTOBER 1990 TO SEPIEMBER 1991 DAILY MEAN VALUES

\begin{tabular}{|c|c|c|c|c|c|c|c|c|c|c|c|c|}
\hline DAY & $\mathrm{OCI}$ & NOV & DEC & JAN & FEB & MAR & APR & MAY & JUN & JUL & AUG & SEP \\
\hline $\begin{array}{l}1 \\
2 \\
3 \\
4 \\
5\end{array}$ & $\begin{array}{r}66 \\
65 \\
64 \\
129 \\
99\end{array}$ & $\begin{array}{l}116 \\
114 \\
112 \\
110 \\
128\end{array}$ & $\begin{array}{l}207 \\
197 \\
777 \\
518 \\
245\end{array}$ & $\begin{array}{l}845 \\
599 \\
474 \\
394 \\
366\end{array}$ & $\begin{array}{l}220 \\
241 \\
306 \\
303 \\
343\end{array}$ & $\begin{array}{l}208 \\
226 \\
208 \\
195 \\
187\end{array}$ & $\begin{array}{l}346 \\
320 \\
305 \\
302 \\
316\end{array}$ & $\begin{array}{l}216 \\
208 \\
201 \\
214 \\
260\end{array}$ & $\begin{array}{l}142 \\
136 \\
132 \\
121 \\
111\end{array}$ & $\begin{array}{l}72 \\
70 \\
68 \\
67 \\
65\end{array}$ & $\begin{array}{r}\text { e } 50 \\
\text { e } 49 \\
52 \\
55 \\
54\end{array}$ & $\begin{array}{l}27 \\
26 \\
36 \\
39 \\
35\end{array}$ \\
\hline $\begin{array}{r}6 \\
7 \\
8 \\
9 \\
10\end{array}$ & $\begin{array}{r}85 \\
77 \\
75 \\
437 \\
1010\end{array}$ & $\begin{array}{l}133 \\
121 \\
115 \\
117 \\
141\end{array}$ & $\begin{array}{l}195 \\
169 \\
152 \\
142 \\
136\end{array}$ & $\begin{array}{l}362 \\
335 \\
307 \\
293 \\
279\end{array}$ & $\begin{array}{l}802 \\
967 \\
493 \\
366 \\
309\end{array}$ & $\begin{array}{l}205 \\
207 \\
188 \\
181 \\
176\end{array}$ & $\begin{array}{l}292 \\
278 \\
289 \\
375 \\
373\end{array}$ & $\begin{array}{l}301 \\
238 \\
213 \\
202 \\
196\end{array}$ & $\begin{array}{r}105 \\
103 \\
102 \\
99 \\
96\end{array}$ & $\begin{array}{r}64 \\
62 \\
232 \\
99 \\
108\end{array}$ & $\begin{array}{l}60 \\
57 \\
63 \\
73 \\
57\end{array}$ & $\begin{array}{l}35 \\
32 \\
30 \\
30 \\
31\end{array}$ \\
\hline $\begin{array}{l}11 \\
12 \\
13 \\
14 \\
15\end{array}$ & $\begin{array}{l}473 \\
250 \\
193 \\
165 \\
148\end{array}$ & $\begin{array}{l}131 \\
122 \\
116 \\
112 \\
109\end{array}$ & $\begin{array}{l}131 \\
128 \\
125 \\
120 \\
460\end{array}$ & $\begin{array}{l}547 \\
774 \\
444 \\
364 \\
344\end{array}$ & $\begin{array}{l}269 \\
243 \\
254 \\
316 \\
264\end{array}$ & $\begin{array}{l}172 \\
186 \\
838 \\
861 \\
792\end{array}$ & $\begin{array}{l}293 \\
270 \\
810 \\
856 \\
669\end{array}$ & $\begin{array}{l}189 \\
184 \\
180 \\
178 \\
175\end{array}$ & $\begin{array}{r}98 \\
106 \\
95 \\
91 \\
87\end{array}$ & $\begin{array}{r}89 \\
106 \\
94 \\
79 \\
73\end{array}$ & $\begin{array}{l}50 \\
47 \\
40 \\
40 \\
36\end{array}$ & $\begin{array}{l}31 \\
34 \\
37 \\
43 \\
32\end{array}$ \\
\hline $\begin{array}{l}16 \\
17 \\
18 \\
19 \\
20\end{array}$ & $\begin{array}{l}139 \\
132 \\
307 \\
245 \\
181\end{array}$ & $\begin{array}{l}109 \\
108 \\
105 \\
103 \\
103\end{array}$ & $\begin{array}{r}322 \\
250 \\
2620 \\
1720 \\
520\end{array}$ & $\begin{array}{l}476 \\
491 \\
370 \\
320 \\
309\end{array}$ & $\begin{array}{l}222 \\
226 \\
446 \\
891 \\
122\end{array}$ & $\begin{array}{r}108 \\
640 \\
1140 \\
552 \\
394\end{array}$ & $\begin{array}{l}490 \\
383 \\
329 \\
432 \\
417\end{array}$ & $\begin{array}{r}183 \\
215 \\
1210 \\
486 \\
278\end{array}$ & $\begin{array}{r}106 \\
92 \\
86 \\
82 \\
78\end{array}$ & $\begin{array}{l}69 \\
67 \\
64 \\
62 \\
60\end{array}$ & $\begin{array}{l}32 \\
40 \\
66 \\
48 \\
40\end{array}$ & $\begin{array}{l}29 \\
29 \\
29 \\
28 \\
27\end{array}$ \\
\hline $\begin{array}{l}21 \\
22 \\
23 \\
24 \\
25\end{array}$ & $\begin{array}{l}159 \\
172 \\
172 \\
157 \\
146\end{array}$ & $\begin{array}{l}102 \\
163 \\
194 \\
172 \\
168\end{array}$ & $\begin{array}{r}1000 \\
1550 \\
1290 \\
581 \\
354\end{array}$ & $\begin{array}{r}291 \\
e 250 \\
e 235 \\
e 220 \\
\text { e210 }\end{array}$ & $\begin{array}{l}435 \\
334 \\
278 \\
257 \\
237\end{array}$ & $\begin{array}{r}335 \\
2780 \\
2150 \\
769 \\
579\end{array}$ & $\begin{array}{l}347 \\
317 \\
292 \\
293 \\
265\end{array}$ & $\begin{array}{l}211 \\
197 \\
179 \\
162 \\
148\end{array}$ & $\begin{array}{r}76 \\
191 \\
162 \\
111 \\
96\end{array}$ & $\begin{array}{l}59 \\
59 \\
57 \\
57 \\
56\end{array}$ & $\begin{array}{l}34 \\
32 \\
32 \\
30 \\
29\end{array}$ & $\begin{array}{l}28 \\
28 \\
36 \\
30 \\
29\end{array}$ \\
\hline $\begin{array}{l}26 \\
27 \\
28 \\
29 \\
30 \\
31\end{array}$ & $\begin{array}{l}135 \\
129 \\
125 \\
120 \\
118 \\
118\end{array}$ & $\begin{array}{l}170 \\
179 \\
254 \\
255 \\
222 \\
\cdots\end{array}$ & $\begin{array}{r}278 \\
243 \\
234 \\
1410 \\
9990 \\
2740\end{array}$ & $\begin{array}{l}e 200 \\
\text { e1 } 195 \\
\text { e1 } \\
\text { e200 } \\
301 \\
241\end{array}$ & $\begin{array}{l}222 \\
215 \\
208 \\
\ldots \\
\ldots \\
\ldots\end{array}$ & $\begin{array}{l}741 \\
746 \\
562 \\
463 \\
397 \\
361\end{array}$ & $\begin{array}{l}262 \\
252 \\
243 \\
240 \\
227 \\
\cdots\end{array}$ & $\begin{array}{l}235 \\
216 \\
168 \\
154 \\
152 \\
137\end{array}$ & $\begin{array}{l}89 \\
82 \\
79 \\
76 \\
74 \\
\cdots-\end{array}$ & $\begin{array}{r}56 \\
54 \\
51 \\
51 \\
e 52 \\
\text { e } 51\end{array}$ & $\begin{array}{l}29 \\
28 \\
28 \\
29 \\
28 \\
27\end{array}$ & $\begin{array}{l}28 \\
27 \\
27 \\
26 \\
26 \\
-\cdots\end{array}$ \\
\hline $\begin{array}{l}\text { TOTAL } \\
\text { MEAN } \\
\text { MAX } \\
\text { MIN } \\
\text { CF SM } \\
\text { IN. }\end{array}$ & $\begin{array}{r}5891 \\
190 \\
1010 \\
64 \\
.95 \\
1.10\end{array}$ & $\begin{array}{r}4204 \\
140 \\
255 \\
102 \\
.70 \\
.78\end{array}$ & $\begin{array}{r}28804 \\
929 \\
9990 \\
120 \\
4.65 \\
5.36\end{array}$ & $\begin{array}{r}11226 \\
362 \\
845 \\
190 \\
1.81 \\
2.09\end{array}$ & $\begin{array}{r}10389 \\
371 \\
967 \\
208 \\
1.86 \\
1.93\end{array}$ & $\begin{array}{r}18147 \\
585 \\
2780 \\
172 \\
2.93 \\
3.38\end{array}$ & $\begin{array}{c}10883 \\
363 \\
856 \\
227 \\
1.81 \\
2.02\end{array}$ & $\begin{array}{r}7486 \\
241 \\
1210 \\
137 \\
1.21 \\
1.39\end{array}$ & $\begin{array}{c}3104 \\
103 \\
191 \\
74 \\
.52 \\
.58\end{array}$ & $\begin{array}{r}2273 \\
73.3 \\
232 \\
51 \\
.37 \\
.42\end{array}$ & $\begin{array}{r}1335 \\
43.1 \\
73 \\
27 \\
.22 \\
.25\end{array}$ & $\begin{array}{r}925 \\
30.8 \\
43 \\
26 \\
.15 \\
.17\end{array}$ \\
\hline
\end{tabular}

e Estimated

SIATISIICS OF MONTHLY MEAN DATA FOK WATER YEARS 1966 - 1991, BY WATER YEAR (WY)

\begin{tabular}{|c|c|c|c|c|c|c|c|c|c|c|c|c|}
\hline $\begin{array}{l}\text { ME AN } \\
\text { MAX } \\
\text { (WY) } \\
\text { MI }) \\
\text { (WY) }\end{array}$ & $\begin{array}{r}84.9 \\
615 \\
1987 \\
22.5 \\
1989\end{array}$ & $\begin{array}{r}166 \\
558 \\
1973 \\
32.7 \\
1977\end{array}$ & $\begin{array}{r}307 \\
929 \\
1991 \\
26.5 \\
1977\end{array}$ & $\begin{array}{r}255 \\
708 \\
1969 \\
21.3 \\
1977\end{array}$ & $\begin{array}{r}349 \\
901 \\
1975 \\
85.3 \\
1978\end{array}$ & $\begin{array}{r}390 \\
884 \\
1978 \\
113 \\
1983\end{array}$ & $\begin{array}{r}355 \\
748 \\
1970 \\
88.7 \\
1976\end{array}$ & $\begin{array}{r}329 \\
1049 \\
1968 \\
55.9 \\
1976\end{array}$ & $\begin{array}{r}163 \\
419 \\
1980 \\
24.6 \\
1988\end{array}$ & $\begin{array}{r}159 \\
773 \\
1979 \\
22.9 \\
1988\end{array}$ & $\begin{array}{r}119 \\
773 \\
1979 \\
18.6 \\
1988\end{array}$ & $\begin{array}{r}59.5 \\
242 \\
1979 \\
19.9 \\
1983\end{array}$ \\
\hline
\end{tabular}

SUMMARY SIAIISIICS

ANMUAL TOIAL

ANNUAL MEAN

HIGHESI ANNUAL MEAN

LOHEST AMNUAL MEAM

HIGHESI DAILY MEAM

LOWEST DAIIY MEAN

AMNUAL SEVEN-DAY MINIMUM

INSTAMIANEOUS PEAK FLOW

INSIANIANEOUS PEAK SIAGE

ANNUAL RUNOFF (CFSM)

ANNUAL RUNOF F (INCHES)

10 PERCENT EXCEEDS

50 PERCEHI EXCEEDS

90 PERCENT EXCEEDS

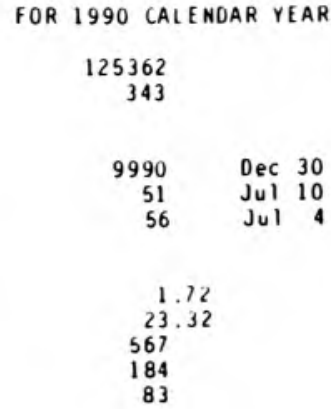

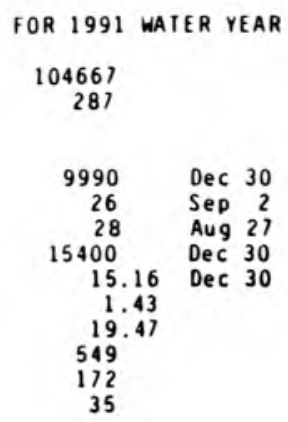

WATER YEARS 1966 - 1991

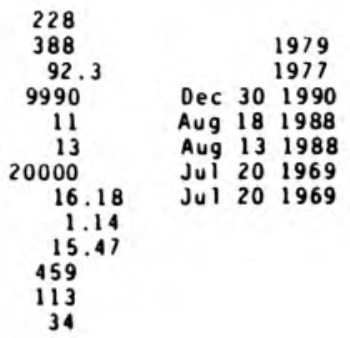




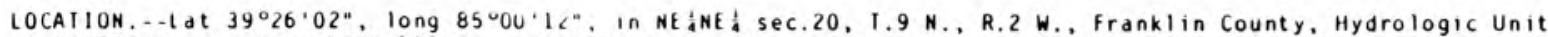

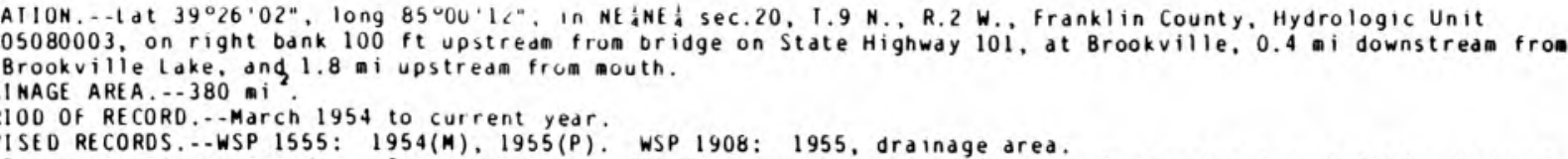
Brookville lake, dnd $1.8 \mathrm{mi}$ upstredm frum mouth.

DRAINAGE AREA --380 mi

PERIOD OF RECORD..-March 1954 to current year.

REVISED RECORDS.--WSP 1555: 1954(M), 1955(P). WSP 1908: 1955, drainage area.

GAGE.--Water-stage recorder. Datum of gage is $621.76 \mathrm{ft}$ above National Geodetic Vertical Datum of 1929 . Prior to May 22, 1954, nonrecording gage at site $100 \mathrm{ft}$ downstream at datum 2.00 ft higher. May 22,1954 to Aug. 20. 1965. water-stage recorder at site $165 \mathrm{ft}$ downstrean at datum $2.00 \mathrm{ft}$ higher. Aug. 21 , 1965 to Sept. 30 , 1981. water-stage recorder at same site and datum. Oct. 1, 1981 to Sept. 30, 1986, daily discharge provided by U.S. Army Corps of Engineers.

REMARKS.-.Records good. Water teaperature probe connected to a Data Collection Platform since Nov. 5 , 1986. Flow regulated by Brookville Lake since January 1974.

DISCHARGE, CUBIC FEEI PER SECOND, WATER YEAR OCTOBER 1990 TO SEPIEMBER 1991 DAILY MEAN VALUES

\begin{tabular}{|c|c|c|c|c|c|c|c|c|c|c|c|c|}
\hline DAY & $0 \mathrm{CI}$ & NOV & DEC & JAN & FEB & MAR & APR & MAY & JUN & Jut & AUG & SEP \\
\hline $\begin{array}{l}1 \\
2 \\
3 \\
4 \\
5\end{array}$ & $\begin{array}{r}64 \\
64 \\
64 \\
194 \\
248\end{array}$ & $\begin{array}{l}825 \\
825 \\
823 \\
823 \\
490\end{array}$ & $\begin{array}{l}146 \\
146 \\
410 \\
539 \\
735\end{array}$ & $\begin{array}{r}210 \\
158 \\
158 \\
1110 \\
2000\end{array}$ & $\begin{array}{l}517 \\
279 \\
279 \\
411 \\
505\end{array}$ & $\begin{array}{l}196 \\
196 \\
363 \\
473 \\
473\end{array}$ & $\begin{array}{r}596 \\
478 \\
479 \\
229 \\
93\end{array}$ & $\begin{array}{l}62 \\
64 \\
65 \\
66 \\
67\end{array}$ & $\begin{array}{r}277 \\
278 \\
278 \\
180 \\
90\end{array}$ & $\begin{array}{l}64 \\
64 \\
64 \\
64 \\
63\end{array}$ & $\begin{array}{l}35 \\
35 \\
35 \\
35 \\
35\end{array}$ & $\begin{array}{l}38 \\
38 \\
38 \\
38 \\
38\end{array}$ \\
\hline $\begin{array}{r}6 \\
7 \\
8 \\
9 \\
10\end{array}$ & $\begin{array}{l}246 \\
246 \\
246 \\
442 \\
630\end{array}$ & $\begin{array}{l}230 \\
443 \\
582 \\
582 \\
582\end{array}$ & $\begin{array}{l}886 \\
886 \\
886 \\
886 \\
640\end{array}$ & $\begin{array}{l}2000 \\
2520 \\
2880 \\
2860 \\
2850\end{array}$ & $\begin{array}{r}671 \\
1230 \\
1710 \\
1700 \\
1690\end{array}$ & $\begin{array}{l}412 \\
386 \\
308 \\
309 \\
310\end{array}$ & $\begin{array}{r}97 \\
97 \\
97 \\
98 \\
569\end{array}$ & $\begin{array}{r}91 \\
193 \\
238 \\
239 \\
239\end{array}$ & $\begin{array}{l}91 \\
91 \\
92 \\
93 \\
84\end{array}$ & $\begin{array}{l}63 \\
62 \\
63 \\
61 \\
62\end{array}$ & $\begin{array}{l}35 \\
35 \\
35 \\
34 \\
33\end{array}$ & $\begin{array}{l}38 \\
38 \\
38 \\
38 \\
37\end{array}$ \\
\hline $\begin{array}{l}11 \\
12 \\
13 \\
14 \\
15\end{array}$ & $\begin{array}{r}1070 \\
1440 \\
848 \\
526 \\
810\end{array}$ & $\begin{array}{l}582 \\
578 \\
767 \\
887 \\
886\end{array}$ & $\begin{array}{l}399 \\
298 \\
299 \\
301 \\
313\end{array}$ & $\begin{array}{l}2850 \\
2840 \\
2820 \\
2810 \\
2790\end{array}$ & $\begin{array}{r}1690 \\
1020 \\
463 \\
466 \\
465\end{array}$ & $\begin{array}{l}208 \\
123 \\
398 \\
751 \\
862\end{array}$ & $\begin{array}{l}870 \\
464 \\
282 \\
143 \\
333\end{array}$ & $\begin{array}{l}238 \\
234 \\
231 \\
228 \\
433\end{array}$ & $\begin{array}{l}88 \\
89 \\
89 \\
90 \\
90\end{array}$ & $\begin{array}{r}97 \\
249 \\
392 \\
389 \\
181\end{array}$ & $\begin{array}{l}33 \\
33 \\
33 \\
33 \\
33\end{array}$ & $\begin{array}{l}37 \\
37 \\
37 \\
37 \\
37\end{array}$ \\
\hline $\begin{array}{l}16 \\
17 \\
18 \\
19 \\
20\end{array}$ & $\begin{array}{r}134 \\
552 \\
1170 \\
1630 \\
926\end{array}$ & $\begin{array}{l}886 \\
886 \\
886 \\
886 \\
662\end{array}$ & $\begin{array}{r}584 \\
963 \\
768 \\
486 \\
1490\end{array}$ & $\begin{array}{r}2780 \\
2760 \\
2350 \\
1810 \\
819\end{array}$ & $\begin{array}{r}464 \\
463 \\
478 \\
956 \\
1330\end{array}$ & $\begin{array}{l}863 \\
870 \\
870 \\
628 \\
478\end{array}$ & $\begin{array}{l}1320 \\
1890 \\
2010 \\
2000 \\
1640\end{array}$ & $\begin{array}{r}567 \\
570 \\
577 \\
565 \\
1340\end{array}$ & $\begin{array}{l}90 \\
90 \\
90 \\
71 \\
61\end{array}$ & $\begin{array}{l}67 \\
67 \\
55 \\
47 \\
47\end{array}$ & $\begin{array}{l}33 \\
33 \\
33 \\
37 \\
33\end{array}$ & $\begin{array}{l}151 \\
222 \\
219 \\
208 \\
192\end{array}$ \\
\hline $\begin{array}{l}21 \\
22 \\
23 \\
24 \\
25\end{array}$ & $\begin{array}{r}542 \\
1010 \\
1120 \\
680 \\
489\end{array}$ & $\begin{array}{l}489 \\
493 \\
494 \\
493 \\
494\end{array}$ & $\begin{array}{l}1910 \\
1910 \\
1910 \\
1900 \\
2250\end{array}$ & $\begin{array}{l}275 \\
276 \\
276 \\
275 \\
276\end{array}$ & $\begin{array}{r}1330 \\
1320 \\
742 \\
463 \\
462\end{array}$ & $\begin{array}{l}478 \\
496 \\
488 \\
483 \\
642\end{array}$ & $\begin{array}{r}1070 \\
607 \\
456 \\
457 \\
457\end{array}$ & $\begin{array}{r}1920 \\
1340 \\
1030 \\
679 \\
400\end{array}$ & $\begin{array}{l}62 \\
62 \\
62 \\
62 \\
62\end{array}$ & $\begin{array}{l}47 \\
40 \\
35 \\
35 \\
35\end{array}$ & $\begin{array}{l}33 \\
33 \\
32 \\
32 \\
33\end{array}$ & $\begin{array}{l}180 \\
178 \\
174 \\
169 \\
168\end{array}$ \\
\hline $\begin{array}{l}26 \\
27 \\
28 \\
29 \\
30 \\
31\end{array}$ & $\begin{array}{l}492 \\
494 \\
631 \\
758 \\
829 \\
827\end{array}$ & $\begin{array}{r}496 \\
732 \\
1270 \\
1510 \\
633 \\
\ldots-\end{array}$ & $\begin{array}{r}3440 \\
3770 \\
2920 \\
1600 \\
546 \\
143\end{array}$ & $\begin{array}{l}276 \\
277 \\
278 \\
278 \\
588 \\
858\end{array}$ & $\begin{array}{l}463 \\
301 \\
196 \\
\ldots \\
\cdots \\
\cdots\end{array}$ & $\begin{array}{r}1180 \\
1610 \\
1600 \\
1230 \\
685 \\
687\end{array}$ & $\begin{array}{l}397 \\
319 \\
319 \\
323 \\
146 \\
\cdots\end{array}$ & $\begin{array}{l}275 \\
275 \\
275 \\
275 \\
276 \\
276\end{array}$ & $\begin{array}{l}62 \\
62 \\
62 \\
63 \\
63 \\
\cdots\end{array}$ & $\begin{array}{l}35 \\
35 \\
35 \\
35 \\
35 \\
35\end{array}$ & $\begin{array}{l}33 \\
33 \\
36 \\
50 \\
44 \\
38\end{array}$ & $\begin{array}{l}166 \\
164 \\
163 \\
160 \\
157 \\
\cdots\end{array}$ \\
\hline $\begin{array}{l}\text { IOIAL } \\
\text { MEAN } \\
\text { MAX } \\
\text { MIN }\end{array}$ & $\begin{array}{r}20022 \\
646 \\
1630 \\
64\end{array}$ & $\begin{array}{r}21215 \\
707 \\
1510 \\
230\end{array}$ & $\begin{array}{r}34360 \\
1108 \\
3770 \\
143\end{array}$ & $\begin{array}{r}45308 \\
1462 \\
2880 \\
158\end{array}$ & $\begin{array}{r}22064 \\
788 \\
1710 \\
196\end{array}$ & $\begin{array}{r}19116 \\
617 \\
1610 \\
123\end{array}$ & $\begin{array}{c}18336 \\
611 \\
2010 \\
93\end{array}$ & $\begin{array}{r}13334 \\
430 \\
1920 \\
62\end{array}$ & $\begin{array}{c}3024 \\
101 \\
278 \\
61\end{array}$ & $\begin{array}{c}2623 \\
84.6 \\
392 \\
35\end{array}$ & $\begin{array}{c}1078 \\
34.8 \\
50 \\
32\end{array}$ & $\begin{array}{c}3235 \\
108 \\
222 \\
31\end{array}$ \\
\hline
\end{tabular}

SIATISIICS OF MONTHLY MEAN DATA FOR WAIER YEARS 1955 - 1991, BY WATER YEAR (WY)

$\begin{array}{lrrrrrrrrrrrr}\text { MEAN } & 222 & 417 & 484 & 466 & 610 & 668 & 556 & 578 & 327 & 230 & 181 & 112 \\ \text { MAX } & 936 & 1107 & 1513 & 1570 & 2003 & 1785 & 1458 & 2068 & 1507 & 1073 & 1497 & 358 \\ \text { (WY) } & 1987 & 1980 & 1986 & 1959 & 1982 & 1963 & 1964 & 1968 & 1958 & 1958 & 1979 & 1979 \\ \text { MIN } & 24.8 & 38.0 & 35.4 & 35.0 & 36.1 & 34.9 & 41.8 & 37.2 & 34.8 & 25.4 & 26.2 & 26.4 \\ \text { (WY) } & 1965 & 1964 & 1964 & 1977 & 1974 & 1974 & 1976 & 1976 & 1976 & 1988 & 1988 & 1964\end{array}$

SUMMARY SIAIISTICS

ANNUAL TOIAL

ANNUAL MEAN

HIGHEST ANNUAL MEAN

LOWEST ANNUAL MEAN

HIGHESI DAIIY MEAN

LOWEST DAILY MEAN

ANNUAL SEVEN-DAY MINIMUM

INSTANTANEOUS PEAK FLOW

INSTANTANEOUS PEAK SIAGE

10 PERCENT EXCEEUS

50 PERCENT EXCEEDS

90 PERCENT EXCEEDS
FOR 1990 LAIENUAR YEAR

FOR 1991 WATER YEAR

221961
608

4790

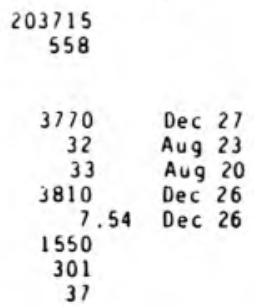

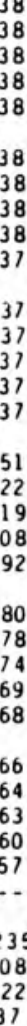


03276500 WHIIEWATER RIVER AT BROOKVILLE, IN

(Former National stream-quality accounting network station)

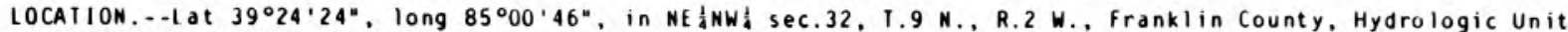
05080003 , on right bank at downstrea side of highway bridge, 0.3 a downstrea from East fork Whitewater River, 1 .1 i south of Brookville, and at mile 29.3 .

DRAI NAGE AREA. $-1,224$ a $i^{2}$.

PERIOD OF RECORD. - June 1915 to September 1917 , October 1917 to May 1920 (gage heights only), and July 1923 to current year. Monthly discharge only for some periods, published in WSP 1305.

REVISED RECOROS...WSP 1335: 1915-1), 1929, 1930(M), 1933(M), 1934, 1935(M), 1936. WSP 1505: 1916(M). WSP 1908: Drainage area.

GAGE. - Water-stage recorder. Datum of gage is $595.71 \mathrm{ft}$ above National Geodetic Vertical Datue of 1929 . Prior to July 1923, nonrecording gage at same site at datue $1.5 \mathrm{ft}$ higher. July 1923 to Sept. 27 , 1928 , nonrecording gage at sane site and datum.

REMARKS. - Records good except for estimated daily discharges, which are fair. Flow regulated by Brookville Lake since January 1974 .

EXIREMES OUTSIDE PERIOD OF RECORD. - Flood of Mar. 25, 1913, reached a stage of 39.0 ft, at present datum, froa floodmarks (discharge not deterained).

DISCHARGE, CUBIC FEET PER SECOND, WATER YEAR OCTOBER 1990 TO SEPIEMBER 1991 DAILY MEAN VALUES

\begin{tabular}{|c|c|c|c|c|c|c|c|c|c|c|c|c|}
\hline DAY & $\mathrm{OCT}$ & MOV & DEC & JAN & FEB & MAR & APR & MAY & JUN & JUL & $A \cup G$ & SEP \\
\hline $\begin{array}{l}1 \\
2 \\
3 \\
4 \\
5\end{array}$ & $\begin{array}{r}375 \\
365 \\
357 \\
1580 \\
958\end{array}$ & $\begin{array}{r}1280 \\
1250 \\
1250 \\
1240 \\
885\end{array}$ & $\begin{array}{r}989 \\
851 \\
4810 \\
4000 \\
2700\end{array}$ & $\begin{array}{l}8020 \\
3790 \\
2740 \\
3230 \\
4030\end{array}$ & $\begin{array}{l}1620 \\
1380 \\
1470 \\
1670 \\
2190\end{array}$ & $\begin{array}{l}1240 \\
1320 \\
1420 \\
1460 \\
1420\end{array}$ & $\begin{array}{l}2190 \\
1930 \\
1820 \\
1520 \\
1450\end{array}$ & $\begin{array}{l}996 \\
960 \\
916 \\
900 \\
934\end{array}$ & $\begin{array}{r}1090 \\
1230 \\
1090 \\
915 \\
692\end{array}$ & $\begin{array}{l}300 \\
298 \\
291 \\
284 \\
284\end{array}$ & $\begin{array}{l}193 \\
192 \\
191 \\
192 \\
190\end{array}$ & $\begin{array}{l}188 \\
185 \\
185 \\
410 \\
344\end{array}$ \\
\hline $\begin{array}{r}6 \\
7 \\
8 \\
9 \\
10\end{array}$ & $\begin{array}{r}701 \\
553 \\
482 \\
2930 \\
4100\end{array}$ & $\begin{array}{r}628 \\
844 \\
969 \\
961 \\
1180\end{array}$ & $\begin{array}{l}2380 \\
2130 \\
1980 \\
1870 \\
1470\end{array}$ & $\begin{array}{l}4110 \\
4530 \\
4600 \\
4480 \\
4370\end{array}$ & $\begin{array}{l}8430 \\
7970 \\
5220 \\
4290 \\
3790\end{array}$ & $\begin{array}{l}1420 \\
1380 \\
1210 \\
1170 \\
1150\end{array}$ & $\begin{array}{l}1350 \\
1290 \\
1250 \\
2320 \\
2630\end{array}$ & $\begin{array}{l}1060 \\
1170 \\
1100 \\
1050 \\
1020\end{array}$ & $\begin{array}{l}630 \\
586 \\
552 \\
521 \\
485\end{array}$ & $\begin{array}{l}284 \\
284 \\
283 \\
284 \\
284\end{array}$ & $\begin{array}{l}195 \\
197 \\
197 \\
198 \\
196\end{array}$ & $\begin{array}{l}228 \\
205 \\
197 \\
192 \\
190\end{array}$ \\
\hline $\begin{array}{l}11 \\
12 \\
13 \\
14 \\
15\end{array}$ & $\begin{array}{l}3660 \\
3090 \\
2020 \\
1400 \\
1530\end{array}$ & $\begin{array}{l}1100 \\
1040 \\
1240 \\
1420 \\
1400\end{array}$ & $\begin{array}{r}1110 \\
932 \\
877 \\
829 \\
1880\end{array}$ & $\begin{array}{l}5630 \\
6830 \\
5400 \\
4850 \\
4630\end{array}$ & $\begin{array}{l}3500 \\
2580 \\
1850 \\
2220 \\
1960\end{array}$ & $\begin{array}{r}1040 \\
983 \\
8560 \\
6800 \\
4880\end{array}$ & $\begin{array}{r}2260 \\
1670 \\
11000 \\
5480 \\
4220\end{array}$ & $\begin{array}{r}985 \\
952 \\
931 \\
1030 \\
1450\end{array}$ & $\begin{array}{l}465 \\
475 \\
468 \\
435 \\
428\end{array}$ & $\begin{array}{l}324 \\
478 \\
654 \\
622 \\
402\end{array}$ & $\begin{array}{l}191 \\
189 \\
189 \\
187 \\
186\end{array}$ & $\begin{array}{l}187 \\
186 \\
187 \\
199 \\
191\end{array}$ \\
\hline $\begin{array}{l}16 \\
17 \\
18 \\
19 \\
20\end{array}$ & $\begin{array}{l}1360 \\
1070 \\
2710 \\
2970 \\
1910\end{array}$ & $\begin{array}{l}1400 \\
1380 \\
1370 \\
1360 \\
1030\end{array}$ & $\begin{array}{r}2720 \\
2740 \\
12600 \\
9690 \\
5320\end{array}$ & $\begin{array}{l}4770 \\
5100 \\
4440 \\
3580 \\
2410\end{array}$ & $\begin{array}{l}1640 \\
1690 \\
3210 \\
4440 \\
4680\end{array}$ & $\begin{array}{l}4130 \\
3670 \\
6040 \\
3930 \\
2700\end{array}$ & $\begin{array}{l}4140 \\
4140 \\
4000 \\
4190 \\
4100\end{array}$ & $\begin{array}{l}1360 \\
1370 \\
4050 \\
2810 \\
2770\end{array}$ & $\begin{array}{l}418 \\
412 \\
403 \\
396 \\
376\end{array}$ & $\begin{array}{l}261 \\
254 \\
239 \\
226 \\
225\end{array}$ & $\begin{array}{l}187 \\
187 \\
192 \\
219 \\
206\end{array}$ & $\begin{array}{l}274 \\
347 \\
342 \\
317 \\
288\end{array}$ \\
\hline $\begin{array}{l}21 \\
22 \\
23 \\
24 \\
25\end{array}$ & $\begin{array}{l}1250 \\
1800 \\
2010 \\
1440 \\
1090\end{array}$ & $\begin{array}{l}818 \\
1150 \\
1390 \\
1260 \\
1130\end{array}$ & $\begin{array}{l}5540 \\
8410 \\
8180 \\
5860 \\
4870\end{array}$ & $\begin{array}{r}1730 \\
\mathrm{e} 1550 \\
\mathrm{e} 1450 \\
\mathrm{e} 1350 \\
1320\end{array}$ & $\begin{array}{l}3820 \\
3280 \\
2370 \\
1850 \\
1730\end{array}$ & $\begin{array}{r}2340 \\
5100 \\
13000 \\
5260 \\
3420\end{array}$ & $\begin{array}{l}3120 \\
2280 \\
1910 \\
1810 \\
1740\end{array}$ & $\begin{array}{l}3180 \\
2490 \\
2330 \\
1770 \\
1270\end{array}$ & $\begin{array}{l}357 \\
347 \\
335 \\
334 \\
334\end{array}$ & $\begin{array}{l}221 \\
214 \\
208 \\
205 \\
203\end{array}$ & $\begin{array}{l}199 \\
193 \\
190 \\
188 \\
186\end{array}$ & $\begin{array}{l}217 \\
274 \\
278 \\
277 \\
273\end{array}$ \\
\hline $\begin{array}{l}26 \\
27 \\
28 \\
29 \\
30 \\
31\end{array}$ & $\begin{array}{r}1020 \\
984 \\
1110 \\
1240 \\
1300 \\
1290\end{array}$ & $\begin{array}{c}1060 \\
1400 \\
2630 \\
3390 \\
1720 \\
\ldots\end{array}$ & $\begin{array}{r}5370 \\
5360 \\
4600 \\
7450 \\
26900 \\
25100\end{array}$ & $\begin{array}{r}\mathrm{e} 1270 \\
1260 \\
\mathrm{e} 1250 \\
1250 \\
2350 \\
2150\end{array}$ & $\begin{array}{r}1630 \\
1430 \\
1210 \\
\ldots \\
\ldots \\
\ldots\end{array}$ & $\begin{array}{l}6050 \\
7110 \\
5250 \\
3990 \\
2710 \\
2440\end{array}$ & $\begin{array}{c}1600 \\
1470 \\
1420 \\
1390 \\
1170 \\
\ldots\end{array}$ & $\begin{array}{l}1290 \\
1500 \\
1230 \\
1190 \\
1310 \\
1200\end{array}$ & $\begin{array}{l}330 \\
320 \\
317 \\
316 \\
304 \\
\cdots\end{array}$ & $\begin{array}{l}202 \\
199 \\
196 \\
196 \\
194 \\
194\end{array}$ & $\begin{array}{l}184 \\
183 \\
184 \\
191 \\
190 \\
195\end{array}$ & $\begin{array}{l}263 \\
258 \\
258 \\
254 \\
247 \\
---\end{array}$ \\
\hline $\begin{array}{l}\text { IOIAL } \\
\text { MEAN } \\
\text { MAX } \\
\text { MIN } \\
\text { CF SM } \\
\text { IN. }\end{array}$ & $\begin{array}{r}48655 \\
1570 \\
4100 \\
357 \\
1.28 \\
1.48\end{array}$ & $\begin{array}{r}39175 \\
1306 \\
3390 \\
628 \\
1.07 \\
1.19\end{array}$ & $\begin{array}{r}169518 \\
5468 \\
26900 \\
829 \\
4.47 \\
5.15\end{array}$ & $\begin{array}{r}108470 \\
3499 \\
8020 \\
1250 \\
2.86 \\
3.30\end{array}$ & $\begin{array}{r}83180 \\
2971 \\
8430 \\
1270 \\
2.43 \\
2.53\end{array}$ & $\begin{array}{r}112593 \\
3632 \\
13000 \\
983 \\
2.97 \\
3.42\end{array}$ & $\begin{array}{r}80860 \\
2695 \\
11000 \\
1170 \\
2.20 \\
2.46\end{array}$ & $\begin{array}{r}46574 \\
1502 \\
4050 \\
900 \\
1.23 \\
1.42\end{array}$ & $\begin{array}{r}15361 \\
512 \\
1230 \\
304 \\
.42 \\
.47\end{array}$ & $\begin{array}{l}8793 \\
284 \\
654 \\
194 \\
.23 \\
.27\end{array}$ & $\begin{array}{l}5957 \\
192 \\
219 \\
183 \\
.16 \\
.18\end{array}$ & $\begin{array}{r}7501 \\
250 \\
410 \\
185 \\
.20 \\
.23\end{array}$ \\
\hline
\end{tabular}

e Estinated

SIATISIICS OF MONIHLY MEAM DATA FOR WATER YEARS 1916 - 1991. BY WATER YEAR (WY)

\begin{tabular}{|c|c|c|c|c|c|c|c|c|c|c|c|c|}
\hline $\begin{array}{l}\text { MEAN } \\
\text { MAX } \\
\text { (WY) } \\
\text { MIN } \\
\text { (WY) }\end{array}$ & $\begin{array}{r}465 \\
2796 \\
1927 \\
95.5 \\
1935\end{array}$ & $\begin{array}{r}843 \\
3238 \\
1956 \\
98.1 \\
1935\end{array}$ & $\begin{array}{l}1300 \\
5210 \\
1991 \\
95.1 \\
1935\end{array}$ & $\begin{array}{r}1972 \\
9401 \\
1937 \\
102 \\
1977\end{array}$ & $\begin{array}{r}2045 \\
6290 \\
1950 \\
122 \\
1935\end{array}$ & $\begin{array}{r}2329 \\
5909 \\
1963 \\
294 \\
1941\end{array}$ & $\begin{array}{r}2138 \\
4664 \\
1964 \\
275 \\
1941\end{array}$ & $\begin{array}{r}1643 \\
5738 \\
1968 \\
186 \\
1941\end{array}$ & $\begin{array}{c}1113 \\
4710 \\
1958 \\
161 \\
1934\end{array}$ & $\begin{array}{r}725 \\
3390 \\
1958 \\
138 \\
1934\end{array}$ & $\begin{array}{r}505 \\
4271 \\
1979 \\
102 \\
1930\end{array}$ & $\begin{array}{r}418 \\
4239 \\
1926 \\
98.9 \\
1940\end{array}$ \\
\hline
\end{tabular}

SUMMARY STATISIICS

ANNUAL TOTAL

ANNUAL MEAN

HIGHEST ANNUAL MEAM

LOWEST AMMUAL MEAN

HIGHESI DAILY MEAN

LOWEST DAILY MEAM

ANNUAL SEVEN-DAY MINIMUM

INSTANTANEOUS PEAK FLOW

INSIANTANEOUS PEAK STAGE

ANMUAL RUNOFF (CFSM)

ANNUAL RUNOFF (INCHES)

10 PERCENT EXCEEDS

50 PERCENT EXCEEDS

90 PERCENT EXCEEDS
FOR 1990 CALENDAR YEAR

$\begin{aligned} 810952 & \\ 2222 & \\ & \\ 26900 & \text { Dec } 30 \\ 304 & \text { Aug } 17 \\ 321 & \text { Aug } 12 \\ & \\ 1.82 & \\ 24.65 & \\ 4640 & \\ 1310 & \\ 480 & \end{aligned}$

FOR 1991 WATER YEAR

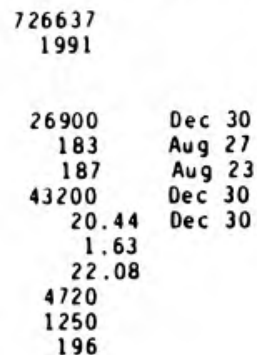

WATER YEARS $1916-1991$

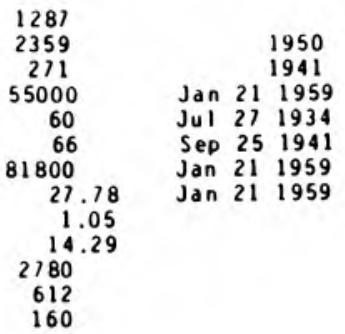


LOCAIION.- Lat $39^{\circ} 01^{\prime} 47^{\prime \prime}$, Iong $85^{\circ} 06^{\prime} 17^{\prime \prime}$, in SWHWl sec.7, T.4 N., R.2 W., Dearborn County, Hydrologic Unit 05090203 , on left downstrea doutment of bridge on county rodd at Dillsboro Station, 1.2 i northeast of

Dillsboro, and 1.5 is downstream from Whitaker Creek.

DRAI NAGE AREA. . - 38,1 i $i^{2}$

\section{WAIER-DISCHARGE RECOROS}

PERIOD OF RECORD.--July 1961 to current year. Occasional low-flow measurements, water year 1960. REVISED RE CORDS.-.WDR IN-72-1: Drainage area.

GAGE. - Water-stage recorder and crest-stage gage. Datue of gage is $571.00 \mathrm{ft}$ above Mational Geodetic Vertical Datun of 1929 .

REMARKS.--Records poor.

EXTREMES OUTSIDE PERIOD OF RECORD. - Flood of Jan. 21, 1959, reached a stage of $1.4 .00 \mathrm{ft}$, discharge, 16,300 ft/s on basis of contracted-opening aedsurement.

DISCHARGE, CUBIC FEE PER SECOND, WATER YEAR OCIOBER 1990 TO SEPIEMBER 1991

\begin{tabular}{|c|c|c|c|c|c|c|c|c|c|c|c|c|}
\hline DAY & $O C \mathrm{~T}$ & NOV & DEC & JAN & FEB & MAR & $A P R$ & MAY & JUN & JUL & AUG & SEP \\
\hline $\begin{array}{l}1 \\
2 \\
3 \\
4 \\
5\end{array}$ & $\begin{array}{r}1.8 \\
1.3 \\
1.2 \\
194 \\
46\end{array}$ & $\begin{array}{l}8.4 \\
6.9 \\
6.2 \\
5.6 \\
6.4\end{array}$ & $\begin{array}{r}21 \\
19 \\
614 \\
116 \\
\text { e74 }\end{array}$ & $\begin{array}{l}\text { e } 93 \\
\text { e } 68 \\
\text { e } 55 \\
\text { e } 44 \\
\text { e } 38\end{array}$ & $\begin{array}{l}\text { e } 74 \\
\text { e } 58 \\
\text { e } 49 \\
\text { e } 44 \\
\text { e } 80\end{array}$ & $\begin{array}{r}e 40 \\
56 \\
46 \\
25 \\
21\end{array}$ & $\begin{array}{l}27 \\
23 \\
20 \\
17 \\
19\end{array}$ & $\begin{array}{r}10 \\
9.1 \\
7.9 \\
8.6 \\
9.8\end{array}$ & $\begin{array}{l}2.6 \\
5.2 \\
7.6 \\
4.0 \\
2.1\end{array}$ & $\begin{array}{l}.05 \\
.05 \\
.05 \\
.05 \\
.04\end{array}$ & $\begin{array}{l}.00 \\
.00 \\
.00 \\
.00 \\
.00\end{array}$ & $\begin{array}{r}.41 \\
.20 \\
.09 \\
24 \\
8.7\end{array}$ \\
\hline $\begin{array}{r}6 \\
7 \\
8 \\
9 \\
10\end{array}$ & $\begin{array}{c}20 \\
13 \\
9.2 \\
361 \\
480\end{array}$ & $\begin{array}{l}9.8 \\
10 \\
7.1 \\
13 \\
45\end{array}$ & $\begin{array}{l}\text { e51 } \\
\text { e } 43 \\
\text { e37 } \\
\text { e35 } \\
\text { e } 32\end{array}$ & $\begin{array}{r}221 \\
126 \\
68 \\
51 \\
53\end{array}$ & $\begin{array}{r}965 \\
514 \\
142 \\
95 \\
\text { e } 80\end{array}$ & $\begin{array}{r}25 \\
35 \\
e 23 \\
e 20 \\
\text { e18 }\end{array}$ & $\begin{array}{l}17 \\
14 \\
13 \\
78 \\
73\end{array}$ & $\begin{array}{r}11 \\
8.9 \\
7.1 \\
9.2 \\
9.1\end{array}$ & $\begin{array}{r}1.3 \\
.94 \\
.75 \\
.59 \\
.44\end{array}$ & $\begin{array}{l}.02 \\
.01 \\
.01 \\
.06 \\
.20\end{array}$ & $\begin{array}{l}.14 \\
3.4 \\
1.2 \\
4.5 \\
3.2\end{array}$ & $\begin{array}{l}1.8 \\
.60 \\
.22 \\
.11 \\
.08\end{array}$ \\
\hline $\begin{array}{l}11 \\
12 \\
13 \\
14 \\
15\end{array}$ & $\begin{array}{l}86 \\
46 \\
30 \\
22 \\
18\end{array}$ & $\begin{array}{r}20 \\
13 \\
10 \\
8.3 \\
7.5\end{array}$ & $\begin{array}{l}\text { e } 30 \\
\text { e2 } 8 \\
\text { e27 } \\
\text { e26 } \\
332\end{array}$ & $\begin{array}{r}372 \\
182 \\
92 \\
71 \\
60\end{array}$ & $\begin{array}{r}e 73 \\
e 65 \\
99 \\
274 \\
e 126\end{array}$ & $\begin{array}{r}e 15 \\
e 80 \\
642 \\
164 \\
78\end{array}$ & $\begin{array}{r}28 \\
22 \\
991 \\
312 \\
263\end{array}$ & $\begin{array}{r}7.6 \\
6.6 \\
5.4 \\
8.5 \\
10\end{array}$ & $\begin{array}{l}.39 \\
.34 \\
.29 \\
.24 \\
.18\end{array}$ & $\begin{array}{r}.18 \\
.49 \\
1.5 \\
.89 \\
.39\end{array}$ & $\begin{array}{l}1.6 \\
.66 \\
.35 \\
.20 \\
.13\end{array}$ & $\begin{array}{r}.05 \\
.18 \\
.13 \\
2.5 \\
.71\end{array}$ \\
\hline $\begin{array}{l}16 \\
17 \\
18 \\
19 \\
20\end{array}$ & $\begin{array}{r}14 \\
11 \\
531 \\
54 \\
26\end{array}$ & $\begin{array}{l}7.5 \\
7.2 \\
6.7 \\
5.8 \\
5.2\end{array}$ & $\begin{array}{r}95 \\
184 \\
2220 \\
232 \\
71\end{array}$ & $\begin{array}{r}78 \\
77 \\
60 \\
51 \\
\mathrm{e} 46\end{array}$ & $\begin{array}{r}992 \\
70 \\
518 \\
212 \\
121\end{array}$ & $\begin{array}{r}59 \\
185 \\
304 \\
95 \\
64\end{array}$ & $\begin{array}{l}85 \\
52 \\
38 \\
37 \\
35\end{array}$ & $\begin{array}{r}6.1 \\
5.1 \\
5.8 \\
13 \\
6.6\end{array}$ & $\begin{array}{l}.18 \\
.35 \\
.29 \\
.73 \\
.48\end{array}$ & $\begin{array}{l}.21 \\
.12 \\
.09 \\
.07 \\
.06\end{array}$ & $\begin{array}{ll} & .08 \\
42 & .32 \\
14 \\
22\end{array}$ & $\begin{array}{l}.34 \\
.15 \\
.09 \\
.08 \\
.06\end{array}$ \\
\hline $\begin{array}{l}21 \\
22 \\
23 \\
24 \\
25\end{array}$ & $\begin{array}{l}18 \\
84 \\
57 \\
27 \\
21\end{array}$ & $\begin{array}{l}4.5 \\
62 \\
59 \\
31 \\
24\end{array}$ & $\begin{array}{r}88 \\
259 \\
e 160 \\
\text { e115 } \\
e 88\end{array}$ & $\begin{array}{l}\text { e } 41 \\
\text { e } 36 \\
\text { e } 32 \\
\text { e } 28 \\
\text { e24 }\end{array}$ & $\begin{array}{r}84 \\
70 \\
62 \\
\text { e } 54 \\
\text { e48 }\end{array}$ & $\begin{array}{r}53 \\
685 \\
580 \\
89 \\
57\end{array}$ & $\begin{array}{l}28 \\
23 \\
21 \\
21 \\
16\end{array}$ & $\begin{array}{r}4.6 \\
5.9 \\
9.3 \\
13 \\
6.3\end{array}$ & $\begin{array}{l}.35 \\
.29 \\
.21 \\
.17 \\
.14\end{array}$ & $\begin{array}{l}.04 \\
.02 \\
.00 \\
.00 \\
.00\end{array}$ & $\begin{array}{l}6.2 \\
2.7 \\
1.3 \\
.71 \\
.44\end{array}$ & $\begin{array}{l}.05 \\
.04 \\
.04 \\
.04 \\
.03\end{array}$ \\
\hline $\begin{array}{l}26 \\
27 \\
28 \\
29 \\
30 \\
31\end{array}$ & $\begin{array}{l}19 \\
17 \\
15 \\
12 \\
9.9 \\
8.7\end{array}$ & $\begin{array}{l}20 \\
20 \\
51 \\
40 \\
25 \\
\ldots\end{array}$ & $\begin{array}{r}\text { e70 } \\
\text { e56 } \\
\text { e48 } \\
617 \\
1320 \\
\text { e170 }\end{array}$ & $\begin{array}{r}e 22 \\
e 40 \\
72 \\
62 \\
206 \\
e 120\end{array}$ & $\begin{array}{l}\text { e43 } \\
\text { e39 } \\
\text { e36 } \\
\cdots- \\
\cdots \\
\cdots\end{array}$ & $\begin{array}{r}785 \\
185 \\
105 \\
59 \\
41 \\
31\end{array}$ & $\begin{array}{l}16 \\
14 \\
13 \\
14 \\
13 \\
\cdots\end{array}$ & $\begin{array}{l}5.5 \\
7.5 \\
6.2 \\
4.2 \\
3.3 \\
2.8\end{array}$ & $\begin{array}{l}.10 \\
.09 \\
.07 \\
.07 \\
.06 \\
\cdots\end{array}$ & $\begin{array}{l}.00 \\
.00 \\
.00 \\
.00 \\
.00 \\
.00\end{array}$ & $\begin{array}{l}.28 \\
.18 \\
.24 \\
.49 \\
1.8 \\
2.6\end{array}$ & $\begin{array}{l}.03 \\
.02 \\
.01 \\
.01 \\
.00 \\
\ldots . .\end{array}$ \\
\hline $\begin{array}{l}\text { IOIAL } \\
\text { MEAN } \\
\text { MAX } \\
\text { MIN } \\
\text { CF SM } \\
\text { IN. }\end{array}$ & $\begin{array}{r}2254.1 \\
72.7 \\
531 \\
1.2 \\
1.91 \\
2.20\end{array}$ & $\begin{array}{r}546.1 \\
18.2 \\
62 \\
4.5 \\
.48 \\
.53\end{array}$ & $\begin{array}{r}7278 \\
235 \\
2220 \\
19 \\
6.16 \\
7.11\end{array}$ & $\begin{array}{r}2589 \\
83.5 \\
372 \\
22 \\
2.19 \\
2.53\end{array}$ & $\begin{array}{r}4187 \\
150 \\
965 \\
36 \\
3.92 \\
4.09\end{array}$ & $\begin{array}{r}4665 \\
150 \\
785 \\
15 \\
3.95 \\
4.55\end{array}$ & $\begin{array}{c}2343 \\
78.1 \\
991 \\
13 \\
2.05 \\
2.29\end{array}$ & $\begin{array}{r}234.0 \\
1.55 \\
13 \\
2.8 \\
.20 \\
.23\end{array}$ & $\begin{array}{r}30.54 \\
1.02 \\
7.6 \\
.06 \\
.03 \\
.03\end{array}$ & $\begin{array}{l}4.60 \\
.15 \\
1.5 \\
.00 \\
.00 \\
.00\end{array}$ & $\begin{array}{r}110.12 \\
3.51 \\
42 \\
.00 \\
.09 \\
.11\end{array}$ & $\begin{array}{c}41.43 \\
1.38 \\
24 \\
.00 \\
.04 \\
.04\end{array}$ \\
\hline
\end{tabular}

e Estinated

SIATISIICS OF MONTHLY MEAN DATA FUR WAIER YEARS 1961 - 1991, BY WAIER YEAR (WY)

$\begin{array}{lrrrrrrrrrrrr}\text { MEAN } & 11.6 & 35.8 & 59.3 & 57.3 & 77.6 & 101 & 76.9 & 56.3 & 19.4 & 15.1 & 9.66 & 8.29 \\ \text { MAX } & 72.7 & 180 & 235 & 189 & 190 & 260 & 237 & 322 & 150 & 110 & 64.4 & 62.3 \\ \text { (WY) } & 1991 & 1986 & 1991 & 1982 & 1979 & 1963 & 1970 & 1968 & 1981 & 1962 & 1979 & 1979 \\ \text { MIN } & 1000 & 1000 & .097 & .95 & 5.61 & 13.1 & 8.65 & 2.43 & 049 & .000 & .000 & .000 \\ \text { (WY) } & 1964 & 1964 & 1964 & 1977 & 1964 & 1969 & 1976 & 1988 & 1988 & 1966 & 1963 & 1963\end{array}$

SUMMARY SIAIISIICS

ANWUAL TOTAL

ANMUAL MEAN

HIGHESI ANNUAL MEAN

LOWEST ANNUAL MEAN

HIGHESI DAILY MEAM

LOWEST DAILY MEAN

ANMUAL SEVEN-DAY MINIMUM

INSIANTANEOUS PEAK FLOW

INSIANTANEOUS PEAK SIAGE

AMNUAL RUNOF F (CFSM)

ANMUAL RUNOF F (INCHES)

10 PERCENT EXCEEDS

50 PERCENT EXCEEDS

90 PFRCENT EXIEFUS
FOR 1990 CALENDAR YEAR

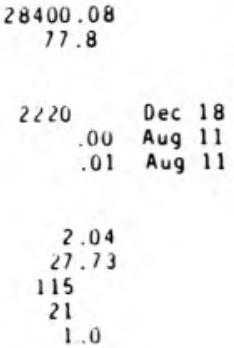

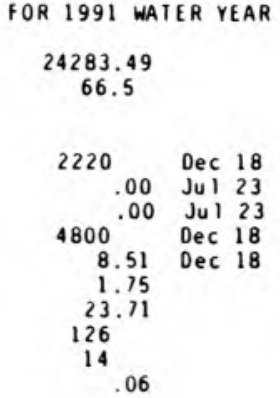

WAIER YEARS 1961 - 1991

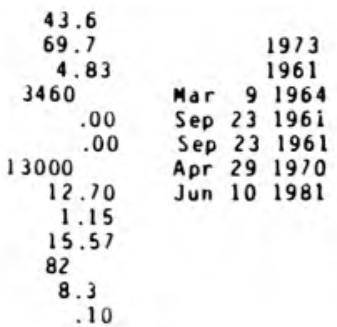


PERIOD OF RECORD.--

CHEMICAL ANALYSES: OCtober 1968 to current year.

SEOIMENI DISCHARGE: August 1969 to current year (partial-record station).

WAIER QUAIIIY DAIA, WAIER YEAR OCIOBER 1990 TO SEPTEMBER 1991

\begin{tabular}{|c|c|c|c|c|c|c|c|c|c|c|c|c|}
\hline DATE & TIME & $\begin{array}{l}\text { DIS. } \\
\text { CHARGE, } \\
\text { INST. } \\
\text { CUBIC } \\
\text { FEE I } \\
\text { PER } \\
\text { SECOND } \\
(00061)\end{array}$ & $\begin{array}{l}\text { SPE - } \\
\text { CIFIC } \\
\text { CON- } \\
\text { DUCI - } \\
\text { ANCE } \\
\text { (US/CM) } \\
(00095)\end{array}$ & $\begin{array}{c}\text { SPE - } \\
\text { CIFIC } \\
\text { CON- } \\
\text { DUCT- } \\
\text { ANCE } \\
\text { LAB } \\
(U S / C M) \\
(90095)\end{array}$ & $\begin{array}{l}\text { PH } \\
\text { (SIAND- } \\
\text { ARD } \\
\text { UNIIS) } \\
(00400)\end{array}$ & $\begin{array}{l}\text { PH } \\
\text { LAB } \\
\text { (SIANO- } \\
\text { ARD } \\
\text { UNIIS) } \\
(00403 \text { ) }\end{array}$ & $\begin{array}{l}\text { IEMPER- } \\
\text { AIURE } \\
\text { AIR } \\
(D E G C) \\
(00020)\end{array}$ & $\begin{array}{l}\text { TEMPER- } \\
\text { AIURE } \\
\text { WAIER } \\
(D E G C) \\
(00010)\end{array}$ & $\begin{array}{l}\text { BARO- } \\
\text { ME IRIC } \\
\text { PRES- } \\
\text { SURE } \\
\text { (MM } \\
\text { OF } \\
\text { HG) } \\
(00025)\end{array}$ & $\begin{array}{c}\text { OXYGEN, } \\
\text { DIS. } \\
\text { SOI VED } \\
\text { (NG/L) } \\
(00300)\end{array}$ & $\begin{array}{l}\text { OXYGEN, } \\
\text { DIS. } \\
\text { SOIVED } \\
\text { (PER- } \\
\text { CENI } \\
\text { SATUR- } \\
\text { AIION) } \\
(00301 \text { ) }\end{array}$ & $\begin{array}{l}\text { IUR- } \\
\text { BID - } \\
\text { ITY } \\
(\text { NTU) } \\
(00076)\end{array}$ \\
\hline $\begin{array}{l}C T \\
25 \ldots \\
\text { IAR }\end{array}$ & 1000 & 21 & 486 & 490 & 8.5 & 8.2 & 11.0 & 10.5 & 760 & 10.9 & 98 & 5.5 \\
\hline${ }_{A Y Y}^{13} \ldots$ & 1430 & 616 & 279 & 228 & 8.3 & 8.1 & 3.0 & 4.0 & 736 & 12.8 & 102 & 69 \\
\hline $01 \ldots$ & 1500 & 9.8 & 465 & 454 & 8.4 & 8. 4 & 21.0 & 19.5 & 746 & 11.7 & 130 & 1.9 \\
\hline $28 \ldots$ & 1200 & 0.15 & 464 & 451 & 8.1 & 8.0 & 33.0 & 27.5 & 752 & 8.9 & 114 & 4.0 \\
\hline DATE & $\begin{array}{l}\text { COLI- } \\
\text { FORM, } \\
\text { FECAL. } \\
0.7 \\
\text { UM-MF } \\
\text { (COLS.I } \\
100 \mathrm{ML}) \\
(31625)\end{array}$ & $\begin{array}{l}\text { SIREP- } \\
\text { IOCOCCI } \\
\text { FECAL, } \\
\text { KF AGAR } \\
\text { (COLS. } \\
\text { PER } \\
100 \text { ML) } \\
(31673)\end{array}$ & $\begin{array}{l}\text { HAKD - } \\
\text { MESS } \\
\text { TOTAL } \\
(\text { MG/L } \\
\text { AS } \\
\text { CAC03) } \\
(00900)\end{array}$ & $\begin{array}{l}\text { HARO- } \\
\text { NESS } \\
\text { NONCARB } \\
\text { DISSOLV } \\
\text { FIO. AS } \\
\text { CACO3 } \\
(\text { MG/L) } \\
(00904)\end{array}$ & $\begin{array}{l}\text { CALCIUM } \\
\text { DIS- } \\
\text { SOI VE D } \\
\text { (MG/L } \\
\text { AS CA) } \\
(00915)\end{array}$ & $\begin{array}{l}\text { MAGNE- } \\
\text { SIUM, } \\
\text { DIS- } \\
\text { SOIVED } \\
\text { (MG/L } \\
\text { AS MG) } \\
(00925)\end{array}$ & $\begin{array}{l}\text { SODIUM, } \\
\text { DIS- } \\
\text { SOL VED } \\
\text { (MG/L } \\
\text { AS MA) } \\
(00930)\end{array}$ & $\begin{array}{l}\text { POIAS- } \\
\text { SIUM, } \\
\text { DIS- } \\
\text { SOLVED } \\
(\text { MG/L } \\
\text { AS K) } \\
(00935)\end{array}$ & $\begin{array}{l}\text { ALKA- } \\
\text { LINIIY } \\
\text { WAT DIS } \\
\text { FIX END } \\
\text { FIELD } \\
\text { CACO3 } \\
(\text { MG/L) } \\
(39036)\end{array}$ & $\begin{array}{l}\text { ALKA- } \\
\text { IINIIY } \\
\text { WAI DIS } \\
\text { TOI II } \\
\text { FIEID } \\
\text { MG/L AS } \\
\text { CACO3 } \\
(39086)\end{array}$ & $\begin{array}{l}\text { ALKA- } \\
\text { LINIIY } \\
\text { LAB } \\
(M G / L \\
\text { AS } \\
\text { CACO3) } \\
(90410)\end{array}$ & $\begin{array}{l}\text { BICAR- } \\
\text { BONAIE } \\
\text { WATER } \\
\text { DIS IT } \\
\text { FIELD } \\
\text { MG/L AS } \\
\text { HC03 } \\
(00453)\end{array}$ \\
\hline
\end{tabular}

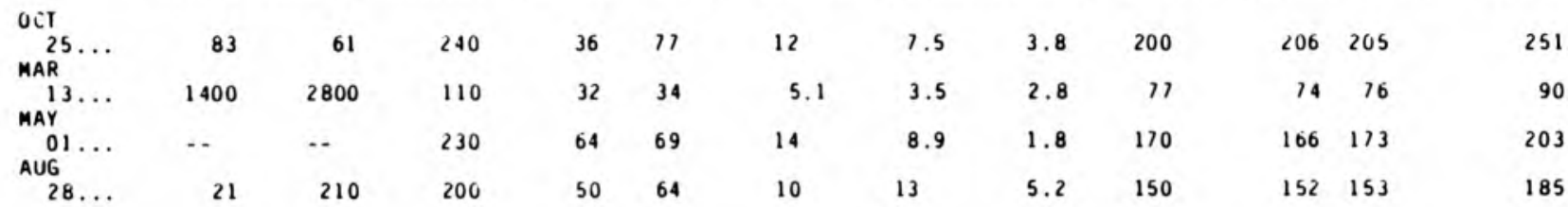

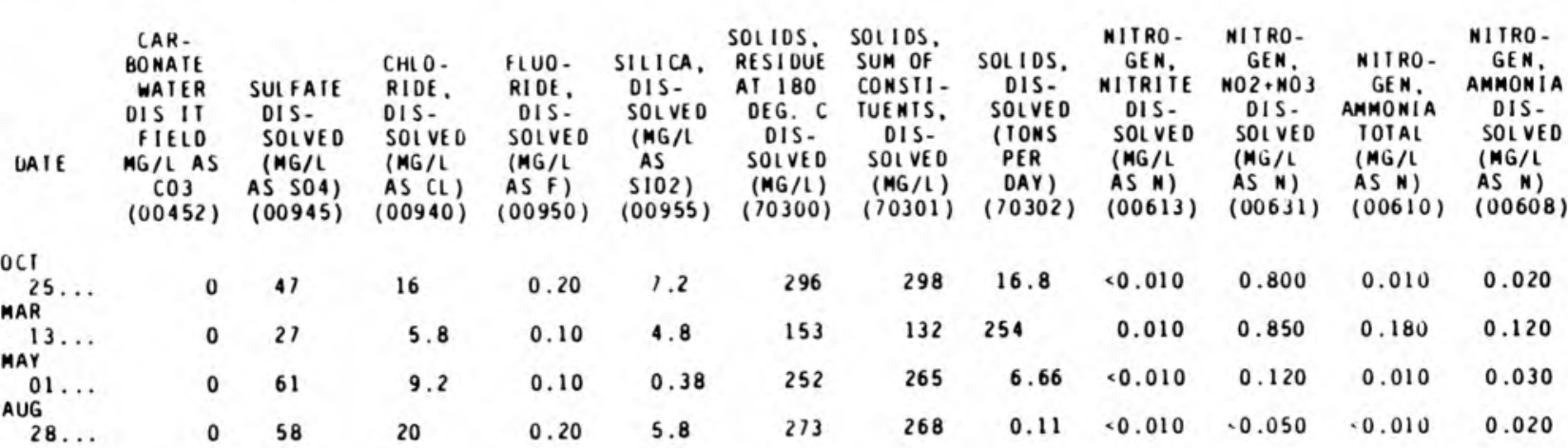

\begin{tabular}{|c|c|c|c|c|c|c|c|c|c|c|c|c|}
\hline UAI $\mathrm{t}$ & $\begin{array}{l}\text { NIIRO- } \\
\text { GEN,AM- } \\
\text { MONIIA } \\
\text { ORGANIC } \\
\text { TOIAL } \\
(\text { MG/L } \\
\text { AS N ) } \\
(00625)\end{array}$ & $\begin{array}{l}\text { PHOS - } \\
\text { PHORUS } \\
\text { TOTAL } \\
\text { (MG/L } \\
\text { AS P) } \\
(00665)\end{array}$ & $\begin{array}{l}\text { PHOS- } \\
\text { PHORUS } \\
\text { DIS- } \\
\text { SOI VED } \\
\text { (MG/L } \\
\text { AS P) } \\
(00666)\end{array}$ & $\begin{array}{l}\text { PHOS - } \\
\text { PHORUS } \\
\text { ORIHO. } \\
\text { DIS- } \\
\text { SOIVED } \\
(\text { MG/L } \\
\text { AS P) } \\
(00671)\end{array}$ & $\begin{array}{l}\text { ALUM- } \\
\text { I NUM, } \\
\text { DIS- } \\
\text { SOI VE D } \\
\text { (UG/L } \\
\text { AS AL) } \\
(01106)\end{array}$ & $\begin{array}{l}\text { ARSENIC } \\
\text { DIS- } \\
\text { SOIVED } \\
\text { (UG/L } \\
\text { AS AS) } \\
(01000)\end{array}$ & $\begin{array}{l}\text { BARIUM, } \\
\text { DIS- } \\
\text { SOIVED } \\
\text { (UG/L } \\
\text { AS BA) } \\
(01005)\end{array}$ & $\begin{array}{l}\text { BERYL- } \\
\text { LIUM, } \\
\text { DIS- } \\
\text { SOLVED } \\
\text { (UG/L } \\
\text { AS BE) } \\
(01010)\end{array}$ & $\begin{array}{l}\text { CADMIUM } \\
\text { DIS- } \\
\text { SOL VED } \\
\text { (UG/L } \\
\text { AS CD) } \\
(01025)\end{array}$ & $\begin{array}{l}\text { CHRO- } \\
\text { MIUM, } \\
\text { DIS- } \\
\text { SOI VED } \\
\text { (UG/L } \\
\text { AS CR) } \\
(01030)\end{array}$ & $\begin{array}{l}\text { COBALI. } \\
\text { DIS- } \\
\text { SOIVED } \\
(U G / L \\
\text { AS CO) } \\
(01035)\end{array}$ & $\begin{array}{l}\text { COPPER, } \\
\text { DIS- } \\
\text { SOLVED } \\
\text { (UG/L } \\
\text { AS CU) } \\
(01040)\end{array}$ \\
\hline
\end{tabular}

\begin{tabular}{|c|c|c|c|c|c|c|c|c|c|c|c|}
\hline $\begin{array}{l}0 C 1 \\
25 \ldots\end{array}$ & 0.30 & 0.070 & 0.040 & 0.050 & 10 & 1 & 40 & $<0.5$ & $<1.0$ & 1 & -3 \\
\hline $\begin{array}{l}\text { MAR } \\
13 \ldots \\
\text { MAY }\end{array}$ & 0.90 & 0.340 & 0.100 & 0.090 & 10 & $<1$ & 21 & 0.5 & $\cdot 1.0$ & -1 & $\cdot 3$ \\
\hline AUG $1 \ldots$ & 0.30 & 0.030 & 0.010 & .0 .010 & 10 & $<1$ & 36 & 0.5 & -1.0 & 1 & $\cdot 3$ \\
\hline $28 \ldots$ & 0.40 & 0.050 & 0.040 & 0.020 & 20 & $<1$ & 43 & $<0.5$ & -1.0 & -1 & $\cdot 3$ \\
\hline
\end{tabular}


WAIER QUALIIY OATA, WAIER YEAR OCTOBER 1990 TO SEPTEMBER 1991

\begin{tabular}{|c|c|c|c|c|c|c|c|c|c|c|c|}
\hline $\begin{array}{l}\text { IRON, } \\
\text { DIS- } \\
\text { SOLVED } \\
\text { (UG/L } \\
\text { AS FE) } \\
(01046)\end{array}$ & $\begin{array}{l}\text { LEAD, } \\
\text { DIS: } \\
\text { SOLVED } \\
\text { (UG/L } \\
\text { AS PB) } \\
(01049)\end{array}$ & $\begin{array}{l}\text { LIIHIUM } \\
\text { DIS- } \\
\text { SOIVED } \\
\text { (UG/L } \\
\text { AS II) } \\
(011130)\end{array}$ & $\begin{array}{l}\text { MANGA- } \\
\text { NESE, } \\
\text { DIS: } \\
\text { SOIVED } \\
\text { (UG/L } \\
\text { AS MN) } \\
(01056)\end{array}$ & $\begin{array}{l}\text { MERCURY } \\
\text { DIS- } \\
\text { SOL VE D } \\
\text { (UG/L } \\
\text { AS HG) } \\
(71890)\end{array}$ & $\begin{array}{l}\text { MOLYB- } \\
\text { DENUM, } \\
\text { DIS- } \\
\text { SOLVED } \\
(U G / L \\
\text { AS MO) } \\
(01060)\end{array}$ & $\begin{array}{l}\text { NICKEL, } \\
\text { DIS- } \\
\text { SOL VED } \\
\text { (UG/L } \\
\text { AS NI) } \\
(01065)\end{array}$ & $\begin{array}{l}\text { SELE - } \\
\text { NIUM, } \\
\text { DIS - } \\
\text { SOLVED } \\
\text { (UG/L } \\
\text { AS SE) } \\
(01145)\end{array}$ & $\begin{array}{l}\text { SILVER, } \\
\text { DIS- } \\
\text { SOLVED } \\
\text { (UG/L } \\
\text { AS AG) } \\
(01075)\end{array}$ & $\begin{array}{l}\text { SIRON- } \\
\text { IIUM. } \\
\text { DIS- } \\
\text { SOLVED } \\
\text { (UG/L } \\
\text { AS SR) } \\
(01080)\end{array}$ & $\begin{array}{l}\text { VANA - } \\
\text { DIUM, } \\
\text { DIS- } \\
\text { SOIVED } \\
(\text { UG/L } \\
\text { AS V) } \\
(01085)\end{array}$ & $\begin{array}{l}\text { ZINC, } \\
\text { DIS- } \\
\text { SOLVED } \\
\text { (UG/L } \\
\text { AS ZN) } \\
(01090)\end{array}$ \\
\hline
\end{tabular}

\begin{tabular}{|c|c|c|c|c|c|c|c|c|c|c|c|}
\hline $\begin{array}{l}0 \mathrm{Cl} \\
25 \ldots \\
\text { MAR }\end{array}$ & 31 & 1 & 7 & 11 & .0 .1 & -10 & 1 & -1 & -1.0 & 210 & .6 \\
\hline $\operatorname{MAY}^{13 \ldots}$ & 26 & $\cdot 1$ & -4 & 13 & $<0.1$ & $\cdot 10$ & 1 & -1 & 1.0 & 82 & .6 \\
\hline$\underset{A U G}{01} \cdots$ & 14 & 4 & 6 & 11 & $<0.1$ & .10 & $<1$ & $<1$ & $<1.0$ & 220 & $=0$ \\
\hline $28 \ldots$ & $\cdot 3$ & $\therefore 1$ & 5 & 19 & $<0.1$ & $<10$ & $<1$ & $\cdot 1$ & $<1.0$ & 200 & .6 \\
\hline DATE & $\begin{array}{l}\text { GROSS } \\
\text { ALPHA, } \\
\text { OIS- } \\
\text { SOLVED } \\
\text { (UG/L } \\
\text { AS } \\
\text { U-NAT) } \\
(80030)\end{array}$ & $\begin{array}{l}\text { GROSS } \\
\text { ALPHA, } \\
\text { SUSP. } \\
\text { TOTAL } \\
\text { (UG/L } \\
\text { AS } \\
\text { U-NAT) } \\
(80040)\end{array}$ & $\begin{array}{l}\text { GROSS } \\
\text { BEIA. } \\
\text { DIS- } \\
\text { SOIVEU } \\
(P C I / L \\
\text { AS } \\
\text { CS-137) } \\
(03515)\end{array}$ & $\begin{array}{l}\text { GROSS } \\
\text { BEIA, } \\
\text { SUSP: } \\
\text { TOIAL } \\
(P C 1 / L \\
\text { AS } \\
\text { (S-137) } \\
(03516)\end{array}$ & $\begin{array}{l}\text { GROSS } \\
\text { BETA, } \\
\text { DIS- } \\
\text { SOLVED } \\
\text { (PCI/L } \\
\text { AS SR/ } \\
\text { YT-90) } \\
(80050)\end{array}$ & $\begin{array}{l}\text { GROSS } \\
\text { BE IA, } \\
\text { SUSP, } \\
\text { TOTAL } \\
(P C I / L \\
\text { AS SR/ } \\
Y T-90) \\
(80060)\end{array}$ & $\begin{array}{l}\text { RADIUM } \\
226 . \\
\text { DIS- } \\
\text { SOIVED, } \\
\text { RADON } \\
\text { MEIHOD } \\
(\text { PCI/L) } \\
(09511)\end{array}$ & $\begin{array}{l}\text { URANIUM } \\
\text { NATURAL } \\
\text { DIS- } \\
\text { SOL VED } \\
(U G / L \\
\text { AS U) } \\
(22703)\end{array}$ & $\begin{array}{l}\text { SEDI - } \\
\text { MENT, } \\
\text { SUS- } \\
\text { PENDED } \\
(\text { MG/L) } \\
(80154)\end{array}$ & $\begin{array}{l}\text { SEUI - } \\
\text { MENI, } \\
\text { DIS- } \\
\text { CHARGE, } \\
\text { SUS- } \\
\text { PENDE D } \\
\text { (I/DAY) } \\
(80155)\end{array}$ & $\begin{array}{l}\text { SED. } \\
\text { SUSP. } \\
\text { SIEVE } \\
\text { DIAM. } \\
\times \text { FINER } \\
\text { IHAN } \\
\text { OH2 MM } \\
(70331)\end{array}$ \\
\hline
\end{tabular}

\begin{tabular}{|c|c|c|c|c|c|c|c|c|c|c|c|}
\hline$O C \mathrm{I}$ & & & & & & & & & & & \\
\hline $\begin{array}{l}25 \ldots \\
\text { MAR }\end{array}$ & $\cdots$ & $\cdots$ & $\cdots$ & . & -. & .. & $\cdots$ & -. & 10 & 0.60 & 85 \\
\hline${ }_{\text {MAY }} 13 \ldots$ & 1.1 & 5.3 & 4. 1 & 4.6 & 3.4 & 4.2 & 0.04 & 0.15 & 114 & 190 & 94 \\
\hline $\begin{array}{c}01 \ldots \\
\text { AUG }\end{array}$ & $\cdots$ & - & $\cdots$ & $\cdots$ & $\cdots$ & - & $\cdots$ & $\cdots$ & 4 & 0.11 & 15 \\
\hline $28 \ldots$ & $<0.6$ & $<0.6$ & $1, y$ & 1.0 & 5.6 & 0.9 & 0.05 & 0.21 & 5 & 0.00 & 61 \\
\hline
\end{tabular}


LOCAIION.--Lat $38^{\circ} 52^{\prime} 41^{\circ}$, Iong $85^{\circ} 15^{\circ} 26^{\prime \prime}$, in SW! 05140101 , On downstrean end of left pier of bridge on State Highway $62,1,500 \mathrm{ft}$ ustrea from wilson fork, 2.0 -i northeast of Canąz, and at mile 16.7 .

DRAI MAGE AREA. - - $27.5 \bullet i^{2}$.

PERIOD OF RECORD..--0ctober 1969 to current yedr.

GAGE. - Water-stage recorder. Elevation of gage is $590 \mathrm{ft}$ dbove National Geodetic Vertical Datun of 1929 , from topographic $\bullet$ ap.

REMARKS. - - Records good except for estiated daily discharges and those below $1 \mathrm{ft} / \mathrm{s}$, which are poor.

DISCHARGE, CUBIC FEET PER SECOND, WATER YEAR OCTOBER 1990 TO SEPTEMBER 1991 DAILY MEAN VALUES

\begin{tabular}{|c|c|c|c|c|c|c|c|c|c|c|c|c|}
\hline DAY & $O C T$ & NOV & $\mathrm{OEC}$ & JAN & FEB & MAR & $A P R$ & MAY & JUN & JUL & AUG & SEP \\
\hline $\begin{array}{l}1 \\
2 \\
3 \\
4 \\
5\end{array}$ & $\begin{array}{r}.77 \\
.57 \\
86^{.42} \\
14\end{array}$ & $\begin{array}{l}5.1 \\
4.6 \\
4.3 \\
4.0 \\
4.9\end{array}$ & $\begin{array}{r}17 \\
14 \\
406 \\
86 \\
40\end{array}$ & $\begin{array}{l}71 \\
45 \\
32 \\
28 \\
27\end{array}$ & $\begin{array}{r}e 45 \\
e 30 \\
26 \\
26 \\
44\end{array}$ & $\begin{array}{l}14 \\
19 \\
14 \\
12 \\
11\end{array}$ & $\begin{array}{l}27 \\
22 \\
19 \\
18 \\
18\end{array}$ & $\begin{array}{l}6.2 \\
5.3 \\
4.4 \\
4.7 \\
5.7\end{array}$ & $\begin{array}{r}3.2 \\
9.2 \\
10 \\
3.4 \\
2.6\end{array}$ & $\begin{array}{r}.33 \\
.38 \\
.56 \\
.36 \\
.28\end{array}$ & $\begin{array}{l}.00 \\
.00 \\
.00 \\
.00 \\
.00\end{array}$ & $\begin{array}{r}.25 \\
.12 \\
11.08 \\
5.1\end{array}$ \\
\hline $\begin{array}{r}6 \\
7 \\
8 \\
9 \\
10\end{array}$ & $\begin{array}{r}5.0 \\
3.5 \\
3.1 \\
134 \\
143\end{array}$ & $\begin{array}{l}7.4 \\
5.1 \\
4.1 \\
10 \\
38\end{array}$ & $\begin{array}{l}29 \\
23 \\
19 \\
16 \\
14\end{array}$ & $\begin{array}{r}247 \\
147 \\
79 \\
55 \\
48\end{array}$ & $\begin{array}{r}587 \\
268 \\
99 \\
60 \\
43\end{array}$ & $\begin{array}{l}24 \\
28 \\
17 \\
15 \\
14\end{array}$ & $\begin{array}{l}15 \\
13 \\
13 \\
71 \\
58\end{array}$ & $\begin{array}{l}6.0 \\
3.9 \\
3.3 \\
13 \\
15\end{array}$ & $\begin{array}{c}2.1 \\
1.7 \\
1.3 \\
1.2 \\
.99\end{array}$ & $\begin{array}{c}.19 \\
30 \\
4.12 \\
2.7\end{array}$ & $\begin{array}{l}.08 \\
.17 \\
.27 \\
3.3 \\
2.4\end{array}$ & $\begin{array}{l}1.9 \\
.96 \\
.52 \\
.37 \\
.29\end{array}$ \\
\hline $\begin{array}{l}11 \\
12 \\
13 \\
14 \\
15\end{array}$ & $\begin{array}{l}31 \\
18 \\
12 \\
8.4 \\
5.8\end{array}$ & $\begin{array}{l}18 \\
14 \\
11 \\
8.8 \\
7.6\end{array}$ & $\begin{array}{c}13 \\
12 \\
11 \\
8.7 \\
255\end{array}$ & $\begin{array}{r}277 \\
137 \\
70 \\
51 \\
43\end{array}$ & $\begin{array}{r}32 \\
26 \\
62 \\
216 \\
e 90\end{array}$ & $\begin{array}{r}13 \\
39 \\
404 \\
118 \\
57\end{array}$ & $\begin{array}{r}26 \\
22 \\
676 \\
253 \\
205\end{array}$ & $\begin{array}{l}24 \\
19 \\
30 \\
22 \\
17\end{array}$ & $\begin{array}{l}.82 \\
.65 \\
.55 \\
.46 \\
.35\end{array}$ & $\begin{array}{l}2.1 \\
2.3 \\
2.2 \\
1.4 \\
.78\end{array}$ & $\begin{array}{l}.97 \\
.50 \\
.33 \\
.25 \\
.16\end{array}$ & $\begin{array}{l}.22 \\
.16 \\
.18 \\
.13 \\
.08\end{array}$ \\
\hline $\begin{array}{l}16 \\
17 \\
18 \\
19 \\
20\end{array}$ & $\begin{array}{r}4.7 \\
4.1 \\
457 \\
42 \\
23\end{array}$ & $\begin{array}{l}6.7 \\
6.6 \\
5.6 \\
5.2 \\
5.1\end{array}$ & $\begin{array}{r}59 \\
150 \\
1580 \\
208 \\
81\end{array}$ & $\begin{array}{l}59 \\
52 \\
39 \\
35 \\
33\end{array}$ & $\begin{array}{r}e 50 \\
e 40 \\
290 \\
142 \\
80\end{array}$ & $\begin{array}{r}40 \\
123 \\
212 \\
85 \\
52\end{array}$ & $\begin{array}{l}83 \\
49 \\
35 \\
33 \\
27\end{array}$ & $\begin{array}{l}11 \\
7.4 \\
44 \\
20 \\
12\end{array}$ & $\begin{array}{r}139 \\
23 \\
7.2 \\
9.4 \\
3.7\end{array}$ & $\begin{array}{l}.45 \\
.33 \\
.23 \\
.18 \\
.15\end{array}$ & $\begin{array}{l}.10 \\
.17 \\
.57 \\
.57 \\
.48\end{array}$ & $\begin{array}{l}.04 \\
.05 \\
.05 \\
.07 \\
.03\end{array}$ \\
\hline $\begin{array}{l}21 \\
22 \\
23 \\
24 \\
25\end{array}$ & $\begin{array}{l}17 \\
63 \\
44 \\
25 \\
18\end{array}$ & $\begin{array}{l}4.8 \\
60 \\
40 \\
23 \\
18\end{array}$ & $\begin{array}{r}114 \\
256 \\
266 \\
85 \\
e 50\end{array}$ & $\begin{array}{r}30 \\
\text { e25 } \\
\text { e23 } \\
\text { e21 } \\
\text { e19 }\end{array}$ & $\begin{array}{l}51 \\
38 \\
29 \\
24 \\
20\end{array}$ & $\begin{array}{r}38 \\
570 \\
314 \\
91 \\
54\end{array}$ & $\begin{array}{l}22 \\
20 \\
17 \\
16 \\
13\end{array}$ & $\begin{array}{l}8.2 \\
27 \\
65 \\
38 \\
17\end{array}$ & $\begin{array}{l}2.8 \\
2.5 \\
5.4 \\
2.5 \\
1.8\end{array}$ & $\begin{array}{l}.12 \\
.09 \\
.08 \\
.08 \\
.08\end{array}$ & $\begin{array}{l}.87 \\
.72 \\
.44 \\
.31 \\
.21\end{array}$ & $\begin{array}{l}.00 \\
.00 \\
.02 \\
.00 \\
.00\end{array}$ \\
\hline $\begin{array}{l}26 \\
27 \\
28 \\
29 \\
30 \\
31\end{array}$ & $\begin{array}{l}15 \\
13 \\
11 \\
8.4 \\
6.6 \\
5.9\end{array}$ & $\begin{array}{l}15 \\
14 \\
41 \\
27 \\
20 \\
\ldots\end{array}$ & $\begin{array}{l}\text { e } 38 \\
\text { e34 } \\
\text { e30 } \\
423 \\
852 \\
169\end{array}$ & $\begin{array}{r}\text { e17 } \\
\text { e20 } \\
\text { e40 } \\
\text { e } 30 \\
\text { e140 } \\
\text { e60 }\end{array}$ & $\begin{array}{l}17 \\
16 \\
14 \\
\cdots \\
\cdots \\
\cdots\end{array}$ & $\begin{array}{r}212 \\
149 \\
100 \\
56 \\
39 \\
32\end{array}$ & $\begin{array}{r}12 \\
12 \\
10 \\
9.9 \\
7.8 \\
\cdots\end{array}$ & $\begin{array}{r}14 \\
14 \\
10 \\
6.0 \\
4.5 \\
3.6\end{array}$ & $\begin{array}{l}1.4 \\
1.1 \\
.77 \\
.61 \\
.43 \\
\cdots\end{array}$ & $\begin{array}{l}.06 \\
.04 \\
.02 \\
.02 \\
.02 \\
.00\end{array}$ & $\begin{array}{l}.14 \\
.11 \\
.07 \\
.04 \\
.09 \\
.17\end{array}$ & $\begin{array}{l}.00 \\
.00 \\
.00 \\
.00 \\
.00 \\
\ldots\end{array}$ \\
\hline $\begin{array}{l}\text { TOIAL } \\
\text { MEAN } \\
\text { MAX } \\
\text { MIN } \\
\text { CF SM } \\
\text { IN. }\end{array}$ & $\begin{array}{r}1223.26 \\
39.5 \\
457 \\
.42 \\
1.43 \\
1.65\end{array}$ & $\begin{array}{r}438.9 \\
14.6 \\
60 \\
4.0 \\
.53 \\
.59\end{array}$ & $\begin{array}{r}5358.7 \\
173 \\
1580 \\
8.7 \\
6.29 \\
7.25\end{array}$ & $\begin{array}{r}2000 \\
64.5 \\
277 \\
17 \\
2.35 \\
2.71\end{array}$ & $\begin{array}{r}2465 \\
88.0 \\
587 \\
14 \\
3.20 \\
3.33\end{array}$ & $\begin{array}{c}2966 \\
95.7 \\
570 \\
11 \\
3.48 \\
4.01\end{array}$ & $\begin{array}{r}1822.7 \\
60.8 \\
676 \\
7.8 \\
2.21 \\
2.47\end{array}$ & $\begin{array}{r}481.2 \\
15.5 \\
65 \\
3.3 \\
.56 \\
.65\end{array}$ & $\begin{array}{c}240.13 \\
8.00 \\
139 \\
.35 \\
.29 \\
.32\end{array}$ & $\begin{array}{c}50.45 \\
1.63 \\
30 \\
.00 \\
.06 \\
.07\end{array}$ & $\begin{array}{c}13.49 \\
.44 \\
3.3 \\
.00 \\
.02 \\
.02\end{array}$ & $\begin{array}{c}27.62 \\
.92 \\
17 \\
.00 \\
.03 \\
.04\end{array}$ \\
\hline
\end{tabular}

e Estinated

SIATISIICS OF MONIHLY MEAN DATA FOR WATER YEARS 1970 - 1991, BY WAIER YEAR (WY)

$\begin{array}{lrrrrrrrrrrrr}\text { MEAN } & 12.3 & 37.2 & 51.9 & 44.8 & 59.9 & 69.1 & 57.1 & 41.1 & 18.5 & 10.7 & 11.2 & 8.03 \\ \text { MAX } & 83.6 & 137 & 173 & 169 & 136 & 134 & 104 & 193 & 57.7 & 40.8 & 58.6 & 57.9 \\ \text { (WY) } & 1984 & 1980 & 1991 & 1982 & 1990 & 1975 & 1981 & 1983 & 1981 & 1973 & 1979 & 1979 \\ \text { MIN } & 1000 & .22 & 3.95 & .60 & 9.74 & 11.7 & 6.55 & 4.63 & .44 & .12 & .001 & .000 \\ \text { (WY) } & 1988 & 1988 & 1977 & 1977 & 1978 & 1983 & 1976 & 1976 & 1988 & 1975 & 1975 & 1987\end{array}$

SUMMARY STATISTICS

ANMUAL TOTAL

AMMUAL MEAN

HIGHEST ANNUAL MEAN

LOWEST ANNUAL MEAN

HIGHEST DAILY MEAN

LOWEST DAILY MEAN

ANMUAL SEVEN-DAY MINIMUM

INSTANIANEOUS PEAK FLOW

INSIANTANEOUS PEAK STAGE

ANNUAL RUNOFF (CF SM)

ANNUAL RUNOFF (INCHES)

10 PERCENT EXCEEDS

50 PERCENT EXCEEDS

90 PERCENT EXCEEDS
FOR 1990 CALENDAR YEAR

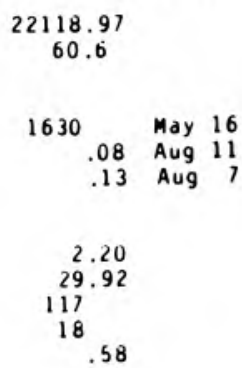

FOR 1991 WATER YEAR

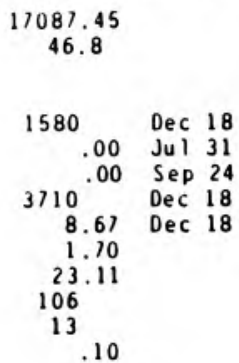

WATER YEARS $1970-1991$

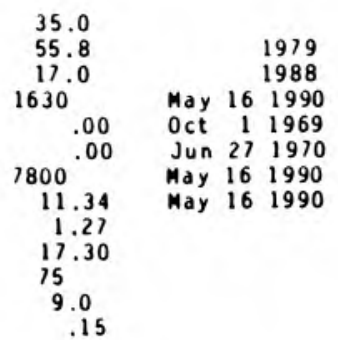


LOCAIIUN.--Lat $38^{\circ} 22^{\prime} 15^{\prime \prime}$, Iong $85^{\circ} 43^{\prime} 35^{\prime \prime}$, In lot 68, Clark Military Grant, Clark County, Hydrologic Unit 05140101, on downstream side of Straws Mill bridge on Watson Rodd, 0.3 mi downstream from Pleasant Run, 2.4 mi southeast of Sellersburg, and 12.2 mi upstream from mouth.

DRAINAGE AREA, . $189 \mathrm{mi}^{2}$.

PERIOD OF RECORD.--OCtober 1954 to current yedr.

REVISFD RECORDS.--WSP 1705: 1955-58. WDR IN-72-1: Drainage area.

GAGE.- Water-stage recorder and crest-stage gage. Datum of gage is $429.78 \mathrm{ft}$ above National Geodetic Vertical Datum of 1929 (levels by State of Indiand, Department of Natural Resources). Prior to 0ct. 6, 1976, and

Feb. 15 to Sept. 20, 1984 nonrecording gage and grest-stage gage at same site and datum.

REMARKS. - Records good except for those below $10 \mathrm{ft} / \mathrm{s}$, which are poor. Some regulation by Deam Iake.

DISCHARGE, CUBIC FEEI PER SECOND, WATER YEAR OCTOBER 1990 TO SEPIEMBER 1991 DAILY MEAN VALUES

\begin{tabular}{|c|c|c|c|c|c|c|c|c|c|c|c|c|}
\hline DAY & $O C I$ & NOV & $\mathrm{DEC}$ & JAN & FEB & MAR & APR & MAY & JUN & JUL & AUG & SEP \\
\hline $\begin{array}{l}1 \\
2 \\
3 \\
4 \\
5\end{array}$ & $\begin{array}{r}12 \\
e 11 \\
\text { e11 } \\
119 \\
136\end{array}$ & $\begin{array}{l}23 \\
20 \\
18 \\
18 \\
18\end{array}$ & $\begin{array}{r}79 \\
68 \\
920 \\
687 \\
293\end{array}$ & $\begin{array}{l}864 \\
559 \\
438 \\
351 \\
292\end{array}$ & $\begin{array}{l}244 \\
232 \\
207 \\
196 \\
197\end{array}$ & $\begin{array}{l}113 \\
232 \\
179 \\
132 \\
111\end{array}$ & $\begin{array}{l}194 \\
157 \\
134 \\
121 \\
129\end{array}$ & $\begin{array}{l}76 \\
65 \\
57 \\
51 \\
49\end{array}$ & $\begin{array}{r}124 \\
94 \\
271 \\
258 \\
99\end{array}$ & $\begin{array}{c}3.5 \\
2.6 \\
10 \\
12 \\
7.7\end{array}$ & $\begin{array}{l}3.1 \\
3.1 \\
3.1 \\
3.0 \\
2.8\end{array}$ & $\begin{array}{l}3.2 \\
2.3 \\
1.8 \\
3.9 \\
37\end{array}$ \\
\hline $\begin{array}{r}6 \\
7 \\
8 \\
9 \\
10\end{array}$ & $\begin{array}{r}41 \\
26 \\
21 \\
19 \\
118\end{array}$ & $\begin{array}{r}28 \\
36 \\
23 \\
21 \\
175\end{array}$ & $\begin{array}{r}210 \\
144 \\
115 \\
104 \\
94\end{array}$ & $\begin{array}{r}822 \\
1970 \\
1100 \\
652 \\
490\end{array}$ & $\begin{array}{r}2180 \\
2250 \\
835 \\
540 \\
416\end{array}$ & $\begin{array}{r}114 \\
176 \\
133 \\
104 \\
94\end{array}$ & $\begin{array}{r}122 \\
107 \\
99 \\
633 \\
2090\end{array}$ & $\begin{array}{l}71 \\
50 \\
40 \\
44 \\
50\end{array}$ & $\begin{array}{l}53 \\
37 \\
27 \\
20 \\
16\end{array}$ & $\begin{array}{l}4.3 \\
2.9 \\
3.7 \\
3.8 \\
3.4\end{array}$ & $\begin{array}{l}2.7 \\
2.6 \\
3.8 \\
19 \\
32\end{array}$ & $\begin{array}{r}21 \\
7.7 \\
4.0 \\
2.8 \\
3.7\end{array}$ \\
\hline $\begin{array}{l}11 \\
12 \\
13 \\
14 \\
15\end{array}$ & $\begin{array}{l}90 \\
47 \\
38 \\
25 \\
21\end{array}$ & $\begin{array}{r}123 \\
76 \\
54 \\
42 \\
35\end{array}$ & $\begin{array}{r}81 \\
72 \\
65 \\
57 \\
298\end{array}$ & $\begin{array}{r}1270 \\
1550 \\
656 \\
480 \\
393\end{array}$ & $\begin{array}{r}317 \\
249 \\
308 \\
2080 \\
917\end{array}$ & $\begin{array}{r}87 \\
87 \\
1350 \\
1050 \\
568\end{array}$ & $\begin{array}{r}541 \\
359 \\
1760 \\
946 \\
726\end{array}$ & $\begin{array}{r}40 \\
33 \\
33 \\
60 \\
546\end{array}$ & $\begin{array}{l}13 \\
21 \\
11 \\
11 \\
10\end{array}$ & $\begin{array}{l}5.4 \\
6.0 \\
4.8 \\
3.8 \\
2.8\end{array}$ & $\begin{array}{r}13 \\
4.2 \\
2.2 \\
1.6 \\
1.6\end{array}$ & $\begin{array}{l}3.8 \\
3.3 \\
3.1 \\
6.1 \\
6.3\end{array}$ \\
\hline $\begin{array}{l}16 \\
17 \\
18 \\
19 \\
20\end{array}$ & $\begin{array}{r}17 \\
\mathrm{e} 15 \\
918 \\
302 \\
115\end{array}$ & $\begin{array}{r}31 \\
30 \\
30 \\
28 \\
\mathrm{e} 26\end{array}$ & $\begin{array}{r}396 \\
290 \\
3620 \\
4650 \\
1090\end{array}$ & $\begin{array}{l}441 \\
374 \\
315 \\
279 \\
272\end{array}$ & $\begin{array}{l}436 \\
370 \\
965 \\
989 \\
594\end{array}$ & $\begin{array}{l}390 \\
338 \\
990 \\
583 \\
402\end{array}$ & $\begin{array}{l}552 \\
381 \\
285 \\
285 \\
276\end{array}$ & $\begin{array}{r}142 \\
87 \\
62 \\
48 \\
38\end{array}$ & $\begin{array}{l}8.1 \\
15 \\
13 \\
9.6 \\
16\end{array}$ & $\begin{array}{l}2.1 \\
1.9 \\
1.6 \\
1.6 \\
1.6\end{array}$ & $\begin{array}{c}1.5 \\
1.4 \\
256 \\
58 \\
18\end{array}$ & $\begin{array}{l}5.3 \\
4.3 \\
3.5 \\
3.5 \\
2.9\end{array}$ \\
\hline $\begin{array}{l}21 \\
22 \\
23 \\
24 \\
25\end{array}$ & $\begin{array}{r}72 \\
118 \\
278 \\
122 \\
86\end{array}$ & $\begin{array}{l}24 \\
120 \\
384 \\
162 \\
104\end{array}$ & $\begin{array}{r}573 \\
1500 \\
1330 \\
749 \\
447\end{array}$ & $\begin{array}{l}242 \\
178 \\
168 \\
159 \\
136\end{array}$ & $\begin{array}{l}424 \\
337 \\
266 \\
219 \\
180\end{array}$ & $\begin{array}{r}340 \\
3410 \\
6650 \\
3410 \\
731\end{array}$ & $\begin{array}{l}211 \\
170 \\
143 \\
189 \\
148\end{array}$ & $\begin{array}{r}31 \\
27 \\
31 \\
279 \\
101\end{array}$ & $\begin{array}{r}12 \\
9.0 \\
7.8 \\
6.3 \\
5.8\end{array}$ & $\begin{array}{l}2.5 \\
3.4 \\
3.5 \\
2.9 \\
2.8\end{array}$ & $\begin{array}{l}8.2 \\
4.8 \\
3.1 \\
2.2 \\
2.0\end{array}$ & $\begin{array}{l}2.5 \\
2.2 \\
2.0 \\
1.8 \\
1.8\end{array}$ \\
\hline $\begin{array}{l}26 \\
27 \\
28 \\
29 \\
30 \\
31\end{array}$ & $\begin{array}{l}58 \\
44 \\
35 \\
3 ! \\
\vdots \\
4\end{array}$ & $\begin{array}{r}79 \\
69 \\
87 \\
58 \\
96 \\
\cdots\end{array}$ & $\begin{array}{r}351 \\
282 \\
269 \\
1060 \\
3150 \\
3260\end{array}$ & $\begin{array}{l}133 \\
125 \\
224 \\
199 \\
381 \\
337\end{array}$ & $\begin{array}{l}149 \\
130 \\
118 \\
\cdots \\
\cdots \\
\cdots\end{array}$ & $\begin{array}{l}526 \\
599 \\
688 \\
408 \\
308 \\
243\end{array}$ & $\begin{array}{r}123 \\
109 \\
100 \\
99 \\
94 \\
\ldots\end{array}$ & $\begin{array}{r}104 \\
90 \\
73 \\
241 \\
1060 \\
239\end{array}$ & $\begin{array}{r}15 \\
9.8 \\
5.7 \\
4.6 \\
4.0 \\
\ldots . .\end{array}$ & $\begin{array}{l}2.8 \\
2.8 \\
2.8 \\
2.8 \\
3.2 \\
3.3\end{array}$ & $\begin{array}{r}3.5 \\
\mathrm{e} 4.5 \\
\mathrm{e} 6.8 \\
5.6 \\
5.0 \\
5.3\end{array}$ & $\begin{array}{l}1.1 \\
1.3 \\
1.1 \\
1.1 \\
1.4 \\
\ldots .\end{array}$ \\
\hline $\begin{array}{l}\text { IOIAL } \\
\text { MEAN } \\
\text { MAX } \\
\text { MIN } \\
\text { CF SM } \\
\text { IN. }\end{array}$ & $\begin{array}{r}0.1 \\
90.1 \\
9 \div 8 \\
11 \\
.51 \\
.59\end{array}$ & $\begin{array}{r}2130 \\
334 \\
18 \\
.38 \\
.42\end{array}$ & $\begin{array}{r}26304 \\
849 \\
4650 \\
57 \\
4.49 \\
5.18\end{array}$ & $\begin{array}{r}15850 \\
511 \\
1970 \\
125 \\
2.71 \\
3.12\end{array}$ & $\begin{array}{r}16345 \\
584 \\
2250 \\
118 \\
3.09 \\
3.22\end{array}$ & $\begin{array}{r}24546 \\
792 \\
6650 \\
87 \\
4.19 \\
4.83\end{array}$ & $\begin{array}{r}11283 \\
376 \\
2090 \\
94 \\
1.99 \\
2.22\end{array}$ & $\begin{array}{c}3918 \\
126 \\
1060 \\
27 \\
.67 \\
.77\end{array}$ & $\begin{array}{r}1206.7 \\
40.2 \\
271 \\
4.0 \\
.21 \\
.24\end{array}$ & $\begin{array}{r}118.3 \\
3.82 \\
12 \\
1.6 \\
.02 \\
.02\end{array}$ & $\begin{array}{c}483.7 \\
15.6 \\
256 \\
1.4 \\
.08 \\
.10\end{array}$ & $\begin{array}{r}146.4 \\
4.88 \\
37 \\
1.1 \\
.03 \\
.03\end{array}$ \\
\hline
\end{tabular}

E Estimated

SIAIISIILS OF MONTHLY MEAN DAIA FOR WAIER YEARS 1955 - 1991. BY WATER YEAR (WY)

$\begin{array}{lrrrrrrrrrrrr}\text { MEAN } & 32.4 & 129 & 257 & 298 & 433 & 515 & 409 & 292 & 149 & 74.1 & 41.1 & 36.4 \\ \text { MAX } & 143 & 805 & 862 & 1150 & 1323 & 2252 & 1117 & 1369 & 1337 & 316 & 514 & 390 \\ \text { (WY) } & 1978 & 1980 & 1979 & 1959 & 1956 & 1964 & 1970 & 1983 & 1960 & 1973 & 1978 & 1979 \\ \text { MIN } & .21 & .61 & .60 & 5.43 & 45.0 & 112 & 72.3 & 25.4 & 3.07 & 2.75 & 1.86 & 24 \\ \text { (WY) } & 1965 & 1964 & 1964 & 1977 & 1963 & 1981 & 1976 & 1988 & 1988 & 1959 & 1965 & 1957\end{array}$

SUMF:ARY SIAIISIICS

ANNUAL TOIAL

ANNUAL MEAN

HIGHESI ANNUAL MEAN

IOIEST ANNUAL MEAN

HIGHESI DAILY MEAN

LOWEST DAILY MEAN

ANMUAL SEVEN-DAY MINIMUM

INSIANIANEOUS PEAK FLOW

INSIANTANE OUS PEAK STAGE

ANNIJAL RUNOFF (CFSM)

ANA AL RUNOFF (INCHES)

10 PERCENT EXCEEDS

50 HERCENT EXCEEDS

90 PERCENT EXCEEDS
FOR 1990 CALENDAR YEAR

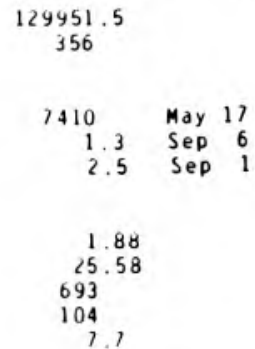

FOR 1991 WAIER YEAR

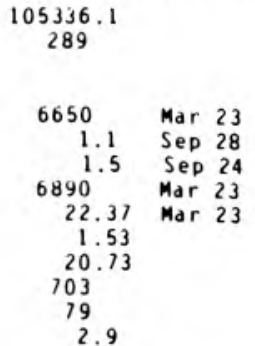

WATER YEARS $1955 \cdot 1991$

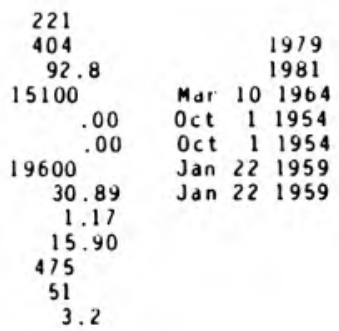




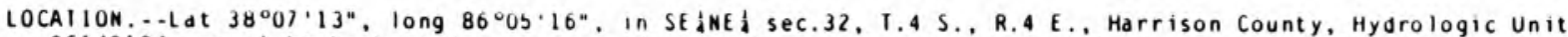
05140104, on right bank at downstream side of bridge on State Highway 337 (revised). 0.6 mi downstresm froe South Fork Buck Creek, 3.6 i southwest of New Middletown, and 14.4 upstrean from mouth.

DRAINAGE AREA.- $65.2 \mathrm{i}^{2}$, of which $28.1 \mathrm{mi} i^{2}$ does not contribule directly to surface runoff.

PERIOD OF RECORD.--October 1969 to current year.

REVISED RECORDS...-WOR IN-72-1: $1911(\mathrm{P})$.

GAGE.--Water-stage recorder. Datum of $9 \mathrm{dge}$ is $501.63 \mathrm{ft}$ above National Geodetic Vertical Datum of 1929 (levels by State of Indiana. Departaent of Natural Resources).

REMARKS. - Records good except for estimated daily discharges and those below $10 \mathrm{ft} / \mathrm{s}$, which are poor.

DISCHARGE, CUBIC FEET PER SECOND, WAIER YEAR OCTOBER 1990 TO SEPIEMBER 1991 DAILY MEAN VALUES

\begin{tabular}{|c|c|c|c|c|c|c|c|c|c|c|c|c|}
\hline DAY & $O C T$ & NOV & DEC & JAN & FEB & MAR & APR & MAY & JUN & JUL & AUG & SEP \\
\hline $\begin{array}{l}1 \\
2 \\
3 \\
4 \\
5\end{array}$ & $\begin{array}{c}\text { e2.4 } \\
\mathrm{e} 2.3 \\
\mathrm{e} 2.3 \\
100 \\
36\end{array}$ & $\begin{array}{l}9.8 \\
8.1 \\
7.1 \\
7.0 \\
9.2\end{array}$ & $\begin{array}{r}40 \\
32 \\
273 \\
169 \\
110\end{array}$ & $\begin{array}{l}312 \\
169 \\
131 \\
117 \\
143\end{array}$ & $\begin{array}{r}110 \\
91 \\
77 \\
69 \\
78\end{array}$ & $\begin{array}{l}76 \\
66 \\
55 \\
50 \\
41\end{array}$ & $\begin{array}{l}49 \\
43 \\
44 \\
61 \\
43\end{array}$ & $\begin{array}{l}21 \\
19 \\
15 \\
14 \\
28\end{array}$ & $\begin{array}{l}38 \\
31 \\
34 \\
24 \\
17\end{array}$ & $\begin{array}{r}10 \\
8.6 \\
8.8 \\
9.4 \\
9.0\end{array}$ & $\begin{array}{l}3.1 \\
2.1 \\
2.9 \\
4.0 \\
4.1\end{array}$ & $\begin{array}{l}3.6 \\
1.6 \\
1.5 \\
6.3 \\
6.1\end{array}$ \\
\hline $\begin{array}{r}6 \\
7 \\
8 \\
9 \\
10\end{array}$ & $\begin{array}{l}11 \\
10 \\
7.8 \\
21 \\
91\end{array}$ & $\begin{array}{c}12 \\
10 \\
8.7 \\
17 \\
85\end{array}$ & $\begin{array}{l}86 \\
66 \\
52 \\
41 \\
34\end{array}$ & $\begin{array}{l}576 \\
559 \\
297 \\
208 \\
191\end{array}$ & $\begin{array}{l}742 \\
467 \\
292 \\
220 \\
184\end{array}$ & $\begin{array}{l}51 \\
51 \\
45 \\
43 \\
40\end{array}$ & $\begin{array}{r}30 \\
29 \\
94 \\
110 \\
78\end{array}$ & $\begin{array}{l}28 \\
20 \\
16 \\
90 \\
90\end{array}$ & $\begin{array}{l}15 \\
12 \\
10 \\
8.9 \\
7.3\end{array}$ & $\begin{array}{r}7.8 \\
7.0 \\
6.1 \\
7.5 \\
33\end{array}$ & $\begin{array}{l}4.9 \\
5.5 \\
2.8 \\
5.5 \\
8.0\end{array}$ & $\begin{array}{l}2.7 \\
1.4 \\
1.2 \\
1.6 \\
2.8\end{array}$ \\
\hline $\begin{array}{l}11 \\
12 \\
13 \\
14 \\
15\end{array}$ & $\begin{array}{r}39 \\
24 \\
17 \\
12 \\
9.0\end{array}$ & $\begin{array}{l}48 \\
32 \\
24 \\
20 \\
17\end{array}$ & $\begin{array}{r}30 \\
28 \\
34 \\
26 \\
204\end{array}$ & $\begin{array}{l}324 \\
253 \\
197 \\
171 \\
159\end{array}$ & $\begin{array}{l}159 \\
129 \\
191 \\
496 \\
242\end{array}$ & $\begin{array}{r}38 \\
43 \\
217 \\
237 \\
164\end{array}$ & $\begin{array}{r}58 \\
52 \\
107 \\
91 \\
80\end{array}$ & $\begin{array}{r}66 \\
87 \\
101 \\
90 \\
155\end{array}$ & $\begin{array}{l}6.7 \\
6.4 \\
5.7 \\
6.5 \\
6.8\end{array}$ & $\begin{array}{r}20 \\
13 \\
11 \\
6.5 \\
5.6\end{array}$ & $\begin{array}{l}6.0 \\
5.7 \\
15 \\
14 \\
4.1\end{array}$ & $\begin{array}{l}2.4 \\
2.5 \\
4.5 \\
2.4 \\
1.6\end{array}$ \\
\hline $\begin{array}{l}16 \\
17 \\
18 \\
19 \\
20\end{array}$ & $\begin{array}{l}7.6 \\
7.8 \\
83 \\
28 \\
20\end{array}$ & $\begin{array}{c}14 \\
13 \\
11 \\
10 \\
9.4\end{array}$ & $\begin{array}{r}152 \\
160 \\
2030 \\
648 \\
312\end{array}$ & $\begin{array}{r}148 \\
101 \\
90 \\
87 \\
85\end{array}$ & $\begin{array}{l}174 \\
155 \\
540 \\
319 \\
234\end{array}$ & $\begin{array}{l}133 \\
162 \\
285 \\
201 \\
167\end{array}$ & $\begin{array}{l}69 \\
66 \\
57 \\
60 \\
49\end{array}$ & $\begin{array}{r}101 \\
81 \\
59 \\
43 \\
36\end{array}$ & $\begin{array}{l}5.6 \\
5.0 \\
13 \\
32 \\
9.9\end{array}$ & $\begin{array}{r}4.7 \\
4.3 \\
4.2 \\
12 \\
6.2\end{array}$ & $\begin{array}{l}2.4 \\
3.4 \\
5.7 \\
3.4 \\
2.3\end{array}$ & $\begin{array}{l}1.2 \\
1.1 \\
1.5 \\
2.9 \\
1.8\end{array}$ \\
\hline $\begin{array}{l}21 \\
22 \\
23 \\
24 \\
25\end{array}$ & $\begin{array}{l}14 \\
77 \\
95 \\
55 \\
36\end{array}$ & $\begin{array}{l}9.2 \\
28 \\
60 \\
41 \\
31\end{array}$ & $\begin{array}{l}210 \\
263 \\
352 \\
231 \\
167\end{array}$ & $\begin{array}{r}10 \\
\text { e } 60 \\
\text { e } 50 \\
\text { e } 46 \\
\text { e } 40\end{array}$ & $\begin{array}{l}189 \\
152 \\
131 \\
120 \\
108\end{array}$ & $\begin{array}{r}163 \\
1110 \\
739 \\
363 \\
230\end{array}$ & $\begin{array}{l}43 \\
40 \\
37 \\
38 \\
32\end{array}$ & $\begin{array}{r}30 \\
26 \\
157 \\
240 \\
141\end{array}$ & $\begin{array}{r}223 \\
134 \\
66 \\
41 \\
29\end{array}$ & $\begin{array}{l}4.6 \\
4.1 \\
3.9 \\
3.4 \\
3.5\end{array}$ & $\begin{array}{l}2.0 \\
1.8 \\
1.7 \\
1.5 \\
1.5\end{array}$ & $\begin{array}{c}1.0 \\
.91 \\
1.2 \\
1.4 \\
2.8\end{array}$ \\
\hline $\begin{array}{l}26 \\
27 \\
28 \\
29 \\
30 \\
31\end{array}$ & $\begin{array}{l}26 \\
22 \\
22 \\
17 \\
14 \\
12\end{array}$ & $\begin{array}{c}43 \\
31 \\
69 \\
68 \\
49 \\
\ldots\end{array}$ & $\begin{array}{r}127 \\
109 \\
100 \\
389 \\
1060 \\
601\end{array}$ & $\begin{array}{r}e 34 \\
\text { e33 } \\
90 \\
66 \\
236 \\
153\end{array}$ & $\begin{array}{c}93 \\
86 \\
81 \\
\ldots- \\
\cdots- \\
\cdots\end{array}$ & $\begin{array}{r}150 \\
127 \\
106 \\
93 \\
79 \\
63\end{array}$ & $\begin{array}{l}30 \\
28 \\
21 \\
27 \\
23 \\
\cdots\end{array}$ & $\begin{array}{r}151 \\
115 \\
88 \\
69 \\
57 \\
49\end{array}$ & $\begin{array}{l}22 \\
18 \\
17 \\
14 \\
12 \\
\cdots\end{array}$ & $\begin{array}{l}3.9 \\
3.2 \\
2.9 \\
3.6 \\
3.8 \\
3.3\end{array}$ & $\begin{array}{l}1.4 \\
1.5 \\
1.9 \\
1.9 \\
2.0 \\
3.1\end{array}$ & $\begin{array}{l}2.3 \\
1.5 \\
1.5 \\
1.3 \\
.96 \\
\ldots . .\end{array}$ \\
\hline $\begin{array}{l}\text { IOIAL } \\
\text { MEAN } \\
\text { MAX } \\
\text { MIN } \\
\text { CF SM } \\
\text { IN. }\end{array}$ & $\begin{array}{r}927.2 \\
29.9 \\
100 \\
2.3 \\
.81 \\
.93\end{array}$ & $\begin{array}{r}801.5 \\
26.7 \\
85 \\
7.0 \\
.72 \\
.80\end{array}$ & $\begin{array}{r}8136 \\
262 \\
2030 \\
26 \\
7.07 \\
8.16\end{array}$ & $\begin{array}{r}5196 \\
168 \\
576 \\
33 \\
4.52 \\
5.21\end{array}$ & $\begin{array}{r}5935 \\
212 \\
742 \\
69 \\
5.71 \\
5.95\end{array}$ & $\begin{array}{r}5388 \\
174 \\
1110 \\
38 \\
4.68 \\
5.40\end{array}$ & $\begin{array}{r}1595 \\
53.2 \\
110 \\
23 \\
1.43 \\
1.60\end{array}$ & $\begin{array}{r}2283 \\
73.6 \\
240 \\
14 \\
1.99 \\
2.29\end{array}$ & $\begin{array}{r}870.8 \\
29.0 \\
223 \\
5.0 \\
.78 \\
.87\end{array}$ & $\begin{array}{r}234.9 \\
7.58 \\
33 \\
2.9 \\
.20 \\
.24\end{array}$ & $\begin{array}{r}185.0 \\
5.97 \\
15 \\
1.4 \\
.16 \\
.19\end{array}$ & $\begin{array}{r}05.63 \\
2.19 \\
6.3 \\
.96 \\
.06 \\
.07\end{array}$ \\
\hline
\end{tabular}

e Estinated

SIATISIICS OF MONIHLY MEAN DAIA FUR WAIER YLARS 1970 - 1991, BY WATER YEAR (WY)

\begin{tabular}{|c|c|c|c|c|c|c|c|c|c|c|c|c|}
\hline $\begin{array}{l}\text { MEAN } \\
\text { MAX } \\
(W Y) \\
\text { MIN } \\
(W Y)\end{array}$ & $\begin{array}{r}19.4 \\
71.8 \\
1971 \\
.76 \\
1988\end{array}$ & $\begin{array}{r}61.7 \\
228 \\
1980 \\
3.16 \\
1988\end{array}$ & $\begin{array}{r}105 \\
252 \\
1991 \\
6.01 \\
1977\end{array}$ & $\begin{array}{r}101 \\
201 \\
1974 \\
2.64 \\
1977\end{array}$ & $\begin{array}{r}142 \\
368 \\
1989 \\
28.9 \\
1978\end{array}$ & $\begin{array}{r}141 \\
342 \\
1975 \\
40.4 \\
1983\end{array}$ & $\begin{array}{r}156 \\
412 \\
1970 \\
22.4 \\
1986\end{array}$ & $\begin{array}{r}100 \\
558 \\
1983 \\
16.3 \\
1976\end{array}$ & $\begin{array}{r}51.0 \\
222 \\
1990 \\
1.56 \\
1988\end{array}$ & $\begin{array}{r}31.7 \\
219 \\
1979 \\
4.59 \\
1975\end{array}$ & $\begin{array}{l}16.1 \\
66.1 \\
1979 \\
2.11 \\
1987\end{array}$ & $\begin{array}{r}20.0 \\
217 \\
1979 \\
.72 \\
1987\end{array}$ \\
\hline
\end{tabular}

SUMMARY SIAIISIICS

ANNUAL TOIAL

ANNUAL MEAN

HIGHESI ANNUAL MEAN

LOWEST ANNUAL MEAN

HIGHESI DAIIY MEAN

LOWEST DAILY MEAN

ANNUAL SEVEN-DAY MINIMUM

INSTANTANEOUS PEAK FIOW

INSTANTANEOUS PEAK SIAGE

ANMUAL RUNOFF (CFSM)

ANNUAL RUNOFF (I NCHES)

10 PERCENT EXCEEDS

50 PERCENT EXCEEDS

90 PERCENT EXCEEDS
FOR 1990 CAI LNOAR YEAR

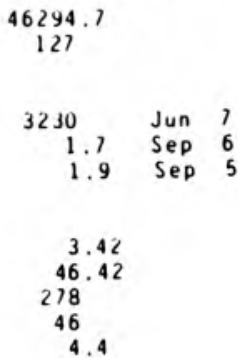

FOR 1991 WATER YEAR

31618.03
86.6

2030 Dec 18

$\begin{array}{rr}1.96 & \text { Sep } 30 \\ 3790 & \text { Sep } 16 \\ 8.94 & \text { Dec } 18\end{array}$

8.94 Dec 18

2. 33

31.70
209

209
34

2. 4
WAIER YLARS 1970 - 1991

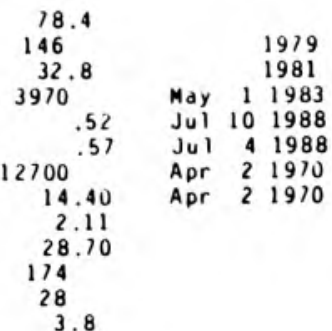




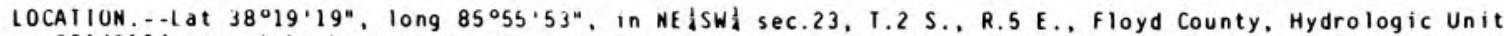

05140104 , on right bank at downstrean side of county road bridge, 2 a south of Galena, 3.6 upstrea from mouth, and 7.0 i nor $r_{2}$ thwest of New Albany.

DRAINAGE AREA . - $16.1 \mathrm{i}^{2}$

PERIOD OF RECORD... October 1968 to current year.

GAGE. - Water-stage recorder. Datu of gage is $703.00 \mathrm{ft}$ above National Geodetic Vertical Datum of 1929.

REMARKS.--Records good except for estimated daily discharges, which are poor.

DISCHARGE, CUBIL FEET PER SECOND, WATER YEAR OCTOBER 1990 TO SEPIEMBER 1991 DAILY MEAN VALUES

\begin{tabular}{|c|c|c|c|c|c|c|c|c|c|c|c|c|}
\hline DAY & $\mathrm{OCI}$ & NOV & DEC & JAN & FEB & MAR & $A P R$ & MAY & JUN & JUL & AUG & SEP \\
\hline $\begin{array}{l}1 \\
2 \\
3 \\
4 \\
5\end{array}$ & $\begin{array}{r}.67 \\
.65 \\
1.0 \\
24 \\
3.9\end{array}$ & $\begin{array}{l}2.6 \\
2.5 \\
2.5 \\
2.5 \\
4.1\end{array}$ & $\begin{array}{r}7.1 \\
6.3 \\
146 \\
40 \\
22\end{array}$ & $\begin{array}{l}16 \\
48 \\
34 \\
27 \\
30\end{array}$ & $\begin{array}{l}32 \\
27 \\
22 \\
20 \\
28\end{array}$ & $\begin{array}{l}18 \\
25 \\
20 \\
18 \\
16\end{array}$ & $\begin{array}{l}16 \\
13 \\
12 \\
12 \\
12\end{array}$ & $\begin{array}{r}6.4 \\
5.7 \\
5.0 \\
6.5 \\
11\end{array}$ & $\begin{array}{l}2.0 \\
1.7 \\
1.5 \\
6.6 \\
2.5\end{array}$ & $\begin{array}{l}.18 \\
.18 \\
.17 \\
.12 \\
.09\end{array}$ & $\begin{array}{l}.00 \\
.00 \\
.00 \\
.00 \\
.00\end{array}$ & $\begin{array}{l}.20 \\
.13 \\
.09 \\
1.0 \\
1.6\end{array}$ \\
\hline $\begin{array}{r}6 \\
7 \\
8 \\
9 \\
10\end{array}$ & $\begin{array}{r}2.3 \\
1.6 \\
1.4 \\
8.0 \\
13\end{array}$ & $\begin{array}{r}6.4 \\
4.6 \\
3.8 \\
9.8 \\
19\end{array}$ & $\begin{array}{r}16 \\
11 \\
9.0 \\
7.6 \\
6.5\end{array}$ & $\begin{array}{r}178 \\
240 \\
106 \\
60 \\
50\end{array}$ & $\begin{array}{r}350 \\
190 \\
89 \\
53 \\
37\end{array}$ & $\begin{array}{l}33 \\
30 \\
25 \\
22 \\
20\end{array}$ & $\begin{array}{l}11 \\
9.7 \\
14 \\
96 \\
98\end{array}$ & $\begin{array}{r}7.4 \\
5.8 \\
4.9 \\
13 \\
8.8\end{array}$ & $\begin{array}{l}1.7 \\
1.4 \\
1.1 \\
1.0 \\
.89\end{array}$ & $\begin{array}{l}.08 \\
.04 \\
.09 \\
.18 \\
.26\end{array}$ & $\begin{array}{l}.00 \\
.00 \\
.00 \\
.00 \\
.00\end{array}$ & $\begin{array}{l}.68 \\
.32 \\
.21 \\
.20 \\
.30\end{array}$ \\
\hline $\begin{array}{l}11 \\
12 \\
13 \\
14 \\
15\end{array}$ & $\begin{array}{l}4.9 \\
3.5 \\
2.9 \\
2.2 \\
2.0\end{array}$ & $\begin{array}{l}8.2 \\
6.0 \\
4.9 \\
4.4 \\
3.8\end{array}$ & $\begin{array}{r}5.8 \\
5.3 \\
5.1 \\
4.5 \\
70\end{array}$ & $\begin{array}{r}217 \\
131 \\
64 \\
42 \\
36\end{array}$ & $\begin{array}{r}30 \\
25 \\
74 \\
237 \\
89\end{array}$ & $\begin{array}{r}18 \\
40 \\
231 \\
137 \\
71\end{array}$ & $\begin{array}{r}44 \\
38 \\
160 \\
83 \\
100\end{array}$ & $\begin{array}{l}6.5 \\
6.0 \\
5.7 \\
6.7 \\
9.7\end{array}$ & $\begin{array}{l}.86 \\
.76 \\
.57 \\
.48 \\
.63\end{array}$ & $\begin{array}{l}.32 \\
.25 \\
.17 \\
.12 \\
.07\end{array}$ & $\begin{array}{l}.00 \\
.00 \\
3.2 \\
.67 \\
.30\end{array}$ & $\begin{array}{l}.26 \\
.16 \\
.13 \\
.09 \\
.05\end{array}$ \\
\hline $\begin{array}{l}16 \\
17 \\
18 \\
19 \\
20\end{array}$ & $\begin{array}{r}1.6 \\
1.7 \\
119 \\
13 \\
6.9\end{array}$ & $\begin{array}{l}3.5 \\
3.5 \\
3.2 \\
3.2 \\
3.0\end{array}$ & $\begin{array}{r}27 \\
108 \\
850 \\
193 \\
87\end{array}$ & $\begin{array}{l}41 \\
33 \\
28 \\
25 \\
24\end{array}$ & $\begin{array}{r}e 48 \\
37 \\
161 \\
100 \\
62\end{array}$ & $\begin{array}{r}45 \\
71 \\
126 \\
68 \\
45\end{array}$ & $\begin{array}{l}65 \\
39 \\
24 \\
33 \\
21\end{array}$ & $\begin{array}{l}5.7 \\
5.4 \\
4.1 \\
3.6 \\
3.5\end{array}$ & $\begin{array}{c}.54 \\
.57 \\
.72 \\
1.0 \\
.87\end{array}$ & $\begin{array}{l}.02 \\
.01 \\
.00 \\
.00 \\
.00\end{array}$ & $\begin{array}{l}.21 \\
.42 \\
1.0 \\
.55 \\
.32\end{array}$ & $\begin{array}{l}.02 \\
.02 \\
.05 \\
.05 \\
.01\end{array}$ \\
\hline $\begin{array}{l}21 \\
22 \\
23 \\
24 \\
25\end{array}$ & $\begin{array}{l}5.2 \\
26 \\
15 \\
8.6 \\
6.2\end{array}$ & $\begin{array}{l}2.7 \\
21 \\
17 \\
9.9 \\
7.6\end{array}$ & $\begin{array}{r}92 \\
169 \\
165 \\
78 \\
47\end{array}$ & $\begin{array}{r}20 \\
\text { e1 } 8 \\
\text { e15 } \\
\text { el } 3 \\
\text { e12 }\end{array}$ & $\begin{array}{l}43 \\
34 \\
29 \\
28 \\
24\end{array}$ & $\begin{array}{r}53 \\
794 \\
250 \\
124 \\
72\end{array}$ & $\begin{array}{l}17 \\
14 \\
13 \\
25 \\
14\end{array}$ & $\begin{array}{l}3.3 \\
3.2 \\
3.4 \\
3.1 \\
2.9\end{array}$ & $\begin{array}{r}3.0 \\
1.7 \\
.89 \\
.63 \\
.45\end{array}$ & $\begin{array}{l}.00 \\
.00 \\
.00 \\
.04 \\
.03\end{array}$ & $\begin{array}{l}.24 \\
.16 \\
.11 \\
.08 \\
.04\end{array}$ & $\begin{array}{l}.01 \\
.01 \\
.02 \\
.02 \\
.04\end{array}$ \\
\hline $\begin{array}{l}26 \\
27 \\
28 \\
29 \\
30 \\
31\end{array}$ & $\begin{array}{l}5.2 \\
4.6 \\
4.1 \\
3.3 \\
3.2 \\
2.9\end{array}$ & $\begin{array}{l}6.2 \\
6.0 \\
18 \\
11 \\
8.5 \\
\cdots\end{array}$ & $\begin{array}{r}34 \\
28 \\
34 \\
248 \\
490 \\
173\end{array}$ & $\begin{array}{r}\text { e10 } \\
\text { e16 } \\
32 \\
22 \\
113 \\
47\end{array}$ & $\begin{array}{l}21 \\
19 \\
16 \\
\cdots \\
\cdots \\
\cdots\end{array}$ & $\begin{array}{l}56 \\
66 \\
55 \\
35 \\
23 \\
19\end{array}$ & $\begin{array}{c}12 \\
11 \\
9.7 \\
9.9 \\
8.0 \\
\ldots . .\end{array}$ & $\begin{array}{l}5.6 \\
5.2 \\
4.1 \\
3.3 \\
3.0 \\
2.5\end{array}$ & $\begin{array}{l}.42 \\
.42 \\
.42 \\
.42 \\
.25 \\
. . .\end{array}$ & $\begin{array}{l}.13 \\
.09 \\
.05 \\
.04 \\
.01 \\
.00\end{array}$ & $\begin{array}{l}.02 \\
.01 \\
.01 \\
.09 \\
.76 \\
.37\end{array}$ & $\begin{array}{l}.02 \\
.01 \\
.00 \\
.00 \\
.00 \\
.-.\end{array}$ \\
\hline $\begin{array}{l}\text { IOIAL } \\
\text { MEAN } \\
\text { MAX } \\
\text { MIN } \\
\text { CFSM } \\
\text { IN. }\end{array}$ & $\begin{array}{r}298.52 \\
9.63 \\
119 \\
.65 \\
.60 \\
.69\end{array}$ & $\begin{array}{r}209.4 \\
6.98 \\
21 \\
2.5 \\
.43 \\
.48\end{array}$ & $\begin{array}{r}3185.2 \\
103 \\
850 \\
4.5 \\
6.38 \\
7.36\end{array}$ & $\begin{array}{r}1808 \\
58.3 \\
240 \\
10 \\
3.62 \\
4.18\end{array}$ & $\begin{array}{r}1925 \\
68.7 \\
350 \\
16 \\
4.27 \\
4.45\end{array}$ & $\begin{array}{r}2626 \\
84.7 \\
794 \\
16 \\
5.26 \\
6.07\end{array}$ & $\begin{array}{c}1034.3 \\
34.5 \\
160 \\
8.0 \\
2.14 \\
2.39\end{array}$ & $\begin{array}{r}171.0 \\
5.52 \\
13 \\
2.5 \\
.34 \\
.40\end{array}$ & $\begin{array}{c}35.99 \\
1.20 \\
6.6 \\
.25 \\
.07 \\
.08\end{array}$ & $\begin{array}{l}2.74 \\
.088 \\
.32 \\
.00 \\
.01 \\
.01\end{array}$ & $\begin{array}{l}8.56 \\
.28 \\
3.2 \\
.00 \\
.02 \\
.02\end{array}$ & $\begin{array}{l}5.70 \\
.19 \\
1.6 \\
.00 \\
.01 \\
.01\end{array}$ \\
\hline
\end{tabular}

e Estimated

SIAIISIICS OF MONIHLY MEAN DAIA FOR WAIEK YEARS 1969 - 1991, BY WAIER YEAR (WY)

$\begin{array}{lrrrrrrrrrrrr}\text { MEAN } & 5.20 & 17.0 & 33.2 & 32.0 & 43.4 & 45.6 & 46.8 & 26.8 & 14.0 & 9.69 & 5.80 & 4.85 \\ \text { MAX } & 42.2 & 70.6 & 103 & 64.3 & 111 & 112 & 120 & 116 & 75.1 & 50.7 & 30.5 & 62.1 \\ \text { (WY) } & 1978 & 1980 & 1991 & 1969 & 1990 & 1975 & 1970 & 1983 & 1990 & 1979 & 1978 & 1979 \\ \text { MIN } & 1000 & .38 & 1.80 & .46 & 11.1 & 10.9 & 7.78 & 1.48 & .002 & .088 & .15 & .000 \\ \text { (WY) } & 1988 & 1988 & 1981 & 1977 & 1977 & 1976 & 1976 & 1988 & 1988 & 1991 & 1987 & 1987\end{array}$

SUMMARY SIAIISIICS

ANHUAL IOTAL

ANMUAL MEAN

HIGHESI ANMUAL MEAN

LOWEST ANNUAL MEAN

HIGHEST DAILY MEAN

LOWEST DAILY MEAN

ANNUAL SEVEN-DAY MINIMUM

INSTANIANEOUS PEAK FLOW

INSIANTANEOUS PEAK STAGE

ANNUAL RUNOFF (CFSM)

ANNUAL RUNOFF (INCHES)

10 PLRCENT EXCEEDS

50 PERCENT EXCEEDS

90 PERCENT EXCEEDS
FOR 1990 CALENDAR YEAR

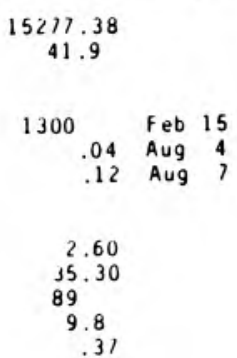

FOR 1991 WAIER YEAR

$$
\begin{gathered}
11310.41 \\
31.0
\end{gathered}
$$

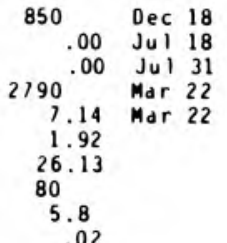

WAIER YEARS 1969 - 1991

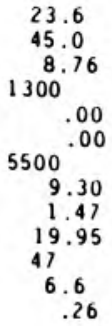

.09

1.0

.68

.21

30

16

.09

02

02

.05

.01

.02

.02
.01
.00

.00

.00

5. 70

1.6

.01 


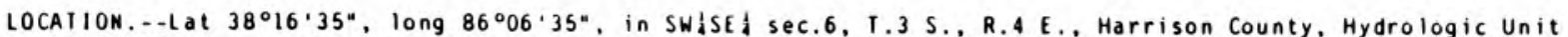
05140104 , on upstrean side of bridge on State Highway $335,0.6$ i upstrean from Raccoon Branch, 4.5 a north of Corydon, and at ile 33.7 .

DRAINAGE AREA. - $129 \mathrm{i}^{2}$, of which $10.6 \mathrm{~m}^{2}$ does not contribute directly to surface runoff.

PERIOD OF RECORD.--October 1943 to current year. Prior to October 1961. published as Big Indian Creek near Corydon.

REVISED RECORDS,--WSP 1275: Drainage area. WSP 1385: $1951(\mathrm{M})$.

GAGE. - -Water-stage recorder. Datue of gage is $577.12 \mathrm{ft}$ above National Geodetic Vertical Datue of 1929. Prior to Dec. 9, 1948, nonrecording gage, and Dec. 9, 1948, to June 12, 1952, recorder records for stages above 6.3 ft at sane site and datur.

REMARKS.--Records good above $10 \mathrm{ft} / \mathrm{s}$ and poor below. Periods of estimated daily discharge are poor.

DISCHARGE, CUBIC FEET PER SECOND, WATER YEAR OCTOBER 1990 TO SEPTEMBER 1991 DAILY MEAN VALUES

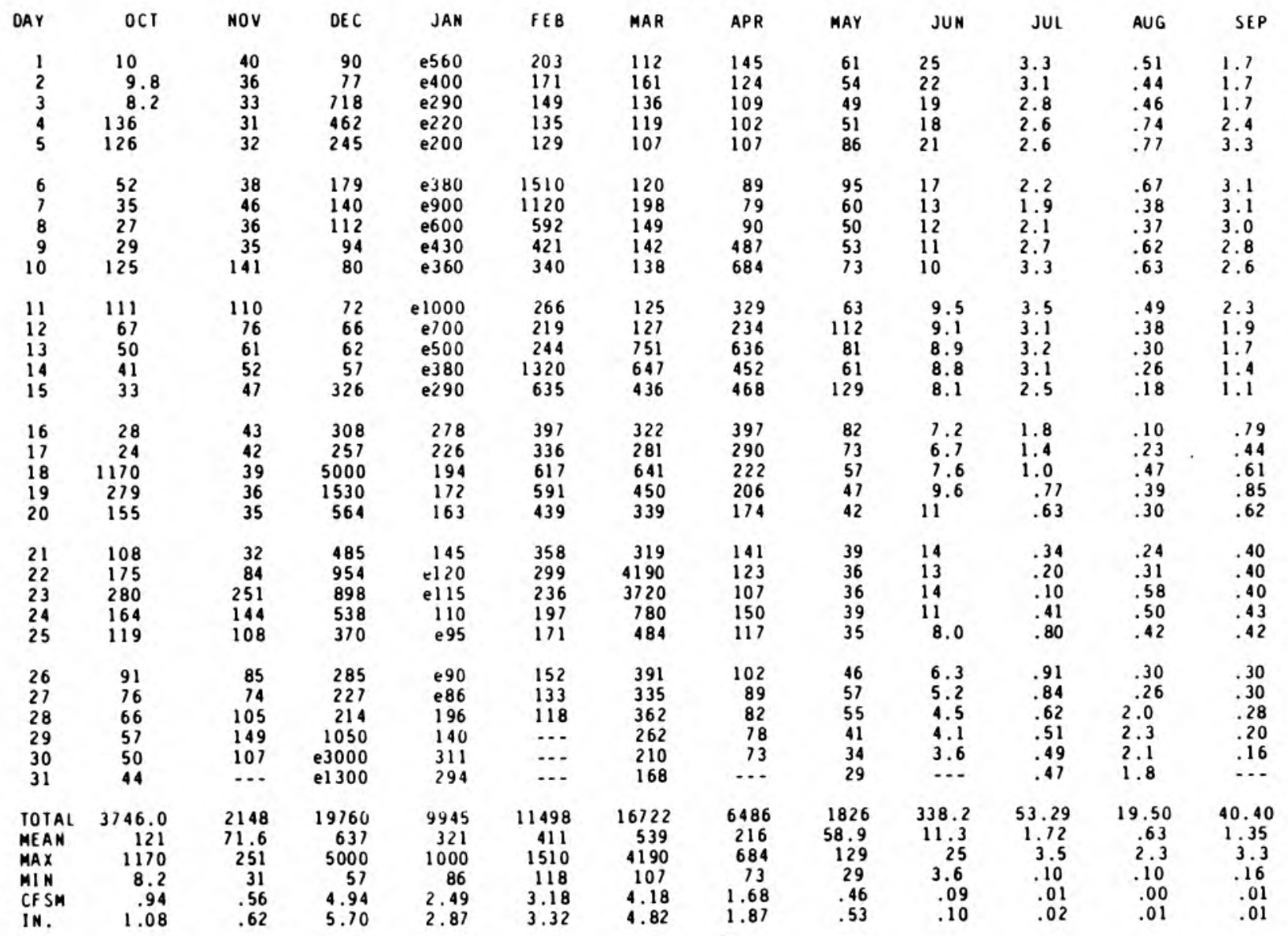

e Estimated

SIATISIICS OF MONIHLY MEAN DAIA FUR WAIER YEARS 1944 - 1991, BY WAIER YEAR (WY)

\begin{tabular}{|c|c|c|c|c|c|c|c|c|c|c|c|c|}
\hline $\begin{array}{l}\text { MEAN } \\
\text { MAX } \\
\text { (WY) } \\
\text { MIN } \\
\text { (WY) }\end{array}$ & $\begin{array}{r}28.0 \\
301 \\
1978 \\
1077 \\
1954\end{array}$ & $\begin{array}{r}101 \\
553 \\
1980 \\
.44 \\
1954\end{array}$ & $\begin{array}{r}193 \\
652 \\
1958 \\
1.16 \\
1944\end{array}$ & $\begin{array}{r}270 \\
1248 \\
1950 \\
5.94 \\
1977\end{array}$ & $\begin{array}{r}325 \\
1008 \\
1950 \\
16.8 \\
1944\end{array}$ & $\begin{array}{r}382 \\
1573 \\
1964 \\
49.3 \\
1947\end{array}$ & $\begin{array}{r}302 \\
943 \\
1970 \\
68.0 \\
1976\end{array}$ & $\begin{array}{r}184 \\
923 \\
1983 \\
17.8 \\
1988\end{array}$ & $\begin{array}{r}112 \\
579 \\
1990 \\
2.24 \\
1988\end{array}$ & $\begin{array}{r}65.5 \\
647 \\
1973 \\
.23 \\
1954\end{array}$ & $\begin{array}{r}42.0 \\
268 \\
1949 \\
.24 \\
1951\end{array}$ & $\begin{array}{r}11.4 \\
281 \\
1979 \\
.060 \\
1953\end{array}$ \\
\hline
\end{tabular}

SUMMARY SIAIISIICS

ANNUAL TOTAL

ANNUAL MEAN

HIGHESI ANMUAL MEAN

LOWEST ANNUAL MEAN

HIGHESI DAILY MEAN

LOWEST DAILY MEAN

ANNUAL SEVEM-DAY MINIMUM

INSTANTANEOUS PEAK FLOW

INSIANTANEOUS PEAK STAGE

ANMUAL RUNOFF (CFSM)

ANNUAL RUNOFF (INCHES)

10 PERCENT EXCEEDS

50 PERCENT EXCEEDS

90 PERCENT EXCEEDS
FOR 1990 CALENDAR YEAR

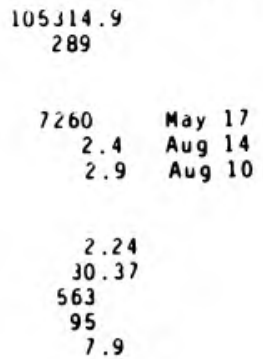

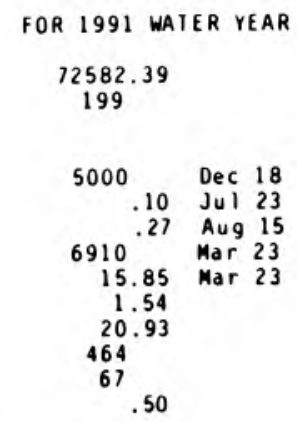

WATER YEARS 1944 - 1991

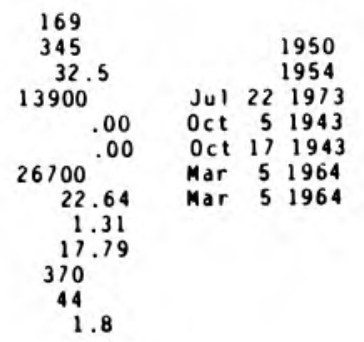




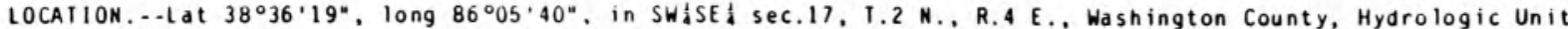
05140104 , on left bank at downstrean side of bridge on East Market Street, 0.35 i east of County Court House in Salen, 6.0 i upstream from Hoggat Branch, and 6.9 i upstream fromouth.

DRAINAGE AREA. $\cdots 19.0$ i

PERIOD OF RECORD.--July 1970 to current year. Prior to December 10, 1970 , nonrecording gage at site 0.55 i downstrean at datum $5.04 \mathrm{ft}$ lower. Low-flow records not equivalent due to effluent froe factory entering strean fron right bank between sites.

GAGE. - Water-stage recorder. Datu of gage is $713.00 \mathrm{ft}$ above National Geodetic Vertical Datum of 1929

REMARKS. - Records good except for estimated daily discharges, which are poor.

DISCHARGE, CUBIC FEET PER SECOND, WATER YEAR OCTOBER 1990 TO SEPTEMBER 1991 DAI IY MEAN VALUES

\begin{tabular}{|c|c|c|c|c|c|c|c|c|c|c|c|c|}
\hline DAY & $O C \mathrm{I}$ & NOV & DEC & JAN & FEB & MAR & APR & MAY & JUN & JUL & AUG & SEP \\
\hline $\begin{array}{l}1 \\
2 \\
3 \\
4 \\
5\end{array}$ & $\begin{array}{r}.66 \\
.67 \\
.68 \\
3.1\end{array}$ & $\begin{array}{l}2.8 \\
2.7 \\
2.6 \\
2.7 \\
4.8\end{array}$ & $\begin{array}{r}14 \\
12 \\
117 \\
57 \\
36\end{array}$ & $\begin{array}{l}79 \\
53 \\
37 \\
28 \\
30\end{array}$ & $\begin{array}{l}\text { ell } \\
\text { el } 5 \\
\text { el } 4 \\
\text { el } 3 \\
\text { el } 2\end{array}$ & $\begin{array}{l}\text { e } 13 \\
\text { e15 } \\
\text { e } 13 \\
\text { e } 12 \\
\text { e11 }\end{array}$ & $\begin{array}{l}24 \\
21 \\
18 \\
18 \\
17\end{array}$ & $\begin{array}{l}5.6 \\
4.8 \\
4.7 \\
4.5 \\
6.8\end{array}$ & $\begin{array}{r}2.1 \\
2.0 \\
11 \\
3.7 \\
2.5\end{array}$ & $\begin{array}{l}.34 \\
.34 \\
.37 \\
.36 \\
.33\end{array}$ & $\begin{array}{l}.11 \\
.11 \\
.11 \\
.11 \\
.11\end{array}$ & $\begin{array}{c}.23 \\
170^{.22} \\
26\end{array}$ \\
\hline $\begin{array}{r}6 \\
7 \\
8 \\
9 \\
10\end{array}$ & $\begin{array}{l}1.6 \\
1.3 \\
1.2 \\
5.5 \\
9.9\end{array}$ & $\begin{array}{r}6.2 \\
4.4 \\
3.4 \\
5.1 \\
11\end{array}$ & $\begin{array}{l}27 \\
21 \\
16 \\
13 \\
11\end{array}$ & $\begin{array}{r}115 \\
109 \\
81 \\
64 \\
56\end{array}$ & $\begin{array}{r}\text { e230 } \\
\text { e160 } \\
\text { e100 } \\
\text { e60 } \\
\text { e50 }\end{array}$ & $\begin{array}{l}\text { e } 10 \\
\text { e11 } \\
\text { e } 10 \\
\text { e } 9.2 \\
\text { e } 8.6\end{array}$ & $\begin{array}{l}14 \\
13 \\
13 \\
16 \\
14\end{array}$ & $\begin{array}{l}5.0 \\
3.8 \\
3.5 \\
4.5 \\
3.7\end{array}$ & $\begin{array}{l}1.9 \\
1.6 \\
1.4 \\
1.3 \\
1.1\end{array}$ & $\begin{array}{r}.52 \\
.39 \\
.39 \\
.34 \\
1.2\end{array}$ & $\begin{array}{c}.12 \\
.13 \\
50.11 \\
4.2\end{array}$ & $\begin{array}{l}7.6 \\
3.9 \\
2.7 \\
2.2 \\
1.8\end{array}$ \\
\hline $\begin{array}{l}11 \\
12 \\
13 \\
14 \\
15\end{array}$ & $\begin{array}{l}5.3 \\
3.0 \\
2.2 \\
1.9 \\
1.6\end{array}$ & $\begin{array}{l}7.3 \\
5.8 \\
4.9 \\
4.3 \\
3.9\end{array}$ & $\begin{array}{l}9.6 \\
8.6 \\
7.8 \\
6.4 \\
10\end{array}$ & $\begin{array}{r}156 \\
101 \\
62 \\
46 \\
37\end{array}$ & $\begin{array}{r}e 38 \\
e 30 \\
e 27 \\
e 150 \\
e 100\end{array}$ & $\begin{array}{l}e 8.1 \\
9.3 \\
59 \\
53 \\
37\end{array}$ & $\begin{array}{r}10 \\
13 \\
117 \\
57 \\
49\end{array}$ & $\begin{array}{l}4.7 \\
5.6 \\
4.3 \\
3.9 \\
4.1\end{array}$ & $\begin{array}{l}1.0 \\
.99 \\
.94 \\
.83 \\
.75\end{array}$ & $\begin{array}{l}.79 \\
.43 \\
.33 \\
.26 \\
.23\end{array}$ & $\begin{array}{l}1.0 \\
.54 \\
.40 \\
.34 \\
.29\end{array}$ & $\begin{array}{r}1.3 \\
1.1 \\
15 \\
6.3 \\
2.4\end{array}$ \\
\hline $\begin{array}{l}16 \\
17 \\
18 \\
19 \\
20\end{array}$ & $\begin{array}{l}1.4 \\
6.0 \\
99 \\
21 \\
12\end{array}$ & $\begin{array}{l}3.7 \\
3.7 \\
3.2 \\
3.3 \\
3.0\end{array}$ & $\begin{array}{r}22 \\
37 \\
709 \\
155 \\
85\end{array}$ & $\begin{array}{r}38 \\
31 \\
27 \\
\mathrm{e} 24 \\
\mathrm{e} 23\end{array}$ & $\begin{array}{l}\text { e } 50 \\
\text { e } 42 \\
\text { e90 } \\
\text { e70 } \\
\text { e } 54\end{array}$ & $\begin{array}{l}30 \\
46 \\
92 \\
58 \\
42\end{array}$ & $\begin{array}{l}36 \\
29 \\
24 \\
24 \\
19\end{array}$ & $\begin{array}{l}2.8 \\
2.5 \\
2.8 \\
2.2 \\
2.1\end{array}$ & $\begin{array}{l}2.4 \\
2.3 \\
1.5 \\
2.2 \\
1.2\end{array}$ & $\begin{array}{l}.21 \\
.19 \\
.17 \\
.17 \\
.17\end{array}$ & $\begin{array}{l}2.28 \\
51 \\
2.8 \\
1.4\end{array}$ & $\begin{array}{l}1.5 \\
1.2 \\
1.4 \\
1.4 \\
.89\end{array}$ \\
\hline $\begin{array}{l}21 \\
22 \\
23 \\
24 \\
25\end{array}$ & $\begin{array}{l}8.3 \\
13 \\
14 \\
11 \\
7.6\end{array}$ & $\begin{array}{l}2.9 \\
23 \\
23 \\
16 \\
12\end{array}$ & $\begin{array}{r}102 \\
171 \\
169 \\
87 \\
56\end{array}$ & $\begin{array}{l}\text { e } 20 \\
\text { e17 } \\
\text { e1 } 6 \\
\text { e15 } \\
\text { e14 }\end{array}$ & $\begin{array}{l}e 40 \\
e 32 \\
e 26 \\
e 22 \\
e 19\end{array}$ & $\begin{array}{r}34 \\
351 \\
230 \\
97 \\
59\end{array}$ & $\begin{array}{c}16 \\
14 \\
13 \\
12 \\
9.8\end{array}$ & $\begin{array}{l}1.9 \\
1.9 \\
2.7 \\
3.9 \\
2.7\end{array}$ & $\begin{array}{l}1.0 \\
1.1 \\
.88 \\
.70 \\
.59\end{array}$ & $\begin{array}{l}.17 \\
.16 \\
.15 \\
.14 \\
.14\end{array}$ & $\begin{array}{l}.96 \\
.70 \\
.54 \\
.42 \\
.36\end{array}$ & $\begin{array}{l}.77 \\
.71 \\
.78 \\
.68 \\
.64\end{array}$ \\
\hline $\begin{array}{l}26 \\
27 \\
28 \\
29 \\
30 \\
31\end{array}$ & $\begin{array}{l}5.8 \\
4.9 \\
4.1 \\
3.4 \\
3.1 \\
2.9\end{array}$ & $\begin{array}{l}9.4 \\
8.2 \\
32 \\
23 \\
17 \\
\ldots\end{array}$ & $\begin{array}{r}39 \\
33 \\
30 \\
330 \\
496 \\
138\end{array}$ & $\begin{array}{l}\text { e } 12 \\
\text { e11 } \\
\text { e17 } \\
\text { e14 } \\
\text { e26 } \\
\text { e21 }\end{array}$ & $\begin{array}{l}\text { e17 } \\
\text { el5 } \\
\text { e14 } \\
\ldots \\
\cdots \\
\cdots\end{array}$ & $\begin{array}{l}52 \\
72 \\
59 \\
44 \\
35 \\
28\end{array}$ & $\begin{array}{l}9.3 \\
8.7 \\
8.6 \\
8.1 \\
6.6 \\
\ldots .\end{array}$ & $\begin{array}{l}4.2 \\
3.5 \\
2.6 \\
7.5 \\
4.2 \\
2.7\end{array}$ & $\begin{array}{l}.56 \\
.50 \\
.46 \\
.41 \\
.36 \\
. . .\end{array}$ & $\begin{array}{l}.14 \\
.14 \\
.13 \\
.16 \\
.15 \\
.12\end{array}$ & $\begin{array}{l}.33 \\
.30 \\
.40 \\
.33 \\
.28 \\
.25\end{array}$ & $\begin{array}{l}.54 \\
.45 \\
.44 \\
.42 \\
.38 \\
. .-\end{array}$ \\
\hline $\begin{array}{l}\text { IOTAL } \\
\text { MEAN } \\
\text { MAX } \\
\text { MIN } \\
\text { CF SM } \\
\text { IN. }\end{array}$ & $\begin{array}{r}282.11 \\
9.10 \\
99 \\
.66 \\
.48 \\
.55\end{array}$ & $\begin{array}{r}255.3 \\
8.51 \\
32 \\
2.6 \\
.45 \\
.50\end{array}$ & $\begin{array}{r}3045.4 \\
98.2 \\
709 \\
6.4 \\
5.17 \\
5.96\end{array}$ & $\begin{array}{r}1380 \\
44.5 \\
156 \\
11 \\
2.34 \\
2.70\end{array}$ & $\begin{array}{c}1507 \\
53.8 \\
230 \\
12 \\
2.83 \\
2.95\end{array}$ & $\begin{array}{r}1608.2 \\
51.9 \\
351 \\
8.1 \\
2.73 \\
3.15\end{array}$ & $\begin{array}{r}652.1 \\
21.7 \\
117 \\
6.6 \\
1.14 \\
1.28\end{array}$ & $\begin{array}{r}119.7 \\
3.86 \\
7.5 \\
1.9 \\
.20 \\
.23\end{array}$ & $\begin{array}{c}49.27 \\
1.64 \\
11 \\
.36 \\
.09 \\
.10\end{array}$ & $\begin{array}{l}9.13 \\
.29 \\
1.2 \\
.12 \\
.02 \\
.02\end{array}$ & $\begin{array}{c}120.13 \\
3.88 \\
51 \\
.11 \\
.20 \\
.24\end{array}$ & $\begin{array}{r}257.15 \\
8.57 \\
170 \\
.22 \\
.45 \\
.50\end{array}$ \\
\hline
\end{tabular}

e Estinated

SIAIISIICS OF MONIHLY MEAN DATA FOR WATER YEARS 1970 - 1991, BY WATER YEAR (WY)

$\begin{array}{lrrrrrrrrrrrrr}\text { MEAN } & 8.04 & 25.5 & 35.0 & 32.6 & 43.8 & 46.2 & 43.7 & 25.5 & 11.4 & 15.7 & 7.32 & 6.94 \\ \text { MAX } & 45.7 & 89.9 & 98.2 & 103 & 106 & 104 & 136 & 140 & 38.0 & 65.7 & 30.5 & 40.0 \\ \text { (WY) } & 1984 & 1986 & 1991 & 1982 & 1989 & 1989 & 1972 & 1983 & 1985 & 1988 & 1985 & 1982 \\ \text { MIN } & .14 & .74 & 2.33 & .97 & 9.74 & 9.65 & 4.21 & 1.91 & 088 & .29 & .13 & .36 \\ \text { (WY) } & 1988 & 1972 & 1977 & 1977 & 1978 & 1976 & 1976 & 1988 & 1988 & 1991 & 1987 & 1984\end{array}$

SUMMARY SIATISIICS

ANNUAL TOIAL

ANNUAL MEAN

HIGHESI ANHUAL MEAN

LOWEST ANMUAL MEAN

HIGHEST DAILY MEAN

LOWEST DAILY MEAN

ANNUAL SEVEN-DAY MINIMUM

INSTANTANEOUS PEAK FLOW

INSIANIANEOUS PEAK SIAGE

ANMUAL RUNOFF (CFSM)

ANNUAL RUNOFF (INCHES)

10 PERCENT EXCEEDS

50 PERCENT EXCEEDS

90 PERCENT EXCEEDS
FOR 1990 CALENOAR YEAR

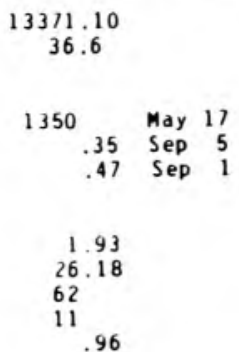

FOR 1991 WATER YEAR

$$
9285.49
$$

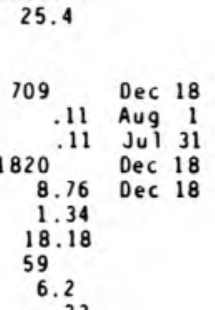

WAIER YEARS $1970-1991$

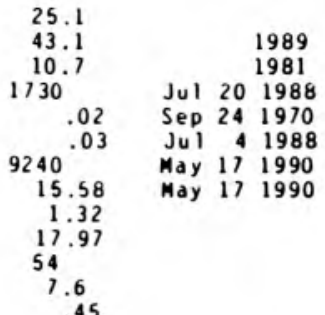




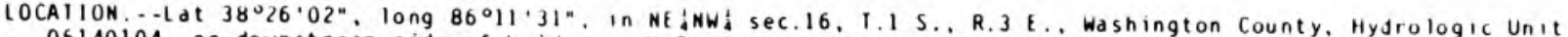

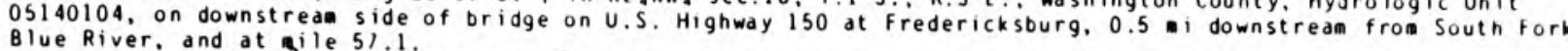

DRAINAGE AREA . $283 \mathrm{mi}^{2}$, of which $70.9 \mathrm{~m}^{2}$ does not contribute directly to surface runoff.

- June 1968 to current year.

GAGE. - Water-stage recorder. Datum of gage is $590.00 \mathrm{ft}$ above National Geodetic Vertical Datum of 1929 .
REMARKS.--Records good. EXTREMES OUTSIDE PERIOD OF RECORO. . Flood of Jan. 21 . 1959, reached a stage of $29.20 \mathrm{ft}$, from floodmark, on left
upstrean wingwall.

DISCHARGE, CUBIC FEET PER SECOND, WATER YEAR OCIOBER 1990 TO SEPIEMBER 1991 DAIIY MEAN VALUES

\begin{tabular}{|c|c|c|c|c|c|c|c|c|c|c|c|c|}
\hline DAY & $\mathrm{OCT}$ & NOV & OEC & JAN & FEB & MAR & APR & MAY & JUN & JUt & AUG & SEP \\
\hline $\begin{array}{l}1 \\
2 \\
3 \\
4 \\
5\end{array}$ & $\begin{array}{c}9.7 \\
9.2 \\
8.9 \\
203 \\
193\end{array}$ & $\begin{array}{l}46 \\
43 \\
39 \\
39 \\
39\end{array}$ & $\begin{array}{l}155 \\
131 \\
832 \\
862 \\
424\end{array}$ & $\begin{array}{r}1240 \\
853 \\
639 \\
498 \\
435\end{array}$ & $\begin{array}{l}228 \\
216 \\
201 \\
193 \\
193\end{array}$ & $\begin{array}{l}221 \\
272 \\
247 \\
213 \\
193\end{array}$ & $\begin{array}{l}414 \\
350 \\
309 \\
279 \\
276\end{array}$ & $\begin{array}{r}123 \\
109 \\
101 \\
98 \\
103\end{array}$ & $\begin{array}{r}157 \\
122 \\
102 \\
112 \\
83\end{array}$ & $\begin{array}{l}19 \\
18 \\
18 \\
17 \\
16\end{array}$ & $\begin{array}{l}5.4 \\
8.1 \\
7.1 \\
5.6 \\
5.0\end{array}$ & $\begin{array}{r}8.5 \\
7.7 \\
6.9 \\
89 \\
464\end{array}$ \\
\hline $\begin{array}{r}6 \\
7 \\
8 \\
9 \\
10\end{array}$ & $\begin{array}{r}75 \\
46 \\
32 \\
35 \\
125\end{array}$ & $\begin{array}{l}45 \\
54 \\
53 \\
44 \\
82\end{array}$ & $\begin{array}{l}308 \\
237 \\
190 \\
160 \\
136\end{array}$ & $\begin{array}{r}977 \\
2010 \\
1320 \\
916 \\
738\end{array}$ & $\begin{array}{r}2470 \\
3490 \\
1360 \\
895 \\
681\end{array}$ & $\begin{array}{l}190 \\
204 \\
178 \\
165 \\
157\end{array}$ & $\begin{array}{l}248 \\
221 \\
201 \\
297 \\
895\end{array}$ & $\begin{array}{r}144 \\
111 \\
92 \\
88 \\
92\end{array}$ & $\begin{array}{l}69 \\
60 \\
55 \\
51 \\
48\end{array}$ & $\begin{array}{l}15 \\
16 \\
23 \\
29 \\
22\end{array}$ & $\begin{array}{r}6.3 \\
6.3 \\
6.6 \\
9.3 \\
254\end{array}$ & $\begin{array}{r}100 \\
52 \\
34 \\
24 \\
19\end{array}$ \\
\hline $\begin{array}{l}11 \\
12 \\
13 \\
14 \\
15\end{array}$ & $\begin{array}{r}148 \\
92 \\
64 \\
50 \\
39\end{array}$ & $\begin{array}{r}116 \\
84 \\
68 \\
59 \\
53\end{array}$ & $\begin{array}{r}121 \\
110 \\
101 \\
91 \\
195\end{array}$ & $\begin{array}{r}1210 \\
1730 \\
980 \\
705 \\
574\end{array}$ & $\begin{array}{r}523 \\
424 \\
419 \\
2250 \\
1300\end{array}$ & $\begin{array}{r}147 \\
148 \\
815 \\
1020 \\
705\end{array}$ & $\begin{array}{l}399 \\
308 \\
935 \\
867 \\
705\end{array}$ & $\begin{array}{r}86 \\
282 \\
189 \\
168 \\
403\end{array}$ & $\begin{array}{l}45 \\
44 \\
41 \\
39 \\
36\end{array}$ & $\begin{array}{l}18 \\
22 \\
19 \\
15 \\
13\end{array}$ & $\begin{array}{l}64 \\
31 \\
20 \\
14 \\
27\end{array}$ & $\begin{array}{l}21 \\
19 \\
17 \\
23 \\
28\end{array}$ \\
\hline $\begin{array}{l}16 \\
17 \\
18 \\
19 \\
20\end{array}$ & $\begin{array}{r}33 \\
62 \\
182 \\
280 \\
167\end{array}$ & $\begin{array}{l}49 \\
47 \\
45 \\
42 \\
39\end{array}$ & $\begin{array}{r}405 \\
291 \\
6140 \\
4290 \\
1260\end{array}$ & $\begin{array}{l}501 \\
477 \\
404 \\
365 \\
353\end{array}$ & $\begin{array}{r}148 \\
621 \\
1240 \\
1400 \\
910\end{array}$ & $\begin{array}{r}526 \\
451 \\
1250 \\
933 \\
670\end{array}$ & $\begin{array}{l}610 \\
465 \\
379 \\
341 \\
308\end{array}$ & $\begin{array}{r}212 \\
148 \\
118 \\
101 \\
93\end{array}$ & $\begin{array}{l}33 \\
41 \\
50 \\
84 \\
65\end{array}$ & $\begin{array}{l}11 \\
11 \\
10 \\
9.6 \\
9.1\end{array}$ & $\begin{array}{r}20 \\
20 \\
162 \\
104 \\
42\end{array}$ & $\begin{array}{c}16 \\
12 \\
12 \\
10 \\
8.3\end{array}$ \\
\hline $\begin{array}{l}21 \\
22 \\
23 \\
24 \\
25\end{array}$ & $\begin{array}{l}114 \\
122 \\
181 \\
140 \\
109\end{array}$ & $\begin{array}{r}38 \\
92 \\
368 \\
222 \\
158\end{array}$ & $\begin{array}{r}924 \\
2150 \\
2080 \\
1280 \\
813\end{array}$ & $\begin{array}{l}312 \\
251 \\
244 \\
230 \\
192\end{array}$ & $\begin{array}{l}696 \\
572 \\
455 \\
393 \\
336\end{array}$ & $\begin{array}{r}548 \\
5010 \\
7210 \\
1890 \\
1090\end{array}$ & $\begin{array}{l}263 \\
239 \\
216 \\
209 \\
189\end{array}$ & $\begin{array}{r}85 \\
76 \\
14 \\
564 \\
218\end{array}$ & $\begin{array}{l}48 \\
42 \\
39 \\
32 \\
29\end{array}$ & $\begin{array}{l}8.5 \\
8.0 \\
7.8 \\
7.4 \\
7.7\end{array}$ & $\begin{array}{l}25 \\
17 \\
13 \\
11 \\
9.3\end{array}$ & $\begin{array}{l}7.6 \\
6.1 \\
5.9 \\
5.3 \\
5.3\end{array}$ \\
\hline $\begin{array}{l}26 \\
27 \\
28 \\
29 \\
30 \\
31\end{array}$ & $\begin{array}{l}88 \\
75 \\
66 \\
59 \\
54 \\
51\end{array}$ & $\begin{array}{l}123 \\
107 \\
180 \\
279 \\
189 \\
\cdots\end{array}$ & $\begin{array}{r}618 \\
491 \\
449 \\
2380 \\
4950 \\
3570\end{array}$ & $\begin{array}{l}181 \\
165 \\
248 \\
216 \\
260 \\
298\end{array}$ & $\begin{array}{l}293 \\
262 \\
237 \\
\ldots \\
\ldots \\
\cdots\end{array}$ & $\begin{array}{r}819 \\
882 \\
1550 \\
832 \\
617 \\
485\end{array}$ & $\begin{array}{l}173 \\
162 \\
153 \\
149 \\
138 \\
\cdots\end{array}$ & $\begin{array}{l}166 \\
192 \\
163 \\
162 \\
557 \\
233\end{array}$ & $\begin{array}{l}30 \\
28 \\
26 \\
25 \\
21 \\
\cdots\end{array}$ & $\begin{array}{l}7.8 \\
6.6 \\
6.0 \\
5.8 \\
5.7 \\
5.2\end{array}$ & $\begin{array}{l}7.7 \\
8.1 \\
16 \\
13 \\
14 \\
10\end{array}$ & $\begin{array}{l}5.1 \\
4.6 \\
3.8 \\
3.5 \\
3.5 \\
\ldots\end{array}$ \\
\hline $\begin{array}{l}\text { TOIAL } \\
\text { MEAN } \\
\text { MAX } \\
\text { MIN } \\
\text { CF SN } \\
\text { IN. }\end{array}$ & $\begin{array}{r}3512.8 \\
113 \\
782 \\
8.9 \\
.40 \\
.46\end{array}$ & $\begin{array}{r}2842 \\
94.7 \\
368 \\
38 \\
.33 \\
.37\end{array}$ & $\begin{array}{r}36144 \\
1166 \\
6140 \\
91 \\
4.12 \\
4.15\end{array}$ & $\begin{array}{r}19582 \\
632 \\
2010 \\
165 \\
2.23 \\
2.57\end{array}$ & $\begin{array}{r}23006 \\
822 \\
3490 \\
193 \\
2.90 \\
3.02\end{array}$ & $\begin{array}{r}29698 \\
958 \\
7210 \\
147 \\
3.39 \\
3.90\end{array}$ & $\begin{array}{c}10698 \\
357 \\
935 \\
138 \\
1.26 \\
1.41\end{array}$ & $\begin{array}{c}5351 \\
173 \\
564 \\
74 \\
.61 \\
.10\end{array}$ & $\begin{array}{c}1657 \\
55.2 \\
157 \\
21 \\
.20 \\
.22\end{array}$ & $\begin{array}{r}407.2 \\
13.1 \\
29 \\
5.2 \\
.05 \\
.05\end{array}$ & $\begin{array}{c}941.8 \\
30.4 \\
234 \\
5.0 \\
.11 \\
.12\end{array}$ & $\begin{array}{c}1022.1 \\
34.1 \\
464 \\
3.5 \\
.12 \\
.13\end{array}$ \\
\hline
\end{tabular}

SIATISTICS OF MONTHLY MEAN DAIA FOR WAIER YEARS 1968 - 1991, BY WATER YEAR (WY)

\begin{tabular}{|c|c|c|c|c|c|c|c|c|c|c|c|c|}
\hline $\begin{array}{l}\text { MEAN } \\
\text { MAX } \\
\text { (WY) } \\
\text { MIN } \\
(W Y)\end{array}$ & $\begin{array}{r}10.8 \\
305 \\
1984 \\
6.35 \\
1988\end{array}$ & $\begin{array}{r}278 \\
1135 \\
1980 \\
12.5 \\
1988\end{array}$ & $\begin{array}{r}441 \\
1166 \\
1991 \\
29.4 \\
1977\end{array}$ & $\begin{array}{l}413 \\
1341 \\
1982 \\
11.6 \\
1917\end{array}$ & $\begin{array}{r}584 \\
1236 \\
1990 \\
129 \\
1987\end{array}$ & $\begin{array}{r}629 \\
1193 \\
1978 \\
142 \\
1969\end{array}$ & $\begin{array}{r}596 \\
1280 \\
1972 \\
86.8 \\
1976\end{array}$ & $\begin{array}{r}369 \\
1808 \\
1983 \\
35.2 \\
1988\end{array}$ & $\begin{array}{r}214 \\
743 \\
1990 \\
8.36 \\
1988\end{array}$ & $\begin{array}{r}163 \\
588 \\
1973 \\
13.1 \\
1991\end{array}$ & $\begin{array}{r}46.3 \\
463 \\
1977 \\
18.8 \\
1975\end{array}$ & $\begin{array}{r}06.2 \\
239 \\
1979 \\
8.37 \\
1987\end{array}$ \\
\hline
\end{tabular}

SUMMARY SIATISIICS

ANNUAL TOIAL
ANNUAL MEAN

HIGHESI AMNUAL MEAN

LOWEST AMNUAL MEAN

HIGHEST DAILY MEAN

LOWEST DAILY MEAN

ANMUAL SEVEN-DAY MIMIMUM

INSTANTANEOUS PEAK FLOW

INSIANTANEOUS PEAK SIAGE

ANNUAL RUNOFF (CFSM)

ANNUAL RUNOFF (INCHES)

10 PERCENT EXCEEDS

50 PERCENI EXCEEDS

90 PERCENT EXCEEDS

\section{FOR 1990 CAIENDAR YEAR}

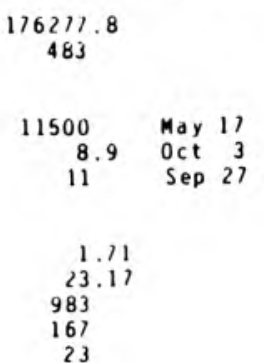

FOR 1991 WATER YEAR

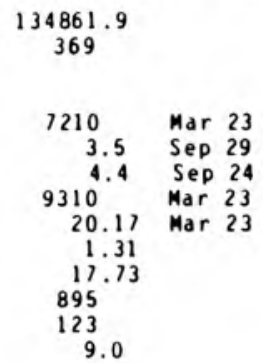

WATER YEARS $1968 \cdot 1991$

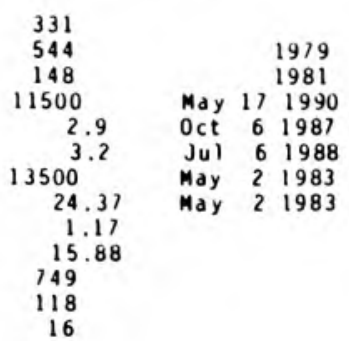


LOCAIION,- Lat $38^{\circ} 22^{\prime} 32^{\prime \prime}$, Iong $86^{\circ} 20^{\prime} 41^{\prime \prime}$, in SW $\frac{1}{4}$ NWl sec.6, T.2 S., R.2 E., Crawford County, Hydrologic Unit 05140104 , on left (north) bank about $100 \mathrm{ft}$ upstrea from bridge and intersection of North Main Street and North Water Street in Marengo, known as 0ld Town.

DRAINAGE AREA. . - $7.02 \mathrm{i}^{2}$.

PERIOD OF RECORD.--October 1986 to current year.

GAGE.- Water-stage recorder. Datum of gage is $561.446 \mathrm{ft}$ above National Geodetic Vertical Datum of 1929 .

REMARKS.--Records fair except for estimated daily discharges, which are poor.

EXIREMES OUTSIDE PERIOD OF RECORD, - - Flood of July 26,1979 appears to be highest known from reports of local residents, and reached a stage of $15.89 \mathrm{ft}$ from levels of high-water ark located in $01 d$ lown grocery store just downstream and across bridge from gage.

DISCHARGE, CUBIC FEET PER SECOND, WATER YEAR OCTOBER 1990 TO SEPTEMBER 1991 DAILY MEAN VALUES

\begin{tabular}{|c|c|c|c|c|c|c|c|c|c|c|c|c|}
\hline DAY & $O C \mathrm{~T}$ & NOV & DEC & JAN & $F \in B$ & MAR & APR & MAY & JUN & JUL & AUG & SEP \\
\hline $\begin{array}{l}1 \\
2 \\
3 \\
4 \\
5\end{array}$ & $\begin{array}{l}.01 \\
.01 \\
.01 \\
4.9 \\
.78\end{array}$ & $\begin{array}{l}.22 \\
.20 \\
.19 \\
.19 \\
.29\end{array}$ & $\begin{array}{c}2.5 \\
1.9 \\
55 \\
13 \\
6.1\end{array}$ & $\begin{array}{r}13 \\
8.1 \\
5.6 \\
4.2 \\
5.4\end{array}$ & $\begin{array}{l}3.5 \\
3.2 \\
3.0 \\
2.7 \\
3.2\end{array}$ & $\begin{array}{l}2.5 \\
4.8 \\
3.5 \\
2.9 \\
2.5\end{array}$ & $\begin{array}{l}3.5 \\
2.8 \\
2.4 \\
2.7 \\
4.1\end{array}$ & $\begin{array}{l}1.4 \\
1.0 \\
.81 \\
.70 \\
.76\end{array}$ & $\begin{array}{l}2.4 \\
1.6 \\
1.1 \\
.71 \\
.50\end{array}$ & $\begin{array}{r}.01 \\
.01 \\
.01 \\
\mathrm{e} .01 \\
.00\end{array}$ & $\begin{array}{l}.00 \\
.00 \\
.00 \\
.00 \\
.00\end{array}$ & $\begin{array}{r}.00 \\
.00 \\
.00 \\
\mathrm{e} .01 \\
.05\end{array}$ \\
\hline $\begin{array}{r}6 \\
7 \\
8 \\
9 \\
10\end{array}$ & $\begin{array}{r}.28 \\
.20 \\
.17 \\
.27 \\
1.2\end{array}$ & $\begin{array}{l}.26 \\
.20 \\
.19 \\
.35 \\
.63\end{array}$ & $\begin{array}{l}4.2 \\
2.9 \\
2.1 \\
1.7 \\
1.4\end{array}$ & $\begin{array}{r}54 \\
60 \\
18 \\
9.8 \\
7.3\end{array}$ & $\begin{array}{r}105 \\
45 \\
14 \\
8.6 \\
6.1\end{array}$ & $\begin{array}{l}2.7 \\
2.7 \\
2.3 \\
2.0 \\
1.8\end{array}$ & $\begin{array}{l}3.3 \\
2.9 \\
3.9 \\
16 \\
12\end{array}$ & $\begin{array}{l}.61 \\
.41 \\
.31 \\
.41 \\
.32\end{array}$ & $\begin{array}{l}.39 \\
.34 \\
.34 \\
.30 \\
.28\end{array}$ & $\begin{array}{l}.00 \\
.00 \\
.12 \\
.07 \\
.02\end{array}$ & $\begin{array}{l}.00 \\
.00 \\
.00 \\
.00 \\
.00\end{array}$ & $\begin{array}{l}.00 \\
.00 \\
.00 \\
.00 \\
.00\end{array}$ \\
\hline $\begin{array}{l}11 \\
12 \\
13 \\
14 \\
15\end{array}$ & $\begin{array}{l}1.2 \\
.52 \\
.33 \\
.25 \\
.22\end{array}$ & $\begin{array}{l}.78 \\
.55 \\
.39 \\
.31 \\
.28\end{array}$ & $\begin{array}{l}1.2 \\
1.0 \\
.92 \\
.71 \\
6.7\end{array}$ & $\begin{array}{l}43 \\
23 \\
11 \\
7.5 \\
6.0\end{array}$ & $\begin{array}{l}4.5 \\
3.7 \\
15 \\
70 \\
17\end{array}$ & $\begin{array}{l}1.7 \\
2.7 \\
53 \\
22 \\
11\end{array}$ & $\begin{array}{l}6.4 \\
5.2 \\
18 \\
16 \\
10\end{array}$ & $\begin{array}{l}.24 \\
.23 \\
.17 \\
.15 \\
.14\end{array}$ & $\begin{array}{l}.26 \\
.25 \\
.20 \\
.18 \\
.17\end{array}$ & $\begin{array}{r}.02 \\
.01 \\
.01 \\
\mathrm{e} .01 \\
.00\end{array}$ & $\begin{array}{l}.00 \\
.00 \\
.00 \\
.00 \\
.00\end{array}$ & $\begin{array}{l}.00 \\
.00 \\
.00 \\
.00 \\
.00\end{array}$ \\
\hline $\begin{array}{l}16 \\
17 \\
18 \\
19 \\
20\end{array}$ & $\begin{array}{l}.19 \\
.73 \\
29 \\
3.3 \\
1.6\end{array}$ & $\begin{array}{l}.26 \\
.25 \\
.24 \\
.23 \\
.20\end{array}$ & $\begin{array}{c}5.0 \\
33 \\
349 \\
48 \\
17\end{array}$ & $\begin{array}{l}7.8 \\
6.0 \\
4.8 \\
4.3 \\
3.9\end{array}$ & $\begin{array}{l}8.4 \\
6.6 \\
41 \\
19 \\
10\end{array}$ & $\begin{array}{l}7.1 \\
14 \\
24 \\
11 \\
7.6\end{array}$ & $\begin{array}{l}6.9 \\
5.1 \\
4.0 \\
5.7 \\
4.9\end{array}$ & $\begin{array}{l}.13 \\
.12 \\
.11 \\
.08 \\
.11\end{array}$ & $\begin{array}{l}.16 \\
.15 \\
.14 \\
.17 \\
.13\end{array}$ & $\begin{array}{l}.00 \\
.00 \\
.00 \\
.00 \\
.00\end{array}$ & $\begin{array}{l}.00 \\
.00 \\
.00 \\
.00 \\
.00\end{array}$ & $\begin{array}{l}.00 \\
.00 \\
.00 \\
.00 \\
.00\end{array}$ \\
\hline $\begin{array}{l}21 \\
22 \\
23 \\
24 \\
25\end{array}$ & $\begin{array}{l}.87 \\
1.7 \\
2.1 \\
1.3 \\
.84\end{array}$ & $\begin{array}{l}.20 \\
8.7 \\
5.8 \\
3.0 \\
1.9\end{array}$ & $\begin{array}{l}37 \\
60 \\
43 \\
15 \\
8.9\end{array}$ & $\begin{array}{l}3.2 \\
2.7 \\
2.6 \\
2.2 \\
1.9\end{array}$ & $\begin{array}{l}7.3 \\
5.6 \\
4.4 \\
3.7 \\
3.1\end{array}$ & $\begin{array}{l}6.2 \\
310 \\
79 \\
21 \\
12\end{array}$ & $\begin{array}{r}4.0 \\
3.4 \\
3.0 \\
\mathrm{e} 15 \\
\mathrm{e} 4.5\end{array}$ & $\begin{array}{l}.04 \\
.03 \\
.13 \\
.20 \\
7.9\end{array}$ & $\begin{array}{l}.57 \\
.33 \\
.16 \\
.13 \\
.12\end{array}$ & $\begin{array}{l}.00 \\
.00 \\
.00 \\
.00 \\
.00\end{array}$ & $\begin{array}{l}.00 \\
.00 \\
.00 \\
.00 \\
.00\end{array}$ & $\begin{array}{l}.00 \\
.00 \\
.00 \\
.00 \\
.00\end{array}$ \\
\hline $\begin{array}{l}26 \\
27 \\
28 \\
29 \\
30 \\
31\end{array}$ & $\begin{array}{l}.57 \\
.42 \\
.35 \\
.31 \\
.27 \\
.24\end{array}$ & $\begin{array}{c}1.4 \\
1.1 \\
16 \\
6.3 \\
3.5 \\
\cdots\end{array}$ & $\begin{array}{c}6.2 \\
5.2 \\
4.7 \\
90 \\
141 \\
35\end{array}$ & $\begin{array}{l}1.8 \\
2.1 \\
3.8 \\
3.5 \\
6.4 \\
4.6\end{array}$ & $\begin{array}{l}2.7 \\
2.4 \\
2.1 \\
\ldots . \\
\cdots \\
\cdots\end{array}$ & $\begin{array}{l}8.7 \\
29 \\
16 \\
8.9 \\
5.8 \\
4.3\end{array}$ & $\begin{array}{l}3.7 \\
3.0 \\
2.7 \\
2.5 \\
1.8 \\
\ldots . .\end{array}$ & $\begin{array}{r}4.4 \\
3.2 \\
1.7 \\
129 \\
52 \\
4.6\end{array}$ & $\begin{array}{l}.09 \\
.05 \\
.03 \\
.02 \\
.02 \\
. .-\end{array}$ & $\begin{array}{l}.00 \\
.00 \\
.00 \\
.00 \\
.00 \\
.00\end{array}$ & $\begin{array}{l}.00 \\
.00 \\
.00 \\
.00 \\
.00 \\
.00\end{array}$ & $\begin{array}{l}.00 \\
.00 \\
.00 \\
.00 \\
.00 \\
\cdots\end{array}$ \\
\hline $\begin{array}{l}\text { IOIAL } \\
\text { MEAN } \\
\text { MAX } \\
\text { MIN } \\
\text { CF SM } \\
\text { IN. }\end{array}$ & $\begin{array}{r}54.14 \\
1.75 \\
29 \\
.01 \\
.25 \\
.29\end{array}$ & $\begin{array}{r}54.11 \\
1.80 \\
16 \\
.19 \\
.26 \\
.29\end{array}$ & $\begin{array}{r}999.33 \\
32.2 \\
349 \\
.71 \\
4.59 \\
5.30\end{array}$ & $\begin{array}{r}337.5 \\
10.9 \\
60 \\
1.8 \\
1.55 \\
1.79\end{array}$ & $\begin{array}{r}420.8 \\
15.0 \\
105 \\
2.1 \\
2.14 \\
2.23\end{array}$ & $\begin{array}{r}682.7 \\
22.0 \\
310 \\
1.7 \\
3.14 \\
3.62\end{array}$ & $\begin{array}{c}179.4 \\
5.98 \\
18 \\
1.8 \\
.85 \\
.95\end{array}$ & $\begin{array}{r}211.41 \\
6.82 \\
129 \\
.03 \\
.97 \\
1.12\end{array}$ & $\begin{array}{r}11.29 \\
.38 \\
2.4 \\
.02 \\
.05 \\
.06\end{array}$ & $\begin{array}{l}0.30 \\
.010 \\
.12 \\
.00 \\
.00 \\
.00\end{array}$ & $\begin{array}{l}0.00 \\
.000 \\
.00 \\
.00 \\
.00 \\
.00\end{array}$ & $\begin{array}{l}0.06 \\
.002 \\
.05 \\
.00 \\
.00 \\
.00\end{array}$ \\
\hline
\end{tabular}

e Estinated

STATISIICS OF MONIHLY MEAN DATA FOR WAIER YEARS 1987 - 1991, BY WATER YEAR (WY)

\begin{tabular}{|c|c|c|c|c|c|c|c|c|c|c|c|c|}
\hline $\begin{array}{l}\text { MEAN } \\
\text { MAX } \\
\text { (WY) } \\
\text { MIN } \\
\text { (WY) }\end{array}$ & $\begin{array}{r}.47 \\
1.75 \\
1991 \\
.000 \\
1988\end{array}$ & $\begin{array}{l}2.50 \\
5.94 \\
1989 \\
1001 \\
1988\end{array}$ & $\begin{array}{l}8.01 \\
32.2 \\
1991 \\
1.10 \\
1988\end{array}$ & $\begin{array}{r}7.75 \\
14.6 \\
1990 \\
190 \\
1987\end{array}$ & $\begin{array}{l}15.8 \\
22.8 \\
1990 \\
6.19 \\
1987\end{array}$ & $\begin{array}{l}11.0 \\
22.0 \\
1991 \\
2.66 \\
1990\end{array}$ & $\begin{array}{l}7.70 \\
13.3 \\
1989 \\
5.17 \\
1988\end{array}$ & $\begin{array}{r}7.48 \\
26.8 \\
1990 \\
.22 \\
1987\end{array}$ & $\begin{array}{r}7.89 \\
37.3 \\
1990 \\
1009 \\
1988\end{array}$ & $\begin{array}{r}.66 \\
1.93 \\
1989 \\
.019 \\
1991\end{array}$ & $\begin{array}{r}.16 \\
.60 \\
1988 \\
.000 \\
1991\end{array}$ & $\begin{array}{l}1.12 \\
5.23 \\
1989 \\
.000 \\
1987\end{array}$ \\
\hline
\end{tabular}

SUMMARY STATISTICS

ANWUAL TOTAL

ANNUAL MEAN

HI GHESI ANMUAL MEAN

LOWEST ANNUAL MEAN

HIGHEST DAILY MEAN

LOWEST DAILY MEAN

ANNUAL SEVEN-DAY MINIMUM

INSTANTANEOUS PEAK FLOW

INSIANIANEOUS PEAK SIAGE

ANMUAL RUNOFF (CFSM)

ANNUAL RUNOFF (INCHES)

10 PERCENT EXCEEDS

50 PERCENT EXCEEDS

90 PERCENT EXCEEDS
FOR 1990 CALENDAR YEAR

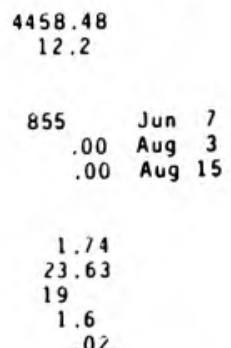

FOR 1991 WATER YEAR

$$
\begin{array}{r}
2951.04 \\
8.09
\end{array}
$$

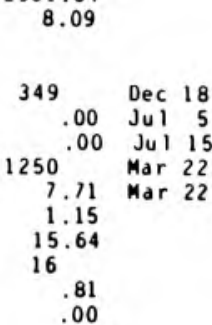

WATER YEARS $1987-1991$

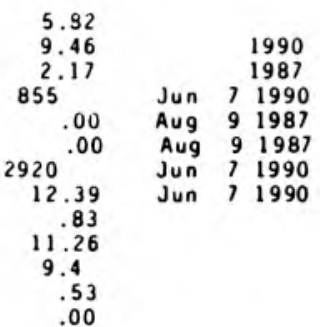


LOCAIION.--Lat $38^{\circ} 14^{\prime} 15^{\prime \prime}$, long $86^{\circ} 13^{\prime} 42^{\prime \prime}$, In NHISEl sec.19, T.3 S., R. 3 E., Harrison County, Hydrologic Unit 05140104 , On left bank $400 \mathrm{ft}$ downstream from Spring Creek, $600 \mathrm{ft}$ upstrea from bridge on Interstate 64 . 0.2 i upstrean frog bridge on State Highway $62,0.8 \mathrm{mi}$ north of white Cloud, and at mile 14.7.

DRAINAGE AREA.-476 $\mathrm{i}$. Of which 192 i does not contribute directly to surface runoff. Also, Dart of flow from Indian Creek, downstrea from Corydon. IN, enters Blue River via solution channel in Karst area through

PERIOD OF RECORD.--0ctober 1930 to current year. Monthly figures only for sone periods, published in WSP 1305.

REVISED RECORDS.--WSP 1335: 1921-32, 1933 (M), 1935-38(M), 1944. WSP 1385: Drainage area. WSP 1555: 1953. WDR IN-75-1: 1973.

GAGE.- -Water-stage recorder. Datum of gage is $434.26 \mathrm{ft}$ above National Geodetic Vertical Datun of 1929 (levels by State of Indiana. Departaent of Natural Resources). Prior to Nov. 16, 1938, nonrecording gage at same site and datue.

REMARKS, - - Records good.

DISCHARGE, CUBIL HEEI PER SECOND. WATER YEAR OCTOBER 1990 TO SEPIEMBER 1991 DAILY MEAN VALUES

\begin{tabular}{|c|c|c|c|c|c|c|c|c|c|c|c|c|}
\hline DAY & OCT & NOV & $\mathrm{DEC}$ & JAN & FEB & MAR & APR & MAY & JUN & JUL & AUG & SEP \\
\hline $\begin{array}{l}1 \\
2 \\
3 \\
4 \\
5\end{array}$ & $\begin{array}{r}58 \\
53 \\
52 \\
179 \\
527\end{array}$ & $\begin{array}{l}184 \\
171 \\
169 \\
128 \\
144\end{array}$ & $\begin{array}{r}490 \\
421 \\
1180 \\
2430 \\
1260\end{array}$ & $\begin{array}{l}3380 \\
2230 \\
1670 \\
1320 \\
1130\end{array}$ & $\begin{array}{l}717 \\
625 \\
599 \\
564 \\
551\end{array}$ & $\begin{array}{l}644 \\
690 \\
719 \\
634 \\
573\end{array}$ & $\begin{array}{r}1050 \\
900 \\
776 \\
701 \\
676\end{array}$ & $\begin{array}{l}361 \\
335 \\
313 \\
302 \\
307\end{array}$ & $\begin{array}{l}427 \\
330 \\
273 \\
245 \\
232\end{array}$ & $\begin{array}{l}77 \\
73 \\
71 \\
67 \\
64\end{array}$ & $\begin{array}{l}31 \\
30 \\
29 \\
29 \\
28\end{array}$ & $\begin{array}{r}37 \\
38 \\
30 \\
29 \\
275\end{array}$ \\
\hline $\begin{array}{r}6 \\
7 \\
8 \\
9 \\
10\end{array}$ & $\begin{array}{l}418 \\
238 \\
166 \\
152 \\
188\end{array}$ & $\begin{array}{l}159 \\
153 \\
159 \\
163 \\
229\end{array}$ & $\begin{array}{l}875 \\
701 \\
571 \\
482 \\
421\end{array}$ & $\begin{array}{l}1870 \\
4330 \\
3270 \\
2300 \\
1800\end{array}$ & $\begin{array}{l}2770 \\
6480 \\
3530 \\
2230 \\
1700\end{array}$ & $\begin{array}{l}564 \\
593 \\
565 \\
515 \\
486\end{array}$ & $\begin{array}{r}637 \\
567 \\
534 \\
704 \\
1740\end{array}$ & $\begin{array}{l}315 \\
330 \\
297 \\
282 \\
270\end{array}$ & $\begin{array}{l}206 \\
187 \\
169 \\
157 \\
146\end{array}$ & $\begin{array}{r}61 \\
57 \\
55 \\
101 \\
116\end{array}$ & $\begin{array}{l}29 \\
29 \\
28 \\
28 \\
29\end{array}$ & $\begin{array}{r}421 \\
162 \\
98 \\
70 \\
58\end{array}$ \\
\hline $\begin{array}{l}11 \\
12 \\
13 \\
14 \\
15\end{array}$ & $\begin{array}{l}306 \\
357 \\
268 \\
211 \\
171\end{array}$ & $\begin{array}{l}231 \\
278 \\
252 \\
224 \\
209\end{array}$ & $\begin{array}{l}377 \\
347 \\
323 \\
297 \\
496\end{array}$ & $\begin{array}{l}2150 \\
3730 \\
2470 \\
1820 \\
1470\end{array}$ & $\begin{array}{l}1350 \\
1110 \\
1060 \\
3460 \\
3620\end{array}$ & $\begin{array}{r}464 \\
458 \\
1380 \\
2560 \\
1950\end{array}$ & $\begin{array}{r}1260 \\
871 \\
1300 \\
2220 \\
1110\end{array}$ & $\begin{array}{l}266 \\
350 \\
553 \\
398 \\
383\end{array}$ & $\begin{array}{l}139 \\
132 \\
127 \\
121 \\
116\end{array}$ & $\begin{array}{l}90 \\
72 \\
64 \\
59 \\
57\end{array}$ & $\begin{array}{r}142 \\
126 \\
17 \\
75 \\
59\end{array}$ & $\begin{array}{l}47 \\
39 \\
38 \\
36 \\
33\end{array}$ \\
\hline $\begin{array}{l}16 \\
17 \\
18 \\
19 \\
20\end{array}$ & $\begin{array}{r}148 \\
132 \\
908 \\
1430 \\
658\end{array}$ & $\begin{array}{l}195 \\
182 \\
171 \\
164 \\
157\end{array}$ & $\begin{array}{r}858 \\
876 \\
1700 \\
10200 \\
3580\end{array}$ & $\begin{array}{r}1350 \\
1260 \\
1070 \\
970 \\
926\end{array}$ & $\begin{array}{l}2090 \\
1580 \\
2020 \\
3330 \\
2300\end{array}$ & $\begin{array}{l}1470 \\
1240 \\
2070 \\
2510 \\
1810\end{array}$ & $\begin{array}{r}1520 \\
1200 \\
989 \\
881 \\
810\end{array}$ & $\begin{array}{l}575 \\
416 \\
325 \\
286 \\
265\end{array}$ & $\begin{array}{l}110 \\
106 \\
110 \\
145 \\
146\end{array}$ & $\begin{array}{l}51 \\
47 \\
45 \\
43 \\
42\end{array}$ & $\begin{array}{r}42 \\
38 \\
53 \\
103 \\
166\end{array}$ & $\begin{array}{l}30 \\
40 \\
37 \\
35 \\
28\end{array}$ \\
\hline $\begin{array}{l}21 \\
22 \\
23 \\
24 \\
25\end{array}$ & $\begin{array}{l}453 \\
410 \\
429 \\
452 \\
398\end{array}$ & $\begin{array}{l}151 \\
215 \\
642 \\
728 \\
508\end{array}$ & $\begin{array}{l}2400 \\
4170 \\
4190 \\
3440 \\
2100\end{array}$ & $\begin{array}{l}863 \\
763 \\
681 \\
652 \\
594\end{array}$ & $\begin{array}{r}1780 \\
1480 \\
1240 \\
1060 \\
939\end{array}$ & $\begin{array}{r}1490 \\
7060 \\
14300 \\
6500 \\
3170\end{array}$ & $\begin{array}{l}695 \\
613 \\
550 \\
580 \\
523\end{array}$ & $\begin{array}{l}253 \\
243 \\
229 \\
396 \\
783\end{array}$ & $\begin{array}{l}216 \\
263 \\
179 \\
140 \\
122\end{array}$ & $\begin{array}{l}40 \\
39 \\
38 \\
38 \\
37\end{array}$ & $\begin{array}{l}95 \\
64 \\
49 \\
40 \\
35\end{array}$ & $\begin{array}{l}24 \\
22 \\
21 \\
20 \\
21\end{array}$ \\
\hline $\begin{array}{l}26 \\
27 \\
28 \\
29 \\
30 \\
31\end{array}$ & $\begin{array}{l}327 \\
288 \\
255 \\
236 \\
218 \\
198\end{array}$ & $\begin{array}{l}402 \\
343 \\
448 \\
742 \\
630 \\
\cdots\end{array}$ & $\begin{array}{l}1580 \\
1260 \\
1110 \\
2550 \\
7170 \\
7820\end{array}$ & $\begin{array}{l}532 \\
527 \\
650 \\
672 \\
728 \\
822\end{array}$ & $\begin{array}{l}832 \\
755 \\
691 \\
\ldots . \\
\cdots \\
\cdots\end{array}$ & $\begin{array}{l}2240 \\
1940 \\
3050 \\
2140 \\
1620 \\
1250\end{array}$ & $\begin{array}{l}477 \\
446 \\
423 \\
411 \\
390 \\
\ldots\end{array}$ & $\begin{array}{r}716 \\
513 \\
451 \\
417 \\
1110 \\
719\end{array}$ & $\begin{array}{r}106 \\
96 \\
91 \\
85 \\
82 \\
\ldots .\end{array}$ & $\begin{array}{l}37 \\
34 \\
34 \\
34 \\
33 \\
31\end{array}$ & $\begin{array}{l}31 \\
29 \\
29 \\
31 \\
50 \\
41\end{array}$ & $\begin{array}{r}19 \\
15 \\
15 \\
14 \\
13 \\
\cdots\end{array}$ \\
\hline $\begin{array}{l}\text { IOIAL } \\
\text { MEAN } \\
\text { MAX } \\
\text { MIN } \\
\text { CF SM } \\
\text { IN. }\end{array}$ & $\begin{array}{r}10284 \\
332 \\
1430 \\
52 \\
.70 \\
.80\end{array}$ & $\begin{array}{r}8531 \\
284 \\
742 \\
128 \\
.60 \\
.67\end{array}$ & $\begin{array}{r}71675 \\
2312 \\
10200 \\
297 \\
4.86 \\
5.60\end{array}$ & $\begin{array}{r}48000 \\
1548 \\
4330 \\
527 \\
3.25 \\
3.75\end{array}$ & $\begin{array}{r}50463 \\
1802 \\
6480 \\
551 \\
3.79 \\
3.94\end{array}$ & $\begin{array}{r}66655 \\
2150 \\
14300 \\
458 \\
4.52 \\
5.21\end{array}$ & $\begin{array}{r}26154 \\
872 \\
2220 \\
390 \\
1.83 \\
2.04\end{array}$ & $\begin{array}{r}12159 \\
412 \\
1110 \\
229 \\
.86 \\
1.00\end{array}$ & $\begin{array}{c}5004 \\
167 \\
427 \\
82 \\
.35 \\
.39\end{array}$ & $\begin{array}{c}1707 \\
55.1 \\
116 \\
31 \\
.12 \\
.13\end{array}$ & $\begin{array}{r}1665 \\
53.7 \\
166 \\
28 \\
.11 \\
.13\end{array}$ & $\begin{array}{r}1765 \\
58.8 \\
421 \\
13 \\
.12 \\
.14\end{array}$ \\
\hline
\end{tabular}

STAIISIICS OF MONIHLY MEAN DATA FOR WATEK YEARS 1932 - 1991, BY WATER YEAR (WY)

\begin{tabular}{|c|c|c|c|c|c|c|c|c|c|c|c|c|}
\hline $\begin{array}{l}\text { MEAN } \\
\text { MAX } \\
\text { (WY) } \\
\text { MIN } \\
\text { (WY) }\end{array}$ & $\begin{array}{r}132 \\
515 \\
1956 \\
14.3 \\
1965\end{array}$ & $\begin{array}{r}380 \\
2057 \\
1980 \\
20.0 \\
1964\end{array}$ & $\begin{array}{l}662 \\
2417 \\
1958 \\
17.6 \\
1964\end{array}$ & $\begin{array}{l}1073 \\
6290 \\
1937 \\
40.3 \\
1977\end{array}$ & $\begin{array}{l}1164 \\
3404 \\
1950 \\
78.0 \\
1934\end{array}$ & $\begin{array}{l}1400 \\
4299 \\
1945 \\
70.8 \\
1941\end{array}$ & $\begin{array}{r}1161 \\
2422 \\
1947 \\
263 \\
1934\end{array}$ & $\begin{array}{r}791 \\
4020 \\
1983 \\
91.2 \\
1934\end{array}$ & $\begin{array}{r}461 \\
2101 \\
1990 \\
41.0 \\
1936\end{array}$ & $\begin{array}{r}296 \\
1655 \\
1979 \\
44.8 \\
1954\end{array}$ & $\begin{array}{r}176 \\
801 \\
1977 \\
29.8 \\
1964\end{array}$ & $\begin{array}{r}137 \\
541 \\
1965 \\
18.8 \\
1953\end{array}$ \\
\hline
\end{tabular}

SUMMARY SIATISTICS

ANMUAL TOTAL

ANNUAL MEAN

HIGHEST ANMUAL MEA

LOWEST ANNUAL MEAN

HIGHESI DAILY MEAN

LOWEST DAILY MEAN

ANHUAL SEVEN-DAY MIMIMUM

INSTANIANEOUS PEAK FLOW

INSTANTANEOUS PEAK STAGE

ANNUAL RUNOF F (CFSM)

ANHUAL RUNOFF (INCHES)

10 PERCENT EXCEEDS

50 PERCEMT EXCEEDS

90 PERCENT EXCEEDS
FOR 1990 CALENDAR YEAR

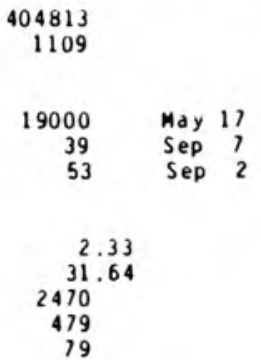

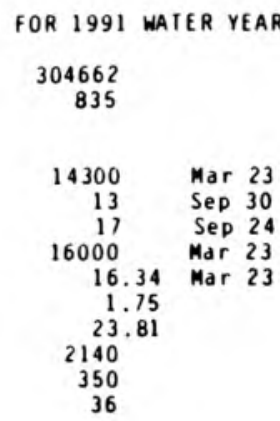

WAIER YEARS 1932 - 1991

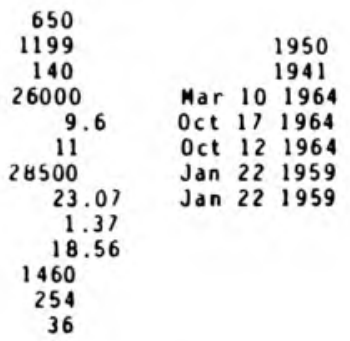




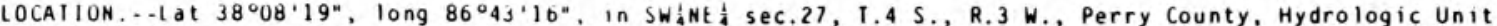
05140201 , on left bank at downstrean side of bridge on State Highway 145 at Bristow, 2.0 mi downstrea from Coon Branch, 5.8 i upstream from Sulphur Fork Creek, and at ile 14.1 .

DRAINAGE AREA. - - 39.8 i $i^{2}$

PERIOD OF RECORD.--August 1961 to current yedr.

REVISED RECORDS.-.WDR IN-72-1: Drainage area.

GAGE.--Water-stage recorder. Datun of gage is $395.00 \mathrm{ft}$ above National Geodetic Vertical Datum of 1929.

REMARKS. - Records fair. Flow regulated by forest Service and Middle Fork Anderson River Conservancy District control structures beginning June 1967 .

EXIREMES OUTSIDE PERIOD OF RECORD. - - Flood of Jan, 21 , 1959 reached a stage of $20.0 \mathrm{ft}$, from floodmark, discharge $15,000 \mathrm{ft} / \mathrm{s}$, from rating curve extended above $7,000 \mathrm{ft} / \mathrm{s}$. This is the oxiaum flood since 1905 , from information by local resident.

DISCHARGE, CUBIC FEE I PER SECOND, WATER YEAR OCTOBER 1990 TO SEPIEMBER 1991 DAIL Y MEAN VALUES

\begin{tabular}{|c|c|c|c|c|c|c|c|c|c|c|c|c|}
\hline DAY & $\mathrm{OCT}$ & NOV & $\mathrm{DEC}$ & JAN & FEB & MAR & APR & MAY & JUN & JUL & AUG & SEP \\
\hline $\begin{array}{l}1 \\
2 \\
3 \\
4 \\
5\end{array}$ & $\begin{array}{r}.33 \\
.13 \\
.11 \\
7.4\end{array}$ & $\begin{array}{l}6.1 \\
5.9 \\
5.9 \\
5.8 \\
7.0\end{array}$ & $\begin{array}{r}27 \\
20 \\
135 \\
130 \\
71\end{array}$ & $\begin{array}{r}407 \\
292 \\
120 \\
77 \\
85\end{array}$ & $\begin{array}{l}75 \\
62 \\
51 \\
44 \\
44\end{array}$ & $\begin{array}{l}36 \\
44 \\
43 \\
39 \\
34\end{array}$ & $\begin{array}{l}63 \\
50 \\
41 \\
38 \\
45\end{array}$ & $\begin{array}{l}30 \\
26 \\
22 \\
19 \\
19\end{array}$ & $\begin{array}{l}7.8 \\
7.0 \\
7.1 \\
29 \\
12\end{array}$ & $\begin{array}{l}.85 \\
1.3 \\
1.6 \\
.86 \\
.60\end{array}$ & $\begin{array}{l}.00 \\
.00 \\
.00 \\
.00 \\
.00\end{array}$ & $\begin{array}{l}.00 \\
.00 \\
.00 \\
.02 \\
.05\end{array}$ \\
\hline $\begin{array}{r}6 \\
7 \\
8 \\
9 \\
10\end{array}$ & $\begin{array}{r}5.5 \\
5.0 \\
4.3 \\
5.4 \\
13\end{array}$ & $\begin{array}{r}8.0 \\
8.4 \\
8.1 \\
9.1 \\
13\end{array}$ & $\begin{array}{l}44 \\
31 \\
23 \\
18 \\
16\end{array}$ & $\begin{array}{l}346 \\
459 \\
365 \\
231 \\
126\end{array}$ & $\begin{array}{l}372 \\
386 \\
277 \\
146 \\
100\end{array}$ & $\begin{array}{l}32 \\
32 \\
31 \\
29 \\
27\end{array}$ & $\begin{array}{r}43 \\
39 \\
41 \\
168 \\
215\end{array}$ & $\begin{array}{l}18 \\
16 \\
14 \\
14 \\
13\end{array}$ & $\begin{array}{l}8.3 \\
6.9 \\
5.9 \\
5.1 \\
4.4\end{array}$ & $\begin{array}{l}.38 \\
24^{.32} \\
29 \\
9.7\end{array}$ & $\begin{array}{l}.00 \\
.00 \\
.00 \\
.00 \\
.00\end{array}$ & $\begin{array}{l}.22 \\
.87 \\
.27 \\
.03 \\
.05\end{array}$ \\
\hline $\begin{array}{l}11 \\
12 \\
13 \\
14 \\
15\end{array}$ & $\begin{array}{l}13 \\
10 \\
8.1 \\
7.0 \\
6.2\end{array}$ & $\begin{array}{l}12 \\
11 \\
10 \\
11 \\
10\end{array}$ & $\begin{array}{l}14 \\
13 \\
11 \\
10 \\
62\end{array}$ & $\begin{array}{r}213 \\
257 \\
170 \\
121 \\
95\end{array}$ & $\begin{array}{r}17 \\
63 \\
116 \\
419 \\
299\end{array}$ & $\begin{array}{r}25 \\
32 \\
200 \\
312 \\
191\end{array}$ & $\begin{array}{r}122 \\
94 \\
152 \\
246 \\
177\end{array}$ & $\begin{array}{l}12 \\
15 \\
15 \\
14 \\
13\end{array}$ & $\begin{array}{l}4.0 \\
3.6 \\
2.8 \\
1.7 \\
1.2\end{array}$ & $\begin{array}{l}4.7 \\
2.2 \\
1.1 \\
.59 \\
.49\end{array}$ & $\begin{array}{c}12^{.00} \\
8.5 \\
1.6 \\
.36\end{array}$ & $\begin{array}{l}.03 \\
.00 \\
.00 \\
.00 \\
.00\end{array}$ \\
\hline $\begin{array}{l}16 \\
17 \\
18 \\
19 \\
20\end{array}$ & $\begin{array}{r}5.7 \\
6.3 \\
107 \\
52 \\
26\end{array}$ & $\begin{array}{l}10 \\
11 \\
11 \\
9.7 \\
8.9\end{array}$ & $\begin{array}{r}58 \\
83 \\
841 \\
531 \\
458\end{array}$ & $\begin{array}{r}102 \\
93 \\
80 \\
70 \\
62\end{array}$ & $\begin{array}{l}163 \\
116 \\
357 \\
332 \\
218\end{array}$ & $\begin{array}{l}124 \\
128 \\
244 \\
183 \\
128\end{array}$ & $\begin{array}{r}127 \\
96 \\
77 \\
105 \\
96\end{array}$ & $\begin{array}{r}12 \\
11 \\
10 \\
9.2 \\
8.2\end{array}$ & $\begin{array}{l}1.1 \\
1.2 \\
1.7 \\
1.0 \\
.80\end{array}$ & $\begin{array}{l}.31 \\
.37 \\
.41 \\
.37 \\
.32\end{array}$ & $\begin{array}{l}.00 \\
.00 \\
.00 \\
.33 \\
1.1\end{array}$ & $\begin{array}{l}.00 \\
.00 \\
.00 \\
.00 \\
.00\end{array}$ \\
\hline $\begin{array}{l}21 \\
22 \\
23 \\
24 \\
25\end{array}$ & $\begin{array}{l}23 \\
22 \\
18 \\
12 \\
11\end{array}$ & $\begin{array}{l}8.2 \\
37 \\
49 \\
30 \\
21\end{array}$ & $\begin{array}{l}503 \\
578 \\
500 \\
402 \\
245\end{array}$ & $\begin{array}{l}53 \\
43 \\
38 \\
34 \\
29\end{array}$ & $\begin{array}{r}139 \\
103 \\
81 \\
66 \\
55\end{array}$ & $\begin{array}{l}105 \\
721 \\
689 \\
507 \\
482\end{array}$ & $\begin{array}{l}80 \\
66 \\
56 \\
68 \\
63\end{array}$ & $\begin{array}{l}7.1 \\
6.3 \\
5.8 \\
32 \\
18\end{array}$ & $\begin{array}{l}47 \\
9.1 \\
4.7 \\
3.1 \\
2.2\end{array}$ & $\begin{array}{l}.35 \\
.43 \\
.40 \\
.27 \\
.25\end{array}$ & $\begin{array}{l}.89 \\
.54 \\
.37 \\
.12 \\
.00\end{array}$ & $\begin{array}{l}.00 \\
.00 \\
.00 \\
.00 \\
.00\end{array}$ \\
\hline $\begin{array}{l}26 \\
27 \\
28 \\
29 \\
30 \\
31\end{array}$ & $\begin{array}{l}8.8 \\
8.3 \\
7.3 \\
6.9 \\
6.4 \\
6.4\end{array}$ & $\begin{array}{l}15 \\
12 \\
98 \\
71 \\
41 \\
-\ldots\end{array}$ & $\begin{array}{r}102 \\
75 \\
73 \\
376 \\
587 \\
471\end{array}$ & $\begin{array}{r}27 \\
32 \\
81 \\
77 \\
107 \\
95\end{array}$ & $\begin{array}{l}47 \\
41 \\
37 \\
\cdots \\
\cdots \\
\cdots\end{array}$ & $\begin{array}{r}453 \\
425 \\
328 \\
156 \\
100 \\
78\end{array}$ & $\begin{array}{l}55 \\
47 \\
41 \\
39 \\
34 \\
\cdots\end{array}$ & $\begin{array}{l}18 \\
19 \\
15 \\
13 \\
10 \\
8.6\end{array}$ & $\begin{array}{l}1.8 \\
1.4 \\
1.2 \\
1.1 \\
.92 \\
\cdots\end{array}$ & $\begin{array}{l}.21 \\
.17 \\
.15 \\
.10 \\
.04 \\
.00\end{array}$ & $\begin{array}{l}.00 \\
.00 \\
.00 \\
.00 \\
.00 \\
.00\end{array}$ & $\begin{array}{l}.00 \\
.00 \\
.00 \\
.00 \\
.00 \\
\cdots\end{array}$ \\
\hline $\begin{array}{l}\text { IOIAL } \\
\text { MEAN } \\
\text { MAX } \\
\text { MIN } \\
\text { CF SM } \\
\text { IN. }\end{array}$ & $\begin{array}{r}426.57 \\
13.8 \\
107 \\
.11 \\
.35 \\
.40\end{array}$ & $\begin{array}{r}564.1 \\
18.8 \\
98 \\
5.8 \\
.47 \\
.53\end{array}$ & $\begin{array}{r}6508 \\
210 \\
841 \\
10 \\
5.27 \\
6.08\end{array}$ & $\begin{array}{r}4387 \\
142 \\
459 \\
27 \\
3.56 \\
4.10\end{array}$ & $\begin{array}{r}4286 \\
153 \\
419 \\
37 \\
3.85 \\
4.01\end{array}$ & $\begin{array}{c}5958 \\
192 \\
721 \\
25 \\
4.83 \\
5.57\end{array}$ & $\begin{array}{r}2584 \\
86.1 \\
246 \\
34 \\
2.16 \\
2.42\end{array}$ & $\begin{array}{r}463.2 \\
14.9 \\
32 \\
5.8 \\
.38 \\
.43\end{array}$ & $\begin{array}{r}185.12 \\
6.17 \\
47 \\
.80 \\
.16 \\
.17\end{array}$ & $\begin{array}{c}81.84 \\
2.64 \\
29 \\
.00 \\
.07 \\
.08\end{array}$ & $\begin{array}{c}25.81 \\
.83 \\
12 \\
.00 \\
.02 \\
.02\end{array}$ & $\begin{array}{l}1.54 \\
.051 \\
.81 \\
.00 \\
.00 \\
.00\end{array}$ \\
\hline
\end{tabular}

SIATISIICS OF MONTHLY MEAN DATA FOR WATER YEARS 1962 - 1991, BY WATER YEAR (WY)

$\begin{array}{lrrrrr}\text { MEAN } & 10.0 & 41.5 & 71.4 & 80.7 & 103 \\ \text { MAX } & 63.7 & 194 & 210 & 223 & 245 \\ \text { (WY) } & 1978 & 1980 & 1991 & 1982 & 1989 \\ \text { MIN } & 1000 & 1000 & 1000 & 2.78 & 7.86 \\ \text { (WY) } & 1965 & 1964 & 1964 & 1964 & 1964\end{array}$

128
393
1964
33.4
1990

117
312
1972
19.6

69.4
405
1983
6.36
1988

28.7
190
1979
1988

$\begin{array}{rrr}18.4 & 12.6 & 11.3 \\ 141 & 162 & 18.8 \\ 1979 & 1979 & 1982 \\ 138 & 1013 & 1000 \\ 1968 & 1965 & 1964\end{array}$

SUMMARY SIATISTICS

ANHUAL TOIAL

ANNUAL MEAN

HIGHESI ANNUAL MEAN

LOWEST ANNUAL MEAN

HIGHESI DAILY MEAN

LOWEST DAILY MEAN

ANNUAL SEVEM-DAY MINIMUM

INSTANTANEOUS PEAK FLOW

INSIANTAMEOUS PEAK SIAGE

ANNUAL RUNOFF (CFSM)

ANNUAL RUNOFF (INCHES)

10 PERCENT EXCEEDS

50 PERCENT EXCEEDS

90 PERCENT EXCEEDS
FOR 1990 CALENDAR YEAR

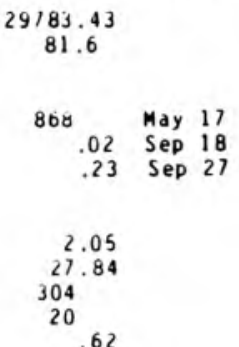

FOR 1991 WAIER YEAR

$$
\begin{gathered}
25471.18 \\
69.8
\end{gathered}
$$

841 Dec 18

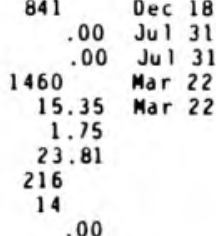

WAIER YEARS $1962-1991$

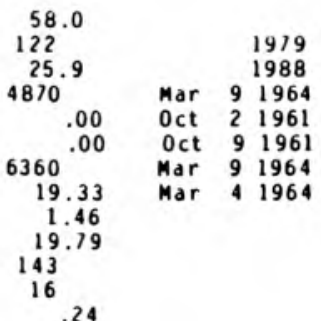




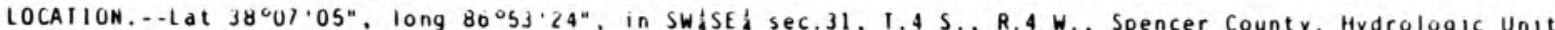

05140201 , on right bank at upstrean side of bridge on county road, 1.3 i east of Santa claus Post 0ffice, and 1.8 i upstrean from, unnamed right-bank tributary.

DRAI NAGE AREA. . - $7.86 \mathrm{i}^{2}$.

PERIOD OF RECORO..-October 1969 to current yedr.

GAGE - -Water-stage recorder. Datum of gage is $404.34 \mathrm{ft}$ above National Geodetic Vertical Datun of 1929.

REMARKS. - - Records fair.

DISCHARGE, CUBIC FEEI PER SECOND, WAIER YEAR OCTOBER 1990 TO SEPTEMBER 1991 DAIIY MEAN VALUES

\begin{tabular}{|c|c|c|c|c|c|c|c|c|c|c|c|c|}
\hline DAY & $O C I$ & NOV & $\mathrm{DEC}$ & JAN & FE B & MAR & APR & MAY & JUN & JUL & AUG & StP \\
\hline $\begin{array}{l}1 \\
2 \\
3 \\
4 \\
5\end{array}$ & $\begin{array}{c}.03 \\
.01 \\
.00 \\
46 \\
1.9\end{array}$ & $\begin{array}{l}1.0 \\
.98 \\
1.1 \\
1.1 \\
2.4\end{array}$ & $\begin{array}{r}4.6 \\
3.8 \\
56 \\
9.9 \\
6.2\end{array}$ & $\begin{array}{c}15 \\
10 \\
7.3 \\
5.4 \\
23\end{array}$ & $\begin{array}{r}7.1 \\
6.0 \\
5.2 \\
5.0 \\
11\end{array}$ & $\begin{array}{l}6.8 \\
8.0 \\
5.2 \\
4.2 \\
3.8\end{array}$ & $\begin{array}{l}7.4 \\
6.6 \\
6.5 \\
8.1 \\
8.0\end{array}$ & $\begin{array}{c}1.2 \\
.81 \\
.67 \\
.64 \\
3.2\end{array}$ & $\begin{array}{l}.11 \\
.11 \\
.09 \\
.33 \\
.07\end{array}$ & $\begin{array}{l}.00 \\
.11 \\
.11 \\
.04 \\
.02\end{array}$ & $\begin{array}{l}.00 \\
.00 \\
.00 \\
.00 \\
.00\end{array}$ & $\begin{array}{l}.00 \\
.00 \\
.00 \\
.00 \\
.03\end{array}$ \\
\hline $\begin{array}{r}6 \\
7 \\
8 \\
9 \\
10\end{array}$ & $\begin{array}{r}.76 \\
.46 \\
51^{.33} \\
34\end{array}$ & $\begin{array}{l}1.2 \\
1.1 \\
.97 \\
3.8 \\
2.8\end{array}$ & $\begin{array}{l}4.9 \\
3.8 \\
3.2 \\
2.8 \\
2.6\end{array}$ & $\begin{array}{r}169 \\
97 \\
23 \\
14 \\
13\end{array}$ & $\begin{array}{r}201 \\
41 \\
17 \\
11 \\
8.5\end{array}$ & $\begin{array}{l}4.1 \\
3.0 \\
2.7 \\
2.5 \\
2.1\end{array}$ & $\begin{array}{l}6.5 \\
6.4 \\
10 \\
22 \\
14\end{array}$ & $\begin{array}{l}1.1 \\
.64 \\
.52 \\
.66 \\
.53\end{array}$ & $\begin{array}{l}.05 \\
.04 \\
.03 \\
.03 \\
.03\end{array}$ & $\begin{array}{l}.01 \\
.00 \\
2.1 \\
.21 \\
.02\end{array}$ & $\begin{array}{l}.00 \\
.00 \\
.00 \\
.00 \\
.00\end{array}$ & $\begin{array}{l}.00 \\
.00 \\
.00 \\
.00 \\
.08\end{array}$ \\
\hline $\begin{array}{l}11 \\
12 \\
13 \\
14 \\
15\end{array}$ & $\begin{array}{l}7.4 \\
3.3 \\
1.9 \\
1.3 \\
.90\end{array}$ & $\begin{array}{r}1.5 \\
1.1 \\
.94 \\
.87 \\
.78\end{array}$ & $\begin{array}{l}2.4 \\
2.3 \\
2.0 \\
1.8 \\
19\end{array}$ & $\begin{array}{c}74 \\
23 \\
13 \\
9.6 \\
13\end{array}$ & $\begin{array}{r}6.4 \\
5.6 \\
73 \\
115 \\
20\end{array}$ & $\begin{array}{l}2.2 \\
5.3 \\
43 \\
38 \\
15\end{array}$ & $\begin{array}{l}9.2 \\
8.9 \\
18 \\
14 \\
12\end{array}$ & $\begin{array}{r}.43 \\
.48 \\
.38 \\
1.5 \\
1.1\end{array}$ & $\begin{array}{l}.02 \\
.02 \\
.02 \\
.01 \\
.01\end{array}$ & $\begin{array}{l}.02 \\
.02 \\
.01 \\
.00 \\
.00\end{array}$ & $\begin{array}{l}.00 \\
.00 \\
.00 \\
.00 \\
.00\end{array}$ & $\begin{array}{l}.06 \\
.01 \\
.00 \\
.00 \\
.00\end{array}$ \\
\hline $\begin{array}{l}16 \\
17 \\
18 \\
19 \\
20\end{array}$ & $\begin{array}{l}.78 \\
4.5 \\
91 \\
7.1 \\
3.6\end{array}$ & $\begin{array}{l}.81 \\
.68 \\
.69 \\
.66 \\
.56\end{array}$ & $\begin{array}{c}6.5 \\
56 \\
531 \\
48 \\
19\end{array}$ & $\begin{array}{l}16 \\
10 \\
7.8 \\
7.2 \\
6.6\end{array}$ & $\begin{array}{r}11 \\
11 \\
151 \\
27 \\
15\end{array}$ & $\begin{array}{l}9.5 \\
11 \\
46 \\
16 \\
11\end{array}$ & $\begin{array}{l}8.4 \\
7.2 \\
7.1 \\
33 \\
12\end{array}$ & $\begin{array}{c}6.9 \\
2.8 \\
.95 \\
.76 \\
1.4\end{array}$ & $\begin{array}{l}.00 \\
.01 \\
.05 \\
.05 \\
.05\end{array}$ & $\begin{array}{l}.00 \\
.00 \\
.00 \\
.00 \\
.00\end{array}$ & $\begin{array}{l}.00 \\
.00 \\
.00 \\
.00 \\
.00\end{array}$ & $\begin{array}{l}.00 \\
.00 \\
.00 \\
.00 \\
.00\end{array}$ \\
\hline $\begin{array}{l}21 \\
22 \\
23 \\
24 \\
25\end{array}$ & $\begin{array}{r}2.4 \\
12 \\
5.8 \\
3.2 \\
2.3\end{array}$ & $\begin{array}{r}31.60 \\
7.6 \\
3.5 \\
2.2\end{array}$ & $\begin{array}{r}123 \\
100 \\
59 \\
17 \\
10\end{array}$ & $\begin{array}{l}4.4 \\
3.7 \\
3.5 \\
2.9 \\
2.3\end{array}$ & $\begin{array}{r}11 \\
8.4 \\
6.8 \\
5.9 \\
5.2\end{array}$ & $\begin{array}{r}27 \\
453 \\
88 \\
24 \\
17\end{array}$ & $\begin{array}{l}9.0 \\
7.8 \\
7.7 \\
7.5 \\
6.2\end{array}$ & $\begin{array}{l}.75 \\
.57 \\
.59 \\
.66 \\
2.5\end{array}$ & $\begin{array}{l}.47 \\
.09 \\
.05 \\
.04 \\
.03\end{array}$ & $\begin{array}{l}.00 \\
.00 \\
.00 \\
.00 \\
.00\end{array}$ & $\begin{array}{l}.00 \\
.00 \\
.00 \\
.00 \\
.00\end{array}$ & $\begin{array}{l}.00 \\
.00 \\
.00 \\
.00 \\
.00\end{array}$ \\
\hline $\begin{array}{l}26 \\
27 \\
28 \\
29 \\
30 \\
31\end{array}$ & $\begin{array}{l}1.8 \\
1.6 \\
1.3 \\
1.1 \\
1.1 \\
1.0\end{array}$ & $\begin{array}{c}1.7 \\
1.6 \\
71 \\
10 \\
6.2 \\
\cdots\end{array}$ & $\begin{array}{r}7.1 \\
6.7 \\
13 \\
219 \\
155 \\
28\end{array}$ & $\begin{array}{l}2.3 \\
8.5 \\
13 \\
11 \\
29 \\
10\end{array}$ & $\begin{array}{l}4.5 \\
4.0 \\
3.7 \\
\ldots . \\
\ldots . \\
\ldots\end{array}$ & $\begin{array}{r}14 \\
19 \\
15 \\
12 \\
9.0 \\
7.8\end{array}$ & $\begin{array}{l}5.5 \\
4.5 \\
3.5 \\
2.7 \\
1.9 \\
\ldots . .\end{array}$ & $\begin{array}{l}3.2 \\
1.1 \\
.52 \\
.38 \\
.27 \\
.18\end{array}$ & $\begin{array}{l}.02 \\
.00 \\
.00 \\
.00 \\
.00 \\
. .-\end{array}$ & $\begin{array}{l}.00 \\
.00 \\
.00 \\
.00 \\
.00 \\
.00\end{array}$ & $\begin{array}{l}.00 \\
.00 \\
.00 \\
.00 \\
.00 \\
.00\end{array}$ & $\begin{array}{l}.00 \\
.00 \\
.00 \\
.00 \\
.00 \\
\ldots\end{array}$ \\
\hline $\begin{array}{l}\text { IOTAL } \\
\text { MEAN } \\
\text { MAX } \\
\text { MIN } \\
\text { CFSM } \\
\text { IN. }\end{array}$ & $\begin{array}{r}295.87 \\
9.54 \\
91 \\
.00 \\
1.21 \\
1.40\end{array}$ & $\begin{array}{r}160.44 \\
5.35 \\
71 \\
.56 \\
.68 \\
76\end{array}$ & $\begin{array}{r}1523.6 \\
49.1 \\
531 \\
1.8 \\
6.25 \\
7.21\end{array}$ & $\begin{array}{r}647.5 \\
20.9 \\
169 \\
2.3 \\
2.66 \\
3.06\end{array}$ & $\begin{array}{c}791.3 \\
28.5 \\
201 \\
3.7 \\
3.62 \\
3.77\end{array}$ & $\begin{array}{c}985.2 \\
31.8 \\
453 \\
2.1 \\
4.04 \\
4.66\end{array}$ & $\begin{array}{r}281.6 \\
9.39 \\
33 \\
1.9 \\
1.19 \\
1.33\end{array}$ & $\begin{array}{c}37.39 \\
1.21 \\
6.9 \\
.18 \\
.15 \\
.18\end{array}$ & $\begin{array}{l}1.83 \\
.061 \\
.47 \\
.00 \\
.01 \\
.01\end{array}$ & $\begin{array}{l}2.67 \\
.086 \\
2.1 \\
.00 \\
.01 \\
.01\end{array}$ & $\begin{array}{l}0.00 \\
.000 \\
.00 \\
.00 \\
.00 \\
.00\end{array}$ & $\begin{array}{l}0.18 \\
.006 \\
.08 \\
.00 \\
.00 \\
.00\end{array}$ \\
\hline
\end{tabular}

STATISIICS OF MONIHLY MEAN DATA FOR WATER YEARS 1970 - 1991, BY WATER YEAR (WY)

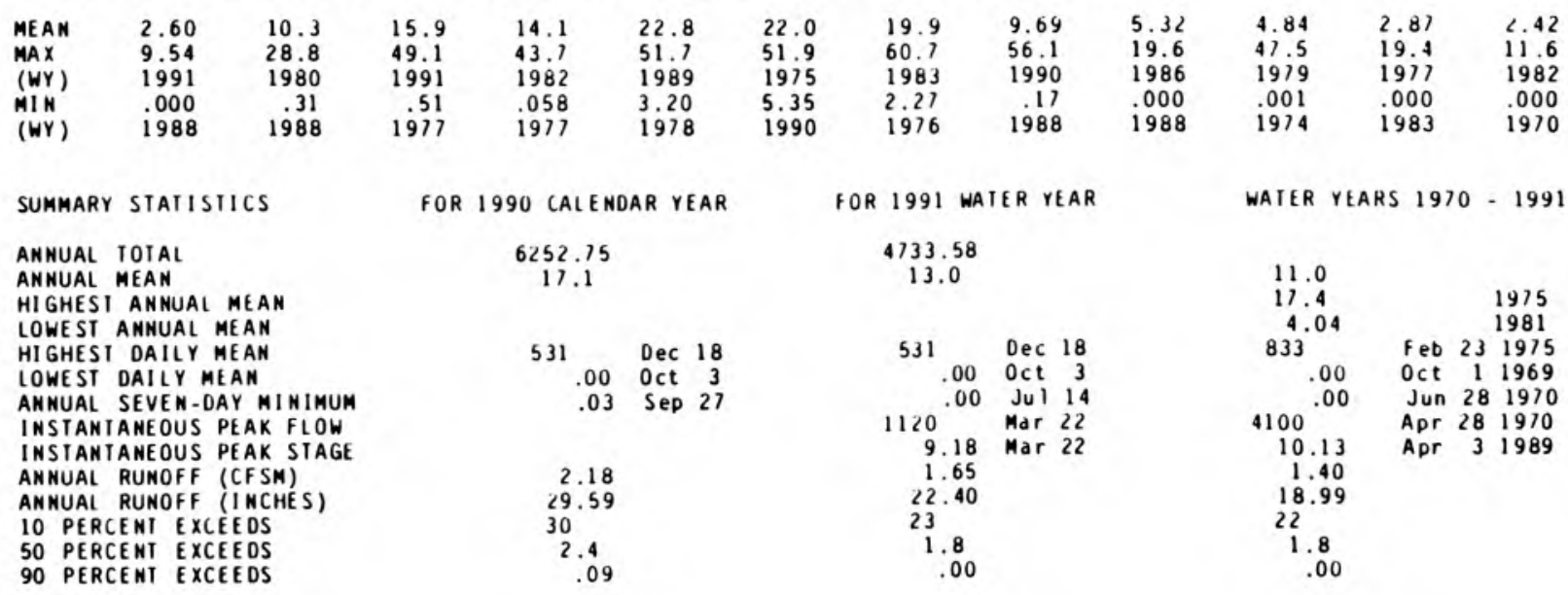




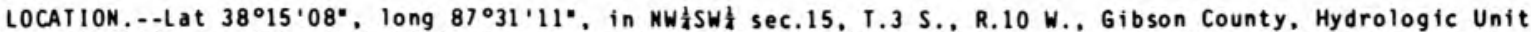
05140202 , on right bank $20 \mathrm{ft}$ downstrean from bridge on State Highway 168 , 1.1 ef upstrean from West Fork Pigeon Creek and $2.6 \mathrm{pi}$ east of intersection of U.S. Highway 41 at Fort Branch.

DRAI NAGE AREA $\ldots 35,4, i 2$

PERIOD OF RECORD.--October 1986 to current year.

GAGE.- Water-stage recorder. Datun of gage is $400.00 \mathrm{ft}$ above National Geodetic Vertical Datua of 1929 .

REMARKS. - - Records fair except for estiated daily discharges, which are poor.

DISCHARGE, CUBIC FEET PER SECONO, WATER YEAR OCTOBER 1990 TO SEPTEMBER 1991 DAILY MEAN VALUES

\begin{tabular}{|c|c|c|c|c|c|c|c|c|c|c|c|c|}
\hline DAY & $\mathrm{OCT}$ & NOV & DEC & JAN & FEB & MAR & APR & MAY & JUN & JUL & AUG & SEP \\
\hline $\begin{array}{l}1 \\
2 \\
3 \\
4 \\
5\end{array}$ & $\begin{array}{r}3.0 \\
3.1 \\
4.4 \\
569 \\
7.7\end{array}$ & $\begin{array}{l}4.3 \\
4.3 \\
4.3 \\
4.3 \\
8.3\end{array}$ & $\begin{array}{l}8.3 \\
7.0 \\
42 \\
11 \\
8.0\end{array}$ & $\begin{array}{r}37 \\
25 \\
20 \\
e 16 \\
73\end{array}$ & $\begin{array}{l}14 \\
14 \\
15 \\
20 \\
97\end{array}$ & $\begin{array}{l}49 \\
56 \\
21 \\
18 \\
16\end{array}$ & $\begin{array}{l}12 \\
11 \\
11 \\
12 \\
15\end{array}$ & $\begin{array}{l}6.6 \\
5.9 \\
5.8 \\
6.0 \\
9.1\end{array}$ & $\begin{array}{l}3.3 \\
3.3 \\
3.1 \\
3.0 \\
2.8\end{array}$ & $\begin{array}{r}e 2.0 \\
\text { e3.0 } \\
5.3 \\
3.1 \\
2.2\end{array}$ & $\begin{array}{r}\text { e. } 52 \\
\text { e. } 51 \\
\text { e. } 51 \\
\text { e. } 50 \\
\text { e2.5 }\end{array}$ & $\begin{array}{c}\text { e1.1 } \\
\text { e1.0 } \\
\text { e. } 94 \\
\text { e12 } \\
\text { e6.0 }\end{array}$ \\
\hline $\begin{array}{r}6 \\
7 \\
8 \\
9 \\
10\end{array}$ & $\begin{array}{r}4.6 \\
5.1 \\
4.8 \\
248 \\
235\end{array}$ & $\begin{array}{l}5.4 \\
4.7 \\
4.4 \\
4.7 \\
4.5\end{array}$ & $\begin{array}{l}7.4 \\
6.7 \\
6.4 \\
6.2 \\
6.2\end{array}$ & $\begin{array}{r}720 \\
518 \\
112 \\
97 \\
210\end{array}$ & $\begin{array}{r}986 \\
151 \\
45 \\
31 \\
25\end{array}$ & $\begin{array}{l}16 \\
13 \\
12 \\
12 \\
11\end{array}$ & $\begin{array}{l}12 \\
34 \\
26 \\
16 \\
11\end{array}$ & $\begin{array}{l}6.4 \\
5.2 \\
5.0 \\
5.5 \\
5.2\end{array}$ & $\begin{array}{l}2.8 \\
2.6 \\
2.6 \\
2.5 \\
2.5\end{array}$ & $\begin{array}{r}2.0 \\
1.9 \\
2.2 \\
3.6 \\
87\end{array}$ & $\begin{array}{l}\text { e2.1 } \\
\text { e1.7 } \\
\text { e1.5 } \\
\text { e1.3 } \\
\text { e1.2 }\end{array}$ & $\begin{array}{r}\text { e3.2 } \\
\text { e1.7 } \\
\text { e1.2 } \\
\text { e. } 90 \\
\text { e2.4 }\end{array}$ \\
\hline $\begin{array}{l}11 \\
12 \\
13 \\
14 \\
15\end{array}$ & $\begin{array}{l}16 \\
8.2 \\
6.2 \\
5.2 \\
4.8\end{array}$ & $\begin{array}{l}4.3 \\
4.2 \\
4.1 \\
4.1 \\
4.1\end{array}$ & $\begin{array}{r}5.9 \\
5.7 \\
5.5 \\
5.3 \\
21\end{array}$ & $\begin{array}{r}584 \\
103 \\
38 \\
32 \\
34\end{array}$ & $\begin{array}{r}18 \\
16 \\
257 \\
700 \\
44\end{array}$ & $\begin{array}{r}11 \\
27 \\
279 \\
296 \\
66\end{array}$ & $\begin{array}{l}9.6 \\
9.8 \\
14 \\
16 \\
74\end{array}$ & $\begin{array}{r}5.4 \\
6.1 \\
5.2 \\
5.2 \\
10\end{array}$ & $\begin{array}{l}2.5 \\
2.5 \\
2.4 \\
2.7 \\
2.3\end{array}$ & $\begin{array}{r}12 \\
5.0 \\
2.2 \\
e 1.7 \\
e 1.4\end{array}$ & $\begin{array}{l}\text { e1.1 } \\
\text { e1 } 11 \\
\text { e1.0 } \\
\text { e2.0 } \\
\text { e2.2 }\end{array}$ & $\begin{array}{l}\text { e1. } 5 \\
\text { e1. } \\
\text { e1.1 } \\
\text { e. } 97 \\
\text { e. } 88\end{array}$ \\
\hline $\begin{array}{l}16 \\
17 \\
18 \\
19 \\
20\end{array}$ & $\begin{array}{l}4.7 \\
4.7 \\
6.1 \\
4.8 \\
4.7\end{array}$ & $\begin{array}{l}4.3 \\
4.2 \\
4.2 \\
4.1 \\
4.1\end{array}$ & $\begin{array}{r}7.5 \\
84 \\
1090 \\
157 \\
34\end{array}$ & $\begin{array}{l}75 \\
34 \\
24 \\
22 \\
24\end{array}$ & $\begin{array}{r}\text { e20 } \\
\text { e16 } \\
329 \\
119 \\
49\end{array}$ & $\begin{array}{r}34 \\
540 \\
338 \\
62 \\
39\end{array}$ & $\begin{array}{l}16 \\
12 \\
10 \\
12 \\
9.5\end{array}$ & $\begin{array}{l}5.8 \\
5.7 \\
4.7 \\
4.5 \\
4.5\end{array}$ & $\begin{array}{l}2.4 \\
2.5 \\
2.4 \\
2.5 \\
2.6\end{array}$ & $\begin{array}{l}\text { e1.1 } \\
\text { e1. } 0 \\
\text { e. } 91 \\
\text { e. } 84 \\
\text { e. } 79\end{array}$ & $\begin{array}{l}\text { e1. } 6 \\
\text { e1.7 } \\
\text { e1. } 1 \\
\text { e1.0 } \\
\text { e. } 94\end{array}$ & $\begin{array}{r}\text { e. } 80 \\
\text { e. } 75 \\
\text { e. } 70 \\
\text { e1.3 } \\
\text { e1.0 }\end{array}$ \\
\hline $\begin{array}{l}21 \\
22 \\
23 \\
24 \\
25\end{array}$ & $\begin{array}{l}4.5 \\
6.4 \\
5.7 \\
5.1 \\
4.9\end{array}$ & $\begin{array}{r}4.0 \\
117 \\
14 \\
7.2 \\
5.9\end{array}$ & $\begin{array}{r}407 \\
436 \\
40 \\
e 15 \\
\text { e11 }\end{array}$ & $\begin{array}{r}17 \\
\text { e13 } \\
\text { e11 } \\
\text { e10 } \\
\text { e } 9.5\end{array}$ & $\begin{array}{l}34 \\
27 \\
22 \\
20 \\
17\end{array}$ & $\begin{array}{r}37 \\
1780 \\
461 \\
68 \\
38\end{array}$ & $\begin{array}{r}8.9 \\
8.5 \\
8.8 \\
17 \\
8.7\end{array}$ & $\begin{array}{l}4.3 \\
4.0 \\
4.1 \\
3.9 \\
4.6\end{array}$ & $\begin{array}{l}18 \\
8.1 \\
4.4 \\
2.5 \\
2.3\end{array}$ & $\begin{array}{l}\text { e. } 73 \\
\text { e. } 69 \\
\text { e. } 66 \\
\text { e. } 63 \\
\text { e. } 61\end{array}$ & $\begin{array}{l}\text { e. } 86 \\
\text { e. } 81 \\
\text { e.77 } \\
\text { e.75 } \\
\text { e. } 73\end{array}$ & $\begin{array}{l}\text { e. } 75 \\
\text { e. } 63 \\
\text { e. } 80 \\
\text { e. } 66 \\
\text { e. } 58\end{array}$ \\
\hline $\begin{array}{l}26 \\
27 \\
28 \\
29 \\
30 \\
31\end{array}$ & $\begin{array}{l}4.7 \\
4.6 \\
4.5 \\
4.4 \\
4.5 \\
4.3\end{array}$ & $\begin{array}{r}5.5 \\
5.3 \\
327 \\
20 \\
11 \\
\ldots . .\end{array}$ & $\begin{array}{c}\text { e8.4 } \\
\mathrm{e} 7.0 \\
11 \\
1070 \\
1740 \\
198\end{array}$ & $\begin{array}{c}e 9.1 \\
e 13 \\
17 \\
18 \\
118 \\
16\end{array}$ & $\begin{array}{l}16 \\
15 \\
14 \\
\cdots \\
\cdots \\
\cdots\end{array}$ & $\begin{array}{l}30 \\
27 \\
21 \\
18 \\
14 \\
13\end{array}$ & $\begin{array}{c}8.4 \\
8.2 \\
8.5 \\
10 \\
7.6 \\
\ldots . .\end{array}$ & $\begin{array}{l}4.8 \\
4.1 \\
3.7 \\
3.6 \\
3.6 \\
3.4\end{array}$ & $\begin{array}{r}2.2 \\
2.1 \\
2.1 \\
\mathrm{e} 2.1 \\
\mathrm{e} 2.0 \\
\ldots\end{array}$ & $\begin{array}{l}\text { e. } 59 \\
\text { e. } 57 \\
\text { e. } 55 \\
\text { e. } 54 \\
\text { e. } 53 \\
\text { e. } 52\end{array}$ & $\begin{array}{r}\text { e.71 } \\
\text { e.70 } \\
\text { e3.0 } \\
\text { e2.5 } \\
\text { e1.7 } \\
\text { e1.3 }\end{array}$ & $\begin{array}{l}\text { e. } 53 \\
\text { e. } 51 \\
\text { e. } 49 \\
\text { e. } 48 \\
\text { e. } 47 \\
. .-\end{array}$ \\
\hline $\begin{array}{l}\text { TOTAL } \\
\text { MEAN } \\
\text { MAX } \\
\text { MIN } \\
\text { CFSM } \\
\text { IN. }\end{array}$ & $\begin{array}{r}1203.7 \\
38.8 \\
569 \\
3.0 \\
1.10 \\
1.26\end{array}$ & $\begin{array}{r}607.8 \\
20.3 \\
327 \\
4.0 \\
.57 \\
.64\end{array}$ & $\begin{array}{r}5468.5 \\
176 \\
1740 \\
5.3 \\
4.98 \\
5.75\end{array}$ & $\begin{array}{r}3049.6 \\
98.4 \\
720 \\
9.1 \\
2.78 \\
3.20\end{array}$ & $\begin{array}{r}3131 \\
112 \\
986 \\
14 \\
3.16 \\
3.29\end{array}$ & $\begin{array}{r}4423 \\
143 \\
1780 \\
11 \\
4.03 \\
4.65\end{array}$ & $\begin{array}{r}437.5 \\
14.6 \\
74 \\
7.6 \\
.41 \\
.46\end{array}$ & $\begin{array}{r}161.9 \\
5.22 \\
10 \\
3.4 \\
.15 \\
.17\end{array}$ & $\begin{array}{r}99.1 \\
3.30 \\
18 \\
2.0 \\
.09 \\
.10\end{array}$ & $\begin{array}{c}145.86 \\
4.71 \\
87 \\
.52 \\
.13 \\
.15\end{array}$ & $\begin{array}{c}40.11 \\
1.29 \\
3.0 \\
.50 \\
.04 \\
.04\end{array}$ & $\begin{array}{c}46.54 \\
1.55 \\
12 \\
.47 \\
.04 \\
.05\end{array}$ \\
\hline
\end{tabular}

STATISTICS OF MONTHLY MEAN DATA FOR WATER YEARS 1987 - 1991, BY WATER YEAR (WY)

\begin{tabular}{|c|c|c|c|c|c|c|c|}
\hline $\begin{array}{l}\text { MEAN } \\
\text { MAX } \\
\text { (WY) } \\
\text { MIN } \\
\text { (WY) }\end{array}$ & $\begin{array}{r}14.6 \\
38.8 \\
1991 \\
.89\end{array}$ & $\begin{array}{l}25.0 \\
62.9 \\
1989 \\
2.13\end{array}$ & $\begin{array}{r}52.6 \\
176 \\
1991 \\
18.4\end{array}$ & $\begin{array}{l}55.6 \\
98.4 \\
1991 \\
6.96\end{array}$ & $\begin{array}{r}103 \\
170 \\
1989 \\
35.5\end{array}$ & $\begin{array}{r}73.1 \\
164 \\
1989 \\
15.3\end{array}$ & $\begin{array}{l}32.9 \\
75.1 \\
1989 \\
14.6 \\
1991\end{array}$ \\
\hline
\end{tabular}

SUMMARY STATISTICS

AMNUAL TOTAL

ANMUAL MEAN

HIGHEST ANMUAL MEAN

LOWEST ANMUAL MEAN

HIGHEST DAILY MEAN

LOWEST DAILY MEAN

ANNUAL SEVEN-DAY MIMIMUM

INSTANTANEOUS PEAK FLOW

INSTANTANEOUS PEAK STAGE

ANMUAL RUNOFF (CFSM)

ANNUAL RUNOFF (INCHES)

10 PERCENT EXCEEDS

50 PERCENT EXCEEDS

90 PERCENT EXCEEDS
FOR 1990 CALENDAR YEAR

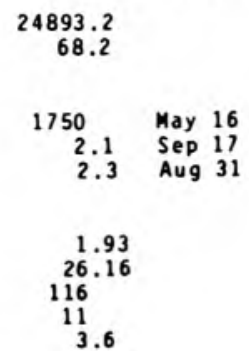

FOR 1991 WATER YEAR

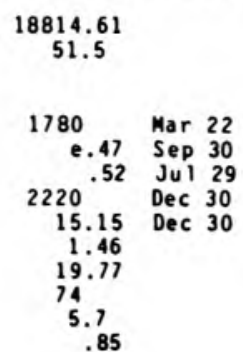

WATER YEARS 1987 - 1991

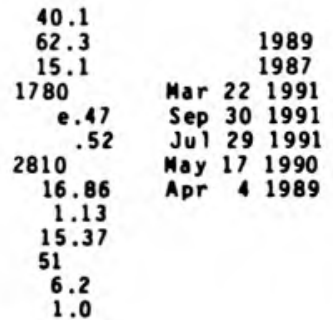




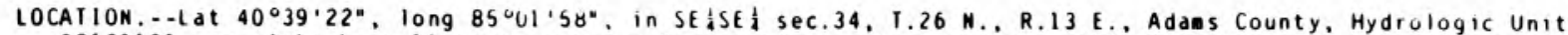
05120101 , on right bank $10 \mathrm{ft}$ downstream from bridge on State Highway $218,800 \mathrm{ft}$ downstrea from Shoeaker ditch, 0.8 i north of $L$ inn Grove, and 2.2 i upstrea from Rice ditch.

DRAINAGE AREA. $-453 \bullet i^{2}$

PERIOD OF RECORD.--September 1964 to current year.

REVISED RECORDS...WSP 2109: Drainage area.

GAGE.--Water-stage recorder. Datun of gage is $808.00 \mathrm{ft}$ above National Geodetic Vertical Datun of 1929 . REMARKS. - Records good except for estimated daily discharges, which are poor. Occasional regulation of Grand Lake,
diversion fro or into St. Marys River basin, and into Miani and Erie Canals.

EXIREMES OULSIDE PERIOD OF RECORD,--Flood April 1964 reached a stage of 13.13 ft, frou floodaark, discharge. $6,900 \mathrm{ft} / \mathrm{s}$.

DISCHARGE, CUBIC FEET PER SECOND, WATER YEAR OCTOBER 1990 TO SEPTEMBER 1991 DAILY MEAN VALUES

\begin{tabular}{|c|c|c|c|c|c|c|c|c|c|c|c|c|}
\hline DAY & $O C \mathrm{~T}$ & NOV & DEC & JAN & FEB & MAR & APR & MAY & JUN & JUL & AUG & SEP \\
\hline $\begin{array}{l}1 \\
2 \\
3 \\
4 \\
5\end{array}$ & $\begin{array}{r}110 \\
111 \\
105 \\
784 \\
1180\end{array}$ & $\begin{array}{l}136 \\
132 \\
125 \\
120 \\
171\end{array}$ & $\begin{array}{r}521 \\
355 \\
1120 \\
2010 \\
2330\end{array}$ & $\begin{array}{r}e 6000 \\
\text { e } 4200 \\
\text { e } 2900 \\
\text { e } 2200 \\
1510\end{array}$ & $\begin{array}{r}\text { e410 } \\
416 \\
410 \\
906 \\
1580\end{array}$ & $\begin{array}{l}385 \\
414 \\
407 \\
366 \\
339\end{array}$ & $\begin{array}{l}385 \\
355 \\
329 \\
319 \\
333\end{array}$ & $\begin{array}{r}125 \\
112 \\
96 \\
91 \\
92\end{array}$ & $\begin{array}{r}1310 \\
886 \\
797 \\
530 \\
240\end{array}$ & $\begin{array}{r}30 \\
145 \\
342 \\
170 \\
622\end{array}$ & $\begin{array}{l}20 \\
20 \\
20 \\
19 \\
19\end{array}$ & $\begin{array}{l}35 \\
17 \\
13 \\
26 \\
23\end{array}$ \\
\hline $\begin{array}{r}6 \\
7 \\
8 \\
9 \\
10\end{array}$ & $\begin{array}{r}581 \\
278 \\
308 \\
424 \\
1830\end{array}$ & $\begin{array}{l}429 \\
344 \\
259 \\
235 \\
240\end{array}$ & $\begin{array}{r}1520 \\
783 \\
496 \\
387 \\
352\end{array}$ & $\begin{array}{r}1010 \\
792 \\
619 \\
546 \\
508\end{array}$ & $\begin{array}{l}1990 \\
2250 \\
2280 \\
1710 \\
1040\end{array}$ & $\begin{array}{l}336 \\
324 \\
301 \\
293 \\
280\end{array}$ & $\begin{array}{l}334 \\
312 \\
302 \\
320 \\
320\end{array}$ & $\begin{array}{r}96 \\
105 \\
91 \\
84 \\
78\end{array}$ & $\begin{array}{r}153 \\
116 \\
96 \\
84 \\
78\end{array}$ & $\begin{array}{r}593 \\
126 \\
75 \\
159 \\
75\end{array}$ & $\begin{array}{l}18 \\
17 \\
18 \\
23 \\
24\end{array}$ & $\begin{array}{l}18 \\
13 \\
11 \\
10 \\
10\end{array}$ \\
\hline $\begin{array}{l}11 \\
12 \\
13 \\
14 \\
15\end{array}$ & $\begin{array}{r}2280 \\
2230 \\
1190 \\
521 \\
318\end{array}$ & $\begin{array}{l}257 \\
241 \\
220 \\
210 \\
206\end{array}$ & $\begin{array}{r}329 \\
308 \\
290 \\
266 \\
\mathrm{e} 700\end{array}$ & $\begin{array}{r}563 \\
1240 \\
1280 \\
878 \\
971\end{array}$ & $\begin{array}{r}730 \\
539 \\
477 \\
508 \\
\mathrm{e} 420\end{array}$ & $\begin{array}{l}273 \\
275 \\
287 \\
310 \\
356\end{array}$ & $\begin{array}{r}284 \\
219 \\
174 \\
1170 \\
1470\end{array}$ & $\begin{array}{l}73 \\
68 \\
66 \\
67 \\
80\end{array}$ & $\begin{array}{l}71 \\
67 \\
66 \\
63 \\
58\end{array}$ & $\begin{array}{l}46 \\
38 \\
34 \\
31 \\
29\end{array}$ & $\begin{array}{l}22 \\
19 \\
17 \\
16 \\
15\end{array}$ & $\begin{array}{l}9.4 \\
11 \\
10 \\
10 \\
12\end{array}$ \\
\hline $\begin{array}{l}16 \\
17 \\
18 \\
19 \\
20\end{array}$ & $\begin{array}{l}244 \\
212 \\
576 \\
738 \\
451\end{array}$ & $\begin{array}{r}203 \\
\mathrm{e} 200 \\
\mathrm{e} 198 \\
194 \\
191\end{array}$ & $\begin{array}{r}\text { el } 200 \\
\text { el } 220 \\
\text { el } 600 \\
1900 \\
2280\end{array}$ & $\begin{array}{r}1660 \\
2200 \\
2230 \\
1470 \\
998\end{array}$ & $\begin{array}{r}\text { e } 330 \\
\text { e } 380 \\
563 \\
1710 \\
2500\end{array}$ & $\begin{array}{r}567 \\
965 \\
1470 \\
1720 \\
1370\end{array}$ & $\begin{array}{r}785 \\
349 \\
207 \\
653 \\
1810\end{array}$ & $\begin{array}{l}67 \\
67 \\
76 \\
88 \\
66\end{array}$ & $\begin{array}{l}57 \\
89 \\
59 \\
50 \\
42\end{array}$ & $\begin{array}{l}29 \\
27 \\
27 \\
26 \\
26\end{array}$ & $\begin{array}{l}15 \\
18 \\
24 \\
28 \\
25\end{array}$ & $\begin{array}{r}11 \\
9.8 \\
8.9 \\
8.4 \\
7.9\end{array}$ \\
\hline $\begin{array}{l}21 \\
22 \\
23 \\
24 \\
25\end{array}$ & $\begin{array}{l}287 \\
270 \\
440 \\
364 \\
266\end{array}$ & $\begin{array}{l}190 \\
215 \\
336 \\
308 \\
251\end{array}$ & $\begin{array}{r}2240 \\
2430 \\
2920 \\
\mathrm{e} 2200 \\
\mathrm{e} 1500\end{array}$ & $\begin{array}{l}\text { e } 820 \\
\text { e700 } \\
\text { e620 } \\
\text { e560 } \\
\text { e520 }\end{array}$ & $\begin{array}{r}2550 \\
1690 \\
916 \\
637 \\
501\end{array}$ & $\begin{array}{r}751 \\
858 \\
1520 \\
1760 \\
1340\end{array}$ & $\begin{array}{r}1960 \\
1170 \\
557 \\
401 \\
312\end{array}$ & $\begin{array}{l}58 \\
52 \\
49 \\
51 \\
50\end{array}$ & $\begin{array}{l}38 \\
36 \\
41 \\
40 \\
36\end{array}$ & $\begin{array}{l}24 \\
25 \\
26 \\
26 \\
24\end{array}$ & $\begin{array}{l}18 \\
17 \\
16 \\
14 \\
13\end{array}$ & $\begin{array}{l}7.9 \\
8.0 \\
7.6 \\
8.3 \\
9.7\end{array}$ \\
\hline $\begin{array}{l}26 \\
27 \\
28 \\
29 \\
30 \\
31\end{array}$ & $\begin{array}{l}220 \\
194 \\
176 \\
162 \\
153 \\
142\end{array}$ & $\begin{array}{r}222 \\
270 \\
978 \\
1430 \\
958 \\
\cdots--\end{array}$ & $\begin{array}{r}\text { e } 840 \\
\text { e640 } \\
492 \\
1550 \\
4790 \\
7350\end{array}$ & $\begin{array}{l}\text { e490 } \\
\text { e470 } \\
\text { e } 440 \\
\text { e430 } \\
\text { e410 } \\
\text { e400 }\end{array}$ & $\begin{array}{l}438 \\
403 \\
380 \\
\ldots \\
\ldots- \\
\ldots\end{array}$ & $\begin{array}{r}994 \\
1550 \\
1120 \\
1210 \\
663 \\
440\end{array}$ & $\begin{array}{l}243 \\
208 \\
180 \\
162 \\
151 \\
\ldots-\end{array}$ & $\begin{array}{r}45 \\
58 \\
65 \\
54 \\
50 \\
702\end{array}$ & $\begin{array}{l}31 \\
33 \\
33 \\
31 \\
28 \\
\cdots\end{array}$ & $\begin{array}{l}22 \\
22 \\
20 \\
20 \\
22 \\
21\end{array}$ & $\begin{array}{l}12 \\
14 \\
13 \\
12 \\
15 \\
31\end{array}$ & $\begin{array}{l}10 \\
8.2 \\
6.9 \\
6.4 \\
6.5 \\
\ldots .-\end{array}$ \\
\hline $\begin{array}{l}\text { TOIAL } \\
\text { MEAN } \\
\text { MAX } \\
\text { MIN } \\
\text { CF SM } \\
\text { IN. }\end{array}$ & $\begin{array}{r}17145 \\
553 \\
2280 \\
105 \\
1.22 \\
1.41\end{array}$ & $\begin{array}{r}9469 \\
316 \\
1430 \\
120 \\
.70 \\
.78\end{array}$ & $\begin{array}{r}46919 \\
1514 \\
7350 \\
266 \\
3.34 \\
3.85\end{array}$ & $\begin{array}{r}39695 \\
1280 \\
6000 \\
400 \\
2.83 \\
3.26\end{array}$ & $\begin{array}{r}28664 \\
1024 \\
2550 \\
330 \\
2.26 \\
2.35\end{array}$ & $\begin{array}{r}23844 \\
769 \\
1760 \\
273 \\
1.70 \\
1.96\end{array}$ & $\begin{array}{r}15774 \\
526 \\
1960 \\
151 \\
1.16 \\
1.30\end{array}$ & $\begin{array}{c}2922 \\
94.3 \\
102 \\
45 \\
.21 \\
.24\end{array}$ & $\begin{array}{r}5259 \\
175 \\
1310 \\
28 \\
.39 \\
.43\end{array}$ & $\begin{array}{c}2902 \\
93.6 \\
622 \\
20 \\
.21 \\
.24\end{array}$ & $\begin{array}{r}572 \\
18.5 \\
31 \\
12 \\
.04 \\
.05\end{array}$ & $\begin{array}{r}353.9 \\
11.8 \\
35 \\
6.4 \\
.03 \\
.03\end{array}$ \\
\hline
\end{tabular}

e Estinated

SIAIISIICS OF MONIHLY MEAN DATA FUR WAIER YLARS 1965 - 1991, BY WATER YEAR (WY)

\begin{tabular}{|c|c|c|c|c|c|c|c|c|c|c|c|c|}
\hline $\begin{array}{l}\text { MEAN } \\
\text { MAX } \\
\text { (WY) } \\
\text { MIN } \\
\text { (WY) }\end{array}$ & $\begin{array}{r}94.3 \\
553 \\
1991 \\
6.84 \\
1965\end{array}$ & $\begin{array}{r}257 \\
1853 \\
1973 \\
7.52 \\
1966\end{array}$ & $\begin{array}{r}552 \\
1514 \\
1991 \\
9.25 \\
1977\end{array}$ & $\begin{array}{l}415 \\
1563 \\
1974 \\
6.19 \\
1977\end{array}$ & $\begin{array}{r}716 \\
1717 \\
1976 \\
86.0 \\
1978\end{array}$ & $\begin{array}{r}805 \\
2397 \\
1978 \\
80.5 \\
1981\end{array}$ & $\begin{array}{r}666 \\
2085 \\
1972 \\
68.2 \\
1971\end{array}$ & $\begin{array}{r}361 \\
1172 \\
1989 \\
25.9 \\
1988\end{array}$ & $\begin{array}{r}329 \\
1914 \\
1981 \\
8.92 \\
1988\end{array}$ & $\begin{array}{r}188 \\
856 \\
1990 \\
11.7 \\
1965\end{array}$ & $\begin{array}{r}107 \\
709 \\
1990 \\
8.20 \\
1966\end{array}$ & $\begin{array}{r}93.1 \\
753 \\
1972 \\
7.64 \\
1967\end{array}$ \\
\hline
\end{tabular}

SUMMARY SIATISTICS

ANMUAL TOIAL

ANNUAL MEAN

HIGHESI ANMUAL MEAN

LOWEST ANNUAL MEAN

HIGHEST DAILY MEAN

LOWEST DAILY MEAN

ANNUAL SEVEN-DAY MINIMUM

INSTANTANEOUS PEAK FLOW

INSTANTANEOUS PEAK STAGE

ANNUAL RUNOFF (CFSM)

ANNUAL RUNOFF (INCHES)

10 PERCENT EXCEEDS

50 PERCENT EXCEEDS

90 PERCENT EXCEEDS
FOR 1990 CALENUAR YEAR

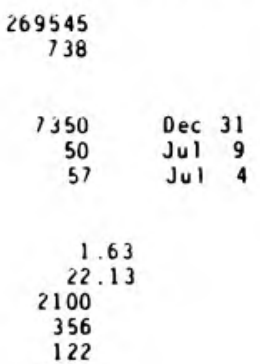

FOR 1991 WATER YEAR

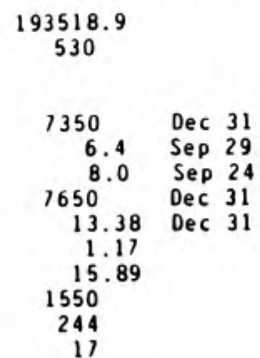

WAIER YEARS 1965 - 1991

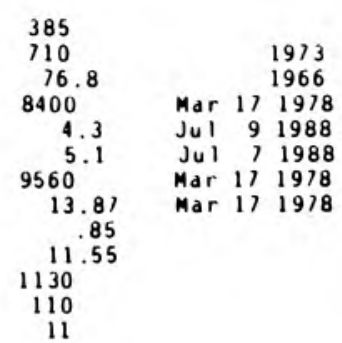




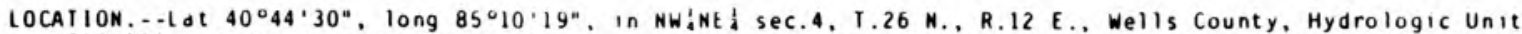
05120101 , on downstrea side of left dtutiment of Main Street (State Highway 1) bridge in Bluffton, 2 mi downstrean from Sixaile Creek, and at mile 434.5 .

DRAINAGE AREA..$-532 \mathrm{ni}^{2}$.

PERIOD OF RECORD.--October 1930 to Septeaber 1971 (discharge). October 1987 to current year (stage only). Gage-height records collected at same site since December 1910 are contained in reports of National Weather Service.

GAGE.--Data-Collection Platfora with Uitrasonic Ranger. Datua of gage is $793.01 \mathrm{ft}$ above National Geodetic Vertical Datum of 1929

REMARKS. - Gage-height accuracy to tenths of a foot during the stage-only period of record. Gage-heights estimated for Dec. 15 and 21, Feb. 18, May 22, and Sept. 20, and 22-23 are reasonably accurate.

EXIREMES FOR PERIOD OF RECORD. - Maximum gage height, $16.07 \mathrm{ft}$ feb. 15, 1950; ninimum gage height, 0.61 ft July 21,1932 .

EXIREMES FOR CURRENT YEAR.--Maximum gage height at $2400 \mathrm{hr} 15.1 \mathrm{ft}$, Dec, 31 ; inimua gage height at $2400 \mathrm{hr}$ $1.0 \mathrm{ft}$ Sept. 11, 20-21, 26-27

GAGE HEIGHI, FEET, WATER YEAR OCTOBER 1990 TO SEPTEMBER 1991 DAILY OBSERVATION AI 24:00 VALUES

\begin{tabular}{|c|c|c|c|c|c|c|c|c|c|c|c|c|}
\hline DAY & $0 \mathrm{CT}$ & NOV & $\mathrm{DEC}$ & JAN & FEB & MAR & $A P R$ & MAY & JUN & JUL & $A \cup G$ & SEP \\
\hline $\begin{array}{l}1 \\
2 \\
3 \\
4 \\
5\end{array}$ & $\begin{array}{l}1.8 \\
1.9 \\
2.2 \\
5.2 \\
5.2\end{array}$ & $\begin{array}{l}1.9 \\
1.9 \\
2.0 \\
1.9 \\
2.7\end{array}$ & $\begin{array}{l}3.3 \\
2.7 \\
7.6 \\
7.3 \\
7.3\end{array}$ & $\begin{array}{r}14.0 \\
11.8 \\
9.5 \\
7.5 \\
5.3\end{array}$ & $\begin{array}{l}3.8 \\
3.8 \\
3.8 \\
5.3 \\
6.4\end{array}$ & $\begin{array}{l}2.9 \\
2.9 \\
2.9 \\
2.6 \\
2.9\end{array}$ & $\begin{array}{l}2.9 \\
2.7 \\
2.7 \\
2.7 \\
2.9\end{array}$ & $\begin{array}{l}1.9 \\
2.0 \\
1.8 \\
1.8 \\
1.8\end{array}$ & $\begin{array}{l}5.4 \\
4.1 \\
4.1 \\
3.0 \\
2.3\end{array}$ & $\begin{array}{l}1.4 \\
1.9 \\
2.7 \\
2.2 \\
4.3\end{array}$ & $\begin{array}{l}1.1 \\
1.1 \\
1.1 \\
1.1 \\
1.1\end{array}$ & $\begin{array}{l}1.4 \\
1.2 \\
1.9 \\
1.4 \\
1.4\end{array}$ \\
\hline $\begin{array}{r}6 \\
7 \\
8 \\
9 \\
10\end{array}$ & $\begin{array}{l}3.3 \\
2.6 \\
3.1 \\
4.9 \\
8.3\end{array}$ & $\begin{array}{l}3.3 \\
2.9 \\
2.6 \\
2.6 \\
2.6\end{array}$ & $\begin{array}{l}5.3 \\
3.7 \\
3.0 \\
2.9 \\
2.7\end{array}$ & $\begin{array}{l}4.3 \\
3.8 \\
3.4 \\
3.3 \\
3.1\end{array}$ & $\begin{array}{l}7.2 \\
7.1 \\
7.3 \\
5.8 \\
4.3\end{array}$ & $\begin{array}{l}2.7 \\
2.6 \\
2.4 \\
2.4 \\
2.3\end{array}$ & $\begin{array}{l}2.7 \\
2.6 \\
3.1 \\
2.9 \\
2.6\end{array}$ & $\begin{array}{l}1.8 \\
2.0 \\
1.8 \\
1.6 \\
1.6\end{array}$ & $\begin{array}{l}1.9 \\
1.9 \\
1.9 \\
1.9 \\
1.6\end{array}$ & $\begin{array}{l}3.0 \\
1.9 \\
1.6 \\
2.2 \\
1.6\end{array}$ & $\begin{array}{l}1.1 \\
1.1 \\
1.1 \\
1.4 \\
1.1\end{array}$ & $\begin{array}{l}1.2 \\
1.1 \\
1.1 \\
1.1 \\
1.1\end{array}$ \\
\hline $\begin{array}{l}11 \\
12 \\
13 \\
14 \\
15\end{array}$ & $\begin{array}{l}7.7 \\
7.3 \\
4.6 \\
3.3 \\
2.7\end{array}$ & $\begin{array}{l}2.4 \\
2.4 \\
2.4 \\
2.2 \\
2.4\end{array}$ & $\begin{array}{l}2.6 \\
2.6 \\
2.6 \\
2.4 \\
5.0\end{array}$ & $\begin{array}{l}3.7 \\
5.2 \\
4.9 \\
4.5 \\
5.3\end{array}$ & $\begin{array}{l}3.1 \\
3.1 \\
3.1 \\
3.1 \\
2.7\end{array}$ & $\begin{array}{l}2.3 \\
2.6 \\
2.6 \\
2.6 \\
2.9\end{array}$ & $\begin{array}{l}2.4 \\
2.3 \\
2.9 \\
6.5 \\
6.1\end{array}$ & $\begin{array}{l}1.6 \\
1.6 \\
1.6 \\
1.6 \\
1.9\end{array}$ & $\begin{array}{l}1.6 \\
1.6 \\
1.6 \\
1.6 \\
1.6\end{array}$ & $\begin{array}{l}1.6 \\
1.5 \\
1.4 \\
1.4 \\
1.2\end{array}$ & $\begin{array}{l}1.4 \\
1.1 \\
1.1 \\
1.1 \\
1.1\end{array}$ & $\begin{array}{l}1.0 \\
1.1 \\
1.1 \\
1.1 \\
1.1\end{array}$ \\
\hline $\begin{array}{l}16 \\
17 \\
18 \\
19 \\
20\end{array}$ & $\begin{array}{l}2.4 \\
2.6 \\
4.1 \\
3.9 \\
2.9\end{array}$ & $\begin{array}{l}\cdots \\
2.2 \\
2.3 \\
2.2\end{array}$ & $\begin{array}{l}5.4 \\
-2.5 \\
6.5 \\
6.9 \\
7.3\end{array}$ & $\begin{array}{l}7.5 \\
7.5 \\
7.2 \\
5.2 \\
4.6\end{array}$ & $\begin{array}{l}2.6 \\
3.1 \\
4.5 \\
7.1 \\
7.7\end{array}$ & $\begin{array}{l}3.5 \\
4.8 \\
6.0 \\
6.1 \\
5.0\end{array}$ & $\begin{array}{l}3.7 \\
2.7 \\
2.3 \\
7.5 \\
6.9\end{array}$ & $\begin{array}{l}1.6 \\
1.6 \\
1.8 \\
1.9 \\
1.6\end{array}$ & $\begin{array}{l}1.6 \\
1.6 \\
1.4 \\
1.4 \\
1.4\end{array}$ & $\begin{array}{l}1.1 \\
1.2 \\
1.2 \\
1.4 \\
1.2\end{array}$ & $\begin{array}{l}1.1 \\
1.1 \\
1.4 \\
1.4 \\
1.4\end{array}$ & $\begin{array}{l}1.1 \\
1.1 \\
1.2 \\
1.1 \\
1.0\end{array}$ \\
\hline $\begin{array}{l}21 \\
22 \\
23 \\
24 \\
25\end{array}$ & $\begin{array}{l}2.7 \\
2.7 \\
3.1 \\
3.0 \\
2.4\end{array}$ & $\begin{array}{l}2.3 \\
2.4 \\
2.9 \\
2.7 \\
2.6\end{array}$ & $\begin{array}{l}8.7 \\
8.1 \\
8.3 \\
7.7 \\
6.5\end{array}$ & $\begin{array}{l}4.5 \\
3.7 \\
3.4 \\
3.9 \\
4.2\end{array}$ & $\begin{array}{l}7.6 \\
5.6 \\
4.1 \\
3.4 \\
3.1\end{array}$ & $\begin{array}{l}3.1 \\
5.0 \\
6.1 \\
6.2 \\
4.8\end{array}$ & $\begin{array}{l}6.8 \\
4.5 \\
3.3 \\
3.0 \\
2.6\end{array}$ & $\begin{array}{l}1.6 \\
1.6 \\
1.6 \\
1.6 \\
1.6\end{array}$ & $\begin{array}{l}1.4 \\
1.4 \\
1.4 \\
1.4 \\
1.4\end{array}$ & $\begin{array}{l}1.4 \\
1.2 \\
1.1 \\
1.1 \\
1.1\end{array}$ & $\begin{array}{l}1.1 \\
1.1 \\
1.1 \\
1.1 \\
1.1\end{array}$ & $\begin{array}{l}1.0 \\
1.1 \\
1.1 \\
1.1 \\
1.1\end{array}$ \\
\hline $\begin{array}{l}26 \\
27 \\
28 \\
29 \\
30 \\
31\end{array}$ & $\begin{array}{l}2.2 \\
2.3 \\
2.0 \\
2.0 \\
2.3 \\
1.9\end{array}$ & $\begin{array}{l}2.3 \\
2.6 \\
5.6 \\
5.7 \\
4.1 \\
\ldots\end{array}$ & $\begin{array}{r}4.5 \\
3.5 \\
3.1 \\
11.0 \\
13.7 \\
15.1\end{array}$ & $\begin{array}{l}4.2 \\
4.2 \\
4.2 \\
3.9 \\
3.7 \\
3.7\end{array}$ & $\begin{array}{l}2.9 \\
2.9 \\
2.7 \\
\ldots . \\
\ldots \\
\ldots\end{array}$ & $\begin{array}{l}5.4 \\
6.0 \\
6.2 \\
4.3 \\
3.4 \\
2.9\end{array}$ & $\begin{array}{l}2.6 \\
2.3 \\
2.2 \\
2.2 \\
2.0 \\
\cdots\end{array}$ & $\begin{array}{l}1.8 \\
1.6 \\
1.6 \\
1.6 \\
1.9 \\
5.4\end{array}$ & $\begin{array}{l}1.4 \\
1.4 \\
1.4 \\
1.4 \\
1.4 \\
\cdots\end{array}$ & $\begin{array}{l}1.1 \\
1.2 \\
1.1 \\
1.1 \\
1.1 \\
1.1\end{array}$ & $\begin{array}{l}1.1 \\
1.1 \\
1.1 \\
1.1 \\
1.1 \\
1.2\end{array}$ & $\begin{array}{l}1.0 \\
1.0 \\
1.1 \\
1.1 \\
1.1 \\
\cdots\end{array}$ \\
\hline $\begin{array}{l}\text { MEAN } \\
\text { MAX } \\
\text { MIN }\end{array}$ & $\begin{array}{l}3.4 \\
8.3 \\
1.8\end{array}$ & $\ldots$ & $\cdots$ & $\begin{array}{r}5.3 \\
14.0 \\
3.1\end{array}$ & $\begin{array}{l}4.6 \\
7.7 \\
2.6\end{array}$ & $\begin{array}{l}3.8 \\
6.2 \\
2.3\end{array}$ & $\begin{array}{l}3.4 \\
7.5 \\
2.0\end{array}$ & $\begin{array}{l}1.8 \\
5.4 \\
1.6\end{array}$ & $\begin{array}{l}1.9 \\
5.4 \\
1.4\end{array}$ & $\begin{array}{l}1.6 \\
4.3 \\
1.1\end{array}$ & $\begin{array}{l}1.2 \\
1.4 \\
1.1\end{array}$ & $\begin{array}{l}1.1 \\
1.9 \\
1.0\end{array}$ \\
\hline
\end{tabular}




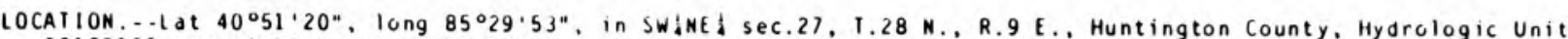
05120101 , on right bank at the Huntington Water and light Plant, 2 i south of Hunt ington. 2.4 mi downstreda frow Huntington Lake. 3.2 i upstrean from Little River, and at ile 409.0 .

DRAINAGE AREA. . $121 \bullet i^{2}$.

PERIOD OF RECORD... January 1951 to current year.

REVISED RECORDS.--WSP 1909: 1959. WSP 2109: Drdinage area.

GAGE.--Data-Collection Platform. Datum of gage was $700.04 \mathrm{ft}$ above National Geodetic Vertical Datum of 1929 (levels by State of Indiana. Department of Natural Resources). July 5, 1951, to Sept. 30 , 1974, water-stage recorder at site described in "LOCATION" Daragraph. Prior to July 5 , igsi. nonrecording gage at same site and datun. Data-Collection Platform installed on June 13, 1986.

REMARKS. - Flow regulated by Huntington Lake since January 1969. Daily discharge conputed from relation between discharge, head, and gate openings for Huntington lake beginning 0ct. 1, 1974.

COOPERAIION. - Records of daily discharge provided by U.S. Aray Corps of Engineers beginning 0ct. 1 , 1976 .

AVERAGE DISCHARGE. -40 yedrs, $600 \mathrm{ft}^{3} / \mathrm{s}$.

EXIREMES FOR PERIOD OF RECORD. - Maximum discharge, $14,900 \mathrm{ft} 3 / \mathrm{s} \mathrm{feg.} \mathrm{10,} 1959$; aximua gage height $23.20 \mathrm{ft}$. Feb. 10. 1959 (backwater from ice): inimun daily discharge, $0.0 \mathrm{ft} / \mathrm{s}$ Sept. 12. 1989.

EXIREMES OUISIDE PERIOD OF RECORO. - flood in March 1913 reached d stage of 22.1 ft, from high-water ark by U.S. Aray Corps of Engineers.

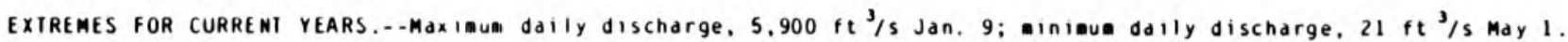

DISCHARGE, CUBIC FEEI PER SECONO, WAIER YEAR OCTOBER 1990 IO SEPIEMBER 1991 DAIIY MEAN VALUES

\begin{tabular}{|c|c|c|c|c|c|c|c|c|c|c|c|c|}
\hline DAY & $O C \mathrm{I}$ & NOV & DEC & JAN & FEB & MAR & $A P R$ & MAY & JUN & JUL & AUG & SEP \\
\hline $\begin{array}{l}1 \\
2 \\
3 \\
4 \\
5\end{array}$ & $\begin{array}{l}188 \\
187 \\
186 \\
133 \\
948\end{array}$ & $\begin{array}{l}188 \\
186 \\
184 \\
182 \\
181\end{array}$ & $\begin{array}{r}1510 \\
1100 \\
879 \\
2010 \\
3300\end{array}$ & $\begin{array}{l}2030 \\
3250 \\
4290 \\
4630 \\
4880\end{array}$ & $\begin{array}{r}261 \\
314 \\
354 \\
437 \\
1340\end{array}$ & $\begin{array}{l}336 \\
384 \\
412 \\
424 \\
383\end{array}$ & $\begin{array}{l}324 \\
274 \\
333 \\
327 \\
325\end{array}$ & $\begin{array}{r}21 \\
43 \\
56 \\
81 \\
119\end{array}$ & $\begin{array}{l}184 \\
192 \\
765 \\
1650 \\
2630\end{array}$ & $\begin{array}{r}61 \\
61 \\
109 \\
218 \\
197\end{array}$ & $\begin{array}{l}27 \\
27 \\
27 \\
27 \\
27\end{array}$ & $\begin{array}{l}21 \\
27 \\
27 \\
27 \\
27\end{array}$ \\
\hline $\begin{array}{r}6 \\
7 \\
8 \\
9 \\
10\end{array}$ & $\begin{array}{r}1320 \\
682 \\
435 \\
525 \\
620\end{array}$ & $\begin{array}{l}308 \\
443 \\
469 \\
313 \\
204\end{array}$ & $\begin{array}{r}3550 \\
2700 \\
1150 \\
509 \\
368\end{array}$ & $\begin{array}{l}5640 \\
5880 \\
5860 \\
5900 \\
4600\end{array}$ & $\begin{array}{l}2330 \\
2710 \\
2780 \\
2650 \\
2180\end{array}$ & $\begin{array}{l}286 \\
276 \\
288 \\
286 \\
283\end{array}$ & $\begin{array}{l}331 \\
337 \\
340 \\
424 \\
555\end{array}$ & $\begin{array}{l}157 \\
201 \\
213 \\
212 \\
211\end{array}$ & $\begin{array}{r}2860 \\
2250 \\
983 \\
257 \\
239\end{array}$ & $\begin{array}{l}214 \\
349 \\
438 \\
286 \\
107\end{array}$ & $\begin{array}{l}27 \\
27 \\
27 \\
50 \\
62\end{array}$ & $\begin{array}{l}38 \\
44 \\
44 \\
44 \\
44\end{array}$ \\
\hline $\begin{array}{l}11 \\
12 \\
13 \\
14 \\
15\end{array}$ & $\begin{array}{r}906 \\
1450 \\
2050 \\
2460 \\
2840\end{array}$ & $\begin{array}{l}207 \\
209 \\
316 \\
362 \\
347\end{array}$ & $\begin{array}{l}334 \\
312 \\
260 \\
269 \\
284\end{array}$ & $\begin{array}{l}2690 \\
1920 \\
1890 \\
1890 \\
2450\end{array}$ & $\begin{array}{r}1300 \\
589 \\
508 \\
455 \\
400\end{array}$ & $\begin{array}{l}262 \\
249 \\
249 \\
248 \\
259\end{array}$ & $\begin{array}{r}475 \\
325 \\
197 \\
532 \\
1600\end{array}$ & $\begin{array}{r}210 \\
172 \\
152 \\
135 \\
80\end{array}$ & $\begin{array}{r}204 \\
164 \\
145 \\
110 \\
83\end{array}$ & $\begin{array}{r}95 \\
100 \\
95 \\
89 \\
78\end{array}$ & $\begin{array}{l}62 \\
62 \\
52 \\
43 \\
43\end{array}$ & $\begin{array}{l}44 \\
44 \\
44 \\
44 \\
64\end{array}$ \\
\hline $\begin{array}{l}16 \\
17 \\
18 \\
19 \\
20\end{array}$ & $\begin{array}{r}1810 \\
992 \\
1060 \\
1950 \\
1600\end{array}$ & $\begin{array}{l}233 \\
226 \\
244 \\
240 \\
237\end{array}$ & $\begin{array}{r}992 \\
1440 \\
1600 \\
2220 \\
2700\end{array}$ & $\begin{array}{l}2380 \\
2440 \\
3000 \\
3260 \\
2770\end{array}$ & $\begin{array}{r}236 \\
250 \\
380 \\
1510 \\
2690\end{array}$ & $\begin{array}{r}373 \\
639 \\
1160 \\
1820 \\
1980\end{array}$ & $\begin{array}{r}2390 \\
2000 \\
837 \\
517 \\
645\end{array}$ & $\begin{array}{l}61 \\
71 \\
102 \\
107 \\
192\end{array}$ & $\begin{array}{r}112 \\
118 \\
95 \\
83 \\
83\end{array}$ & $\begin{array}{l}68 \\
37 \\
27 \\
27 \\
27\end{array}$ & $\begin{array}{l}43 \\
33 \\
27 \\
39 \\
27\end{array}$ & $\begin{array}{r}103 \\
112 \\
111 \\
98 \\
81\end{array}$ \\
\hline $\begin{array}{l}21 \\
22 \\
23 \\
24 \\
25\end{array}$ & $\begin{array}{r}1220 \\
582 \\
422 \\
471 \\
491\end{array}$ & $\begin{array}{r}117 \\
58 \\
189 \\
251 \\
294\end{array}$ & $\begin{array}{l}2560 \\
2620 \\
3130 \\
3430 \\
3350\end{array}$ & $\begin{array}{r}2440 \\
2320 \\
1450 \\
845 \\
508\end{array}$ & $\begin{array}{r}2960 \\
2950 \\
2400 \\
1120 \\
617\end{array}$ & $\begin{array}{r}1760 \\
995 \\
1220 \\
2050 \\
2200\end{array}$ & $\begin{array}{r}1850 \\
2780 \\
2450 \\
1390 \\
551\end{array}$ & $\begin{array}{l}243 \\
255 \\
168 \\
126 \\
205\end{array}$ & $\begin{array}{l}46 \\
83 \\
78 \\
75 \\
66\end{array}$ & $\begin{array}{l}27 \\
27 \\
27 \\
27 \\
27\end{array}$ & $\begin{array}{l}27 \\
27 \\
27 \\
27 \\
27\end{array}$ & $\begin{array}{l}81 \\
81 \\
80 \\
80 \\
79\end{array}$ \\
\hline $\begin{array}{l}26 \\
27 \\
28 \\
29 \\
30 \\
31\end{array}$ & $\begin{array}{l}397 \\
328 \\
302 \\
223 \\
190 \\
189\end{array}$ & $\begin{array}{r}299 \\
247 \\
515 \\
953 \\
1350 \\
\ldots\end{array}$ & $\begin{array}{r}2680 \\
1720 \\
1180 \\
751 \\
535 \\
856\end{array}$ & $\begin{array}{l}311 \\
349 \\
353 \\
356 \\
353 \\
263\end{array}$ & $\begin{array}{l}481 \\
302 \\
224 \\
\cdots \\
\cdots \\
\cdots\end{array}$ & $\begin{array}{r}2130 \\
1950 \\
1960 \\
1910 \\
1010 \\
546\end{array}$ & $\begin{array}{r}257 \\
176 \\
103 \\
53 \\
42 \\
\cdots\end{array}$ & $\begin{array}{l}430 \\
257 \\
151 \\
155 \\
143 \\
161\end{array}$ & $\begin{array}{l}61 \\
61 \\
61 \\
61 \\
61 \\
\cdots\end{array}$ & $\begin{array}{l}27 \\
27 \\
27 \\
27 \\
27 \\
27\end{array}$ & $\begin{array}{l}33 \\
36 \\
36 \\
35 \\
35 \\
31\end{array}$ & $\begin{array}{l}79 \\
79 \\
78 \\
78 \\
78 \\
\cdots\end{array}$ \\
\hline $\begin{array}{l}\text { TOIAL } \\
\text { MEAN } \\
\text { MAX } \\
\text { MIN }\end{array}$ & $\begin{array}{r}27157 \\
876 \\
2840 \\
133\end{array}$ & $\begin{array}{r}9552 \\
318 \\
1350 \\
58\end{array}$ & $\begin{array}{r}50299 \\
1623 \\
3550 \\
260\end{array}$ & $\begin{array}{r}81264 \\
2621 \\
5900 \\
263\end{array}$ & $\begin{array}{r}34728 \\
1240 \\
2960 \\
224\end{array}$ & $\begin{array}{r}28328 \\
914 \\
2200 \\
248\end{array}$ & $\begin{array}{r}22740 \\
758 \\
2780 \\
42\end{array}$ & $\begin{array}{c}4896 \\
158 \\
430 \\
21\end{array}$ & $\begin{array}{r}13860 \\
462 \\
2860 \\
46\end{array}$ & $\begin{array}{c}2980 \\
96.1 \\
438 \\
27\end{array}$ & $\begin{array}{c}1100 \\
35.5 \\
62 \\
27\end{array}$ & $\begin{array}{c}1887 \\
62,9 \\
112 \\
27\end{array}$ \\
\hline
\end{tabular}

CAL YR 1990 TOIAL 361549 MEAN 991 MAX 4720 MIN 37

WTR YR 1991 TOIAL 278791 MEAN 764 MAX 5900 MIN 21 
LOCATION.--Lat $40^{\circ} 54^{\prime} 14^{\prime \prime}$, Iong $85^{\circ} 24^{\prime} 22^{\prime \prime}$, in NE $\frac{1}{4}$ NWA sec.9, T.28 N., R.10 E.. Hunt ington County, Hydrologic Unit 05120101 , on right bank on upstredm side of former highway bridge, 5 i east of Huntington, and d aile 7.5 . DRAINAGE AREA,$-263 . i$.

PERIOD OF RECORD,--0ctober 1943 to current year. Prior to January 1944 monthly discharge only, published in WSP 1305. Published as Little River at Huntington, January 1944 to Septeaber 1948, Litt le River near Huntington, October 1948 to September 1956, and Little Wabash River near Huntington, 0ctober 1956 to Septeaber 1961 .

REVISED RECORDS.--WSP 2109: Dra inage area.

GAGE.--Water-stage recorder. Datum of gage is $128.10 \mathrm{ft}$ above National Geodetic Vertical Datum of 1929 . Prior to 0ct. 1, 1948, nonrecording gage 4 i downstrea at datun $8.79 \mathrm{ft}$ lower, and $0 \mathrm{ct}$. 1 , $1948, \mathrm{to}$ Sept. 5 , 1950 , nonrecording gage at present site and datur.

REMARKS.--Records good. During periods of extreee high water in the St. Marys River, sone water leaves the St. Marys River basin through Junk ditch and flows into Little River basin via Graha McCulloch ditch.

DISCHARGE, CUBIC FEET PER SECONO, WATER YEAR OCTOBER 1990 TO SEPIEMBER 1991 DAIL Y MEAN VALUES

\begin{tabular}{|c|c|c|c|c|c|c|c|c|c|c|c|c|}
\hline DAY & $0 \mathrm{CI}$ & MOV & DEC & JAN & FE B & MAR & APR & MAY & JUM & JUL & AUG & SEP \\
\hline $\begin{array}{l}1 \\
2 \\
3 \\
4 \\
5\end{array}$ & $\begin{array}{r}31 \\
29 \\
28 \\
131 \\
150\end{array}$ & $\begin{array}{r}68 \\
65 \\
62 \\
64 \\
368\end{array}$ & $\begin{array}{r}213 \\
164 \\
1500 \\
2200 \\
916\end{array}$ & $\begin{array}{r}4160 \\
2480 \\
1150 \\
719 \\
501\end{array}$ & $\begin{array}{r}\text { e } 100 \\
\text { e103 } \\
\text { e125 } \\
330 \\
614\end{array}$ & $\begin{array}{l}129 \\
235 \\
241 \\
168 \\
137\end{array}$ & $\begin{array}{l}129 \\
111 \\
100 \\
100 \\
368\end{array}$ & $\begin{array}{l}135 \\
136 \\
112 \\
100 \\
103\end{array}$ & $\begin{array}{r}4600 \\
3640 \\
2230 \\
1020 \\
500\end{array}$ & $\begin{array}{r}54 \\
150 \\
284 \\
95 \\
65\end{array}$ & $\begin{array}{l}20 \\
19 \\
22 \\
30 \\
23\end{array}$ & $\begin{array}{r}31 \\
22 \\
23 \\
110 \\
76\end{array}$ \\
\hline $\begin{array}{r}6 \\
7 \\
8 \\
9 \\
10\end{array}$ & $\begin{array}{r}84 \\
77 \\
79 \\
673 \\
2540\end{array}$ & $\begin{array}{l}912 \\
328 \\
202 \\
158 \\
136\end{array}$ & $\begin{array}{l}408 \\
283 \\
238 \\
198 \\
177\end{array}$ & $\begin{array}{l}381 \\
297 \\
227 \\
181 \\
150\end{array}$ & $\begin{array}{l}598 \\
615 \\
375 \\
297 \\
247\end{array}$ & $\begin{array}{r}135 \\
123 \\
101 \\
95 \\
93\end{array}$ & $\begin{array}{l}274 \\
182 \\
186 \\
570 \\
278\end{array}$ & $\begin{array}{r}146 \\
112 \\
91 \\
85 \\
81\end{array}$ & $\begin{array}{l}305 \\
209 \\
161 \\
132 \\
115\end{array}$ & $\begin{array}{l}53 \\
45 \\
60 \\
56 \\
45\end{array}$ & $\begin{array}{r}18 \\
19 \\
35 \\
113 \\
55\end{array}$ & $\begin{array}{l}41 \\
29 \\
28 \\
23 \\
22\end{array}$ \\
\hline $\begin{array}{l}11 \\
12 \\
13 \\
14 \\
15\end{array}$ & $\begin{array}{r}2440 \\
1310 \\
522 \\
296 \\
212\end{array}$ & $\begin{array}{r}116 \\
101 \\
89 \\
83 \\
80\end{array}$ & $\begin{array}{l}153 \\
142 \\
129 \\
111 \\
438\end{array}$ & $\begin{array}{l}176 \\
402 \\
235 \\
217 \\
477\end{array}$ & $\begin{array}{r}192 \\
\text { el } 40 \\
\text { el } 30 \\
\text { el } 30 \\
\text { e115 }\end{array}$ & $\begin{array}{r}85 \\
81 \\
81 \\
86 \\
137\end{array}$ & $\begin{array}{r}172 \\
138 \\
131 \\
333 \\
1160\end{array}$ & $\begin{array}{l}77 \\
76 \\
75 \\
84 \\
77\end{array}$ & $\begin{array}{r}106 \\
102 \\
88 \\
77 \\
70\end{array}$ & $\begin{array}{l}40 \\
38 \\
40 \\
40 \\
35\end{array}$ & $\begin{array}{l}36 \\
29 \\
24 \\
29 \\
32\end{array}$ & $\begin{array}{l}21 \\
26 \\
68 \\
44 \\
34\end{array}$ \\
\hline $\begin{array}{l}16 \\
17 \\
18 \\
19 \\
20\end{array}$ & $\begin{array}{l}162 \\
136 \\
816 \\
491 \\
249\end{array}$ & $\begin{array}{l}78 \\
75 \\
71 \\
67 \\
65\end{array}$ & $\begin{array}{l}464 \\
263 \\
548 \\
852 \\
390\end{array}$ & $\begin{array}{r}1570 \\
1390 \\
532 \\
317 \\
328\end{array}$ & $\begin{array}{r}\text { e115 } \\
\text { e120 } \\
212 \\
1790 \\
1300\end{array}$ & $\begin{array}{l}163 \\
172 \\
827 \\
444 \\
249\end{array}$ & $\begin{array}{r}817 \\
438 \\
313 \\
626 \\
1940\end{array}$ & $\begin{array}{r}70 \\
103 \\
98 \\
87 \\
70\end{array}$ & $\begin{array}{l}69 \\
64 \\
55 \\
49 \\
45\end{array}$ & $\begin{array}{l}31 \\
30 \\
31 \\
27 \\
25\end{array}$ & $\begin{array}{l}29 \\
26 \\
31 \\
52 \\
89\end{array}$ & $\begin{array}{l}27 \\
21 \\
21 \\
21 \\
21\end{array}$ \\
\hline $\begin{array}{l}21 \\
22 \\
23 \\
24 \\
25\end{array}$ & $\begin{array}{l}181 \\
147 \\
129 \\
118 \\
103\end{array}$ & $\begin{array}{l}62 \\
74 \\
83 \\
74 \\
67\end{array}$ & $\begin{array}{r}1160 \\
2240 \\
1040 \\
453 \\
\text { e340 }\end{array}$ & $\begin{array}{r}425 \\
\text { e } 250 \\
\text { e } 220 \\
\text { e1 } \\
\text { e } 170\end{array}$ & $\begin{array}{l}588 \\
377 \\
251 \\
201 \\
171\end{array}$ & $\begin{array}{l}192 \\
187 \\
317 \\
322 \\
238\end{array}$ & $\begin{array}{l}780 \\
365 \\
255 \\
554 \\
377\end{array}$ & $\begin{array}{r}61 \\
58 \\
57 \\
59 \\
193\end{array}$ & $\begin{array}{l}44 \\
47 \\
45 \\
43 \\
40\end{array}$ & $\begin{array}{l}25 \\
43 \\
48 \\
30 \\
24\end{array}$ & $\begin{array}{l}52 \\
33 \\
27 \\
26 \\
23\end{array}$ & $\begin{array}{l}21 \\
24 \\
22 \\
22 \\
22\end{array}$ \\
\hline $\begin{array}{l}26 \\
27 \\
28 \\
29 \\
30 \\
31\end{array}$ & $\begin{array}{l}93 \\
87 \\
80 \\
74 \\
71 \\
70\end{array}$ & $\begin{array}{r}61 \\
120 \\
1150 \\
785 \\
301 \\
\cdots\end{array}$ & $\begin{array}{l}e 250 \\
e 200 \\
e 190 \\
2070 \\
4630 \\
5100\end{array}$ & $\begin{array}{l}\text { el } 50 \\
\text { el } 40 \\
\text { el } 30 \\
\text { el } 20 \\
\text { el } 10 \\
\text { el } 03\end{array}$ & $\begin{array}{l}143 \\
130 \\
123 \\
\ldots \\
\ldots \\
\ldots\end{array}$ & $\begin{array}{l}401 \\
543 \\
342 \\
206 \\
156 \\
131\end{array}$ & $\begin{array}{l}239 \\
192 \\
166 \\
149 \\
135 \\
\cdots\end{array}$ & $\begin{array}{r}470 \\
214 \\
128 \\
96 \\
530 \\
4040\end{array}$ & $\begin{array}{c}38 \\
36 \\
34 \\
34 \\
33 \\
\cdots\end{array}$ & $\begin{array}{l}23 \\
22 \\
25 \\
25 \\
25 \\
21\end{array}$ & $\begin{array}{l}22 \\
19 \\
20 \\
19 \\
19 \\
47\end{array}$ & $\begin{array}{l}21 \\
21 \\
22 \\
23 \\
21 \\
-\cdots\end{array}$ \\
\hline $\begin{array}{l}\text { IOIAL } \\
\text { MEAN } \\
\text { MAX } \\
\text { MIN } \\
\text { CFSM } \\
\text { IN. }\end{array}$ & $\begin{array}{r}11609 \\
374 \\
2540 \\
28 \\
1.42 \\
1.64\end{array}$ & $\begin{array}{r}5965 \\
199 \\
1150 \\
61 \\
.76 \\
.84\end{array}$ & $\begin{array}{r}27460 \\
886 \\
5100 \\
111 \\
3.37 \\
3.88\end{array}$ & $\begin{array}{r}17898 \\
577 \\
4160 \\
103 \\
2.20 \\
2.53\end{array}$ & $\begin{array}{r}9632 \\
344 \\
1790 \\
100 \\
1.31 \\
1.36\end{array}$ & $\begin{array}{r}6817 \\
220 \\
827 \\
81 \\
.84 \\
.96\end{array}$ & $\begin{array}{r}11578 \\
386 \\
1940 \\
100 \\
1.47 \\
1.64\end{array}$ & $\begin{array}{r}7824 \\
252 \\
4040 \\
57 \\
.96 \\
1.11\end{array}$ & $\begin{array}{r}14031 \\
468 \\
4600 \\
33 \\
1.78 \\
1.98\end{array}$ & $\begin{array}{c}1555 \\
50.2 \\
284 \\
21 \\
.19 \\
.22\end{array}$ & $\begin{array}{c}1038 \\
33.5 \\
113 \\
18 \\
.13 \\
.15\end{array}$ & $\begin{array}{c}928 \\
30.9 \\
110 \\
21 \\
.12 \\
.13\end{array}$ \\
\hline
\end{tabular}

e Estiated

STATISTICS OF MONIHIY MEAN DATA FOR WAIER YEARS 1945 - 1991, BY WATER YEAR (WY)

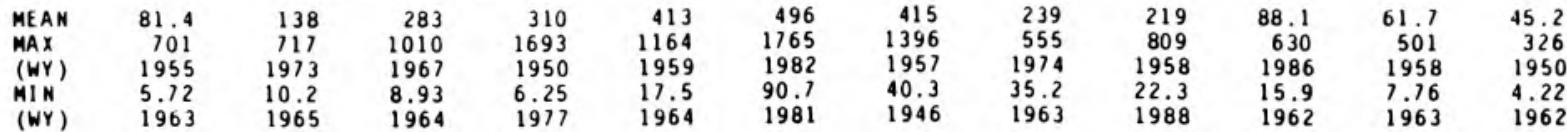

SUMMARY SIAIISIICS

ANMUAL TOTAL

ANNUAL MEAN

HIGHEST ANMUAL MEAN

LOWEST ANNUAL MEAN

HIGHESI OAILY MEAM

LOWEST DAILY MEAN

ANNUAL SEVEN-DAY MINIMUM

INSTANTANEOUS PEAK FLOW

INSIANTANEOUS PEAK STAGE

ANMUAL RUNOFF (CFSM)

ANMUAL RUNOFF (INCHES)

10 PERCENT EXCEEDS

50 PERCENT EXCEEDS

90 PERCENT EXCEEDS
FOR 1990 CALENDAR YEAR

$\begin{array}{rl}141577 & \\ 388 & \\ 5100 & \text { Dec } 31 \\ 28 & 0 \text { ct } 3 \\ 33 & \text { Sep } 27 \\ & \\ 1.47 & \\ 20.03 & \\ 936 & \\ 153 & \\ 62 & \end{array}$

FOR 1991 WATER YEAR

116335
319

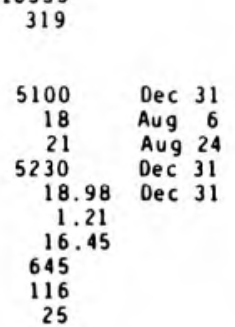

WAIER YEARS 1945 - 1991

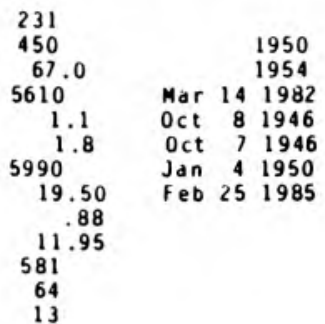


LOCATION.--Lat $40^{\circ} 25^{\prime} 40^{\circ}$. Iong $85^{\circ} 02^{\prime} 20^{\circ}$, in NE $\frac{1}{4}$ SE $\frac{1}{2}$ sec. 23 , T. 23 N., R. 13 E., Jay County, Hydrologic Unit

05120102, on right bank at downstrea side of county road bridge, 2.3 ei downstreal froe Butternut Creek.

3.2 i west of Portląnd, 3.7 i downstrean from Little Salanonie River, and at aile 70.5 .

PERIOD OF RECORD..-Septeaber 1959 to current year.

REVISED RECORDS.--WSP 2109: Drainage area. WDR IN-72-1: 1971.

GAGE.--Water-stage recorder. Datue of gage is $877.59 \mathrm{ft}$ above National Geodetic Vertical Datue of 1929 (levels by State of Indiana. Departaent of Natural Resources). Prior to 0ct. 1, 1960, nonrecording gage at site 1.4 a upstrean at datu $6.43 \mathrm{ft}$ higher.

REMARKS.--Records good except for estinated daily discharges, which are poor. Natural flow partially affected by sewage effluent.

DISCHARGE, CUBIC FEET PER SECONO, WATER YEAR OCTOBER 1990 TO SEPTEMBER 1991 DAI IY MEAN VALUES

\begin{tabular}{|c|c|c|c|c|c|c|c|c|c|c|c|c|}
\hline DAY & OCT & NOV & DEC & JAN & FEB & MAR & $A P R$ & MAY & JUN & JUL & AUG & SEP \\
\hline $\begin{array}{l}1 \\
2 \\
3 \\
4 \\
5\end{array}$ & $\begin{array}{r}5.3 \\
5.7 \\
5.3 \\
347 \\
118\end{array}$ & $\begin{array}{l}12 \\
12 \\
12 \\
11 \\
25\end{array}$ & $\begin{array}{r}49 \\
36 \\
682 \\
338 \\
97\end{array}$ & $\begin{array}{r}175 \\
96 \\
65 \\
49 \\
44\end{array}$ & $\begin{array}{r}e 18 \\
22 \\
67 \\
295 \\
526\end{array}$ & $\begin{array}{l}30 \\
39 \\
36 \\
30 \\
25\end{array}$ & $\begin{array}{l}31 \\
27 \\
23 \\
23 \\
26\end{array}$ & $\begin{array}{l}19 \\
18 \\
15 \\
16 \\
16\end{array}$ & $\begin{array}{r}107 \\
35 \\
23 \\
15 \\
11\end{array}$ & $\begin{array}{c}3.8 \\
101 \\
36 \\
49 \\
253\end{array}$ & $\begin{array}{r}2.0 \\
\mathrm{e} 2.3 \\
\mathrm{e} 2.1 \\
\mathrm{e} 1.4 \\
\mathrm{e} 2.2\end{array}$ & $\begin{array}{l}3.6 \\
2.1 \\
3.3 \\
4.7 \\
2.8\end{array}$ \\
\hline $\begin{array}{r}6 \\
7 \\
8 \\
9 \\
10\end{array}$ & $\begin{array}{r}39 \\
24 \\
23 \\
124 \\
677\end{array}$ & $\begin{array}{l}49 \\
26 \\
17 \\
16 \\
23\end{array}$ & $\begin{array}{l}57 \\
44 \\
36 \\
29 \\
27\end{array}$ & $\begin{array}{l}40 \\
37 \\
33 \\
31 \\
28\end{array}$ & $\begin{array}{r}452 \\
463 \\
168 \\
103 \\
78\end{array}$ & $\begin{array}{l}25 \\
23 \\
18 \\
17 \\
17\end{array}$ & $\begin{array}{l}24 \\
22 \\
22 \\
24 \\
22\end{array}$ & $\begin{array}{l}17 \\
14 \\
11 \\
11 \\
10\end{array}$ & $\begin{array}{l}8.0 \\
6.7 \\
6.3 \\
5.6 \\
4.8\end{array}$ & $\begin{array}{r}40 \\
15 \\
156 \\
65 \\
21\end{array}$ & $\begin{array}{r}\text { e3.0 } \\
\text { e2.1 } \\
3.5 \\
4.6 \\
2.9\end{array}$ & $\begin{array}{l}\text { e1. } \\
\text { e } 3.1 \\
\text { e2 } .0 \\
\text { e2.1 } \\
\text { e2.7 }\end{array}$ \\
\hline $\begin{array}{l}11 \\
12 \\
13 \\
14 \\
15\end{array}$ & $\begin{array}{r}227 \\
79 \\
48 \\
34 \\
26\end{array}$ & $\begin{array}{l}25 \\
17 \\
14 \\
12 \\
11\end{array}$ & $\begin{array}{r}24 \\
23 \\
21 \\
17 \\
473\end{array}$ & $\begin{array}{r}131 \\
264 \\
93 \\
70 \\
122\end{array}$ & $\begin{array}{r}55 \\
e 38 \\
e 35 \\
77 \\
e 50\end{array}$ & $\begin{array}{l}15 \\
15 \\
20 \\
25 \\
40\end{array}$ & $\begin{array}{r}18 \\
14 \\
87 \\
481 \\
173\end{array}$ & $\begin{array}{r}9.7 \\
9.6 \\
11 \\
77 \\
107\end{array}$ & $\begin{array}{l}5.9 \\
7.3 \\
5.9 \\
4.8 \\
6.0\end{array}$ & $\begin{array}{r}13 \\
9.9 \\
8.0 \\
6.0 \\
4.7\end{array}$ & $\begin{array}{l}\mathrm{e} 2.3 \\
\mathrm{e} 1.6 \\
\mathrm{e} 2.3 \\
\mathrm{e} 1.6 \\
\mathrm{e} 2.2\end{array}$ & $\begin{array}{r}\text { e3.0 } \\
\text { e2.9 } \\
\text { e4.5 } \\
6.9 \\
2.3\end{array}$ \\
\hline $\begin{array}{l}16 \\
17 \\
18 \\
19 \\
20\end{array}$ & $\begin{array}{r}19 \\
17 \\
123 \\
70 \\
34\end{array}$ & $\begin{array}{r}12 \\
12 \\
10 \\
10 \\
9.8\end{array}$ & $\begin{array}{l}228 \\
106 \\
680 \\
611 \\
192\end{array}$ & $\begin{array}{r}578 \\
366 \\
116 \\
71 \\
91\end{array}$ & $\begin{array}{l}\text { e41 } \\
\text { e36 } \\
170 \\
733 \\
275\end{array}$ & $\begin{array}{r}173 \\
428 \\
841 \\
210 \\
98\end{array}$ & $\begin{array}{r}78 \\
46 \\
35 \\
364 \\
392\end{array}$ & $\begin{array}{r}25 \\
26 \\
105 \\
41 \\
20\end{array}$ & $\begin{array}{r}17 \\
8.5 \\
5.5 \\
4.4 \\
4.0\end{array}$ & $\begin{array}{l}4.1 \\
3.6 \\
3.8 \\
3.2 \\
3.2\end{array}$ & $\begin{array}{r}\mathrm{e} 2.4 \\
9.5 \\
7.2 \\
\mathrm{e} 3.1 \\
\mathrm{e} 2.5\end{array}$ & $\begin{array}{r}\text { e1. } .9 \\
2.3 \\
\mathrm{e} 2.6 \\
\mathrm{e} 1.8 \\
\mathrm{e} 1.5\end{array}$ \\
\hline $\begin{array}{l}21 \\
22 \\
23 \\
24 \\
25\end{array}$ & $\begin{array}{l}25 \\
55 \\
77 \\
40 \\
28\end{array}$ & $\begin{array}{l}8.4 \\
26 \\
55 \\
28 \\
18\end{array}$ & $\begin{array}{l}582 \\
750 \\
300 \\
148 \\
\text { e67 }\end{array}$ & $\begin{array}{l}118 \\
\text { e } 51 \\
e 43 \\
\text { e } 36 \\
\text { e } 30\end{array}$ & $\begin{array}{r}121 \\
75 \\
51 \\
44 \\
37\end{array}$ & $\begin{array}{r}65 \\
313 \\
593 \\
133 \\
66\end{array}$ & $\begin{array}{r}109 \\
66 \\
48 \\
51 \\
38\end{array}$ & $\begin{array}{l}14 \\
11 \\
13 \\
13 \\
11\end{array}$ & $\begin{array}{l}3.7 \\
10 \\
11 \\
8.1 \\
5.5\end{array}$ & $\begin{array}{l}2.8 \\
2.7 \\
3.5 \\
2.5 \\
2.7\end{array}$ & $\begin{array}{r}\mathrm{e} 2.0 \\
\mathrm{e} 2.2 \\
2.5 \\
\mathrm{e} 3.2 \\
\mathrm{e} 2.6\end{array}$ & $\begin{array}{r}3.5 \\
\mathrm{e} 2.5 \\
5.7 \\
\mathrm{e} 2.3 \\
\mathrm{e} 2.0\end{array}$ \\
\hline $\begin{array}{l}26 \\
27 \\
28 \\
29 \\
30 \\
31\end{array}$ & $\begin{array}{l}21 \\
18 \\
16 \\
14 \\
13 \\
13\end{array}$ & $\begin{array}{r}14 \\
110 \\
531 \\
212 \\
79 \\
\ldots .\end{array}$ & $\begin{array}{r}\text { e48 } \\
\text { e35 } \\
\text { e31 } \\
1050 \\
2950 \\
1810\end{array}$ & $\begin{array}{l}\text { e26 } \\
\text { e25 } \\
\text { e23 } \\
\text { e22 } \\
\text { e21 } \\
\text { e19 }\end{array}$ & $\begin{array}{c}32 \\
30 \\
28 \\
\cdots- \\
\cdots \\
\cdots\end{array}$ & $\begin{array}{r}372 \\
257 \\
104 \\
54 \\
39 \\
32\end{array}$ & $\begin{array}{l}33 \\
31 \\
28 \\
25 \\
22 \\
\cdots\end{array}$ & $\begin{array}{r}11 \\
9.6 \\
8.6 \\
7.1 \\
7.4 \\
193\end{array}$ & $\begin{array}{l}49 \\
13 \\
6.4 \\
5.2 \\
4.1 \\
\cdots\end{array}$ & $\begin{array}{r}2.2 \\
3.0 \\
1.6 \\
2.8 \\
\mathrm{e} 2.5 \\
\mathrm{e} 2.1\end{array}$ & $\begin{array}{l}\text { e2. } 2.3 \\
\text { e2.2 } \\
\text { e2.1 } \\
\text { e2.7 } \\
4.2 \\
6.8\end{array}$ & $\begin{array}{l}\text { e1. } \\
\text { e1. } \\
\text { e3. } 3 \\
\text { e2.0 } \\
\text { e2.1 } \\
. . .\end{array}$ \\
\hline $\begin{array}{l}\text { TOTAL } \\
\text { MEAN } \\
\text { MAX } \\
\text { MIN } \\
\text { CF SM } \\
\text { IN. }\end{array}$ & $\begin{array}{r}2365.3 \\
76.3 \\
677 \\
5.3 \\
.89 \\
1.03\end{array}$ & $\begin{array}{r}1417.2 \\
47.2 \\
531 \\
8.4 \\
.55 \\
.62\end{array}$ & $\begin{array}{r}11541 \\
372 \\
2950 \\
17 \\
4.35 \\
5.02\end{array}$ & $\begin{array}{r}2914 \\
94.0 \\
578 \\
19 \\
1.10 \\
1.27\end{array}$ & $\begin{array}{r}4120 \\
147 \\
733 \\
18 \\
1.72 \\
1.79\end{array}$ & $\begin{array}{r}4153 \\
134 \\
841 \\
15 \\
1.57 \\
1.80\end{array}$ & $\begin{array}{r}2383 \\
79.4 \\
481 \\
14 \\
.93 \\
1.04\end{array}$ & $\begin{array}{r}877.0 \\
28.3 \\
193 \\
7.1 \\
.33 \\
.38\end{array}$ & $\begin{array}{r}407.7 \\
13.6 \\
107 \\
3.7 \\
.16 \\
.18\end{array}$ & $\begin{array}{r}827.7 \\
26.7 \\
253 \\
1.6 \\
.31 \\
.36\end{array}$ & $\begin{array}{c}93.6 \\
3.02 \\
9.5 \\
1.4 \\
.04 \\
.04\end{array}$ & $\begin{array}{r}84.7 \\
2.82 \\
6.9 \\
1.5 \\
.03 \\
.04\end{array}$ \\
\hline
\end{tabular}

STATISTICS OF MONTHLY MEAN DATA FOR WATER YEARS 1960 - 1991, BY WATER YEAR (WY)

$\begin{array}{lrrrrrrrrrrrr}\text { MEAN } & 15.0 & 51.7 & 103 & 91.6 & 123 & 176 & 135 & 62.2 & 56.0 & 36.9 & 24.1 & 19.8 \\ \text { MAX } & 76.3 & 378 & 372 & 391 & 312 & 494 & 436 & 243 & 305 & 185 & 195 & 237 \\ \text { (WY) } & 1991 & 1973 & 1991 & 1962 & 1976 & 1978 & 1964 & 1989 & 1981 & 1979 & 1990 & 1972 \\ \text { MIN } & .90 & 1.75 & 1.95 & 1.83 & 2.62 & 17.5 & 11.5 & 5.65 & 2.82 & 1.89 & 1.57 & 1.34 \\ \text { (WY) } & 1983 & 1966 & 1964 & 1977 & 1964 & 1981 & 1976 & 1988 & 1965 & 1965 & 1965 & 1982\end{array}$

SUMMARY STATISTICS

ANNUAL TOTAL

ANMUAL MEAM

HIGHEST AMMUAL MEAN

LOWEST ANMUAL MEAN

HIGHEST DAILY MEAN

LOWEST DAILY MEAN

ANNUAL SEVEN-DAY MI MIMUM

INSTANTANEOUS PEAK FLOW

INSTANTANEOUS PEAK STAGE

ANMUAL RUNOFF (CFSM)

AMNUAL RUNOFF (INCHES)

10 PERCENT EXCEEDS

50 PERCENT EXCEEDS

90 PERCENT EXCEEDS

e Estiated
FOR 1990 CALENDAR YEAR

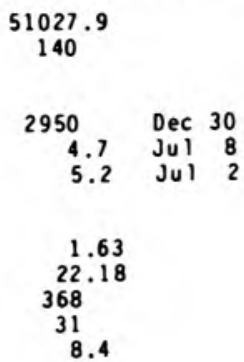

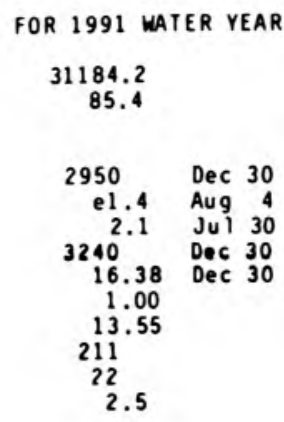

WATER YEARS 1960 - 1991

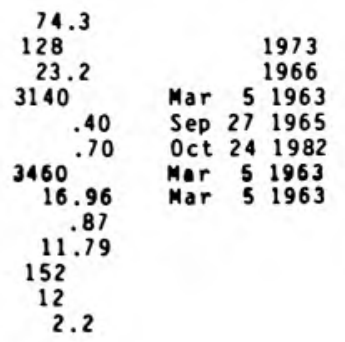




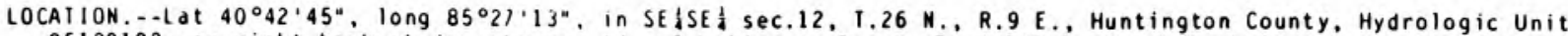
05120102, on right bank at downstream side of bridge on County Road 800 South, 0.4 i downstream from Detamore ditch, 0.4 i downstrea from Interstate $69,0.8$ i upstrea from concrete and stone daa, 2.4 morthwest of Warren, and at ile 30.0 .

DRAI NAGE AREA $\ldots 425 \mathrm{i}^{2}$.

PERIOD OF RECORD.-.March 1957 to current year.

REVISED RECORDS...-WSP 2109: Drainage area.

GAGE.--Water-stage recorder and concrete and stone control. Datue of gage is $784.65 \mathrm{ft}$ above National Geodetic Vertical Datu of 1929 (levels by State of Indiana, Departeent of Matural Resources). Prior to July 28, 1960, nonrecording gage at

REMARKS. - Records good, except those for estinated daily discharges, which are poor.

DISCHARGE, CUBIC FEET PER SECOND, WATER YEAR OCTOBER 1990 TO SEPIEMBER 1991 DAILY MEAN VALUES

\begin{tabular}{|c|c|c|c|c|c|c|c|c|c|c|c|c|}
\hline DAY & $O C T$ & NOV & DEC & JAN & FEB & MAR & APR & MAY & JUN & JUL & $A \cup G$ & SEP \\
\hline $\begin{array}{l}1 \\
2 \\
3 \\
4 \\
5\end{array}$ & $\begin{array}{r}48 \\
48 \\
51 \\
410 \\
1310\end{array}$ & $\begin{array}{r}88 \\
86 \\
86 \\
86 \\
152\end{array}$ & $\begin{array}{r}377 \\
270 \\
1880 \\
3780 \\
1750\end{array}$ & $\begin{array}{r}8180 \\
5460 \\
1230 \\
599 \\
442\end{array}$ & $\begin{array}{r}e 115 \\
120 \\
133 \\
465 \\
2160\end{array}$ & $\begin{array}{l}156 \\
189 \\
223 \\
186 \\
157\end{array}$ & $\begin{array}{l}211 \\
183 \\
159 \\
152 \\
203\end{array}$ & $\begin{array}{l}136 \\
123 \\
110 \\
104 \\
104\end{array}$ & $\begin{array}{r}1010 \\
406 \\
221 \\
134 \\
97\end{array}$ & $\begin{array}{r}53 \\
225 \\
364 \\
130 \\
92\end{array}$ & $\begin{array}{l}14 \\
15 \\
18 \\
20 \\
21\end{array}$ & $\begin{array}{l}23 \\
16 \\
17 \\
23 \\
30\end{array}$ \\
\hline $\begin{array}{r}6 \\
7 \\
8 \\
9 \\
10\end{array}$ & $\begin{array}{r}363 \\
180 \\
207 \\
418 \\
3000\end{array}$ & $\begin{array}{l}418 \\
316 \\
193 \\
149 \\
134\end{array}$ & $\begin{array}{l}527 \\
357 \\
281 \\
232 \\
206\end{array}$ & $\begin{array}{l}358 \\
295 \\
253 \\
227 \\
200\end{array}$ & $\begin{array}{r}1760 \\
2100 \\
1320 \\
649 \\
457\end{array}$ & $\begin{array}{l}146 \\
141 \\
124 \\
115 \\
109\end{array}$ & $\begin{array}{l}230 \\
190 \\
199 \\
520 \\
313\end{array}$ & $\begin{array}{r}110 \\
104 \\
92 \\
87 \\
85\end{array}$ & $\begin{array}{l}79 \\
68 \\
62 \\
59 \\
59\end{array}$ & $\begin{array}{r}294 \\
87 \\
433 \\
608 \\
196\end{array}$ & $\begin{array}{l}21 \\
22 \\
26 \\
18 \\
15\end{array}$ & $\begin{array}{l}17 \\
14 \\
16 \\
16 \\
13\end{array}$ \\
\hline $\begin{array}{l}11 \\
12 \\
13 \\
14 \\
15\end{array}$ & $\begin{array}{r}3420 \\
1310 \\
512 \\
349 \\
254\end{array}$ & $\begin{array}{r}129 \\
125 \\
110 \\
98 \\
92\end{array}$ & $\begin{array}{l}187 \\
175 \\
160 \\
143 \\
481\end{array}$ & $\begin{array}{l}209 \\
889 \\
678 \\
409 \\
817\end{array}$ & $\begin{array}{l}347 \\
249 \\
216 \\
237 \\
269\end{array}$ & $\begin{array}{l}104 \\
102 \\
112 \\
116 \\
140\end{array}$ & $\begin{array}{r}202 \\
153 \\
219 \\
1480 \\
3000\end{array}$ & $\begin{array}{r}82 \\
86 \\
89 \\
91 \\
185\end{array}$ & $\begin{array}{l}60 \\
63 \\
60 \\
64 \\
66\end{array}$ & $\begin{array}{l}74 \\
49 \\
50 \\
34 \\
25\end{array}$ & $\begin{array}{l}13 \\
12 \\
11 \\
11 \\
12\end{array}$ & $\begin{array}{l}14 \\
12 \\
12 \\
13 \\
15\end{array}$ \\
\hline $\begin{array}{l}16 \\
17 \\
18 \\
19 \\
20\end{array}$ & $\begin{array}{l}196 \\
160 \\
317 \\
625 \\
305\end{array}$ & $\begin{array}{l}90 \\
90 \\
86 \\
84 \\
81\end{array}$ & $\begin{array}{r}1700 \\
600 \\
1320 \\
2630 \\
1690\end{array}$ & $\begin{array}{r}2350 \\
2860 \\
1250 \\
560 \\
503\end{array}$ & $\begin{array}{r}138 \\
204 \\
302 \\
2560 \\
2720\end{array}$ & $\begin{array}{r}345 \\
1290 \\
2850 \\
3190 \\
1240\end{array}$ & $\begin{array}{r}1400 \\
545 \\
335 \\
827 \\
2990\end{array}$ & $\begin{array}{l}223 \\
198 \\
174 \\
227 \\
142\end{array}$ & $\begin{array}{l}75 \\
85 \\
87 \\
79 \\
75\end{array}$ & $\begin{array}{l}21 \\
19 \\
17 \\
16 \\
16\end{array}$ & $\begin{array}{l}9.6 \\
13 \\
19 \\
34 \\
27\end{array}$ & $\begin{array}{r}17 \\
21 \\
13 \\
9.9 \\
8.0\end{array}$ \\
\hline $\begin{array}{l}21 \\
22 \\
23 \\
24 \\
25\end{array}$ & $\begin{array}{l}202 \\
167 \\
225 \\
239 \\
112\end{array}$ & $\begin{array}{r}78 \\
82 \\
132 \\
186 \\
134\end{array}$ & $\begin{array}{l}1520 \\
3590 \\
2660 \\
e 800 \\
e 550\end{array}$ & $\begin{array}{r}694 \\
453 \\
295 \\
226 \\
\text { e185 }\end{array}$ & $\begin{array}{r}1040 \\
561 \\
369 \\
281 \\
235\end{array}$ & $\begin{array}{r}591 \\
966 \\
2620 \\
1730 \\
592\end{array}$ & $\begin{array}{r}1630 \\
572 \\
391 \\
404 \\
326\end{array}$ & $\begin{array}{r}92 \\
77 \\
80 \\
75 \\
222\end{array}$ & $\begin{array}{l}75 \\
80 \\
80 \\
91 \\
86\end{array}$ & $\begin{array}{l}16 \\
16 \\
16 \\
15 \\
15\end{array}$ & $\begin{array}{c}16 \\
12 \\
10 \\
9.9 \\
11\end{array}$ & $\begin{array}{l}7.8 \\
8.5 \\
10 \\
12 \\
11\end{array}$ \\
\hline $\begin{array}{l}26 \\
27 \\
28 \\
29 \\
30 \\
31\end{array}$ & $\begin{array}{r}141 \\
121 \\
110 \\
101 \\
94 \\
93\end{array}$ & $\begin{array}{r}109 \\
134 \\
1370 \\
2010 \\
673 \\
\cdots\end{array}$ & $\begin{array}{r}\text { e } 400 \\
e 330 \\
368 \\
3220 \\
10400 \\
9660\end{array}$ & $\begin{array}{l}\text { el } 10 \\
\text { el } 60 \\
\text { el } 50 \\
\text { el } 40 \\
\text { el } 25 \\
\text { e1 } 20\end{array}$ & $\begin{array}{l}199 \\
175 \\
163 \\
\ldots . \\
\ldots . \\
\ldots\end{array}$ & $\begin{array}{r}871 \\
2110 \\
1200 \\
607 \\
336 \\
246\end{array}$ & $\begin{array}{l}248 \\
213 \\
189 \\
169 \\
151 \\
\cdots\end{array}$ & $\begin{array}{r}345 \\
176 \\
100 \\
73 \\
68 \\
1070\end{array}$ & $\begin{array}{r}78 \\
95 \\
94 \\
62 \\
54 \\
--\end{array}$ & $\begin{array}{l}14 \\
14 \\
13 \\
13 \\
15 \\
14\end{array}$ & $\begin{array}{l}13 \\
14 \\
15 \\
16 \\
16 \\
19\end{array}$ & $\begin{array}{l}11 \\
12 \\
10 \\
10 \\
9.7 \\
-.-\end{array}$ \\
\hline $\begin{array}{l}\text { IOTAL } \\
\text { MEAN } \\
\text { MAX } \\
\text { MIN } \\
\text { CF SM } \\
\text { IN. }\end{array}$ & $\begin{array}{r}15148 \\
489 \\
3420 \\
48 \\
1.15 \\
1.33\end{array}$ & $\begin{array}{r}7661 \\
255 \\
2010 \\
78 \\
.60 \\
.67\end{array}$ & $\begin{array}{r}52244 \\
1685 \\
10400 \\
143 \\
3.97 \\
4.57\end{array}$ & $\begin{array}{r}30487 \\
983 \\
8180 \\
120 \\
2.31 \\
2.67\end{array}$ & $\begin{array}{r}19544 \\
698 \\
2720 \\
115 \\
1.64 \\
1.11\end{array}$ & $\begin{array}{r}22904 \\
739 \\
3190 \\
102 \\
1.74 \\
2.00\end{array}$ & $\begin{array}{r}17804 \\
593 \\
3000 \\
151 \\
1.40 \\
1.56\end{array}$ & $\begin{array}{r}4930 \\
159 \\
1070 \\
68 \\
.37 \\
.43\end{array}$ & $\begin{array}{r}3704 \\
123 \\
1010 \\
54 \\
.29 \\
.32\end{array}$ & $\begin{array}{c}2964 \\
95.6 \\
608 \\
13 \\
.22 \\
.26\end{array}$ & $\begin{array}{c}503.5 \\
16.2 \\
34 \\
9.6 \\
.04 \\
.04\end{array}$ & $\begin{array}{r}421.9 \\
14.1 \\
30 \\
7.8 \\
.03 \\
.04\end{array}$ \\
\hline
\end{tabular}

e Estinated

STATISTICS OF MONIHLY MEAN DATA FOR WAIER YEARS 1957 - 1991, BY WATER YEAR (WY)

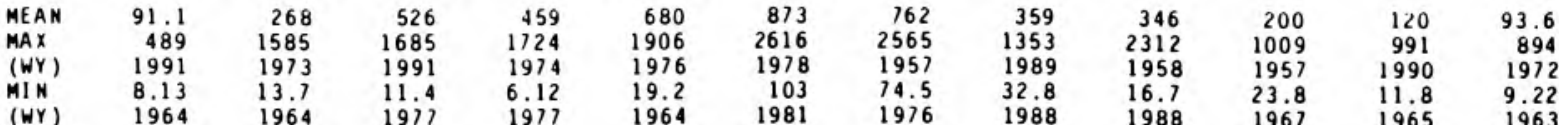

SUMMARY SIAIISIICS

ANNUAL TOTAL

ANNUAL MEAN

HIGHESI ANNUAL MEAN

LOWEST ANNUAL MEAN

HIGHESI DAILY MEAN

LOWEST DAILY MEAN

ANNUAL SEVEN-DAY MINIMUM

INSTANIANEOUS PEAK FLOW

INSIANTANEOUS PEAK SIAGE

ANMUAL RUNOFF (CFSM)

ANHUAL RUNOFF (INCHES)

10 PERCENT EXCEEDS

50 PERCENT EXCEEDS

90 PERCENT EXCEEDS
HOR 1990 CALENDAR YEAR

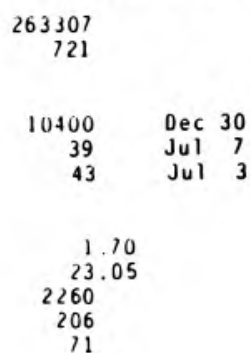

FOR 1991 WATER YEAR

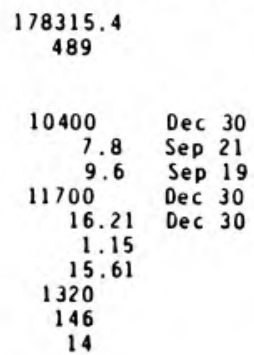

WAIER YEARS 1957 - 1991

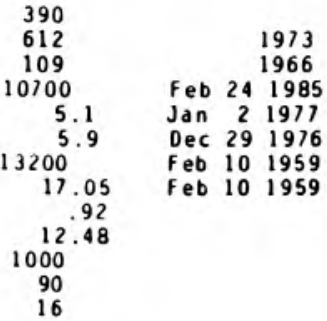




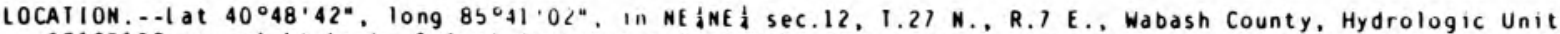
05120102 , on right bank, $0.4 \mathrm{mi}$ downstiedm fro Saldonie lake, 1.5 a northwest of Dord, and 3.0 apstrea frow nouth.

DRAINAGE AREA. - - $557 \cdot i^{2}$.

PERIOD OF RECORD. - Novenber 1923 to current yedr. Monthly discharge only for soae periods, published in wSP 1305 .

REVISED RECOROS, --WSP 1275: 1931(M), 1932,1933(M), 1935-36(M), 1938-40(M), 1941-42, 1945, 1952. WSP 1335: 1934(M). WSP 1555: 1952, 1955-56(M), 1957. WSP 2109: Drainage area.

GAGE.--Data-Collection Platform since May 1, 1986. Datu of gage is $673.96 \mathrm{ft}$ above National Geodetic Vertical Datum of 1929 (levels by State of Indiand. Department of Natural Resources). Prior to 0ct. 1. 1951, nonrecording gage at site 1.5 i upstrean at datu $688.59 \mathrm{ft}$ National Geodetic vertical Datua of 1929 (levels by U.S. Aray Corps of Engineers) and $0 \mathrm{ct}$. 1, 1951, to Oct. 8, 1961, water-stage recorder located on left bank $2,000 \mathrm{ft}$ upstrean at datu $679.17 \mathrm{ft}$ National Geodetic Vertical Datue of 1929 (levels by U.S. Army Corps of Engineers). Oct. 9, 1961, to Sept. 30, 1914, water-stage recorder at site described in "LOCAIION" paragraph.

REMARKS. - Flow regulated by Salamonie Lake since April 1967. Daily discharge conputed from relation between discharge, head, and gate openings for salaonie lake beginning $0 \mathrm{ct}$. 1, 19/4.

COOPERAIION.-Records of daily discharge provided by U.S. Army Corps of Engineers beginning Oct. 1 . 1976 .

AVERAGE DISCHARGE. -67 years (1924 to current yedr), $512 \mathrm{ft}^{3} / \mathrm{s}$.

EXIREMES FOR PERIOD OF RECORD. - Maximum Jischarge, 16,500 ft 3/s May 18, 1943, gage height, $14.75 \mathrm{ft}$, from graph based on gage readings, site and datua then in use: ainiaudaily, $0.10 \mathrm{ft} / \mathrm{s} 0 \mathrm{ct}$. 30 . 1968 , result of abnoral regulation.

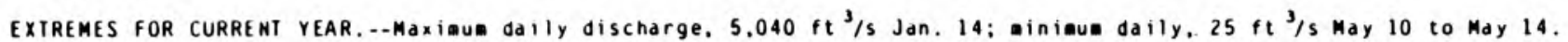

DISCHARGE, CUBIC FEET PER SECOND, WATER YEAR OCTOBER 1990 TO SEPIEMBER 1991 DAILY MEAN VALUES

\begin{tabular}{|c|c|c|c|c|c|c|c|c|c|c|c|c|}
\hline DAY & $\mathrm{OCI}$ & HOV & DEC & JAN & FE B & MAR & APR & MAY & JUN & JUL & AUG & SEP \\
\hline $\begin{array}{l}1 \\
2 \\
3 \\
4 \\
5\end{array}$ & $\begin{array}{r}484 \\
451 \\
291 \\
526 \\
1230\end{array}$ & $\begin{array}{r}185 \\
723 \\
1910 \\
2110 \\
2050\end{array}$ & $\begin{array}{r}1450 \\
1380 \\
724 \\
967 \\
1690\end{array}$ & $\begin{array}{l}127 \\
130 \\
131 \\
131 \\
131\end{array}$ & $\begin{array}{l}183 \\
184 \\
196 \\
304 \\
993\end{array}$ & $\begin{array}{l}252 \\
237 \\
248 \\
283 \\
300\end{array}$ & $\begin{array}{l}243 \\
160 \\
106 \\
106 \\
107\end{array}$ & $\begin{array}{l}35 \\
69 \\
57 \\
47 \\
47\end{array}$ & $\begin{array}{r}297 \\
374 \\
828 \\
1270 \\
1370\end{array}$ & $\begin{array}{r}26 \\
26 \\
46 \\
170 \\
223\end{array}$ & $\begin{array}{l}26 \\
26 \\
26 \\
26 \\
26\end{array}$ & $\begin{array}{l}48 \\
39 \\
26 \\
26 \\
26\end{array}$ \\
\hline $\begin{array}{r}6 \\
7 \\
8 \\
9 \\
10\end{array}$ & $\begin{array}{r}1570 \\
778 \\
1030 \\
1510 \\
241\end{array}$ & $\begin{array}{r}1260 \\
527 \\
527 \\
857 \\
1010\end{array}$ & $\begin{array}{r}2240 \\
2370 \\
2230 \\
1180 \\
391\end{array}$ & $\begin{array}{r}398 \\
818 \\
1000 \\
997 \\
1550\end{array}$ & $\begin{array}{r}1840 \\
2110 \\
1710 \\
993 \\
654\end{array}$ & $\begin{array}{l}212 \\
169 \\
223 \\
220 \\
203\end{array}$ & $\begin{array}{l}107 \\
107 \\
107 \\
108 \\
108\end{array}$ & $\begin{array}{l}47 \\
47 \\
47 \\
32 \\
25\end{array}$ & $\begin{array}{r}1010 \\
509 \\
241 \\
133 \\
151\end{array}$ & $\begin{array}{l}223 \\
223 \\
418 \\
911 \\
731\end{array}$ & $\begin{array}{l}26 \\
26 \\
26 \\
26 \\
26\end{array}$ & $\begin{array}{l}26 \\
26 \\
26 \\
26 \\
26\end{array}$ \\
\hline $\begin{array}{l}11 \\
12 \\
13 \\
14 \\
15\end{array}$ & $\begin{array}{l}120 \\
122 \\
122 \\
123 \\
402\end{array}$ & $\begin{array}{l}752 \\
506 \\
503 \\
644 \\
779\end{array}$ & $\begin{array}{l}315 \\
279 \\
221 \\
221 \\
310\end{array}$ & $\begin{array}{l}3670 \\
4790 \\
4980 \\
5040 \\
4470\end{array}$ & $\begin{array}{l}436 \\
382 \\
396 \\
349 \\
204\end{array}$ & $\begin{array}{l}213 \\
178 \\
177 \\
187 \\
161\end{array}$ & $\begin{array}{l}108 \\
109 \\
109 \\
109 \\
460\end{array}$ & $\begin{array}{l}25 \\
25 \\
25 \\
25 \\
26\end{array}$ & $\begin{array}{r}151 \\
128 \\
85 \\
70 \\
70\end{array}$ & $\begin{array}{r}184 \\
112 \\
70 \\
26 \\
26\end{array}$ & $\begin{array}{l}26 \\
26 \\
26 \\
26 \\
26\end{array}$ & $\begin{array}{l}26 \\
26 \\
26 \\
26 \\
26\end{array}$ \\
\hline $\begin{array}{l}16 \\
17 \\
18 \\
19 \\
20\end{array}$ & $\begin{array}{r}1040 \\
1730 \\
879 \\
499 \\
1430\end{array}$ & $\begin{array}{l}767 \\
754 \\
539 \\
445 \\
459\end{array}$ & $\begin{array}{l}1040 \\
1030 \\
1190 \\
1620 \\
2020\end{array}$ & $\begin{array}{l}3540 \\
2860 \\
2860 \\
2820 \\
2930\end{array}$ & $\begin{array}{r}143 \\
226 \\
286 \\
719 \\
1640\end{array}$ & $\begin{array}{r}243 \\
656 \\
1350 \\
1740 \\
1790\end{array}$ & $\begin{array}{l}833 \\
699 \\
514 \\
515 \\
524\end{array}$ & $\begin{array}{l}26 \\
26 \\
26 \\
26 \\
26\end{array}$ & $\begin{array}{l}10 \\
60 \\
48 \\
33 \\
26\end{array}$ & $\begin{array}{l}26 \\
26 \\
26 \\
26 \\
26\end{array}$ & $\begin{array}{r}26 \\
100 \\
26 \\
26 \\
26\end{array}$ & $\begin{array}{l}189 \\
287 \\
306 \\
335 \\
334\end{array}$ \\
\hline $\begin{array}{l}21 \\
22 \\
23 \\
24 \\
25\end{array}$ & $\begin{array}{l}2200 \\
3120 \\
2910 \\
2230 \\
1200\end{array}$ & $\begin{array}{l}352 \\
119 \\
272 \\
349 \\
403\end{array}$ & $\begin{array}{r}1550 \\
483 \\
372 \\
1050 \\
1540\end{array}$ & $\begin{array}{l}3100 \\
3730 \\
4450 \\
5020 \\
4980\end{array}$ & $\begin{array}{r}2080 \\
2000 \\
1300 \\
590 \\
409\end{array}$ & $\begin{array}{r}1340 \\
774 \\
692 \\
1290 \\
1140\end{array}$ & $\begin{array}{l}750 \\
906 \\
690 \\
537 \\
537\end{array}$ & $\begin{array}{r}26 \\
26 \\
26 \\
26 \\
279\end{array}$ & $\begin{array}{l}26 \\
26 \\
26 \\
26 \\
26\end{array}$ & $\begin{array}{l}26 \\
26 \\
26 \\
26 \\
26\end{array}$ & $\begin{array}{l}26 \\
26 \\
26 \\
26 \\
26\end{array}$ & $\begin{array}{l}333 \\
333 \\
332 \\
331 \\
330\end{array}$ \\
\hline $\begin{array}{l}26 \\
27 \\
28 \\
29 \\
30 \\
31\end{array}$ & $\begin{array}{l}269 \\
239 \\
198 \\
185 \\
185 \\
185\end{array}$ & $\begin{array}{r}430 \\
476 \\
744 \\
1150 \\
1490 \\
\ldots \ldots\end{array}$ & $\begin{array}{r}2140 \\
2400 \\
2020 \\
833 \\
113 \\
122\end{array}$ & $\begin{array}{r}4010 \\
2030 \\
730 \\
318 \\
316 \\
227\end{array}$ & $\begin{array}{l}259 \\
275 \\
274 \\
\ldots \\
\ldots \\
\ldots\end{array}$ & $\begin{array}{r}994 \\
1010 \\
1300 \\
1330 \\
624 \\
337\end{array}$ & $\begin{array}{r}305 \\
118 \\
85 \\
69 \\
69 \\
\ldots-\end{array}$ & $\begin{array}{l}967 \\
948 \\
744 \\
321 \\
233 \\
292\end{array}$ & $\begin{array}{l}26 \\
26 \\
26 \\
26 \\
26 \\
\cdots-\end{array}$ & $\begin{array}{l}26 \\
26 \\
26 \\
26 \\
26 \\
26\end{array}$ & $\begin{array}{l}26 \\
26 \\
26 \\
26 \\
26 \\
41\end{array}$ & $\begin{array}{l}249 \\
388 \\
411 \\
410 \\
408 \\
\cdots\end{array}$ \\
\hline $\begin{array}{l}\text { TOIAL } \\
\text { MEAN } \\
\text { MAX } \\
\text { MI N }\end{array}$ & $\begin{array}{r}27499 \\
887 \\
3120 \\
120\end{array}$ & $\begin{array}{r}23092 \\
710 \\
2110 \\
119\end{array}$ & $\begin{array}{r}35491 \\
1145 \\
2400 \\
113\end{array}$ & $\begin{array}{r}72284 \\
2332 \\
5040 \\
121\end{array}$ & $\begin{array}{r}21135 \\
155 \\
2110 \\
143\end{array}$ & $\begin{array}{r}19873 \\
641 \\
1790 \\
161\end{array}$ & $\begin{array}{c}9305 \\
310 \\
906 \\
69\end{array}$ & $\begin{array}{r}4597 \\
148 \\
967 \\
25\end{array}$ & $\begin{array}{r}7184 \\
239 \\
1370 \\
26\end{array}$ & $\begin{array}{c}3831 \\
124 \\
911 \\
26\end{array}$ & $\begin{array}{r}895 \\
28.9 \\
100 \\
26\end{array}$ & $\begin{array}{c}5401 \\
180 \\
411 \\
26\end{array}$ \\
\hline
\end{tabular}

CAL YR 1990 TOIAL 311008 MEAN 852 MAX 3990 MIN 24 WTR YR 1991 TOIAL 230587 MEAN 632 MAX 5040 MIN 25 


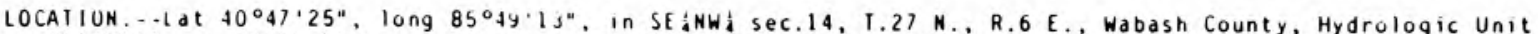
05120101 , on right bank on upstream side of Wabash Street oridge in Wabash, 1.1 mi downstrean from Saldaonie River, and at ile 387,2 .

$\cdots 1,768 \cdot i^{2}$

PERIOD OF RECORD.--August 1923 to current year. Monthly discharge only for some periods, published in wSP 1 sus. REVISED RECORDS. - -WSP 1275: 1931-37(M), 1938-39, 1940(M). WSP 1385: 1942. WSP 1505: 1955. WSP 2109: Orainage area. WDR IN-84-1: 1983.

GAGE. - Water-stage recorder. Datum of gage is $642.66 \mathrm{ft}$ above National Geodetic Vertical Datum of 1929 . Prior to Sept. 30, 1954, nonrecording gage at same site and datun.

REMARKS. - Records good. Flow regulated by Huntington Lake and Salamonie Lake. Annual mean conpulations do not include the 1936 water-year.

EXIREMES OUISIDE PERIOD OF RECORD. - Max imum stage knows, 28.7 ft Mar. 26, 1913, from floodmark, deterpined by U.S. Army Corps of Engineers, discharge, $90,000 \mathrm{ft} / \mathrm{s}$, from rating curve extended above $49,000 \mathrm{ft} / \mathrm{s}$.

DISCHARGE, CUBIL FEET PER SECOND, WATER YEAR OCTOBER 1990 TO SEPIEMBER 1991 DAI IY MEAN VALUES

\begin{tabular}{|c|c|c|c|c|c|c|c|c|c|c|c|}
\hline DAY & $O C \mathrm{~T}$ & NOV & DEC & JAN & FE B & MAR & APR & MAY & JUN & JUL & $A \cup G$ \\
\hline $\begin{array}{l}1 \\
2 \\
3 \\
4 \\
5\end{array}$ & $\begin{array}{r}682 \\
670 \\
541 \\
807 \\
1640\end{array}$ & $\begin{array}{r}617 \\
865 \\
2190 \\
2560 \\
2880\end{array}$ & $\begin{array}{l}3640 \\
3330 \\
4670 \\
5810 \\
6170\end{array}$ & $\begin{array}{l}7060 \\
6570 \\
5980 \\
5980 \\
5820\end{array}$ & $\begin{array}{r}800 \\
841 \\
957 \\
1430 \\
2880\end{array}$ & $\begin{array}{r}964 \\
1230 \\
1380 \\
1300 \\
1240\end{array}$ & $\begin{array}{r}1190 \\
921 \\
772 \\
817 \\
1060\end{array}$ & $\begin{array}{l}402 \\
395 \\
350 \\
315 \\
356\end{array}$ & $\begin{array}{l}8080 \\
5280 \\
4240 \\
4070 \\
4370\end{array}$ & $\begin{array}{l}150 \\
193 \\
546 \\
522 \\
612\end{array}$ & $\begin{array}{l}84 \\
77 \\
78 \\
85 \\
83\end{array}$ \\
\hline $\begin{array}{r}6 \\
7 \\
8 \\
9 \\
10\end{array}$ & $\begin{array}{l}3080 \\
2170 \\
1530 \\
3120 \\
6690\end{array}$ & $\begin{array}{l}3580 \\
1830 \\
1570 \\
1670 \\
1600\end{array}$ & $\begin{array}{l}6410 \\
5960 \\
4650 \\
2790 \\
1450\end{array}$ & $\begin{array}{l}6290 \\
7240 \\
7260 \\
7190 \\
6710\end{array}$ & $\begin{array}{l}4920 \\
5900 \\
5440 \\
4350 \\
3700\end{array}$ & $\begin{array}{r}1080 \\
772 \\
831 \\
840 \\
782\end{array}$ & $\begin{array}{r}1210 \\
997 \\
986 \\
1620 \\
1530\end{array}$ & $\begin{array}{l}454 \\
496 \\
479 \\
452 \\
426\end{array}$ & $\begin{array}{r}4490 \\
3550 \\
2250 \\
717 \\
652\end{array}$ & $\begin{array}{r}495 \\
574 \\
1340 \\
1410 \\
1220\end{array}$ & $\begin{array}{r}87 \\
84 \\
121 \\
164 \\
185\end{array}$ \\
\hline $\begin{array}{l}11 \\
12 \\
13 \\
14 \\
15\end{array}$ & $\begin{array}{l}4970 \\
3660 \\
3080 \\
3130 \\
3480\end{array}$ & $\begin{array}{r}1380 \\
978 \\
953 \\
1210 \\
1430\end{array}$ & $\begin{array}{r}1110 \\
1050 \\
898 \\
824 \\
1340\end{array}$ & $\begin{array}{l}6350 \\
6810 \\
6630 \\
6560 \\
7140\end{array}$ & $\begin{array}{r}2740 \\
1730 \\
1450 \\
\text { e1 } 250 \\
\text { e } 1070\end{array}$ & $\begin{array}{l}788 \\
717 \\
701 \\
727 \\
783\end{array}$ & $\begin{array}{r}1280 \\
972 \\
835 \\
1010 \\
3110\end{array}$ & $\begin{array}{l}415 \\
409 \\
354 \\
359 \\
353\end{array}$ & $\begin{array}{l}599 \\
563 \\
448 \\
385 \\
324\end{array}$ & $\begin{array}{l}440 \\
274 \\
274 \\
192 \\
185\end{array}$ & $\begin{array}{l}151 \\
135 \\
143 \\
114 \\
102\end{array}$ \\
\hline $\begin{array}{l}16 \\
17 \\
18 \\
19 \\
20\end{array}$ & $\begin{array}{l}3910 \\
2760 \\
3960 \\
3650 \\
3460\end{array}$ & $\begin{array}{r}1360 \\
1190 \\
1070 \\
877 \\
879\end{array}$ & $\begin{array}{l}2570 \\
3350 \\
3600 \\
5190 \\
5360\end{array}$ & $\begin{array}{l}8130 \\
7540 \\
6350 \\
6410 \\
6160\end{array}$ & $\begin{array}{r}\epsilon 860 \\
778 \\
1100 \\
4110 \\
6020\end{array}$ & $\begin{array}{l}1060 \\
2030 \\
4470 \\
4670 \\
4450\end{array}$ & $\begin{array}{l}4540 \\
3790 \\
2570 \\
2070 \\
3950\end{array}$ & $\begin{array}{l}246 \\
226 \\
304 \\
326 \\
340\end{array}$ & $\begin{array}{l}307 \\
342 \\
297 \\
242 \\
208\end{array}$ & $\begin{array}{r}162 \\
141 \\
115 \\
100 \\
95\end{array}$ & $\begin{array}{l}104 \\
165 \\
101 \\
156 \\
157\end{array}$ \\
\hline $\begin{array}{l}21 \\
22 \\
23 \\
24 \\
25\end{array}$ & $\begin{array}{l}3790 \\
4010 \\
3770 \\
3060 \\
2280\end{array}$ & $\begin{array}{l}896 \\
990 \\
916 \\
843 \\
914\end{array}$ & $\begin{array}{r}6270 \\
6710 \\
5300 \\
\text { e } 4400 \\
\text { e } 3900\end{array}$ & $\begin{array}{l}5990 \\
6050 \\
6230 \\
5880 \\
5680\end{array}$ & $\begin{array}{l}6010 \\
5630 \\
4840 \\
2840 \\
1850\end{array}$ & $\begin{array}{l}3970 \\
2920 \\
2620 \\
3850 \\
4040\end{array}$ & $\begin{array}{l}3500 \\
4130 \\
3930 \\
3300 \\
2340\end{array}$ & $\begin{array}{r}394 \\
447 \\
740 \\
565 \\
1460\end{array}$ & $\begin{array}{l}204 \\
197 \\
196 \\
184 \\
176\end{array}$ & $\begin{array}{r}94 \\
94 \\
98 \\
109 \\
99\end{array}$ & $\begin{array}{r}153 \\
120 \\
104 \\
92 \\
86\end{array}$ \\
\hline $\begin{array}{l}26 \\
27 \\
28 \\
29 \\
30 \\
31\end{array}$ & $\begin{array}{r}1040 \\
862 \\
792 \\
733 \\
624 \\
618\end{array}$ & $\begin{array}{r}953 \\
1150 \\
3530 \\
3880 \\
3570 \\
\ldots\end{array}$ & $\begin{array}{r}\text { e } 3500 \\
\text { e } 3300 \\
\text { e } 3100 \\
7870 \\
14900 \\
8590\end{array}$ & $\begin{array}{r}5030 \\
3430 \\
1970 \\
1220 \\
e 1050 \\
e 940\end{array}$ & $\begin{array}{r}1370 \\
1240 \\
934 \\
\ldots \\
\cdots \\
\cdots\end{array}$ & $\begin{array}{l}3960 \\
4200 \\
3830 \\
3940 \\
2710 \\
1570\end{array}$ & $\begin{array}{r}1310 \\
806 \\
642 \\
496 \\
418 \\
\cdots\end{array}$ & $\begin{array}{r}2400 \\
2050 \\
1340 \\
836 \\
1440 \\
8860\end{array}$ & $\begin{array}{l}162 \\
151 \\
148 \\
145 \\
145 \\
\cdots\end{array}$ & $\begin{array}{l}92 \\
86 \\
84 \\
81 \\
84 \\
85\end{array}$ & $\begin{array}{l}85 \\
83 \\
87 \\
87 \\
91 \\
83\end{array}$ \\
\hline $\begin{array}{l}\text { IOIAL } \\
\text { MEAN } \\
\text { MAX } \\
\text { MIN } \\
\text { CF SM } \\
\text { IN. }\end{array}$ & $\begin{array}{r}78569 \\
2534 \\
6690 \\
541 \\
1.43 \\
1.65\end{array}$ & $\begin{array}{r}48331 \\
1611 \\
3880 \\
617 \\
.91 \\
1.02\end{array}$ & $\begin{array}{r}138012 \\
4452 \\
14900 \\
824 \\
2.52 \\
2.90\end{array}$ & $\begin{array}{r}177650 \\
5731 \\
8130 \\
940 \\
3.24 \\
3.74\end{array}$ & $\begin{array}{r}77040 \\
2751 \\
6020 \\
178 \\
1.56 \\
1.62\end{array}$ & $\begin{array}{r}68425 \\
2207 \\
4670 \\
101 \\
1.25 \\
1.44\end{array}$ & $\begin{array}{r}56102 \\
1870 \\
4540 \\
418 \\
1.06 \\
1.18\end{array}$ & $\begin{array}{r}27989 \\
903 \\
8860 \\
226 \\
.51 \\
.59\end{array}$ & $\begin{array}{r}43122 \\
1437 \\
8080 \\
145 \\
.81 \\
.91\end{array}$ & $\begin{array}{r}10046 \\
324 \\
1410 \\
81 \\
.18 \\
.21\end{array}$ & $\begin{array}{c}3447 \\
111 \\
185 \\
77 \\
.06 \\
.07\end{array}$ \\
\hline
\end{tabular}

e Estinated

SIAIISIILS OF MONTHIY MEAN DAIA FOR WATEK YEARS 1924 - 1991, BY WATER YEAR (WY)

$\begin{array}{lrrrrrrrrrrrr}\text { MEAN } & 574 & 859 & 1743 & 2225 & 2479 & 3129 & 2742 & 1603 & 1288 & 690 & 440 & 475 \\ \text { MAX } & 3200 & 4971 & 5829 & 13260 & 7764 & 8144 & 11060 & 10410 & 8260 & 3879 & 2179 & 5675 \\ \text { (WY) } & 1927 & 1973 & 1968 & 1950 & 1959 & 1982 & 1957 & 1943 & 1958 & 1957 & 1990 & 1926 \\ \text { MIN } & 32.3 & 61.7 & 56.0 & 72.8 & 114 & 177 & 264 & 135 & 78.3 & 55.4 & 43.4 & 29.9 \\ \text { (WY) } & 1964 & 1965 & 1964 & 1977 & 1964 & 1941 & 1971 & 1941 & 1988 & 1934 & 1941 & 1941\end{array}$

SUMMARY SIAIISTICS

ANNUAL IOIAI

ANNUAL MEAM

HIGHESI ANNUAL MEAN

LOWEST ANHUAL MEAN

HIGHESI DAIIY MEAN

LOWEST DAIIY MEAN

ANHUAL SEVEN-DAY MINIMUM

INSTANIANEOUS PEAK FLOW

INSIANIANEOUS PEAK SIAGE

ANNUAL RUNOFF (CFSM)

ANNUAI RUNOFF (INCHES)

10 PERCENT EXCEEDS

SO PERCENI EXCEEDS

90 PERCENT EXCEEDS
FUR IYGO CALENOAR YEAR

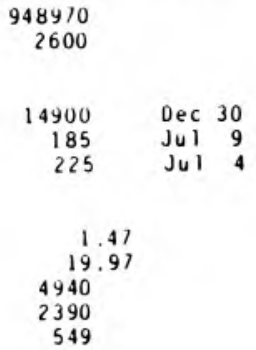

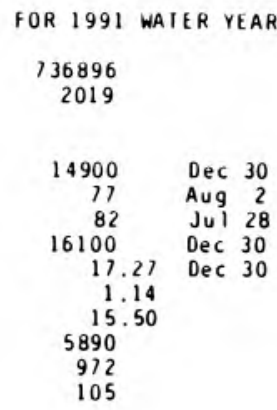

WAIER YEAKS $1924-1991$

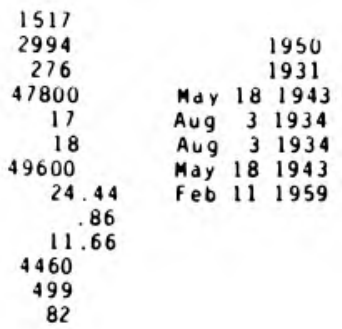




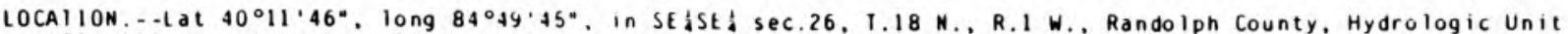
05120103 , on right bank $85 \mathrm{ft}$ downstredm trom Westinghouse Rod, 0.5 i downstrea from Little 0 itch, 0.8 . upstrea fron City Orain, and 1.2 i west of the Post Office in Union City. DRAINAGE AREA $-.9 .67 i^{2}$

PERIOD OF RECORO.--October 1982 to current $y \in d r$

GAGE .- Water-stage recorder. Datun of gage is $1075.50 \mathrm{ft}$ above National Geodetic Vertical Datua of 1929 .

REMARKS.--Records good except for estinated daily discharges in Septenber which dre poor.

DISCHARGE, CUBIC FEET PER SECOND, WATER YEAR OCTOBER 1990 TO SEPIEMBER 1991 DAIIY MEAN VALUES

\begin{tabular}{|c|c|c|c|c|c|c|c|c|c|c|c|c|}
\hline DAY & $\mathrm{OCT}$ & NOV & DEC & JAN & FE B & MAR & APR & MAY & JUN & JUL & AUG & SEP \\
\hline $\begin{array}{l}1 \\
2 \\
3 \\
4 \\
5\end{array}$ & $\begin{array}{l}1.3 \\
1.4 \\
1.6 \\
25 \\
11\end{array}$ & $\begin{array}{l}2.6 \\
2.6 \\
2.4 \\
2.5 \\
4.1\end{array}$ & $\begin{array}{l}7.5 \\
5.4 \\
70 \\
49 \\
24\end{array}$ & $\begin{array}{l}55 \\
34 \\
22 \\
14 \\
11\end{array}$ & $\begin{array}{l}e 4.1 \\
10 \\
21 \\
25 \\
43\end{array}$ & $\begin{array}{l}4.7 \\
5.5 \\
4.3 \\
4.1 \\
3.6\end{array}$ & $\begin{array}{l}5.0 \\
4.0 \\
3.7 \\
3.7 \\
3.6\end{array}$ & $\begin{array}{l}3.3 \\
2.8 \\
2.6 \\
2.7 \\
3.2\end{array}$ & $\begin{array}{l}8.1 \\
4.2 \\
3.0 \\
2.3 \\
1.9\end{array}$ & $\begin{array}{l}.55 \\
.49 \\
.48 \\
.45 \\
.35\end{array}$ & $\begin{array}{l}.07 \\
.06 \\
.75 \\
.19 \\
.03\end{array}$ & $\begin{array}{l}.03 \\
.03 \\
.10 \\
.32 \\
.10\end{array}$ \\
\hline $\begin{array}{r}6 \\
7 \\
8 \\
9 \\
10\end{array}$ & $\begin{array}{l}6.4 \\
4.6 \\
3.8 \\
26 \\
65\end{array}$ & $\begin{array}{l}3.3 \\
2.6 \\
2.3 \\
2.7 \\
3.7\end{array}$ & $\begin{array}{r}16 \\
11 \\
9.1 \\
7.5 \\
6.6\end{array}$ & $\begin{array}{l}8.4 \\
7.2 \\
6.3 \\
5.3 \\
4.6\end{array}$ & $\begin{array}{l}58 \\
55 \\
33 \\
21 \\
15\end{array}$ & $\begin{array}{l}4.4 \\
3.4 \\
3.0 \\
3.1 \\
2.7\end{array}$ & $\begin{array}{l}3.4 \\
3.2 \\
3.3 \\
3.2 \\
2.5\end{array}$ & $\begin{array}{l}3.8 \\
2.6 \\
2.3 \\
2.3 \\
2.1\end{array}$ & $\begin{array}{l}1.7 \\
1.6 \\
1.5 \\
1.4 \\
1.3\end{array}$ & $\begin{array}{r}.29 \\
.24 \\
1.1 \\
.44 \\
.31\end{array}$ & $\begin{array}{l}.05 \\
.05 \\
.07 \\
.13 \\
.09\end{array}$ & $\begin{array}{r}.04 \\
.03 \\
\mathrm{e} .02 \\
\mathrm{e} .02 \\
\mathrm{e} .02\end{array}$ \\
\hline $\begin{array}{l}11 \\
12 \\
13 \\
14 \\
15\end{array}$ & $\begin{array}{r}35 \\
20 \\
13 \\
9.3 \\
6.5\end{array}$ & $\begin{array}{l}2.8 \\
2.3 \\
1.9 \\
1.8 \\
1.8\end{array}$ & $\begin{array}{r}6.0 \\
5.6 \\
4.7 \\
4.1 \\
12\end{array}$ & $\begin{array}{r}22 \\
27 \\
13 \\
9.9 \\
16\end{array}$ & $\begin{array}{l}9.7 \\
\text { e6.3 } \\
\text { e6.6 } \\
11 \\
\text { e6. } 6\end{array}$ & $\begin{array}{r}2.7 \\
2.9 \\
5.4 \\
6.9 \\
12\end{array}$ & $\begin{array}{l}2.1 \\
2.0 \\
29 \\
40 \\
25\end{array}$ & $\begin{array}{l}2.0 \\
2.1 \\
2.0 \\
1.9 \\
1.6\end{array}$ & $\begin{array}{l}1.5 \\
1.4 \\
1.1 \\
1.1 \\
1.1\end{array}$ & $\begin{array}{l}.24 \\
.24 \\
.23 \\
.18 \\
.14\end{array}$ & $\begin{array}{l}.04 \\
.03 \\
.02 \\
.03 \\
.02\end{array}$ & $\begin{array}{r}\text { e.02 } \\
\text { e.03 } \\
.15 \\
.10 \\
.07\end{array}$ \\
\hline $\begin{array}{l}16 \\
17 \\
18 \\
19 \\
20\end{array}$ & $\begin{array}{l}5.2 \\
4.9 \\
31 \\
17 \\
10\end{array}$ & $\begin{array}{l}2.0 \\
1.6 \\
1.6 \\
1.6 \\
1.3\end{array}$ & $\begin{array}{l}48 \\
35 \\
89 \\
84 \\
54\end{array}$ & $\begin{array}{l}43 \\
33 \\
17 \\
12 \\
13\end{array}$ & $\begin{array}{l}\text { e5.2 } \\
\text { e } 4.8 \\
16 \\
51 \\
39\end{array}$ & $\begin{array}{l}35 \\
72 \\
99 \\
50 \\
30\end{array}$ & $\begin{array}{l}13 \\
8.4 \\
6.6 \\
19 \\
20\end{array}$ & $\begin{array}{l}1.5 \\
1.5 \\
1.7 \\
1.4 \\
1.3\end{array}$ & $\begin{array}{r}1.2 \\
.96 \\
.86 \\
.77 \\
.71\end{array}$ & $\begin{array}{l}.12 \\
.11 \\
.11 \\
.10 \\
.09\end{array}$ & $\begin{array}{l}.03 \\
.09 \\
.14 \\
.22 \\
.29\end{array}$ & $\begin{array}{l}\text { e. } 05 \\
\text { e. } 03 \\
\text { e. } 02 \\
\text { e. } 02 \\
\text { e. } 02\end{array}$ \\
\hline $\begin{array}{l}21 \\
22 \\
23 \\
24 \\
25\end{array}$ & $\begin{array}{l}7.5 \\
12 \\
11 \\
8.3 \\
6.2\end{array}$ & $\begin{array}{l}1.4 \\
5.4 \\
5.7 \\
3.8 \\
3.0\end{array}$ & $\begin{array}{l}71 \\
89 \\
73 \\
42 \\
27\end{array}$ & $\begin{array}{r}12 \\
8.5 \\
\mathrm{e} 6.2 \\
\mathrm{e} 5.0 \\
\mathrm{e} 4.4\end{array}$ & $\begin{array}{r}22 \\
14 \\
9.4 \\
8.0 \\
6.4\end{array}$ & $\begin{array}{r}20 \\
42 \\
113 \\
44 \\
27\end{array}$ & $\begin{array}{r}11 \\
8.4 \\
6.7 \\
5.6 \\
4.8\end{array}$ & $\begin{array}{l}1.3 \\
1.3 \\
1.3 \\
1.2 \\
1.2\end{array}$ & $\begin{array}{l}21^{.69} \\
27 \\
7.4 \\
3.2\end{array}$ & $\begin{array}{l}.09 \\
.09 \\
.09 \\
.08 \\
.08\end{array}$ & $\begin{array}{l}.08 \\
.04 \\
.03 \\
.03 \\
.02\end{array}$ & $\begin{array}{l}\text { e. } 02 \\
\text { e.02 } \\
\text { e. } 07 \\
\text { e.06 } \\
\text { e. } 05\end{array}$ \\
\hline $\begin{array}{l}26 \\
27 \\
28 \\
29 \\
30 \\
31\end{array}$ & $\begin{array}{l}4.9 \\
4.4 \\
3.6 \\
3.1 \\
3.0 \\
2.7\end{array}$ & $\begin{array}{c}2.5 \\
5.3 \\
31 \\
18 \\
11 \\
\ldots\end{array}$ & $\begin{array}{c}18 \\
12 \\
9.0 \\
113 \\
480 \\
112\end{array}$ & $\begin{array}{r}\text { e } 4.0 \\
\text { e3.8 } \\
\text { e3.7 } \\
3.7 \\
9.8 \\
\text { e } 5.0\end{array}$ & $\begin{array}{l}5.8 \\
5.3 \\
4.8 \\
\ldots . \\
\ldots . \\
\ldots\end{array}$ & $\begin{array}{r}48 \\
41 \\
23 \\
13 \\
7.5 \\
5.9\end{array}$ & $\begin{array}{l}4.8 \\
4.5 \\
4.1 \\
4.0 \\
3.3 \\
\ldots .-\end{array}$ & $\begin{array}{l}1.6 \\
1.4 \\
1.1 \\
1.1 \\
1.3 \\
2.6\end{array}$ & $\begin{array}{l}2.1 \\
2.2 \\
.91 \\
.81 \\
.68 \\
\ldots\end{array}$ & $\begin{array}{l}.06 \\
.05 \\
.04 \\
.04 \\
.08 \\
.08\end{array}$ & $\begin{array}{l}.02 \\
.02 \\
.03 \\
.03 \\
.04 \\
.04\end{array}$ & $\begin{array}{l}\text { e. } 04 \\
\text { e.03 } \\
\text { e.03 } \\
\text { e.03 } \\
\text { e.02 } \\
. . .\end{array}$ \\
\hline $\begin{array}{l}\text { TOIAL } \\
\text { MEAN } \\
\text { MAX } \\
\text { MI N } \\
\text { CF SM } \\
\text { IN. }\end{array}$ & $\begin{array}{r}364.1 \\
11.8 \\
65 \\
1.3 \\
1.22 \\
1.40\end{array}$ & $\begin{array}{r}134.6 \\
4.49 \\
31 \\
1.3 \\
.46 \\
.52\end{array}$ & $\begin{array}{r}1654.5 \\
53.4 \\
480 \\
4.1 \\
5.52 \\
6.36\end{array}$ & $\begin{array}{r}439.8 \\
14.2 \\
55 \\
3.7 \\
1.47 \\
1.69\end{array}$ & $\begin{array}{r}516.4 \\
18.4 \\
58 \\
4.1 \\
1.91 \\
1.99\end{array}$ & $\begin{array}{r}739.1 \\
23.8 \\
113 \\
2.7 \\
2.47 \\
2.84\end{array}$ & $\begin{array}{r}251.9 \\
8.60 \\
40 \\
2.0 \\
.89 \\
.99\end{array}$ & $\begin{array}{c}60.1 \\
1.94 \\
3.8 \\
1.1 \\
.20 \\
.23\end{array}$ & $\begin{array}{r}103.75 \\
3.46 \\
27 \\
.68 \\
.36 \\
.40\end{array}$ & $\begin{array}{l}7.04 \\
.23 \\
1.1 \\
.04 \\
.02 \\
.03\end{array}$ & $\begin{array}{l}2.78 \\
.090 \\
.75 \\
.02 \\
.01 \\
.01\end{array}$ & $\begin{array}{l}1.59 \\
.053 \\
.32 \\
.02 \\
.01 \\
.01\end{array}$ \\
\hline
\end{tabular}

e Estinated

SIAIISIICS OF MONIHLY MEAN DAIA FUR WAIEK YEARS 1983 - 1991, BY WATER YEAR (WY)

\begin{tabular}{|c|c|c|c|c|c|c|c|c|c|c|c|}
\hline $\begin{array}{l}\text { MEAN } \\
\text { MAX } \\
\text { (WY) } \\
\text { WIN } \\
\text { (WY) }\end{array}$ & $\begin{array}{l}4.40 \\
23.1 \\
1987 \\
1035 \\
1983\end{array}$ & $\begin{array}{l}7.95 \\
28.5 \\
1986 \\
.084 \\
1988\end{array}$ & $\begin{array}{l}15.4 \\
53.4 \\
1991 \\
2.59 \\
1990\end{array}$ & $\begin{array}{l}1.11 \\
15.3 \\
1989 \\
1.19 \\
1988\end{array}$ & $\begin{array}{l}11.4 \\
38.6 \\
1990 \\
4.66 \\
1989\end{array}$ & $\begin{array}{l}16.3 \\
23.8 \\
1991 \\
3.05 \\
1983\end{array}$ & $\begin{array}{l}16.6 \\
33.7 \\
1989 \\
8.60 \\
1991\end{array}$ & $\begin{array}{r}11.4 \\
26.4 \\
1989 \\
.93 \\
1988\end{array}$ & $\begin{array}{r}7.70 \\
24.2 \\
1987 \\
.23 \\
1988\end{array}$ & $\begin{array}{l}7.95 \\
20.3 \\
1986 \\
.065 \\
1988\end{array}$ & $\begin{array}{l}1.99 \\
11.2 \\
1990 \\
1004 \\
1988\end{array}$ \\
\hline
\end{tabular}

SUMMARY SIATISIICS

ANNUAL TOTAL

ANMUAL MEAN

HIGHEST ANNUAL MEAN

LOWEST ANNUAL MEAN

HIGHEST DAILY MEAM

LOWEST DAILY MEAN

AMNUAL SEVEN-DAY MINIMUM

INSIANTANEOUS PEAK FLOW

INSIANTANEOUS PEAK STAGE

AN NUAL RUNOFF (CFSM)

ANHUAL RUNOFF (INCHES

50 PERCENT EXCEEDS

90 PERCENT EXCEEDS
FOR 1990 CALENOAR YEAR

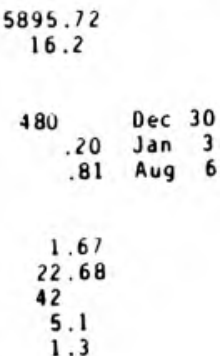

FOR 1991 WATER YEAR

4282.26

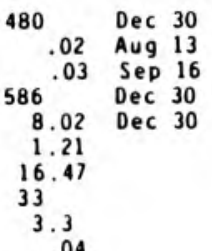

WAIER YEARS 1983 - 1991

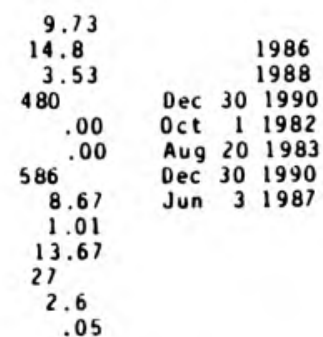




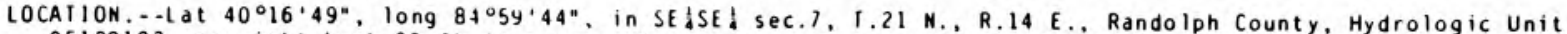

05120103 , on right bank $30 \mathrm{ft}$ downstream from highway bridge, $0.8 \mathrm{mi}$ downstream from Mud Creek, 2 i edst of Ridgevilie, and at ile 99.5 .

DRAINAGE AREA. $\cdots 133 \mathrm{ai}^{2}$.

PERIOD OF RECORD.-August 1946 to current year.

REVISED RECOROS...WSP 1235: 1948. WSP 1s35: 1953. WSP 2109: Drainage area.

GAGE.--Water-stage recorder. Datum of gage is $965.28 \mathrm{ft}$ above National Geodet ic Vertical Datum of 1929 (levels by State of Indiana. Departient of Natural Resources). Prior to 0 ct. 5 , 1950 , nonrecording gage at sae site and datue.

REMARKS.--Records good, except for periods of estimated daily discharges, which are poor.

DISCHARGE, CUBIC FEE T PER SECOND, WAIER YEAR OCTOBER 1990 TO SEPIEMBER 1991 DAIIY MEAN VALUES

\begin{tabular}{|c|c|c|c|c|c|c|c|c|c|c|c|c|}
\hline DAY & $\mathrm{OCT}$ & NOV & DE C & JAN & FEB & MAR & APR & MAY & JUN & JUL & AUG & SEP \\
\hline $\begin{array}{l}1 \\
2 \\
3 \\
4 \\
5\end{array}$ & $\begin{array}{r}32 \\
26 \\
22 \\
649 \\
213\end{array}$ & $\begin{array}{l}36 \\
35 \\
34 \\
33 \\
42\end{array}$ & $\begin{array}{r}95 \\
71 \\
1110 \\
575 \\
203\end{array}$ & $\begin{array}{l}690 \\
321 \\
214 \\
155 \\
128\end{array}$ & $\begin{array}{r}e 56 \\
74 \\
349 \\
527 \\
920\end{array}$ & $\begin{array}{l}55 \\
71 \\
58 \\
51 \\
45\end{array}$ & $\begin{array}{l}69 \\
58 \\
54 \\
52 \\
57\end{array}$ & $\begin{array}{l}45 \\
41 \\
38 \\
39 \\
39\end{array}$ & $\begin{array}{r}265 \\
110 \\
88 \\
55 \\
41\end{array}$ & $\begin{array}{l}9.3 \\
12 \\
10 \\
10 \\
14\end{array}$ & $\begin{array}{l}3.9 \\
3.4 \\
3.2 \\
8.0 \\
6.4\end{array}$ & $\begin{array}{l}3.2 \\
2.5 \\
2.1 \\
13 \\
10\end{array}$ \\
\hline $\begin{array}{r}6 \\
7 \\
8 \\
9 \\
10\end{array}$ & $\begin{array}{r}99 \\
67 \\
54 \\
312 \\
1170\end{array}$ & $\begin{array}{l}57 \\
39 \\
34 \\
35 \\
57\end{array}$ & $\begin{array}{r}132 \\
99 \\
81 \\
66 \\
61\end{array}$ & $\begin{array}{r}111 \\
98 \\
86 \\
79 \\
69\end{array}$ & $\begin{array}{l}945 \\
837 \\
346 \\
221 \\
164\end{array}$ & $\begin{array}{l}49 \\
45 \\
36 \\
36 \\
34\end{array}$ & $\begin{array}{l}51 \\
48 \\
48 \\
49 \\
43\end{array}$ & $\begin{array}{l}55 \\
40 \\
34 \\
33 \\
32\end{array}$ & $\begin{array}{l}34 \\
30 \\
27 \\
24 \\
22\end{array}$ & $\begin{array}{l}9.5 \\
7.7 \\
31 \\
18 \\
10\end{array}$ & $\begin{array}{l}4.1 \\
4.0 \\
4.8 \\
8.3 \\
6.3\end{array}$ & $\begin{array}{l}3.9 \\
2.7 \\
2.1 \\
1.9 \\
1.9\end{array}$ \\
\hline $\begin{array}{l}11 \\
12 \\
13 \\
14 \\
15\end{array}$ & $\begin{array}{r}436 \\
197 \\
125 \\
92 \\
72\end{array}$ & $\begin{array}{l}47 \\
38 \\
34 \\
32 \\
31\end{array}$ & $\begin{array}{r}54 \\
52 \\
47 \\
38 \\
1360\end{array}$ & $\begin{array}{l}270 \\
408 \\
175 \\
134 \\
188\end{array}$ & $\begin{array}{r}114 \\
86 \\
90 \\
142 \\
\mathrm{e} 82\end{array}$ & $\begin{array}{r}32 \\
33 \\
46 \\
68 \\
126\end{array}$ & $\begin{array}{r}35 \\
32 \\
253 \\
555 \\
298\end{array}$ & $\begin{array}{l}31 \\
31 \\
34 \\
31 \\
28\end{array}$ & $\begin{array}{l}24 \\
32 \\
22 \\
20 \\
19\end{array}$ & $\begin{array}{l}9.0 \\
8.4 \\
8.6 \\
7.5 \\
6.5\end{array}$ & $\begin{array}{l}4.4 \\
3.3 \\
2.8 \\
3.3 \\
3.6\end{array}$ & $\begin{array}{r}2.3 \\
2.4 \\
7.8 \\
12 \\
6.3\end{array}$ \\
\hline $\begin{array}{l}16 \\
17 \\
18 \\
19 \\
20\end{array}$ & $\begin{array}{r}57 \\
53 \\
383 \\
178 \\
103\end{array}$ & $\begin{array}{l}31 \\
31 \\
27 \\
27 \\
26\end{array}$ & $\begin{array}{r}540 \\
288 \\
1580 \\
1180 \\
414\end{array}$ & $\begin{array}{l}803 \\
576 \\
229 \\
160 \\
180\end{array}$ & $\begin{array}{r}\text { e7 } 3 \\
\text { e66 } \\
256 \\
1060 \\
622\end{array}$ & $\begin{array}{r}456 \\
1000 \\
1910 \\
524 \\
264\end{array}$ & $\begin{array}{r}153 \\
102 \\
80 \\
336 \\
392\end{array}$ & $\begin{array}{l}26 \\
27 \\
34 \\
32 \\
25\end{array}$ & $\begin{array}{l}21 \\
18 \\
17 \\
16 \\
15\end{array}$ & $\begin{array}{l}5.9 \\
5.7 \\
5.5 \\
5.6 \\
5.7\end{array}$ & $\begin{array}{l}3.0 \\
3.2 \\
9.4 \\
5.9 \\
7.1\end{array}$ & $\begin{array}{r}3.1 \\
2.3 \\
\mathrm{e} 2.1 \\
\mathrm{e} 2.0 \\
\mathrm{e} 2.0\end{array}$ \\
\hline $\begin{array}{l}21 \\
22 \\
23 \\
24 \\
25\end{array}$ & $\begin{array}{r}79 \\
149 \\
143 \\
95 \\
74\end{array}$ & $\begin{array}{r}25 \\
84 \\
107 \\
61 \\
47\end{array}$ & $\begin{array}{r}1090 \\
1430 \\
788 \\
361 \\
200\end{array}$ & $\begin{array}{l}184 \\
114 \\
\text { e } 84 \\
\text { e } 68 \\
\text { e } 60\end{array}$ & $\begin{array}{r}265 \\
164 \\
108 \\
93 \\
16\end{array}$ & $\begin{array}{r}173 \\
528 \\
1550 \\
377 \\
189\end{array}$ & $\begin{array}{r}165 \\
121 \\
94 \\
95 \\
73\end{array}$ & $\begin{array}{r}24 \\
114 \\
123 \\
51 \\
37\end{array}$ & $\begin{array}{l}14 \\
29 \\
94 \\
39 \\
34\end{array}$ & $\begin{array}{l}5.1 \\
4.7 \\
4.3 \\
4.1 \\
4.1\end{array}$ & $\begin{array}{l}6.6 \\
4.0 \\
3.0 \\
2.4 \\
2.0\end{array}$ & $\begin{array}{r}e 1.9 \\
\in 1.9 \\
6.5 \\
7.5 \\
4.7\end{array}$ \\
\hline $\begin{array}{l}26 \\
27 \\
28 \\
29 \\
30 \\
31\end{array}$ & $\begin{array}{l}61 \\
54 \\
49 \\
42 \\
40 \\
39\end{array}$ & $\begin{array}{r}38 \\
122 \\
697 \\
279 \\
133 \\
\cdots-\end{array}$ & $\begin{array}{r}134 \\
106 \\
95 \\
1480 \\
7910 \\
5400\end{array}$ & $\begin{array}{r}e 56 \\
e 54 \\
\text { e51 } \\
47 \\
86 \\
\text { e64 }\end{array}$ & $\begin{array}{c}67 \\
61 \\
55 \\
\cdots \\
\cdots \\
\cdots\end{array}$ & $\begin{array}{r}667 \\
465 \\
203 \\
126 \\
89 \\
73\end{array}$ & $\begin{array}{l}69 \\
64 \\
58 \\
55 \\
50 \\
\cdots\end{array}$ & $\begin{array}{r}53 \\
60 \\
37 \\
32 \\
32 \\
445\end{array}$ & $\begin{array}{r}46 \\
18 \\
14 \\
12 \\
10 \\
--\end{array}$ & $\begin{array}{r}3.9 \\
3.6 \\
3.2 \\
4.9 \\
11 \\
5.5\end{array}$ & $\begin{array}{l}1.9 \\
1.9 \\
2.1 \\
2.2 \\
3.5 \\
5.6\end{array}$ & $\begin{array}{r}\mathrm{e} .5 \\
\mathrm{e} 2.6 \\
\mathrm{e} 2.3 \\
\mathrm{e} 2.1 \\
\mathrm{e} 2.0 \\
\ldots\end{array}$ \\
\hline $\begin{array}{l}\text { IOIAL } \\
\text { MEAN } \\
\text { MAX } \\
\text { MIN } \\
\text { CF SM } \\
\text { IN. }\end{array}$ & $\begin{array}{r}5165 \\
167 \\
1170 \\
22 \\
1.25 \\
1.44\end{array}$ & $\begin{array}{r}2319 \\
77.3 \\
697 \\
25 \\
.58 \\
.65\end{array}$ & $\begin{array}{r}27040 \\
872 \\
7910 \\
38 \\
6.56 \\
7.56\end{array}$ & $\begin{array}{r}5942 \\
192 \\
803 \\
47 \\
1.44 \\
1.66\end{array}$ & $\begin{array}{r}7919 \\
283 \\
1060 \\
55 \\
2.13 \\
2.21\end{array}$ & $\begin{array}{r}9379 \\
303 \\
1910 \\
32 \\
2.27 \\
2.62\end{array}$ & $\begin{array}{c}3609 \\
120 \\
555 \\
32 \\
.90 \\
1.01\end{array}$ & $\begin{array}{c}1703 \\
54.9 \\
445 \\
24 \\
.41 \\
.48\end{array}$ & $\begin{array}{c}1210 \\
40.3 \\
265 \\
10 \\
.30 \\
.34\end{array}$ & $\begin{array}{r}254.3 \\
8.20 \\
31 \\
3.2 \\
.06 \\
.07\end{array}$ & $\begin{array}{r}133.6 \\
4.31 \\
9.4 \\
1.9 \\
.03 \\
.04\end{array}$ & $\begin{array}{r}120.6 \\
4.02 \\
13 \\
1.9 \\
.03 \\
.03\end{array}$ \\
\hline
\end{tabular}

e Estimated

SIAIISIICS OF MONTHLY MEAN DAIA FOR WAIER YEARS 1947 - 1991, BY WATER YEAR (WY)

\begin{tabular}{|c|c|c|c|c|c|c|c|c|c|c|c|c|}
\hline $\begin{array}{l}\text { MEAN } \\
M A X \\
(W Y) \\
M I N \\
(W Y)\end{array}$ & $\begin{array}{r}30.7 \\
272 \\
1987 \\
1.25 \\
1947\end{array}$ & $\begin{array}{r}78.4 \\
589 \\
1973 \\
1.82 \\
1954\end{array}$ & $\begin{array}{r}157 \\
872 \\
1991 \\
2.62 \\
1964\end{array}$ & $\begin{array}{r}179 \\
865 \\
1950 \\
3.25 \\
1977\end{array}$ & $\begin{array}{r}214 \\
548 \\
1950 \\
5.00 \\
1964\end{array}$ & $\begin{array}{r}259 \\
714 \\
1978 \\
46.1 \\
1957\end{array}$ & $\begin{array}{r}219 \\
810 \\
1964 \\
25.8 \\
1976\end{array}$ & $\begin{array}{r}119 \\
352 \\
1981 \\
15.3 \\
1988\end{array}$ & $\begin{array}{l}143 \\
1417 \\
1958 \\
6.52 \\
1988\end{array}$ & $\begin{array}{r}81.4 \\
709 \\
1979 \\
2.37 \\
1952\end{array}$ & $\begin{array}{r}42.0 \\
454 \\
1979 \\
2.13 \\
1983\end{array}$ & $\begin{array}{r}11.6 \\
337 \\
1972 \\
.99 \\
1954\end{array}$ \\
\hline
\end{tabular}

SUMMARY SIAIISIICS

\section{ANNUAL TOTAL}

ANNUAL MEAN

HIGHESI ANNUAL MEAN

LOWEST ANNUAL MEAN

HIGHEST DAILY MEAN

LOWEST DAILY MEAN

ANNUAL SEVEN-DAY MINIMUM

INSTANIANEOUS PEAK FLOW

INSIANTANEOUS PEAK STAGE

ANNUAI RIJNOF F (CFSM)

ANNUAL RUNOFF (INCHES)

10 PERCENT EXCEEDS

50 PERCENT EXCEEDS

90 PERCENI EXCEEDS
FOR 1990 CALENOAR YEAR

$$
\begin{array}{r}
93124 \\
255
\end{array}
$$

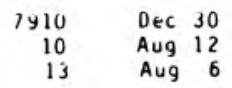

1. 92

26
555

66
23
FOR 1991 WAIER YEAR

64794.5
178

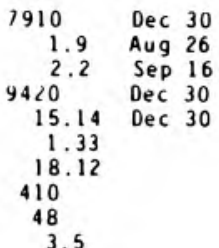

WAIER YEARS $1947-1991$

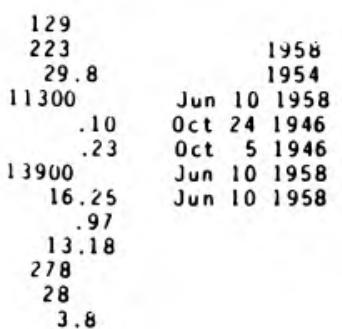


LOCATION.--Lat $40^{\circ} 25^{\prime} 20^{\circ}$, long $85^{\circ} 21^{\prime} 04^{\circ}$, in SE \&SE sec.23, T.23 N., R.10 E., Blackford County, Hydrologic Unit 05120103 , on right bank $6 \mathrm{ft}$ downstrea fro bridge on County Rodi 100 East, and 2.0 ei southeast of Hartford City.

DRAINAGE AREA,$-29.2 \backsim i^{2}$

PERIOD OF RECORD.-.July 1971 to current year.

GAGE - Water-stage recorder. Datur of gage is $865.00 \mathrm{ft}$ above National Geodetic Vertical Datue of 1929 .

REMARKS.--Records good except for estieated dally discharges, which are poor.

DISCHARGE, CUBIC FEET PER SECOND, WATER YEAR OCTOBER 1990 TO SEPTEMBER 1991

DAI IY MEAM VALUES

\begin{tabular}{|c|c|c|c|c|c|c|c|c|c|c|c|c|}
\hline DAY & $\mathrm{OCT}$ & MOV & DEC & JAM & FE B & MAR & APR & MAY & JUN & JUL & AUG & SEP \\
\hline $\begin{array}{l}1 \\
2 \\
3 \\
4 \\
5\end{array}$ & $\begin{array}{r}2.1 \\
2.0 \\
1.9 \\
304 \\
69\end{array}$ & $\begin{array}{r}5.0 \\
4.7 \\
4.5 \\
4.5 \\
45\end{array}$ & $\begin{array}{r}20 \\
14 \\
421 \\
161 \\
51\end{array}$ & $\begin{array}{l}97 \\
56 \\
36 \\
25 \\
19\end{array}$ & $\begin{array}{l}\mathrm{e} 5.2 \\
\mathrm{e} 5.6 \\
20 \\
97 \\
158\end{array}$ & $\begin{array}{l}11 \\
17 \\
13 \\
10 \\
8.6\end{array}$ & $\begin{array}{r}e 16 \\
e 14 \\
13 \\
14 \\
e 25\end{array}$ & $\begin{array}{l}9.1 \\
7.5 \\
6.0 \\
6.1 \\
6.2\end{array}$ & $\begin{array}{r}122 \\
30 \\
9.4 \\
5.8 \\
4.3\end{array}$ & $\begin{array}{c}1.5 \\
29 \\
6.2 \\
3.1 \\
2.2\end{array}$ & $\begin{array}{l}.86 \\
.81 \\
.80 \\
.87 \\
.90\end{array}$ & $\begin{array}{r}.93 \\
.55 \\
.66 \\
2.9 \\
1.5\end{array}$ \\
\hline $\begin{array}{r}6 \\
7 \\
8 \\
9 \\
10\end{array}$ & $\begin{array}{r}23 \\
14 \\
21 \\
148 \\
425\end{array}$ & $\begin{array}{r}53 \\
15 \\
9.4 \\
8.2 \\
9.1\end{array}$ & $\begin{array}{l}30 \\
22 \\
15 \\
12 \\
11\end{array}$ & $\begin{array}{l}17 \\
14 \\
12 \\
11 \\
10\end{array}$ & $\begin{array}{r}185 \\
196 \\
66 \\
39 \\
28\end{array}$ & $\begin{array}{l}9.0 \\
7.4 \\
6.2 \\
6.1 \\
5.7\end{array}$ & $\begin{array}{l}\text { e20 } \\
\text { e15 } \\
\text { e20 } \\
\text { e } 30 \\
\text { e19 }\end{array}$ & $\begin{array}{l}6.6 \\
5.2 \\
4.7 \\
4.6 \\
4.4\end{array}$ & $\begin{array}{l}3.6 \\
3.2 \\
3.1 \\
2.9 \\
2.7\end{array}$ & $\begin{array}{c}1.8 \\
1.6 \\
33 \\
9.1 \\
3.7\end{array}$ & $\begin{array}{l}.93 \\
1.0 \\
.95 \\
1.2 \\
1.2\end{array}$ & $\begin{array}{l}.77 \\
.58 \\
.52 \\
.40 \\
.36\end{array}$ \\
\hline $\begin{array}{l}11 \\
12 \\
13 \\
14 \\
15\end{array}$ & $\begin{array}{r}143 \\
49 \\
27 \\
17 \\
11\end{array}$ & $\begin{array}{l}7.6 \\
6.3 \\
5.5 \\
5.2 \\
4.9\end{array}$ & $\begin{array}{r}10 \\
9.4 \\
8.3 \\
6.8 \\
176\end{array}$ & $\begin{array}{l}43 \\
78 \\
29 \\
35 \\
77\end{array}$ & $\begin{array}{r}18 \\
13 \\
14 \\
27 \\
14\end{array}$ & $\begin{array}{r}5.4 \\
5.6 \\
7.4 \\
9.2 \\
29\end{array}$ & $\begin{array}{r}14 \\
10 \\
e 70 \\
e 140 \\
e 80\end{array}$ & $\begin{array}{l}4.2 \\
4.1 \\
4.1 \\
6.1 \\
9.2\end{array}$ & $\begin{array}{l}2.8 \\
3.2 \\
2.5 \\
2.3 \\
2.4\end{array}$ & $\begin{array}{l}2.3 \\
2.0 \\
2.2 \\
1.6 \\
1.4\end{array}$ & $\begin{array}{l}.88 \\
.77 \\
.74 \\
.74 \\
.74\end{array}$ & $\begin{array}{l}.43 \\
.47 \\
.89 \\
3.5 \\
1.5\end{array}$ \\
\hline $\begin{array}{l}16 \\
17 \\
18 \\
19 \\
20\end{array}$ & $\begin{array}{r}8.1 \\
7.0 \\
177 \\
51 \\
25\end{array}$ & $\begin{array}{l}5.0 \\
4.7 \\
4.3 \\
4.2 \\
4.0\end{array}$ & $\begin{array}{r}73 \\
41 \\
291 \\
210 \\
86\end{array}$ & $\begin{array}{r}252 \\
141 \\
42 \\
29 \\
38\end{array}$ & $\begin{array}{l}\text { e11 } \\
\text { e10 } \\
120 \\
346 \\
150\end{array}$ & $\begin{array}{l}140 \\
299 \\
486 \\
200 \\
e 53\end{array}$ & $\begin{array}{r}e 50 \\
e 27 \\
e 21 \\
e 100 \\
e 90\end{array}$ & $\begin{array}{l}5.2 \\
11 \\
47 \\
23 \\
7.0\end{array}$ & $\begin{array}{l}7.2 \\
3.7 \\
2.5 \\
2.1 \\
2.0\end{array}$ & $\begin{array}{l}1.3 \\
1.2 \\
1.2 \\
1.1 \\
1.1\end{array}$ & $\begin{array}{l}.71 \\
.89 \\
6.6 \\
1.8 \\
1.9\end{array}$ & $\begin{array}{r}.66 \\
.43 \\
e .60 \\
e .52 \\
e .45\end{array}$ \\
\hline $\begin{array}{l}21 \\
22 \\
23 \\
24 \\
25\end{array}$ & $\begin{array}{l}16 \\
26 \\
22 \\
14 \\
11\end{array}$ & $\begin{array}{l}3.8 \\
15 \\
19 \\
8.7 \\
6.4\end{array}$ & $\begin{array}{r}319 \\
250 \\
80 \\
38 \\
\text { e20 }\end{array}$ & $\begin{array}{l}35 \\
\text { e15 } \\
\text { el1 } \\
\text { e } 9.5 \\
\text { e } 8.4\end{array}$ & $\begin{array}{l}69 \\
41 \\
22 \\
17 \\
14\end{array}$ & $\begin{array}{l}\text { e37 } \\
211 \\
249 \\
104 \\
e 37\end{array}$ & $\begin{array}{l}\text { e50 } \\
\text { e34 } \\
\text { e25 } \\
e 23 \\
\text { e20 }\end{array}$ & $\begin{array}{l}5.0 \\
4.4 \\
4.1 \\
3.8 \\
3.7\end{array}$ & $\begin{array}{r}1.9 \\
4.1 \\
4.8 \\
2.6\end{array}$ & $\begin{array}{l}1.2 \\
1.2 \\
1.1 \\
.95 \\
.89\end{array}$ & $\begin{array}{c}1.0 \\
.76 \\
.67 \\
1.2 \\
.83\end{array}$ & $\begin{array}{c}\text { e. } 40 \\
\text { e.50 } \\
2.2 \\
1.5 \\
.71\end{array}$ \\
\hline $\begin{array}{l}26 \\
27 \\
28 \\
29 \\
30 \\
31\end{array}$ & $\begin{array}{l}8.8 \\
7.8 \\
6.8 \\
6.0 \\
5.7 \\
5.4\end{array}$ & $\begin{array}{c}5.3 \\
81 \\
318 \\
104 \\
37 \\
\ldots\end{array}$ & $\begin{array}{r}e 13 \\
e 11 \\
e 10 \\
556 \\
1430 \\
460\end{array}$ & $\begin{array}{r}\text { e7.9 } \\
\text { e7.5 } \\
\text { e7.0 } \\
\text { e6.4 } \\
7.1 \\
\text { e5.5 }\end{array}$ & $\begin{array}{c}11 \\
10 \\
9.7 \\
\ldots . \\
\ldots . \\
\ldots\end{array}$ & $\begin{array}{r}196 \\
e 130 \\
e 60 \\
e 32 \\
e 22 \\
e 18\end{array}$ & $\begin{array}{l}\text { e18 } \\
\text { e16 } \\
\text { e14 } \\
\text { e12 } \\
\text { e11 } \\
\ldots .-\end{array}$ & $\begin{array}{r}4.7 \\
4.3 \\
3.4 \\
3.0 \\
3.2 \\
74\end{array}$ & $\begin{array}{l}1.9 \\
1.7 \\
1.6 \\
1.5 \\
1.4 \\
\ldots . .\end{array}$ & $\begin{array}{r}.81 \\
.79 \\
.74 \\
.87 \\
2.3 \\
1.1\end{array}$ & $\begin{array}{l}.61 \\
.60 \\
.61 \\
.61 \\
.70 \\
.98\end{array}$ & $\begin{array}{l}.59 \\
.53 \\
.56 \\
.54 \\
.50 \\
. .-\end{array}$ \\
\hline $\begin{array}{l}\text { TOTAL } \\
\text { MEAN } \\
\text { MAX } \\
\text { MIN } \\
\text { CF SN } \\
\text { IN. }\end{array}$ & $\begin{array}{r}1654.6 \\
53.4 \\
425 \\
1.9 \\
1.83 \\
2.11\end{array}$ & $\begin{array}{r}808.3 \\
26.9 \\
31.8 \\
3.8 \\
.92 \\
1.03\end{array}$ & $\begin{array}{r}4855.5 \\
157 \\
1430 \\
6.8 \\
5.36 \\
6.19\end{array}$ & $\begin{array}{r}1181.3 \\
38.1 \\
252 \\
5.5 \\
1.31 \\
1.50\end{array}$ & $\begin{array}{r}1716.5 \\
61.3 \\
346 \\
5.2 \\
2.10 \\
2.19\end{array}$ & $\begin{array}{r}2424.6 \\
78.2 \\
486 \\
5.4 \\
2.68 \\
3.09\end{array}$ & $\begin{array}{c}1011 \\
33.7 \\
140 \\
10 \\
1.15 \\
1.29\end{array}$ & $\begin{array}{c}294.9 \\
9.51 \\
74 \\
3.0 \\
.33 \\
.38\end{array}$ & $\begin{array}{c}270.2 \\
9.01 \\
122 \\
1.4 \\
.31 \\
.34\end{array}$ & $\begin{array}{c}118.55 \\
3.82 \\
33 \\
.74 \\
.13 \\
.15\end{array}$ & $\begin{array}{c}33.86 \\
1.09 \\
6.6 \\
.60 \\
.04 \\
.04\end{array}$ & $\begin{array}{r}26.65 \\
.89 \\
3.5 \\
.36 \\
.03 \\
.03\end{array}$ \\
\hline
\end{tabular}

e Estiated

STATISTICS OF MONTHLY MEAN DATA FOR WATER YEARS 1972 - 1991, BY WATER YEAR (WN)

\begin{tabular}{|c|c|c|c|c|c|c|c|c|c|c|c|c|}
\hline $\begin{array}{l}\text { MEAN } \\
\text { MAX } \\
\text { (WY) } \\
\text { MIN } \\
\text { (WY) }\end{array}$ & $\begin{array}{r}8.14 \\
53.4 \\
1991 \\
192 \\
1983\end{array}$ & $\begin{array}{r}23.5 \\
135 \\
1986 \\
1.26 \\
1977\end{array}$ & $\begin{array}{r}42.6 \\
157 \\
1991 \\
1.63 \\
1977\end{array}$ & $\begin{array}{r}29.1 \\
92.7 \\
1974 \\
.76 \\
1977\end{array}$ & $\begin{array}{r}49.2 \\
124 \\
1990 \\
3.41 \\
1978\end{array}$ & $\begin{array}{r}61.6 \\
152 \\
1978 \\
9.38 \\
1983\end{array}$ & $\begin{array}{r}41.6 \\
112 \\
1972 \\
4.85 \\
1976\end{array}$ & $\begin{array}{r}25.4 \\
114 \\
1981 \\
2.37 \\
1988\end{array}$ & $\begin{array}{r}27.7 \\
148 \\
1981 \\
1.21 \\
1988\end{array}$ & $\begin{array}{l}14.4 \\
78.7 \\
1990 \\
1.11 \\
1977\end{array}$ & $\begin{array}{r}9.67 \\
45.9 \\
1980 \\
.95 \\
1988\end{array}$ & $\begin{array}{r}8.01 \\
55.0 \\
1972 \\
1981\end{array}$ \\
\hline
\end{tabular}

\section{SUMMARY STATISTICS}

ANMUAL TOTAL

ANMUAL MEAN

HIGHEST ANNUAL MEAN

LOWEST ANNUAL MEAN

HIGHEST DAILY MEAN

LOWEST DAILY MEAN

ANNUAL SEVEN-DAY MINIMUM

INSTANTANEOUS PEAK FLOW

INSTANTANEOUS PEAK STAGE

ANNUAL RUNOFF (CFSM)

ANMUAL RUNOFF (INCHES)

10 PERCENT EXCEEDS

50 PERCENT EXCEEDS

90 PERCENT EXCEEDS
FOR 1990 CALENDAR YEAR

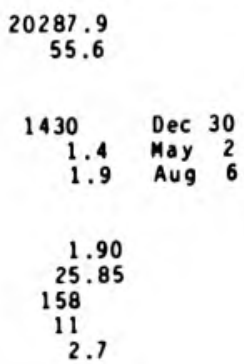

FOR 1991 WATER YEAR

14395.96
39.4

1430 Dec 30

$\begin{array}{rr}.36 & \text { Sep } 10 \\ 1640^{.50} & \text { Sep } 6 \\ \text { Dec } 30\end{array}$

15.45 Dec 30
1.35

1.35

102.3

8. 1
WATER YEARS 1972 - 1991

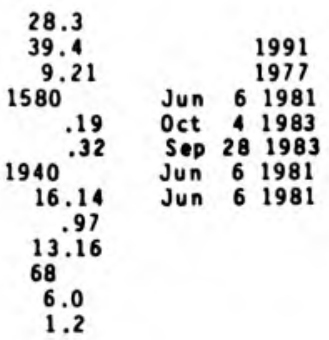




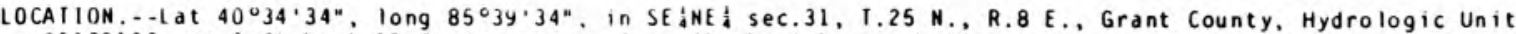
05120103 , on left bank $12 \mathrm{ft}$ downstrea from Highland Avenue bridge in Marion, 0.1 a downstrea from old ill dan, 1.0 i upstreas from Humel Creek, 4.6 i downstrea froe Lugar Creek, and at aile 35.8 .

DRAINAGE AREA, -682 i i $^{2}$

PERIOD OF RECORD.--Septeaber 1923 to current year. Monthly discharge only for sone periods, published in wSP 1305 . REVISED RECORDS...WSP 1335: 1927(M). WSP 1385: 1948. WSP 2109: Drainage area.

GAGE.--Water-stage recorder. Datum of gage is $774.56 \mathrm{ft}$ above National Geodetic Vertical Datun of 1929 . Prior to Dec. 9, 1933, nonrecording gage at same site and datum.

REMARKS. - Records good except for estiated daily discharges, which are poor. Flow periodically regulated by dae 0.1 ile above station. 1930 water year not used in suadry statistics.

EXTREMES OUTSIDE PERIOD OF RECORD. - Flood in March 1913 reached a stage of $19.20 \mathrm{ft}$ from inforation by State of Indiana. Departant of Natural Resources.

DISCHARGE, CUBIL FEET PER SECOND, WATER YEAR OCTOBER 1990 TO SEPTEMBER 1991 DAILY MEAN VALUES

\begin{tabular}{|c|c|c|c|c|c|c|c|c|c|c|c|c|}
\hline DAY & $O C T$ & MOV & DEC & JAN & FEB & MAR & APR & MAY & JUN & JUL & AUG & SEP \\
\hline $\begin{array}{l}1 \\
2 \\
3 \\
4 \\
5\end{array}$ & $\begin{array}{r}212 \\
198 \\
163 \\
700 \\
2570\end{array}$ & $\begin{array}{l}248 \\
241 \\
234 \\
226 \\
300\end{array}$ & $\begin{array}{r}872 \\
642 \\
2410 \\
4780 \\
2720\end{array}$ & $\begin{array}{r}14200 \\
4500 \\
1670 \\
1140 \\
891\end{array}$ & $\begin{array}{r}339 \\
324 \\
316 \\
820 \\
2200\end{array}$ & $\begin{array}{l}364 \\
391 \\
406 \\
382 \\
340\end{array}$ & $\begin{array}{l}597 \\
537 \\
485 \\
459 \\
526\end{array}$ & $\begin{array}{l}325 \\
303 \\
278 \\
267 \\
277\end{array}$ & $\begin{array}{r}1360 \\
1190 \\
668 \\
404 \\
309\end{array}$ & $\begin{array}{l}100 \\
385 \\
251 \\
176 \\
140\end{array}$ & $\begin{array}{l}62 \\
60 \\
64 \\
63 \\
60\end{array}$ & $\begin{array}{l}51 \\
48 \\
47 \\
54 \\
53\end{array}$ \\
\hline $\begin{array}{r}6 \\
7 \\
8 \\
9 \\
10\end{array}$ & $\begin{array}{r}1210 \\
624 \\
593 \\
670 \\
3750\end{array}$ & $\begin{array}{l}648 \\
572 \\
414 \\
330 \\
306\end{array}$ & $\begin{array}{r}1200 \\
822 \\
648 \\
540 \\
475\end{array}$ & $\begin{array}{l}146 \\
642 \\
567 \\
510 \\
459\end{array}$ & $\begin{array}{l}2840 \\
3400 \\
2800 \\
1470 \\
1030\end{array}$ & $\begin{array}{l}321 \\
307 \\
286 \\
267 \\
251\end{array}$ & $\begin{array}{l}554 \\
493 \\
560 \\
912 \\
684\end{array}$ & $\begin{array}{l}291 \\
271 \\
257 \\
240 \\
225\end{array}$ & $\begin{array}{r}249 \\
176 \\
94 \\
175 \\
162\end{array}$ & $\begin{array}{l}116 \\
106 \\
488 \\
395 \\
243\end{array}$ & $\begin{array}{l}61 \\
61 \\
81 \\
81 \\
68\end{array}$ & $\begin{array}{r}53 \\
50 \\
49 \\
50 \\
128\end{array}$ \\
\hline $\begin{array}{l}11 \\
12 \\
13 \\
14 \\
15\end{array}$ & $\begin{array}{r}5060 \\
2540 \\
1260 \\
878 \\
662\end{array}$ & $\begin{array}{l}292 \\
299 \\
275 \\
250 \\
238\end{array}$ & $\begin{array}{l}428 \\
397 \\
367 \\
330 \\
705\end{array}$ & $\begin{array}{r}485 \\
1190 \\
1400 \\
848 \\
1110\end{array}$ & $\begin{array}{l}797 \\
614 \\
526 \\
562 \\
614\end{array}$ & $\begin{array}{l}244 \\
246 \\
277 \\
325 \\
481\end{array}$ & $\begin{array}{r}522 \\
408 \\
462 \\
1610 \\
3550\end{array}$ & $\begin{array}{l}218 \\
215 \\
212 \\
209 \\
311\end{array}$ & $\begin{array}{l}160 \\
152 \\
152 \\
148 \\
145\end{array}$ & $\begin{array}{r}155 \\
130 \\
116 \\
101 \\
91\end{array}$ & $\begin{array}{l}63 \\
59 \\
57 \\
57 \\
56\end{array}$ & $\begin{array}{l}72 \\
13 \\
13 \\
14 \\
15\end{array}$ \\
\hline $\begin{array}{l}16 \\
17 \\
18 \\
19 \\
20\end{array}$ & $\begin{array}{r}528 \\
446 \\
599 \\
1280 \\
873\end{array}$ & $\begin{array}{l}230 \\
226 \\
219 \\
212 \\
209\end{array}$ & $\begin{array}{l}2590 \\
2240 \\
1910 \\
4260 \\
3690\end{array}$ & $\begin{array}{r}2400 \\
3380 \\
2150 \\
1170 \\
961\end{array}$ & $\begin{array}{r}431 \\
432 \\
584 \\
2710 \\
3180\end{array}$ & $\begin{array}{r}933 \\
2750 \\
6690 \\
6450 \\
2900\end{array}$ & $\begin{array}{r}2190 \\
1180 \\
865 \\
1050 \\
3100\end{array}$ & $\begin{array}{l}286 \\
414 \\
373 \\
410 \\
318\end{array}$ & $\begin{array}{l}150 \\
200 \\
167 \\
141 \\
125\end{array}$ & $\begin{array}{l}84 \\
79 \\
76 \\
74 \\
70\end{array}$ & $\begin{array}{r}54 \\
56 \\
57 \\
104 \\
72\end{array}$ & $\begin{array}{l}31 \\
40 \\
40 \\
41 \\
41\end{array}$ \\
\hline $\begin{array}{l}21 \\
22 \\
23 \\
24 \\
25\end{array}$ & $\begin{array}{l}574 \\
479 \\
519 \\
611 \\
477\end{array}$ & $\begin{array}{l}203 \\
217 \\
257 \\
417 \\
355\end{array}$ & $\begin{array}{l}2500 \\
4840 \\
4090 \\
2210 \\
1290\end{array}$ & $\begin{array}{r}1050 \\
862 \\
644 \\
529 \\
403\end{array}$ & $\begin{array}{r}1960 \\
1110 \\
782 \\
608 \\
513\end{array}$ & $\begin{array}{l}1660 \\
1790 \\
3740 \\
3300 \\
1710\end{array}$ & $\begin{array}{r}1930 \\
1050 \\
835 \\
756 \\
686\end{array}$ & $\begin{array}{l}255 \\
237 \\
352 \\
367 \\
330\end{array}$ & $\begin{array}{l}117 \\
114 \\
360 \\
269 \\
181\end{array}$ & $\begin{array}{l}68 \\
67 \\
67 \\
66 \\
64\end{array}$ & $\begin{array}{l}64 \\
59 \\
58 \\
54 \\
53\end{array}$ & $\begin{array}{l}40 \\
40 \\
41 \\
39 \\
40\end{array}$ \\
\hline $\begin{array}{l}26 \\
27 \\
28 \\
29 \\
30 \\
31\end{array}$ & $\begin{array}{l}399 \\
347 \\
313 \\
288 \\
270 \\
257\end{array}$ & $\begin{array}{r}285 \\
303 \\
1840 \\
3110 \\
1660 \\
\cdots\end{array}$ & $\begin{array}{r}852 \\
620 \\
554 \\
3790 \\
18100 \\
20500\end{array}$ & $\begin{array}{r}\text { e } 385 \\
\text { e } 365 \\
\text { e } 350 \\
\text { e } 335 \\
\text { e325 } \\
317\end{array}$ & $\begin{array}{l}449 \\
403 \\
375 \\
\ldots \\
\cdots \\
\cdots\end{array}$ & $\begin{array}{r}1570 \\
2860 \\
2340 \\
1290 \\
871 \\
685\end{array}$ & $\begin{array}{l}467 \\
433 \\
402 \\
378 \\
348 \\
\cdots\end{array}$ & $\begin{array}{l}298 \\
403 \\
272 \\
239 \\
232 \\
453\end{array}$ & $\begin{array}{r}129 \\
107 \\
109 \\
97 \\
86 \\
\cdots\end{array}$ & $\begin{array}{l}64 \\
63 \\
61 \\
59 \\
60 \\
63\end{array}$ & $\begin{array}{l}53 \\
52 \\
52 \\
51 \\
73 \\
58\end{array}$ & $\begin{array}{l}39 \\
39 \\
38 \\
39 \\
39 \\
-\end{array}$ \\
\hline $\begin{array}{l}\text { IOTAL } \\
\text { MEAN } \\
\text { MAX } \\
\text { MIN } \\
\text { CF SM } \\
\text { IN. }\end{array}$ & $\begin{array}{r}29350 \\
947 \\
5060 \\
163 \\
1.39 \\
1.60\end{array}$ & $\begin{array}{r}14616 \\
487 \\
3110 \\
203 \\
.71 \\
.80\end{array}$ & $\begin{array}{r}91372 \\
2947 \\
20500 \\
330 \\
4.32 \\
4.98\end{array}$ & $\begin{array}{r}45984 \\
1483 \\
14200 \\
317 \\
2.18 \\
2.51\end{array}$ & $\begin{array}{r}32189 \\
1150 \\
3400 \\
316 \\
1.69 \\
1.76\end{array}$ & $\begin{array}{r}46427 \\
1498 \\
6690 \\
244 \\
2.20 \\
2.53\end{array}$ & $\begin{array}{r}28029 \\
934 \\
3550 \\
348 \\
1.37 \\
1.53\end{array}$ & $\begin{array}{c}9138 \\
295 \\
453 \\
209 \\
.43 \\
.50\end{array}$ & $\begin{array}{r}7896 \\
263 \\
1360 \\
86 \\
.39 \\
.43\end{array}$ & $\begin{array}{c}4078 \\
132 \\
488 \\
59 \\
.19 \\
.22\end{array}$ & $\begin{array}{c}1929 \\
62.2 \\
104 \\
51 \\
.09 \\
.11\end{array}$ & $\begin{array}{c}1297 \\
43.2 \\
128 \\
13 \\
.06 \\
.07\end{array}$ \\
\hline
\end{tabular}

e Estinated

SIATISTICS OF MONIHLY MEAN DATA FOR WATER YEARS 1924 - 1991, BY WATER YEAR (WY)

\begin{tabular}{|c|c|c|c|c|c|c|c|c|c|c|c|c|}
\hline $\begin{array}{l}\text { MEAN } \\
\text { MAX } \\
\text { (WY) } \\
\text { MIN } \\
\text { (WY) }\end{array}$ & $\begin{array}{l}171 \\
1072 \\
1927 \\
22.8 \\
1929\end{array}$ & $\begin{array}{r}364 \\
2495 \\
1973 \\
28.0 \\
1929\end{array}$ & $\begin{array}{r}717 \\
2947 \\
1991 \\
36.9 \\
1964\end{array}$ & $\begin{array}{r}903 \\
5129 \\
1930 \\
36.1 \\
1945\end{array}$ & $\begin{array}{r}975 \\
2707 \\
1990 \\
52.5 \\
1964\end{array}$ & $\begin{array}{l}1281 \\
3181 \\
1982 \\
65.3 \\
1941\end{array}$ & $\begin{array}{r}1149 \\
3699 \\
1964 \\
123 \\
1941\end{array}$ & $\begin{array}{l}706 \\
3776 \\
1933 \\
40.5 \\
1941\end{array}$ & $\begin{array}{r}604 \\
4765 \\
1958 \\
49.3 \\
1988\end{array}$ & $\begin{array}{r}334 \\
2159 \\
1962 \\
32.6 \\
1936\end{array}$ & $\begin{array}{r}190 \\
1293 \\
1926 \\
25.4 \\
1940\end{array}$ & $\begin{array}{r}230 \\
4222 \\
1926 \\
24.1 \\
1940\end{array}$ \\
\hline
\end{tabular}

FUR 1990 CALENUAR YEAR

\begin{tabular}{|c|c|}
\hline $\begin{array}{r}20500 \\
113 \\
127\end{array}$ & $\begin{array}{l}\text { Dec } 3 \\
\text { Jul } \\
\text { Jul }\end{array}$ \\
\hline $\begin{array}{r}1.72 \\
23.29 \\
1100 \\
480 \\
196\end{array}$ & \\
\hline
\end{tabular}

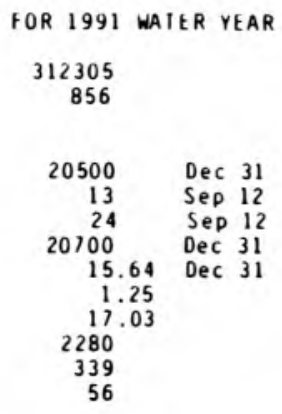

WAIER YEARS 1924 - 1991

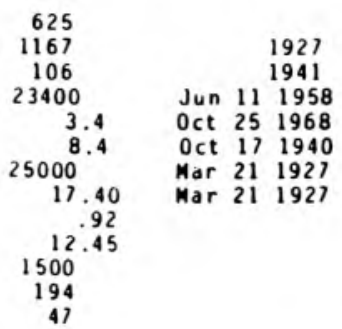


LOCATION.--Lat $40^{\circ} 43^{\prime} 24^{\prime \prime}$, Iong $85^{\circ} 57^{\prime} 27^{\prime \prime}$, in SW:SWl sec.3, I.26 N., R.5 E., Miani County, Hydrologic Unit 05120103 , on right bank at Peorid, 0.6 a i downstrea frumississinewa iake, 6.5 a southeast of Peru, and $6.7 . i$ upstrea from auth.

DRAINAGE AREA. $\cdots 808 \bullet i^{2}$.

PERIOD OF RECORD..-OCtober 1952 to current year.

REVISED RECORDS.-.WSP 1335: 1953. WSP 2109: Drainage area.

GAGE.--Data-Collection Platform. Datum of gage was $660.00 \mathrm{ft}$ above National Geodetic Vertical Datun of 1929 . 0ct. 1. 1962. to Sept. 30, 1974, water-stage recorder at site described in "LOCATION" paragraph. Prior to 0ct. 7. 1954, nonrecording gage and crest-stage gage on highway bridge 2,500 ft upstrean, and $0 \mathrm{ct}$. 7 , 1954 , to Sept. 30, 1962, water-stage recorder on right bank at site $2,500 \mathrm{ft}$ upstrea at sane datua. Uata-Coilection Platfore installed on Aug. 21, 1986.

REMARKS. - Flow regulated by Mississinewa Lake since April 1968. Daily discharge coaputed froe relation between discharge, head, and gate openings for Mississinewa Lake beginning $0 \mathrm{ct} .1,1974$.

COOPERAIION. - Records of daily discharge provided by U.S. Aray Corps of Engineers beginning 0ct. 1.1916 .

AVERAGE DISCHARGE. . 39 years. $125 \mathrm{ft} \%$

EXIREMES FOR PERIOD OF RECORD. - Maximundischarge, $28,000 \mathrm{ft} / \mathrm{s}$ June 11 , 1958 , gage height 19.26 ft, site then in use: zero flow. Sept. 11 to $0 \mathrm{ct}$. L, 1985.

EXIREMES FOR CURRENT YEAR. -. Maximum dally discharge, 6,090 $\mathrm{ft}^{3} / \mathrm{s}$ Mar. 4; inimun daily, 37 ft $3 / 5$ Aug. 21 to Sept. 10.

DISCHARGE, CUBIC FEET PER SECOND, WATER YEAR OCTOBER 1990 TO SEPIEMBER 1991 DAIIY MEAN VALUES

\begin{tabular}{|c|c|c|c|c|c|c|c|c|c|c|c|c|}
\hline DAY & $O C \mathrm{I}$ & NOV & $\mathrm{DEC}$ & JAN & FEB & MAR & $A P R$ & MAY & JUN & JUL & AUG & SEP \\
\hline $\begin{array}{l}1 \\
2 \\
3 \\
4 \\
5\end{array}$ & $\begin{array}{r}161 \\
161 \\
204 \\
336 \\
2060\end{array}$ & $\begin{array}{l}721 \\
691 \\
669 \\
667 \\
744\end{array}$ & $\begin{array}{r}2330 \\
2590 \\
1870 \\
957 \\
1800\end{array}$ & $\begin{array}{r}55 \\
\angle 60 \\
900 \\
1960 \\
2940\end{array}$ & $\begin{array}{r}355 \\
389 \\
389 \\
534 \\
1710\end{array}$ & $\begin{array}{l}441 \\
490 \\
457 \\
403 \\
382\end{array}$ & $\begin{array}{r}1740 \\
283 \\
152 \\
88 \\
73\end{array}$ & $\begin{array}{l}195 \\
354 \\
395 \\
394 \\
305\end{array}$ & $\begin{array}{r}653 \\
656 \\
881 \\
1010 \\
909\end{array}$ & $\begin{array}{l}110 \\
175 \\
380 \\
467 \\
365\end{array}$ & $\begin{array}{l}47 \\
47 \\
47 \\
47 \\
47\end{array}$ & $\begin{array}{l}37 \\
37 \\
37 \\
37 \\
37\end{array}$ \\
\hline $\begin{array}{r}6 \\
7 \\
8 \\
9 \\
10\end{array}$ & $\begin{array}{r}1900 \\
1140 \\
687 \\
521 \\
241\end{array}$ & $\begin{array}{r}799 \\
799 \\
797 \\
943 \\
1010\end{array}$ & $\begin{array}{l}2360 \\
2330 \\
2300 \\
2260 \\
2210\end{array}$ & $\begin{array}{l}3240 \\
3220 \\
3200 \\
3190 \\
3170\end{array}$ & $\begin{array}{l}2850 \\
3600 \\
3950 \\
3600 \\
1590\end{array}$ & $\begin{array}{l}382 \\
382 \\
382 \\
339 \\
290\end{array}$ & $\begin{array}{l}74 \\
75 \\
76 \\
77 \\
79\end{array}$ & $\begin{array}{l}252 \\
252 \\
252 \\
266 \\
275\end{array}$ & $\begin{array}{l}577 \\
352 \\
192 \\
192 \\
152\end{array}$ & $\begin{array}{l}217 \\
171 \\
305 \\
564 \\
487\end{array}$ & $\begin{array}{r}73 \\
89 \\
131 \\
193 \\
193\end{array}$ & $\begin{array}{l}37 \\
37 \\
37 \\
37 \\
37\end{array}$ \\
\hline $\begin{array}{l}11 \\
12 \\
13 \\
14 \\
15\end{array}$ & $\begin{array}{r}85 \\
97 \\
98 \\
98 \\
691\end{array}$ & $\begin{array}{l}927 \\
820 \\
810 \\
805 \\
801\end{array}$ & $\begin{array}{r}1270 \\
517 \\
471 \\
416 \\
547\end{array}$ & $\begin{array}{l}3200 \\
2970 \\
3610 \\
3900 \\
3870\end{array}$ & $\begin{array}{l}868 \\
966 \\
782 \\
649 \\
649\end{array}$ & $\begin{array}{l}277 \\
277 \\
322 \\
355 \\
508\end{array}$ & $\begin{array}{r}79 \\
80 \\
81 \\
81 \\
262\end{array}$ & $\begin{array}{l}275 \\
275 \\
274 \\
274 \\
274\end{array}$ & $\begin{array}{l}132 \\
146 \\
179 \\
193 \\
193\end{array}$ & $\begin{array}{l}288 \\
202 \\
110 \\
110 \\
110\end{array}$ & $\begin{array}{r}148 \\
127 \\
154 \\
154 \\
96\end{array}$ & $\begin{array}{r}82 \\
111 \\
209 \\
360 \\
359\end{array}$ \\
\hline $\begin{array}{l}16 \\
17 \\
18 \\
19 \\
20\end{array}$ & $\begin{array}{l}1470 \\
1990 \\
1980 \\
1970 \\
1970\end{array}$ & $\begin{array}{l}796 \\
192 \\
741 \\
645 \\
592\end{array}$ & $\begin{array}{l}1720 \\
1700 \\
1330 \\
1610 \\
1670\end{array}$ & $\begin{array}{l}3490 \\
1880 \\
1690 \\
2650 \\
3580\end{array}$ & $\begin{array}{r}431 \\
399 \\
798 \\
1620 \\
2170\end{array}$ & $\begin{array}{r}626 \\
634 \\
879 \\
1110 \\
1140\end{array}$ & $\begin{array}{r}932 \\
1530 \\
1120 \\
675 \\
1130\end{array}$ & $\begin{array}{l}274 \\
275 \\
384 \\
488 \\
488\end{array}$ & $\begin{array}{l}193 \\
193 \\
211 \\
223 \\
223\end{array}$ & $\begin{array}{r}110 \\
111 \\
91 \\
77 \\
17\end{array}$ & $\begin{array}{r}68 \\
68 \\
68 \\
115 \\
70\end{array}$ & $\begin{array}{l}399 \\
464 \\
276 \\
233 \\
244\end{array}$ \\
\hline $\begin{array}{l}21 \\
22 \\
23 \\
24 \\
25\end{array}$ & $\begin{array}{l}1960 \\
2360 \\
2540 \\
2520 \\
2910\end{array}$ & $\begin{array}{l}298 \\
165 \\
492 \\
143 \\
862\end{array}$ & $\begin{array}{l}1430 \\
1100 \\
1130 \\
1520 \\
1820\end{array}$ & $\begin{array}{l}4170 \\
4880 \\
5540 \\
5970 \\
6020\end{array}$ & $\begin{array}{r}2610 \\
2850 \\
1780 \\
682 \\
743\end{array}$ & $\begin{array}{l}1380 \\
1700 \\
2250 \\
2530 \\
2770\end{array}$ & $\begin{array}{r}1730 \\
1860 \\
1270 \\
736 \\
373\end{array}$ & $\begin{array}{l}353 \\
261 \\
261 \\
317 \\
455\end{array}$ & $\begin{array}{l}223 \\
178 \\
128 \\
146 \\
213\end{array}$ & $\begin{array}{l}71 \\
64 \\
60 \\
68 \\
68\end{array}$ & $\begin{array}{l}37 \\
37 \\
37 \\
37 \\
37\end{array}$ & $\begin{array}{l}463 \\
462 \\
462 \\
328 \\
328\end{array}$ \\
\hline $\begin{array}{l}26 \\
27 \\
28 \\
29 \\
30 \\
31\end{array}$ & $\begin{array}{r}3150 \\
3110 \\
1900 \\
1050 \\
899 \\
749\end{array}$ & $\begin{array}{r}795 \\
745 \\
885 \\
1020 \\
1550 \\
\ldots\end{array}$ & $\begin{array}{r}1940 \\
2020 \\
2000 \\
1100 \\
47 \\
52\end{array}$ & $\begin{array}{l}5 y 06 \\
6030 \\
6090 \\
5910 \\
4800 \\
1450\end{array}$ & $\begin{array}{l}586 \\
412 \\
372 \\
\ldots \\
\ldots \\
\ldots\end{array}$ & $\begin{array}{l}3350 \\
3150 \\
3080 \\
3540 \\
3500 \\
3540\end{array}$ & $\begin{array}{r}99 \\
109 \\
109 \\
110 \\
130 \\
\ldots\end{array}$ & $\begin{array}{l}639 \\
706 \\
594 \\
323 \\
261 \\
524\end{array}$ & $\begin{array}{l}223 \\
234 \\
239 \\
239 \\
151 \\
\cdots\end{array}$ & $\begin{array}{l}68 \\
68 \\
68 \\
68 \\
57 \\
47\end{array}$ & $\begin{array}{l}37 \\
37 \\
37 \\
37 \\
37 \\
37\end{array}$ & $\begin{array}{l}460 \\
459 \\
408 \\
386 \\
385 \\
\cdots\end{array}$ \\
\hline $\begin{array}{l}\text { TOTAL } \\
\text { MEAN } \\
\text { MAX } \\
\text { MIN }\end{array}$ & $\begin{array}{r}41008 \\
1323 \\
3150 \\
85\end{array}$ & $\begin{array}{r}23124 \\
771 \\
1550 \\
165\end{array}$ & $\begin{array}{r}46417 \\
1497 \\
2590 \\
47\end{array}$ & $\begin{array}{r}109735 \\
3540 \\
6090 \\
55\end{array}$ & $\begin{array}{r}38134 \\
1369 \\
3950 \\
355\end{array}$ & $\begin{array}{r}40866 \\
1318 \\
3540 \\
277\end{array}$ & $\begin{array}{r}15213 \\
507 \\
1860 \\
73\end{array}$ & $\begin{array}{r}10915 \\
352 \\
706 \\
195\end{array}$ & $\begin{array}{r}9434 \\
314 \\
1010 \\
128\end{array}$ & $\begin{array}{c}5240 \\
169 \\
564 \\
47\end{array}$ & $\begin{array}{c}2389 \\
77.1 \\
193 \\
37\end{array}$ & $\begin{array}{c}7248 \\
242 \\
464 \\
37\end{array}$ \\
\hline
\end{tabular}

CAL YR 1990 TOTAL 404483 MEAN 1108 MAX 5350 MIN 47 WTR YR 1991 TOIAL 349923 MEAN 959 MAX 6090 MIN 37 


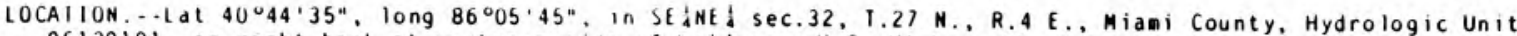
05120101 , on right bank at upstream side of bridge on U.S. Highway $31,0.5 \mathrm{mi}$ southwest of Peru, $4.4 \mathrm{mi}$ downstrean from Missişsinewa River, and at mile 370.5 .

DRAINAGE AREA. $\cdots 2,686 \mathrm{~m}^{2}$

PERIOD OF RECORD...August 1943 to current yedr.

REVISED RECORDS.--WSP 2109: Drainage ared. WDR IN-74-1: 1973. WDR IN-81-1: 1979.

GAGE. - Water-stage recorder. Datum of gage is $617.94 \mathrm{ft}$ above National Geodetic Vertical Datum of 1929 (levels by U.S. Army Corps of Engineers). Prior to June 20,1961, nonrecording gage at same site and datum.

REMARKS.--Records good. Flow regulated by Huntington Lake, Salanonie Lake and Mississinewa Lake. EXTREMES OUISIDE PERIOD OF RECORD. - Flood of Mar. 26,1913 , reached a stage of $28.1 \mathrm{ft}$, discharge, $115,000 \mathrm{ft} / \mathrm{s}$,
from rating curve extended above $63,000 \mathrm{ft} / \mathrm{s}$.

DISCHARGE, CUBIC FEEI PER SECONO, WATER YEAR OCTOBER 1990 TO SEPIEMBER 1991 DAILY MEAN VALUES

\begin{tabular}{|c|c|c|c|c|c|c|c|c|c|c|c|c|}
\hline DAY & $\mathrm{OCI}$ & NOV & $\mathrm{DEC}$ & JAN & FEB & MAR & APR & MAY & JUN & JUL & AUG & SEP \\
\hline $\begin{array}{l}1 \\
2 \\
3 \\
4 \\
5\end{array}$ & $\begin{array}{r}931 \\
935 \\
914 \\
1120 \\
2980\end{array}$ & $\begin{array}{l}1520 \\
1490 \\
2690 \\
3390 \\
3920\end{array}$ & $\begin{array}{l}6350 \\
6530 \\
7330 \\
7640 \\
8500\end{array}$ & $\begin{array}{l}8220 \\
7690 \\
7640 \\
8640 \\
9510\end{array}$ & $\begin{array}{l}1380 \\
1390 \\
1470 \\
1920 \\
3880\end{array}$ & $\begin{array}{l}1580 \\
1860 \\
2030 \\
1890 \\
1750\end{array}$ & $\begin{array}{l}3860 \\
1490 \\
1110 \\
1050 \\
1120\end{array}$ & $\begin{array}{l}736 \\
906 \\
951 \\
898 \\
869\end{array}$ & $\begin{array}{r}10300 \\
6990 \\
5620 \\
5520 \\
5640\end{array}$ & $\begin{array}{r}356 \\
480 \\
806 \\
1080 \\
1140\end{array}$ & $\begin{array}{l}181 \\
167 \\
151 \\
150 \\
155\end{array}$ & $\begin{array}{l}163 \\
175 \\
199 \\
196 \\
216\end{array}$ \\
\hline $\begin{array}{r}6 \\
7 \\
8 \\
9 \\
10\end{array}$ & $\begin{array}{l}5620 \\
3950 \\
2420 \\
3760 \\
8540\end{array}$ & $\begin{array}{l}5110 \\
3260 \\
2760 \\
2810 \\
3000\end{array}$ & $\begin{array}{l}9500 \\
9110 \\
7700 \\
5880 \\
4090\end{array}$ & $\begin{array}{l}10300 \\
11400 \\
11500 \\
11400 \\
11000\end{array}$ & $\begin{array}{l}7750 \\
9860 \\
9960 \\
8500 \\
6150\end{array}$ & $\begin{array}{l}1710 \\
1340 \\
1340 \\
1360 \\
1240\end{array}$ & $\begin{array}{l}1440 \\
1230 \\
1160 \\
1600 \\
1780\end{array}$ & $\begin{array}{l}849 \\
900 \\
886 \\
862 \\
844\end{array}$ & $\begin{array}{r}5780 \\
4520 \\
2990 \\
1430 \\
912\end{array}$ & $\begin{array}{r}860 \\
822 \\
1640 \\
1990 \\
2160\end{array}$ & $\begin{array}{l}166 \\
194 \\
232 \\
358 \\
338\end{array}$ & 17 \\
\hline $\begin{array}{l}11 \\
12 \\
13 \\
14 \\
15\end{array}$ & $\begin{array}{l}6390 \\
4420 \\
3510 \\
3430 \\
4120\end{array}$ & $\begin{array}{l}2850 \\
2150 \\
2090 \\
2220 \\
2540\end{array}$ & $\begin{array}{l}3040 \\
1860 \\
1660 \\
1460 \\
1830\end{array}$ & $\begin{array}{l}10400 \\
10700 \\
11000 \\
11500 \\
11800\end{array}$ & $\begin{array}{l}3990 \\
3080 \\
2490 \\
2350 \\
2120\end{array}$ & $\begin{array}{l}1140 \\
1160 \\
1140 \\
1220 \\
1340\end{array}$ & $\begin{array}{l}1510 \\
1240 \\
1090 \\
1160 \\
2800\end{array}$ & $\begin{array}{l}831 \\
819 \\
796 \\
746 \\
763\end{array}$ & $\begin{array}{l}842 \\
815 \\
734 \\
669 \\
609\end{array}$ & $\begin{array}{l}991 \\
649 \\
440 \\
395 \\
349\end{array}$ & $\begin{array}{l}324 \\
276 \\
284 \\
267 \\
248\end{array}$ & 51 \\
\hline $\begin{array}{l}16 \\
17 \\
18 \\
19 \\
20\end{array}$ & $\begin{array}{l}5670 \\
5140 \\
7020 \\
6290 \\
5880\end{array}$ & $\begin{array}{l}2530 \\
2290 \\
2210 \\
1830 \\
1740\end{array}$ & $\begin{array}{l}3940 \\
5730 \\
4850 \\
7310 \\
7540\end{array}$ & $\begin{array}{r}12900 \\
11100 \\
8790 \\
9750 \\
10500\end{array}$ & $\begin{array}{l}1650 \\
1310 \\
1910 \\
4910 \\
8740\end{array}$ & $\begin{array}{l}1720 \\
2620 \\
5890 \\
6710 \\
6280\end{array}$ & $\begin{array}{l}5790 \\
5930 \\
4340 \\
2860 \\
5120\end{array}$ & $\begin{array}{l}695 \\
653 \\
754 \\
952 \\
968\end{array}$ & $\begin{array}{l}596 \\
588 \\
583 \\
515 \\
483\end{array}$ & $\begin{array}{l}348 \\
325 \\
291 \\
247 \\
236\end{array}$ & $\begin{array}{l}186 \\
187 \\
236 \\
302 \\
313\end{array}$ & $\begin{array}{l}511 \\
835 \\
769 \\
701 \\
699\end{array}$ \\
\hline $\begin{array}{l}21 \\
22 \\
23 \\
24 \\
25\end{array}$ & $\begin{array}{l}6240 \\
6680 \\
7020 \\
6140 \\
5840\end{array}$ & $\begin{array}{l}1740 \\
1900 \\
1860 \\
1770 \\
1960\end{array}$ & $\begin{array}{r}8730 \\
9260 \\
7520 \\
7010 \\
e 6200\end{array}$ & $\begin{array}{l}10800 \\
11200 \\
12300 \\
12200 \\
12100\end{array}$ & $\begin{array}{l}9310 \\
9130 \\
7840 \\
4000 \\
2960\end{array}$ & $\begin{array}{l}6010 \\
5160 \\
5150 \\
6650 \\
7540\end{array}$ & $\begin{array}{l}5390 \\
6470 \\
6070 \\
4410 \\
3330\end{array}$ & $\begin{array}{r}916 \\
798 \\
882 \\
1170 \\
1490\end{array}$ & $\begin{array}{l}508 \\
493 \\
424 \\
393 \\
430\end{array}$ & $\begin{array}{l}220 \\
209 \\
213 \\
216 \\
225\end{array}$ & $\begin{array}{l}223 \\
206 \\
179 \\
177 \\
168\end{array}$ & $\begin{array}{l}880 \\
926 \\
776 \\
775 \\
773\end{array}$ \\
\hline $\begin{array}{l}26 \\
27 \\
28 \\
29 \\
30 \\
31\end{array}$ & $\begin{array}{l}4690 \\
4400 \\
3420 \\
2030 \\
1820 \\
1590\end{array}$ & $\begin{array}{c}2000 \\
2050 \\
4380 \\
5650 \\
5410 \\
\ldots\end{array}$ & $\begin{array}{l}\text { e } 5600 \\
\text { e } 5200 \\
\text { e } 5000 \\
10200 \\
17400 \\
11400\end{array}$ & $\begin{array}{r}11500 \\
9820 \\
8030 \\
6860 \\
6040 \\
3250\end{array}$ & $\begin{array}{c}2280 \\
1960 \\
1580 \\
\ldots \\
\ldots \\
\ldots\end{array}$ & $\begin{array}{l}7810 \\
8330 \\
7190 \\
8200 \\
6950 \\
5480\end{array}$ & $\begin{array}{r}1790 \\
1170 \\
948 \\
794 \\
713 \\
\ldots\end{array}$ & $\begin{array}{l}3070 \\
3160 \\
2340 \\
1530 \\
1620 \\
8930\end{array}$ & $\begin{array}{l}439 \\
441 \\
494 \\
495 \\
448 \\
\ldots\end{array}$ & $\begin{array}{l}217 \\
210 \\
185 \\
188 \\
182 \\
177\end{array}$ & $\begin{array}{l}166 \\
162 \\
163 \\
169 \\
187 \\
184\end{array}$ & $\begin{array}{l}908 \\
841 \\
946 \\
912 \\
902 \\
\cdots--\end{array}$ \\
\hline $\begin{array}{l}\text { IOIAL } \\
\text { MEAN } \\
\text { MAX } \\
\text { MIN } \\
\text { CFSM } \\
\text { IN. }\end{array}$ & $\begin{array}{r}132916 \\
4288 \\
8540 \\
914 \\
1.60 \\
1.84\end{array}$ & $\begin{array}{r}81120 \\
2704 \\
5650 \\
1490 \\
1.01 \\
1.12\end{array}$ & $\begin{array}{r}205370 \\
6625 \\
17400 \\
1460 \\
2.47 \\
2.84\end{array}$ & $\begin{array}{r}309900 \\
9997 \\
12900 \\
3250 \\
3.72 \\
4.29\end{array}$ & $\begin{array}{r}123870 \\
4424 \\
9960 \\
1310 \\
1.65 \\
1.72\end{array}$ & $\begin{array}{r}119790 \\
3864 \\
8330 \\
1140 \\
1.44 \\
1.66\end{array}$ & $\begin{array}{r}78765 \\
2625 \\
6470 \\
713 \\
.98 \\
1.09\end{array}$ & $\begin{array}{r}42584 \\
1374 \\
8930 \\
653 \\
.51 \\
.59\end{array}$ & $\begin{array}{r}60761 \\
2025 \\
10300 \\
393 \\
.75 \\
.84\end{array}$ & $\begin{array}{r}17847 \\
516 \\
2160 \\
177 \\
.21 \\
.25\end{array}$ & $\begin{array}{l}6699 \\
216 \\
358 \\
150 \\
.08 \\
.09\end{array}$ & $\begin{array}{c}15678 \\
523 \\
946 \\
163 \\
.19 \\
.22\end{array}$ \\
\hline
\end{tabular}

e Estimated

SIAIISIICS OF MONIHLY MEAN DAIA FOK WAIEH YEARS 1944 - 1991, BY WAIER YEAR (WY)

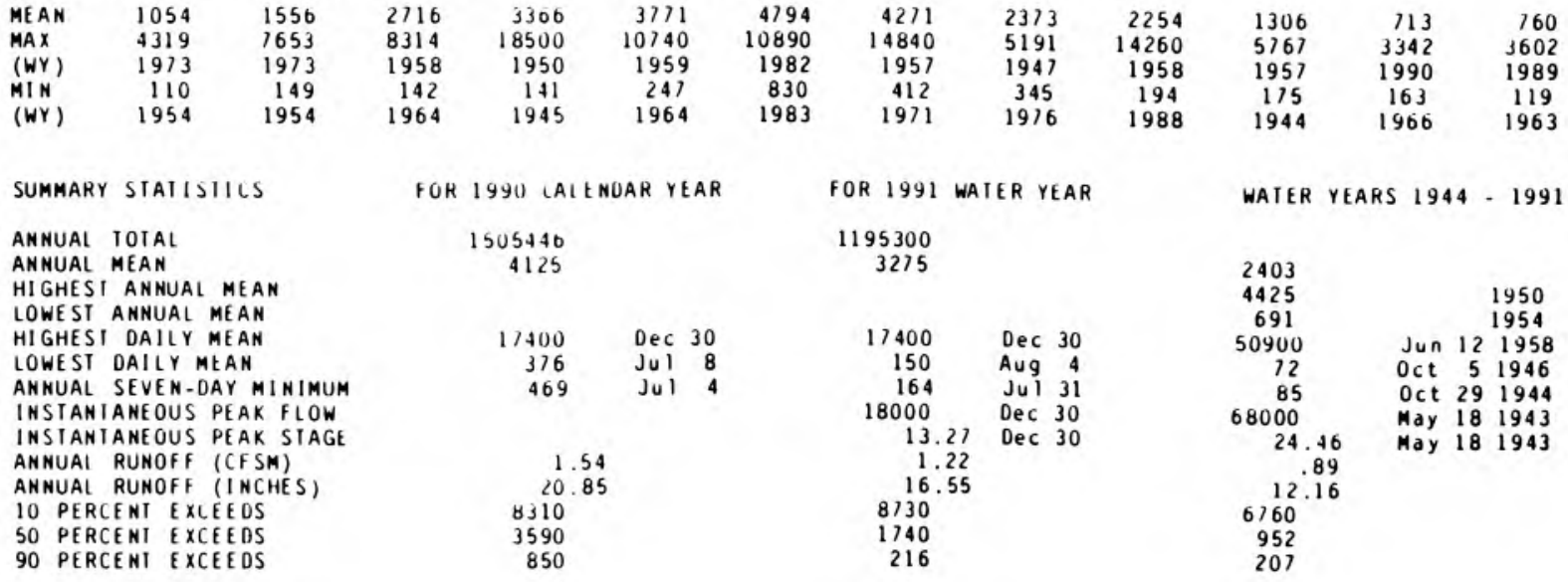


LOCATION, - Lat $40^{\circ} 40^{\prime} 06^{\prime \prime}$, long $86^{\circ} 05^{\prime} 44^{\circ}$, in NE $\frac{1}{4}$ SE $\frac{1}{4}$ sec. 29 . T.26 N., R.4 E., Miani County, Hydrologic Unit

05120101 , on right bank $150 \mathrm{ft}$ downstrea from bridge on County Rod 125 West, 0.5 a northeast of Bunker Hill. and at ile 11.4 .

DRAINAGE AREA.- -159 - $1^{2}$

PERIOD OF RECORD.--0ccasional low-flow measurements, water years 1960-67; May 1968 to current year.

GAGE. - Water-stage recorder. Datue of gage is $736.00 \mathrm{ft}$ above National Geodetic Vertical Datul of 1929.

REMARKS. - Records good except for estinated dally discharges, which are poor.

DISCHARGE, CUBIC FEET PER SECOND, WAIER YEAR OCTOBER 1990 TO SEPTEMBER 1991 DAILY MEAN VALUES

\begin{tabular}{|c|c|c|c|c|c|c|c|c|c|c|c|c|}
\hline DAY & $\mathrm{OCT}$ & NOV & DEC & JAN & FE B & MAR & APR & MAY & JUN & JUL & AUG & SEP \\
\hline $\begin{array}{l}1 \\
2 \\
3 \\
4 \\
5\end{array}$ & $\begin{array}{l}12 \\
12 \\
12 \\
59 \\
55\end{array}$ & $\begin{array}{r}49 \\
48 \\
45 \\
44 \\
160\end{array}$ & $\begin{array}{l}215 \\
156 \\
526 \\
726 \\
437\end{array}$ & $\begin{array}{r}2230 \\
788 \\
432 \\
318 \\
250\end{array}$ & $\begin{array}{r}e 56 \\
63 \\
76 \\
136 \\
226\end{array}$ & $\begin{array}{l}82 \\
92 \\
89 \\
80 \\
75\end{array}$ & $\begin{array}{l}143 \\
121 \\
107 \\
101 \\
107\end{array}$ & $\begin{array}{l}93 \\
86 \\
79 \\
76 \\
78\end{array}$ & $\begin{array}{r}464 \\
237 \\
141 \\
103 \\
80\end{array}$ & $\begin{array}{r}17 \\
99 \\
126 \\
53 \\
62\end{array}$ & $\begin{array}{l}7.5 \\
7.0 \\
6.7 \\
6.9 \\
6.3\end{array}$ & $\begin{array}{l}4.9 \\
4.4 \\
4.3 \\
4.8 \\
5.9\end{array}$ \\
\hline $\begin{array}{r}6 \\
7 \\
8 \\
9 \\
10\end{array}$ & $\begin{array}{r}35 \\
33 \\
127 \\
404 \\
1350\end{array}$ & $\begin{array}{r}276 \\
179 \\
120 \\
98 \\
86\end{array}$ & $\begin{array}{l}291 \\
210 \\
167 \\
137 \\
121\end{array}$ & $\begin{array}{l}197 \\
156 \\
137 \\
123 \\
105\end{array}$ & $\begin{array}{l}314 \\
442 \\
334 \\
268 \\
224\end{array}$ & $\begin{array}{l}75 \\
72 \\
62 \\
58 \\
56\end{array}$ & $\begin{array}{r}104 \\
99 \\
98 \\
131 \\
136\end{array}$ & $\begin{array}{l}84 \\
73 \\
65 \\
62 \\
60\end{array}$ & $\begin{array}{l}67 \\
59 \\
54 \\
50 \\
46\end{array}$ & $\begin{array}{r}74 \\
41 \\
73 \\
130 \\
65\end{array}$ & $\begin{array}{l}7.7 \\
11 \\
13 \\
22 \\
13\end{array}$ & $\begin{array}{l}5.9 \\
4.7 \\
3.9 \\
3.9 \\
4.0\end{array}$ \\
\hline $\begin{array}{l}11 \\
12 \\
13 \\
14 \\
15\end{array}$ & $\begin{array}{r}1220 \\
655 \\
426 \\
309 \\
226\end{array}$ & $\begin{array}{l}73 \\
63 \\
55 \\
51 \\
49\end{array}$ & $\begin{array}{r}108 \\
102 \\
93 \\
78 \\
168\end{array}$ & $\begin{array}{l}132 \\
286 \\
210 \\
183 \\
315\end{array}$ & $\begin{array}{l}177 \\
140 \\
132 \\
132 \\
100\end{array}$ & $\begin{array}{l}53 \\
54 \\
63 \\
63 \\
64\end{array}$ & $\begin{array}{r}103 \\
88 \\
90 \\
172 \\
339\end{array}$ & $\begin{array}{l}59 \\
58 \\
57 \\
56 \\
63\end{array}$ & $\begin{array}{l}44 \\
42 \\
39 \\
36 \\
36\end{array}$ & $\begin{array}{l}41 \\
31 \\
26 \\
21 \\
18\end{array}$ & $\begin{array}{l}13 \\
11 \\
8.6 \\
5.9 \\
5.3\end{array}$ & $\begin{array}{l}4.2 \\
4.1 \\
5.3 \\
7.7 \\
5.6\end{array}$ \\
\hline $\begin{array}{l}16 \\
17 \\
18 \\
19 \\
20\end{array}$ & $\begin{array}{l}164 \\
138 \\
525 \\
378 \\
243\end{array}$ & $\begin{array}{l}48 \\
46 \\
43 \\
42 \\
41\end{array}$ & $\begin{array}{l}256 \\
200 \\
379 \\
515 \\
362\end{array}$ & $\begin{array}{l}639 \\
708 \\
456 \\
324 \\
300\end{array}$ & $\begin{array}{r}e 74 \\
e 76 \\
93 \\
246 \\
316\end{array}$ & $\begin{array}{r}91 \\
310 \\
1140 \\
1390 \\
953\end{array}$ & $\begin{array}{l}338 \\
227 \\
170 \\
182 \\
462\end{array}$ & $\begin{array}{r}75 \\
62 \\
72 \\
103 \\
68\end{array}$ & $\begin{array}{l}39 \\
34 \\
32 \\
29 \\
26\end{array}$ & $\begin{array}{l}16 \\
14 \\
13 \\
12 \\
11\end{array}$ & $\begin{array}{r}5.0 \\
4.9 \\
4.9 \\
6.7 \\
13\end{array}$ & $\begin{array}{l}5.4 \\
5.2 \\
4.9 \\
5.1 \\
5.3\end{array}$ \\
\hline $\begin{array}{l}21 \\
22 \\
23 \\
24 \\
25\end{array}$ & $\begin{array}{r}179 \\
139 \\
118 \\
101 \\
88\end{array}$ & $\begin{array}{l}39 \\
42 \\
42 \\
40 \\
39\end{array}$ & $\begin{array}{r}610 \\
1060 \\
631 \\
381 \\
e 250\end{array}$ & $\begin{array}{r}302 \\
235 \\
192 \\
152 \\
e 120\end{array}$ & $\begin{array}{l}236 \\
189 \\
147 \\
130 \\
110\end{array}$ & $\begin{array}{l}586 \\
486 \\
805 \\
589 \\
383\end{array}$ & $\begin{array}{l}348 \\
243 \\
188 \\
182 \\
151\end{array}$ & $\begin{array}{r}56 \\
70 \\
229 \\
172 \\
245\end{array}$ & $\begin{array}{l}25 \\
24 \\
23 \\
22 \\
21\end{array}$ & $\begin{array}{r}11 \\
10 \\
9.6 \\
9.1 \\
8.8\end{array}$ & $\begin{array}{l}9.6 \\
8.8 \\
8.2 \\
7.9 \\
9.8\end{array}$ & $\begin{array}{l}5.4 \\
5.5 \\
5.6 \\
5.6 \\
6.3\end{array}$ \\
\hline $\begin{array}{l}26 \\
27 \\
28 \\
29 \\
30 \\
31\end{array}$ & $\begin{array}{l}78 \\
72 \\
65 \\
58 \\
55 \\
53\end{array}$ & $\begin{array}{r}36 \\
80 \\
543 \\
523 \\
312 \\
\cdots\end{array}$ & $\begin{array}{r}\text { e180 } \\
\text { e135 } \\
\text { e118 } \\
1030 \\
\text { e3700 } \\
\text { e4100 }\end{array}$ & $\begin{array}{r}\text { e100 } \\
\text { e90 } \\
\text { e84 } \\
\text { e77 } \\
\text { e70 } \\
\text { e66 }\end{array}$ & \begin{tabular}{r}
98 \\
92 \\
86 \\
$\ldots-$ \\
\hdashline-- \\
$-\cdots$
\end{tabular} & $\begin{array}{l}395 \\
612 \\
436 \\
289 \\
210 \\
163\end{array}$ & $\begin{array}{l}136 \\
127 \\
116 \\
109 \\
100 \\
\cdots\end{array}$ & $\begin{array}{l}291 \\
190 \\
126 \\
100 \\
213 \\
205\end{array}$ & $\begin{array}{l}21 \\
20 \\
19 \\
18 \\
18 \\
\cdots\end{array}$ & $\begin{array}{l}8.4 \\
8.1 \\
7.9 \\
8.2 \\
8.1 \\
7.8\end{array}$ & $\begin{array}{l}6.4 \\
6.1 \\
4.6 \\
4.1 \\
4.5 \\
6.2\end{array}$ & $\begin{array}{l}5.9 \\
5.3 \\
5.2 \\
5.2 \\
5.2 \\
-\cdots\end{array}$ \\
\hline $\begin{array}{l}\text { TOTAL } \\
\text { MEAN } \\
\text { MAX } \\
\text { MIN } \\
\text { CF SM } \\
\text { IN. }\end{array}$ & $\begin{array}{r}7389 \\
238 \\
1350 \\
12 \\
1.50 \\
1.73\end{array}$ & $\begin{array}{r}3312 \\
110 \\
543 \\
36 \\
.69 \\
.77\end{array}$ & $\begin{array}{r}17442 \\
563 \\
4100 \\
78 \\
3.54 \\
4.08\end{array}$ & $\begin{array}{r}9777 \\
315 \\
2230 \\
66 \\
1.98 \\
2.29\end{array}$ & $\begin{array}{r}4713 \\
168 \\
442 \\
56 \\
1.06 \\
1.10\end{array}$ & $\begin{array}{r}9876 \\
319 \\
1390 \\
53 \\
2.00 \\
2.31\end{array}$ & $\begin{array}{r}5018 \\
167 \\
462 \\
88 \\
1.05 \\
1.17\end{array}$ & $\begin{array}{c}3326 \\
107 \\
291 \\
56 \\
.67 \\
.78\end{array}$ & $\begin{array}{r}1869 \\
62.3 \\
464 \\
18 \\
.39 \\
.44\end{array}$ & $\begin{array}{r}1040.0 \\
33.5 \\
130 \\
7.8 \\
.21 \\
.24\end{array}$ & $\begin{array}{c}255.6 \\
8.25 \\
22 \\
4.1 \\
.05 \\
.06\end{array}$ & $\begin{array}{r}154.7 \\
5.16 \\
7.7 \\
3.9 \\
.03 \\
.04\end{array}$ \\
\hline
\end{tabular}

STATISTICS OF MONTHLY MEAN DATA FOR WATER YEARS 1968 - 1991, BY WATER YEAR (WY)

$\begin{array}{lrrrrrrrrrrrr}\text { MEAN } & 53.1 & 116 & 196 & 164 & 245 & 313 & 233 & 163 & 132 & 75.3 & 52.3 & 36.2 \\ \text { MAX } & 238 & 660 & 563 & 731 & 648 & 902 & 637 & 411 & 429 & 334 & 296 & 226 \\ \text { (WY) } & 1991 & 1986 & 1991 & 1974 & 1990 & 1982 & 1972 & 1989 & 1980 & 1986 & 1973 & 1972 \\ \text { MIN } & 6.66 & 8.79 & 6.57 & 3.70 & 25.1 & 49.7 & 45.6 & 28.5 & 12.4 & 8.17 & 7.63 & 5.16 \\ \text { (WY) } & 1989 & 1981 & 1977 & 1977 & 1978 & 1981 & 1971 & 1976 & 1988 & 1988 & 1971 & 1991\end{array}$

SUMMARY STATISIICS

ANNUAL TOTAL

HIGHEST ANMUAL MEAN

LOWEST AMNUAL MEAN

HIGHEST DAILY MEAK

LOWEST DAILY MEAM

ANHUAL SEVEN-DAY MIMIMUM

INSTANTANEOUS PEAK FLOW

INSTANTANEOUS PEAK STAGE

ANHUAL RUNOFF (CFSM)

ANNUAL RUNOFF (INCHES)

10 PERCENT EXCEEDS

50 PERCENT EXCEEDS

90 PERCENT EXCEEDS
FOR 1990 CALENDAR YEAR

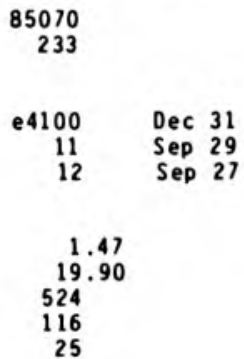

FOR 1991 WATER YEAR

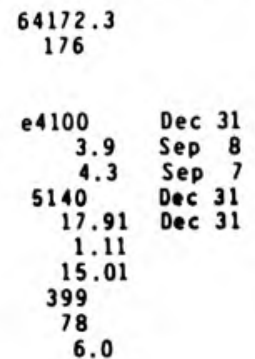

WATER YEARS 1968 - 1991

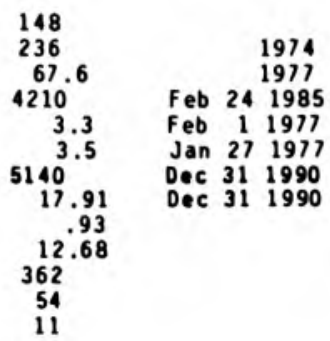




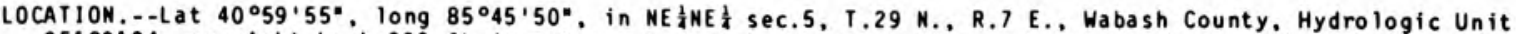
05120104 , on right bank $200 \mathrm{ft}$ downstrea from Main Street bridge in North Manchester. 1.3 a ustrea froe Pony Creek, and at ile 52.7 .

DRAINAGE AREA. $-417 m i$, includes that of Pony Creek.

PERIOD OF RECORD.--0ctober 1929 to current year. Prior to April 1930, monthly discharge only, published in wSP

1305. Gage-height records since November 20, 1923 are available from the district office.

REVISED RECORDS...-WSP 1275: 1930-37, 1939, 1940(W). 1942, 1948. WSP 1909: 1957. WSP 2109: Dra inage area.

GAGE.- Water-stage recorder. Datum of gage is $738.00 \mathrm{ft}$ above National Geodetic Vertical Datun of 1929 . Prior to July 24, 1953, nonrecording gage on downstrea side of Second Street bridge, $700 \mathrm{ft}$ upstrean at sane datum.

REMARKS.--Records good except for estimated daily discharges, which are poor. Records include flow of Pony Creek. Maximu instantaneous and mean daily discharges for period of record are estimated, maximum gage height is unknown.

DISCHARGE, CUBIC FEET PER SECOND, WATER YEAR OCTOBER 1990 TO SEPTEMBER 1991 DAILY MEAM VALUES

\begin{tabular}{|c|c|c|c|c|c|c|c|c|c|c|c|c|}
\hline DAY & $O C T$ & NOV & DEC & JAN & FEB & MAR & APR & MAY & JUN & JUL & AUG & SEP \\
\hline $\begin{array}{l}1 \\
2 \\
3 \\
4 \\
5\end{array}$ & $\begin{array}{l}168 \\
161 \\
158 \\
811 \\
835\end{array}$ & $\begin{array}{l}295 \\
282 \\
273 \\
266 \\
892\end{array}$ & $\begin{array}{r}491 \\
404 \\
1230 \\
2090 \\
1260\end{array}$ & $\begin{array}{r}\text { } 5750 \\
4170 \\
3090 \\
2030 \\
e 1320\end{array}$ & $\begin{array}{l}307 \\
287 \\
357 \\
587 \\
782\end{array}$ & $\begin{array}{l}332 \\
632 \\
801 \\
561 \\
442\end{array}$ & $\begin{array}{l}352 \\
327 \\
308 \\
296 \\
412\end{array}$ & $\begin{array}{l}488 \\
458 \\
395 \\
357 \\
346\end{array}$ & $\begin{array}{r}3510 \\
2980 \\
2450 \\
1450 \\
876\end{array}$ & $\begin{array}{l}173 \\
195 \\
190 \\
151 \\
137\end{array}$ & $\begin{array}{l}86 \\
86 \\
88 \\
92 \\
92\end{array}$ & $\begin{array}{r}103 \\
89 \\
89 \\
94 \\
90\end{array}$ \\
\hline $\begin{array}{r}6 \\
7 \\
8 \\
9 \\
10\end{array}$ & $\begin{array}{r}454 \\
333 \\
377 \\
2140 \\
4340\end{array}$ & $\begin{array}{r}2350 \\
1520 \\
907 \\
677 \\
555\end{array}$ & $\begin{array}{l}816 \\
638 \\
528 \\
461 \\
429\end{array}$ & $\begin{array}{r}\text { e1020 } \\
\text { e } 880 \\
\text { e740 } \\
\text { e660 } \\
\text { e600 }\end{array}$ & $\begin{array}{l}774 \\
770 \\
609 \\
558 \\
516\end{array}$ & $\begin{array}{l}402 \\
369 \\
327 \\
310 \\
301\end{array}$ & $\begin{array}{l}460 \\
379 \\
383 \\
873 \\
629\end{array}$ & $\begin{array}{l}450 \\
402 \\
339 \\
315 \\
299\end{array}$ & $\begin{array}{l}661 \\
513 \\
422 \\
360 \\
319\end{array}$ & $\begin{array}{l}129 \\
122 \\
276 \\
169 \\
142\end{array}$ & $\begin{array}{r}92 \\
91 \\
104 \\
136 \\
114\end{array}$ & $\begin{array}{l}84 \\
82 \\
81 \\
78 \\
78\end{array}$ \\
\hline $\begin{array}{l}11 \\
12 \\
13 \\
14 \\
15\end{array}$ & $\begin{array}{l}4880 \\
3800 \\
2770 \\
1550 \\
1120\end{array}$ & $\begin{array}{l}474 \\
415 \\
371 \\
346 \\
331\end{array}$ & $\begin{array}{l}394 \\
372 \\
357 \\
330 \\
557\end{array}$ & $\begin{array}{l}e 560 \\
e 840 \\
e 700 \\
e 600 \\
e 800\end{array}$ & $\begin{array}{r}444 \\
372 \\
353 \\
352 \\
\mathrm{e} 320\end{array}$ & $\begin{array}{l}288 \\
278 \\
272 \\
283 \\
322\end{array}$ & $\begin{array}{l}452 \\
386 \\
334 \\
374 \\
764\end{array}$ & $\begin{array}{l}281 \\
269 \\
274 \\
308 \\
274\end{array}$ & $\begin{array}{l}285 \\
269 \\
257 \\
236 \\
219\end{array}$ & $\begin{array}{l}132 \\
124 \\
123 \\
120 \\
116\end{array}$ & $\begin{array}{r}101 \\
95 \\
92 \\
90 \\
89\end{array}$ & $\begin{array}{r}75 \\
79 \\
124 \\
115 \\
90\end{array}$ \\
\hline $\begin{array}{l}16 \\
17 \\
18 \\
19 \\
20\end{array}$ & $\begin{array}{r}919 \\
769 \\
1430 \\
1300 \\
887\end{array}$ & $\begin{array}{l}321 \\
307 \\
307 \\
280 \\
269\end{array}$ & $\begin{array}{l}867 \\
624 \\
733 \\
939 \\
679\end{array}$ & $\begin{array}{r}1860 \\
2000 \\
1160 \\
825 \\
762\end{array}$ & $\begin{array}{r}e 280 \\
e 300 \\
332 \\
1450 \\
1480\end{array}$ & $\begin{array}{r}431 \\
501 \\
1360 \\
1080 \\
685\end{array}$ & $\begin{array}{r}934 \\
1070 \\
1200 \\
959 \\
2190\end{array}$ & $\begin{array}{l}252 \\
265 \\
265 \\
247 \\
229\end{array}$ & $\begin{array}{l}255 \\
231 \\
208 \\
193 \\
183\end{array}$ & $\begin{array}{r}111 \\
107 \\
102 \\
99 \\
98\end{array}$ & $\begin{array}{r}88 \\
87 \\
90 \\
108 \\
116\end{array}$ & $\begin{array}{l}79 \\
75 \\
74 \\
74 \\
74\end{array}$ \\
\hline $\begin{array}{l}21 \\
22 \\
23 \\
24 \\
25\end{array}$ & $\begin{array}{l}704 \\
599 \\
530 \\
477 \\
429\end{array}$ & $\begin{array}{l}262 \\
267 \\
268 \\
262 \\
251\end{array}$ & $\begin{array}{r}794 \\
1970 \\
1350 \\
867 \\
e 685\end{array}$ & $\begin{array}{l}\text { e } 700 \\
\text { e600 } \\
e 516 \\
e 460 \\
\text { e425 }\end{array}$ & $\begin{array}{l}940 \\
724 \\
559 \\
463 \\
406\end{array}$ & $\begin{array}{l}527 \\
449 \\
428 \\
461 \\
440\end{array}$ & $\begin{array}{r}1670 \\
993 \\
735 \\
1420 \\
1260\end{array}$ & $\begin{array}{l}218 \\
211 \\
241 \\
316 \\
327\end{array}$ & $\begin{array}{l}175 \\
164 \\
158 \\
150 \\
146\end{array}$ & $\begin{array}{r}97 \\
129 \\
148 \\
107 \\
99\end{array}$ & $\begin{array}{r}104 \\
96 \\
91 \\
87 \\
85\end{array}$ & $\begin{array}{l}74 \\
73 \\
73 \\
72 \\
71\end{array}$ \\
\hline $\begin{array}{l}26 \\
27 \\
28 \\
29 \\
30 \\
31\end{array}$ & $\begin{array}{l}391 \\
367 \\
346 \\
331 \\
320 \\
307\end{array}$ & $\begin{array}{r}239 \\
250 \\
998 \\
1100 \\
649 \\
-2\end{array}$ & $\begin{array}{r}\text { e } 580 \\
\text { e520 } \\
\text { e458 } \\
2470 \\
\text { e7 } 760 \\
\text { e } 7770\end{array}$ & $\begin{array}{r}\text { e390 } \\
\text { e360 } \\
\text { e330 } \\
\text { e315 } \\
\text { e307 } \\
305\end{array}$ & $\begin{array}{l}359 \\
331 \\
317 \\
\ldots \\
\cdots \\
\cdots\end{array}$ & $\begin{array}{l}523 \\
752 \\
785 \\
591 \\
437 \\
373\end{array}$ & $\begin{array}{l}810 \\
627 \\
884 \\
722 \\
575 \\
\cdots-\end{array}$ & $\begin{array}{r}488 \\
406 \\
301 \\
255 \\
677 \\
2530\end{array}$ & $\begin{array}{l}145 \\
144 \\
140 \\
134 \\
130 \\
\ldots-\end{array}$ & $\begin{array}{l}95 \\
91 \\
87 \\
88 \\
89 \\
86\end{array}$ & $\begin{array}{r}83 \\
83 \\
82 \\
80 \\
100 \\
152\end{array}$ & $\begin{array}{r}71 \\
71 \\
71 \\
69 \\
68 \\
-\cdots\end{array}$ \\
\hline $\begin{array}{l}\text { TOTAL } \\
\text { MEAN } \\
\text { MAX } \\
\text { MIN } \\
\text { CF SM } \\
\text { IN. }\end{array}$ & $\begin{array}{r}34003 \\
1097 \\
4880 \\
158 \\
2.63 \\
3.03\end{array}$ & $\begin{array}{r}15984 \\
533 \\
2350 \\
239 \\
1.28 \\
1.43\end{array}$ & $\begin{array}{r}39423 \\
1272 \\
7770 \\
330 \\
3.05 \\
3.52\end{array}$ & $\begin{array}{r}35075 \\
1131 \\
5750 \\
305 \\
2.71 \\
3.13\end{array}$ & $\begin{array}{r}15329 \\
547 \\
1480 \\
280 \\
1.31 \\
1.37\end{array}$ & $\begin{array}{r}15743 \\
508 \\
1360 \\
272 \\
1.22 \\
1.40\end{array}$ & $\begin{array}{r}22778 \\
759 \\
2190 \\
296 \\
1.82 \\
2.03\end{array}$ & $\begin{array}{r}12483 \\
403 \\
2530 \\
211 \\
.97 \\
1.11\end{array}$ & $\begin{array}{r}17363 \\
579 \\
3510 \\
130 \\
1.39 \\
1.55\end{array}$ & $\begin{array}{c}3932 \\
127 \\
276 \\
86 \\
.30 \\
.35\end{array}$ & $\begin{array}{c}2980 \\
96.1 \\
152 \\
80 \\
.23 \\
.27\end{array}$ & $\begin{array}{r}2440 \\
81.3 \\
124 \\
68 \\
.20 \\
.22\end{array}$ \\
\hline
\end{tabular}

STATISTICS OF MONTHLY MEAN DATA FOR WATER YEARS 1930 - 1991, BY WATER YEAR (WY)

\begin{tabular}{|c|c|c|c|c|c|c|c|c|c|c|c|c|}
\hline $\begin{array}{l}\text { MEAN } \\
\text { MAX } \\
\text { (WY) } \\
\text { MIN } \\
\text { (WY) }\end{array}$ & $\begin{array}{r}168 \\
1165 \\
1955 \\
46.2 \\
1947\end{array}$ & $\begin{array}{r}255 \\
1037 \\
1973 \\
53.4 \\
1940\end{array}$ & $\begin{array}{r}401 \\
1717 \\
1967 \\
49.4 \\
1964\end{array}$ & $\begin{array}{r}453 \\
2258 \\
1950 \\
43.2 \\
1977\end{array}$ & $\begin{array}{r}587 \\
1772 \\
1959 \\
62.0 \\
1964\end{array}$ & $\begin{array}{r}721 \\
2425 \\
1982 \\
200 \\
1941\end{array}$ & $\begin{array}{r}664 \\
1768 \\
1957 \\
141 \\
1946\end{array}$ & $\begin{array}{r}419 \\
2021 \\
1943 \\
86.1 \\
1931\end{array}$ & $\begin{array}{r}326 \\
1376 \\
1981 \\
68.1 \\
1934\end{array}$ & $\begin{array}{r}195 \\
767 \\
1951 \\
44.2 \\
1941\end{array}$ & $\begin{array}{r}156 \\
1031 \\
1990 \\
30.7 \\
1941\end{array}$ & $\begin{array}{r}121 \\
449 \\
1972 \\
27.6 \\
1941\end{array}$ \\
\hline
\end{tabular}

SUMMARY STATISIICS

ANNUAL TOTAL

ANNUAL MEAN

HIGHEST ANMUAL MEAN

LOWEST ANNUAL MEAN

HIGHEST DAILY MEAN

LOWEST DAILY MEAM

ANNUAL SEVEN-DAY MINIMUM

INSTANTANEOUS PEAK FLOW

INSTANTANEOUS PEAK STAGE

ANMUAL RUNOFF (CFSM)

ANNUAL RUNOFF (INCHES)

10 PERCENT EXCEEDS

50 PERCENT EXCEEOS

90 PERCENT EXCEEDS
FOR 1990 CALENDAR YEAR

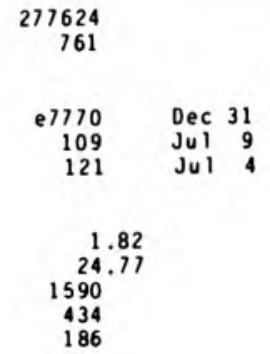

FOR 1991 WATER YEAR

$$
217533
$$

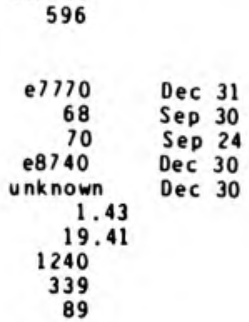

WATER YEARS $1930-1991$

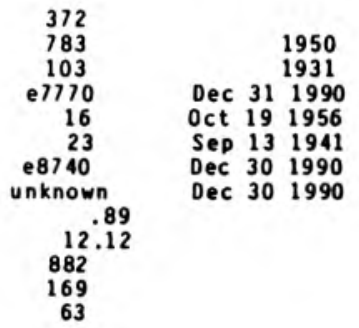




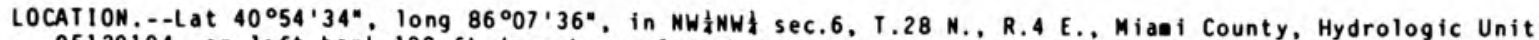

05120104 , on left bank $100 \mathrm{ft}$ downstrean fro bridge on County Rodd 1000 North, and 1.5 west of Deedsville.

PERIOD OF RECORD.--0 ctober 1970 to current year.

GAGE.-Water-stage recorder. Datun of gage is $785.00 \mathrm{ft}$ above National Geodetic Vertical Datue of 1929 .

REMARKS. - Records good, except for estinated daily discharges, which are poor.

DISCHARGE, CUBIC FEET PER SECONO, WATER YEAR OCTOBER 1990 TO SEPTEMBER 1991 DAILY MEAN VALUES

\begin{tabular}{|c|c|c|c|c|c|c|c|c|c|c|c|c|}
\hline DAY & $\mathrm{OCT}$ & NOV & DEC & JAN & FEB & MAR & APR & MAY & JUN & JUL & AUG & SEP \\
\hline $\begin{array}{l}1 \\
2 \\
3 \\
4 \\
5\end{array}$ & $\begin{array}{l}.49 \\
1.47 \\
55 \\
10\end{array}$ & $\begin{array}{c}5.1 \\
5.0 \\
4.8 \\
4.8 \\
70\end{array}$ & $\begin{array}{l}11 \\
8.2 \\
76 \\
45 \\
22\end{array}$ & $\begin{array}{r}70 \\
52 \\
42 \\
34 \\
\mathrm{e} 25\end{array}$ & $\begin{array}{l}\text { e6.2 } \\
\text { e7.2 } \\
14 \\
19 \\
23\end{array}$ & $\begin{array}{l}7.3 \\
18 \\
15 \\
10 \\
9.0\end{array}$ & $\begin{array}{l}12 \\
10 \\
9.5 \\
9.4 \\
15\end{array}$ & $\begin{array}{l}8.1 \\
7.7 \\
6.9 \\
6.5 \\
6.5\end{array}$ & $\begin{array}{l}5.3 \\
4.4 \\
3.8 \\
3.3 \\
3.2\end{array}$ & $\begin{array}{l}1.6 \\
1.6 \\
1.7 \\
1.4 \\
1.4\end{array}$ & $\begin{array}{l}1.2 \\
1.1 \\
1.3 \\
1.3 \\
1.2\end{array}$ & $\begin{array}{l}1.1 \\
.86 \\
1.8 \\
2.7 \\
1.1\end{array}$ \\
\hline $\begin{array}{r}6 \\
7 \\
8 \\
9 \\
10\end{array}$ & $\begin{array}{r}3.9 \\
4.1 \\
16 \\
156 \\
228\end{array}$ & $\begin{array}{l}56 \\
27 \\
17 \\
13 \\
11\end{array}$ & $\begin{array}{l}16 \\
13 \\
11 \\
9.5 \\
9.5\end{array}$ & $\begin{array}{l}\text { e } 20 \\
\text { e18 } \\
\text { e16 } \\
\text { e15 } \\
14\end{array}$ & $\begin{array}{l}24 \\
24 \\
18 \\
16 \\
13\end{array}$ & $\begin{array}{l}8.7 \\
7.4 \\
6.6 \\
6.4 \\
5.9\end{array}$ & $\begin{array}{l}13 \\
11 \\
10 \\
11 \\
9.8\end{array}$ & $\begin{array}{l}8.2 \\
8.4 \\
8.0 \\
7.1 \\
6.7\end{array}$ & $\begin{array}{l}3.0 \\
2.9 \\
2.8 \\
2.7 \\
2.6\end{array}$ & $\begin{array}{r}1.4 \\
1.3 \\
20 \\
7.0 \\
3.1\end{array}$ & $\begin{array}{l}1.3 \\
1.2 \\
2.9 \\
2.1 \\
1.2\end{array}$ & $\begin{array}{l}.91 \\
.86 \\
.80 \\
.80 \\
.84\end{array}$ \\
\hline $\begin{array}{l}11 \\
12 \\
13 \\
14 \\
15\end{array}$ & $\begin{array}{l}93 \\
52 \\
38 \\
28 \\
22\end{array}$ & $\begin{array}{l}9.0 \\
8.1 \\
7.4 \\
6.9 \\
6.5\end{array}$ & $\begin{array}{r}8.9 \\
8.6 \\
7.9 \\
7.0 \\
15\end{array}$ & $\begin{array}{l}20 \\
25 \\
19 \\
20 \\
28\end{array}$ & $\begin{array}{r}11 \\
8.7 \\
8.3 \\
8.1 \\
e 6.2\end{array}$ & $\begin{array}{r}5.7 \\
5.6 \\
14 \\
7.5 \\
9.8\end{array}$ & $\begin{array}{l}8.5 \\
7.9 \\
7.9 \\
21 \\
59\end{array}$ & $\begin{array}{l}6.4 \\
6.1 \\
6.1 \\
6.0 \\
6.0\end{array}$ & $\begin{array}{l}3.1 \\
3.0 \\
2.6 \\
2.4 \\
3.1\end{array}$ & $\begin{array}{l}2.2 \\
2.0 \\
1.9 \\
1.7 \\
1.6\end{array}$ & $\begin{array}{l}1.1 \\
1.0 \\
1.0 \\
.97 \\
.95\end{array}$ & $\begin{array}{l}.85 \\
.99 \\
.97 \\
.86 \\
.82\end{array}$ \\
\hline $\begin{array}{l}16 \\
17 \\
18 \\
19 \\
20\end{array}$ & $\begin{array}{l}17 \\
14 \\
29 \\
20 \\
15\end{array}$ & $\begin{array}{l}6.3 \\
5.9 \\
5.8 \\
5.5 \\
5.1\end{array}$ & $\begin{array}{l}13 \\
11 \\
16 \\
16 \\
12\end{array}$ & $\begin{array}{l}80 \\
47 \\
25 \\
21 \\
22\end{array}$ & $\begin{array}{l}e 6.2 \\
e 6.4 \\
12 \\
46 \\
24\end{array}$ & $\begin{array}{l}16 \\
36 \\
91 \\
43 \\
26\end{array}$ & $\begin{array}{l}29 \\
19 \\
15 \\
14 \\
15\end{array}$ & $\begin{array}{r}5.3 \\
5.0 \\
12 \\
9.4 \\
6.9\end{array}$ & $\begin{array}{l}4.1 \\
2.9 \\
2.5 \\
2.3 \\
2.2\end{array}$ & $\begin{array}{l}1.5 \\
1.5 \\
1.4 \\
1.4 \\
1.4\end{array}$ & $\begin{array}{r}.91 \\
.93 \\
.96 \\
1.8 \\
1.2\end{array}$ & $\begin{array}{l}\text { e. } 82 \\
\text { e. } 80 \\
\text { e.78 } \\
\text { e. } 78 \\
\text { e. } 77\end{array}$ \\
\hline $\begin{array}{l}21 \\
22 \\
23 \\
24 \\
25\end{array}$ & $\begin{array}{r}11 \\
9.4 \\
8.5 \\
7.9 \\
7.2\end{array}$ & $\begin{array}{l}5.0 \\
5.2 \\
5.1 \\
4.7 \\
4.8\end{array}$ & $\begin{array}{l}48 \\
53 \\
24 \\
18 \\
14\end{array}$ & $\begin{array}{r}20 \\
16 \\
\mathrm{e} 12 \\
\mathrm{e} 10 \\
\mathrm{e} 9.0\end{array}$ & $\begin{array}{l}18 \\
15 \\
11 \\
9.8 \\
8.6\end{array}$ & $\begin{array}{l}21 \\
17 \\
18 \\
20 \\
17\end{array}$ & $\begin{array}{l}12 \\
11 \\
10 \\
16 \\
12\end{array}$ & $\begin{array}{l}5.9 \\
5.3 \\
5.5 \\
5.7 \\
5.0\end{array}$ & $\begin{array}{l}2.1 \\
2.1 \\
1.9 \\
1.9 \\
1.8\end{array}$ & $\begin{array}{l}1.4 \\
1.4 \\
1.3 \\
1.3 \\
1.4\end{array}$ & $\begin{array}{l}1.0 \\
.92 \\
.90 \\
.85 \\
.85\end{array}$ & $\begin{array}{l}\text { e. } 77 \\
\text { e. } 90 \\
\text { e. } 84 \\
\text { e. } .71 \\
\text { e. }\end{array}$ \\
\hline $\begin{array}{l}26 \\
27 \\
28 \\
29 \\
30 \\
31\end{array}$ & $\begin{array}{l}6.8 \\
6.6 \\
6.0 \\
5.8 \\
5.7 \\
5.4\end{array}$ & $\begin{array}{c}4.7 \\
5.2 \\
65 \\
27 \\
15 \\
\ldots\end{array}$ & $\begin{array}{c}11 \\
10 \\
9.6 \\
247 \\
233 \\
109\end{array}$ & $\begin{array}{l}\text { e8. } 8 \\
\text { e7.8 } \\
\text { e7.4 } \\
\text { e7.0 } \\
\text { e6.7 } \\
\text { e6.5 }\end{array}$ & $\begin{array}{l}7.6 \\
7.1 \\
6.8 \\
\ldots . \\
\ldots . \\
\ldots .\end{array}$ & $\begin{array}{l}31 \\
27 \\
36 \\
19 \\
14 \\
12\end{array}$ & $\begin{array}{l}10 \\
9.4 \\
8.7 \\
8.6 \\
8.0 \\
\ldots .-\end{array}$ & $\begin{array}{l}4.9 \\
4.4 \\
3.8 \\
3.4 \\
3.7 \\
6.3\end{array}$ & $\begin{array}{l}1.7 \\
1.7 \\
1.6 \\
1.7 \\
1.6 \\
\ldots . .\end{array}$ & $\begin{array}{l}1.3 \\
1.3 \\
1.2 \\
1.4 \\
1.3 \\
1.2\end{array}$ & $\begin{array}{r}.83 \\
.84 \\
.85 \\
.84 \\
5.1 \\
2.3\end{array}$ & $\begin{array}{l}\text { e. } 78 \\
\text { e.78 } \\
\text { e.77 } \\
\text { e.76 } \\
\text { e.76 } \\
. . .\end{array}$ \\
\hline $\begin{array}{l}\text { TOTAL } \\
\text { MEAN } \\
\text { MAX } \\
\text { MIN } \\
\text { CF SM } \\
\text { IN. }\end{array}$ & $\begin{array}{r}883.96 \\
28.5 \\
228 \\
.47 \\
3.21 \\
3.71\end{array}$ & $\begin{array}{r}421.9 \\
14.1 \\
70 \\
4.7 \\
1.59 \\
1.77\end{array}$ & $\begin{array}{r}1113.2 \\
35.9 \\
247 \\
7.0 \\
4.05 \\
4.67\end{array}$ & $\begin{array}{r}723.8 \\
23.3 \\
80 \\
6.5 \\
2.63 \\
3.04\end{array}$ & $\begin{array}{r}385.2 \\
13.8 \\
46 \\
6.2 \\
1.55 \\
1.62\end{array}$ & $\begin{array}{c}580.9 \\
18.7 \\
91 \\
5.6 \\
2.11 \\
2.44\end{array}$ & $\begin{array}{r}412.7 \\
13.8 \\
59 \\
7.9 \\
1.55 \\
1.73\end{array}$ & $\begin{array}{c}197.2 \\
6.36 \\
12 \\
3.4 \\
.72 \\
.83\end{array}$ & $\begin{array}{l}80.3 \\
2.68 \\
5.3 \\
1.6 \\
.30 \\
.34\end{array}$ & $\begin{array}{r}71.6 \\
2.31 \\
20 \\
1.2 \\
.26 \\
.30\end{array}$ & $\begin{array}{c}40.90 \\
1.32 \\
5.1 \\
.83 \\
.15 \\
.17\end{array}$ & $\begin{array}{r}28.17 \\
.94 \\
2.7 \\
.76 \\
.11 \\
.12\end{array}$ \\
\hline
\end{tabular}

e Estinated

STATISTICS OF MONTHLY MEAN DATA FOR WATER YEARS 1971 - 1991, BY WATER YEAR (WY)

$\begin{array}{lrrrrrrrrrrrr}\text { MEAN } & 4.97 & 8.51 & 13.8 & 9.89 & 17.9 & 21.9 & 15.8 & 10.9 & 8.66 & 4.60 & 4.75 & 4.03 \\ \text { MAX } & 28.5 & 28.2 & 35.9 & 25.8 & 47.6 & 53.7 & 34.5 & 24.6 & 31.6 & 20.3 & 47.0 & 21.6 \\ \text { (WY) } & 1991 & 1986 & 1991 & 1974 & 1985 & 1982 & 1983 & 1983 & 1986 & 1990 & 1990 & 1989 \\ \text { MIN } & .79 & .95 & .61 & .30 & 2.62 & 3.50 & 4.60 & 3.30 & 1.17 & .80 & .66 & .45 \\ \text { (WY) } & 1975 & 1977 & 1977 & 1977 & 1978 & 1981 & 1971 & 1977 & 1988 & 1988 & 1988 & 1988\end{array}$

SUMMARY STATISTICS

ANMUAL TOTAL

ANNUAL MEAK

HIGHEST ANNUAL MEAN

LOWEST ANNUAL MEAN

HIGHEST DAILY MEAN

LOWEST DAILY MEAN

ANNUAL SEVEN-DAY MINIMUM

INSTANTANEOUS PEAK FLOW

INSTANTANEOUS PEAK STAGE

ANNUAL RUNOFF (CFSM)

ANMUAL RUNOFF (INCHES)

10 PERCENT EXCEEDS

50 PERCENT EXCEEDS

90 PERCENT EXCEEDS
FOR 1990 CALENDAR YEAR

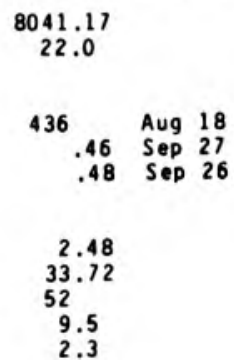

FOR 1991 WATER YEAR

$$
\begin{gathered}
4939.83 \\
13.5
\end{gathered}
$$

247 Dec 29

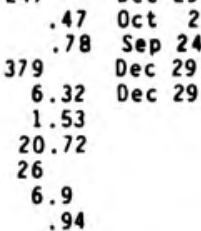

WATER YEARS $1971-1991$

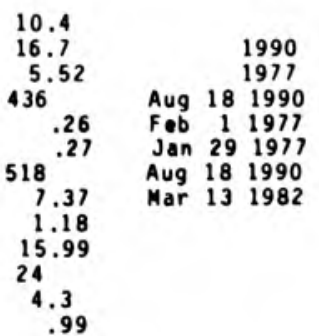


LOCATION.--Lat $40^{\circ} 46^{\prime} 55^{\prime \prime}$, long $86^{\circ} 15^{\prime} 50^{\circ}$, in NE $\frac{1}{4}$ SE $\frac{1}{4}$ sec.14, T. 27 N., R.2 E., Cass County, Hydrologic Unit

05120104 , on right bank at downstrea side of bridge on Adasboro Road, 5.5 ai northeast of Logansport. and 7.4 mi upstrean from moyth.

DRAINAGE AREA ..-789 i $^{2}$

PERIOD OF RECORD.--July 1943 to current year. Monthly discharge only for some periods, published in wSP 1305.

REVISED RECORDS.--WSP 2109: Drainage area.

GAGE. - Water-stage recorder. Datum of gage is $621.50 \mathrm{ft}$ above National Geodetic Vertical Datua of 1929 . Prior to Aug. 16, 1956, nonrecording gage at same site and datue.

REMARKS. - Records good except for estieated daily discharges, which are poor. EXTREMES OUTSIDE PERIOD OF RECORD. . -Flood of May 18, 1943 , reached a stage of $13.2 \mathrm{ft}$, from floodeark, discharge,
$17,000 \mathrm{ft} / \mathrm{s}$.

DISCHARGE, CUBIC FEET PER SECOND, WATER YEAR OCTOBER 1990 TO SEPTEMBER 1991 DAI IY MEAN VALUES

\begin{tabular}{|c|c|c|c|c|c|c|c|c|c|c|c|c|}
\hline DAY & $O C T$ & NOV & DEC & JAN & FEB & MAR & APR & MAY & JUN & JUL & AUG & SEP \\
\hline $\begin{array}{l}1 \\
2 \\
3 \\
4 \\
5\end{array}$ & $\begin{array}{r}330 \\
323 \\
325 \\
503 \\
1180\end{array}$ & $\begin{array}{l}528 \\
509 \\
493 \\
480 \\
984\end{array}$ & $\begin{array}{r}1020 \\
831 \\
1610 \\
3800 \\
2690\end{array}$ & $\begin{array}{r}11000 \\
7130 \\
5130 \\
3580 \\
2450\end{array}$ & $\begin{array}{r}e 600 \\
603 \\
644 \\
848 \\
1180\end{array}$ & $\begin{array}{r}684 \\
786 \\
1230 \\
1130 \\
883\end{array}$ & $\begin{array}{l}780 \\
749 \\
696 \\
664 \\
733\end{array}$ & $\begin{array}{l}842 \\
780 \\
730 \\
675 \\
645\end{array}$ & $\begin{array}{l}4640 \\
4210 \\
3160 \\
2350 \\
1420\end{array}$ & $\begin{array}{l}262 \\
312 \\
346 \\
344 \\
281\end{array}$ & $\begin{array}{l}167 \\
161 \\
159 \\
161 \\
166\end{array}$ & $\begin{array}{l}213 \\
181 \\
192 \\
272 \\
200\end{array}$ \\
\hline $\begin{array}{r}6 \\
7 \\
8 \\
9 \\
10\end{array}$ & $\begin{array}{r}955 \\
674 \\
600 \\
1920 \\
6500\end{array}$ & $\begin{array}{l}3440 \\
3030 \\
1870 \\
1280 \\
1020\end{array}$ & $\begin{array}{r}1670 \\
1220 \\
1000 \\
870 \\
798\end{array}$ & $\begin{array}{l}1950 \\
1650 \\
1420 \\
1260 \\
1130\end{array}$ & $\begin{array}{l}1420 \\
1530 \\
1330 \\
1130 \\
1040\end{array}$ & $\begin{array}{l}782 \\
741 \\
689 \\
645 \\
623\end{array}$ & $\begin{array}{r}896 \\
840 \\
767 \\
1020 \\
1250\end{array}$ & $\begin{array}{l}710 \\
756 \\
664 \\
598 \\
564\end{array}$ & $\begin{array}{r}1030 \\
843 \\
710 \\
623 \\
562\end{array}$ & $\begin{array}{l}254 \\
240 \\
469 \\
918 \\
456\end{array}$ & $\begin{array}{l}173 \\
168 \\
187 \\
221 \\
241\end{array}$ & $\begin{array}{l}177 \\
161 \\
154 \\
149 \\
146\end{array}$ \\
\hline $\begin{array}{l}11 \\
12 \\
13 \\
14 \\
15\end{array}$ & $\begin{array}{l}7880 \\
6960 \\
4820 \\
3250 \\
2070\end{array}$ & $\begin{array}{l}868 \\
765 \\
693 \\
644 \\
609\end{array}$ & $\begin{array}{l}752 \\
718 \\
685 \\
647 \\
677\end{array}$ & $\begin{array}{l}1080 \\
1450 \\
1520 \\
1200 \\
1410\end{array}$ & $\begin{array}{l}918 \\
796 \\
736 \\
723 \\
673\end{array}$ & $\begin{array}{l}605 \\
593 \\
595 \\
594 \\
623\end{array}$ & $\begin{array}{r}936 \\
777 \\
737 \\
905 \\
1630\end{array}$ & $\begin{array}{l}537 \\
518 \\
504 \\
510 \\
545\end{array}$ & $\begin{array}{l}520 \\
558 \\
510 \\
456 \\
436\end{array}$ & $\begin{array}{l}341 \\
298 \\
270 \\
255 \\
243\end{array}$ & $\begin{array}{l}208 \\
187 \\
175 \\
170 \\
165\end{array}$ & $\begin{array}{l}146 \\
145 \\
152 \\
163 \\
185\end{array}$ \\
\hline $\begin{array}{l}16 \\
17 \\
18 \\
19 \\
20\end{array}$ & $\begin{array}{l}1620 \\
1340 \\
1940 \\
2590 \\
1730\end{array}$ & $\begin{array}{l}587 \\
565 \\
542 \\
534 \\
508\end{array}$ & $\begin{array}{l}1170 \\
1190 \\
1070 \\
1490 \\
1370\end{array}$ & $\begin{array}{l}2750 \\
3850 \\
2580 \\
1700 \\
1440\end{array}$ & $\begin{array}{r}563 \\
589 \\
702 \\
1540 \\
2710\end{array}$ & $\begin{array}{r}739 \\
1160 \\
2890 \\
2910 \\
1880\end{array}$ & $\begin{array}{l}2040 \\
1500 \\
1800 \\
1520 \\
2500\end{array}$ & $\begin{array}{l}504 \\
477 \\
699 \\
612 \\
511\end{array}$ & $\begin{array}{l}496 \\
510 \\
434 \\
391 \\
362\end{array}$ & $\begin{array}{l}234 \\
223 \\
209 \\
199 \\
193\end{array}$ & $\begin{array}{l}161 \\
159 \\
167 \\
195 \\
199\end{array}$ & $\begin{array}{l}166 \\
152 \\
144 \\
138 \\
137\end{array}$ \\
\hline $\begin{array}{l}21 \\
22 \\
23 \\
24 \\
25\end{array}$ & $\begin{array}{r}1270 \\
1050 \\
917 \\
829 \\
754\end{array}$ & $\begin{array}{l}493 \\
495 \\
496 \\
487 \\
474\end{array}$ & $\begin{array}{r}1310 \\
3230 \\
2970 \\
1880 \\
\text { el } 300\end{array}$ & $\begin{array}{r}\text { e1300 } \\
\text { e1140 } \\
\text { e1010 } \\
\text { e910 } \\
\text { e850 }\end{array}$ & $\begin{array}{r}1900 \\
1420 \\
1150 \\
949 \\
836\end{array}$ & $\begin{array}{l}1360 \\
1110 \\
1060 \\
1100 \\
1080\end{array}$ & $\begin{array}{l}2710 \\
1880 \\
1340 \\
1460 \\
2000\end{array}$ & $\begin{array}{l}464 \\
727 \\
822 \\
701 \\
691\end{array}$ & $\begin{array}{l}345 \\
333 \\
316 \\
304 \\
296\end{array}$ & $\begin{array}{l}187 \\
183 \\
218 \\
243 \\
202\end{array}$ & $\begin{array}{l}206 \\
192 \\
175 \\
166 \\
160\end{array}$ & $\begin{array}{l}139 \\
142 \\
145 \\
143 \\
146\end{array}$ \\
\hline $\begin{array}{l}26 \\
27 \\
28 \\
29 \\
30 \\
31\end{array}$ & $\begin{array}{l}695 \\
652 \\
619 \\
586 \\
562 \\
547\end{array}$ & $\begin{array}{r}459 \\
469 \\
1280 \\
2430 \\
1490 \\
\ldots\end{array}$ & $\begin{array}{r}\text { 1050 } \\
\text { e } 910 \\
\text { e } 820 \\
3700 \\
11500 \\
14300\end{array}$ & $\begin{array}{l}\text { e780 } \\
\text { e720 } \\
\text { e670 } \\
\text { e640 } \\
\text { e620 } \\
\text { e610 }\end{array}$ & $\begin{array}{l}762 \\
719 \\
688 \\
\ldots \\
\ldots \\
\ldots\end{array}$ & $\begin{array}{r}1120 \\
1690 \\
1590 \\
1380 \\
1020 \\
847\end{array}$ & $\begin{array}{r}1480 \\
1120 \\
985 \\
1200 \\
980 \\
\ldots\end{array}$ & $\begin{array}{r}713 \\
763 \\
621 \\
517 \\
498 \\
1750\end{array}$ & $\begin{array}{l}286 \\
280 \\
275 \\
264 \\
257 \\
\ldots-\end{array}$ & $\begin{array}{l}184 \\
177 \\
173 \\
170 \\
175 \\
171\end{array}$ & $\begin{array}{l}156 \\
153 \\
156 \\
152 \\
150 \\
209\end{array}$ & $\begin{array}{l}143 \\
140 \\
140 \\
137 \\
137 \\
\ldots-2\end{array}$ \\
\hline $\begin{array}{l}\text { TOTAL } \\
\text { MEAN } \\
\text { MAX } \\
\text { MIN } \\
\text { CF SM } \\
\text { IN. }\end{array}$ & $\begin{array}{r}55991 \\
1806 \\
7880 \\
323 \\
2.29 \\
2.64\end{array}$ & $\begin{array}{r}28522 \\
951 \\
3440 \\
459 \\
1.20 \\
1.34\end{array}$ & $\begin{array}{r}68248 \\
2202 \\
14300 \\
647 \\
2.79 \\
3.22\end{array}$ & $\begin{array}{r}64930 \\
2095 \\
11000 \\
610 \\
2.65 \\
3.06\end{array}$ & $\begin{array}{r}28699 \\
1025 \\
2710 \\
563 \\
1.30 \\
1.35\end{array}$ & $\begin{array}{r}34139 \\
1101 \\
2910 \\
593 \\
1.40 \\
1.61\end{array}$ & $\begin{array}{r}37895 \\
1263 \\
2710 \\
664 \\
1.60 \\
1.79\end{array}$ & $\begin{array}{r}20648 \\
666 \\
1750 \\
464 \\
.84 \\
.97\end{array}$ & $\begin{array}{r}27177 \\
906 \\
4640 \\
257 \\
1.15 \\
1.28\end{array}$ & $\begin{array}{c}8430 \\
272 \\
918 \\
170 \\
.34 \\
.40\end{array}$ & $\begin{array}{c}5465 \\
176 \\
241 \\
150 \\
.22 \\
.26\end{array}$ & $\begin{array}{r}4785 \\
159 \\
272 \\
137 \\
.20 \\
.23\end{array}$ \\
\hline
\end{tabular}

e Estinated

STATISTICS OF MONTHLY MEAN DATA FOR WATER YEARS 1944 - 1991, BY WATER YEAR (WY)

$\begin{array}{lrrrrrrrrrrrr}\text { MEAN } & 354 & 487 & 837 & 906 & 1165 & 1386 & 1299 & 858 & 757 & 421 & 358 & 289 \\ \text { MAX } & 1806 & 1821 & 2898 & 4507 & 3090 & 4612 & 3285 & 1827 & 2208 & 1311 & 2115 & 1051 \\ \text { (WY) } & 1991 & 1973 & 1967 & 1950 & 1959 & 1982 & 1950 & 1983 & 1975 & 1969 & 1990 & 1972 \\ \text { MIN } & 95.1 & 110 & 98.2 & 101 & 184 & 353 & 366 & 245 & 176 & 140 & 128 & 101 \\ \text { (WY) } & 1964 & 1964 & 1964 & 1977 & 1964 & 1966 & 1966 & 1958 & 1988 & 1988 & 1966 & 1963\end{array}$

SUMMARY STATISTICS

ANMUAL TOTAL

ANMUAL MEAN

HIGHEST ANNUAL MEAM

LOWEST ANMUAL MEAN

HIGHEST DAILY MEAN

LOWEST DAILY MEAM

ANNUAL SEVEN-DAY MINIMUM

INSTANTANEOUS PEAK FLOW

INSTANTANEOUS PEAK STAGE

ANMUAL RUNOFF (CFSM)

ANNUAL RUNOFF (INCHES)

10 PERCENT EXCEEDS

50 PERCENT EXCEEDS

90 PERCENT EXCEEDS
FOR 1990 CALENDAR YEAR

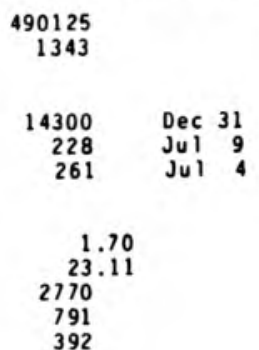

FOR 1991 WATER YEAR

384929
1055

$\begin{aligned} 1055 & \\ & \\ 14300 & \text { Dec 31 } \\ 137 & \text { Sep 20 } \\ 141 & \text { Sep 24 } \\ 14700 & \text { DeC 31 } \\ 11.75 & \text { Dec 31 } \\ 1.34 & \\ 18.15 & \\ 1970 & \\ 688 & \\ 166 & \end{aligned}$

WATER YEARS 1944 - 1991

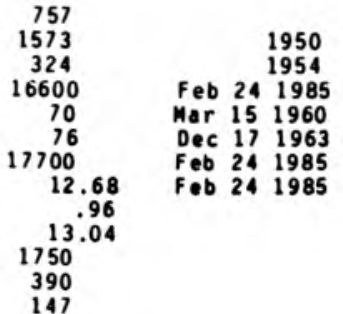




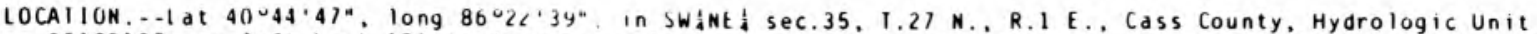
05120105 , on left bank $150 \mathrm{ft}$ downstream trom Cicott Street bridge in logansport. $1.000 \mathrm{ft}$ downstrean from Eel River, and at nile 353.7 .

DRAI NAGE AREA $\cdots 3,719 \mathrm{i}^{2}$

PERIOD OF RECORD.--April to Septemuer. Nuventer and Decenber 1903, March to November 1904 , March 1905 to July 1906. May 1923 to current year. January. February, and December 1904, January and February 1905 (gage heights on ly). Gage-height records collected at same site Decenber 1910 to Decenber 1916, and since January 1926 are contained in reports of National Weather Service.

REVISED RECORDS.--WSP 183: 1934. WSP 1335: 1904,1925(M), 1926-30, 1931(M), 1932-35, 1937-39, 1948. WSP 1385: 1903,1905-6,1923-25. WSP 1505: 1906(M). WSP 2109: Drainage area. WDR in-81-1: ig79.

GAGE.- Water-stage recorder. Datum of gage is $573.28 \mathrm{ft}$ above National Geodetic Vertical Datum of 1929 (levels by U.S. Army Corps of Engineers). See WSP 1705 for history of changes prior to 0ct. 1. 1927.

REMARKS.--Records good. Flow partially regulated by Huntington Lake, Salanonie Lake, and Mississinewa Lake.

EXIREMES OUTS JDE PERIOD OF RECORO... Maximum stage known, $25.3 \mathrm{ft}$ March 26,1913 , fro floodearks, discharge. $140,000 \mathrm{ft}^{3} / \mathrm{s}$.

DISCHARGE, CUBIC FEET PER SECOND, WATER YEAR OCTOBER 1990 TO SEPIEMBER 1991 DAILY MEAN VALUES

\begin{tabular}{|c|c|c|c|c|c|c|c|c|c|c|c|c|}
\hline DAY & $0 \mathrm{CT}$ & NOV & DEC & JAN & FEB & MAR & $A P R$ & MAY & JUN & JuL & AUG & SEP \\
\hline $\begin{array}{l}1 \\
2 \\
3 \\
4 \\
5\end{array}$ & $\begin{array}{l}1380 \\
1370 \\
1380 \\
1620 \\
3260\end{array}$ & $\begin{array}{l}2290 \\
2250 \\
2900 \\
3950 \\
5100\end{array}$ & $\begin{array}{r}1580 \\
7650 \\
9200 \\
12200 \\
11500\end{array}$ & $\begin{array}{l}22200 \\
16400 \\
13800 \\
12900 \\
12600\end{array}$ & $\begin{array}{l}2320 \\
2290 \\
2340 \\
2840 \\
4590\end{array}$ & $\begin{array}{l}2430 \\
2790 \\
3430 \\
3290 \\
2890\end{array}$ & $\begin{array}{l}5690 \\
2740 \\
2230 \\
2070 \\
2150\end{array}$ & $\begin{array}{l}1880 \\
1880 \\
1930 \\
1810 \\
1800\end{array}$ & $\begin{array}{r}15400 \\
11800 \\
8980 \\
8090 \\
7180\end{array}$ & $\begin{array}{r}760 \\
998 \\
1390 \\
1650 \\
1560\end{array}$ & $\begin{array}{l}406 \\
397 \\
396 \\
395 \\
396\end{array}$ & $\begin{array}{l}457 \\
422 \\
556 \\
701 \\
506\end{array}$ \\
\hline $\begin{array}{r}6 \\
7 \\
8 \\
9 \\
10\end{array}$ & $\begin{array}{r}6770 \\
5030 \\
3550 \\
5740 \\
16700\end{array}$ & $\begin{array}{l}8910 \\
6930 \\
4970 \\
4220 \\
4320\end{array}$ & $\begin{array}{r}11600 \\
11000 \\
9410 \\
7560 \\
5480\end{array}$ & $\begin{array}{l}12700 \\
13500 \\
13400 \\
13100 \\
12700\end{array}$ & $\begin{array}{r}9030 \\
11600 \\
11700 \\
10100 \\
8050\end{array}$ & $\begin{array}{l}2730 \\
2410 \\
2210 \\
2190 \\
2050\end{array}$ & $\begin{array}{l}2570 \\
2430 \\
2260 \\
2690 \\
3410\end{array}$ & $\begin{array}{l}1850 \\
1910 \\
1800 \\
1690 \\
1640\end{array}$ & $\begin{array}{l}6980 \\
5610 \\
4110 \\
2590 \\
1730\end{array}$ & $\begin{array}{l}1390 \\
1200 \\
1150 \\
3250 \\
3010\end{array}$ & $\begin{array}{l}442 \\
459 \\
563 \\
737 \\
744\end{array}$ & $\begin{array}{l}482 \\
445 \\
392 \\
361 \\
353\end{array}$ \\
\hline $\begin{array}{l}11 \\
12 \\
13 \\
14 \\
15\end{array}$ & $\begin{array}{r}16500 \\
12600 \\
9240 \\
7360 \\
6360\end{array}$ & $\begin{array}{l}3980 \\
3260 \\
2970 \\
2990 \\
3260\end{array}$ & $\begin{array}{l}4590 \\
2990 \\
2760 \\
2450 \\
2670\end{array}$ & $\begin{array}{l}11800 \\
12700 \\
13000 \\
13100 \\
13600\end{array}$ & $\begin{array}{l}5410 \\
4310 \\
3640 \\
3370 \\
3140\end{array}$ & $\begin{array}{l}1960 \\
1920 \\
1980 \\
2010 \\
2080\end{array}$ & $\begin{array}{l}2800 \\
2380 \\
2150 \\
2590 \\
4480\end{array}$ & $\begin{array}{l}1580 \\
1550 \\
1520 \\
1470 \\
1510\end{array}$ & $\begin{array}{l}1570 \\
1540 \\
1440 \\
1290 \\
1230\end{array}$ & $\begin{array}{r}1840 \\
1250 \\
955 \\
853 \\
761\end{array}$ & $\begin{array}{l}699 \\
615 \\
577 \\
562 \\
544\end{array}$ & $\begin{array}{l}347 \\
368 \\
459 \\
599 \\
776\end{array}$ \\
\hline $\begin{array}{l}16 \\
17 \\
18 \\
19 \\
20\end{array}$ & $\begin{array}{l}7320 \\
7010 \\
9740 \\
9650 \\
8100\end{array}$ & $\begin{array}{l}3290 \\
3090 \\
2980 \\
2630 \\
2460\end{array}$ & $\begin{array}{l}4920 \\
7480 \\
6200 \\
9340 \\
9460\end{array}$ & $\begin{array}{l}16400 \\
16600 \\
12200 \\
11700 \\
12300\end{array}$ & $\begin{array}{r}e 2500 \\
e 2000 \\
e 2400 \\
5490 \\
11400\end{array}$ & $\begin{array}{r}2590 \\
3870 \\
9990 \\
12100 \\
9880\end{array}$ & $\begin{array}{l}7960 \\
8000 \\
6830 \\
4860 \\
7440\end{array}$ & $\begin{array}{l}1450 \\
1340 \\
1720 \\
1820 \\
1700\end{array}$ & $\begin{array}{l}1300 \\
1250 \\
1180 \\
1110 \\
1020\end{array}$ & $\begin{array}{l}724 \\
675 \\
641 \\
572 \\
532\end{array}$ & $\begin{array}{l}416 \\
440 \\
490 \\
702 \\
728\end{array}$ & $\begin{array}{r}748 \\
895 \\
1090 \\
885 \\
900\end{array}$ \\
\hline $\begin{array}{l}21 \\
22 \\
23 \\
24 \\
25\end{array}$ & $\begin{array}{l}7850 \\
7860 \\
8370 \\
7350 \\
6860\end{array}$ & $\begin{array}{l}2420 \\
2570 \\
2590 \\
2450 \\
2570\end{array}$ & $\begin{array}{r}10600 \\
14100 \\
11700 \\
9260 \\
\in 8400\end{array}$ & $\begin{array}{l}12600 \\
12600 \\
13500 \\
13300 \\
13100\end{array}$ & $\begin{array}{r}11400 \\
10800 \\
9710 \\
5590 \\
4220\end{array}$ & $\begin{array}{l}8500 \\
7170 \\
7280 \\
8300 \\
9220\end{array}$ & $\begin{array}{l}8640 \\
8610 \\
8060 \\
6300 \\
5930\end{array}$ & $\begin{array}{l}1630 \\
1830 \\
2610 \\
2320 \\
2270\end{array}$ & $\begin{array}{l}962 \\
936 \\
877 \\
822 \\
808\end{array}$ & $\begin{array}{l}513 \\
482 \\
491 \\
535 \\
516\end{array}$ & $\begin{array}{l}593 \\
524 \\
465 \\
424 \\
397\end{array}$ & $\begin{array}{r}920 \\
1110 \\
1090 \\
974 \\
978\end{array}$ \\
\hline $\begin{array}{l}26 \\
27 \\
28 \\
29 \\
30 \\
31\end{array}$ & $\begin{array}{l}5880 \\
5330 \\
4760 \\
2900 \\
2720 \\
2410\end{array}$ & $\begin{array}{c}2650 \\
2670 \\
5620 \\
9030 \\
7260 \\
\cdots\end{array}$ & $\begin{array}{l}e 7500 \\
e 6900 \\
e 6500 \\
15300 \\
34800 \\
32000\end{array}$ & $\begin{array}{r}12500 \\
10900 \\
9160 \\
7910 \\
7240 \\
4850\end{array}$ & $\begin{array}{c}3430 \\
2960 \\
2560 \\
\ldots \\
\ldots \\
\ldots\end{array}$ & $\begin{array}{r}9290 \\
11100 \\
9330 \\
9980 \\
8560 \\
6730\end{array}$ & $\begin{array}{c}3800 \\
2760 \\
2320 \\
2360 \\
2040 \\
\ldots\end{array}$ & $\begin{array}{l}4020 \\
4420 \\
3420 \\
2520 \\
2150 \\
8860\end{array}$ & $\begin{array}{l}840 \\
824 \\
848 \\
855 \\
846 \\
\cdots\end{array}$ & $\begin{array}{l}487 \\
463 \\
450 \\
435 \\
440 \\
422\end{array}$ & $\begin{array}{l}384 \\
371 \\
372 \\
377 \\
384 \\
477\end{array}$ & $\begin{array}{r}992 \\
1040 \\
1120 \\
1110 \\
1100 \\
\ldots\end{array}$ \\
\hline $\begin{array}{l}\text { IOIAL } \\
\text { MEAN } \\
\text { MAX } \\
\text { MIN } \\
\text { CFSM } \\
\text { IN. }\end{array}$ & $\begin{array}{r}202970 \\
6547 \\
16700 \\
1370 \\
1.73 \\
2.00\end{array}$ & $\begin{array}{r}116580 \\
3886 \\
9030 \\
2250 \\
1.03 \\
1.15\end{array}$ & $\begin{array}{r}303100 \\
9777 \\
34800 \\
2450 \\
2.59 \\
2.98\end{array}$ & $\begin{array}{r}194360 \\
12720 \\
22200 \\
4850 \\
3.37 \\
3.88\end{array}$ & $\begin{array}{r}159190 \\
5685 \\
11700 \\
2000 \\
1.50 \\
1.57\end{array}$ & $\begin{array}{r}170260 \\
5492 \\
12100 \\
1920 \\
1.45 \\
1.68\end{array}$ & $\begin{array}{r}128550 \\
4285 \\
8640 \\
2040 \\
1.13 \\
1.27\end{array}$ & $\begin{array}{r}69900 \\
2255 \\
8860 \\
1340 \\
.60 \\
.69\end{array}$ & $\begin{array}{c}94018 \\
3134 \\
15400 \\
808 \\
.83 \\
.93\end{array}$ & $\begin{array}{c}30995 \\
1000 \\
3250 \\
422 \\
.26 \\
.31\end{array}$ & $\begin{array}{c}15536 \\
501 \\
744 \\
371 \\
.13 \\
.15\end{array}$ & $\begin{array}{r}22116 \\
739 \\
1120 \\
347 \\
.20 \\
.22\end{array}$ \\
\hline
\end{tabular}

e Estimated

SIAIISTICS OF MONTHIY MEAN DATA FOR WAIEK YEARS 1924 - 1991, BY WATER YEAR (WY)

\begin{tabular}{|c|c|c|c|c|c|c|c|c|c|c|c|c|}
\hline $\begin{array}{l}\text { MEAN } \\
\text { MAX } \\
\text { (WY) } \\
\text { MI }) \\
(W Y)\end{array}$ & $\begin{array}{r}1380 \\
6547 \\
1991 \\
197 \\
1964\end{array}$ & $\begin{array}{r}2029 \\
10940 \\
1973 \\
296 \\
1964\end{array}$ & $\begin{array}{r}3674 \\
12340 \\
1968 \\
252 \\
1964\end{array}$ & $\begin{array}{r}4606 \\
\angle 5590 \\
1950 \\
290 \\
1945\end{array}$ & $\begin{array}{r}5245 \\
15880 \\
1959 \\
417 \\
1964\end{array}$ & $\begin{array}{r}6538 \\
18180 \\
1982 \\
638 \\
1941\end{array}$ & $\begin{array}{r}5966 \\
17520 \\
1957 \\
929 \\
1971\end{array}$ & $\begin{array}{r}3765 \\
21310 \\
1943 \\
600 \\
1941\end{array}$ & $\begin{array}{r}3003 \\
16440 \\
1958 \\
388 \\
1988\end{array}$ & $\begin{array}{r}1752 \\
6521 \\
1957 \\
269 \\
1936\end{array}$ & $\begin{array}{c}1194 \\
5576 \\
1990 \\
203 \\
1941\end{array}$ & $\begin{array}{r}1164 \\
10710 \\
1926 \\
170 \\
1941\end{array}$ \\
\hline
\end{tabular}

SUMMARY STAIISIICS

ANNUAL IOTAL

HIGHESI ANNUAI MEAN

LOWESI ANNUAI MEAN

HIGHESI DAILY MEAN

LOWEST DAILY MLAN

ANNUAL SEVEN-UAY MINIMUM

INSIANTANEOUS PEAK FIOW

INSTANIANEOUS PEAK SIAGE

ANNUAL RUNOFF (CFSM)

ANNUAL RUNOFF (INCHES)

10 PERCENT EXLEEDS

50 PERCENT EXCEEDS

90 PERCENI EXIEEDS
FOR IYYO CAIENUAR YEAR

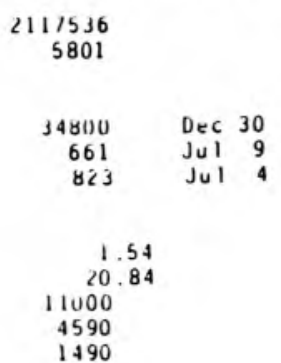

FOR 1991 WAIER YEAR

WAIER YEARS 1924 - 1991

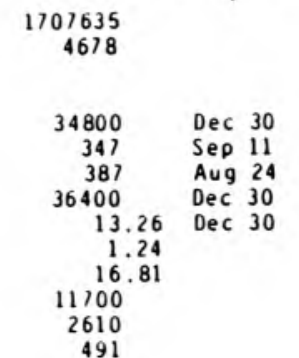

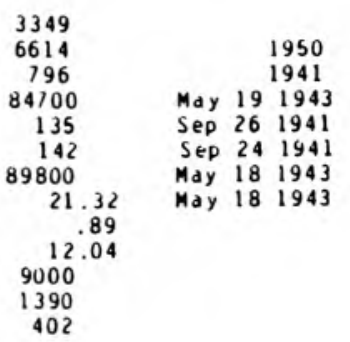


LOCATION.--Lat $40^{\circ} 42^{\prime} 46^{\circ}$, long $86^{\circ} 41^{\prime} 49^{\prime \prime}$, in NWt $\frac{1}{4}$ SW sec.7. T.26 N., R.2 W., Carroll County, Hydrologic Unit 05120105 , on left bank $5 \mathrm{ft}$ downstrea fro bridge on County Road 900 West, and 2.5 a northeast of Patton. DRAI NAGE AREA.

PERIOD OF RECORD.--October 1968 to current year.

GAGE.- Water-stage recorder. Datun of gage is $644.97 \mathrm{ft}$ above National Geodetic Vertical Datua of 1929 . Prior to Nov, 28, 1979, at datun $1.00 \mathrm{ft}$ higher.

REMARKS. --Records good, except for estimated daily discharges, which are poor.

DISCHARGE, CUBIC FEET PER SECOND, WATER YEAR OCTOBER 1990 TO SEPTEMBER 1991 DAI IY MEAN VALUES

\begin{tabular}{|c|c|c|c|c|c|c|c|c|c|c|c|c|}
\hline DAY & $O C T$ & MOV & DEC & JAN & FEB & MAR & APR & MAY & JUN & JUL & AUG & SEP \\
\hline $\begin{array}{l}1 \\
2 \\
3 \\
4 \\
5\end{array}$ & $\begin{array}{l}1.6 \\
1.7 \\
2.2 \\
3.0 \\
2.3\end{array}$ & $\begin{array}{r}3.2 \\
3.1 \\
2.8 \\
2.8 \\
32\end{array}$ & $\begin{array}{r}7.0 \\
5.9 \\
22 \\
14 \\
9.7\end{array}$ & $\begin{array}{r}23 \\
18 \\
\text { e14 } \\
\text { e11 } \\
\text { e10 }\end{array}$ & $\begin{array}{l}\text { e3.9 } \\
\text { e } 4.1 \\
\text { e } 4.8 \\
\text { e7.0 } \\
10\end{array}$ & $\begin{array}{l}4.4 \\
9.5 \\
7.4 \\
6.3 \\
5.8\end{array}$ & $\begin{array}{l}9.2 \\
8.4 \\
8.0 \\
8.1 \\
7.6\end{array}$ & $\begin{array}{l}6.7 \\
6.3 \\
6.1 \\
6.0 \\
9.8\end{array}$ & $\begin{array}{l}5.2 \\
4.5 \\
4.2 \\
3.9 \\
3.6\end{array}$ & $\begin{array}{l}1.6 \\
1.7 \\
1.6 \\
1.4 \\
1.4\end{array}$ & $\begin{array}{l}.37 \\
.36 \\
.41 \\
.40 \\
.39\end{array}$ & $\begin{array}{l}.28 \\
.29 \\
.48 \\
.37 \\
.28\end{array}$ \\
\hline $\begin{array}{r}6 \\
7 \\
8 \\
9 \\
10\end{array}$ & $\begin{array}{r}2.2 \\
3.6 \\
4.4 \\
41 \\
102\end{array}$ & $\begin{array}{c}30 \\
18 \\
12 \\
10 \\
8.2\end{array}$ & $\begin{array}{l}8.1 \\
6.8 \\
6.2 \\
5.6 \\
5.3\end{array}$ & $\begin{array}{l}8.7 \\
8.0 \\
7.7 \\
7.0 \\
6.6\end{array}$ & $\begin{array}{r}10 \\
9.6 \\
8.6 \\
8.0 \\
7.4\end{array}$ & $\begin{array}{l}5.6 \\
4.6 \\
4.4 \\
4.3 \\
4.0\end{array}$ & $\begin{array}{l}7.2 \\
6.9 \\
7.3 \\
7.4 \\
6.4\end{array}$ & $\begin{array}{r}11 \\
8.1 \\
7.2 \\
6.8 \\
6.3\end{array}$ & $\begin{array}{l}3.5 \\
3.4 \\
3.3 \\
3.1 \\
3.1\end{array}$ & $\begin{array}{l}1.3 \\
1.3 \\
1.5 \\
1.2 \\
1.2\end{array}$ & $\begin{array}{l}.51 \\
.40 \\
.57 \\
.49 \\
.38\end{array}$ & $\begin{array}{l}.27 \\
.27 \\
.27 \\
.28 \\
.29\end{array}$ \\
\hline $\begin{array}{l}11 \\
12 \\
13 \\
14 \\
15\end{array}$ & $\begin{array}{l}44 \\
28 \\
19 \\
13 \\
10\end{array}$ & $\begin{array}{l}6.9 \\
6.1 \\
5.6 \\
5.3 \\
5.0\end{array}$ & $\begin{array}{l}5.1 \\
4.8 \\
4.1 \\
3.9 \\
6.8\end{array}$ & $\begin{array}{l}10 \\
11 \\
8.5 \\
11 \\
17\end{array}$ & $\begin{array}{r}6.5 \\
6.0 \\
6.3 \\
5.8 \\
\mathrm{e} 4.2\end{array}$ & $\begin{array}{l}4.0 \\
4.3 \\
5.3 \\
5.3 \\
6.6\end{array}$ & $\begin{array}{l}5.9 \\
5.8 \\
6.4 \\
14 \\
37\end{array}$ & $\begin{array}{l}6.9 \\
7.4 \\
6.6 \\
17 \\
12\end{array}$ & $\begin{array}{l}3.1 \\
2.9 \\
2.7 \\
2.7 \\
2.7\end{array}$ & $\begin{array}{l}1.1 \\
1.1 \\
1.0 \\
.95 \\
.87\end{array}$ & $\begin{array}{l}.38 \\
.37 \\
.36 \\
.35 \\
.34\end{array}$ & $\begin{array}{l}.30 \\
.30 \\
.68 \\
.94 \\
.43\end{array}$ \\
\hline $\begin{array}{l}16 \\
17 \\
18 \\
19 \\
20\end{array}$ & $\begin{array}{c}8.3 \\
7.7 \\
19 \\
11 \\
8.7\end{array}$ & $\begin{array}{l}4.8 \\
4.3 \\
4.2 \\
4.0 \\
3.6\end{array}$ & $\begin{array}{l}5.7 \\
6.0 \\
7.6 \\
7.3 \\
6.7\end{array}$ & $\begin{array}{l}54 \\
27 \\
15 \\
13 \\
13\end{array}$ & $\begin{array}{r}\text { e } 4.1 \\
\text { e4.3 } \\
5.8 \\
8.5 \\
7.2\end{array}$ & $\begin{array}{l}14 \\
40 \\
96 \\
53 \\
29\end{array}$ & $\begin{array}{l}21 \\
15 \\
12 \\
11 \\
9.9\end{array}$ & $\begin{array}{l}10 \\
10 \\
45 \\
18 \\
11\end{array}$ & $\begin{array}{l}2.6 \\
2.5 \\
2.4 \\
2.2 \\
2.1\end{array}$ & $\begin{array}{l}.83 \\
.76 \\
.72 \\
.63 \\
.57\end{array}$ & $\begin{array}{l}.33 \\
.33 \\
.33 \\
.46 \\
.39\end{array}$ & $\begin{array}{l}.31 \\
.27 \\
.29 \\
.27 \\
.27\end{array}$ \\
\hline $\begin{array}{l}21 \\
22 \\
23 \\
24 \\
25\end{array}$ & $\begin{array}{l}7.0 \\
5.7 \\
5.3 \\
4.8 \\
4.4\end{array}$ & $\begin{array}{l}3.7 \\
3.7 \\
3.5 \\
3.4 \\
3.1\end{array}$ & $\begin{array}{r}17 \\
19 \\
12 \\
8.5 \\
\text { e6.6 }\end{array}$ & $\begin{array}{l}11 \\
\text { e } 9.0 \\
\text { e } 7.4 \\
\text { e } 6.6 \\
\text { e5.9 }\end{array}$ & $\begin{array}{l}6.6 \\
5.9 \\
5.4 \\
5.2 \\
4.7\end{array}$ & $\begin{array}{l}21 \\
19 \\
22 \\
18 \\
15\end{array}$ & $\begin{array}{l}9.3 \\
8.7 \\
8.6 \\
8.4 \\
7.8\end{array}$ & $\begin{array}{l}8.6 \\
7.8 \\
7.5 \\
7.1 \\
6.8\end{array}$ & $\begin{array}{l}2.1 \\
2.1 \\
2.0 \\
2.0 \\
1.9\end{array}$ & $\begin{array}{l}.52 \\
.51 \\
.45 \\
.47 \\
.47\end{array}$ & $\begin{array}{l}.33 \\
.33 \\
.31 \\
.30 \\
.30\end{array}$ & $\begin{array}{l}.27 \\
\text { e.31 } \\
\text { e.29 } \\
\text { e.28 } \\
\text { e.27 }\end{array}$ \\
\hline $\begin{array}{l}26 \\
27 \\
28 \\
29 \\
30 \\
31\end{array}$ & $\begin{array}{l}4.2 \\
4.2 \\
3.9 \\
3.7 \\
3.6 \\
3.4\end{array}$ & $\begin{array}{c}3.0 \\
3.4 \\
23 \\
12 \\
8.4 \\
\ldots\end{array}$ & $\begin{array}{c}e 5.7 \\
e 5.4 \\
e 5.2 \\
193 \\
143 \\
39\end{array}$ & $\begin{array}{l}\text { e5.3 } \\
\text { e4.9 } \\
\text { e4.6 } \\
\text { e4.3 } \\
\text { e4.1 } \\
\text { e } 4.0\end{array}$ & $\begin{array}{l}4.5 \\
4.4 \\
4.4 \\
\ldots .- \\
\ldots . . \\
\ldots .-\end{array}$ & $\begin{array}{l}23 \\
21 \\
20 \\
14 \\
11 \\
10\end{array}$ & $\begin{array}{l}7.6 \\
7.5 \\
7.0 \\
7.5 \\
6.8 \\
\ldots .\end{array}$ & $\begin{array}{l}6.3 \\
5.6 \\
5.1 \\
5.1 \\
4.9 \\
4.7\end{array}$ & $\begin{array}{l}1.8 \\
1.8 \\
1.7 \\
1.7 \\
1.7 \\
\ldots-.\end{array}$ & $\begin{array}{l}.45 \\
.44 \\
.41 \\
.41 \\
.41 \\
.39\end{array}$ & $\begin{array}{l}.29 \\
.30 \\
.29 \\
.30 \\
.34 \\
.31\end{array}$ & $\begin{array}{l}\text { e. } 27 \\
\text { e.26 } \\
\text { e.26 } \\
\text { e.26 } \\
\text { e.26 } \\
. .-\end{array}$ \\
\hline $\begin{array}{l}\text { TOTAL } \\
\text { MEAN } \\
\text { MAX } \\
\text { MIN } \\
\text { CF SM } \\
\text { IN. }\end{array}$ & $\begin{array}{r}382.9 \\
12.4 \\
102 \\
1.6 \\
1.81 \\
2.09\end{array}$ & $\begin{array}{r}239.1 \\
7.97 \\
32 \\
2.8 \\
1.17 \\
1.30\end{array}$ & $\begin{array}{r}603.0 \\
19.5 \\
193 \\
3.9 \\
2.85 \\
3.28\end{array}$ & $\begin{array}{r}360.6 \\
11.6 \\
54 \\
4.0 \\
1.70 \\
1.96\end{array}$ & $\begin{array}{r}173.2 \\
6.19 \\
10 \\
3.9 \\
.91 \\
.94\end{array}$ & $\begin{array}{r}507.8 \\
16.4 \\
96 \\
4.0 \\
2.40 \\
2.77\end{array}$ & $\begin{array}{r}293.7 \\
9.79 \\
37 \\
5.8 \\
1.43 \\
1.60\end{array}$ & $\begin{array}{r}287.7 \\
9.28 \\
45 \\
4.7 \\
1.36 \\
1.57\end{array}$ & $\begin{array}{l}82.5 \\
2.75 \\
5.2 \\
1.7 \\
.40 \\
.45\end{array}$ & $\begin{array}{r}27.66 \\
.89 \\
1.7 \\
.39 \\
.13 \\
.15\end{array}$ & $\begin{array}{c}11.32 \\
.37 \\
.57 \\
.29 \\
.05 \\
.06\end{array}$ & $\begin{array}{l}9.87 \\
.33 \\
.94 \\
.26 \\
.05 \\
.05\end{array}$ \\
\hline
\end{tabular}

STATISTICS OF MONTHLY MEAN DATA FOR WATER YEARS 1969 - 1991, BY WATER YEAR (WY)

\begin{tabular}{|c|c|c|c|c|c|c|c|c|c|c|c|c|}
\hline $\begin{array}{l}\text { MEAN } \\
\text { MAX } \\
\text { (WY) } \\
\text { MI } N \\
(W Y)\end{array}$ & $\begin{array}{r}3.00 \\
12.4 \\
1991 \\
.27 \\
1989\end{array}$ & $\begin{array}{r}4.49 \\
17.2 \\
1973 \\
.39 \\
1977\end{array}$ & $\begin{array}{r}7.78 \\
19.5 \\
1991 \\
111 \\
1977\end{array}$ & $\begin{array}{l}6.58 \\
20.6 \\
1969 \\
.069 \\
1977\end{array}$ & $\begin{array}{l}9.53 \\
27.4 \\
1990 \\
1.73 \\
1978\end{array}$ & $\begin{array}{l}11.7 \\
29.2 \\
1982 \\
1.57 \\
1981\end{array}$ & $\begin{array}{l}10.8 \\
23.6 \\
1974 \\
2.38 \\
1971\end{array}$ & $\begin{array}{l}9.63 \\
28.4 \\
1981 \\
2.04 \\
1976\end{array}$ & $\begin{array}{r}7.76 \\
22.1 \\
1975 \\
.93 \\
1977\end{array}$ & $\begin{array}{r}3.90 \\
19.5 \\
1969 \\
.45 \\
1977\end{array}$ & $\begin{array}{r}2.94 \\
22.5 \\
1990 \\
.19 \\
1988\end{array}$ & $\begin{array}{l}3.29 \\
21.5 \\
1977 \\
.073 \\
1988\end{array}$ \\
\hline
\end{tabular}

SUMMARY STATISTICS

ANNUAL TOTAL

ANNUAL MEAN

HIGHEST ANNUAL MEAN

LOWEST AHMUAL MEAN

HIGHEST OAILY MEAM

LOWEST DAILY MEAN

ANMUAL SEVEN-DAY MINIMUM

INSTANTANEOUS PEAK FLOW

INSTANTANEOUS PEAK STAGE

ANNUAL RUNOFF (CFSM)

10 PERCENT EXCEE OS

50 PERCENT EXCEEDS

90 PERCENT EXCEEDS
FOR 1990 CALENDAR YEAR

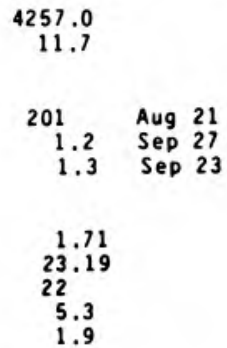

FOR 1991 WATER YEAR

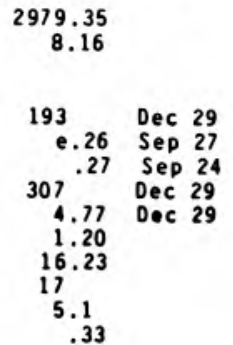

WATER YEARS $1969-1991$

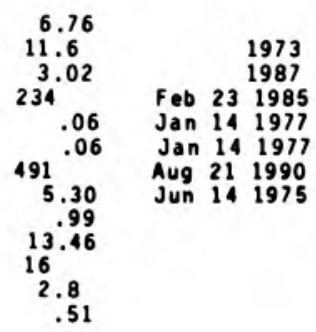

e Estinated 


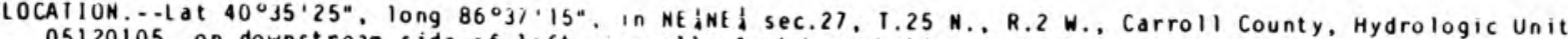
05120105 , on downstrean side of left wingwdil of nighway bridge, 2.6 a northedst of Delphi Post 0 ffice, and 4.8 i upstrea frog auth.

DRAINAGE AREA $=274 i^{2}$

PERIOD OF RECORD.--0ctober 1943 to current year. Prior to March 1944 monthly discharge only, published in wSP 1305 .

REVISED RECORDS. - -WSP 1275: 1944, 1947-48, WSP 2109: Drainage area.

GAGE.--Water-stage recorder. Datua of gage is 553.81 ft above National Geodetic Vertical Datum of 1929 (U.S. Army REMARKS.--Records good.

EXIREMES OUTSIIDE PERIOD OF RECORD,...Flood in May 1943 reached a stage of 19.8 ft, from floodadrks, discharge. $18,000 \mathrm{ft} / \mathrm{s}$ from rating curve extended above $8,000 \mathrm{ft} / \mathrm{s}$.

DISCHARGE, CUBIC FEET PER SECONO, WAIER YEAR OCTOBER 1990 TO SEPIEMBER 1991 DAILY MEAN VALUES

\begin{tabular}{|c|c|c|c|c|c|c|c|c|c|c|c|c|}
\hline DAY & $\mathrm{OCI}$ & NOV & $\mathrm{DEC}$ & JAN & FEB & MAR & APR & MAY & JUN & JUL & AUG & SEP \\
\hline $\begin{array}{l}1 \\
2 \\
3 \\
4 \\
5\end{array}$ & $\begin{array}{r}48 \\
46 \\
50 \\
137 \\
110\end{array}$ & $\begin{array}{l}160 \\
155 \\
149 \\
144 \\
488\end{array}$ & $\begin{array}{r}434 \\
344 \\
674 \\
1130 \\
660\end{array}$ & $\begin{array}{r}2180 \\
1230 \\
870 \\
657 \\
548\end{array}$ & $\begin{array}{r}e 170 \\
\text { e180 } \\
\text { e } 200 \\
\text { e270 } \\
414\end{array}$ & $\begin{array}{l}216 \\
234 \\
229 \\
210 \\
201\end{array}$ & $\begin{array}{l}332 \\
292 \\
268 \\
260 \\
263\end{array}$ & $\begin{array}{l}214 \\
201 \\
186 \\
184 \\
200\end{array}$ & $\begin{array}{l}235 \\
228 \\
171 \\
141 \\
121\end{array}$ & $\begin{array}{c}39 \\
79 \\
202 \\
108 \\
72\end{array}$ & $\begin{array}{l}22 \\
21 \\
21 \\
23 \\
23\end{array}$ & $\begin{array}{l}23 \\
26 \\
25 \\
28 \\
25\end{array}$ \\
\hline $\begin{array}{r}6 \\
7 \\
8 \\
9 \\
10\end{array}$ & $\begin{array}{r}114 \\
102 \\
112 \\
918 \\
2990\end{array}$ & $\begin{array}{l}926 \\
563 \\
393 \\
330 \\
289\end{array}$ & $\begin{array}{l}483 \\
381 \\
325 \\
287 \\
265\end{array}$ & $\begin{array}{l}449 \\
371 \\
334 \\
310 \\
281\end{array}$ & $\begin{array}{l}480 \\
635 \\
548 \\
463 \\
410\end{array}$ & $\begin{array}{l}202 \\
192 \\
173 \\
166 \\
162\end{array}$ & $\begin{array}{l}249 \\
236 \\
241 \\
253 \\
238\end{array}$ & $\begin{array}{l}247 \\
206 \\
179 \\
166 \\
160\end{array}$ & $\begin{array}{r}110 \\
101 \\
97 \\
93 \\
89\end{array}$ & $\begin{array}{l}56 \\
52 \\
61 \\
57 \\
58\end{array}$ & $\begin{array}{l}29 \\
28 \\
41 \\
46 \\
47\end{array}$ & $\begin{array}{l}22 \\
21 \\
20 \\
18 \\
18\end{array}$ \\
\hline $\begin{array}{l}11 \\
12 \\
13 \\
14 \\
15\end{array}$ & $\begin{array}{r}3040 \\
1540 \\
937 \\
669 \\
495\end{array}$ & $\begin{array}{l}250 \\
224 \\
200 \\
189 \\
181\end{array}$ & $\begin{array}{l}249 \\
242 \\
228 \\
203 \\
299\end{array}$ & $\begin{array}{l}323 \\
583 \\
449 \\
385 \\
599\end{array}$ & $\begin{array}{r}350 \\
300 \\
295 \\
301 \\
\text { e230 }\end{array}$ & $\begin{array}{l}151 \\
171 \\
264 \\
356 \\
496\end{array}$ & $\begin{array}{r}209 \\
192 \\
200 \\
367 \\
1060\end{array}$ & $\begin{array}{l}156 \\
161 \\
152 \\
144 \\
142\end{array}$ & $\begin{array}{l}86 \\
85 \\
82 \\
76 \\
74\end{array}$ & $\begin{array}{l}54 \\
55 \\
49 \\
45 \\
42\end{array}$ & $\begin{array}{l}39 \\
32 \\
28 \\
27 \\
25\end{array}$ & $\begin{array}{l}19 \\
18 \\
26 \\
39 \\
23\end{array}$ \\
\hline $\begin{array}{l}16 \\
17 \\
18 \\
19 \\
20\end{array}$ & $\begin{array}{r}387 \\
336 \\
1280 \\
1020 \\
637\end{array}$ & $\begin{array}{l}178 \\
170 \\
161 \\
159 \\
152\end{array}$ & $\begin{array}{l}446 \\
363 \\
475 \\
729 \\
558\end{array}$ & $\begin{array}{r}1220 \\
1290 \\
832 \\
617 \\
580\end{array}$ & $\begin{array}{r}\text { e } 190 \\
\text { e } 210 \\
\text { e } 240 \\
472 \\
528\end{array}$ & $\begin{array}{r}773 \\
1210 \\
2740 \\
2860 \\
2060\end{array}$ & $\begin{array}{l}817 \\
528 \\
402 \\
365 \\
411\end{array}$ & $\begin{array}{l}136 \\
130 \\
230 \\
181 \\
157\end{array}$ & $\begin{array}{r}120 \\
103 \\
88 \\
75 \\
67\end{array}$ & $\begin{array}{l}39 \\
36 \\
35 \\
33 \\
31\end{array}$ & $\begin{array}{l}24 \\
24 \\
25 \\
48 \\
38\end{array}$ & $\begin{array}{l}20 \\
20 \\
21 \\
21 \\
20\end{array}$ \\
\hline $\begin{array}{l}21 \\
22 \\
23 \\
24 \\
25\end{array}$ & $\begin{array}{l}472 \\
379 \\
323 \\
283 \\
251\end{array}$ & $\begin{array}{l}148 \\
152 \\
151 \\
147 \\
141\end{array}$ & $\begin{array}{r}705 \\
1800 \\
1130 \\
700 \\
\mathrm{e} 490\end{array}$ & $\begin{array}{r}554 \\
\text { e } 420 \\
\text { e } 330 \\
\text { e } 290 \\
\text { e270 }\end{array}$ & $\begin{array}{l}425 \\
366 \\
311 \\
289 \\
262\end{array}$ & $\begin{array}{r}1280 \\
963 \\
1450 \\
1110 \\
749\end{array}$ & $\begin{array}{l}409 \\
345 \\
315 \\
314 \\
283\end{array}$ & $\begin{array}{l}135 \\
124 \\
825 \\
631 \\
450\end{array}$ & $\begin{array}{l}61 \\
59 \\
57 \\
54 \\
51\end{array}$ & $\begin{array}{l}30 \\
29 \\
28 \\
26 \\
27\end{array}$ & $\begin{array}{l}35 \\
32 \\
28 \\
26 \\
24\end{array}$ & $\begin{array}{l}20 \\
21 \\
22 \\
21 \\
21\end{array}$ \\
\hline $\begin{array}{l}26 \\
27 \\
28 \\
29 \\
30 \\
31\end{array}$ & $\begin{array}{l}226 \\
208 \\
194 \\
180 \\
172 \\
166\end{array}$ & $\begin{array}{r}135 \\
144 \\
774 \\
1030 \\
589 \\
\cdots \cdots\end{array}$ & $\begin{array}{l}\text { e } 400 \\
\text { e } 320 \\
\text { e } 310 \\
2140 \\
7580 \\
6120\end{array}$ & $\begin{array}{l}\text { e2 } 40 \\
\text { e220 } \\
\text { e210 } \\
\text { e1 } 90 \\
\text { e1 } 85 \\
\text { e1 } 15\end{array}$ & $\begin{array}{l}239 \\
229 \\
221 \\
\cdots \\
\cdots \\
\cdots\end{array}$ & $\begin{array}{r}756 \\
1080 \\
800 \\
576 \\
440 \\
366\end{array}$ & $\begin{array}{l}262 \\
254 \\
242 \\
235 \\
220 \\
\cdots\end{array}$ & $\begin{array}{l}516 \\
326 \\
235 \\
191 \\
184 \\
255\end{array}$ & $\begin{array}{l}48 \\
45 \\
43 \\
41 \\
40 \\
--\end{array}$ & $\begin{array}{l}26 \\
25 \\
25 \\
24 \\
24 \\
23\end{array}$ & $\begin{array}{l}23 \\
22 \\
22 \\
29 \\
36 \\
26\end{array}$ & $\begin{array}{l}21 \\
20 \\
21 \\
20 \\
20 \\
\cdots\end{array}$ \\
\hline $\begin{array}{l}\text { IOIAL } \\
\text { MEAN } \\
\text { MAX } \\
\text { MIN } \\
\text { CF SM } \\
\text { IN. }\end{array}$ & $\begin{array}{r}17822 \\
575 \\
3040 \\
46 \\
2.10 \\
2.42\end{array}$ & $\begin{array}{r}8872 \\
296 \\
1030 \\
135 \\
1.08 \\
1.20\end{array}$ & $\begin{array}{r}30470 \\
983 \\
7580 \\
203 \\
3.59 \\
4.14\end{array}$ & $\begin{array}{r}17198 \\
555 \\
2180 \\
175 \\
2.02 \\
2.33\end{array}$ & $\begin{array}{c}9228 \\
330 \\
635 \\
170 \\
1.20 \\
1.25\end{array}$ & $\begin{array}{c}22642 \\
730 \\
2860 \\
157 \\
2.67 \\
3.07\end{array}$ & $\begin{array}{r}10062 \\
335 \\
1060 \\
192 \\
1.22 \\
1.37\end{array}$ & $\begin{array}{c}7464 \\
241 \\
825 \\
124 \\
.88 \\
1.01\end{array}$ & $\begin{array}{r}2741 \\
91.4 \\
235 \\
40 \\
.33 \\
.37\end{array}$ & $\begin{array}{c}1490 \\
48.1 \\
202 \\
23 \\
.18 \\
.20\end{array}$ & $\begin{array}{r}914 \\
29.5 \\
48 \\
21 \\
.11 \\
.12\end{array}$ & $\begin{array}{r}660 \\
22.0 \\
39 \\
18 \\
.08 \\
.09\end{array}$ \\
\hline
\end{tabular}

e Estimated

SIATISIICS OF MONIHLY MEAN DAIA FOR WAILR YEARS 1944 - 1991, BY WAIER YEAR (WY)

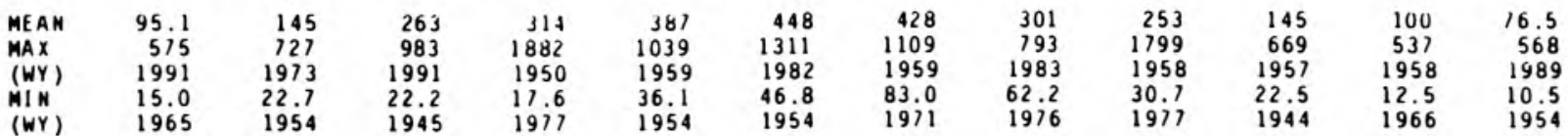

SUMMARY SIAIISIICS

ANMUAL TOIAL

HIGHESI ANNUAL MEAN

LOWEST ANNUAL MEAN

HIGHEST DAILY MEAN

LOWEST DAILY MEAN

ANNUAL SEVEN-DAY MINIMUM

INSIANIANEOUS PEAK FLOW

INSIANIANEOUS PEAK SIAGE

ANNUAL RUNOFF (CFSM)

ANNUAL RUNOFF (INCHES)

10 PERCENT EXCEEDS

50 PERCENT EXCEEDS

90 PERCENT EXCEEDS
FOR 1990 CAIENDAR YEAR

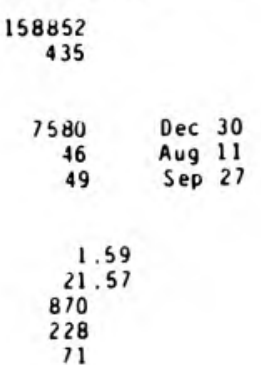

FOR 1991 WAIER YEAR

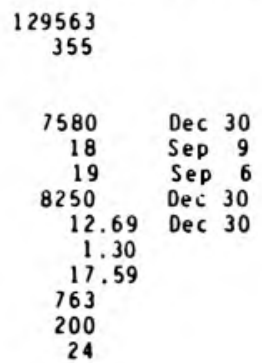

WAIER YEARS 1944 - 1991

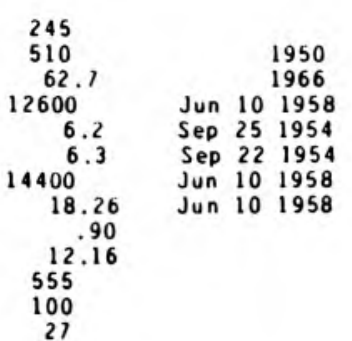




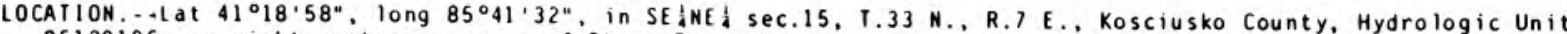
05120106 , on right upstrea corner of State Rodd 13 bridge, at the intersection of State Road 13 and County Road 550 North, and 2.4 i southeast of North Webster.

DRAINAGE AREA,$-49.3 \cdot i^{2}$

PERIOD OF RECORD.-. May 1986 to current year.

GAGE. - Water-stage recorder. Datum of gage is $840.00 \mathrm{ft}$ above National Geodetic Vertical Datun of 1929 (levels by State of Indiana, Departinent of Naturai Resources).

REMARKS. - Records good. Flow regulated at times by dans at Webster lake, 0.25 i upstrean.

DISCHARGE, CUBIC FEET PER SECOND, WATER YEAR OCTOBER 1990 TO SEPIEMBER 1991 DAILY MEAN VALUES

\begin{tabular}{|c|c|c|c|c|c|c|c|c|c|c|c|c|}
\hline DAY & OCT & MOV & $\mathrm{DEC}$ & JAN & FEB & MAR & APR & MAY & JUN & JUL & AUG & SEP \\
\hline $\begin{array}{l}1 \\
2 \\
3 \\
4 \\
5\end{array}$ & $\begin{array}{l}13 \\
14 \\
17 \\
27 \\
52\end{array}$ & $\begin{array}{l}61 \\
60 \\
70 \\
65 \\
48\end{array}$ & $\begin{array}{l}66 \\
65 \\
62 \\
61 \\
61\end{array}$ & $\begin{array}{l}339 \\
353 \\
359 \\
342 \\
325\end{array}$ & $\begin{array}{l}69 \\
68 \\
56 \\
40 \\
40\end{array}$ & $\begin{array}{l}64 \\
66 \\
64 \\
64 \\
64\end{array}$ & $\begin{array}{l}52 \\
51 \\
51 \\
27 \\
12\end{array}$ & $\begin{array}{r}131 \\
118 \\
70 \\
69 \\
71\end{array}$ & $\begin{array}{l}144 \\
154 \\
160 \\
163 \\
163\end{array}$ & $\begin{array}{l}9.6 \\
10 \\
11 \\
12 \\
13\end{array}$ & $\begin{array}{l}11 \\
11 \\
13 \\
13 \\
12\end{array}$ & $\begin{array}{l}24 \\
23 \\
22 \\
22 \\
21\end{array}$ \\
\hline $\begin{array}{r}6 \\
7 \\
8 \\
9 \\
10\end{array}$ & $\begin{array}{l}118 \\
117 \\
115 \\
122 \\
217\end{array}$ & $\begin{array}{l}89 \\
154 \\
152 \\
151 \\
148\end{array}$ & $\begin{array}{r}62 \\
62 \\
\text { e63 } \\
\text { e63 } \\
\text { e63 }\end{array}$ & $\begin{array}{l}302 \\
268 \\
249 \\
232 \\
219\end{array}$ & $\begin{array}{l}40 \\
40 \\
40 \\
41 \\
48\end{array}$ & $\begin{array}{l}65 \\
65 \\
64 \\
64 \\
63\end{array}$ & $\begin{array}{l}12 \\
12 \\
36 \\
96 \\
95\end{array}$ & $\begin{array}{l}72 \\
71 \\
70 \\
52 \\
13\end{array}$ & $\begin{array}{r}161 \\
156 \\
150 \\
144 \\
75\end{array}$ & $\begin{array}{l}14 \\
14 \\
15 \\
14 \\
13\end{array}$ & $\begin{array}{l}12 \\
11 \\
22 \\
48 \\
45\end{array}$ & $\begin{array}{l}20 \\
20 \\
19 \\
18 \\
18\end{array}$ \\
\hline $\begin{array}{l}11 \\
12 \\
13 \\
14 \\
15\end{array}$ & $\begin{array}{l}277 \\
288 \\
295 \\
297 \\
290\end{array}$ & $\begin{array}{r}145 \\
142 \\
97 \\
40 \\
38\end{array}$ & $\begin{array}{l}\text { e63 } \\
\text { e63 } \\
\text { e63 } \\
\text { e63 } \\
\text { e64 }\end{array}$ & $\begin{array}{r}210 \\
203 \\
165 \\
96 \\
96\end{array}$ & $\begin{array}{l}68 \\
67 \\
67 \\
68 \\
68\end{array}$ & $\begin{array}{l}62 \\
61 \\
61 \\
60 \\
55\end{array}$ & $\begin{array}{l}93 \\
78 \\
56 \\
57 \\
59\end{array}$ & $\begin{array}{l}12 \\
12 \\
13 \\
20 \\
29\end{array}$ & $\begin{array}{l}28 \\
56 \\
54 \\
52 \\
36\end{array}$ & $\begin{array}{l}12 \\
12 \\
13 \\
15 \\
15\end{array}$ & $\begin{array}{l}38 \\
15 \\
12 \\
11 \\
10\end{array}$ & $\begin{array}{l}16 \\
16 \\
16 \\
17 \\
16\end{array}$ \\
\hline $\begin{array}{l}16 \\
17 \\
18 \\
19 \\
20\end{array}$ & $\begin{array}{l}270 \\
249 \\
223 \\
178 \\
173\end{array}$ & $\begin{array}{r}38 \\
38 \\
38 \\
81 \\
121\end{array}$ & $\begin{array}{l}\text { e64 } \\
\text { e64 } \\
\text { e64 } \\
\text { e64 } \\
64\end{array}$ & $\begin{array}{r}99 \\
100 \\
103 \\
106 \\
125\end{array}$ & $\begin{array}{l}66 \\
64 \\
63 \\
64 \\
63\end{array}$ & $\begin{array}{l}36 \\
36 \\
37 \\
37 \\
38\end{array}$ & $\begin{array}{r}60 \\
71 \\
94 \\
107 \\
126\end{array}$ & $\begin{array}{l}29 \\
28 \\
25 \\
24 \\
24\end{array}$ & $\begin{array}{l}16 \\
15 \\
14 \\
17 \\
19\end{array}$ & $\begin{array}{r}15 \\
14 \\
14 \\
12 \\
6.8\end{array}$ & $\begin{array}{l}9.8 \\
9.4 \\
9.0 \\
10 \\
11\end{array}$ & $\begin{array}{l}4.2 \\
4.0 \\
3.8 \\
3.4 \\
4.4\end{array}$ \\
\hline $\begin{array}{l}21 \\
22 \\
23 \\
24 \\
25\end{array}$ & $\begin{array}{l}143 \\
125 \\
125 \\
125 \\
122\end{array}$ & $\begin{array}{r}117 \\
90 \\
70 \\
58 \\
37\end{array}$ & $\begin{array}{l}76 \\
105 \\
104 \\
103 \\
103\end{array}$ & $\begin{array}{l}143 \\
138 \\
134 \\
131 \\
127\end{array}$ & $\begin{array}{l}64 \\
65 \\
65 \\
66 \\
66\end{array}$ & $\begin{array}{r}38 \\
39 \\
68 \\
112 \\
109\end{array}$ & $\begin{array}{l}129 \\
132 \\
133 \\
143 \\
153\end{array}$ & $\begin{array}{l}16 \\
7.2 \\
9.5 \\
29 \\
39\end{array}$ & $\begin{array}{l}20 \\
20 \\
21 \\
20 \\
20\end{array}$ & $\begin{array}{l}6.5 \\
10 \\
11 \\
11 \\
12\end{array}$ & $\begin{array}{l}9.9 \\
9.5 \\
9.3 \\
8.9 \\
8.3\end{array}$ & $\begin{array}{l}3.8 \\
3.3 \\
3.1 \\
2.7 \\
2.5\end{array}$ \\
\hline $\begin{array}{l}26 \\
27 \\
28 \\
29 \\
30 \\
31\end{array}$ & $\begin{array}{l}96 \\
66 \\
66 \\
65 \\
63 \\
62\end{array}$ & $\begin{array}{l}37 \\
37 \\
52 \\
67 \\
67 \\
\cdots-\end{array}$ & $\begin{array}{r}102 \\
100 \\
99 \\
113 \\
201 \\
305\end{array}$ & $\begin{array}{r}115 \\
79 \\
77 \\
75 \\
74 \\
72\end{array}$ & $\begin{array}{r}65 \\
65 \\
64 \\
\cdots \\
\ldots \\
\ldots\end{array}$ & $\begin{array}{r}108 \\
106 \\
80 \\
54 \\
52 \\
52\end{array}$ & $\begin{array}{l}149 \\
145 \\
141 \\
137 \\
133 \\
\cdots\end{array}$ & $\begin{array}{r}60 \\
81 \\
54 \\
26 \\
37 \\
113\end{array}$ & $\begin{array}{l}20 \\
20 \\
18 \\
6.6 \\
7.4 \\
\cdots\end{array}$ & $\begin{array}{l}11 \\
11 \\
11 \\
11 \\
12 \\
11\end{array}$ & $\begin{array}{l}8.3 \\
8.0 \\
14 \\
12 \\
17 \\
25\end{array}$ & $\begin{array}{l}2.3 \\
2.2 \\
2.5 \\
3.4 \\
2.8 \\
\ldots . .\end{array}$ \\
\hline $\begin{array}{l}\text { TOIAL } \\
\text { MEAN } \\
\text { MAX } \\
\text { MIN } \\
\text { CF SH } \\
\text { IN. }\end{array}$ & $\begin{array}{r}4410 \\
142 \\
297 \\
13 \\
2.89 \\
3.33\end{array}$ & $\begin{array}{r}2408 \\
80.3 \\
154 \\
37 \\
1.63 \\
1.82\end{array}$ & $\begin{array}{r}2675 \\
86.3 \\
305 \\
61 \\
1.75 \\
2.02\end{array}$ & $\begin{array}{r}5456 \\
176 \\
359 \\
72 \\
3.57 \\
4.12\end{array}$ & $\begin{array}{r}1660 \\
59.3 \\
69 \\
40 \\
1.20 \\
1.25\end{array}$ & $\begin{array}{r}1944 \\
62.7 \\
112 \\
36 \\
1.27 \\
1.47\end{array}$ & $\begin{array}{r}2640 \\
88.0 \\
153 \\
12 \\
1.78 \\
1.99\end{array}$ & $\begin{array}{r}1424.7 \\
46.0 \\
131 \\
7.2 \\
.93 \\
1.08\end{array}$ & $\begin{array}{r}1950.0 \\
65.0 \\
163 \\
6.6 \\
1.32 \\
1.47\end{array}$ & $\begin{array}{c}371.9 \\
12.0 \\
15 \\
6.5 \\
.24 \\
.28\end{array}$ & $\begin{array}{r}463.4 \\
14.9 \\
48 \\
8.0 \\
.30 \\
.35\end{array}$ & $\begin{array}{r}336.4 \\
11.2 \\
24 \\
2.2 \\
.23 \\
.25\end{array}$ \\
\hline
\end{tabular}

e Estimated

SIATISIICS OF MONIHLY MEAN DATA FOR WAIER YEARS 1987 - 1991, BY WATER YEAR (WY)

\begin{tabular}{|c|c|c|c|c|c|c|c|c|c|}
\hline $\begin{array}{l}\text { MEAN } \\
\text { MAX } \\
\text { (WY) } \\
\text { MIN } \\
(W Y)\end{array}$ & $\begin{array}{r}62.0 \\
142 \\
1991 \\
15.2\end{array}$ & $\begin{array}{l}52.9 \\
99.2 \\
1989 \\
23.7\end{array}$ & $\begin{array}{l}64.3 \\
98.8 \\
1987 \\
14.0\end{array}$ & $\begin{array}{r}82.1 \\
176 \\
1991 \\
46.3\end{array}$ & $\begin{array}{r}66.1 \\
119 \\
1990 \\
31.5\end{array}$ & $\begin{array}{r}61.8 \\
102 \\
1990 \\
30.6\end{array}$ & $\begin{array}{l}68.0 \\
88.0 \\
1991 \\
50.1\end{array}$ & $\begin{array}{l}46.8 \\
77.4 \\
1987 \\
15.4 \\
1988\end{array}$ & $\begin{array}{l}44.4 \\
93.9 \\
1989 \\
3.07\end{array}$ \\
\hline
\end{tabular}

SUMMARY SIAIISIICS

ANHUAL TOTAL

ANMUAL MEAN

HIGHEST ANNUAL MEAN

LOWEST AMNUAL MEAN

HIGHEST DAILY MEAN

LOWEST DAILY MEAN

ANNUAL SEVEN-DAY MINIMUM

INSTANTANEOUS PEAK FLOW

INSIANTANEOUS PEAK SIAGE

ANNUAL RUNOFF (CFSM)

ANNUAL RUNOFF (INCHES)

10 PERCENT EXCEEDS

50 PERCENT EXCEEDS

90 PERCENT EXCEEDS
FOR 1990 CALENDAR YEAR

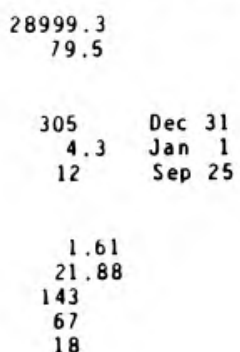

FOR 1991 WAIER YEAR

WATER YEARS 1987 - 1991

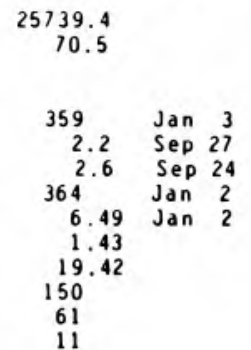

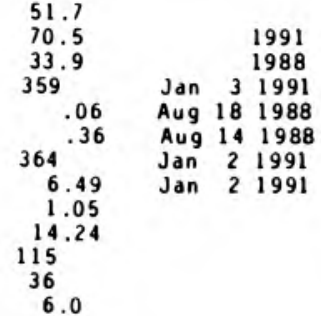




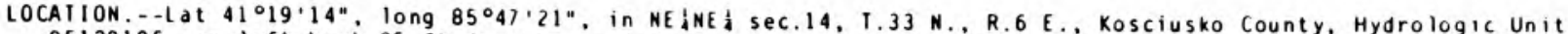
05120106 , on left bank $25 \mathrm{ft}$ downstrean from dam at Tippecanoe lake Out let in 0 swego, 3 i east of leesburg. and at ile 158,9

DRAI NAGE AREA. $-113 \mathrm{i}^{2}$

PERIOD OF RECORD.--OCtober 1949 to current year.

REVISED RE CORDS...-WSP 2109: Drainage area.

GAGE.- -Water-stage recorder. Datum of gage is $830.00 \mathrm{ft}$ above National Geodetic Vertical Datun of 1929 . Prior to Aug. 12, 1953, nonrecording gage at sane site and datun.

REMARKS.--Records fair. Periodic regulation by gates at lake outlet.

DISCHARGE, CUBIC FEET PER SECOND, WATER YEAR OCIOBER 1990 TO SEPIEMBER 1991 DAII Y MEAN VALUES

\begin{tabular}{|c|c|c|c|c|c|c|c|c|c|c|c|c|}
\hline DAY & $O C I$ & NOV & $\mathrm{DEC}$ & JAN & FEB & MAR & $A P R$ & MAY & JUN & JUL & AUG & SEP \\
\hline $\begin{array}{l}1 \\
2 \\
3 \\
4 \\
5\end{array}$ & $\begin{array}{l}28 \\
34 \\
62 \\
66 \\
69\end{array}$ & $\begin{array}{l}194 \\
182 \\
172 \\
167 \\
176\end{array}$ & $\begin{array}{l}148 \\
152 \\
157 \\
161 \\
167\end{array}$ & $\begin{array}{l}443 \\
533 \\
598 \\
615 \\
605\end{array}$ & $\begin{array}{r}e 205 \\
e 190 \\
e 175 \\
e 163 \\
156\end{array}$ & $\begin{array}{l}146 \\
150 \\
154 \\
154 \\
155\end{array}$ & $\begin{array}{l}166 \\
160 \\
155 \\
150 \\
145\end{array}$ & $\begin{array}{l}274 \\
268 \\
258 \\
244 \\
234\end{array}$ & $\begin{array}{l}231 \\
245 \\
257 \\
263 \\
261\end{array}$ & $\begin{array}{l}31 \\
31 \\
31 \\
30 \\
28\end{array}$ & $\begin{array}{l}15 \\
14 \\
14 \\
14 \\
14\end{array}$ & $\begin{array}{r}19 \\
19 \\
\text { e18 } \\
\text { e18 } \\
\text { e18 }\end{array}$ \\
\hline $\begin{array}{r}6 \\
7 \\
8 \\
9 \\
10\end{array}$ & $\begin{array}{l}115 \\
170 \\
192 \\
215 \\
258\end{array}$ & $\begin{array}{l}185 \\
198 \\
218 \\
232 \\
240\end{array}$ & $\begin{array}{l}171 \\
173 \\
174 \\
173 \\
172\end{array}$ & $\begin{array}{l}580 \\
541 \\
503 \\
468 \\
437\end{array}$ & $\begin{array}{l}151 \\
149 \\
146 \\
146 \\
144\end{array}$ & $\begin{array}{l}155 \\
155 \\
155 \\
152 \\
151\end{array}$ & $\begin{array}{l}139 \\
127 \\
108 \\
114 \\
126\end{array}$ & $\begin{array}{l}226 \\
218 \\
213 \\
203 \\
188\end{array}$ & $\begin{array}{l}258 \\
254 \\
247 \\
240 \\
231\end{array}$ & $\begin{array}{l}27 \\
29 \\
28 \\
28 \\
26\end{array}$ & $\begin{array}{l}14 \\
14 \\
14 \\
15 \\
17\end{array}$ & $\begin{array}{l}\text { e1 } 8 \\
\text { e17 } \\
\text { e17 } \\
\text { e17 } \\
\text { e17 }\end{array}$ \\
\hline $\begin{array}{l}11 \\
12 \\
13 \\
14 \\
15\end{array}$ & $\begin{array}{l}314 \\
359 \\
408 \\
447 \\
473\end{array}$ & $\begin{array}{l}245 \\
246 \\
245 \\
229 \\
211\end{array}$ & $\begin{array}{l}168 \\
165 \\
161 \\
157 \\
157\end{array}$ & $\begin{array}{l}415 \\
399 \\
378 \\
348 \\
327\end{array}$ & $\begin{array}{l}144 \\
145 \\
145 \\
146 \\
145\end{array}$ & $\begin{array}{l}149 \\
147 \\
150 \\
146 \\
142\end{array}$ & $\begin{array}{l}145 \\
162 \\
158 \\
157 \\
163\end{array}$ & $\begin{array}{r}171 \\
156 \\
145 \\
126 \\
88\end{array}$ & $\begin{array}{l}212 \\
197 \\
184 \\
169 \\
152\end{array}$ & $\begin{array}{l}24 \\
24 \\
24 \\
24 \\
24\end{array}$ & $\begin{array}{l}17 \\
17 \\
17 \\
17 \\
17\end{array}$ & $\begin{array}{l}\text { e17 } \\
\text { e17 } \\
\text { e1 } 6 \\
\text { el } 16 \\
\text { el }\end{array}$ \\
\hline $\begin{array}{l}16 \\
17 \\
18 \\
19 \\
20\end{array}$ & $\begin{array}{l}472 \\
455 \\
436 \\
413 \\
393\end{array}$ & $\begin{array}{l}195 \\
183 \\
170 \\
161 \\
162\end{array}$ & $\begin{array}{l}156 \\
156 \\
156 \\
157 \\
157\end{array}$ & $\begin{array}{l}318 \\
309 \\
303 \\
297 \\
293\end{array}$ & $\begin{array}{l}144 \\
143 \\
143 \\
143 \\
144\end{array}$ & $\begin{array}{l}139 \\
137 \\
137 \\
136 \\
137\end{array}$ & $\begin{array}{l}168 \\
182 \\
194 \\
210 \\
232\end{array}$ & $\begin{array}{r}89 \\
90 \\
103 \\
93 \\
85\end{array}$ & $\begin{array}{r}141 \\
124 \\
52 \\
33 \\
34\end{array}$ & $\begin{array}{l}23 \\
23 \\
23 \\
23 \\
26\end{array}$ & $\begin{array}{l}17 \\
16 \\
17 \\
17 \\
18\end{array}$ & $\begin{array}{l}\text { e } 16 \\
\text { e16 } \\
\text { e } 16 \\
\text { el6 } \\
\text { e15 }\end{array}$ \\
\hline $\begin{array}{l}21 \\
22 \\
23 \\
24 \\
25\end{array}$ & $\begin{array}{l}312 \\
348 \\
330 \\
314 \\
300\end{array}$ & $\begin{array}{l}165 \\
167 \\
161 \\
158 \\
151\end{array}$ & $\begin{array}{l}159 \\
168 \\
181 \\
190 \\
196\end{array}$ & $\begin{array}{r}292 \\
289 \\
e 285 \\
e 282 \\
e 280\end{array}$ & $\begin{array}{l}146 \\
148 \\
150 \\
150 \\
150\end{array}$ & $\begin{array}{l}138 \\
140 \\
140 \\
149 \\
158\end{array}$ & $\begin{array}{l}248 \\
261 \\
269 \\
280 \\
285\end{array}$ & $\begin{array}{r}85 \\
82 \\
92 \\
109 \\
117\end{array}$ & $\begin{array}{l}35 \\
51 \\
56 \\
32 \\
32\end{array}$ & $\begin{array}{l}30 \\
30 \\
29 \\
29 \\
29\end{array}$ & $\begin{array}{l}18 \\
19 \\
19 \\
19 \\
19\end{array}$ & $\begin{array}{l}\text { e } 15 \\
\text { e15 } \\
\text { e15 } \\
\text { el } \\
\text { e15 }\end{array}$ \\
\hline $\begin{array}{l}26 \\
27 \\
28 \\
29 \\
30 \\
31\end{array}$ & $\begin{array}{l}287 \\
269 \\
251 \\
233 \\
218 \\
205\end{array}$ & $\begin{array}{l}144 \\
138 \\
141 \\
143 \\
145 \\
\cdots\end{array}$ & $\begin{array}{l}199 \\
201 \\
201 \\
236 \\
304 \\
370\end{array}$ & $\begin{array}{l}e 275 \\
e 265 \\
e 258 \\
e 245 \\
e 235 \\
e 220\end{array}$ & $\begin{array}{l}148 \\
146 \\
146 \\
\ldots \\
\ldots \\
\ldots\end{array}$ & $\begin{array}{l}167 \\
173 \\
185 \\
187 \\
179 \\
171\end{array}$ & $\begin{array}{l}288 \\
287 \\
286 \\
284 \\
275 \\
\cdots-\end{array}$ & $\begin{array}{l}136 \\
140 \\
143 \\
141 \\
142 \\
197\end{array}$ & $\begin{array}{c}32 \\
32 \\
31 \\
31 \\
31 \\
\cdots\end{array}$ & $\begin{array}{l}28 \\
28 \\
28 \\
28 \\
18 \\
15\end{array}$ & $\begin{array}{l}19 \\
18 \\
18 \\
18 \\
19 \\
19\end{array}$ & $\begin{array}{l}\text { el } \\
\text { el } \\
\text { el } \\
\text { el } \\
\text { el } \\
-\cdots\end{array}$ \\
\hline $\begin{array}{l}\text { TOIAL } \\
\text { MEAN } \\
\text { MAX } \\
\text { MIN } \\
\text { CF SM } \\
\text { IN. }\end{array}$ & $\begin{array}{r}8506 \\
274 \\
473 \\
28 \\
2.43 \\
2.80\end{array}$ & $\begin{array}{r}5524 \\
184 \\
246 \\
138 \\
1.63 \\
1.82\end{array}$ & $\begin{array}{r}5643 \\
182 \\
370 \\
148 \\
1.61 \\
1.86\end{array}$ & $\begin{array}{r}11636 \\
375 \\
615 \\
220 \\
3.32 \\
3.83\end{array}$ & $\begin{array}{r}4251 \\
152 \\
205 \\
143 \\
1.34 \\
1.40\end{array}$ & $\begin{array}{r}4734 \\
153 \\
187 \\
136 \\
1.35 \\
1.56\end{array}$ & $\begin{array}{r}5924 \\
197 \\
288 \\
108 \\
1.75 \\
1.95\end{array}$ & $\begin{array}{r}4856 \\
157 \\
274 \\
82 \\
1.39 \\
1.60\end{array}$ & $\begin{array}{c}4148 \\
138 \\
263 \\
31 \\
1.22 \\
1.37\end{array}$ & $\begin{array}{r}819 \\
26.4 \\
31 \\
15 \\
.23 \\
.27\end{array}$ & $\begin{array}{r}520 \\
16.8 \\
19 \\
14 \\
.15 \\
.17\end{array}$ & $\begin{array}{r}484 \\
16.1 \\
19 \\
14 \\
.14 \\
.16\end{array}$ \\
\hline
\end{tabular}

e Estimated

STATISIICS OF MUNTHIY MEAN DATA FUR WATER YEARS 1950 - 1991, BY WATER YEAR (WY)

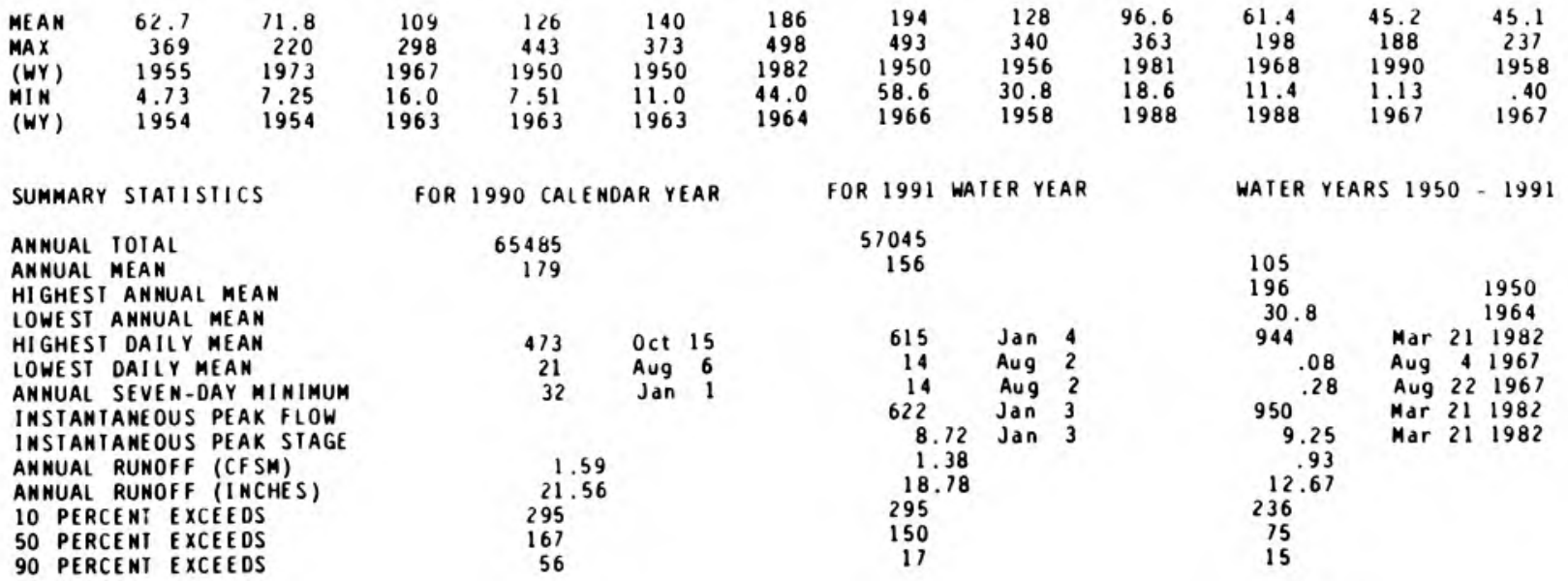




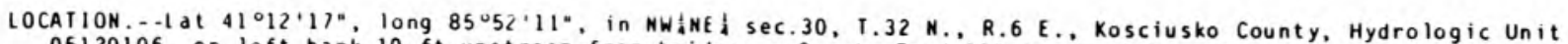
05120106 , on left bank $10 \mathrm{ft}$ upstream from bridge on County Road 200 South, 0.3 a downstrean from small right-bank tributary and 2.5 mi south of court house in warsaw.

DRAINAGE AREA. $\cdots 19.6 \mathrm{i}^{2}$.

PERIOD OF RECORD.-.0 October 1969 to current year.

GAGE - - Water-stage recorder. Datua of gage is $823.00 \mathrm{ft}$ above National Geodetic Vertical Datua of 1929. REMARKS. - - Records good, except for estinated daily discharges, which are poor. flow occasionally regulated by
lakes upstrean.

DISCHARGE, CUBIC FEET PER SECOND, WATER YEAR OCTOBER 1990 TO SEPTEMBER 1991 DAILY MEAN VALUES

\begin{tabular}{|c|c|c|c|c|c|c|c|c|c|c|c|c|}
\hline DAY & $\mathrm{OCI}$ & NOV & DEC & JAN & FE B & MAR & APR & MAY & JUN & JUL & AUG & SEP \\
\hline $\begin{array}{l}1 \\
2 \\
3 \\
4 \\
5\end{array}$ & $\begin{array}{l}16 \\
15 \\
15 \\
34 \\
40\end{array}$ & $\begin{array}{l}20 \\
19 \\
17 \\
16 \\
41\end{array}$ & $\begin{array}{l}30 \\
26 \\
36 \\
50 \\
46\end{array}$ & $\begin{array}{r}194 \\
127 \\
92 \\
74 \\
63\end{array}$ & $\begin{array}{r}\text { e16 } \\
17 \\
19 \\
23 \\
31\end{array}$ & $\begin{array}{l}16 \\
29 \\
34 \\
31 \\
26\end{array}$ & $\begin{array}{l}33 \\
33 \\
31 \\
31 \\
33\end{array}$ & $\begin{array}{l}23 \\
21 \\
20 \\
18 \\
20\end{array}$ & $\begin{array}{l}37 \\
37 \\
29 \\
20 \\
12\end{array}$ & $\begin{array}{l}37 \\
27 \\
18 \\
13 \\
11\end{array}$ & $\begin{array}{l}2.4 \\
2.2 \\
2.1 \\
2.0 \\
1.9\end{array}$ & $\begin{array}{l}1.2 \\
1.1 \\
1.2 \\
1.3 \\
1.2\end{array}$ \\
\hline $\begin{array}{r}6 \\
7 \\
8 \\
9 \\
10\end{array}$ & $\begin{array}{r}39 \\
36 \\
35 \\
69 \\
189\end{array}$ & $\begin{array}{l}69 \\
67 \\
55 \\
43 \\
37\end{array}$ & $\begin{array}{l}39 \\
33 \\
28 \\
24 \\
22\end{array}$ & $\begin{array}{l}56 \\
50 \\
44 \\
40 \\
38\end{array}$ & $\begin{array}{l}36 \\
36 \\
34 \\
32 \\
30\end{array}$ & $\begin{array}{l}23 \\
21 \\
19 \\
17 \\
16\end{array}$ & $\begin{array}{l}34 \\
34 \\
33 \\
35 \\
35\end{array}$ & $\begin{array}{l}29 \\
29 \\
28 \\
24 \\
19\end{array}$ & $\begin{array}{l}9.6 \\
8.3 \\
7.4 \\
6.8 \\
6.2\end{array}$ & $\begin{array}{l}8.9 \\
7.8 \\
19 \\
19 \\
15\end{array}$ & $\begin{array}{l}1.8 \\
1.8 \\
2.9 \\
3.2 \\
2.8\end{array}$ & $\begin{array}{l}1.1 \\
1.1 \\
1.2 \\
1.0 \\
.84\end{array}$ \\
\hline $\begin{array}{l}11 \\
12 \\
13 \\
14 \\
15\end{array}$ & $\begin{array}{r}201 \\
158 \\
116 \\
89 \\
75\end{array}$ & $\begin{array}{l}33 \\
29 \\
26 \\
24 \\
23\end{array}$ & $\begin{array}{l}20 \\
19 \\
17 \\
16 \\
19\end{array}$ & $\begin{array}{l}38 \\
44 \\
42 \\
39 \\
40\end{array}$ & $\begin{array}{r}27 \\
24 \\
21 \\
\mathrm{e} 19 \\
\mathrm{e} 11\end{array}$ & $\begin{array}{l}15 \\
15 \\
15 \\
16 \\
16\end{array}$ & $\begin{array}{l}35 \\
33 \\
31 \\
36 \\
41\end{array}$ & $\begin{array}{l}16 \\
16 \\
17 \\
17 \\
17\end{array}$ & $\begin{array}{l}5.9 \\
5.6 \\
5.2 \\
4.7 \\
4.9\end{array}$ & $\begin{array}{r}12 \\
10 \\
8.9 \\
7.9 \\
6.8\end{array}$ & $\begin{array}{l}2.5 \\
2.4 \\
2.2 \\
2.1 \\
2.0\end{array}$ & $\begin{array}{l}.83 \\
1.0 \\
1.1 \\
1.1 \\
.96\end{array}$ \\
\hline $\begin{array}{l}16 \\
17 \\
18 \\
19 \\
20\end{array}$ & $\begin{array}{l}64 \\
54 \\
54 \\
50 \\
44\end{array}$ & $\begin{array}{l}21 \\
19 \\
18 \\
17 \\
16\end{array}$ & $\begin{array}{l}23 \\
24 \\
24 \\
24 \\
23\end{array}$ & $\begin{array}{r}59 \\
70 \\
61 \\
49 \\
e 42\end{array}$ & $\begin{array}{r}e 16 \\
15 \\
16 \\
28 \\
34\end{array}$ & $\begin{array}{l}18 \\
22 \\
38 \\
41 \\
38\end{array}$ & $\begin{array}{l}42 \\
53 \\
47 \\
49 \\
60\end{array}$ & $\begin{array}{l}17 \\
16 \\
12 \\
11 \\
11\end{array}$ & $\begin{array}{l}6.0 \\
6.2 \\
5.8 \\
5.6 \\
5.2\end{array}$ & $\begin{array}{l}6.1 \\
5.6 \\
5.0 \\
4.6 \\
4.2\end{array}$ & $\begin{array}{l}1.8 \\
1.8 \\
1.8 \\
2.4 \\
2.5\end{array}$ & $\begin{array}{l}.88 \\
.81 \\
.80 \\
.74 \\
.71\end{array}$ \\
\hline $\begin{array}{l}21 \\
22 \\
23 \\
24 \\
25\end{array}$ & $\begin{array}{l}39 \\
36 \\
33 \\
31 \\
28\end{array}$ & $\begin{array}{l}15 \\
15 \\
16 \\
17 \\
16\end{array}$ & $\begin{array}{l}25 \\
36 \\
38 \\
35 \\
29\end{array}$ & $\begin{array}{l}\text { e } 39 \\
\text { e35 } \\
\text { e31 } \\
\text { e2 } \\
\text { e26 }\end{array}$ & $\begin{array}{l}32 \\
28 \\
25 \\
21 \\
19\end{array}$ & $\begin{array}{l}34 \\
29 \\
26 \\
27 \\
26\end{array}$ & $\begin{array}{l}55 \\
45 \\
42 \\
42 \\
42\end{array}$ & $\begin{array}{l}11 \\
11 \\
12 \\
14 \\
15\end{array}$ & $\begin{array}{l}4.9 \\
4.7 \\
4.2 \\
3.8 \\
3.8\end{array}$ & $\begin{array}{l}4.1 \\
3.9 \\
3.6 \\
3.3 \\
3.0\end{array}$ & $\begin{array}{l}1.9 \\
1.5 \\
1.3 \\
1.3 \\
1.2\end{array}$ & $\begin{array}{l}.67 \\
.69 \\
.67 \\
.70 \\
.71\end{array}$ \\
\hline $\begin{array}{l}26 \\
27 \\
28 \\
29 \\
30 \\
31\end{array}$ & $\begin{array}{l}26 \\
25 \\
23 \\
19 \\
19 \\
20\end{array}$ & $\begin{array}{r}15 \\
17 \\
33 \\
38 \\
36 \\
--\end{array}$ & $\begin{array}{r}\text { e25 } \\
22 \\
20 \\
155 \\
304 \\
266\end{array}$ & $\begin{array}{l}\text { e } 24 \\
\text { e22 } \\
\text { e20 } \\
\text { e19 } \\
\text { e18 } \\
\text { e17 }\end{array}$ & $\begin{array}{l}18 \\
16 \\
15 \\
\cdots \\
\cdots \\
\cdots\end{array}$ & $\begin{array}{l}31 \\
38 \\
39 \\
39 \\
37 \\
34\end{array}$ & $\begin{array}{l}37 \\
29 \\
26 \\
25 \\
25 \\
\cdots-\end{array}$ & $\begin{array}{l}17 \\
17 \\
17 \\
16 \\
16 \\
20\end{array}$ & $\begin{array}{l}3.5 \\
3.2 \\
3.2 \\
3.0 \\
30 \\
\ldots\end{array}$ & $\begin{array}{l}2.9 \\
2.7 \\
2.5 \\
2.6 \\
2.6 \\
2.4\end{array}$ & $\begin{array}{l}1.2 \\
1.1 \\
1.1 \\
1.1 \\
1.4 \\
1.6\end{array}$ & $\begin{array}{l}.58 \\
.50 \\
.50 \\
.50 \\
.47 \\
. .-\end{array}$ \\
\hline $\begin{array}{l}\text { TOTAL } \\
\text { MEAN } \\
\text { MAX } \\
\text { MIN } \\
\text { CF SM } \\
\text { IN. }\end{array}$ & $\begin{array}{r}1692 \\
54.6 \\
201 \\
15 \\
2.78 \\
3.21\end{array}$ & $\begin{array}{r}828 \\
27.6 \\
69 \\
15 \\
1.41 \\
1.57\end{array}$ & $\begin{array}{r}1498 \\
48.3 \\
304 \\
16 \\
2.47 \\
2.84\end{array}$ & $\begin{array}{c}1541 \\
49.7 \\
194 \\
17 \\
2.54 \\
2.92\end{array}$ & $\begin{array}{r}665 \\
23.7 \\
36 \\
15 \\
1.21 \\
1.26\end{array}$ & $\begin{array}{r}826 \\
26.6 \\
41 \\
15 \\
1.36 \\
1.57\end{array}$ & $\begin{array}{c}1127 \\
37.6 \\
60 \\
25 \\
1.92 \\
2.14\end{array}$ & $\begin{array}{c}547 \\
17.6 \\
29 \\
11 \\
.90 \\
1.04\end{array}$ & $\begin{array}{c}292.7 \\
9.76 \\
37 \\
3.0 \\
.50 \\
.56\end{array}$ & $\begin{array}{c}280.4 \\
9.05 \\
37 \\
2.4 \\
.46 \\
.53\end{array}$ & $\begin{array}{l}59.3 \\
1.91 \\
3.2 \\
1.1 \\
.10 \\
.11\end{array}$ & $\begin{array}{c}26.16 \\
.87 \\
1.3 \\
.47 \\
.04 \\
.05\end{array}$ \\
\hline
\end{tabular}

e Estinated

STATISIICS OF MONIHLY MEAN DATA FOR WAIER YEARS 1970 - 1991, BY WAIER YEAR (WY)

\begin{tabular}{|c|c|c|c|c|c|c|c|c|c|c|c|c|}
\hline $\begin{array}{l}\text { MEA } \\
\text { MAX } \\
\text { (WY) } \\
\text { MIN } \\
(W Y)\end{array}$ & $\begin{array}{l}8.81 \\
54.6 \\
1991 \\
1.04 \\
1977\end{array}$ & $\begin{array}{l}13.6 \\
40.2 \\
1973 \\
2.18 \\
1979\end{array}$ & $\begin{array}{l}21.8 \\
48.3 \\
1991 \\
1.43 \\
1977\end{array}$ & $\begin{array}{r}17.7 \\
49.7 \\
1991 \\
91 \\
1977\end{array}$ & $\begin{array}{l}25.5 \\
60.6 \\
1985 \\
2.87 \\
1979\end{array}$ & $\begin{array}{r}37.0 \\
110 \\
1982 \\
14.0 \\
1989\end{array}$ & $\begin{array}{l}35.2 \\
66.5 \\
1981 \\
14.3 \\
1976\end{array}$ & $\begin{array}{l}20.9 \\
60.8 \\
1981 \\
6.35 \\
1988\end{array}$ & $\begin{array}{l}17.7 \\
80.3 \\
1981 \\
2.34 \\
1988\end{array}$ & $\begin{array}{l}6.67 \\
20.9 \\
1981 \\
1.73 \\
1988\end{array}$ & $\begin{array}{l}6.12 \\
53.7 \\
1990 \\
1.07 \\
1971\end{array}$ & $\begin{array}{r}6.46 \\
27.0 \\
1980 \\
.80 \\
1976\end{array}$ \\
\hline
\end{tabular}

SUMMARY STATISIICS

ANNUAL TOIAL

ANMUAL MEAN

HIGHEST ANMUAL MEAN

LOWEST ANNUAL MEAN

HIGHEST DAILY MEAN

LOWEST DAILY MEAN

ANMUAL SEVEN-DAY MINIMUM

INSTANIANEOUS PEAK FLOW

INSIANIANEOUS PEAK STAGE

AN WUAL RUNOFF (CFSM)

ANNUAL RUNOFF (I NCHES)

10 PERCENT EXCEEDS

50 PERCENT EXCEEDS

90 PERCENT EXCEEDS
FOR 1990 CALENDAR YEAR

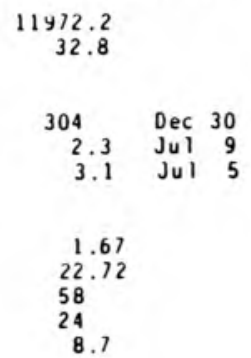

FOR 1991 WATER YEAR

9382.56

25.7

$304 \quad$ Dec 30

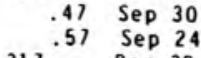

$\begin{array}{rr}317 & \text { Dec } 30 \\ 4.31 & \text { Dec } 30\end{array}$

1. 31

17.81

44

19
1.3
WATER YEARS 1970 - 1991

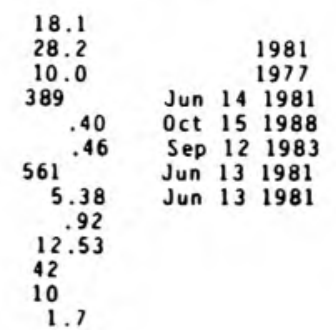




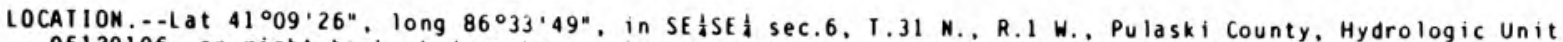
05120106, on right bank at downstrean'side of bridge on County Road 700 East. 1.0 . upstrea from Bartee ditch, 1.3 i southwest of $0 \mathrm{ra}$, and at ile 78.5 .

DRAI NAGE AREA $\cdots 856 i^{2}$

PERIOD OF RECORD.--September 1943 to current year. Monthly discharge only for sone periods, published in wSP 1305.

REVISED RECOROS.--WSP 1335: 1944(M). WSP 1505: 1949-50(P). WSP 2109: Drainage area.

GAGE.- Water-stage recorder. Datun of gage is $692.91 \mathrm{ft}$ above National Geodetic Vertical Datun of 1929 (levels by U.S. Aray Corps of Engineers). Prior to July 30, 1956 , nonrecording gage on upstreas side of old highway bridge, $120 \mathrm{ft}$ downstrean. July 30, 1956, to Dec. 20, 1964, water-stage recorder on right bank at downstrea side of old highway bridge, and Dec. 21, 1964, to Aug. 19, 1965, nonrecording gage on right bank $500 \mathrm{ft}$ downstrean. All gages at sane datum.

REMARKS.--Records good below $1,000 \mathrm{ft} / \mathrm{s}$ and fair above except for estinated daily discharges, which are poor.

DISCHARGE, CUBIC FEET PER SECOND, WATER YEAR OCTOBER 1990 TO SEPTEMBER 1991 DAILY MEAN VALUES

\begin{tabular}{|c|c|c|c|c|c|c|c|c|c|c|c|c|}
\hline DAY & $\mathrm{OCT}$ & NOV & DEC & JAN & FEB & MAR & APR & MAY & JUN & JUL & $A \cup G$ & SEP \\
\hline $\begin{array}{l}1 \\
2 \\
3 \\
4 \\
5\end{array}$ & $\begin{array}{l}655 \\
606 \\
584 \\
609 \\
698\end{array}$ & $\begin{array}{l}1190 \\
1140 \\
1100 \\
1090 \\
1330\end{array}$ & $\begin{array}{l}1530 \\
1450 \\
1470 \\
1770 \\
1840\end{array}$ & $\begin{array}{r}6720 \\
6230 \\
\text { e } 5640 \\
\text { e } 5060 \\
\text { e4500 }\end{array}$ & $\begin{array}{r}\text { e } 950 \\
\text { e } 925 \\
\text { e } 900 \\
\text { e } 1040 \\
\text { e } 1200\end{array}$ & $\begin{array}{l}1160 \\
1290 \\
1630 \\
1710 \\
1620\end{array}$ & $\begin{array}{l}1690 \\
1590 \\
1490 \\
1440 \\
1430\end{array}$ & $\begin{array}{l}1840 \\
1780 \\
1700 \\
1630 \\
1610\end{array}$ & $\begin{array}{l}1780 \\
2130 \\
2090 \\
2010 \\
1820\end{array}$ & $\begin{array}{l}416 \\
404 \\
513 \\
547 \\
507\end{array}$ & $\begin{array}{l}232 \\
219 \\
214 \\
213 \\
212\end{array}$ & $\begin{array}{l}220 \\
219 \\
210 \\
225 \\
228\end{array}$ \\
\hline $\begin{array}{r}6 \\
7 \\
8 \\
9 \\
10\end{array}$ & $\begin{array}{r}726 \\
743 \\
801 \\
1090 \\
2330\end{array}$ & $\begin{array}{l}2160 \\
2680 \\
2610 \\
2390 \\
2260\end{array}$ & $\begin{array}{l}1710 \\
1630 \\
1570 \\
1500 \\
1420\end{array}$ & $\begin{array}{l}\text { e } 3800 \\
\text { e } 3200 \\
\text { e } 2700 \\
\text { e } 2350 \\
\text { e } 2100\end{array}$ & $\begin{array}{l}\text { e } 1500 \\
\text { el } 760 \\
\text { e } 1790 \\
\text { el } 600 \\
\text { el } 480\end{array}$ & $\begin{array}{l}1570 \\
1480 \\
1370 \\
1270 \\
1200\end{array}$ & $\begin{array}{l}1420 \\
1370 \\
1330 \\
1400 \\
1420\end{array}$ & $\begin{array}{l}1630 \\
1610 \\
1520 \\
1450 \\
1400\end{array}$ & $\begin{array}{l}1600 \\
1430 \\
1290 \\
1150 \\
1040\end{array}$ & $\begin{array}{l}442 \\
400 \\
561 \\
981 \\
673\end{array}$ & $\begin{array}{l}211 \\
210 \\
236 \\
282 \\
279\end{array}$ & $\begin{array}{l}221 \\
217 \\
209 \\
202 \\
195\end{array}$ \\
\hline $\begin{array}{l}11 \\
12 \\
13 \\
14 \\
15\end{array}$ & $\begin{array}{l}3710 \\
4660 \\
4670 \\
4380 \\
4100\end{array}$ & $\begin{array}{l}2110 \\
1930 \\
1750 \\
1600 \\
1500\end{array}$ & $\begin{array}{l}1350 \\
1290 \\
1240 \\
1170 \\
1200\end{array}$ & $\begin{array}{l}\text { e } 1900 \\
\text { e } 1750 \\
\text { e } 1630 \\
\text { e } 1550 \\
\text { e } 1500\end{array}$ & $\begin{array}{r}\text { el } 390 \\
\text { el } 310 \\
\text { el } 250 \\
1260 \\
1200\end{array}$ & $\begin{array}{l}1150 \\
1110 \\
1090 \\
1080 \\
1110\end{array}$ & $\begin{array}{l}1340 \\
1290 \\
1250 \\
1300 \\
1860\end{array}$ & $\begin{array}{l}1340 \\
1260 \\
1190 \\
1140 \\
1210\end{array}$ & $\begin{array}{l}967 \\
925 \\
885 \\
840 \\
799\end{array}$ & $\begin{array}{l}563 \\
496 \\
444 \\
403 \\
380\end{array}$ & $\begin{array}{l}219 \\
265 \\
250 \\
240 \\
229\end{array}$ & $\begin{array}{l}186 \\
191 \\
205 \\
211 \\
228\end{array}$ \\
\hline $\begin{array}{l}16 \\
17 \\
18 \\
19 \\
20\end{array}$ & $\begin{array}{l}3710 \\
3430 \\
3150 \\
2940 \\
2730\end{array}$ & $\begin{array}{l}1430 \\
1360 \\
1290 \\
1230 \\
1170\end{array}$ & $\begin{array}{l}1310 \\
1310 \\
1320 \\
1360 \\
1330\end{array}$ & $\begin{array}{r}\mathrm{e} 1700 \\
2700 \\
3210 \\
\mathrm{e} 2900 \\
\mathrm{e} 2550\end{array}$ & $\begin{array}{l}1130 \\
1060 \\
1080 \\
1370 \\
1690\end{array}$ & $\begin{array}{l}1200 \\
1410 \\
1870 \\
2410 \\
2390\end{array}$ & $\begin{array}{l}2790 \\
3170 \\
3160 \\
3070 \\
2840\end{array}$ & $\begin{array}{l}1100 \\
1270 \\
1260 \\
1340 \\
1170\end{array}$ & $\begin{array}{l}899 \\
942 \\
854 \\
767 \\
687\end{array}$ & $\begin{array}{l}357 \\
336 \\
321 \\
307 \\
298\end{array}$ & $\begin{array}{l}221 \\
219 \\
217 \\
243 \\
279\end{array}$ & $\begin{array}{l}219 \\
207 \\
200 \\
195 \\
194\end{array}$ \\
\hline $\begin{array}{l}21 \\
22 \\
23 \\
24 \\
25\end{array}$ & $\begin{array}{l}2470 \\
2260 \\
2050 \\
1900 \\
1780\end{array}$ & $\begin{array}{l}1120 \\
1110 \\
1080 \\
1030 \\
1010\end{array}$ & $\begin{array}{r}1320 \\
1570 \\
1780 \\
1700 \\
e 1570\end{array}$ & $\begin{array}{l}\text { e } 2250 \\
\text { e } 2000 \\
\text { e } 1800 \\
\text { e } 1600 \\
\text { e } 1450\end{array}$ & $\begin{array}{l}1780 \\
1720 \\
1640 \\
1540 \\
1430\end{array}$ & $\begin{array}{l}2210 \\
2060 \\
1960 \\
1910 \\
1850\end{array}$ & $\begin{array}{l}2640 \\
2470 \\
2320 \\
2270 \\
2250\end{array}$ & $\begin{array}{r}1050 \\
976 \\
990 \\
1320 \\
1370\end{array}$ & $\begin{array}{l}611 \\
553 \\
521 \\
494 \\
478\end{array}$ & $\begin{array}{l}287 \\
280 \\
275 \\
267 \\
265\end{array}$ & $\begin{array}{l}281 \\
275 \\
260 \\
245 \\
235\end{array}$ & $\begin{array}{l}193 \\
190 \\
195 \\
195 \\
194\end{array}$ \\
\hline $\begin{array}{l}26 \\
27 \\
28 \\
29 \\
30 \\
31\end{array}$ & $\begin{array}{l}1650 \\
1560 \\
1470 \\
1390 \\
1320 \\
1250\end{array}$ & $\begin{array}{r}980 \\
1000 \\
1310 \\
1710 \\
1650 \\
\cdots\end{array}$ & $\begin{array}{r}\text { e } 1430 \\
\text { e1 } 380 \\
\text { e2 } 2000 \\
\text { e } 3300 \\
4780 \\
6460\end{array}$ & $\begin{array}{r}\text { e } 1300 \\
\text { e } 1200 \\
\text { e } 1130 \\
\text { e } 1070 \\
\text { e } 1020 \\
\text { e } 980\end{array}$ & $\begin{array}{r}1320 \\
1230 \\
1170 \\
\ldots \\
\ldots \\
\ldots\end{array}$ & $\begin{array}{l}1780 \\
1960 \\
2070 \\
2050 \\
1910 \\
1770\end{array}$ & $\begin{array}{c}2170 \\
2080 \\
2010 \\
1960 \\
1920 \\
\ldots\end{array}$ & $\begin{array}{l}1380 \\
1360 \\
1290 \\
1180 \\
1160 \\
1350\end{array}$ & $\begin{array}{l}461 \\
438 \\
416 \\
406 \\
396 \\
\cdots\end{array}$ & $\begin{array}{l}258 \\
250 \\
244 \\
239 \\
238 \\
232\end{array}$ & $\begin{array}{l}229 \\
219 \\
212 \\
208 \\
222 \\
223\end{array}$ & $\begin{array}{l}195 \\
194 \\
194 \\
193 \\
190 \\
\cdots\end{array}$ \\
\hline $\begin{array}{l}\text { TOTAL } \\
\text { MEAN } \\
\text { MAX } \\
\text { MIN } \\
\text { CF SM } \\
\text { IN. }\end{array}$ & $\begin{array}{r}65482 \\
2112 \\
4670 \\
584 \\
2.47 \\
2.85\end{array}$ & $\begin{array}{r}45320 \\
1511 \\
2680 \\
980 \\
1.76 \\
1.97\end{array}$ & $\begin{array}{r}56060 \\
1808 \\
6460 \\
1170 \\
2.11 \\
2.44\end{array}$ & $\begin{array}{r}79490 \\
2564 \\
6720 \\
980 \\
3.00 \\
3.45\end{array}$ & $\begin{array}{r}37715 \\
1347 \\
1790 \\
900 \\
1.57 \\
1.64\end{array}$ & $\begin{array}{r}50650 \\
1634 \\
2410 \\
1080 \\
1.91 \\
2.20\end{array}$ & $\begin{array}{r}58140 \\
1958 \\
3170 \\
1250 \\
2.29 \\
2.55\end{array}$ & $\begin{array}{r}41876 \\
1351 \\
1840 \\
976 \\
1.58 \\
1.82\end{array}$ & $\begin{array}{r}29679 \\
989 \\
2130 \\
396 \\
1.16 \\
1.29\end{array}$ & $\begin{array}{r}12184 \\
393 \\
981 \\
232 \\
.46 \\
.53\end{array}$ & $\begin{array}{c}7359 \\
237 \\
282 \\
208 \\
.28 \\
.32\end{array}$ & $\begin{array}{l}6115 \\
204 \\
228 \\
186 \\
.24 \\
.27\end{array}$ \\
\hline
\end{tabular}

e Estinated

STATISIICS OF MONTHLY MEAN DATA FOR WAIER YEARS 1944 - 1991, BY WAIER YEAR (WY)

$\begin{array}{lrrrrrrrrrrrr}\text { MEAN } & 461 & 561 & 799 & 939 & 1172 & 1475 & 1542 & 1114 & 867 & 538 & 414 & 355 \\ \text { MAX } & 2112 & 1933 & 2478 & 3552 & 3020 & 4239 & 4116 & 2869 & 3468 & 1311 & 2699 & 1224 \\ \text { (WY) } & 1991 & 1973 & 1967 & 1950 & 1959 & 1982 & 1950 & 1981 & 1981 & 1951 & 1990 & 1958 \\ \text { MIN } & 134 & 155 & 177 & 183 & 192 & 451 & 525 & 337 & 243 & 180 & 155 & 107 \\ \text { (WY) } & 1954 & 1954 & 1964 & 1963 & 1963 & 1957 & 1958 & 1958 & 1988 & 1988 & 1988 & 1966\end{array}$

SUMMARY SIATISIICS

ANNUAL TOTAL

ANNUAL MEAN

HIGHEST ANMUAL MEAN

LOWEST ANMUAL MEAN

HIGHEST DAILY MEAM

LOWEST DAILY MEAM

ANHUAL SEVEN-DAY MI MIMUM

INSTANTANEOUS PEAK FLOW

INSTANTANEOUS PEAK SIAGE

ANNUAL RUNOFF (CFSM)

ANNUAL RUNOFF (INCHES)

10 PERCENT EXCEEDS

50 PERCENT EXCEEDS

90 PERCENT EXCEEDS
FOR 1990 CALENUAR YEAR

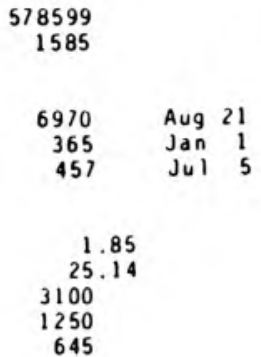

FOR 1991 WAIER YEAR

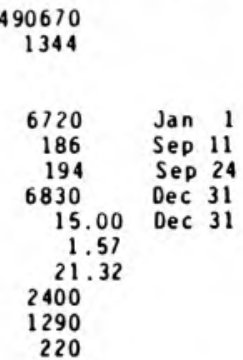

WATER YEARS $1944-1991$

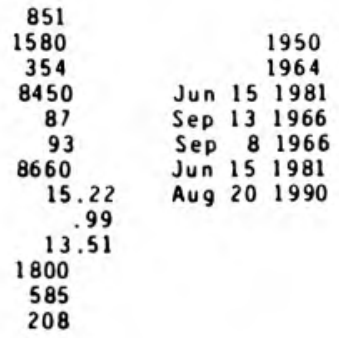




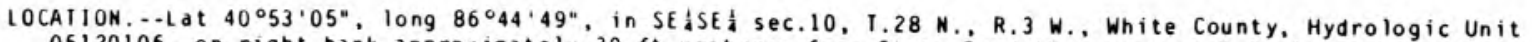
05120106 , on right bank approxiately $30 \mathrm{ft}$ upstrean fro State Road 16 bridge at Buffalo. 0.2 ai downstream from Harp ditch, 10.8 i upstream from Norway dan.

DRAI NAGE AREA, $-1,284 \oplus i^{2}$.

PERIOD OF RECORD..-APril 1986 to current yedr.

GAGE.- -Water-stage recorder. Datum of gage is $640.000 \mathrm{ft}$ above National Geodetic Vertical Datum of 1929 .

REMARKS. - - Stage possibly affected by backwater from Norway dam.

EXIREMES FOR PERIOD OF RECORD. - Maximum gage height, $15.46 \mathrm{ft}$ Aug. 21,1990 ; minimum gage height, $6.98 \mathrm{ft}$ Sept. 30, 1986 .

EXIREMES FOR CURRENT YEAR.--Maximum gage height, $15.42 \mathrm{ft}$ Dec. 31,1990 ; inimum gage height, 7,79 ft Aug. 2, Sept. 11 and 12 .

GAGE HEIGHT, FEET, WATER YEAR OCTOBER 1990 TO SEPIEMBER 1991 DAILY OBSERVATION AT 24:00 VALUES

\begin{tabular}{|c|c|c|c|c|c|c|c|c|c|c|c|c|}
\hline DAY & $O C T$ & NOV & DEC & JAN & FEB & MAR & APR & MAY & JUN & JUL & AUG & SEP \\
\hline $\begin{array}{l}1 \\
2 \\
3 \\
4 \\
5\end{array}$ & $\begin{array}{l}8.36 \\
8.34 \\
8.44 \\
8.38 \\
8.47\end{array}$ & $\begin{array}{r}8.98 \\
8.93 \\
8.89 \\
8.91 \\
10.38\end{array}$ & $\begin{array}{l}9.40 \\
9.24 \\
9.81 \\
9.62 \\
9.70\end{array}$ & $\begin{array}{l}15.29 \\
15.12 \\
14.26 \\
13.09 \\
12.11\end{array}$ & $\begin{array}{r}11.16 \\
9.38 \\
9.27 \\
9.45 \\
9.67\end{array}$ & $\begin{array}{l}9.13 \\
9.45 \\
9.56 \\
9.58 \\
9.47\end{array}$ & $\begin{array}{l}9.43 \\
9.35 \\
9.27 \\
9.26 \\
9.22\end{array}$ & $\begin{array}{l}9.39 \\
9.27 \\
9.22 \\
9.10 \\
9.23\end{array}$ & $\begin{array}{l}9.34 \\
9.53 \\
9.55 \\
9.45 \\
9.29\end{array}$ & $\begin{array}{l}8.21 \\
8.52 \\
8.27 \\
8.22 \\
8.23\end{array}$ & $\begin{array}{l}7.95 \\
7.96 \\
7.84 \\
7.97 \\
7.85\end{array}$ & $\begin{array}{l}7.89 \\
7.94 \\
7.99 \\
7.90 \\
7.97\end{array}$ \\
\hline $\begin{array}{r}6 \\
7 \\
8 \\
9 \\
10\end{array}$ & $\begin{array}{r}8.42 \\
8.53 \\
8.73 \\
10.55 \\
12.82\end{array}$ & $\begin{array}{r}10.41 \\
10.41 \\
10.37 \\
10.19 \\
9.98\end{array}$ & $\begin{array}{l}9.52 \\
9.45 \\
9.38 \\
9.33 \\
9.22\end{array}$ & $\begin{array}{l}12.07 \\
11.45 \\
11.13 \\
10.90 \\
10.66\end{array}$ & $\begin{array}{l}9.71 \\
9.77 \\
9.73 \\
9.67 \\
9.57\end{array}$ & $\begin{array}{l}9.37 \\
9.33 \\
9.17 \\
9.07 \\
8.98\end{array}$ & $\begin{array}{l}9.13 \\
9.08 \\
9.02 \\
9.08 \\
9.15\end{array}$ & $\begin{array}{l}9.21 \\
9.11 \\
9.03 \\
8.99 \\
8.86\end{array}$ & $\begin{array}{l}9.14 \\
8.98 \\
8.82 \\
8.70 \\
8.71\end{array}$ & $\begin{array}{l}8.22 \\
8.14 \\
8.19 \\
8.47 \\
8.35\end{array}$ & $\begin{array}{l}7.95 \\
7.89 \\
7.94 \\
7.94 \\
7.98\end{array}$ & $\begin{array}{l}7.93 \\
7.84 \\
7.89 \\
7.86 \\
7.87\end{array}$ \\
\hline $\begin{array}{l}11 \\
12 \\
13 \\
14 \\
15\end{array}$ & $\begin{array}{l}12.17 \\
12.31 \\
12.50 \\
12.18 \\
11.82\end{array}$ & $\begin{array}{l}9.83 \\
9.69 \\
9.52 \\
9.42 \\
9.31\end{array}$ & $\begin{array}{l}9.17 \\
9.11 \\
9.05 \\
8.97 \\
9.10\end{array}$ & $\begin{array}{l}10.71 \\
10.65 \\
10.57 \\
10.50 \\
10.59\end{array}$ & $\begin{array}{l}9.45 \\
9.37 \\
9.26 \\
9.22 \\
9.11\end{array}$ & $\begin{array}{l}8.92 \\
8.98 \\
8.89 \\
8.93 \\
8.98\end{array}$ & $\begin{array}{r}8.98 \\
8.99 \\
8.98 \\
9.15 \\
11.07\end{array}$ & $\begin{array}{l}8.81 \\
8.74 \\
8.71 \\
9.09 \\
8.90\end{array}$ & $\begin{array}{l}8.62 \\
8.61 \\
8.49 \\
8.52 \\
8.50\end{array}$ & $\begin{array}{l}8.31 \\
8.24 \\
8.11 \\
8.05 \\
8.07\end{array}$ & $\begin{array}{l}7.92 \\
7.92 \\
7.97 \\
7.94 \\
7.91\end{array}$ & $\begin{array}{l}7.83 \\
7.88 \\
7.94 \\
8.01 \\
8.01\end{array}$ \\
\hline $\begin{array}{l}16 \\
17 \\
18 \\
19 \\
20\end{array}$ & $\begin{array}{l}11.47 \\
11.15 \\
11.03 \\
10.70 \\
10.47\end{array}$ & $\begin{array}{l}9.20 \\
9.10 \\
9.06 \\
9.02 \\
8.99\end{array}$ & $\begin{array}{l}9.14 \\
9.19 \\
9.21 \\
9.18 \\
9.17\end{array}$ & $\begin{array}{l}11.99 \\
11.54 \\
11.42 \\
11.31 \\
11.17\end{array}$ & $\begin{array}{r}11.95 \\
11.29 \\
9.24 \\
9.62 \\
9.10\end{array}$ & $\begin{array}{r}9.03 \\
9.42 \\
11.37 \\
11.31 \\
10.97\end{array}$ & $\begin{array}{l}10.81 \\
11.15 \\
10.91 \\
10.75 \\
10.55\end{array}$ & $\begin{array}{r}9.35 \\
9.11 \\
10.39 \\
9.67 \\
9.27\end{array}$ & $\begin{array}{l}8.53 \\
8.61 \\
8.47 \\
8.39 \\
8.38\end{array}$ & $\begin{array}{l}8.06 \\
7.97 \\
8.01 \\
7.99 \\
7.96\end{array}$ & $\begin{array}{l}8.02 \\
7.95 \\
7.91 \\
7.99 \\
7.99\end{array}$ & $\begin{array}{l}7.88 \\
7.96 \\
8.03 \\
7.85 \\
7.88\end{array}$ \\
\hline $\begin{array}{l}21 \\
22 \\
23 \\
24 \\
25\end{array}$ & $\begin{array}{r}10.25 \\
10.07 \\
9.87 \\
9.75 \\
9.57\end{array}$ & $\begin{array}{l}8.99 \\
8.93 \\
8.89 \\
8.82 \\
8.77\end{array}$ & $\begin{array}{r}9.40 \\
9.66 \\
9.67 \\
9.75 \\
12.92\end{array}$ & $\begin{array}{l}10.85 \\
10.70 \\
10.39 \\
10.30 \\
11.63\end{array}$ & $\begin{array}{l}9.69 \\
9.55 \\
9.50 \\
9.38 \\
9.26\end{array}$ & $\begin{array}{r}10.55 \\
10.25 \\
10.29 \\
10.21 \\
9.95\end{array}$ & $\begin{array}{r}10.29 \\
10.08 \\
9.94 \\
9.83 \\
9.77\end{array}$ & $\begin{array}{r}9.01 \\
8.89 \\
9.10 \\
9.23 \\
10.07\end{array}$ & $\begin{array}{l}8.30 \\
8.18 \\
8.19 \\
8.19 \\
8.14\end{array}$ & $\begin{array}{l}7.95 \\
8.08 \\
8.05 \\
8.04 \\
7.99\end{array}$ & $\begin{array}{l}8.03 \\
7.93 \\
8.01 \\
7.97 \\
7.89\end{array}$ & $\begin{array}{l}7.92 \\
7.92 \\
7.92 \\
7.95 \\
7.98\end{array}$ \\
\hline $\begin{array}{l}26 \\
27 \\
28 \\
29 \\
30 \\
31\end{array}$ & $\begin{array}{l}9.50 \\
9.38 \\
9.26 \\
9.20 \\
9.12 \\
9.01\end{array}$ & $\begin{array}{l}8.82 \\
8.87 \\
9.66 \\
9.58 \\
9.57 \\
. .-\end{array}$ & $\begin{array}{l}11.98 \\
11.38 \\
11.85 \\
14.29 \\
15.40 \\
15.07\end{array}$ & $\begin{array}{l}12.43 \\
13.09 \\
12.79 \\
11.47 \\
10.53 \\
11.64\end{array}$ & $\begin{array}{c}9.17 \\
9.05 \\
9.09 \\
\ldots . \\
\ldots . \\
\ldots\end{array}$ & $\begin{array}{r}10.48 \\
10.38 \\
10.19 \\
9.95 \\
9.77 \\
9.59\end{array}$ & $\begin{array}{c}9.71 \\
9.62 \\
9.55 \\
9.51 \\
9.43 \\
\ldots . .\end{array}$ & $\begin{array}{l}9.54 \\
9.23 \\
9.07 \\
8.95 \\
8.88 \\
9.01\end{array}$ & $\begin{array}{c}8.14 \\
8.22 \\
8.18 \\
8.14 \\
8.42 \\
\ldots .\end{array}$ & $\begin{array}{l}7.93 \\
7.92 \\
8.00 \\
7.94 \\
7.95 \\
7.95\end{array}$ & $\begin{array}{l}7.90 \\
7.95 \\
7.91 \\
7.97 \\
7.87 \\
7.97\end{array}$ & $\begin{array}{r}8.04 \\
7.96 \\
7.94 \\
7.88 \\
7.95 \\
. . .\end{array}$ \\
\hline $\begin{array}{l}\text { MEAN } \\
\text { MAX } \\
\text { MIN }\end{array}$ & $\begin{array}{r}10.06 \\
12.82 \\
8.34\end{array}$ & $\begin{array}{r}9.38 \\
10.41 \\
8.77\end{array}$ & $\begin{array}{r}10.24 \\
15.40 \\
8.97\end{array}$ & $\begin{array}{l}11.71 \\
15.29 \\
10.30\end{array}$ & $\begin{array}{r}9.65 \\
11.95 \\
9.05\end{array}$ & $\begin{array}{r}9.73 \\
11.37 \\
8.89\end{array}$ & $\begin{array}{r}9.70 \\
11.15 \\
8.98\end{array}$ & $\begin{array}{r}9.18 \\
10.39 \\
8.71\end{array}$ & $\begin{array}{l}8.62 \\
9.55 \\
8.14\end{array}$ & $\begin{array}{l}8.11 \\
8.52 \\
7.92\end{array}$ & $\begin{array}{l}7.94 \\
8.03 \\
1.84\end{array}$ & $\begin{array}{l}7.93 \\
8.04 \\
7.83\end{array}$ \\
\hline
\end{tabular}


LOCAIION. - - Lat $40^{\circ} 35^{\prime} 38^{\prime \prime}$, Iong $86^{\circ} 46^{\prime} 12^{\prime \prime}$, in SW'SWa sec.21, T.25 N., R. 3 W., Carroll County, Hydrologic Unit 05120106 , on left bank $20 \mathrm{ft}$ upstream from bridge on State Highway 18, 1,400 ft east of Springboro, 8.1 . downstrean fro Big C çeek, 5 mi west of Delphi, and at aile 8.7

DRAINAGE AREA, $\cdots 1,869 \cdot i^{2}$.

PERIOD OF RECORD.--March to December 1903. March to Decenber 1904, March 1905 to July 1906 , Movemter and December 1908. July 1939 to Septeaber 1987. October 1987 to current year. Published as "at Springboro" $1903-08$. Published as "03333000 Tippcanoe River near Delphi:" July 1939 to Septeuber 1981.

REVISED RECORDS.-.WSP 973: 1942. WSP 1335: 1905-6. WSP 2109: Drainage area.

GAGE. - Water-stage recorder. Datum of gage is $535.00 \mathrm{ft}$ above National Geodetic Vertical Datue of 1929 . Mar. 14, 1903, to July 20, 1906, and Nov. 2 to Dec. 31, 1908, nonrecording gage at present site at different datun. July 1939 to Sept. 30, 1987, at site 6.4 i upstrea at datun $17.01 \mathrm{ft}$ higher.

REMARKS.--Records good. Flow regulated by upstrea reservoirs.

DISCHARGE, CUBIL FEET PER SECOND, WATER YEAR OCTOBER 1990 TO SEPIEMBER 1991

\begin{tabular}{|c|c|c|c|c|c|c|c|c|c|c|c|c|}
\hline DAY & $\mathrm{OCI}$ & MOV & DEC & JAN & FEB & MAR & APR & MAY & JUN & JUL & AUG & SEP \\
\hline $\begin{array}{l}1 \\
2 \\
3 \\
4 \\
5\end{array}$ & $\begin{array}{r}1180 \\
926 \\
1170 \\
1350 \\
1330\end{array}$ & $\begin{array}{r}1060 \\
263 \\
1320 \\
1880 \\
3390\end{array}$ & $\begin{array}{l}3220 \\
2800 \\
3120 \\
4040 \\
3110\end{array}$ & $\begin{array}{r}14900 \\
13500 \\
12100 \\
9600 \\
8080\end{array}$ & $\begin{array}{l}2490 \\
2680 \\
2790 \\
2980 \\
3500\end{array}$ & $\begin{array}{l}2560 \\
3000 \\
3500 \\
3310 \\
3200\end{array}$ & $\begin{array}{l}3650 \\
3030 \\
2790 \\
2940 \\
2900\end{array}$ & $\begin{array}{l}3170 \\
2840 \\
2710 \\
2700 \\
2640\end{array}$ & $\begin{array}{l}2850 \\
3080 \\
3150 \\
2830 \\
2710\end{array}$ & $\begin{array}{r}950 \\
759 \\
1120 \\
863 \\
925\end{array}$ & $\begin{array}{l}335 \\
386 \\
345 \\
384 \\
346\end{array}$ & $\begin{array}{l}353 \\
338 \\
382 \\
432 \\
406\end{array}$ \\
\hline $\begin{array}{r}6 \\
7 \\
8 \\
9 \\
10\end{array}$ & $\begin{array}{r}1180 \\
1570 \\
1800 \\
4320 \\
11100\end{array}$ & $\begin{array}{l}6270 \\
5140 \\
4550 \\
4360 \\
3860\end{array}$ & $\begin{array}{l}3500 \\
2640 \\
2880 \\
2370 \\
2430\end{array}$ & $\begin{array}{l}7030 \\
6150 \\
5390 \\
5100 \\
4590\end{array}$ & $\begin{array}{l}3690 \\
3830 \\
3590 \\
3580 \\
3490\end{array}$ & $\begin{array}{l}3090 \\
2910 \\
2590 \\
2650 \\
2290\end{array}$ & $\begin{array}{l}2800 \\
2680 \\
2750 \\
2550 \\
2550\end{array}$ & $\begin{array}{l}2700 \\
2690 \\
2450 \\
2130 \\
2460\end{array}$ & $\begin{array}{l}2640 \\
2170 \\
2150 \\
1950 \\
1680\end{array}$ & $\begin{array}{r}725 \\
660 \\
964 \\
745 \\
1560\end{array}$ & $\begin{array}{l}401 \\
376 \\
753 \\
436 \\
561\end{array}$ & $\begin{array}{l}338 \\
338 \\
380 \\
363 \\
338\end{array}$ \\
\hline $\begin{array}{l}11 \\
12 \\
13 \\
14 \\
15\end{array}$ & $\begin{array}{r}11400 \\
8890 \\
8120 \\
7370 \\
6670\end{array}$ & $\begin{array}{l}3470 \\
3310 \\
2860 \\
2900 \\
2400\end{array}$ & $\begin{array}{l}2350 \\
2370 \\
2190 \\
1880 \\
2540\end{array}$ & $\begin{array}{l}4630 \\
5040 \\
4590 \\
4450 \\
4830\end{array}$ & $\begin{array}{l}3290 \\
2920 \\
3050 \\
2830 \\
2320\end{array}$ & $\begin{array}{l}2220 \\
2320 \\
2980 \\
3100 \\
3210\end{array}$ & $\begin{array}{l}2430 \\
2250 \\
2380 \\
2730 \\
5360\end{array}$ & $\begin{array}{l}2220 \\
2150 \\
2140 \\
2150 \\
2610\end{array}$ & $\begin{array}{l}1780 \\
1590 \\
1450 \\
1450 \\
1470\end{array}$ & $\begin{array}{r}1000 \\
1020 \\
833 \\
728 \\
724\end{array}$ & $\begin{array}{l}495 \\
462 \\
443 \\
409 \\
333\end{array}$ & $\begin{array}{l}339 \\
348 \\
407 \\
468 \\
430\end{array}$ \\
\hline $\begin{array}{l}16 \\
17 \\
18 \\
19 \\
20\end{array}$ & $\begin{array}{l}5980 \\
5470 \\
5510 \\
4940 \\
4560\end{array}$ & $\begin{array}{l}2450 \\
2250 \\
2230 \\
1970 \\
1980\end{array}$ & $\begin{array}{l}2340 \\
2540 \\
2760 \\
2530 \\
2570\end{array}$ & $\begin{array}{l}7610 \\
8720 \\
6800 \\
6270 \\
6140\end{array}$ & $\begin{array}{l}2010 \\
2380 \\
2720 \\
3350 \\
3490\end{array}$ & $\begin{array}{r}3650 \\
5030 \\
9250 \\
10500 \\
9120\end{array}$ & $\begin{array}{l}6910 \\
6050 \\
6160 \\
5490 \\
4900\end{array}$ & $\begin{array}{l}2590 \\
3520 \\
6560 \\
6280 \\
4130\end{array}$ & $\begin{array}{l}1420 \\
1410 \\
1400 \\
1400 \\
1210\end{array}$ & $\begin{array}{l}447 \\
668 \\
481 \\
689 \\
425\end{array}$ & $\begin{array}{l}371 \\
450 \\
407 \\
651 \\
407\end{array}$ & $\begin{array}{l}484 \\
300 \\
236 \\
376 \\
373\end{array}$ \\
\hline $\begin{array}{l}21 \\
22 \\
23 \\
24 \\
25\end{array}$ & $\begin{array}{l}4310 \\
3740 \\
3500 \\
3240 \\
3110\end{array}$ & $\begin{array}{l}1850 \\
1920 \\
1830 \\
1860 \\
1680\end{array}$ & $\begin{array}{l}2140 \\
4110 \\
3840 \\
3200 \\
2170\end{array}$ & $\begin{array}{l}5690 \\
4860 \\
4500 \\
3820 \\
3220\end{array}$ & $\begin{array}{l}3540 \\
3430 \\
3060 \\
3090 \\
2820\end{array}$ & $\begin{array}{l}7370 \\
5960 \\
6080 \\
5870 \\
5190\end{array}$ & $\begin{array}{l}4650 \\
4100 \\
3910 \\
3910 \\
3390\end{array}$ & $\begin{array}{l}3440 \\
2890 \\
2690 \\
3150 \\
4320\end{array}$ & $\begin{array}{r}1070 \\
1080 \\
755 \\
911 \\
811\end{array}$ & $\begin{array}{l}502 \\
443 \\
451 \\
403 \\
408\end{array}$ & $\begin{array}{l}512 \\
484 \\
470 \\
461 \\
358\end{array}$ & $\begin{array}{l}403 \\
403 \\
374 \\
276 \\
353\end{array}$ \\
\hline $\begin{array}{l}26 \\
27 \\
28 \\
29 \\
30 \\
31\end{array}$ & $\begin{array}{l}2820 \\
2810 \\
2570 \\
3560 \\
4180 \\
2920\end{array}$ & $\begin{array}{c}1680 \\
1700 \\
3220 \\
4360 \\
3290 \\
\ldots\end{array}$ & $\begin{array}{r}2540 \\
1950 \\
1840 \\
8040 \\
21400 \\
18000\end{array}$ & $\begin{array}{l}3140 \\
3090 \\
2940 \\
3050 \\
2970 \\
2700\end{array}$ & $\begin{array}{r}2610 \\
2530 \\
2190 \\
\ldots \\
\ldots \\
\ldots\end{array}$ & $\begin{array}{l}5210 \\
6260 \\
5430 \\
4850 \\
3780 \\
3720\end{array}$ & $\begin{array}{c}3510 \\
3350 \\
3310 \\
3130 \\
3200 \\
\cdots\end{array}$ & $\begin{array}{l}5110 \\
3740 \\
3100 \\
2680 \\
2640 \\
2390\end{array}$ & $\begin{array}{l}895 \\
751 \\
704 \\
695 \\
688 \\
\cdots\end{array}$ & $\begin{array}{l}383 \\
458 \\
401 \\
299 \\
441 \\
403\end{array}$ & $\begin{array}{l}446 \\
352 \\
334 \\
443 \\
358 \\
396\end{array}$ & $\begin{array}{l}364 \\
347 \\
317 \\
356 \\
403 \\
\cdots\end{array}$ \\
\hline $\begin{array}{l}\text { TOIAL } \\
\text { MEAN } \\
\text { MAX } \\
\text { MI N } \\
\text { CF SM } \\
\text { IN. }\end{array}$ & $\begin{array}{r}131596 \\
4245 \\
11400 \\
926 \\
2.27 \\
2.62\end{array}$ & $\begin{array}{r}81303 \\
2710 \\
6270 \\
263 \\
1.45 \\
1.62\end{array}$ & $\begin{array}{r}124010 \\
4000 \\
21400 \\
1840 \\
2.14 \\
2.47\end{array}$ & $\begin{array}{r}185500 \\
5984 \\
14900 \\
2700 \\
3.20 \\
3.69\end{array}$ & $\begin{array}{r}84250 \\
3009 \\
3830 \\
2010 \\
1.61 \\
1.68\end{array}$ & $\begin{array}{r}140200 \\
4523 \\
10500 \\
2220 \\
2.42 \\
2.19\end{array}$ & $\begin{array}{r}109820 \\
3661 \\
6970 \\
2250 \\
1.96 \\
2.19\end{array}$ & $\begin{array}{c}96990 \\
3129 \\
6560 \\
2130 \\
1.67 \\
1.93\end{array}$ & $\begin{array}{r}48150 \\
1605 \\
3150 \\
688 \\
.86 \\
.96\end{array}$ & $\begin{array}{c}20878 \\
673 \\
1560 \\
299 \\
.36 \\
.42\end{array}$ & $\begin{array}{c}13365 \\
431 \\
753 \\
333 \\
.23 \\
.27\end{array}$ & $\begin{array}{c}11085 \\
369 \\
484 \\
236 \\
.20 \\
.22\end{array}$ \\
\hline
\end{tabular}

STATISIICS OF MONTHLY MEAN DATA FOR WATER YEARS 1988 - 1991, BY WATER YEAR (WY)

\begin{tabular}{|c|c|c|c|c|c|c|c|c|}
\hline $\begin{array}{l}\text { MEAN } \\
\text { MAX } \\
\text { (WY) } \\
\text { MIN } \\
\text { (WY) }\end{array}$ & $\begin{array}{r}1575 \\
4245 \\
1991 \\
518\end{array}$ & $\begin{array}{r}1554 \\
2710 \\
1991 \\
929\end{array}$ & $\begin{array}{r}2448 \\
4000 \\
1991 \\
810\end{array}$ & $\begin{array}{l}3026 \\
5984 \\
1991 \\
1680\end{array}$ & $\begin{array}{l}2989 \\
4812 \\
1990 \\
1324\end{array}$ & $\begin{array}{l}3313 \\
5044 \\
1990 \\
1326\end{array}$ & $\begin{array}{l}2888 \\
3661 \\
1991 \\
1787\end{array}$ & $\begin{array}{r}2202 \\
3129 \\
1991 \\
983 \\
1988\end{array}$ \\
\hline
\end{tabular}

SUMMARY SIATISTICS

ANMUAL TOTAL

ANMUAL MEAM

HIGHEST ANMUAL MEAN

LOWEST ANMUAL MEAM

HIGHEST DAILY MEAN

LOWEST DAILY MEAN

ANNUAL SEVEN-DAY MININUM

INSTANIANEOUS PEAK FLOW

INSTANTANEOUS PEAK STAGE

ANNUAL RUNOFF (CFSM)

ANNUAL RUNOFF (INCHES)

10 PERCENT EXCEEDS

50 PERCENT EXCEEDS

90 PERCENT EXCEEDS

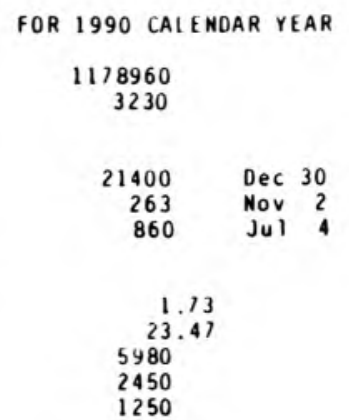

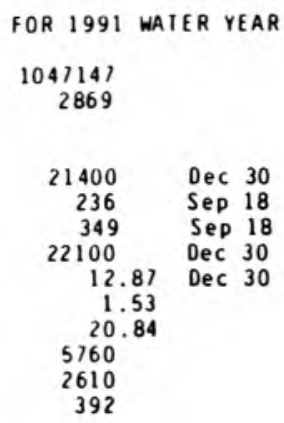

WATER YEARS 1988 - 1991

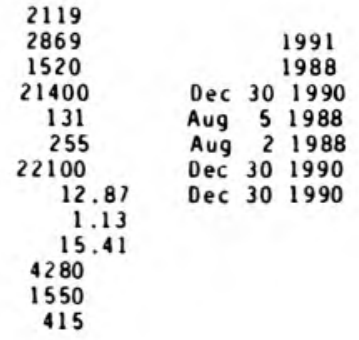




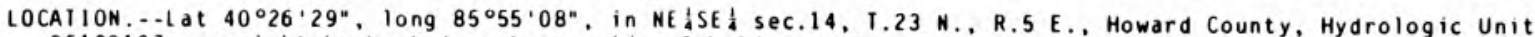

05120107, on right bank at downstrean side of bridge on County Road 1100 East, 0.5 mi downstream from Mud Creek, 1.5 i southeast of Jerone, and at aile 79.9.

DRAINAGE AREA, ..146 i

PERIOD OF RECORD.-.July 1961 to current yedr.

REVISED RECORDS...WSP 2109: Drainage area.

GAGE. - Water-stage recorder. Datun of gage is $820.04 \mathrm{ft}$ above National Geodetic Vertical Datun of 1929 .

REMARKS. - Records good except for Sept. 12-30. which are poor.

EXIREMES OUTSIDE PERIOD OF RECORD.--Flood in March 1913 reached a stage of about $18 \mathrm{ft}$, from information by local residents.

DISCHARGE, CUBIC FEET PER SECOND, WATER YEAR OCTOBER 1990 TO SEPTEMBER 1991 DAILY MEAN VALUES

\begin{tabular}{|c|c|c|c|c|c|c|c|c|c|c|c|c|}
\hline DAY & $O C \mathrm{~T}$ & NOV & DEC & JAN & FEB & MAR & APR & MAY & JUN & JUL & AUG & SEP \\
\hline $\begin{array}{l}1 \\
2 \\
3 \\
4 \\
5\end{array}$ & $\begin{array}{r}15 \\
15 \\
17 \\
106 \\
113\end{array}$ & $\begin{array}{l}49 \\
47 \\
45 \\
46 \\
86\end{array}$ & $\begin{array}{l}226 \\
167 \\
547 \\
878 \\
475\end{array}$ & $\begin{array}{r}1320 \\
759 \\
500 \\
350 \\
270\end{array}$ & $\begin{array}{l}\text { e68 } \\
\text { e70 } \\
\text { e80 } \\
160 \\
274\end{array}$ & $\begin{array}{r}101 \\
115 \\
111 \\
101 \\
94\end{array}$ & $\begin{array}{l}154 \\
129 \\
114 \\
109 \\
113\end{array}$ & $\begin{array}{l}84 \\
78 \\
71 \\
71 \\
71\end{array}$ & $\begin{array}{l}682 \\
347 \\
312 \\
214 \\
138\end{array}$ & $\begin{array}{l}13 \\
83 \\
45 \\
25 \\
18\end{array}$ & $\begin{array}{l}4.1 \\
3.9 \\
3.9 \\
4.8 \\
4.5\end{array}$ & $\begin{array}{l}5.3 \\
3.1 \\
2.4 \\
4.8 \\
2.9\end{array}$ \\
\hline $\begin{array}{r}6 \\
7 \\
8 \\
9 \\
10\end{array}$ & $\begin{array}{r}72 \\
61 \\
124 \\
205 \\
1130\end{array}$ & $\begin{array}{r}227 \\
151 \\
111 \\
96 \\
88\end{array}$ & $\begin{array}{l}322 \\
237 \\
191 \\
157 \\
141\end{array}$ & $\begin{array}{l}212 \\
170 \\
149 \\
135 \\
115\end{array}$ & $\begin{array}{l}388 \\
551 \\
398 \\
313 \\
261\end{array}$ & $\begin{array}{l}97 \\
88 \\
73 \\
71 \\
68\end{array}$ & $\begin{array}{l}106 \\
102 \\
102 \\
176 \\
133\end{array}$ & $\begin{array}{l}73 \\
66 \\
56 \\
53 \\
52\end{array}$ & $\begin{array}{r}101 \\
81 \\
71 \\
61 \\
54\end{array}$ & $\begin{array}{l}15 \\
12 \\
64 \\
45 \\
25\end{array}$ & $\begin{array}{l}4.4 \\
4.5 \\
5.1 \\
6.2 \\
5.9\end{array}$ & $\begin{array}{l}2.2 \\
2.0 \\
1.7 \\
1.4 \\
1.5\end{array}$ \\
\hline $\begin{array}{l}11 \\
12 \\
13 \\
14 \\
15\end{array}$ & $\begin{array}{r}1170 \\
643 \\
412 \\
285 \\
206\end{array}$ & $\begin{array}{l}75 \\
65 \\
57 \\
53 \\
54\end{array}$ & $\begin{array}{r}126 \\
120 \\
109 \\
91 \\
186\end{array}$ & $\begin{array}{l}142 \\
368 \\
264 \\
219 \\
423\end{array}$ & $\begin{array}{r}208 \\
164 \\
\text { e156 } \\
\text { e150 } \\
\text { e1 } 100\end{array}$ & $\begin{array}{r}64 \\
70 \\
120 \\
440 \\
485\end{array}$ & $\begin{array}{r}101 \\
87 \\
107 \\
314 \\
568\end{array}$ & $\begin{array}{r}50 \\
53 \\
67 \\
66 \\
115\end{array}$ & $\begin{array}{l}51 \\
48 \\
43 \\
37 \\
35\end{array}$ & $\begin{array}{l}17 \\
16 \\
14 \\
12 \\
9.9\end{array}$ & $\begin{array}{l}4.9 \\
4.2 \\
3.6 \\
3.3 \\
3.0\end{array}$ & $\begin{array}{l}1.6 \\
\text { e1.5 } \\
\text { e } 1.5 \\
\text { e2.7 } \\
\text { e2 } 2.0\end{array}$ \\
\hline $\begin{array}{l}16 \\
17 \\
18 \\
19 \\
20\end{array}$ & $\begin{array}{l}153 \\
130 \\
222 \\
251 \\
179\end{array}$ & $\begin{array}{l}50 \\
49 \\
48 \\
49 \\
45\end{array}$ & $\begin{array}{l}267 \\
202 \\
353 \\
567 \\
397\end{array}$ & $\begin{array}{l}859 \\
893 \\
548 \\
398 \\
390\end{array}$ & $\begin{array}{r}\text { e93 } \\
\text { e97 } \\
\text { e120 } \\
435 \\
439\end{array}$ & $\begin{array}{r}660 \\
1110 \\
1800 \\
1340 \\
819\end{array}$ & $\begin{array}{l}520 \\
305 \\
213 \\
278 \\
595\end{array}$ & $\begin{array}{l}85 \\
74 \\
67 \\
56 \\
48\end{array}$ & $\begin{array}{l}42 \\
39 \\
32 \\
28 \\
25\end{array}$ & $\begin{array}{l}8.8 \\
8.1 \\
7.6 \\
7.0 \\
6.6\end{array}$ & $\begin{array}{l}2.8 \\
3.0 \\
3.6 \\
4.4 \\
4.6\end{array}$ & $\begin{array}{l}\text { e } 1.7 \\
\text { e } 1.6 \\
\text { e1 } .5 \\
\text { e } 3.0 \\
\text { e } 2.5\end{array}$ \\
\hline $\begin{array}{l}21 \\
22 \\
23 \\
24 \\
25\end{array}$ & $\begin{array}{r}143 \\
120 \\
106 \\
96 \\
84\end{array}$ & $\begin{array}{l}42 \\
48 \\
49 \\
50 \\
44\end{array}$ & $\begin{array}{r}566 \\
1050 \\
638 \\
380 \\
260\end{array}$ & $\begin{array}{r}387 \\
275 \\
226 \\
169 \\
\text { e140 }\end{array}$ & $\begin{array}{l}309 \\
242 \\
186 \\
163 \\
136\end{array}$ & $\begin{array}{l}574 \\
530 \\
903 \\
661 \\
410\end{array}$ & $\begin{array}{l}393 \\
269 \\
206 \\
174 \\
141\end{array}$ & $\begin{array}{r}44 \\
213 \\
242 \\
126 \\
123\end{array}$ & $\begin{array}{l}22 \\
23 \\
58 \\
42 \\
27\end{array}$ & $\begin{array}{l}6.2 \\
6.0 \\
5.8 \\
5.6 \\
5.5\end{array}$ & $\begin{array}{l}4.1 \\
3.6 \\
2.8 \\
2.7 \\
2.3\end{array}$ & 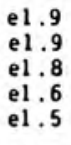 \\
\hline $\begin{array}{l}26 \\
27 \\
28 \\
29 \\
30 \\
31\end{array}$ & $\begin{array}{l}75 \\
67 \\
64 \\
56 \\
53 \\
52\end{array}$ & $\begin{array}{r}40 \\
57 \\
472 \\
583 \\
322 \\
\cdots\end{array}$ & $\begin{array}{r}194 \\
\text { e150 } \\
\text { e140 } \\
879 \\
5980 \\
3280\end{array}$ & $\begin{array}{l}\text { el23 } \\
\text { e110 } \\
\text { el } 00 \\
\text { e } 92 \\
\text { e } 85 \\
\text { e75 }\end{array}$ & $\begin{array}{l}121 \\
114 \\
105 \\
\cdots \\
\cdots \\
\cdots\end{array}$ & $\begin{array}{l}487 \\
772 \\
509 \\
326 \\
231 \\
178\end{array}$ & $\begin{array}{r}125 \\
117 \\
108 \\
101 \\
92 \\
\cdots\end{array}$ & $\begin{array}{r}195 \\
132 \\
89 \\
72 \\
74 \\
564\end{array}$ & $\begin{array}{l}22 \\
19 \\
16 \\
14 \\
13 \\
\cdots\end{array}$ & $\begin{array}{l}5.1 \\
4.8 \\
4.5 \\
4.3 \\
4.7 \\
4.4\end{array}$ & $\begin{array}{l}2.0 \\
2.0 \\
2.1 \\
2.2 \\
3.3 \\
8.1\end{array}$ & $\begin{array}{l}\text { el. } 1.5 \\
\text { e1.4 } \\
\text { e1.4 } \\
\text { el. } 1.5 \\
\text { e1.4 } \\
\ldots\end{array}$ \\
\hline $\begin{array}{l}\text { TOIAL } \\
\text { MEAN } \\
\text { MAX } \\
\text { MIN } \\
\text { CF SM } \\
\text { IN. }\end{array}$ & $\begin{array}{r}6425 \\
207 \\
1170 \\
15 \\
1.42 \\
1.64\end{array}$ & $\begin{array}{r}3198 \\
107 \\
583 \\
40 \\
.73 \\
.81\end{array}$ & $\begin{array}{r}19216 \\
622 \\
5980 \\
91 \\
4.26 \\
4.91\end{array}$ & $\begin{array}{r}10266 \\
331 \\
1320 \\
75 \\
2.27 \\
2.62\end{array}$ & $\begin{array}{r}5901 \\
211 \\
551 \\
68 \\
1.44 \\
1.50\end{array}$ & $\begin{array}{c}13408 \\
433 \\
1800 \\
64 \\
2.96 \\
3.42\end{array}$ & $\begin{array}{c}6052 \\
202 \\
595 \\
87 \\
1.38 \\
1.54\end{array}$ & $\begin{array}{c}3230 \\
104 \\
564 \\
44 \\
.71 \\
.82\end{array}$ & $\begin{array}{r}2697 \\
89.9 \\
682 \\
13 \\
.62 \\
.69\end{array}$ & $\begin{array}{r}508.9 \\
16.4 \\
83 \\
4.3 \\
.11 \\
.13\end{array}$ & $\begin{array}{c}119.9 \\
3.87 \\
8.1 \\
2.0 \\
.03 \\
.03\end{array}$ & $\begin{array}{c}62.8 \\
2.09 \\
5.3 \\
1.4 \\
.01 \\
.02\end{array}$ \\
\hline
\end{tabular}

e Estimated

SIATISIICS OF MONTHIY MEAN DATA FOR WAIER YEARS 1962 - 1991, BY WATER YEAR (WY)

\begin{tabular}{|c|c|c|c|c|c|c|c|c|c|c|c|c|}
\hline $\begin{array}{l}\text { MEAN } \\
\text { MAX } \\
\text { (WY) } \\
\text { MIN } \\
(W Y)\end{array}$ & $\begin{array}{r}46.0 \\
252 \\
1970 \\
1.72 \\
1967\end{array}$ & $\begin{array}{r}94.2 \\
541 \\
1973 \\
2.95 \\
1977\end{array}$ & $\begin{array}{r}176 \\
622 \\
1991 \\
2.49 \\
1977\end{array}$ & $\begin{array}{r}145 \\
687 \\
1974 \\
1.02 \\
1977\end{array}$ & $\begin{array}{r}216 \\
649 \\
1976 \\
11.2 \\
1963\end{array}$ & $\begin{array}{r}295 \\
793 \\
1982 \\
52.6 \\
1981\end{array}$ & $\begin{array}{r}222 \\
689 \\
1964 \\
38.7 \\
1971\end{array}$ & $\begin{array}{r}146 \\
372 \\
1989 \\
17.9 \\
1976\end{array}$ & $\begin{array}{r}112 \\
544 \\
1980 \\
8.20 \\
1988\end{array}$ & $\begin{array}{r}66.4 \\
327 \\
1962 \\
7.13 \\
1988\end{array}$ & $\begin{array}{c}37.6 \\
199 \\
1973 \\
3.80 \\
1966\end{array}$ & $\begin{array}{r}48.4 \\
589 \\
1989 \\
2.09 \\
1991\end{array}$ \\
\hline
\end{tabular}

SUMMARY SIAIISIICS

ANNUAL TOTAL

ANNUAL MEAN

HIGHEST ANMUAL MEAM

LOWEST ANNUAL MEAN

HIGHESI DAILY MEAN

LOWEST DAILY MEAN

ANNUAL SEVEN-DAY MINIMUM

INSIANIANEOUS PEAK FIOW

INSTANIANEOUS PEAK STAGE

ANMUAL RUNOFF (CFSM)

ANNUAL RUNOFF (INCHES)

10 PERCENT EXCEEDS

50 PERCENT EXCEEDS

90 PERCENT EXCEEDS
FOR 1990 CALENUAR YEAR

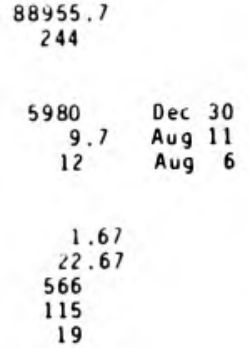

FOR 1991 WAIER YEAR

71144.6

195

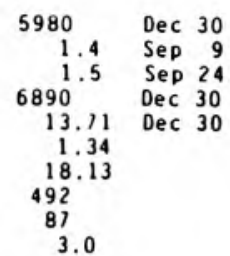

WAIER YEARS 1962 - 1991

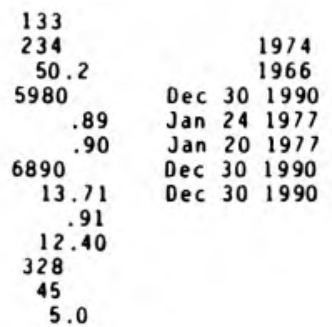


LOCAIION.--Lat $40^{\circ} 26^{\prime} 28^{\prime \prime}$, Iong $86^{\circ} 05^{\prime} 20^{\prime \prime}$, in NWtSWi sec.16, T.23 N., R.4 E., Howard County, Hydrologic Unit

05120107 , on left bank at upstream side of bridge on County Rodd 200 East, 2.6 a southeast of intersection of U.S. Highways 31 and 35 in Kokomo, and 4.2 i upstrean fromouth.

DRAINAGE AREA...24.1 $i^{2}$

PERIOD OF RECORD...July 1959 to current year.

REVISED RECORDS.--WSP 2109: Drainage area. WOR IN-72-1: 1970-71(P).

GAGE.- Water-stage recorder. Datum of gage is $807.68 \mathrm{ft}$ above National Geodetic Vertical Datue of 1929 .

REMARKS. - Records good except for estimated daily discharges, which are poor.

DISCHARGE, CUBIC FEET PER SECOND, WATER YEAR OCTOBER 1990 TO SEPIEMBER 1991

DAILY MEAN VALUES

\begin{tabular}{|c|c|c|c|c|c|c|c|c|c|c|c|c|}
\hline DAY & $0 \mathrm{CI}$ & NOV & DEC & JAN & FEB & MAR & $A P R$ & MAY & JUN & JUL & AUG & SEP \\
\hline $\begin{array}{l}1 \\
2 \\
3 \\
4 \\
5\end{array}$ & $\begin{array}{l}2.3 \\
2.4 \\
3.6 \\
17 \\
15\end{array}$ & $\begin{array}{l}9.8 \\
9.6 \\
9.6 \\
12 \\
39\end{array}$ & $\begin{array}{r}40 \\
31 \\
149 \\
127 \\
68\end{array}$ & $\begin{array}{r}169 \\
120 \\
87 \\
65 \\
54\end{array}$ & $\begin{array}{r}\text { e17 } \\
\text { e17 } \\
\text { e18 } \\
\text { e27 } \\
55\end{array}$ & $\begin{array}{l}20 \\
23 \\
20 \\
19 \\
18\end{array}$ & $\begin{array}{l}30 \\
26 \\
24 \\
23 \\
23\end{array}$ & $\begin{array}{l}16 \\
15 \\
13 \\
14 \\
14\end{array}$ & $\begin{array}{l}57 \\
32 \\
29 \\
22 \\
16\end{array}$ & $\begin{array}{c}2.2 \\
11 \\
7.0 \\
3.4 \\
3.2\end{array}$ & $\begin{array}{r}\text { e. } 58 \\
\text { e. } 55 \\
\text { e. } 54 \\
.76 \\
.70\end{array}$ & $\begin{array}{l}.30 \\
.22 \\
.20 \\
.21 \\
.21\end{array}$ \\
\hline $\begin{array}{r}6 \\
7 \\
8 \\
9 \\
10\end{array}$ & $\begin{array}{c}9.8 \\
16 \\
48 \\
76 \\
323\end{array}$ & $\begin{array}{l}53 \\
32 \\
24 \\
20 \\
17\end{array}$ & $\begin{array}{l}50 \\
38 \\
32 \\
27 \\
25\end{array}$ & $\begin{array}{l}45 \\
39 \\
35 \\
33 \\
31\end{array}$ & $\begin{array}{l}76 \\
89 \\
67 \\
59 \\
52\end{array}$ & $\begin{array}{l}18 \\
15 \\
13 \\
12 \\
12\end{array}$ & $\begin{array}{l}21 \\
20 \\
21 \\
22 \\
18\end{array}$ & $\begin{array}{l}14 \\
12 \\
10 \\
9.7 \\
9.2\end{array}$ & $\begin{array}{l}12 \\
10 \\
8.9 \\
7.8 \\
6.9\end{array}$ & $\begin{array}{r}2.3 \\
1.9 \\
11 \\
4.1 \\
2.5\end{array}$ & $\begin{array}{l}.86 \\
.90 \\
1.4 \\
1.3 \\
1.1\end{array}$ & $\begin{array}{l}.17 \\
\text { e.15 } \\
\text { e.13 } \\
\text { e.11 } \\
\text { e.12 }\end{array}$ \\
\hline $\begin{array}{l}11 \\
12 \\
13 \\
14 \\
15\end{array}$ & $\begin{array}{r}228 \\
126 \\
82 \\
57 \\
39\end{array}$ & $\begin{array}{r}14 \\
12 \\
10 \\
9.3 \\
9.0\end{array}$ & $\begin{array}{l}22 \\
21 \\
19 \\
16 \\
40\end{array}$ & $\begin{array}{l}47 \\
76 \\
52 \\
50 \\
81\end{array}$ & $\begin{array}{l}43 \\
37 \\
38 \\
37 \\
27\end{array}$ & $\begin{array}{l}11 \\
13 \\
29 \\
55 \\
70\end{array}$ & $\begin{array}{l}15 \\
14 \\
17 \\
32 \\
72\end{array}$ & $\begin{array}{l}9.5 \\
9.7 \\
10 \\
11 \\
13\end{array}$ & $\begin{array}{l}6.5 \\
6.1 \\
5.1 \\
4.4 \\
4.4\end{array}$ & $\begin{array}{r}1.8 \\
1.8 \\
1.7 \\
1.3 \\
\text { e1.1 }\end{array}$ & $\begin{array}{l}.96 \\
.80 \\
.65 \\
.57 \\
.77\end{array}$ & $\begin{array}{r}\text { e. } 11 \\
\text { e. } 11 \\
.22 \\
.22 \\
.11\end{array}$ \\
\hline $\begin{array}{l}16 \\
17 \\
18 \\
19 \\
20\end{array}$ & $\begin{array}{r}30 \\
26 \\
162 \\
98 \\
60\end{array}$ & $\begin{array}{r}9.0 \\
\mathrm{e} 8.8 \\
\mathrm{e} 8.5 \\
\mathrm{e} 8.2 \\
\mathrm{e} 8.0\end{array}$ & $\begin{array}{l}40 \\
36 \\
74 \\
92 \\
62\end{array}$ & $\begin{array}{r}170 \\
142 \\
87 \\
70 \\
72\end{array}$ & $\begin{array}{r}\mathrm{e} 22 \\
\mathrm{e} 23 \\
\mathrm{e} 31 \\
86 \\
71\end{array}$ & $\begin{array}{l}144 \\
282 \\
411 \\
246 \\
137\end{array}$ & $\begin{array}{l}54 \\
37 \\
30 \\
50 \\
73\end{array}$ & $\begin{array}{l}10 \\
12 \\
11 \\
8.3 \\
7.2\end{array}$ & $\begin{array}{l}5.8 \\
4.6 \\
3.7 \\
3.1 \\
2.7\end{array}$ & $\begin{array}{l}\text { e1. } 0 \\
\text { e. } 92 \\
\text { e. } 85 \\
\text { e. } 80 \\
\text { e. } 75\end{array}$ & $\begin{array}{c}.54 \\
.47 \\
.75 \\
2.1 \\
.92\end{array}$ & $\begin{array}{l}.17 \\
.15 \\
.19 \\
.18 \\
.17\end{array}$ \\
\hline $\begin{array}{l}21 \\
22 \\
23 \\
24 \\
25\end{array}$ & $\begin{array}{l}42 \\
33 \\
28 \\
24 \\
20\end{array}$ & $\begin{array}{l}\text { e7. } 8 \\
\text { e10 } \\
\text { e8.7 } \\
\text { e7. } 7 \\
\text { e7. } 5\end{array}$ & $\begin{array}{r}158 \\
199 \\
105 \\
62 \\
45\end{array}$ & $\begin{array}{l}68 \\
51 \\
45 \\
36 \\
31\end{array}$ & $\begin{array}{l}50 \\
41 \\
33 \\
30 \\
26\end{array}$ & $\begin{array}{r}94 \\
97 \\
207 \\
103 \\
66\end{array}$ & $\begin{array}{l}49 \\
39 \\
33 \\
31 \\
26\end{array}$ & $\begin{array}{l}6.8 \\
6.8 \\
17 \\
11 \\
34\end{array}$ & $\begin{array}{l}2.7 \\
3.3 \\
30 \\
16 \\
7.5\end{array}$ & $\begin{array}{l}\text { e. } 72 \\
\text { e. } 68 \\
\text { e. } 64 \\
\text { e. } 61 \\
\text { e. } 58\end{array}$ & $\begin{array}{l}.67 \\
.62 \\
.62 \\
.54 \\
.43\end{array}$ & $\begin{array}{l}.15 \\
.13 \\
.16 \\
.14 \\
.15\end{array}$ \\
\hline $\begin{array}{l}26 \\
27 \\
28 \\
29 \\
30 \\
31\end{array}$ & $\begin{array}{l}17 \\
16 \\
14 \\
12 \\
11 \\
11\end{array}$ & $\begin{array}{c}\text { e7.3 } \\
25 \\
148 \\
95 \\
54 \\
\ldots\end{array}$ & $\begin{array}{r}33 \\
29 \\
27 \\
276 \\
757 \\
462\end{array}$ & $\begin{array}{l}e 29 \\
e 27 \\
e 25 \\
e 22 \\
e 21 \\
e 18\end{array}$ & $\begin{array}{l}24 \\
22 \\
20 \\
\cdots- \\
\cdots \\
\cdots\end{array}$ & $\begin{array}{r}115 \\
123 \\
83 \\
56 \\
41 \\
34\end{array}$ & $\begin{array}{l}25 \\
23 \\
21 \\
20 \\
18 \\
\cdots\end{array}$ & $\begin{array}{r}45 \\
25 \\
17 \\
14 \\
13 \\
102\end{array}$ & $\begin{array}{l}4.5 \\
3.2 \\
2.5 \\
2.3 \\
2.3 \\
\ldots . .\end{array}$ & $\begin{array}{l}\text { e. } 55 \\
\text { e. } 53 \\
\text { e. } 51 \\
\text { e. } 49 \\
\text { e. } 71 \\
\text { e. } 61\end{array}$ & $\begin{array}{l}.33 \\
.27 \\
.25 \\
.24 \\
.23 \\
.41\end{array}$ & $\begin{array}{l}.15 \\
.14 \\
.11 \\
.11 \\
.12 \\
\cdots\end{array}$ \\
\hline $\begin{array}{l}\text { IOIAL } \\
\text { MEAN } \\
\text { MAX } \\
\text { MIN } \\
\text { CF SM } \\
\text { IN. }\end{array}$ & $\begin{array}{r}1649.1 \\
53.2 \\
323 \\
2.3 \\
2.15 \\
2.48\end{array}$ & $\begin{array}{r}693.8 \\
23.1 \\
148 \\
7.3 \\
.94 \\
1.04\end{array}$ & $\begin{array}{r}3162 \\
102 \\
757 \\
16 \\
4.13 \\
4.16\end{array}$ & $\begin{array}{r}1898 \\
61.2 \\
170 \\
18 \\
2.48 \\
2.86\end{array}$ & $\begin{array}{r}1138 \\
40.6 \\
89 \\
17 \\
1.65 \\
1.71\end{array}$ & $\begin{array}{r}2587 \\
83.5 \\
411 \\
11 \\
3.38 \\
3.90\end{array}$ & $\begin{array}{r}907 \\
30.2 \\
13 \\
14 \\
1.22 \\
1.37\end{array}$ & $\begin{array}{c}520.2 \\
16.8 \\
102 \\
6.8 \\
.68 \\
.78\end{array}$ & $\begin{array}{r}322.3 \\
10.7 \\
57 \\
2.3 \\
.43 \\
.49\end{array}$ & $\begin{array}{r}67.25 \\
2.17 \\
11 \\
.49 \\
.09 \\
.10\end{array}$ & $\begin{array}{r}21.83 \\
.70 \\
2.1 \\
.23 \\
.03 \\
.03\end{array}$ & $\begin{array}{l}4.87 \\
.16 \\
.30 \\
.11 \\
.01 \\
.01\end{array}$ \\
\hline
\end{tabular}

e Estinated

STAIISIICS OF MONIHLY MEAN DATA FUR WAIER YEARS 1960 - 1991. BY WATER YEAR (WY)

\begin{tabular}{|c|c|c|c|c|c|c|c|c|c|c|c|c|}
\hline $\begin{array}{l}\text { MEAN } \\
\text { MAX } \\
\text { (WY) } \\
\text { MIN } \\
\text { (WY) }\end{array}$ & $\begin{array}{r}10.2 \\
68.1 \\
1970 \\
.55 \\
1965\end{array}$ & $\begin{array}{r}16.4 \\
108 \\
1986 \\
.57 \\
1977\end{array}$ & $\begin{array}{r}27.6 \\
102 \\
1991 \\
.44 \\
1977\end{array}$ & $\begin{array}{r}23.4 \\
114 \\
1974 \\
.33 \\
1977\end{array}$ & $\begin{array}{r}36.3 \\
129 \\
1990 \\
1.98 \\
1964\end{array}$ & $\begin{array}{r}50.9 \\
150 \\
1982 \\
7.87 \\
1981\end{array}$ & $\begin{array}{c}40.2 \\
117 \\
1964 \\
6.91 \\
1976\end{array}$ & $\begin{array}{l}23.9 \\
78.0 \\
1990 \\
2.52 \\
1976\end{array}$ & $\begin{array}{l}16.3 \\
99.7 \\
1980 \\
1.20 \\
1988\end{array}$ & $\begin{array}{l}9.60 \\
42.8 \\
1962 \\
1.07 \\
1988\end{array}$ & $\begin{array}{r}6.53 \\
34.7 \\
1990 \\
.50 \\
1988\end{array}$ & $\begin{array}{r}6.84 \\
66.7 \\
1989 \\
.16 \\
1991\end{array}$ \\
\hline
\end{tabular}

SUMMARY SIAIISIICS

ANHUAL TOTAL

ANNUAL MEAN

HIGHESI ANMUAL MEAN

LOWEST ANMUAL MEAN

HIGHESI DAILY MEAH

LOWEST DAILY MEAN

ANNUAL SEVEN-DAY MINIMUM

INSIANTANEOUS PEAK FLOW

INSIANTANEOUS PEAK SIAGE

ANMUAL RUNOFF (CFSM)

ANMUAL RUNOFF (INCHES)

10 PERCENT EXCEEDS

50 PERCENT EXCEEDS

90 PERCENT EXCEEDS
FOR I990 CALENDAR YEAR

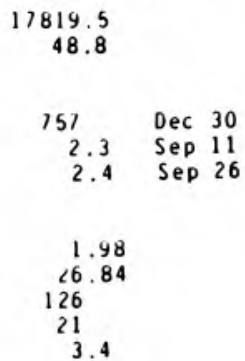

FOR 1991 WATER YEAR

12971.35

$$
35.5
$$

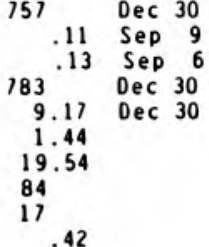

WATER YEARS $1960-1991$

$$
\begin{array}{r}
22.3 \\
40.6 \\
8.76 \\
757 \\
.07 \\
.11 \\
1040 . \\
9.88 \\
.90 \\
12.25 \\
53 \\
7.2 \\
.88
\end{array}
$$

.20

.17
.15

. 13

.12

11

.22

17

19
.18

.16

.15

.11

87

30

.01 


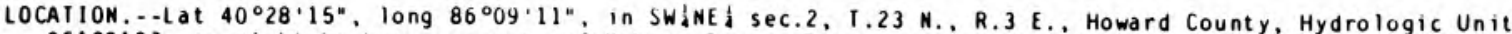
05120107 , on right bank on property of kokomo Sewage Treatment Plant in kokono, 250 ft downstream from Kokomo Creek, 1.0 i upstrean from Dixon Road bridge, and at aile 62.9 .

DRAIMAGE AREA $\ldots 242$ ?

PERIOD OF RECORD.--October 1955 to current year.

REVISED RECORDS.--WSP 2109: Drainage area. WDR-IN-83: 1980, 1981(P), 1982. WDR-IN-88: 1986(P), 1987 (M).

GAGE.- Water-stage recorder. Datum of gage is $775.62 \mathrm{ft}$ above National Geodet ic Vertical Datum of 1929 (levels by State of Indiana, Department of Natural Resources). Prior to May 9, 1986, recording gage at site 0.4 a downstrea at present datun.

REMARKS.--Records good. Sone regulation of Kokomo Reservoirs No. 1 and 2 , combined capacity, 4,170 acre-ft, for unicipal water supply and by Kokomo Sewage Ireatment Plant.

DISCHARGE, CUBIC FEEI PER SECONO, WATER YEAR OCIOBER 1990 TO SEPIEMBER 1991 DAI IY MEAN VALUES

\begin{tabular}{|c|c|c|c|c|c|c|c|c|c|c|c|c|}
\hline DAY & $\mathrm{OCI}$ & MOV & DEC & JAN & FEB & MAR & $A P R$ & MAY & JUN & JUL & AUG & SEP \\
\hline $\begin{array}{l}1 \\
2 \\
3 \\
4 \\
5\end{array}$ & $\begin{array}{r}37 \\
38 \\
59 \\
116 \\
51\end{array}$ & $\begin{array}{r}123 \\
118 \\
87 \\
80 \\
212\end{array}$ & $\begin{array}{r}379 \\
290 \\
735 \\
1360 \\
884\end{array}$ & $\begin{array}{r}3120 \\
1580 \\
1030 \\
712 \\
529\end{array}$ & $\begin{array}{l}121 \\
123 \\
126 \\
200 \\
360\end{array}$ & $\begin{array}{l}169 \\
177 \\
177 \\
152 \\
150\end{array}$ & $\begin{array}{l}286 \\
250 \\
209 \\
196 \\
209\end{array}$ & $\begin{array}{l}166 \\
137 \\
138 \\
134 \\
131\end{array}$ & $\begin{array}{r}1050 \\
618 \\
396 \\
346 \\
209\end{array}$ & $\begin{array}{r}46 \\
137 \\
100 \\
73 \\
56\end{array}$ & $\begin{array}{l}23 \\
24 \\
23 \\
22 \\
21\end{array}$ & $\begin{array}{l}19 \\
19 \\
25 \\
25 \\
23\end{array}$ \\
\hline $\begin{array}{r}6 \\
7 \\
8 \\
9 \\
10\end{array}$ & $\begin{array}{r}44 \\
90 \\
180 \\
349 \\
1780\end{array}$ & $\begin{array}{l}287 \\
272 \\
208 \\
164 \\
143\end{array}$ & $\begin{array}{l}526 \\
383 \\
301 \\
251 \\
224\end{array}$ & $\begin{array}{l}416 \\
330 \\
276 \\
250 \\
225\end{array}$ & $\begin{array}{l}576 \\
870 \\
740 \\
557 \\
448\end{array}$ & $\begin{array}{l}136 \\
135 \\
122 \\
103 \\
102\end{array}$ & $\begin{array}{l}186 \\
174 \\
210 \\
226 \\
231\end{array}$ & $\begin{array}{r}131 \\
121 \\
111 \\
101 \\
97\end{array}$ & $\begin{array}{r}151 \\
111 \\
93 \\
82 \\
74\end{array}$ & $\begin{array}{r}41 \\
33 \\
136 \\
72 \\
54\end{array}$ & $\begin{array}{l}24 \\
21 \\
75 \\
35 \\
25\end{array}$ & $\begin{array}{l}23 \\
23 \\
23 \\
25 \\
25\end{array}$ \\
\hline $\begin{array}{l}11 \\
12 \\
13 \\
14 \\
15\end{array}$ & $\begin{array}{r}2090 \\
1180 \\
686 \\
454 \\
334\end{array}$ & $\begin{array}{r}127 \\
111 \\
102 \\
93 \\
90\end{array}$ & $\begin{array}{l}204 \\
190 \\
174 \\
162 \\
249\end{array}$ & $\begin{array}{l}311 \\
518 \\
513 \\
398 \\
593\end{array}$ & $\begin{array}{l}363 \\
292 \\
271 \\
265 \\
221\end{array}$ & $\begin{array}{l}100 \\
120 \\
247 \\
479 \\
838\end{array}$ & $\begin{array}{l}191 \\
151 \\
202 \\
477 \\
894\end{array}$ & $\begin{array}{r}92 \\
90 \\
100 \\
176 \\
280\end{array}$ & $\begin{array}{r}74 \\
69 \\
64 \\
58 \\
101\end{array}$ & $\begin{array}{l}40 \\
41 \\
30 \\
26 \\
26\end{array}$ & $\begin{array}{l}22 \\
22 \\
22 \\
28 \\
26\end{array}$ & $\begin{array}{l}25 \\
25 \\
33 \\
30 \\
22\end{array}$ \\
\hline $\begin{array}{l}16 \\
17 \\
18 \\
19 \\
20\end{array}$ & $\begin{array}{l}257 \\
210 \\
461 \\
453 \\
318\end{array}$ & $\begin{array}{l}88 \\
88 \\
82 \\
81 \\
79\end{array}$ & $\begin{array}{l}376 \\
349 \\
482 \\
806 \\
655\end{array}$ & $\begin{array}{r}1250 \\
1570 \\
1110 \\
748 \\
657\end{array}$ & $\begin{array}{l}160 \\
170 \\
225 \\
525 \\
756\end{array}$ & $\begin{array}{l}1110 \\
1930 \\
3020 \\
2810 \\
1790\end{array}$ & $\begin{array}{l}958 \\
582 \\
407 \\
474 \\
913\end{array}$ & $\begin{array}{r}179 \\
134 \\
193 \\
113 \\
98\end{array}$ & $\begin{array}{l}82 \\
62 \\
56 \\
49 \\
43\end{array}$ & $\begin{array}{l}26 \\
26 \\
25 \\
25 \\
25\end{array}$ & $\begin{array}{l}22 \\
36 \\
24 \\
71 \\
28\end{array}$ & $\begin{array}{l}23 \\
24 \\
24 \\
21 \\
21\end{array}$ \\
\hline $\begin{array}{l}21 \\
22 \\
23 \\
24 \\
25\end{array}$ & $\begin{array}{l}243 \\
225 \\
213 \\
191 \\
183\end{array}$ & $\begin{array}{l}71 \\
90 \\
80 \\
74 \\
80\end{array}$ & $\begin{array}{r}972 \\
1680 \\
1250 \\
691 \\
450\end{array}$ & $\begin{array}{l}672 \\
520 \\
399 \\
312 \\
230\end{array}$ & $\begin{array}{l}557 \\
420 \\
332 \\
265 \\
231\end{array}$ & $\begin{array}{r}1200 \\
1090 \\
1560 \\
1400 \\
913\end{array}$ & $\begin{array}{l}744 \\
495 \\
401 \\
341 \\
269\end{array}$ & $\begin{array}{r}82 \\
194 \\
681 \\
287 \\
355\end{array}$ & $\begin{array}{l}38 \\
49 \\
77 \\
56 \\
53\end{array}$ & $\begin{array}{l}25 \\
26 \\
24 \\
25 \\
26\end{array}$ & $\begin{array}{l}25 \\
24 \\
24 \\
22 \\
21\end{array}$ & $\begin{array}{l}19 \\
19 \\
22 \\
20 \\
21\end{array}$ \\
\hline $\begin{array}{l}26 \\
27 \\
28 \\
29 \\
30 \\
31\end{array}$ & $\begin{array}{r}176 \\
172 \\
165 \\
163 \\
155 \\
82\end{array}$ & $\begin{array}{r}80 \\
172 \\
662 \\
951 \\
586 \\
\cdots\end{array}$ & $\begin{array}{r}335 \\
268 \\
251 \\
1500 \\
6770 \\
6850\end{array}$ & $\begin{array}{l}217 \\
191 \\
182 \\
162 \\
152 \\
127\end{array}$ & $\begin{array}{l}197 \\
179 \\
174 \\
\cdots \\
\cdots \\
\cdots\end{array}$ & $\begin{array}{r}847 \\
940 \\
1070 \\
692 \\
460 \\
350\end{array}$ & $\begin{array}{l}231 \\
211 \\
194 \\
188 \\
153 \\
\ldots\end{array}$ & $\begin{array}{l}342 \\
272 \\
181 \\
153 \\
139 \\
660\end{array}$ & $\begin{array}{l}45 \\
40 \\
35 \\
32 \\
29 \\
-\cdots\end{array}$ & $\begin{array}{l}25 \\
22 \\
21 \\
24 \\
25 \\
24\end{array}$ & $\begin{array}{l}27 \\
25 \\
24 \\
25 \\
41 \\
24\end{array}$ & $\begin{array}{l}20 \\
19 \\
19 \\
17 \\
19 \\
\cdots\end{array}$ \\
\hline $\begin{array}{l}\text { TOTAL } \\
\text { MEAN } \\
\text { MAX } \\
\text { MIN } \\
\text { CF SM } \\
\text { IN. }\end{array}$ & $\begin{array}{r}11155 \\
360 \\
2090 \\
37 \\
1.49 \\
1.71\end{array}$ & $\begin{array}{r}5487 \\
183 \\
951 \\
74 \\
.76 \\
.84\end{array}$ & $\begin{array}{r}29997 \\
968 \\
6850 \\
162 \\
4.00 \\
4.61\end{array}$ & $\begin{array}{r}19300 \\
623 \\
3120 \\
127 \\
2.57 \\
2.97\end{array}$ & $\begin{array}{c}9724 \\
341 \\
870 \\
121 \\
1.44 \\
1.49\end{array}$ & $\begin{array}{r}24389 \\
787 \\
3020 \\
100 \\
3.25 \\
3.75\end{array}$ & $\begin{array}{c}10653 \\
355 \\
958 \\
151 \\
1.47 \\
1.64\end{array}$ & $\begin{array}{c}6068 \\
196 \\
681 \\
82 \\
.81 \\
.93\end{array}$ & $\begin{array}{r}4242 \\
141 \\
1050 \\
29 \\
.58 \\
.65\end{array}$ & $\begin{array}{c}1305 \\
42.1 \\
137 \\
21 \\
.17 \\
.20\end{array}$ & $\begin{array}{r}876 \\
28.3 \\
15 \\
21 \\
.12 \\
.13\end{array}$ & $\begin{array}{c}673 \\
22.4 \\
33 \\
17 \\
.09 \\
.10\end{array}$ \\
\hline
\end{tabular}

STATISTICS OF MONTHLY MEAN DATA FOR WAIER YEARS 1956 - 1991, BY WATER YEAR (WY)

$\begin{array}{lrrrrrrrrr}\text { MEAN } & 87.5 & 167 & 278 & 240 & 358 & 454 & 417 & 257 & 228 \\ \text { MAX } & 469 & 949 & 968 & 1375 & 1097 & 1376 & 1117 & 626 & 1432 \\ \text { (WY) } & 1970 & 1986 & 1991 & 1974 & 1990 & 1982 & 1957 & 1989 & 1958 \\ \text { MIN } & 11.2 & 15.5 & 13.8 & 16.5 & 25.8 & 67.4 & 71.7 & 53.6 & 28.2 \\ \text { (WY) } & 1957 & 1957 & 1964 & 1961 & 1964 & 1981 & 1966 & 1988 & 1988\end{array}$

$\begin{array}{rrr}140 & 89.5 & 87.1 \\ 606 & 383 & 879 \\ 1962 & 1973 & 1989 \\ 28.6 & 25.2 & 12.8 \\ 1988 & 1966 & 1956\end{array}$

SUMMARY STATISIICS

ANNUAL TOTAL

ANNUAL MEAN

HIGHEST ANNUAL MEAN

LOWEST ANHUAL MEAN

HIGHEST DAILY MEAN

LOWEST DAILY MEAN

ANMUAL SEVEN-DAY MINIMUM

INSTANTANEOUS PEAK FLOW

INSTANTANEOUS PEAK STAGE

ANHUAL RUNOFF (CFSM)

ANNUAL RUNOFF (INCHES)

10 PERCENT EXCEEDS

50 PERCENT EXCEEDS

90 PERCENT EXCEEDS
FOR 1990 CALENUAR YEAR

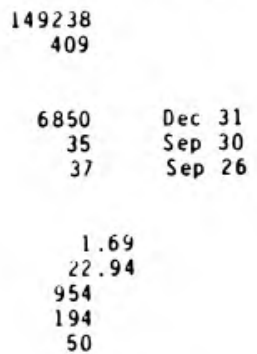

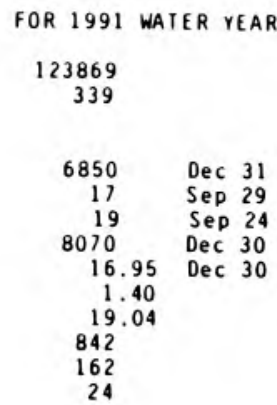

WATER YEARS 1956 - 1991

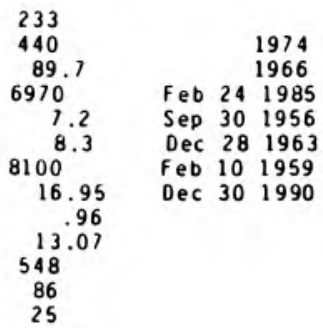




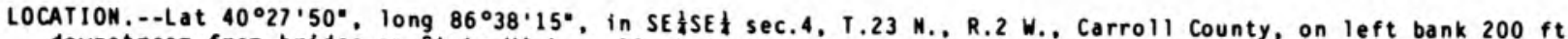
downstrea froe bridge on State Highway 39.0 .5 a northwest of Owasco, and 15 a ustreas froa South Fork

DRAI MAGE AREA.--396 $i^{2}$

PERIOD OF RECORD.--0ctober 1943 to Septeaber 1973. Annual maxinun, water years $1975-81.0 \mathrm{ctober} 1988$ to current year. Prior to March 1944 monthly discharge only, published in WSP 1305 .

REVISED RECORDS.--WSP 1625: 1958. WSP 2109: Drainage area.

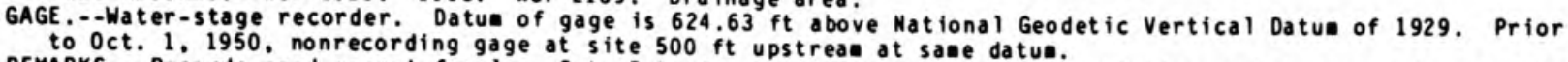

REMARKS.--Records good except for Jan. 1 to Feb. 20, which are fair. Soue regulation at low stages for eunicipal

EXTREMES OUTSIDE PERIOD OF RECORD.--Flood of May 18,1943 , reached a stage of $14.00 \mathrm{ft}$, fron floodearks.

DISCHARGE, CUBIC FEET PER SECOND, WATER YEAR OCTOBER 1990 TO SEPTEMBER 1991 DAILY MEAM VALUES

\begin{tabular}{|c|c|c|c|c|c|c|c|c|c|c|c|c|}
\hline DAY & $\mathrm{OCT}$ & Nov & DEC & JAN & FEB & MAR & APR & MAY & JUN & JUL & AUG & SEP \\
\hline $\begin{array}{l}1 \\
2 \\
3 \\
4 \\
5\end{array}$ & $\begin{array}{r}68 \\
66 \\
69 \\
115 \\
189\end{array}$ & $\begin{array}{l}180 \\
194 \\
211 \\
168 \\
302\end{array}$ & $\begin{array}{r}839 \\
612 \\
810 \\
1550 \\
1560\end{array}$ & $\begin{array}{r}8670 \\
4640 \\
1830 \\
1230 \\
972\end{array}$ & $\begin{array}{l}e 250 \\
e 250 \\
e 260 \\
e 350 \\
e 500\end{array}$ & $\begin{array}{l}350 \\
365 \\
358 \\
345 \\
320\end{array}$ & $\begin{array}{l}607 \\
506 \\
448 \\
399 \\
396\end{array}$ & $\begin{array}{l}293 \\
297 \\
260 \\
262 \\
270\end{array}$ & $\begin{array}{r}804 \\
1020 \\
1350 \\
826 \\
574\end{array}$ & $\begin{array}{r}79 \\
131 \\
215 \\
173 \\
127\end{array}$ & $\begin{array}{l}42 \\
42 \\
41 \\
40 \\
41\end{array}$ & $\begin{array}{l}51 \\
49 \\
42 \\
38 \\
36\end{array}$ \\
\hline $\begin{array}{r}6 \\
7 \\
8 \\
9 \\
10\end{array}$ & $\begin{array}{r}113 \\
101 \\
143 \\
504 \\
1650\end{array}$ & $\begin{array}{l}615 \\
548 \\
456 \\
377 \\
324\end{array}$ & $\begin{array}{r}1080 \\
785 \\
611 \\
503 \\
436\end{array}$ & $\begin{array}{r}809 \\
\text { e680 } \\
\text { e590 } \\
\text { e } 520 \\
\text { e470 }\end{array}$ & $\begin{array}{r}\text { e660 } \\
\text { e920 } \\
\text { e1150 } \\
\text { e } 1000 \\
\text { e830 }\end{array}$ & $\begin{array}{l}319 \\
303 \\
288 \\
274 \\
255\end{array}$ & $\begin{array}{l}386 \\
352 \\
336 \\
388 \\
379\end{array}$ & $\begin{array}{l}283 \\
266 \\
240 \\
224 \\
208\end{array}$ & $\begin{array}{l}382 \\
288 \\
232 \\
199 \\
177\end{array}$ & $\begin{array}{r}123 \\
93 \\
85 \\
196 \\
138\end{array}$ & $\begin{array}{l}44 \\
41 \\
55 \\
82 \\
98\end{array}$ & $\begin{array}{l}39 \\
37 \\
35 \\
35 \\
36\end{array}$ \\
\hline $\begin{array}{l}11 \\
12 \\
13 \\
14 \\
15\end{array}$ & $\begin{array}{r}2540 \\
2420 \\
1450 \\
988 \\
727\end{array}$ & $\begin{array}{l}291 \\
263 \\
239 \\
225 \\
212\end{array}$ & $\begin{array}{l}398 \\
370 \\
347 \\
317 \\
383\end{array}$ & $\begin{array}{l}\text { e600 } \\
e 930 \\
\text { e930 } \\
\text { e } 860 \\
\text { e } 800\end{array}$ & $\begin{array}{l}e 650 \\
e 580 \\
e 550 \\
e 520 \\
e 450\end{array}$ & $\begin{array}{r}246 \\
265 \\
542 \\
961 \\
1270\end{array}$ & $\begin{array}{r}358 \\
315 \\
292 \\
500 \\
1170\end{array}$ & $\begin{array}{l}203 \\
195 \\
189 \\
197 \\
259\end{array}$ & $\begin{array}{l}161 \\
152 \\
147 \\
135 \\
136\end{array}$ & $\begin{array}{r}117 \\
104 \\
96 \\
86 \\
75\end{array}$ & $\begin{array}{l}63 \\
54 \\
49 \\
45 \\
42\end{array}$ & $\begin{array}{l}36 \\
36 \\
38 \\
40 \\
41\end{array}$ \\
\hline $\begin{array}{l}16 \\
17 \\
18 \\
19 \\
20\end{array}$ & $\begin{array}{l}552 \\
450 \\
840 \\
903 \\
736\end{array}$ & $\begin{array}{l}207 \\
201 \\
197 \\
192 \\
186\end{array}$ & $\begin{array}{r}542 \\
615 \\
701 \\
1020 \\
1120\end{array}$ & $\begin{array}{l}\text { e } 1200 \\
\text { e } 1600 \\
\text { e } 2000 \\
\text { e } 1400 \\
\text { e } 1200\end{array}$ & $\begin{array}{r}e 330 \\
e 350 \\
e 470 \\
e 660 \\
e 1000\end{array}$ & $\begin{array}{l}1670 \\
2110 \\
3080 \\
4090 \\
3780\end{array}$ & $\begin{array}{r}1240 \\
1120 \\
808 \\
656 \\
797\end{array}$ & $\begin{array}{l}374 \\
284 \\
267 \\
297 \\
216\end{array}$ & $\begin{array}{l}241 \\
216 \\
144 \\
126 \\
113\end{array}$ & $\begin{array}{l}66 \\
61 \\
59 \\
57 \\
54\end{array}$ & $\begin{array}{l}42 \\
46 \\
42 \\
84 \\
92\end{array}$ & $\begin{array}{l}49 \\
44 \\
38 \\
36 \\
36\end{array}$ \\
\hline $\begin{array}{l}21 \\
22 \\
23 \\
24 \\
25\end{array}$ & $\begin{array}{l}547 \\
442 \\
403 \\
373 \\
339\end{array}$ & $\begin{array}{l}184 \\
186 \\
199 \\
188 \\
177\end{array}$ & $\begin{array}{l}1100 \\
2090 \\
2120 \\
1450 \\
e 960\end{array}$ & $\begin{array}{r}e 980 \\
e 1000 \\
e 770 \\
e 600 \\
e 470\end{array}$ & $\begin{array}{l}920 \\
749 \\
613 \\
525 \\
458\end{array}$ & $\begin{array}{l}2340 \\
1550 \\
1720 \\
1990 \\
1630\end{array}$ & $\begin{array}{r}1060 \\
895 \\
701 \\
625 \\
529\end{array}$ & $\begin{array}{l}189 \\
170 \\
258 \\
658 \\
397\end{array}$ & $\begin{array}{r}103 \\
93 \\
443 \\
375 \\
193\end{array}$ & $\begin{array}{l}52 \\
51 \\
49 \\
49 \\
47\end{array}$ & $\begin{array}{l}80 \\
59 \\
54 \\
50 \\
46\end{array}$ & $\begin{array}{l}36 \\
36 \\
36 \\
36 \\
36\end{array}$ \\
\hline $\begin{array}{l}26 \\
27 \\
28 \\
29 \\
30 \\
31\end{array}$ & $\begin{array}{l}321 \\
308 \\
298 \\
279 \\
272 \\
262\end{array}$ & $\begin{array}{r}179 \\
189 \\
890 \\
1350 \\
1200 \\
\ldots \ldots\end{array}$ & $\begin{array}{l}e 720 \\
e 560 \\
e 500 \\
1410 \\
4810 \\
9160\end{array}$ & $\begin{array}{l}\text { e440 } \\
\text { e380 } \\
\text { e370 } \\
\text { e330 } \\
\text { e310 } \\
\text { e270 }\end{array}$ & $\begin{array}{l}412 \\
380 \\
359 \\
\cdots \\
\cdots \\
\cdots\end{array}$ & $\begin{array}{r}1270 \\
1480 \\
1420 \\
1290 \\
935 \\
726\end{array}$ & $\begin{array}{l}440 \\
395 \\
366 \\
345 \\
329 \\
\ldots\end{array}$ & $\begin{array}{l}527 \\
492 \\
393 \\
298 \\
256 \\
250\end{array}$ & $\begin{array}{r}150 \\
121 \\
105 \\
94 \\
84 \\
-\end{array}$ & $\begin{array}{l}46 \\
46 \\
44 \\
42 \\
40 \\
40\end{array}$ & $\begin{array}{l}43 \\
40 \\
41 \\
44 \\
42 \\
42\end{array}$ & $\begin{array}{r}35 \\
35 \\
35 \\
34 \\
34 \\
\cdots\end{array}$ \\
\hline $\begin{array}{l}\text { TOTAL } \\
\text { MEAN } \\
\text { MAX } \\
\text { MIN } \\
\text { CF SM } \\
\text { IN. }\end{array}$ & $\begin{array}{r}18468 \\
596 \\
2540 \\
66 \\
1.50 \\
1.73\end{array}$ & $\begin{array}{r}10330 \\
344 \\
1350 \\
168 \\
.87 \\
.97\end{array}$ & $\begin{array}{r}39479 \\
1274 \\
9160 \\
317 \\
3.22 \\
3.71\end{array}$ & $\begin{array}{r}37851 \\
1221 \\
8670 \\
270 \\
3.08 \\
3.56\end{array}$ & $\begin{array}{r}16146 \\
577 \\
1150 \\
250 \\
1.46 \\
1.52\end{array}$ & $\begin{array}{r}37542 \\
1211 \\
4090 \\
246 \\
3.06 \\
3.53\end{array}$ & $\begin{array}{c}17138 \\
571 \\
1240 \\
292 \\
1.44 \\
1.61\end{array}$ & $\begin{array}{c}8972 \\
289 \\
658 \\
170 \\
.73 \\
.84\end{array}$ & $\begin{array}{r}9184 \\
306 \\
1350 \\
84 \\
.77 \\
.86\end{array}$ & $\begin{array}{r}2641 \\
85.2 \\
215 \\
40 \\
.22 \\
.25\end{array}$ & $\begin{array}{r}1626 \\
52.5 \\
98 \\
40 \\
.13 \\
.15\end{array}$ & $\begin{array}{r}1145 \\
38.2 \\
51 \\
34 \\
.10 \\
.11\end{array}$ \\
\hline
\end{tabular}

e Estieated

STATISTICS OF MONTHLY MEAN DATA FOR WATER YEARS 1945 - 1991, BY WATER YEAR (WY)

\begin{tabular}{|c|c|c|c|c|c|c|c|c|c|c|c|c|}
\hline $\begin{array}{l}\text { MEAN } \\
\text { MAX } \\
\text { (WY) } \\
\text { MIN } \\
\text { (WY) }\end{array}$ & $\begin{array}{r}153 \\
670 \\
1970 \\
20.0 \\
1945\end{array}$ & $\begin{array}{r}211 \\
1176 \\
1973 \\
30.3 \\
1945\end{array}$ & $\begin{array}{r}347 \\
1325 \\
1958 \\
25.9 \\
1945\end{array}$ & $\begin{array}{r}550 \\
3083 \\
1950 \\
24.6 \\
1945\end{array}$ & $\begin{array}{r}552 \\
1725 \\
1959 \\
50.0 \\
1963\end{array}$ & $\begin{array}{r}636 \\
1270 \\
1973 \\
154 \\
1954\end{array}$ & $\begin{array}{r}699 \\
1857 \\
1957 \\
137 \\
1971\end{array}$ & $\begin{array}{r}441 \\
984 \\
1952 \\
120 \\
1954\end{array}$ & $\begin{array}{r}363 \\
2536 \\
1958 \\
84.8 \\
1949\end{array}$ & $\begin{array}{r}234 \\
1158 \\
1957 \\
41.5 \\
1954\end{array}$ & $\begin{array}{r}132 \\
707 \\
1958 \\
37.1 \\
1954\end{array}$ & $\begin{array}{r}138 \\
1339 \\
1989 \\
20.6 \\
1954\end{array}$ \\
\hline
\end{tabular}

SUMMARY STATISTICS

ANMUAL TOTAL

ANMUAL MEAN

HIGHEST ANNUAL MEAN

LOWEST AWHUAL MEAN

HIGHEST DAILY MEAN

LOWEST DAILY MEAM

ANMUAL SEVEN-DAY MIMIMUM

INSTANTAMEOUS PEAK FLOW

INSTANTANEOUS PEAK STAGE

ANNUAL RUNOFF (CFSM)

ANMUAL RUNOFF (INCHES)

10 PERCENT EXCEEDS

50 PERCENT EXCEEDS

90 PERCENT EXCEEDS
FOR 1990 CALEMDAR YEAR

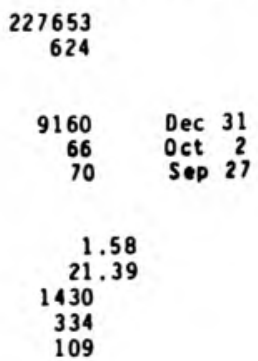

FOR 1991 WATER YEAR

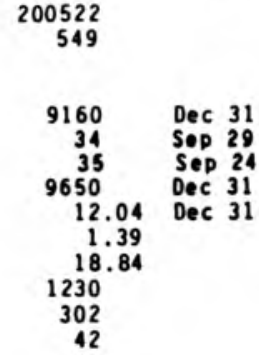

WATER YEARS 1945 - 1991

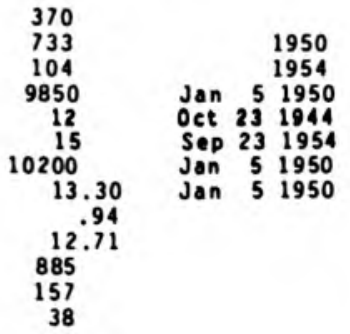




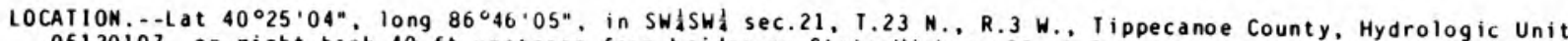
05120107 , on right bank $40 \mathrm{ft}$ upstrean from bridge on State Highway 26 , 0.5 i upstrea fro Middle Fork.

4,4 i upstrean from outh, and 5 i east of Lafayette. DRAI MAGE AREA. . - 243 -i

PERIOD OF RECORD.--October 1943 to current year. Prior to March 1944 monthly discharge only, published in WSP 1305. REVISED RECORDS.--WSP 1335: 1948(M). WSP 1505: 1947. WSP 1725: 1951-53(M). 1955(M). WSP 1909: 1955(P).

GAGE. - Water-stage recorder. Datum of gage is $566.60 \mathrm{ft}$ above National Geodetic Vertical Datua of 1929 (Indiana

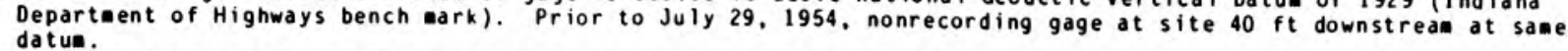

REMARKS. - -Records good. Backwater from Middle Fork at times on peaks.

EXTREMES OUTŞIDE PERIOD OF RECORD. - - Flood in May 1943 reached a stage of $16.8 \mathrm{ft}$, from floodmarks, discharge, $17,900 \mathrm{ft} / \mathrm{s}$ by contracted-opening measurement.

DISCHARGE, CUBIC FEET PER SECOND, WATER YEAR OCTOBER 1990 TO SEPTEMBER 1991 DAIIY MEAH VALUES

\begin{tabular}{|c|c|c|c|c|c|c|c|c|c|c|c|c|}
\hline DAY & $\mathrm{OCT}$ & HOV & DEC & JAN & FEB & MAR & APR & MAY & JUN & JUL & AUG & SEP \\
\hline $\begin{array}{l}1 \\
2 \\
3 \\
4 \\
5\end{array}$ & $\begin{array}{l}44 \\
43 \\
42 \\
66 \\
91\end{array}$ & $\begin{array}{r}102 \\
99 \\
97 \\
96 \\
235\end{array}$ & $\begin{array}{l}449 \\
352 \\
623 \\
975 \\
589\end{array}$ & $\begin{array}{r}2120 \\
1260 \\
900 \\
679 \\
560\end{array}$ & $\begin{array}{r}\text { e200 } \\
\text { e200 } \\
214 \\
314 \\
447\end{array}$ & $\begin{array}{l}228 \\
244 \\
238 \\
219 \\
211\end{array}$ & $\begin{array}{l}325 \\
295 \\
273 \\
261 \\
264\end{array}$ & $\begin{array}{l}206 \\
199 \\
184 \\
199 \\
202\end{array}$ & $\begin{array}{l}603 \\
456 \\
345 \\
336 \\
253\end{array}$ & $\begin{array}{l}53 \\
55 \\
49 \\
50 \\
46\end{array}$ & $\begin{array}{l}28 \\
27 \\
27 \\
28 \\
29\end{array}$ & $\begin{array}{l}26 \\
24 \\
24 \\
24 \\
25\end{array}$ \\
\hline $\begin{array}{r}6 \\
7 \\
8 \\
9 \\
10\end{array}$ & $\begin{array}{r}61 \\
59 \\
96 \\
297 \\
1320\end{array}$ & $\begin{array}{l}445 \\
301 \\
226 \\
192 \\
174\end{array}$ & $\begin{array}{l}424 \\
347 \\
303 \\
267 \\
248\end{array}$ & $\begin{array}{l}484 \\
420 \\
381 \\
357 \\
331\end{array}$ & $\begin{array}{l}546 \\
741 \\
576 \\
485 \\
432\end{array}$ & $\begin{array}{l}208 \\
204 \\
187 \\
178 \\
174\end{array}$ & $\begin{array}{l}247 \\
232 \\
232 \\
260 \\
234\end{array}$ & $\begin{array}{l}261 \\
232 \\
203 \\
185 \\
177\end{array}$ & $\begin{array}{l}197 \\
167 \\
149 \\
135 \\
125\end{array}$ & $\begin{array}{l}44 \\
43 \\
42 \\
44 \\
43\end{array}$ & $\begin{array}{l}31 \\
33 \\
43 \\
45 \\
41\end{array}$ & $\begin{array}{l}26 \\
24 \\
24 \\
23 \\
22\end{array}$ \\
\hline $\begin{array}{l}11 \\
12 \\
13 \\
14 \\
15\end{array}$ & $\begin{array}{r}1650 \\
885 \\
472 \\
310 \\
249\end{array}$ & $\begin{array}{l}158 \\
144 \\
132 \\
125 \\
120\end{array}$ & $\begin{array}{l}229 \\
220 \\
209 \\
187 \\
262\end{array}$ & $\begin{array}{l}353 \\
623 \\
502 \\
420 \\
550\end{array}$ & $\begin{array}{r}381 \\
332 \\
315 \\
316 \\
\text { e } 270\end{array}$ & $\begin{array}{r}168 \\
213 \\
1510 \\
1920 \\
1890\end{array}$ & $\begin{array}{l}211 \\
193 \\
207 \\
328 \\
677\end{array}$ & $\begin{array}{l}172 \\
191 \\
184 \\
175 \\
183\end{array}$ & $\begin{array}{r}118 \\
113 \\
107 \\
101 \\
98\end{array}$ & $\begin{array}{l}43 \\
47 \\
53 \\
45 \\
41\end{array}$ & $\begin{array}{l}34 \\
30 \\
29 \\
28 \\
29\end{array}$ & $\begin{array}{r}23 \\
24 \\
30 \\
185 \\
144\end{array}$ \\
\hline $\begin{array}{l}16 \\
17 \\
18 \\
19 \\
20\end{array}$ & $\begin{array}{l}204 \\
194 \\
458 \\
313 \\
239\end{array}$ & $\begin{array}{l}118 \\
114 \\
110 \\
109 \\
108\end{array}$ & $\begin{array}{l}354 \\
310 \\
390 \\
558 \\
456\end{array}$ & $\begin{array}{r}976 \\
1080 \\
736 \\
551 \\
504\end{array}$ & $\begin{array}{r}\text { e } 210 \\
\text { e220 } \\
\text { e } 250 \\
452 \\
520\end{array}$ & $\begin{array}{l}1390 \\
1150 \\
1990 \\
1580 \\
1010\end{array}$ & $\begin{array}{l}613 \\
444 \\
361 \\
329 \\
332\end{array}$ & $\begin{array}{l}161 \\
163 \\
190 \\
189 \\
154\end{array}$ & $\begin{array}{l}96 \\
95 \\
86 \\
79 \\
74\end{array}$ & $\begin{array}{l}39 \\
38 \\
37 \\
36 \\
35\end{array}$ & $\begin{array}{l}28 \\
28 \\
28 \\
39 \\
40\end{array}$ & $\begin{array}{l}72 \\
53 \\
45 \\
41 \\
39\end{array}$ \\
\hline $\begin{array}{l}21 \\
22 \\
23 \\
24 \\
25\end{array}$ & $\begin{array}{l}199 \\
173 \\
156 \\
145 \\
134\end{array}$ & $\begin{array}{l}103 \\
110 \\
114 \\
106 \\
103\end{array}$ & $\begin{array}{r}663 \\
1630 \\
987 \\
619 \\
\mathrm{e} 480\end{array}$ & $\begin{array}{l}\text { e } 470 \\
\text { e } 410 \\
\text { e } 360 \\
\text { e } 330 \\
\text { e2 } 90\end{array}$ & $\begin{array}{l}427 \\
372 \\
325 \\
297 \\
275\end{array}$ & $\begin{array}{r}100 \\
609 \\
1010 \\
888 \\
618\end{array}$ & $\begin{array}{l}318 \\
296 \\
278 \\
279 \\
256\end{array}$ & $\begin{array}{l}141 \\
135 \\
135 \\
134 \\
138\end{array}$ & $\begin{array}{r}71 \\
67 \\
64 \\
134 \\
94\end{array}$ & $\begin{array}{l}33 \\
33 \\
31 \\
31 \\
31\end{array}$ & $\begin{array}{l}38 \\
33 \\
29 \\
28 \\
27\end{array}$ & $\begin{array}{l}37 \\
37 \\
37 \\
36 \\
37\end{array}$ \\
\hline $\begin{array}{l}26 \\
27 \\
28 \\
29 \\
30 \\
31\end{array}$ & $\begin{array}{l}124 \\
118 \\
113 \\
110 \\
107 \\
104\end{array}$ & $\begin{array}{r}99 \\
111 \\
1080 \\
1030 \\
634 \\
\ldots-\end{array}$ & $\begin{array}{l}\text { e } 380 \\
\text { e } 340 \\
\text { e } 330 \\
1890 \\
8280 \\
6220\end{array}$ & $\begin{array}{l}\text { e } 270 \\
e 260 \\
e 240 \\
e 230 \\
e 220 \\
\text { e210 }\end{array}$ & $\begin{array}{l}253 \\
242 \\
234 \\
\cdots \\
\cdots \\
\cdots\end{array}$ & $\begin{array}{l}612 \\
909 \\
710 \\
517 \\
417 \\
358\end{array}$ & $\begin{array}{l}240 \\
235 \\
229 \\
225 \\
218 \\
\cdots\end{array}$ & $\begin{array}{l}284 \\
306 \\
220 \\
192 \\
237 \\
405\end{array}$ & $\begin{array}{r}73 \\
65 \\
61 \\
57 \\
54 \\
\ldots\end{array}$ & $\begin{array}{l}31 \\
30 \\
30 \\
29 \\
28 \\
28\end{array}$ & $\begin{array}{l}26 \\
25 \\
25 \\
25 \\
29 \\
28\end{array}$ & $\begin{array}{r}36 \\
35 \\
36 \\
35 \\
35 \\
-\end{array}$ \\
\hline $\begin{array}{l}\text { TOTAL } \\
\text { MEAN } \\
\text { MAX } \\
\text { MIN } \\
\text { CFSM } \\
\text { IN. }\end{array}$ & $\begin{array}{r}8576 \\
277 \\
1650 \\
42 \\
1.14 \\
1.31\end{array}$ & $\begin{array}{r}6695 \\
223 \\
1080 \\
96 \\
.92 \\
1.02\end{array}$ & $\begin{array}{r}29571 \\
954 \\
8280 \\
187 \\
3.93 \\
4.53\end{array}$ & $\begin{array}{r}17017 \\
551 \\
2120 \\
210 \\
2.27 \\
2.61\end{array}$ & $\begin{array}{r}9846 \\
352 \\
741 \\
200 \\
1.45 \\
1.51\end{array}$ & $\begin{array}{r}22260 \\
718 \\
1990 \\
168 \\
2.95 \\
3.41\end{array}$ & $\begin{array}{c}8892 \\
296 \\
677 \\
193 \\
1.22 \\
1.36\end{array}$ & $\begin{array}{r}6137 \\
198 \\
405 \\
134 \\
.81 \\
.94\end{array}$ & $\begin{array}{c}4473 \\
149 \\
603 \\
54 \\
.61 \\
.68\end{array}$ & $\begin{array}{c}1218 \\
39.3 \\
55 \\
28 \\
.16 \\
.19\end{array}$ & $\begin{array}{c}958 \\
30.9 \\
45 \\
25 \\
.13 \\
.15\end{array}$ & $\begin{array}{r}1259 \\
42.0 \\
185 \\
22 \\
.17 \\
.19\end{array}$ \\
\hline
\end{tabular}

e Estinated

STATISTICS OF MONTHLY MEAN DATA FOR WATER YEARS 1944 - 1991, BY WATER YEAR (WY)

\begin{tabular}{|c|c|c|c|c|c|c|c|c|c|c|c|c|}
\hline $\begin{array}{l}\text { MEAH } \\
\text { MAX } \\
\text { (WY) } \\
\text { MIN } \\
\text { (WY) }\end{array}$ & $\begin{array}{r}99.4 \\
426 \\
1970 \\
22.9 \\
1964\end{array}$ & $\begin{array}{r}153 \\
827 \\
1986 \\
27.8 \\
1957\end{array}$ & $\begin{array}{r}255 \\
954 \\
1991 \\
23.5 \\
1964\end{array}$ & $\begin{array}{r}296 \\
1808 \\
1950 \\
19.5 \\
1977\end{array}$ & $\begin{array}{r}353 \\
929 \\
1985 \\
37.5 \\
1963\end{array}$ & $\begin{array}{r}422 \\
1143 \\
1982 \\
78.2 \\
1981\end{array}$ & $\begin{array}{r}411 \\
1172 \\
1964 \\
102 \\
1971\end{array}$ & $\begin{array}{r}301 \\
881 \\
1983 \\
67.6 \\
1976\end{array}$ & $\begin{array}{r}268 \\
1674 \\
1958 \\
40.6 \\
1977\end{array}$ & $\begin{array}{r}149 \\
668 \\
1957 \\
26.2 \\
1977\end{array}$ & $\begin{array}{r}102 \\
510 \\
1958 \\
18.3 \\
1944\end{array}$ & $\begin{array}{r}102 \\
849 \\
1989 \\
18.0 \\
1944\end{array}$ \\
\hline
\end{tabular}

SUMMARY STATISIICS

ANNUAL TOTAL

ANNUAL MEAM

HIGHEST ANMUAL MEAN

LOWEST ANHUAL MEAN

HIGHEST DAILY MEAK

LOWEST DAILY MEAN

ANNUAL SEVEN-DAY MINIMUM

INSTANTANEOUS PEAK FLOW

INSIANTANEOUS PEAK STAGE

ANMUAL RUNOFF (CFSM)

ANMUAL RUNOFF (INCHES)

10 PERCENT EXCEEDS

50 PERCENT EXCEEDS

90 PERCENT EXCEEDS
FOR 1990 CALENUAR YEAR

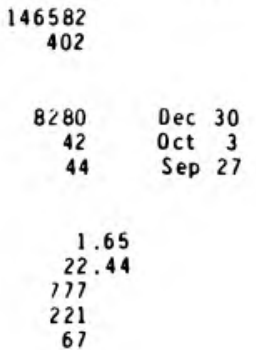

FOR 1991 WAIER YEAR

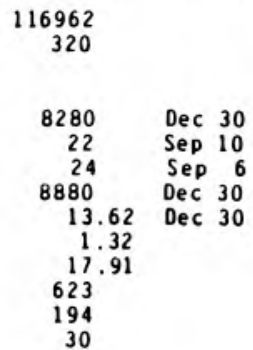

WATER YEARS 1944 - 1991

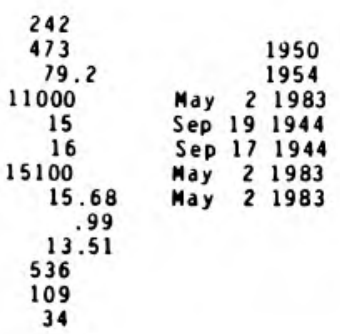




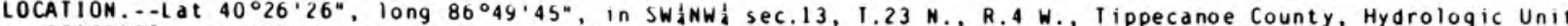
05120107 , on right bank about $200 \mathrm{ft}$ downstream of bridge on County Road $2 \mathrm{~A}$ Edst, 2.8 i downstrean from South Fork Wildcat Creek, 3.7 i northeast of courthouse in Lafayette, and 4.8 upstream from aouth.

DRAI NAGE AREA...794 $i^{2}$

PERIOD OF RECORD.--May 1954 to current year.

REVISED RECORDS..-WSP 1555: 1955, 1957(M). WSP 2109: Dra inage area.

GAGE.--Water-stage recorder. Datum of gage is $527.66 \mathrm{ft}$ above National Geodetic Vertical Datum of 1929 (Indiana Flood Control and Water Resources Comission bench ark). Nonrecording gage prior to June 13, 1957 . and August 31,1974 , to May 20,1976, at present site and datum.

REMARKS. - - Records fa ir.

EXIREMES OUISIDE PERIOD OF RECORO.--Flood of March 1913 reached a stage of about 25.4 ft. from profile by State of Indiana, Departaent of Natural Resources.

DISCHARGE, CUBIC FEET PER SECOND, WATER YEAR OCTOBER 1990 TO SEPTEMBER 1991 DAILY MEAN VALUES

\begin{tabular}{|c|c|c|c|c|c|c|c|c|c|c|c|c|}
\hline DAY & $\mathrm{OCT}$ & NOV & $\mathrm{DEC}$ & JAN & FEB & MAR & APR & MAY & JUN & JUL & AUG & SEP \\
\hline $\begin{array}{l}1 \\
2 \\
3 \\
4 \\
5\end{array}$ & $\begin{array}{l}141 \\
138 \\
136 \\
214 \\
287\end{array}$ & $\begin{array}{l}391 \\
342 \\
389 \\
345 \\
713\end{array}$ & $\begin{array}{l}1500 \\
1140 \\
1560 \\
2640 \\
2280\end{array}$ & $\begin{array}{r}12500 \\
8130 \\
3250 \\
2110 \\
1610\end{array}$ & $\begin{array}{r}\text { e } 500 \\
\text { e } 490 \\
\text { e } 520 \\
735 \\
1060\end{array}$ & $\begin{array}{l}636 \\
654 \\
662 \\
621 \\
591\end{array}$ & $\begin{array}{r}1020 \\
886 \\
796 \\
737 \\
729\end{array}$ & $\begin{array}{l}562 \\
536 \\
495 \\
502 \\
538\end{array}$ & $\begin{array}{r}1150 \\
1290 \\
1390 \\
1260 \\
799\end{array}$ & $\begin{array}{l}199 \\
251 \\
272 \\
284 \\
244\end{array}$ & $\begin{array}{r}e 83 \\
e 85 \\
e 86 \\
90 \\
86\end{array}$ & $\begin{array}{l}91 \\
99 \\
98 \\
93 \\
90\end{array}$ \\
\hline $\begin{array}{r}6 \\
7 \\
8 \\
9 \\
10\end{array}$ & $\begin{array}{r}222 \\
207 \\
255 \\
1170 \\
4280\end{array}$ & $\begin{array}{r}1430 \\
1080 \\
875 \\
719 \\
622\end{array}$ & $\begin{array}{r}1730 \\
1310 \\
1080 \\
917 \\
813\end{array}$ & $\begin{array}{r}1300 \\
1080 \\
922 \\
837 \\
781\end{array}$ & $\begin{array}{l}1380 \\
1930 \\
1780 \\
1520 \\
1300\end{array}$ & $\begin{array}{l}582 \\
570 \\
532 \\
513 \\
491\end{array}$ & $\begin{array}{l}709 \\
659 \\
643 \\
697 \\
614\end{array}$ & $\begin{array}{l}623 \\
581 \\
513 \\
477 \\
453\end{array}$ & $\begin{array}{l}598 \\
491 \\
425 \\
378 \\
349\end{array}$ & $\begin{array}{l}221 \\
198 \\
183 \\
225 \\
285\end{array}$ & $\begin{array}{l}101 \\
103 \\
129 \\
138 \\
152\end{array}$ & $\begin{array}{l}89 \\
88 \\
82 \\
78 \\
76\end{array}$ \\
\hline $\begin{array}{l}11 \\
12 \\
13 \\
14 \\
15\end{array}$ & $\begin{array}{l}4330 \\
3460 \\
2310 \\
1610 \\
1230\end{array}$ & $\begin{array}{l}551 \\
495 \\
445 \\
416 \\
398\end{array}$ & $\begin{array}{l}738 \\
693 \\
645 \\
587 \\
755\end{array}$ & $\begin{array}{l}197 \\
1390 \\
1280 \\
1120 \\
1320\end{array}$ & $\begin{array}{r}1120 \\
970 \\
895 \\
879 \\
\mathrm{e} 740\end{array}$ & $\begin{array}{r}480 \\
547 \\
2360 \\
3270 \\
3620\end{array}$ & $\begin{array}{r}621 \\
574 \\
570 \\
770 \\
2090\end{array}$ & $\begin{array}{l}437 \\
469 \\
447 \\
443 \\
446\end{array}$ & $\begin{array}{l}326 \\
314 \\
307 \\
289 \\
294\end{array}$ & $\begin{array}{l}236 \\
214 \\
191 \\
176 \\
154\end{array}$ & $\begin{array}{r}121 \\
103 \\
95 \\
89 \\
88\end{array}$ & $\begin{array}{r}73 \\
77 \\
90 \\
216 \\
233\end{array}$ \\
\hline $\begin{array}{l}16 \\
17 \\
18 \\
19 \\
20\end{array}$ & $\begin{array}{r}971 \\
823 \\
1750 \\
1560 \\
1240\end{array}$ & $\begin{array}{l}381 \\
372 \\
359 \\
352 \\
346\end{array}$ & $\begin{array}{l}1080 \\
1060 \\
1270 \\
1750 \\
1740\end{array}$ & $\begin{array}{l}2350 \\
3030 \\
2690 \\
2130 \\
1790\end{array}$ & $\begin{array}{r}e 600 \\
e 620 \\
695 \\
1060 \\
1430\end{array}$ & $\begin{array}{l}3420 \\
3350 \\
5290 \\
5550 \\
5000\end{array}$ & $\begin{array}{l}1990 \\
1670 \\
1260 \\
1030 \\
1040\end{array}$ & $\begin{array}{l}553 \\
535 \\
549 \\
527 \\
435\end{array}$ & $\begin{array}{l}424 \\
391 \\
308 \\
272 \\
257\end{array}$ & $\begin{array}{r}142 \\
132 \\
125 \\
\text { e116 } \\
\text { el1 }\end{array}$ & $\begin{array}{r}86 \\
86 \\
86 \\
131 \\
160\end{array}$ & $\begin{array}{l}148 \\
124 \\
113 \\
106 \\
112\end{array}$ \\
\hline $\begin{array}{l}21 \\
22 \\
23 \\
24 \\
25\end{array}$ & $\begin{array}{l}982 \\
807 \\
700 \\
653 \\
578\end{array}$ & $\begin{array}{l}331 \\
338 \\
349 \\
337 \\
322\end{array}$ & $\begin{array}{r}1890 \\
4120 \\
\text { e } 3500 \\
\text { e2300 } \\
\text { e1 } 800\end{array}$ & $\begin{array}{r}1530 \\
1300 \\
1180 \\
991 \\
831\end{array}$ & $\begin{array}{r}1390 \\
1180 \\
995 \\
886 \\
790\end{array}$ & $\begin{array}{l}3520 \\
2450 \\
3000 \\
3070 \\
2570\end{array}$ & $\begin{array}{r}1240 \\
1170 \\
974 \\
898 \\
813\end{array}$ & $\begin{array}{l}381 \\
356 \\
351 \\
655 \\
619\end{array}$ & $\begin{array}{l}240 \\
231 \\
249 \\
637 \\
393\end{array}$ & $\begin{array}{r}\text { e } 110 \\
\text { e1 } 05 \\
\text { e } 103 \\
\text { e } 99 \\
\text { e } 99\end{array}$ & $\begin{array}{l}163 \\
130 \\
113 \\
107 \\
102\end{array}$ & $\begin{array}{l}118 \\
114 \\
115 \\
105 \\
105\end{array}$ \\
\hline $\begin{array}{l}26 \\
27 \\
28 \\
29 \\
30 \\
31\end{array}$ & $\begin{array}{l}531 \\
498 \\
476 \\
454 \\
437 \\
429\end{array}$ & $\begin{array}{r}314 \\
335 \\
1900 \\
2610 \\
2020 \\
\ldots\end{array}$ & $\begin{array}{r}\text { el } 300 \\
\text { el } 150 \\
\text { el } 050 \\
3600 \\
14400 \\
16300\end{array}$ & $\begin{array}{l}\text { e } 740 \\
\text { e } 700 \\
\text { e640 } \\
\text { e600 } \\
\text { e550 } \\
\text { e530 }\end{array}$ & $\begin{array}{l}720 \\
676 \\
649 \\
\cdots \\
\cdots \\
\cdots\end{array}$ & $\begin{array}{l}2170 \\
2790 \\
2280 \\
2020 \\
1510 \\
1200\end{array}$ & $\begin{array}{l}727 \\
678 \\
641 \\
620 \\
594 \\
\ldots\end{array}$ & $\begin{array}{l}682 \\
780 \\
614 \\
537 \\
544 \\
690\end{array}$ & $\begin{array}{l}314 \\
283 \\
246 \\
228 \\
217 \\
\cdots\end{array}$ & $\begin{array}{l}\text { e } 95 \\
\text { e } 93 \\
\text { e } 93 \\
\text { e } 93 \\
\text { e } 88 \\
\text { e } 83\end{array}$ & $\begin{array}{r}93 \\
92 \\
85 \\
92 \\
101 \\
96\end{array}$ & $\begin{array}{l}104 \\
105 \\
105 \\
107 \\
109 \\
\cdots\end{array}$ \\
\hline $\begin{array}{l}\text { IOTAL } \\
\text { MEAN } \\
\text { MAX } \\
\text { MIN } \\
\text { CF SM } \\
\text { IN. }\end{array}$ & $\begin{array}{r}32879 \\
1061 \\
4330 \\
136 \\
1.34 \\
1.54\end{array}$ & $\begin{array}{r}19883 \\
663 \\
2610 \\
314 \\
.83 \\
.93\end{array}$ & $\begin{array}{r}76698 \\
2474 \\
16300 \\
587 \\
3.12 \\
3.59\end{array}$ & $\begin{array}{r}60009 \\
1936 \\
12500 \\
530 \\
2.44 \\
2.81\end{array}$ & $\begin{array}{r}27510 \\
982 \\
1930 \\
490 \\
1.24 \\
1.29\end{array}$ & $\begin{array}{r}65325 \\
2107 \\
5550 \\
480 \\
2.65 \\
3.06\end{array}$ & $\begin{array}{r}27520 \\
917 \\
2090 \\
570 \\
1.16 \\
1.29\end{array}$ & $\begin{array}{c}16330 \\
527 \\
780 \\
351 \\
.66 \\
.77\end{array}$ & $\begin{array}{r}14350 \\
478 \\
1390 \\
217 \\
.60 \\
.67\end{array}$ & $\begin{array}{c}5023 \\
162 \\
285 \\
83 \\
.20 \\
.24\end{array}$ & $\begin{array}{c}3272 \\
106 \\
163 \\
83 \\
.13 \\
.15\end{array}$ & $\begin{array}{c}3263 \\
109 \\
233 \\
73 \\
.14 \\
.15\end{array}$ \\
\hline
\end{tabular}

e Estiated

SIATISIICS OF MONIHLY MEAN DATA FOR WAIER YEARS 1955 - 1991. BY WATER YEAR (WY)

$\begin{array}{lrrrrrrrrrrrrr}\text { MEAN } & 311 & 510 & 866 & 791 & 1133 & 1414 & 1306 & 908 & 808 & 511 & 345 & 307 \\ \text { MAX } & 1298 & 2519 & 2474 & 3711 & 3227 & 3991 & 3657 & 2614 & 5210 & 2495 & 1511 & 2546 \\ \text { (WY) } & 1970 & 1986 & 1991 & 1974 & 1976 & 1982 & 1964 & 1983 & 1958 & 1957 & 1958 & 1989 \\ \text { MIN } & 67.9 & 85.6 & 67.0 & 61.6 & 104 & 290 & 310 & 231 & 130 & 84.4 & 79.8 & 68.8 \\ \text { (WY) } & 1964 & 1964 & 1964 & 1977 & 1963 & 1981 & 1971 & 1976 & 1988 & 1977 & 1966 & 1956\end{array}$

$\begin{array}{llll}\text { (WY } & 1964 & 1964 & 1964\end{array}$

SUMMARY SIATISIICS

ANNUAL TOIAL

ANNUAL MEAM

HIGHESI ANNUAI MEAN

LOWEST ANNUAL MEAN

HIGHEST DAIIY MEAN

LOWEST DAILY MEAN

ANNUAL SEVEN-DAY MINIMUM

INSTAMIANEOUS PEAK FLOW

INSIANTANE OUS PEAK STAGE

ANNUAL RUNOFF (CFSM)

ANNUAL RUNOFF (INCHES)

10 PERCENT EXCEEDS

50 PERCENT EXCEEDS

90 PERCENI EXCEEDS
FOR 1990 CAIENDAR YEAR

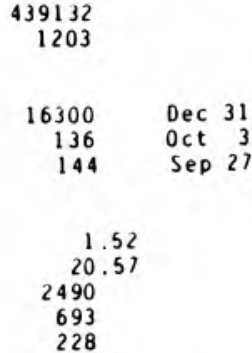

FOR 1991 WAIER YEAR

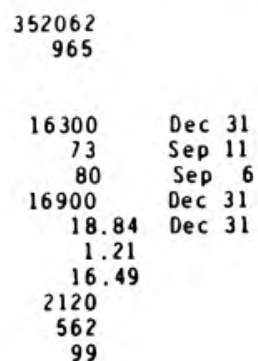

WAIER YEARS $1955-1991$

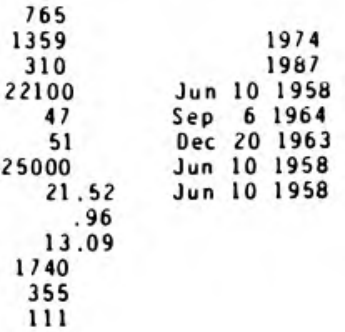




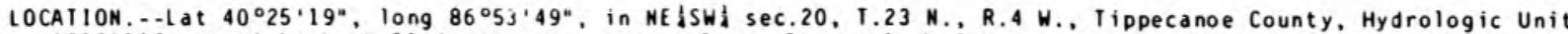
05120108 , on right bank $20 \mathrm{ft}$ downstred fro Brown Street in Lafayette, 0.2 i upstrea fro Main Street bridge, 0.3 mi downstrea from Harrison Memorial Bridge, 5.1 mi downstrea fron Wildcat Creek, and at aile 311.9 .

DRAINAGE AREA $\cdots 7,267: i^{2}$

PERIOD OF RECORD.--February 1901 to January 1902. March to December 1902, January to May 1903 (gage heights only). October 1923 to current year. Monthly discharge only for sone periods. published in wSP 1305 . Gage-height records collected at present site since October 1913 are contained in reports of National Weather Service.

REVISED RECORDS.--WSP 1335: 1929, 1932-33, 1936. WSP 1505: 1950. WSP 1555: 1928(M). WSP 2109: Ora inage a rea. WDR IN-81-1: 1979 .

GAGE. - -Water-stage recorder. Datun of gage is $504.14 \mathrm{ft}$ above National Geodetic Vertical Datue of 1929 . Prior to May 2, 1903, nonrecording gage $0.5 \mathrm{mi}$ upstrean at different datum. 0ct. 1, 1923, to Nov. 20 , 1933, nonrecording gage at sane site and datum.

REMARKS. - - Records good except for estimated daily discharges, which are poor. Flow partially regulated by upstrean reservoirs and power development.

EXIREMES OUISIDE PERIOD OF RECORO...Flood of Mar. 26, 1913, reached a stage of $32.9 \mathrm{ft}, \mathrm{from} f \mathrm{flood}$ ark deterained by National Weather Service, discharge, $190,000 \mathrm{ft} / \mathrm{s}$.

DISCHARGE, CUBIC FEET PER SECOND, WATER YEAR OCTOBER 1990 TO SEPTEMBER 1991

\begin{tabular}{|c|c|c|c|c|c|c|c|c|c|c|c|c|}
\hline DAY & $\mathrm{OCT}$ & nov & $\mathrm{OEC}$ & JAN & FEB & MAR & APR & MAY & JUN & JUL & AUG & SEP \\
\hline $\begin{array}{l}1 \\
2 \\
3 \\
4 \\
5\end{array}$ & $\begin{array}{l}3220 \\
3100 \\
2980 \\
3610 \\
3810\end{array}$ & $\begin{array}{l}5500 \\
3890 \\
4150 \\
6180 \\
8330\end{array}$ & $\begin{array}{l}13200 \\
12600 \\
13200 \\
19500 \\
19400\end{array}$ & $\begin{array}{l}70300 \\
54200 \\
40000 \\
30400 \\
25400\end{array}$ & $\begin{array}{r}\text { } 5000 \\
2900 \\
2970 \\
3380 \\
5030\end{array}$ & $\begin{array}{l}6350 \\
6690 \\
7970 \\
8250 \\
7720\end{array}$ & $\begin{array}{r}13500 \\
10900 \\
8180 \\
7680 \\
7440\end{array}$ & $\begin{array}{l}6870 \\
6220 \\
6310 \\
5970 \\
5900\end{array}$ & $\begin{array}{l}18100 \\
20500 \\
16900 \\
14600 \\
12500\end{array}$ & $\begin{array}{l}2230 \\
2160 \\
2980 \\
3070 \\
3260\end{array}$ & $\begin{array}{r}1010 \\
974 \\
1020 \\
968 \\
985\end{array}$ & $\begin{array}{l}1180 \\
1130 \\
1120 \\
1490 \\
1650\end{array}$ \\
\hline $\begin{array}{r}6 \\
7 \\
8 \\
9 \\
10\end{array}$ & $\begin{array}{r}6320 \\
7950 \\
6960 \\
8930 \\
23900\end{array}$ & $\begin{array}{r}15900 \\
17000 \\
13000 \\
10800 \\
9850\end{array}$ & $\begin{array}{l}18000 \\
16800 \\
15200 \\
13200 \\
11000\end{array}$ & $\begin{array}{l}23500 \\
22300 \\
21700 \\
20900 \\
20100\end{array}$ & $\begin{array}{r}8350 \\
12800 \\
14200 \\
13200 \\
11200\end{array}$ & $\begin{array}{l}7200 \\
6970 \\
6040 \\
5900 \\
5480\end{array}$ & $\begin{array}{l}7580 \\
7620 \\
7290 \\
7240 \\
7820\end{array}$ & $\begin{array}{l}6490 \\
6120 \\
5960 \\
5510 \\
5470\end{array}$ & $\begin{array}{r}11500 \\
10500 \\
8470 \\
7010 \\
5190\end{array}$ & $\begin{array}{l}2930 \\
2640 \\
2570 \\
3580 \\
4960\end{array}$ & $\begin{array}{l}1020 \\
1130 \\
1330 \\
1850 \\
1720\end{array}$ & $\begin{array}{l}1240 \\
1180 \\
1160 \\
1190 \\
1080\end{array}$ \\
\hline $\begin{array}{l}11 \\
12 \\
13 \\
14 \\
15\end{array}$ & $\begin{array}{l}37800 \\
36900 \\
27800 \\
21000 \\
16700\end{array}$ & $\begin{array}{l}9190 \\
8410 \\
7320 \\
7040 \\
6790\end{array}$ & $\begin{array}{l}9280 \\
7930 \\
6840 \\
6160 \\
6310\end{array}$ & $\begin{array}{l}19300 \\
20600 \\
21000 \\
20500 \\
21100\end{array}$ & $\begin{array}{r}\text { e8900 } \\
\text { e8400 } \\
\text { e8600 } \\
8230 \\
7690\end{array}$ & $\begin{array}{r}5460 \\
5500 \\
7790 \\
10600 \\
11100\end{array}$ & $\begin{array}{r}7680 \\
6880 \\
6570 \\
6960 \\
11500\end{array}$ & $\begin{array}{l}5300 \\
5290 \\
5160 \\
5010 \\
5590\end{array}$ & $\begin{array}{l}4480 \\
4140 \\
4050 \\
3740 \\
3550\end{array}$ & $\begin{array}{l}4560 \\
3370 \\
2700 \\
2290 \\
2040\end{array}$ & $\begin{array}{l}1710 \\
1530 \\
1390 \\
1330 \\
1220\end{array}$ & $\begin{array}{l}1070 \\
1080 \\
1120 \\
1480 \\
1620\end{array}$ \\
\hline $\begin{array}{l}16 \\
17 \\
18 \\
19 \\
20\end{array}$ & $\begin{array}{l}15000 \\
14900 \\
16300 \\
19300 \\
16700\end{array}$ & $\begin{array}{l}6970 \\
6630 \\
6440 \\
6110 \\
5520\end{array}$ & $\begin{array}{r}7880 \\
10700 \\
12000 \\
13300 \\
15400\end{array}$ & $\begin{array}{l}25100 \\
31500 \\
28900 \\
23600 \\
22300\end{array}$ & $\begin{array}{r}6160 \\
6100 \\
6370 \\
8130 \\
14700\end{array}$ & $\begin{array}{l}11500 \\
13500 \\
22800 \\
31700 \\
32100\end{array}$ & $\begin{array}{l}18300 \\
18700 \\
17100 \\
14800 \\
12900\end{array}$ & $\begin{array}{r}5330 \\
5870 \\
8000 \\
10600 \\
7860\end{array}$ & $\begin{array}{l}3890 \\
3740 \\
3490 \\
3300 \\
3100\end{array}$ & $\begin{array}{l}1780 \\
1610 \\
1620 \\
1480 \\
1530\end{array}$ & $\begin{array}{l}1170 \\
1250 \\
1270 \\
1770 \\
1860\end{array}$ & $\begin{array}{l}1740 \\
1590 \\
1570 \\
1850 \\
1660\end{array}$ \\
\hline $\begin{array}{l}21 \\
22 \\
23 \\
24 \\
25\end{array}$ & $\begin{array}{l}14600 \\
13500 \\
13300 \\
12900 \\
11600\end{array}$ & $\begin{array}{l}5460 \\
5580 \\
5500 \\
5450 \\
5200\end{array}$ & $\begin{array}{r}15400 \\
22200 \\
23800 \\
\mathrm{e} 20000 \\
\mathrm{e} 16900\end{array}$ & $\begin{array}{l}\text { e } 20400 \\
\text { e1 } 9000 \\
\text { e } 18000 \\
\text { e1 } 7500 \\
\text { el } 7100\end{array}$ & $\begin{array}{r}18000 \\
17300 \\
16100 \\
13300 \\
9760\end{array}$ & $\begin{array}{l}26400 \\
21600 \\
20300 \\
21300 \\
20700\end{array}$ & $\begin{array}{l}16400 \\
15900 \\
15400 \\
14000 \\
12200\end{array}$ & $\begin{array}{l}6600 \\
5750 \\
6490 \\
7840 \\
7650\end{array}$ & $\begin{array}{l}2740 \\
2640 \\
2400 \\
2650 \\
2380\end{array}$ & $\begin{array}{l}1280 \\
1310 \\
1210 \\
1140 \\
1210\end{array}$ & $\begin{array}{l}1680 \\
1660 \\
1470 \\
1340 \\
1210\end{array}$ & $\begin{array}{l}1730 \\
1800 \\
2030 \\
1840 \\
1760\end{array}$ \\
\hline $\begin{array}{l}26 \\
27 \\
28 \\
29 \\
30 \\
31\end{array}$ & $\begin{array}{r}11000 \\
9620 \\
9160 \\
8100 \\
8290 \\
7020\end{array}$ & $\begin{array}{r}5290 \\
5450 \\
8270 \\
16400 \\
15300 \\
\cdots\end{array}$ & $\begin{array}{r}\text { e } 14700 \\
\text { e13500 } \\
14300 \\
20000 \\
54800 \\
75200\end{array}$ & $\begin{array}{r}\text { el } 6900 \\
\text { el } 6200 \\
\text { el } 14800 \\
\text { el } 3000 \\
\text { el } 1000 \\
\text { e } 8000\end{array}$ & $\begin{array}{r}8220 \\
7360 \\
6850 \\
\ldots \\
\ldots \\
\ldots\end{array}$ & $\begin{array}{l}19700 \\
23000 \\
23000 \\
20400 \\
18300 \\
15500\end{array}$ & $\begin{array}{r}10900 \\
8740 \\
7810 \\
7400 \\
7230 \\
\cdots\end{array}$ & $\begin{array}{r}9930 \\
10100 \\
9020 \\
7460 \\
6740 \\
7450\end{array}$ & $\begin{array}{c}2200 \\
2280 \\
2050 \\
2040 \\
2020 \\
\ldots\end{array}$ & $\begin{array}{l}1140 \\
1150 \\
1140 \\
1010 \\
1020 \\
1100\end{array}$ & $\begin{array}{l}1220 \\
1170 \\
1080 \\
1130 \\
1160 \\
1150\end{array}$ & $\begin{array}{c}1780 \\
1810 \\
1850 \\
1970 \\
1950 \\
--.\end{array}$ \\
\hline $\begin{array}{l}\text { TOIAL } \\
\text { MEAN } \\
\text { MAX } \\
\text { MIN } \\
\text { CF SM } \\
\text { IN. }\end{array}$ & $\begin{array}{r}412270 \\
13300 \\
37800 \\
2980 \\
1.83 \\
2.11\end{array}$ & $\begin{array}{r}242920 \\
8097 \\
17000 \\
3890 \\
1.11 \\
1.24\end{array}$ & $\begin{array}{r}538700 \\
17380 \\
75200 \\
6160 \\
2.39 \\
2.76\end{array}$ & $\begin{array}{r}134600 \\
23700 \\
70300 \\
8000 \\
3.26 \\
3.76\end{array}$ & $\begin{array}{r}259200 \\
9257 \\
18000 \\
2900 \\
1.27 \\
1.33\end{array}$ & $\begin{array}{r}450820 \\
14540 \\
32100 \\
5460 \\
2.00 \\
2.31\end{array}$ & $\begin{array}{r}322620 \\
10750 \\
18700 \\
6570 \\
1.48 \\
1.65\end{array}$ & $\begin{array}{r}209860 \\
6710 \\
10600 \\
5010 \\
.93 \\
1.07\end{array}$ & $\begin{array}{r}186150 \\
6205 \\
20500 \\
2020 \\
.85 \\
.95\end{array}$ & $\begin{array}{c}66070 \\
2131 \\
4960 \\
1010 \\
.29 \\
.34\end{array}$ & $\begin{array}{c}40177 \\
1315 \\
1860 \\
968 \\
.18 \\
.21\end{array}$ & $\begin{array}{c}45720 \\
1524 \\
2030 \\
1070 \\
.21 \\
.23\end{array}$ \\
\hline
\end{tabular}

e Estimated

SIATISTICS OF MONTHLY MEAN DATA FOR WAIER YEARS 1924 - 1991, BY WATER YEAR (WY)

$\begin{array}{lrrrrrrrrrrrr}\text { MEAN } & 2923 & 3979 & 6748 & 8391 & 9696 & 11890 & 11680 & 8240 & 6278 & 3771 & 2619 & 2565 \\ \text { MAX } & 14750 & 18800 & 25250 & 42040 & 28000 & 33560 & 28000 & 37290 & 31830 & 14820 & 12090 & 20120 \\ \text { (WY) } & 1927 & 1973 & 1928 & 1950 & 1959 & 1982 & 1957 & 1943 & 1958 & 1957 & 1990 & 1926 \\ \text { MIN } & 652 & 828 & 747 & 735 & 1232 & 1663 & 3135 & 1460 & 1029 & 655 & 484 & 435 \\ \text { (WY) } & 1964 & 1965 & 1964 & 1977 & 1964 & 1941 & 1941 & 1934 & 1934 & 1936 & 1941 & 1941\end{array}$

SUMMARY STATISTICS

ANNUAL TOIAL

AN NUAL MEAM

HIGHEST ANNUAL MEAM

LOWEST ANMUAL MEAN

HIGHESI DAILY MEAN

LOWEST DAIIY MEAN

ANMUAL SEVEN-DAY MINIMUM

INSIANTANEOUS PEAK FLOW

INSTANTANEOUS PEAK SIAGE

AN NUAL RUNOFF (CFSM)

ANNUAL RUNOFF (INCHES)

10 PERCENT EXCEEDS

50 PERCENT EXCEEOS

90 PERCENT EXCEEDS

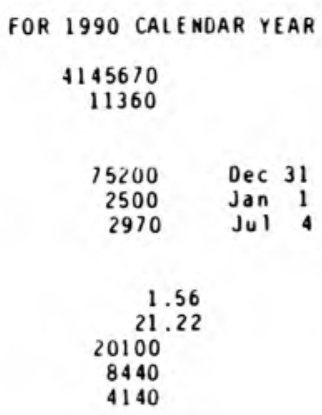

WATER YEARS 1924 - 1991

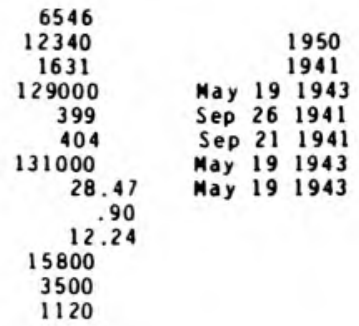




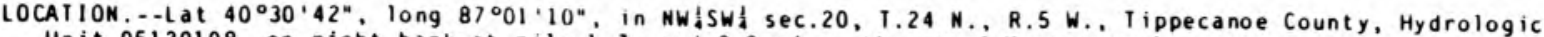
Unit 05120108, on right bank at ile i.1. and 2.9 a northeast of Montaorenci.

DRAI NAGE AREA. .- $1.58 \mathrm{i}^{2}$

PERIOD OF RECORD.--0 ctober 1990 to current year.

GAGE.-Data Collection Platfora. Datun of gage is $710.00 \mathrm{ft}$. above National Geodetic Vertical Datue of 1929 .

REMARKS. - - Records good except for estiaded daily discharges which are poor. Minieue daily discharge. no flow for any days.

DISCHARGE, CUBIC FEET PER SECOND, WATER YEAR OCTOBER 1990 TO SEPTEMBER 1991 DAILY MEAN VALUES

\begin{tabular}{|c|c|c|c|c|c|c|c|c|c|c|c|c|}
\hline DAY & $\mathrm{OCI}$ & NOV & DEC & JAN & FEB & MAR & APR & MAY & JUN & JUL & AUG & SEP \\
\hline $\begin{array}{l}1 \\
2 \\
3 \\
4 \\
5\end{array}$ & $\begin{array}{l}.01 \\
.01 \\
.04 \\
.12 \\
.03\end{array}$ & $\begin{array}{l}.23 \\
.21 \\
.19 \\
.20 \\
3.3\end{array}$ & $\begin{array}{l}.68 \\
.54 \\
3.6 \\
1.6 \\
1.1\end{array}$ & $\begin{array}{l}1.8 \\
1.4 \\
1.0 \\
\text { e. } 74 \\
\text { e. } 66\end{array}$ & $\begin{array}{l}\text { e. } 29 \\
.97 \\
1.5 \\
1.2 \\
1.2\end{array}$ & $\begin{array}{l}.56 \\
.45 \\
.43 \\
.40 \\
.46\end{array}$ & $\begin{array}{l}.66 \\
.59 \\
.57 \\
.59 \\
.55\end{array}$ & $\begin{array}{l}.51 \\
.46 \\
.43 \\
.42 \\
.52\end{array}$ & $\begin{array}{l}1.5 \\
.96 \\
.75 \\
.59 \\
.52\end{array}$ & $\begin{array}{l}.06 \\
.55 \\
.42 \\
.21 \\
.15\end{array}$ & $\begin{array}{l}.02 \\
.01 \\
.00 \\
.00 \\
.00\end{array}$ & $\begin{array}{l}.00 \\
.00 \\
.00 \\
.00 \\
.00\end{array}$ \\
\hline $\begin{array}{r}6 \\
7 \\
8 \\
9 \\
10\end{array}$ & $\begin{array}{l}.02 \\
.07 \\
11.0 \\
27\end{array}$ & $\begin{array}{l}1.8 \\
1.1 \\
.81 \\
.71 \\
.58\end{array}$ & $\begin{array}{l}.82 \\
.69 \\
.60 \\
.54 \\
.49\end{array}$ & $\begin{array}{r}\text { e. } 62 \\
.61 \\
.61 \\
.51 \\
.49\end{array}$ & $\begin{array}{r}1.3 \\
1.1 \\
.93 \\
.87 \\
.82\end{array}$ & $\begin{array}{l}.30 \\
.28 \\
.30 \\
.25 \\
.26\end{array}$ & $\begin{array}{l}.55 \\
.52 \\
.54 \\
.53 \\
.40\end{array}$ & $\begin{array}{l}.50 \\
.40 \\
.38 \\
.36 \\
.34\end{array}$ & $\begin{array}{l}.49 \\
.49 \\
.42 \\
.39 \\
.38\end{array}$ & $\begin{array}{l}.12 \\
.10 \\
.08 \\
.07 \\
.07\end{array}$ & $\begin{array}{l}.00 \\
.00 \\
.02 \\
.02 \\
.02\end{array}$ & $\begin{array}{l}.00 \\
.00 \\
.00 \\
.00 \\
.00\end{array}$ \\
\hline $\begin{array}{l}11 \\
12 \\
13 \\
14 \\
15\end{array}$ & $\begin{array}{l}3.5 \\
1.9 \\
1.4 \\
1.0 \\
.72\end{array}$ & $\begin{array}{l}.47 \\
.39 \\
.36 \\
.35 \\
.32\end{array}$ & $\begin{array}{r}.50 \\
.48 \\
.36 \\
.37 \\
1.2\end{array}$ & $\begin{array}{l}1.2 \\
1.1 \\
.70 \\
2.7 \\
4.5\end{array}$ & $\begin{array}{r}.66 \\
.60 \\
.50 \\
.39 \\
\mathrm{e} .39\end{array}$ & $\begin{array}{l}10^{.32} \\
8.1 \\
19 \\
6.3\end{array}$ & $\begin{array}{l}.35 \\
.35 \\
.46 \\
2.6 \\
3.4\end{array}$ & $\begin{array}{l}.41 \\
.54 \\
.48 \\
.42 \\
.39\end{array}$ & $\begin{array}{l}.38 \\
.34 \\
.30 \\
.31 \\
.30\end{array}$ & $\begin{array}{l}.07 \\
.06 \\
.06 \\
.05 \\
.04\end{array}$ & $\begin{array}{l}.01 \\
.01 \\
.01 \\
.00 \\
.00\end{array}$ & $\begin{array}{l}.00 \\
.00 \\
.00 \\
.00 \\
.00\end{array}$ \\
\hline $\begin{array}{l}16 \\
17 \\
18 \\
19 \\
20\end{array}$ & $\begin{array}{r}.64 \\
.85 \\
2.9 \\
1.3 \\
.93\end{array}$ & $\begin{array}{l}.30 \\
.26 \\
.27 \\
.24 \\
.22\end{array}$ & $\begin{array}{l}.80 \\
.92 \\
1.5 \\
1.2 \\
1.0\end{array}$ & $\begin{array}{l}13 \\
2.7 \\
1.5 \\
1.3 \\
1.3\end{array}$ & $\begin{array}{l}\text { e. } 35 \\
\text { e. } 54 \\
1.1 \\
.85 \\
.76\end{array}$ & $\begin{array}{r}2.9 \\
17 \\
3.9 \\
2.3 \\
1.8\end{array}$ & $\begin{array}{l}1.6 \\
1.2 \\
1.0 \\
.91 \\
.78\end{array}$ & $\begin{array}{l}.39 \\
.36 \\
3.3 \\
1.0 \\
.71\end{array}$ & $\begin{array}{l}.27 \\
.24 \\
.20 \\
.18 \\
.17\end{array}$ & $\begin{array}{l}.04 \\
.04 \\
.04 \\
.04 \\
.04\end{array}$ & $\begin{array}{l}.00 \\
.00 \\
.00 \\
.00 \\
.00\end{array}$ & $\begin{array}{l}.00 \\
.00 \\
.00 \\
.00 \\
.00\end{array}$ \\
\hline $\begin{array}{l}21 \\
22 \\
23 \\
24 \\
25\end{array}$ & $\begin{array}{l}.74 \\
.62 \\
.54 \\
.47 \\
.39\end{array}$ & $\begin{array}{l}.24 \\
.22 \\
.23 \\
.20 \\
.16\end{array}$ & $\begin{array}{l}5.2 \\
3.2 \\
1.6 \\
1.2 \\
.94\end{array}$ & $\begin{array}{l}\text { e. } 80 \\
\text { e. } 65 \\
\text { e. } 55 \\
\text { e. } 49 \\
\text { e. } 44\end{array}$ & $\begin{array}{l}.64 \\
.60 \\
.54 \\
.47 \\
.45\end{array}$ & $\begin{array}{l}1.4 \\
4.3 \\
2.5 \\
1.6 \\
1.3\end{array}$ & $\begin{array}{l}.74 \\
.70 \\
.67 \\
.57 \\
.54\end{array}$ & $\begin{array}{r}.59 \\
.63 \\
1.8 \\
1.2 \\
.76\end{array}$ & $\begin{array}{l}.16 \\
.15 \\
.11 \\
.11 \\
.10\end{array}$ & $\begin{array}{l}.04 \\
.02 \\
.02 \\
.02 \\
.03\end{array}$ & $\begin{array}{l}.00 \\
.00 \\
.00 \\
.00 \\
.00\end{array}$ & $\begin{array}{l}.00 \\
.00 \\
.00 \\
.00 \\
.00\end{array}$ \\
\hline $\begin{array}{l}26 \\
27 \\
28 \\
29 \\
30 \\
31\end{array}$ & $\begin{array}{l}.37 \\
.34 \\
.26 \\
.26 \\
.26 \\
.23\end{array}$ & $\begin{array}{c}.17 \\
.28 \\
3.5 \\
1.2 \\
.89 \\
. .-\end{array}$ & $\begin{array}{r}\text { e. } 68 \\
\text { e. } 62 \\
\text { e. } .55 \\
128 \\
29 \\
2.9\end{array}$ & $\begin{array}{l}\text { e. } 40 \\
\text { e. } 36 \\
\text { e. } 33 \\
\text { e. } 31 \\
\text { e. } 29 \\
\text { e. } 27\end{array}$ & $\begin{array}{l}.42 \\
.41 \\
.42 \\
. . . \\
\ldots . \\
\ldots\end{array}$ & $\begin{array}{l}4.7 \\
2.2 \\
1.4 \\
1.0 \\
.81 \\
.77\end{array}$ & $\begin{array}{l}.59 \\
.54 \\
.51 \\
.61 \\
.52 \\
. . .\end{array}$ & $\begin{array}{l}.62 \\
.52 \\
.49 \\
.49 \\
1.4 \\
8.0\end{array}$ & $\begin{array}{l}.09 \\
.08 \\
.07 \\
.07 \\
.06 \\
\cdots\end{array}$ & $\begin{array}{l}.03 \\
.07 \\
.02 \\
.02 \\
.03 \\
.03\end{array}$ & $\begin{array}{l}.00 \\
.00 \\
.00 \\
.00 \\
.00 \\
.00\end{array}$ & $\begin{array}{l}.00 \\
.00 \\
.00 \\
.00 \\
.00 \\
. .\end{array}$ \\
\hline $\begin{array}{l}\text { TOIAL } \\
\text { MEAN } \\
\text { MAX } \\
\text { MI N } \\
\text { CF SM } \\
\text { IN. }\end{array}$ & $\begin{array}{r}58.08 \\
1.87 \\
27 \\
.01 \\
1.19 \\
1.37\end{array}$ & $\begin{array}{r}19.40 \\
.65 \\
3.5 \\
.16 \\
.41 \\
.46\end{array}$ & $\begin{array}{r}192.88 \\
6.22 \\
128 \\
.36 \\
3.94 \\
4.54\end{array}$ & $\begin{array}{r}43.33 \\
1.40 \\
13 \\
.27 \\
.88 \\
1.02\end{array}$ & $\begin{array}{r}20.27 \\
.12 \\
1.5 \\
.29 \\
.46 \\
.48\end{array}$ & $\begin{array}{c}97.29 \\
3.14 \\
19 \\
.25 \\
1.99 \\
2.29\end{array}$ & $\begin{array}{r}24.14 \\
.80 \\
3.4 \\
.35 \\
.51 \\
.57\end{array}$ & $\begin{array}{r}28.82 \\
.93 \\
8.0 \\
.34 \\
.59 \\
.68\end{array}$ & $\begin{array}{c}10.18 \\
.34 \\
1.5 \\
.06 \\
.21 \\
.24\end{array}$ & $\begin{array}{l}2.64 \\
.085 \\
.55 \\
.02 \\
.05 \\
.06\end{array}$ & $\begin{array}{l}0.12 \\
.004 \\
.02 \\
.00 \\
.00 \\
.00\end{array}$ & $\begin{array}{l}0.00 \\
.000 \\
.00 \\
.00 \\
.00 \\
.00\end{array}$ \\
\hline
\end{tabular}

e Estinated

STATISIICS OF MONTHLY MEAN DATA FOR WAIER YEARS 1990 - 1991, BY WATER YEAR (WY)

$\begin{array}{lrrrrrrrrrrrr}\text { MEAN } & 1.87 & .65 & 6.20 & 1.40 & .10 & 3.14 & .80 & .91 & .35 & .11 & .005 & .000 \\ \text { MAX } & 1.87 & .65 & 6.20 & 1.40 & .70 & 3.14 & .80 & .91 & .35 & .11 & .005 & .000 \\ \text { (WY) } & 1991 & 1991 & 1991 & 1991 & 1991 & 1991 & 1991 & 1991 & 1991 & 1991 & 1991 & 1991 \\ \text { MIN } & 1.87 & .65 & 6.20 & 1.40 & .70 & 3.14 & .80 & .91 & .35 & .11 & .005 & .000 \\ \text { (WY) } & 1991 & 1991 & 1991 & 1991 & 1991 & 1991 & 1991 & 1991 & 1991 & 1991 & 1991 & 1991\end{array}$

ANNUAL TOIAL

ANNUAL MEAN

HIGHEST ANMUAL MEAN

LOWEST ANNUAL MEAM

HIGHEST DAILY MEAN

LOWEST DAILY MEAN

ANNUAL SEVEN-DAY MINIMUM

INSTANTANEOUS PEAK FLOW

INSTANTANEOUS PEAK STAGE

ANMUAL RUNOFF (CFSM)

AMNUAL RUMOFF (INCHES)

10 PERCENT EXCEEDS

50 PERCENT EXCEEDS

90 PERCENT EXCEEDS

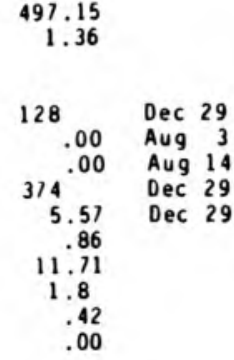

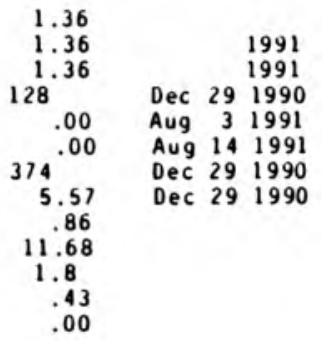


LOCAIION.--Lat 40 $25^{\prime} 53^{\prime \prime}$, Iong $87^{\circ} 02^{\prime} 16^{\prime \prime}$, In SE \&SEl sec.13, T.23 N., R.6 W. Tippecanoe County. Hydrologic Unit 05120108 , on right bank 1.8 mile upstrean from aouth, 1.4 aile downstrean from Goose Creek and 3.0

-iles southwest on Mgntmorenci.

DRAI NAGE AREA, $-27.8 \mathrm{~m} \mathrm{i}^{2}$

PERIOD OF RECORD.--OCtober 1990 to current year.

GAGE.--Data-Collection Platfora. Datun of gage is $530.05 \mathrm{ft}$ above National Geodetic Vertical Datua of 1929 .

REMARKS. - - Records good except for estimated daily discharges, which are poor.

DISCHARGE, CUBIC FEET PER SECONO, WATER YEAR OCTOBER 1990 TO SEPIEMBER 1991 DAI IY MEAN VALUES

\begin{tabular}{|c|c|c|c|c|c|c|c|c|c|c|c|c|}
\hline DAY & $O C \mathrm{~T}$ & NOV & DEC & JAN & FE B & MAR & APR & MAY & JUN & JUL & $A \cup G$ & SEP \\
\hline $\begin{array}{l}1 \\
2 \\
3 \\
4 \\
5\end{array}$ & $\begin{array}{l}.34 \\
.26 \\
.69 \\
5.3 \\
1.4\end{array}$ & $\begin{array}{l}5.0 \\
5.5 \\
5.1 \\
5.0 \\
76\end{array}$ & $\begin{array}{l}13 \\
10 \\
73 \\
36 \\
22\end{array}$ & $\begin{array}{r}66 \\
43 \\
29 \\
e 20 \\
e 18\end{array}$ & $\begin{array}{l}\text { el1 } \\
\text { el1 } \\
16 \\
19 \\
25\end{array}$ & $\begin{array}{l}13 \\
16 \\
14 \\
14 \\
13\end{array}$ & $\begin{array}{l}23 \\
21 \\
21 \\
21 \\
22\end{array}$ & $\begin{array}{l}14 \\
13 \\
12 \\
13 \\
14\end{array}$ & $\begin{array}{r}19 \\
14 \\
15 \\
9.7 \\
8.0\end{array}$ & $\begin{array}{l}1.8 \\
2.1 \\
1.9 \\
2.1 \\
1.9\end{array}$ & $\begin{array}{l}1.2 \\
.75 \\
.98 \\
2.2 \\
2.5\end{array}$ & $\begin{array}{l}.15 \\
.15 \\
.23 \\
.19 \\
.12\end{array}$ \\
\hline $\begin{array}{r}6 \\
7 \\
8 \\
9 \\
10\end{array}$ & $\begin{array}{c}4.62 \\
8.3 \\
80 \\
90 \\
238\end{array}$ & $\begin{array}{l}49 \\
23 \\
15 \\
13 \\
11\end{array}$ & $\begin{array}{l}18 \\
15 \\
13 \\
12 \\
11\end{array}$ & $\begin{array}{r}\text { e15 } \\
14 \\
14 \\
13 \\
12\end{array}$ & $\begin{array}{l}29 \\
30 \\
25 \\
24 \\
22\end{array}$ & $\begin{array}{l}13 \\
12 \\
11 \\
11 \\
10\end{array}$ & $\begin{array}{l}21 \\
21 \\
25 \\
26 \\
22\end{array}$ & $\begin{array}{l}14 \\
12 \\
11 \\
11 \\
11\end{array}$ & $\begin{array}{l}6.9 \\
6.2 \\
5.9 \\
5.7 \\
5.4\end{array}$ & $\begin{array}{l}1.7 \\
1.6 \\
1.6 \\
1.8 \\
1.8\end{array}$ & $\begin{array}{c}3.4 \\
2.3 \\
17 \\
3.4 \\
.67\end{array}$ & $\begin{array}{l}.12 \\
.12 \\
.08 \\
.11 \\
.12\end{array}$ \\
\hline $\begin{array}{l}11 \\
12 \\
13 \\
14 \\
15\end{array}$ & $\begin{array}{l}70 \\
36 \\
22 \\
16 \\
12\end{array}$ & $\begin{array}{l}9.3 \\
8.1 \\
6.9 \\
6.4 \\
5.8\end{array}$ & $\begin{array}{l}11 \\
11 \\
9.4 \\
7.9 \\
26\end{array}$ & $\begin{array}{l}28 \\
27 \\
17 \\
25 \\
47\end{array}$ & $\begin{array}{r}19 \\
19 \\
19 \\
18 \\
e 17\end{array}$ & $\begin{array}{r}9.9 \\
44 \\
282 \\
170 \\
148\end{array}$ & $\begin{array}{l}20 \\
20 \\
22 \\
49 \\
75\end{array}$ & $\begin{array}{l}15 \\
20 \\
14 \\
12 \\
11\end{array}$ & $\begin{array}{l}5.2 \\
5.0 \\
4.6 \\
4.1 \\
3.8\end{array}$ & $\begin{array}{l}1.8 \\
4.5 \\
3.6 \\
3.1 \\
2.8\end{array}$ & $\begin{array}{l}.46 \\
.37 \\
.37 \\
.37 \\
.37\end{array}$ & $\begin{array}{l}.11 \\
.12 \\
.29 \\
.19 \\
.12\end{array}$ \\
\hline $\begin{array}{l}16 \\
17 \\
18 \\
19 \\
20\end{array}$ & $\begin{array}{l}11 \\
10 \\
52 \\
24 \\
16\end{array}$ & $\begin{array}{l}5.5 \\
5.0 \\
4.7 \\
4.7 \\
4.3\end{array}$ & $\begin{array}{l}19 \\
18 \\
31 \\
27 \\
20\end{array}$ & $\begin{array}{r}170 \\
65 \\
36 \\
31 \\
33\end{array}$ & $\begin{array}{l}\text { e16 } \\
\text { e15 } \\
17 \\
27 \\
22\end{array}$ & $\begin{array}{r}95 \\
120 \\
200 \\
69 \\
51\end{array}$ & $\begin{array}{l}41 \\
25 \\
20 \\
20 \\
17\end{array}$ & $\begin{array}{l}11 \\
11 \\
92 \\
24 \\
15\end{array}$ & $\begin{array}{r}4.3 \\
3.8 \\
3.4 \\
\mathrm{e} 3.0 \\
\mathrm{e} 2.9\end{array}$ & $\begin{array}{l}2.7 \\
2.4 \\
2.4 \\
2.3 \\
2.3\end{array}$ & $\begin{array}{l}.36 \\
.42 \\
.45 \\
.95 \\
.48\end{array}$ & $\begin{array}{l}.14 \\
.17 \\
.26 \\
.26 \\
.29\end{array}$ \\
\hline $\begin{array}{l}21 \\
22 \\
23 \\
24 \\
25\end{array}$ & $\begin{array}{l}13 \\
10 \\
9.4 \\
8.3 \\
7.4\end{array}$ & $\begin{array}{l}4.1 \\
4.7 \\
4.1 \\
4.1 \\
3.8\end{array}$ & $\begin{array}{r}93 \\
81 \\
38 \\
\text { e } 31 \\
e 25\end{array}$ & $\begin{array}{r}29 \\
\text { e25 } \\
\text { e23 } \\
\text { e20 } \\
\text { e18 }\end{array}$ & $\begin{array}{l}20 \\
18 \\
16 \\
16 \\
14\end{array}$ & $\begin{array}{l}43 \\
55 \\
95 \\
47 \\
36\end{array}$ & $\begin{array}{l}16 \\
15 \\
15 \\
14 \\
13\end{array}$ & $\begin{array}{l}12 \\
11 \\
12 \\
12 \\
11\end{array}$ & $\begin{array}{l}2.8 \\
2.8 \\
2.6 \\
2.3 \\
2.0\end{array}$ & $\begin{array}{l}2.1 \\
2.0 \\
1.5 \\
2.2 \\
2.5\end{array}$ & $\begin{array}{l}.26 \\
.19 \\
.15 \\
.15 \\
.14\end{array}$ & $\begin{array}{l}.31 \\
.38 \\
.39 \\
.31 \\
.32\end{array}$ \\
\hline $\begin{array}{l}26 \\
27 \\
28 \\
29 \\
30 \\
31\end{array}$ & $\begin{array}{l}6.7 \\
6.5 \\
5.9 \\
5.1 \\
4.9 \\
4.9\end{array}$ & $\begin{array}{l}3.5 \\
4.9 \\
56 \\
26 \\
16 \\
\cdots\end{array}$ & $\begin{array}{l}\text { e22 } \\
\text { e20 } \\
\text { e18 } \\
997 \\
686 \\
118\end{array}$ & $\begin{array}{l}\text { el } 6 \\
\text { e15 } \\
\text { el } 14 \\
\text { e } 14 \\
\text { e13 } \\
\text { el } 12\end{array}$ & $\begin{array}{l}15 \\
14 \\
13 \\
\cdots \\
\cdots \\
\cdots\end{array}$ & $\begin{array}{l}79 \\
60 \\
39 \\
31 \\
26 \\
25\end{array}$ & $\begin{array}{l}13 \\
13 \\
13 \\
14 \\
13 \\
\cdots\end{array}$ & $\begin{array}{r}9.5 \\
8.2 \\
7.2 \\
9.5 \\
12 \\
74\end{array}$ & $\begin{array}{l}2.0 \\
1.9 \\
1.7 \\
1.6 \\
1.5 \\
\ldots\end{array}$ & $\begin{array}{l}2.0 \\
1.7 \\
1.6 \\
1.7 \\
1.9 \\
1.6\end{array}$ & $\begin{array}{l}.14 \\
.15 \\
.15 \\
.16 \\
.20 \\
.20\end{array}$ & $\begin{array}{l}.32 \\
.35 \\
.40 \\
.37 \\
.36 \\
. .\end{array}$ \\
\hline $\begin{array}{l}\text { TOTAL } \\
\text { MEAN } \\
\text { MAX } \\
\text { MIN } \\
\text { CF SM } \\
\text { IN. }\end{array}$ & $\begin{array}{r}700.11 \\
22.6 \\
238 \\
.26 \\
.81 \\
.94\end{array}$ & $\begin{array}{r}395.5 \\
13.2 \\
76 \\
3.5 \\
.47 \\
.53\end{array}$ & $\begin{array}{r}2532.3 \\
81.7 \\
997 \\
7.9 \\
2.94 \\
3.39\end{array}$ & $\begin{array}{r}922 \\
29.7 \\
110 \\
12 \\
1.07 \\
1.23\end{array}$ & $\begin{array}{r}527 \\
18.8 \\
30 \\
11 \\
.68 \\
.71\end{array}$ & $\begin{array}{r}1851.9 \\
59.7 \\
282 \\
9.9 \\
2.15 \\
2.48\end{array}$ & $\begin{array}{r}671 \\
22.4 \\
75 \\
13 \\
.80 \\
.90\end{array}$ & $\begin{array}{r}528.4 \\
17.0 \\
92 \\
7.2 \\
.61 \\
.71\end{array}$ & $\begin{array}{r}157.1 \\
5.24 \\
19 \\
1.5 \\
.19 \\
.21\end{array}$ & $\begin{array}{l}67.0 \\
2.16 \\
4.5 \\
1.5 \\
.08 \\
.09\end{array}$ & $\begin{array}{c}40.89 \\
1.32 \\
17 \\
.14 \\
.05 \\
.05\end{array}$ & $\begin{array}{l}6.85 \\
.23 \\
.40 \\
.08 \\
.01 \\
.01\end{array}$ \\
\hline
\end{tabular}

e Estinated

SIATISIICS OF MONTHLY MEAN DATA FOR WAIER YEARS 1990 - 1991, BY WATER YEAR (WY)

\begin{tabular}{|c|c|c|c|c|c|c|c|c|c|c|c|c|}
\hline $\begin{array}{l}\text { MEAN } \\
\text { MAX } \\
\text { (WY) } \\
\text { MIN } \\
(W Y)\end{array}$ & $\begin{array}{l}21.7 \\
21.7 \\
1991 \\
21.7 \\
1991\end{array}$ & $\begin{array}{l}12.8 \\
12.8 \\
1991 \\
12.8 \\
1991\end{array}$ & $\begin{array}{l}81.7 \\
81.7 \\
1991 \\
81.7 \\
1991\end{array}$ & $\begin{array}{l}28.6 \\
28.6 \\
1991 \\
28.6 \\
1991\end{array}$ & $\begin{array}{l}18.3 \\
18.3 \\
1991 \\
18.3 \\
1991\end{array}$ & $\begin{array}{l}56.8 \\
56.8 \\
1991 \\
56.8 \\
1991\end{array}$ & $\begin{array}{l}21.7 \\
21.7 \\
1991 \\
21.7 \\
1991\end{array}$ & $\begin{array}{l}16.7 \\
16.7 \\
1991 \\
16.7 \\
1991\end{array}$ & $\begin{array}{l}5.23 \\
5.23 \\
1991 \\
5.23 \\
1991\end{array}$ & $\begin{array}{l}2.17 \\
2.17 \\
1991 \\
2.17 \\
1991\end{array}$ & $\begin{array}{l}1.30 \\
1.30 \\
1991 \\
1.30 \\
1.991\end{array}$ & $\begin{array}{r}.21 \\
.21 \\
1991 \\
.21 \\
1991\end{array}$ \\
\hline
\end{tabular}

SUMMARY SIATISIICS

ANMUAL TOTAL

ANNUAL MEAN

HI GHEST ANNUAL MEAN

LOWEST ANHUAL MEAN

HIGHESI DAILY MEAM

LOWEST DAILY MEAN

ANNUAL SEVEM-DAY MINIMUM

INSTANTANEOUS PEAK FIOW

INSIANTANEOUS PEAK SIAGE

ANNUAL RUNOFF (CFSM)

ANNUAL RUNOFF (INCHES)

10 PERCENT EXCEEDS

50 PERCENT EXCEEDS

90 PERCENT EXCEEDS
FOR 1991 WATER YEAR

WAIER YEARS $1990 \quad 1991$

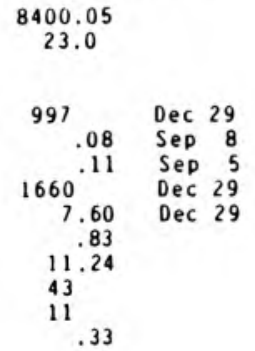




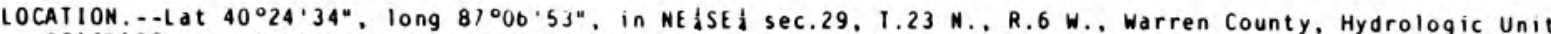
05120108 , On right bank at southwest edge of Green Hill, 1.2 ille downstrea from Arastrong Creek and at - ile 6.1.

DRAINAGE AREA,$-42.3 \mathrm{i}^{2}$

PERIOD OF RECORD.--October 1990 to current year.

GAGE.--Data-Collection Platfora. Datun of gage is $599.90 \mathrm{ft}$ above National Geodetic Vertical Datua of 1929.

REMARKS. - - Records fair except for estiedted daily discharges, which are poor.

DISCHARGE, CUBIC FEET PER SECOND, WATER YEAR OCTOBER 1990 TO SEPTEMBER 1991

DAIIY MEAN VALUES

\begin{tabular}{|c|c|c|c|c|c|c|c|c|c|c|c|c|}
\hline DAY & $\mathrm{OCT}$ & NOV & DEC & JAN & FEB & MAR & APR & MAY & JUN & JUL & AUG & SEP \\
\hline $\begin{array}{l}1 \\
2 \\
3 \\
4 \\
5\end{array}$ & $\begin{array}{l}2.1 \\
1.9 \\
4.0 \\
19 \\
12\end{array}$ & $\begin{array}{l}13 \\
12 \\
12 \\
12 \\
82\end{array}$ & $\begin{array}{r}46 \\
35 \\
105 \\
107 \\
70\end{array}$ & $\begin{array}{r}271 \\
196 \\
151 \\
113 \\
94\end{array}$ & $\begin{array}{r}\text { e22 } \\
\text { e23 } \\
41 \\
57 \\
70\end{array}$ & $\begin{array}{l}23 \\
34 \\
32 \\
29 \\
26\end{array}$ & $\begin{array}{l}46 \\
40 \\
35 \\
33 \\
33\end{array}$ & $\begin{array}{l}27 \\
25 \\
24 \\
29 \\
29\end{array}$ & $\begin{array}{r}122 \\
69 \\
52 \\
40 \\
32\end{array}$ & $\begin{array}{l}\mathrm{e} 3.6 \\
\mathrm{e} 3.4 \\
\mathrm{e} 3.2 \\
\mathrm{e} 5.2 \\
\mathrm{e} 3.9\end{array}$ & $\begin{array}{l}\text { e } 3.0 \\
\text { e } 2.6 \\
\text { e } 3.1 \\
\text { e } 4.5 \\
\text { e } 6.0\end{array}$ & $\begin{array}{l}\text { e. } 87 \\
\text { e. } 87 \\
\text { e } 1.1 \\
\text { e } 1.0 \\
\text { e. } 76\end{array}$ \\
\hline $\begin{array}{r}6 \\
7 \\
8 \\
9 \\
10\end{array}$ & $\begin{array}{l}7.9 \\
14 \\
23 \\
130 \\
272\end{array}$ & $\begin{array}{r}145 \\
85 \\
53 \\
41 \\
29\end{array}$ & $\begin{array}{l}58 \\
45 \\
38 \\
32 \\
30\end{array}$ & $\begin{array}{l}80 \\
68 \\
61 \\
54 \\
48\end{array}$ & $\begin{array}{l}72 \\
70 \\
59 \\
54 \\
48\end{array}$ & $\begin{array}{l}27 \\
22 \\
19 \\
18 \\
19\end{array}$ & $\begin{array}{l}30 \\
29 \\
33 \\
37 \\
29\end{array}$ & $\begin{array}{l}32 \\
27 \\
26 \\
24 \\
22\end{array}$ & $\begin{array}{l}27 \\
24 \\
23 \\
21 \\
20\end{array}$ & $\begin{array}{l}\text { e } 3.6 \\
\text { e3.0 } \\
\text { e2.7 } \\
\text { e2. } 2 \\
\text { e2.4 }\end{array}$ & $\begin{array}{r}\mathrm{e} 9.4 \\
\mathrm{e} 8.0 \\
\mathrm{e} 21 \\
\mathrm{e} 6.0 \\
\mathrm{e} 2.7\end{array}$ & $\begin{array}{l}\text { e. } 76 \\
\text { e. } 75 \\
\text { e. } 55 \\
\text { e. } 64 \\
\text { e. } 68\end{array}$ \\
\hline $\begin{array}{l}11 \\
12 \\
13 \\
14 \\
15\end{array}$ & $\begin{array}{r}263 \\
193 \\
144 \\
99 \\
72\end{array}$ & $\begin{array}{l}23 \\
19 \\
17 \\
16 \\
15\end{array}$ & $\begin{array}{l}27 \\
27 \\
25 \\
23 \\
51\end{array}$ & $\begin{array}{r}63 \\
80 \\
56 \\
59 \\
101\end{array}$ & $\begin{array}{r}39 \\
34 \\
36 \\
34 \\
\text { e24 }\end{array}$ & $\begin{array}{r}17 \\
30 \\
235 \\
251 \\
256\end{array}$ & $\begin{array}{l}25 \\
50 \\
39 \\
65 \\
99\end{array}$ & $\begin{array}{l}22 \\
52 \\
40 \\
31 \\
30\end{array}$ & $\begin{array}{l}18 \\
17 \\
15 \\
14 \\
14\end{array}$ & $\begin{array}{l}\text { e2.7 } \\
\text { e8.5 } \\
\text { e6.0 } \\
\text { e } 5.1 \\
\text { e4.8 }\end{array}$ & $\begin{array}{l}\text { e2.7 } \\
\text { e2.7 } \\
\text { e2.7 } \\
\text { e2.7 } \\
\text { e2.7 }\end{array}$ & $\begin{array}{r}\text { e. } 70 \\
\text { e. } 10 \\
\text { e1.0 } \\
\text { e1. } 3 \\
\text { e1. } 0\end{array}$ \\
\hline $\begin{array}{l}16 \\
17 \\
18 \\
19 \\
20\end{array}$ & $\begin{array}{r}58 \\
52 \\
113 \\
93 \\
69\end{array}$ & $\begin{array}{l}15 \\
13 \\
12 \\
12 \\
11\end{array}$ & $\begin{array}{l}50 \\
45 \\
66 \\
64 \\
53\end{array}$ & $\begin{array}{r}252 \\
207 \\
122 \\
98 \\
\mathrm{e} 79\end{array}$ & $\begin{array}{r}e 22 \\
e 24 \\
e 27 \\
47 \\
40\end{array}$ & $\begin{array}{l}192 \\
158 \\
272 \\
195 \\
125\end{array}$ & $\begin{array}{l}88 \\
66 \\
56 \\
62 \\
48\end{array}$ & $\begin{array}{r}33 \\
45 \\
125 \\
132 \\
73\end{array}$ & $\begin{array}{r}13 \\
12 \\
11 \\
9.9 \\
8.8\end{array}$ & $\begin{array}{l}\mathrm{e} 4.6 \\
\mathrm{e} 4.4 \\
\mathrm{e} 4.3 \\
\mathrm{e} 4.2 \\
\mathrm{e} 4.0\end{array}$ & $\begin{array}{l}\mathrm{e} 2.7 \\
\mathrm{e} 2.2 \\
\mathrm{e} 2.4 \\
\mathrm{e} 4.8 \\
\mathrm{e} 3.0\end{array}$ & $\begin{array}{r}\text { e. } 80 \\
\text { e. } 86 \\
\text { e1. } 0 \\
\text { e1. } \\
\text { e1. } 2\end{array}$ \\
\hline $\begin{array}{l}21 \\
22 \\
23 \\
24 \\
25\end{array}$ & $\begin{array}{l}52 \\
41 \\
31 \\
24 \\
20\end{array}$ & $\begin{array}{c}11 \\
12 \\
11 \\
11 \\
9.7\end{array}$ & $\begin{array}{r}109 \\
205 \\
125 \\
93 \\
e 67\end{array}$ & $\begin{array}{l}\text { e } 62 \\
\text { e } 51 \\
\text { e } 45 \\
\text { e } 40 \\
\text { e } 35\end{array}$ & $\begin{array}{l}36 \\
33 \\
28 \\
28 \\
25\end{array}$ & $\begin{array}{r}99 \\
94 \\
143 \\
101 \\
82\end{array}$ & $\begin{array}{l}41 \\
38 \\
35 \\
32 \\
28\end{array}$ & $\begin{array}{l}52 \\
43 \\
62 \\
93 \\
57\end{array}$ & $\begin{array}{r}7.8 \\
\mathrm{e} 7.3 \\
\mathrm{e} 7.0 \\
\mathrm{e} 6.2 \\
\mathrm{e} 6.0\end{array}$ & $\begin{array}{l}\text { e } 3.6 \\
\text { e3.3 } \\
\text { e } 3.0 \\
\text { e2. } 2.8 \\
\text { e } 4.7\end{array}$ & $\begin{array}{l}\text { e2. } 3 \\
\text { el } .5 \\
\text { e1. } \\
\text { e. } 88 \\
\text { e. } 88\end{array}$ & $\begin{array}{l}\text { el. } \\
\text { e1 } \\
\text { e } 1.3 \\
\text { e1. } \\
\text { e } 1.0\end{array}$ \\
\hline $\begin{array}{l}26 \\
27 \\
28 \\
29 \\
30 \\
31\end{array}$ & $\begin{array}{l}19 \\
18 \\
17 \\
15 \\
15 \\
14\end{array}$ & $\begin{array}{c}8.5 \\
10 \\
104 \\
87 \\
57 \\
\ldots .\end{array}$ & $\begin{array}{r}e 59 \\
\text { e48 } \\
\text { e44 } \\
649 \\
1250 \\
482\end{array}$ & $\begin{array}{l}\text { e } 32 \\
\text { e28 } \\
\text { e } 26 \\
\text { e } 25 \\
\text { e24 } \\
\text { e23 }\end{array}$ & $\begin{array}{l}24 \\
24 \\
23 \\
\cdots \\
\cdots \\
\cdots\end{array}$ & $\begin{array}{r}113 \\
124 \\
89 \\
71 \\
57 \\
51\end{array}$ & $\begin{array}{l}29 \\
28 \\
26 \\
27 \\
26 \\
\cdots-\end{array}$ & $\begin{array}{r}47 \\
38 \\
32 \\
29 \\
34 \\
181\end{array}$ & $\begin{array}{l}\text { e } 5.2 \\
\text { e } 4.8 \\
\text { e } 4.3 \\
\text { e } 4.2 \\
\text { e } 3.7 \\
\ldots . .\end{array}$ & $\begin{array}{l}\text { e } 3.9 \\
\text { e } 3.4 \\
\text { e } 3.1 \\
\text { e } 3.9 \\
\text { e } 4.5 \\
\text { e } 3.7\end{array}$ & $\begin{array}{r}\text { e. } 88 \\
\text { e. } 88 \\
\text { e. } 88 \\
\text { e. } .91 \\
\text { e1 } 1.0 \\
\text { e } 1.0\end{array}$ & $\begin{array}{l}\text { e1. } \\
\text { e1.5 } \\
\text { e1.6 } \\
\text { e1. } 1.6 \\
\text { e1.6 } \\
-\ldots\end{array}$ \\
\hline $\begin{array}{l}\text { IOIAL } \\
\text { MEAN } \\
\text { MAX } \\
\text { MIN } \\
\text { CF SM } \\
\text { IN. }\end{array}$ & $\begin{array}{r}1907.9 \\
61.5 \\
272 \\
1.9 \\
1.45 \\
1.68\end{array}$ & $\begin{array}{r}958.2 \\
31.9 \\
145 \\
8.5 \\
.76 \\
.84\end{array}$ & $\begin{array}{r}4128 \\
133 \\
1250 \\
23 \\
3.15 \\
3.63\end{array}$ & $\begin{array}{r}2644 \\
85.3 \\
271 \\
23 \\
2.02 \\
2.33\end{array}$ & $\begin{array}{r}1064 \\
38.0 \\
72 \\
22 \\
.90 \\
.94\end{array}$ & $\begin{array}{r}3004 \\
96.9 \\
272 \\
17 \\
2.29 \\
2.64\end{array}$ & $\begin{array}{r}1253 \\
41.8 \\
99 \\
25 \\
.99 \\
1.10\end{array}$ & $\begin{array}{r}1516 \\
48.9 \\
181 \\
22 \\
1.16 \\
1.33\end{array}$ & $\begin{array}{r}619.2 \\
20.6 \\
122 \\
3.7 \\
.49 \\
.54\end{array}$ & $\begin{array}{r}121.9 \\
3.93 \\
8.5 \\
2.4 \\
.09 \\
.11\end{array}$ & $\begin{array}{r}107.11 \\
3.46 \\
21 \\
.88 \\
.08 \\
.09\end{array}$ & $\begin{array}{c}31.74 \\
1.06 \\
1.6 \\
.55 \\
.03 \\
.03\end{array}$ \\
\hline
\end{tabular}

e Estinated

STAIISIICS OF MONIHLY MEAN DATA FOR WAIER YEARS 1990 - 1991, BY WAIER YEAR (WY)

\begin{tabular}{|c|c|c|c|c|c|c|c|c|c|c|c|c|}
\hline $\begin{array}{l}\text { MEAN } \\
\text { MAX } \\
\text { (WY) } \\
\text { MIN } \\
\text { (WY) }\end{array}$ & $\begin{array}{l}61.5 \\
61.5 \\
1991 \\
61.5 \\
1991\end{array}$ & $\begin{array}{l}31.9 \\
31.9 \\
1991 \\
31.9 \\
1991\end{array}$ & $\begin{array}{r}133 \\
133 \\
1991 \\
133 \\
1991\end{array}$ & $\begin{array}{l}85.3 \\
85.3 \\
1991 \\
85.3 \\
1991\end{array}$ & $\begin{array}{l}38.0 \\
38.0 \\
1991 \\
38.0 \\
1991\end{array}$ & $\begin{array}{l}96.9 \\
96.9 \\
1991 \\
96.9 \\
1991\end{array}$ & $\begin{array}{l}41.8 \\
41.8 \\
1991 \\
41.8 \\
1991\end{array}$ & $\begin{array}{l}48.9 \\
48.9 \\
1991 \\
48.9 \\
1991\end{array}$ & $\begin{array}{l}20.6 \\
20.6 \\
1991 \\
20.6 \\
1991\end{array}$ & $\begin{array}{l}3.93 \\
3.93 \\
1991 \\
3.93 \\
1991\end{array}$ & $\begin{array}{l}3.46 \\
3.46 \\
1991 \\
3.46 \\
1991\end{array}$ & $\begin{array}{l}1.06 \\
1.06 \\
1991 \\
1.06 \\
1991\end{array}$ \\
\hline
\end{tabular}

SUMMARY SIAIISIICS

AMNUAL TOTAL

ANMUAL MEAN

HIGHEST ANMUAL MEAN

LOWEST ANMUAL MEAN

HIGHEST DAILY MEAN

LOWEST DAILY MEAN

ANMUAL SEVEN-DAY MINIMUM

INSTANTANEOUS PEAK FLOW

INSIANIANEOUS PEAK SIAGE

ANNUAL RUNOFF (CFSM)

ANNUAL RUNOFF (INCHES)

10 PERCENT EXCEEDS

50 PERCENT EXCEEDS

90 PERCENT EXCEEDS
FOR 1991 WATER YEAR

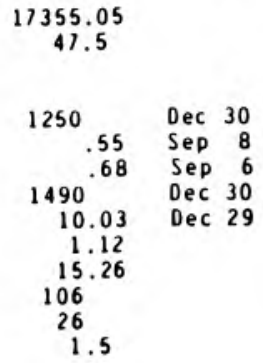

WAIER YEARS 1990 - 1991

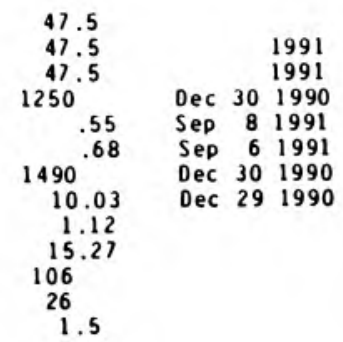




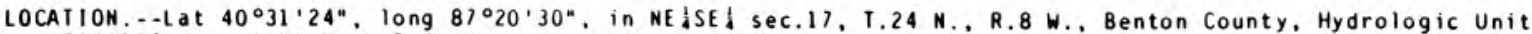

05120108 , on right bank $5 \mathrm{ft}$ downstream from county road bridge, 0.3 north of Chase, 2 a east of Boswell,

and 5 i west of $0 \times$ ford.

DRAINAGE AREA. $\ldots 39.4 \bullet i^{2}$.

PERIOD OF RECORD.-.June igl1 to current year.

RE VISED RE CORDS.--WDR IN-80-1: 1971-79 (P).

GAGE.-- Water-stage recorder. Datum of gage is $718.00 \mathrm{ft}$ above National Geodetic Vertical Datum of 1929.

REMARKS. - Records good except for estinated daily discharges, which are poor.

DISCHARGE, CUBIC FEET PER SECOND, WATER YEAR OCTOBER 1990 TO SEPIEMBER 1991 DAILY MEAN VALUES

\begin{tabular}{|c|c|c|c|c|c|c|c|c|c|c|c|c|}
\hline DAY & $\mathrm{OCI}$ & NOV & DEC & JAN & FEB & MAR & APR & MAY & JUN & JUL & AUG & SEP \\
\hline $\begin{array}{l}1 \\
2 \\
3 \\
4 \\
5\end{array}$ & $\begin{array}{l}1.4 \\
1.4 \\
1.6 \\
3.3 \\
1.7\end{array}$ & $\begin{array}{r}17 \\
17 \\
16 \\
16 \\
166\end{array}$ & $\begin{array}{r}50 \\
40 \\
102 \\
82 \\
58\end{array}$ & $\begin{array}{r}163 \\
120 \\
90 \\
75 \\
\text { e66 }\end{array}$ & $\begin{array}{r}\text { e22 } \\
27 \\
66 \\
83 \\
100\end{array}$ & $\begin{array}{l}31 \\
82 \\
68 \\
54 \\
48\end{array}$ & $\begin{array}{l}45 \\
41 \\
39 \\
40 \\
39\end{array}$ & $\begin{array}{l}26 \\
24 \\
23 \\
24 \\
31\end{array}$ & $\begin{array}{l}30 \\
26 \\
25 \\
21 \\
18\end{array}$ & $\begin{array}{l}3.9 \\
4.6 \\
5.7 \\
3.8 \\
3.4\end{array}$ & $\begin{array}{l}1.3 \\
1.3 \\
1.3 \\
1.7 \\
1.5\end{array}$ & $\begin{array}{c}1.0 \\
.82 \\
.84 \\
1.4 \\
1.3\end{array}$ \\
\hline $\begin{array}{r}6 \\
7 \\
8 \\
9 \\
10\end{array}$ & $\begin{array}{r}1.5 \\
3.7 \\
6.0 \\
159 \\
571\end{array}$ & $\begin{array}{r}171 \\
102 \\
71 \\
58 \\
47\end{array}$ & $\begin{array}{l}49 \\
40 \\
35 \\
32 \\
30\end{array}$ & $\begin{array}{r}\text { e } 55 \\
\text { e } 51 \\
\text { e } 45 \\
\text { e } 42 \\
39\end{array}$ & $\begin{array}{l}88 \\
80 \\
65 \\
62 \\
61\end{array}$ & $\begin{array}{l}46 \\
35 \\
32 \\
31 \\
28\end{array}$ & $\begin{array}{l}37 \\
36 \\
35 \\
35 \\
29\end{array}$ & $\begin{array}{l}29 \\
24 \\
22 \\
22 \\
22\end{array}$ & $\begin{array}{l}17 \\
16 \\
15 \\
14 \\
14\end{array}$ & $\begin{array}{l}3.0 \\
2.6 \\
2.4 \\
2.3 \\
2.3\end{array}$ & $\begin{array}{r}2.6 \\
2.3 \\
4.6 \\
11 \\
2.5\end{array}$ & $\begin{array}{l}.89 \\
.73 \\
.63 \\
.59 \\
.78\end{array}$ \\
\hline $\begin{array}{l}11 \\
12 \\
13 \\
14 \\
15\end{array}$ & $\begin{array}{r}258 \\
153 \\
107 \\
78 \\
59\end{array}$ & $\begin{array}{l}38 \\
32 \\
30 \\
28 \\
27\end{array}$ & $\begin{array}{l}29 \\
28 \\
24 \\
22 \\
61\end{array}$ & $\begin{array}{r}56 \\
62 \\
45 \\
54 \\
116\end{array}$ & $\begin{array}{l}51 \\
44 \\
45 \\
38 \\
29\end{array}$ & $\begin{array}{r}28 \\
41 \\
212 \\
167 \\
221\end{array}$ & $\begin{array}{r}27 \\
27 \\
30 \\
68 \\
255\end{array}$ & $\begin{array}{l}21 \\
22 \\
22 \\
21 \\
19\end{array}$ & $\begin{array}{l}13 \\
14 \\
11 \\
11 \\
14\end{array}$ & $\begin{array}{l}2.2 \\
4.0 \\
2.8 \\
2.3 \\
2.1\end{array}$ & $\begin{array}{l}1.9 \\
1.7 \\
1.6 \\
1.5 \\
1.4\end{array}$ & $\begin{array}{r}.87 \\
.70 \\
.68 \\
1.8 \\
.90\end{array}$ \\
\hline $\begin{array}{l}16 \\
17 \\
18 \\
19 \\
20\end{array}$ & $\begin{array}{r}50 \\
46 \\
101 \\
67 \\
54\end{array}$ & $\begin{array}{l}26 \\
22 \\
23 \\
22 \\
19\end{array}$ & $\begin{array}{l}49 \\
46 \\
54 \\
49 \\
45\end{array}$ & $\begin{array}{r}395 \\
178 \\
108 \\
87 \\
81\end{array}$ & $\begin{array}{l}\text { e27 } \\
\text { e32 } \\
\text { e40 } \\
79 \\
63\end{array}$ & $\begin{array}{l}247 \\
269 \\
447 \\
178 \\
123\end{array}$ & $\begin{array}{r}152 \\
91 \\
69 \\
59 \\
49\end{array}$ & $\begin{array}{l}19 \\
20 \\
66 \\
46 \\
34\end{array}$ & $\begin{array}{c}46 \\
17 \\
13 \\
11 \\
9.6\end{array}$ & $\begin{array}{l}2.0 \\
1.8 \\
1.7 \\
1.6 \\
1.5\end{array}$ & $\begin{array}{l}1.3 \\
1.7 \\
2.0 \\
2.7 \\
2.5\end{array}$ & $\begin{array}{l}.49 \\
.32 \\
.45 \\
.45 \\
.33\end{array}$ \\
\hline $\begin{array}{l}21 \\
22 \\
23 \\
24 \\
25\end{array}$ & $\begin{array}{l}45 \\
37 \\
33 \\
30 \\
26\end{array}$ & $\begin{array}{l}21 \\
20 \\
20 \\
18 \\
16\end{array}$ & $\begin{array}{r}129 \\
171 \\
96 \\
e 62 \\
\text { e } 50\end{array}$ & $\begin{array}{r}63 \\
\text { e } 50 \\
\text { e } 40 \\
\text { e } 36 \\
\text { e } 34\end{array}$ & $\begin{array}{l}55 \\
50 \\
45 \\
42 \\
36\end{array}$ & $\begin{array}{r}95 \\
83 \\
163 \\
106 \\
83\end{array}$ & $\begin{array}{l}45 \\
42 \\
38 \\
33 \\
30\end{array}$ & $\begin{array}{r}29 \\
31 \\
41 \\
38 \\
157\end{array}$ & $\begin{array}{l}9.1 \\
9.3 \\
7.9 \\
6.8 \\
6.2\end{array}$ & $\begin{array}{l}1.5 \\
1.5 \\
1.3 \\
1.4 \\
1.4\end{array}$ & $\begin{array}{l}1.7 \\
1.5 \\
1.5 \\
1.3 \\
1.2\end{array}$ & $\begin{array}{c}.44 \\
.69 \\
1.1 \\
.85 \\
.70\end{array}$ \\
\hline $\begin{array}{l}26 \\
27 \\
28 \\
29 \\
30 \\
31\end{array}$ & $\begin{array}{l}24 \\
24 \\
20 \\
19 \\
19 \\
18\end{array}$ & $\begin{array}{r}15 \\
19 \\
167 \\
92 \\
64 \\
-\cdots\end{array}$ & $\begin{array}{r}\text { e40 } \\
\text { e37 } \\
\text { e35 } \\
1430 \\
1520 \\
294\end{array}$ & $\begin{array}{l}\text { e } 31 \\
\text { e2 } \\
\text { e } 26 \\
\text { e } 25 \\
\text { e23 } \\
\text { e22 }\end{array}$ & $\begin{array}{c}33 \\
32 \\
30 \\
\cdots \\
\cdots \\
\cdots\end{array}$ & $\begin{array}{r}130 \\
125 \\
86 \\
67 \\
55 \\
51\end{array}$ & $\begin{array}{l}30 \\
30 \\
28 \\
31 \\
27 \\
\cdots\end{array}$ & $\begin{array}{r}117 \\
134 \\
66 \\
49 \\
41 \\
34\end{array}$ & $\begin{array}{l}5.7 \\
5.3 \\
4.8 \\
4.6 \\
4.3 \\
\ldots .-\end{array}$ & $\begin{array}{l}1.3 \\
1.3 \\
1.3 \\
1.3 \\
1.4 \\
1.3\end{array}$ & $\begin{array}{l}1.1 \\
1.1 \\
1.2 \\
1.2 \\
1.2 \\
1.1\end{array}$ & $\begin{array}{l}.52 \\
.45 \\
.52 \\
.54 \\
.47 \\
. .-\end{array}$ \\
\hline $\begin{array}{l}\text { TOTAL } \\
\text { MEAN } \\
\text { MAX } \\
\text { MIN } \\
\text { CFSM } \\
\text { IN. }\end{array}$ & $\begin{array}{r}2018.6 \\
65.1 \\
571 \\
1.4 \\
1.65 \\
1.91\end{array}$ & $\begin{array}{r}1400 \\
46.7 \\
171 \\
15 \\
1.18 \\
1.32\end{array}$ & $\begin{array}{r}4789 \\
154 \\
1520 \\
22 \\
3.92 \\
4.52\end{array}$ & $\begin{array}{r}2306 \\
74.4 \\
395 \\
22 \\
1.89 \\
2.18\end{array}$ & $\begin{array}{r}1425 \\
50.9 \\
100 \\
22 \\
1.29 \\
1.35\end{array}$ & $\begin{array}{r}3432 \\
111 \\
447 \\
28 \\
2.81 \\
3.24\end{array}$ & $\begin{array}{r}1537 \\
51.2 \\
255 \\
27 \\
1.30 \\
1.45\end{array}$ & $\begin{array}{c}1274 \\
41.1 \\
157 \\
19 \\
1.04 \\
1.20\end{array}$ & $\begin{array}{r}419.6 \\
14.0 \\
46 \\
4.3 \\
.35 \\
.40\end{array}$ & $\begin{array}{r}71.0 \\
2.29 \\
5.7 \\
1.3 \\
.06 \\
.07\end{array}$ & $\begin{array}{c}62.5 \\
2.02 \\
11 \\
1.1 \\
.05 \\
.06\end{array}$ & $\begin{array}{r}22.25 \\
.74 \\
1.8 \\
.32 \\
.02 \\
.02\end{array}$ \\
\hline
\end{tabular}

e Estimated

STATISIICS OF MONIHLY MEAN DATA FOR WATER YEARS 1972 - 1991, BY WATER YEAR (WY)

$\begin{array}{lrrrrrrrrrrrr}\text { MEAN } & 13.3 & 25.2 & 50.5 & 34.8 & 63.8 & 76.4 & 61.9 & 59.4 & 45.9 & 13.4 & 16.7 & 14.6 \\ \text { MAX } & 91.2 & 169 & 154 & 123 & 158 & 237 & 147 & 159 & 145 & 66.7 & 122 & 94.4 \\ \text { (WY) } & 1978 & 1986 & 1991 & 1974 & 1990 & 1979 & 1979 & 1981 & 1980 & 1979 & 1981 & 1977 \\ \text { MIN } & .89 & .79 & .98 & .47 & 3.41 & 6.54 & 17.2 & 8.49 & 2.85 & .65 & .79 & .40 \\ \text { (WY) } & 1981 & 1981 & 1977 & 1977 & 1977 & 1981 & 1977 & 1976 & 1988 & 1988 & 1988 & 1983\end{array}$

SUMMARY SIAIISIICS

ANNUAL IOTAL

ANNUAL MEAN

HIGHEST ANMUAL MEAM

LOWEST ANNUAL MEAM

HIGHEST DAILY MEAM

LOWEST DAILY MEAN

ANHUAL SEVEN-DAY MINIMUM

INSTAMTANEOUS PEAK FLOW

INSTANTANEOUS PEAK SIAGE

ANNUAL RUMOFF (CFSM)

ANNUAL RUNOFF (INCHES)

10 PERCENT EXCEEDS

50 PERCENT EXCEEDS

90 PERCENT EXCEEDS
FOR 1990 CALENDAR YEAR

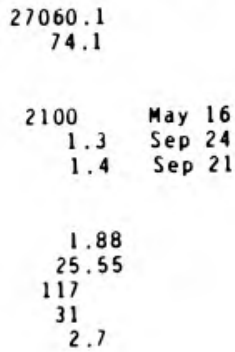

FOR 1991 WAIER YEAR

18756.95

51.4

1520 Dec 30

$\begin{array}{rr}.32 & \text { Sep 17 } \\ 3100^{.45} & \text { Sep 16 } \\ & \text { Dec 29 }\end{array}$

11.45 Dec 29

1. 30

104

28
WATER YEARS 1972 - 1991

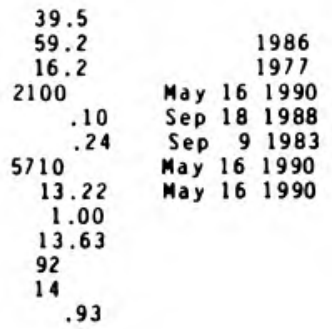




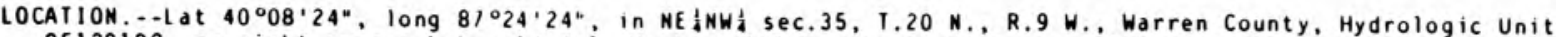
05120108 , on right approach to old U.S. Highway 136 bridge at Covington, 2.9 ai downstrea from Oppossue Run, 3.6 i upstrean from Spring Creek, and at ile 271.1 .

DRAINAGE AREA, $--8,218 \cdots i$.

PERIOD OF RECORD.--October 1939 to current year. Gage-height records collected at site 0.4 ai downstrea January 1927 to Decenber 1930, and at present site since January 1931 are contained in reports of National Weather Service.

REVISED RECORDS.-.WDR IN-73-1: Drainage area.

GAGE.--Water-stage recorder. Datum of gage is $473.97 \mathrm{ft}$ above National Geodetic Vertical Datua of 1929 . Prior to Oct. 1, 1979, nonrecording gage on old bridge.

REMARKS. - Records good. Flow partially regulated by upstrean reservoirs and power developaent.

EXIREMES OUISIDE PERIOD OF RECORD. - - Flood in March 1913 reached a stage of $35.1 \mathrm{ft}$, from $\mathrm{floodad}$. deterained by Wational Weather SErvice, discharge, $200,000 \mathrm{ft} / \mathrm{s}$.

DISCHARGE, CUBIC FEET PER SECOND, WATER YEAR OCTOBER 1990 TO SEPIEMBER 1991 DAILY MEAM VALUES

\begin{tabular}{|c|c|c|c|c|c|c|c|c|c|c|c|c|}
\hline DAY & $\mathrm{OCI}$ & NOV & DEC & JAN & FEB & MAR & APR & MAY & JUM & JUL & AUG & SEP \\
\hline $\begin{array}{l}1 \\
2 \\
3 \\
4 \\
5\end{array}$ & $\begin{array}{l}3560 \\
3490 \\
3390 \\
3550 \\
3960\end{array}$ & $\begin{array}{l}7160 \\
5670 \\
4540 \\
5050 \\
7250\end{array}$ & $\begin{array}{l}15700 \\
13800 \\
14200 \\
17200 \\
20700\end{array}$ & $\begin{array}{l}84600 \\
78200 \\
58400 \\
44000 \\
35800\end{array}$ & $\begin{array}{r}10200 \\
8150 \\
7660 \\
8100 \\
9290\end{array}$ & $\begin{array}{l}7620 \\
7560 \\
8280 \\
9150 \\
9080\end{array}$ & $\begin{array}{r}14700 \\
12800 \\
9870 \\
8210 \\
7830\end{array}$ & $\begin{array}{l}7430 \\
7080 \\
6520 \\
6530 \\
6310\end{array}$ & $\begin{array}{l}11200 \\
18400 \\
18500 \\
15600 \\
13400\end{array}$ & $\begin{array}{l}2410 \\
2580 \\
2540 \\
3160 \\
3270\end{array}$ & $\begin{array}{l}1410 \\
1330 \\
1260 \\
1310 \\
1270\end{array}$ & $\begin{array}{l}1190 \\
1220 \\
1230 \\
1230 \\
1500\end{array}$ \\
\hline $\begin{array}{r}6 \\
7 \\
8 \\
9 \\
10\end{array}$ & $\begin{array}{r}4380 \\
7430 \\
8020 \\
9100 \\
18600\end{array}$ & $\begin{array}{l}12500 \\
18100 \\
16800 \\
13100 \\
11100\end{array}$ & $\begin{array}{l}20000 \\
18700 \\
17200 \\
16400 \\
15200\end{array}$ & $\begin{array}{l}30200 \\
25600 \\
22200 \\
20200 \\
19500\end{array}$ & $\begin{array}{l}11900 \\
16600 \\
18400 \\
18600 \\
18100\end{array}$ & $\begin{array}{l}8560 \\
8100 \\
7670 \\
6980 \\
6830\end{array}$ & $\begin{array}{l}7680 \\
7800 \\
8030 \\
8050 \\
7690\end{array}$ & $\begin{array}{l}6480 \\
6790 \\
6370 \\
6090 \\
5680\end{array}$ & $\begin{array}{r}11900 \\
11100 \\
9900 \\
8440 \\
7010\end{array}$ & $\begin{array}{l}3360 \\
3100 \\
2800 \\
2800 \\
3880\end{array}$ & $\begin{array}{l}1320 \\
1340 \\
1420 \\
1710 \\
1890\end{array}$ & $\begin{array}{l}1610 \\
1310 \\
1270 \\
1250 \\
1250\end{array}$ \\
\hline $\begin{array}{l}11 \\
12 \\
13 \\
14 \\
15\end{array}$ & $\begin{array}{l}26200 \\
31200 \\
34500 \\
33100 \\
28100\end{array}$ & $\begin{array}{r}10200 \\
9420 \\
8570 \\
7700 \\
7440\end{array}$ & $\begin{array}{r}12000 \\
9710 \\
8180 \\
\text { e } 7400 \\
\text { e } 8600\end{array}$ & $\begin{array}{l}19100 \\
19100 \\
19300 \\
19400 \\
19400\end{array}$ & $\begin{array}{r}16500 \\
\text { e } 14000 \\
\text { e } 12000 \\
\text { e } 9800 \\
\text { e } 8600\end{array}$ & $\begin{array}{r}6520 \\
6480 \\
9710 \\
14000 \\
14300\end{array}$ & $\begin{array}{l}8050 \\
7680 \\
7000 \\
7320 \\
9230\end{array}$ & $\begin{array}{l}5630 \\
5530 \\
5500 \\
5320 \\
5300\end{array}$ & $\begin{array}{l}5530 \\
5030 \\
4730 \\
4570 \\
4290\end{array}$ & $\begin{array}{l}4900 \\
4510 \\
3500 \\
2910 \\
2540\end{array}$ & $\begin{array}{l}1820 \\
1810 \\
1640 \\
1520 \\
1500\end{array}$ & $\begin{array}{l}1180 \\
1170 \\
1180 \\
1280 \\
1530\end{array}$ \\
\hline $\begin{array}{l}16 \\
17 \\
18 \\
19 \\
20\end{array}$ & $\begin{array}{l}21300 \\
17200 \\
17000 \\
19400 \\
19900\end{array}$ & $\begin{array}{l}7270 \\
7320 \\
7030 \\
6790 \\
6440\end{array}$ & $\begin{array}{r}\text { e } 10000 \\
\text { e } 11600 \\
\text { e } 13500 \\
15300 \\
16200\end{array}$ & $\begin{array}{l}20900 \\
25500 \\
30100 \\
30500 \\
26500\end{array}$ & $\begin{array}{l}\text { e } 7800 \\
\text { e } 7600 \\
\text { e } 7800 \\
\text { e } 8600 \\
11200\end{array}$ & $\begin{array}{l}13900 \\
14200 \\
17800 \\
21700 \\
27500\end{array}$ & $\begin{array}{l}15100 \\
18100 \\
18300 \\
16600 \\
14000\end{array}$ & $\begin{array}{r}5660 \\
6120 \\
9230 \\
12200 \\
11400\end{array}$ & $\begin{array}{l}4210 \\
4470 \\
4270 \\
4000 \\
3790\end{array}$ & $\begin{array}{l}2330 \\
2070 \\
1930 \\
1850 \\
1830\end{array}$ & $\begin{array}{l}1420 \\
1360 \\
1360 \\
1380 \\
1760\end{array}$ & $\begin{array}{l}1630 \\
1710 \\
1550 \\
1530 \\
1710\end{array}$ \\
\hline $\begin{array}{l}21 \\
22 \\
23 \\
24 \\
25\end{array}$ & $\begin{array}{l}17300 \\
15200 \\
14100 \\
13900 \\
12900\end{array}$ & $\begin{array}{l}6050 \\
5950 \\
5970 \\
5930 \\
5840\end{array}$ & $\begin{array}{l}17200 \\
20500 \\
24100 \\
24900 \\
21000\end{array}$ & $\begin{array}{l}22900 \\
21000 \\
19800 \\
19400 \\
18900\end{array}$ & $\begin{array}{l}16800 \\
17100 \\
17400 \\
16100 \\
12800\end{array}$ & $\begin{array}{l}30100 \\
27700 \\
23100 \\
20300 \\
19600\end{array}$ & $\begin{array}{l}13800 \\
15700 \\
15200 \\
14500 \\
12900\end{array}$ & $\begin{array}{l}8670 \\
7270 \\
6500 \\
7910 \\
8450\end{array}$ & $\begin{array}{l}3560 \\
3250 \\
3120 \\
2890 \\
3050\end{array}$ & $\begin{array}{l}1790 \\
1670 \\
1640 \\
1560 \\
1510\end{array}$ & $\begin{array}{l}1790 \\
1630 \\
1590 \\
1440 \\
1320\end{array}$ & $\begin{array}{l}1620 \\
1670 \\
1760 \\
1880 \\
1740\end{array}$ \\
\hline $\begin{array}{l}26 \\
27 \\
28 \\
29 \\
30 \\
31\end{array}$ & $\begin{array}{r}11900 \\
10900 \\
9880 \\
9270 \\
8450 \\
8360\end{array}$ & $\begin{array}{r}5670 \\
5850 \\
7490 \\
13100 \\
17800 \\
\ldots\end{array}$ & $\begin{array}{l}16700 \\
15000 \\
14100 \\
19600 \\
34400 \\
60000\end{array}$ & $\begin{array}{l}18500 \\
18200 \\
17300 \\
15400 \\
13800 \\
12500\end{array}$ & $\begin{array}{r}10200 \\
8870 \\
8210 \\
\ldots \\
\ldots \\
\ldots\end{array}$ & $\begin{array}{l}19300 \\
19500 \\
20300 \\
19800 \\
18800 \\
17400\end{array}$ & $\begin{array}{r}11800 \\
10200 \\
8700 \\
7980 \\
7660 \\
\ldots\end{array}$ & $\begin{array}{r}9000 \\
10600 \\
10200 \\
9070 \\
8350 \\
8080\end{array}$ & $\begin{array}{l}2830 \\
2670 \\
2660 \\
2490 \\
2440 \\
\cdots\end{array}$ & $\begin{array}{l}1520 \\
1470 \\
1480 \\
1440 \\
1340 \\
1330\end{array}$ & $\begin{array}{l}1240 \\
1230 \\
1190 \\
1120 \\
1190 \\
1270\end{array}$ & $\begin{array}{c}1680 \\
1700 \\
1750 \\
1820 \\
1890 \\
\cdots-\end{array}$ \\
\hline $\begin{array}{l}\text { TOIAL } \\
\text { MEAN } \\
\text { MAX } \\
\text { MI N } \\
\text { CF SM } \\
\text { IN. }\end{array}$ & $\begin{array}{r}445540 \\
14370 \\
34500 \\
3390 \\
1.75 \\
2.02\end{array}$ & $\begin{array}{r}259100 \\
8637 \\
18100 \\
4540 \\
1.05 \\
1.17\end{array}$ & $\begin{array}{r}549090 \\
17710 \\
60000 \\
7400 \\
2.16 \\
2.49\end{array}$ & $\begin{array}{r}846200 \\
21300 \\
84600 \\
12500 \\
3.32 \\
3.83\end{array}$ & $\begin{array}{r}338980 \\
12110 \\
18600 \\
7600 \\
1.47 \\
1.53\end{array}$ & $\begin{array}{r}461840 \\
14900 \\
30100 \\
6480 \\
1.81 \\
2.09\end{array}$ & $\begin{array}{r}333080 \\
11100 \\
18700 \\
7000 \\
1.35 \\
1.51\end{array}$ & $\begin{array}{r}231270 \\
7460 \\
12200 \\
5300 \\
.91 \\
1.05\end{array}$ & $\begin{array}{r}199300 \\
6643 \\
18500 \\
2440 \\
.81 \\
.90\end{array}$ & $\begin{array}{c}75020 \\
2420 \\
4900 \\
1330 \\
.29 \\
.34\end{array}$ & $\begin{array}{c}44840 \\
1446 \\
1890 \\
1120 \\
.18 \\
.20\end{array}$ & $\begin{array}{c}45040 \\
1501 \\
1890 \\
1170 \\
.18 \\
.20\end{array}$ \\
\hline
\end{tabular}

e Estinated

SIATISIICS OF MONTHLY MEAN DAIA FOR WAIER YEARS 1940 - 1991, BY WATER YEAR (WY)

$\begin{array}{lrrrrrrrrrrrr}\text { MEAN } & 3301 & 4414 & 1281 & 8933 & 11090 & 13350 & 13210 & 9852 & 7882 & 4713 & 3269 & 2807 \\ \text { MAX } & 14370 & 20110 & 22080 & 49700 & 34450 & 34840 & 28470 & 43540 & 36010 & 17520 & 12230 & 11960 \\ \text { (WY) } & 1991 & 1973 & 1968 & 1950 & 1959 & 1982 & 1957 & 1943 & 1958 & 1957 & 1990 & 1989 \\ \text { MIN } & 738 & 919 & 810 & 896 & 1357 & 1915 & 3536 & 1814 & 1542 & 1212 & 640 & 545 \\ \text { (WY) } & 1965 & 1965 & 1964 & 1977 & 1963 & 1941 & 1941 & 1941 & 1988 & 1988 & 1941 & 1941\end{array}$

SUMMARY SIATISIICS

ANNUAL TOTAL

HIGHEST ANMUAL MEAM

LOWE ST ANNUAL MEAM

HIGHEST DAILY MEAK

LOWEST DAILY MEAN

ANMUAL SEVEN-DAY MINIMUM

INSTANTANEOUS PEAK FLOW

INSTANIANEOUS PEAK STAGE

AMNUAL RUNOFF (CFSM)

ANNUAL RUNOFF (INCHES)

10 PERCENT EXCEEDS

50 PERCENT EXCEEDS

90 PERCENT EXCEEDS
FOR I990 CAIENDAR YEAR

FOR 1991 WAIER YEAR

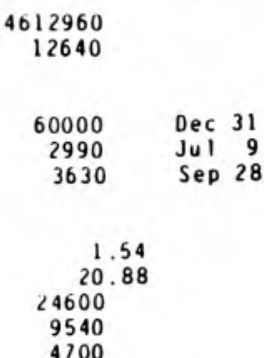

3829300
10490

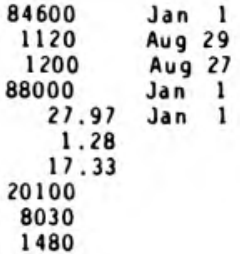

WAIER YEARS $1940-1991$

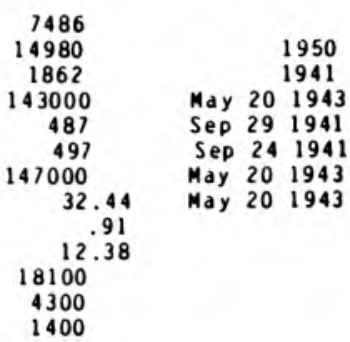




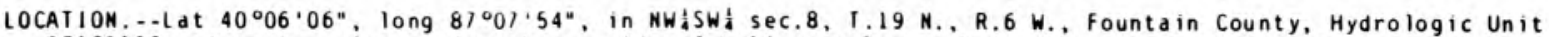

05120108, at center pier on downstredm side of bridge on County Road 700 fast, 1.5 mi east of Hillsboro,

$3.7 \mathrm{~m}$ northwest of Waynetown, and 9.6 i upstrea from auth. DRAI NAGE AREA $\ldots 33.4 i^{2}$

PERIOD OF RECORD... September 1968 to current year.

GAGE. - Water-stage recorder. Datum of gage is $673.76 \mathrm{ft}$ above National Geodetic Vertical Datum of 1929.

REMARKS. - - Records good except for estinated daily discharges, which are poor.

DISCHARGE, CUBIC FEET PER SECOND, WATER YEAR OCTOBER 1990 TO SEPTEMBER 1991 DAILY MEAN VALUES

\begin{tabular}{|c|c|c|c|c|c|c|c|c|c|c|c|c|}
\hline DAY & $O C T$ & NOV & $\mathrm{DEC}$ & JAN & FEB & MAR & APR & MAY & JUN & JUL & AUG & SEP \\
\hline $\begin{array}{l}1 \\
2 \\
3 \\
4 \\
5\end{array}$ & $\begin{array}{l}14 \\
13 \\
17 \\
74 \\
24\end{array}$ & $\begin{array}{r}25 \\
26 \\
25 \\
26 \\
118\end{array}$ & $\begin{array}{r}47 \\
41 \\
105 \\
67 \\
50\end{array}$ & $\begin{array}{r}101 \\
83 \\
70 \\
62 \\
+56\end{array}$ & $\begin{array}{r}e 27 \\
\text { e } 32 \\
48 \\
62 \\
87\end{array}$ & $\begin{array}{l}35 \\
41 \\
36 \\
34 \\
33\end{array}$ & $\begin{array}{l}42 \\
39 \\
38 \\
39 \\
38\end{array}$ & $\begin{array}{l}30 \\
28 \\
27 \\
31 \\
38\end{array}$ & $\begin{array}{l}30 \\
26 \\
24 \\
21 \\
20\end{array}$ & $\begin{array}{l}8.6 \\
8.4 \\
8.7 \\
8.3 \\
8.2\end{array}$ & $\begin{array}{l}4.3 \\
4.2 \\
4.2 \\
4.7 \\
4.8\end{array}$ & $\begin{array}{l}4.2 \\
3.7 \\
3.9 \\
4.7 \\
4.3\end{array}$ \\
\hline $\begin{array}{r}6 \\
7 \\
8 \\
9 \\
10\end{array}$ & $\begin{array}{r}17 \\
61 \\
44 \\
112 \\
269\end{array}$ & $\begin{array}{l}66 \\
42 \\
34 \\
31 \\
28\end{array}$ & $\begin{array}{l}46 \\
42 \\
38 \\
36 \\
34\end{array}$ & $\begin{array}{r}e 53 \\
51 \\
49 \\
47 \\
45\end{array}$ & $\begin{array}{r}104 \\
87 \\
67 \\
58 \\
53\end{array}$ & $\begin{array}{l}34 \\
30 \\
29 \\
29 \\
28\end{array}$ & $\begin{array}{l}36 \\
35 \\
42 \\
42 \\
35\end{array}$ & $\begin{array}{l}62 \\
39 \\
34 \\
31 \\
29\end{array}$ & $\begin{array}{l}19 \\
18 \\
18 \\
17 \\
17\end{array}$ & $\begin{array}{l}7.7 \\
7.2 \\
7.1 \\
7.3 \\
8.5\end{array}$ & $\begin{array}{r}12 \\
7.4 \\
7.0 \\
7.5 \\
6.8\end{array}$ & $\begin{array}{l}3.9 \\
3.7 \\
3.5 \\
3.7 \\
4.0\end{array}$ \\
\hline $\begin{array}{l}11 \\
12 \\
13 \\
14 \\
15\end{array}$ & $\begin{array}{l}73 \\
51 \\
42 \\
36 \\
32\end{array}$ & $\begin{array}{l}26 \\
24 \\
23 \\
23 \\
22\end{array}$ & $\begin{array}{l}33 \\
32 \\
30 \\
28 \\
76\end{array}$ & $\begin{array}{l}88 \\
86 \\
61 \\
66 \\
91\end{array}$ & $\begin{array}{r}47 \\
43 \\
46 \\
46 \\
e 38\end{array}$ & $\begin{array}{r}29 \\
45 \\
205 \\
95 \\
65\end{array}$ & $\begin{array}{l}33 \\
32 \\
37 \\
53 \\
75\end{array}$ & $\begin{array}{l}28 \\
28 \\
26 \\
25 \\
24\end{array}$ & $\begin{array}{l}17 \\
17 \\
15 \\
15 \\
15\end{array}$ & $\begin{array}{r}8.9 \\
12 \\
8.9 \\
8.0 \\
1.7\end{array}$ & $\begin{array}{l}6.0 \\
5.4 \\
5.1 \\
5.3 \\
5.6\end{array}$ & $\begin{array}{l}4.1 \\
3.9 \\
4.3 \\
5.8 \\
4.6\end{array}$ \\
\hline $\begin{array}{l}16 \\
17 \\
18 \\
19 \\
20\end{array}$ & $\begin{array}{l}28 \\
28 \\
65 \\
39 \\
33\end{array}$ & $\begin{array}{l}22 \\
22 \\
22 \\
21 \\
21\end{array}$ & $\begin{array}{l}54 \\
51 \\
81 \\
71 \\
56\end{array}$ & $\begin{array}{r}162 \\
104 \\
71 \\
65 \\
68\end{array}$ & $\begin{array}{r}e 34 \\
\text { e } 31 \\
\text { e } 42 \\
67 \\
52\end{array}$ & $\begin{array}{l}53 \\
61 \\
95 \\
63 \\
53\end{array}$ & $\begin{array}{l}53 \\
44 \\
40 \\
41 \\
37\end{array}$ & $\begin{array}{r}25 \\
143 \\
476 \\
83 \\
58\end{array}$ & $\begin{array}{l}16 \\
15 \\
14 \\
13 \\
12\end{array}$ & $\begin{array}{l}7.2 \\
6.6 \\
6.2 \\
5.9 \\
5.7\end{array}$ & $\begin{array}{l}5.1 \\
5.0 \\
4.9 \\
5.3 \\
6.3\end{array}$ & $\begin{array}{l}4.2 \\
4.4 \\
4.7 \\
5.0 \\
5.0\end{array}$ \\
\hline $\begin{array}{l}21 \\
22 \\
23 \\
24 \\
25\end{array}$ & $\begin{array}{l}30 \\
28 \\
27 \\
26 \\
25\end{array}$ & $\begin{array}{l}21 \\
23 \\
22 \\
21 \\
21\end{array}$ & $\begin{array}{r}212 \\
131 \\
73 \\
e 63 \\
e 53\end{array}$ & $\begin{array}{r}60 \\
e 53 \\
e 48 \\
e 42 \\
e 41\end{array}$ & $\begin{array}{l}47 \\
43 \\
40 \\
39 \\
36\end{array}$ & $\begin{array}{r}48 \\
266 \\
195 \\
85 \\
64\end{array}$ & $\begin{array}{l}35 \\
33 \\
33 \\
31 \\
30\end{array}$ & $\begin{array}{l}46 \\
40 \\
60 \\
50 \\
38\end{array}$ & $\begin{array}{l}12 \\
13 \\
13 \\
11 \\
11\end{array}$ & $\begin{array}{l}5.6 \\
5.5 \\
5.0 \\
4.9 \\
5.4\end{array}$ & $\begin{array}{l}5.6 \\
4.7 \\
4.4 \\
4.2 \\
4.1\end{array}$ & $\begin{array}{l}5.0 \\
5.6 \\
6.7 \\
5.9 \\
5.9\end{array}$ \\
\hline $\begin{array}{l}26 \\
27 \\
28 \\
29 \\
30 \\
31\end{array}$ & $\begin{array}{l}25 \\
25 \\
25 \\
24 \\
25 \\
25\end{array}$ & $\begin{array}{r}20 \\
33 \\
211 \\
78 \\
57 \\
- \\
-\end{array}$ & $\begin{array}{r}\text { e 46 } \\
\text { e41 } \\
\text { e38 } \\
850 \\
1140 \\
150\end{array}$ & $\begin{array}{l}\text { e } 38 \\
\text { e } 37 \\
\text { e } 35 \\
\text { e } 32 \\
\text { e29 } \\
\text { e } 28\end{array}$ & $\begin{array}{l}35 \\
34 \\
35 \\
\cdots \\
\cdots \\
\cdots\end{array}$ & $\begin{array}{r}212 \\
110 \\
72 \\
57 \\
48 \\
45\end{array}$ & $\begin{array}{l}30 \\
31 \\
30 \\
31 \\
28 \\
\cdots\end{array}$ & $\begin{array}{l}32 \\
28 \\
26 \\
31 \\
66 \\
42\end{array}$ & $\begin{array}{l}11 \\
10 \\
10 \\
9.6 \\
9.2 \\
\cdots\end{array}$ & $\begin{array}{l}4.9 \\
4.6 \\
4.6 \\
4.7 \\
5.0 \\
4.5\end{array}$ & $\begin{array}{l}3.9 \\
4.1 \\
4.2 \\
4.0 \\
4.5 \\
4.9\end{array}$ & $\begin{array}{l}5.5 \\
5.5 \\
6.0 \\
5.7 \\
5.2 \\
\cdots\end{array}$ \\
\hline $\begin{array}{l}\text { TOTAL } \\
\text { MEAN } \\
\text { MAX } \\
\text { MIN } \\
\text { CF SM } \\
\text { IN. }\end{array}$ & $\begin{array}{r}1357 \\
43.8 \\
269 \\
13 \\
1.31 \\
1.51\end{array}$ & $\begin{array}{r}1154 \\
38.5 \\
211 \\
20 \\
1.15 \\
1.29\end{array}$ & $\begin{array}{r}3815 \\
123 \\
1140 \\
28 \\
3.68 \\
4.25\end{array}$ & $\begin{array}{r}1922 \\
62.0 \\
162 \\
28 \\
1.86 \\
2.14\end{array}$ & $\begin{array}{r}1380 \\
49.3 \\
104 \\
27 \\
1.48 \\
1.54\end{array}$ & $\begin{array}{r}2295 \\
74.0 \\
266 \\
28 \\
2.22 \\
2.56\end{array}$ & $\begin{array}{r}1143 \\
38.1 \\
75 \\
28 \\
1.14 \\
1.27\end{array}$ & $\begin{array}{r}1724 \\
55.6 \\
476 \\
24 \\
1.67 \\
1.92\end{array}$ & $\begin{array}{r}468.8 \\
15.6 \\
30 \\
9.2 \\
.47 \\
.52\end{array}$ & $\begin{array}{r}211.8 \\
6.83 \\
12 \\
4.5 \\
.20 \\
.24\end{array}$ & $\begin{array}{r}165.5 \\
5.34 \\
12 \\
3.9 \\
.16 \\
.18\end{array}$ & $\begin{array}{r}142.6 \\
4.75 \\
6.7 \\
3.5 \\
.14 \\
.16\end{array}$ \\
\hline
\end{tabular}

e Estinated

SIATISIICS OF MONIHLY MEAN DATA FOR WAIER YEARS 1969 - 1991, BY WATER YEAR (WY)

\begin{tabular}{|c|c|c|c|c|c|c|c|c|c|c|c|c|}
\hline $\begin{array}{l}\text { MEAN } \\
\text { MAX } \\
\text { (WY) } \\
\text { MIN } \\
(W Y)\end{array}$ & $\begin{array}{r}19.8 \\
106 \\
1978 \\
6.21 \\
1988\end{array}$ & $\begin{array}{r}32.0 \\
157 \\
1986 \\
6.35 \\
1977\end{array}$ & $\begin{array}{r}42.1 \\
123 \\
1991 \\
5.93 \\
1977\end{array}$ & $\begin{array}{r}35.9 \\
120 \\
1974 \\
4.04 \\
1977\end{array}$ & $\begin{array}{r}50.6 \\
128 \\
1985 \\
8.28 \\
1978\end{array}$ & $\begin{array}{r}59.4 \\
162 \\
1979 \\
10.2 \\
1981\end{array}$ & $\begin{array}{r}53.4 \\
136 \\
1972 \\
10.7 \\
1971\end{array}$ & $\begin{array}{r}50.3 \\
119 \\
1974 \\
9.98 \\
1987\end{array}$ & $\begin{array}{l}38.6 \\
96.8 \\
1980 \\
6.25 \\
1977\end{array}$ & $\begin{array}{l}26.6 \\
70.7 \\
1990 \\
5.07 \\
1988\end{array}$ & $\begin{array}{l}23.0 \\
62.4 \\
1979 \\
3.03 \\
1988\end{array}$ & $\begin{array}{l}17.2 \\
111 \\
1989 \\
4.71 \\
1983\end{array}$ \\
\hline
\end{tabular}

SUMMARY SIAIISTICS

ANNUAL TOTAL

ANMUAL MEAN

HIGHESI ANMUAL MEAM

LOWEST AMNUAL MEAN

HIGHEST DAILY MEAN

LOWEST DAILY MEAN

ANNUAL SEVEN-DAY MINIMUM

INSTANTANEOUS PEAK FLOW

INSTANTANEOUS PEAK SIAGE

ANMUAL RUNOFF (CFSM)

ANNUAL RUNOFF (INCHES)

10 PERCENT EXCEEDS

50 PERCENT EXCEEDS

90 PERCENT EXCEEDS
FOR 1990 CALENDAR YEAR

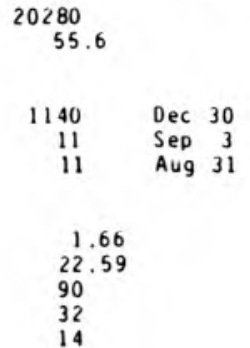

FOR 1991 WAIER YEAR

15778.7
43.2

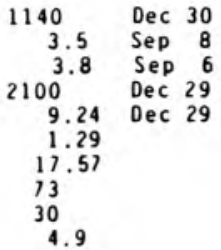

WATER YEARS 1969 - 1991

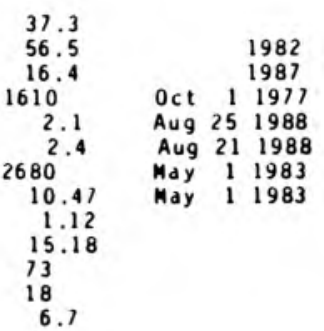


LOCATION.--Lat $40^{\circ} 06^{\prime} 16^{\circ}$, long $86^{\circ} 31^{\prime} 32^{\circ}$, in MWtswł sec.10, T.19 M., R.1 W. Boone County, Hydrologic Unit

05120110 , on right bank $50 \mathrm{ft}$ upstrea from bridge on County Road 450 North, 4.0 ei upstrea frou Deer Creek. $4.9 . i$ northwest of Lebanon, and 7.7 a ustreas froe nouth.

DRAI NAGE AREA. $\ldots 33.2 \div 1$.

PERIOD OF RECORD.--October 1987 to current year.

GAGE . - Water-stage recorder. Datue of gage is $860.00 \mathrm{ft}$ above National Geodetic Vertical Datue of 1929.

REMARKS. - Records good except those for estieated daily discharges. Which are poor. Maxieun daily wean discharge for period of record is estinated.

DISCHARGE, CUBIC FEET PER SECONO, WATER YEAR OCTOBER 1990 TO SEPTEMBER 1991 DAILY MEAM VALUES

\begin{tabular}{|c|c|c|c|c|c|c|c|c|c|c|c|c|}
\hline DAY & $\mathrm{OCT}$ & NOV & DEC & JAN & FEB & MAR & APR & MAY & JUN & JUL & AUG & SEP \\
\hline $\begin{array}{l}1 \\
2 \\
3 \\
4 \\
5\end{array}$ & $\begin{array}{r}3.5 \\
3.6 \\
3.6 \\
35 \\
7.8\end{array}$ & $\begin{array}{r}7.2 \\
7.5 \\
7.6 \\
7.5 \\
35\end{array}$ & $\begin{array}{r}39 \\
28 \\
279 \\
172 \\
85\end{array}$ & $\begin{array}{r}e 220 \\
e 120 \\
e 70 \\
e 50 \\
e 43\end{array}$ & $\begin{array}{l}\text { e26 } \\
e 24 \\
e 32 \\
\text { e30 } \\
\text { e70 }\end{array}$ & $\begin{array}{l}22 \\
33 \\
28 \\
24 \\
22\end{array}$ & $\begin{array}{l}30 \\
26 \\
24 \\
25 \\
30\end{array}$ & $\begin{array}{l}\text { e20 } \\
\text { e18 } \\
\text { e16 } \\
\text { e25 } \\
\text { e24 }\end{array}$ & $\begin{array}{l}59 \\
32 \\
24 \\
19 \\
15\end{array}$ & $\begin{array}{l}3.6 \\
3.9 \\
3.5 \\
3.9 \\
3.5\end{array}$ & $\begin{array}{l}2.2 \\
1.9 \\
2.4 \\
2.2 \\
1.8\end{array}$ & $\begin{array}{l}2.5 \\
1.5 \\
2.0 \\
8.7 \\
1.7\end{array}$ \\
\hline $\begin{array}{r}6 \\
7 \\
8 \\
9 \\
10\end{array}$ & $\begin{array}{c}3.8 \\
16 \\
11 \\
27 \\
233\end{array}$ & $\begin{array}{l}24 \\
14 \\
11 \\
11 \\
9.3\end{array}$ & $\begin{array}{l}59 \\
43 \\
35 \\
28 \\
27\end{array}$ & $\begin{array}{l}\text { e } 39 \\
\text { e } 36 \\
\text { e34 } \\
\text { e } 31 \\
\text { e } 30\end{array}$ & $\begin{array}{l}\text { e } 180 \\
\text { e1 } 40 \\
\text { e100 } \\
\text { e70 } \\
\text { e52 }\end{array}$ & $\begin{array}{l}23 \\
18 \\
16 \\
16 \\
14\end{array}$ & $\begin{array}{l}27 \\
24 \\
32 \\
32 \\
24\end{array}$ & $\begin{array}{l}\text { e25 } \\
\text { e15 } \\
\text { e14 } \\
\text { e13 } \\
\text { e13 }\end{array}$ & $\begin{array}{l}13 \\
12 \\
11 \\
11 \\
10\end{array}$ & $\begin{array}{l}3.3 \\
3.2 \\
3.1 \\
3.1 \\
3.6\end{array}$ & $\begin{array}{r}12 \\
5.8 \\
5.5 \\
8.8 \\
3.5\end{array}$ & $\begin{array}{l}1.9 \\
1.9 \\
1.7 \\
1.9 \\
2.0\end{array}$ \\
\hline $\begin{array}{l}11 \\
12 \\
13 \\
14 \\
15\end{array}$ & $\begin{array}{l}96 \\
41 \\
24 \\
18 \\
13\end{array}$ & $\begin{array}{l}7.8 \\
7.2 \\
6.8 \\
6.7 \\
6.9\end{array}$ & $\begin{array}{r}23 \\
20 \\
18 \\
15 \\
216\end{array}$ & $\begin{array}{l}\text { e } 100 \\
\text { e } 84 \\
\text { e66 } \\
\text { e } 48 \\
\text { e60 }\end{array}$ & $\begin{array}{l}\text { e } 38 \\
e 26 \\
\text { e } 30 \\
\text { e } 36 \\
\text { e29 }\end{array}$ & $\begin{array}{r}14 \\
67 \\
671 \\
292 \\
158\end{array}$ & $\begin{array}{r}20 \\
18 \\
62 \\
125 \\
116\end{array}$ & $\begin{array}{l}\text { e12 } \\
\text { e12 } \\
\text { e12 } \\
\text { e } 21 \\
\text { e } 42\end{array}$ & $\begin{array}{l}10 \\
10 \\
8.8 \\
7.8 \\
11\end{array}$ & $\begin{array}{l}3.8 \\
7.6 \\
4.7 \\
3.6 \\
3.0\end{array}$ & $\begin{array}{l}2.9 \\
2.4 \\
2.7 \\
5.3 \\
7.2\end{array}$ & $\begin{array}{l}2.0 \\
2.1 \\
2.2 \\
3.9 \\
2.0\end{array}$ \\
\hline $\begin{array}{l}16 \\
17 \\
18 \\
19 \\
20\end{array}$ & $\begin{array}{l}11 \\
10 \\
47 \\
26 \\
17\end{array}$ & $\begin{array}{l}8.1 \\
6.9 \\
6.6 \\
6.8 \\
6.5\end{array}$ & $\begin{array}{r}123 \\
85 \\
\mathrm{e} 190 \\
\mathrm{e} 140 \\
\mathrm{e} 92\end{array}$ & $\begin{array}{l}\text { e } 76 \\
\text { e } 60 \\
\text { e } 45 \\
\text { e } 36 \\
\text { e } 31\end{array}$ & $\begin{array}{r}e 24 \\
e 19 \\
e 48 \\
e 120 \\
e 90\end{array}$ & $\begin{array}{r}99 \\
103 \\
200 \\
106 \\
72\end{array}$ & $\begin{array}{r}70 \\
e 47 \\
e 33 \\
e 100 \\
e 84\end{array}$ & $\begin{array}{r}e 20 \\
e 18 \\
e 120 \\
e 70 \\
e 35\end{array}$ & $\begin{array}{c}19 \\
9.0 \\
7.6 \\
6.8 \\
6.3\end{array}$ & $\begin{array}{l}3.0 \\
2.6 \\
2.9 \\
2.5 \\
2.5\end{array}$ & $\begin{array}{l}2.1 \\
1.3 \\
1.3 \\
6.8 \\
3.9\end{array}$ & $\begin{array}{l}1.7 \\
2.0 \\
1.5 \\
2.1 \\
1.9\end{array}$ \\
\hline $\begin{array}{l}21 \\
22 \\
23 \\
24 \\
25\end{array}$ & $\begin{array}{l}14 \\
13 \\
12 \\
11 \\
11\end{array}$ & $\begin{array}{c}6.3 \\
13 \\
8.4 \\
7.0 \\
6.9\end{array}$ & $\begin{array}{l}e 200 \\
e 110 \\
e 72 \\
e 52 \\
e 40\end{array}$ & $\begin{array}{l}\text { e26 } \\
\text { e23 } \\
\text { e21 } \\
\text { e19 } \\
\text { e18 }\end{array}$ & $\begin{array}{r}e 68 \\
49 \\
37 \\
33 \\
29\end{array}$ & $\begin{array}{r}57 \\
171 \\
287 \\
120 \\
73\end{array}$ & $\begin{array}{l}e 64 \\
e 54 \\
e 44 \\
e 33 \\
e 27\end{array}$ & $\begin{array}{r}19 \\
17 \\
18 \\
18 \\
18\end{array}$ & $\begin{array}{l}6.0 \\
6.2 \\
5.6 \\
5.9 \\
5.1\end{array}$ & $\begin{array}{l}2.4 \\
2.3 \\
2.5 \\
2.3 \\
2.4\end{array}$ & $\begin{array}{l}1.5 \\
1.8 \\
3.3 \\
1.6 \\
1.7\end{array}$ & $\begin{array}{l}1.9 \\
1.8 \\
4.7 \\
1.8 \\
1.6\end{array}$ \\
\hline $\begin{array}{l}26 \\
27 \\
28 \\
29 \\
30 \\
31\end{array}$ & $\begin{array}{r}10 \\
11 \\
9.7 \\
8.5 \\
8.4 \\
11\end{array}$ & $\begin{array}{c}6.5 \\
43 \\
258 \\
116 \\
58 \\
\ldots .-\end{array}$ & $\begin{array}{r}e 32 \\
e 26 \\
e 22 \\
e 250 \\
e 1900 \\
e 470\end{array}$ & $\begin{array}{l}\text { e17 } \\
\text { e17 } \\
\text { e17 } \\
\text { e18 } \\
\text { e31 } \\
\text { e29 }\end{array}$ & $\begin{array}{r}24 \\
23 \\
22 \\
\cdots- \\
\cdots \ldots \\
\cdots\end{array}$ & $\begin{array}{r}197 \\
157 \\
83 \\
57 \\
41 \\
34\end{array}$ & $\begin{array}{l}\text { e25 } \\
\text { e23 } \\
\text { e22 } \\
\text { e24 } \\
\text { e22 } \\
-\cdots\end{array}$ & $\begin{array}{r}16 \\
14 \\
12 \\
11 \\
27 \\
324\end{array}$ & $\begin{array}{l}4.8 \\
4.7 \\
4.6 \\
4.4 \\
3.9 \\
\ldots . .\end{array}$ & $\begin{array}{l}2.2 \\
2.2 \\
2.0 \\
2.0 \\
2.0 \\
2.2\end{array}$ & $\begin{array}{l}1.6 \\
1.8 \\
2.1 \\
2.1 \\
2.6 \\
3.5\end{array}$ & $\begin{array}{l}1.5 \\
1.4 \\
1.5 \\
1.4 \\
1.7 \\
\ldots\end{array}$ \\
\hline $\begin{array}{l}\text { TOTAL } \\
\text { MEAN } \\
\text { MAX } \\
\text { MIN } \\
\text { CF SM } \\
\text { IN. }\end{array}$ & $\begin{array}{r}766.9 \\
24.7 \\
233 \\
3.5 \\
.75 \\
.86\end{array}$ & $\begin{array}{r}727.5 \\
24.2 \\
258 \\
6.3 \\
.73 \\
.82\end{array}$ & $\begin{array}{r}4891 \\
158 \\
1900 \\
15 \\
4.75 \\
5.48\end{array}$ & $\begin{array}{r}1515 \\
48.9 \\
220 \\
17 \\
1.47 \\
1.70\end{array}$ & $\begin{array}{r}1469 \\
52.5 \\
180 \\
19 \\
1.58 \\
1.65\end{array}$ & $\begin{array}{r}3275 \\
106 \\
671 \\
14 \\
3.18 \\
3.67\end{array}$ & $\begin{array}{r}1287 \\
42.9 \\
125 \\
18 \\
1.29 \\
1.44\end{array}$ & $\begin{array}{r}1039 \\
33.5 \\
324 \\
11 \\
1.01 \\
1.16\end{array}$ & $\begin{array}{r}353.5 \\
11.8 \\
59 \\
3.9 \\
.35 \\
.40\end{array}$ & $\begin{array}{r}95.4 \\
3.08 \\
7.6 \\
2.0 \\
.09 \\
.11\end{array}$ & $\begin{array}{r}105.6 \\
3.41 \\
12 \\
1.3 \\
.10 \\
.12\end{array}$ & $\begin{array}{r}66.5 \\
2.22 \\
8.7 \\
1.4 \\
.07 \\
.07\end{array}$ \\
\hline
\end{tabular}

STATISTICS OF MONTHLY MEAN DATA FOR WATER YEARS 1988 - 1991, BY WATER YEAR (WY)

\begin{tabular}{|c|c|c|c|c|c|c|c|c|c|c|c|}
\hline $\begin{array}{l}\text { MEAN } \\
\text { MAX } \\
\text { (WY) } \\
\text { MIN } \\
\text { (WY) }\end{array}$ & $\begin{array}{l}11.0 \\
24.7 \\
1991 \\
3.52 \\
1989\end{array}$ & $\begin{array}{l}17.0 \\
29.7 \\
1990 \\
6.68 \\
1988\end{array}$ & $\begin{array}{r}48.8 \\
158 \\
1991 \\
6.03 \\
1989\end{array}$ & $\begin{array}{l}29.3 \\
48.9 \\
1991 \\
11.0 \\
1989\end{array}$ & $\begin{array}{r}62.5 \\
139 \\
1990 \\
8.62 \\
1989\end{array}$ & $\begin{array}{r}68.4 \\
109 \\
1990 \\
26.9 \\
1989\end{array}$ & $\begin{array}{l}64.8 \\
96.7 \\
1989 \\
39.0 \\
1990\end{array}$ & $\begin{array}{l}51.3 \\
86.3 \\
1989 \\
6.45 \\
1988\end{array}$ & $\begin{array}{l}28.2 \\
80.0 \\
1990 \\
4.34 \\
1988\end{array}$ & $\begin{array}{l}34.8 \\
95.6 \\
1989 \\
3.08 \\
1991\end{array}$ & $\begin{array}{l}12.0 \\
34.8 \\
1989 \\
2.45 \\
1988\end{array}$ \\
\hline
\end{tabular}

SUMMARY STATISTICS

ANNUAL TOTAL

ANMUAL MEAK

HIGHEST ANHUAL MEAM

LOWEST ANHUAL MEAN

HIGHEST DAILY MEAK

LOWEST DAILY MEAN

AMNUAL SEVEN-DAY MINIMUM

INSTANTANEOUS PEAK FLOW

INSTANTANEOUS PEAK STAGE

ANMUAL RUNOFF (CFSM)

AMNUAL RUMOFF (INCHES)

10 PERCENT EXCEEDS

50 PERCENT EXCEEDS

90 PERCENT EXCEEDS
FOR 1990 CALENDAR YEAR

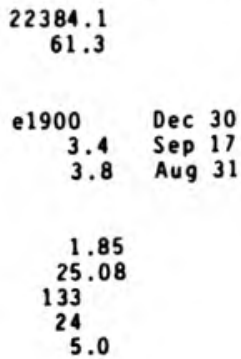

FOR 1991 WATER YEAR

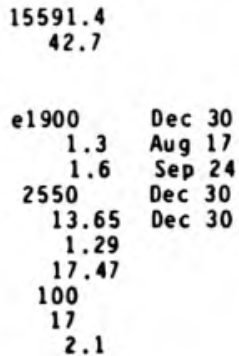

WATER YEARS 1988 - 1991

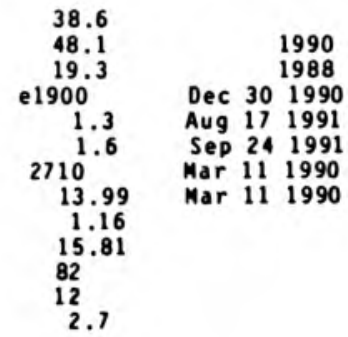




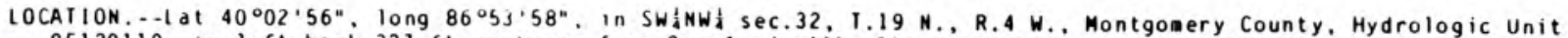
05120110 , on left bank $327 \mathrm{ft}$ upstream fron Crawfordsville Electric Light and Power Co.'s dan at Crawfordsville, 0.5 mi upstream from bridge on U.S. Highway $231,1.0$ a downstream from Walnut fork Sugar Creek, and at DRAINAGE AREA...509 $i^{2}$.

PERIOD OF RECORD..- June 1938 to current year.

REVISED RECORDS.-.WSP 973: $1939(M)$. WSP 1275: Drainage area, WSP 1335: 1949.

GAGE, - Water-stage recorder and concrete control. Datum of gage is 657.77 ft above National Geodetic Vertical Datum of 1929

REMARKS. - Records good.

EXTREMES OUISIDE PERIOD OF RECORD...Flogd in March 1913 reached a stage of $17.3 \mathrm{ft} f$ roa information by Iocal resident, discharge, about $36,000 \mathrm{ft} / \mathrm{s}$.

DISCHARGE, CUBIC FEET PER SECOND, WATER YEAR OCTOBER 1990 TO SEPIEMBER 1991 DAILY MEAN VALUES

\begin{tabular}{|c|c|c|c|c|c|c|c|c|c|c|c|c|}
\hline DAY & OCI & NOV & DE C & JAN & FEB & MAR & APR & MAY & JUN & JUL & AUG & SEP \\
\hline $\begin{array}{l}1 \\
2 \\
3 \\
4 \\
5\end{array}$ & $\begin{array}{r}45 \\
43 \\
44 \\
172 \\
163\end{array}$ & $\begin{array}{l}138 \\
127 \\
123 \\
123 \\
473\end{array}$ & $\begin{array}{r}987 \\
718 \\
1850 \\
2260 \\
1110\end{array}$ & $\begin{array}{l}4360 \\
2480 \\
1820 \\
1470 \\
1250\end{array}$ & $\begin{array}{r}342 \\
350 \\
346 \\
651 \\
1100\end{array}$ & $\begin{array}{l}339 \\
392 \\
378 \\
333 \\
311\end{array}$ & $\begin{array}{l}552 \\
469 \\
412 \\
398 \\
418\end{array}$ & $\begin{array}{l}310 \\
290 \\
266 \\
289 \\
298\end{array}$ & $\begin{array}{r}5380 \\
1820 \\
1220 \\
896 \\
568\end{array}$ & $\begin{array}{l}63 \\
59 \\
56 \\
52 \\
52\end{array}$ & $\begin{array}{l}21 \\
20 \\
20 \\
19 \\
19\end{array}$ & $\begin{array}{l}17 \\
17 \\
17 \\
19 \\
19\end{array}$ \\
\hline $\begin{array}{r}6 \\
7 \\
8 \\
9 \\
10\end{array}$ & $\begin{array}{r}98 \\
154 \\
372 \\
677 \\
2640\end{array}$ & $\begin{array}{r}1030 \\
605 \\
396 \\
326 \\
280\end{array}$ & $\begin{array}{l}814 \\
658 \\
586 \\
484 \\
441\end{array}$ & $\begin{array}{r}1030 \\
852 \\
757 \\
702 \\
621\end{array}$ & $\begin{array}{r}1650 \\
2170 \\
1500 \\
1180 \\
991\end{array}$ & $\begin{array}{l}313 \\
295 \\
242 \\
226 \\
217\end{array}$ & $\begin{array}{l}393 \\
362 \\
390 \\
470 \\
398\end{array}$ & $\begin{array}{l}460 \\
382 \\
308 \\
273 \\
258\end{array}$ & $\begin{array}{l}417 \\
331 \\
280 \\
245 \\
217\end{array}$ & $\begin{array}{l}48 \\
44 \\
42 \\
40 \\
41\end{array}$ & $\begin{array}{l}32 \\
31 \\
32 \\
27 \\
26\end{array}$ & $\begin{array}{l}21 \\
19 \\
16 \\
15 \\
16\end{array}$ \\
\hline $\begin{array}{l}11 \\
12 \\
13 \\
14 \\
15\end{array}$ & $\begin{array}{r}2400 \\
1340 \\
886 \\
619 \\
464\end{array}$ & $\begin{array}{l}245 \\
210 \\
187 \\
174 \\
173\end{array}$ & $\begin{array}{r}398 \\
369 \\
323 \\
266 \\
1090\end{array}$ & $\begin{array}{l}931 \\
1880 \\
1330 \\
1090 \\
1640\end{array}$ & $\begin{array}{r}797 \\
619 \\
586 \\
604 \\
e 520\end{array}$ & $\begin{array}{r}208 \\
266 \\
4310 \\
4990 \\
2980\end{array}$ & $\begin{array}{r}322 \\
282 \\
329 \\
1060 \\
2180\end{array}$ & $\begin{array}{l}245 \\
371 \\
353 \\
301 \\
506\end{array}$ & $\begin{array}{l}201 \\
193 \\
175 \\
156 \\
145\end{array}$ & $\begin{array}{l}42 \\
55 \\
52 \\
46 \\
41\end{array}$ & $\begin{array}{l}25 \\
22 \\
20 \\
21 \\
22\end{array}$ & $\begin{array}{l}17 \\
15 \\
15 \\
18 \\
44\end{array}$ \\
\hline $\begin{array}{l}16 \\
17 \\
18 \\
19 \\
20\end{array}$ & $\begin{array}{l}360 \\
309 \\
445 \\
536 \\
405\end{array}$ & $\begin{array}{l}167 \\
161 \\
157 \\
152 \\
146\end{array}$ & $\begin{array}{l}1510 \\
1050 \\
1500 \\
2050 \\
1430\end{array}$ & $\begin{array}{l}2900 \\
2860 \\
1860 \\
1480 \\
1410\end{array}$ & $\begin{array}{l}\text { e } 380 \\
\text { e } 400 \\
\text { e } 450 \\
1430 \\
1450\end{array}$ & $\begin{array}{l}1970 \\
1530 \\
2780 \\
2110 \\
1400\end{array}$ & $\begin{array}{r}1570 \\
1040 \\
773 \\
707 \\
783\end{array}$ & $\begin{array}{r}330 \\
666 \\
2320 \\
1240 \\
696\end{array}$ & $\begin{array}{l}177 \\
186 \\
148 \\
124 \\
109\end{array}$ & $\begin{array}{l}37 \\
34 \\
32 \\
31 \\
29\end{array}$ & $\begin{array}{l}28 \\
24 \\
20 \\
21 \\
30\end{array}$ & $\begin{array}{l}51 \\
33 \\
21 \\
23 \\
22\end{array}$ \\
\hline $\begin{array}{l}21 \\
22 \\
23 \\
24 \\
25\end{array}$ & $\begin{array}{l}329 \\
282 \\
256 \\
226 \\
200\end{array}$ & $\begin{array}{l}145 \\
162 \\
166 \\
155 \\
145\end{array}$ & $\begin{array}{l}2300 \\
3630 \\
1570 \\
e 740 \\
e 500\end{array}$ & $\begin{array}{r}\text { e } 1300 \\
\text { e } 1000 \\
\text { e } 840 \\
\text { e7 } 00 \\
\text { e600 }\end{array}$ & $\begin{array}{r}1050 \\
836 \\
640 \\
553 \\
469\end{array}$ & $\begin{array}{l}1090 \\
2530 \\
4210 \\
2410 \\
1400\end{array}$ & $\begin{array}{l}679 \\
589 \\
522 \\
520 \\
436\end{array}$ & $\begin{array}{r}467 \\
378 \\
370 \\
354 \\
1690\end{array}$ & $\begin{array}{r}100 \\
98 \\
355 \\
215 \\
136\end{array}$ & $\begin{array}{l}28 \\
27 \\
26 \\
24 \\
25\end{array}$ & $\begin{array}{l}30 \\
26 \\
22 \\
20 \\
19\end{array}$ & $\begin{array}{l}22 \\
23 \\
24 \\
24 \\
24\end{array}$ \\
\hline $\begin{array}{l}26 \\
27 \\
28 \\
29 \\
30 \\
31\end{array}$ & $\begin{array}{l}186 \\
174 \\
160 \\
147 \\
140 \\
137\end{array}$ & $\begin{array}{r}135 \\
476 \\
2890 \\
2460 \\
1420 \\
\ldots-\end{array}$ & $\begin{array}{r}\text { e } 390 \\
\text { e } 370 \\
\text { e360 } \\
3740 \\
17500 \\
13600\end{array}$ & $\begin{array}{r}\text { e540 } \\
\text { e480 } \\
\text { e430 } \\
\text { e390 } \\
\text { e360 } \\
336\end{array}$ & $\begin{array}{l}406 \\
375 \\
350 \\
\ldots \\
\ldots \\
\ldots\end{array}$ & $\begin{array}{r}2050 \\
2540 \\
1580 \\
1100 \\
815 \\
629\end{array}$ & $\begin{array}{l}396 \\
388 \\
374 \\
363 \\
336 \\
\ldots\end{array}$ & $\begin{array}{r}1270 \\
673 \\
423 \\
330 \\
646 \\
3540\end{array}$ & $\begin{array}{r}110 \\
93 \\
82 \\
75 \\
69 \\
\cdots\end{array}$ & $\begin{array}{l}24 \\
24 \\
22 \\
22 \\
22 \\
21\end{array}$ & $\begin{array}{l}19 \\
18 \\
18 \\
18 \\
17 \\
17\end{array}$ & $\begin{array}{r}24 \\
24 \\
24 \\
24 \\
23 \\
-\cdots\end{array}$ \\
\hline $\begin{array}{l}\text { TOIAL } \\
\text { MEAN } \\
\text { MAX } \\
\text { MIN } \\
\text { CF SM } \\
\text { IN. }\end{array}$ & $\begin{array}{r}14409 \\
465 \\
2640 \\
43 \\
.91 \\
1.05\end{array}$ & $\begin{array}{r}13547 \\
452 \\
2890 \\
123 \\
.89 \\
.99\end{array}$ & $\begin{array}{r}64594 \\
2084 \\
17500 \\
266 \\
4.09 \\
4.72\end{array}$ & $\begin{array}{r}39699 \\
1281 \\
4360 \\
336 \\
2.52 \\
2.90\end{array}$ & $\begin{array}{r}22195 \\
793 \\
2170 \\
342 \\
1.56 \\
1.62\end{array}$ & $\begin{array}{r}45944 \\
1482 \\
4990 \\
208 \\
2.91 \\
3.36\end{array}$ & $\begin{array}{r}17911 \\
597 \\
2180 \\
282 \\
1.17 \\
1.31\end{array}$ & $\begin{array}{r}20303 \\
655 \\
3540 \\
245 \\
1.29 \\
1.48\end{array}$ & $\begin{array}{r}14321 \\
477 \\
5380 \\
69 \\
.94 \\
1.05\end{array}$ & $\begin{array}{c}1161 \\
37.5 \\
63 \\
21 \\
.07 \\
.08\end{array}$ & $\begin{array}{r}704 \\
22.7 \\
32 \\
17 \\
.04 \\
.05\end{array}$ & $\begin{array}{r}677 \\
22.6 \\
51 \\
15 \\
.04 \\
.05\end{array}$ \\
\hline
\end{tabular}

e Estimated

STATISTICS OF MUNTHLY MEAN DAIA FOR WAIER YEARS 1939 - 1991. BY WAIER YEAR (WY)

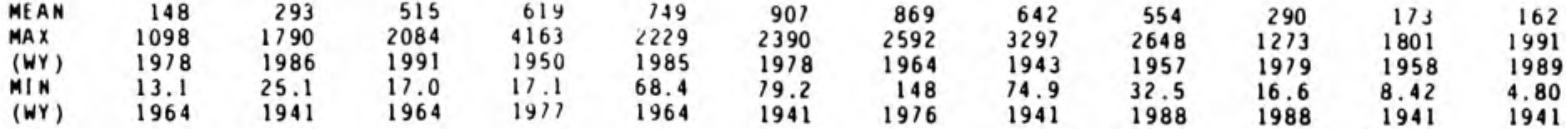

SUMMARY SIATISIICS

ANMUAL TOTAL

ANMUAL MEAM

HIGHESI ANNUAL MEAN

LOWEST ANNUAL MEAN

HIGHEST DAIIY MEAN

LOWEST DAILY MEAN

ANNUAL SEVEN-DAY MINIMUM

INSIANIANEOUS PEAK FIOW

INSIANIANEOUS PEAK SIAGE

ANNUAL RUNOFF (CFSM)

ANMUAL RUNOFF (I NCHES)

10 PERCENT EXCEEDS

50 PERCENT EXCEEDS

90 PERCENT EXCEEDS
FOR 1990 CALENUAR YEAR

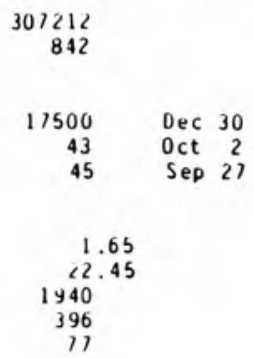

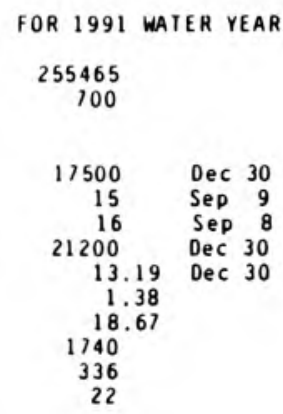

WAIER YEARS 1939 - 1991

$$
\begin{aligned}
& 492 \\
& 1986 \\
& \begin{array}{cc}
65.0 & 1941 \\
20100 & \text { Jun } 291957
\end{array} \\
& 2.4 \text { Sep } 241941 \\
& 2.7 \text { Sep } 211941 \\
& 14.48 \text { Jun } 281957 \\
& \begin{array}{r}
.97 \\
13.12
\end{array} \\
& 1150 \\
& 176
\end{aligned}
$$




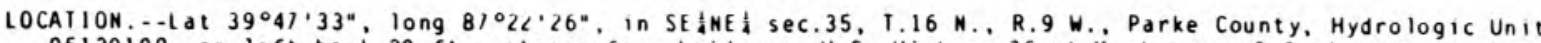
05120108 , on left bank $20 \mathrm{ft}$ upstreda from bridge on U.S. Highway 36 at Montezuma, 2.0 i upstrean from Big Raccoon Creek, 4.9 i downstrean fron Sugar Creek, and at a ile 240.0.

DRAI NAGE AREA ...11,118 i

PERIOD OF RECORO.--OCtober 1927 to current year. July 1924 to Septenber 1927 (gage height only) in reports uf State of Indiana. Departaent of Natural Resources.

REVISED RECORDS, --WSP 1335: 1929, 1931(M). WSP 1505: 1954. WSP 1915: 1954(a). WSP 2109: Drainage ared. WDR IN-74-1: 1973 .

GAGE. - Water-stage recorder. Datum of gage is $457.75 \mathrm{ft}$ above National Geodetic Vertical Datue of 1929 (1evels by U.S. Aray Corps of Engineers). Oct. 1, 1927, to July 12, 1950, nonrecording gage on downstreae side of bridge and at sane datum. July 12, 1950, to July 27,1988 , recording gage in downstrean side of first pier from left bank at same datua.

REMARKS. - -Records good. Flow partially reguldted by upstrean reservoirs.

EXIREMES OUTSIDE PERIOD gF RECORD...Flood of March 27, 1913 , reached a stage of $34.0 \mathrm{ft}$, froe floodadiks. discharge, $230,000 \mathrm{ft} / \mathrm{s}$.

DISCHARGE, CUBIC FEEI PER SECOND, WATER YEAR OCTOBER 1990 TO SEPTEMBER 1991 DAILY MEAN VALUES

\begin{tabular}{|c|c|c|c|c|c|c|c|c|c|c|c|c|}
\hline DAY & OCT & NOV & DEC & JAN & FEB & MAR & $A P R$ & MAY & JUN & JUL & $A \cup G$ & SEP \\
\hline $\begin{array}{l}1 \\
2 \\
3 \\
4 \\
5\end{array}$ & $\begin{array}{l}4190 \\
4090 \\
4040 \\
4440 \\
4750\end{array}$ & $\begin{array}{l}9500 \\
8260 \\
6780 \\
6200 \\
7880\end{array}$ & $\begin{array}{l}22800 \\
19100 \\
19200 \\
24000 \\
25000\end{array}$ & $\begin{array}{r}102000 \\
101000 \\
88000 \\
71800 \\
58900\end{array}$ & $\begin{array}{l}15000 \\
13000 \\
11700 \\
12500 \\
16000\end{array}$ & $\begin{array}{r}10300 \\
9990 \\
10800 \\
12100 \\
11900\end{array}$ & $\begin{array}{l}21000 \\
18300 \\
15700 \\
13000 \\
12200\end{array}$ & $\begin{array}{l}9750 \\
9360 \\
8690 \\
8630 \\
8560\end{array}$ & $\begin{array}{l}15700 \\
20900 \\
21100 \\
18900 \\
16200\end{array}$ & $\begin{array}{l}3000 \\
2960 \\
3070 \\
3180 \\
3640\end{array}$ & $\begin{array}{l}1680 \\
1700 \\
1630 \\
1590 \\
1600\end{array}$ & $\begin{array}{l}1490 \\
1450 \\
1500 \\
1500 \\
1510\end{array}$ \\
\hline $\begin{array}{r}6 \\
7 \\
8 \\
9 \\
10\end{array}$ & $\begin{array}{r}4790 \\
6380 \\
9660 \\
11000 \\
23100\end{array}$ & $\begin{array}{l}13800 \\
19800 \\
20600 \\
17300 \\
14200\end{array}$ & $\begin{array}{l}24300 \\
22800 \\
21100 \\
19400 \\
17200\end{array}$ & $\begin{array}{l}48800 \\
39800 \\
33800 \\
30100 \\
27900\end{array}$ & $\begin{array}{l}19700 \\
24000 \\
25900 \\
25800 \\
24900\end{array}$ & $\begin{array}{r}11200 \\
10600 \\
10000 \\
9130 \\
8690\end{array}$ & $\begin{array}{l}11300 \\
10900 \\
10800 \\
11300 \\
10700\end{array}$ & $\begin{array}{r}9110 \\
10800 \\
10100 \\
9040 \\
8390\end{array}$ & $\begin{array}{r}14100 \\
12900 \\
11900 \\
10400 \\
9120\end{array}$ & $\begin{array}{l}3680 \\
3600 \\
3360 \\
3100 \\
4240\end{array}$ & $\begin{array}{l}1650 \\
1750 \\
1780 \\
1860 \\
2110\end{array}$ & $\begin{array}{l}1720 \\
1720 \\
1540 \\
1490 \\
1460\end{array}$ \\
\hline $\begin{array}{l}11 \\
12 \\
13 \\
14 \\
15\end{array}$ & $\begin{array}{l}31100 \\
33600 \\
35800 \\
36600 \\
34900\end{array}$ & $\begin{array}{r}12800 \\
12000 \\
10900 \\
9970 \\
9410\end{array}$ & $\begin{array}{l}15100 \\
13400 \\
12000 \\
10500 \\
11200\end{array}$ & $\begin{array}{l}26000 \\
27400 \\
27400 \\
26900 \\
26800\end{array}$ & $\begin{array}{l}23200 \\
20100 \\
16800 \\
15200 \\
13900\end{array}$ & $\begin{array}{r}8390 \\
8460 \\
15000 \\
24600 \\
24500\end{array}$ & $\begin{array}{r}10500 \\
10400 \\
9880 \\
10100 \\
12800\end{array}$ & $\begin{array}{l}7900 \\
7800 \\
8040 \\
8000 \\
9100\end{array}$ & $\begin{array}{l}7650 \\
6570 \\
6140 \\
5810 \\
5470\end{array}$ & $\begin{array}{l}5210 \\
5460 \\
4670 \\
3820 \\
3250\end{array}$ & $\begin{array}{l}2070 \\
2060 \\
1990 \\
1890 \\
1790\end{array}$ & $\begin{array}{l}1430 \\
1370 \\
1360 \\
1380 \\
1450\end{array}$ \\
\hline $\begin{array}{l}16 \\
17 \\
18 \\
19 \\
20\end{array}$ & $\begin{array}{l}30200 \\
23700 \\
20600 \\
21900 \\
22900\end{array}$ & $\begin{array}{l}9080 \\
8940 \\
8750 \\
8430 \\
7990\end{array}$ & $\begin{array}{l}13500 \\
13900 \\
16700 \\
20400 \\
20200\end{array}$ & $\begin{array}{l}29100 \\
33600 \\
36100 \\
36600 \\
36000\end{array}$ & $\begin{array}{l}12000 \\
10600 \\
10600 \\
11700 \\
14000\end{array}$ & $\begin{array}{l}21600 \\
19600 \\
22300 \\
26600 \\
28700\end{array}$ & $\begin{array}{l}18300 \\
22500 \\
22900 \\
21300 \\
18800\end{array}$ & $\begin{array}{l}10000 \\
10300 \\
16600 \\
20800 \\
19000\end{array}$ & $\begin{array}{l}5190 \\
5420 \\
5510 \\
5000 \\
4630\end{array}$ & $\begin{array}{l}2880 \\
2690 \\
2420 \\
2390 \\
2280\end{array}$ & $\begin{array}{l}1760 \\
1670 \\
1650 \\
1690 \\
1680\end{array}$ & $\begin{array}{l}1650 \\
1710 \\
1770 \\
1650 \\
1670\end{array}$ \\
\hline $\begin{array}{l}21 \\
22 \\
23 \\
24 \\
25\end{array}$ & $\begin{array}{l}21300 \\
18800 \\
16900 \\
15800 \\
15000\end{array}$ & $\begin{array}{l}7540 \\
7330 \\
7230 \\
7150 \\
7070\end{array}$ & $\begin{array}{l}22400 \\
30700 \\
31800 \\
31000 \\
28400\end{array}$ & $\begin{array}{l}33700 \\
30700 \\
28400 \\
26800 \\
25400\end{array}$ & $\begin{array}{l}18100 \\
20600 \\
20600 \\
19500 \\
17300\end{array}$ & $\begin{array}{l}30600 \\
33300 \\
38300 \\
36200 \\
31500\end{array}$ & $\begin{array}{l}16500 \\
17500 \\
17700 \\
17100 \\
16100\end{array}$ & $\begin{array}{r}14600 \\
11400 \\
9940 \\
10800 \\
11500\end{array}$ & $\begin{array}{l}4390 \\
4180 \\
4180 \\
3950 \\
3750\end{array}$ & $\begin{array}{l}2250 \\
2140 \\
2050 \\
1980 \\
1910\end{array}$ & $\begin{array}{l}2000 \\
1980 \\
1910 \\
1800 \\
1700\end{array}$ & $\begin{array}{l}1780 \\
1750 \\
1800 \\
1880 \\
1930\end{array}$ \\
\hline $\begin{array}{l}26 \\
27 \\
28 \\
29 \\
30 \\
31\end{array}$ & $\begin{array}{l}13800 \\
13100 \\
12100 \\
11400 \\
10600 \\
10200\end{array}$ & $\begin{array}{r}6860 \\
7180 \\
15500 \\
21600 \\
23800 \\
\cdots\end{array}$ & $\begin{array}{l}23700 \\
19200 \\
17800 \\
24500 \\
56600 \\
83300\end{array}$ & $\begin{array}{l}24200 \\
23100 \\
22300 \\
20700 \\
18700 \\
17100\end{array}$ & $\begin{array}{r}13900 \\
11800 \\
10900 \\
\ldots \\
\ldots \\
\ldots\end{array}$ & $\begin{array}{l}29600 \\
31400 \\
30800 \\
29400 \\
27100 \\
24200\end{array}$ & $\begin{array}{r}14700 \\
13600 \\
11800 \\
10700 \\
10200 \\
\cdots\end{array}$ & $\begin{array}{l}12500 \\
12900 \\
13000 \\
11900 \\
12300 \\
11900\end{array}$ & $\begin{array}{c}3670 \\
3400 \\
3310 \\
3170 \\
3050 \\
\cdots\end{array}$ & $\begin{array}{l}1850 \\
1840 \\
1800 \\
1790 \\
1750 \\
1670\end{array}$ & $\begin{array}{l}1630 \\
1520 \\
1510 \\
1490 \\
1440 \\
1510\end{array}$ & $\begin{array}{c}1810 \\
1780 \\
1810 \\
1860 \\
1890 \\
-\cdots\end{array}$ \\
\hline $\begin{array}{l}\text { IOIAL } \\
\text { MEAN } \\
\text { MAX } \\
\text { MIN } \\
\text { CF SM } \\
\text { IN. }\end{array}$ & $\begin{array}{r}526740 \\
16990 \\
36600 \\
4040 \\
1.53 \\
1.76\end{array}$ & $\begin{array}{r}333850 \\
11130 \\
23800 \\
6200 \\
1.00 \\
1.12\end{array}$ & $\begin{array}{r}731200 \\
23590 \\
83300 \\
10500 \\
2.12 \\
2.45\end{array}$ & $\begin{array}{r}1179700 \\
38050 \\
102000 \\
17100 \\
3.42 \\
3.95\end{array}$ & $\begin{array}{r}469300 \\
16760 \\
25900 \\
10600 \\
1.51 \\
1.57\end{array}$ & $\begin{array}{r}646860 \\
20870 \\
38300 \\
8390 \\
1.88 \\
2.16\end{array}$ & $\begin{array}{r}438580 \\
14620 \\
22900 \\
9880 \\
1.31 \\
1.47\end{array}$ & $\begin{array}{r}342710 \\
11060 \\
20800 \\
7800 \\
1.99 \\
1.15\end{array}$ & $\begin{array}{r}245660 \\
8189 \\
21100 \\
3050 \\
.74 \\
.82\end{array}$ & $\begin{array}{r}89930 \\
2901 \\
5460 \\
1670 \\
.26 \\
.30\end{array}$ & $\begin{array}{r}54090 \\
1745 \\
2110 \\
1440 \\
.16 \\
.18\end{array}$ & $\begin{array}{r}49110 \\
1637 \\
1930 \\
1360 \\
.15 \\
.16\end{array}$ \\
\hline
\end{tabular}

SIATISIICS OF MONTHLY MEAN DATA FOR WATER YEARS 1928 - 1991, BY WATER YEAR (WY)

\begin{tabular}{|c|c|c|c|c|c|c|c|c|c|c|c|c|}
\hline $\begin{array}{l}\text { MEAN } \\
\text { MAX } \\
(W Y) \\
\text { MIN } \\
(W Y)\end{array}$ & $\begin{array}{r}4092 \\
16990 \\
1991 \\
973 \\
1964\end{array}$ & $\begin{array}{r}5598 \\
27040 \\
1973 \\
1202 \\
1965\end{array}$ & $\begin{array}{r}9461 \\
40350 \\
1928 \\
1041 \\
1964\end{array}$ & $\begin{array}{r}12490 \\
66690 \\
1950 \\
1107 \\
1977\end{array}$ & $\begin{array}{r}14470 \\
40610 \\
1959 \\
1789 \\
1931\end{array}$ & $\begin{array}{r}17310 \\
49690 \\
1982 \\
2370 \\
1941\end{array}$ & $\begin{array}{r}17510 \\
37650 \\
1938 \\
4941 \\
1931\end{array}$ & $\begin{array}{r}13670 \\
58400 \\
1943 \\
2082 \\
1934\end{array}$ & $\begin{array}{r}10180 \\
42730 \\
1958 \\
1357 \\
1934\end{array}$ & $\begin{array}{r}6699 \\
23450 \\
1957 \\
1210 \\
1934\end{array}$ & $\begin{array}{r}4186 \\
18840 \\
1958 \\
815 \\
1941\end{array}$ & $\begin{array}{r}3460 \\
17800 \\
1989 \\
710 \\
1941\end{array}$ \\
\hline
\end{tabular}

SUMMARY SIAIISIICS

ANNUAL TOTAL

ANNUAL MEAN

HIGHESI ANNUAL MEAM

LOWEST ANNUAL MEAN

HIGHESI DAILY MEAN

LOWEST DAILY MEAN

ANNUAL SEVEN-DAY MINIMUM

INSIANTANEOUS PEAK FIOW

INSIANTANEOUS PEAK SIAGE

ANNUAL RUNOFF (CFSN)

ANNUAI RUNOFF (INCHES)

10 PERCENT EXCEEDS

50 PERCENT EXCEEDS

90 PERCENT EXCEEDS
FUR 1990 CALENDAR YEAR

$\begin{aligned} 5999140 & \\ 16440 & \\ & \\ 83300 & \text { Dec } 31 \\ 3600 & \text { Jan } 1 \\ 4280 & \text { Sep } 28 \\ & \\ 1.48 & \\ 20.07 & \\ 31000 & \\ 12700 & \\ 6010 & \end{aligned}$

FOR 1991 WAIER YEAR

WATER YEARS 1928 - 1991

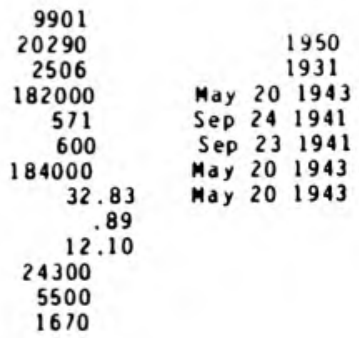




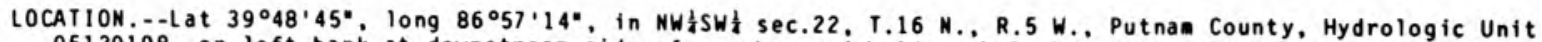
05120108 , on left bank at downstrea side of county road bridge, 1.6 ipstrea from Ran Creek, 3 . 1 i west of Fincastle, and at mile 48.8 .

DRAINAGE AREA $\ldots 139$ i

PERIOD OF RECORD.--August 1957 to current year. Prior to October 1963, published as Raccoon Creek near Fincastle. REVISED RECORDS.--WSP 1909: 1958. WSP 2109: Drainage area. WDR IN-79-1: 1978.

GAGE, - Water-stage recorder. Datue of gage is $686.03 \mathrm{ft}$ above National Geodetic Vertical Datue of 1929.

REMARKS.--Records good except for estinated daily discharges, which are poor.

EXTREMES OUTSIDE PERIOD OF RECORD. - - Flood of June 28,1957 , reached a stage of $19.10 \mathrm{ft}$ discharge, $39,900 \mathrm{ft} 3 / \mathrm{s}$. from slope-area measurewent.

DISCHARGE, CUBIC FEET PER SECOND, WATER YEAR OCTOBER 1990 TO SEPTEMBER 1991 DAILY MEAN VALUES

\begin{tabular}{|c|c|c|c|c|c|c|c|c|c|c|c|c|}
\hline DAY & $O C T$ & NOV & DEC & JAN & FEB & MAR & APR & MAY & JUN & JUL & AUG & SEP \\
\hline $\begin{array}{l}1 \\
2 \\
3 \\
4 \\
5\end{array}$ & $\begin{array}{l}18 \\
18 \\
18 \\
39 \\
43\end{array}$ & $\begin{array}{r}34 \\
32 \\
32 \\
32 \\
112\end{array}$ & $\begin{array}{l}258 \\
198 \\
987 \\
721 \\
379\end{array}$ & $\begin{array}{l}564 \\
406 \\
315 \\
254 \\
233\end{array}$ & $\begin{array}{l}\text { e100 } \\
110 \\
136 \\
173 \\
221\end{array}$ & $\begin{array}{l}121 \\
144 \\
134 \\
121 \\
114\end{array}$ & $\begin{array}{l}151 \\
131 \\
120 \\
118 \\
124\end{array}$ & $\begin{array}{l}76 \\
72 \\
67 \\
75 \\
75\end{array}$ & $\begin{array}{r}198 \\
105 \\
76 \\
61 \\
48\end{array}$ & $\begin{array}{l}6.9 \\
6.6 \\
6.6 \\
6.6 \\
6.4\end{array}$ & $\begin{array}{l}2.1 \\
2.4 \\
2.2 \\
1.6 \\
1.8\end{array}$ & $\begin{array}{l}2.1 \\
2.0 \\
2.1 \\
2.7 \\
2.1\end{array}$ \\
\hline $\begin{array}{r}6 \\
7 \\
8 \\
9 \\
10\end{array}$ & $\begin{array}{r}31 \\
49 \\
124 \\
139 \\
823\end{array}$ & $\begin{array}{r}213 \\
117 \\
82 \\
70 \\
63\end{array}$ & $\begin{array}{l}290 \\
230 \\
194 \\
165 \\
149\end{array}$ & $\begin{array}{l}212 \\
188 \\
175 \\
167 \\
152\end{array}$ & $\begin{array}{l}335 \\
458 \\
326 \\
265 \\
228\end{array}$ & $\begin{array}{r}115 \\
107 \\
94 \\
92 \\
88\end{array}$ & $\begin{array}{l}113 \\
107 \\
110 \\
118 \\
104\end{array}$ & $\begin{array}{l}87 \\
77 \\
67 \\
63 \\
63\end{array}$ & $\begin{array}{l}39 \\
33 \\
31 \\
29 \\
26\end{array}$ & $\begin{array}{r}6.2 \\
4.8 \\
4.3 \\
4.0 \\
14\end{array}$ & $\begin{array}{l}5.6 \\
4.3 \\
4.8 \\
5.2 \\
4.8\end{array}$ & $\begin{array}{l}1.7 \\
1.4 \\
1.4 \\
1.4 \\
1.5\end{array}$ \\
\hline $\begin{array}{l}11 \\
12 \\
13 \\
14 \\
15\end{array}$ & $\begin{array}{r}472 \\
257 \\
165 \\
117 \\
87\end{array}$ & $\begin{array}{l}56 \\
48 \\
43 \\
41 \\
40\end{array}$ & $\begin{array}{l}136 \\
129 \\
117 \\
102 \\
435\end{array}$ & $\begin{array}{l}237 \\
432 \\
281 \\
235 \\
314\end{array}$ & $\begin{array}{r}195 \\
169 \\
168 \\
173 \\
e 155\end{array}$ & $\begin{array}{r}85 \\
120 \\
1110 \\
641 \\
390\end{array}$ & $\begin{array}{r}92 \\
85 \\
97 \\
172 \\
439\end{array}$ & $\begin{array}{l}61 \\
60 \\
59 \\
58 \\
58\end{array}$ & $\begin{array}{l}25 \\
25 \\
22 \\
20 \\
18\end{array}$ & $\begin{array}{l}7.6 \\
7.4 \\
7.3 \\
6.1 \\
5.4\end{array}$ & $\begin{array}{l}3.6 \\
3.0 \\
2.9 \\
2.5 \\
2.4\end{array}$ & $\begin{array}{l}1.6 \\
1.6 \\
1.6 \\
1.6 \\
1.6\end{array}$ \\
\hline $\begin{array}{l}16 \\
17 \\
18 \\
19 \\
20\end{array}$ & $\begin{array}{l}69 \\
61 \\
82 \\
93 \\
74\end{array}$ & $\begin{array}{l}39 \\
38 \\
37 \\
36 \\
36\end{array}$ & $\begin{array}{l}437 \\
306 \\
687 \\
801 \\
474\end{array}$ & $\begin{array}{r}566 \\
538 \\
358 \\
299 \\
e 275\end{array}$ & $\begin{array}{r}\text { e } 135 \\
\text { e } 120 \\
\text { e210 } \\
464 \\
397\end{array}$ & $\begin{array}{l}292 \\
269 \\
489 \\
351 \\
274\end{array}$ & $\begin{array}{l}328 \\
220 \\
175 \\
168 \\
167\end{array}$ & $\begin{array}{l}51 \\
65 \\
59 \\
66 \\
57\end{array}$ & $\begin{array}{l}21 \\
20 \\
17 \\
15 \\
14\end{array}$ & $\begin{array}{l}4.7 \\
4.6 \\
4.2 \\
3.6 \\
3.5\end{array}$ & $\begin{array}{l}2.1 \\
2.1 \\
2.4 \\
2.3 \\
2.5\end{array}$ & $\begin{array}{l}1.5 \\
1.5 \\
1.5 \\
1.5 \\
1.5\end{array}$ \\
\hline $\begin{array}{l}21 \\
22 \\
23 \\
24 \\
25\end{array}$ & $\begin{array}{l}64 \\
57 \\
52 \\
48 \\
43\end{array}$ & $\begin{array}{l}35 \\
46 \\
52 \\
46 \\
42\end{array}$ & $\begin{array}{r}921 \\
1230 \\
555 \\
331 \\
268\end{array}$ & $\begin{array}{l}\text { e250 } \\
\text { e225 } \\
\text { e205 } \\
\text { e185 } \\
\text { e170 }\end{array}$ & $\begin{array}{l}289 \\
233 \\
189 \\
172 \\
151\end{array}$ & $\begin{array}{l}237 \\
372 \\
795 \\
407 \\
285\end{array}$ & $\begin{array}{r}143 \\
130 \\
120 \\
112 \\
97\end{array}$ & $\begin{array}{l}49 \\
45 \\
42 \\
52 \\
81\end{array}$ & $\begin{array}{c}13 \\
12 \\
12 \\
11 \\
9.9\end{array}$ & $\begin{array}{l}3.2 \\
3.0 \\
3.0 \\
2.7 \\
2.5\end{array}$ & $\begin{array}{l}2.7 \\
3.0 \\
2.6 \\
2.1 \\
2.1\end{array}$ & $\begin{array}{l}1.6 \\
2.2 \\
2.8 \\
2.4 \\
1.6\end{array}$ \\
\hline $\begin{array}{l}26 \\
27 \\
28 \\
29 \\
30 \\
31\end{array}$ & $\begin{array}{l}41 \\
39 \\
37 \\
37 \\
35 \\
34\end{array}$ & $\begin{array}{r}38 \\
94 \\
1150 \\
625 \\
356 \\
\ldots-\end{array}$ & $\begin{array}{r}213 \\
197 \\
179 \\
1650 \\
12200 \\
3350\end{array}$ & $\begin{array}{l}\text { el } 55 \\
\text { el } 45 \\
\text { e } 138 \\
\text { el } 30 \\
\text { el } 20 \\
\text { el } 10\end{array}$ & $\begin{array}{l}136 \\
129 \\
123 \\
\ldots- \\
\cdots \\
\ldots\end{array}$ & $\begin{array}{l}424 \\
472 \\
313 \\
235 \\
189 \\
165\end{array}$ & $\begin{array}{r}95 \\
92 \\
89 \\
88 \\
82 \\
-\end{array}$ & $\begin{array}{r}75 \\
55 \\
44 \\
36 \\
149 \\
331\end{array}$ & $\begin{array}{l}9.0 \\
8.5 \\
8.1 \\
7.8 \\
7.3 \\
\ldots . .\end{array}$ & $\begin{array}{l}3.0 \\
2.5 \\
2.4 \\
2.4 \\
2.2 \\
2.1\end{array}$ & $\begin{array}{l}2.0 \\
2.0 \\
2.0 \\
2.0 \\
2.1 \\
2.1\end{array}$ & $\begin{array}{l}1.6 \\
1.5 \\
1.5 \\
1.4 \\
1.2 \\
\ldots-2\end{array}$ \\
\hline $\begin{array}{l}\text { TOTAL } \\
\text { MEAN } \\
\text { MAX } \\
\text { MIN } \\
\text { CF SM } \\
\text { IN. }\end{array}$ & $\begin{array}{r}3266 \\
105 \\
823 \\
18 \\
.76 \\
.87\end{array}$ & $\begin{array}{r}3685 \\
123 \\
1150 \\
32 \\
.88 \\
.99\end{array}$ & $\begin{array}{r}28289 \\
913 \\
12200 \\
102 \\
6.57 \\
7.57\end{array}$ & $\begin{array}{r}8034 \\
259 \\
566 \\
110 \\
1.86 \\
2.15\end{array}$ & $\begin{array}{r}5960 \\
213 \\
464 \\
100 \\
1.53 \\
1.60\end{array}$ & $\begin{array}{r}9045 \\
292 \\
1110 \\
85 \\
2.10 \\
2.42\end{array}$ & $\begin{array}{r}4187 \\
140 \\
439 \\
82 \\
1.00 \\
1.12\end{array}$ & $\begin{array}{r}2275 \\
73.4 \\
331 \\
36 \\
.53 \\
.61\end{array}$ & $\begin{array}{r}941.6 \\
31.4 \\
198 \\
7.3 \\
.23 \\
.25\end{array}$ & $\begin{array}{r}149.8 \\
4.83 \\
14 \\
2.1 \\
.03 \\
.04\end{array}$ & $\begin{array}{r}85.3 \\
2.75 \\
5.6 \\
1.6 \\
.02 \\
.02\end{array}$ & $\begin{array}{r}51.7 \\
1.72 \\
2.8 \\
1.2 \\
.01 \\
.01\end{array}$ \\
\hline
\end{tabular}

e Estimated

STATISTICS OF MONTHLY MEAN DATA FOR WATER YEARS 1958 - 1991, BY WATER YEAR (WY)

\begin{tabular}{|c|c|c|c|c|c|c|c|c|c|c|c|c|}
\hline $\begin{array}{l}\text { MEAN } \\
\text { MAX } \\
\text { (WY) } \\
\text { MIN } \\
\text { (WY) }\end{array}$ & $\begin{array}{r}53.0 \\
312 \\
1970 \\
3.13 \\
1967\end{array}$ & $\begin{array}{r}114 \\
684 \\
1986 \\
5.89 \\
1964\end{array}$ & $\begin{array}{r}212 \\
913 \\
1991 \\
4.93 \\
1964\end{array}$ & $\begin{array}{r}163 \\
616 \\
1974 \\
4.69 \\
1977\end{array}$ & $\begin{array}{r}217 \\
694 \\
1985 \\
26.2 \\
1964\end{array}$ & $\begin{array}{r}275 \\
683 \\
1978 \\
28.6 \\
1981\end{array}$ & $\begin{array}{r}227 \\
730 \\
1964 \\
43.5 \\
1976\end{array}$ & $\begin{array}{r}173 \\
540 \\
1974 \\
19.5 \\
1976\end{array}$ & $\begin{array}{r}112 \\
496 \\
1974 \\
11.1 \\
1988\end{array}$ & $\begin{array}{r}93.4 \\
430 \\
1979 \\
4.83 \\
1991\end{array}$ & $\begin{array}{r}54.0 \\
268 \\
1979 \\
2.75 \\
1991\end{array}$ & $\begin{array}{r}39.8 \\
545 \\
1989 \\
1.72 \\
1991\end{array}$ \\
\hline
\end{tabular}

SUMMARY STATISTICS

ANNUAL TOTAL

ANNUAL MEAN

HIGHEST ANNUAL MEAN

LOWEST ANNUAL MEAN

HIGHEST DAILY MEAN

LOWEST DAILY MEAN

ANNUAL SEVEN-DAY MINIMUM

INSTANTANEOUS PEAK FLOW

INSTANTANEOUS PEAK STAGE

ANNUAL RUNOFF (CFSM)

ANNUAL RUNOFF (INCHES)

10 PERCENT EXCEEDS

50 PERCENT EXCEEDS

90 PERCENT EXCEEDS
FOR 1990 CALENDAR YEAR

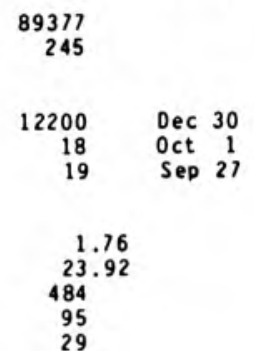

FOR 1991 WATER YEAR

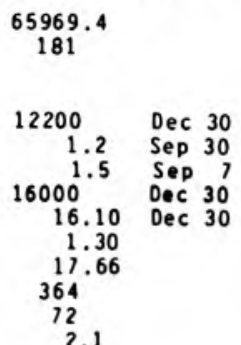

WATER YEARS 1958 - 1991

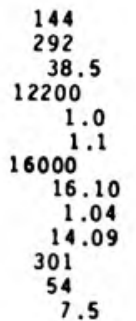




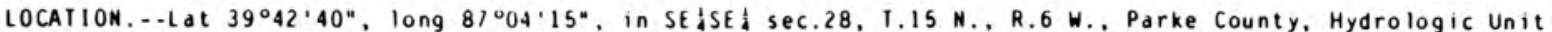
05120108 , on right bank at upstrean side of bridge on New Oiscovery Road, 0.5 i downstrea from Cecil M. Harden Lake, 3.7 i upstrean from Rocky Fork Creek, and at mile 33.3.

DRAINAGE AREA. . $222 i^{2}$.

PERIOD OF RECORD.--October 1956 to current yedr. Prior to October 1963, published as Raccoon Creek at ferndale.

REVISED RECOROS...WSP 2109: Drainage area.

GAGE.--Data-Collection Platform. Datum of gage is $590.00 \mathrm{ft}$ above National Geodetic Vertical Datum of 1929 (U.S. Aray Corps of Engineers bench mark). Prior to 0ct. 1, 19/4, water-stage recorder at site 1.7 i downstrean and at datua $7.64 \mathrm{ft}$ lower. Data-Collection Platform installed on June $27,1986$.

REMARKS. - Flow regulated by Cecil M. Harden Lake since Deceaber 1960 . Daily discharge conputed from relation between discharge, head, and gate openings for Cecil M. Harden lake beginning $0 \mathrm{ct} .1,1974$.

COOPERATION. - Records of daily discharge provided by U.S. Army Corps of Engineers beginning 0ct. 1 . 1976 .

AVERAGE DISCHARGE. -35 years, $232 \mathrm{ft} / \mathrm{s}$.

EXIREMES FOR PERIOD OF RECORD. - Maximum discharge, $40,500 \mathrm{ft} / \mathrm{s}$ June 28,1957 , gage height 19.87 ft, from rating curve extendeg above $5,000 \mathrm{ft} / \mathrm{s}$ on basis of records for station at Big Raccoon Creek at Mansfield; ainiaum da ily, 2.7 ft $/ \mathrm{s} \mathrm{Oct.11,1956;} \mathrm{no} \mathrm{tlow,} \mathrm{Aug.} \mathrm{23,} \mathrm{24,} \mathrm{1977,} \mathrm{July} \mathrm{26,} \mathrm{1986,} \mathrm{Mar.} \mathrm{11,} \mathrm{12,} \mathrm{18,} \mathrm{19,} \mathrm{1987,} \mathrm{due} \mathrm{to}$ regulation.

ExIREMES FOR CURRENT YEAR. ..Maximum daily discharge, $1,690 \mathrm{ft} / \mathrm{s}, \mathrm{Jan}$. 27 ; inimum daily $10 \mathrm{ft} / \mathrm{s}$, July 16 .

DISCHARGE, CUBIL FEET PER SECOND. WATER YEAR OCTOBER 1990 TO SEPTEMBER 1991 DAIIY MEAN VALUES

\begin{tabular}{|c|c|c|c|c|c|c|c|c|c|c|c|c|}
\hline DAY & $O C \mathrm{~T}$ & NOV & DEC & JAN & $F E B$ & MAR & APR & MAY & JUN & JUL & AUG & SEP \\
\hline $\begin{array}{l}1 \\
2 \\
3 \\
4 \\
5\end{array}$ & $\begin{array}{l}67 \\
48 \\
48 \\
48 \\
48\end{array}$ & $\begin{array}{r}1030 \\
1050 \\
1050 \\
845 \\
391\end{array}$ & $\begin{array}{l}132 \\
133 \\
136 \\
140 \\
142\end{array}$ & $\begin{array}{l}138 \\
139 \\
139 \\
139 \\
139\end{array}$ & $\begin{array}{l}1590 \\
1570 \\
1550 \\
1530 \\
1510\end{array}$ & $\begin{array}{r}159 \\
131 \\
132 \\
94 \\
43\end{array}$ & $\begin{array}{l}675 \\
903 \\
997 \\
987 \\
639\end{array}$ & $\begin{array}{l}21 \\
21 \\
21 \\
21 \\
21\end{array}$ & $\begin{array}{l}22 \\
22 \\
22 \\
22 \\
22\end{array}$ & $\begin{array}{l}22 \\
22 \\
22 \\
22 \\
22\end{array}$ & $\begin{array}{l}22 \\
22 \\
22 \\
22 \\
22\end{array}$ & $\begin{array}{l}22 \\
22 \\
22 \\
22 \\
22\end{array}$ \\
\hline $\begin{array}{r}6 \\
7 \\
8 \\
9 \\
10\end{array}$ & $\begin{array}{l}48 \\
48 \\
48 \\
49 \\
49\end{array}$ & $\begin{array}{r}346 \\
185 \\
98 \\
98 \\
238\end{array}$ & $\begin{array}{l}143 \\
392 \\
736 \\
838 \\
984\end{array}$ & $\begin{array}{l}140 \\
140 \\
140 \\
140 \\
140\end{array}$ & $\begin{array}{l}1430 \\
1280 \\
1270 \\
1250 \\
1240\end{array}$ & $\begin{array}{l}28 \\
30 \\
30 \\
30 \\
30\end{array}$ & $\begin{array}{l}146 \\
146 \\
146 \\
147 \\
193\end{array}$ & $\begin{array}{l}21 \\
21 \\
21 \\
22 \\
22\end{array}$ & $\begin{array}{l}22 \\
22 \\
22 \\
22 \\
22\end{array}$ & $\begin{array}{l}22 \\
22 \\
22 \\
22 \\
22\end{array}$ & $\begin{array}{l}22 \\
22 \\
22 \\
22 \\
22\end{array}$ & $\begin{array}{l}22 \\
22 \\
22 \\
22 \\
22\end{array}$ \\
\hline $\begin{array}{l}11 \\
12 \\
13 \\
14 \\
15\end{array}$ & $\begin{array}{l}50 \\
50 \\
79 \\
51 \\
51\end{array}$ & $\begin{array}{l}405 \\
499 \\
721 \\
863 \\
852\end{array}$ & $\begin{array}{r}1150 \\
1180 \\
1160 \\
1060 \\
916\end{array}$ & $\begin{array}{l}140 \\
320 \\
622 \\
695 \\
859\end{array}$ & $\begin{array}{r}1220 \\
1200 \\
1180 \\
1160 \\
981\end{array}$ & $\begin{array}{r}30 \\
30 \\
32 \\
271 \\
469\end{array}$ & $\begin{array}{l}220 \\
220 \\
220 \\
220 \\
319\end{array}$ & $\begin{array}{l}22 \\
22 \\
22 \\
22 \\
22\end{array}$ & $\begin{array}{l}22 \\
22 \\
22 \\
22 \\
22\end{array}$ & $\begin{array}{l}22 \\
22 \\
22 \\
22 \\
11\end{array}$ & $\begin{array}{l}22 \\
22 \\
22 \\
22 \\
18\end{array}$ & $\begin{array}{l}22 \\
22 \\
22 \\
22 \\
22\end{array}$ \\
\hline $\begin{array}{l}16 \\
17 \\
18 \\
19 \\
20\end{array}$ & $\begin{array}{r}51 \\
51 \\
400 \\
788 \\
471\end{array}$ & $\begin{array}{l}840 \\
829 \\
817 \\
586 \\
441\end{array}$ & $\begin{array}{l}909 \\
676 \\
301 \\
307 \\
310\end{array}$ & $\begin{array}{l}y 60 \\
578 \\
104 \\
105 \\
105\end{array}$ & $\begin{array}{l}422 \\
178 \\
158 \\
159 \\
384\end{array}$ & $\begin{array}{l}469 \\
316 \\
204 \\
205 \\
206\end{array}$ & $\begin{array}{l}457 \\
457 \\
457 \\
338 \\
173\end{array}$ & $\begin{array}{l}22 \\
22 \\
22 \\
22 \\
22\end{array}$ & $\begin{array}{l}22 \\
22 \\
22 \\
22 \\
22\end{array}$ & $\begin{array}{l}10 \\
22 \\
22 \\
22 \\
22\end{array}$ & $\begin{array}{l}22 \\
22 \\
22 \\
22 \\
22\end{array}$ & $\begin{array}{l}22 \\
22 \\
22 \\
22 \\
22\end{array}$ \\
\hline $\begin{array}{l}21 \\
22 \\
23 \\
24 \\
25\end{array}$ & $\begin{array}{r}632 \\
424 \\
99 \\
99 \\
99\end{array}$ & $\begin{array}{l}344 \\
263 \\
292 \\
320 \\
357\end{array}$ & $\begin{array}{l}203 \\
100 \\
103 \\
104 \\
105\end{array}$ & $\begin{array}{r}105 \\
243 \\
407 \\
728 \\
1160\end{array}$ & $\begin{array}{l}533 \\
532 \\
529 \\
526 \\
320\end{array}$ & $\begin{array}{r}206 \\
148 \\
51 \\
52 \\
52\end{array}$ & $\begin{array}{r}173 \\
78 \\
21 \\
21 \\
21\end{array}$ & $\begin{array}{l}22 \\
22 \\
22 \\
22 \\
22\end{array}$ & $\begin{array}{l}22 \\
22 \\
22 \\
22 \\
22\end{array}$ & $\begin{array}{l}22 \\
22 \\
22 \\
22 \\
22\end{array}$ & $\begin{array}{l}22 \\
22 \\
22 \\
22 \\
22\end{array}$ & $\begin{array}{l}22 \\
22 \\
22 \\
22 \\
22\end{array}$ \\
\hline $\begin{array}{l}26 \\
27 \\
28 \\
29 \\
30 \\
31\end{array}$ & $\begin{array}{l}374 \\
829 \\
982 \\
974 \\
966 \\
956\end{array}$ & $\begin{array}{r}170 \\
47 \\
49 \\
52 \\
105 \\
\ldots\end{array}$ & $\begin{array}{l}105 \\
355 \\
338 \\
109 \\
125 \\
136\end{array}$ & $\begin{array}{l}1570 \\
1690 \\
1670 \\
1660 \\
1640 \\
1620\end{array}$ & $\begin{array}{l}191 \\
197 \\
197 \\
\ldots \\
\ldots \\
\ldots\end{array}$ & $\begin{array}{r}53 \\
54 \\
54 \\
54 \\
305 \\
526\end{array}$ & $\begin{array}{l}21 \\
21 \\
21 \\
21 \\
21 \\
\cdots\end{array}$ & $\begin{array}{l}22 \\
22 \\
22 \\
22 \\
22 \\
22\end{array}$ & $\begin{array}{r}22 \\
22 \\
22 \\
22 \\
22 \\
\cdots\end{array}$ & $\begin{array}{l}22 \\
22 \\
22 \\
22 \\
22 \\
22\end{array}$ & $\begin{array}{l}22 \\
22 \\
22 \\
22 \\
22 \\
22\end{array}$ & $\begin{array}{r}22 \\
22 \\
22 \\
22 \\
22 \\
\cdots\end{array}$ \\
\hline $\begin{array}{l}\text { TOIAL } \\
\text { MEAN } \\
\text { MAX } \\
\text { MIN }\end{array}$ & $\begin{array}{r}8977 \\
290 \\
982 \\
48\end{array}$ & $\begin{array}{r}14183 \\
473 \\
1050 \\
47\end{array}$ & $\begin{array}{r}13528 \\
436 \\
1180 \\
100\end{array}$ & $\begin{array}{r}18381 \\
593 \\
1690 \\
104\end{array}$ & $\begin{array}{r}24<99 \\
868 \\
1590 \\
158\end{array}$ & $\begin{array}{r}4494 \\
145 \\
526 \\
28\end{array}$ & $\begin{array}{c}8479 \\
283 \\
997 \\
21\end{array}$ & $\begin{array}{r}674 \\
21.7 \\
22 \\
21\end{array}$ & $\begin{array}{r}660 \\
22.0 \\
22 \\
22\end{array}$ & $\begin{array}{r}659 \\
21.3 \\
22 \\
10\end{array}$ & $\begin{array}{r}678 \\
21.9 \\
22 \\
18\end{array}$ & $\begin{array}{r}660 \\
22.0 \\
22 \\
22\end{array}$ \\
\hline
\end{tabular}

CAL YR 1990 IOIAL 109930 MEAN 301 MAX 1530 MIN 17 WTR YR 1991 TOIAL 95672 MEAN 262 MAX 1690 MIN 10 


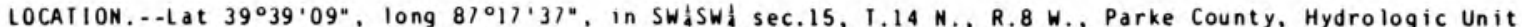
05120108 , on right bank at downstream side of covered bridge on county road at Coxville, 0.8 i upstrean from Rock Run, 1.5 i downstrea from little Raccoon Creek, 2.1 morthwest of Rosedale, and at mile 13.1 .

DRAINAGE AREA. $-448 \mathrm{mi} \mathrm{i}^{2}$.

PERIOD OF RECORD.--0ctober 1956 to September 1988 (discharge). October 1988 to current year (gage height on Iy). Prior to October 1963, published as Raccoon Creek at Coxville.

REVISED RECORDS.-.WSP 2109: Drainage area. WOR IN-74-1: 1973.

GAGE.- -Water-stage recorder. Datum of gage is $494.00 \mathrm{ft}$ above National Geodetic Vertical Datum of 1929 (Indiana flood Control and Water Resources Comission bench ark).

REMARKS. - Gage heights are very doubtful on 0ct, 8-18, Dec, 4-30, Feb. 7-18, May 23-30, June 20-30 and July 9-15 due to lagging intakes. Flow regulated by Cecil M. Harden Lake.

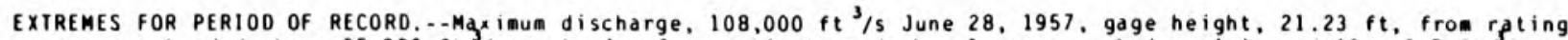
curve extended above $35,000 \mathrm{ft} / \mathrm{s}$ on basis of an estimate made by slope-area study: inimu daily, $6.5 \mathrm{ft} / \mathrm{s}$ $0 \mathrm{ct} .10,1956$

EXIREMES FOR CURRENT YEAR.--Maximum gage height. $15.25 \mathrm{ft}$ Dec. 30, mimimumgage height, 2.87 ft July 29.

GAGE HEIGHT, FEET, WATER YEAR OCTOBER 1990 TO SEPTEMBER 1991 DAILY OBSERVATION AT 24:00 VALUES

\begin{tabular}{|c|c|c|c|c|c|c|c|c|c|c|c|c|}
\hline DAY & $\mathrm{OCI}$ & NOV & DEC & JAN & FEB & MAR & APR & MAY & JUN & JUL & $A \cup G$ & SEP \\
\hline $\begin{array}{l}1 \\
2 \\
3 \\
4 \\
5\end{array}$ & $\begin{array}{l}3.99 \\
3.87 \\
3.88 \\
5.12 \\
4.60\end{array}$ & $\begin{array}{l}7.82 \\
8.00 \\
8.00 \\
7.92 \\
7.06\end{array}$ & $\begin{array}{l}6.39 \\
6.02 \\
8.06 \\
7.44 \\
6.68\end{array}$ & $\begin{array}{r}10.18 \\
8.98 \\
8.11 \\
7.60 \\
7.16\end{array}$ & $\begin{array}{l}10.09 \\
10.16 \\
10.11 \\
10.21 \\
10.40\end{array}$ & $\begin{array}{l}5.62 \\
5.72 \\
5.51 \\
5.26 \\
5.02\end{array}$ & $\begin{array}{l}7.45 \\
8.01 \\
8.10 \\
8.22 \\
7.56\end{array}$ & $\begin{array}{l}4.51 \\
4.41 \\
4.41 \\
4.50 \\
4.70\end{array}$ & $\begin{array}{l}4.49 \\
4.31 \\
4.18 \\
4.06 \\
3.98\end{array}$ & $\begin{array}{l}3.56 \\
3.55 \\
3.54 \\
3.55 \\
3.59\end{array}$ & $\begin{array}{l}\cdots \\
\cdots \\
\cdots \\
\cdots \\
\cdots\end{array}$ & $\begin{array}{l}3.39 \\
3.34 \\
3.34 \\
3.41 \\
3.36\end{array}$ \\
\hline $\begin{array}{r}6 \\
7 \\
8 \\
9 \\
10\end{array}$ & $\begin{array}{l}4.41 \\
4.37 \\
4.55 \\
5.59 \\
8.22\end{array}$ & $\begin{array}{l}6.65 \\
6.24 \\
5.37 \\
5.18 \\
5.17\end{array}$ & $\begin{array}{l}6.27 \\
6.27 \\
7.15 \\
7.60 \\
7.89\end{array}$ & $\begin{array}{l}6.73 \\
6.34 \\
6.15 \\
6.03 \\
5.98\end{array}$ & $\begin{array}{r}10.70 \\
9.87 \\
9.65 \\
9.51 \\
9.37\end{array}$ & $\begin{array}{l}4.92 \\
4.77 \\
4.70 \\
4.66 \\
4.60\end{array}$ & $\begin{array}{l}5.89 \\
5.67 \\
6.11 \\
5.91 \\
5.83\end{array}$ & $\begin{array}{l}4.68 \\
4.49 \\
4.40 \\
4.34 \\
4.30\end{array}$ & $\begin{array}{l}3.92 \\
3.93 \\
3.87 \\
3.83 \\
3.81\end{array}$ & $\begin{array}{l}3.55 \\
3.54 \\
3.51 \\
3.50 \\
4.05\end{array}$ & $\begin{array}{l}\ldots . . \\
3.44 \\
3.43 \\
3.40\end{array}$ & $\begin{array}{l}3.33 \\
3.32 \\
3.33 \\
3.31 \\
3.32\end{array}$ \\
\hline $\begin{array}{l}11 \\
12 \\
13 \\
14 \\
15\end{array}$ & $\begin{array}{l}6.67 \\
5.93 \\
5.55 \\
5.25 \\
5.00\end{array}$ & $\begin{array}{l}5.71 \\
6.15 \\
6.47 \\
7.34 \\
7.41\end{array}$ & $\begin{array}{l}8.39 \\
8.61 \\
8.57 \\
8.50 \\
8.92\end{array}$ & $\begin{array}{l}8.62 \\
7.85 \\
8.17 \\
8.18 \\
9.07\end{array}$ & $\begin{array}{l}9.24 \\
8.98 \\
9.04 \\
8.95 \\
8.13\end{array}$ & $\begin{array}{l}4.58 \\
4.91 \\
7.55 \\
7.23 \\
6.87\end{array}$ & $\begin{array}{l}5.75 \\
5.67 \\
5.93 \\
6.12 \\
6.91\end{array}$ & $\begin{array}{l}4.37 \\
4.28 \\
4.23 \\
4.39 \\
4.28\end{array}$ & $\begin{array}{l}3.79 \\
3.77 \\
3.74 \\
3.71 \\
3.71\end{array}$ & $\begin{array}{r}3.99 \\
3.90 \\
3.82 \\
3.76 \\
\ldots .\end{array}$ & $\begin{array}{l}3.38 \\
3.37 \\
3.36 \\
3.36 \\
3.35\end{array}$ & $\begin{array}{l}3.30 \\
3.30 \\
3.43 \\
3.30 \\
3.29\end{array}$ \\
\hline $\begin{array}{l}16 \\
17 \\
18 \\
19 \\
20\end{array}$ & $\begin{array}{l}4.85 \\
4.75 \\
4.97 \\
7.01 \\
6.41\end{array}$ & $\begin{array}{l}7.46 \\
7.44 \\
7.43 \\
7.02 \\
6.17\end{array}$ & $\begin{array}{l}8.69 \\
8.58 \\
8.89 \\
8.70 \\
7.98\end{array}$ & $\begin{array}{r}10.13 \\
9.01 \\
6.82 \\
6.52 \\
6.34\end{array}$ & $\begin{array}{l}6.48 \\
6.04 \\
7.22 \\
7.13 \\
7.33\end{array}$ & $\begin{array}{l}6.46 \\
7.66 \\
6.86 \\
6.40 \\
6.16\end{array}$ & $\begin{array}{l}6.89 \\
6.71 \\
6.61 \\
6.53 \\
5.66\end{array}$ & $\begin{array}{l}4.18 \\
4.14 \\
4.28 \\
4.16 \\
4.14\end{array}$ & $\begin{array}{l}3.79 \\
3.71 \\
3.67 \\
3.65 \\
3.62\end{array}$ & $\begin{array}{l}\ldots . . \\
3.16 \\
3.14 \\
3.11\end{array}$ & $\begin{array}{l}3.36 \\
3.37 \\
3.37 \\
3.44 \\
3.39\end{array}$ & $\begin{array}{l}3.29 \\
3.29 \\
3.31 \\
3.30 \\
3.31\end{array}$ \\
\hline $\begin{array}{l}21 \\
22 \\
23 \\
24 \\
25\end{array}$ & $\begin{array}{l}6.43 \\
6.57 \\
4.97 \\
4.79 \\
4.70\end{array}$ & $\begin{array}{l}6.02 \\
5.79 \\
5.67 \\
5.72 \\
5.72\end{array}$ & $\begin{array}{l}9.87 \\
9.59 \\
8.05 \\
7.05 \\
6.54\end{array}$ & $\begin{array}{l}6.10 \\
6.37 \\
6.12 \\
7.19 \\
8.66\end{array}$ & $\begin{array}{l}7.28 \\
7.12 \\
7.01 \\
6.94 \\
6.17\end{array}$ & $\begin{array}{l}6.01 \\
9.96 \\
8.11 \\
6.78 \\
6.23\end{array}$ & $\begin{array}{l}5.53 \\
5.18 \\
4.88 \\
4.77 \\
4.70\end{array}$ & $\begin{array}{l}4.04 \\
4.00 \\
4.05 \\
4.06 \\
4.14\end{array}$ & $\begin{array}{l}3.63 \\
3.70 \\
3.65 \\
3.63 \\
3.61\end{array}$ & $\begin{array}{l}3.08 \\
3.06 \\
3.03 \\
3.01 \\
3.00\end{array}$ & $\begin{array}{l}3.37 \\
3.35 \\
3.34 \\
3.34 \\
3.33\end{array}$ & $\begin{array}{l}3.31 \\
3.36 \\
3.35 \\
3.35 \\
3.33\end{array}$ \\
\hline $\begin{array}{l}26 \\
27 \\
28 \\
29 \\
30 \\
31\end{array}$ & $\begin{array}{l}5.22 \\
6.81 \\
7.56 \\
7.63 \\
7.62 \\
7.62\end{array}$ & $\begin{array}{l}5.73 \\
5.99 \\
9.85 \\
8.10 \\
6.87 \\
\ldots\end{array}$ & $\begin{array}{r}6.23 \\
6.17 \\
6.76 \\
13.05 \\
13.92 \\
11.44\end{array}$ & $\begin{array}{l}10.04 \\
10.26 \\
10.24 \\
10.26 \\
10.20 \\
10.13\end{array}$ & $\begin{array}{r}5.92 \\
5.84 \\
5.79 \\
\ldots . \\
\ldots . \\
\ldots\end{array}$ & $\begin{array}{l}9.32 \\
7.39 \\
6.48 \\
6.03 \\
6.91 \\
6.96\end{array}$ & $\begin{array}{c}4.67 \\
4.67 \\
4.59 \\
4.60 \\
4.49 \\
\ldots .\end{array}$ & $\begin{array}{l}4.07 \\
4.02 \\
3.95 \\
4.90 \\
5.49 \\
4.83\end{array}$ & $\begin{array}{l}3.60 \\
3.59 \\
3.58 \\
3.58 \\
3.58 \\
\ldots . .\end{array}$ & $\begin{array}{r}2.97 \\
2.89 \\
2.88 \\
2.87 \\
-\cdots \\
\cdots\end{array}$ & $\begin{array}{l}3.33 \\
3.33 \\
3.32 \\
3.32 \\
3.51 \\
3.42\end{array}$ & $\begin{array}{l}3.32 \\
3.32 \\
3.30 \\
3.30 \\
3.28 \\
\ldots\end{array}$ \\
\hline $\begin{array}{l}\text { MEAN } \\
\text { MAX } \\
\text { MIN }\end{array}$ & $\begin{array}{l}5.64 \\
8.22 \\
3.87\end{array}$ & $\begin{array}{l}6.72 \\
9.85 \\
5.17\end{array}$ & $\begin{array}{r}8.20 \\
13.92 \\
6.02\end{array}$ & $\begin{array}{r}8.07 \\
10.26 \\
5.98\end{array}$ & $\begin{array}{r}8.24 \\
10.70 \\
5.79\end{array}$ & $\begin{array}{l}6.31 \\
9.96 \\
4.58\end{array}$ & $\begin{array}{l}5.99 \\
8.22 \\
4.49\end{array}$ & $\begin{array}{l}4.35 \\
5.49 \\
3.95\end{array}$ & $\begin{array}{l}3.79 \\
4.49 \\
3.58\end{array}$ & $\cdots$ & $\ldots$ & $\begin{array}{l}3.33 \\
3.43 \\
3.28\end{array}$ \\
\hline
\end{tabular}




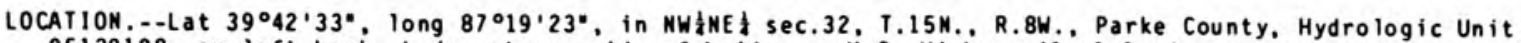
05120108 , on left bank at downstrean side of bridge on U.S. Highway $41,1.2$ a southeast of Mecca, 4.8 .

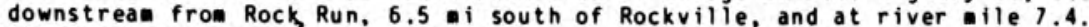
DRAINAGE AREA,$-.473 \mathrm{i}^{2}$.

PERIOD OF RECORD.--0ctober 1988 to current year.

GAGE.- -Water-stage recorder. Datue of gage is $475.00 \mathrm{ft}$ above National Geodetic Vertical Datua of 1929.

REMARKS.--Records poor. Flow regulated by Cecil M. Harden Lake. Maxinue instantaneous and daily aean

discharges for period of record are estimated. Periods of high flow occassionaly are in backwater.

DISCHARGE, CUBIC FEET PER SECOND, WATER YEAR OCTOBER 1990 TO SEPTEMBER 1991 DAI IY MEAN VALUES

\begin{tabular}{|c|c|c|c|c|c|c|c|c|c|c|c|c|}
\hline DAY & $\mathrm{OCT}$ & NOV & DEC & JAN & FEB & MAR & APR & MAY & JUN & JUL & AUG & SEP \\
\hline $\begin{array}{l}1 \\
2 \\
3 \\
4 \\
5\end{array}$ & $\begin{array}{r}120 \\
105 \\
90 \\
330 \\
190\end{array}$ & $\begin{array}{r}943 \\
1070 \\
1080 \\
1070 \\
747\end{array}$ & $\begin{array}{r}714 \\
609 \\
1510 \\
1200 \\
781\end{array}$ & $\begin{array}{l}\text { e } 2500 \\
\text { e1 } 1800 \\
\text { e1 } 1500 \\
\text { e1 } 200 \\
\text { e1 } 1000\end{array}$ & $\begin{array}{l}1940 \\
1950 \\
1970 \\
1970 \\
2040\end{array}$ & $\begin{array}{l}524 \\
537 \\
500 \\
456 \\
378\end{array}$ & $\begin{array}{r}959 \\
1180 \\
1440 \\
1480 \\
1510\end{array}$ & $\begin{array}{l}259 \\
255 \\
242 \\
255 \\
263\end{array}$ & $\begin{array}{l}250 \\
204 \\
172 \\
149 \\
133\end{array}$ & $\begin{array}{l}64 \\
63 \\
63 \\
64 \\
70\end{array}$ & $\begin{array}{l}50 \\
48 \\
47 \\
47 \\
46\end{array}$ & $\begin{array}{l}50 \\
47 \\
44 \\
46 \\
48\end{array}$ \\
\hline $\begin{array}{r}6 \\
7 \\
8 \\
9 \\
10\end{array}$ & $\begin{array}{r}140 \\
130 \\
180 \\
215 \\
1210\end{array}$ & $\begin{array}{l}670 \\
555 \\
325 \\
268 \\
245\end{array}$ & $\begin{array}{r}654 \\
607 \\
957 \\
1160 \\
1190\end{array}$ & $\begin{array}{r}e 860 \\
728 \\
631 \\
583 \\
547\end{array}$ & $\begin{array}{l}2070 \\
2010 \\
1880 \\
1830 \\
1790\end{array}$ & $\begin{array}{l}341 \\
315 \\
291 \\
279 \\
270\end{array}$ & $\begin{array}{l}736 \\
568 \\
562 \\
668 \\
581\end{array}$ & $\begin{array}{l}330 \\
280 \\
254 \\
242 \\
233\end{array}$ & $\begin{array}{l}121 \\
119 \\
114 \\
106 \\
101\end{array}$ & $\begin{array}{l}66 \\
62 \\
60 \\
59 \\
81\end{array}$ & $\begin{array}{l}83 \\
77 \\
59 \\
54 \\
53\end{array}$ & $\begin{array}{l}45 \\
44 \\
45 \\
44 \\
42\end{array}$ \\
\hline $\begin{array}{l}11 \\
12 \\
13 \\
14 \\
15\end{array}$ & $\begin{array}{l}716 \\
422 \\
300 \\
238 \\
190\end{array}$ & $\begin{array}{l}341 \\
462 \\
529 \\
842 \\
887\end{array}$ & $\begin{array}{l}1430 \\
1550 \\
1520 \\
1510 \\
1610\end{array}$ & $\begin{array}{r}844 \\
1260 \\
\mathrm{e} 1100 \\
\mathrm{e} 1000 \\
\mathrm{e} 1200\end{array}$ & $\begin{array}{l}1750 \\
1710 \\
1710 \\
1710 \\
1630\end{array}$ & $\begin{array}{r}263 \\
275 \\
1070 \\
986 \\
1030\end{array}$ & $\begin{array}{l}579 \\
553 \\
570 \\
685 \\
908\end{array}$ & $\begin{array}{l}226 \\
232 \\
222 \\
220 \\
205\end{array}$ & $\begin{array}{l}98 \\
97 \\
93 \\
89 \\
86\end{array}$ & $\begin{array}{r}129 \\
103 \\
85 \\
76 \\
70\end{array}$ & $\begin{array}{l}51 \\
49 \\
48 \\
47 \\
47\end{array}$ & $\begin{array}{l}41 \\
40 \\
42 \\
46 \\
41\end{array}$ \\
\hline $\begin{array}{l}16 \\
17 \\
18 \\
19 \\
20\end{array}$ & $\begin{array}{l}161 \\
154 \\
170 \\
546 \\
667\end{array}$ & $\begin{array}{l}905 \\
924 \\
947 \\
928 \\
564\end{array}$ & $\begin{array}{l}1610 \\
1510 \\
1510 \\
1610 \\
1140\end{array}$ & $\begin{array}{r}1910 \\
1890 \\
1000 \\
726 \\
642\end{array}$ & $\begin{array}{r}1130 \\
661 \\
675 \\
1090 \\
908\end{array}$ & $\begin{array}{r}824 \\
796 \\
1200 \\
854 \\
721\end{array}$ & $\begin{array}{l}999 \\
916 \\
860 \\
845 \\
615\end{array}$ & $\begin{array}{l}174 \\
163 \\
160 \\
169 \\
152\end{array}$ & $\begin{array}{l}92 \\
91 \\
85 \\
80 \\
77\end{array}$ & $\begin{array}{l}63 \\
57 \\
58 \\
57 \\
57\end{array}$ & $\begin{array}{l}45 \\
45 \\
47 \\
49 \\
51\end{array}$ & $\begin{array}{l}40 \\
40 \\
40 \\
40 \\
39\end{array}$ \\
\hline $\begin{array}{l}21 \\
22 \\
23 \\
24 \\
25\end{array}$ & $\begin{array}{l}379 \\
664 \\
268 \\
192 \\
171\end{array}$ & $\begin{array}{l}512 \\
432 \\
430 \\
432 \\
427\end{array}$ & $\begin{array}{r}1010 \\
2070 \\
1260 \\
856 \\
682\end{array}$ & $\begin{array}{r}583 \\
503 \\
689 \\
766 \\
1240\end{array}$ & $\begin{array}{r}1090 \\
1020 \\
964 \\
939 \\
885\end{array}$ & $\begin{array}{r}663 \\
1100 \\
2030 \\
1190 \\
816\end{array}$ & $\begin{array}{l}523 \\
492 \\
368 \\
334 \\
310\end{array}$ & $\begin{array}{l}146 \\
137 \\
153 \\
153 \\
146\end{array}$ & $\begin{array}{l}75 \\
78 \\
80 \\
75 \\
72\end{array}$ & $\begin{array}{l}55 \\
54 \\
53 \\
52 \\
52\end{array}$ & $\begin{array}{l}48 \\
46 \\
44 \\
44 \\
43\end{array}$ & $\begin{array}{l}41 \\
41 \\
45 \\
43 \\
43\end{array}$ \\
\hline $\begin{array}{l}26 \\
27 \\
28 \\
29 \\
30 \\
31\end{array}$ & $\begin{array}{l}177 \\
417 \\
817 \\
872 \\
909 \\
928\end{array}$ & $\begin{array}{r}456 \\
360 \\
2280 \\
1490 \\
856 \\
\ldots-\end{array}$ & $\begin{array}{r}594 \\
\text { e540 } \\
e 900 \\
e 1700 \\
e 5600 \\
\text { e3 } 300\end{array}$ & $\begin{array}{l}1720 \\
1940 \\
1970 \\
1980 \\
1980 \\
1950\end{array}$ & $\begin{array}{l}590 \\
563 \\
546 \\
\ldots . \\
\ldots . \\
\ldots\end{array}$ & $\begin{array}{r}1310 \\
1490 \\
981 \\
736 \\
635 \\
945\end{array}$ & $\begin{array}{l}306 \\
295 \\
290 \\
284 \\
274 \\
\ldots\end{array}$ & $\begin{array}{l}147 \\
137 \\
128 \\
189 \\
485 \\
376\end{array}$ & $\begin{array}{l}70 \\
69 \\
67 \\
65 \\
66 \\
\cdots\end{array}$ & $\begin{array}{l}51 \\
50 \\
49 \\
49 \\
49 \\
49\end{array}$ & $\begin{array}{l}43 \\
42 \\
43 \\
42 \\
43 \\
53\end{array}$ & $\begin{array}{r}42 \\
40 \\
41 \\
40 \\
40 \\
-\cdots\end{array}$ \\
\hline $\begin{array}{l}\text { TOTAL } \\
\text { MEAN } \\
\text { MAX } \\
\text { MIN } \\
\text { CFSN } \\
\text { IN. }\end{array}$ & $\begin{array}{r}12068 \\
389 \\
1210 \\
90 \\
.82 \\
.95\end{array}$ & $\begin{array}{r}21977 \\
733 \\
2280 \\
245 \\
1.55 \\
1.73\end{array}$ & $\begin{array}{r}43394 \\
1400 \\
5600 \\
540 \\
2.96 \\
3.41\end{array}$ & $\begin{array}{r}38242 \\
1234 \\
2500 \\
503 \\
2.61 \\
3.01\end{array}$ & $\begin{array}{r}39021 \\
1394 \\
2070 \\
546 \\
2.95 \\
3.07\end{array}$ & $\begin{array}{r}23806 \\
768 \\
2030 \\
263 \\
1.62 \\
1.87\end{array}$ & $\begin{array}{r}20690 \\
690 \\
1510 \\
274 \\
1.46 \\
1.63\end{array}$ & $\begin{array}{l}6733 \\
217 \\
485 \\
128 \\
.46 \\
.53\end{array}$ & $\begin{array}{r}3074 \\
102 \\
250 \\
65 \\
.22 \\
.24\end{array}$ & $\begin{array}{c}1970 \\
63.5 \\
129 \\
49 \\
.13 \\
.15\end{array}$ & $\begin{array}{r}1534 \\
49.5 \\
83 \\
42 \\
.10 \\
.12\end{array}$ & $\begin{array}{r}1280 \\
42.7 \\
50 \\
39 \\
.09 \\
.10\end{array}$ \\
\hline
\end{tabular}

STATISTICS OF MONTHLY MEAN DATA FOR WATER YEARS 1989 - 1991 , BY WATER YEAR (WY)

$\begin{array}{lrrrrrrrrrrrr}\text { MEAN } & 460 & 563 & 643 & 641 & 869 & 788 & 598 & 718 & 640 & 362 & 375 & 528 \\ \text { MAX } & 887 & 733 & 1400 & 1234 & 1394 & 1314 & 690 & 988 & 1004 & 528 & 671 & 1423 \\ \text { (WY) } & 1990 & 1991 & 1991 & 1991 & 1991 & 1990 & 1991 & 1989 & 1990 & 1990 & 1989 & 1989 \\ \text { MIN } & 105 & 315 & 151 & 339 & 193 & 281 & 460 & 217 & 102 & 63.5 & 49.5 & 42.7 \\ \text { (WY) } & 1989 & 1989 & 1990 & 1990 & 1989 & 1989 & 1990 & 1991 & 1991 & 1991 & 1991 & 1991\end{array}$

SUMMARY STATISTICS

ANMUAL TOTAL

ANMUAL MEAN

HIGHEST ANNUAL MEAM

LOWEST ANNUAL MEAN

HIGHEST DAILY MEAN

LOWEST DAILY MEAN

ANMUAL SEVEN-DAY MINIMUM

INSTANTANEOUS PEAK FLOW

INSTANTAMEOUS PEAK STAGE

ANNUAL RUNOFF (CFSM)

ANNUAL RUNOFF (INCHES)

10 PERCENT EXCEEDS

50 PERCENT EXCEEDS

90 PERCENT EXCEEDS

e Estinated

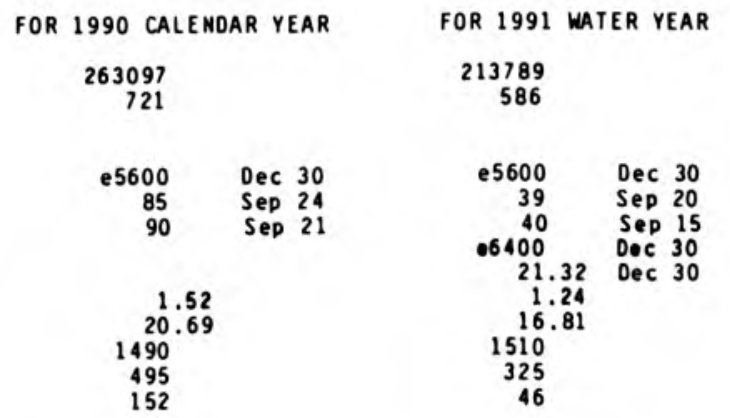

WATER YEARS 1989 - 1991

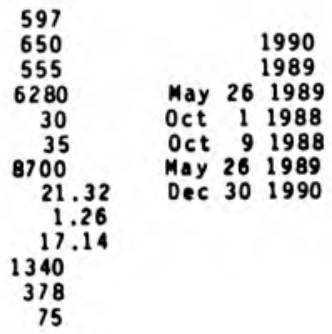


LOCATION.--Lat $39^{\circ} 28^{\circ} 33^{\prime \prime}$, Iong $8^{\circ} 25^{\circ} 07^{\prime \prime}$, In NEdNWd sec.21, T.12 N., R.9 W., Vigo County, Hydrologic Unit 05120111 , on left bank at Indiana America Water Company, Inc., Ist and El Streets in Ierre Haute. 3.0 a upstream from Sugar Cręek, and 3.6 mi downstream fron Lost Creek and at ile 215.

DRAINAGE AREA , . 12,263 i

PERIOD OF RECORD. - August 1902 to December 1903 (gage height only). February 1905 to July 1906 , 0ctober 1927 to current year. Gage-height records collected at site $100 \mathrm{ft}$ downstrean June 1891 to June 1897 and since December 1904 are contained in reports of National Weather Service.

REVISED RECORDS.--WSP 205: 1905. WSP 1335: 1944. WOR IN-13-1: Drainage area. WOR IN-84-1: 1983. WDR IN-86-1: 1913 (Gage height).

GAGE. - Water-stage recorder. Datum of gage is $445.78 \mathrm{ft}$ above National Geodetic Vertical Datun of 1929 . Prior to $0 \mathrm{ct}$. 11, 1984, water-stage recorder at Wabash Avenue bridge 3,400 $\mathrm{ft}$ downstrean at datum $2.88 \mathrm{ft}$ lower. See WSP 1725 for history of changes prior to $0 \mathrm{ct} .27,1928$.

REMARKS.-. Records good. Flow partially regulated by upstream reservoirs.

EXIREMES OUISIDE PERIOD GF RECORO..-Flood of March 27, 1913, reached a stage of $31.1 \mathrm{ft}$, present site and datum, discharge, $245,000 \mathrm{ft} / \mathrm{s}$.

DISCHARGE, CUBIC FEET PER SECOND, WATER YEAR OCTOBER 1990 TO SEPTEMBER 1991 DAILY MEAN VALUES

\begin{tabular}{|c|c|c|c|c|c|c|c|c|c|c|c|c|}
\hline DAY & $0 \mathrm{CI}$ & NOV & DEC & JAN & FEB & MAR & APR & MAY & JUN & JUL & AUG & SEP \\
\hline $\begin{array}{l}1 \\
2 \\
3 \\
4 \\
5\end{array}$ & $\begin{array}{l}4320 \\
4140 \\
4120 \\
5000 \\
5170\end{array}$ & $\begin{array}{r}10600 \\
9640 \\
8380 \\
7340 \\
7860\end{array}$ & $\begin{array}{l}26300 \\
23000 \\
22000 \\
26300 \\
28000\end{array}$ & $\begin{array}{r}91500 \\
106000 \\
101000 \\
86400 \\
73600\end{array}$ & $\begin{array}{l}18800 \\
16600 \\
14800 \\
14600 \\
17600\end{array}$ & $\begin{array}{l}12000 \\
11800 \\
12100 \\
13200 \\
13200\end{array}$ & $\begin{array}{l}26800 \\
22700 \\
19700 \\
16400 \\
14700\end{array}$ & $\begin{array}{r}10700 \\
10400 \\
9720 \\
9050 \\
9180\end{array}$ & $\begin{array}{l}15300 \\
20800 \\
23100 \\
21800 \\
18800\end{array}$ & $\begin{array}{l}3170 \\
3080 \\
3130 \\
3150 \\
3590\end{array}$ & $\begin{array}{l}1650 \\
1720 \\
1660 \\
1560 \\
1550\end{array}$ & $\begin{array}{l}1520 \\
1400 \\
1370 \\
1540 \\
1440\end{array}$ \\
\hline $\begin{array}{r}6 \\
7 \\
8 \\
9 \\
10\end{array}$ & $\begin{array}{r}4980 \\
5390 \\
8890 \\
10500 \\
20500\end{array}$ & $\begin{array}{l}12100 \\
18600 \\
21900 \\
20000 \\
16100\end{array}$ & $\begin{array}{l}21900 \\
26300 \\
24300 \\
22200 \\
20000\end{array}$ & $\begin{array}{l}63000 \\
54300 \\
48200 \\
43000 \\
38300\end{array}$ & $\begin{array}{l}21600 \\
26200 \\
29400 \\
30200 \\
29700\end{array}$ & $\begin{array}{r}12500 \\
11800 \\
11100 \\
10400 \\
9640\end{array}$ & $\begin{array}{l}13400 \\
12100 \\
11800 \\
12300 \\
12100\end{array}$ & $\begin{array}{r}10000 \\
11200 \\
11500 \\
10200 \\
9290\end{array}$ & $\begin{array}{l}16200 \\
14400 \\
13300 \\
11900 \\
10400\end{array}$ & $\begin{array}{l}3780 \\
3800 \\
3560 \\
3270 \\
3600\end{array}$ & $\begin{array}{l}2050 \\
2130 \\
1980 \\
2180 \\
2250\end{array}$ & $\begin{array}{l}1490 \\
1830 \\
1630 \\
1400 \\
1380\end{array}$ \\
\hline $\begin{array}{l}11 \\
12 \\
13 \\
14 \\
15\end{array}$ & $\begin{array}{l}32000 \\
35500 \\
38400 \\
40200 \\
41200\end{array}$ & $\begin{array}{l}14000 \\
13000 \\
12000 \\
11100 \\
10400\end{array}$ & $\begin{array}{l}17600 \\
15600 \\
14000 \\
12500 \\
12100\end{array}$ & $\begin{array}{l}35500 \\
35300 \\
34900 \\
34000 \\
33400\end{array}$ & $\begin{array}{l}28000 \\
24100 \\
20900 \\
18800 \\
17000\end{array}$ & $\begin{array}{r}9260 \\
9090 \\
12600 \\
24100 \\
27100\end{array}$ & $\begin{array}{l}11500 \\
11400 \\
11000 \\
11100 \\
13300\end{array}$ & $\begin{array}{l}8790 \\
8520 \\
8740 \\
8800 \\
9960\end{array}$ & $\begin{array}{l}9010 \\
7740 \\
7080 \\
6680 \\
6320\end{array}$ & $\begin{array}{l}5200 \\
6390 \\
5760 \\
4520 \\
3760\end{array}$ & $\begin{array}{l}2530 \\
2370 \\
2350 \\
2220 \\
2070\end{array}$ & $\begin{array}{l}1310 \\
1240 \\
1180 \\
1150 \\
1190\end{array}$ \\
\hline $\begin{array}{l}16 \\
17 \\
18 \\
19 \\
20\end{array}$ & $\begin{array}{l}39800 \\
33800 \\
25700 \\
24100 \\
25100\end{array}$ & $\begin{array}{l}9980 \\
9710 \\
9600 \\
9330 \\
8930\end{array}$ & $\begin{array}{l}14800 \\
15600 \\
18400 \\
23400 \\
23400\end{array}$ & $\begin{array}{l}35100 \\
38600 \\
41300 \\
42500 \\
43400\end{array}$ & $\begin{array}{l}14700 \\
12800 \\
12300 \\
13900 \\
15700\end{array}$ & $\begin{array}{l}24900 \\
22200 \\
24100 \\
28200 \\
30900\end{array}$ & $\begin{array}{l}17700 \\
22700 \\
24500 \\
23700 \\
21400\end{array}$ & $\begin{array}{l}10800 \\
11300 \\
14800 \\
22100 \\
22300\end{array}$ & $\begin{array}{l}5990 \\
5870 \\
6200 \\
5730 \\
5270\end{array}$ & $\begin{array}{l}3200 \\
2950 \\
2890 \\
2790 \\
2720\end{array}$ & $\begin{array}{l}1960 \\
1830 \\
1710 \\
1730 \\
1800\end{array}$ & $\begin{array}{l}1380 \\
1630 \\
1750 \\
1730 \\
1560\end{array}$ \\
\hline $\begin{array}{l}21 \\
22 \\
23 \\
24 \\
25\end{array}$ & $\begin{array}{l}24300 \\
21700 \\
19200 \\
17300 \\
16300\end{array}$ & $\begin{array}{l}8420 \\
8160 \\
8040 \\
7890 \\
7790\end{array}$ & $\begin{array}{l}25000 \\
34300 \\
38100 \\
38200 \\
36800\end{array}$ & $\begin{array}{l}43000 \\
40900 \\
38000 \\
35000 \\
32700\end{array}$ & $\begin{array}{l}18800 \\
22200 \\
23400 \\
22500 \\
20800\end{array}$ & $\begin{array}{l}33200 \\
36600 \\
40800 \\
41700 \\
40300\end{array}$ & $\begin{array}{l}18500 \\
17600 \\
18300 \\
17500 \\
16500\end{array}$ & $\begin{array}{l}18200 \\
14100 \\
11900 \\
11400 \\
12400\end{array}$ & $\begin{array}{l}4930 \\
4890 \\
5060 \\
4580 \\
4250\end{array}$ & $\begin{array}{l}2550 \\
2520 \\
2310 \\
2230 \\
2090\end{array}$ & $\begin{array}{l}1970 \\
2290 \\
2130 \\
2070 \\
1870\end{array}$ & $\begin{array}{l}1720 \\
1780 \\
1780 \\
1800 \\
1960\end{array}$ \\
\hline $\begin{array}{l}26 \\
27 \\
28 \\
29 \\
30 \\
31\end{array}$ & $\begin{array}{l}15100 \\
14100 \\
13300 \\
12500 \\
11700 \\
11000\end{array}$ & $\begin{array}{r}7640 \\
7950 \\
16800 \\
24500 \\
25900 \\
\ldots\end{array}$ & $\begin{array}{l}32400 \\
25000 \\
21100 \\
25300 \\
50100 \\
76000\end{array}$ & $\begin{array}{l}30500 \\
28900 \\
27000 \\
25100 \\
23200 \\
21000\end{array}$ & $\begin{array}{r}17400 \\
14300 \\
12900 \\
\ldots \\
\ldots \\
\ldots\end{array}$ & $\begin{array}{l}37800 \\
37600 \\
36900 \\
35600 \\
33600 \\
30400\end{array}$ & $\begin{array}{r}15900 \\
14800 \\
12900 \\
11700 \\
11200 \\
\cdots\end{array}$ & $\begin{array}{l}13200 \\
13700 \\
14000 \\
13600 \\
14000 \\
13600\end{array}$ & $\begin{array}{c}4100 \\
3840 \\
3620 \\
3490 \\
3290 \\
\cdots\end{array}$ & $\begin{array}{l}2010 \\
1950 \\
1920 \\
1890 \\
1870 \\
1760\end{array}$ & $\begin{array}{l}1750 \\
1610 \\
1490 \\
1470 \\
1410 \\
1420\end{array}$ & $\begin{array}{c}1920 \\
1770 \\
1780 \\
1800 \\
1850 \\
\cdots\end{array}$ \\
\hline $\begin{array}{l}\text { IOIAL } \\
\text { MEAN } \\
\text { MAX } \\
\text { MIN } \\
\text { CF SM } \\
\text { IN. }\end{array}$ & $\begin{array}{r}585310 \\
18880 \\
41200 \\
4120 \\
1.54 \\
1.78\end{array}$ & $\begin{array}{r}363660 \\
12120 \\
25900 \\
7340 \\
.99 \\
1.10\end{array}$ & $\begin{array}{r}816000 \\
26320 \\
16000 \\
12100 \\
2.15 \\
2.47\end{array}$ & $\begin{array}{r}1424600 \\
45950 \\
106000 \\
21000 \\
3.75 \\
4.32\end{array}$ & $\begin{array}{r}550600 \\
19660 \\
30200 \\
12300 \\
1.60 \\
1.67\end{array}$ & $\begin{array}{r}734690 \\
23700 \\
41700 \\
9090 \\
1.93 \\
2.23\end{array}$ & $\begin{array}{r}485200 \\
16110 \\
26800 \\
11000 \\
1.32 \\
1.47\end{array}$ & $\begin{array}{r}371450 \\
12180 \\
22300 \\
8520 \\
.99 \\
1.14\end{array}$ & $\begin{array}{r}273940 \\
9131 \\
23100 \\
3290 \\
.74 \\
.83\end{array}$ & $\begin{array}{r}97410 \\
3142 \\
6390 \\
1760 \\
.26 \\
.30\end{array}$ & $\begin{array}{r}58780 \\
1896 \\
2530 \\
1410 \\
.15 \\
.18\end{array}$ & $\begin{array}{r}47280 \\
1576 \\
1960 \\
1150 \\
.13 \\
.14\end{array}$ \\
\hline
\end{tabular}

STATISIICS OF MONTHLY MEAN DAIA FOR WAIER YEARS 1928 - 1991, BY WATER YEAR (WY)

\begin{tabular}{|c|c|c|c|c|c|c|c|c|c|c|c|c|}
\hline $\begin{array}{l}\text { MEAN } \\
\text { MAX } \\
\text { (WY) } \\
\text { MIN } \\
(W Y)\end{array}$ & $\begin{array}{r}4535 \\
18880 \\
1991 \\
1103 \\
1957\end{array}$ & $\begin{array}{r}6082 \\
29880 \\
1973 \\
1405 \\
1954\end{array}$ & $\begin{array}{r}10330 \\
44490 \\
1928 \\
1145 \\
1964\end{array}$ & $\begin{array}{r}13180 \\
17540 \\
1950 \\
1216 \\
1977\end{array}$ & $\begin{array}{r}15860 \\
47990 \\
1950 \\
1998 \\
1963\end{array}$ & $\begin{array}{r}18850 \\
51250 \\
1982 \\
2645 \\
1941\end{array}$ & $\begin{array}{r}19180 \\
41940 \\
1938 \\
5250 \\
1931\end{array}$ & $\begin{array}{r}15350 \\
64810 \\
1943 \\
2405 \\
1934\end{array}$ & $\begin{array}{r}11380 \\
44130 \\
1958 \\
1492 \\
1934\end{array}$ & $\begin{array}{r}1555 \\
27840 \\
1957 \\
1292 \\
1936\end{array}$ & $\begin{array}{r}4749 \\
21330 \\
1958 \\
1002 \\
1941\end{array}$ & $\begin{array}{r}3888 \\
21440 \\
1989 \\
966 \\
1941\end{array}$ \\
\hline
\end{tabular}

SUMMARY SIATISIICS

ANNUAL IOIAL

ANHUAL MEAN

HI GHESI ANNUAL MEAM

LOWE ST ANHUAL MEAN

HIGHEST DAILY MEAN

LOWEST DAILY MEAN

ANNUAL SEVEN-DAY MINIMUM

INSTANTANEOUS PEAK FLOW

INSTAMTANEOUS PEAK STAGE

ANMUAL RUNOFF (CFSM)

ANNUAL RUNOFF (INCHES)

10 PERCENT EXLEEDS

50 PERCENT EXCEEDS

90 PERCENT EXCEEDS
FOR 1990 CALENOAR YEAR

FOR 1991 WAIER YEAR

WAIER YEARS $1928 \cdot 1991$

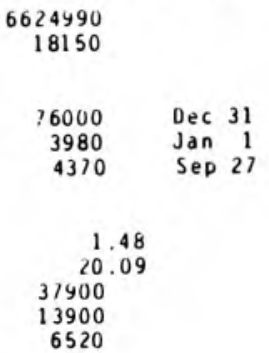




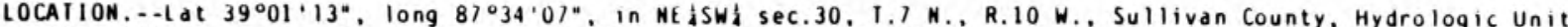
05120111 , on left bank at downstrean side of lllinois Central Rallroad bridge at Riverton, 0.5 ai downstrean frow Turtle Creek, and $\mathrm{ft}$ ile 162.0 .

DRAI NAGE AREA.-13,161 $: i$.

PERIOD OF RECORD.--October 1938 to current year. Prior to April 1939 monthly discharge only, published in WsP 1305. June 1911 to Deceaber 1914 (gage heights only) available in the U.S. Aray Corps of Engineers office. Lou isville, Ky.

REVISED RECORDS.--WSP 1335: 1939, 1950. WDR IN-73-1: Orainage area.

GAGE.- Water-stage recorder. Datun of 9 dge is $414.65 \mathrm{ft}$ above National Geodetic Vertical Datua of 1929 . Prior to July 17, 1951. nonrecording gage at sane site and datue.

REMARKS. - Records good. Flow partially regulated by upstrean reservoirs.

EXTREMES OUISIDE PERIOD OF RECORD...Flood of March 28, 1913, reached a stage of $26.4 \mathrm{ft}$, from graph based on once-daily readings by 111 inois Central Railroad Co., discharge, $250,000 \mathrm{ft} / \mathrm{s}$.

OISCHARGE, CUBIC FEET PER SECOND, WATER YEAR OCTOBER 1990 TO SEPIEMBER 1991 DAIIY MEAN VALUES

\begin{tabular}{|c|c|c|c|c|c|c|c|c|c|c|c|c|}
\hline OAY & $\mathrm{OCT}$ & NOV & DEC & JAM & FE B & MAR & $A P R$ & MAY & JUN & JUL & AUG & SEP \\
\hline $\begin{array}{l}1 \\
2 \\
3 \\
4 \\
5\end{array}$ & $\begin{array}{l}4660 \\
4530 \\
4380 \\
5550 \\
6130\end{array}$ & $\begin{array}{r}11600 \\
11000 \\
9930 \\
8650 \\
7920\end{array}$ & $\begin{array}{l}26300 \\
26000 \\
25400 \\
26600 \\
27000\end{array}$ & $\begin{array}{r}60400 \\
74400 \\
87800 \\
97800 \\
101000\end{array}$ & $\begin{array}{l}23200 \\
20600 \\
18500 \\
17100 \\
17500\end{array}$ & $\begin{array}{l}13700 \\
13200 \\
13200 \\
13200 \\
14100\end{array}$ & $\begin{array}{l}35100 \\
32900 \\
29200 \\
24100 \\
19800\end{array}$ & $\begin{array}{l}12300 \\
11700 \\
11200 \\
10600 \\
10400\end{array}$ & $\begin{array}{l}13900 \\
16200 \\
20300 \\
21600 \\
20500\end{array}$ & $\begin{array}{l}4010 \\
4010 \\
3950 \\
3900 \\
3900\end{array}$ & $\begin{array}{l}2190 \\
2110 \\
2110 \\
2090 \\
2030\end{array}$ & $\begin{array}{l}1830 \\
1850 \\
1790 \\
1920 \\
2560\end{array}$ \\
\hline $\begin{array}{r}6 \\
7 \\
8 \\
9 \\
10\end{array}$ & $\begin{array}{r}5560 \\
5390 \\
6450 \\
9460 \\
13700\end{array}$ & $\begin{array}{r}9340 \\
13900 \\
18900 \\
20800 \\
19100\end{array}$ & $\begin{array}{l}27500 \\
27500 \\
26700 \\
25200 \\
23300\end{array}$ & $\begin{array}{l}96700 \\
85500 \\
73500 \\
62300 \\
53900\end{array}$ & $\begin{array}{l}21000 \\
24900 \\
26900 \\
28400 \\
29300\end{array}$ & $\begin{array}{l}14100 \\
13500 \\
12700 \\
12000 \\
11200\end{array}$ & $\begin{array}{l}17200 \\
15400 \\
14300 \\
14600 \\
14500\end{array}$ & $\begin{array}{l}10800 \\
11300 \\
12200 \\
12100 \\
11100\end{array}$ & $\begin{array}{l}18100 \\
16000 \\
14500 \\
13400 \\
12000\end{array}$ & $\begin{array}{l}4240 \\
4350 \\
4320 \\
4150 \\
3940\end{array}$ & $\begin{array}{l}2380 \\
3410 \\
2810 \\
2520 \\
2990\end{array}$ & $\begin{array}{l}2020 \\
1880 \\
2030 \\
1970 \\
1830\end{array}$ \\
\hline $\begin{array}{l}11 \\
12 \\
13 \\
14 \\
15\end{array}$ & $\begin{array}{l}21900 \\
26100 \\
28700 \\
30400 \\
32100\end{array}$ & $\begin{array}{l}16200 \\
14400 \\
13400 \\
12300 \\
11400\end{array}$ & $\begin{array}{l}21000 \\
18600 \\
16700 \\
15000 \\
13600\end{array}$ & $\begin{array}{l}48900 \\
46100 \\
42700 \\
39800 \\
37800\end{array}$ & $\begin{array}{l}29600 \\
28900 \\
26700 \\
24900 \\
22100\end{array}$ & $\begin{array}{l}10500 \\
10200 \\
12500 \\
18700 \\
24600\end{array}$ & $\begin{array}{l}13800 \\
13100 \\
13000 \\
13300 \\
14500\end{array}$ & $\begin{array}{r}10300 \\
9990 \\
9720 \\
9610 \\
9760\end{array}$ & $\begin{array}{r}10700 \\
9250 \\
8080 \\
7460 \\
7050\end{array}$ & $\begin{array}{l}4350 \\
7130 \\
8460 \\
6370 \\
5210\end{array}$ & $\begin{array}{l}2650 \\
2710 \\
2610 \\
2570 \\
2630\end{array}$ & $\begin{array}{l}1770 \\
1710 \\
1650 \\
1610 \\
1580\end{array}$ \\
\hline $\begin{array}{l}16 \\
17 \\
18 \\
19 \\
20\end{array}$ & $\begin{array}{l}33300 \\
34200 \\
34500 \\
32600 \\
29500\end{array}$ & $\begin{array}{r}10800 \\
10300 \\
10100 \\
9910 \\
9600\end{array}$ & $\begin{array}{l}14100 \\
16000 \\
20300 \\
24700 \\
25600\end{array}$ & $\begin{array}{l}31200 \\
36900 \\
36600 \\
37000 \\
38100\end{array}$ & $\begin{array}{l}18700 \\
16200 \\
14600 \\
16600 \\
17500\end{array}$ & $\begin{array}{l}26500 \\
26300 \\
29200 \\
29000 \\
29300\end{array}$ & $\begin{array}{l}17100 \\
20100 \\
23200 \\
24900 \\
24800\end{array}$ & $\begin{array}{l}10700 \\
11600 \\
12000 \\
15900 \\
20400\end{array}$ & $\begin{array}{l}6810 \\
6550 \\
6440 \\
6540 \\
6170\end{array}$ & $\begin{array}{l}4480 \\
3950 \\
3630 \\
3360 \\
3150\end{array}$ & $\begin{array}{l}2570 \\
2320 \\
2190 \\
2080 \\
2060\end{array}$ & $\begin{array}{l}1580 \\
1650 \\
1850 \\
1940 \\
1950\end{array}$ \\
\hline $\begin{array}{l}21 \\
22 \\
23 \\
24 \\
25\end{array}$ & $\begin{array}{l}26900 \\
25100 \\
22800 \\
20100 \\
18200\end{array}$ & $\begin{array}{l}9120 \\
8830 \\
8840 \\
8510 \\
8240\end{array}$ & $\begin{array}{l}26300 \\
31400 \\
32700 \\
33500 \\
34200\end{array}$ & $\begin{array}{l}39300 \\
40300 \\
40800 \\
40300 \\
38300\end{array}$ & $\begin{array}{l}18000 \\
20300 \\
22400 \\
23000 \\
22400\end{array}$ & $\begin{array}{l}30200 \\
32400 \\
36700 \\
39700 \\
40900\end{array}$ & $\begin{array}{l}22700 \\
20100 \\
19600 \\
19700 \\
19200\end{array}$ & $\begin{array}{l}20500 \\
17500 \\
14100 \\
12200 \\
12100\end{array}$ & $\begin{array}{l}5870 \\
5630 \\
5920 \\
5800 \\
5320\end{array}$ & $\begin{array}{l}3050 \\
2920 \\
2870 \\
2690 \\
2590\end{array}$ & $\begin{array}{l}2090 \\
2160 \\
2360 \\
2300 \\
2240\end{array}$ & $\begin{array}{l}1850 \\
1930 \\
2020 \\
2010 \\
2050\end{array}$ \\
\hline $\begin{array}{l}26 \\
27 \\
28 \\
29 \\
30 \\
31\end{array}$ & $\begin{array}{l}17000 \\
15800 \\
14800 \\
13900 \\
13000 \\
12200\end{array}$ & $\begin{array}{r}8060 \\
9090 \\
17100 \\
25000 \\
26100 \\
\ldots\end{array}$ & $\begin{array}{r}\text { e } 34700 \\
\text { e } 34300 \\
\text { e } 32000 \\
29100 \\
39700 \\
49300\end{array}$ & $\begin{array}{l}36200 \\
34200 \\
32800 \\
31300 \\
29200 \\
26100\end{array}$ & $\begin{array}{c}20600 \\
17600 \\
15100 \\
\ldots \\
\ldots- \\
\ldots\end{array}$ & $\begin{array}{l}41600 \\
41900 \\
41300 \\
40200 \\
38800 \\
37000\end{array}$ & $\begin{array}{c}18200 \\
17000 \\
15800 \\
14100 \\
12700 \\
\ldots\end{array}$ & $\begin{array}{l}12700 \\
13400 \\
13900 \\
14000 \\
14400 \\
14500\end{array}$ & $\begin{array}{r}4980 \\
4800 \\
4550 \\
4350 \\
4230 \\
\ldots\end{array}$ & $\begin{array}{l}2480 \\
2410 \\
2360 \\
2330 \\
2280 \\
2250\end{array}$ & $\begin{array}{l}2120 \\
2020 \\
1930 \\
1840 \\
1880 \\
1940\end{array}$ & $\begin{array}{c}2130 \\
2110 \\
2010 \\
2000 \\
2010 \\
\cdots\end{array}$ \\
\hline $\begin{array}{l}\text { IOIAL } \\
\text { MEAN } \\
\text { MAX } \\
\text { MIN } \\
\text { CF SM } \\
\text { IN. }\end{array}$ & $\begin{array}{r}568910 \\
18350 \\
34500 \\
4380 \\
1.39 \\
1.61\end{array}$ & $\begin{array}{r}378440 \\
12610 \\
26100 \\
7920 \\
.96 \\
1.07\end{array}$ & $\begin{array}{r}824300 \\
26590 \\
49300 \\
13600 \\
2.02 \\
2.33\end{array}$ & $\begin{array}{r}1583200 \\
51070 \\
101000 \\
26100 \\
3.88 \\
4.47\end{array}$ & $\begin{array}{r}602600 \\
21520 \\
29600 \\
14600 \\
1.64 \\
1.10\end{array}$ & $\begin{array}{r}768400 \\
24790 \\
41900 \\
10200 \\
1.88 \\
2.17\end{array}$ & $\begin{array}{c}574000 \\
19130 \\
35100 \\
12700 \\
1.45 \\
1.62\end{array}$ & $\begin{array}{r}392980 \\
12680 \\
20500 \\
9610 \\
.96 \\
1.11\end{array}$ & $\begin{array}{r}293000 \\
9167 \\
21600 \\
4230 \\
.74 \\
.83\end{array}$ & $\begin{array}{r}119150 \\
3844 \\
8460 \\
2250 \\
.29 \\
.34\end{array}$ & $\begin{array}{r}71910 \\
2320 \\
3410 \\
1840 \\
.18 \\
.20\end{array}$ & $\begin{array}{c}57100 \\
1903 \\
2560 \\
1580 \\
.14 \\
.16\end{array}$ \\
\hline
\end{tabular}

e Estimated

SIATISIICS OF MONTHLY MEAN DAIA FOR WAIER YEARS 1940 - 1991, BY WAIER YEAR (WY)

$\begin{array}{lrrrrrrrrrrrr}\text { MEAN } & 4770 & 6538 & 10940 & 13180 & 17410 & 21110 & 21280 & 17000 & 13170 & 8440 & 5427 & 4415 \\ \text { MAX } & 18350 & 31150 & 39250 & 80210 & 54530 & 60520 & 41840 & 68010 & 45640 & 36240 & 23680 & 25370 \\ \text { (WY) } & 1991 & 1973 & 1986 & 1950 & 1950 & 1982 & 1957 & 1943 & 1958 & 1957 & 1958 & 1989 \\ \text { MIN } & 1382 & 1437 & 1213 & 1318 & 2057 & 2763 & 6363 & 3435 & 2601 & 1968 & 1215 & 1261 \\ \text { (WY) } & 1957 & 1954 & 1964 & 1977 & 1963 & 1941 & 1941 & 1941 & 1977 & 1988 & 1941 & 1940\end{array}$

SUMMARY SIAIISIICS

ANMUAL TOTAL

HIGHESI ANNUAL MEAN

LOWEST ANNUAL MEAN

LOWEST ANNUAL MEAN

HIGHEST DAILY MEAN

ANNUAL SEVEN-DAY MINIMUM

INSTANIANEOUS PEAK FLOW

INSTANTANEOUS PEAK SIAGE

ANMUAL RUNOFF (CFSM)

ANNUAL RUNOFF (INCHES)

10 PERCENT EXCEEDS

50 PERCENT EXCEEOS

90 PERCENT EXCEEDS
FOR 1990 CALENUAR YEAR

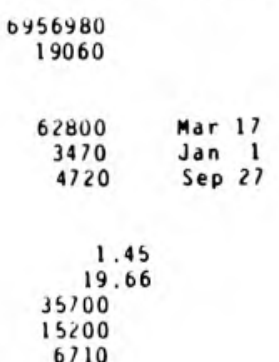

6710
FOR 1991 WAIER YEAR

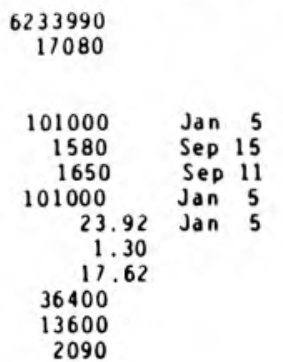

WAIER YEARS $1940-1991$

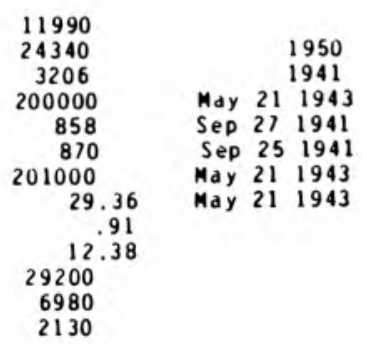




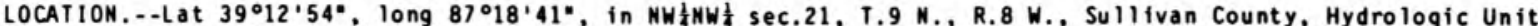
05120111 , on right bank at downstrea side of bridge on County Road 900 North, 1.3 ai upstrean fron East Fork Busseron Creek, 1.9 i northwest of Hyera, 4.1 i upstrea fro West Fork Busseron Creek, and at alle 30.3. DRAINAGE AREA. $-16.7 \cdot i^{2}$

PERIOD OF RECORD.--June 1966 to current year.

REVISED RECORDS.--WDR IN-72-1: 1971. WDR IN-87-1: 1982-86.

GAGE. - Water-stage recorder. Datue of gage is $480.00 \mathrm{ft}$ above National Geodetic Vertical Datua of 1929 (U.S. Soil Conservation Service benchark).

REMARKS. - Records good, except for periods of estiated daily discharges, which are poor. Flow affected by U.S. Soil Conservation Service floodwater-retarding structures.

DISCHARGE, CUBIC FEET PER SECOND, WATER YEAR OCTOBER 1990 TO SEPTEMBER 1991 DAILY MEAN VALUES

\begin{tabular}{|c|c|c|c|c|c|c|c|c|c|c|c|c|}
\hline DAY & $\mathrm{OCT}$ & MOV & DEC & JAN & FEB & MAR & APR & MAY & JUN & JUL & AUG & SEP \\
\hline $\begin{array}{l}1 \\
2 \\
3 \\
4 \\
5\end{array}$ & $\begin{array}{r}.14 \\
.12 \\
41.41 \\
4.9\end{array}$ & $\begin{array}{l}.84 \\
.79 \\
.79 \\
1.2 \\
6.3\end{array}$ & $\begin{array}{r}20 \\
13 \\
262 \\
63 \\
24\end{array}$ & $\begin{array}{r}81 \\
38 \\
27 \\
19 \\
e 18\end{array}$ & $\begin{array}{l}\text { e } 4.5 \\
\text { e5.3 } \\
\text { e6.7 } \\
\text { e } 8.7 \\
19\end{array}$ & $\begin{array}{r}7.6 \\
12 \\
9.2 \\
7.5 \\
6.6\end{array}$ & $\begin{array}{l}14 \\
12 \\
11 \\
13 \\
13\end{array}$ & $\begin{array}{l}4.3 \\
3.7 \\
3.7 \\
4.0 \\
4.7\end{array}$ & $\begin{array}{l}1.1 \\
1.1 \\
1.1 \\
1.0 \\
.97\end{array}$ & $\begin{array}{l}4.7 \\
2.5 \\
1.3 \\
.69 \\
.52\end{array}$ & $\begin{array}{l}.06 \\
.05 \\
.04 \\
.04 \\
.07\end{array}$ & $\begin{array}{l}.21 \\
.13 \\
.36 \\
3.1 \\
2.0\end{array}$ \\
\hline $\begin{array}{r}6 \\
7 \\
8 \\
9 \\
10\end{array}$ & $\begin{array}{c}1.5 \\
24 \\
17 \\
40 \\
169\end{array}$ & $\begin{array}{l}6.4 \\
5.2 \\
3.8 \\
2.8 \\
1.9\end{array}$ & $\begin{array}{r}15 \\
11 \\
9.5 \\
8.2 \\
7.1\end{array}$ & $\begin{array}{r}17 \\
\mathrm{e} 15 \\
\mathrm{e} 14 \\
13 \\
12\end{array}$ & $\begin{array}{r}121 \\
55 \\
24 \\
16 \\
12\end{array}$ & $\begin{array}{l}8.1 \\
7.7 \\
6.0 \\
5.2 \\
4.4\end{array}$ & $\begin{array}{l}12 \\
12 \\
48 \\
40 \\
16\end{array}$ & $\begin{array}{l}3.9 \\
3.1 \\
2.7 \\
2.5 \\
2.3\end{array}$ & $\begin{array}{l}1.0 \\
1.0 \\
1.1 \\
1.0 \\
.99\end{array}$ & $\begin{array}{l}.37 \\
.21 \\
.14 \\
.10 \\
.27\end{array}$ & $\begin{array}{c}.72 \\
1.2 \\
.67 \\
.82 \\
2.0\end{array}$ & $\begin{array}{l}1.3 \\
.78 \\
.45 \\
.29 \\
.25\end{array}$ \\
\hline $\begin{array}{l}11 \\
12 \\
13 \\
14 \\
15\end{array}$ & $\begin{array}{r}31 \\
12 \\
7.4 \\
4.9 \\
3.1\end{array}$ & $\begin{array}{l}1.9 \\
1.6 \\
1.4 \\
1.3 \\
1.2\end{array}$ & $\begin{array}{r}6.3 \\
5.7 \\
5.1 \\
4.3 \\
24\end{array}$ & $\begin{array}{r}120 \\
86 \\
33 \\
26 \\
37\end{array}$ & $\begin{array}{r}9.0 \\
7.6 \\
23 \\
113 \\
32\end{array}$ & $\begin{array}{r}4.3 \\
17 \\
167 \\
49 \\
24\end{array}$ & $\begin{array}{c}9.8 \\
8.8 \\
79 \\
66 \\
165\end{array}$ & $\begin{array}{l}3.4 \\
3.7 \\
2.5 \\
4.1 \\
4.0\end{array}$ & $\begin{array}{l}.96 \\
.89 \\
.81 \\
.80 \\
1.5\end{array}$ & $\begin{array}{c}4.7 \\
181 \\
56 \\
41 \\
26\end{array}$ & $\begin{array}{c}2.0 \\
1.5 \\
1.2 \\
.98 \\
1.2\end{array}$ & $\begin{array}{l}.16 \\
.10 \\
.08 \\
.07 \\
.05\end{array}$ \\
\hline $\begin{array}{l}16 \\
17 \\
18 \\
19 \\
20\end{array}$ & $\begin{array}{c}1.9 \\
1.7 \\
10 \\
5.8 \\
3.4\end{array}$ & $\begin{array}{l}1.2 \\
1.1 \\
1.1 \\
1.1 \\
.96\end{array}$ & $\begin{array}{r}15 \\
96 \\
295 \\
110 \\
37\end{array}$ & $\begin{array}{r}106 \\
43 \\
23 \\
\mathrm{e} 17 \\
\mathrm{e} 15\end{array}$ & $\begin{array}{r}\text { e17 } \\
\text { e12 } \\
100 \\
106 \\
41\end{array}$ & $\begin{array}{r}16 \\
158 \\
146 \\
47 \\
29\end{array}$ & $\begin{array}{l}66 \\
35 \\
24 \\
23 \\
18\end{array}$ & $\begin{array}{l}2.5 \\
2.0 \\
1.6 \\
1.5 \\
1.5\end{array}$ & $\begin{array}{l}4.0 \\
1.7 \\
1.5 \\
2.5 \\
4.5\end{array}$ & $\begin{array}{l}18 \\
12 \\
7.4 \\
4.9 \\
2.7\end{array}$ & $\begin{array}{l}.81 \\
.88 \\
.82 \\
.45 \\
.28\end{array}$ & $\begin{array}{l}.03 \\
e .02 \\
e .02 \\
e .02 \\
\text { e.01 }\end{array}$ \\
\hline $\begin{array}{l}21 \\
22 \\
23 \\
24 \\
25\end{array}$ & $\begin{array}{l}2.1 \\
2.2 \\
2.0 \\
1.8 \\
3.6\end{array}$ & $\begin{array}{r}14^{.97} \\
9.6 \\
5.7 \\
4.2\end{array}$ & $\begin{array}{r}268 \\
126 \\
40 \\
e 20 \\
\text { e13 }\end{array}$ & $\begin{array}{l}\text { e13 } \\
\text { e10 } \\
\text { e9.0 } \\
\text { e7.8 } \\
\text { e6.7 }\end{array}$ & $\begin{array}{l}23 \\
16 \\
12 \\
10 \\
8.5\end{array}$ & $\begin{array}{r}22 \\
385 \\
220 \\
63 \\
41\end{array}$ & $\begin{array}{l}13 \\
11 \\
9.2 \\
7.6 \\
6.6\end{array}$ & $\begin{array}{l}1.4 \\
1.4 \\
1.6 \\
3.8 \\
3.1\end{array}$ & $\begin{array}{l}1.5 \\
2.1 \\
1.8 \\
1.0 \\
.69\end{array}$ & $\begin{array}{r}1.4 \\
.86 \\
.56 \\
.51 \\
.47\end{array}$ & $\begin{array}{l}.24 \\
.17 \\
.14 \\
.11 \\
.10\end{array}$ & $\begin{array}{l}\text { e. } 01 \\
\text { e. } 08 \\
\text { e.15 } \\
\text { e.12 } \\
\text { e.08 }\end{array}$ \\
\hline $\begin{array}{l}26 \\
27 \\
28 \\
29 \\
30 \\
31\end{array}$ & $\begin{array}{l}2.3 \\
3.2 \\
2.1 \\
.90 \\
.80 \\
.78\end{array}$ & $\begin{array}{r}3.4 \\
261 \\
436 \\
70 \\
31 \\
\ldots\end{array}$ & $\begin{array}{l}\text { elo } \\
e 9.0 \\
e 8.0 \\
395 \\
793 \\
268\end{array}$ & $\begin{array}{l}\text { e5.7 } \\
\text { e5.2 } \\
\text { e4.8 } \\
\text { e4.3 } \\
\text { e4.1 } \\
\text { e } 4.0\end{array}$ & $\begin{array}{l}6.9 \\
6.3 \\
5.8 \\
\ldots . . \\
\ldots . . \\
\ldots .\end{array}$ & $\begin{array}{r}226 \\
97 \\
48 \\
33 \\
22 \\
18\end{array}$ & $\begin{array}{l}6.3 \\
5.8 \\
5.4 \\
6.1 \\
4.9 \\
\cdots .-\end{array}$ & $\begin{array}{l}2.4 \\
2.0 \\
1.7 \\
1.5 \\
1.4 \\
1.2\end{array}$ & $\begin{array}{l}.54 \\
1.5 \\
9.6 \\
8.1 \\
6.6 \\
\ldots . .\end{array}$ & $\begin{array}{l}.33 \\
.21 \\
.14 \\
.11 \\
.09 \\
.07\end{array}$ & $\begin{array}{l}.09 \\
.09 \\
.08 \\
.08 \\
.12 \\
.26\end{array}$ & $\begin{array}{l}\text { e.06 } \\
\text { e.05 } \\
\text { e.05 } \\
e .05 \\
\text { e.06 } \\
\ldots . .\end{array}$ \\
\hline $\begin{array}{l}\text { TOTAL } \\
\text { MEAN } \\
\text { MAX } \\
\text { MIN } \\
\text { CF SM } \\
\text { IN. }\end{array}$ & $\begin{array}{r}401.05 \\
12.9 \\
169 \\
.12 \\
.77 \\
.89\end{array}$ & $\begin{array}{r}878.75 \\
29.3 \\
436 \\
.79 \\
1.75 \\
1.96\end{array}$ & $\begin{array}{r}2981.2 \\
96.2 \\
793 \\
4.3 \\
5.76 \\
6.64\end{array}$ & $\begin{array}{r}834.6 \\
26.9 \\
120 \\
4.0 \\
1.61 \\
1.86\end{array}$ & $\begin{array}{r}821.3 \\
29.3 \\
1.21 \\
4.5 \\
1.76 \\
1.83\end{array}$ & $\begin{array}{r}1906.6 \\
61.5 \\
385 \\
4.3 \\
3.68 \\
4.25\end{array}$ & $\begin{array}{r}761.5 \\
25.4 \\
165 \\
4.9 \\
1.52 \\
1.70\end{array}$ & $\begin{array}{c}83.2 \\
2.68 \\
4.7 \\
1.2 \\
.16 \\
.19\end{array}$ & $\begin{array}{r}62.95 \\
2.10 \\
9.6 \\
.54 \\
.13 \\
.14\end{array}$ & $\begin{array}{c}369.25 \\
11.9 \\
181 \\
.07 \\
.71 \\
.82\end{array}$ & $\begin{array}{c}17.27 \\
.56 \\
2.0 \\
.04 \\
.03 \\
.04\end{array}$ & $\begin{array}{c}10.14 \\
.34 \\
3.1 \\
.01 \\
.02 \\
.02\end{array}$ \\
\hline
\end{tabular}

STATISTICS OF MONTHLY MEAN DATA FOR WATER YEARS 1967 - 1991, BY WATER YEAR (WY)

\begin{tabular}{|c|c|c|c|c|c|c|c|c|c|}
\hline $\begin{array}{l}\text { MEAN } \\
\text { MAX } \\
\text { (WY) } \\
\text { MIN } \\
\text { (WY) }\end{array}$ & $\begin{array}{l}2.62 \\
14.7 \\
1970 \\
.020 \\
1988\end{array}$ & $\begin{array}{l}14.1 \\
72.6 \\
1986 \\
058\end{array}$ & $\begin{array}{l}27.9 \\
96.8 \\
1983 \\
.026\end{array}$ & $\begin{array}{r}22.4 \\
105 \\
1969 \\
1006\end{array}$ & $\begin{array}{l}29.6 \\
67.4 \\
1971 \\
1.63 \\
1978\end{array}$ & $\begin{array}{r}37.7 \\
112 \\
1973 \\
7.23 \\
1960\end{array}$ & $\begin{array}{l}31.5 \\
72.5 \\
1972 \\
1.48 \\
1971\end{array}$ & $\begin{array}{l}22.8 \\
86.2 \\
1981 \\
1.23 \\
1976\end{array}$ & \\
\hline
\end{tabular}

SUMMARY STATISTICS

AMNUAL TOTAL

ANMUAL MEAN

HIGHEST ANNUAL MEAM

LOWEST ANNUAL MEAM

HIGHEST DAILY MEAN

LOWEST DAILY MEAN

ANNUAL SEVEN-DAY MINIMUM

INSTANTANEOUS PEAK FLOW

INSTANTANEOUS PEAK STAGE

ANMUAL RUNOFF (CFSM)

ANNUAL RUNOFF (INCHES)

10 PERCENT EXCEEDS

50 PERCENT EXCEEOS

90 PERCENT EXCEEDS
FOR 1990 CALENDAR YEAR

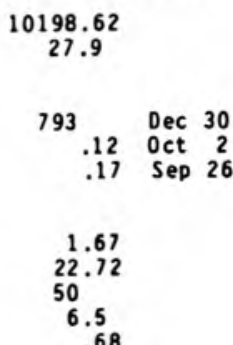

FOR 1991 WATER YEAR

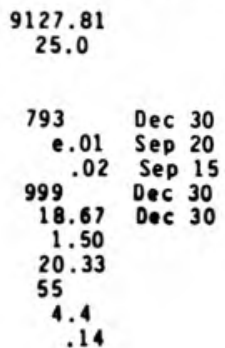

WATER YEARS 1967 - 1991

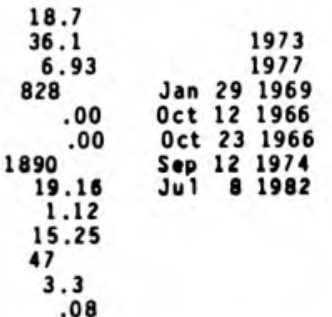




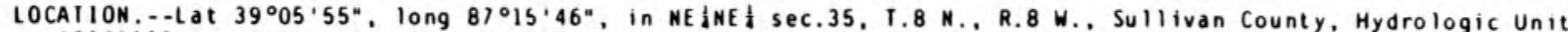
05120111 . On left upstrea wingwall of bridge on County Road 100 North, 1.0 a northeast of Cass, and 2.9 . 1 above outh.

DRAINAGE AREA.-.9.16 $i^{2}$

PERIOD OF RECORD.--October 1981 to current year.

GAGE. - Water-stage recorder. Datun of gage is $474.00 \mathrm{ft}$ above National Geodetic Vertical Datue of 1929 .

REMARKS. - Records fair except for estimated daily discharges which are poor. flow affected by surface-ined areas.

DISCHARGE, CUBIC FEET PER SECOND, WAIER YEAR OCTOBER 1990 TO SEPTEMBER 1991 DAI IY MEAN VALUES

\begin{tabular}{|c|c|c|c|c|c|c|c|c|c|c|c|c|}
\hline DAY & $\mathrm{OCI}$ & NOV & DEC & JAN & FEB & MAR & APR & MAY & JUN & JUL & $A \cup G$ & SEP \\
\hline $\begin{array}{l}1 \\
2 \\
3 \\
4 \\
5\end{array}$ & $\begin{array}{r}2.9 \\
2.9 \\
8.6 \\
22 \\
4.1\end{array}$ & $\begin{array}{l}3.0 \\
2.9 \\
2.9 \\
2.9 \\
8.0\end{array}$ & $\begin{array}{r}5.4 \\
5.0 \\
23 \\
7.4 \\
5.7\end{array}$ & $\begin{array}{l}\text { e } 22 \\
\text { e15 } \\
\text { e13 } \\
\text { e11 } \\
\text { e15 }\end{array}$ & $\begin{array}{l}e 5.2 \\
e 6.0 \\
e 7.8 \\
10 \\
15\end{array}$ & $\begin{array}{l}11 \\
17 \\
11 \\
9.1 \\
8.5\end{array}$ & $\begin{array}{l}\text { e1 } 8 \\
\text { e11 } \\
\text { e16 } \\
\text { e33 } \\
\text { e24 }\end{array}$ & $\begin{array}{l}\text { e } 8.4 \\
\text { e } 8.0 \\
\text { e } 7.8 \\
\text { e } 10 \\
\text { e14 }\end{array}$ & $\begin{array}{l}5.7 \\
6.0 \\
5.8 \\
5.3 \\
5.3\end{array}$ & $\begin{array}{l}2.2 \\
3.5 \\
2.5 \\
2.8 \\
2.5\end{array}$ & $\begin{array}{l}\text { e1. } \\
\text { el. } \\
\text { e. } 94 \\
\text { e. } 91 \\
\text { e. } 90\end{array}$ & $\begin{array}{r}\text { e. } 97 \\
\text { e. } 93 \\
\text { e2.0 } \\
\text { e } 4.0 \\
\text { e2.3 }\end{array}$ \\
\hline $\begin{array}{r}6 \\
7 \\
8 \\
9 \\
10\end{array}$ & $\begin{array}{r}2.9 \\
9.0 \\
4.9 \\
8.4 \\
28\end{array}$ & $\begin{array}{r}5.7 \\
3.4 \\
2.9 \\
\mathrm{e} 2.7 \\
\mathrm{e} 2.5\end{array}$ & $\begin{array}{l}5.3 \\
4.9 \\
4.9 \\
4.6 \\
4.6\end{array}$ & $\begin{array}{r}e 20 \\
18 \\
16 \\
15 \\
15\end{array}$ & $\begin{array}{l}64 \\
32 \\
18 \\
14 \\
12\end{array}$ & $\begin{array}{l}11 \\
11 \\
9.6 \\
\mathrm{e} 8.9 \\
\mathrm{e} 8.3\end{array}$ & $\begin{array}{l}\text { e } 19 \\
\text { el } 6 \\
\text { e } 80 \\
\text { e } 64 \\
\text { e } 34\end{array}$ & $\begin{array}{r}\text { e11 } \\
\text { e8.8 } \\
\text { e7.7 } \\
\text { e6.9 } \\
\text { e6.6 }\end{array}$ & $\begin{array}{l}5.0 \\
4.6 \\
5.0 \\
5.0 \\
4.6\end{array}$ & $\begin{array}{r}2.7 \\
2.4 \\
\mathrm{e} 2.3 \\
\mathrm{e} 2.2 \\
3.5\end{array}$ & $\begin{array}{l}30 \\
3.6 \\
2.2 \\
2.9 \\
2.1\end{array}$ & $\begin{array}{l}\text { e1.7 } \\
\text { e1:3 } \\
\text { e1.2 } \\
\text { e2.1 } \\
\text { e1.7 }\end{array}$ \\
\hline $\begin{array}{l}11 \\
12 \\
13 \\
14 \\
15\end{array}$ & $\begin{array}{l}6.1 \\
4.4 \\
3.8 \\
3.5 \\
3.5\end{array}$ & $\begin{array}{l}\text { e2.3 } \\
\text { e2.2 } \\
\text { e2.2 } \\
\text { e2.1 } \\
\text { e2.1 }\end{array}$ & $\begin{array}{l}4.5 \\
4.4 \\
4.2 \\
4.1 \\
8.1\end{array}$ & $\begin{array}{l}48 \\
29 \\
18 \\
16 \\
16\end{array}$ & $\begin{array}{l}11 \\
10 \\
17 \\
33 \\
16\end{array}$ & $\begin{array}{l}e 8.0 \\
23 \\
73 \\
32 \\
22\end{array}$ & $\begin{array}{l}e 17 \\
14 \\
61 \\
40 \\
59\end{array}$ & $\begin{array}{l}\text { e } 11 \\
\text { e } 10 \\
\text { e } 7.4 \\
\text { e } 6.3 \\
\text { e } 6.0\end{array}$ & $\begin{array}{l}\text { e4.5 } \\
\text { e4.3 } \\
\text { e4.1 } \\
\text { e4.0 } \\
\text { e4.0 }\end{array}$ & $\begin{array}{l}3.4 \\
31 \\
\text { e } 7.2 \\
\text { e } 5.9 \\
\text { e } 4.8\end{array}$ & $\begin{array}{l}1.9 \\
1.8 \\
1.8 \\
2.4 \\
2.2\end{array}$ & $\begin{array}{r}\text { e } .2 \\
\text { e. } 96 \\
\text { e. } 90 \\
\text { e. } 91 \\
\text { e1. } 0\end{array}$ \\
\hline $\begin{array}{l}16 \\
17 \\
18 \\
19 \\
20\end{array}$ & $\begin{array}{l}3.8 \\
4.0 \\
4.7 \\
4.3 \\
3.6\end{array}$ & $\begin{array}{l}\text { e2.1 } \\
\text { e2.1 } \\
\text { e2.0 } \\
\text { e2.0 } \\
\text { e2.0 }\end{array}$ & $\begin{array}{c}5.1 \\
38 \\
61 \\
18 \\
8.1\end{array}$ & $\begin{array}{l}23 \\
17 \\
14 \\
13 \\
12\end{array}$ & $\begin{array}{r}\text { el2 } \\
\text { el } \\
68 \\
40 \\
21\end{array}$ & $\begin{array}{l}20 \\
92 \\
62 \\
33 \\
25\end{array}$ & $\begin{array}{l}23 \\
16 \\
14 \\
23 \\
16\end{array}$ & $\begin{array}{l}\text { e20 } \\
\text { e } 10 \\
\text { e } 7.9 \\
\text { e } 6.6 \\
\text { e } 5.9\end{array}$ & $\begin{array}{l}10 \\
6.0 \\
5.9 \\
5.0 \\
4.5\end{array}$ & $\begin{array}{l}\text { e3.9 } \\
\text { e3. } 3 \\
\text { e2. } \\
\text { e2. } \\
\text { e2. } 2\end{array}$ & $\begin{array}{r}1.8 \\
2.2 \\
2.3 \\
1.9 \\
\text { e1.7 }\end{array}$ & $\begin{array}{r}\text { e. } 90 \\
\text { e. } 80 \\
\text { e1. } 9 \\
.86 \\
.72\end{array}$ \\
\hline $\begin{array}{l}21 \\
22 \\
23 \\
24 \\
25\end{array}$ & $\begin{array}{l}3.6 \\
4.3 \\
4.1 \\
3.8 \\
3.8\end{array}$ & $\begin{array}{l}\text { e2.0 } \\
12 \\
4.0 \\
3.3 \\
2.6\end{array}$ & $\begin{array}{l}60 \\
19 \\
8.4 \\
6.3 \\
e 5.6\end{array}$ & $\begin{array}{r}9.6 \\
+7.6 \\
\mathrm{e} 6.7 \\
\mathrm{e} 8.0 \\
\mathrm{e} 6.4\end{array}$ & $\begin{array}{c}15 \\
13 \\
11 \\
10 \\
9.1\end{array}$ & $\begin{array}{r}25 \\
163 \\
88 \\
47 \\
36\end{array}$ & $\begin{array}{l}13 \\
12 \\
11 \\
11 \\
10\end{array}$ & $\begin{array}{r}\text { e5.3 } \\
\text { e5.1 } \\
5.9 \\
5.3 \\
5.7\end{array}$ & $\begin{array}{l}5.4 \\
17 \\
\text { e } 9.0 \\
\text { e7.0 } \\
\text { e } 4.7\end{array}$ & $\begin{array}{l}\text { el } 1.9 \\
\text { e1.7 } \\
\text { el } 1.5 \\
\text { el } 1.4 \\
\text { e } 1.3\end{array}$ & $\begin{array}{ll}\text { el } & .5 \\
\text { el } & .4 \\
\text { el } & .3 \\
\text { el } & .3 \\
\text { el } & .2\end{array}$ & $\begin{array}{l}.79 \\
1.1 \\
1.5 \\
.96 \\
.93\end{array}$ \\
\hline $\begin{array}{l}26 \\
27 \\
28 \\
29 \\
30 \\
31\end{array}$ & $\begin{array}{r}3.4 \\
3.4 \\
\mathrm{e} 3.2 \\
\mathrm{e} 3.1 \\
\mathrm{e} 3.1 \\
3.1\end{array}$ & $\begin{array}{l}2.7 \\
45 \\
80 \\
8.4 \\
5.9 \\
\ldots . .\end{array}$ & $\begin{array}{r}5.1 \\
\mathrm{e} 4.8 \\
\mathrm{e} 4.7 \\
108 \\
357 \\
44\end{array}$ & $\begin{array}{l}\text { e6.0 } \\
\text { e5.6 } \\
\text { e5. } \\
\text { e5.2 } \\
\text { e5.1 } \\
\text { e5.0 }\end{array}$ & $\begin{array}{l}7.8 \\
7.4 \\
7.3 \\
\ldots . \\
\ldots . . \\
\ldots .\end{array}$ & $\begin{array}{l}e 32 \\
e 29 \\
e 26 \\
e 23 \\
e 21 \\
e 20\end{array}$ & $\begin{array}{r}\text { e9.5 } \\
\text { e9.2 } \\
\text { e } 9.0 \\
\text { e10 } \\
\text { e9.2 } \\
\cdots . .\end{array}$ & $\begin{array}{l}5.6 \\
5.2 \\
5.0 \\
6.3 \\
5.6 \\
5.5\end{array}$ & $\begin{array}{r}3.4 \\
\mathrm{e} 2.2 \\
2.5 \\
3.3 \\
2.8 \\
\ldots .\end{array}$ & $\begin{array}{l}\text { el. } 1.2 \\
\text { el } 1.1 \\
\text { el } 1.0 \\
\text { e1.5 } \\
\text { el. } 1.4 \\
\text { el. }\end{array}$ & $\begin{array}{l}\text { el.2 } \\
\text { el.1 } \\
\text { el.1 } \\
\text { el.0 } \\
\text { el. } \\
\text { el.1 }\end{array}$ & $\begin{array}{l}.87 \\
.83 \\
.86 \\
.82 \\
.80 \\
.-.\end{array}$ \\
\hline $\begin{array}{l}\text { TOIAL } \\
\text { MEAN } \\
\text { MAX } \\
\text { MIN } \\
\text { CF SM } \\
\text { IN. }\end{array}$ & $\begin{array}{r}174.3 \\
5.62 \\
28 \\
2.9 \\
.61 \\
.71\end{array}$ & $\begin{array}{r}223.9 \\
7.46 \\
80 \\
2.0 \\
.81 \\
.91\end{array}$ & $\begin{array}{r}849.2 \\
27.4 \\
357 \\
4.1 \\
2.99 \\
3.45\end{array}$ & $\begin{array}{r}436.5 \\
14.1 \\
48 \\
5.0 \\
1.54 \\
1.17\end{array}$ & $\begin{array}{r}502.6 \\
17.9 \\
68 \\
5.2 \\
1.96 \\
2.04\end{array}$ & $\begin{array}{r}1005.4 \\
32.4 \\
163 \\
8.0 \\
3.54 \\
4.08\end{array}$ & $\begin{array}{r}107.9 \\
23.6 \\
80 \\
9.0 \\
2.58 \\
2.87\end{array}$ & $\begin{array}{c}240.8 \\
7.77 \\
20 \\
5.0 \\
.85 \\
.98\end{array}$ & $\begin{array}{r}161.9 \\
5.40 \\
17 \\
2.2 \\
.59 \\
.66\end{array}$ & $\begin{array}{c}108.9 \\
3.51 \\
31 \\
1.0 \\
.38 \\
.44\end{array}$ & $\begin{array}{c}78.85 \\
2.54 \\
30 \\
.90 \\
.28 \\
.32\end{array}$ & $\begin{array}{c}37.81 \\
1.26 \\
4.0 \\
.72 \\
.14 \\
.15\end{array}$ \\
\hline
\end{tabular}

e Estinated

STAIISTICS OF MONIHIY MEAM DAIA FUR WAIER YEARS 1982 - 1991, BY WATER YEAR (WY)

$\begin{array}{lcccccccccccc}\text { MEAN } & 5.87 & 18.1 & 19.2 & 11.6 & 19.4 & 21.1 & 21.3 & 19.7 & 7.83 & 10.9 & 3.16 & 6.10 \\ \text { MAX } & 10.2 & 91.9 & 37.5 & 22.1 & 41.3 & 32.4 & 40.9 & 35.0 & 17.1 & 28.9 & 7.45 & 26.5 \\ \text { (WY) } & 1990 & 1986 & 1983 & 1982 & 1990 & 1991 & 1984 & 1990 & 1986 & 1989 & 1989 & 1989 \\ \text { MIN } & .92 & 2.85 & 6.36 & 3.20 & 6.78 & 7.73 & 12.5 & 3.52 & .96 & 2.47 & 1.25 & .82 \\ \text { (WY) } & 1988 & 1988 & 1990 & 1984 & 1987 & 1987 & 1988 & 1987 & 1988 & 1988 & 1988 & 1987\end{array}$

SUMMARY SIAIISIICS

ANMUAL TOTAL

ANWUAL MEAN

HIGHESI ANMUAL MEAN

LOWEST ANNUAL MEAN

HIGHEST DAILY MEAN

LOWEST DAILY MEAN

ANNUAL SEVEN-DAY MINIMUM

IMSTANTANEOUS PEAK FLOW

INSTANTANEOUS PEAK STAGE

ANNUAL RUNOFF (CFSH)

ANNUAL RUNOFF (INCHES)

10 PERCENT EXCEEDS

50 PERCENT EXCEEDS

90 PERCENT EXCEEOS
FOR 1990 CALENDAR YEAR

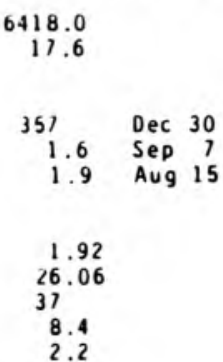

FOR 1991 WAIER YEAR

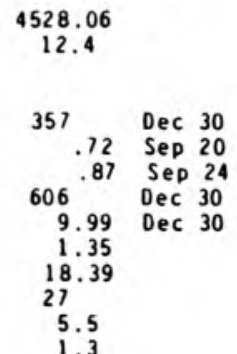

WATER YEARS $1982-1991$

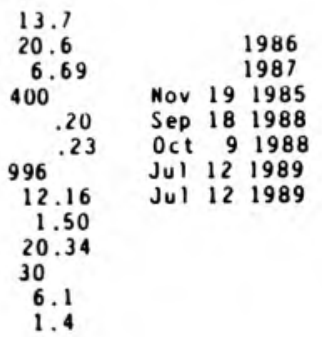




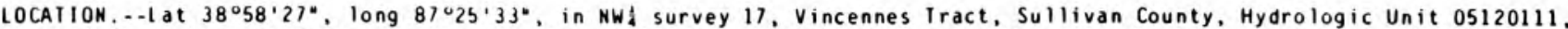
on left bank $10 \mathrm{ft}$ downstrea from bridge on State Highway 58, 1.5 a northwest of Carlisle, and 6.7 i (revised) upstream from mouth,

DRAINAGE AREA $\cdots 228 i^{2}$.

PERIOD OF RECORD..-OCtober 1943 to current year.

REVISED RECOROS.--WSP 1335: Drainage area.

GAGE.--Water-stage recorder. Datum of gage is $425.36 \mathrm{ft}$ above National Geodetic Vertical Datua of 1929 (Indiana Departaent of Highways bench mark). Prior to Nov. 8, 1950, nonrecording gage at sane site and datum. Nov. 8 , 1950, to $0 \mathrm{ct}$. 31, 1969, at site $200 \mathrm{ft}$ upstrea at same datum.

REMARKS.--Records good except for estimated daily discharges, which are poor. Flow affected by U.S. Soil Conservation Service floodwater-retarding structures and surface-ined areas.

DISCHARGE, CUBIC FEET PER SECONO, WATER YEAR OCTOBER 1990 TO SEPTEMBER 1991 DAILY MEAN VALUES

\begin{tabular}{|c|c|c|c|c|c|c|c|c|c|c|c|c|}
\hline DAY & $0 \mathrm{CI}$ & NOV & DEC & JAN & $F E B$ & MAR & APR & MAY & JUN & JUL & AUG & SEP \\
\hline $\begin{array}{l}1 \\
2 \\
3 \\
4 \\
5\end{array}$ & $\begin{array}{l}14 \\
14 \\
17 \\
287 \\
161\end{array}$ & $\begin{array}{l}24 \\
28 \\
28 \\
27 \\
33\end{array}$ & $\begin{array}{l}850 \\
473 \\
533 \\
742 \\
652\end{array}$ & $\begin{array}{l}4250 \\
3490 \\
2310 \\
1470 \\
1160\end{array}$ & $\begin{array}{l}\text { e61 } \\
\text { e66 } \\
\text { e75 } \\
\text { e90 } \\
142\end{array}$ & $\begin{array}{l}151 \\
235 \\
215 \\
175 \\
153\end{array}$ & $\begin{array}{l}235 \\
200 \\
174 \\
165 \\
182\end{array}$ & $\begin{array}{l}92 \\
82 \\
75 \\
76 \\
78\end{array}$ & $\begin{array}{l}41 \\
38 \\
36 \\
33 \\
30\end{array}$ & $\begin{array}{l}24 \\
23 \\
23 \\
20 \\
20\end{array}$ & $\begin{array}{l}4.5 \\
4.0 \\
3.8 \\
3.7 \\
3.8\end{array}$ & $\begin{array}{l}8.9 \\
7.5 \\
6.8 \\
7.0 \\
9.9\end{array}$ \\
\hline $\begin{array}{r}6 \\
7 \\
8 \\
9 \\
10\end{array}$ & $\begin{array}{l}66 \\
131 \\
225 \\
160 \\
509\end{array}$ & $\begin{array}{l}60 \\
61 \\
45 \\
41 \\
39\end{array}$ & $\begin{array}{l}370 \\
245 \\
188 \\
153 \\
133\end{array}$ & $\begin{array}{r}1040 \\
861 \\
629 \\
442 \\
343\end{array}$ & $\begin{array}{l}640 \\
890 \\
627 \\
372 \\
288\end{array}$ & $\begin{array}{l}148 \\
152 \\
132 \\
123 \\
115\end{array}$ & $\begin{array}{l}165 \\
147 \\
332 \\
631 \\
426\end{array}$ & $\begin{array}{l}84 \\
73 \\
67 \\
63 \\
61\end{array}$ & $\begin{array}{l}27 \\
26 \\
25 \\
24 \\
24\end{array}$ & $\begin{array}{l}22 \\
21 \\
19 \\
18 \\
19\end{array}$ & $\begin{array}{l}19 \\
56 \\
17 \\
16 \\
21\end{array}$ & $\begin{array}{r}12 \\
8.9 \\
7.3 \\
6.4 \\
6.8\end{array}$ \\
\hline $\begin{array}{l}11 \\
12 \\
13 \\
14 \\
15\end{array}$ & $\begin{array}{r}541 \\
254 \\
152 \\
112 \\
85\end{array}$ & $\begin{array}{l}35 \\
32 \\
29 \\
28 \\
27\end{array}$ & $\begin{array}{r}118 \\
102 \\
91 \\
82 \\
157\end{array}$ & $\begin{array}{l}621 \\
863 \\
720 \\
427 \\
349\end{array}$ & $\begin{array}{l}237 \\
206 \\
217 \\
512 \\
567\end{array}$ & $\begin{array}{l}106 \\
121 \\
670 \\
813 \\
538\end{array}$ & $\begin{array}{l}271 \\
225 \\
466 \\
567 \\
725\end{array}$ & $\begin{array}{r}118 \\
184 \\
93 \\
74 \\
77\end{array}$ & $\begin{array}{l}24 \\
23 \\
23 \\
22 \\
21\end{array}$ & $\begin{array}{r}20 \\
210 \\
327 \\
114 \\
75\end{array}$ & $\begin{array}{r}16 \\
13 \\
11 \\
9.4 \\
9.8\end{array}$ & $\begin{array}{l}6.5 \\
6.1 \\
5.8 \\
5.7 \\
5.8\end{array}$ \\
\hline $\begin{array}{l}16 \\
17 \\
18 \\
19 \\
20\end{array}$ & $\begin{array}{l}70 \\
60 \\
65 \\
80 \\
64\end{array}$ & $\begin{array}{l}27 \\
27 \\
30 \\
26 \\
24\end{array}$ & $\begin{array}{r}235 \\
276 \\
1020 \\
1160 \\
1130\end{array}$ & $\begin{array}{l}467 \\
498 \\
342 \\
262 \\
230\end{array}$ & $\begin{array}{r}\text { e } 260 \\
\text { e } 180 \\
\text { e } 400 \\
889 \\
799\end{array}$ & $\begin{array}{r}326 \\
592 \\
1290 \\
1160 \\
913\end{array}$ & $\begin{array}{l}840 \\
619 \\
391 \\
348 \\
338\end{array}$ & $\begin{array}{l}80 \\
89 \\
69 \\
66 \\
63\end{array}$ & $\begin{array}{l}25 \\
35 \\
29 \\
25 \\
23\end{array}$ & $\begin{array}{l}54 \\
39 \\
31 \\
23 \\
19\end{array}$ & $\begin{array}{c}16 \\
11 \\
9.8 \\
9.6 \\
8.8\end{array}$ & $\begin{array}{l}6.3 \\
6.1 \\
5.5 \\
6.0 \\
6.6\end{array}$ \\
\hline $\begin{array}{l}21 \\
22 \\
23 \\
24 \\
25\end{array}$ & $\begin{array}{l}53 \\
46 \\
47 \\
41 \\
37\end{array}$ & $\begin{array}{r}23 \\
68 \\
141 \\
95 \\
70\end{array}$ & $\begin{array}{r}1110 \\
1320 \\
1200 \\
901 \\
506\end{array}$ & $\begin{array}{r}198 \\
158 \\
\text { el } 20 \\
\text { el } 00 \\
\text { e } 90\end{array}$ & $\begin{array}{l}536 \\
362 \\
285 \\
248 \\
214\end{array}$ & $\begin{array}{r}565 \\
783 \\
1740 \\
1670 \\
1710\end{array}$ & $\begin{array}{l}262 \\
220 \\
189 \\
166 \\
145\end{array}$ & $\begin{array}{l}57 \\
51 \\
49 \\
53 \\
53\end{array}$ & $\begin{array}{l}30 \\
29 \\
65 \\
45 \\
30\end{array}$ & $\begin{array}{l}15 \\
12 \\
10 \\
8.7 \\
7.5\end{array}$ & $\begin{array}{l}8.3 \\
7.7 \\
7.2 \\
7.0 \\
6.9\end{array}$ & $\begin{array}{l}5.4 \\
5.4 \\
6.1 \\
7.5 \\
6.8\end{array}$ \\
\hline $\begin{array}{l}26 \\
27 \\
28 \\
29 \\
30 \\
31\end{array}$ & $\begin{array}{l}33 \\
32 \\
30 \\
28 \\
28 \\
26\end{array}$ & $\begin{array}{r}56 \\
393 \\
1070 \\
1080 \\
1130 \\
\ldots\end{array}$ & $\begin{array}{r}302 \\
233 \\
216 \\
853 \\
3210 \\
3770\end{array}$ & $\begin{array}{l}\text { e } 82 \\
\text { e } 75 \\
\text { e } 70 \\
\text { e65 } \\
\text { e } 62 \\
\text { e } 60\end{array}$ & $\begin{array}{l}181 \\
171 \\
161 \\
\ldots \\
\cdots \\
\cdots\end{array}$ & $\begin{array}{r}1160 \\
897 \\
734 \\
467 \\
341 \\
274\end{array}$ & $\begin{array}{l}133 \\
124 \\
116 \\
110 \\
105 \\
\cdots\end{array}$ & $\begin{array}{l}60 \\
56 \\
60 \\
50 \\
55 \\
46\end{array}$ & $\begin{array}{l}27 \\
27 \\
24 \\
23 \\
25 \\
\cdots\end{array}$ & $\begin{array}{l}6.7 \\
5.8 \\
5.2 \\
4.9 \\
6.0 \\
5.6\end{array}$ & $\begin{array}{l}6.8 \\
6.7 \\
8.5 \\
9.4 \\
9.6 \\
9.5\end{array}$ & $\begin{array}{l}5.9 \\
5.4 \\
4.9 \\
4.2 \\
3.9 \\
. . .\end{array}$ \\
\hline $\begin{array}{l}\text { TOIAL } \\
\text { MEAN } \\
\text { MAX } \\
\text { MIN } \\
\text { CF SM } \\
\text { IN. }\end{array}$ & $\begin{array}{r}3468 \\
112 \\
541 \\
14 \\
.49 \\
.57\end{array}$ & $\begin{array}{r}4797 \\
160 \\
1130 \\
23 \\
.70 \\
.78\end{array}$ & $\begin{array}{r}22331 \\
720 \\
3770 \\
82 \\
3.16 \\
3.64\end{array}$ & $\begin{array}{r}21854 \\
705 \\
4250 \\
60 \\
3.09 \\
3.57\end{array}$ & $\begin{array}{r}9742 \\
348 \\
890 \\
61 \\
1.53 \\
1.59\end{array}$ & $\begin{array}{r}18469 \\
596 \\
1740 \\
106 \\
2.61 \\
3.01\end{array}$ & $\begin{array}{c}9017 \\
301 \\
840 \\
105 \\
1.32 \\
1.47\end{array}$ & $\begin{array}{c}2254 \\
72.7 \\
184 \\
46 \\
.32 \\
.37\end{array}$ & $\begin{array}{r}879 \\
29.3 \\
65 \\
21 \\
.13 \\
.14\end{array}$ & $\begin{array}{r}1208.4 \\
39.0 \\
327 \\
4.9 \\
.17 \\
.20\end{array}$ & $\begin{array}{c}350.8 \\
11.3 \\
56 \\
3.7 \\
.05 \\
.06\end{array}$ & $\begin{array}{r}197.4 \\
6.58 \\
12 \\
3.9 \\
.03 \\
.03\end{array}$ \\
\hline
\end{tabular}

e Estinated

SIATISIICS OF MONTHLY MEAN DATA FUR WAIER YEARS 1944 - 1991, BY WATER YEAR (WY)

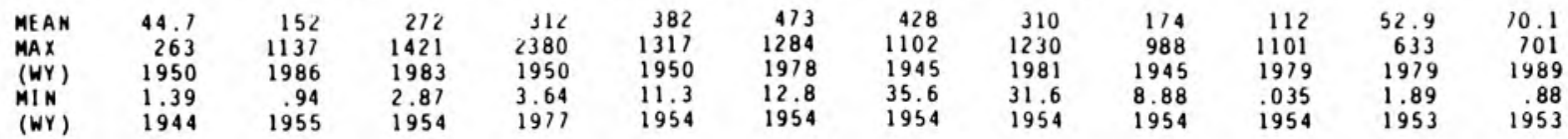

SUMMARY STATISIICS

ANMUAL TOIAL

ANHUAL MEAN

HIGHESI ANNUAL MEAN

LOWE ST ANHUAL MEAM

HIGHEST DAILY MEAM

LOWEST DAILY MEAN

ANNUAL SEVEN-DAY MINIMUM

INSTANTANEOUS PEAK FLOW

INSIANTANEOUS PEAK STAGE

ANNUAL RUNOFF (CFSM)

ANNUAL RUNOFF (1 NCHES)

10 PERCENT EXCEEDS

50 PERCENT EXCEEDS

90 PERCENT EXCEEDS
FOR 1990 CALENDAR YEAR

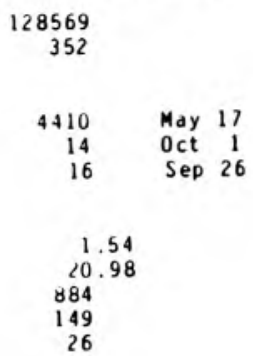

FOR 1991 WAIER YEAR

94567.6

9567.
259

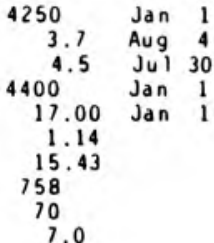

WAIER YEARS $1944-1991$

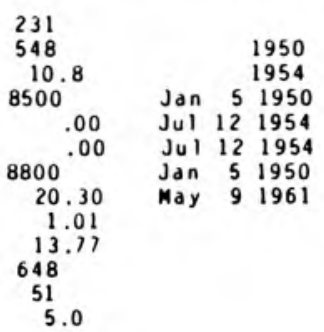




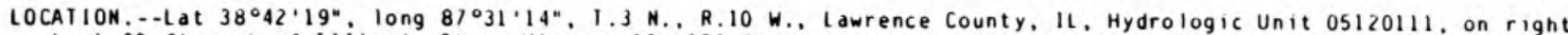
bank $30 \mathrm{ft}$ east of 111 inois State Highwdy $33,300 \mathrm{ft}$ upstrean from Kelso Creek, $570 \mathrm{ft}$ downstream from U.S. Highway 50 bridge, 5.1 i downstrea from Maria Creek, 7.5 mi upstream from Eabarras River and at mile 129.6 . DRAINAGE AREA $\ldots 13,706$ i ${ }^{2}$

PERIOD OF RECORD.--October 1929 to current year. Prior to Decener 1929 nonthly discharge only, published in wSP 1305. Gage-height records for flood peaks in 1867 and 1883 , interaittent records $1887-1904$, and continuous since November 1904, collected at site $1.8 \mathrm{mi}$ downstrean, are contained in reports of National Weather Service.

REVISED RECORDS.--WSP 1113: 1943 (maximun gage height only). WSP 1335: 1930-31, 1933, 1936. WSP 1909: 1955. WDR IM-13-1: Drainage area.

GAGE.--Water-stage recorder. Datum of gage is $394.43 \mathrm{ft}$ above National Geodetic Vertical Datum of 1929 . Oct. 1. 1968, to June 19, 1979, recording gage at site $570 \mathrm{ft}$ upstrean at same datum. 0ct. 1 . 1960, to September 30 , 1968, nonrecording gage at site 1.8 i downstrean at saae datum. 0ct. 1, 1960, to Sept. 30. 1968, auxiliary water-stage recorder at site 2.8 i upstrean from base gage at datum 0.80 ft lower. See wSp 1725 for history of changes prior to $0 \mathrm{ct} .1,1960$.

REMARKS.-- Records good. Flow partially regulded by upstream reservoirs.

EXIREMES OUISIDE PERIOD OF RECORD. - Flood of Mar. 29, 1913, reached a stage of $26.3 \mathrm{ft}$, at former site 1.8 i downstrean and at present datun, fron floodarks, deterined by U.S. Army Corps of Engineers, discharge, $255,000 \mathrm{ft}^{3} / \mathrm{s}$.

DISCHARGE, CUBIC FEET PER SECOND, WATER YEAR OCTOBER 1990 TO SEPIEMBER 1991 DAILY MEAN VALUES

\begin{tabular}{|c|c|c|c|c|c|c|c|c|c|c|c|c|}
\hline DAY & $O C I$ & NOV & $\mathrm{DEC}$ & JAN & $F E B$ & MAR & APR & MAY & JUN & JUL & AUG & SEP \\
\hline $\begin{array}{l}1 \\
2 \\
3 \\
4 \\
5\end{array}$ & $\begin{array}{l}4450 \\
4280 \\
4160 \\
5600 \\
6510\end{array}$ & $\begin{array}{r}12800 \\
12200 \\
11300 \\
10000 \\
8830\end{array}$ & $\begin{array}{l}28800 \\
29000 \\
28500 \\
28500 \\
28900\end{array}$ & $\begin{array}{l}51400 \\
61900 \\
74000 \\
84300 \\
90700\end{array}$ & $\begin{array}{l}25400 \\
23100 \\
20900 \\
19200 \\
18500\end{array}$ & $\begin{array}{l}14900 \\
14100 \\
14000 \\
13900 \\
14300\end{array}$ & $\begin{array}{l}35200 \\
33500 \\
31100 \\
27500 \\
23100\end{array}$ & $\begin{array}{r}13000 \\
12300 \\
11800 \\
11200 \\
\mathrm{e} 10700\end{array}$ & $\begin{array}{r}\text { e } 14100 \\
\text { e } 16500 \\
\text { e } 20500 \\
\text { e } 22000 \\
20300\end{array}$ & $\begin{array}{l}4360 \\
4250 \\
4330 \\
4090 \\
4050\end{array}$ & $\begin{array}{l}2670 \\
2520 \\
2440 \\
2430 \\
2480\end{array}$ & $\begin{array}{l}2210 \\
2170 \\
2200 \\
2210 \\
2570\end{array}$ \\
\hline $\begin{array}{r}6 \\
7 \\
8 \\
9 \\
10\end{array}$ & $\begin{array}{r}5960 \\
5470 \\
6090 \\
8760 \\
13100\end{array}$ & $\begin{array}{r}8850 \\
12000 \\
17100 \\
20300 \\
20500\end{array}$ & $\begin{array}{l}29000 \\
28300 \\
27900 \\
27000 \\
25500\end{array}$ & $\begin{array}{l}90800 \\
85000 \\
76600 \\
67200 \\
58200\end{array}$ & $\begin{array}{l}22100 \\
26100 \\
27500 \\
28300 \\
28700\end{array}$ & $\begin{array}{l}14600 \\
14200 \\
13500 \\
12800 \\
12000\end{array}$ & $\begin{array}{l}19500 \\
17000 \\
15800 \\
16200 \\
15700\end{array}$ & $\begin{array}{r}\text { e } 11300 \\
\text { e1 } 2000 \\
\text { e1 } 2700 \\
\text { e1 } 2600 \\
11700\end{array}$ & $\begin{array}{l}18700 \\
16700 \\
15100 \\
13900 \\
12900\end{array}$ & $\begin{array}{l}4190 \\
4490 \\
4530 \\
4450 \\
4280\end{array}$ & $\begin{array}{l}2460 \\
3200 \\
3560 \\
3050 \\
2990\end{array}$ & $\begin{array}{l}2680 \\
2390 \\
2300 \\
2470 \\
2370\end{array}$ \\
\hline $\begin{array}{l}11 \\
12 \\
13 \\
14 \\
15\end{array}$ & $\begin{array}{l}20100 \\
25100 \\
27000 \\
28100 \\
29000\end{array}$ & $\begin{array}{l}18300 \\
16100 \\
14700 \\
13700 \\
12600\end{array}$ & $\begin{array}{l}23500 \\
21100 \\
19100 \\
17000 \\
15500\end{array}$ & $\begin{array}{l}51500 \\
47800 \\
45000 \\
42500 \\
40400\end{array}$ & $\begin{array}{l}28800 \\
28600 \\
27900 \\
27100 \\
25800\end{array}$ & $\begin{array}{l}11200 \\
10800 \\
13300 \\
18100 \\
23300\end{array}$ & $\begin{array}{l}14900 \\
14000 \\
13100 \\
14100 \\
15400\end{array}$ & $\begin{array}{r}10900 \\
10800 \\
10300 \\
9950 \\
10000\end{array}$ & $\begin{array}{r}11600 \\
10300 \\
9010 \\
8140 \\
7690\end{array}$ & $\begin{array}{l}4190 \\
5370 \\
9110 \\
7710 \\
6090\end{array}$ & $\begin{array}{l}3130 \\
2870 \\
2850 \\
2950 \\
2870\end{array}$ & $\begin{array}{l}2320 \\
2290 \\
2290 \\
2220 \\
2210\end{array}$ \\
\hline $\begin{array}{l}16 \\
17 \\
18 \\
19 \\
20\end{array}$ & $\begin{array}{l}29900 \\
30800 \\
31600 \\
31700 \\
30600\end{array}$ & $\begin{array}{l}11800 \\
11200 \\
10800 \\
10600 \\
10300\end{array}$ & $\begin{array}{l}15000 \\
16700 \\
22200 \\
27100 \\
28800\end{array}$ & $\begin{array}{l}38900 \\
38300 \\
37900 \\
37700 \\
37600\end{array}$ & $\begin{array}{l}22600 \\
18900 \\
16800 \\
17900 \\
19300\end{array}$ & $\begin{array}{l}25500 \\
26200 \\
29600 \\
30400 \\
30500\end{array}$ & $\begin{array}{l}17200 \\
19300 \\
21700 \\
23500 \\
24200\end{array}$ & $\begin{array}{l}10700 \\
11700 \\
12200 \\
13900 \\
18700\end{array}$ & $\begin{array}{l}7470 \\
7030 \\
6940 \\
6930 \\
6710\end{array}$ & $\begin{array}{l}5090 \\
4430 \\
3950 \\
3640 \\
3350\end{array}$ & $\begin{array}{l}2870 \\
2740 \\
2610 \\
2490 \\
2400\end{array}$ & $\begin{array}{l}2160 \\
2110 \\
2220 \\
2260 \\
2330\end{array}$ \\
\hline $\begin{array}{l}21 \\
22 \\
23 \\
24 \\
25\end{array}$ & $\begin{array}{l}28700 \\
27100 \\
25200 \\
22600 \\
20300\end{array}$ & $\begin{array}{l}9930 \\
9620 \\
9530 \\
9300 \\
8920\end{array}$ & $\begin{array}{l}29800 \\
32400 \\
33800 \\
34800 \\
35500\end{array}$ & $\begin{array}{l}37500 \\
37600 \\
37800 \\
37700 \\
36800\end{array}$ & $\begin{array}{l}19500 \\
20100 \\
21700 \\
22600 \\
22600\end{array}$ & $\begin{array}{l}30800 \\
31200 \\
34900 \\
37300 \\
39000\end{array}$ & $\begin{array}{l}23500 \\
21500 \\
20000 \\
19900 \\
19600\end{array}$ & $\begin{array}{l}20300 \\
18800 \\
15600 \\
13300 \\
12400\end{array}$ & $\begin{array}{l}6500 \\
6250 \\
6000 \\
6290 \\
5830\end{array}$ & $\begin{array}{l}3200 \\
3170 \\
3140 \\
3040 \\
2910\end{array}$ & $\begin{array}{l}2390 \\
2420 \\
2600 \\
2690 \\
2540\end{array}$ & $\begin{array}{l}2270 \\
2210 \\
2330 \\
2370 \\
2400\end{array}$ \\
\hline $\begin{array}{l}26 \\
27 \\
28 \\
29 \\
30 \\
31\end{array}$ & $\begin{array}{l}18800 \\
17500 \\
16400 \\
15400 \\
14500 \\
13600\end{array}$ & $\begin{array}{r}8630 \\
9490 \\
16900 \\
24900 \\
27900 \\
\ldots\end{array}$ & $\begin{array}{l}36100 \\
36500 \\
35500 \\
33700 \\
38900 \\
45500\end{array}$ & $\begin{array}{l}35900 \\
34300 \\
32800 \\
31300 \\
29800 \\
27700\end{array}$ & $\begin{array}{r}21700 \\
19400 \\
16700 \\
\ldots \\
\ldots \\
\ldots\end{array}$ & $\begin{array}{l}40600 \\
41200 \\
40800 \\
39600 \\
38100 \\
36600\end{array}$ & $\begin{array}{c}18900 \\
17900 \\
16700 \\
15400 \\
14000 \\
\ldots\end{array}$ & $\begin{array}{r}12700 \\
13200 \\
13700 \\
\text { e } 14100 \\
\text { e } 14300 \\
\text { el } 14600\end{array}$ & $\begin{array}{c}5400 \\
5090 \\
4900 \\
4650 \\
4500 \\
\ldots\end{array}$ & $\begin{array}{l}2900 \\
2870 \\
2890 \\
2890 \\
2850 \\
2810\end{array}$ & $\begin{array}{l}2460 \\
2390 \\
2320 \\
2260 \\
2240 \\
2300\end{array}$ & $\begin{array}{l}2440 \\
2480 \\
2460 \\
2450 \\
2440 \\
\cdots\end{array}$ \\
\hline $\begin{array}{l}\text { IOIAL } \\
\text { MEAN } \\
\text { MAX } \\
\text { MIN } \\
\text { CF SM } \\
\text { IN. }\end{array}$ & $\begin{array}{r}568380 \\
18330 \\
31700 \\
4160 \\
1.34 \\
1.54\end{array}$ & $\begin{array}{r}399100 \\
13300 \\
27900 \\
8630 \\
.97 \\
1.08\end{array}$ & $\begin{array}{r}879900 \\
28380 \\
45500 \\
15000 \\
2.07 \\
2.39\end{array}$ & $\begin{array}{r}1536900 \\
49580 \\
90800 \\
27700 \\
3.62 \\
4.17\end{array}$ & $\begin{array}{r}637800 \\
22780 \\
28800 \\
16700 \\
1.66 \\
1.73\end{array}$ & $\begin{array}{r}767300 \\
24750 \\
41200 \\
10800 \\
1.81 \\
2.08\end{array}$ & $\begin{array}{r}600000 \\
20000 \\
35200 \\
13700 \\
1.46 \\
1.63\end{array}$ & $\begin{array}{r}401450 \\
12950 \\
20300 \\
9950 \\
.94 \\
1.09\end{array}$ & $\begin{array}{r}307930 \\
10260 \\
22000 \\
4500 \\
.75 \\
.84\end{array}$ & $\begin{array}{r}128620 \\
4149 \\
9110 \\
2810 \\
.30 \\
.35\end{array}$ & $\begin{array}{c}82190 \\
2651 \\
3560 \\
2240 \\
.19 \\
.22\end{array}$ & $\begin{array}{r}69830 \\
2328 \\
2680 \\
2110 \\
.17 \\
.19\end{array}$ \\
\hline
\end{tabular}

e Estimated

STAIISTICS OF MONTHLY MEAN DATA FOR WATER YEARS 1931 - 1991, BY WATER YEAR (WY)

\begin{tabular}{|c|c|c|c|c|c|c|c|c|c|c|c|c|}
\hline $\begin{array}{l}\text { MEAN } \\
\text { MAX } \\
(W Y) \\
\text { MIN } \\
(W Y)\end{array}$ & $\begin{array}{r}4813 \\
18330 \\
1991 \\
1244 \\
1957\end{array}$ & $\begin{array}{r}6707 \\
30610 \\
1973 \\
1496 \\
1957\end{array}$ & $\begin{array}{r}10580 \\
39370 \\
1986 \\
1347 \\
1964\end{array}$ & $\begin{array}{r}14370 \\
79760 \\
1950 \\
1410 \\
1977\end{array}$ & $\begin{array}{r}16960 \\
57040 \\
1950 \\
2037 \\
1931\end{array}$ & $\begin{array}{r}21340 \\
54760 \\
1982 \\
3005 \\
1941\end{array}$ & $\begin{array}{r}21690 \\
49960 \\
1938 \\
5247 \\
1931\end{array}$ & $\begin{array}{r}17710 \\
67770 \\
1943 \\
3076 \\
1934\end{array}$ & $\begin{array}{r}12970 \\
42370 \\
1958 \\
1612 \\
1934\end{array}$ & $\begin{array}{r}8845 \\
36090 \\
1957 \\
1474 \\
1934\end{array}$ & $\begin{array}{r}5640 \\
24680 \\
1919 \\
1303 \\
1936\end{array}$ & $\begin{array}{r}4543 \\
\angle 6040 \\
1989 \\
1498 \\
1940\end{array}$ \\
\hline
\end{tabular}

SUMMARY STATISTICS

ANMUAL TOTAL

ANNUAL MEAN

HIGHESI ANNUAI MEAN

LOWEST AMNUAL MEAN

HIGHESI DAIIY MEAN

LOWEST DAILY MEAM

ANNUAL SEVEN-DAY MINIMUM

INSTANIANEOUS PEAK FLOW

INSIANTANEOUS PEAK STAGE

ANMUAL RUNOFF (CFSM)

ANMUAL RUNOFF (INCHES)

10 PERLENT EXI.EEDS

50 PERCENT EXCEEDS

90 PERLEMI I XI,LEUS
FOR 1990 CALENOAR YEAR

7358270
20160

20160

62100
$3400 \quad$ Jay 22
4490

1.47

36900

17400

7380
FOR 1991 WATER YEAR

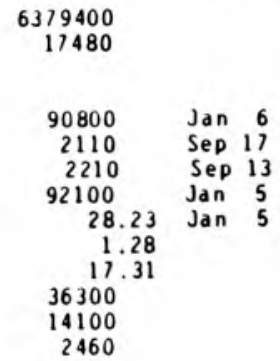

WAIER YEARS 1931 - 1991

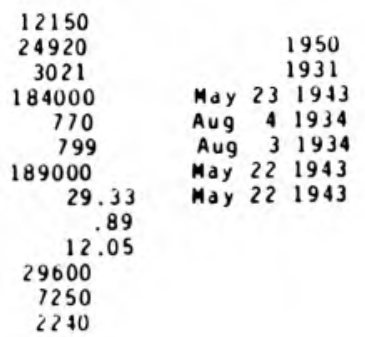


LOCATION.--Lat $40^{\circ} 12^{\prime} 15^{\prime \prime}$, Iong $85^{\circ} 23^{\prime} 14^{\prime \prime}$, in SE $\frac{1}{3}$ NW' Hackley Reserve, Delaware County, Hydrologic Unit 05120201, on right bank $200 \mathrm{ft}$ downstrea fro Walnut Street bridge in Muncie, 6 i upstrea froe Bell Creek. and at 11 ile 315.8 . DRAINAGE AREA -241

PERIOD OF RECORD.--Novener 1930 to current year. Prior to October 1948, published as West Fork White River at Muncie. Daily gage heights frod July 1923 to Deceber 1929 are avallable in the district office.

REVISED RECORDS..-WSP 1335: 1931-32(M), 1936(M), 1938, 1948. WSP 1435: 1955. WSP 2109: Drainage area.

GAGE. - Water-stage recorder. Datu of gage is $917.10 \mathrm{ft}$ above National Geodetic Vertical Datue of 1929 (city of Muncie bench eark). See WSP 1705 for history of changes prior to Jan. 28, 1942. Jan. 28, 1942, to Apr. 27, 1964, water-stage recorder at present site at datua $3.00 \mathrm{ft}$ higher.

REMARKS. - Records good except for estinated daily discharges, which are fair. Natural flow affected by regulation of Prairie Creek Reservoir and by diversion of aunicipal water supply by Muncie Water Works Co. above gage. Records of diversion available since October 1937.

EXTREMES OUTSIDE PERIOD OF RECORD.--Maximua stage known, $22.6 \mathrm{ft}$ in March 1913 , present datum, discharge, $20.000 \mathrm{ft} 3 / \mathrm{s}$.

DISCHARGE, CUBIC FEET PER SECOND, WATER YEAR OCTOBER 1990 TO SEPTEMBER 1991 DAI IY MEAN VALUES

\begin{tabular}{|c|c|c|c|c|c|c|c|c|c|c|c|c|}
\hline DAY & $\mathrm{OCT}$ & NOV & DEC & JAN & FEB & MAR & APR & MAY & JUN & JUL & AUG & SEP \\
\hline $\begin{array}{l}1 \\
2 \\
3 \\
4 \\
5\end{array}$ & $\begin{array}{r}85 \\
73 \\
73 \\
757 \\
537\end{array}$ & $\begin{array}{r}105 \\
101 \\
100 \\
98 \\
130\end{array}$ & $\begin{array}{r}285 \\
222 \\
775 \\
1160 \\
572\end{array}$ & $\begin{array}{r}2480 \\
942 \\
668 \\
518 \\
439\end{array}$ & $\begin{array}{l}212 \\
193 \\
319 \\
568 \\
868\end{array}$ & $\begin{array}{l}190 \\
209 \\
207 \\
185 \\
175\end{array}$ & $\begin{array}{l}253 \\
227 \\
211 \\
207 \\
214\end{array}$ & $\begin{array}{l}151 \\
143 \\
131 \\
138 \\
139\end{array}$ & $\begin{array}{l}476 \\
312 \\
200 \\
151 \\
122\end{array}$ & $\begin{array}{l}91 \\
70 \\
73 \\
83 \\
76\end{array}$ & $\begin{array}{l}5.5 \\
4.2 \\
7.8 \\
16 \\
14\end{array}$ & $\begin{array}{r}7.3 \\
9.0 \\
9.5 \\
14 \\
22\end{array}$ \\
\hline $\begin{array}{r}6 \\
7 \\
8 \\
9 \\
10\end{array}$ & $\begin{array}{r}297 \\
212 \\
174 \\
180 \\
1110\end{array}$ & $\begin{array}{l}189 \\
151 \\
126 \\
116 \\
131\end{array}$ & $\begin{array}{l}355 \\
275 \\
232 \\
203 \\
180\end{array}$ & $\begin{array}{l}397 \\
351 \\
317 \\
294 \\
271\end{array}$ & $\begin{array}{r}982 \\
1490 \\
843 \\
555 \\
422\end{array}$ & $\begin{array}{l}169 \\
165 \\
154 \\
145 \\
139\end{array}$ & $\begin{array}{l}208 \\
189 \\
185 \\
186 \\
170\end{array}$ & $\begin{array}{l}144 \\
145 \\
129 \\
117 \\
110\end{array}$ & $\begin{array}{r}103 \\
91 \\
86 \\
81 \\
76\end{array}$ & $\begin{array}{r}65 \\
60 \\
114 \\
127 \\
93\end{array}$ & $\begin{array}{l}13 \\
12 \\
13 \\
13 \\
14\end{array}$ & $\begin{array}{r}12 \\
5.1 \\
4.3 \\
4.2 \\
4.1\end{array}$ \\
\hline $\begin{array}{l}11 \\
12 \\
13 \\
14 \\
15\end{array}$ & $\begin{array}{l}951 \\
514 \\
345 \\
268 \\
216\end{array}$ & $\begin{array}{r}135 \\
117 \\
102 \\
95 \\
91\end{array}$ & $\begin{array}{l}167 \\
158 \\
144 \\
132 \\
989\end{array}$ & $\begin{array}{l}357 \\
834 \\
517 \\
384 \\
364\end{array}$ & $\begin{array}{l}343 \\
283 \\
257 \\
306 \\
298\end{array}$ & $\begin{array}{l}133 \\
133 \\
205 \\
576 \\
717\end{array}$ & $\begin{array}{l}149 \\
138 \\
234 \\
980 \\
779\end{array}$ & $\begin{array}{r}105 \\
100 \\
93 \\
88 \\
89\end{array}$ & $\begin{array}{l}74 \\
76 \\
68 \\
64 \\
62\end{array}$ & $\begin{array}{l}77 \\
77 \\
77 \\
73 \\
61\end{array}$ & $\begin{array}{r}12 \\
9.4 \\
6.3 \\
5.6 \\
7.4\end{array}$ & $\begin{array}{l}4.1 \\
9.0 \\
19 \\
21 \\
32\end{array}$ \\
\hline $\begin{array}{l}16 \\
17 \\
18 \\
19 \\
20\end{array}$ & $\begin{array}{l}184 \\
177 \\
361 \\
351 \\
273\end{array}$ & $\begin{array}{l}90 \\
88 \\
85 \\
81 \\
81\end{array}$ & $\begin{array}{r}1160 \\
592 \\
1270 \\
2200 \\
1080\end{array}$ & $\begin{array}{r}689 \\
789 \\
520 \\
390 \\
\mathrm{e} 380\end{array}$ & $\begin{array}{r}e 270 \\
e 260 \\
258 \\
950 \\
1030\end{array}$ & $\begin{array}{r}1130 \\
1660 \\
2170 \\
1270 \\
670\end{array}$ & $\begin{array}{l}499 \\
340 \\
265 \\
417 \\
737\end{array}$ & $\begin{array}{r}96 \\
125 \\
316 \\
247 \\
157\end{array}$ & $\begin{array}{l}70 \\
63 \\
54 \\
48 \\
41\end{array}$ & $\begin{array}{l}52 \\
48 \\
45 \\
39 \\
40\end{array}$ & $\begin{array}{l}7.1 \\
9.1 \\
8.9 \\
42 \\
27\end{array}$ & $\begin{array}{r}12 \\
8.8 \\
7.9 \\
6.3 \\
8.3\end{array}$ \\
\hline $\begin{array}{l}21 \\
22 \\
23 \\
24 \\
25\end{array}$ & $\begin{array}{l}215 \\
214 \\
242 \\
216 \\
180\end{array}$ & $\begin{array}{r}82 \\
115 \\
201 \\
158 \\
133\end{array}$ & $\begin{array}{r}938 \\
2000 \\
1220 \\
805 \\
546\end{array}$ & $\begin{array}{l}e 350 \\
e 325 \\
e 300 \\
e 270 \\
e 265\end{array}$ & $\begin{array}{l}645 \\
428 \\
327 \\
278 \\
245\end{array}$ & $\begin{array}{r}487 \\
1060 \\
2180 \\
1360 \\
628\end{array}$ & $\begin{array}{l}451 \\
335 \\
280 \\
257 \\
227\end{array}$ & $\begin{array}{r}126 \\
124 \\
118 \\
110 \\
98\end{array}$ & $\begin{array}{r}39 \\
59 \\
168 \\
257 \\
143\end{array}$ & $\begin{array}{l}43 \\
39 \\
30 \\
28 \\
25\end{array}$ & $\begin{array}{r}20 \\
12 \\
6.8 \\
4.9 \\
4.4\end{array}$ & $\begin{array}{l}10 \\
14 \\
16 \\
15 \\
17\end{array}$ \\
\hline $\begin{array}{l}26 \\
27 \\
28 \\
29 \\
30 \\
31\end{array}$ & $\begin{array}{l}157 \\
146 \\
132 \\
119 \\
111 \\
107\end{array}$ & $\begin{array}{l}110 \\
184 \\
868 \\
813 \\
408 \\
\cdots\end{array}$ & $\begin{array}{r}381 \\
\text { e370 } \\
\text { e340 } \\
1400 \\
6380 \\
8150\end{array}$ & $\begin{array}{r}\text { e245 } \\
\text { e225 } \\
\text { e212 } \\
\text { e200 } \\
\text { e210 } \\
246\end{array}$ & $\begin{array}{l}221 \\
206 \\
193 \\
\ldots . \\
\ldots . \\
\ldots-\end{array}$ & $\begin{array}{r}725 \\
1080 \\
616 \\
420 \\
333 \\
282\end{array}$ & $\begin{array}{l}213 \\
203 \\
191 \\
182 \\
169 \\
\cdots\end{array}$ & $\begin{array}{r}100 \\
103 \\
88 \\
81 \\
177 \\
266\end{array}$ & $\begin{array}{r}116 \\
96 \\
110 \\
105 \\
99 \\
--\end{array}$ & $\begin{array}{l}20 \\
11 \\
6.8 \\
6.9 \\
11 \\
14\end{array}$ & $\begin{array}{l}4.4 \\
4.3 \\
4.2 \\
8.2 \\
5.5 \\
8.6\end{array}$ & $\begin{array}{l}11 \\
12 \\
15 \\
16 \\
11 \\
\ldots\end{array}$ \\
\hline $\begin{array}{l}\text { TOTAL } \\
\text { MEAN } \\
\text { MAX } \\
\text { MIN } \\
\text { CF SM } \\
\text { IN. }\end{array}$ & $\begin{array}{r}8977 \\
290 \\
1110 \\
73 \\
1.20 \\
1.39\end{array}$ & $\begin{array}{r}5284 \\
176 \\
868 \\
81 \\
.73 \\
.82\end{array}$ & $\begin{array}{r}34681 \\
1119 \\
8150 \\
132 \\
4.64 \\
5.35\end{array}$ & $\begin{array}{r}14749 \\
476 \\
2480 \\
200 \\
1.97 \\
2.28\end{array}$ & $\begin{array}{r}13250 \\
473 \\
1490 \\
193 \\
1.96 \\
2.05\end{array}$ & $\begin{array}{r}19573 \\
631 \\
2180 \\
133 \\
2.62 \\
3.02\end{array}$ & $\begin{array}{c}9096 \\
303 \\
980 \\
138 \\
1.26 \\
1.40\end{array}$ & $\begin{array}{c}4154 \\
134 \\
316 \\
81 \\
.56 \\
.64\end{array}$ & $\begin{array}{c}3510 \\
117 \\
476 \\
39 \\
.49 \\
.54\end{array}$ & $\begin{array}{r}1675.7 \\
54.1 \\
127 \\
6.8 \\
.22 \\
.26\end{array}$ & $\begin{array}{r}330.6 \\
10.7 \\
42 \\
4.2 \\
.04 \\
.05\end{array}$ & $\begin{array}{r}356.9 \\
11.9 \\
32 \\
4.1 \\
.05 \\
.06\end{array}$ \\
\hline
\end{tabular}

e Estinated

STATISTICS OF MONTHLY MEAN DATA FOR WATER YEARS 1932 - 1991, BY WATER YEAR (WY)

\begin{tabular}{|c|c|c|c|c|c|c|c|c|c|}
\hline $\begin{array}{l}\text { MEAN } \\
\text { MAX } \\
\text { (WY) } \\
\text { MIN } \\
\text { (WY) }\end{array}$ & $\begin{array}{r}55.8 \\
409 \\
1987 \\
2.30 \\
1957\end{array}$ & $\begin{array}{r}126 \\
947 \\
1973 \\
7.33\end{array}$ & $\begin{array}{r}230 \\
1119 \\
1991 \\
6.57\end{array}$ & $\begin{array}{r}296 \\
1654 \\
1950 \\
6.38\end{array}$ & $\begin{array}{r}350 \\
1122 \\
1950 \\
21.2\end{array}$ & $\begin{array}{r}423 \\
963 \\
1978 \\
39.0\end{array}$ & $\begin{array}{r}398 \\
1476 \\
1964 \\
46.4\end{array}$ & $\begin{array}{r}258 \\
1239 \\
1933 \\
16.4\end{array}$ & $\begin{array}{r}58.1 \\
825 \\
1989 \\
1.96\end{array}$ \\
\hline
\end{tabular}

\section{SUMMARY STATISTICS}

ANNUAL TOTAL

ANNUAL MEAN

HIGHEST ANMUAL MEAN

LOWEST ANNUAL MEAN

HIGHEST DAILY MEAN

LOWEST DAILY MEAN

ANNUAL SEVEN-DAY MINIMUM

INSTANTANEOUS PEAK FLOW

INSTAMTANEOUS PEAK STAGE

ANMUAL RUNOFF (CFSM)

AN NUAL RUNOFF (INCHES)

10 PERCENT EXCEEDS

50 PERCENT EXCEEDS

90 PERCENT EXCEEDS

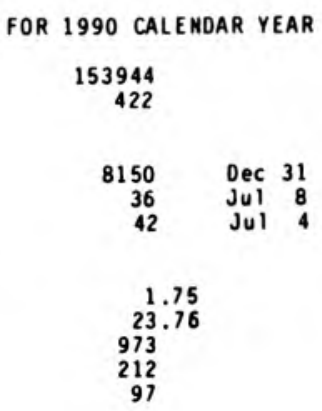

FOR 1991 WATER YEAR

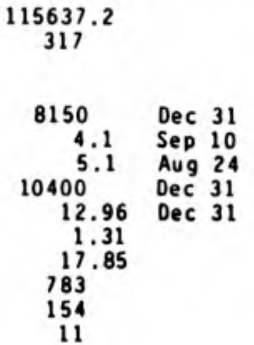

WATER YEARS 1932 - 1991

$$
\begin{array}{rrr}
213 & & 1950 \\
421 & & 1941 \\
42.1 & & \\
11600 & \text { Apr 21 } 1964 \\
1.1 & \text { Sep 16 } 1954 \\
1.2 & \text { Sep 21 } 1954 \\
14300 & \text { Apr 21 } 1964 \\
21.07 & \text { Jan 15 } 1937 \\
12.09 & & \\
480 & & \\
12 & & \\
11 & &
\end{array}
$$




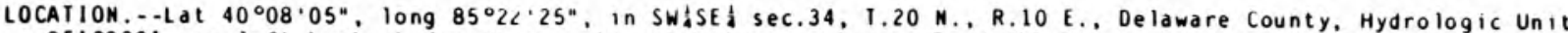
05120201 , on left bank at downstrean side of bridge on County Road 400 South, 1.0 ei upstrean from Muncie Water Works Co. pumping stątion, 4.2 a southeast of court house in Muncie, and at aile 10.6 .

DRAI MAGE AREA. $-35.5 \mathrm{i}^{2}$

PERIOD OF RECORD.--0 Ctober 1954 to current yedr.

REVISED RECORDS.--WSP 1909: 1955, 1957. WSP 2109: Drainage area.

GAGE.--Water-stage recorder. Datur of gage is $944.67 \mathrm{ft}$ above National Geodetic Vertical Datue of 1929 . Prior to May 5, 1955, nonrecording gage at sane site and datun.

REMARKS.--Records good except for estinated daily discharges, which are poor.

EXTREMES OUTSIDE PERIOD OF RECORD. - Maximun stage known, about $15 \mathrm{ft}$, from information by local residents. Date unknown.

DISCHARGE, CUBIC FEEI PER SECOND, WATER YEAR OCTOBER 1990 TO SEPIEMBER 1991 DAILY MEAN VALUES

\begin{tabular}{|c|c|c|c|c|c|c|c|c|c|c|c|c|}
\hline DAY & $\mathrm{OCI}$ & MOV & DEC & JAN & $F E B$ & MAR & $A P R$ & MAY & JUN & JUL & AUG & SEP \\
\hline $\begin{array}{l}1 \\
2 \\
3 \\
4 \\
5\end{array}$ & $\begin{array}{r}33 \\
32 \\
33 \\
147 \\
71\end{array}$ & $\begin{array}{l}\text { e } 38.5 \\
\text { e } 38 \\
\text { e } 36 \\
\text { e } 35 \\
\text { e } 34.5\end{array}$ & $\begin{array}{r}\text { e60 } \\
\text { e50 } \\
\text { e80 } \\
\text { e120 } \\
\text { e90 }\end{array}$ & $\begin{array}{r}154 \\
116 \\
97 \\
85 \\
80\end{array}$ & $\begin{array}{r}\text { e45 } \\
\text { e53 } \\
\text { e64 } \\
\text { e } 80 \\
\text { e120 }\end{array}$ & $\begin{array}{l}\text { e54 } \\
\text { e } 56 \\
\text { e } 52 \\
\text { e47 } \\
\text { e } 46\end{array}$ & $\begin{array}{l}63 \\
59 \\
57 \\
58 \\
65\end{array}$ & $\begin{array}{l}47 \\
45 \\
44 \\
46 \\
46\end{array}$ & $\begin{array}{r}112 \\
57 \\
47 \\
41 \\
38\end{array}$ & $\begin{array}{l}23 \\
22 \\
24 \\
24 \\
22\end{array}$ & $\begin{array}{l}17 \\
17 \\
17 \\
18 \\
17\end{array}$ & $\begin{array}{l}16 \\
15 \\
16 \\
18 \\
16\end{array}$ \\
\hline $\begin{array}{r}6 \\
7 \\
8 \\
9 \\
10\end{array}$ & $\begin{array}{r}52 \\
46 \\
44 \\
57 \\
166\end{array}$ & $\begin{array}{l}\text { e } 39 \\
\text { e34 } \\
\text { e } 30 \\
\text { e } 31 \\
\text { e32 }\end{array}$ & $\begin{array}{l}\text { e66 } \\
\text { e56 } \\
\text { e49 } \\
\text { e44 } \\
\text { e39 }\end{array}$ & $\begin{array}{l}76 \\
71 \\
67 \\
64 \\
63\end{array}$ & $\begin{array}{l}\text { e } 173 \\
\text { el } 80 \\
\text { e } 130 \\
\text { el } 00 \\
\text { e84 }\end{array}$ & $\begin{array}{l}\text { e } 48 \\
\text { e } 47 \\
\text { e } 43 \\
\text { e } 42 \\
\text { e } 41\end{array}$ & $\begin{array}{l}60 \\
56 \\
56 \\
57 \\
53\end{array}$ & $\begin{array}{l}45 \\
43 \\
42 \\
41 \\
40\end{array}$ & $\begin{array}{l}35 \\
34 \\
33 \\
32 \\
31\end{array}$ & $\begin{array}{l}22 \\
21 \\
35 \\
25 \\
24\end{array}$ & $\begin{array}{l}18 \\
18 \\
18 \\
19 \\
18\end{array}$ & $\begin{array}{l}16 \\
15 \\
15 \\
15 \\
15\end{array}$ \\
\hline $\begin{array}{l}11 \\
12 \\
13 \\
14 \\
15\end{array}$ & $\begin{array}{l}95 \\
66 \\
56 \\
51 \\
46\end{array}$ & $\begin{array}{l}\text { e } 31 \\
\text { e2 } 8.5 \\
\text { e2 } 27.8 \\
\text { e2 } 8 \\
\text { e2 } 27.3\end{array}$ & $\begin{array}{l}\text { e37 } \\
\text { e36 } \\
\text { e } 35 \\
\text { e34 } \\
\text { e } 66\end{array}$ & $\begin{array}{r}115 \\
116 \\
79 \\
70 \\
75\end{array}$ & $\begin{array}{l}\text { e } 69 \\
\text { e60 } \\
\text { e } 61 \\
\text { e66 } \\
\text { e } 60\end{array}$ & $\begin{array}{r}e 40 \\
e 80 \\
\text { e230 } \\
\text { e220 } \\
\text { e1 } 70\end{array}$ & $\begin{array}{r}50 \\
49 \\
111 \\
140 \\
112\end{array}$ & $\begin{array}{l}40 \\
39 \\
39 \\
39 \\
38\end{array}$ & $\begin{array}{l}30 \\
30 \\
29 \\
29 \\
28\end{array}$ & $\begin{array}{l}23 \\
24 \\
23 \\
22 \\
21\end{array}$ & $\begin{array}{l}17 \\
17 \\
16 \\
17 \\
18\end{array}$ & $\begin{array}{l}16 \\
16 \\
17 \\
17 \\
16\end{array}$ \\
\hline $\begin{array}{l}16 \\
17 \\
18 \\
19 \\
20\end{array}$ & $\begin{array}{r}43 \\
43 \\
112 \\
70 \\
56\end{array}$ & $\begin{array}{l}\text { e } 27 \\
\text { e } 26.3 \\
\text { e26 } \\
\text { e } 25.5 \\
\text { e25 }\end{array}$ & $\begin{array}{r}\text { e88 } \\
\text { e72 } \\
\text { e130 } \\
\text { e250 } \\
\text { e114 }\end{array}$ & $\begin{array}{r}122 \\
106 \\
78 \\
70 \\
70\end{array}$ & $\begin{array}{r}\text { e52 } \\
\text { e52 } \\
\text { e } 90 \\
\text { e150 } \\
\text { e130 }\end{array}$ & $\begin{array}{r}\text { e135 } \\
\text { e110 } \\
\text { e193 } \\
108 \\
82\end{array}$ & $\begin{array}{r}81 \\
67 \\
60 \\
120 \\
117\end{array}$ & $\begin{array}{r}40 \\
62 \\
231 \\
91 \\
59\end{array}$ & $\begin{array}{l}30 \\
28 \\
27 \\
27 \\
26\end{array}$ & $\begin{array}{l}21 \\
20 \\
20 \\
20 \\
20\end{array}$ & $\begin{array}{l}17 \\
18 \\
20 \\
26 \\
25\end{array}$ & $\begin{array}{l}16 \\
16 \\
17 \\
17 \\
16\end{array}$ \\
\hline $\begin{array}{l}21 \\
22 \\
23 \\
24 \\
25\end{array}$ & $\begin{array}{l}50 \\
57 \\
53 \\
48 \\
45\end{array}$ & $\begin{array}{l}\text { e } 31 \\
\text { e } 45 \\
\text { e } 46 \\
\text { e } 37.5 \\
\text { e33 }\end{array}$ & $\begin{array}{r}194 \\
209 \\
134 \\
99 \\
83\end{array}$ & $\begin{array}{r}66 \\
e 60 \\
e 56 \\
e 52 \\
e 48\end{array}$ & $\begin{array}{r}\text { el } 00 \\
\text { e82 } \\
\text { e71 } \\
\text { e63 } \\
\text { e58 }\end{array}$ & $\begin{array}{r}71 \\
241 \\
301 \\
125 \\
93\end{array}$ & $\begin{array}{l}80 \\
69 \\
63 \\
60 \\
56\end{array}$ & $\begin{array}{l}49 \\
61 \\
60 \\
47 \\
42\end{array}$ & $\begin{array}{l}26 \\
28 \\
28 \\
26 \\
25\end{array}$ & $\begin{array}{l}19 \\
19 \\
19 \\
19 \\
19\end{array}$ & $\begin{array}{l}19 \\
18 \\
17 \\
17 \\
16\end{array}$ & $\begin{array}{l}17 \\
18 \\
19 \\
18 \\
16\end{array}$ \\
\hline $\begin{array}{l}26 \\
27 \\
28 \\
29 \\
30 \\
31\end{array}$ & $\begin{array}{l}43 \\
42 \\
41 \\
40 \\
39 \\
39\end{array}$ & $\begin{array}{r}\text { e } 31 \\
\text { e60 } \\
\text { e150 } \\
\text { e120 } \\
\text { e84 } \\
. . .\end{array}$ & $\begin{array}{r}75 \\
70 \\
69 \\
279 \\
353 \\
301\end{array}$ & $\begin{array}{r}e 47 \\
e 46 \\
e 47 \\
49 \\
63 \\
e 54\end{array}$ & $\begin{array}{l}\text { e55 } \\
\text { e52 } \\
\text { e52 } \\
\ldots . \\
\cdots \\
\cdots\end{array}$ & $\begin{array}{r}144 \\
128 \\
92 \\
78 \\
69 \\
66\end{array}$ & $\begin{array}{l}55 \\
53 \\
51 \\
50 \\
48 \\
\cdots\end{array}$ & $\begin{array}{r}42 \\
39 \\
37 \\
59 \\
102 \\
61\end{array}$ & $\begin{array}{r}25 \\
25 \\
24 \\
24 \\
23 \\
\cdots\end{array}$ & $\begin{array}{l}18 \\
18 \\
18 \\
18 \\
18 \\
18\end{array}$ & $\begin{array}{l}16 \\
16 \\
17 \\
17 \\
16 \\
16\end{array}$ & $\begin{array}{l}16 \\
16 \\
16 \\
15 \\
15 \\
-\cdots\end{array}$ \\
\hline $\begin{array}{l}\text { IOIAL } \\
\text { MEAN } \\
\text { MAX } \\
\text { MIN } \\
\text { CF SM } \\
\text { IN. }\end{array}$ & $\begin{array}{r}1816 \\
58.6 \\
166 \\
32 \\
1.65 \\
1.90\end{array}$ & $\begin{array}{r}1257.9 \\
41.9 \\
150 \\
25 \\
1.18 \\
1.32\end{array}$ & $\begin{array}{r}3382 \\
109 \\
353 \\
34 \\
3.07 \\
3.54\end{array}$ & $\begin{array}{r}2362 \\
76.2 \\
154 \\
46 \\
2.15 \\
2.48\end{array}$ & $\begin{array}{r}2352 \\
84.0 \\
180 \\
45 \\
2.37 \\
2.46\end{array}$ & $\begin{array}{r}3252 \\
105 \\
301 \\
40 \\
2.96 \\
3.41\end{array}$ & $\begin{array}{r}2076 \\
69.2 \\
140 \\
48 \\
1.95 \\
2.18\end{array}$ & $\begin{array}{r}1716 \\
55.4 \\
231 \\
37 \\
1.56 \\
1.80\end{array}$ & $\begin{array}{r}998 \\
33.3 \\
112 \\
23 \\
.94 \\
1.05\end{array}$ & $\begin{array}{r}659 \\
21.3 \\
35 \\
18 \\
.60 \\
.69\end{array}$ & $\begin{array}{r}553 \\
17.8 \\
26 \\
16 \\
.50 \\
.58\end{array}$ & $\begin{array}{r}487 \\
16.2 \\
19 \\
15 \\
.46 \\
.51\end{array}$ \\
\hline
\end{tabular}

e Estimated

SIATISIICS OF MONIHLY MEAN DATA FOR WAIER YEARS 1955 - 1991, BY WATER YEAR (WY)

\begin{tabular}{|c|c|c|c|c|c|c|c|c|c|c|c|c|}
\hline $\begin{array}{l}\text { MEAN } \\
\text { MAX } \\
(W Y) \\
\text { MIN } \\
(W Y)\end{array}$ & $\begin{array}{l}20.3 \\
58.6 \\
1991 \\
8.73 \\
1964\end{array}$ & $\begin{array}{l}28.3 \\
99.3 \\
1973 \\
9.30 \\
1964\end{array}$ & $\begin{array}{r}38.3 \\
107 \\
1991 \\
8.77 \\
1965\end{array}$ & $\begin{array}{l}39.6 \\
96.2 \\
1959 \\
6.36 \\
1977\end{array}$ & $\begin{array}{r}52.4 \\
123 \\
1971 \\
11.2 \\
1964\end{array}$ & $\begin{array}{r}58.5 \\
117 \\
1982 \\
16.4 \\
1966\end{array}$ & $\begin{array}{r}56.4 \\
166 \\
1964 \\
16.7 \\
1966\end{array}$ & $\begin{array}{l}43.0 \\
89.6 \\
1968 \\
17.2 \\
1988\end{array}$ & $\begin{array}{c}39.0 \\
153 \\
1958 \\
11.3 \\
1988\end{array}$ & $\begin{array}{l}27.2 \\
70.8 \\
1979 \\
8.64 \\
1966\end{array}$ & $\begin{array}{r}23.5 \\
108 \\
1979 \\
9.00 \\
1965\end{array}$ & $\begin{array}{l}18.5 \\
16.4 \\
1989 \\
8.13 \\
1963\end{array}$ \\
\hline
\end{tabular}

SUMMARY SIAIISIICS

ANNUAL TOTAL

AMNUAL MEAN

HI GHEST ANNUAL MEAN

LOWEST ANNUAL MEAN

HIGHEST DAILY MEAN

LOWESI DAILY MEAN

ANNUAL SEVEM-DAY MINIMUM

INSIANTANEOUS PEAK FLOW

INSIANTANEOUS PEAK STAGE

ANMUAL RUNOFF (CFSM)

ANNUAL RUNOFF (INCHES)

10 PERCENT EXCEEDS

50 PERCENT EXCEEDS

90 PERCENT EXCEEDS
FOR 1990 CALENUAR YEAR

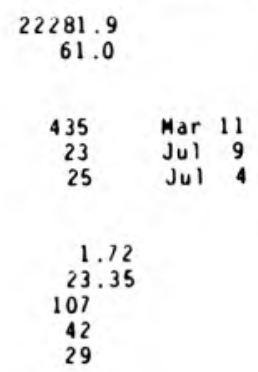

FOR 1991 WAIER YEAR

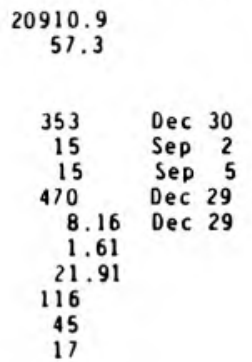

WATER YEARS 1955 - 1991

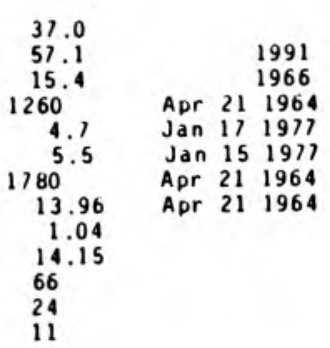


LOCATION.--Lat $40^{\circ} 06^{\prime} 20^{\prime \prime}$, long $85^{\circ} 40^{\prime} 16^{\prime \prime}$, in NWtawl sec.18, T.19 N., R.8 E., Madison County, Hydrologic Unit 05120201 . On downstrea side of abandoned Twelfth Street bridge abutaent, 250 ft upstrean from anicipal water-supply plant y̧ Anderson, 1 i upstrea from Killbuck Creek, and at ile 293.3.

DRAINAGE AREA..-406 i

PERIOD OF RECORD...July 1925 to Septenber 1926, October 1931 to current year. Monthly discharge only for sone periods. published in WSP 1305. Gage-height records collected at site $950 \mathrm{ft}$ downstrean Deceaber 1910 to February 1918 , $250 \mathrm{ft}$ downstrea fro february 1918 to Sept. 14.1973, and at present site since Sept. 15, 1973 , are contained in reports of National Weather Service. Prior to October 1948, published as West Fork White River at Anderson.

REVISED RECORDS.--WSP 1335: 1932, 1934-35, 1936(M), 1938-40. WSP 1385: 1950(P). WSP 1725: 1956 (P). WSP 1909: 1956. WSP 2109: Drainage area.

GAGE. - Water-stage recorder and crest-stage gage. Datun of gage is 825.02 ft above Mational Geodetic Vertical Datua of 1929. Prior to May 12, 1934, nonrecording gage at present site and datua. May 12, 1934, to Sept. 14, 1973 nonrecord-ing gage at site $250 \mathrm{ft}$ downstrean at saee datum. Sept. 15, 1973, to Sept. 23, 1976. nonrecording gage at present site and datue.

REMARKS. - Records good except for estinated daily discharges, which are poor. Prior to Sept. 15. 1973, the City of Anderson diverted water for its unicipal supply above the gage then in use.

EXTREMES OUTSIDE PERIOD OF RECORD.--Maxiau stage known, $23.6 \mathrm{ft}$ Mar. 25, 1913, at site $250 \mathrm{ft}$ downstrean and at present datum, based on deternination of National Weather Service at site then in use, discharge, 28,000 ft $/ 5$.

DISCHARGE, CUBIC FEET PER SECOND, WATER YEAR OCTOBER 1990 TO SEPTEMBER 1991 DAILY MEAN VALUES

\begin{tabular}{|c|c|c|c|c|c|c|c|c|c|c|c|c|}
\hline DAY & $\mathrm{OCT}$ & NOV & DEC & JAN & FEB & MAR & APR & MAY & JUN & JUL & AUG & SEP \\
\hline $\begin{array}{l}1 \\
2 \\
3 \\
4 \\
5\end{array}$ & $\begin{array}{r}283 \\
265 \\
259 \\
1170 \\
1210\end{array}$ & $\begin{array}{l}277 \\
271 \\
269 \\
263 \\
303\end{array}$ & $\begin{array}{r}605 \\
477 \\
983 \\
1940 \\
1030\end{array}$ & $\begin{array}{l}8350 \\
2080 \\
1450 \\
1170 \\
1030\end{array}$ & $\begin{array}{r}\text { e } 390 \\
e 400 \\
617 \\
1020 \\
1380\end{array}$ & $\begin{array}{l}437 \\
467 \\
462 \\
430 \\
402\end{array}$ & $\begin{array}{l}559 \\
510 \\
473 \\
454 \\
509\end{array}$ & $\begin{array}{l}386 \\
369 \\
353 \\
358 \\
361\end{array}$ & $\begin{array}{r}1010 \\
846 \\
522 \\
396 \\
329\end{array}$ & $\begin{array}{l}161 \\
155 \\
153 \\
143 \\
144\end{array}$ & $\begin{array}{l}81 \\
79 \\
74 \\
89 \\
86\end{array}$ & $\begin{array}{l}69 \\
66 \\
72 \\
99 \\
86\end{array}$ \\
\hline $\begin{array}{r}6 \\
7 \\
8 \\
9 \\
10\end{array}$ & $\begin{array}{r}686 \\
504 \\
440 \\
426 \\
1570\end{array}$ & $\begin{array}{l}394 \\
350 \\
306 \\
290 \\
296\end{array}$ & $\begin{array}{l}709 \\
567 \\
479 \\
427 \\
393\end{array}$ & $\begin{array}{l}945 \\
853 \\
778 \\
718 \\
658\end{array}$ & $\begin{array}{r}1680 \\
2280 \\
1520 \\
1100 \\
904\end{array}$ & $\begin{array}{l}397 \\
388 \\
367 \\
353 \\
340\end{array}$ & $\begin{array}{l}477 \\
438 \\
434 \\
443 \\
415\end{array}$ & $\begin{array}{l}371 \\
360 \\
329 \\
307 \\
309\end{array}$ & $\begin{array}{l}292 \\
262 \\
241 \\
229 \\
219\end{array}$ & $\begin{array}{l}129 \\
119 \\
282 \\
236 \\
203\end{array}$ & $\begin{array}{r}90 \\
91 \\
85 \\
118 \\
88\end{array}$ & $\begin{array}{l}86 \\
72 \\
63 \\
60 \\
63\end{array}$ \\
\hline $\begin{array}{l}11 \\
12 \\
13 \\
14 \\
15\end{array}$ & $\begin{array}{r}1940 \\
1010 \\
718 \\
584 \\
483\end{array}$ & $\begin{array}{l}297 \\
286 \\
271 \\
261 \\
257\end{array}$ & $\begin{array}{r}375 \\
357 \\
342 \\
319 \\
1010\end{array}$ & $\begin{array}{r}756 \\
1420 \\
1090 \\
866 \\
814\end{array}$ & $\begin{array}{r}754 \\
644 \\
600 \\
663 \\
e 640\end{array}$ & $\begin{array}{r}334 \\
348 \\
565 \\
1230 \\
1460\end{array}$ & $\begin{array}{r}376 \\
349 \\
474 \\
1250 \\
1450\end{array}$ & $\begin{array}{l}311 \\
310 \\
295 \\
305 \\
304\end{array}$ & $\begin{array}{l}215 \\
216 \\
196 \\
186 \\
183\end{array}$ & $\begin{array}{l}161 \\
151 \\
151 \\
136 \\
125\end{array}$ & $\begin{array}{l}85 \\
80 \\
77 \\
68 \\
69\end{array}$ & $\begin{array}{r}63 \\
62 \\
87 \\
131 \\
96\end{array}$ \\
\hline $\begin{array}{l}16 \\
17 \\
18 \\
19 \\
20\end{array}$ & $\begin{array}{l}409 \\
381 \\
595 \\
776 \\
575\end{array}$ & $\begin{array}{l}252 \\
252 \\
243 \\
238 \\
234\end{array}$ & $\begin{array}{l}1970 \\
1030 \\
1550 \\
3340 \\
1970\end{array}$ & $\begin{array}{r}1160 \\
1480 \\
1130 \\
890 \\
807\end{array}$ & $\begin{array}{l}\text { e } 520 \\
e 500 \\
e 540 \\
1420 \\
1580\end{array}$ & $\begin{array}{l}1840 \\
2400 \\
3160 \\
2540 \\
1330\end{array}$ & $\begin{array}{r}1030 \\
754 \\
597 \\
721 \\
1320\end{array}$ & $\begin{array}{r}306 \\
404 \\
1090 \\
950 \\
545\end{array}$ & $\begin{array}{l}210 \\
189 \\
177 \\
166 \\
160\end{array}$ & $\begin{array}{r}115 \\
110 \\
107 \\
104 \\
97\end{array}$ & $\begin{array}{r}71 \\
77 \\
104 \\
89 \\
312\end{array}$ & $\begin{array}{l}98 \\
86 \\
75 \\
73 \\
69\end{array}$ \\
\hline $\begin{array}{l}21 \\
22 \\
23 \\
24 \\
25\end{array}$ & $\begin{array}{l}471 \\
448 \\
487 \\
449 \\
400\end{array}$ & $\begin{array}{l}231 \\
283 \\
364 \\
353 \\
317\end{array}$ & $\begin{array}{r}1420 \\
2990 \\
2100 \\
1350 \\
936\end{array}$ & $\begin{array}{l}794 \\
e 660 \\
e 580 \\
e 510 \\
e 470\end{array}$ & $\begin{array}{r}1170 \\
872 \\
702 \\
609 \\
546\end{array}$ & $\begin{array}{l}1010 \\
1460 \\
3230 \\
2610 \\
1290\end{array}$ & $\begin{array}{l}949 \\
741 \\
621 \\
583 \\
522\end{array}$ & $\begin{array}{l}420 \\
377 \\
421 \\
346 \\
303\end{array}$ & $\begin{array}{l}159 \\
183 \\
250 \\
391 \\
276\end{array}$ & $\begin{array}{r}102 \\
96 \\
96 \\
88 \\
87\end{array}$ & $\begin{array}{r}128 \\
101 \\
87 \\
80 \\
71\end{array}$ & $\begin{array}{r}71 \\
74 \\
104 \\
96 \\
84\end{array}$ \\
\hline $\begin{array}{l}26 \\
27 \\
28 \\
29 \\
30 \\
31\end{array}$ & $\begin{array}{l}357 \\
338 \\
324 \\
308 \\
297 \\
288\end{array}$ & $\begin{array}{r}287 \\
385 \\
1100 \\
1550 \\
824 \\
-\cdots\end{array}$ & $\begin{array}{r}735 \\
596 \\
582 \\
1550 \\
10100 \\
16700\end{array}$ & $\begin{array}{l}\text { e } 450 \\
\text { e } 440 \\
\text { e } 425 \\
\text { e410 } \\
\text { e412 } \\
\text { e420 }\end{array}$ & $\begin{array}{l}493 \\
464 \\
446 \\
\ldots- \\
\cdots- \\
-.-\end{array}$ & $\begin{array}{r}1160 \\
1860 \\
1240 \\
905 \\
728 \\
615\end{array}$ & $\begin{array}{l}480 \\
458 \\
444 \\
426 \\
399 \\
\ldots-\end{array}$ & $\begin{array}{l}315 \\
297 \\
279 \\
263 \\
526 \\
979\end{array}$ & $\begin{array}{l}213 \\
181 \\
165 \\
172 \\
164 \\
\cdots-\end{array}$ & $\begin{array}{l}86 \\
80 \\
80 \\
80 \\
89 \\
83\end{array}$ & $\begin{array}{l}67 \\
66 \\
76 \\
68 \\
90 \\
83\end{array}$ & $\begin{array}{l}87 \\
82 \\
80 \\
76 \\
77 \\
-\cdots\end{array}$ \\
\hline $\begin{array}{l}\text { TOTAL } \\
\text { MEAN } \\
\text { MAX } \\
\text { MIN } \\
\text { CF SM } \\
\text { IN. }\end{array}$ & $\begin{array}{r}18451 \\
595 \\
1940 \\
259 \\
1.47 \\
1.69\end{array}$ & $\begin{array}{r}11304 \\
377 \\
1550 \\
231 \\
.93 \\
1.04\end{array}$ & $\begin{array}{r}58932 \\
1901 \\
16700 \\
319 \\
4.68 \\
5.40\end{array}$ & $\begin{array}{r}34016 \\
1097 \\
8350 \\
410 \\
2.70 \\
3.12\end{array}$ & $\begin{array}{r}24454 \\
873 \\
2280 \\
390 \\
2.15 \\
2.24\end{array}$ & $\begin{array}{r}35358 \\
1141 \\
3230 \\
334 \\
2.81 \\
3.24\end{array}$ & $\begin{array}{r}18656 \\
622 \\
1450 \\
349 \\
1.53 \\
1.71\end{array}$ & $\begin{array}{c}12849 \\
414 \\
1090 \\
253 \\
1.02 \\
1.18\end{array}$ & $\begin{array}{c}8398 \\
280 \\
1010 \\
159 \\
.69 \\
.77\end{array}$ & $\begin{array}{c}3949 \\
127 \\
282 \\
80 \\
.31 \\
.36\end{array}$ & $\begin{array}{c}2830 \\
91.3 \\
312 \\
66 \\
.22 \\
.26\end{array}$ & $\begin{array}{c}2407 \\
80.2 \\
131 \\
60 \\
.20 \\
.22\end{array}$ \\
\hline
\end{tabular}

e Estiated

STATISTICS OF MONTHLY MEAN DATA FOR WATER YEARS 1932 - 1991, BY WATER YEAR (WY)

\begin{tabular}{|c|c|c|c|c|c|c|c|c|c|}
\hline $\begin{array}{l}\text { MEAN } \\
\text { MAX } \\
\text { (WY) } \\
\text { MIN } \\
\text { (WY) }\end{array}$ & $\begin{array}{r}139 \\
619 \\
1987 \\
30.3\end{array}$ & $\begin{array}{r}237 \\
1321 \\
1973 \\
45.4\end{array}$ & $\begin{array}{r}389 \\
1901 \\
1991 \\
45.1\end{array}$ & $\begin{array}{r}498 \\
2740 \\
1950 \\
44.4\end{array}$ & $\begin{array}{r}599 \\
1882 \\
1950 \\
67.5\end{array}$ & $\begin{array}{r}722 \\
1621 \\
1978 \\
81.5\end{array}$ & $\begin{array}{r}691 \\
2164 \\
1964 \\
94.0\end{array}$ & $\begin{array}{r}475 \\
1949 \\
1933 \\
41.5 \\
1941\end{array}$ & \\
\hline
\end{tabular}

SUMMARY STATISTICS

ANNUAL TOTAL

ANNUAL MEAM

HIGHEST ANMUAL MEAN

LOWEST ANWUAL MEAN

HIGHEST DAILY MEAM

LOWEST DAILY MEAM

AMNUAL SEVEM-DAY MINIMUM

INSTANTANEOUS PEAK FLOW

INSTANTANEOUS PEAK STAGE

AN NUAL RUNOFF (CFSM)

ANMUAL RUNOFF (INCHES)

10 PERCENT EXCEEDS

50 PERCENT EXCEEDS

90 PERCENT EXCEEDS
FOR 1990 CALENDAR YEAR

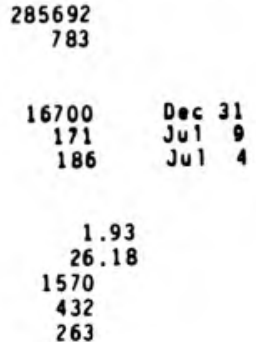

FOR 1991 WATER YEAR

231604

635

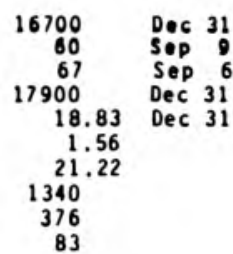

WATER YEARS 1932 - 1991

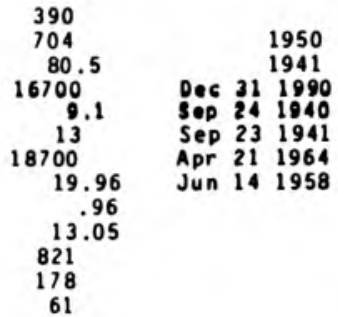


LOCATION.--Lat $40^{\circ} 15^{\prime} 45^{\circ}$, long $85^{\circ} 30^{\prime} 53^{\circ}$, in SE 4 SWl sec.16, T.21 N., R.9 E., Delaware County. Hydrologic Unit 05120201 , On right bank $30 \mathrm{ft}$ upstreas froe bridge on County Road 500 Morth, 3.6 . il southwest of Gaston, and at -ile 15.6.

DRAI NAGE AREA. $\ldots 25.5-i^{2}$

PERIOD OF RECORD.--June i 968 to current year.

GAGE.- Water-stage recorder. Datue of gage is $873.00 \mathrm{ft}$ above National Geodetic Vertical Datue of 1929.

REMARKS.--Records good except for estinated daily discharges, which are poor.

DISCHARGE, CUBIC FEET PER SECOND. WATER YEAR OCTOBER 1990 TO SEPIEMBER 1991 DAILY MEAN VALUES

\begin{tabular}{|c|c|c|c|c|c|c|c|c|c|c|c|c|}
\hline DAY & $O C T$ & NOV & DEC & JAN & FEB & MAR & APR & MAY & JUN & JUL & AUG & SEP \\
\hline $\begin{array}{l}1 \\
2 \\
3 \\
4 \\
5\end{array}$ & $\begin{array}{r}16 \\
16 \\
16 \\
132 \\
65\end{array}$ & $\begin{array}{l}19 \\
19 \\
18 \\
18 \\
28\end{array}$ & $\begin{array}{r}32 \\
25 \\
195 \\
154 \\
57\end{array}$ & $\begin{array}{r}157 \\
73 \\
55 \\
42 \\
37\end{array}$ & $\begin{array}{r}18 \\
18 \\
28 \\
62 \\
109\end{array}$ & $\begin{array}{l}20 \\
21 \\
19 \\
18 \\
17\end{array}$ & $\begin{array}{l}31 \\
28 \\
27 \\
26 \\
30\end{array}$ & $\begin{array}{l}22 \\
21 \\
20 \\
20 \\
20\end{array}$ & $\begin{array}{l}85 \\
53 \\
56 \\
37 \\
30\end{array}$ & $\begin{array}{l}11 \\
13 \\
16 \\
13 \\
12\end{array}$ & $\begin{array}{l}4.2 \\
3.9 \\
3.7 \\
4.6 \\
4.9\end{array}$ & $\begin{array}{l}e 2.8 \\
e 2.6 \\
e 2.5 \\
e 3.5 \\
\text { e2.7 }\end{array}$ \\
\hline $\begin{array}{r}6 \\
7 \\
8 \\
9 \\
10\end{array}$ & $\begin{array}{r}40 \\
33 \\
42 \\
73 \\
280\end{array}$ & $\begin{array}{l}36 \\
22 \\
19 \\
18 \\
17\end{array}$ & $\begin{array}{l}40 \\
32 \\
27 \\
23 \\
21\end{array}$ & $\begin{array}{l}35 \\
32 \\
29 \\
27 \\
25\end{array}$ & $\begin{array}{r}108 \\
161 \\
76 \\
52 \\
41\end{array}$ & $\begin{array}{l}17 \\
16 \\
15 \\
15 \\
14\end{array}$ & $\begin{array}{l}29 \\
27 \\
27 \\
30 \\
26\end{array}$ & $\begin{array}{l}20 \\
19 \\
18 \\
19 \\
19\end{array}$ & $\begin{array}{l}27 \\
25 \\
24 \\
23 \\
22\end{array}$ & $\begin{array}{l}11 \\
10 \\
28 \\
20 \\
14\end{array}$ & $\begin{array}{l}4.2 \\
4.3 \\
4.2 \\
5.2 \\
5.0\end{array}$ & $\begin{array}{l}e 2.5 \\
e 2.4 \\
e 2.4 \\
e 2.3 \\
\text { e2.7 }\end{array}$ \\
\hline $\begin{array}{l}11 \\
12 \\
13 \\
14 \\
15\end{array}$ & $\begin{array}{r}175 \\
73 \\
53 \\
44 \\
39\end{array}$ & $\begin{array}{l}16 \\
15 \\
14 \\
14 \\
14\end{array}$ & $\begin{array}{r}20 \\
18 \\
17 \\
16 \\
116\end{array}$ & $\begin{array}{l}41 \\
67 \\
39 \\
35 \\
50\end{array}$ & $\begin{array}{l}33 \\
28 \\
27 \\
32 \\
27\end{array}$ & $\begin{array}{l}14 \\
15 \\
23 \\
42 \\
52\end{array}$ & $\begin{array}{r}24 \\
23 \\
64 \\
127 \\
104\end{array}$ & $\begin{array}{l}19 \\
19 \\
19 \\
21 \\
22\end{array}$ & $\begin{array}{l}22 \\
23 \\
21 \\
20 \\
19\end{array}$ & $\begin{array}{r}12 \\
12 \\
12 \\
9.9 \\
8.8\end{array}$ & $\begin{array}{l}4.2 \\
3.8 \\
3.7 \\
3.5 \\
3.5\end{array}$ & $\begin{array}{l}\text { e2.5 } \\
\text { e2.3 } \\
\text { e3.3 } \\
\text { e5.0 } \\
\text { e2.5 }\end{array}$ \\
\hline $\begin{array}{l}16 \\
17 \\
18 \\
19 \\
20\end{array}$ & $\begin{array}{l}34 \\
31 \\
57 \\
41 \\
33\end{array}$ & $\begin{array}{l}13 \\
13 \\
12 \\
12 \\
12\end{array}$ & $\begin{array}{r}77 \\
46 \\
139 \\
159 \\
70\end{array}$ & $\begin{array}{r}124 \\
98 \\
51 \\
40 \\
40\end{array}$ & $\begin{array}{r}24 \\
22 \\
35 \\
111 \\
73\end{array}$ & $\begin{array}{r}94 \\
190 \\
350 \\
187 \\
84\end{array}$ & $\begin{array}{r}62 \\
41 \\
33 \\
85 \\
100\end{array}$ & $\begin{array}{r}26 \\
56 \\
134 \\
61 \\
36\end{array}$ & $\begin{array}{l}39 \\
27 \\
22 \\
20 \\
19\end{array}$ & $\begin{array}{l}8.4 \\
8.0 \\
7.6 \\
7.2 \\
7.0\end{array}$ & $\begin{array}{l}3.5 \\
4.2 \\
7.4 \\
8.0 \\
9.3\end{array}$ & $\begin{array}{l}e 2.5 \\
e 2.3 \\
e 2.2 \\
\text { e2.0 } \\
\text { e1.9 }\end{array}$ \\
\hline $\begin{array}{l}21 \\
22 \\
23 \\
24 \\
25\end{array}$ & $\begin{array}{l}30 \\
33 \\
34 \\
29 \\
26\end{array}$ & $\begin{array}{l}12 \\
16 \\
20 \\
16 \\
14\end{array}$ & $\begin{array}{r}129 \\
201 \\
82 \\
49 \\
35\end{array}$ & $\begin{array}{l}39 \\
32 \\
29 \\
25 \\
23\end{array}$ & $\begin{array}{l}46 \\
35 \\
30 \\
27 \\
24\end{array}$ & $\begin{array}{r}61 \\
99 \\
149 \\
65 \\
43\end{array}$ & $\begin{array}{l}50 \\
39 \\
33 \\
31 \\
28\end{array}$ & $\begin{array}{l}28 \\
24 \\
22 \\
21 \\
22\end{array}$ & $\begin{array}{r}18 \\
87 \\
135 \\
33 \\
21\end{array}$ & $\begin{array}{l}6.8 \\
6.7 \\
6.2 \\
5.8 \\
5.9\end{array}$ & $\begin{array}{l}7.8 \\
5.2 \\
4.0 \\
3.3 \\
2.8\end{array}$ & $\begin{array}{l}\text { e1. } 1.9 \\
\text { e2.3 } \\
\text { e3.0 } \\
\text { e2.5 } \\
\text { e2 } 2.0\end{array}$ \\
\hline $\begin{array}{l}26 \\
27 \\
28 \\
29 \\
30 \\
31\end{array}$ & $\begin{array}{l}23 \\
22 \\
21 \\
19 \\
19 \\
19\end{array}$ & $\begin{array}{r}13 \\
45 \\
160 \\
85 \\
43 \\
-.\end{array}$ & $\begin{array}{r}29 \\
25 \\
24 \\
227 \\
903 \\
654\end{array}$ & $\begin{array}{l}23 \\
22 \\
21 \\
20 \\
21 \\
19\end{array}$ & $\begin{array}{c}22 \\
21 \\
20 \\
-. \\
\cdots \\
\cdots\end{array}$ & $\begin{array}{r}108 \\
106 \\
67 \\
47 \\
38 \\
33\end{array}$ & $\begin{array}{r}27 \\
26 \\
25 \\
24 \\
23 \\
\cdots\end{array}$ & $\begin{array}{r}33 \\
25 \\
21 \\
18 \\
18 \\
201\end{array}$ & $\begin{array}{l}17 \\
15 \\
13 \\
12 \\
11 \\
-.-\end{array}$ & $\begin{array}{l}5.7 \\
5.0 \\
4.8 \\
4.8 \\
4.8 \\
4.5\end{array}$ & $\begin{array}{r}2.7 \\
2.7 \\
2.6 \\
\mathrm{e} 2.8 \\
\mathrm{e} 3.2 \\
\mathrm{e} 3.0\end{array}$ & $\begin{array}{r}\text { e2.1 } \\
\text { e1.9 } \\
\text { el.7 } \\
\text { el.6 } \\
\text { e1.6 } \\
. . .\end{array}$ \\
\hline $\begin{array}{l}\text { TOTAL } \\
\text { MEAN } \\
\text { MAX } \\
\text { MIN } \\
\text { CFSM } \\
\text { IN. }\end{array}$ & $\begin{array}{r}1568 \\
50.6 \\
280 \\
16 \\
1.98 \\
2.29\end{array}$ & $\begin{array}{r}773 \\
25.8 \\
160 \\
12 \\
1.01 \\
1.13\end{array}$ & $\begin{array}{r}3642 \\
117 \\
903 \\
16 \\
4.61 \\
5.31\end{array}$ & $\begin{array}{r}1371 \\
44.2 \\
157 \\
19 \\
1.73 \\
2.00\end{array}$ & $\begin{array}{r}1310 \\
46.8 \\
161 \\
18 \\
1.83 \\
1.91\end{array}$ & $\begin{array}{r}2039 \\
65.8 \\
350 \\
14 \\
2.58 \\
2.97\end{array}$ & $\begin{array}{r}1250 \\
41.7 \\
127 \\
23 \\
1.63 \\
1.82\end{array}$ & $\begin{array}{r}1044 \\
33.7 \\
201 \\
18 \\
1.32 \\
1.52\end{array}$ & $\begin{array}{r}976 \\
32.5 \\
135 \\
11 \\
1.28 \\
1.42\end{array}$ & $\begin{array}{r}301.9 \\
9.74 \\
28 \\
4.5 \\
.38 \\
.44\end{array}$ & $\begin{array}{r}135.4 \\
4.37 \\
9.3 \\
2.6 \\
.17 \\
.20\end{array}$ & $\begin{array}{r}73.5 \\
2.45 \\
5.0 \\
1.6 \\
.10 \\
.11\end{array}$ \\
\hline
\end{tabular}

STATISTICS OF MONTHLY MEAN DATA FOR WATER YEARS 1969 - 1991, BY WATER YEAR (WY)

\begin{tabular}{|c|c|c|c|c|c|c|c|c|c|c|c|c|}
\hline $\begin{array}{l}\text { MEAN } \\
\text { MAX } \\
\text { (WY) } \\
\text { MIN } \\
\text { (WY) }\end{array}$ & $\begin{array}{l}9.11 \\
50.6 \\
1991 \\
1.86 \\
1977\end{array}$ & $\begin{array}{l}18.9 \\
90.6 \\
1973 \\
1.77 \\
1977\end{array}$ & $\begin{array}{r}32.7 \\
117 \\
1991 \\
1.40 \\
1977\end{array}$ & $\begin{array}{r}28.8 \\
86.1 \\
1974 \\
.89 \\
1977\end{array}$ & $\begin{array}{r}44.1 \\
110 \\
1990 \\
4.69 \\
1978\end{array}$ & $\begin{array}{r}51.1 \\
139 \\
1982 \\
11.8 \\
1983\end{array}$ & $\begin{array}{l}40.8 \\
97.4 \\
1972 \\
9.91 \\
1976\end{array}$ & $\begin{array}{l}26.6 \\
84.0 \\
1981 \\
6.56 \\
1988\end{array}$ & $\begin{array}{r}28.1 \\
123 \\
1980 \\
2.61 \\
1988\end{array}$ & $\begin{array}{l}13.7 \\
50.4 \\
1990 \\
2.07 \\
1977\end{array}$ & $\begin{array}{l}12.2 \\
79.5 \\
1990 \\
2.05 \\
1988\end{array}$ & $\begin{array}{r}11.5 \\
111 \\
1989 \\
1.21 \\
1983\end{array}$ \\
\hline
\end{tabular}

\section{SUMMARY STATISTICS}

ANMUAL TOTAL

ANNUAL MEAN

HIGHEST ANMUAL MEAN

LOWEST AMNUAL MEAN

HIGHEST DAILY MEAM

LOWEST DAILY MEAN

ANNUAL SEVEN-DAY MI INIMUM

INSTANTANEOUS PEAK FLOW

INSTANTANEOUS PEAK STAGE

ANMUAL RUMOFF (CF SM)

ANMUAL RUMOFF (INCHES)

10 PERCEMT EXCEEDS

SO PERCEMT EXCEEDS

90 PERCENT EXCEEDS

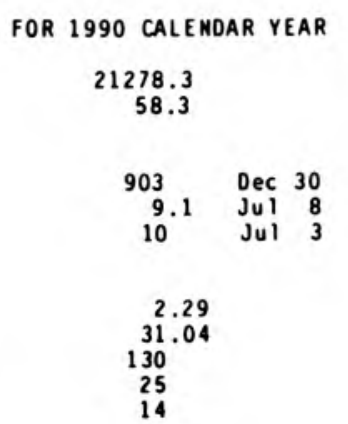

WATER YEARS 1969 - 1991

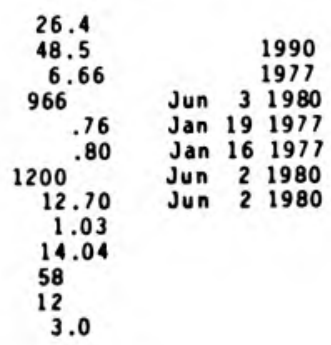




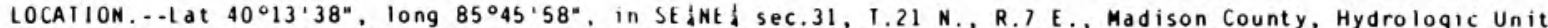

05120201 , on right bank $20 \mathrm{ft}$ downstream from bridge on County Road 500 West, at northedst edge of frankton. DRAINAGE AREA

PERIOD OF RECORD..-May 1968 to current year.

GAGE.--Water-stage recorder. Datum of gage is $810.00 \mathrm{ft}$ above National Geodetic Vertical Datum of 1929.

REMARKS.--Records good.

EXTREMES OUTSIDE PERIOD OF RECORD. - Flood of June 10, 1958, reached a stage of $15.5 \mathrm{ft}$, from floodmark determined by State of Indiana. Departaent of Natural Resources, discharge, $4,900 \mathrm{ft} / \mathrm{s}$.

DISCHARGE, CUBIC FEET PER SECOND, WATER YEAR OCTOBER 1990 TO SEPTEMBER 1991 DAI IY MEAM VALUES

\begin{tabular}{|c|c|c|c|c|c|c|c|c|c|c|c|c|}
\hline DAY & $O C \mathrm{I}$ & NOV & DEC & JAN & FEB & MAR & APR & MAY & JUN & JUL & AUG & SEP \\
\hline $\begin{array}{l}1 \\
2 \\
3 \\
4 \\
5\end{array}$ & $\begin{array}{r}26 \\
25 \\
25 \\
245 \\
280\end{array}$ & $\begin{array}{l}46 \\
44 \\
43 \\
45 \\
59\end{array}$ & $\begin{array}{l}146 \\
108 \\
481 \\
941 \\
433\end{array}$ & $\begin{array}{r}1090 \\
620 \\
361 \\
265 \\
220\end{array}$ & $\begin{array}{r}66 \\
65 \\
81 \\
160 \\
270\end{array}$ & $\begin{array}{l}80 \\
89 \\
86 \\
78 \\
73\end{array}$ & $\begin{array}{r}138 \\
115 \\
100 \\
94 \\
112\end{array}$ & $\begin{array}{l}67 \\
63 \\
58 \\
58 \\
60\end{array}$ & $\begin{array}{r}648 \\
326 \\
226 \\
146 \\
93\end{array}$ & $\begin{array}{l}24 \\
26 \\
54 \\
37 \\
27\end{array}$ & $\begin{array}{l}9.7 \\
9.5 \\
9.1 \\
10 \\
9.5\end{array}$ & $\begin{array}{l}7.5 \\
6.9 \\
6.7 \\
9.2 \\
7.1\end{array}$ \\
\hline $\begin{array}{r}6 \\
7 \\
8 \\
9 \\
10\end{array}$ & $\begin{array}{l}154 \\
105 \\
148 \\
189 \\
655\end{array}$ & $\begin{array}{r}116 \\
81 \\
64 \\
57 \\
55\end{array}$ & $\begin{array}{l}255 \\
198 \\
162 \\
138 \\
125\end{array}$ & $\begin{array}{l}188 \\
165 \\
150 \\
139 \\
128\end{array}$ & $\begin{array}{l}330 \\
513 \\
339 \\
235 \\
187\end{array}$ & $\begin{array}{l}73 \\
70 \\
63 \\
61 \\
60\end{array}$ & $\begin{array}{r}113 \\
98 \\
94 \\
143 \\
128\end{array}$ & $\begin{array}{l}65 \\
57 \\
51 \\
50 \\
47\end{array}$ & $\begin{array}{l}71 \\
58 \\
51 \\
46 \\
42\end{array}$ & $\begin{array}{l}22 \\
19 \\
45 \\
56 \\
32\end{array}$ & $\begin{array}{l}9.9 \\
10 \\
11 \\
14 \\
10\end{array}$ & $\begin{array}{l}6.2 \\
6.2 \\
6.6 \\
6.6 \\
7.6\end{array}$ \\
\hline $\begin{array}{l}11 \\
12 \\
13 \\
14 \\
15\end{array}$ & $\begin{array}{l}869 \\
490 \\
276 \\
202 \\
152\end{array}$ & $\begin{array}{l}49 \\
45 \\
42 \\
40 \\
39\end{array}$ & $\begin{array}{r}111 \\
102 \\
93 \\
81 \\
267\end{array}$ & $\begin{array}{l}153 \\
271 \\
195 \\
165 \\
244\end{array}$ & $\begin{array}{r}150 \\
123 \\
118 \\
130 \\
e 110\end{array}$ & $\begin{array}{r}58 \\
60 \\
118 \\
232 \\
293\end{array}$ & $\begin{array}{r}95 \\
79 \\
107 \\
351 \\
537\end{array}$ & $\begin{array}{r}45 \\
45 \\
45 \\
52 \\
166\end{array}$ & $\begin{array}{l}41 \\
40 \\
36 \\
34 \\
32\end{array}$ & $\begin{array}{l}25 \\
23 \\
23 \\
20 \\
17\end{array}$ & $\begin{array}{l}9.5 \\
8.8 \\
8.1 \\
7.9 \\
7.5\end{array}$ & $\begin{array}{r}7.5 \\
7.1 \\
9.4 \\
14 . \\
6.3\end{array}$ \\
\hline $\begin{array}{l}16 \\
17 \\
18 \\
19 \\
20\end{array}$ & $\begin{array}{l}121 \\
101 \\
200 \\
209 \\
139\end{array}$ & $\begin{array}{l}39 \\
38 \\
37 \\
36 \\
35\end{array}$ & $\begin{array}{l}318 \\
205 \\
374 \\
587 \\
339\end{array}$ & $\begin{array}{l}449 \\
501 \\
301 \\
222 \\
210\end{array}$ & $\begin{array}{r}e 100 \\
92 \\
105 \\
322 \\
289\end{array}$ & $\begin{array}{r}431 \\
737 \\
1160 \\
996 \\
627\end{array}$ & $\begin{array}{l}578 \\
270 \\
174 \\
302 \\
693\end{array}$ & $\begin{array}{l}120 \\
145 \\
363 \\
256 \\
135\end{array}$ & $\begin{array}{r}151 \\
76 \\
49 \\
40 \\
35\end{array}$ & $\begin{array}{l}16 \\
15 \\
14 \\
13 \\
12\end{array}$ & $\begin{array}{l}7.4 \\
8.3 \\
11 \\
12 \\
12\end{array}$ & $\begin{array}{l}6.2 \\
5.4 \\
5.2 \\
5.2 \\
5.2\end{array}$ \\
\hline $\begin{array}{l}21 \\
22 \\
23 \\
24 \\
25\end{array}$ & $\begin{array}{r}107 \\
102 \\
111 \\
94 \\
79\end{array}$ & $\begin{array}{l}34 \\
42 \\
54 \\
49 \\
44\end{array}$ & $\begin{array}{l}361 \\
742 \\
431 \\
251 \\
183\end{array}$ & $\begin{array}{l}212 \\
164 \\
141 \\
119 \\
106\end{array}$ & $\begin{array}{l}194 \\
154 \\
125 \\
113 \\
100\end{array}$ & $\begin{array}{l}397 \\
460 \\
773 \\
507 \\
275\end{array}$ & $\begin{array}{l}363 \\
229 \\
168 \\
148 \\
119\end{array}$ & $\begin{array}{l}92 \\
72 \\
78 \\
67 \\
58\end{array}$ & $\begin{array}{r}32 \\
116 \\
532 \\
136 \\
78\end{array}$ & $\begin{array}{l}14 \\
13 \\
12 \\
12 \\
11\end{array}$ & $\begin{array}{l}9.7 \\
8.3 \\
8.2 \\
7.5 \\
7.1\end{array}$ & $\begin{array}{l}5.3 \\
6.4 \\
8.3 \\
6.0 \\
5.7\end{array}$ \\
\hline $\begin{array}{l}26 \\
27 \\
28 \\
29 \\
30 \\
31\end{array}$ & $\begin{array}{l}69 \\
63 \\
58 \\
53 \\
50 \\
49\end{array}$ & $\begin{array}{r}40 \\
62 \\
372 \\
449 \\
208 \\
\cdots\end{array}$ & $\begin{array}{r}145 \\
123 \\
114 \\
663 \\
3820 \\
2630\end{array}$ & $\begin{array}{l}94 \\
92 \\
85 \\
78 \\
77 \\
70\end{array}$ & $\begin{array}{c}91 \\
85 \\
81 \\
\ldots- \\
\cdots \\
\cdots\end{array}$ & $\begin{array}{l}339 \\
631 \\
620 \\
370 \\
216 \\
161\end{array}$ & $\begin{array}{r}105 \\
95 \\
87 \\
82 \\
74 \\
--\end{array}$ & $\begin{array}{r}57 \\
54 \\
47 \\
44 \\
44 \\
394\end{array}$ & $\begin{array}{l}54 \\
40 \\
33 \\
29 \\
26 \\
\cdots-\end{array}$ & $\begin{array}{l}11 \\
10 \\
11 \\
10 \\
12 \\
10\end{array}$ & $\begin{array}{l}7.1 \\
7.3 \\
7.2 \\
7.1 \\
7.2 \\
7.2\end{array}$ & $\begin{array}{l}6.0 \\
5.6 \\
5.3 \\
5.1 \\
5.1 \\
-.-\end{array}$ \\
\hline $\begin{array}{l}\text { IOIAL } \\
\text { MEAN } \\
\text { MAX } \\
\text { MIN } \\
\text { CF SM } \\
\text { IN. }\end{array}$ & $\begin{array}{r}5446 \\
176 \\
869 \\
25 \\
1.55 \\
1.79\end{array}$ & $\begin{array}{r}2364 \\
78.8 \\
449 \\
34 \\
.70 \\
.78\end{array}$ & $\begin{array}{r}14927 \\
482 \\
3820 \\
81 \\
4.26 \\
4.91\end{array}$ & $\begin{array}{r}7275 \\
235 \\
1090 \\
70 \\
2.08 \\
2.39\end{array}$ & $\begin{array}{r}4728 \\
169 \\
513 \\
65 \\
1.49 \\
1.56\end{array}$ & $\begin{array}{r}10194 \\
329 \\
1160 \\
58 \\
2.91 \\
3.36\end{array}$ & $\begin{array}{r}5791 \\
193 \\
693 \\
74 \\
1.71 \\
1.91\end{array}$ & $\begin{array}{c}2955 \\
95.3 \\
394 \\
44 \\
.84 \\
.97\end{array}$ & $\begin{array}{c}3317 \\
111 \\
648 \\
26 \\
.98 \\
1.09\end{array}$ & $\begin{array}{c}646 \\
20.8 \\
56 \\
10 \\
.18 \\
.21\end{array}$ & $\begin{array}{c}279.1 \\
9.00 \\
14 \\
7.1 \\
.08 \\
.09\end{array}$ & $\begin{array}{c}200.9 \\
6.70 \\
14 \\
5.1 \\
.06 \\
.07\end{array}$ \\
\hline
\end{tabular}

e Estimated

STATISIICS OF MONIHLY MEAN DATA FUR WAIER YEAKS 1969 - 1991, BY WATER YEAR (WY)

$\begin{array}{lrrrrrrrrrrrr}\text { MEAN } & 34.8 & 78.7 & 146 & 119 & 180 & 212 & 170 & 94.0 & 103 & 48.0 & 46.4 & 45.9 \\ \text { MAX } & 176 & 416 & 482 & 409 & 416 & 544 & 467 & 224 & 409 & 142 & 234 & 529 \\ \text { (WY) } & 1991 & 1973 & 1991 & 1974 & 1990 & 1982 & 1972 & 1989 & 1980 & 1976 & 1990 & 1989 \\ \text { MIN } & 5.70 & 7.95 & 7.31 & 5.29 & 19.2 & 42.4 & 33.3 & 19.1 & 10.3 & 7.94 & 4.97 & 4.76 \\ \text { (WY) } & 1989 & 1977 & 1977 & 1977 & 1978 & 1981 & 1971 & 1976 & 1988 & 1977 & 1988 & 1983\end{array}$

SUMMARY SIATISIICS

ANNUAL TOIAL

ANMUAL MEAM

HIGHESI ANNUAL MEAN

LOWEST ANNUAL MEAN

HIGHESI DAILY MEAN

LOWEST DAILY MEAN

ANNUAL SEVEN-DAY MINIMUM

INSIANIANE OUS PEAK FLOW

INSTANTANE OUS PEAK STAGE

ANNUAL RUNOFF (CFSM)

ANNUAL RUNOFF (INCHES)

10 PERCENT EXIEEDS

50 PERCENT EXCEEDS

90 PERCENT EXCEEDS
FOR 1990 CALENDAR YEAR

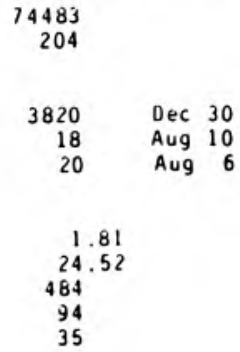

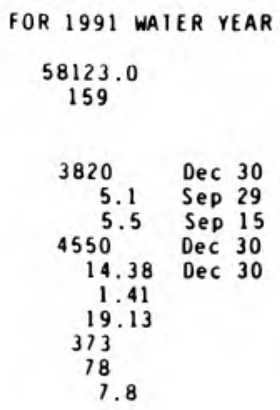

WAIER YEARS $1969-1991$

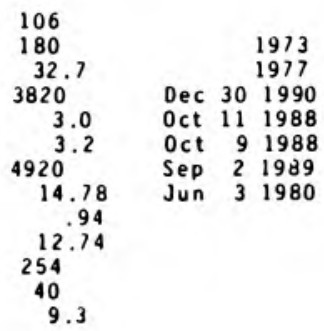




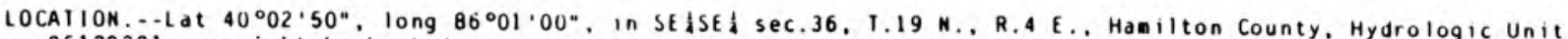

05120201 , on right bank at downstream side of logan Street bridge in Noblesville, $1.5 . i$ upstream from Cicero

Creek, 5.1 i downstrean from dan at Clare, and at ile 263.5.

DRAINAGE AREA --858 -

PERIOD OF RECORD.--0ctober 1946 to current year. Gage-height records collected at present site fron Decenter 1913 to Deceaber 1935. and at site $400 \mathrm{ft}$ downstream January 1936 to May 1951 . are contained in reports of National

Weather Service. Prior to October 1948, published as West Fork White River at Noblesville.

REVISED RECOROS.--WSP 1335: 1949. WSP 2109: Drainage area.

GAGE - -Water-stage recorder. Datum of gage is $738.16 \mathrm{ft}$ above National Geodetic Vertical Datue of 1929 .

REMARKS.--Records good. Flow slightly regulated by powerplant above station.

DISCHARGE, CUBIC FEET PER SECOMD, WATER YEAR OCTOBER 1990 TO SEPIEMBER 1991 DAILY MEAM VALUES

\begin{tabular}{|c|c|c|c|c|c|c|c|c|c|c|c|c|}
\hline DAY & $\mathrm{OCT}$ & NOV & $\mathrm{DEC}$ & JAN & $F \in B$ & MAR & $A P R$ & MAY & JUN & JUL & AUG & SEP \\
\hline $\begin{array}{l}1 \\
2 \\
3 \\
4 \\
5\end{array}$ & $\begin{array}{r}424 \\
379 \\
362 \\
1050 \\
2580\end{array}$ & $\begin{array}{l}421 \\
409 \\
394 \\
381 \\
436\end{array}$ & $\begin{array}{l}1440 \\
1080 \\
2280 \\
5110 \\
3890\end{array}$ & $\begin{array}{r}20800 \\
8190 \\
3680 \\
2670 \\
2170\end{array}$ & $\begin{array}{l}709 \\
691 \\
760 \\
1240 \\
1940\end{array}$ & $\begin{array}{l}747 \\
775 \\
776 \\
721 \\
675\end{array}$ & $\begin{array}{r}1190 \\
1050 \\
950 \\
904 \\
1000\end{array}$ & $\begin{array}{l}718 \\
674 \\
634 \\
626 \\
626\end{array}$ & $\begin{array}{r}4220 \\
3860 \\
2260 \\
1340 \\
887\end{array}$ & $\begin{array}{l}334 \\
308 \\
306 \\
330 \\
299\end{array}$ & $\begin{array}{l}169 \\
160 \\
161 \\
161 \\
173\end{array}$ & $\begin{array}{l}145 \\
132 \\
133 \\
174 \\
176\end{array}$ \\
\hline $\begin{array}{r}6 \\
7 \\
8 \\
9 \\
10\end{array}$ & $\begin{array}{r}1490 \\
1010 \\
979 \\
1030 \\
3050\end{array}$ & $\begin{array}{l}747 \\
726 \\
577 \\
491 \\
469\end{array}$ & $\begin{array}{r}2110 \\
1490 \\
1200 \\
1010 \\
906\end{array}$ & $\begin{array}{l}1800 \\
1520 \\
1350 \\
1230 \\
1110\end{array}$ & $\begin{array}{l}2930 \\
3970 \\
3700 \\
2370 \\
1780\end{array}$ & $\begin{array}{l}653 \\
641 \\
602 \\
571 \\
553\end{array}$ & $\begin{array}{r}1020 \\
933 \\
917 \\
1180 \\
1060\end{array}$ & $\begin{array}{l}662 \\
620 \\
585 \\
555 \\
532\end{array}$ & $\begin{array}{l}684 \\
591 \\
531 \\
486 \\
455\end{array}$ & $\begin{array}{l}283 \\
258 \\
455 \\
565 \\
438\end{array}$ & $\begin{array}{l}188 \\
194 \\
190 \\
199 \\
218\end{array}$ & $\begin{array}{l}155 \\
149 \\
135 \\
124 \\
121\end{array}$ \\
\hline $\begin{array}{l}11 \\
12 \\
13 \\
14 \\
15\end{array}$ & $\begin{array}{l}5280 \\
3820 \\
2140 \\
1510 \\
1180\end{array}$ & $\begin{array}{l}453 \\
430 \\
399 \\
377 \\
365\end{array}$ & $\begin{array}{r}839 \\
777 \\
730 \\
672 \\
1360\end{array}$ & $\begin{array}{l}1200 \\
2280 \\
2180 \\
1570 \\
1680\end{array}$ & $\begin{array}{l}1440 \\
1180 \\
1070 \\
1100 \\
1100\end{array}$ & $\begin{array}{r}531 \\
553 \\
1650 \\
3110 \\
3730\end{array}$ & $\begin{array}{r}879 \\
760 \\
905 \\
1830 \\
3610\end{array}$ & $\begin{array}{l}524 \\
511 \\
504 \\
489 \\
840\end{array}$ & $\begin{array}{l}438 \\
433 \\
415 \\
392 \\
375\end{array}$ & $\begin{array}{l}351 \\
321 \\
308 \\
290 \\
268\end{array}$ & $\begin{array}{l}180 \\
167 \\
159 \\
154 \\
158\end{array}$ & $\begin{array}{l}122 \\
123 \\
131 \\
174 \\
207\end{array}$ \\
\hline $\begin{array}{l}16 \\
17 \\
18 \\
19 \\
20\end{array}$ & $\begin{array}{r}964 \\
839 \\
960 \\
1520 \\
1170\end{array}$ & $\begin{array}{l}366 \\
357 \\
342 \\
333 \\
327\end{array}$ & $\begin{array}{l}3610 \\
2570 \\
2570 \\
4850 \\
4650\end{array}$ & $\begin{array}{l}2650 \\
3640 \\
2780 \\
1920 \\
1670\end{array}$ & $\begin{array}{r}860 \\
874 \\
880 \\
1760 \\
2890\end{array}$ & $\begin{array}{l}3830 \\
4360 \\
5570 \\
6290 \\
4400\end{array}$ & $\begin{array}{l}3570 \\
2280 \\
1540 \\
1800 \\
3370\end{array}$ & $\begin{array}{r}737 \\
926 \\
2250 \\
2590 \\
1480\end{array}$ & $\begin{array}{l}438 \\
527 \\
420 \\
371 \\
344\end{array}$ & $\begin{array}{l}248 \\
234 \\
225 \\
215 \\
210\end{array}$ & $\begin{array}{l}143 \\
148 \\
171 \\
207 \\
268\end{array}$ & $\begin{array}{l}155 \\
155 \\
137 \\
124 \\
120\end{array}$ \\
\hline $\begin{array}{l}21 \\
22 \\
23 \\
24 \\
25\end{array}$ & $\begin{array}{l}943 \\
847 \\
860 \\
836 \\
742\end{array}$ & $\begin{array}{l}319 \\
358 \\
462 \\
532 \\
463\end{array}$ & $\begin{array}{l}3180 \\
5010 \\
5130 \\
3130 \\
2060\end{array}$ & $\begin{array}{r}1630 \\
1400 \\
1180 \\
1040 \\
896\end{array}$ & $\begin{array}{r}2280 \\
1630 \\
1260 \\
1070 \\
955\end{array}$ & $\begin{array}{l}2740 \\
2610 \\
4740 \\
5310 \\
3250\end{array}$ & $\begin{array}{l}3000 \\
1930 \\
1490 \\
1280 \\
1110\end{array}$ & $\begin{array}{r}1020 \\
885 \\
921 \\
1030 \\
747\end{array}$ & $\begin{array}{r}326 \\
360 \\
901 \\
1010 \\
671\end{array}$ & $\begin{array}{l}203 \\
257 \\
207 \\
196 \\
189\end{array}$ & $\begin{array}{l}321 \\
218 \\
186 \\
163 \\
146\end{array}$ & $\begin{array}{l}117 \\
122 \\
150 \\
163 \\
148\end{array}$ \\
\hline $\begin{array}{l}26 \\
27 \\
28 \\
29 \\
30 \\
31\end{array}$ & $\begin{array}{l}662 \\
601 \\
545 \\
496 \\
466 \\
444\end{array}$ & $\begin{array}{r}418 \\
495 \\
1850 \\
3810 \\
2380 \\
\ldots .\end{array}$ & $\begin{array}{r}1510 \\
1240 \\
1080 \\
2450 \\
14300 \\
25400\end{array}$ & $\begin{array}{l}833 \\
813 \\
794 \\
734 \\
728 \\
755\end{array}$ & $\begin{array}{l}862 \\
802 \\
760 \\
\ldots . \\
\ldots- \\
\ldots-\end{array}$ & $\begin{array}{l}2480 \\
3700 \\
3590 \\
2510 \\
1720 \\
1360\end{array}$ & $\begin{array}{l}989 \\
924 \\
865 \\
815 \\
710 \\
\cdots\end{array}$ & $\begin{array}{r}662 \\
651 \\
588 \\
541 \\
579 \\
2060\end{array}$ & $\begin{array}{l}478 \\
404 \\
362 \\
341 \\
326 \\
\cdots\end{array}$ & $\begin{array}{l}181 \\
176 \\
169 \\
166 \\
170 \\
175\end{array}$ & $\begin{array}{l}138 \\
137 \\
134 \\
174 \\
144 \\
172\end{array}$ & $\begin{array}{l}136 \\
135 \\
128 \\
122 \\
119 \\
\cdots\end{array}$ \\
\hline $\begin{array}{l}\text { TOIAL } \\
\text { MEAN } \\
\text { MAX } \\
\text { MIN } \\
\text { CFSM } \\
\text { IN. }\end{array}$ & $\begin{array}{r}39179 \\
1264 \\
5280 \\
362 \\
1.47 \\
1.70\end{array}$ & $\begin{array}{r}19887 \\
663 \\
3810 \\
319 \\
.77 \\
.86\end{array}$ & $\begin{array}{r}107634 \\
3472 \\
25400 \\
672 \\
4.05 \\
4.67\end{array}$ & $\begin{array}{r}76893 \\
2480 \\
20800 \\
728 \\
2.89 \\
3.33\end{array}$ & $\begin{array}{r}42863 \\
1531 \\
3970 \\
691 \\
1.78 \\
1.86\end{array}$ & $\begin{array}{c}74748 \\
2411 \\
6290 \\
531 \\
2.81 \\
3.24\end{array}$ & $\begin{array}{r}43921 \\
1464 \\
3610 \\
160 \\
1.71 \\
1.90\end{array}$ & $\begin{array}{r}26767 \\
863 \\
2590 \\
489 \\
1.01 \\
1.16\end{array}$ & $\begin{array}{r}24646 \\
822 \\
4220 \\
326 \\
.96 \\
1.07\end{array}$ & $\begin{array}{c}8341 \\
269 \\
565 \\
166 \\
.31 \\
.36\end{array}$ & $\begin{array}{l}5501 \\
117 \\
321 \\
134 \\
.21 \\
.24\end{array}$ & $\begin{array}{l}4232 \\
141 \\
207 \\
117 \\
.16 \\
.18\end{array}$ \\
\hline
\end{tabular}

STATISIICS OF MUNTHLY MEAN DATA FOR WATER YEARS 1947 - 1991, BY WATER YEAR (WY)

$\begin{array}{lrrrrrrrrrrrr}\text { MEAN } & 285 & 529 & 913 & 1153 & 1339 & 1612 & 1501 & 927 & 827 & 502 & 362 & 302 \\ \text { MAX } & 1264 & 2805 & 3472 & 6494 & 3485 & 3732 & 4281 & 2213 & 4432 & 1574 & 2264 & 1143 \\ \text { (WY) } & 1991 & 1973 & 1991 & 1950 & 1950 & 1978 & 1964 & 1981 & 1958 & 1979 & 1979 & 1989 \\ \text { MIN } & 88.4 & 109 & 107 & 102 & 141 & 368 & 322 & 249 & 143 & 138 & 93.8 & 69.3 \\ \text { (WY) } & 1964 & 1964 & 1964 & 1977 & 1964 & 1981 & 1971 & 1988 & 1988 & 1966 & 1988 & 1954\end{array}$

SUMMARY STAIISIICS

ANNUAL TOTAL

ANNUAL MEAN

HIGHESI ANNUAL MEAN

LOWEST ANNUAL MEAN

HIGHEST DAILY MEAN

LOWEST DAILY MEAN

AMNUAL SEVEN-DAY MINIMUM

IMSTANTANEOUS PEAK FLOW

INSIANTANEOUS PEAK STAGE

ANHUAL RUNOFF (CFSM)

ANNUAL RUNOFF (INCHES)

10 PERLENT EXLEEDS

50 PERCENT EXCEEDS

90 PERCENT EXCEEDS
FOR IY9O CALENDAR YEAR

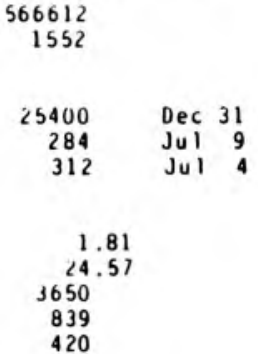

FOR 1991 WAIER YEAR

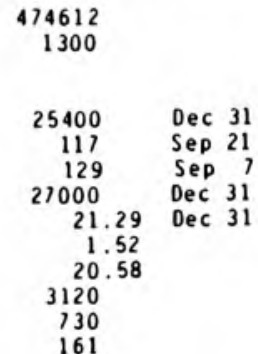

WAIER YEARS 1941 - 1991

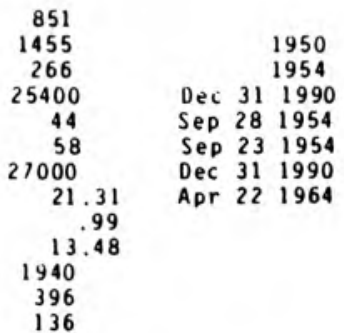


LOCATION. - Lat $40^{\circ} 03^{\prime} 20^{\circ}$, long $86^{\circ} 02^{\prime} 30^{\circ}$, in NWtaE $\frac{1}{4}$ sec. 35 , T.19 N., R.4 E., Hanilton County, Hydrologic Unit 05120201 , on right bank $150 \mathrm{ft}$ downstrea froe bridge on Stage Highway $38,1.0$. 1.6 i downstream from Morse Reservoir, 1.9 i downstrea fro Hinkle Creek. and 3.2 i upstrea from aouth. DRAINAGE AREA . -216 i2.

PERIOD OF RECORD.--July 1950 to September 1980 and October 1985 to current year.

REVISED RECORDS.--WSP 2109: Drainage area.

GAGE. - Water-stage recorder. Datua of gage is $750.00 \mathrm{ft}$ above National Geodetic Vertical Datua of 1929 (1evels by State of Indiana, Department of Natural Resources).

REMARKS. - Records good except for estimated daily discharges, which are poor. Flow regulated by Morse Reservoir. Computation of sumary statistics does not include water years $1981-1985$.

DISCHARGE, CUBIC FEET PER SECOND, WATER YEAR OCTOBER 1990 TO SEPTEMBER 1991 DAILY MEAN VALUES

\begin{tabular}{|c|c|c|c|c|c|c|c|c|c|c|c|c|}
\hline DAY & $\mathrm{OCT}$ & NOV & DEC & JAM & FEB & MAR & $A P R$ & MAY & JUN & JUL & AUG & SEP \\
\hline $\begin{array}{l}1 \\
2 \\
3 \\
4 \\
5\end{array}$ & $\begin{array}{r}2.0 \\
2.2 \\
3.3 \\
113 \\
109\end{array}$ & $\begin{array}{l}52 \\
49 \\
50 \\
54 \\
87\end{array}$ & $\begin{array}{r}328 \\
258 \\
727 \\
1280 \\
692\end{array}$ & $\begin{array}{r}3190 \\
1280 \\
772 \\
556 \\
441\end{array}$ & $\begin{array}{r}e 129 \\
\text { e130 } \\
147 \\
198 \\
296\end{array}$ & $\begin{array}{l}177 \\
206 \\
219 \\
171 \\
157\end{array}$ & $\begin{array}{l}236 \\
191 \\
170 \\
169 \\
206\end{array}$ & $\begin{array}{l}156 \\
134 \\
120 \\
131 \\
127\end{array}$ & $\begin{array}{r}3080 \\
2640 \\
1490 \\
820 \\
481\end{array}$ & $\begin{array}{l}10 \\
14 \\
12 \\
26 \\
15\end{array}$ & $\begin{array}{l}\text { e29 } \\
\text { e } 30 \\
\text { e } 52 \\
\text { e33 } \\
\text { e4. } 1\end{array}$ & $\begin{array}{l}.58 \\
.53 \\
.61 \\
.96 \\
.82\end{array}$ \\
\hline $\begin{array}{r}6 \\
7 \\
8 \\
9 \\
10\end{array}$ & $\begin{array}{r}81 \\
78 \\
96 \\
142 \\
833\end{array}$ & $\begin{array}{r}131 \\
146 \\
114 \\
99 \\
90\end{array}$ & $\begin{array}{l}462 \\
338 \\
276 \\
230 \\
209\end{array}$ & $\begin{array}{l}366 \\
304 \\
265 \\
244 \\
221\end{array}$ & $\begin{array}{l}506 \\
826 \\
664 \\
500 \\
412\end{array}$ & $\begin{array}{l}174 \\
159 \\
137 \\
142 \\
122\end{array}$ & $\begin{array}{l}185 \\
169 \\
184 \\
217 \\
196\end{array}$ & $\begin{array}{r}120 \\
112 \\
105 \\
98 \\
96\end{array}$ & $\begin{array}{l}324 \\
241 \\
197 \\
160 \\
125\end{array}$ & $\begin{array}{r}11 \\
11 \\
\mathrm{e} 43 \\
\mathrm{e} 9.0 \\
\mathrm{e} 8.5\end{array}$ & $\begin{array}{r}\text { e24 } \\
\text { e1. } 2 \\
\text { e. } 70 \\
\text { e. } 85 \\
.79\end{array}$ & $\begin{array}{l}.73 \\
.68 \\
.68 \\
.68 \\
.79\end{array}$ \\
\hline $\begin{array}{l}11 \\
12 \\
13 \\
14 \\
15\end{array}$ & $\begin{array}{r}1130 \\
645 \\
399 \\
280 \\
211\end{array}$ & $\begin{array}{l}72 \\
70 \\
55 \\
50 \\
50\end{array}$ & $\begin{array}{l}185 \\
168 \\
172 \\
129 \\
380\end{array}$ & $\begin{array}{l}248 \\
509 \\
453 \\
349 \\
459\end{array}$ & $\begin{array}{l}337 \\
277 \\
261 \\
268 \\
235\end{array}$ & $\begin{array}{r}115 \\
168 \\
931 \\
1820 \\
1880\end{array}$ & $\begin{array}{r}152 \\
125 \\
206 \\
496 \\
1030\end{array}$ & $\begin{array}{r}96 \\
98 \\
90 \\
91 \\
287\end{array}$ & $\begin{array}{r}111 \\
108 \\
97 \\
80 \\
79\end{array}$ & $\begin{array}{l}\text { e7.5 } \\
\text { e9.0 } \\
\text { e9.0 } \\
\text { e4.1 } \\
\text { e2.1 }\end{array}$ & $\begin{array}{l}.74 \\
.68 \\
.68 \\
.75 \\
.83\end{array}$ & $\begin{array}{r}11 \\
26 \\
27 \\
17 \\
5.3\end{array}$ \\
\hline $\begin{array}{l}16 \\
17 \\
18 \\
19 \\
20\end{array}$ & $\begin{array}{l}159 \\
127 \\
190 \\
196 \\
180\end{array}$ & $\begin{array}{l}63 \\
46 \\
39 \\
41 \\
42\end{array}$ & $\begin{array}{l}580 \\
425 \\
564 \\
881 \\
653\end{array}$ & $\begin{array}{r}862 \\
1020 \\
733 \\
526 \\
481\end{array}$ & $\begin{array}{l}145 \\
177 \\
211 \\
397 \\
514\end{array}$ & $\begin{array}{r}1570 \\
1400 \\
1600 \\
1470 \\
949\end{array}$ & $\begin{array}{l}928 \\
564 \\
368 \\
542 \\
886\end{array}$ & $\begin{array}{l}310 \\
249 \\
489 \\
461 \\
285\end{array}$ & $\begin{array}{r}97 \\
112 \\
99 \\
79 \\
61\end{array}$ & $\begin{array}{l}\text { e } 1.7 \\
\text { e } 1.4 \\
\text { e1.5 } \\
\text { e } 1.7 \\
\text { e } 1.5\end{array}$ & $\begin{array}{l}.85 \\
1.8 \\
1.2 \\
1.2 \\
1.1\end{array}$ & $\begin{array}{l}.98 \\
.80 \\
.72 \\
.71 \\
.68\end{array}$ \\
\hline $\begin{array}{l}21 \\
22 \\
23 \\
24 \\
25\end{array}$ & $\begin{array}{r}151 \\
151 \\
120 \\
112 \\
98\end{array}$ & $\begin{array}{l}38 \\
68 \\
69 \\
45 \\
47\end{array}$ & $\begin{array}{r}685 \\
1370 \\
975 \\
549 \\
e 330\end{array}$ & $\begin{array}{l}479 \\
374 \\
316 \\
270 \\
216\end{array}$ & $\begin{array}{l}424 \\
363 \\
276 \\
252 \\
228\end{array}$ & $\begin{array}{r}663 \\
729 \\
1170 \\
1100 \\
683\end{array}$ & $\begin{array}{l}647 \\
432 \\
330 \\
291 \\
238\end{array}$ & $\begin{array}{l}193 \\
155 \\
185 \\
353 \\
217\end{array}$ & $\begin{array}{l}48 \\
53 \\
92 \\
82 \\
70\end{array}$ & $\begin{array}{r}\mathrm{e} 1.7 \\
\mathrm{e} 1.7 \\
\mathrm{e} 1.7 \\
\mathrm{e} 3.3 \\
\mathrm{e} 44\end{array}$ & $\begin{array}{l}1.0 \\
1.0 \\
1.1 \\
1.1 \\
1.2\end{array}$ & $\begin{array}{l}.68 \\
.76 \\
.87 \\
.77 \\
.69\end{array}$ \\
\hline $\begin{array}{l}26 \\
27 \\
28 \\
29 \\
30 \\
31\end{array}$ & $\begin{array}{l}65 \\
66 \\
68 \\
52 \\
52 \\
56\end{array}$ & $\begin{array}{r}45 \\
93 \\
508 \\
799 \\
478 \\
\cdots-\end{array}$ & $\begin{array}{r}e 255 \\
e 220 \\
e 230 \\
891 \\
6730 \\
5240\end{array}$ & $\begin{array}{l}\text { e190 } \\
\text { e175 } \\
\text { e162 } \\
\text { e } 154 \\
\text { el50 } \\
\text { el } 131\end{array}$ & $\begin{array}{l}196 \\
185 \\
176 \\
\ldots- \\
\cdots \\
\cdots\end{array}$ & $\begin{array}{l}643 \\
910 \\
812 \\
530 \\
332 \\
254\end{array}$ & $\begin{array}{l}217 \\
197 \\
189 \\
170 \\
156 \\
\cdots\end{array}$ & $\begin{array}{r}160 \\
149 \\
108 \\
95 \\
98 \\
1330\end{array}$ & $\begin{array}{r}45 \\
33 \\
24 \\
32 \\
30 \\
-\cdots\end{array}$ & $\begin{array}{l}\text { e } 41 \\
\text { e38 } \\
\text { e39 } \\
\text { e } 40 \\
\text { e35 } \\
\text { e30 }\end{array}$ & $\begin{array}{ll}11 & \\
25 & \\
25 & \\
25 & \\
14 & \\
& .91\end{array}$ & $\begin{array}{c}.86 \\
1.0 \\
.82 \\
.77 \\
.77 \\
.2\end{array}$ \\
\hline $\begin{array}{l}\text { TOTAL } \\
\text { MEAN } \\
\text { MAX } \\
\text { MIN } \\
\text { CF SM } \\
\text { IN. }\end{array}$ & $\begin{array}{r}5967.5 \\
192 \\
1130 \\
2.0 \\
.89 \\
1.03\end{array}$ & $\begin{array}{r}3590 \\
120 \\
799 \\
38 \\
.55 \\
.62\end{array}$ & $\begin{array}{r}26412 \\
852 \\
6730 \\
129 \\
3.94 \\
4.55\end{array}$ & $\begin{array}{r}15896 \\
513 \\
3190 \\
131 \\
2.37 \\
2.74\end{array}$ & $\begin{array}{r}8730 \\
312 \\
826 \\
129 \\
1.44 \\
1.50\end{array}$ & $\begin{array}{r}21393 \\
690 \\
1880 \\
115 \\
3.19 \\
3.68\end{array}$ & $\begin{array}{r}10087 \\
336 \\
1030 \\
125 \\
1.56 \\
1.74\end{array}$ & $\begin{array}{r}6698 \\
216 \\
1330 \\
90 \\
1.00 \\
1.15\end{array}$ & $\begin{array}{r}10990 \\
366 \\
3080 \\
24 \\
1.70 \\
1.89\end{array}$ & $\begin{array}{r}474.4 \\
15.3 \\
44 \\
1.4 \\
.07 \\
.08\end{array}$ & $\begin{array}{c}291.78 \\
9.41 \\
52 \\
.68 \\
.04 \\
.05\end{array}$ & $\begin{array}{r}105.24 \\
3.51 \\
27 \\
.53 \\
.02 \\
.02\end{array}$ \\
\hline
\end{tabular}

e Estinated

STATISTICS OF MONTHLY MEAN DATA FOR MATER YEARS 1951 - 1991, BY WATER YEAR (WY)

\begin{tabular}{|c|c|c|c|c|c|c|c|c|c|c|c|c|}
\hline $\begin{array}{l}\text { MEAN } \\
\text { MAX } \\
\text { (WY) } \\
\text { MIN } \\
\text { (WY) }\end{array}$ & $\begin{array}{r}57.5 \\
341 \\
1970 \\
1.81 \\
1988\end{array}$ & $\begin{array}{r}136 \\
705 \\
1986 \\
1.18 \\
1968\end{array}$ & $\begin{array}{r}236 \\
852 \\
1991 \\
1.12 \\
1989\end{array}$ & $\begin{array}{r}233 \\
939 \\
1974 \\
1.13 \\
1977\end{array}$ & $\begin{array}{r}288 \\
865 \\
1976 \\
2.54 \\
1964\end{array}$ & $\begin{array}{r}398 \\
1076 \\
1978 \\
98.0 \\
1966\end{array}$ & $\begin{array}{r}353 \\
1130 \\
1957 \\
67.9 \\
1971\end{array}$ & $\begin{array}{r}213 \\
551 \\
1956 \\
24.5 \\
1976\end{array}$ & $\begin{array}{r}201 \\
1052 \\
1958 \\
20.4 \\
1988\end{array}$ & $\begin{array}{r}129 \\
518 \\
1979 \\
9.10 \\
1967\end{array}$ & $\begin{array}{r}69.2 \\
356 \\
1958 \\
3.82 \\
1959\end{array}$ & $\begin{array}{r}50.4 \\
726 \\
1989 \\
1.05 \\
1977\end{array}$ \\
\hline
\end{tabular}

SUMMARY STATISTICS

ANNUAL TOTAL

ANNUAL MEAN

HIGHEST ANMUAL MEAN

LOWEST ANNUAL MEAN

HIGHEST DAILY MEAN

LOWEST DAILY MEAN

ANHUAL SEVEN-DAY MINIMUM

INSTANTANEOUS PEAK FLOW

INSTANTANEOUS PEAK STAGE

ANMUAL RUMOFF (CFSM)

ANNUAL RUNOFF (INCHES)

10 PERCENT EXCEEDS

50 PERCENT EXCEEDS

90 PERCENT EXCEEDS

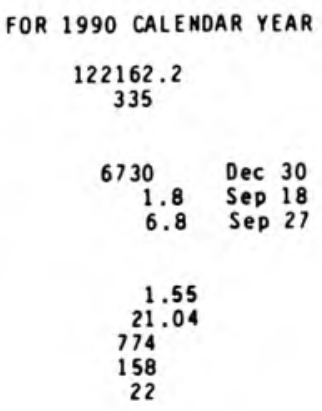

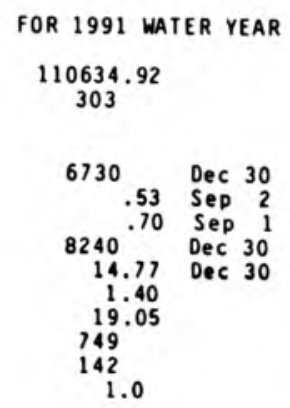

WATER YEARS 1951 - 1991

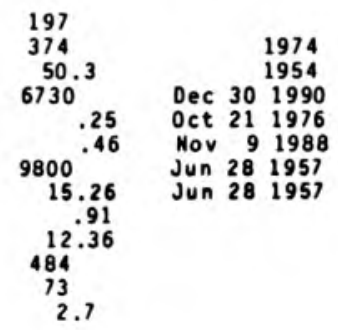


LOCAIION (Revised).-.lat 40001'44", long 85059'44", in Ne the sec.7. T.18 N., R.5 E., Hamilton County, Hydrologic Unit 05120201 , on right bank, between dual bridges on State Highway $37,1.1$ ipstrea from mouth, and 1.4 mi southeast of Noblesville.

DRAI NAGE AREA, $\ldots 50.8, i$

PERIOD OF RECORD.--July 1967 to current year

REVISEO RECORDS.--WDR IN-82-1: 1981 .

GAGE.- -Water-stage recorder. Datum of $9 \mathrm{dge}$ is $749.00 \mathrm{ft}$ above Nationd Geodetic Vertical Datum of 1929 (Indiana Departaent of Highways bench mark). Prior to 0ct. 1, 1988, water-stage recorder at county road bridge 200 ft upstrea at sane datu

REMARKS.--Records good except those for periods of estimated daily discharges, which are poor.

DISCHARGE, CUBIC FEET PER SECOND, WAIER YEAR OCTOBER 1990 TO SEPTEMBER 1991 DAILY MEAN VALUES

\begin{tabular}{|c|c|c|c|c|c|c|c|c|c|c|c|c|}
\hline DAY & $O C T$ & NOV & $\mathrm{OEC}$ & JAN & FE B & MAR & $A P R$ & MAY & JUN & JUL & AUG & SEP \\
\hline $\begin{array}{l}1 \\
2 \\
3 \\
4 \\
5\end{array}$ & $\begin{array}{r}11 \\
9.9 \\
11 \\
139 \\
108\end{array}$ & $\begin{array}{l}25 \\
23 \\
23 \\
22 \\
38\end{array}$ & $\begin{array}{r}96 \\
73 \\
313 \\
332 \\
167\end{array}$ & $\begin{array}{l}434 \\
225 \\
166 \\
130 \\
111\end{array}$ & $\begin{array}{l}\text { e36.0 } \\
\text { e } 38.0 \\
\text { e } 49.0 \\
\text { e } 82.0 \\
\text { e124 }\end{array}$ & $\begin{array}{l}40 \\
43 \\
38 \\
34 \\
33\end{array}$ & $\begin{array}{l}60 \\
51 \\
47 \\
47 \\
60\end{array}$ & $\begin{array}{l}40 \\
37 \\
34 \\
37 \\
38\end{array}$ & $\begin{array}{l}70 \\
51 \\
93 \\
49 \\
35\end{array}$ & $\begin{array}{r}12 \\
13 \\
9.3 \\
8.4 \\
7.7\end{array}$ & $\begin{array}{l}4.7 \\
4.1 \\
4.1 \\
4.2 \\
3.9\end{array}$ & $\begin{array}{c}2.9 \\
2.6 \\
3.7 \\
16 \\
6.1\end{array}$ \\
\hline $\begin{array}{r}6 \\
7 \\
8 \\
9 \\
10\end{array}$ & $\begin{array}{r}60 \\
45 \\
60 \\
74 \\
269\end{array}$ & $\begin{array}{l}57 \\
36 \\
30 \\
28 \\
27\end{array}$ & $\begin{array}{r}126 \\
103 \\
88 \\
77 \\
68\end{array}$ & $\begin{array}{l}94 \\
83 \\
74 \\
67 \\
60\end{array}$ & $\begin{array}{l}221 \\
287 \\
181 \\
140 \\
114\end{array}$ & $\begin{array}{l}34 \\
30 \\
26 \\
26 \\
24\end{array}$ & $\begin{array}{l}53 \\
48 \\
55 \\
63 \\
50\end{array}$ & $\begin{array}{l}45 \\
36 \\
31 \\
29 \\
29\end{array}$ & $\begin{array}{l}29 \\
24 \\
22 \\
20 \\
18\end{array}$ & $\begin{array}{l}6.8 \\
6.1 \\
40 \\
42 \\
19\end{array}$ & $\begin{array}{l}5.5 \\
5.6 \\
5.6 \\
7.4 \\
5.7\end{array}$ & $\begin{array}{l}4.4 \\
3.9 \\
3.4 \\
3.3 \\
3.2\end{array}$ \\
\hline $\begin{array}{l}11 \\
12 \\
13 \\
14 \\
15\end{array}$ & $\begin{array}{r}229 \\
150 \\
111 \\
82 \\
62\end{array}$ & $\begin{array}{l}25 \\
23 \\
22 \\
22 \\
21\end{array}$ & $\begin{array}{r}61 \\
56 \\
48 \\
68 \\
194\end{array}$ & $\begin{array}{r}104 \\
168 \\
110 \\
90 \\
112\end{array}$ & $\begin{array}{r}90 \\
74 \\
72 \\
73 \\
\text { e58 }\end{array}$ & $\begin{array}{r}24 \\
36 \\
444 \\
400 \\
272\end{array}$ & $\begin{array}{r}41 \\
38 \\
91 \\
151 \\
239\end{array}$ & $\begin{array}{l}28 \\
31 \\
36 \\
32 \\
29\end{array}$ & $\begin{array}{l}17 \\
17 \\
16 \\
15 \\
15\end{array}$ & $\begin{array}{r}15 \\
14 \\
12 \\
10 \\
8.7\end{array}$ & $\begin{array}{l}4.8 \\
4.3 \\
3.9 \\
3.6 \\
6.1\end{array}$ & $\begin{array}{l}2.8 \\
3.6 \\
4.0 \\
4.8 \\
3.9\end{array}$ \\
\hline $\begin{array}{l}16 \\
17 \\
18 \\
19 \\
20\end{array}$ & $\begin{array}{l}48 \\
42 \\
82 \\
66 \\
50\end{array}$ & $\begin{array}{l}21 \\
21 \\
20 \\
19 \\
19\end{array}$ & $\begin{array}{l}121 \\
207 \\
293 \\
176 \\
153\end{array}$ & $\begin{array}{ll}117 \\
188 \\
135 \\
\text { e1 } 21 \\
\text { el } 20\end{array}$ & $\begin{array}{r}e 41 \\
46 \\
65 \\
144 \\
131\end{array}$ & $\begin{array}{l}187 \\
157 \\
232 \\
165 \\
126\end{array}$ & $\begin{array}{r}182 \\
114 \\
85 \\
255 \\
269\end{array}$ & $\begin{array}{r}28 \\
57 \\
154 \\
91 \\
61\end{array}$ & $\begin{array}{l}17 \\
15 \\
14 \\
13 \\
11\end{array}$ & $\begin{array}{l}8.0 \\
7.4 \\
7.0 \\
6.7 \\
6.5\end{array}$ & $\begin{array}{l}7.3 \\
5.0 \\
4.7 \\
4.7 \\
5.0\end{array}$ & $\begin{array}{l}3.2 \\
3.0 \\
2.8 \\
2.6 \\
2.5\end{array}$ \\
\hline $\begin{array}{l}21 \\
22 \\
23 \\
24 \\
25\end{array}$ & $\begin{array}{l}42 \\
47 \\
54 \\
46 \\
38\end{array}$ & $\begin{array}{l}19 \\
22 \\
29 \\
25 \\
23\end{array}$ & $\begin{array}{r}196 \\
377 \\
289 \\
168 \\
e 105\end{array}$ & $\begin{array}{l}\text { el15 } \\
\text { e } 93.0 \\
\text { e } 77.0 \\
\text { e } 63.0 \\
\text { e55.0 }\end{array}$ & $\begin{array}{l}99 \\
81 \\
65 \\
59 \\
50\end{array}$ & $\begin{array}{l}105 \\
197 \\
310 \\
181 \\
127\end{array}$ & $\begin{array}{r}163 \\
121 \\
96 \\
80 \\
65\end{array}$ & $\begin{array}{r}47 \\
95 \\
109 \\
79 \\
56\end{array}$ & $\begin{array}{l}11 \\
11 \\
26 \\
17 \\
14\end{array}$ & $\begin{array}{c}7.5 \\
15 \\
8.8 \\
7.1 \\
6.4\end{array}$ & $\begin{array}{l}6.2 \\
4.4 \\
3.9 \\
3.4 \\
3.0\end{array}$ & $\begin{array}{l}2.1 \\
3.0 \\
4.0 \\
3.7 \\
2.6\end{array}$ \\
\hline $\begin{array}{l}26 \\
27 \\
28 \\
29 \\
30 \\
31\end{array}$ & $\begin{array}{l}33 \\
31 \\
29 \\
27 \\
26 \\
26\end{array}$ & $\begin{array}{r}21 \\
61 \\
255 \\
207 \\
129 \\
\cdots\end{array}$ & $\begin{array}{r}\text { e82 } \\
\text { e70 } \\
\text { e74 } \\
505 \\
1760 \\
846\end{array}$ & $\begin{array}{l}\text { e } 49.0 \\
\text { e } 46.0 \\
\text { e } 44.0 \\
\text { e } 43.0 \\
\text { e } 41.0 \\
\text { e } 3 ? .0\end{array}$ & $\begin{array}{l}45 \\
42 \\
40 \\
\ldots \\
\ldots \\
\ldots\end{array}$ & $\begin{array}{r}157 \\
181 \\
134 \\
101 \\
79 \\
67\end{array}$ & $\begin{array}{l}59 \\
55 \\
50 \\
47 \\
42 \\
\cdots\end{array}$ & $\begin{array}{l}54 \\
48 \\
39 \\
35 \\
39 \\
45\end{array}$ & $\begin{array}{r}12 \\
11 \\
9.6 \\
9.1 \\
8.6 \\
\ldots\end{array}$ & $\begin{array}{l}6.0 \\
5.3 \\
5.0 \\
5.2 \\
5.1 \\
4.5\end{array}$ & $\begin{array}{l}2.8 \\
2.7 \\
2.5 \\
2.8 \\
3.9 \\
5.6\end{array}$ & $\begin{array}{l}2.5 \\
2.1 \\
2.1 \\
2.0 \\
1.8 \\
\cdots\end{array}$ \\
\hline $\begin{array}{l}\text { TOTAL } \\
\text { MEAN } \\
\text { MAX } \\
\text { MIN } \\
\text { CF SM } \\
\text { IN. }\end{array}$ & $\begin{array}{r}2107.9 \\
68.0 \\
269 \\
9.9 \\
1.34 \\
1.54\end{array}$ & $\begin{array}{r}1313 \\
43.8 \\
255 \\
19 \\
.86 \\
.96\end{array}$ & $\begin{array}{r}7292 \\
235 \\
1760 \\
48 \\
4.63 \\
5.34\end{array}$ & $\begin{array}{r}3432.0 \\
111 \\
434 \\
31 \\
2.18 \\
2.51\end{array}$ & $\begin{array}{r}2547.0 \\
91.0 \\
287 \\
36 \\
1.79 \\
1.87\end{array}$ & $\begin{array}{r}4010 \\
129 \\
444 \\
24 \\
2.55 \\
2.94\end{array}$ & $\begin{array}{r}2777 \\
92.6 \\
269 \\
38 \\
1.82 \\
2.03\end{array}$ & $\begin{array}{c}1549 \\
50.0 \\
154 \\
28 \\
.98 \\
1.13\end{array}$ & $\begin{array}{r}690.3 \\
23.0 \\
93 \\
8.6 \\
.45 \\
.51\end{array}$ & $\begin{array}{r}335.5 \\
10.8 \\
42 \\
4.5 \\
.21 \\
.25\end{array}$ & $\begin{array}{c}141.4 \\
4.56 \\
7.4 \\
2.5 \\
.09 \\
.10\end{array}$ & $\begin{array}{c}108.6 \\
3.62 \\
16 \\
1.8 \\
.07 \\
.08\end{array}$ \\
\hline
\end{tabular}

e Estimated

SIATISIICS OF MONIHLY MEAN DAIA FUR WAIER YEARS 1968 - 1991. BY WATER YEAR (WY)

$\begin{array}{lrrrrrrrrrrrr}\text { MEAN } & 17.5 & 35.2 & 62.8 & 53.3 & 85.4 & 91.6 & 80.2 & 55.8 & 42.5 & 27.5 & 24.7 & 19.4 \\ \text { MAX } & 68.0 & 152 & 235 & 145 & 190 & 203 & 160 & 146 & 142 & 128 & 80.5 & 210 \\ \text { (WY) } & 1991 & 1973 & 1991 & 1974 & 1990 & 1978 & 1972 & 1981 & 1974 & 1979 & 1979 & 1989 \\ \text { MIN } & 3.63 & 5.51 & 5.84 & 3.87 & 11.0 & 17.6 & 16.9 & 16.1 & 6.50 & 3.25 & 3.84 & 3.62 \\ \text { (WY) } & 1988 & 1988 & 1977 & 1977 & 1978 & 1981 & 1971 & 1988 & 1988 & 1977 & 1988 & 1991\end{array}$

SUMMARY STAIISIICS

AMHUAL TOIAL

ANNUAL MEAN

HIGHESI ANNUAL MEAN

LOWEST ANNUAL MEAN

HIGHEST DAILY MEAN

LOWEST DAILY MEAN

ANMUAL SEVEN-DAY MINIMUM

INSIANIANE OUS PEAK FLOW

INSIANTANEOUS PEAK STAGE

ANNUAL RUNOFF (CFSM)

ANNUAL RUNOFF (INCHES)

10 PERCENT EXCEEDS

50 PERCENT EXCEEDS

90 PERCENT EXCEEDS
FOR 1990 LALENDAR YEAR

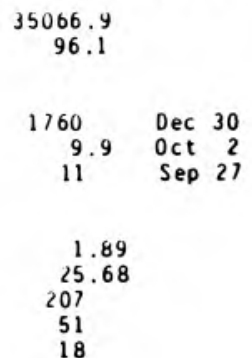

FOR 1991 WAIER YEAR

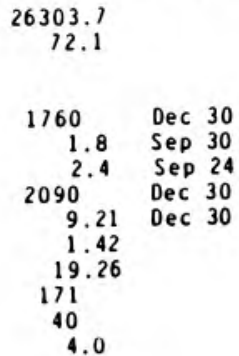

WAIER YEARS $1968-1991$

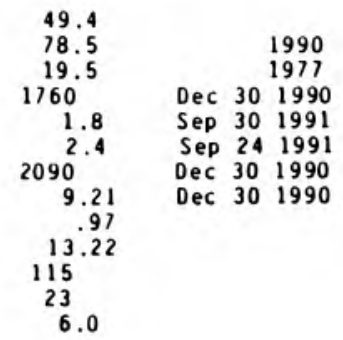




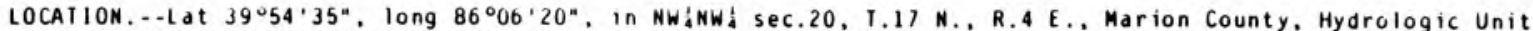
05120201 , on downstream side of center pier of bridge on 82 nd Street, 2 i east of Nora, 14 i upstream froe Fall Creek, and at il ze 247.9.

DRAINAGE AREA ..-1,219 $i^{2}$

PERIOD OF RECORD.--October 1929 to current year. Prior to April 1930, monthly discharge only, published in WSP 1305. Prior to October 1948, published as West Fork White River near Nora.

REVISED RECORDS..-WSP 1335: 1930-31, 1934(a), 1936, 1941, 1943, 1945, 1947-48. WSP 2109: Drdinage area.

GAGE. - Water-stage recorder. Datu of gage is $710.94 \mathrm{ft}$ above National Geodetic Vertical Datua of 1929 (ievels by U.S. Aray Corps of Engineers). 0ct. 26, 1929 to July 29, 1942, at site 200 ft downstrean at sane datua. Supplenental water-stage recorder $4.5 \mathrm{mi}$ downstrean.

REMARKS. - Records good. Flow slightly regulated by Morse Reservoir.

EXIREMES OUTSIDE PERIOD OF RECORD, .-Flood of Mar. 26, 1913, reached a stage of 22.4 ft, from floodmark, determined by Indiana Departaent of Highways, discharge, $58,500 \mathrm{ft} / 3 / \mathrm{s}$.

DISCHARGE, CUBIC FEEI PER SECOND, WAIER YEAR OCTOBER 1990 TO SEPIEMBER 1991 DAIL Y MEAN VALUES

\begin{tabular}{|c|c|c|c|c|c|c|c|c|c|c|c|c|}
\hline OAY & $0 C \mathrm{~T}$ & NOV & DEC & JAN & FEB & MAR & APR & MAY & JUN & JUL & $A \cup G$ & SEP \\
\hline $\begin{array}{l}1 \\
2 \\
3 \\
4 \\
5\end{array}$ & $\begin{array}{r}497 \\
445 \\
421 \\
1060 \\
2690\end{array}$ & $\begin{array}{l}688 \\
668 \\
645 \\
626 \\
710\end{array}$ & $\begin{array}{l}2300 \\
1750 \\
2820 \\
6070 \\
5780\end{array}$ & $\begin{array}{r}27800 \\
19200 \\
6450 \\
3960 \\
3140\end{array}$ & $\begin{array}{l}1170 \\
1150 \\
1210 \\
1530 \\
2330\end{array}$ & $\begin{array}{l}1160 \\
1210 \\
1230 \\
1150 \\
1060\end{array}$ & $\begin{array}{l}1770 \\
1580 \\
1430 \\
1370 \\
1490\end{array}$ & $\begin{array}{l}1170 \\
1090 \\
1030 \\
1030 \\
1020\end{array}$ & $\begin{array}{l}5350 \\
5750 \\
4080 \\
2530 \\
1700\end{array}$ & $\begin{array}{l}399 \\
365 \\
348 \\
369 \\
364\end{array}$ & $\begin{array}{l}215 \\
204 \\
205 \\
220 \\
197\end{array}$ & $\begin{array}{l}182 \\
150 \\
158 \\
210 \\
207\end{array}$ \\
\hline $\begin{array}{r}6 \\
7 \\
8 \\
9 \\
10\end{array}$ & $\begin{array}{l}2220 \\
1450 \\
1270 \\
1340 \\
3150\end{array}$ & $\begin{array}{r}1000 \\
1180 \\
997 \\
849 \\
791\end{array}$ & $\begin{array}{l}3300 \\
2360 \\
1910 \\
1620 \\
1420\end{array}$ & $\begin{array}{l}2680 \\
2340 \\
2120 \\
1950 \\
1790\end{array}$ & $\begin{array}{l}3590 \\
4850 \\
5120 \\
3520 \\
2680\end{array}$ & $\begin{array}{r}1030 \\
1020 \\
950 \\
903 \\
873\end{array}$ & $\begin{array}{l}1510 \\
1400 \\
1410 \\
1730 \\
1610\end{array}$ & $\begin{array}{r}1050 \\
1000 \\
950 \\
895 \\
860\end{array}$ & $\begin{array}{r}1270 \\
1050 \\
914 \\
809 \\
727\end{array}$ & $\begin{array}{l}327 \\
298 \\
367 \\
734 \\
628\end{array}$ & $\begin{array}{l}267 \\
233 \\
219 \\
236 \\
249\end{array}$ & $\begin{array}{l}193 \\
171 \\
162 \\
149 \\
142\end{array}$ \\
\hline $\begin{array}{l}11 \\
12 \\
13 \\
14 \\
15\end{array}$ & $\begin{array}{l}6260 \\
5540 \\
3280 \\
2320 \\
1820\end{array}$ & $\begin{array}{l}747 \\
709 \\
667 \\
625 \\
599\end{array}$ & $\begin{array}{l}1310 \\
1210 \\
1140 \\
1030 \\
1610\end{array}$ & $\begin{array}{l}1820 \\
2720 \\
3260 \\
2450 \\
2340\end{array}$ & $\begin{array}{l}2220 \\
1880 \\
1690 \\
1690 \\
1680\end{array}$ & $\begin{array}{r}825 \\
1020 \\
3350 \\
4850 \\
5350\end{array}$ & $\begin{array}{l}1370 \\
1200 \\
1480 \\
2210 \\
4650\end{array}$ & $\begin{array}{r}844 \\
830 \\
818 \\
792 \\
1060\end{array}$ & $\begin{array}{l}675 \\
653 \\
625 \\
574 \\
530\end{array}$ & $\begin{array}{l}485 \\
427 \\
391 \\
382 \\
342\end{array}$ & $\begin{array}{l}222 \\
192 \\
182 \\
182 \\
170\end{array}$ & $\begin{array}{l}137 \\
160 \\
215 \\
208 \\
236\end{array}$ \\
\hline $\begin{array}{l}16 \\
17 \\
18 \\
19 \\
20\end{array}$ & $\begin{array}{l}1490 \\
1270 \\
1310 \\
1830 \\
1780\end{array}$ & $\begin{array}{l}596 \\
597 \\
562 \\
546 \\
539\end{array}$ & $\begin{array}{l}3850 \\
3770 \\
3340 \\
5480 \\
6250\end{array}$ & $\begin{array}{l}3210 \\
4680 \\
4220 \\
3000 \\
2530\end{array}$ & $\begin{array}{l}1400 \\
1330 \\
1470 \\
2070 \\
3620\end{array}$ & $\begin{array}{l}5200 \\
5520 \\
7070 \\
8100 \\
6720\end{array}$ & $\begin{array}{l}5120 \\
3570 \\
2430 \\
2750 \\
4310\end{array}$ & $\begin{array}{l}1320 \\
1240 \\
2360 \\
3260 \\
2310\end{array}$ & $\begin{array}{l}565 \\
709 \\
650 \\
546 \\
478\end{array}$ & $\begin{array}{l}305 \\
284 \\
271 \\
255 \\
241\end{array}$ & $\begin{array}{l}171 \\
178 \\
181 \\
224 \\
232\end{array}$ & $\begin{array}{l}203 \\
178 \\
167 \\
152 \\
141\end{array}$ \\
\hline $\begin{array}{l}21 \\
22 \\
23 \\
24 \\
25\end{array}$ & $\begin{array}{l}1420 \\
1280 \\
1240 \\
1230 \\
1120\end{array}$ & $\begin{array}{l}530 \\
585 \\
682 \\
764 \\
731\end{array}$ & $\begin{array}{l}4470 \\
5940 \\
7100 \\
4620 \\
3090\end{array}$ & $\begin{array}{l}2450 \\
2230 \\
1920 \\
1730 \\
1520\end{array}$ & $\begin{array}{l}3220 \\
2440 \\
1920 \\
1610 \\
1470\end{array}$ & $\begin{array}{l}4040 \\
3700 \\
5700 \\
6990 \\
5080\end{array}$ & $\begin{array}{l}4370 \\
2970 \\
2290 \\
1960 \\
1710\end{array}$ & $\begin{array}{l}1510 \\
1220 \\
1300 \\
1610 \\
1280\end{array}$ & $\begin{array}{r}435 \\
432 \\
698 \\
1270 \\
967\end{array}$ & $\begin{array}{l}234 \\
282 \\
246 \\
224 \\
240\end{array}$ & $\begin{array}{l}384 \\
279 \\
223 \\
190 \\
170\end{array}$ & $\begin{array}{l}138 \\
148 \\
175 \\
178 \\
185\end{array}$ \\
\hline $\begin{array}{l}26 \\
27 \\
28 \\
29 \\
30 \\
31\end{array}$ & $\begin{array}{l}990 \\
893 \\
839 \\
779 \\
736 \\
714\end{array}$ & $\begin{array}{r}665 \\
899 \\
2200 \\
4400 \\
3700 \\
\ldots \ldots\end{array}$ & $\begin{array}{r}2340 \\
1890 \\
1700 \\
3070 \\
16600 \\
26200\end{array}$ & $\begin{array}{l}1410 \\
1340 \\
1300 \\
1260 \\
1240 \\
1210\end{array}$ & $\begin{array}{c}1330 \\
1240 \\
1180 \\
\ldots \\
\ldots \\
\ldots\end{array}$ & $\begin{array}{l}3530 \\
4510 \\
4950 \\
3630 \\
2590 \\
2030\end{array}$ & $\begin{array}{c}1530 \\
1420 \\
1340 \\
1290 \\
1220 \\
\ldots\end{array}$ & $\begin{array}{r}1070 \\
996 \\
905 \\
826 \\
853 \\
1560\end{array}$ & $\begin{array}{l}686 \\
546 \\
469 \\
421 \\
405 \\
\cdots\end{array}$ & $\begin{array}{l}238 \\
229 \\
223 \\
218 \\
217 \\
215\end{array}$ & $\begin{array}{l}158 \\
161 \\
171 \\
178 \\
211 \\
179\end{array}$ & $\begin{array}{l}163 \\
159 \\
154 \\
146 \\
142 \\
\cdots\end{array}$ \\
\hline $\begin{array}{l}\text { TOIAL } \\
\text { MEAN } \\
\text { MAX } \\
\text { MI N } \\
\text { CF SM } \\
\text { IN. }\end{array}$ & $\begin{array}{r}52684 \\
1699 \\
6260 \\
421 \\
1.39 \\
1.61\end{array}$ & $\begin{array}{r}29497 \\
983 \\
4400 \\
530 \\
.81 \\
.90\end{array}$ & $\begin{array}{r}135340 \\
4366 \\
26200 \\
1030 \\
3.58 \\
4.13\end{array}$ & $\begin{array}{r}119270 \\
3847 \\
27800 \\
1210 \\
3.16 \\
3.64\end{array}$ & $\begin{array}{r}60610 \\
2165 \\
5120 \\
1150 \\
1.78 \\
1.85\end{array}$ & $\begin{array}{r}105341 \\
3398 \\
8100 \\
825 \\
2.79 \\
3.21\end{array}$ & $\begin{array}{r}64490 \\
2150 \\
5120 \\
1200 \\
1.76 \\
1.97\end{array}$ & $\begin{array}{r}38059 \\
1228 \\
3260 \\
792 \\
1.01 \\
1.16\end{array}$ & $\begin{array}{r}36514 \\
1217 \\
5750 \\
405 \\
1.00 \\
1.11\end{array}$ & $\begin{array}{c}10148 \\
327 \\
734 \\
215 \\
.27 \\
.31\end{array}$ & $\begin{array}{c}6483 \\
209 \\
384 \\
158 \\
.17 \\
.20\end{array}$ & $\begin{array}{c}5109 \\
170 \\
236 \\
137 \\
.14 \\
.16\end{array}$ \\
\hline
\end{tabular}

SIAIISTICS OF MONTHLY MEAN DATA FOR WAIER YEARS 1930 - 1991, BY WATER YEAR (WY)

$\begin{array}{lrrrrrrrrrrrr}\text { MEAN } & 361 & 636 & 1118 & 1583 & 1718 & 2120 & 2058 & 1377 & 1073 & 645 & 441 & 371 \\ \text { MAX } & 1699 & 3651 & 4366 & 9015 & 4805 & 5113 & 5878 & 6815 & 6093 & 2538 & 2612 & 4397 \\ \text { (WY) } & 1991 & 1973 & 1991 & 1950 & 1950 & 1978 & 1964 & 1943 & 1958 & 1957 & 1979 & 1989 \\ \text { MIN } & 108 & 110 & 119 & 119 & 182 & 194 & 280 & 141 & 200 & 102 & 82.5 & 72.3 \\ \text { (WY) } & 1941 & 1935 & 1935 & 1945 & 1964 & 1941 & 1941 & 1941 & 1931 & 1936 & 1941 & 1941\end{array}$

SUMMARY STAIISIICS

ANMUAL TOIAL

ANMUAL MEAM

HIGHESI ANHUAL MEAM

LOWEST ANNUAL MEAN

HIGHESI DAILY MEAN

LOWEST DAILY MEAN

ANMUAL SEVEN-DAY MINIMUM

INSTANTANEOUS PEAK FLOW

INSIANTANEOUS PEAK STAGE

ANNUAL RUNOFF (CFSM)

ANHUAL RUNOFF (INCHES)

10 PERCENT EXCEEDS

50 PERCENT EXCEEDS

90 PERCENT EXCEEDS
FOR IGGU (AI ENDAR YEAR

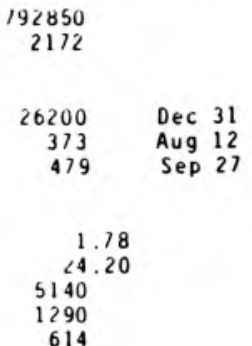

FOR 1991 WATER YEAR

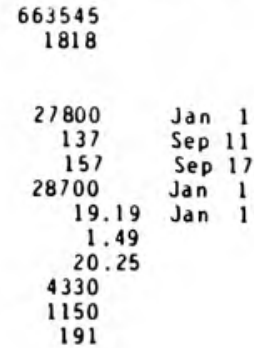

WATER YLARS 1930 - 1991

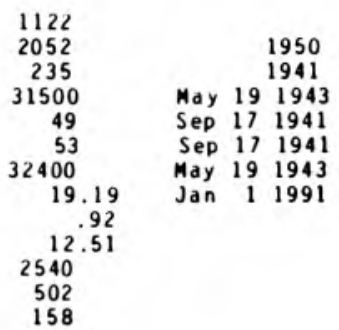




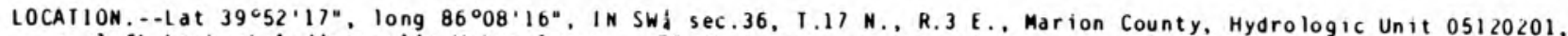
on left bank at Indiandpolis Water Compan, $75 \mathrm{ft}$ downstrea from diversion canal, and 500 ft upstrea fro Broad Ripple dan.

DRAINAGE AREA. $-1,238 \cdot \mathrm{i}^{2}$.

PERIOD OF RECORD.-.0ctober 1989 to current year. Fragmentary record Novenber 1927 to Jan. 24,1947 and continuous record, Jan. 24, 1947 to Sept. 30, 1989, dvailable in District office.

GAGE.--Water-stage recorder. Datum of gage is $709.91 \mathrm{ft}$ above National Geodetic Vertical Datua of 1929 .

REMARKS. - Record good. Stage affected by diversion through canal for water supply.

EXIREMES FOR PERIOD OF RECORD...Maximum gage height, $10.16 \mathrm{ft}, \mathrm{Jan} .1,1991 ;$ inieun, $2.51 \mathrm{ft}$, Sept. $11,1991$.

EXIREMES FOR CURRENT YEAR,--Maximum gage height, $10.16 \mathrm{ft}$, Jan. 1; wininu $2.51 \mathrm{ft}$, Sept. 11.

GAGE HEIGHI, FEET, WATER YEAR OCTOBER 1990 TO SEPTEMBER 1991 DAILY OBSERVATION AI 24:00 VALUES

\begin{tabular}{|c|c|c|c|c|c|c|c|c|c|c|c|c|}
\hline DAY & $\mathrm{OCT}$ & MOV & DEC & JAN & FE B & MAR & APR & MAY & JUN & JUL & AUG & SEP \\
\hline $\begin{array}{l}1 \\
2 \\
3 \\
4 \\
5\end{array}$ & $\begin{array}{l}3.06 \\
3.02 \\
3.14 \\
3.65 \\
4.24\end{array}$ & $\begin{array}{l}3.18 \\
3.16 \\
3.15 \\
3.16 \\
3.27\end{array}$ & $\begin{array}{l}3.90 \\
3.69 \\
4.85 \\
5.42 \\
4.75\end{array}$ & $\begin{array}{l}9.31 \\
6.33 \\
4.12 \\
4.35 \\
4.14\end{array}$ & $\begin{array}{l}3.34 \\
3.35 \\
3.38 \\
3.67 \\
4.06\end{array}$ & $\begin{array}{l}3.40 \\
3.43 \\
3.43 \\
3.37 \\
3.32\end{array}$ & $\begin{array}{l}3.68 \\
3.58 \\
3.53 \\
3.53 \\
3.59\end{array}$ & $\begin{array}{l}3.42 \\
3.37 \\
3.36 \\
3.36 \\
3.35\end{array}$ & $\begin{array}{l}5.06 \\
4.92 \\
4.26 \\
3.86 \\
3.59\end{array}$ & $\begin{array}{l}2.88 \\
2.84 \\
2.85 \\
2.91 \\
2.87\end{array}$ & $\begin{array}{l}2.64 \\
2.61 \\
2.71 \\
2.73 \\
2.69\end{array}$ & $\begin{array}{l}2.65 \\
2.60 \\
2.67 \\
2.16 \\
2.74\end{array}$ \\
\hline $\begin{array}{r}6 \\
7 \\
8 \\
9 \\
10\end{array}$ & $\begin{array}{l}3.73 \\
3.58 \\
3.52 \\
3.65 \\
4.88\end{array}$ & $\begin{array}{l}3.47 \\
3.46 \\
3.34 \\
3.27 \\
3.25\end{array}$ & $\begin{array}{l}4.23 \\
3.96 \\
3.81 \\
3.68 \\
3.60\end{array}$ & $\begin{array}{l}3.99 \\
3.86 \\
3.77 \\
3.68 \\
3.63\end{array}$ & $\begin{array}{l}4.62 \\
4.90 \\
4.61 \\
4.19 \\
3.97\end{array}$ & $\begin{array}{l}3.32 \\
3.31 \\
3.26 \\
3.24 \\
3.22\end{array}$ & $\begin{array}{l}3.56 \\
3.51 \\
3.64 \\
3.68 \\
3.60\end{array}$ & $\begin{array}{l}3.36 \\
3.34 \\
3.31 \\
3.29 \\
3.27\end{array}$ & $\begin{array}{l}3.43 \\
3.31 \\
3.25 \\
3.19 \\
3.15\end{array}$ & $\begin{array}{l}2.84 \\
2.78 \\
2.97 \\
3.13 \\
3.04\end{array}$ & $\begin{array}{l}2.86 \\
2.78 \\
2.73 \\
2.79 \\
2.82\end{array}$ & $\begin{array}{l}2.70 \\
2.67 \\
2.64 \\
2.59 \\
2.55\end{array}$ \\
\hline $\begin{array}{l}11 \\
12 \\
13 \\
14 \\
15\end{array}$ & $\begin{array}{l}5.35 \\
4.68 \\
4.14 \\
3.87 \\
3.68\end{array}$ & $\begin{array}{l}3.23 \\
3.21 \\
3.18 \\
3.15 \\
3.14\end{array}$ & $\begin{array}{l}3.55 \\
3.51 \\
3.47 \\
3.40 \\
4.13\end{array}$ & $\begin{array}{l}3.79 \\
4.30 \\
4.09 \\
3.86 \\
3.98\end{array}$ & $\begin{array}{l}3.80 \\
3.66 \\
3.62 \\
3.63 \\
3.60\end{array}$ & $\begin{array}{l}3.20 \\
3.70 \\
4.73 \\
4.77 \\
4.91\end{array}$ & $\begin{array}{l}3.46 \\
3.40 \\
3.69 \\
4.13 \\
4.93\end{array}$ & $\begin{array}{l}3.25 \\
3.24 \\
3.24 \\
3.18 \\
3.47\end{array}$ & $\begin{array}{l}3.14 \\
3.10 \\
3.07 \\
3.03 \\
3.04\end{array}$ & $\begin{array}{l}2.96 \\
2.94 \\
2.92 \\
2.91 \\
2.83\end{array}$ & $\begin{array}{l}2.75 \\
2.66 \\
2.69 \\
2.70 \\
2.67\end{array}$ & $\begin{array}{l}2.51 \\
2.77 \\
2.14 \\
2.75 \\
2.80\end{array}$ \\
\hline $\begin{array}{l}16 \\
17 \\
18 \\
19 \\
20\end{array}$ & $\begin{array}{l}3.55 \\
3.46 \\
3.59 \\
3.86 \\
3.63\end{array}$ & $\begin{array}{l}3.14 \\
3.14 \\
3.12 \\
3.11 \\
3.10\end{array}$ & $\begin{array}{l}4.88 \\
4.37 \\
4.67 \\
5.29 \\
5.03\end{array}$ & $\begin{array}{l}4.49 \\
4.15 \\
4.36 \\
4.05 \\
3.96\end{array}$ & $\begin{array}{l}3.40 \\
3.44 \\
3.60 \\
4.13 \\
4.40\end{array}$ & $\begin{array}{l}4.88 \\
5.13 \\
5.45 \\
5.62 \\
4.87\end{array}$ & $\begin{array}{l}4.70 \\
4.16 \\
3.88 \\
4.42 \\
4.79\end{array}$ & $\begin{array}{l}3.46 \\
3.49 \\
4.20 \\
4.27 \\
3.76\end{array}$ & $\begin{array}{c}3.10 \\
3.18 \\
3.09 \\
\ldots . \\
\ldots\end{array}$ & $\begin{array}{l}2.80 \\
2.78 \\
2.75 \\
2.75 \\
2.73\end{array}$ & $\begin{array}{l}2.67 \\
2.73 \\
2.70 \\
2.81 \\
2.79\end{array}$ & $\begin{array}{l}2.69 \\
2.68 \\
2.71 \\
2.67 \\
2.61\end{array}$ \\
\hline $\begin{array}{l}21 \\
22 \\
23 \\
24 \\
25\end{array}$ & $\begin{array}{l}3.52 \\
3.48 \\
3.47 \\
3.45 \\
3.40\end{array}$ & $\begin{array}{l}3.09 \\
3.19 \\
3.25 \\
3.30 \\
3.24\end{array}$ & $\begin{array}{l}4.84 \\
5.45 \\
5.24 \\
4.53 \\
4.15\end{array}$ & $\begin{array}{l}3.94 \\
3.78 \\
3.67 \\
3.59 \\
3.47\end{array}$ & $\begin{array}{l}4.12 \\
3.88 \\
3.69 \\
3.60 \\
3.53\end{array}$ & $\begin{array}{l}4.36 \\
4.66 \\
5.25 \\
5.28 \\
4.50\end{array}$ & $\begin{array}{l}4.46 \\
4.08 \\
3.89 \\
3.79 \\
3.69\end{array}$ & $\begin{array}{l}3.53 \\
3.47 \\
3.52 \\
3.61 \\
3.42\end{array}$ & $\begin{array}{l}\cdots \\
\cdots \\
\cdots \\
\cdots \\
-22\end{array}$ & $\begin{array}{l}2.70 \\
2.82 \\
2.70 \\
2.70 \\
2.73\end{array}$ & $\begin{array}{l}2.89 \\
2.79 \\
2.73 \\
2.69 \\
2.63\end{array}$ & $\begin{array}{l}2.63 \\
2.15 \\
2.12 \\
2.73 \\
2.76\end{array}$ \\
\hline $\begin{array}{l}26 \\
27 \\
28 \\
29 \\
30 \\
31\end{array}$ & $\begin{array}{l}3.32 \\
3.29 \\
3.26 \\
3.22 \\
3.21 \\
3.20\end{array}$ & $\begin{array}{l}3.19 \\
3.44 \\
4.45 \\
4.88 \\
4.22 \\
\ldots .\end{array}$ & $\begin{array}{l}3.92 \\
3.77 \\
3.72 \\
5.70 \\
8.73 \\
9.83\end{array}$ & $\begin{array}{l}3.46 \\
3.43 \\
3.39 \\
3.40 \\
3.37 \\
3.36\end{array}$ & $\begin{array}{r}3.46 \\
3.41 \\
3.39 \\
\ldots . \\
\ldots . \\
\ldots\end{array}$ & $\begin{array}{l}4.44 \\
4.82 \\
4.65 \\
4.25 \\
3.92 \\
3.75\end{array}$ & $\begin{array}{r}3.60 \\
3.55 \\
3.52 \\
3.48 \\
3.43 \\
\ldots\end{array}$ & $\begin{array}{l}3.35 \\
3.31 \\
3.24 \\
3.22 \\
3.22 \\
4.32\end{array}$ & $\begin{array}{l}3.08 \\
3.00 \\
2.95 \\
2.90 \\
2.89 \\
\ldots-.\end{array}$ & $\begin{array}{l}2.70 \\
2.70 \\
2.69 \\
2.69 \\
2.71 \\
2.66\end{array}$ & $\begin{array}{l}2.58 \\
2.60 \\
2.61 \\
2.74 \\
2.70 \\
2.66\end{array}$ & $\begin{array}{l}2.71 \\
2.70 \\
2.71 \\
2.69 \\
2.62 \\
\ldots\end{array}$ \\
\hline $\begin{array}{l}\text { MEAN } \\
\text { MAX } \\
\text { MIN }\end{array}$ & $\begin{array}{l}3.65 \\
5.35 \\
3.02\end{array}$ & $\begin{array}{l}3.35 \\
4.88 \\
3.09\end{array}$ & $\begin{array}{l}4.65 \\
9.83 \\
3.40\end{array}$ & $\begin{array}{l}4.14 \\
9.31 \\
3.36\end{array}$ & $\begin{array}{l}3.80 \\
4.90 \\
3.34\end{array}$ & $\begin{array}{l}4.21 \\
5.62 \\
3.20\end{array}$ & $\begin{array}{l}3.83 \\
4.93 \\
3.40\end{array}$ & $\begin{array}{l}3.46 \\
4.32 \\
3.18\end{array}$ & 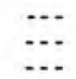 & $\begin{array}{l}2.82 \\
3.13 \\
2.66\end{array}$ & $\begin{array}{l}2.71 \\
2.89 \\
2.58\end{array}$ & $\begin{array}{l}2.68 \\
2.80 \\
2.51\end{array}$ \\
\hline
\end{tabular}


LOCATION. - - Lat $39^{\circ} 49^{\prime} 47^{\prime \prime}$, Iong $86^{\circ} 12^{\prime} 22^{\prime \prime}$, in NWiSE sec.16, T.16 N., R.3 E., Marion County, Hydrologic Unit 05120201 , on left bazk $150 \mathrm{ft}$ downstrean from 42 nd Street bridge in Indianapolis, and at aile 1.6.

DRAINAGE AREA $-117.9 . i^{2}$

PERIOD OF RECORD..-.June i 1969 to current year.

GAGE. - - Water-stage recorder. Datum of gage is $711.00 \mathrm{ft}$ above National Geodetic Vertical Datum of 1929 (Indiana Departaent of Highways bench mark)

REMARKS.--Records fair except those for estimated daily discharges, which are poor.

DISCHARGE, CUBIC FEET PER SECOND, WATER YEAR OCTOBER 1990 TO SEPTEMBER 1991 DAI IY MEAN VALUES

\begin{tabular}{|c|c|c|c|c|c|c|c|c|c|c|c|c|}
\hline DAY & $\mathrm{OCI}$ & NOV & DEC & JAN & FEB & MAR & APR & MAY & JUN & JUL & AUG & SEP \\
\hline $\begin{array}{l}1 \\
2 \\
3 \\
4 \\
5\end{array}$ & $\begin{array}{c}.79 \\
.61 \\
3.7 \\
102 \\
7.5\end{array}$ & $\begin{array}{r}3.2 \\
3.3 \\
3.3 \\
3.5 \\
37\end{array}$ & $\begin{array}{r}18 \\
15 \\
271 \\
60 \\
30\end{array}$ & $\begin{array}{r}58 \\
43 \\
33 \\
e 25 \\
\text { e23 }\end{array}$ & $\begin{array}{l}11 \\
15 \\
17 \\
16 \\
41\end{array}$ & $\begin{array}{l}13 \\
22 \\
13 \\
11 \\
11\end{array}$ & $\begin{array}{l}14 \\
12 \\
11 \\
11 \\
17\end{array}$ & $\begin{array}{l}12 \\
11 \\
10 \\
16 \\
15\end{array}$ & $\begin{array}{l}9.5 \\
7.3 \\
6.4 \\
5.4 \\
4.6\end{array}$ & $\begin{array}{l}1.5 \\
1.4 \\
1.4 \\
1.3 \\
1.6\end{array}$ & $\begin{array}{l}.71 \\
.66 \\
.62 \\
.69 \\
.72\end{array}$ & $\begin{array}{c}.58 \\
.54 \\
.73 \\
1.4 \\
.98\end{array}$ \\
\hline $\begin{array}{r}6 \\
7 \\
8 \\
9 \\
10\end{array}$ & $\begin{array}{l}3.3 \\
30 \\
17 \\
34 \\
181\end{array}$ & $\begin{array}{r}15 \\
6.4 \\
4.9 \\
4.0 \\
4.3\end{array}$ & $\begin{array}{l}24 \\
19 \\
16 \\
13 \\
12\end{array}$ & $\begin{array}{l}\text { e } 21 \\
\text { e } 20 \\
\text { e19 } \\
\text { e18 } \\
\text { e11 }\end{array}$ & $\begin{array}{r}103 \\
68 \\
39 \\
28 \\
24\end{array}$ & $\begin{array}{l}11 \\
10 \\
9.2 \\
8.9 \\
8.7\end{array}$ & $\begin{array}{l}24 \\
14 \\
11 \\
51 \\
47\end{array}$ & $\begin{array}{r}16 \\
11 \\
9.5 \\
9.1 \\
8.5\end{array}$ & $\begin{array}{l}4.1 \\
3.7 \\
3.4 \\
3.1 \\
3.0\end{array}$ & $\begin{array}{r}1.6 \\
1.5 \\
2.3 \\
1.9 \\
21\end{array}$ & $\begin{array}{r}13 \\
4.6 \\
3.3 \\
5.2 \\
2.1\end{array}$ & $\begin{array}{l}.60 \\
.56 \\
.56 \\
.65 \\
.75\end{array}$ \\
\hline $\begin{array}{l}11 \\
12 \\
13 \\
14 \\
15\end{array}$ & $\begin{array}{l}31 \\
14 \\
9.5 \\
7.2 \\
5.7\end{array}$ & $\begin{array}{l}3.4 \\
2.8 \\
2.6 \\
2.6 \\
2.6\end{array}$ & $\begin{array}{l}11 \\
11 \\
9.5 \\
8.4 \\
74\end{array}$ & $\begin{array}{l}57 \\
52 \\
32 \\
26 \\
27\end{array}$ & $\begin{array}{l}17 \\
14 \\
17 \\
25 \\
17\end{array}$ & $\begin{array}{l}174^{8.1} \\
611 \\
104 \\
51\end{array}$ & $\begin{array}{r}18 \\
\mathrm{e} 10 \\
\mathrm{e} 19 \\
\mathrm{e} 45 \\
\mathrm{e} 100\end{array}$ & $\begin{array}{r}16 \\
17 \\
11 \\
9.3 \\
8.4\end{array}$ & $\begin{array}{l}2.8 \\
5.8 \\
3.4 \\
2.7 \\
2.4\end{array}$ & $\begin{array}{l}5.3 \\
10 \\
5.0 \\
2.8 \\
1.9\end{array}$ & $\begin{array}{l}1.2 \\
.77 \\
.65 \\
.64 \\
.70\end{array}$ & $\begin{array}{l}.82 \\
1.2 \\
1.5 \\
.86 \\
.39\end{array}$ \\
\hline $\begin{array}{l}16 \\
17 \\
18 \\
19 \\
20\end{array}$ & $\begin{array}{r}4.6 \\
4.6 \\
19 \\
7.7 \\
5.0\end{array}$ & $\begin{array}{l}2.7 \\
2.8 \\
2.3 \\
2.3 \\
2.2\end{array}$ & $\begin{array}{r}30 \\
32 \\
108 \\
64 \\
35\end{array}$ & $\begin{array}{r}43 \\
38 \\
24 \\
\text { e19 } \\
\text { e16 }\end{array}$ & $\begin{array}{r}12 \\
+10 \\
64 \\
67 \\
40\end{array}$ & $\begin{array}{l}33 \\
67 \\
87 \\
44 \\
30\end{array}$ & $\begin{array}{l}\text { e58 } \\
\text { e33 } \\
\text { e1 } 8 \\
\text { e90 } \\
\text { e68 }\end{array}$ & $\begin{array}{r}16 \\
17 \\
42 \\
14 \\
9.9\end{array}$ & $\begin{array}{l}9.9 \\
4.6 \\
2.6 \\
1.5 \\
1.2\end{array}$ & $\begin{array}{l}1.5 \\
1.5 \\
1.5 \\
1.3 \\
1.3\end{array}$ & $\begin{array}{l}.77 \\
1.7 \\
3.4 \\
5.7 \\
4.1\end{array}$ & $\begin{array}{l}.33 \\
.37 \\
.44 \\
.50 \\
.58\end{array}$ \\
\hline $\begin{array}{l}21 \\
22 \\
23 \\
24 \\
25\end{array}$ & $\begin{array}{r}4.5 \\
13 \\
8.3 \\
5.6 \\
4.4\end{array}$ & $\begin{array}{r}2.0 \\
17 \\
8.2 \\
4.8 \\
3.5\end{array}$ & $\begin{array}{r}111 \\
70 \\
38 \\
25 \\
20\end{array}$ & $\begin{array}{r}\text { e } 14 \\
\text { e12 } \\
\text { e } 11 \\
\text { e } 10 \\
\text { e } 9.8\end{array}$ & $\begin{array}{l}21 \\
21 \\
15 \\
14 \\
12\end{array}$ & $\begin{array}{r}25 \\
174 \\
114 \\
47 \\
30\end{array}$ & $\begin{array}{r}\text { e50 } \\
\text { e38 } \\
\text { e28 } \\
22 \\
15\end{array}$ & $\begin{array}{l}8.7 \\
8.0 \\
30 \\
25 \\
11\end{array}$ & $\begin{array}{r}1.0 \\
5.0 \\
19 \\
4.4 \\
3.0\end{array}$ & $\begin{array}{l}1.2 \\
1.2 \\
1.2 \\
1.1 \\
1.0\end{array}$ & $\begin{array}{r}1.7 \\
1.0 \\
.75 \\
.66 \\
.82\end{array}$ & $\begin{array}{l}.68 \\
1.2 \\
5.2 \\
2.1 \\
.74\end{array}$ \\
\hline $\begin{array}{l}26 \\
27 \\
28 \\
29 \\
30 \\
31\end{array}$ & $\begin{array}{l}3.8 \\
3.5 \\
3.2 \\
3.4 \\
3.1 \\
3.1\end{array}$ & $\begin{array}{c}3.0 \\
86 \\
182 \\
42 \\
25 \\
\ldots .\end{array}$ & $\begin{array}{r}16 \\
14 \\
\mathrm{e} 12 \\
537 \\
1140 \\
115\end{array}$ & $\begin{array}{l}\text { e } 9.6 \\
\text { e } 9.4 \\
\text { e } 9.2 \\
\text { e } 9.6 \\
18 \\
11\end{array}$ & $\begin{array}{l}12 \\
11 \\
11 \\
\cdots \\
\cdots \\
\cdots\end{array}$ & $\begin{array}{r}103 \\
61 \\
35 \\
25 \\
19 \\
15\end{array}$ & $\begin{array}{l}14 \\
13 \\
13 \\
14 \\
12 \\
\cdots\end{array}$ & $\begin{array}{c}13 \\
10 \\
8.3 \\
7.7 \\
33 \\
14\end{array}$ & $\begin{array}{l}2.4 \\
2.1 \\
2.0 \\
1.7 \\
1.6 \\
\cdots\end{array}$ & $\begin{array}{l}.88 \\
.16 \\
.71 \\
.74 \\
.74 \\
.72\end{array}$ & $\begin{array}{l}.72 \\
.60 \\
.62 \\
.63 \\
.64 \\
.65\end{array}$ & $\begin{array}{l}.75 \\
.47 \\
.18 \\
.15 \\
.16 \\
\cdots\end{array}$ \\
\hline $\begin{array}{l}\text { TOIAL } \\
\text { MEAN } \\
\text { MAX } \\
\text { MIN } \\
\text { CF SM } \\
\text { IN. }\end{array}$ & $\begin{array}{r}544.10 \\
17.6 \\
181 \\
.61 \\
.98 \\
1.13\end{array}$ & $\begin{array}{r}484.7 \\
16.2 \\
182 \\
2.0 \\
.90 \\
1.01\end{array}$ & $\begin{array}{r}2958.9 \\
95.4 \\
1140 \\
8.4 \\
5.33 \\
6.15\end{array}$ & $\begin{array}{r}734.6 \\
23.7 \\
58 \\
9.2 \\
1.32 \\
1.53\end{array}$ & $\begin{array}{r}768 \\
27.4 \\
103 \\
10 \\
1.53 \\
1.60\end{array}$ & $\begin{array}{r}1974.9 \\
63.7 \\
611 \\
8.1 \\
3.56 \\
4.10\end{array}$ & $\begin{array}{r}890 \\
29.7 \\
100 \\
10 \\
1.66 \\
1.85\end{array}$ & $\begin{array}{r}447.4 \\
14.4 \\
42 \\
7.7 \\
.81 \\
.93\end{array}$ & $\begin{array}{r}129.6 \\
4.32 \\
19 \\
1.0 \\
.24 \\
.27\end{array}$ & $\begin{array}{c}77.85 \\
2.51 \\
21 \\
.71 \\
.14 \\
.16\end{array}$ & $\begin{array}{c}60.02 \\
1.94 \\
13 \\
.60 \\
.11 \\
.12\end{array}$ & $\begin{array}{c}31.97 \\
1.07 \\
7.5 \\
.15 \\
.06 \\
.07\end{array}$ \\
\hline
\end{tabular}

e Estimated

SIATISTICS OF MONIHLY MEAN DAIA FUK WATER YEARS 1970 - 1991, BY WATER YEAR (WY)

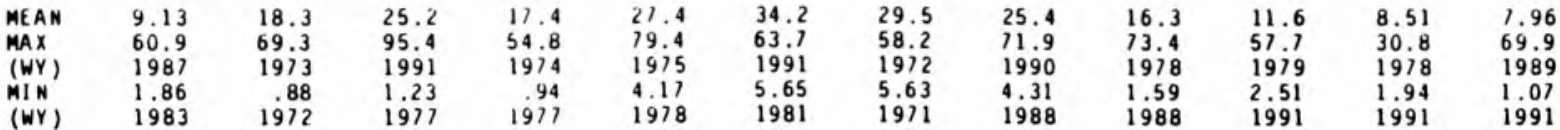

SUMMARY SIAIISIICS

ANNUAL TOIAL

ANNUAL MEAN

HIGHESI ANMUAL MEAN

LOWEST ANNUAL MEAM

HIGHEST DAILY MEAN

LOWEST DAILY MEAN

ANNUAL SEVEN-DAY MINIMUM

INSTANIANEOUS PEAK FLOW

INSIANTANEOUS PEAK SIAGE

ANNUAL RUNOF F (CFSM)

ANNUAL RUNOFF (INCHES)

10 PERCENT EXCEEDS

50 PERCENT EXCEEDS

90 PERCENT EXCEEDS
FOR I YYO LALENUAR YEAR

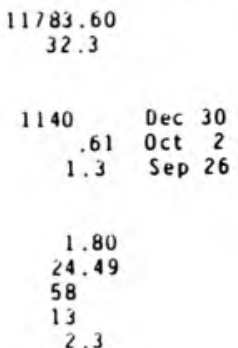

FOR 1991 WAIER YEAR

9102.04

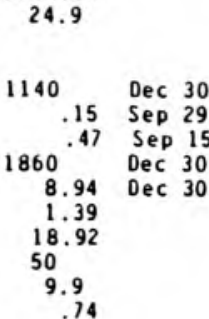

WAIER YEARS 1970 - 1991

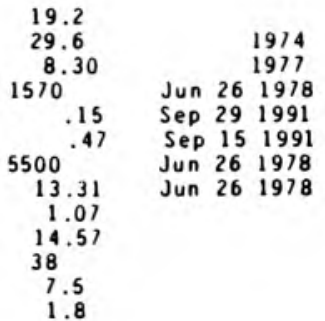




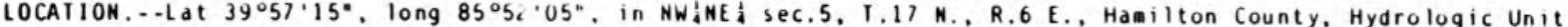

05120201 , on right bank $100 \mathrm{ft}$ downstream from bridge on State Highway 238 , 0.2 a downstrean froa Lick Creek,

2 i northwest of fortville, and at mile 26.1 .

DRAI HAGE AREA. $-169 \mathrm{mi}$,

PERIOD OF RECORD..-.July 1941 to current yedr.

REVISED RECORDS.--WSP 1435: 1949(P). WSP 2109: Draindge area.

GAGE. - Water-stage recorder. Datum of gage is $787.43 \mathrm{ft}$ above National Geodetic Vertical Datum of 1929 (levels by Indianapolis Water Co.). Prior to June 27,1942 , nonrecording gage at saee site and datua.

REMARKS.--Records good except for estiated daily discharges, which are poor.

EXTREMES OUTSIDE PERIOD OF RECORD, - Maximum stage known, about $12 \mathrm{ft}$ March 1913 (information by local resident).

DISCHARGE, CUBIL FELI PER SECOND, WATER YEAR OCTOBER 1990 TO SEPIEMBER 1991 DAILY MEAN VALUES

\begin{tabular}{|c|c|c|c|c|c|c|c|c|c|c|c|c|}
\hline DAY & $O C \mathrm{~T}$ & NOV & DEC & JAN & FEB & MAR & APR & MAY & JUN & JUL & AUG & SEP \\
\hline $\begin{array}{l}1 \\
2 \\
3 \\
4 \\
5\end{array}$ & $\begin{array}{r}100 \\
94 \\
91 \\
484 \\
507\end{array}$ & $\begin{array}{l}143 \\
136 \\
133 \\
134 \\
151\end{array}$ & $\begin{array}{l}296 \\
257 \\
469 \\
612 \\
377\end{array}$ & $\begin{array}{r}1520 \\
754 \\
556 \\
448 \\
398\end{array}$ & $\begin{array}{l}205 \\
208 \\
292 \\
377 \\
519\end{array}$ & $\begin{array}{l}206 \\
227 \\
213 \\
195 \\
183\end{array}$ & $\begin{array}{l}264 \\
239 \\
226 \\
222 \\
266\end{array}$ & $\begin{array}{l}183 \\
176 \\
168 \\
171 \\
182\end{array}$ & $\begin{array}{r}\text { e } 350 \\
\text { e } 320 \\
\text { e } 282 \\
210 \\
164\end{array}$ & $\begin{array}{l}77 \\
68 \\
65 \\
65 \\
62\end{array}$ & $\begin{array}{l}37 \\
36 \\
35 \\
37 \\
36\end{array}$ & $\begin{array}{l}46 \\
40 \\
39 \\
50 \\
45\end{array}$ \\
\hline $\begin{array}{r}6 \\
7 \\
8 \\
9 \\
10\end{array}$ & $\begin{array}{l}307 \\
240 \\
227 \\
220 \\
670\end{array}$ & $\begin{array}{l}220 \\
184 \\
160 \\
150 \\
153\end{array}$ & $\begin{array}{l}301 \\
258 \\
227 \\
205 \\
194\end{array}$ & $\begin{array}{l}312 \\
342 \\
308 \\
291 \\
271\end{array}$ & $\begin{array}{r}771 \\
1070 \\
673 \\
487 \\
405\end{array}$ & $\begin{array}{l}182 \\
177 \\
163 \\
160 \\
156\end{array}$ & $\begin{array}{l}266 \\
240 \\
232 \\
242 \\
222\end{array}$ & $\begin{array}{l}197 \\
173 \\
161 \\
153 \\
148\end{array}$ & $\begin{array}{l}143 \\
131 \\
122 \\
116 \\
109\end{array}$ & $\begin{array}{r}58 \\
56 \\
114 \\
125 \\
91\end{array}$ & $\begin{array}{l}38 \\
42 \\
39 \\
43 \\
42\end{array}$ & $\begin{array}{l}39 \\
37 \\
35 \\
34 \\
34\end{array}$ \\
\hline $\begin{array}{l}11 \\
12 \\
13 \\
14 \\
15\end{array}$ & $\begin{array}{l}908 \\
505 \\
365 \\
300 \\
256\end{array}$ & $\begin{array}{l}148 \\
139 \\
132 \\
129 \\
126\end{array}$ & $\begin{array}{l}181 \\
178 \\
169 \\
154 \\
337\end{array}$ & $\begin{array}{l}143 \\
621 \\
436 \\
354 \\
361\end{array}$ & $\begin{array}{l}343 \\
299 \\
284 \\
286 \\
278\end{array}$ & $\begin{array}{r}151 \\
173 \\
1010 \\
1520 \\
978\end{array}$ & $\begin{array}{l}198 \\
185 \\
283 \\
539 \\
511\end{array}$ & $\begin{array}{l}144 \\
146 \\
143 \\
139 \\
165\end{array}$ & $\begin{array}{r}109 \\
113 \\
107 \\
100 \\
97\end{array}$ & $\begin{array}{l}88 \\
82 \\
79 \\
69 \\
63\end{array}$ & $\begin{array}{l}38 \\
36 \\
34 \\
34 \\
54\end{array}$ & $\begin{array}{l}34 \\
35 \\
37 \\
37 \\
34\end{array}$ \\
\hline $\begin{array}{l}16 \\
17 \\
18 \\
19 \\
20\end{array}$ & $\begin{array}{l}223 \\
205 \\
289 \\
355 \\
267\end{array}$ & $\begin{array}{l}124 \\
124 \\
121 \\
119 \\
116\end{array}$ & $\begin{array}{r}489 \\
340 \\
618 \\
1060 \\
642\end{array}$ & $\begin{array}{l}509 \\
594 \\
448 \\
369 \\
345\end{array}$ & $\begin{array}{l}196 \\
205 \\
253 \\
567 \\
600\end{array}$ & $\begin{array}{l}650 \\
498 \\
649 \\
529 \\
407\end{array}$ & $\begin{array}{l}442 \\
330 \\
276 \\
404 \\
565\end{array}$ & $\begin{array}{l}168 \\
302 \\
608 \\
503 \\
296\end{array}$ & $\begin{array}{r}113 \\
103 \\
94 \\
88 \\
78\end{array}$ & $\begin{array}{l}57 \\
54 \\
51 \\
49 \\
48\end{array}$ & $\begin{array}{l}43 \\
40 \\
55 \\
47 \\
53\end{array}$ & $\begin{array}{l}32 \\
33 \\
33 \\
35 \\
35\end{array}$ \\
\hline $\begin{array}{l}21 \\
22 \\
23 \\
24 \\
25\end{array}$ & $\begin{array}{l}232 \\
227 \\
241 \\
221 \\
200\end{array}$ & $\begin{array}{l}115 \\
136 \\
192 \\
165 \\
148\end{array}$ & $\begin{array}{l}559 \\
991 \\
682 \\
440 \\
345\end{array}$ & $\begin{array}{r}135 \\
t 270 \\
e 250 \\
\text { e230 } \\
\text { e210 }\end{array}$ & $\begin{array}{l}430 \\
341 \\
288 \\
265 \\
243\end{array}$ & $\begin{array}{r}355 \\
638 \\
1180 \\
780 \\
475\end{array}$ & $\begin{array}{l}401 \\
329 \\
283 \\
273 \\
242\end{array}$ & $\begin{array}{r}235 \\
\text { e210 } \\
\text { e235 } \\
\text { e210 } \\
\text { e190 }\end{array}$ & $\begin{array}{r}76 \\
83 \\
156 \\
103 \\
92\end{array}$ & $\begin{array}{r}69 \\
113 \\
64 \\
53 \\
49\end{array}$ & $\begin{array}{l}47 \\
42 \\
39 \\
37 \\
36\end{array}$ & $\begin{array}{l}33 \\
34 \\
44 \\
43 \\
39\end{array}$ \\
\hline $\begin{array}{l}26 \\
27 \\
28 \\
29 \\
30 \\
31\end{array}$ & $\begin{array}{l}183 \\
170 \\
162 \\
153 \\
147 \\
148\end{array}$ & $\begin{array}{l}138 \\
190 \\
535 \\
598 \\
376 \\
\cdots\end{array}$ & $\begin{array}{r}298 \\
263 \\
255 \\
653 \\
4540 \\
6140\end{array}$ & $\begin{array}{l}\text { e } 200 \\
\text { e } 195 \\
\text { e } 190 \\
\text { e } 185 \\
242 \\
238\end{array}$ & $\begin{array}{l}228 \\
219 \\
209 \\
\ldots \\
\cdots \\
\cdots\end{array}$ & $\begin{array}{l}479 \\
644 \\
461 \\
363 \\
310 \\
278\end{array}$ & $\begin{array}{l}232 \\
223 \\
214 \\
207 \\
193 \\
\cdots\end{array}$ & $\begin{array}{l}\text { e } 210 \\
\text { e } 180 \\
\text { e } 150 \\
\text { e } 140 \\
\text { e } 450 \\
\text { e } 400\end{array}$ & $\begin{array}{r}107 \\
97 \\
77 \\
76 \\
74 \\
\cdots\end{array}$ & $\begin{array}{l}46 \\
43 \\
41 \\
40 \\
40 \\
39\end{array}$ & $\begin{array}{l}34 \\
34 \\
34 \\
40 \\
43 \\
77\end{array}$ & $\begin{array}{l}37 \\
36 \\
35 \\
34 \\
35 \\
-\cdots\end{array}$ \\
\hline $\begin{array}{l}\text { IOIAL } \\
\text { MEAN } \\
\text { MAX } \\
\text { MIN } \\
\text { CF SM } \\
\text { IN. }\end{array}$ & $\begin{array}{r}8697 \\
281 \\
908 \\
91 \\
1.66 \\
1.91\end{array}$ & $\begin{array}{r}5435 \\
181 \\
598 \\
115 \\
1.07 \\
1.20\end{array}$ & $\begin{array}{r}22530 \\
727 \\
6140 \\
154 \\
4.30 \\
4.96\end{array}$ & $\begin{array}{r}12191 \\
393 \\
1520 \\
185 \\
2.33 \\
2.68\end{array}$ & $\begin{array}{r}10541 \\
376 \\
1070 \\
196 \\
2.23 \\
2.32\end{array}$ & $\begin{array}{r}14390 \\
464 \\
1520 \\
151 \\
2.75 \\
3.17\end{array}$ & $\begin{array}{l}8749 \\
292 \\
565 \\
185 \\
1.73 \\
1.93\end{array}$ & $\begin{array}{c}6942 \\
224 \\
608 \\
139 \\
1.33 \\
1.53\end{array}$ & $\begin{array}{c}3890 \\
130 \\
350 \\
74 \\
.17 \\
.86\end{array}$ & $\begin{array}{c}2018 \\
65.1 \\
125 \\
39 \\
.39 \\
.44\end{array}$ & $\begin{array}{r}1282 \\
41.4 \\
71 \\
34 \\
.24 \\
.28\end{array}$ & $\begin{array}{r}1114 \\
37.1 \\
50 \\
32 \\
.22 \\
.25\end{array}$ \\
\hline
\end{tabular}

e Estimated

SIAIISIICS OF MONTHIY MEAN DATA FOR WAIEK YEAKS 1942 - 1991, B! WAIER YEAR (WY)

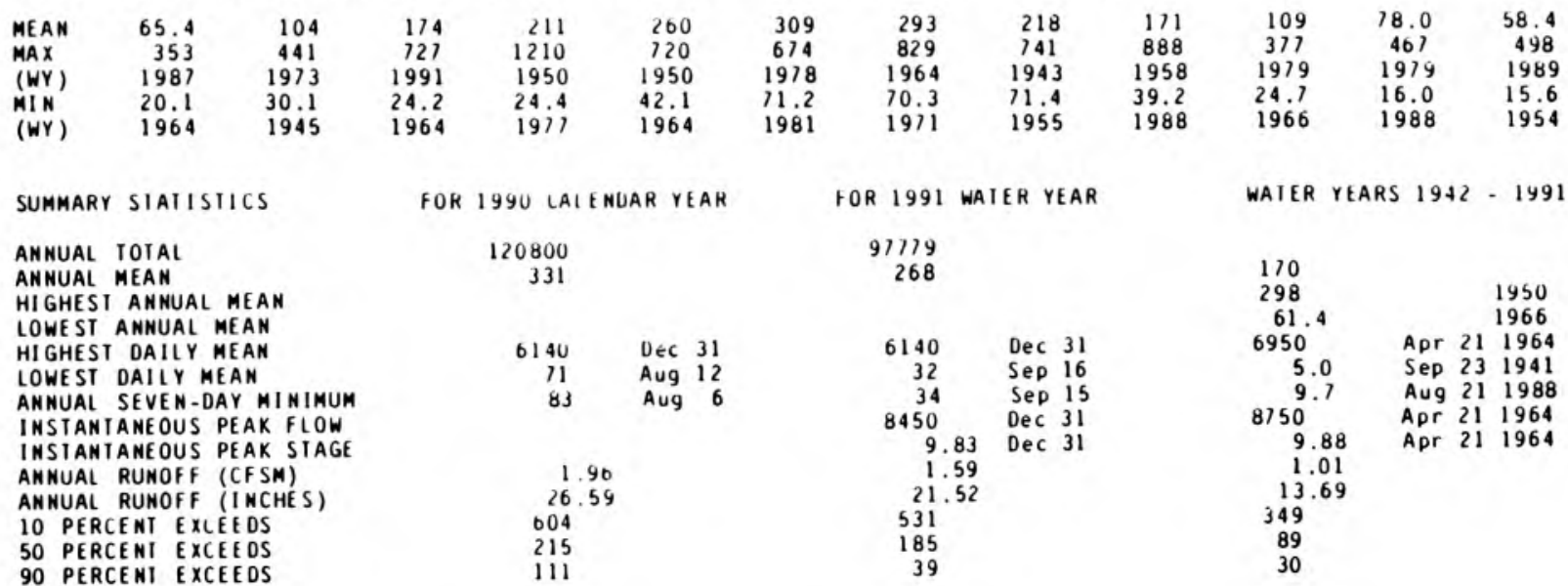




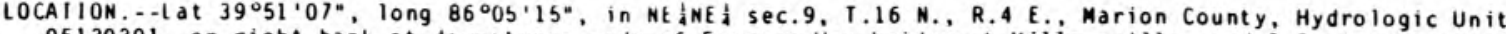
05120201 , on right bank at downstrean side of Eaerson Way bridge at Miliersville, and 9.2 apstrean from mouth.

DRAINAGE AREA., $298 \backsim i^{2}$.

PERIOD OF RECORD.--0ctober 1929 to current yedr. Monthly discharge only for 0ctober 1929 , published in wSP 1305. Twice-daily chain gage readings at former site fro July 1925 to Septeber 1926 are available in the district office.

REVISED RE CORDS.--WSP 1335: 1930-31, 1933, 1936-38,1942-43. WSP 2109: Drainage area.

GAGE. - Water-stage recorder. Datua of gage is $722.16 \mathrm{ft}$ above National Geodetic Vertical Datum of 1929 . Prior to $0 \mathrm{ct}$. 21, 1961, water-stage recorder at site $500 \mathrm{ft}$ downstrean at sane datun.

REMARKS. - - Records good. Flow regulated by Geist Reservoir. EXTREMES OUT 1 IDE PERIOD OF RECORD.--Maximum stage known, $16.3 \mathrm{ft}$ Mar. 26,1913, from floodmarks, discharge,
$22,000 \mathrm{ft} / \mathrm{s}$ by slope-area measureant.

DISCHARGE, CUBIC FEET PER SECONO, WATER YEAR OCTOBER 1990 TO SEPIEMBER 1991 DAII Y MEAN VALUES

\begin{tabular}{|c|c|c|c|c|c|c|c|c|c|c|c|c|}
\hline DAY & $\mathrm{OCT}$ & NOV & DEC & JAN & FEB & MAR & APR & MAY & JUN & JUL & AUG & SEP \\
\hline $\begin{array}{l}1 \\
2 \\
3 \\
4 \\
5\end{array}$ & $\begin{array}{r}101 \\
99 \\
98 \\
621 \\
813\end{array}$ & $\begin{array}{l}159 \\
151 \\
149 \\
148 \\
195\end{array}$ & $\begin{array}{r}545 \\
449 \\
895 \\
1170 \\
806\end{array}$ & $\begin{array}{r}4470 \\
1810 \\
1090 \\
819 \\
691\end{array}$ & $\begin{array}{l}317 \\
316 \\
398 \\
491 \\
728\end{array}$ & $\begin{array}{l}288 \\
307 \\
315 \\
266 \\
250\end{array}$ & $\begin{array}{l}396 \\
367 \\
331 \\
325 \\
378\end{array}$ & $\begin{array}{l}258 \\
236 \\
233 \\
249 \\
262\end{array}$ & $\begin{array}{l}523 \\
420 \\
358 \\
325 \\
225\end{array}$ & $\begin{array}{l}77 \\
79 \\
71 \\
83 \\
80\end{array}$ & $\begin{array}{l}67 \\
67 \\
67 \\
69 \\
69\end{array}$ & $\begin{array}{l}55 \\
54 \\
66 \\
70 \\
57\end{array}$ \\
\hline $\begin{array}{r}6 \\
7 \\
8 \\
9 \\
10\end{array}$ & $\begin{array}{l}577 \\
444 \\
410 \\
379 \\
882\end{array}$ & $\begin{array}{l}264 \\
242 \\
209 \\
186 \\
182\end{array}$ & $\begin{array}{l}567 \\
451 \\
375 \\
325 \\
293\end{array}$ & $\begin{array}{l}620 \\
556 \\
489 \\
448 \\
426\end{array}$ & $\begin{array}{r}1390 \\
2000 \\
1410 \\
950 \\
713\end{array}$ & $\begin{array}{l}243 \\
238 \\
224 \\
206 \\
203\end{array}$ & $\begin{array}{l}375 \\
353 \\
337 \\
338 \\
313\end{array}$ & $\begin{array}{l}320 \\
281 \\
247 \\
230 \\
220\end{array}$ & $\begin{array}{l}181 \\
147 \\
139 \\
133 \\
121\end{array}$ & $\begin{array}{r}72 \\
72 \\
92 \\
95 \\
117\end{array}$ & $\begin{array}{l}71 \\
60 \\
56 \\
56 \\
54\end{array}$ & $\begin{array}{l}55 \\
53 \\
53 \\
52 \\
52\end{array}$ \\
\hline $\begin{array}{l}11 \\
12 \\
13 \\
14 \\
15\end{array}$ & $\begin{array}{r}1320 \\
997 \\
644 \\
464 \\
374\end{array}$ & $\begin{array}{l}168 \\
160 \\
149 \\
141 \\
135\end{array}$ & $\begin{array}{l}268 \\
246 \\
233 \\
221 \\
436\end{array}$ & $\begin{array}{l}528 \\
929 \\
815 \\
620 \\
593\end{array}$ & $\begin{array}{l}561 \\
474 \\
431 \\
429 \\
398\end{array}$ & $\begin{array}{r}202 \\
388 \\
2160 \\
2620 \\
1850\end{array}$ & $\begin{array}{l}301 \\
266 \\
414 \\
743 \\
977\end{array}$ & $\begin{array}{l}212 \\
213 \\
209 \\
197 \\
196\end{array}$ & $\begin{array}{l}117 \\
150 \\
135 \\
117 \\
104\end{array}$ & $\begin{array}{l}84 \\
83 \\
86 \\
85 \\
74\end{array}$ & $\begin{array}{l}51 \\
51 \\
58 \\
61 \\
60\end{array}$ & $\begin{array}{r}52 \\
116 \\
153 \\
75 \\
57\end{array}$ \\
\hline $\begin{array}{l}16 \\
17 \\
18 \\
19 \\
20\end{array}$ & $\begin{array}{l}306 \\
256 \\
298 \\
407 \\
366\end{array}$ & $\begin{array}{l}135 \\
137 \\
131 \\
129 \\
125\end{array}$ & $\begin{array}{r}701 \\
613 \\
993 \\
1560 \\
1250\end{array}$ & $\begin{array}{l}750 \\
933 \\
806 \\
639 \\
559\end{array}$ & $\begin{array}{l}341 \\
332 \\
411 \\
783 \\
977\end{array}$ & $\begin{array}{r}1230 \\
946 \\
1200 \\
998 \\
746\end{array}$ & $\begin{array}{r}866 \\
624 \\
471 \\
1010 \\
1200\end{array}$ & $\begin{array}{l}230 \\
316 \\
780 \\
905 \\
586\end{array}$ & $\begin{array}{r}130 \\
131 \\
111 \\
103 \\
89\end{array}$ & $\begin{array}{l}70 \\
69 \\
71 \\
71 \\
80\end{array}$ & $\begin{array}{l}51 \\
60 \\
66 \\
68 \\
60\end{array}$ & $\begin{array}{l}52 \\
52 \\
54 \\
54 \\
49\end{array}$ \\
\hline $\begin{array}{l}21 \\
22 \\
23 \\
24 \\
25\end{array}$ & $\begin{array}{l}301 \\
305 \\
287 \\
274 \\
254\end{array}$ & $\begin{array}{l}119 \\
180 \\
210 \\
209 \\
187\end{array}$ & $\begin{array}{r}1060 \\
1450 \\
1290 \\
827 \\
582\end{array}$ & $\begin{array}{l}529 \\
468 \\
422 \\
380 \\
337\end{array}$ & $\begin{array}{l}718 \\
590 \\
470 \\
392 \\
360\end{array}$ & $\begin{array}{r}593 \\
1190 \\
1920 \\
1530 \\
958\end{array}$ & $\begin{array}{l}829 \\
604 \\
483 \\
433 \\
379\end{array}$ & $\begin{array}{l}409 \\
327 \\
332 \\
307 \\
276\end{array}$ & $\begin{array}{r}95 \\
91 \\
135 \\
117 \\
88\end{array}$ & $\begin{array}{l}81 \\
79 \\
78 \\
79 \\
78\end{array}$ & $\begin{array}{l}48 \\
50 \\
56 \\
56 \\
56\end{array}$ & $\begin{array}{l}52 \\
60 \\
75 \\
63 \\
55\end{array}$ \\
\hline $\begin{array}{l}26 \\
27 \\
28 \\
29 \\
30 \\
31\end{array}$ & $\begin{array}{l}214 \\
191 \\
183 \\
174 \\
160 \\
158\end{array}$ & $\begin{array}{r}171 \\
338 \\
1120 \\
1140 \\
772 \\
\ldots\end{array}$ & $\begin{array}{r}474 \\
401 \\
381 \\
986 \\
5690 \\
7290\end{array}$ & $\begin{array}{l}326 \\
311 \\
306 \\
298 \\
351 \\
348\end{array}$ & $\begin{array}{l}322 \\
303 \\
292 \\
\ldots \\
\ldots \\
\ldots\end{array}$ & $\begin{array}{r}924 \\
1050 \\
845 \\
669 \\
491 \\
417\end{array}$ & $\begin{array}{l}346 \\
319 \\
308 \\
296 \\
261 \\
\ldots\end{array}$ & $\begin{array}{l}293 \\
270 \\
219 \\
199 \\
313 \\
562\end{array}$ & $\begin{array}{l}99 \\
99 \\
90 \\
83 \\
80 \\
\ldots-\end{array}$ & $\begin{array}{l}78 \\
77 \\
76 \\
76 \\
72 \\
63\end{array}$ & $\begin{array}{l}60 \\
70 \\
64 \\
60 \\
61 \\
56\end{array}$ & $\begin{array}{l}54 \\
52 \\
51 \\
50 \\
50 \\
\cdots\end{array}$ \\
\hline $\begin{array}{l}\text { TOTAL } \\
\text { MEAN } \\
\text { MAX } \\
\text { MIN } \\
\text { CF SM } \\
\text { IN. }\end{array}$ & $\begin{array}{r}12357 \\
399 \\
1320 \\
98 \\
1.34 \\
1.54\end{array}$ & $\begin{array}{r}7141 \\
258 \\
1140 \\
119 \\
.87 \\
.97\end{array}$ & $\begin{array}{r}32828 \\
1059 \\
7290 \\
221 \\
3.55 \\
4.10\end{array}$ & $\begin{array}{r}22667 \\
731 \\
4470 \\
298 \\
2.45 \\
2.83\end{array}$ & $\begin{array}{r}17357 \\
620 \\
2000 \\
292 \\
2.08 \\
2.17\end{array}$ & $\begin{array}{r}25467 \\
822 \\
2620 \\
202 \\
2.76 \\
3.18\end{array}$ & $\begin{array}{r}14643 \\
488 \\
1200 \\
261 \\
1.64 \\
1.83\end{array}$ & $\begin{array}{r}9887 \\
319 \\
905 \\
196 \\
1.07 \\
1.23\end{array}$ & $\begin{array}{r}4736 \\
158 \\
523 \\
80 \\
.53 \\
.59\end{array}$ & $\begin{array}{r}2454 \\
19.2 \\
117 \\
63 \\
.27 \\
.31\end{array}$ & $\begin{array}{r}1865 \\
60.2 \\
i 7 \\
48 \\
.20 \\
.23\end{array}$ & $\begin{array}{r}1843 \\
61.4 \\
153 \\
49 \\
.21 \\
.23\end{array}$ \\
\hline
\end{tabular}

SIATISIICS OF MONTHIY MEAN DATA FUR WAIER YEARS 1930 - 1991, BY WATER YEAR (WY)

\begin{tabular}{|c|c|c|c|c|c|c|c|c|c|c|c|c|}
\hline $\begin{array}{l}\text { MEAN } \\
\text { MAX } \\
\text { (WY) } \\
\text { MI N } \\
\text { (WY) }\end{array}$ & $\begin{array}{r}99.2 \\
713 \\
1987 \\
23.4 \\
1941\end{array}$ & $\begin{array}{r}162 \\
857 \\
1973 \\
32.1 \\
1935\end{array}$ & $\begin{array}{r}284 \\
1059 \\
1991 \\
38.2 \\
1935\end{array}$ & $\begin{array}{r}404 \\
2390 \\
1950 \\
31.1 \\
1945\end{array}$ & $\begin{array}{r}441 \\
1278 \\
1950 \\
50.4 \\
1935\end{array}$ & $\begin{array}{r}528 \\
1399 \\
1963 \\
47.5 \\
1941\end{array}$ & $\begin{array}{r}514 \\
1503 \\
1964 \\
59.7 \\
1941\end{array}$ & $\begin{array}{r}375 \\
1524 \\
1943 \\
33.6 \\
1941\end{array}$ & $\begin{array}{r}210 \\
1449 \\
1958 \\
42.2 \\
1934\end{array}$ & $\begin{array}{r}179 \\
796 \\
1979 \\
29.1 \\
1936\end{array}$ & $\begin{array}{r}120 \\
739 \\
1979 \\
15.5 \\
1941\end{array}$ & $\begin{array}{r}94.8 \\
965 \\
1989 \\
11.5 \\
1941\end{array}$ \\
\hline
\end{tabular}

SUMMARY SIAIISTICS

ANMUAL TOTAL

AN HUAL MEAN

HIGHESI ANNUAL MEAN

LOWEST ANNUAL MEAN

HIGHESI DAILY MEAN

LOWEST DAILY MEAM

ANNUAL SEVEN-DAY MIMIMUM

INSTANTANEOUS PEAK FLOW

INSIAKIANEOUS PEAK SIAGE

ANMUAL RUNOFF (CFSM)

ANNUAL RUNOFF (INCHES)

10 PERCENT EXCEEDS

50 PERCENT EXCEEDS

90 PERCENT EXCEEDS
FOR 1990 CAIENDAR YEAR FOR 1991 WAIER YEAR

153845
421

$\begin{array}{rrr}184681 & & \\ 506 & & \\ 1290 & 0 e c & 31 \\ 90 & \text { Jul } & 9 \\ 107 & \text { Jul } & 4 \\ & & \\ 1.70 & \\ \angle 3.05 & \\ 995 & \\ 307 & \\ 138 & \end{array}$

WAIER YEARS $1930 \cdots 1991$

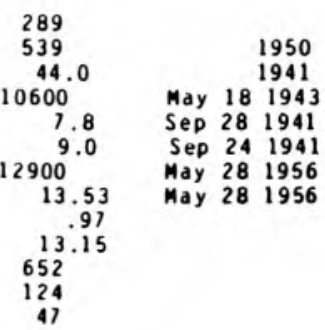




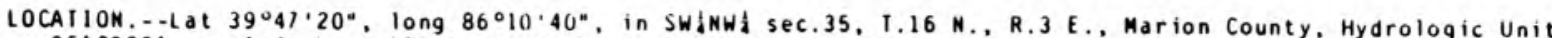
05120201 , on left bąnk $120 \mathrm{ft}$ upstredin from $16 \mathrm{th}$ Street on Aqueduct Street. 1.3 . i upstrean from aouth. DRAI NAGE AREA . - 317 i

PERIOD OF RECORD -.-0ctober 1985 to current year.

GAGE.-Water-stage recorder. Datua of 9 dge is $675.00 \mathrm{ft}$ above National Geodetic Vertical Datua of 1929 .

REMARKS. - Records fair except those for estinated daily discharges. which are poor. Natural flow affected by regulation of Geist Reservoir, and by diversion of aunicipal water supply by the Indianapolis water Comany.

DISCHARGE, CUBIC FEET PER SECONO, WATER YEAR OCTOBER 1990 TO SEPIEMBER 1991 DAILY MEAM VALUES

\begin{tabular}{|c|c|c|c|c|c|c|c|c|c|c|c|c|}
\hline DAY & $\mathrm{OCT}$ & NOV & DEC & JAN & FEB & MAR & APR & MAY & JUN & JUL & AUG & SEP \\
\hline $\begin{array}{l}1 \\
2 \\
3 \\
4 \\
5\end{array}$ & $\begin{array}{l}127 \\
116 \\
125 \\
635 \\
750\end{array}$ & $\begin{array}{l}195 \\
185 \\
175 \\
170 \\
235\end{array}$ & $\begin{array}{r}545 \\
440 \\
845 \\
1060 \\
860\end{array}$ & $\begin{array}{r}4760 \\
3080 \\
1320 \\
767 \\
637\end{array}$ & $\begin{array}{l}303 \\
293 \\
338 \\
409 \\
578\end{array}$ & $\begin{array}{l}290 \\
303 \\
306 \\
273 \\
251\end{array}$ & $\begin{array}{l}368 \\
344 \\
331 \\
316 \\
454\end{array}$ & $\begin{array}{l}272 \\
226 \\
214 \\
232 \\
239\end{array}$ & $\begin{array}{l}355 \\
282 \\
236 \\
225 \\
182\end{array}$ & $\begin{array}{l}64 \\
61 \\
68 \\
67 \\
79\end{array}$ & $\begin{array}{l}28 \\
36 \\
43 \\
51 \\
32\end{array}$ & $\begin{array}{l}40 \\
40 \\
43 \\
74 \\
51\end{array}$ \\
\hline $\begin{array}{r}6 \\
7 \\
8 \\
9 \\
10\end{array}$ & $\begin{array}{l}570 \\
450 \\
410 \\
380 \\
800\end{array}$ & $\begin{array}{l}280 \\
285 \\
250 \\
220 \\
220\end{array}$ & $\begin{array}{l}586 \\
461 \\
392 \\
353 \\
318\end{array}$ & $\begin{array}{l}568 \\
507 \\
455 \\
416 \\
394\end{array}$ & $\begin{array}{r}1230 \\
1850 \\
1470 \\
916 \\
684\end{array}$ & $\begin{array}{l}250 \\
242 \\
229 \\
222 \\
213\end{array}$ & $\begin{array}{l}444 \\
402 \\
425 \\
416 \\
375\end{array}$ & $\begin{array}{l}283 \\
257 \\
232 \\
212 \\
185\end{array}$ & $\begin{array}{l}147 \\
124 \\
119 \\
122 \\
108\end{array}$ & $\begin{array}{r}47 \\
45 \\
70 \\
86 \\
124\end{array}$ & $\begin{array}{l}98 \\
45 \\
48 \\
49 \\
29\end{array}$ & $\begin{array}{l}41 \\
37 \\
29 \\
28 \\
28\end{array}$ \\
\hline $\begin{array}{l}11 \\
12 \\
13 \\
14 \\
15\end{array}$ & $\begin{array}{r}1390 \\
1090 \\
663 \\
500 \\
404\end{array}$ & $\begin{array}{l}210 \\
195 \\
185 \\
165 \\
160\end{array}$ & $\begin{array}{l}304 \\
287 \\
269 \\
256 \\
438\end{array}$ & $\begin{array}{l}453 \\
765 \\
717 \\
550 \\
515\end{array}$ & $\begin{array}{r}540 \\
459 \\
413 \\
407 \\
e 365\end{array}$ & $\begin{array}{r}204 \\
463 \\
2010 \\
2380 \\
1860\end{array}$ & $\begin{array}{r}360 \\
331 \\
565 \\
930 \\
1190\end{array}$ & $\begin{array}{l}166 \\
166 \\
159 \\
147 \\
150\end{array}$ & $\begin{array}{r}103 \\
123 \\
115 \\
100 \\
91\end{array}$ & $\begin{array}{l}87 \\
84 \\
73 \\
70 \\
66\end{array}$ & $\begin{array}{l}28 \\
24 \\
27 \\
25 \\
36\end{array}$ & $\begin{array}{r}19 \\
55 \\
138 \\
66 \\
45\end{array}$ \\
\hline $\begin{array}{l}16 \\
17 \\
18 \\
19 \\
20\end{array}$ & $\begin{array}{l}335 \\
300 \\
325 \\
400 \\
390\end{array}$ & $\begin{array}{l}160 \\
165 \\
165 \\
155 \\
150\end{array}$ & $\begin{array}{r}662 \\
615 \\
932 \\
1560 \\
1390\end{array}$ & $\begin{array}{l}622 \\
792 \\
720 \\
564 \\
488\end{array}$ & $\begin{array}{r}\text { e } 330 \\
\text { e290 } \\
396 \\
670 \\
904\end{array}$ & $\begin{array}{r}1310 \\
995 \\
1320 \\
1180 \\
825\end{array}$ & $\begin{array}{r}924 \\
605 \\
436 \\
1140 \\
1540\end{array}$ & $\begin{array}{l}187 \\
206 \\
457 \\
627 \\
444\end{array}$ & $\begin{array}{r}135 \\
122 \\
101 \\
87 \\
81\end{array}$ & $\begin{array}{l}57 \\
57 \\
46 \\
49 \\
52\end{array}$ & $\begin{array}{l}33 \\
51 \\
61 \\
66 \\
50\end{array}$ & $\begin{array}{l}34 \\
28 \\
40 \\
33 \\
30\end{array}$ \\
\hline $\begin{array}{l}21 \\
22 \\
23 \\
24 \\
25\end{array}$ & $\begin{array}{l}330 \\
325 \\
320 \\
310 \\
295\end{array}$ & $\begin{array}{l}150 \\
190 \\
230 \\
235 \\
225\end{array}$ & $\begin{array}{r}1110 \\
1530 \\
1500 \\
898 \\
630\end{array}$ & $\begin{array}{r}458 \\
\mathrm{e} 425 \\
392 \\
356 \\
319\end{array}$ & $\begin{array}{l}745 \\
573 \\
461 \\
382 \\
355\end{array}$ & $\begin{array}{r}579 \\
1300 \\
1870 \\
1690 \\
1030\end{array}$ & $\begin{array}{r}1000 \\
674 \\
524 \\
457 \\
406\end{array}$ & $\begin{array}{l}329 \\
288 \\
274 \\
260 \\
249\end{array}$ & $\begin{array}{r}87 \\
92 \\
109 \\
102 \\
78\end{array}$ & $\begin{array}{l}56 \\
60 \\
61 \\
69 \\
65\end{array}$ & $\begin{array}{l}31 \\
21 \\
24 \\
32 \\
29\end{array}$ & $\begin{array}{l}28 \\
49 \\
66 \\
43 \\
39\end{array}$ \\
\hline $\begin{array}{l}26 \\
27 \\
28 \\
29 \\
30 \\
31\end{array}$ & $\begin{array}{l}255 \\
230 \\
210 \\
210 \\
190 \\
185\end{array}$ & $\begin{array}{r}210 \\
235 \\
1010 \\
1080 \\
770 \\
\cdots\end{array}$ & $\begin{array}{r}512 \\
427 \\
405 \\
980 \\
4240 \\
5550\end{array}$ & $\begin{array}{l}314 \\
293 \\
289 \\
289 \\
319 \\
320\end{array}$ & $\begin{array}{l}321 \\
304 \\
299 \\
\ldots . \\
\ldots . \\
\ldots\end{array}$ & $\begin{array}{r}964 \\
1060 \\
840 \\
641 \\
472 \\
399\end{array}$ & $\begin{array}{l}359 \\
344 \\
330 \\
316 \\
282 \\
\cdots-\end{array}$ & $\begin{array}{l}261 \\
244 \\
211 \\
192 \\
239 \\
391\end{array}$ & $\begin{array}{r}86 \\
78 \\
83 \\
71 \\
72 \\
\cdots\end{array}$ & $\begin{array}{l}53 \\
59 \\
64 \\
53 \\
44 \\
30\end{array}$ & $\begin{array}{l}24 \\
39 \\
46 \\
49 \\
47 \\
48\end{array}$ & $\begin{array}{l}24 \\
18 \\
21 \\
20 \\
25 \\
\cdots\end{array}$ \\
\hline $\begin{array}{l}\text { IOIAL } \\
\text { MEAN } \\
\text { MAX } \\
\text { MIN } \\
\text { CF SM } \\
\text { IN. }\end{array}$ & $\begin{array}{r}13020 \\
420 \\
1390 \\
116 \\
1.32 \\
1.53\end{array}$ & $\begin{array}{r}8260 \\
275 \\
1080 \\
150 \\
.87 \\
.97\end{array}$ & $\begin{array}{r}30355 \\
979 \\
5550 \\
256 \\
3.09 \\
3.56\end{array}$ & $\begin{array}{r}22864 \\
738 \\
4760 \\
289 \\
2.33 \\
2.68\end{array}$ & $\begin{array}{r}16285 \\
582 \\
1850 \\
290 \\
1.83 \\
1.91\end{array}$ & $\begin{array}{r}25971 \\
838 \\
2380 \\
204 \\
2.64 \\
3.05\end{array}$ & $\begin{array}{c}16588 \\
553 \\
1540 \\
282 \\
1.74 \\
1.95\end{array}$ & $\begin{array}{c}7999 \\
258 \\
627 \\
147 \\
.81 \\
.94\end{array}$ & $\begin{array}{c}3816 \\
127 \\
355 \\
71 \\
.40 \\
.45\end{array}$ & $\begin{array}{c}1966 \\
63.4 \\
124 \\
30 \\
.20 \\
.23\end{array}$ & $\begin{array}{c}1250 \\
40.3 \\
98 \\
21 \\
.13 \\
.15\end{array}$ & $\begin{array}{r}1232 \\
41.1 \\
138 \\
18 \\
.13 \\
.14\end{array}$ \\
\hline
\end{tabular}

e Estimated

STATISTICS OF MONIHLY MEAN DATA FUR WATER YEARS 1986 - 1991, BY WATER YEAR (WY)

$\begin{array}{lrrrrrrrrrrrr}\text { MEAN } & 252 & 273 & 421 & 318 & 523 & 526 & 462 & 471 & 234 & 198 & 129 & 243 \\ \text { MAX } & 807 & 688 & 979 & 738 & 1055 & 838 & 757 & 942 & 493 & 337 & 336 & 1053 \\ \text { (WY) } & 1987 & 1986 & 1991 & 1991 & 1990 & 1991 & 1989 & 1990 & 1990 & 1987 & 1990 & 1989 \\ \text { MIN } & 38.8 & 63.2 & 56.8 & 139 & 119 & 219 & 201 & 13.5 & 45.0 & 63.4 & 40.3 & 36.6 \\ \text { (WY) } & 1988 & 1988 & 1989 & 1989 & 1989 & 1987 & 1987 & 1988 & 1988 & 1991 & 1991 & 1987\end{array}$

SUMMARY SIATISIICS

ANNUAL TOIAL

ANMUAL MEAN

HIGHEST ANMUAL MEAN

LOWEST ANNUAL MEAM

HIGHESI DAILY MEAN

LOWEST DAILY MEAN

ANNUAL SEVEN-DAY MINIMUM

INSTANTANEOUS PEAK FLOW

INSTANTAMEOUS PEAK STAGE

ANMUAL RUNOFF (CFSM)

AMNUAL RUNOFF (INCHES)

10 PERCENT EXCELDS

50 PERCENT EXCEEDS

90 PERCENI EXCEEDS
FOR 1990 CALENDAR YEAR

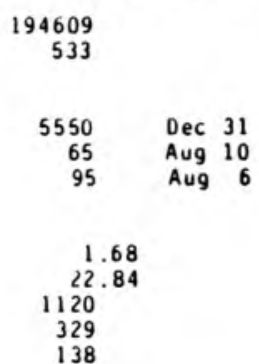

FOR 1991 WATER YEAR

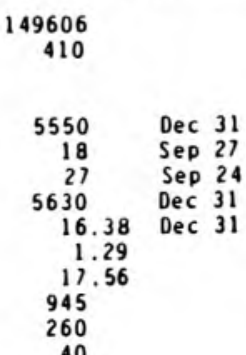

WATER YEARS 1986 - 1991

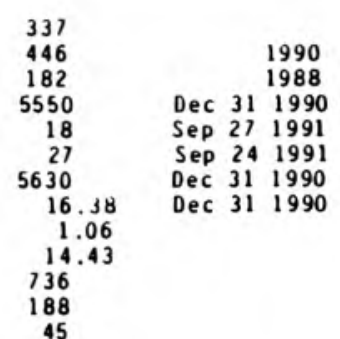




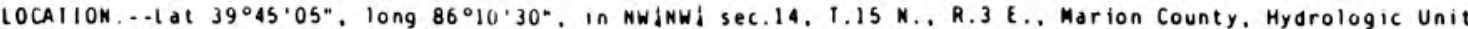
05120201 . On downstrea side of second pier fro right bank of Morris Street bridge in indianapolis, 2.6 a downstrea fro fall Creek. 3.4 i upstrea fro Eagle Creek, 4.0 upstrea fro Indianapolis Power and light Coepany dae. and at ille 230.3 .

DRAINAGE AREA, - - $1.635 . i$

PERIOD OF RECORD.--March 1904 to July 1906 and April 1930 to current year. Gage-height record published in reports of Mational Weather Service for site 1.1 . i upstrea Feb. 8. 1911, to Mar. 25,1913 , and at site 2.3 . upstreas since Oct. 16, 1913. Prior to October 1948, published as West Fork White River at Indianapolis.

REVISED RECORDS.-.WSP 1335: 1932-33,1937,1939-41. WSP 1505: 1938. WSP 2109: Drainage drea.

GAGE. - Water-stage recorder. Datua of gage is $662.26 \mathrm{ft}$ above National Geodetic Vertical Datue of 1929 . March 1904 to July 1906, nonrecording gage at railroad bridge 0.8 i upstrea de datue approxinately 2.9 ft higher. April 1930 to July 20, 1931, nonrecording gage dt Indiandpolis sanitation plant, 2.5 a downtrean at datue $660.00 \mathrm{ft}$ lower. July 21, 1931 to Mar. 2. 1932. nonrecording gage and March 3. 1932. to Septeaber 30. 1960. water-stage recorder at present site at datun $660.00 \mathrm{ft}$ lower.

REMARKS. - Records good except for estiated daily discharges, which are poor. Matural flow affected by regulation of Morse Reservoir and Geist Reservoir, dnd by diversion of municipal water supply by the Indianapolis Water Comany. Stage-discharge relation affected at tiaes by large releases fro Eagle Creek and by variable leakage at Indianapolis Power and light Condany dae.

ExIREMES OUTSIDE PERIOD OF RECORD. - Flood of Mar. 26, 1913, reached a stage of $30.0 \mathrm{ft}$, froe floodearks deterained by Indianapolis Water Comany, discharge, $70,000 \mathrm{ft} / \mathrm{s}$.

DISCHARGE, CUBIC FEEI PER SECONO, WATER YEAR OCTOBER 1990 TO SEPTEMBER 1991 DAILY MEAN VALUES

\begin{tabular}{|c|c|c|c|c|c|c|c|c|c|c|c|c|}
\hline DAY & $\mathrm{OCI}$ & MOV & DEC & JAN & $F E B$ & MAR & APR & MAY & JUW & JUL & AUG & SEP \\
\hline $\begin{array}{l}1 \\
2 \\
3 \\
4 \\
5\end{array}$ & $\begin{array}{r}500 \\
478 \\
509 \\
2260 \\
2740\end{array}$ & $\begin{array}{l}739 \\
711 \\
681 \\
663 \\
943\end{array}$ & $\begin{array}{l}3040 \\
2300 \\
4250 \\
6990 \\
6790\end{array}$ & $\begin{array}{r}35400 \\
24100 \\
9130 \\
4940 \\
3860\end{array}$ & $\begin{array}{l}1370 \\
1300 \\
1430 \\
1690 \\
2680\end{array}$ & $\begin{array}{l}1450 \\
1550 \\
1520 \\
1450 \\
1340\end{array}$ & $\begin{array}{l}2300 \\
2070 \\
1840 \\
1810 \\
1990\end{array}$ & $\begin{array}{l}1420 \\
1290 \\
1200 \\
1310 \\
1290\end{array}$ & $\begin{array}{l}4670 \\
5700 \\
4490 \\
2830 \\
1970\end{array}$ & $\begin{array}{l}306 \\
290 \\
272 \\
246 \\
245\end{array}$ & $\begin{array}{l}\text { e } 100 \\
\text { e } 98.0 \\
\text { e } 130 \\
\text { e } 220 \\
\text { e } 310\end{array}$ & $\begin{array}{r}99 \\
85 \\
83 \\
179 \\
145\end{array}$ \\
\hline $\begin{array}{r}6 \\
7 \\
8 \\
9 \\
10\end{array}$ & $\begin{array}{l}2890 \\
2120 \\
1760 \\
1710 \\
3900\end{array}$ & $\begin{array}{r}1040 \\
1250 \\
1110 \\
945 \\
859\end{array}$ & $\begin{array}{l}4180 \\
2970 \\
2450 \\
2020 \\
1790\end{array}$ & $\begin{array}{l}3280 \\
2800 \\
2530 \\
2230 \\
2020\end{array}$ & $\begin{array}{l}4820 \\
6740 \\
6600 \\
4700 \\
3410\end{array}$ & $\begin{array}{l}1240 \\
1250 \\
1150 \\
1120 \\
1030\end{array}$ & $\begin{array}{l}1990 \\
1880 \\
1940 \\
2350 \\
2110\end{array}$ & $\begin{array}{l}1410 \\
1260 \\
1160 \\
1080 \\
1070\end{array}$ & $\begin{array}{r}1460 \\
1180 \\
978 \\
840 \\
725\end{array}$ & $\begin{array}{l}243 \\
238 \\
234 \\
315 \\
725\end{array}$ & $\begin{array}{r}\text { e 465 } \\
209 \\
186 \\
192 \\
149\end{array}$ & $\begin{array}{r}132 \\
106 \\
81 \\
71 \\
74\end{array}$ \\
\hline $\begin{array}{l}11 \\
12 \\
13 \\
14 \\
15\end{array}$ & $\begin{array}{l}7020 \\
6800 \\
1260 \\
2910 \\
2310\end{array}$ & $\begin{array}{l}815 \\
766 \\
734 \\
693 \\
665\end{array}$ & $\begin{array}{l}1640 \\
1520 \\
1370 \\
1310 \\
2230\end{array}$ & $\begin{array}{l}2260 \\
3220 \\
3840 \\
3000 \\
2680\end{array}$ & $\begin{array}{l}2800 \\
2370 \\
2120 \\
2090 \\
2030\end{array}$ & $\begin{array}{r}991 \\
1900 \\
8290 \\
8480 \\
7320\end{array}$ & $\begin{array}{l}1820 \\
1590 \\
2440 \\
3160 \\
5910\end{array}$ & $\begin{array}{l}1040 \\
1040 \\
1000 \\
1060 \\
1070\end{array}$ & $\begin{array}{l}656 \\
642 \\
597 \\
523 \\
468\end{array}$ & $\begin{array}{r}444 \\
463 \\
359 \\
\text { e290 } \\
\text { e230 }\end{array}$ & $\begin{array}{r}143 \\
116 \\
83 \\
86 \\
100\end{array}$ & $\begin{array}{l}71 \\
143 \\
405 \\
192 \\
134\end{array}$ \\
\hline $\begin{array}{l}16 \\
17 \\
18 \\
19 \\
20\end{array}$ & $\begin{array}{l}1890 \\
1610 \\
1680 \\
2010 \\
2230\end{array}$ & $\begin{array}{l}670 \\
670 \\
651 \\
621 \\
609\end{array}$ & $\begin{array}{l}3960 \\
4680 \\
4810 \\
6900 \\
7550\end{array}$ & $\begin{array}{l}3430 \\
5110 \\
5100 \\
3590 \\
2950\end{array}$ & $\begin{array}{l}1750 \\
1540 \\
2020 \\
2810 \\
4280\end{array}$ & $\begin{array}{l}6530 \\
6610 \\
8240 \\
8700 \\
7870\end{array}$ & $\begin{array}{l}6320 \\
4560 \\
3120 \\
4310 \\
5560\end{array}$ & $\begin{array}{l}1530 \\
1550 \\
2890 \\
3840 \\
3070\end{array}$ & $\begin{array}{l}799 \\
641 \\
640 \\
481 \\
383\end{array}$ & $\begin{array}{l}\text { e2 } 00 \\
\text { el } 80 \\
\text { el } 100 \\
\text { el } 60 \\
\text { el } 52\end{array}$ & $\begin{array}{r}76 \\
138 \\
163 \\
200 \\
190\end{array}$ & $\begin{array}{r}131 \\
109 \\
83 \\
70 \\
58\end{array}$ \\
\hline $\begin{array}{l}21 \\
22 \\
23 \\
24 \\
25\end{array}$ & $\begin{array}{l}1840 \\
1660 \\
1510 \\
1360 \\
1210\end{array}$ & $\begin{array}{l}614 \\
857 \\
819 \\
845 \\
857\end{array}$ & $\begin{array}{l}6310 \\
7370 \\
8430 \\
6070 \\
3920\end{array}$ & $\begin{array}{l}2810 \\
2590 \\
2260 \\
1980 \\
1710\end{array}$ & $\begin{array}{l}4040 \\
3100 \\
2530 \\
2100 \\
1870\end{array}$ & $\begin{array}{l}4990 \\
6200 \\
8120 \\
8510 \\
6680\end{array}$ & $\begin{array}{l}5400 \\
3870 \\
2950 \\
2480 \\
2180\end{array}$ & $\begin{array}{l}1990 \\
1740 \\
1850 \\
2000 \\
1710\end{array}$ & $\begin{array}{r}340 \\
314 \\
418 \\
1110 \\
1010\end{array}$ & $\begin{array}{l}\text { el } 45 \\
\text { el } 50 \\
\text { el } 58 \\
\text { e } 150 \\
\text { e } 141\end{array}$ & $\begin{array}{r}184 \\
219 \\
143 \\
113 \\
89\end{array}$ & $\begin{array}{l}90 \\
244 \\
152 \\
126\end{array}$ \\
\hline $\begin{array}{l}26 \\
27 \\
28 \\
29 \\
30 \\
31\end{array}$ & $\begin{array}{r}1080 \\
969 \\
882 \\
844 \\
796 \\
760\end{array}$ & $\begin{array}{r}784 \\
1480 \\
3850 \\
5150 \\
4700 \\
\cdots\end{array}$ & $\begin{array}{r}\text { e2900 } \\
\text { e2500 } \\
\text { e2350 } \\
4900 \\
26300 \\
36800\end{array}$ & $\begin{array}{l}1590 \\
1510 \\
1450 \\
1390 \\
1530 \\
1390\end{array}$ & $\begin{array}{r}1690 \\
1550 \\
1450 \\
\ldots . \\
\ldots \\
\ldots\end{array}$ & $\begin{array}{l}5270 \\
5730 \\
5970 \\
4550 \\
3240 \\
2620\end{array}$ & $\begin{array}{c}1930 \\
1760 \\
1660 \\
1630 \\
1470 \\
\ldots\end{array}$ & $\begin{array}{l}1590 \\
1410 \\
1200 \\
1100 \\
1220 \\
1520\end{array}$ & $\begin{array}{l}824 \\
525 \\
409 \\
334 \\
308 \\
\cdots\end{array}$ & $\begin{array}{l}\text { e } 137 \\
\text { e } 130 \\
\text { e } 123 \\
\text { el } 117 \\
\text { el } 110 \\
\text { e } 105\end{array}$ & $\begin{array}{r}76 \\
68 \\
89 \\
142 \\
127 \\
132\end{array}$ & $\begin{array}{r}127 \\
104 \\
73 \\
64 \\
81 \\
\cdots\end{array}$ \\
\hline $\begin{array}{l}\text { IOTAL } \\
\text { MEAN } \\
\text { MAX } \\
\text { MIN } \\
\text { CF SM } \\
\text { IN. }\end{array}$ & $\begin{array}{r}64498 \\
2081 \\
7020 \\
478 \\
1.27 \\
1.47\end{array}$ & $\begin{array}{r}35791 \\
1193 \\
5150 \\
609 \\
.73 \\
.81\end{array}$ & $\begin{array}{r}180600 \\
5826 \\
36800 \\
1310 \\
3.56 \\
4.11\end{array}$ & $\begin{array}{r}145680 \\
4699 \\
35400 \\
1390 \\
2.87 \\
3.31\end{array}$ & $\begin{array}{r}76880 \\
2746 \\
6740 \\
1300 \\
1.68 \\
1.75\end{array}$ & $\begin{array}{r}139911 \\
4513 \\
8700 \\
991 \\
2.76 \\
3.18\end{array}$ & $\begin{array}{r}84400 \\
2813 \\
6320 \\
1470 \\
1.72 \\
1.92\end{array}$ & $\begin{array}{r}47910 \\
1545 \\
3840 \\
1000 \\
.95 \\
1.09\end{array}$ & $\begin{array}{r}36265 \\
1209 \\
5700 \\
308 \\
.74 \\
.83\end{array}$ & $\begin{array}{c}7228 \\
233 \\
125 \\
105 \\
.14 \\
.16\end{array}$ & $\begin{array}{r}4736.0 \\
153 \\
465 \\
68 \\
.09 \\
.11\end{array}$ & $\begin{array}{r}3574 \\
119 \\
405 \\
56 \\
.07 \\
.08\end{array}$ \\
\hline
\end{tabular}

e Estiated

SIATISTICS OF MONTHIY MEAN DATA FOR WATER YEARS 1931 - 1991. BY WATER YEAR (WY)

$\begin{array}{lrrrrrrrrrrrr}\text { MEAN } & 424 & 175 & 1405 & 1917 & 2209 & 2769 & 2704 & 1857 & 1368 & 814 & 534 & 410 \\ \text { MAX } & 2081 & 4518 & 5826 & 12120 & 6452 & 6610 & 1777 & 8594 & 7910 & 3149 & 3399 & 5063 \\ \text { (WY) } & 1991 & 1973 & 1991 & 1950 & 1950 & 1963 & 1964 & 1943 & 1958 & 1957 & 1979 & 1989 \\ \text { MIN } & 10.1 & 110 & 77.3 & 78.4 & 178 & 207 & 274 & 113 & 126 & 90.3 & 42.5 & 31.5 \\ \text { (WY) } & 1941 & 1935 & 1964 & 1977 & 1964 & 1941 & 1941 & 1941 & 1988 & 1936 & 1941 & 1941\end{array}$

SUMMARY SIAIISIICS

ANMUAL IOIAL

AMNUAL MEAN

HI GHESI AMNUAL MEAN

LOWEST AMNUAL MEAM

HIGHESI DAILY MEAM

LOWEST DAIIY MEAM

ANHUAL SEVEM-DAY MIMIMUM

INSTAMTANE OUS PEAK FION

INSTANTAMEOUS PEAK STAGE

ANMUAL RUNOFF (CFSM)

ANMUAL RUNOF F (INCHES)

10 PERCENT EXLEEDS

50 PERCENT EXI ILOS

90 PLRLENT EXCLLOS
FOR 1990 CALE MUAR YEAR

FOR 1991 WAIER YEAR

WAIER YEARS 1931 - 199

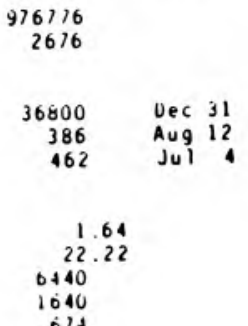

827473.0

368000

$\begin{array}{rr}36800 & \text { Dec } 31 \\ 56 & \text { Sep } 21 \\ 86 & \text { Sep } 16 \\ 38000 & \text { Dec } 31\end{array}$

20.51 Dec 31

1.39
18.83

5320

1410
127

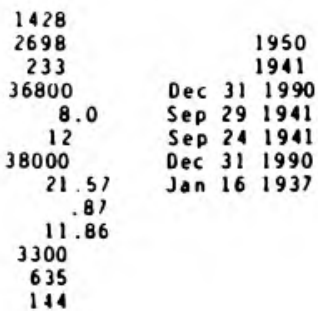




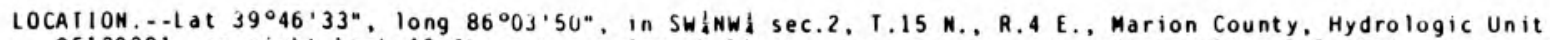
05120201 , on right bank $46 \mathrm{ft}$ upstredi from Arlington Avenue bridge in Indianapolis. 0.5 a downstrea frum small left-bank tributary, and at mile $7,9$. DRAINAGE AREA...7.58

PERIOD OF RECORO.--Decenber 1959 to current year.

REVISED RECORDS.-.WSP 2109: Drainage dred.

GAGE.- Water-stage recorder. Datun of gage is $780.00 \mathrm{ft}$ above Mational Geodetic Vertical Datum of 1929 (levels by State of Indiana, Departaent of Natural Resources).

REMARKS. - Records good except those for estimated daily discharges, which are fair.

EXIREMES OUISIDE PERIOD OF RECORD. - Flood in May 1956 reached a stage of 16.0 ft, from inforation by local resident.

DISCHARGE, CUBIC FEET PER SECOND, WATER YEAR OCTOBER 1990 TO SEPTEMBER 1991 DAILY MEAN VALUES

\begin{tabular}{|c|c|c|c|c|c|c|c|c|c|c|c|c|}
\hline DAY & $\mathrm{OCT}$ & NOV & DEC & JAN & $F \in B$ & MAR & APR & MAY & JUN & JUL & AUG & SEP \\
\hline $\begin{array}{l}1 \\
2 \\
3 \\
4 \\
5\end{array}$ & $\begin{array}{r}1.97 \\
32.1 \\
105 \\
6.0\end{array}$ & $\begin{array}{l}.99 \\
1.5 \\
2.7 \\
3.6 \\
30\end{array}$ & $\begin{array}{l}4.3 \\
3.2 \\
69 \\
11 \\
6.2\end{array}$ & $\begin{array}{r}11 \\
7.4 \\
5.3 \\
+3.9 \\
\mathrm{e} 3.6\end{array}$ & $\begin{array}{r}7.0 \\
7.5 \\
6.1 \\
5.6 \\
22\end{array}$ & $\begin{array}{l}4.8 \\
5.5 \\
2.2 \\
1.3 \\
1.2\end{array}$ & $\begin{array}{r}2.1 \\
1.5 \\
1.3 \\
11 \\
6.6\end{array}$ & $\begin{array}{c}1.4 \\
.87 \\
.93 \\
6.3 \\
21\end{array}$ & $\begin{array}{l}.62 \\
.60 \\
.56 \\
.47 \\
.46\end{array}$ & $\begin{array}{l}1.2 \\
.68 \\
1.3 \\
.57 \\
.68\end{array}$ & $\begin{array}{l}.22 \\
.20 \\
.22 \\
.30 \\
.34\end{array}$ & $\begin{array}{c}.20 \\
.14 \\
.92 \\
3.2 \\
.27\end{array}$ \\
\hline $\begin{array}{r}6 \\
7 \\
8 \\
9 \\
10\end{array}$ & $\begin{array}{l}2.7 \\
19 \\
6.0 \\
23 \\
66\end{array}$ & $\begin{array}{l}4.4 \\
2.3 \\
1.7 \\
3.0 \\
2.4\end{array}$ & $\begin{array}{l}4.8 \\
3.4 \\
2.9 \\
2.3 \\
2.1\end{array}$ & $\begin{array}{l}\mathrm{e} 3.4 \\
\mathrm{e} 3.2 \\
\mathrm{e} 3.1 \\
\mathrm{e} 3.0 \\
\mathrm{e} 2.9\end{array}$ & $\begin{array}{r}104 \\
27 \\
11 \\
7.0 \\
4.9\end{array}$ & $\begin{array}{l}3.6 \\
1.3 \\
1.0 \\
.92 \\
.86\end{array}$ & $\begin{array}{l}2.4 \\
1.6 \\
9.5 \\
3.1 \\
1.5\end{array}$ & $\begin{array}{r}6.4 \\
1.4 \\
.99 \\
.84 \\
.93\end{array}$ & $\begin{array}{l}.43 \\
.39 \\
.38 \\
.40 \\
.38\end{array}$ & $\begin{array}{c}.47 \\
1.58 \\
30^{.9}\end{array}$ & $\begin{array}{r}42 \\
1.7 \\
9.5 \\
2.0 \\
.85\end{array}$ & $\begin{array}{l}.22 \\
.15 \\
.13 \\
.17 \\
.26\end{array}$ \\
\hline $\begin{array}{l}11 \\
12 \\
13 \\
14 \\
15\end{array}$ & $\begin{array}{r}11 \\
5.3 \\
3.4 \\
2.5 \\
2.3\end{array}$ & $\begin{array}{l}1.4 \\
1.2 \\
1.1 \\
1.7 \\
1.2\end{array}$ & $\begin{array}{r}1.9 \\
1.8 \\
1.6 \\
1.4 \\
59\end{array}$ & $\begin{array}{r}37 \\
14 \\
7.3 \\
5.7 \\
8.3\end{array}$ & $\begin{array}{l}3.4 \\
2.6 \\
5.9 \\
6.7 \\
3.2\end{array}$ & $\begin{array}{l}156^{.86} \\
149 \\
20 \\
9.1\end{array}$ & $\begin{array}{l}1.2 \\
1.1 \\
61 \\
15 \\
33\end{array}$ & $\begin{array}{l}2.1 \\
.89 \\
.85 \\
.82 \\
.73\end{array}$ & $\begin{array}{l}.41 \\
.43 \\
.36 \\
.37 \\
.39\end{array}$ & $\begin{array}{r}1.2 \\
14.91 \\
.52 \\
.36\end{array}$ & $\begin{array}{l}.35 \\
.27 \\
.26 \\
.26 \\
.23\end{array}$ & $\begin{array}{l}56^{.25} \\
17 \\
1.4 \\
.51\end{array}$ \\
\hline $\begin{array}{l}16 \\
17 \\
18 \\
19 \\
20\end{array}$ & $\begin{array}{r}1.9 \\
2.1 \\
27 \\
2.5 \\
1.5\end{array}$ & $\begin{array}{l}1.7 \\
1.3 \\
.99 \\
1.0 \\
.97\end{array}$ & $\begin{array}{l}8.4 \\
27 \\
81 \\
21 \\
9.5\end{array}$ & $\begin{array}{r}13 \\
11 \\
5.8 \\
\in 4.8 \\
\mathrm{e} 4.0\end{array}$ & $\begin{array}{l}2.0 \\
1.9 \\
46 \\
26 \\
12\end{array}$ & $\begin{array}{l}5.7 \\
51 \\
23 \\
9.0 \\
5.4\end{array}$ & $\begin{array}{r}8.1 \\
5.6 \\
2.8 \\
127 \\
18\end{array}$ & $\begin{array}{l}15 \\
2.6 \\
69 \\
4.9 \\
1.5\end{array}$ & $\begin{array}{l}8.0 \\
.75 \\
.42 \\
.36 \\
.30\end{array}$ & $\begin{array}{l}.45 \\
.28 \\
.30 \\
.31 \\
.30\end{array}$ & $\begin{array}{l}.17 \\
7.0 \\
.81 \\
7.6 \\
4.4\end{array}$ & $\begin{array}{l}.56 \\
.32 \\
.31 \\
.31 \\
.26\end{array}$ \\
\hline $\begin{array}{l}21 \\
22 \\
23 \\
24 \\
25\end{array}$ & $\begin{array}{r}1.2 \\
1.6 \\
.77 \\
.69\end{array}$ & $\begin{array}{r}1.2 \\
42 \\
5.5 \\
3.4 \\
2.7\end{array}$ & $\begin{array}{l}54 \\
21 \\
10 \\
6.7 \\
4.8\end{array}$ & $\begin{array}{l}\text { e } 3.3 \\
\text { e2. } \\
\text { e2.4 } \\
\text { e2 } 2.1 \\
\text { e1. } 18\end{array}$ & $\begin{array}{l}6.6 \\
4.4 \\
2.8 \\
2.4 \\
1.9\end{array}$ & $\begin{array}{r}4.0 \\
174 \\
37 \\
12 \\
7.0\end{array}$ & $\begin{array}{l}8.4 \\
5.1 \\
6.5 \\
4.4 \\
2.2\end{array}$ & $\begin{array}{l}.99 \\
1.1 \\
2.5 \\
1.1 \\
2.0\end{array}$ & $\begin{array}{l}.28 \\
.26 \\
.36 \\
.22 \\
.25\end{array}$ & $\begin{array}{l}.57 \\
.36 \\
.43 \\
.24 \\
.22\end{array}$ & $\begin{array}{l}.45 \\
.28 \\
.20 \\
.13 \\
.30\end{array}$ & $\begin{array}{c}24^{.27} \\
8.7 \\
1.2 \\
.59\end{array}$ \\
\hline $\begin{array}{l}26 \\
27 \\
28 \\
29 \\
30 \\
31\end{array}$ & $\begin{array}{l}.70 \\
.83 \\
1.6 \\
1.6 \\
1.2 \\
1.0\end{array}$ & $\begin{array}{c}2.5 \\
46 \\
104 \\
12 \\
6.2 \\
\ldots\end{array}$ & $\begin{array}{r}3.8 \\
\text { e3.1 } \\
\text { e2.8 } \\
201 \\
379 \\
24\end{array}$ & $\begin{array}{c}\text { e1.6 } \\
\text { e1.5 } \\
\text { e3.0 } \\
5.6 \\
16 \\
4.7\end{array}$ & $\begin{array}{l}1.5 \\
1.4 \\
1.3 \\
\ldots . \\
\ldots . \\
\ldots\end{array}$ & $\begin{array}{l}67 \\
15 \\
7.4 \\
4.8 \\
3.2 \\
2.6\end{array}$ & $\begin{array}{l}1.9 \\
1.4 \\
1.7 \\
2.7 \\
1.1 \\
\ldots\end{array}$ & $\begin{array}{c}26 \\
2.2 \\
1.0 \\
.93 \\
1.4 \\
.71\end{array}$ & $\begin{array}{c}62 \\
1.8 \\
.72 \\
.47 \\
2.0 \\
\ldots\end{array}$ & $\begin{array}{l}.21 \\
.19 \\
.51 \\
.28 \\
.28 \\
.18\end{array}$ & $\begin{array}{c}.20 \\
.19 \\
2.3 \\
11.34 \\
1.4\end{array}$ & $\begin{array}{c}1.5 \\
.32 \\
.19 \\
.21 \\
.22 \\
. .\end{array}$ \\
\hline $\begin{array}{l}\text { TOTAL } \\
\text { MEAN } \\
\text { MAX } \\
\text { MIN } \\
\text { CF SM } \\
\text { IN. }\end{array}$ & $\begin{array}{r}344.46 \\
11.1 \\
105 \\
.69 \\
1.47 \\
1.69\end{array}$ & $\begin{array}{r}290.65 \\
9.69 \\
104 \\
.97 \\
1.28 \\
1.43\end{array}$ & $\begin{array}{r}1032.0 \\
33.3 \\
379 \\
1.4 \\
4.39 \\
5.06\end{array}$ & $\begin{array}{r}202.5 \\
6.53 \\
31 \\
1.5 \\
.86 \\
.99\end{array}$ & $\begin{array}{r}334.1 \\
11.9 \\
104 \\
1.3 \\
1.57 \\
1.64\end{array}$ & $\begin{array}{r}785.74 \\
25.3 \\
174 \\
.86 \\
3.34 \\
3.86\end{array}$ & $\begin{array}{c}348.8 \\
11.6 \\
127 \\
1.1 \\
1.53 \\
1.71\end{array}$ & $\begin{array}{c}179.38 \\
5.79 \\
69 \\
.71 \\
.76 \\
.88\end{array}$ & $\begin{array}{c}84.84 \\
2.83 \\
62 \\
.22 \\
.37 \\
.42\end{array}$ & $\begin{array}{c}59.88 \\
1.93 \\
30 \\
.18 \\
.25 \\
.29\end{array}$ & $\begin{array}{c}95.47 \\
3.08 \\
42 \\
.13 \\
.41 \\
.47\end{array}$ & $\begin{array}{c}119.78 \\
3.99 \\
56 \\
.13 \\
.53 \\
.59\end{array}$ \\
\hline
\end{tabular}

e Estinated

STATISIICS OF MONIHIY MEAN DATA FOR WAIER YEARS 1960 - 1991, BY WATER YEAR (WY)

$\begin{array}{lcccccccccccc}\text { MEAN } & 4.32 & 7.63 & 9.48 & 1.33 & 9.49 & 13.8 & 11.0 & 9.33 & 6.40 & 8.50 & 5.28 & 3.96 \\ \text { MAX } & 27.5 & 33.2 & 33.3 & 25.0 & 25.7 & 42.3 & 295 & 28.6 & 21.6 & 33.8 & 21.3 & 23.2 \\ \text { (WY) } & 1987 & 1986 & 1991 & 1969 & 1971 & 1963 & 1901 & 1981 & 1973 & 1979 & 1979 & 1989 \\ \text { MIN } & .38 & 1.28 & .72 & .45 & 1.11 & 2.08 & 1.61 & 1.12 & .69 & .61 & .67 & .49 \\ \text { (WY) } & 1964 & 1964 & 1964 & 1977 & 1978 & 1969 & 1971 & 1964 & 1967 & 1967 & 1967 & 1967\end{array}$

SUMMARY STAIISTICS

\section{ANNUAL TOTAL}

ANNUAL MEAN

HIGHESI ANMUAL MEAM

LOWEST ANNUAL MEAN

HIGHEST DAII Y MEAN

LOWEST DAILY MEAM

ANNUAL SEVEN-DAY MINIMUM

INSTANIANEOUS PEAK FLOW

INSTANTANEOUS PEAK STAGE

AM NUAL RUMOFF (CFSM)

ANMUAL RUNOFF (INCHES)

10 PERLENT EXLEIOS

50 PERCENI EXCEEDS

90 PERCENT EXCEEDS
FOR 1990 CALENDAR YEAR

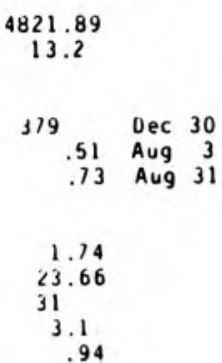

FOR 1991 WATER YEAR

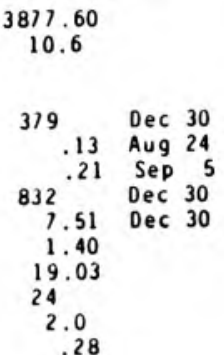

WAIER YEARS 1960 - 1991

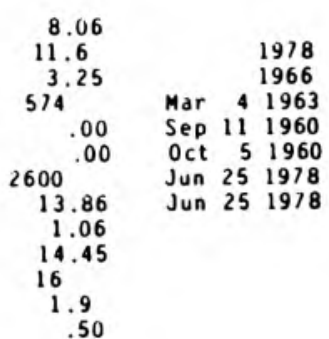


LOCATION.--Lat $39^{\circ} 43^{\prime} 45^{\prime \prime}$, long $86^{\circ} \mathrm{Gl} \cdot 14^{\prime \prime}$, In NWdSW sec. 20 , T.15 N., R.4 E., Marion County, Hydrologic Unit 05120201 , on left bank $80 \mathrm{ft}$ upstrean from Keystone Avenue bridge and west edge of Sarah Shank Golf Course in Indianapolis, and at ile 1,8

DRAINAGE AREA ...4.40 $\mathrm{i}^{2}$

PERIOD OF RECORD.--October 1970 to current yedr.

GAGE. - Water-stage recorder. Datum of gage is $735.00 \mathrm{ft}$ above National Geodetic Vertical Datue of 1929.

REMARKS.--Records good except for estimated daily discharges, which are fair.

DISCHARGE, CUBIL FEET PER SECOND, WATER YEAR OCTOBER 1990 TO SEPIEMBER 1991 DAILY MEAN VALUES

\begin{tabular}{|c|c|c|c|c|c|c|c|c|c|c|c|c|}
\hline DAY & $O C T$ & NOV & DEC & JAN & FEB & MAR & APR & MAY & JUN & JUL & $A \cup G$ & SEP \\
\hline $\begin{array}{l}1 \\
2 \\
3 \\
4 \\
5\end{array}$ & $\begin{array}{c}1.1 \\
1.1 \\
8.9 \\
34 \\
4.0\end{array}$ & $\begin{array}{l}2.0 \\
2.0 \\
1.9 \\
1.8 \\
8.4\end{array}$ & $\begin{array}{c}3.4 \\
2.9 \\
20 \\
5.5 \\
3.9\end{array}$ & $\begin{array}{r}15 \\
12 \\
10 \\
8.5 \\
\text { e8.4 }\end{array}$ & $\begin{array}{c}8.4 \\
10 \\
7.9 \\
7.7 \\
14\end{array}$ & $\begin{array}{l}8.5 \\
9.3 \\
7.2 \\
7.0 \\
6.9\end{array}$ & $\begin{array}{l}\text { e8.4 } \\
\text { e7.7 } \\
e 8.3 \\
\text { e13 } \\
10\end{array}$ & $\begin{array}{l}2.5 \\
2.3 \\
2.3 \\
3.4 \\
9.4\end{array}$ & $\begin{array}{l}1.9 \\
1.7 \\
1.7 \\
1.7 \\
1.6\end{array}$ & $\begin{array}{l}.73 \\
1.1 \\
.89 \\
.78 \\
.69\end{array}$ & $\begin{array}{l}.63 \\
.63 \\
.61 \\
.58 \\
.59\end{array}$ & $\begin{array}{c}.78 \\
.71 \\
.74 \\
1.5 \\
.77\end{array}$ \\
\hline $\begin{array}{r}6 \\
7 \\
8 \\
9 \\
10\end{array}$ & $\begin{array}{r}3.1 \\
7.4 \\
4.1 \\
9.6 \\
24\end{array}$ & $\begin{array}{l}2.3 \\
1.9 \\
1.8 \\
2.2 \\
2.0\end{array}$ & $\begin{array}{l}3.5 \\
3.0 \\
2.6 \\
2.3 \\
2.2\end{array}$ & $\begin{array}{l}\text { e } 7.8 \\
\text { e7. } \\
\text { e } 7.0 \\
\text { e6.7 } \\
\text { e } 8.0\end{array}$ & $\begin{array}{r}38 \\
21 \\
14 \\
11 \\
9.6\end{array}$ & $\begin{array}{l}8.5 \\
7.0 \\
6.6 \\
6.2 \\
5.9\end{array}$ & $\begin{array}{r}8.5 \\
7.7 \\
11 \\
8.7 \\
7.5\end{array}$ & $\begin{array}{l}4.6 \\
2.4 \\
2.1 \\
2.0 \\
2.0\end{array}$ & $\begin{array}{l}1.5 \\
1.5 \\
1.4 \\
1.3 \\
1.3\end{array}$ & $\begin{array}{l}.64 \\
.63 \\
.14 \\
.55 \\
5.0\end{array}$ & $\begin{array}{l}9.5 \\
1.2 \\
2.7 \\
1.3 \\
1.0\end{array}$ & $\begin{array}{l}.72 \\
.68 \\
.56 \\
.62 \\
.85\end{array}$ \\
\hline $\begin{array}{l}11 \\
12 \\
13 \\
14 \\
15\end{array}$ & $\begin{array}{l}6.5 \\
4.5 \\
3.5 \\
2.9 \\
2.6\end{array}$ & $\begin{array}{l}1.8 \\
1.6 \\
1.6 \\
1.6 \\
1.6\end{array}$ & $\begin{array}{l}2.1 \\
2.0 \\
1.9 \\
2.0 \\
14\end{array}$ & $\begin{array}{c}21 \\
15 \\
11 \\
9.6 \\
10\end{array}$ & $\begin{array}{r}8.6 \\
8.0 \\
9.4 \\
e 9.0 \\
\text { e8.3 }\end{array}$ & $\begin{array}{l}5.7 \\
48 \\
56 \\
20 \\
\text { e15 }\end{array}$ & $\begin{array}{l}7.2 \\
6.8 \\
26 \\
13 \\
22\end{array}$ & $\begin{array}{l}4.5 \\
2.9 \\
1.8 \\
8.8 \\
3.1\end{array}$ & $\begin{array}{l}1.6 \\
1.5 \\
1.3 \\
1.3 \\
1.3\end{array}$ & $\begin{array}{l}1.1 \\
4.9 \\
.83 \\
.64 \\
.64\end{array}$ & $\begin{array}{l}.80 \\
.81 \\
.87 \\
.84 \\
.83\end{array}$ & $\begin{array}{c}11 \\
4.2 \\
.95 \\
.73\end{array}$ \\
\hline $\begin{array}{l}16 \\
17 \\
18 \\
19 \\
20\end{array}$ & $\begin{array}{l}2.6 \\
2.6 \\
9.1 \\
2.7 \\
2.3\end{array}$ & $\begin{array}{l}1.8 \\
1.6 \\
1.5 \\
1.5 \\
1.5\end{array}$ & $\begin{array}{l}3.6 \\
11 \\
28 \\
9.1 \\
5.6\end{array}$ & $\begin{array}{r}14 \\
13 \\
10 \\
9.0 \\
8.7\end{array}$ & $\begin{array}{c}\text { e7.7 } \\
7.2 \\
23 \\
18 \\
14\end{array}$ & $\begin{array}{l}\text { e8.9 } \\
\text { e21 } \\
\text { e21 } \\
\text { e11 } \\
\text { e7. } 8\end{array}$ & $\begin{array}{c}11 \\
9.0 \\
8.3 \\
43 \\
9.2\end{array}$ & $\begin{array}{r}4.8 \\
3.4 \\
13 \\
2.9 \\
2.4\end{array}$ & $\begin{array}{l}4.5 \\
1.4 \\
1.3 \\
1.3 \\
1.2\end{array}$ & $\begin{array}{l}.60 \\
.59 \\
.59 \\
.55 \\
.53\end{array}$ & $\begin{array}{l}.76 \\
3.3 \\
1.3 \\
2.5 \\
1.1\end{array}$ & $\begin{array}{l}.75 \\
.93 \\
.99 \\
.92 \\
.92\end{array}$ \\
\hline $\begin{array}{l}21 \\
22 \\
23 \\
24 \\
25\end{array}$ & $\begin{array}{l}2.0 \\
5.5 \\
2.7 \\
2.3 \\
2.3\end{array}$ & $\begin{array}{r}1.5 \\
13 \\
2.9 \\
2.4 \\
2.0\end{array}$ & $\begin{array}{r}19 \\
9.7 \\
6.1 \\
\mathrm{e} 5.0 \\
4.0\end{array}$ & $\begin{array}{l}8.1 \\
7.8 \\
7.3 \\
7.0 \\
6.4\end{array}$ & $\begin{array}{r}11 \\
9.5 \\
8.5 \\
8.0 \\
7.6\end{array}$ & $\begin{array}{l}\text { e6.9 } \\
\text { e } 76 \\
\text { e } 26 \\
\text { e } 15 \\
\text { e } 9.6\end{array}$ & $\begin{array}{l}6.1 \\
4.8 \\
5.1 \\
4.1 \\
3.2\end{array}$ & $\begin{array}{r}2.4 \\
11 \\
7.3 \\
3.5 \\
3.3\end{array}$ & $\begin{array}{l}1.2 \\
1.1 \\
.95 \\
.94 \\
1.1\end{array}$ & $\begin{array}{l}.50 \\
.53 \\
.64 \\
.73 \\
.70\end{array}$ & $\begin{array}{l}.80 \\
.78 \\
.74 \\
.72 \\
.68\end{array}$ & $\begin{array}{l}.85 \\
4.3 \\
2.0 \\
.71 \\
.17\end{array}$ \\
\hline $\begin{array}{l}26 \\
27 \\
28 \\
29 \\
30 \\
31\end{array}$ & $\begin{array}{l}2.3 \\
2.2 \\
2.0 \\
2.0 \\
2.1 \\
2.0\end{array}$ & $\begin{array}{l}2.2 \\
14 \\
33 \\
5.7 \\
4.1 \\
\cdots\end{array}$ & $\begin{array}{l}3.5 \\
3.2 \\
3.2 \\
70 \\
201 \\
24\end{array}$ & $\begin{array}{r}6.1 \\
9.3 \\
6.2 \\
7.1 \\
12 . \\
7.5\end{array}$ & $\begin{array}{l}7.4 \\
7.4 \\
7.1 \\
\ldots \\
\ldots \\
\ldots\end{array}$ & $\begin{array}{l}\text { e } 34 \\
\text { e13 } \\
\text { e11 } \\
\text { e10 } \\
\text { e9.6 } \\
\text { e8.8 }\end{array}$ & $\begin{array}{l}3.2 \\
3.0 \\
3.0 \\
3.3 \\
2.6 \\
\ldots\end{array}$ & $\begin{array}{r}12 \\
3.3 \\
2.5 \\
2.4 \\
2.3 \\
2.0\end{array}$ & $\begin{array}{c}1.5 \\
.90 \\
.75 \\
.73 \\
.73 \\
\ldots\end{array}$ & $\begin{array}{l}.67 \\
.62 \\
.54 \\
.56 \\
.67 \\
.65\end{array}$ & $\begin{array}{c}13.69 \\
1.9 \\
1.6 \\
1.2\end{array}$ & $\begin{array}{l}.68 \\
.66 \\
.64 \\
.60 \\
.59 \\
\cdots\end{array}$ \\
\hline $\begin{array}{l}\text { IOIAL } \\
\text { MEAN } \\
\text { MAX } \\
\text { MIN } \\
\text { CF SM } \\
\text { IN. }\end{array}$ & $\begin{array}{r}164.0 \\
5.29 \\
34 \\
1.1 \\
1.20 \\
1.39\end{array}$ & $\begin{array}{r}123.2 \\
4.11 \\
33 \\
1.5 \\
.93 \\
1.04\end{array}$ & $\begin{array}{r}477.3 \\
15.4 \\
201 \\
1.9 \\
3.50 \\
4.04\end{array}$ & $\begin{array}{c}296.8 \\
9.57 \\
21 \\
6.1 \\
2.18 \\
2.51\end{array}$ & $\begin{array}{r}321.3 \\
11.5 \\
38 \\
7.1 \\
2.61 \\
2.72\end{array}$ & $\begin{array}{r}507.4 \\
16.4 \\
76 \\
5.7 \\
3.72 \\
4.29\end{array}$ & $\begin{array}{r}284.7 \\
9.49 \\
43 \\
2.6 \\
2.16 \\
2.41\end{array}$ & $\begin{array}{r}132.6 \\
4.28 \\
13 \\
1.8 \\
.97 \\
1.12\end{array}$ & $\begin{array}{c}42.20 \\
1.41 \\
4.5 \\
.73 \\
.32 \\
.36\end{array}$ & $\begin{array}{c}29.53 \\
.95 \\
5.0 \\
.50 \\
.22 \\
.25\end{array}$ & $\begin{array}{c}54.76 \\
1.77 \\
13 \\
.58 \\
.40 \\
.46\end{array}$ & $\begin{array}{c}41.89 \\
1.40 \\
11 \\
.56 \\
.32 \\
.35\end{array}$ \\
\hline
\end{tabular}

e Estimated

SIATISIICS OF MONIHLY MEAN DAIA FOR WAIEK YLARS 1911 - 1991, BY WAIER YEAR (WY)

\begin{tabular}{|c|c|c|c|c|c|c|c|c|c|c|c|c|}
\hline $\begin{array}{l}\text { MEAN } \\
\text { MAX } \\
\text { (WY) } \\
\text { MI N } \\
(W Y)\end{array}$ & $\begin{array}{l}3.20 \\
12.5 \\
1987 \\
1.37 \\
1983\end{array}$ & $\begin{array}{l}5.03 \\
16.2 \\
1986 \\
1.57 \\
1982\end{array}$ & $\begin{array}{l}6.12 \\
15.4 \\
1991 \\
1.49 \\
1977\end{array}$ & $\begin{array}{r}4.55 \\
10.0 \\
1975 \\
.82 \\
1977\end{array}$ & $\begin{array}{l}6.78 \\
16.0 \\
1971 \\
1.72 \\
1978\end{array}$ & $\begin{array}{l}8.43 \\
16.4 \\
1991 \\
2.10 \\
1981\end{array}$ & $\begin{array}{l}6.61 \\
12.2 \\
1972 \\
2.31 \\
1976\end{array}$ & $\begin{array}{l}6.66 \\
18.9 \\
1981 \\
1.76 \\
1988\end{array}$ & $\begin{array}{l}4.34 \\
11.4 \\
1973 \\
1.32 \\
1988\end{array}$ & $\begin{array}{r}5.03 \\
13.7 \\
1919 \\
.95 \\
1991\end{array}$ & $\begin{array}{l}3.89 \\
11.6 \\
1979 \\
1.23 \\
1983\end{array}$ & $\begin{array}{r}2.81 \\
11.5 \\
1989 \\
.93 \\
1983\end{array}$ \\
\hline
\end{tabular}

SUMMARY SIATISIICS

ANNUAL TOTAL

ANNUAL MEAN

HIGHEST ANNUAL MEAK

LOWEST ANMUAL MEAN

HIGHESI DAILY MEAN

LOWEST OAILY MEAN

ANNUAL SEVEN-DAY MINIMUM

IMSTANIANEOUS PEAK FIOW

INSIANTANEOUS PEAK STAGE

ANHUAL RUNOFF (CFSM)

ANNUAL RUNOFF (INCHES)

10 PERCENT EXLEEDS

50 PERCENT EXCEEDS

90 PERCENT EXCEEOS
FOR 1990 CALENDAR YEAR

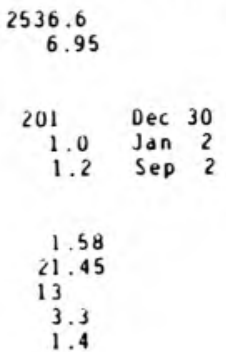

FOR 1991 WATER YEAR

$$
\begin{array}{r}
2475.68 \\
6.78
\end{array}
$$

201 Dec 30

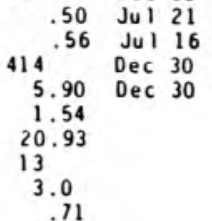

WAIER YEARS $1971 \cdot 1991$

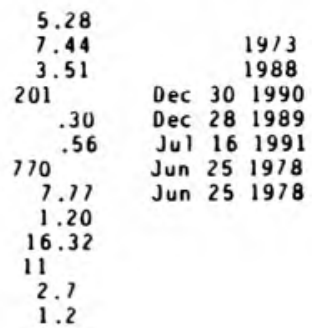




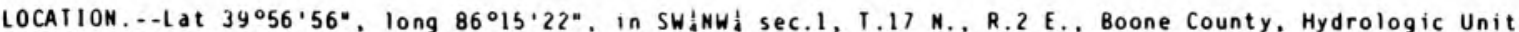
05120201 , on downstreas side of second pier from right bank of bridge on State Highway 334 at $Z$ ionsuille, $200 \mathrm{ft}$ upstrea fro long Branch, and at ile 24.1.

ORAI NAGE AREA, $-103=i^{2}$

PERIOD OF RECORD.--OCtober 1957 to current year.

REVISED RECORDS...WSP 2109: Drainage area.

GAGE.--Water-stage recorder. Datus of gage is $816.85 \mathrm{ft}$ above National Geodetic Vertical Datua of 1929 . Prior to Oct. 9, 1957 , nonrecording gage at sane site and datue.

REMARKS. - Records good, except those for estinated daily discharges, which are poor. Low flow affected by the Zionsville well field located on the right bank below the gage betore 1989.

EXIEMES OUISIDE PERIOD OF RECORD.--Flood of June 28, 1957, reached a stage of $19.20 \mathrm{ft}$. fron floodark.

OISCHARGE, CUBIC FEET PER SECONO, WATER YEAR OCTOBER 1990 TO SEPIEMBER 1991

\begin{tabular}{|c|c|c|c|c|c|c|c|c|c|c|c|c|}
\hline DAY & $O C \mathrm{~T}$ & NOV & DEC & JAN & FEB & MAR & $A P R$ & MAY & JUN & JUL & $A \cup G$ & SEP \\
\hline $\begin{array}{l}1 \\
2 \\
3 \\
4 \\
5\end{array}$ & $\begin{array}{l}1.3 \\
1.1 \\
1.5 \\
37 \\
15\end{array}$ & $\begin{array}{l}17 \\
20 \\
16 \\
14 \\
46\end{array}$ & $\begin{array}{r}125 \\
89 \\
905 \\
467 \\
246\end{array}$ & $\begin{array}{r}427 \\
239 \\
167 \\
\text { e1 } 20 \\
\text { e1 } 00\end{array}$ & $\begin{array}{r}e 80 \\
e 80 \\
e 100 \\
e 130 \\
172\end{array}$ & $\begin{array}{l}56 \\
78 \\
76 \\
66 \\
57\end{array}$ & $\begin{array}{l}84 \\
72 \\
68 \\
70 \\
91\end{array}$ & $\begin{array}{l}52 \\
48 \\
44 \\
50 \\
50\end{array}$ & $\begin{array}{r}110 \\
72 \\
84 \\
64 \\
43\end{array}$ & $\begin{array}{l}3.5 \\
3.1 \\
2.8 \\
2.4 \\
2.4\end{array}$ & $\begin{array}{l}.07 \\
.00 \\
.00 \\
.00 \\
.00\end{array}$ & $\begin{array}{l}.00 \\
.00 \\
.00 \\
.00 \\
.00\end{array}$ \\
\hline $\begin{array}{r}6 \\
7 \\
8 \\
9 \\
10\end{array}$ & $\begin{array}{r}6.4 \\
7.7 \\
19 \\
55 \\
729\end{array}$ & $\begin{array}{l}90 \\
52 \\
37 \\
32 \\
29\end{array}$ & $\begin{array}{r}182 \\
139 \\
110 \\
91 \\
80\end{array}$ & $\begin{array}{r}88 \\
77 \\
70 \\
+64 \\
61\end{array}$ & $\begin{array}{l}346 \\
358 \\
211 \\
157 \\
129\end{array}$ & $\begin{array}{l}59 \\
51 \\
43 \\
41 \\
39\end{array}$ & $\begin{array}{r}82 \\
73 \\
104 \\
153 \\
96\end{array}$ & $\begin{array}{l}50 \\
43 \\
38 \\
36 \\
36\end{array}$ & $\begin{array}{l}33 \\
27 \\
24 \\
22 \\
19\end{array}$ & $\begin{array}{l}2.3 \\
2.2 \\
2.0 \\
1.9 \\
2.1\end{array}$ & $\begin{array}{l}.24 \\
.57 \\
.52 \\
.66 \\
.65\end{array}$ & $\begin{array}{l}.00 \\
.00 \\
.00 \\
.00 \\
.00\end{array}$ \\
\hline $\begin{array}{l}11 \\
12 \\
13 \\
14 \\
15\end{array}$ & $\begin{array}{r}374 \\
191 \\
116 \\
79 \\
57\end{array}$ & $\begin{array}{l}24 \\
19 \\
17 \\
15 \\
15\end{array}$ & $\begin{array}{r}70 \\
66 \\
58 \\
47 \\
461\end{array}$ & $\begin{array}{l}152 \\
257 \\
145 \\
123 \\
223\end{array}$ & $\begin{array}{r}96 \\
77 \\
76 \\
84 \\
e 86\end{array}$ & $\begin{array}{r}35 \\
298 \\
2650 \\
898 \\
481\end{array}$ & $\begin{array}{r}72 \\
62 \\
259 \\
386 \\
453\end{array}$ & $\begin{array}{r}34 \\
34 \\
34 \\
88 \\
134\end{array}$ & $\begin{array}{l}19 \\
19 \\
18 \\
15 \\
14\end{array}$ & $\begin{array}{l}2.0 \\
2.4 \\
2.2 \\
2.0 \\
1.7\end{array}$ & $\begin{array}{l}.50 \\
.41 \\
.29 \\
.21 \\
.19\end{array}$ & $\begin{array}{l}.00 \\
.00 \\
.00 \\
.00 \\
.00\end{array}$ \\
\hline $\begin{array}{l}16 \\
17 \\
18 \\
19 \\
20\end{array}$ & $\begin{array}{r}40 \\
35 \\
100 \\
82 \\
56\end{array}$ & $\begin{array}{l}15 \\
15 \\
14 \\
13 \\
13\end{array}$ & $\begin{array}{l}328 \\
230 \\
559 \\
486 \\
284\end{array}$ & $\begin{array}{r}482 \\
371 \\
207 \\
166 \\
e 150\end{array}$ & $\begin{array}{l}\text { e76 } \\
\text { e74 } \\
\text { e8 } 8 \\
392 \\
266\end{array}$ & $\begin{array}{l}315 \\
316 \\
568 \\
305 \\
209\end{array}$ & $\begin{array}{l}242 \\
147 \\
109 \\
296 \\
266\end{array}$ & $\begin{array}{r}62 \\
58 \\
421 \\
162 \\
96\end{array}$ & $\begin{array}{c}19 \\
20 \\
15 \\
12 \\
8.9\end{array}$ & $\begin{array}{l}1.7 \\
1.4 \\
1.4 \\
1.2 \\
1.1\end{array}$ & $\begin{array}{l}.06 \\
.19 \\
.05 \\
.00 \\
.00\end{array}$ & $\begin{array}{l}.00 \\
.00 \\
.00 \\
.00 \\
.00\end{array}$ \\
\hline $\begin{array}{l}21 \\
22 \\
23 \\
24 \\
25\end{array}$ & $\begin{array}{l}44 \\
41 \\
38 \\
34 \\
29\end{array}$ & $\begin{array}{l}12 \\
18 \\
23 \\
20 \\
17\end{array}$ & $\begin{array}{r}524 \\
582 \\
287 \\
\mathrm{e} 200 \\
\mathrm{e} 160\end{array}$ & $\begin{array}{l}\text { el } 35 \\
\text { el } 20 \\
\text { el } 05 \\
\text { e } 95 \\
\text { e } 86\end{array}$ & $\begin{array}{r}180 \\
137 \\
102 \\
90 \\
73\end{array}$ & $\begin{array}{l}165 \\
508 \\
679 \\
289 \\
184\end{array}$ & $\begin{array}{r}163 \\
125 \\
103 \\
90 \\
76\end{array}$ & $\begin{array}{r}69 \\
55 \\
63 \\
118 \\
74\end{array}$ & $\begin{array}{l}7.6 \\
13 \\
12 \\
8.9 \\
7.1\end{array}$ & $\begin{array}{l}.90 \\
.66 \\
.58 \\
.58 \\
.58\end{array}$ & $\begin{array}{l}.00 \\
.00 \\
.00 \\
.00 \\
.00\end{array}$ & $\begin{array}{r}.00 \\
.00 \\
\text { e.00 } \\
\text { e.00 } \\
\text { e.00 }\end{array}$ \\
\hline $\begin{array}{l}26 \\
27 \\
28 \\
29 \\
30 \\
31\end{array}$ & $\begin{array}{l}26 \\
24 \\
26 \\
23 \\
19 \\
17\end{array}$ & $\begin{array}{r}15 \\
86 \\
649 \\
319 \\
180 \\
\ldots-\end{array}$ & $\begin{array}{r}e 130 \\
\text { e110 } \\
\text { e100 } \\
1530 \\
6840 \\
944\end{array}$ & $\begin{array}{l}\text { e } 81 \\
\text { e } 80 \\
\text { e } 77 \\
\text { e } 75 \\
\text { e } 90 \\
\text { e } 85\end{array}$ & $\begin{array}{c}63 \\
60 \\
56 \\
\cdots \\
\cdots \\
\cdots\end{array}$ & $\begin{array}{r}449 \\
392 \\
246 \\
157 \\
112 \\
94\end{array}$ & $\begin{array}{l}71 \\
67 \\
63 \\
63 \\
58 \\
\cdots\end{array}$ & $\begin{array}{r}101 \\
63 \\
47 \\
40 \\
85 \\
165\end{array}$ & $\begin{array}{l}6.5 \\
5.2 \\
4.6 \\
4.4 \\
3.7 \\
\ldots . .\end{array}$ & $\begin{array}{l}.50 \\
.50 \\
.45 \\
.30 \\
.23 \\
.19\end{array}$ & $\begin{array}{l}.00 \\
.00 \\
.00 \\
.00 \\
.00 \\
.00\end{array}$ & $\begin{array}{l}\text { e. } 00 \\
\text { e. } 00 \\
\text { e. } 00 \\
\text { e. } 00 \\
\text { e. } 00 \\
\cdots .\end{array}$ \\
\hline $\begin{array}{l}\text { IOIAL } \\
\text { MEAN } \\
\text { MAX } \\
\text { MIN } \\
\text { CFSM } \\
\text { IN. }\end{array}$ & $\begin{array}{r}2324.0 \\
75.0 \\
729 \\
1.1 \\
.73 \\
.84\end{array}$ & $\begin{array}{r}1852 \\
61.7 \\
649 \\
12 \\
.60 \\
.67\end{array}$ & $\begin{array}{r}16430 \\
530 \\
6840 \\
47 \\
5.15 \\
5.93\end{array}$ & $\begin{array}{r}4719 \\
152 \\
482 \\
61 \\
1.48 \\
1.70\end{array}$ & $\begin{array}{r}3839 \\
137 \\
392 \\
56 \\
1.33 \\
1.39\end{array}$ & $\begin{array}{r}9916 \\
320 \\
2650 \\
35 \\
3.11 \\
3.58\end{array}$ & $\begin{array}{r}4064 \\
135 \\
453 \\
58 \\
1.32 \\
1.47\end{array}$ & $\begin{array}{r}2450 \\
19.0 \\
421 \\
34 \\
.17 \\
.88\end{array}$ & $\begin{array}{r}730.9 \\
24.4 \\
110 \\
3.7 \\
.24 \\
.26\end{array}$ & $\begin{array}{r}47.21 \\
1.52 \\
3.5 \\
.19 \\
.01 \\
.02\end{array}$ & $\begin{array}{l}4.61 \\
.15 \\
.66 \\
.00 \\
.00 \\
.00\end{array}$ & $\begin{array}{l}0.00 \\
.000 \\
.00 \\
.00 \\
.00 \\
.00\end{array}$ \\
\hline
\end{tabular}

e Estimated

SIATISTICS OF MUNIHIY MEAN DAIA FUR WAIER YEARS 1958 - 1991, BY WATER YEAR (WY)

$\begin{array}{lrrrrrrrrrrrr}\text { MEAN } & 23.1 & 75.2 & 140 & 115 & 159 & 208 & 180 & 95.1 & 89.5 & 61.0 & 42.1 & 20.0 \\ \text { MAX } & 131 & 410 & 530 & 452 & 423 & 459 & 532 & 289 & 523 & 520 & 444 & 332 \\ \text { (WY) } & 1970 & 1986 & 1991 & 1974 & 1976 & 1963 & 1964 & 1974 & 1958 & 1979 & 1958 & 1989 \\ \text { MIN } & 1000 & 1.16 & 1.65 & 1.23 & 9.05 & 28.7 & 30.0 & 12.0 & 1.55 & 1.52 & .000 & .000 \\ \text { (WY) } & 1967 & 1965 & 1977 & 1977 & 1964 & 1966 & 1971 & 1988 & 1988 & 1966 & 1966 & 1966\end{array}$

SUMMARY SIAIISIICS

ANMUAL IOTAL

AMNUAL MEAN

HIGHESI ANNUAL MEAN

LOWEST ANNUAL MEAN

HIGHEST DAILY MEAN

LOWEST DAIIY MEAN

ANNUAL SEVEN-DAY MINIMUM

INSTANTANEOUS PEAK FLOW

INSTANIANEOUS PEAK SIAGE

ANNUAL RUNOFF (CFSM)

ANNUAL RUNOFF (INCHES)

10 PERCENT EXLEEOS

50 PERCENT EXCEEDS

90 PERCENT EXCEEDS
FOR 1990 (AIENOAR YEAR

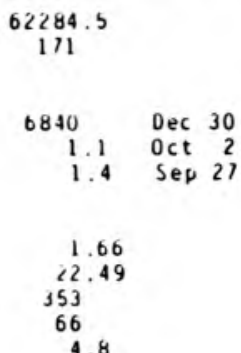

FOR 1991 WAIER YEAR

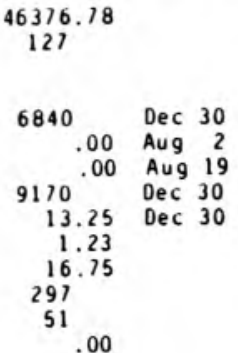

WATER YEARS 1958 - 1991

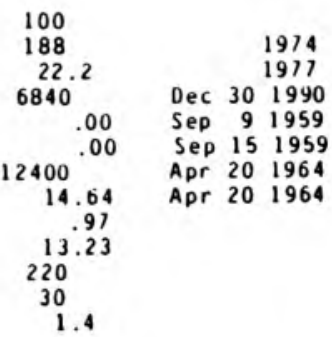




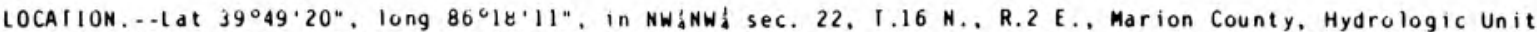
05120201 , in outlet structure of reservoir on Eagle Creek, $800 \mathrm{ft}$ upstrean from Interstate Highway 74 . 0.5 mi downstream from School Branch, 1.0 mi northeast of Clermont, and 2 west of Indianapolis.

DRAINAGE AREA...162 mi $\mathrm{i}^{2}$,

PERIOD OF RECORO..-March 1970 to current year.

GAGE.- Water-stage recorder. Datum of gage is $780.00 \mathrm{ft}$ above National Geodetic Vertical Datum of 1929 .

REMARKS. - Reservoir is formed by earth-fill dam. Low flow is controlled through a 48-inch diameter conduit. Spiliway elevation, $783 \mathrm{ft}$ is an ogee section with 6 taintor gates, edch $40 \mathrm{ft}$ wide and $25 \mathrm{ft}$ high. Peradnent pool capacity is 24,000 acre-ft, elevation, $790.00 \mathrm{ft}$. Reservoir is used for flood control. low-fiow a intenance, water supply, and recreation. Reservoir put into operation Nov. $27,1969$.

COOPERAIION. - Water-stage elevations and capacity tables furnished by Indianapolis Flood Control District.

EXIREMES FOR PERIOD OF RECORD, --Maximum contents, 30,580 acre-ft Dec. 30, 1990, elevation, 794.61 ft; ninimum, 13,370 acre-ft Sept. 30,1991 , elevation, $780.87 \mathrm{ft}$.

EXIREMES FOR CURRENT YEAR.--Maximum contents, 30,580 acre-ft Dec. 30, elevation, $194.61 \mathrm{ft}$; inimum, 13,310 dcre$\mathrm{ft}$ Sept. 30, elevation, $780.87 \mathrm{ft}$.

MONTHEND ELEVATION AND CONTENIS, AT 2400, WATER YEAR OCTOBER 1990 TO SEPTEMBER 1991 Date

Elevation (feet)

188.24

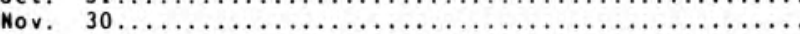

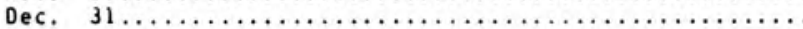

CAL YR 1990

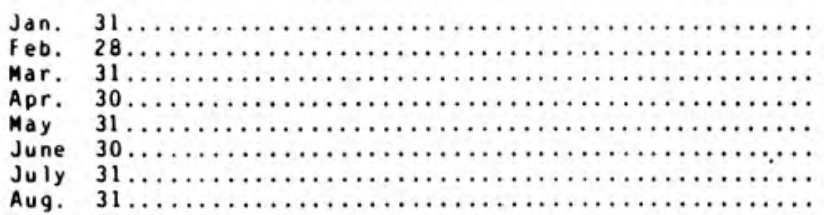

Aug. 31

Sept. 30

WIR YR 1991

\section{Contents \\ Change in contents \\ (acre-feet) (acre-feet)}

789.94

790.21

792.76

$+2.210$

190.07

790.07

790.07

790.07

790.06

788.69

785.99

783.54

780.87
+370
$+3,570$

$+9,760$

21,710

24,290

27.860

24,100

24,010

24,100

24,100

24,080

22,300

18,890

16,090

13,370
$-3.760$

-90
+90

+90
0

$-20$

$-1.780$

$-3.410$

$-2,800$

$-2,720$ 


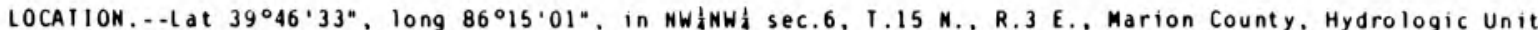
05120201 , on right bank at downstrean side of bridge on Lynhurst Drive, approxiately $600 \mathrm{ft}$ south of intersection of West 10 th Street and Lynhurst Drive, 0.5 i downstrea fro West 10 th Street bridge, 1.0 i upstrea from Vermozt Street oridge, 3.0 i upstrea from Little Eagle Creek, and 7.1 i upstrean from mouth.

DRAINAGE AREA ..174 ${ }^{2}$

PERIOD OF RECORO... November 1938 to current year.

REVISED RECORDS.--WSP 953: 1939. WSP 1625: 1958. WSP 2109: Drainage area.

GAGE.-Water-stage recorder. Datun of gage is $699.00 \mathrm{ft}$ above National Geodetic Vertical Datue of 1929 . Aug. 8 , 1957 to June 30,1958 , teeporary site during reconstruction of bridge on Lynhurst Drive, a nonrecording gage on downstrea side of 10 th Street bridge. Mar. 10, 1966 to Aug. 16, 1967, during channelization of Eagle Creek. a nonrecording gage on downstrea side of Lynhurst Orive bridge. Prior to 0ct. 1, 1967, at datua 7.21 ft higher.

REMARKS. - Records good except for estimated daily discharges, which are fair. Flow regulated since Novener 1969 by Eagle Creek Reservoir, 4,7 ai upstream (see station 03353450).

EXIREMES OUISIDE PERIOD OF RECORO.-.Flood in March 1913 reached a stage of $23.2 \mathrm{ft}$ present datum, from information by local residents.

OISCHARGE, CUBIL FEET PER SECOND, WAIER YEAR OCTOBER 1990 TO SEPIEMBER 1991 DAII Y MEAN VALUES

\begin{tabular}{|c|c|c|c|c|c|c|c|c|c|c|c|c|}
\hline DAY & $0 \mathrm{CI}$ & NOV & DEC & JAN & FE B & MAR & APR & MAY & JUN & JUL & AUG & SEP \\
\hline $\begin{array}{l}1 \\
2 \\
3 \\
4 \\
5\end{array}$ & $\begin{array}{l}7.4 \\
7.9 \\
13 \\
51 \\
11\end{array}$ & $\begin{array}{l}30 \\
30 \\
31 \\
30 \\
48\end{array}$ & $\begin{array}{r}281 \\
160 \\
1430 \\
1390 \\
358\end{array}$ & $\begin{array}{l}859 \\
775 \\
751 \\
723 \\
663\end{array}$ & $\begin{array}{r}128 \\
47 \\
134 \\
184 \\
395\end{array}$ & $\begin{array}{l}132 \\
169 \\
199 \\
109 \\
193\end{array}$ & $\begin{array}{l}193 \\
167 \\
145 \\
179 \\
187\end{array}$ & $\begin{array}{r}156 \\
38 \\
42 \\
187 \\
41\end{array}$ & $\begin{array}{r}173 \\
225 \\
49 \\
37 \\
37\end{array}$ & $\begin{array}{r}24 \\
24 \\
\mathrm{e} 21 \\
\mathrm{e} 23 \\
\mathrm{e} 22\end{array}$ & $\begin{array}{l}16 \\
16 \\
16 \\
16 \\
16\end{array}$ & $\begin{array}{l}20 \\
20 \\
25 \\
23 \\
20\end{array}$ \\
\hline $\begin{array}{r}6 \\
7 \\
8 \\
9 \\
10\end{array}$ & $\begin{array}{l}7.6 \\
29 \\
16 \\
21 \\
372\end{array}$ & $\begin{array}{r}47 \\
105 \\
34 \\
33 \\
32\end{array}$ & $\begin{array}{r}277 \\
146 \\
238 \\
35 \\
127\end{array}$ & $\begin{array}{r}592 \\
233 \\
298 \\
46 \\
46\end{array}$ & $\begin{array}{l}882 \\
831 \\
522 \\
379 \\
357\end{array}$ & $\begin{array}{r}43 \\
147 \\
42 \\
141 \\
43\end{array}$ & $\begin{array}{l}138 \\
145 \\
343 \\
361 \\
197\end{array}$ & $\begin{array}{r}149 \\
38 \\
36 \\
36 \\
145\end{array}$ & $\begin{array}{l}39 \\
45 \\
34 \\
28 \\
28\end{array}$ & $\begin{array}{l}\text { e } 21 \\
\text { e21 } \\
\text { e } 19 \\
\text { e18 } \\
\text { e } 30\end{array}$ & $\begin{array}{l}39 \\
16 \\
20 \\
17 \\
16\end{array}$ & $\begin{array}{l}19 \\
19 \\
19 \\
19 \\
19\end{array}$ \\
\hline $\begin{array}{l}11 \\
12 \\
13 \\
14 \\
15\end{array}$ & $\begin{array}{r}761 \\
206 \\
377 \\
35 \\
31\end{array}$ & $\begin{array}{l}31 \\
31 \\
31 \\
31 \\
30\end{array}$ & $\begin{array}{r}113 \\
115 \\
68 \\
64 \\
589\end{array}$ & $\begin{array}{l}320 \\
475 \\
329 \\
203 \\
288\end{array}$ & $\begin{array}{l}181 \\
180 \\
260 \\
181 \\
185\end{array}$ & $\begin{array}{r}41 \\
421 \\
4070 \\
2300 \\
700\end{array}$ & $\begin{array}{l}117 \\
141 \\
661 \\
791 \\
933\end{array}$ & $\begin{array}{r}39 \\
47 \\
53 \\
160 \\
138\end{array}$ & $\begin{array}{l}28 \\
27 \\
26 \\
26 \\
29\end{array}$ & $\begin{array}{l}\text { e } 21 \\
\text { e } 23 \\
\text { e22 } \\
\text { e21 } \\
\text { e21 }\end{array}$ & $\begin{array}{l}16 \\
16 \\
15 \\
22 \\
16\end{array}$ & $\begin{array}{l}19 \\
22 \\
21 \\
19 \\
18\end{array}$ \\
\hline $\begin{array}{l}16 \\
17 \\
18 \\
19 \\
20\end{array}$ & $\begin{array}{r}31 \\
30 \\
37 \\
131 \\
33\end{array}$ & $\begin{array}{l}30 \\
31 \\
31 \\
31 \\
30\end{array}$ & $\begin{array}{r}438 \\
345 \\
669 \\
1140 \\
373\end{array}$ & $\begin{array}{r}552 \\
785 \\
661 \\
\mathrm{e} 450 \\
293\end{array}$ & $\begin{array}{r}173 \\
50 \\
409 \\
838 \\
635\end{array}$ & $\begin{array}{r}730 \\
769 \\
1170 \\
718 \\
385\end{array}$ & $\begin{array}{l}682 \\
389 \\
225 \\
737 \\
612\end{array}$ & $\begin{array}{r}124 \\
79 \\
531 \\
190 \\
157\end{array}$ & $\begin{array}{l}33 \\
28 \\
27 \\
26 \\
25\end{array}$ & $\begin{array}{r}\text { e21 } \\
\text { e21 } \\
\text { e20 } \\
\text { e19 } \\
19\end{array}$ & $\begin{array}{l}15 \\
17 \\
16 \\
22 \\
16\end{array}$ & $\begin{array}{l}18 \\
18 \\
18 \\
18 \\
18\end{array}$ \\
\hline $\begin{array}{l}21 \\
22 \\
23 \\
24 \\
25\end{array}$ & $\begin{array}{r}133 \\
35 \\
31 \\
30 \\
30\end{array}$ & $\begin{array}{l}30 \\
41 \\
34 \\
33 \\
31\end{array}$ & $\begin{array}{r}662 \\
1140 \\
504 \\
225 \\
207\end{array}$ & $\begin{array}{r}263 \\
200 \\
190 \\
173 \\
45\end{array}$ & $\begin{array}{l}404 \\
196 \\
262 \\
230 \\
172\end{array}$ & $\begin{array}{r}381 \\
1020 \\
1710 \\
663 \\
395\end{array}$ & $\begin{array}{l}331 \\
325 \\
275 \\
212 \\
156\end{array}$ & $\begin{array}{r}32 \\
134 \\
62 \\
185 \\
39\end{array}$ & $\begin{array}{l}24 \\
25 \\
28 \\
24 \\
23\end{array}$ & $\begin{array}{l}18 \\
18 \\
18 \\
17 \\
17\end{array}$ & $\begin{array}{l}15 \\
15 \\
16 \\
18 \\
18\end{array}$ & $\begin{array}{l}18 \\
30 \\
15 \\
12 \\
12\end{array}$ \\
\hline $\begin{array}{l}26 \\
27 \\
28 \\
29 \\
30 \\
31\end{array}$ & $\begin{array}{l}30 \\
30 \\
29 \\
30 \\
30 \\
30\end{array}$ & $\begin{array}{r}32 \\
184 \\
1290 \\
559 \\
159 \\
\ldots-\end{array}$ & $\begin{array}{r}123 \\
72 \\
96 \\
1780 \\
9890 \\
5040\end{array}$ & $\begin{array}{r}157 \\
122 \\
121 \\
45 \\
169 \\
46\end{array}$ & $\begin{array}{l}177 \\
150 \\
126 \\
\cdots \\
\cdots \\
\cdots\end{array}$ & $\begin{array}{l}870 \\
984 \\
552 \\
347 \\
209 \\
207\end{array}$ & $\begin{array}{r}179 \\
147 \\
154 \\
163 \\
40 \\
\cdots\end{array}$ & $\begin{array}{r}199 \\
229 \\
37 \\
136 \\
176 \\
142\end{array}$ & $\begin{array}{l}23 \\
23 \\
23 \\
23 \\
23 \\
--\end{array}$ & $\begin{array}{l}17 \\
17 \\
17 \\
16 \\
16 \\
16\end{array}$ & $\begin{array}{l}18 \\
19 \\
19 \\
20 \\
20 \\
20\end{array}$ & $\begin{array}{l}12 \\
13 \\
13 \\
13 \\
17 \\
\cdots\end{array}$ \\
\hline $\begin{array}{l}\text { IOIAL } \\
\text { MEAN } \\
\text { MAX } \\
\text { MI N } \\
\text { CF SM } \\
\text { IN. }\end{array}$ & $\begin{array}{r}2645.9 \\
85.4 \\
761 \\
7.4 \\
.49 \\
.57\end{array}$ & $\begin{array}{r}3120 \\
104 \\
1290 \\
30 \\
.60 \\
.67\end{array}$ & $\begin{array}{r}28095 \\
906 \\
9890 \\
35 \\
5.21 \\
6.01\end{array}$ & $\begin{array}{r}10879 \\
351 \\
859 \\
45 \\
2.02 \\
2.33\end{array}$ & $\begin{array}{r}8668 \\
310 \\
882 \\
47 \\
1.78 \\
1.85\end{array}$ & $\begin{array}{r}19860 \\
641 \\
4070 \\
41 \\
3.68 \\
4.25\end{array}$ & $\begin{array}{c}9325 \\
311 \\
933 \\
40 \\
1.79 \\
1.99\end{array}$ & $\begin{array}{c}3757 \\
121 \\
531 \\
32 \\
.70 \\
.80\end{array}$ & $\begin{array}{c}1209 \\
40.3 \\
225 \\
23 \\
.23 \\
.26\end{array}$ & $\begin{array}{c}618 \\
19.9 \\
30 \\
16 \\
.11 \\
.13\end{array}$ & $\begin{array}{c}557 \\
18.0 \\
39 \\
15 \\
.10 \\
.12\end{array}$ & $\begin{array}{r}547 \\
18.2 \\
30 \\
12 \\
.10 \\
.12\end{array}$ \\
\hline
\end{tabular}

e Estimated

SIAIISTICS OF MONIHLY MEAN DATA FOR WATER YEARS 1939 - 1991, BY WATER YEAR (WY)

\begin{tabular}{|c|c|c|c|c|c|c|c|c|c|c|c|c|}
\hline $\begin{array}{l}\text { MEAN } \\
\text { MAX } \\
(W Y) \\
\text { MI }) \\
(W Y)\end{array}$ & $\begin{array}{r}34.0 \\
201 \\
1970 \\
1.52 \\
1941\end{array}$ & $\begin{array}{r}95.5 \\
612 \\
1973 \\
3.05 \\
1941\end{array}$ & $\begin{array}{r}171 \\
906 \\
1991 \\
3.48 \\
1945\end{array}$ & $\begin{array}{r}203 \\
1485 \\
1950 \\
4.06 \\
1945\end{array}$ & $\begin{array}{r}251 \\
765 \\
1976 \\
20.6 \\
1978\end{array}$ & $\begin{array}{r}319 \\
900 \\
1978 \\
27.7 \\
1941\end{array}$ & $\begin{array}{r}310 \\
906 \\
1964 \\
28.0 \\
1976\end{array}$ & $\begin{array}{r}205 \\
1127 \\
1943 \\
14.3 \\
1976\end{array}$ & $\begin{array}{r}144 \\
904 \\
1957 \\
4.66 \\
1988\end{array}$ & $\begin{array}{r}83.3 \\
800 \\
1979 \\
3.69 \\
1968\end{array}$ & $\begin{array}{r}42.0 \\
490 \\
1958 \\
19 \\
1941\end{array}$ & $\begin{array}{r}37.6 \\
625 \\
1989 \\
.40 \\
1941\end{array}$ \\
\hline
\end{tabular}

SUMMARY SIATISIICS

ANMUAL TOTAL

HIGHEST ANMUAL MEAM

LOWEST ANNUAL MEAN

HIGHESI DAILY MEAN

LOWEST DAILY MEAN

ANNUAI SEVEM-DAY MINIMUM

INSTANTANEOUS PEAK FLOW

INSTANTANE OUS PEAK STAGE

ANMUAL RUNOFF (CFSM)

ANMUAL RUNOF F (INCHES)

10 PERCEMT EXCEEDS

50 PERCENI EXCEEDS

90 PERCENI EXCEEDS
FOR 1990 CALENDAR YEAR

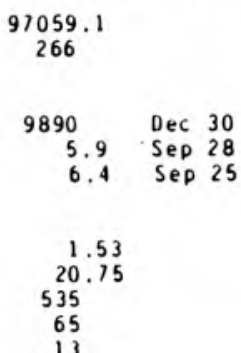

FOR 1991 WATER YEAR

$$
\begin{gathered}
89280.9 \\
245
\end{gathered}
$$

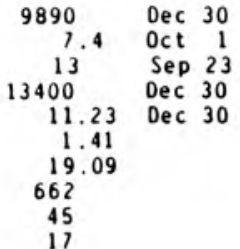

WAIER YEARS 1939 - 1991

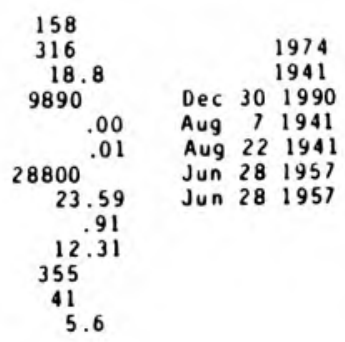




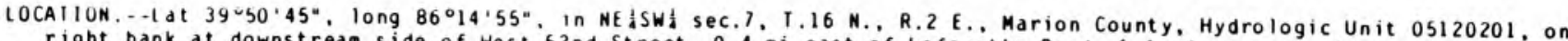
right bank at downstrean side of West 52 nd Street, 0.4 i east of Lafayete Road, 1.1 i upstrean from Guion Creek.

and a t ile 7,2 . DRAINAGE AREA. $\ldots 6.94 \mathrm{i}^{2}$

PERIOD OF RECORD.--October 1989 to current year.

GAGE.- Water-stage recorder. Datum of gage is $766.34 \mathrm{ft}$ above National Geodetic Vertical Datum of 1929.

REMARKS. - Records fair except for estinated daily discharges, and for discharges less than $10 \mathrm{ft} / \mathrm{s}$, which are poor.

DISCHARGE, CUBIC FEET PER SECOND, WATER YEAR OCTOBER 1990 TO SEPTEMBER 1991

\begin{tabular}{|c|c|c|c|c|c|c|c|c|c|c|c|c|}
\hline DAY & $\mathrm{OCI}$ & NOV & $\mathrm{DEC}$ & JAN & FEB & MAR & APR & MAY & JUN & JUL & AUG & SEP \\
\hline $\begin{array}{l}1 \\
2 \\
3 \\
4 \\
5\end{array}$ & $\begin{array}{l}.27 \\
.23 \\
6.7 \\
90 \\
2.7\end{array}$ & $\begin{array}{c}1.1 \\
1.0 \\
.97 \\
39^{.98}\end{array}$ & $\begin{array}{r}5.5 \\
4.3 \\
171 \\
21 \\
9.8\end{array}$ & $\begin{array}{r}13 \\
9.2 \\
6.8 \\
7.9 \\
6.8\end{array}$ & $\begin{array}{r}5.7 \\
11 \\
8.0 \\
\text { e6.8 } \\
\text { e22 }\end{array}$ & $\begin{array}{l}\text { e) } .2 \\
\text { e } 9.0 \\
\text { e5.6 } \\
\text { e } 4.0 \\
\text { e2.9 }\end{array}$ & $\begin{array}{l}4.3 \\
3.6 \\
3.3 \\
11 \\
11\end{array}$ & $\begin{array}{l}3.5 \\
2.4 \\
2.1 \\
7.4 \\
6.3\end{array}$ & $\begin{array}{l}1.9 \\
2.5 \\
1.6 \\
1.4 \\
.87\end{array}$ & $\begin{array}{l}.48 \\
.32 \\
.38 \\
.45 \\
.54\end{array}$ & $\begin{array}{r}.76 \\
.87 \\
.64 \\
.75 \\
1.7\end{array}$ & $\begin{array}{l}.66 \\
.52 \\
.70 \\
.74 \\
.49\end{array}$ \\
\hline $\begin{array}{r}6 \\
7 \\
8 \\
9 \\
10\end{array}$ & $\begin{array}{l}1.1 \\
38 \\
10 \\
45 \\
151\end{array}$ & $\begin{array}{l}7.2 \\
2.9 \\
2.2 \\
2.1 \\
2.3\end{array}$ & $\begin{array}{l}7.5 \\
5.9 \\
5.0 \\
4.3 \\
4.0\end{array}$ & $\begin{array}{l}7.2 \\
5.0 \\
4.3 \\
4.2 \\
4.1\end{array}$ & $\begin{array}{l}\text { e } 82 \\
\text { e } 40 \\
\text { el } \\
\text { el1 } \\
\text { e7. } 8\end{array}$ & $\begin{array}{l}\text { e2.7 } \\
\text { e2.3 } \\
\text { e2.1 } \\
\text { e1.9 } \\
\text { e1.8 }\end{array}$ & $\begin{array}{l}5.5 \\
4.1 \\
42 \\
16 \\
7.6\end{array}$ & $\begin{array}{l}4.6 \\
2.3 \\
2.0 \\
1.8 \\
1.7\end{array}$ & $\begin{array}{l}.75 \\
.70 \\
.67 \\
.67 \\
.64\end{array}$ & $\begin{array}{l}.44 \\
.37 \\
1.9 \\
1.0 \\
31\end{array}$ & $\begin{array}{c}21 \\
2.5 \\
4.2 \\
3.1 \\
.93\end{array}$ & $\begin{array}{l}.69 \\
.30 \\
.21 \\
.19 \\
.21\end{array}$ \\
\hline $\begin{array}{l}11 \\
12 \\
13 \\
14 \\
15\end{array}$ & $\begin{array}{r}14 \\
5.4 \\
3.2 \\
2.3 \\
1.8\end{array}$ & $\begin{array}{l}1.7 \\
1.4 \\
1.3 \\
1.3 \\
1.3\end{array}$ & $\begin{array}{r}3.9 \\
3.4 \\
3.5 \\
2.9 \\
53\end{array}$ & $\begin{array}{c}41 \\
18 \\
8.9 \\
8.2 \\
12\end{array}$ & $\begin{array}{l}\text { e } 5.6 \\
\text { e } 4.7 \\
\text { e } 5.7 \\
\text { e } 7.8 \\
\text { e5. } 3\end{array}$ & $\begin{array}{l}\text { e } 1.8 \\
\text { e } 80 \\
240 \\
29 \\
13\end{array}$ & $\begin{array}{l}5.2 \\
4.4 \\
64 \\
23 \\
76\end{array}$ & $\begin{array}{l}5.8 \\
6.5 \\
3.0 \\
3.0 \\
2.5\end{array}$ & $\begin{array}{c}.62 \\
1.5 \\
.68 \\
.58 \\
1.3\end{array}$ & $\begin{array}{c}4.6 \\
11 \\
2.4 \\
1.1 \\
.74\end{array}$ & $\begin{array}{l}.51 \\
.35 \\
.29 \\
.30 \\
.42\end{array}$ & $\begin{array}{r}.24 \\
.25 \\
7.5 \\
1.2 \\
.34\end{array}$ \\
\hline $\begin{array}{l}16 \\
17 \\
18 \\
19 \\
20\end{array}$ & $\begin{array}{r}1.7 \\
1.5 \\
12 \\
2.2 \\
1.7\end{array}$ & $\begin{array}{l}1.4 \\
1.5 \\
1.3 \\
1.3 \\
1.2\end{array}$ & $\begin{array}{l}10 \\
22 \\
71 \\
24 \\
12\end{array}$ & $\begin{array}{l}23 \\
15 \\
8.0 \\
6.8 \\
7.3\end{array}$ & $\begin{array}{l}\text { e } 4.1 \\
\text { e } 3.9 \\
\text { e26 } \\
\text { e29 } \\
\text { e16 }\end{array}$ & $\begin{array}{l}8.6 \\
42 \\
29 \\
12 \\
8.2\end{array}$ & $\begin{array}{c}14 \\
8.7 \\
6.5 \\
78 \\
17\end{array}$ & $\begin{array}{r}9.6 \\
6.0 \\
16 \\
3.0 \\
1.9\end{array}$ & $\begin{array}{c}10 \\
1.7 \\
1.0 \\
.71 \\
.61\end{array}$ & $\begin{array}{l}.59 \\
.62 \\
.65 \\
.71 \\
.80\end{array}$ & $\begin{array}{l}.44 \\
1.0 \\
.97 \\
3.1 \\
1.5\end{array}$ & $\begin{array}{l}.22 \\
.69 \\
.54 \\
.23 \\
.20\end{array}$ \\
\hline $\begin{array}{l}21 \\
22 \\
23 \\
24 \\
25\end{array}$ & $\begin{array}{l}1.5 \\
8.1 \\
2.9 \\
1.9 \\
1.5\end{array}$ & $\begin{array}{r}1.1 \\
17 \\
4.4 \\
2.6 \\
2.1\end{array}$ & $\begin{array}{l}69 \\
27 \\
13 \\
10 \\
6.6\end{array}$ & $\begin{array}{r}6.2 \\
5.2 \\
\mathrm{e} 3.5 \\
\mathrm{e} 3.0 \\
\mathrm{e} 2.5\end{array}$ & $\begin{array}{l}\text { e } 10 \\
\text { e } 7.6 \\
\text { e6.0 } \\
\text { e } 4.8 \\
\text { e } 4.2\end{array}$ & $\begin{array}{l}6.8 \\
99 \\
35 \\
12 \\
8.0\end{array}$ & $\begin{array}{l}8.7 \\
6.3 \\
5.5 \\
5.9 \\
3.7\end{array}$ & $\begin{array}{r}1.6 \\
1.4 \\
16 \\
6.8 \\
3.6\end{array}$ & $\begin{array}{l}.74 \\
8.6 \\
3.7 \\
1.2 \\
.87\end{array}$ & $\begin{array}{l}.74 \\
.70 \\
.57 \\
.54 \\
.81\end{array}$ & $\begin{array}{l}.49 \\
.28 \\
.23 \\
.20 \\
.20\end{array}$ & $\begin{array}{l}.15 \\
2.7 \\
8.2 \\
1.2 \\
.44\end{array}$ \\
\hline $\begin{array}{l}26 \\
27 \\
28 \\
29 \\
30 \\
31\end{array}$ & $\begin{array}{l}1.3 \\
1.1 \\
1.1 \\
.98 \\
1.1 \\
1.1\end{array}$ & $\begin{array}{r}1.8 \\
84^{8} \\
114 \\
14 \\
7.6 \\
\ldots\end{array}$ & $\begin{array}{l}5.3 \\
5.2 \\
5.9 \\
385 \\
542 \\
30\end{array}$ & $\begin{array}{c}\mathrm{e} 2.4 \\
\mathrm{e} 2.3 \\
\mathrm{e} 2.2 \\
\mathrm{e} 3.7 \\
13 \\
4.6\end{array}$ & $\begin{array}{c}\text { e } 4.0 \\
\text { e } 3.9 \\
\text { e } 3.9 \\
\ldots . \\
\ldots . \\
\ldots\end{array}$ & $\begin{array}{l}67 \\
18 \\
9.2 \\
6.7 \\
5.0 \\
4.5\end{array}$ & $\begin{array}{l}3.6 \\
3.2 \\
2.9 \\
4.5 \\
2.8 \\
\ldots .\end{array}$ & $\begin{array}{r}6.1 \\
2.7 \\
1.7 \\
4.8 \\
22 \\
3.5\end{array}$ & $\begin{array}{l}.92 \\
.59 \\
.50 \\
.54 \\
.85 \\
\cdots\end{array}$ & $\begin{array}{l}1.3 \\
.66 \\
.69 \\
.67 \\
.88 \\
.75\end{array}$ & $\begin{array}{l}.22 \\
.34 \\
.77 \\
.83 \\
.85 \\
1.0\end{array}$ & $\begin{array}{l}.71 \\
.46 \\
.56 \\
.58 \\
.51 \\
\ldots\end{array}$ \\
\hline $\begin{array}{l}\text { IOTAL } \\
\text { MEAM } \\
\text { MAX } \\
\text { MIN } \\
\text { CF SM } \\
\text { IN. }\end{array}$ & $\begin{array}{r}413.38 \\
13.3 \\
151 \\
.23 \\
1.92 \\
2.22\end{array}$ & $\begin{array}{r}322.05 \\
10.7 \\
114 \\
.97 \\
1.55 \\
1.73\end{array}$ & $\begin{array}{r}1543.0 \\
49.8 \\
542 \\
2.9 \\
7.17 \\
8.27\end{array}$ & $\begin{array}{r}265.3 \\
8.56 \\
41 \\
2.2 \\
1.23 \\
1.42\end{array}$ & $\begin{array}{r}363.8 \\
13.0 \\
82 \\
3.9 \\
1.87 \\
1.95\end{array}$ & $\begin{array}{r}774.3 \\
25.0 \\
240 \\
1.8 \\
3.60 \\
4.15\end{array}$ & $\begin{array}{r}452.3 \\
15.1 \\
18 \\
2.8 \\
2.17 \\
2.42\end{array}$ & $\begin{array}{c}161.6 \\
5.21 \\
22 \\
1.4 \\
.75 \\
.87\end{array}$ & $\begin{array}{c}48.91 \\
1.63 \\
10 \\
.50 \\
.23 \\
.26\end{array}$ & $\begin{array}{c}68.40 \\
2.21 \\
31 \\
.32 \\
.32 \\
.37\end{array}$ & $\begin{array}{c}50.74 \\
1.64 \\
21 \\
.20 \\
.24 \\
.27\end{array}$ & $\begin{array}{c}31.63 \\
1.05 \\
8.2 \\
.15 \\
.15 \\
.17\end{array}$ \\
\hline
\end{tabular}

e Estimated

SIATISTICS OF MONTHLY MEAN DATA FUR WAIER YEARS 1989 - 1991, BY WATER YEAR (WY)

\begin{tabular}{|c|c|c|c|c|c|c|c|c|c|c|c|}
\hline $\begin{array}{l}\text { MEAN } \\
\text { MAX } \\
(W Y) \\
\text { MIN } \\
(W Y)\end{array}$ & $\begin{array}{l}1.51 \\
13.3 \\
1991 \\
1.69 \\
1990\end{array}$ & $\begin{array}{l}9.61 \\
10.7 \\
1991 \\
8.49 \\
1990\end{array}$ & $\begin{array}{l}25.5 \\
49.8 \\
1991 \\
1.15 \\
1990\end{array}$ & $\begin{array}{l}7.85 \\
8.56 \\
1991 \\
7.13 \\
1990\end{array}$ & $\begin{array}{l}22.1 \\
31.1 \\
1990 \\
13.0 \\
1991\end{array}$ & $\begin{array}{l}19.1 \\
25.0 \\
1991 \\
13.2 \\
1990\end{array}$ & $\begin{array}{l}11.7 \\
15.1 \\
1991 \\
8.38 \\
1990\end{array}$ & $\begin{array}{l}18.1 \\
31.0 \\
1990 \\
5.21 \\
1991\end{array}$ & $\begin{array}{l}3.58 \\
5.53 \\
1990 \\
1.63 \\
1991\end{array}$ & $\begin{array}{l}3.84 \\
5.47 \\
1990 \\
2.21 \\
1991\end{array}$ & $\begin{array}{l}3.10 \\
4.56 \\
1990 \\
1.64 \\
1991\end{array}$ \\
\hline
\end{tabular}

SUMMARY SIATISIICS

ANNUAL TOIAL

ANHUAL MEAN

HIGHEST ANNUAL MEAN

IOWEST ANNUAL MEAN

HIGHESI DAILY MEAM

LOWEST DAILY MEAN

ANNUAL SEVEN-DAY MINIMUM

INSTANIANE OUS PEAK FLOW

INSTANTANEOUS PEAK STAGE

ANMUAL RUNOFF (CFSM)

ANNUAL RUNOFF (INCHES)

10 PERLENT EXCEEDS

SO PERCENT EXCEEDS

90 PERCENT EXCEEDS
FOR 1990 (ALENUAR YEAR

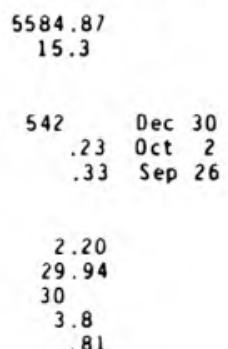

FOR 1991 WATER YEAR

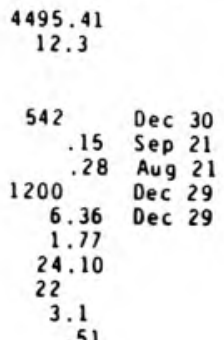

WATER YEARS $1989-1991$

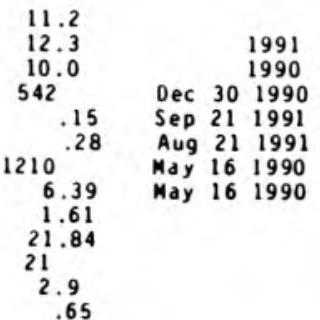




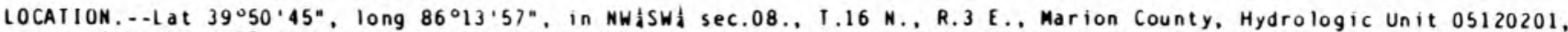
on right bank $25 \mathrm{ft}$ upstrean from private bridge, 0.2 a north of West 52 nd Street along Guion Road, and 1.25 a upstrean of the confluence with Little Eagle Creek.

DRAI NAGE AREA,$-3.91 \bullet i 2$

PERIOD OF RECORD.--0ctober 1989 to current year.

GAGE.--Water-stage recorder. Datum of gage is $760.11 \mathrm{ft}$ above National Geodetic Vertical Datup of 1929

REMARKS. - Records fair except for estinated daily discharges, and discharges 1 ess than $2.0 \mathrm{ft} / \mathrm{s}$, which are poor.

DISCHARGE, CUBIC FEET PER SECONO, WATER YEAR OCTOBER 1990 TO SEPTEMBER 1991 DAILY MEAN VALUES

\begin{tabular}{|c|c|c|c|c|c|c|c|c|c|c|c|c|}
\hline DAY & $O C T$ & NOV & $\mathrm{DEC}$ & JAN & FEB & MAR & APR & MAY & JUN & JUL & AUG & SEP \\
\hline $\begin{array}{l}1 \\
2 \\
3 \\
4 \\
5\end{array}$ & $\begin{array}{c}.27 \\
.48 \\
2.9 \\
19 \\
3.2\end{array}$ & $\begin{array}{l}1.3 \\
2.5 \\
3.0 \\
3.4 \\
9.8\end{array}$ & $\begin{array}{c}4.3 \\
3.1 \\
57 \\
14 \\
7.4\end{array}$ & $\begin{array}{r}12 \\
7.9 \\
5.2 \\
3.6 \\
3.4\end{array}$ & $\begin{array}{l}\text { e2.0 } \\
\text { e } 4.0 \\
\text { e } 3.2 \\
\text { e2.7 } \\
11\end{array}$ & $\begin{array}{l}2.0 \\
3.3 \\
2.2 \\
1.6 \\
1.2\end{array}$ & $\begin{array}{l}2.2 \\
1.7 \\
1.4 \\
2.9 \\
3.8\end{array}$ & $\begin{array}{l}1.7 \\
1.3 \\
1.2 \\
2.6 \\
2.1\end{array}$ & $\begin{array}{l}2.4 \\
2.0 \\
1.6 \\
1.2 \\
.83\end{array}$ & $\begin{array}{l}.02 \\
.02 \\
.03 \\
.05 \\
.08\end{array}$ & $\begin{array}{l}.02 \\
.02 \\
.02 \\
.04 \\
.06\end{array}$ & $\begin{array}{l}.01 \\
.01 \\
.01 \\
.04 \\
.01\end{array}$ \\
\hline $\begin{array}{r}6 \\
7 \\
8 \\
9 \\
10\end{array}$ & $\begin{array}{l}1.5 \\
8.6 \\
5.4 \\
12 \\
51\end{array}$ & $\begin{array}{l}5.0 \\
4.2 \\
2.1 \\
1.3 \\
.86\end{array}$ & $\begin{array}{l}5.3 \\
3.9 \\
3.1 \\
2.6 \\
2.2\end{array}$ & $\begin{array}{l}3.0 \\
2.4 \\
2.0 \\
1.8 \\
1.6\end{array}$ & $\begin{array}{l}37 \\
17 \\
8.8 \\
6.0 \\
4.4\end{array}$ & $\begin{array}{l}1.4 \\
1.1 \\
.87 \\
.70 \\
.68\end{array}$ & $\begin{array}{c}3.1 \\
2.0 \\
13 \\
9.7 \\
4.7\end{array}$ & $\begin{array}{l}2.0 \\
1.2 \\
1.0 \\
1.2 \\
1.5\end{array}$ & $\begin{array}{l}.69 \\
.65 \\
.62 \\
.57 \\
.52\end{array}$ & $\begin{array}{l}.04 \\
.03 \\
.05 \\
.02 \\
4.3\end{array}$ & $\begin{array}{l}2.7 \\
.24 \\
.38 \\
.33 \\
.07\end{array}$ & $\begin{array}{l}.00 \\
.02 \\
.44 \\
.64 \\
.77\end{array}$ \\
\hline $\begin{array}{l}11 \\
12 \\
13 \\
14 \\
15\end{array}$ & $\begin{array}{r}11 \\
6.1 \\
4.3 \\
3.3 \\
2.4\end{array}$ & $\begin{array}{l}.64 \\
.56 \\
.52 \\
.56 \\
.59\end{array}$ & $\begin{array}{r}2.0 \\
1.8 \\
1.5 \\
1.2 \\
16\end{array}$ & $\begin{array}{l}12 \\
10 \\
5.2 \\
4.4 \\
5.8\end{array}$ & $\begin{array}{l}3.1 \\
2.4 \\
3.0 \\
3.8 \\
3.0\end{array}$ & $\begin{array}{c}34^{.62} \\
108 \\
20 \\
9.3\end{array}$ & $\begin{array}{l}3.2 \\
2.4 \\
22 \\
11 \\
40\end{array}$ & $\begin{array}{l}5.1 \\
5.1 \\
3.1 \\
2.7 \\
2.2\end{array}$ & $\begin{array}{l}.54 \\
.54 \\
.51 \\
.47 \\
.73\end{array}$ & $\begin{array}{l}2.5 \\
2.5 \\
.25 \\
.09 \\
.03\end{array}$ & $\begin{array}{l}.02 \\
.01 \\
.01 \\
.01 \\
.01\end{array}$ & $\begin{array}{l}.36 \\
.10 \\
.32 \\
.21 \\
.18\end{array}$ \\
\hline $\begin{array}{l}16 \\
17 \\
18 \\
19 \\
20\end{array}$ & $\begin{array}{l}1.9 \\
1.8 \\
4.4 \\
2.1 \\
1.7\end{array}$ & $\begin{array}{l}1.6 \\
1.5 \\
1.2 \\
1.1 \\
1.0\end{array}$ & $\begin{array}{l}6.7 \\
8.2 \\
29 \\
15 \\
7.8\end{array}$ & $\begin{array}{r}11 \\
7.6 \\
4.6 \\
3.8 \\
\mathrm{e} 3.0\end{array}$ & $\begin{array}{c}2.0 \\
1.7 \\
13 \\
15 \\
8.4\end{array}$ & $\begin{array}{l}6.1 \\
17 \\
17 \\
7.5 \\
5.2\end{array}$ & $\begin{array}{l}11 \\
5.9 \\
4.3 \\
29 \\
11\end{array}$ & $\begin{array}{r}4.8 \\
4.1 \\
16 \\
4.2 \\
2.8\end{array}$ & $\begin{array}{l}1.1 \\
.42 \\
.25 \\
.18 \\
.12\end{array}$ & $\begin{array}{l}.02 \\
.02 \\
.02 \\
.02 \\
.02\end{array}$ & $\begin{array}{l}.01 \\
.16 \\
.03 \\
.24 \\
.06\end{array}$ & $\begin{array}{l}.17 \\
.15 \\
.15 \\
.17 \\
.08\end{array}$ \\
\hline $\begin{array}{l}21 \\
22 \\
23 \\
24 \\
25\end{array}$ & $\begin{array}{l}1.5 \\
3.6 \\
2.9 \\
3.0 \\
2.4\end{array}$ & $\begin{array}{l}.92 \\
5.0 \\
2.6 \\
1.7 \\
1.5\end{array}$ & $\begin{array}{l}33 \\
18 \\
9.0 \\
5.7 \\
4.2\end{array}$ & $\begin{array}{l}\text { e2. } \\
\text { e1.9 } \\
\text { el. } 5 \\
\text { e1.3 } \\
\text { el. } 1\end{array}$ & $\begin{array}{l}5.4 \\
3.8 \\
2.8 \\
2.2 \\
1.9\end{array}$ & $\begin{array}{l}4.4 \\
44 \\
23 \\
8.1 \\
5.5\end{array}$ & $\begin{array}{l}6.4 \\
4.7 \\
4.2 \\
3.4 \\
2.6\end{array}$ & $\begin{array}{l}2.3 \\
2.1 \\
8.0 \\
5.4 \\
3.5\end{array}$ & $\begin{array}{l}.09 \\
.10 \\
.15 \\
.10 \\
.08\end{array}$ & $\begin{array}{l}.02 \\
.02 \\
.02 \\
.02 \\
.02\end{array}$ & $\begin{array}{l}.02 \\
.01 \\
.01 \\
.01 \\
.01\end{array}$ & $\begin{array}{r}.02 \\
.53 \\
\mathrm{e} .35 \\
\mathrm{e} .10 \\
\mathrm{e} .03\end{array}$ \\
\hline $\begin{array}{l}26 \\
27 \\
28 \\
29 \\
30 \\
31\end{array}$ & $\begin{array}{l}2.2 \\
2.6 \\
2.4 \\
2.0 \\
1.5 \\
1.6\end{array}$ & $\begin{array}{l}1.2 \\
24 \\
45 \\
11 \\
6.3 \\
\ldots\end{array}$ & $\begin{array}{r}3.2 \\
2.7 \\
2.8 \\
114 \\
201 \\
22\end{array}$ & $\begin{array}{l}\text { e. } 98 \\
\text { e. } 92 \\
\text { e } 1.3 \\
\text { e } 1.8 \\
\text { e } 4.5 \\
\text { e1.5 }\end{array}$ & $\begin{array}{l}1.6 \\
1.5 \\
1.1 \\
\ldots \\
\ldots \\
\ldots\end{array}$ & $\begin{array}{l}30 \\
14 \\
6.0 \\
4.6 \\
4.0 \\
2.9\end{array}$ & $\begin{array}{l}2.4 \\
2.2 \\
1.9 \\
2.5 \\
1.7 \\
\ldots .\end{array}$ & $\begin{array}{l}3.7 \\
2.8 \\
2.3 \\
2.4 \\
8.9 \\
3.4\end{array}$ & $\begin{array}{l}.07 \\
.05 \\
.06 \\
.07 \\
.04 \\
.-\end{array}$ & $\begin{array}{l}.01 \\
.01 \\
.01 \\
.02 \\
.01 \\
.01\end{array}$ & $\begin{array}{l}.01 \\
.01 \\
.00 \\
.00 \\
.01 \\
.02\end{array}$ & $\begin{array}{l}\text { e. } 08 \\
\text { e.04 } \\
\text { e.05 } \\
\text { e.07 } \\
\text { e.02 } \\
. . .\end{array}$ \\
\hline $\begin{array}{l}\text { TOIAL } \\
\text { MEAN } \\
\text { MAX } \\
\text { MIN } \\
\text { CF SM } \\
\text { IN. }\end{array}$ & $\begin{array}{r}169.05 \\
5.45 \\
51 \\
.27 \\
1.39 \\
1.61\end{array}$ & $\begin{array}{r}141.95 \\
4.73 \\
45 \\
.52 \\
1.21 \\
1.35\end{array}$ & $\begin{array}{r}607.7 \\
19.6 \\
201 \\
1.2 \\
5.01 \\
5.78\end{array}$ & $\begin{array}{r}129.50 \\
4.18 \\
12 \\
.92 \\
1.07 \\
1.23\end{array}$ & $\begin{array}{r}171.8 \\
6.14 \\
37 \\
1.1 \\
1.57 \\
1.63\end{array}$ & $\begin{array}{r}386.27 \\
12.5 \\
108 \\
.62 \\
3.19 \\
3.67\end{array}$ & $\begin{array}{r}216.3 \\
7.21 \\
40 \\
1.4 \\
1.84 \\
2.06\end{array}$ & $\begin{array}{r}110.7 \\
3.57 \\
16 \\
1.0 \\
.91 \\
1.05\end{array}$ & $\begin{array}{r}16.75 \\
.56 \\
2.4 \\
.04 \\
.14 \\
.16\end{array}$ & $\begin{array}{c}10.28 \\
.33 \\
4.3 \\
.01 \\
.08 \\
.10\end{array}$ & $\begin{array}{l}4.55 \\
.15 \\
2.7 \\
.00 \\
.04 \\
.04\end{array}$ & $\begin{array}{l}5.13 \\
.17 \\
.17 \\
.00 \\
.04 \\
.05\end{array}$ \\
\hline
\end{tabular}

e Estimated

SIATISIICS OF MONTHLY MEAN DATA FOR WAIER YEARS 1990 - 1991, BY WAIER YEAR (WY)

\begin{tabular}{|c|c|c|c|c|c|c|c|c|c|c|c|c|}
\hline $\begin{array}{l}\text { MEAN } \\
\text { MAX } \\
\text { (WY) } \\
\text { MI N } \\
\text { (WY) }\end{array}$ & $\begin{array}{r}3.07 \\
5.45 \\
1991 \\
.68 \\
1990\end{array}$ & $\begin{array}{l}4.17 \\
4.73 \\
1991 \\
3.61 \\
1990\end{array}$ & $\begin{array}{r}10.1 \\
19.6 \\
1991 \\
.52 \\
1990\end{array}$ & $\begin{array}{l}4.03 \\
4.18 \\
1991 \\
3.89 \\
1990\end{array}$ & $\begin{array}{l}11.2 \\
16.4 \\
1990 \\
6.14 \\
1991\end{array}$ & $\begin{array}{l}9.38 \\
12.5 \\
1991 \\
6.30 \\
1990\end{array}$ & $\begin{array}{l}5.38 \\
7.21 \\
1991 \\
3.55 \\
1990\end{array}$ & $\begin{array}{l}10.1 \\
16.7 \\
1990 \\
3.57 \\
1991\end{array}$ & $\begin{array}{r}1.10 \\
2.84 \\
1990 \\
.56 \\
1991\end{array}$ & $\begin{array}{r}1.15 \\
1.98 \\
1990 \\
.33 \\
1991\end{array}$ & $\begin{array}{r}.51 \\
.87 \\
1990 \\
.15 \\
1991\end{array}$ & $\begin{array}{r}1.12 \\
2.08 \\
1990 \\
.11 \\
1991\end{array}$ \\
\hline
\end{tabular}

SUMMARY SIATISIICS

ANMUAL TOTAL

ANHUAL MEAK

HI GHEST ANNUAL MEAM

LOWEST ANNUAL MEAM

HIGHEST DAILY MEAN

LOWEST DAILY MEAN

ANNUAL SEVEM-DAY MINIMUM

INSIANTANEOUS PEAK FLOW

INSIANTANEOUS PEAK SIAGE

ANMUAL RUNOFF (CFSM)

ANMUAL RUNOFF (INCHES)

10 PERCENT EXCEEDS

50 PERCEMT EXCEEDS

90 PERCENT EXCEEDS
FOR 1990 CALENDAR YEAR

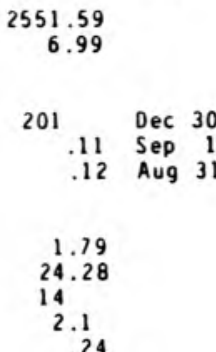

FOR 1991 WATER YEAR

1969.98
5.40

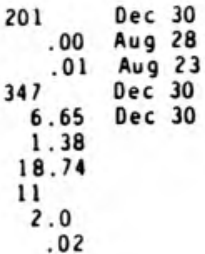

WATER YEARS $1990-1991$

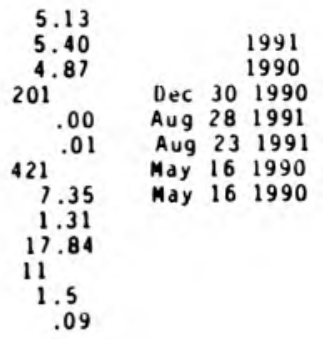




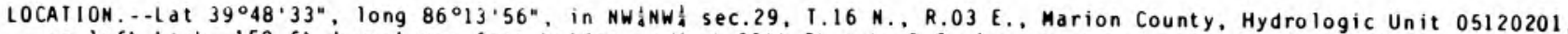
on left bank, $150 \mathrm{ft}$ downstream frow bridge on West $30 \mathrm{th}$ Street, 0.6 ai west of lafayette Road, and 0.6 i ustreal DRAINAGE AREA.--2.95 i $i$.

PERIOD OF RECORD.--October 1989 to current year.

GAGE.- Water-stage recorder. Datun of gage is $727.27 \mathrm{ft}$ above National Geodetic Vertical Datun pf 1929 .

REMARKS. - Records fair except for estiated daily discharges and for discharges less than 1 ft $/ 5$. which are poor.

DISCHARGE, CUBIC FEET PER SECOND, WATER YEAR OCTOBER 1990 TO SEPIEMBER 1991 DAI I Y MEAN VALUES

\begin{tabular}{|c|c|c|c|c|c|c|c|c|c|c|c|c|}
\hline DAY & $O C \mathrm{~T}$ & NOV & DEC & JAN & FEB & MAR & $A P R$ & MAY & JUN & JUL & AUG & SEP \\
\hline $\begin{array}{l}1 \\
2 \\
3 \\
4 \\
5\end{array}$ & $\begin{array}{l}.37 \\
11.40 \\
22 \\
1.5\end{array}$ & $\begin{array}{r}\text { e. } 31 \\
\text { e. } 27 \\
\text { e. } 25 \\
\text { e. } 25 \\
\text { e } 12\end{array}$ & $\begin{array}{l}3.3 \\
2.5 \\
60 \\
12 \\
5.4\end{array}$ & $\begin{array}{l}8.5 \\
5.6 \\
4.0 \\
2.9 \\
4.3\end{array}$ & $\begin{array}{r}2.7 \\
2.8 \\
3.0 \\
3.1 \\
11\end{array}$ & $\begin{array}{l}4.4 \\
4.1 \\
2.8 \\
2.3 \\
1.9\end{array}$ & $\begin{array}{l}2.2 \\
2.0 \\
1.9 \\
5.0 \\
4.5\end{array}$ & $\begin{array}{l}2.3 \\
1.3 \\
1.8 \\
3.8 \\
3.6\end{array}$ & $\begin{array}{l}.79 \\
8.7 \\
2.4 \\
.54 \\
.36\end{array}$ & $\begin{array}{l}.26 \\
.25 \\
.21 \\
.34 \\
.40\end{array}$ & $\begin{array}{l}.11 \\
.18 \\
.19 \\
.23 \\
.24\end{array}$ & $\begin{array}{l}.16 \\
.15 \\
3.2 \\
.77 \\
.11\end{array}$ \\
\hline $\begin{array}{r}6 \\
7 \\
8 \\
9 \\
10\end{array}$ & $\begin{array}{l}15^{.51} \\
3.7 \\
11 \\
41\end{array}$ & $\begin{array}{l}\text { e } 3.2 \\
\text { e } 1.6 \\
\text { e } 1.1 \\
\text { e. } 91 \\
\text { e. } 84\end{array}$ & $\begin{array}{l}3.9 \\
2.8 \\
2.3 \\
2.0 \\
1.9\end{array}$ & $\begin{array}{l}3.3 \\
2.8 \\
2.5 \\
2.3 \\
2.5\end{array}$ & $\begin{array}{l}33 \\
17 \\
8.0 \\
5.5 \\
4.3\end{array}$ & $\begin{array}{l}2.1 \\
1.1 \\
1.3 \\
1.2 \\
1.1\end{array}$ & $\begin{array}{r}3.1 \\
2.5 \\
14 \\
11 \\
4.9\end{array}$ & $\begin{array}{l}2.1 \\
1.3 \\
1.2 \\
1.0 \\
.84\end{array}$ & $\begin{array}{l}.34 \\
.32 \\
.31 \\
.31 \\
.36\end{array}$ & $\begin{array}{l}.23 \\
.27 \\
.32 \\
.26 \\
5.9\end{array}$ & $\begin{array}{c}15 \\
.32 \\
5.2 \\
.60 \\
.26\end{array}$ & $\begin{array}{l}.04 \\
.03 \\
.13 \\
.14 \\
.15\end{array}$ \\
\hline $\begin{array}{l}11 \\
12 \\
13 \\
14 \\
15\end{array}$ & $\begin{array}{l}\text { e } 8.3 \\
\text { e } 3.0 \\
\text { e } 1.2 \\
\text { e. } 80 \\
\text { e. } 60\end{array}$ & $\begin{array}{l}\text { e. } 66 \\
\text { e. } 46 \\
\text { e. } 31 \\
\text { e. } 16 \\
\text { e. } 16\end{array}$ & $\begin{array}{r}1.7 \\
1.5 \\
1.3 \\
1.1 \\
17\end{array}$ & $\begin{array}{l}14 \\
10 \\
5.9 \\
4.8 \\
6.0\end{array}$ & $\begin{array}{l}3.2 \\
2.6 \\
3.8 \\
4.2 \\
2.6\end{array}$ & $\begin{array}{l}31^{.99} \\
89 \\
19 \\
8.0\end{array}$ & $\begin{array}{l}3.0 \\
2.5 \\
26 \\
14 \\
37\end{array}$ & $\begin{array}{r}1.5 \\
.86 \\
.66 \\
1.1 \\
.54\end{array}$ & $\begin{array}{r}.34 \\
.34 \\
.36 \\
.77 \\
1.7\end{array}$ & $\begin{array}{l}2.4 \\
4.0 \\
.27 \\
.24 \\
.25\end{array}$ & $\begin{array}{c}.25 \\
.22 \\
.22 \\
1.1 \\
.18\end{array}$ & $\begin{array}{l}.08 \\
2.0 \\
.49 \\
.15 \\
.14\end{array}$ \\
\hline $\begin{array}{l}16 \\
17 \\
18 \\
19 \\
20\end{array}$ & $\begin{array}{l}\text { e. } 54 \\
\text { e. } 48 \\
\text { e } 4.1 \\
\text { e } 1.2 \\
\text { e. } .64\end{array}$ & $\begin{array}{l}\text { e. } 36 \\
\text { e. } 61 \\
\text { e. } 45 \\
\text { e. } 31 \\
\text { e. } 21\end{array}$ & $\begin{array}{c}5.4 \\
9.0 \\
26 \\
13 \\
6.0\end{array}$ & $\begin{array}{l}8.9 \\
6.8 \\
4.6 \\
3.8 \\
4.0\end{array}$ & $\begin{array}{l}1.9 \\
1.8 \\
18 \\
13 \\
7.6\end{array}$ & $\begin{array}{l}5.3 \\
18 \\
16 \\
7.7 \\
5.1\end{array}$ & $\begin{array}{l}10 \\
5.5 \\
3.8 \\
32 \\
12\end{array}$ & $\begin{array}{r}7.8 \\
1.8 \\
19 \\
2.1 \\
5.5\end{array}$ & $\begin{array}{l}2.5 \\
.30 \\
.24 \\
.25 \\
.22\end{array}$ & $\begin{array}{l}.26 \\
.20 \\
.19 \\
.24 \\
.23\end{array}$ & $\begin{array}{c}.18 \\
1.5 \\
.25 \\
3.4 \\
.28\end{array}$ & $\begin{array}{l}.14 \\
.14 \\
.12 \\
.07 \\
.02\end{array}$ \\
\hline $\begin{array}{l}21 \\
22 \\
23 \\
24 \\
25\end{array}$ & $\begin{array}{l}\text { e. } 52 \\
\text { e } 2.8 \\
\text { e } 1.3 \\
\text { e1.0 } \\
\text { e. } 64\end{array}$ & $\begin{array}{l}e .18 \\
7.9 \\
1.5 \\
1.0 \\
.55\end{array}$ & $\begin{array}{c}26 \\
14 \\
6.9 \\
4.2 \\
3.1\end{array}$ & $\begin{array}{l}3.0 \\
2.3 \\
2.0 \\
1.6 \\
1.3\end{array}$ & $\begin{array}{l}5.0 \\
3.7 \\
2.8 \\
2.5 \\
2.2\end{array}$ & $\begin{array}{l}4.0 \\
59 \\
26 \\
8.7 \\
5.3\end{array}$ & $\begin{array}{l}6.3 \\
4.5 \\
4.7 \\
3.3 \\
2.5\end{array}$ & $\begin{array}{r}1.9 \\
1.8 \\
17 \\
3.8 \\
2.7\end{array}$ & $\begin{array}{l}.24 \\
.30 \\
.30 \\
.32 \\
.35\end{array}$ & $\begin{array}{l}.25 \\
.21 \\
.19 \\
.17 \\
.17\end{array}$ & $\begin{array}{l}.19 \\
.16 \\
.16 \\
.16 \\
.17\end{array}$ & $\begin{array}{l}.00 \\
5.7 \\
1.0 \\
.12 \\
.09\end{array}$ \\
\hline $\begin{array}{l}26 \\
27 \\
28 \\
29 \\
30 \\
31\end{array}$ & $\begin{array}{l}\text { e. } 43 \\
\text { e. } 32 \\
\text { e. } 32 \\
\text { e. } 26 \\
\text { e. } 31 \\
\text { e. } 31\end{array}$ & $\begin{array}{l}30^{.49} \\
42 \\
9.0 \\
4.8 \\
-\cdots\end{array}$ & $\begin{array}{r}2.4 \\
2.1 \\
2.8 \\
107 \\
185 \\
20\end{array}$ & $\begin{array}{l}1.3 \\
1.2 \\
1.3 \\
3.0 \\
4.0 \\
2.1\end{array}$ & $\begin{array}{l}1.9 \\
1.8 \\
1.8 \\
\ldots . \\
\cdots . \\
\ldots\end{array}$ & $\begin{array}{r}27 \\
13 \\
6.3 \\
4.1 \\
2.9 \\
2.5\end{array}$ & $\begin{array}{l}2.5 \\
2.2 \\
2.1 \\
3.7 \\
1.8 \\
\ldots\end{array}$ & $\begin{array}{l}3.2 \\
1.3 \\
.64 \\
1.2 \\
5.7 \\
1.8\end{array}$ & $\begin{array}{l}.27 \\
.25 \\
.27 \\
.30 \\
.46 \\
. .-\end{array}$ & $\begin{array}{l}.21 \\
.22 \\
.24 \\
.24 \\
.24 \\
.18\end{array}$ & $\begin{array}{l}.17 \\
.18 \\
.15 \\
.10 \\
.10 \\
.17\end{array}$ & $\begin{array}{l}.25 \\
.09 \\
.07 \\
.04 \\
.03 \\
\cdots\end{array}$ \\
\hline $\begin{array}{l}\text { TOTAL } \\
\text { MEAN } \\
\text { MAX } \\
\text { MIN } \\
\text { CF SM } \\
\text { IN. }\end{array}$ & $\begin{array}{r}135.55 \\
4.37 \\
41 \\
.26 \\
1.48 \\
1.71\end{array}$ & $\begin{array}{r}121.84 \\
4.06 \\
42 \\
.16 \\
1.38 \\
1.54\end{array}$ & $\begin{array}{r}551.6 \\
17.8 \\
185 \\
1.1 \\
6.03 \\
6.96\end{array}$ & $\begin{array}{r}130.6 \\
4.21 \\
14 \\
1.2 \\
1.43 \\
1.65\end{array}$ & $\begin{array}{r}170.8 \\
6.10 \\
33 \\
1.8 \\
2.07 \\
2.15\end{array}$ & $\begin{array}{r}381.79 \\
12.3 \\
89 \\
.99 \\
4.17 \\
4.81\end{array}$ & $\begin{array}{c}230.5 \\
7.68 \\
37 \\
1.8 \\
2.60 \\
2.91\end{array}$ & $\begin{array}{c}101.14 \\
3.26 \\
19 \\
.54 \\
1.11 \\
1.28\end{array}$ & $\begin{array}{c}24.51 \\
.82 \\
8.7 \\
.22 \\
.28 \\
.31\end{array}$ & $\begin{array}{c}19.04 \\
.61 \\
5.9 \\
.17 \\
.21 \\
.24\end{array}$ & $\begin{array}{c}31.62 \\
1.02 \\
15 \\
.10 \\
.35 \\
.40\end{array}$ & $\begin{array}{c}15.62 \\
.52 \\
5.7 \\
.00 \\
.18 \\
.20\end{array}$ \\
\hline
\end{tabular}

e Estimated

SIAIISIICS OF MONTHLY MEAN DATA FUR WAIER YLARS 1989 - 1991, BY WAIER YEAR (WY)

\begin{tabular}{|c|c|c|c|c|c|c|c|c|c|c|c|c|}
\hline $\begin{array}{l}\text { MEAN } \\
\text { MAX } \\
\text { (WY) } \\
\text { MIN } \\
(W Y)\end{array}$ & $\begin{array}{l}2.13 \\
4.37 \\
1991 \\
1.09 \\
1990\end{array}$ & $\begin{array}{l}3.86 \\
4.06 \\
1991 \\
3.66 \\
1990\end{array}$ & $\begin{array}{l}9.73 \\
17.8 \\
1991 \\
1.66 \\
1990\end{array}$ & $\begin{array}{l}1.81 \\
4.21 \\
1991 \\
3.40 \\
1990\end{array}$ & $\begin{array}{l}9.90 \\
13.7 \\
1990 \\
6.10 \\
1991\end{array}$ & $\begin{array}{l}9.46 \\
12.3 \\
1991 \\
6.61 \\
1990\end{array}$ & $\begin{array}{l}5.60 \\
7.68 \\
1991 \\
3.53 \\
1990\end{array}$ & $\begin{array}{l}9.02 \\
14.8 \\
1990 \\
3.26 \\
1991\end{array}$ & $\begin{array}{r}1.68 \\
2.54 \\
1990 \\
.82 \\
1991\end{array}$ & $\begin{array}{r}1.62 \\
2.63 \\
1990 \\
.61 \\
1991\end{array}$ & $\begin{array}{l}1.41 \\
1.19 \\
1990 \\
1.02 \\
1991\end{array}$ & $\begin{array}{r}.89 \\
1.26 \\
1990 \\
.52 \\
1991\end{array}$ \\
\hline
\end{tabular}

SUMMARY STATISIICS

ANNUAL TOIAL

ANMUAL MEAM

HIGHEST ANNUAL MEAN

LOWEST ANNUAL MEAN

HIGHESI DAILY MEAN

LOWEST DAILY MEAN

ANNUAL SEVEN-DAY MINIMUM

INSTANTANEOUS PEAK FLOW

INSTANTANEOUS PEAK STAGE

ANMUAL RUNOFF (CFSM)

ANNUAL RUMOFF (INCHES)

10 PERCENT EXLEEDS

50 PERCENT EXCEEDS

90 PERCENT EXCEEDS
FOR 1990 CALENDAR YEAR

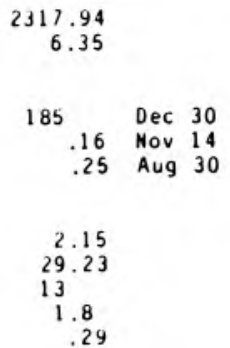

FOR 1991 WATER YEAR

$$
\begin{array}{r}
1914.61 \\
5.25
\end{array}
$$

185 Dec 30

$\begin{array}{rr}.00 & \text { Sep } 21 \\ 303.09 & \text { Sep } 15 \\ & \text { Dec } 30\end{array}$

$\begin{array}{rlll}5.51 & \text { Dec } & 30\end{array}$

1. 78

24.14

12

1.8
.17
WATER YEARS $1989 \cdot 1991$

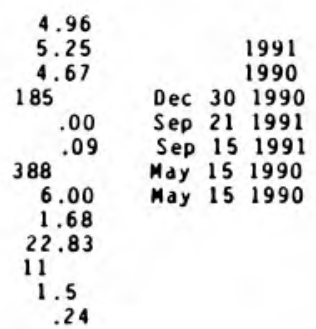




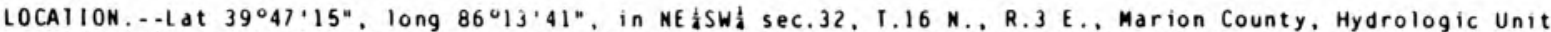
05120201 , on right bank at upstream side of 16 th Street bridge in Speedway, 0.6 i upstrea from Dry Run, and 2.3 i upstrean from mouth.

DRAINAGE AREA. - 23.9 $i^{2}$ including $5.57 \mathrm{mi}^{2}$ from Dry Run basin. Since June 1964 part of the flow fron the $5.57 i^{2}$ of Dry Run basin has been diverted into Little Eagle Creek above gage.

PERIOD OF RECORD.--0ctober 1959 to current year. Figures of runoff for June 1964 to Septenber 1966 have been found to be in error and should not be used.

GAGE.- -Water-stage recorder. Datum of gage is $707.82 \mathrm{ft}$ above National Geodetic Vertical Datun of 1929 (levels by State of Indiana. Department of Natural Resources). Prior to June 13,1975, at datue $3.00 \mathrm{ft}$ higher.

REMARKS. - -Records fair except for estiated daily discharges, which are poor.

DISCHARGE, CUBIL FEET PER SECONO, WATER YEAR OCTOBER 1990 TO SEPIEMBER 1991 DAILY MEAN VALUES

\begin{tabular}{|c|c|c|c|c|c|c|c|c|c|c|c|c|}
\hline DAY & $O C \mathrm{~T}$ & MOV & DEC & JAN & FE B & MAR & APR & MAY & JUN & JUL & AUG & SEP \\
\hline $\begin{array}{l}1 \\
2 \\
3 \\
4 \\
5\end{array}$ & $\begin{array}{r}2.8 \\
2.6 \\
15 \\
204 \\
18\end{array}$ & $\begin{array}{r}8.4 \\
8.7 \\
8.7 \\
8.7 \\
81\end{array}$ & $\begin{array}{r}19 \\
14 \\
330 \\
86 \\
36\end{array}$ & $\begin{array}{l}51 \\
34 \\
23 \\
16 \\
23\end{array}$ & $\begin{array}{l}15 \\
20 \\
21 \\
17 \\
68\end{array}$ & $\begin{array}{rl} & 9.1 \\
\mathrm{e} & 20 \\
\mathrm{e} & 13 \\
\mathrm{e} & 9.4 \\
\mathrm{e} & 7.4\end{array}$ & $\begin{array}{l}14 \\
12 \\
11 \\
29 \\
35\end{array}$ & $\begin{array}{l}13 \\
10 \\
8.7 \\
25 \\
21\end{array}$ & $\begin{array}{l}11 \\
38 \\
17 \\
7.0 \\
4.8\end{array}$ & $\begin{array}{l}1.8 \\
1.1 \\
1.1 \\
1.2 \\
2.6\end{array}$ & $\begin{array}{l}.90 \\
.90 \\
.90 \\
.90 \\
.97\end{array}$ & $\begin{array}{r}.93 \\
.71 \\
6.4 \\
11 \\
1.0\end{array}$ \\
\hline $\begin{array}{r}6 \\
7 \\
8 \\
9 \\
10\end{array}$ & $\begin{array}{c}7.9 \\
94 \\
39 \\
82 \\
315\end{array}$ & $\begin{array}{r}25 \\
13 \\
9.0 \\
7.4 \\
6.8\end{array}$ & $\begin{array}{l}24 \\
18 \\
14 \\
12 \\
10\end{array}$ & $\begin{array}{l}23 \\
17 \\
15 \\
14 \\
12\end{array}$ & $\begin{array}{r}199 \\
97 \\
43 \\
29 \\
22\end{array}$ & $\begin{array}{l}\text { e } 8.5 \\
\text { e6.6 } \\
\text { e5.3 } \\
\text { e4.2 } \\
\text { e4.1 }\end{array}$ & $\begin{array}{l}20 \\
15 \\
87 \\
62 \\
26\end{array}$ & $\begin{array}{l}19 \\
11 \\
8.8 \\
7.8 \\
8.0\end{array}$ & $\begin{array}{l}3.7 \\
3.2 \\
2.8 \\
2.5 \\
2.0\end{array}$ & $\begin{array}{c}1.2 \\
.91 \\
1.5 \\
2.5 \\
81\end{array}$ & $\begin{array}{l}85 \\
7.5 \\
23 \\
11 \\
3.0\end{array}$ & $\begin{array}{l}.64 \\
.57 \\
.55 \\
.56 \\
.90\end{array}$ \\
\hline $\begin{array}{l}11 \\
12 \\
13 \\
14 \\
15\end{array}$ & $\begin{array}{l}58 \\
24 \\
15 \\
11 \\
8.2\end{array}$ & $\begin{array}{l}5.4 \\
4.3 \\
3.5 \\
3.0 \\
3.0\end{array}$ & $\begin{array}{r}9.1 \\
8.4 \\
7.8 \\
6.8 \\
117\end{array}$ & $\begin{array}{l}92 \\
67 \\
32 \\
24 \\
27\end{array}$ & $\begin{array}{l}16 \\
13 \\
17 \\
23 \\
18\end{array}$ & $\begin{aligned} & \text { e } 3.8 \\
& \text { e } 220 \\
& \text { e } 540 \\
& \text { e } 110 \\
& \text { e } 60\end{aligned}$ & $\begin{array}{r}17 \\
13 \\
155 \\
78 \\
208\end{array}$ & $\begin{array}{l}19 \\
26 \\
16 \\
14 \\
15\end{array}$ & $\begin{array}{l}1.9 \\
2.6 \\
2.4 \\
2.3 \\
4.1\end{array}$ & $\begin{array}{l}17 \\
50 \\
7.0 \\
3.7 \\
2.6\end{array}$ & $\begin{array}{l}1.8 \\
1.3 \\
1.1 \\
6.4 \\
1.3\end{array}$ & $\begin{array}{c}2.85 \\
13 \\
2.3 \\
1.4\end{array}$ \\
\hline $\begin{array}{l}16 \\
17 \\
18 \\
19 \\
20\end{array}$ & $\begin{array}{c}6.9 \\
6.3 \\
30 \\
9.6 \\
6.7\end{array}$ & $\begin{array}{l}3.4 \\
5.1 \\
4.4 \\
3.8 \\
3.7\end{array}$ & $\begin{array}{r}33 \\
47 \\
171 \\
85 \\
37\end{array}$ & $\begin{array}{l}58 \\
45 \\
27 \\
21 \\
20\end{array}$ & $\begin{array}{r}12 \\
10 \\
105 \\
88 \\
43\end{array}$ & $\begin{array}{r}\text { e } 37 \\
\text { e1 } 20 \\
\text { e } 98 \\
42 \\
27\end{array}$ & $\begin{array}{r}61 \\
31 \\
22 \\
180 \\
67\end{array}$ & $\begin{array}{r}41 \\
37 \\
110 \\
33 \\
24\end{array}$ & $\begin{array}{l}40 \\
5.3 \\
3.1 \\
2.4 \\
1.9\end{array}$ & $\begin{array}{l}2.1 \\
1.7 \\
1.5 \\
1.8 \\
1.8\end{array}$ & $\begin{array}{c}.64 \\
3.9 \\
1.8 \\
17.8 \\
3.7\end{array}$ & $\begin{array}{l}.80 \\
.59 \\
.50 \\
.10 \\
.53\end{array}$ \\
\hline $\begin{array}{l}21 \\
22 \\
23 \\
24 \\
25\end{array}$ & $\begin{array}{l}5.6 \\
22 \\
11 \\
8.1 \\
6.9\end{array}$ & $\begin{array}{l}3.5 \\
45 \\
13 \\
6.8 \\
5.2\end{array}$ & $\begin{array}{r}158 \\
101 \\
47 \\
28 \\
27\end{array}$ & $\begin{array}{l}19 \\
15 \\
12 \\
11 \\
8.4\end{array}$ & $\begin{array}{l}27 \\
20 \\
15 \\
13 \\
11\end{array}$ & $\begin{array}{r}21 \\
287 \\
154 \\
51 \\
31\end{array}$ & $\begin{array}{l}34 \\
24 \\
23 \\
21 \\
14\end{array}$ & $\begin{array}{l}17 \\
15 \\
88 \\
56 \\
24\end{array}$ & $\begin{array}{r}1.6 \\
1.9 \\
17 \\
2.9 \\
2.1\end{array}$ & $\begin{array}{l}1.1 \\
1.6 \\
1.3 \\
1.3 \\
1.2\end{array}$ & $\begin{array}{r}1.2 \\
.68 \\
.50 \\
.51 \\
.49\end{array}$ & $\begin{array}{l}3.1 \\
17 \\
23 \\
2.7 \\
1.0\end{array}$ \\
\hline $\begin{array}{l}26 \\
27 \\
28 \\
29 \\
30 \\
31\end{array}$ & $\begin{array}{l}6.0 \\
5.7 \\
5.7 \\
5.3 \\
5.5 \\
7.7\end{array}$ & $\begin{array}{c}4.4 \\
172 \\
250 \\
58 \\
28 \\
\cdots\end{array}$ & $\begin{array}{r}19 \\
14 \\
12 \\
561 \\
1230 \\
145\end{array}$ & $\begin{array}{r}8.2 \\
8.2 \\
7.9 \\
11 \\
29 \\
13\end{array}$ & $\begin{array}{l}9.8 \\
9.2 \\
8.5 \\
\ldots . \\
\ldots . \\
\ldots\end{array}$ & $\begin{array}{r}164 \\
79 \\
37 \\
24 \\
20 \\
16\end{array}$ & $\begin{array}{c}14 \\
12 \\
11 \\
18 \\
12 \\
\cdots-\end{array}$ & $\begin{array}{l}32 \\
16 \\
9.6 \\
18 \\
72 \\
21\end{array}$ & $\begin{array}{l}1.9 \\
1.7 \\
1.3 \\
1.2 \\
2.3 \\
\ldots . .\end{array}$ & $\begin{array}{l}1.1 \\
1.1 \\
.91 \\
.90 \\
.99 \\
.99\end{array}$ & $\begin{array}{l}.48 \\
.48 \\
.96 \\
.63 \\
.73 \\
1.3\end{array}$ & $\begin{array}{l}1.2 \\
.86 \\
.57 \\
.81 \\
.63 \\
\ldots .\end{array}$ \\
\hline $\begin{array}{l}\text { TOTAL } \\
\text { MEAN } \\
\text { MAX } \\
\text { MIN } \\
\text { CF SM } \\
\text { IN. }\end{array}$ & $\begin{array}{r}1045.5 \\
33.7 \\
315 \\
2.6 \\
1.41 \\
1.63\end{array}$ & $\begin{array}{r}802.2 \\
26.7 \\
250 \\
3.0 \\
1.12 \\
1.25\end{array}$ & $\begin{array}{r}3427.1 \\
111 \\
1230 \\
6.8 \\
4.63 \\
5.33\end{array}$ & $\begin{array}{r}789.7 \\
25.5 \\
92 \\
1.9 \\
1.07 \\
1.23\end{array}$ & $\begin{array}{r}989.5 \\
35.3 \\
199 \\
8.5 \\
1.48 \\
1.54\end{array}$ & $\begin{array}{r}2229.4 \\
71.9 \\
540 \\
3.8 \\
3.01 \\
3.47\end{array}$ & $\begin{array}{r}1326 \\
44.2 \\
208 \\
11 \\
1.85 \\
2.06\end{array}$ & $\begin{array}{c}835.9 \\
27.0 \\
110 \\
7.8 \\
1.13 \\
1.30\end{array}$ & $\begin{array}{r}191.9 \\
6.40 \\
40 \\
1.2 \\
.27 \\
.30\end{array}$ & $\begin{array}{r}197.20 \\
6.36 \\
81 \\
.90 \\
.27 \\
.31\end{array}$ & $\begin{array}{c}180.97 \\
5.84 \\
85 \\
.48 \\
.24 \\
.28\end{array}$ & $\begin{array}{c}97.30 \\
3.24 \\
23 \\
.50 \\
.14 \\
.15\end{array}$ \\
\hline
\end{tabular}

e Estinated

SIATISIICS OF MONTHLY MEAN DATA FOR WAIER YEARS 1965 - 1991, BY WATER YEAR (WY)

$\begin{array}{lrrrrrrrrrrrr}\text { MEAN } & 10.9 & 20.4 & 31.9 & 23.6 & 33.0 & 39.6 & 33.5 & 30.3 & 15.1 & 15.3 & 11.1 & 9.07 \\ \text { MAX } & 88.9 & 113 & 111 & 78.3 & 75.5 & 87.8 & 68.3 & 103 & 63.4 & 92.3 & 44.7 & 101 \\ \text { (WY) } & 1987 & 1986 & 1991 & 1969 & 1990 & 1978 & 1972 & 1981 & 1978 & 1979 & 1979 & 1989 \\ \text { MIN } & .81 & 1.50 & .85 & .32 & 3.82 & 4.84 & 5.51 & 4.84 & .98 & .67 & .15 & .20 \\ \text { (WY) } & 1967 & 1966 & 1977 & 1977 & 1978 & 1981 & 1976 & 1976 & 1988 & 1966 & 1966 & 1966\end{array}$

SUMMARY SIAIISIICS

ANMUAL TOTAL

ANMUAL MEAN

HIGHEST ANNUAL MEAN

LOWEST ANNUAL MEAN

HIGHEST DAILY MEAN

LOWEST DAILY MEAN

ANMUAL SEVEN-DAY MINIMUM

INSTANTANEOUS PEAK FLOW

INSTANTANEOUS PEAK STIAGE

ANMUAL RUNOFF (CFSM)

ANMUAL RUNOFF (I MCHES)

10 PERCENT EXCEEDS

50 PERCENT EXCEEDS

90 PERCENI EXCEEDS
FOR 1990 CALENDAR YEAR

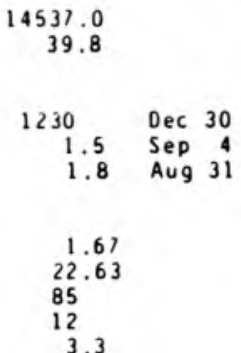

FOR 1991 WAIER YEAR

$\begin{array}{rrr}12112.61 & & \\ 33.2 & & \\ 1230 & & \\ & \text { Dec } 30 \\ .48 & \text { Aug } & 26 \\ .58 & \text { Aug } & 23 \\ 1880 & \text { Dec } 30 \\ 8.49 & \text { Dec } 30 \\ 1.39 & & \\ 18.85 & & \\ 81 & & \\ 11 & & \\ .99 & & \end{array}$

WATER YEARS 1965 - 1991

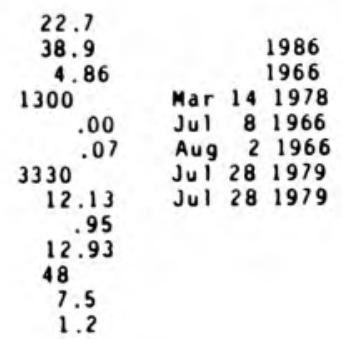


LOCATION. - L at $39^{\circ} 42^{\prime} 21^{\prime \prime}$, Iong $8^{\circ} 06^{\prime} 13^{\prime \prime}$, in NE $\frac{1}{2}$ NE $\frac{1}{4}$ sec.32, T.15 N., R.4 E., Marion County, Hydrologic Unit 05120201 , on left bazk at upstream side of Sheran Drive bridge in Indianapolis, and at mile 6.2 .

DRAINAGE AREA $\cdots 15,6 i^{2}$

PERIOD OF RECORD.--October 1970 to current year.

GAGE.- Water-stage recorder. Datum of gage is $742.00 \mathrm{ft}$ above National Geodetic Vertical Datua of 1929 (Indiana Flood Control and Water Resources Commission bench mark).

REMARKS. - Records good except those for estimated daily discharges, which are poor.

DISCHARGE, CUBIC FEET PER SECOND, WATER YEAR OCTOBER 1990 TO SEPTEMBER 1991 DAILY MEAN VALUES

\begin{tabular}{|c|c|c|c|c|c|c|c|c|c|c|c|c|}
\hline DAY & $\mathrm{OCT}$ & NOV & $\mathrm{DEC}$ & JAN & FEB & MAR & APR & MAY & JUN & JUL & AUG & SEP \\
\hline $\begin{array}{l}1 \\
2 \\
3 \\
4 \\
5\end{array}$ & $\begin{array}{r}1.3 \\
1.4 \\
13 \\
140 \\
18\end{array}$ & $\begin{array}{r}2.2 \\
2.1 \\
2.1 \\
2.2 \\
29\end{array}$ & $\begin{array}{r}17 \\
13 \\
100 \\
33 \\
20\end{array}$ & $\begin{array}{r}53 \\
34 \\
21 \\
\text { e18 } \\
\text { el } 16\end{array}$ & $\begin{array}{r}\text { e11 } \\
21 \\
24 \\
22 \\
53\end{array}$ & $\begin{array}{c}9.1 \\
15 \\
9.1 \\
6.9 \\
5.8\end{array}$ & $\begin{array}{l}8.9 \\
6.9 \\
5.9 \\
13 \\
14\end{array}$ & $\begin{array}{l}6.5 \\
6.1 \\
6.0 \\
10 \\
37\end{array}$ & $\begin{array}{l}3.8 \\
3.3 \\
2.7 \\
2.2 \\
1.5\end{array}$ & $\begin{array}{l}1.7 \\
4.7 \\
1.3 \\
2.8 \\
1.2\end{array}$ & $\begin{array}{l}.43 \\
.43 \\
.34 \\
.35 \\
.30\end{array}$ & $\begin{array}{l}2.0 \\
.46 \\
1.7 \\
.98 \\
.85\end{array}$ \\
\hline $\begin{array}{r}6 \\
7 \\
8 \\
9 \\
10\end{array}$ & $\begin{array}{l}8.5 \\
14 \\
12 \\
30 \\
111\end{array}$ & $\begin{array}{r}14 \\
8.5 \\
4.5 \\
4.7 \\
6.2\end{array}$ & $\begin{array}{l}16 \\
13 \\
10 \\
8.4 \\
7.6\end{array}$ & $\begin{array}{r}\text { e } 15 \\
\text { e } 12 \\
\text { e } 11 \\
\text { e } 9.7 \\
\text { e } 9.6\end{array}$ & $\begin{array}{r}199 \\
93 \\
48 \\
32 \\
24\end{array}$ & $\begin{array}{r}12 \\
8.4 \\
5.4 \\
4.9 \\
4.2\end{array}$ & $\begin{array}{l}7.6 \\
6.1 \\
9.8 \\
10 \\
7.5\end{array}$ & $\begin{array}{l}33 \\
11 \\
7.8 \\
6.5 \\
7.3\end{array}$ & $\begin{array}{l}1.2 \\
1.2 \\
1.3 \\
1.3 \\
1.0\end{array}$ & $\begin{array}{c}.69 \\
.38 \\
1.2 \\
1.2 \\
23\end{array}$ & $\begin{array}{r}27 \\
3.8 \\
4.1 \\
6.7 \\
3.1\end{array}$ & $\begin{array}{l}.35 \\
.19 \\
.13 \\
.10 \\
.14\end{array}$ \\
\hline $\begin{array}{l}11 \\
12 \\
13 \\
14 \\
15\end{array}$ & $\begin{array}{l}35 \\
18 \\
11 \\
7.6 \\
5.4\end{array}$ & $\begin{array}{l}3.9 \\
3.1 \\
2.7 \\
2.6 \\
2.5\end{array}$ & $\begin{array}{r}6.8 \\
6.4 \\
5.5 \\
4.4 \\
64\end{array}$ & $\begin{array}{l}71 \\
55 \\
28 \\
22 \\
26\end{array}$ & $\begin{array}{r}16 \\
12 \\
17 \\
21 \\
\text { e13 }\end{array}$ & $\begin{array}{c}3.8 \\
181 \\
325 \\
82 \\
43\end{array}$ & $\begin{array}{l}5.9 \\
3.5 \\
79 \\
43 \\
82\end{array}$ & $\begin{array}{l}8.4 \\
8.9 \\
5.2 \\
9.4 \\
5.2\end{array}$ & $\begin{array}{c}.99 \\
1.1 \\
.89 \\
.73 \\
.59\end{array}$ & $\begin{array}{r}4.8 \\
23 \\
4.9 \\
1.8 \\
1.5\end{array}$ & $\begin{array}{c}2.3 \\
.73 \\
.24 \\
1.0 \\
.43\end{array}$ & $\begin{array}{l}23^{.16} \\
31 \\
2.2 \\
.61\end{array}$ \\
\hline $\begin{array}{l}16 \\
17 \\
18 \\
19 \\
20\end{array}$ & $\begin{array}{c}4.0 \\
3.6 \\
36 \\
12 \\
6.4\end{array}$ & $\begin{array}{l}6.6 \\
3.0 \\
2.2 \\
2.2 \\
2.1\end{array}$ & $\begin{array}{r}21 \\
47 \\
180 \\
69 \\
33\end{array}$ & $\begin{array}{l}46 \\
42 \\
24 \\
18 \\
18\end{array}$ & $\begin{array}{l}\text { e } 9.2 \\
\text { e } 8.8 \\
72 \\
69 \\
46\end{array}$ & $\begin{array}{l}25 \\
72 \\
76 \\
37 \\
22\end{array}$ & $\begin{array}{r}30 \\
19 \\
15 \\
194 \\
62\end{array}$ & $\begin{array}{c}13 \\
8.5 \\
43 \\
8.8 \\
5.3\end{array}$ & $\begin{array}{l}4.5 \\
2.0 \\
.75 \\
.47 \\
.34\end{array}$ & $\begin{array}{l}.84 \\
.55 \\
.36 \\
.34 \\
.32\end{array}$ & $\begin{array}{l}.15 \\
8.5 \\
7.0 \\
8.5 \\
3.0\end{array}$ & $\begin{array}{r}.37 \\
.23 \\
.16 \\
.51 \\
1.9\end{array}$ \\
\hline $\begin{array}{l}21 \\
22 \\
23 \\
24 \\
25\end{array}$ & $\begin{array}{c}4.8 \\
16 \\
8.6 \\
6.0 \\
4.9\end{array}$ & $\begin{array}{l}2.0 \\
49 \\
18 \\
11 \\
8.0\end{array}$ & $\begin{array}{r}116 \\
70 \\
35 \\
\mathrm{e} 21 \\
\mathrm{e} 15\end{array}$ & $\begin{array}{r}15 \\
\text { e } 12 \\
\text { e } 9.0 \\
\text { e7. } \\
\text { e } 6.2\end{array}$ & $\begin{array}{l}27 \\
19 \\
14 \\
12 \\
9.4\end{array}$ & $\begin{array}{r}17 \\
352 \\
131 \\
49 \\
30\end{array}$ & $\begin{array}{l}35 \\
24 \\
19 \\
19 \\
12\end{array}$ & $\begin{array}{l}4.0 \\
67 \\
59 \\
26 \\
16\end{array}$ & $\begin{array}{l}.44 \\
.34 \\
.34 \\
.32 \\
.32\end{array}$ & $\begin{array}{l}.23 \\
.19 \\
.16 \\
.16 \\
.16\end{array}$ & $\begin{array}{l}.90 \\
.38 \\
.25 \\
.19 \\
.15\end{array}$ & $\begin{array}{c}1.1 \\
5.7 \\
12 \\
1.4 \\
.60\end{array}$ \\
\hline $\begin{array}{l}26 \\
27 \\
28 \\
29 \\
30 \\
31\end{array}$ & $\begin{array}{l}4.0 \\
3.5 \\
3.1 \\
2.7 \\
2.9 \\
2.5\end{array}$ & $\begin{array}{c}6.7 \\
61 \\
190 \\
43 \\
25 \\
\ldots . .\end{array}$ & $\begin{array}{l}\text { el2 } \\
\text { el0 } \\
\text { el5 } \\
313 \\
981 \\
105\end{array}$ & $\begin{array}{l}\text { e } 6.0 \\
\text { e6. } \\
\text { e } 7.2 \\
\text { e } 8.8 \\
\text { e13 } \\
\text { e11 }\end{array}$ & $\begin{array}{l}7.8 \\
7.3 \\
6.9 \\
\cdots . \\
\cdots \\
\cdots\end{array}$ & $\begin{array}{r}122 \\
60 \\
30 \\
19 \\
13 \\
11\end{array}$ & $\begin{array}{c}11 \\
10 \\
9.7 \\
11 \\
8.0 \\
\ldots\end{array}$ & $\begin{array}{l}49 \\
20 \\
12 \\
7.8 \\
6.8 \\
5.0\end{array}$ & $\begin{array}{r}72 \\
11 \\
6.2 \\
4.6 \\
3.8 \\
-.-\end{array}$ & $\begin{array}{l}.14 \\
.19 \\
.19 \\
.23 \\
.42 \\
.46\end{array}$ & $\begin{array}{l}.12 \\
47^{.12} \\
17 \\
2.8 \\
3.8\end{array}$ & $\begin{array}{l}.41 \\
.45 \\
.23 \\
.19 \\
.14 \\
. . .\end{array}$ \\
\hline $\begin{array}{l}\text { TOTAL } \\
\text { MEAN } \\
\text { MAX } \\
\text { MIN } \\
\text { CFSM } \\
\text { IN. }\end{array}$ & $\begin{array}{r}547.2 \\
17.7 \\
140 \\
1.3 \\
1.13 \\
1.30\end{array}$ & $\begin{array}{r}520.1 \\
17.3 \\
190 \\
2.0 \\
1.11 \\
1.24\end{array}$ & $\begin{array}{r}2368.1 \\
76.4 \\
981 \\
4.4 \\
4.90 \\
5.65\end{array}$ & $\begin{array}{r}651.0 \\
21.0 \\
71 \\
6.0 \\
1.35 \\
1.55\end{array}$ & $\begin{array}{r}914.4 \\
32.7 \\
199 \\
6.9 \\
2.09 \\
2.18\end{array}$ & $\begin{array}{r}1781.6 \\
57.5 \\
352 \\
3.8 \\
3.68 \\
4.25\end{array}$ & $\begin{array}{c}781.8 \\
26.1 \\
194 \\
3.5 \\
1.67 \\
1.86\end{array}$ & $\begin{array}{c}519.5 \\
16.8 \\
67 \\
4.0 \\
1.07 \\
1.24\end{array}$ & $\begin{array}{r}131.22 \\
4.37 \\
72 \\
.32 \\
.28 \\
.31\end{array}$ & $\begin{array}{c}79.11 \\
2.55 \\
23 \\
.14 \\
.16 \\
.19\end{array}$ & $\begin{array}{c}151.11 \\
4.87 \\
47 \\
.12 \\
.31 \\
.36\end{array}$ & $\begin{array}{c}89.26 \\
2.98 \\
31 \\
.10 \\
.19 \\
.21\end{array}$ \\
\hline
\end{tabular}

estimated

STATISIICS OF MONTHLY MEAN DATA FOR WATER YEARS 1971 - 1991, BY WATER YEAR (WY)

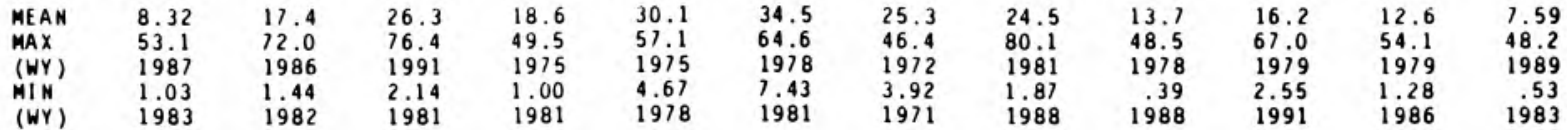

SUMMARY SIATISTICS

ANNUAL TOTAL

ANNUAL MEAN

HIGHEST ANMUAL MEAN

LOWEST ANNUAL MEAN

HIGHESI DAILY MEAN

LOWESI DAILY MEAN

ANNUAL SEVEN-DAY MINIMUM

INSTANIANEOUS PEAK FLOW

INSIANIANEOUS PEAK STAGE

ANNUAL RUNOFF (CFSM)

ANHUAL RUNOFF (INCHES)

10 PERCENT EXCEEDS

50 PERCENT EXCEEDS

90 PERCENT EXCEEOS
FOR 1990 CALENDAR YEAR

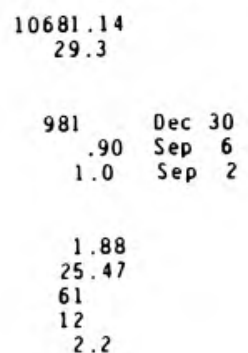

FOR 1991 WATER YEAR

$$
\begin{gathered}
8534.40 \\
23.4
\end{gathered}
$$

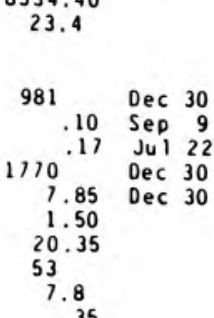

WATER YEARS 1971 - 1991

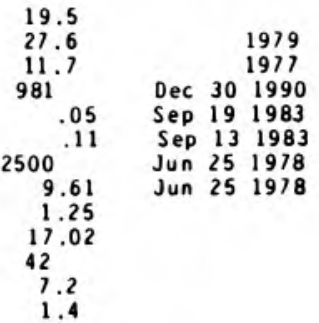




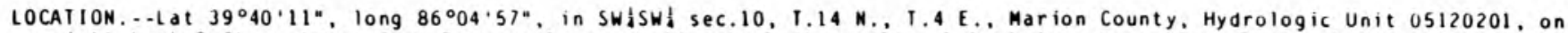
right bank $5 \mathrm{ft}$ upstream from Eaerson Avenue bridge in Indianapolis, 1.1 i downstrean fro Bunker Creek, and 2.5 a upstrean from Derbyshire Creek.

DRAINAGE AREA $\ldots 5,73 \cdot i^{2}$

PERIOD OF RECORD.--0ctober 1989 to current year.

GAGE.- - Water-stage recorder. Datum of gage is $783.17 \mathrm{ft}$ above National Geodetic Vertical Datun of 1929.

REMARKS.--Records fair except for estiated dally discharges, which are poor.

DISCHARGE, CUBIC FEET PER SECOND, WAIER YEAR OCTOBER 1990 TO SEPIEMBER 1991 DAI IY MEAN VALUES

\begin{tabular}{|c|c|c|c|c|c|c|c|c|c|c|c|c|}
\hline DAY & $\mathrm{OCT}$ & NOV & DEC & JAN & FE B & MAR & APR & MAY & JUN & JUL & AUG & SEP \\
\hline $\begin{array}{l}1 \\
2 \\
3 \\
4 \\
5\end{array}$ & $\begin{array}{r}.79 \\
.70 \\
45 \\
6.1\end{array}$ & $\begin{array}{l}1.5 \\
1.3 \\
1.4 \\
1.4 \\
7.3\end{array}$ & $\begin{array}{l}6.8 \\
5.1 \\
44 \\
14 \\
8.4\end{array}$ & $\begin{array}{r}\mathrm{e} 17 \\
\mathrm{e} 13 \\
\mathrm{e} 9.0 \\
\mathrm{e} 7.8 \\
7.7\end{array}$ & $\begin{array}{l}\text { e6. } 8 \\
\text { e11 } \\
12 \\
11 \\
18\end{array}$ & $\begin{array}{l}3.8 \\
5.6 \\
4.0 \\
3.3 \\
2.9\end{array}$ & $\begin{array}{l}4.5 \\
3.7 \\
3.2 \\
4.6 \\
5.9\end{array}$ & $\begin{array}{l}2.3 \\
1.8 \\
1.5 \\
1.9 \\
6.3\end{array}$ & $\begin{array}{l}.66 \\
.56 \\
.49 \\
.35 \\
.66\end{array}$ & $\begin{array}{l}.00 \\
.00 \\
.00 \\
.00 \\
.00\end{array}$ & $\begin{array}{l}.00 \\
.00 \\
.00 \\
.00 \\
.00\end{array}$ & $\begin{array}{l}.33 \\
.12 \\
.06 \\
.39 \\
.18\end{array}$ \\
\hline $\begin{array}{r}6 \\
7 \\
8 \\
9 \\
10\end{array}$ & $\begin{array}{r}2.9 \\
2.6 \\
2.7 \\
8.5 \\
45\end{array}$ & $\begin{array}{l}4.3 \\
2.6 \\
1.9 \\
1.9 \\
2.2\end{array}$ & $\begin{array}{l}6.7 \\
5.2 \\
4.2 \\
3.4 \\
3.0\end{array}$ & $\begin{array}{l}8.7 \\
7.0 \\
5.8 \\
5.3 \\
5.1\end{array}$ & $\begin{array}{r}123 \\
47 \\
20 \\
13 \\
10\end{array}$ & $\begin{array}{l}4.5 \\
3.7 \\
2.9 \\
2.5 \\
2.2\end{array}$ & $\begin{array}{l}3.9 \\
3.3 \\
3.9 \\
3.6 \\
2.6\end{array}$ & $\begin{array}{l}5.9 \\
2.9 \\
2.0 \\
1.7 \\
1.5\end{array}$ & $\begin{array}{l}.29 \\
.21 \\
.21 \\
.19 \\
.19\end{array}$ & $\begin{array}{l}.00 \\
.00 \\
.00 \\
.00 \\
3.5\end{array}$ & $\begin{array}{l}.00 \\
.11 \\
.00 \\
.06 \\
.03\end{array}$ & $\begin{array}{l}.07 \\
.02 \\
.00 \\
.00 \\
.00\end{array}$ \\
\hline $\begin{array}{l}11 \\
12 \\
13 \\
14 \\
15\end{array}$ & $\begin{array}{r}14 \\
7.8 \\
5.6 \\
3.9 \\
2.9\end{array}$ & $\begin{array}{l}1.8 \\
1.6 \\
1.4 \\
1.3 \\
1.3\end{array}$ & $\begin{array}{l}2.7 \\
2.6 \\
2.2 \\
1.9 \\
14\end{array}$ & $\begin{array}{l}41 \\
26 \\
14 \\
11 \\
13\end{array}$ & $\begin{array}{r}7.5 \\
6.0 \\
7.0 \\
7.8 \\
e 5.7\end{array}$ & $\begin{array}{c}2.2 \\
50 \\
158 \\
36 \\
16\end{array}$ & $\begin{array}{l}2.3 \\
1.9 \\
21 \\
14 \\
29\end{array}$ & $\begin{array}{l}1.4 \\
1.6 \\
1.4 \\
1.3 \\
1.3\end{array}$ & $\begin{array}{l}.20 \\
.24 \\
.16 \\
.13 \\
.10\end{array}$ & $\begin{array}{c}.66 \\
2.2 \\
.51 \\
.22 \\
.11\end{array}$ & $\begin{array}{l}.00 \\
.00 \\
.00 \\
.28 \\
.56\end{array}$ & $\begin{array}{l}.00 \\
.00 \\
.63 \\
.12 \\
.04\end{array}$ \\
\hline $\begin{array}{l}16 \\
17 \\
18 \\
19 \\
20\end{array}$ & $\begin{array}{r}2.3 \\
2.1 \\
12 . \\
4.8 \\
3.4\end{array}$ & $\begin{array}{l}1.2 \\
1.5 \\
1.2 \\
1.2 \\
1.1\end{array}$ & $\begin{array}{l}7.2 \\
20 \\
92 \\
35 \\
15\end{array}$ & $\begin{array}{l}22 \\
18 \\
11 \\
9.6 \\
9.1\end{array}$ & $\begin{array}{l}\text { e } 4.3 \\
\text { e } 4.3 \\
15 \\
22 \\
17\end{array}$ & $\begin{array}{l}11 \\
32 \\
34 \\
15 \\
11\end{array}$ & $\begin{array}{l}12 \\
7.1 \\
5.2 \\
16 \\
24\end{array}$ & $\begin{array}{l}1.1 \\
1.7 \\
7.8 \\
2.8 \\
1.7\end{array}$ & $\begin{array}{l}.14 \\
.26 \\
.11 \\
.06 \\
.03\end{array}$ & $\begin{array}{l}.05 \\
.00 \\
.00 \\
.00 \\
.00\end{array}$ & $\begin{array}{r}.06 \\
.00 \\
.22 \\
1.1 \\
.57\end{array}$ & $\begin{array}{l}.00 \\
.00 \\
.00 \\
.00 \\
.00\end{array}$ \\
\hline $\begin{array}{l}21 \\
22 \\
23 \\
24 \\
25\end{array}$ & $\begin{array}{l}2.5 \\
4.8 \\
4.0 \\
3.1 \\
2.5\end{array}$ & $\begin{array}{c}10^{.99} \\
5.8 \\
3.8 \\
3.2\end{array}$ & $\begin{array}{l}63 \\
39 \\
16 \\
11 \\
8.4\end{array}$ & $\begin{array}{r}7.6 \\
\mathrm{e} 5.8 \\
\mathrm{e} 4.9 \\
\mathrm{e} 4.0 \\
\mathrm{e} 3.2\end{array}$ & $\begin{array}{r}10 \\
7.8 \\
6.0 \\
5.4 \\
4.4\end{array}$ & $\begin{array}{c}8.3 \\
171 \\
70 \\
20 \\
11\end{array}$ & $\begin{array}{r}13 \\
8.9 \\
7.1 \\
6.3 \\
4.4\end{array}$ & $\begin{array}{c}1.1 \\
7.0 \\
19 \\
8.3 \\
4.4\end{array}$ & $\begin{array}{l}.02 \\
.02 \\
.01 \\
.01 \\
.01\end{array}$ & $\begin{array}{l}.00 \\
.00 \\
.00 \\
.00 \\
.00\end{array}$ & $\begin{array}{l}.26 \\
.15 \\
.11 \\
.10 \\
.08\end{array}$ & $\begin{array}{l}.00 \\
.00 \\
.00 \\
.00 \\
.00\end{array}$ \\
\hline $\begin{array}{l}26 \\
27 \\
28 \\
29 \\
30 \\
31\end{array}$ & $\begin{array}{l}2.1 \\
1.8 \\
1.6 \\
1.6 \\
1.6 \\
1.6\end{array}$ & $\begin{array}{c}2.9 \\
24 \\
85 \\
18 \\
9.9 \\
. \cdots\end{array}$ & $\begin{array}{r}5.4 \\
5.0 \\
4.9 \\
150 \\
418 \\
49\end{array}$ & $\begin{array}{l}\text { e } 3.2 \\
\text { e } 3.2 \\
\text { e2.9 } \\
\text { e2 } 2.6 \\
\text { e } 9.0 \\
\text { e5 } 5.6\end{array}$ & $\begin{array}{l}3.9 \\
3.8 \\
3.6 \\
\ldots . \\
\ldots . \\
\ldots\end{array}$ & $\begin{array}{l}86 \\
33 \\
14 \\
9.3 \\
6.7 \\
5.4\end{array}$ & $\begin{array}{l}4.0 \\
3.6 \\
3.5 \\
3.9 \\
2.8 \\
\ldots .\end{array}$ & $\begin{array}{l}8.3 \\
4.4 \\
2.4 \\
1.7 \\
1.5 \\
.97\end{array}$ & $\begin{array}{l}.01 \\
.00 \\
.00 \\
.00 \\
.00 \\
\cdots\end{array}$ & $\begin{array}{l}.00 \\
.00 \\
.00 \\
.00 \\
.00 \\
.00\end{array}$ & $\begin{array}{l}.07 \\
.05 \\
9.2 \\
6.5 \\
2.8 \\
.50\end{array}$ & $\begin{array}{l}.00 \\
.00 \\
.00 \\
.00 \\
.00 \\
. .\end{array}$ \\
\hline $\begin{array}{l}\text { TOIAL } \\
\text { MEAN } \\
\text { MAX } \\
\text { MIN } \\
\text { CF SM } \\
\text { IN. }\end{array}$ & $\begin{array}{r}201.59 \\
6.50 \\
45 \\
.70 \\
1.13 \\
1.31\end{array}$ & $\begin{array}{r}202.99 \\
6.77 \\
85 \\
.99 \\
1.18 \\
1.32\end{array}$ & $\begin{array}{r}1063.1 \\
34.3 \\
41.8 \\
1.9 \\
5.98 \\
6.90\end{array}$ & $\begin{array}{r}313.1 \\
10.1 \\
41 \\
2.6 \\
1.76 \\
2.03\end{array}$ & $\begin{array}{r}413.3 \\
14.8 \\
123 \\
3.6 \\
2.58 \\
2.68\end{array}$ & $\begin{array}{r}835.3 \\
26.9 \\
171 \\
2.2 \\
4.70 \\
5.42\end{array}$ & $\begin{array}{c}289.2 \\
9.64 \\
16 \\
1.9 \\
1.68 \\
1.88\end{array}$ & $\begin{array}{r}108.97 \\
3.52 \\
19 \\
.97 \\
.61 \\
.71\end{array}$ & $\begin{array}{l}5.32 \\
.18 \\
.66 \\
.00 \\
.03 \\
.03\end{array}$ & $\begin{array}{l}7.25 \\
.23 \\
3.5 \\
.00 \\
.04 \\
.05\end{array}$ & $\begin{array}{c}22.81 \\
.74 \\
9.2 \\
.00 \\
.13 \\
.15\end{array}$ & $\begin{array}{l}1.96 \\
.065 \\
.63 \\
.00 \\
.01 \\
.01\end{array}$ \\
\hline
\end{tabular}

e Estiated

STATISTICS OF MONIHLY MEAN DATA FOR WATER YEARS 1990 - 1991. BY WATER YEAR (WY)

\begin{tabular}{|c|c|c|c|c|c|c|c|c|c|c|c|}
\hline $\begin{array}{l}\text { MEAN } \\
\text { MAX } \\
(W Y) \\
\text { MIN } \\
(W Y)\end{array}$ & $\begin{array}{r}3.73 \\
6.50 \\
1991 \\
.96 \\
1990\end{array}$ & $\begin{array}{l}6.68 \\
6.77 \\
1991 \\
6.60 \\
1990\end{array}$ & $\begin{array}{l}18.3 \\
34.3 \\
1991 \\
2.32 \\
1990\end{array}$ & $\begin{array}{l}8.75 \\
10.1 \\
1991 \\
7.40 \\
1990\end{array}$ & $\begin{array}{l}19.0 \\
23.2 \\
1990 \\
14.8 \\
1991\end{array}$ & $\begin{array}{l}19.7 \\
26.9 \\
1991 \\
12.5 \\
1990\end{array}$ & $\begin{array}{l}8.83 \\
9.64 \\
1991 \\
8.03 \\
1990\end{array}$ & $\begin{array}{l}17.0 \\
30.6 \\
1990 \\
3.52 \\
1991\end{array}$ & $\begin{array}{r}1.40 \\
2.63 \\
1990 \\
.18 \\
1991\end{array}$ & $\begin{array}{r}3.73 \\
7.22 \\
1990 \\
.23 \\
1991\end{array}$ & $\begin{array}{r}2.84 \\
4.94 \\
1990 \\
.14 \\
1991\end{array}$ \\
\hline
\end{tabular}

SUMMARY SIATISTICS

ANNUAL TOTAL

ANNUAL MEAN

LOWEST ANNUAL MEAN

LOWEST ANWUAL MEAN

HIGHEST DAILY MEAM
LOWEST DAILY MEAN

ANNUAL SEVEN-DAY MINIMUM

INSTAMIANEOUS PEAK FLOW

INSTANTANEOUS PEAK STAGE

ANHUAL RUNOFF (CFSM)

AN NUAL RUNOFF (INCHES)

10 PERCENT EXCEEDS

50 PERCENT EXCEEDS

90 PERCENT EXCEEDS
FOR 1990 CALENUAR YEAR

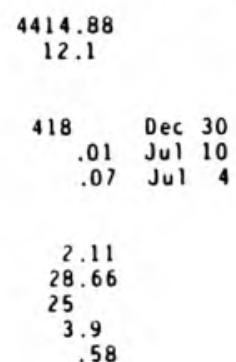

FOR 1991 WATER YEAR

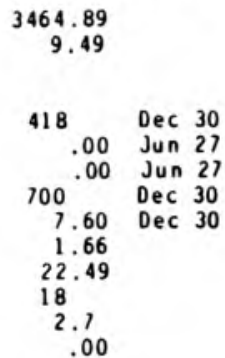

WAIER YEARS 1990 - 1991

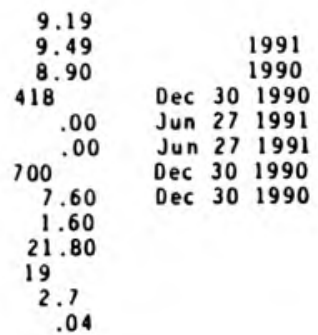




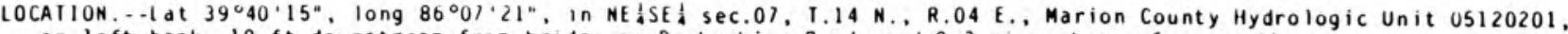
on left bank, $10 \mathrm{ft}$ downstream frum bridge on Derbyshire Rodd, and 0.3 . upstrean from mouth. DRAINAGE AREA . . 1.19 ${ }^{2}$

PERIOD OF RECORD.--Septenber 1989 to current yedr.

GAGE.- - Water-stage recorder. Datum of gage is $746.37 \mathrm{ft}$ above National Geodetic Vertical Datua of 1929 .

REMARKS. - - Records poor.

DISCHARGE, CUBIC FEET PER SECOND, WATER YEAR OCTOBER 1990 TO SEPTEMBER 1991 DAI IY MEAN VALUES

\begin{tabular}{|c|c|c|c|c|c|c|c|c|c|c|c|c|}
\hline DAY & $O C \mathrm{~T}$ & NOV & $\mathrm{OEC}$ & JAN & FEB & MAR & APR & MAY & JUN & JuL & AUG & SEP \\
\hline $\begin{array}{l}1 \\
2 \\
3 \\
4 \\
5\end{array}$ & $\begin{array}{c}.67 \\
.65 \\
3.9 \\
18 \\
1.6\end{array}$ & $\begin{array}{l}.65 \\
.65 \\
.61 \\
.58 \\
1.6\end{array}$ & $\begin{array}{l}2.0 \\
1.6 \\
16 \\
4.3 \\
2.6\end{array}$ & $\begin{array}{l}5.2 \\
4.0 \\
3.0 \\
2.5 \\
2.7\end{array}$ & $\begin{array}{l}2.2 \\
3.5 \\
3.2 \\
3.0 \\
4.7\end{array}$ & $\begin{array}{l}2.1 \\
2.6 \\
2.1 \\
1.9 \\
1.8\end{array}$ & $\begin{array}{l}1.4 \\
1.3 \\
1.1 \\
1.4 \\
1.5\end{array}$ & $\begin{array}{r}.68 \\
.55 \\
.54 \\
.60 \\
4.4\end{array}$ & $\begin{array}{l}.54 \\
.45 \\
.39 \\
.30 \\
.24\end{array}$ & $\begin{array}{l}.24 \\
.25 \\
.25 \\
.25 \\
.25\end{array}$ & $\begin{array}{l}.15 \\
.15 \\
.12 \\
.12 \\
.14\end{array}$ & $\begin{array}{l}.06 \\
.06 \\
.05 \\
.05 \\
.05\end{array}$ \\
\hline $\begin{array}{r}6 \\
7 \\
8 \\
9 \\
10\end{array}$ & $\begin{array}{r}1.0 \\
1.2 \\
1.0 \\
3.4 \\
15\end{array}$ & $\begin{array}{l}.89 \\
.70 \\
.63 \\
.69 \\
.67\end{array}$ & $\begin{array}{l}2.1 \\
1.7 \\
1.5 \\
1.3 \\
1.2\end{array}$ & $\begin{array}{l}2.7 \\
2.5 \\
2.2 \\
2.1 \\
2.2\end{array}$ & $\begin{array}{r}26 \\
10 \\
5.2 \\
4.1 \\
3.4\end{array}$ & $\begin{array}{l}2.2 \\
1.9 \\
1.7 \\
1.6 \\
1.5\end{array}$ & $\begin{array}{r}1.3 \\
1.1 \\
1.3 \\
1.2 \\
.99\end{array}$ & $\begin{array}{l}2.4 \\
1.3 \\
1.1 \\
1.0 \\
.94\end{array}$ & $\begin{array}{l}.31 \\
.27 \\
.25 \\
.25 \\
.25\end{array}$ & $\begin{array}{r}.25 \\
.25 \\
.25 \\
.25 \\
1.7\end{array}$ & $\begin{array}{l}.63 \\
.16 \\
.13 \\
.15 \\
.13\end{array}$ & $\begin{array}{l}.06 \\
.05 \\
.05 \\
.05 \\
.06\end{array}$ \\
\hline $\begin{array}{l}11 \\
12 \\
13 \\
14 \\
15\end{array}$ & $\begin{array}{l}3.4 \\
1.9 \\
1.4 \\
1.1 \\
.96\end{array}$ & $\begin{array}{l}.60 \\
.58 \\
.57 \\
.55 \\
.51\end{array}$ & $\begin{array}{l}1.1 \\
1.0 \\
.96 \\
1.0 \\
5.3\end{array}$ & $\begin{array}{l}9.7 \\
6.2 \\
4.1 \\
3.5 \\
3.8\end{array}$ & $\begin{array}{l}2.8 \\
2.7 \\
3.2 \\
3.3 \\
2.5\end{array}$ & $\begin{array}{l}1.5 \\
15 \\
40 \\
6.6 \\
4.0\end{array}$ & $\begin{array}{c}.92 \\
.95 \\
4.9 \\
2.7 \\
11\end{array}$ & $\begin{array}{l}.95 \\
1.1 \\
1.0 \\
1.7 \\
1.1\end{array}$ & $\begin{array}{l}.25 \\
.25 \\
.25 \\
.25 \\
.25\end{array}$ & $\begin{array}{l}.25 \\
.63 \\
.25 \\
.25 \\
.25\end{array}$ & $\begin{array}{l}.14 \\
.15 \\
.15 \\
.18 \\
.12\end{array}$ & $\begin{array}{l}.06 \\
.07 \\
.04 \\
.03 \\
.04\end{array}$ \\
\hline $\begin{array}{l}16 \\
17 \\
18 \\
19 \\
20\end{array}$ & $\begin{array}{l}.83 \\
.86 \\
6.9 \\
1.7 \\
1.3\end{array}$ & $\begin{array}{l}.52 \\
.50 \\
.50 \\
.46 \\
.45\end{array}$ & $\begin{array}{r}2.1 \\
8.8 \\
33 \\
9.9 \\
4.5\end{array}$ & $\begin{array}{l}4.9 \\
4.4 \\
3.0 \\
2.7 \\
2.7\end{array}$ & $\begin{array}{l}2.1 \\
2.1 \\
5.3 \\
6.4 \\
5.1\end{array}$ & $\begin{array}{r}3.0 \\
12 \\
7.0 \\
4.1 \\
3.1\end{array}$ & $\begin{array}{c}3.2 \\
1.9 \\
1.6 \\
29 \\
6.0\end{array}$ & $\begin{array}{r}1.1 \\
1.0 \\
3.0 \\
1.2 \\
.90\end{array}$ & $\begin{array}{l}.60 \\
.25 \\
.25 \\
.25 \\
.25\end{array}$ & $\begin{array}{l}.23 \\
.18 \\
.18 \\
.16 \\
.16\end{array}$ & $\begin{array}{l}.11 \\
.16 \\
.12 \\
.29 \\
.15\end{array}$ & $\begin{array}{l}.06 \\
.04 \\
.04 \\
.04 \\
.04\end{array}$ \\
\hline $\begin{array}{l}21 \\
22 \\
23 \\
24 \\
25\end{array}$ & $\begin{array}{l}1.1 \\
1.7 \\
1.2 \\
1.0 \\
.87\end{array}$ & $\begin{array}{l}.48 \\
3.1 \\
1.3 \\
.97 \\
.85\end{array}$ & $\begin{array}{l}23 \\
10 \\
5.0 \\
3.2 \\
2.5\end{array}$ & $\begin{array}{l}2.4 \\
2.0 \\
1.9 \\
1.7 \\
1.4\end{array}$ & $\begin{array}{l}3.7 \\
2.9 \\
2.7 \\
2.5 \\
2.3\end{array}$ & $\begin{array}{l}13 \\
70 \\
12 \\
3.6 \\
2.5\end{array}$ & $\begin{array}{l}3.3 \\
2.4 \\
2.1 \\
1.9 \\
1.5\end{array}$ & $\begin{array}{l}11.70 \\
8.0 \\
3.4 \\
2.1\end{array}$ & $\begin{array}{l}.25 \\
.25 \\
.25 \\
.25 \\
.25\end{array}$ & $\begin{array}{l}.15 \\
.16 \\
.12 \\
.12 \\
.12\end{array}$ & $\begin{array}{l}.16 \\
.27 \\
.21 \\
.20 \\
.19\end{array}$ & $\begin{array}{l}.04 \\
.13 \\
.06 \\
.06 \\
.05\end{array}$ \\
\hline $\begin{array}{l}26 \\
27 \\
28 \\
29 \\
30 \\
31\end{array}$ & $\begin{array}{l}.82 \\
.81 \\
.74 \\
.73 \\
.72 \\
.68\end{array}$ & $\begin{array}{c}.82 \\
7.9 \\
32 \\
4.7 \\
2.8 \\
. .\end{array}$ & $\begin{array}{r}2.0 \\
1.8 \\
1.8 \\
92 \\
273 \\
12\end{array}$ & $\begin{array}{l}1.4 \\
1.4 \\
1.3 \\
1.5 \\
2.9 \\
1.9\end{array}$ & $\begin{array}{l}2.1 \\
2.1 \\
1.9 \\
\cdots \\
\ldots \\
\cdots\end{array}$ & $\begin{array}{r}25 \\
5.8 \\
3.0 \\
2.1 \\
1.6 \\
1.4\end{array}$ & $\begin{array}{l}1.4 \\
1.2 \\
1.1 \\
1.0 \\
.78 \\
\ldots .\end{array}$ & $\begin{array}{l}7.0 \\
2.7 \\
1.6 \\
1.2 \\
.96 \\
.74\end{array}$ & $\begin{array}{l}.25 \\
.24 \\
.25 \\
.24 \\
.19 \\
\ldots\end{array}$ & $\begin{array}{l}.15 \\
.13 \\
.13 \\
.12 \\
.14 \\
.13\end{array}$ & $\begin{array}{l}.19 \\
.18 \\
.19 \\
.19 \\
.08 \\
.08\end{array}$ & $\begin{array}{l}.05 \\
.04 \\
.04 \\
.04 \\
.04 \\
\cdots\end{array}$ \\
\hline $\begin{array}{l}\text { IOIAL } \\
\text { MEAN } \\
\text { MAX } \\
\text { MIN } \\
\text { CF SM } \\
\text { IN. }\end{array}$ & $\begin{array}{r}17.14 \\
2.49 \\
18 \\
.65 \\
1.39 \\
1.60\end{array}$ & $\begin{array}{r}67.83 \\
2.26 \\
32 \\
.45 \\
1.26 \\
1.41\end{array}$ & $\begin{array}{r}528.26 \\
17.0 \\
273 \\
.96 \\
9.52 \\
10.98\end{array}$ & $\begin{array}{r}93.9 \\
3.03 \\
9.1 \\
1.3 \\
1.69 \\
1.95\end{array}$ & $\begin{array}{r}121.0 \\
4.32 \\
26 \\
1.9 \\
2.41 \\
2.51\end{array}$ & $\begin{array}{r}255.7 \\
8.25 \\
70 \\
1.4 \\
4.61 \\
5.31\end{array}$ & $\begin{array}{r}91.44 \\
3.05 \\
29 \\
.78 \\
1.70 \\
1.90\end{array}$ & $\begin{array}{c}65.96 \\
2.13 \\
11 \\
.54 \\
1.19 \\
1.37\end{array}$ & $\begin{array}{l}8.52 \\
.28 \\
.60 \\
.19 \\
.16 \\
.18\end{array}$ & $\begin{array}{l}7.95 \\
.26 \\
1.7 \\
.12 \\
.14 \\
.17\end{array}$ & $\begin{array}{l}5.39 \\
.11 \\
.63 \\
.08 \\
.10 \\
.11\end{array}$ & $\begin{array}{l}1.55 \\
.052 \\
.13 \\
.03 \\
.03 \\
.03\end{array}$ \\
\hline
\end{tabular}

STATISTICS OF MONTHLY MEAN DATA FOR WATER YEARS 1990 - 1991, BY WATER YEAR (WY)

$\begin{array}{lllllllllllll}\text { MEAN } & 1.39 & 2.18 & 9.16 & 4.39 & 8.71 & 7.79 & 3.18 & 6.84 & .84 & .99 & 1.36 & .63 \\ \text { MAX } & 2.49 & 2.26 & 17.0 & 5.74 & 13.1 & 8.25 & 3.31 & 11.5 & 1.40 & 1.73 & 2.54 & 1.21 \\ \text { (WY) } & 1991 & 1991 & 1991 & 1990 & 1990 & 1991 & 1990 & 1990 & 1990 & 1990 & 1990 & 1990 \\ \text { MIN } & .30 & 2.11 & 1.27 & 3.03 & 4.32 & 1.33 & 3.05 & 2.13 & .28 & .26 & .17 & .052 \\ \text { (WY) } & 1990 & 1990 & 1990 & 1991 & 1991 & 1990 & 1991 & 1991 & 1991 & 1991 & 1991 & 1991\end{array}$

SUMMARY SIATISTICS

ANNUAL TOIAL

ANNUAL MEAN

HIGHESI ANNUAL MEAM

IOWEST ANNUAL MEAN

HIGHEST DAILY MEAN

LOWEST DAILY MEAN

ANNUAL SEVEN-DAY MINIMUM

INSTANIANEOUS PEAK FLOW

INSTANTANEOUS PEAK SIAGE

INSTANTANEOUS IOW FLOW

ANNUAL RUNOFF (CFSM)

ANMUAL RUNOFF (INCHES)

10 PERCENT EXCEEDS

50 PERCENT EXCEEDS

90 PERCENI EXCEEDS
FOR 1990 CALENDAR YEAR

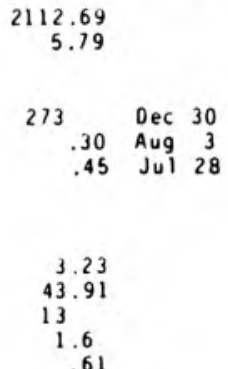

FOR 1991 WATER YEAR

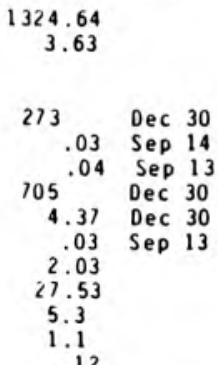

WATER YEARS $1990-\mid 991$

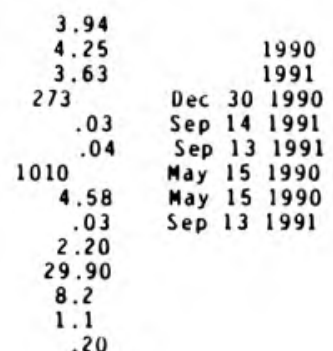




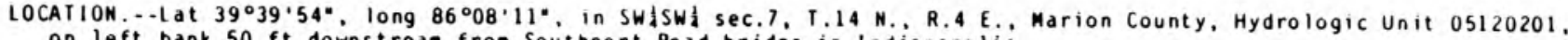
on left bank $50 \mathrm{ft}$ dewnstrea froe Southport Rodd bridge in Indianapolis.

DRAI NAGE AREA. $-12.3 \cdot i^{2}$.

PERIOD OF RECORD.--October 1989 to current year.

GAGE.- Water-stage recorder. Datun of gage is $725.50 \mathrm{ft}$ above National Geodetic Vertical Datun of 1929.

REMARKS. - Records fair except for estieated daily discharges, which are poor.

DISCHARGE, CUBIC FEET PER SECOND, WAIER YEAR OCTOBER 1990 TO SEPIEMBER 1991 DAILY MEAN VALUES

\begin{tabular}{|c|c|c|c|c|c|c|c|c|c|c|c|c|}
\hline DAY & $\mathrm{OCI}$ & NOV & DEC & JAN & FEB & MAR & APR & MAY & JUN & JUL & AUG & SEP \\
\hline $\begin{array}{l}1 \\
2 \\
3 \\
4 \\
5\end{array}$ & $\begin{array}{l}2.4 \\
2.6 \\
9.5 \\
86 \\
15\end{array}$ & $\begin{array}{l}\mathrm{e} 3.5 \\
\mathrm{e} 2.9 \\
\mathrm{e} 2.6 \\
\mathrm{e} 2.6 \\
\mathrm{e} 12\end{array}$ & $\begin{array}{l}13 \\
11 \\
72 \\
27 \\
16\end{array}$ & $\begin{array}{l}44 \\
25 \\
17 \\
13 \\
14\end{array}$ & $\begin{array}{l}e 8.8 \\
15 \\
16 \\
14 \\
25\end{array}$ & $\begin{array}{l}13 \\
18 \\
14 \\
12 \\
11\end{array}$ & $\begin{array}{l}14 \\
11 \\
9.6 \\
12 \\
16\end{array}$ & $\begin{array}{r}6.5 \\
5.7 \\
5.2 \\
6.2 \\
24\end{array}$ & $\begin{array}{l}3.8 \\
3.3 \\
2.9 \\
2.3 \\
2.1\end{array}$ & $\begin{array}{l}.56 \\
.64 \\
.67 \\
.58 \\
.63\end{array}$ & $\begin{array}{l}.23 \\
.24 \\
.21 \\
.23 \\
.23\end{array}$ & $\begin{array}{l}.42 \\
.33 \\
.27 \\
.41 \\
.37\end{array}$ \\
\hline $\begin{array}{r}6 \\
7 \\
8 \\
9 \\
10\end{array}$ & $\begin{array}{l}9.5 \\
9.6 \\
9.2 \\
19 \\
78\end{array}$ & $\begin{array}{l}\mathrm{e} 6.4 \\
\mathrm{e} 4.4 \\
\mathrm{e} 4.3 \\
\mathrm{e} 4.7 \\
\mathrm{e} 4.6\end{array}$ & $\begin{array}{l}13 \\
11 \\
9.1 \\
7.9 \\
7.3\end{array}$ & $\begin{array}{l}15 \\
12 \\
10 \\
9.6 \\
9.5\end{array}$ & $\begin{array}{r}192 \\
92 \\
45 \\
34 \\
27\end{array}$ & $\begin{array}{l}15 \\
13 \\
10 \\
9.5 \\
8.6\end{array}$ & $\begin{array}{l}11 \\
9.7 \\
12 \\
11 \\
8.3\end{array}$ & $\begin{array}{r}19 \\
10 \\
7.1 \\
5.9 \\
5.5\end{array}$ & $\begin{array}{l}1.8 \\
1.5 \\
1.3 \\
1.2 \\
1.1\end{array}$ & $\begin{array}{r}.49 \\
.44 \\
.40 \\
20^{.41}\end{array}$ & $\begin{array}{l}6.5 \\
1.3 \\
1.0 \\
.93 \\
.57\end{array}$ & $\begin{array}{l}.25 \\
.19 \\
.16 \\
.16 \\
.17\end{array}$ \\
\hline $\begin{array}{l}11 \\
12 \\
13 \\
14 \\
15\end{array}$ & $\begin{array}{r}26 \\
16 \\
12 \\
9.4 \\
7.6\end{array}$ & $\begin{array}{l}\text { e } 4.3 \\
\text { e } 3.9 \\
\text { e } 3.6 \\
\text { e } 3.2 \\
\text { e } 3.0\end{array}$ & $\begin{array}{r}6.6 \\
6.3 \\
6.0 \\
5.3 \\
27\end{array}$ & $\begin{array}{l}62 \\
47 \\
22 \\
16 \\
19\end{array}$ & $\begin{array}{r}22 \\
19 \\
21 \\
e 23 \\
\text { e18 }\end{array}$ & $\begin{array}{c}8.2 \\
76 \\
264 \\
69 \\
38\end{array}$ & $\begin{array}{l}7.5 \\
6.6 \\
40 \\
31 \\
58\end{array}$ & $\begin{array}{r}5.0 \\
6.9 \\
5.2 \\
11 \\
6.5\end{array}$ & $\begin{array}{r}1.5 \\
1.4 \\
1.1 \\
.93 \\
.90\end{array}$ & $\begin{array}{l}4.0 \\
9.0 \\
2.8 \\
1.2 \\
.76\end{array}$ & $\begin{array}{r}.40 \\
.35 \\
.31 \\
2.1 \\
.52\end{array}$ & $\begin{array}{l}.18 \\
.35 \\
.41 \\
.48 \\
.24\end{array}$ \\
\hline $\begin{array}{l}16 \\
17 \\
18 \\
19 \\
20\end{array}$ & $\begin{array}{r}6.6 \\
\mathrm{e} 7.0 \\
\mathrm{e} 28 \\
\mathrm{e} 10 \\
\mathrm{e} 7.2\end{array}$ & $\begin{array}{l}\mathrm{e} 3.0 \\
\mathrm{e} 3.0 \\
\mathrm{e} 3.0 \\
\mathrm{e} 2.6 \\
\mathrm{e} 2.2\end{array}$ & $\begin{array}{r}14 \\
33 \\
139 \\
61 \\
28\end{array}$ & $\begin{array}{r}34 \\
29 \\
17 \\
13 \\
\text { e13 }\end{array}$ & $\begin{array}{r}\text { 14 } \\
14 \\
33 \\
46 \\
39\end{array}$ & $\begin{array}{l}27 \\
62 \\
73 \\
37 \\
27\end{array}$ & $\begin{array}{r}28 \\
18 \\
14 \\
135 \\
49\end{array}$ & $\begin{array}{r}7.1 \\
7.5 \\
22 \\
9.0 \\
6.0\end{array}$ & $\begin{array}{l}5.7 \\
1.7 \\
1.1 \\
.80 \\
.72\end{array}$ & $\begin{array}{l}.60 \\
.55 \\
.47 \\
.41 \\
.40\end{array}$ & $\begin{array}{l}.45 \\
.64 \\
.41 \\
2.0 \\
1.6\end{array}$ & $\begin{array}{l}.41 \\
.26 \\
.23 \\
.21 \\
.26\end{array}$ \\
\hline $\begin{array}{l}21 \\
22 \\
23 \\
24 \\
25\end{array}$ & $\begin{array}{l}\text { e } 5.6 \\
\text { e } 9.9 \\
\text { e } 8.5 \\
\text { e6.4 } \\
\text { e5.8 }\end{array}$ & $\begin{array}{l}\text { e2.0 } \\
19 \\
10 \\
6.8 \\
5.4\end{array}$ & $\begin{array}{l}94 \\
66 \\
32 \\
19 \\
15\end{array}$ & $\begin{array}{r}\text { e11 } \\
\text { e8.6 } \\
\text { e8.0 } \\
\text { e6.6 } \\
\text { e5.0 }\end{array}$ & $\begin{array}{l}27 \\
22 \\
18 \\
17 \\
15\end{array}$ & $\begin{array}{r}22 \\
326 \\
138 \\
43 \\
29\end{array}$ & $\begin{array}{l}30 \\
22 \\
18 \\
17 \\
12\end{array}$ & $\begin{array}{l}4.6 \\
26 \\
45 \\
23 \\
15\end{array}$ & $\begin{array}{l}.70 \\
.70 \\
.70 \\
.64 \\
.77\end{array}$ & $\begin{array}{l}.38 \\
.35 \\
.32 \\
.31 \\
.29\end{array}$ & $\begin{array}{l}.54 \\
.46 \\
.39 \\
.35 \\
.34\end{array}$ & $\begin{array}{l}.40 \\
1.8 \\
1.5 \\
.27 \\
.19\end{array}$ \\
\hline $\begin{array}{l}26 \\
27 \\
28 \\
29 \\
30 \\
31\end{array}$ & $\begin{array}{l}\text { e } 5.0 \\
\text { e } 4.9 \\
\text { e } 4.6 \\
\text { e } 4.4 \\
\text { e } 4.2 \\
\text { e } 4.0\end{array}$ & $\begin{array}{c}5.0 \\
39 \\
129 \\
33 \\
18 \\
-\cdots\end{array}$ & $\begin{array}{r}12 \\
11 \\
11 \\
271 \\
1110 \\
94\end{array}$ & $\begin{array}{r}\text { e5.0 } \\
\text { e5. } 0 \\
\text { e4. } 6 \\
\text { e5.0 } \\
\text { e12 } \\
\text { e8. } 3\end{array}$ & $\begin{array}{c}13 \\
13 \\
12 \\
\ldots \\
\ldots \\
\cdots\end{array}$ & $\begin{array}{r}151 \\
64 \\
33 \\
24 \\
18 \\
16\end{array}$ & $\begin{array}{r}11 \\
9.8 \\
9.7 \\
11 \\
7.9 \\
\ldots\end{array}$ & $\begin{array}{l}31 \\
17 \\
10 \\
7.6 \\
6.5 \\
4.8\end{array}$ & $\begin{array}{c}3.0 \\
3.3 \\
1.9 \\
.91 \\
.68 \\
. . .\end{array}$ & $\begin{array}{l}.27 \\
.25 \\
.25 \\
.25 \\
.25 \\
.24\end{array}$ & $\begin{array}{c}.33 \\
.34 \\
4.6 \\
7.8 \\
7.0 \\
.86\end{array}$ & $\begin{array}{l}.18 \\
.17 \\
.16 \\
.14 \\
.13 \\
\cdots\end{array}$ \\
\hline $\begin{array}{l}\text { TOIAL } \\
\text { MEAN } \\
\text { MAX } \\
\text { MIN } \\
\text { CF SM } \\
\text { IN. }\end{array}$ & $\begin{array}{r}433.9 \\
14.0 \\
86 \\
2.4 \\
1.14 \\
1.31\end{array}$ & $\begin{array}{r}347.0 \\
11.6 \\
129 \\
2.0 \\
.94 \\
1.05\end{array}$ & $\begin{array}{r}2248.5 \\
12.5 \\
1110 \\
5.3 \\
5.90 \\
6.80\end{array}$ & $\begin{array}{r}520.2 \\
16.8 \\
62 \\
4.6 \\
1.36 \\
1.57\end{array}$ & $\begin{array}{r}854.8 \\
30.5 \\
192 \\
8.8 \\
2.48 \\
2.59\end{array}$ & $\begin{array}{r}1669.3 \\
53.8 \\
326 \\
8.2 \\
4.38 \\
5.05\end{array}$ & $\begin{array}{r}650.1 \\
21.7 \\
135 \\
6.6 \\
1.76 \\
1.97\end{array}$ & $\begin{array}{r}371.8 \\
12.0 \\
45 \\
4.6 \\
.98 \\
1.12\end{array}$ & $\begin{array}{c}50.45 \\
1.68 \\
5.7 \\
.64 \\
.14 \\
.15\end{array}$ & $\begin{array}{c}48.17 \\
1.55 \\
20 \\
.24 \\
.13 \\
.15\end{array}$ & $\begin{array}{c}43.23 \\
1.39 \\
7.8 \\
.21 \\
.11 \\
.13\end{array}$ & $\begin{array}{r}10.10 \\
.36 \\
1.8 \\
.13 \\
.03 \\
.03\end{array}$ \\
\hline
\end{tabular}

e Estimated

STAIISIICS OF MUNTHIY MEAN DATA FOR WAIER YEARS 1990 - 1991, BY WATER YEAR (WY)

\begin{tabular}{|c|c|c|c|c|c|c|c|c|c|c|c|c|}
\hline $\begin{array}{l}\text { MEAN } \\
\text { MAX } \\
\text { (WY) } \\
\text { MIN } \\
(W Y)\end{array}$ & $\begin{array}{l}8.74 \\
14.0 \\
1991 \\
3.48 \\
1990\end{array}$ & $\begin{array}{l}12.9 \\
14.2 \\
1990 \\
11.6 \\
1991\end{array}$ & $\begin{array}{l}38.8 \\
12.5 \\
1991 \\
4.99 \\
1990\end{array}$ & $\begin{array}{l}15.3 \\
16.8 \\
1991 \\
13.9 \\
1990\end{array}$ & $\begin{array}{l}39.3 \\
48.1 \\
1990 \\
30.5 \\
1991\end{array}$ & $\begin{array}{l}40.7 \\
53.8 \\
1991 \\
27.6 \\
1990\end{array}$ & $\begin{array}{l}19.1 \\
21.7 \\
1991 \\
16.6 \\
1990\end{array}$ & $\begin{array}{l}35.2 \\
58.3 \\
1990 \\
12.0 \\
1991\end{array}$ & $\begin{array}{l}3.68 \\
5.67 \\
1990 \\
1.68 \\
1991\end{array}$ & $\begin{array}{l}1.48 \\
13.4 \\
1990 \\
1.55 \\
1991\end{array}$ & $\begin{array}{l}1.16 \\
12.9 \\
1990 \\
1.39 \\
1991\end{array}$ & $\begin{array}{r}2.45 \\
4.54 \\
1990 \\
.36 \\
1991\end{array}$ \\
\hline
\end{tabular}

SUMMARY SIAIISIICS

ANMUAL IOIAL

ANMUAL MEAM

HIGHEST ANHUAL MEAN

LOWEST ANNUAL MEAM

HIGHESI DAILY MEAN

LOWEST DAILY MEAM

AN NUAL SEVEN-DAY MINIMUM

INSTANTANEOUS PEAK FLOW

INSTANIANEOUS PEAK SIAGE

ANNUAL RUNOFF (CFSM)

ANNUAL RUNOFF (INCHES)

10 PERCENT EXCEEDS

50 PERCENT EXCEEDS

90 PERCENT EXCEEDS
FOR 1990 CALENDAR YEAR

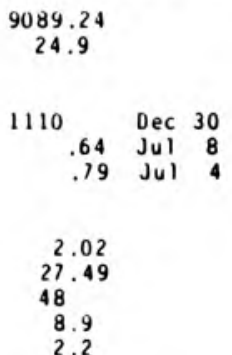

FOR 1991 WATER YEAR

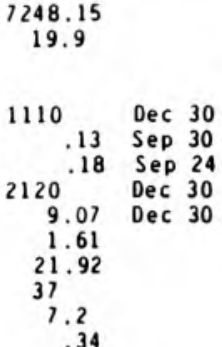

WATER YEARS 1990 - 1991

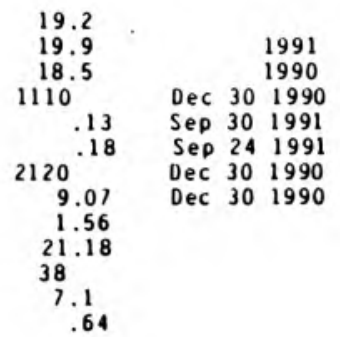


LOCATION.--Lat $39^{\circ} 40^{\prime} 00^{\prime \prime}$, long $86^{\circ} 11^{\prime 4} 48^{\prime \prime}$, in SWlSWa sec.10, T.14 N., R.3 E., Marion County, Hydrologic Unit 05120201. on right bank, $10 \mathrm{ft}$ upstrea fron bridge on South Belaont Street, and 2.2 above ${ }^{\circ}$ auth.

DRAINAGE ARE $A,-16.6 \cdot i^{2}$.

PERIOD OF RECORD.-.OCtober 1989 to current year.

GAGE.--Handar Data Collection Platform and water-stage recorder. Datun of gage is 666.20 above National Geodetic Vertical Datu of 1929

REMARKS. - Records good except for estimated daily discharges, which are poor.

DISCHARGE, CUBIC FEET PER SECOND, WATER YEAR OCTOBER 1990 TO SEPTEMBER 1991 DAILY MEAN VALUES

\begin{tabular}{|c|c|c|c|c|c|c|c|c|c|c|c|c|}
\hline DAY & $\mathrm{OCT}$ & MOV & DEC & JAN & FEB & MAR & $A P R$ & MAY & JUN & JUL & AUG & SEP \\
\hline $\begin{array}{l}1 \\
2 \\
3 \\
4 \\
5\end{array}$ & $\begin{array}{r}2.9 \\
2.8 \\
3.1 \\
137 \\
23\end{array}$ & $\begin{array}{r}6.9 \\
6.3 \\
5.9 \\
5.9 \\
19\end{array}$ & $\begin{array}{r}23 \\
17 \\
105 \\
47 \\
28\end{array}$ & $\begin{array}{l}\text { e } 54 \\
\text { e } 42 \\
\text { e } 33 \\
\text { e } 28 \\
\text { e } 30\end{array}$ & $\begin{array}{l}18 \\
26 \\
30 \\
26 \\
39\end{array}$ & $\begin{array}{l}19 \\
27 \\
20 \\
17 \\
14\end{array}$ & $\begin{array}{l}15 \\
14 \\
13 \\
14 \\
17\end{array}$ & $\begin{array}{r}9.8 \\
9.4 \\
8.8 \\
9.8 \\
29\end{array}$ & $\begin{array}{l}8.7 \\
7.8 \\
7.1 \\
6.3 \\
5.6\end{array}$ & $\begin{array}{l}2.0 \\
2.0 \\
2.0 \\
1.8 \\
1.9\end{array}$ & $\begin{array}{l}.24 \\
.16 \\
.13 \\
.13 \\
.13\end{array}$ & $\begin{array}{l}.30 \\
.10 \\
.09 \\
.41 \\
.11\end{array}$ \\
\hline $\begin{array}{r}6 \\
7 \\
8 \\
9 \\
10\end{array}$ & $\begin{array}{r}12 \\
12 \\
11 \\
23 \\
109\end{array}$ & $\begin{array}{r}14 \\
9.5 \\
7.7 \\
7.4 \\
8.1\end{array}$ & $\begin{array}{l}22 \\
18 \\
15 \\
13 \\
12\end{array}$ & $\begin{array}{l}34 \\
28 \\
24 \\
23 \\
22\end{array}$ & $\begin{array}{r}229 \\
131 \\
61 \\
49 \\
43\end{array}$ & $\begin{array}{l}20 \\
18 \\
14 \\
13 \\
12\end{array}$ & $\begin{array}{l}14 \\
13 \\
13 \\
14 \\
12\end{array}$ & $\begin{array}{r}26 \\
13 \\
10 \\
9.2 \\
8.5\end{array}$ & $\begin{array}{l}5.6 \\
4.9 \\
4.6 \\
4.2 \\
4.0\end{array}$ & $\begin{array}{r}1.6 \\
1.2 \\
1.1 \\
1.1 \\
27\end{array}$ & $\begin{array}{c}7.7 \\
2.4 \\
1.1 \\
1.7 \\
.99\end{array}$ & $\begin{array}{l}.07 \\
.04 \\
.00 \\
.00 \\
.00\end{array}$ \\
\hline $\begin{array}{l}11 \\
12 \\
13 \\
14 \\
15\end{array}$ & $\begin{array}{l}44 \\
26 \\
19 \\
13 \\
11\end{array}$ & $\begin{array}{l}6.6 \\
6.2 \\
5.8 \\
5.3 \\
5.2\end{array}$ & $\begin{array}{l}11 \\
11 \\
11 \\
9.9 \\
41\end{array}$ & $\begin{array}{l}89 \\
76 \\
42 \\
33 \\
34\end{array}$ & $\begin{array}{l}36 \\
31 \\
34 \\
37 \\
30\end{array}$ & $\begin{array}{r}11 \\
68 \\
339 \\
85 \\
44\end{array}$ & $\begin{array}{l}11 \\
10 \\
27 \\
40 \\
64\end{array}$ & $\begin{array}{l}7.9 \\
9.8 \\
8.3 \\
20 \\
11\end{array}$ & $\begin{array}{l}4.6 \\
4.7 \\
3.8 \\
3.4 \\
3.2\end{array}$ & $\begin{array}{c}6.3 \\
10 \\
4.9 \\
3.1 \\
2.3\end{array}$ & $\begin{array}{r}.60 \\
.38 \\
.28 \\
1.6 \\
1.4\end{array}$ & $\begin{array}{l}.00 \\
.00 \\
.00 \\
.00 \\
.00\end{array}$ \\
\hline $\begin{array}{l}16 \\
17 \\
18 \\
19 \\
20\end{array}$ & $\begin{array}{l}9.0 \\
7.7 \\
41 \\
15 \\
11\end{array}$ & $\begin{array}{l}5.2 \\
5.2 \\
5.2 \\
5.0 \\
4.9\end{array}$ & $\begin{array}{r}24 \\
40 \\
208 \\
104 \\
47\end{array}$ & $\begin{array}{l}53 \\
49 \\
32 \\
27 \\
26\end{array}$ & $\begin{array}{l}26 \\
21 \\
44 \\
64 \\
58\end{array}$ & $\begin{array}{l}33 \\
66 \\
91 \\
48 \\
35\end{array}$ & $\begin{array}{r}42 \\
25 \\
19 \\
151 \\
58\end{array}$ & $\begin{array}{l}9.5 \\
11 \\
28 \\
13 \\
9.7\end{array}$ & $\begin{array}{l}22 \\
6.3 \\
4.4 \\
3.7 \\
3.4\end{array}$ & $\begin{array}{l}1.9 \\
1.7 \\
1.5 \\
1.4 \\
1.2\end{array}$ & $\begin{array}{l}.51 \\
1.1 \\
.93 \\
2.9 \\
1.9\end{array}$ & $\begin{array}{l}.00 \\
.00 \\
.00 \\
.00 \\
.00\end{array}$ \\
\hline $\begin{array}{l}21 \\
22 \\
23 \\
24 \\
25\end{array}$ & $\begin{array}{l}10 \\
15 \\
13 \\
10 \\
9.2\end{array}$ & $\begin{array}{l}4.7 \\
26 \\
17 \\
11 \\
9.8\end{array}$ & $\begin{array}{r}131 \\
108 \\
53 \\
34 \\
27\end{array}$ & $\begin{array}{l}24 \\
20 \\
19 \\
18 \\
15\end{array}$ & $\begin{array}{l}43 \\
36 \\
30 \\
27 \\
24\end{array}$ & $\begin{array}{r}29 \\
388 \\
230 \\
62 \\
37\end{array}$ & $\begin{array}{l}38 \\
27 \\
20 \\
18 \\
15\end{array}$ & $\begin{array}{l}8.1 \\
68 \\
77 \\
36 \\
22\end{array}$ & $\begin{array}{l}3.1 \\
3.0 \\
2.9 \\
2.7 \\
2.6\end{array}$ & $\begin{array}{r}1.1 \\
.96 \\
.75 \\
.70 \\
.63\end{array}$ & $\begin{array}{r}.91 \\
.48 \\
.34 \\
.22 \\
.16\end{array}$ & $\begin{array}{r}.00 \\
.20 \\
2.4 \\
.06 \\
.00\end{array}$ \\
\hline $\begin{array}{l}26 \\
27 \\
28 \\
29 \\
30 \\
31\end{array}$ & $\begin{array}{l}8.6 \\
8.7 \\
8.4 \\
8.0 \\
7.9 \\
7.7\end{array}$ & $\begin{array}{c}9.1 \\
56 \\
196 \\
56 \\
32 \\
\ldots .\end{array}$ & $\begin{array}{r}21 \\
17 \\
19 \\
316 \\
1390 \\
159\end{array}$ & $\begin{array}{l}15 \\
15 \\
14 \\
14 \\
27 \\
19\end{array}$ & $\begin{array}{l}21 \\
20 \\
19 \\
\cdots \\
\cdots \\
\cdots\end{array}$ & $\begin{array}{r}178 \\
86 \\
42 \\
26 \\
20 \\
17\end{array}$ & $\begin{array}{l}13 \\
12 \\
11 \\
11 \\
10 \\
\ldots-\end{array}$ & $\begin{array}{c}43 \\
24 \\
15 \\
12 \\
12 \\
9.9\end{array}$ & $\begin{array}{l}3.7 \\
4.6 \\
3.7 \\
2.7 \\
2.3 \\
\ldots . .\end{array}$ & $\begin{array}{l}.53 \\
.52 \\
.44 \\
.40 \\
.34 \\
.31\end{array}$ & $\begin{array}{l}.11 \\
.10 \\
.09 \\
7.2 \\
4.7 \\
1.4\end{array}$ & $\begin{array}{l}.00 \\
.00 \\
.00 \\
.00 \\
.00 \\
. .-\end{array}$ \\
\hline $\begin{array}{l}\text { TOIAL } \\
\text { MEAN } \\
\text { MAX } \\
\text { MIN } \\
\text { CF SM } \\
\text { IN. }\end{array}$ & $\begin{array}{r}639.0 \\
20.6 \\
137 \\
2.8 \\
1.24 \\
1.43\end{array}$ & $\begin{array}{r}562.9 \\
18.8 \\
196 \\
4.7 \\
1.13 \\
1.26\end{array}$ & $\begin{array}{r}3081.9 \\
99.4 \\
1390 \\
9.9 \\
5.99 \\
6.91\end{array}$ & $\begin{array}{r}979 \\
31.6 \\
89 \\
14 \\
1.90 \\
2.19\end{array}$ & $\begin{array}{r}1253 \\
44.7 \\
229 \\
18 \\
2.70 \\
2.81\end{array}$ & $\begin{array}{r}2109 \\
68.0 \\
388 \\
11 \\
4.10 \\
4.73\end{array}$ & $\begin{array}{r}761 \\
25.4 \\
151 \\
10 \\
1.53 \\
1.71\end{array}$ & $\begin{array}{r}588.7 \\
19.0 \\
77 \\
7.9 \\
1.14 \\
1.32\end{array}$ & $\begin{array}{r}149.6 \\
4.99 \\
22 \\
2.3 \\
.30 \\
.34\end{array}$ & $\begin{array}{r}82.68 \\
2.67 \\
27 \\
.31 \\
.16 \\
.19\end{array}$ & $\begin{array}{c}41.99 \\
1.35 \\
7.7 \\
.09 \\
.08 \\
.09\end{array}$ & $\begin{array}{l}3.78 \\
.13 \\
2.4 \\
.00 \\
.01 \\
.01\end{array}$ \\
\hline
\end{tabular}

e Estinated

SIATISIICS OF MONIHLY MEAN DATA FOR WAIER YEARS 1990 - 1991, BY WATER YEAR (WY)

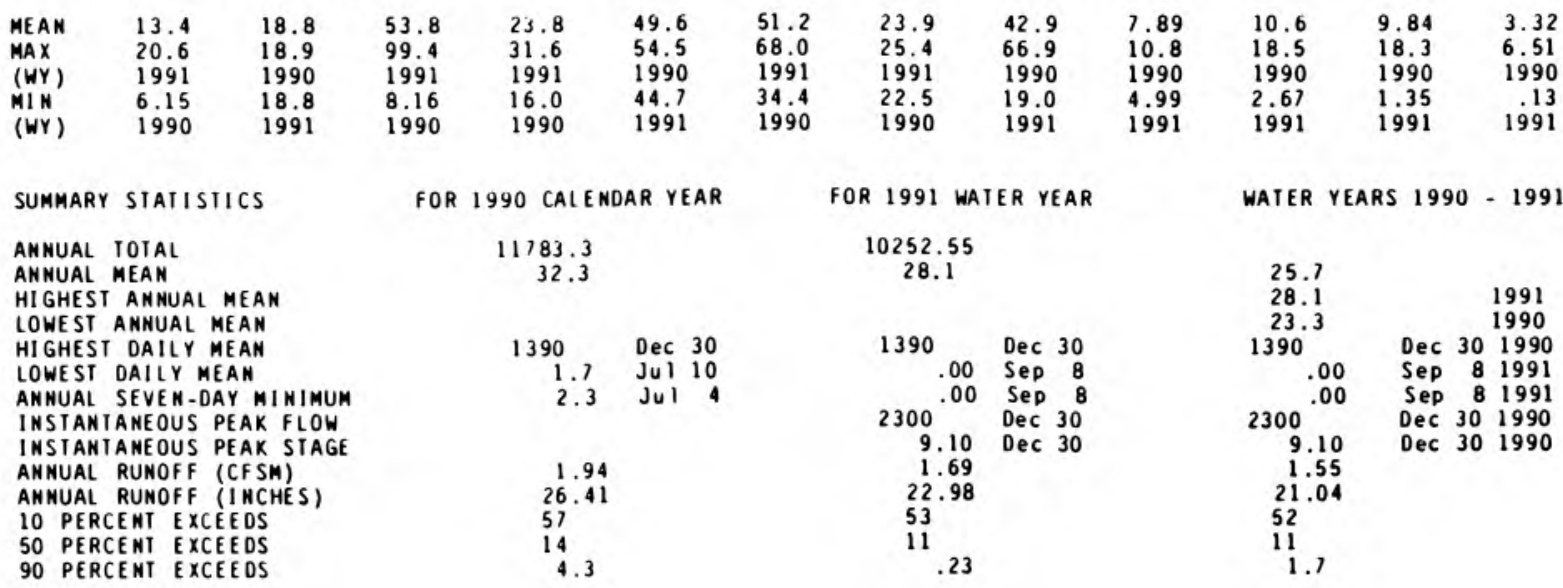




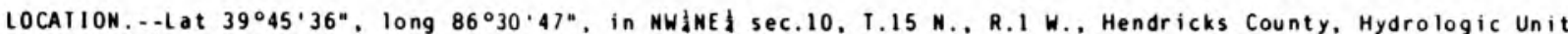
05120201 , on downstrean side of bridge on U.S. Highway 36, 0.5 a upstrea froe saall left-bank tributary. and 7 i west of Avoz.

PERIOD OF RECORD.--May 1958 to current year.

REVISED RECORDS.-.WSP 2109: Drainage area.

GAGE, - Water-stage recorder. Datum of gage is $828,83 \mathrm{ft}$ above National Geodetic Vertical Datun of 1929 . Prior to $0 \mathrm{ct} .23,1968$, nonrecording gage and crest-stage gage on upstrean side of bridge at sane datua. $0 \mathrm{ct}$. 23 , 1968, to Aug. 6, 1970, water-stage recorder on upstrean side of bridge at sane datur.

REMARKS. - Records fair except for estiaded daily discharges, which are poor. Low flow affected by releases froe Danville filtration Plant.

EXTREMES OUISIDE PERIOQ OF RECORD, - Flood of June 28, 1957, reached a stage of $16.0 \mathrm{ft}$, fron floodearks. discharge, $6,660 \mathrm{ft} / \mathrm{s}$, fron contracted-opening easureant.

DISCHARGE, CUBIC FEET PER SECOND, WATER YEAR OCTOBER 1990 TO SEPTEMBER 1991 DAILY MEAM VALUES

\begin{tabular}{|c|c|c|c|c|c|c|c|c|c|c|c|c|}
\hline DAY & $O C T$ & NOV & DEC & JAN & FEB & MAR & APR & MAY & JUN & JUL & AUG & SEP \\
\hline $\begin{array}{l}1 \\
2 \\
3 \\
4 \\
5\end{array}$ & $\begin{array}{r}1.0 \\
1.1 \\
9.0 \\
116 \\
31\end{array}$ & $\begin{array}{c}. .80 \\
1.6 \\
1.2 \\
43^{.83}\end{array}$ & $\begin{array}{r}43 \\
26 \\
337 \\
170 \\
82\end{array}$ & $\begin{array}{r}185 \\
\text { e120 } \\
\text { e } 90 \\
\text { e74 } \\
\text { e63 }\end{array}$ & $\begin{array}{r}\text { e17 } \\
\text { e20 } \\
\text { e31 } \\
60 \\
126\end{array}$ & $\begin{array}{l}23 \\
45 \\
32 \\
27 \\
22\end{array}$ & $\begin{array}{l}27 \\
22 \\
21 \\
22 \\
23\end{array}$ & $\begin{array}{l}18 \\
16 \\
15 \\
16 \\
21\end{array}$ & $\begin{array}{l}4.9 \\
4.2 \\
3.8 \\
3.0 \\
2.4\end{array}$ & $\begin{array}{l}.25 \\
.21 \\
.19 \\
.17 \\
.21\end{array}$ & $\begin{array}{l}.00 \\
.00 \\
.00 \\
.00 \\
.00\end{array}$ & $\begin{array}{l}.05 \\
.07 \\
.43 \\
.22 \\
.06\end{array}$ \\
\hline $\begin{array}{r}6 \\
7 \\
8 \\
9 \\
10\end{array}$ & $\begin{array}{l}6.6 \\
39 \\
59 \\
74 \\
378\end{array}$ & $\begin{array}{l}33 \\
10 \\
4.5 \\
3.7 \\
2.3\end{array}$ & $\begin{array}{l}58 \\
39 \\
29 \\
19 \\
15\end{array}$ & $\begin{array}{l}\text { e } 55 \\
\text { e } 50 \\
\text { e } 46 \\
\text { e } 43 \\
\text { e } 40\end{array}$ & $\begin{array}{r}189 \\
154 \\
107 \\
86 \\
68\end{array}$ & $\begin{array}{r}25 \\
15 \\
12 \\
13 \\
9.8\end{array}$ & $\begin{array}{l}20 \\
19 \\
34 \\
47 \\
28\end{array}$ & $\begin{array}{l}22 \\
17 \\
15 \\
14 \\
13\end{array}$ & $\begin{array}{l}2.2 \\
2.0 \\
2.0 \\
2.0 \\
1.7\end{array}$ & $\begin{array}{l}.11 \\
.09 \\
.07 \\
.07 \\
.96\end{array}$ & $\begin{array}{l}.57 \\
.12 \\
.37 \\
.14 \\
.08\end{array}$ & $\begin{array}{l}.03 \\
.02 \\
.02 \\
.03 \\
.03\end{array}$ \\
\hline $\begin{array}{l}11 \\
12 \\
13 \\
14 \\
15\end{array}$ & $\begin{array}{r}160 \\
73 \\
38 \\
21 \\
9.4\end{array}$ & $\begin{array}{l}1.5 \\
1.2 \\
1.0 \\
.93 \\
.89\end{array}$ & $\begin{array}{l}12 \\
10 \\
7.1 \\
4.6 \\
93\end{array}$ & $\begin{array}{r}116 \\
135 \\
91 \\
84 \\
117\end{array}$ & $\begin{array}{r}50 \\
41 \\
44 \\
42 \\
\mathrm{e} 30\end{array}$ & $\begin{array}{r}10 \\
53 \\
347 \\
163 \\
92\end{array}$ & $\begin{array}{r}21 \\
19 \\
139 \\
166 \\
160\end{array}$ & $\begin{array}{l}13 \\
13 \\
12 \\
11 \\
11\end{array}$ & $\begin{array}{l}2.0 \\
1.8 \\
1.6 \\
1.4 \\
2.1\end{array}$ & $\begin{array}{l}.40 \\
.49 \\
.29 \\
.21 \\
.17\end{array}$ & $\begin{array}{l}.06 \\
.05 \\
.04 \\
.16 \\
.15\end{array}$ & $\begin{array}{l}.02 \\
.01 \\
.01 \\
.01 \\
.01\end{array}$ \\
\hline $\begin{array}{l}16 \\
17 \\
18 \\
19 \\
20\end{array}$ & $\begin{array}{l}4.6 \\
4.0 \\
28 \\
12 \\
6.2\end{array}$ & $\begin{array}{l}1.2 \\
.78 \\
.72 \\
.71 \\
.65\end{array}$ & $\begin{array}{r}56 \\
52 \\
218 \\
160 \\
82\end{array}$ & $\begin{array}{r}179 \\
139 \\
101 \\
90 \\
89\end{array}$ & $\begin{array}{r}e 23 \\
e 29 \\
92 \\
173 \\
113\end{array}$ & $\begin{array}{r}58 \\
88 \\
152 \\
82 \\
53\end{array}$ & $\begin{array}{l}82 \\
54 \\
39 \\
83 \\
67\end{array}$ & $\begin{array}{l}9.5 \\
11 \\
13 \\
11 \\
8.8\end{array}$ & $\begin{array}{l}7.0 \\
1.9 \\
1.1 \\
.85 \\
.70\end{array}$ & $\begin{array}{l}.11 \\
.08 \\
.07 \\
.06 \\
.06\end{array}$ & $\begin{array}{l}.08 \\
.05 \\
.02 \\
.38 \\
.07\end{array}$ & $\begin{array}{l}.00 \\
.00 \\
.00 \\
.00 \\
.00\end{array}$ \\
\hline $\begin{array}{l}21 \\
22 \\
23 \\
24 \\
25\end{array}$ & $\begin{array}{l}4.1 \\
5.9 \\
5.8 \\
3.8 \\
2.2\end{array}$ & $\begin{array}{l}.62 \\
4.3 \\
3.1 \\
1.6 \\
1.5\end{array}$ & $\begin{array}{l}199 \\
196 \\
e 80 \\
e 37 \\
e 25\end{array}$ & $\begin{array}{r}78 \\
\text { e } 61 \\
\text { e } 48 \\
\text { e37 } \\
\text { e } 31\end{array}$ & $\begin{array}{l}83 \\
60 \\
45 \\
39 \\
30\end{array}$ & $\begin{array}{r}40 \\
254 \\
228 \\
93 \\
56\end{array}$ & $\begin{array}{l}47 \\
38 \\
31 \\
26 \\
23\end{array}$ & $\begin{array}{l}8.1 \\
7.4 \\
7.3 \\
7.2 \\
7.7\end{array}$ & $\begin{array}{c}.62 \\
.60 \\
1.2 \\
.65 \\
.52\end{array}$ & $\begin{array}{l}.04 \\
.04 \\
.03 \\
.02 \\
.02\end{array}$ & $\begin{array}{l}.03 \\
.02 \\
.01 \\
.01 \\
.01\end{array}$ & $\begin{array}{l}.00 \\
.09 \\
.14 \\
.09 \\
.04\end{array}$ \\
\hline $\begin{array}{l}26 \\
27 \\
28 \\
29 \\
30 \\
31\end{array}$ & $\begin{array}{l}2.2 \\
1.5 \\
1.1 \\
.92 \\
.94 \\
.89\end{array}$ & $\begin{array}{r}1.0 \\
118 \\
340 \\
140 \\
71\end{array}$ & $\begin{array}{r}\text { el } \\
\text { el6 } \\
\text { e15 } \\
562 \\
1310 \\
\text { e800 }\end{array}$ & $\begin{array}{l}\text { e26 } \\
\text { e21 } \\
\text { e19 } \\
\text { e17 } \\
\text { e15 } \\
\text { e15 }\end{array}$ & $\begin{array}{c}24 \\
22 \\
20 \\
\cdots \\
\cdots \\
\cdots\end{array}$ & $\begin{array}{r}210 \\
149 \\
76 \\
53 \\
36 \\
30\end{array}$ & $\begin{array}{l}23 \\
22 \\
21 \\
21 \\
17 \\
\cdots\end{array}$ & $\begin{array}{l}7.4 \\
6.3 \\
5.2 \\
8.4 \\
9.2 \\
6.6\end{array}$ & $\begin{array}{l}.47 \\
.42 \\
.34 \\
.33 \\
.30 \\
\cdots\end{array}$ & $\begin{array}{l}.02 \\
.02 \\
.01 \\
.01 \\
.01 \\
.00\end{array}$ & $\begin{array}{l}.03 \\
.08 \\
.48 \\
.08 \\
.03 \\
.04\end{array}$ & $\begin{array}{l}.02 \\
.02 \\
.02 \\
.01 \\
.01 \\
\cdots . .\end{array}$ \\
\hline $\begin{array}{l}\text { TOTAL } \\
\text { MEAN } \\
\text { MAX } \\
\text { MI N } \\
\text { CF SM } \\
\text { IN. }\end{array}$ & $\begin{array}{r}1100.25 \\
35.5 \\
378 \\
.89 \\
1.23 \\
1.42\end{array}$ & $\begin{array}{r}791.63 \\
26.4 \\
340 \\
.62 \\
.92 \\
1.02\end{array}$ & $\begin{array}{r}470.7 \\
154 \\
1310 \\
4.6 \\
5.34 \\
6.16\end{array}$ & $\begin{array}{r}2275 \\
73.4 \\
185 \\
15 \\
2.55 \\
2.94\end{array}$ & $\begin{array}{r}1818 \\
64.9 \\
189 \\
17 \\
2.25 \\
2.35\end{array}$ & $\begin{array}{r}2546.8 \\
82.2 \\
347 \\
9.8 \\
2.85 \\
3.29\end{array}$ & $\begin{array}{r}1362 \\
45.4 \\
166 \\
17 \\
1.58 \\
1.76\end{array}$ & $\begin{array}{r}361.1 \\
11.6 \\
22 \\
5.2 \\
.40 \\
.47\end{array}$ & $\begin{array}{r}54.10 \\
1.80 \\
7.0 \\
.30 \\
.06 \\
.07\end{array}$ & $\begin{array}{l}4.49 \\
.14 \\
.96 \\
.00 \\
.01 \\
.01\end{array}$ & $\begin{array}{l}3.16 \\
.10 \\
.57 \\
.00 \\
.00 \\
.00\end{array}$ & $\begin{array}{l}1.46 \\
.049 \\
.43 \\
.00 \\
.00 \\
.00\end{array}$ \\
\hline
\end{tabular}

e Estinated

STATISTICS OF MONIHLY MEAN DATA FOR WATER YEARS 1959 - 1991, BY WATER YEAR (WN)

$\begin{array}{lrrrrrrrrrrrr}\text { MEAN } & 9.74 & 24.9 & 43.1 & 36.1 & 51.4 & 63.7 & 50.5 & 36.5 & 17.2 & 19.3 & 8.56 & 5.73 \\ \text { MAX } & 82.0 & 156 & 154 & 131 & 151 & 145 & 119 & 130 & 75.9 & 134 & 69.4 & 109 \\ \text { (WY) } & 1987 & 1986 & 1991 & 1974 & 1990 & 1978 & 1964 & 1981 & 1974 & 1979 & 1979 & 1989 \\ \text { MIN } & .000 & 1053 & 1035 & 1062 & 2.82 & 11.2 & 9.14 & 3.87 & .51 & .14 & .026 & .003 \\ \text { (WY) } & 1965 & 1965 & 1964 & 1977 & 1964 & 1981 & 1971 & 1976 & 1988 & 1991 & 1964 & 1963\end{array}$

SUMMARY STATISTICS

ANNUAL TOTAL

ANMUAL MEAK

HIGHEST ANMUAL MEAN

LOWEST ANMUAL MEAM

HIGHEST DAILY MEAN

LOWEST DAILY MEAN

AMNUAL SEVEN-OAY MINIMUM

INSTANTAMEOUS PEAK FLOW

INSTANTANEOUS PEAK STAGE

ANNUAL RUNOFF (CFSM)

ANMUAL RUNOFF (INCHES)

10 PERCENT EXCEEDS

50 PERCENT EXCEEDS

90 PERCENT EXCEEDS
FOR 1990 CALENDAR YEAR

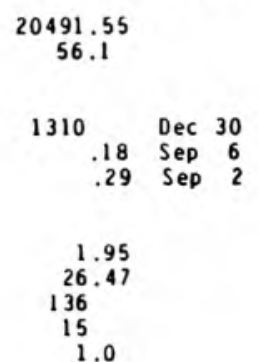

FOR 1991 WATER YEAR

15088.69

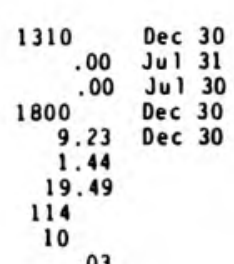

WAIER YEARS 1959 - 1991

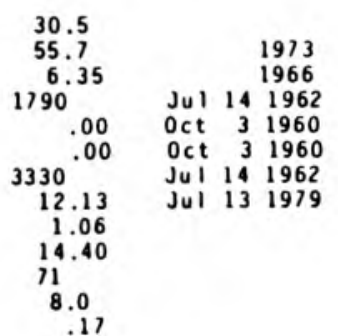


LOCATION, - L at $39^{\circ} 36^{\prime} 28^{\prime \prime}$, Iong $86^{\circ} 22^{\prime} 56^{\prime \prime}$, in NE 4 SE 05120201 , on right bank at downstrea side of bridge on State Highwa 42 at Mooresville, 0.9 i downstrea fro McCracken Creek, 2.,$i$ upstrea from East Fork white Lick Creek, and at ile 11.4 .

DRAI NAGE AREA, $-212 \mathbf{i}^{2}$

PERIOD OF RECORD.--August 1957 to current year.

GAGE.- Water-stage recorder. Datum of gage is $644.64 \mathrm{ft}$ above National Geodetic Vertical Datul of 1929 . Dec. 10. 1963 to Sept. 30,1964, nonrecording gage at bridge $1.950 \mathrm{ft}$ upstrea at datue $1.39 \mathrm{ft} \mathrm{higher}$.

REMARKS. - -Records good except for estinated daily discharges for Dec. 24-28, which are fair and estiated daily discharges for Jan. $2-10$ and Jan. 22 to Feb. 3, which are poor. Punage from a well field above gage affects low flows.

EXIREMES OUTSIDE PERIOD OF RECORD...flood of June 28 , 1957, reached a stage of $22.5 \mathrm{ft}$, from levels to high-water -ark by State of Indiana, Department of Natural Resources.

DISCHARGE, CUBIC FEET PER SECOND, WATER YEAR OCTOBER 1990 TO SEPIEMBER 1991

\begin{tabular}{|c|c|c|c|c|c|c|c|c|c|c|c|c|}
\hline DAY & $O C T$ & NOV & DEC & JAN & FEB & MAR & APR & MAY & JUN & JUL & $A \cup G$ & SEP \\
\hline $\begin{array}{l}1 \\
2 \\
3 \\
4 \\
5\end{array}$ & $\begin{array}{r}19 \\
19 \\
21 \\
287 \\
177\end{array}$ & $\begin{array}{l}60 \\
58 \\
58 \\
58 \\
99\end{array}$ & $\begin{array}{r}315 \\
263 \\
1470 \\
1050 \\
530\end{array}$ & $\begin{array}{l}1140 \\
e 680 \\
\text { e } 520 \\
\text { e } 440 \\
\text { e } 380\end{array}$ & $\begin{array}{r}\text { e } 150 \\
\text { e1 } \\
\text { e } 210 \\
274 \\
490\end{array}$ & $\begin{array}{l}174 \\
230 \\
223 \\
193 \\
176\end{array}$ & $\begin{array}{l}240 \\
211 \\
193 \\
198 \\
245\end{array}$ & $\begin{array}{l}148 \\
141 \\
128 \\
136 \\
144\end{array}$ & $\begin{array}{r}110 \\
96 \\
86 \\
80 \\
74\end{array}$ & $\begin{array}{l}17 \\
18 \\
17 \\
17 \\
20\end{array}$ & $\begin{array}{l}8.6 \\
8.2 \\
7.8 \\
7.9 \\
7.4\end{array}$ & $\begin{array}{l}4.9 \\
3.9 \\
3.8 \\
5.4 \\
6.3\end{array}$ \\
\hline $\begin{array}{r}6 \\
7 \\
8 \\
9 \\
10\end{array}$ & $\begin{array}{r}83 \\
100 \\
242 \\
178 \\
1480\end{array}$ & $\begin{array}{r}229 \\
146 \\
110 \\
96 \\
91\end{array}$ & $\begin{array}{l}380 \\
296 \\
247 \\
209 \\
184\end{array}$ & $\begin{array}{l}\text { e } 340 \\
\text { e } 310 \\
\text { e290 } \\
\text { e270 } \\
\text { e2 } 270\end{array}$ & $\begin{array}{r}1190 \\
1060 \\
623 \\
459 \\
374\end{array}$ & $\begin{array}{l}174 \\
165 \\
144 \\
136 \\
131\end{array}$ & $\begin{array}{l}203 \\
178 \\
228 \\
366 \\
246\end{array}$ & $\begin{array}{l}171 \\
141 \\
120 \\
112 \\
107\end{array}$ & $\begin{array}{l}68 \\
61 \\
55 \\
50 \\
46\end{array}$ & $\begin{array}{r}17 \\
15 \\
14 \\
13 \\
215\end{array}$ & $\begin{array}{l}23 \\
35 \\
20 \\
23 \\
19\end{array}$ & $\begin{array}{l}4.8 \\
3.8 \\
3.6 \\
3.1 \\
2.9\end{array}$ \\
\hline $\begin{array}{l}11 \\
12 \\
13 \\
14 \\
15\end{array}$ & $\begin{array}{l}911 \\
439 \\
279 \\
200 \\
151\end{array}$ & $\begin{array}{l}82 \\
74 \\
68 \\
65 \\
63\end{array}$ & $\begin{array}{l}165 \\
156 \\
144 \\
126 \\
377\end{array}$ & $\begin{array}{l}498 \\
847 \\
502 \\
394 \\
458\end{array}$ & $\begin{array}{r}308 \\
258 \\
250 \\
264 \\
e 210\end{array}$ & $\begin{array}{r}125 \\
220 \\
2820 \\
1300 \\
667\end{array}$ & $\begin{array}{l}192 \\
168 \\
560 \\
760 \\
920\end{array}$ & $\begin{array}{l}102 \\
123 \\
138 \\
243 \\
233\end{array}$ & $\begin{array}{l}44 \\
46 \\
42 \\
37 \\
35\end{array}$ & $\begin{array}{r}86 \\
109 \\
78 \\
49 \\
35\end{array}$ & $\begin{array}{c}13 \\
10 \\
9.1 \\
8.7 \\
12\end{array}$ & $\begin{array}{l}2.5 \\
2.2 \\
2.1 \\
2.0 \\
2.5\end{array}$ \\
\hline $\begin{array}{l}16 \\
17 \\
18 \\
19 \\
20\end{array}$ & $\begin{array}{l}121 \\
105 \\
120 \\
143 \\
117\end{array}$ & $\begin{array}{l}63 \\
63 \\
62 \\
60 \\
58\end{array}$ & $\begin{array}{r}457 \\
345 \\
1100 \\
1100 \\
576\end{array}$ & $\begin{array}{l}854 \\
822 \\
530 \\
424 \\
397\end{array}$ & $\begin{array}{r}\text { e } 162 \\
\text { e190 } \\
372 \\
933 \\
682\end{array}$ & $\begin{array}{r}440 \\
464 \\
1060 \\
582 \\
412\end{array}$ & $\begin{array}{l}585 \\
370 \\
289 \\
793 \\
632\end{array}$ & $\begin{array}{l}181 \\
214 \\
290 \\
218 \\
171\end{array}$ & $\begin{array}{l}48 \\
58 \\
45 \\
37 \\
31\end{array}$ & $\begin{array}{l}28 \\
23 \\
21 \\
19 \\
17\end{array}$ & $\begin{array}{l}9.7 \\
11 \\
12 \\
12 \\
13\end{array}$ & $\begin{array}{l}2.2 \\
2.1 \\
2.2 \\
2.1 \\
1.7\end{array}$ \\
\hline $\begin{array}{l}21 \\
22 \\
23 \\
24 \\
25\end{array}$ & $\begin{array}{r}102 \\
106 \\
110 \\
100 \\
89\end{array}$ & $\begin{array}{r}57 \\
112 \\
127 \\
99 \\
84\end{array}$ & $\begin{array}{r}622 \\
1200 \\
645 \\
e 360 \\
e 280\end{array}$ & $\begin{array}{r}385 \\
\text { e2 } 80 \\
\text { e240 } \\
\text { e210 } \\
\text { e1 } 190\end{array}$ & $\begin{array}{l}449 \\
349 \\
281 \\
250 \\
220\end{array}$ & $\begin{array}{r}340 \\
2040 \\
2040 \\
783 \\
482\end{array}$ & $\begin{array}{l}404 \\
326 \\
277 \\
257 \\
219\end{array}$ & $\begin{array}{l}146 \\
143 \\
207 \\
161 \\
151\end{array}$ & $\begin{array}{l}29 \\
27 \\
25 \\
26 \\
25\end{array}$ & $\begin{array}{l}16 \\
15 \\
13 \\
12 \\
11\end{array}$ & $\begin{array}{r}10 \\
8.9 \\
7.9 \\
6.9 \\
6.4\end{array}$ & $\begin{array}{l}1.9 \\
2.9 \\
6.7 \\
7.1 \\
6.0\end{array}$ \\
\hline $\begin{array}{l}26 \\
27 \\
28 \\
29 \\
30 \\
31\end{array}$ & $\begin{array}{l}80 \\
75 \\
70 \\
67 \\
65 \\
62\end{array}$ & $\begin{array}{r}76 \\
430 \\
1610 \\
810 \\
437 \\
\cdots\end{array}$ & $\begin{array}{r}e 220 \\
e 190 \\
e 180 \\
1860 \\
12100 \\
3070\end{array}$ & $\begin{array}{l}\text { el } 80 \\
\text { el } 70 \\
\text { el } 65 \\
\text { el } 60 \\
\text { el } 56 \\
\text { el } 53\end{array}$ & $\begin{array}{l}196 \\
187 \\
178 \\
\cdots \\
\cdots \\
\cdots\end{array}$ & $\begin{array}{r}1240 \\
1070 \\
569 \\
396 \\
313 \\
266\end{array}$ & $\begin{array}{l}205 \\
192 \\
184 \\
185 \\
167 \\
\cdots\end{array}$ & $\begin{array}{l}157 \\
139 \\
121 \\
113 \\
137 \\
124\end{array}$ & $\begin{array}{l}23 \\
22 \\
21 \\
20 \\
19 \\
\cdots\end{array}$ & $\begin{array}{l}11 \\
9.4 \\
9.7 \\
9.4 \\
9.1 \\
8.8\end{array}$ & $\begin{array}{l}5.5 \\
5.2 \\
5.6 \\
5.5 \\
6.1 \\
5.3\end{array}$ & $\begin{array}{l}5.4 \\
4.2 \\
3.4 \\
2.0 \\
1.6 \\
\ldots .\end{array}$ \\
\hline $\begin{array}{l}\text { TOIAL } \\
\text { MEAN } \\
\text { MAX } \\
\text { MIN } \\
\text { CF SM } \\
\text { IN. }\end{array}$ & $\begin{array}{r}6118 \\
197 \\
1480 \\
19 \\
.93 \\
1.07\end{array}$ & $\begin{array}{r}5505 \\
183 \\
1610 \\
57 \\
.87 \\
.97\end{array}$ & $\begin{array}{r}30217 \\
975 \\
12100 \\
126 \\
4.60 \\
5.30\end{array}$ & $\begin{array}{r}12655 \\
408 \\
1140 \\
153 \\
1.93 \\
2.22\end{array}$ & $\begin{array}{r}10739 \\
384 \\
1190 \\
150 \\
1.81 \\
1.88\end{array}$ & $\begin{array}{r}19375 \\
625 \\
2820 \\
125 \\
2.95 \\
3.40\end{array}$ & $\begin{array}{c}9993 \\
333 \\
920 \\
167 \\
1.57 \\
1.75\end{array}$ & $\begin{array}{l}4860 \\
157 \\
290 \\
102 \\
.74 \\
.85\end{array}$ & $\begin{array}{c}1386 \\
46.2 \\
110 \\
19 \\
.22 \\
.24\end{array}$ & $\begin{array}{r}952.4 \\
30.7 \\
215 \\
8.8 \\
.14 \\
.17\end{array}$ & $\begin{array}{r}343.7 \\
11.1 \\
35 \\
5.2 \\
.05 \\
.06\end{array}$ & $\begin{array}{c}105.3 \\
3.51 \\
7.1 \\
1.6 \\
.02 \\
.02\end{array}$ \\
\hline
\end{tabular}

e Estinated

STATISTICS OF MONTHLY MEAN DATA FOR WAIER YEARS 1957 - 1991, BY WATER YEAR (WY)

\begin{tabular}{|c|c|c|c|c|c|c|c|c|c|c|c|c|}
\hline $\begin{array}{l}\text { MEAN } \\
\text { MAX } \\
\text { (WY) } \\
\text { MIN } \\
\text { (WY) }\end{array}$ & $\begin{array}{r}71.4 \\
547 \\
1987 \\
5.97 \\
1965\end{array}$ & $\begin{array}{r}167 \\
920 \\
1973 \\
9.86 \\
1968\end{array}$ & $\begin{array}{r}293 \\
975 \\
1991 \\
8.83 \\
1964\end{array}$ & $\begin{array}{r}252 \\
845 \\
1969 \\
9.60 \\
1977\end{array}$ & $\begin{array}{r}350 \\
942 \\
1971 \\
35.7 \\
1964\end{array}$ & $\begin{array}{r}453 \\
1154 \\
1963 \\
98.2 \\
1966\end{array}$ & $\begin{array}{r}376 \\
1327 \\
1964 \\
83.1 \\
1971\end{array}$ & $\begin{array}{r}280 \\
997 \\
1981 \\
46.3 \\
1976\end{array}$ & $\begin{array}{r}147 \\
550 \\
1974 \\
12.9 \\
1988\end{array}$ & $\begin{array}{r}140 \\
764 \\
1979 \\
11.7 \\
1966\end{array}$ & $\begin{array}{r}81.5 \\
567 \\
1979 \\
5.10 \\
1966\end{array}$ & $\begin{array}{r}54.9 \\
712 \\
1989 \\
3.51 \\
1991\end{array}$ \\
\hline
\end{tabular}

SUMMARY SIATISIICS

ANNUAL TOIAL

ANMUAL MEAM

HIGHESI ANNUAL MEAN

LOWEST ANNUAL MEAN

HIGHEST DAILY MEAN

LOHESI DAILY MEAN

ANMUAL SEVEM-DAY MINIMUM

INSIANTANEOUS PEAK FLOW

INSIANIANEOUS PEAK STAGE

ANHUAL RUNOFF (CFSM)

ANNUAL RUNOF F (INCHES)

10 PERCENT EXLEEDS

50 PERCENT EXCEEDS

90 PERCENT EXCEEDS
FOR 1990 CALENDAR YEAR

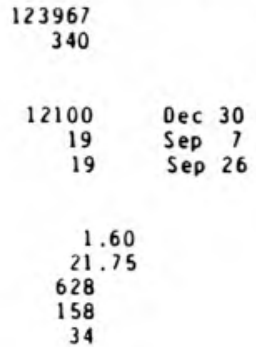

FOR 1991 WAIER YEAR

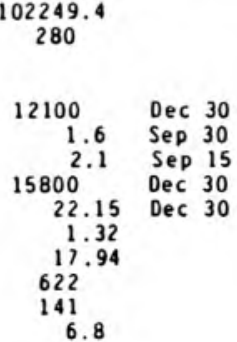

WAIER YEARS 1957 - 1991

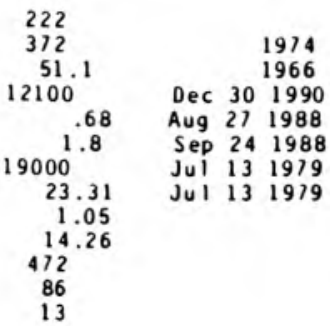




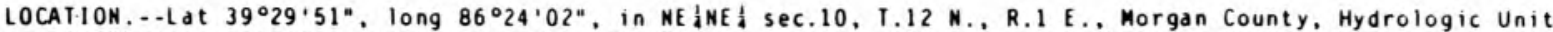

05120201 , on right bank at upstrean side of bridge on Bive Bluff Rodd, 0.8 ei downstream from White lick Creek, 1 i south of Centertgh, and at mile 199.3.

DRAINAGE AREA, $\cdots 2,444: i^{2}$.

\section{WATER-DISCHARGE RECOROS}

PERIOD OF RECORD.--July 1925 to September 1930 (gage heights only), October 1930 to March 1932 , October 1946 to current year. Monthly discharge only for October and Noveber 1946, published in WSP 1305. Published as West fork White River at Martinsville prior to March 1932, and as West Fork White River near Centerton October 1946 to Septeaber 1948. REVISED RE CORDS.--WSP 1335: 1948-49. WSP 1909: 1931(N). WSP 2109: Drainage area.

GAGE.- Water-stage recorder. Datun of gage is $595.44 \mathrm{ft}$ above Mational Geodetic Vertical Datun of 1929 (Corps of Engineers bench ark), levels by Indianapolis Power and Light Co. See WSP 1725 for history of changes prior to July 1953. July 1953 to Aug. 1, 1975, water-stage recorder at site 0.4 i downstrean at sane datua.

REMARKS.--Records good. Flow reguiated by upstrean reservoirs.

EXTREMES OUTSIDE PERIOD OF RECORD. - Flood in March 1913 reached a stage of $22.8 \mathrm{ft}$ at Martinsville site (froa inforation by Indiana State Highway Coma ission) and $21.9 \mathrm{ft}$ at 5 ite 0.4 a downstreas (froe inforation by Corps of Engineers). discharge, $90,000 \mathrm{ft} / \mathrm{s}$.

DISCHARGE, CUBIC FEET PER SECOND, WAIER YEAR OCTOBER 1990 TO SEPIEMBER 1991 DAILY MEAN VALUES

\begin{tabular}{|c|c|c|c|c|c|c|c|c|c|c|c|c|}
\hline DAY & $\mathrm{OCT}$ & NOV & $\mathrm{DEC}$ & JAN & FE B & MAR & $A P R$ & MAY & JUN & JUL & AUG & SEP \\
\hline $\begin{array}{l}1 \\
2 \\
3 \\
4 \\
5\end{array}$ & $\begin{array}{r}935 \\
947 \\
909 \\
3280 \\
3080\end{array}$ & $\begin{array}{l}1360 \\
1320 \\
1270 \\
1240 \\
1340\end{array}$ & $\begin{array}{l}5250 \\
4020 \\
6510 \\
9780 \\
9320\end{array}$ & $\begin{array}{r}40600 \\
37200 \\
27500 \\
13000 \\
7790\end{array}$ & $\begin{array}{l}2510 \\
2580 \\
2800 \\
2960 \\
4040\end{array}$ & $\begin{array}{l}2530 \\
2740 \\
2730 \\
2590 \\
2370\end{array}$ & $\begin{array}{l}4030 \\
3630 \\
3240 \\
3090 \\
3470\end{array}$ & $\begin{array}{l}2300 \\
2210 \\
2040 \\
2150 \\
2110\end{array}$ & $\begin{array}{l}3620 \\
6140 \\
6070 \\
4340 \\
3160\end{array}$ & $\begin{array}{l}739 \\
733 \\
690 \\
706 \\
711\end{array}$ & $\begin{array}{l}426 \\
411 \\
400 \\
379 \\
378\end{array}$ & $\begin{array}{l}397 \\
348 \\
346 \\
423 \\
449\end{array}$ \\
\hline $\begin{array}{r}6 \\
7 \\
8 \\
9 \\
10\end{array}$ & $\begin{array}{l}3820 \\
2990 \\
3100 \\
2510 \\
5730\end{array}$ & $\begin{array}{l}2030 \\
1970 \\
1900 \\
1690 \\
1570\end{array}$ & $\begin{array}{l}7220 \\
4990 \\
4080 \\
3370 \\
3030\end{array}$ & $\begin{array}{r}6610 \\
5660 \\
4860 \\
\mathrm{e} 4200 \\
\mathrm{e} 3900\end{array}$ & $\begin{array}{r}8630 \\
11200 \\
9950 \\
8350 \\
6260\end{array}$ & $\begin{array}{l}2310 \\
2260 \\
2080 \\
1970 \\
1900\end{array}$ & $\begin{array}{l}3350 \\
3170 \\
2990 \\
4000 \\
3590\end{array}$ & $\begin{array}{l}2390 \\
2170 \\
1970 \\
1850 \\
1810\end{array}$ & $\begin{array}{l}2420 \\
1990 \\
1700 \\
1530 \\
1380\end{array}$ & $\begin{array}{r}705 \\
619 \\
579 \\
615 \\
1560\end{array}$ & $\begin{array}{r}562 \\
1030 \\
649 \\
693 \\
595\end{array}$ & $\begin{array}{l}415 \\
395 \\
366 \\
336 \\
335\end{array}$ \\
\hline $\begin{array}{l}11 \\
12 \\
13 \\
14 \\
15\end{array}$ & $\begin{array}{l}8020 \\
8710 \\
6550 \\
4570 \\
3420\end{array}$ & $\begin{array}{l}1460 \\
1390 \\
1330 \\
1270 \\
1210\end{array}$ & $\begin{array}{l}2760 \\
2550 \\
2390 \\
2250 \\
3200\end{array}$ & $\begin{array}{r}e 4450 \\
6540 \\
6460 \\
5850 \\
5010\end{array}$ & $\begin{array}{l}5050 \\
4300 \\
3810 \\
3760 \\
3600\end{array}$ & $\begin{array}{r}1800 \\
1960 \\
12200 \\
15400 \\
11600\end{array}$ & $\begin{array}{l}3110 \\
2760 \\
3710 \\
5770 \\
7680\end{array}$ & $\begin{array}{l}1740 \\
1800 \\
1760 \\
1790 \\
2160\end{array}$ & $\begin{array}{l}1300 \\
1290 \\
1230 \\
1150 \\
1060\end{array}$ & $\begin{array}{r}1430 \\
1200 \\
1090 \\
860 \\
783\end{array}$ & $\begin{array}{l}541 \\
513 \\
494 \\
450 \\
530\end{array}$ & $\begin{array}{l}330 \\
315 \\
636 \\
616 \\
453\end{array}$ \\
\hline $\begin{array}{l}16 \\
17 \\
18 \\
19 \\
20\end{array}$ & $\begin{array}{l}2850 \\
2460 \\
2500 \\
2550 \\
2890\end{array}$ & $\begin{array}{l}1180 \\
1180 \\
1150 \\
1110 \\
1110\end{array}$ & $\begin{array}{r}5040 \\
6270 \\
8830 \\
10400 \\
9830\end{array}$ & $\begin{array}{l}6100 \\
7650 \\
8240 \\
6660 \\
5430\end{array}$ & $\begin{array}{l}3120 \\
2860 \\
3220 \\
5550 \\
6420\end{array}$ & $\begin{array}{r}9410 \\
8900 \\
11900 \\
11500 \\
11000\end{array}$ & $\begin{array}{l}9320 \\
1610 \\
5510 \\
6950 \\
8950\end{array}$ & $\begin{array}{l}2030 \\
2670 \\
3370 \\
4760 \\
4650\end{array}$ & $\begin{array}{l}1220 \\
1480 \\
1250 \\
1130 \\
1000\end{array}$ & $\begin{array}{l}730 \\
651 \\
605 \\
567 \\
550\end{array}$ & $\begin{array}{l}467 \\
440 \\
600 \\
546 \\
663\end{array}$ & $\begin{array}{l}402 \\
404 \\
357 \\
347 \\
328\end{array}$ \\
\hline $\begin{array}{l}21 \\
22 \\
23 \\
24 \\
25\end{array}$ & $\begin{array}{l}2690 \\
2390 \\
2300 \\
2190 \\
2070\end{array}$ & $\begin{array}{l}1080 \\
1450 \\
1710 \\
1500 \\
1500\end{array}$ & $\begin{array}{r}9470 \\
11100 \\
10600 \\
9580 \\
6480\end{array}$ & $\begin{array}{l}4910 \\
4520 \\
4110 \\
3640 \\
3190\end{array}$ & $\begin{array}{l}6630 \\
5490 \\
4470 \\
3770 \\
3310\end{array}$ & $\begin{array}{r}8640 \\
11800 \\
17100 \\
12500 \\
10700\end{array}$ & $\begin{array}{l}7910 \\
6640 \\
5110 \\
4350 \\
3720\end{array}$ & $\begin{array}{l}3320 \\
2640 \\
3440 \\
3640 \\
2970\end{array}$ & $\begin{array}{r}896 \\
845 \\
829 \\
1110 \\
1540\end{array}$ & $\begin{array}{l}523 \\
516 \\
511 \\
526 \\
492\end{array}$ & $\begin{array}{l}561 \\
567 \\
556 \\
480 \\
427\end{array}$ & $\begin{array}{l}312 \\
306 \\
512 \\
508 \\
429\end{array}$ \\
\hline $\begin{array}{l}26 \\
21 \\
28 \\
29 \\
30 \\
31\end{array}$ & $\begin{array}{l}1910 \\
1740 \\
1600 \\
1530 \\
1460 \\
1390\end{array}$ & $\begin{array}{c}1420 \\
2290 \\
7360 \\
7840 \\
7060 \\
\ldots .\end{array}$ & $\begin{array}{r}4970 \\
4110 \\
3710 \\
7190 \\
32100 \\
44800\end{array}$ & $\begin{array}{l}2980 \\
2770 \\
2720 \\
2570 \\
2900 \\
2590\end{array}$ & $\begin{array}{r}3010 \\
2760 \\
2630 \\
\ldots \\
\ldots \\
\ldots\end{array}$ & $\begin{array}{r}10500 \\
10900 \\
9100 \\
7800 \\
5940 \\
4650\end{array}$ & $\begin{array}{c}3260 \\
2950 \\
2790 \\
2690 \\
2520 \\
\ldots .\end{array}$ & $\begin{array}{l}2720 \\
2490 \\
2190 \\
1890 \\
2110 \\
2110\end{array}$ & $\begin{array}{r}1350 \\
1150 \\
937 \\
848 \\
775 \\
\cdots\end{array}$ & $\begin{array}{l}470 \\
453 \\
436 \\
440 \\
439 \\
432\end{array}$ & $\begin{array}{l}390 \\
384 \\
375 \\
432 \\
410 \\
432\end{array}$ & $\begin{array}{l}392 \\
385 \\
353 \\
334 \\
321 \\
\cdots\end{array}$ \\
\hline $\begin{array}{l}\text { TOIAL } \\
\text { MEAN } \\
\text { MAX } \\
\text { MIN } \\
\text { CF SM } \\
\text { IN. }\end{array}$ & $\begin{array}{r}93091 \\
3003 \\
8710 \\
909 \\
1.23 \\
1.42\end{array}$ & $\begin{array}{r}61290 \\
2043 \\
7840 \\
1080 \\
.84 \\
.93\end{array}$ & $\begin{array}{r}255200 \\
8232 \\
44800 \\
2250 \\
3.37 \\
3.88\end{array}$ & $\begin{array}{r}250670 \\
8086 \\
40600 \\
2570 \\
3.31 \\
3.82\end{array}$ & $\begin{array}{r}133040 \\
4751 \\
11200 \\
2510 \\
1.94 \\
2.02\end{array}$ & $\begin{array}{r}228780 \\
7380 \\
17100 \\
1800 \\
3.02 \\
3.48\end{array}$ & $\begin{array}{r}137870 \\
4596 \\
9320 \\
2520 \\
1.88 \\
2.10\end{array}$ & $\begin{array}{r}77250 \\
2492 \\
4760 \\
1740 \\
1.02 \\
1.18\end{array}$ & $\begin{array}{r}54740 \\
1825 \\
6140 \\
775 \\
.75 \\
.83\end{array}$ & $\begin{array}{r}21361 \\
689 \\
1560 \\
432 \\
.28 \\
.33\end{array}$ & $\begin{array}{r}15781 \\
509 \\
1030 \\
375 \\
.21 \\
.24\end{array}$ & $\begin{array}{c}11850 \\
395 \\
636 \\
306 \\
.16 \\
.18\end{array}$ \\
\hline
\end{tabular}

e Estimated

STAIISTICS OF MONTHLY MEAN DATA FOR WAIER YEARS 1948 - 1991, BY WATER YEAR (WY)

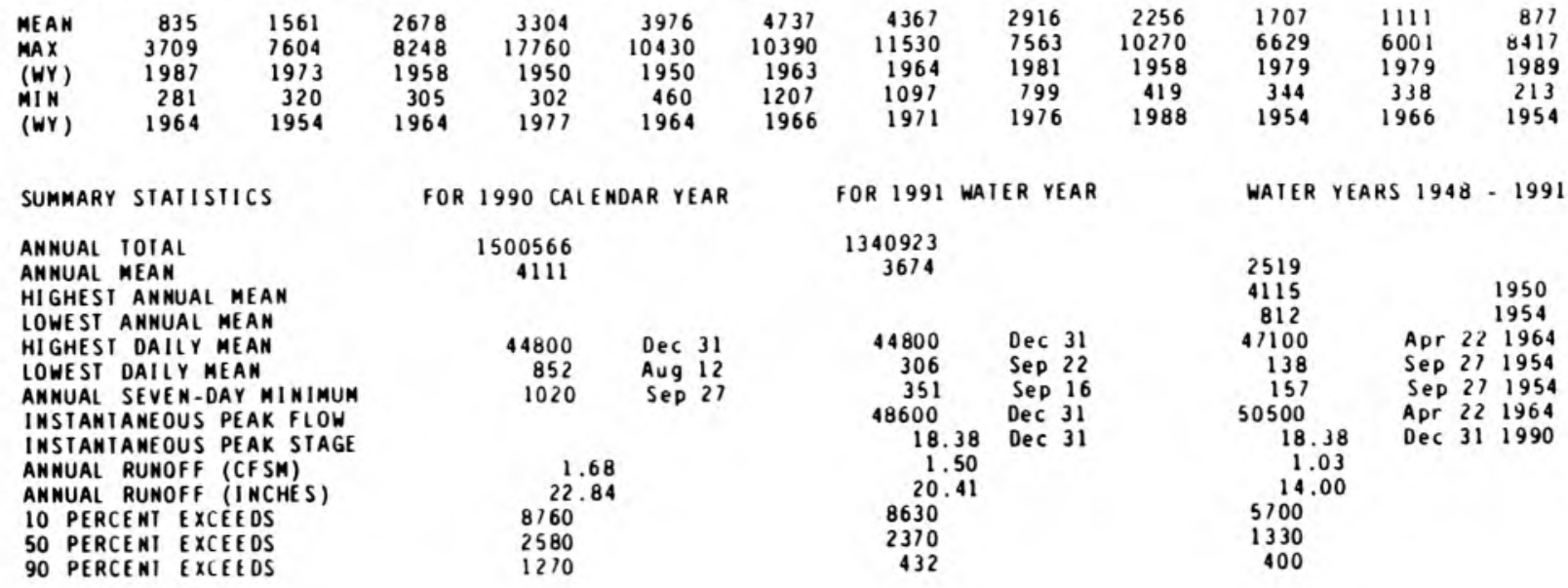


PERIOD OF RECORD..-

CHEMICAL ANALYSIS: October 1986 to current year.

WATER TEMPERATURE: September 1953 to April 1956, October 1966 to September 1967 , May 1970 to September 1972 ,

October 1977 to July 1980 , October 1982 to June 1985.

SEDIMENT DISCHARGE: March 1965 to Septeaber 1977. October 1986 to current year (partial-record station).

EXTREMES FOR PERIOD OF RECORD. - - Water temperature: Maximum, $33{ }^{\circ} \mathrm{C}$ July 3,1970 ; minimum, $-0.5{ }^{\circ} \mathrm{C}$, several days during winters.

WAIER QUALITY DATA, WAIER YEAR OCTOBER 1990 TO SEPIEMBER 1991

\begin{tabular}{|c|c|c|c|c|c|c|c|c|c|c|c|}
\hline DAIE & TIME & $\begin{array}{l}\text { DIS- } \\
\text { CHARGE, } \\
\text { INST, } \\
\text { CUBIC } \\
\text { FEET } \\
\text { PER } \\
\text { SECOND } \\
(00061)\end{array}$ & $\begin{array}{l}\text { SPE- } \\
\text { CIFIC } \\
\text { CON- } \\
\text { DUCI- } \\
\text { ANCE } \\
\text { (US / CM) } \\
(00095)\end{array}$ & $\begin{array}{l}\text { SPE - } \\
\text { CIFIC } \\
\text { CON- } \\
\text { DUCT - } \\
\text { ANCE } \\
\text { LAB } \\
(\text { US /CM) } \\
(90095)\end{array}$ & $\begin{array}{c}\text { PH } \\
\text { (SIAND- } \\
\text { ARD } \\
\text { UNIIS) } \\
(00400)\end{array}$ & $\begin{array}{l}\text { PH } \\
\text { LAB } \\
\text { (SIAND- } \\
\text { ARD } \\
\text { UNIIS) } \\
(00403)\end{array}$ & $\begin{array}{l}\text { TEMPER- } \\
\text { AIURE } \\
\text { AIR } \\
(\text { DEG C) } \\
(00020)\end{array}$ & $\begin{array}{l}\text { TEMPER- } \\
\text { AIURE } \\
\text { WAIER } \\
\text { (DEG C) } \\
(00010)\end{array}$ & $\begin{array}{l}\text { BARO- } \\
\text { ME IRIC } \\
\text { PRES- } \\
\text { SURE } \\
\text { (MM } \\
\text { OF } \\
\text { HG) } \\
(00025)\end{array}$ & $\begin{array}{c}\text { OXYGEN, } \\
\text { DIS- } \\
\text { SOLVED } \\
\text { (MG/L) } \\
(00300)\end{array}$ & $\begin{array}{l}\text { OXYGEN, } \\
\text { DIS- } \\
\text { SOIVED } \\
\text { (PER- } \\
\text { CENT } \\
\text { SAIUR- } \\
\text { AIION) } \\
(00301\end{array}$ \\
\hline \multicolumn{12}{|l|}{ OCT } \\
\hline JAN $23 \cdots$ & 1400 & 2380 & 707 & 717 & 8.1 & 8.0 & 14.5 & 13.5 & 757 & 9.5 & 92 \\
\hline${ }_{\text {MAR }}^{23} \cdots$ & 1300 & 4070 & 672 & 687 & E7.7 & 7.9 & 4.5 & 2.0 & 744 & 12.5 & 93 \\
\hline $12 \ldots$ & 1400 & 1710 & 821 & 830 & 8.1 & 8.0 & 2.5 & 7.0 & 740 & 11.2 & 95 \\
\hline Jui $30 \ldots$ & 1545 & 2450 & 734 & 737 & 8.1 & 8.1 & 24.0 & 19.0 & 746 & 11.3 & 125 \\
\hline $16 \ldots$ & 1330 & 742 & 887 & 892 & 8.5 & 8.5 & 29.0 & 27.0 & 752 & 16.8 & 215 \\
\hline $27 \ldots$ & 1500 & 393 & 1140 & 1180 & 8.3 & 8.4 & 35.0 & 27.0 & 749 & 14.6 & 188 \\
\hline DAIE & $\begin{array}{c}\text { TUR- } \\
\text { BID- } \\
\text { IIY } \\
\text { (NIU) } \\
(00076)\end{array}$ & $\begin{array}{l}\text { COLI- } \\
\text { FORM, } \\
\text { FECAL, } \\
0.7 \\
\text { UH-MF } \\
\text { (COLS.I } \\
100 \mathrm{ML}) \\
(31625)\end{array}$ & $\begin{array}{l}\text { SIREP- } \\
\text { IOCOCCI } \\
\text { FECAL, } \\
\text { KF AGAR } \\
\text { (COLS. } \\
\text { PER } \\
100 \mathrm{ML}) \\
(31673)\end{array}$ & $\begin{array}{l}\text { HARD- } \\
\text { NESS } \\
\text { TOIAL } \\
\text { (NG/L } \\
\text { AS } \\
\text { CACO3) } \\
(00900)\end{array}$ & $\begin{array}{l}\text { HARD- } \\
\text { NESS } \\
\text { NONCARB } \\
\text { OISSOL V } \\
\text { FLD. AS } \\
\text { CACO3 } \\
(\text { MG/L) } \\
(00904)\end{array}$ & $\begin{array}{l}\text { CALCIUM } \\
\text { DIS- } \\
\text { SOLVED } \\
\text { (MG/L } \\
\text { AS CA) } \\
(00915)\end{array}$ & $\begin{array}{l}\text { MAGNE - } \\
\text { SIUH, } \\
\text { DIS- } \\
\text { SOL VED } \\
\text { (MG/L } \\
\text { AS MG) } \\
(00925)\end{array}$ & $\begin{array}{l}\text { SODIUM, } \\
\text { DIS- } \\
\text { SOLVED } \\
\text { (MG/L } \\
\text { AS NA) } \\
(00930)\end{array}$ & $\begin{array}{l}\text { POTAS- } \\
\text { SIUA, } \\
\text { DIS- } \\
\text { SOL VED } \\
\text { (MG/L } \\
\text { AS K) } \\
(00935)\end{array}$ & $\begin{array}{l}\text { ALKA- } \\
\text { IINITY } \\
\text { WAT DIS } \\
\text { FIX END } \\
\text { FIELD } \\
\text { CACO3 } \\
(\text { MG/L) } \\
(39036)\end{array}$ & $\begin{array}{l}\text { ALKA- } \\
\text { WINIIY } \\
\text { WAI DIS } \\
\text { TOT IT } \\
\text { FIELD } \\
\text { MG IL AS } \\
\text { CACO3 } \\
(39086)\end{array}$ \\
\hline \multicolumn{12}{|l|}{ OCT } \\
\hline JAN $^{23 \cdots}$ & 13 & 560 & 72 & 290 & 50 & 17 & 24 & 33 & 3.9 & 240 & 241 \\
\hline${ }_{\text {MAR }}^{23} \cdots$ & 18 & 1100 & 180 & 310 & 64 & 81 & 25 & 31 & 2.7 & 240 & 241 \\
\hline${ }_{A P R}^{12 \cdots}$ & 3.0 & 1600 & 170 & 340 & 77 & 88 & 29 & 47 & 3.2 & 260 & 262 \\
\hline jui $30 . .$. & 14 & 83 & K7 & 320 & 66 & 85 & 26 & 35 & 2.3 & 250 & 253 \\
\hline AUG $16 \cdots$ & 12 & 490 & 87 & 300 & 59 & 78 & 25 & 78 & 6.7 & 240 & 239 \\
\hline $27 \ldots$ & 1.5 & 43 & 27 & 330 & 72 & 81 & 30 & 120 & 8.0 & 250 & 253 \\
\hline DAIE & $\begin{array}{c}\text { ALKA- } \\
\text { LINITY } \\
\text { LAB } \\
\text { (NG/L } \\
\text { AS } \\
\text { CACO3) } \\
(90410)\end{array}$ & $\begin{array}{l}\text { BICAR- } \\
\text { BONAIE } \\
\text { WATER } \\
\text { DIS II } \\
\text { FIELD } \\
\text { MG/L AS } \\
\text { HCO3 } \\
(00453)\end{array}$ & $\begin{array}{l}\text { CAR- } \\
\text { BONATE } \\
\text { WATER } \\
\text { OIS I I } \\
\text { FIELL } \\
\text { MG } / \mathrm{L} \text { AS } \\
\text { CO3 } \\
(00452)\end{array}$ & $\begin{array}{l}\text { SULFATE } \\
\text { DIS- } \\
\text { SOLVED } \\
\text { (MG/L } \\
\text { AS SO4) } \\
(00945)\end{array}$ & $\begin{array}{l}\text { CHLO- } \\
\text { RIDE, } \\
\text { DIS- } \\
\text { SOL VED } \\
\text { (MG/L } \\
\text { AS CL) } \\
(00940)\end{array}$ & $\begin{array}{l}\text { FLUO- } \\
\text { RIDE. } \\
\text { OIS- } \\
\text { SOLVED } \\
\text { (MG/L } \\
\text { AS F) } \\
(00950)\end{array}$ & $\begin{array}{l}\text { SILICA, } \\
\text { DIS- } \\
\text { SOLVED } \\
\text { (MG/L } \\
\text { AS } \\
\text { SI02) } \\
(00955)\end{array}$ & $\begin{array}{l}\text { SOLIDS, } \\
\text { RESIDUE } \\
\text { AT } 180 \\
\text { DEG. C } \\
\text { DIS- } \\
\text { SOLVED } \\
(M G / L) \\
(70300)\end{array}$ & $\begin{array}{l}\text { SOLIDS. } \\
\text { SUM OF } \\
\text { CONSII - } \\
\text { TUENTS. } \\
\text { DIS- } \\
\text { SOLVED } \\
\text { (MG/L) } \\
(70301)\end{array}$ & $\begin{array}{l}\text { SOLIDS, } \\
\text { DIS- } \\
\text { SOL VED } \\
\text { (TONS } \\
\text { PER } \\
\text { DAY) } \\
(70302)\end{array}$ & $\begin{array}{l}\text { NIIRO- } \\
\text { GEN, } \\
\text { HITRIIE } \\
\text { DIS- } \\
\text { SOIVED } \\
(\text { MG/L } \\
\text { AS N) } \\
(00613)\end{array}$ \\
\hline \multicolumn{12}{|l|}{ OCT } \\
\hline JAN $23 \ldots$ & 243 & 294 & 0 & 53 & 50 & 0.2 & 8.5 & 417 & 406 & 2680 & 0.03 \\
\hline${ }_{\text {MAR }}^{23 \ldots}$ & 237 & 294 & 0 & 55 & 51 & 0.2 & 8.4 & 408 & 415 & 4490 & 0.03 \\
\hline${ }_{A P R}^{12 \ldots}$ & 261 & 320 & 0 & 82 & 67 & 0.3 & 4.6 & 482 & 493 & 2230 & 0.07 \\
\hline JuL $30 . \cdots$ & 251 & 309 & 0 & 63 & 50 & 0.2 & 4.6 & 434 & 431 & 2870 & 0.04 \\
\hline $\begin{array}{l}16 \ldots \\
\text { AUG }\end{array}$ & 242 & 267 & 12 & 100 & 89 & 0.2 & 1.9 & 545 & 532 & 1090 & 0.12 \\
\hline $27 \ldots$ & 255 & 287 & 11 & 150 & 130 & 0.6 & 6.2 & 692 & 695 & 734 & 0.04 \\
\hline
\end{tabular}


03354000 WHIIE RIVER NEAR CENIERTON, IN --Continued

(Mational strea-quality accounting network station)

\begin{tabular}{|c|c|c|c|c|c|c|c|c|c|c|}
\hline DATE & $\begin{array}{l}\text { NIIRO- } \\
\text { GEN, } \\
\text { NO2+NO3 } \\
\text { DIS- } \\
\text { SOLVEO } \\
\text { (MG/L } \\
\text { AS N) } \\
(00631)\end{array}$ & $\begin{array}{l}\text { ATER QUAL } \\
\text { NIIRO- } \\
\text { GEN, } \\
\text { AMMONIA } \\
\text { TOTAL } \\
(\text { MG/L } \\
\text { AS N) } \\
(00610)\end{array}$ & $\begin{array}{l}\text { IIY DAIA, } \\
\text { NIIRO- } \\
\text { GEN, } \\
\text { AMMONIA } \\
\text { OIS- } \\
\text { SOIVED } \\
\text { (MG/L } \\
\text { AS N) } \\
(00608)\end{array}$ & $\begin{array}{l}\text { WAIER YE } \\
\text { NIIRO- } \\
\text { GEN,AM- } \\
\text { MONIA + } \\
\text { ORGANIC } \\
\text { TOTAL } \\
(\text { MG/L } \\
\text { AS N) } \\
(00625)\end{array}$ & $\begin{array}{l}\text { PHOS- } \\
\text { PHORUS } \\
\text { TOTAL } \\
\text { (MG/L } \\
\text { AS P) } \\
(00665)\end{array}$ & $\begin{array}{l}\text { R } 1990 \text { IO } \\
\text { PHOS- } \\
\text { PHORUS } \\
\text { DIS. } \\
\text { SOLVED } \\
(\text { MG/L } \\
\text { AS P) } \\
(00666)\end{array}$ & $\begin{array}{l}\text { SEPIEMBER } \\
\text { PHOS- } \\
\text { PHORUS } \\
\text { ORTHO, } \\
\text { DIS- } \\
\text { SOLVED } \\
(\text { MG/L } \\
\text { AS P) } \\
(00671)\end{array}$ & $\begin{array}{l}\text { ALUM- } \\
\text { I NUM, } \\
\text { DIS - } \\
\text { SOL VEO } \\
\text { (UG/L } \\
\text { AS AL) } \\
(01106)\end{array}$ & $\begin{array}{l}\text { ARSENIC } \\
\text { DIS- } \\
\text { SOLVED } \\
\text { (UG/L } \\
\text { AS AS) } \\
(01000)\end{array}$ & $\begin{array}{l}\text { BARIUM, } \\
\text { DIS- } \\
\text { SOLVED } \\
\text { (UG/L } \\
\text { AS BA) } \\
(01005)\end{array}$ \\
\hline
\end{tabular}

$$
\text { OCI }
$$

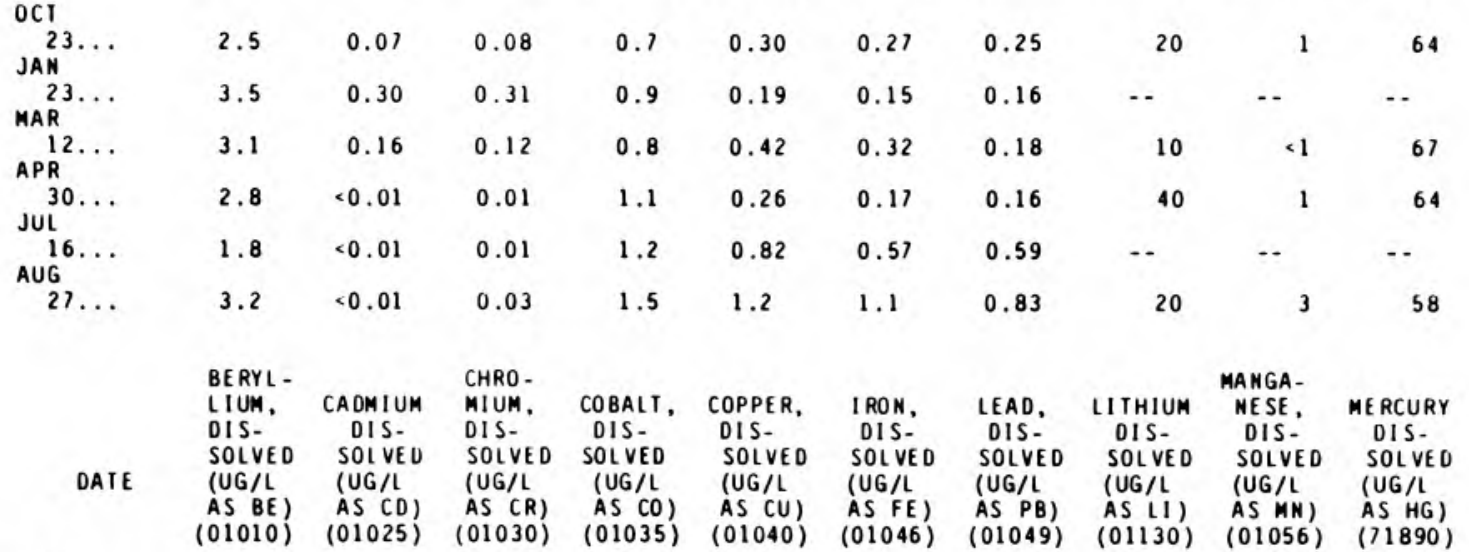

OCT

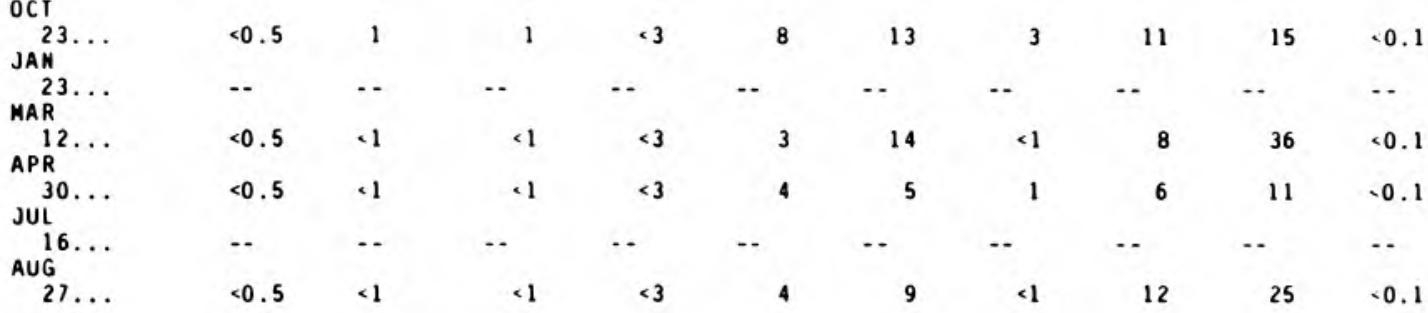

SIRON VANA- SEDI - SED.

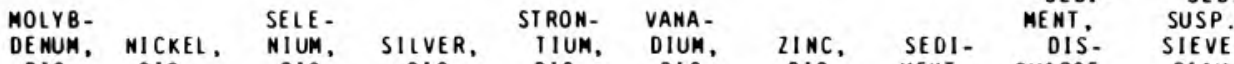

DIS- DIS- DIS: DIS- DIS- DIS- DIS- MENT, CHARGE, DIAM.

SOLVED SOLVED SOLVED SOLVED SOIVED SOLVED SOLVED SUS-

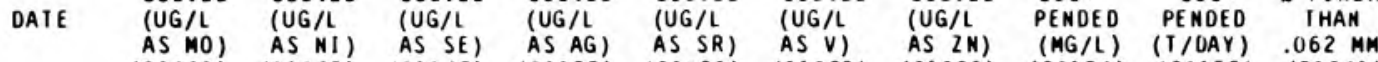

$\begin{array}{llllllllll}(01060) & (01065) & (01145) & (01075) & (01080) & (01085) & (01090) & (80154) & (80155) & (70331)\end{array}$

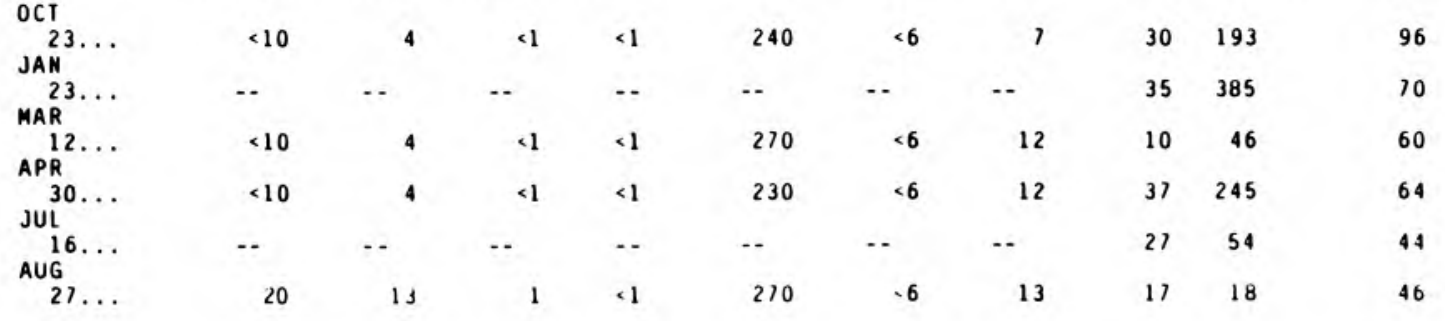




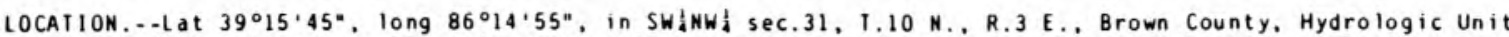

05120202 , on right bank $15 \mathrm{ft}$ downstream from bridge on State Highway $135,0.3$ mi south of Beanblossom, 2.7 mi upstrean from North Eork Beanblosson Creek, and at ile 42.1.

DRAINAGE AREA,$-14.6 \cdot i^{2}$

PERIOD OF RECORD.--October 1951 to current year. Prior to October 1965, published as Bean Blossoa Creek at Bean Blosson.

REVISED RECORDS, -.WSP 1555: 1952, $1953(\mathrm{M}), 1956-57$. WSP 1705: 1952(P), WDR IN-79-1: 1978,

GAGE - - Water-stage recorder. Datum of gage is $673.65 \mathrm{ft}$ above National Geodetic Vertical Datua of 1929.

REMARKS. - - Records good except for estimated daily discharges, which are fair.

DISCHARGE, CUBIC FEET PER SECOND, WATER YEAR OCTOBER 1990 TO SEPTEMBER 1991 DAILY MEAM VALUES

\begin{tabular}{|c|c|c|c|c|c|c|c|c|c|c|c|c|}
\hline DAY & $O C T$ & NOV & DEC & JAN & FEB & MAR & APR & MAY & JUN & JUL & AUG & SEP \\
\hline $\begin{array}{l}1 \\
2 \\
3 \\
4 \\
5\end{array}$ & $\begin{array}{r}.74 \\
.68 \\
11.82 \\
3.1\end{array}$ & $\begin{array}{r}.80 \\
.69 \\
.66 \\
.94 \\
2.2\end{array}$ & $\begin{array}{l}9.5 \\
7.4 \\
46 \\
23 \\
14\end{array}$ & $\begin{array}{r}40 \\
26 \\
18 \\
\text { e14 } \\
\text { e12 }\end{array}$ & $\begin{array}{l}10 \\
12 \\
14 \\
15 \\
27\end{array}$ & $\begin{array}{l}9.6 \\
14 \\
12 \\
10 \\
9.2\end{array}$ & $\begin{array}{l}14 \\
12 \\
10 \\
15 \\
24\end{array}$ & $\begin{array}{l}6.7 \\
5.5 \\
4.9 \\
5.0 \\
7.5\end{array}$ & $\begin{array}{l}3.9 \\
3.2 \\
2.4 \\
1.9 \\
1.4\end{array}$ & $\begin{array}{l}.17 \\
.16 \\
.18 \\
.19 \\
.37\end{array}$ & $\begin{array}{l}.00 \\
.00 \\
.04 \\
.11 \\
.07\end{array}$ & $\begin{array}{l}.00 \\
2.00 \\
27 \\
2.2\end{array}$ \\
\hline $\begin{array}{r}6 \\
7 \\
8 \\
9 \\
10\end{array}$ & $\begin{array}{r}1.8 \\
1.3 \\
1.2 \\
9.8 \\
29\end{array}$ & $\begin{array}{l}2.9 \\
1.9 \\
1.6 \\
1.7 \\
2.2\end{array}$ & $\begin{array}{l}10 \\
8.1 \\
6.8 \\
5.8 \\
5.2\end{array}$ & $\begin{array}{l}\text { e } 16 \\
18 \\
16 \\
14 \\
13\end{array}$ & $\begin{array}{r}211 \\
76 \\
40 \\
28 \\
21\end{array}$ & $\begin{array}{r}11 \\
11 \\
9.2 \\
8.5 \\
7.7\end{array}$ & $\begin{array}{l}18 \\
15 \\
14 \\
13 \\
11\end{array}$ & $\begin{array}{l}8.7 \\
6.1 \\
5.0 \\
5.5 \\
4.8\end{array}$ & $\begin{array}{r}1.1 \\
.98 \\
.86 \\
.74 \\
.73\end{array}$ & $\begin{array}{l}.21 \\
.13 \\
.11 \\
.13 \\
.56\end{array}$ & $\begin{array}{l}3.6 \\
1.4 \\
.36 \\
1.4 \\
.57\end{array}$ & $\begin{array}{l}.81 \\
.43 \\
.25 \\
.21 \\
.18\end{array}$ \\
\hline $\begin{array}{l}11 \\
12 \\
13 \\
14 \\
15\end{array}$ & $\begin{array}{r}10 \\
5.8 \\
4.0 \\
3.0 \\
2.2\end{array}$ & $\begin{array}{l}1.8 \\
1.6 \\
1.4 \\
1.4 \\
1.3\end{array}$ & $\begin{array}{r}4.7 \\
4.3 \\
3.9 \\
3.5 \\
19\end{array}$ & $\begin{array}{l}61 \\
53 \\
32 \\
23 \\
20\end{array}$ & $\begin{array}{r}16 \\
13 \\
16 \\
25 \\
\text { e18 }\end{array}$ & $\begin{array}{r}7.3 \\
11 \\
113 \\
49 \\
29\end{array}$ & $\begin{array}{l}9.6 \\
8.7 \\
48 \\
48 \\
42\end{array}$ & $\begin{array}{l}4.3 \\
5.9 \\
9.0 \\
6.9 \\
5.0\end{array}$ & $\begin{array}{c}.81 \\
1.3 \\
.80 \\
.59 \\
.81\end{array}$ & $\begin{array}{r}11^{.42} \\
1.7 \\
.65 \\
.42\end{array}$ & $\begin{array}{l}.21 \\
.16 \\
.15 \\
.15 \\
.13\end{array}$ & $\begin{array}{l}.18 \\
.13 \\
.11 \\
.10 \\
.09\end{array}$ \\
\hline $\begin{array}{l}16 \\
17 \\
18 \\
19 \\
20\end{array}$ & $\begin{array}{l}1.8 \\
1.6 \\
4.1 \\
2.8 \\
2.3\end{array}$ & $\begin{array}{l}1.1 \\
1.1 \\
.93 \\
.88 \\
.88\end{array}$ & $\begin{array}{r}13 \\
78 \\
274 \\
82 \\
36\end{array}$ & $\begin{array}{l}30 \\
28 \\
22 \\
18 \\
16\end{array}$ & $\begin{array}{r}\text { e1 } 5 \\
\text { e1 } 3 \\
44 \\
53 \\
45\end{array}$ & $\begin{array}{l}21 \\
66 \\
82 \\
42 \\
29\end{array}$ & $\begin{array}{r}30 \\
22 \\
17 \\
137 \\
58\end{array}$ & $\begin{array}{l}4.4 \\
4.5 \\
51 \\
20 \\
11\end{array}$ & $\begin{array}{l}3.3 \\
1.7 \\
1.4 \\
.62 \\
.50\end{array}$ & $\begin{array}{l}.30 \\
.23 \\
.19 \\
.17 \\
.17\end{array}$ & $\begin{array}{l}.14 \\
.13 \\
.15 \\
.17 \\
.15\end{array}$ & $\begin{array}{l}.08 \\
.15 \\
.15 \\
.12 \\
.09\end{array}$ \\
\hline $\begin{array}{l}21 \\
22 \\
23 \\
24 \\
25\end{array}$ & $\begin{array}{l}2.0 \\
2.6 \\
2.6 \\
2.1 \\
1.9\end{array}$ & $\begin{array}{l}.88 \\
4.3 \\
4.4 \\
3.2 \\
2.7\end{array}$ & $\begin{array}{r}50 \\
65 \\
39 \\
\text { e21 } \\
\text { e15 }\end{array}$ & $\begin{array}{r}13 \\
\mathrm{e} 10 \\
\mathrm{e} 9.0 \\
\mathrm{e} 8.0 \\
\mathrm{e} 7.2\end{array}$ & $\begin{array}{l}30 \\
22 \\
17 \\
15 \\
12\end{array}$ & $\begin{array}{r}23 \\
252 \\
140 \\
49 \\
32\end{array}$ & $\begin{array}{l}36 \\
26 \\
20 \\
17 \\
14\end{array}$ & $\begin{array}{l}8.0 \\
6.5 \\
17 \\
18 \\
22\end{array}$ & $\begin{array}{l}.48 \\
.45 \\
.41 \\
.31 \\
.27\end{array}$ & $\begin{array}{l}.15 \\
.14 \\
.10 \\
.10 \\
.09\end{array}$ & $\begin{array}{l}.11 \\
.10 \\
.09 \\
.07 \\
.04\end{array}$ & $\begin{array}{l}.09 \\
.13 \\
.18 \\
.16 \\
.14\end{array}$ \\
\hline $\begin{array}{l}26 \\
27 \\
28 \\
29 \\
30 \\
31\end{array}$ & $\begin{array}{l}1.8 \\
1.6 \\
1.3 \\
1.0 \\
.96 \\
.88\end{array}$ & $\begin{array}{l}2.4 \\
23 \\
82 \\
24 \\
13 \\
\ldots\end{array}$ & $\begin{array}{c}\text { el1 } \\
\text { e10 } \\
\text { e9.8 } \\
190 \\
850 \\
92\end{array}$ & $\begin{array}{l}\text { e6.8 } \\
\text { e6.6 } \\
\text { e7.0 } \\
7.4 \\
14 \\
11\end{array}$ & $\begin{array}{c}11 \\
9.8 \\
8.9 \\
\ldots . \\
\ldots . \\
\ldots\end{array}$ & $\begin{array}{r}217 \\
75 \\
41 \\
29 \\
21 \\
17\end{array}$ & $\begin{array}{r}12 \\
11 \\
10 \\
9.5 \\
7.7 \\
\ldots\end{array}$ & $\begin{array}{l}34 \\
22 \\
13 \\
8.8 \\
7.0 \\
5.0\end{array}$ & $\begin{array}{l}.25 \\
.23 \\
.19 \\
.19 \\
.18 \\
\cdots\end{array}$ & $\begin{array}{l}.06 \\
.03 \\
.00 \\
.00 \\
.00 \\
.00\end{array}$ & $\begin{array}{l}.01 \\
.00 \\
.00 \\
.00 \\
.00 \\
.00\end{array}$ & $\begin{array}{l}.12 \\
.10 \\
.09 \\
.09 \\
.08 \\
\cdots\end{array}$ \\
\hline $\begin{array}{l}\text { TOIAL } \\
\text { MEAN } \\
\text { MAX } \\
\text { MIN } \\
\text { CF SM } \\
\text { IN. }\end{array}$ & $\begin{array}{r}115.78 \\
3.73 \\
29 \\
.68 \\
.26 \\
.30\end{array}$ & $\begin{array}{r}187.86 \\
6.26 \\
82 \\
.66 \\
.43 \\
.48\end{array}$ & $\begin{array}{r}2007.0 \\
64.7 \\
850 \\
3.5 \\
4.43 \\
5.11\end{array}$ & $\begin{array}{r}590.0 \\
19.0 \\
61 \\
6.6 \\
1.30 \\
1.50\end{array}$ & $\begin{array}{r}837.7 \\
29.9 \\
211 \\
8.9 \\
2.05 \\
2.13\end{array}$ & $\begin{array}{r}1447.5 \\
46.7 \\
252 \\
7.3 \\
3.20 \\
3.69\end{array}$ & $\begin{array}{c}729.5 \\
24.3 \\
137 \\
7.7 \\
1.67 \\
1.86\end{array}$ & $\begin{array}{c}343.0 \\
11.1 \\
51 \\
4.3 \\
.76 \\
.87\end{array}$ & $\begin{array}{c}32.00 \\
1.07 \\
3.9 \\
.18 \\
.07 \\
.08\end{array}$ & $\begin{array}{c}18.13 \\
.58 \\
11 \\
.00 \\
.04 \\
.05\end{array}$ & $\begin{array}{l}9.51 \\
.31 \\
3.6 \\
.00 \\
.02 \\
.02\end{array}$ & $\begin{array}{c}36.16 \\
1.21 \\
27 \\
.00 \\
.08 \\
.09\end{array}$ \\
\hline
\end{tabular}

e Estinated

STATISIICS OF MONTHLY MEAN DAIA FUR WAIER YEARS 1952 - 1991, BY WATER YEAR (WY)

\begin{tabular}{|c|c|c|c|c|c|c|c|c|c|}
\hline $\begin{array}{l}\text { MEAN } \\
\text { MAX } \\
\text { (WY) } \\
\text { MIN } \\
(W Y)\end{array}$ & $\begin{array}{l}1.42 \\
8.03 \\
1987 \\
.000\end{array}$ & $\begin{array}{l}9.92 \\
56.0 \\
1986 \\
.000 \\
1954\end{array}$ & $\begin{array}{r}22.0 \\
115 \\
1952 \\
026\end{array}$ & $\begin{array}{r}19.2 \\
73.3 \\
1969 \\
16\end{array}$ & $\begin{array}{l}27.1 \\
66.6 \\
1971 \\
2.06\end{array}$ & $\begin{array}{l}34.9 \\
80.9 \\
1963 \\
7.55 \\
1954\end{array}$ & $\begin{array}{l}32.8 \\
77.8 \\
1972 \\
5.65 \\
1976\end{array}$ & $\begin{array}{l}26.2 \\
90.6 \\
1981 \\
1.23\end{array}$ & \\
\hline
\end{tabular}

SUMMARY SIATISIICS

ANNUAL TOTAL

ANMUAL MEAM

HIGHESI ANMUAL MEAN

LOWEST ANNUAL MEAN

HIGHEST DAILY MEAM

LOWEST DAILY MEAN

ANMUAL SEVEN-DAY MINIMUM

INSTANTANEOUS PEAK FLOW

INSIANTANEOUS PEAK STAGE

ANNUAL RUNOFF (CFSM)

ANNUAL RUNOFF (INCHES)

10 PERCEMT EXCEEDS

50 PERCENT EXCEEDS

90 PERCENT EXCEEDS
FOR 1990 CALENDAR YEAR

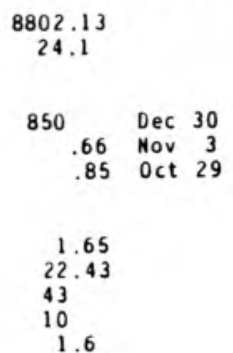

FOR 1991 WATER YEAR

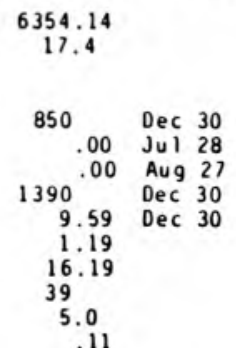

WATER YEARS 1952 - 1991

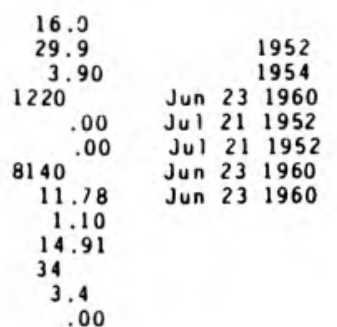




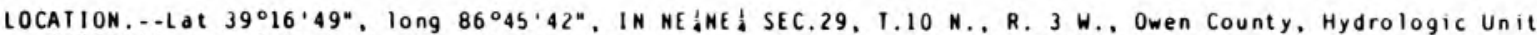
05120202 , on right bank at downstreda side of county rodd bridge at the south edge of Spencer, 3.3 a $i$ strean frov McBrides Creek, and at aile 165.9.

DRAINAGE AREA. $-2,980 \mathrm{i}^{2}$.

PERIOD OF RECORD.--July 1925 to September 1971 (discharge). October 1971 to current year (gage heights only).

GAGE.--Data-Collection Platfora. Datun of gage is $526.04 \mathrm{ft}$ above National Geodetic Vertical Datun of 1929 . Prior to Dec. 26, 1940, nonrecording gage at same site and datum.

REMARKS. - - Records good.

EXIREMES FOR PERIOD OF RECORD. - Maximum gage height, $23.99 \mathrm{ft}$ Jan. 1, 1991; minimum gage height, 0.88 ft Sept. 25, 30, and $0 \mathrm{ct}, 1,1941$.

EXIREMES OUTSIDE PERIOD OF RECORD. - Maximum stage known, $28.5 \mathrm{ft}$ Mar. 26, 1913, from flood aarks.

EXIREMES FOR CURRENT YEAR. -.Maxiaum gage height, $23.99 \mathrm{ft}$ Jan. 1; inimugage height, $2.23 \mathrm{ft}$ Sept. 30 .

GAGE HEIGHT, FEET, WAIER YEAR OCTOBER 1990 TO SEPTEMBER 1991 DAILY OBSERVATION AT 24:00 VALUES

\begin{tabular}{|c|c|c|c|c|c|c|c|c|c|c|c|c|}
\hline DAY & $\mathrm{OCI}$ & NOV & $D E C$ & JAN & FEB & MAR & $A P R$ & MAY & JUN & JUL & AUG & SEP \\
\hline $\begin{array}{l}1 \\
2 \\
3 \\
4 \\
5\end{array}$ & $\begin{array}{l}3.48 \\
3.50 \\
3.71 \\
6.44 \\
6.23\end{array}$ & $\begin{array}{l}4.21 \\
4.16 \\
4.08 \\
4.03 \\
4.23\end{array}$ & $\begin{array}{r}9.57 \\
8.10 \\
9.60 \\
13.35 \\
13.24\end{array}$ & $\begin{array}{l}23.43 \\
22.76 \\
22.06 \\
20.11 \\
14.93\end{array}$ & $\begin{array}{l}6.41 \\
6.57 \\
6.78 \\
6.96 \\
8.02\end{array}$ & $\begin{array}{l}6.57 \\
6.82 \\
6.69 \\
6.51 \\
6.23\end{array}$ & $\begin{array}{l}8.80 \\
8.23 \\
7.77 \\
7.61 \\
8.00\end{array}$ & $\begin{array}{l}6.25 \\
6.11 \\
5.86 \\
5.84 \\
5.94\end{array}$ & $\begin{array}{l}6.15 \\
9.08 \\
9.61 \\
8.10 \\
6.81\end{array}$ & $\begin{array}{l}3.36 \\
3.37 \\
3.27 \\
3.30 \\
3.23\end{array}$ & $\begin{array}{l}2.59 \\
2.57 \\
2.54 \\
2.53 \\
2.51\end{array}$ & $\begin{array}{l}2.50 \\
2.39 \\
2.43 \\
2.52 \\
2.63\end{array}$ \\
\hline $\begin{array}{r}6 \\
7 \\
8 \\
9 \\
10\end{array}$ & $\begin{array}{l}6.99 \\
6.38 \\
6.50 \\
5.86 \\
8.93\end{array}$ & $\begin{array}{l}5.14 \\
4.95 \\
5.00 \\
4.77 \\
4.57\end{array}$ & $\begin{array}{r}11.94 \\
9.38 \\
8.13 \\
7.37 \\
6.18\end{array}$ & $\begin{array}{r}11.73 \\
10.62 \\
9.61 \\
8.97 \\
8.51\end{array}$ & $\begin{array}{l}13.32 \\
15.93 \\
15.61 \\
14.08 \\
11.23\end{array}$ & $\begin{array}{l}6.23 \\
6.09 \\
5.91 \\
5.71 \\
5.65\end{array}$ & $\begin{array}{l}7.73 \\
7.44 \\
7.34 \\
8.25 \\
7.81\end{array}$ & $\begin{array}{l}6.27 \\
5.99 \\
5.61 \\
5.41 \\
5.26\end{array}$ & $\begin{array}{l}5.93 \\
5.38 \\
4.99 \\
4.73 \\
4.54\end{array}$ & $\begin{array}{l}3.28 \\
3.15 \\
3.06 \\
3.03 \\
4.10\end{array}$ & $\begin{array}{l}2.92 \\
3.76 \\
3.11 \\
3.04 \\
2.98\end{array}$ & $\begin{array}{l}2.50 \\
2.45 \\
2.40 \\
2.35 \\
2.32\end{array}$ \\
\hline $\begin{array}{l}11 \\
12 \\
13 \\
14 \\
15\end{array}$ & $\begin{array}{r}11.25 \\
11.87 \\
10.82 \\
8.70 \\
7.24\end{array}$ & $\begin{array}{l}4.41 \\
4.28 \\
4.18 \\
4.10 \\
3.99\end{array}$ & $\begin{array}{l}6.42 \\
6.13 \\
5.91 \\
5.66 \\
6.62\end{array}$ & $\begin{array}{r}9.27 \\
11.49 \\
11.09 \\
10.57 \\
9.62\end{array}$ & $\begin{array}{l}9.75 \\
8.79 \\
8.34 \\
8.60 \\
8.12\end{array}$ & $\begin{array}{r}5.50 \\
5.75 \\
13.35 \\
16.45 \\
16.67\end{array}$ & $\begin{array}{r}7.25 \\
6.86 \\
7.78 \\
10.30 \\
12.15\end{array}$ & $\begin{array}{l}5.20 \\
5.24 \\
5.18 \\
5.12 \\
5.82\end{array}$ & $\begin{array}{l}4.41 \\
4.35 \\
4.25 \\
4.13 \\
4.06\end{array}$ & $\begin{array}{l}4.58 \\
4.47 \\
4.20 \\
3.64 \\
3.41\end{array}$ & $\begin{array}{l}2.82 \\
2.72 \\
2.65 \\
2.60 \\
2.62\end{array}$ & $\begin{array}{l}2.30 \\
2.28 \\
2.25 \\
2.87 \\
2.57\end{array}$ \\
\hline $\begin{array}{l}16 \\
17 \\
18 \\
19 \\
20\end{array}$ & $\begin{array}{l}6.48 \\
5.99 \\
5.79 \\
5.80 \\
6.18\end{array}$ & $\begin{array}{l}3.92 \\
3.92 \\
3.89 \\
3.82 \\
3.82\end{array}$ & $\begin{array}{r}8.65 \\
10.87 \\
14.14 \\
15.41 \\
15.11\end{array}$ & $\begin{array}{r}10.43 \\
11.50 \\
12.09 \\
11.14 \\
9.17\end{array}$ & $\begin{array}{r}7.53 \\
7.26 \\
8.21 \\
10.71 \\
11.17\end{array}$ & $\begin{array}{l}14.29 \\
13.82 \\
15.45 \\
15.97 \\
15.25\end{array}$ & $\begin{array}{l}13.66 \\
12.47 \\
10.31 \\
11.72 \\
14.09\end{array}$ & $\begin{array}{l}5.41 \\
6.23 \\
6.52 \\
8.16 \\
8.26\end{array}$ & $\begin{array}{l}4.14 \\
4.69 \\
4.26 \\
4.10 \\
3.91\end{array}$ & $\begin{array}{l}3.28 \\
3.15 \\
3.02 \\
2.94 \\
2.88\end{array}$ & $\begin{array}{l}2.63 \\
2.57 \\
2.65 \\
2.75 \\
2.91\end{array}$ & $\begin{array}{l}2.43 \\
2.38 \\
2.35 \\
2.29 \\
2.28\end{array}$ \\
\hline $\begin{array}{l}21 \\
22 \\
23 \\
24 \\
25\end{array}$ & $\begin{array}{l}6.01 \\
5.67 \\
5.61 \\
5.41 \\
5.26\end{array}$ & $\begin{array}{l}3.76 \\
4.09 \\
4.90 \\
4.55 \\
4.44\end{array}$ & $\begin{array}{l}15.05 \\
15.32 \\
15.30 \\
14.57 \\
11.56\end{array}$ & $\begin{array}{l}9.20 \\
8.65 \\
8.29 \\
7.76 \\
7.29\end{array}$ & $\begin{array}{r}11.25 \\
10.13 \\
8.97 \\
8.14 \\
7.55\end{array}$ & $\begin{array}{l}14.12 \\
15.97 \\
18.59 \\
18.26 \\
16.65\end{array}$ & $\begin{array}{r}12.93 \\
11.60 \\
9.85 \\
8.97 \\
8.23\end{array}$ & $\begin{array}{l}7.05 \\
6.20 \\
7.13 \\
7.28 \\
6.80\end{array}$ & $\begin{array}{l}3.74 \\
3.64 \\
3.54 \\
3.68 \\
4.44\end{array}$ & $\begin{array}{l}2.82 \\
2.80 \\
2.77 \\
2.79 \\
2.74\end{array}$ & $\begin{array}{l}2.77 \\
2.67 \\
2.74 \\
2.62 \\
2.52\end{array}$ & $\begin{array}{l}2.26 \\
2.27 \\
2.27 \\
2.65 \\
2.49\end{array}$ \\
\hline $\begin{array}{l}26 \\
27 \\
28 \\
29 \\
30 \\
31\end{array}$ & $\begin{array}{l}5.07 \\
4.84 \\
4.63 \\
4.49 \\
4.41 \\
4.30\end{array}$ & $\begin{array}{r}4.34 \\
5.39 \\
11.63 \\
12.59 \\
11.31 \\
. \ldots\end{array}$ & $\begin{array}{r}9.61 \\
8.59 \\
7.94 \\
12.90 \\
20.20 \\
23.76\end{array}$ & $\begin{array}{l}1.01 \\
6.75 \\
6.69 \\
6.57 \\
6.86 \\
6.58\end{array}$ & $\begin{array}{c}7.14 \\
6.87 \\
6.67 \\
\ldots \\
\ldots . \\
\ldots\end{array}$ & $\begin{array}{r}16.66 \\
17.37 \\
15.65 \\
13.76 \\
11.25 \\
9.66\end{array}$ & $\begin{array}{c}7.66 \\
7.30 \\
7.06 \\
6.85 \\
6.65 \\
\ldots\end{array}$ & $\begin{array}{l}6.21 \\
6.15 \\
5.76 \\
6.72 \\
5.83 \\
5.56\end{array}$ & $\begin{array}{r}4.24 \\
4.11 \\
3.78 \\
3.59 \\
3.45 \\
\ldots . .\end{array}$ & $\begin{array}{l}2.71 \\
2.67 \\
2.64 \\
2.64 \\
2.64 \\
2.60\end{array}$ & $\begin{array}{l}2.47 \\
2.41 \\
2.40 \\
2.39 \\
2.51 \\
2.47\end{array}$ & $\begin{array}{r}2.40 \\
2.37 \\
2.33 \\
2.27 \\
2.23 \\
\ldots\end{array}$ \\
\hline $\begin{array}{l}\text { MEAN } \\
\text { MAX } \\
\text { MI N }\end{array}$ & $\begin{array}{r}6.25 \\
11.87 \\
3.48\end{array}$ & $\begin{array}{r}5.08 \\
12.59 \\
3.76\end{array}$ & $\begin{array}{r}11.20 \\
23.76 \\
5.66\end{array}$ & $\begin{array}{r}11.01 \\
23.43 \\
6.57\end{array}$ & $\begin{array}{r}9.29 \\
15.93 \\
6.41\end{array}$ & $\begin{array}{r}11.70 \\
18.59 \\
5.50\end{array}$ & $\begin{array}{r}9.09 \\
14.09 \\
6.65\end{array}$ & $\begin{array}{l}6.14 \\
8.26 \\
5.12\end{array}$ & $\begin{array}{l}4.86 \\
9.61 \\
3.45\end{array}$ & $\begin{array}{l}3.18 \\
4.58 \\
2.60\end{array}$ & $\begin{array}{l}2.69 \\
3.76 \\
2.39\end{array}$ & $\begin{array}{l}2.40 \\
2.87 \\
2.23\end{array}$ \\
\hline
\end{tabular}




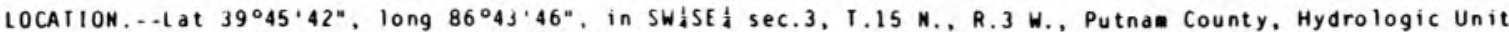

05120203 , on right upstrean wingwall of bridge on U.S. Highway $36,0.5$ west of Groveland, and 4.5 i east of

Bainbridge.

PERIOD OF RECORD...July 1969 to current yedr.

GAGE.- - Water-stage recorder. Datu of gage is $828.44 \mathrm{ft}$ above National Geodetic Vertical Datum of 1929 (Indiand Departeent of Highways bench nark).

REMARKS.--Records fair except for estimated daily discharges, which are poor.

DISCHARGE, CUBIC FEET PER SECOND, WATER YEAR OCTOBER 1990 TO SEPTEMBER 1991 DAIIY MEAM VALUES

\begin{tabular}{|c|c|c|c|c|c|c|c|c|c|c|c|c|}
\hline DAY & $O C T$ & NOV & DEC & JAN & FEB & MAR & $A P R$ & MAY & JUN & JUL & AUG & SEP \\
\hline $\begin{array}{l}1 \\
2 \\
3 \\
4 \\
5\end{array}$ & $\begin{array}{c}.13 \\
1.13 \\
14 \\
3.1\end{array}$ & $\begin{array}{l}.88 \\
.85 \\
.81 \\
.82 \\
5.2\end{array}$ & $\begin{array}{l}5.0 \\
4.3 \\
50 \\
11 \\
7.5\end{array}$ & $\begin{array}{r}8.5 \\
6.5 \\
5.0 \\
\mathrm{e} \\
\mathrm{e} .8 \\
\mathrm{e} 3.5\end{array}$ & $\begin{array}{l}1.7 \\
4.5 \\
5.3 \\
5.3 \\
8.8\end{array}$ & $\begin{array}{l}\text { e3. } 3 \\
\text { e4.4 } \\
\text { e } 4.0 \\
\text { e3.7 } \\
\text { e3.5 }\end{array}$ & $\begin{array}{l}4.3 \\
3.7 \\
3.3 \\
4.0 \\
4.0\end{array}$ & $\begin{array}{l}2.1 \\
1.6 \\
1.6 \\
2.1 \\
4.5\end{array}$ & $\begin{array}{l}1.2 \\
.75 \\
.53 \\
.40 \\
.32\end{array}$ & $\begin{array}{l}.05 \\
.05 \\
.05 \\
.05 \\
.05\end{array}$ & $\begin{array}{l}.00 \\
.00 \\
.00 \\
.00 \\
.00\end{array}$ & $\begin{array}{l}.00 \\
.00 \\
.00 \\
.00 \\
.00\end{array}$ \\
\hline $\begin{array}{r}6 \\
7 \\
8 \\
9 \\
10\end{array}$ & $\begin{array}{r}1.5 \\
4.1 \\
4.6 \\
12 \\
35\end{array}$ & $\begin{array}{l}3.5 \\
2.2 \\
1.7 \\
1.6 \\
1.4\end{array}$ & $\begin{array}{l}6.3 \\
5.2 \\
4.5 \\
3.7 \\
3.2\end{array}$ & $\begin{array}{r}\text { e } 3.2 \\
\text { e } 2.9 \\
\text { e2.7 } \\
2.5 \\
2.4\end{array}$ & $\begin{array}{r}17 \\
12 \\
8.2 \\
6.8 \\
5.7\end{array}$ & $\begin{array}{l}\text { e3.3 } \\
\text { e3.4 } \\
\text { e } 3.3 \\
\text { e } 3.1 \\
\text { e } 3.0\end{array}$ & $\begin{array}{l}3.2 \\
2.8 \\
4.4 \\
4.8 \\
3.3\end{array}$ & $\begin{array}{l}3.3 \\
2.0 \\
1.5 \\
1.3 \\
1.2\end{array}$ & $\begin{array}{l}.27 \\
.24 \\
.22 \\
.20 \\
.18\end{array}$ & $\begin{array}{l}.04 \\
.04 \\
.04 \\
.03 \\
.08\end{array}$ & $\begin{array}{l}.01 \\
.00 \\
.01 \\
.00 \\
.00\end{array}$ & $\begin{array}{l}.00 \\
.00 \\
.00 \\
.00 \\
.00\end{array}$ \\
\hline $\begin{array}{l}11 \\
12 \\
13 \\
14 \\
15\end{array}$ & $\begin{array}{l}8.6 \\
5.6 \\
4.5 \\
3.4 \\
2.3\end{array}$ & $\begin{array}{r}1.1 \\
1.0 \\
.91 \\
.87 \\
.90\end{array}$ & $\begin{array}{r}2.8 \\
2.5 \\
1.9 \\
1.6 \\
11\end{array}$ & $\begin{array}{r}13 \\
8.4 \\
5.6 \\
5.8 \\
7.8\end{array}$ & $\begin{array}{r}4.6 \\
3.9 \\
\mathrm{e} 4.3 \\
\mathrm{e} 3.3 \\
\mathrm{e} 2.5\end{array}$ & $\begin{array}{l}3.7 \\
12 \\
46 \\
15 \\
11\end{array}$ & $\begin{array}{l}2.5 \\
2.3 \\
8.5 \\
14 \\
24\end{array}$ & $\begin{array}{l}1.1 \\
1.2 \\
1.0 \\
3.0 \\
1.9\end{array}$ & $\begin{array}{l}.17 \\
.17 \\
.13 \\
.11 \\
.11\end{array}$ & $\begin{array}{l}.04 \\
.04 \\
.02 \\
.02 \\
.01\end{array}$ & $\begin{array}{l}.00 \\
.00 \\
.00 \\
.00 \\
.00\end{array}$ & $\begin{array}{l}.00 \\
.00 \\
.00 \\
.00 \\
.00\end{array}$ \\
\hline $\begin{array}{l}16 \\
17 \\
18 \\
19 \\
20\end{array}$ & $\begin{array}{l}1.9 \\
1.8 \\
7.3 \\
3.9 \\
2.8\end{array}$ & $\begin{array}{l}.89 \\
.78 \\
.77 \\
.76 \\
.69\end{array}$ & $\begin{array}{c}6.7 \\
8.9 \\
24 \\
13 \\
8.8\end{array}$ & $\begin{array}{l}15 \\
10 \\
7.1 \\
\text { e5.6 } \\
\text { e4.5 }\end{array}$ & $\begin{array}{l}\text { e2.4 } \\
\mathrm{e} 2.3 \\
10 \\
17 \\
9.6\end{array}$ & $\begin{array}{l}9.2 \\
16 \\
16 \\
11 \\
9.7\end{array}$ & $\begin{array}{l}9.5 \\
7.0 \\
5.7 \\
8.0 \\
6.4\end{array}$ & $\begin{array}{c}2.5 \\
1.8 \\
1.4 \\
1.0 \\
.88\end{array}$ & $\begin{array}{l}.22 \\
.14 \\
.10 \\
.09 \\
.08\end{array}$ & $\begin{array}{l}.01 \\
.01 \\
.01 \\
.01 \\
.00\end{array}$ & $\begin{array}{l}.00 \\
.00 \\
.00 \\
.00 \\
.00\end{array}$ & $\begin{array}{l}.00 \\
.00 \\
.00 \\
.00 \\
.00\end{array}$ \\
\hline $\begin{array}{l}21 \\
22 \\
23 \\
24 \\
25\end{array}$ & $\begin{array}{l}2.3 \\
2.5 \\
2.1 \\
1.8 \\
1.5\end{array}$ & $\begin{array}{l}.69 \\
2.5 \\
1.6 \\
1.2 \\
1.0\end{array}$ & $\begin{array}{r}32 \\
14 \\
8.3 \\
\text { e6.0 } \\
\text { e4.8 }\end{array}$ & $\begin{array}{l}\text { e } 3.8 \\
\text { e } 3.2 \\
\text { e2. } 2 \\
\text { e2.5 } \\
\text { e2.3 }\end{array}$ & $\begin{array}{r}7.3 \\
5.8 \\
4.8 \\
\mathrm{e} 4.4 \\
\mathrm{e} 4.1\end{array}$ & $\begin{array}{l}8.8 \\
46 \\
23 \\
13 \\
10\end{array}$ & $\begin{array}{l}5.6 \\
4.9 \\
4.3 \\
3.4 \\
2.9\end{array}$ & $\begin{array}{l}.73 \\
.64 \\
.59 \\
.58 \\
.57\end{array}$ & $\begin{array}{l}.08 \\
.08 \\
.08 \\
.08 \\
.07\end{array}$ & $\begin{array}{l}.00 \\
.00 \\
.00 \\
.00 \\
.00\end{array}$ & $\begin{array}{l}.00 \\
.00 \\
.00 \\
.00 \\
.00\end{array}$ & $\begin{array}{l}.00 \\
.00 \\
.00 \\
.00 \\
.00\end{array}$ \\
\hline $\begin{array}{l}26 \\
27 \\
28 \\
29 \\
30 \\
31\end{array}$ & $\begin{array}{l}1.3 \\
1.2 \\
1.1 \\
.99 \\
.98 \\
.94\end{array}$ & $\begin{array}{c}9.90 \\
9.8 \\
52 \\
9.3 \\
6.2 \\
-.-\end{array}$ & $\begin{array}{c}\text { e4.0 } \\
\text { e3.3 } \\
\text { e2.9 } \\
149 \\
149 \\
14\end{array}$ & $\begin{array}{l}\text { e2.1 } \\
\text { e1.9 } \\
\text { e1.7 } \\
\text { e1.6 } \\
\text { e1.5 } \\
1.4\end{array}$ & $\begin{array}{r}\text { e3.8 } \\
\text { e } 3.6 \\
\text { e3.5 } \\
\ldots . \\
\ldots \\
\ldots\end{array}$ & $\begin{array}{c}37 \\
13 \\
8.3 \\
6.8 \\
5.4 \\
5.0\end{array}$ & $\begin{array}{l}2.9 \\
2.9 \\
2.6 \\
2.9 \\
2.0 \\
\ldots .\end{array}$ & $\begin{array}{l}.62 \\
.48 \\
.40 \\
4.6 \\
8.7 \\
3.2\end{array}$ & $\begin{array}{l}.07 \\
.07 \\
.06 \\
.06 \\
.06 \\
\cdots\end{array}$ & $\begin{array}{l}.00 \\
.00 \\
.00 \\
.00 \\
.00 \\
.00\end{array}$ & $\begin{array}{l}.00 \\
.00 \\
.00 \\
.00 \\
.00 \\
.00\end{array}$ & $\begin{array}{l}.00 \\
.00 \\
.00 \\
.00 \\
.00 \\
. .-\end{array}$ \\
\hline $\begin{array}{l}\text { IOIAL } \\
\text { MEAN } \\
\text { MAX } \\
\text { MIN } \\
\text { CF SM } \\
\text { IN. }\end{array}$ & $\begin{array}{r}135.07 \\
4.36 \\
35 \\
.13 \\
1.45 \\
1.67\end{array}$ & $\begin{array}{r}112.82 \\
3.76 \\
52 \\
.69 \\
1.25 \\
1.40\end{array}$ & $\begin{array}{r}569.2 \\
18.4 \\
149 \\
1.6 \\
6.12 \\
7.06\end{array}$ & $\begin{array}{r}148.6 \\
4.79 \\
15 \\
1.4 \\
1.60 \\
1.84\end{array}$ & $\begin{array}{r}172.5 \\
6.16 \\
17 \\
1.7 \\
2.05 \\
2.14\end{array}$ & $\begin{array}{r}360.9 \\
11.6 \\
46 \\
3.0 \\
3.88 \\
4.48\end{array}$ & $\begin{array}{c}160.1 \\
5.34 \\
24 \\
2.0 \\
1.78 \\
1.99\end{array}$ & $\begin{array}{c}58.09 \\
1.87 \\
8.7 \\
.40 \\
.62 \\
.72\end{array}$ & $\begin{array}{l}6.34 \\
.21 \\
1.2 \\
.06 \\
.07 \\
.08\end{array}$ & $\begin{array}{l}0.65 \\
.021 \\
.08 \\
.00 \\
.01 \\
.01\end{array}$ & $\begin{array}{l}0.02 \\
.001 \\
.01 \\
.00 \\
.00 \\
.00\end{array}$ & $\begin{array}{l}0.00 \\
.000 \\
.00 \\
.00 \\
.00 \\
.00\end{array}$ \\
\hline
\end{tabular}

e Estinated

STATISTICS OF MONTHLY MEAN DATA FOR WAIER YEARS 1969 - 1991, BY WATER YEAR (WY)

\begin{tabular}{|c|c|c|c|c|c|c|c|c|c|c|c|c|}
\hline $\begin{array}{l}\text { MEAN } \\
\text { MAX } \\
(W Y) \\
\text { MI N } \\
(W Y)\end{array}$ & $\begin{array}{l}1.29 \\
5.80 \\
1987 \\
.000 \\
1989\end{array}$ & $\begin{array}{l}3.62 \\
20.6 \\
1986 \\
019 \\
1977\end{array}$ & $\begin{array}{l}5.74 \\
18.3 \\
1991 \\
1011 \\
1977\end{array}$ & $\begin{array}{l}3.53 \\
13.5 \\
1914 \\
000 \\
1977\end{array}$ & $\begin{array}{r}6.36 \\
17.1 \\
1971 \\
.76 \\
1978\end{array}$ & $\begin{array}{l}7.27 \\
19.1 \\
1978 \\
1.46 \\
1981\end{array}$ & $\begin{array}{r}5.12 \\
9.71 \\
1970 \\
.92 \\
1971\end{array}$ & $\begin{array}{r}4.05 \\
16.1 \\
1981 \\
.14 \\
1976\end{array}$ & $\begin{array}{l}2.00 \\
6.53 \\
1973 \\
.007 \\
1988\end{array}$ & $\begin{array}{l}2.49 \\
12.9 \\
1979 \\
.019 \\
1988\end{array}$ & $\begin{array}{l}1.44 \\
7.90 \\
1979 \\
.001 \\
1991\end{array}$ & $\begin{array}{r}.95 \\
12.8 \\
1989 \\
1000 \\
1988\end{array}$ \\
\hline
\end{tabular}

SUMMARY STAIISTICS

ANNUAL TOTAL

ANNUAL MEAN

HI GHEST ANNUAL MEAM

LOWEST ANNUAL MEAN

HIGHEST DAILY MEAN

LOWEST DAILY MEAM

ANNUAL SEVEM-DAY MINIMUM

INSTANTANEOUS PEAK FLOW

INSTAMTANEOUS PEAK SIAGE

ANMUAL RUNOFF (CFSN)

ANMUAL RUNOFF (INCHES)

10 PERCENT EXCEEDS

SO PERCENT EXCEEDS

90 PERCENT EXCEEDS
FOR 1990 CALENDAR YEAR

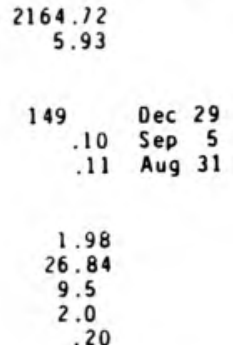

FOR 1991 WATER YEAR

$$
\begin{array}{r}
1724.29 \\
4.72
\end{array}
$$

149 Dec 29

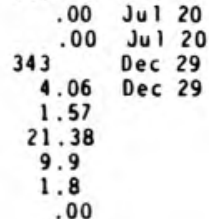

WAIER YEARS $1969-1991$

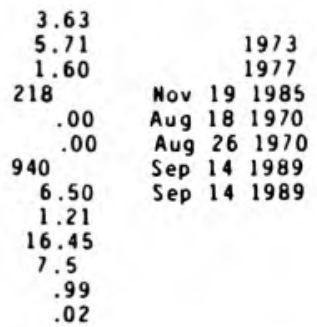




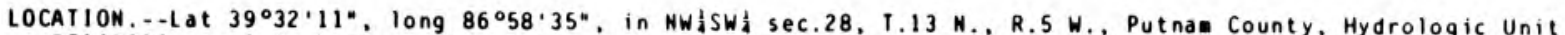
05120203 , on left bank at downstrean side of county highway bridge. 1.5 a southwest of Reelsuille, and 4 . 1 in upstrea from Mill Creek.

DRAI MAGE AREA $--326 \cdot i^{2}$

PERIOD OF RECORD.--July 1949 to current yedr. Published as Eel River near Reelsville, 0ctober 1952 to September 1956.

REVISED RECORDS.-.WSP 1335: 1950. WSP 2109: Drainage area.

GAGE.--Water-stage recorder. Datu of gage is $588.24 \mathrm{ft}$ above National Geodetic Vertical Datue of 1929 (levels by State of Indiana. Departaent of Natural Resurces). Prior to Dec. 10, 1949, nonrecording gage at same site and datur.

REMARKS.--Records good except for estindted daily discharges, which are fair. Flow partly regulated by Soil Conservation Service control structures on tributaries to Little Walnut Creek beginning in 1971 .

DISCHARGE, CUBIC FEE PER SECONO, WATER YEAR OCTOBER 1990 TO SEPIEMBER 1991 DAILY MEAM VALUES

\begin{tabular}{|c|c|c|c|c|c|c|c|c|c|c|c|c|}
\hline DAY & $\mathrm{OCT}$ & NOV & DEC & JAN & FEB & MAR & APR & MAY & JUN & JUL & $A \cup G$ & SEP \\
\hline $\begin{array}{l}1 \\
2 \\
3 \\
4 \\
5\end{array}$ & $\begin{array}{r}32 \\
30 \\
35 \\
764 \\
391\end{array}$ & $\begin{array}{r}106 \\
101 \\
97 \\
93 \\
254\end{array}$ & $\begin{array}{r}100 \\
538 \\
2280 \\
1980 \\
1060\end{array}$ & $\begin{array}{r}2810 \\
1870 \\
1370 \\
962 \\
830\end{array}$ & $\begin{array}{r}\text { e280 } \\
322 \\
385 \\
440 \\
660\end{array}$ & $\begin{array}{l}322 \\
449 \\
452 \\
390 \\
350\end{array}$ & $\begin{array}{l}452 \\
395 \\
353 \\
341 \\
418\end{array}$ & $\begin{array}{l}234 \\
227 \\
212 \\
209 \\
222\end{array}$ & $\begin{array}{l}163 \\
137 \\
117 \\
100 \\
88\end{array}$ & $\begin{array}{l}29 \\
28 \\
27 \\
27 \\
45\end{array}$ & $\begin{array}{l}12 \\
12 \\
11 \\
11 \\
11\end{array}$ & $\begin{array}{l}7.1 \\
7.1 \\
6.1 \\
13 \\
11\end{array}$ \\
\hline $\begin{array}{r}6 \\
7 \\
8 \\
9 \\
10\end{array}$ & $\begin{array}{r}196 \\
282 \\
432 \\
557 \\
2060\end{array}$ & $\begin{array}{l}447 \\
309 \\
231 \\
197 \\
179\end{array}$ & $\begin{array}{l}714 \\
611 \\
496 \\
422 \\
373\end{array}$ & $\begin{array}{l}765 \\
679 \\
618 \\
574 \\
i 32\end{array}$ & $\begin{array}{r}986 \\
1380 \\
1010 \\
774 \\
651\end{array}$ & $\begin{array}{l}333 \\
321 \\
289 \\
212 \\
261\end{array}$ & $\begin{array}{l}358 \\
317 \\
465 \\
572 \\
417\end{array}$ & $\begin{array}{l}272 \\
238 \\
211 \\
193 \\
182\end{array}$ & $\begin{array}{l}18 \\
71 \\
67 \\
65 \\
61\end{array}$ & $\begin{array}{r}28 \\
24 \\
23 \\
22 \\
304\end{array}$ & $\begin{array}{l}27 \\
27 \\
19 \\
18 \\
17\end{array}$ & $\begin{array}{l}7.8 \\
6.6 \\
5.9 \\
5.8 \\
5.6\end{array}$ \\
\hline $\begin{array}{l}11 \\
12 \\
13 \\
14 \\
15\end{array}$ & $\begin{array}{r}1500 \\
875 \\
590 \\
414 \\
309\end{array}$ & $\begin{array}{l}159 \\
142 \\
128 \\
119 \\
113\end{array}$ & $\begin{array}{l}337 \\
311 \\
288 \\
261 \\
577\end{array}$ & $\begin{array}{r}707 \\
1160 \\
842 \\
697 \\
726\end{array}$ & $\begin{array}{l}549 \\
465 \\
437 \\
460 \\
414\end{array}$ & $\begin{array}{r}254 \\
289 \\
2240 \\
2020 \\
1170\end{array}$ & $\begin{array}{r}330 \\
291 \\
720 \\
1310 \\
1880\end{array}$ & $\begin{array}{l}173 \\
175 \\
175 \\
169 \\
199\end{array}$ & $\begin{array}{l}59 \\
60 \\
57 \\
53 \\
46\end{array}$ & $\begin{array}{r}125 \\
83 \\
57 \\
45 \\
38\end{array}$ & $\begin{array}{l}15 \\
14 \\
13 \\
12 \\
11\end{array}$ & $\begin{array}{l}5.3 \\
5.0 \\
5.0 \\
5.0 \\
5.0\end{array}$ \\
\hline $\begin{array}{l}16 \\
17 \\
18 \\
19 \\
20\end{array}$ & $\begin{array}{l}246 \\
213 \\
482 \\
459 \\
327\end{array}$ & $\begin{array}{r}110 \\
105 \\
101 \\
98 \\
95\end{array}$ & $\begin{array}{l}790 \\
660 \\
1470 \\
1750 \\
1100\end{array}$ & $\begin{array}{r}1210 \\
1340 \\
972 \\
778 \\
\mathrm{e} 700\end{array}$ & $\begin{array}{r}347 \\
329 \\
490 \\
1240 \\
1220\end{array}$ & $\begin{array}{r}853 \\
821 \\
1470 \\
1080 \\
807\end{array}$ & $\begin{array}{r}1330 \\
851 \\
653 \\
587 \\
645\end{array}$ & $\begin{array}{l}172 \\
161 \\
160 \\
147 \\
142\end{array}$ & $\begin{array}{r}100 \\
78 \\
57 \\
48 \\
44\end{array}$ & $\begin{array}{l}34 \\
30 \\
28 \\
25 \\
24\end{array}$ & $\begin{array}{l}11 \\
10 \\
10 \\
12 \\
17\end{array}$ & $\begin{array}{l}4.5 \\
4.2 \\
4.2 \\
4.2 \\
4.0\end{array}$ \\
\hline $\begin{array}{l}21 \\
22 \\
23 \\
24 \\
25\end{array}$ & $\begin{array}{l}259 \\
240 \\
221 \\
198 \\
175\end{array}$ & $\begin{array}{r}91 \\
190 \\
210 \\
174 \\
149\end{array}$ & $\begin{array}{r}1750 \\
2410 \\
1350 \\
859 \\
634\end{array}$ & $\begin{array}{l}\text { e } 600 \\
\text { e } 520 \\
\text { e } 460 \\
\text { e } 410 \\
\text { e } 370\end{array}$ & $\begin{array}{l}851 \\
681 \\
551 \\
478 \\
426\end{array}$ & $\begin{array}{r}683 \\
2050 \\
2760 \\
1470 \\
1010\end{array}$ & $\begin{array}{l}532 \\
449 \\
392 \\
365 \\
314\end{array}$ & $\begin{array}{l}130 \\
122 \\
122 \\
128 \\
124\end{array}$ & $\begin{array}{l}42 \\
41 \\
39 \\
37 \\
36\end{array}$ & $\begin{array}{l}22 \\
21 \\
19 \\
18 \\
17\end{array}$ & $\begin{array}{r}12 \\
11 \\
9.8 \\
8.8 \\
8.2\end{array}$ & $\begin{array}{r}4.2 \\
4.6 \\
6.4 \\
\mathrm{e} 8.0 \\
\mathrm{e} 6.0\end{array}$ \\
\hline $\begin{array}{l}26 \\
27 \\
28 \\
29 \\
30 \\
.31\end{array}$ & $\begin{array}{l}157 \\
145 \\
132 \\
120 \\
116 \\
111\end{array}$ & $\begin{array}{r}133 \\
641 \\
3020 \\
1710 \\
954 \\
-\cdots\end{array}$ & $\begin{array}{r}\text { e } 500 \\
\text { e } 400 \\
\text { e } 350 \\
2960 \\
11800 \\
9870\end{array}$ & $\begin{array}{l}\text { e } 350 \\
\text { e330 } \\
\text { e } 320 \\
\text { e310 } \\
\text { e } 300 \\
\text { e2 } 90\end{array}$ & $\begin{array}{l}374 \\
354 \\
337 \\
\cdots \\
\cdots \\
\cdots\end{array}$ & $\begin{array}{r}1780 \\
1880 \\
1160 \\
813 \\
634 \\
515\end{array}$ & $\begin{array}{l}293 \\
278 \\
272 \\
262 \\
256 \\
\cdots\end{array}$ & $\begin{array}{l}123 \\
117 \\
104 \\
115 \\
200 \\
195\end{array}$ & $\begin{array}{c}35 \\
34 \\
33 \\
32 \\
31 \\
\cdots\end{array}$ & $\begin{array}{l}16 \\
15 \\
14 \\
15 \\
14 \\
13\end{array}$ & $\begin{array}{l}7.8 \\
7.5 \\
7.0 \\
6.6 \\
6.5 \\
6.8\end{array}$ & $\begin{array}{l}\text { e } 5.2 \\
\text { e } 4.8 \\
\text { e } 4.5 \\
\text { e } 4.4 \\
\text { e } 4.3 \\
\ldots . . .\end{array}$ \\
\hline $\begin{array}{l}\text { TOTAL } \\
\text { MEAN } \\
\text { MAX } \\
\text { MIN } \\
\text { CF SM } \\
\text { IN. }\end{array}$ & $\begin{array}{r}12068 \\
389 \\
2060 \\
30 \\
1.19 \\
1.38\end{array}$ & $\begin{array}{r}10456 \\
349 \\
3020 \\
91 \\
1.07 \\
1.19\end{array}$ & $\begin{array}{r}49661 \\
1602 \\
11800 \\
261 \\
4.91 \\
5.67\end{array}$ & $\begin{array}{r}24402 \\
787 \\
2810 \\
290 \\
2.41 \\
2.18\end{array}$ & $\begin{array}{r}16891 \\
603 \\
1380 \\
280 \\
1.85 \\
1.93\end{array}$ & $\begin{array}{r}29198 \\
942 \\
2760 \\
254 \\
2.89 \\
3.33\end{array}$ & $\begin{array}{r}16098 \\
537 \\
1880 \\
256 \\
1.65 \\
1.84\end{array}$ & $\begin{array}{c}5353 \\
173 \\
272 \\
104 \\
.53 \\
.61\end{array}$ & $\begin{array}{c}1909 \\
63.6 \\
163 \\
31 \\
.20 \\
.22\end{array}$ & $\begin{array}{c}1230 \\
39.7 \\
304 \\
13 \\
.12 \\
.14\end{array}$ & $\begin{array}{r}382.0 \\
12.3 \\
27 \\
6.5 \\
.04 \\
.04\end{array}$ & $\begin{array}{c}174.8 \\
5.83 \\
13 \\
4.0 \\
.02 \\
.02\end{array}$ \\
\hline
\end{tabular}

e Estinated

STAIISIICS OF MONIHLY MEAN DATA FOR WAIER YEARS 1950 - 1991, BY WAIER YEAR (WY)

$\begin{array}{lrrrrrrrrrrrr}\text { MEAN } & 101 & 236 & 434 & 463 & 549 & 668 & 590 & 449 & 308 & 221 & 126 & 109 \\ \text { MAX } & 642 & 1655 & 1602 & 2947 & 1402 & 1636 & 1459 & 1423 & 2183 & 1221 & 1047 & 1248 \\ \text { (WY) } & 1987 & 1986 & 1991 & 1950 & 1950 & 1978 & 1957 & 1981 & 1957 & 1979 & 1979 & 1989 \\ \text { MIN } & 4.79 & 13.7 & 9.71 & 13.6 & 65.1 & 151 & 142 & 69.5 & 26.7 & 19.4 & 9.49 & 4.76 \\ \text { (WY) } & 1965 & 1964 & 1964 & 1977 & 1964 & 1966 & 1971 & 1976 & 1988 & 1954 & 1966 & 1954\end{array}$

SUMMARY SIAIISIICS

ANNUAL TOTAL

HIGHEST ANNUAL MEAM

LOWEST ANNUAL MEAN

HIGHEST DAILY MEAN

LOWEST DAILY MEAN

AMNUAL SEVEN-DAY MINIMUM

INSIANTANEOUS PEAK FLOW

INSTANIANEOUS PEAK SIAGE

ANMUAL RUNOFF (CFSH)

ANNUAL RUNOFF (INCHES)

10 PERCENT EXCEEDS

50 PERCENT EXCEEOS

90 PERCENT EXCEEDS
FOR 1990 CALENDAR YEAR

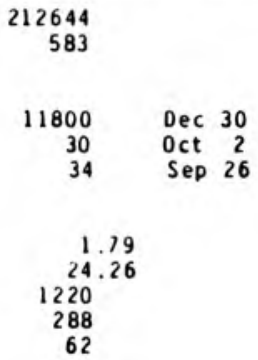

FOR 1991 WATER YEAR

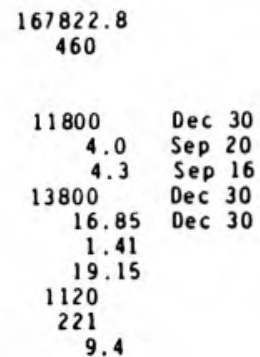

WAIER YEARS $1950-1991$

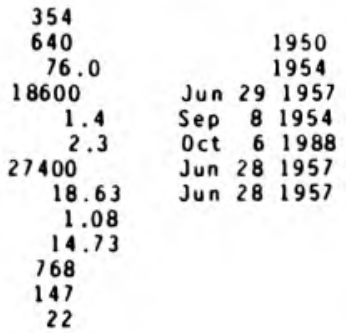


LOCATION,--Lat $39^{\circ} 26^{\prime} 00^{\circ}$, long $86^{\circ} 45^{\prime} 48^{\prime \prime}$, in NE $\frac{1}{4}$ SE $\frac{1}{4}$ sec.32, T.12 N., R. 3 W. Owen County, Hydrologic Unit 05120203 , on left bank at downstrea side of bridge on U.S. Highway 231 , 3 a east of Cataract, and at aile 17.5

DRAINAGE AREA. $--245 \mathrm{i}^{2}$

PERIOD OF RECORD.--July 1949 to current year.

REVISED RECORDS...-WSP 1505: 1956(P). WSP 2109: Drainage area.

GAGE.--Water-stage recorder. Datue of gage is $706.40 \mathrm{ft}$ above National Geodetic Vertical Datua of 1929 . Prior to Nov. 8, 1949, nonrecording gage, and Nov. 8, 1949, to Sept. 22, 1968, water-stage recorder at site 100 ft upstrean at sane datun.

REMARKS. - Records fair except for estiaated daily discharges, which are poor. Maximu instantaneous and aean daily discharges for period of record are estiated. Maxious gage height is unknown.

DISCHARGE, CUBIC FEET PER SECOND, WATER YEAR OCTOBER 1990 TO SEPTEMBER 1991 DAI Y MEAM VALUES

\begin{tabular}{|c|c|c|c|c|c|c|c|c|c|c|c|c|}
\hline DAY & $O C T$ & NOV & DEC & JAN & FE B & MAR & APR & MAY & JUN & JUL & AUG & SEP \\
\hline $\begin{array}{l}1 \\
2 \\
3 \\
4 \\
5\end{array}$ & $\begin{array}{r}20 \\
19 \\
19 \\
808 \\
445\end{array}$ & $\begin{array}{r}77 \\
74 \\
72 \\
69 \\
\mathrm{e} 200\end{array}$ & $\begin{array}{r}\text { e } 460 \\
\text { e } 360 \\
\text { e } 1500 \\
\text { e } 1000 \\
\text { e } 600\end{array}$ & $\begin{array}{r}\text { e1000 } \\
\text { e } 450 \\
\text { e } 360 \\
\text { e } 310 \\
\text { e280 }\end{array}$ & $\begin{array}{r}e 140 \\
e 170 \\
e 210 \\
324 \\
e 700\end{array}$ & $\begin{array}{l}182 \\
276 \\
229 \\
196 \\
178\end{array}$ & $\begin{array}{l}244 \\
211 \\
193 \\
191 \\
294\end{array}$ & $\begin{array}{l}\text { e } 134 \\
\text { el } 25 \\
\text { el } 113 \\
\text { e } 120 \\
\text { e } 133\end{array}$ & $\begin{array}{r}112 \\
88 \\
105 \\
67 \\
49\end{array}$ & $\begin{array}{l}13 \\
13 \\
12 \\
12 \\
17\end{array}$ & $\begin{array}{l}11 \\
11 \\
10 \\
10 \\
10\end{array}$ & $\begin{array}{l}6.1 \\
5.8 \\
5.1 \\
7.7 \\
6.9\end{array}$ \\
\hline $\begin{array}{r}6 \\
7 \\
8 \\
9 \\
10\end{array}$ & $\begin{array}{r}195 \\
261 \\
\mathrm{e} 850 \\
\mathrm{e} 430 \\
\mathrm{e} 1700\end{array}$ & $\begin{array}{l}\text { e } 400 \\
\text { e270 } \\
\text { e2 } 200 \\
\text { e1 } 60 \\
\text { e1 } 32\end{array}$ & $\begin{array}{l}\text { e } 390 \\
e 310 \\
e 260 \\
e 220 \\
e 200\end{array}$ & $\begin{array}{l}e 250 \\
e 230 \\
e 220 \\
e 205 \\
e 200\end{array}$ & $\begin{array}{r}\text { e1 } 300 \\
\text { e1 } 000 \\
\text { e } 630 \\
458 \\
361\end{array}$ & $\begin{array}{l}182 \\
176 \\
146 \\
140 \\
132\end{array}$ & $\begin{array}{r}e 263 \\
e 212 \\
263 \\
e 560 \\
e 308\end{array}$ & $\begin{array}{l}\text { e1 } 80 \\
\text { el } 40 \\
\text { e1 } 28 \\
\text { e115 } \\
106\end{array}$ & $\begin{array}{l}41 \\
39 \\
39 \\
38 \\
37\end{array}$ & $\begin{array}{r}18 \\
13 \\
11 \\
11 \\
742\end{array}$ & $\begin{array}{l}38 \\
52 \\
18 \\
12 \\
13\end{array}$ & $\begin{array}{l}6.1 \\
5.0 \\
4.4 \\
4.3 \\
4.4\end{array}$ \\
\hline $\begin{array}{l}11 \\
12 \\
13 \\
14 \\
15\end{array}$ & $\begin{array}{r}\text { e1100 } \\
\text { e } 600 \\
\text { e } 370 \\
264 \\
205\end{array}$ & $\begin{array}{r}114 \\
100 \\
90 \\
86 \\
85\end{array}$ & $\begin{array}{r}e 185 \\
e 180 \\
165 \\
142 \\
e 430\end{array}$ & $\begin{array}{r}e 450 \\
e 850 \\
e 520 \\
387 \\
516\end{array}$ & $\begin{array}{l}290 \\
247 \\
253 \\
325 \\
244\end{array}$ & $\begin{array}{r}126 \\
184 \\
\mathrm{e} 1800 \\
1140 \\
590\end{array}$ & $\begin{array}{r}e 227 \\
\text { e194 } \\
e 600 \\
\text { e } 940 \\
\text { e1 } 300\end{array}$ & $\begin{array}{r}98 \\
96 \\
102 \\
90 \\
\mathrm{e} 250\end{array}$ & $\begin{array}{l}36 \\
36 \\
34 \\
31 \\
29\end{array}$ & $\begin{array}{r}533 \\
420 \\
220 \\
89 \\
53\end{array}$ & $\begin{array}{r}11 \\
8.9 \\
8.0 \\
7.6 \\
8.4\end{array}$ & $\begin{array}{l}4.3 \\
4.2 \\
4.0 \\
4.1 \\
4.1\end{array}$ \\
\hline $\begin{array}{l}16 \\
17 \\
18 \\
19 \\
20\end{array}$ & $\begin{array}{l}162 \\
146 \\
191 \\
\text { e180 } \\
\text { e143 }\end{array}$ & $\begin{array}{l}83 \\
80 \\
73 \\
74 \\
71\end{array}$ & $\begin{array}{r}\text { e } 570 \\
\text { e } 460 \\
\text { e1 } 1200 \\
\text { e1 } 300 \\
\text { e750 }\end{array}$ & $\begin{array}{r}\text { e960 } \\
\text { e } 900 \\
492 \\
395 \\
366\end{array}$ & $\begin{array}{r}e 195 \\
\text { e240 } \\
e 600 \\
\text { e1100 } \\
\text { e } 770\end{array}$ & $\begin{array}{r}389 \\
466 \\
e 1200 \\
657 \\
432\end{array}$ & $\begin{array}{l}\text { e } 862 \\
e 449 \\
\text { e } 331 \\
\text { e } 840 \\
\text { e } 700\end{array}$ & $\begin{array}{l}150 \\
296 \\
319 \\
233 \\
141\end{array}$ & $\begin{array}{l}41 \\
50 \\
34 \\
27 \\
24\end{array}$ & $\begin{array}{l}39 \\
30 \\
26 \\
22 \\
20\end{array}$ & $\begin{array}{l}9.4 \\
8.5 \\
10 \\
10 \\
17\end{array}$ & $\begin{array}{l}4.0 \\
3.8 \\
3.8 \\
3.8 \\
3.7\end{array}$ \\
\hline $\begin{array}{l}21 \\
22 \\
23 \\
24 \\
25\end{array}$ & $\begin{array}{l}\text { e125 } \\
\text { e132 } \\
\text { e162 } \\
\text { e145 } \\
125\end{array}$ & $\begin{array}{r}68 \\
e 160 \\
e 250 \\
e 190 \\
153\end{array}$ & $\begin{array}{r}\text { e1 } 000 \\
\text { e } 1600 \\
\text { e } 900 \\
\text { e } 530 \\
\text { e } 330\end{array}$ & $\begin{array}{r}325 \\
e 280 \\
e 230 \\
e 204 \\
e 187\end{array}$ & $\begin{array}{l}483 \\
359 \\
283 \\
257 \\
224\end{array}$ & $\begin{array}{r}350 \\
\text { e2000 } \\
\text { e1600 } \\
913 \\
638\end{array}$ & $\begin{array}{l}\text { e } 460 \\
e 331 \\
e 251 \\
e 236 \\
e 190\end{array}$ & $\begin{array}{r}111 \\
95 \\
85 \\
81 \\
81\end{array}$ & $\begin{array}{l}22 \\
21 \\
20 \\
19 \\
18\end{array}$ & $\begin{array}{l}18 \\
17 \\
15 \\
14 \\
14\end{array}$ & $\begin{array}{r}12 \\
8.3 \\
6.6 \\
6.0 \\
5.9\end{array}$ & $\begin{array}{l}3.8 \\
4.0 \\
5.5 \\
7.3 \\
5.7\end{array}$ \\
\hline $\begin{array}{l}26 \\
27 \\
28 \\
29 \\
30 \\
31\end{array}$ & $\begin{array}{r}109 \\
103 \\
95 \\
84 \\
82 \\
81\end{array}$ & $\begin{array}{r}125 \\
861 \\
\text { e1 } 1900 \\
\text { e1 } 100 \\
\text { e620 } \\
\cdots-.\end{array}$ & $\begin{array}{r}\mathrm{e} 270 \\
\mathrm{e} 235 \\
\mathrm{e} 210 \\
\mathrm{e} 2200 \\
\mathrm{e} 11500 \\
\mathrm{e} 4000\end{array}$ & $\begin{array}{l}\text { e175 } \\
\text { el } 65 \\
\text { e } 158 \\
\text { e } 152 \\
\text { e1 } 149 \\
\text { el } 44\end{array}$ & $\begin{array}{l}201 \\
193 \\
186 \\
\ldots . \\
\cdots \ldots \\
\ldots-\end{array}$ & $\begin{array}{r}1720 \\
2460 \\
759 \\
460 \\
331 \\
271\end{array}$ & $\begin{array}{l}\text { e184 } \\
\text { e170 } \\
\text { e165 } \\
\text { e175 } \\
\text { e157 } \\
\ldots \ldots\end{array}$ & $\begin{array}{r}105 \\
85 \\
70 \\
127 \\
450 \\
182\end{array}$ & $\begin{array}{l}17 \\
16 \\
15 \\
14 \\
14 \\
-0\end{array}$ & $\begin{array}{l}13 \\
12 \\
12 \\
13 \\
24 \\
14\end{array}$ & $\begin{array}{l}5.7 \\
5.5 \\
5.6 \\
5.4 \\
5.2 \\
6.3\end{array}$ & $\begin{array}{l}4.8 \\
4.2 \\
4.2 \\
4.4 \\
4.4 \\
\cdots . .\end{array}$ \\
\hline $\begin{array}{l}\text { TOTAL } \\
\text { MEAN } \\
\text { MAX } \\
\text { MIN } \\
\text { CF SM } \\
\text { IN. }\end{array}$ & $\begin{array}{r}9351 \\
302 \\
1700 \\
19 \\
1.23 \\
1.42\end{array}$ & $\begin{array}{r}7937 \\
265 \\
1900 \\
68 \\
1.08 \\
1.21\end{array}$ & $\begin{array}{r}33457 \\
1079 \\
11500 \\
142 \\
4.41 \\
5.08\end{array}$ & $\begin{array}{r}11510 \\
371 \\
1000 \\
144 \\
1.52 \\
1.75\end{array}$ & $\begin{array}{r}11743 \\
419 \\
1300 \\
140 \\
1.71 \\
1.78\end{array}$ & $\begin{array}{r}20323 \\
656 \\
2460 \\
126 \\
2.68 \\
3.09\end{array}$ & $\begin{array}{r}11501 \\
383 \\
1300 \\
157 \\
1.56 \\
1.75\end{array}$ & $\begin{array}{c}4541 \\
146 \\
450 \\
70 \\
.60 \\
.69\end{array}$ & $\begin{array}{r}1133 \\
37.8 \\
112 \\
14 \\
.15 \\
.17\end{array}$ & $\begin{array}{c}2480 \\
80.0 \\
742 \\
11 \\
.33 \\
.38\end{array}$ & $\begin{array}{c}356.3 \\
11.5 \\
52 \\
5.2 \\
.05 \\
.05\end{array}$ & $\begin{array}{r}143.9 \\
4.80 \\
7.7 \\
3.7 \\
.02 \\
.02\end{array}$ \\
\hline
\end{tabular}

STATISTICS OF MONTHLY MEAN DATA FOR WATER YEARS 1950 - 1991, BY WATER YEAR (WY)

\begin{tabular}{|c|c|c|c|c|c|c|c|c|c|c|c|}
\hline $\begin{array}{l}\text { MEAN } \\
\text { MAX } \\
\text { (WY) } \\
\text { MIN } \\
(W Y)\end{array}$ & $\begin{array}{r}59.2 \\
435 \\
1987 \\
2.88 \\
1965\end{array}$ & $\begin{array}{r}199 \\
1239 \\
1986 \\
4.46 \\
1965\end{array}$ & $\begin{array}{r}333 \\
1135 \\
1958 \\
4.05 \\
1964\end{array}$ & $\begin{array}{r}338 \\
2214 \\
1950 \\
6.55 \\
1977\end{array}$ & $\begin{array}{r}434 \\
1088 \\
1971 \\
41.1 \\
1954\end{array}$ & $\begin{array}{r}523 \\
1425 \\
1963 \\
108 \\
1969\end{array}$ & $\begin{array}{r}405 \\
1064 \\
1964 \\
74.5 \\
1971\end{array}$ & $\begin{array}{r}312 \\
1522 \\
1981 \\
35.1 \\
1954\end{array}$ & $\begin{array}{r}217 \\
1120 \\
1957 \\
11.2 \\
1988\end{array}$ & $\begin{array}{r}192 \\
1694 \\
1979 \\
6.84 \\
1954\end{array}$ & $\begin{array}{l}93.3 \\
1059 \\
1979 \\
3.72 \\
1954\end{array}$ \\
\hline
\end{tabular}

SUMMARY STATISTICS

ANNUAL TOTAL

ANNUAL MEAN

HIGHEST ANHUAL MEAN

LOWEST ANNUAL MEAN

HIGHEST DAILY MEAN

LOWEST DAILY MEAN

ANMUAL SEVEN-DAY MINIMUM

INSTANTANEOUS PEAK FLOW

INSTANTANEOUS PEAK STAGE

ANNUAL RUNOFF (CFSM)

ANNUAL RUNOFF (INCHES)

10 PERCENT EXCEEDS

50 PERCENT EXCEEDS

90 PERCENT EXCEEDS
FOR 1990 CALENDAR YEAR

142576
391
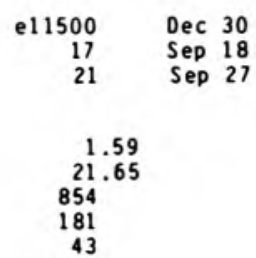

FOR 1991 WATER YEAR

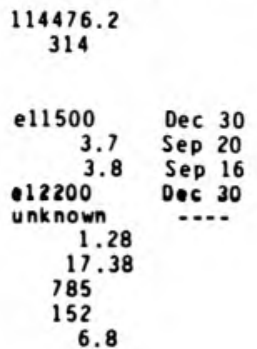

WATER YEARS $1950-1991$

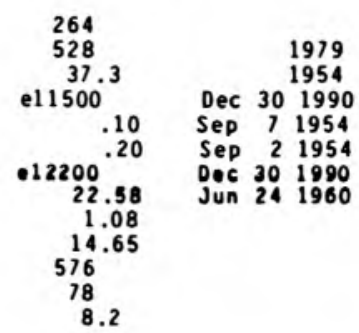




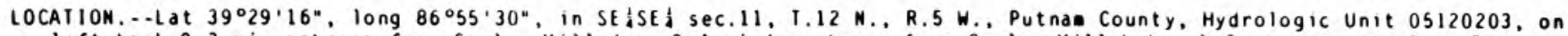
left bank 0.3 a i upstrea fron Cagles Mill da 0.4 a downstrea from Cagles Mill Lake, 1.3 a ustrea fro Deer Creek. 5.0 i south of Manhatian, and at ile 2.3 .

DRAINAGE AREA. $-294 \cdot i^{2}$.

PERIOD OF RECORD.--May to Septeaber 1931 (fragmentary), October 1938 to current year. Monthly discharge only for soee periods, published in WSP 1305.

REVISED RECORDS.-.WSP 1335: 1940-41. WSP 2109: Drainage area.

GAGE.--Data-Collection Platform. Datum of gage is $581.83 \mathrm{ft}$ above National Geodetic Vertical Datua of 1929 . May 12 , 1941 to Sept. 30,1974, water-stage recorder at site 0.3 a downstrean. Data-Collection Platfora installed on Apr. 22. 1986. See WSP 1725 for history of changes prior to May 12,1941 .

REMARKS. - Flow regulated by Cagles Mill Lake since July 1953. Daily discharge conputed froe relation between discharge. head, and gate openings for Cagles Mill Lake beginning Oct. 1, 1974 .

COOPERAIION. - Records of daily discharge provided by U.S. Aray Corps of Engineers beginning 0ct. 1 . 1976.

AVERAGE DISCHARGE. -53 years ( 1938 to current year), $315 \mathrm{ft}^{3} / \mathrm{s}$.

EXIREMES FOR PERIOD OF RECORD. - Maximun discharge, 8,960 $\mathrm{ft} / \mathrm{s}$. Jan. 5, 1950, gage height, $18.38 \mathrm{ft}$; no flow Aug. 7 , 1953.

EXTREMES FOR CURRENT YEAR. - Maximum daily discharge, $1,940 \mathrm{ft}^{3} / \mathrm{s} \mathrm{Jan}$. $27 ;$ ainieue daily, $18 \mathrm{ft} 3 / \mathrm{s} \mathrm{Aug.} 12$.

DISCHARGE, CUBIC FEET PER SECOND, WATER YEAR OCIOBER 1990 TO SEPIEMBER 1991 DAILY MEAN VALUES

\begin{tabular}{|c|c|c|c|c|c|c|c|c|c|c|c|c|}
\hline DAY & $O C T$ & NOV & OEC & JAN & FEB & MAR & APR & MAY & JUN & JUL & $A \cup G$ & SEP \\
\hline $\begin{array}{l}1 \\
2 \\
3 \\
4 \\
5\end{array}$ & $\begin{array}{r}68 \\
68 \\
68 \\
280 \\
715\end{array}$ & $\begin{array}{l}103 \\
103 \\
102 \\
102 \\
103\end{array}$ & $\begin{array}{l}182 \\
364 \\
239 \\
110 \\
111\end{array}$ & $\begin{array}{l}102 \\
104 \\
104 \\
105 \\
105\end{array}$ & $\begin{array}{l}1840 \\
1820 \\
1800 \\
1780 \\
1510\end{array}$ & $\begin{array}{l}1650 \\
1630 \\
1610 \\
1590 \\
1310\end{array}$ & $\begin{array}{l}1190 \\
1450 \\
1570 \\
1560 \\
1540\end{array}$ & $\begin{array}{l}1670 \\
1650 \\
1620 \\
1600 \\
1570\end{array}$ & $\begin{array}{r}90 \\
162 \\
209 \\
124 \\
89\end{array}$ & $\begin{array}{l}20 \\
20 \\
20 \\
20 \\
20\end{array}$ & $\begin{array}{l}20 \\
20 \\
20 \\
20 \\
20\end{array}$ & $\begin{array}{l}20 \\
20 \\
20 \\
20 \\
20\end{array}$ \\
\hline $\begin{array}{r}6 \\
7 \\
8 \\
9 \\
10\end{array}$ & $\begin{array}{l}835 \\
466 \\
209 \\
211 \\
157\end{array}$ & $\begin{array}{l}139 \\
281 \\
414 \\
296 \\
205\end{array}$ & $\begin{array}{r}237 \\
425 \\
806 \\
961 \\
1240\end{array}$ & $\begin{array}{l}105 \\
105 \\
105 \\
419 \\
590\end{array}$ & $\begin{array}{l}919 \\
499 \\
284 \\
284 \\
285\end{array}$ & $\begin{array}{r}1100 \\
1090 \\
1070 \\
1060 \\
858\end{array}$ & $\begin{array}{r}1530 \\
1520 \\
1130 \\
509 \\
679\end{array}$ & $\begin{array}{r}1550 \\
1520 \\
1490 \\
1320 \\
512\end{array}$ & $\begin{array}{l}80 \\
63 \\
45 \\
42 \\
42\end{array}$ & $\begin{array}{l}20 \\
20 \\
20 \\
20 \\
20\end{array}$ & $\begin{array}{l}20 \\
20 \\
55 \\
83 \\
47\end{array}$ & $\begin{array}{l}20 \\
20 \\
20 \\
20 \\
20\end{array}$ \\
\hline $\begin{array}{l}11 \\
12 \\
13 \\
14 \\
15\end{array}$ & $\begin{array}{l}103 \\
105 \\
105 \\
339 \\
792\end{array}$ & $\begin{array}{r}205 \\
156 \\
64 \\
71 \\
95\end{array}$ & $\begin{array}{l}1510 \\
1610 \\
1580 \\
1560 \\
1120\end{array}$ & $\begin{array}{l}589 \\
591 \\
592 \\
592 \\
817\end{array}$ & $\begin{array}{r}768 \\
1050 \\
1050 \\
1040 \\
1040\end{array}$ & $\begin{array}{l}498 \\
223 \\
152 \\
121 \\
124\end{array}$ & $\begin{array}{r}1090 \\
1240 \\
908 \\
262 \\
118\end{array}$ & $\begin{array}{r}70 \\
83 \\
142 \\
175 \\
175\end{array}$ & $\begin{array}{l}42 \\
42 \\
42 \\
42 \\
42\end{array}$ & $\begin{array}{l}283 \\
426 \\
427 \\
320 \\
340\end{array}$ & $\begin{array}{l}25 \\
18 \\
20 \\
20 \\
20\end{array}$ & $\begin{array}{l}20 \\
20 \\
20 \\
20 \\
20\end{array}$ \\
\hline $\begin{array}{l}16 \\
17 \\
18 \\
19 \\
20\end{array}$ & $\begin{array}{r}1100 \\
941 \\
782 \\
873 \\
864\end{array}$ & $\begin{array}{r}102 \\
102 \\
90 \\
82 \\
95\end{array}$ & $\begin{array}{r}886 \\
809 \\
265 \\
83 \\
84\end{array}$ & $\begin{array}{l}1200 \\
1480 \\
1650 \\
1760 \\
1750\end{array}$ & $\begin{array}{r}1030 \\
1020 \\
1020 \\
485 \\
282\end{array}$ & $\begin{array}{l}124 \\
125 \\
127 \\
129 \\
129\end{array}$ & $\begin{array}{l}120 \\
254 \\
520 \\
520 \\
523\end{array}$ & $\begin{array}{l}277 \\
317 \\
317 \\
381 \\
262\end{array}$ & $\begin{array}{l}42 \\
42 \\
53 \\
70 \\
69\end{array}$ & $\begin{array}{r}422 \\
252 \\
93 \\
70 \\
70\end{array}$ & $\begin{array}{l}20 \\
20 \\
20 \\
20 \\
20\end{array}$ & $\begin{array}{l}20 \\
20 \\
20 \\
20 \\
19\end{array}$ \\
\hline $\begin{array}{l}21 \\
22 \\
23 \\
24 \\
25\end{array}$ & $\begin{array}{l}855 \\
846 \\
837 \\
579 \\
181\end{array}$ & $\begin{array}{l}100 \\
194 \\
253 \\
365 \\
337\end{array}$ & $\begin{array}{l}85 \\
87 \\
88 \\
89 \\
89\end{array}$ & $\begin{array}{l}1740 \\
1730 \\
1720 \\
1790 \\
1830\end{array}$ & $\begin{array}{r}531 \\
615 \\
896 \\
1030 \\
1330\end{array}$ & $\begin{array}{r}130 \\
132 \\
136 \\
112 \\
93\end{array}$ & $\begin{array}{r}523 \\
872 \\
1040 \\
1180 \\
1260\end{array}$ & $\begin{array}{r}106 \\
107 \\
171 \\
116 \\
70\end{array}$ & $\begin{array}{l}60 \\
42 \\
42 \\
39 \\
24\end{array}$ & $\begin{array}{l}44 \\
33 \\
24 \\
20 \\
20\end{array}$ & $\begin{array}{l}20 \\
20 \\
20 \\
20 \\
20\end{array}$ & $\begin{array}{l}19 \\
19 \\
19 \\
19 \\
19\end{array}$ \\
\hline $\begin{array}{l}26 \\
27 \\
28 \\
29 \\
30 \\
31\end{array}$ & $\begin{array}{r}80 \\
102 \\
131 \\
151 \\
150 \\
134\end{array}$ & $\begin{array}{l}185 \\
151 \\
130 \\
124 \\
126 \\
\cdots\end{array}$ & $\begin{array}{r}305 \\
582 \\
361 \\
90 \\
94 \\
99\end{array}$ & $\begin{array}{l}1810 \\
1940 \\
1920 \\
1900 \\
1880 \\
1860\end{array}$ & $\begin{array}{r}1560 \\
1700 \\
1680 \\
\cdots \\
\cdots \\
\cdots\end{array}$ & $\begin{array}{r}94 \\
108 \\
97 \\
97 \\
357 \\
881\end{array}$ & $\begin{array}{c}1410 \\
1490 \\
1480 \\
1460 \\
1600 \\
\cdots\end{array}$ & $\begin{array}{r}90 \\
214 \\
156 \\
89 \\
389 \\
470\end{array}$ & $\begin{array}{l}20 \\
20 \\
20 \\
20 \\
20 \\
\cdots\end{array}$ & $\begin{array}{l}20 \\
20 \\
20 \\
20 \\
20 \\
20\end{array}$ & $\begin{array}{l}20 \\
20 \\
20 \\
20 \\
20 \\
20\end{array}$ & $\begin{array}{l}19 \\
19 \\
19 \\
19 \\
19 \\
\cdots\end{array}$ \\
\hline $\begin{array}{l}\text { TOIAL } \\
\text { MEAN } \\
\text { MAX } \\
\text { MIN }\end{array}$ & $\begin{array}{r}13127 \\
423 \\
1100 \\
68\end{array}$ & $\begin{array}{r}4875 \\
162 \\
414 \\
64\end{array}$ & $\begin{array}{r}16151 \\
521 \\
1610 \\
83\end{array}$ & $\begin{array}{r}33105 \\
1068 \\
1940 \\
102\end{array}$ & $\begin{array}{r}29148 \\
1041 \\
1840 \\
282\end{array}$ & $\begin{array}{r}16957 \\
547 \\
1650 \\
93\end{array}$ & $\begin{array}{r}30548 \\
1018 \\
1600 \\
118\end{array}$ & $\begin{array}{r}18679 \\
603 \\
1670 \\
70\end{array}$ & $\begin{array}{c}1739 \\
58.0 \\
209 \\
20\end{array}$ & $\begin{array}{c}3164 \\
102 \\
427 \\
20\end{array}$ & $\begin{array}{r}748 \\
24.1 \\
83 \\
18\end{array}$ & $\begin{array}{r}589 \\
19.6 \\
20 \\
19\end{array}$ \\
\hline
\end{tabular}

CAL YR 1990 TOIAL 165344 MEAN 453 MAX 1840 MIN 33 WTR YR 1991 TOTAL 168830 MEAN 463 MAX 1940 MIN 18 
LOCATION.--Lat $39^{\circ} 22^{\prime} 58^{\prime \prime}$, long $87^{\circ} 01^{\prime} 14^{\prime \prime}$, in NE $\frac{1}{2}$, IE $\frac{1}{4}$ sec. 24 , T.11 N., R.6 W. C Clay County, Hydrologic Unit 05120203 , on left bank $500 \mathrm{ft}$ downstrean frov bridge on State Highway 46 at Bowling Green, 0.2 ai downstreas from Jordan Creek, and at ile 38.4 .

DRAI NAGE AREA $\ldots 830$ i

PERIOD OF RECORD...January 1931 to current year. Prior to October 1934, published as "near Centerpoint".

REVISED RECORDS.--WSP 893: 1935, 1937-39. WSP 973: 1937-38, 1939(M). WSP 1335: 1931(M). WSP 2109: Drainage area.

GAGE.- Water-stage recorder. Datun of gage is $548.02 \mathrm{ft}$ above National Geodetic Vertical Datua of 1929 (levels by U.S. Aray Corps of Engineers). See WSP 1725 for history of changes prior to Dec. 1.1949.

REMARKS. - Records good except for periods of estiated daily discharges, Dec. 31 to Jan. 1 , Feb. $16-17$. Which are fair and Jan. 22 to Feb. 1. which are poor. Flow regulated by Cataract Lake.

EXTREMES OUTSIDE PERIOD OF RECORD.--Maximu stage known, about 30.0 ft in 1875, present datua, froe inforaation by U.S. Aray Corps of Engineers.

DISCHARGE, CUBIC FEET PER SECOND, WATER YEAR OCTOBER 1990 TO SEPTEMBER 1991 DAILY MEAN VALUES

\begin{tabular}{|c|c|c|c|c|c|c|c|c|c|c|c|c|}
\hline DAY & $\mathrm{OCT}$ & NOV & DEC & JAN & FEB & MAR & APR & MAY & JUN & JUL & AUG & SEP \\
\hline $\begin{array}{l}1 \\
2 \\
3 \\
4 \\
5\end{array}$ & $\begin{array}{r}119 \\
113 \\
112 \\
1150 \\
1250\end{array}$ & $\begin{array}{l}285 \\
274 \\
271 \\
263 \\
378\end{array}$ & $\begin{array}{l}1220 \\
1130 \\
3600 \\
4340 \\
1870\end{array}$ & $\begin{array}{r}\text { e } 5000 \\
\text { e } 3000 \\
\text { e } 2100 \\
\text { e } 1500 \\
1300\end{array}$ & $\begin{array}{r}\text { e2170 } \\
\text { e2190 } \\
\text { e2270 } \\
2470 \\
2830\end{array}$ & $\begin{array}{l}2110 \\
2350 \\
2310 \\
2170 \\
1990\end{array}$ & $\begin{array}{l}1900 \\
2030 \\
2160 \\
2130 \\
2230\end{array}$ & $\begin{array}{l}2030 \\
1990 \\
1940 \\
1920 \\
1950\end{array}$ & $\begin{array}{l}445 \\
376 \\
465 \\
375 \\
258\end{array}$ & $\begin{array}{r}81 \\
79 \\
79 \\
77 \\
103\end{array}$ & $\begin{array}{l}58 \\
55 \\
54 \\
53 \\
52\end{array}$ & $\begin{array}{l}49 \\
44 \\
43 \\
63 \\
58\end{array}$ \\
\hline $\begin{array}{r}6 \\
7 \\
8 \\
9 \\
10\end{array}$ & $\begin{array}{r}1130 \\
1210 \\
1200 \\
934 \\
3260\end{array}$ & $\begin{array}{l}735 \\
660 \\
727 \\
658 \\
452\end{array}$ & $\begin{array}{l}1370 \\
1320 \\
1430 \\
1640 \\
1670\end{array}$ & $\begin{array}{l}1250 \\
1110 \\
1000 \\
1060 \\
1370\end{array}$ & $\begin{array}{l}3070 \\
2960 \\
1880 \\
1450 \\
1250\end{array}$ & $\begin{array}{l}1660 \\
1620 \\
1530 \\
1480 \\
1390\end{array}$ & $\begin{array}{l}2200 \\
2090 \\
2310 \\
2140 \\
1470\end{array}$ & $\begin{array}{l}2120 \\
1960 \\
1850 \\
1770 \\
1230\end{array}$ & $\begin{array}{l}237 \\
208 \\
190 \\
176 \\
169\end{array}$ & $\begin{array}{r}157 \\
90 \\
76 \\
71 \\
496\end{array}$ & $\begin{array}{r}126 \\
133 \\
86 \\
134 \\
111\end{array}$ & $\begin{array}{l}50 \\
45 \\
43 \\
42 \\
42\end{array}$ \\
\hline $\begin{array}{l}11 \\
12 \\
13 \\
14 \\
15\end{array}$ & $\begin{array}{r}2610 \\
1280 \\
853 \\
742 \\
983\end{array}$ & $\begin{array}{l}428 \\
400 \\
276 \\
245 \\
248\end{array}$ & $\begin{array}{l}1930 \\
2030 \\
1980 \\
1920 \\
2180\end{array}$ & $\begin{array}{l}1760 \\
2680 \\
2000 \\
1680 \\
1780\end{array}$ & $\begin{array}{l}1290 \\
1740 \\
1700 \\
1880 \\
1740\end{array}$ & $\begin{array}{r}1030 \\
740 \\
3660 \\
3780 \\
1890\end{array}$ & $\begin{array}{l}1690 \\
1810 \\
2540 \\
2930 \\
3360\end{array}$ & $\begin{array}{l}555 \\
847 \\
516 \\
546 \\
560\end{array}$ & $\begin{array}{l}164 \\
165 \\
157 \\
149 \\
144\end{array}$ & $\begin{array}{r}818 \\
1010 \\
650 \\
372 \\
345\end{array}$ & $\begin{array}{l}79 \\
64 \\
58 \\
58 \\
53\end{array}$ & $\begin{array}{l}41 \\
40 \\
39 \\
38 \\
37\end{array}$ \\
\hline $\begin{array}{l}16 \\
17 \\
18 \\
19 \\
20\end{array}$ & $\begin{array}{l}1410 \\
1350 \\
1250 \\
1470 \\
1310\end{array}$ & $\begin{array}{l}277 \\
272 \\
262 \\
218 \\
213\end{array}$ & $\begin{array}{l}2120 \\
1960 \\
3730 \\
3640 \\
2000\end{array}$ & $\begin{array}{l}2790 \\
3440 \\
3020 \\
2870 \\
2750\end{array}$ & $\begin{array}{r}\text { e } 1440 \\
\text { e1 } 400 \\
\text { e } 1700 \\
3100 \\
2220\end{array}$ & $\begin{array}{l}1320 \\
1420 \\
2960 \\
1920 \\
1360\end{array}$ & $\begin{array}{l}2540 \\
1560 \\
1600 \\
1580 \\
1660\end{array}$ & $\begin{array}{l}562 \\
601 \\
644 \\
620 \\
655\end{array}$ & $\begin{array}{l}258 \\
335 \\
202 \\
178 \\
164\end{array}$ & $\begin{array}{l}480 \\
428 \\
203 \\
149 \\
132\end{array}$ & $\begin{array}{l}54 \\
57 \\
65 \\
64 \\
63\end{array}$ & $\begin{array}{l}37 \\
37 \\
37 \\
37 \\
37\end{array}$ \\
\hline $\begin{array}{l}21 \\
22 \\
23 \\
24 \\
25\end{array}$ & $\begin{array}{r}1210 \\
1170 \\
1160 \\
1020 \\
594\end{array}$ & $\begin{array}{l}249 \\
579 \\
708 \\
588 \\
644\end{array}$ & $\begin{array}{l}2440 \\
4590 \\
2450 \\
1520 \\
1130\end{array}$ & $\begin{array}{r}2680 \\
\mathrm{e} 2480 \\
\mathrm{e} 2380 \\
\mathrm{e} 2310 \\
\mathrm{e} 2290 \\
t\end{array}$ & $\begin{array}{l}1870 \\
1590 \\
1660 \\
1760 \\
1800\end{array}$ & $\begin{array}{l}1130 \\
4380 \\
6550 \\
3070 \\
1730\end{array}$ & $\begin{array}{l}1480 \\
1490 \\
1740 \\
1770 \\
1830\end{array}$ & $\begin{array}{l}369 \\
340 \\
362 \\
502 \\
322\end{array}$ & $\begin{array}{l}154 \\
136 \\
129 \\
122 \\
113\end{array}$ & $\begin{array}{r}123 \\
98 \\
91 \\
78 \\
73\end{array}$ & $\begin{array}{l}63 \\
56 \\
52 \\
50 \\
47\end{array}$ & $\begin{array}{l}36 \\
39 \\
47 \\
43 \\
41\end{array}$ \\
\hline $\begin{array}{l}26 \\
27 \\
28 \\
29 \\
30 \\
31\end{array}$ & $\begin{array}{l}333 \\
328 \\
316 \\
337 \\
327 \\
317\end{array}$ & $\begin{array}{r}426 \\
1840 \\
5110 \\
4240 \\
1710 \\
\ldots\end{array}$ & $\begin{array}{r}985 \\
1270 \\
1230 \\
3280 \\
16800 \\
\mathrm{e} 13000\end{array}$ & $\begin{array}{l}\text { e2260 } \\
\text { e2230 } \\
\text { e2220 } \\
\text { e2230 } \\
\text { e2270 } \\
\text { e2220 }\end{array}$ & $\begin{array}{r}2030 \\
2170 \\
2150 \\
\ldots \\
\ldots \\
\ldots\end{array}$ & $\begin{array}{l}3220 \\
4110 \\
2110 \\
1470 \\
1270 \\
1600\end{array}$ & $\begin{array}{c}1850 \\
1970 \\
1950 \\
1930 \\
1950 \\
\cdots\end{array}$ & $\begin{array}{r}320 \\
368 \\
413 \\
498 \\
1230 \\
1100\end{array}$ & $\begin{array}{r}100 \\
95 \\
90 \\
88 \\
85 \\
-\cdots\end{array}$ & $\begin{array}{l}70 \\
66 \\
63 \\
62 \\
63 \\
60\end{array}$ & $\begin{array}{l}46 \\
45 \\
44 \\
43 \\
43 \\
43\end{array}$ & $\begin{array}{r}39 \\
38 \\
37 \\
37 \\
36 \\
\cdots\end{array}$ \\
\hline $\begin{array}{l}\text { TOTAL } \\
\text { MEAN } \\
\text { MAX } \\
\text { MIN } \\
\text { CF SM } \\
\text { IN. }\end{array}$ & $\begin{array}{r}30848 \\
995 \\
3260 \\
112 \\
1.20 \\
1.38\end{array}$ & $\begin{array}{r}23636 \\
788 \\
5110 \\
213 \\
.95 \\
1.06\end{array}$ & $\begin{array}{r}91775 \\
2960 \\
16800 \\
985 \\
3.57 \\
4.11\end{array}$ & $\begin{array}{r}69030 \\
2227 \\
5000 \\
1000 \\
2.68 \\
3.09\end{array}$ & $\begin{array}{r}55780 \\
1992 \\
3100 \\
1250 \\
2.40 \\
2.50\end{array}$ & $\begin{array}{r}69330 \\
2236 \\
6550 \\
740 \\
2.69 \\
3.11\end{array}$ & $\begin{array}{r}59890 \\
1996 \\
3360 \\
1470 \\
2.41 \\
2.68\end{array}$ & $\begin{array}{r}30690 \\
990 \\
2120 \\
320 \\
1.19 \\
1.38\end{array}$ & $\begin{array}{r}5927 \\
198 \\
465 \\
85 \\
.24 \\
.27\end{array}$ & $\begin{array}{r}6743 \\
218 \\
1010 \\
60 \\
.26 \\
.30\end{array}$ & $\begin{array}{r}2009 \\
64.8 \\
134 \\
43 \\
.08 \\
.09\end{array}$ & $\begin{array}{r}1252 \\
41.7 \\
63 \\
36 \\
.05 \\
.06\end{array}$ \\
\hline
\end{tabular}

e Estiated

STATISTICS, OF MONTHLY MEAN DATA FOR WATER YEARS 1931 - 1991, BY WATER YEAR (WY)

$\begin{array}{lrrrrrrrrrrrr}\text { MEAN } & 264 & 533 & 909 & 1242 & 1323 & 1594 & 1612 & 1207 & 821 & 561 & 304 & 287 \\ \text { MAX } & 1393 & 3076 & 2960 & 7212 & 3249 & 3843 & 4120 & 5090 & 4077 & 2746 & 2656 & 2488 \\ \text { (WY) } & 1987 & 1986 & 1991 & 1950 & 1950 & 1938 & 1944 & 1943 & 1957 & 1987 & 1979 & 1989 \\ \text { MIN } & 22.5 & 29.7 & 29.0 & 27.5 & 107 & 125 & 285 & 129 & 66.9 & 39.4 & 24.1 & 13.9 \\ \text { (WY) } & 1941 & 1965 & 1964 & 1977 & 1934 & 1941 & 1971 & 1934 & 1988 & 1954 & 1936 & 1954\end{array}$

SUMMARY STATISTICS

ANMUAL TOTAL

ANNUAL MEAN

HIGHEST ANNUAL MEAN

LOWEST ANNUAL MEAM

HIGHEST DAILY MEAN

LOWEST DAILY MEAM

ANMUAL SEVEN-DAY MINIMUM

INSTANTANEOUS PEAK FLOW

INSTANTANEOUS PEAK STAGE

ANNUAL RUNOFF (CFSM)

ANNUAL RUNOFF (INCHES)

10 PERCENT EXCEEDS

50 PERCENT EXCEEDS

90 PERCENT EXCEEDS

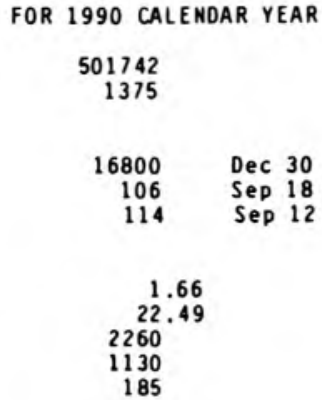

FOR 1991 WATER YEAR

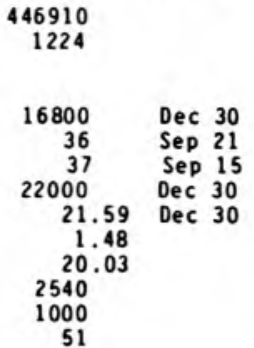

WATER YEARS 1931 - 1991

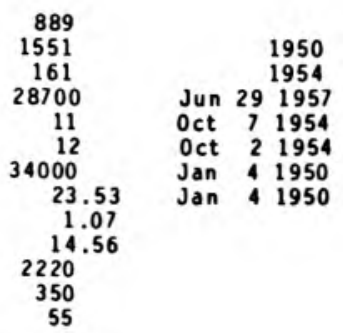




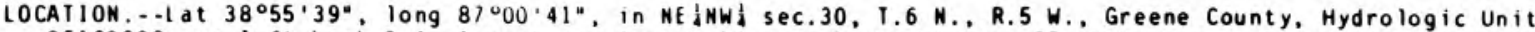
05120202 , on left bank 0.4 mi upstrean from bridge on State Highway 57 at Newberry, 1.9 ei downstrean from Doans Creek, and at ile 113.0 .

DRAI NAGE AREA $\ldots 4,688 \cdots i 2$

PERIOD OF RECORD.--Septenber 1928 to current year. Prior to October 1948, published as West Fork White River at Newberry.

REVISED RECORDS.--WSP 873: 1937(M). WSP 2109: Drainage area.

GAGE.- - Water-stage recorder. Datun of gage is $465.59 \mathrm{ft}$ above National Geodetic Vertical Datue of 1929 . Nonrecording gage prior to 0ct. 21, 1928. Prior to Aug. 5, 1982, recorting gage 0.3 a downstrean at sane datue.

REMARKS. - Records good. Flow regulated by upstrean reservoirs.

EXTREMES OUTSIDE PERIOD OF RECORD. - Maximum stage since at least 1875, 27.5 ft Mar. 27, 1913, from floodearks by Indiana Department of Highways, discharge, $130,000 \mathrm{ft} / \mathrm{s}$.

DISCHARGE, CUBIC FEET PER SECOND, WATER YEAR OCTOBER 1990 TO SEPTEMBER 1991 DAILY MEAN VALUES

\begin{tabular}{|c|c|c|c|c|c|c|c|c|c|c|c|c|}
\hline DAY & $O C T$ & NOV & DEC & JAN & FEB & MAR & APR & MAY & JUN & JUL & AUG & SEP \\
\hline $\begin{array}{l}1 \\
2 \\
3 \\
4 \\
5\end{array}$ & $\begin{array}{l}1490 \\
1410 \\
1350 \\
2750 \\
4050\end{array}$ & $\begin{array}{l}2240 \\
2140 \\
2050 \\
1990 \\
2020\end{array}$ & $\begin{array}{r}13800 \\
9900 \\
8540 \\
11500 \\
14100\end{array}$ & $\begin{array}{l}53100 \\
86000 \\
85900 \\
66900 \\
47900\end{array}$ & $\begin{array}{l}6440 \\
6170 \\
6300 \\
6600 \\
7020\end{array}$ & $\begin{array}{l}6300 \\
6430 \\
6660 \\
6560 \\
6200\end{array}$ & $\begin{array}{l}9820 \\
8590 \\
7910 \\
7510 \\
7360\end{array}$ & $\begin{array}{l}5910 \\
5710 \\
5480 \\
5230 \\
5120\end{array}$ & $\begin{array}{l}3960 \\
3690 \\
5490 \\
6470 \\
5680\end{array}$ & $\begin{array}{l}1380 \\
1310 \\
1260 \\
1250 \\
1200\end{array}$ & $\begin{array}{l}741 \\
726 \\
707 \\
695 \\
671\end{array}$ & $\begin{array}{l}616 \\
626 \\
604 \\
637 \\
696\end{array}$ \\
\hline $\begin{array}{r}6 \\
7 \\
8 \\
9 \\
10\end{array}$ & $\begin{array}{l}4710 \\
4550 \\
5400 \\
5000 \\
6150\end{array}$ & $\begin{array}{l}2540 \\
3000 \\
3080 \\
3070 \\
2990\end{array}$ & $\begin{array}{r}14400 \\
12300 \\
9450 \\
7530 \\
6820\end{array}$ & $\begin{array}{r}33100 \\
21900 \\
13800 \\
10500 \\
9110\end{array}$ & $\begin{array}{l}10900 \\
15400 \\
16600 \\
17100 \\
15700\end{array}$ & $\begin{array}{l}5920 \\
5640 \\
5340 \\
5060 \\
4780\end{array}$ & $\begin{array}{l}7450 \\
7390 \\
7070 \\
8220 \\
8150\end{array}$ & $\begin{array}{l}5290 \\
5440 \\
5310 \\
4870 \\
4600\end{array}$ & $\begin{array}{l}4460 \\
3680 \\
3130 \\
2770 \\
2520\end{array}$ & $\begin{array}{l}1190 \\
1260 \\
1230 \\
1110 \\
1080\end{array}$ & $\begin{array}{r}767 \\
1040 \\
1180 \\
1230 \\
1110\end{array}$ & $\begin{array}{l}704 \\
676 \\
617 \\
583 \\
574\end{array}$ \\
\hline $\begin{array}{l}11 \\
12 \\
13 \\
14 \\
15\end{array}$ & $\begin{array}{r}9240 \\
10600 \\
10000 \\
9220 \\
7160\end{array}$ & $\begin{array}{l}2680 \\
2470 \\
2320 \\
2170 \\
2020\end{array}$ & $\begin{array}{l}6180 \\
6020 \\
5830 \\
5540 \\
5800\end{array}$ & $\begin{array}{r}9350 \\
11900 \\
12700 \\
12000 \\
11100\end{array}$ & $\begin{array}{r}12400 \\
9460 \\
8510 \\
9720 \\
9900\end{array}$ & $\begin{array}{r}4620 \\
4300 \\
6650 \\
11900 \\
15300\end{array}$ & $\begin{array}{r}7130 \\
6570 \\
7400 \\
9610 \\
12300\end{array}$ & $\begin{array}{l}4210 \\
3890 \\
3700 \\
3410 \\
3330\end{array}$ & $\begin{array}{l}2330 \\
2200 \\
2100 \\
2040 \\
1950\end{array}$ & $\begin{array}{l}1190 \\
4370 \\
5300 \\
3140 \\
2190\end{array}$ & $\begin{array}{r}1090 \\
950 \\
851 \\
827 \\
1110\end{array}$ & $\begin{array}{l}551 \\
536 \\
522 \\
509 \\
615\end{array}$ \\
\hline $\begin{array}{l}16 \\
17 \\
18 \\
19 \\
20\end{array}$ & $\begin{array}{l}5770 \\
5250 \\
4860 \\
4620 \\
4620\end{array}$ & $\begin{array}{l}1940 \\
1880 \\
1850 \\
1830 \\
1770\end{array}$ & $\begin{array}{r}7270 \\
8310 \\
14500 \\
18800 \\
19300\end{array}$ & $\begin{array}{l}10500 \\
11200 \\
12100 \\
12600 \\
12300\end{array}$ & $\begin{array}{r}8130 \\
7200 \\
7810 \\
11300 \\
12400\end{array}$ & $\begin{array}{l}17200 \\
16900 \\
18600 \\
18700 \\
18000\end{array}$ & $\begin{array}{l}14100 \\
14400 \\
13200 \\
11300 \\
11000\end{array}$ & $\begin{array}{l}3650 \\
3490 \\
3690 \\
4180 \\
5120\end{array}$ & $\begin{array}{l}2040 \\
2140 \\
2300 \\
2120 \\
1950\end{array}$ & $\begin{array}{l}1760 \\
1660 \\
1590 \\
1390 \\
1200\end{array}$ & $\begin{array}{l}818 \\
760 \\
747 \\
718 \\
786\end{array}$ & $\begin{array}{l}708 \\
613 \\
568 \\
546 \\
514\end{array}$ \\
\hline $\begin{array}{l}21 \\
22 \\
23 \\
24 \\
25\end{array}$ & $\begin{array}{l}4560 \\
4550 \\
4330 \\
4160 \\
3920\end{array}$ & $\begin{array}{l}1710 \\
1880 \\
2880 \\
3230 \\
2900\end{array}$ & $\begin{array}{l}19000 \\
19900 \\
20100 \\
19400 \\
17200\end{array}$ & $\begin{array}{r}10800 \\
9570 \\
8830 \\
8220 \\
7640\end{array}$ & $\begin{array}{r}12100 \\
11200 \\
10000 \\
8690 \\
7770\end{array}$ & $\begin{array}{l}16900 \\
16400 \\
22100 \\
25200 \\
27500\end{array}$ & $\begin{array}{r}12500 \\
12800 \\
11500 \\
9820 \\
8450\end{array}$ & $\begin{array}{l}5580 \\
4890 \\
4050 \\
4050 \\
4650\end{array}$ & $\begin{array}{l}1860 \\
1790 \\
1730 \\
1570 \\
1510\end{array}$ & $\begin{array}{r}1090 \\
1030 \\
980 \\
932 \\
897\end{array}$ & $\begin{array}{l}791 \\
807 \\
760 \\
736 \\
723\end{array}$ & $\begin{array}{l}495 \\
494 \\
508 \\
508 \\
561\end{array}$ \\
\hline $\begin{array}{l}26 \\
27 \\
28 \\
29 \\
30 \\
31\end{array}$ & $\begin{array}{l}3460 \\
3000 \\
2740 \\
2550 \\
2420 \\
2330\end{array}$ & $\begin{array}{r}2730 \\
3520 \\
10200 \\
13800 \\
15000 \\
\ldots\end{array}$ & $\begin{array}{r}13900 \\
9890 \\
8280 \\
10700 \\
22700 \\
38100\end{array}$ & $\begin{array}{l}7120 \\
6710 \\
6560 \\
6440 \\
6580 \\
6590\end{array}$ & $\begin{array}{c}7050 \\
6770 \\
6540 \\
\ldots \\
\ldots \\
\ldots\end{array}$ & $\begin{array}{l}26100 \\
23900 \\
23400 \\
22500 \\
18400 \\
13000\end{array}$ & $\begin{array}{c}7680 \\
7070 \\
6780 \\
6450 \\
6220 \\
\cdots\end{array}$ & $\begin{array}{l}4 i 00 \\
4010 \\
3830 \\
3610 \\
4120 \\
4500\end{array}$ & $\begin{array}{c}1720 \\
1870 \\
1770 \\
1610 \\
1470 \\
\cdots\end{array}$ & $\begin{array}{l}868 \\
833 \\
803 \\
789 \\
780 \\
753\end{array}$ & $\begin{array}{l}674 \\
638 \\
614 \\
599 \\
608 \\
676\end{array}$ & $\begin{array}{l}629 \\
570 \\
530 \\
518 \\
497 \\
-\cdots\end{array}$ \\
\hline $\begin{array}{l}\text { IOIAL } \\
\text { MEAN } \\
\text { MAX } \\
\text { MIN } \\
\text { CF SM } \\
\text { IN. }\end{array}$ & $\begin{array}{r}146220 \\
4717 \\
10600 \\
1350 \\
1.01 \\
1.16\end{array}$ & $\begin{array}{r}103900 \\
3463 \\
15000 \\
1710 \\
.74 \\
.82\end{array}$ & $\begin{array}{r}405060 \\
13070 \\
38100 \\
5540 \\
2.79 \\
3.21\end{array}$ & $\begin{array}{r}629020 \\
20290 \\
86000 \\
6440 \\
4.33 \\
4.99\end{array}$ & $\begin{array}{r}275180 \\
9828 \\
17100 \\
6170 \\
2.10 \\
2.18\end{array}$ & $\begin{array}{r}426460 \\
13760 \\
27500 \\
4300 \\
2.93 \\
3.38\end{array}$ & $\begin{array}{r}275750 \\
9192 \\
14400 \\
6220 \\
1.96 \\
2.19\end{array}$ & $\begin{array}{r}139380 \\
4496 \\
5970 \\
3330 \\
.96 \\
1.11\end{array}$ & $\begin{array}{r}79920 \\
2664 \\
6470 \\
1470 \\
.57 \\
.63\end{array}$ & $\begin{array}{r}45815 \\
1478 \\
5300 \\
753 \\
.32 \\
.36\end{array}$ & $\begin{array}{r}25150 \\
811 \\
1230 \\
599 \\
.17 \\
.20\end{array}$ & $\begin{array}{c}17325 \\
577 \\
708 \\
494 \\
.12 \\
.14\end{array}$ \\
\hline
\end{tabular}

STATISTICS OF MONTHLY MEAN DATA FOR WAIER YEARS 1929 - 1991, BY WAIER YEAR (WY)

$\begin{array}{lrrrrrrrrrrrr}\text { MEAN } & 1393 & 2656 & 4637 & 6811 & 7152 & 8852 & 8860 & 6686 & 4359 & 3090 & 1871 & 1526 \\ \text { MAX } & 5542 & 13890 & 16780 & 36920 & 21870 & 19150 & 20340 & 25090 & 15080 & 13270 & 15900 & 13510 \\ \text { (WY) } & 1987 & 1973 & 1958 & 1950 & 1950 & 1963 & 1944 & 1943 & 1958 & 1979 & 1979 & 1989 \\ \text { MIN } & 259 & 408 & 386 & 405 & 105 & 686 & 1539 & 677 & 171 & 536 & 308 & 317 \\ \text { (WY) } & 1941 & 1945 & 1945 & 1945 & 1931 & 1941 & 1941 & 1941 & 1988 & 1936 & 1941 & 1940\end{array}$

SUMMARY SIAIISIICS

ANNUAL TOTAL

ANNUAL MEAN

HIGHEST ANMUAL MEAN

LOWEST AMNUAL MEAM

HIGHESI DAILY MEAM

LOWEST DAILY MEAM

ANNUAL SEVEN-DAY MINIMUM

INSTANTANEOUS PEAK FLOW

INSTANTANEOUS PEAK STAGE

AMNUAL RUNOFF (CFSM)

ANMUAL RUNOFF (INCHES)

10 PERCENT EXCEEDS

50 PERCENT EXCEEDS

90 PERCENT EXCEEDS
FOR 1990 CALENDAR YEAR

FOR 1991 WATER YEAR

WAIER YEARS 1929 - 1991

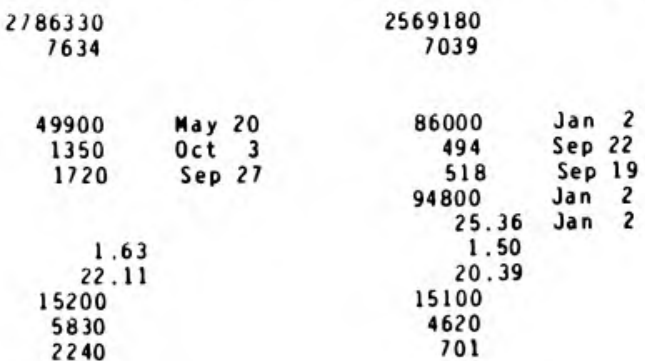

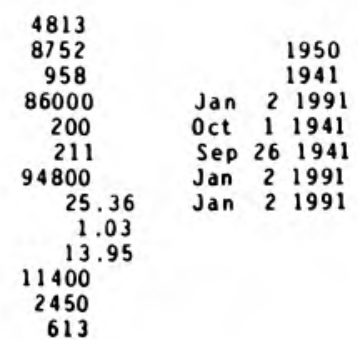


LOCAIION.--Lat $39^{\circ} 44^{\prime} 38^{\prime \prime}$, Iong $85^{\circ} 34^{\prime} 33^{\prime \prime}$, in SW

05120204 , on right bank $300 \mathrm{ft}$ upstred from highway bridge, 0.5 mi northwest of Carthage, 2.2 mi downstrean from Three Mile Creek, and at ile 50.7 .

DRAINAGE AREA . - 184 i

PERIOD OF RECORD.--0ctober 1950 to current year. Prior to October 1961, published as Blue River at Carthage.

REVISED RECORDS.--WSP 2109: Drainage area.

GAGE.- -Water-stage recorder. Datun of gage is $859.33 \mathrm{ft}$ above National Geodetic Vertical Datua of 1929 . Prior to July 19, 1951, nonrecording gage at site $300 \mathrm{ft}$ downstrea at sane datun.

REMARKS. - - Records good. Flow partly regulated by Big Blue River Conservancy District control structures on tributaries to Big Blue River beginning in 1969.

DISCHARGE, CUBIC FEET PER SECOND, WATER YEAR OCTOBER 1990 TO SEPTEMBER 1991 DAILY MEAN VAIUES

\begin{tabular}{|c|c|c|c|c|c|c|c|c|c|c|c|c|}
\hline DAY & $\mathrm{OCI}$ & NOV & $\mathrm{DEC}$ & JAN & FEB & MAR & $A P R$ & MAY & JUN & JUL & AUG & SEP \\
\hline $\begin{array}{l}1 \\
2 \\
3 \\
4 \\
5\end{array}$ & $\begin{array}{r}104 \\
101 \\
99 \\
367 \\
266\end{array}$ & $\begin{array}{l}126 \\
124 \\
120 \\
120 \\
146\end{array}$ & $\begin{array}{l}250 \\
212 \\
617 \\
590 \\
361\end{array}$ & $\begin{array}{r}1350 \\
852 \\
521 \\
436 \\
398\end{array}$ & $\begin{array}{l}212 \\
229 \\
327 \\
366 \\
523\end{array}$ & $\begin{array}{l}228 \\
261 \\
234 \\
222 \\
211\end{array}$ & $\begin{array}{l}323 \\
294 \\
280 \\
273 \\
295\end{array}$ & $\begin{array}{l}220 \\
211 \\
204 \\
212 \\
212\end{array}$ & $\begin{array}{l}448 \\
339 \\
288 \\
238 \\
206\end{array}$ & $\begin{array}{r}106 \\
102 \\
137 \\
108 \\
99\end{array}$ & $\begin{array}{l}70 \\
69 \\
68 \\
75 \\
69\end{array}$ & $\begin{array}{l}61 \\
57 \\
61 \\
89 \\
67\end{array}$ \\
\hline $\begin{array}{r}6 \\
7 \\
8 \\
9 \\
10\end{array}$ & $\begin{array}{l}183 \\
152 \\
144 \\
214 \\
734\end{array}$ & $\begin{array}{l}173 \\
143 \\
132 \\
132 \\
142\end{array}$ & $\begin{array}{l}283 \\
239 \\
212 \\
192 \\
183\end{array}$ & $\begin{array}{l}379 \\
345 \\
313 \\
293 \\
275\end{array}$ & $\begin{array}{r}912 \\
1030 \\
583 \\
450 \\
382\end{array}$ & $\begin{array}{l}221 \\
217 \\
198 \\
194 \\
188\end{array}$ & $\begin{array}{l}213 \\
258 \\
257 \\
257 \\
238\end{array}$ & $\begin{array}{l}218 \\
197 \\
184 \\
180 \\
177\end{array}$ & $\begin{array}{l}187 \\
174 \\
166 \\
159 \\
153\end{array}$ & $\begin{array}{r}96 \\
91 \\
195 \\
139 \\
174\end{array}$ & $\begin{array}{l}84 \\
81 \\
76 \\
80 \\
76\end{array}$ & $\begin{array}{l}60 \\
58 \\
55 \\
55 \\
55\end{array}$ \\
\hline $\begin{array}{l}11 \\
12 \\
13 \\
14 \\
15\end{array}$ & $\begin{array}{l}513 \\
330 \\
252 \\
211 \\
185\end{array}$ & $\begin{array}{l}132 \\
125 \\
120 \\
121 \\
117\end{array}$ & $\begin{array}{l}173 \\
166 \\
159 \\
147 \\
418\end{array}$ & $\begin{array}{l}418 \\
602 \\
411 \\
346 \\
350\end{array}$ & $\begin{array}{l}322 \\
281 \\
283 \\
327 \\
281\end{array}$ & $\begin{array}{r}184 \\
218 \\
1590 \\
1490 \\
888\end{array}$ & $\begin{array}{l}230 \\
229 \\
454 \\
686 \\
597\end{array}$ & $\begin{array}{l}172 \\
172 \\
171 \\
175 \\
170\end{array}$ & $\begin{array}{l}151 \\
164 \\
145 \\
139 \\
134\end{array}$ & $\begin{array}{l}152 \\
147 \\
126 \\
108 \\
101\end{array}$ & $\begin{array}{l}73 \\
70 \\
68 \\
80 \\
86\end{array}$ & $\begin{array}{l}54 \\
57 \\
60 \\
54 \\
51\end{array}$ \\
\hline $\begin{array}{l}16 \\
17 \\
18 \\
19 \\
20\end{array}$ & $\begin{array}{l}166 \\
156 \\
339 \\
280 \\
213\end{array}$ & $\begin{array}{l}117 \\
115 \\
112 \\
112 \\
109\end{array}$ & $\begin{array}{r}403 \\
298 \\
1020 \\
1190 \\
593\end{array}$ & $\begin{array}{l}509 \\
524 \\
398 \\
346 \\
335\end{array}$ & $\begin{array}{l}246 \\
241 \\
391 \\
825 \\
708\end{array}$ & $\begin{array}{l}602 \\
495 \\
751 \\
516 \\
417\end{array}$ & $\begin{array}{l}453 \\
372 \\
324 \\
431 \\
503\end{array}$ & $\begin{array}{l}160 \\
164 \\
484 \\
360 \\
245\end{array}$ & $\begin{array}{l}144 \\
136 \\
129 \\
124 \\
120\end{array}$ & $\begin{array}{l}98 \\
97 \\
92 \\
89 \\
87\end{array}$ & $\begin{array}{r}72 \\
85 \\
124 \\
95 \\
101\end{array}$ & $\begin{array}{l}50 \\
49 \\
48 \\
49 \\
49\end{array}$ \\
\hline $\begin{array}{l}21 \\
22 \\
23 \\
24 \\
25\end{array}$ & $\begin{array}{l}186 \\
203 \\
206 \\
184 \\
165\end{array}$ & $\begin{array}{l}110 \\
184 \\
215 \\
170 \\
148\end{array}$ & $\begin{array}{r}661 \\
1070 \\
677 \\
480 \\
376\end{array}$ & $\begin{array}{r}323 \\
e 270 \\
e 240 \\
e 220 \\
e 205\end{array}$ & $\begin{array}{l}480 \\
391 \\
324 \\
295 \\
265\end{array}$ & $\begin{array}{r}371 \\
1120 \\
2000 \\
830 \\
570\end{array}$ & $\begin{array}{l}387 \\
339 \\
306 \\
309 \\
271\end{array}$ & $\begin{array}{l}205 \\
220 \\
221 \\
190 \\
175\end{array}$ & $\begin{array}{l}118 \\
120 \\
124 \\
122 \\
126\end{array}$ & $\begin{array}{l}86 \\
85 \\
82 \\
80 \\
78\end{array}$ & $\begin{array}{l}84 \\
77 \\
73 \\
68 \\
66\end{array}$ & $\begin{array}{l}49 \\
49 \\
62 \\
53 \\
53\end{array}$ \\
\hline $\begin{array}{l}26 \\
27 \\
28 \\
29 \\
30 \\
31\end{array}$ & $\begin{array}{l}154 \\
146 \\
141 \\
135 \\
132 \\
129\end{array}$ & $\begin{array}{l}136 \\
243 \\
691 \\
498 \\
318 \\
\ldots\end{array}$ & $\begin{array}{r}313 \\
273 \\
262 \\
1060 \\
5240 \\
3650\end{array}$ & $\begin{array}{r}\text { e2 } 00 \\
\text { e1 } 90 \\
\text { e1 } 80 \\
\text { e1 } 90 \\
276 \\
240\end{array}$ & $\begin{array}{l}246 \\
238 \\
229 \\
\ldots \\
\ldots \\
\ldots\end{array}$ & $\begin{array}{l}725 \\
719 \\
596 \\
461 \\
388 \\
345\end{array}$ & $\begin{array}{l}271 \\
263 \\
249 \\
243 \\
230 \\
\ldots\end{array}$ & $\begin{array}{r}186 \\
174 \\
160 \\
433 \\
2730 \\
575\end{array}$ & $\begin{array}{l}150 \\
123 \\
116 \\
112 \\
109 \\
\ldots\end{array}$ & $\begin{array}{l}76 \\
74 \\
74 \\
74 \\
76 \\
73\end{array}$ & $\begin{array}{l}64 \\
63 \\
63 \\
66 \\
67 \\
64\end{array}$ & $\begin{array}{r}51 \\
48 \\
49 \\
49 \\
48 \\
\cdots\end{array}$ \\
\hline $\begin{array}{l}\text { IOTAL } \\
\text { MEAN } \\
\text { MAX } \\
\text { MIN } \\
\text { CF SM } \\
\text { IN. }\end{array}$ & $\begin{array}{r}6790 \\
219 \\
734 \\
99 \\
1.19 \\
1.37\end{array}$ & $\begin{array}{r}5251 \\
175 \\
691 \\
109 \\
.95 \\
1.06\end{array}$ & $\begin{array}{r}21768 \\
702 \\
5240 \\
147 \\
3.82 \\
4.40\end{array}$ & $\begin{array}{r}11935 \\
385 \\
1350 \\
180 \\
2.09 \\
2.41\end{array}$ & $\begin{array}{r}11387 \\
407 \\
1030 \\
212 \\
2.21 \\
2.30\end{array}$ & $\begin{array}{r}17450 \\
563 \\
2000 \\
184 \\
3.06 \\
3.53\end{array}$ & $\begin{array}{c}9895 \\
330 \\
686 \\
229 \\
1.79 \\
2.00\end{array}$ & $\begin{array}{r}9557 \\
308 \\
2730 \\
160 \\
1.68 \\
1.93\end{array}$ & $\begin{array}{c}4964 \\
165 \\
448 \\
109 \\
.90 \\
1.00\end{array}$ & $\begin{array}{c}3202 \\
103 \\
195 \\
73 \\
.56 \\
.65\end{array}$ & $\begin{array}{c}2357 \\
76.0 \\
124 \\
63 \\
.41 \\
.48\end{array}$ & $\begin{array}{r}1650 \\
55.0 \\
89 \\
48 \\
.30 \\
.33\end{array}$ \\
\hline
\end{tabular}

e Estimated

SIATISIICS OF MONIHLY MEAN DATA FOR WAIER YEARS 1951 - 1991, BY WATER YEAR (WY)

\begin{tabular}{|c|c|c|c|c|c|c|c|c|c|c|c|c|}
\hline $\begin{array}{l}\text { MEAN } \\
\text { MAX } \\
\text { (WY) } \\
\text { MIN } \\
(W Y)\end{array}$ & $\begin{array}{r}92.6 \\
579 \\
1987 \\
34.2 \\
1964\end{array}$ & $\begin{array}{r}151 \\
586 \\
1973 \\
38.6 \\
1977\end{array}$ & $\begin{array}{r}222 \\
702 \\
1991 \\
33.2 \\
1977\end{array}$ & $\begin{array}{r}225 \\
619 \\
1959 \\
27.9 \\
1977\end{array}$ & $\begin{array}{r}302 \\
741 \\
1951 \\
59.6 \\
1964\end{array}$ & $\begin{array}{r}342 \\
967 \\
1963 \\
84.2 \\
1981\end{array}$ & $\begin{array}{r}325 \\
829 \\
1964 \\
97.8 \\
1971\end{array}$ & $\begin{array}{r}245 \\
582 \\
1990 \\
81.5 \\
1976\end{array}$ & $\begin{array}{r}190 \\
848 \\
1958 \\
48.1 \\
1988\end{array}$ & $\begin{array}{c}144 \\
581 \\
1979 \\
32.5 \\
1977\end{array}$ & $\begin{array}{r}107 \\
649 \\
1979 \\
30.5 \\
1988\end{array}$ & $\begin{array}{r}16.1 \\
400 \\
1989 \\
24.4 \\
1954\end{array}$ \\
\hline
\end{tabular}

SUMMARY SIAIISTICS

ANMUAL TOIAL

ANMUAL MEAN

HIGHEST ANMUAL MEAN

LOWEST ANNUAL MEAN

HIGHEST DAILY MEAN

LOWEST DAILY MEAH

ANNUAL SEVEN-DAY MINIMUM

INSTANIANEOUS PEAK FLOW

INSTANTANEOUS PEAK STAGE

ANMUAL RUNOFF (CFSM)

ANNUAL RUNOFF (INCHES)

10 PERCENT EXCEEDS

50 PERCENT EXCEEDS

90 PERCENT EXCEEDS
FOR 1990 CALENUAR YEAR

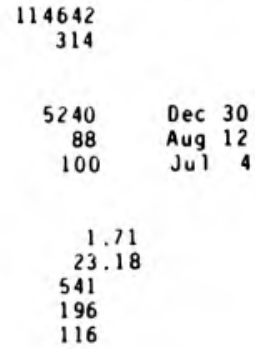

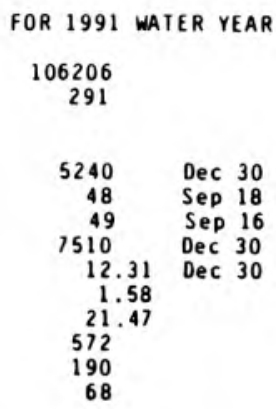

WAIER YEARS 1951 - 1991

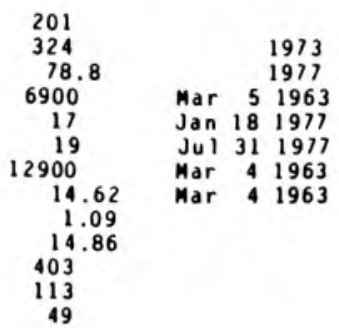




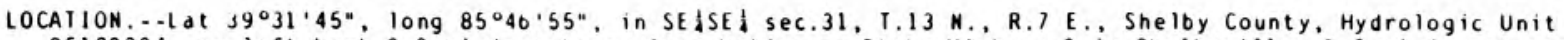
05120204 , on left bank 0.2 mi downstream from bridge on State Highway 9 in Shelbyville, 0.6 a downstream fro Little Blue River, and at ile 23.9 .

DRAINAGE AREA. . -

PERIOD OF RECORD.--September 1943 to current year. Prior to October 1961, published as Blue River dt Shelbyville. REVISED RECORDS.--WSP 1505: 1944. WSP 1909: 1959(M). WSP 2109: Draindge drea. WDR IN-79-1: 19/5.

GAGE.--Water-stage recorder. Datu of gage is $737.67 \mathrm{ft}$ above National Geodetic Vertical Datua of 1929 . Prior to 0ct. 1, 1953, nonrecording gage at bridge 0.2 i upstrean at datum $3.5 \mathrm{ft} \mathrm{higher}$.

REMARKS. - Records good except for estimated daily discharges, which are poor.

EXTREMES OUTSIDE PERIOD OF RECORD. - - Flood in March 1913 reached a stage of about $20.2 \mathrm{ft} f \mathrm{from} f \mathrm{floodmarks.}$

DISCHARGE, CUBIC FEEI PER SECONO, WATER YEAR OCIOBER 1990 TO SEPTEMBER 1991 DAILIY MEAN VALUES

\begin{tabular}{|c|c|c|c|c|c|c|c|c|c|c|c|c|}
\hline DAY & $O C \mathrm{~T}$ & NOV & DEC & JAN & FEB & MAR & $A P R$ & MAY & JUN & JUL & AUG & SEP \\
\hline $\begin{array}{l}1 \\
2 \\
3 \\
4 \\
5\end{array}$ & $\begin{array}{l}161 \\
161 \\
161 \\
364 \\
595\end{array}$ & $\begin{array}{l}228 \\
222 \\
215 \\
213 \\
223\end{array}$ & $\begin{array}{r}692 \\
545 \\
914 \\
1600 \\
980\end{array}$ & $\begin{array}{l}6410 \\
2370 \\
1570 \\
1250 \\
1080\end{array}$ & $\begin{array}{r}544 \\
566 \\
765 \\
869 \\
1040\end{array}$ & $\begin{array}{l}553 \\
584 \\
566 \\
527 \\
505\end{array}$ & $\begin{array}{l}759 \\
679 \\
624 \\
589 \\
598\end{array}$ & $\begin{array}{l}407 \\
388 \\
366 \\
360 \\
372\end{array}$ & $\begin{array}{l}868 \\
653 \\
564 \\
460 \\
379\end{array}$ & $\begin{array}{l}163 \\
156 \\
196 \\
385 \\
209\end{array}$ & $\begin{array}{l}89 \\
83 \\
83 \\
84 \\
87\end{array}$ & $\begin{array}{r}87 \\
81 \\
78 \\
102 \\
112\end{array}$ \\
\hline $\begin{array}{r}6 \\
7 \\
8 \\
9 \\
10\end{array}$ & $\begin{array}{r}380 \\
290 \\
254 \\
283 \\
1180\end{array}$ & $\begin{array}{l}289 \\
277 \\
249 \\
238 \\
248\end{array}$ & $\begin{array}{l}720 \\
580 \\
497 \\
439 \\
405\end{array}$ & $\begin{array}{r}1040 \\
969 \\
876 \\
807 \\
756\end{array}$ & $\begin{array}{l}2110 \\
2730 \\
1850 \\
1360 \\
1100\end{array}$ & $\begin{array}{l}506 \\
517 \\
476 \\
456 \\
444\end{array}$ & $\begin{array}{l}578 \\
539 \\
517 \\
521 \\
486\end{array}$ & $\begin{array}{l}388 \\
355 \\
328 \\
311 \\
306\end{array}$ & $\begin{array}{l}335 \\
307 \\
290 \\
275 \\
261\end{array}$ & $\begin{array}{l}171 \\
154 \\
214 \\
337 \\
254\end{array}$ & $\begin{array}{r}103 \\
112 \\
102 \\
102 \\
99\end{array}$ & $\begin{array}{l}91 \\
82 \\
77 \\
74 \\
75\end{array}$ \\
\hline $\begin{array}{l}11 \\
12 \\
13 \\
14 \\
15\end{array}$ & $\begin{array}{r}1550 \\
901 \\
630 \\
491 \\
401\end{array}$ & $\begin{array}{l}244 \\
229 \\
218 \\
213 \\
207\end{array}$ & $\begin{array}{l}376 \\
358 \\
340 \\
312 \\
567\end{array}$ & $\begin{array}{r}981 \\
1720 \\
1310 \\
1040 \\
1010\end{array}$ & $\begin{array}{l}914 \\
782 \\
740 \\
793 \\
745\end{array}$ & $\begin{array}{r}429 \\
483 \\
2440 \\
4010 \\
2590\end{array}$ & $\begin{array}{r}445 \\
430 \\
600 \\
1630 \\
1440\end{array}$ & $\begin{array}{l}298 \\
291 \\
296 \\
316 \\
326\end{array}$ & $\begin{array}{l}256 \\
268 \\
252 \\
234 \\
223\end{array}$ & $\begin{array}{l}300 \\
250 \\
257 \\
199 \\
173\end{array}$ & $\begin{array}{l}91 \\
86 \\
81 \\
79 \\
96\end{array}$ & $\begin{array}{r}73 \\
88 \\
234 \\
142 \\
102\end{array}$ \\
\hline $\begin{array}{l}16 \\
17 \\
18 \\
19 \\
20\end{array}$ & $\begin{array}{l}334 \\
304 \\
536 \\
733 \\
510\end{array}$ & $\begin{array}{l}205 \\
203 \\
197 \\
194 \\
192\end{array}$ & $\begin{array}{r}998 \\
736 \\
1910 \\
3250 \\
1980\end{array}$ & $\begin{array}{r}1260 \\
1440 \\
1180 \\
1010 \\
917\end{array}$ & $\begin{array}{r}e 580 \\
e 570 \\
716 \\
1740 \\
1860\end{array}$ & $\begin{array}{l}1670 \\
1310 \\
1900 \\
1540 \\
1150\end{array}$ & $\begin{array}{r}1200 \\
883 \\
717 \\
846 \\
1260\end{array}$ & $\begin{array}{r}296 \\
310 \\
824 \\
1070 \\
641\end{array}$ & $\begin{array}{l}224 \\
224 \\
209 \\
197 \\
189\end{array}$ & $\begin{array}{l}158 \\
149 \\
142 \\
135 \\
130\end{array}$ & $\begin{array}{r}96 \\
87 \\
130 \\
120 \\
128\end{array}$ & $\begin{array}{l}88 \\
80 \\
79 \\
78 \\
77\end{array}$ \\
\hline $\begin{array}{l}21 \\
22 \\
23 \\
24 \\
25\end{array}$ & $\begin{array}{l}412 \\
383 \\
431 \\
391 \\
340\end{array}$ & $\begin{array}{l}187 \\
256 \\
490 \\
394 \\
317\end{array}$ & $\begin{array}{r}1470 \\
2420 \\
1890 \\
1350 \\
979\end{array}$ & $\begin{array}{r}878 \\
\text { e} 720 \\
\text { e } 660 \\
\text { e } 620 \\
\text { e } 580\end{array}$ & $\begin{array}{r}1350 \\
1050 \\
865 \\
765 \\
692\end{array}$ & $\begin{array}{r}946 \\
1770 \\
4230 \\
3720 \\
1780\end{array}$ & $\begin{array}{l}945 \\
767 \\
665 \\
632 \\
561\end{array}$ & $\begin{array}{l}474 \\
397 \\
590 \\
448 \\
370\end{array}$ & $\begin{array}{l}183 \\
179 \\
184 \\
178 \\
182\end{array}$ & $\begin{array}{l}124 \\
120 \\
117 \\
113 \\
109\end{array}$ & $\begin{array}{r}129 \\
111 \\
100 \\
92 \\
86\end{array}$ & $\begin{array}{l}76 \\
79 \\
87 \\
96 \\
86\end{array}$ \\
\hline $\begin{array}{l}26 \\
27 \\
28 \\
29 \\
30 \\
31\end{array}$ & $\begin{array}{l}308 \\
283 \\
271 \\
253 \\
242 \\
236\end{array}$ & $\begin{array}{r}275 \\
439 \\
1380 \\
1610 \\
969 \\
-\cdots\end{array}$ & $\begin{array}{r}175 \\
645 \\
598 \\
1430 \\
1200 \\
11800\end{array}$ & $\begin{array}{r}\text { e } 550 \\
\text { e } 520 \\
\text { e } 500 \\
\text { e510 } \\
\text { e580 } \\
627\end{array}$ & $\begin{array}{l}632 \\
598 \\
570 \\
\ldots . \\
\ldots \\
\ldots\end{array}$ & $\begin{array}{r}1820 \\
2510 \\
1840 \\
1340 \\
1030 \\
846\end{array}$ & $\begin{array}{l}523 \\
513 \\
484 \\
464 \\
438 \\
\cdots\end{array}$ & $\begin{array}{r}342 \\
339 \\
301 \\
279 \\
1720 \\
2790\end{array}$ & $\begin{array}{l}218 \\
195 \\
178 \\
167 \\
162 \\
\cdots\end{array}$ & $\begin{array}{r}104 \\
98 \\
93 \\
93 \\
93 \\
93\end{array}$ & $\begin{array}{l}82 \\
83 \\
84 \\
85 \\
91 \\
96\end{array}$ & $\begin{array}{l}84 \\
79 \\
77 \\
75 \\
76 \\
\cdots-\end{array}$ \\
\hline $\begin{array}{l}\text { IOIAL } \\
\text { MEAN } \\
\text { MAX } \\
\text { MIN } \\
\text { CF SM } \\
\text { IN. }\end{array}$ & $\begin{array}{r}13775 \\
444 \\
1550 \\
161 \\
1.06 \\
1.22\end{array}$ & $\begin{array}{r}10821 \\
361 \\
1610 \\
187 \\
.86 \\
.96\end{array}$ & $\begin{array}{r}48756 \\
1573 \\
11800 \\
312 \\
3.74 \\
4.31\end{array}$ & $\begin{array}{r}35761 \\
1154 \\
6430 \\
500 \\
2.74 \\
3.16\end{array}$ & $\begin{array}{r}28896 \\
1032 \\
2730 \\
544 \\
2.45 \\
2.55\end{array}$ & $\begin{array}{r}44488 \\
1435 \\
4230 \\
429 \\
3.41 \\
3.93\end{array}$ & $\begin{array}{r}21333 \\
711 \\
1630 \\
430 \\
1.69 \\
1.89\end{array}$ & $\begin{array}{r}16299 \\
526 \\
2790 \\
279 \\
1.25 \\
1.44\end{array}$ & $\begin{array}{c}8494 \\
283 \\
868 \\
162 \\
.67 \\
.75\end{array}$ & $\begin{array}{c}5289 \\
171 \\
385 \\
93 \\
.41 \\
.47\end{array}$ & $\begin{array}{c}2977 \\
96.0 \\
130 \\
79 \\
.23 \\
.26\end{array}$ & $\begin{array}{c}2715 \\
90.5 \\
234 \\
73 \\
.21 \\
.24\end{array}$ \\
\hline
\end{tabular}

e Estimated

SIATISIICS OF MONTHLY MEAN DATA FUR WAIER YEARS 1944 - 1991, BY WATER YEAR (WY)

$\begin{array}{lrr}\text { MEAN } & 167 & 325 \\ \text { MAX } & 1199 & 1423 \\ \text { (WY) } & 1987 & 1973 \\ \text { MIN } & 41.7 & 52.5 \\ \text { (WY) } & 1964 & 1954\end{array}$

$\begin{array}{rr}497 & 045 \\ 1575 & 4319 \\ 1967 & 1950 \\ 52.3 & 38.3 \\ 1964 & 1917\end{array}$

145
2208
1950
92.0
1964

$$
\begin{array}{r}
828 \\
1970 \\
1963 \\
204
\end{array}
$$$$
\begin{array}{r}
781 \\
1973 \\
1964
\end{array}
$$

567
1611
1968
149

183

1971

1976

419
1574
1958
81.2
1988

$\begin{array}{rrr}316 & 207 & 145 \\ 1363 & 1404 & 953 \\ 1979 & 1979 & 1989 \\ 56.1 & 46.4 & 43.2 \\ 1954 & 1988 & 1953\end{array}$

SUMMARY SIATISIICS

ANMUAL TOTAL

ANNUAL MEAN

HIGHESI ANNUAL MEAM

LOWEST ANNUAL MEAM

HIGHESI DAILY MEAN

LOWEST DAILY MEAN

ANNUAL SEVEM-DAY MINIMUM

INSTANTANE OUS PEAK FLOW

INSTANIANEOUS PEAK STAGE

ANNUAL RUNOFF (CFSM)

ANNUAL RUNOFF (INCHES)

10 PERCENT EXCEEDS

50 PERCENT EXCEEDS

90 PERCENT EXCEEDS

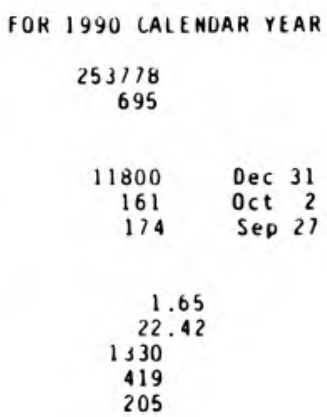

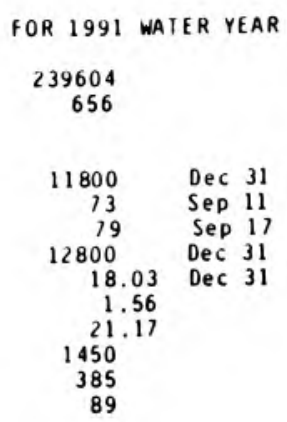

WATER YEARS 1944 - 1991

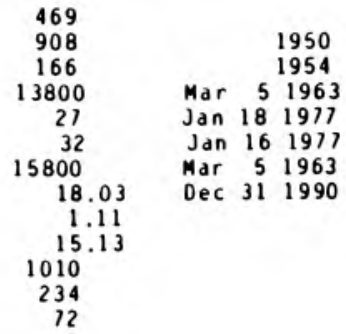




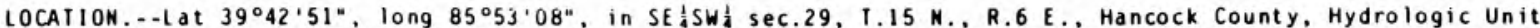
05120204 , on left bank $10 \mathrm{ft}$ downstream from bridge on County Road 450 West, 0.5 mi south of New Palestine, 3.1 i upstrean from ${ }_{2}$ ittle Sugar Creek, and 37.3 i upstrea from nouth.

DRAI NAGE AREA. $-93.9=i^{2}$

PERIOD OF RECORD.--October 1967 to current year.

REVISED RE CORDS.- - WDR IN-76-1: 1975.

GAGE. - Water-stage recorder. Datum of gage is $786.00 \mathrm{ft}$ above National Geodetic Vertical Datum of 1929.

REMARKS. - Records good except for estimated daily discharges, which are poor.

DISCHARGE, CUBIC FEET PER SECOND, WATER YEAR OCTOBER 1990 TO SEPTEMBER 1991 DAI IY MEAM VALUES

\begin{tabular}{|c|c|c|c|c|c|c|c|c|c|c|c|c|}
\hline DAY & $O C \mathrm{~T}$ & NOV & DE C & JAM & FEB & MAR & APR & MAY & JUN & JUL & AUG & SEP \\
\hline $\begin{array}{l}1 \\
2 \\
3 \\
4 \\
5\end{array}$ & $\begin{array}{r}23 \\
22 \\
21 \\
203 \\
272\end{array}$ & $\begin{array}{l}42 \\
43 \\
40 \\
38 \\
45\end{array}$ & $\begin{array}{l}185 \\
139 \\
261 \\
343 \\
235\end{array}$ & $\begin{array}{r}1250 \\
469 \\
295 \\
227 \\
191\end{array}$ & $\begin{array}{l}e 95 \\
105 \\
149 \\
199 \\
300\end{array}$ & $\begin{array}{l}88 \\
93 \\
90 \\
82 \\
76\end{array}$ & $\begin{array}{r}114 \\
100 \\
90 \\
88 \\
96\end{array}$ & $\begin{array}{l}57 \\
53 \\
51 \\
51 \\
52\end{array}$ & $\begin{array}{r}367 \\
124 \\
126 \\
94 \\
66\end{array}$ & $\begin{array}{l}67 \\
23 \\
32 \\
45 \\
20\end{array}$ & $\begin{array}{l}6.2 \\
5.8 \\
5.4 \\
5.4 \\
5.7\end{array}$ & $\begin{array}{l}3.4 \\
3.1 \\
2.9 \\
3.1 \\
4.8\end{array}$ \\
\hline $\begin{array}{r}6 \\
7 \\
8 \\
9 \\
10\end{array}$ & $\begin{array}{r}160 \\
98 \\
74 \\
74 \\
304\end{array}$ & $\begin{array}{l}61 \\
74 \\
56 \\
50 \\
48\end{array}$ & $\begin{array}{r}167 \\
135 \\
114 \\
102 \\
92\end{array}$ & $\begin{array}{l}171 \\
153 \\
136 \\
123 \\
114\end{array}$ & $\begin{array}{l}600 \\
670 \\
528 \\
311 \\
236\end{array}$ & $\begin{array}{l}77 \\
74 \\
67 \\
62 \\
60\end{array}$ & $\begin{array}{l}98 \\
92 \\
88 \\
91 \\
82\end{array}$ & $\begin{array}{l}55 \\
51 \\
46 \\
43 \\
41\end{array}$ & $\begin{array}{l}53 \\
45 \\
41 \\
37 \\
35\end{array}$ & $\begin{array}{l}15 \\
13 \\
33 \\
23 \\
40\end{array}$ & $\begin{array}{l}9.3 \\
9.0 \\
7.6 \\
7.6 \\
7.2\end{array}$ & $\begin{array}{l}4.5 \\
3.7 \\
3.2 \\
2.7 \\
2.6\end{array}$ \\
\hline $\begin{array}{l}11 \\
12 \\
13 \\
14 \\
15\end{array}$ & $\begin{array}{l}445 \\
359 \\
206 \\
146 \\
109\end{array}$ & $\begin{array}{l}46 \\
44 \\
40 \\
38 \\
36\end{array}$ & $\begin{array}{r}85 \\
80 \\
75 \\
69 \\
152\end{array}$ & $\begin{array}{l}186 \\
326 \\
264 \\
194 \\
200\end{array}$ & $\begin{array}{r}189 \\
154 \\
140 \\
144 \\
e 125\end{array}$ & $\begin{array}{r}58 \\
103 \\
813 \\
840 \\
706\end{array}$ & $\begin{array}{r}72 \\
66 \\
187 \\
329 \\
311\end{array}$ & $\begin{array}{l}40 \\
39 \\
38 \\
37 \\
36\end{array}$ & $\begin{array}{l}33 \\
35 \\
33 \\
29 \\
27\end{array}$ & $\begin{array}{l}30 \\
39 \\
29 \\
21 \\
17\end{array}$ & $\begin{array}{l}6.6 \\
6.1 \\
5.4 \\
5.1 \\
5.0\end{array}$ & $\begin{array}{c}2.6 \\
6.5 \\
35 \\
13 \\
1.9\end{array}$ \\
\hline $\begin{array}{l}16 \\
17 \\
18 \\
19 \\
20\end{array}$ & $\begin{array}{r}85 \\
71 \\
117 \\
206 \\
143\end{array}$ & $\begin{array}{l}35 \\
35 \\
35 \\
34 \\
32\end{array}$ & $\begin{array}{l}270 \\
220 \\
458 \\
615 \\
528\end{array}$ & $\begin{array}{l}282 \\
344 \\
268 \\
204 \\
182\end{array}$ & $\begin{array}{r}\text { e105 } \\
\text { e94 } \\
155 \\
357 \\
412\end{array}$ & $\begin{array}{l}356 \\
280 \\
390 \\
324 \\
229\end{array}$ & $\begin{array}{l}248 \\
174 \\
133 \\
221 \\
276\end{array}$ & $\begin{array}{r}35 \\
117 \\
266 \\
407 \\
221\end{array}$ & $\begin{array}{l}27 \\
26 \\
24 \\
22 \\
20\end{array}$ & $\begin{array}{l}15 \\
13 \\
12 \\
11 \\
10\end{array}$ & $\begin{array}{l}4.9 \\
5.6 \\
9.1 \\
8.6 \\
8.1\end{array}$ & $\begin{array}{l}5.5 \\
5.0 \\
4.6 \\
4.1 \\
3.9\end{array}$ \\
\hline $\begin{array}{l}21 \\
22 \\
23 \\
24 \\
25\end{array}$ & $\begin{array}{l}98 \\
88 \\
91 \\
90 \\
75\end{array}$ & $\begin{array}{l}32 \\
59 \\
77 \\
79 \\
62\end{array}$ & $\begin{array}{l}409 \\
566 \\
545 \\
303 \\
213\end{array}$ & $\begin{array}{r}172 \\
\text { el } 50 \\
\text { el } 30 \\
\text { el1 } \\
\text { e } 98\end{array}$ & $\begin{array}{l}294 \\
216 \\
169 \\
142 \\
123\end{array}$ & $\begin{array}{l}186 \\
454 \\
785 \\
669 \\
345\end{array}$ & $\begin{array}{r}203 \\
148 \\
117 \\
101 \\
85\end{array}$ & $\begin{array}{r}129 \\
96 \\
123 \\
94 \\
75\end{array}$ & $\begin{array}{l}19 \\
19 \\
21 \\
23 \\
21\end{array}$ & $\begin{array}{l}10 \\
17 \\
18 \\
11 \\
9.7\end{array}$ & $\begin{array}{l}7.0 \\
6.3 \\
5.4 \\
4.7 \\
4.3\end{array}$ & $\begin{array}{l}3.8 \\
4.7 \\
6.4 \\
6.5 \\
5.7\end{array}$ \\
\hline $\begin{array}{l}26 \\
27 \\
28 \\
29 \\
30 \\
31\end{array}$ & $\begin{array}{l}65 \\
59 \\
54 \\
50 \\
46 \\
43\end{array}$ & $\begin{array}{r}52 \\
83 \\
296 \\
380 \\
272 \\
\cdots-\end{array}$ & $\begin{array}{r}165 \\
\text { e140 } \\
\text { e } 125 \\
390 \\
1850 \\
1870\end{array}$ & $\begin{array}{r}\text { e } 88 \\
\text { e } 82 \\
\text { e } 80 \\
\text { e } 82 \\
\text { e } 94 \\
\text { el1 } 10\end{array}$ & $\begin{array}{r}108 \\
100 \\
93 \\
\cdots \\
\cdots \\
\cdots\end{array}$ & $\begin{array}{l}356 \\
395 \\
282 \\
206 \\
158 \\
128\end{array}$ & $\begin{array}{l}80 \\
75 \\
71 \\
69 \\
63 \\
\cdots\end{array}$ & $\begin{array}{r}66 \\
58 \\
51 \\
47 \\
137 \\
486\end{array}$ & $\begin{array}{l}18 \\
17 \\
16 \\
14 \\
16 \\
\cdots\end{array}$ & $\begin{array}{l}8.9 \\
8.0 \\
7.7 \\
7.3 \\
6.8 \\
6.6\end{array}$ & $\begin{array}{l}4.1 \\
3.8 \\
3.7 \\
3.8 \\
4.4 \\
4.1\end{array}$ & $\begin{array}{l}5.7 \\
5.1 \\
4.8 \\
4.4 \\
4.3 \\
\ldots . .\end{array}$ \\
\hline $\begin{array}{l}\text { IOIAL } \\
\text { MEAN } \\
\text { MAX } \\
\text { MIN } \\
\text { CF SM } \\
\text { IN. }\end{array}$ & $\begin{array}{r}3897 \\
126 \\
445 \\
21 \\
1.34 \\
1.54\end{array}$ & $\begin{array}{r}2264 \\
75.5 \\
380 \\
32 \\
.80 \\
.90\end{array}$ & $\begin{array}{r}10901 \\
352 \\
1870 \\
69 \\
3.74 \\
4.32\end{array}$ & $\begin{array}{r}6175 \\
219 \\
1250 \\
80 \\
2.33 \\
2.68\end{array}$ & $\begin{array}{r}6313 \\
225 \\
670 \\
93 \\
2.40 \\
2.50\end{array}$ & $\begin{array}{r}8832 \\
285 \\
840 \\
58 \\
3.03 \\
3.50\end{array}$ & $\begin{array}{r}3968 \\
132 \\
329 \\
63 \\
1.41 \\
1.57\end{array}$ & $\begin{array}{c}3098 \\
99.9 \\
486 \\
35 \\
1.06 \\
1.23\end{array}$ & $\begin{array}{r}1448 \\
48.3 \\
367 \\
14 \\
.51 \\
.57\end{array}$ & $\begin{array}{r}619.0 \\
20.0 \\
67 \\
6.6 \\
.21 \\
.25\end{array}$ & $\begin{array}{c}185.3 \\
5.98 \\
9.3 \\
3.7 \\
.06 \\
.07\end{array}$ & $\begin{array}{r}173.5 \\
5.78 \\
35 \\
2.6 \\
.06 \\
.07\end{array}$ \\
\hline
\end{tabular}

e Estiated

SIATISIICS OF MONTHLY MEAN DATA FOR WATER YEARS 1968 - 1991. BY WATER YEAR (WY)

$\begin{array}{lrrrrrrrrrrrr}\text { MEAN } & 38.9 & 80.1 & 136 & 126 & 183 & 181 & 152 & 116 & 77.4 & 60.9 & 52.0 & 31.2 \\ \text { MAX } & 309 & 328 & 352 & 345 & 439 & 413 & 279 & 321 & 232 & 241 & 306 & 314 \\ \text { (WY) } & 1987 & 1973 & 1991 & 1969 & 1982 & 1978 & 1972 & 1990 & 1973 & 1969 & 1979 & 1989 \\ \text { MIN } & 4.14 & 10.4 & 9.11 & 5.35 & 35.7 & 35.0 & 30.0 & 23.4 & 8.47 & 9.21 & 4.06 & 3.42 \\ \text { (WY) } & 1989 & 1988 & 1977 & 1977 & 1978 & 1981 & 1971 & 1976 & 1988 & 1977 & 1988 & 1983\end{array}$

SUMMARY SIATISIICS

ANNUAL TOIAL

ANNUAL MEAM

HIGHESI ANHUAL MEAN

LOWEST AMNUAL MEAM

HIGHESI DAILY MEAN

LOWEST DAILY MEAN

ANNUAL SEVEN-DAY MINIMUM

INSTANTANE OUS PEAK FLOW

INSTANIANEOUS PEAK SIAGE

ANMUAL RUNOFF (CFSM)

ANHUAL RUMOFF (INCHES)

10 PERCENT EXCEEDS

50 PERCENT EXCEEDS

90 PERCENT EXCEEDS
FOR 1990 CALENDAR YEAR

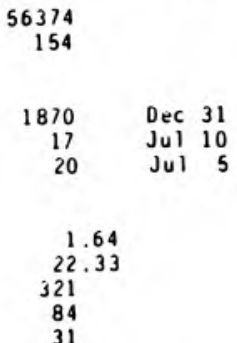

FOR 1991 WAIER YEAR

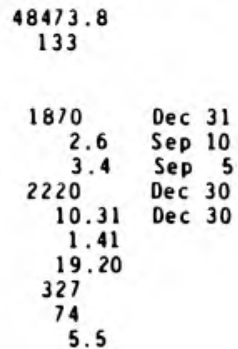

WAIER YEARS 1968 - 1991

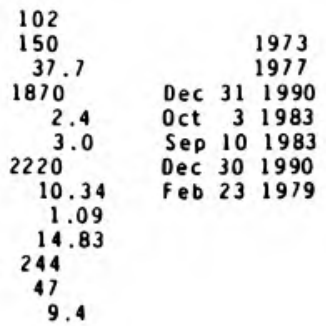


LOCATION. - - Lat $39^{\circ} 39^{\prime} 25^{\prime \prime}$. long $85^{\circ} 57^{\prime} 27^{\circ}$, in NHłsEł sec.15, T.14 N., R.5 E.. Marion County, Hydrologic Unit 05120204 , on left bank $30 \mathrm{ft}$ downstrean frov McGregor Road bridge, $0.5 \bullet 1$ east of Acton, and 4.1 i upstreas

DRAI MAGE AREA. $-78.8 \cdot i^{2}$

PERIOD OF RECORD.--OCtober 1967 to current year.

REVISED RE CORDS.--WDR IN-79-1: 1969 (M).

GAGE.- -Water-stage recorder. Datur of gage is $757.00 \mathrm{ft}$ above Wational Geodetic Vertical Datue of 1929.

REMARKS.--Records good above $20 \mathrm{ft} / \mathrm{s}$ and fair below, except for estiated daily discharges, which are poor. Low flow is affected by regulation.

DISCHARGE, CUBIC FEET PER SECONO, WATER YEAR OCTOBER 1990 TO SEPTEMBER 1991 DAILY MEAM VALUES

\begin{tabular}{|c|c|c|c|c|c|c|c|c|c|c|c|c|}
\hline DAY & $\mathrm{OCT}$ & nOV & DEC & JAN & FEB & MAR & APR & MAY & JUN & JUL & AUG & SEP \\
\hline $\begin{array}{l}1 \\
2 \\
3 \\
4 \\
5\end{array}$ & $\begin{array}{c}8.5 \\
11 \\
8.1 \\
362 \\
171\end{array}$ & $\begin{array}{l}21 \\
20 \\
19 \\
19 \\
46\end{array}$ & $\begin{array}{r}122 \\
87 \\
434 \\
308 \\
154\end{array}$ & $\begin{array}{l}\text { e500 } \\
\text { e250 } \\
\text { e160 } \\
\text { e130 } \\
\text { e112 }\end{array}$ & $\begin{array}{r}52 \\
71 \\
124 \\
128 \\
227\end{array}$ & $\begin{array}{l}50 \\
60 \\
55 \\
48 \\
43\end{array}$ & $\begin{array}{l}71 \\
60 \\
54 \\
54 \\
71\end{array}$ & $\begin{array}{l}40 \\
35 \\
32 \\
34 \\
44\end{array}$ & $\begin{array}{l}22 \\
19 \\
17 \\
15 \\
14\end{array}$ & $\begin{array}{l}9.9 \\
8.5 \\
7.5 \\
6.4 \\
6.3\end{array}$ & $\begin{array}{l}1.8 \\
1.8 \\
2.3 \\
3.5 \\
3.1\end{array}$ & $\begin{array}{l}7.6 \\
6.8 \\
4.8 \\
4.8 \\
5.2\end{array}$ \\
\hline $\begin{array}{r}6 \\
7 \\
8 \\
9 \\
10\end{array}$ & $\begin{array}{r}79 \\
51 \\
49 \\
64 \\
432\end{array}$ & $\begin{array}{l}67 \\
41 \\
30 \\
28 \\
31\end{array}$ & $\begin{array}{r}116 \\
90 \\
75 \\
63 \\
55\end{array}$ & $\begin{array}{l}\text { e96 } \\
\text { e86 } \\
\text { e76 } \\
\text { e70 } \\
\text { e65 }\end{array}$ & $\begin{array}{l}811 \\
849 \\
357 \\
224 \\
158\end{array}$ & $\begin{array}{l}47 \\
50 \\
40 \\
38 \\
36\end{array}$ & $\begin{array}{l}61 \\
54 \\
60 \\
81 \\
60\end{array}$ & $\begin{array}{l}95 \\
59 \\
41 \\
35 \\
33\end{array}$ & $\begin{array}{l}12 \\
11 \\
11 \\
11 \\
10\end{array}$ & $\begin{array}{r}5.8 \\
5.2 \\
5.4 \\
5.3 \\
11\end{array}$ & $\begin{array}{r}5.2 \\
11 \\
7.2 \\
7.0 \\
6.3\end{array}$ & $\begin{array}{l}4.2 \\
3.5 \\
2.8 \\
1.8 \\
1.1\end{array}$ \\
\hline $\begin{array}{l}11 \\
12 \\
13 \\
14 \\
15\end{array}$ & $\begin{array}{r}296 \\
153 \\
96 \\
67 \\
51\end{array}$ & $\begin{array}{l}22 \\
20 \\
21 \\
20 \\
20\end{array}$ & $\begin{array}{r}51 \\
47 \\
43 \\
36 \\
199\end{array}$ & $\begin{array}{l}\text { e320 } \\
\text { e235 } \\
\text { e1 } 85 \\
\text { e1 } 40 \\
\text { e220 }\end{array}$ & $\begin{array}{r}115 \\
90 \\
85 \\
93 \\
78\end{array}$ & $\begin{array}{r}35 \\
191 \\
1720 \\
981 \\
380\end{array}$ & $\begin{array}{r}48 \\
45 \\
240 \\
357 \\
286\end{array}$ & $\begin{array}{l}30 \\
31 \\
31 \\
29 \\
28\end{array}$ & $\begin{array}{l}10 \\
10 \\
10 \\
9.4 \\
9.0\end{array}$ & $\begin{array}{l}15 \\
16 \\
16 \\
9.7 \\
6.9\end{array}$ & $\begin{array}{l}3.7 \\
2.7 \\
2.2 \\
2.1 \\
2.4\end{array}$ & $\begin{array}{l}1.0 \\
2.3 \\
72 \\
21 \\
6.4\end{array}$ \\
\hline $\begin{array}{l}16 \\
17 \\
18 \\
19 \\
20\end{array}$ & $\begin{array}{r}40 \\
34 \\
120 \\
96 \\
62\end{array}$ & $\begin{array}{l}20 \\
20 \\
19 \\
19 \\
18\end{array}$ & $\begin{array}{l}176 \\
138 \\
714 \\
630 \\
275\end{array}$ & $\begin{array}{l}\text { e340 } \\
\text { e240 } \\
\text { e1 } 90 \\
\text { e1 } 40 \\
\text { e1 } 25\end{array}$ & $\begin{array}{r}63 \\
60 \\
135 \\
386 \\
305\end{array}$ & $\begin{array}{l}222 \\
206 \\
510 \\
260 \\
161\end{array}$ & $\begin{array}{r}216 \\
121 \\
88 \\
463 \\
440\end{array}$ & $\begin{array}{r}24 \\
24 \\
74 \\
142 \\
78\end{array}$ & $\begin{array}{l}9.3 \\
9.9 \\
8.9 \\
7.8 \\
7.1\end{array}$ & $\begin{array}{l}5.5 \\
4.7 \\
4.3 \\
4.0 \\
3.8\end{array}$ & $\begin{array}{l}3.1 \\
4.0 \\
8.4 \\
12 \\
12\end{array}$ & $\begin{array}{l}3.0 \\
2.1 \\
1.7 \\
1.4 \\
1.3\end{array}$ \\
\hline $\begin{array}{l}21 \\
22 \\
23 \\
24 \\
25\end{array}$ & $\begin{array}{l}49 \\
57 \\
64 \\
51 \\
41\end{array}$ & $\begin{array}{l}17 \\
86 \\
98 \\
62 \\
47\end{array}$ & $\begin{array}{l}457 \\
599 \\
287 \\
163 \\
114\end{array}$ & $\begin{array}{l}e 100 \\
e 84 \\
e 72 \\
e 62 \\
e 56\end{array}$ & $\begin{array}{r}186 \\
128 \\
95 \\
81 \\
69\end{array}$ & $\begin{array}{r}121 \\
886 \\
1230 \\
385 \\
208\end{array}$ & $\begin{array}{r}203 \\
130 \\
98 \\
86 \\
68\end{array}$ & $\begin{array}{l}46 \\
37 \\
75 \\
57 \\
40\end{array}$ & $\begin{array}{l}6.5 \\
6.2 \\
5.9 \\
5.7 \\
5.7\end{array}$ & $\begin{array}{l}3.5 \\
3.4 \\
3.1 \\
2.8 \\
2.5\end{array}$ & $\begin{array}{l}9.6 \\
7.9 \\
6.3 \\
5.6 \\
5.4\end{array}$ & $\begin{array}{l}1.3 \\
1.3 \\
4.3 \\
6.4 \\
4.9\end{array}$ \\
\hline $\begin{array}{l}26 \\
27 \\
28 \\
29 \\
30 \\
31\end{array}$ & $\begin{array}{l}35 \\
31 \\
28 \\
25 \\
23 \\
22\end{array}$ & $\begin{array}{r}38 \\
161 \\
673 \\
351 \\
181 \\
\cdots\end{array}$ & $\begin{array}{r}89 \\
e 74 \\
e 64 \\
e 450 \\
e 3200 \\
e 1000\end{array}$ & $\begin{array}{r}\text { e52 } \\
\text { e50 } \\
\text { e49 } \\
\text { e54 } \\
87 \\
76\end{array}$ & $\begin{array}{l}61 \\
56 \\
52 \\
\ldots- \\
\ldots- \\
\ldots-\end{array}$ & $\begin{array}{r}494 \\
459 \\
227 \\
141 \\
102 \\
81\end{array}$ & $\begin{array}{c}61 \\
57 \\
52 \\
50 \\
46 \\
-\cdots\end{array}$ & $\begin{array}{l}36 \\
36 \\
27 \\
23 \\
24 \\
25\end{array}$ & $\begin{array}{c}20 \\
17 \\
9.8 \\
7.2 \\
10 \\
\cdots\end{array}$ & $\begin{array}{l}2.3 \\
2.0 \\
1.9 \\
2.1 \\
2.3 \\
1.9\end{array}$ & $\begin{array}{l}4.7 \\
4.8 \\
4.2 \\
3.3 \\
7.8 \\
8.8\end{array}$ & $\begin{array}{l}4.4 \\
3.8 \\
3.5 \\
4.7 \\
5.5 \\
-. .\end{array}$ \\
\hline $\begin{array}{l}\text { TOTAL } \\
\text { MEAN } \\
\text { MAX } \\
\text { MI N } \\
\text { CF SM } \\
\text { IN. }\end{array}$ & $\begin{array}{r}2676.6 \\
86.3 \\
432 \\
8.1 \\
1.10 \\
1.26\end{array}$ & $\begin{array}{r}2235 \\
74.5 \\
673 \\
17 \\
.95 \\
1.06\end{array}$ & $\begin{array}{r}10310 \\
333 \\
3200 \\
36 \\
4.22 \\
4.87\end{array}$ & $\begin{array}{r}4422 \\
143 \\
500 \\
49 \\
1.81 \\
2.09\end{array}$ & $\begin{array}{r}5139 \\
184 \\
849 \\
52 \\
2.33 \\
2.43\end{array}$ & $\begin{array}{r}9467 \\
305 \\
1720 \\
35 \\
3.88 \\
4.47\end{array}$ & $\begin{array}{r}3781 \\
126 \\
463 \\
45 \\
1.60 \\
1.78\end{array}$ & $\begin{array}{c}1365 \\
44.0 \\
142 \\
23 \\
.56 \\
.64\end{array}$ & $\begin{array}{r}327.4 \\
10.9 \\
22 \\
5.7 \\
.14 \\
.15\end{array}$ & $\begin{array}{r}185.0 \\
5.97 \\
16 \\
1.9 \\
.08 \\
.09\end{array}$ & $\begin{array}{r}170.2 \\
5.49 \\
12 \\
1.8 \\
.07 \\
.08\end{array}$ & $\begin{array}{r}194.9 \\
6.50 \\
72 \\
1.0 \\
.08 \\
.09\end{array}$ \\
\hline
\end{tabular}

STATISTICS OF MONTHLY MEAN DATA FOR WATER YEARS 1968 - 1991, BY WATER YEAR (WN)

\begin{tabular}{|c|c|c|c|c|c|c|c|c|c|c|c|c|}
\hline $\begin{array}{l}\text { MEAY } \\
\text { MAX } \\
\text { (WY) } \\
\text { MIN } \\
\text { (WY) }\end{array}$ & $\begin{array}{r}32.7 \\
312 \\
1987 \\
4.08 \\
1969\end{array}$ & $\begin{array}{r}80.6 \\
353 \\
1986 \\
6.90 \\
1972\end{array}$ & $\begin{array}{r}126 \\
333 \\
1991 \\
8.11 \\
1977\end{array}$ & $\begin{array}{r}112 \\
352 \\
1969 \\
4.09 \\
1977\end{array}$ & $\begin{array}{r}155 \\
349 \\
1971 \\
18.8 \\
1978\end{array}$ & $\begin{array}{r}168 \\
347 \\
1978 \\
27.8 \\
1969\end{array}$ & $\begin{array}{r}130 \\
245 \\
1972 \\
18.5 \\
1971\end{array}$ & $\begin{array}{r}108 \\
386 \\
1981 \\
17.4 \\
1976\end{array}$ & $\begin{array}{r}62.2 \\
196 \\
1974 \\
6.04 \\
1988\end{array}$ & $\begin{array}{r}64.3 \\
324 \\
1969 \\
5.97 \\
1991\end{array}$ & $\begin{array}{c}43.2 \\
216 \\
1979 \\
3.74 \\
1983\end{array}$ & $\begin{array}{r}20.5 \\
166 \\
1989 \\
2.42 \\
1983\end{array}$ \\
\hline
\end{tabular}

SUMMARY STATISTICS

AMMUAL TOTAL

AMNUAL MEAN

HIGHEST ANMUAL MEAM

LOWEST ANNUAL MEAN

HIGHEST DAILY MEAN

LOWEST DAILY MEAM

ANMUAL SEVEN-DAY MINIMUM

INSTANTAMEOUS PEAK FLOW

INSTANTANEOUS PEAK STAGE

ANMUAL RUMOFF (CFSM)

ANMUAL RUNOFF (INCHES)

10 PERCENT EXCEEDS

50 PERCENT EXCEEDS

90 PERCENT EXCEEDS

- Estinated
FOR 1990 CALENDAR YEAR
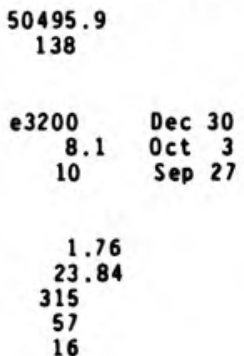

FOR 1991 WATER YEAR

40273.1

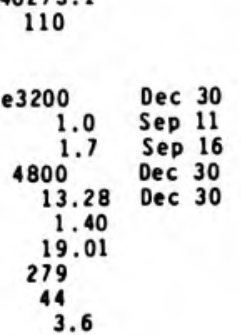

WATER YEARS 1968 - 1991

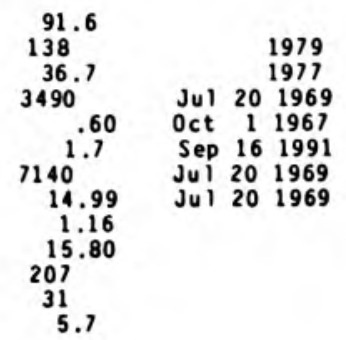


LOCATION, - - Lat $39^{\circ} 25^{\prime} 08^{\prime \prime}$, long $86^{\circ} 00^{\prime} 18^{\circ}$, in SE $\frac{1}{4}$ SWl sec.5, T.11 N., R.5 E., Johnson County, Hydrologic Unit 05120204 , on left bank at upstrea side of county highway bridge, 0.5 i southwest of A®ity, 2.0 apstrean from mouth, and $5 \mathrm{~m}$ northwest of Edinburgh.

DRAI NAGE AREA. -107 : $i^{2}$

PERIOD OF RECORD.--October 1942 to current year. Prior to Deceber 1942 nonthly discharge only, published in WSP 1305. Prior to October 1977, published as "near Edinburg".

REVISED RECORDS.--WSP 1335: 1944. WSP 1909: 1958, WSP 2109: Orainage area.

GAGE.--Water-stage recorder. Datun of gage is $670.20 \mathrm{ft}$ above National Geodetic Vertical Datun of 1929 . Prior to June 30,1955 , nonrecording gage at same site and datun. REMARKS. - Records good, except for Dec. $27-28$; Jan. 5-6, 23-28; Feb. 15-17, which are fair, and estieated period
July 9 to Aug. 5, which are poor.

DISCHARGE, CUBIC FEET PER SECOND, WATER YEAR OCTOBER 1990 TO SEPTEMBER 1991 DAILY MEAN VALUES

\begin{tabular}{|c|c|c|c|c|c|c|c|c|c|c|c|c|}
\hline DAY & $\mathrm{OCT}$ & NOV & DEC & JAN & FEB & MAR & $A P R$ & MAY & JUN & JUL & AUG & SEP \\
\hline $\begin{array}{l}1 \\
2 \\
3 \\
4 \\
5\end{array}$ & $\begin{array}{r}11 \\
11 \\
11 \\
130 \\
84\end{array}$ & $\begin{array}{l}24 \\
23 \\
23 \\
23 \\
31\end{array}$ & $\begin{array}{l}145 \\
106 \\
388 \\
351 \\
172\end{array}$ & $\begin{array}{r}650 \\
363 \\
237 \\
172 \\
\text { e140 }\end{array}$ & $\begin{array}{r}73 \\
97 \\
151 \\
146 \\
213\end{array}$ & $\begin{array}{l}82 \\
98 \\
83 \\
75 \\
65\end{array}$ & $\begin{array}{r}121 \\
109 \\
98 \\
96 \\
107\end{array}$ & $\begin{array}{l}53 \\
50 \\
47 \\
48 \\
55\end{array}$ & $\begin{array}{l}42 \\
37 \\
35 \\
30 \\
27\end{array}$ & $\begin{array}{l}8.8 \\
9.9 \\
15 \\
11 \\
12\end{array}$ & $\begin{array}{l}\text { e } 3.1 \\
\text { e3.0 } \\
\text { e2.8 } \\
\text { e2.7 } \\
\text { e2. } 2.5\end{array}$ & $\begin{array}{l}1.9 \\
1.7 \\
1.8 \\
3.5 \\
3.5\end{array}$ \\
\hline $\begin{array}{r}6 \\
7 \\
8 \\
9 \\
10\end{array}$ & $\begin{array}{r}44 \\
30 \\
26 \\
52 \\
333\end{array}$ & $\begin{array}{l}55 \\
38 \\
30 \\
28 \\
33\end{array}$ & $\begin{array}{r}128 \\
101 \\
87 \\
76 \\
70\end{array}$ & $\begin{array}{l}\text { e160 } \\
177 \\
138 \\
119 \\
109\end{array}$ & $\begin{array}{r}1190 \\
1500 \\
724 \\
534 \\
269\end{array}$ & $\begin{array}{l}71 \\
73 \\
59 \\
57 \\
52\end{array}$ & $\begin{array}{l}96 \\
88 \\
87 \\
97 \\
81\end{array}$ & $\begin{array}{l}71 \\
52 \\
45 \\
43 \\
41\end{array}$ & $\begin{array}{l}24 \\
23 \\
22 \\
21 \\
21\end{array}$ & $\begin{array}{r}10 \\
7.7 \\
6.3 \\
\mathrm{e} 5.4 \\
\mathrm{e} 33\end{array}$ & $\begin{array}{c}17 \\
16 \\
9.6 \\
11 \\
9.0\end{array}$ & $\begin{array}{l}2.9 \\
2.5 \\
2.3 \\
2.1 \\
2.6\end{array}$ \\
\hline $\begin{array}{l}11 \\
12 \\
13 \\
14 \\
15\end{array}$ & $\begin{array}{r}245 \\
121 \\
84 \\
64 \\
51\end{array}$ & $\begin{array}{l}30 \\
26 \\
24 \\
22 \\
22\end{array}$ & $\begin{array}{r}64 \\
60 \\
57 \\
49 \\
158\end{array}$ & $\begin{array}{l}371 \\
681 \\
317 \\
229 \\
272\end{array}$ & $\begin{array}{r}193 \\
156 \\
152 \\
165 \\
e 130\end{array}$ & $\begin{array}{r}49 \\
59 \\
938 \\
722 \\
323\end{array}$ & $\begin{array}{r}70 \\
66 \\
102 \\
245 \\
206\end{array}$ & $\begin{array}{l}48 \\
84 \\
55 \\
48 \\
68\end{array}$ & $\begin{array}{l}35 \\
65 \\
32 \\
24 \\
21\end{array}$ & $\begin{array}{l}\text { e27 } \\
\text { e28 } \\
\text { e16 } \\
\text { e13 } \\
\text { e11 }\end{array}$ & $\begin{array}{l}5.4 \\
4.0 \\
3.7 \\
3.2 \\
3.1\end{array}$ & $\begin{array}{l}2.3 \\
2.3 \\
2.4 \\
2.2 \\
2.1\end{array}$ \\
\hline $\begin{array}{l}16 \\
17 \\
18 \\
19 \\
20\end{array}$ & $\begin{array}{l}41 \\
36 \\
76 \\
72 \\
52\end{array}$ & $\begin{array}{l}22 \\
22 \\
21 \\
21 \\
21\end{array}$ & $\begin{array}{l}156 \\
166 \\
974 \\
947 \\
399\end{array}$ & $\begin{array}{l}488 \\
433 \\
263 \\
203 \\
179\end{array}$ & $\begin{array}{r}\text { e100 } \\
\text { e95 } \\
159 \\
345 \\
383\end{array}$ & $\begin{array}{l}209 \\
222 \\
692 \\
331 \\
214\end{array}$ & $\begin{array}{l}164 \\
124 \\
109 \\
384 \\
426\end{array}$ & $\begin{array}{l}45 \\
40 \\
70 \\
65 \\
45\end{array}$ & $\begin{array}{l}25 \\
30 \\
22 \\
17 \\
15\end{array}$ & $\begin{array}{l}e 9.5 \\
e 8.6 \\
e 7.8 \\
e 7.2 \\
e 6.8\end{array}$ & $\begin{array}{r}3.5 \\
4.1 \\
7.0 \\
11 \\
8.9\end{array}$ & $\begin{array}{l}2.1 \\
2.4 \\
2.7 \\
2.1 \\
2.1\end{array}$ \\
\hline $\begin{array}{l}21 \\
22 \\
23 \\
24 \\
25\end{array}$ & $\begin{array}{l}44 \\
45 \\
53 \\
47 \\
39\end{array}$ & $\begin{array}{l}21 \\
52 \\
90 \\
59 \\
49\end{array}$ & $\begin{array}{l}363 \\
708 \\
365 \\
216 \\
157\end{array}$ & $\begin{array}{l}153 \\
119 \\
\text { e } 98 \\
\text { e } 83 \\
\text { e75 }\end{array}$ & $\begin{array}{l}235 \\
177 \\
142 \\
128 \\
110\end{array}$ & $\begin{array}{r}169 \\
739 \\
1850 \\
603 \\
299\end{array}$ & $\begin{array}{r}198 \\
143 \\
114 \\
97 \\
82\end{array}$ & $\begin{array}{r}39 \\
55 \\
165 \\
197 \\
114\end{array}$ & $\begin{array}{l}14 \\
13 \\
12 \\
12 \\
11\end{array}$ & $\begin{array}{l}\text { e6. } 4 \\
\text { e6.0 } \\
\text { e5.6 } \\
\text { e8.6 } \\
\text { e7.0 }\end{array}$ & $\begin{array}{l}4.9 \\
4.2 \\
3.1 \\
2.5 \\
2.4\end{array}$ & $\begin{array}{l}2.2 \\
1.9 \\
2.6 \\
3.5 \\
3.0\end{array}$ \\
\hline $\begin{array}{l}26 \\
27 \\
28 \\
29 \\
30 \\
31\end{array}$ & $\begin{array}{l}34 \\
31 \\
29 \\
26 \\
26 \\
25\end{array}$ & $\begin{array}{r}39 \\
192 \\
689 \\
444 \\
219 \\
---\end{array}$ & $\begin{array}{r}123 \\
e 100 \\
e 95 \\
606 \\
4530 \\
2640\end{array}$ & $\begin{array}{r}\text { e } 70 \\
\text { e64 } \\
\text { e65 } \\
66 \\
95 \\
82\end{array}$ & $\begin{array}{r}99 \\
91 \\
85 \\
\cdots \\
\cdots \\
\cdots\end{array}$ & $\begin{array}{l}669 \\
752 \\
354 \\
222 \\
162 \\
135\end{array}$ & $\begin{array}{r}77 \\
71 \\
68 \\
68 \\
61 \\
\cdots\end{array}$ & $\begin{array}{l}93 \\
85 \\
65 \\
54 \\
63 \\
52\end{array}$ & $\begin{array}{r}12 \\
11 \\
9.5 \\
8.8 \\
8.2 \\
\ldots .-\end{array}$ & $\begin{array}{l}e 5.2 \\
\text { e } 4.6 \\
\text { e3.9 } \\
\text { e3.6 } \\
\text { e3.4 } \\
\text { e3.3 }\end{array}$ & $\begin{array}{l}2.5 \\
2.6 \\
3.0 \\
2.5 \\
2.2 \\
2.1\end{array}$ & $\begin{array}{l}2.6 \\
2.6 \\
2.5 \\
2.1 \\
1.7 \\
-. .\end{array}$ \\
\hline $\begin{array}{l}\text { TOTAL } \\
\text { MEAN } \\
\text { MAX } \\
\text { MIN } \\
\text { CF SM } \\
\text { IN. }\end{array}$ & $\begin{array}{r}1973 \\
63.6 \\
333 \\
11 \\
.59 \\
.69\end{array}$ & $\begin{array}{r}2393 \\
79.8 \\
689 \\
21 \\
.75 \\
.83\end{array}$ & $\begin{array}{r}14557 \\
470 \\
4530 \\
49 \\
4.39 \\
5.06\end{array}$ & $\begin{array}{r}6671 \\
215 \\
681 \\
64 \\
2.01 \\
2.32\end{array}$ & $\begin{array}{r}7842 \\
280 \\
1500 \\
73 \\
2.62 \\
2.73\end{array}$ & $\begin{array}{r}10428 \\
336 \\
1850 \\
49 \\
3.14 \\
3.63\end{array}$ & $\begin{array}{r}3855 \\
128 \\
426 \\
61 \\
1.20 \\
1.34\end{array}$ & $\begin{array}{r}2055 \\
66.3 \\
197 \\
39 \\
.62 \\
.71\end{array}$ & $\begin{array}{r}679.5 \\
22.6 \\
65 \\
8.2 \\
.21 \\
.24\end{array}$ & $\begin{array}{c}311.6 \\
10.1 \\
33 \\
3.3 \\
.09 \\
.11\end{array}$ & $\begin{array}{c}162.6 \\
5.25 \\
17 \\
2.1 \\
.05 \\
.06\end{array}$ & $\begin{array}{r}72.2 \\
2.41 \\
3.5 \\
1.7 \\
.02 \\
.03\end{array}$ \\
\hline
\end{tabular}

e Estimated

STATISTICS OF MONTHLY MEAN DATA FOR WATER YEARS 1944 - 1991, BY WATER YEAR (WY)

\begin{tabular}{|c|c|c|c|c|c|c|c|c|c|c|c|c|}
\hline $\begin{array}{l}\text { MEAN } \\
\text { MAX } \\
\text { (WY) } \\
\text { MIN } \\
(W Y)\end{array}$ & $\begin{array}{l}17.4 \\
90.6 \\
1946 \\
1.82 \\
1954\end{array}$ & $\begin{array}{r}73.6 \\
458 \\
1986 \\
3.91 \\
1954\end{array}$ & $\begin{array}{r}123 \\
470 \\
1991 \\
2.90 \\
1964\end{array}$ & $\begin{array}{r}156 \\
837 \\
1950 \\
3.13 \\
1977\end{array}$ & $\begin{array}{r}183 \\
441 \\
1971 \\
15.1 \\
1954\end{array}$ & $\begin{array}{r}218 \\
498 \\
1963 \\
40.9 \\
1969\end{array}$ & $\begin{array}{r}175 \\
516 \\
1964 \\
28.3 \\
1971\end{array}$ & $\begin{array}{r}140 \\
512 \\
1981 \\
20.7 \\
1988\end{array}$ & $\begin{array}{r}84.6 \\
463 \\
1958 \\
6.73 \\
1988\end{array}$ & $\begin{array}{r}70.8 \\
492 \\
1979 \\
2.03 \\
1944\end{array}$ & $\begin{array}{r}28.4 \\
231 \\
1979 \\
2.43 \\
1954\end{array}$ & $\begin{array}{r}20.0 \\
228 \\
1989 \\
2.36 \\
1954\end{array}$ \\
\hline
\end{tabular}

SUMMARY STATISTICS

AMNUAL TOTAL

ANMUAL MEAN

HIGHEST ANMUAL MEAN

LOWEST ANNUAL MEAN

HIGHEST DAILY MEAN

LOWEST DAILY MEAN

ANMUAL SEVEN-DAY MINIMUM

INSTANTANEOUS PEAK FLOW

INSTANTANEOUS PEAK STAGE

ANMUAL RUNOFF (CFSM)

ANMUAL RUNOFF (INCHES)

10 PERCENT EXCEEDS

50 PERCENT EXCEEDS

90 PERCENT EXCEEDS
FOR 1990 CALENDAR YEAR

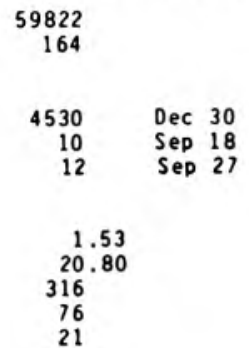

FOR 1991 WATER YEAR

50999.9

50999
140

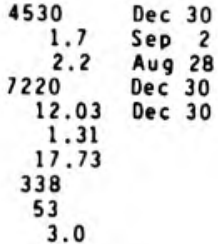

WATER YEARS 1944 - 1991

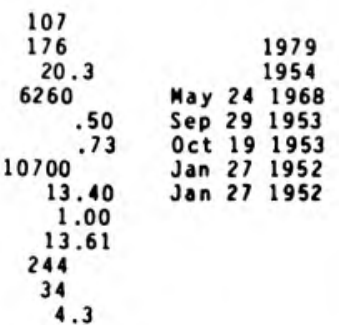




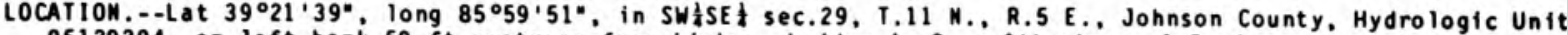
05120204 , on left bank $50 \mathrm{ft}$ upstrea froe highway bridge in Caep Atterbury. 1.3 a upstreas froe confluence with Blue River, 1.5 ai northwest of Edinburgh, and at atle 1.3 .

DRAI MAGE AREA. . -474 :

PERIOD OF RECORD.--0ctober 1942 to current year. Prior to February 1943 monthly discharge only, published in WSP 1305. Prior to October 1971 , published as "near Edinburg".

REVISED RECORDS.--WSP 2109: Drainage area.

GAGE.--Water-stage recorder. Datue of gage is $646.23 \mathrm{ft}$ above National Geodetic Vertical Datue of 1929 . Prior to Oct. 1. 1952, nonrecording gage on downstreae side of old highway bridge, $100 \mathrm{ft}$ downstrean at saee datua. REMARKS.--Records good except for estiated dally discharges, which are poor.

DISCHARGE, CUBIC FEET PER SECONO, WATER YEAR OCTOBER 1990 TO SEPTEMBER 1991

\begin{tabular}{|c|c|c|c|c|c|c|c|c|c|c|c|c|}
\hline DAY & $\mathrm{OCT}$ & Nov & DEC & JAM & FEB & MAR & APR & MAY & JUN & JUL & AUG & SEP \\
\hline $\begin{array}{l}1 \\
2 \\
3 \\
4 \\
5\end{array}$ & $\begin{array}{l}104 \\
101 \\
100 \\
309 \\
815\end{array}$ & $\begin{array}{l}172 \\
164 \\
159 \\
158 \\
160\end{array}$ & $\begin{array}{r}847 \\
621 \\
945 \\
1840 \\
1110\end{array}$ & $\begin{array}{r}10300 \\
4200 \\
1710 \\
1260 \\
1050\end{array}$ & $\begin{array}{r}521 \\
547 \\
772 \\
861 \\
1050\end{array}$ & $\begin{array}{l}405 \\
424 \\
413 \\
380 \\
355\end{array}$ & $\begin{array}{l}646 \\
556 \\
491 \\
462 \\
494\end{array}$ & $\begin{array}{l}355 \\
334 \\
319 \\
314 \\
321\end{array}$ & $\begin{array}{l}684 \\
425 \\
295 \\
283 \\
251\end{array}$ & $\begin{array}{l}116 \\
187 \\
149 \\
154 \\
177\end{array}$ & $\begin{array}{l}53 \\
51 \\
50 \\
49 \\
49\end{array}$ & $\begin{array}{l}e 45 \\
e 40 \\
e 38 \\
e 39 \\
e 40\end{array}$ \\
\hline $\begin{array}{r}6 \\
7 \\
8 \\
9 \\
10\end{array}$ & $\begin{array}{l}501 \\
313 \\
246 \\
240 \\
746\end{array}$ & $\begin{array}{l}220 \\
246 \\
225 \\
199 \\
192\end{array}$ & $\begin{array}{l}778 \\
608 \\
495 \\
422 \\
375\end{array}$ & $\begin{array}{r}1020 \\
993 \\
880 \\
807 \\
752\end{array}$ & $\begin{array}{l}2800 \\
4700 \\
3140 \\
1760 \\
1260\end{array}$ & $\begin{array}{l}350 \\
362 \\
333 \\
313 \\
299\end{array}$ & $\begin{array}{l}488 \\
450 \\
421 \\
450 \\
420\end{array}$ & $\begin{array}{l}370 \\
379 \\
323 \\
300 \\
287\end{array}$ & $\begin{array}{l}222 \\
203 \\
188 \\
178 \\
170\end{array}$ & $\begin{array}{r}126 \\
107 \\
97 \\
101 \\
170\end{array}$ & $\begin{array}{l}74 \\
87 \\
84 \\
83 \\
79\end{array}$ & $\begin{array}{l}e 46 \\
e 42 \\
e 39 \\
e 37 \\
e 35\end{array}$ \\
\hline $\begin{array}{l}11 \\
12 \\
13 \\
14 \\
15\end{array}$ & $\begin{array}{r}1530 \\
1050 \\
694 \\
471 \\
359\end{array}$ & $\begin{array}{l}189 \\
173 \\
162 \\
156 \\
153\end{array}$ & $\begin{array}{l}343 \\
322 \\
302 \\
276 \\
389\end{array}$ & $\begin{array}{l}1010 \\
2270 \\
1690 \\
1240 \\
1220\end{array}$ & $\begin{array}{l}967 \\
770 \\
695 \\
708 \\
649\end{array}$ & $\begin{array}{r}289 \\
294 \\
2460 \\
4830 \\
3620\end{array}$ & $\begin{array}{r}365 \\
333 \\
402 \\
1570 \\
1350\end{array}$ & $\begin{array}{l}281 \\
330 \\
300 \\
281 \\
295\end{array}$ & $\begin{array}{l}170 \\
265 \\
198 \\
173 \\
160\end{array}$ & $\begin{array}{l}209 \\
187 \\
185 \\
155 \\
123\end{array}$ & $\begin{array}{r}66 \\
60 \\
55 \\
52 \\
51\end{array}$ & $\begin{array}{r}e 34 \\
e 36 \\
e 45 \\
e 110 \\
e 90\end{array}$ \\
\hline $\begin{array}{l}16 \\
17 \\
18 \\
19 \\
20\end{array}$ & $\begin{array}{l}295 \\
256 \\
297 \\
570 \\
463\end{array}$ & $\begin{array}{l}150 \\
145 \\
143 \\
141 \\
139\end{array}$ & $\begin{array}{r}899 \\
756 \\
2100 \\
3530 \\
2430\end{array}$ & $\begin{array}{l}1590 \\
1830 \\
1500 \\
1160 \\
1020\end{array}$ & $\begin{array}{r}518 \\
500 \\
557 \\
1450 \\
1870\end{array}$ & $\begin{array}{l}1770 \\
1220 \\
2270 \\
1830 \\
1240\end{array}$ & $\begin{array}{r}1250 \\
844 \\
638 \\
926 \\
1970\end{array}$ & $\begin{array}{l}275 \\
263 \\
373 \\
716 \\
678\end{array}$ & $\begin{array}{l}160 \\
161 \\
152 \\
139 \\
131\end{array}$ & $\begin{array}{r}108 \\
99 \\
93 \\
88 \\
83\end{array}$ & $\begin{array}{l}e 50 \\
e 56 \\
e 80 \\
e 76 \\
e 72\end{array}$ & $\begin{array}{r}\text { e72 } \\
55 \\
47 \\
42 \\
39\end{array}$ \\
\hline $\begin{array}{l}21 \\
22 \\
23 \\
24 \\
25\end{array}$ & $\begin{array}{l}352 \\
304 \\
316 \\
315 \\
283\end{array}$ & $\begin{array}{l}136 \\
162 \\
396 \\
350 \\
291\end{array}$ & $\begin{array}{r}1620 \\
2870 \\
2340 \\
1460 \\
957\end{array}$ & $\begin{array}{l}933 \\
e 790 \\
e 680 \\
e 600 \\
e 520\end{array}$ & $\begin{array}{r}1400 \\
1010 \\
777 \\
655 \\
565\end{array}$ & $\begin{array}{r}949 \\
1830 \\
5120 \\
5170 \\
2100\end{array}$ & $\begin{array}{r}1200 \\
863 \\
698 \\
605 \\
527\end{array}$ & $\begin{array}{l}443 \\
383 \\
546 \\
585 \\
426\end{array}$ & $\begin{array}{l}125 \\
120 \\
116 \\
116 \\
115\end{array}$ & $\begin{array}{l}80 \\
75 \\
73 \\
80 \\
74\end{array}$ & $\begin{array}{l}e 70 \\
e 64 \\
e 59 \\
e 54 \\
e 50\end{array}$ & $\begin{array}{l}38 \\
39 \\
42 \\
42 \\
45\end{array}$ \\
\hline $\begin{array}{l}26 \\
27 \\
28 \\
29 \\
30 \\
31\end{array}$ & $\begin{array}{l}251 \\
230 \\
214 \\
199 \\
188 \\
180\end{array}$ & $\begin{array}{r}245 \\
345 \\
1550 \\
2150 \\
1260 \\
\ldots . .\end{array}$ & $\begin{array}{r}732 \\
577 \\
543 \\
1120 \\
6700 \\
15700\end{array}$ & $\begin{array}{l}e 490 \\
e 470 \\
e 450 \\
e 450 \\
536 \\
593\end{array}$ & $\begin{array}{l}498 \\
458 \\
426 \\
\ldots- \\
\ldots . . \\
\ldots-\end{array}$ & $\begin{array}{r}1910 \\
3440 \\
2040 \\
1310 \\
947 \\
747\end{array}$ & $\begin{array}{l}473 \\
446 \\
422 \\
407 \\
386 \\
\cdots-.\end{array}$ & $\begin{array}{l}364 \\
340 \\
303 \\
274 \\
268 \\
359\end{array}$ & $\begin{array}{l}125 \\
129 \\
124 \\
111 \\
104 \\
\cdots\end{array}$ & $\begin{array}{l}67 \\
64 \\
60 \\
58 \\
57 \\
55\end{array}$ & $\begin{array}{l}e 47 \\
e 45 \\
e 43 \\
e 45 \\
e 47 \\
e 50\end{array}$ & $\begin{array}{r}48 \\
44 \\
41 \\
41 \\
39 \\
-\cdots\end{array}$ \\
\hline $\begin{array}{l}\text { TOTAL } \\
\text { MEAN } \\
\text { MAX } \\
\text { MIN } \\
\text { CF SM } \\
\text { IN. }\end{array}$ & $\begin{array}{r}12292 \\
397 \\
1530 \\
100 \\
.84 \\
.96\end{array}$ & $\begin{array}{r}10331 \\
344 \\
2150 \\
136 \\
.73 \\
.81\end{array}$ & $\begin{array}{r}54007 \\
1742 \\
15700 \\
276 \\
3.68 \\
4.24\end{array}$ & $\begin{array}{r}44014 \\
1420 \\
10300 \\
450 \\
3.00 \\
3.45\end{array}$ & $\begin{array}{r}31884 \\
1139 \\
4700 \\
426 \\
2.40 \\
2.50\end{array}$ & $\begin{array}{r}49020 \\
1581 \\
5170 \\
289 \\
3.34 \\
3.85\end{array}$ & $\begin{array}{r}20553 \\
685 \\
1970 \\
333 \\
1.45 \\
1.61\end{array}$ & $\begin{array}{r}11385 \\
367 \\
716 \\
263 \\
.77 \\
.89\end{array}$ & $\begin{array}{l}5793 \\
193 \\
684 \\
104 \\
.41 \\
.45\end{array}$ & $\begin{array}{c}3457 \\
112 \\
209 \\
55 \\
.24 \\
.27\end{array}$ & $\begin{array}{r}1851 \\
59.7 \\
87 \\
43 \\
.13 \\
.15\end{array}$ & $\begin{array}{c}1390 \\
46.3 \\
110 \\
34 \\
.10 \\
.11\end{array}$ \\
\hline
\end{tabular}

STATISTICS OF MONTHLY MEAN DATA FOR WATER YEARS 1943 - 1991. BY WATER YEAR (WW)

\begin{tabular}{|c|c|c|c|c|c|c|c|c|c|c|c|}
\hline $\begin{array}{l}\text { MEAN } \\
\text { MAX } \\
(W Y) \\
\text { MIN } \\
(W Y)\end{array}$ & $\begin{array}{r}124 \\
983 \\
1987 \\
22.2 \\
1945\end{array}$ & $\begin{array}{r}328 \\
1795 \\
1986 \\
33.4 \\
1954\end{array}$ & $\begin{array}{r}531 \\
1742 \\
1991 \\
30.4 \\
1964\end{array}$ & $\begin{array}{r}703 \\
4000 \\
1950 \\
36.5 \\
1977\end{array}$ & $\begin{array}{r}833 \\
2192 \\
1950 \\
74.8 \\
1964\end{array}$ & $\begin{array}{r}975 \\
2281 \\
1961 \\
215 \\
1981\end{array}$ & $\begin{array}{r}827 \\
2076 \\
1964 \\
170 \\
1971\end{array}$ & $\begin{array}{r}651 \\
2011 \\
1981 \\
120 \\
1976\end{array}$ & $\begin{array}{r}409 \\
1608 \\
1958 \\
58.7 \\
1988\end{array}$ & $\begin{array}{r}313 \\
1564 \\
1979 \\
29.5 \\
1954\end{array}$ & $\begin{array}{r}182 \\
1348 \\
1979 \\
25.4 \\
1954\end{array}$ \\
\hline
\end{tabular}

SUMMARY STATISTICS

ANMUAL TOTAL

AMNUAL MEAM

HIGHEST AMMUAL MEAM

LOWEST AMHUAL MEAN

HIGHEST DAILY MEAN

LOWEST DAILY MEAM

ANHUAL SEVEN-DAY MINIMUM

INSTANTANEOUS PEAK FLOW

INSTANTANEOUS PEAK STAGE

AN NUAL RUNOFF (CFSM)

AM NUAL RUNOFF (INCHES)

10 PERCENT EXCEEDS

50 PERCENT EXCEEDS

90 PERCENT EXCEEDS

$$
\text { e Estiuated }
$$

\section{FOR 1990 CALEMDAR YEAR}

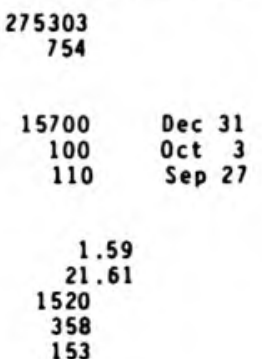

FOR 1991 WATER YEAR

245977
674

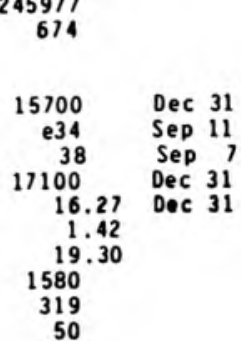

WATER YEARS 1943 - 1991

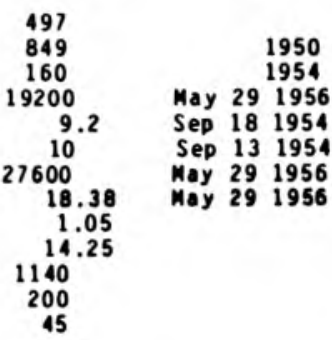




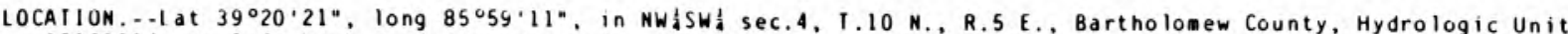
05120204 , on left bank at downstream side of highway bridge, $0.8 \mathrm{mi}$ downstream from confluence of $B$ ig $B 1$ lue

River and Sugar Creek, $1.5 \mathrm{mi}$ southwest of Edinburgh, and at mile 14.1 .

DRAINAGE AREA $-1,060 \mathrm{i}^{2}$

PERIOD OF RECORD.--0ctober 1940 to current yedr. Prior to July 1941 monthly discharge only, published in WSP 1305 . Prior to October 1977, publ ished ds "near Edinburg".

REVISED RECORDS...-WSP 2109: Drainage area.

GAGE.--Water-stage recorder. Datum of gage is $636.99 \mathrm{ft}$ above National Geodetic Vertical Datun of 1929 . Prior to 0ct. 7, 1941, nonrecording gage at same site and datun.

REMARKS. - Records good except for estinated daily discharges, which are fair.

EXTREMES OUTSIDE PERIOD OF RECORD. . - Flood in March 1913 reached a stage of $20.3 \mathrm{ft}$

DISCHARGE, CUBIC FEET PER SECOND, WATER YEAR OCTOBER 1990 TO SEPIEMBER 1991 DAILY MEAN VALUES

\begin{tabular}{|c|c|c|c|c|c|c|c|c|c|c|c|c|}
\hline DAY & $0 C \mathrm{I}$ & NOV & DEC & JAK & FE B & MAR & APR & MAY & JUN & JUL & AUG & SEP \\
\hline $\begin{array}{l}1 \\
2 \\
3 \\
4 \\
5\end{array}$ & $\begin{array}{r}395 \\
387 \\
380 \\
527 \\
1310\end{array}$ & $\begin{array}{l}\text { e520 } \\
\text { e510 } \\
\text { e500 } \\
\text { e490 } \\
\text { e } 510\end{array}$ & $\begin{array}{l}1740 \\
1270 \\
1530 \\
3620 \\
2570\end{array}$ & $\begin{array}{r}25100 \\
12300 \\
5180 \\
3250 \\
2560\end{array}$ & $\begin{array}{l}1170 \\
1170 \\
1420 \\
1660 \\
1920\end{array}$ & $\begin{array}{l}1140 \\
1160 \\
1150 \\
1100 \\
1050\end{array}$ & $\begin{array}{l}1760 \\
1600 \\
1470 \\
1400 \\
1410\end{array}$ & $\begin{array}{l}931 \\
889 \\
852 \\
834 \\
840\end{array}$ & $\begin{array}{r}2560 \\
1270 \\
962 \\
883 \\
775\end{array}$ & $\begin{array}{l}373 \\
417 \\
391 \\
499 \\
494\end{array}$ & $\begin{array}{l}233 \\
228 \\
224 \\
221 \\
217\end{array}$ & $\begin{array}{l}186 \\
178 \\
171 \\
187 \\
185\end{array}$ \\
\hline $\begin{array}{r}6 \\
7 \\
8 \\
9 \\
10\end{array}$ & $\begin{array}{r}1030 \\
718 \\
595 \\
571 \\
1210\end{array}$ & $\begin{array}{l}e 550 \\
e 630 \\
e 580 \\
e 560 \\
e 550\end{array}$ & $\begin{array}{r}1660 \\
1280 \\
1060 \\
918 \\
825\end{array}$ & $\begin{array}{l}2350 \\
2240 \\
2000 \\
1820 \\
1690\end{array}$ & $\begin{array}{l}4790 \\
8200 \\
7410 \\
4400 \\
2980\end{array}$ & $\begin{array}{r}1030 \\
1040 \\
996 \\
951 \\
919\end{array}$ & $\begin{array}{l}1390 \\
1320 \\
1270 \\
1280 \\
1240\end{array}$ & $\begin{array}{l}878 \\
878 \\
806 \\
770 \\
749\end{array}$ & $\begin{array}{l}696 \\
645 \\
609 \\
581 \\
556\end{array}$ & $\begin{array}{l}402 \\
364 \\
341 \\
426 \\
469\end{array}$ & $\begin{array}{l}252 \\
258 \\
255 \\
252 \\
248\end{array}$ & $\begin{array}{l}186 \\
174 \\
168 \\
165 \\
163\end{array}$ \\
\hline $\begin{array}{l}11 \\
12 \\
13 \\
14 \\
15\end{array}$ & $\begin{array}{r}3310 \\
2400 \\
1530 \\
1090 \\
855\end{array}$ & $\begin{array}{l}\text { e } 550 \\
\text { e } 520 \\
\text { e } 490 \\
\text { e } 480 \\
\text { e470 }\end{array}$ & $\begin{array}{l}764 \\
719 \\
682 \\
637 \\
736\end{array}$ & $\begin{array}{l}1960 \\
4360 \\
3880 \\
2690 \\
2410\end{array}$ & $\begin{array}{l}2260 \\
1840 \\
1650 \\
1650 \\
1610\end{array}$ & $\begin{array}{r}891 \\
893 \\
3750 \\
8420 \\
8590\end{array}$ & $\begin{array}{l}1150 \\
1090 \\
1170 \\
2930 \\
3200\end{array}$ & $\begin{array}{l}738 \\
766 \\
739 \\
720 \\
771\end{array}$ & $\begin{array}{l}547 \\
650 \\
567 \\
527 \\
502\end{array}$ & $\begin{array}{l}508 \\
493 \\
466 \\
433 \\
381\end{array}$ & $\begin{array}{l}235 \\
227 \\
220 \\
215 \\
211\end{array}$ & $\begin{array}{l}161 \\
159 \\
171 \\
347 \\
255\end{array}$ \\
\hline $\begin{array}{l}16 \\
17 \\
18 \\
19 \\
20\end{array}$ & $\begin{array}{r}\text { e } 712 \\
\text { e } 710 \\
\text { e } 1000 \\
\text { e } 1400 \\
\text { el } 200\end{array}$ & $\begin{array}{r}\text { e } 460 \\
\text { e } 450 \\
\text { e440 } \\
\text { e } 430 \\
424\end{array}$ & $\begin{array}{l}1680 \\
1550 \\
3650 \\
6880 \\
6710\end{array}$ & $\begin{array}{l}2930 \\
3690 \\
3260 \\
2440 \\
2100\end{array}$ & $\begin{array}{r}\text { el } 400 \\
\text { e } 1300 \\
1340 \\
2760 \\
4330\end{array}$ & $\begin{array}{l}4970 \\
3070 \\
4490 \\
4360 \\
2910\end{array}$ & $\begin{array}{l}2820 \\
2000 \\
1560 \\
1790 \\
3450\end{array}$ & $\begin{array}{r}738 \\
730 \\
934 \\
1810 \\
1580\end{array}$ & $\begin{array}{l}495 \\
492 \\
475 \\
455 \\
439\end{array}$ & $\begin{array}{l}356 \\
339 \\
327 \\
316 \\
307\end{array}$ & $\begin{array}{l}216 \\
215 \\
220 \\
250 \\
252\end{array}$ & $\begin{array}{l}204 \\
181 \\
172 \\
166 \\
162\end{array}$ \\
\hline $\begin{array}{l}21 \\
22 \\
23 \\
24 \\
25\end{array}$ & $\begin{array}{r}\text { e } 1000 \\
\text { e } 910 \\
\text { e } 1000 \\
\text { e } 900 \\
\text { e } 800\end{array}$ & $\begin{array}{l}420 \\
448 \\
757 \\
810 \\
696\end{array}$ & $\begin{array}{l}4210 \\
5520 \\
6000 \\
3850 \\
2350\end{array}$ & $\begin{array}{r}1940 \\
\text { e } 1750 \\
\text { e } 1580 \\
\text { e } 1430 \\
\text { e } 1300\end{array}$ & $\begin{array}{l}3530 \\
2430 \\
1900 \\
1620 \\
1460\end{array}$ & $\begin{array}{r}2190 \\
3200 \\
8410 \\
10700 \\
6550\end{array}$ & $\begin{array}{l}2470 \\
1810 \\
1510 \\
1350 \\
1240\end{array}$ & $\begin{array}{r}1140 \\
975 \\
1120 \\
1180 \\
971\end{array}$ & $\begin{array}{l}427 \\
417 \\
408 \\
412 \\
400\end{array}$ & $\begin{array}{l}298 \\
289 \\
281 \\
279 \\
271\end{array}$ & $\begin{array}{l}247 \\
235 \\
221 \\
211 \\
203\end{array}$ & $\begin{array}{l}161 \\
162 \\
168 \\
171 \\
177\end{array}$ \\
\hline $\begin{array}{l}26 \\
27 \\
28 \\
29 \\
30 \\
31\end{array}$ & $\begin{array}{l}\text { e } 730 \\
\text { e } 680 \\
\text { e } 650 \\
\text { e } 610 \\
\text { e570 } \\
\text { e540 }\end{array}$ & $\begin{array}{r}611 \\
682 \\
2270 \\
4380 \\
2800 \\
\cdots\end{array}$ & $\begin{array}{l}1730 \\
1410 \\
1230 \\
1930 \\
10100 \\
26000\end{array}$ & $\begin{array}{r}\text { e } 1230 \\
\text { e } 1160 \\
\text { el160 } \\
\text { e } 1100 \\
1180 \\
1290\end{array}$ & $\begin{array}{r}1330 \\
1250 \\
1190 \\
\ldots \\
\ldots \\
\ldots\end{array}$ & $\begin{array}{l}4460 \\
7070 \\
5380 \\
3490 \\
2480 \\
1990\end{array}$ & $\begin{array}{r}1150 \\
1100 \\
1060 \\
1020 \\
985 \\
\ldots\end{array}$ & $\begin{array}{r}863 \\
816 \\
762 \\
710 \\
915 \\
2420\end{array}$ & $\begin{array}{l}407 \\
449 \\
414 \\
391 \\
374 \\
\ldots\end{array}$ & $\begin{array}{l}262 \\
254 \\
248 \\
243 \\
241 \\
235\end{array}$ & $\begin{array}{l}198 \\
194 \\
192 \\
190 \\
188 \\
188\end{array}$ & $\begin{array}{l}174 \\
170 \\
167 \\
164 \\
164 \\
\cdots\end{array}$ \\
\hline $\begin{array}{l}\text { IOIAL } \\
\text { MEAN } \\
\text { MAX } \\
\text { MIN } \\
\text { CF SM } \\
\text { IN. }\end{array}$ & $\begin{array}{r}29720 \\
959 \\
3310 \\
380 \\
.90 \\
1.04\end{array}$ & $\begin{array}{r}23988 \\
800 \\
4380 \\
420 \\
.75 \\
.84\end{array}$ & $\begin{array}{r}104811 \\
3381 \\
26000 \\
637 \\
3.19 \\
3.68\end{array}$ & $\begin{array}{r}103330 \\
3333 \\
25100 \\
1100 \\
3.14 \\
3.63\end{array}$ & $\begin{array}{r}69970 \\
2499 \\
8200 \\
1110 \\
2.36 \\
2.46\end{array}$ & $\begin{array}{r}108800 \\
3510 \\
10700 \\
891 \\
3.31 \\
3.82\end{array}$ & $\begin{array}{c}48995 \\
1633 \\
3450 \\
985 \\
1.54 \\
1.72\end{array}$ & $\begin{array}{r}29825 \\
962 \\
2420 \\
710 \\
.91 \\
1.05\end{array}$ & $\begin{array}{r}18785 \\
626 \\
2560 \\
374 \\
.59 \\
.66\end{array}$ & $\begin{array}{c}11003 \\
355 \\
508 \\
235 \\
.33 \\
.39\end{array}$ & $\begin{array}{c}6916 \\
223 \\
258 \\
188 \\
.21 \\
.24\end{array}$ & $\begin{array}{c}5419 \\
181 \\
347 \\
159 \\
.17 \\
.19\end{array}$ \\
\hline
\end{tabular}

e Estimated

SIATISIICS OF MONTHLY MEAN DAIA FUR WAIER YEARS 1942 - 1991, BY WAIER YEAR (WY)

$\begin{array}{lrrrrrrrrrrrr}\text { MEAN } & 362 & 180 & 1208 & 1578 & 1935 & 2232 & 1977 & 1526 & 1066 & 794 & 496 & 334 \\ \text { MAX } & 2590 & 4035 & 3840 & 8315 & 5062 & 5011 & 4785 & 4125 & 3731 & 3180 & 3485 & 2815 \\ \text { (WY) } & 1987 & 1956 & 1967 & 1950 & 1950 & 1961 & 1964 & 1968 & 1958 & 1979 & 1979 & 1989 \\ \text { MIN } & 102 & 136 & 125 & 119 & 227 & 550 & 493 & 359 & 204 & 117 & 99.7 & 68.8 \\ \text { (WY) } & 1965 & 1954 & 1964 & 1977 & 1964 & 1981 & 1971 & 1976 & 1988 & 1954 & 1954 & 1954\end{array}$

SUMMARY SIATISIICS

ANNUAL TOIAL

HIGHESI ANMUAL MEAM

LOWEST ANNUAL MEAN

LOWEST ANNUAL MEAN

HIGHEST DAILY MEA

ANNUAL SEVEN-DAY MINIMUM

INSTANTANEOUS PEAK FLOW

INSIANTANEOUS PEAK SIAGE

ANMUAL RUNOFF (CFSH)

ANNUAL RUNOFF (INCHES)

10 PERCENT EXLEEDS

50 PERCENT EXCEEDS

90 PERCENT EXCEEDS
FOR 1990 CALENUAR YEAR

$\begin{array}{rrr}619979 & \\ 1699 & & \\ & & \\ 26000 & \text { Dec } & 31 \\ 380 & \text { Oct } & 3 \\ 408 & \text { Sep } & 27 \\ & & \\ 1.60 & \\ 21.76 & \\ 3580 & \\ 1020 & & \\ 495 & & \end{array}$

FOR 1991 WAIER YEAR

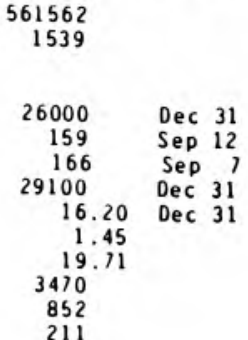

WAIER YEARS 1942 - 1991

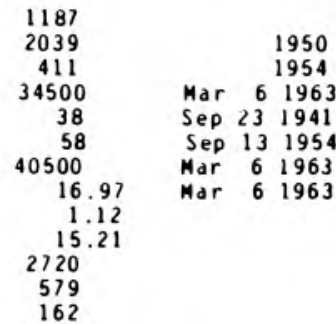




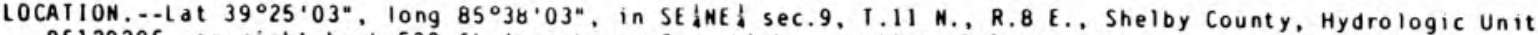
05120205 , on right bank $500 \mathrm{ft}$ downstred from highway oridge, 0.8 a southwest of St. Paul, 1.5 a downstrea from Mili Creek, and at ile 34.4 .

DRAI NAGE AREA. -303 i

PERIOD OF RECORD.--0ctober 1930 to current year. Prior to October 1958, published as flatrock Creek at St. Paul. REVISED RECORDS.-.WSP 853: 1934-36. WSP 973: 1942. WSP 1335: 1933.1936. WSP 1725: 1957(M). WSP 2109: Drainage area.

GAGE. - Water-stage recorder. Datum of gage is $764.84 \mathrm{ft}$ above National Geodetic Vertical Datua of 1929 (levels by State of Indiand. Departaent of Natural Resources). Prior to 0ct. 21, 1938, nonrecording gage at site 500 ft upstrean at sane datua.

REMARKS. - Records good except for estinated daily discharges, which are poor. EXIREMES OUISIDE PERIOD OF RECORO. - Flood in March 1913 reached a stage of approximately 20.5 ft, froe information
by local residents.

DISCHARGE, CUBIC FEET PER SECOND, WAIER YEAR OCTOBER 1990 TO SEPIEMBER 1991 DAIIY MEAN VALUES

\begin{tabular}{|c|c|c|c|c|c|c|c|c|c|c|c|c|}
\hline DAY & $\mathrm{OCI}$ & NOV & $\mathrm{DEC}$ & JAN & FEB & MAR & APR & MAY & JUN & JUL & AUG & SEP \\
\hline $\begin{array}{l}1 \\
2 \\
3 \\
4 \\
5\end{array}$ & $\begin{array}{r}60 \\
56 \\
55 \\
168 \\
269\end{array}$ & $\begin{array}{r}110 \\
104 \\
97 \\
94 \\
102\end{array}$ & $\begin{array}{r}383 \\
308 \\
618 \\
1090 \\
864\end{array}$ & $\begin{array}{r}3850 \\
1650 \\
965 \\
715 \\
565\end{array}$ & $\begin{array}{l}228 \\
256 \\
356 \\
405 \\
506\end{array}$ & $\begin{array}{l}260 \\
272 \\
263 \\
250 \\
242\end{array}$ & $\begin{array}{r}\text { e } 460 \\
\text { e } 410 \\
\text { e } 360 \\
\text { e } 345 \\
319\end{array}$ & $\begin{array}{r}e 255 \\
e 240 \\
\text { e230 } \\
230 \\
226\end{array}$ & $\begin{array}{l}257 \\
319 \\
247 \\
208 \\
163\end{array}$ & $\begin{array}{l}34 \\
29 \\
28 \\
30 \\
34\end{array}$ & $\begin{array}{c}9.9 \\
9.7 \\
8.7 \\
8.3 \\
10\end{array}$ & $\begin{array}{c}12 \\
8.1 \\
6.9 \\
10 \\
7.6\end{array}$ \\
\hline $\begin{array}{r}6 \\
7 \\
8 \\
9 \\
10\end{array}$ & $\begin{array}{l}207 \\
145 \\
119 \\
326 \\
887\end{array}$ & $\begin{array}{l}118 \\
120 \\
111 \\
105 \\
113\end{array}$ & $\begin{array}{l}537 \\
420 \\
350 \\
300 \\
270\end{array}$ & $\begin{array}{l}568 \\
555 \\
453 \\
391 \\
344\end{array}$ & $\begin{array}{r}1790 \\
1940 \\
1540 \\
931 \\
652\end{array}$ & $\begin{array}{l}238 \\
240 \\
228 \\
216 \\
205\end{array}$ & $\begin{array}{l}303 \\
289 \\
277 \\
217 \\
285\end{array}$ & $\begin{array}{l}220 \\
215 \\
206 \\
189 \\
175\end{array}$ & $\begin{array}{l}140 \\
124 \\
114 \\
109 \\
105\end{array}$ & $\begin{array}{l}28 \\
25 \\
24 \\
41 \\
80\end{array}$ & $\begin{array}{l}14 \\
17 \\
17 \\
16 \\
16\end{array}$ & $\begin{array}{l}9.0 \\
7.6 \\
6.8 \\
6.0 \\
5.9\end{array}$ \\
\hline $\begin{array}{l}11 \\
12 \\
13 \\
14 \\
15\end{array}$ & $\begin{array}{l}816 \\
560 \\
373 \\
283 \\
231\end{array}$ & $\begin{array}{r}123 \\
116 \\
107 \\
97 \\
93\end{array}$ & $\begin{array}{l}249 \\
234 \\
222 \\
195 \\
363\end{array}$ & $\begin{array}{r}580 \\
1180 \\
972 \\
671 \\
608\end{array}$ & $\begin{array}{r}483 \\
383 \\
357 \\
415 \\
e 330\end{array}$ & $\begin{array}{r}196 \\
208 \\
\mathrm{e} 700 \\
\mathrm{e} 2300 \\
\mathrm{e} 1700\end{array}$ & $\begin{array}{r}284 \\
275 \\
\mathrm{e} 340 \\
\mathrm{e} 1100 \\
\mathrm{e} 850\end{array}$ & $\begin{array}{l}165 \\
162 \\
156 \\
171 \\
279\end{array}$ & $\begin{array}{r}101 \\
108 \\
102 \\
91 \\
85\end{array}$ & $\begin{array}{l}59 \\
69 \\
56 \\
45 \\
36\end{array}$ & $\begin{array}{l}11 \\
10 \\
8.5 \\
7.6 \\
9.2\end{array}$ & $\begin{array}{l}5.2 \\
4.9 \\
36 \\
43 \\
18\end{array}$ \\
\hline $\begin{array}{l}16 \\
17 \\
18 \\
19 \\
20\end{array}$ & $\begin{array}{l}190 \\
163 \\
313 \\
392 \\
300\end{array}$ & $\begin{array}{l}91 \\
91 \\
89 \\
85 \\
85\end{array}$ & $\begin{array}{r}779 \\
668 \\
3000 \\
3080 \\
2410\end{array}$ & $\begin{array}{l}803 \\
946 \\
820 \\
605 \\
515\end{array}$ & $\begin{array}{r}\text { e290 } \\
e 280 \\
372 \\
1020 \\
1210\end{array}$ & $\begin{array}{r}\text { e1250 } \\
e 950 \\
\text { e } 1200 \\
\text { e1000 } \\
\text { e } 860\end{array}$ & $\begin{array}{l}\text { e } 700 \\
\text { e } 580 \\
\text { e } 500 \\
\text { e } 530 \\
\text { e } 800\end{array}$ & $\begin{array}{r}189 \\
156 \\
619 \\
1210 \\
545\end{array}$ & $\begin{array}{l}82 \\
81 \\
76 \\
68 \\
61\end{array}$ & $\begin{array}{l}31 \\
27 \\
24 \\
22 \\
21\end{array}$ & $\begin{array}{l}12 \\
11 \\
8.7 \\
17 \\
24\end{array}$ & $\begin{array}{r}12 \\
8.4 \\
7.3 \\
6.1 \\
5.2\end{array}$ \\
\hline $\begin{array}{l}21 \\
22 \\
23 \\
24 \\
25\end{array}$ & $\begin{array}{l}242 \\
224 \\
235 \\
233 \\
199\end{array}$ & $\begin{array}{r}82 \\
141 \\
279 \\
267 \\
210\end{array}$ & $\begin{array}{r}1640 \\
1910 \\
1970 \\
1510 \\
932\end{array}$ & $\begin{array}{l}\text { e } 450 \\
\text { e } 350 \\
\text { e } 300 \\
\text { e2 } 80 \\
\text { e } 250\end{array}$ & $\begin{array}{l}932 \\
618 \\
450 \\
375 \\
321\end{array}$ & $\begin{array}{r}\text { e700 } \\
\text { e } 900 \\
\text { e } 2900 \\
\text { e } 2000 \\
\text { e } 1400\end{array}$ & $\begin{array}{r}709 \\
636 \\
540 \\
e 430 \\
e 400\end{array}$ & $\begin{array}{l}317 \\
282 \\
327 \\
270 \\
234\end{array}$ & $\begin{array}{l}58 \\
55 \\
54 \\
54 \\
46\end{array}$ & $\begin{array}{l}19 \\
19 \\
17 \\
19 \\
16\end{array}$ & $\begin{array}{l}19 \\
14 \\
10 \\
9.6 \\
7.9\end{array}$ & $\begin{array}{l}4.6 \\
5.1 \\
7.2 \\
7.6 \\
8.2\end{array}$ \\
\hline $\begin{array}{l}26 \\
27 \\
28 \\
29 \\
30 \\
31\end{array}$ & $\begin{array}{l}170 \\
151 \\
142 \\
129 \\
118 \\
115\end{array}$ & $\begin{array}{l}174 \\
161 \\
399 \\
736 \\
543 \\
\cdots\end{array}$ & $\begin{array}{r}651 \\
509 \\
452 \\
1650 \\
10100 \\
10900\end{array}$ & $\begin{array}{l}e 235 \\
e 220 \\
e 210 \\
\text { e210 } \\
274 \\
275\end{array}$ & $\begin{array}{l}292 \\
278 \\
266 \\
\ldots \\
\ldots- \\
\ldots\end{array}$ & $\begin{array}{r}\text { e } 1000 \\
\text { e1960 } \\
\text { e } 1250 \\
\text { e } 950 \\
\text { e } 700 \\
\text { e } 550\end{array}$ & $\begin{array}{l}\text { e } 350 \\
\text { e } 330 \\
\text { e } 300 \\
\text { e280 } \\
\text { e270 } \\
\cdots\end{array}$ & $\begin{array}{l}419 \\
513 \\
291 \\
240 \\
395 \\
350\end{array}$ & $\begin{array}{c}43 \\
40 \\
38 \\
37 \\
34 \\
\cdots\end{array}$ & $\begin{array}{l}15 \\
14 \\
12 \\
11 \\
11 \\
11\end{array}$ & $\begin{array}{l}8.7 \\
6.7 \\
6.0 \\
7.9 \\
8.2 \\
8.4\end{array}$ & $\begin{array}{l}8.3 \\
7.2 \\
5.8 \\
6.2 \\
6.2 \\
\cdots . .\end{array}$ \\
\hline $\begin{array}{l}\text { IOTAL } \\
\text { MEAN } \\
\text { MAX } \\
\text { MIN } \\
\text { CF SM } \\
\text { IN. }\end{array}$ & $\begin{array}{r}7931 \\
256 \\
887 \\
55 \\
.84 \\
.97\end{array}$ & $\begin{array}{r}5043 \\
168 \\
736 \\
82 \\
.55 \\
.62\end{array}$ & $\begin{array}{r}48564 \\
1567 \\
10900 \\
195 \\
5.17 \\
5.96\end{array}$ & $\begin{array}{r}20810 \\
671 \\
3850 \\
210 \\
2.22 \\
2.55\end{array}$ & $\begin{array}{r}17276 \\
617 \\
1940 \\
228 \\
2.04 \\
2.12\end{array}$ & $\begin{array}{r}27088 \\
874 \\
2900 \\
196 \\
2.88 \\
3.33\end{array}$ & $\begin{array}{r}13529 \\
451 \\
1100 \\
270 \\
1.49 \\
1.66\end{array}$ & $\begin{array}{r}9476 \\
306 \\
1210 \\
156 \\
1.01 \\
1.16\end{array}$ & $\begin{array}{c}3100 \\
103 \\
319 \\
34 \\
.34 \\
.38\end{array}$ & $\begin{array}{r}907 \\
29.3 \\
80 \\
11 \\
.10 \\
.11\end{array}$ & $\begin{array}{r}352.0 \\
11.4 \\
24 \\
6.0 \\
.04 \\
.04\end{array}$ & $\begin{array}{r}292.4 \\
9.75 \\
43 \\
4.6 \\
.03 \\
.04\end{array}$ \\
\hline
\end{tabular}

e Estinated

STATISIICS OF MONTHLY MEAN DATA FOR WAIER YEARS 1931 - 1991, BY WATER YEAR (WY)

\begin{tabular}{|c|c|c|c|c|c|c|c|c|c|c|}
\hline $\begin{array}{l}\text { MEAN } \\
\text { MAX } \\
\text { (WY) } \\
\text { MIN } \\
\text { (WY) }\end{array}$ & $\begin{array}{r}83.4 \\
585 \\
1937 \\
1.96 \\
1964\end{array}$ & $\begin{array}{r}205 \\
1115 \\
1956 \\
9.67 \\
1954\end{array}$ & $\begin{array}{r}354 \\
1567 \\
1991 \\
9.98 \\
1964\end{array}$ & $\begin{array}{r}498 \\
3450 \\
1937 \\
15.1 \\
1971\end{array}$ & $\begin{array}{r}545 \\
1808 \\
1950 \\
27.7\end{array}$ & $\begin{array}{r}604 \\
1605 \\
1961 \\
41.8 \\
1941\end{array}$ & $\begin{array}{r}558 \\
1534 \\
1964 \\
51.9 \\
1941\end{array}$ & $\begin{array}{r}427 \\
1284 \\
1968 \\
42.9 \\
1934\end{array}$ & $\begin{array}{r}257 \\
991 \\
1947 \\
19.7 \\
1934\end{array}$ & $\begin{array}{r}95.6 \\
716 \\
1979 \\
4.06 \\
1988\end{array}$ \\
\hline
\end{tabular}

SUMMARY STAIISIICS

ANNUAL TOTAL

HIGHEST ANMUAL MEAN

LOWEST AMNUAL MEAN

HIGHEST DAILY MEAN

LOWEST DAILY MEAN

ANNUAL SEVEM-DAY MINIMUM

INSTANIANEOUS PEAK FLOW

INSIANTANEOUS PEAK SIAGE

ANNUAI RUNOFF (CFSM)

ANNUAL RUNOFF (INCHES)

10 PERCENT EXCEEDS

50 PERCENT EXCEEDS

90 PERCENT EXCEEDS
FOR 1990 CALENOAR YEAR

\begin{tabular}{|c|c|}
\hline $\begin{array}{r}195165 \\
535\end{array}$ & \\
\hline $\begin{array}{r}10900 \\
50 \\
62\end{array}$ & $\begin{array}{ll}\text { Dec } & 31 \\
\text { Jul } & 10 \\
\text { Aug } & 13\end{array}$ \\
\hline $\begin{aligned} & 1.76 \\
& 23.96 \\
& 1100 \\
& 263 \\
& 90\end{aligned}$ & \\
\hline
\end{tabular}

FOR 1991 WATER YEAR

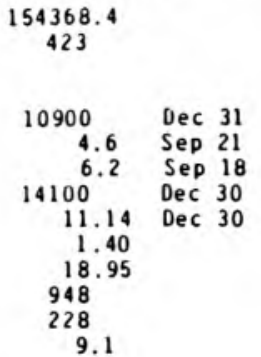

WATER YEARS 1931 - 1991

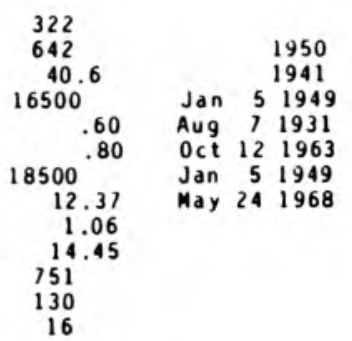




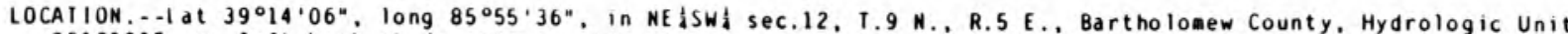
05120205 , on left bank at downstrean side of bridge on U.S. Highway $31,0.2$ i northwest of Colunbus city 1 inits, and 2.6 i upstream from mouth.

DRAI NAGE AREA . . $534 . i^{2}$.

PERIOD OF RECORD,.--0ctober 1967 to current year.

GAGE - Water-stage recorder. Datum of gage is $610.14 \mathrm{ft}$ above National Geodetic Vertical Datua of 1929. REMARKS. - Records good.

DISCHARGE, CUBIC FEET PER SECONO, WATER YEAR OCTOBER 1990 TO SEPIEMBER 1991 DAILY MEAN VALUES

\begin{tabular}{|c|c|c|c|c|c|c|c|c|c|c|c|c|}
\hline DAY & $O C I$ & NOV & DEC & JAN & FEB & MAR & APR & MAY & JUN & JUI & AUG & SEP \\
\hline $\begin{array}{l}1 \\
2 \\
3 \\
4 \\
5\end{array}$ & $\begin{array}{l}143 \\
135 \\
131 \\
142 \\
286\end{array}$ & $\begin{array}{l}220 \\
213 \\
206 \\
199 \\
198\end{array}$ & $\begin{array}{r}666 \\
537 \\
578 \\
1320 \\
1240\end{array}$ & $\begin{array}{r}12700 \\
4770 \\
2350 \\
1750 \\
1500\end{array}$ & $\begin{array}{r}\text { e } 650 \\
\text { e } 630 \\
\text { e } 710 \\
897 \\
958\end{array}$ & $\begin{array}{l}706 \\
707 \\
706 \\
674 \\
646\end{array}$ & $\begin{array}{l}862 \\
785 \\
721 \\
687 \\
675\end{array}$ & $\begin{array}{l}516 \\
488 \\
461 \\
445 \\
438\end{array}$ & $\begin{array}{l}507 \\
443 \\
474 \\
382 \\
335\end{array}$ & $\begin{array}{r}106 \\
101 \\
105 \\
101 \\
91\end{array}$ & $\begin{array}{l}48 \\
47 \\
47 \\
47 \\
44\end{array}$ & $\begin{array}{l}35 \\
36 \\
37 \\
58 \\
46\end{array}$ \\
\hline $\begin{array}{r}6 \\
7 \\
8 \\
9 \\
10\end{array}$ & $\begin{array}{l}356 \\
280 \\
238 \\
232 \\
844\end{array}$ & $\begin{array}{l}206 \\
216 \\
214 \\
206 \\
203\end{array}$ & $\begin{array}{l}879 \\
683 \\
570 \\
496 \\
435\end{array}$ & $\begin{array}{l}1410 \\
1410 \\
1290 \\
1180 \\
1100\end{array}$ & $\begin{array}{l}2250 \\
4630 \\
3220 \\
2170 \\
1550\end{array}$ & $\begin{array}{l}627 \\
622 \\
599 \\
571 \\
551\end{array}$ & $\begin{array}{l}653 \\
626 \\
608 \\
613 \\
608\end{array}$ & $\begin{array}{l}453 \\
442 \\
436 \\
414 \\
392\end{array}$ & $\begin{array}{l}294 \\
267 \\
246 \\
231 \\
221\end{array}$ & $\begin{array}{l}99 \\
89 \\
82 \\
77 \\
92\end{array}$ & $\begin{array}{l}54 \\
59 \\
57 \\
56 \\
55\end{array}$ & $\begin{array}{l}42 \\
40 \\
38 \\
37 \\
37\end{array}$ \\
\hline $\begin{array}{l}11 \\
12 \\
13 \\
14 \\
15\end{array}$ & $\begin{array}{r}1310 \\
980 \\
675 \\
515 \\
406\end{array}$ & $\begin{array}{l}211 \\
217 \\
209 \\
197 \\
191\end{array}$ & $\begin{array}{l}396 \\
368 \\
347 \\
321 \\
322\end{array}$ & $\begin{array}{l}1170 \\
2160 \\
2030 \\
1550 \\
1360\end{array}$ & $\begin{array}{r}1260 \\
1070 \\
968 \\
1010 \\
e 950\end{array}$ & $\begin{array}{r}532 \\
525 \\
1300 \\
3590 \\
3260\end{array}$ & $\begin{array}{r}583 \\
543 \\
701 \\
1750 \\
1620\end{array}$ & $\begin{array}{l}376 \\
366 \\
356 \\
344 \\
521\end{array}$ & $\begin{array}{l}209 \\
276 \\
244 \\
219 \\
199\end{array}$ & $\begin{array}{l}134 \\
153 \\
137 \\
120 \\
106\end{array}$ & $\begin{array}{l}53 \\
51 \\
49 \\
46 \\
44\end{array}$ & $\begin{array}{l}36 \\
36 \\
36 \\
35 \\
58\end{array}$ \\
\hline $\begin{array}{l}16 \\
17 \\
18 \\
19 \\
20\end{array}$ & $\begin{array}{l}337 \\
293 \\
325 \\
617 \\
554\end{array}$ & $\begin{array}{l}188 \\
185 \\
182 \\
177 \\
173\end{array}$ & $\begin{array}{r}799 \\
854 \\
2090 \\
5380 \\
4390\end{array}$ & $\begin{array}{l}1440 \\
1620 \\
1550 \\
1310 \\
1180\end{array}$ & $\begin{array}{l}\text { e } 780 \\
\text { e } 760 \\
e 800 \\
1400 \\
1970\end{array}$ & $\begin{array}{l}2120 \\
1500 \\
1800 \\
1830 \\
1420\end{array}$ & $\begin{array}{r}1360 \\
1030 \\
844 \\
908 \\
1230\end{array}$ & $\begin{array}{r}473 \\
401 \\
430 \\
1350 \\
1080\end{array}$ & $\begin{array}{l}193 \\
186 \\
178 \\
168 \\
158\end{array}$ & $\begin{array}{l}96 \\
87 \\
79 \\
73 \\
70\end{array}$ & $\begin{array}{l}43 \\
45 \\
46 \\
50 \\
49\end{array}$ & $\begin{array}{l}55 \\
45 \\
40 \\
37 \\
34\end{array}$ \\
\hline $\begin{array}{l}21 \\
22 \\
23 \\
24 \\
25\end{array}$ & $\begin{array}{l}436 \\
376 \\
365 \\
376 \\
346\end{array}$ & $\begin{array}{l}169 \\
179 \\
315 \\
421 \\
355\end{array}$ & $\begin{array}{l}2930 \\
2990 \\
3020 \\
2620 \\
1760\end{array}$ & $\begin{array}{l}1090 \\
\text { e } 940 \\
\text { e } 850 \\
\text { e7 } 80 \\
\text { e) } 20\end{array}$ & $\begin{array}{r}1740 \\
1340 \\
1090 \\
950 \\
868\end{array}$ & $\begin{array}{l}1120 \\
1240 \\
3460 \\
3950 \\
2660\end{array}$ & $\begin{array}{r}1030 \\
869 \\
713 \\
703 \\
647\end{array}$ & $\begin{array}{l}680 \\
556 \\
611 \\
551 \\
477\end{array}$ & $\begin{array}{l}148 \\
146 \\
142 \\
139 \\
137\end{array}$ & $\begin{array}{l}68 \\
65 \\
62 \\
60 \\
58\end{array}$ & $\begin{array}{l}50 \\
53 \\
49 \\
46 \\
43\end{array}$ & $\begin{array}{l}33 \\
33 \\
33 \\
33 \\
32\end{array}$ \\
\hline $\begin{array}{l}26 \\
27 \\
28 \\
29 \\
30 \\
31\end{array}$ & $\begin{array}{l}309 \\
281 \\
264 \\
249 \\
236 \\
227\end{array}$ & $\begin{array}{l}298 \\
276 \\
402 \\
982 \\
911 \\
\ldots\end{array}$ & $\begin{array}{r}1240 \\
965 \\
834 \\
1260 \\
6350 \\
18200\end{array}$ & $\begin{array}{l}\text { e6 } 60 \\
\text { e6 } 30 \\
\text { e } 620 \\
\text { e6 } 10 \\
\text { e6 } 30 \\
\text { e6 } 70\end{array}$ & $\begin{array}{l}806 \\
767 \\
733 \\
\cdots \\
\cdots \\
\ldots\end{array}$ & $\begin{array}{r}1750 \\
3380 \\
2670 \\
1640 \\
1210 \\
979\end{array}$ & $\begin{array}{l}616 \\
596 \\
580 \\
563 \\
541 \\
\ldots-\end{array}$ & $\begin{array}{l}436 \\
711 \\
605 \\
475 \\
468 \\
608\end{array}$ & $\begin{array}{l}127 \\
120 \\
115 \\
115 \\
112 \\
\ldots\end{array}$ & $\begin{array}{l}58 \\
55 \\
53 \\
53 \\
51 \\
49\end{array}$ & $\begin{array}{l}41 \\
40 \\
39 \\
38 \\
37 \\
35\end{array}$ & $\begin{array}{r}32 \\
32 \\
32 \\
31 \\
31 \\
-\end{array}$ \\
\hline $\begin{array}{l}\text { TOTAL } \\
\text { MEAN } \\
\text { MAX } \\
\text { MIN } \\
\text { CF SM } \\
\text { IN. }\end{array}$ & $\begin{array}{r}12264 \\
396 \\
1310 \\
131 \\
.74 \\
.85\end{array}$ & $\begin{array}{c}8319 \\
277 \\
982 \\
169 \\
.52 \\
.58\end{array}$ & $\begin{array}{r}64840 \\
2092 \\
18200 \\
321 \\
3.92 \\
4.52\end{array}$ & $\begin{array}{r}53030 \\
1711 \\
12700 \\
610 \\
3.20 \\
3.69\end{array}$ & $\begin{array}{r}36927 \\
1319 \\
4630 \\
630 \\
2.47 \\
2.57\end{array}$ & $\begin{array}{r}48345 \\
1560 \\
3950 \\
525 \\
2.92 \\
3.37\end{array}$ & $\begin{array}{r}24325 \\
811 \\
1750 \\
541 \\
1.52 \\
1.69\end{array}$ & $\begin{array}{r}16360 \\
528 \\
1350 \\
344 \\
.99 \\
1.14\end{array}$ & $\begin{array}{c}6731 \\
224 \\
507 \\
112 \\
.42 \\
.47\end{array}$ & $\begin{array}{c}2636 \\
85.0 \\
153 \\
49 \\
.16 \\
.18\end{array}$ & $\begin{array}{c}1461 \\
47.1 \\
59 \\
35 \\
.09 \\
.10\end{array}$ & $\begin{array}{r}1140 \\
38.0 \\
58 \\
31 \\
.07 \\
.08\end{array}$ \\
\hline
\end{tabular}

e Estiated

STATISIICS OF MONTHLY MEAN DATA FOR WATER YEARS 1968 - 1991, BY WAIER YEAR (WY)

\begin{tabular}{|c|c|c|c|c|c|c|c|c|c|c|c|}
\hline $\begin{array}{l}\text { MEAN } \\
\text { MAX } \\
\text { (WY) } \\
\text { WI } N \\
(W Y)\end{array}$ & $\begin{array}{r}151 \\
547 \\
1987 \\
35.8 \\
1989\end{array}$ & $\begin{array}{r}417 \\
1452 \\
1986 \\
47.6 \\
1917\end{array}$ & $\begin{array}{r}754 \\
2092 \\
1991 \\
44.8 \\
1917\end{array}$ & $\begin{array}{l}132 \\
1827 \\
1969 \\
30.6 \\
1977\end{array}$ & $\begin{array}{r}1063 \\
2524 \\
1982 \\
215 \\
1978\end{array}$ & $\begin{array}{r}1034 \\
2223 \\
1978 \\
261 \\
1983\end{array}$ & $\begin{array}{r}936 \\
1768 \\
1989 \\
251 \\
1976\end{array}$ & $\begin{array}{r}843 \\
2281 \\
1968 \\
132 \\
1976\end{array}$ & $\begin{array}{r}462 \\
1100 \\
1968 \\
77.2 \\
1988\end{array}$ & $\begin{array}{r}399 \\
1556 \\
1979 \\
50.8 \\
1988\end{array}$ & $\begin{array}{r}281 \\
1296 \\
1979 \\
35.0 \\
1988\end{array}$ \\
\hline
\end{tabular}

SUMMARY SIAIISIICS

ANWUAL TOTAL

ANNUAL MEAN

HIGHESI ANNUAL MEAM

LOWE ST AMNUAL MEAN

HIGHESI DAILY MEAN

LOWE SI DAILY MEAN

ANNUAL SEVEN-DAY MINIMUM

INSTANTANEOUS PEAK FLOW

INSIANTANEOUS PEAK STAGE

ANNUAL RUNOFF (CFSM)

ANNUAL RUNOF F (INCHES)

10 PERCENT EXCEEDS

50 PERCENT EXCEEDS

90 PERCENI EXCEEDS
FOR 1990 CALENDAR YEAR

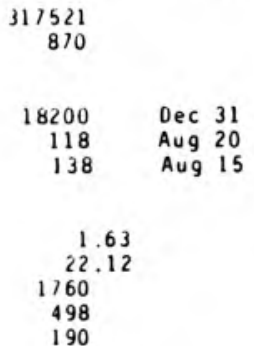

FOR 1991 WATER YEAR

$$
\begin{array}{r}
276378 \\
757
\end{array}
$$

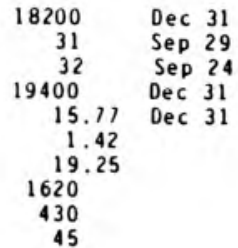

WATER YEARS 1968 - 1991

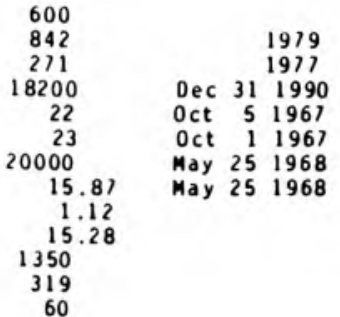


LOCATION.--Lat $39^{\circ} 12^{\circ} 00^{\prime \prime}$, Iong $85^{\circ} 55^{\prime} 32^{\prime \prime}$, In NE 05120205 , on left bank at abutment of abandoned bridge di west end of Second Street in Columbus, 0.6 i downstrean from confluence of Driftwood River and Flatrock River, 1.3 i upstrea from Haw Creek, and at -ile 238.7.

DRAI NAGE AREA . - 1, $101 \mathrm{i}^{2}$

PERIOD OF RECORD.--October 1947 to current year. Prior to January 1948 monthly discharge only, published in WSP 1305.

REVISED RECORDS.--WSP 1335: 1948-49. WSP 2109: Drainage area.

GAGE - - Water-stage recorder above concrete control. Datu of gage is $603.12 \mathrm{ft}$ above National Geodetic Vertical Datu of 1929. Prior to 0ct. 22, 1952, nonrecording gage $600 \mathrm{ft}$ upstrea at sane datua

REMARKS. - - Records good.

DISCHARGE, CUBIL FEET PER SECOND, WATER YEAR OCTOBER 1990 TO SEPTEMBER 1991 DAIIY MEAM VALUES

\begin{tabular}{|c|c|c|c|c|c|c|c|c|c|c|c|c|}
\hline DAY & $\mathrm{OCT}$ & NOV & $\mathrm{DEC}$ & JAN & FE B & MAR & APR & MAY & JUN & JUL & AUG & SEP \\
\hline $\begin{array}{l}1 \\
2 \\
3 \\
4 \\
5\end{array}$ & $\begin{array}{r}472 \\
473 \\
425 \\
564 \\
1530\end{array}$ & $\begin{array}{l}837 \\
807 \\
778 \\
754 \\
763\end{array}$ & $\begin{array}{l}3260 \\
2420 \\
2670 \\
5400 \\
5090\end{array}$ & $\begin{array}{r}44500 \\
24800 \\
9820 \\
5450 \\
4410\end{array}$ & $\begin{array}{l}2060 \\
2010 \\
2310 \\
2810 \\
3190\end{array}$ & $\begin{array}{l}2080 \\
2110 \\
2110 \\
1980 \\
1870\end{array}$ & $\begin{array}{l}3150 \\
2820 \\
2540 \\
2420 \\
2450\end{array}$ & $\begin{array}{l}1710 \\
1640 \\
1600 \\
1580 \\
1570\end{array}$ & $\begin{array}{l}3750 \\
2370 \\
1900 \\
1650 \\
1440\end{array}$ & $\begin{array}{l}408 \\
483 \\
476 \\
547 \\
716\end{array}$ & $\begin{array}{l}261 \\
255 \\
252 \\
254 \\
238\end{array}$ & $\begin{array}{l}204 \\
198 \\
198 \\
388 \\
264\end{array}$ \\
\hline $\begin{array}{r}6 \\
7 \\
8 \\
9 \\
10\end{array}$ & $\begin{array}{r}1620 \\
1180 \\
929 \\
880 \\
1870\end{array}$ & $\begin{array}{l}802 \\
967 \\
925 \\
868 \\
836\end{array}$ & $\begin{array}{l}3490 \\
2640 \\
2170 \\
1860 \\
1640\end{array}$ & $\begin{array}{l}4060 \\
4000 \\
3600 \\
3270 \\
2990\end{array}$ & $\begin{array}{r}6820 \\
12000 \\
11600 \\
7410 \\
5270\end{array}$ & $\begin{array}{l}1820 \\
1830 \\
1760 \\
1660 \\
1590\end{array}$ & $\begin{array}{l}2330 \\
2190 \\
2130 \\
2110 \\
2050\end{array}$ & $\begin{array}{l}1610 \\
1620 \\
1550 \\
1470 \\
1400\end{array}$ & $\begin{array}{r}1230 \\
1100 \\
993 \\
925 \\
868\end{array}$ & $\begin{array}{l}523 \\
421 \\
371 \\
423 \\
649\end{array}$ & $\begin{array}{l}302 \\
335 \\
312 \\
312 \\
299\end{array}$ & $\begin{array}{l}253 \\
236 \\
221 \\
214 \\
211\end{array}$ \\
\hline $\begin{array}{l}11 \\
12 \\
13 \\
14 \\
15\end{array}$ & $\begin{array}{l}4820 \\
4270 \\
2840 \\
2020 \\
1600\end{array}$ & $\begin{array}{l}843 \\
827 \\
787 \\
754 \\
732\end{array}$ & $\begin{array}{l}1510 \\
1430 \\
1350 \\
1270 \\
1330\end{array}$ & $\begin{array}{l}3370 \\
6000 \\
6220 \\
4830 \\
4150\end{array}$ & $\begin{array}{l}4210 \\
3510 \\
3140 \\
3220 \\
3140\end{array}$ & $\begin{array}{r}1540 \\
1550 \\
4310 \\
10100 \\
12200\end{array}$ & $\begin{array}{l}1910 \\
1780 \\
3200 \\
4930 \\
5460\end{array}$ & $\begin{array}{l}1340 \\
1370 \\
1330 \\
1410 \\
1650\end{array}$ & $\begin{array}{r}817 \\
1120 \\
959 \\
839 \\
758\end{array}$ & $\begin{array}{r}800 \\
1090 \\
815 \\
755 \\
628\end{array}$ & $\begin{array}{l}281 \\
263 \\
249 \\
239 \\
231\end{array}$ & $\begin{array}{l}206 \\
201 \\
203 \\
349 \\
413\end{array}$ \\
\hline $\begin{array}{l}16 \\
17 \\
18 \\
19 \\
20\end{array}$ & $\begin{array}{l}1370 \\
1200 \\
1240 \\
2060 \\
2050\end{array}$ & $\begin{array}{l}718 \\
702 \\
696 \\
678 \\
668\end{array}$ & $\begin{array}{r}2880 \\
3230 \\
6190 \\
11900 \\
12100\end{array}$ & $\begin{array}{l}4530 \\
5430 \\
5280 \\
4290 \\
3740\end{array}$ & $\begin{array}{l}2560 \\
2460 \\
2740 \\
4280 \\
6210\end{array}$ & $\begin{array}{l}8420 \\
5540 \\
6370 \\
6600 \\
5270\end{array}$ & $\begin{array}{l}4850 \\
3830 \\
3060 \\
3710 \\
5010\end{array}$ & $\begin{array}{l}1490 \\
1370 \\
1520 \\
3030 \\
3050\end{array}$ & $\begin{array}{l}747 \\
716 \\
697 \\
639 \\
591\end{array}$ & $\begin{array}{l}548 \\
500 \\
458 \\
428 \\
402\end{array}$ & $\begin{array}{l}228 \\
246 \\
246 \\
265 \\
301\end{array}$ & $\begin{array}{l}321 \\
274 \\
246 \\
229 \\
218\end{array}$ \\
\hline $\begin{array}{l}21 \\
22 \\
23 \\
24 \\
25\end{array}$ & $\begin{array}{l}1630 \\
1420 \\
1360 \\
1400 \\
1300\end{array}$ & $\begin{array}{r}652 \\
697 \\
1120 \\
1500 \\
1310\end{array}$ & $\begin{array}{l}8300 \\
8220 \\
9540 \\
7380 \\
5310\end{array}$ & $\begin{array}{l}3430 \\
3090 \\
2760 \\
2610 \\
2280\end{array}$ & $\begin{array}{l}5890 \\
4550 \\
3660 \\
3130 \\
2780\end{array}$ & $\begin{array}{r}4160 \\
5320 \\
10900 \\
14200 \\
11700\end{array}$ & $\begin{array}{l}4310 \\
3410 \\
2880 \\
2530 \\
2270\end{array}$ & $\begin{array}{l}2220 \\
1840 \\
2200 \\
2160 \\
1860\end{array}$ & $\begin{array}{l}548 \\
518 \\
496 \\
491 \\
505\end{array}$ & $\begin{array}{l}382 \\
361 \\
346 \\
336 \\
332\end{array}$ & $\begin{array}{l}285 \\
280 \\
257 \\
234 \\
220\end{array}$ & $\begin{array}{l}212 \\
214 \\
222 \\
220 \\
228\end{array}$ \\
\hline $\begin{array}{l}26 \\
27 \\
28 \\
29 \\
30 \\
31\end{array}$ & $\begin{array}{r}1190 \\
1100 \\
1020 \\
964 \\
908 \\
868\end{array}$ & $\begin{array}{c}1140 \\
1110 \\
2550 \\
5590 \\
4880 \\
\ldots-.\end{array}$ & $\begin{array}{r}3890 \\
3030 \\
2630 \\
3730 \\
15900 \\
40800\end{array}$ & $\begin{array}{l}2130 \\
2010 \\
2030 \\
1940 \\
2010 \\
2230\end{array}$ & $\begin{array}{c}2490 \\
2310 \\
2170 \\
\ldots \\
\ldots \\
\ldots\end{array}$ & $\begin{array}{l}7230 \\
9960 \\
8990 \\
6000 \\
4490 \\
3620\end{array}$ & $\begin{array}{c}2100 \\
2010 \\
1940 \\
1880 \\
1790 \\
\ldots\end{array}$ & $\begin{array}{l}1740 \\
1870 \\
1720 \\
1470 \\
1430 \\
3070\end{array}$ & $\begin{array}{l}479 \\
540 \\
503 \\
454 \\
424 \\
\cdots\end{array}$ & $\begin{array}{l}310 \\
291 \\
281 \\
275 \\
274 \\
265\end{array}$ & $\begin{array}{l}210 \\
206 \\
202 \\
200 \\
197 \\
210\end{array}$ & $\begin{array}{l}224 \\
219 \\
215 \\
212 \\
209 \\
\cdots-\end{array}$ \\
\hline $\begin{array}{l}\text { TOIAL } \\
\text { MEAN } \\
\text { MAX } \\
\text { MIN } \\
\text { CF SM } \\
\text { IN. }\end{array}$ & $\begin{array}{r}46573 \\
1502 \\
4820 \\
425 \\
.88 \\
1.01\end{array}$ & $\begin{array}{r}36291 \\
1210 \\
5590 \\
652 \\
.71 \\
.79\end{array}$ & $\begin{array}{r}182560 \\
5889 \\
40800 \\
1270 \\
3.45 \\
3.98\end{array}$ & $\begin{array}{r}181260 \\
5847 \\
44500 \\
1940 \\
3.43 \\
3.95\end{array}$ & $\begin{array}{r}117930 \\
4212 \\
12000 \\
2010 \\
2.47 \\
2.57\end{array}$ & $\begin{array}{r}167280 \\
5396 \\
14200 \\
1540 \\
3.16 \\
3.65\end{array}$ & $\begin{array}{r}87050 \\
2902 \\
5460 \\
1780 \\
1.70 \\
1.90\end{array}$ & $\begin{array}{c}54890 \\
1771 \\
3070 \\
1330 \\
1.04 \\
1.20\end{array}$ & $\begin{array}{r}29067 \\
969 \\
3750 \\
424 \\
.57 \\
.63\end{array}$ & $\begin{array}{r}14894 \\
480 \\
1090 \\
265 \\
.28 \\
.32\end{array}$ & $\begin{array}{l}7870 \\
254 \\
335 \\
197 \\
.15 \\
.17\end{array}$ & $\begin{array}{c}1222 \\
241 \\
413 \\
198 \\
.14 \\
.16\end{array}$ \\
\hline
\end{tabular}

STATISIICS OF MONTHLY MEAN DATA FOR WAIER YEARS 1949 - 1991, BY WATER YEAR (WY)

$\begin{array}{lrrrrrrrrrrrr}\text { MEAN } & 523 & 1239 & 2057 & 2673 & 3185 & 3370 & 3006 & 2407 & 1489 & 1263 & 785 & 515 \\ \text { MAX } & 2957 & 5284 & 6004 & 14400 & 8640 & 8014 & 7466 & 6501 & 5565 & 4990 & 5185 & 3696 \\ \text { (WY) } & 1987 & 1956 & 1967 & 1950 & 1950 & 1963 & 1964 & 1968 & 1958 & 1958 & 1979 & 1989 \\ \text { MIN } & 138 & 172 & 191 & 163 & 342 & 829 & 852 & 532 & 325 & 161 & 136 & 101 \\ \text { (WY) } & 1965 & 1955 & 1964 & 1977 & 1964 & 1954 & 1971 & 1976 & 1988 & 1954 & 1954 & 1954\end{array}$

SUMMARY SIAIISIICS

ANNUAL TOIAL

ANNUAL MEAN

HIGHESI ANMUAL MEAM

LOWEST ANNUAL MEAN

HIGHEST DAILY MEAN

LOWEST DAIIY MEAN

ANNUAL SEVEN-DAY MINIMUM

INSTANIANEOUS PEAK FLOW

INSIANTANEOUS PEAK STAGE

ANMUAL RUNOFF (CFSM)

ANMUAL RUNOFF (INCHES)

10 PERCENT EXIEEDS

50 PERCENT EXCEEDS

90 PERCENT EXCEEDS
FOR 1990 CAIENDAR YEAR

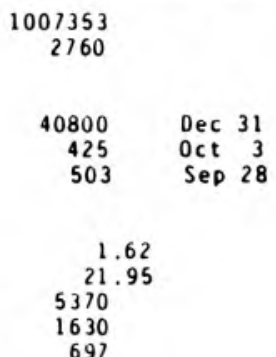

FOR 1991 WATER YEAR

932887
2556

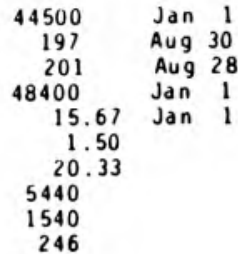

WAIER YEARS $1949 \cdot 1991$

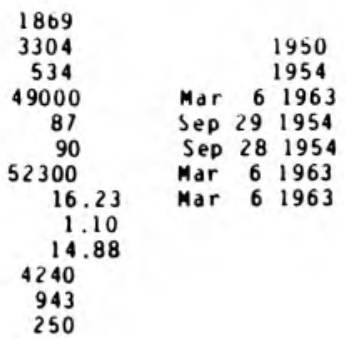




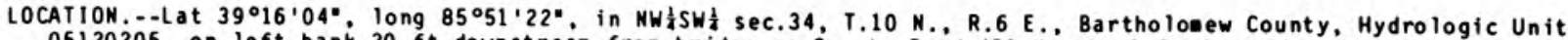
05120205 , on left bank $20 \mathrm{ft}$ downstrean from bridge on County Road 450 North, 1.2 ai southeast of Clifford.

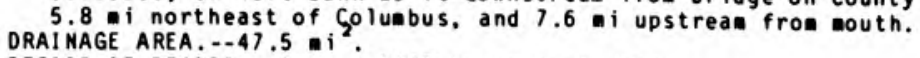

PERIOD OF RECORD.--August 1967 to current year GAGE - -Water-stage recorder and crest-stage gage. Datue of gage is $643.00 \mathrm{ft}$ above National Geodetic Vertical
Datum of 1929 .

REMARKS. - Records good except for estimated daily discharges and Mar. 13-22 and Apr. 13-26, which are fair.

DISCHARGE, CUBIC FEET PER SECOND, WATER YEAR OCTOBER 1990 TO SEPTEMBER 1991

\begin{tabular}{|c|c|c|c|c|c|c|c|c|c|c|c|c|}
\hline DAY & OCT & NOV & DEC & JAN & FEB & MAR & APR & MAY & JUN & JUL & AUG & SEP \\
\hline $\begin{array}{l}1 \\
2 \\
3 \\
4 \\
5\end{array}$ & $\begin{array}{r}4.5 \\
3.7 \\
3.7 \\
63 \\
37\end{array}$ & $\begin{array}{l}15 \\
14 \\
13 \\
13 \\
15\end{array}$ & $\begin{array}{r}35 \\
29 \\
177 \\
109 \\
60\end{array}$ & $\begin{array}{r}\text { e1 } 80 \\
\text { e120 } \\
\text { e95 } \\
\text { e80 } \\
\text { e } 77\end{array}$ & $\begin{array}{l}\text { e40 } \\
\text { e42 } \\
\text { e46 } \\
\text { e51 } \\
\text { e60 }\end{array}$ & $\begin{array}{r}39 \\
44 \\
40 \\
38 \\
e 37\end{array}$ & $\begin{array}{l}52 \\
47 \\
45 \\
42 \\
41\end{array}$ & $\begin{array}{l}33 \\
30 \\
28 \\
27 \\
31\end{array}$ & $\begin{array}{l}19 \\
18 \\
17 \\
16 \\
14\end{array}$ & $\begin{array}{l}8.0 \\
7.0 \\
7.6 \\
7.4 \\
7.0\end{array}$ & $\begin{array}{l}3.7 \\
3.6 \\
3.5 \\
3.3 \\
3.3\end{array}$ & $\begin{array}{l}\text { e6.0 } \\
\text { e4.5 } \\
\text { e3.9 } \\
89 \\
21\end{array}$ \\
\hline $\begin{array}{r}6 \\
7 \\
8 \\
9 \\
10\end{array}$ & $\begin{array}{r}24 \\
17 \\
15 \\
166 \\
250\end{array}$ & $\begin{array}{l}16 \\
15 \\
13 \\
13 \\
18\end{array}$ & $\begin{array}{l}47 \\
38 \\
34 \\
31 \\
28\end{array}$ & $\begin{array}{r}102 \\
103 \\
89 \\
80 \\
78\end{array}$ & $\begin{array}{l}\text { e } 700 \\
\text { e } 450 \\
\text { e200 } \\
\text { e130 } \\
\text { e100 }\end{array}$ & $\begin{array}{r}e 38 \\
e 37 \\
e 30 \\
29 \\
28\end{array}$ & $\begin{array}{l}38 \\
34 \\
34 \\
38 \\
33\end{array}$ & $\begin{array}{l}40 \\
31 \\
27 \\
26 \\
26\end{array}$ & $\begin{array}{l}13 \\
13 \\
13 \\
12 \\
12\end{array}$ & $\begin{array}{l}6.7 \\
6.4 \\
6.1 \\
5.7 \\
5.8\end{array}$ & $\begin{array}{l}6.9 \\
5.0 \\
3.4 \\
3.1 \\
3.1\end{array}$ & $\begin{array}{r}8.8 \\
6.3 \\
\text { e5.0 } \\
\text { e4.3 } \\
\text { e3.9 }\end{array}$ \\
\hline $\begin{array}{l}11 \\
12 \\
13 \\
14 \\
15\end{array}$ & $\begin{array}{r}122 \\
67 \\
44 \\
34 \\
29\end{array}$ & $\begin{array}{l}18 \\
15 \\
13 \\
13 \\
12\end{array}$ & $\begin{array}{l}27 \\
26 \\
24 \\
22 \\
36\end{array}$ & $\begin{array}{r}246 \\
273 \\
144 \\
102 \\
96\end{array}$ & $\begin{array}{l}\text { e76 } \\
\text { e62 } \\
\text { e62 } \\
\text { e87 } \\
\text { e68 }\end{array}$ & $\begin{array}{r}26 \\
27 \\
232 \\
161 \\
90\end{array}$ & $\begin{array}{r}29 \\
28 \\
349 \\
279 \\
205\end{array}$ & $\begin{array}{l}26 \\
36 \\
34 \\
31 \\
40\end{array}$ & $\begin{array}{r}18 \\
127 \\
38 \\
23 \\
19\end{array}$ & $\begin{array}{l}5.9 \\
31 \\
15 \\
9.5 \\
7.6\end{array}$ & $\begin{array}{l}3.1 \\
3.1 \\
3.1 \\
3.1 \\
3.1\end{array}$ & $\begin{array}{l}\text { e3.6 } \\
\text { e } 3.4 \\
\text { e3.3 } \\
\text { e3.2 } \\
\text { e3.1 }\end{array}$ \\
\hline $\begin{array}{l}16 \\
17 \\
18 \\
19 \\
20\end{array}$ & $\begin{array}{l}23 \\
20 \\
64 \\
47 \\
32\end{array}$ & $\begin{array}{l}12 \\
12 \\
13 \\
12 \\
11\end{array}$ & $\begin{array}{r}38 \\
47 \\
797 \\
431 \\
181\end{array}$ & $\begin{array}{r}129 \\
106 \\
84 \\
77 \\
70\end{array}$ & $\begin{array}{r}\text { e47 } \\
\text { e50 } \\
\text { e100 } \\
\text { e210 } \\
130\end{array}$ & $\begin{array}{r}70 \\
89 \\
229 \\
113 \\
80\end{array}$ & $\begin{array}{r}120 \\
89 \\
72 \\
254 \\
164\end{array}$ & $\begin{array}{l}31 \\
31 \\
30 \\
30 \\
25\end{array}$ & $\begin{array}{l}18 \\
17 \\
14 \\
12 \\
10\end{array}$ & $\begin{array}{l}6.8 \\
6.1 \\
5.8 \\
5.5 \\
5.2\end{array}$ & $\begin{array}{l}3.1 \\
4.7 \\
7.1 \\
7.3 \\
5.6\end{array}$ & $\begin{array}{l}\text { e6.0 } \\
\text { e } 4.8 \\
\text { e4.1 } \\
\text { e3.5 } \\
\text { e3.2 }\end{array}$ \\
\hline $\begin{array}{l}21 \\
22 \\
23 \\
24 \\
25\end{array}$ & $\begin{array}{l}26 \\
27 \\
32 \\
29 \\
24\end{array}$ & $\begin{array}{l}9.8 \\
28 \\
43 \\
30 \\
25\end{array}$ & $\begin{array}{r}231 \\
361 \\
\text { e220 } \\
\text { e100 } \\
\text { e76 }\end{array}$ & $\begin{array}{l}\text { e } 54 \\
\text { e } 46 \\
\text { e45 } \\
\text { e41 } \\
\text { e37 }\end{array}$ & $\begin{array}{l}89 \\
73 \\
61 \\
55 \\
49\end{array}$ & $\begin{array}{r}73 \\
662 \\
619 \\
157 \\
98\end{array}$ & $\begin{array}{l}94 \\
75 \\
65 \\
58 \\
56\end{array}$ & $\begin{array}{l}23 \\
43 \\
67 \\
42 \\
32\end{array}$ & $\begin{array}{l}9.4 \\
9.2 \\
8.5 \\
7.8 \\
8.3\end{array}$ & $\begin{array}{l}5.0 \\
4.9 \\
4.7 \\
4.6 \\
4.4\end{array}$ & $\begin{array}{l}4.4 \\
\text { e } 4.1 \\
\text { e3.8 } \\
\text { e3.5 } \\
\text { e3.3 }\end{array}$ & $\begin{array}{l}\text { e3.0 } \\
\text { e2.9 } \\
\text { e3.5 } \\
\text { e3.2 } \\
\text { e3.0 }\end{array}$ \\
\hline $\begin{array}{l}26 \\
27 \\
28 \\
29 \\
30 \\
31\end{array}$ & $\begin{array}{l}22 \\
20 \\
18 \\
16 \\
17 \\
15\end{array}$ & $\begin{array}{c}22 \\
22 \\
76 \\
62 \\
42 \\
-\cdots\end{array}$ & $\begin{array}{r}e 64 \\
e 57 \\
e 53 \\
e 500 \\
e 1300 \\
e 300\end{array}$ & $\begin{array}{l}\text { e } 35 \\
e 34 \\
e 33 \\
\text { e } 33 \\
\text { e43 } \\
\text { e41 }\end{array}$ & \begin{tabular}{r}
46 \\
43 \\
40 \\
$-\cdots$ \\
\hdashline- \\
$\cdots-$
\end{tabular} & $\begin{array}{r}372 \\
193 \\
111 \\
83 \\
66 \\
59\end{array}$ & $\begin{array}{l}52 \\
47 \\
43 \\
41 \\
36 \\
--\end{array}$ & $\begin{array}{l}31 \\
35 \\
27 \\
24 \\
23 \\
21\end{array}$ & $\begin{array}{l}7.5 \\
7.0 \\
6.8 \\
6.8 \\
6.8 \\
\cdots . .\end{array}$ & $\begin{array}{l}4.4 \\
4.2 \\
4.1 \\
4.1 \\
4.0 \\
3.8\end{array}$ & $\begin{array}{l}\text { e3.1 } \\
\text { e3.0 } \\
\text { e2 } 2.9 \\
\text { e2.8 } \\
\text { e2.8 } \\
\text { e2.7 }\end{array}$ & $\begin{array}{l}\mathrm{e} 2.9 \\
\mathrm{e} 2.8 \\
\mathrm{e} 2.7 \\
\mathrm{e} 2.7 \\
\mathrm{e} 2.6 \\
\ldots\end{array}$ \\
\hline $\begin{array}{l}\text { TOTAL } \\
\text { MEAN } \\
\text { MAX } \\
\text { MIN } \\
\text { CF SM } \\
\text { IN. }\end{array}$ & $\begin{array}{r}1311.9 \\
42.3 \\
250 \\
3.7 \\
.89 \\
1.03\end{array}$ & $\begin{array}{r}635.8 \\
21.2 \\
76 \\
9.8 \\
.45 \\
.50\end{array}$ & $\begin{array}{r}5479 \\
177 \\
1300 \\
22 \\
3.72 \\
4.29\end{array}$ & $\begin{array}{r}2773 \\
89.5 \\
273 \\
33 \\
1.88 \\
2.17\end{array}$ & $\begin{array}{r}3167 \\
113 \\
700 \\
40 \\
2.38 \\
2.48\end{array}$ & $\begin{array}{r}3970 \\
128 \\
662 \\
26 \\
2.70 \\
3.11\end{array}$ & $\begin{array}{r}2560 \\
85.3 \\
349 \\
28 \\
1.80 \\
2.00\end{array}$ & $\begin{array}{r}981 \\
31.6 \\
67 \\
21 \\
.67 \\
.77\end{array}$ & $\begin{array}{r}521.1 \\
17.4 \\
127 \\
6.8 \\
.37 \\
.41\end{array}$ & $\begin{array}{c}214.3 \\
6.91 \\
31 \\
3.8 \\
.15 \\
.17\end{array}$ & $\begin{array}{c}118.6 \\
3.83 \\
7.3 \\
2.7 \\
.08 \\
.09\end{array}$ & $\begin{array}{r}220.2 \\
7.34 \\
89 \\
2.6 \\
.15 \\
.17\end{array}$ \\
\hline
\end{tabular}

STATISTICS OF MONTHLY MEAN DATA FOR WATER YEARS 1968 - 1991, BY WATER YEAR (WN)

\begin{tabular}{|c|c|c|c|c|c|c|c|c|c|c|c|c|}
\hline $\begin{array}{l}\text { MEAN } \\
\text { MAX } \\
\text { (WY) } \\
\text { MIN } \\
\text { (WY) }\end{array}$ & $\begin{array}{r}10.5 \\
42.3 \\
1991 \\
.73 \\
1968\end{array}$ & $\begin{array}{r}37.8 \\
189 \\
1986 \\
1.92 \\
1988\end{array}$ & $\begin{array}{r}69.2 \\
177 \\
1991 \\
3.55 \\
1977\end{array}$ & $\begin{array}{r}63.3 \\
205 \\
1982 \\
.96 \\
1977\end{array}$ & $\begin{array}{r}82.5 \\
201 \\
1975 \\
11.8 \\
1987\end{array}$ & $\begin{array}{r}90.9 \\
205 \\
1978 \\
14.5 \\
1983\end{array}$ & $\begin{array}{r}86.5 \\
192 \\
1989 \\
11.7 \\
1976\end{array}$ & $\begin{array}{r}69.2 \\
209 \\
1968 \\
7.16 \\
1976\end{array}$ & $\begin{array}{l}26.8 \\
76.7 \\
1973 \\
2.92 \\
1988\end{array}$ & $\begin{array}{l}27.9 \\
122 \\
1979 \\
1.77 \\
1988\end{array}$ & $\begin{array}{l}18.3 \\
93.5 \\
1978 \\
1.47 \\
1988\end{array}$ & $\begin{array}{r}14.3 \\
171 \\
1974 \\
.56 \\
1988\end{array}$ \\
\hline
\end{tabular}

SUMMARY STAIISTICS

\section{AMNUAL TOTAL}

ANNUAL MEAN

HIGHEST ANMUAL MEAN

LOWEST ANHUAL MEAN

HIGHEST DAILY MEAN

LOWEST DAILY MEAN

ANNUAL SEVEN-DAY MINIMUM

INSTANTANEOUS PEAK FLOW

INSTANTANEOUS PEAK STAGE

ANNUAL RUNOFF (CF SM)

ANMUAL RUMOFF (INCHES)

10 PERCENT EXCEEDS

50 PERCENT EXCEEDS

90 PERCENT EXCEEDS
FOR 1990 CALENDAR YEAR

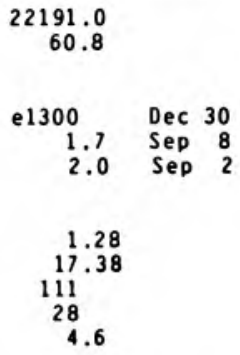

FOR 1991 WATER YEAR

21951.9

60.1

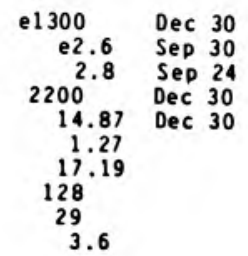

WATER YEARS 1968 - 1991

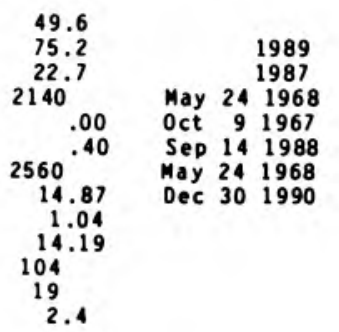




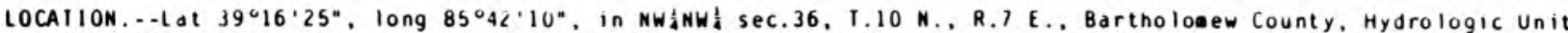
05120206, at downstrean side of left abutment of county highwdy bridge, 0.2 i north of Hartsville, 5.9 .

upstrea from Duck Creek, and at mile 20.0 . DRAI MAGE AREA - $91.4 i^{2}$

PERIOD OF RECORD.--February 1948 to current year.

REVISED RECORDS..-WSP 1335: 1950. WSP 1725: 1949(M). WSP 2109: Drainage area. WOR IM-74-1: 1973.

GAGE.- Water-stage recorder. Datun of gage is $671.34 \mathrm{ft}$ above Mational Geodetic Vertical Datue of 1929 . Prior to Sept. 24, 1952, nonrecording gage at save site and datue.

REMARKS. - Records good, except for estinated daily discharges which are fair.

EXIREMES OUISIDE PERIOD OF RECORD..-Flood in 1913 reached an elevation of $102.4 \mathrm{ft}$ National Geodetic Vertical Datue of 1929, froe floodearks, upstrean fron bridge.

DISCHARGE, CUBIC FEET PER SECOND, WATER YEAR OCTOBER 1990 TO SEPIEMBER 1991 DAIIY MEAN VALUES

\begin{tabular}{|c|c|c|c|c|c|c|c|c|c|c|c|c|}
\hline DAY & $O C T$ & NOV & DEC & JAM & FE B & MAR & APR & MAY & JUN & JUL & AUG & SEP \\
\hline $\begin{array}{l}1 \\
2 \\
3 \\
4 \\
5\end{array}$ & $\begin{array}{r}3.8 \\
4.3 \\
3.7 \\
156 \\
132\end{array}$ & $\begin{array}{l}24 \\
24 \\
24 \\
23 \\
27\end{array}$ & $\begin{array}{r}106 \\
87 \\
342 \\
359 \\
195\end{array}$ & $\begin{array}{l}357 \\
234 \\
170 \\
132 \\
123\end{array}$ & $\begin{array}{r}\text { e66 } \\
\text { e70 } \\
\text { e74 } \\
\text { e85 } \\
\text { e100 }\end{array}$ & $\begin{array}{l}66 \\
76 \\
66 \\
58 \\
53\end{array}$ & $\begin{array}{l}90 \\
77 \\
69 \\
66 \\
72\end{array}$ & $\begin{array}{l}44 \\
41 \\
38 \\
39 \\
40\end{array}$ & $\begin{array}{l}17 \\
16 \\
17 \\
16 \\
13\end{array}$ & $\begin{array}{l}4.8 \\
3.8 \\
2.1 \\
1.6 \\
2.3\end{array}$ & $\begin{array}{l}.00 \\
.00 \\
.00 \\
.00 \\
.00\end{array}$ & $\begin{array}{r}.05 \\
.00 \\
28.00 \\
2.6\end{array}$ \\
\hline $\begin{array}{r}6 \\
7 \\
8 \\
9 \\
10\end{array}$ & $\begin{array}{r}38 \\
21 \\
14 \\
262 \\
606\end{array}$ & $\begin{array}{l}35 \\
35 \\
27 \\
26 \\
35\end{array}$ & $\begin{array}{r}147 \\
116 \\
98 \\
87 \\
76\end{array}$ & $\begin{array}{l}160 \\
172 \\
133 \\
115 \\
102\end{array}$ & $\begin{array}{r}1310 \\
922 \\
401 \\
257 \\
190\end{array}$ & $\begin{array}{l}56 \\
55 \\
44 \\
42 \\
40\end{array}$ & $\begin{array}{l}65 \\
59 \\
58 \\
77 \\
69\end{array}$ & $\begin{array}{l}46 \\
35 \\
31 \\
31 \\
30\end{array}$ & $\begin{array}{r}11 \\
9.4 \\
8.8 \\
8.6 \\
8.3\end{array}$ & $\begin{array}{l}1.8 \\
1.2 \\
.99 \\
.83 \\
1.6\end{array}$ & $\begin{array}{l}.48 \\
.64 \\
.18 \\
.10 \\
.09\end{array}$ & $\begin{array}{l}.62 \\
.79 \\
.45 \\
.29 \\
.21\end{array}$ \\
\hline $\begin{array}{l}11 \\
12 \\
13 \\
14 \\
15\end{array}$ & $\begin{array}{r}302 \\
137 \\
82 \\
58 \\
44\end{array}$ & $\begin{array}{l}50 \\
38 \\
32 \\
27 \\
25\end{array}$ & $\begin{array}{l}69 \\
66 \\
61 \\
53 \\
89\end{array}$ & $\begin{array}{l}260 \\
513 \\
265 \\
186 \\
183\end{array}$ & $\begin{array}{l}145 \\
117 \\
116 \\
168 \\
144\end{array}$ & $\begin{array}{r}38 \\
49 \\
805 \\
557 \\
264\end{array}$ & $\begin{array}{r}56 \\
48 \\
1060 \\
781 \\
440\end{array}$ & $\begin{array}{r}29 \\
30 \\
29 \\
31 \\
304\end{array}$ & $\begin{array}{c}78 \\
80 \\
18 \\
11 \\
8.9\end{array}$ & $\begin{array}{r}4.3 \\
12 \\
6.1 \\
3.7 \\
2.4\end{array}$ & $\begin{array}{l}.06 \\
.01 \\
.00 \\
.00 \\
.00\end{array}$ & $\begin{array}{l}.13 \\
.10 \\
.06 \\
1.4 \\
7.5\end{array}$ \\
\hline $\begin{array}{l}16 \\
17 \\
18 \\
19 \\
20\end{array}$ & $\begin{array}{r}34 \\
28 \\
175 \\
173 \\
86\end{array}$ & $\begin{array}{l}24 \\
24 \\
22 \\
21 \\
21\end{array}$ & $\begin{array}{r}152 \\
128 \\
1640 \\
1320 \\
460\end{array}$ & $\begin{array}{l}255 \\
250 \\
187 \\
149 \\
135\end{array}$ & $\begin{array}{l}e 90 \\
e 94 \\
172 \\
410 \\
293\end{array}$ & $\begin{array}{l}170 \\
173 \\
416 \\
246 \\
167\end{array}$ & $\begin{array}{l}260 \\
171 \\
128 \\
215 \\
190\end{array}$ & $\begin{array}{r}87 \\
53 \\
146 \\
120 \\
60\end{array}$ & $\begin{array}{l}8.3 \\
8.6 \\
8.2 \\
6.4 \\
5.0\end{array}$ & $\begin{array}{l}1.7 \\
1.3 \\
.91 \\
.67 \\
.52\end{array}$ & $\begin{array}{l}.00 \\
.00 \\
.01 \\
.40 \\
.18\end{array}$ & $\begin{array}{l}3.9 \\
2.2 \\
1.1 \\
.79 \\
.54\end{array}$ \\
\hline $\begin{array}{l}21 \\
22 \\
23 \\
24 \\
25\end{array}$ & $\begin{array}{l}62 \\
63 \\
79 \\
66 \\
54\end{array}$ & $\begin{array}{r}19 \\
48 \\
140 \\
86 \\
63\end{array}$ & $\begin{array}{r}510 \\
941 \\
e 500 \\
e 250 \\
e 170\end{array}$ & $\begin{array}{r}\text { el } 00 \\
\text { e } 76 \\
\text { e } 73 \\
\text { e67 } \\
\text { e60 }\end{array}$ & $\begin{array}{r}195 \\
148 \\
117 \\
105 \\
89\end{array}$ & $\begin{array}{r}135 \\
828 \\
1250 \\
354 \\
202\end{array}$ & $\begin{array}{r}136 \\
113 \\
97 \\
83 \\
70\end{array}$ & $\begin{array}{l}43 \\
35 \\
69 \\
40 \\
31\end{array}$ & $\begin{array}{l}4.3 \\
4.2 \\
3.7 \\
3.0 \\
2.7\end{array}$ & $\begin{array}{l}.37 \\
.26 \\
.15 \\
.06 \\
.01\end{array}$ & $\begin{array}{l}.15 \\
\text { e. } 05 \\
\text { e.00 } \\
\text { e. } 00 \\
\text { e. } 00\end{array}$ & $\begin{array}{l}.38 \\
.28 \\
.35 \\
.29 \\
.17\end{array}$ \\
\hline $\begin{array}{l}26 \\
27 \\
28 \\
29 \\
30 \\
31\end{array}$ & $\begin{array}{l}44 \\
37 \\
34 \\
30 \\
27 \\
26\end{array}$ & $\begin{array}{r}50 \\
51 \\
174 \\
224 \\
134 \\
\cdots\end{array}$ & $\begin{array}{l}\text { e130 } \\
\text { e } 120 \\
\text { e115 } \\
1040 \\
4830 \\
1700\end{array}$ & $\begin{array}{l}\text { e } 56 \\
\text { e55 } \\
\text { e54 } \\
\text { e54 } \\
\text { e } 70 \\
\text { e68 }\end{array}$ & $\begin{array}{l}79 \\
74 \\
67 \\
\cdots \\
\cdots \\
\cdots\end{array}$ & $\begin{array}{l}452 \\
430 \\
242 \\
166 \\
124 \\
100\end{array}$ & $\begin{array}{l}66 \\
62 \\
59 \\
57 \\
50 \\
\cdots\end{array}$ & $\begin{array}{l}35 \\
54 \\
34 \\
25 \\
22 \\
20\end{array}$ & $\begin{array}{r}2.5 \\
2.3 \\
2.0 \\
2.7 \\
2.2 \\
\cdots\end{array}$ & $\begin{array}{l}.00 \\
.00 \\
.00 \\
.00 \\
.00 \\
.00\end{array}$ & $\begin{array}{l}\text { e. } 00 \\
\text { e. } 00 \\
\text { e. } 00 \\
.00 \\
.00 \\
.04\end{array}$ & $\begin{array}{l}.09 \\
.04 \\
.01 \\
.00 \\
.00 \\
. .-\end{array}$ \\
\hline $\begin{array}{l}\text { IOIAL } \\
\text { MEAN } \\
\text { MAX } \\
\text { MIN } \\
\text { CFSM } \\
\text { IN. }\end{array}$ & $\begin{array}{r}2881.8 \\
93.0 \\
606 \\
3.7 \\
1.02 \\
1.17\end{array}$ & $\begin{array}{r}1553 \\
51.8 \\
224 \\
19 \\
.57 \\
.63\end{array}$ & $\begin{array}{r}15951 \\
515 \\
4830 \\
53 \\
5.63 \\
6.49\end{array}$ & $\begin{array}{r}4814 \\
155 \\
513 \\
54 \\
1.70 \\
1.96\end{array}$ & $\begin{array}{r}6098 \\
218 \\
1310 \\
66 \\
2.38 \\
2.48\end{array}$ & $\begin{array}{r}7124 \\
249 \\
1250 \\
38 \\
2.73 \\
3.14\end{array}$ & $\begin{array}{r}4844 \\
161 \\
1060 \\
48 \\
1.77 \\
1.97\end{array}$ & $\begin{array}{c}1672 \\
53.9 \\
304 \\
20 \\
.59 \\
.68\end{array}$ & $\begin{array}{r}387.1 \\
12.9 \\
80 \\
2.0 \\
.14 \\
.16\end{array}$ & $\begin{array}{c}55.47 \\
1.79 \\
12 \\
.00 \\
.02 \\
.02\end{array}$ & $\begin{array}{c}2.39 \\
.017 \\
.64 \\
.00 \\
.00 \\
.00\end{array}$ & $\begin{array}{c}52.34 \\
1.74 \\
28 \\
.00 \\
.02 \\
.02\end{array}$ \\
\hline
\end{tabular}

e Estinated

SIATISTICS OF MONTHLY MEAM DATA FOR WAIER YEARS 1949 - 1991. BY WATER YEAR (WY)

$\begin{array}{lrrrrrrrrrrrr}\text { MEAN } & 18.6 & 10.3 & 124 & 100 & 176 & 189 & 147 & 127 & 60.3 & 54.0 & 29.0 & 19.5 \\ \text { MAX } & 183 & 431 & 515 & 874 & 551 & 465 & 360 & 424 & 209 & 231 & 194 & 261 \\ \text { (WY) } & 1978 & 1986 & 1991 & 1949 & 1950 & 1961 & 1964 & 1968 & 1958 & 1979 & 1978 & 1974 \\ \text { MIN } & 1000 & 000 & 13 & 1.47 & 7.17 & 21.1 & 17.7 & 10.9 & 1.16 & .000 & .000 & .000 \\ \text { (WY) } & 1954 & 1954 & 1954 & 1977 & 1954 & 1954 & 1976 & 1976 & 1988 & 1954 & 1954 & 1953\end{array}$

SUMMARY SIAIISIICS

ANNUAL TOTAL

ANNUAL MEAN

HIGHESI ANNUAL MEAN

LOWEST ANNUAL MEAM

HIGHESI DAILY MEAM

LOWEST DAILY MEAN

ANMUAL SEVEN-DAY MINIMUM

INSTANTANEOUS PEAK FLOW

INSTANTANEOUS PEAK STAGE

ANNUAL RUNOFF (CFSM)

ANMUAL RUNOFF (INCHES)

10 PERCENT EXLEEDS

50 PERCENT EXCEEDS

90 PERCENT EXCEEDS
FOR I9YO CALENOAR YEAR

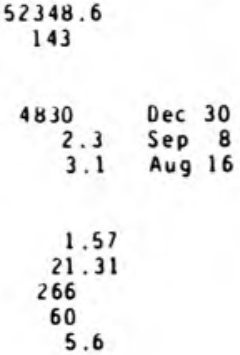

FOR 1991 WATER YEAR

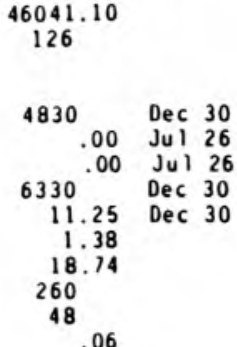

WATER YEARS 1949 - 1991

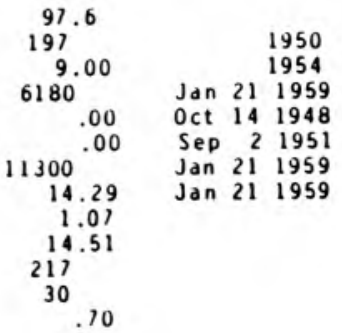




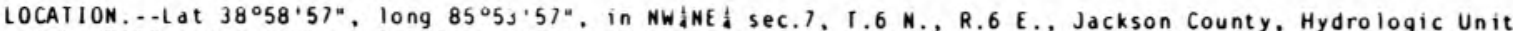
05120206 , on left bank $1,700 \mathrm{ft}$ downstream from highwa bridge, 1 a north of Seymour, 9.5 a downstreda fro Sand Creek, dnd at aile 214.6

DRAINAGE AREA, $\cdots 2,341 \mathrm{i}^{2}$.

PERIOD OF RECORD.--0ctober 1927 to current yedr. Yearly adimum discharge only for water years $1924-27$ published in WSP 1305. Daily gage heights from May 1923 to Septeaber 1927 are available in the district office.

REVISED RECORDS.-.WSP 143: 1928-29, 1931-32. WSP 783: 1934. WSP 873: 1938. WSP 1335: 1928(M), 1929-30, 1932-33(M), 1937(M), 1942. WSP 1435: 1949. WSP 1705: 1958. WSP 2109: Orainage area.

GAGE. - Water-stage recorder. Datue of gage is $550.67 \mathrm{ft}$ above National Geodetic Vertical Datun of 1929 . Oct. 1 . 1921 to July 2, 1931 , nonrecording gage $1,700 \mathrm{ft}$ upstrean at datum $7.61 \mathrm{ft} \mathrm{higher}$. July 3 , 1931 to July 16. 1934, nonrecording gage at site $100 \mathrm{ft}$ downstrea at present datu.

REMARKS.-. Records good.

EXTREMES OUTSIDE PERIDD OF RECORD..-Flood of Mar. 26, 1913, reached a stagf of $21.0 \mathrm{ft}$, from information by Corps of Engineers and Indiana Department of Highways, discharge, $120,000 \mathrm{ft} / \mathrm{s}$.

DISCHARGE, CUBIC FEET PER SECONO, WAIER YEAR OCIOBER 1990 TO SEPTEMBER 1991 DAILY MEAN VALUES

\begin{tabular}{|c|c|c|c|c|c|c|c|c|c|c|c|c|}
\hline DAY & $\mathrm{OCT}$ & NOV & $\mathrm{DEC}$ & JAN & FEB & MAR & APR & MAY & JUN & JUL & AUG & SEP \\
\hline $\begin{array}{l}1 \\
2 \\
3 \\
4 \\
5\end{array}$ & $\begin{array}{r}643 \\
620 \\
609 \\
958 \\
1940\end{array}$ & $\begin{array}{r}1080 \\
1040 \\
996 \\
962 \\
955\end{array}$ & $\begin{array}{l}4080 \\
3040 \\
3560 \\
6330 \\
6240\end{array}$ & $\begin{array}{r}50400 \\
42700 \\
24600 \\
10400 \\
6660\end{array}$ & $\begin{array}{l}2890 \\
2650 \\
2680 \\
3060 \\
3410\end{array}$ & $\begin{array}{l}2680 \\
2700 \\
2710 \\
2570 \\
2400\end{array}$ & $\begin{array}{l}4570 \\
4040 \\
3630 \\
3350 \\
3320\end{array}$ & $\begin{array}{l}2300 \\
2150 \\
2040 \\
1960 \\
1920\end{array}$ & $\begin{array}{l}3320 \\
3040 \\
2260 \\
1820 \\
1590\end{array}$ & $\begin{array}{l}577 \\
572 \\
634 \\
605 \\
688\end{array}$ & $\begin{array}{l}365 \\
357 \\
352 \\
363 \\
338\end{array}$ & $\begin{array}{r}296 \\
282 \\
271 \\
393 \\
1590\end{array}$ \\
\hline $\begin{array}{r}6 \\
7 \\
8 \\
9 \\
10\end{array}$ & $\begin{array}{l}2020 \\
1680 \\
1320 \\
1350 \\
4480\end{array}$ & $\begin{array}{r}964 \\
1060 \\
1120 \\
1070 \\
1040\end{array}$ & $\begin{array}{l}4780 \\
3540 \\
2880 \\
2470 \\
2200\end{array}$ & $\begin{array}{l}5600 \\
5770 \\
5180 \\
4540 \\
4140\end{array}$ & $\begin{array}{r}6910 \\
17400 \\
17600 \\
13400 \\
9120\end{array}$ & $\begin{array}{l}2300 \\
2270 \\
2220 \\
2100 \\
2000\end{array}$ & $\begin{array}{l}3300 \\
3100 \\
2920 \\
2850 \\
4550\end{array}$ & $\begin{array}{l}1960 \\
1990 \\
1910 \\
1800 \\
1720\end{array}$ & $\begin{array}{l}1390 \\
1240 \\
1140 \\
1070 \\
1010\end{array}$ & $\begin{array}{l}688 \\
601 \\
552 \\
522 \\
587\end{array}$ & $\begin{array}{l}353 \\
428 \\
416 \\
438 \\
409\end{array}$ & $\begin{array}{l}622 \\
453 \\
385 \\
352 \\
336\end{array}$ \\
\hline $\begin{array}{l}11 \\
12 \\
13 \\
14 \\
15\end{array}$ & $\begin{array}{l}4780 \\
5090 \\
3960 \\
2890 \\
2260\end{array}$ & $\begin{array}{r}1080 \\
1090 \\
1030 \\
971 \\
932\end{array}$ & $\begin{array}{l}2010 \\
1870 \\
1760 \\
1660 \\
1680\end{array}$ & $\begin{array}{l}4330 \\
7430 \\
8830 \\
7800 \\
5860\end{array}$ & $\begin{array}{l}6420 \\
4990 \\
4220 \\
4690 \\
4730\end{array}$ & $\begin{array}{r}1930 \\
1880 \\
3290 \\
9290 \\
12600\end{array}$ & $\begin{array}{r}2970 \\
2600 \\
4170 \\
11300 \\
9690\end{array}$ & $\begin{array}{l}1660 \\
1640 \\
1720 \\
1630 \\
1990\end{array}$ & $\begin{array}{r}970 \\
1120 \\
1410 \\
1100 \\
970\end{array}$ & $\begin{array}{r}677 \\
898 \\
1210 \\
865 \\
739\end{array}$ & $\begin{array}{l}401 \\
377 \\
355 \\
341 \\
332\end{array}$ & $\begin{array}{l}320 \\
309 \\
302 \\
295 \\
412\end{array}$ \\
\hline $\begin{array}{l}16 \\
17 \\
18 \\
19 \\
20\end{array}$ & $\begin{array}{l}1890 \\
1640 \\
1720 \\
2490 \\
2670\end{array}$ & $\begin{array}{l}910 \\
889 \\
865 \\
851 \\
831\end{array}$ & $\begin{array}{r}2510 \\
3450 \\
5960 \\
17200 \\
19000\end{array}$ & $\begin{array}{l}5460 \\
6150 \\
6640 \\
6010 \\
4990\end{array}$ & $\begin{array}{l}3810 \\
3300 \\
3990 \\
7400 \\
7740\end{array}$ & $\begin{array}{r}13300 \\
9260 \\
8710 \\
9760 \\
8420\end{array}$ & $\begin{array}{l}8530 \\
6510 \\
4870 \\
4350 \\
6400\end{array}$ & $\begin{array}{l}2170 \\
1770 \\
1700 \\
2410 \\
3740\end{array}$ & $\begin{array}{l}904 \\
875 \\
849 \\
812 \\
773\end{array}$ & $\begin{array}{l}650 \\
597 \\
564 \\
534 \\
512\end{array}$ & $\begin{array}{l}323 \\
338 \\
907 \\
615 \\
497\end{array}$ & $\begin{array}{l}431 \\
385 \\
350 \\
329 \\
307\end{array}$ \\
\hline $\begin{array}{l}21 \\
22 \\
23 \\
24 \\
25\end{array}$ & $\begin{array}{l}2270 \\
1950 \\
1870 \\
1870 \\
1770\end{array}$ & $\begin{array}{r}815 \\
866 \\
1320 \\
1740 \\
1670\end{array}$ & $\begin{array}{r}14400 \\
12600 \\
14100 \\
13500 \\
9570\end{array}$ & $\begin{array}{l}4450 \\
4000 \\
3550 \\
3380 \\
3100\end{array}$ & $\begin{array}{l}8280 \\
6920 \\
5200 \\
4280 \\
3770\end{array}$ & $\begin{array}{r}6160 \\
6130 \\
16700 \\
19300 \\
18300\end{array}$ & $\begin{array}{l}6590 \\
5230 \\
4250 \\
3700 \\
3310\end{array}$ & $\begin{array}{l}3040 \\
2320 \\
2830 \\
2670 \\
2340\end{array}$ & $\begin{array}{l}735 \\
714 \\
688 \\
666 \\
666\end{array}$ & $\begin{array}{l}496 \\
476 \\
462 \\
448 \\
440\end{array}$ & $\begin{array}{l}497 \\
420 \\
385 \\
352 \\
330\end{array}$ & $\begin{array}{l}299 \\
294 \\
297 \\
292 \\
289\end{array}$ \\
\hline $\begin{array}{l}26 \\
27 \\
28 \\
29 \\
30 \\
31\end{array}$ & $\begin{array}{l}1610 \\
1460 \\
1350 \\
1250 \\
1180 \\
1120\end{array}$ & $\begin{array}{c}1450 \\
1320 \\
1780 \\
4360 \\
5320 \\
\cdots\end{array}$ & $\begin{array}{r}6380 \\
4720 \\
4010 \\
5240 \\
19100 \\
55500\end{array}$ & $\begin{array}{l}2800 \\
2670 \\
2570 \\
2570 \\
2920 \\
3320\end{array}$ & $\begin{array}{c}3320 \\
3010 \\
2820 \\
\ldots \\
\ldots \\
\ldots\end{array}$ & $\begin{array}{r}12800 \\
17400 \\
14200 \\
10700 \\
7450 \\
5520\end{array}$ & $\begin{array}{c}3010 \\
2800 \\
2660 \\
2560 \\
2440 \\
\ldots .\end{array}$ & $\begin{array}{l}2050 \\
2100 \\
2170 \\
1800 \\
1560 \\
1990\end{array}$ & $\begin{array}{l}701 \\
655 \\
669 \\
633 \\
603 \\
\ldots .\end{array}$ & $\begin{array}{l}430 \\
414 \\
398 \\
387 \\
383 \\
374\end{array}$ & $\begin{array}{l}312 \\
303 \\
294 \\
286 \\
280 \\
275\end{array}$ & $\begin{array}{l}292 \\
288 \\
283 \\
278 \\
275 \\
\cdots\end{array}$ \\
\hline $\begin{array}{l}\text { IOIAL } \\
\text { MEAN } \\
\text { MAX } \\
\text { MIN } \\
\text { CFSH } \\
\text { IN. }\end{array}$ & $\begin{array}{r}62710 \\
2023 \\
5090 \\
609 \\
.86 \\
1.00\end{array}$ & $\begin{array}{r}40377 \\
1346 \\
5320 \\
815 \\
.57 \\
.64\end{array}$ & $\begin{array}{r}255340 \\
8237 \\
55500 \\
1660 \\
3.52 \\
4.06\end{array}$ & $\begin{array}{r}258820 \\
8349 \\
50400 \\
2570 \\
3.57 \\
4.11\end{array}$ & $\begin{array}{r}168010 \\
6000 \\
17600 \\
2650 \\
2.56 \\
2.67\end{array}$ & $\begin{array}{r}237050 \\
7647 \\
19300 \\
1880 \\
3.27 \\
3.77\end{array}$ & $\begin{array}{r}133570 \\
4452 \\
11300 \\
2440 \\
1.90 \\
2.12\end{array}$ & $\begin{array}{r}65050 \\
2098 \\
3740 \\
1560 \\
.90 \\
1.03\end{array}$ & $\begin{array}{c}34393 \\
1146 \\
3320 \\
603 \\
.49 \\
.55\end{array}$ & $\begin{array}{r}17980 \\
580 \\
1210 \\
374 \\
.25 \\
.29\end{array}$ & $\begin{array}{c}12039 \\
388 \\
907 \\
275 \\
.17 \\
.19\end{array}$ & $\begin{array}{r}11307 \\
377 \\
1590 \\
271 \\
.16 \\
.18\end{array}$ \\
\hline
\end{tabular}

STAIISIICS OF MONTHLY MEAN DATA FOR WATER YEARS 1928 - 1991, BY WATER YEAR (WY)

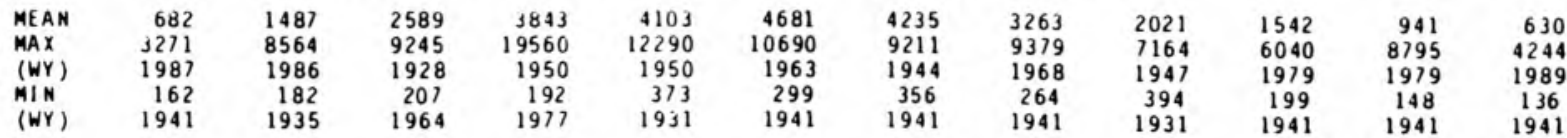

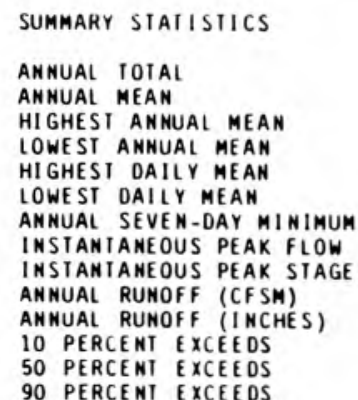

FOR 1990 CALENOAR YEAR

FOR 1991 WAIER YEAR

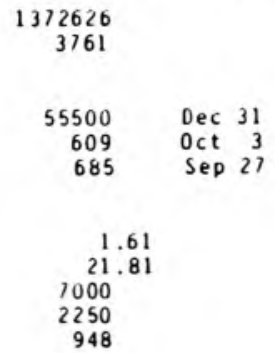

WAIER YEARS $1928-1991$

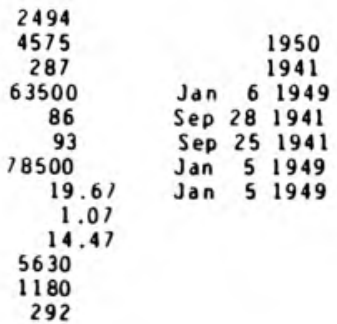




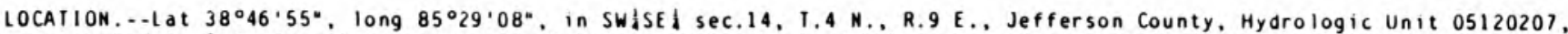
attached to left downstrean wingwall of bridge on County Road 533 West, 0.2 a west of Sayrna, 3.7 upstrean fro Big Creek, and 4 i northwest of Madison.

DRAINAGE AREA $,--9,31$ i 2

PERIOD OF RECORD.--August 1968 to current year.

GAGE.- Water-stage recorder. Datun of gage is $125.75 \mathrm{ft}$ above National Geodetic Vertical Uatue of 1929.

REMARKS. - Records fair.

DISCHARGE, CUBIC FEET PER SECONO, WATER YEAR OCTOBER 1990 TO SEPTEMBER 1991 DAILY MEAN VALUES

\begin{tabular}{|c|c|c|c|c|c|c|c|c|c|c|c|c|}
\hline DAY & $0 \mathrm{CI}$ & NOV & DEC & JAN & FEB & MAR & APR & MAY & JUN & JUL & AUG & SEP \\
\hline $\begin{array}{l}1 \\
2 \\
3 \\
4 \\
5\end{array}$ & $\begin{array}{r}.34 \\
.21 \\
56.24 \\
7.2\end{array}$ & $\begin{array}{l}1.5 \\
1.4 \\
1.3 \\
1.3 \\
1.8\end{array}$ & $\begin{array}{r}4.5 \\
3.7 \\
152 \\
27 \\
11\end{array}$ & $\begin{array}{l}24 \\
17 \\
14 \\
11 \\
13\end{array}$ & $\begin{array}{l}11 \\
10 \\
10 \\
11 \\
21\end{array}$ & $\begin{array}{l}3.7 \\
9.8 \\
6.6 \\
4.7 \\
3.5\end{array}$ & $\begin{array}{l}8.3 \\
6.7 \\
5.5 \\
5.0 \\
5.2\end{array}$ & $\begin{array}{l}1.5 \\
1.2 \\
.94 \\
1.1 \\
2.1\end{array}$ & $\begin{array}{l}8.95 \\
23 \\
3.6 \\
1.4\end{array}$ & $\begin{array}{l}.00 \\
.00 \\
.00 \\
.00 \\
.00\end{array}$ & $\begin{array}{l}.00 \\
.00 \\
.00 \\
.00 \\
.00\end{array}$ & $\begin{array}{l}.00 \\
.00 \\
.00 \\
5.3\end{array}$ \\
\hline $\begin{array}{r}6 \\
7 \\
8 \\
9 \\
10\end{array}$ & $\begin{array}{l}3.4 \\
2.3 \\
1.9 \\
54 \\
62\end{array}$ & $\begin{array}{l}2.8 \\
1.9 \\
1.5 \\
6.2 \\
24\end{array}$ & $\begin{array}{l}7.9 \\
5.9 \\
4.6 \\
3.7 \\
3.1\end{array}$ & $\begin{array}{r}110 \\
64 \\
35 \\
27 \\
23\end{array}$ & $\begin{array}{r}201 \\
80 \\
25 \\
16 \\
12\end{array}$ & $\begin{array}{r}6.9 \\
11 \\
5.3 \\
3.8 \\
2.9\end{array}$ & $\begin{array}{l}4.5 \\
3.8 \\
4.2 \\
92 \\
38\end{array}$ & $\begin{array}{l}4.1 \\
1.7 \\
1.1 \\
2.8 \\
9.4\end{array}$ & $\begin{array}{l}.84 \\
.53 \\
.46 \\
.35 \\
.26\end{array}$ & $\begin{array}{l}.00 \\
.00 \\
3.3 \\
1.8 \\
.85\end{array}$ & $\begin{array}{l}.74 \\
.74 \\
.36 \\
1.3 \\
1.2\end{array}$ & $\begin{array}{l}.68 \\
.22 \\
.08 \\
.04 \\
.03\end{array}$ \\
\hline $\begin{array}{l}11 \\
12 \\
13 \\
14 \\
15\end{array}$ & $\begin{array}{r}14 \\
7.9 \\
6.0 \\
5.1 \\
4.5\end{array}$ & $\begin{array}{l}7.4 \\
4.5 \\
3.1 \\
2.4 \\
2.0\end{array}$ & $\begin{array}{r}2.9 \\
2.5 \\
2.2 \\
2.1 \\
91\end{array}$ & $\begin{array}{l}99 \\
48 \\
24 \\
17 \\
15\end{array}$ & $\begin{array}{r}9.4 \\
7.3 \\
27 \\
122 \\
24\end{array}$ & $\begin{array}{r}2.5 \\
3.7 \\
130 \\
35 \\
17\end{array}$ & $\begin{array}{r}14 \\
12 \\
382 \\
78 \\
51\end{array}$ & $\begin{array}{l}5.2 \\
5.8 \\
3.9 \\
2.4 \\
1.8\end{array}$ & $\begin{array}{l}.17 \\
.19 \\
.14 \\
.09 \\
.08\end{array}$ & $\begin{array}{l}.45 \\
.09 \\
.04 \\
.02 \\
.00\end{array}$ & $\begin{array}{l}.61 \\
.26 \\
.07 \\
.02 \\
.00\end{array}$ & $\begin{array}{l}.02 \\
.00 \\
.00 \\
.00 \\
.00\end{array}$ \\
\hline $\begin{array}{l}16 \\
17 \\
18 \\
19 \\
20\end{array}$ & $\begin{array}{r}3.7 \\
3.2 \\
247 \\
16 \\
7.8\end{array}$ & $\begin{array}{l}2.0 \\
1.9 \\
1.7 \\
1.5 \\
1.3\end{array}$ & $\begin{array}{r}19 \\
39 \\
616 \\
77 \\
28\end{array}$ & $\begin{array}{l}25 \\
23 \\
15 \\
12 \\
12\end{array}$ & $\begin{array}{r}\text { e12 } \\
10 \\
71 \\
35 \\
21\end{array}$ & $\begin{array}{l}12 \\
28 \\
67 \\
24 \\
15\end{array}$ & $\begin{array}{r}21 \\
13 \\
9.7 \\
9.0 \\
7.8\end{array}$ & $\begin{array}{l}1.4 \\
1.2 \\
1.1 \\
1.5 \\
1.0\end{array}$ & $\begin{array}{r}.59 \\
.90 \\
1.1 \\
7.6 \\
.87\end{array}$ & $\begin{array}{l}.00 \\
.00 \\
.00 \\
.00 \\
.00\end{array}$ & $\begin{array}{l}.00 \\
.05 \\
3.3 \\
.68 \\
1.9\end{array}$ & $\begin{array}{l}.00 \\
.00 \\
.00 \\
.00 \\
.00\end{array}$ \\
\hline $\begin{array}{l}21 \\
22 \\
23 \\
24 \\
25\end{array}$ & $\begin{array}{l}5.3 \\
31 \\
18 \\
8.6 \\
5.9\end{array}$ & $\begin{array}{l}1.2 \\
38 \\
20 \\
8.9 \\
5.8\end{array}$ & $\begin{array}{r}54 \\
102 \\
91 \\
29 \\
18\end{array}$ & $\begin{array}{r}\text { elo } \\
\text { e9.0 } \\
\text { e8.0 } \\
\text { e7.0 } \\
\text { e6.0 }\end{array}$ & $\begin{array}{l}13 \\
11 \\
7.9 \\
6.6 \\
5.4\end{array}$ & $\begin{array}{r}12 \\
213 \\
132 \\
24 \\
15\end{array}$ & $\begin{array}{l}6.0 \\
4.9 \\
4.0 \\
3.7 \\
2.9\end{array}$ & $\begin{array}{r}.71 \\
.59 \\
.99 \\
6.3\end{array}$ & $\begin{array}{l}.24 \\
.14 \\
.10 \\
.06 \\
.05\end{array}$ & $\begin{array}{l}.00 \\
.00 \\
.00 \\
.00 \\
.00\end{array}$ & $\begin{array}{l}.21 \\
.06 \\
.02 \\
.00 \\
.00\end{array}$ & $\begin{array}{l}.00 \\
.00 \\
.00 \\
.00 \\
.00\end{array}$ \\
\hline $\begin{array}{l}26 \\
27 \\
28 \\
29 \\
30 \\
31\end{array}$ & $\begin{array}{l}4.7 \\
3.8 \\
3.1 \\
2.6 \\
2.3 \\
1.9\end{array}$ & $\begin{array}{l}4.4 \\
4.0 \\
21 \\
11 \\
5.8 \\
\cdots\end{array}$ & $\begin{array}{r}14 \\
\text { e12 } \\
\text { e10 } \\
169 \\
327 \\
59\end{array}$ & $\begin{array}{l}5.3 \\
7.6 \\
21 \\
13 \\
54 \\
19\end{array}$ & $\begin{array}{l}4.5 \\
4.0 \\
3.5 \\
\ldots . \\
\ldots .\end{array}$ & $\begin{array}{r}109 \\
93 \\
48 \\
19 \\
13 \\
10\end{array}$ & $\begin{array}{l}2.5 \\
2.2 \\
2.1 \\
2.3 \\
2.0 \\
\cdots\end{array}$ & $\begin{array}{l}5.9 \\
8.7 \\
5.6 \\
3.3 \\
1.9 \\
1.4\end{array}$ & $\begin{array}{l}.04 \\
.03 \\
.02 \\
.01 \\
.01 \\
\cdots . .\end{array}$ & $\begin{array}{l}.00 \\
.00 \\
.00 \\
.00 \\
.00 \\
.00\end{array}$ & $\begin{array}{l}.00 \\
.00 \\
.00 \\
.00 \\
.00 \\
.00\end{array}$ & $\begin{array}{l}.00 \\
.00 \\
.00 \\
.00 \\
.00 \\
\cdots\end{array}$ \\
\hline $\begin{array}{l}\text { IOTAL } \\
\text { MEAM } \\
\text { MAX } \\
\text { MIN } \\
\text { CF SM } \\
\text { IN. }\end{array}$ & $\begin{array}{r}589.99 \\
19.0 \\
247 \\
.21 \\
2.04 \\
2.36\end{array}$ & $\begin{array}{r}191.6 \\
6.39 \\
38 \\
1.2 \\
.69 \\
.71\end{array}$ & $\begin{array}{r}1988.1 \\
64.1 \\
616 \\
2.1 \\
6.89 \\
7.94\end{array}$ & $\begin{array}{r}787.9 \\
25.4 \\
110 \\
5.3 \\
2.73 \\
3.15\end{array}$ & $\begin{array}{r}851.6 \\
30.4 \\
261 \\
3.5 \\
3.27 \\
3.40\end{array}$ & $\begin{array}{r}1080.4 \\
34.9 \\
213 \\
2.5 \\
3.74 \\
4.32\end{array}$ & $\begin{array}{c}803.3 \\
26.8 \\
382 \\
2.0 \\
2.88 \\
3.21\end{array}$ & $\begin{array}{c}100.63 \\
3.25 \\
14 \\
.59 \\
.35 \\
.40\end{array}$ & $\begin{array}{c}52.62 \\
1.75 \\
23 \\
.01 \\
.19 \\
.21\end{array}$ & $\begin{array}{l}6.55 \\
.21 \\
3.3 \\
.00 \\
.02 \\
.03\end{array}$ & $\begin{array}{c}17.52 \\
.57 \\
7.3 \\
.00 \\
.06 \\
.07\end{array}$ & $\begin{array}{c}19.37 \\
.65 \\
13 \\
.00 \\
.07 \\
.08\end{array}$ \\
\hline
\end{tabular}

e Estimated

SIATISTICS OF MONTHLY MEAN DATA FOR HATER YLARS 1969 - 1991 , BY WATER YEAR (WY)

\begin{tabular}{|c|c|c|c|c|c|c|c|c|c|c|c|c|}
\hline $\begin{array}{l}\text { MEAN } \\
\text { MAX } \\
\text { (WY) } \\
\text { MI } \\
\text { (WY) }\end{array}$ & $\begin{array}{r}4.44 \\
28.8 \\
1984 \\
1081 \\
1970\end{array}$ & $\begin{array}{r}13.9 \\
48.6 \\
1980 \\
1.29 \\
1982\end{array}$ & $\begin{array}{l}19.7 \\
64.1 \\
1991 \\
1.52 \\
1977\end{array}$ & $\begin{array}{r}17.7 \\
57.5 \\
1982 \\
.49 \\
1977\end{array}$ & $\begin{array}{l}22.4 \\
51.9 \\
1971 \\
1.95 \\
1978\end{array}$ & $\begin{array}{l}26.6 \\
52.0 \\
1915 \\
4.12 \\
1969\end{array}$ & $\begin{array}{l}23.0 \\
44.1 \\
1972 \\
2.65 \\
1976\end{array}$ & $\begin{array}{l}15.2 \\
61.1 \\
1983 \\
1.12 \\
1976\end{array}$ & $\begin{array}{l}6.33 \\
27.2 \\
1982 \\
.083 \\
1988\end{array}$ & $\begin{array}{r}3.68 \\
12.3 \\
1971 \\
.21 \\
1991\end{array}$ & $\begin{array}{r}3.15 \\
21.4 \\
1979 \\
191 \\
1975\end{array}$ & $\begin{array}{l}1.97 \\
18.7 \\
1919 \\
.003 \\
1983\end{array}$ \\
\hline
\end{tabular}

SUMMARY STAIISIICS

ANNUAL TOIAL

HIGHEST ANNUAL MEAN

LOWE ST ANHUAL MEAN

HIGHEST DAILY MEAN

LOWEST DAILY MEAN

ANNUAL SEVEN-DAY MINIMUM

INSIANIANEOUS PEAK FLOW

INSIANIANEOUS PEAK STAGE

ANNUAL RUNOFF (CFSM)

ANNUAL RUNOFF (INCHES)

10 PERCENT EXCEEDS

50 PERCENT EXCEEDS

90 PERCENT EXCEEDS
FOR 1990 CALENUAR YEAR

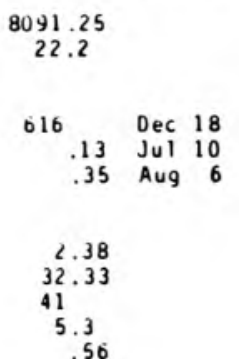

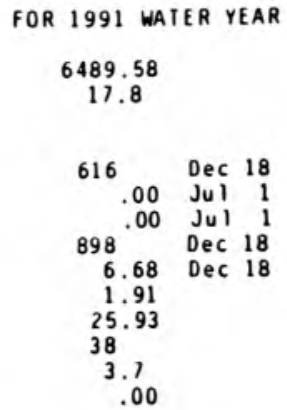

WATER YEARS 1969 - 1991

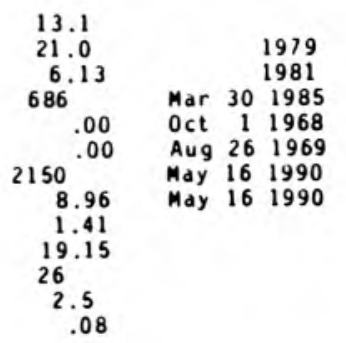


LOCATION, - Lat $38^{\circ} 48^{\prime} 15^{\prime \prime}$, long $85^{\circ} 40^{\prime} 26^{\prime \prime}$, In SW'NE sec.7. T.4 N., R.8 E., Jefferson County, Hydrologic Unit

05120201 , on left bank at downstream side of highway bridge, 1.4 morthwest of Deputy. 1.9 mi upstrean froa Coffee Creek. 2.4 i downstredm fron confluence of Grahan Creek and Big Creek, and at ile 50.0 .

DRAINAGE AREA, - $293 \mathrm{ni}^{2}$.

PERIOD OF RECORD. - - Novenber 1947 to current year.

REVISED RECORDS.--WSP 1335: 1948. WSP 2109: Drainage area.

GAGE.- -Water-stage recorder. Datum of gage is $540.00 \mathrm{ft}$ above National Geodetic Vertical Datua of 1929 . Prior to June 22, 1955, nonrecording gage at same site. Prior to Aug. 25, 1983, at datum $1.17 \mathrm{ft} h i g h e r$.

REMARKS. - Records good.

DISCHARGE, CUBIC FEET PER SECOND, WATER YEAR OCTOBER 1990 TO SEPIEMBER 1991 DAILY MEAN VALUES

\begin{tabular}{|c|c|c|c|c|c|c|c|c|c|c|c|c|}
\hline DAY & $O C T$ & NOV & DEC & JAN & FEB & MAR & APR & MAY & JUN & JUL & AUG & SEP \\
\hline $\begin{array}{l}1 \\
2 \\
3 \\
4 \\
5\end{array}$ & $\begin{array}{r}3.3 \\
3.5 \\
4.4 \\
413 \\
362\end{array}$ & $\begin{array}{l}53 \\
46 \\
41 \\
37 \\
40\end{array}$ & $\begin{array}{r}163 \\
126 \\
1430 \\
1910 \\
523\end{array}$ & $\begin{array}{r}1130 \\
624 \\
451 \\
339 \\
281\end{array}$ & $\begin{array}{l}362 \\
273 \\
233 \\
229 \\
250\end{array}$ & $\begin{array}{l}155 \\
192 \\
212 \\
186 \\
156\end{array}$ & $\begin{array}{l}265 \\
219 \\
187 \\
168 \\
165\end{array}$ & $\begin{array}{l}91 \\
82 \\
74 \\
72 \\
73\end{array}$ & $\begin{array}{r}42 \\
919 \\
500 \\
175 \\
91\end{array}$ & $\begin{array}{l}7.6 \\
6.5 \\
5.8 \\
5.1 \\
4.5\end{array}$ & $\begin{array}{l}.41 \\
.44 \\
.57 \\
.69 \\
.72\end{array}$ & $\begin{array}{r}1.5 \\
1.1 \\
1.1 \\
79 \\
136\end{array}$ \\
\hline $\begin{array}{r}6 \\
7 \\
8 \\
9 \\
10\end{array}$ & $\begin{array}{r}133 \\
71 \\
47 \\
240 \\
1280\end{array}$ & $\begin{array}{r}47 \\
48 \\
48 \\
51 \\
211\end{array}$ & $\begin{array}{l}294 \\
212 \\
163 \\
133 \\
114\end{array}$ & $\begin{array}{r}1300 \\
2590 \\
1290 \\
764 \\
603\end{array}$ & $\begin{array}{r}4290 \\
6230 \\
1670 \\
778 \\
531\end{array}$ & $\begin{array}{l}159 \\
288 \\
227 \\
173 \\
143\end{array}$ & $\begin{array}{r}160 \\
150 \\
137 \\
564 \\
2020\end{array}$ & $\begin{array}{l}90 \\
81 \\
72 \\
78 \\
96\end{array}$ & $\begin{array}{l}63 \\
49 \\
42 \\
36 \\
30\end{array}$ & $\begin{array}{c}4.1 \\
3.6 \\
89 \\
163 \\
43\end{array}$ & $\begin{array}{l}4.97 \\
14 \\
15 \\
41\end{array}$ & $\begin{array}{r}43 \\
22 \\
14 \\
9.6 \\
6.5\end{array}$ \\
\hline $\begin{array}{l}11 \\
12 \\
13 \\
14 \\
15\end{array}$ & $\begin{array}{r}592 \\
220 \\
129 \\
94 \\
12\end{array}$ & $\begin{array}{r}254 \\
159 \\
107 \\
85 \\
73\end{array}$ & $\begin{array}{r}101 \\
93 \\
87 \\
80 \\
740\end{array}$ & $\begin{array}{r}1380 \\
2320 \\
908 \\
559 \\
429\end{array}$ & $\begin{array}{r}396 \\
305 \\
302 \\
2540 \\
1480\end{array}$ & $\begin{array}{r}127 \\
124 \\
1970 \\
2070 \\
714\end{array}$ & $\begin{array}{r}610 \\
337 \\
5200 \\
3660 \\
1780\end{array}$ & $\begin{array}{r}110 \\
135 \\
95 \\
98 \\
83\end{array}$ & $\begin{array}{l}25 \\
21 \\
19 \\
17 \\
15\end{array}$ & $\begin{array}{l}39 \\
26 \\
20 \\
18 \\
14\end{array}$ & $\begin{array}{l}29 \\
18 \\
14 \\
11 \\
7.1\end{array}$ & $\begin{array}{l}6.0 \\
4.9 \\
3.9 \\
3.3 \\
2.5\end{array}$ \\
\hline $\begin{array}{l}16 \\
17 \\
18 \\
19 \\
20\end{array}$ & $\begin{array}{r}58 \\
48 \\
2510 \\
1100 \\
312\end{array}$ & $\begin{array}{l}65 \\
62 \\
58 \\
54 \\
52\end{array}$ & $\begin{array}{r}1350 \\
501 \\
11800 \\
6770 \\
1320\end{array}$ & $\begin{array}{l}493 \\
578 \\
460 \\
334 \\
287\end{array}$ & $\begin{array}{r}586 \\
420 \\
1380 \\
2590 \\
1100\end{array}$ & $\begin{array}{r}416 \\
351 \\
1880 \\
1110 \\
557\end{array}$ & $\begin{array}{r}1280 \\
567 \\
379 \\
306 \\
286\end{array}$ & $\begin{array}{r}70 \\
70 \\
123 \\
105 \\
71\end{array}$ & $\begin{array}{r}19 \\
84 \\
65 \\
100 \\
51\end{array}$ & $\begin{array}{l}10 \\
8.1 \\
6.8 \\
5.5 \\
15\end{array}$ & $\begin{array}{l}4.1 \\
3.7 \\
15 \\
16 \\
42\end{array}$ & $\begin{array}{l}1.7 \\
1.3 \\
1.1 \\
1.2 \\
.91\end{array}$ \\
\hline $\begin{array}{l}21 \\
22 \\
23 \\
24 \\
25\end{array}$ & $\begin{array}{l}176 \\
216 \\
572 \\
325 \\
182\end{array}$ & $\begin{array}{r}49 \\
202 \\
782 \\
379 \\
208\end{array}$ & $\begin{array}{r}154 \\
2440 \\
2740 \\
1600 \\
663\end{array}$ & $\begin{array}{l}286 \\
242 \\
204 \\
200 \\
165\end{array}$ & $\begin{array}{l}636 \\
444 \\
339 \\
275 \\
234\end{array}$ & $\begin{array}{r}391 \\
2010 \\
6400 \\
1430 \\
608\end{array}$ & $\begin{array}{l}253 \\
205 \\
175 \\
157 \\
138\end{array}$ & $\begin{array}{r}65 \\
55 \\
50 \\
129 \\
118\end{array}$ & $\begin{array}{l}34 \\
27 \\
27 \\
21 \\
15\end{array}$ & $\begin{array}{l}7.0 \\
3.7 \\
2.6 \\
1.9 \\
1.5\end{array}$ & $\begin{array}{l}41 \\
31 \\
19 \\
12 \\
7.9\end{array}$ & $\begin{array}{l}.62 \\
.48 \\
.61 \\
.69 \\
.69\end{array}$ \\
\hline $\begin{array}{l}26 \\
27 \\
28 \\
29 \\
30 \\
31\end{array}$ & $\begin{array}{r}121 \\
100 \\
83 \\
73 \\
66 \\
59\end{array}$ & $\begin{array}{l}143 \\
115 \\
211 \\
486 \\
259 \\
\cdots-\end{array}$ & $\begin{array}{r}437 \\
323 \\
312 \\
3080 \\
7780 \\
5360\end{array}$ & $\begin{array}{l}161 \\
131 \\
266 \\
282 \\
727 \\
822\end{array}$ & $\begin{array}{l}201 \\
179 \\
165 \\
\cdots \\
\cdots \\
\cdots\end{array}$ & $\begin{array}{r}1290 \\
2640 \\
1920 \\
773 \\
468 \\
330\end{array}$ & $\begin{array}{l}126 \\
115 \\
109 \\
107 \\
100 \\
\cdots\end{array}$ & $\begin{array}{r}138 \\
131 \\
107 \\
79 \\
62 \\
50\end{array}$ & $\begin{array}{c}13 \\
13 \\
12 \\
10 \\
8.9 \\
\cdots\end{array}$ & $\begin{array}{l}1.3 \\
.92 \\
.64 \\
.59 \\
.58 \\
.44\end{array}$ & $\begin{array}{l}5.3 \\
3.5 \\
2.0 \\
2.0 \\
1.9 \\
1.9\end{array}$ & $\begin{array}{l}.48 \\
.32 \\
.28 \\
.31 \\
.33 \\
. .-\end{array}$ \\
\hline $\begin{array}{l}\text { IOTAL } \\
\text { MEAN } \\
\text { MAX } \\
\text { MIN } \\
\text { CF SM } \\
\text { IN. }\end{array}$ & $\begin{array}{r}9671.2 \\
312 \\
2510 \\
3.3 \\
1.06 \\
1.23\end{array}$ & $\begin{array}{r}4425 \\
147 \\
782 \\
37 \\
.50 \\
.56\end{array}$ & $\begin{array}{r}53399 \\
1723 \\
11800 \\
80 \\
5.88 \\
6.78\end{array}$ & $\begin{array}{r}20606 \\
665 \\
2590 \\
131 \\
2.27 \\
2.62\end{array}$ & $\begin{array}{c}28418 \\
1015 \\
6230 \\
165 \\
3.46 \\
3.61\end{array}$ & $\begin{array}{r}29470 \\
951 \\
6400 \\
124 \\
3.24 \\
3.74\end{array}$ & $\begin{array}{r}19925 \\
664 \\
5200 \\
100 \\
2.27 \\
2.53\end{array}$ & $\begin{array}{c}2753 \\
88.8 \\
138 \\
50 \\
.30 \\
.35\end{array}$ & $\begin{array}{r}2543.9 \\
84.8 \\
919 \\
8.9 \\
.29 \\
.32\end{array}$ & $\begin{array}{r}515.77 \\
16.6 \\
163 \\
.44 \\
.06 \\
.07\end{array}$ & $\begin{array}{c}365.90 \\
11.8 \\
42 \\
.41 \\
.04 \\
.05\end{array}$ & $\begin{array}{c}345.42 \\
11.5 \\
136 \\
.28 \\
.04 \\
.04\end{array}$ \\
\hline
\end{tabular}

SIATISTICS OF MONTHLY MEAN DATA FOR WATER YEARS 1949 - 1991, BY WATER YEAR (WY)

\begin{tabular}{|c|c|c|c|c|c|c|c|c|c|c|c|c|}
\hline $\begin{array}{l}\text { MEAN } \\
\text { MAX } \\
(W Y) \\
\text { MIN } \\
(W Y)\end{array}$ & $\begin{array}{r}64.1 \\
720 \\
1984 \\
1000 \\
1954\end{array}$ & $\begin{array}{r}259 \\
1438 \\
1980 \\
.15 \\
1964\end{array}$ & $\begin{array}{r}453 \\
1723 \\
1991 \\
.21 \\
1964\end{array}$ & $\begin{array}{r}611 \\
2896 \\
1950 \\
9.24 \\
1971\end{array}$ & $\begin{array}{r}672 \\
1826 \\
1950 \\
18.1 \\
1954\end{array}$ & $\begin{array}{r}747 \\
2055 \\
1964 \\
65.2 \\
1954\end{array}$ & $\begin{array}{r}543 \\
1497 \\
1972 \\
73.2 \\
1976\end{array}$ & $\begin{array}{r}416 \\
1967 \\
1983 \\
23.8 \\
1976\end{array}$ & $\begin{array}{r}201 \\
879 \\
1960 \\
9.46 \\
1988\end{array}$ & $\begin{array}{r}149 \\
661 \\
1958 \\
.42 \\
1954\end{array}$ & $\begin{array}{r}12.7 \\
533 \\
1979 \\
1000 \\
1954\end{array}$ & $\begin{array}{r}47.6 \\
480 \\
1974 \\
.000 \\
1954\end{array}$ \\
\hline
\end{tabular}

SUMMARY SIATISIICS

ANWUAL TOTAL

ANNUAL MEAN

HIGHESI ANNUAL MEAN

LOWEST ANHUAL MEAN

HIGHESI DAILY MEAN

LOWEST DAILY MEAM

ANMUAL SEVEN-DAY MINIMUM

INSTANTANEOUS PEAK FLOW

INSTANTANEOUS PEAK SIAGE

ANNUAL RUNOFF (CFSM)

ANNUAL RUNOFF (INCHES)

10 PERCENT EXCEEDS

50 PERCENI EXCEEDS

90 PERCENT EXCEEDS
FOR 1990 CAIENOAR YEAR

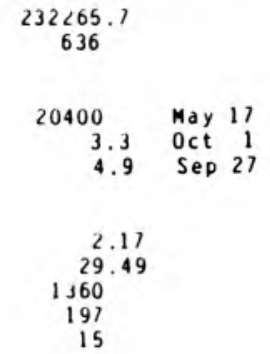

FOR 1991 WAIER YEAR

172438.19

472

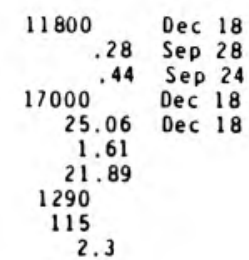

WAIER YEARS $1949-1991$

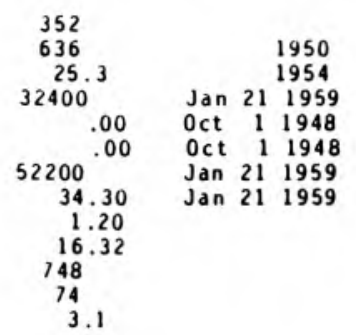




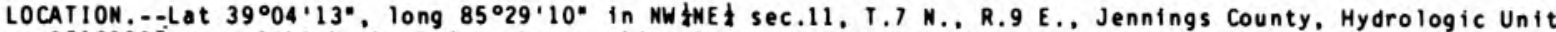
05120207 , on right bank at downstrean side of county road bridge, 1.5 . 1 northwest of Nebraska, 2.9 . northeast of Butlerville, and 3.6 a upstrean from Brush Creek Das.

DRAI NAGE AREA. $-11.4 \cdot i 2$

PERIOD OF RECORD.--May 1955 to current year.

REVISED RECORDS.--WSP 2109: Drainage area.

GAGE.--Water-stage recorder. Datun of gage is $717.17 \mathrm{ft}$ above National Geodetic Vertical Datua of 1929 (levels by State of Indiana. Departeent of Natural Resources).

REMARKS.--Records fair, except those for estinated daily discharges, which are poor.

DISCHARGE, CUBIC FEET PER SECOND, WATER YEAR OCTOBER 1990 TO SEPTEMBER 1991 DAILY MEAN VALUES

\begin{tabular}{|c|c|c|c|c|c|c|c|c|c|c|c|c|}
\hline DAY & $\mathrm{OCT}$ & NOV & DEC & JAN & FEB & MAR & $A P R$ & MAY & JUN & JUL & AUG & SEP \\
\hline $\begin{array}{l}1 \\
2 \\
3 \\
4 \\
5\end{array}$ & $\begin{array}{c}.04 \\
.03 \\
.02 \\
44^{.7} \\
1.7\end{array}$ & $\begin{array}{l}1.6 \\
1.8 \\
1.8 \\
3.9 \\
6.6\end{array}$ & $\begin{array}{c}2.8 \\
163 \\
18 \\
8.7 \\
6.0\end{array}$ & $\begin{array}{r}17 \\
12 \\
9.2 \\
6.4 \\
6.3\end{array}$ & $\begin{array}{r}8.5 \\
7.6 \\
7.4 \\
8.4 \\
31\end{array}$ & $\begin{array}{l}4.2 \\
6.2 \\
5.0 \\
4.1 \\
3.5\end{array}$ & $\begin{array}{l}7.2 \\
6.1 \\
5.4 \\
5.4 \\
8.4\end{array}$ & $\begin{array}{l}2.9 \\
2.7 \\
2.5 \\
2.6 \\
4.0\end{array}$ & $\begin{array}{r}14 \\
367 \\
7.8 \\
3.5 \\
2.3\end{array}$ & $\begin{array}{l}.13 \\
.11 \\
.09 \\
.08 \\
.07\end{array}$ & $\begin{array}{l}.00 \\
.00 \\
.00 \\
.00 \\
.00\end{array}$ & $\begin{array}{r}.28 \\
.23 \\
63^{.42} \\
4.4\end{array}$ \\
\hline $\begin{array}{r}6 \\
7 \\
8 \\
9 \\
10\end{array}$ & $\begin{array}{r}.65 \\
.51 \\
17^{.64} \\
15\end{array}$ & $\begin{array}{r}4.7 \\
4.4 \\
6.8 \\
11 \\
2.8\end{array}$ & $\begin{array}{l}4.4 \\
3.5 \\
3.0 \\
2.7 \\
2.4\end{array}$ & $\begin{array}{l}58 \\
29 \\
16 \\
15 \\
14\end{array}$ & $\begin{array}{r}341 \\
116 \\
27 \\
16 \\
12\end{array}$ & $\begin{array}{l}3.9 \\
3.6 \\
3.0 \\
2.9 \\
2.6\end{array}$ & $\begin{array}{r}6.1 \\
5.3 \\
5.5 \\
185 \\
41\end{array}$ & $\begin{array}{l}3.2 \\
2.5 \\
2.3 \\
2.7 \\
2.4\end{array}$ & $\begin{array}{c}1.7 \\
1.4 \\
1.2 \\
1.1 \\
.88\end{array}$ & $\begin{array}{l}.05 \\
.04 \\
.05 \\
.05 \\
.06\end{array}$ & $\begin{array}{l}.00 \\
.00 \\
.00 \\
.01 \\
.01\end{array}$ & $\begin{array}{l}1.8 \\
1.2 \\
.93 \\
.81 \\
.72\end{array}$ \\
\hline $\begin{array}{l}11 \\
12 \\
13 \\
14 \\
15\end{array}$ & $\begin{array}{l}3.1 \\
1.3 \\
.90 \\
.77 \\
.81\end{array}$ & $\begin{array}{l}1.8 \\
1.3 \\
1.1 \\
1.0 \\
1.1\end{array}$ & $\begin{array}{l}2.3 \\
2.1 \\
1.8 \\
40 \\
11\end{array}$ & $\begin{array}{r}103 \\
38 \\
17 \\
12 \\
11\end{array}$ & $\begin{array}{l}9.3 \\
7.3 \\
28 \\
79 \\
19\end{array}$ & $\begin{array}{c}2.5 \\
5.0 \\
200 \\
35 \\
15\end{array}$ & $\begin{array}{r}15 \\
11 \\
257 \\
68 \\
62\end{array}$ & $\begin{array}{l}2.3 \\
3.1 \\
2.2 \\
2.1 \\
3.1\end{array}$ & $\begin{array}{l}.83 \\
.81 \\
.74 \\
.65 \\
.64\end{array}$ & $\begin{array}{l}.05 \\
8.6 \\
1.3 \\
.49 \\
.24\end{array}$ & $\begin{array}{l}.00 \\
.00 \\
.00 \\
.00 \\
.00\end{array}$ & $\begin{array}{l}.65 \\
.54 \\
.62 \\
.79 \\
.48\end{array}$ \\
\hline $\begin{array}{l}16 \\
17 \\
18 \\
19 \\
20\end{array}$ & $\begin{array}{l}1.72 \\
46 \\
2.1 \\
.75\end{array}$ & $\begin{array}{r}1.1 \\
.96 \\
.91 \\
.85 \\
.77\end{array}$ & $\begin{array}{r}43 \\
e 710 \\
e 400 \\
e 72 \\
\text { e20 }\end{array}$ & $\begin{array}{r}23 \\
19 \\
10 \\
8.0 \\
\text { e7.0 }\end{array}$ & $\begin{array}{c}11 \\
9.8 \\
182 \\
47 \\
22\end{array}$ & $\begin{array}{l}11 \\
73 \\
68 \\
20 \\
13\end{array}$ & $\begin{array}{l}18 \\
12 \\
8.8 \\
16 \\
11\end{array}$ & $\begin{array}{l}1.9 \\
1.6 \\
1.9 \\
1.6 \\
1.4\end{array}$ & $\begin{array}{l}1.0 \\
1.1 \\
.75 \\
.65 \\
.55\end{array}$ & $\begin{array}{l}.16 \\
.13 \\
.10 \\
.08 \\
.07\end{array}$ & $\begin{array}{c}117^{.00} \\
78 \\
26 \\
4.3\end{array}$ & $\begin{array}{l}.35 \\
.27 \\
.25 \\
.23 \\
.21\end{array}$ \\
\hline $\begin{array}{l}21 \\
22 \\
23 \\
24 \\
25\end{array}$ & $\begin{array}{l}.49 \\
3.2 \\
1.9 \\
.73 \\
.63\end{array}$ & $\begin{array}{r}12 \\
7.4 \\
3.5 \\
2.6 \\
2.2\end{array}$ & $\begin{array}{r}53 \\
90 \\
112 \\
23 \\
12\end{array}$ & $\begin{array}{l}\text { e5.8 } \\
\text { e } 4.9 \\
\text { e } 4.5 \\
\text { e3.7 } \\
\text { e3.2 }\end{array}$ & $\begin{array}{r}14 \\
11 \\
8.4 \\
7.2 \\
6.0\end{array}$ & $\begin{array}{r}10 \\
259 \\
111 \\
21 \\
13\end{array}$ & $\begin{array}{l}8.1 \\
6.8 \\
5.9 \\
5.8 \\
4.7\end{array}$ & $\begin{array}{l}1.3 \\
16 \\
6.2 \\
2.9 \\
2.0\end{array}$ & $\begin{array}{l}.48 \\
.72 \\
.81 \\
.46 \\
.34\end{array}$ & $\begin{array}{l}.05 \\
.04 \\
.03 \\
.02 \\
.01\end{array}$ & $\begin{array}{l}1.8 \\
1.2 \\
.86 \\
.66 \\
.53\end{array}$ & $\begin{array}{l}.20 \\
.19 \\
.19 \\
.17 \\
.17\end{array}$ \\
\hline $\begin{array}{l}26 \\
27 \\
28 \\
29 \\
30 \\
31\end{array}$ & $\begin{array}{l}.79 \\
.88 \\
1.1 \\
1.1 \\
.98 \\
1.2\end{array}$ & $\begin{array}{c}2.7 \\
25 \\
8.1 \\
4.4 \\
3.4 \\
-. .\end{array}$ & $\begin{array}{c}8.5 \\
6.3 \\
8.0 \\
299 \\
523 \\
43\end{array}$ & $\begin{array}{l}\text { e2.9 } \\
\text { e2.8 } \\
\text { e3.1 } \\
\text { e3.8 } \\
82 \\
14\end{array}$ & $\begin{array}{l}5.0 \\
4.6 \\
4.2 \\
\ldots . . \\
\ldots . \\
\ldots\end{array}$ & $\begin{array}{c}277 \\
63 \\
30 \\
15 \\
11 \\
8.4\end{array}$ & $\begin{array}{l}4.4 \\
4.0 \\
3.9 \\
3.7 \\
3.2 \\
\ldots . .\end{array}$ & $\begin{array}{l}5.1 \\
3.1 \\
2.1 \\
1.8 \\
1.7 \\
1.4\end{array}$ & $\begin{array}{l}.30 \\
.26 \\
.23 \\
.20 \\
.17 \\
\cdots . .\end{array}$ & $\begin{array}{l}.01 \\
.00 \\
.00 \\
.00 \\
.00 \\
.00\end{array}$ & $\begin{array}{l}.47 \\
.42 \\
.38 \\
.34 \\
.33 \\
.30\end{array}$ & $\begin{array}{l}.16 \\
.15 \\
.14 \\
.13 \\
.13 \\
. . .\end{array}$ \\
\hline $\begin{array}{l}\text { TOTAL } \\
\text { MEAN } \\
\text { MAX } \\
\text { MIN } \\
\text { CFSM } \\
\text { IM. }\end{array}$ & $\begin{array}{r}150.34 \\
4.85 \\
46 \\
.02 \\
.43 \\
.49\end{array}$ & $\begin{array}{r}127.59 \\
4.25 \\
25 \\
.77 \\
.37 \\
.42\end{array}$ & $\begin{array}{r}2694.5 \\
86.9 \\
710 \\
1.8 \\
7.62 \\
8.79\end{array}$ & $\begin{array}{r}561.6 \\
18.1 \\
103 \\
2.8 \\
1.59 \\
1.83\end{array}$ & $\begin{array}{r}1049.7 \\
37.5 \\
341 \\
4.2 \\
3.29 \\
3.43\end{array}$ & $\begin{array}{r}1299.9 \\
41.9 \\
277 \\
2.5 \\
3.68 \\
4.24\end{array}$ & $\begin{array}{c}804.7 \\
26.8 \\
257 \\
3.2 \\
2.35 \\
2.63\end{array}$ & $\begin{array}{c}92.6 \\
2.99 \\
16 \\
1.3 \\
.26 \\
.30\end{array}$ & $\begin{array}{c}412.57 \\
13.8 \\
367 \\
.17 \\
1.21 \\
1.35\end{array}$ & $\begin{array}{c}12.11 \\
.39 \\
8.6 \\
.00 \\
.03 \\
.04\end{array}$ & $\begin{array}{c}232.61 \\
7.50 \\
117 \\
.00 \\
.66 \\
.76\end{array}$ & $\begin{array}{c}79.81 \\
2.66 \\
63 \\
.13 \\
.23 \\
.26\end{array}$ \\
\hline
\end{tabular}

STATISTICS OF MONTHLY MEAN DATA FOR WATER YEARS 1956 - 1991, BY WATER YEAR (WY)

\begin{tabular}{|c|c|c|c|c|c|c|c|c|c|c|c|}
\hline $\begin{array}{l}\text { MEAN } \\
\text { MAX } \\
\text { (WY) } \\
\text { MI } \\
\text { (WY) }\end{array}$ & $\begin{array}{l}2.34 \\
19.7 \\
1984 \\
1000 \\
1958\end{array}$ & $\begin{array}{l}9.78 \\
64.5 \\
1986 \\
.000 \\
1964\end{array}$ & $\begin{array}{r}17.7 \\
86.9 \\
1991 \\
1000 \\
1964\end{array}$ & $\begin{array}{l}18.2 \\
70.4 \\
1959 \\
063 \\
1977\end{array}$ & $\begin{array}{l}23.0 \\
51.8 \\
1971 \\
1.44 \\
1964\end{array}$ & $\begin{array}{l}29.4 \\
89.6 \\
1963 \\
4.22 \\
1969\end{array}$ & $\begin{array}{l}22.7 \\
59.8 \\
1972 \\
2.12 \\
1976\end{array}$ & $\begin{array}{r}18.6 \\
80.7 \\
1968 \\
.76 \\
1976\end{array}$ & $\begin{array}{r}7.29 \\
45.2 \\
1981 \\
.12 \\
1965\end{array}$ & $\begin{array}{l}7.03 \\
72.0 \\
1962 \\
.025 \\
1970\end{array}$ & $\begin{array}{r}3.46 \\
41.9 \\
1978 \\
000 \\
1964\end{array}$ \\
\hline
\end{tabular}

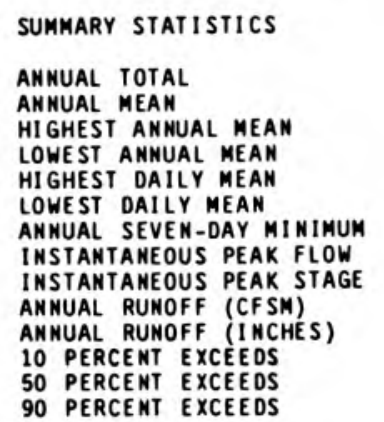

FOR 1990 CALENDAR YEAR

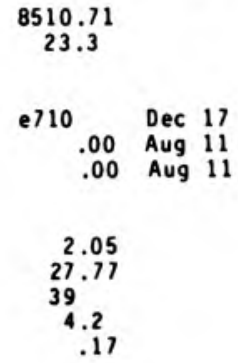

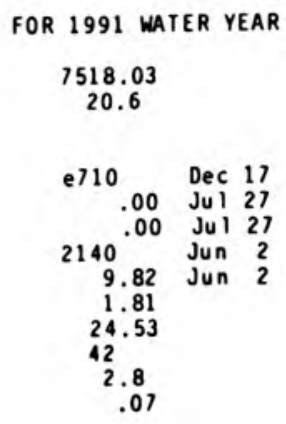

WATER YEARS 1956 - 1991

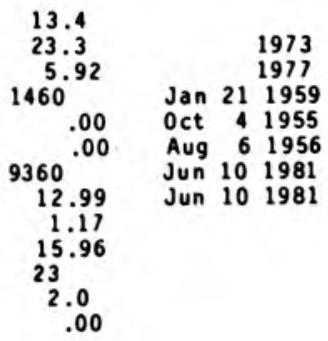

Estinated 


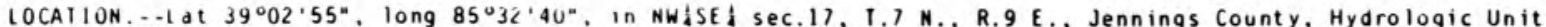
05120201 , on left bank 0.3 i downstream from Muscatatuck State School dan, 1.1 i downstrean fron Brush Creek, $2 \mathrm{~m} i$ northwest of Buţlerville, and at mile 50.6

DRAINAGE AREA.--85.9 is

PERIOD OF RECURD.--February 1942 to current year. Prior to October 1960, published as North Fork of Vernon fork near Butlerville, and as Vernon fork near Butlerville, October 1960 to Septeaber 1979.

REVISED RECORDS, - -WSP 2109: Drainage ared.

GAGE. - Water-stage recorder. Datum of gage is $669.40 \mathrm{ft}$ above National Geodetic Vertical Datun of 1929 . Prior to Aug. 19, 1942, nonrecording gage at same site and datue.

REMARKS. - Records good. Water supply for the Muscatatuck State School is diverted and the sewage effluent returned above station. Flow regulated by Brush Creek Reservoir.

DISCHARGE, CUBIC FEET PER SECOND, WATER YEAR OCTOBER 1990 TO SEPTEMBER 1991 DAI IY MEAN VALUES

\begin{tabular}{|c|c|c|c|c|c|c|c|c|c|c|c|c|}
\hline DAY & $O C \mathrm{~T}$ & NOV & DEC & JAN & FEB & MAR & APR & MAY & JUN & JUL & AUG & SEP \\
\hline $\begin{array}{l}1 \\
2 \\
3 \\
4 \\
5\end{array}$ & $\begin{array}{c}3.4 \\
3.8 \\
3.6 \\
549 \\
97\end{array}$ & $\begin{array}{l}11 \\
10 \\
9.6 \\
9.3 \\
11\end{array}$ & $\begin{array}{r}51 \\
41 \\
1040 \\
264 \\
120\end{array}$ & $\begin{array}{l}201 \\
139 \\
106 \\
\text { e72 } \\
\text { e68 }\end{array}$ & $\begin{array}{r}e 80 \\
e 71 \\
71 \\
72 \\
129\end{array}$ & $\begin{array}{l}48 \\
59 \\
56 \\
47 \\
42\end{array}$ & $\begin{array}{l}75 \\
63 \\
54 \\
52 \\
72\end{array}$ & $\begin{array}{l}24 \\
21 \\
19 \\
19 \\
26\end{array}$ & $\begin{array}{l}9.5 \\
689 \\
122 \\
39 \\
19\end{array}$ & $\begin{array}{l}1.4 \\
1.5 \\
1.6 \\
1.5 \\
1.4\end{array}$ & $\begin{array}{l}68 \\
55 \\
5.1 \\
4.8 \\
5.0\end{array}$ & $\begin{array}{r}4.0 \\
4.9 \\
7.9 \\
741 \\
124\end{array}$ \\
\hline $\begin{array}{r}6 \\
7 \\
8 \\
9 \\
10\end{array}$ & $\begin{array}{r}42 \\
24 \\
16 \\
702 \\
416\end{array}$ & $\begin{array}{l}28 \\
22 \\
14 \\
13 \\
68\end{array}$ & $\begin{array}{l}82 \\
62 \\
48 \\
40 \\
35\end{array}$ & $\begin{array}{l}204 \\
212 \\
136 \\
111 \\
105\end{array}$ & $\begin{array}{r}1720 \\
1200 \\
268 \\
169 \\
130\end{array}$ & $\begin{array}{l}41 \\
44 \\
36 \\
33 \\
30\end{array}$ & $\begin{array}{r}60 \\
50 \\
47 \\
838 \\
520\end{array}$ & $\begin{array}{l}45 \\
24 \\
19 \\
19 \\
19\end{array}$ & $\begin{array}{r}12 \\
9.5 \\
7.6 \\
6.5 \\
5.4\end{array}$ & $\begin{array}{l}1.1 \\
1.2 \\
2.8 \\
2.3 \\
5.0\end{array}$ & $\begin{array}{l}11 \\
12 \\
13 \\
21 \\
16\end{array}$ & $\begin{array}{l}34 \\
17 \\
12 \\
8.5 \\
7.6\end{array}$ \\
\hline $\begin{array}{l}11 \\
12 \\
13 \\
14 \\
15\end{array}$ & $\begin{array}{r}131 \\
68 \\
45 \\
31 \\
22\end{array}$ & $\begin{array}{l}43 \\
26 \\
20 \\
17 \\
15\end{array}$ & $\begin{array}{r}31 \\
28 \\
26 \\
23 \\
182\end{array}$ & $\begin{array}{l}560 \\
407 \\
178 \\
129 \\
119\end{array}$ & $\begin{array}{r}101 \\
81 \\
95 \\
413 \\
\mathrm{e} 170\end{array}$ & $\begin{array}{r}29 \\
33 \\
1180 \\
361 \\
159\end{array}$ & $\begin{array}{r}168 \\
112 \\
1800 \\
551 \\
439\end{array}$ & $\begin{array}{l}17 \\
24 \\
17 \\
16 \\
32\end{array}$ & $\begin{array}{l}4.8 \\
6.8 \\
8.0 \\
5.3 \\
4.1\end{array}$ & $\begin{array}{r}4.6 \\
186 \\
26 \\
8.1 \\
4.6\end{array}$ & $\begin{array}{l}7.8 \\
5.5 \\
4.2 \\
2.8 \\
2.5\end{array}$ & $\begin{array}{l}7.0 \\
6.3 \\
87 \\
24 \\
11\end{array}$ \\
\hline $\begin{array}{l}16 \\
17 \\
18 \\
19 \\
20\end{array}$ & $\begin{array}{r}11 \\
15 \\
375 \\
111 \\
61\end{array}$ & $\begin{array}{l}14 \\
14 \\
13 \\
13 \\
13\end{array}$ & $\begin{array}{r}129 \\
132 \\
2870 \\
727 \\
204\end{array}$ & $\begin{array}{r}171 \\
174 \\
114 \\
89 \\
83\end{array}$ & $\begin{array}{r}e 90 \\
e 86 \\
1010 \\
489 \\
230\end{array}$ & $\begin{array}{l}111 \\
230 \\
708 \\
213 \\
138\end{array}$ & $\begin{array}{r}197 \\
129 \\
97 \\
139 \\
128\end{array}$ & $\begin{array}{l}17 \\
13 \\
41 \\
30 \\
15\end{array}$ & $\begin{array}{l}5.7 \\
4.4 \\
4.2 \\
4.0 \\
3.2\end{array}$ & $\begin{array}{l}2.9 \\
2.3 \\
1.9 \\
1.7 \\
1.6\end{array}$ & $\begin{array}{c}2.3 \\
177 \\
686 \\
145 \\
69\end{array}$ & $\begin{array}{l}8.0 \\
6.5 \\
6.0 \\
5.2 \\
4.8\end{array}$ \\
\hline $\begin{array}{l}21 \\
22 \\
23 \\
24 \\
25\end{array}$ & $\begin{array}{l}43 \\
57 \\
76 \\
46 \\
32\end{array}$ & $\begin{array}{r}12 \\
89 \\
112 \\
57 \\
40\end{array}$ & $\begin{array}{r}260 \\
674 \\
779 \\
242 \\
\mathrm{e} 130\end{array}$ & $\begin{array}{l}\text { e } 72 \\
\text { e } 50 \\
\text { e } 45 \\
\text { e } 42 \\
\text { e } 34\end{array}$ & $\begin{array}{r}150 \\
117 \\
93 \\
80 \\
69\end{array}$ & $\begin{array}{r}109 \\
1170 \\
1190 \\
230 \\
140\end{array}$ & $\begin{array}{l}90 \\
75 \\
63 \\
59 \\
48\end{array}$ & $\begin{array}{l}11 \\
21 \\
37 \\
23 \\
16\end{array}$ & $\begin{array}{l}2.7 \\
4.8 \\
4.6 \\
2.1 \\
2.2\end{array}$ & $\begin{array}{l}1.5 \\
1.5 \\
1.5 \\
1.3 \\
1.1\end{array}$ & $\begin{array}{l}20 \\
11 \\
8.0 \\
6.4 \\
5.5\end{array}$ & $\begin{array}{l}4.7 \\
4.9 \\
4.8 \\
4.4 \\
4.4\end{array}$ \\
\hline $\begin{array}{l}26 \\
27 \\
28 \\
29 \\
30 \\
31\end{array}$ & $\begin{array}{l}25 \\
21 \\
18 \\
15 \\
14 \\
12\end{array}$ & $\begin{array}{r}32 \\
35 \\
218 \\
122 \\
69 \\
\ldots\end{array}$ & $\begin{array}{r}e 86 \\
e 64 \\
e 68 \\
e 1200 \\
e 2000 \\
592\end{array}$ & $\begin{array}{l}\text { e } 32 \\
\text { e } 32 \\
\text { e36 } \\
\text { e } 43 \\
397 \\
\text { e } 130\end{array}$ & $\begin{array}{c}59 \\
54 \\
50 \\
\cdots \\
\cdots \\
\cdots\end{array}$ & $\begin{array}{r}1300 \\
546 \\
322 \\
162 \\
115 \\
88\end{array}$ & $\begin{array}{c}44 \\
39 \\
37 \\
35 \\
30 \\
\cdots\end{array}$ & $\begin{array}{l}46 \\
46 \\
22 \\
15 \\
13 \\
11\end{array}$ & $\begin{array}{l}2.2 \\
1.7 \\
1.7 \\
1.7 \\
1.6 \\
\ldots . .\end{array}$ & $\begin{array}{l}1.0 \\
.99 \\
17^{.99} \\
70 \\
70\end{array}$ & $\begin{array}{l}4.1 \\
4.6 \\
4.6 \\
4.1 \\
4.1 \\
4.2\end{array}$ & $\begin{array}{l}4.2 \\
4.0 \\
4.4 \\
4.6 \\
4.2 \\
\ldots . .\end{array}$ \\
\hline $\begin{array}{l}\text { IOIAL } \\
\text { MEAN } \\
\text { MAX } \\
\text { MIN } \\
\text { CF SN } \\
\text { IN. }\end{array}$ & $\begin{array}{r}3091.8 \\
99.7 \\
702 \\
3.4 \\
1.16 \\
1.34\end{array}$ & $\begin{array}{r}1169.9 \\
39.0 \\
218 \\
9.3 \\
.45 \\
.51\end{array}$ & $\begin{array}{r}12230 \\
395 \\
2870 \\
23 \\
4.59 \\
5.30\end{array}$ & $\begin{array}{r}4297 \\
139 \\
560 \\
32 \\
1.61 \\
1.86\end{array}$ & $\begin{array}{r}7347 \\
262 \\
1720 \\
50 \\
3.05 \\
3.18\end{array}$ & $\begin{array}{r}8970 \\
289 \\
1300 \\
29 \\
3.37 \\
3.88\end{array}$ & $\begin{array}{r}6111 \\
204 \\
1800 \\
30 \\
2.31 \\
2.65\end{array}$ & $\begin{array}{c}718 \\
23.2 \\
46 \\
11 \\
.27 \\
.31\end{array}$ & $\begin{array}{c}995.3 \\
33.2 \\
689 \\
1.6 \\
.39 \\
.43\end{array}$ & $\begin{array}{r}426.38 \\
13.8 \\
186 \\
.99 \\
.16 \\
.18\end{array}$ & $\begin{array}{c}1390.2 \\
44.8 \\
686 \\
2.3 \\
.52 \\
.60\end{array}$ & $\begin{array}{r}1171.3 \\
39.0 \\
741 \\
4.0 \\
.45 \\
.51\end{array}$ \\
\hline
\end{tabular}

e Estimated

SIATISIICS OF MONIHLY MEAN DAIA FUR WAIER YEARS 1943 - 1991, BY WAIER YEAR (WY)

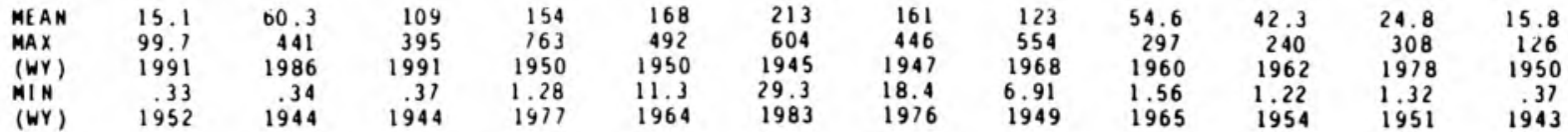

\section{SUMMARY SIAIISIICS}

\section{ANMUAL TOIAL}

ANNUAL MEAN

HIGHEST ANNUAL MEAN

LOWEST ANMUAL MEAM

HIGHEST DAILY MEAN

IOWEST DAILY MEAN

ANNUAL SEVEM-DAY MINIMUM

INSTAMIANEOUS PEAK FIOW

INSIANIANEOUS PEAK SIAGE

ANHUAL RUNOFF (CFSM)

ANNUAL RUNOFF (I NCHES)

10 PERCENT EXCEEDS

50 PERCENI EXCEEDS

90 PERCENI EXCEEDS
FOR 1990 CALENDAR YEAR

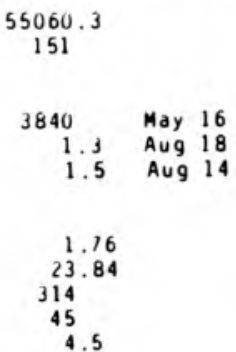

FOR 1991 WATER YEAR

47917.88

131

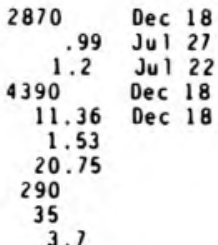

WATER YEARS 1943 - 1991

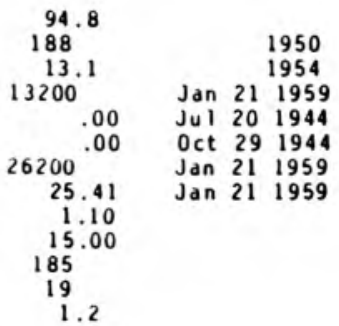




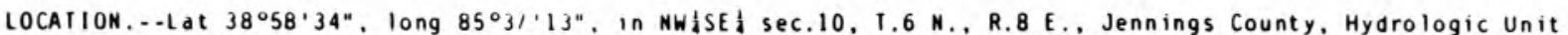
05120207 , at downstream end of left bank bridge pier, 1 a southwest of vernon, 3.1 a downstrea from $0 t$ ter Creek, and at ile 36.4 .

DRAI NAGE AREA. . $198 \mathrm{i}^{2}$.

PERIOD OF RECORD..-OCtober 1939 to current year. Monthly discharge only for soue periods, published in wSP 1305 . Prior to October 1979 , published as Vernon Fork at Vernon.

REVISED RECORDS.--WSP 1335: 1940, 1953. WSP 1909: 1952-53. WSP 2109: Drainage area. WOR IN-91-1: 1990.

GAGE. - Water-stage recorder. Datum of gage is $585.00 \mathrm{ft}$ above National Geodetic Vertical Datue of 1929 . (levels by State of Indiana. Departaent of Natural Resources). Prior to Jan. 14, 1940, and June 23 to Nov. i3, 1967 , nonrecording gage, and Jan. 14, 1940, to June 22, 1967 , water-stage recorder at site on right bank. Prior to Aug. 8, 1983 , datu $2.30 \mathrm{ft}$ higher.

REMARKS. - Records good. Diversion above station for municipal water supply of North Vernon and Vernon. Part of this diverson returned above gage as sewage effluent by North Vernon Sewage Ireateent Plant. Soee regulation at tiaes at low flow by Old Iinbers Lake on Jefferson Proving Grounds and Brush Creek Reservoir.

DISCHARGE, CUBIC FEET PER SECOND, WATER YEAR OCTOBER 1989 TO SEPIEMBER 1990 DAIIY MEAN VALUES

\begin{tabular}{|c|c|c|c|c|c|c|c|c|c|c|c|c|}
\hline DAY & $\mathrm{OCT}$ & NOV & DEC & JAN & FEB & MAR & APR & MAY & JUN & JUL & AUG & SEP \\
\hline $\begin{array}{l}1 \\
2 \\
3 \\
4 \\
5\end{array}$ & $\begin{array}{l}2.2 \\
2.1 \\
2.8 \\
3.2 \\
2.5\end{array}$ & $\begin{array}{l}15 \\
14 \\
13 \\
13 \\
12\end{array}$ & $\begin{array}{l}38 \\
35 \\
32 \\
30 \\
30\end{array}$ & $\begin{array}{l}665 \\
255 \\
207 \\
276 \\
392\end{array}$ & $\begin{array}{r}342 \\
917 \\
665 \\
2800 \\
953\end{array}$ & $\begin{array}{l}220 \\
178 \\
169 \\
142 \\
128\end{array}$ & $\begin{array}{l}326 \\
421 \\
243 \\
190 \\
163\end{array}$ & $\begin{array}{r}147 \\
195 \\
140 \\
2390 \\
2340\end{array}$ & $\begin{array}{r}56 \\
55 \\
344 \\
147 \\
78\end{array}$ & $\begin{array}{l}15 \\
14 \\
12 \\
11 \\
9.4\end{array}$ & $\begin{array}{l}5.7 \\
5.9 \\
4.6 \\
4.2 \\
6.2\end{array}$ & $\begin{array}{l}16 \\
38 \\
25 \\
19 \\
14\end{array}$ \\
\hline $\begin{array}{r}6 \\
7 \\
8 \\
9 \\
10\end{array}$ & $\begin{array}{l}2.9 \\
5.6 \\
3.9 \\
2.3 \\
2.0\end{array}$ & $\begin{array}{r}24 \\
90 \\
342 \\
356 \\
129\end{array}$ & $\begin{array}{l}31 \\
32 \\
32 \\
30 \\
28\end{array}$ & $\begin{array}{l}209 \\
155 \\
133 \\
121 \\
116\end{array}$ & $\begin{array}{r}420 \\
366 \\
315 \\
889 \\
1140\end{array}$ & $\begin{array}{r}117 \\
104 \\
97 \\
101 \\
112\end{array}$ & $\begin{array}{r}139 \\
119 \\
106 \\
98 \\
2000\end{array}$ & $\begin{array}{r}1010 \\
583 \\
315 \\
223 \\
195\end{array}$ & $\begin{array}{r}92 \\
954 \\
416 \\
209 \\
147\end{array}$ & $\begin{array}{l}36 \\
68 \\
23 \\
14 \\
11\end{array}$ & $\begin{array}{l}9.0 \\
19 \\
11 \\
7.0 \\
5.6\end{array}$ & $\begin{array}{r}11 \\
8.8 \\
6.8 \\
6.0 \\
123\end{array}$ \\
\hline $\begin{array}{l}11 \\
12 \\
13 \\
14 \\
15\end{array}$ & $\begin{array}{l}2.8 \\
3.0 \\
2.9 \\
3.1 \\
4.6\end{array}$ & $\begin{array}{r}71 \\
52 \\
44 \\
38 \\
690\end{array}$ & $\begin{array}{l}29 \\
29 \\
25 \\
21 \\
20\end{array}$ & $\begin{array}{r}112 \\
99 \\
85 \\
76 \\
77\end{array}$ & $\begin{array}{r}438 \\
296 \\
226 \\
187 \\
3450\end{array}$ & $\begin{array}{l}498 \\
264 \\
177 \\
150 \\
136\end{array}$ & $\begin{array}{r}2190 \\
495 \\
294 \\
228 \\
201\end{array}$ & $\begin{array}{r}147 \\
186 \\
3130 \\
704 \\
1890\end{array}$ & $\begin{array}{r}103 \\
78 \\
61 \\
67 \\
160\end{array}$ & $\begin{array}{l}9.5 \\
597 \\
393 \\
113 \\
55\end{array}$ & $\begin{array}{l}4.1 \\
2.9 \\
2.6 \\
2.7 \\
2.6\end{array}$ & $\begin{array}{r}39 \\
137 \\
238 \\
48 \\
198\end{array}$ \\
\hline $\begin{array}{l}16 \\
17 \\
18 \\
19 \\
20\end{array}$ & $\begin{array}{l}9.1 \\
79 \\
87 \\
63 \\
93\end{array}$ & $\begin{array}{r}2220 \\
404 \\
209 \\
125 \\
91\end{array}$ & $\begin{array}{l}18 \\
16 \\
14 \\
13 \\
12\end{array}$ & $\begin{array}{r}77 \\
85 \\
394 \\
227 \\
2380\end{array}$ & $\begin{array}{r}3110 \\
685 \\
398 \\
290 \\
196\end{array}$ & $\begin{array}{r}1270 \\
548 \\
286 \\
207 \\
171\end{array}$ & $\begin{array}{l}167 \\
149 \\
127 \\
108 \\
103\end{array}$ & $\begin{array}{r}8300 \\
6270 \\
876 \\
465 \\
362\end{array}$ & $\begin{array}{l}68 \\
42 \\
38 \\
38 \\
89\end{array}$ & $\begin{array}{l}37 \\
29 \\
23 \\
20 \\
25\end{array}$ & $\begin{array}{r}2.6 \\
2.5 \\
2.5 \\
2.3 \\
42\end{array}$ & $\begin{array}{r}102 \\
34 \\
19 \\
234 \\
316\end{array}$ \\
\hline $\begin{array}{l}21 \\
22 \\
23 \\
24 \\
25\end{array}$ & $\begin{array}{l}83 \\
61 \\
46 \\
35 \\
28\end{array}$ & $\begin{array}{l}17 \\
65 \\
56 \\
49 \\
44\end{array}$ & $\begin{array}{l}11 \\
10 \\
9.0 \\
8.4 \\
8.4\end{array}$ & $\begin{array}{l}882 \\
380 \\
235 \\
190 \\
162\end{array}$ & $\begin{array}{l}162 \\
161 \\
165 \\
149 \\
126\end{array}$ & $\begin{array}{l}146 \\
132 \\
122 \\
124 \\
159\end{array}$ & $\begin{array}{r}1090 \\
472 \\
260 \\
191 \\
152\end{array}$ & $\begin{array}{l}294 \\
285 \\
209 \\
157 \\
136\end{array}$ & $\begin{array}{r}167 \\
93 \\
54 \\
41 \\
37\end{array}$ & $\begin{array}{r}185 \\
87 \\
81 \\
45 \\
24\end{array}$ & $\begin{array}{r}345 \\
692 \\
167 \\
66 \\
32\end{array}$ & $\begin{array}{l}96 \\
47 \\
33 \\
25 \\
19\end{array}$ \\
\hline $\begin{array}{l}26 \\
27 \\
28 \\
29 \\
30 \\
31\end{array}$ & $\begin{array}{l}22 \\
21 \\
14 \\
13 \\
13 \\
11\end{array}$ & $\begin{array}{r}46 \\
47 \\
48 \\
45 \\
44 \\
-\cdots\end{array}$ & $\begin{array}{c}8.6 \\
10 \\
13 \\
16 \\
43 \\
1390\end{array}$ & $\begin{array}{l}141 \\
122 \\
109 \\
188 \\
332 \\
354\end{array}$ & $\begin{array}{l}103 \\
135 \\
407 \\
\cdots \\
\ldots . \\
\ldots\end{array}$ & $\begin{array}{l}221 \\
111 \\
140 \\
129 \\
148 \\
397\end{array}$ & $\begin{array}{l}129 \\
110 \\
101 \\
152 \\
121 \\
\cdots\end{array}$ & $\begin{array}{r}127 \\
118 \\
100 \\
87 \\
75 \\
63\end{array}$ & $\begin{array}{l}30 \\
27 \\
22 \\
18 \\
16 \\
-\cdots\end{array}$ & $\begin{array}{l}17 \\
14 \\
10 \\
7.7 \\
6.4 \\
6.0\end{array}$ & $\begin{array}{r}22 \\
16 \\
13 \\
897 \\
437 \\
167\end{array}$ & $\begin{array}{r}14 \\
11 \\
8.2 \\
7.1 \\
5.9 \\
\ldots\end{array}$ \\
\hline $\begin{array}{l}\text { IOIAL } \\
\text { MEAN } \\
\text { MAX } \\
\text { MIN } \\
\text { CF SM } \\
\text { IN. }\end{array}$ & $\begin{array}{r}724.0 \\
23.4 \\
93 \\
2.0 \\
.12 \\
.14\end{array}$ & $\begin{array}{r}5473 \\
182 \\
2220 \\
12 \\
.92 \\
1.03\end{array}$ & $\begin{array}{r}2042.4 \\
65.9 \\
1390 \\
8.4 \\
.33 \\
.38\end{array}$ & $\begin{array}{r}9236 \\
298 \\
2380 \\
76 \\
1.50 \\
1.74\end{array}$ & $\begin{array}{r}20091 \\
718 \\
3710 \\
103 \\
3.62 \\
3.77\end{array}$ & $\begin{array}{r}6964 \\
225 \\
1270 \\
97 \\
1.13 \\
1.31\end{array}$ & $\begin{array}{r}10645 \\
355 \\
2190 \\
98 \\
1.79 \\
2.00\end{array}$ & $\begin{array}{c}31519 \\
1017 \\
8300 \\
63 \\
5.14 \\
5.92\end{array}$ & $\begin{array}{c}3747 \\
125 \\
954 \\
16 \\
.63 \\
.70\end{array}$ & $\begin{array}{r}1998.0 \\
64.5 \\
597 \\
6.0 \\
.33 \\
.38\end{array}$ & $\begin{array}{c}2999.0 \\
96.7 \\
897 \\
2.3 \\
.49 \\
.56\end{array}$ & $\begin{array}{r}1958.8 \\
65.3 \\
316 \\
5.9 \\
.33 \\
.37\end{array}$ \\
\hline
\end{tabular}

CAL YR 1989 TOIAL 106795.8 MLAN 293 MAX 5510 MIN 1.1 CFSM 1.48 IN. 20.06

WTR YR 1990 TOIAL 97397.2 MEAN 267 MAX 8300 MIN 2.0 CFSM 1.35 IN. 18.30 
03369500 VERNON FORK MUSCATATUCK RIVER AT VERNON, IN --. Cont inued

DISCHARGE, CUBIC FEET PER SECOND, WAIER YEAR OCTOBER 1990 TO SEPIEMBER 1991 DAILY MEAN VALUES

\begin{tabular}{|c|c|c|c|c|c|c|c|c|c|c|c|c|}
\hline DAY & $\mathrm{OCT}$ & NOV & DE C & JAN & FEB & MAR & APR & MAY & JUN & JUL & AUG & SEP \\
\hline $\begin{array}{l}1 \\
2 \\
3 \\
4 \\
5\end{array}$ & $\begin{array}{r}4.0 \\
4.2 \\
4.1 \\
803 \\
315\end{array}$ & $\begin{array}{l}25 \\
23 \\
20 \\
18 \\
21\end{array}$ & $\begin{array}{r}120 \\
101 \\
1590 \\
740 \\
278\end{array}$ & $\begin{array}{r}553 \\
362 \\
261 \\
\text { e170 } \\
\text { el } 60\end{array}$ & $\begin{array}{l}e 210 \\
\text { e180 } \\
169 \\
168 \\
228\end{array}$ & $\begin{array}{l}117 \\
132 \\
138 \\
121 \\
108\end{array}$ & $\begin{array}{l}172 \\
148 \\
132 \\
124 \\
147\end{array}$ & $\begin{array}{l}77 \\
67 \\
60 \\
57 \\
60\end{array}$ & $\begin{array}{r}25 \\
1690 \\
436 \\
214 \\
116\end{array}$ & $\begin{array}{l}4.3 \\
4.5 \\
6.0 \\
5.0 \\
4.0\end{array}$ & $\begin{array}{l}69 \\
62 \\
40 \\
12 \\
5.1\end{array}$ & $\begin{array}{r}12 \\
7.7 \\
5.2 \\
192 \\
390\end{array}$ \\
\hline $\begin{array}{r}6 \\
7 \\
8 \\
9 \\
10\end{array}$ & $\begin{array}{r}132 \\
66 \\
38 \\
524 \\
926\end{array}$ & $\begin{array}{l}24 \\
58 \\
45 \\
32 \\
89\end{array}$ & $\begin{array}{r}187 \\
150 \\
124 \\
106 \\
94\end{array}$ & $\begin{array}{l}512 \\
711 \\
379 \\
285 \\
264\end{array}$ & $\begin{array}{r}3170 \\
3130 \\
724 \\
424 \\
310\end{array}$ & $\begin{array}{r}105 \\
110 \\
101 \\
89 \\
84\end{array}$ & $\begin{array}{r}141 \\
125 \\
118 \\
1320 \\
1600\end{array}$ & $\begin{array}{l}87 \\
69 \\
52 \\
51 \\
49\end{array}$ & $\begin{array}{l}69 \\
44 \\
33 \\
27 \\
23\end{array}$ & $\begin{array}{l}3.4 \\
3.0 \\
2.9 \\
7.7 \\
9.0\end{array}$ & $\begin{array}{l}6.6 \\
18 \\
14 \\
26 \\
25\end{array}$ & $\begin{array}{r}141 \\
50 \\
30 \\
21 \\
16\end{array}$ \\
\hline $\begin{array}{l}11 \\
12 \\
13 \\
14 \\
15\end{array}$ & $\begin{array}{r}327 \\
176 \\
121 \\
86 \\
60\end{array}$ & $\begin{array}{r}140 \\
78 \\
54 \\
43 \\
37\end{array}$ & $\begin{array}{r}85 \\
79 \\
74 \\
68 \\
337\end{array}$ & $\begin{array}{r}933 \\
1130 \\
441 \\
300 \\
254\end{array}$ & $\begin{array}{r}239 \\
193 \\
202 \\
1100 \\
e 470\end{array}$ & $\begin{array}{r}79 \\
82 \\
2120 \\
995 \\
395\end{array}$ & $\begin{array}{r}419 \\
262 \\
3330 \\
1440 \\
944\end{array}$ & $\begin{array}{r}48 \\
44 \\
52 \\
79 \\
108\end{array}$ & $\begin{array}{l}19 \\
17 \\
15 \\
17 \\
15\end{array}$ & $\begin{array}{r}13 \\
126 \\
173 \\
39 \\
18\end{array}$ & $\begin{array}{l}18 \\
10 \\
6.5 \\
4.9 \\
4.1\end{array}$ & $\begin{array}{r}11 \\
9.0 \\
74 \\
124 \\
37\end{array}$ \\
\hline $\begin{array}{l}16 \\
17 \\
18 \\
19 \\
20\end{array}$ & $\begin{array}{r}41 \\
30 \\
743 \\
309 \\
160\end{array}$ & $\begin{array}{l}33 \\
32 \\
30 \\
29 \\
28\end{array}$ & $\begin{array}{r}378 \\
218 \\
5390 \\
2170 \\
573\end{array}$ & $\begin{array}{l}351 \\
384 \\
264 \\
202 \\
186\end{array}$ & $\begin{array}{r}\mathrm{e} 220 \\
\mathrm{e} 210 \\
1890 \\
1300 \\
605\end{array}$ & $\begin{array}{r}259 \\
292 \\
1580 \\
543 \\
331\end{array}$ & $\begin{array}{l}519 \\
313 \\
229 \\
244 \\
300\end{array}$ & $\begin{array}{r}67 \\
42 \\
56 \\
104 \\
52\end{array}$ & $\begin{array}{r}137 \\
128 \\
26 \\
15 \\
12\end{array}$ & $\begin{array}{r}11 \\
7.1 \\
5.0 \\
3.9 \\
3.0\end{array}$ & $\begin{array}{c}3.1 \\
77 \\
1540 \\
302 \\
374\end{array}$ & $\begin{array}{r}19 \\
12 \\
\mathrm{e} 10 \\
\mathrm{e} 8.4 \\
\mathrm{e} 7.4\end{array}$ \\
\hline $\begin{array}{l}21 \\
22 \\
23 \\
24 \\
25\end{array}$ & $\begin{array}{r}115 \\
111 \\
176 \\
132 \\
95\end{array}$ & $\begin{array}{r}29 \\
72 \\
291 \\
145 \\
101\end{array}$ & $\begin{array}{r}451 \\
1600 \\
1690 \\
685 \\
e 290\end{array}$ & $\begin{array}{r}\text { el } 70 \\
\text { e } 130 \\
\text { el } 10 \\
\text { e } 105 \\
\text { e } 84\end{array}$ & $\begin{array}{l}362 \\
268 \\
212 \\
182 \\
163\end{array}$ & $\begin{array}{r}253 \\
1830 \\
3130 \\
613 \\
348\end{array}$ & $\begin{array}{l}203 \\
172 \\
149 \\
139 \\
126\end{array}$ & $\begin{array}{r}35 \\
42 \\
199 \\
88 \\
54\end{array}$ & $\begin{array}{l}9.9 \\
8.3 \\
38 \\
24 \\
11\end{array}$ & $\begin{array}{l}2.5 \\
2.3 \\
2.3 \\
2.8 \\
2.7\end{array}$ & $\begin{array}{r}101 \\
42 \\
25 \\
17 \\
13\end{array}$ & $\begin{array}{l}\text { e } 6.7 \\
\text { e } 7.0 \\
\text { e6. } \\
\text { e6.0 } \\
\text { e } 5.7\end{array}$ \\
\hline $\begin{array}{l}26 \\
27 \\
28 \\
29 \\
30 \\
31\end{array}$ & $\begin{array}{l}10 \\
56 \\
45 \\
40 \\
31 \\
27\end{array}$ & $\begin{array}{r}80 \\
71 \\
274 \\
311 \\
156 \\
\cdots\end{array}$ & $\begin{array}{l}\text { e200 } \\
\text { e150 } \\
\text { e } 160 \\
3040 \\
6970 \\
1710\end{array}$ & $\begin{array}{r}\text { e } 80 \\
\text { e } 80 \\
\text { e } 91 \\
\text { e110 } \\
826 \\
\text { e330 }\end{array}$ & $\begin{array}{l}144 \\
132 \\
123 \\
\ldots \\
\ldots \\
\ldots\end{array}$ & $\begin{array}{r}1990 \\
1300 \\
873 \\
394 \\
264 \\
201\end{array}$ & $\begin{array}{r}112 \\
105 \\
101 \\
97 \\
89 \\
\cdots\end{array}$ & $\begin{array}{r}63 \\
154 \\
84 \\
47 \\
36 \\
31\end{array}$ & $\begin{array}{l}7.8 \\
6.1 \\
5.3 \\
5.0 \\
4.4 \\
\ldots . .\end{array}$ & $\begin{array}{r}2.5 \\
2.4 \\
2.3 \\
1.9 \\
1.9 \\
65\end{array}$ & $\begin{array}{r}10 \\
8.1 \\
6.3 \\
5.3 \\
4.6 \\
4.8\end{array}$ & $\begin{array}{r}\text { e5.5 } \\
\text { e5.4 } \\
\text { e } 6.0 \\
\text { e } 6.0 \\
\text { e5.6 } \\
. . .\end{array}$ \\
\hline $\begin{array}{l}\text { IOIAL } \\
\text { MEAN } \\
\text { MAX } \\
\text { MIN } \\
\text { CF SM } \\
\text { IN. }\end{array}$ & $\begin{array}{r}5767.3 \\
186 \\
926 \\
4.0 \\
.94 \\
1.08\end{array}$ & $\begin{array}{r}2389 \\
79.6 \\
311 \\
18 \\
.40 \\
.45\end{array}$ & $\begin{array}{r}29808 \\
962 \\
6970 \\
68 \\
4.86 \\
5.60\end{array}$ & $\begin{array}{r}10218 \\
330 \\
1130 \\
80 \\
1.66 \\
1.92\end{array}$ & $\begin{array}{r}16728 \\
597 \\
3170 \\
123 \\
3.02 \\
3.14\end{array}$ & $\begin{array}{r}18977 \\
612 \\
3130 \\
79 \\
3.09 \\
3.57\end{array}$ & $\begin{array}{r}13326 \\
444 \\
3330 \\
89 \\
2.24 \\
2.50\end{array}$ & $\begin{array}{c}2114 \\
68.2 \\
199 \\
31 \\
.34 \\
.40\end{array}$ & $\begin{array}{c}3197.8 \\
107 \\
1690 \\
4.4 \\
.54 \\
.60\end{array}$ & $\begin{array}{c}537.4 \\
17.3 \\
173 \\
1.9 \\
.09 \\
.10\end{array}$ & $\begin{array}{c}2854.4 \\
92.1 \\
1540 \\
3.1 \\
.47 \\
.54\end{array}$ & $\begin{array}{c}1837.1 \\
61.2 \\
792 \\
5.2 \\
.31 \\
.35\end{array}$ \\
\hline
\end{tabular}

e Estimated

SIAIISTICS OF MONTHLY MEAN DATA FOR WAIER YEARS 1940 - 1991, BY WAIER YEAR (WY)

\begin{tabular}{|c|c|c|c|c|c|c|c|c|c|c|c|c|}
\hline $\begin{array}{l}\text { MEAN } \\
\text { MAX } \\
(W Y) \\
\text { MIN } \\
(W Y)\end{array}$ & $\begin{array}{r}35.9 \\
292 \\
1984 \\
.22 \\
1941\end{array}$ & $\begin{array}{r}140 \\
986 \\
1986 \\
.61 \\
1954\end{array}$ & $\begin{array}{r}261 \\
962 \\
1991 \\
1.03 \\
1944\end{array}$ & $\begin{array}{r}356 \\
2049 \\
1950 \\
4.23 \\
1977\end{array}$ & $\begin{array}{r}405 \\
1188 \\
1950 \\
24.4 \\
1964\end{array}$ & $\begin{array}{r}494 \\
1798 \\
1945 \\
19.0 \\
1941\end{array}$ & $\begin{array}{r}383 \\
1014 \\
1947 \\
37.3 \\
1941\end{array}$ & $\begin{array}{r}280 \\
1440 \\
1968 \\
8.77 \\
1941\end{array}$ & $\begin{array}{r}142 \\
963 \\
1960 \\
1.80 \\
1988\end{array}$ & $\begin{array}{r}95.5 \\
581 \\
1962 \\
.63 \\
1954\end{array}$ & $\begin{array}{r}57.8 \\
639 \\
1978 \\
003 \\
1940\end{array}$ & $\begin{array}{r}34.8 \\
284 \\
197 \\
.19 \\
1943\end{array}$ \\
\hline
\end{tabular}

SUMMARY SIATISTICS

ANMUAL TOTAL

ANNUAL MEAN

HIGHESI ANNUAL MEAN

LOWEST ANNUAL MEAN

HIGHEST DAILY MEAN

LOWEST DAIIY MEAN

ANNUAL SEVEN-DAY MINIMUM

INSTANIANEOUS PEAK FLOW

INSIANTANEOUS PEAK STAGE

ANNUAL RUNOFF (CFSM)

ANNUAL RUNOFF (INCHES)

10 PERCENT EXCEEDS

50 PERCENT EXCEEDS

90 PERCENT EXCEEDS
FOR 1990 CALENDAR YEAR

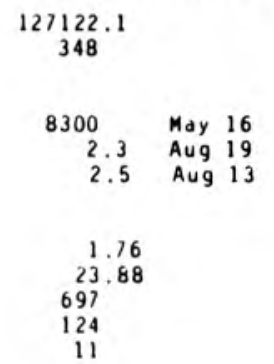

FOR 1991 WATER YEAR

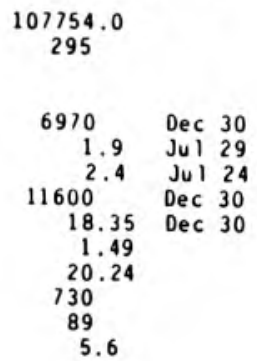

WATER YEARS $1940-1991$

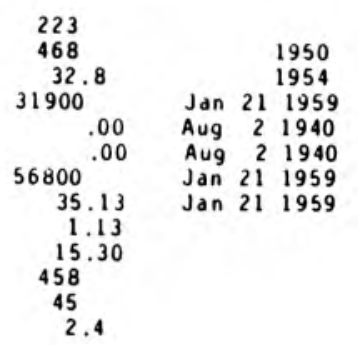




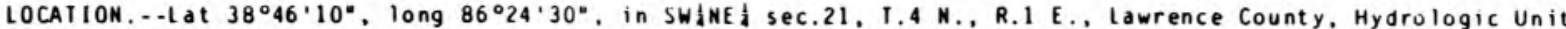
05120208 , on downstrean side of center pier of bridge on county road, 0.4 upstrea fro. Mill Creek, 2.9 . downstrea from Sugar ${ }_{2}$ Creek, 3.9 i northeast of Mitchell, 7.8 ai southeast of Bedford, and at ile 153.3 . DRAI NAGE AREA . . - 3,861 $1 i^{2}$

PERIOD OF RECORD. - May 1939 to current yedr (high-water records only 0ctober 1943 to Septeaber 1957 ).

REVISED RECORDS...WSP 2109: Drainage ared. WDR IN-73-1: 1972.

GAGE.--Water-stage recorder. Datue of gage is $473.59 \mathrm{ft}$ above National Geodetic Vertical Datua of 1929 . Prior to Feb. 6, 1940, nonrecording gage, and Feb. 6, 1940, to Sept. 24, 1957, water-stage recorder, at site 9.8 ei downstrea at datue $4.39 \mathrm{ft}$ lower.

REMARKS. - - Records good except for estimated daily discharges, which are poor.

EXTREMES OUTSIDE PERIOD OF RECORD. - - Flood in March 1913 reached a stage of $47.5 \mathrm{ft}$, froe floodaark deterained by U.S. Aray Corps of Engineers, discharge, $155,000 \mathrm{ft} / \mathrm{s}$, at foraer site.

DISCHARGE, CUBIC FEET PER SECOND, WATER YEAR OCTOBER 1990 TO SEPIEMBER 1991 DAI I Y MEAN VALUES

\begin{tabular}{|c|c|c|c|c|c|c|c|c|c|c|c|c|}
\hline DAY & $O C I$ & NOV & DEC & JAN & FEB & MAR & APR & MAY & JUN & JUL & AUG & SEP \\
\hline $\begin{array}{l}1 \\
2 \\
3 \\
4 \\
5\end{array}$ & $\begin{array}{r}938 \\
902 \\
868 \\
1090 \\
1210\end{array}$ & $\begin{array}{l}1830 \\
1730 \\
1640 \\
1570 \\
1530\end{array}$ & $\begin{array}{l}5730 \\
5780 \\
5780 \\
6590 \\
7770\end{array}$ & $\begin{array}{l}27700 \\
49200 \\
53900 \\
47200 \\
36900\end{array}$ & $\begin{array}{l}5640 \\
5560 \\
4770 \\
4340 \\
4420\end{array}$ & $\begin{array}{l}4530 \\
4310 \\
4250 \\
4230 \\
4050\end{array}$ & $\begin{array}{r}14100 \\
10600 \\
8030 \\
6050 \\
5270\end{array}$ & $\begin{array}{l}3540 \\
3340 \\
3110 \\
2910 \\
2750\end{array}$ & $\begin{array}{l}2400 \\
2950 \\
3640 \\
4120 \\
3920\end{array}$ & $\begin{array}{l}915 \\
883 \\
872 \\
905 \\
994\end{array}$ & $\begin{array}{l}561 \\
549 \\
538 \\
546 \\
555\end{array}$ & $\begin{array}{l}476 \\
467 \\
465 \\
539 \\
943\end{array}$ \\
\hline $\begin{array}{r}6 \\
7 \\
8 \\
9 \\
10\end{array}$ & $\begin{array}{l}2310 \\
2900 \\
2550 \\
2570 \\
2920\end{array}$ & $\begin{array}{l}1490 \\
1460 \\
1470 \\
1570 \\
1630\end{array}$ & $\begin{array}{l}8110 \\
8890 \\
7310 \\
5420 \\
4410\end{array}$ & $\begin{array}{l}28200 \\
21000 \\
15100 \\
12300 \\
11100\end{array}$ & $\begin{array}{r}8100 \\
12100 \\
13700 \\
18100 \\
22500\end{array}$ & $\begin{array}{l}3840 \\
3620 \\
3500 \\
3470 \\
3310\end{array}$ & $\begin{array}{l}4970 \\
4870 \\
4610 \\
4310 \\
4490\end{array}$ & $\begin{array}{l}2630 \\
2570 \\
2570 \\
2560 \\
2500\end{array}$ & $\begin{array}{l}3000 \\
2370 \\
2020 \\
1790 \\
1640\end{array}$ & $\begin{array}{l}961 \\
973 \\
917 \\
862 \\
828\end{array}$ & $\begin{array}{l}565 \\
573 \\
593 \\
686 \\
663\end{array}$ & $\begin{array}{r}1690 \\
1740 \\
1140 \\
840 \\
699\end{array}$ \\
\hline $\begin{array}{l}11 \\
12 \\
13 \\
14 \\
15\end{array}$ & $\begin{array}{l}4510 \\
6200 \\
6320 \\
5600 \\
4430\end{array}$ & $\begin{array}{l}1640 \\
1720 \\
1870 \\
1840 \\
1700\end{array}$ & $\begin{array}{l}3850 \\
3450 \\
3160 \\
2920 \\
2870\end{array}$ & $\begin{array}{l}10600 \\
10600 \\
10600 \\
11700 \\
12700\end{array}$ & $\begin{array}{r}22600 \\
19100 \\
14600 \\
11800 \\
\mathrm{e} 10000\end{array}$ & $\begin{array}{l}3090 \\
2930 \\
3540 \\
6130 \\
8640\end{array}$ & $\begin{array}{r}6390 \\
7120 \\
8220 \\
10200 \\
11800\end{array}$ & $\begin{array}{l}2420 \\
2340 \\
2270 \\
2240 \\
2250\end{array}$ & $\begin{array}{l}1530 \\
1450 \\
1390 \\
1570 \\
1590\end{array}$ & $\begin{array}{r}947 \\
1030 \\
1010 \\
1210 \\
1260\end{array}$ & $\begin{array}{l}760 \\
701 \\
645 \\
609 \\
584\end{array}$ & $\begin{array}{l}621 \\
571 \\
534 \\
510 \\
483\end{array}$ \\
\hline $\begin{array}{l}16 \\
17 \\
18 \\
19 \\
20\end{array}$ & $\begin{array}{l}3520 \\
2920 \\
2670 \\
3020 \\
4540\end{array}$ & $\begin{array}{l}1590 \\
1520 \\
1470 \\
1420 \\
1390\end{array}$ & $\begin{array}{r}3180 \\
4390 \\
8730 \\
11800 \\
12000\end{array}$ & $\begin{array}{r}12200 \\
10700 \\
9710 \\
9290 \\
8920\end{array}$ & $\begin{array}{r}e 9000 \\
\text { e8900 } \\
9010 \\
9320 \\
9980\end{array}$ & $\begin{array}{l}11100 \\
14000 \\
16400 \\
15200 \\
13800\end{array}$ & $\begin{array}{l}14900 \\
16300 \\
15900 \\
14200 \\
11500\end{array}$ & $\begin{array}{l}2360 \\
2810 \\
2790 \\
2580 \\
2550\end{array}$ & $\begin{array}{l}1470 \\
1640 \\
1420 \\
1440 \\
1410\end{array}$ & $\begin{array}{r}1130 \\
990 \\
894 \\
831 \\
785\end{array}$ & $\begin{array}{r}558 \\
533 \\
525 \\
858 \\
1620\end{array}$ & $\begin{array}{l}484 \\
574 \\
583 \\
543 \\
504\end{array}$ \\
\hline $\begin{array}{l}21 \\
22 \\
23 \\
24 \\
25\end{array}$ & $\begin{array}{l}5080 \\
4420 \\
3640 \\
3300 \\
3300\end{array}$ & $\begin{array}{l}1370 \\
1400 \\
1500 \\
1860 \\
2750\end{array}$ & $\begin{array}{r}15700 \\
22700 \\
26300 \\
26000 \\
\mathrm{e} 23500\end{array}$ & $\begin{array}{r}7940 \\
6810 \\
6060 \\
5460 \\
e 4800\end{array}$ & $\begin{array}{r}11300 \\
12300 \\
12400 \\
11200 \\
8950\end{array}$ & $\begin{array}{l}13600 \\
13300 \\
14600 \\
14500 \\
18200\end{array}$ & $\begin{array}{r}10000 \\
9520 \\
8400 \\
6800 \\
5680\end{array}$ & $\begin{array}{l}3460 \\
3730 \\
3240 \\
3420 \\
3740\end{array}$ & $\begin{array}{l}1350 \\
1230 \\
1130 \\
1050 \\
1000\end{array}$ & $\begin{array}{l}752 \\
731 \\
746 \\
702 \\
677\end{array}$ & $\begin{array}{r}1260 \\
1040 \\
872 \\
744 \\
669\end{array}$ & $\begin{array}{l}480 \\
472 \\
465 \\
453 \\
446\end{array}$ \\
\hline $\begin{array}{l}26 \\
27 \\
28 \\
29 \\
30 \\
31\end{array}$ & $\begin{array}{l}3090 \\
2740 \\
2450 \\
2230 \\
2060 \\
1920\end{array}$ & $\begin{array}{r}2920 \\
2600 \\
2480 \\
2700 \\
4070 \\
\cdots\end{array}$ & $\begin{array}{r}\text { e } 20000 \\
\text { e16000 } \\
\text { e13800 } \\
12900 \\
14800 \\
17700\end{array}$ & $\begin{array}{r}\text { e } 4300 \\
\text { e } 4000 \\
\text { e } 3800 \\
3880 \\
4100 \\
4600\end{array}$ & $\begin{array}{c}6700 \\
5580 \\
4950 \\
\ldots \\
\ldots \\
\ldots\end{array}$ & $\begin{array}{l}22900 \\
25000 \\
23700 \\
23100 \\
21600 \\
18300\end{array}$ & $\begin{array}{r}4990 \\
4490 \\
4120 \\
3920 \\
3730 \\
\ldots .\end{array}$ & $\begin{array}{l}3460 \\
3170 \\
3000 \\
3030 \\
3150 \\
2740\end{array}$ & $\begin{array}{r}971 \\
1050 \\
1020 \\
976 \\
950 \\
\cdots\end{array}$ & $\begin{array}{l}657 \\
637 \\
620 \\
605 \\
590 \\
511\end{array}$ & $\begin{array}{l}614 \\
512 \\
546 \\
526 \\
508 \\
491\end{array}$ & $\begin{array}{l}435 \\
428 \\
423 \\
418 \\
414 \\
\cdots\end{array}$ \\
\hline $\begin{array}{l}\text { TOIAL } \\
\text { MEAN } \\
\text { MAX } \\
\text { MIN } \\
\text { CF SM } \\
\text { IN. }\end{array}$ & $\begin{array}{r}96218 \\
3104 \\
6320 \\
868 \\
.80 \\
.93\end{array}$ & $\begin{array}{r}55730 \\
1858 \\
4070 \\
1370 \\
.48 \\
.54\end{array}$ & $\begin{array}{r}332200 \\
10720 \\
26300 \\
2870 \\
2.78 \\
3.20\end{array}$ & $\begin{array}{r}465370 \\
15010 \\
53900 \\
3800 \\
3.89 \\
4.48\end{array}$ & $\begin{array}{r}296920 \\
10600 \\
22600 \\
4340 \\
2.75 \\
2.86\end{array}$ & $\begin{array}{r}342740 \\
11060 \\
25000 \\
2930 \\
2.86 \\
3.30\end{array}$ & $\begin{array}{r}245480 \\
8183 \\
16300 \\
3730 \\
2.12 \\
2.37\end{array}$ & $\begin{array}{r}89230 \\
2878 \\
3740 \\
2240 \\
.75 \\
.86\end{array}$ & $\begin{array}{r}53493 \\
1783 \\
4120 \\
950 \\
.46 \\
.52\end{array}$ & $\begin{array}{r}26491 \\
855 \\
1260 \\
577 \\
.22 \\
.26\end{array}$ & $\begin{array}{r}21064 \\
679 \\
1620 \\
491 \\
.18 \\
.20\end{array}$ & $\begin{array}{r}18840 \\
628 \\
1740 \\
414 \\
.16 \\
.18\end{array}$ \\
\hline
\end{tabular}

e Estimated

SIATISIICS OF MONIHLY MEAN DAIA FOR WAIER YEARS 1940 - 1991, BY WATER YEAR (WY)

$\begin{array}{lrr}\text { MEAN } & 1002 & 21 \\ \text { MAX } & 3421 & 111 \\ \text { (WY) } & 1987 & 1980 \\ \text { MIN } & 228 & 297 \\ \text { (WY) } & 1941 & 196\end{array}$

SUMMARY STAIISIICS

ANMUAL TOTAL

ANMUAL MEAM

HIGHEST ANMUAL MEAN

LOWEST ANNUAL MEAM

HIGHESI DAIIY MEAM

LOWE ST DAIIY MEAN

ANNUAL SEVEM-DAY MINIMUM

IMSTAMTAMEOUS PEAK FLOW

INSIANTANEOUS PEAK STAGE

ANWUAL RUNOFF (CFSM)

AN WUAL RUNOF F (I MCHES)

10 PERCENT EXCEEDS

50 PERCENT EXCEEDS

90 PERCENT EXCEEDS

$\begin{array}{rr}4448 & 4864 \\ 12090 & 15010 \\ 1958 & 1991 \\ 272 & 300 \\ 1964 & 1977\end{array}$

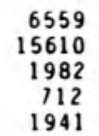

8387
18710
1964
450

1941

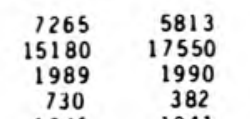

1941

382
1941
FOR 1991 WAIER YEAR

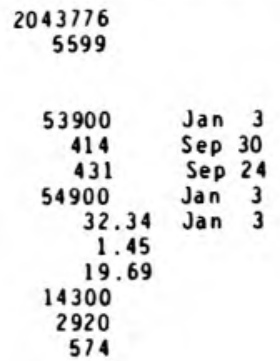

$\begin{array}{ccc}2352 & 1691 & 1081 \\ 9649 & 11280 & 5234 \\ 1958 & 1979 & 1989 \\ 603 & 291 & 244 \\ 1941 & 1941 & 1941\end{array}$

WAIER YEARS $1940-1991$
4054

6710
643

73100

138

196

75700

35.97
1.05

14.27

10100

2040 
LOCAIION, - Lat $38^{\circ} 50^{\circ} 48^{\prime \prime}$, Iong $86^{\circ} 18^{\circ} 06^{\prime \prime}$, in SW 4 SE $\frac{1}{4}$ Sec. 21 , T.5 N., R.2 E.. Lawrence County, Hydrolugic Unit

05120208 , on left bank at downstream side of county road bridge, 0.9 mi west of leesville, 2.5 mi upstream from

Jones Defeat Hollow, and 7 i above mouth.

DRAINAGE AREA $-24.1 \mathrm{i}^{2}$

PERIOD OF RECORD.--OCtober 1970 to current year.

REVISED RECORDS.--WDR IN-72-1: 1971 .

GAGE. - Water-stage recorder. Datun of gage is $575.00 \mathrm{ft}$ above National Geodetic Vertical Datum of 1929.

REMARKS. - Records good, except for estimated daily discharges, which are poor.

EXTREMES OUTSIDE PERIOD OF RECORD.--Flood in 1913 reached a stage of 18.1 ft from information by local resident.

DISCHARGE, CUBIC FEET PER SECOND, WATER YEAR OCTOBER 1990 TO SEPIEMBER 1991 DAILY MEAN VALUES

\begin{tabular}{|c|c|c|c|c|c|c|c|c|c|c|c|c|}
\hline DAY & $\mathrm{OCT}$ & NOV & $\mathrm{DEC}$ & JAN & FEB & MAR & APR & MAY & JUN & JUL & AUG & SEP \\
\hline $\begin{array}{l}1 \\
2 \\
3 \\
4 \\
5\end{array}$ & $\begin{array}{r}.15 \\
.13 \\
71.13 \\
2.5\end{array}$ & $\begin{array}{l}4.2 \\
3.8 \\
3.4 \\
3.5 \\
4.1\end{array}$ & $\begin{array}{r}8.8 \\
6.4 \\
170 \\
58 \\
32\end{array}$ & $\begin{array}{l}12 \\
50 \\
36 \\
26 \\
24\end{array}$ & $\begin{array}{l}22 \\
18 \\
17 \\
16 \\
29\end{array}$ & $\begin{array}{l}16 \\
20 \\
16 \\
14 \\
13\end{array}$ & $\begin{array}{l}30 \\
24 \\
20 \\
24 \\
38\end{array}$ & $\begin{array}{l}8.7 \\
7.6 \\
6.9 \\
7.3 \\
8.3\end{array}$ & $\begin{array}{l}1.6 \\
1.6 \\
6.3 \\
2.5 \\
1.6\end{array}$ & $\begin{array}{l}.02 \\
.02 \\
.01 \\
.01 \\
.01\end{array}$ & $\begin{array}{l}.00 \\
.00 \\
.00 \\
.00 \\
.00\end{array}$ & $\begin{array}{r}.00 \\
.00 \\
81.00 \\
6.2\end{array}$ \\
\hline $\begin{array}{r}6 \\
7 \\
8 \\
9 \\
10\end{array}$ & $\begin{array}{l}1.3 \\
1.2 \\
1.1 \\
49 \\
28\end{array}$ & $\begin{array}{l}6.3 \\
6.7 \\
5.7 \\
5.9 \\
7.8\end{array}$ & $\begin{array}{l}18 \\
11 \\
7.7 \\
6.4 \\
5.6\end{array}$ & $\begin{array}{l}77 \\
70 \\
54 \\
44 \\
38\end{array}$ & $\begin{array}{r}536 \\
158 \\
79 \\
56 \\
45\end{array}$ & $\begin{array}{l}14 \\
13 \\
11 \\
10 \\
9.6\end{array}$ & $\begin{array}{l}29 \\
25 \\
24 \\
25 \\
22\end{array}$ & $\begin{array}{l}7.8 \\
6.1 \\
5.3 \\
5.7 \\
5.4\end{array}$ & $\begin{array}{l}1.1 \\
.85 \\
.69 \\
.53 \\
.40\end{array}$ & $\begin{array}{l}.02 \\
.01 \\
.01 \\
.09 \\
.10\end{array}$ & $\begin{array}{c}24 \\
3.1 \\
.25 \\
3.7 \\
3.6\end{array}$ & $\begin{array}{r}1.4 \\
.55 \\
.23 \\
.12 \\
.09\end{array}$ \\
\hline $\begin{array}{l}11 \\
12 \\
13 \\
14 \\
15\end{array}$ & $\begin{array}{l}7.9 \\
3.8 \\
2.6 \\
1.9 \\
1.8\end{array}$ & $\begin{array}{l}8.0 \\
6.7 \\
5.9 \\
5.3 \\
5.0\end{array}$ & $\begin{array}{r}4.9 \\
4.5 \\
4.0 \\
3.4 \\
33\end{array}$ & $\begin{array}{l}94 \\
78 \\
53 \\
42 \\
35\end{array}$ & $\begin{array}{r}36 \\
29 \\
38 \\
127 \\
65\end{array}$ & $\begin{array}{c}9.2 \\
11 \\
104 \\
70 \\
50\end{array}$ & $\begin{array}{r}19 \\
17 \\
224 \\
121 \\
107\end{array}$ & $\begin{array}{l}5.0 \\
4.7 \\
4.4 \\
4.1 \\
4.0\end{array}$ & $\begin{array}{l}.32 \\
.29 \\
.21 \\
.17 \\
.11\end{array}$ & $\begin{array}{l}.04 \\
.03 \\
.02 \\
.01 \\
.01\end{array}$ & $\begin{array}{l}.75 \\
.19 \\
.05 \\
.02 \\
.02\end{array}$ & $\begin{array}{l}.08 \\
.07 \\
.07 \\
.07 \\
.06\end{array}$ \\
\hline $\begin{array}{l}16 \\
17 \\
18 \\
19 \\
20\end{array}$ & $\begin{array}{r}1.6 \\
1.4 \\
30 \\
6.3 \\
3.8\end{array}$ & $\begin{array}{l}4.7 \\
4.7 \\
4.4 \\
4.2 \\
3.9\end{array}$ & $\begin{array}{r}19 \\
30 \\
513 \\
134 \\
60\end{array}$ & $\begin{array}{l}44 \\
38 \\
31 \\
27 \\
25\end{array}$ & $\begin{array}{r}e 45 \\
39 \\
140 \\
103 \\
72\end{array}$ & $\begin{array}{r}40 \\
99 \\
135 \\
73 \\
54\end{array}$ & $\begin{array}{l}74 \\
55 \\
44 \\
65 \\
52\end{array}$ & $\begin{array}{l}3.9 \\
6.7 \\
5.3 \\
4.4 \\
3.4\end{array}$ & $\begin{array}{l}.10 \\
.09 \\
.10 \\
.11 \\
.08\end{array}$ & $\begin{array}{l}.01 \\
.01 \\
.01 \\
.00 \\
.00\end{array}$ & $\begin{array}{l}.02 \\
.01 \\
.01 \\
.01 \\
.00\end{array}$ & $\begin{array}{l}.05 \\
.03 \\
.04 \\
.03 \\
.03\end{array}$ \\
\hline $\begin{array}{l}21 \\
22 \\
23 \\
24 \\
25\end{array}$ & $\begin{array}{l}2.9 \\
5.3 \\
5.6 \\
4.6 \\
4.9\end{array}$ & $\begin{array}{l}3.6 \\
25 \\
17 \\
7.9 \\
5.6\end{array}$ & $\begin{array}{l}124 \\
135 \\
\text { e } 60 \\
\text { e } 35 \\
\text { e24 }\end{array}$ & $\begin{array}{l}\text { e } 18 \\
\text { e } 15 \\
\text { e13 } \\
\text { e } 11 \\
\text { e10 }\end{array}$ & $\begin{array}{l}56 \\
46 \\
37 \\
31 \\
25\end{array}$ & $\begin{array}{r}45 \\
334 \\
244 \\
99 \\
68\end{array}$ & $\begin{array}{l}44 \\
36 \\
30 \\
25 \\
20\end{array}$ & $\begin{array}{l}2.9 \\
2.6 \\
2.4 \\
2.4 \\
2.6\end{array}$ & $\begin{array}{l}.07 \\
.07 \\
.06 \\
.05 \\
.03\end{array}$ & $\begin{array}{l}.00 \\
.00 \\
.00 \\
.00 \\
.00\end{array}$ & $\begin{array}{l}.00 \\
.00 \\
.00 \\
.00 \\
.00\end{array}$ & $\begin{array}{l}.03 \\
.03 \\
.03 \\
.03 \\
.02\end{array}$ \\
\hline $\begin{array}{l}26 \\
27 \\
28 \\
29 \\
30 \\
31\end{array}$ & $\begin{array}{l}4.9 \\
5.1 \\
5.6 \\
5.4 \\
5.1 \\
4.6\end{array}$ & $\begin{array}{c}4.6 \\
9.7 \\
89 \\
30 \\
14 \\
\ldots\end{array}$ & $\begin{array}{r}\text { e17 } \\
\text { e16 } \\
\text { e15 } \\
278 \\
1130 \\
142\end{array}$ & $\begin{array}{l}\text { e } 9.5 \\
\text { e9.1 } \\
\text { e } 8.8 \\
\text { e10 } \\
52 \\
30\end{array}$ & $\begin{array}{l}20 \\
18 \\
16 \\
\cdots \\
\cdots \\
\cdots\end{array}$ & $\begin{array}{l}97 \\
89 \\
71 \\
56 \\
44 \\
36\end{array}$ & $\begin{array}{r}18 \\
16 \\
14 \\
13 \\
10 \\
\cdots\end{array}$ & $\begin{array}{l}6.7 \\
5.7 \\
3.8 \\
2.9 \\
2.4 \\
2.0\end{array}$ & $\begin{array}{l}.03 \\
.03 \\
.03 \\
.03 \\
.02 \\
. .\end{array}$ & $\begin{array}{l}.00 \\
.00 \\
.00 \\
.00 \\
.00 \\
.00\end{array}$ & $\begin{array}{l}.00 \\
.00 \\
.00 \\
.00 \\
.00 \\
.00\end{array}$ & $\begin{array}{l}.02 \\
.02 \\
.02 \\
.02 \\
.02 \\
.--\end{array}$ \\
\hline $\begin{array}{l}\text { TOIAL } \\
\text { MEAN } \\
\text { MAX } \\
\text { MIN } \\
\text { CF SH } \\
\text { IN. }\end{array}$ & $\begin{array}{r}269.61 \\
8.70 \\
71 \\
.13 \\
.36 \\
.42\end{array}$ & $\begin{array}{r}310.6 \\
10.4 \\
89 \\
3.4 \\
.43 \\
.48\end{array}$ & $\begin{array}{r}3105.7 \\
100 \\
1130 \\
3.4 \\
4.16 \\
4.19\end{array}$ & $\begin{array}{r}1144.4 \\
36.9 \\
94 \\
8.8 \\
1.53 \\
1.17\end{array}$ & $\begin{array}{c}1919 \\
68.5 \\
536 \\
16 \\
2.84 \\
2.96\end{array}$ & $\begin{array}{r}1964.8 \\
63.4 \\
334 \\
9.2 \\
2.63 \\
3.03\end{array}$ & $\begin{array}{r}1265 \\
42.2 \\
224 \\
10 \\
1.75 \\
1.95\end{array}$ & $\begin{array}{c}151.4 \\
4.88 \\
8.7 \\
2.0 \\
.20 \\
.23\end{array}$ & $\begin{array}{c}19.17 \\
.64 \\
6.3 \\
.02 \\
.03 \\
.03\end{array}$ & $\begin{array}{l}0.44 \\
.014 \\
.10 \\
.00 \\
.00 \\
.00\end{array}$ & $\begin{array}{c}35.73 \\
1.15 \\
24 \\
.00 \\
.05 \\
.06\end{array}$ & $\begin{array}{c}90.36 \\
3.01 \\
81 \\
.00 \\
.12 \\
.14\end{array}$ \\
\hline
\end{tabular}

e Estimated

SIATISIICS OF MONTHLY MEAN DAIA FUR WAIER YEARS 1971 - 1991, BY WAIER YEAR (WY)

$\begin{array}{lrrrrr}\text { MEAN } & 9.26 & 31.2 & 44.2 & 37.9 & 54.0 \\ \text { MAX } & 48.0 & 132 & 101 & 147 & 105 \\ \text { (WY) } & 1984 & 1986 & 1983 & 1982 & 1979 \\ \text { MIN } & .000 & 1.05 & 2.37 & .98 & 10.3 \\ \text { (WY) } & 1989 & 1988 & 1990 & 1977 & 197\end{array}$

$\begin{array}{rrr}68.5 & 57.8 & 36.9 \\ 168 & 176 & 150 \\ 1989 & 1972 & 1990 \\ 9.74 & 8.62 & 2.70 \\ 1981 & 1976 & 1988\end{array}$

15.2
63.3
1973
.25

21.2

$13.2 \quad 5.92$

$1973 \quad 1979 \quad 1974$

$014 \quad .080 \quad .000$

SUMMARY SIAIISTICS

ANNUAL TOIAL

ANHUAL MEAM

HIGHEST ANNUAL MEAM

LOWEST ANNUAL MEAN

HIGHESI DAIIY MEAN

LOWEST DAILY MEAN

ANMUAL SEVEN-DAY MIMIMUM

INSIANIANEOUS PEAK FLOW

INSIANTANEOUS PEAK STAGE

ANNUAL RUNOFF (CFSM)

ANNUAL RUNOFF (INCHES)

10 PERCENT EXLEEDS

50 PERCENT EXCEEDS

90 PERCENT EXCEEDS
FOR 1990 CALENDAR YEAR

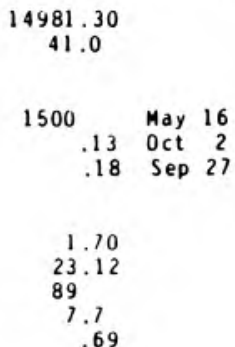

FOR 1991 WAIER YEAR

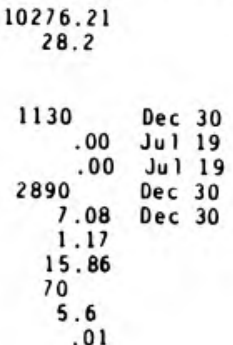

WATER YEARS 1971 - 1991

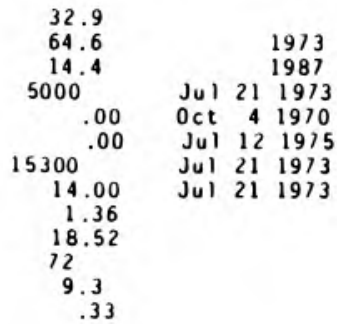




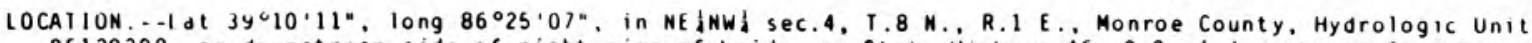

05120208 , on downstrea side of right pier of bridge on State Highway $46,0.2$ i downstrean from kerr Creek, $4.0 \mathrm{mi}$ west of Belmozt, and $6.1 \mathrm{mi}$ edst of Bloonington.

DRAI NAGE AREA $\cdots 10.9 \cdot i^{2}$.

PERIOD OF RECORD.--October 1970 to current yedr.

GAGE.- Water-stage recorder. Datum of gage is $550.00 \mathrm{ft}$ above National Geodetic Vertical Datua of 1929.

REMARKS. - -Records poor.

DISCHARGE, CUBIC FEET PER SECOND, WATER YEAR OCTOBER 1990 TO SEPTEMBER 1991 DAIIY MEAN VALUES

\begin{tabular}{|c|c|c|c|c|c|c|c|c|c|c|c|c|}
\hline DAY & $\mathrm{OCT}$ & NOV & DEC & JAN & FE B & MAR & APR & MAY & JUN & JUL & AUG & SEP \\
\hline $\begin{array}{l}1 \\
2 \\
3 \\
4 \\
5\end{array}$ & $\begin{array}{r}\text { e. } 60 \\
\text { e. } 86 \\
\text { e } 1.4 \\
8.2 \\
3.1\end{array}$ & $\begin{array}{r}\text { e. } 53 \\
\text { e. } 48 \\
\text { e. } 49 \\
\text { e. } 94 \\
\text { e } 1.8\end{array}$ & $\begin{array}{c}6.9 \\
5.2 \\
26 \\
16 \\
9.7\end{array}$ & $\begin{array}{r}\text { e } 45 \\
\text { e22 } \\
\text { e16 } \\
\text { e11 } \\
\text { e } 9.0\end{array}$ & $\begin{array}{l}\text { e } 8.4 \\
\text { e } 9.4 \\
\text { el1 } \\
13 \\
16\end{array}$ & $\begin{array}{l}6.2 \\
9.0 \\
7.4 \\
6.8 \\
6.3\end{array}$ & $\begin{array}{l}13 \\
11 \\
9.5 \\
12 \\
17\end{array}$ & $\begin{array}{l}4.9 \\
4.1 \\
3.6 \\
3.5 \\
3.5\end{array}$ & $\begin{array}{l}.51 \\
.79 \\
.91 \\
.57 \\
.46\end{array}$ & $\begin{array}{l}.16 \\
.22 \\
.17 \\
.19 \\
.21\end{array}$ & $\begin{array}{l}\text { e. } 09 \\
\text { e. } 08 \\
\text { e. } 06 \\
\text { e. } 11 \\
\text { e. } 08\end{array}$ & $\begin{array}{l}\text { e. } 04 \\
\text { e. } 03 \\
\text { e. } 05 \\
.10 \\
.08\end{array}$ \\
\hline $\begin{array}{r}6 \\
7 \\
8 \\
9 \\
10\end{array}$ & $\begin{array}{l}2.5 \\
2.3 \\
2.1 \\
6.3 \\
19\end{array}$ & $\begin{array}{l}\text { e } 2.2 \\
\text { e1.5 } \\
\text { e } 1.3 \\
\text { e1.5 } \\
\text { e1.7 }\end{array}$ & $\begin{array}{l}7.1 \\
5.4 \\
4.3 \\
3.6 \\
3.1\end{array}$ & $\begin{array}{l}\text { e13 } \\
15 \\
14 \\
13 \\
12\end{array}$ & $\begin{array}{r}174 \\
59 \\
28 \\
19 \\
15\end{array}$ & $\begin{array}{l}6.7 \\
6.2 \\
5.5 \\
5.1 \\
4.8\end{array}$ & $\begin{array}{l}15 \\
14 \\
14 \\
15 \\
13\end{array}$ & $\begin{array}{l}3.5 \\
3.2 \\
3.0 \\
3.0 \\
2.8\end{array}$ & $\begin{array}{l}.42 \\
.38 \\
.35 \\
.33 \\
.32\end{array}$ & $\begin{array}{l}.29 \\
.17 \\
.15 \\
.16 \\
.17\end{array}$ & $\begin{array}{l}\text { e. } 15 \\
\text { e. } 24 \\
\text { e. } 14 \\
\text { e. } 20 \\
\text { e. } 23\end{array}$ & $\begin{array}{l}\text { e. } 06 \\
\text { e. } 05 \\
\text { e. } 04 \\
\text { e. } 03 \\
\text { e.03 }\end{array}$ \\
\hline $\begin{array}{l}11 \\
12 \\
13 \\
14 \\
15\end{array}$ & $\begin{array}{r}8.1 \\
4.7 \\
3.4 \\
\mathrm{e} 2.8 \\
\mathrm{e} 2.0\end{array}$ & $\begin{array}{l}\text { e } 1.5 \\
\text { e } 1.3 \\
\text { e } 1.2 \\
\text { e } 1.0 \\
\text { e. } 90\end{array}$ & $\begin{array}{l}2.8 \\
2.6 \\
2.5 \\
2.3 \\
10\end{array}$ & $\begin{array}{l}35 \\
38 \\
24 \\
19 \\
16\end{array}$ & $\begin{array}{r}11 \\
9.1 \\
10 \\
37 \\
\text { e25 }\end{array}$ & $\begin{array}{l}4.4 \\
5.3 \\
39 \\
25 \\
17\end{array}$ & $\begin{array}{l}12 \\
10 \\
27 \\
31 \\
37\end{array}$ & $\begin{array}{l}2.7 \\
2.6 \\
2.5 \\
2.4 \\
2.3\end{array}$ & $\begin{array}{l}.90 \\
.83 \\
.47 \\
.40 \\
.36\end{array}$ & $\begin{array}{r}11^{.18} \\
.27 \\
\text { e. } 23 \\
\text { e. } 21\end{array}$ & $\begin{array}{l}\text { e. } 16 \\
\text { e.11 } \\
\text { e.10 } \\
\text { e.09 } \\
\text { e. } 08\end{array}$ & $\begin{array}{l}\text { e. } 02 \\
\text { e.02 } \\
\text { e. } 01 \\
\text { e. } 00 \\
\text { e. } 00\end{array}$ \\
\hline $\begin{array}{l}16 \\
17 \\
18 \\
19 \\
20\end{array}$ & $\begin{array}{l}\text { e } 1.5 \\
\text { e } 3.1 \\
\text { e } 7.0 \\
\text { e } 5.5 \\
\text { e } 3.0\end{array}$ & $\begin{array}{l}\text { e. } 80 \\
\text { e. } 90 \\
\text { e. } 78 \\
\text { e. } 73 \\
\text { e. } 72\end{array}$ & $\begin{array}{c}8.4 \\
58 \\
192 \\
56 \\
25\end{array}$ & $\begin{array}{l}22 \\
20 \\
17 \\
15 \\
13\end{array}$ & $\begin{array}{r}\text { e } 15 \\
\text { e14 } \\
46 \\
45 \\
31\end{array}$ & $\begin{array}{l}13 \\
50 \\
64 \\
28 \\
19\end{array}$ & $\begin{array}{r}30 \\
23 \\
18 \\
115 \\
45\end{array}$ & $\begin{array}{l}2.1 \\
2.1 \\
6.2 \\
3.2 \\
2.7\end{array}$ & $\begin{array}{l}.41 \\
.37 \\
.32 \\
.27 \\
.26\end{array}$ & $\begin{array}{r}.19 \\
.29 \\
.36 \\
\text { e. } 32 \\
\text { e. } 25\end{array}$ & $\begin{array}{l}\text { e. } 07 \\
\text { e. } 10 \\
\text { e. } 16 \\
\text { e. } 10 \\
\text { e. } 13\end{array}$ & $\begin{array}{l}.00 \\
.00 \\
.00 \\
.00 \\
.00\end{array}$ \\
\hline $\begin{array}{l}21 \\
22 \\
23 \\
24 \\
25\end{array}$ & $\begin{array}{l}\text { e } 1.5 \\
\text { e } 1.7 \\
\text { e } 1.8 \\
\text { e } 1.4 \\
\text { e } 1.7\end{array}$ & $\begin{array}{l}\text { e } 1.2 \\
\text { e } 3.6 \\
\text { e } 3.3 \\
\text { e } 2.6 \\
\text { e2.2 }\end{array}$ & $\begin{array}{r}40 \\
47 \\
27 \\
\text { e } 21 \\
\text { e16 }\end{array}$ & $\begin{array}{l}\text { el1 } \\
\text { e } 9.5 \\
\text { e } 8.2 \\
\text { e7.0 } \\
\text { e6. } 4\end{array}$ & $\begin{array}{c}22 \\
16 \\
13 \\
10 \\
8.6\end{array}$ & $\begin{array}{r}15 \\
127 \\
114 \\
36 \\
22\end{array}$ & $\begin{array}{l}27 \\
20 \\
17 \\
14 \\
12\end{array}$ & $\begin{array}{l}2.4 \\
2.2 \\
2.1 \\
2.1 \\
2.5\end{array}$ & $\begin{array}{l}.25 \\
.23 \\
.24 \\
.22 \\
.21\end{array}$ & $\begin{array}{l}\text { e. } 19 \\
\text { e. } 16 \\
\text { e. } 14 \\
\text { e. } 15 \\
\text { e. } 15\end{array}$ & $\begin{array}{l}\text { e. } 10 \\
\text { e. } 09 \\
\text { e. } 08 \\
\text { e.07 } \\
\text { e.06 }\end{array}$ & $\begin{array}{l}.00 \\
.00 \\
.00 \\
.00 \\
.00\end{array}$ \\
\hline $\begin{array}{l}26 \\
27 \\
28 \\
29 \\
30 \\
31\end{array}$ & $\begin{array}{l}\text { e2.0 } \\
\text { e2 } 2.1 \\
\text { e1 } 1.3 \\
\text { e1.0 } \\
\text { e. } 74 \\
\text { e. } 62\end{array}$ & $\begin{array}{c}e 4.5 \\
18 \\
59 \\
17 \\
9.7 \\
\ldots\end{array}$ & $\begin{array}{l}\text { elo } \\
\text { e } 8.2 \\
\text { e18 } \\
180 \\
691 \\
\text { e } 81\end{array}$ & $\begin{array}{l}\text { e5. } 6 \\
\text { e5.2 } \\
\text { e5.2 } \\
\text { e } 5.7 \\
\text { e } 10 \\
\text { e } 9.0\end{array}$ & $\begin{array}{l}7.3 \\
6.4 \\
5.8 \\
\ldots . \\
\ldots . \\
\ldots .\end{array}$ & $\begin{array}{r}239 \\
79 \\
37 \\
25 \\
19 \\
15\end{array}$ & $\begin{array}{r}10 \\
8.8 \\
7.5 \\
6.7 \\
5.8 \\
\ldots .-\end{array}$ & $\begin{array}{r}3.6 \\
\mathrm{e} 3.0 \\
\mathrm{e} 2.0 \\
\mathrm{e} 1.4 \\
\mathrm{e} 1.0 \\
.69\end{array}$ & $\begin{array}{l}.21 \\
.20 \\
.18 \\
.18 \\
.17 \\
\cdots\end{array}$ & $\begin{array}{l}\text { e. } 12 \\
\text { e. } 10 \\
\text { e. } 09 \\
\text { e. } 08 \\
\text { e. } 09 \\
\text { e. } 10\end{array}$ & $\begin{array}{l}\text { e. } 06 \\
\text { e. } 05 \\
\text { e.05 } \\
\text { e.07 } \\
\text { e.06 } \\
\text { e.05 }\end{array}$ & $\begin{array}{l}.00 \\
.00 \\
.00 \\
.00 \\
.00 \\
\cdots .\end{array}$ \\
\hline $\begin{array}{l}\text { IOTAL } \\
\text { MEAM } \\
\text { MAX } \\
\text { MIN } \\
\text { CF SM } \\
\text { IN. }\end{array}$ & $\begin{array}{r}103.32 \\
3.33 \\
19 \\
.60 \\
.31 \\
.35\end{array}$ & $\begin{array}{r}143.37 \\
4.78 \\
59 \\
.48 \\
.44 \\
.49\end{array}$ & $\begin{array}{r}1586.1 \\
51.2 \\
691 \\
2.3 \\
4.69 \\
5.41\end{array}$ & $\begin{array}{r}471.8 \\
15.2 \\
45 \\
5.2 \\
1.40 \\
1.61\end{array}$ & $\begin{array}{r}685.0 \\
24.5 \\
174 \\
5.8 \\
2.24 \\
2.34\end{array}$ & $\begin{array}{r}1056.7 \\
34.1 \\
239 \\
4.4 \\
3.13 \\
3.61\end{array}$ & $\begin{array}{c}610.3 \\
20.3 \\
115 \\
5.8 \\
1.87 \\
2.08\end{array}$ & $\begin{array}{c}86.89 \\
2.80 \\
6.2 \\
.69 \\
.26 \\
.30\end{array}$ & $\begin{array}{c}11.72 \\
.39 \\
.91 \\
.17 \\
.04 \\
.04\end{array}$ & $\begin{array}{c}16.56 \\
.53 \\
11 \\
.08 \\
.05 \\
.06\end{array}$ & $\begin{array}{l}3.22 \\
.10 \\
.24 \\
.05 \\
.01 \\
.01\end{array}$ & $\begin{array}{l}0.56 \\
.019 \\
.10 \\
.00 \\
.00 \\
.00\end{array}$ \\
\hline
\end{tabular}

e Est imated

SIAIISIICS OF MONIHLY MEAN DAIA FOR WAIER YEARS 1971 - 1991, BY WAIER YEAR (WY)

\begin{tabular}{|c|c|c|c|c|c|c|c|c|c|c|c|}
\hline $\begin{array}{l}\text { MEAN } \\
\text { MAX } \\
\text { (WY) } \\
\text { MI N } \\
\text { (WY) }\end{array}$ & $\begin{array}{l}2.10 \\
8.19 \\
1986 \\
.000 \\
1988\end{array}$ & $\begin{array}{r}13.6 \\
55.4 \\
1986 \\
.47 \\
1988\end{array}$ & $\begin{array}{r}20.1 \\
59.1 \\
1983 \\
.24 \\
1977\end{array}$ & $\begin{array}{r}14.4 \\
39.9 \\
1982 \\
.078 \\
1977\end{array}$ & $\begin{array}{l}24.2 \\
50.2 \\
1990 \\
3.68 \\
1978\end{array}$ & $\begin{array}{l}31.4 \\
52.3 \\
1973 \\
11.9 \\
1987\end{array}$ & $\begin{array}{l}27.9 \\
56.0 \\
1984 \\
5.01 \\
1976\end{array}$ & $\begin{array}{r}19.1 \\
62.3 \\
1981 \\
.91 \\
1988\end{array}$ & $\begin{array}{l}4.47 \\
13.4 \\
1975 \\
.073 \\
1988\end{array}$ & $\begin{array}{r}4.95 \\
48.6 \\
1979 \\
.10 \\
1988\end{array}$ & $\begin{array}{l}2.46 \\
13.3 \\
1979 \\
.005 \\
1988\end{array}$ \\
\hline
\end{tabular}

SUMMARY SIAIISIICS

AMMUAL TOTAL

ANWUAL MEAN

HIGHEST ANMUAL MEAN

LOWEST ANNUAL MEAN

HIGHEST DAILY MEAN

LOWEST DAILY MEAN

ANNUAL SEVEN-DAY MINIMUM

INSIANIANEOUS PEAK FLLW

INSTANIANEOUS PEAK STAGE

ANMUAL RUNOFF (CFSH)

ANMUAL RUNOF F (INCHES)

10 PERCENT EXCELDS

50 PERCENT EXCEEDS

90 PERCENT EXCEEDS
FOR I9Y0 CALENDAR YEAR

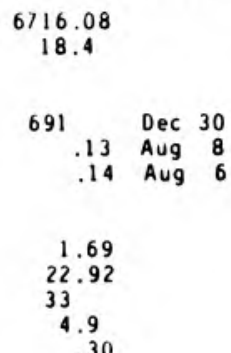

FOR 1991 WATER YEAR

4775.54
13.1

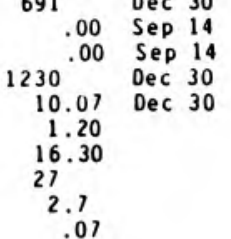

WAIER YEARS $1971-1991$

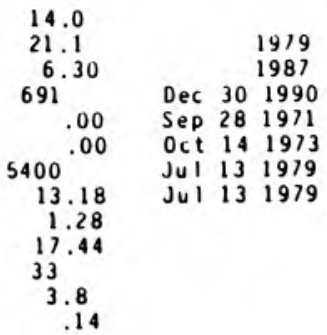




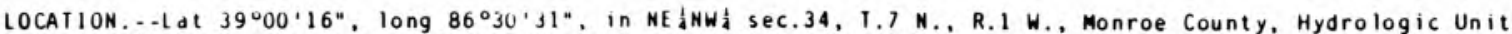
05120208 , on right bank 0.35 i downstream from Monroe Lake, 0.9 i upstrean from Clear Creek, 2.2 ni southeast of Harrodsburg, and 25.7 i upstredm from mouth.

DRAINAGE AREA. $-432 \mathrm{i}^{2}$

PERIOD OF RECORD.--May 1955 to current year.

REVISED RECORDS.-.WSP 1705: 1959. WSP 1725: 1956(M). WSP 2109: Drainage area.

GAGE.--Data-Collection Platform installed on May 13, 1988. Datum of gage was $480.00 \mathrm{ft}$ above National Geodetic Vertical Datua of 1929 (levels by U.S. Army Corps of Engineers). Oct. 1, 1960, to Sept. 30, 1974, water-stage recorder at site described in "LOCAIION" paragraph. Prior to Oct. 1, 1960, nonrecording gage at site 0.7 . upstrean at datum $2.41 \mathrm{ft}$ higher.

REMARKS. - Flow regulated by Monroe lake since April 1966. Daily discharge computed fron relation between discharge, head, and gate openings for Monroe Lake beginning 0ct. 1, 1974.

COOPERATION. - Records of daily discharge provided by U.S. Aray Corps of Engineers beginning 0ct. 1 , 1976 .

AVERAGE DISCHARGE. -36 years, $493 \mathrm{ft} 3 / \mathrm{s}$.

EXIREMES FOR PERIOD OF RECORD. - Maximum discharge, $22,000 \mathrm{ft} / \mathrm{s}$ June 25,1960 , gage height, $32.76 \mathrm{ft}$ site and datum then in use: aximum gage height at present site and datum, 35.35 ft May 9, 1961 ; no flow Sept. 29 to Dec. 2, 1964 .

EXIREMES FOR CURRENT YEAR, -.Maximum daily discharge, $2,160 \mathrm{ft} / \mathrm{s} \mathrm{Jan}$. 24 ; inimum daily, $50 \mathrm{ft} / \mathrm{s}$ Aug. $21 \mathrm{to}$ Sept. 30 .

DISCHARGE, CUBIL FEET PER SECONO, WATER YEAR OCIOBER 1990 TO SEPIEMBER 1991 DAILY MEAN VALUES

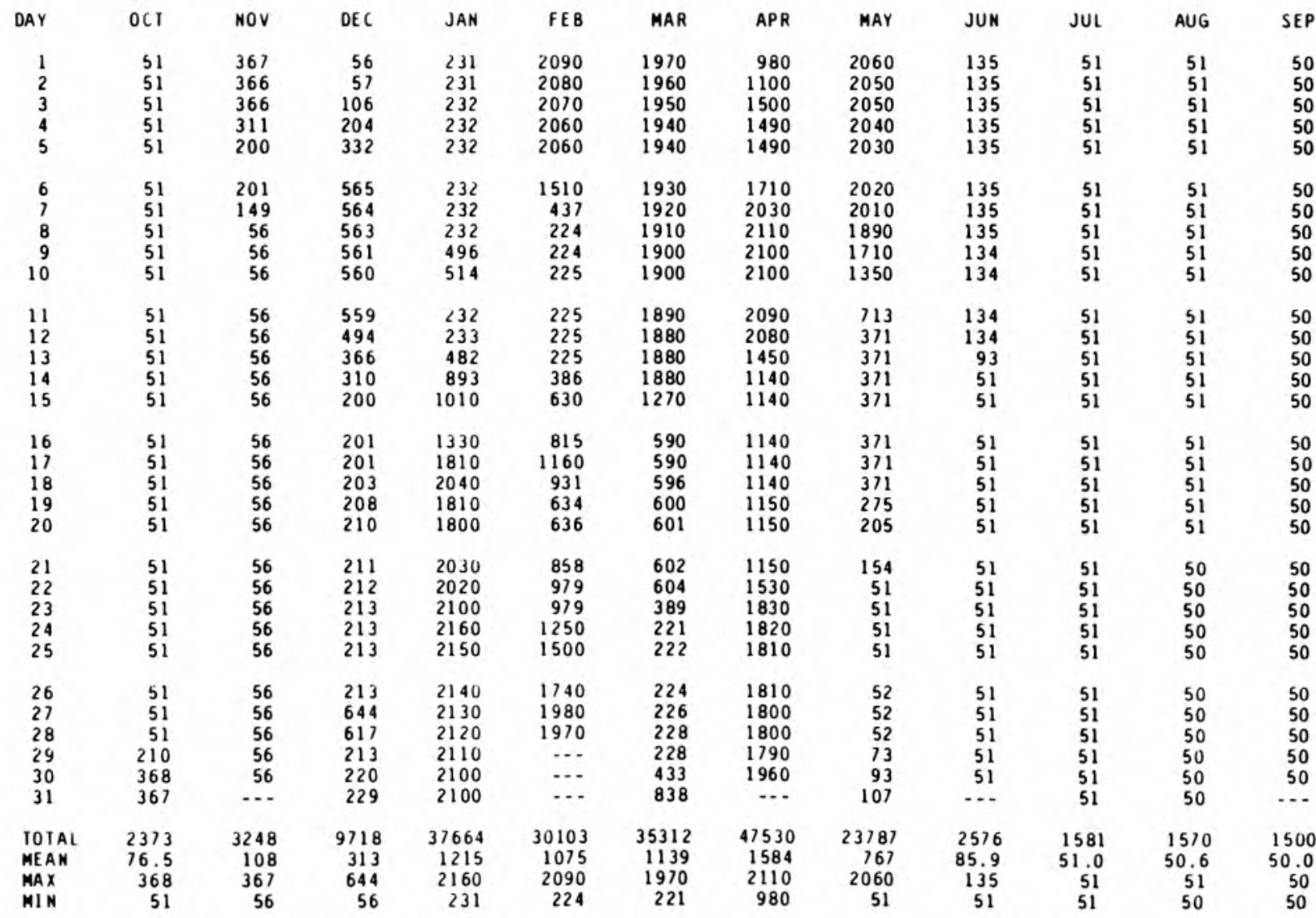

CAL YR 1990 TOTAL 206128 MEAN 565 MAX 2060 MIN 51

WTR YR 1991 IOIAL 196962 MEAN 540 MAX 2160 MIN 50 


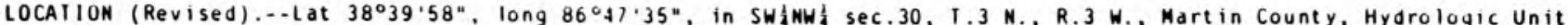
05120208 , on left bank 100 feet downstream of Baltimore and Ohio Railroad bridge, 440 feet downstrea from U.S. Highway 50 bridge at Shoals, 0.9 mi upstrean from Beaver Creek, 6.6 a downstrea from Indian Creek, and at aile 105.2 .

DRAI NAGE AREA. $,-4,927 \cdot i^{2}$.

PERIOD OF RECORD.--June 1903 to July 1906, October 1908 to Septeaber 1916, June 1923 to current year. Monthly discharge only for sone periods. published in WSP 1305 . Published as East Branch White River at Shoals, 1903-06, 1908-16. Gage-height records collected at sace site since May 1908 are contained in reports of the National Weather Service.

REVISED RECORDS, --WSP 353: 1912. WSP 1335: 1903-6. WSP 2109: Drainage area.

GAGE. - Water-stage recorder. Datu of gage is $442.25 \mathrm{ft}$ above National Geodetic Vertical Datum of 1929 . 0ct. 26 , 1932 to Dec. 13, 1989, water-stage recorder located at U.S. Highway 50 bridge 440 ft upstrean. See wSP 1725 for history of changes prior to $0 \mathrm{ct} .26,1932$.

REMARKS. - Records good except for estindted daily discharges, which are poor. Flow partially regulated by upstrean reservoirs.

DISCHARGE, CUBIC FEET PER SECOND. WATER YEAR OCTOBER 1990 TO SEPTEMBER 1991

DAILY MEAN VALUES

\begin{tabular}{|c|c|c|c|c|c|c|c|c|c|c|c|c|}
\hline DAY & $\mathrm{OCT}$ & NOV & DEC & JAN & FEB & MAR & APR & MAY & JUN & JUL & $A \cup G$ & SEP \\
\hline $\begin{array}{l}1 \\
2 \\
3 \\
4 \\
5\end{array}$ & $\begin{array}{l}1190 \\
1200 \\
1150 \\
1580 \\
2160\end{array}$ & $\begin{array}{l}2750 \\
2620 \\
2520 \\
2440 \\
2360\end{array}$ & $\begin{array}{l}5470 \\
6180 \\
6370 \\
7790 \\
8050\end{array}$ & $\begin{array}{l}29500 \\
31200 \\
38800 \\
47200 \\
50100\end{array}$ & $\begin{array}{l}1940 \\
8590 \\
8040 \\
7260 \\
1000\end{array}$ & $\begin{array}{l}7420 \\
7170 \\
7050 \\
6900 \\
6770\end{array}$ & $\begin{array}{r}20300 \\
16300 \\
12600 \\
9790 \\
8330\end{array}$ & $\begin{array}{l}5980 \\
5940 \\
5800 \\
5600 \\
5580\end{array}$ & $\begin{array}{l}3360 \\
3280 \\
4120 \\
4690 \\
5060\end{array}$ & $\begin{array}{l}1230 \\
1180 \\
1140 \\
1110 \\
1130\end{array}$ & $\begin{array}{r}e 610 \\
564 \\
548 \\
532 \\
531\end{array}$ & $\begin{array}{l}459 \\
430 \\
410 \\
480 \\
645\end{array}$ \\
\hline $\begin{array}{r}6 \\
7 \\
8 \\
9 \\
10\end{array}$ & $\begin{array}{l}2080 \\
2960 \\
3260 \\
3040 \\
3900\end{array}$ & $\begin{array}{l}2160 \\
2060 \\
2000 \\
1880 \\
1900\end{array}$ & $\begin{array}{r}9280 \\
10300 \\
9800 \\
7650 \\
6180\end{array}$ & $\begin{array}{l}47300 \\
41000 \\
31500 \\
21500 \\
16000\end{array}$ & $\begin{array}{l}11900 \\
19200 \\
18800 \\
18500 \\
20900\end{array}$ & $\begin{array}{l}6510 \\
6340 \\
6180 \\
6060 \\
5970\end{array}$ & $\begin{array}{l}7750 \\
7530 \\
7590 \\
7450 \\
7120\end{array}$ & $\begin{array}{l}5490 \\
5420 \\
5370 \\
5310 \\
5120\end{array}$ & $\begin{array}{l}4320 \\
3520 \\
3010 \\
2670 \\
2360\end{array}$ & $\begin{array}{l}1250 \\
1250 \\
1240 \\
1200 \\
1090\end{array}$ & $\begin{array}{l}551 \\
602 \\
647 \\
699 \\
813\end{array}$ & $\begin{array}{l}1150 \\
2020 \\
2070 \\
1470 \\
1060\end{array}$ \\
\hline $\begin{array}{l}11 \\
12 \\
13 \\
14 \\
15\end{array}$ & $\begin{array}{l}4680 \\
5880 \\
6510 \\
6230 \\
5420\end{array}$ & $\begin{array}{l}1950 \\
1940 \\
2070 \\
2080 \\
1930\end{array}$ & $\begin{array}{l}5540 \\
5150 \\
4670 \\
4190 \\
4040\end{array}$ & $\begin{array}{r}14400 \\
14900 \\
14400 \\
14300 \\
+15100\end{array}$ & $\begin{array}{l}23100 \\
23100 \\
20600 \\
17800 \\
15700\end{array}$ & $\begin{array}{r}5800 \\
5660 \\
6640 \\
9760 \\
11300\end{array}$ & $\begin{array}{r}7130 \\
9510 \\
11600 \\
16300 \\
16300\end{array}$ & $\begin{array}{l}4600 \\
4030 \\
3420 \\
3300 \\
3300\end{array}$ & $\begin{array}{l}2190 \\
2240 \\
2220 \\
2060 \\
2130\end{array}$ & $\begin{array}{l}1020 \\
1150 \\
1360 \\
1420 \\
1540\end{array}$ & $\begin{array}{l}806 \\
868 \\
823 \\
729 \\
651\end{array}$ & $\begin{array}{l}821 \\
672 \\
588 \\
523 \\
481\end{array}$ \\
\hline $\begin{array}{l}16 \\
17 \\
18 \\
19 \\
20\end{array}$ & $\begin{array}{l}4470 \\
3710 \\
3350 \\
3260 \\
3790\end{array}$ & $\begin{array}{l}1820 \\
1750 \\
1780 \\
1720 \\
1660\end{array}$ & $\begin{array}{r}4190 \\
4700 \\
9690 \\
19000 \\
17800\end{array}$ & $\begin{array}{l}\text { e } 15900 \\
\text { e1 } 15000 \\
\text { e1 } 1400 \\
\text { e1 } 1600 \\
\text { el } 12800\end{array}$ & $\begin{array}{l}13500 \\
12600 \\
13100 \\
15400 \\
14200\end{array}$ & $\begin{array}{l}12700 \\
15000 \\
19900 \\
21000 \\
18900\end{array}$ & $\begin{array}{l}17500 \\
19000 \\
19400 \\
19200 \\
18400\end{array}$ & $\begin{array}{l}3270 \\
3680 \\
3970 \\
3740 \\
3510\end{array}$ & $\begin{array}{l}2090 \\
2010 \\
2060 \\
1880 \\
1890\end{array}$ & $\begin{array}{l}1670 \\
1500 \\
1320 \\
1160 \\
1040\end{array}$ & $\begin{array}{l}608 \\
572 \\
535 \\
503 \\
888\end{array}$ & $\begin{array}{l}456 \\
443 \\
506 \\
563 \\
517\end{array}$ \\
\hline $\begin{array}{l}21 \\
22 \\
23 \\
24 \\
25\end{array}$ & $\begin{array}{l}5000 \\
5170 \\
4550 \\
4000 \\
3750\end{array}$ & $\begin{array}{l}1650 \\
1790 \\
2000 \\
2210 \\
2710\end{array}$ & $\begin{array}{l}16500 \\
20900 \\
24900 \\
26600 \\
26600\end{array}$ & $\begin{array}{r}\text { e11700 } \\
\text { e } 9300 \\
\text { e } 8500 \\
\text { e } 7800 \\
\text { e } 7250\end{array}$ & $\begin{array}{l}14100 \\
15100 \\
15700 \\
15200 \\
13400\end{array}$ & $\begin{array}{l}17300 \\
17700 \\
20500 \\
20100 \\
19000\end{array}$ & $\begin{array}{r}15100 \\
13200 \\
12300 \\
10800 \\
9140\end{array}$ & $\begin{array}{l}3650 \\
4400 \\
4240 \\
3870 \\
4420\end{array}$ & $\begin{array}{l}1880 \\
1780 \\
1650 \\
1510 \\
1410\end{array}$ & $\begin{array}{l}972 \\
912 \\
869 \\
855 \\
820\end{array}$ & $\begin{array}{r}1830 \\
1590 \\
1290 \\
1070 \\
881\end{array}$ & $\begin{array}{l}460 \\
432 \\
434 \\
409 \\
395\end{array}$ \\
\hline $\begin{array}{l}26 \\
27 \\
28 \\
29 \\
30 \\
31\end{array}$ & $\begin{array}{l}3650 \\
3410 \\
2990 \\
2700 \\
2540 \\
2730\end{array}$ & $\begin{array}{c}3370 \\
3430 \\
3850 \\
5210 \\
4530 \\
\ldots\end{array}$ & $\begin{array}{l}25100 \\
24100 \\
21400 \\
19200 \\
23500 \\
29100\end{array}$ & $\begin{array}{r}e 7000 \\
\text { e } 6800 \\
\text { e } 6750 \\
6790 \\
6980 \\
7420\end{array}$ & $\begin{array}{r}10800 \\
8850 \\
7990 \\
\ldots . \\
\ldots \\
\ldots\end{array}$ & $\begin{array}{l}21100 \\
24300 \\
26000 \\
25400 \\
24300 \\
23000\end{array}$ & $\begin{array}{l}8030 \\
7380 \\
6890 \\
6500 \\
6170 \\
\ldots\end{array}$ & $\begin{array}{l}4730 \\
4420 \\
4070 \\
3860 \\
3910 \\
3750\end{array}$ & $\begin{array}{c}1340 \\
1300 \\
1350 \\
1360 \\
1290 \\
\cdots\end{array}$ & $\begin{array}{r}766 \\
\text { e } 720 \\
\text { e } 700 \\
\text { e } 670 \\
\text { e650 } \\
\text { e630 }\end{array}$ & $\begin{array}{l}748 \\
662 \\
597 \\
545 \\
500 \\
483\end{array}$ & $\begin{array}{l}379 \\
357 \\
344 \\
337 \\
336 \\
\cdots\end{array}$ \\
\hline $\begin{array}{l}\text { TOTAL } \\
\text { MEAN } \\
\text { MAX } \\
\text { MIN } \\
\text { CF SM } \\
\text { IN. }\end{array}$ & $\begin{array}{r}110310 \\
3558 \\
6510 \\
1150 \\
.72 \\
.83\end{array}$ & $\begin{array}{r}72140 \\
2405 \\
5210 \\
1650 \\
.49 \\
.54\end{array}$ & $\begin{array}{r}414540 \\
13370 \\
29100 \\
4040 \\
2.71 \\
3.13\end{array}$ & $\begin{array}{r}585790 \\
18900 \\
50100 \\
6750 \\
3.84 \\
4.42\end{array}$ & $\begin{array}{r}398370 \\
14230 \\
23100 \\
7000 \\
2.89 \\
3.01\end{array}$ & $\begin{array}{r}431790 \\
13930 \\
26000 \\
5660 \\
2.83 \\
3.26\end{array}$ & $\begin{array}{r}355210 \\
11840 \\
20300 \\
6170 \\
2.40 \\
2.68\end{array}$ & $\begin{array}{r}137750 \\
4444 \\
5980 \\
3270 \\
.90 \\
1.04\end{array}$ & $\begin{array}{r}72030 \\
2401 \\
5060 \\
1290 \\
.49 \\
.54\end{array}$ & $\begin{array}{c}33564 \\
1083 \\
1670 \\
630 \\
.22 \\
.25\end{array}$ & $\begin{array}{r}23216 \\
751 \\
1830 \\
483 \\
.15 \\
.18\end{array}$ & $\begin{array}{r}19647 \\
655 \\
2070 \\
336 \\
.13 \\
.15\end{array}$ \\
\hline
\end{tabular}

e Estimated

SIAIISTICS OF MONIHIY MEAN DAIA FUR WAIER YEARS 1904 - 1991, BY WATER YEAR (WY)

$\begin{array}{lrrrrrrrrrrrr}\text { MEAN } & 1591 & 2798 & 5341 & 8835 & 8802 & 11310 & 10070 & 7165 & 4146 & 2841 & 1837 & 1355 \\ \text { MAX } & 12520 & 13390 & 17890 & 47640 & 30870 & 34300 & 24000 & 24990 & 14840 & 13520 & 15220 & 9154 \\ \text { (WY) } & 1911 & 1986 & 1928 & 1937 & 1950 & 1945 & 1913 & 1961 & 1947 & 1958 & 1919 & 1926 \\ \text { MIN } & 262 & 293 & 305 & 432 & 589 & 562 & 1029 & 529 & 696 & 365 & 265 & 233 \\ \text { (WY } & 1941 & 1955 & 1964 & 1931 & 1931 & 1941 & 1915 & 1941 & 1936 & 1954 & 1936 & 1954\end{array}$

SUMMARY SIAIISIICS

ANNUAL TOIAL

ANNUAL MEAN

HIGHESI ANNUAI MEAN

LOWEST AMNUAL MEAN

HIGHEST DAILY MEAM

LOWEST DAILY MEAN

ANNUAL SEVEN-OAY MINIMUM

INSTANTANEOUS PEAK STAGE

ANMUAL RUNOFF (CFSM)

ANMUAL RUNOFF (I NCHES)

10 PERCENT EXCEEDS

50 PERCENT EXCEEDS

90 PERCENT EXCEEDS

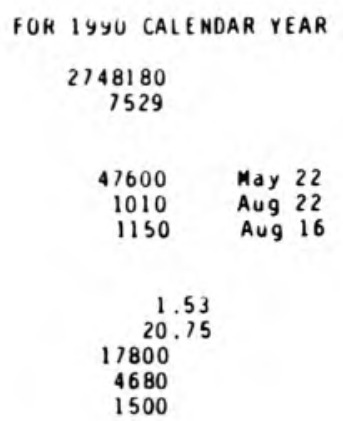

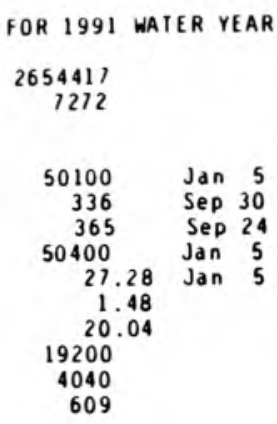

WAIER YEARS $1904-1991$

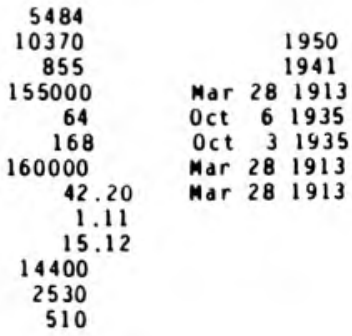




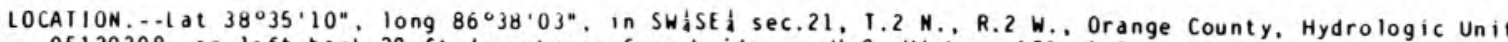
05120208 , on left bank $20 \mathrm{ft}$ downstredn from bridge on U.S. Highway $150 ; 1.7$ a northwest of West Baden Springs, 3.8 a i downstrean from 1 ick Creek, and at ile 34.8 .

DRAI NAGE AREA. . 287 i $i^{2}$.

PERIOD OF RECORO,.-December 1964 to current year. Prior to October 1965, published as Lost River near West Badtn. GAGE. - Water-stage recorder. Datum of gage is $457.92 \mathrm{ft}$ above National Geodetic Vertical Datue of 1929 (levels by State of Indiand. Departiment of Maturai Resources).

REMARKS. - - Records poor. EXIREMES OUT $\$$ IDE PERIOD OF RECORDS. - Flood in March 1964 reached a stage of $28.1 \mathrm{ft}$, from floodaarks, discharge,
$14,500 \mathrm{ft} / \mathrm{s}$.

DISCHARGE, CUBIC FEET PER SECOND, WAIER YEAR OCTOBER 1990 TO SEPIEMBER 1991

\begin{tabular}{|c|c|c|c|c|c|c|c|c|c|c|c|c|}
\hline DAY & $O C T$ & NOV & DEC & JAN & FEB & MAR & APR & MAY & JUN & JUL & AUG & SEP \\
\hline $\begin{array}{l}1 \\
2 \\
3 \\
4 \\
5\end{array}$ & $\begin{array}{r}21 \\
31 \\
33 \\
93 \\
201\end{array}$ & $\begin{array}{l}60 \\
60 \\
59 \\
58 \\
64\end{array}$ & $\begin{array}{r}219 \\
171 \\
747 \\
1100 \\
682\end{array}$ & $\begin{array}{r}2870 \\
2080 \\
1490 \\
\mathrm{e} 1100 \\
\mathrm{e} 740\end{array}$ & $\begin{array}{l}392 \\
322 \\
295 \\
281 \\
280\end{array}$ & $\begin{array}{l}\text { e } 270 \\
e 255 \\
\text { e } 280 \\
\text { e } 260 \\
\text { e240 }\end{array}$ & $\begin{array}{l}\text { e } 500 \\
\text { e } 440 \\
\text { e } 380 \\
\text { e } 340 \\
\text { e } 320\end{array}$ & $\begin{array}{l}178 \\
158 \\
142 \\
135 \\
132\end{array}$ & $\begin{array}{r}136 \\
114 \\
137 \\
108 \\
89\end{array}$ & $\begin{array}{l}26 \\
25 \\
25 \\
26 \\
26\end{array}$ & $\begin{array}{l}15 \\
15 \\
15 \\
14 \\
14\end{array}$ & $\begin{array}{l}12 \\
11 \\
11 \\
13 \\
24\end{array}$ \\
\hline $\begin{array}{r}6 \\
7 \\
8 \\
9 \\
10\end{array}$ & $\begin{array}{r}79 \\
42 \\
31 \\
283 \\
718\end{array}$ & $\begin{array}{l}69 \\
70 \\
65 \\
62 \\
73\end{array}$ & $\begin{array}{l}499 \\
384 \\
306 \\
253 \\
218\end{array}$ & $\begin{array}{l}e 480 \\
1780 \\
1780 \\
1450 \\
1040\end{array}$ & $\begin{array}{r}1240 \\
2210 \\
\mathrm{e} 1700 \\
\mathrm{e} 1300 \\
\mathrm{e} 970\end{array}$ & $\begin{array}{l}\text { e220 } \\
\text { e200 } \\
\text { e220 } \\
\text { e200 } \\
\text { e1 } 80\end{array}$ & $\begin{array}{l}e 310 \\
e 275 \\
e 240 \\
e 270 \\
e 300\end{array}$ & $\begin{array}{l}134 \\
117 \\
105 \\
102 \\
100\end{array}$ & $\begin{array}{l}79 \\
71 \\
67 \\
63 \\
59\end{array}$ & $\begin{array}{l}24 \\
23 \\
22 \\
21 \\
25\end{array}$ & $\begin{array}{l}14 \\
15 \\
14 \\
16 \\
22\end{array}$ & $\begin{array}{l}35 \\
23 \\
17 \\
14 \\
15\end{array}$ \\
\hline $\begin{array}{l}11 \\
12 \\
13 \\
14 \\
15\end{array}$ & $\begin{array}{r}515 \\
255 \\
148 \\
104 \\
78\end{array}$ & $\begin{array}{l}80 \\
18 \\
71 \\
64 \\
59\end{array}$ & $\begin{array}{l}190 \\
170 \\
153 \\
135 \\
221\end{array}$ & $\begin{array}{r}1030 \\
1450 \\
1290 \\
938 \\
714\end{array}$ & $\begin{array}{r}\text { e } 720 \\
\text { e } 630 \\
\text { e } 580 \\
\text { e } 900 \\
\text { el } 600\end{array}$ & $\begin{array}{l}\text { el } 60 \\
\text { e150 } \\
\text { e360 } \\
\text { e7 } 40 \\
\text { e680 }\end{array}$ & $\begin{array}{r}\text { e250 } \\
\text { e210 } \\
\text { e } 415 \\
\text { e1070 } \\
\text { e } 910\end{array}$ & $\begin{array}{l}93 \\
90 \\
87 \\
88 \\
81\end{array}$ & $\begin{array}{l}56 \\
54 \\
51 \\
49 \\
46\end{array}$ & $\begin{array}{l}25 \\
23 \\
22 \\
22 \\
20\end{array}$ & $\begin{array}{l}22 \\
21 \\
16 \\
15 \\
15\end{array}$ & $\begin{array}{l}13 \\
12 \\
11 \\
10 \\
10\end{array}$ \\
\hline $\begin{array}{l}16 \\
17 \\
18 \\
19 \\
20\end{array}$ & $\begin{array}{r}65 \\
54 \\
117 \\
227 \\
165\end{array}$ & $\begin{array}{l}57 \\
56 \\
53 \\
51 \\
49\end{array}$ & $\begin{array}{r}443 \\
399 \\
1890 \\
3470 \\
e 2900\end{array}$ & $\begin{array}{l}650 \\
628 \\
560 \\
506 \\
479\end{array}$ & $\begin{array}{r}\text { el100 } \\
\text { e } 800 \\
\text { e } 900 \\
\text { e } 1150 \\
\text { e } 975\end{array}$ & $\begin{array}{r}\text { e600 } \\
\text { e560 } \\
\text { e } 780 \\
\text { e } 1000 \\
\text { e910 }\end{array}$ & $\begin{array}{l}\text { e } 760 \\
\text { e } 620 \\
\text { e540 } \\
\text { e465 } \\
\text { e420 }\end{array}$ & $\begin{array}{l}78 \\
91 \\
87 \\
73 \\
68\end{array}$ & $\begin{array}{l}46 \\
49 \\
55 \\
51 \\
48\end{array}$ & $\begin{array}{l}19 \\
19 \\
19 \\
19 \\
18\end{array}$ & $\begin{array}{l}13 \\
14 \\
15 \\
14 \\
15\end{array}$ & $\begin{array}{l}9.8 \\
10 \\
10 \\
11 \\
9.8\end{array}$ \\
\hline $\begin{array}{l}21 \\
22 \\
23 \\
24 \\
25\end{array}$ & $\begin{array}{l}101 \\
101 \\
126 \\
128 \\
110\end{array}$ & $\begin{array}{r}47 \\
141 \\
353 \\
258 \\
166\end{array}$ & $\begin{array}{l}\text { e1 } 380 \\
\text { e1 } 800 \\
\text { e2210 } \\
\text { el } 810 \\
\text { el } 450\end{array}$ & $\begin{array}{l}443 \\
387 \\
346 \\
328 \\
297\end{array}$ & $\begin{array}{l}\text { e } 830 \\
\text { e } 640 \\
\text { e } 520 \\
\text { e } 430 \\
\text { e } 380\end{array}$ & $\begin{array}{l}e 700 \\
1480 \\
3080 \\
2760 \\
2100\end{array}$ & $\begin{array}{l}\text { e } 375 \\
\text { e } 335 \\
\text { e } 305 \\
\text { e265 } \\
\text { e250 }\end{array}$ & $\begin{array}{r}15 \\
72 \\
64 \\
249 \\
517\end{array}$ & $\begin{array}{l}43 \\
45 \\
43 \\
38 \\
34\end{array}$ & $\begin{array}{l}17 \\
17 \\
16 \\
16 \\
16\end{array}$ & $\begin{array}{l}15 \\
13 \\
13 \\
12 \\
12\end{array}$ & $\begin{array}{l}10 \\
9.8 \\
10 \\
10 \\
10\end{array}$ \\
\hline $\begin{array}{l}26 \\
27 \\
28 \\
29 \\
30 \\
31\end{array}$ & $\begin{array}{l}92 \\
81 \\
75 \\
71 \\
68 \\
64\end{array}$ & $\begin{array}{l}126 \\
107 \\
288 \\
459 \\
318 \\
\cdots\end{array}$ & $\begin{array}{l}\text { e } 940 \\
\text { e } 650 \\
\text { e } 530 \\
\text { e } 460 \\
2830 \\
3860\end{array}$ & $\begin{array}{l}282 \\
268 \\
307 \\
312 \\
388 \\
470\end{array}$ & $\begin{array}{r}\text { e340 } \\
\text { e315 } \\
\text { e290 } \\
\ldots- \\
\ldots \\
\ldots\end{array}$ & $\begin{array}{l}1480 \\
\text { e690 } \\
\text { e } 800 \\
\text { e } 710 \\
\text { e } 640 \\
\text { e } 560\end{array}$ & $\begin{array}{r}\text { e228 } \\
\text { e210 } \\
\text { e } 200 \\
\text { e185 } \\
\text { e170 } \\
\cdots\end{array}$ & $\begin{array}{l}360 \\
423 \\
320 \\
237 \\
207 \\
203\end{array}$ & $\begin{array}{r}32 \\
30 \\
29 \\
28 \\
27 \\
\cdots\end{array}$ & $\begin{array}{l}16 \\
15 \\
16 \\
15 \\
15 \\
15\end{array}$ & $\begin{array}{ll}11 \\
11 \\
11 \\
11 \\
13 \\
13\end{array}$ & $\begin{array}{l}10 \\
10 \\
9.8 \\
9.2 \\
9.0 \\
\cdots\end{array}$ \\
\hline $\begin{array}{l}\text { TOIAL } \\
\text { MEAN } \\
\text { MAX } \\
\text { MIN } \\
\text { CF SM } \\
\text { IN. }\end{array}$ & $\begin{array}{r}4283 \\
138 \\
718 \\
21 \\
.48 \\
.56\end{array}$ & $\begin{array}{r}3521 \\
117 \\
459 \\
47 \\
.41 \\
.46\end{array}$ & $\begin{array}{r}32470 \\
1047 \\
3860 \\
135 \\
3.65 \\
4.21\end{array}$ & $\begin{array}{r}26883 \\
867 \\
2870 \\
268 \\
3.02 \\
3.48\end{array}$ & $\begin{array}{r}22090 \\
789 \\
2210 \\
280 \\
2.75 \\
2.86\end{array}$ & $\begin{array}{r}23265 \\
750 \\
3080 \\
150 \\
2.61 \\
3.02\end{array}$ & $\begin{array}{r}11558 \\
385 \\
1070 \\
170 \\
1.34 \\
1.50\end{array}$ & $\begin{array}{c}4866 \\
157 \\
517 \\
64 \\
.55 \\
.63\end{array}$ & $\begin{array}{c}1777 \\
59.2 \\
137 \\
27 \\
.21 \\
.23\end{array}$ & $\begin{array}{c}623 \\
20.1 \\
26 \\
15 \\
.07 \\
.08\end{array}$ & $\begin{array}{r}44 y \\
14.5 \\
22 \\
11 \\
.05 \\
.06\end{array}$ & $\begin{array}{r}319.4 \\
12.6 \\
35 \\
9.0 \\
.04 \\
.05\end{array}$ \\
\hline
\end{tabular}

e Estimated

SIATISIICS OF MONTHLY MEAN DATA FUR WAIER YEARS 1966 - 1991, BY WAIER YEAR (WY)

\begin{tabular}{|c|c|c|c|c|c|c|c|c|c|c|c|}
\hline $\begin{array}{l}\text { MEAN } \\
\text { MAX } \\
(W Y) \\
\text { MIN } \\
(W Y)\end{array}$ & $\begin{array}{r}80.7 \\
203 \\
1984 \\
10.9 \\
1988\end{array}$ & $\begin{array}{r}304 \\
1463 \\
1986 \\
14.7 \\
1988\end{array}$ & $\begin{array}{r}468 \\
1069 \\
1978 \\
19.5 \\
1981\end{array}$ & $\begin{array}{r}463 \\
1123 \\
1982 \\
12.7 \\
1981\end{array}$ & $\begin{array}{r}583 \\
1166 \\
1982 \\
110 \\
1978\end{array}$ & $\begin{array}{r}692 \\
1306 \\
1978 \\
112 \\
1981\end{array}$ & $\begin{array}{r}690 \\
1402 \\
1972 \\
97.1 \\
1976\end{array}$ & $\begin{array}{r}498 \\
2326 \\
1983 \\
52.9 \\
1988\end{array}$ & $\begin{array}{r}259 \\
935 \\
1990 \\
18.6 \\
1988\end{array}$ & $\begin{array}{r}187 \\
969 \\
1973 \\
19.7 \\
1991\end{array}$ & $\begin{array}{r}135 \\
739 \\
1979 \\
14.2 \\
1991\end{array}$ \\
\hline
\end{tabular}

SUMMARY STATISTICS

ANNUAL TOTAL

ANNUAL MEAN

HIGHESI AMNUAL MEAN

LOWEST ANHUAL MEAN

HIGHEST DAILY MEAN

LOWEST DAILY MEAN

ANNUAL SEVEN-DAY MINIMUM

INSTANTANE OUS PEAK FLOW

INSTANTANEOUS PEAK SIAGE

ANNUAL RUNOFF (CFSM)

ANNUAL RUNOFF (INCHES)

10 PERCENT EXCEEDS

50 PERCENT EXCEEDS

90 PERCENT EXCEEDS
FOR 1990 CALENDAR YEAR

$\begin{array}{rr}200692 & \\ 550 & \\ 12800 & \text { May } 17 \\ 17 & \text { Sep } 30 \\ 19 & \text { Sep } 24 \\ & \\ 1.92 & \\ 26.01 & \\ 1440 & \\ 236 & \\ 29 & \end{array}$

FOR 1991 WATER YEAR

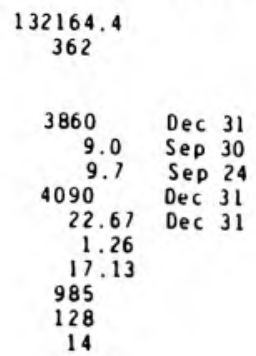

WAIER YEARS $1966-1991$

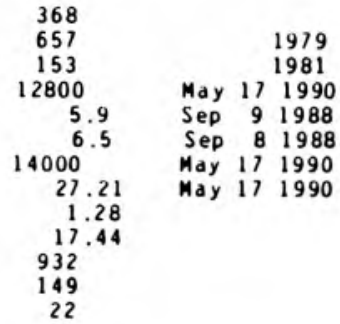


LOCATION.--Lat $38^{\circ} 31^{\prime} 42^{\prime \prime}$. long $87^{\circ} 15^{\prime} 12^{\prime \prime}$, in NE $\{$ SWt sec.12, T.1 N., R.8 W.. Pike County, Hydrologic Unit 05120202 , on left bank $300 \mathrm{ft}$ upstrean froe intake structure of Indianapolis Power and Light Coopany's generating plant, 1.5 a downstrean fron East Fork White River, 2.2 ai upstrean froe State Highway $61,2.9$ a northeast of Petersburg, and at ile 48.0 .

DRAINAGE AREA. $--11,123 \cdot i^{2}$.

PERIOD OF RECORD.--0ctober 1976 to current year.

GAGE.--Water-stage recorder. Datue of gage is $401.52 \mathrm{ft}$ above National Geodetic Vertical Datun of 1929.

REMARKS.-- Discharges below $1,500 \mathrm{ft}^{3} / \mathrm{s}$ only published. Records poor. For a conplete record of White River in this vicinity use records of White River at Petersburg. IN (sta. 03374000), 2.3 gi downstreas.

DISCHARGE, CUBIC FEET PER SECOND, WATER YEAR OCTOBER 1990 TO SEPTEMBER 1991 DAILY MEAN VALUES

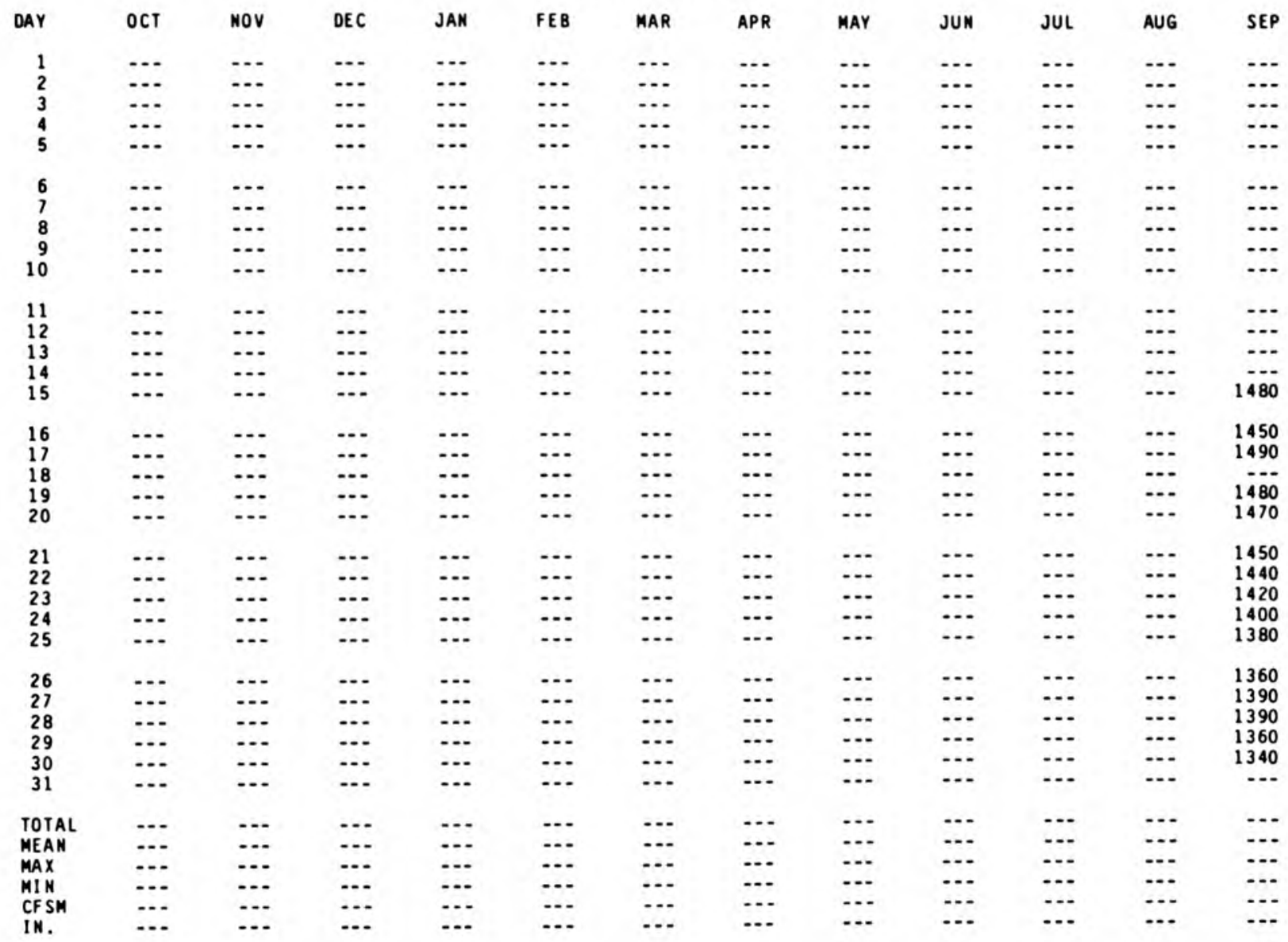

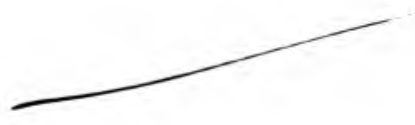




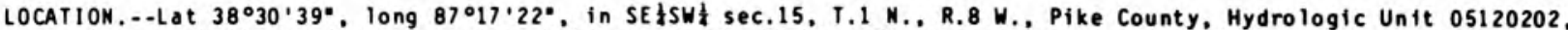
on left bank $300 \mathrm{ft}$ downstrea fros bridge on State Highway $61,0.4$ upstreas froe Prides Creek, 1.4 ei north of Petersburg. and at ile 45.7 .

DRAINAGE AREA ...11,125 i ${ }^{2}$

PERIOD OF RECORD -.-October 1927 to current year. Monthly discharge only for 0ctober 1927 , published in wSP 1305. Published as "at Hazleton" October 1927 to Septeaber 1938. Records published for both sites October 1937 to Septeaber 1938. Gage-height records collected at present site and datua since January 1935 are contained in reports of National Weather Service.

REVISED RECORDS...WSP 1305: 1930(M). WSP 2109: Drainage area.

GAGE,--Water-stage recorder. Datue of gage is $400.00 \mathrm{ft}$ above Wational Geodetic Vertical Datue of 1929. See WSP 1725 for history of changes prior to Apr. 1, 1941.

REMARKS.--Records good. Flow partially regulated by upstreae reservoirs.

EXTREMES OUTSIDE PERIOD OF RECORD.--Flood in March 1913, reached a stage of $29.5 \mathrm{ft}$, present site and datua, froe floodarks by U.S. Arny Corps of Engineers, discharge, $235,000 \mathrm{ft} / \mathrm{s}$.

DISCHARGE, CUBIC FEET PER SECOND, WATER YEAR OCTOBER 1990 TO SEPTEMBER 1991 DAILY MEAN VALUES

\begin{tabular}{|c|c|c|c|c|c|c|c|c|c|c|c|c|}
\hline DAY & $O C T$ & NOV & DEC & JAM & FEB & MAR & APR & MAY & JUN & JUL & AUG & SEP \\
\hline $\begin{array}{l}1 \\
2 \\
3 \\
4 \\
5\end{array}$ & $\begin{array}{l}2690 \\
2580 \\
2490 \\
4600 \\
5090\end{array}$ & $\begin{array}{l}5190 \\
5060 \\
4900 \\
4720 \\
4670\end{array}$ & $\begin{array}{l}18400 \\
19500 \\
19400 \\
18500 \\
19700\end{array}$ & $\begin{array}{r}61700 \\
73300 \\
88300 \\
104000 \\
109000\end{array}$ & $\begin{array}{l}15700 \\
15900 \\
15900 \\
15600 \\
15400\end{array}$ & $\begin{array}{l}16500 \\
15900 \\
15600 \\
15500 \\
15100\end{array}$ & $\begin{array}{l}48100 \\
41700 \\
32800 \\
24800 \\
20400\end{array}$ & $\begin{array}{l}14100 \\
13600 \\
13100 \\
12600 \\
12200\end{array}$ & $\begin{array}{r}8920 \\
8300 \\
7870 \\
9270 \\
11000\end{array}$ & $\begin{array}{l}3540 \\
3430 \\
3580 \\
3260 \\
3130\end{array}$ & $\begin{array}{l}1840 \\
1810 \\
1780 \\
1760 \\
1740\end{array}$ & $\begin{array}{l}1600 \\
1570 \\
1510 \\
1620 \\
1580\end{array}$ \\
\hline $\begin{array}{r}6 \\
7 \\
8 \\
9 \\
10\end{array}$ & $\begin{array}{r}5460 \\
6050 \\
6440 \\
8000 \\
10300\end{array}$ & $\begin{array}{l}4720 \\
4720 \\
4910 \\
5060 \\
5030\end{array}$ & $\begin{array}{l}21100 \\
22600 \\
23000 \\
20900 \\
17200\end{array}$ & $\begin{array}{r}106000 \\
98800 \\
87300 \\
73100 \\
57800\end{array}$ & $\begin{array}{l}21900 \\
30300 \\
34700 \\
37000 \\
38300\end{array}$ & $\begin{array}{l}14700 \\
14100 \\
13500 \\
13100 \\
12600\end{array}$ & $\begin{array}{l}18200 \\
17300 \\
16900 \\
16800 \\
17100\end{array}$ & $\begin{array}{l}11900 \\
11700 \\
11700 \\
11600 \\
11200\end{array}$ & $\begin{array}{r}11000 \\
9670 \\
8270 \\
7270 \\
6590\end{array}$ & $\begin{array}{l}3050 \\
3040 \\
3050 \\
3050 \\
3050\end{array}$ & $\begin{array}{l}1740 \\
1790 \\
1920 \\
2110 \\
2260\end{array}$ & $\begin{array}{l}1590 \\
1830 \\
2380 \\
2750 \\
2470\end{array}$ \\
\hline $\begin{array}{l}11 \\
12 \\
13 \\
14 \\
15\end{array}$ & $\begin{array}{l}11600 \\
13600 \\
15600 \\
16100 \\
15500\end{array}$ & $\begin{array}{l}4970 \\
4790 \\
4570 \\
4480 \\
4480\end{array}$ & $\begin{array}{l}14300 \\
12400 \\
11500 \\
10800 \\
10400\end{array}$ & $\begin{array}{l}44600 \\
37200 \\
32700 \\
30700 \\
29900\end{array}$ & $\begin{array}{l}40200 \\
41400 \\
40100 \\
38400 \\
35000\end{array}$ & $\begin{array}{l}12200 \\
11800 \\
13400 \\
17600 \\
22000\end{array}$ & $\begin{array}{l}17000 \\
16900 \\
17900 \\
21000 \\
26200\end{array}$ & $\begin{array}{r}10800 \\
10500 \\
9510 \\
8660 \\
8210\end{array}$ & $\begin{array}{l}6070 \\
5660 \\
5420 \\
5250 \\
5050\end{array}$ & $\begin{array}{l}2920 \\
2800 \\
4110 \\
6230 \\
5190\end{array}$ & $\begin{array}{l}2230 \\
2200 \\
2170 \\
2150 \\
2130\end{array}$ & $\begin{array}{l}2130 \\
1860 \\
1680 \\
1540 \\
1460\end{array}$ \\
\hline $\begin{array}{l}16 \\
17 \\
18 \\
19 \\
20\end{array}$ & $\begin{array}{r}13500 \\
10800 \\
9180 \\
8350 \\
7960\end{array}$ & $\begin{array}{l}4400 \\
4170 \\
3970 \\
3830 \\
3730\end{array}$ & $\begin{array}{l}10600 \\
11700 \\
18400 \\
29300 \\
34500\end{array}$ & $\begin{array}{l}29800 \\
29400 \\
28300 \\
27300 \\
26800\end{array}$ & $\begin{array}{l}30400 \\
26100 \\
24300 \\
26300 \\
28100\end{array}$ & $\begin{array}{l}24900 \\
28000 \\
36000 \\
40700 \\
42900\end{array}$ & $\begin{array}{l}28500 \\
30900 \\
33200 \\
34600 \\
34500\end{array}$ & $\begin{array}{l}8040 \\
8350 \\
8340 \\
8520 \\
8700\end{array}$ & $\begin{array}{l}5000 \\
4940 \\
4930 \\
4970 \\
4870\end{array}$ & $\begin{array}{l}4320 \\
3850 \\
3540 \\
3310 \\
3080\end{array}$ & $\begin{array}{l}2040 \\
2030 \\
1870 \\
1780 \\
1730\end{array}$ & $\begin{array}{l}1420 \\
1460 \\
1510 \\
1460 \\
1430\end{array}$ \\
\hline $\begin{array}{l}21 \\
22 \\
23 \\
24 \\
25\end{array}$ & $\begin{array}{l}8230 \\
9170 \\
9520 \\
8840 \\
8120\end{array}$ & $\begin{array}{l}3630 \\
3820 \\
4550 \\
4970 \\
5530\end{array}$ & $\begin{array}{l}37500 \\
40800 \\
44600 \\
47800 \\
50200\end{array}$ & $\begin{array}{l}26200 \\
24600 \\
22300 \\
20200 \\
18600\end{array}$ & $\begin{array}{l}28400 \\
28400 \\
28300 \\
27700 \\
25900\end{array}$ & $\begin{array}{l}42500 \\
42400 \\
46000 \\
46800 \\
47400\end{array}$ & $\begin{array}{l}32700 \\
29400 \\
27400 \\
26000 \\
23300\end{array}$ & $\begin{array}{l}9090 \\
9660 \\
9940 \\
9240 \\
8840\end{array}$ & $\begin{array}{l}4820 \\
4670 \\
4510 \\
4290 \\
4010\end{array}$ & $\begin{array}{l}2830 \\
2630 \\
2510 \\
2410 \\
2310\end{array}$ & $\begin{array}{l}1730 \\
2330 \\
2530 \\
2330 \\
2150\end{array}$ & $\begin{array}{l}1410 \\
1370 \\
1370 \\
1340 \\
1300\end{array}$ \\
\hline $\begin{array}{l}26 \\
27 \\
28 \\
29 \\
30 \\
31\end{array}$ & $\begin{array}{l}7640 \\
7200 \\
6620 \\
6020 \\
5590 \\
5270\end{array}$ & $\begin{array}{r}5640 \\
6040 \\
9600 \\
15500 \\
18000 \\
\ldots\end{array}$ & $\begin{array}{l}51100 \\
49700 \\
45500 \\
40900 \\
45500 \\
54500\end{array}$ & $\begin{array}{l}17400 \\
16400 \\
15600 \\
15100 \\
15400 \\
15500\end{array}$ & $\begin{array}{r}23000 \\
19900 \\
17700 \\
\ldots \\
\ldots \\
\ldots\end{array}$ & $\begin{array}{l}49000 \\
52400 \\
54700 \\
54600 \\
53600 \\
51600\end{array}$ & $\begin{array}{c}20300 \\
18000 \\
16600 \\
15600 \\
14800 \\
\cdots\end{array}$ & $\begin{array}{r}10100 \\
10300 \\
9510 \\
8910 \\
8460 \\
8550\end{array}$ & $\begin{array}{c}3810 \\
3720 \\
3830 \\
3810 \\
3710 \\
\cdots\end{array}$ & $\begin{array}{l}2230 \\
2160 \\
2090 \\
2010 \\
1960 \\
1900\end{array}$ & $\begin{array}{l}2010 \\
1870 \\
1770 \\
1690 \\
1640 \\
1590\end{array}$ & $\begin{array}{c}1280 \\
1310 \\
1320 \\
1290 \\
1240 \\
\ldots .\end{array}$ \\
\hline $\begin{array}{l}\text { TOTAL } \\
\text { MEAN } \\
\text { MAX } \\
\text { MIN } \\
\text { CF SM } \\
\text { IN. }\end{array}$ & $\begin{array}{r}258110 \\
8326 \\
16100 \\
2490 \\
.75 \\
.86\end{array}$ & $\begin{array}{r}169650 \\
5655 \\
18000 \\
3630 \\
.51 \\
.57\end{array}$ & $\begin{array}{r}872300 \\
28140 \\
54500 \\
10400 \\
2.53 \\
2.92\end{array}$ & $\begin{array}{r}1383300 \\
44620 \\
109000 \\
15100 \\
4.01 \\
4.63\end{array}$ & $\begin{array}{r}770300 \\
27510 \\
41400 \\
15400 \\
2.47 \\
2.58\end{array}$ & $\begin{array}{r}937100 \\
30230 \\
54700 \\
11800 \\
2.72 \\
3.13\end{array}$ & $\begin{array}{r}738900 \\
24630 \\
48100 \\
14800 \\
2.21 \\
2.47\end{array}$ & $\begin{array}{r}315930 \\
10190 \\
14100 \\
8040 \\
.92 \\
1.06\end{array}$ & $\begin{array}{r}181500 \\
6050 \\
11000 \\
3710 \\
.54 \\
.61\end{array}$ & $\begin{array}{r}96570 \\
3115 \\
6230 \\
1900 \\
.28 \\
.32\end{array}$ & $\begin{array}{c}60720 \\
1959 \\
2530 \\
1590 \\
.18 \\
.20\end{array}$ & $\begin{array}{c}48080 \\
1603 \\
2750 \\
1240 \\
.14 \\
.16\end{array}$ \\
\hline
\end{tabular}

STATISTICS OF MONTHLY MEAN DATA FOR WATER YEARS 1928 - 1991, BY WATER YEAR (WY)

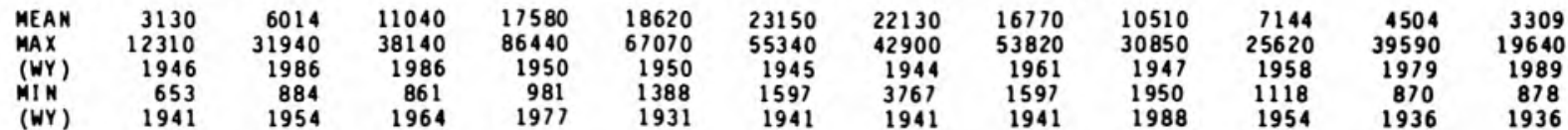

\section{SUMMARY STATISTICS}

\section{ANMUAL TOTAL}

HIGHEST ANMUAL MEAN

LOWEST ANNUAL MEAM

HIGHEST DAILY MEAM

LOWEST DAILY MEAN

AMNUAL SEVEN-DAY MINIMUM

INSTANTANEOUS PEAK FLOH

INSTANTANEOUS PEAK STAGE

ANNUAL RUNOFF (CFSM)

ANNUAL RUNOFF (INCHES)

10 PERCENT EXCEEDS

50 PERCENT EXCEEDS

90 PERCENT EXCEEDS

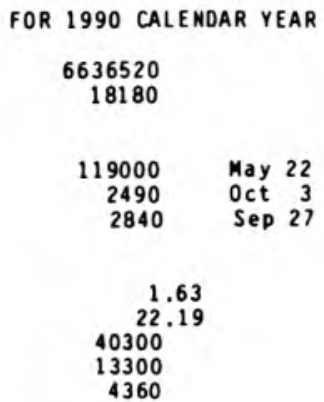

WATER YEARS 1928 - 1991

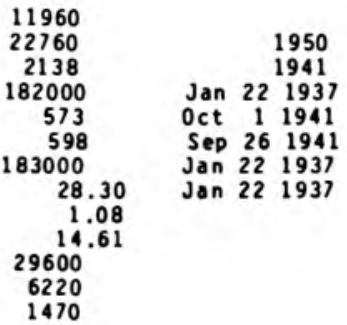


LOCAIION..-Lat $38^{\circ} 20^{\circ} 41^{\prime \prime}$. Iong $86^{\circ} 23^{\prime} 14^{\prime \prime}$, In NWfSEl sec.10, T.1 S.. R.1 E.., Orange County, Hydrologic Unit

05120209. On downstream edge of center pier of county road bridge, 0.3 i downstream from fudge Creek. 0.1 mi northeast of Valeene, $6.0 \mathrm{i}$ southwest of Hardinsburg, and at ile 158.0.

DRAINAGE AREA. - - $12.8 \mathrm{mi}^{2}$.

PERIOD OF RECORD... October 1968 to current year.

GAGE.- Water-stage recorder and concrete control. Datum of gage is 606.89 ft above National Geodetic Vertical Datun of 1929 .

REMARKS. - Records good except for estinated dally discharges, which are fair.

OISCHARGE, CUBIC FEET PER SECONO, WATER YEAR OCTOBER 1990 TO SEPIEMBER 1991

\begin{tabular}{|c|c|c|c|c|c|c|c|c|c|c|c|c|}
\hline DAY & $\mathrm{OCI}$ & NOV & DEC & JAN & FE B & MAR & APR & MAY & JUM & JUL & AUG & SEP \\
\hline $\begin{array}{l}1 \\
2 \\
3 \\
4 \\
5\end{array}$ & $\begin{array}{l}.14 \\
.14 \\
.14 \\
9.2 \\
2.9\end{array}$ & $\begin{array}{l}3.8 \\
3.8 \\
3.9 \\
3.9 \\
5.2\end{array}$ & $\begin{array}{c}12 \\
8.9 \\
188 \\
63 \\
27\end{array}$ & $\begin{array}{l}68 \\
39 \\
25 \\
18 \\
21\end{array}$ & $\begin{array}{l}15 \\
12 \\
11 \\
10 \\
11\end{array}$ & $\begin{array}{l}8.6 \\
18 \\
13 \\
11 \\
9.0\end{array}$ & $\begin{array}{l}16 \\
13 \\
11 \\
11 \\
15\end{array}$ & $\begin{array}{l}8.9 \\
7.6 \\
7.1 \\
6.9 \\
6.8\end{array}$ & $\begin{array}{l}4.1 \\
3.5 \\
3.1 \\
2.7 \\
2.2\end{array}$ & $\begin{array}{l}.44 \\
.72 \\
.92 \\
.61 \\
.52\end{array}$ & $\begin{array}{l}.00 \\
.00 \\
.00 \\
.00 \\
.00\end{array}$ & $\begin{array}{l}.00 \\
.00 \\
.00 \\
.02 \\
.02\end{array}$ \\
\hline $\begin{array}{r}6 \\
7 \\
8 \\
9 \\
10\end{array}$ & $\begin{array}{c}1.3 \\
1.1 \\
31.88 \\
30\end{array}$ & $\begin{array}{r}5.7 \\
5.0 \\
4.4 \\
4.8 \\
11\end{array}$ & $\begin{array}{c}18 \\
12 \\
9.5 \\
7.7 \\
6.7\end{array}$ & $\begin{array}{r}1 / 8 \\
202 \\
98 \\
52 \\
36\end{array}$ & $\begin{array}{r}345 \\
189 \\
73 \\
40 \\
27\end{array}$ & $\begin{array}{c}9.3 \\
10 \\
8.7 \\
7.8 \\
6.9\end{array}$ & $\begin{array}{l}13 \\
11 \\
13 \\
47 \\
57\end{array}$ & $\begin{array}{l}6.4 \\
5.7 \\
5.3 \\
5.8 \\
5.5\end{array}$ & $\begin{array}{l}2.0 \\
1.9 \\
1.7 \\
1.5 \\
1.4\end{array}$ & $\begin{array}{l}.47 \\
.36 \\
.56 \\
.77 \\
.58\end{array}$ & $\begin{array}{l}.00 \\
.00 \\
.00 \\
.00 \\
.00\end{array}$ & $\begin{array}{l}.00 \\
.02 \\
.03 \\
.00 \\
.00\end{array}$ \\
\hline $\begin{array}{l}11 \\
12 \\
13 \\
14 \\
15\end{array}$ & $\begin{array}{r}11 \\
5.7 \\
3.8 \\
3.0 \\
2.5\end{array}$ & $\begin{array}{l}1.0 \\
5.5 \\
4.3 \\
4.0 \\
3.8\end{array}$ & $\begin{array}{l}5.8 \\
5.4 \\
5.0 \\
4.4 \\
38\end{array}$ & $\begin{array}{r}144 \\
115 \\
52 \\
34 \\
25\end{array}$ & $\begin{array}{r}19 \\
15 \\
53 \\
274 \\
88\end{array}$ & $\begin{array}{r}6.4 \\
6.9 \\
107 \\
72 \\
38\end{array}$ & $\begin{array}{r}27 \\
20 \\
142 \\
144 \\
64\end{array}$ & $\begin{array}{l}5.0 \\
5.1 \\
5.1 \\
4.6 \\
4.3\end{array}$ & $\begin{array}{l}1.3 \\
1.2 \\
1.2 \\
1.1 \\
1.0\end{array}$ & $\begin{array}{l}.55 \\
.98 \\
.60 \\
.44 \\
.34\end{array}$ & $\begin{array}{l}.00 \\
.00 \\
.00 \\
.00 \\
.00\end{array}$ & $\begin{array}{l}.00 \\
.00 \\
.00 \\
.00 \\
.00\end{array}$ \\
\hline $\begin{array}{l}16 \\
17 \\
18 \\
19 \\
20\end{array}$ & $\begin{array}{r}2.3 \\
6.9 \\
139 \\
23 \\
11\end{array}$ & $\begin{array}{l}3.7 \\
3.5 \\
3.1 \\
3.1 \\
2.9\end{array}$ & $\begin{array}{r}28 \\
79 \\
942 \\
207 \\
77\end{array}$ & $\begin{array}{l}35 \\
28 \\
21 \\
18 \\
17\end{array}$ & $\begin{array}{r}e 35 \\
e 29 \\
168 \\
99 \\
49\end{array}$ & $\begin{array}{r}25 \\
56 \\
170 \\
67 \\
37\end{array}$ & $\begin{array}{l}37 \\
27 \\
22 \\
27 \\
24\end{array}$ & $\begin{array}{l}4.0 \\
3.7 \\
3.4 \\
3.2 \\
3.2\end{array}$ & $\begin{array}{l}1.3 \\
1.3 \\
1.2 \\
1.5 \\
1.2\end{array}$ & $\begin{array}{l}.29 \\
.22 \\
.19 \\
.17 \\
.14\end{array}$ & $\begin{array}{l}.00 \\
.00 \\
.00 \\
.00 \\
.00\end{array}$ & $\begin{array}{l}.00 \\
.00 \\
.00 \\
.00 \\
.00\end{array}$ \\
\hline $\begin{array}{l}21 \\
22 \\
23 \\
24 \\
25\end{array}$ & $\begin{array}{l}7.4 \\
12 \\
15 \\
9.7 \\
8.2\end{array}$ & $\begin{array}{l}2.8 \\
91 \\
48 \\
19 \\
12\end{array}$ & $\begin{array}{r}93 \\
216 \\
156 \\
68 \\
\mathrm{e} 30\end{array}$ & $\begin{array}{l}13 \\
11 \\
9.6 \\
8.4 \\
7.3\end{array}$ & $\begin{array}{l}32 \\
23 \\
17 \\
15 \\
12\end{array}$ & $\begin{array}{r}27 \\
839 \\
301 \\
94 \\
46\end{array}$ & $\begin{array}{l}20 \\
17 \\
16 \\
16 \\
15\end{array}$ & $\begin{array}{l}3.0 \\
2.8 \\
2.9 \\
7.5 \\
6.2\end{array}$ & $\begin{array}{l}1.3 \\
1.3 \\
1.1 \\
.86 \\
.69\end{array}$ & $\begin{array}{l}.12 \\
.10 \\
.08 \\
.07 \\
.05\end{array}$ & $\begin{array}{l}.00 \\
.00 \\
.00 \\
.00 \\
.00\end{array}$ & $\begin{array}{l}.00 \\
.00 \\
.00 \\
.00 \\
.00\end{array}$ \\
\hline $\begin{array}{l}26 \\
27 \\
28 \\
29 \\
30 \\
31\end{array}$ & $\begin{array}{l}6.0 \\
5.9 \\
5.5 \\
4.8 \\
4.3 \\
4.0\end{array}$ & $\begin{array}{l}8.3 \\
7.3 \\
66 \\
31 \\
16 \\
-\ldots\end{array}$ & $\begin{array}{l}\text { e21 } \\
\text { e17 } \\
\text { e15 } \\
324 \\
523 \\
167\end{array}$ & $\begin{array}{l}6.8 \\
7.0 \\
12 \\
13 \\
31 \\
22\end{array}$ & $\begin{array}{c}10 \\
9.3 \\
8.3 \\
\ldots . \\
\ldots . \\
\ldots\end{array}$ & $\begin{array}{l}34 \\
76 \\
87 \\
42 \\
26 \\
19\end{array}$ & $\begin{array}{l}13 \\
12 \\
12 \\
12 \\
10 \\
\cdots\end{array}$ & $\begin{array}{l}44 \\
16 \\
7.6 \\
9.6 \\
9.9 \\
5.7\end{array}$ & $\begin{array}{l}.64 \\
.56 \\
.53 \\
.48 \\
.46 \\
. . .\end{array}$ & $\begin{array}{l}.03 \\
.02 \\
.00 \\
.00 \\
.00 \\
.00\end{array}$ & $\begin{array}{l}.00 \\
.00 \\
.00 \\
.00 \\
.00 \\
.00\end{array}$ & $\begin{array}{l}.00 \\
.00 \\
.00 \\
.00 \\
.00 \\
. .\end{array}$ \\
\hline $\begin{array}{l}\text { IOIAL } \\
\text { MEAN } \\
\text { MAX } \\
\text { MIN } \\
\text { CF SM } \\
\text { IN. }\end{array}$ & $\begin{array}{r}367.80 \\
11.9 \\
139 \\
.14 \\
.93 \\
1.07\end{array}$ & $\begin{array}{r}393.8 \\
13.1 \\
91 \\
2.8 \\
1.03 \\
1.14\end{array}$ & $\begin{array}{r}3374.4 \\
109 \\
942 \\
4.4 \\
8.50 \\
9.81\end{array}$ & $\begin{array}{r}1367.1 \\
44.1 \\
202 \\
6.8 \\
3.45 \\
3.97\end{array}$ & $\begin{array}{r}1688.6 \\
60.3 \\
345 \\
8.3 \\
4.71 \\
4.91\end{array}$ & $\begin{array}{r}2278.6 \\
73.5 \\
839 \\
6.4 \\
5.74 \\
6.62\end{array}$ & $\begin{array}{r}884 \\
29.5 \\
144 \\
10 \\
2.30 \\
2.57\end{array}$ & $\begin{array}{c}222.8 \\
7.19 \\
44 \\
2.8 \\
.56 \\
.65\end{array}$ & $\begin{array}{c}44.32 \\
1.48 \\
4.1 \\
.46 \\
.12 \\
.13\end{array}$ & $\begin{array}{c}10.34 \\
.33 \\
.98 \\
.00 \\
.03 \\
.03\end{array}$ & $\begin{array}{l}0.00 \\
.000 \\
.00 \\
.00 \\
.00 \\
.00\end{array}$ & $\begin{array}{l}0.09 \\
.003 \\
.03 \\
.00 \\
.00 \\
.00\end{array}$ \\
\hline
\end{tabular}

e Estimated

SIATISIICS OF MUNIHLY MEAN DATA FOR WATER YEARS 1969 - 1991, BY WATER YEAR (WY)

$\begin{array}{lrrrrrrrrrrrr}\text { MEAN } & 3.83 & 21.6 & 34.8 & 33.8 & 41.9 & 51.0 & 48.3 & 31.5 & 15.2 & 10.7 & 5.22 & 3.68 \\ \text { MAX } & 11.9 & 77.3 & 109 & 107 & 89.6 & 101 & 102 & 138 & 59.0 & 89.6 & 33.4 & 18.9 \\ \text { (WY) } & 1991 & 1980 & 1991 & 1982 & 1990 & 1973 & 1972 & 1983 & 1990 & 1979 & 1977 & 1981 \\ \text { MIN } & 1021 & .54 & 1.17 & .61 & 6.92 & 8.80 & 6.79 & 2.66 & .46 & .26 & .000 & .003 \\ \text { (WY) } & 1988 & 1988 & 1981 & 1981 & 1978 & 1981 & 1976 & 1988 & 1988 & 1983 & 1991 & 1991\end{array}$

SUMMARY SIAIISIICS

ANMUAL TOTAL

HIGHESI ANNUAL MEAM

LOWEST ANNUAL MEAN

HIGHESI DAILY MEAN

LOWEST DAILY MEAN

ANMUAL SEVEN-DAY MINIMUM

INSTAMTANEOUS PEAK FLOW

INSTAMTANEOUS PEAK STAGE

ANNUAL RUNOFF (CFSM)

ANHUAL RUNOFF (INCHES)

10 PERCENT EXCEEOS

50 PERCENI EXCEEDS

90 PERCENT EXCEEDS
FOR 1990 CALENOAR YEAR

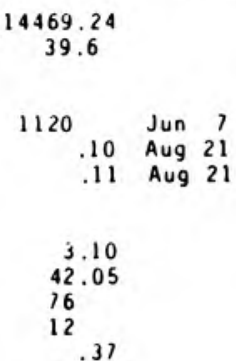

FOR 1991 WATER YEAR

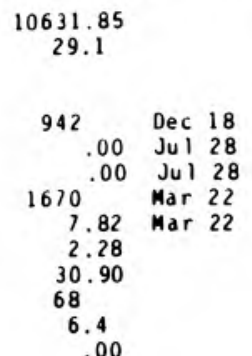

WAIER YEARS $1969-1991$

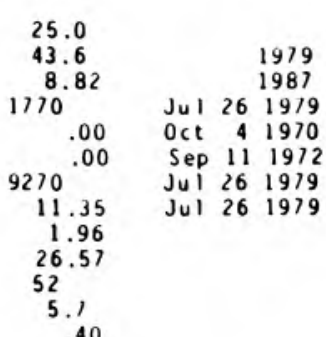




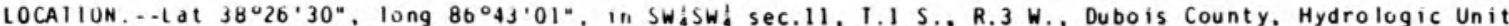
05120209 , on right bank $20 \mathrm{ft}$ upstream from bridge on Cuzco Rod South, 2.3 a south of Cuzco, 0.7 mi downstream from Patoka Lake, 4.5 i upstream from 0 illon Creek, and at ile 117.8 .

DRAI NAGE AREA. - - $170 \bullet i^{2}$.

PERIOD OF RECORD... June 1961 to current $y \in a r$

GAGE.--Data-Collection Platform. Datum of gage is $477,00 \mathrm{ft}$ above National Geodetic Vertical Datum of 1929 (levels by State of Indiana. Department of Natural Resources). Prior to 0ct. 1, 1961 , nonrecording gage on downstrea side of bridge, 1.7 a downstrean at same datum. Oct. 1, 1961 to Sept. 30, 1981. water-stage recorder at site described above. Prior to October 1979, published as "near Ellsworth". Data-Collection Platfora installed on July $25,1985$.

REMARKS. - Flow regulated by Patoka lake since february 1978. Daily discharge computed from relation between discharge, head, and gate openings for Patoka lake beginning 0ct. 1, 1981 .

COOPERATION.-.Records of daily discharge provided by U.S. Army Corps of Engineers beginning 0ct. 1, 1981.

AVERAGE DISCHARGE.- - 30 years, $225 \mathrm{ft} / \mathrm{s}$.

EXIREMES FOR PERIOD OF RECORD. - Maximum discharge 14,700 ft $3 / \mathrm{s} \mathrm{Mar.} \mathrm{10,} \mathrm{1964,} \mathrm{gage} \mathrm{height,} 20.02 \mathrm{ft}$; no flow Oct. 30, 1964

EXIREMES OUISIDE PERIOD OF RECORD..-Flogd in March 1913 reached a stage of 19.1 ft according to information by local resident, discharge, $12,300 \mathrm{ft} / \mathrm{s}$.

EXIREMES FOR CURRENI YEAR. --Maximum daily discharge, $1,830 \mathrm{ft} / \mathrm{s} \mathrm{Jan}$. 26 ; inimum daily, $25 \mathrm{ft} / \mathrm{s} \mathrm{June} 16-20 \mathrm{and}$ June 28 to Sept. 30 .

OISCHARGE, CUBIL FEEI PER SECOND, WATER YEAR OCTOBER 1990 TO SEPTEMBER 1991 DAILY MEAN VALUES

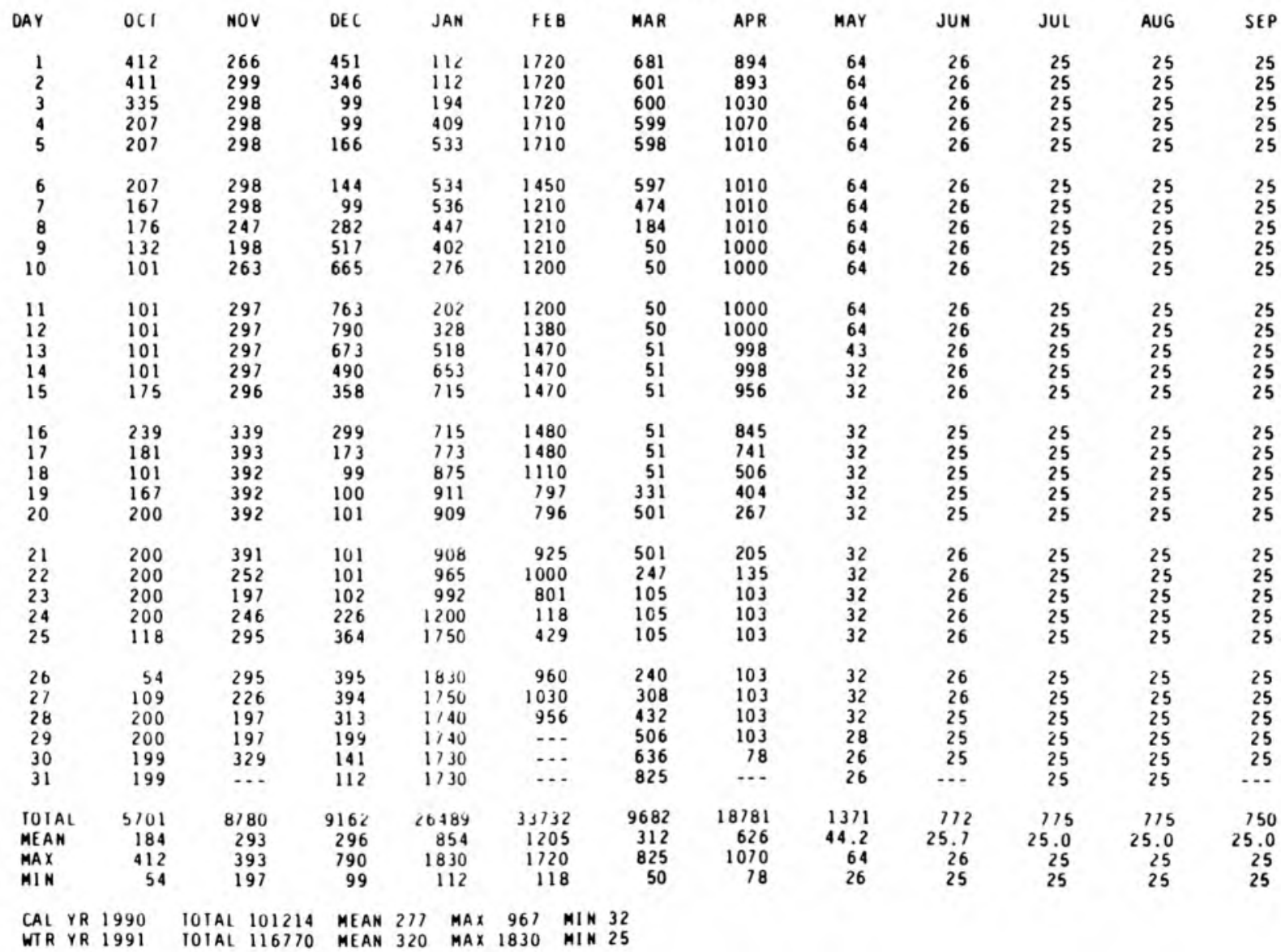




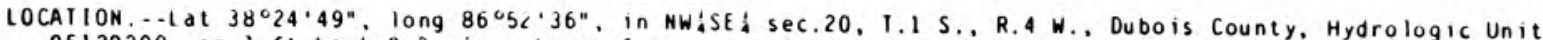
05120209 , on left bank 0.3 mi upstrean from unnamed out let of jasper Lake, 1.0 . downstream from Coon Seit bridge, 1.2 i downştrean fron Bedver Creek, 3.3 i northedst of Jasper, and at aile 91.5 .

DRAINAGE ARE

PERIOD OF RECORD..- November 1947 to current year.

REVISED RECORDS...WSP 1909: 1958. WSP 210y: Drainage area.

GAGE.- Water-stage recorder. Datum of gage is $446.00 \mathrm{ft}$ above Nationd Geodetic Vertical Datua of 1929 (levels by State of Indiana. Departaent of Natural Resources). Nonrecording gage at bridge 5.6 a downstrea. used for high-water periods when flow exceeds about $2,500 \mathrm{ft} / \mathrm{s}$, at datum $0.34 \mathrm{ft}$ lower. Prior to Sept. 18 , 1956 , nonrecording gage at bridge $5.6 \mathrm{mi}$ downstrean at datu $0.34 \mathrm{ft}$ lower. REMARKS. - Records good. Flow regulated by Beaver Creek Reservoir beginning 0ct. 11, 1955 , and by Patoka Lake

EXIREMES OUISIDE PERIOD OF RECORD. - Flood in March 1913 reached a stage of $15.9 \mathrm{ft}$ at downstrean site, froe floodmark furnished by local residents, discharge $16.000 \mathrm{ft} / \mathrm{s}$.

DISCHARGE, CUBIC FEET PER SECONO, WATER YEAR OCTOBER 1990 IO SEPIEMBER 1991 DAILIY MEAN VALUES

\begin{tabular}{|c|c|c|c|c|c|c|c|c|c|c|c|c|}
\hline DAY & $\mathrm{OCl}$ & NOV & $D E C$ & JAN & FEB & MAR & APR & MAY & JUN & JUL & AUG & SEP \\
\hline $\begin{array}{l}1 \\
2 \\
3 \\
4 \\
5\end{array}$ & $\begin{array}{l}409 \\
411 \\
413 \\
530 \\
333\end{array}$ & $\begin{array}{l}233 \\
297 \\
326 \\
326 \\
348\end{array}$ & $\begin{array}{l}454 \\
533 \\
790 \\
698 \\
330\end{array}$ & $\begin{array}{r}1770 \\
940 \\
406 \\
432 \\
726\end{array}$ & $\begin{array}{l}1880 \\
1870 \\
1850 \\
1840 \\
1840\end{array}$ & $\begin{array}{r}1060 \\
933 \\
799 \\
754 \\
736\end{array}$ & $\begin{array}{r}908 \\
966 \\
977 \\
1030 \\
1100\end{array}$ & $\begin{array}{l}133 \\
112 \\
107 \\
107 \\
109\end{array}$ & $\begin{array}{l}50 \\
49 \\
48 \\
48 \\
45\end{array}$ & $\begin{array}{l}36 \\
39 \\
39 \\
35 \\
34\end{array}$ & $\begin{array}{l}31 \\
30 \\
21 \\
22 \\
25\end{array}$ & $\begin{array}{l}30 \\
30 \\
28 \\
38 \\
53\end{array}$ \\
\hline $\begin{array}{r}6 \\
7 \\
8 \\
9 \\
10\end{array}$ & $\begin{array}{l}242 \\
230 \\
189 \\
490 \\
925\end{array}$ & $\begin{array}{l}361 \\
343 \\
334 \\
287 \\
269\end{array}$ & $\begin{array}{l}317 \\
258 \\
194 \\
376 \\
573\end{array}$ & $\begin{array}{l}1100 \\
1360 \\
1480 \\
1350 \\
1000\end{array}$ & $\begin{array}{l}1980 \\
2110 \\
2100 \\
1930 \\
1770\end{array}$ & $\begin{array}{l}730 \\
720 \\
593 \\
255 \\
124\end{array}$ & $\begin{array}{l}1110 \\
1110 \\
1100 \\
1090 \\
1090\end{array}$ & $\begin{array}{l}111 \\
103 \\
100 \\
101 \\
101\end{array}$ & $\begin{array}{l}44 \\
43 \\
43 \\
43 \\
42\end{array}$ & $\begin{array}{r}34 \\
34 \\
34 \\
36 \\
155\end{array}$ & $\begin{array}{l}27 \\
30 \\
28 \\
30 \\
29\end{array}$ & $\begin{array}{l}35 \\
28 \\
28 \\
28 \\
29\end{array}$ \\
\hline $\begin{array}{l}11 \\
12 \\
13 \\
14 \\
15\end{array}$ & $\begin{array}{l}507 \\
245 \\
188 \\
166 \\
153\end{array}$ & $\begin{array}{l}324 \\
341 \\
334 \\
330 \\
328\end{array}$ & $\begin{array}{l}763 \\
864 \\
892 \\
799 \\
766\end{array}$ & $\begin{array}{l}785 \\
892 \\
807 \\
878 \\
937\end{array}$ & $\begin{array}{l}1630 \\
1510 \\
1470 \\
1650 \\
1820\end{array}$ & $\begin{array}{l}115 \\
119 \\
521 \\
754 \\
403\end{array}$ & $\begin{array}{l}1080 \\
1070 \\
1070 \\
1080 \\
1100\end{array}$ & $\begin{array}{r}128 \\
147 \\
111 \\
95 \\
70\end{array}$ & $\begin{array}{l}37 \\
36 \\
36 \\
36 \\
36\end{array}$ & $\begin{array}{l}44 \\
45 \\
44 \\
36 \\
34\end{array}$ & $\begin{array}{l}27 \\
27 \\
27 \\
28 \\
32\end{array}$ & $\begin{array}{l}30 \\
30 \\
29 \\
29 \\
29\end{array}$ \\
\hline $\begin{array}{l}16 \\
17 \\
18 \\
19 \\
20\end{array}$ & $\begin{array}{l}197 \\
254 \\
295 \\
224 \\
225\end{array}$ & $\begin{array}{l}327 \\
380 \\
415 \\
413 \\
409\end{array}$ & $\begin{array}{r}638 \\
530 \\
1290 \\
1710 \\
1910\end{array}$ & $\begin{array}{l}1000 \\
1030 \\
1030 \\
1050 \\
1070\end{array}$ & $\begin{array}{l}1880 \\
1820 \\
1800 \\
1820 \\
1770\end{array}$ & $\begin{array}{l}255 \\
325 \\
992 \\
690 \\
601\end{array}$ & $\begin{array}{r}1100 \\
1040 \\
905 \\
643 \\
558\end{array}$ & $\begin{array}{l}65 \\
67 \\
63 \\
59 \\
57\end{array}$ & $\begin{array}{l}37 \\
37 \\
36 \\
36 \\
36\end{array}$ & $\begin{array}{l}36 \\
33 \\
33 \\
32 \\
32\end{array}$ & $\begin{array}{l}30 \\
29 \\
29 \\
29 \\
28\end{array}$ & $\begin{array}{l}28 \\
28 \\
30 \\
30 \\
28\end{array}$ \\
\hline $\begin{array}{l}21 \\
22 \\
23 \\
24 \\
25\end{array}$ & $\begin{array}{l}244 \\
275 \\
319 \\
281 \\
261\end{array}$ & $\begin{array}{l}407 \\
624 \\
662 \\
383 \\
354\end{array}$ & $\begin{array}{r}1260 \\
1000 \\
785 \\
492 \\
529\end{array}$ & $\begin{array}{l}1070 \\
1060 \\
1070 \\
1100 \\
1140\end{array}$ & $\begin{array}{r}1570 \\
1360 \\
1260 \\
1070 \\
369\end{array}$ & $\begin{array}{r}638 \\
1360 \\
1920 \\
1940 \\
1240\end{array}$ & $\begin{array}{l}371 \\
300 \\
222 \\
201 \\
186\end{array}$ & $\begin{array}{l}56 \\
56 \\
55 \\
54 \\
86\end{array}$ & $\begin{array}{l}36 \\
48 \\
46 \\
48 \\
38\end{array}$ & $\begin{array}{l}31 \\
31 \\
31 \\
31 \\
31\end{array}$ & $\begin{array}{l}28 \\
28 \\
28 \\
28 \\
28\end{array}$ & $\begin{array}{l}28 \\
28 \\
29 \\
29 \\
28\end{array}$ \\
\hline $\begin{array}{l}26 \\
27 \\
28 \\
29 \\
30 \\
31\end{array}$ & $\begin{array}{l}183 \\
106 \\
142 \\
234 \\
237 \\
235\end{array}$ & $\begin{array}{l}367 \\
356 \\
630 \\
604 \\
376 \\
\cdots-\end{array}$ & $\begin{array}{r}642 \\
637 \\
632 \\
1070 \\
1590 \\
1890\end{array}$ & $\begin{array}{l}1220 \\
1330 \\
1500 \\
1710 \\
1840 \\
1870\end{array}$ & $\begin{array}{r}665 \\
975 \\
1050 \\
\cdots \\
\cdots \\
\cdots\end{array}$ & $\begin{array}{l}514 \\
450 \\
462 \\
547 \\
574 \\
768\end{array}$ & $\begin{array}{l}176 \\
169 \\
165 \\
165 \\
159 \\
\cdots\end{array}$ & $\begin{array}{r}120 \\
90 \\
71 \\
63 \\
58 \\
55\end{array}$ & $\begin{array}{r}36 \\
35 \\
35 \\
34 \\
35 \\
\cdots\end{array}$ & $\begin{array}{l}31 \\
31 \\
31 \\
31 \\
31 \\
31\end{array}$ & $\begin{array}{l}28 \\
28 \\
28 \\
28 \\
28 \\
29\end{array}$ & $\begin{array}{l}28 \\
27 \\
28 \\
28 \\
28 \\
\cdots\end{array}$ \\
\hline $\begin{array}{l}\text { IOIAL } \\
\text { MEAN } \\
\text { MAX } \\
\text { MIN } \\
\text { CF SM } \\
\text { IN. }\end{array}$ & $\begin{array}{r}9143 \\
295 \\
925 \\
106 \\
1.13 \\
1.30\end{array}$ & $\begin{array}{r}11488 \\
383 \\
662 \\
233 \\
1.46 \\
1.63\end{array}$ & $\begin{array}{r}25212 \\
813 \\
1910 \\
194 \\
3.10 \\
3.58\end{array}$ & $\begin{array}{r}34953 \\
1128 \\
1870 \\
406 \\
4.30 \\
4.96\end{array}$ & $\begin{array}{r}44659 \\
1595 \\
2110 \\
369 \\
6.09 \\
6.34\end{array}$ & $\begin{array}{r}21892 \\
706 \\
1940 \\
115 \\
2.70 \\
3.11\end{array}$ & $\begin{array}{r}22241 \\
741 \\
1110 \\
159 \\
2.83 \\
3.16\end{array}$ & $\begin{array}{r}2710 \\
87.4 \\
147 \\
54 \\
.33 \\
.38\end{array}$ & $\begin{array}{c}1209 \\
40.3 \\
50 \\
34 \\
.15 \\
.17\end{array}$ & $\begin{array}{c}1186 \\
38.3 \\
155 \\
31 \\
.15 \\
.17\end{array}$ & $\begin{array}{c}868 \\
28.0 \\
32 \\
21 \\
.11 \\
.12\end{array}$ & $\begin{array}{r}899 \\
30.0 \\
53 \\
27 \\
.11 \\
.13\end{array}$ \\
\hline
\end{tabular}

SIATISIICS OF MONIHLY MEAN DATA FOR WAIER YEARS 1949 - 1991, BY WAIER YEAR (WY)

\begin{tabular}{|c|c|c|c|c|c|c|c|c|c|c|c|c|}
\hline $\begin{array}{l}\text { MEAN } \\
\text { MAX } \\
\text { (WY) } \\
\text { MIN } \\
\text { (WY) }\end{array}$ & $\begin{array}{r}93.4 \\
494 \\
1980 \\
.000 \\
1949\end{array}$ & $\begin{array}{r}242 \\
800 \\
1975 \\
1000 \\
1954\end{array}$ & $\begin{array}{r}428 \\
1506 \\
1952 \\
.17 \\
1954\end{array}$ & $\begin{array}{r}625 \\
2742 \\
1950 \\
17.5 \\
1964\end{array}$ & $\begin{array}{r}688 \\
1898 \\
1950 \\
27.7 \\
1964\end{array}$ & $\begin{array}{r}814 \\
2543 \\
1964 \\
187 \\
1957\end{array}$ & $\begin{array}{r}633 \\
1574 \\
1972 \\
130 \\
1976\end{array}$ & $\begin{array}{r}418 \\
2001 \\
1961 \\
37.5 \\
1952\end{array}$ & $\begin{array}{r}198 \\
668 \\
1949 \\
8.66 \\
1953\end{array}$ & $\begin{array}{r}118 \\
787 \\
1958 \\
.074 \\
1954\end{array}$ & $\begin{array}{r}92.9 \\
530 \\
1977 \\
1000 \\
1952\end{array}$ & $\begin{array}{r}76.4 \\
484 \\
1979 \\
.000 \\
1953\end{array}$ \\
\hline
\end{tabular}

SUMMARY SIAIISTICS

ANMUAL TOTAL

ANMUAL MEAN

HIGHESI ANNUAI MEAN

LOWE ST ANNUAL MEAN

HIGHEST DAILY MEAN

LOWEST DAILY MEAN

ANNUAL SEVEN-DAY MINIMUM

INSTAMTAMEOUS PEAK FLOW

INSTANTANEOUS PEAK STAGE

AMNUAL RUMOFF (CFSM)

ANHUAL RUNOFF (INCHES)

10 PERCENT EXCEEDS

50 PERCENT EXCEEOS

90 PERCENT EXCEEDS
FOR IYYO CALENDAR YEAR

$\begin{aligned} 189294 & \\ 519 & \\ & \\ 3500 & \text { Jun } 8 \\ 106 & \text { Oct } 27 \\ 169 & \text { Jun } 13 \\ & \\ 1.98 & \\ 26.88 & \\ 976 & \\ 380 & \\ 196 & \end{aligned}$

FOR 1991 WATER YEAR

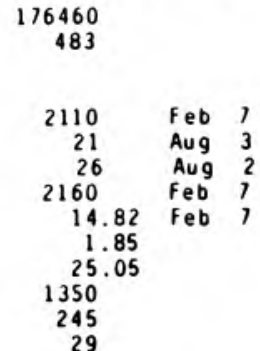

WAIER YEARS 194Y - 1991

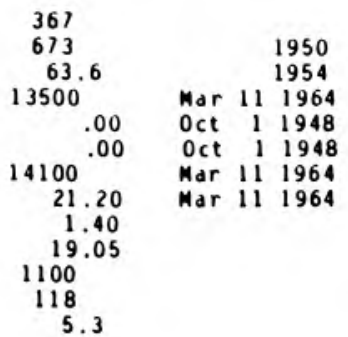


LOCATION..-Lat $38^{\circ} 21^{\prime} 45^{\prime \prime}$, Iong $86^{\circ} 49^{\circ} 43^{\prime \prime}$, in NW'AWh sec.11, T.2 S., R.4 W. Dubois County, Hydrologic Unit 05120209 , on downstrean side of right pier of bridge on County Road 125 South, 0.7 i upstrean from Grassy Fork, 3.3 i north of St. Anthony, and dt aile 4.1 .

DRAI NAGE AREA, $\cdots 21.8 \cdot i^{2}$

PERIOD OF RECORD..-OCtober 1910 to current yedr.

REVISED RECORDS.-.WDR IN-75-1: 1971-74.

GAGE. - -Water-stage recorder. Datun of gage is $459.22 \mathrm{ft}$ above National Geodetic Vertical Datum of 1929 (levels by State of Indiand. Departinent of Matural Resources).

REMARKS. - Records fair except for estinated daily dischargs, which are poor.

DISCHARGE, CUBIL FEET PER SECONO, WATER YEAR OCIOBER 1990 TO SEPIEMBER 1991 DAIIY MEAN VALUES

\begin{tabular}{|c|c|c|c|c|c|c|c|c|c|c|c|c|}
\hline DAY & $O C T$ & NOV & DEC & JAN & FEB & MAR & $A P R$ & MAY & JUN & JUL & AUG & SEP \\
\hline $\begin{array}{l}1 \\
2 \\
3 \\
4 \\
5\end{array}$ & $\begin{array}{c}.09 \\
.08 \\
.12 \\
58 \\
2.4\end{array}$ & $\begin{array}{c}2.0 \\
2.3 \\
4.7 \\
5.3 \\
10\end{array}$ & $\begin{array}{r}19 \\
15 \\
233 \\
46 \\
25\end{array}$ & $\begin{array}{l}57 \\
38 \\
27 \\
19 \\
56\end{array}$ & $\begin{array}{l}21 \\
18 \\
17 \\
16 \\
26\end{array}$ & $\begin{array}{l}20 \\
24 \\
15 \\
13 \\
12\end{array}$ & $\begin{array}{l}15 \\
12 \\
12 \\
20 \\
25\end{array}$ & $\begin{array}{r}7.5 \\
5.3 \\
4.4 \\
4.1 \\
13\end{array}$ & $\begin{array}{r}1.9 \\
1.4 \\
12 \\
1.8 \\
1.1\end{array}$ & $\begin{array}{l}.09 \\
.10 \\
.13 \\
.13 \\
.28\end{array}$ & $\begin{array}{l}.04 \\
.03 \\
.01 \\
.00 \\
.00\end{array}$ & $\begin{array}{r}.06 \\
.01 \\
.00 \\
4.8\end{array}$ \\
\hline $\begin{array}{r}6 \\
7 \\
8 \\
9 \\
10\end{array}$ & $\begin{aligned} .91 \\
.52 \\
282 \\
.45 \\
130\end{aligned}$ & $\begin{array}{r}8.3 \\
5.0 \\
4.0 \\
8.6 \\
15\end{array}$ & $\begin{array}{l}20 \\
17 \\
14 \\
12 \\
10\end{array}$ & $\begin{array}{r}118 \\
240 \\
81 \\
52 \\
45\end{array}$ & $\begin{array}{r}468 \\
169 \\
71 \\
46 \\
33\end{array}$ & $\begin{array}{l}14 \\
13 \\
11 \\
10 \\
9.5\end{array}$ & $\begin{array}{l}15 \\
12 \\
19 \\
33 \\
29\end{array}$ & $\begin{array}{l}6.1 \\
3.6 \\
2.8 \\
4.9 \\
3.6\end{array}$ & $\begin{array}{l}.69 \\
.47 \\
.33 \\
.32 \\
.29\end{array}$ & $\begin{array}{r}.16 \\
1.13 \\
16 \\
340\end{array}$ & $\begin{array}{l}.00 \\
.00 \\
.00 \\
.00 \\
.00\end{array}$ & $\begin{array}{l}.24 \\
.07 \\
.03 \\
.02 \\
.01\end{array}$ \\
\hline $\begin{array}{l}11 \\
12 \\
13 \\
14 \\
15\end{array}$ & $\begin{array}{r}28 \\
14 \\
7.7 \\
4.6 \\
2.8\end{array}$ & $\begin{array}{l}8.7 \\
6.7 \\
5.4 \\
4.8 \\
4.4\end{array}$ & $\begin{array}{l}8.9 \\
8.2 \\
7.4 \\
6.3 \\
65\end{array}$ & $\begin{array}{r}179 \\
89 \\
51 \\
37 \\
35\end{array}$ & $\begin{array}{r}23 \\
19 \\
139 \\
332 \\
77\end{array}$ & $\begin{array}{c}9.1 \\
21 \\
203 \\
123 \\
59\end{array}$ & $\begin{array}{l}15 \\
16 \\
71 \\
71 \\
70\end{array}$ & $\begin{array}{l}48 \\
23 \\
8.1 \\
7.5 \\
6.6\end{array}$ & $\begin{array}{l}.33 \\
.28 \\
.33 \\
.24 \\
.18\end{array}$ & $\begin{array}{r}15 \\
7.9 \\
3.1 \\
1.7 \\
1.3\end{array}$ & $\begin{array}{l}.00 \\
.00 \\
.62 \\
.11 \\
.03\end{array}$ & $\begin{array}{l}.00 \\
.00 \\
.00 \\
.00 \\
.00\end{array}$ \\
\hline $\begin{array}{l}16 \\
17 \\
18 \\
19 \\
20\end{array}$ & $\begin{array}{r}1.9 \\
1.6 \\
31 \\
7.2 \\
4.7\end{array}$ & $\begin{array}{l}4.4 \\
4.2 \\
3.7 \\
3.5 \\
3.1\end{array}$ & $\begin{array}{r}29 \\
159 \\
1180 \\
156 \\
68\end{array}$ & $\begin{array}{l}58 \\
41 \\
30 \\
25 \\
24\end{array}$ & $\begin{array}{r}\mathrm{e} 3 \\
36 \\
218 \\
82 \\
49\end{array}$ & $\begin{array}{r}35 \\
139 \\
153 \\
56 \\
37\end{array}$ & $\begin{array}{l}51 \\
37 \\
30 \\
77 \\
44\end{array}$ & $\begin{array}{l}7.9 \\
6.6 \\
3.7 \\
3.0 \\
2.8\end{array}$ & $\begin{array}{l}.32 \\
.41 \\
.34 \\
.37 \\
.43\end{array}$ & $\begin{array}{l}.86 \\
.80 \\
.68 \\
.59 \\
.49\end{array}$ & $\begin{array}{l}.00 \\
.00 \\
.00 \\
.00 \\
.00\end{array}$ & $\begin{array}{l}.00 \\
.00 \\
.01 \\
.00 \\
.00\end{array}$ \\
\hline $\begin{array}{l}21 \\
22 \\
23 \\
24 \\
25\end{array}$ & $\begin{array}{l}3.4 \\
18 \\
13 \\
7.4 \\
5.7\end{array}$ & $\begin{array}{c}3.0 \\
160 \\
45 \\
23 \\
18\end{array}$ & $\begin{array}{r}104 \\
192 \\
146 \\
58 \\
e 37\end{array}$ & $\begin{aligned} & 18 \\
& \text { e} 16.3 \\
& \text { el } 15 \\
& \text { e } 13.5 \\
& \text { e} 12\end{aligned}$ & $\begin{array}{l}35 \\
27 \\
21 \\
18 \\
15\end{array}$ & $\begin{array}{r}31 \\
1120 \\
280 \\
99 \\
62\end{array}$ & $\begin{array}{l}35 \\
26 \\
30 \\
69 \\
29\end{array}$ & $\begin{array}{r}9.7 \\
2.9 \\
2.5 \\
2.3 \\
21\end{array}$ & $\begin{array}{r}.58 \\
1.1 \\
.52 \\
.37 \\
.33\end{array}$ & $\begin{array}{r}.43 \\
.41 \\
.41 \\
.36 \\
.35\end{array}$ & $\begin{array}{l}.00 \\
.00 \\
.00 \\
.00 \\
.00\end{array}$ & $\begin{array}{l}.01 \\
.04 \\
.04 \\
.02 \\
.01\end{array}$ \\
\hline $\begin{array}{l}26 \\
27 \\
28 \\
29 \\
30 \\
31\end{array}$ & $\begin{array}{l}4.4 \\
3.5 \\
2.8 \\
2.2 \\
2.0 \\
1.8\end{array}$ & $\begin{array}{r}14 \\
12 \\
156 \\
36 \\
23 \\
\cdots\end{array}$ & $\begin{array}{l}e 26 \\
e 23 \\
e 22 \\
517 \\
544 \\
116\end{array}$ & $\begin{array}{l}\text { ey.40 } \\
\text { e16 } \\
25 \\
20 \\
80 \\
32\end{array}$ & $\begin{array}{c}13 \\
12 \\
12 \\
\cdots \\
\cdots \\
\cdots\end{array}$ & $\begin{array}{l}50 \\
71 \\
47 \\
32 \\
22 \\
18\end{array}$ & $\begin{array}{l}21 \\
15 \\
14 \\
16 \\
9.1 \\
\cdots\end{array}$ & $\begin{array}{l}38 \\
17 \\
5.2 \\
3.0 \\
2.2 \\
1.9\end{array}$ & $\begin{array}{l}.37 \\
.25 \\
.19 \\
.15 \\
.13 \\
\cdots\end{array}$ & $\begin{array}{l}.35 \\
.32 \\
.32 \\
.32 \\
.19 \\
.07\end{array}$ & $\begin{array}{l}.00 \\
.00 \\
.00 \\
.00 \\
.00 \\
.39\end{array}$ & $\begin{array}{l}.00 \\
.00 \\
.00 \\
.00 \\
.00 \\
\cdots\end{array}$ \\
\hline $\begin{array}{l}\text { TOIAL } \\
\text { MEAN } \\
\text { MAX } \\
\text { MIN } \\
\text { CF SM } \\
\text { IN. }\end{array}$ & $\begin{array}{r}642.21 \\
20.7 \\
282 \\
.08 \\
.95 \\
1.10\end{array}$ & $\begin{array}{r}604.1 \\
20.1 \\
160 \\
2.0 \\
1.92 \\
1.03\end{array}$ & $\begin{array}{r}3883.8 \\
125 \\
1180 \\
6.3 \\
5.75 \\
6.63\end{array}$ & $\begin{array}{r}1759.20 \\
56.1 \\
318 \\
9.4 \\
2.60 \\
3.00\end{array}$ & $\begin{array}{r}2056 \\
73.4 \\
468 \\
12 \\
3.37 \\
3.51\end{array}$ & $\begin{array}{r}2808.6 \\
90.6 \\
1120 \\
9.1 \\
4.16 \\
4.79\end{array}$ & $\begin{array}{r}938.1 \\
31.3 \\
77 \\
9.1 \\
1.43 \\
1.60\end{array}$ & $\begin{array}{r}278.2 \\
8.97 \\
48 \\
1.9 \\
.41 \\
.47\end{array}$ & $\begin{array}{c}27.52 \\
.92 \\
12 \\
.13 \\
.04 \\
.05\end{array}$ & $\begin{array}{c}394.47 \\
12.7 \\
340 \\
.07 \\
.58 \\
.67\end{array}$ & $\begin{array}{l}1.23 \\
.040 \\
.62 \\
.00 \\
.00 \\
.00\end{array}$ & $\begin{array}{c}32.37 \\
1.08 \\
27 \\
.00 \\
.05 \\
.06\end{array}$ \\
\hline
\end{tabular}

e Estinated

SIAIISIICS OF MONIHLY MEAN DATA FOK WAIEK YLARS 1971 - 1991, BY WAIER YEAR (WY)

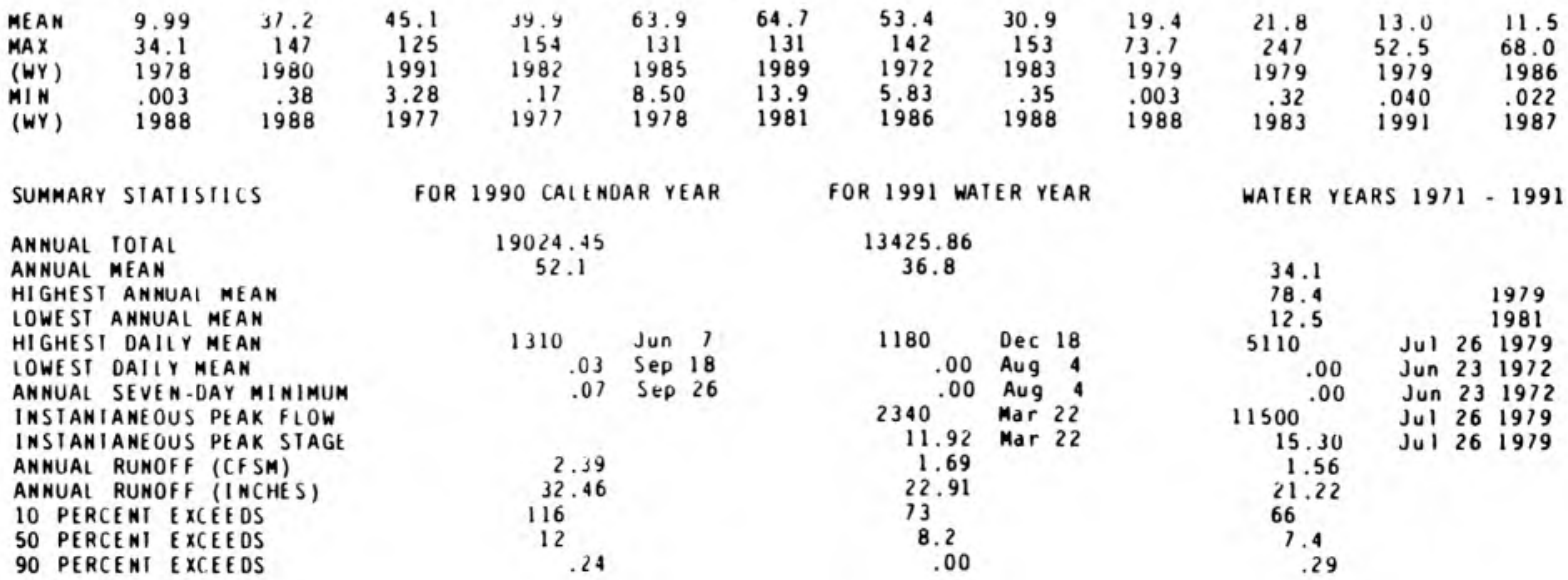


LOCAIION.--Lat $38^{\circ} 22^{\prime} 48^{\prime \prime}$, long 8/\%1j'00", in SW/SWl sec.32, I.1 S., R.7 W., Pike County, Hydrologic Unit 05120209. on right bank at abandoned bridge abutment, $65 \mathrm{ft}$ upstream from bridge on State Highway 61 , 100 ft downstream from da. of Winslow water Company, and 41.3 mi above nouth.

DRAINAGE AREA. -603 : ${ }^{2}$

PERIOD OF RECORD.--October 1963 to September 1974, May 1986 to current year. Discharge aeasureaents and gage readings June 1961 to September 1963, obtained by State of Indiana, Departaent of Matural Resources, are available in the district office.

GAGE. - Water-stage recorder. Datun of gage is $400.00 \mathrm{ft}$ above National Geodetic Vertical Datun of 1929 (levels by State of Indiana, Department of Natural Resources). Prior to Nov, 21, 1963, nonrecording gage on downstreae side of bridge $65 \mathrm{ft}$ downstream at same datun.

REMARKS.--Records good except for estimated daily discharges, which are fair. An average 0.13 ft $3 / \mathrm{s}$ is diverted for unicipal water supply $100 \mathrm{ft}$ above gage.

EXIREMES OUISIDE PERIOD OF RECORD. - - Flood in January 1937 reached a stage of $28.9 \mathrm{ft}$, from floodarks, information from State of Indiana. Department of Natural Resources.

DISCHARGE, CUBIC FEET PER SECOND, WATER YEAR OCIOBER 1990 TO SEPIEMBER 1991 DAIIY MEAN VALUES

\begin{tabular}{|c|c|c|c|c|c|c|c|c|c|c|c|c|}
\hline DAY & $\mathrm{OCI}$ & NOV & DEC & JAN & FEB & MAR & APR & MAY & JUN & JUL & AUG & SEP \\
\hline $\begin{array}{l}1 \\
2 \\
3 \\
4 \\
5\end{array}$ & $\begin{array}{l}402 \\
398 \\
398 \\
744 \\
948\end{array}$ & $\begin{array}{l}306 \\
302 \\
304 \\
358 \\
405\end{array}$ & $\begin{array}{l}1240 \\
1020 \\
1190 \\
1430 \\
1430\end{array}$ & $\begin{array}{l}4090 \\
4420 \\
4450 \\
4160 \\
3730\end{array}$ & $\begin{array}{l}1610 \\
1650 \\
1700 \\
1750 \\
1820\end{array}$ & $\begin{array}{l}1750 \\
1700 \\
1600 \\
1510 \\
1400\end{array}$ & $\begin{array}{l}1870 \\
1600 \\
1460 \\
1380 \\
1370\end{array}$ & $\begin{array}{l}323 \\
278 \\
222 \\
189 \\
187\end{array}$ & $\begin{array}{r}107 \\
94 \\
92 \\
431 \\
261\end{array}$ & $\begin{array}{r}43 \\
45 \\
52 \\
141 \\
100\end{array}$ & $\begin{array}{l}32 \\
32 \\
30 \\
29 \\
28\end{array}$ & $\begin{array}{l}37 \\
35 \\
36 \\
47 \\
82\end{array}$ \\
\hline $\begin{array}{r}6 \\
7 \\
8 \\
9 \\
10\end{array}$ & $\begin{array}{r}721 \\
438 \\
306 \\
542 \\
1280\end{array}$ & $\begin{array}{l}485 \\
520 \\
473 \\
439 \\
448\end{array}$ & $\begin{array}{r}1390 \\
1180 \\
895 \\
644 \\
529\end{array}$ & $\begin{array}{l}3520 \\
3490 \\
3270 \\
3100 \\
3090\end{array}$ & $\begin{array}{l}2430 \\
2660 \\
2780 \\
3170 \\
3520\end{array}$ & $\begin{array}{r}1290 \\
1190 \\
1110 \\
1010 \\
824\end{array}$ & $\begin{array}{l}1340 \\
1310 \\
1320 \\
1320 \\
1280\end{array}$ & $\begin{array}{l}208 \\
236 \\
197 \\
174 \\
166\end{array}$ & $\begin{array}{r}175 \\
93 \\
69 \\
60 \\
55\end{array}$ & $\begin{array}{l}57 \\
46 \\
44 \\
44 \\
46\end{array}$ & $\begin{array}{l}27 \\
25 \\
27 \\
31 \\
32\end{array}$ & $\begin{array}{r}247 \\
154 \\
70 \\
47 \\
\text { e } 40\end{array}$ \\
\hline $\begin{array}{l}11 \\
12 \\
13 \\
14 \\
15\end{array}$ & $\begin{array}{r}1400 \\
1380 \\
1280 \\
940 \\
587\end{array}$ & $\begin{array}{l}473 \\
446 \\
450 \\
452 \\
440\end{array}$ & $\begin{array}{r}632 \\
776 \\
887 \\
941 \\
1040\end{array}$ & $\begin{array}{l}3220 \\
3290 \\
3160 \\
2930 \\
2650\end{array}$ & $\begin{array}{l}3650 \\
3590 \\
3440 \\
3620 \\
3530\end{array}$ & $\begin{array}{r}556 \\
398 \\
749 \\
1440 \\
1530\end{array}$ & $\begin{array}{l}1270 \\
1260 \\
1280 \\
1300 \\
1370\end{array}$ & $\begin{array}{l}182 \\
364 \\
452 \\
311 \\
226\end{array}$ & $\begin{array}{l}52 \\
51 \\
48 \\
44 \\
43\end{array}$ & $\begin{array}{r}260 \\
290 \\
134 \\
85 \\
e 54\end{array}$ & $\begin{array}{l}32 \\
33 \\
33 \\
34 \\
34\end{array}$ & $\begin{array}{l}\text { e } 34 \\
\text { e } 31 \\
\text { e29 } \\
429 \\
t 28\end{array}$ \\
\hline $\begin{array}{l}16 \\
17 \\
18 \\
19 \\
20\end{array}$ & $\begin{array}{l}319 \\
286 \\
324 \\
523 \\
495\end{array}$ & $\begin{array}{l}426 \\
416 \\
424 \\
473 \\
490\end{array}$ & $\begin{array}{l}1140 \\
1170 \\
2400 \\
2860 \\
2620\end{array}$ & $\begin{array}{l}2410 \\
2220 \\
2070 \\
1960 \\
1870\end{array}$ & $\begin{array}{l}3410 \\
3350 \\
3410 \\
3430 \\
3360\end{array}$ & $\begin{array}{l}1530 \\
1570 \\
2050 \\
1950 \\
1890\end{array}$ & $\begin{array}{l}1310 \\
1350 \\
1320 \\
1400 \\
1380\end{array}$ & $\begin{array}{l}215 \\
190 \\
184 \\
154 \\
124\end{array}$ & $\begin{array}{l}43 \\
43 \\
52 \\
51 \\
48\end{array}$ & $\begin{array}{l}\text { e } 46 \\
\text { e } 41 \\
\text { e } 38 \\
\text { e } 37 \\
\text { e } 36\end{array}$ & $\begin{array}{l}32 \\
32 \\
34 \\
34 \\
35\end{array}$ & $\begin{array}{l}\text { e } 28 \\
\text { e } 30 \\
\text { e } 31 \\
\text { e } 30 \\
\text { e } 29\end{array}$ \\
\hline $\begin{array}{l}21 \\
22 \\
23 \\
24 \\
25\end{array}$ & $\begin{array}{l}372 \\
387 \\
527 \\
584 \\
510\end{array}$ & $\begin{array}{r}489 \\
712 \\
1170 \\
1230 \\
1130\end{array}$ & $\begin{array}{l}2990 \\
3650 \\
4070 \\
4160 \\
3950\end{array}$ & $\begin{array}{l}1760 \\
1660 \\
1590 \\
1520 \\
1450\end{array}$ & $\begin{array}{l}3300 \\
3210 \\
3060 \\
2850 \\
2600\end{array}$ & $\begin{array}{l}1870 \\
2930 \\
3690 \\
3720 \\
4290\end{array}$ & $\begin{array}{r}1260 \\
1040 \\
819 \\
739 \\
668\end{array}$ & $\begin{array}{r}111 \\
106 \\
101 \\
94 \\
145\end{array}$ & $\begin{array}{r}59 \\
88 \\
157 \\
97 \\
65\end{array}$ & $\begin{array}{l}\text { e } 37 \\
\text { e } 39 \\
\text { e } 37 \\
\text { e } 36 \\
\text { e } 35\end{array}$ & $\begin{array}{l}35 \\
33 \\
32 \\
31 \\
31\end{array}$ & $\begin{array}{l}\text { e } 30 \\
e 29 \\
e 30 \\
\text { e28 } \\
\text { e27 }\end{array}$ \\
\hline $\begin{array}{l}26 \\
27 \\
28 \\
29 \\
30 \\
31\end{array}$ & $\begin{array}{l}433 \\
376 \\
281 \\
202 \\
222 \\
297\end{array}$ & $\begin{array}{r}879 \\
690 \\
1060 \\
1390 \\
1370 \\
\cdots\end{array}$ & $\begin{array}{l}3580 \\
3050 \\
2520 \\
2670 \\
3560 \\
3880\end{array}$ & $\begin{array}{l}1410 \\
1380 \\
1410 \\
1430 \\
1550 \\
1590\end{array}$ & $\begin{array}{r}2350 \\
2140 \\
1920 \\
\ldots \\
\ldots \\
\ldots\end{array}$ & $\begin{array}{l}4940 \\
4840 \\
4300 \\
3620 \\
2850 \\
2220\end{array}$ & $\begin{array}{l}537 \\
440 \\
386 \\
371 \\
357 \\
\cdots\end{array}$ & $\begin{array}{l}595 \\
574 \\
381 \\
228 \\
160 \\
127\end{array}$ & $\begin{array}{l}59 \\
51 \\
46 \\
43 \\
43 \\
--\end{array}$ & $\begin{array}{r}\text { e } 34 \\
\text { e33 } \\
33 \\
33 \\
32 \\
32\end{array}$ & $\begin{array}{l}31 \\
31 \\
32 \\
32 \\
38 \\
39\end{array}$ & $\begin{array}{l}\text { e27 } \\
\text { e } 27 \\
\text { e26 } \\
\text { e } 24 \\
\text { e23 } \\
-\cdots\end{array}$ \\
\hline $\begin{array}{l}\text { IOIAL } \\
\text { MEAN } \\
\text { MAX } \\
\text { MIN } \\
\text { CF SM } \\
\text { IN. }\end{array}$ & $\begin{array}{r}17962 \\
579 \\
1400 \\
202 \\
.96 \\
1.11\end{array}$ & $\begin{array}{r}18650 \\
622 \\
1390 \\
302 \\
1.03 \\
1.15\end{array}$ & $\begin{array}{r}63494 \\
2048 \\
4160 \\
529 \\
3.40 \\
3.92\end{array}$ & $\begin{array}{r}79850 \\
2576 \\
4450 \\
1380 \\
4.27 \\
4.93\end{array}$ & $\begin{array}{r}79310 \\
2832 \\
3650 \\
1610 \\
4.10 \\
4.89\end{array}$ & $\begin{array}{r}66317 \\
2139 \\
4940 \\
398 \\
3.55 \\
4.09\end{array}$ & $\begin{array}{r}34167 \\
1139 \\
1870 \\
357 \\
1.89 \\
2.11\end{array}$ & $\begin{array}{r}1204 \\
232 \\
595 \\
94 \\
.39 \\
.44\end{array}$ & $\begin{array}{r}2620 \\
87.3 \\
431 \\
43 \\
.14 \\
.16\end{array}$ & $\begin{array}{r}2020 \\
65.2 \\
290 \\
32 \\
.11 \\
.12\end{array}$ & $\begin{array}{r}991 \\
32.0 \\
39 \\
25 \\
.05 \\
.06\end{array}$ & $\begin{array}{c}1365 \\
45.5 \\
247 \\
23 \\
.08 \\
.08\end{array}$ \\
\hline
\end{tabular}

e Lstimated

SIAIISIICS OF MONIHLY MEAN DATA FOR WAIER YLARS 1964 - 1991, BY WATER YEAR (WY)

\begin{tabular}{|c|c|c|c|c|c|c|c|c|c|c|c|c|}
\hline $\begin{array}{l}\text { MEAN } \\
\text { MAX } \\
\text { (WY) } \\
\text { MIN } \\
\text { (WY) }\end{array}$ & $\begin{array}{r}120 \\
579 \\
1991 \\
2.84 \\
1965\end{array}$ & $\begin{array}{r}316 \\
959 \\
1989 \\
6.83 \\
1964\end{array}$ & $\begin{array}{r}709 \\
2048 \\
1991 \\
13.8 \\
1964\end{array}$ & $\begin{array}{r}985 \\
2576 \\
1991 \\
56.3 \\
1964\end{array}$ & $\begin{array}{l}1414 \\
2832 \\
1991 \\
45.5 \\
1964\end{array}$ & $\begin{array}{r}1706 \\
5126 \\
1964 \\
428 \\
1969\end{array}$ & $\begin{array}{r}1510 \\
3426 \\
1972 \\
349 \\
1967\end{array}$ & $\begin{array}{r}924 \\
2909 \\
1990 \\
85.7 \\
1988\end{array}$ & $\begin{array}{r}410 \\
1360 \\
1990 \\
13.4 \\
1972\end{array}$ & $\begin{array}{r}269 \\
1305 \\
1969 \\
13.5 \\
1966\end{array}$ & $\begin{array}{r}148 \\
457 \\
1990 \\
7.46 \\
1965\end{array}$ & $\begin{array}{r}147 \\
408 \\
1974 \\
.94 \\
1972\end{array}$ \\
\hline
\end{tabular}

$\begin{array}{lll}1964 & 1964 & 1964\end{array}$

SUMMARY SIATISIICS

ANNUAL TOTAL

ANNUAL MEAM

HIGHESI ANNUAL MEAN

LOWEST ANHUAL MEAN

HIGHEST DAILY MEAN

LOWEST DAIIY MEAN

ANNUAL SEVEN-DAY MINIMUM

INSTANIANEOUS PEAK FLOW

INSIANTANE OUS PEAK SIAGE

ANMUAL RUNOFF (CFSM)

ANNUAL RUNOFF (INCHES)

10 PERCENT EXLEEDS

50 PERCENT EXCEEOS

90 PERCENT EXCEEDS
FOR 1990 CALENDAR YEAR

$\begin{aligned} 444409 & \\ 1218 & \\ & \\ 7590 & \text { May } 20 \\ 169 & \text { Sep } 11 \\ 237 & \text { Sep } 10 \\ & \\ 2.02 & \\ 27.42 & \\ 2110 & \\ 806 & \\ 336 & \end{aligned}$

FOR 1991 WATER YEAR

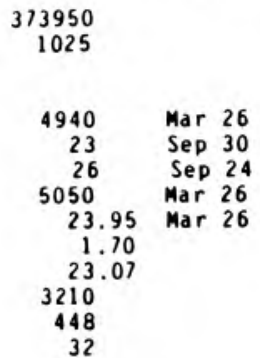

WAIER YEARS $1964-1991$

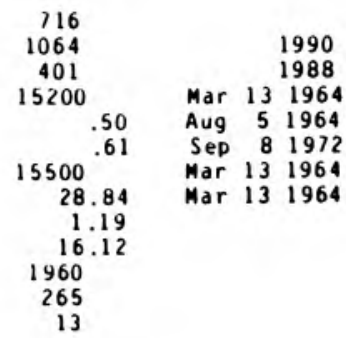




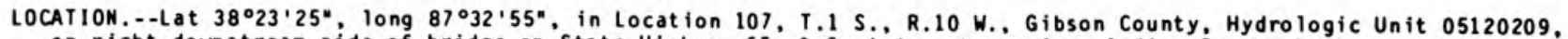
on right downstreas side of bridge on State Highwy $65,0.5$ i downstrea fro Indian Creek, 2 ai northeast of Princeton, and at ile 21.4 .

DRAINAGE AREA $\ldots 822$ i

PERIOD OF RECORD.--August 1934 to current year. Published as "at Patoka" August 1934 to Septeaber 1940. Records published for both sites October 1939 to Septeaber 1940 (monthly discharge only at present site. for October. Movenber 1939. published in WSP 1305).

REVISED RECORDS.-.WSP 1275: 1952. WSP 1335: 1935-36, 1938-39, 1949(M), 1940-50. WSP 1385: 1951-52. WSP 2109: Drainage area.

GAGE. - Water-stage recorder and Data-Collection Platfora. Datua of gage is $390.00 \mathrm{ft}$ above Mational Geodetic Vertical Datus of 1929. Jan. 21, 1941 to 0ct. 23, 1986, water-stage recorder at dav 0.1 d downstrea and at datue 4.14 ft higher. See WSP 1725 for history of changes prior to Jan. $21,1941$.

REMARKS. - Records good except for estieated daily discharges, which are fair. Flow regulated by Patoka Lake.

DISCHARGE, CUBIC FEET PER SECOND, WATER YEAR OCTOBER 1990 TO SEPTEMBER 1991 DAI IY MEAM VALUES

\begin{tabular}{|c|c|c|c|c|c|c|c|c|c|c|c|c|}
\hline DAY & OCT & NOV & DEC & JAN & FEB & MAR & APR & MAY & JUN & JUL & AUG & SEP \\
\hline $\begin{array}{l}1 \\
2 \\
3 \\
4 \\
5\end{array}$ & $\begin{array}{r}420 \\
419 \\
421 \\
1210 \\
1120\end{array}$ & $\begin{array}{l}328 \\
330 \\
322 \\
345 \\
422\end{array}$ & $\begin{array}{l}1520 \\
1480 \\
1460 \\
1470 \\
1510\end{array}$ & $\begin{array}{r}4880 \\
4830 \\
\text { e } 4810 \\
\text { e } 4780 \\
\text { e } 4870\end{array}$ & $\begin{array}{l}1820 \\
1830 \\
1840 \\
1850 \\
1910\end{array}$ & $\begin{array}{l}2840 \\
2700 \\
2550 \\
2400 \\
2270\end{array}$ & $\begin{array}{l}3840 \\
3510 \\
3130 \\
2770 \\
2510\end{array}$ & $\begin{array}{l}443 \\
388 \\
332 \\
290 \\
285\end{array}$ & $\begin{array}{l}182 \\
176 \\
211 \\
937 \\
688\end{array}$ & $\begin{array}{l}75 \\
114 \\
150 \\
143 \\
168\end{array}$ & $\begin{array}{l}54 \\
52 \\
52 \\
52 \\
53\end{array}$ & $\begin{array}{r}70 \\
66 \\
56 \\
106 \\
146\end{array}$ \\
\hline $\begin{array}{r}6 \\
7 \\
8 \\
9 \\
10\end{array}$ & $\begin{array}{r}1060 \\
735 \\
454 \\
720 \\
1450\end{array}$ & $\begin{array}{l}522 \\
556 \\
540 \\
491 \\
480\end{array}$ & $\begin{array}{r}1530 \\
1530 \\
1450 \\
1200 \\
824\end{array}$ & $\begin{array}{r}\text { e } 4950 \\
\text { e } 4900 \\
4880 \\
4740 \\
4580\end{array}$ & $\begin{array}{l}2450 \\
2530 \\
2590 \\
2670 \\
2750\end{array}$ & $\begin{array}{l}2130 \\
1940 \\
1750 \\
1570 \\
1410\end{array}$ & $\begin{array}{l}2280 \\
2060 \\
1900 \\
1760 \\
1640\end{array}$ & $\begin{array}{l}309 \\
314 \\
293 \\
257 \\
241\end{array}$ & $\begin{array}{l}390 \\
244 \\
172 \\
144 \\
132\end{array}$ & $\begin{array}{r}114 \\
88 \\
78 \\
73 \\
233\end{array}$ & $\begin{array}{l}56 \\
50 \\
47 \\
49 \\
56\end{array}$ & $\begin{array}{r}216 \\
224 \\
126 \\
81 \\
71\end{array}$ \\
\hline $\begin{array}{l}11 \\
12 \\
13 \\
14 \\
15\end{array}$ & $\begin{array}{l}1470 \\
1480 \\
1490 \\
1450 \\
1210\end{array}$ & $\begin{array}{l}493 \\
492 \\
473 \\
475 \\
466\end{array}$ & $\begin{array}{r}673 \\
771 \\
889 \\
962 \\
1090\end{array}$ & $\begin{array}{l}4530 \\
4400 \\
4200 \\
4070 \\
3910\end{array}$ & $\begin{array}{l}2840 \\
2980 \\
3180 \\
3670 \\
3720\end{array}$ & $\begin{array}{r}1180 \\
886 \\
1200 \\
1620 \\
1660\end{array}$ & $\begin{array}{l}1560 \\
1510 \\
1520 \\
1520 \\
1610\end{array}$ & $\begin{array}{l}248 \\
531 \\
571 \\
497 \\
378\end{array}$ & $\begin{array}{l}128 \\
120 \\
113 \\
107 \\
103\end{array}$ & $\begin{array}{r}116 \\
351 \\
227 \\
124 \\
95\end{array}$ & $\begin{array}{l}55 \\
55 \\
55 \\
68 \\
94\end{array}$ & $\begin{array}{l}66 \\
57 \\
53 \\
54 \\
54\end{array}$ \\
\hline $\begin{array}{l}16 \\
17 \\
18 \\
19 \\
20\end{array}$ & $\begin{array}{l}826 \\
491 \\
386 \\
447 \\
567\end{array}$ & $\begin{array}{l}455 \\
441 \\
433 \\
459 \\
501\end{array}$ & $\begin{array}{l}1200 \\
1310 \\
1950 \\
2130 \\
2260\end{array}$ & $\begin{array}{l}3750 \\
3570 \\
3390 \\
3170 \\
2970\end{array}$ & $\begin{array}{l}3790 \\
3880 \\
3990 \\
4050 \\
3980\end{array}$ & $\begin{array}{l}1730 \\
2000 \\
2380 \\
2340 \\
2370\end{array}$ & $\begin{array}{l}1590 \\
1590 \\
1560 \\
1540 \\
1550\end{array}$ & $\begin{array}{l}318 \\
308 \\
269 \\
252 \\
218\end{array}$ & $\begin{array}{r}99 \\
100 \\
102 \\
109 \\
107\end{array}$ & $\begin{array}{l}84 \\
73 \\
66 \\
63 \\
62\end{array}$ & $\begin{array}{l}65 \\
58 \\
65 \\
60 \\
56\end{array}$ & $\begin{array}{l}52 \\
51 \\
51 \\
57 \\
54\end{array}$ \\
\hline $\begin{array}{l}21 \\
22 \\
23 \\
24 \\
25\end{array}$ & $\begin{array}{l}475 \\
416 \\
514 \\
621 \\
609\end{array}$ & $\begin{array}{r}509 \\
785 \\
1170 \\
1260 \\
1290\end{array}$ & $\begin{array}{l}2550 \\
2860 \\
3060 \\
3240 \\
3430\end{array}$ & $\begin{array}{l}2750 \\
2600 \\
2470 \\
2340 \\
2200\end{array}$ & $\begin{array}{l}3920 \\
3820 \\
3690 \\
3590 \\
3460\end{array}$ & $\begin{array}{l}2400 \\
2920 \\
3470 \\
3680 \\
3890\end{array}$ & $\begin{array}{l}1560 \\
1510 \\
1370 \\
1210 \\
1040\end{array}$ & $\begin{array}{l}193 \\
181 \\
174 \\
170 \\
198\end{array}$ & $\begin{array}{l}179 \\
209 \\
222 \\
182 \\
127\end{array}$ & $\begin{array}{l}60 \\
60 \\
62 \\
61 \\
58\end{array}$ & $\begin{array}{l}58 \\
58 \\
54 \\
51 \\
50\end{array}$ & $\begin{array}{l}55 \\
56 \\
55 \\
56 \\
53\end{array}$ \\
\hline $\begin{array}{l}26 \\
27 \\
28 \\
29 \\
30 \\
31\end{array}$ & $\begin{array}{l}520 \\
450 \\
382 \\
288 \\
235 \\
283\end{array}$ & $\begin{array}{c}1230 \\
1010 \\
1470 \\
1490 \\
1510 \\
\ldots\end{array}$ & $\begin{array}{r}3590 \\
3670 \\
3680 \\
4000 \\
\mathrm{e} 4850 \\
4930\end{array}$ & $\begin{array}{l}2050 \\
1910 \\
1830 \\
1760 \\
1850 \\
1810\end{array}$ & $\begin{array}{c}3320 \\
3180 \\
3010 \\
\ldots \\
\ldots \\
\ldots\end{array}$ & $\begin{array}{l}4050 \\
4120 \\
4160 \\
4200 \\
4140 \\
4060\end{array}$ & $\begin{array}{l}834 \\
671 \\
586 \\
548 \\
515 \\
\ldots .\end{array}$ & $\begin{array}{l}499 \\
717 \\
560 \\
366 \\
258 \\
207\end{array}$ & $\begin{array}{r}105 \\
97 \\
88 \\
81 \\
78 \\
\cdots-\end{array}$ & $\begin{array}{l}56 \\
54 \\
52 \\
53 \\
53 \\
53\end{array}$ & $\begin{array}{l}49 \\
49 \\
53 \\
53 \\
54 \\
60\end{array}$ & $\begin{array}{r}51 \\
52 \\
49 \\
46 \\
45 \\
- \\
-\end{array}$ \\
\hline $\begin{array}{l}\text { TOTAL } \\
\text { MEAN } \\
\text { MAX } \\
\text { MIN } \\
\text { CF SM } \\
\text { IN. }\end{array}$ & $\begin{array}{r}22619 \\
730 \\
1490 \\
235 \\
.89 \\
1.02\end{array}$ & $\begin{array}{r}20748 \\
692 \\
1510 \\
322 \\
.84 \\
.94\end{array}$ & $\begin{array}{r}67069 \\
2164 \\
4930 \\
673 \\
2.63 \\
3.04\end{array}$ & $\begin{array}{r}109750 \\
3540 \\
4950 \\
1760 \\
4.31 \\
4.97\end{array}$ & $\begin{array}{r}86310 \\
3082 \\
4050 \\
1820 \\
3.75 \\
3.91\end{array}$ & $\begin{array}{r}80016 \\
2581 \\
4200 \\
886 \\
3.14 \\
3.62\end{array}$ & $\begin{array}{r}50794 \\
1693 \\
3840 \\
515 \\
2.06 \\
2.30\end{array}$ & $\begin{array}{c}10265 \\
331 \\
717 \\
170 \\
.40 \\
.46\end{array}$ & $\begin{array}{c}5732 \\
191 \\
937 \\
78 \\
.23 \\
.26\end{array}$ & $\begin{array}{c}3119 \\
101 \\
351 \\
52 \\
.12 \\
.14\end{array}$ & $\begin{array}{r}1741 \\
56.2 \\
94 \\
47 \\
.07 \\
.08\end{array}$ & $\begin{array}{r}2229 \\
74.3 \\
224 \\
45 \\
.09 \\
.10\end{array}$ \\
\hline
\end{tabular}

STATISTICS OF MONTHLY MEAN DATA FOR WATER YEARS 1935 - 1991, BY WATER YEAR (WY)

\begin{tabular}{|c|c|c|c|c|c|c|c|c|c|c|c|c|}
\hline $\begin{array}{l}\text { MEAN } \\
\text { MAX } \\
\text { (WY) } \\
\text { MIN } \\
\text { (WY) }\end{array}$ & $\begin{array}{r}248 \\
2573 \\
1946 \\
1.53 \\
1943\end{array}$ & $\begin{array}{r}493 \\
2501 \\
1986 \\
9.83 \\
1944\end{array}$ & $\begin{array}{r}963 \\
3735 \\
1952 \\
10.2 \\
1944\end{array}$ & $\begin{array}{l}1547 \\
8365 \\
1937 \\
44.3 \\
1944\end{array}$ & $\begin{array}{l}1837 \\
5570 \\
1950 \\
64.2 \\
1964\end{array}$ & $\begin{array}{l}2279 \\
8531 \\
1945 \\
61.5 \\
1941\end{array}$ & $\begin{array}{r}2015 \\
4664 \\
1989 \\
373 \\
1976\end{array}$ & $\begin{array}{r}1409 \\
6810 \\
1961 \\
117 \\
1941\end{array}$ & $\begin{array}{r}749 \\
3172 \\
1957 \\
7.93 \\
1936\end{array}$ & $\begin{array}{r}437 \\
3075 \\
1958 \\
15.0 \\
1944\end{array}$ & $\begin{array}{r}314 \\
3915 \\
1979 \\
4.60 \\
1936\end{array}$ & $\begin{array}{r}214 \\
1125 \\
1979 \\
8.12 \\
1942\end{array}$ \\
\hline
\end{tabular}

\section{SUMMARY STATISTICS}

AMNUAL TOTAL

ANMUAL MEAM

HIGHEST ANMUAL MEAN

LOWEST ANNUAL MEAN

HIGHEST DAILY MEAN

LOWEST DAILY MEAN

ANMUAL SEVEN-DAY MINIMUM

INSTANTANEOUS PEAK FLOW

INSTANTANEOUS PEAK STAGE

ANNUAL RUNOFF (CFSM)

ANMUAL RUNOFF (I NCHES)

10 PERCENT EXCEEDS

50 PERCENT EXCEEDS

90 PERCENT EXCEEDS
FOR 1990 CALENOAR YEAR

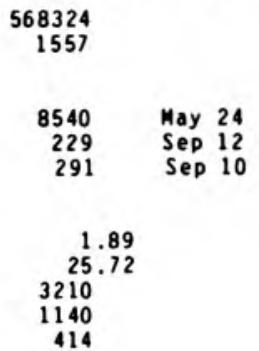

FOR 1991 WATER YEAR

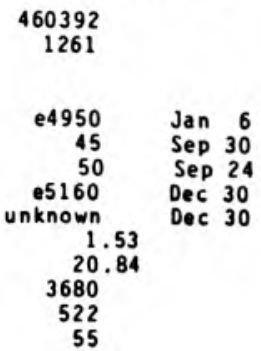

WATER YEARS 1935 - 1991

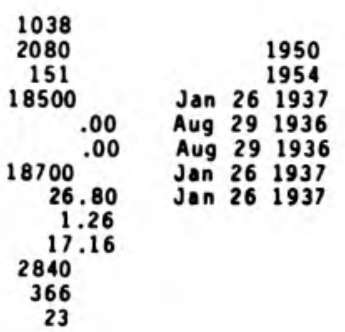




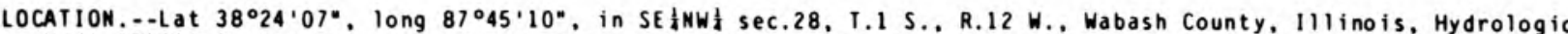
Unit 05120113 , on right bank on downstrea side of Southern Railway bridge at Mount Carmel, 0.2 ei downstrea fro. Patoka River, and at 1 ile 94.4 .

DRAI NAGE AREA, $--28,635 . i^{2}$

PERIOD OF RECORD.--January 1908 to Septenber 1913 (gage heights only), October 1927 to current year. Gage-height records collected in this vicinity Noveaber 1874 to Deceaber 1878, are contained in files of Louisvilie office of the U.S. Aray Corps of Engineers and since June 1884, are contained in reports of National Weather Service. REVISED RECORDS.--WDR IN-73-1: Drainage area.

GAGE. - - Water-stage recorder. Datun of gage is $369.46 \mathrm{ft}$ above National Geodetic Vertical Datue of 1929 . Oct. 1. 1949, to Feb. 8, 1977 , at datue $2.00 \mathrm{ft}$ higher. See WSP 1725 for history of changes prior to Sept. 30.1949 . REMARKS.--Records good. Flow partially regulated by upstrean reservoirs.

EXTREMES OUTSIDE THE PERIOD OF RECORD.--(1874-78, 1884 to 1985) Maxieum discharge, $428,000 \mathrm{ft} 3 / \mathrm{s}$ Mar. $30,1913$. from rating curve extended above $310,000 \mathrm{ft} / \mathrm{s}$, gage height, $33.0 \mathrm{ft}$, present site and datul.

DISCHARGE, CUBIC FEET PER SECONO, WATER YEAR OCTOBER 1990 TO SEPTEMBER 1991 DAILY MEAM VALUES

\begin{tabular}{|c|c|c|c|c|c|c|c|c|c|c|c|c|}
\hline DAY & $O C T$ & MOV & DEC & JAN & FEB & MAR & APR & MAY & JUN & JUL & AUG & SEP \\
\hline $\begin{array}{l}1 \\
2 \\
3 \\
4 \\
5\end{array}$ & $\begin{array}{r}9000 \\
8690 \\
8500 \\
10600 \\
13300\end{array}$ & $\begin{array}{l}19300 \\
18500 \\
17700 \\
16500 \\
15400\end{array}$ & $\begin{array}{l}51100 \\
52700 \\
53800 \\
52800 \\
52500\end{array}$ & $\begin{array}{l}\text { e } 112000 \\
\text { el } 28000 \\
\text { e151000 } \\
\text { e1 } 18000 \\
\text { e } 205000\end{array}$ & $\begin{array}{l}48000 \\
45500 \\
43200 \\
41300 \\
40300\end{array}$ & $\begin{array}{l}39900 \\
37400 \\
36400 \\
36400 \\
35700\end{array}$ & $\begin{array}{l}99800 \\
95200 \\
87900 \\
76900 \\
63600\end{array}$ & $\begin{array}{l}30900 \\
29200 \\
27800 \\
26700 \\
25600\end{array}$ & $\begin{array}{l}25100 \\
24600 \\
25500 \\
29400 \\
32100\end{array}$ & $\begin{array}{l}8280 \\
8090 \\
8250 \\
8140 \\
7650\end{array}$ & $\begin{array}{l}4790 \\
4710 \\
4580 \\
4570 \\
4480\end{array}$ & $\begin{array}{l}4210 \\
3960 \\
3960 \\
4620 \\
4220\end{array}$ \\
\hline $\begin{array}{r}6 \\
7 \\
8 \\
9 \\
10\end{array}$ & $\begin{array}{l}13800 \\
13300 \\
13600 \\
14900 \\
21200\end{array}$ & $\begin{array}{l}14700 \\
15800 \\
20100 \\
24600 \\
26500\end{array}$ & $\begin{array}{l}54000 \\
54300 \\
54500 \\
53600 \\
49600\end{array}$ & $\begin{array}{r}\text { e221000 } \\
e 224000 \\
\text { e218000 } \\
\text { e2200000 } \\
178000\end{array}$ & $\begin{array}{l}46700 \\
58800 \\
65000 \\
68800 \\
71300\end{array}$ & $\begin{array}{l}35100 \\
34200 \\
32700 \\
31000 \\
29400\end{array}$ & $\begin{array}{l}51100 \\
43600 \\
40000 \\
39700 \\
38500\end{array}$ & $\begin{array}{l}25000 \\
25100 \\
25800 \\
26200 \\
25800\end{array}$ & $\begin{array}{l}32300 \\
29900 \\
26500 \\
23500 \\
21300\end{array}$ & $\begin{array}{l}7500 \\
7580 \\
7700 \\
7620 \\
7800\end{array}$ & $\begin{array}{l}4390 \\
4600 \\
5620 \\
6930 \\
5870\end{array}$ & $\begin{array}{l}4520 \\
4470 \\
4430 \\
4820 \\
5270\end{array}$ \\
\hline $\begin{array}{l}11 \\
12 \\
13 \\
14 \\
15\end{array}$ & $\begin{array}{l}28700 \\
36700 \\
42000 \\
45100 \\
46500\end{array}$ & $\begin{array}{l}25600 \\
23300 \\
21200 \\
19800 \\
18700\end{array}$ & $\begin{array}{l}43600 \\
38500 \\
34800 \\
31700 \\
29400\end{array}$ & $\begin{array}{r}154000 \\
132000 \\
114000 \\
102000 \\
94100\end{array}$ & $\begin{array}{l}72600 \\
73700 \\
74900 \\
76600 \\
74900\end{array}$ & $\begin{array}{l}27700 \\
26400 \\
28800 \\
39000 \\
48000\end{array}$ & $\begin{array}{l}37600 \\
36100 \\
35900 \\
37900 \\
42500\end{array}$ & $\begin{array}{l}24300 \\
23800 \\
23500 \\
21900 \\
20800\end{array}$ & $\begin{array}{l}19400 \\
17400 \\
15500 \\
14100 \\
13100\end{array}$ & $\begin{array}{r}7550 \\
7660 \\
9960 \\
12800 \\
13200\end{array}$ & $\begin{array}{l}5730 \\
5710 \\
5590 \\
5420 \\
5360\end{array}$ & $\begin{array}{l}4860 \\
4450 \\
4150 \\
3910 \\
3750\end{array}$ \\
\hline $\begin{array}{l}16 \\
17 \\
18 \\
19 \\
20\end{array}$ & $\begin{array}{l}46500 \\
45300 \\
43600 \\
42600 \\
41800\end{array}$ & $\begin{array}{l}17700 \\
16900 \\
16200 \\
15700 \\
15400\end{array}$ & $\begin{array}{l}28000 \\
29000 \\
37700 \\
53500 \\
62000\end{array}$ & $\begin{array}{l}88500 \\
84600 \\
82400 \\
80600 \\
78900\end{array}$ & $\begin{array}{l}70500 \\
63500 \\
55900 \\
53900 \\
55700\end{array}$ & $\begin{array}{l}54400 \\
57600 \\
65300 \\
71100 \\
75700\end{array}$ & $\begin{array}{l}47800 \\
51100 \\
54700 \\
58600 \\
61300\end{array}$ & $\begin{array}{l}20400 \\
21400 \\
22500 \\
22900 \\
26900\end{array}$ & $\begin{array}{l}12500 \\
12100 \\
11700 \\
11500 \\
11700\end{array}$ & $\begin{array}{r}11300 \\
9670 \\
8540 \\
7860 \\
7370\end{array}$ & $\begin{array}{l}5300 \\
5280 \\
4980 \\
4740 \\
4470\end{array}$ & $\begin{array}{l}3650 \\
3530 \\
3690 \\
3780 \\
3790\end{array}$ \\
\hline $\begin{array}{l}21 \\
22 \\
23 \\
24 \\
25\end{array}$ & $\begin{array}{l}40100 \\
38400 \\
37300 \\
35100 \\
31800\end{array}$ & $\begin{array}{l}15100 \\
15000 \\
15600 \\
16100 \\
16400\end{array}$ & $\begin{array}{l}67100 \\
73300 \\
78500 \\
82400 \\
86200\end{array}$ & $\begin{array}{l}77300 \\
75600 \\
73200 \\
70100 \\
66800\end{array}$ & $\begin{array}{l}57500 \\
57600 \\
57500 \\
58100 \\
57900\end{array}$ & $\begin{array}{l}79600 \\
82200 \\
86100 \\
90800 \\
94500\end{array}$ & $\begin{array}{l}62100 \\
60300 \\
55900 \\
52600 \\
50400\end{array}$ & $\begin{array}{l}30600 \\
31300 \\
29500 \\
26600 \\
23800\end{array}$ & $\begin{array}{l}11800 \\
11800 \\
10900 \\
10800 \\
10600\end{array}$ & $\begin{array}{l}6910 \\
6580 \\
6290 \\
6020 \\
5730\end{array}$ & $\begin{array}{l}4340 \\
4330 \\
4720 \\
5190 \\
5120\end{array}$ & $\begin{array}{l}3830 \\
3860 \\
3890 \\
3890 \\
3890\end{array}$ \\
\hline $\begin{array}{l}26 \\
27 \\
28 \\
29 \\
30 \\
31\end{array}$ & $\begin{array}{l}29000 \\
27000 \\
25100 \\
23400 \\
21800 \\
20400\end{array}$ & $\begin{array}{r}16500 \\
17000 \\
24500 \\
38500 \\
47400 \\
\cdots\end{array}$ & $\begin{array}{r}89800 \\
92700 \\
94100 \\
92700 \\
96600 \\
104000\end{array}$ & $\begin{array}{l}63500 \\
60400 \\
57300 \\
54400 \\
52400 \\
50400\end{array}$ & $\begin{array}{r}55700 \\
51000 \\
44800 \\
\ldots \\
\cdots \\
\cdots\end{array}$ & $\begin{array}{r}98300 \\
102000 \\
106000 \\
107000 \\
106000 \\
104000\end{array}$ & $\begin{array}{r}46800 \\
42400 \\
38700 \\
35900 \\
33200 \\
\ldots\end{array}$ & $\begin{array}{l}23200 \\
25000 \\
25400 \\
24800 \\
24200 \\
24000\end{array}$ & $\begin{array}{r}10200 \\
9480 \\
9070 \\
8780 \\
8490 \\
\ldots\end{array}$ & $\begin{array}{l}5480 \\
5300 \\
5160 \\
5080 \\
4960 \\
4850\end{array}$ & $\begin{array}{l}4800 \\
4600 \\
4400 \\
4340 \\
4110 \\
4120\end{array}$ & $\begin{array}{c}3850 \\
3870 \\
3920 \\
3870 \\
3810 \\
\ldots-\end{array}$ \\
\hline $\begin{array}{l}\text { TOTAL } \\
\text { MEAN } \\
\text { MAX } \\
\text { MIN } \\
\text { CF SM } \\
\text { IN. }\end{array}$ & $\begin{array}{r}875090 \\
28230 \\
46500 \\
8500 \\
.99 \\
1.14\end{array}$ & $\begin{array}{r}601700 \\
20060 \\
47400 \\
14700 \\
.70 \\
.78\end{array}$ & $\begin{array}{r}1874500 \\
60470 \\
104000 \\
28000 \\
2.11 \\
2.44\end{array}$ & $\begin{array}{r}3527500 \\
113800 \\
224000 \\
50400 \\
3.97 \\
4.58\end{array}$ & $\begin{array}{r}1641200 \\
58610 \\
76600 \\
40300 \\
2.05 \\
2.13\end{array}$ & $\begin{array}{r}1898700 \\
61250 \\
107000 \\
26400 \\
2.14 \\
2.47\end{array}$ & $\begin{array}{r}1578100 \\
52600 \\
99800 \\
33200 \\
1.84 \\
2.05\end{array}$ & $\begin{array}{r}784900 \\
25320 \\
31300 \\
20400 \\
.88 \\
1.02\end{array}$ & $\begin{array}{r}511120 \\
17040 \\
32300 \\
8490 \\
.59 \\
.66\end{array}$ & $\begin{array}{r}236880 \\
7641 \\
13200 \\
4850 \\
.27 \\
.31\end{array}$ & $\begin{array}{r}153190 \\
4942 \\
6930 \\
4110 \\
.17 \\
.20\end{array}$ & $\begin{array}{c}122720 \\
4091 \\
5270 \\
3530 \\
.14 \\
.16\end{array}$ \\
\hline
\end{tabular}

STATISTICS OF MONTHLY MEAN DATA FOR WATER YEARS 1928 - 1991, BY WATER YEAR (WY)

\begin{tabular}{|c|c|c|c|c|c|c|c|c|c|c|c|c|}
\hline $\begin{array}{l}\text { MEAN } \\
\text { MAX } \\
\text { (WY) } \\
\text { MIN } \\
(W Y)\end{array}$ & $\begin{array}{r}8990 \\
30700 \\
1946 \\
2465 \\
1941\end{array}$ & $\begin{array}{r}14050 \\
63500 \\
1986 \\
2632 \\
1931\end{array}$ & $\begin{array}{r}25610 \\
92340 \\
1986 \\
2266 \\
1964\end{array}$ & $\begin{array}{r}38130 \\
199300 \\
1950 \\
2861 \\
1977\end{array}$ & $\begin{array}{r}41420 \\
147100 \\
1950 \\
3757 \\
1931\end{array}$ & $\begin{array}{r}51000 \\
108700 \\
1985 \\
4815 \\
1941\end{array}$ & $\begin{array}{r}50550 \\
106400 \\
1938 \\
11900 \\
1941\end{array}$ & $\begin{array}{r}40260 \\
129400 \\
1961 \\
5805 \\
1934\end{array}$ & $\begin{array}{r}26940 \\
74500 \\
1958 \\
5035 \\
1988\end{array}$ & $\begin{array}{c}18290 \\
73580 \\
1958 \\
3366 \\
1936\end{array}$ & $\begin{array}{l}11440 \\
75530 \\
1979 \\
2372 \\
1936\end{array}$ & $\begin{array}{r}8720 \\
50670 \\
1989 \\
2572 \\
1940\end{array}$ \\
\hline
\end{tabular}

SUMMARY STATISTICS

ANMUAL TOTAL

ANNUAL MEAN

HIGHEST ANNUAL MEAK

LOWEST ANNUAL MEAN

HIGHEST DAILY MEAN

LOWEST DAILY MEAN

ANMUAL SEVEN-DAY MINIMUM

INSTANTANEOUS PEAK FLOW

INSTANTANEOUS PEAK STAGE

ANNUAL RUNOFF (CFSM)

ANNUAL RUNOFF (INCHES)

10 PERCENT EXCEEDS

50 PERCENT EXCEEDS

90 PERCENT EXCEEDS
FOR 1990 CALENDAR YEAR

$\begin{array}{rl}15577500 & \\ 42680 & \\ & \\ 199000 & \text { May } 23 \\ 8500 & 0 \text { ct } 3 \\ 9190 & \text { Sed } 27 \\ & \\ & \\ 20.49 & \\ 81300 & \\ 35100 & \\ 15100 & \end{array}$

FOR 1991 WATER YEAR

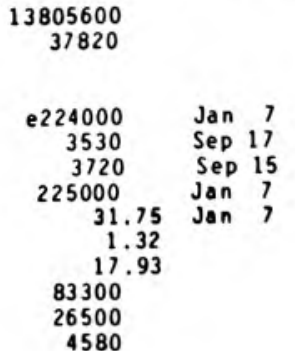

WATER YEARS 1928 - 1991

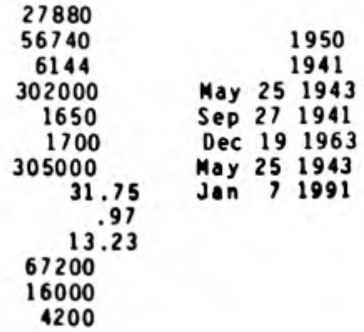


OSSI8SUO WABASH RIVER AT NEW HARMONY, IN

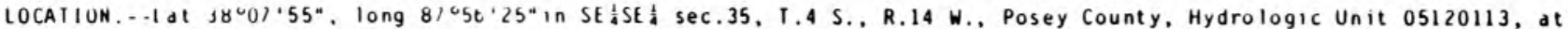
bridge on U.S. Highwdy 66 at New Harmony, dt Indiand-lilinois state line, and at mile 51.5 .

DRAINAGE AREA. $-29,234: 1^{2}$.

PERIOD OF RECORO.--August 1988 to current year. Water discharge published 0ctober 1938 to Septeaber 1947.

GAGE. - Water-stage recorder. Datum of gage is $353.30 \mathrm{ft}$. above National Geodetic Vertical Datua of 1929 . (Furnished by National Weather Service).

REMARKS.--Recurds good. Water-quality data collected October 1974 to September 1986.

EXIREMES FOR PERIOD OF RECORO,--Maximua gage height, $23.84 \mathrm{ft}$. May 26,1943 . Beginning August 1988 , minimua gage height $0.46 \mathrm{ft}$. $0 \mathrm{ct}$. 12,1988 .

EXIREMES OUISIUE PERIOD OF RECORO,..Floos of March 1913 reached a stage of $27.7 \mathrm{ft}$. Flood of Jan. 31 , 1937 , reached a stage of $24.4 \mathrm{ft}$.

EXTREMES FOR CURRENT YEAR..-Maximum gage height, $21.65 \mathrm{ft}$. June 8 ; ainimum gage height, $0.66 \mathrm{ft}$, Sept. 18 .

GAGE HEIGHI, FEET, WAIER YEAR OCTOBER 1990 TO SEPIEMBER 1991 DAILY OBSERVATION AT 24:00 VALUES

\begin{tabular}{|c|c|c|c|c|c|c|c|c|c|c|c|c|}
\hline DAY & $O C T$ & NOV & DEC & JAN & FEB & MAR & $A P R$ & MAY & JUN & JUL & $A \cup G$ & SEP \\
\hline $\begin{array}{l}1 \\
2 \\
3 \\
4 \\
5\end{array}$ & $\begin{array}{l}2.27 \\
2.20 \\
2.30 \\
2.87 \\
3.36\end{array}$ & $\begin{array}{l}4.37 \\
4.20 \\
4.05 \\
3.83 \\
3.60\end{array}$ & $\begin{array}{l}10.13 \\
11.03 \\
11.25 \\
11.17 \\
11.08\end{array}$ & $\begin{array}{r}11.40 \\
17.94 \\
18.66 \\
\ldots \\
\ldots\end{array}$ & $\begin{array}{r}10.66 \\
10.14 \\
9.66 \\
9.24 \\
9.08\end{array}$ & $\begin{array}{l}9.16 \\
8.57 \\
8.23 \\
8.19 \\
8.03\end{array}$ & $\begin{array}{l}16.63 \\
16.43 \\
16.07 \\
15.43 \\
14.10\end{array}$ & $\begin{array}{l}7.00 \\
6.63 \\
6.34 \\
6.08 \\
5.85\end{array}$ & $\begin{array}{l}5.75 \\
5.61 \\
5.74 \\
6.53 \\
7.09\end{array}$ & $\begin{array}{l}2.15 \\
2.08 \\
2.12 \\
2.08 \\
1.96\end{array}$ & $\begin{array}{l}1.10 \\
1.06 \\
1.01 \\
1.00 \\
1.00\end{array}$ & $\begin{array}{r}.93 \\
.85 \\
.83 \\
1.32 \\
1.20\end{array}$ \\
\hline $\begin{array}{r}6 \\
7 \\
8 \\
9 \\
10\end{array}$ & $\begin{array}{l}3.34 \\
3.24 \\
3.31 \\
3.64 \\
4.91\end{array}$ & $\begin{array}{l}3.45 \\
3.61 \\
4.40 \\
5.34 \\
5.77\end{array}$ & $\begin{array}{l}11.27 \\
11.37 \\
11.42 \\
11.32 \\
10.68\end{array}$ & $\begin{array}{l}20.95 \\
21.57 \\
21.52 \\
21.08 \\
20.55\end{array}$ & $\begin{array}{l}10.80 \\
12.53 \\
13.50 \\
14.03 \\
14.33\end{array}$ & $\begin{array}{l}7.89 \\
7.69 \\
7.39 \\
7.03 \\
6.69\end{array}$ & $\begin{array}{r}12.11 \\
10.38 \\
9.41 \\
9.15 \\
8.75\end{array}$ & $\begin{array}{l}5.70 \\
5.72 \\
5.86 \\
5.94 \\
5.88\end{array}$ & $\begin{array}{l}7.16 \\
6.71 \\
6.03 \\
5.42 \\
4.97\end{array}$ & $\begin{array}{l}1.90 \\
1.90 \\
1.94 \\
1.94 \\
1.99\end{array}$ & $\begin{array}{r}.97 \\
.99 \\
1.25 \\
1.66 \\
1.45\end{array}$ & $\begin{array}{r}1.06 \\
1.03 \\
.99 \\
1.07 \\
1.23\end{array}$ \\
\hline $\begin{array}{l}11 \\
12 \\
13 \\
14 \\
15\end{array}$ & $\begin{array}{l}6.34 \\
7.89 \\
8.85 \\
9.44 \\
9.71\end{array}$ & $\begin{array}{l}5.63 \\
5.17 \\
4.74 \\
4.46 \\
4.21\end{array}$ & $\begin{array}{r}9.58 \\
8.53 \\
1.74 \\
1.08 \\
\ldots .\end{array}$ & $\begin{array}{l}19.83 \\
18.98 \\
18.11 \\
17.37 \\
16.83\end{array}$ & $\begin{array}{l}14.42 \\
14.54 \\
14.81 \\
15.03 \\
14.85\end{array}$ & $\begin{array}{r}6.34 \\
6.07 \\
6.70 \\
8.84 \\
10.50\end{array}$ & $\begin{array}{l}8.50 \\
8.21 \\
8.14 \\
8.53 \\
9.46\end{array}$ & $\begin{array}{l}5.59 \\
5.50 \\
5.40 \\
5.08 \\
4.88\end{array}$ & $\begin{array}{l}4.55 \\
4.15 \\
3.77 \\
3.45 \\
3.27\end{array}$ & $\begin{array}{l}1.98 \\
1.91 \\
2.38 \\
3.09 \\
3.17\end{array}$ & $\begin{array}{l}1.36 \\
1.37 \\
1.34 \\
1.28 \\
1.26\end{array}$ & $\begin{array}{r}1.16 \\
1.01 \\
.92 \\
.82 \\
.75\end{array}$ \\
\hline $\begin{array}{l}16 \\
17 \\
18 \\
19 \\
20\end{array}$ & $\begin{array}{l}9.12 \\
9.48 \\
9.18 \\
9.02 \\
8.86\end{array}$ & $\begin{array}{l}4.02 \\
3.86 \\
3.73 \\
3.63 \\
3.57\end{array}$ & $\begin{array}{r}6.27 \\
6.47 \\
8.62 \\
11.25 \\
12.71\end{array}$ & $\begin{array}{l}16.32 \\
15.96 \\
15.10 \\
15.48 \\
15.30\end{array}$ & $\begin{array}{l}14.85 \\
13.65 \\
12.65 \\
12.14 \\
12.16\end{array}$ & $\begin{array}{l}11.67 \\
12.50 \\
13.59 \\
14.31 \\
14.74\end{array}$ & $\begin{array}{l}10.38 \\
10.96 \\
11.63 \\
12.28 \\
12.79\end{array}$ & $\begin{array}{l}4.80 \\
4.94 \\
5.18 \\
5.28 \\
6.13\end{array}$ & $\begin{array}{l}3.13 \\
3.04 \\
2.94 \\
2.89 \\
2.93\end{array}$ & $\begin{array}{l}2.82 \\
2.48 \\
2.21 \\
2.02 \\
1.88\end{array}$ & $\begin{array}{r}1.23 \\
1.25 \\
1.15 \\
1.06 \\
.99\end{array}$ & $\begin{array}{l}.10 \\
.67 \\
.11 \\
.73 \\
.75\end{array}$ \\
\hline $\begin{array}{l}21 \\
22 \\
23 \\
24 \\
25\end{array}$ & $\begin{array}{l}8.52 \\
8.22 \\
8.04 \\
7.62 \\
6.99\end{array}$ & $\begin{array}{l}3.53 \\
3.55 \\
3.63 \\
3.73 \\
3.76\end{array}$ & $\begin{array}{r}13.75 \\
14.51 \\
14.93 \\
\ldots . \\
\ldots\end{array}$ & $\begin{array}{l}\cdots \\
\cdots \\
\cdots \\
\cdots\end{array}$ & $\begin{array}{l}12.34 \\
12.35 \\
12.31 \\
12.39 \\
12.35\end{array}$ & $\begin{array}{l}15.03 \\
15.50 \\
15.65 \\
15.84 \\
16.10\end{array}$ & $\begin{array}{l}12.95 \\
12.73 \\
12.10 \\
11.48 \\
11.00\end{array}$ & $\begin{array}{l}6.85 \\
6.99 \\
6.65 \\
6.07 \\
5.48\end{array}$ & $\begin{array}{l}2.97 \\
2.98 \\
2.77 \\
2.73 \\
2.69\end{array}$ & $\begin{array}{l}1.75 \\
1.65 \\
1.54 \\
1.48 \\
1.40\end{array}$ & $\begin{array}{r}.94 \\
.92 \\
1.01 \\
1.19 \\
1.20\end{array}$ & $\begin{array}{l}.17 \\
.81 \\
.79 \\
.79 \\
.77\end{array}$ \\
\hline $\begin{array}{l}26 \\
27 \\
28 \\
29 \\
30 \\
31\end{array}$ & $\begin{array}{l}6.40 \\
5.96 \\
5.58 \\
5.21 \\
4.88 \\
4.60\end{array}$ & $\begin{array}{c}3.80 \\
4.01 \\
5.63 \\
8.31 \\
9.98 \\
\ldots\end{array}$ & $\begin{array}{r}\ldots \\
\cdots \\
16.32 \\
\cdots \\
\cdots\end{array}$ & $\begin{array}{l}\cdots \\
\cdots \\
\cdots \\
\cdots\end{array}$ & $\begin{array}{r}12.07 \\
11.32 \\
10.17 \\
\ldots . \\
\ldots \\
\ldots\end{array}$ & $\begin{array}{l}16.29 \\
16.55 \\
16.71 \\
16.86 \\
16.84 \\
16.80\end{array}$ & $\begin{array}{r}10.33 \\
9.47 \\
8.69 \\
8.09 \\
7.49 \\
\ldots .\end{array}$ & $\begin{array}{l}5.32 \\
5.66 \\
5.76 \\
5.64 \\
5.50 \\
5.43\end{array}$ & $\begin{array}{l}2.61 \\
2.45 \\
2.35 \\
2.28 \\
2.20 \\
\ldots . .\end{array}$ & $\begin{array}{l}1.34 \\
1.28 \\
1.23 \\
1.18 \\
1.16 \\
1.13\end{array}$ & $\begin{array}{r}1.11 \\
1.03 \\
.97 \\
1.05 \\
.91 \\
.87\end{array}$ & $\begin{array}{l}.75 \\
.77 \\
.79 \\
.79 \\
.75 \\
. .\end{array}$ \\
\hline $\begin{array}{l}\text { MEAN } \\
\text { MAX } \\
\text { MIN }\end{array}$ & $\begin{array}{l}6.19 \\
9.72 \\
2.20\end{array}$ & $\begin{array}{l}4.52 \\
9.98 \\
3.45\end{array}$ & $\cdots$ & $\cdots$ & $\begin{array}{r}12.44 \\
15.03 \\
9.08\end{array}$ & $\begin{array}{r}11.69 \\
16.86 \\
6.07\end{array}$ & $\begin{array}{r}11.12 \\
16.63 \\
7.49\end{array}$ & $\begin{array}{l}5.78 \\
7.00 \\
4.80\end{array}$ & $\begin{array}{l}4.04 \\
7.16 \\
2.20\end{array}$ & $\begin{array}{l}1.91 \\
3.17 \\
1.13\end{array}$ & $\begin{array}{r}1.13 \\
1.66 \\
.87\end{array}$ & $\begin{array}{r}.88 \\
1.32 \\
.67\end{array}$ \\
\hline
\end{tabular}




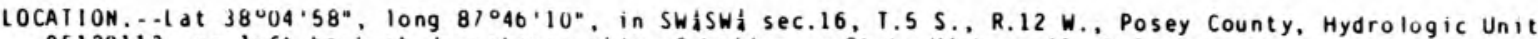

05120113 , on left bank at downstrean side of bridge on State Highway $66,0.6$ a northwest of Blalrsville, and 1.6 i southeast of fladesville.

DRAI NAGE AREA. $\cdots 104$ i .

PERIOD OF RECORD..-July 1965 to current yedr.

GAGE. - Water-stage recorder. Datur of gage is $370.00 \mathrm{ft}$ above National Geodetic Vertical Datua of 1929 .

REMARKS. - Records fair except for estimated daily discharges, which are poor.

DISCHARGE, CUBIL FEEI PER SECONO. WATER YEAR OCTOBER 1990 TO SEPIEMBER 1991 DAILY MEAN VALUES

\begin{tabular}{|c|c|c|c|c|c|c|c|c|c|c|c|c|}
\hline DAY & $O C T$ & NOV & DEC & JAN & FEB & MAR & APR & MAY & JUN & JUL & AUG & SEP \\
\hline $\begin{array}{l}1 \\
2 \\
3 \\
4 \\
5\end{array}$ & $\begin{array}{l}\text { e.12 } \\
\text { e.11 } \\
\text { e.11 } \\
577 \\
29\end{array}$ & $\begin{array}{l}1.6 \\
1.6 \\
1.6 \\
1.4 \\
3.7\end{array}$ & $\begin{array}{r}25 \\
21 \\
123 \\
82 \\
31\end{array}$ & $\begin{array}{r}225 \\
124 \\
89 \\
70 \\
132\end{array}$ & $\begin{array}{l}63 \\
59 \\
62 \\
75 \\
88\end{array}$ & $\begin{array}{r}51 \\
222 \\
83 \\
64 \\
55\end{array}$ & $\begin{array}{l}36 \\
32 \\
30 \\
33 \\
41\end{array}$ & $\begin{array}{l}19 \\
17 \\
15 \\
16 \\
18\end{array}$ & $\begin{array}{l}4.8 \\
4.4 \\
4.2 \\
3.6 \\
2.9\end{array}$ & $\begin{array}{l}.05 \\
.19 \\
.26 \\
.48 \\
.27\end{array}$ & $\begin{array}{l}\text { e.01 } \\
.00 \\
.00 \\
.00 \\
.00\end{array}$ & $\begin{array}{l}\text { e. } 06 \\
\text { e. } 06 \\
\text { e. } 05 \\
16 \\
24\end{array}$ \\
\hline $\begin{array}{r}6 \\
7 \\
8 \\
9 \\
10\end{array}$ & $\begin{array}{r}4.1 \\
3.9 \\
7.1 \\
515 \\
532\end{array}$ & $\begin{array}{r}11 \\
5.6 \\
3.4 \\
\mathrm{e} 2.7 \\
\mathrm{e} 2.2\end{array}$ & $\begin{array}{l}26 \\
21 \\
19 \\
17 \\
16\end{array}$ & $\begin{array}{r}1240 \\
1710 \\
543 \\
376 \\
374\end{array}$ & $\begin{array}{r}1240 \\
733 \\
237 \\
152 \\
116\end{array}$ & $\begin{array}{l}56 \\
40 \\
35 \\
33 \\
29\end{array}$ & $\begin{array}{l}33 \\
32 \\
48 \\
43 \\
30\end{array}$ & $\begin{array}{l}19 \\
15 \\
13 \\
14 \\
14\end{array}$ & $\begin{array}{l}2.4 \\
2.0 \\
1.9 \\
1.9 \\
1.7\end{array}$ & $\begin{array}{l}.28 \\
.40 \\
.40 \\
.23 \\
.13\end{array}$ & $\begin{array}{l}.00 \\
.00 \\
.00 \\
.00 \\
.00\end{array}$ & $\begin{array}{l}5.5 \\
2.5 \\
.50 \\
.23 \\
.11\end{array}$ \\
\hline $\begin{array}{l}11 \\
12 \\
13 \\
14 \\
15\end{array}$ & $\begin{array}{r}59 \\
14 \\
8.2 \\
5.5 \\
4.0\end{array}$ & $\begin{array}{l}\text { el. } \\
\text { el. } \\
\text { e } 1.5 \\
\text { e } 1.4 \\
\text { el. } 1.3\end{array}$ & $\begin{array}{l}16 \\
16 \\
15 \\
13 \\
30\end{array}$ & $\begin{array}{r}1100 \\
588 \\
208 \\
145 \\
128\end{array}$ & $\begin{array}{r}85 \\
72 \\
224 \\
1410 \\
273\end{array}$ & $\begin{array}{r}30 \\
38 \\
85 \\
354 \\
255\end{array}$ & $\begin{array}{l}25 \\
24 \\
34 \\
38 \\
44\end{array}$ & $\begin{array}{l}36 \\
68 \\
26 \\
17 \\
15\end{array}$ & $\begin{array}{l}1.6 \\
1.4 \\
1.5 \\
1.3 \\
1.0\end{array}$ & $\begin{array}{l}1.8 \\
1.5 \\
1.6 \\
1.1 \\
\text { e. } 80\end{array}$ & $\begin{array}{r}.00 \\
.00 \\
.00 \\
.00\end{array}$ & $\begin{array}{c}.23 \\
.25 \\
1.1 \\
.84 \\
.37\end{array}$ \\
\hline $\begin{array}{l}16 \\
17 \\
18 \\
19 \\
20\end{array}$ & $\begin{array}{l}3.1 \\
2.5 \\
2.6 \\
2.6 \\
2.0\end{array}$ & $\begin{array}{ll}\text { e } 1.5 \\
\text { e } 1.3 \\
\text { e } 1.2 \\
\text { e } 1.1 \\
\text { e } 1.3\end{array}$ & $\begin{array}{r}34 \\
40 \\
1430 \\
1100 \\
238\end{array}$ & $\begin{array}{r}197 \\
145 \\
106 \\
94 \\
91\end{array}$ & $\begin{array}{r}\text { e } 100 \\
91 \\
447 \\
454 \\
204\end{array}$ & $\begin{array}{l}122 \\
274 \\
969 \\
252 \\
148\end{array}$ & $\begin{array}{l}37 \\
27 \\
24 \\
66 \\
36\end{array}$ & $\begin{array}{l}14 \\
18 \\
15 \\
12 \\
13\end{array}$ & $\begin{array}{c}.91 \\
1.2 \\
1.2 \\
.99 \\
.88\end{array}$ & $\begin{array}{l}\text { e. } 54 \\
\text { e. } 37 \\
\text { e. } 25 \\
\text { e. } 19 \\
\text { e. } 14\end{array}$ & $\begin{array}{l}4.7 \\
1.1 \\
.82 \\
\text { e. } 70 \\
\text { e.50 }\end{array}$ & $\begin{array}{l}.25 \\
.12 \\
.18 \\
.29 \\
.17\end{array}$ \\
\hline $\begin{array}{l}21 \\
22 \\
23 \\
24 \\
25\end{array}$ & $\begin{array}{l}1.8 \\
3.2 \\
7.6 \\
5.9 \\
4.1\end{array}$ & $\begin{array}{l}\text { e1.5 } \\
48 \\
56 \\
19 \\
14\end{array}$ & $\begin{array}{r}443 \\
1270 \\
306 \\
131 \\
84\end{array}$ & $\begin{array}{r}69 \\
e 52 \\
e 43 \\
\text { e } 35 \\
\text { e } 30\end{array}$ & $\begin{array}{r}138 \\
107 \\
83 \\
14 \\
61\end{array}$ & $\begin{array}{r}120 \\
4050 \\
2570 \\
386 \\
152\end{array}$ & $\begin{array}{l}27 \\
24 \\
23 \\
27 \\
22\end{array}$ & $\begin{array}{l}13 \\
11 \\
8.5 \\
8.6 \\
9.6\end{array}$ & $\begin{array}{c}2.9 \\
46 \\
5.8 \\
3.2 \\
1.5\end{array}$ & $\begin{array}{l}\text { e. } 10 \\
\text { e. } 08 \\
\text { e. } 06 \\
\text { e. } 05 \\
\text { e.04 }\end{array}$ & $\begin{array}{l}\text { e. } 40 \\
\text { e. } 30 \\
\text { e. } 24 \\
\text { e. } 20 \\
\text { e.17 }\end{array}$ & $\begin{array}{l}\text { e. } 11 \\
\text { e.07 } \\
\text { e.10 } \\
\text { e.07 } \\
\text { e.06 }\end{array}$ \\
\hline $\begin{array}{l}26 \\
27 \\
28 \\
29 \\
30 \\
31\end{array}$ & $\begin{array}{l}3.2 \\
2.7 \\
2.5 \\
2.1 \\
1.9 \\
1.8\end{array}$ & $\begin{array}{c}13 \\
12 \\
343 \\
89 \\
33 \\
\cdots\end{array}$ & $\begin{array}{r}60 \\
49 \\
51 \\
1610 \\
4190 \\
1440\end{array}$ & $\begin{array}{r}\text { e27 } \\
\text { e35 } \\
79 \\
53 \\
269 \\
90\end{array}$ & $\begin{array}{c}54 \\
51 \\
47 \\
\cdots \\
\cdots \\
\cdots\end{array}$ & $\begin{array}{r}108 \\
90 \\
72 \\
59 \\
44 \\
38\end{array}$ & $\begin{array}{l}21 \\
21 \\
23 \\
30 \\
25 \\
\cdots\end{array}$ & $\begin{array}{l}13 \\
10 \\
1.8 \\
6.6 \\
5.9 \\
5.4\end{array}$ & $\begin{array}{l}.85 \\
.59 \\
.45 \\
.29 \\
.15 \\
. . .\end{array}$ & $\begin{array}{l}\text { e. } 03 \\
\text { e. } 02 \\
\text { e. } 02 \\
\text { e. } 02 \\
\text { e. } 01 \\
\text { e. } 01\end{array}$ & $\begin{array}{l}\text { e.14 } \\
\text { e.12 } \\
\text { e.10 } \\
\text { e.09 } \\
\text { e.08 } \\
\text { e.07 }\end{array}$ & $\begin{array}{l}\text { e. } 05 \\
\text { e.04 } \\
\text { e.03 } \\
\text { e.02 } \\
\text { e.02 } \\
\ldots . .\end{array}$ \\
\hline $\begin{array}{l}\text { TOIAL } \\
\text { MEAN } \\
\text { MAX } \\
\text { MIN } \\
\text { CF SM } \\
\text { IN. }\end{array}$ & $\begin{array}{r}1808.74 \\
58.3 \\
577 \\
.11 \\
.56 \\
.65\end{array}$ & $\begin{array}{r}671.5 \\
22.6 \\
343 \\
1.1 \\
.22 \\
.24\end{array}$ & $\begin{array}{r}12947 \\
418 \\
4190 \\
13 \\
4.02 \\
4.63\end{array}$ & $\begin{array}{r}8467 \\
273 \\
1710 \\
27 \\
2.63 \\
3.03\end{array}$ & $\begin{array}{r}6800 \\
243 \\
1410 \\
47 \\
2.34 \\
2.43\end{array}$ & $\begin{array}{r}10890 \\
351 \\
4050 \\
29 \\
3.38 \\
3.90\end{array}$ & $\begin{array}{r}956 \\
31.9 \\
66 \\
21 \\
.31 \\
.34\end{array}$ & $\begin{array}{r}493.4 \\
15.9 \\
68 \\
5.4 \\
.15 \\
.18\end{array}$ & $\begin{array}{r}103.51 \\
3.45 \\
46 \\
.15 \\
.03 \\
.04\end{array}$ & $\begin{array}{r}11.42 \\
.37 \\
1.8 \\
.01 \\
.00 \\
.00\end{array}$ & $\begin{array}{r}21.74 \\
.10 \\
12 \\
.00 \\
.01 \\
.01\end{array}$ & $\begin{array}{c}53.38 \\
1.78 \\
24 \\
.02 \\
.02 \\
.02\end{array}$ \\
\hline
\end{tabular}

e Estinated

SIATISTICS OF MUNIHLY MEAN DAIA FOR WAILR YEARS 1966 - 1991, BY WATER YEAR (WY)

$\begin{array}{lrrrrrrrrrrrr}\text { MEAN } & 22.7 & 82.8 & 147 & 141 & 215 & 234 & 192 & 152 & 81.1 & 68.1 & 46.7 & 31.1 \\ \text { MAX } & 131 & 513 & 710 & 559 & 727 & 581 & 577 & 142 & 285 & 257 & 341 & 233 \\ \text { (WY) } & 1978 & 1986 & 1983 & 1982 & 1990 & 1975 & 1983 & 1990 & 1973 & 1969 & 1977 & 1982 \\ \text { MIN } & 019 & .96 & .30 & 193 & 26.3 & 14.3 & 8.73 & 2.98 & .62 & .36 & .18 & .000 \\ \text { (WY) } & 1969 & 1966 & 1966 & 1977 & 1978 & 1981 & 1981 & 1988 & 1988 & 1991 & 1988 & 1983\end{array}$

SUMMARY SIATISTICS

ANMUAL TOTAL

ANNUAL MEAM

HIGHESI ANNUAL MEAN

LOHEST AMMUAL MEAM

HIGHESI DAILY MEAM

LOWEST DAILY MEAN

ANNUAL SEVEN-DAY MINIMUM

INSIANIANEOUS PEAK FLOW

INSIANIANEOUS PEAK STAGE

ANMUAL RUNOFF (CFSM)

ANNUAL RUNOFF (INCHES)

10 PERCENT EXCEEDS

50 PERCENT EXCEEDS

90 PERCENT EXCEEDS
FOR 1990 CALENOAR YEAR
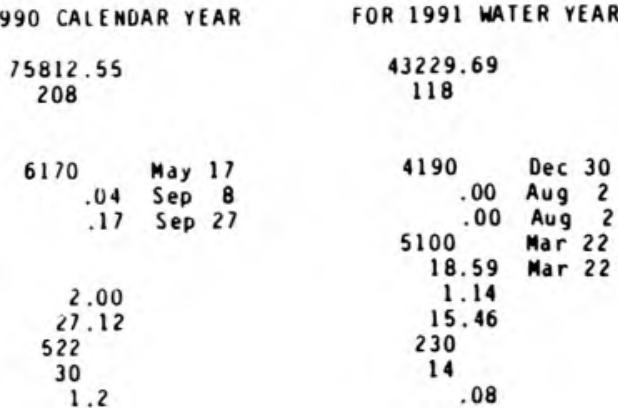

WATER YEARS 1966 - 1991

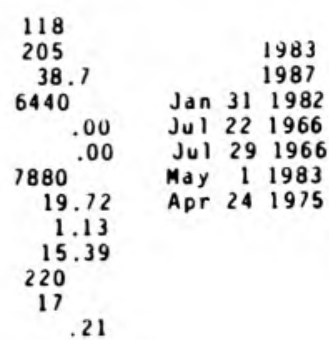




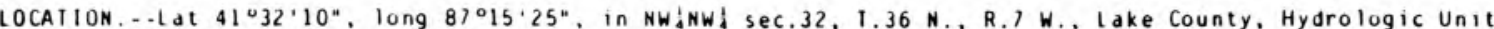
04040001 , on left bank at upstream side of bridge on Center Street in Hobart, $300 \mathrm{ft}$ upstream from Ouck Creek, and $400 \mathrm{ft}$ downstrean from Lake George Dam.

DRAINAGE AREA $\cdots 124$ i

PERIOD OF RECORD..-Aprii 1947 to current year.

REVISED RECORDS.--WSP 1337: 1953. WSP 1507: 1956. WDR 1N-72-1: Drainage area.

GAGE. - - Water-stage recorder. Datum of gage is $588.17 \mathrm{ft}$ above National Geodetic Vertical Datum of 1929 (levels by State of Indiana, Department of Natural Resources). Prior to July 29, 1952, nonrecording gage, and July 30, 1952, to July 20,1955, water-stage recorder at site $400 \mathrm{ft}$ upstrean at datum $11.80 \mathrm{ft}$ higher.

REMARKS. - - Records good except for estimated daily discharges, which are poor. Flow subject to regulation by operation of Lake George dan.

DISCHARGE, CUBIL FEET PER SECOND, WAIER YEAR OCTOBER 1990 TO SEPIEMBER 1991 DAIIY MEAN VALUES

\begin{tabular}{|c|c|c|c|c|c|c|c|c|c|c|c|c|}
\hline DAY & $\mathrm{OCT}$ & NOV & DEC & JAN & FEB & MAR & $A P R$ & MAY & JUN & JUL & $A \cup G$ & SEP \\
\hline $\begin{array}{l}1 \\
2 \\
3 \\
4 \\
5\end{array}$ & $\begin{array}{r}32 \\
29 \\
37 \\
120 \\
132\end{array}$ & $\begin{array}{r}62 \\
59 \\
57 \\
58 \\
359\end{array}$ & $\begin{array}{r}1250 \\
924 \\
728 \\
578 \\
420\end{array}$ & $\begin{array}{l}886 \\
629 \\
415 \\
248 \\
182\end{array}$ & $\begin{array}{r}85 \\
84 \\
83 \\
152 \\
425\end{array}$ & $\begin{array}{r}103 \\
516 \\
1000 \\
769 \\
489\end{array}$ & $\begin{array}{l}160 \\
102 \\
102 \\
110 \\
131\end{array}$ & $\begin{array}{r}122 \\
128 \\
110 \\
64 \\
107\end{array}$ & $\begin{array}{r}162 \\
130 \\
98 \\
80 \\
69\end{array}$ & $\begin{array}{l}20 \\
18 \\
18 \\
18 \\
19\end{array}$ & $\begin{array}{l}16 \\
21 \\
26 \\
29 \\
24\end{array}$ & $\begin{array}{l}27 \\
25 \\
39 \\
71 \\
58\end{array}$ \\
\hline $\begin{array}{r}6 \\
7 \\
8 \\
9 \\
10\end{array}$ & $\begin{array}{r}77 \\
62 \\
152 \\
410 \\
1090\end{array}$ & $\begin{array}{r}1010 \\
858 \\
535 \\
332 \\
231\end{array}$ & $\begin{array}{l}305 \\
243 \\
202 \\
180 \\
162\end{array}$ & $\begin{array}{l}163 \\
140 \\
129 \\
126 \\
116\end{array}$ & $\begin{array}{l}540 \\
445 \\
345 \\
281 \\
250\end{array}$ & $\begin{array}{l}349 \\
275 \\
219 \\
182 \\
155\end{array}$ & $\begin{array}{l}137 \\
120 \\
108 \\
109 \\
112\end{array}$ & $\begin{array}{l}274 \\
239 \\
177 \\
140 \\
115\end{array}$ & $\begin{array}{l}61 \\
58 \\
47 \\
12 \\
30\end{array}$ & $\begin{array}{l}19 \\
20 \\
40 \\
32 \\
23\end{array}$ & $\begin{array}{l}22 \\
22 \\
45 \\
69 \\
47\end{array}$ & $\begin{array}{l}38 \\
28 \\
24 \\
23 \\
21\end{array}$ \\
\hline $\begin{array}{l}11 \\
12 \\
13 \\
14 \\
15\end{array}$ & $\begin{array}{r}1340 \\
898 \\
541 \\
341 \\
256\end{array}$ & $\begin{array}{l}178 \\
145 \\
103 \\
102 \\
102\end{array}$ & $\begin{array}{l}136 \\
122 \\
124 \\
114 \\
131\end{array}$ & $\begin{array}{l}118 \\
133 \\
123 \\
114 \\
112\end{array}$ & $\begin{array}{l}197 \\
151 \\
146 \\
165 \\
141\end{array}$ & $\begin{array}{r}137 \\
93 \\
118 \\
130 \\
156\end{array}$ & $\begin{array}{r}104 \\
91 \\
89 \\
116 \\
623\end{array}$ & $\begin{array}{r}100 \\
88 \\
79 \\
89 \\
79\end{array}$ & $\begin{array}{l}41 \\
52 \\
47 \\
41 \\
36\end{array}$ & $\begin{array}{r}21 \\
24 \\
30 \\
\text { e25 } \\
\text { e19 }\end{array}$ & $\begin{array}{l}31 \\
25 \\
23 \\
23 \\
22\end{array}$ & $\begin{array}{l}21 \\
28 \\
47 \\
48 \\
35\end{array}$ \\
\hline $\begin{array}{l}16 \\
17 \\
18 \\
19 \\
20\end{array}$ & $\begin{array}{l}177 \\
158 \\
186 \\
203 \\
169\end{array}$ & $\begin{array}{l}94 \\
87 \\
82 \\
78 \\
75\end{array}$ & $\begin{array}{l}141 \\
134 \\
137 \\
133 \\
121\end{array}$ & $\begin{array}{l}196 \\
378 \\
365 \\
268 \\
250\end{array}$ & $\begin{array}{l}103 \\
110 \\
129 \\
241 \\
276\end{array}$ & $\begin{array}{l}208 \\
274 \\
578 \\
722 \\
540\end{array}$ & $\begin{array}{r}1170 \\
1340 \\
979 \\
649 \\
426\end{array}$ & $\begin{array}{r}71 \\
68 \\
114 \\
186 \\
148\end{array}$ & $\begin{array}{l}37 \\
39 \\
33 \\
30 \\
29\end{array}$ & $\begin{array}{l}\text { el } \\
\text { el } \\
\text { e } 15 \\
\text { el } \\
\text { el } 12\end{array}$ & $\begin{array}{ll}21 \\
2 & 1 \\
21 \\
2 & 1 \\
5 & 3\end{array}$ & $\begin{array}{l}27 \\
21 \\
19 \\
16 \\
15\end{array}$ \\
\hline $\begin{array}{l}21 \\
22 \\
23 \\
24 \\
25\end{array}$ & $\begin{array}{r}136 \\
113 \\
101 \\
92 \\
88\end{array}$ & $\begin{array}{l}81 \\
94 \\
95 \\
81 \\
76\end{array}$ & $\begin{array}{l}131 \\
230 \\
230 \\
169 \\
135\end{array}$ & $\begin{array}{l}274 \\
234 \\
199 \\
130 \\
110\end{array}$ & $\begin{array}{l}228 \\
199 \\
171 \\
147 \\
127\end{array}$ & $\begin{array}{l}375 \\
269 \\
244 \\
231 \\
205\end{array}$ & $\begin{array}{l}300 \\
159 \\
158 \\
180 \\
175\end{array}$ & $\begin{array}{l}112 \\
129 \\
205 \\
214 \\
206\end{array}$ & $\begin{array}{l}28 \\
33 \\
35 \\
31 \\
27\end{array}$ & $\begin{array}{r}\mathrm{e} 18 \\
\mathrm{e} 15 \\
\mathrm{e} 40 \\
\mathrm{e} 33 \\
\quad .08\end{array}$ & $\begin{array}{l}49 \\
33 \\
26 \\
23 \\
21\end{array}$ & $\begin{array}{l}16 \\
20 \\
20 \\
19 \\
19\end{array}$ \\
\hline $\begin{array}{l}26 \\
27 \\
28 \\
29 \\
30 \\
31\end{array}$ & $\begin{array}{l}88 \\
83 \\
74 \\
70 \\
66 \\
63\end{array}$ & $\begin{array}{r}73 \\
616 \\
3900 \\
3170 \\
1900 \\
\ldots-\end{array}$ & $\begin{array}{r}116 \\
99 \\
95 \\
688 \\
1980 \\
1440\end{array}$ & $\begin{array}{r}111 \\
102 \\
95 \\
88 \\
83 \\
77\end{array}$ & $\begin{array}{r}111 \\
101 \\
96 \\
\cdots \\
\cdots \\
\cdots\end{array}$ & $\begin{array}{l}217 \\
453 \\
543 \\
373 \\
251 \\
192\end{array}$ & $\begin{array}{l}150 \\
124 \\
113 \\
113 \\
124 \\
\cdots\end{array}$ & $\begin{array}{l}244 \\
292 \\
251 \\
170 \\
140 \\
136\end{array}$ & $\begin{array}{l}26 \\
24 \\
22 \\
21 \\
19 \\
\cdots\end{array}$ & $\begin{array}{c}.00 \\
.00 \\
.00 \\
.97 \\
4.9 \\
12\end{array}$ & $\begin{array}{l}20 \\
20 \\
19 \\
20 \\
25 \\
28\end{array}$ & $\begin{array}{l}16 \\
14 \\
14 \\
14 \\
16 \\
\cdots\end{array}$ \\
\hline $\begin{array}{l}\text { TOIAL } \\
\text { MEAN } \\
\text { MAX } \\
\text { MIN } \\
\text { CF SM } \\
\text { IN. }\end{array}$ & $\begin{array}{r}7384 \\
238 \\
1340 \\
29 \\
1.92 \\
2.22\end{array}$ & $\begin{array}{r}14693 \\
490 \\
3900 \\
57 \\
3.95 \\
4.41\end{array}$ & $\begin{array}{r}11598 \\
374 \\
1980 \\
95 \\
3.02 \\
3.48\end{array}$ & $\begin{array}{r}6594 \\
213 \\
886 \\
77 \\
1.72 \\
1.98\end{array}$ & $\begin{array}{c}5529 \\
197 \\
540 \\
83 \\
1.59 \\
1.66\end{array}$ & $\begin{array}{r}10366 \\
334 \\
1000 \\
93 \\
2.70 \\
3.11\end{array}$ & $\begin{array}{r}8374 \\
279 \\
1340 \\
89 \\
2.25 \\
2.51\end{array}$ & $\begin{array}{c}4597 \\
148 \\
292 \\
64 \\
1.20 \\
1.38\end{array}$ & $\begin{array}{c}1398 \\
46.6 \\
162 \\
12 \\
.38 \\
.42\end{array}$ & $\begin{array}{r}537.95 \\
17.4 \\
40 \\
.00 \\
.14 \\
.16\end{array}$ & $\begin{array}{c}872 \\
28.1 \\
69 \\
16 \\
.23 \\
.26\end{array}$ & $\begin{array}{r}799 \\
26.6 \\
71 \\
14 \\
.21 \\
.24\end{array}$ \\
\hline
\end{tabular}

e Estimated

SIATISIICS OF MONTHLY MEAN DATA FUR WAIER YEARS 1948 - 1991, BY WAIER YEAR (WY)

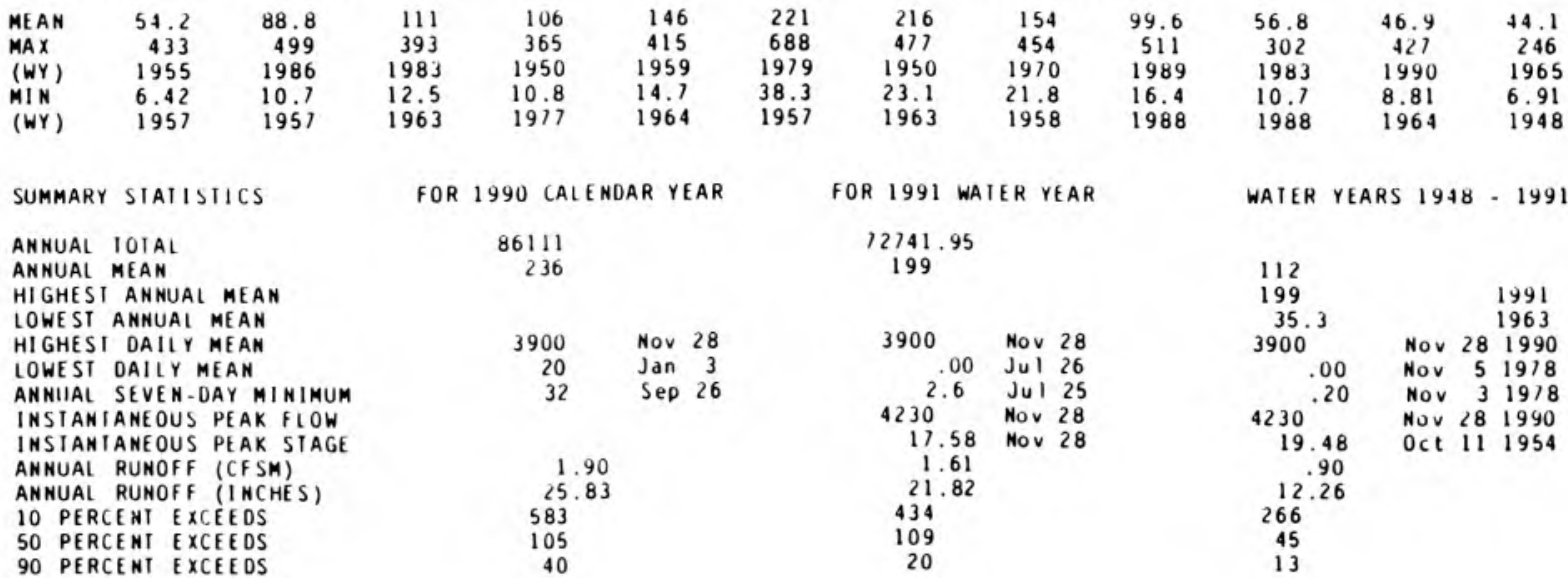




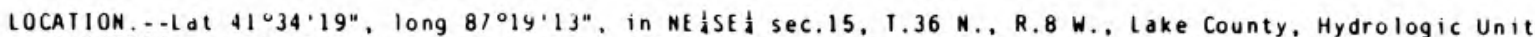
04040001 , on right bank $100 \mathrm{ft}$ upstream of Pennsylvania Railroad bridge, $800 \mathrm{ft}$ upstrea of Martin Luther King Avenue bridge at Gary, 1.3 mi downstream of highway 53 , and 1.5 mi upstrean from confluence with Deep River.

DRAINAGE AREA. $-5.8 \cdot a^{2}$, approximately.

PERIOD OF RECORD..- June 1958 to September 1967, October 1968 to September 30,1971 (discharge), Decenber 13,1984 to current year (gage heights only).

GAGE.--Water-stage recorder. Wooden control since Dec. 13, 1984. Datum of gage is 580.00 ft above National Geodetic Vertical Datun of 1929.

REMARKS. - Stage affected by backwater from Deep River during tiaes of flood. Miniaungage height for the period of record ay have been lower prior to Decenber 13, 1984 .

EXIREMES FOR PERIOD OF RECORD.--Maximum gage height, $13.31 \mathrm{ft}$, Nov. 30, 1990; inimungage height, 5.27 ft, Aug. 1,8, 1991. Miniaue gage height was not published prior to Decenber 13, 1984.

EXIREMES OUISIDE PERIOD OF RECORO. - Flood in October 1954 reached a stage of $13.09 \mathrm{ft}$, from flood mark.

EXIREMES FOR CURRENT YEAR.--Maximum gage height, $13.31 \mathrm{ft}$, Mov. 30; minimumgage height, $5.27 \mathrm{ft}$, Aug. 7 . 8 .

GAGE HEIGHT, FEET, WATER YEAR OCTOBER 1990 TO SEPIEMBER 1991

\begin{tabular}{|c|c|c|c|c|c|c|c|c|c|c|c|c|}
\hline DAY & $O C T$ & NOV & DEC & JAN & FEB & MAR & $A P R$ & MAY & JUN & JUL & $A \cup G$ & SEP \\
\hline $\begin{array}{l}1 \\
2 \\
3 \\
4 \\
5\end{array}$ & $\begin{array}{l}6.35 \\
6.29 \\
7.75 \\
7.88 \\
7.85\end{array}$ & $\begin{array}{l}7.11 \\
7.08 \\
6.98 \\
7.60 \\
8.69\end{array}$ & $\begin{array}{l}12.80 \\
12.08 \\
11.34 \\
10.78 \\
10.44\end{array}$ & $\begin{array}{r}10.04 \\
9.93 \\
\ldots . \\
\ldots \\
\ldots\end{array}$ & $\begin{array}{l}7.36 \\
7.46 \\
7.76 \\
8.36 \\
8.66\end{array}$ & $\begin{array}{l}8.13 \\
8.99 \\
9.40 \\
9.84 \\
9.90\end{array}$ & $\begin{array}{l}9.08 \\
8.86 \\
8.65 \\
8.45 \\
8.35\end{array}$ & $\begin{array}{l}7.95 \\
7.90 \\
7.78 \\
7.63 \\
8.37\end{array}$ & $\begin{array}{l}\ldots- \\
\ldots \\
\cdots \\
\cdots \\
7.68\end{array}$ & $\begin{array}{l}6.10 \\
6.06 \\
6.05 \\
6.05 \\
6.08\end{array}$ & $\begin{array}{l}5.49 \\
5.41 \\
5.40 \\
5.38 \\
5.34\end{array}$ & $\begin{array}{l}5.81 \\
5.72 \\
6.73 \\
6.65 \\
6.55\end{array}$ \\
\hline $\begin{array}{r}6 \\
7 \\
8 \\
9 \\
10\end{array}$ & $\begin{array}{l}7.58 \\
7.43 \\
8.06 \\
8.79 \\
9.31\end{array}$ & $\begin{array}{l}9.21 \\
9.38 \\
9.45 \\
9.42 \\
9.28\end{array}$ & $\begin{array}{r}10.11 \\
9.86 \\
9.64 \\
9.48 \\
9.30\end{array}$ & $\begin{array}{l}8.30 \\
8.18 \\
8.07\end{array}$ & $\begin{array}{l}8.85 \\
8.96 \\
8.95 \\
8.87 \\
8.74\end{array}$ & $\begin{array}{l}9.80 \\
9.64 \\
9.50 \\
9.33 \\
9.18\end{array}$ & $\begin{array}{l}8.25 \\
8.10 \\
7.99 \\
7.95 \\
7.90\end{array}$ & $\begin{array}{l}8.62 \\
8.76 \\
8.76 \\
8.63 \\
8.34\end{array}$ & $\begin{array}{l}7.48 \\
7.25 \\
7.11 \\
6.94 \\
6.79\end{array}$ & $\begin{array}{l}6.04 \\
7.10 \\
6.80 \\
6.60 \\
6.51\end{array}$ & $\begin{array}{l}5.30 \\
5.27 \\
7.35 \\
7.33 \\
7.19\end{array}$ & $\begin{array}{l}6.38 \\
6.13 \\
5.97 \\
5.83 \\
6.00\end{array}$ \\
\hline $\begin{array}{l}11 \\
12 \\
13 \\
14 \\
15\end{array}$ & $\begin{array}{l}9.64 \\
9.72 \\
9.62 \\
9.53 \\
9.37\end{array}$ & $\begin{array}{l}9.06 \\
8.80 \\
8.51 \\
8.25 \\
8.12\end{array}$ & $\begin{array}{l}9.12 \\
8.93 \\
8.76 \\
8.57 \\
8.46\end{array}$ & $\begin{array}{l}7.98 \\
8.01 \\
8.00 \\
7.98 \\
7.98\end{array}$ & $\begin{array}{l}8.65 \\
8.38 \\
8.53 \\
8.51 \\
8.32\end{array}$ & $\begin{array}{l}8.97 \\
8.83 \\
8.68 \\
8.58 \\
8.54\end{array}$ & $\begin{array}{l}7.84 \\
7.70 \\
7.64 \\
7.96 \\
9.00\end{array}$ & $\begin{array}{c}8.02 \\
7.75 \\
\ldots \\
\ldots . \\
\ldots\end{array}$ & $\begin{array}{l}7.45 \\
7.14 \\
6.96 \\
6.86 \\
6.73\end{array}$ & $\begin{array}{l}6.45 \\
6.36 \\
6.26 \\
6.17 \\
6.05\end{array}$ & $\begin{array}{l}7.04 \\
6.84 \\
6.58 \\
6.23 \\
6.04\end{array}$ & $\begin{array}{l}6.05 \\
6.39 \\
6.85 \\
6.78 \\
6.41\end{array}$ \\
\hline $\begin{array}{l}16 \\
17 \\
18 \\
19 \\
20\end{array}$ & $\begin{array}{l}9.17 \\
8.96 \\
8.86 \\
8.75 \\
8.55\end{array}$ & $\begin{array}{l}7.86 \\
7.70 \\
7.55 \\
7.50 \\
7.40\end{array}$ & $\begin{array}{l}8.37 \\
8.30 \\
8.26 \\
8.19 \\
8.12\end{array}$ & $\begin{array}{l}8.46 \\
8.59 \\
8.64 \\
8.64 \\
8.62\end{array}$ & $\begin{array}{l}8.11 \\
7.99 \\
8.39 \\
8.62 \\
8.75\end{array}$ & $\begin{array}{l}8.54 \\
8.73 \\
9.00 \\
9.27 \\
9.41\end{array}$ & $\begin{array}{r}9.59 \\
10.03 \\
10.11 \\
10.03 \\
9.90\end{array}$ & $\begin{array}{l}\cdots \\
\cdots \\
\cdots \\
\cdots\end{array}$ & $\begin{array}{l}6.62 \\
6.54 \\
6.48 \\
6.41 \\
6.35\end{array}$ & $\begin{array}{l}6.01 \\
5.91 \\
5.85 \\
5.79 \\
5.71\end{array}$ & $\begin{array}{l}5.92 \\
6.09 \\
5.81 \\
7.02 \\
7.46\end{array}$ & $\begin{array}{l}6.14 \\
6.01 \\
5.92 \\
5.83 \\
5.77\end{array}$ \\
\hline $\begin{array}{l}21 \\
22 \\
23 \\
24 \\
25\end{array}$ & $\begin{array}{l}8.35 \\
8.13 \\
7.92 \\
7.80 \\
7.70\end{array}$ & $\begin{array}{l}7.64 \\
7.83 \\
7.90 \\
7.83 \\
7.72\end{array}$ & $\begin{array}{l}8.22 \\
8.31 \\
8.38 \\
8.27 \\
8.11\end{array}$ & $\begin{array}{l}8.57 \\
8.45 \\
8.31 \\
8.14 \\
7.98\end{array}$ & $\begin{array}{l}8.81 \\
8.74 \\
8.61 \\
8.49 \\
8.46\end{array}$ & $\begin{array}{l}9.43 \\
9.34 \\
9.22 \\
9.11 \\
8.92\end{array}$ & $\begin{array}{l}9.64 \\
9.47 \\
9.32 \\
9.11 \\
8.84\end{array}$ & $\begin{array}{l}\ldots \\
\ldots \\
\ldots \\
\ldots\end{array}$ & $\begin{array}{l}6.27 \\
6.38 \\
6.53 \\
6.46 \\
6.41\end{array}$ & $\begin{array}{l}5.69 \\
5.65 \\
5.76 \\
5.70 \\
5.66\end{array}$ & $\begin{array}{l}7.35 \\
7.13 \\
6.54 \\
6.33 \\
6.16\end{array}$ & $\begin{array}{l}5.12 \\
5.88 \\
5.89 \\
5.83 \\
5.81\end{array}$ \\
\hline $\begin{array}{l}26 \\
27 \\
28 \\
29 \\
30 \\
31\end{array}$ & $\begin{array}{l}7.61 \\
7.51 \\
7.38 \\
7.25 \\
7.20 \\
7.12\end{array}$ & $\begin{array}{r}7.61 \\
8.95 \\
11.62 \\
13.21 \\
13.31 \\
\ldots\end{array}$ & $\begin{array}{r}7.97 \\
7.86 \\
7.83 \\
8.89 \\
9.70 \\
10.09\end{array}$ & $\begin{array}{l}7.88 \\
7.73 \\
7.65 \\
7.60 \\
7.64 \\
7.54\end{array}$ & $\begin{array}{r}8.32 \\
8.09 \\
7.92 \\
\ldots . \\
\ldots . \\
\ldots\end{array}$ & $\begin{array}{l}8.86 \\
9.12 \\
9.29 \\
9.41 \\
9.37 \\
9.26\end{array}$ & $\begin{array}{l}8.60 \\
8.34 \\
8.14 \\
8.03 \\
7.95 \\
. .-\end{array}$ & $\begin{array}{l}\cdots \\
\cdots \\
\cdots \\
\cdots \\
\cdots\end{array}$ & $\begin{array}{l}6.45 \\
6.33 \\
6.27 \\
6.21 \\
6.15 \\
\ldots\end{array}$ & $\begin{array}{l}5.64 \\
5.60 \\
5.56 \\
5.55 \\
5.52 \\
5.49\end{array}$ & $\begin{array}{l}6.13 \\
6.04 \\
5.97 \\
5.92 \\
6.50 \\
5.91\end{array}$ & $\begin{array}{l}5.81 \\
5.71 \\
5.69 \\
5.67 \\
5.65 \\
\ldots\end{array}$ \\
\hline $\begin{array}{l}\text { MEAN } \\
\text { MAX } \\
\text { MIN }\end{array}$ & $\begin{array}{l}8.18 \\
9.12 \\
6.29\end{array}$ & $\begin{array}{r}8.62 \\
13.31 \\
6.98\end{array}$ & $\begin{array}{r}9.18 \\
12.80 \\
7.83\end{array}$ & $\cdots$ & $\begin{array}{l}8.42 \\
8.96 \\
7.36\end{array}$ & $\begin{array}{l}9.15 \\
9.90 \\
8.13\end{array}$ & $\begin{array}{r}8.69 \\
10.11 \\
7.64\end{array}$ & $\cdots$ & $\ldots$ & $\begin{array}{l}5.99 \\
7.10 \\
5.49\end{array}$ & $\begin{array}{l}6.28 \\
7.46 \\
5.27\end{array}$ & $\begin{array}{l}6.05 \\
6.85 \\
5.65\end{array}$ \\
\hline
\end{tabular}


LOCAIION.--Lat $41^{\circ} 34^{\prime} 30^{\prime \prime}$, Iong $87^{\circ} 17^{\prime} 20^{\prime \prime}$, in SE 04040001 , on left bank at downstream side of bridge on Central Avenue, 0.4 ast of Gary, and 0.4 mi downstrean from confluence of Deep River and Little Calunet River.

DRAINAGE AREA. - $160 \mathrm{i}^{2}$. During times of floods flow may leave the basin by flowing west through $\mathrm{l}$ ittle Calumet River into the western portion of Calumet River basin; or during times of floods of Hart ditch, flow ma enter the basin from western portion of the little Calumet River basin.

PERIOD OF RECORD.--OCtober 1943 to current year (since 1951 water year, backwater free periods only).

REVISED RECORDS...WSP 1034: 1944. WSP 1337: Drainage area.

GAGE.--Water-stage recorder. Datum of gage is $577.04 \mathrm{ft}$ above National Geodetic Vertical Datua of 1929 . Prior to July 28,1955 , nonrecording gage at same site and datum.

REMARKS.--Records good, except for estinated daily discharges, which are poor. Burns ditch is an artificial channel which reverses the direction of flow of part of Little Calumet River and flows into Lake Michigan at 0 gden Dunes. During high levels on Lake Michigan, only periods free from backwater are shown.

DISCHARGE, CUBIC FEET PER SECOND, WATER YEAR OCTOBER 1990 TO SEPTEMBER 1991 DAILY MEAN VALUES

\begin{tabular}{|c|c|c|c|c|c|c|c|c|c|c|c|c|}
\hline DAY & $\mathrm{OCT}$ & NOV & DEC & JAN & FEB & MAR & APR & MAY & JUN & JUL & AUG & SEP \\
\hline $\begin{array}{l}1 \\
2 \\
3 \\
4 \\
5\end{array}$ & $\begin{array}{r}44 \\
41 \\
56 \\
170 \\
209\end{array}$ & $\begin{array}{r}91 \\
88 \\
82 \\
88 \\
434\end{array}$ & $\begin{array}{r}2030 \\
1640 \\
1330 \\
1120 \\
882\end{array}$ & $\begin{array}{r}1400 \\
1060 \\
774 \\
556 \\
416\end{array}$ & $\begin{array}{l}137 \\
148 \\
145 \\
230 \\
522\end{array}$ & $\begin{array}{r}165 \\
581 \\
1140 \\
1120 \\
866\end{array}$ & $\begin{array}{l}356 \\
275 \\
220 \\
224 \\
237\end{array}$ & $\begin{array}{l}207 \\
210 \\
188 \\
153 \\
181\end{array}$ & $\begin{array}{l}303 \\
270 \\
211 \\
173 \\
137\end{array}$ & $\begin{array}{l}50 \\
45 \\
33 \\
33 \\
29\end{array}$ & $\begin{array}{l}14 \\
19 \\
35 \\
38 \\
34\end{array}$ & $\begin{array}{l}33 \\
25 \\
44 \\
86 \\
81\end{array}$ \\
\hline $\begin{array}{r}6 \\
7 \\
8 \\
9 \\
10\end{array}$ & $\begin{array}{r}150 \\
119 \\
194 \\
546 \\
1070\end{array}$ & $\begin{array}{r}980 \\
1110 \\
858 \\
608 \\
466\end{array}$ & $\begin{array}{l}696 \\
560 \\
475 \\
418 \\
377\end{array}$ & $\begin{array}{l}367 \\
303 \\
252 \\
225 \\
206\end{array}$ & $\begin{array}{l}689 \\
666 \\
561 \\
478 \\
427\end{array}$ & $\begin{array}{l}669 \\
557 \\
465 \\
398 \\
348\end{array}$ & $\begin{array}{l}241 \\
214 \\
188 \\
190 \\
198\end{array}$ & $\begin{array}{l}394 \\
413 \\
343 \\
288 \\
237\end{array}$ & $\begin{array}{r}113 \\
96 \\
85 \\
46 \\
41\end{array}$ & $\begin{array}{l}26 \\
44 \\
82 \\
51 \\
42\end{array}$ & $\begin{array}{r}27 \\
29 \\
90 \\
116 \\
85\end{array}$ & $\begin{array}{l}54 \\
37 \\
29 \\
25 \\
27\end{array}$ \\
\hline $\begin{array}{l}11 \\
12 \\
13 \\
14 \\
15\end{array}$ & $\begin{array}{r}1450 \\
1330 \\
973 \\
682 \\
540\end{array}$ & $\begin{array}{l}378 \\
316 \\
250 \\
207 \\
197\end{array}$ & $\begin{array}{l}334 \\
273 \\
267 \\
238 \\
245\end{array}$ & $\begin{array}{l}212 \\
235 \\
209 \\
191 \\
189\end{array}$ & $\begin{array}{r}374 \\
278 \\
272 \\
308 \\
\mathrm{e} 310\end{array}$ & $\begin{array}{l}299 \\
247 \\
237 \\
255 \\
276\end{array}$ & $\begin{array}{l}173 \\
154 \\
149 \\
188 \\
658\end{array}$ & $\begin{array}{l}190 \\
154 \\
133 \\
129 \\
126\end{array}$ & $\begin{array}{l}61 \\
82 \\
79 \\
65 \\
61\end{array}$ & $\begin{array}{l}36 \\
36 \\
52 \\
44 \\
30\end{array}$ & $\begin{array}{l}55 \\
44 \\
39 \\
31 \\
25\end{array}$ & $\begin{array}{l}23 \\
35 \\
55 \\
64 \\
51\end{array}$ \\
\hline $\begin{array}{l}16 \\
17 \\
18 \\
19 \\
20\end{array}$ & $\begin{array}{l}424 \\
347 \\
372 \\
387 \\
338\end{array}$ & $\begin{array}{l}177 \\
154 \\
136 \\
125 \\
120\end{array}$ & $\begin{array}{l}263 \\
245 \\
246 \\
239 \\
216\end{array}$ & $\begin{array}{l}294 \\
505 \\
543 \\
451 \\
419\end{array}$ & $\begin{array}{r}\text { e225 } \\
192 \\
212 \\
351 \\
435\end{array}$ & $\begin{array}{l}334 \\
414 \\
653 \\
886 \\
810\end{array}$ & $\begin{array}{r}1220 \\
1490 \\
1420 \\
1120 \\
815\end{array}$ & $\begin{array}{l}109 \\
116 \\
171 \\
266 \\
253\end{array}$ & $\begin{array}{l}56 \\
59 \\
57 \\
49 \\
45\end{array}$ & $\begin{array}{l}22 \\
22 \\
24 \\
20 \\
19\end{array}$ & $\begin{array}{l}22 \\
23 \\
29 \\
83 \\
97\end{array}$ & $\begin{array}{l}35 \\
26 \\
22 \\
21 \\
19\end{array}$ \\
\hline $\begin{array}{l}21 \\
22 \\
23 \\
24 \\
25\end{array}$ & $\begin{array}{l}283 \\
238 \\
202 \\
178 \\
164\end{array}$ & $\begin{array}{l}130 \\
158 \\
164 \\
147 \\
132\end{array}$ & $\begin{array}{r}227 \\
340 \\
385 \\
\mathrm{e} 326 \\
\mathrm{e} 290\end{array}$ & $\begin{array}{r}454 \\
e 413 \\
e 365 \\
e 300 \\
e 250\end{array}$ & $\begin{array}{l}402 \\
359 \\
313 \\
270 \\
234\end{array}$ & $\begin{array}{l}644 \\
513 \\
465 \\
443 \\
397\end{array}$ & $\begin{array}{l}612 \\
440 \\
354 \\
384 \\
350\end{array}$ & $\begin{array}{l}203 \\
223 \\
312 \\
316 \\
323\end{array}$ & $\begin{array}{l}58 \\
86 \\
62 \\
54 \\
47\end{array}$ & $\begin{array}{l}27 \\
23 \\
48 \\
65 \\
29\end{array}$ & $\begin{array}{l}83 \\
59 \\
46 \\
38 \\
28\end{array}$ & $\begin{array}{l}19 \\
23 \\
26 \\
25 \\
25\end{array}$ \\
\hline $\begin{array}{l}26 \\
27 \\
28 \\
29 \\
30 \\
31\end{array}$ & $\begin{array}{r}155 \\
139 \\
125 \\
111 \\
102 \\
97\end{array}$ & $\begin{array}{r}121 \\
558 \\
2280 \\
2780 \\
2490 \\
\ldots-\end{array}$ & $\begin{array}{r}\text { e245 } \\
215 \\
186 \\
632 \\
1540 \\
1750\end{array}$ & $\begin{array}{r}\text { e2 } 30 \\
\text { e200 } \\
180 \\
159 \\
151 \\
\text { e1 } 35\end{array}$ & $\begin{array}{l}204 \\
178 \\
160 \\
\ldots \\
\ldots \\
\ldots\end{array}$ & $\begin{array}{l}393 \\
659 \\
796 \\
675 \\
515 \\
415\end{array}$ & $\begin{array}{l}316 \\
254 \\
224 \\
211 \\
205 \\
\ldots\end{array}$ & $\begin{array}{l}347 \\
406 \\
402 \\
311 \\
252 \\
246\end{array}$ & $\begin{array}{r}40 \\
33 \\
30 \\
32 \\
54 \\
\cdots\end{array}$ & $\begin{array}{l}23 \\
21 \\
18 \\
30 \\
27 \\
9.3\end{array}$ & $\begin{array}{l}23 \\
21 \\
21 \\
21 \\
31 \\
55\end{array}$ & $\begin{array}{l}25 \\
22 \\
20 \\
20 \\
21 \\
\ldots\end{array}$ \\
\hline $\begin{array}{l}\text { TOIAL } \\
\text { MEAN } \\
\text { MAX } \\
\text { MIN } \\
\text { CF SM } \\
\text { IN. }\end{array}$ & $\begin{array}{r}11236 \\
362 \\
1450 \\
41 \\
2.27 \\
2.61\end{array}$ & $\begin{array}{r}15825 \\
527 \\
2780 \\
82 \\
3.30 \\
3.68\end{array}$ & $\begin{array}{r}18230 \\
588 \\
2030 \\
186 \\
3.68 \\
4.24\end{array}$ & $\begin{array}{r}11644 \\
376 \\
1400 \\
135 \\
2.35 \\
2.71\end{array}$ & $\begin{array}{c}9080 \\
324 \\
689 \\
137 \\
2.03 \\
2.11\end{array}$ & $\begin{array}{r}16635 \\
537 \\
1140 \\
165 \\
3.35 \\
3.87\end{array}$ & $\begin{array}{r}13080 \\
436 \\
1490 \\
149 \\
2.72 \\
3.04\end{array}$ & $\begin{array}{l}7602 \\
245 \\
413 \\
109 \\
1.53 \\
1.77\end{array}$ & $\begin{array}{c}2585 \\
86.2 \\
303 \\
30 \\
.54 \\
.60\end{array}$ & $\begin{array}{r}1060.3 \\
34.2 \\
82 \\
9.3 \\
.21 \\
.25\end{array}$ & $\begin{array}{r}1361 \\
43.9 \\
116 \\
14 \\
.27 \\
.32\end{array}$ & $\begin{array}{c}1018 \\
33.9 \\
86 \\
19 \\
.21 \\
.24\end{array}$ \\
\hline
\end{tabular}

e Estinated

SIATISTICS OF MONTHLY MEAN DATA FOR WATER YEARS 1944 - 1991. BY WATER YEAR (WY)

\begin{tabular}{|c|c|c|c|c|c|c|c|c|c|c|c|c|}
\hline $\begin{array}{l}\text { MEAN } \\
\text { MAX } \\
\text { (WY) } \\
\text { MIN } \\
(W Y)\end{array}$ & $\begin{array}{r}69.0 \\
362 \\
1991 \\
11.8 \\
1948\end{array}$ & $\begin{array}{r}109 \\
527 \\
1991 \\
15.6 \\
1957\end{array}$ & $\begin{array}{r}150 \\
588 \\
1991 \\
17.1 \\
1964\end{array}$ & $\begin{array}{r}138 \\
447 \\
1950 \\
16.5 \\
1977\end{array}$ & $\begin{array}{r}179 \\
519 \\
1959 \\
23.4 \\
1963\end{array}$ & $\begin{array}{r}307 \\
898 \\
1982 \\
82.2 \\
1957\end{array}$ & $\begin{array}{r}320 \\
782 \\
1947 \\
26.0 \\
1963\end{array}$ & $\begin{array}{r}238 \\
588 \\
1970 \\
32.0 \\
1958\end{array}$ & $\begin{array}{r}143 \\
698 \\
1989 \\
20.8 \\
1988\end{array}$ & $\begin{array}{r}71.9 \\
294 \\
1957 \\
12.5 \\
1944\end{array}$ & $\begin{array}{r}66.0 \\
546 \\
1990 \\
10.2 \\
1964\end{array}$ & $\begin{array}{r}70.8 \\
355 \\
1981 \\
10.1 \\
1948\end{array}$ \\
\hline
\end{tabular}

SUMMARY SIAIISIICS

ANNUAL IOTAL

ANNUAL MEAN

HIGHESI ANNUAL MEAN

LOWEST ANNUAL MEAN

HIGHESI DAIIY MEAN

LOWEST DAILY MEAN

ANNUAL SEVEN-DAY MINIMUM

INSTANIANEOUS PEAK FLOW

INSTANIANEOUS PEAK SIAGE

ANNUAL RUNOFF (CFSM)

ANNUAL RUNOFF (INCHES)

10 PERCENT EXCEEOS

50 PERCENT EXCEEDS

90 PERCENI EXCEEDS
FOR 1990 CALENDAR YEAR

$\begin{aligned} 119874 & \\ 328 & \\ & \\ 2780 & \text { Nov } 29 \\ 32 & \text { Jan } 1 \\ 45 & \text { Sep } 26 \\ & \\ 2.05 & \\ 27.87 & \\ 857 & \\ 178 & \\ 62 & \end{aligned}$

FOR 1991 WATER YEAR

109356.3

300

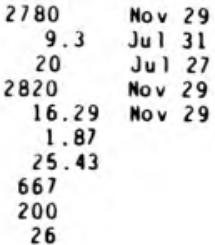

WAIER YEARS 1944 - 1991

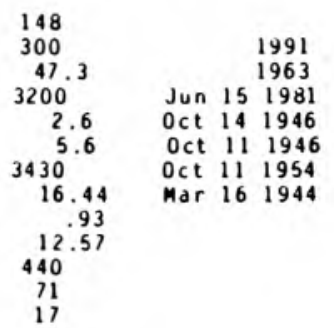




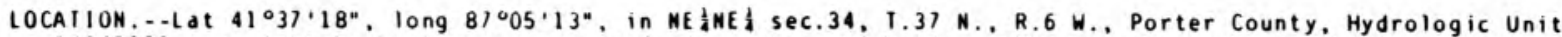
04040001 , on right bank at downstrea end of county road bridge, 200 ft upstrean froe bridge on U.S. Highway 20, 0.8 i northwest of Porter, and 4.5 . upstrean fro Salt Creek.

DRAI NAGE AREA $\ldots 66.2 \bullet i^{2}$

PERIOD OF RECORD.- May 1945 to current yedr.

REVISED RECORDS.--WSP 1084: 1945. WSP 1337: 1946-47. WOR IN-12-1: Drainage area. WDR IN-83-1: 1982.

GAGE.--Water-stage recorder. Datue of gage is $603.48 \mathrm{ft}$ above National Geodetic Vertical Datua of 1929 . Prior to June 26, 1952, nonrecording gage at same site and datue.

REMARKS. - Records good except for estimated daily discharges, which are poor.

DISCHARGE, CUBIC FEET PER SECOND, WATER YEAR OCTOBER 1990 TO SEPTEMBER 1991 DAILIY MEAN VALUES

\begin{tabular}{|c|c|c|c|c|c|c|c|c|c|c|c|c|}
\hline DAY & $\mathrm{OCT}$ & NOV & DEC & JAN & FE B & MAR & APR & MAY & JUN & JUL & AUG & SEP \\
\hline $\begin{array}{l}1 \\
2 \\
3 \\
4 \\
5\end{array}$ & $\begin{array}{r}50 \\
48 \\
54 \\
185 \\
142\end{array}$ & $\begin{array}{r}62 \\
62 \\
62 \\
65 \\
265\end{array}$ & $\begin{array}{l}324 \\
250 \\
216 \\
204 \\
170\end{array}$ & $\begin{array}{l}\text { e } 318 \\
\text { e21 } \\
\text { e152 } \\
\text { e11 } \\
\text { e107 }\end{array}$ & $\begin{array}{r}e 59 \\
e 62 \\
81 \\
163 \\
294\end{array}$ & $\begin{array}{r}85 \\
280 \\
465 \\
281 \\
191\end{array}$ & $\begin{array}{r}100 \\
86 \\
80 \\
80 \\
112\end{array}$ & $\begin{array}{r}103 \\
104 \\
82 \\
75 \\
194\end{array}$ & $\begin{array}{r}458 \\
363 \\
178 \\
120 \\
90\end{array}$ & $\begin{array}{l}39 \\
38 \\
38 \\
39 \\
38\end{array}$ & $\begin{array}{l}32 \\
32 \\
32 \\
33 \\
33\end{array}$ & $\begin{array}{l}33 \\
32 \\
37 \\
58 \\
39\end{array}$ \\
\hline $\begin{array}{r}6 \\
7 \\
8 \\
9 \\
10\end{array}$ & $\begin{array}{r}83 \\
81 \\
112 \\
253 \\
626\end{array}$ & $\begin{array}{l}823 \\
435 \\
262 \\
200 \\
158\end{array}$ & $\begin{array}{r}157 \\
135 \\
114 \\
100 \\
94\end{array}$ & $\begin{array}{l}\text { e } 98 \\
\text { e } 91 \\
\text { e } 87 \\
\text { e } 83 \\
\text { e } 79\end{array}$ & $\begin{array}{r}218 \\
\text { el } 185 \\
\text { e148 } \\
\text { e124 } \\
\text { e106 }\end{array}$ & $\begin{array}{r}155 \\
127 \\
100 \\
92 \\
84\end{array}$ & $\begin{array}{r}95 \\
82 \\
77 \\
81 \\
147\end{array}$ & $\begin{array}{r}396 \\
218 \\
137 \\
105 \\
87\end{array}$ & $\begin{array}{l}74 \\
65 \\
59 \\
54 \\
51\end{array}$ & $\begin{array}{l}38 \\
44 \\
79 \\
52 \\
45\end{array}$ & $\begin{array}{l}32 \\
32 \\
61 \\
60 \\
40\end{array}$ & $\begin{array}{l}35 \\
33 \\
32 \\
31 \\
32\end{array}$ \\
\hline $\begin{array}{l}11 \\
12 \\
13 \\
14 \\
15\end{array}$ & $\begin{array}{l}621 \\
295 \\
195 \\
139 \\
154\end{array}$ & $\begin{array}{r}123 \\
100 \\
85 \\
78 \\
76\end{array}$ & $\begin{array}{l}87 \\
83 \\
80 \\
75 \\
96\end{array}$ & $\begin{array}{l}e 95 \\
112 \\
108 \\
105 \\
107\end{array}$ & $\begin{array}{r}\text { e } 88 \\
\text { e72 } \\
85 \\
116 \\
\text { e79 }\end{array}$ & $\begin{array}{r}80 \\
77 \\
81 \\
86 \\
111\end{array}$ & $\begin{array}{r}133 \\
93 \\
82 \\
118 \\
328\end{array}$ & $\begin{array}{l}17 \\
70 \\
65 \\
61 \\
58\end{array}$ & $\begin{array}{l}55 \\
59 \\
53 \\
49 \\
47\end{array}$ & $\begin{array}{l}42 \\
41 \\
40 \\
41 \\
39\end{array}$ & $\begin{array}{l}36 \\
35 \\
34 \\
34 \\
33\end{array}$ & $\begin{array}{l}32 \\
36 \\
45 \\
39 \\
37\end{array}$ \\
\hline $\begin{array}{l}16 \\
17 \\
18 \\
19 \\
20\end{array}$ & $\begin{array}{r}123 \\
94 \\
199 \\
214 \\
134\end{array}$ & $\begin{array}{l}73 \\
68 \\
65 \\
64 \\
63\end{array}$ & $\begin{array}{r}104 \\
91 \\
104 \\
102 \\
87\end{array}$ & $\begin{array}{r}185 \\
301 \\
\text { e200 } \\
\text { e1 } 10 \\
193\end{array}$ & $\begin{array}{l}\text { e66 } \\
\text { e75 } \\
103 \\
207 \\
208\end{array}$ & $\begin{array}{l}140 \\
144 \\
274 \\
225 \\
147\end{array}$ & $\begin{array}{l}440 \\
349 \\
302 \\
185 \\
141\end{array}$ & $\begin{array}{r}56 \\
66 \\
113 \\
95 \\
72\end{array}$ & $\begin{array}{l}56 \\
49 \\
46 \\
44 \\
42\end{array}$ & $\begin{array}{l}38 \\
37 \\
36 \\
36 \\
35\end{array}$ & $\begin{array}{l}33 \\
33 \\
34 \\
44 \\
70\end{array}$ & $\begin{array}{l}34 \\
33 \\
32 \\
32 \\
31\end{array}$ \\
\hline $\begin{array}{l}21 \\
22 \\
23 \\
24 \\
25\end{array}$ & $\begin{array}{l}98 \\
81 \\
74 \\
70 \\
68\end{array}$ & $\begin{array}{l}64 \\
73 \\
70 \\
64 \\
12\end{array}$ & $\begin{array}{l}97 \\
157 \\
123 \\
e 97 \\
\text { e81 }\end{array}$ & $\begin{array}{l}\text { el } 74 \\
\text { el } 46 \\
\text { el17 } \\
\text { e } 90 \\
\text { e } 59\end{array}$ & $\begin{array}{r}165 \\
142 \\
106 \\
89 \\
81\end{array}$ & $\begin{array}{r}117 \\
100 \\
100 \\
101 \\
89\end{array}$ & $\begin{array}{r}114 \\
97 \\
91 \\
103 \\
88\end{array}$ & $\begin{array}{r}64 \\
95 \\
155 \\
296 \\
222\end{array}$ & $\begin{array}{l}42 \\
54 \\
49 \\
44 \\
42\end{array}$ & $\begin{array}{l}34 \\
36 \\
36 \\
34 \\
33\end{array}$ & $\begin{array}{l}43 \\
37 \\
35 \\
34 \\
33\end{array}$ & $\begin{array}{l}31 \\
33 \\
34 \\
33 \\
32\end{array}$ \\
\hline $\begin{array}{l}26 \\
27 \\
28 \\
29 \\
30 \\
31\end{array}$ & $\begin{array}{l}71 \\
68 \\
66 \\
65 \\
64 \\
63\end{array}$ & $\begin{array}{r}59 \\
380 \\
3040 \\
1070 \\
459 \\
\cdots\end{array}$ & $\begin{array}{r}\text { e68 } \\
\text { e60 } \\
\text { e70 } \\
383 \\
819 \\
\text { e717 }\end{array}$ & $\begin{array}{l}\text { e } 61 \\
\text { e } 59 \\
\text { e } 59 \\
\text { e } 58 \\
\text { e } 58 \\
\text { e } 58\end{array}$ & $\begin{array}{l}73 \\
10 \\
71 \\
\cdots \\
\cdots \\
\cdots\end{array}$ & $\begin{array}{l}121 \\
289 \\
363 \\
212 \\
140 \\
113\end{array}$ & $\begin{array}{r}81 \\
80 \\
88 \\
95 \\
109 \\
\cdots\end{array}$ & $\begin{array}{l}409 \\
414 \\
279 \\
145 \\
105 \\
152\end{array}$ & $\begin{array}{r}41 \\
40 \\
40 \\
39 \\
39 \\
\cdots\end{array}$ & $\begin{array}{l}34 \\
33 \\
33 \\
33 \\
33 \\
32\end{array}$ & $\begin{array}{l}32 \\
32 \\
32 \\
32 \\
32 \\
35\end{array}$ & $\begin{array}{c}32 \\
31 \\
32 \\
31 \\
31 \\
\cdots\end{array}$ \\
\hline $\begin{array}{l}\text { IOIAL } \\
\text { MEAN } \\
\text { MAX } \\
\text { MIN } \\
\text { CF SM } \\
\text { IN. }\end{array}$ & $\begin{array}{r}4590 \\
148 \\
626 \\
48 \\
2.24 \\
2.58\end{array}$ & $\begin{array}{r}8540 \\
285 \\
3040 \\
59 \\
4.30 \\
4.80\end{array}$ & $\begin{array}{r}5345 \\
172 \\
819 \\
60 \\
2.60 \\
3.00\end{array}$ & $\begin{array}{r}3802 \\
123 \\
318 \\
58 \\
1.85 \\
2.14\end{array}$ & $\begin{array}{r}3396 \\
121 \\
294 \\
59 \\
1.83 \\
1.91\end{array}$ & $\begin{array}{r}4970 \\
160 \\
465 \\
17 \\
2.42 \\
2.79\end{array}$ & $\begin{array}{r}4057 \\
135 \\
440 \\
77 \\
2.04 \\
2.28\end{array}$ & $\begin{array}{r}4570 \\
147 \\
414 \\
56 \\
2.23 \\
2.57\end{array}$ & $\begin{array}{r}2442 \\
81.4 \\
458 \\
39 \\
1.23 \\
1.37\end{array}$ & $\begin{array}{r}1206 \\
38.9 \\
79 \\
32 \\
.59 \\
.68\end{array}$ & $\begin{array}{r}1150 \\
37.1 \\
10 \\
32 \\
.56 \\
.65\end{array}$ & $\begin{array}{c}1033 \\
34.4 \\
58 \\
31 \\
.52 \\
.58\end{array}$ \\
\hline
\end{tabular}

e Estinated

SIAIISIICS OF MONTHLY MEAN DAIA FOR WAIER YEARS 1946 - 1991, BY WATER YEAR (WY)

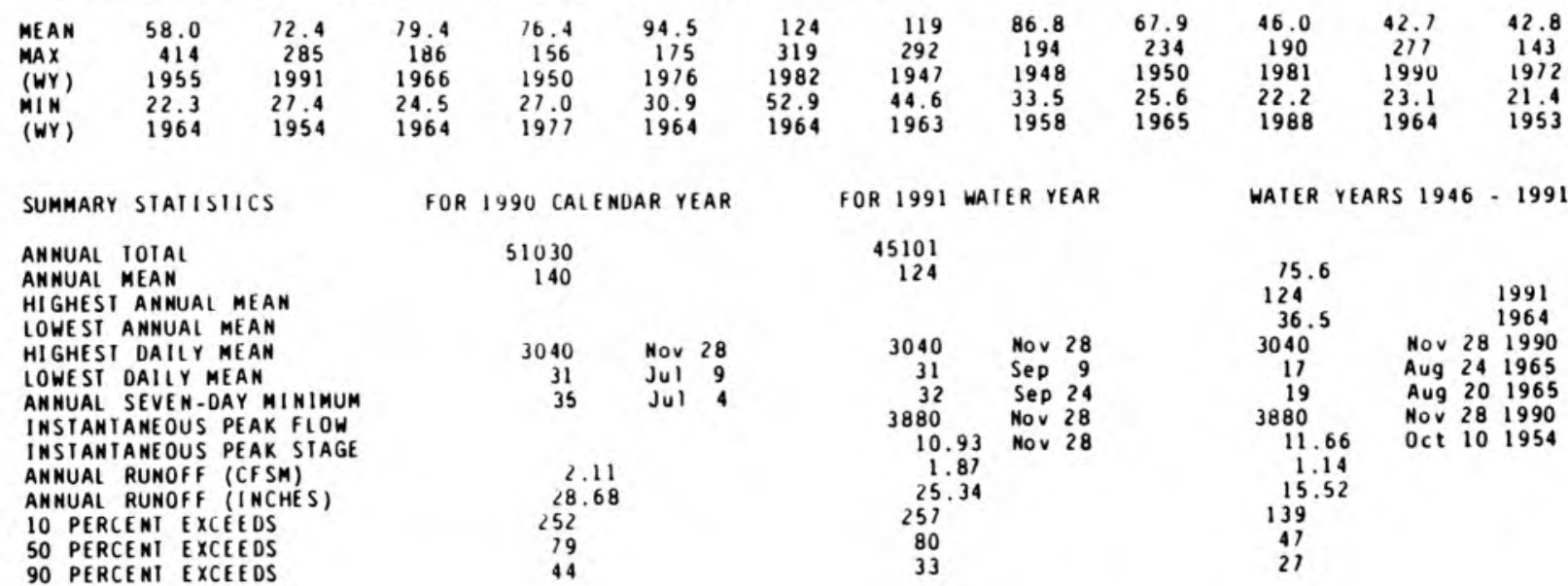




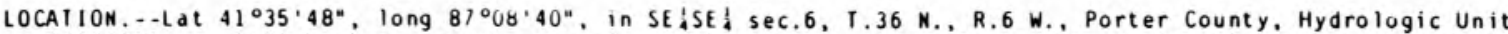

04040001 , on left bank on downstream side of highway bridge, 50 ft downstream fron Conrail Railroad bridge,

1.2 i north of McCogl, and 1.6 i upstream from Little Calumet River.

DRAINAGE AREA, .74.6. $i^{2}$.

PERIOD OF RECORO. - May 1945 to current year

REVISED RECORDS.-.WSP 1337: 1946-48(M), 1950(M). WSP 1911: 1958. WDR 1N-72-1: Drainage drea.

GAGE.- - Hater-stage recorder. Datum of gage is $594.10 \mathrm{ft}$ above National Geodetic Vertical Datu of 1929 (levels by State of Indiana, Department of Natural Resources). Prior to July 25, 1955, nonrecording gage at same site and

datur.

REMARKS. - Records fair except for estimated daily discharges, which are poor.

DISCHARGE, CUBIC FEET PER SECOND, WATER YEAR OCTOBER 1990 TO SEPTEMBER 1991 DAILY MEAN VALUES

\begin{tabular}{|c|c|c|c|c|c|c|c|c|c|c|c|c|}
\hline DAY & $O C I$ & HOV & DEC & JAN & FEB & MAR & APR & MAY & JUN & JUL & AUG & SEP \\
\hline $\begin{array}{l}1 \\
2 \\
3 \\
4 \\
5\end{array}$ & $\begin{array}{r}46 \\
46 \\
54 \\
135 \\
105\end{array}$ & $\begin{array}{r}57 \\
57 \\
54 \\
62 \\
276\end{array}$ & $\begin{array}{r}271 \\
115 \\
102 \\
105 \\
97\end{array}$ & $\begin{array}{r}e 210 \\
125 \\
98 \\
84 \\
93\end{array}$ & $\begin{array}{r}\text { e66 } \\
69 \\
77 \\
96 \\
132\end{array}$ & $\begin{array}{r}80 \\
223 \\
373 \\
132 \\
91\end{array}$ & $\begin{array}{l}87 \\
87 \\
84 \\
85 \\
99\end{array}$ & $\begin{array}{r}100 \\
98 \\
89 \\
86 \\
152\end{array}$ & $\begin{array}{r}160 \\
182 \\
121 \\
107 \\
98\end{array}$ & $\begin{array}{r}\text { 52 } \\
51 \\
51 \\
51 \\
54\end{array}$ & $\begin{array}{l}31 \\
31 \\
34 \\
38 \\
36\end{array}$ & $\begin{array}{l}38 \\
36 \\
46 \\
66 \\
45\end{array}$ \\
\hline $\begin{array}{r}6 \\
7 \\
8 \\
9 \\
10\end{array}$ & $\begin{array}{r}74 \\
85 \\
146 \\
273 \\
609\end{array}$ & $\begin{array}{r}603 \\
464 \\
201 \\
106 \\
91\end{array}$ & $\begin{array}{l}94 \\
90 \\
87 \\
86 \\
89\end{array}$ & $\begin{array}{l}84 \\
82 \\
83 \\
85 \\
85\end{array}$ & $\begin{array}{r}123 \\
104 \\
97 \\
94 \\
94\end{array}$ & $\begin{array}{l}91 \\
90 \\
86 \\
83 \\
79\end{array}$ & $\begin{array}{l}94 \\
87 \\
84 \\
86 \\
88\end{array}$ & $\begin{array}{r}300 \\
134 \\
102 \\
97 \\
90\end{array}$ & $\begin{array}{l}88 \\
81 \\
80 \\
79 \\
74\end{array}$ & $\begin{array}{l}52 \\
53 \\
85 \\
68 \\
58\end{array}$ & $\begin{array}{l}35 \\
36 \\
69 \\
83 \\
55\end{array}$ & $\begin{array}{l}39 \\
34 \\
32 \\
32 \\
36\end{array}$ \\
\hline $\begin{array}{l}11 \\
12 \\
13 \\
14 \\
15\end{array}$ & $\begin{array}{l}695 \\
415 \\
159 \\
112 \\
117\end{array}$ & $\begin{array}{l}82 \\
76 \\
73 \\
70 \\
70\end{array}$ & $\begin{array}{l}89 \\
88 \\
86 \\
81 \\
95\end{array}$ & $\begin{array}{l}84 \\
91 \\
87 \\
82 \\
85\end{array}$ & $\begin{array}{l}92 \\
87 \\
90 \\
95 \\
85\end{array}$ & $\begin{array}{l}75 \\
74 \\
77 \\
81 \\
87\end{array}$ & $\begin{array}{r}82 \\
76 \\
75 \\
93 \\
269\end{array}$ & $\begin{array}{l}87 \\
85 \\
82 \\
80 \\
79\end{array}$ & $\begin{array}{l}76 \\
80 \\
75 \\
69 \\
67\end{array}$ & $\begin{array}{l}51 \\
52 \\
51 \\
51 \\
48\end{array}$ & $\begin{array}{l}42 \\
40 \\
38 \\
36 \\
34\end{array}$ & $\begin{array}{l}35 \\
40 \\
49 \\
43 \\
38\end{array}$ \\
\hline $\begin{array}{l}16 \\
17 \\
18 \\
19 \\
20\end{array}$ & $\begin{array}{r}105 \\
92 \\
143 \\
130 \\
102\end{array}$ & $\begin{array}{l}71 \\
67 \\
66 \\
65 \\
63\end{array}$ & $\begin{array}{l}96 \\
91 \\
95 \\
92 \\
87\end{array}$ & $\begin{array}{r}108 \\
149 \\
111 \\
99 \\
101\end{array}$ & $\begin{array}{l}76 \\
81 \\
84 \\
99 \\
92\end{array}$ & $\begin{array}{r}90 \\
102 \\
235 \\
179 \\
100\end{array}$ & $\begin{array}{r}384 \\
442 \\
\text { e } 340 \\
\text { e150 } \\
95\end{array}$ & $\begin{array}{r}79 \\
86 \\
116 \\
107 \\
90\end{array}$ & $\begin{array}{r}71 \\
67 \\
62 \\
60 \\
\text { e58 }\end{array}$ & $\begin{array}{l}43 \\
38 \\
37 \\
37 \\
39\end{array}$ & $\begin{array}{r}33 \\
34 \\
37 \\
53 \\
100\end{array}$ & $\begin{array}{l}36 \\
35 \\
34 \\
34 \\
33\end{array}$ \\
\hline $\begin{array}{l}21 \\
22 \\
23 \\
24 \\
25\end{array}$ & $\begin{array}{l}86 \\
78 \\
74 \\
72 \\
68\end{array}$ & $\begin{array}{l}67 \\
75 \\
74 \\
72 \\
68\end{array}$ & $\begin{array}{r}94 \\
112 \\
97 \\
86 \\
\mathrm{e} 79\end{array}$ & $\begin{array}{r}98 \\
92 \\
95 \\
\text { e } 80 \\
\text { e } 63\end{array}$ & $\begin{array}{l}89 \\
87 \\
85 \\
83 \\
77\end{array}$ & $\begin{array}{l}94 \\
93 \\
95 \\
94 \\
91\end{array}$ & $\begin{array}{l}92 \\
91 \\
89 \\
93 \\
90\end{array}$ & $\begin{array}{r}83 \\
112 \\
113 \\
185 \\
227\end{array}$ & $\begin{array}{l}\text { e } 61 \\
\text { e68 } \\
\text { e65 } \\
\text { e61 } \\
\text { e57 }\end{array}$ & $\begin{array}{l}42 \\
44 \\
38 \\
35 \\
34\end{array}$ & $\begin{array}{l}61 \\
44 \\
38 \\
32 \\
30\end{array}$ & $\begin{array}{l}35 \\
35 \\
38 \\
36 \\
35\end{array}$ \\
\hline $\begin{array}{l}26 \\
27 \\
28 \\
29 \\
30 \\
31\end{array}$ & $\begin{array}{l}66 \\
64 \\
60 \\
59 \\
60 \\
58\end{array}$ & $\begin{array}{r}66 \\
443 \\
2030 \\
1040 \\
562 \\
\ldots-\end{array}$ & $\begin{array}{r}\text { e } 70 \\
\text { e64 } \\
\text { e74 } \\
416 \\
979 \\
\text { e } 436\end{array}$ & $\begin{array}{l}\text { e } 70 \\
\text { e } 67 \\
\text { e } 66 \\
\text { e } 66 \\
\text { e } 65 \\
\text { e65 }\end{array}$ & $\begin{array}{l}71 \\
71 \\
71 \\
\cdots \\
\cdots \\
\cdots\end{array}$ & $\begin{array}{r}95 \\
139 \\
121 \\
98 \\
93 \\
91\end{array}$ & $\begin{array}{r}87 \\
85 \\
89 \\
93 \\
100 \\
\ldots-\end{array}$ & $\begin{array}{l}291 \\
314 \\
150 \\
106 \\
101 \\
105\end{array}$ & $\begin{array}{l}\text { e } 54 \\
\text { e } 53 \\
\text { e52 } \\
\text { e52 } \\
\text { e52 } \\
-\cdots\end{array}$ & $\begin{array}{l}33 \\
32 \\
32 \\
31 \\
32 \\
30\end{array}$ & $\begin{array}{l}30 \\
31 \\
31 \\
31 \\
33 \\
32\end{array}$ & $\begin{array}{r}35 \\
35 \\
35 \\
35 \\
34 \\
\cdots\end{array}$ \\
\hline $\begin{array}{l}\text { TOTAL } \\
\text { MEAN } \\
\text { MAX } \\
\text { MIN } \\
\text { CF SM } \\
\text { IN. }\end{array}$ & $\begin{array}{r}4388 \\
142 \\
695 \\
46 \\
1.90 \\
2.19\end{array}$ & $\begin{array}{r}7171 \\
239 \\
2030 \\
54 \\
3.20 \\
3.58\end{array}$ & $\begin{array}{r}4543 \\
147 \\
979 \\
64 \\
1.96 \\
2.27\end{array}$ & $\begin{array}{r}2853 \\
92.0 \\
210 \\
63 \\
1.23 \\
1.42\end{array}$ & $\begin{array}{r}2467 \\
88.1 \\
132 \\
66 \\
1.18 \\
1.23\end{array}$ & $\begin{array}{r}3532 \\
114 \\
373 \\
74 \\
1.53 \\
1.76\end{array}$ & $\begin{array}{r}3796 \\
127 \\
442 \\
75 \\
1.70 \\
1.89\end{array}$ & $\begin{array}{c}3926 \\
127 \\
314 \\
79 \\
1.70 \\
1.96\end{array}$ & $\begin{array}{r}2330 \\
77.7 \\
182 \\
52 \\
1.04 \\
1.16\end{array}$ & $\begin{array}{c}1405 \\
45.3 \\
85 \\
30 \\
.61 \\
.70\end{array}$ & $\begin{array}{c}1288 \\
41.5 \\
100 \\
30 \\
.56 \\
.64\end{array}$ & $\begin{array}{r}1134 \\
37.8 \\
66 \\
32 \\
.51 \\
.57\end{array}$ \\
\hline
\end{tabular}

e Estinated

SIATISTICS OF MONIHIY MEAN DATA FOR WAIER YEARS 1946 - 1991, BY WAIER YEAR (WY)

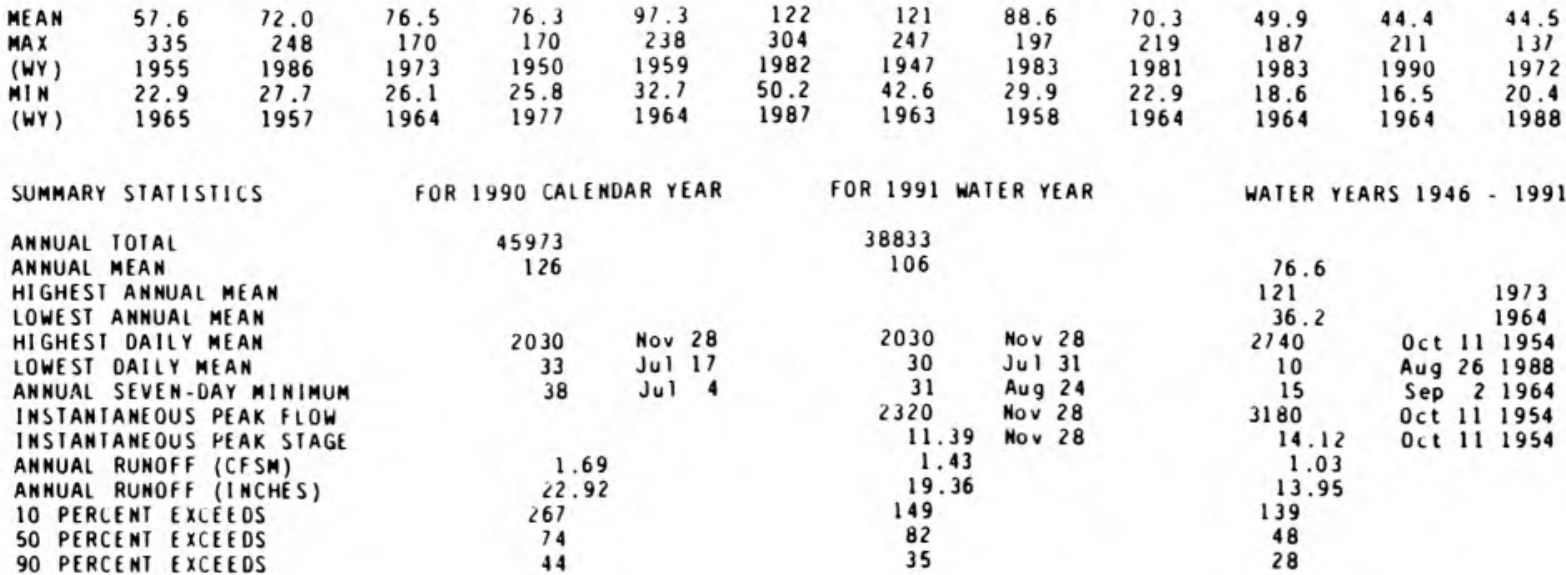


LOCAIION. - L at $41^{\circ} 43^{\prime} 00^{\prime \prime}$, long $86^{\circ} 51^{\prime} 35^{\prime \prime}$, in NE tSE \& sec. 27 . T.38 N., R.4 W., LaPorte County, Hydrologic Unit 04040001 , on right upstrean side of bridge on Springland Avenue in Michigan City, 1.0 . Creek, and 4.2 in upştream from mouth.

DRAINAGE AREA...54.1 $\mathrm{mi}^{2}$

PERIOD OF RECORD..-June 1969 to current year.

GAGE. - Water-stage recorder. Datun of gage is $584.02 \mathrm{ft}$ above National Geodetic Vertical Datum of 1929 .

REMARKS. - Records good except for estimated daily discharges, which are fair.

DISCHARGE, CUBIC FEET PER SECOND, WAIER YEAR OCIOBER 1990 TO SEPIEMBER 1991 DAII Y MEAN VALUES

\begin{tabular}{|c|c|c|c|c|c|c|c|c|c|c|c|c|}
\hline DAY & $O C I$ & NOV & $\mathrm{DEC}$ & JAN & FEB & MAR & APR & MAY & JUN & JUL & AUG & SEP \\
\hline $\begin{array}{l}1 \\
2 \\
3 \\
4 \\
5\end{array}$ & $\begin{array}{r}50 \\
48 \\
78 \\
293 \\
125\end{array}$ & $\begin{array}{r}60 \\
59 \\
59 \\
69 \\
475\end{array}$ & $\begin{array}{l}202 \\
147 \\
146 \\
139 \\
114\end{array}$ & $\begin{array}{r}186 \\
135 \\
109 \\
85 \\
92\end{array}$ & $\begin{array}{r}62 \\
66 \\
86 \\
174 \\
240\end{array}$ & $\begin{array}{r}91 \\
361 \\
314 \\
173 \\
123\end{array}$ & $\begin{array}{r}87 \\
79 \\
75 \\
82 \\
101\end{array}$ & $\begin{array}{r}113 \\
94 \\
79 \\
74 \\
304\end{array}$ & $\begin{array}{r}549 \\
222 \\
124 \\
95 \\
82\end{array}$ & $\begin{array}{l}43 \\
41 \\
41 \\
44 \\
41\end{array}$ & $\begin{array}{l}31 \\
31 \\
31 \\
33 \\
32\end{array}$ & $\begin{array}{l}33 \\
32 \\
46 \\
48 \\
37\end{array}$ \\
\hline $\begin{array}{r}6 \\
7 \\
8 \\
9 \\
10\end{array}$ & $\begin{array}{r}74 \\
74 \\
90 \\
389 \\
728\end{array}$ & $\begin{array}{l}574 \\
251 \\
160 \\
116 \\
100\end{array}$ & $\begin{array}{r}112 \\
105 \\
99 \\
94 \\
91\end{array}$ & $\begin{array}{l}87 \\
84 \\
80 \\
81 \\
79\end{array}$ & $\begin{array}{r}165 \\
124 \\
104 \\
98 \\
90\end{array}$ & $\begin{array}{r}113 \\
98 \\
89 \\
89 \\
84\end{array}$ & $\begin{array}{r}83 \\
74 \\
72 \\
83 \\
145\end{array}$ & $\begin{array}{r}229 \\
124 \\
95 \\
85 \\
16\end{array}$ & $\begin{array}{l}73 \\
68 \\
64 \\
61 \\
59\end{array}$ & $\begin{array}{l}39 \\
51 \\
50 \\
41 \\
40\end{array}$ & $\begin{array}{r}32 \\
31 \\
115 \\
55 \\
40\end{array}$ & $\begin{array}{l}35 \\
34 \\
33 \\
32 \\
35\end{array}$ \\
\hline $\begin{array}{l}11 \\
12 \\
13 \\
14 \\
15\end{array}$ & $\begin{array}{l}407 \\
209 \\
133 \\
107 \\
134\end{array}$ & $\begin{array}{l}88 \\
82 \\
77 \\
75 \\
73\end{array}$ & $\begin{array}{r}88 \\
87 \\
85 \\
81 \\
106\end{array}$ & $\begin{array}{r}90 \\
108 \\
101 \\
100 \\
102\end{array}$ & $\begin{array}{r}76 \\
67 \\
\text { e } 85 \\
\text { e80 } \\
\text { e77 }\end{array}$ & $\begin{array}{r}81 \\
78 \\
84 \\
94 \\
123\end{array}$ & $\begin{array}{r}91 \\
76 \\
74 \\
136 \\
349\end{array}$ & $\begin{array}{l}71 \\
68 \\
66 \\
64 \\
62\end{array}$ & $\begin{array}{l}70 \\
66 \\
58 \\
55 \\
53\end{array}$ & $\begin{array}{l}38 \\
38 \\
38 \\
39 \\
36\end{array}$ & $\begin{array}{l}37 \\
36 \\
35 \\
35 \\
34\end{array}$ & $\begin{array}{l}34 \\
46 \\
49 \\
39 \\
37\end{array}$ \\
\hline $\begin{array}{l}16 \\
17 \\
18 \\
19 \\
20\end{array}$ & $\begin{array}{r}98 \\
94 \\
259 \\
141 \\
98\end{array}$ & $\begin{array}{l}72 \\
69 \\
68 \\
68 \\
66\end{array}$ & $\begin{array}{r}97 \\
92 \\
108 \\
98 \\
87\end{array}$ & $\begin{array}{l}236 \\
267 \\
154 \\
119 \\
185\end{array}$ & $\begin{array}{l}\text { e71 } \\
\text { e79 } \\
106 \\
279 \\
194\end{array}$ & $\begin{array}{l}123 \\
126 \\
237 \\
137 \\
103\end{array}$ & $\begin{array}{r}277 \\
226 \\
133 \\
104 \\
92\end{array}$ & $\begin{array}{l}68 \\
90 \\
98 \\
76 \\
67\end{array}$ & $\begin{array}{l}54 \\
51 \\
49 \\
48 \\
47\end{array}$ & $\begin{array}{l}36 \\
36 \\
34 \\
33 \\
33\end{array}$ & $\begin{array}{l}33 \\
36 \\
38 \\
85 \\
77\end{array}$ & $\begin{array}{l}35 \\
34 \\
34 \\
34 \\
33\end{array}$ \\
\hline $\begin{array}{l}21 \\
22 \\
23 \\
24 \\
25\end{array}$ & $\begin{array}{l}84 \\
78 \\
73 \\
71 \\
75\end{array}$ & $\begin{array}{l}70 \\
79 \\
73 \\
68 \\
66\end{array}$ & $\begin{array}{r}103 \\
125 \\
99 \\
87 \\
\mathrm{e} 80\end{array}$ & $\begin{array}{r}162 \\
114 \\
e 94 \\
\text { e76 } \\
64\end{array}$ & $\begin{array}{r}144 \\
116 \\
88 \\
82 \\
75\end{array}$ & $\begin{array}{l}91 \\
84 \\
87 \\
87 \\
77\end{array}$ & $\begin{array}{r}84 \\
79 \\
83 \\
130 \\
97\end{array}$ & $\begin{array}{r}64 \\
72 \\
95 \\
116 \\
200\end{array}$ & $\begin{array}{l}47 \\
52 \\
50 \\
47 \\
45\end{array}$ & $\begin{array}{l}33 \\
35 \\
35 \\
35 \\
33\end{array}$ & $\begin{array}{l}44 \\
40 \\
38 \\
37 \\
35\end{array}$ & $\begin{array}{l}33 \\
37 \\
37 \\
34 \\
35\end{array}$ \\
\hline $\begin{array}{l}26 \\
27 \\
28 \\
29 \\
30 \\
31\end{array}$ & $\begin{array}{l}13 \\
69 \\
64 \\
62 \\
62 \\
61\end{array}$ & $\begin{array}{r}65 \\
649 \\
2550 \\
510 \\
285 \\
\cdots\end{array}$ & $\begin{array}{r}\text { e73 } \\
67 \\
78 \\
740 \\
669 \\
290\end{array}$ & $\begin{array}{l}73 \\
\text { e } 62 \\
\text { e } 62 \\
\text { e } 61 \\
\text { e } 61 \\
\text { e } 61\end{array}$ & $\begin{array}{r}10 \\
69 \\
74 \\
\cdots \\
\cdots \\
\cdots\end{array}$ & $\begin{array}{r}138 \\
403 \\
299 \\
167 \\
111 \\
93\end{array}$ & $\begin{array}{r}84 \\
87 \\
93 \\
108 \\
100 \\
\cdots--\end{array}$ & $\begin{array}{r}320 \\
282 \\
126 \\
87 \\
80 \\
201\end{array}$ & $\begin{array}{r}44 \\
43 \\
42 \\
41 \\
44 \\
\cdots--\end{array}$ & $\begin{array}{l}32 \\
32 \\
32 \\
32 \\
33 \\
32\end{array}$ & $\begin{array}{l}35 \\
34 \\
34 \\
34 \\
34 \\
34\end{array}$ & $\begin{array}{r}34 \\
33 \\
33 \\
33 \\
32 \\
\cdots\end{array}$ \\
\hline $\begin{array}{l}\text { IOTAL } \\
\text { MEAN } \\
\text { MAX } \\
\text { MIN } \\
\text { CF SM } \\
\text { IN. }\end{array}$ & $\begin{array}{r}4401 \\
142 \\
728 \\
48 \\
2.62 \\
3.03\end{array}$ & $\begin{array}{r}1076 \\
236 \\
2550 \\
59 \\
4.36 \\
4.87\end{array}$ & $\begin{array}{r}4589 \\
148 \\
740 \\
67 \\
2.74 \\
3.16\end{array}$ & $\begin{array}{r}3370 \\
109 \\
267 \\
61 \\
2.01 \\
2.32\end{array}$ & $\begin{array}{r}3041 \\
109 \\
279 \\
62 \\
2.01 \\
2.09\end{array}$ & $\begin{array}{c}4358 \\
141 \\
403 \\
77 \\
2.60 \\
3.00\end{array}$ & $\begin{array}{r}3384 \\
113 \\
349 \\
72 \\
2.09 \\
2.33\end{array}$ & $\begin{array}{c}3646 \\
118 \\
320 \\
62 \\
2.17 \\
2.51\end{array}$ & $\begin{array}{c}2403 \\
80.1 \\
549 \\
41 \\
1.48 \\
1.65\end{array}$ & $\begin{array}{c}1156 \\
37.3 \\
51 \\
32 \\
.69 \\
.79\end{array}$ & $\begin{array}{c}1276 \\
41.2 \\
115 \\
31 \\
.76 \\
.88\end{array}$ & $\begin{array}{c}1081 \\
36.0 \\
49 \\
32 \\
.67 \\
.14\end{array}$ \\
\hline
\end{tabular}

e Estimated

SIAIISIICS OF MONIHLY MEAN DAIA FOR WAIER YEARS 1970 - 1991, BY WAIER YEAR (WY)

$\begin{array}{lrrrrrrrrrrrr}\text { MEAN } & 54.5 & 80.4 & 81.5 & 72.0 & 90.1 & 116 & 106 & 89.6 & 68.7 & 49.5 & 47.8 & 46.2 \\ \text { MAX } & 142 & 236 & 147 & 118 & 189 & 249 & 172 & 159 & 137 & 121 & 190 & 88.6 \\ \text { (WY) } & 1991 & 1991 & 1991 & 1973 & 1985 & 1982 & 1983 & 1990 & 1981 & 1986 & 1990 & 1981 \\ \text { MIN } & 35.3 & 37.6 & 40.4 & 38.7 & 51.8 & 56.8 & 47.1 & 46.5 & 33.7 & 28.9 & 28.8 & 29.2 \\ \text { (WY) } & 1980 & 1972 & 1990 & 1977 & 1978 & 1981 & 1971 & 1977 & 1971 & 1971 & 1970 & 1988\end{array}$

SUMMARY SIATISTICS

ANNUAL TOTAL

ANNUAL MEAM

HIGHEST ANNUAL MEAN

LOWEST ANNUAL MEAN

HIGHESI DAILY MEAM

IOWEST DAILY MEAN

ANNUAL SEVEN-DAY MINIMUM

INSTANIANEOUS PEAK FLOW

INSTAMTANEOUS PEAK SIAGE

ANMUAL RUMOFF (CFSM)

ANNUAL RUNOFF (INCHES)

10 PERCENT EXCEEDS

50 PERCENT EXCEEDS

90 PERCENT EXCEEDS
FOR 1990 CALENDAR YEAR

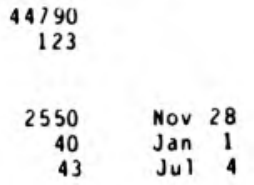

2.27

30.80

226

51
FOR 1991 WAIER YEAR

39181

109

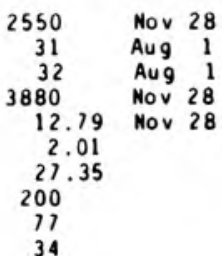

WAIER YEARS $1970-1991$

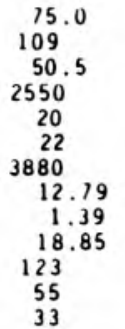

991 Nov 281990 Aug 11917 Jul $27 \quad 1977$ Nov 281990 Nov 281990 
PERIOD OF RECORU...June 1990 to curient yedr.

PERIOD OF DAIIY RECORD..-

SUSPENDED-SEDIMENT DISCHARGE: June 1990 to current year.

EXIREMES FOR PERIOD OF DAILY RECORO..

SEDIMENT CONCENTRATIONS: Maximum daily mean, $358 \mathrm{mg} / \mathrm{L}$. Nov. 27,$1990 ;$ minimum daily mean, $4 \mathrm{mg} / \mathrm{L}$, April 3 , 1991. SEDIMENT LOADS: Maximum daily, 927 tons, Mov. 28, 1990; inimu daily, 0.4 ton, Sept. 28, 1991.

EXIREMES FOR CURRENT YEAR, -.

SEDIMENT CONCENTRATIONS: Maximum daily mean, $358 \mathrm{~g} / \mathrm{L}$, Nov. 27; minimum daily mean, $4 \mathrm{mg} / \mathrm{l}$, April 3.

SEDIMENT LOADS: Maximua daily, 927 tons, Mov. 28; ininu daily, 0.4 ton, Sept. 28.

WAIER QUALITY DATA, WAIER YEAR OCTOBER 1989 TO SEPTEMBER 1990

\begin{tabular}{|c|c|c|c|c|c|c|}
\hline DAIE & TIME & $\begin{array}{c}\text { GAGE } \\
\text { HEIGHT } \\
\text { (FEEI) } \\
(00065)\end{array}$ & $\begin{array}{l}\text { DIS- } \\
\text { CHARGE, } \\
\text { INSI } \\
\text { CUBIC } \\
\text { FEET } \\
\text { PER } \\
\text { SECOND } \\
(00061)\end{array}$ & $\begin{array}{l}\text { SEDI - } \\
\text { MENT, } \\
\text { SUS- } \\
\text { PENOED } \\
(\text { MG/L) } \\
(80154)\end{array}$ & $\begin{array}{l}\text { SEDI - } \\
\text { MENT, } \\
\text { DIS- } \\
\text { CHARGE, } \\
\text { SUS- } \\
\text { PENDED } \\
\text { (I/DAY) } \\
\text { (80155) }\end{array}$ & $\begin{array}{l}\text { SED. } \\
\text { SUSP. } \\
\text { SIEVE } \\
\text { DIAM. } \\
\times \text { FINER } \\
\text { THAN } \\
.062 \text { MM } \\
(70331)\end{array}$ \\
\hline \multicolumn{7}{|l|}{ JUN } \\
\hline Jul $14 \ldots$ & 1455 & 2.47 & 53 & 58 & 8.3 & 86 \\
\hline $\begin{array}{c}03 \ldots \\
A \cup G\end{array}$ & 0845 & 2.35 & 46 & E118 & E15 & [87 \\
\hline $\begin{array}{r}03 \ldots \\
20 \ldots \\
21 \ldots \\
21 \ldots \\
21 \ldots \\
21 \ldots \\
\text { SEP }\end{array}$ & $\begin{array}{l}1030 \\
2015 \\
0755 \\
0840 \\
1020 \\
1225\end{array}$ & $\begin{array}{l}2.28 \\
9.41 \\
6.58 \\
6.41 \\
6.10 \\
5.80\end{array}$ & $\begin{array}{r}42 \\
769 \\
442 \\
423 \\
389 \\
357\end{array}$ & $\begin{array}{l}43 \\
159 \\
107 \\
109 \\
120 \\
126\end{array}$ & $\begin{array}{l}4.9 \\
330 \\
128 \\
124 \\
126 \\
121\end{array}$ & $\begin{array}{l}66 \\
51 \\
54 \\
56 \\
54 \\
64\end{array}$ \\
\hline $\begin{array}{l}13 \ldots \\
14 \ldots\end{array}$ & $\begin{array}{l}1053 \\
1150\end{array}$ & $\begin{array}{l}2.45 \\
3.16\end{array}$ & $\begin{array}{r}52 \\
102\end{array}$ & $\begin{array}{r}20 \\
101\end{array}$ & $28^{2.8}$ & $\begin{array}{l}80 \\
91\end{array}$ \\
\hline
\end{tabular}

WATER QUALIIY DATA, WATER YEAR OCTOBER 1990 TO SEPTEMBER 1991

\begin{tabular}{|c|c|c|c|c|c|c|}
\hline DAIE & I INE & $\begin{array}{c}\text { GAGE } \\
\text { HEIGHT } \\
\text { (FEET) } \\
(00065)\end{array}$ & $\begin{array}{l}\text { DIS- } \\
\text { CHARGE, } \\
\text { INST. } \\
\text { CUBIC } \\
\text { FEET } \\
\text { PER } \\
\text { SECOND } \\
(00061)\end{array}$ & $\begin{array}{l}\text { SEDI - } \\
\text { MENT, } \\
\text { SUS- } \\
\text { PENDED } \\
(\text { MG/L) } \\
(80154)\end{array}$ & $\begin{array}{l}\text { SEDI - } \\
\text { MENT, } \\
\text { DIS:- } \\
\text { CHARGE, } \\
\text { SUS- } \\
\text { PENDED } \\
\text { (T/DAY) } \\
(80155)\end{array}$ & $\begin{array}{l}\text { SED. } \\
\text { SUSP. } \\
\text { SIEVE } \\
\text { DIAM. } \\
\times \text { FINER } \\
\text { THAN } \\
\text { OO62 MM } \\
(70331)\end{array}$ \\
\hline \multicolumn{7}{|l|}{$\mathrm{OCT}$} \\
\hline $\begin{array}{l}09 \ldots \\
09 \ldots \\
10 \ldots \\
10 \ldots \\
10 \ldots \\
10 \ldots \\
10 \ldots \\
17 \ldots \\
17 \ldots \\
17 \ldots \\
18 \ldots \\
18 \ldots \\
18 \ldots\end{array}$ & $\begin{array}{l}1820 \\
2305 \\
1005 \\
1205 \\
1530 \\
1700 \\
1810 \\
2047 \\
2216 \\
2324 \\
0119 \\
0631 \\
0817\end{array}$ & $\begin{array}{l}6.19 \\
6.78 \\
9.00 \\
9.35 \\
9.68 \\
9.75 \\
9.75 \\
2.89 \\
3.88 \\
3.70 \\
4.26 \\
5.05 \\
5.11\end{array}$ & $\begin{array}{l}399 \\
463 \\
719 \\
761 \\
802 \\
811 \\
811 \\
81 \\
171 \\
152 \\
205 \\
280 \\
286\end{array}$ & $\begin{array}{r}143 \\
155 \\
165 \\
150 \\
154 \\
142 \\
134 \\
24 \\
190 \\
63 \\
150 \\
204 \\
185\end{array}$ & $\begin{array}{c}154 \\
194 \\
320 \\
308 \\
333 \\
311 \\
293 \\
5.2 \\
88 \\
26 \\
83 \\
154 \\
143\end{array}$ & $\begin{array}{l}52 \\
49 \\
56 \\
59 \\
47 \\
45 \\
45 \\
53 \\
45 \\
75 \\
71 \\
76 \\
76\end{array}$ \\
\hline \multicolumn{7}{|l|}{ NOV } \\
\hline $\begin{array}{l}05 \ldots \\
30 \ldots \\
D E C\end{array}$ & $\begin{array}{l}1640 \\
1606\end{array}$ & $\begin{array}{l}8.31 \\
4.58\end{array}$ & $\begin{array}{l}636 \\
267\end{array}$ & $\begin{array}{r}205 \\
71\end{array}$ & $\begin{array}{r}352 \\
51\end{array}$ & ${ }^{39}$ \\
\hline $\begin{array}{r}01 \\
07 \ldots \\
\text { JAN }\end{array}$ & $\begin{array}{l}1101 \\
0858\end{array}$ & $\begin{array}{l}4.04 \\
3.13\end{array}$ & $\begin{array}{l}208 \\
107\end{array}$ & $\begin{array}{l}46 \\
25\end{array}$ & $\begin{array}{l}26 \\
7.2\end{array}$ & $\cdots$ \\
\hline$\underset{F \in B}{11 \ldots}$ & 1135 & 3.01 & 85 & 21 & 4.8 & $\cdots$ \\
\hline $\begin{array}{r}19 \ldots \\
28 \ldots \\
A P R\end{array}$ & $\begin{array}{l}1400 \\
1620\end{array}$ & $\begin{array}{l}4.96 \\
2.84\end{array}$ & $\begin{array}{r}283 \\
75\end{array}$ & $\begin{array}{r}129 \\
14\end{array}$ & $\begin{array}{l}99 \\
2.8\end{array}$ & $\begin{array}{l}57 \\
64\end{array}$ \\
\hline $17 \ldots$ & 1350 & \multicolumn{4}{|c|}{ JUN } & 68 \\
\hline $\begin{array}{l}01 \ldots \\
01 \ldots \\
01 \ldots \\
01 \ldots \\
01 \ldots \\
01 \ldots \\
01 \ldots \\
06 \ldots\end{array}$ & $\begin{array}{l}0016 \\
0214 \\
0410 \\
0612 \\
0809 \\
1008 \\
1207 \\
0814\end{array}$ & $\begin{array}{l}8.18 \\
8.33 \\
8.61 \\
8.82 \\
8.91 \\
8.70 \\
8.13 \\
2.16\end{array}$ & $\begin{array}{l}621 \\
640 \\
666 \\
691 \\
706 \\
675 \\
605 \\
75\end{array}$ & $\begin{array}{l}211 \\
294 \\
278 \\
273 \\
221 \\
228 \\
191 \\
23\end{array}$ & $\begin{array}{r}354 \\
508 \\
500 \\
509 \\
421 \\
416 \\
312 \\
4.7\end{array}$ & $\begin{array}{l}77 \\
78 \\
72 \\
74 \\
68 \\
73 \\
69 \\
70\end{array}$ \\
\hline \multicolumn{7}{|l|}{ Jul } \\
\hline $\begin{array}{c}09 \\
\text { AUG }\end{array}$ & 0820 & 2.35 & $\cdots$ & 22 & $\cdots$ & 55 \\
\hline $22 \ldots$ & 1300 & 2.34 & 41 & 29 & 3.2 & $\cdots$ \\
\hline
\end{tabular}


04095300 IRAIL CREEK AT MICHIGAN CITY, IN

SEOIMENT DISCHARGE, SUSPENDED (TONS/DAY), WATER YEAR OCTOBER 1989 TO SEPIEMBER 1990

$\begin{array}{lll}\text { MEAN } & \text { CONCEN- } & \text { SEDIMENT } \\ \text { DISCHARGE } & \text { TRAIION } & \text { DISCHARGE }\end{array}$ $\begin{array}{lll}(\mathrm{CFS}) & (\mathrm{MG} / \mathrm{L}) \quad \text { (IONS/DAY) }\end{array}$

APRI L

\begin{tabular}{|c|c|c|c|c|c|c|c|c|c|}
\hline $\begin{array}{l}1 \\
2 \\
3 \\
4 \\
5\end{array}$ & $\begin{array}{l}76 \\
90 \\
96 \\
79 \\
18\end{array}$ & $\begin{array}{l}\cdots \\
\cdots \\
\cdots \\
\cdots \\
\cdots\end{array}$ & $\begin{array}{l}\cdots \\
\cdots \\
\cdots \\
\cdots\end{array}$ & $\begin{array}{r}57 \\
55 \\
55 \\
188 \\
161\end{array}$ & $\begin{array}{l}\cdots \\
\cdots \\
\cdots \\
\cdots \\
\cdots\end{array}$ & $\begin{array}{l}\ldots \\
\cdots \\
\cdots \\
\cdots \\
\cdots\end{array}$ & $\begin{array}{l}57 \\
61 \\
58 \\
53 \\
53\end{array}$ & $\begin{array}{l}\cdots \\
\cdots \\
\cdots \\
\cdots \\
\cdots\end{array}$ & $\begin{array}{l}\cdots \\
\cdots \\
\cdots \\
\cdots\end{array}$ \\
\hline $\begin{array}{r}6 \\
7 \\
8 \\
9 \\
10\end{array}$ & $\begin{array}{r}69 \\
64 \\
60 \\
60 \\
120\end{array}$ & $\begin{array}{l}\cdots \\
\cdots \\
\cdots \\
\cdots \\
\cdots\end{array}$ & $\begin{array}{l}\cdots \\
\cdots \\
\cdots \\
\cdots\end{array}$ & $\begin{array}{r}90 \\
74 \\
66 \\
74 \\
487\end{array}$ & $\begin{array}{l}\cdots \\
\cdots \\
\cdots \\
\cdots\end{array}$ & $\begin{array}{l}\ldots \\
\ldots \\
\ldots \\
\cdots \\
\cdots\end{array}$ & $\begin{array}{l}52 \\
50 \\
71 \\
60 \\
52\end{array}$ & $\begin{array}{l}\cdots \\
\cdots \\
\cdots \\
\cdots\end{array}$ & $\begin{array}{l}\cdots \\
\cdots \\
\cdots \\
\cdots\end{array}$ \\
\hline $\begin{array}{l}11 \\
12 \\
13 \\
14 \\
15\end{array}$ & $\begin{array}{r}134 \\
93 \\
75 \\
138 \\
106\end{array}$ & $\begin{array}{l}\cdots \\
\cdots \\
\cdots \\
\cdots\end{array}$ & $\begin{array}{l}\cdots \\
\cdots \\
\cdots \\
\cdots\end{array}$ & $\begin{array}{l}255 \\
205 \\
520 \\
310 \\
159\end{array}$ & $\begin{array}{l}\cdots \\
\cdots \\
\cdots \\
\cdots\end{array}$ & $\begin{array}{l}\ldots \\
\ldots \\
\cdots \\
\cdots \\
\cdots\end{array}$ & $\begin{array}{l}49 \\
47 \\
45 \\
51 \\
47\end{array}$ & $\ldots$ & $\begin{array}{l}\ldots \\
\ldots \\
\ldots \\
4\end{array}$ \\
\hline $\begin{array}{l}16 \\
17 \\
18 \\
19 \\
20\end{array}$ & $\begin{array}{l}80 \\
92 \\
75 \\
67 \\
84\end{array}$ & $\begin{array}{l}\cdots \\
\cdots \\
\cdots \\
\cdots\end{array}$ & $\begin{array}{l}\cdots \\
\cdots \\
\cdots \\
\cdots\end{array}$ & $\begin{array}{l}145 \\
527 \\
247 \\
129 \\
110\end{array}$ & $\begin{array}{l}\cdots \\
\cdots \\
\cdots \\
\cdots\end{array}$ & $\begin{array}{l}\cdots \\
\ldots \\
\cdots \\
\cdots\end{array}$ & $\begin{array}{l}44 \\
43 \\
42 \\
40 \\
46\end{array}$ & $\begin{array}{l}62 \\
59 \\
54 \\
54 \\
55\end{array}$ & $\begin{array}{l}7.4 \\
6.9 \\
6.1 \\
5.9 \\
6.9\end{array}$ \\
\hline $\begin{array}{l}21 \\
22 \\
23 \\
24 \\
25\end{array}$ & $\begin{array}{r}315 \\
156 \\
94 \\
79 \\
71\end{array}$ & $\begin{array}{l}\cdots \\
\cdots \\
\cdots \\
\cdots\end{array}$ & $\begin{array}{l}\cdots \\
\cdots \\
\cdots \\
\cdots\end{array}$ & $\begin{array}{l}88 \\
76 \\
70 \\
66 \\
99\end{array}$ & $\begin{array}{l}\cdots \\
\cdots \\
\cdots \\
\cdots\end{array}$ & $\begin{array}{l}\cdots \\
\ldots \\
\cdots \\
\cdots \\
\cdots\end{array}$ & $\begin{array}{l}49 \\
57 \\
73 \\
59 \\
50\end{array}$ & $\begin{array}{l}83 \\
63 \\
78 \\
61 \\
58\end{array}$ & $\begin{array}{r}11 \\
9.9 \\
16 \\
9.7 \\
7.7\end{array}$ \\
\hline $\begin{array}{l}26 \\
27 \\
28 \\
29 \\
30 \\
31\end{array}$ & $\begin{array}{l}67 \\
64 \\
62 \\
59 \\
58 \\
\cdots\end{array}$ & $\begin{array}{l}\ldots \\
\cdots \\
\cdots \\
\cdots \\
\cdots \\
\cdots\end{array}$ & $\begin{array}{l}\cdots \\
\cdots \\
\cdots \\
\cdots \\
\cdots\end{array}$ & $\begin{array}{r}224 \\
113 \\
81 \\
70 \\
64 \\
60\end{array}$ & $\begin{array}{l}\cdots \\
\cdots \\
\cdots \\
\cdots \\
\cdots\end{array}$ & $\begin{array}{l}\cdots \\
\cdots \\
\cdots \\
\cdots \\
\cdots\end{array}$ & $\begin{array}{r}61 \\
57 \\
66 \\
124 \\
81 \\
-\cdots\end{array}$ & $\begin{array}{r}83 \\
70 \\
79 \\
146 \\
126 \\
\cdots\end{array}$ & $\begin{array}{l}15 \\
11 \\
15 \\
53 \\
28 \\
\ldots\end{array}$ \\
\hline IOTAL & 2761 & $\cdots$ & $\cdots$ & 4925 & $\cdots$ & $\cdots$ & 1698 & $\cdots$ & $\cdots$ \\
\hline
\end{tabular}

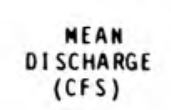

MEAK

CONCEN- SEDIMENT

IRATION DISCHARGE

(MG/L) (IONS/DAY)

MAY

\begin{tabular}{|c|c|c|c|c|c|c|c|c|c|}
\hline $\begin{array}{l}1 \\
2 \\
3 \\
4 \\
5\end{array}$ & $\begin{array}{l}76 \\
90 \\
96 \\
79 \\
18\end{array}$ & $\begin{array}{l}\cdots \\
\cdots \\
\cdots \\
\cdots \\
\cdots\end{array}$ & $\begin{array}{l}\cdots \\
\cdots \\
\cdots \\
\cdots\end{array}$ & $\begin{array}{r}57 \\
55 \\
55 \\
188 \\
161\end{array}$ & $\begin{array}{l}\cdots \\
\cdots \\
\cdots \\
\cdots \\
\cdots\end{array}$ & $\begin{array}{l}\ldots \\
\cdots \\
\cdots \\
\cdots \\
\cdots\end{array}$ & $\begin{array}{l}57 \\
61 \\
58 \\
53 \\
53\end{array}$ & $\begin{array}{l}\cdots \\
\cdots \\
\cdots \\
\cdots \\
\cdots\end{array}$ & $\begin{array}{l}\cdots \\
\cdots \\
\cdots \\
\cdots\end{array}$ \\
\hline $\begin{array}{r}6 \\
7 \\
8 \\
9 \\
10\end{array}$ & $\begin{array}{r}69 \\
64 \\
60 \\
60 \\
120\end{array}$ & $\begin{array}{l}\cdots \\
\cdots \\
\cdots \\
\cdots \\
\cdots\end{array}$ & $\begin{array}{l}\cdots \\
\cdots \\
\cdots \\
\cdots\end{array}$ & $\begin{array}{r}90 \\
74 \\
66 \\
74 \\
487\end{array}$ & $\begin{array}{l}\cdots \\
\cdots \\
\cdots \\
\cdots\end{array}$ & $\begin{array}{l}\ldots \\
\ldots \\
\ldots \\
\cdots \\
\cdots\end{array}$ & $\begin{array}{l}52 \\
50 \\
71 \\
60 \\
52\end{array}$ & $\begin{array}{l}\cdots \\
\cdots \\
\cdots \\
\cdots\end{array}$ & $\begin{array}{l}\cdots \\
\cdots \\
\cdots \\
\cdots\end{array}$ \\
\hline $\begin{array}{l}11 \\
12 \\
13 \\
14 \\
15\end{array}$ & $\begin{array}{r}134 \\
93 \\
75 \\
138 \\
106\end{array}$ & $\begin{array}{l}\cdots \\
\cdots \\
\cdots \\
\cdots\end{array}$ & $\begin{array}{l}\cdots \\
\cdots \\
\cdots \\
\cdots\end{array}$ & $\begin{array}{l}255 \\
205 \\
520 \\
310 \\
159\end{array}$ & $\begin{array}{l}\cdots \\
\cdots \\
\cdots \\
\cdots\end{array}$ & $\begin{array}{l}\ldots \\
\ldots \\
\cdots \\
\cdots \\
\cdots\end{array}$ & $\begin{array}{l}49 \\
47 \\
45 \\
51 \\
47\end{array}$ & $\ldots$ & $\begin{array}{l}\ldots \\
\ldots \\
\ldots \\
4\end{array}$ \\
\hline $\begin{array}{l}16 \\
17 \\
18 \\
19 \\
20\end{array}$ & $\begin{array}{l}80 \\
92 \\
75 \\
67 \\
84\end{array}$ & $\begin{array}{l}\cdots \\
\cdots \\
\cdots \\
\cdots\end{array}$ & $\begin{array}{l}\cdots \\
\cdots \\
\cdots \\
\cdots\end{array}$ & $\begin{array}{l}145 \\
527 \\
247 \\
129 \\
110\end{array}$ & $\begin{array}{l}\cdots \\
\cdots \\
\cdots \\
\cdots\end{array}$ & $\begin{array}{l}\cdots \\
\ldots \\
\cdots \\
\cdots\end{array}$ & $\begin{array}{l}44 \\
43 \\
42 \\
40 \\
46\end{array}$ & $\begin{array}{l}62 \\
59 \\
54 \\
54 \\
55\end{array}$ & $\begin{array}{l}7.4 \\
6.9 \\
6.1 \\
5.9 \\
6.9\end{array}$ \\
\hline $\begin{array}{l}21 \\
22 \\
23 \\
24 \\
25\end{array}$ & $\begin{array}{r}315 \\
156 \\
94 \\
79 \\
71\end{array}$ & $\begin{array}{l}\cdots \\
\cdots \\
\cdots \\
\cdots\end{array}$ & $\begin{array}{l}\cdots \\
\cdots \\
\cdots \\
\cdots\end{array}$ & $\begin{array}{l}88 \\
76 \\
70 \\
66 \\
99\end{array}$ & $\begin{array}{l}\cdots \\
\cdots \\
\cdots \\
\cdots\end{array}$ & $\begin{array}{l}\cdots \\
\ldots \\
\cdots \\
\cdots \\
\cdots\end{array}$ & $\begin{array}{l}49 \\
57 \\
73 \\
59 \\
50\end{array}$ & $\begin{array}{l}83 \\
63 \\
78 \\
61 \\
58\end{array}$ & $\begin{array}{r}11 \\
9.9 \\
16 \\
9.7 \\
7.7\end{array}$ \\
\hline $\begin{array}{l}26 \\
27 \\
28 \\
29 \\
30 \\
31\end{array}$ & $\begin{array}{l}67 \\
64 \\
62 \\
59 \\
58 \\
\cdots\end{array}$ & $\begin{array}{l}\ldots \\
\cdots \\
\cdots \\
\cdots \\
\cdots \\
\cdots\end{array}$ & $\begin{array}{l}\cdots \\
\cdots \\
\cdots \\
\cdots \\
\cdots\end{array}$ & $\begin{array}{r}224 \\
113 \\
81 \\
70 \\
64 \\
60\end{array}$ & $\begin{array}{l}\cdots \\
\cdots \\
\cdots \\
\cdots \\
\cdots\end{array}$ & $\begin{array}{l}\cdots \\
\cdots \\
\cdots \\
\cdots \\
\cdots\end{array}$ & $\begin{array}{r}61 \\
57 \\
66 \\
124 \\
81 \\
-\cdots\end{array}$ & $\begin{array}{r}83 \\
70 \\
79 \\
146 \\
126 \\
\cdots\end{array}$ & $\begin{array}{l}15 \\
11 \\
15 \\
53 \\
28 \\
\ldots\end{array}$ \\
\hline IOTAL & 2761 & $\cdots$ & $\cdots$ & 4925 & $\cdots$ & $\cdots$ & 1698 & $\cdots$ & $\cdots$ \\
\hline
\end{tabular}

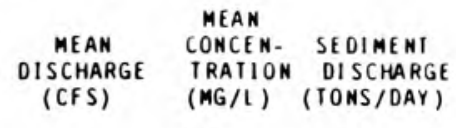

JUNE

SEDIMENT DISCHARGE, SUSPENDED (TONS/DAY), WATER YEAR OCTOBER 1989 TO SEPIEMBER 1990

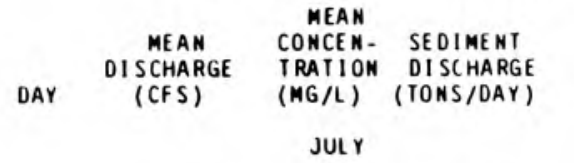

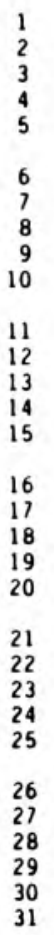

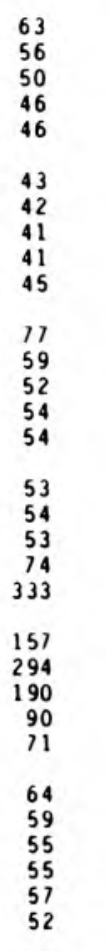

IOTAL

$\begin{array}{rr}103 & 18 \\ 88 & 13 \\ 73 & 9.8 \\ 62 & 7.8 \\ 70 & 8.7 \\ 56 & 6.6 \\ 51 & 5.8 \\ 46 & 5.0 \\ 59 & 6.5 \\ 59 & 7.2\end{array}$

$\begin{array}{ll}92 & 20 \\ 69 & 11 \\ 52 & 7.3 \\ 46 & 6.6 \\ 43 & 6.3\end{array}$

$\begin{array}{rr}42 & 6.0 \\ 47 & 6.9 \\ 62 & 9.7 \\ 79 & 18 \\ 273 & 269\end{array}$

$\begin{array}{rr}81 & 38 \\ 203 & 207 \\ 84 & 47 \\ 47 & 11 \\ 47 & 9.1\end{array}$

$\begin{array}{ll}58 & 10 \\ 57 & 9.1 \\ 56 & 8.2 \\ 63 & 9.3 \\ 53 & 8.1 \\ 47 & 6.6\end{array}$

1480

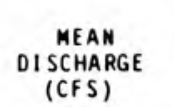

CONCEN - SEDIMENT TRATION DISCHARGE (MG/L) (IONS/OAY)

AUGUSI

50
48
46
228
105

46
45
46
256
65

$\begin{array}{rc}46 & 6.1 \\ 45 & 5.7 \\ 46 & 5.7 \\ 256 & 198 \\ 65 & 19\end{array}$

6.1
5.7
5.7
198
19

MEAN
DISCHARGE

(CFS)
MEAN

CONCEN- SEOIMENI

TRAIION DISCHARGE (MG/L) (IONS/DAY)

SEPIEMBER 
04095300 TRAIL CREEK AT MICHIGAN CITY, IN

SEDIMENT DISCHARGE, SUSPENDED (IONS/DAY), WATER YEAR OCTOBER 1990 TO SEPTEMBER 1991

\begin{tabular}{|c|c|c|c|c|c|c|c|c|c|}
\hline \multirow[t]{2}{*}{ DAY } & $\begin{array}{l}\text { MEAN } \\
\text { DI SCHARGE } \\
\text { (CFS) }\end{array}$ & $\begin{array}{l}\text { MEAN } \\
\text { CONCEN- } \\
\text { IRATION } \\
(M G / L)\end{array}$ & $\begin{array}{l}\text { SE DIME NT } \\
\text { DISCHARGE } \\
\text { (TONS/DAY) }\end{array}$ & $\begin{array}{l}\text { MEAN } \\
\text { DI SCHARGE } \\
\text { (CFS) }\end{array}$ & $\begin{array}{l}\text { MEAN } \\
\text { CONCEN- } \\
\text { TRATION } \\
(M G / L)\end{array}$ & $\begin{array}{l}\text { SEDIMENT } \\
\text { DISCHARGE } \\
\text { (TONS/DAY) }\end{array}$ & $\begin{array}{l}\text { MEAN } \\
\text { DISCHARGE } \\
\text { (CFS) }\end{array}$ & $\begin{array}{l}\text { MEAN } \\
\text { CONCEN- } \\
\text { TRAIION } \\
(\text { MG/L) }\end{array}$ & $\begin{array}{l}\text { SEDIMENT } \\
\text { DI SCHARGE } \\
\text { (TONS/DAY) }\end{array}$ \\
\hline & \multicolumn{3}{|c|}{ OCIOBER } & \multicolumn{3}{|c|}{ NOVEMBER } & \multicolumn{3}{|c|}{ DECEMBER } \\
\hline $\begin{array}{l}1 \\
2 \\
3 \\
4 \\
5\end{array}$ & $\begin{array}{r}50 \\
48 \\
78 \\
293 \\
125\end{array}$ & $\begin{array}{r}27 \\
14 \\
37 \\
251 \\
57\end{array}$ & $\begin{array}{r}3.6 \\
1.8 \\
18 \\
220 \\
19\end{array}$ & $\begin{array}{r}60 \\
59 \\
59 \\
69 \\
475\end{array}$ & $\begin{array}{l}\cdots \\
\cdots \\
\cdots \\
\cdots\end{array}$ & $\begin{array}{r}3.3 \\
3.2 \\
3.2 \\
4.8 \\
420\end{array}$ & $\begin{array}{l}202 \\
147 \\
146 \\
139 \\
114\end{array}$ & $\begin{array}{l}50 \\
29 \\
53 \\
28 \\
14\end{array}$ & $\begin{array}{l}27 \\
12 \\
22 \\
11 \\
4.2\end{array}$ \\
\hline $\begin{array}{r}6 \\
7 \\
8 \\
9 \\
10\end{array}$ & $\begin{array}{r}74 \\
74 \\
90 \\
389 \\
728\end{array}$ & $\begin{array}{r}39 \\
40 \\
36 \\
181 \\
162\end{array}$ & $\begin{array}{r}7.8 \\
8.1 \\
11 \\
197 \\
327\end{array}$ & $\begin{array}{l}574 \\
251 \\
160 \\
116 \\
100\end{array}$ & $\begin{array}{l}\cdots \\
\cdots \\
\cdots \\
48\end{array}$ & $\begin{array}{r}630 \\
95 \\
34 \\
16 \\
13\end{array}$ & $\begin{array}{r}112 \\
105 \\
99 \\
94 \\
91\end{array}$ & $\begin{array}{l}16 \\
15 \\
15 \\
13 \\
10\end{array}$ & $\begin{array}{l}4.8 \\
4.1 \\
3.9 \\
3.4 \\
2.6\end{array}$ \\
\hline $\begin{array}{l}11 \\
12 \\
13 \\
14 \\
15\end{array}$ & $\begin{array}{l}407 \\
209 \\
133 \\
107 \\
134\end{array}$ & $\begin{array}{r}111 \\
59 \\
38 \\
25 \\
34\end{array}$ & $\begin{array}{c}128 \\
33 \\
14 \\
7.6 \\
12\end{array}$ & $\begin{array}{l}88 \\
82 \\
77 \\
75 \\
73\end{array}$ & $\begin{array}{l}40 \\
33 \\
27 \\
20 \\
13\end{array}$ & $\begin{array}{l}9.5 \\
7.4 \\
5.5 \\
4.1 \\
2.6\end{array}$ & $\begin{array}{r}88 \\
87 \\
85 \\
81 \\
106\end{array}$ & $\begin{array}{l}9 \\
10 \\
11 \\
11 \\
17\end{array}$ & $\begin{array}{l}2.1 \\
2.4 \\
2.4 \\
2.4 \\
4.9\end{array}$ \\
\hline $\begin{array}{l}16 \\
17 \\
18 \\
19 \\
20\end{array}$ & $\begin{array}{r}98 \\
94 \\
259 \\
141 \\
98\end{array}$ & $\begin{array}{r}20 \\
25 \\
125 \\
34 \\
28\end{array}$ & $\begin{array}{l}5.3 \\
8.7 \\
95 \\
13 \\
7.3\end{array}$ & $\begin{array}{l}12 \\
69 \\
68 \\
68 \\
66\end{array}$ & $\begin{array}{r}10 \\
9 \\
8 \\
8 \\
8\end{array}$ & $\begin{array}{l}2.0 \\
1.7 \\
1.5 \\
1.5 \\
1.4\end{array}$ & $\begin{array}{r}97 \\
92 \\
108 \\
98 \\
87\end{array}$ & $\begin{array}{r}13 \\
9 \\
13 \\
11 \\
10\end{array}$ & $\begin{array}{l}3.4 \\
2.4 \\
3.7 \\
2.8 \\
2.3\end{array}$ \\
\hline $\begin{array}{l}21 \\
22 \\
23 \\
24 \\
25\end{array}$ & $\begin{array}{l}84 \\
78 \\
73 \\
71 \\
75\end{array}$ & $\begin{array}{r}21 \\
21 \\
17 \\
13 \\
\cdots\end{array}$ & $\begin{array}{l}4.8 \\
4.3 \\
3.4 \\
2.5 \\
5.6\end{array}$ & $\begin{array}{l}70 \\
79 \\
73 \\
68 \\
66\end{array}$ & $\begin{array}{r}8 \\
11 \\
10 \\
9 \\
9\end{array}$ & $\begin{array}{l}1.5 \\
2.4 \\
2.0 \\
1.7 \\
1.6\end{array}$ & $\begin{array}{r}103 \\
125 \\
99 \\
87 \\
80\end{array}$ & $\begin{array}{r}21 \\
28 \\
9 \\
11 \\
18\end{array}$ & $\begin{array}{l}6.9 \\
9.9 \\
2.4 \\
2.6 \\
4.1\end{array}$ \\
\hline $\begin{array}{l}26 \\
27 \\
28 \\
29 \\
30 \\
31\end{array}$ & $\begin{array}{l}13 \\
69 \\
64 \\
62 \\
62 \\
61\end{array}$ & $\begin{array}{l}\cdots \\
\cdots \\
\cdots \\
\cdots \\
\cdots\end{array}$ & $\begin{array}{l}5.3 \\
4.8 \\
3.9 \\
3.6 \\
3.6 \\
3.5\end{array}$ & $\begin{array}{r}65 \\
649 \\
2550 \\
510 \\
285 \\
\cdots\end{array}$ & $\begin{array}{r}8 \\
358 \\
117 \\
10 \\
80 \\
\cdots\end{array}$ & $\begin{array}{c}1.4 \\
888 \\
927 \\
91 \\
62 \\
\ldots\end{array}$ & $\begin{array}{r}73 \\
67 \\
78 \\
740 \\
669 \\
290\end{array}$ & $\begin{array}{r}18 \\
15 \\
12 \\
270 \\
66 \\
35\end{array}$ & $\begin{array}{r}3.8 \\
2.7 \\
2.6 \\
478 \\
124 \\
27\end{array}$ \\
\hline TOTAL & 4401 & $\cdots$ & 1182.5 & 7076 & $\cdots$ & 3238.3 & 4589 & $\cdots$ & 187.8 \\
\hline DAY & $\begin{array}{c}\text { MEAN } \\
\text { DI SCHARGE } \\
\text { (CFS) }\end{array}$ & $\begin{array}{l}\text { MEAN } \\
\text { CONCEN- } \\
\text { IRAIION } \\
(M G / L)\end{array}$ & $\begin{array}{l}\text { SEOIMENI } \\
\text { DISCHARGE } \\
\text { ( TONS/OAY) }\end{array}$ & $\begin{array}{l}\text { MEAN } \\
\text { DI SCHARGE } \\
\text { (CFS) }\end{array}$ & $\begin{array}{l}\text { MEAN } \\
\text { CONCEN- } \\
\text { TRATION } \\
(M G / L)\end{array}$ & $\begin{array}{l}\text { SEDIMENT } \\
\text { DISCHARGE } \\
\text { (IONS/DAY) }\end{array}$ & $\begin{array}{c}\text { MEAN } \\
\text { DISCHARGE } \\
\text { (CFS) }\end{array}$ & $\begin{array}{l}\text { MEAN } \\
\text { CONCEN- } \\
\text { TRAIION } \\
(M G / L)\end{array}$ & $\begin{array}{l}\text { SEDIMENI } \\
\text { DISCHARGE } \\
\text { (TONS/DAY) }\end{array}$ \\
\hline & & JANUARY & & & EBRUARY & & & IARCH & \\
\hline
\end{tabular}

$\begin{array}{rr}29 & 15 \\ 19 & 6.8 \\ 17 & 5.1 \\ 20 & 4.8 \\ 20 & 5.0 \\ 16 & 3.8 \\ 13 & 2.8 \\ 11 & 2.3 \\ 9 & 1.9 \\ 6 & 1.3\end{array}$

62
66
86
174
240
165
124
104
98
90

16
11
17
51
53

$$
\begin{aligned}
& 2.6 \\
& 2.0 \\
& 4.5 \\
& 25 \\
& 36
\end{aligned}
$$

$\begin{array}{lr}22 & 10 \\ 16 & 5.3 \\ 12 & 3.3 \\ 11 & 2.9\end{array}$

$$
\begin{aligned}
& 3.8 \\
& 4.6 \\
& 2.6 \\
& 2.8 \\
& 2.9
\end{aligned}
$$$$
\begin{aligned}
& 76 \\
& 67 \\
& 85 \\
& 80 \\
& 77
\end{aligned}
$$$$
\begin{aligned}
& 60 \\
& 23 \\
& 7.7 \\
& 7.7 \\
& 28
\end{aligned}
$$

$\begin{array}{llc}236 & 84 & 60 \\ 267 & 31 & 23 \\ 154 & 19 & 7.7 \\ 119 & 23 & 7.7 \\ 185 & 55 & 28\end{array}$

$\begin{array}{ll}20 & 9.0 \\ 14 & 4.2 \\ 16 & 4.7 \\ 16 & 3.7 \\ 22 & 4.2\end{array}$

$\begin{array}{rr}21 & 4.2 \\ 23 & 4.0 \\ 14 & 2.4 \\ 11 & 1.9 \\ 6 & 1.1 \\ 10 & 1.6\end{array}$

IOTAL

$\begin{array}{rr}6 & 1.3 \\ 8 & 1.4 \\ 26 & 8.6 \\ 19 & 6.4 \\ 11 & 2.2\end{array}$

$\begin{array}{rrr}10 & 7 & 1.4 \\ 69 & 9 & 1.8 \\ 14 & 10 & 2.1 \\ \cdots & \cdots & \cdots \\ \cdots & \cdots & \cdots\end{array}$

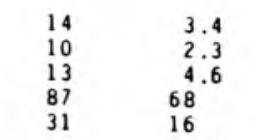

91
361
314
173
123
113
98
89
89
84
81
78
84
94
123
123
126
237
137
103

$\begin{array}{rc}10 & 2.5 \\ 251 & 289 \\ 88 & 78 \\ 51 & 24 \\ 26 & 8.6 \\ & \\ 14 & 4.3 \\ 10 & 2.6 \\ 8 & 2.0 \\ 12 & 2.9 \\ 11 & 2.4\end{array}$

$\begin{array}{rr}12 & 2.7 \\ 12 & 2.5 \\ 9 & 2.0 \\ 10 & 2.8 \\ 19 & 6.6\end{array}$

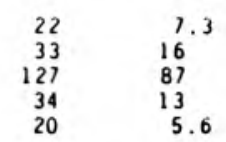

$\begin{array}{rr}25 & 9.9 \\ 14 & 4.3 \\ 9 & 2.1 \\ 7 & 1.7 \\ 6 & 1.2\end{array}$

91
84
87
87
77
138
403
299
167
111
93

$\begin{array}{rr}11 & 2.6 \\ 14 & 3.1 \\ 15 & 3.5 \\ 12 & 2.8 \\ 9 & 1.9\end{array}$

$\begin{array}{rr}56 & 25 \\ 341 & 434 \\ 89 & 76 \\ 44 & 20 \\ 22 & 6.7 \\ 19 & 4.7\end{array}$


04095300 TRAIL CREEK AT MICHIGAN CITY, IN

SEDIMENT DISCHARGE, SUSPENDEO (IONS/DAY), WATER YEAR OCTOBER 1990 TO SEPIEMBER 199I

\begin{tabular}{|c|c|c|c|c|c|c|c|c|c|}
\hline \multirow[t]{2}{*}{ DAY } & $\begin{array}{l}\text { MEAN } \\
\text { DI SCHARGE } \\
\text { (CFS) }\end{array}$ & $\begin{array}{l}\text { MEAN } \\
\text { CONCEN- } \\
\text { IRATION } \\
(M G / L)\end{array}$ & $\begin{array}{l}\text { SE DIMENI } \\
\text { DISCHARGE } \\
\text { (TONS/DAY) }\end{array}$ & $\begin{array}{l}\text { MEAN } \\
\text { DI SCHARGE } \\
\text { (CFS) }\end{array}$ & $\begin{array}{l}\text { MEAN } \\
\text { CONCEN- } \\
\text { TRAIION } \\
(\text { MG/L) }\end{array}$ & $\begin{array}{l}\text { SEDIMENT } \\
\text { DI SCHARGE } \\
\text { (IONS/DAY) }\end{array}$ & $\begin{array}{l}\text { MEAN } \\
\text { DISCHARGE } \\
\text { (CFS) }\end{array}$ & $\begin{array}{l}\text { MEAN } \\
\text { CONCEN- } \\
\text { TRATION } \\
(\text { MG/L) }\end{array}$ & $\begin{array}{l}\text { SEDIMENT } \\
\text { DISCHARGE } \\
\text { (IONS/OAY) }\end{array}$ \\
\hline & \multicolumn{3}{|c|}{ APRIL } & \multicolumn{3}{|c|}{ MAY } & \multicolumn{3}{|c|}{ JUNE } \\
\hline $\begin{array}{l}1 \\
2 \\
3 \\
4 \\
5\end{array}$ & $\begin{array}{r}87 \\
19 \\
75 \\
82 \\
101\end{array}$ & $\begin{array}{r}11 \\
9 \\
4 \\
9 \\
15\end{array}$ & $\begin{array}{l}4.0 \\
1.9 \\
.82 \\
2.2 \\
4.1\end{array}$ & $\begin{array}{r}113 \\
94 \\
79 \\
74 \\
304\end{array}$ & $\begin{array}{r}25 \\
14 \\
9 \\
7 \\
307\end{array}$ & $\begin{array}{r}8.5 \\
3.6 \\
2.0 \\
1.4 \\
326\end{array}$ & $\begin{array}{r}549 \\
222 \\
124 \\
95 \\
82\end{array}$ & $\begin{array}{r}216 \\
81 \\
48 \\
27 \\
20\end{array}$ & $\begin{array}{r}343 \\
50 \\
16 \\
6.8 \\
4.3\end{array}$ \\
\hline $\begin{array}{r}6 \\
7 \\
8 \\
9 \\
10\end{array}$ & $\begin{array}{r}83 \\
74 \\
72 \\
83 \\
145\end{array}$ & $\begin{array}{r}7 \\
5 \\
8 \\
17 \\
60\end{array}$ & $\begin{array}{r}1.5 \\
1.1 \\
1.5 \\
3.9 \\
26\end{array}$ & $\begin{array}{r}229 \\
124 \\
95 \\
85 \\
76\end{array}$ & $\begin{array}{r}126 \\
38 \\
19 \\
11 \\
12\end{array}$ & $\begin{array}{l}83 \\
13 \\
5.0 \\
2.5 \\
2.4\end{array}$ & $\begin{array}{l}73 \\
68 \\
64 \\
61 \\
59\end{array}$ & $\begin{array}{l}20 \\
20 \\
17 \\
18 \\
16\end{array}$ & $\begin{array}{l}3.9 \\
3.6 \\
3.0 \\
3.0 \\
2.5\end{array}$ \\
\hline $\begin{array}{l}11 \\
12 \\
13 \\
14 \\
15\end{array}$ & $\begin{array}{r}91 \\
76 \\
74 \\
136 \\
349\end{array}$ & $\begin{array}{r}13 \\
10 \\
12 \\
53 \\
130\end{array}$ & $\begin{array}{r}3.2 \\
2.1 \\
2.5 \\
24 \\
145\end{array}$ & $\begin{array}{l}71 \\
68 \\
66 \\
64 \\
62\end{array}$ & $\begin{array}{l}15 \\
13 \\
14 \\
18 \\
16\end{array}$ & $\begin{array}{l}2.9 \\
2.4 \\
2.5 \\
3.1 \\
2.6\end{array}$ & $\begin{array}{l}70 \\
66 \\
58 \\
55 \\
53\end{array}$ & $\begin{array}{l}23 \\
15 \\
18 \\
15 \\
13\end{array}$ & $\begin{array}{l}4.7 \\
2.8 \\
2.9 \\
2.2 \\
1.8\end{array}$ \\
\hline $\begin{array}{l}16 \\
17 \\
18 \\
19 \\
20\end{array}$ & $\begin{array}{r}277 \\
226 \\
133 \\
104 \\
92\end{array}$ & $\begin{array}{l}79 \\
87 \\
33 \\
18 \\
11\end{array}$ & $\begin{array}{r}60 \\
55 \\
12 \\
5.2 \\
2.1\end{array}$ & $\begin{array}{l}68 \\
90 \\
98 \\
76 \\
67\end{array}$ & $\begin{array}{l}34 \\
35 \\
31 \\
20 \\
17\end{array}$ & $\begin{array}{l}7.1 \\
9.0 \\
8.3 \\
4.2 \\
3.2\end{array}$ & $\begin{array}{l}54 \\
51 \\
49 \\
48 \\
47\end{array}$ & $\begin{array}{l}16 \\
21 \\
18 \\
17 \\
16\end{array}$ & $\begin{array}{l}2.3 \\
2.9 \\
2.4 \\
2.2 \\
2.0\end{array}$ \\
\hline $\begin{array}{l}21 \\
22 \\
23 \\
24 \\
25\end{array}$ & $\begin{array}{r}84 \\
19 \\
83 \\
130 \\
97\end{array}$ & $\begin{array}{r}9 \\
8 \\
9 \\
21 \\
5\end{array}$ & $\begin{array}{l}2.1 \\
1.7 \\
2.2 \\
7.6 \\
1.4\end{array}$ & $\begin{array}{r}64 \\
72 \\
95 \\
116 \\
200\end{array}$ & $\begin{array}{r}16 \\
24 \\
61 \\
96 \\
264\end{array}$ & $\begin{array}{r}2.8 \\
4.9 \\
21 \\
31 \\
222\end{array}$ & $\begin{array}{l}47 \\
52 \\
50 \\
47 \\
45\end{array}$ & $\begin{array}{r}16 \\
18 \\
16 \\
12 \\
9\end{array}$ & $\begin{array}{l}2.1 \\
2.5 \\
2.2 \\
1.5 \\
1.1\end{array}$ \\
\hline $\begin{array}{l}26 \\
27 \\
28 \\
29 \\
30 \\
31\end{array}$ & $\begin{array}{r}84 \\
87 \\
93 \\
108 \\
100 \\
\cdots\end{array}$ & $\begin{array}{r}5 \\
9 \\
9 \\
16 \\
14 \\
\cdots\end{array}$ & $\begin{array}{c}1.2 \\
2.3 \\
2.4 \\
5.4 \\
4.0 \\
\ldots\end{array}$ & $\begin{array}{r}320 \\
282 \\
126 \\
87 \\
80 \\
201\end{array}$ & $\begin{array}{r}82 \\
131 \\
60 \\
38 \\
32 \\
264\end{array}$ & $\begin{array}{c}14 \\
104 \\
21 \\
8.9 \\
7.0 \\
292\end{array}$ & $\begin{array}{r}44 \\
43 \\
42 \\
41 \\
44 \\
-\cdots\end{array}$ & $\begin{array}{l}7 \\
10 \\
12 \\
11 \\
11 \\
\cdots\end{array}$ & $\begin{array}{l}.81 \\
1.2 \\
1.3 \\
1.3 \\
1.4 \\
. .-\end{array}$ \\
\hline \multirow[t]{2}{*}{ TOTAL } & 3384 & $\cdots$ & 389.02 & 3646 & $\cdots$ & 1281.3 & 2403 & $\cdots$ & 477.71 \\
\hline & $\begin{array}{c}\text { MEAN } \\
\text { DI SCHARGE } \\
\text { (CFS) }\end{array}$ & $\begin{array}{l}\text { MEAN } \\
\text { CONCEN- } \\
\text { TRATION } \\
(M G / L)\end{array}$ & $\begin{array}{l}\text { SE DIMENT } \\
\text { DI SCHARGE } \\
\text { (TONS/DAY) }\end{array}$ & $\begin{array}{c}\text { MEAN } \\
\text { DI SCHARGE } \\
\text { (CFS) }\end{array}$ & $\begin{array}{l}\text { MEAN } \\
\text { CONCEN- } \\
\text { TRATION } \\
(\text { MG } / L)\end{array}$ & $\begin{array}{c}\text { SEDIMENT } \\
\text { DISCHARGE } \\
\text { (IONS/OAY) }\end{array}$ & $\begin{array}{l}\text { MEAN } \\
\text { DISCHARGE } \\
\text { (CFS) }\end{array}$ & $\begin{array}{l}\text { MEAN } \\
\text { CONCEN- } \\
\text { TRATION } \\
(\text { MG/L) }\end{array}$ & $\begin{array}{l}\text { SE DIMENT } \\
\text { DI SCHARGE } \\
\text { (IONS/DAY) }\end{array}$ \\
\hline DAY & & JULY & & & AUGUST & & \multicolumn{3}{|c|}{ EMBER } \\
\hline
\end{tabular}

\begin{tabular}{|c|c|c|c|c|c|c|c|c|c|}
\hline $\begin{array}{l}1 \\
2 \\
3 \\
4 \\
5\end{array}$ & $\begin{array}{l}43 \\
41 \\
41 \\
44 \\
41\end{array}$ & $\begin{array}{r}14 \\
13 \\
13 \\
12 \\
9\end{array}$ & $\begin{array}{l}1.6 \\
1.5 \\
1.4 \\
1.4 \\
.98\end{array}$ & $\begin{array}{l}31 \\
31 \\
31 \\
33 \\
32\end{array}$ & $\begin{array}{r}10 \\
12 \\
10 \\
7 \\
10\end{array}$ & $\begin{array}{l}.87 \\
1.0 \\
.82 \\
.65 \\
.89\end{array}$ & $\begin{array}{l}33 \\
32 \\
46 \\
48 \\
37\end{array}$ & $\begin{array}{r}13 \\
9 \\
37 \\
24 \\
15\end{array}$ & $\begin{array}{l}1.2 \\
.80 \\
6.1 \\
3.3 \\
1.5\end{array}$ \\
\hline $\begin{array}{r}6 \\
7 \\
8 \\
9 \\
10\end{array}$ & $\begin{array}{l}39 \\
51 \\
50 \\
41 \\
40\end{array}$ & $\begin{array}{r}11 \\
18 \\
21 \\
7 \\
16\end{array}$ & $\begin{array}{l}1.2 \\
2.8 \\
2.9 \\
.78 \\
1.8\end{array}$ & $\begin{array}{r}32 \\
31 \\
115 \\
55 \\
40\end{array}$ & $\begin{array}{r}11 \\
11 \\
188 \\
55 \\
10\end{array}$ & $\begin{array}{c}.90 \\
78^{.92} \\
8.9 \\
1.1\end{array}$ & $\begin{array}{l}35 \\
34 \\
33 \\
32 \\
35\end{array}$ & $\begin{array}{l}17 \\
18 \\
13 \\
14 \\
17\end{array}$ & $\begin{array}{l}1.6 \\
1.7 \\
1.2 \\
1.2 \\
1.6\end{array}$ \\
\hline $\begin{array}{l}11 \\
12 \\
13 \\
14 \\
15\end{array}$ & $\begin{array}{l}38 \\
38 \\
38 \\
39 \\
36\end{array}$ & $\begin{array}{l}15 \\
14 \\
16 \\
21 \\
20\end{array}$ & $\begin{array}{l}1.5 \\
1.4 \\
1.7 \\
2.2 \\
1.9\end{array}$ & $\begin{array}{l}37 \\
36 \\
35 \\
35 \\
34\end{array}$ & $\begin{array}{l}9 \\
10 \\
13 \\
14 \\
13\end{array}$ & $\begin{array}{r}.94 \\
.97 \\
1.3 \\
1.3 \\
1.2\end{array}$ & $\begin{array}{l}34 \\
46 \\
49 \\
39 \\
37\end{array}$ & $\begin{array}{l}16 \\
23 \\
22 \\
11 \\
14\end{array}$ & $\begin{array}{l}1.5 \\
3.2 \\
3.0 \\
1.1 \\
1.4\end{array}$ \\
\hline $\begin{array}{l}16 \\
17 \\
18 \\
19 \\
20\end{array}$ & $\begin{array}{l}36 \\
36 \\
34 \\
33 \\
33\end{array}$ & $\begin{array}{r}12 \\
15 \\
14 \\
10 \\
7\end{array}$ & $\begin{array}{l}1.1 \\
1.4 \\
1.3 \\
.95 \\
.65\end{array}$ & $\begin{array}{l}33 \\
36 \\
38 \\
85 \\
77\end{array}$ & $\begin{array}{l}12 \\
19 \\
20 \\
97 \\
72\end{array}$ & $\begin{array}{l}1.1 \\
2.0 \\
2.0 \\
36 \\
18\end{array}$ & $\begin{array}{l}35 \\
34 \\
34 \\
34 \\
33\end{array}$ & $\begin{array}{l}18 \\
17 \\
16 \\
14 \\
13\end{array}$ & $\begin{array}{l}1.7 \\
1.5 \\
1.5 \\
1.3 \\
1.2\end{array}$ \\
\hline $\begin{array}{l}21 \\
22 \\
23 \\
24 \\
25\end{array}$ & $\begin{array}{l}33 \\
35 \\
35 \\
35 \\
33\end{array}$ & $\begin{array}{r}11 \\
19 \\
15 \\
11 \\
8\end{array}$ & $\begin{array}{l}.98 \\
1.8 \\
1.4 \\
1.0 \\
.76\end{array}$ & $\begin{array}{l}44 \\
40 \\
38 \\
37 \\
35\end{array}$ & $\begin{array}{l}21 \\
13 \\
15 \\
18 \\
18\end{array}$ & $\begin{array}{l}2.5 \\
1.3 \\
1.5 \\
1.8 \\
1.7\end{array}$ & $\begin{array}{l}33 \\
37 \\
37 \\
34 \\
35\end{array}$ & $\begin{array}{r}7 \\
17 \\
11 \\
7 \\
9\end{array}$ & $\begin{array}{l}.64 \\
1.7 \\
1.1 \\
.68 \\
.82\end{array}$ \\
\hline $\begin{array}{l}26 \\
27 \\
28 \\
29 \\
30 \\
31\end{array}$ & $\begin{array}{l}32 \\
32 \\
32 \\
32 \\
33 \\
32\end{array}$ & $\begin{array}{l}7 \\
8 \\
8 \\
8 \\
7 \\
8\end{array}$ & $\begin{array}{l}.60 \\
.67 \\
.73 \\
.66 \\
.63 \\
.12\end{array}$ & $\begin{array}{l}35 \\
34 \\
34 \\
34 \\
34 \\
34\end{array}$ & $\begin{array}{l}24 \\
24 \\
22 \\
18 \\
16 \\
15\end{array}$ & $\begin{array}{l}2.3 \\
2.2 \\
2.0 \\
1.6 \\
1.5 \\
1.4\end{array}$ & $\begin{array}{r}34 \\
33 \\
33 \\
33 \\
32 \\
\cdots\end{array}$ & $\begin{array}{r}7 \\
5 \\
5 \\
9 \\
10 \\
\cdots\end{array}$ & $\begin{array}{l}.64 \\
.43 \\
.40 \\
.83 \\
.89 \\
. .\end{array}$ \\
\hline IOTAL & 1156 & $\cdots$ & 40.41 & 1276 & $\cdots$ & 178.66 & 1081 & $\cdots$ & 45.73 \\
\hline
\end{tabular}


LOCATION.--Lat $41^{\circ} 44^{\prime} 54^{\circ}$, long $86^{\circ} 40^{\prime} 30^{\circ}$, in SE $\frac{1}{4} N W \frac{1}{z}$ sec.17. T. 38 N., R.2 W.. LaPorte County, Hydrologic Unit 04040001 . On left bank at downstrea side of bridge on County Rod 125 East, 1.3 ai upstrean froe Indiana Michigan State line, and 9.8 i north of Courthouse in LaPorte.

DRAINAGE AREA. $-17.2 \mathrm{i}^{2}$, of which $2.30 \mathrm{i}^{2}$ does not contribute directly to surface runoff.

PERIOD OF RECORD.--October 1969 to current year.

REVISED RECORDS.--WDR IN-80-1: 1970, 1971(P), 1972, 1973, 1974(P), 1975 (M), 1976 (P), and 1978 (P).

GAGE. - Water-stage recorder. Datum of gage is $625.00 \mathrm{ft}$ above National Geodetic Vertical Datue of ig29.

REMARKS. - Records good except for estiated daily discharges, which are poor. Maximum instantaneous and ean daily discharges for period of record are estinated, maxidu gage height is unknown.

DISCHARGE, CUBIC FEET PER SECOND, WATER YEAR OCTOBER 1990 TO SEPTEMBER 1991 DAILY MEAN VALUES

\begin{tabular}{|c|c|c|c|c|c|c|c|c|c|c|c|c|}
\hline DAY & $\mathrm{OCT}$ & NOV & $\mathrm{DEC}$ & JAN & FEB & MAR & APR & MAY & JUN & JUL & AUG & SEP \\
\hline $\begin{array}{l}1 \\
2 \\
3 \\
4 \\
5\end{array}$ & $\begin{array}{l}17 \\
17 \\
21 \\
80 \\
41\end{array}$ & $\begin{array}{r}23 \\
23 \\
23 \\
26 \\
127\end{array}$ & $\begin{array}{l}47 \\
42 \\
43 \\
41 \\
36\end{array}$ & $\begin{array}{l}\text { e50 } \\
\text { e } 40 \\
\text { e } 35 \\
\text { e28 } \\
\text { e } 31\end{array}$ & $\begin{array}{l}\text { e20 } \\
\text { e21 } \\
\text { e25 } \\
\text { e40 } \\
\text { e66 }\end{array}$ & $\begin{array}{l}\text { e } 35 \\
e 70 \\
e 60 \\
e 42 \\
e 38\end{array}$ & $\begin{array}{l}\text { e27 } \\
e 25 \\
e 23 \\
e 27 \\
e 35\end{array}$ & $\begin{array}{l}32 \\
28 \\
25 \\
24 \\
40\end{array}$ & $\begin{array}{r}148 \\
49 \\
35 \\
29 \\
27\end{array}$ & $\begin{array}{l}13 \\
13 \\
12 \\
15 \\
14\end{array}$ & $\begin{array}{l}10 \\
10 \\
9.8 \\
10 \\
10\end{array}$ & $\begin{array}{l}11 \\
12 \\
16 \\
18 \\
14\end{array}$ \\
\hline $\begin{array}{r}6 \\
7 \\
8 \\
9 \\
10\end{array}$ & $\begin{array}{r}27 \\
28 \\
31 \\
117 \\
224\end{array}$ & $\begin{array}{r}150 \\
56 \\
43 \\
37 \\
33\end{array}$ & $\begin{array}{l}\text { e33 } \\
\text { e32 } \\
\text { e31 } \\
\text { e } 30 \\
\text { e } 30\end{array}$ & $\begin{array}{l}\text { e } 30 \\
\text { e2 } 8 \\
e 27 \\
\text { e26 } \\
\text { e27 }\end{array}$ & $\begin{array}{r}e 42 \\
40 \\
37 \\
35 \\
33\end{array}$ & $\begin{array}{l}\text { e } 34 \\
\text { e31 } \\
\text { e29 } \\
\text { e27 } \\
\text { e26 }\end{array}$ & $\begin{array}{l}\text { e29 } \\
e 26 \\
e 33 \\
e 32 \\
e 40\end{array}$ & $\begin{array}{l}39 \\
29 \\
24 \\
23 \\
22\end{array}$ & $\begin{array}{l}25 \\
22 \\
21 \\
20 \\
21\end{array}$ & $\begin{array}{l}13 \\
14 \\
17 \\
15 \\
14\end{array}$ & $\begin{array}{l}10 \\
9.9 \\
24 \\
23 \\
15\end{array}$ & $\begin{array}{l}13 \\
12 \\
11 \\
11 \\
11\end{array}$ \\
\hline $\begin{array}{l}11 \\
12 \\
13 \\
14 \\
15\end{array}$ & $\begin{array}{r}107 \\
48 \\
36 \\
32 \\
40\end{array}$ & $\begin{array}{l}30 \\
28 \\
26 \\
25 \\
25\end{array}$ & $\begin{array}{l}\text { e29 } \\
\text { e28 } \\
\text { e28 } \\
\text { e27 } \\
\text { e } 35\end{array}$ & $\begin{array}{l}\text { e } 30 \\
\text { e36 } \\
\text { e } 34 \\
\text { e } 33 \\
\text { e34 }\end{array}$ & $\begin{array}{r}29 \\
27 \\
e 30 \\
e 28 \\
e 27\end{array}$ & $\begin{array}{l}\text { e } 26 \\
e 25 \\
e 28 \\
e 32 \\
e 40\end{array}$ & $\begin{array}{l}\text { e } 30 \\
\text { e25 } \\
\text { e23 } \\
\text { e } 40 \\
\text { e64 }\end{array}$ & $\begin{array}{l}21 \\
20 \\
19 \\
18 \\
18\end{array}$ & $\begin{array}{l}23 \\
25 \\
21 \\
19 \\
18\end{array}$ & $\begin{array}{l}13 \\
14 \\
14 \\
14 \\
13\end{array}$ & $\begin{array}{l}14 \\
13 \\
13 \\
13 \\
12\end{array}$ & $\begin{array}{l}13 \\
16 \\
17 \\
15 \\
15\end{array}$ \\
\hline $\begin{array}{l}16 \\
17 \\
18 \\
19 \\
20\end{array}$ & $\begin{array}{l}32 \\
30 \\
60 \\
42 \\
33\end{array}$ & $\begin{array}{l}24 \\
23 \\
23 \\
23 \\
22\end{array}$ & $\begin{array}{l}\text { e } 32 \\
\text { e } 30 \\
\text { e } 36 \\
\text { e } 32 \\
\text { e } 30\end{array}$ & $\begin{array}{l}\text { e } 66 \\
\text { e } 56 \\
\text { e } 45 \\
\text { e } 39 \\
\text { e56 }\end{array}$ & $\begin{array}{l}e 29 \\
e 40 \\
e 56 \\
e 72 \\
e 53\end{array}$ & $\begin{array}{l}\text { e } 41 \\
e 50 \\
e 70 \\
e 47 \\
\text { e } 36\end{array}$ & $\begin{array}{r}\text { e } 100 \\
\text { e56 } \\
\text { e36 } \\
30 \\
29\end{array}$ & $\begin{array}{l}24 \\
39 \\
37 \\
29 \\
23\end{array}$ & $\begin{array}{l}18 \\
17 \\
17 \\
16 \\
15\end{array}$ & $\begin{array}{l}12 \\
12 \\
11 \\
13 \\
11\end{array}$ & $\begin{array}{l}12 \\
12 \\
13 \\
17 \\
19\end{array}$ & $\begin{array}{l}13 \\
12 \\
13 \\
12 \\
11\end{array}$ \\
\hline $\begin{array}{l}21 \\
22 \\
23 \\
24 \\
25\end{array}$ & $\begin{array}{l}31 \\
29 \\
28 \\
27 \\
28\end{array}$ & $\begin{array}{l}23 \\
27 \\
25 \\
23 \\
22\end{array}$ & $\begin{array}{l}\text { e } 34 \\
\text { e } 37 \\
\text { e30 } \\
\text { e27 } \\
\text { e26 }\end{array}$ & $\begin{array}{l}\text { e } 45 \\
\text { e } 36 \\
\text { e } 30 \\
\text { e } 25 \\
\text { e21 }\end{array}$ & $\begin{array}{l}\text { e39 } \\
\text { e32 } \\
\text { e30 } \\
\text { e28 } \\
\text { e26 }\end{array}$ & $\begin{array}{l}\text { e } 30 \\
\text { e } 27 \\
e 28 \\
e 29 \\
e 26\end{array}$ & $\begin{array}{l}27 \\
27 \\
28 \\
50 \\
34\end{array}$ & $\begin{array}{l}22 \\
21 \\
25 \\
33 \\
62\end{array}$ & $\begin{array}{l}15 \\
16 \\
16 \\
15 \\
15\end{array}$ & $\begin{array}{l}11 \\
12 \\
13 \\
12 \\
11\end{array}$ & $\begin{array}{l}15 \\
14 \\
13 \\
14 \\
12\end{array}$ & $\begin{array}{l}11 \\
12 \\
13 \\
12 \\
12\end{array}$ \\
\hline $\begin{array}{l}26 \\
27 \\
28 \\
29 \\
30 \\
31\end{array}$ & $\begin{array}{l}27 \\
26 \\
26 \\
25 \\
24 \\
23\end{array}$ & $\begin{array}{r}22 \\
\text { e150 } \\
\text { e650 } \\
131 \\
68 \\
\cdots\end{array}$ & $\begin{array}{r}e 24 \\
e 22 \\
e 25 \\
e 220 \\
e 120 \\
e 80\end{array}$ & $\begin{array}{l}\text { e22 } \\
\text { e21 } \\
\text { e20 } \\
\text { e20 } \\
\text { e19 } \\
\text { e19 }\end{array}$ & $\begin{array}{l}\text { e25 } \\
\text { e26 } \\
\text { e28 } \\
\ldots- \\
\cdots \\
\cdots\end{array}$ & $\begin{array}{l}\text { e } 50 \\
\text { e74 } \\
\text { e58 } \\
\text { e } 40 \\
\text { e34 } \\
\text { e30 }\end{array}$ & $\begin{array}{l}29 \\
27 \\
28 \\
33 \\
30 \\
\cdots\end{array}$ & $\begin{array}{r}128 \\
63 \\
40 \\
33 \\
29 \\
51\end{array}$ & $\begin{array}{l}15 \\
14 \\
13 \\
13 \\
13 \\
\cdots\end{array}$ & $\begin{array}{l}11 \\
11 \\
10 \\
13 \\
12 \\
11\end{array}$ & $\begin{array}{l}11 \\
11 \\
10 \\
10 \\
13 \\
12\end{array}$ & $\begin{array}{l}12 \\
11 \\
11 \\
11 \\
11 \\
-\cdots\end{array}$ \\
\hline $\begin{array}{l}\text { TOTAL } \\
\text { MEAN } \\
\text { MAX } \\
\text { MIN } \\
\text { CFSM } \\
\text { IN. }\end{array}$ & $\begin{array}{r}1357 \\
43.8 \\
224 \\
17 \\
2.55 \\
2.93\end{array}$ & $\begin{array}{r}1931 \\
64.4 \\
650 \\
22 \\
3.74 \\
4.18\end{array}$ & $\begin{array}{r}1317 \\
42.5 \\
220 \\
22 \\
2.47 \\
2.85\end{array}$ & $\begin{array}{r}1029 \\
33.2 \\
66 \\
19 \\
1.93 \\
2.23\end{array}$ & $\begin{array}{r}984 \\
35.1 \\
72 \\
20 \\
2.04 \\
2.13\end{array}$ & $\begin{array}{r}1213 \\
39.1 \\
74 \\
25 \\
2.27 \\
2.62\end{array}$ & $\begin{array}{c}1043 \\
34.8 \\
100 \\
23 \\
2.02 \\
2.26\end{array}$ & $\begin{array}{c}1041 \\
33.6 \\
128 \\
18 \\
1.95 \\
2.25\end{array}$ & $\begin{array}{c}731 \\
24.4 \\
148 \\
13 \\
1.42 \\
1.58\end{array}$ & $\begin{array}{c}394 \\
12.7 \\
17 \\
10 \\
.74 \\
.85\end{array}$ & $\begin{array}{c}404.7 \\
13.1 \\
24 \\
9.8 \\
.76 \\
.88\end{array}$ & $\begin{array}{c}382 \\
12.7 \\
18 \\
11 \\
.74 \\
.83\end{array}$ \\
\hline
\end{tabular}

STATISTICS OF MONTHLY MEAN DATA FOR WATER YEARS 1970 - 1991, BY WATER YEAR (WY)

\begin{tabular}{|c|c|c|c|c|c|c|c|c|c|c|c|}
\hline $\begin{array}{l}\text { MEAN } \\
\text { MAX } \\
\text { (WY) } \\
\text { MIN } \\
(W Y)\end{array}$ & $\begin{array}{l}22.4 \\
43.8 \\
1991 \\
14.8 \\
1990\end{array}$ & $\begin{array}{l}29.1 \\
64.4 \\
1991 \\
16.8 \\
1981\end{array}$ & $\begin{array}{l}30.9 \\
51.8 \\
1973 \\
15.6 \\
1990\end{array}$ & $\begin{array}{l}25.9 \\
40.4 \\
1974 \\
15.0 \\
1976\end{array}$ & $\begin{array}{l}31.0 \\
51.6 \\
1985 \\
19.2 \\
1980\end{array}$ & $\begin{array}{l}38.9 \\
70.1 \\
1982 \\
19.4 \\
1981\end{array}$ & $\begin{array}{l}35.0 \\
56.0 \\
1970 \\
18.2 \\
1971\end{array}$ & $\begin{array}{l}27.6 \\
45.2 \\
1981 \\
16.0 \\
1980\end{array}$ & $\begin{array}{l}21.9 \\
38.1 \\
1973 \\
12.3 \\
1971\end{array}$ & $\begin{array}{l}15.7 \\
26.2 \\
1978 \\
10.3 \\
1988\end{array}$ & $\begin{array}{l}14.8 \\
26.3 \\
1990 \\
9.71 \\
1970\end{array}$ \\
\hline
\end{tabular}

\section{SUMMARY STATISTICS}

AMNUAL TOTAL

ANNUAL MEAN

HIGHEST ANMUAL MEAN

LOWEST ANNUAL MEAN

HIGHEST DAILY MEAM

LOWEST DAILY MEAN

ANNUAL SEVEN-DAY MINIMUM

INSTANTANEOUS PEAK FLOW

INSTANTANEOUS PEAK STAGE

ANNUAL RUNOFF (CFSM)

ANNUAL RUNOFF (INCHES)

10 PERCENT EXCEEDS

50 PERCENT EXCEEDS

90 PERCENT EXCEEDS

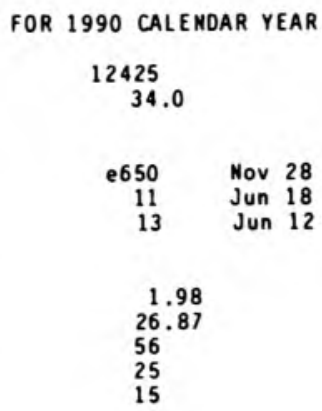

e Estiated

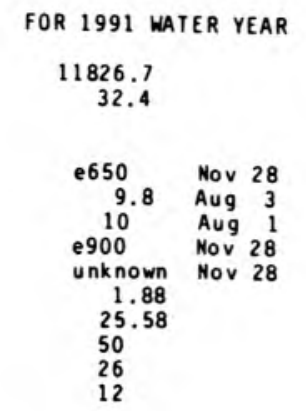

WATER YEARS $1970=1991$

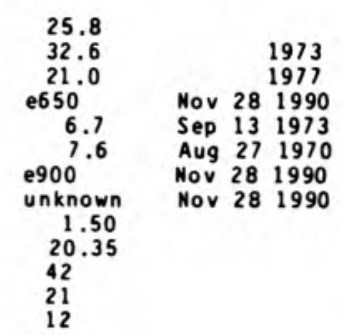




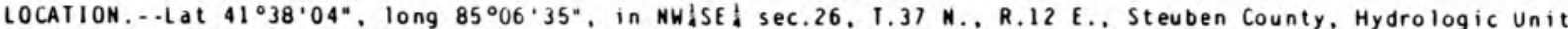
04050001 , on left bank $5 \mathrm{ft}$ upstrean from bridge on U.S. Highway $20,1.3$ ei downstrea froe out let of Hogback Lake, $1.3=i$ southe ģst of Flint, and 5.8 i west of Angola.

DRAINAGE AREA..-106 i of which 22.5 i does not contribute directly to surface runoff.

PERIOD OF RECORD..-October 1945 to current year. Prior to October 1947, published as "near Flint". Published as Pigeon Creek at Hogback Lake Outlet near Angola, October 1947 to Septemer 1971, and Pigeon Creek and Hogback Lake near Angola, October 1971 to September 1974.

REVISED RECORDS.-.WSP 1144: 1948. WSP 2111: Orainage area.

GAGE.- Water-stage recorder. Datun of gage is $940.00 \mathrm{ft}$ above National Geodetic Vertical Datua of 1929 . Prior to October 1947, nonrecording gage at site 0.3 ei downstrea at different datum. 0ct. 1947 to Aug. 3, 1953,

nonrecording gage at site 1.2 i upstrean at sane datua. Aug. 4, 1953, to Apr. 3, 1974, recording gage at site $1.3 . i$ upstrean at sane datun. Apr. 18, 1974, to Sept. 2, 1974, nonrecording gage at sane site and datua. REMARKS. - Records good.

DISCHARGE, CUBIL FEET PER SECOND, WATER YEAR OCTOBER 1990 TO SEPIEMBER 1991 DAI IY MEAN VALUES

\begin{tabular}{|c|c|c|c|c|c|c|c|c|c|c|c|c|}
\hline DAY & OCI & NOV & DEC & JAN & FE B & MAR & APR & MAY & JUN & JUL & AUG & SEP \\
\hline $\begin{array}{l}1 \\
2 \\
3 \\
4 \\
5\end{array}$ & $\begin{array}{l}32 \\
31 \\
31 \\
37 \\
41\end{array}$ & $\begin{array}{l}67 \\
64 \\
62 \\
60 \\
72\end{array}$ & $\begin{array}{r}97 \\
96 \\
100 \\
111 \\
132\end{array}$ & $\begin{array}{l}553 \\
579 \\
569 \\
537 \\
491\end{array}$ & $\begin{array}{r}95 \\
90 \\
89 \\
92 \\
101\end{array}$ & $\begin{array}{l}111 \\
116 \\
140 \\
165 \\
177\end{array}$ & $\begin{array}{l}136 \\
128 \\
120 \\
113 \\
110\end{array}$ & $\begin{array}{l}199 \\
181 \\
166 \\
152 \\
142\end{array}$ & $\begin{array}{l}109 \\
130 \\
143 \\
149 \\
143\end{array}$ & $\begin{array}{l}33 \\
47 \\
56 \\
61 \\
60\end{array}$ & $\begin{array}{l}21 \\
20 \\
22 \\
21 \\
22\end{array}$ & $\begin{array}{l}27 \\
28 \\
29 \\
29 \\
27\end{array}$ \\
\hline $\begin{array}{r}6 \\
7 \\
8 \\
9 \\
10\end{array}$ & $\begin{array}{r}44 \\
47 \\
48 \\
61 \\
112\end{array}$ & $\begin{array}{l}106 \\
151 \\
180 \\
188 \\
181\end{array}$ & $\begin{array}{l}145 \\
147 \\
142 \\
134 \\
126\end{array}$ & $\begin{array}{l}439 \\
389 \\
340 \\
297 \\
260\end{array}$ & $\begin{array}{l}112 \\
120 \\
122 \\
122 \\
119\end{array}$ & $\begin{array}{l}176 \\
166 \\
157 \\
146 \\
137\end{array}$ & $\begin{array}{l}108 \\
107 \\
107 \\
115 \\
127\end{array}$ & $\begin{array}{l}137 \\
131 \\
126 \\
119 \\
111\end{array}$ & $\begin{array}{r}130 \\
117 \\
104 \\
92 \\
83\end{array}$ & $\begin{array}{l}57 \\
53 \\
49 \\
45 \\
41\end{array}$ & $\begin{array}{l}21 \\
20 \\
22 \\
22 \\
22\end{array}$ & $\begin{array}{l}26 \\
24 \\
23 \\
23 \\
22\end{array}$ \\
\hline $\begin{array}{l}11 \\
12 \\
13 \\
14 \\
15\end{array}$ & $\begin{array}{l}192 \\
253 \\
283 \\
288 \\
266\end{array}$ & $\begin{array}{l}172 \\
155 \\
139 \\
125 \\
114\end{array}$ & $\begin{array}{l}121 \\
116 \\
110 \\
106 \\
103\end{array}$ & $\begin{array}{l}234 \\
218 \\
204 \\
191 \\
180\end{array}$ & $\begin{array}{l}116 \\
111 \\
107 \\
107 \\
103\end{array}$ & $\begin{array}{l}128 \\
121 \\
114 \\
107 \\
100\end{array}$ & $\begin{array}{l}139 \\
144 \\
139 \\
135 \\
140\end{array}$ & $\begin{array}{r}104 \\
98 \\
92 \\
88 \\
84\end{array}$ & $\begin{array}{l}76 \\
73 \\
69 \\
64 \\
61\end{array}$ & $\begin{array}{l}38 \\
36 \\
35 \\
34 \\
32\end{array}$ & $\begin{array}{l}22 \\
22 \\
22 \\
21 \\
21\end{array}$ & $\begin{array}{l}21 \\
23 \\
24 \\
24 \\
23\end{array}$ \\
\hline $\begin{array}{l}16 \\
17 \\
18 \\
19 \\
20\end{array}$ & $\begin{array}{l}236 \\
207 \\
185 \\
167 \\
153\end{array}$ & $\begin{array}{r}105 \\
97 \\
92 \\
89 \\
82\end{array}$ & $\begin{array}{l}102 \\
103 \\
106 \\
110 \\
114\end{array}$ & $\begin{array}{l}182 \\
202 \\
218 \\
219 \\
212\end{array}$ & $\begin{array}{r}101 \\
96 \\
94 \\
101 \\
125\end{array}$ & $\begin{array}{l}95 \\
92 \\
91 \\
90 \\
90\end{array}$ & $\begin{array}{l}156 \\
174 \\
190 \\
195 \\
237\end{array}$ & $\begin{array}{l}81 \\
80 \\
71 \\
73 \\
70\end{array}$ & $\begin{array}{l}57 \\
54 \\
52 \\
48 \\
46\end{array}$ & $\begin{array}{l}31 \\
29 \\
28 \\
26 \\
26\end{array}$ & $\begin{array}{l}20 \\
21 \\
22 \\
25 \\
33\end{array}$ & $\begin{array}{l}23 \\
21 \\
20 \\
19 \\
18\end{array}$ \\
\hline $\begin{array}{l}21 \\
22 \\
23 \\
24 \\
25\end{array}$ & $\begin{array}{lll}1 & 40 \\
1 & 31 \\
1 & 23 \\
1 & 13 \\
1 & 04\end{array}$ & $\begin{array}{l}78 \\
76 \\
74 \\
73 \\
71\end{array}$ & $\begin{array}{l}117 \\
128 \\
145 \\
153 \\
152\end{array}$ & $\begin{array}{l}203 \\
192 \\
178 \\
164 \\
149\end{array}$ & $\begin{array}{l}151 \\
163 \\
165 \\
159 \\
149\end{array}$ & $\begin{array}{l}89 \\
88 \\
89 \\
91 \\
94\end{array}$ & $\begin{array}{l}300 \\
335 \\
342 \\
336 \\
324\end{array}$ & $\begin{array}{l}67 \\
64 \\
61 \\
60 \\
63\end{array}$ & $\begin{array}{l}44 \\
42 \\
39 \\
38 \\
36\end{array}$ & $\begin{array}{l}25 \\
25 \\
24 \\
23 \\
23\end{array}$ & $\begin{array}{l}38 \\
45 \\
49 \\
48 \\
43\end{array}$ & $\begin{array}{l}18 \\
17 \\
17 \\
17 \\
17\end{array}$ \\
\hline $\begin{array}{l}26 \\
27 \\
28 \\
29 \\
30 \\
31\end{array}$ & $\begin{array}{l}96 \\
88 \\
82 \\
77 \\
73 \\
69\end{array}$ & $\begin{array}{r}70 \\
70 \\
74 \\
83 \\
93 \\
\cdots\end{array}$ & $\begin{array}{l}144 \\
134 \\
126 \\
159 \\
318 \\
479\end{array}$ & $\begin{array}{r}137 \\
127 \\
118 \\
110 \\
105 \\
99\end{array}$ & $\begin{array}{l}137 \\
126 \\
117 \\
\ldots \\
\cdots \\
\cdots\end{array}$ & $\begin{array}{r}99 \\
106 \\
117 \\
129 \\
139 \\
141\end{array}$ & $\begin{array}{l}303 \\
279 \\
258 \\
238 \\
216 \\
\ldots\end{array}$ & $\begin{array}{l}68 \\
73 \\
74 \\
73 \\
71 \\
82\end{array}$ & $\begin{array}{r}35 \\
34 \\
33 \\
32 \\
31 \\
\cdots\end{array}$ & $\begin{array}{l}22 \\
22 \\
22 \\
22 \\
22 \\
21\end{array}$ & $\begin{array}{l}38 \\
34 \\
30 \\
28 \\
27 \\
28\end{array}$ & $\begin{array}{l}17 \\
16 \\
16 \\
16 \\
15 \\
\cdots\end{array}$ \\
\hline $\begin{array}{l}\text { TOIAL } \\
\text { MEAN } \\
\text { MAX } \\
\text { MIN } \\
\text { CF SM }\end{array}$ & $\begin{array}{r}3810 \\
123 \\
288 \\
31 \\
1.47 \\
1.70\end{array}$ & $\begin{array}{r}3063 \\
102 \\
188 \\
60 \\
1.22 \\
1.36\end{array}$ & $\begin{array}{r}4376 \\
141 \\
479 \\
96 \\
1.69 \\
1.95\end{array}$ & $\begin{array}{r}8096 \\
261 \\
579 \\
99 \\
3.13 \\
3.61\end{array}$ & $\begin{array}{r}3290 \\
117 \\
165 \\
89 \\
1.41 \\
1.47\end{array}$ & $\begin{array}{r}3701 \\
119 \\
177 \\
88 \\
1.43 \\
1.65\end{array}$ & $\begin{array}{l}5751 \\
192 \\
342 \\
107 \\
2.30 \\
2.56\end{array}$ & $\begin{array}{c}3067 \\
98.9 \\
199 \\
60 \\
1.18 \\
1.37\end{array}$ & $\begin{array}{c}2164 \\
72.1 \\
149 \\
31 \\
.86 \\
.96\end{array}$ & $\begin{array}{c}1068 \\
34.5 \\
61 \\
21 \\
.41 \\
.48\end{array}$ & $\begin{array}{r}850 \\
27.4 \\
49 \\
20 \\
.33 \\
.38\end{array}$ & $\begin{array}{r}640 \\
21.3 \\
29 \\
15 \\
.26 \\
.29\end{array}$ \\
\hline
\end{tabular}

SIATISIICS OF MONTHLY MEAN DATA FOR WAIER YEARS 1946 - 1991, BY WATER YEAR (WY)

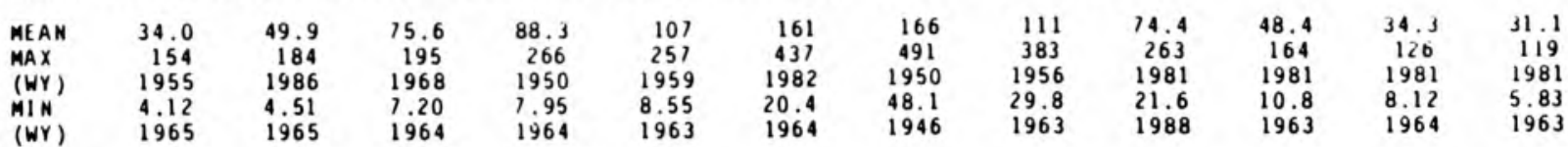

SUMMARY SIATISTICS

ANMUAL TOIAL

ANMUAL MEAN

HIGHEST ANNUAL MEAN

LOWEST AMNUAL MEAN

HIGHESI DAILY MEAN

LOWEST DAILY MEAM

ANHUAL SEVEN-DAY MINIMUM

INSTANIANEOUS PEAK FLOW

INSIANTANEOUS PEAK SIAGE

ANMUAL RUNOFF (CFSN)

ANNUAL RUNOFF (INCHES)

10 PERCENT EXCEEDS

50 PERCENT EXCEEDS

90 PERCENT EXCEEDS
FOR 1990 CALENDAR YEAR

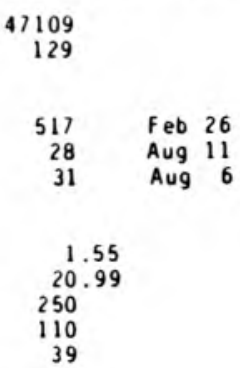

FOR 1991 WAIER YEAR

39816
109

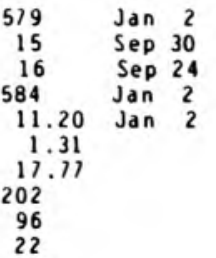

WAIER YEARS 1946 - 1991

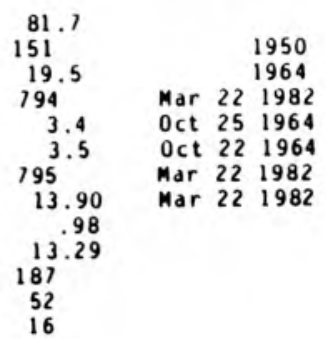




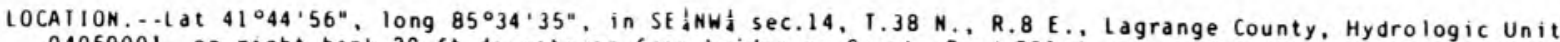
04050001 , on right bank $20 \mathrm{ft}$ downstream from bridge on County Rodd 750 North, $1,200 \mathrm{ft}$ downstrea from Page ditch, 0.7 a south of Indiana-Michigan State line, and 1.2 i northwest of Scoti.

DRAINAGE AREA . 361 mi of which $53.9 \mathrm{i}^{2}$ does not contribute directly to surface runoff.

PERIOD OF RECORD..- June 1968 to current year.

REVISED RECORDS ...WSP 2111: Drainage area.

GAGE.-Water-stage recorder. Datum of gage is $815.00 \mathrm{ft}$ above National Geodetic Vertical Datue of 1929 .

REMARKS. - - Records good except for estimated daily discharges, which are fair.

DISCHARGE, CUBIC FEET PER SECOND, WATER YEAR OCTOBER 1990 TO SEPTEMBER 1991

\begin{tabular}{|c|c|c|c|c|c|c|c|c|c|c|c|c|}
\hline DAY & $0 C \mathrm{~T}$ & NOV & OEC & JAN & FEB & MAR & APR & MAY & JUN & JUL & $A \cup G$ & SEP \\
\hline $\begin{array}{l}1 \\
2 \\
3 \\
4 \\
5\end{array}$ & $\begin{array}{l}196 \\
190 \\
187 \\
212 \\
215\end{array}$ & $\begin{array}{l}323 \\
314 \\
306 \\
303 \\
407\end{array}$ & $\begin{array}{l}413 \\
399 \\
403 \\
479 \\
486\end{array}$ & $\begin{array}{l}\text { e } 1610 \\
\text { e } 1550 \\
\text { e } 1430 \\
\text { e } 1300 \\
\text { e } 1210\end{array}$ & $\begin{array}{r}\mathrm{e} 425 \\
\mathrm{e} 420 \\
443 \\
465 \\
494\end{array}$ & $\begin{array}{l}499 \\
535 \\
583 \\
570 \\
576\end{array}$ & $\begin{array}{l}487 \\
479 \\
465 \\
454 \\
475\end{array}$ & $\begin{array}{l}727 \\
690 \\
637 \\
591 \\
572\end{array}$ & $\begin{array}{l}534 \\
603 \\
536 \\
511 \\
500\end{array}$ & $\begin{array}{l}266 \\
442 \\
506 \\
392 \\
349\end{array}$ & $\begin{array}{l}140 \\
135 \\
140 \\
144 \\
149\end{array}$ & $\begin{array}{l}152 \\
146 \\
150 \\
162 \\
177\end{array}$ \\
\hline $\begin{array}{r}6 \\
7 \\
8 \\
9 \\
10\end{array}$ & $\begin{array}{l}209 \\
212 \\
237 \\
384 \\
655\end{array}$ & $\begin{array}{l}598 \\
593 \\
557 \\
547 \\
560\end{array}$ & $\begin{array}{l}462 \\
460 \\
471 \\
460 \\
445\end{array}$ & $\begin{array}{r}\text { e } 1130 \\
\text { e } 1050 \\
\text { e } 980 \\
\text { e } 910 \\
\text { e } 860\end{array}$ & $\begin{array}{l}504 \\
519 \\
514 \\
511 \\
506\end{array}$ & $\begin{array}{l}582 \\
571 \\
561 \\
542 \\
529\end{array}$ & $\begin{array}{l}468 \\
447 \\
438 \\
450 \\
447\end{array}$ & $\begin{array}{l}564 \\
563 \\
533 \\
510 \\
503\end{array}$ & $\begin{array}{l}488 \\
471 \\
448 \\
421 \\
395\end{array}$ & $\begin{array}{l}324 \\
305 \\
284 \\
242 \\
223\end{array}$ & $\begin{array}{l}138 \\
114 \\
146 \\
215 \\
201\end{array}$ & $\begin{array}{l}165 \\
143 \\
123 \\
124 \\
146\end{array}$ \\
\hline $\begin{array}{l}11 \\
12 \\
13 \\
14 \\
15\end{array}$ & $\begin{array}{l}823 \\
801 \\
739 \\
744 \\
763\end{array}$ & $\begin{array}{l}549 \\
524 \\
497 \\
469 \\
448\end{array}$ & $\begin{array}{l}432 \\
418 \\
404 \\
393 \\
400\end{array}$ & $\begin{array}{l}\text { e } 810 \\
\text { e } 770 \\
\text { e } 730 \\
\text { e } 700 \\
\text { e690 }\end{array}$ & $\begin{array}{l}493 \\
475 \\
468 \\
502 \\
491\end{array}$ & $\begin{array}{l}512 \\
492 \\
474 \\
454 \\
440\end{array}$ & $\begin{array}{l}444 \\
442 \\
442 \\
466 \\
519\end{array}$ & $\begin{array}{l}475 \\
426 \\
427 \\
432 \\
413\end{array}$ & $\begin{array}{l}371 \\
368 \\
339 \\
323 \\
318\end{array}$ & $\begin{array}{l}211 \\
204 \\
216 \\
219 \\
207\end{array}$ & $\begin{array}{l}175 \\
148 \\
134 \\
136 \\
136\end{array}$ & $\begin{array}{l}144 \\
164 \\
204 \\
188 \\
150\end{array}$ \\
\hline $\begin{array}{l}16 \\
17 \\
18 \\
19 \\
20\end{array}$ & $\begin{array}{l}751 \\
706 \\
683 \\
664 \\
601\end{array}$ & $\begin{array}{l}426 \\
402 \\
365 \\
354 \\
352\end{array}$ & $\begin{array}{l}398 \\
392 \\
406 \\
406 \\
376\end{array}$ & $\begin{array}{l}748 \\
811 \\
794 \\
759 \\
755\end{array}$ & $\begin{array}{r}e 460 \\
e 435 \\
e 430 \\
517 \\
578\end{array}$ & $\begin{array}{l}433 \\
425 \\
445 \\
452 \\
437\end{array}$ & $\begin{array}{l}545 \\
536 \\
530 \\
569 \\
696\end{array}$ & $\begin{array}{l}400 \\
400 \\
384 \\
368 \\
337\end{array}$ & $\begin{array}{l}314 \\
306 \\
293 \\
279 \\
252\end{array}$ & $\begin{array}{l}195 \\
180 \\
159 \\
154 \\
172\end{array}$ & $\begin{array}{l}135 \\
139 \\
153 \\
176 \\
228\end{array}$ & $\begin{array}{l}131 \\
141 \\
143 \\
138 \\
136\end{array}$ \\
\hline $\begin{array}{l}21 \\
22 \\
23 \\
24 \\
25\end{array}$ & $\begin{array}{l}549 \\
496 \\
446 \\
441 \\
430\end{array}$ & $\begin{array}{l}334 \\
346 \\
357 \\
346 \\
335\end{array}$ & $\begin{array}{r}404 \\
440 \\
442 \\
447 \\
e 450\end{array}$ & $\begin{array}{r}750 \\
706 \\
667 \\
e 620 \\
e 580\end{array}$ & $\begin{array}{l}577 \\
586 \\
605 \\
583 \\
564\end{array}$ & $\begin{array}{l}430 \\
424 \\
429 \\
440 \\
439\end{array}$ & $\begin{array}{l}809 \\
774 \\
779 \\
860 \\
916\end{array}$ & $\begin{array}{l}334 \\
333 \\
360 \\
384 \\
383\end{array}$ & $\begin{array}{l}246 \\
246 \\
249 \\
239 \\
233\end{array}$ & $\begin{array}{l}189 \\
188 \\
157 \\
129 \\
155\end{array}$ & $\begin{array}{l}215 \\
193 \\
182 \\
170 \\
167\end{array}$ & $\begin{array}{l}135 \\
135 \\
137 \\
134 \\
135\end{array}$ \\
\hline $\begin{array}{l}26 \\
27 \\
28 \\
29 \\
30 \\
31\end{array}$ & $\begin{array}{l}417 \\
397 \\
376 \\
337 \\
331 \\
328\end{array}$ & $\begin{array}{l}327 \\
344 \\
448 \\
498 \\
446 \\
\cdots\end{array}$ & $\begin{array}{r}e 440 \\
e 410 \\
e 390 \\
632 \\
1130 \\
\text { e1530 }\end{array}$ & $\begin{array}{l}\text { e550 } \\
\text { e520 } \\
\text { e495 } \\
\text { e } 480 \\
\text { e } 460 \\
\text { e440 }\end{array}$ & $\begin{array}{l}543 \\
519 \\
501 \\
\cdots \\
\cdots \\
\cdots\end{array}$ & $\begin{array}{l}446 \\
474 \\
505 \\
520 \\
491 \\
482\end{array}$ & $\begin{array}{l}892 \\
858 \\
852 \\
824 \\
785 \\
\cdots\end{array}$ & $\begin{array}{l}405 \\
389 \\
370 \\
357 \\
349 \\
388\end{array}$ & $\begin{array}{l}229 \\
220 \\
214 \\
203 \\
208 \\
\ldots\end{array}$ & $\begin{array}{l}149 \\
140 \\
139 \\
141 \\
154 \\
147\end{array}$ & $\begin{array}{l}169 \\
152 \\
142 \\
151 \\
148 \\
149\end{array}$ & $\begin{array}{l}139 \\
134 \\
130 \\
128 \\
127 \\
\cdots\end{array}$ \\
\hline $\begin{array}{l}\text { IOTAL } \\
\text { MEAN } \\
\text { MAX } \\
\text { MI N } \\
\text { CF SM } \\
\text { IN. }\end{array}$ & $\begin{array}{r}14520 \\
468 \\
823 \\
187 \\
1.53 \\
1.76\end{array}$ & $\begin{array}{r}12675 \\
422 \\
598 \\
303 \\
1.38 \\
1.54\end{array}$ & $\begin{array}{r}15218 \\
491 \\
1530 \\
376 \\
1.60 \\
1.84\end{array}$ & $\begin{array}{r}25865 \\
834 \\
1610 \\
440 \\
2.12 \\
3.13\end{array}$ & $\begin{array}{r}14128 \\
505 \\
605 \\
420 \\
1.64 \\
1.71\end{array}$ & $\begin{array}{r}15198 \\
490 \\
583 \\
424 \\
1.60 \\
1.84\end{array}$ & $\begin{array}{r}18148 \\
605 \\
916 \\
438 \\
1.97 \\
2.20\end{array}$ & $\begin{array}{c}14004 \\
452 \\
727 \\
333 \\
1.47 \\
1.70\end{array}$ & $\begin{array}{c}10357 \\
345 \\
603 \\
203 \\
1.12 \\
1.25\end{array}$ & $\begin{array}{l}6938 \\
224 \\
506 \\
129 \\
.73 \\
.84\end{array}$ & $\begin{array}{l}4920 \\
159 \\
228 \\
114 \\
.52 \\
.60\end{array}$ & $\begin{array}{l}4361 \\
145 \\
204 \\
123 \\
.47 \\
.53\end{array}$ \\
\hline
\end{tabular}

STATISTICS OF MONTHLY MEAN DATA FOR WATER YEARS 1968 - 1991, BY WATER YEAR (WY)

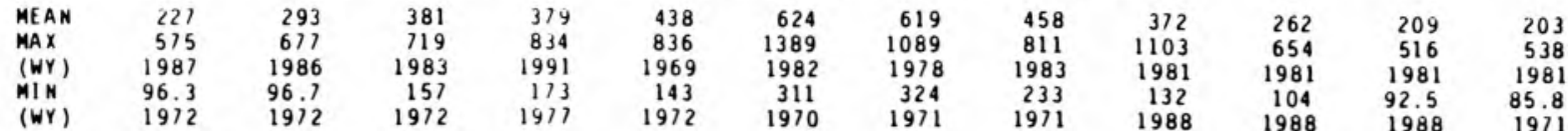

SUMMARY SIAIISIICS

ANNUAL IOIAL

ANMUAL MEAN

HIGHEST ANNUAL MEAN

IOWEST ANNUAL MEAM

HIGHEST DAILY MEAN

LOWEST DAILY MEAN

ANNUAL SEVEN-DAY MINIMUM

INSTANTANEOUS PEAK FLOW

INSTANTANEOUS PEAK STAGE

ANMUAL RUMOFF (CFSM)

AN NUAL RUNOFF (INCHES)

10 PERCENT EXCEEDS

50 PERCENT EXCEEDS

90 PERCENT EXCEEDS
FOR 1990 CALENDAR YEAR

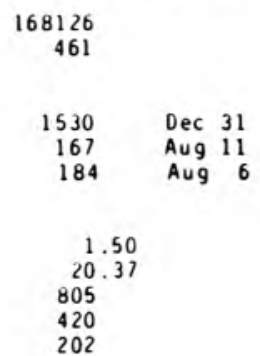

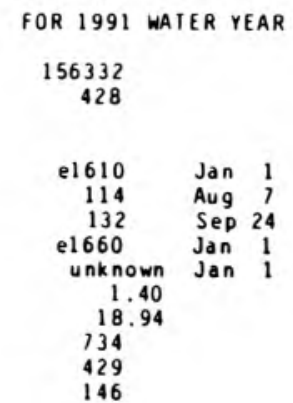

WATER YEARS 1968 - 1991

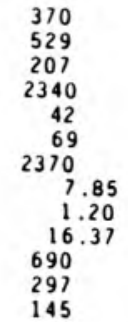

1982

Mar 211982

Oct $21 \quad 1971$

Aug $27 \quad 1971$

Mar $21 \quad 1982$

Mar 211982

e Estiaded 


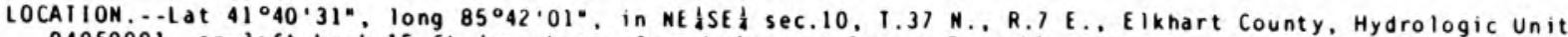
04050001 , on left bank $15 \mathrm{ft}$ downstream from bridge on County Rodd $16,0.1$ a i east of Middlebury, and 1.7 a downstrean fron Rowe Eden ditch.

DRAINAGE AREA. - $97.6 \mathrm{i}^{2}$, of which $5.89 \mathrm{mi}^{2}$ does not contribute directly to surface runoff.

PERIOD OF RECORD.-. October 1979 to current year.

RE VISE 0 RE COROS..-WDR IN-82-1: 1980, 1981

GAGE - - Water-stage recorder. Datue of gage is $810.00 \mathrm{ft}$ above National Geodetic Vertical Datua of 1929 .

REMARKS. - - Records good.

DISCHARGE, CUBIC FEET PER SECOND, WATER YEAR OCTOBER 1990 TO SEPTEMBER 1991 DAILY MEAN VALUES

\begin{tabular}{|c|c|c|c|c|c|c|c|c|c|c|c|c|}
\hline DAY & $\mathrm{OCT}$ & NOV & DEC & JAN & FEB & MAR & APR & MAY & JUN & JUL & AUG & SEP \\
\hline $\begin{array}{l}1 \\
2 \\
3 \\
4 \\
5\end{array}$ & $\begin{array}{l}64 \\
63 \\
63 \\
83 \\
76\end{array}$ & $\begin{array}{r}92 \\
91 \\
89 \\
90 \\
252\end{array}$ & $\begin{array}{l}139 \\
128 \\
166 \\
202 \\
159\end{array}$ & $\begin{array}{l}443 \\
343 \\
310 \\
249 \\
226\end{array}$ & $\begin{array}{l}115 \\
115 \\
126 \\
146 \\
161\end{array}$ & $\begin{array}{l}118 \\
168 \\
182 \\
147 \\
135\end{array}$ & $\begin{array}{r}101 \\
96 \\
94 \\
95 \\
104\end{array}$ & $\begin{array}{l}137 \\
129 \\
120 \\
115 \\
114\end{array}$ & $\begin{array}{r}253 \\
170 \\
131 \\
111 \\
97\end{array}$ & $\begin{array}{l}51 \\
62 \\
60 \\
57 \\
53\end{array}$ & $\begin{array}{l}39 \\
36 \\
40 \\
45 \\
45\end{array}$ & $\begin{array}{l}44 \\
43 \\
48 \\
48 \\
43\end{array}$ \\
\hline $\begin{array}{r}6 \\
7 \\
8 \\
9 \\
10\end{array}$ & $\begin{array}{r}71 \\
71 \\
85 \\
334 \\
722\end{array}$ & $\begin{array}{l}376 \\
235 \\
196 \\
177 \\
161\end{array}$ & $\begin{array}{l}145 \\
134 \\
127 \\
122 \\
118\end{array}$ & $\begin{array}{l}210 \\
197 \\
188 \\
180 \\
170\end{array}$ & $\begin{array}{l}151 \\
142 \\
136 \\
134 \\
129\end{array}$ & $\begin{array}{l}134 \\
125 \\
117 \\
114 \\
111\end{array}$ & $\begin{array}{l}99 \\
95 \\
94 \\
96 \\
94\end{array}$ & $\begin{array}{l}130 \\
116 \\
108 \\
104 \\
100\end{array}$ & $\begin{array}{l}91 \\
85 \\
81 \\
78 \\
76\end{array}$ & $\begin{array}{l}51 \\
53 \\
68 \\
56 \\
53\end{array}$ & $\begin{array}{l}40 \\
40 \\
53 \\
58 \\
51\end{array}$ & $\begin{array}{l}41 \\
40 \\
38 \\
39 \\
39\end{array}$ \\
\hline $\begin{array}{l}11 \\
12 \\
13 \\
14 \\
15\end{array}$ & $\begin{array}{l}570 \\
354 \\
262 \\
214 \\
201\end{array}$ & $\begin{array}{l}148 \\
138 \\
131 \\
126 \\
122\end{array}$ & $\begin{array}{l}114 \\
112 \\
108 \\
103 \\
119\end{array}$ & $\begin{array}{l}179 \\
200 \\
178 \\
168 \\
178\end{array}$ & $\begin{array}{l}120 \\
114 \\
116 \\
126 \\
114\end{array}$ & $\begin{array}{r}109 \\
106 \\
104 \\
101 \\
99\end{array}$ & $\begin{array}{r}91 \\
88 \\
81 \\
96 \\
146\end{array}$ & $\begin{array}{l}97 \\
95 \\
93 \\
91 \\
89\end{array}$ & $\begin{array}{l}78 \\
77 \\
72 \\
69 \\
68\end{array}$ & $\begin{array}{l}51 \\
58 \\
70 \\
61 \\
57\end{array}$ & $\begin{array}{l}49 \\
47 \\
47 \\
44 \\
43\end{array}$ & $\begin{array}{l}37 \\
77 \\
75 \\
60 \\
55\end{array}$ \\
\hline $\begin{array}{l}16 \\
17 \\
18 \\
19 \\
20\end{array}$ & $\begin{array}{l}174 \\
159 \\
188 \\
170 \\
152\end{array}$ & $\begin{array}{l}118 \\
113 \\
110 \\
108 \\
105\end{array}$ & $\begin{array}{l}124 \\
119 \\
129 \\
123 \\
115\end{array}$ & $\begin{array}{l}311 \\
302 \\
226 \\
202 \\
207\end{array}$ & $\begin{array}{l}109 \\
109 \\
113 \\
232 \\
208\end{array}$ & $\begin{array}{r}98 \\
101 \\
122 \\
112 \\
105\end{array}$ & $\begin{array}{l}137 \\
146 \\
124 \\
134 \\
278\end{array}$ & $\begin{array}{l}88 \\
90 \\
85 \\
82 \\
81\end{array}$ & $\begin{array}{l}67 \\
65 \\
62 \\
59 \\
57\end{array}$ & $\begin{array}{l}50 \\
47 \\
48 \\
48 \\
46\end{array}$ & $\begin{array}{l}42 \\
44 \\
50 \\
80 \\
77\end{array}$ & $\begin{array}{l}51 \\
48 \\
47 \\
46 \\
44\end{array}$ \\
\hline $\begin{array}{l}21 \\
22 \\
23 \\
24 \\
25\end{array}$ & $\begin{array}{l}141 \\
132 \\
125 \\
120 \\
114\end{array}$ & $\begin{array}{l}103 \\
114 \\
111 \\
105 \\
101\end{array}$ & $\begin{array}{l}122 \\
153 \\
134 \\
125 \\
118\end{array}$ & $\begin{array}{l}196 \\
175 \\
164 \\
151 \\
141\end{array}$ & $\begin{array}{l}185 \\
169 \\
146 \\
136 \\
128\end{array}$ & $\begin{array}{r}102 \\
99 \\
102 \\
106 \\
100\end{array}$ & $\begin{array}{l}190 \\
159 \\
148 \\
251 \\
202\end{array}$ & $\begin{array}{r}79 \\
76 \\
82 \\
102 \\
129\end{array}$ & $\begin{array}{l}53 \\
52 \\
51 \\
51 \\
49\end{array}$ & $\begin{array}{l}48 \\
48 \\
44 \\
41 \\
40\end{array}$ & $\begin{array}{l}63 \\
57 \\
54 \\
52 \\
50\end{array}$ & $\begin{array}{l}43 \\
43 \\
42 \\
41 \\
41\end{array}$ \\
\hline $\begin{array}{l}26 \\
27 \\
28 \\
29 \\
30 \\
31\end{array}$ & $\begin{array}{r}109 \\
107 \\
103 \\
99 \\
97 \\
94\end{array}$ & $\begin{array}{r}98 \\
108 \\
235 \\
191 \\
155 \\
\cdots\end{array}$ & $\begin{array}{r}112 \\
108 \\
108 \\
666 \\
1500 \\
663\end{array}$ & $\begin{array}{l}137 \\
132 \\
128 \\
124 \\
123 \\
119\end{array}$ & $\begin{array}{l}121 \\
116 \\
115 \\
\ldots \\
\cdots \\
\cdots\end{array}$ & $\begin{array}{l}110 \\
118 \\
142 \\
116 \\
105 \\
102\end{array}$ & $\begin{array}{l}169 \\
158 \\
179 \\
161 \\
148 \\
\cdots\end{array}$ & $\begin{array}{r}156 \\
115 \\
97 \\
88 \\
84 \\
209\end{array}$ & $\begin{array}{l}48 \\
47 \\
47 \\
48 \\
49 \\
--\end{array}$ & $\begin{array}{l}40 \\
42 \\
41 \\
42 \\
44 \\
42\end{array}$ & $\begin{array}{l}49 \\
48 \\
46 \\
48 \\
47 \\
47\end{array}$ & $\begin{array}{r}40 \\
40 \\
38 \\
38 \\
37 \\
\cdots\end{array}$ \\
\hline $\begin{array}{l}\text { TOIAL } \\
\text { MEAN } \\
\text { MAX } \\
\text { MIN } \\
\text { CF SM } \\
\text { IN. }\end{array}$ & $\begin{array}{r}5317 \\
172 \\
722 \\
63 \\
1.87 \\
2.16\end{array}$ & $\begin{array}{r}4299 \\
143 \\
376 \\
89 \\
1.56 \\
1.74\end{array}$ & $\begin{array}{r}6415 \\
207 \\
1500 \\
103 \\
2.26 \\
2.60\end{array}$ & $\begin{array}{r}6257 \\
202 \\
443 \\
119 \\
2.20 \\
2.54\end{array}$ & $\begin{array}{r}3832 \\
137 \\
232 \\
109 \\
1.49 \\
1.55\end{array}$ & $\begin{array}{r}3610 \\
116 \\
182 \\
98 \\
1.27 \\
1.46\end{array}$ & $\begin{array}{r}4060 \\
135 \\
278 \\
87 \\
1.48 \\
1.65\end{array}$ & $\begin{array}{r}3281 \\
106 \\
209 \\
76 \\
1.15 \\
1.33\end{array}$ & $\begin{array}{c}2344 \\
78.1 \\
253 \\
47 \\
.85 \\
.95\end{array}$ & $\begin{array}{r}1572 \\
50.7 \\
70 \\
40 \\
.55 \\
.64\end{array}$ & $\begin{array}{c}1531 \\
49.4 \\
80 \\
36 \\
.54 \\
.62\end{array}$ & $\begin{array}{c}1366 \\
45.5 \\
77 \\
37 \\
.50 \\
55\end{array}$ \\
\hline
\end{tabular}

SIATISIICS OF MONTHLY MEAN DATA FOR WATER YEARS 1979 - 1991, BY WATER YEAR (WY)

$\begin{array}{lrrrrrrrrrrrr}\text { MEAN } & 84.1 & 100 & 121 & 106 & 132 & 159 & 144 & 108 & 96.1 & 71.8 & 51.3 & 58.5 \\ \text { MAX } & 172 & 202 & 207 & 202 & 280 & 404 & 210 & 191 & 268 & 189 & 117 & 118 \\ \text { (WY) } & 1991 & 1986 & 1991 & 1991 & 1985 & 1982 & 1985 & 1983 & 1981 & 1981 & 1981 & 1981 \\ \text { MIN } & 43.1 & 38.6 & 42.9 & 53.8 & 75.2 & 84.5 & 93.3 & 55.3 & 36.7 & 37.9 & 39.9 & 40.5 \\ \text { (WY) } & 1988 & 1981 & 1990 & 1981 & 1980 & 1981 & 1986 & 1988 & 1988 & 1988 & 1987 & 1983\end{array}$

SUMMARY SIAIISIICS

ANNUAL TOTAL

ANHUAL MEAN

HIGHESI AMMUAL MEAM

LOWESI ANNUAL MEAN

HIGHEST DAILY MEAN

LOWEST DAILY MEAM

ANNUAL SEVEN-DAY MINIMUM

INSTANTANEOUS PEAK FLOW

INSIANIANEOUS PEAK SIAGE

ANNUAL RUNOFF (CFSM)

ANNUAL RUNOFF (INCHES)

10 PERCENT EXCEEDS

50 PERCENT EXCEEDS

90 PERCENI EXCEEDS
FOR 1990 CALENDAR YEAR

49645
136

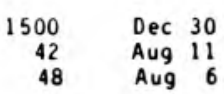

1.48

20.14

219

105
58

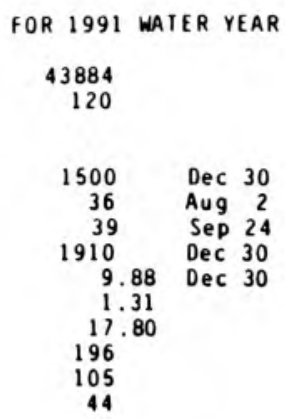

WAIER YEARS $1979-1991$

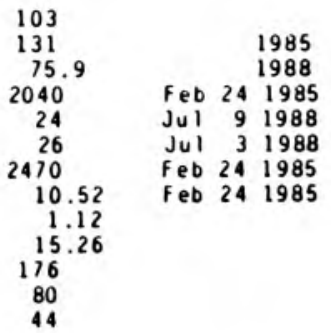


LOCATION.--Lat $41^{\circ} 40^{\prime} 53^{\prime \prime}$, long $85^{\circ} 52^{\prime} 57^{\prime \prime}$, in NE 04050001 , on right bank $50 \mathrm{ft}$ upstream from bridge on County Rodd $14,0.3$ east of the intersection of County Roads 17 and 14 , and 3.1 i east of Eikhart.

DRAINAGE AREA.-. $31.0 i^{2}$, of which $8.75 \mathrm{mi}^{2}$ does not contribute directly to surface runoff.

PERIOD OF RECORD.--October 1979 to current year.

GAGE.- -Water-stage recorder. Datum of gage is $755.00 \mathrm{ft}$ above National Geodetic Vertical Datua of 1929.

REMARKS. - - Records good.

DISCHARGE, CUBIC FEET PER SECOND, WATER YEAR OCTOBER 1990 TO SEPIEMBER 1991 DAILY MEAN VALUES

\begin{tabular}{|c|c|c|c|c|c|c|c|c|c|c|c|c|}
\hline DAY & $O C T$ & NOV & $\mathrm{DEC}$ & JAN & FEB & MAR & APR & MAY & JUN & JUL & AUG & SEP \\
\hline $\begin{array}{l}1 \\
2 \\
3 \\
4 \\
5\end{array}$ & $\begin{array}{l}16 \\
16 \\
16 \\
28 \\
23\end{array}$ & $\begin{array}{l}19 \\
19 \\
19 \\
19 \\
66\end{array}$ & $\begin{array}{l}31 \\
27 \\
38 \\
43 \\
32\end{array}$ & $\begin{array}{l}70 \\
55 \\
47 \\
41 \\
38\end{array}$ & $\begin{array}{l}25 \\
25 \\
27 \\
29 \\
33\end{array}$ & $\begin{array}{l}26 \\
45 \\
44 \\
32 \\
29\end{array}$ & $\begin{array}{l}22 \\
21 \\
20 \\
20 \\
30\end{array}$ & $\begin{array}{l}31 \\
30 \\
28 \\
27 \\
28\end{array}$ & $\begin{array}{l}33 \\
25 \\
22 \\
20 \\
19\end{array}$ & $\begin{array}{l}14 \\
15 \\
14 \\
14 \\
13\end{array}$ & $\begin{array}{l}8.3 \\
8.6 \\
9.3 \\
9.8 \\
9.2\end{array}$ & $\begin{array}{l}12 \\
12 \\
23 \\
32 \\
17\end{array}$ \\
\hline $\begin{array}{r}6 \\
7 \\
8 \\
9 \\
10\end{array}$ & $\begin{array}{r}19 \\
18 \\
19 \\
101 \\
216\end{array}$ & $\begin{array}{l}82 \\
41 \\
32 \\
28 \\
26\end{array}$ & $\begin{array}{l}29 \\
27 \\
26 \\
25 \\
24\end{array}$ & $\begin{array}{l}37 \\
35 \\
34 \\
33 \\
32\end{array}$ & $\begin{array}{l}32 \\
30 \\
29 \\
30 \\
29\end{array}$ & $\begin{array}{l}29 \\
26 \\
24 \\
24 \\
23\end{array}$ & $\begin{array}{l}28 \\
22 \\
28 \\
24 \\
21\end{array}$ & $\begin{array}{l}28 \\
27 \\
25 \\
25 \\
25\end{array}$ & $\begin{array}{l}18 \\
18 \\
17 \\
17 \\
17\end{array}$ & $\begin{array}{l}13 \\
13 \\
13 \\
12 \\
12\end{array}$ & $\begin{array}{l}9.0 \\
8.8 \\
13 \\
12 \\
11\end{array}$ & $\begin{array}{l}15 \\
13 \\
13 \\
13 \\
12\end{array}$ \\
\hline $\begin{array}{l}11 \\
12 \\
13 \\
14 \\
15\end{array}$ & $\begin{array}{r}232 \\
69 \\
46 \\
40 \\
40\end{array}$ & $\begin{array}{l}24 \\
23 \\
22 \\
21 \\
21\end{array}$ & $\begin{array}{l}23 \\
23 \\
23 \\
21 \\
25\end{array}$ & $\begin{array}{l}34 \\
37 \\
34 \\
33 \\
33\end{array}$ & $\begin{array}{l}27 \\
26 \\
26 \\
28 \\
25\end{array}$ & $\begin{array}{l}23 \\
22 \\
22 \\
22 \\
21\end{array}$ & $\begin{array}{l}21 \\
21 \\
25 \\
31 \\
94\end{array}$ & $\begin{array}{l}24 \\
24 \\
24 \\
24 \\
23\end{array}$ & $\begin{array}{l}18 \\
18 \\
17 \\
17 \\
17\end{array}$ & $\begin{array}{l}11 \\
12 \\
13 \\
12 \\
12\end{array}$ & $\begin{array}{r}10 \\
9.6 \\
9.4 \\
9.1 \\
8.9\end{array}$ & $\begin{array}{l}12 \\
79 \\
52 \\
27 \\
24\end{array}$ \\
\hline $\begin{array}{l}16 \\
17 \\
18 \\
19 \\
20\end{array}$ & $\begin{array}{l}34 \\
31 \\
37 \\
33 \\
30\end{array}$ & $\begin{array}{l}21 \\
20 \\
19 \\
19 \\
19\end{array}$ & $\begin{array}{l}26 \\
24 \\
27 \\
25 \\
23\end{array}$ & $\begin{array}{l}66 \\
59 \\
40 \\
36 \\
40\end{array}$ & $\begin{array}{r}\text { e24 } \\
26 \\
27 \\
64 \\
48\end{array}$ & $\begin{array}{l}21 \\
22 \\
29 \\
25 \\
23\end{array}$ & $\begin{array}{l}62 \\
47 \\
39 \\
44 \\
74\end{array}$ & $\begin{array}{l}23 \\
26 \\
24 \\
22 \\
22\end{array}$ & $\begin{array}{l}17 \\
17 \\
16 \\
15 \\
15\end{array}$ & $\begin{array}{l}11 \\
10 \\
10 \\
10 \\
10\end{array}$ & $\begin{array}{l}9.0 \\
9.1 \\
9.8 \\
35 \\
32\end{array}$ & $\begin{array}{l}21 \\
18 \\
17 \\
17 \\
16\end{array}$ \\
\hline $\begin{array}{l}21 \\
22 \\
23 \\
24 \\
25\end{array}$ & $\begin{array}{l}28 \\
26 \\
25 \\
24 \\
23\end{array}$ & $\begin{array}{l}19 \\
21 \\
21 \\
20 \\
19\end{array}$ & $\begin{array}{l}26 \\
31 \\
27 \\
25 \\
24\end{array}$ & $\begin{array}{l}31 \\
32 \\
31 \\
29 \\
28\end{array}$ & $\begin{array}{l}41 \\
36 \\
30 \\
28 \\
26\end{array}$ & $\begin{array}{l}23 \\
22 \\
23 \\
25 \\
23\end{array}$ & $\begin{array}{l}47 \\
38 \\
36 \\
63 \\
49\end{array}$ & $\begin{array}{l}21 \\
21 \\
21 \\
22 \\
23\end{array}$ & $\begin{array}{l}14 \\
15 \\
15 \\
15 \\
14\end{array}$ & $\begin{array}{r}10 \\
9.9 \\
9.5 \\
9.1 \\
9.1\end{array}$ & $\begin{array}{l}17 \\
15 \\
14 \\
13 \\
13\end{array}$ & $\begin{array}{l}16 \\
16 \\
16 \\
15 \\
15\end{array}$ \\
\hline $\begin{array}{l}26 \\
27 \\
28 \\
29 \\
30 \\
31\end{array}$ & $\begin{array}{l}22 \\
22 \\
21 \\
20 \\
20 \\
20\end{array}$ & $\begin{array}{r}18 \\
41 \\
146 \\
61 \\
37 \\
---\end{array}$ & $\begin{array}{r}23 \\
22 \\
22 \\
190 \\
532 \\
169\end{array}$ & $\begin{array}{l}27 \\
27 \\
26 \\
26 \\
26 \\
25\end{array}$ & $\begin{array}{r}25 \\
24 \\
24 \\
\cdots \\
\cdots \\
\cdots\end{array}$ & $\begin{array}{l}26 \\
28 \\
26 \\
26 \\
22 \\
21\end{array}$ & $\begin{array}{r}40 \\
33 \\
39 \\
36 \\
33 \\
\cdots\end{array}$ & $\begin{array}{l}23 \\
22 \\
21 \\
21 \\
21 \\
26\end{array}$ & $\begin{array}{l}13 \\
13 \\
13 \\
13 \\
13 \\
\cdots\end{array}$ & $\begin{array}{l}8.9 \\
8.8 \\
8.8 \\
9.1 \\
9.5 \\
8.7\end{array}$ & $\begin{array}{l}12 \\
12 \\
11 \\
11 \\
17 \\
13\end{array}$ & $\begin{array}{l}15 \\
14 \\
14 \\
14 \\
13 \\
\cdots\end{array}$ \\
\hline $\begin{array}{l}\text { IOIAL } \\
\text { MEAN } \\
\text { MAX } \\
\text { MIN } \\
\text { CF SM } \\
\text { IN. }\end{array}$ & $\begin{array}{r}1315 \\
42.4 \\
232 \\
16 \\
1.37 \\
1.58\end{array}$ & $\begin{array}{r}963 \\
32.1 \\
146 \\
18 \\
1.04 \\
1.16\end{array}$ & $\begin{array}{r}1633 \\
52.7 \\
532 \\
21 \\
1.70 \\
1.96\end{array}$ & $\begin{array}{r}1148 \\
37.0 \\
70 \\
25 \\
1.19 \\
1.38\end{array}$ & $\begin{array}{r}844 \\
30.1 \\
64 \\
24 \\
.97 \\
1.01\end{array}$ & $\begin{array}{c}797 \\
25.7 \\
45 \\
21 \\
.83 \\
.96\end{array}$ & $\begin{array}{c}1108 \\
36.9 \\
94 \\
20 \\
1.19 \\
1.33\end{array}$ & $\begin{array}{c}752 \\
24.3 \\
31 \\
21 \\
.78 \\
.90\end{array}$ & $\begin{array}{c}511 \\
17.0 \\
33 \\
13 \\
.55 \\
.61\end{array}$ & $\begin{array}{c}345.4 \\
11.1 \\
15 \\
8.7 \\
.36 \\
.41\end{array}$ & $\begin{array}{c}388.9 \\
12.5 \\
35 \\
8.3 \\
.40 \\
.47\end{array}$ & $\begin{array}{c}593 \\
19.8 \\
79 \\
12 \\
.64 \\
.71\end{array}$ \\
\hline
\end{tabular}

e Estinated

STATISTICS OF MONTHLY MEAN DATA FOR WATER YEARS 1980 - 1991, BY WATER YEAR (WY)

\begin{tabular}{|c|c|c|c|c|c|c|c|c|c|c|c|c|}
\hline $\begin{array}{l}\text { MEAN } \\
\text { MAX } \\
\text { (WY) } \\
\text { MIN } \\
(W Y)\end{array}$ & $\begin{array}{l}14.8 \\
42.4 \\
1991 \\
7.27 \\
1990\end{array}$ & $\begin{array}{l}17.2 \\
32.8 \\
1986 \\
7.39 \\
1981\end{array}$ & $\begin{array}{l}21.9 \\
52.7 \\
1991 \\
6.93 \\
1990\end{array}$ & $\begin{array}{l}18.4 \\
37.0 \\
1991 \\
8.23 \\
1981\end{array}$ & $\begin{array}{l}23.7 \\
47.6 \\
1985 \\
11.7 \\
1980\end{array}$ & $\begin{array}{l}28.4 \\
82.3 \\
1982 \\
14.4 \\
1981\end{array}$ & $\begin{array}{l}27.0 \\
38.4 \\
1982 \\
16.3 \\
1981\end{array}$ & $\begin{array}{l}21.6 \\
40.6 \\
1983 \\
11.9 \\
1988\end{array}$ & $\begin{array}{l}18.9 \\
39.7 \\
1981 \\
7.79 \\
1988\end{array}$ & $\begin{array}{l}16.0 \\
39.2 \\
1981 \\
6.58 \\
1988\end{array}$ & $\begin{array}{l}12.7 \\
25.5 \\
1981 \\
6.75 \\
1988\end{array}$ & $\begin{array}{l}12.4 \\
23.7 \\
1981 \\
6.34 \\
1988\end{array}$ \\
\hline
\end{tabular}

SUMMARY SIATISIICS

ANMUAL TOIAL

ANMUAL MEAN

HIGHEST ANMUAL MEAM

LOWEST AMNUAL MEAN

HIGHEST DAIIY MEAN

LOWEST DAILY MEAM

ANNUAL SEVEN-DAY MINIMUM

INSIANTANEOUS PEAK FIOW

INSIANTANE OUS PEAK SIAGE

AN WUAL RUNOFF (CFSM)

ANNUAL RUNOFF (INCHES)

10 PERCEMT EXCEEDS

50 PERCENT EXCEEDS

90 PERCENT EXCEEDS
FOR 1990 CALENDAR YEAR

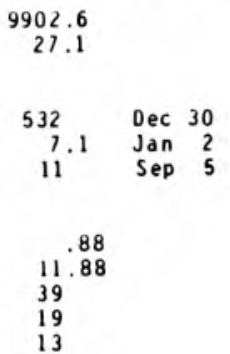

FOR 1991 WATER YEAR

WATER YEARS 1980 - 1991

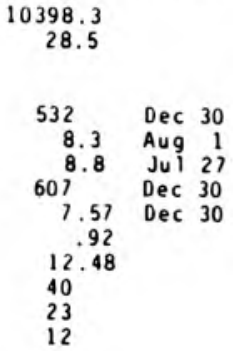

\begin{tabular}{l} 
P \\
2 \\
2 \\
3 \\
2 \\
7 \\
5 \\
3 \\
3 \\
3 \\
2 \\
2 \\
9 \\
5 \\
7 \\
4 \\
1 \\
8 \\
7 \\
7 \\
6 \\
6 \\
6 \\
6 \\
6 \\
5 \\
5 \\
5 \\
5 \\
1 \\
4 \\
\hline
\end{tabular} 
LOCATION.--Lat $41^{\circ} 28^{\prime} 54^{\prime \prime}$, long $85^{\circ} 28^{\prime} 32^{\prime \prime}$, in NE iNHA sec.22, T.35 N., R.9 E., Noble County, Hydrologic Unit 04050001 . On right bank at downstream side of bridge on County Road 900 North at Cosperville, $1,300 \mathrm{ft}$ downstrea fro Boygditch, 1.7 i upstrean fro Hustin ditch, and 3.1 mi downstrea from Waidron Lake. DRAI NAGE AREA. .-142

PERIOD OF RECORD.--October 1971 to current yedr.

GAGE. - Water-stage recorder. Datua of gage is $880.12 \mathrm{ft}$ above National Geodetic Vertical Datua of 1929 (levels by State of Indiana, Departeent of Natural Resources). REMARKS. - Records good except estimated daily discharges, which are fair. Flow regulated at tiaes by daa at
Waldron Lake.

DISCHARGE, CUBIC FEET PER SECOND, WATER YEAR OCTOBER 1990 TO SEPIEMBER 1991 DAILY MEAN VALUES

\begin{tabular}{|c|c|c|c|c|c|c|c|c|c|c|c|c|}
\hline DAY & $\mathrm{OCI}$ & NOV & DEC & JAN & FE B & MAR & $A P R$ & MAY & JUN & JUL & $A \cup G$ & SEP \\
\hline $\begin{array}{l}1 \\
2 \\
3 \\
4 \\
5\end{array}$ & $\begin{array}{r}86 \\
83 \\
81 \\
94 \\
103\end{array}$ & $\begin{array}{l}166 \\
157 \\
148 \\
142 \\
189\end{array}$ & $\begin{array}{l}166 \\
166 \\
179 \\
193 \\
199\end{array}$ & $\begin{array}{l}619 \\
637 \\
639 \\
627 \\
604\end{array}$ & $\begin{array}{r}\text { e169 } \\
\text { e168 } \\
\text { e172 } \\
189 \\
202\end{array}$ & $\begin{array}{l}182 \\
201 \\
225 \\
226 \\
225\end{array}$ & $\begin{array}{l}175 \\
173 \\
168 \\
162 \\
161\end{array}$ & $\begin{array}{l}347 \\
334 \\
321 \\
305 \\
292\end{array}$ & $\begin{array}{l}349 \\
391 \\
411 \\
417 \\
412\end{array}$ & $\begin{array}{r}92 \\
152 \\
161 \\
159 \\
154\end{array}$ & $\begin{array}{l}27 \\
26 \\
41 \\
48 \\
46\end{array}$ & $\begin{array}{l}64 \\
55 \\
50 \\
52 \\
48\end{array}$ \\
\hline $\begin{array}{r}6 \\
7 \\
8 \\
9 \\
10\end{array}$ & $\begin{array}{l}105 \\
106 \\
108 \\
155 \\
263\end{array}$ & $\begin{array}{l}243 \\
262 \\
273 \\
270 \\
265\end{array}$ & $\begin{array}{l}199 \\
194 \\
190 \\
183 \\
179\end{array}$ & $\begin{array}{l}577 \\
548 \\
517 \\
489 \\
463\end{array}$ & $\begin{array}{l}210 \\
211 \\
208 \\
207 \\
202\end{array}$ & $\begin{array}{l}223 \\
217 \\
213 \\
204 \\
197\end{array}$ & $\begin{array}{l}159 \\
155 \\
154 \\
158 \\
163\end{array}$ & $\begin{array}{l}286 \\
276 \\
264 \\
249 \\
231\end{array}$ & $\begin{array}{l}397 \\
375 \\
348 \\
318 \\
289\end{array}$ & $\begin{array}{l}149 \\
142 \\
136 \\
126 \\
119\end{array}$ & $\begin{array}{l}43 \\
39 \\
46 \\
58 \\
57\end{array}$ & $\begin{array}{l}44 \\
40 \\
37 \\
36 \\
37\end{array}$ \\
\hline $\begin{array}{l}11 \\
12 \\
13 \\
14 \\
15\end{array}$ & $\begin{array}{l}320 \\
354 \\
369 \\
375 \\
379\end{array}$ & $\begin{array}{l}259 \\
249 \\
238 \\
228 \\
219\end{array}$ & $\begin{array}{l}174 \\
167 \\
162 \\
158 \\
162\end{array}$ & $\begin{array}{l}443 \\
432 \\
412 \\
393 \\
381\end{array}$ & $\begin{array}{l}196 \\
188 \\
182 \\
180 \\
175\end{array}$ & $\begin{array}{l}190 \\
183 \\
178 \\
169 \\
162\end{array}$ & $\begin{array}{l}168 \\
167 \\
162 \\
162 \\
177\end{array}$ & $\begin{array}{l}208 \\
189 \\
174 \\
164 \\
155\end{array}$ & $\begin{array}{l}266 \\
246 \\
227 \\
207 \\
189\end{array}$ & $\begin{array}{r}112 \\
107 \\
106 \\
100 \\
94\end{array}$ & $\begin{array}{l}53 \\
49 \\
45 \\
41 \\
37\end{array}$ & $\begin{array}{l}36 \\
63 \\
73 \\
73 \\
70\end{array}$ \\
\hline $\begin{array}{l}16 \\
17 \\
18 \\
19 \\
20\end{array}$ & $\begin{array}{l}372 \\
357 \\
357 \\
348 \\
336\end{array}$ & $\begin{array}{l}209 \\
200 \\
190 \\
182 \\
175\end{array}$ & $\begin{array}{l}166 \\
171 \\
175 \\
179 \\
181\end{array}$ & $\begin{array}{l}387 \\
384 \\
366 \\
355 \\
356\end{array}$ & $\begin{array}{r}\text { e161 } \\
\text { e156 } \\
\text { e158 } \\
186 \\
205\end{array}$ & $\begin{array}{l}157 \\
153 \\
160 \\
163 \\
161\end{array}$ & $\begin{array}{l}191 \\
225 \\
242 \\
259 \\
307\end{array}$ & $\begin{array}{l}144 \\
138 \\
136 \\
132 \\
123\end{array}$ & $\begin{array}{l}174 \\
160 \\
146 \\
133 \\
120\end{array}$ & $\begin{array}{l}88 \\
81 \\
76 \\
70 \\
65\end{array}$ & $\begin{array}{l}35 \\
33 \\
32 \\
37 \\
47\end{array}$ & $\begin{array}{l}66 \\
61 \\
56 \\
50 \\
43\end{array}$ \\
\hline $\begin{array}{l}21 \\
22 \\
23 \\
24 \\
25\end{array}$ & $\begin{array}{l}324 \\
310 \\
291 \\
276 \\
260\end{array}$ & $\begin{array}{l}165 \\
161 \\
156 \\
151 \\
143\end{array}$ & $\begin{array}{r}182 \\
198 \\
211 \\
\mathrm{e} 204 \\
\mathrm{e} 192\end{array}$ & $\begin{array}{r}350 \\
331 \\
315 \\
\mathrm{e} 287 \\
\mathrm{e} 265\end{array}$ & $\begin{array}{l}213 \\
217 \\
217 \\
211 \\
205\end{array}$ & $\begin{array}{l}156 \\
152 \\
149 \\
153 \\
156\end{array}$ & $\begin{array}{l}324 \\
327 \\
331 \\
352 \\
361\end{array}$ & $\begin{array}{l}114 \\
107 \\
124 \\
129 \\
130\end{array}$ & $\begin{array}{r}109 \\
99 \\
90 \\
81 \\
72\end{array}$ & $\begin{array}{l}62 \\
60 \\
55 \\
50 \\
26\end{array}$ & $\begin{array}{l}47 \\
44 \\
42 \\
39 \\
36\end{array}$ & $\begin{array}{l}38 \\
34 \\
31 \\
29 \\
28\end{array}$ \\
\hline $\begin{array}{l}26 \\
27 \\
28 \\
29 \\
30 \\
31\end{array}$ & $\begin{array}{l}245 \\
229 \\
214 \\
202 \\
189 \\
175\end{array}$ & $\begin{array}{l}137 \\
137 \\
158 \\
168 \\
168 \\
\cdots\end{array}$ & $\begin{array}{r}\text { el } 80 \\
\text { e176 } \\
\text { e175 } \\
297 \\
487 \\
579\end{array}$ & $\begin{array}{l}\text { e241 } \\
\text { e220 } \\
\text { e205 } \\
\text { e } 190 \\
\text { e1 } 180 \\
\text { e } 173\end{array}$ & $\begin{array}{l}196 \\
187 \\
182 \\
\cdots \cdots \\
\cdots \cdots \\
\cdots\end{array}$ & $\begin{array}{l}158 \\
166 \\
179 \\
187 \\
182 \\
178\end{array}$ & $\begin{array}{l}359 \\
355 \\
356 \\
359 \\
351 \\
\cdots\end{array}$ & $\begin{array}{l}136 \\
134 \\
128 \\
121 \\
138 \\
262\end{array}$ & $\begin{array}{l}64 \\
57 \\
52 \\
46 \\
57 \\
\cdots\end{array}$ & $\begin{array}{l}21 \\
22 \\
23 \\
24 \\
28 \\
28\end{array}$ & $\begin{array}{l}34 \\
32 \\
30 \\
29 \\
46 \\
71\end{array}$ & $\begin{array}{l}26 \\
27 \\
41 \\
38 \\
34 \\
\cdots\end{array}$ \\
\hline $\begin{array}{l}\text { TOTAL } \\
\text { MEAN } \\
\text { MAX } \\
\text { MIN } \\
\text { CF SM } \\
\text { IN. }\end{array}$ & $\begin{array}{r}7466 \\
241 \\
379 \\
81 \\
1.70 \\
1.96\end{array}$ & $\begin{array}{r}5808 \\
194 \\
273 \\
137 \\
1.36 \\
1.52\end{array}$ & $\begin{array}{r}6424 \\
207 \\
579 \\
158 \\
1.46 \\
1.68\end{array}$ & $\begin{array}{r}12386 \\
400 \\
639 \\
173 \\
2.81 \\
3.24\end{array}$ & $\begin{array}{r}5353 \\
191 \\
217 \\
156 \\
1.35 \\
1.40\end{array}$ & $\begin{array}{r}5605 \\
181 \\
226 \\
149 \\
1.27 \\
1.47\end{array}$ & $\begin{array}{l}7163 \\
239 \\
361 \\
154 \\
1.68 \\
1.88\end{array}$ & $\begin{array}{l}5991 \\
193 \\
347 \\
107 \\
1.36 \\
1.57\end{array}$ & $\begin{array}{r}6302 \\
210 \\
417 \\
46 \\
1.48 \\
1.65\end{array}$ & $\begin{array}{c}2688 \\
86.7 \\
161 \\
21 \\
.61 \\
.70\end{array}$ & $\begin{array}{r}1290 \\
41.6 \\
71 \\
26 \\
.29 \\
.34\end{array}$ & $\begin{array}{r}1380 \\
46.0 \\
73 \\
26 \\
.32 \\
.36\end{array}$ \\
\hline
\end{tabular}

e Estinated

SIATISIICS OF MONTHLY MEAM DAIA FOR WAIER YEARS 1972 - 1991, BY WATER YEAR (WY)

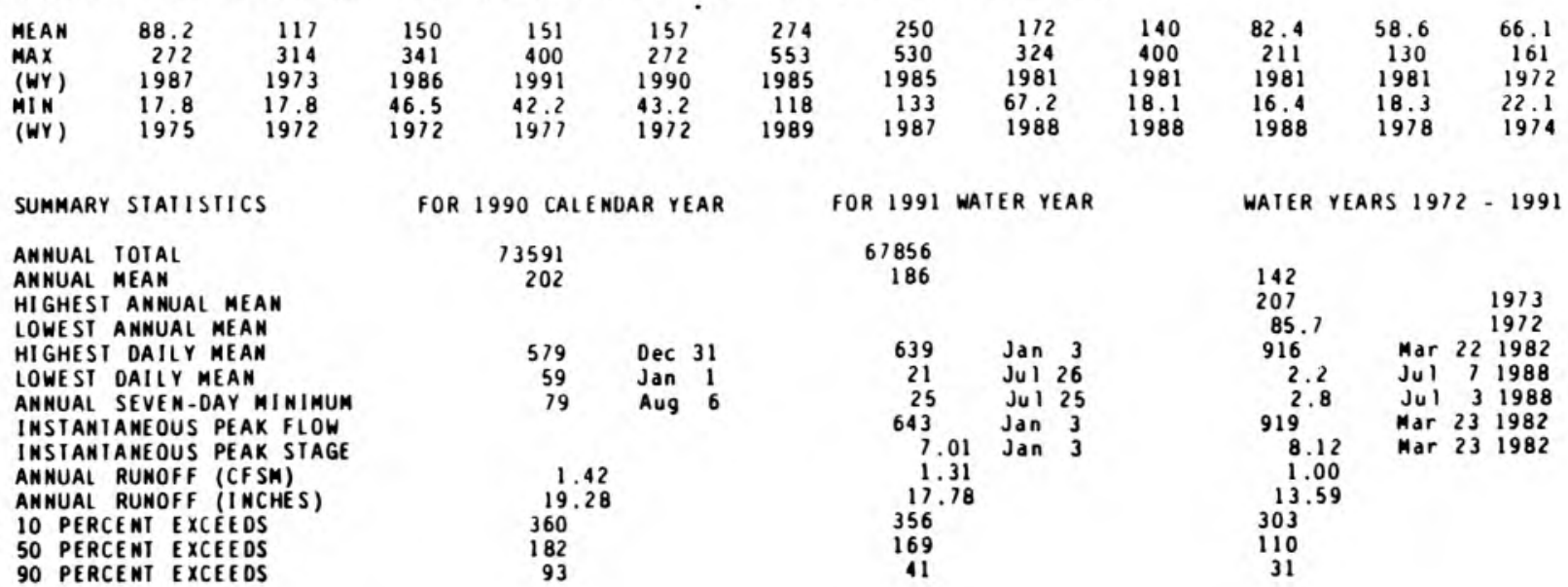


LOCAIION. - - Lat $41^{\circ} 19^{\prime} 58^{\circ}$, long $85^{\circ} 25^{\prime} 25^{\prime \prime}$, in SE $\frac{1}{4}$, I sec.12, T.33 N., R.9 E., Noble County, Hydrologic Unit 04050001 . On right bank $300 \mathrm{ft}$ downstrean froe bridge on State Highway 9 , $400 \mathrm{ft}$ downstrean from Miller Lake Outlet, $0.8 \mathrm{mi}$ northegst of Burr Oak, and 4.5 a south of Albion.

DRAINAGE AREA. $-19.2 \backsim i$.

PERIOD OF RECORO...June 1969 to current year.

GAGE.--Water-stage recorder. Datum of gage is $889.00 \mathrm{ft}$ above National Geodetic Vertical Datun of 1929 (Indiana Departaent of Highways bench adr).

REMARKS.--Records good. Occasional regulation at Miller Lake Outlet.

DISCHARGE, CUBIC FEET PER SECOND, WATER YEAR OCTOBER 1990 TO SEPIEMBER 1991 DAI IY MEAN VALUES

\begin{tabular}{|c|c|c|c|c|c|c|c|c|c|c|c|c|}
\hline DAY & $O C \mathrm{~T}$ & NOV & DEC & JAN & FEB & MAR & APR & MAY & JUN & JUL & AUG & SEP \\
\hline $\begin{array}{l}1 \\
2 \\
3 \\
4 \\
5\end{array}$ & $\begin{array}{l}19 \\
17 \\
17 \\
29 \\
35\end{array}$ & $\begin{array}{l}20 \\
19 \\
18 \\
18 \\
27\end{array}$ & $\begin{array}{l}30 \\
29 \\
33 \\
42 \\
48\end{array}$ & $\begin{array}{r}210 \\
140 \\
97 \\
73 \\
59\end{array}$ & $\begin{array}{l}13 \\
13 \\
13 \\
15 \\
21\end{array}$ & $\begin{array}{l}16 \\
24 \\
36 \\
38 \\
34\end{array}$ & $\begin{array}{l}19 \\
17 \\
16 \\
14 \\
17\end{array}$ & $\begin{array}{l}35 \\
31 \\
27 \\
23 \\
22\end{array}$ & $\begin{array}{r}216 \\
188 \\
142 \\
102 \\
73\end{array}$ & $\begin{array}{l}5.1 \\
5.4 \\
5.2 \\
5.0 \\
4.8\end{array}$ & $\begin{array}{l}1.0 \\
.99 \\
1.3 \\
1.6 \\
1.8\end{array}$ & $\begin{array}{l}.91 \\
.69 \\
.67 \\
.67 \\
.69\end{array}$ \\
\hline $\begin{array}{r}6 \\
7 \\
8 \\
9 \\
10\end{array}$ & $\begin{array}{r}39 \\
38 \\
36 \\
58 \\
156\end{array}$ & $\begin{array}{l}49 \\
63 \\
56 \\
44 \\
38\end{array}$ & $\begin{array}{l}42 \\
38 \\
34 \\
31 \\
29\end{array}$ & $\begin{array}{l}50 \\
44 \\
39 \\
34 \\
31\end{array}$ & $\begin{array}{l}27 \\
29 \\
27 \\
25 \\
23\end{array}$ & $\begin{array}{l}30 \\
25 \\
22 \\
19 \\
17\end{array}$ & $\begin{array}{l}18 \\
19 \\
20 \\
24 \\
27\end{array}$ & $\begin{array}{l}22 \\
20 \\
19 \\
17 \\
15\end{array}$ & $\begin{array}{l}54 \\
41 \\
34 \\
27 \\
23\end{array}$ & $\begin{array}{l}4.5 \\
4.1 \\
3.7 \\
3.5 \\
3.4\end{array}$ & $\begin{array}{l}1.5 \\
1.1 \\
1.3 \\
1.6 \\
1.6\end{array}$ & $\begin{array}{l}.73 \\
.75 \\
.76 \\
.75 \\
.72\end{array}$ \\
\hline $\begin{array}{l}11 \\
12 \\
13 \\
14 \\
15\end{array}$ & $\begin{array}{r}197 \\
161 \\
114 \\
84 \\
64\end{array}$ & $\begin{array}{l}34 \\
31 \\
28 \\
26 \\
24\end{array}$ & $\begin{array}{l}28 \\
26 \\
25 \\
23 \\
24\end{array}$ & $\begin{array}{l}31 \\
34 \\
35 \\
33 \\
33\end{array}$ & $\begin{array}{l}21 \\
18 \\
17 \\
17 \\
16\end{array}$ & $\begin{array}{l}16 \\
15 \\
15 \\
13 \\
13\end{array}$ & $\begin{array}{l}27 \\
25 \\
22 \\
21 \\
23\end{array}$ & $\begin{array}{l}14 \\
12 \\
11 \\
10 \\
9.6\end{array}$ & $\begin{array}{l}22 \\
21 \\
18 \\
15 \\
12\end{array}$ & $\begin{array}{l}3.1 \\
2.8 \\
2.7 \\
2.6 \\
2.4\end{array}$ & $\begin{array}{l}2.1 \\
2.1 \\
1.9 \\
1.6 \\
1.4\end{array}$ & $\begin{array}{l}.73 \\
1.4 \\
1.8 \\
1.8 \\
1.7\end{array}$ \\
\hline $\begin{array}{l}16 \\
17 \\
18 \\
19 \\
20\end{array}$ & $\begin{array}{l}51 \\
42 \\
41 \\
41 \\
39\end{array}$ & $\begin{array}{l}23 \\
22 \\
20 \\
19 \\
18\end{array}$ & $\begin{array}{l}28 \\
30 \\
30 \\
31 \\
30\end{array}$ & $\begin{array}{l}42 \\
53 \\
50 \\
44 \\
40\end{array}$ & $\begin{array}{l}15 \\
14 \\
14 \\
19 \\
32\end{array}$ & $\begin{array}{l}14 \\
16 \\
23 \\
28 \\
28\end{array}$ & $\begin{array}{l}29 \\
45 \\
61 \\
63 \\
81\end{array}$ & $\begin{array}{l}8.9 \\
9.1 \\
9.0 \\
8.1 \\
7.5\end{array}$ & $\begin{array}{r}14 \\
22 \\
16 \\
12 \\
9.5\end{array}$ & $\begin{array}{l}2.2 \\
2.1 \\
2.0 \\
1.9 \\
1.7\end{array}$ & $\begin{array}{l}1.4 \\
1.4 \\
1.5 \\
1.7 \\
1.8\end{array}$ & $\begin{array}{l}1.7 \\
1.7 \\
1.6 \\
1.5 \\
1.4\end{array}$ \\
\hline $\begin{array}{l}21 \\
22 \\
23 \\
24 \\
25\end{array}$ & $\begin{array}{l}36 \\
33 \\
31 \\
29 \\
27\end{array}$ & $\begin{array}{l}18 \\
18 \\
17 \\
17 \\
17\end{array}$ & $\begin{array}{l}30 \\
37 \\
41 \\
38 \\
34\end{array}$ & $\begin{array}{l}37 \\
33 \\
29 \\
24 \\
21\end{array}$ & $\begin{array}{l}37 \\
35 \\
31 \\
26 \\
22\end{array}$ & $\begin{array}{l}26 \\
23 \\
21 \\
22 \\
22\end{array}$ & $\begin{array}{l}84 \\
68 \\
54 \\
59 \\
63\end{array}$ & $\begin{array}{r}7.0 \\
6.7 \\
7.5 \\
8.6 \\
11\end{array}$ & $\begin{array}{l}8.2 \\
7.4 \\
6.5 \\
5.8 \\
5.1\end{array}$ & $\begin{array}{l}1.6 \\
2.1 \\
1.8 \\
1.6 \\
1.5\end{array}$ & $\begin{array}{l}1.7 \\
1.7 \\
1.7 \\
1.5 \\
1.1\end{array}$ & $\begin{array}{l}1.4 \\
1.3 \\
1.3 \\
1.3 \\
1.3\end{array}$ \\
\hline $\begin{array}{l}26 \\
27 \\
28 \\
29 \\
30 \\
31\end{array}$ & $\begin{array}{l}26 \\
24 \\
23 \\
22 \\
21 \\
20\end{array}$ & $\begin{array}{r}16 \\
16 \\
22 \\
28 \\
31 \\
\cdots\end{array}$ & $\begin{array}{r}30 \\
27 \\
25 \\
74 \\
279 \\
295\end{array}$ & $\begin{array}{l}18 \\
16 \\
15 \\
15 \\
14 \\
14\end{array}$ & $\begin{array}{l}19 \\
17 \\
16 \\
\cdots \\
\cdots \\
\cdots\end{array}$ & $\begin{array}{l}23 \\
25 \\
27 \\
27 \\
24 \\
21\end{array}$ & $\begin{array}{c}54 \\
45 \\
42 \\
42 \\
38 \\
\cdots\end{array}$ & $\begin{array}{r}20 \\
29 \\
29 \\
24 \\
25 \\
121\end{array}$ & $\begin{array}{l}4.7 \\
4.4 \\
4.0 \\
3.7 \\
4.0 \\
\ldots\end{array}$ & $\begin{array}{l}1.4 \\
1.3 \\
1.2 \\
1.1 \\
1.1 \\
1.0\end{array}$ & $\begin{array}{l}1.1 \\
1.0 \\
1.0 \\
1.0 \\
1.1 \\
1.1\end{array}$ & $\begin{array}{l}1.3 \\
1.2 \\
1.0 \\
1.0 \\
.94 \\
. . .\end{array}$ \\
\hline $\begin{array}{l}\text { IOIAL } \\
\text { MEAN } \\
\text { MAX } \\
\text { MIN } \\
\text { CF SM } \\
\text { IN. }\end{array}$ & $\begin{array}{r}1570 \\
50.6 \\
197 \\
17 \\
2.64 \\
3.04\end{array}$ & $\begin{array}{r}797 \\
26.6 \\
63 \\
16 \\
1.38 \\
1.54\end{array}$ & $\begin{array}{r}1541 \\
49.7 \\
295 \\
23 \\
2.59 \\
2.99\end{array}$ & $\begin{array}{r}1408 \\
45.4 \\
210 \\
14 \\
2.37 \\
2.73\end{array}$ & $\begin{array}{r}592 \\
21.1 \\
37 \\
13 \\
1.10 \\
1.15\end{array}$ & $\begin{array}{r}703 \\
22.7 \\
38 \\
13 \\
1.18 \\
1.36\end{array}$ & $\begin{array}{r}1137 \\
37.9 \\
84 \\
14 \\
1.97 \\
2.20\end{array}$ & $\begin{array}{c}619.0 \\
20.0 \\
121 \\
6.7 \\
1.04 \\
1.20\end{array}$ & $\begin{array}{r}1115.3 \\
37.2 \\
216 \\
3.7 \\
1.94 \\
2.16\end{array}$ & $\begin{array}{c}83.9 \\
2.71 \\
5.4 \\
1.0 \\
.14 \\
.16\end{array}$ & $\begin{array}{c}44.69 \\
1.44 \\
2.1 \\
.99 \\
.08 \\
.09\end{array}$ & $\begin{array}{c}34.71 \\
1.16 \\
1.8 \\
.67 \\
.06 \\
.07\end{array}$ \\
\hline
\end{tabular}

SIATISIICS OF MONIHLY MEAN DATA FOR WAIER YEARS 1970 - 1991, BY WATER YEAR (WY)

$\begin{array}{lrrrrrrrrrrrr}\text { MEAN } & 8.90 & 14.1 & 20.9 & 16.4 & 26.6 & 39.1 & 35.3 & 19.2 & 21.1 & 9.58 & 5.51 & 6.04 \\ \text { MAX } & 50.6 & 48.8 & 52.5 & 49.5 & 62.5 & 111 & 60.5 & 41.1 & 90.7 & 49.5 & 36.4 & 33.4 \\ \text { (WY) } & 1991 & 1989 & 1978 & 1974 & 1985 & 1982 & 1978 & 1983 & 1981 & 1986 & 1990 & 1990 \\ \text { MIN } & .36 & .28 & 2.59 & 1.22 & 2.96 & 13.6 & 9.61 & 4.70 & 1.98 & .41 & .25 & .23 \\ \text { (WY) } & 1972 & 1972 & 1977 & 1977 & 1979 & 1989 & 1971 & 1988 & 1988 & 1971 & 1971 & 1978\end{array}$

SUMMARY SIATISIICS

\section{ANMUAL TOIAL}

ANMUAL MEAM

HIGHESI ANNUAL MEAN

LOWEST ANNUAL MEAN

HIGHEST DAILY MEAN

LOWEST DAILY MEAN

ANHUAL SEVEN-DAY MINIMUM

INSTANTANEOUS PEAK FLOW

INSIANTANEOUS PEAK STAGE

ANMUAL RUNOFF (CFSM)

AN NUAL RUNOFF (INCHES)

10 PERCENT EXCEEDS

50 PERCENT EXCEEDS

90 PERCENI EXCEEDS
FOR 1990 CALENDAR YEAR

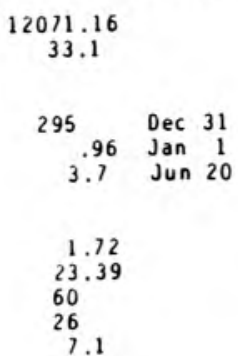

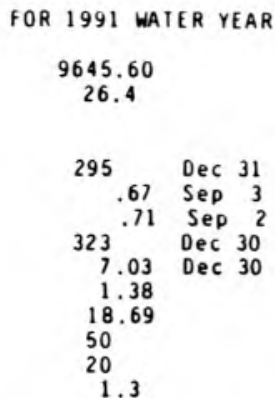

WATER YEARS $1970-1991$

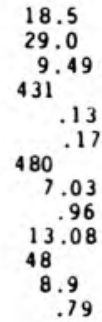

$\begin{array}{ccc} & & 1982 \\ & 1979 \\ \text { Feb } & 25 & 1985 \\ \text { Sep } & 10 & 1972 \\ \text { Sep } & 6 & 1978 \\ \text { Feb } & 24 & 1985 \\ \text { Dec } & 30 & 1990\end{array}$ 
LOCATION. - Lat $41^{\circ} 23^{\prime} 07^{\prime \prime}$, Iong $85^{\circ} 2 \mathrm{C}^{\prime} 14^{\prime \prime}$, in NE isE sec.21, T.34 N., R.10 E., Noble County, Hydrologic Unit 04050001 . On right bank $900 \mathrm{ft}$ downstredm from culvert on County Road 300 East, $0.75 \mathrm{mi}$ south of State Highway 8, 3.0 i eaşt of intersection of State Highway 9 and State Highway 8 in Albion.

DRAINAGE AREA. - $10.1 \div i^{2}$

PERIOD OF RECORD.-. November 1979 to current year.

GAGE.- - Water-stage recorder. Datua of gage is $934.49 \mathrm{ft}$ (revised 1991 WY) above National Geodetic Vertical Datun of 1929

REMARKS. - - Records good except for estiated daily discharges, which are fair

EXTREMES OUTSIDE PERIOD OF RECORD...-Miniaun daily discharge, $0.14 \mathrm{ft} / \mathrm{s}$, many days during 1980.

DISCHARGE, CUBIC FEET PER SECONO, WATER YEAR OCTOBER 1990 TO SEPTEMBER 1991 DAI IY MEAN VALUES

\begin{tabular}{|c|c|c|c|c|c|c|c|c|c|c|c|c|}
\hline DAY & $0 \mathrm{CT}$ & NOV & DEC & JAN & FEB & MAR & APR & MAY & JUN & JUL & AUG & SEP \\
\hline $\begin{array}{l}1 \\
2 \\
3 \\
4 \\
5\end{array}$ & $\begin{array}{c}2.8 \\
2.6 \\
4.4 \\
50 \\
18\end{array}$ & $\begin{array}{r}5.7 \\
5.8 \\
5.7 \\
5.9 \\
72\end{array}$ & $\begin{array}{l}11 \\
9.0 \\
47 \\
40 \\
21\end{array}$ & $\begin{array}{r}80 \\
63 \\
48 \\
34 \\
e 25\end{array}$ & $\begin{array}{l}7.0 \\
5.6 \\
11 \\
16 \\
21\end{array}$ & $\begin{array}{l}9.8 \\
38 \\
28 \\
15 \\
13\end{array}$ & $\begin{array}{r}8.8 \\
8.1 \\
7.6 \\
7.6 \\
12\end{array}$ & $\begin{array}{c}14 \\
12 \\
11 \\
9.6 \\
10\end{array}$ & $\begin{array}{r}166 \\
65 \\
39 \\
26 \\
17\end{array}$ & $\begin{array}{l}5.2 \\
8.8 \\
3.2 \\
2.0 \\
2.9\end{array}$ & $\begin{array}{r}.66 \\
.64 \\
1.9 \\
.95 \\
.78\end{array}$ & $\begin{array}{l}.50 \\
.50 \\
.52 \\
.54 \\
.52\end{array}$ \\
\hline $\begin{array}{r}6 \\
7 \\
8 \\
9 \\
10\end{array}$ & $\begin{array}{r}9.5 \\
7.2 \\
7.3 \\
104 \\
200\end{array}$ & $\begin{array}{l}60 \\
31 \\
20 \\
15 \\
12\end{array}$ & $\begin{array}{l}16 \\
14 \\
12 \\
11 \\
10\end{array}$ & $\begin{array}{l}\text { e19 } \\
\text { e15 } \\
\text { e11 } \\
\text { e10 } \\
\text { e } 9.7\end{array}$ & $\begin{array}{l}16 \\
13 \\
12 \\
12 \\
11\end{array}$ & $\begin{array}{c}12 \\
10 \\
8.6 \\
8.5 \\
8.2\end{array}$ & $\begin{array}{l}9.7 \\
8.4 \\
12 \\
15 \\
15\end{array}$ & $\begin{array}{r}13 \\
9.9 \\
8.8 \\
8.1 \\
7.3\end{array}$ & $\begin{array}{r}11 \\
8.9 \\
7.9 \\
6.7 \\
5.7\end{array}$ & $\begin{array}{l}1.8 \\
1.4 \\
1.2 \\
1.1 \\
1.1\end{array}$ & $\begin{array}{l}.71 \\
.67 \\
1.1 \\
1.2 \\
.82\end{array}$ & $\begin{array}{l}.51 \\
.51 \\
.50 \\
.51 \\
.54\end{array}$ \\
\hline $\begin{array}{l}11 \\
12 \\
13 \\
14 \\
15\end{array}$ & $\begin{array}{r}105 \\
54 \\
36 \\
28 \\
22\end{array}$ & $\begin{array}{r}11 \\
9.1 \\
8.1 \\
7.6 \\
7.2\end{array}$ & $\begin{array}{l}9.2 \\
8.7 \\
8.1 \\
7.3 \\
18\end{array}$ & $\begin{array}{l}16 \\
22 \\
14 \\
15 \\
25\end{array}$ & $\begin{array}{r}8.6 \\
\text { e } 7.6 \\
\text { e6.8 } \\
\text { e6.4 } \\
\text { e6 } 6.0\end{array}$ & $\begin{array}{l}7.8 \\
7.2 \\
7.2 \\
7.7 \\
9.6\end{array}$ & $\begin{array}{l}12 \\
9.6 \\
8.9 \\
14 \\
23\end{array}$ & $\begin{array}{l}6.6 \\
6.4 \\
6.1 \\
5.8 \\
5.4\end{array}$ & $\begin{array}{l}6.4 \\
6.9 \\
5.3 \\
4.2 \\
3.7\end{array}$ & $\begin{array}{l}1.0 \\
1.0 \\
1.1 \\
.97 \\
.94\end{array}$ & $\begin{array}{l}.72 \\
.66 \\
.63 \\
.59 \\
.59\end{array}$ & $\begin{array}{l}.51 \\
5.4 \\
2.4 \\
1.0 \\
.83\end{array}$ \\
\hline $\begin{array}{l}16 \\
17 \\
18 \\
19 \\
20\end{array}$ & $\begin{array}{l}16 \\
13 \\
28 \\
18 \\
14\end{array}$ & $\begin{array}{l}7.0 \\
6.4 \\
6.1 \\
5.9 \\
5.6\end{array}$ & $\begin{array}{l}18 \\
15 \\
21 \\
18 \\
14\end{array}$ & $\begin{array}{l}53 \\
30 \\
18 \\
16 \\
18\end{array}$ & $\begin{array}{c}\text { e5.8 } \\
\text { e5.6 } \\
8.1 \\
40 \\
22\end{array}$ & $\begin{array}{l}10 \\
11 \\
22 \\
15 \\
12\end{array}$ & $\begin{array}{l}17 \\
63 \\
26 \\
49 \\
71\end{array}$ & $\begin{array}{l}5.3 \\
7.4 \\
5.9 \\
5.3 \\
4.8\end{array}$ & $\begin{array}{l}3.5 \\
3.1 \\
2.7 \\
2.4 \\
2.1\end{array}$ & $\begin{array}{l}.87 \\
.82 \\
.78 \\
.17 \\
.73\end{array}$ & $\begin{array}{r}.55 \\
.55 \\
.67 \\
1.2 \\
1.0\end{array}$ & $\begin{array}{l}.77 \\
.73 \\
.73 \\
.70 \\
.71\end{array}$ \\
\hline $\begin{array}{l}21 \\
22 \\
23 \\
24 \\
25\end{array}$ & $\begin{array}{r}13 \\
12 \\
10 \\
8.8 \\
7.9\end{array}$ & $\begin{array}{l}5.5 \\
6.1 \\
6.0 \\
5.7 \\
5.4\end{array}$ & $\begin{array}{r}34 \\
41 \\
23 \\
\text { e17 } \\
\text { e14 }\end{array}$ & $\begin{array}{l}\text { e } 15 \\
\text { e } 12 \\
\text { e } 10 \\
\text { e } 9.1 \\
\text { e } 8.2\end{array}$ & $\begin{array}{r}17 \\
15 \\
11 \\
9.6 \\
8.3\end{array}$ & $\begin{array}{l}11 \\
9.2 \\
11 \\
15 \\
12\end{array}$ & $\begin{array}{l}37 \\
24 \\
22 \\
50 \\
27\end{array}$ & $\begin{array}{l}4.3 \\
4.0 \\
4.2 \\
4.6 \\
8.8\end{array}$ & $\begin{array}{l}2.0 \\
1.9 \\
1.8 \\
1.6 \\
1.5\end{array}$ & $\begin{array}{l}.73 \\
.73 \\
.69 \\
.64 \\
.64\end{array}$ & $\begin{array}{l}.79 \\
.70 \\
.65 \\
.61 \\
.58\end{array}$ & $\begin{array}{l}.69 \\
.71 \\
.74 \\
.70 \\
.70\end{array}$ \\
\hline $\begin{array}{l}26 \\
27 \\
28 \\
29 \\
30 \\
31\end{array}$ & $\begin{array}{l}7.3 \\
7.1 \\
6.7 \\
6.2 \\
6.2 \\
5.9\end{array}$ & $\begin{array}{l}5.1 \\
6.9 \\
38 \\
19 \\
13 \\
\ldots\end{array}$ & $\begin{array}{l}\text { el2 } \\
\text { e10 } \\
\text { e9. } 6 \\
229 \\
329 \\
153\end{array}$ & $\begin{array}{r}\text { e6. } 6 \\
\text { e6. } \\
\text { e6.0 } \\
\text { e6.0 } \\
5.4 \\
8.3\end{array}$ & $\begin{array}{r}\text { e).2 } \\
\text { e6.2 } \\
\text { e6.6 } \\
\ldots . \\
\ldots \\
\cdots\end{array}$ & $\begin{array}{l}16 \\
16 \\
13 \\
11 \\
8.8 \\
8.4\end{array}$ & $\begin{array}{l}19 \\
20 \\
27 \\
20 \\
16 \\
\ldots\end{array}$ & $\begin{array}{r}18 \\
10 \\
7.6 \\
5.9 \\
8.4 \\
124\end{array}$ & $\begin{array}{l}1.4 \\
1.3 \\
1.2 \\
1.1 \\
3.7 \\
\ldots . .\end{array}$ & $\begin{array}{c}.63 \\
.59 \\
.59 \\
1.1 \\
1.2 \\
.74\end{array}$ & $\begin{array}{l}.55 \\
.55 \\
.55 \\
.53 \\
.51 \\
.53\end{array}$ & $\begin{array}{l}.69 \\
.68 \\
.64 \\
.64 \\
.66 \\
\cdots\end{array}$ \\
\hline $\begin{array}{l}\text { IOIAL } \\
\text { MEAN } \\
\text { MAX } \\
\text { MIN } \\
\text { CF SM } \\
\text { IN. }\end{array}$ & $\begin{array}{r}830.9 \\
26.8 \\
200 \\
2.6 \\
2.50 \\
2.89\end{array}$ & $\begin{array}{r}417.8 \\
13.9 \\
72 \\
5.1 \\
1.30 \\
1.45\end{array}$ & $\begin{array}{r}1199.9 \\
38.7 \\
329 \\
7.3 \\
3.62 \\
4.17\end{array}$ & $\begin{array}{r}634.9 \\
20.5 \\
80 \\
5.4 \\
1.91 \\
2.21\end{array}$ & $\begin{array}{r}322.4 \\
11.5 \\
40 \\
5.6 \\
1.08 \\
1.12\end{array}$ & $\begin{array}{r}392.0 \\
12.6 \\
38 \\
7.2 \\
1.18 \\
1.36\end{array}$ & $\begin{array}{c}659.7 \\
22.0 \\
71 \\
7.6 \\
2.06 \\
2.29\end{array}$ & $\begin{array}{c}362.5 \\
11.7 \\
124 \\
4.0 \\
1.09 \\
1.26\end{array}$ & $\begin{array}{c}411.0 \\
13.7 \\
166 \\
1.1 \\
1.28 \\
1.43\end{array}$ & $\begin{array}{c}45.96 \\
1.48 \\
8.8 \\
.59 \\
.14 \\
.16\end{array}$ & $\begin{array}{c}23.14 \\
.75 \\
1.9 \\
.51 \\
.07 \\
.08\end{array}$ & $\begin{array}{c}25.78 \\
.86 \\
5.4 \\
.50 \\
.08 \\
.09\end{array}$ \\
\hline
\end{tabular}

e Estimated

STATISIICS OF MONTHLY MEAN DATA FOR WATER YEARS 1981 - 1991, BY WATER YEAR (WY)

$\begin{array}{lcccccccccccc}\text { MEAN } & 1.62 & 12.0 & 14.8 & 9.49 & 20.1 & 22.9 & 18.7 & 10.8 & 10.6 & 6.24 & 3.10 & 1.18 \\ \text { MAX } & 26.8 & 31.2 & 38.7 & 20.5 & 44.8 & 69.9 & 31.8 & 24.9 & 39.1 & 33.0 & 16.1 & 5.68 \\ \text { (WY) } & 1991 & 1989 & 1991 & 1991 & 1985 & 1982 & 1981 & 1990 & 1981 & 1986 & 1990 & 1981 \\ \text { MIN } & .62 & 1.38 & 1.00 & 2.27 & 5.48 & 6.68 & 5.94 & 2.05 & .72 & .51 & .31 & .37 \\ \text { (WY) } & 1984 & 1981 & 1990 & 1981 & 1989 & 1981 & 1986 & 1985 & 1988 & 1988 & 1988 & 1987\end{array}$

SUMMARY SIATISIICS

AMNUAL TOTAL

ANMUAL MEAN

HIGHEST ANMUAL MEAN

LOWEST ANMUAL MEAN

HIGHEST DAILY MEAN

LOWEST DAILY MEAN

ANNUAL SEVEN-DAY MINIMUM

INSIANIANEOUS PEAK FLOW

INSIANIANEOUS PEAK SIAGE

ANNUAL RUNOFF (CFSM)

ANNUAL RUNOFF (I NCHES)

10 PERCENT EXCEEDS

50 PERCENT EXCEEDS

90 PERCENT EXCEEDS
FOR 1990 CALENOAR YEAR

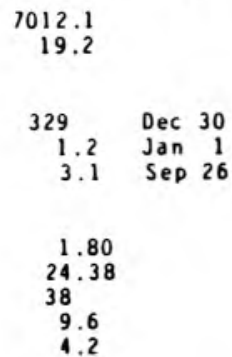

FOR 1991 WAIER YEAR

5325.98

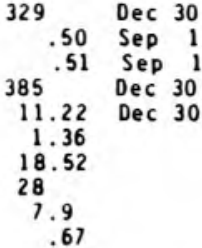

WATER YEARS 1981 - 1991

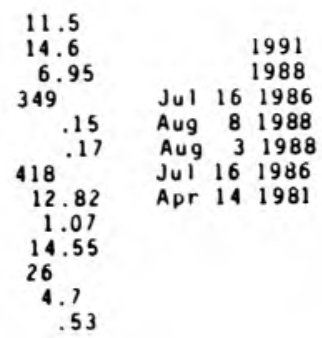


LOCAIION...Lat $41^{\circ} 27^{\prime} 30^{\prime \prime}$, Iong $85^{\circ} 43^{\prime} 12^{\prime \prime}$, in NWtSE sec.28, T.35 N., R.7 E., Elkhart County, Hydrologic Unit 04050001 , on right bank $40 \mathrm{ft}$ upstreai from County Road 52 East bridge over Solonon Creek, and 2.5 a northeast of Syracuse. DRAINAGE AREA. - 36.1 i

PERIOD OF RECORD..-October 1987 to current year.

GAGE.--Water-stage recorder. Datum of gage is $840.00 \mathrm{ft}$ above National Geodetic Vertical Datue of 1929 .

REMARKS. - Records good, except those for estimated daily discharges, which are fair.

DISCHARGE, CUBIC FEET PER SECOND, WATER YEAR OCTOBER 1990 TO SEPIEMBER 1991 DAI IY MEAN VALUES

\begin{tabular}{|c|c|c|c|c|c|c|c|c|c|c|c|c|}
\hline DAY & $\mathrm{OCT}$ & NOV & DEC & JAN & FEB & MAR & $A P R$ & MAY & JUN & JUL & AUG & SEP \\
\hline $\begin{array}{l}1 \\
2 \\
3 \\
4 \\
5\end{array}$ & $\begin{array}{l}42 \\
40 \\
38 \\
39 \\
38\end{array}$ & $\begin{array}{l}46 \\
46 \\
45 \\
45 \\
71\end{array}$ & $\begin{array}{l}50 \\
47 \\
55 \\
61 \\
56\end{array}$ & $\begin{array}{r}117 \\
102 \\
93 \\
86 \\
82\end{array}$ & $\begin{array}{l}50 \\
50 \\
50 \\
51 \\
52\end{array}$ & $\begin{array}{l}43 \\
54 \\
59 \\
55 \\
52\end{array}$ & $\begin{array}{l}47 \\
45 \\
43 \\
43 \\
45\end{array}$ & $\begin{array}{l}62 \\
60 \\
59 \\
58 \\
58\end{array}$ & $\begin{array}{r}149 \\
113 \\
95 \\
85 \\
79\end{array}$ & $\begin{array}{l}37 \\
38 \\
35 \\
31 \\
31\end{array}$ & $\begin{array}{l}19 \\
18 \\
22 \\
21 \\
20\end{array}$ & $\begin{array}{l}17 \\
16 \\
17 \\
18 \\
17\end{array}$ \\
\hline $\begin{array}{r}6 \\
7 \\
8 \\
9 \\
10\end{array}$ & $\begin{array}{r}36 \\
33 \\
31 \\
72 \\
129\end{array}$ & $\begin{array}{l}90 \\
77 \\
70 \\
66 \\
63\end{array}$ & $\begin{array}{l}54 \\
52 \\
50 \\
49 \\
48\end{array}$ & $\begin{array}{l}78 \\
74 \\
71 \\
69 \\
67\end{array}$ & $\begin{array}{l}53 \\
52 \\
51 \\
51 \\
50\end{array}$ & $\begin{array}{l}52 \\
49 \\
47 \\
45 \\
43\end{array}$ & $\begin{array}{l}44 \\
43 \\
43 \\
45 \\
45\end{array}$ & $\begin{array}{l}59 \\
57 \\
55 \\
55 \\
54\end{array}$ & $\begin{array}{l}74 \\
70 \\
68 \\
66 \\
64\end{array}$ & $\begin{array}{l}29 \\
30 \\
29 \\
27 \\
26\end{array}$ & $\begin{array}{l}20 \\
19 \\
23 \\
24 \\
22\end{array}$ & $\begin{array}{l}17 \\
16 \\
16 \\
16 \\
16\end{array}$ \\
\hline $\begin{array}{l}11 \\
12 \\
13 \\
14 \\
15\end{array}$ & $\begin{array}{r}122 \\
103 \\
89 \\
81 \\
76\end{array}$ & $\begin{array}{l}59 \\
56 \\
54 \\
52 \\
51\end{array}$ & $\begin{array}{l}47 \\
46 \\
45 \\
44 \\
47\end{array}$ & $\begin{array}{l}68 \\
70 \\
67 \\
65 \\
66\end{array}$ & $\begin{array}{l}48 \\
46 \\
46 \\
46 \\
43\end{array}$ & $\begin{array}{l}42 \\
41 \\
42 \\
41 \\
41\end{array}$ & $\begin{array}{l}44 \\
42 \\
42 \\
44 \\
54\end{array}$ & $\begin{array}{l}54 \\
53 \\
53 \\
53 \\
52\end{array}$ & $\begin{array}{l}64 \\
63 \\
61 \\
59 \\
57\end{array}$ & $\begin{array}{l}25 \\
25 \\
24 \\
23 \\
22\end{array}$ & $\begin{array}{l}21 \\
20 \\
20 \\
20 \\
19\end{array}$ & $\begin{array}{l}15 \\
40 \\
39 \\
29 \\
25\end{array}$ \\
\hline $\begin{array}{l}16 \\
17 \\
18 \\
19 \\
20\end{array}$ & $\begin{array}{l}12 \\
69 \\
72 \\
69 \\
66\end{array}$ & $\begin{array}{l}50 \\
49 \\
48 \\
47 \\
46\end{array}$ & $\begin{array}{l}49 \\
49 \\
51 \\
51 \\
49\end{array}$ & $\begin{array}{l}81 \\
82 \\
74 \\
70 \\
69\end{array}$ & $\begin{array}{r}\text { e } 41 \\
\text { e } 42 \\
42 \\
55 \\
58\end{array}$ & $\begin{array}{l}43 \\
45 \\
58 \\
56 \\
52\end{array}$ & $\begin{array}{l}57 \\
10 \\
66 \\
66 \\
84\end{array}$ & $\begin{array}{l}51 \\
51 \\
52 \\
51 \\
49\end{array}$ & $\begin{array}{l}56 \\
55 \\
52 \\
49 \\
46\end{array}$ & $\begin{array}{l}22 \\
20 \\
20 \\
19 \\
19\end{array}$ & $\begin{array}{l}19 \\
18 \\
17 \\
19 \\
19\end{array}$ & $\begin{array}{l}23 \\
22 \\
21 \\
20 \\
20\end{array}$ \\
\hline $\begin{array}{l}21 \\
22 \\
23 \\
24 \\
25\end{array}$ & $\begin{array}{l}63 \\
60 \\
58 \\
56 \\
54\end{array}$ & $\begin{array}{l}46 \\
46 \\
46 \\
45 \\
44\end{array}$ & $\begin{array}{l}50 \\
58 \\
56 \\
53 \\
51\end{array}$ & $\begin{array}{l}67 \\
64 \\
63 \\
60 \\
58\end{array}$ & $\begin{array}{l}56 \\
55 \\
52 \\
50 \\
47\end{array}$ & $\begin{array}{l}51 \\
48 \\
49 \\
49 \\
47\end{array}$ & $\begin{array}{l}73 \\
68 \\
65 \\
73 \\
70\end{array}$ & $\begin{array}{l}49 \\
48 \\
50 \\
52 \\
54\end{array}$ & $\begin{array}{l}45 \\
45 \\
45 \\
42 \\
39\end{array}$ & $\begin{array}{l}18 \\
24 \\
24 \\
22 \\
21\end{array}$ & $\begin{array}{l}18 \\
18 \\
18 \\
18 \\
17\end{array}$ & $\begin{array}{l}19 \\
19 \\
19 \\
18 \\
18\end{array}$ \\
\hline $\begin{array}{l}26 \\
27 \\
28 \\
29 \\
30 \\
31\end{array}$ & $\begin{array}{l}52 \\
51 \\
50 \\
49 \\
48 \\
47\end{array}$ & $\begin{array}{l}44 \\
44 \\
59 \\
56 \\
52 \\
\cdots\end{array}$ & $\begin{array}{r}49 \\
47 \\
47 \\
120 \\
190 \\
149\end{array}$ & $\begin{array}{l}57 \\
56 \\
55 \\
54 \\
53 \\
51\end{array}$ & $\begin{array}{c}45 \\
43 \\
43 \\
\cdots \\
\cdots \\
\cdots\end{array}$ & $\begin{array}{l}48 \\
52 \\
57 \\
53 \\
50 \\
48\end{array}$ & $\begin{array}{l}66 \\
65 \\
66 \\
65 \\
63 \\
\cdots\end{array}$ & $\begin{array}{r}56 \\
54 \\
52 \\
51 \\
61 \\
130\end{array}$ & $\begin{array}{l}38 \\
37 \\
35 \\
34 \\
35 \\
\cdots\end{array}$ & $\begin{array}{l}19 \\
17 \\
17 \\
17 \\
18 \\
18\end{array}$ & $\begin{array}{l}17 \\
17 \\
17 \\
17 \\
17 \\
18\end{array}$ & $\begin{array}{l}18 \\
17 \\
17 \\
17 \\
17 \\
\cdots\end{array}$ \\
\hline $\begin{array}{l}\text { TOIAL } \\
\text { MEAN } \\
\text { MAX } \\
\text { MIN } \\
\text { CF SM } \\
\text { IN. }\end{array}$ & $\begin{array}{r}1905 \\
61.5 \\
129 \\
31 \\
1.70 \\
1.96\end{array}$ & $\begin{array}{r}1613 \\
53.8 \\
90 \\
44 \\
1.49 \\
1.66\end{array}$ & $\begin{array}{r}1870 \\
60.3 \\
190 \\
44 \\
1.67 \\
1.93\end{array}$ & $\begin{array}{r}2189 \\
70.6 \\
117 \\
51 \\
1.96 \\
2.26\end{array}$ & $\begin{array}{r}1368 \\
48.9 \\
58 \\
41 \\
1.35 \\
1.41\end{array}$ & $\begin{array}{c}1512 \\
48.8 \\
59 \\
41 \\
1.35 \\
1.56\end{array}$ & $\begin{array}{c}1686 \\
56.2 \\
84 \\
42 \\
1.56 \\
1.14\end{array}$ & $\begin{array}{c}1753 \\
56.5 \\
130 \\
48 \\
1.57 \\
1.81\end{array}$ & $\begin{array}{c}1820 \\
60.7 \\
149 \\
34 \\
1.68 \\
1.88\end{array}$ & $\begin{array}{c}747 \\
24.1 \\
38 \\
17 \\
.67 \\
.77\end{array}$ & $\begin{array}{c}592 \\
19.1 \\
24 \\
17 \\
.53 \\
.61\end{array}$ & $\begin{array}{c}599 \\
20.0 \\
40 \\
15 \\
.55 \\
.62\end{array}$ \\
\hline
\end{tabular}

e Estimated

SIATISTICS OF MONTHLY MEAN DATA FOR WAIER YEARS 1988 - 1991, BY WATER YEAR (WY)

\begin{tabular}{|c|c|c|c|c|c|c|c|c|c|c|c|c|}
\hline $\begin{array}{l}\text { MEAN } \\
\text { MAX } \\
\text { (WY) } \\
\text { MIN } \\
\text { (WY) }\end{array}$ & $\begin{array}{l}28.4 \\
61.5 \\
1991 \\
12.9 \\
1988\end{array}$ & $\begin{array}{l}34.6 \\
53.8 \\
1991 \\
14.0 \\
1988\end{array}$ & $\begin{array}{l}37.4 \\
60.3 \\
1991 \\
14.8 \\
1990\end{array}$ & $\begin{array}{l}44.8 \\
70.6 \\
1991 \\
27.4 \\
1988\end{array}$ & $\begin{array}{l}42.0 \\
49.1 \\
1990 \\
32.8 \\
1989\end{array}$ & $\begin{array}{l}42.8 \\
58.1 \\
1990 \\
30.8 \\
1989\end{array}$ & $\begin{array}{l}49.2 \\
56.2 \\
1991 \\
37.9 \\
1989\end{array}$ & $\begin{array}{l}41.3 \\
59.4 \\
1990 \\
24.4 \\
1989\end{array}$ & $\begin{array}{l}47.8 \\
60.7 \\
1991 \\
16.5 \\
1988\end{array}$ & $\begin{array}{l}24.8 \\
38.7 \\
1990 \\
12.1 \\
1988\end{array}$ & $\begin{array}{l}20.6 \\
33.2 \\
1990 \\
10.5 \\
1988\end{array}$ & $\begin{array}{l}22.7 \\
36.5 \\
1990 \\
13.7 \\
1988\end{array}$ \\
\hline
\end{tabular}

SUMMARY SIATISIICS

ANNUAL TOIAL

AMNUAL MEAN

HIGHEST ANMUAL MEAM

LOWEST ANNUAL MEAN

HIGHEST DAILY MEAN

LOWEST DAILY MEAN

ANNUAL SEVEN-DAY MINIMUM

INSTANIANEOUS PEAK FIOW

INSIANTANEOUS PEAK SIAGE

ANMUAL RUNOFF (CFSM)

ANHUAL RUNOFF (INCHES)

10 PERCENT EXCEEDS

50 PERCENT EXCEEDS

90 PERCENT EXCEEDS
FOR 1990 CALENDAR YEAR

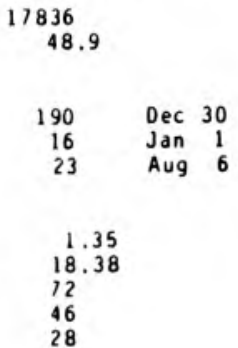

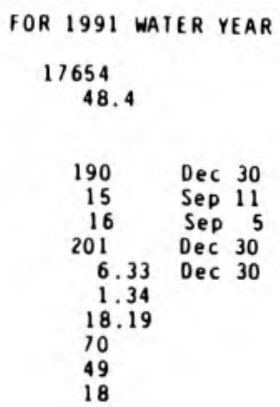

WAIER YEARS $1988-1991$

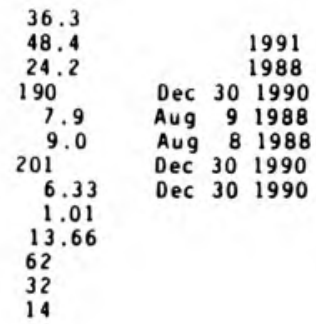




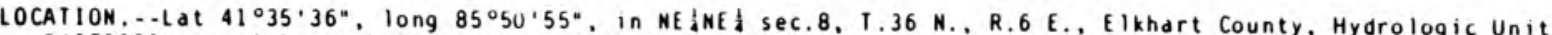
04050001 , on right bank $20 \mathrm{ft}$ downstream from River Avenue bridge dt Goshen, 0.4 i upstream from Rock Run. and at ile 16.1 .

DRAI NAGE AREA. $-594 i^{2}$

PERIOD OF RECORD.--APrii 1931 to current year.

REVISED RECORDS...WSP 1337: 1939(M). WSP 1557: 1954. WSP 2111: Orainage area.

GAGE.- Water-stage recorder. Datum of gage is $769.43 \mathrm{ft}$ above National Geodetic Vertical Datua of 1929 . Prior to Nov. 20, 1931, nonrecording gage at sane site and datum. REMARKS. - Records good except for estinated daily discharges, which are fair. Occasional low-flow regulation at
Goshen Dam, 3.4 i upstrean.

DISCHARGE, CUBIC FEET PER SECOND, WATER YEAR OCTOBER 1990 TO SEPTEMBER 1991 DAILY MEAN VALUES

\begin{tabular}{|c|c|c|c|c|c|c|c|c|c|c|c|c|}
\hline DAY & $\mathrm{OCI}$ & NOV & $\mathrm{DEC}$ & JAN & FEB & MAR & APR & MAY & JUN & JUL & AUG & SEP \\
\hline $\begin{array}{l}1 \\
2 \\
3 \\
4 \\
5\end{array}$ & $\begin{array}{l}507 \\
493 \\
486 \\
536 \\
570\end{array}$ & $\begin{array}{l}794 \\
767 \\
741 \\
732 \\
947\end{array}$ & $\begin{array}{r}829 \\
789 \\
811 \\
1010 \\
984\end{array}$ & $\begin{array}{l}\text { e } 3500 \\
\text { e } 2900 \\
\text { e } 2600 \\
\text { e } 2450 \\
\text { e } 2200\end{array}$ & $\begin{array}{r}\text { e } 760 \\
\text { e } 770 \\
\text { e } 800 \\
852 \\
904\end{array}$ & $\begin{array}{r}828 \\
936 \\
1160 \\
1100 \\
978\end{array}$ & $\begin{array}{l}802 \\
778 \\
755 \\
747 \\
760\end{array}$ & $\begin{array}{l}1210 \\
1170 \\
1110 \\
1060 \\
1030\end{array}$ & $\begin{array}{l}2760 \\
2450 \\
2050 \\
1810 \\
1650\end{array}$ & $\begin{array}{l}460 \\
454 \\
468 \\
452 \\
421\end{array}$ & $\begin{array}{l}194 \\
184 \\
221 \\
263 \\
249\end{array}$ & $\begin{array}{l}223 \\
211 \\
229 \\
232 \\
212\end{array}$ \\
\hline $\begin{array}{r}6 \\
7 \\
8 \\
9 \\
10\end{array}$ & $\begin{array}{r}535 \\
524 \\
572 \\
1100 \\
2500\end{array}$ & $\begin{array}{l}1590 \\
1620 \\
1280 \\
1110 \\
1060\end{array}$ & $\begin{array}{l}911 \\
898 \\
888 \\
873 \\
860\end{array}$ & $\begin{array}{l}\text { e } 2050 \\
\text { e } 1900 \\
\text { e } 1760 \\
\text { e } 1650 \\
\text { e } 1590\end{array}$ & $\begin{array}{l}942 \\
933 \\
918 \\
917 \\
914\end{array}$ & $\begin{array}{l}948 \\
941 \\
902 \\
880 \\
860\end{array}$ & $\begin{array}{l}744 \\
725 \\
710 \\
719 \\
740\end{array}$ & $\begin{array}{r}1070 \\
1030 \\
965 \\
913 \\
876\end{array}$ & $\begin{array}{l}1540 \\
1470 \\
1390 \\
1300 \\
1190\end{array}$ & $\begin{array}{l}402 \\
395 \\
391 \\
368 \\
355\end{array}$ & $\begin{array}{l}238 \\
231 \\
263 \\
309 \\
286\end{array}$ & $\begin{array}{l}198 \\
187 \\
175 \\
175 \\
173\end{array}$ \\
\hline $\begin{array}{l}11 \\
12 \\
13 \\
14 \\
15\end{array}$ & $\begin{array}{l}3220 \\
2430 \\
2010 \\
1820 \\
1710\end{array}$ & $\begin{array}{r}1030 \\
996 \\
967 \\
937 \\
909\end{array}$ & $\begin{array}{l}841 \\
821 \\
802 \\
755 \\
799\end{array}$ & $\begin{array}{r}\text { e } 1490 \\
\text { e } 1400 \\
\text { e } 1340 \\
\text { e } 1300 \\
1340\end{array}$ & $\begin{array}{l}890 \\
856 \\
840 \\
847 \\
819\end{array}$ & $\begin{array}{l}835 \\
802 \\
775 \\
758 \\
763\end{array}$ & $\begin{array}{r}731 \\
719 \\
717 \\
770 \\
1060\end{array}$ & $\begin{array}{l}843 \\
816 \\
791 \\
766 \\
736\end{array}$ & $\begin{array}{r}1110 \\
1050 \\
976 \\
907 \\
847\end{array}$ & $\begin{array}{l}342 \\
337 \\
327 \\
320 \\
311\end{array}$ & $\begin{array}{l}210 \\
257 \\
245 \\
226 \\
219\end{array}$ & $\begin{array}{l}169 \\
329 \\
443 \\
347 \\
299\end{array}$ \\
\hline $\begin{array}{l}16 \\
17 \\
18 \\
19 \\
20\end{array}$ & $\begin{array}{l}1660 \\
1570 \\
1540 \\
1550 \\
1460\end{array}$ & $\begin{array}{l}881 \\
851 \\
818 \\
792 \\
769\end{array}$ & $\begin{array}{l}879 \\
860 \\
863 \\
882 \\
854\end{array}$ & $\begin{array}{l}1520 \\
1890 \\
1710 \\
1470 \\
1380\end{array}$ & $\begin{array}{r}715 \\
755 \\
816 \\
969 \\
1170\end{array}$ & $\begin{array}{r}775 \\
789 \\
913 \\
1000 \\
896\end{array}$ & $\begin{array}{l}1400 \\
1450 \\
1560 \\
1270 \\
1510\end{array}$ & $\begin{array}{l}723 \\
709 \\
676 \\
650 \\
603\end{array}$ & $\begin{array}{l}794 \\
748 \\
684 \\
603 \\
546\end{array}$ & $\begin{array}{l}296 \\
277 \\
263 \\
254 \\
239\end{array}$ & $\begin{array}{l}200 \\
200 \\
195 \\
269 \\
317\end{array}$ & $\begin{array}{l}275 \\
257 \\
243 \\
231 \\
220\end{array}$ \\
\hline $\begin{array}{l}21 \\
22 \\
23 \\
24 \\
25\end{array}$ & $\begin{array}{l}1350 \\
1270 \\
1200 \\
1130 \\
1060\end{array}$ & $\begin{array}{l}749 \\
752 \\
740 \\
718 \\
694\end{array}$ & $\begin{array}{r}851 \\
986 \\
1040 \\
921 \\
838\end{array}$ & $\begin{array}{r}1380 \\
\text { e } 1240 \\
\text { e } 1140 \\
\text { e } 1050 \\
\text { e } 1000\end{array}$ & $\begin{array}{r}1070 \\
1020 \\
970 \\
923 \\
895\end{array}$ & $\begin{array}{l}839 \\
814 \\
807 \\
825 \\
819\end{array}$ & $\begin{array}{l}1620 \\
1370 \\
1290 \\
1410 \\
1500\end{array}$ & $\begin{array}{l}567 \\
545 \\
547 \\
637 \\
850\end{array}$ & $\begin{array}{l}496 \\
464 \\
445 \\
422 \\
396\end{array}$ & $\begin{array}{l}238 \\
261 \\
249 \\
228 \\
217\end{array}$ & $\begin{array}{l}274 \\
251 \\
237 \\
224 \\
212\end{array}$ & $\begin{array}{l}211 \\
203 \\
198 \\
193 \\
188\end{array}$ \\
\hline $\begin{array}{l}26 \\
27 \\
28 \\
29 \\
30 \\
31\end{array}$ & $\begin{array}{r}1010 \\
961 \\
918 \\
881 \\
846 \\
822\end{array}$ & $\begin{array}{r}6 / 5 \\
693 \\
883 \\
1110 \\
932 \\
-\ldots\end{array}$ & $\begin{array}{r}\text { e } 800 \\
\text { e } 760 \\
\text { e } 820 \\
1670 \\
4940 \\
\text { e4200 }\end{array}$ & $\begin{array}{l}\text { e } 950 \\
\text { e890 } \\
\text { e860 } \\
\text { e830 } \\
\text { e800 } \\
\text { e } 770\end{array}$ & $\begin{array}{l}864 \\
842 \\
825 \\
\ldots \\
\ldots \\
\ldots\end{array}$ & $\begin{array}{l}840 \\
921 \\
971 \\
932 \\
851 \\
814\end{array}$ & $\begin{array}{c}1350 \\
1290 \\
1370 \\
1370 \\
1280 \\
\ldots\end{array}$ & $\begin{array}{r}960 \\
827 \\
705 \\
651 \\
681 \\
1730\end{array}$ & $\begin{array}{l}370 \\
351 \\
329 \\
311 \\
340 \\
\cdots-\end{array}$ & $\begin{array}{l}201 \\
183 \\
179 \\
196 \\
204 \\
197\end{array}$ & $\begin{array}{l}205 \\
209 \\
185 \\
163 \\
186 \\
197\end{array}$ & $\begin{array}{l}185 \\
179 \\
173 \\
179 \\
182 \\
\cdots\end{array}$ \\
\hline $\begin{array}{l}\text { TOIAL } \\
\text { MEAN } \\
\text { MAX } \\
\text { MIN } \\
\text { CF SM } \\
\text { IN. }\end{array}$ & $\begin{array}{r}38241 \\
1234 \\
3220 \\
486 \\
2.08 \\
2.39\end{array}$ & $\begin{array}{r}27537 \\
918 \\
1620 \\
675 \\
1.55 \\
1.72\end{array}$ & $\begin{array}{r}35035 \\
1130 \\
4940 \\
755 \\
1.90 \\
2.19\end{array}$ & $\begin{array}{r}48350 \\
1560 \\
3500 \\
770 \\
2.63 \\
3.03\end{array}$ & $\begin{array}{r}24796 \\
886 \\
1170 \\
715 \\
1.49 \\
1.55\end{array}$ & $\begin{array}{r}27272 \\
880 \\
1160 \\
758 \\
1.48 \\
1.71\end{array}$ & $\begin{array}{r}32517 \\
1084 \\
1620 \\
710 \\
1.82 \\
2.04\end{array}$ & $\begin{array}{r}26447 \\
853 \\
1730 \\
545 \\
1.44 \\
1.66\end{array}$ & $\begin{array}{r}29799 \\
993 \\
2760 \\
311 \\
1.67 \\
1.87\end{array}$ & $\begin{array}{c}9485 \\
306 \\
468 \\
179 \\
.52 \\
.59\end{array}$ & $\begin{array}{c}7179 \\
232 \\
317 \\
163 \\
.39 \\
.45\end{array}$ & $\begin{array}{l}6719 \\
224 \\
443 \\
169 \\
.38 \\
.42\end{array}$ \\
\hline
\end{tabular}

e Estiated

SIAIISIICS OF MONIHLY MEAN DATA FOR WAIER YEARS 1932 - 1991, BY WATER YEAR (WY)

$\begin{array}{lrrrrrrrrrrrr}\text { MEAN } & 313 & 377 & 492 & 512 & 696 & 949 & 947 & 707 & 484 & 349 & 267 & 246 \\ \text { MAX } & 1652 & 1132 & 1276 & 1866 & 1657 & 2497 & 2424 & 2354 & 1516 & 1079 & 712 & 784 \\ \text { (WY) } & 1955 & 1973 & 1983 & 1950 & 1959 & 1982 & 1950 & 1943 & 1981 & 1951 & 1958 & 1958 \\ \text { MIN } & 75.9 & 95.9 & 122 & 122 & 108 & 301 & 363 & 222 & 101 & 94.0 & 73.0 & 58.5 \\ \text { (WY) } & 1965 & 1965 & 1964 & 1963 & 1963 & 1964 & 1946 & 1958 & 1934 & 1934 & 1941 & 1941\end{array}$

SUMMARY SIATISTICS

ANMUAL TOTAL

ANMUAL MEAN

HIGHESI ANNUAL MEAN

LOWEST ANNUAL MEAN

HIGHEST DAILY MEAN

LOWEST DAILY MEAN

ANNUAL SEVEN-DAY MINIMUM

INSTANTANEOUS PEAK FLOW

INSIANTANEOUS PEAK SIAGE

ANMUAL RUNOFF (CFSM)

ANNUAL RUNOFF (INCHES)

10 PERCENT EXCEEDS

50 PERCENT EXCEEDS

90 PERCENT EXCEEDS

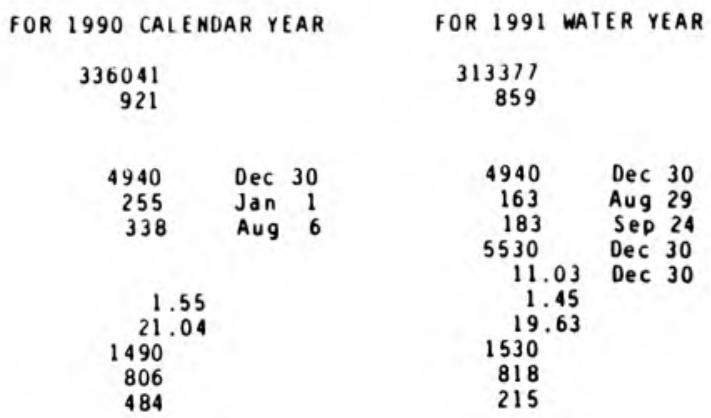

WATER YEARS 1932 - 1991

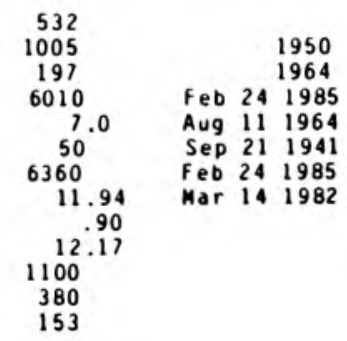


04101000 ST. JOSEPH RIVER AT ELKHART, IN

LOCATION, - - Lat $41^{\circ} 41^{\prime} 30^{\circ}$, long $85^{\circ} 58^{\prime} 30^{\circ}$, in SW4NE $\frac{1}{4}$ sec.5, T. 37 N., R.5 E., Elkhart County, Hydrologic Unit 04050001 . On left bank $200 \mathrm{ft}$ downstrean fros Elkhart River, $200 \mathrm{ft}$ upstrean from Main Street bridge in Elkhart. 2,000 ft downstrea fro Christiana Creek. 0.5 a downstrean fro Elkhart Hydroelectric Plant, and at

DRAINAGE AREA. $--3,370 \cdot i^{2}$.

PERIOD OF RECORD.--August 1947 to current year. Gage heights at site 0.8 a downstrea at different datue froe Septenber 1924 to March 1926 are available from the district of ice.

REVISED RECORDS.--WSP 2111: Drainage area.

GAGE. - Water-stage recorder. Datue of gage is $700.00 \mathrm{ft}$ above National Geodetic Vertical Datue of 1929 .

REMARKS.--Records good. The flow is regulated by Elkhart Hydroelectric Plant.

DISCHARGE, CUBIC FEET PER SECOND, WATER YEAR OCTOBER 1990 TO SEPTEMBER 1991 DAILY MEAN VALUES

\begin{tabular}{|c|c|c|c|c|c|c|c|c|c|c|c|c|}
\hline DAY & $O C T$ & NOV & DEC & JAN & FEB & MAR & APR & MAY & JUN & JUL & AUG & SEP \\
\hline $\begin{array}{l}1 \\
2 \\
3 \\
4 \\
5\end{array}$ & $\begin{array}{l}2020 \\
2340 \\
2380 \\
2580 \\
2620\end{array}$ & $\begin{array}{l}3440 \\
3300 \\
3330 \\
3250 \\
4220\end{array}$ & $\begin{array}{l}7100 \\
6700 \\
6660 \\
6680 \\
6320\end{array}$ & $\begin{array}{l}11000 \\
11600 \\
11400 \\
10400 \\
10000\end{array}$ & $\begin{array}{l}4440 \\
4740 \\
4630 \\
4710 \\
4780\end{array}$ & $\begin{array}{l}4600 \\
5020 \\
5450 \\
5630 \\
5490\end{array}$ & $\begin{array}{l}4810 \\
4570 \\
4420 \\
4380 \\
4410\end{array}$ & $\begin{array}{l}6460 \\
6090 \\
5910 \\
5610 \\
5310\end{array}$ & $\begin{array}{l}6170 \\
6400 \\
6100 \\
5640 \\
5070\end{array}$ & $\begin{array}{l}2050 \\
2720 \\
3070 \\
3030 \\
2920\end{array}$ & $\begin{array}{l}1400 \\
1410 \\
1460 \\
1540 \\
1520\end{array}$ & $\begin{array}{l}1550 \\
1530 \\
1630 \\
1780 \\
1760\end{array}$ \\
\hline $\begin{array}{r}6 \\
7 \\
8 \\
9 \\
10\end{array}$ & $\begin{array}{l}2680 \\
2450 \\
2530 \\
4030 \\
6080\end{array}$ & $\begin{array}{l}5550 \\
5660 \\
5730 \\
5480 \\
5250\end{array}$ & $\begin{array}{l}5850 \\
6000 \\
5760 \\
5530 \\
5390\end{array}$ & $\begin{array}{r}10000 \\
9350 \\
8560 \\
8280 \\
8040\end{array}$ & $\begin{array}{l}5030 \\
5170 \\
5260 \\
5180 \\
5290\end{array}$ & $\begin{array}{l}5550 \\
5330 \\
5440 \\
4990 \\
5020\end{array}$ & $\begin{array}{l}4170 \\
4240 \\
4250 \\
4170 \\
4270\end{array}$ & $\begin{array}{l}5180 \\
5170 \\
5120 \\
4930 \\
4840\end{array}$ & $\begin{array}{l}5050 \\
4720 \\
4510 \\
4300 \\
3960\end{array}$ & $\begin{array}{l}2900 \\
2750 \\
2640 \\
2630 \\
2490\end{array}$ & $\begin{array}{l}1550 \\
1550 \\
1840 \\
1950 \\
2140\end{array}$ & $\begin{array}{l}1720 \\
1630 \\
1550 \\
1530 \\
1610\end{array}$ \\
\hline $\begin{array}{l}11 \\
12 \\
13 \\
14 \\
15\end{array}$ & $\begin{array}{l}7810 \\
7600 \\
7160 \\
6910 \\
6600\end{array}$ & $\begin{array}{l}5360 \\
5200 \\
4650 \\
4890 \\
4380\end{array}$ & $\begin{array}{l}5540 \\
4960 \\
4790 \\
4560 \\
5130\end{array}$ & $\begin{array}{l}7630 \\
7350 \\
7050 \\
6890 \\
6640\end{array}$ & $\begin{array}{l}5040 \\
4750 \\
4660 \\
4830 \\
4760\end{array}$ & $\begin{array}{l}4840 \\
4530 \\
4410 \\
4170 \\
4140\end{array}$ & $\begin{array}{l}4230 \\
4030 \\
3980 \\
4160 \\
5240\end{array}$ & $\begin{array}{l}4750 \\
4560 \\
4140 \\
3950 \\
3740\end{array}$ & $\begin{array}{l}3780 \\
3750 \\
3620 \\
3430 \\
3240\end{array}$ & $\begin{array}{l}2290 \\
2150 \\
2090 \\
1980 \\
1780\end{array}$ & $\begin{array}{l}1990 \\
1890 \\
1810 \\
1750 \\
1690\end{array}$ & $\begin{array}{l}1580 \\
2310 \\
2440 \\
2130 \\
2010\end{array}$ \\
\hline $\begin{array}{l}16 \\
17 \\
18 \\
19 \\
20\end{array}$ & $\begin{array}{l}6430 \\
6340 \\
6180 \\
6160 \\
5650\end{array}$ & $\begin{array}{l}4340 \\
4220 \\
4070 \\
4000 \\
3820\end{array}$ & $\begin{array}{l}4850 \\
4910 \\
4690 \\
4960 \\
4530\end{array}$ & $\begin{array}{l}7110 \\
7590 \\
7320 \\
7120 \\
7120\end{array}$ & $\begin{array}{l}4210 \\
4280 \\
4500 \\
4880 \\
5290\end{array}$ & $\begin{array}{l}4130 \\
4150 \\
4430 \\
4750 \\
4430\end{array}$ & $\begin{array}{l}5820 \\
5990 \\
6030 \\
5910 \\
6260\end{array}$ & $\begin{array}{l}3670 \\
3810 \\
3910 \\
3730 \\
3530\end{array}$ & $\begin{array}{l}2950 \\
3120 \\
2990 \\
2780 \\
2640\end{array}$ & $\begin{array}{l}1790 \\
1730 \\
1660 \\
1540 \\
1500\end{array}$ & $\begin{array}{l}1600 \\
1660 \\
1620 \\
2130 \\
2310\end{array}$ & $\begin{array}{l}1910 \\
1820 \\
1800 \\
1770 \\
1730\end{array}$ \\
\hline $\begin{array}{l}21 \\
22 \\
23 \\
24 \\
25\end{array}$ & $\begin{array}{l}5410 \\
5060 \\
4830 \\
4800 \\
4480\end{array}$ & $\begin{array}{l}3720 \\
3780 \\
3650 \\
3510 \\
3630\end{array}$ & $\begin{array}{l}4770 \\
4920 \\
5240 \\
4910 \\
4060\end{array}$ & $\begin{array}{l}6950 \\
6460 \\
6280 \\
5980 \\
5690\end{array}$ & $\begin{array}{l}5460 \\
5440 \\
5340 \\
5450 \\
5270\end{array}$ & $\begin{array}{l}4360 \\
4240 \\
4190 \\
4330 \\
4350\end{array}$ & $\begin{array}{l}6380 \\
6320 \\
6670 \\
7040 \\
7150\end{array}$ & $\begin{array}{l}3440 \\
3250 \\
3150 \\
3190 \\
3470\end{array}$ & $\begin{array}{l}2430 \\
2260 \\
2100 \\
2170 \\
2240\end{array}$ & $\begin{array}{l}1520 \\
1570 \\
1820 \\
1850 \\
1780\end{array}$ & $\begin{array}{l}2370 \\
2110 \\
1950 \\
1970 \\
1850\end{array}$ & $\begin{array}{l}1730 \\
1640 \\
1680 \\
1650 \\
1520\end{array}$ \\
\hline $\begin{array}{l}26 \\
27 \\
28 \\
29 \\
30 \\
31\end{array}$ & $\begin{array}{l}4260 \\
3970 \\
3900 \\
3740 \\
3550 \\
3590\end{array}$ & $\begin{array}{r}3540 \\
3940 \\
5990 \\
6630 \\
6880 \\
\ldots-.\end{array}$ & $\begin{array}{r}4350 \\
3910 \\
4470 \\
6790 \\
11800 \\
13500\end{array}$ & $\begin{array}{l}5270 \\
4870 \\
5260 \\
5330 \\
5240 \\
4590\end{array}$ & $\begin{array}{r}4990 \\
5050 \\
4730 \\
\ldots- \\
\ldots- \\
\ldots\end{array}$ & $\begin{array}{l}4500 \\
4680 \\
4800 \\
5280 \\
5000 \\
4490\end{array}$ & $\begin{array}{c}6850 \\
6800 \\
6880 \\
6750 \\
6530 \\
\ldots\end{array}$ & $\begin{array}{l}3790 \\
3930 \\
3830 \\
3560 \\
3560 \\
4390\end{array}$ & $\begin{array}{c}2040 \\
1940 \\
1840 \\
1820 \\
1770 \\
-\ldots\end{array}$ & $\begin{array}{l}1750 \\
1650 \\
1510 \\
1600 \\
1440 \\
1540\end{array}$ & $\begin{array}{l}1800 \\
1800 \\
1780 \\
1630 \\
1610 \\
1580\end{array}$ & $\begin{array}{c}1740 \\
1600 \\
1570 \\
1550 \\
1530 \\
.--\end{array}$ \\
\hline $\begin{array}{l}\text { TOTAL } \\
\text { MEAN } \\
\text { MAX } \\
\text { MIN } \\
\text { CF SM } \\
\text { IN. }\end{array}$ & $\begin{array}{r}144140 \\
4650 \\
7810 \\
2020 \\
1.38 \\
1.59\end{array}$ & $\begin{array}{r}135410 \\
4514 \\
6880 \\
3250 \\
1.34 \\
1.49\end{array}$ & $\begin{array}{r}79630 \\
5795 \\
13500 \\
3910 \\
1.72 \\
1.98\end{array}$ & $\begin{array}{r}232370 \\
7496 \\
11600 \\
4590 \\
2.22 \\
2.57\end{array}$ & $\begin{array}{r}138160 \\
4934 \\
5460 \\
4210 \\
1.46 \\
1.53\end{array}$ & $\begin{array}{r}146720 \\
4733 \\
5630 \\
4130 \\
1.40 \\
1.62\end{array}$ & $\begin{array}{r}162710 \\
5424 \\
7150 \\
3980 \\
1.61 \\
1.80\end{array}$ & $\begin{array}{c}133970 \\
4322 \\
6460 \\
3150 \\
1.28 \\
1.48\end{array}$ & $\begin{array}{c}104830 \\
3494 \\
6400 \\
1770 \\
1.04 \\
1.16\end{array}$ & $\begin{array}{c}63740 \\
2056 \\
3070 \\
1440 \\
.61 \\
.70\end{array}$ & $\begin{array}{r}55260 \\
1783 \\
2370 \\
1400 \\
.53 \\
.61\end{array}$ & $\begin{array}{r}52000 \\
1733 \\
2440 \\
1520 \\
.51 \\
.57\end{array}$ \\
\hline STATIS & TICS OF & MONTHLY MEAN & DATA F & FOR WATER Y & YEARS 1948 & -1991 & BY WATER & YEAR (WY) & & & & \\
\hline $\begin{array}{l}\text { MEAM } \\
\text { MAX } \\
(W Y) \\
\text { MIN } \\
(W Y)\end{array}$ & $\begin{array}{r}2151 \\
5752 \\
1987 \\
791 \\
1964\end{array}$ & $\begin{array}{r}2513 \\
4878 \\
1989 \\
856 \\
1965\end{array}$ & $\begin{array}{r}3166 \\
5795 \\
1991 \\
958 \\
1964\end{array}$ & $\begin{array}{l}3483 \\
7496 \\
1991 \\
1127 \\
1964\end{array}$ & $\begin{array}{l}3851 \\
7039 \\
1968 \\
1120 \\
1963\end{array}$ & $\begin{array}{r}5164 \\
10760 \\
1982 \\
1679 \\
1964\end{array}$ & $\begin{array}{r}5281 \\
12690 \\
1950 \\
2633 \\
1958\end{array}$ & $\begin{array}{l}4133 \\
7725 \\
1956 \\
1911 \\
1958\end{array}$ & $\begin{array}{l}3201 \\
7535 \\
1989 \\
1280 \\
1988\end{array}$ & $\begin{array}{r}2366 \\
4409 \\
1968 \\
898 \\
1988\end{array}$ & $\begin{array}{r}1921 \\
4180 \\
1981 \\
737 \\
1964\end{array}$ & $\begin{array}{r}1832 \\
3855 \\
1981 \\
721 \\
1964\end{array}$ \\
\hline SUMMARY & Y STATIS & TICS & FOR & 1990 CALEM & MDAR YEAR & & OR $1991 \mathrm{WA}$ & ATER YEAR & & WATER YEARS & IRS $1948=$ & -1991 \\
\hline $\begin{array}{l}\text { AMNUAL } \\
\text { ANNUAL } \\
\text { HI GHEST } \\
\text { LOWEST } \\
\text { HI GHEST } \\
\text { LOWE ST } \\
\text { ANNUAL } \\
\text { INSTANT } \\
\text { INSTANT } \\
\text { ANNUAL } \\
\text { ANNUAL } \\
10 \text { PERC } \\
50 \text { PERC } \\
90 \text { PERC }\end{array}$ & $\begin{array}{l}\text { TOTAL } \\
\text { MEAN } \\
\text { T ANMUAL } \\
\text { ANNUAL } \\
\text { T DAILY } \\
\text { DAILY M } \\
\text { SEVEN-D } \\
\text { TANEOUS } \\
\text { TANE OUS } \\
\text { RUNOFF } \\
\text { RUNOFF } \\
\text { CENT EXC } \\
\text { CENT EXC } \\
\text { CENT EXC }\end{array}$ & $\begin{array}{l}\text { MEAN } \\
\text { MEAN } \\
\text { MEAN } \\
\text { EAN } \\
\text { AY MINIMUM } \\
\text { PEAK FLOW } \\
\text { PEAK STAGE } \\
\text { (CF SM) } \\
\text { (I NCHES) } \\
\text { EEDS } \\
\text { EEDS } \\
\text { EEDS }\end{array}$ & & $\begin{array}{r}13500 \\
1630 \\
1870 \\
\\
1.30 \\
17.66 \\
6890 \\
4030 \\
2380\end{array}$ & $\begin{array}{cc}\text { Dec } & 31 \\
\text { Aug } & 11 \\
\text { Aug } & 6\end{array}$ & & $\begin{array}{r}13500 \\
1400 \\
1470 \\
14400 \\
25.60 \\
1.26 \\
17.10 \\
6690 \\
4330 \\
1660\end{array}$ & $\begin{array}{cc}\text { Dec } & 31 \\
\text { Aug } & 1 \\
\text { Ju } 1 & 30 \\
\text { Dec } & 31 \\
\text { Dec } & 31\end{array}$ & & $\begin{array}{c}3251 \\
5264 \\
1283 \\
18500 \\
336 \\
561 \\
18800 \\
27.91 \\
.96 \\
13.11 \\
5830 \\
2740 \\
1340\end{array}$ & $\begin{array}{ll} & \\
\text { Mar } 21 \\
\text { Aug } 5 \\
\text { Aug } 2 \\
\text { Feb } 27 \\
\text { Mar } 21\end{array}$ & $\begin{array}{c}1950 \\
1964 \\
1982 \\
1964 \\
1964 \\
1985 \\
1982\end{array}$ \\
\hline
\end{tabular}




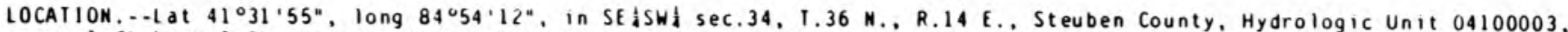
on left bank $6 \mathrm{ft}$ upstream fron bridge on County Road 75 South, 0.5 a downstrea from Hanilton Lake out let, and 0.5 i southeast of Hzanilton.

DRAI NAGE AREA. $\cdots 37.5$ i

PERIOD OF RECORD,--0ctober 1969 to current yedr

GAGE. - Water-stage recorder. Datum of gage is $876.00 \mathrm{ft}$ above National Geodetic Vertical Datun of 1929 .

REMARKS. - Records good.

DISCHARGE, CUBIC FEE T PER SECONO, WAIER YEAR OCTOBER 1990 TO SEPIEMBER 1991 DAIIY MEAM VALUES

\begin{tabular}{|c|c|c|c|c|c|c|c|c|c|c|c|c|}
\hline DAY & $O C \mathrm{~T}$ & NOV & DEC & JAN & FEB & MAR & $A P R$ & MAY & JUN & JUL & AUG & SEP \\
\hline $\begin{array}{l}1 \\
2 \\
3 \\
4 \\
5\end{array}$ & $\begin{array}{l}6.3 \\
5.4 \\
6.0 \\
50 \\
37\end{array}$ & $\begin{array}{r}14 \\
14 \\
14 \\
16 \\
100\end{array}$ & $\begin{array}{r}34 \\
29 \\
69 \\
111 \\
77\end{array}$ & $\begin{array}{r}310 \\
206 \\
151 \\
112 \\
90\end{array}$ & $\begin{array}{l}20 \\
21 \\
27 \\
37 \\
49\end{array}$ & $\begin{array}{r}35 \\
92 \\
118 \\
82 \\
65\end{array}$ & $\begin{array}{l}30 \\
26 \\
23 \\
25 \\
45\end{array}$ & $\begin{array}{l}47 \\
41 \\
33 \\
29 \\
34\end{array}$ & $\begin{array}{r}118 \\
100 \\
93 \\
63 \\
45\end{array}$ & $\begin{array}{l}15 \\
59 \\
35 \\
25 \\
18\end{array}$ & $\begin{array}{l}2.7 \\
2.6 \\
5.4 \\
4.1 \\
3.1\end{array}$ & $\begin{array}{l}3.2 \\
2.5 \\
3.2 \\
4.3 \\
3.3\end{array}$ \\
\hline $\begin{array}{r}6 \\
7 \\
8 \\
9 \\
10\end{array}$ & $\begin{array}{r}25 \\
21 \\
23 \\
131 \\
348\end{array}$ & $\begin{array}{r}180 \\
117 \\
80 \\
63 \\
53\end{array}$ & $\begin{array}{l}62 \\
51 \\
44 \\
39 \\
36\end{array}$ & $\begin{array}{l}75 \\
64 \\
54 \\
49 \\
45\end{array}$ & $\begin{array}{l}49 \\
43 \\
41 \\
40 \\
37\end{array}$ & $\begin{array}{l}60 \\
53 \\
43 \\
39 \\
36\end{array}$ & $\begin{array}{l}40 \\
35 \\
35 \\
43 \\
46\end{array}$ & $\begin{array}{l}45 \\
37 \\
31 \\
31 \\
28\end{array}$ & $\begin{array}{l}34 \\
28 \\
23 \\
20 \\
17\end{array}$ & $\begin{array}{r}13 \\
11 \\
8.9 \\
6.1 \\
5.3\end{array}$ & $\begin{array}{l}2.8 \\
2.6 \\
4.7 \\
5.1 \\
3.8\end{array}$ & $\begin{array}{l}2.9 \\
2.9 \\
2.9 \\
5.2 \\
4.8\end{array}$ \\
\hline $\begin{array}{l}11 \\
12 \\
13 \\
14 \\
15\end{array}$ & $\begin{array}{r}325 \\
197 \\
130 \\
92 \\
72\end{array}$ & $\begin{array}{l}41 \\
34 \\
28 \\
27 \\
25\end{array}$ & $\begin{array}{l}32 \\
31 \\
30 \\
24 \\
36\end{array}$ & $\begin{array}{l}52 \\
63 \\
53 \\
48 \\
53\end{array}$ & $\begin{array}{l}33 \\
29 \\
30 \\
38 \\
33\end{array}$ & $\begin{array}{l}32 \\
29 \\
26 \\
24 \\
23\end{array}$ & $\begin{array}{r}37 \\
30 \\
29 \\
46 \\
107\end{array}$ & $\begin{array}{l}26 \\
24 \\
23 \\
22 \\
19\end{array}$ & $\begin{array}{l}22 \\
27 \\
19 \\
15 \\
13\end{array}$ & $\begin{array}{r}4.8 \\
5.5 \\
11 \\
7.6 \\
5.2\end{array}$ & $\begin{array}{l}3.1 \\
2.8 \\
3.1 \\
3.4 \\
3.0\end{array}$ & $\begin{array}{l}3.6 \\
6.5 \\
5.7 \\
4.3 \\
4.1\end{array}$ \\
\hline $\begin{array}{l}16 \\
17 \\
18 \\
19 \\
20\end{array}$ & $\begin{array}{l}56 \\
46 \\
59 \\
50 \\
40\end{array}$ & $\begin{array}{l}25 \\
21 \\
19 \\
18 \\
18\end{array}$ & $\begin{array}{l}43 \\
40 \\
51 \\
54 \\
46\end{array}$ & $\begin{array}{r}99 \\
100 \\
74 \\
63 \\
63\end{array}$ & $\begin{array}{l}28 \\
26 \\
32 \\
95 \\
96\end{array}$ & $\begin{array}{l}22 \\
23 \\
35 \\
33 \\
29\end{array}$ & $\begin{array}{r}104 \\
111 \\
85 \\
109 \\
313\end{array}$ & $\begin{array}{l}18 \\
21 \\
18 \\
15 \\
13\end{array}$ & $\begin{array}{l}12 \\
10 \\
8.5 \\
7.5 \\
6.6\end{array}$ & $\begin{array}{l}4.6 \\
4.1 \\
3.7 \\
3.8 \\
3.5\end{array}$ & $\begin{array}{l}2.9 \\
3.3 \\
5.4 \\
13 \\
20\end{array}$ & $\begin{array}{l}3.6 \\
2.9 \\
2.7 \\
2.4 \\
2.2\end{array}$ \\
\hline $\begin{array}{l}21 \\
22 \\
23 \\
24 \\
25\end{array}$ & $\begin{array}{l}34 \\
30 \\
27 \\
25 \\
22\end{array}$ & $\begin{array}{l}17 \\
22 \\
22 \\
19 \\
18\end{array}$ & $\begin{array}{l}60 \\
91 \\
77 \\
62 \\
50\end{array}$ & $\begin{array}{l}62 \\
50 \\
43 \\
36 \\
31\end{array}$ & $\begin{array}{l}79 \\
72 \\
60 \\
50 \\
43\end{array}$ & $\begin{array}{l}29 \\
28 \\
34 \\
40 \\
34\end{array}$ & $\begin{array}{r}214 \\
142 \\
106 \\
120 \\
93\end{array}$ & $\begin{array}{l}12 \\
12 \\
11 \\
13 \\
17\end{array}$ & $\begin{array}{l}6.0 \\
5.5 \\
5.1 \\
4.7 \\
4.8\end{array}$ & $\begin{array}{l}3.4 \\
3.6 \\
3.2 \\
2.4 \\
2.4\end{array}$ & $\begin{array}{l}9.0 \\
6.3 \\
4.7 \\
4.1 \\
3.7\end{array}$ & $\begin{array}{l}2.2 \\
2.5 \\
2.9 \\
2.6 \\
2.9\end{array}$ \\
\hline $\begin{array}{l}26 \\
27 \\
28 \\
29 \\
30 \\
31\end{array}$ & $\begin{array}{l}18 \\
18 \\
16 \\
14 \\
14 \\
14\end{array}$ & $\begin{array}{r}16 \\
24 \\
62 \\
56 \\
42 \\
\cdots\end{array}$ & $\begin{array}{r}42 \\
36 \\
35 \\
246 \\
656 \\
535\end{array}$ & $\begin{array}{l}28 \\
26 \\
25 \\
23 \\
23 \\
22\end{array}$ & $\begin{array}{l}35 \\
31 \\
32 \\
\cdots \\
\cdots \\
\cdots\end{array}$ & $\begin{array}{l}40 \\
50 \\
47 \\
37 \\
30 \\
27\end{array}$ & $\begin{array}{l}75 \\
65 \\
66 \\
61 \\
54 \\
\cdots\end{array}$ & $\begin{array}{l}35 \\
28 \\
23 \\
19 \\
21 \\
74\end{array}$ & $\begin{array}{l}4.9 \\
4.7 \\
4.4 \\
4.2 \\
9.2 \\
\ldots . .\end{array}$ & $\begin{array}{l}2.4 \\
2.4 \\
2.4 \\
2.7 \\
3.3 \\
2.9\end{array}$ & $\begin{array}{l}3.5 \\
3.5 \\
3.4 \\
3.6 \\
3.8 \\
4.2\end{array}$ & $\begin{array}{l}3.5 \\
2.4 \\
2.5 \\
2.7 \\
2.9 \\
\cdots\end{array}$ \\
\hline $\begin{array}{l}\text { IOTAL } \\
\text { MEAN } \\
\text { MAX } \\
\text { MIN } \\
\text { CF SM } \\
\text { IN. }\end{array}$ & $\begin{array}{r}1951.7 \\
63.0 \\
348 \\
5.4 \\
1.68 \\
1.94\end{array}$ & $\begin{array}{r}1205 \\
40.2 \\
180 \\
14 \\
1.07 \\
1.20\end{array}$ & $\begin{array}{r}2829 \\
91.3 \\
656 \\
24 \\
2.43 \\
2.81\end{array}$ & $\begin{array}{r}2193 \\
70.7 \\
310 \\
22 \\
1.89 \\
2.18\end{array}$ & $\begin{array}{r}1206 \\
43.1 \\
96 \\
20 \\
1.15 \\
1.20\end{array}$ & $\begin{array}{r}1295 \\
41.8 \\
118 \\
22 \\
1.11 \\
1.28\end{array}$ & $\begin{array}{r}2315 \\
77.2 \\
313 \\
23 \\
2.06 \\
2.30\end{array}$ & $\begin{array}{r}820 \\
26.5 \\
74 \\
11 \\
.71 \\
.81\end{array}$ & $\begin{array}{c}735.1 \\
24.5 \\
118 \\
4.2 \\
.65 \\
.73\end{array}$ & $\begin{array}{r}281.2 \\
9.07 \\
59 \\
2.4 \\
.24 \\
.28\end{array}$ & $\begin{array}{c}146.7 \\
4.73 \\
20 \\
2.6 \\
.13 \\
.15\end{array}$ & $\begin{array}{r}100.3 \\
3.34 \\
6.5 \\
2.2 \\
.09 \\
.10\end{array}$ \\
\hline
\end{tabular}

STAIISIICS OF MONTHIY MEAN DATA FOR WATER YEARS 1970 - 1991, BY WATER YEAR (WY)

\begin{tabular}{|c|c|c|c|c|c|c|c|c|c|c|c|c|}
\hline $\begin{array}{l}\text { MEAN } \\
\text { MAX } \\
\text { (WY) } \\
\text { MIN } \\
\text { (WY) }\end{array}$ & $\begin{array}{l}13.9 \\
69.5 \\
1987 \\
2.70 \\
1977\end{array}$ & $\begin{array}{l}27.1 \\
87.3 \\
1986 \\
2.46 \\
1972\end{array}$ & $\begin{array}{l}39.1 \\
91.3 \\
1991 \\
7.25 \\
1977\end{array}$ & $\begin{array}{l}32.7 \\
99.2 \\
1974 \\
5.96 \\
1977\end{array}$ & $\begin{array}{r}50.7 \\
129 \\
1976 \\
7.84 \\
1979\end{array}$ & $\begin{array}{r}75.3 \\
219 \\
1982 \\
28.1 \\
1981\end{array}$ & $\begin{array}{r}61.6 \\
112 \\
1978 \\
18.7 \\
1971\end{array}$ & $\begin{array}{l}36.8 \\
88.4 \\
1990 \\
8.24 \\
1985\end{array}$ & $\begin{array}{r}29.2 \\
118 \\
1981 \\
2.05 \\
1988\end{array}$ & $\begin{array}{l}14.4 \\
63.0 \\
1973 \\
2.02 \\
1988\end{array}$ & $\begin{array}{l}11.2 \\
35.0 \\
1979 \\
1.89 \\
1970\end{array}$ & $\begin{array}{l}10.4 \\
47.1 \\
1981 \\
1.88 \\
1988\end{array}$ \\
\hline
\end{tabular}

SUMMARY SIATISTICS

ANMUAL TOTAL

ANNUAL MEAN

HIGHEST ANMUAL MEAN

LOWEST AMNUAL MEAN

HIGHEST DAILY MEAN

LOWEST DAILY MEAN

ANNUAL SEVEN-DAY MIMIMUM

INSTANTANEOUS PEAK FLOW

INSIANTANEOUS PEAK STAGE

ANMUAL RUNOFF (CFSM)

ANMUAL RUNOF F (INCHES)

10 PERCENT EXCEEDS

50 PERCENT EXCEEDS

90 PERCENT EXCEEDS
FOR 1990 CALENDAR YEAR

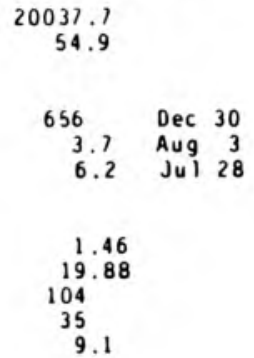

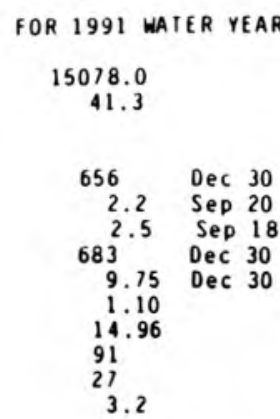

WAIER YEARS $1970-1991$

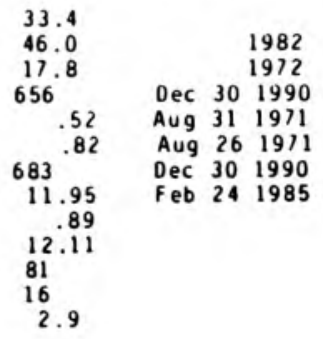


04178000 ST. JOSEPH RIVER NEAR NEWVILLE, IN

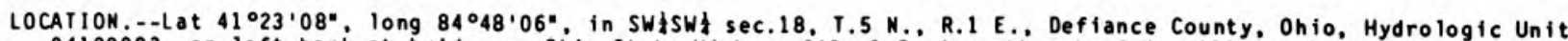
04100003 , on left bank at bridge on Ohio State Highway 249.3 .5 i northeast of Newville. 6.5 is northwest of Hicksvilie. Ohio, and at aile 42.3 .

DRAI NAGE AREA: -610 i?

PERIOD OF RECORD.--October 1946 to current year. Monthly discharge only for soee periods, published in wSP 1307. REVISED RECORDS...WSP 2112: Drainage area.

GAGE. - Water-stage recorder. Datum of gage is $795.40 \mathrm{ft}$ above National Geodetic Vertical Datua of 1929 . Prior to Oct. 22, 1947, nonrecording gage at same site and datun.

REMARKS.--Records good, except for estinated daily discharges, which are poor.

DISCHARGE, CUBIC FEET PER SECOND, WATER YEAR OCTOBER 1990 TO SEPTEMBER 1991 DAI IY MEAN VALUES

\begin{tabular}{|c|c|c|c|c|c|c|c|c|c|c|c|c|}
\hline DAY & $O C T$ & NOV & DEC & JAN & FEB & MAR & APR & MAY & JUN & JUL & AUG & SEP \\
\hline $\begin{array}{l}1 \\
2 \\
3 \\
4 \\
5\end{array}$ & $\begin{array}{r}85 \\
82 \\
81 \\
128 \\
203\end{array}$ & $\begin{array}{l}216 \\
210 \\
251 \\
359 \\
564\end{array}$ & $\begin{array}{r}580 \\
492 \\
708 \\
1360 \\
1420\end{array}$ & $\begin{array}{l}\text { e } 6800 \\
\text { e } 5820 \\
\text { e } 4730 \\
\text { e } 3710 \\
\text { e } 2870\end{array}$ & $\begin{array}{r}\text { e350 } \\
e 330 \\
\text { e360 } \\
500 \\
653\end{array}$ & $\begin{array}{r}504 \\
843 \\
1210 \\
1380 \\
1300\end{array}$ & $\begin{array}{l}585 \\
523 \\
479 \\
441 \\
663\end{array}$ & $\begin{array}{l}839 \\
745 \\
656 \\
582 \\
531\end{array}$ & $\begin{array}{r}1290 \\
1280 \\
1030 \\
718 \\
492\end{array}$ & $\begin{array}{r}88 \\
256 \\
277 \\
221 \\
162\end{array}$ & $\begin{array}{l}44 \\
44 \\
61 \\
65 \\
50\end{array}$ & $\begin{array}{l}62 \\
57 \\
55 \\
60 \\
57\end{array}$ \\
\hline $\begin{array}{r}6 \\
7 \\
8 \\
9 \\
10\end{array}$ & $\begin{array}{r}203 \\
183 \\
167 \\
349 \\
1490\end{array}$ & $\begin{array}{l}1360 \\
1570 \\
1610 \\
1460 \\
1320\end{array}$ & $\begin{array}{r}1310 \\
1120 \\
927 \\
760 \\
666\end{array}$ & $\begin{array}{r}\text { e2220 } \\
1730 \\
1330 \\
1050 \\
899\end{array}$ & $\begin{array}{r}774 \\
768 \\
702 \\
e 650 \\
e 560\end{array}$ & $\begin{array}{r}1170 \\
1050 \\
915 \\
793 \\
690\end{array}$ & $\begin{array}{l}738 \\
697 \\
637 \\
680 \\
732\end{array}$ & $\begin{array}{l}551 \\
552 \\
543 \\
497 \\
448\end{array}$ & $\begin{array}{l}369 \\
299 \\
255 \\
227 \\
205\end{array}$ & $\begin{array}{r}148 \\
115 \\
99 \\
89 \\
82\end{array}$ & $\begin{array}{l}49 \\
48 \\
49 \\
54 \\
53\end{array}$ & $\begin{array}{l}55 \\
54 \\
49 \\
47 \\
47\end{array}$ \\
\hline $\begin{array}{l}11 \\
12 \\
13 \\
14 \\
15\end{array}$ & $\begin{array}{l}2170 \\
2420 \\
2400 \\
2140 \\
1920\end{array}$ & $\begin{array}{r}1120 \\
859 \\
672 \\
551 \\
476\end{array}$ & $\begin{array}{l}630 \\
575 \\
517 \\
468 \\
515\end{array}$ & $\begin{array}{l}791 \\
810 \\
803 \\
751 \\
776\end{array}$ & $\begin{array}{l}e 470 \\
e 430 \\
e 400 \\
e 380 \\
e 360\end{array}$ & $\begin{array}{l}613 \\
552 \\
502 \\
460 \\
423\end{array}$ & $\begin{array}{r}754 \\
655 \\
539 \\
589 \\
1250\end{array}$ & $\begin{array}{l}412 \\
381 \\
357 \\
380 \\
392\end{array}$ & $\begin{array}{l}192 \\
201 \\
215 \\
213 \\
197\end{array}$ & $\begin{array}{l}75 \\
72 \\
84 \\
87 \\
79\end{array}$ & $\begin{array}{l}55 \\
58 \\
56 \\
53 \\
50\end{array}$ & $\begin{array}{l}51 \\
58 \\
64 \\
62 \\
57\end{array}$ \\
\hline $\begin{array}{l}16 \\
17 \\
18 \\
19 \\
20\end{array}$ & $\begin{array}{r}1650 \\
1080 \\
824 \\
809 \\
685\end{array}$ & $\begin{array}{l}424 \\
383 \\
350 \\
323 \\
302\end{array}$ & $\begin{array}{l}684 \\
686 \\
732 \\
910 \\
842\end{array}$ & $\begin{array}{r}1160 \\
1470 \\
1440 \\
\mathrm{e} 1270 \\
\mathrm{e} 1100\end{array}$ & $\begin{array}{l}\text { e } 340 \\
e 330 \\
e 410 \\
1010 \\
1450\end{array}$ & $\begin{array}{l}395 \\
375 \\
392 \\
440 \\
458\end{array}$ & $\begin{array}{l}1820 \\
2140 \\
2140 \\
2040 \\
2640\end{array}$ & $\begin{array}{l}331 \\
293 \\
304 \\
354 \\
284\end{array}$ & $\begin{array}{l}180 \\
165 \\
152 \\
140 \\
130\end{array}$ & $\begin{array}{l}70 \\
65 \\
61 \\
58 \\
55\end{array}$ & $\begin{array}{r}48 \\
49 \\
66 \\
244 \\
738\end{array}$ & $\begin{array}{l}53 \\
49 \\
46 \\
43 \\
41\end{array}$ \\
\hline $\begin{array}{l}21 \\
22 \\
23 \\
24 \\
25\end{array}$ & $\begin{array}{l}566 \\
478 \\
418 \\
371 \\
337\end{array}$ & $\begin{array}{l}291 \\
283 \\
282 \\
286 \\
286\end{array}$ & $\begin{array}{r}854 \\
1310 \\
1330 \\
e 1000 \\
e 860\end{array}$ & $\begin{array}{l}\text { e950 } \\
e 800 \\
e 700 \\
e 600 \\
e 540\end{array}$ & $\begin{array}{l}1520 \\
1500 \\
1440 \\
1270 \\
1040\end{array}$ & $\begin{array}{l}442 \\
380 \\
338 \\
339 \\
369\end{array}$ & $\begin{array}{l}2830 \\
2850 \\
2820 \\
2720 \\
2340\end{array}$ & $\begin{array}{l}250 \\
232 \\
218 \\
211 \\
223\end{array}$ & $\begin{array}{r}121 \\
114 \\
107 \\
102 \\
98\end{array}$ & $\begin{array}{l}54 \\
55 \\
51 \\
48 \\
47\end{array}$ & $\begin{array}{l}560 \\
373 \\
229 \\
155 \\
115\end{array}$ & $\begin{array}{l}38 \\
37 \\
37 \\
37 \\
37\end{array}$ \\
\hline $\begin{array}{l}26 \\
27 \\
28 \\
29 \\
30 \\
31\end{array}$ & $\begin{array}{l}309 \\
282 \\
261 \\
247 \\
235 \\
223\end{array}$ & $\begin{array}{l}277 \\
268 \\
461 \\
747 \\
710 \\
\ldots-\end{array}$ & $\begin{array}{l}\text { e } 730 \\
\text { e690 } \\
\text { e680 } \\
1470 \\
4170 \\
6300\end{array}$ & $\begin{array}{l}\text { e500 } \\
\text { e460 } \\
\text { e430 } \\
\text { e400 } \\
\text { e380 } \\
\text { e360 }\end{array}$ & $\begin{array}{l}815 \\
650 \\
550 \\
\cdots- \\
\cdots- \\
\cdots\end{array}$ & $\begin{array}{l}389 \\
512 \\
860 \\
844 \\
771 \\
683\end{array}$ & $\begin{array}{r}2030 \\
1710 \\
1390 \\
1130 \\
956 \\
\ldots--\end{array}$ & $\begin{array}{l}438 \\
487 \\
416 \\
354 \\
303 \\
820\end{array}$ & $\begin{array}{r}94 \\
90 \\
87 \\
83 \\
78 \\
---\end{array}$ & $\begin{array}{l}46 \\
45 \\
44 \\
44 \\
47 \\
44\end{array}$ & $\begin{array}{l}95 \\
83 \\
76 \\
69 \\
66 \\
77\end{array}$ & $\begin{array}{r}37 \\
36 \\
35 \\
34 \\
34 \\
--\end{array}$ \\
\hline $\begin{array}{l}\text { TOTAL } \\
\text { MEAN } \\
\text { MAX } \\
\text { MIN } \\
\text { CF SM } \\
\text { IN. }\end{array}$ & $\begin{array}{r}22796 \\
735 \\
2420 \\
81 \\
1.21 \\
1.39\end{array}$ & $\begin{array}{r}18271 \\
609 \\
1610 \\
210 \\
1.00 \\
1.11\end{array}$ & $\begin{array}{r}35296 \\
1139 \\
6300 \\
468 \\
1.87 \\
2.15\end{array}$ & $\begin{array}{r}47650 \\
1537 \\
6800 \\
360 \\
2.52 \\
2.91\end{array}$ & $\begin{array}{r}20012 \\
715 \\
1520 \\
330 \\
1.17 \\
1.22\end{array}$ & $\begin{array}{r}20392 \\
658 \\
1380 \\
338 \\
1.08 \\
1.24\end{array}$ & $\begin{array}{c}41518 \\
1384 \\
2850 \\
441 \\
2.27 \\
2.53\end{array}$ & $\begin{array}{r}13384 \\
432 \\
839 \\
211 \\
.71 \\
.82\end{array}$ & $\begin{array}{r}8924 \\
297 \\
1290 \\
78 \\
.49 \\
.54\end{array}$ & $\begin{array}{r}2768 \\
89.3 \\
277 \\
44 \\
.15 \\
.17\end{array}$ & $\begin{array}{c}3832 \\
124 \\
738 \\
44 \\
.20 \\
.23\end{array}$ & $\begin{array}{r}1429 \\
47.6 \\
64 \\
34 \\
.08 \\
.09\end{array}$ \\
\hline
\end{tabular}

STATISTICS OF MONTHLY MEAM DATA FOR WATER YEARS 1947 - 1991, BY WATER YEAR (WY)

\begin{tabular}{|c|c|c|c|c|c|c|c|c|c|c|c|c|}
\hline $\begin{array}{l}\text { MEAN } \\
\text { MAX } \\
\text { (WY) } \\
\text { MIN } \\
\text { (WY) }\end{array}$ & $\begin{array}{r}176 \\
1066 \\
1987 \\
21.0 \\
1964\end{array}$ & $\begin{array}{r}354 \\
1368 \\
1986 \\
30.5 \\
1965\end{array}$ & $\begin{array}{r}606 \\
2085 \\
1968 \\
31.1 \\
1964\end{array}$ & $\begin{array}{r}633 \\
2545 \\
1950 \\
38.3 \\
1963\end{array}$ & $\begin{array}{r}860 \\
2302 \\
1976 \\
41.4 \\
1963\end{array}$ & $\begin{array}{r}1240 \\
3512 \\
1982 \\
312 \\
1964\end{array}$ & $\begin{array}{r}1089 \\
3102 \\
1950 \\
321 \\
1971\end{array}$ & $\begin{array}{r}624 \\
2499 \\
1956 \\
148 \\
1988\end{array}$ & $\begin{array}{r}379 \\
1864 \\
1989 \\
51.4 \\
1988\end{array}$ & $\begin{array}{r}230 \\
1045 \\
1951 \\
32.2 \\
1988\end{array}$ & $\begin{array}{r}134 \\
563 \\
1979 \\
29.1 \\
1967\end{array}$ & $\begin{array}{r}124 \\
582 \\
1958 \\
20.3 \\
1963\end{array}$ \\
\hline
\end{tabular}

SUMMARY STAIISTICS

ANMUAL TOTAL

ANNUAL MEAN

HIGHEST ANMUAL MEAN

LOWEST AMNUAL MEAM

HIGHEST DAILY MEAN

LOWEST DAILY MEAM

ANHUAL SEVEN-DAY MIMIMUM

INSTANTANEOUS PEAK FLOW

INSTANTANEOUS PEAK STAGE

ANHUAL RUNOFF (CF SM)

ANNUAL RUNOFF (INCHES)

10 PERCENT EXCEEDS

50 PERCENT EXCEEDS

90 PERCENT EXCEEDS

e Estinated
FOR 1990 CALENDAR YEAR

FOR 1991 WATER YEAR

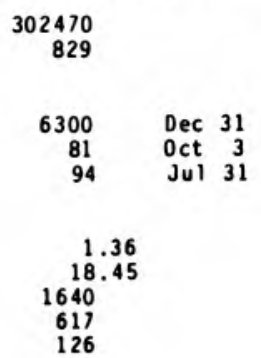

236272
647

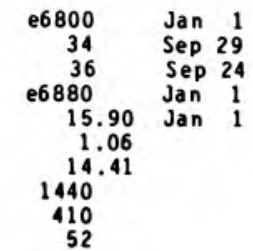

WATER YEARS 1947 - 1991

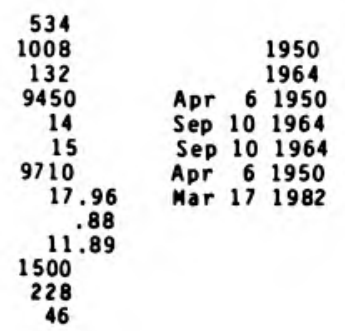




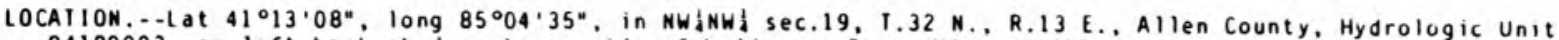

04100003 , on left bank at downstrean side of bridge on State Highway 427,3 northwest of Cedarville, 5.8 a upstrean fromouth and 10 i south of Auburn. DRAI NAGE AREA. - 270 i

PERIOD OF RECORD.-.0 Ctober 1946 to current year.

REVISED RECORDS...WSP 1912: Drainage area.

GAGE.--Water-stage recorder. Datum of gage is $780.09 \mathrm{ft}$ above National Geodetic Vertical Datua of 1929 . Prior to Nov. 4, 1947, nonrecording gage at sane site and datua.

REMARKS.--Records good except for estinated daily discharges, which are poor.

DISCHARGE, CUBIC FEET PER SECOND, WATER YEAR OCTOBER 1990 TO SEPIEMBER 1991 DAILY MEAM VALUES

\begin{tabular}{|c|c|c|c|c|c|c|c|c|c|c|c|c|}
\hline DAY & $\mathrm{OCI}$ & NOV & DEC & JAN & FE B & MAR & APR & MAY & JUN & JUL & AUG & SEP \\
\hline $\begin{array}{l}1 \\
2 \\
3 \\
4 \\
5\end{array}$ & $\begin{array}{r}68 \\
68 \\
66 \\
615 \\
574\end{array}$ & $\begin{array}{l}130 \\
126 \\
120 \\
118 \\
539\end{array}$ & $\begin{array}{r}304 \\
247 \\
701 \\
1540 \\
814\end{array}$ & $\begin{array}{r}3300 \\
1980 \\
1410 \\
1030 \\
809\end{array}$ & $\begin{array}{l}204 \\
164 \\
205 \\
367 \\
487\end{array}$ & $\begin{array}{l}231 \\
614 \\
853 \\
536 \\
389\end{array}$ & $\begin{array}{l}215 \\
200 \\
188 \\
183 \\
367\end{array}$ & $\begin{array}{l}325 \\
290 \\
259 \\
231 \\
229\end{array}$ & $\begin{array}{r}2770 \\
1820 \\
1040 \\
668 \\
451\end{array}$ & $\begin{array}{r}69 \\
158 \\
166 \\
132 \\
101\end{array}$ & $\begin{array}{l}37 \\
35 \\
78 \\
58 \\
44\end{array}$ & $\begin{array}{l}44 \\
35 \\
33 \\
38 \\
33\end{array}$ \\
\hline $\begin{array}{r}6 \\
7 \\
8 \\
9 \\
10\end{array}$ & $\begin{array}{r}283 \\
190 \\
180 \\
1120 \\
2550\end{array}$ & $\begin{array}{r}1990 \\
1250 \\
740 \\
500 \\
385\end{array}$ & $\begin{array}{l}507 \\
392 \\
322 \\
279 \\
258\end{array}$ & $\begin{array}{l}646 \\
534 \\
458 \\
406 \\
j 53\end{array}$ & $\begin{array}{l}484 \\
410 \\
345 \\
327 \\
306\end{array}$ & $\begin{array}{l}339 \\
307 \\
256 \\
238 \\
223\end{array}$ & $\begin{array}{l}333 \\
268 \\
266 \\
522 \\
433\end{array}$ & $\begin{array}{l}297 \\
255 \\
216 \\
198 \\
188\end{array}$ & $\begin{array}{l}341 \\
271 \\
222 \\
189 \\
166\end{array}$ & $\begin{array}{l}86 \\
73 \\
67 \\
61 \\
58\end{array}$ & $\begin{array}{l}40 \\
38 \\
50 \\
86 \\
49\end{array}$ & $\begin{array}{l}30 \\
29 \\
27 \\
25 \\
34\end{array}$ \\
\hline $\begin{array}{l}11 \\
12 \\
13 \\
14 \\
15\end{array}$ & $\begin{array}{r}3120 \\
2000 \\
1220 \\
813 \\
576\end{array}$ & $\begin{array}{l}314 \\
267 \\
233 \\
211 \\
196\end{array}$ & $\begin{array}{l}238 \\
223 \\
208 \\
188 \\
388\end{array}$ & $\begin{array}{l}351 \\
555 \\
427 \\
364 \\
462\end{array}$ & $\begin{array}{l}269 \\
228 \\
218 \\
234 \\
204\end{array}$ & $\begin{array}{l}201 \\
196 \\
190 \\
190 \\
218\end{array}$ & $\begin{array}{l}353 \\
276 \\
244 \\
338 \\
786\end{array}$ & $\begin{array}{l}174 \\
168 \\
166 \\
161 \\
154\end{array}$ & $\begin{array}{r}163 \\
204 \\
e 163 \\
141 \\
130\end{array}$ & $\begin{array}{l}57 \\
54 \\
77 \\
56 \\
51\end{array}$ & $\begin{array}{l}41 \\
39 \\
36 \\
35 \\
38\end{array}$ & $\begin{array}{r}33 \\
75 \\
107 \\
63 \\
48\end{array}$ \\
\hline $\begin{array}{l}16 \\
17 \\
18 \\
19 \\
20\end{array}$ & $\begin{array}{l}438 \\
354 \\
600 \\
522 \\
363\end{array}$ & $\begin{array}{l}186 \\
175 \\
164 \\
157 \\
151\end{array}$ & $\begin{array}{l}610 \\
418 \\
515 \\
628 \\
421\end{array}$ & $\begin{array}{r}1030 \\
1100 \\
628 \\
460 \\
453\end{array}$ & $\begin{array}{r}111 \\
192 \\
201 \\
823 \\
1030\end{array}$ & $\begin{array}{l}238 \\
232 \\
507 \\
412 \\
310\end{array}$ & $\begin{array}{r}844 \\
1410 \\
1270 \\
840 \\
2340\end{array}$ & $\begin{array}{l}145 \\
155 \\
153 \\
140 \\
131\end{array}$ & $\begin{array}{r}129 \\
117 \\
109 \\
101 \\
97\end{array}$ & $\begin{array}{l}49 \\
48 \\
46 \\
44 \\
43\end{array}$ & $\begin{array}{l}36 \\
35 \\
40 \\
59 \\
75\end{array}$ & $\begin{array}{l}43 \\
41 \\
40 \\
38 \\
38\end{array}$ \\
\hline $\begin{array}{l}21 \\
22 \\
23 \\
24 \\
25\end{array}$ & $\begin{array}{l}298 \\
255 \\
221 \\
205 \\
182\end{array}$ & $\begin{array}{l}149 \\
164 \\
158 \\
153 \\
144\end{array}$ & $\begin{array}{r}535 \\
1330 \\
805 \\
561 \\
e 500\end{array}$ & $\begin{array}{l}\text { e } 410 \\
\text { e340 } \\
\text { e } 290 \\
\text { e260 } \\
\text { e2 } 40\end{array}$ & $\begin{array}{l}655 \\
537 \\
413 \\
333 \\
287\end{array}$ & $\begin{array}{l}267 \\
241 \\
242 \\
267 \\
261\end{array}$ & $\begin{array}{r}1160 \\
997 \\
688 \\
1300 \\
893\end{array}$ & $\begin{array}{l}126 \\
120 \\
117 \\
120 \\
145\end{array}$ & $\begin{array}{l}91 \\
85 \\
83 \\
77 \\
76\end{array}$ & $\begin{array}{l}41 \\
49 \\
45 \\
41 \\
40\end{array}$ & $\begin{array}{l}51 \\
41 \\
38 \\
36 \\
33\end{array}$ & $\begin{array}{l}38 \\
37 \\
38 \\
39 \\
39\end{array}$ \\
\hline $\begin{array}{l}26 \\
27 \\
28 \\
29 \\
30 \\
31\end{array}$ & $\begin{array}{l}167 \\
157 \\
148 \\
139 \\
137 \\
134\end{array}$ & $\begin{array}{l}138 \\
152 \\
693 \\
738 \\
404 \\
\cdots\end{array}$ & $\begin{array}{l}\text { e470 } \\
e 430 \\
e 420 \\
1450 \\
4840 \\
5220\end{array}$ & $\begin{array}{l}\text { e220 } \\
\text { e2 } 05 \\
\text { e1 } 90 \\
\text { e1 } 80 \\
\text { e1 } 70 \\
\text { el } 65\end{array}$ & $\begin{array}{l}247 \\
222 \\
208 \\
\ldots- \\
\ldots- \\
\cdots\end{array}$ & $\begin{array}{l}286 \\
391 \\
469 \\
328 \\
260 \\
222\end{array}$ & $\begin{array}{l}578 \\
449 \\
552 \\
466 \\
387 \\
\cdots-\end{array}$ & $\begin{array}{r}463 \\
286 \\
195 \\
156 \\
204 \\
1960\end{array}$ & $\begin{array}{l}73 \\
70 \\
66 \\
63 \\
60 \\
\cdots\end{array}$ & $\begin{array}{l}38 \\
37 \\
35 \\
34 \\
62 \\
41\end{array}$ & $\begin{array}{l}31 \\
32 \\
31 \\
34 \\
34 \\
62\end{array}$ & $\begin{array}{l}39 \\
38 \\
37 \\
36 \\
34 \\
\cdots\end{array}$ \\
\hline $\begin{array}{l}\text { IOIAL } \\
\text { MEAN } \\
\text { MAX } \\
\text { MI M } \\
\text { CF SM } \\
\text { IN. }\end{array}$ & $\begin{array}{r}17769 \\
573 \\
3120 \\
66 \\
2.12 \\
2.45\end{array}$ & $\begin{array}{r}10845 \\
361 \\
1990 \\
118 \\
1.34 \\
1.49\end{array}$ & $\begin{array}{r}25762 \\
831 \\
5220 \\
188 \\
3.08 \\
3.55\end{array}$ & $\begin{array}{r}19426 \\
627 \\
3300 \\
165 \\
2.32 \\
2.68\end{array}$ & $\begin{array}{r}9717 \\
349 \\
1030 \\
164 \\
1.29 \\
1.35\end{array}$ & $\begin{array}{c}9920 \\
320 \\
853 \\
190 \\
1.19 \\
1.37\end{array}$ & $\begin{array}{r}19746 \\
658 \\
2340 \\
183 \\
2.44 \\
2.12\end{array}$ & $\begin{array}{r}7927 \\
256 \\
1960 \\
117 \\
.95 \\
1.09\end{array}$ & $\begin{array}{r}10036 \\
335 \\
2770 \\
60 \\
1.24 \\
1.38\end{array}$ & $\begin{array}{c}1959 \\
63.2 \\
166 \\
34 \\
.23 \\
.27\end{array}$ & $\begin{array}{c}1372 \\
44.3 \\
86 \\
31 \\
.16 \\
.19\end{array}$ & $\begin{array}{c}1229 \\
41.0 \\
107 \\
25 \\
.15 \\
.17\end{array}$ \\
\hline
\end{tabular}

e Estinated

SIATISTICS OF MONTHIY MEAN DATA FOR WAILR YEARS 1941 - 1991, BY WATER YEAR (WY)

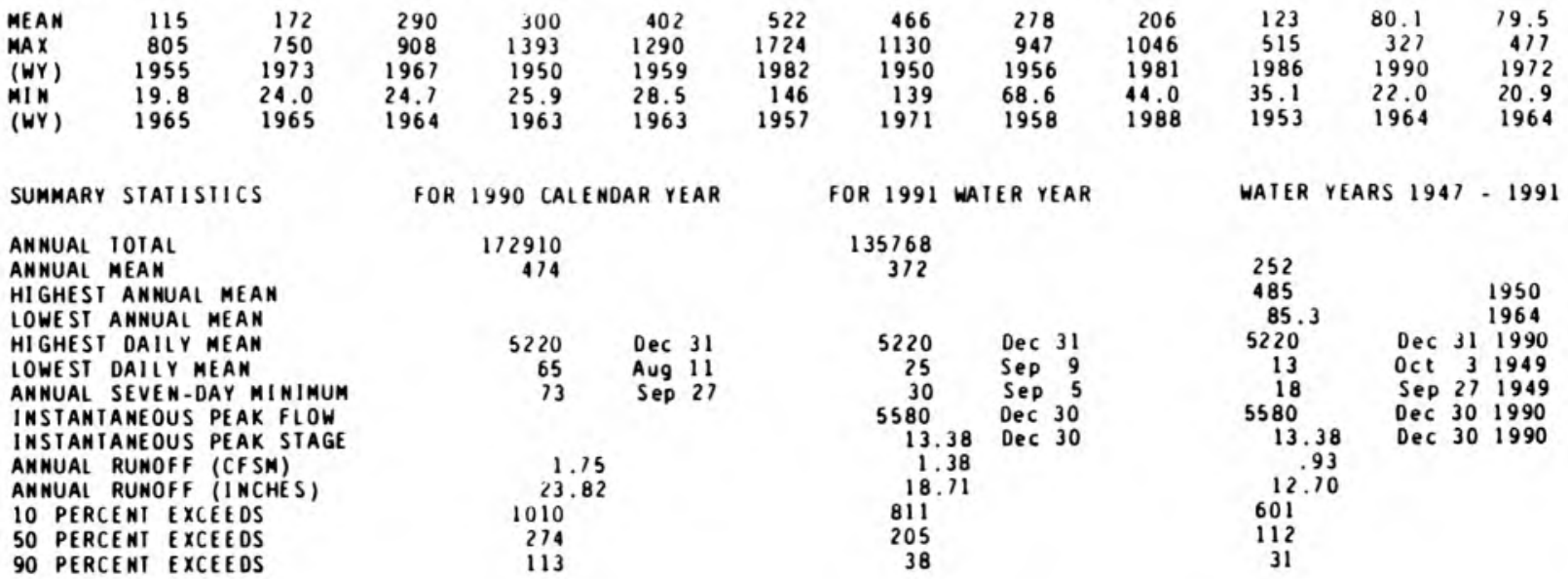




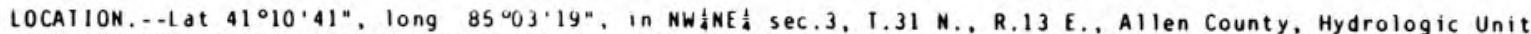
04100003 , on left bank 0.8 mi downstrean from Ely Run, 1.3 a upstream from Ely Bridge and Mayhew Road, 8.0 ei northeast of the Fort wayne Court House.

DRAINAGE AREA $\cdots 1,060$ i

PERIOD OF RECORD.--October 1983 to current year. July 1941 to September 1955 gage located 1.3 ai downstream at Ely Bridge.

GAGE - - Water-stage recorder. Datum of gage is $750.00 \mathrm{ft}$ above National Geodetic Vertical Datum of 1929 (levels by State of Indiana).

REMARKS. - Records good except for estimated daily discharges, which are poor. Flow regulated by Cedarville Reservoir and sone flow diverted into storage of Hurshtown Reservoir. Instantaneous peak flow for period of record of $13,200 \mathrm{ft}^{3} / \mathrm{s}$ al so occurred $\mathrm{feb}$. 26, 1985 .

DISCHARGE, CUBIC FEET PER SECOND, WATER YEAR OCTOBER 1990 TO SEPIEMBER 1991 DAILY MEAN VALUES

\begin{tabular}{|c|c|c|c|c|c|c|c|c|c|c|c|c|}
\hline DAY & $O C T$ & NOV & $\mathrm{DEC}$ & JAN & FEB & MAR & APR & MAY & JUN & JUL & AUG & SEP \\
\hline $\begin{array}{l}1 \\
2 \\
3 \\
4 \\
5\end{array}$ & $\begin{array}{l}600 \\
102 \\
162 \\
559 \\
869\end{array}$ & $\begin{array}{r}397 \\
381 \\
350 \\
409 \\
1010\end{array}$ & $\begin{array}{r}1230 \\
863 \\
1690 \\
3620 \\
2500\end{array}$ & $\begin{array}{r}12100 \\
9950 \\
8160 \\
6490 \\
5100\end{array}$ & $\begin{array}{r}e 810 \\
647 \\
668 \\
1040 \\
1470\end{array}$ & $\begin{array}{r}950 \\
1630 \\
2360 \\
1960 \\
1920\end{array}$ & $\begin{array}{r}993 \\
847 \\
783 \\
781 \\
1330\end{array}$ & $\begin{array}{r}1460 \\
1280 \\
1130 \\
1040 \\
929\end{array}$ & $\begin{array}{l}4930 \\
3540 \\
2350 \\
1590 \\
1260\end{array}$ & $\begin{array}{l}191 \\
399 \\
474 \\
491 \\
392\end{array}$ & $\begin{array}{l}105 \\
102 \\
141 \\
168 \\
176\end{array}$ & $\begin{array}{l}150 \\
134 \\
113 \\
119 \\
127\end{array}$ \\
\hline $\begin{array}{r}6 \\
7 \\
8 \\
9 \\
10\end{array}$ & $\begin{array}{r}615 \\
415 \\
640 \\
1130 \\
5210\end{array}$ & $\begin{array}{l}3440 \\
2940 \\
2380 \\
2180 \\
1970\end{array}$ & $\begin{array}{l}2150 \\
1850 \\
1520 \\
1480 \\
1150\end{array}$ & $\begin{array}{l}3940 \\
2910 \\
2270 \\
1870 \\
1550\end{array}$ & $\begin{array}{l}1600 \\
1560 \\
1410 \\
1290 \\
1220\end{array}$ & $\begin{array}{l}1710 \\
1560 \\
1370 \\
1230 \\
1140\end{array}$ & $\begin{array}{l}1530 \\
1120 \\
1040 \\
1510 \\
1340\end{array}$ & $\begin{array}{r}1080 \\
946 \\
946 \\
871 \\
822\end{array}$ & $\begin{array}{l}925 \\
807 \\
648 \\
531 \\
434\end{array}$ & $\begin{array}{r}255 \\
221 \\
215 \\
\text { e199 } \\
179\end{array}$ & $\begin{array}{l}150 \\
118 \\
128 \\
195 \\
158\end{array}$ & $\begin{array}{l}126 \\
128 \\
127 \\
121 \\
121\end{array}$ \\
\hline $\begin{array}{l}11 \\
12 \\
13 \\
14 \\
15\end{array}$ & $\begin{array}{l}6200 \\
4960 \\
3850 \\
3420 \\
2770\end{array}$ & $\begin{array}{r}1700 \\
1340 \\
1040 \\
774 \\
883\end{array}$ & $\begin{array}{r}977 \\
1060 \\
932 \\
824 \\
1110\end{array}$ & $\begin{array}{l}1470 \\
1670 \\
1580 \\
1380 \\
1580\end{array}$ & $\begin{array}{l}1110 \\
e 900 \\
\text { e } 820 \\
\text { e } 740 \\
\text { e670 }\end{array}$ & $\begin{array}{l}938 \\
878 \\
868 \\
753 \\
747\end{array}$ & $\begin{array}{l}1320 \\
1160 \\
1010 \\
1040 \\
2610\end{array}$ & $\begin{array}{l}648 \\
662 \\
654 \\
584 \\
565\end{array}$ & $\begin{array}{l}508 \\
463 \\
397 \\
418 \\
390\end{array}$ & $\begin{array}{l}160 \\
164 \\
190 \\
186 \\
181\end{array}$ & $\begin{array}{ll}1 & 31 \\
1 & 21 \\
1 & 21 \\
1 & 25 \\
1 & 22\end{array}$ & $\begin{array}{l}122 \\
201 \\
279 \\
153 \\
104\end{array}$ \\
\hline $\begin{array}{l}16 \\
17 \\
18 \\
19 \\
20\end{array}$ & $\begin{array}{l}2440 \\
2210 \\
1870 \\
1820 \\
1390\end{array}$ & $\begin{array}{l}777 \\
697 \\
578 \\
561 \\
495\end{array}$ & $\begin{array}{l}1670 \\
1460 \\
1550 \\
1940 \\
1630\end{array}$ & $\begin{array}{l}2610 \\
3220 \\
2410 \\
2160 \\
2000\end{array}$ & $\begin{array}{r}e 620 \\
e 590 \\
696 \\
2050 \\
\text { e } 3130\end{array}$ & $\begin{array}{r}858 \\
738 \\
1170 \\
1180 \\
904\end{array}$ & $\begin{array}{r}3120 \\
\mathrm{e} 4100 \\
4340 \\
3620 \\
6490\end{array}$ & $\begin{array}{l}631 \\
525 \\
472 \\
422 \\
561\end{array}$ & $\begin{array}{l}418 \\
360 \\
298 \\
297 \\
274\end{array}$ & $\begin{array}{l}168 \\
164 \\
156 \\
134 \\
125\end{array}$ & $\begin{array}{l}127 \\
130 \\
135 \\
172 \\
451\end{array}$ & $\begin{array}{l}101 \\
108 \\
114 \\
113 \\
108\end{array}$ \\
\hline $\begin{array}{l}21 \\
22 \\
23 \\
24 \\
25\end{array}$ & $\begin{array}{r}1290 \\
945 \\
777 \\
857 \\
701\end{array}$ & $\begin{array}{l}450 \\
535 \\
535 \\
425 \\
416\end{array}$ & $\begin{array}{l}1720 \\
3470 \\
2380 \\
1970 \\
1740\end{array}$ & $\begin{array}{r}2030 \\
\text { e1 } 1500 \\
\text { e } 1270 \\
\text { e } 1080 \\
\text { e } 970\end{array}$ & $\begin{array}{l}2430 \\
2390 \\
2140 \\
1970 \\
1680\end{array}$ & $\begin{array}{l}927 \\
826 \\
731 \\
739 \\
718\end{array}$ & $\begin{array}{l}5980 \\
4540 \\
4240 \\
5120 \\
4610\end{array}$ & $\begin{array}{l}440 \\
319 \\
327 \\
419 \\
354\end{array}$ & $\begin{array}{l}259 \\
255 \\
241 \\
217 \\
212\end{array}$ & $\begin{array}{l}139 \\
170 \\
155 \\
135 \\
129\end{array}$ & $\begin{array}{r}1050 \\
543 \\
379 \\
291 \\
236\end{array}$ & $\begin{array}{r}103 \\
100 \\
102 \\
95 \\
101\end{array}$ \\
\hline $\begin{array}{l}26 \\
27 \\
28 \\
29 \\
30 \\
31\end{array}$ & $\begin{array}{l}483 \\
672 \\
568 \\
343 \\
427 \\
408\end{array}$ & $\begin{array}{r}547 \\
467 \\
1060 \\
1760 \\
1460 \\
\cdots\end{array}$ & $\begin{array}{r}\text { el } 620 \\
\text { el } 580 \\
\text { el } 1490 \\
4260 \\
11000 \\
12600\end{array}$ & $\begin{array}{l}\text { e } 880 \\
\text { e } 840 \\
\text { e7 } 80 \\
\text { e7 } 40 \\
\text { e7 } 20 \\
\text { e7 } 00\end{array}$ & $\begin{array}{r}1380 \\
1160 \\
999 \\
\ldots \\
\cdots \\
\cdots\end{array}$ & $\begin{array}{r}801 \\
1070 \\
1350 \\
e 1480 \\
1250 \\
1050\end{array}$ & $\begin{array}{c}3300 \\
2690 \\
2240 \\
1900 \\
1610 \\
\ldots\end{array}$ & $\begin{array}{r}1130 \\
1100 \\
798 \\
640 \\
679 \\
5100\end{array}$ & $\begin{array}{l}210 \\
211 \\
206 \\
197 \\
185 \\
\cdots\end{array}$ & $\begin{array}{l}129 \\
114 \\
100 \\
103 \\
125 \\
102\end{array}$ & $\begin{array}{r}189 \\
135 \\
e 150 \\
177 \\
188 \\
175\end{array}$ & $\begin{array}{l}88 \\
99 \\
98 \\
94 \\
91 \\
-\cdots\end{array}$ \\
\hline $\begin{array}{l}\text { IOIAL } \\
\text { MEAN } \\
\text { MAX } \\
\text { MIN } \\
\text { CF SM } \\
\text { IN. }\end{array}$ & $\begin{array}{r}48703 \\
1571 \\
6200 \\
102 \\
1.48 \\
1.71\end{array}$ & $\begin{array}{r}31957 \\
1065 \\
3440 \\
350 \\
1.00 \\
1.12\end{array}$ & $\begin{array}{r}75036 \\
2421 \\
12600 \\
824 \\
2.28 \\
2.63\end{array}$ & $\begin{array}{r}85930 \\
2772 \\
12100 \\
700 \\
2.62 \\
3.02\end{array}$ & $\begin{array}{r}37190 \\
1328 \\
3130 \\
590 \\
1.25 \\
1.31\end{array}$ & $\begin{array}{r}35806 \\
1155 \\
2360 \\
718 \\
1.09 \\
1.26\end{array}$ & $\begin{array}{c}76314 \\
2544 \\
6490 \\
781 \\
2.40 \\
2.68\end{array}$ & $\begin{array}{r}27534 \\
888 \\
5100 \\
319 \\
.84 \\
.97\end{array}$ & $\begin{array}{r}23031 \\
768 \\
4930 \\
185 \\
.72 \\
.81\end{array}$ & $\begin{array}{l}6045 \\
195 \\
491 \\
100 \\
.18 \\
.21\end{array}$ & $\begin{array}{c}6589 \\
213 \\
1050 \\
102 \\
.20 \\
.23\end{array}$ & $\begin{array}{c}3640 \\
121 \\
219 \\
88 \\
.11 \\
.13\end{array}$ \\
\hline
\end{tabular}

e Estinated

SIAIISIICS OF MONTHIY MEAN DATA FOR WAIER YEARS 1984 - 1991, BY WAIER YEAR (WY)

$\begin{array}{lrrrrrrrrrrrr}\text { MEAN } & 719 & 1120 & 1529 & 1302 & 1825 & 2024 & 1774 & 926 & 942 & 452 & 297 & 320 \\ \text { MAX } & 1984 & 2404 & 2421 & 2713 & 3315 & 3612 & 2843 & 2270 & 2915 & 1413 & 748 & 701 \\ \text { (WY) } & 1987 & 1986 & 1991 & 1991 & 1990 & 1985 & 1985 & 1990 & 1989 & 1986 & 1990 & 1989 \\ \text { MIN } & 144 & 447 & 167 & 305 & 605 & 980 & 607 & 272 & 153 & 122 & 125 & 121 \\ \text { (WY) } & 1988 & 1988 & 1990 & 1984 & 1989 & 1989 & 1986 & 1988 & 1988 & 1988 & 1988 & 1991\end{array}$

SUMMARY SIATISIICS

ANHUAL TOTAL

ANHUAL MEAM

HIGHEST ANMUAL MEAN

LOWEST ANNUAL MEAN

HIGHEST DAILY MEAN

LOWEST DAILY MEAN

ANNUAL SEVEN-DAY MINIMUM

INSTANTANEOUS PEAK FLOW

INSIANIANEOUS PEAK STAGE

ANNUAL RUNOFF (CFSM)

ANNUAL RUNOFF (INCHES)

10 PERCENT EXCEE OS

50 PERCENT EXCEEDS

90 PERCENT EXCEEDS
FOR 1990 CALENOAR YEAR

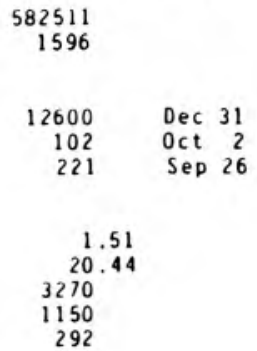

FOR 1991 WATER YEAR

457775

1254

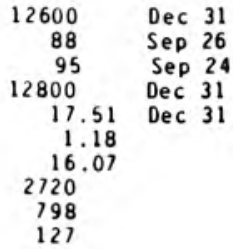

WATER YEARS 1984 - 1991

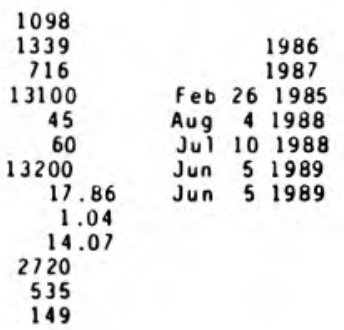




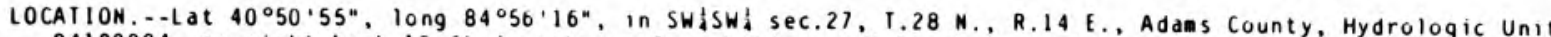
04100004 , on right bank $10 \mathrm{ft}$ downstrean from bridge on U.S. Highway $27,0.5$ upstrea from Holthouse ditch. 1.3 i north of Deçztur, and at i ile 29.1 .

DRAI NAGE AREA. $\cdots 621 \cdot i^{2}$

PERIOD OF RECORD.--0ctober 1946 to current year. Monthly discharge only for sone periods, published in wSP 1301. Gage-height records collected at site $0.5 \mathrm{mi}$ upstrea January 1932 to Novenber 1954 , and at present site thereafter are contained in reports of National Weather Service.

REVISED RECORDS.--WSP 1174: 1948. WSP 1337: 1947. WSP 1627: 1950. WSP 1912: 1955, drainage area.

GAGE. - Water-stage recorder. Datun of gage is $760.44 \mathrm{ft}$ above National Geodetic Vertical Datua of 1929 . Prior to REMARKS. - Records good except for estiated daily discharges, which are poor. Flow regulated by Grand Lake. SIight
diversion from or into Wabash River basin and into Miai and Erie Cands.

DISCHARGE, CUBIC FEET PER SECOND, WATER YEAR OCTOBER 1990 TO SEPIEMBER 1991 DAIIY MEAN VALUES

\begin{tabular}{|c|c|c|c|c|c|c|c|c|c|c|c|c|}
\hline DAY & $\mathrm{OCT}$ & NOV & DEC & JAN & FEB & MAR & APR & MAY & JUN & JUL & AUG & SEP \\
\hline $\begin{array}{l}1 \\
2 \\
3 \\
4 \\
5\end{array}$ & $\begin{array}{r}68 \\
61 \\
57 \\
430 \\
937\end{array}$ & $\begin{array}{l}147 \\
132 \\
123 \\
114 \\
191\end{array}$ & $\begin{array}{r}662 \\
600 \\
1570 \\
3160 \\
2350\end{array}$ & $\begin{array}{r}9440 \\
8430 \\
\text { e } 7600 \\
\text { e } 5800 \\
\text { e } 3900\end{array}$ & $\begin{array}{r}\text { e250 } \\
\text { e230 } \\
\text { e } 300 \\
\text { e } 690 \\
\text { e1500 }\end{array}$ & $\begin{array}{l}277 \\
299 \\
293 \\
252 \\
236\end{array}$ & $\begin{array}{l}560 \\
389 \\
287 \\
245 \\
274\end{array}$ & $\begin{array}{l}267 \\
237 \\
195 \\
164 \\
155\end{array}$ & $\begin{array}{r}2100 \\
1620 \\
2900 \\
1750 \\
808\end{array}$ & $\begin{array}{r}35 \\
44 \\
182 \\
202 \\
254\end{array}$ & $\begin{array}{l}23 \\
22 \\
26 \\
24 \\
23\end{array}$ & $\begin{array}{r}27 \\
27 \\
38 \\
58 \\
120\end{array}$ \\
\hline $\begin{array}{r}6 \\
7 \\
8 \\
9 \\
10\end{array}$ & $\begin{array}{r}494 \\
391 \\
453 \\
673 \\
2520\end{array}$ & $\begin{array}{l}642 \\
391 \\
292 \\
267 \\
250\end{array}$ & $\begin{array}{r}1510 \\
1510 \\
1420 \\
1040 \\
665\end{array}$ & $\begin{array}{r}\text { e } 1700 \\
\text { e } 860 \\
\text { e540 } \\
\text { e410 } \\
\text { e3 } 30\end{array}$ & $\begin{array}{l}\text { e } 1800 \\
\text { el } 900 \\
\text { e2 } 000 \\
\text { e1 } 700 \\
\text { e1 } 500\end{array}$ & $\begin{array}{l}218 \\
202 \\
165 \\
147 \\
143\end{array}$ & $\begin{array}{l}259 \\
230 \\
245 \\
432 \\
350\end{array}$ & $\begin{array}{l}155 \\
142 \\
131 \\
142 \\
137\end{array}$ & $\begin{array}{l}583 \\
406 \\
260 \\
168 \\
125\end{array}$ & $\begin{array}{r}231 \\
229 \\
165 \\
85 \\
62\end{array}$ & $\begin{array}{l}22 \\
22 \\
40 \\
48 \\
51\end{array}$ & $\begin{array}{r}108 \\
105 \\
70 \\
47 \\
35\end{array}$ \\
\hline $\begin{array}{l}11 \\
12 \\
13 \\
14 \\
15\end{array}$ & $\begin{array}{l}3020 \\
2150 \\
1540 \\
1480 \\
1290\end{array}$ & $\begin{array}{l}221 \\
181 \\
162 \\
159 \\
153\end{array}$ & $\begin{array}{l}462 \\
361 \\
298 \\
247 \\
650\end{array}$ & $\begin{array}{r}e 300 \\
e 520 \\
e 680 \\
e 630 \\
e 1020\end{array}$ & $\begin{array}{r}\text { e } 1200 \\
\text { e } 900 \\
\text { e } 580 \\
\text { e } 430 \\
\text { e } 330\end{array}$ & $\begin{array}{l}134 \\
124 \\
123 \\
121 \\
179\end{array}$ & $\begin{array}{r}262 \\
212 \\
208 \\
1240 \\
1630\end{array}$ & $\begin{array}{l}121 \\
110 \\
106 \\
118 \\
125\end{array}$ & $\begin{array}{r}104 \\
102 \\
105 \\
91 \\
97\end{array}$ & $\begin{array}{l}51 \\
44 \\
41 \\
38 \\
33\end{array}$ & $\begin{array}{l}38 \\
33 \\
31 \\
30 \\
27\end{array}$ & $\begin{array}{l}28 \\
42 \\
38 \\
36 \\
33\end{array}$ \\
\hline $\begin{array}{l}16 \\
17 \\
18 \\
19 \\
20\end{array}$ & $\begin{array}{l}942 \\
601 \\
748 \\
840 \\
531\end{array}$ & $\begin{array}{l}142 \\
132 \\
119 \\
110 \\
105\end{array}$ & $\begin{array}{r}1150 \\
761 \\
1380 \\
2550 \\
2260\end{array}$ & $\begin{array}{l}\text { e } 2200 \\
\text { e } 3300 \\
\text { e } 2100 \\
\text { e } 1700 \\
\text { e } 1300\end{array}$ & $\begin{array}{r}e 260 \\
e 240 \\
e 390 \\
e 1500 \\
e 2900\end{array}$ & $\begin{array}{l}287 \\
365 \\
749 \\
758 \\
599\end{array}$ & $\begin{array}{r}800 \\
446 \\
359 \\
984 \\
3110\end{array}$ & $\begin{array}{r}109 \\
108 \\
126 \\
127 \\
99\end{array}$ & $\begin{array}{r}114 \\
99 \\
79 \\
66 \\
57\end{array}$ & $\begin{array}{l}31 \\
30 \\
28 \\
27 \\
26\end{array}$ & $\begin{array}{l}24 \\
27 \\
49 \\
82 \\
83\end{array}$ & $\begin{array}{l}33 \\
34 \\
33 \\
30 \\
26\end{array}$ \\
\hline $\begin{array}{l}21 \\
22 \\
23 \\
24 \\
25\end{array}$ & $\begin{array}{l}529 \\
611 \\
701 \\
593 \\
504\end{array}$ & $\begin{array}{l}100 \\
118 \\
234 \\
211 \\
220\end{array}$ & $\begin{array}{r}2400 \\
3690 \\
3810 \\
3350 \\
\mathrm{e} 2700\end{array}$ & $\begin{array}{l}\text { e } 920 \\
\text { e820 } \\
\text { e7 } 00 \\
\text { e650 } \\
\text { e590 }\end{array}$ & $\begin{array}{r}\mathrm{e} 2500 \\
2280 \\
1990 \\
1340 \\
854\end{array}$ & $\begin{array}{r}588 \\
763 \\
1190 \\
982 \\
726\end{array}$ & $\begin{array}{l}2610 \\
2080 \\
1870 \\
1700 \\
1120\end{array}$ & $\begin{array}{r}86 \\
83 \\
83 \\
80 \\
105\end{array}$ & $\begin{array}{l}51 \\
46 \\
44 \\
42 \\
40\end{array}$ & $\begin{array}{l}26 \\
70 \\
67 \\
44 \\
44\end{array}$ & $\begin{array}{l}51 \\
42 \\
36 \\
30 \\
27\end{array}$ & $\begin{array}{l}23 \\
22 \\
22 \\
21 \\
22\end{array}$ \\
\hline $\begin{array}{l}26 \\
27 \\
28 \\
29 \\
30 \\
31\end{array}$ & $\begin{array}{l}460 \\
399 \\
326 \\
261 \\
205 \\
167\end{array}$ & $\begin{array}{r}245 \\
257 \\
962 \\
1350 \\
754 \\
\ldots .\end{array}$ & $\begin{array}{r}\text { e21 } 100 \\
\text { e1 } 700 \\
\text { e1 } 370 \\
2320 \\
7060 \\
9340\end{array}$ & $\begin{array}{l}\text { e520 } \\
\text { e460 } \\
\text { e400 } \\
\text { e } 350 \\
\text { e290 } \\
\text { e270 }\end{array}$ & $\begin{array}{l}548 \\
398 \\
319 \\
\ldots . \\
\ldots . \\
\ldots\end{array}$ & $\begin{array}{r}1090 \\
1810 \\
1540 \\
1430 \\
1080 \\
810\end{array}$ & $\begin{array}{l}721 \\
547 \\
450 \\
366 \\
306 \\
\cdots\end{array}$ & $\begin{array}{r}109 \\
95 \\
110 \\
139 \\
171 \\
2550\end{array}$ & $\begin{array}{l}37 \\
40 \\
42 \\
39 \\
36 \\
--\end{array}$ & $\begin{array}{l}50 \\
43 \\
34 \\
29 \\
25 \\
24\end{array}$ & $\begin{array}{l}26 \\
24 \\
22 \\
21 \\
22 \\
23\end{array}$ & $\begin{array}{l}23 \\
21 \\
23 \\
24 \\
24 \\
-\cdot\end{array}$ \\
\hline $\begin{array}{l}\text { TOIAL } \\
\text { MEAN } \\
\text { MAX } \\
\text { MIN } \\
\text { CF SN } \\
\text { IN. }\end{array}$ & $\begin{array}{r}23982 \\
774 \\
3020 \\
57 \\
1.25 \\
1.44\end{array}$ & $\begin{array}{r}8484 \\
283 \\
1350 \\
100 \\
.46 \\
.51\end{array}$ & $\begin{array}{r}64446 \\
2079 \\
9340 \\
247 \\
3.35 \\
3.86\end{array}$ & $\begin{array}{r}58730 \\
1895 \\
9440 \\
270 \\
3.05 \\
3.52\end{array}$ & $\begin{array}{r}30829 \\
1101 \\
2900 \\
230 \\
1.77 \\
1.85\end{array}$ & $\begin{array}{r}17680 \\
570 \\
1810 \\
121 \\
.92 \\
1.06\end{array}$ & $\begin{array}{r}24292 \\
810 \\
3110 \\
208 \\
1.30 \\
1.46\end{array}$ & $\begin{array}{r}6485 \\
209 \\
2550 \\
80 \\
.34 \\
.39\end{array}$ & $\begin{array}{r}12051 \\
402 \\
2900 \\
36 \\
.65 \\
.72\end{array}$ & $\begin{array}{c}2294 \\
14.0 \\
254 \\
24 \\
.12 \\
.14\end{array}$ & $\begin{array}{c}1049 \\
33.8 \\
83 \\
21 \\
.05 \\
.06\end{array}$ & $\begin{array}{c}1193 \\
39.8 \\
120 \\
21 \\
.06 \\
.07\end{array}$ \\
\hline
\end{tabular}

e Estinated

STATISIICS OF MONTHLY MEAN DAIA FOR WAIER YEARS 1947 - 1991, BY WAIER YEAR (WY)

\begin{tabular}{|c|c|c|c|c|c|c|c|c|c|c|c|c|}
\hline $\begin{array}{l}\text { MEAN } \\
\text { MAX } \\
(W Y) \\
\text { MIN } \\
(W Y)\end{array}$ & $\begin{array}{r}127 \\
866 \\
1955 \\
7.52 \\
1964\end{array}$ & $\begin{array}{r}273 \\
1985 \\
1973 \\
13.7 \\
1965\end{array}$ & $\begin{array}{r}594 \\
2079 \\
1991 \\
12.8 \\
1964\end{array}$ & $\begin{array}{r}721 \\
3834 \\
1950 \\
21.0 \\
1961\end{array}$ & $\begin{array}{r}925 \\
2546 \\
1950 \\
30.5 \\
1964\end{array}$ & $\begin{array}{r}1127 \\
3263 \\
1978 \\
125 \\
1981\end{array}$ & $\begin{array}{r}964 \\
3409 \\
1957 \\
79.3 \\
1966\end{array}$ & $\begin{array}{r}485 \\
1491 \\
1947 \\
55.6 \\
1988\end{array}$ & $\begin{array}{r}402 \\
2075 \\
1981 \\
28.1 \\
1988\end{array}$ & $\begin{array}{c}222 \\
1248 \\
1990 \\
20.6 \\
1965\end{array}$ & $\begin{array}{r}121 \\
848 \\
1958 \\
15.5 \\
1963\end{array}$ & $\begin{array}{r}88.7 \\
381 \\
1989 \\
12.6 \\
1963\end{array}$ \\
\hline
\end{tabular}

SUMMARY SIAIISIICS

ANNUAL TOTAL

ANMUAL MEAN

HIGHEST ANNUAL MEAN

LOWEST AMNUAL MEAM

HIGHEST DAILY MEAN

LOWEST DAILY MEAN

ANMUAL SEVEN-DAY MINIMUM

INSTANTANEOUS PEAK FI.OW

INSIANTANEOUS PEAK SIAGE

ANNUAL RUNOFF (CFSM)

ANMUAL RUNOFF (INCHES)

10 PERCENT EXCEEDS

50 PERCEMT EXCEEDS

90 PERCENT EXCEEDS
FOR 1990 CALENDAR YEAR

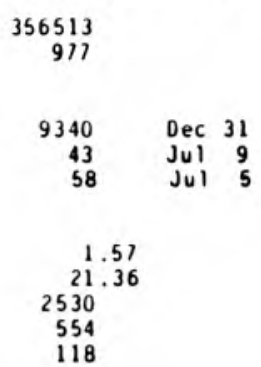

FOR 1991 WAIER YEAR

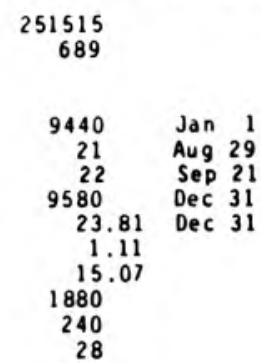

WAIER YEARS 1947 - 1991

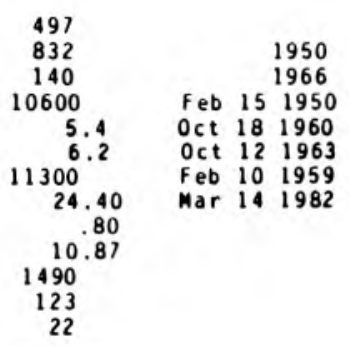


LOCATION.--Lat $40^{\circ} 59^{\prime} 16^{\circ}$, long $85^{\circ} 06^{\prime} 03^{\prime \prime}$, in A. Lafontaine Reserve, T.29 N., R.12 E., Allen County, Hydrologic Unit 04100004 , on left bank $130 \mathrm{ft}$ downstrean from Anthony Boulevard Extension, 0.8 a downstrea from Houk ditch, 5 ai south of Fort Wayne, and $10.8 \mathrm{mi}$ upstreas from mouth.

DRAI NAGE AREA. . 762 : ${ }^{2}$.

PERIOD OF RECORD.--October 1930 to current year. Monthly discharge only for sone periods, published in wSP 1307. Fragmentary gage-height records for period November 1924 to October 1927 are available from the District Office.

REVISED RECORDS.--WSP 974: 1942. WSP 1337: 1933, 1947. WSP 1912: 1954, 1955, 1960, drainage area. WDR IN-82-1: $1973,1974,1978,1979$.

GAGE.--Water-stage recorder. Datun of gage is $748.97 \mathrm{ft}$ above National Geodetic Vertical Datua of 1929 (1evels by State of Indiana, Departeent of Natural Resources). Prior to Apr. 13, 1939, nonrecording gage on upstrean highway bridge at sane datun.

REMARKS. - Records good except for estimated daily discharges, which are poor. The flow is sometimes regulated by Grand Lake. Slight diversion from or into Wabash River basin and into Miani and Erie Canal. During extreme floods, some water bypasses gage and flows through Houk ditch and Paul Trier ditch into the Maumee River. Period of record computations do not include 1934 water year.

DISCHARGE, CUBIC FEET PER SECOND, WATER YEAR OCTOBER 1990 TO SEPTEMBER 1991 DAILY MEAN VALUES

\begin{tabular}{|c|c|c|c|c|c|c|c|c|c|c|c|c|}
\hline DAY & OCT & NOV & DEC & JAN & FEB & MAR & APR & MAY & JUN & JUL & AUG & SEP \\
\hline $\begin{array}{l}1 \\
2 \\
3 \\
4 \\
5\end{array}$ & $\begin{array}{r}77 \\
71 \\
65 \\
99 \\
876\end{array}$ & $\begin{array}{l}167 \\
150 \\
141 \\
134 \\
186\end{array}$ & $\begin{array}{r}672 \\
620 \\
1980 \\
3900 \\
3220\end{array}$ & $\begin{array}{r}10600 \\
10400 \\
9550 \\
7480 \\
4650\end{array}$ & $\begin{array}{r}e 280 \\
e 270 \\
320 \\
613 \\
1700\end{array}$ & $\begin{array}{l}325 \\
356 \\
394 \\
314 \\
269\end{array}$ & $\begin{array}{l}671 \\
474 \\
342 \\
268 \\
354\end{array}$ & $\begin{array}{l}303 \\
266 \\
221 \\
188 \\
174\end{array}$ & $\begin{array}{l}5070 \\
2180 \\
3950 \\
2710 \\
1140\end{array}$ & $\begin{array}{r}40 \\
44 \\
59 \\
194 \\
219\end{array}$ & $\begin{array}{l}28 \\
27 \\
28 \\
30 \\
30\end{array}$ & $\begin{array}{l}28 \\
33 \\
35 \\
47 \\
76\end{array}$ \\
\hline $\begin{array}{r}6 \\
7 \\
8 \\
9 \\
10\end{array}$ & $\begin{array}{r}647 \\
420 \\
393 \\
645 \\
2570\end{array}$ & $\begin{array}{l}572 \\
553 \\
350 \\
294 \\
268\end{array}$ & $\begin{array}{r}1710 \\
1430 \\
1390 \\
1090 \\
765\end{array}$ & $\begin{array}{r}1800 \\
908 \\
626 \\
469 \\
386\end{array}$ & $\begin{array}{l}1970 \\
2060 \\
2290 \\
2220 \\
1840\end{array}$ & $\begin{array}{l}254 \\
237 \\
204 \\
178 \\
167\end{array}$ & $\begin{array}{l}349 \\
280 \\
267 \\
603 \\
459\end{array}$ & $\begin{array}{l}189 \\
169 \\
147 \\
145 \\
151\end{array}$ & $\begin{array}{l}712 \\
527 \\
361 \\
236 \\
170\end{array}$ & $\begin{array}{r}226 \\
212 \\
201 \\
141 \\
98\end{array}$ & $\begin{array}{l}29 \\
28 \\
40 \\
55 \\
54\end{array}$ & $\begin{array}{r}121 \\
115 \\
93 \\
65 \\
49\end{array}$ \\
\hline $\begin{array}{l}11 \\
12 \\
13 \\
14 \\
15\end{array}$ & $\begin{array}{l}3840 \\
3110 \\
1770 \\
1490 \\
1330\end{array}$ & $\begin{array}{l}243 \\
210 \\
183 \\
170 \\
168\end{array}$ & $\begin{array}{l}536 \\
419 \\
345 \\
281 \\
465\end{array}$ & $\begin{array}{r}342 \\
656 \\
782 \\
701 \\
1080\end{array}$ & $\begin{array}{r}1400 \\
1000 \\
719 \\
e 470 \\
e 350\end{array}$ & $\begin{array}{l}161 \\
149 \\
145 \\
142 \\
174\end{array}$ & $\begin{array}{r}320 \\
237 \\
207 \\
833 \\
2430\end{array}$ & $\begin{array}{l}140 \\
128 \\
120 \\
116 \\
132\end{array}$ & $\begin{array}{l}134 \\
118 \\
116 \\
114 \\
105\end{array}$ & $\begin{array}{l}66 \\
52 \\
45 \\
42 \\
40\end{array}$ & $\begin{array}{l}55 \\
43 \\
38 \\
36 \\
35\end{array}$ & $\begin{array}{l}38 \\
50 \\
51 \\
43 \\
38\end{array}$ \\
\hline $\begin{array}{l}16 \\
17 \\
18 \\
19 \\
20\end{array}$ & $\begin{array}{r}1020 \\
700 \\
611 \\
925 \\
616\end{array}$ & $\begin{array}{l}161 \\
148 \\
137 \\
128 \\
123\end{array}$ & $\begin{array}{r}1180 \\
862 \\
1140 \\
2570 \\
2560\end{array}$ & $\begin{array}{r}2640 \\
3800 \\
3240 \\
2080 \\
\mathrm{e} 1550\end{array}$ & $\begin{array}{r}e 290 \\
e 270 \\
367 \\
2070 \\
3390\end{array}$ & $\begin{array}{l}277 \\
384 \\
779 \\
945 \\
703\end{array}$ & $\begin{array}{r}1500 \\
795 \\
591 \\
1180 \\
3950\end{array}$ & $\begin{array}{l}125 \\
127 \\
120 \\
140 \\
126\end{array}$ & $\begin{array}{r}115 \\
117 \\
102 \\
80 \\
65\end{array}$ & $\begin{array}{l}35 \\
33 \\
32 \\
31 \\
30\end{array}$ & $\begin{array}{r}32 \\
29 \\
33 \\
98 \\
153\end{array}$ & $\begin{array}{l}36 \\
36 \\
35 \\
35 \\
33\end{array}$ \\
\hline $\begin{array}{l}21 \\
22 \\
23 \\
24 \\
25\end{array}$ & $\begin{array}{l}508 \\
546 \\
647 \\
624 \\
518\end{array}$ & $\begin{array}{l}117 \\
117 \\
161 \\
228 \\
207\end{array}$ & $\begin{array}{r}2680 \\
4230 \\
4520 \\
\mathrm{e} 3600 \\
\mathrm{e} 2800\end{array}$ & $\begin{array}{r}\text { e1200 } \\
\text { e950 } \\
\text { e820 } \\
\text { e740 } \\
\text { e680 }\end{array}$ & $\begin{array}{l}2590 \\
2290 \\
2150 \\
1530 \\
1030\end{array}$ & $\begin{array}{r}636 \\
722 \\
1240 \\
1240 \\
851\end{array}$ & $\begin{array}{l}3660 \\
2470 \\
2090 \\
2080 \\
1440\end{array}$ & $\begin{array}{r}104 \\
93 \\
85 \\
87 \\
95\end{array}$ & $\begin{array}{l}58 \\
52 \\
51 \\
49 \\
44\end{array}$ & $\begin{array}{l}30 \\
46 \\
85 \\
74 \\
47\end{array}$ & $\begin{array}{r}106 \\
56 \\
44 \\
39 \\
33\end{array}$ & $\begin{array}{l}28 \\
26 \\
27 \\
26 \\
24\end{array}$ \\
\hline $\begin{array}{l}26 \\
27 \\
28 \\
29 \\
30 \\
31\end{array}$ & $\begin{array}{l}463 \\
419 \\
356 \\
290 \\
232 \\
192\end{array}$ & $\begin{array}{r}227 \\
261 \\
787 \\
1570 \\
923 \\
\cdots-\end{array}$ & $\begin{array}{r}\text { e2200 } \\
\text { e1 } 1800 \\
\text { e1 } 600 \\
2950 \\
8360 \\
10300\end{array}$ & $\begin{array}{l}\text { e590 } \\
\text { e510 } \\
\text { e460 } \\
\text { e400 } \\
\text { e340 } \\
\text { e300 }\end{array}$ & $\begin{array}{l}694 \\
492 \\
387 \\
\ldots- \\
\ldots- \\
\ldots-\end{array}$ & $\begin{array}{r}1000 \\
1840 \\
1600 \\
1480 \\
1160 \\
912\end{array}$ & $\begin{array}{l}911 \\
651 \\
528 \\
438 \\
358 \\
\cdots\end{array}$ & $\begin{array}{r}164 \\
138 \\
111 \\
130 \\
382 \\
6740\end{array}$ & $\begin{array}{r}42 \\
39 \\
40 \\
43 \\
43 \\
---\end{array}$ & $\begin{array}{l}43 \\
49 \\
45 \\
39 \\
34 \\
30\end{array}$ & $\begin{array}{l}31 \\
29 \\
28 \\
27 \\
26 \\
26\end{array}$ & $\begin{array}{l}24 \\
25 \\
24 \\
24 \\
26 \\
---\end{array}$ \\
\hline $\begin{array}{l}\text { TOTAL } \\
\text { MEAN } \\
\text { MAX } \\
\text { MIN } \\
\text { CF SM } \\
\text { IN. }\end{array}$ & $\begin{array}{r}26070 \\
841 \\
3840 \\
65 \\
1.10 \\
1.27\end{array}$ & $\begin{array}{r}9084 \\
303 \\
1570 \\
117 \\
.40 \\
.44\end{array}$ & $\begin{array}{r}72175 \\
2328 \\
10300 \\
281 \\
3.06 \\
3.52\end{array}$ & $\begin{array}{r}70730 \\
2282 \\
10600 \\
300 \\
2.99 \\
3.45\end{array}$ & $\begin{array}{r}35052 \\
1252 \\
3390 \\
270 \\
1.64 \\
1.71\end{array}$ & $\begin{array}{r}19238 \\
621 \\
1840 \\
142 \\
.81 \\
.94\end{array}$ & $\begin{array}{c}30736 \\
1025 \\
3950 \\
207 \\
1.34 \\
1.50\end{array}$ & $\begin{array}{r}11356 \\
366 \\
6740 \\
85 \\
.48 \\
.55\end{array}$ & $\begin{array}{r}18583 \\
619 \\
5070 \\
39 \\
.81 \\
.91\end{array}$ & $\begin{array}{c}2362 \\
76.2 \\
226 \\
30 \\
.10 \\
.12\end{array}$ & $\begin{array}{c}1346 \\
43.4 \\
153 \\
26 \\
.06 \\
.07\end{array}$ & $\begin{array}{c}1311 \\
43.7 \\
121 \\
24 \\
.06 \\
.06\end{array}$ \\
\hline
\end{tabular}

e Estiated

STATISTICS OF MONTHLY MEAN DATA FOR WATER YEARS 1931 - 1991, BY WATER YEAR (WY)

\begin{tabular}{|c|c|c|c|c|c|c|c|c|c|c|c|c|}
\hline $\begin{array}{l}\text { MEAN } \\
\text { MAX } \\
\text { (WY) } \\
\text { MIN } \\
\text { (WY) }\end{array}$ & $\begin{array}{r}149 \\
1299 \\
1955 \\
8.28 \\
1964\end{array}$ & $\begin{array}{r}292 \\
2612 \\
1973 \\
16.9 \\
1965\end{array}$ & $\begin{array}{r}644 \\
2349 \\
1978 \\
16.7 \\
1964\end{array}$ & $\begin{array}{r}850 \\
4897 \\
1950 \\
21.3 \\
1977\end{array}$ & $\begin{array}{l}1062 \\
3404 \\
1959 \\
45.4 \\
1964\end{array}$ & $\begin{array}{l}1338 \\
4070 \\
1978 \\
87.0 \\
1941\end{array}$ & $\begin{array}{l}1141 \\
4119 \\
1957 \\
90.7 \\
1946\end{array}$ & $\begin{array}{r}642 \\
3866 \\
1943 \\
59.9 \\
1931\end{array}$ & $\begin{array}{r}468 \\
2545 \\
1981 \\
34.3 \\
1988\end{array}$ & $\begin{array}{r}261 \\
1428 \\
1986 \\
11.9 \\
1936\end{array}$ & $\begin{array}{r}142 \\
1074 \\
1958 \\
13.9 \\
1932\end{array}$ & $\begin{array}{r}97.3 \\
470 \\
1972 \\
11.6 \\
1944\end{array}$ \\
\hline
\end{tabular}

\section{SUMMARY STATISTICS}

ANMUAL TOTAL

ANNUAL MEAM

HIGHEST ANNUAL MEAN

LOWEST ANMUAL MEAN

HIGHEST DAILY MEAN

LOWEST DAILY MEAM

ANNUAL SEVEN-DAY MINIMUM

INSTANTANEOUS PEAK FLOW

INSTANTANEOUS PEAK STAGE

ANMUAL RUNOFF (CFSM)

ANNUAL RUNOFF (INCHES)

10 PERCENT EXCEEDS

50 PERCENT EXCEEDS

90 PERCENT EXCEEDS

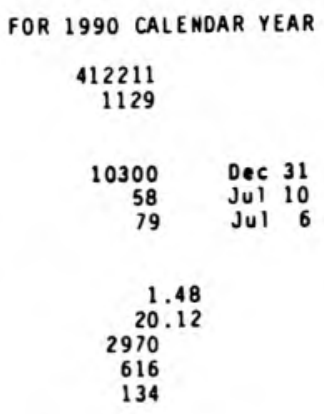

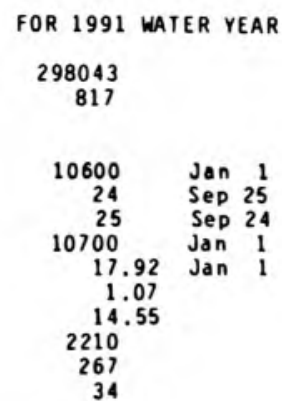

WATER YEARS 1931 - 1991

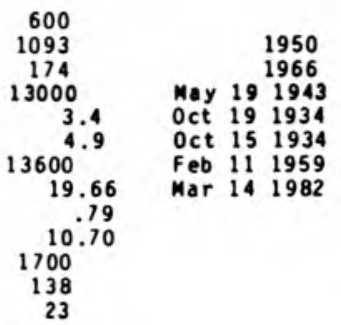




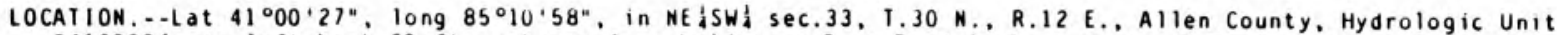
04100004 , on left bank $50 \mathrm{ft}$ upstrean from bridge on Baer Road in Fort Wayne, 3.2 upstrean from mouth. The strea. name changes to Fairfield Ditch 0.7 i downstream at bridge on Lower Huntington Road.

DRAINAGE AREA. $-21.9 . i^{2}$

PERIOD OF RECORD.--May 1964 to current year. Discharge neasurenents available 0 ctober 1960 to May 1964 and gage heights January 1961 to May 1964 at site 0.7 ai downstrean.

REVISED RECORDS.-.WDR IN-82-1: 1980 (P), 1981 (P).

GAGE.- Water-stage recorder. Datum of gage is $757.00 \mathrm{ft}$ above National Geodetic Vertical Datue of 1929.

REMARKS.--Records good except for estimated daily discharges, which are poor.

DISCHARGE, CUBIC FEET PER SECOND, WATER YEAR OCTOBER 1990 TO SEPIEMBER 1991 DAILY MEAN VALUES

\begin{tabular}{|c|c|c|c|c|c|c|c|c|c|c|c|c|}
\hline DAY & $\mathrm{OCT}$ & NOV & DE C & JAN & FEB & MAR & APR & MAY & JUN & JUL & AUG & SEP \\
\hline $\begin{array}{l}1 \\
2 \\
3 \\
4 \\
5\end{array}$ & $\begin{array}{l}.70 \\
1.68 \\
16.8 \\
3.0\end{array}$ & $\begin{array}{r}3.8 \\
3.9 \\
4.2 \\
3.6 \\
45\end{array}$ & $\begin{array}{c}12 \\
9.1 \\
293 \\
128 \\
42\end{array}$ & $\begin{array}{l}86 \\
40 \\
21 \\
14 \\
11\end{array}$ & $\begin{array}{l}3.8 \\
5.4 \\
11 \\
30 \\
51\end{array}$ & $\begin{array}{l}9.3 \\
17 \\
14 \\
10 \\
8.7\end{array}$ & $\begin{array}{r}8.7 \\
6.7 \\
6.1 \\
12 \\
32\end{array}$ & $\begin{array}{r}11 \\
6.3 \\
5.0 \\
4.4 \\
7.5\end{array}$ & $\begin{array}{r}345 \\
192 \\
97 \\
32 \\
15\end{array}$ & $\begin{array}{r}4.3 \\
29 \\
8.1 \\
3.9 \\
1.2\end{array}$ & $\begin{array}{l}.16 \\
.13 \\
2.0 \\
.54 \\
.26\end{array}$ & $\begin{array}{l}.16 \\
.10 \\
3.7 \\
4.3 \\
.58\end{array}$ \\
\hline $\begin{array}{r}6 \\
7 \\
8 \\
9 \\
10\end{array}$ & $\begin{array}{c}2.5 \\
6.0 \\
7.9 \\
50 \\
312\end{array}$ & $\begin{array}{r}35 \\
14 \\
9.3 \\
7.8 \\
6.7\end{array}$ & $\begin{array}{l}25 \\
17 \\
13 \\
11 \\
11\end{array}$ & $\begin{array}{r}8.8 \\
\in 6.4 \\
e 5.6 \\
e 5.2 \\
\text { e4.7 }\end{array}$ & $\begin{array}{l}50 \\
46 \\
28 \\
21 \\
17\end{array}$ & $\begin{array}{l}8.9 \\
7.3 \\
5.8 \\
5.6 \\
5.3\end{array}$ & $\begin{array}{l}17 \\
12 \\
16 \\
34 \\
16\end{array}$ & $\begin{array}{l}8.7 \\
5.0 \\
3.9 \\
3.8 \\
3.4\end{array}$ & $\begin{array}{l}9.5 \\
6.6 \\
5.0 \\
3.8 \\
3.1\end{array}$ & $\begin{array}{l}.69 \\
.56 \\
3.2 \\
.69 \\
.60\end{array}$ & $\begin{array}{r}.20 \\
21.20 \\
6.4 \\
1.8\end{array}$ & $\begin{array}{l}.27 \\
.13 \\
.19 \\
.17 \\
.13\end{array}$ \\
\hline $\begin{array}{l}11 \\
12 \\
13 \\
14 \\
15\end{array}$ & $\begin{array}{r}112 \\
41 \\
20 \\
12 \\
9.0\end{array}$ & $\begin{array}{l}5.4 \\
4.6 \\
4.0 \\
3.8 \\
3.7\end{array}$ & $\begin{array}{r}9.6 \\
9.2 \\
8.0 \\
6.3 \\
51\end{array}$ & $\begin{array}{l}16 \\
19 \\
10 \\
13 \\
43\end{array}$ & $\begin{array}{r}12 \\
9.2 \\
\mathrm{e} 9.2 \\
\mathrm{e} 9.8 \\
\mathrm{e} 5.0\end{array}$ & $\begin{array}{r}4.9 \\
4.8 \\
5.0 \\
5.9 \\
11\end{array}$ & $\begin{array}{r}9.9 \\
8.1 \\
9.1 \\
71 \\
207\end{array}$ & $\begin{array}{l}3.2 \\
3.2 \\
3.3 \\
3.6 \\
2.9\end{array}$ & $\begin{array}{l}4.0 \\
3.6 \\
2.2 \\
1.8 \\
2.1\end{array}$ & $\begin{array}{l}.40 \\
.54 \\
.51 \\
.42 \\
.39\end{array}$ & $\begin{array}{c}.66 \\
.41 \\
.69 \\
1.0 \\
.41\end{array}$ & $\begin{array}{c}11^{.13} \\
2.6 \\
1.1 \\
.76\end{array}$ \\
\hline $\begin{array}{l}16 \\
17 \\
18 \\
19 \\
20\end{array}$ & $\begin{array}{l}6.2 \\
5.5 \\
44 \\
18 \\
11\end{array}$ & $\begin{array}{l}4.0 \\
3.9 \\
3.4 \\
3.4 \\
3.4\end{array}$ & $\begin{array}{l}30 \\
22 \\
55 \\
58 \\
29\end{array}$ & $\begin{array}{r}114 \\
96 \\
32 \\
21 \\
28\end{array}$ & $\begin{array}{r}\mathrm{e} 4.0 \\
5.6 \\
24 \\
169 \\
76\end{array}$ & $\begin{array}{l}12 \\
16 \\
48 \\
22 \\
15\end{array}$ & $\begin{array}{r}63 \\
36 \\
19 \\
165 \\
158\end{array}$ & $\begin{array}{l}7.3 \\
15 \\
\text { e } 6.4 \\
\text { e } 4.3 \\
\text { e } 3.5\end{array}$ & $\begin{array}{l}2.7 \\
1.7 \\
1.2 \\
.94 \\
1.1\end{array}$ & $\begin{array}{l}.29 \\
.27 \\
.16 \\
.30 \\
.34\end{array}$ & $\begin{array}{l}.19 \\
.27 \\
1.6 \\
8.5 \\
3.3\end{array}$ & $\begin{array}{r}.52 \\
.45 \\
.42 \\
.37 \\
.31\end{array}$ \\
\hline $\begin{array}{l}21 \\
22 \\
23 \\
24 \\
25\end{array}$ & $\begin{array}{l}7.8 \\
6.4 \\
5.4 \\
4.6 \\
4.2\end{array}$ & $\begin{array}{l}3.3 \\
6.6 \\
4.2 \\
3.5 \\
3.4\end{array}$ & $\begin{array}{r}193 \\
156 \\
53 \\
26 \\
e 16\end{array}$ & $\begin{array}{r}32 \\
\text { e15 } \\
\text { e } 13 \\
\text { e } 9.3 \\
\text { e } 7.2\end{array}$ & $\begin{array}{l}39 \\
25 \\
16 \\
13 \\
11\end{array}$ & $\begin{array}{l}12 \\
15 \\
31 \\
27 \\
16\end{array}$ & $\begin{array}{l}46 \\
23 \\
21 \\
44 \\
22\end{array}$ & $\begin{array}{r}\text { e2.5 } \\
\text { e2.0 } \\
\text { e3.3 } \\
\text { e15 } \\
\text { e } 70\end{array}$ & $\begin{array}{c}.88 \\
.87 \\
.94 \\
1.0 \\
.87\end{array}$ & $\begin{array}{l}.10 \\
7.9 \\
1.1 \\
.46 \\
.28\end{array}$ & $\begin{array}{l}1.5 \\
.67 \\
.33 \\
.32 \\
.25\end{array}$ & $\begin{array}{l}.29 \\
.24 \\
.26 \\
.29 \\
.25\end{array}$ \\
\hline $\begin{array}{l}26 \\
27 \\
28 \\
29 \\
30 \\
31\end{array}$ & $\begin{array}{l}4.1 \\
3.7 \\
3.5 \\
3.4 \\
3.4 \\
3.8\end{array}$ & $\begin{array}{c}3.6 \\
17 \\
106 \\
34 \\
17 \\
\cdots\end{array}$ & $\begin{array}{r}\text { e11 } \\
\text { e10 } \\
11 \\
402 \\
777 \\
294\end{array}$ & $\begin{array}{l}\text { e6. } 6 \\
\text { e5.8 } \\
\text { e5.1 } \\
\text { e } 4.6 \\
\text { e } 4.3 \\
\text { e3.9 }\end{array}$ & $\begin{array}{l}8.9 \\
7.6 \\
8.0 \\
\ldots . \\
\ldots . \\
\ldots\end{array}$ & $\begin{array}{c}45 \\
37 \\
22 \\
14 \\
10 \\
8.6\end{array}$ & $\begin{array}{r}15 \\
12 \\
9.8 \\
8.9 \\
7.1 \\
\ldots . .\end{array}$ & $\begin{array}{c}\text { e25 } \\
\text { e12 } \\
\text { e5.0 } \\
\text { e3.2 } \\
152 \\
941\end{array}$ & $\begin{array}{r}.81 \\
.79 \\
.79 \\
.81 \\
\ldots\end{array}$ & $\begin{array}{c}.13 \\
.10 \\
.09 \\
2.4 \\
.87 \\
.23\end{array}$ & $\begin{array}{l}.22 \\
.16 \\
.20 \\
.20 \\
.20 \\
.20\end{array}$ & $\begin{array}{l}.24 \\
.14 \\
.09 \\
.08 \\
.06 \\
\ldots .\end{array}$ \\
\hline $\begin{array}{l}\text { TOIAL } \\
\text { MEAN } \\
\text { MAX } \\
\text { MIN } \\
\text { CF SM } \\
\text { IN. }\end{array}$ & $\begin{array}{r}729.58 \\
23.5 \\
312 \\
.68 \\
1.07 \\
1.24\end{array}$ & $\begin{array}{r}371.5 \\
12.4 \\
106 \\
3.3 \\
.57 \\
.63\end{array}$ & $\begin{array}{r}2788.2 \\
89.9 \\
777 \\
6.3 \\
4.11 \\
4.74\end{array}$ & $\begin{array}{r}761.3 \\
24.6 \\
114 \\
3.9 \\
1.12 \\
1.29\end{array}$ & $\begin{array}{r}715.5 \\
25.6 \\
169 \\
3.8 \\
1.17 \\
1.22\end{array}$ & $\begin{array}{r}474.1 \\
15.3 \\
48 \\
4.8 \\
.70 \\
.81\end{array}$ & $\begin{array}{r}1115.4 \\
37.2 \\
207 \\
6.1 \\
1.70 \\
1.89\end{array}$ & $\begin{array}{c}1342.7 \\
43.3 \\
941 \\
2.0 \\
1.98 \\
2.28\end{array}$ & $\begin{array}{c}749.10 \\
25.0 \\
345 \\
.79 \\
1.14 \\
1.27\end{array}$ & $\begin{array}{c}69.52 \\
2.24 \\
29 \\
.09 \\
.10 \\
.12\end{array}$ & $\begin{array}{c}53.97 \\
1.74 \\
21 \\
.13 \\
.08 \\
.09\end{array}$ & $\begin{array}{c}29.33 \\
.98 \\
11 \\
.06 \\
.04 \\
.05\end{array}$ \\
\hline
\end{tabular}

e Estimated

STATISTICS OF MONTHLY MEAN DATA FOR WAIER YEARS 1965 - 1991, BY WATER YEAR (WY)

$\begin{array}{lcccccccccccc}\text { MEAN } & 5.45 & 13.9 & 29.7 & 21.1 & 33.3 & 40.2 & 29.7 & 20.8 & 15.8 & 6.02 & 4.02 & 3.86 \\ \text { MAX } & 35.0 & 64.5 & 89.9 & 93.5 & 94.5 & 130 & 73.7 & 56.5 & 56.0 & 68.5 & 14.2 & 16.4 \\ \text { (WY) } & 1987 & 1973 & 1991 & 1974 & 1976 & 1982 & 1972 & 1974 & 1981 & 1986 & 1977 & 1977 \\ \text { MIN } & .27 & .32 & .28 & .12 & 1.27 & 4.27 & 4.22 & 2.22 & .33 & .34 & .36 & .32 \\ \text { (WY) } & 1965 & 1965 & 1977 & 1977 & 1978 & 1981 & 1971 & 1988 & 1988 & 1974 & 1969 & 1973\end{array}$

SUMMARY SIAIISIICS

ANNUAL TOTAL

ANNUAL MEAN

HIGHESI ANNUAL MEAM

LOWEST ANNUAL MEAN

HIGHEST DAILY MEAN

LOWEST DAILY MEAN

AN WUAL SEVEN-DAY MINIMUM

INSIANTANEOUS PEAK FLOW

INSIANTANEOUS PEAK SIAGE

ANMUAL RUNOFF (CFSM)

ANMUAL RUNOFF (INCHES)

10 PERCENT EXCEEDS

SO PERCENT EXCEEDS

90 PERCEMT EXCEEDS
FOR 1990 CALENDAR YEAR

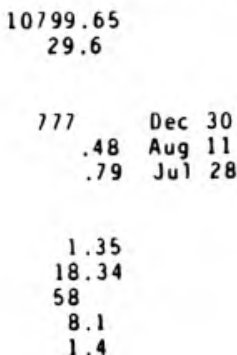

FOR 1991 WATER YEAR

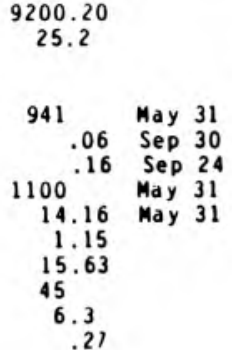

WAIER YEARS 1965 - 1991

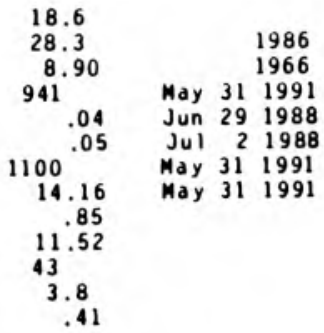


LOCAIION, - Lat $41^{\circ} 06^{\prime} 18^{\prime \prime}$, Iong $85^{\circ} 0 y^{\prime} 12^{\prime \prime}$, in SW $\frac{1}{3}$ SW sec.26, T.31 H., R.12 E., Allen County, Hydrologic Unit 04100004 , on right bąnk $50 \mathrm{ft}$ upstream from Sheraan Boulevard bridge in Fort Wayne, and at aile 2.2 .

PERIOD OF RECORD.--October 1983 to current year.

GAGE.- - Water-stage recorder. Datum of gage is $760.00 \mathrm{ft}$ above National Geodetic Vertical Datua of 1929 (levels by City of Fort Wayne).

REMARKS.-- Records good except for estinated daily discharges, which are poor.

EXTREMES OUTSIDE PERIOD OF RECORD. - - Flood of March 14, 1982 reached a stage of $10.75 \mathrm{ft}$, present site and datum.

DISCHARGE, CUBIC FEET PER SECOND, WATER YEAR OCTOBER 1990 TO SEPTEMBER 1991 DAILY MEAN VALUES

\begin{tabular}{|c|c|c|c|c|c|c|c|c|c|c|c|c|}
\hline DAY & $\mathrm{OCT}$ & MOV & $\mathrm{DEC}$ & JAN & FEB & MAR & APR & MAY & JUN & JUL & AUG & SEP \\
\hline $\begin{array}{l}1 \\
2 \\
3 \\
4 \\
5\end{array}$ & $\begin{array}{r}2.7 \\
3.0 \\
4.0 \\
62 \\
8.3\end{array}$ & $\begin{array}{r}3.1 \\
3.2 \\
3.0 \\
3.0 \\
156\end{array}$ & $\begin{array}{r}7.7 \\
6.0 \\
253 \\
41 \\
17\end{array}$ & $\begin{array}{r}22 \\
16 \\
12 \\
7.7 \\
6.3\end{array}$ & $\begin{array}{r}\text { e2.6 } \\
4.4 \\
11 \\
18 \\
27\end{array}$ & $\begin{array}{l}11 \\
34 \\
16 \\
8.4 \\
7.2\end{array}$ & $\begin{array}{l}8.2 \\
5.6 \\
4.9 \\
21 \\
79\end{array}$ & $\begin{array}{r}16 \\
7.8 \\
5.1 \\
4.7 \\
15\end{array}$ & $\begin{array}{l}58 \\
94 \\
32 \\
15 \\
11\end{array}$ & $\begin{array}{l}8.0 \\
24 \\
10 \\
5.8 \\
3.5\end{array}$ & $\begin{array}{l}2.2 \\
2.4 \\
7.4 \\
3.6 \\
2.9\end{array}$ & $\begin{array}{c}1.2 \\
1.0 \\
25 \\
18 \\
4.7\end{array}$ \\
\hline $\begin{array}{r}6 \\
7 \\
8 \\
9 \\
10\end{array}$ & $\begin{array}{r}4.3 \\
4.8 \\
12 \\
143 \\
307\end{array}$ & $\begin{array}{l}38 \\
15 \\
9.3 \\
7.4 \\
6.6\end{array}$ & $\begin{array}{r}12 \\
9.3 \\
7.2 \\
6.2 \\
5.6\end{array}$ & $\begin{array}{l}\text { e5.1 } \\
\text { e } 4.7 \\
\text { e } 4.3 \\
\text { e } 3.9 \\
\text { e } 3.6\end{array}$ & $\begin{array}{l}22 \\
20 \\
13 \\
10 \\
8.1\end{array}$ & $\begin{array}{l}7.2 \\
6.0 \\
4.4 \\
4.0 \\
3.5\end{array}$ & $\begin{array}{l}18 \\
10 \\
38 \\
39 \\
13\end{array}$ & $\begin{array}{r}11 \\
5.4 \\
4.4 \\
3.9 \\
3.7\end{array}$ & $\begin{array}{l}7.4 \\
5.5 \\
4.6 \\
4.1 \\
3.8\end{array}$ & $\begin{array}{l}2.7 \\
2.0 \\
2.1 \\
2.2 \\
2.3\end{array}$ & $\begin{array}{c}2.9 \\
2.8 \\
32 \\
12 \\
4.7\end{array}$ & $\begin{array}{l}3.1 \\
2.2 \\
1.8 \\
1.9 \\
2.1\end{array}$ \\
\hline $\begin{array}{l}11 \\
12 \\
13 \\
14 \\
15\end{array}$ & $\begin{array}{l}31 \\
16 \\
9.4 \\
6.4 \\
6.1\end{array}$ & $\begin{array}{l}5.3 \\
4.8 \\
4.7 \\
5.1 \\
5.0\end{array}$ & $\begin{array}{r}5.0 \\
4.8 \\
4.5 \\
4.0 \\
57\end{array}$ & $\begin{array}{l}28 \\
23 \\
9.3 \\
16 \\
29\end{array}$ & $\begin{array}{r}5.9 \\
4.4 \\
\mathrm{e} 4.7 \\
\mathrm{e} 6.4 \\
\mathrm{e} 4.6\end{array}$ & $\begin{array}{r}3.4 \\
3.7 \\
4.6 \\
9.7 \\
14\end{array}$ & $\begin{array}{r}8.3 \\
6.3 \\
7.1 \\
61 \\
131\end{array}$ & $\begin{array}{l}3.4 \\
3.4 \\
4.3 \\
5.4 \\
3.7\end{array}$ & $\begin{array}{l}3.9 \\
4.8 \\
3.8 \\
3.1 \\
3.7\end{array}$ & $\begin{array}{l}2.2 \\
4.4 \\
3.4 \\
2.6 \\
2.3\end{array}$ & $\begin{array}{l}3.0 \\
2.7 \\
2.7 \\
4.1 \\
3.0\end{array}$ & $\begin{array}{r}1.9 \\
136 \\
18 \\
7.0 \\
3.9\end{array}$ \\
\hline $\begin{array}{l}16 \\
17 \\
18 \\
19 \\
20\end{array}$ & $\begin{array}{l}5.0 \\
4.3 \\
84 \\
14 \\
7.4\end{array}$ & $\begin{array}{l}5.1 \\
4.5 \\
3.8 \\
3.8 \\
3.9\end{array}$ & $\begin{array}{l}19 \\
19 \\
60 \\
34 \\
17\end{array}$ & $\begin{array}{c}95 \\
33 \\
14 \\
9.2 \\
15\end{array}$ & $\begin{array}{l}\text { e } 3.1 \\
\text { e } 4.0 \\
57 \\
92 \\
26\end{array}$ & $\begin{array}{l}13 \\
20 \\
73 \\
18 \\
10\end{array}$ & $\begin{array}{r}27 \\
75 \\
19 \\
178 \\
76\end{array}$ & $\begin{array}{l}7.5 \\
8.5 \\
4.2 \\
3.0 \\
2.6\end{array}$ & $\begin{array}{l}5.5 \\
3.6 \\
3.2 \\
3.2 \\
2.9\end{array}$ & $\begin{array}{l}2.6 \\
3.0 \\
2.9 \\
2.5 \\
2.2\end{array}$ & $\begin{array}{l}2.7 \\
15 \\
14 \\
34 \\
22\end{array}$ & $\begin{array}{l}2.8 \\
2.3 \\
2.0 \\
2.1 \\
2.4\end{array}$ \\
\hline $\begin{array}{l}21 \\
22 \\
23 \\
24 \\
25\end{array}$ & $\begin{array}{l}5.5 \\
4.9 \\
4.4 \\
3.8 \\
3.3\end{array}$ & $\begin{array}{r}3.8 \\
13 \\
6.0 \\
4.1 \\
3.1\end{array}$ & $\begin{array}{r}185 \\
57 \\
21 \\
\text { e14 } \\
\text { e9.0 }\end{array}$ & $\begin{array}{r}17 \\
9.5 \\
7.1 \\
5.5 \\
3.8\end{array}$ & $\begin{array}{r}15 \\
11 \\
7.2 \\
6.0 \\
5.3\end{array}$ & $\begin{array}{r}8.0 \\
7.7 \\
11 \\
22 \\
9.9\end{array}$ & $\begin{array}{l}22 \\
15 \\
22 \\
65 \\
17\end{array}$ & $\begin{array}{r}2.5 \\
2.4 \\
2.6 \\
4.1 \\
36\end{array}$ & $\begin{array}{l}2.9 \\
2.7 \\
2.4 \\
2.6 \\
2.8\end{array}$ & $\begin{array}{l}2.2 \\
3.5 \\
2.8 \\
2.5 \\
2.5\end{array}$ & $\begin{array}{l}5.5 \\
3.7 \\
3.7 \\
2.3 \\
1.9\end{array}$ & $\begin{array}{l}1.7 \\
1.5 \\
1.8 \\
1.9 \\
1.9\end{array}$ \\
\hline $\begin{array}{l}26 \\
27 \\
28 \\
29 \\
30 \\
31\end{array}$ & $\begin{array}{l}3.1 \\
3.0 \\
3.4 \\
3.3 \\
3.4 \\
3.3\end{array}$ & $\begin{array}{c}3.3 \\
28 \\
113 \\
20 \\
12 \\
\ldots\end{array}$ & $\begin{array}{c}\text { e7.0 } \\
\text { e6.2 } \\
7.0 \\
627 \\
483 \\
48\end{array}$ & $\begin{array}{l}\text { e } 3.3 \\
\text { e } 3.0 \\
\text { e2 } 2.8 \\
\text { e2 } 2.6 \\
\text { e2.5 } \\
\text { e2. } 2.4\end{array}$ & $\begin{array}{l}4.4 \\
3.9 \\
7.0 \\
\ldots . \\
\ldots . \\
\ldots .\end{array}$ & $\begin{array}{l}32 \\
22 \\
17 \\
8.3 \\
5.7 \\
5.2\end{array}$ & $\begin{array}{r}11 \\
8.6 \\
7.5 \\
7.8 \\
6.0 \\
\ldots\end{array}$ & $\begin{array}{c}34 \\
7.9 \\
4.7 \\
3.9 \\
34 \\
392\end{array}$ & $\begin{array}{l}3.0 \\
2.8 \\
2.8 \\
2.5 \\
3.6 \\
\ldots .-\end{array}$ & $\begin{array}{l}2.6 \\
2.3 \\
2.0 \\
2.6 \\
3.1 \\
2.4\end{array}$ & $\begin{array}{l}2.0 \\
2.3 \\
2.1 \\
2.1 \\
2.0 \\
1.6\end{array}$ & $\begin{array}{l}1.9 \\
1.7 \\
1.5 \\
1.5 \\
1.5 \\
\cdots . .\end{array}$ \\
\hline $\begin{array}{l}\text { TOIAL } \\
\text { MEAN } \\
\text { MAX } \\
\text { MI N } \\
\text { CF SM } \\
\text { IN. }\end{array}$ & $\begin{array}{r}776.1 \\
25.0 \\
307 \\
2.7 \\
1.79 \\
2.06\end{array}$ & $\begin{array}{r}496.9 \\
16.6 \\
156 \\
3.0 \\
1.18 \\
1.32\end{array}$ & $\begin{array}{r}2053.5 \\
66.2 \\
627 \\
4.0 \\
4.73 \\
5.46\end{array}$ & $\begin{array}{r}416.6 \\
13.4 \\
95 \\
2.4 \\
.96 \\
1.11\end{array}$ & $\begin{array}{r}404.0 \\
14.4 \\
92 \\
2.6 \\
1.03 \\
1.07\end{array}$ & $\begin{array}{r}419.9 \\
13.5 \\
73 \\
3.4 \\
.97 \\
1.12\end{array}$ & $\begin{array}{r}1007.3 \\
33.6 \\
178 \\
4.9 \\
2.40 \\
2.68\end{array}$ & $\begin{array}{c}647.1 \\
20.9 \\
392 \\
2.4 \\
1.49 \\
1.72\end{array}$ & $\begin{array}{r}301.2 \\
10.0 \\
94 \\
2.4 \\
.72 \\
.80\end{array}$ & $\begin{array}{c}119.2 \\
3.85 \\
24 \\
2.0 \\
.27 \\
.32\end{array}$ & $\begin{array}{c}205.3 \\
6.62 \\
34 \\
1.6 \\
.47 \\
.55\end{array}$ & $\begin{array}{c}256.3 \\
8.54 \\
136 \\
1.0 \\
.61 \\
.68\end{array}$ \\
\hline
\end{tabular}

e Estinated

SIATISIICS OF MONTHLY MEAN DATA FOR WATER YEARS 1984 - 1991, BY WATER YEAR (WY)

\begin{tabular}{|c|c|c|c|c|c|c|c|c|c|c|c|c|}
\hline $\begin{array}{l}\text { MEAN } \\
\text { MAX } \\
(W Y) \\
\text { MIN } \\
(W Y)\end{array}$ & $\begin{array}{l}12.7 \\
25.0 \\
1991 \\
2.79 \\
1988\end{array}$ & $\begin{array}{l}18.1 \\
35.8 \\
1986 \\
10.2 \\
1985\end{array}$ & $\begin{array}{l}25.4 \\
66.2 \\
1991 \\
3.03 \\
1990\end{array}$ & $\begin{array}{l}13.8 \\
23.9 \\
1990 \\
3.76 \\
1984\end{array}$ & $\begin{array}{l}29.6 \\
64.6 \\
1990 \\
5.32 \\
1989\end{array}$ & $\begin{array}{l}25.6 \\
46.6 \\
1984 \\
11.4 \\
1987\end{array}$ & $\begin{array}{l}22.9 \\
36.6 \\
1988 \\
8.56 \\
1986\end{array}$ & $\begin{array}{l}16.8 \\
34.2 \\
1984 \\
4.15 \\
1988\end{array}$ & $\begin{array}{l}12.3 \\
34.3 \\
1989 \\
2.16 \\
1988\end{array}$ & $\begin{array}{l}14.9 \\
48.3 \\
1986 \\
3.85 \\
1991\end{array}$ & $\begin{array}{l}8.59 \\
21.7 \\
1990 \\
4.10 \\
1984\end{array}$ & $\begin{array}{l}7.74 \\
14.8 \\
1989 \\
3.94 \\
1988\end{array}$ \\
\hline
\end{tabular}

SUMMARY STAIISIICS

ANMUAL IOIAL

HIGHEST ANNUAL MEAM

LOWEST ANMUAL MEAN

HIGHEST DAIIY MEAN

LOWEST DAILY MEAN

ANNUAL SEVEN-DAY MINIMUM

INSIANIANEOUS PEAK FLOW

INSTANTANEOUS PEAK SIAGE

ANNUAL RUNOFF (CFSM)

ANNUAL RUNOFF (INCHES)

10 PERCENT EXCEEDS

50 PERCENT EXCEEDS

90 PERCENI EXCEEOS
FOR 1990 CALENDAR YEAR

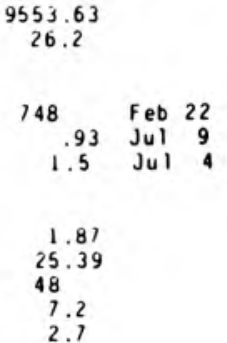

FOR 1991 WAIER YEAR

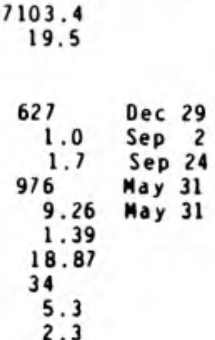

WATER YEARS $1984-1991$

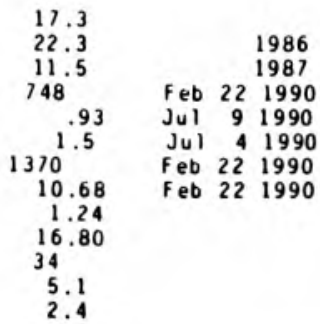




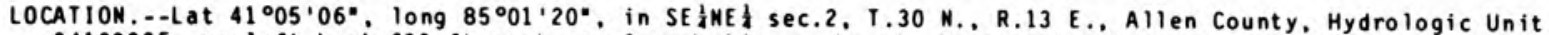
04100005 , on left bank $600 \mathrm{ft}$ upstrea fro bridge on Landin Road, 1,400 ft upstrean froe the Norfolk and Western Railroad bridge, 1.1 -i northwest of New Haven, 2.8 i upstrea from Sixaile Creek and at aile 129.0 . DRAI NAGE AREA. $\cdots 1,967 \mathrm{i}^{2}$.

PERIOD OF RECORD.--Deceaber 1946 to September 1956 (high-water records only), 0ctober 1956 to current year. REVISED RECORDS.

GAGE.- -Water-stage recorder. Datum of gage is $724.51 \mathrm{ft}$ above National Geodetic Vertical Datun of 1929 . Prior to Sept. 1. 1956, nonrecording gage and Sept. 7, 1956, to Sept. 14, 1965, water-stage recorder at site 500 ft downstreas at sane datun.

REMARKS.--Records good except for estimated daily discharges, which are poor. Flow regulated by hydro-powerplant on the St. Joseph River 10.3 i. upstrea from station. Flow slightly regulated by upstrean reservoirs.

DISCHARGE, CUBIC FEET PER SECOND, WATER YEAR OCTOBER 1990 TO SEPTEMBER 1991 DAILY MEAN VALUES

\begin{tabular}{|c|c|c|c|c|c|c|c|c|c|c|c|c|}
\hline DAY & $\mathrm{OCT}$ & NOV & DEC & JAN & FEB & MAR & APR & MAY & JUN & JUL & AUG & SEP \\
\hline $\begin{array}{l}1 \\
2 \\
3 \\
4 \\
5\end{array}$ & $\begin{array}{r}723 \\
186 \\
228 \\
872 \\
1560\end{array}$ & $\begin{array}{r}651 \\
626 \\
576 \\
578 \\
1800\end{array}$ & $\begin{array}{l}2110 \\
1680 \\
4530 \\
8290 \\
7020\end{array}$ & $\begin{array}{l}\text { e22700 } \\
\text { e21900 } \\
\text { e1 } 8000 \\
\text { e1 } 4100 \\
\text { e1 } 0700\end{array}$ & $\begin{array}{l}\text { e } 820 \\
\text { e } 780 \\
1030 \\
1410 \\
2600\end{array}$ & $\begin{array}{l}1390 \\
1720 \\
3100 \\
2430 \\
2310\end{array}$ & $\begin{array}{l}1820 \\
1500 \\
1190 \\
1150 \\
1900\end{array}$ & $\begin{array}{l}1980 \\
1730 \\
1480 \\
1380 \\
1400\end{array}$ & $\begin{array}{r}13900 \\
9070 \\
7500 \\
5660 \\
3110\end{array}$ & $\begin{array}{l}325 \\
756 \\
699 \\
696 \\
658\end{array}$ & $\begin{array}{l}162 \\
126 \\
133 \\
135 \\
133\end{array}$ & $\begin{array}{l}\text { el } 90 \\
\text { el } 60 \\
\text { el } 25 \\
\text { el } 30 \\
\text { e1 } 35\end{array}$ \\
\hline $\begin{array}{r}6 \\
7 \\
8 \\
9 \\
10\end{array}$ & $\begin{array}{r}1530 \\
809 \\
1330 \\
1950 \\
7590\end{array}$ & $\begin{array}{l}3970 \\
4390 \\
3220 \\
2820 \\
2550\end{array}$ & $\begin{array}{l}4660 \\
3720 \\
3190 \\
2890 \\
2280\end{array}$ & $\begin{array}{r}\text { e } 7400 \\
\text { e } 5100 \\
3510 \\
2610 \\
2220\end{array}$ & $\begin{array}{l}3840 \\
3770 \\
3760 \\
3660 \\
3250\end{array}$ & $\begin{array}{l}2080 \\
1860 \\
1680 \\
1430 \\
1360\end{array}$ & $\begin{array}{l}2040 \\
1610 \\
1410 \\
2240 \\
1920\end{array}$ & $\begin{array}{l}1440 \\
1300 \\
1220 \\
1170 \\
1110\end{array}$ & $\begin{array}{r}1790 \\
1430 \\
1110 \\
838 \\
789\end{array}$ & $\begin{array}{l}548 \\
459 \\
456 \\
372 \\
298\end{array}$ & $\begin{array}{l}169 \\
174 \\
282 \\
374 \\
318\end{array}$ & $\begin{array}{l}\text { e } 135 \\
\text { el } 35 \\
\text { el } 35 \\
\text { e } 130 \\
\text { e } 130\end{array}$ \\
\hline $\begin{array}{l}11 \\
12 \\
13 \\
14 \\
15\end{array}$ & $\begin{array}{r}10400 \\
9830 \\
7070 \\
5650 \\
4840\end{array}$ & $\begin{array}{l}2250 \\
1710 \\
1240 \\
1080 \\
1090\end{array}$ & $\begin{array}{l}1680 \\
1570 \\
1390 \\
1200 \\
1670\end{array}$ & $\begin{array}{l}1950 \\
2370 \\
2530 \\
2260 \\
2650\end{array}$ & $\begin{array}{r}2710 \\
2180 \\
1720 \\
\mathrm{e} 1300 \\
\mathrm{e} 1060\end{array}$ & $\begin{array}{r}1200 \\
1090 \\
1090 \\
1040 \\
997\end{array}$ & $\begin{array}{l}1700 \\
1500 \\
1320 \\
1820 \\
5560\end{array}$ & $\begin{array}{r}1040 \\
951 \\
1020 \\
960 \\
893\end{array}$ & $\begin{array}{l}843 \\
647 \\
560 \\
587 \\
552\end{array}$ & $\begin{array}{l}249 \\
221 \\
245 \\
241 \\
220\end{array}$ & $\begin{array}{l}253 \\
204 \\
164 \\
159 \\
166\end{array}$ & $\begin{array}{l}\text { e } 130 \\
\text { e2 } 10 \\
\text { e } 330 \\
\text { e2 } 10 \\
\text { e } 140\end{array}$ \\
\hline $\begin{array}{l}16 \\
17 \\
18 \\
19 \\
20\end{array}$ & $\begin{array}{l}4020 \\
3390 \\
3190 \\
3010 \\
2380\end{array}$ & $\begin{array}{l}909 \\
813 \\
813 \\
775 \\
724\end{array}$ & $\begin{array}{l}3000 \\
2720 \\
2900 \\
4750 \\
4650\end{array}$ & $\begin{array}{l}5410 \\
7740 \\
6370 \\
4820 \\
3950\end{array}$ & $\begin{array}{r}\text { e950 } \\
\text { e900 } \\
\text { e } 1060 \\
3640 \\
6980\end{array}$ & $\begin{array}{l}1160 \\
1240 \\
2030 \\
2430 \\
1790\end{array}$ & $\begin{array}{r}5850 \\
4980 \\
5540 \\
5450 \\
10500\end{array}$ & $\begin{array}{l}968 \\
974 \\
786 \\
744 \\
831\end{array}$ & $\begin{array}{l}606 \\
553 \\
446 \\
407 \\
362\end{array}$ & $\begin{array}{l}199 \\
178 \\
165 \\
169 \\
169\end{array}$ & $\begin{array}{l}142 \\
151 \\
194 \\
402 \\
567\end{array}$ & $\begin{array}{l}\text { e } 120 \\
\text { e } 125 \\
\text { e } 130 \\
\text { e } 125 \\
\text { e } 120\end{array}$ \\
\hline $\begin{array}{l}21 \\
22 \\
23 \\
24 \\
25\end{array}$ & $\begin{array}{l}1900 \\
1920 \\
1350 \\
1530 \\
1370\end{array}$ & $\begin{array}{l}657 \\
759 \\
756 \\
772 \\
716\end{array}$ & $\begin{array}{r}5150 \\
8380 \\
\text { e } 7000 \\
\text { e } 5600 \\
\text { e } 4500\end{array}$ & $\begin{array}{l}\text { e } 3000 \\
\text { e } 2300 \\
\text { e } 1900 \\
\text { e } 1600 \\
\text { e } 1400\end{array}$ & $\begin{array}{l}5700 \\
4920 \\
4610 \\
3860 \\
2960\end{array}$ & $\begin{array}{l}1640 \\
1580 \\
2070 \\
2320 \\
1820\end{array}$ & $\begin{array}{r}11000 \\
8630 \\
7370 \\
7980 \\
7390\end{array}$ & $\begin{array}{l}792 \\
584 \\
500 \\
676 \\
772\end{array}$ & $\begin{array}{l}325 \\
318 \\
311 \\
450 \\
390\end{array}$ & $\begin{array}{l}159 \\
171 \\
176 \\
251 \\
269\end{array}$ & $\begin{array}{l}986 \\
720 \\
509 \\
594 \\
282\end{array}$ & $\begin{array}{l}\text { el 115 } \\
\text { el } 122 \\
\text { el15 } \\
\text { el } 108 \\
\text { el } 110\end{array}$ \\
\hline $\begin{array}{l}26 \\
27 \\
28 \\
29 \\
30 \\
31\end{array}$ & $\begin{array}{r}712 \\
946 \\
1050 \\
821 \\
717 \\
722\end{array}$ & $\begin{array}{r}792 \\
957 \\
2090 \\
3570 \\
2880 \\
\ldots \ldots\end{array}$ & $\begin{array}{r}\text { e3700 } \\
\text { e3300 } \\
\text { e2900 } \\
6980 \\
\text { e1 } 8000 \\
\text { e21300 }\end{array}$ & $\begin{array}{r}\text { e } 1250 \\
\text { e1150 } \\
\text { e } 1080 \\
\text { e } 980 \\
\text { e } 930 \\
\text { e } 860\end{array}$ & $\begin{array}{c}2270 \\
1710 \\
1510 \\
\ldots \\
\ldots \\
\ldots\end{array}$ & $\begin{array}{l}1910 \\
2950 \\
3110 \\
3120 \\
2560 \\
2120\end{array}$ & $\begin{array}{c}5200 \\
3890 \\
3190 \\
2670 \\
2160 \\
\ldots\end{array}$ & $\begin{array}{r}1420 \\
1450 \\
1140 \\
905 \\
1680 \\
12000\end{array}$ & $\begin{array}{r}240 \\
178 \\
80 \\
96 \\
190 \\
\cdots\end{array}$ & $\begin{array}{l}210 \\
176 \\
155 \\
147 \\
144 \\
211\end{array}$ & $\begin{array}{l}161 \\
\text { e150 } \\
\text { e180 } \\
\text { e200 } \\
\text { e225 } \\
\text { e210 }\end{array}$ & $\begin{array}{l}\text { e } 108 \\
\text { e1 } 06 \\
\text { e } 104 \\
\text { e1 } 02 \\
\text { e1 } 00 \\
\ldots-\end{array}$ \\
\hline $\begin{array}{l}\text { TOTAL } \\
\text { MEAN } \\
\text { MAX } \\
\text { MI N } \\
\text { CFSM } \\
\text { IN. }\end{array}$ & $\begin{array}{r}83596 \\
2697 \\
10400 \\
186 \\
1.37 \\
1.58\end{array}$ & $\begin{array}{r}46534 \\
1551 \\
4390 \\
576 \\
.79 \\
.88\end{array}$ & $\begin{array}{r}152710 \\
4926 \\
21300 \\
1200 \\
2.50 \\
2.89\end{array}$ & $\begin{array}{r}164740 \\
5314 \\
22700 \\
860 \\
2.70 \\
3.12\end{array}$ & $\begin{array}{r}75020 \\
2679 \\
6980 \\
780 \\
1.36 \\
1.42\end{array}$ & $\begin{array}{r}58627 \\
1891 \\
3120 \\
997 \\
.96 \\
1.11\end{array}$ & $\begin{array}{r}120480 \\
4016 \\
11000 \\
1150 \\
2.04 \\
2.28\end{array}$ & $\begin{array}{r}45296 \\
1461 \\
12000 \\
500 \\
.74 \\
.86\end{array}$ & $\begin{array}{r}53338 \\
1778 \\
13900 \\
80 \\
.90 \\
1.01\end{array}$ & $\begin{array}{c}9392 \\
303 \\
756 \\
144 \\
.15 \\
.18\end{array}$ & $\begin{array}{c}8625 \\
278 \\
986 \\
126 \\
.14 \\
.16\end{array}$ & $\begin{array}{l}4125 \\
137 \\
330 \\
100 \\
.07 \\
.08\end{array}$ \\
\hline
\end{tabular}

STATISTICS OF MONTHLY MEAN DATA FOR WATER YEARS 1957 - 1991, BY WATER YEAR (WY)

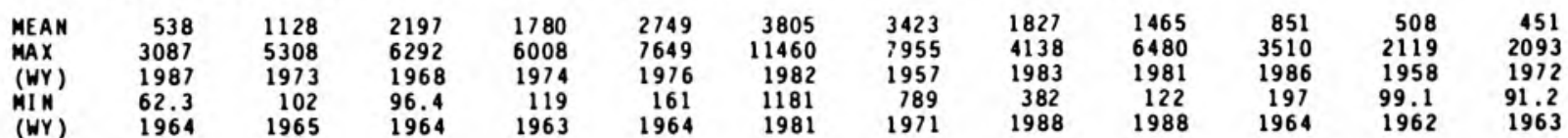

\section{SUMMARY STATISTICS}

AMNUAL TOTAL

AHNUAL MEAM

LOWEST AMNUAL MEAN

HIGHEST DAILY MEAN

LOWEST DAILY MEAN

ANMUAL SEVEN-DAY MINIMUM

INSTANTAMEOUS PEAK FLOW

INSTANTANEOUS PEAK STAGE

ANMUAL RUNOFF (CFSM)

ANNUAL RUNOFF (INCHES)

10 PERCENT EXCEEDS

50 PERCENT EXCEEDS

90 PERCENT EXCEEDS

e Estinated

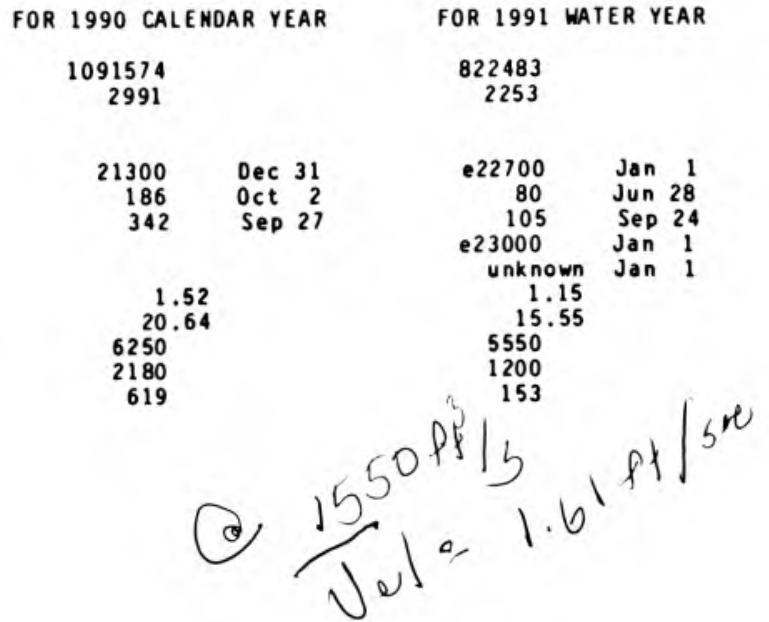

WATER YEARS 1957 - 1991
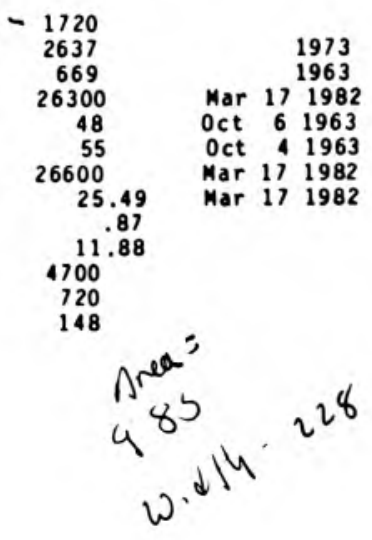


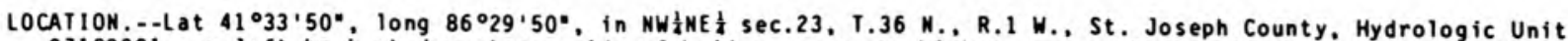
07120001 , on left bank at downstrean side of bridge on county highway naeed "New Road". 2.7 . 1 upstreas fro

Little Kankakee River, 4 ai northwest gf North Liberty, and at aile 126.9 .

DRAINAGE AREA..-174 $i^{2}$, of which 58.2 is does not contribute directly to surface runoff.

PERIOD OF RECORD..-January 1951 to current year.

REVISED RECORDS.--WSP 1915: 1952, 1956-59. WSP 2115: Drainage area.

GAGE.--Water-stage recorder. Datue of gage is $680.04 \mathrm{ft}$ above National Geodetic Vertical Datue of 1929 (levels by State of Indiana, Departaent of Natural Resources). Prior to June 26, 1956, nonrecording gage at saee site and

REMARKS.--Records good below $300 \mathrm{ft} / \mathrm{s}$ and poor above.

DISCHARGE, CUBIC FEET PER SECOND, WATER YEAR OCTOBER 1990 TO SEPTEMBER 1991 DAILY MEAN VALUES

\begin{tabular}{|c|c|c|c|c|c|c|c|c|c|c|c|c|}
\hline DAY & $\mathrm{OCT}$ & HOV & DEC & JAK & FEB & MAR & APR & MAY & JUN & JUL & AUG & SEP \\
\hline $\begin{array}{l}1 \\
2 \\
3 \\
4 \\
5\end{array}$ & $\begin{array}{l}143 \\
139 \\
141 \\
337 \\
323\end{array}$ & $\begin{array}{l}236 \\
232 \\
227 \\
225 \\
371\end{array}$ & $\begin{array}{l}\text { e } 490 \\
\text { e } 470 \\
\text { e } 450 \\
\text { e } 430 \\
\text { e } 400\end{array}$ & $\begin{array}{l}e 540 \\
e 530 \\
e 510 \\
e 500 \\
e 470\end{array}$ & $\begin{array}{l}243 \\
242 \\
248 \\
277 \\
333\end{array}$ & $\begin{array}{l}276 \\
328 \\
352 \\
325 \\
304\end{array}$ & $\begin{array}{l}247 \\
239 \\
231 \\
230 \\
244\end{array}$ & $\begin{array}{l}292 \\
285 \\
266 \\
257 \\
256\end{array}$ & $\begin{array}{l}352 \\
310 \\
255 \\
232 \\
220\end{array}$ & $\begin{array}{l}155 \\
135 \\
123 \\
119 \\
126\end{array}$ & $\begin{array}{l}68 \\
73 \\
82 \\
83 \\
67\end{array}$ & $\begin{array}{r}95 \\
93 \\
99 \\
114 \\
107\end{array}$ \\
\hline $\begin{array}{r}6 \\
7 \\
8 \\
9 \\
10\end{array}$ & $\begin{array}{r}264 \\
235 \\
220 \\
348 \\
\mathrm{e} 400\end{array}$ & $\begin{array}{r}\text { e430 } \\
\text { e460 } \\
\text { e420 } \\
\text { e370 } \\
358\end{array}$ & $\begin{array}{l}\text { e } 370 \\
\text { e } 360 \\
\text { e } 350 \\
\text { e } 330 \\
\text { e } 320\end{array}$ & $\begin{array}{r}e 450 \\
e 410 \\
\text { e380 } \\
\text { e360 } \\
351\end{array}$ & $\begin{array}{l}344 \\
336 \\
323 \\
317 \\
305\end{array}$ & $\begin{array}{l}297 \\
281 \\
267 \\
261 \\
256\end{array}$ & $\begin{array}{l}237 \\
230 \\
227 \\
225 \\
225\end{array}$ & $\begin{array}{l}261 \\
249 \\
239 \\
231 \\
226\end{array}$ & $\begin{array}{l}212 \\
206 \\
200 \\
197 \\
195\end{array}$ & $\begin{array}{l}120 \\
124 \\
133 \\
124 \\
113\end{array}$ & $\begin{array}{r}66 \\
68 \\
133 \\
149 \\
120\end{array}$ & $\begin{array}{r}102 \\
99 \\
96 \\
93 \\
94\end{array}$ \\
\hline $\begin{array}{l}11 \\
12 \\
13 \\
14 \\
15\end{array}$ & $\begin{array}{l}\text { e500 } \\
\text { e520 } \\
\text { e } 520 \\
\text { e } 510 \\
\text { e } 490\end{array}$ & $\begin{array}{l}326 \\
304 \\
286 \\
276 \\
267\end{array}$ & $\begin{array}{r}\mathrm{e} 310 \\
\mathrm{e} 300 \\
\mathrm{e} 295 \\
291 \\
307\end{array}$ & $\begin{array}{l}345 \\
347 \\
334 \\
326 \\
316\end{array}$ & $\begin{array}{l}289 \\
271 \\
269 \\
281 \\
236\end{array}$ & $\begin{array}{l}254 \\
246 \\
247 \\
243 \\
247\end{array}$ & $\begin{array}{r}218 \\
213 \\
213 \\
221 \\
\mathrm{e} 340\end{array}$ & $\begin{array}{l}220 \\
217 \\
214 \\
211 \\
207\end{array}$ & $\begin{array}{l}195 \\
196 \\
189 \\
180 \\
180\end{array}$ & $\begin{array}{l}106 \\
110 \\
109 \\
105 \\
100\end{array}$ & $\begin{array}{l}112 \\
107 \\
107 \\
119 \\
109\end{array}$ & $\begin{array}{r}94 \\
105 \\
120 \\
116 \\
115\end{array}$ \\
\hline $\begin{array}{l}16 \\
17 \\
18 \\
19 \\
20\end{array}$ & $\begin{array}{l}\text { e } 470 \\
\text { e } 440 \\
\text { e } 420 \\
\text { e } 380 \\
\text { e } 360\end{array}$ & $\begin{array}{l}259 \\
250 \\
244 \\
239 \\
233\end{array}$ & $\begin{array}{l}312 \\
300 \\
306 \\
297 \\
285\end{array}$ & $\begin{array}{r}356 \\
439 \\
419 \\
386 \\
\mathrm{e} 370\end{array}$ & $\begin{array}{r}252 \\
253 \\
258 \\
360 \\
\mathrm{e} 370\end{array}$ & $\begin{array}{l}243 \\
244 \\
297 \\
293 \\
271\end{array}$ & $\begin{array}{l}\text { e } 470 \\
\text { e } 490 \\
\text { e } 480 \\
\text { e } 430 \\
\text { e390 }\end{array}$ & $\begin{array}{l}204 \\
214 \\
212 \\
208 \\
203\end{array}$ & $\begin{array}{l}182 \\
171 \\
165 \\
165 \\
162\end{array}$ & $\begin{array}{l}93 \\
92 \\
86 \\
83 \\
83\end{array}$ & $\begin{array}{l}102 \\
104 \\
103 \\
108 \\
123\end{array}$ & $\begin{array}{l}109 \\
107 \\
106 \\
104 \\
104\end{array}$ \\
\hline $\begin{array}{l}21 \\
22 \\
23 \\
24 \\
25\end{array}$ & $\begin{array}{r}\text { 340 } \\
320 \\
306 \\
295 \\
283\end{array}$ & $\begin{array}{l}232 \\
233 \\
232 \\
228 \\
222\end{array}$ & $\begin{array}{l}284 \\
311 \\
307 \\
290 \\
277\end{array}$ & $\begin{array}{r}e 350 \\
\text { e340 } \\
e 330 \\
320 \\
299\end{array}$ & $\begin{array}{r}e 370 \\
\text { e360 } \\
e 340 \\
330 \\
307\end{array}$ & $\begin{array}{l}259 \\
248 \\
257 \\
264 \\
247\end{array}$ & $\begin{array}{l}377 \\
342 \\
317 \\
381 \\
367\end{array}$ & $\begin{array}{l}200 \\
197 \\
198 \\
249 \\
244\end{array}$ & $\begin{array}{l}159 \\
158 \\
155 \\
153 \\
146\end{array}$ & $\begin{array}{l}84 \\
98 \\
90 \\
75 \\
75\end{array}$ & $\begin{array}{r}114 \\
108 \\
103 \\
100 \\
96\end{array}$ & $\begin{array}{l}104 \\
107 \\
111 \\
112 \\
112\end{array}$ \\
\hline $\begin{array}{l}26 \\
27 \\
28 \\
29 \\
30 \\
31\end{array}$ & $\begin{array}{l}269 \\
263 \\
255 \\
248 \\
245 \\
238\end{array}$ & $\begin{array}{r}215 \\
311 \\
\text { e400 } \\
\text { e500 } \\
e 510 \\
-.-\end{array}$ & $\begin{array}{r}264 \\
257 \\
255 \\
e 370 \\
e 450 \\
e 540\end{array}$ & $\begin{array}{l}287 \\
279 \\
268 \\
259 \\
255 \\
250\end{array}$ & $\begin{array}{l}291 \\
280 \\
271 \\
\ldots \\
\ldots . \\
\ldots\end{array}$ & $\begin{array}{l}253 \\
287 \\
307 \\
283 \\
264 \\
253\end{array}$ & $\begin{array}{l}329 \\
309 \\
314 \\
306 \\
300 \\
\ldots\end{array}$ & $\begin{array}{l}346 \\
325 \\
270 \\
245 \\
233 \\
280\end{array}$ & $\begin{array}{l}140 \\
131 \\
130 \\
128 \\
134 \\
\ldots-\end{array}$ & $\begin{array}{l}71 \\
72 \\
82 \\
74 \\
64 \\
65\end{array}$ & $\begin{array}{r}93 \\
89 \\
87 \\
89 \\
96 \\
101\end{array}$ & $\begin{array}{l}109 \\
107 \\
105 \\
104 \\
104 \\
-\end{array}$ \\
\hline $\begin{array}{l}\text { TOTAL } \\
\text { MEAN } \\
\text { MAX } \\
\text { MIN } \\
\text { CFSM } \\
\text { IN. }\end{array}$ & $\begin{array}{r}10222 \\
330 \\
520 \\
139 \\
1.90 \\
2.19\end{array}$ & $\begin{array}{r}9096 \\
303 \\
510 \\
215 \\
1.74 \\
1.94\end{array}$ & $\begin{array}{r}10578 \\
341 \\
540 \\
255 \\
1.96 \\
2.26\end{array}$ & $\begin{array}{r}11376 \\
367 \\
540 \\
250 \\
2.11 \\
2.43\end{array}$ & $\begin{array}{r}8356 \\
298 \\
370 \\
236 \\
1.72 \\
1.79\end{array}$ & $\begin{array}{r}8454 \\
273 \\
352 \\
243 \\
1.57 \\
1.81\end{array}$ & $\begin{array}{r}9142 \\
305 \\
490 \\
213 \\
1.75 \\
1.95\end{array}$ & $\begin{array}{c}7459 \\
241 \\
346 \\
197 \\
1.38 \\
1.59\end{array}$ & $\begin{array}{c}5598 \\
187 \\
352 \\
128 \\
1.07 \\
1.20\end{array}$ & $\begin{array}{c}3089 \\
99.6 \\
155 \\
64 \\
.57 \\
.66\end{array}$ & $\begin{array}{r}3079 \\
99.3 \\
149 \\
66 \\
.57 \\
.66\end{array}$ & $\begin{array}{r}3147 \\
105 \\
120 \\
93 \\
.60 \\
.67\end{array}$ \\
\hline
\end{tabular}

STATISTICS OF MONTHLY MEAN DATA FOR WATER YEARS 1951 - 1991, BY WATER YEAR (WY)

\begin{tabular}{|c|c|c|c|c|c|c|c|c|c|c|c|c|}
\hline $\begin{array}{l}\text { MEAN } \\
\text { MAX } \\
\text { (WY) } \\
\text { MIN } \\
\text { (WY) }\end{array}$ & $\begin{array}{r}132 \\
330 \\
1991 \\
70.1 \\
1954\end{array}$ & $\begin{array}{r}149 \\
303 \\
1991 \\
67.3 \\
1965\end{array}$ & $\begin{array}{r}168 \\
341 \\
1991 \\
77.5 \\
1961\end{array}$ & $\begin{array}{r}163 \\
367 \\
1991 \\
78.0 \\
1961\end{array}$ & $\begin{array}{r}176 \\
298 \\
1991 \\
76.3 \\
1963\end{array}$ & $\begin{array}{r}224 \\
471 \\
1982 \\
112 \\
1957\end{array}$ & $\begin{array}{r}216 \\
310 \\
1985 \\
112 \\
1987\end{array}$ & $\begin{array}{c}179 \\
327 \\
1983 \\
98.4 \\
1958\end{array}$ & $\begin{array}{r}149 \\
298 \\
1981 \\
84.0 \\
1971\end{array}$ & $\begin{array}{c}118 \\
207 \\
1981 \\
64.2 \\
1971\end{array}$ & $\begin{array}{c}101 \\
218 \\
1990 \\
63.1 \\
1964\end{array}$ & $\begin{array}{c}101 \\
185 \\
1972 \\
64.4 \\
1953\end{array}$ \\
\hline
\end{tabular}

SUMMARY STATISTICS

ANNUAL TOTAL

ANNUAL MEAN

HI GHEST AMNUAL MEAN

LOWEST ANNUAL MEAN

HIGHEST DAILY MEAN

LOWEST DAILY MEAN

ANNUAL SEVEN-DAY MI INIMUM

INSTANTANEOUS PEAK FLOW

INSTANTANEOUS PEAK STAGE

ANNUAL RUNOFF (CFSM)

ANNUAL RUNOFF (INCHES)

10 PERCENT EXCEEDS

50 PERCENT EXCEEDS

90 PERCENT EXCEEDS
FOR 1990 CALENDAR YEAR

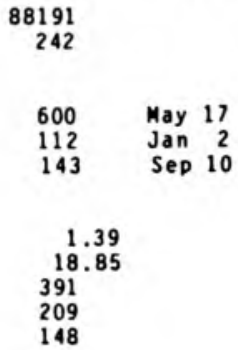

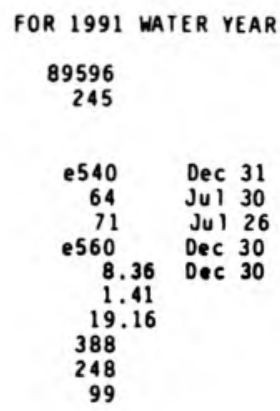

WATER YEARS 1951 - 1991

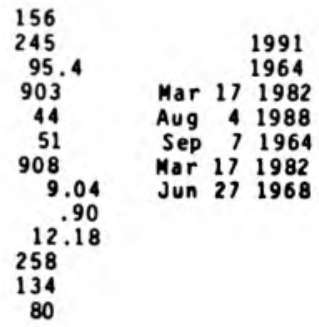




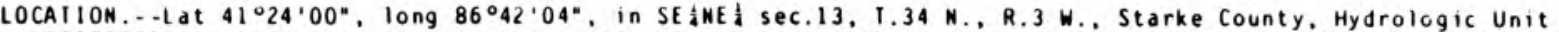
07120001 , on left bank at downstrean side of bridge on U.S. Highway 30 at Davis, 0.5 a downstrea from Mill Creek, 4 i east of Hanna, and at ile 110.9 .

DRAINAGE AREA. . 537 i of which 137 , does not contribute directly to surface runoff.

PERIOD OF RECORD.--July 1905 to July 1906 and 0ctober 1924 to current year. Monthly discharge only for soae periods, published in WSP 1308.

REVISED RECOROS, --WSP 1338: 1953. WSP 2115: Drainage area.

GAGE. - -Water-stage recorder. Datum of gage is $664.68 \mathrm{ft}$ above National Geodetic Vertical Datua of 1929 . July 13 , 1905 , to July 21, 1906, nonrecording gage at site $50 \mathrm{ft}$ downstrea at different datua. July 28 , 1925 , to May 18, 1929. nonrecording gage on bridge 0.5 i downstrea at different datua. Apr. 19, 1931. to Mov. 3, 1953, nonrecording gage at present site and datue.

REMARKS. - - Records good.

DISCHARGE, CUBIC FEET PER SECOND, WATER YEAR OCTOBER 1990 TO SEPTEMBER 1991 DAI IY MEAN VALUES

\begin{tabular}{|c|c|c|c|c|c|c|c|c|c|c|c|c|}
\hline DAY & $O C T$ & NOV & DEC & JAN & FEB & MAR & APR & MAY & JUN & JUL & AUG & SEP \\
\hline $\begin{array}{l}1 \\
2 \\
3 \\
4 \\
5\end{array}$ & $\begin{array}{l}524 \\
515 \\
519 \\
814 \\
959\end{array}$ & $\begin{array}{l}798 \\
776 \\
751 \\
744 \\
971\end{array}$ & $\begin{array}{l}1520 \\
1490 \\
1450 \\
1410 \\
1370\end{array}$ & $\begin{array}{l}1510 \\
1570 \\
1560 \\
1540 \\
1520\end{array}$ & $\begin{array}{r}862 \\
839 \\
851 \\
916 \\
1020\end{array}$ & $\begin{array}{r}938 \\
1020 \\
1090 \\
1060 \\
1020\end{array}$ & $\begin{array}{l}850 \\
818 \\
785 \\
764 \\
793\end{array}$ & $\begin{array}{l}990 \\
973 \\
927 \\
881 \\
864\end{array}$ & $\begin{array}{r}1200 \\
1220 \\
1090 \\
971 \\
871\end{array}$ & $\begin{array}{l}403 \\
405 \\
375 \\
366 \\
369\end{array}$ & $\begin{array}{l}261 \\
259 \\
272 \\
281 \\
273\end{array}$ & $\begin{array}{l}371 \\
334 \\
332 \\
386 \\
362\end{array}$ \\
\hline $\begin{array}{r}6 \\
7 \\
8 \\
9 \\
10\end{array}$ & $\begin{array}{r}882 \\
791 \\
744 \\
965 \\
1440\end{array}$ & $\begin{array}{l}1370 \\
1390 \\
1350 \\
1280 \\
1210\end{array}$ & $\begin{array}{l}1330 \\
1280 \\
1240 \\
1200 \\
1160\end{array}$ & $\begin{array}{l}1490 \\
1460 \\
1420 \\
1380 \\
1340\end{array}$ & $\begin{array}{l}1060 \\
1070 \\
1050 \\
1050 \\
1030\end{array}$ & $\begin{array}{l}994 \\
966 \\
928 \\
904 \\
881\end{array}$ & $\begin{array}{l}792 \\
767 \\
755 \\
749 \\
743\end{array}$ & $\begin{array}{l}888 \\
858 \\
813 \\
770 \\
745\end{array}$ & $\begin{array}{l}795 \\
736 \\
695 \\
659 \\
636\end{array}$ & $\begin{array}{l}363 \\
359 \\
557 \\
539 \\
469\end{array}$ & $\begin{array}{l}263 \\
258 \\
318 \\
427 \\
381\end{array}$ & $\begin{array}{l}337 \\
323 \\
312 \\
305 \\
303\end{array}$ \\
\hline $\begin{array}{l}11 \\
12 \\
13 \\
14 \\
15\end{array}$ & $\begin{array}{l}1570 \\
1580 \\
1560 \\
1530 \\
1500\end{array}$ & $\begin{array}{r}1140 \\
1080 \\
1020 \\
970 \\
934\end{array}$ & $\begin{array}{l}1130 \\
1090 \\
1060 \\
1020 \\
1020\end{array}$ & $\begin{array}{l}1300 \\
1280 \\
1250 \\
1220 \\
1190\end{array}$ & $\begin{array}{r}1000 \\
970 \\
954 \\
958 \\
918\end{array}$ & $\begin{array}{l}857 \\
838 \\
837 \\
828 \\
839\end{array}$ & $\begin{array}{l}724 \\
699 \\
684 \\
719 \\
998\end{array}$ & $\begin{array}{l}717 \\
700 \\
684 \\
672 \\
659\end{array}$ & $\begin{array}{l}633 \\
640 \\
616 \\
591 \\
573\end{array}$ & $\begin{array}{l}423 \\
402 \\
392 \\
375 \\
362\end{array}$ & $\begin{array}{l}346 \\
330 \\
321 \\
319 \\
317\end{array}$ & $\begin{array}{l}299 \\
309 \\
346 \\
342 \\
340\end{array}$ \\
\hline $\begin{array}{l}16 \\
17 \\
18 \\
19 \\
20\end{array}$ & $\begin{array}{l}1470 \\
1420 \\
1410 \\
1380 \\
1320\end{array}$ & $\begin{array}{l}903 \\
854 \\
818 \\
792 \\
771\end{array}$ & $\begin{array}{r}1040 \\
1020 \\
1020 \\
1010 \\
983\end{array}$ & $\begin{array}{l}1210 \\
1270 \\
1270 \\
1260 \\
1250\end{array}$ & $\begin{array}{r}861 \\
867 \\
885 \\
1030 \\
1150\end{array}$ & $\begin{array}{r}856 \\
874 \\
1010 \\
1050 \\
994\end{array}$ & $\begin{array}{l}1350 \\
1460 \\
1480 \\
1440 \\
1380\end{array}$ & $\begin{array}{l}657 \\
721 \\
744 \\
751 \\
703\end{array}$ & $\begin{array}{l}585 \\
558 \\
523 \\
502 \\
492\end{array}$ & $\begin{array}{l}347 \\
331 \\
324 \\
317 \\
312\end{array}$ & $\begin{array}{l}302 \\
300 \\
304 \\
318 \\
392\end{array}$ & $\begin{array}{l}330 \\
320 \\
314 \\
313 \\
311\end{array}$ \\
\hline $\begin{array}{l}21 \\
22 \\
23 \\
24 \\
25\end{array}$ & $\begin{array}{l}1260 \\
1200 \\
1140 \\
1090 \\
1050\end{array}$ & $\begin{array}{l}749 \\
754 \\
751 \\
733 \\
713\end{array}$ & $\begin{array}{r}970 \\
1020 \\
1020 \\
980 \\
943\end{array}$ & $\begin{array}{l}1240 \\
1220 \\
1180 \\
1150 \\
1090\end{array}$ & $\begin{array}{l}1150 \\
1150 \\
1110 \\
1070 \\
1030\end{array}$ & $\begin{array}{l}946 \\
915 \\
909 \\
988 \\
953\end{array}$ & $\begin{array}{l}1300 \\
1240 \\
1170 \\
1160 \\
1150\end{array}$ & $\begin{array}{l}667 \\
644 \\
641 \\
709 \\
778\end{array}$ & $\begin{array}{l}484 \\
481 \\
474 \\
463 \\
448\end{array}$ & $\begin{array}{l}304 \\
312 \\
322 \\
295 \\
291\end{array}$ & $\begin{array}{l}363 \\
336 \\
319 \\
308 \\
296\end{array}$ & $\begin{array}{l}309 \\
313 \\
330 \\
328 \\
326\end{array}$ \\
\hline $\begin{array}{l}26 \\
27 \\
28 \\
29 \\
30 \\
31\end{array}$ & $\begin{array}{r}1010 \\
969 \\
935 \\
893 \\
849 \\
817\end{array}$ & $\begin{array}{r}691 \\
789 \\
1460 \\
1540 \\
1530 \\
\ldots-\end{array}$ & $\begin{array}{r}912 \\
881 \\
862 \\
1210 \\
1600 \\
1600\end{array}$ & $\begin{array}{r}1050 \\
1020 \\
981 \\
948 \\
926 \\
894\end{array}$ & $\begin{array}{l}986 \\
956 \\
933 \\
\ldots . \\
\ldots \\
\ldots\end{array}$ & $\begin{array}{r}932 \\
983 \\
1010 \\
989 \\
930 \\
884\end{array}$ & $\begin{array}{c}1100 \\
1050 \\
1030 \\
1020 \\
1010 \\
\cdots\end{array}$ & $\begin{array}{r}1110 \\
1170 \\
1070 \\
949 \\
868 \\
971\end{array}$ & $\begin{array}{l}431 \\
423 \\
411 \\
405 \\
401 \\
\ldots\end{array}$ & $\begin{array}{l}284 \\
279 \\
281 \\
281 \\
275 \\
264\end{array}$ & $\begin{array}{l}290 \\
287 \\
279 \\
275 \\
308 \\
415\end{array}$ & $\begin{array}{l}326 \\
319 \\
316 \\
311 \\
312 \\
\ldots\end{array}$ \\
\hline $\begin{array}{l}\text { TOIAL } \\
\text { MEAN } \\
\text { MAX } \\
\text { MIN } \\
\text { CF SM }\end{array}$ & $\begin{array}{r}34106 \\
1100 \\
1580 \\
515 \\
2.05\end{array}$ & $\begin{array}{r}29632 \\
988 \\
1540 \\
691 \\
1.84 \\
2.05\end{array}$ & $\begin{array}{r}35841 \\
1156 \\
1600 \\
862 \\
2.15 \\
2.48\end{array}$ & $\begin{array}{r}39049 \\
1260 \\
1570 \\
894 \\
2.35 \\
2.71\end{array}$ & $\begin{array}{r}21726 \\
990 \\
1150 \\
839 \\
1.84 \\
1.92\end{array}$ & $\begin{array}{r}29223 \\
943 \\
1090 \\
828 \\
1.76 \\
2.02\end{array}$ & $\begin{array}{r}29980 \\
999 \\
1480 \\
684 \\
1.86 \\
2.08\end{array}$ & $\begin{array}{r}25294 \\
816 \\
1170 \\
641 \\
1.52 \\
1.75\end{array}$ & $\begin{array}{c}19007 \\
634 \\
1220 \\
401 \\
1.18 \\
1.32\end{array}$ & $\begin{array}{c}10978 \\
354 \\
557 \\
264 \\
.66 \\
.76\end{array}$ & $\begin{array}{l}9718 \\
313 \\
427 \\
258 \\
.58 \\
.67\end{array}$ & $\begin{array}{c}9179 \\
326 \\
386 \\
299 \\
.61 \\
.68\end{array}$ \\
\hline
\end{tabular}

SIATISTICS OF MONIHLY MEAN DATA FOR WAIER YEARS 1926 - 1991, BY WAIER YEAR (WY)

\begin{tabular}{|c|c|c|c|c|c|c|c|c|c|c|c|c|}
\hline $\begin{array}{l}\text { MEAN } \\
\text { MAX } \\
\text { (WY) } \\
\text { MIN } \\
(W Y)\end{array}$ & $\begin{array}{r}402 \\
1162 \\
1955 \\
198 \\
1964\end{array}$ & $\begin{array}{r}461 \\
988 \\
1991 \\
230 \\
1965\end{array}$ & $\begin{array}{r}514 \\
1190 \\
1928 \\
236 \\
1964\end{array}$ & $\begin{array}{r}531 \\
1260 \\
1991 \\
235 \\
1963\end{array}$ & $\begin{array}{r}577 \\
990 \\
1991 \\
236 \\
1964\end{array}$ & $\begin{array}{r}716 \\
1376 \\
1985 \\
325 \\
1934\end{array}$ & $\begin{array}{r}745 \\
1218 \\
1982 \\
420 \\
1987\end{array}$ & $\begin{array}{c}632 \\
1067 \\
1983 \\
296 \\
1934\end{array}$ & $\begin{array}{r}514 \\
1057 \\
1950 \\
248 \\
1934\end{array}$ & $\begin{array}{r}408 \\
839 \\
1950 \\
205 \\
1934\end{array}$ & $\begin{array}{c}350 \\
791 \\
1990 \\
174 \\
1941\end{array}$ & $\begin{array}{c}341 \\
718 \\
1972 \\
179 \\
1941\end{array}$ \\
\hline
\end{tabular}

SUMMARY SIAIISIICS

ANNUAL TOTAL

ANNUAL MEAN

HIGHESI ANMUAL MEAN

LOWEST ANNUAL MEAN

HIGHEST DAILY MEAN

LOWEST DAILY MEAN

ANMUAL SEVEN-DAY MINIMUM

INSTAMTANEOUS PEAK FLOW

INSTANTANEOUS PEAK STAGE

ANNUAL RUNOFF (CFSM)

ANMUAL RUNOF F (INCHES)

10 PERCENT EXCEEDS

50 PERCENT EXCEEDS

90 PERCENT EXCEEDS
FOR 1990 CALENDAR YEAR

FOR 1991 WATER YEAR

292571

802

$\begin{array}{rrr}1600 & \text { Dec } & 30 \\ 330 & \text { Jan } 2\end{array}$

437 Jan 1

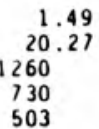

300333

823

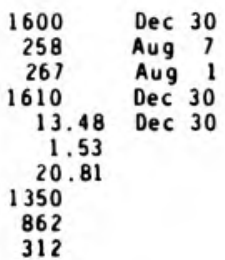

WAIER YEARS $1926-1991$

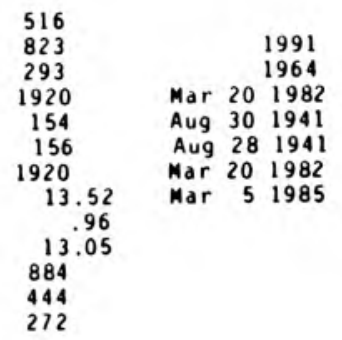




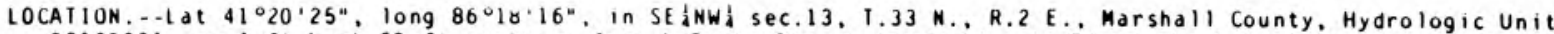

07120001 , on left bank $50 \mathrm{ft}$ upstream from LaPorte Street footbridge in Plymouth, 1.1 i downstream from Elmer Seltenright (formerly Baker) ditch, 8.1 a upstrean from Wolf Creek, and at $\bullet i l e 40.3$.

DRAINAGE AREA. - 294 $i^{2}$, of which $22 \mathrm{~m}^{2}$ does not contribute directly to surface runoff.

PERIOD OF RECORD..-July 1948 to current yedr.

REVISED RECORDS.--WSP 1338: 1950-51. WSP 2i15: Drainage area. WDR IN-73-1: 1972(M).

GAGE. - Water-stage recorder. Datum of gage is $764.78 \mathrm{ft}$ above National Geodetic Vertical Datum of 1929 (levels by State of Indiand, Departaent of Natural Resources). Prior to Aug. 27,1959 , nonrecording gage at same site and datur.

REMARKS. - - Records good except est imated daily discharges, which are fair.

DISCHARGE, CUBIC FEET PER SECOND, WAIER YEAR OCTOBER 1990 TO SEPTEMBER 1991 DAILY MEAN VALUES

\begin{tabular}{|c|c|c|c|c|c|c|c|c|c|c|c|c|}
\hline DAY & $O C \mathrm{~T}$ & HOV & DEC & JAN & FEB & MAR & APR & MAY & JUN & JUL & AUG & SEP \\
\hline $\begin{array}{l}1 \\
2 \\
3 \\
4 \\
5\end{array}$ & $\begin{array}{l}124 \\
118 \\
117 \\
340 \\
639\end{array}$ & $\begin{array}{l}200 \\
193 \\
188 \\
184 \\
483\end{array}$ & $\begin{array}{r}1070 \\
704 \\
570 \\
793 \\
791\end{array}$ & $\begin{array}{l}3830 \\
3430 \\
2750 \\
2140 \\
1490\end{array}$ & $\begin{array}{l}207 \\
210 \\
225 \\
356 \\
553\end{array}$ & $\begin{array}{l}281 \\
572 \\
916 \\
861 \\
584\end{array}$ & $\begin{array}{l}296 \\
262 \\
240 \\
238 \\
276\end{array}$ & $\begin{array}{l}390 \\
352 \\
307 \\
275 \\
311\end{array}$ & $\begin{array}{r}1450 \\
\text { e1 } 1920 \\
\text { e } 1770 \\
\text { e } 1260 \\
\text { e } 722\end{array}$ & $\begin{array}{r}240 \\
247 \\
134 \\
104 \\
89\end{array}$ & $\begin{array}{l}48 \\
46 \\
62 \\
56 \\
50\end{array}$ & $\begin{array}{l}55 \\
51 \\
53 \\
54 \\
59\end{array}$ \\
\hline $\begin{array}{r}6 \\
7 \\
8 \\
9 \\
10\end{array}$ & $\begin{array}{r}391 \\
235 \\
203 \\
662 \\
1530\end{array}$ & $\begin{array}{r}1120 \\
1580 \\
1510 \\
1110 \\
748\end{array}$ & $\begin{array}{l}603 \\
516 \\
461 \\
399 \\
375\end{array}$ & $\begin{array}{r}1030 \\
725 \\
567 \\
479 \\
413\end{array}$ & $\begin{array}{l}616 \\
552 \\
479 \\
469 \\
439\end{array}$ & $\begin{array}{l}457 \\
402 \\
329 \\
297 \\
275\end{array}$ & $\begin{array}{l}283 \\
256 \\
238 \\
235 \\
228\end{array}$ & $\begin{array}{l}485 \\
422 \\
314 \\
274 \\
250\end{array}$ & $\begin{array}{l}\text { e } 381 \\
\text { e } 275 \\
\text { e } 235 \\
\text { e } 206 \\
\text { e } 188\end{array}$ & $\begin{array}{r}81 \\
82 \\
163 \\
103 \\
87\end{array}$ & $\begin{array}{l}49 \\
48 \\
76 \\
82 \\
62\end{array}$ & $\begin{array}{l}53 \\
46 \\
42 \\
41 \\
40\end{array}$ \\
\hline $\begin{array}{l}11 \\
12 \\
13 \\
14 \\
15\end{array}$ & $\begin{array}{l}2260 \\
2620 \\
2630 \\
2350 \\
1850\end{array}$ & $\begin{array}{l}503 \\
391 \\
331 \\
300 \\
283\end{array}$ & $\begin{array}{l}342 \\
318 \\
292 \\
254 \\
321\end{array}$ & $\begin{array}{r}\text { e3 } 80 \\
\text { e370 } \\
\text { e360 } \\
\text { e352 } \\
513\end{array}$ & $\begin{array}{r}374 \\
303 \\
\mathrm{e} 270 \\
\mathrm{e} 240 \\
\mathrm{e} 220\end{array}$ & $\begin{array}{l}254 \\
242 \\
230 \\
252 \\
282\end{array}$ & $\begin{array}{l}217 \\
201 \\
196 \\
257 \\
934\end{array}$ & $\begin{array}{l}232 \\
218 \\
207 \\
195 \\
183\end{array}$ & $\begin{array}{l}\text { e } 196 \\
\text { el } 185 \\
\text { e } 169 \\
\text { e } 158 \\
\text { e } 152\end{array}$ & $\begin{array}{l}81 \\
78 \\
75 \\
70 \\
69\end{array}$ & $\begin{array}{l}53 \\
50 \\
50 \\
57 \\
50\end{array}$ & $\begin{array}{l}40 \\
47 \\
54 \\
52 \\
49\end{array}$ \\
\hline $\begin{array}{l}16 \\
17 \\
18 \\
19 \\
20\end{array}$ & $\begin{array}{r}1390 \\
1070 \\
897 \\
934 \\
837\end{array}$ & $\begin{array}{l}265 \\
246 \\
228 \\
220 \\
209\end{array}$ & $\begin{array}{l}523 \\
462 \\
443 \\
463 \\
386\end{array}$ & $\begin{array}{r}757 \\
1190 \\
1360 \\
1070 \\
818\end{array}$ & $\begin{array}{r}190 \\
\mathrm{e} 230 \\
269 \\
639 \\
1020\end{array}$ & $\begin{array}{l}365 \\
422 \\
690 \\
864 \\
685\end{array}$ & $\begin{array}{l}1400 \\
1870 \\
2010 \\
1890 \\
1470\end{array}$ & $\begin{array}{l}182 \\
240 \\
244 \\
239 \\
202\end{array}$ & $\begin{array}{l}\text { e } 211 \\
\text { e1 } 19 \\
\text { e } 156 \\
\text { e1 } 42 \\
\text { e } 131\end{array}$ & $\begin{array}{l}67 \\
62 \\
61 \\
61 \\
61\end{array}$ & $\begin{array}{r}44 \\
42 \\
41 \\
66 \\
120\end{array}$ & $\begin{array}{l}53 \\
62 \\
57 \\
53 \\
51\end{array}$ \\
\hline $\begin{array}{l}21 \\
22 \\
23 \\
24 \\
25\end{array}$ & $\begin{array}{l}635 \\
488 \\
406 \\
351 \\
310\end{array}$ & $\begin{array}{l}204 \\
215 \\
221 \\
212 \\
200\end{array}$ & $\begin{array}{r}368 \\
\text { e } 347 \\
\text { e } 327 \\
\text { e } 311 \\
\text { e } 308\end{array}$ & $\begin{array}{l}805 \\
711 \\
556 \\
426 \\
341\end{array}$ & $\begin{array}{r}1060 \\
915 \\
720 \\
501 \\
390\end{array}$ & $\begin{array}{l}483 \\
390 \\
382 \\
490 \\
468\end{array}$ & $\begin{array}{r}1190 \\
913 \\
684 \\
673 \\
771\end{array}$ & $\begin{array}{l}180 \\
168 \\
221 \\
222 \\
252\end{array}$ & $\begin{array}{l}\text { e124 } \\
\text { e119 } \\
\text { e112 } \\
\text { e108 } \\
106\end{array}$ & $\begin{array}{l}58 \\
59 \\
56 \\
54 \\
53\end{array}$ & $\begin{array}{r}103 \\
70 \\
59 \\
53 \\
52\end{array}$ & $\begin{array}{l}48 \\
48 \\
47 \\
46 \\
45\end{array}$ \\
\hline $\begin{array}{l}26 \\
27 \\
28 \\
29 \\
30 \\
31\end{array}$ & $\begin{array}{l}276 \\
255 \\
239 \\
221 \\
216 \\
207\end{array}$ & $\begin{array}{r}189 \\
228 \\
760 \\
1210 \\
1360 \\
-\cdots\end{array}$ & $\begin{array}{r}e 303 \\
301 \\
302 \\
1040 \\
2420 \\
3330\end{array}$ & $\begin{array}{r}e 300 \\
e 270 \\
e 250 \\
e 240 \\
e 225 \\
211\end{array}$ & $\begin{array}{l}325 \\
289 \\
268 \\
\ldots \\
\ldots \\
\ldots\end{array}$ & $\begin{array}{l}433 \\
628 \\
663 \\
585 \\
399 \\
318\end{array}$ & $\begin{array}{l}635 \\
496 \\
490 \\
514 \\
458 \\
\cdots\end{array}$ & $\begin{array}{l}276 \\
264 \\
213 \\
181 \\
171 \\
659\end{array}$ & $\begin{array}{r}103 \\
102 \\
102 \\
99 \\
98 \\
\ldots-\end{array}$ & $\begin{array}{l}51 \\
50 \\
49 \\
51 \\
54 \\
50\end{array}$ & $\begin{array}{l}51 \\
50 \\
49 \\
47 \\
47 \\
52\end{array}$ & $\begin{array}{r}44 \\
42 \\
41 \\
39 \\
38 \\
-\cdots\end{array}$ \\
\hline $\begin{array}{l}\text { IOIAL } \\
\text { MEAN } \\
\text { MAX } \\
\text { MIN } \\
\text { CF SM } \\
\text { IN. }\end{array}$ & $\begin{array}{r}24801 \\
800 \\
2630 \\
117 \\
2.72 \\
3.14\end{array}$ & $\begin{array}{r}15091 \\
503 \\
1580 \\
184 \\
1.71 \\
1.91\end{array}$ & $\begin{array}{r}19443 \\
627 \\
3330 \\
254 \\
2.13 \\
2.46\end{array}$ & $\begin{array}{r}28359 \\
915 \\
3830 \\
211 \\
3.11 \\
3.59\end{array}$ & $\begin{array}{r}12329 \\
440 \\
1060 \\
190 \\
1.50 \\
1.56\end{array}$ & $\begin{array}{r}14499 \\
468 \\
916 \\
230 \\
1.59 \\
1.83\end{array}$ & $\begin{array}{c}19821 \\
661 \\
2010 \\
196 \\
2.25 \\
2.51\end{array}$ & $\begin{array}{c}8329 \\
269 \\
659 \\
168 \\
.91 \\
1.05\end{array}$ & $\begin{array}{r}11159 \\
372 \\
1920 \\
98 \\
1.27 \\
1.41\end{array}$ & $\begin{array}{c}2600 \\
83.9 \\
247 \\
49 \\
.29 \\
.33\end{array}$ & $\begin{array}{c}1785 \\
57.6 \\
120 \\
41 \\
.20 \\
.23\end{array}$ & $\begin{array}{r}1450 \\
48.3 \\
62 \\
38 \\
.16 \\
.18\end{array}$ \\
\hline
\end{tabular}

e Estinated

SIATISIICS OF MONTHLY MEAN DAIA FOR WAILR YEARS 1949 - 1991, BY WAIER YEAR (WY)

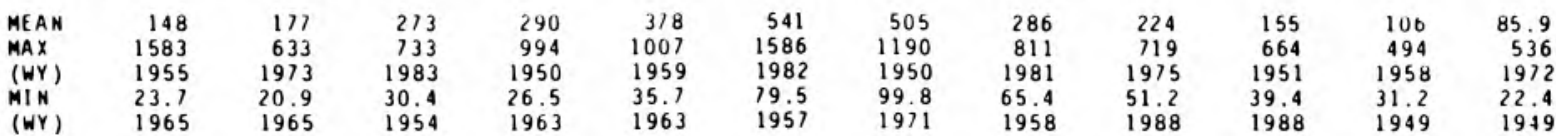

SUMMARY SIAIISIICS

AMNUAL TOIAL

ANNUAL MEAN

HIGHESI ANMUAI MEAN

LOWESI ANNUAL MEAN

HIGHESI DAILY MEAM

LOWEST DALLY MEAN

ANNUAL SEVEN-DAY MINIMUM

INSIAMIANEOUS PEAK FLOW

INSIANIANEOUS PEAK STAGE

ANNUAL RUNOFF (CFSM)

ANNUAL RUNOF F (INCHES)

10 PERCENT EXCEEDS

50 PERCENT EXCEEDS

90 PERCENT EXCEEDS
FOR 1990 CALENUAR YEAR FOR 1991 WAIER YEAR

159666

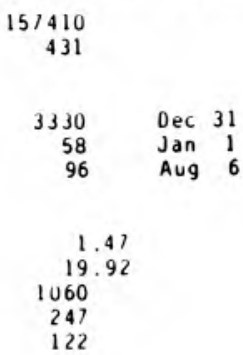

WAIER YEARS 1949 - 1991

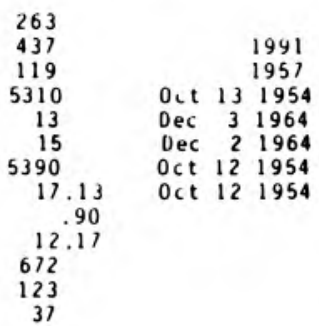


LOCATION. - - Lat $41^{\circ} 18^{\prime} 10^{*}$. Iong $86^{\circ} 37^{\prime} 14^{*}$, in SWtSWl sec.14, T.33 N., R.2 W. Starke County, Hydrologic Unit 07120001 . On right bank $40 \mathrm{ft}$ upstrea froe bridge on U.S. Highway 35 in Knox, 1.4 a downtreas froe Eagle

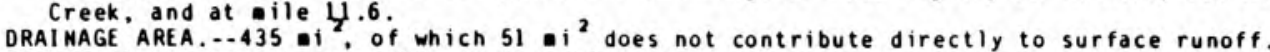

PERIOD OF RECORD.--August 1905 to July 1906 . August 1943 to current year.

REVISED RECORDS.--WSP 1278: 1952. WSP 2115: Drainage area.

GAGE.--Water-stage recorder. Datue of gage is $679.93 \mathrm{ft}$ above National Geodetic Vertical Datue of 1929 (levels by State of Indiana. Departeent of Natural Resources). August 1905 to July 1906, nonrecording gage at saee site at different datue. August 1943 to July 11, 1952, nonrecording gage at sale site and datua.

REMARKS. - - Records good except those for estinated daily discharges, which are poor.

DISCHARGE, CUBIC FEET PER SECOND, WATER YEAR OCTOBER 1990 TO SEPIEMBER 1991 DAILY MEAN VALUES

\begin{tabular}{|c|c|c|c|c|c|c|c|c|c|c|c|c|}
\hline DAY & $\mathrm{OCI}$ & NOV & DEC & JAN & FEB & MAR & APR & MAY & JUM & JUL & AUG & SEP \\
\hline $\begin{array}{l}1 \\
2 \\
3 \\
4 \\
5\end{array}$ & $\begin{array}{l}255 \\
245 \\
233 \\
270 \\
485\end{array}$ & $\begin{array}{l}402 \\
386 \\
373 \\
364 \\
463\end{array}$ & $\begin{array}{r}1420 \\
1330 \\
1020 \\
889 \\
965\end{array}$ & $\begin{array}{l}3130 \\
3660 \\
3730 \\
3000 \\
2680\end{array}$ & $\begin{array}{r}e 410 \\
e 420 \\
e 440 \\
532 \\
715\end{array}$ & $\begin{array}{r}529 \\
643 \\
944 \\
1180 \\
1160\end{array}$ & $\begin{array}{l}593 \\
556 \\
511 \\
489 \\
515\end{array}$ & $\begin{array}{l}768 \\
701 \\
646 \\
597 \\
572\end{array}$ & $\begin{array}{l}1080 \\
1630 \\
2000 \\
2090 \\
1870\end{array}$ & $\begin{array}{l}210 \\
345 \\
332 \\
243 \\
210\end{array}$ & $\begin{array}{l}120 \\
116 \\
120 \\
130 \\
123\end{array}$ & $\begin{array}{l}134 \\
131 \\
127 \\
130 \\
127\end{array}$ \\
\hline $\begin{array}{r}6 \\
7 \\
8 \\
9 \\
10\end{array}$ & $\begin{array}{r}653 \\
491 \\
385 \\
523 \\
1140\end{array}$ & $\begin{array}{r}931 \\
1170 \\
1500 \\
1660 \\
1460\end{array}$ & $\begin{array}{l}993 \\
869 \\
777 \\
716 \\
653\end{array}$ & $\begin{array}{r}2160 \\
\text { e } 1400 \\
\text { e1000 } \\
\text { e } 870 \\
\text { e } 790\end{array}$ & $\begin{array}{l}883 \\
914 \\
854 \\
789 \\
764\end{array}$ & $\begin{array}{l}862 \\
719 \\
638 \\
570 \\
533\end{array}$ & $\begin{array}{l}535 \\
526 \\
498 \\
484 \\
477\end{array}$ & $\begin{array}{l}642 \\
735 \\
666 \\
577 \\
532\end{array}$ & $\begin{array}{r}1280 \\
700 \\
535 \\
466 \\
420\end{array}$ & $\begin{array}{l}194 \\
182 \\
370 \\
431 \\
300\end{array}$ & $\begin{array}{l}119 \\
119 \\
138 \\
182 \\
165\end{array}$ & $\begin{array}{l}129 \\
122 \\
119 \\
119 \\
115\end{array}$ \\
\hline $\begin{array}{l}11 \\
12 \\
13 \\
14 \\
15\end{array}$ & $\begin{array}{l}1680 \\
2070 \\
2400 \\
2530 \\
2400\end{array}$ & $\begin{array}{r}1070 \\
787 \\
649 \\
578 \\
537\end{array}$ & $\begin{array}{l}620 \\
585 \\
559 \\
523 \\
511\end{array}$ & $\begin{array}{r}\text { e) } 30 \\
\text { e710 } \\
\text { e680 } \\
\text { e660 } \\
851\end{array}$ & $\begin{array}{r}712 \\
630 \\
565 \\
\mathrm{e} 500 \\
\mathrm{e} 440\end{array}$ & $\begin{array}{l}502 \\
480 \\
477 \\
468 \\
497\end{array}$ & $\begin{array}{l}461 \\
436 \\
420 \\
444 \\
830\end{array}$ & $\begin{array}{l}500 \\
475 \\
455 \\
444 \\
431\end{array}$ & $\begin{array}{l}395 \\
399 \\
373 \\
348 \\
332\end{array}$ & $\begin{array}{l}250 \\
225 \\
210 \\
196 \\
180\end{array}$ & $\begin{array}{l}143 \\
128 \\
123 \\
124 \\
121\end{array}$ & $\begin{array}{l}110 \\
114 \\
129 \\
138 \\
134\end{array}$ \\
\hline $\begin{array}{l}16 \\
17 \\
18 \\
19 \\
20\end{array}$ & $\begin{array}{l}2100 \\
1740 \\
1450 \\
1220 \\
1130\end{array}$ & $\begin{array}{l}510 \\
482 \\
461 \\
440 \\
422\end{array}$ & $\begin{array}{l}602 \\
718 \\
694 \\
679 \\
672\end{array}$ & $\begin{array}{l}1010 \\
1390 \\
1670 \\
1840 \\
1670\end{array}$ & $\begin{array}{r}\text { e370 } \\
e 450 \\
502 \\
644 \\
979\end{array}$ & $\begin{array}{r}557 \\
645 \\
828 \\
1060 \\
1170\end{array}$ & $\begin{array}{l}1560 \\
1850 \\
2120 \\
2210 \\
2190\end{array}$ & $\begin{array}{l}423 \\
446 \\
506 \\
516 \\
485\end{array}$ & $\begin{array}{l}401 \\
418 \\
350 \\
319 \\
298\end{array}$ & $\begin{array}{l}168 \\
164 \\
159 \\
155 \\
151\end{array}$ & $\begin{array}{l}114 \\
117 \\
118 \\
132 \\
173\end{array}$ & $\begin{array}{l}127 \\
122 \\
130 \\
127 \\
143\end{array}$ \\
\hline $\begin{array}{l}21 \\
22 \\
23 \\
24 \\
25\end{array}$ & $\begin{array}{r}1060 \\
886 \\
748 \\
655 \\
592\end{array}$ & $\begin{array}{l}406 \\
406 \\
417 \\
412 \\
396\end{array}$ & $\begin{array}{l}623 \\
\text { e615 } \\
\text { e600 } \\
\text { e598 } \\
\text { e585 }\end{array}$ & $\begin{array}{l}1350 \\
1220 \\
1080 \\
\text { e820 } \\
\text { e680 }\end{array}$ & $\begin{array}{r}1260 \\
1390 \\
1250 \\
1010 \\
761\end{array}$ & $\begin{array}{l}988 \\
760 \\
704 \\
732 \\
791\end{array}$ & $\begin{array}{l}1980 \\
1750 \\
1460 \\
1160 \\
1050\end{array}$ & $\begin{array}{l}438 \\
407 \\
395 \\
441 \\
459\end{array}$ & $\begin{array}{l}279 \\
265 \\
258 \\
250 \\
241\end{array}$ & $\begin{array}{l}148 \\
147 \\
143 \\
139 \\
137\end{array}$ & $\begin{array}{l}197 \\
187 \\
157 \\
141 \\
132\end{array}$ & $\begin{array}{l}134 \\
129 \\
126 \\
123 \\
123\end{array}$ \\
\hline $\begin{array}{l}26 \\
27 \\
28 \\
29 \\
30 \\
31\end{array}$ & $\begin{array}{l}544 \\
504 \\
471 \\
448 \\
428 \\
416\end{array}$ & $\begin{array}{r}374 \\
384 \\
609 \\
992 \\
1200 \\
\ldots\end{array}$ & $\begin{array}{r}e 580 \\
e 570 \\
e 560 \\
902 \\
1970 \\
2760\end{array}$ & $\begin{array}{l}\text { e600 } \\
\text { e550 } \\
\text { e520 } \\
\text { e } 480 \\
\text { e450 } \\
\text { e430 }\end{array}$ & $\begin{array}{l}641 \\
573 \\
536 \\
\ldots \\
\ldots \\
\ldots\end{array}$ & $\begin{array}{l}764 \\
812 \\
944 \\
951 \\
841 \\
665\end{array}$ & $\begin{array}{r}1080 \\
984 \\
843 \\
808 \\
808 \\
-\cdots\end{array}$ & $\begin{array}{l}530 \\
532 \\
488 \\
424 \\
393 \\
584\end{array}$ & $\begin{array}{l}232 \\
221 \\
215 \\
210 \\
205 \\
\cdots\end{array}$ & $\begin{array}{l}131 \\
129 \\
128 \\
124 \\
122 \\
124\end{array}$ & $\begin{array}{l}132 \\
127 \\
123 \\
121 \\
147 \\
147\end{array}$ & $\begin{array}{l}122 \\
121 \\
118 \\
118 \\
117 \\
\cdots-\end{array}$ \\
\hline $\begin{array}{l}\text { IOIAL } \\
\text { MEAN } \\
\text { MAX } \\
\text { MI N } \\
\text { CF SM } \\
\text { IN. }\end{array}$ & $\begin{array}{r}30152 \\
973 \\
2530 \\
233 \\
2.24 \\
2.58\end{array}$ & $\begin{array}{r}20241 \\
675 \\
1660 \\
364 \\
1.55 \\
1.73\end{array}$ & $\begin{array}{r}26158 \\
844 \\
2760 \\
511 \\
1.94 \\
2.24\end{array}$ & $\begin{array}{r}41811 \\
1349 \\
3730 \\
430 \\
3.10 \\
3.58\end{array}$ & $\begin{array}{r}19934 \\
712 \\
1390 \\
370 \\
1.64 \\
1.70\end{array}$ & $\begin{array}{r}23414 \\
755 \\
1180 \\
468 \\
1.74 \\
2.00\end{array}$ & $\begin{array}{r}29628 \\
988 \\
2210 \\
420 \\
2.27 \\
2.53\end{array}$ & $\begin{array}{c}16208 \\
523 \\
768 \\
393 \\
1.20 \\
1.39\end{array}$ & $\begin{array}{c}18080 \\
603 \\
2090 \\
205 \\
1.39 \\
1.55\end{array}$ & $\begin{array}{c}6147 \\
198 \\
431 \\
122 \\
.46 \\
.53\end{array}$ & $\begin{array}{c}4236 \\
137 \\
197 \\
114 \\
.31 \\
.36\end{array}$ & $\begin{array}{l}3758 \\
125 \\
143 \\
110 \\
.29 \\
.32\end{array}$ \\
\hline
\end{tabular}

e Estinated

SIATISIICS OF MONIHLY MEAN DATA FOR WATER YEARS 1944 - 1991, BY WATER YEAR (WY)

\begin{tabular}{|c|c|c|c|c|c|c|c|c|c|c|c|c|}
\hline $\begin{array}{l}\text { MEAN } \\
\text { MAX } \\
\text { (WY) } \\
\text { MIN } \\
\text { (WY) }\end{array}$ & $\begin{array}{r}254 \\
1939 \\
1955 \\
77.5 \\
1965\end{array}$ & $\begin{array}{r}283 \\
883 \\
1973 \\
83.3 \\
1965\end{array}$ & $\begin{array}{r}389 \\
1070 \\
1967 \\
91.6 \\
1964\end{array}$ & $\begin{array}{r}428 \\
1349 \\
1991 \\
71.3 \\
1963\end{array}$ & $\begin{array}{r}519 \\
1193 \\
1959 \\
107 \\
1963\end{array}$ & $\begin{array}{r}731 \\
2127 \\
1982 \\
194 \\
1957\end{array}$ & $\begin{array}{r}727 \\
1714 \\
1950 \\
243 \\
1958\end{array}$ & $\begin{array}{r}496 \\
1113 \\
1981 \\
169 \\
1958\end{array}$ & $\begin{array}{r}386 \\
1113 \\
1975 \\
146 \\
1988\end{array}$ & $\begin{array}{r}260 \\
737 \\
1951 \\
115 \\
1971\end{array}$ & $\begin{array}{r}202 \\
652 \\
1958 \\
93.6 \\
1964\end{array}$ & $\begin{array}{r}171 \\
692 \\
1972 \\
75.9 \\
1964\end{array}$ \\
\hline
\end{tabular}

SUMMARY STAIISIICS

ANMUAL IOTAL

ANMUAL MEAN

HIGHESI ANMUAL MEAN

LOWEST ANNUAL MEAN

HIGHESI DAILY MEAM

LOWEST DAILY MEAN

ANMUAL SEVEN-DAY MINIMUM

INSTANTANEOUS PEAK FLOW

INSIANIANEOUS PEAK SIAGE

ANNUAL RUNOFF (CFSM)

ANNUAL RUNOFF (INCHES)

10 PERCENT EXCEEDS

50 PERCENT EXCEEDS

90 PERCENT EXCEEDS
FOR 1990 CALENDAR YEAR

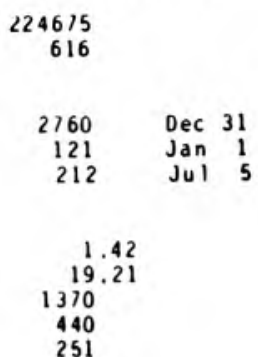

FOR 1991 WATER YEAR

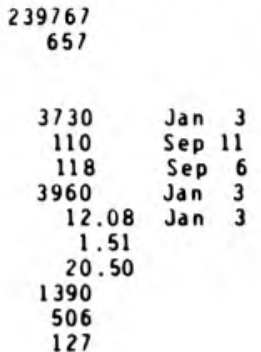

WATER YEARS $1944-1991$

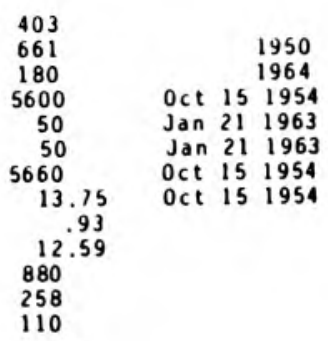




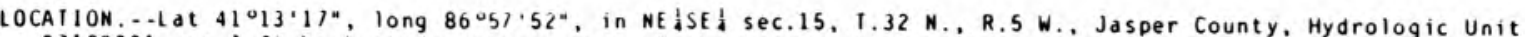
07120001 , on left bank at downstream side of abandoned bridge at Dunns Bridge, $1.8 \mathrm{mi}$ north of Tefft, 3.6 a upstrean from Davis ditch, and at mile 99.8 .

DRAINAGE AREA, - 1,352 $\mathrm{i}^{2}$, of which $192 \mathrm{mi}$ does not contribute directly to surface runoff.

PERIOD OF RECORD...July 1948 to current year.

REVISED RECORDS.--WSP 1728: 1954(n). WSP 2115: Orainage area.

GAGE.--Water-stage recorder. Datun of gage is $649.65 \mathrm{ft}$ above National Geodetic Vertical Datua of 1929 (levels by State of Indiana. Department of Natural Resources). Prior to July 17, 1956, nonrecording gage at same site and

REMARKS. - Records good except for estimated daily discharges, which are fair.

DISCHARGE, CUBIC FEET PER SECOND, WATER YEAR OCTOBER 1990 TO SEPIEMBER 1991 DAILY MEAN VALUES

\begin{tabular}{|c|c|c|c|c|c|c|c|c|c|c|c|c|}
\hline DAY & $\mathrm{OCT}$ & MOV & $\mathrm{DEC}$ & JAN & FEB & MAR & APR & MAY & JUN & JUL & AUG & SEP \\
\hline $\begin{array}{l}1 \\
2 \\
3 \\
4 \\
5\end{array}$ & $\begin{array}{l}1210 \\
1180 \\
1170 \\
1360 \\
1660\end{array}$ & $\begin{array}{l}2110 \\
2010 \\
1910 \\
1830 \\
2020\end{array}$ & $\begin{array}{l}3280 \\
3380 \\
3450 \\
3410 \\
3300\end{array}$ & $\begin{array}{l}4630 \\
4840 \\
4920 \\
4920 \\
4910\end{array}$ & $\begin{array}{l}2440 \\
2370 \\
2340 \\
2390 \\
2530\end{array}$ & $\begin{array}{l}2380 \\
2440 \\
2550 \\
2640 \\
2710\end{array}$ & $\begin{array}{l}2390 \\
2300 \\
2210 \\
2160 \\
2140\end{array}$ & $\begin{array}{l}2760 \\
2670 \\
2560 \\
2440 \\
2350\end{array}$ & $\begin{array}{l}2840 \\
3080 \\
3190 \\
3290 \\
3350\end{array}$ & $\begin{array}{r}947 \\
971 \\
1080 \\
994 \\
929\end{array}$ & $\begin{array}{l}530 \\
509 \\
517 \\
550 \\
551\end{array}$ & $\begin{array}{l}752 \\
677 \\
638 \\
677 \\
688\end{array}$ \\
\hline $\begin{array}{r}6 \\
7 \\
8 \\
9 \\
10\end{array}$ & $\begin{array}{l}1870 \\
1900 \\
1780 \\
1930 \\
2720\end{array}$ & $\begin{array}{l}2580 \\
2870 \\
3040 \\
3180 \\
3280\end{array}$ & $\begin{array}{l}3220 \\
3160 \\
3070 \\
2970 \\
2870\end{array}$ & $\begin{array}{l}4880 \\
4820 \\
4730 \\
4520 \\
4340\end{array}$ & $\begin{array}{l}2660 \\
2760 \\
2790 \\
2780 \\
2770\end{array}$ & $\begin{array}{l}2720 \\
2640 \\
2530 \\
2450 \\
2350\end{array}$ & $\begin{array}{l}2130 \\
2100 \\
2070 \\
2030 \\
1980\end{array}$ & $\begin{array}{l}2300 \\
2280 \\
2260 \\
2170 \\
2060\end{array}$ & $\begin{array}{l}3330 \\
3140 \\
2750 \\
2340 \\
2080\end{array}$ & $\begin{array}{r}899 \\
857 \\
1020 \\
1450 \\
1340\end{array}$ & $\begin{array}{l}535 \\
525 \\
553 \\
815 \\
864\end{array}$ & $\begin{array}{l}560 \\
509 \\
494 \\
491 \\
501\end{array}$ \\
\hline $\begin{array}{l}11 \\
12 \\
13 \\
14 \\
15\end{array}$ & $\begin{array}{l}3280 \\
3540 \\
3680 \\
3840 \\
4050\end{array}$ & $\begin{array}{l}3300 \\
3190 \\
3010 \\
2820 \\
2630\end{array}$ & $\begin{array}{l}2760 \\
2660 \\
2570 \\
2450 \\
2400\end{array}$ & $\begin{array}{l}4180 \\
3960 \\
3790 \\
3670 \\
3570\end{array}$ & $\begin{array}{l}2730 \\
2650 \\
2570 \\
2510 \\
2400\end{array}$ & $\begin{array}{l}2270 \\
2220 \\
2160 \\
2100 \\
2090\end{array}$ & $\begin{array}{l}1920 \\
1870 \\
1830 \\
1850 \\
2090\end{array}$ & $\begin{array}{l}1980 \\
1910 \\
1850 \\
1810 \\
1820\end{array}$ & $\begin{array}{l}1900 \\
1820 \\
1750 \\
1670 \\
1600\end{array}$ & $\begin{array}{r}1160 \\
1060 \\
1010 \\
969 \\
922\end{array}$ & $\begin{array}{l}711 \\
702 \\
658 \\
642 \\
634\end{array}$ & $\begin{array}{l}491 \\
502 \\
563 \\
611 \\
635\end{array}$ \\
\hline $\begin{array}{l}16 \\
17 \\
18 \\
19 \\
20\end{array}$ & $\begin{array}{l}4210 \\
4230 \\
4290 \\
4250 \\
4090\end{array}$ & $\begin{array}{l}2470 \\
2340 \\
2240 \\
2130 \\
2010\end{array}$ & $\begin{array}{l}2400 \\
2430 \\
2460 \\
2450 \\
2430\end{array}$ & $\begin{array}{l}3520 \\
3550 \\
3590 \\
3620 \\
3650\end{array}$ & $\begin{array}{l}2200 \\
2160 \\
2230 \\
2330 \\
2470\end{array}$ & $\begin{array}{l}2150 \\
2250 \\
2460 \\
2690 \\
2830\end{array}$ & $\begin{array}{l}2610 \\
3040 \\
3330 \\
3570 \\
3750\end{array}$ & $\begin{array}{l}1750 \\
1840 \\
2020 \\
2130 \\
2100\end{array}$ & $\begin{array}{l}1610 \\
1650 \\
1560 \\
1450 \\
1350\end{array}$ & $\begin{array}{l}873 \\
832 \\
800 \\
774 \\
746\end{array}$ & $\begin{array}{l}607 \\
588 \\
601 \\
640 \\
781\end{array}$ & $\begin{array}{l}622 \\
600 \\
585 \\
583 \\
578\end{array}$ \\
\hline $\begin{array}{l}21 \\
22 \\
23 \\
24 \\
25\end{array}$ & $\begin{array}{l}3890 \\
3720 \\
3540 \\
3330 \\
3140\end{array}$ & $\begin{array}{l}1940 \\
1920 \\
1910 \\
1870 \\
1810\end{array}$ & $\begin{array}{r}2400 \\
2410 \\
2460 \\
2510 \\
\mathrm{e} 2350\end{array}$ & $\begin{array}{r}3660 \\
\text { e } 3670 \\
\text { e } 3550 \\
\text { e } 3460 \\
\text { e } 3300\end{array}$ & $\begin{array}{l}2640 \\
2760 \\
2840 \\
2850 \\
2770\end{array}$ & $\begin{array}{l}2870 \\
2820 \\
2710 \\
2600 \\
2570\end{array}$ & $\begin{array}{l}3850 \\
3850 \\
3760 \\
3640 \\
3450\end{array}$ & $\begin{array}{l}2010 \\
1920 \\
1830 \\
1840 \\
2090\end{array}$ & $\begin{array}{l}1280 \\
1250 \\
1210 \\
1160 \\
1120\end{array}$ & $\begin{array}{l}724 \\
716 \\
711 \\
661 \\
623\end{array}$ & $\begin{array}{l}841 \\
806 \\
735 \\
673 \\
624\end{array}$ & $\begin{array}{l}583 \\
584 \\
611 \\
616 \\
615\end{array}$ \\
\hline $\begin{array}{l}26 \\
27 \\
28 \\
29 \\
30 \\
31\end{array}$ & $\begin{array}{l}2950 \\
2730 \\
2550 \\
2410 \\
2310 \\
2210\end{array}$ & $\begin{array}{c}1760 \\
1790 \\
2510 \\
3060 \\
3190 \\
\cdots\end{array}$ & $\begin{array}{r}\mathrm{e} 2270 \\
\mathrm{e} 2200 \\
2330 \\
2740 \\
3750 \\
4280\end{array}$ & $\begin{array}{r}\text { e } 3190 \\
2990 \\
2850 \\
2730 \\
2650 \\
2540\end{array}$ & $\begin{array}{r}2640 \\
2520 \\
2420 \\
\ldots \\
\ldots \\
\ldots\end{array}$ & $\begin{array}{l}2570 \\
2590 \\
2620 \\
2650 \\
2620 \\
2530\end{array}$ & $\begin{array}{c}3250 \\
3120 \\
3030 \\
2930 \\
2840 \\
\ldots\end{array}$ & $\begin{array}{l}2900 \\
3080 \\
3040 \\
2900 \\
2680 \\
2520\end{array}$ & $\begin{array}{r}1080 \\
1040 \\
1000 \\
973 \\
949 \\
\cdots\end{array}$ & $\begin{array}{l}601 \\
580 \\
573 \\
575 \\
565 \\
547\end{array}$ & $\begin{array}{l}599 \\
577 \\
563 \\
546 \\
545 \\
693\end{array}$ & $\begin{array}{l}611 \\
595 \\
589 \\
588 \\
569 \\
\cdots\end{array}$ \\
\hline $\begin{array}{l}\text { IOIAL } \\
\text { MEAN } \\
\text { MAX } \\
\text { MIN } \\
\text { CF SM } \\
\text { IN. }\end{array}$ & $\begin{array}{r}89020 \\
2872 \\
4290 \\
1170 \\
2.12 \\
2.45\end{array}$ & $\begin{array}{r}72730 \\
2424 \\
3300 \\
1760 \\
1.79 \\
2.00\end{array}$ & $\begin{array}{r}86820 \\
2801 \\
4280 \\
2200 \\
2.07 \\
2.39\end{array}$ & $\begin{array}{r}119200 \\
3845 \\
4920 \\
2540 \\
2.84 \\
3.28\end{array}$ & $\begin{array}{r}11520 \\
2554 \\
2850 \\
2160 \\
1.89 \\
1.97\end{array}$ & $\begin{array}{r}7780 \\
2509 \\
2870 \\
2090 \\
1.86 \\
2.14\end{array}$ & $\begin{array}{r}81090 \\
2703 \\
3850 \\
1830 \\
2.00 \\
2.23\end{array}$ & $\begin{array}{r}69870 \\
2254 \\
3080 \\
1750 \\
1.67 \\
1.92\end{array}$ & $\begin{array}{r}56812 \\
1894 \\
3350 \\
949 \\
1.40 \\
1.56\end{array}$ & $\begin{array}{r}26509 \\
855 \\
1450 \\
547 \\
.63 \\
.73\end{array}$ & $\begin{array}{r}19781 \\
638 \\
864 \\
509 \\
.47 \\
.54\end{array}$ & $\begin{array}{c}17718 \\
591 \\
752 \\
491 \\
.44 \\
.49\end{array}$ \\
\hline
\end{tabular}

e Estimated

STAIISIICS OF MONIHLY MEAN DATA FOR WAIER YEARS 1949 - 1991, BY WATER YEAR (WY)

\begin{tabular}{|c|c|c|c|c|c|c|c|c|c|c|c|c|}
\hline $\begin{array}{l}\text { MEAN } \\
\text { MAX } \\
\text { (WY) } \\
\text { MI } N \\
(W Y)\end{array}$ & $\begin{array}{r}917 \\
3378 \\
1955 \\
350 \\
1964\end{array}$ & $\begin{array}{r}1082 \\
2562 \\
1973 \\
398 \\
1965\end{array}$ & $\begin{array}{r}1352 \\
2816 \\
1983 \\
447 \\
1964\end{array}$ & $\begin{array}{r}1439 \\
3845 \\
1991 \\
449 \\
1963\end{array}$ & $\begin{array}{c}1568 \\
2874 \\
1968 \\
391 \\
1963\end{array}$ & $\begin{array}{r}2077 \\
4229 \\
1985 \\
719 \\
1957\end{array}$ & $\begin{array}{l}2235 \\
4376 \\
1950 \\
1082 \\
1958\end{array}$ & $\begin{array}{c}1757 \\
3231 \\
1983 \\
767 \\
1958\end{array}$ & $\begin{array}{r}1374 \\
3167 \\
1981 \\
657 \\
1988\end{array}$ & $\begin{array}{r}1022 \\
1938 \\
1950 \\
419 \\
1988\end{array}$ & $\begin{array}{r}807 \\
2316 \\
1990 \\
311 \\
1964\end{array}$ & $\begin{array}{r}105 \\
1810 \\
1972 \\
360 \\
1964\end{array}$ \\
\hline
\end{tabular}

SUMMARY SIAIISIICS

ANNUAL IOIAL

ANNUAL MEAM

HIGHESI ANNUAI MEAN

LOWEST ANNUAL MEAN

HIGHEST DAILY MEAN

LOWEST DAIIY MEAN

ANMUAL SEVEN-UAY MINIMUM

INSIANIANEOUS PEAK FLOW

INSIANTANEOUS PEAK SIAGE

ANHUAL RUNOFF (CFSM)

ANNUAL RUNOFF (INCHES)

10 PERCENT EXCEEDS

$5 O$ PERCENT EXCEEDS

90 PERCENT EXCEEDS
FOR 1990 CALENDAR YEAR

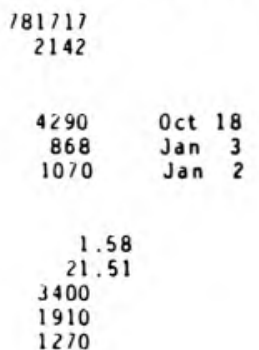

FOR 1991 WAIER YEAR

788850
2161

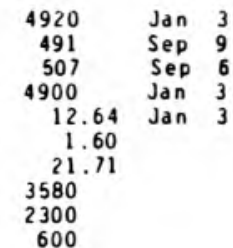

WAIER YEARS 1949 - 1991

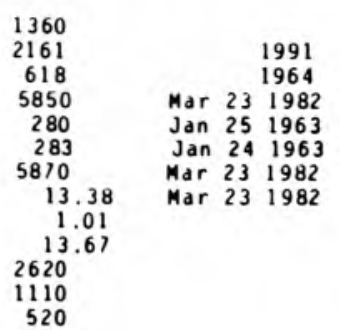




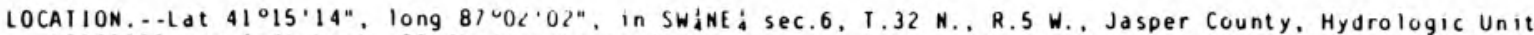
07120001 . On left bank, $20 \mathrm{ft}$ downstreda from bridge on State Highway 49.4 .5 i south of Kouts, 0.7 . upstream from Cook diţch, and at mile 86,7 .

DRAINAGE AREA...1,376 i $i^{2}$, Of which $194 \mathrm{mi}^{2}$ does not contribute directly to surface runoff.

PERIOD OF RECORD.--OCtober 1974 to current year.

REVISED RE CORDS.--WDR IN-71-1: 1975(M).

GAGE.--Water-stage recorder. Datun of gage is $645.00 \mathrm{ft}$ above National Geodetic Vertical Datua of 1929

REMARKS.--Records poor.

DISCHARGE, CUBIC FEET PER SECOND, WAIER YEAR OCTOBER 1990 TO SEPIEMBER 1991 DAILY MEAN VALUES

\begin{tabular}{|c|c|c|c|c|c|c|c|c|c|c|c|c|}
\hline DAY & $\mathrm{OCI}$ & NOV & DEC & JAN & FEB & MAR & APR & MAY & JUN & JUL & AUG & SEP \\
\hline $\begin{array}{l}1 \\
2 \\
3 \\
4 \\
5\end{array}$ & $\begin{array}{l}\text { e } 1050 \\
\text { e } 1000 \\
\text { e } 1020 \\
\text { e } 1080 \\
\text { e } 1200\end{array}$ & $\begin{array}{l}\text { e } 2010 \\
\text { e } 2000 \\
\text { e } 1900 \\
\text { e } 1800 \\
\text { e } 2000\end{array}$ & $\begin{array}{r}\text { e3320 } \\
3520 \\
3510 \\
3510 \\
3410\end{array}$ & $\begin{array}{l}4350 \\
4420 \\
4470 \\
4480 \\
4480\end{array}$ & $\begin{array}{l}\text { e2 } 2550 \\
\text { e2 } 2500 \\
\text { e2 } 400 \\
\text { e2 } 450 \\
\text { e2 } 550\end{array}$ & $\begin{array}{l}\text { e } 2420 \\
\text { e } 2490 \\
\text { e } 2560 \\
\text { e } 2650 \\
\text { e } 2700\end{array}$ & $\begin{array}{l}\text { e } 2450 \\
\text { e } 2350 \\
\text { e2280 } \\
\text { e22220 } \\
\text { e } 2200\end{array}$ & $\begin{array}{l}2820 \\
2710 \\
2620 \\
2530 \\
2450\end{array}$ & $\begin{array}{l}3220 \\
3340 \\
3320 \\
3370 \\
3400\end{array}$ & $\begin{array}{l}1000 \\
1010 \\
1100 \\
1090 \\
1040\end{array}$ & $\begin{array}{l}\text { e } 475 \\
\text { e } 470 \\
\text { e } 490 \\
\text { e } 470 \\
\text { e } 480\end{array}$ & $\begin{array}{l}696 \\
624 \\
574 \\
646 \\
710\end{array}$ \\
\hline $\begin{array}{r}6 \\
7 \\
8 \\
9 \\
10\end{array}$ & $\begin{array}{r}\text { e } 1300 \\
\text { e } 1400 \\
\text { e } 1600 \\
1980 \\
2890\end{array}$ & $\begin{array}{l}\text { e } 2500 \\
\text { e } 2850 \\
\text { e } 3000 \\
\text { e } 3100 \\
\text { e } 3200\end{array}$ & $\begin{array}{l}3350 \\
3230 \\
3120 \\
3050 \\
2960\end{array}$ & $\begin{array}{l}4480 \\
4480 \\
4430 \\
4350 \\
4270\end{array}$ & $\begin{array}{l}\text { e } 2700 \\
\text { e2 } 800 \\
\text { e2 } 850 \\
\text { e2 } 850 \\
\text { e2 } 2800\end{array}$ & $\begin{array}{l}\text { e } 2760 \\
\text { e } 2700 \\
\text { e } 2600 \\
\text { e } 2500 \\
\text { e } 2450\end{array}$ & $\begin{array}{l}\text { e } 2180 \\
\text { e } 2120 \\
\text { e } 2100 \\
\text { e } 2080 \\
\text { e2 } 2020\end{array}$ & $\begin{array}{l}2430 \\
2400 \\
2380 \\
2240 \\
2100\end{array}$ & $\begin{array}{l}3390 \\
3250 \\
2860 \\
2430 \\
2190\end{array}$ & $\begin{array}{r}947 \\
861 \\
959 \\
\text { e } 1100 \\
\text { e } 1300\end{array}$ & $\begin{array}{r}\text { e } 490 \\
e 510 \\
e 540 \\
\text { e600 } \\
799\end{array}$ & $\begin{array}{l}568 \\
497 \\
464 \\
437 \\
453\end{array}$ \\
\hline $\begin{array}{l}11 \\
12 \\
13 \\
14 \\
15\end{array}$ & $\begin{array}{r}3470 \\
\text { e } 3500 \\
\text { e } 3630 \\
\text { e } 3800 \\
\text { e } 3950\end{array}$ & $\begin{array}{l}\text { e } 3200 \\
\text { e } 3150 \\
\text { e } 3000 \\
\text { e } 2750 \\
\text { e } 2600\end{array}$ & $\begin{array}{r}2860 \\
2740 \\
2690 \\
e 2550 \\
e 2500\end{array}$ & $\begin{array}{l}4160 \\
4030 \\
3880 \\
3770 \\
3660\end{array}$ & $\begin{array}{l}\text { e2 } 780 \\
\text { e} 2700 \\
\text { e2 } 650 \\
\text { e2 } 550 \\
\text { e2 } 450\end{array}$ & $\begin{array}{l}\text { e } 2350 \\
\text { e22 } \\
\text { e2200 } \\
\text { e2 } 2150 \\
\text { e21 } 20\end{array}$ & $\begin{array}{l}\text { e } 2000 \\
\text { e } 1920 \\
\text { e } 1900 \\
\text { e } 1900 \\
\text { e } 2100\end{array}$ & $\begin{array}{l}2030 \\
1940 \\
1870 \\
1850 \\
1850\end{array}$ & $\begin{array}{l}1990 \\
1860 \\
1810 \\
1740 \\
1640\end{array}$ & $\begin{array}{r}\text { e } 1190 \\
\text { e } 1080 \\
\text { e } 980 \\
\text { e } 920 \\
\text { e } 880\end{array}$ & $\begin{array}{l}721 \\
646 \\
592 \\
594 \\
599\end{array}$ & $\begin{array}{l}447 \\
471 \\
531 \\
619 \\
599\end{array}$ \\
\hline $\begin{array}{l}16 \\
17 \\
18 \\
19 \\
20\end{array}$ & $\begin{array}{l}\text { e } 4100 \\
\text { e } 4150 \\
\text { e } 4200 \\
\text { e } 4150 \\
\text { e } 4050\end{array}$ & $\begin{array}{l}\text { e } 2450 \\
\text { e } 2300 \\
\text { e2200 } \\
\text { e } 2100 \\
\text { e } 2000\end{array}$ & $\begin{array}{l}\text { e2520 } \\
\text { e2 } 540 \\
\text { e} 2550 \\
\text { e2 } 530 \\
\text { e2 } 500\end{array}$ & $\begin{array}{l}\text { e } 3600 \\
\text { e } 3600 \\
\text { e } 3650 \\
\text { e } 3700 \\
\text { e } 3700\end{array}$ & $\begin{array}{l}\text { e } 2350 \\
\text { e } 2250 \\
\text { e } 2290 \\
\text { e } 2400 \\
\text { e } 2500\end{array}$ & $\begin{array}{l}\text { e } 2200 \\
\text { e } 2300 \\
\text { e2450 } \\
\text { e } 2700 \\
\text { e } 2850\end{array}$ & $\begin{array}{l}\text { e2 } 700 \\
\text { e2 } 900 \\
\text { e3100 } \\
\text { e3250 } \\
\text { e3300 }\end{array}$ & $\begin{array}{l}1770 \\
1820 \\
2030 \\
2160 \\
2160\end{array}$ & $\begin{array}{l}1690 \\
1740 \\
1630 \\
1540 \\
1390\end{array}$ & $\begin{array}{l}\text { e } 820 \\
\text { e7 } 80 \\
\text { e7 } 40 \\
\text { e7 } 00 \\
\text { e660 }\end{array}$ & $\begin{array}{l}585 \\
542 \\
565 \\
630 \\
766\end{array}$ & $\begin{array}{l}588 \\
603 \\
574 \\
550 \\
557\end{array}$ \\
\hline $\begin{array}{l}21 \\
22 \\
23 \\
24 \\
25\end{array}$ & $\begin{array}{l}\text { e } 3850 \\
\text { e } 3650 \\
\text { e } 3450 \\
\text { e } 3250 \\
\text { e } 3100\end{array}$ & $\begin{array}{l}\text { e } 1950 \\
\text { e } 1900 \\
\text { e } 1890 \\
\text { e } 1820 \\
\text { e } 1800\end{array}$ & $\begin{array}{r}e 2510 \\
e 2530 \\
e 2590 \\
2500 \\
e 2400\end{array}$ & $\begin{array}{l}\text { e } 3700 \\
\text { e } 3650 \\
\text { e } 3600 \\
\text { e } 3550 \\
\text { e } 3400\end{array}$ & $\begin{array}{l}\text { e } 2650 \\
\text { e2 } 790 \\
\text { e } 2880 \\
\text { e } 2900 \\
\text { e } 2800\end{array}$ & $\begin{array}{l}\text { e } 2900 \\
\text { e } 2880 \\
\text { e } 2780 \\
\text { e } 2700 \\
\text { e } 2700\end{array}$ & $\begin{array}{l}\text { e3 } 400 \\
\text { e3 } 380 \\
\text { e3350 } \\
\text { e3320 } \\
\text { e3300 }\end{array}$ & $\begin{array}{l}2110 \\
2020 \\
1920 \\
1960 \\
2200\end{array}$ & $\begin{array}{l}1280 \\
1280 \\
1240 \\
1170 \\
1130\end{array}$ & $\begin{array}{l}\text { e620 } \\
e 600 \\
e 580 \\
e 560 \\
e 540\end{array}$ & $\begin{array}{l}811 \\
788 \\
722 \\
633 \\
566\end{array}$ & $\begin{array}{l}535 \\
527 \\
541 \\
549 \\
562\end{array}$ \\
\hline $\begin{array}{l}26 \\
27 \\
28 \\
29 \\
30 \\
31\end{array}$ & $\begin{array}{l}\text { e } 2900 \\
\text { e2 } 750 \\
\text { e2550 } \\
\text { e } 2400 \\
\text { e2280 } \\
\text { e2160 }\end{array}$ & $\begin{array}{r}\text { e } 1790 \\
\text { e1800 } \\
\text { e } 2500 \\
\text { e } 3000 \\
\text { e } 3150 \\
\ldots\end{array}$ & $\begin{array}{r}\mathrm{e} 2320 \\
\mathrm{e} 2200 \\
2330 \\
2940 \\
4040 \\
4180\end{array}$ & $\begin{array}{l}\text { e } 3200 \\
\text { e } 3100 \\
\text { e } 3000 \\
\text { e } 2850 \\
\text { e } 2750 \\
\text { e } 2650\end{array}$ & $\begin{array}{r}\text { e2 } 100 \\
\text { e2600 } \\
\text { e2500 } \\
\ldots \\
\cdots \\
\cdots\end{array}$ & $\begin{array}{l}\text { e } 2720 \\
\text { e } 2750 \\
\text { e2 } 2720 \\
\text { e } 2700 \\
\text { e } 2600 \\
e 2550\end{array}$ & $\begin{array}{r}\text { e3280 } \\
\text { e3200 } \\
3090 \\
2990 \\
2900 \\
\cdots\end{array}$ & $\begin{array}{l}3140 \\
3250 \\
3160 \\
2990 \\
2770 \\
2650\end{array}$ & $\begin{array}{l}1120 \\
1090 \\
1060 \\
1040 \\
1010 \\
\cdots\end{array}$ & $\begin{array}{l}\text { e520 } \\
\text { e510 } \\
\text { e500 } \\
\text { e } 490 \\
\text { e } 480 \\
\text { e480 }\end{array}$ & $\begin{array}{l}543 \\
533 \\
520 \\
522 \\
535 \\
621\end{array}$ & $\begin{array}{l}557 \\
557 \\
571 \\
621 \\
567 \\
\cdots\end{array}$ \\
\hline $\begin{array}{l}\text { IOIAL } \\
\text { MEAN } \\
\text { MAX } \\
\text { MIN } \\
\text { CF SM } \\
\text { IN. }\end{array}$ & $\begin{array}{r}85860 \\
2770 \\
4200 \\
1000 \\
2.01 \\
2.32\end{array}$ & $\begin{array}{r}71770 \\
2392 \\
3200 \\
1790 \\
1.74 \\
1.94\end{array}$ & $\begin{array}{r}89560 \\
2889 \\
4180 \\
2200 \\
2.10 \\
2.42\end{array}$ & $\begin{array}{r}117410 \\
3787 \\
4480 \\
2650 \\
2.75 \\
3.17\end{array}$ & $\begin{array}{r}73190 \\
2614 \\
2900 \\
2250 \\
1.90 \\
1.98\end{array}$ & $\begin{array}{r}79430 \\
2562 \\
2900 \\
2120 \\
1.86 \\
2.15\end{array}$ & $\begin{array}{r}79280 \\
2643 \\
3400 \\
1900 \\
1.92 \\
2.14\end{array}$ & $\begin{array}{r}12330 \\
2333 \\
3250 \\
1770 \\
1.70 \\
1.96\end{array}$ & $\begin{array}{r}59220 \\
1914 \\
3400 \\
1010 \\
1.43 \\
1.60\end{array}$ & $\begin{array}{r}25037 \\
808 \\
1300 \\
480 \\
.59 \\
.68\end{array}$ & $\begin{array}{r}18358 \\
592 \\
811 \\
470 \\
.43 \\
.50\end{array}$ & $\begin{array}{r}16795 \\
560 \\
710 \\
437 \\
.41 \\
.45\end{array}$ \\
\hline
\end{tabular}

e Estimated

SIAIISTICS OF MONTHLY MEAN DAIA FUR WAIER YEARS 1975 - 1991, BY WATER YEAR (WY)

$\begin{array}{lrrrrrrrrrrrrr}\text { MEAN } & 979 & 1180 & 1631 & 1458 & 1618 & 2474 & 2603 & 1933 & 1616 & 1063 & 902 & 190 \\ \text { MAX } & 2770 & 2392 & 2887 & 3787 & 2614 & 4613 & 4229 & 3255 & 3172 & 1828 & 2432 & 1496 \\ \text { (WY) } & 1991 & 1991 & 1991 & 1991 & 1991 & 1985 & 1985 & 1983 & 1981 & 1981 & 1990 & 1990 \\ \text { M1N } & 477 & 542 & 704 & 634 & 718 & 1423 & 1144 & 1130 & 619 & 411 & 398 & 479 \\ \text { (WY) } & 1979 & 1979 & 1979 & 1977 & 1978 & 1987 & 1987 & 1989 & 1988 & 1988 & 1988 & 1918\end{array}$

SUMMARY STAIISIICS

ANNUAL TOTAL

ANNUAL MEAM

HIGHEST ANNUAI MEAM

LOWEST ANNUAL MEAN

HIGHESI DAILY MEAN

LOWEST DAILY MEAN

ANNUAL SEVEN-DAY MINIMUM

INSTANTANEOUS PEAK FLOW

INSTANTANE OUS PEAK SIAGE

ANMUAL RUNOFF (CFSM)

ANNUAL RUNOFF (INCHES)

10 PERCENT EXCEEDS

50 PERCENT EXCEEDS

90 PERCENT EXCEEDS
FOR 1990 CALENDAR YEAR

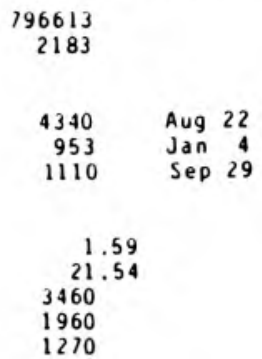

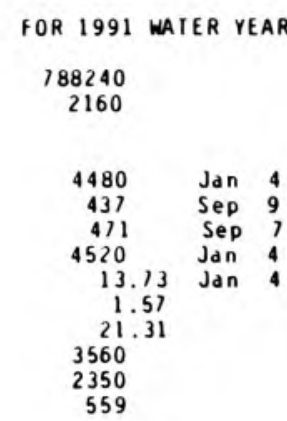

WATER YEARS 1975 - 1991

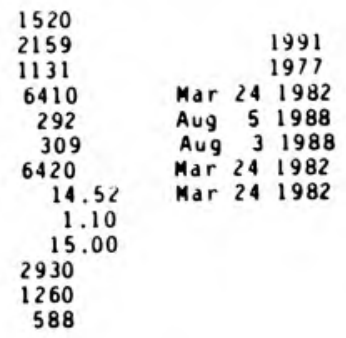


LOCATION.--Lat $41^{\circ} 20^{\prime} 19^{\prime \prime}$, Iong $81^{\circ} 04^{\prime 3} 30^{\prime \prime}$, in NW $\frac{1}{4}$ SE 4 Sec. 2, T.33 N., R.6 W. Porter County, Hydrologic Unit

01120001 , on left bank $15 \mathrm{ft}$ upstream from bridge on County Road 50 West, 1.6 apstrea from mouth, and 3 an northwest of Kouts.

DRAINAGE AREA... 30.3 i ${ }^{2}$

PERIOD OF RECORD...July 1968 to current year. Prior to October 1971, published as State ditch near Kouts.

GAGE. - Water-stage recorder. Datum of gage is $652.00 \mathrm{ft}$ above National Geodetic Vertical Datum of 1929 (Indiana Department of Highways bench mark). Prior to 0ct. 19, 1978, water-stage recorder at site 1.4 a downstrean at same datua.

REMARKS. - Records fair except estimated daily discharges, which are poor.

DISCHARGE, CUBIC FEET PER SECOND, WATER YEAR OCTOBER 1990 TO SEPTEMBER 1991 DAILY MEAN VALUES

\begin{tabular}{|c|c|c|c|c|c|c|c|c|c|c|c|c|}
\hline DAY & $O C T$ & NOV & DEC & JAN & FEB & MAR & APR & MAY & JUN & JUL & AUG & SEP \\
\hline $\begin{array}{l}1 \\
2 \\
3 \\
4 \\
5\end{array}$ & $\begin{array}{l}25 \\
25 \\
27 \\
58 \\
34\end{array}$ & $\begin{array}{r}33 \\
32 \\
32 \\
32 \\
215\end{array}$ & $\begin{array}{r}123 \\
96 \\
85 \\
73 \\
61\end{array}$ & $\begin{array}{r}\text { e1 } 28 \\
89 \\
71 \\
61 \\
57\end{array}$ & $\begin{array}{c}\mathrm{e} 32.0 \\
33 \\
36 \\
67 \\
126\end{array}$ & $\begin{array}{r}33 \\
109 \\
93 \\
65 \\
56\end{array}$ & $\begin{array}{l}39 \\
38 \\
37 \\
39 \\
50\end{array}$ & $\begin{array}{r}40 \\
38 \\
36 \\
35 \\
121\end{array}$ & $\begin{array}{r}340 \\
95 \\
71 \\
59 \\
52\end{array}$ & $\begin{array}{l}23 \\
23 \\
23 \\
22 \\
22\end{array}$ & $\begin{array}{l}16 \\
15 \\
17 \\
16 \\
16\end{array}$ & $\begin{array}{l}17 \\
16 \\
18 \\
19 \\
17\end{array}$ \\
\hline $\begin{array}{r}6 \\
7 \\
8 \\
9 \\
10\end{array}$ & $\begin{array}{r}30 \\
96 \\
79 \\
168 \\
382\end{array}$ & $\begin{array}{r}195 \\
93 \\
70 \\
58 \\
51\end{array}$ & $\begin{array}{l}57 \\
53 \\
50 \\
47 \\
46\end{array}$ & $\begin{array}{l}52 \\
49 \\
48 \\
46 \\
45\end{array}$ & $\begin{array}{l}91 \\
78 \\
64 \\
62 \\
59\end{array}$ & $\begin{array}{l}54 \\
49 \\
45 \\
43 \\
41\end{array}$ & $\begin{array}{l}44 \\
40 \\
40 \\
40 \\
39\end{array}$ & $\begin{array}{l}88 \\
48 \\
38 \\
34 \\
31\end{array}$ & $\begin{array}{l}45 \\
41 \\
38 \\
36 \\
35\end{array}$ & $\begin{array}{l}21 \\
21 \\
21 \\
21 \\
21\end{array}$ & $\begin{array}{l}16 \\
16 \\
22 \\
18 \\
17\end{array}$ & $\begin{array}{l}17 \\
17 \\
16 \\
16 \\
16\end{array}$ \\
\hline $\begin{array}{l}11 \\
12 \\
13 \\
14 \\
15\end{array}$ & $\begin{array}{r}155 \\
96 \\
77 \\
62 \\
61\end{array}$ & $\begin{array}{l}46 \\
43 \\
42 \\
40 \\
39\end{array}$ & $\begin{array}{l}44 \\
43 \\
41 \\
39 \\
47\end{array}$ & $\begin{array}{l}46 \\
46 \\
45 \\
45 \\
43\end{array}$ & $\begin{array}{l}48 \\
42 \\
40 \\
40 \\
36\end{array}$ & $\begin{array}{l}40 \\
41 \\
39 \\
44 \\
45\end{array}$ & $\begin{array}{r}37 \\
36 \\
36 \\
55 \\
233\end{array}$ & $\begin{array}{l}30 \\
29 \\
28 \\
27 \\
27\end{array}$ & $\begin{array}{l}35 \\
34 \\
33 \\
32 \\
33\end{array}$ & $\begin{array}{l}20 \\
20 \\
20 \\
20 \\
19\end{array}$ & $\begin{array}{l}16 \\
16 \\
15 \\
13 \\
15\end{array}$ & $\begin{array}{l}16 \\
17 \\
19 \\
17 \\
17\end{array}$ \\
\hline $\begin{array}{l}16 \\
17 \\
18 \\
19 \\
20\end{array}$ & $\begin{array}{l}52 \\
48 \\
93 \\
66 \\
52\end{array}$ & $\begin{array}{l}37 \\
36 \\
35 \\
35 \\
34\end{array}$ & $\begin{array}{l}46 \\
43 \\
46 \\
43 \\
40\end{array}$ & $\begin{array}{l}66 \\
85 \\
63 \\
54 \\
58\end{array}$ & $\begin{array}{l}34 \\
33 \\
40 \\
72 \\
52\end{array}$ & $\begin{array}{r}62 \\
93 \\
191 \\
97 \\
73\end{array}$ & $\begin{array}{r}116 \\
148 \\
85 \\
65 \\
55\end{array}$ & $\begin{array}{l}28 \\
30 \\
44 \\
36 \\
31\end{array}$ & $\begin{array}{l}32 \\
31 \\
29 \\
28 \\
28\end{array}$ & $\begin{array}{l}19 \\
18 \\
18 \\
18 \\
18\end{array}$ & $\begin{array}{l}15 \\
15 \\
15 \\
39 \\
29\end{array}$ & $\begin{array}{l}16 \\
16 \\
17 \\
16 \\
16\end{array}$ \\
\hline $\begin{array}{l}21 \\
22 \\
23 \\
24 \\
25\end{array}$ & $\begin{array}{l}46 \\
43 \\
41 \\
39 \\
38\end{array}$ & $\begin{array}{l}34 \\
34 \\
34 \\
33 \\
33\end{array}$ & $\begin{array}{l}45 \\
61 \\
46 \\
42 \\
39\end{array}$ & $\begin{array}{l}58 \\
50 \\
47 \\
43 \\
40\end{array}$ & $\begin{array}{l}50 \\
47 \\
39 \\
36 \\
34\end{array}$ & $\begin{array}{l}63 \\
56 \\
56 \\
55 \\
50\end{array}$ & $\begin{array}{l}49 \\
46 \\
44 \\
44 \\
40\end{array}$ & $\begin{array}{l}29 \\
30 \\
66 \\
80 \\
86\end{array}$ & $\begin{array}{l}27 \\
27 \\
27 \\
27 \\
26\end{array}$ & $\begin{array}{l}18 \\
18 \\
17 \\
17 \\
17\end{array}$ & $\begin{array}{l}21 \\
19 \\
18 \\
18 \\
17\end{array}$ & $\begin{array}{l}16 \\
17 \\
17 \\
17 \\
17\end{array}$ \\
\hline $\begin{array}{l}26 \\
27 \\
28 \\
29 \\
30 \\
31\end{array}$ & $\begin{array}{l}37 \\
36 \\
35 \\
34 \\
34 \\
33\end{array}$ & $\begin{array}{r}32 \\
307 \\
955 \\
361 \\
171 \\
\cdots\end{array}$ & $\begin{array}{r}36 \\
35 \\
35 \\
536 \\
e 572 \\
e 187\end{array}$ & $\begin{array}{l}39 \\
38 \\
36 \\
35 \\
34 \\
34\end{array}$ & $\begin{array}{l}32 \\
31 \\
30 \\
\ldots \\
\ldots \\
\ldots\end{array}$ & $\begin{array}{l}56 \\
68 \\
60 \\
47 \\
43 \\
41\end{array}$ & $\begin{array}{r}39 \\
38 \\
38 \\
41 \\
43 \\
\cdots\end{array}$ & $\begin{array}{r}120 \\
69 \\
51 \\
44 \\
90 \\
170\end{array}$ & $\begin{array}{l}26 \\
25 \\
25 \\
24 \\
24 \\
\cdots\end{array}$ & $\begin{array}{l}17 \\
17 \\
17 \\
17 \\
16 \\
16\end{array}$ & $\begin{array}{l}17 \\
17 \\
17 \\
17 \\
17 \\
17\end{array}$ & $\begin{array}{l}17 \\
17 \\
17 \\
17 \\
16 \\
\cdots\end{array}$ \\
\hline $\begin{array}{l}\text { TOTAL } \\
\text { MEAM } \\
\text { MAX } \\
\text { MIN } \\
\text { CF SM } \\
\text { IN. }\end{array}$ & $\begin{array}{r}2102 \\
67.8 \\
382 \\
25 \\
2.14 \\
2.47\end{array}$ & $\begin{array}{r}3192 \\
106 \\
955 \\
32 \\
3.36 \\
3.75\end{array}$ & $\begin{array}{r}2757 \\
88.9 \\
572 \\
35 \\
2.81 \\
3.24\end{array}$ & $\begin{array}{r}1651 \\
53.3 \\
128 \\
34 \\
1.68 \\
1.94\end{array}$ & $\begin{array}{r}1384.0 \\
49.4 \\
126 \\
30 \\
1.56 \\
1.62\end{array}$ & $\begin{array}{c}1908 \\
61.5 \\
191 \\
33 \\
1.94 \\
2.24\end{array}$ & $\begin{array}{c}1694 \\
56.5 \\
233 \\
36 \\
1.78 \\
1.99\end{array}$ & $\begin{array}{c}1654 \\
53.4 \\
110 \\
27 \\
1.68 \\
1.94\end{array}$ & $\begin{array}{c}1385 \\
46.2 \\
340 \\
24 \\
1.46 \\
1.63\end{array}$ & $\begin{array}{c}595 \\
19.2 \\
23 \\
16 \\
.61 \\
.70\end{array}$ & $\begin{array}{c}552 \\
17.8 \\
39 \\
13 \\
.56 \\
.65\end{array}$ & $\begin{array}{c}504 \\
16.8 \\
19 \\
16 \\
.53 \\
.59\end{array}$ \\
\hline
\end{tabular}

e Estimated

STAIISIICS OF MONTHLY MEAN DAIA FOR WAIER YEARS 1969 - 1991, BY WATER YEAR (WY)

$\begin{array}{lrrrrrrrrrrrr}\text { MEAN } & 20.6 & 30.3 & 33.4 & 31.4 & 40.2 & 55.9 & 52.6 & 43.8 & 35.2 & 24.9 & 21.0 & 17.6 \\ \text { MAX } & 67.8 & 112 & 88.7 & 63.6 & 19.3 & 142 & 103 & 89.4 & 95.4 & 71.5 & 99.0 & 39.3 \\ \text { (WY) } & 1991 & 1986 & 1991 & 1973 & 1976 & 1982 & 1975 & 1974 & 1981 & 1983 & 1990 & 1981 \\ \text { MIN } & 11.5 & 11.0 & 14.4 & 11.0 & 10.6 & 18.0 & 20.8 & 14.9 & 14.6 & 12.0 & 10.8 & 12.0 \\ \text { (WY) } & 1981 & 1981 & 1990 & 1971 & 1978 & 1981 & 1986 & 1980 & 1988 & 1988 & 1988 & 1988\end{array}$

SUMMARY SIATISTICS

ANMUAL TOTAL

ANNUAL MEAN

HIGHEST ANNUAL MEAN

LOWEST ANNUAL MEAN

HIGHESI DAILY MEAN

LOWESI DAILY MEAM

ANHUAL SEVEN-OAY MIMIMUM

INSIANTANEOUS PEAK FIOW

INSIANTANEOUS PEAK SIAGE

AN NUAL RUNOFF (CFSM)

ANHUAL RUNOFF (INCHES)

10 PERCENT EXLEEDS

50 PERCENI EXCEEDS

90 PERCENT EXCEEDS

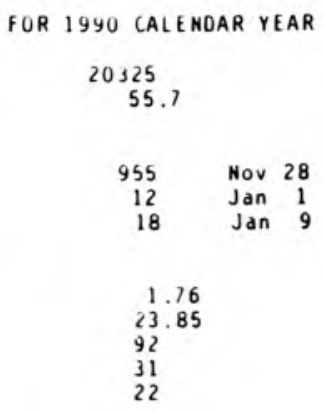

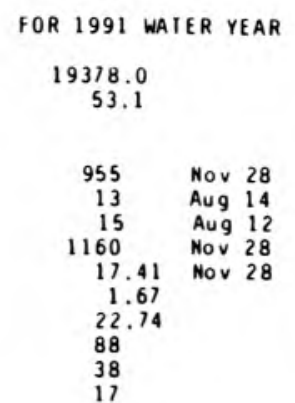

WATER YEARS $1969-1991$

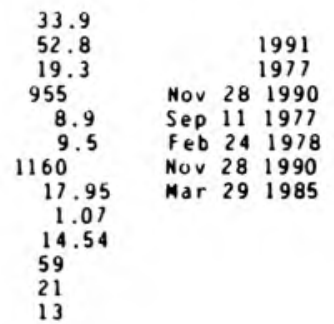


05518000 KANKAKEE RIVER AT SHELBY, IN

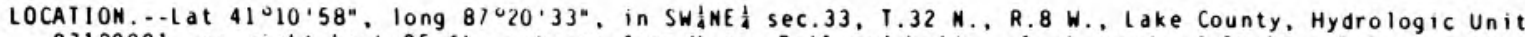
07120001 , on right bank $25 \mathrm{ft}$ upstrean from Monon Railroad bridge, 1 i south of Shelby, 7.7 apstrea froe Beaver lake ditch, and at mile 67.9 .

DRAINAGE AREA...1.779 i $i^{2}$ of which $20 \mathrm{i} \mathbf{m}^{2}$ does not contribute directly to surface runoff.

PERIOD OF RECORD.--0ctober 1922 to current year. Monthly discharge only for sone periods, published in wSP 1308. REVISED RECORDS.-.WSP 1005: 1928(M). WSP 2115: Drainage area.

GAGE.- -Water-stage recorder. Datum of gage is $628.13 \mathrm{ft}$ above National Geodetic Vertical Datue of 1929 . Prior to Dec. 19, 1934, nonrecording gage at highway bridge about $400 \mathrm{ft}$ upstrean. Dec. 19, 1934, to 0ct. 4, 1965,

water-stage recorder on left bank $50 \mathrm{ft}$ downstrean, and $0 \mathrm{ct}$. 5, 1965, to Sept. 21, 1966 , nonrecording gage on upstreav. All at sam

REMARKS. - Records good except for estinated daily dischargs, which are fair.

DISCHARGE, CUBIC FEET PER SECOND, WAIER YEAR OCTOBER 1990 TO SEPTEMBER 1991 DAILY MEAN VALUES

\begin{tabular}{|c|c|c|c|c|c|c|c|c|c|c|c|c|}
\hline DAY & OCT & NOV & DEC & JAN & FE B & MAR & APR & MAY & JUN & JUL & AUG & SEP \\
\hline $\begin{array}{l}1 \\
2 \\
3 \\
4 \\
5\end{array}$ & $\begin{array}{l}1390 \\
1350 \\
1350 \\
1550 \\
1720\end{array}$ & $\begin{array}{l}2810 \\
2640 \\
2470 \\
2340 \\
2540\end{array}$ & $\begin{array}{l}4660 \\
4530 \\
4480 \\
4440 \\
4370\end{array}$ & $\begin{array}{l}5510 \\
5650 \\
5660 \\
5660 \\
5660\end{array}$ & $\begin{array}{l}3280 \\
3140 \\
3080 \\
3120 \\
3350\end{array}$ & $\begin{array}{l}3070 \\
3130 \\
3300 \\
3340 \\
3350\end{array}$ & $\begin{array}{l}3180 \\
3100 \\
3010 \\
2900 \\
2870\end{array}$ & $\begin{array}{l}3600 \\
3480 \\
3340 \\
3220 \\
3130\end{array}$ & $\begin{array}{l}4000 \\
4390 \\
4380 \\
4280 \\
4200\end{array}$ & $\begin{array}{l}1130 \\
1110 \\
1120 \\
1140 \\
1060\end{array}$ & $\begin{array}{l}498 \\
487 \\
519 \\
500 \\
502\end{array}$ & $\begin{array}{l}765 \\
754 \\
697 \\
709 \\
779\end{array}$ \\
\hline $\begin{array}{r}6 \\
7 \\
8 \\
9 \\
10\end{array}$ & $\begin{array}{l}1890 \\
2090 \\
2250 \\
2390 \\
3260\end{array}$ & $\begin{array}{l}3420 \\
3900 \\
3970 \\
3980 \\
4000\end{array}$ & $\begin{array}{l}4270 \\
4170 \\
4060 \\
3950 \\
3850\end{array}$ & $\begin{array}{l}5590 \\
5520 \\
5520 \\
5470 \\
5410\end{array}$ & $\begin{array}{l}3520 \\
3610 \\
3650 \\
3670 \\
3660\end{array}$ & $\begin{array}{l}3370 \\
3350 \\
3270 \\
3170 \\
3080\end{array}$ & $\begin{array}{l}2840 \\
2780 \\
2710 \\
2680 \\
2620\end{array}$ & $\begin{array}{l}3200 \\
3140 \\
3020 \\
2890 \\
2720\end{array}$ & $\begin{array}{l}4140 \\
4090 \\
3920 \\
3560 \\
3160\end{array}$ & $\begin{array}{r}980 \\
926 \\
925 \\
1240 \\
1410\end{array}$ & $\begin{array}{l}519 \\
531 \\
576 \\
742 \\
864\end{array}$ & $\begin{array}{l}723 \\
649 \\
604 \\
575 \\
573\end{array}$ \\
\hline $\begin{array}{l}11 \\
12 \\
13 \\
14 \\
15\end{array}$ & $\begin{array}{l}4270 \\
4560 \\
4590 \\
4580 \\
4610\end{array}$ & $\begin{array}{l}4010 \\
3980 \\
3890 \\
3740 \\
3560\end{array}$ & $\begin{array}{l}3730 \\
3600 \\
3480 \\
3360 \\
3260\end{array}$ & $\begin{array}{l}5370 \\
5290 \\
5160 \\
5010 \\
4880\end{array}$ & $\begin{array}{l}3640 \\
3570 \\
3470 \\
3380 \\
3250\end{array}$ & $\begin{array}{l}2960 \\
2900 \\
2880 \\
2770 \\
2730\end{array}$ & $\begin{array}{l}2530 \\
2450 \\
2410 \\
2420 \\
2700\end{array}$ & $\begin{array}{l}2570 \\
2480 \\
2370 \\
2310 \\
2300\end{array}$ & $\begin{array}{l}2820 \\
2560 \\
2370 \\
2250 \\
2110\end{array}$ & $\begin{array}{r}1280 \\
1180 \\
1050 \\
980 \\
916\end{array}$ & $\begin{array}{l}828 \\
741 \\
684 \\
634 \\
636\end{array}$ & $\begin{array}{l}571 \\
629 \\
653 \\
706 \\
695\end{array}$ \\
\hline $\begin{array}{l}16 \\
17 \\
18 \\
19 \\
20\end{array}$ & $\begin{array}{l}4660 \\
4720 \\
4810 \\
4930 \\
4800\end{array}$ & $\begin{array}{l}3380 \\
3170 \\
2990 \\
2850 \\
2680\end{array}$ & $\begin{array}{l}3230 \\
3210 \\
3190 \\
3150 \\
3120\end{array}$ & $\begin{array}{l}4820 \\
4800 \\
4780 \\
4730 \\
4700\end{array}$ & $\begin{array}{l}3030 \\
2880 \\
2880 \\
2970 \\
3070\end{array}$ & $\begin{array}{l}2730 \\
2860 \\
3260 \\
3680 \\
3860\end{array}$ & $\begin{array}{l}3260 \\
3640 \\
4010 \\
4170 \\
4240\end{array}$ & $\begin{array}{l}2260 \\
2290 \\
2460 \\
2680 \\
2740\end{array}$ & $\begin{array}{l}2060 \\
2070 \\
2030 \\
1910 \\
1760\end{array}$ & $\begin{array}{l}892 \\
838 \\
817 \\
769 \\
698\end{array}$ & $\begin{array}{l}673 \\
629 \\
624 \\
685 \\
888\end{array}$ & $\begin{array}{l}680 \\
680 \\
670 \\
639 \\
655\end{array}$ \\
\hline $\begin{array}{l}21 \\
22 \\
23 \\
24 \\
25\end{array}$ & $\begin{array}{l}4840 \\
4760 \\
4620 \\
4430 \\
4250\end{array}$ & $\begin{array}{l}2520 \\
2470 \\
2430 \\
2350 \\
2260\end{array}$ & $\begin{array}{r}3090 \\
3100 \\
3110 \\
\mathrm{e} 3050 \\
\mathrm{e} 3000\end{array}$ & $\begin{array}{l}4680 \\
4630 \\
4560 \\
4460 \\
4350\end{array}$ & $\begin{array}{l}3170 \\
3280 \\
3340 \\
3370 \\
3360\end{array}$ & $\begin{array}{l}3910 \\
3900 \\
3840 \\
3730 \\
3590\end{array}$ & $\begin{array}{l}4310 \\
4370 \\
4410 \\
4430 \\
4380\end{array}$ & $\begin{array}{l}2680 \\
2610 \\
2650 \\
2690 \\
2770\end{array}$ & $\begin{array}{l}1570 \\
1470 \\
1440 \\
1370 \\
1290\end{array}$ & $\begin{array}{l}674 \\
659 \\
630 \\
608 \\
583\end{array}$ & $\begin{array}{l}922 \\
897 \\
857 \\
785 \\
704\end{array}$ & $\begin{array}{l}651 \\
660 \\
650 \\
660 \\
681\end{array}$ \\
\hline $\begin{array}{l}26 \\
27 \\
28 \\
29 \\
30 \\
31\end{array}$ & $\begin{array}{l}4040 \\
3790 \\
3520 \\
3300 \\
3130 \\
2960\end{array}$ & $\begin{array}{r}2190 \\
2290 \\
3410 \\
4500 \\
4760 \\
\ldots \ldots\end{array}$ & $\begin{array}{r}e 2950 \\
\text { e2900 } \\
3450 \\
3950 \\
5110 \\
5440\end{array}$ & $\begin{array}{l}4230 \\
4080 \\
3910 \\
3730 \\
3570 \\
3430\end{array}$ & $\begin{array}{r}3300 \\
3220 \\
3140 \\
\ldots \\
\ldots \\
\ldots\end{array}$ & $\begin{array}{l}3490 \\
3480 \\
3470 \\
3430 \\
3350 \\
3270\end{array}$ & $\begin{array}{c}4260 \\
4110 \\
3960 \\
3830 \\
3710 \\
\ldots\end{array}$ & $\begin{array}{l}3540 \\
4190 \\
4320 \\
4190 \\
3980 \\
3850\end{array}$ & $\begin{array}{c}1240 \\
1230 \\
1180 \\
1120 \\
1100 \\
\ldots\end{array}$ & $\begin{array}{l}573 \\
545 \\
537 \\
535 \\
527 \\
505\end{array}$ & $\begin{array}{l}659 \\
630 \\
632 \\
601 \\
620 \\
675\end{array}$ & $\begin{array}{l}676 \\
672 \\
667 \\
699 \\
673 \\
\cdots\end{array}$ \\
\hline $\begin{array}{l}\text { IOIAL } \\
\text { MEAN } \\
\text { MAX } \\
\text { MIN } \\
\text { CF SM } \\
\text { IN. }\end{array}$ & $\begin{array}{r}109410 \\
3529 \\
4930 \\
1350 \\
1.98 \\
2.29\end{array}$ & $\begin{array}{r}95500 \\
3183 \\
4760 \\
2190 \\
1.79 \\
2.00\end{array}$ & $\begin{array}{r}115260 \\
3718 \\
5440 \\
2900 \\
2.09 \\
2.41\end{array}$ & $\begin{array}{r}150880 \\
4867 \\
5660 \\
3430 \\
2.74 \\
3.15\end{array}$ & $\begin{array}{r}92400 \\
3300 \\
3670 \\
2880 \\
1.85 \\
1.93\end{array}$ & $\begin{array}{r}102520 \\
3307 \\
3910 \\
2730 \\
1.86 \\
2.14\end{array}$ & $\begin{array}{r}102290 \\
3410 \\
4430 \\
2410 \\
1.92 \\
2.14\end{array}$ & $\begin{array}{r}93610 \\
3022 \\
4320 \\
2260 \\
1.70 \\
1.96\end{array}$ & $\begin{array}{c}75070 \\
2502 \\
4390 \\
1100 \\
1.41 \\
1.57\end{array}$ & $\begin{array}{r}26837 \\
866 \\
1410 \\
505 \\
.49 \\
.56\end{array}$ & $\begin{array}{c}20742 \\
669 \\
922 \\
487 \\
.38 \\
.43\end{array}$ & $\begin{array}{r}20095 \\
670 \\
779 \\
571 \\
.38 \\
.42\end{array}$ \\
\hline
\end{tabular}

e Estionated

STATISTICS OF MONIHLY MEAN DAIA FOR WAIER YEARS 1924 - 1991, BY WATER YEAR (WY)

$\begin{array}{lrrrrrrrrrrrr}\text { MEAN } & 1045 & 1278 & 1595 & 1718 & 1939 & 2533 & 2780 & 2302 & 1740 & 1206 & 928 & 837 \\ \text { MAX } & 3529 & 3413 & 4502 & 4867 & 3658 & 5570 & 5365 & 4409 & 4347 & 2478 & 3058 & 2191 \\ \text { (WY) } & 1991 & 1973 & 1928 & 1991 & 1950 & 1985 & 1982 & 1943 & 1981 & 1981 & 1990 & 1972 \\ \text { MIN } & 455 & 519 & 540 & 460 & 462 & 848 & 1226 & 189 & 569 & 441 & 402 & 356 \\ \text { (WY) } & 1954 & 1954 & 1964 & 1940 & 1963 & 1934 & 1925 & 1934 & 1934 & 1988 & 1988 & 1941\end{array}$

SUMMARY SIATISIICS

ANMUAL TOTAL

ANWUAL MEAN

HIGHEST ANNUAL MEAN

LOWEST AMNUAL MEAN

HIGHEST DAILY MEAM

LOWEST DAILY MEAN

ANNUAL SEVEN-DAY MINIMUM

INSTANTANEOUS PEAK FLOW

INSTANTANEOUS PEAK STAGE

ANNUAL RUNOFF (CFSM)

ANNUAL RUNOFF (INCHES)

10 PERCENT EXLEEDS

50 PERCENI EXCEEDS

90 PERCENT EXCEEDS
FOR 1990 CALENDAR YEAR

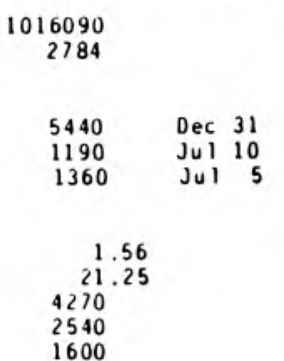

FOR 1991 WATER YEAR

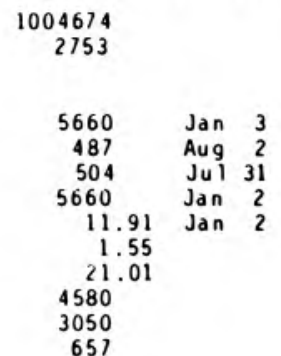

WAIER YEARS 1924 - 1991

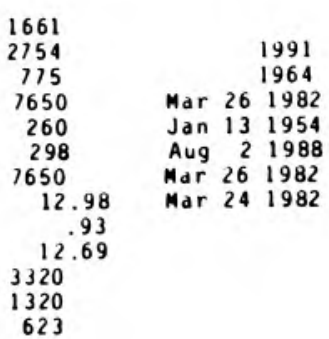




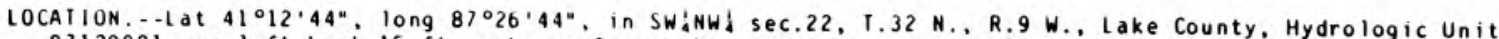

07120001 , on left bank $15 \mathrm{ft}$ upstream from bridge on Ackerman Avenue, 0.5 i upstream from Bruce ditch. $1.5 \mathrm{mi}$ downstream from Cedar Creek, $1.6 \mathrm{mi}$ north of Schneider, and at ile 10.1 .

PERIOD OF RECORD.-.July 1948 to current yedr.

REVISED RECORDS.-.WSP 1915: 1956-59. WSP 2ils: Drainage area.

GAGE. - Water-stage recorder. Datum of gage is $623.67 \mathrm{ft}$ above National Geodetic Vertical Datum of 1929 . Prior

to 0ct. 1, 1949, nonrecording gage at same site at datum $2.00 \mathrm{ft}$ higher. 0ct. 1, 1949, to Aug. 13, ig51,

REMARKS. - - Records good except those for estimated daily discharges, which are poor.

DISCHARGE, CUBIC FEE PER SECOND, WAIER YEAR OCTOBER 1990 TO SEPIEMBER 1991 DAILY MEAN VALUES

\begin{tabular}{|c|c|c|c|c|c|c|c|c|c|c|c|c|}
\hline DAY & $O C T$ & NOV & $\mathrm{DEC}$ & JAN & FEB & MAR & $A P R$ & MAY & JUN & JUL & AUG & SEP \\
\hline $\begin{array}{l}1 \\
2 \\
3 \\
4 \\
5\end{array}$ & $\begin{array}{r}87 \\
94 \\
95 \\
129 \\
114\end{array}$ & $\begin{array}{r}96 \\
93 \\
89 \\
89 \\
417\end{array}$ & $\begin{array}{r}1310 \\
1010 \\
853 \\
725 \\
585\end{array}$ & $\begin{array}{l}e 560 \\
e 400 \\
e 300 \\
e 270 \\
e 250\end{array}$ & $\begin{array}{l}108 \\
107 \\
120 \\
237 \\
432\end{array}$ & $\begin{array}{l}133 \\
378 \\
450 \\
289 \\
239\end{array}$ & $\begin{array}{l}211 \\
196 \\
175 \\
171 \\
193\end{array}$ & $\begin{array}{l}149 \\
144 \\
132 \\
124 \\
153\end{array}$ & $\begin{array}{l}325 \\
209 \\
163 \\
138 \\
122\end{array}$ & $\begin{array}{l}29 \\
29 \\
29 \\
28 \\
27\end{array}$ & $\begin{array}{l}9.4 \\
9.3 \\
9.7 \\
11 \\
10\end{array}$ & $\begin{array}{l}18 \\
16 \\
23 \\
38 \\
31\end{array}$ \\
\hline $\begin{array}{r}6 \\
7 \\
8 \\
9 \\
10\end{array}$ & $\begin{array}{r}94 \\
103 \\
167 \\
283 \\
836\end{array}$ & $\begin{array}{l}725 \\
427 \\
316 \\
267 \\
233\end{array}$ & $\begin{array}{l}513 \\
448 \\
398 \\
360 \\
330\end{array}$ & $\begin{array}{l}\text { e } 230 \\
\text { e } 220 \\
\text { e2 } 25 \\
\text { e2 } 10 \\
\text { e2 } 05\end{array}$ & $\begin{array}{l}365 \\
338 \\
294 \\
273 \\
271\end{array}$ & $\begin{array}{l}220 \\
201 \\
174 \\
164 \\
151\end{array}$ & $\begin{array}{l}191 \\
178 \\
173 \\
173 \\
173\end{array}$ & $\begin{array}{l}212 \\
169 \\
145 \\
133 \\
124\end{array}$ & $\begin{array}{r}111 \\
102 \\
98 \\
93 \\
89\end{array}$ & $\begin{array}{l}25 \\
26 \\
25 \\
23 \\
21\end{array}$ & $\begin{array}{l}11 \\
9.8 \\
22 \\
29 \\
19\end{array}$ & $\begin{array}{l}28 \\
26 \\
25 \\
24 \\
25\end{array}$ \\
\hline $\begin{array}{l}11 \\
12 \\
13 \\
14 \\
15\end{array}$ & $\begin{array}{l}724 \\
505 \\
385 \\
315 \\
273\end{array}$ & $\begin{array}{l}207 \\
186 \\
158 \\
138 \\
130\end{array}$ & $\begin{array}{l}303 \\
285 \\
264 \\
245 \\
277\end{array}$ & $\begin{array}{l}\text { e } 240 \\
\text { e2 } 80 \\
\text { e240 } \\
\text { e220 } \\
\text { e } 310\end{array}$ & $\begin{array}{l}235 \\
200 \\
190 \\
182 \\
160\end{array}$ & $\begin{array}{l}143 \\
144 \\
132 \\
138 \\
145\end{array}$ & $\begin{array}{l}161 \\
152 \\
148 \\
162 \\
786\end{array}$ & $\begin{array}{l}118 \\
124 \\
113 \\
141 \\
151\end{array}$ & $\begin{array}{l}88 \\
86 \\
80 \\
76 \\
73\end{array}$ & $\begin{array}{l}18 \\
19 \\
21 \\
21 \\
19\end{array}$ & $\begin{array}{l}17 \\
14 \\
13 \\
14 \\
12\end{array}$ & $\begin{array}{l}25 \\
27 \\
31 \\
30 \\
30\end{array}$ \\
\hline $\begin{array}{l}16 \\
17 \\
18 \\
19 \\
20\end{array}$ & $\begin{array}{l}237 \\
211 \\
286 \\
259 \\
211\end{array}$ & $\begin{array}{r}123 \\
114 \\
109 \\
104 \\
99\end{array}$ & $\begin{array}{r}281 \\
\text { e250 } \\
\text { e270 } \\
\text { e290 } \\
\text { e270 }\end{array}$ & $\begin{array}{l}\text { e } 440 \\
\text { e620 } \\
\text { e } 480 \\
\text { e } 350 \\
\text { e } 280\end{array}$ & $\begin{array}{l}211 \\
163 \\
153 \\
245 \\
228\end{array}$ & $\begin{array}{r}186 \\
384 \\
1180 \\
991 \\
684\end{array}$ & $\begin{array}{l}852 \\
757 \\
596 \\
423 \\
332\end{array}$ & $\begin{array}{l}124 \\
120 \\
205 \\
196 \\
158\end{array}$ & $\begin{array}{l}72 \\
68 \\
61 \\
58 \\
52\end{array}$ & $\begin{array}{l}17 \\
14 \\
14 \\
13 \\
11\end{array}$ & $\begin{array}{l}11 \\
13 \\
16 \\
17 \\
28\end{array}$ & $\begin{array}{l}29 \\
28 \\
28 \\
27 \\
31\end{array}$ \\
\hline $\begin{array}{l}21 \\
22 \\
23 \\
24 \\
25\end{array}$ & $\begin{array}{l}192 \\
174 \\
166 \\
158 \\
144\end{array}$ & $\begin{array}{r}96 \\
101 \\
100 \\
95 \\
91\end{array}$ & $\begin{array}{l}\text { e } 340 \\
\text { e } 440 \\
\text { e } 370 \\
\text { e } 320 \\
\text { e280 }\end{array}$ & $\begin{array}{l}\text { e } 310 \\
\text { e2 } 60 \\
\text { e220 } \\
\text { e1 } 90 \\
\text { e } 160\end{array}$ & $\begin{array}{l}216 \\
218 \\
195 \\
174 \\
157\end{array}$ & $\begin{array}{l}524 \\
417 \\
402 \\
376 \\
322\end{array}$ & $\begin{array}{l}280 \\
218 \\
190 \\
191 \\
174\end{array}$ & $\begin{array}{l}138 \\
139 \\
176 \\
225 \\
225\end{array}$ & $\begin{array}{l}48 \\
48 \\
48 \\
47 \\
43\end{array}$ & $\begin{array}{c}10 \\
9.2 \\
9.4 \\
10 \\
9.8\end{array}$ & $\begin{array}{l}23 \\
21 \\
19 \\
17 \\
17\end{array}$ & $\begin{array}{l}29 \\
30 \\
31 \\
30 \\
30\end{array}$ \\
\hline $\begin{array}{l}26 \\
27 \\
28 \\
29 \\
30 \\
31\end{array}$ & $\begin{array}{l}153 \\
142 \\
120 \\
110 \\
106 \\
101\end{array}$ & $\begin{array}{r}86 \\
611 \\
2210 \\
2010 \\
1710 \\
\ldots\end{array}$ & $\begin{array}{r}\text { e } 250 \\
\text { e } 230 \\
\text { e } 240 \\
\text { e } 520 \\
\text { e1 } 100 \\
\text { e } 800\end{array}$ & $\begin{array}{l}\text { e } 170 \\
\text { el } 50 \\
\text { el } 35 \\
\text { el } 25 \\
117 \\
112\end{array}$ & $\begin{array}{l}145 \\
138 \\
132 \\
\ldots \\
\ldots \\
\ldots\end{array}$ & $\begin{array}{l}335 \\
390 \\
369 \\
287 \\
249 \\
229\end{array}$ & $\begin{array}{l}164 \\
155 \\
151 \\
152 \\
162 \\
\cdots\end{array}$ & $\begin{array}{l}496 \\
387 \\
275 \\
213 \\
194 \\
252\end{array}$ & $\begin{array}{l}37 \\
34 \\
28 \\
28 \\
26 \\
\cdots\end{array}$ & $\begin{array}{l}9.7 \\
10 \\
14 \\
14 \\
12 \\
9.1\end{array}$ & $\begin{array}{l}17 \\
15 \\
15 \\
15 \\
15 \\
16\end{array}$ & $\begin{array}{l}30 \\
29 \\
29 \\
28 \\
29 \\
\cdots\end{array}$ \\
\hline $\begin{array}{l}\text { TOIAL } \\
\text { MEAN } \\
\text { MAX } \\
\text { MIN } \\
\text { CF SM } \\
\text { IN. }\end{array}$ & $\begin{array}{r}6974 \\
225 \\
836 \\
87 \\
1.83 \\
2.11\end{array}$ & $\begin{array}{r}11230 \\
374 \\
2210 \\
86 \\
3.04 \\
3.40\end{array}$ & $\begin{array}{r}14157 \\
457 \\
1310 \\
230 \\
3.71 \\
4.28\end{array}$ & $\begin{array}{r}8269 \\
267 \\
620 \\
112 \\
2.17 \\
2.50\end{array}$ & $\begin{array}{r}5887 \\
210 \\
432 \\
107 \\
1.71 \\
1.78\end{array}$ & $\begin{array}{r}10426 \\
336 \\
1180 \\
132 \\
2.73 \\
3.15\end{array}$ & $\begin{array}{r}8040 \\
268 \\
852 \\
148 \\
2.18 \\
2.43\end{array}$ & $\begin{array}{l}5655 \\
182 \\
496 \\
113 \\
1.48 \\
1.71\end{array}$ & $\begin{array}{c}2551 \\
85.0 \\
325 \\
26 \\
.69 \\
.77\end{array}$ & $\begin{array}{c}546.8 \\
17.6 \\
29 \\
9.2 \\
.14 \\
.17\end{array}$ & $\begin{array}{r}485.2 \\
15.7 \\
29 \\
9.3 \\
.13 \\
.15\end{array}$ & $\begin{array}{r}835 \\
27.8 \\
38 \\
16 \\
.23 \\
.25\end{array}$ \\
\hline
\end{tabular}

e Estinded

STATISIICS OF MONTHLY MEAN DATA FUR WAIER YEARS 1949 - 1991, BY WATER YEAR (WY)

$\begin{array}{lrrrrrrrrr}\text { MEAN } & 56.8 & 81.4 & 113 & 117 & 150 & 211 & 215 & 147 & 110 \\ \text { MAX } & 237 & 471 & 457 & 311 & 486 & 634 & 477 & 421 & 463 \\ \text { (WY) } & 1955 & 1986 & 1991 & 1950 & 1959 & 1982 & 1950 & 1974 & 1989 \\ \text { MIN } & 7.54 & 11.8 & 8.13 & 17.5 & 15.6 & 34.3 & 48.6 & 30.6 & 26.3 \\ \text { (WY) } & 1964 & 1957 & 1964 & 1977 & 1964 & 1957 & 1963 & 1958\end{array}$

SUMMARY SIAIISIICS

ANNUAI TOTAL

ANNUAL MEAN

HIGHESI ANNUAL MEAN

IOWEST ANNUAL MEAN

HIGHESI DAILY MEAN

LOWEST DAILY MEAN

ANHUAL SEVEN-DAY MINIMUM

INSTANIANEOUS PEAK FLOW

INSIANIANEOUS PEAK SIAGE

ANNUAL RUNOFF (CFSM)

ANNUAL RUNOFF (INCHES)

10 PERCENT EXCEEDS

50 PERCEMT EXCEEDS

90 PERCENT EXCEEDS
FOR 1990 CALENDAR YEAR

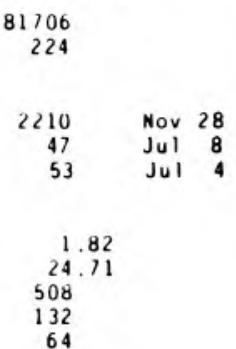

FOR 1991 WATER YEAR

75056.0

206

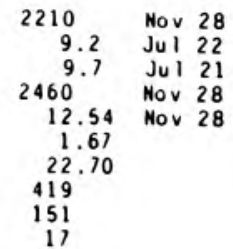

$\begin{array}{rrr}62.8 & 43.7 & 40.2 \\ 275 & 237 & 195 \\ 1981 & 1990 & 1972 \\ 10.6 & 7.09 & 7.78 \\ 1988 & 1964 & 1964\end{array}$

WATER YEARS $1949-1991$

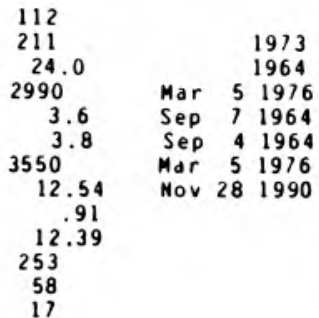




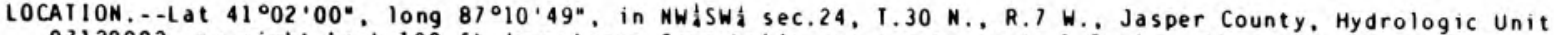
07120002 , On right bank $100 \mathrm{ft}$ downstrea from bridge on county road, 0.5 north of Rosebud, 0.5 . $i$

downstrean fro confluence of Swain and Dexter ditches, 1.5 i upstrea from Davidson ditch, 2 i east of Parr,

DRAINAGE AREA. $-35.6 . i^{2}$.

PERIOD OF RECORD...July i 1948 to current year.

REVISED RECORDS.--WSP 1338: 1950-53. WSP 1728: 1959-60(M). WSP 1915: 1949-60. WSP 2115: Drainage area.

GAGE.- Water-stage recorder. Datue of gage is $661.47 \mathrm{ft}$ above National Geodetic Vertical Datua of 1929 (levels by State of Indiana. Departaent of Natural Resources). Prior to 0ct. 1, 1953, nonrecording gage on downstrean side of county road bridge at sane datue

REMARKS. - Records fair, except for estiated daily discharges, which are poor.

DISCHARGE, CUBIC FEET PER SECOND, WATER YEAR OCTOBER 1990 TO SEPIEMBER 1991 DAIIY MEAN VALUES

\begin{tabular}{|c|c|c|c|c|c|c|c|c|c|c|c|c|}
\hline DAY & $\mathrm{OCT}$ & NOV & DEC & JAN & FEB & MAR & $A P R$ & MAY & JUN & JUL & AUG & SEP \\
\hline $\begin{array}{l}1 \\
2 \\
3 \\
4 \\
5\end{array}$ & $\begin{array}{l}12 \\
12 \\
15 \\
33 \\
21\end{array}$ & $\begin{array}{l}\text { e27 } \\
\text { e26 } \\
\text { e26 } \\
\text { e26 } \\
\text { e } 60\end{array}$ & $\begin{array}{r}\text { e120 } \\
\text { e90 } \\
\text { e75 } \\
\text { e90 } \\
\text { e72 }\end{array}$ & $\begin{array}{r}233 \\
158 \\
113 \\
85 \\
72\end{array}$ & $\begin{array}{r}\text { e26 } \\
\text { 227 } \\
48 \\
70 \\
79\end{array}$ & $\begin{array}{l}39 \\
63 \\
56 \\
47 \\
45\end{array}$ & $\begin{array}{l}47 \\
43 \\
41 \\
43 \\
47\end{array}$ & $\begin{array}{l}47 \\
44 \\
39 \\
36 \\
48\end{array}$ & $\begin{array}{l}41 \\
37 \\
32 \\
28 \\
26\end{array}$ & $\begin{array}{l}20 \\
14 \\
12 \\
11 \\
10\end{array}$ & $\begin{array}{l}3.4 \\
3.3 \\
3.4 \\
3.5 \\
3.5\end{array}$ & $\begin{array}{l}3.6 \\
3.6 \\
4.0 \\
4.5 \\
3.9\end{array}$ \\
\hline $\begin{array}{r}6 \\
7 \\
8 \\
9 \\
10\end{array}$ & $\begin{array}{r}17 \\
34 \\
45 \\
196 \\
334\end{array}$ & $\begin{array}{r}\text { e230 } \\
\text { e150 } \\
\text { e110 } \\
\text { e } 82 \\
\text { e66 }\end{array}$ & $\begin{array}{l}\text { e61 } \\
\text { e52 } \\
\text { e46 } \\
\text { e43 } \\
\text { e42 }\end{array}$ & $\begin{array}{l}63 \\
58 \\
53 \\
48 \\
45\end{array}$ & $\begin{array}{l}66 \\
59 \\
53 \\
52 \\
52\end{array}$ & $\begin{array}{l}44 \\
37 \\
37 \\
37 \\
34\end{array}$ & $\begin{array}{l}44 \\
40 \\
38 \\
39 \\
35\end{array}$ & $\begin{array}{l}55 \\
42 \\
38 \\
36 \\
34\end{array}$ & $\begin{array}{l}24 \\
23 \\
23 \\
22 \\
21\end{array}$ & $\begin{array}{l}9.8 \\
9.4 \\
9.1 \\
8.6 \\
8.6\end{array}$ & $\begin{array}{l}3.7 \\
3.8 \\
6.0 \\
5.2 \\
4.0\end{array}$ & $\begin{array}{l}3.8 \\
3.7 \\
3.6 \\
3.8 \\
3.9\end{array}$ \\
\hline $\begin{array}{l}11 \\
12 \\
13 \\
14 \\
15\end{array}$ & $\begin{array}{r}\text { e240 } \\
\text { e } 190 \\
\text { e140 } \\
\text { e110 } \\
\text { e } 92\end{array}$ & $\begin{array}{l}\text { e } 52 \\
\text { e } 46 \\
\text { e } 42 \\
\text { e } 39 \\
\text { e } 36\end{array}$ & $\begin{array}{l}41 \\
40 \\
37 \\
35 \\
58\end{array}$ & $\begin{array}{l}49 \\
51 \\
45 \\
43 \\
43\end{array}$ & $\begin{array}{r}45 \\
40 \\
40 \\
39 \\
\mathrm{e} 34\end{array}$ & $\begin{array}{l}34 \\
34 \\
34 \\
53 \\
38\end{array}$ & $\begin{array}{r}33 \\
32 \\
33 \\
44 \\
189\end{array}$ & $\begin{array}{l}33 \\
32 \\
31 \\
37 \\
41\end{array}$ & $\begin{array}{l}20 \\
20 \\
19 \\
18 \\
18\end{array}$ & $\begin{array}{l}8.2 \\
7.9 \\
7.6 \\
7.3 \\
6.9\end{array}$ & $\begin{array}{l}3.7 \\
3.6 \\
3.6 \\
3.5 \\
3.6\end{array}$ & $\begin{array}{l}4.2 \\
4.3 \\
4.2 \\
4.2 \\
4.2\end{array}$ \\
\hline $\begin{array}{l}16 \\
17 \\
18 \\
19 \\
20\end{array}$ & $\begin{array}{r}\text { e82 } \\
\text { e74 } \\
\text { e100 } \\
\text { e } 85 \\
\text { e72 }\end{array}$ & $\begin{array}{l}\text { e34 } \\
\text { e } 32 \\
\text { e } 30 \\
\text { e30 } \\
\text { e29 }\end{array}$ & $\begin{array}{l}53 \\
49 \\
56 \\
51 \\
46\end{array}$ & $\begin{array}{r}126 \\
112 \\
73 \\
64 \\
\mathrm{e} 70\end{array}$ & $\begin{array}{r}e 33 \\
\text { e33 } \\
46 \\
70 \\
55\end{array}$ & $\begin{array}{r}39 \\
65 \\
201 \\
271 \\
303\end{array}$ & $\begin{array}{r}146 \\
135 \\
97 \\
76 \\
64\end{array}$ & $\begin{array}{r}36 \\
34 \\
107 \\
81 \\
58\end{array}$ & $\begin{array}{l}18 \\
16 \\
16 \\
15 \\
12\end{array}$ & $\begin{array}{l}6.5 \\
6.2 \\
6.0 \\
5.5 \\
5.4\end{array}$ & $\begin{array}{l}3.4 \\
3.3 \\
3.4 \\
4.1 \\
4.4\end{array}$ & $\begin{array}{l}4.1 \\
4.0 \\
4.1 \\
4.0 \\
4.0\end{array}$ \\
\hline $\begin{array}{l}21 \\
22 \\
23 \\
24 \\
25\end{array}$ & $\begin{array}{l}\text { e } 60 \\
\text { e } 52 \\
\text { e } 46 \\
\text { e } 41 \\
\text { e } 38\end{array}$ & $\begin{array}{l}\text { e } 29 \\
\text { e } 32 \\
\text { e } 32 \\
\text { e } 30 \\
\text { e27 }\end{array}$ & $\begin{array}{r}61 \\
82 \\
59 \\
\text { e } 51 \\
\text { e44 }\end{array}$ & $\begin{array}{l}\text { e } 57 \\
\text { e } 48 \\
\text { e } 41 \\
\text { e } 38 \\
\text { e } 35\end{array}$ & $\begin{array}{l}51 \\
49 \\
44 \\
43 \\
39\end{array}$ & $\begin{array}{l}230 \\
167 \\
145 \\
133 \\
110\end{array}$ & $\begin{array}{l}55 \\
50 \\
48 \\
46 \\
42\end{array}$ & $\begin{array}{l}47 \\
43 \\
44 \\
45 \\
44\end{array}$ & $\begin{array}{l}12 \\
13 \\
13 \\
12 \\
12\end{array}$ & $\begin{array}{l}5.2 \\
5.0 \\
4.7 \\
4.7 \\
4.6\end{array}$ & $\begin{array}{l}4.5 \\
3.8 \\
3.6 \\
3.5 \\
3.6\end{array}$ & $\begin{array}{l}4.1 \\
4.4 \\
4.5 \\
4.4 \\
4.2\end{array}$ \\
\hline $\begin{array}{l}26 \\
27 \\
28 \\
29 \\
30 \\
31\end{array}$ & $\begin{array}{l}\text { e } 35 \\
\text { e } 32 \\
\text { e } 30 \\
\text { e29 } \\
\text { e28 } \\
\text { e27 }\end{array}$ & $\begin{array}{r}\text { e26 } \\
\text { e35 } \\
\text { e110 } \\
\text { e230 } \\
\text { el } 60 \\
\ldots \ldots\end{array}$ & $\begin{array}{l}\text { e40 } \\
\text { e37 } \\
\text { e35 } \\
411 \\
621 \\
403\end{array}$ & $\begin{array}{r}e 33 \\
e 31 \\
\text { e30 } \\
e 29 \\
29 \\
e 27\end{array}$ & $\begin{array}{l}37 \\
36 \\
35 \\
\cdots \\
\cdots \\
\cdots\end{array}$ & $\begin{array}{r}116 \\
117 \\
89 \\
70 \\
57 \\
51\end{array}$ & $\begin{array}{r}40 \\
41 \\
41 \\
46 \\
45 \\
\cdots\end{array}$ & $\begin{array}{l}50 \\
42 \\
36 \\
33 \\
31 \\
30\end{array}$ & $\begin{array}{l}11 \\
11 \\
11 \\
10 \\
11 \\
\cdots\end{array}$ & $\begin{array}{l}4.4 \\
4.2 \\
4.1 \\
4.0 \\
3.9 \\
3.5\end{array}$ & $\begin{array}{l}3.5 \\
3.4 \\
3.5 \\
3.2 \\
3.9 \\
3.8\end{array}$ & $\begin{array}{l}4.2 \\
4.2 \\
4.4 \\
4.3 \\
4.2 \\
\cdots . .\end{array}$ \\
\hline $\begin{array}{l}\text { TOTAL } \\
\text { MEAN } \\
\text { MAX } \\
\text { MIN } \\
\text { CF SM } \\
\text { IN. }\end{array}$ & $\begin{array}{r}2322 \\
74.9 \\
334 \\
12 \\
2.10 \\
2.43\end{array}$ & $\begin{array}{r}1884 \\
62.8 \\
230 \\
26 \\
1.76 \\
1.97\end{array}$ & $\begin{array}{r}3001 \\
96.8 \\
621 \\
35 \\
2.72 \\
3.14\end{array}$ & $\begin{array}{r}2002 \\
64.6 \\
233 \\
27 \\
1.81 \\
2.09\end{array}$ & $\begin{array}{r}1301 \\
46.5 \\
79 \\
26 \\
1.31 \\
1.36\end{array}$ & $\begin{array}{c}2796 \\
90.2 \\
303 \\
34 \\
2.53 \\
2.92\end{array}$ & $\begin{array}{r}1720 \\
57.3 \\
189 \\
32 \\
1.61 \\
1.80\end{array}$ & $\begin{array}{c}1354 \\
43.7 \\
107 \\
30 \\
1.23 \\
1.41\end{array}$ & $\begin{array}{c}565 \\
18.8 \\
41 \\
10 \\
.53 \\
.59\end{array}$ & $\begin{array}{r}228.3 \\
7.36 \\
20 \\
3.5 \\
.21 \\
.24\end{array}$ & $\begin{array}{c}116.7 \\
3.76 \\
6.0 \\
3.2 \\
.11 \\
.12\end{array}$ & $\begin{array}{r}122.6 \\
4.09 \\
4.5 \\
3.6 \\
.11 \\
.13\end{array}$ \\
\hline
\end{tabular}

e Estimated

STATISTICS OF MONTHLY MEAM DATA FOR WAIER YEARS 1949 - 1991, BY WATER YEAR (WY)

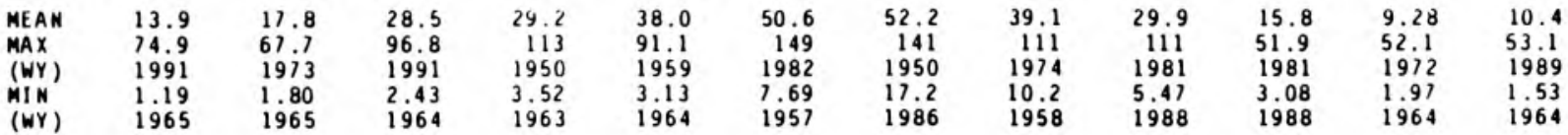

SUMMARY STATISIICS

ANNUAL TOTAL

ANMUAL MEAN

HIGHEST ANNUAL MEAN

LOWEST ANNUAL MEAN

HIGHEST DAILY MEAN

LOWEST DAILY MEAN

ANHUAL SEVEN-DAY MINIMUM

INSTANTANEOUS PEAK FLOW

INSIANTANEOUS PEAK STAGE

AN NUAL RUNOFF (CFSM)

ANNUAL RUNOFF (INCHES)

10 PERCENT EXCEEDS

50 PERCENT EXCEEDS

90 PERCENT EXCEEDS
FOR 1990 CALENDAR YEAR

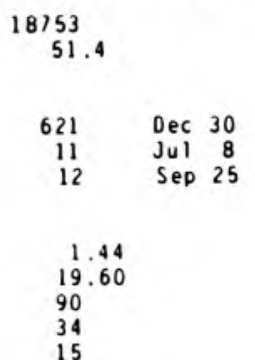

FOR 1991 WATER YEAR

$$
\begin{array}{r}
17412.6 \\
47.7
\end{array}
$$

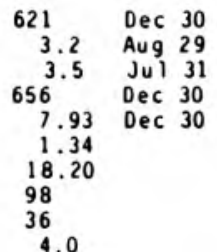

WATER YEARS $1949-1991$

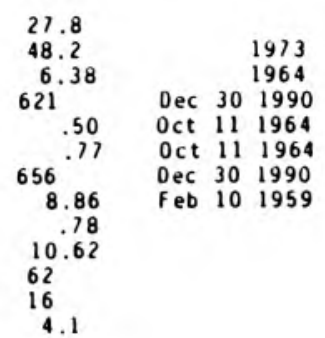


LOCATION.-Lat $40^{\circ} 58^{\prime} 12^{\circ}$, Iong $87^{\circ} 06^{\prime} 50^{\circ}$, in NE $\frac{1}{4} N W \frac{1}{4}$ sec.16, T.29 N.. R.6 W. Jasper County, Hydrologic Unit 07120002 , on downstrea side of county highway bridge, 1.2 a upstrea from Ryan ditch, 2 ai east of Morth Marion, 3.5 i northeast of Rensselaer, and at 1 ile 87.7 . DRAINAGE AREA -144 i 2

PERIOD OF RECORD.--Decenber 1948 to current year.

REVISED RECORDS.--WSP 2115: Drainage area.

GAGE.--Water-stage recorder. Datun of gage is $646.68 \mathrm{ft}$ above National Geodetic Vertical Datua of 1929 . Prior to Sept. 6, 1955, nonrecording gage at se

REMARKS. - Records good. Water from 01 iver ditch, an upstrean tributary, can be diverted to Ryan ditch and thus enter the Iroquois River below station. Streanflow affected by irrigation. Variable backwater conditions exist on sone rises.

DISCHARGE, CUBIC FEET PER SECOND, WATER YEAR OCTOBER 1990 TO SEPTEMBER 1991 DAILY MEAN VALUES

\begin{tabular}{|c|c|c|c|c|c|c|c|c|c|c|c|c|}
\hline DAY & $\mathrm{OCT}$ & NOV & DEC & JAN & FEB & MAR & APR & MAY & JUN & JUL & AUG & SEP \\
\hline $\begin{array}{l}1 \\
2 \\
3 \\
4 \\
5\end{array}$ & $\begin{array}{r}41 \\
40 \\
44 \\
109 \\
96\end{array}$ & $\begin{array}{l}122 \\
121 \\
120 \\
118 \\
348\end{array}$ & $\begin{array}{l}615 \\
466 \\
401 \\
447 \\
398\end{array}$ & $\begin{array}{l}\text { e } 1680 \\
\text { e } 1620 \\
\text { e } 1400 \\
\text { e } 1200 \\
\text { e } 1000\end{array}$ & $\begin{array}{r}\text { e } 112 \\
\text { e125 } \\
\text { e150 } \\
\text { e250 } \\
358\end{array}$ & $\begin{array}{l}154 \\
228 \\
296 \\
262 \\
230\end{array}$ & $\begin{array}{l}247 \\
219 \\
208 \\
200 \\
217\end{array}$ & $\begin{array}{l}196 \\
194 \\
179 \\
153 \\
155\end{array}$ & $\begin{array}{l}206 \\
229 \\
177 \\
146 \\
125\end{array}$ & $\begin{array}{l}31 \\
30 \\
26 \\
24 \\
23\end{array}$ & $\begin{array}{l}8.1 \\
7.6 \\
7.2 \\
7.1 \\
6.4\end{array}$ & $\begin{array}{l}5.4 \\
4.7 \\
5.2 \\
6.1 \\
5.6\end{array}$ \\
\hline $\begin{array}{r}6 \\
7 \\
8 \\
9 \\
10\end{array}$ & $\begin{array}{r}76 \\
102 \\
171 \\
473 \\
e 900\end{array}$ & $\begin{array}{l}804 \\
842 \\
677 \\
501 \\
376\end{array}$ & $\begin{array}{l}331 \\
284 \\
238 \\
212 \\
201\end{array}$ & $\begin{array}{l}733 \\
494 \\
353 \\
288 \\
257\end{array}$ & $\begin{array}{l}376 \\
345 \\
307 \\
283 \\
280\end{array}$ & $\begin{array}{l}215 \\
192 \\
169 \\
158 \\
143\end{array}$ & $\begin{array}{l}210 \\
191 \\
181 \\
180 \\
167\end{array}$ & $\begin{array}{l}185 \\
164 \\
142 \\
133 \\
124\end{array}$ & $\begin{array}{r}110 \\
100 \\
95 \\
90 \\
84\end{array}$ & $\begin{array}{l}23 \\
20 \\
21 \\
21 \\
21\end{array}$ & $\begin{array}{c}7.9 \\
8.1 \\
14 \\
13 \\
9.2\end{array}$ & $\begin{array}{l}5.8 \\
5.4 \\
4.7 \\
4.1 \\
4.9\end{array}$ \\
\hline $\begin{array}{l}11 \\
12 \\
13 \\
14 \\
15\end{array}$ & $\begin{array}{r}\text { e } 1200 \\
\text { e } 1200 \\
\text { e } 1100 \\
\text { e } 950 \\
\text { e } 770\end{array}$ & $\begin{array}{l}290 \\
236 \\
206 \\
190 \\
176\end{array}$ & $\begin{array}{l}193 \\
184 \\
172 \\
156 \\
215\end{array}$ & $\begin{array}{l}246 \\
290 \\
272 \\
247 \\
248\end{array}$ & $\begin{array}{l}257 \\
221 \\
201 \\
196 \\
140\end{array}$ & $\begin{array}{r}137 \\
149 \\
90 \\
164 \\
211\end{array}$ & $\begin{array}{l}149 \\
141 \\
141 \\
177 \\
396\end{array}$ & $\begin{array}{l}117 \\
113 \\
109 \\
120 \\
248\end{array}$ & $\begin{array}{l}84 \\
81 \\
70 \\
59 \\
64\end{array}$ & $\begin{array}{l}20 \\
19 \\
18 \\
17 \\
15\end{array}$ & $\begin{array}{l}8.3 \\
7.9 \\
8.0 \\
7.5 \\
6.8\end{array}$ & $\begin{array}{l}5.2 \\
5.9 \\
7.1 \\
7.5 \\
6.5\end{array}$ \\
\hline $\begin{array}{l}16 \\
17 \\
18 \\
19 \\
20\end{array}$ & $\begin{array}{l}625 \\
468 \\
478 \\
522 \\
441\end{array}$ & $\begin{array}{l}165 \\
152 \\
146 \\
140 \\
133\end{array}$ & $\begin{array}{l}275 \\
248 \\
257 \\
269 \\
235\end{array}$ & $\begin{array}{r}460 \\
737 \\
\text { e } 692 \\
\text { e565 } \\
\text { e } 455\end{array}$ & $\begin{array}{l}\text { e } 160 \\
\text { e160 } \\
183 \\
307 \\
322\end{array}$ & $\begin{array}{r}186 \\
239 \\
576 \\
e 900 \\
\mathrm{e} 1100\end{array}$ & $\begin{array}{l}707 \\
709 \\
670 \\
533 \\
396\end{array}$ & $\begin{array}{l}210 \\
176 \\
396 \\
546 \\
430\end{array}$ & $\begin{array}{l}63 \\
60 \\
42 \\
43 \\
40\end{array}$ & $\begin{array}{l}17 \\
31 \\
23 \\
18 \\
15\end{array}$ & $\begin{array}{l}6.3 \\
6.6 \\
6.2 \\
7.7 \\
9.2\end{array}$ & $\begin{array}{r}5.9 \\
5.6 \\
6.3 \\
6.0 \\
12\end{array}$ \\
\hline $\begin{array}{l}21 \\
22 \\
23 \\
24 \\
25\end{array}$ & $\begin{array}{l}350 \\
282 \\
239 \\
211 \\
190\end{array}$ & $\begin{array}{l}134 \\
147 \\
150 \\
140 \\
126\end{array}$ & $\begin{array}{r}254 \\
406 \\
e 390 \\
\text { e } 340 \\
e 260\end{array}$ & $\begin{array}{l}\text { e } 360 \\
\text { e290 } \\
\text { e250 } \\
\text { e220 } \\
\text { e190 }\end{array}$ & $\begin{array}{l}281 \\
258 \\
231 \\
205 \\
182\end{array}$ & $\begin{array}{r}\text { e } 1120 \\
\text { e } 1050 \\
\text { e } 920 \\
\text { e } 800 \\
732\end{array}$ & $\begin{array}{l}306 \\
251 \\
221 \\
212 \\
190\end{array}$ & $\begin{array}{l}291 \\
211 \\
196 \\
193 \\
200\end{array}$ & $\begin{array}{l}39 \\
39 \\
38 \\
35 \\
31\end{array}$ & $\begin{array}{l}14 \\
12 \\
11 \\
10 \\
9.5\end{array}$ & $\begin{array}{l}7.9 \\
7.9 \\
7.6 \\
7.2 \\
6.0\end{array}$ & $\begin{array}{c}18 \\
9.1 \\
9.8 \\
9.3 \\
9.3\end{array}$ \\
\hline $\begin{array}{l}26 \\
27 \\
28 \\
29 \\
30 \\
31\end{array}$ & $\begin{array}{l}174 \\
163 \\
151 \\
138 \\
135 \\
129\end{array}$ & $\begin{array}{l}119 \\
155 \\
569 \\
871 \\
783 \\
\cdots\end{array}$ & $\begin{array}{r}\text { e210 } \\
\text { e190 } \\
\text { e1 } 80 \\
824 \\
\text { e1500 } \\
\text { e1 } 1700\end{array}$ & $\begin{array}{l}\text { el } 170 \\
\text { el } 60 \\
\text { el } 48 \\
\text { el } 40 \\
\text { e1 } 35 \\
\text { el } 20\end{array}$ & $\begin{array}{l}164 \\
152 \\
148 \\
\ldots- \\
\ldots- \\
\ldots-\end{array}$ & $\begin{array}{l}596 \\
589 \\
525 \\
412 \\
325 \\
275\end{array}$ & $\begin{array}{l}173 \\
167 \\
174 \\
187 \\
209 \\
\cdots\end{array}$ & $\begin{array}{l}371 \\
489 \\
429 \\
293 \\
210 \\
178\end{array}$ & $\begin{array}{l}31 \\
27 \\
25 \\
24 \\
23 \\
-\end{array}$ & $\begin{array}{l}8.9 \\
8.9 \\
8.1 \\
7.1 \\
7.8 \\
8.1\end{array}$ & $\begin{array}{l}5.6 \\
5.9 \\
5.7 \\
5.4 \\
5.5 \\
6.2\end{array}$ & $\begin{array}{l}8.7 \\
12 \\
10 \\
7.8 \\
5.3 \\
\cdots\end{array}$ \\
\hline $\begin{array}{l}\text { TOTAL } \\
\text { MEAN } \\
\text { MAX } \\
\text { MIN } \\
\text { CF SM } \\
\text { IN. }\end{array}$ & $\begin{array}{r}11968 \\
386 \\
1200 \\
40 \\
2.68 \\
3.09\end{array}$ & $\begin{array}{r}9057 \\
302 \\
871 \\
118 \\
2.10 \\
2.34\end{array}$ & $\begin{array}{r}12051 \\
389 \\
1700 \\
156 \\
2.70 \\
3.11\end{array}$ & $\begin{array}{r}15420 \\
497 \\
1680 \\
120 \\
3.45 \\
3.98\end{array}$ & $\begin{array}{r}6354 \\
227 \\
376 \\
112 \\
1.58 \\
1.64\end{array}$ & $\begin{array}{r}13143 \\
424 \\
1120 \\
90 \\
2.94 \\
3.40\end{array}$ & $\begin{array}{c}8129 \\
271 \\
709 \\
141 \\
1.88 \\
2.10\end{array}$ & $\begin{array}{l}7151 \\
231 \\
546 \\
109 \\
1.60 \\
1.85\end{array}$ & $\begin{array}{r}2280 \\
76.0 \\
229 \\
23 \\
.53 \\
.59\end{array}$ & $\begin{array}{r}538.4 \\
17.4 \\
31 \\
7.1 \\
.12 \\
.14\end{array}$ & $\begin{array}{r}234.0 \\
7.55 \\
14 \\
5.4 \\
.05 \\
.06\end{array}$ & $\begin{array}{c}219.2 \\
7.31 \\
18 \\
4.1 \\
.05 \\
.06\end{array}$ \\
\hline
\end{tabular}

STATISTICS OF MONTHLY MEAN DATA FOR WATER YEARS 1950 - 1991. BY WATER YEAR (WY)

\begin{tabular}{|c|c|c|c|c|c|c|c|c|c|c|c|c|}
\hline $\begin{array}{l}\text { MEAN } \\
\text { MAX } \\
\text { (WY) } \\
\text { MIN } \\
\text { (WY) }\end{array}$ & $\begin{array}{r}62.2 \\
386 \\
1991 \\
5.69 \\
1957\end{array}$ & $\begin{array}{r}87.1 \\
320 \\
1973 \\
5.95 \\
1965\end{array}$ & $\begin{array}{r}142 \\
389 \\
1991 \\
5.97 \\
1964\end{array}$ & $\begin{array}{r}145 \\
497 \\
1991 \\
13.2 \\
1963\end{array}$ & $\begin{array}{r}191 \\
480 \\
1976 \\
12.7 \\
1964\end{array}$ & $\begin{array}{r}258 \\
788 \\
1982 \\
36.7 \\
1957\end{array}$ & $\begin{array}{r}267 \\
604 \\
1950 \\
73.2 \\
1956\end{array}$ & $\begin{array}{c}188 \\
566 \\
1974 \\
41.6 \\
1958\end{array}$ & $\begin{array}{c}145 \\
632 \\
1958 \\
15.1 \\
1988\end{array}$ & $\begin{array}{r}69.6 \\
266 \\
1957 \\
9.22 \\
1988\end{array}$ & $\begin{array}{r}39.3 \\
169 \\
1990 \\
3.57 \\
1964\end{array}$ & $\begin{array}{r}44.7 \\
276 \\
1989 \\
5.38 \\
1964\end{array}$ \\
\hline
\end{tabular}

SUMMARY STATISIICS

ANNUAL TOTAL

ANNUAL MEAN

HIGHEST ANMUAL MEAM

LOWEST ANNUAL MEAM

HIGHEST DAILY MEAN

LOWEST DAILY MEAN

ANNUAL SEVEN-DAY MINIMUM

INSTANTANEOUS PEAK FLOW

INSTANTANEOUS PEAK STAGE

ANNUAL RUNOFF (CFSM)

ANNUAL RUNOFF (INCHES)

10 PERCENT EXCEEDS

50 PERCENT EXCEEDS

90 PERCENT EXCEEDS
FOR 1990 CALENDAR YEAR

\begin{tabular}{|c|c|}
\hline $\begin{array}{r}90316 \\
247\end{array}$ & \\
\hline $\begin{array}{r}e 1700 \\
35 \\
42\end{array}$ & $\begin{array}{lr}\text { Dec } & 31 \\
\text { Jul } & 9 \\
\text { Sep } & 26\end{array}$ \\
\hline $\begin{array}{r}1.72 \\
23.33 \\
581 \\
157 \\
58\end{array}$ & \\
\hline
\end{tabular}

WATER YEARS 1950 - 1991

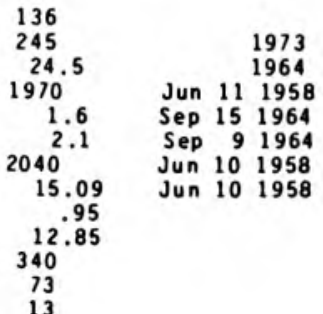

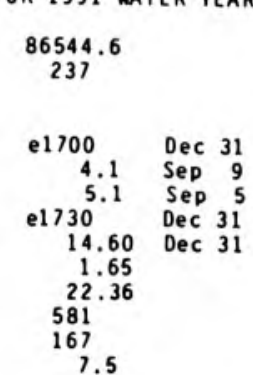




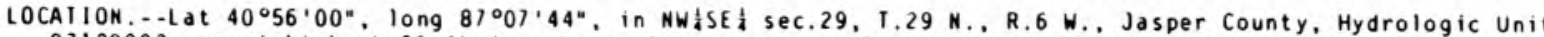
07120002 , on right bank $20 \mathrm{ft}$ downstrean from bridge on State Highway $114,0.8$. east of Rensselaer, 1.5 a downstrean fron Ryaz ditch, 5.5 i upstrean from Slough Creek, and at ile 84.9 .

DRAI NAGE AREA $\cdots 203 \mathrm{mi}^{2}$

PERIOD OF RECORD...July 1948 to current yedr.

REVISED RECORDS...-WSP 2115: Drainage area.

GAGE.--Water-stage recorder. Datum of gage is $642.29 \mathrm{ft}$ above Mational Geodetic Vertical Datue of 1929 (levels by State of Indiand. Departaent of Natural Resources). Prior to July 8, 1949, nonrecording gage at sane site and datur.

REMARKS. - Records good except for Aug. 2 to Sept. 2, which are fair. Streaflow affected by irrigation.

DISCHARGE, CUBIC FEET PER SECONO, WATER YEAR OCTOBER 1990 TO SEPTEMBER 1991 DAILY MEAN VALUES

\begin{tabular}{|c|c|c|c|c|c|c|c|c|c|c|c|c|}
\hline DAY & $O C T$ & NOV & DEC & JAN & FEB & MAR & APR & MAY & JUN & JUL & AUG & SEP \\
\hline $\begin{array}{l}1 \\
2 \\
3 \\
4 \\
5\end{array}$ & $\begin{array}{r}53 \\
51 \\
59 \\
137 \\
127\end{array}$ & $\begin{array}{l}166 \\
165 \\
163 \\
159 \\
529\end{array}$ & $\begin{array}{l}833 \\
663 \\
602 \\
657 \\
585\end{array}$ & $\begin{array}{l}2340 \\
2160 \\
1900 \\
1600 \\
1260\end{array}$ & $\begin{array}{r}\text { e } 140 \\
\text { e150 } \\
\text { e } 190 \\
372 \\
485\end{array}$ & $\begin{array}{l}198 \\
303 \\
392 \\
342 \\
301\end{array}$ & $\begin{array}{l}315 \\
279 \\
262 \\
254 \\
274\end{array}$ & $\begin{array}{l}254 \\
250 \\
231 \\
199 \\
199\end{array}$ & $\begin{array}{l}269 \\
300 \\
239 \\
195 \\
167\end{array}$ & $\begin{array}{l}48 \\
45 \\
39 \\
33 \\
32\end{array}$ & $\begin{array}{r}8.7 \\
\text { e } 9.0 \\
\text { e } 8.6 \\
\text { e } 8.5 \\
\text { e8.0 }\end{array}$ & $\begin{array}{r}\mathrm{e} 9.0 \\
\mathrm{e} 7.6 \\
7.1 \\
7.9 \\
7.6\end{array}$ \\
\hline $\begin{array}{r}6 \\
7 \\
8 \\
9 \\
10\end{array}$ & $\begin{array}{r}100 \\
134 \\
241 \\
721 \\
1460\end{array}$ & $\begin{array}{r}1050 \\
1040 \\
843 \\
646 \\
492\end{array}$ & $\begin{array}{l}491 \\
425 \\
349 \\
307 \\
286\end{array}$ & $\begin{array}{l}922 \\
653 \\
470 \\
382 \\
343\end{array}$ & $\begin{array}{l}505 \\
459 \\
407 \\
376 \\
371\end{array}$ & $\begin{array}{l}282 \\
248 \\
216 \\
203 \\
182\end{array}$ & $\begin{array}{l}269 \\
246 \\
235 \\
232 \\
213\end{array}$ & $\begin{array}{l}234 \\
210 \\
183 \\
172 \\
161\end{array}$ & $\begin{array}{l}148 \\
135 \\
127 \\
121 \\
113\end{array}$ & $\begin{array}{l}30 \\
27 \\
25 \\
26 \\
27\end{array}$ & $\begin{array}{l}\text { e } 9.5 \\
\text { e11 } \\
\text { e15 } \\
\text { e22 } \\
\text { e16 }\end{array}$ & $\begin{array}{l}8.5 \\
7.7 \\
7.9 \\
6.1 \\
6.6\end{array}$ \\
\hline $\begin{array}{l}11 \\
12 \\
13 \\
14 \\
15\end{array}$ & $\begin{array}{r}1680 \\
1660 \\
1500 \\
1250 \\
992\end{array}$ & $\begin{array}{l}379 \\
311 \\
271 \\
253 \\
236\end{array}$ & $\begin{array}{l}277 \\
259 \\
240 \\
212 \\
304\end{array}$ & $\begin{array}{l}333 \\
406 \\
371 \\
338 \\
352\end{array}$ & $\begin{array}{l}337 \\
291 \\
265 \\
256 \\
183\end{array}$ & $\begin{array}{l}174 \\
189 \\
125 \\
190 \\
267\end{array}$ & $\begin{array}{l}188 \\
175 \\
178 \\
229 \\
574\end{array}$ & $\begin{array}{l}155 \\
154 \\
149 \\
158 \\
335\end{array}$ & $\begin{array}{r}112 \\
108 \\
95 \\
80 \\
85\end{array}$ & $\begin{array}{l}26 \\
25 \\
24 \\
22 \\
18\end{array}$ & $\begin{array}{r}13 \\
\mathrm{e} 12 \\
\mathrm{e} 10 \\
\mathrm{e} 9.0 \\
\mathrm{e} 8.2\end{array}$ & $\begin{array}{l}7.0 \\
7.4 \\
8.8 \\
12 \\
11\end{array}$ \\
\hline $\begin{array}{l}16 \\
17 \\
18 \\
19 \\
20\end{array}$ & $\begin{array}{l}778 \\
607 \\
673 \\
695 \\
585\end{array}$ & $\begin{array}{l}221 \\
201 \\
193 \\
185 \\
175\end{array}$ & $\begin{array}{l}418 \\
371 \\
386 \\
411 \\
352\end{array}$ & $\begin{array}{l}101 \\
984 \\
884 \\
696 \\
601\end{array}$ & $\begin{array}{r}\text { e220 } \\
\text { e230 } \\
234 \\
413 \\
429\end{array}$ & $\begin{array}{r}245 \\
340 \\
867 \\
1340 \\
1610\end{array}$ & $\begin{array}{l}912 \\
913 \\
856 \\
689 \\
517\end{array}$ & $\begin{array}{l}289 \\
255 \\
640 \\
763 \\
601\end{array}$ & $\begin{array}{l}84 \\
80 \\
62 \\
60 \\
55\end{array}$ & $\begin{array}{l}19 \\
36 \\
29 \\
23 \\
20\end{array}$ & $\begin{array}{l}\text { e7.6 } \\
\text { e7.3 } \\
7.0 \\
10 \\
16\end{array}$ & $\begin{array}{r}8.4 \\
7.3 \\
7.4 \\
7.6 \\
13\end{array}$ \\
\hline $\begin{array}{l}21 \\
22 \\
23 \\
24 \\
25\end{array}$ & $\begin{array}{l}464 \\
377 \\
321 \\
285 \\
257\end{array}$ & $\begin{array}{l}175 \\
193 \\
197 \\
187 \\
166\end{array}$ & $\begin{array}{r}401 \\
643 \\
585 \\
429 \\
340\end{array}$ & $\begin{array}{l}\text { e } 480 \\
\text { e } 380 \\
\text { e } 310 \\
\text { e } 270 \\
\text { e } 240\end{array}$ & $\begin{array}{l}377 \\
344 \\
305 \\
271 \\
239\end{array}$ & $\begin{array}{r}1630 \\
1490 \\
1320 \\
1160 \\
951\end{array}$ & $\begin{array}{l}396 \\
327 \\
288 \\
271 \\
246\end{array}$ & $\begin{array}{l}413 \\
302 \\
275 \\
268 \\
273\end{array}$ & $\begin{array}{l}53 \\
50 \\
47 \\
44 \\
39\end{array}$ & $\begin{array}{l}18 \\
16 \\
13 \\
12 \\
12\end{array}$ & $\begin{array}{r}14 \\
\mathrm{e} 12 \\
\mathrm{e} 10 \\
\mathrm{e} 9.2 \\
\mathrm{e} 8.2\end{array}$ & $\begin{array}{l}35 \\
13 \\
13 \\
11 \\
12\end{array}$ \\
\hline $\begin{array}{l}26 \\
27 \\
28 \\
29 \\
30 \\
31\end{array}$ & $\begin{array}{l}236 \\
220 \\
205 \\
186 \\
182 \\
177\end{array}$ & $\begin{array}{r}156 \\
202 \\
827 \\
1150 \\
1030 \\
-\cdots\end{array}$ & $\begin{array}{l}\text { e290 } \\
e 260 \\
\text { e240 } \\
1120 \\
2200 \\
2380\end{array}$ & $\begin{array}{l}\text { e210 } \\
\text { e2 } 00 \\
\text { el } 90 \\
\text { e180 } \\
171 \\
\text { el } 45\end{array}$ & $\begin{array}{l}216 \\
199 \\
192 \\
\ldots . \\
\ldots \\
\ldots\end{array}$ & $\begin{array}{l}805 \\
780 \\
689 \\
541 \\
417 \\
350\end{array}$ & $\begin{array}{l}226 \\
218 \\
227 \\
241 \\
271 \\
\cdots\end{array}$ & $\begin{array}{l}522 \\
650 \\
558 \\
386 \\
286 \\
245\end{array}$ & $\begin{array}{l}39 \\
38 \\
34 \\
35 \\
34 \\
-2\end{array}$ & $\begin{array}{l}11 \\
14 \\
10 \\
7.5 \\
7.4 \\
9.0\end{array}$ & $\begin{array}{l}\text { e } 7.3 \\
\text { e } 7.1 \\
\text { e } 7.0 \\
\text { e6.9 } \\
\text { e } 7.2 \\
\text { e } 8.0\end{array}$ & $\begin{array}{l}11 \\
16 \\
15 \\
13 \\
7.3 \\
\cdots\end{array}$ \\
\hline $\begin{array}{l}\text { IOIAL } \\
\text { MEAN } \\
\text { MAX } \\
\text { MIN } \\
\text { CFSM } \\
\text { IN. }\end{array}$ & $\begin{array}{r}16413 \\
529 \\
1680 \\
51 \\
2.61 \\
3.01\end{array}$ & $\begin{array}{r}11961 \\
399 \\
1150 \\
156 \\
1.96 \\
2.19\end{array}$ & $\begin{array}{r}17316 \\
559 \\
2380 \\
212 \\
2.75 \\
3.17\end{array}$ & $\begin{array}{r}20472 \\
660 \\
2340 \\
145 \\
3.25 \\
3.75\end{array}$ & $\begin{array}{r}8456 \\
302 \\
505 \\
140 \\
1.49 \\
1.55\end{array}$ & $\begin{array}{r}18147 \\
585 \\
1630 \\
125 \\
2.88 \\
3.33\end{array}$ & $\begin{array}{r}10521 \\
351 \\
913 \\
175 \\
1.73 \\
1.93\end{array}$ & $\begin{array}{r}9770 \\
315 \\
763 \\
149 \\
1.55 \\
1.79\end{array}$ & $\begin{array}{c}3048 \\
102 \\
300 \\
34 \\
.50 \\
.56\end{array}$ & $\begin{array}{r}703.9 \\
22.7 \\
48 \\
7.4 \\
.11 \\
.13\end{array}$ & $\begin{array}{c}313.3 \\
10.1 \\
22 \\
6.9 \\
.05 \\
.06\end{array}$ & $\begin{array}{c}312.2 \\
10.4 \\
35 \\
6.1 \\
.05 \\
.06\end{array}$ \\
\hline
\end{tabular}

e Estinated

STAIISIICS OF MONIHLY MEAN DAIA FOR WAIER YEARS 1949 - 1991, BY WAIER YEAR (WY)

$\begin{array}{lrrr}\text { MEAN } & 15.1 & 107 & 1 \\ \text { MAX } & 529 & 415 & 559 \\ \text { (WY) } & 1991 & 1986 & 19 \\ \text { MIN } & 5.77 & 7.75 & 1.04 \\ \text { (WY) } & 1965 & 1965 & 19\end{array}$

$\begin{array}{rrr}179 & 194 & 25 \\ 559 & 774 & 613 \\ 1991 & 1950 & 197 \\ 1.04 & 14.5 & 13.9 \\ 1964 & 1963 & 196\end{array}$

$\begin{array}{rr}332 & 340 \\ 935 & 886 \\ 1982 & 1950 \\ 40.8 & 87.8 \\ 1957 & 1986\end{array}$

238
766
1974
47.6
1958

$\begin{array}{rrr}87.6 & 48.0 & 55.7 \\ 378 & 238 & 357 \\ 1957 & 1990 & 1989 \\ 12.5 & 4.61 & 5.26 \\ 1964 & 1964 & 1964\end{array}$

SUMMARY SIAIISIICS

ANMUAL IOIAL

ANNUAL MEAM

HIGHESI ANNUAL MEAN

LOWEST ANNUAL MEAN

HIGHEST DAILY MEAN

LOWEST DAILY MEAN

ANMUAL SEVEN-DAY MINIMUM

INSTANIANEOUS PEAK FLOW

INSIANTANEOUS PEAK SIAGE

ANNUAL RUNOFF (CFSM)

ANNUAL RUNOFF (INCHES)

10 PERCENT EXCEEDS

50 PERCENT EXCEEDS

90 PERCENT EXCEEDS

\section{FOR 1990 CALENDAR YEAR}

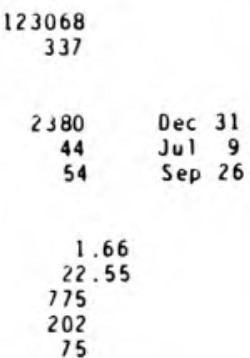

FOR 1991 WAIER YEAR

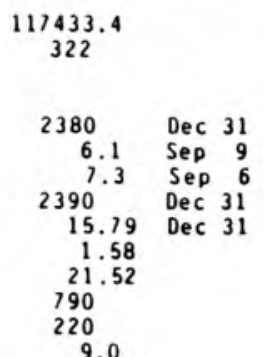

WATER YEARS $1949-1991$

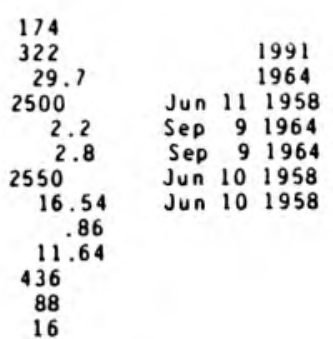




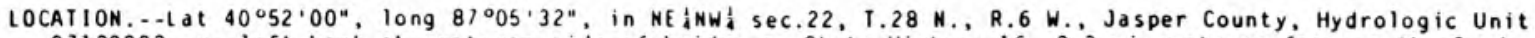
07120002 , on left bank at upstream side of bridge on State Highway $16,2.3$ mi upstrea from mouth, 3 mi southeast of South Mąrion, and $5 \mathrm{mi}$ southeast of Rensselaer.

DRAINAGE AREA $\cdots 21.8 \mathrm{mi}^{2}$

PERIOD OF RECORD..-December 1948 to current year.

REVISED RECORDS.--WSP 1508: 1950. WSP 2115: Drainage area.

GAGE. - Water-stage recorder. Datum of gage is $651.30 \mathrm{ft}$ above National Geodetic Vertical Datun of 1929 . Prior to Aug. 5, 1955, nonrecording gage, and Aug. 5, 1955, to Sept. 30, 1965, water-stage recorder at present site at datu $2.00 \mathrm{ft}$ higher.

REMARKS. - Records fair except estimated daily discharges, for Dec. 31 to Jan. 30 , which are poor. Low flows in suaner ay be affected by irrigation.

DISCHARGE, CUBIC FEET PER SECOND, WATER YEAR OCTOBER 1990 TO SEPTEMBER 1991

\begin{tabular}{|c|c|c|c|c|c|c|c|c|c|c|c|c|}
\hline DAY & $\mathrm{OCT}$ & NOV & DEC & JAN & FEB & MAR & APR & MAY & JUN & JUL & $A \cup G$ & SEP \\
\hline $\begin{array}{l}1 \\
2 \\
3 \\
4 \\
5\end{array}$ & $\begin{array}{l}3.4 \\
3.6 \\
4.0 \\
6.2 \\
5.3\end{array}$ & $\begin{array}{r}8.6 \\
8.4 \\
7.7 \\
8.1 \\
95\end{array}$ & $\begin{array}{l}32 \\
24 \\
47 \\
49 \\
30\end{array}$ & $\begin{array}{r}\text { e } 100 \\
\text { e } 66 \\
\text { e } 52 \\
\text { e } 41 \\
\text { e } 35\end{array}$ & $\begin{array}{l}\text { e5. } 4 \\
\text { e5.6 } \\
\text { e11 } \\
28 \\
38\end{array}$ & $\begin{array}{l}16 \\
43 \\
41 \\
29 \\
25\end{array}$ & $\begin{array}{l}21 \\
18 \\
17 \\
18 \\
23\end{array}$ & $\begin{array}{r}12 \\
11 \\
9.6 \\
9.2 \\
9.6\end{array}$ & $\begin{array}{l}8.2 \\
7.4 \\
6.6 \\
5.8 \\
5.1\end{array}$ & $\begin{array}{l}.78 \\
.22 \\
.19 \\
.29 \\
.17\end{array}$ & $\begin{array}{l}.20 \\
.21 \\
.23 \\
.25 \\
.17\end{array}$ & $\begin{array}{l}.14 \\
.14 \\
.14 \\
.17 \\
.16\end{array}$ \\
\hline $\begin{array}{r}6 \\
7 \\
8 \\
9 \\
10\end{array}$ & $\begin{array}{r}4.7 \\
9.1 \\
15 \\
143 \\
395\end{array}$ & $\begin{array}{r}125 \\
75 \\
51 \\
40 \\
31\end{array}$ & $\begin{array}{l}26 \\
22 \\
19 \\
18 \\
18\end{array}$ & $\begin{array}{l}\text { e29 } \\
e 26 \\
e 24 \\
e 22 \\
e 21\end{array}$ & $\begin{array}{l}37 \\
34 \\
31 \\
31 \\
33\end{array}$ & $\begin{array}{l}24 \\
17 \\
15 \\
14 \\
12\end{array}$ & $\begin{array}{l}20 \\
18 \\
17 \\
17 \\
13\end{array}$ & $\begin{array}{l}9.6 \\
7.8 \\
7.4 \\
7.4 \\
7.0\end{array}$ & $\begin{array}{l}4.8 \\
4.6 \\
4.4 \\
4.2 \\
4.1\end{array}$ & $\begin{array}{l}.43 \\
.51 \\
.61 \\
.61 \\
1.0\end{array}$ & $\begin{aligned} .28 \\
.19 \\
.76 \\
1.4 \\
.60\end{aligned}$ & $\begin{array}{l}.15 \\
.15 \\
.14 \\
.15 \\
.16\end{array}$ \\
\hline $\begin{array}{l}11 \\
12 \\
13 \\
14 \\
15\end{array}$ & $\begin{array}{r}204 \\
106 \\
71 \\
55 \\
46\end{array}$ & $\begin{array}{l}25 \\
21 \\
19 \\
18 \\
17\end{array}$ & $\begin{array}{l}17 \\
16 \\
13 \\
11 \\
27\end{array}$ & $\begin{array}{l}\text { e22 } \\
\text { e23 } \\
\text { e21 } \\
\text { e } 20 \\
e 20\end{array}$ & $\begin{array}{r}26 \\
21 \\
22 \\
21 \\
\mathrm{e} 12\end{array}$ & $\begin{array}{l}12 \\
16 \\
56 \\
55 \\
59\end{array}$ & $\begin{array}{r}11 \\
10 \\
13 \\
42 \\
134\end{array}$ & $\begin{array}{l}6.8 \\
7.0 \\
6.9 \\
7.2 \\
6.8\end{array}$ & $\begin{array}{l}4.1 \\
4.4 \\
3.9 \\
3.3 \\
3.5\end{array}$ & $\begin{array}{l}.52 \\
.17 \\
.29 \\
.85 \\
.40\end{array}$ & $\begin{array}{l}.28 \\
.23 \\
.19 \\
.15 \\
.15\end{array}$ & $\begin{array}{l}.18 \\
.20 \\
.20 \\
.32 \\
.32\end{array}$ \\
\hline $\begin{array}{l}16 \\
17 \\
18 \\
19 \\
20\end{array}$ & $\begin{array}{l}37 \\
31 \\
70 \\
45 \\
33\end{array}$ & $\begin{array}{l}17 \\
14 \\
13 \\
13 \\
11\end{array}$ & $\begin{array}{l}27 \\
24 \\
27 \\
24 \\
22\end{array}$ & $\begin{array}{l}\text { e } 30 \\
\text { e } 26 \\
\text { e } 22 \\
\text { e1 } 8 \\
\text { e15 }\end{array}$ & $\begin{array}{r}\text { el } 2 \\
\text { el } \\
23 \\
55 \\
42\end{array}$ & $\begin{array}{r}91 \\
169 \\
354 \\
196 \\
107\end{array}$ & $\begin{array}{l}94 \\
63 \\
42 \\
32 \\
26\end{array}$ & $\begin{array}{r}8.0 \\
15 \\
174 \\
89 \\
47\end{array}$ & $\begin{array}{l}4.3 \\
3.5 \\
3.1 \\
2.7 \\
1.9\end{array}$ & $\begin{array}{l}.25 \\
.38 \\
.18 \\
.42 \\
.69\end{array}$ & $\begin{array}{l}.27 \\
.65 \\
.28 \\
1.9 \\
1.6\end{array}$ & $\begin{array}{l}.24 \\
.22 \\
.19 \\
.21 \\
.22\end{array}$ \\
\hline $\begin{array}{l}21 \\
22 \\
23 \\
24 \\
25\end{array}$ & $\begin{array}{l}26 \\
21 \\
18 \\
16 \\
14\end{array}$ & $\begin{array}{l}11 \\
12 \\
13 \\
11 \\
9.8\end{array}$ & $\begin{array}{r}44 \\
83 \\
e 40 \\
\text { e26 } \\
\text { e20 }\end{array}$ & $\begin{array}{r}\text { e } 12 \\
\text { e11 } \\
\text { e } 9.5 \\
\text { e } 8.6 \\
\text { e } 7.9\end{array}$ & $\begin{array}{l}36 \\
32 \\
25 \\
23 \\
19\end{array}$ & $\begin{array}{r}76 \\
59 \\
126 \\
98 \\
68\end{array}$ & $\begin{array}{l}21 \\
19 \\
17 \\
15 \\
13\end{array}$ & $\begin{array}{l}30 \\
21 \\
17 \\
14 \\
19\end{array}$ & $\begin{array}{l}2.4 \\
1.8 \\
1.6 \\
.99 \\
1.5\end{array}$ & $\begin{array}{l}.20 \\
.26 \\
.23 \\
.20 \\
.15\end{array}$ & $\begin{array}{l}.16 \\
.33 \\
.25 \\
.20 \\
.18\end{array}$ & $\begin{array}{l}.22 \\
.29 \\
.35 \\
.37 \\
.33\end{array}$ \\
\hline $\begin{array}{l}26 \\
27 \\
28 \\
29 \\
30 \\
31\end{array}$ & $\begin{array}{l}13 \\
12 \\
11 \\
9.5 \\
9.6 \\
9.0\end{array}$ & $\begin{array}{l}8.8 \\
12 \\
87 \\
63 \\
43 \\
-\cdots\end{array}$ & $\begin{array}{r}\text { e18 } \\
\text { e17 } \\
\text { e17 } \\
344 \\
590 \\
\text { e230 }\end{array}$ & $\begin{array}{l}\text { e) } 7.3 \\
\text { e7. } \\
\text { e6. } 6 \\
\text { e6. } 6 \\
\text { e5. } 5 \\
\text { e5.5 }\end{array}$ & $\begin{array}{c}16 \\
14 \\
13 \\
\ldots \\
\ldots \\
\cdots\end{array}$ & $\begin{array}{l}88 \\
84 \\
60 \\
39 \\
28 \\
25\end{array}$ & $\begin{array}{l}12 \\
12 \\
12 \\
15 \\
14 \\
\cdots\end{array}$ & $\begin{array}{c}38 \\
27 \\
17 \\
13 \\
12 \\
9.4\end{array}$ & $\begin{array}{l}.87 \\
.32 \\
.88 \\
.60 \\
.17 \\
\cdots\end{array}$ & $\begin{array}{l}.14 \\
.16 \\
.29 \\
.20 \\
.17 \\
.15\end{array}$ & $\begin{array}{l}.17 \\
.19 \\
.18 \\
.19 \\
.20 \\
.17\end{array}$ & $\begin{array}{l}.29 \\
.31 \\
.32 \\
.34 \\
.36 \\
\ldots\end{array}$ \\
\hline $\begin{array}{l}\text { TOTAL } \\
\text { MEAN } \\
\text { MAX } \\
\text { MIN } \\
\text { CF SM } \\
\text { IN. }\end{array}$ & $\begin{array}{r}1446.4 \\
46.7 \\
395 \\
3.4 \\
2.14 \\
2.47\end{array}$ & $\begin{array}{r}888.4 \\
29.6 \\
125 \\
7.7 \\
1.36 \\
1.52\end{array}$ & $\begin{array}{r}1922 \\
62.0 \\
590 \\
11 \\
2.84 \\
3.28\end{array}$ & $\begin{array}{r}720.5 \\
23.2 \\
100 \\
5.5 \\
1.07 \\
1.23\end{array}$ & $\begin{array}{r}679.0 \\
24.2 \\
55 \\
5.4 \\
1.11 \\
1.16\end{array}$ & $\begin{array}{r}2102 \\
67.8 \\
354 \\
12 \\
3.11 \\
3.59\end{array}$ & $\begin{array}{r}799 \\
26.6 \\
134 \\
10 \\
1.22 \\
1.36\end{array}$ & $\begin{array}{c}675.7 \\
21.8 \\
174 \\
6.8 \\
1.00 \\
1.15\end{array}$ & $\begin{array}{r}101.03 \\
3.37 \\
8.2 \\
.17 \\
.15 \\
.17\end{array}$ & $\begin{array}{r}11.11 \\
.36 \\
1.0 \\
.14 \\
.02 \\
.02\end{array}$ & $\begin{array}{r}12.81 \\
.41 \\
1.9 \\
.15 \\
.02 \\
.02\end{array}$ & $\begin{array}{l}6.98 \\
.23 \\
.37 \\
.14 \\
.01 \\
.01\end{array}$ \\
\hline
\end{tabular}

e Estinated

SIATISIICS OF MONTHLY MEAN DATA FOR WAIER YEARS 1950 - 1991, BY WAIER YEAR (WY)

\begin{tabular}{|c|c|c|c|c|c|c|c|c|c|}
\hline $\begin{array}{l}\text { MEAN } \\
\text { MAX } \\
\text { (WY) } \\
\text { MIN } \\
\text { (WY) }\end{array}$ & $\begin{array}{r}6.36 \\
46.7 \\
1991 \\
.084 \\
1965\end{array}$ & $\begin{array}{l}10.2 \\
64.3 \\
1986 \\
.097 \\
1965\end{array}$ & $\begin{array}{r}20.4 \\
81.0 \\
1968 \\
.15 \\
1964\end{array}$ & $\begin{array}{r}17.1 \\
92.8 \\
1950 \\
.25 \\
1977\end{array}$ & $\begin{array}{r}26.3 \\
82.7 \\
1982 \\
.59 \\
1964\end{array}$ & $\begin{array}{l}35.9 \\
94.3 \\
1979 \\
1.89 \\
1957\end{array}$ & $\begin{array}{l}33.2 \\
85.9 \\
1950 \\
5.50 \\
1986\end{array}$ & $\begin{array}{l}22.8 \\
74.2 \\
1981 \\
2.93 \\
1988\end{array}$ & \\
\hline
\end{tabular}

SUMMARY SIAIISIICS

ANMUAL TOTAL

ANMUAL MEAN

HIGHESI AHNUAL MEAN

LOWEST ANNUAL MEAN

HIGHEST DAILY MEAM

LOWEST DAIIY MEAN

ANNUAL SEVEN-DAY MINIMUM

INSTANTANEOUS PEAK FLOW

INSIANTANEOUS PEAK SIAGE

ANHUAL RUNOFF (CFSM)

ANNUAL RUNOFF (INCHES)

10 PERCENT EXCEEDS

50 PERCENT EXCEEDS

90 PERCENT EXCEEDS
FOR 1990 CALENDAR YEAR

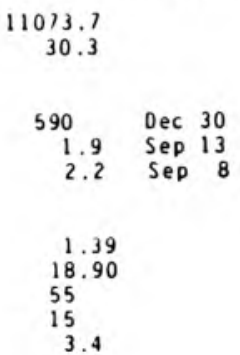

FOR 1991 WAIER YEAR

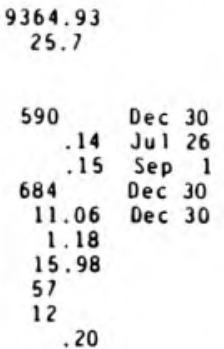

WAIER YEARS $1950-1991$

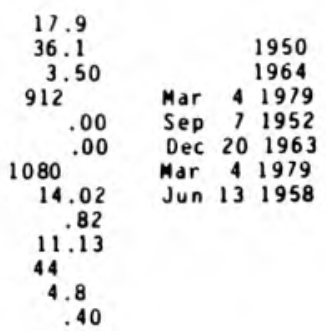


LOCATION.--Lat $40^{\circ} 52^{\prime} 14^{\prime \prime}$, Iong $87^{\circ} 18^{\prime} 24^{\prime \prime}$, in NEISE sec.15, T.28 N., R.8 W. Newton County, Hydrologic Unit

07120002 , on right bank at downstrean side of bridge on State Highway 55 , 0.2 . Highways 16 and 55, 0.5 i downstream from Mosquito Creek, $0.6 \mathrm{~m} i$ west of Foresaan, 3 ai east of Brook, and at - ile 72.7 .

DRAI NAGE AREA,$-449 \backsim i^{2}$

PERIOD OF RECORD.--Decenber 1948 to current year.

REVISEO RECORDS.-.WSP 1338: 1953. WSP 1438: 1955. WSP 1508: 1956. WSP 2115: Draindge area.

GAGE.--Water-stage recorder. Datum of gage is $624.00 \mathrm{ft}$ above National Geodetic Vertical Datun of 1929 . Prior to Sept. 7 , 1955, nonrecording gage 2.5 i upstrea at datu $3.54 \mathrm{ft}$ higher.

REMARKS. - Records good except for estimated daily discharges, which are fair.

DISCHARGE, CUBIC FEET PER SECOND, WATER YEAR OCTOBER 1990 TO SEPTEMBER 1991 DAILY MEAN VALUES

\begin{tabular}{|c|c|c|c|c|c|c|c|c|c|c|c|c|}
\hline DAY & $\mathrm{OCT}$ & NOV & DEC & JAN & FEB & MAR & APR & MAY & JUN & JUL & AUG & SEP \\
\hline $\begin{array}{l}1 \\
2 \\
3 \\
4 \\
5\end{array}$ & $\begin{array}{l}102 \\
100 \\
108 \\
168 \\
224\end{array}$ & $\begin{array}{l}366 \\
360 \\
356 \\
349 \\
617\end{array}$ & $\begin{array}{l}1210 \\
1130 \\
1060 \\
1050 \\
1000\end{array}$ & $\begin{array}{r}5570 \\
\text { e } 5080 \\
\text { e } 4490 \\
\text { e } 3940 \\
\text { e } 3210\end{array}$ & $\begin{array}{r}\text { e } 320 \\
\text { e } 340 \\
\text { e } 410 \\
\text { e } 600 \\
788\end{array}$ & $\begin{array}{l}451 \\
553 \\
721 \\
740 \\
701\end{array}$ & $\begin{array}{l}\text { e } 870 \\
\text { e790 } \\
\text { e } 760 \\
\text { e } 740 \\
\text { e730 }\end{array}$ & $\begin{array}{l}\text { e } 540 \\
\text { e } 510 \\
\text { e } 480 \\
\text { e } 450 \\
\text { e440 }\end{array}$ & $\begin{array}{l}\text { e } 620 \\
\text { e } 590 \\
\text { e } 540 \\
\text { e } 440 \\
\text { e } 380\end{array}$ & $\begin{array}{l}\text { el } 40 \\
\text { e } 130 \\
\text { e } 100 \\
\text { e } 85 \\
\text { e } 73\end{array}$ & $\begin{array}{l}15 \\
15 \\
14 \\
14 \\
13\end{array}$ & $\begin{array}{r}12 \\
9.7 \\
11 \\
12 \\
10\end{array}$ \\
\hline $\begin{array}{r}6 \\
7 \\
8 \\
9 \\
10\end{array}$ & $\begin{array}{r}194 \\
204 \\
397 \\
793 \\
1480\end{array}$ & $\begin{array}{l}1130 \\
1310 \\
1350 \\
1280 \\
1170\end{array}$ & $\begin{array}{l}914 \\
810 \\
718 \\
637 \\
580\end{array}$ & $\begin{array}{r}\mathrm{e} 2270 \\
\mathrm{e} 1710 \\
\mathrm{e} 1360 \\
1120 \\
\mathrm{e} 880\end{array}$ & $\begin{array}{l}846 \\
849 \\
816 \\
777 \\
760\end{array}$ & $\begin{array}{l}669 \\
626 \\
558 \\
510 \\
470\end{array}$ & $\begin{array}{l}\text { e } 720 \\
e 700 \\
e 670 \\
e 630 \\
\text { e580 }\end{array}$ & $\begin{array}{l}\text { e } 430 \\
\text { e } 410 \\
\text { e } 360 \\
\text { e } 340 \\
\text { e } 320\end{array}$ & $\begin{array}{l}\text { e } 320 \\
\text { e } 280 \\
e 250 \\
\text { e } 230 \\
e 220\end{array}$ & $\begin{array}{l}\text { e67 } \\
\text { e62 } \\
\text { e } 58 \\
\text { e59 } \\
\text { e } 60\end{array}$ & $\begin{array}{l}\text { e } 16 \\
\text { e18 } \\
\text { e22 } \\
\text { e37 } \\
\text { e28 }\end{array}$ & $\begin{array}{l}9.0 \\
9.2 \\
9.1 \\
8.6 \\
8.4\end{array}$ \\
\hline $\begin{array}{l}11 \\
12 \\
13 \\
14 \\
15\end{array}$ & $\begin{array}{l}2590 \\
3040 \\
3040 \\
2460 \\
2390\end{array}$ & $\begin{array}{r}1030 \\
877 \\
734 \\
624 \\
552\end{array}$ & $\begin{array}{l}541 \\
517 \\
486 \\
441 \\
485\end{array}$ & $\begin{array}{r}\text { e7 } 32 \\
\text { e732 } \\
\text { e720 } \\
675 \\
664\end{array}$ & $\begin{array}{r}732 \\
673 \\
619 \\
589 \\
\mathrm{e} 420\end{array}$ & $\begin{array}{l}431 \\
435 \\
633 \\
813 \\
925\end{array}$ & $\begin{array}{r}e 540 \\
e 490 \\
e 480 \\
e 560 \\
922\end{array}$ & $\begin{array}{l}\text { e } 310 \\
\text { e } 300 \\
\text { e } 300 \\
\text { e } 300 \\
\text { e } 460\end{array}$ & $\begin{array}{l}\text { e215 } \\
\text { e210 } \\
\text { e200 } \\
\text { e160 } \\
\text { e165 }\end{array}$ & $\begin{array}{l}\text { e } 58 \\
\text { e } 56 \\
\text { e } 54 \\
\text { e } 46 \\
\text { e } 42\end{array}$ & $\begin{array}{l}\text { e22 } \\
\text { e19 } \\
\text { e1 } \\
\text { e15 } \\
\text { e13 }\end{array}$ & $\begin{array}{l}8.5 \\
8.0 \\
9.6 \\
10 \\
12\end{array}$ \\
\hline $\begin{array}{l}16 \\
17 \\
18 \\
19 \\
20\end{array}$ & $\begin{array}{l}1970 \\
1660 \\
1480 \\
1370 \\
1250\end{array}$ & $\begin{array}{l}503 \\
460 \\
424 \\
406 \\
383\end{array}$ & $\begin{array}{l}629 \\
649 \\
661 \\
675 \\
654\end{array}$ & $\begin{array}{r}902 \\
1240 \\
1360 \\
1300 \\
1220\end{array}$ & $\begin{array}{r}e 370 \\
\text { e } 430 \\
498 \\
684 \\
798\end{array}$ & $\begin{array}{l}1010 \\
1210 \\
1810 \\
2810 \\
3360\end{array}$ & $\begin{array}{l}1300 \\
1490 \\
1560 \\
1510 \\
1410\end{array}$ & $\begin{array}{r}678 \\
697 \\
963 \\
1320 \\
1470\end{array}$ & $\begin{array}{l}\text { el65 } \\
\text { e160 } \\
\text { e125 } \\
\text { e115 } \\
\text { e110 }\end{array}$ & $\begin{array}{r}\text { e } 39 \\
47 \\
65 \\
57 \\
47\end{array}$ & $\begin{array}{l}\text { el } \\
\text { e } 12 \\
\text { el } 1 \\
\text { el } 16 \\
\text { e25 }\end{array}$ & $\begin{array}{l}12 \\
10 \\
9.4 \\
9.8 \\
9.8\end{array}$ \\
\hline $\begin{array}{l}21 \\
22 \\
23 \\
24 \\
25\end{array}$ & $\begin{array}{r}1130 \\
982 \\
833 \\
707 \\
604\end{array}$ & $\begin{array}{l}365 \\
391 \\
415 \\
406 \\
374\end{array}$ & $\begin{array}{r}659 \\
899 \\
982 \\
\text { e } 860 \\
\text { e } 760\end{array}$ & $\begin{array}{r}\text { e } 1000 \\
\text { e } 850 \\
\text { e730 } \\
\text { e630 } \\
\text { e560 }\end{array}$ & $\begin{array}{l}796 \\
768 \\
726 \\
674 \\
615\end{array}$ & $\begin{array}{l}3490 \\
3350 \\
3120 \\
2940 \\
2660\end{array}$ & $\begin{array}{r}\text { e } 1200 \\
\text { el } 000 \\
\text { e } 800 \\
\text { e } 630 \\
\text { e } 570\end{array}$ & $\begin{array}{r}1440 \\
e 1100 \\
\text { e } 800 \\
\text { e } 600 \\
\text { e } 550\end{array}$ & $\begin{array}{r}\text { e } 105 \\
\text { e100 } \\
\text { e } 92 \\
\text { e } 85 \\
\text { e } 80\end{array}$ & $\begin{array}{l}40 \\
35 \\
31 \\
29 \\
28\end{array}$ & $\begin{array}{l}\text { e23 } \\
\text { e20 } \\
\text { e18 } \\
\text { e15 } \\
\text { e14 }\end{array}$ & $\begin{array}{l}31 \\
35 \\
22 \\
17 \\
14\end{array}$ \\
\hline $\begin{array}{l}26 \\
27 \\
28 \\
29 \\
30 \\
31\end{array}$ & $\begin{array}{l}528 \\
481 \\
450 \\
409 \\
388 \\
380\end{array}$ & $\begin{array}{r}342 \\
373 \\
873 \\
1160 \\
1230 \\
\ldots\end{array}$ & $\begin{array}{l}\text { e690 } \\
\text { e630 } \\
\text { e600 } \\
1390 \\
4420 \\
5500\end{array}$ & $\begin{array}{r}\text { e510 } \\
\text { e } 460 \\
\text { e430 } \\
390 \\
\text { e360 } \\
\text { e330 }\end{array}$ & $\begin{array}{l}555 \\
503 \\
461 \\
\cdots \\
\cdots \\
\cdots\end{array}$ & $\begin{array}{r}2340 \\
2160 \\
1960 \\
e 1600 \\
e 1250 \\
e 1000\end{array}$ & $\begin{array}{l}\text { e } 520 \\
\text { e } 480 \\
\text { e } 500 \\
\text { e } 540 \\
\text { e } 550 \\
\ldots .-\end{array}$ & $\begin{array}{l}\text { e } 900 \\
1040 \\
1050 \\
1020 \\
\text { e840 } \\
\text { e } 700\end{array}$ & $\begin{array}{l}\text { e } 76 \\
\text { e71 } \\
\text { e66 } \\
\text { e63 } \\
\text { e72 } \\
\cdots\end{array}$ & $\begin{array}{l}25 \\
23 \\
21 \\
18 \\
16 \\
16\end{array}$ & $\begin{array}{c}\text { e12 } \\
10 \\
9.7 \\
9.5 \\
10 \\
11\end{array}$ & $\begin{array}{l}16 \\
19 \\
22 \\
18 \\
14 \\
\ldots\end{array}$ \\
\hline $\begin{array}{l}\text { IOTAL } \\
\text { MEAN } \\
\text { MAX } \\
\text { MIN } \\
\text { CF SM } \\
\text { IN. }\end{array}$ & $\begin{array}{r}31912 \\
1029 \\
3040 \\
100 \\
2.29 \\
2.64\end{array}$ & $\begin{array}{r}20210 \\
674 \\
1350 \\
342 \\
1.50 \\
1.67\end{array}$ & $\begin{array}{r}32237 \\
1040 \\
5500 \\
441 \\
2.32 \\
2.67\end{array}$ & $\begin{array}{r}45425 \\
1465 \\
5570 \\
330 \\
3.26 \\
3.76\end{array}$ & $\begin{array}{r}17417 \\
622 \\
849 \\
320 \\
1.39 \\
1.44\end{array}$ & $\begin{array}{r}45306 \\
1461 \\
3490 \\
431 \\
3.25 \\
3.75\end{array}$ & $\begin{array}{r}24242 \\
808 \\
1560 \\
480 \\
1.80 \\
2.01\end{array}$ & $\begin{array}{c}21118 \\
681 \\
1470 \\
300 \\
1.52 \\
1.75\end{array}$ & $\begin{array}{c}6305 \\
210 \\
620 \\
63 \\
.47 \\
.52\end{array}$ & $\begin{array}{c}1627 \\
52.5 \\
140 \\
16 \\
.12 \\
.13\end{array}$ & $\begin{array}{c}507.2 \\
16.4 \\
37 \\
9.5 \\
.04 \\
.04\end{array}$ & $\begin{array}{r}406.1 \\
13.5 \\
35 \\
8.0 \\
.03 \\
.03\end{array}$ \\
\hline
\end{tabular}

e Estinated

SIATISIICS OF MONTHLY MEAN DATA FOR WAIER YEARS 1950 - 1991, BY WATER YEAR (WY)

\begin{tabular}{|c|c|c|c|c|c|c|c|c|c|c|c|}
\hline $\begin{array}{l}\text { MEAN } \\
\text { MAX } \\
\text { (WY) } \\
\text { MIN } \\
\text { (WY) }\end{array}$ & $\begin{array}{r}155 \\
1029 \\
1991 \\
9.70 \\
1957\end{array}$ & $\begin{array}{r}231 \\
1033 \\
1986 \\
16.1 \\
1965\end{array}$ & $\begin{array}{r}407 \\
1274 \\
1968 \\
15.3 \\
1964\end{array}$ & $\begin{array}{r}414 \\
1634 \\
1950 \\
27.0 \\
1963\end{array}$ & $\begin{array}{r}578 \\
1490 \\
1968 \\
31.4 \\
1964\end{array}$ & $\begin{array}{r}748 \\
2266 \\
1982 \\
81.7 \\
1957\end{array}$ & $\begin{array}{r}711 \\
1672 \\
1950 \\
199 \\
1986\end{array}$ & $\begin{array}{r}554 \\
1360 \\
1974 \\
108 \\
1958\end{array}$ & $\begin{array}{r}444 \\
2314 \\
1958 \\
39.8 \\
1988\end{array}$ & $\begin{array}{r}223 \\
964 \\
1957 \\
17.7 \\
1988\end{array}$ & $\begin{array}{r}95.1 \\
435 \\
1990 \\
12.2 \\
1988\end{array}$ \\
\hline
\end{tabular}

SUMMARY SIAIISIICS

ANNUAL TOTAL

ANNUAL MEAN

HIGHESI ANNUAL MEAN

LOWEST ANNUAL MEAN

HIGHEST DAILY MEAM

LOWEST DAILY MEAN

ANMUAL SEVEN-DAY MINIMUM

INSTAMIANEOUS PEAK FLOW

INSTANTANEOUS PEAK STAGE

ANNUAL RUNOFF (CFSM)

ANNUAL RUNOFF (INCHES)

10 PERCEMT EXCEEDS

50 PERCENT EXCEEDS

90 PERCENT EXCEEDS

FOR 1990 CALENDAR YEAR

248814
682

$\begin{array}{rrr}5500 & \text { Dec } & 31 \\ 89 & \text { Jul } & 9 \\ 101 & \text { Sep } & 26\end{array}$

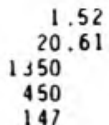

FOR 1991 WATER YEAR

$$
\begin{gathered}
246712.3 \\
676
\end{gathered}
$$

5570 Jan 1

$\begin{array}{rrr}8.0 & \text { Sep } 12 \\ 8.7 & \text { Sep } 6 \\ 670 & \text { Dec } 31\end{array}$

22.19 Dec 31

1.51

1400

498

498
15
WATER YEARS $1950-1991$

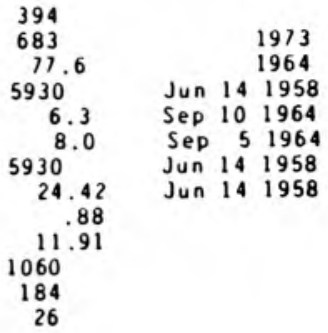


LOCAIION.--1 at 41030'28", Iong 87030'36", in NE iNE d sec.12, T.35 N., R.10 W., Lake County, Hydrologic Unit 0 120003, on right bank $50 \mathrm{ft}$ upstream from $213 \mathrm{th}$ Street in Dyer, 0.8 i upstrea from Dyer ditch.

DRAINAGE AREA. $\cdots 37.6 \mathrm{i}^{2}$.

PERIOD OF RECORD,-.0ctober 1989 to current year.

GAGE. - Water-stage recorder. Datum of gage is $607.38 \mathrm{ft}$ above National Geodetic Vertical Datun of 1929 .

REMARKS.--Records good except those above $1,000 \mathrm{ft} / \mathrm{s}$, which are fair. Low-flow affected by sewage effluent.

DISCHARGE, CUBIC FEET PER SECOND, WATER YEAR OCTOBER 1990 TO SEPTEMBER 1991

\begin{tabular}{|c|c|c|c|c|c|c|c|c|c|c|c|c|}
\hline DAY & $0 \mathrm{CT}$ & NOV & DEC & JAN & FEB & MAR & $A P R$ & MAY & JUN & JUL & AUG & SEP \\
\hline $\begin{array}{l}1 \\
2 \\
3 \\
4 \\
5\end{array}$ & $\begin{array}{l}5.7 \\
5.0 \\
12 \\
32 \\
14\end{array}$ & $\begin{array}{r}10 \\
9.1 \\
9.3 \\
12 \\
271\end{array}$ & $\begin{array}{r}240 \\
164 \\
124 \\
107 \\
72\end{array}$ & $\begin{array}{r}\text { el } 30 \\
\text { e } 70 \\
\text { e } 40 \\
\text { e } 35 \\
\text { e } 30\end{array}$ & $\begin{array}{l}\text { e } 8.3 \\
\text { e10 } \\
\text { e15 } \\
67 \\
235\end{array}$ & $\begin{array}{r}45 \\
842 \\
628 \\
213 \\
142\end{array}$ & $\begin{array}{l}46 \\
36 \\
31 \\
34 \\
66\end{array}$ & $\begin{array}{r}33 \\
35 \\
23 \\
18 \\
261\end{array}$ & $\begin{array}{l}71 \\
48 \\
35 \\
26 \\
20\end{array}$ & $\begin{array}{l}4.5 \\
4.7 \\
4.7 \\
5.1 \\
4.5\end{array}$ & $\begin{array}{l}4.4 \\
4.6 \\
6.4 \\
5.3 \\
5.5\end{array}$ & $\begin{array}{c}4.8 \\
3.4 \\
7.5 \\
13 \\
6.3\end{array}$ \\
\hline $\begin{array}{r}6 \\
7 \\
8 \\
9 \\
10\end{array}$ & $\begin{array}{l}8.4 \\
15 \\
32 \\
183 \\
414\end{array}$ & $\begin{array}{r}342 \\
167 \\
105 \\
12 \\
52\end{array}$ & $\begin{array}{l}63 \\
54 \\
45 \\
39 \\
35\end{array}$ & $\begin{array}{r}\text { e26 } \\
23 \\
20 \\
19 \\
18\end{array}$ & $\begin{array}{r}189 \\
138 \\
89 \\
73 \\
72\end{array}$ & $\begin{array}{r}105 \\
81 \\
56 \\
46 \\
38\end{array}$ & $\begin{array}{l}47 \\
36 \\
32 \\
33 \\
31\end{array}$ & $\begin{array}{r}207 \\
102 \\
62 \\
43 \\
33\end{array}$ & $\begin{array}{l}17 \\
14 \\
12 \\
10 \\
9.5\end{array}$ & $\begin{array}{l}4.2 \\
5.0 \\
4.8 \\
5.0 \\
4.5\end{array}$ & $\begin{array}{l}4.4 \\
4.8 \\
14 \\
10 \\
5.5\end{array}$ & $\begin{array}{l}3.6 \\
2.7 \\
2.5 \\
2.6 \\
3.3\end{array}$ \\
\hline $\begin{array}{l}11 \\
12 \\
13 \\
14 \\
15\end{array}$ & $\begin{array}{r}261 \\
142 \\
92 \\
64 \\
55\end{array}$ & $\begin{array}{l}38 \\
30 \\
26 \\
23 \\
21\end{array}$ & $\begin{array}{l}32 \\
30 \\
28 \\
23 \\
35\end{array}$ & $\begin{array}{l}17 \\
19 \\
19 \\
17 \\
18\end{array}$ & $\begin{array}{l}\text { e } 35 \\
\text { e } 26 \\
\text { e } 35 \\
\text { e } 36 \\
\text { e } 20\end{array}$ & $\begin{array}{l}31 \\
35 \\
39 \\
41 \\
57\end{array}$ & $\begin{array}{r}24 \\
20 \\
19 \\
67 \\
568\end{array}$ & $\begin{array}{l}26 \\
26 \\
20 \\
17 \\
16\end{array}$ & $\begin{array}{l}11 \\
10 \\
8.7 \\
7.7 \\
7.3\end{array}$ & $\begin{array}{l}4.5 \\
4.4 \\
4.7 \\
4.5 \\
4.7\end{array}$ & $\begin{array}{l}3.5 \\
3.1 \\
2.8 \\
2.8 \\
2.7\end{array}$ & $\begin{array}{c}2.7 \\
6.1 \\
16 \\
6.7 \\
3.8\end{array}$ \\
\hline $\begin{array}{l}16 \\
17 \\
18 \\
19 \\
20\end{array}$ & $\begin{array}{l}44 \\
36 \\
66 \\
57 \\
39\end{array}$ & $\begin{array}{l}20 \\
18 \\
16 \\
16 \\
14\end{array}$ & $\begin{array}{l}44 \\
36 \\
45 \\
43 \\
33\end{array}$ & $\begin{array}{r}49 \\
134 \\
\mathrm{e} 80 \\
63 \\
65\end{array}$ & $\begin{array}{r}\text { e17 } \\
\text { e15 } \\
33 \\
131 \\
88\end{array}$ & $\begin{array}{l}116 \\
269 \\
592 \\
336 \\
195\end{array}$ & $\begin{array}{r}419 \\
357 \\
179 \\
98 \\
59\end{array}$ & $\begin{array}{r}18 \\
25 \\
263 \\
172 \\
88\end{array}$ & $\begin{array}{l}7.3 \\
7.6 \\
6.8 \\
6.3 \\
5.9\end{array}$ & $\begin{array}{l}4.3 \\
4.5 \\
4.4 \\
4.5 \\
4.3\end{array}$ & $\begin{array}{l}2.8 \\
2.9 \\
2.7 \\
12 \\
15\end{array}$ & $\begin{array}{l}3.0 \\
2.4 \\
2.5 \\
2.0 \\
2.0\end{array}$ \\
\hline $\begin{array}{l}21 \\
22 \\
23 \\
24 \\
25\end{array}$ & $\begin{array}{l}32 \\
27 \\
24 \\
21 \\
18\end{array}$ & $\begin{array}{l}23 \\
48 \\
46 \\
33 \\
27\end{array}$ & $\begin{array}{r}55 \\
144 \\
e 50 \\
e 28 \\
\text { e20 }\end{array}$ & $\begin{array}{l}\text { e } 38 \\
\text { e28 } \\
\text { e20 } \\
\text { e } 16 \\
\text { e14 }\end{array}$ & $\begin{array}{l}69 \\
75 \\
54 \\
36 \\
30\end{array}$ & $\begin{array}{r}121 \\
80 \\
76 \\
70 \\
51\end{array}$ & $\begin{array}{l}41 \\
32 \\
27 \\
26 \\
23\end{array}$ & $\begin{array}{l}56 \\
42 \\
48 \\
54 \\
69\end{array}$ & $\begin{array}{l}9.4 \\
10 \\
7.0 \\
6.3 \\
4.5\end{array}$ & $\begin{array}{l}4.0 \\
4.6 \\
4.4 \\
4.4 \\
4.0\end{array}$ & $\begin{array}{l}6.4 \\
4.1 \\
2.9 \\
2.2 \\
2.5\end{array}$ & $\begin{array}{l}2.3 \\
2.9 \\
2.6 \\
2.4 \\
2.5\end{array}$ \\
\hline $\begin{array}{l}26 \\
27 \\
28 \\
29 \\
30 \\
31\end{array}$ & $\begin{array}{l}17 \\
15 \\
14 \\
14 \\
13 \\
12\end{array}$ & $\begin{array}{r}22 \\
561 \\
2580 \\
864 \\
363 \\
-\ldots\end{array}$ & $\begin{array}{r}\text { e16 } \\
\text { e14 } \\
\text { e15 } \\
606 \\
832 \\
\text { e210 }\end{array}$ & $\begin{array}{l}\text { e12 } \\
\text { e11 } \\
\text { e10 } \\
\text { e } 9.7 \\
\text { e } 9.8 \\
\text { e9.0 }\end{array}$ & $\begin{array}{l}24 \\
22 \\
20 \\
\ldots \\
\ldots \\
\ldots\end{array}$ & $\begin{array}{r}81 \\
341 \\
278 \\
116 \\
74 \\
58\end{array}$ & $\begin{array}{l}21 \\
20 \\
20 \\
23 \\
27 \\
\cdots\end{array}$ & $\begin{array}{r}238 \\
138 \\
80 \\
113 \\
310 \\
116\end{array}$ & $\begin{array}{l}4.0 \\
4.4 \\
4.9 \\
4.7 \\
4.2 \\
\cdots . .\end{array}$ & $\begin{array}{l}4.1 \\
3.7 \\
3.7 \\
4.4 \\
4.5 \\
4.6\end{array}$ & $\begin{array}{l}2.4 \\
2.4 \\
2.1 \\
2.1 \\
2.9 \\
4.1\end{array}$ & $\begin{array}{l}2.2 \\
2.0 \\
2.3 \\
2.5 \\
3.2 \\
\cdots\end{array}$ \\
\hline $\begin{array}{l}\text { IOTAL } \\
\text { MEAN } \\
\text { MAX } \\
\text { MIN } \\
\text { CF SM } \\
\text { IN. }\end{array}$ & $\begin{array}{r}1784.1 \\
57.6 \\
414 \\
5.0 \\
1.53 \\
1.77\end{array}$ & $\begin{array}{r}5838.4 \\
195 \\
2580 \\
9.1 \\
5.18 \\
5.78\end{array}$ & $\begin{array}{r}3282 \\
106 \\
832 \\
14 \\
2.82 \\
3.25\end{array}$ & $\begin{array}{r}1069.5 \\
34.5 \\
134 \\
9.0 \\
.92 \\
1.06\end{array}$ & $\begin{array}{r}1662.3 \\
59.4 \\
235 \\
8.3 \\
1.58 \\
1.64\end{array}$ & $\begin{array}{r}5253 \\
169 \\
842 \\
31 \\
4.51 \\
5.20\end{array}$ & $\begin{array}{c}2462 \\
82.1 \\
568 \\
19 \\
2.18 \\
2.44\end{array}$ & $\begin{array}{c}2752 \\
88.8 \\
310 \\
16 \\
2.36 \\
2.72\end{array}$ & $\begin{array}{r}400.5 \\
13.3 \\
71 \\
4.0 \\
.36 \\
.40\end{array}$ & $\begin{array}{c}138.2 \\
4.46 \\
5.1 \\
3.7 \\
.12 \\
.14\end{array}$ & $\begin{array}{c}149.3 \\
4.82 \\
15 \\
2.1 \\
.13 \\
.15\end{array}$ & $\begin{array}{c}121.8 \\
4.06 \\
16 \\
2.0 \\
.11 \\
.12\end{array}$ \\
\hline
\end{tabular}

e Estimated

SIATISIICS OF MONIHLY MEAN DAIA FOR WAIER YEARS 1990 - 1991, BY WATER YEAR (WY)

\begin{tabular}{|c|c|c|c|c|c|c|c|c|c|c|c|c|}
\hline $\begin{array}{l}\text { MEAN } \\
\text { MAX } \\
\text { (WY) } \\
\text { MIN } \\
\text { (WY) }\end{array}$ & $\begin{array}{l}32.6 \\
57.6 \\
1991 \\
7.72 \\
1990\end{array}$ & $\begin{array}{r}107 \\
195 \\
1991 \\
19.6 \\
1990\end{array}$ & $\begin{array}{r}55.4 \\
106 \\
1991 \\
4.92 \\
1990\end{array}$ & $\begin{array}{l}38.1 \\
41.7 \\
1990 \\
34.5 \\
1991\end{array}$ & $\begin{array}{l}65.0 \\
70.7 \\
1990 \\
59.4 \\
1991\end{array}$ & $\begin{array}{r}124 \\
169 \\
1991 \\
79.1 \\
1990\end{array}$ & $\begin{array}{l}54.7 \\
82.1 \\
1991 \\
27.4 \\
1990\end{array}$ & $\begin{array}{r}94.7 \\
101 \\
1990 \\
88.8 \\
1991\end{array}$ & $\begin{array}{l}13.1 \\
13.3 \\
1991 \\
12.9 \\
1990\end{array}$ & $\begin{array}{l}5.15 \\
7.05 \\
1990 \\
4.46 \\
1991\end{array}$ & $\begin{array}{l}20.3 \\
35.7 \\
1990 \\
4.82\end{array}$ & $\begin{array}{l}5.14 \\
6.22 \\
1990 \\
4.06\end{array}$ \\
\hline
\end{tabular}

SUMMARY SIATISIICS

ANMUAL TOTAL

ANNUAL MEAM

HIGHESI ANNUAL MEAM

LOWEST ANNUAL MEAN

HIGHEST DAILY MEAN

LOWESI DAILY MEA

ANNUAL SEVEN-DAY MINIMUM

INSIANIANE OUS PEAK FLOW

INSTANIANE OUS PEAK SIAGE

ANMUAL RUNOFF (CFSM)

AN NUAL RUNOFF (I NCHES

50 PERCENI EXCEEDS

90 PERCENI EXCEEDS
FOR 1990 CALENDAR YEAR

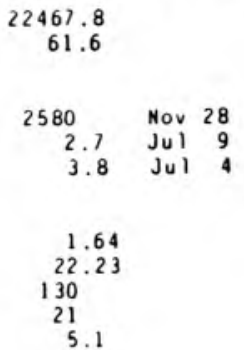

FOR 1991 WAIER YEAR

24913.1

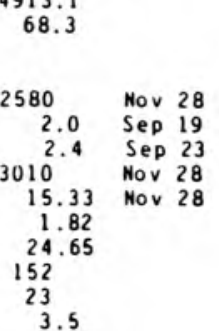

WAIER YEARS $1990 \quad-1991$

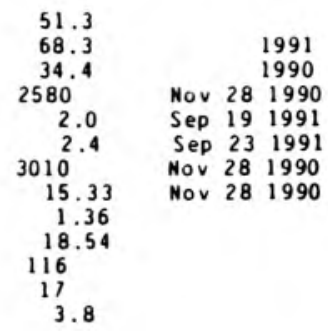




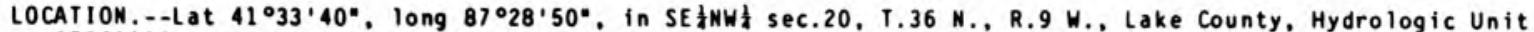
07120003 , on left bank at city liaits of Munster, 0.2 a downstrean from Ridge Road, and 0.4 a upstrea froe mouth.

DRAI NAGE AREA,$-70.7 \cdot 1^{2}$

PERIOD OF RECORD, - - Septenber 1942 to current year.

REVISED RECORDS.--WDR IN-72-1: Ora inage area.

GAGE. - Water-stage recorder and concrete control. Datua of gage is $591.27 \mathrm{ft}$ above National Geodetic Vertical Datun of 1929 (levels by State of Indiana. Departaent of Natural Resources). Since Sept. 11. 1959. auxiliary water-stage recorder $1,200 \mathrm{ft}$ upstrean fron base gage, at sane datue.

REMARKS.--Records good below $200 \mathrm{ft} / \mathrm{s}$ and fair above. High flow occasionally in backwater from Little Caluaet River.

DISCHARGE, CUBIC FEET PER SECOND, WATER YEAR OCTOBER 1990 TO SEPTEMBER 1991 DAILY MEAN VALUES

\begin{tabular}{|c|c|c|c|c|c|c|c|c|c|c|c|c|}
\hline DAY & $\mathrm{OCT}$ & NOV & DEC & JAN & FEB & MAR & APR & MAY & JUN & JUL & AUG & SEP \\
\hline $\begin{array}{l}1 \\
2 \\
3 \\
4 \\
5\end{array}$ & $\begin{array}{r}14 \\
13 \\
107 \\
97 \\
39\end{array}$ & $\begin{array}{r}25 \\
22 \\
22 \\
49 \\
e 560\end{array}$ & $\begin{array}{l}\text { e } 350 \\
\text { e } 300 \\
\text { e250 } \\
\text { e200 } \\
\text { e } 160\end{array}$ & $\begin{array}{r}e 370 \\
e 250 \\
e 120 \\
e 82 \\
e 68\end{array}$ & $\begin{array}{r}e 25 \\
e 27 \\
54 \\
166 \\
570\end{array}$ & $\begin{array}{r}140 \\
\text { e1600 } \\
\text { e } 1100 \\
\text { e520 } \\
\text { e } 280\end{array}$ & $\begin{array}{r}95 \\
79 \\
69 \\
85 \\
113\end{array}$ & $\begin{array}{r}87 \\
71 \\
54 \\
47 \\
648\end{array}$ & $\begin{array}{r}102 \\
75 \\
60 \\
49 \\
41\end{array}$ & $\begin{array}{l}14 \\
11 \\
17 \\
15 \\
14\end{array}$ & $\begin{array}{l}6.4 \\
6.1 \\
22 \\
11 \\
11\end{array}$ & $\begin{array}{l}13 \\
11 \\
54 \\
31 \\
17\end{array}$ \\
\hline $\begin{array}{r}6 \\
7 \\
8 \\
9 \\
10\end{array}$ & $\begin{array}{r}24 \\
43 \\
132 \\
735 \\
+900\end{array}$ & $\begin{array}{r}\text { e700 } \\
\text { e210 } \\
\text { e130 } \\
\text { e100 } \\
\text { e } 80\end{array}$ & $\begin{array}{r}\text { e130 } \\
\text { e110 } \\
\text { e94 } \\
\text { e80 } \\
\text { e72 }\end{array}$ & $\begin{array}{l}61 \\
54 \\
48 \\
46 \\
44\end{array}$ & $\begin{array}{l}455 \\
300 \\
174 \\
138 \\
129\end{array}$ & $\begin{array}{r}\text { e210 } \\
\text { e160 } \\
\text { e130 } \\
106 \\
88\end{array}$ & $\begin{array}{l}88 \\
72 \\
66 \\
75 \\
72\end{array}$ & $\begin{array}{r}488 \\
170 \\
105 \\
81 \\
65\end{array}$ & $\begin{array}{l}37 \\
34 \\
28 \\
25 \\
23\end{array}$ & $\begin{array}{c}11 \\
30 \\
23 \\
12 \\
8.9\end{array}$ & $\begin{array}{r}8.8 \\
8.1 \\
153 \\
25 \\
15\end{array}$ & $\begin{array}{l}12 \\
10 \\
9.5 \\
10 \\
26\end{array}$ \\
\hline $\begin{array}{l}11 \\
12 \\
13 \\
14 \\
15\end{array}$ & $\begin{array}{r}e 500 \\
\text { e250 } \\
160 \\
116 \\
99\end{array}$ & $\begin{array}{l}66 \\
55 \\
49 \\
45 \\
43\end{array}$ & $\begin{array}{l}67 \\
64 \\
58 \\
49 \\
81\end{array}$ & $\begin{array}{l}47 \\
51 \\
49 \\
50 \\
50\end{array}$ & $\begin{array}{r}89 \\
64 \\
183 \\
108 \\
e 60\end{array}$ & $\begin{array}{r}76 \\
87 \\
92 \\
108 \\
149\end{array}$ & $\begin{array}{r}58 \\
51 \\
49 \\
168 \\
\mathrm{e} 1400\end{array}$ & $\begin{array}{l}56 \\
54 \\
47 \\
44 \\
41\end{array}$ & $\begin{array}{l}41 \\
26 \\
23 \\
20 \\
20\end{array}$ & $\begin{array}{r}8.7 \\
9.9 \\
12 \\
12 \\
12\end{array}$ & $\begin{array}{r}12 \\
11 \\
9.3 \\
9.6 \\
9.7\end{array}$ & $\begin{array}{l}10 \\
47 \\
54 \\
19 \\
12\end{array}$ \\
\hline $\begin{array}{l}16 \\
17 \\
18 \\
19 \\
20\end{array}$ & $\begin{array}{r}75 \\
79 \\
121 \\
87 \\
65\end{array}$ & $\begin{array}{l}40 \\
37 \\
35 \\
34 \\
32\end{array}$ & $\begin{array}{l}75 \\
72 \\
81 \\
72 \\
59\end{array}$ & $\begin{array}{r}188 \\
285 \\
176 \\
130 \\
e 135\end{array}$ & $\begin{array}{r}e 48 \\
e 46 \\
87 \\
271 \\
175\end{array}$ & $\begin{array}{r}216 \\
566 \\
1210 \\
766 \\
392\end{array}$ & $\begin{array}{l}e 800 \\
e 700 \\
e 400 \\
e 200 \\
e 130\end{array}$ & $\begin{array}{r}45 \\
46 \\
441 \\
284 \\
114\end{array}$ & $\begin{array}{l}21 \\
19 \\
18 \\
16 \\
14\end{array}$ & $\begin{array}{l}8.5 \\
7.5 \\
8.6 \\
6.6 \\
7.4\end{array}$ & $\begin{array}{r}8.2 \\
8.0 \\
8.0 \\
111 \\
61\end{array}$ & $\begin{array}{r}11 \\
8.9 \\
8.1 \\
7.2 \\
7.5\end{array}$ \\
\hline $\begin{array}{l}21 \\
22 \\
23 \\
24 \\
25\end{array}$ & $\begin{array}{l}55 \\
49 \\
44 \\
39 \\
38\end{array}$ & $\begin{array}{l}70 \\
83 \\
68 \\
52 \\
45\end{array}$ & $\begin{array}{l}160 \\
324 \\
113 \\
\text { e } 60 \\
\text { e45 }\end{array}$ & $\begin{array}{l}\text { e100 } \\
\text { e70 } \\
e 54 \\
\text { e45 } \\
\text { e39 }\end{array}$ & $\begin{array}{r}128 \\
128 \\
94 \\
70 \\
59\end{array}$ & $\begin{array}{l}212 \\
143 \\
170 \\
142 \\
108\end{array}$ & $\begin{array}{r}\text { e110 } \\
\text { e100 } \\
86 \\
74 \\
63\end{array}$ & $\begin{array}{r}78 \\
70 \\
77 \\
96 \\
156\end{array}$ & $\begin{array}{l}25 \\
41 \\
22 \\
19 \\
17\end{array}$ & $\begin{array}{r}10 \\
8.8 \\
8.0 \\
7.6 \\
7.3\end{array}$ & $\begin{array}{l}20 \\
15 \\
12 \\
10 \\
10\end{array}$ & $\begin{array}{r}7.5 \\
21 \\
8.4 \\
7.5 \\
7.8\end{array}$ \\
\hline $\begin{array}{l}26 \\
27 \\
28 \\
29 \\
30 \\
31\end{array}$ & $\begin{array}{l}36 \\
34 \\
31 \\
30 \\
28 \\
26\end{array}$ & $\begin{array}{r}40 \\
1240 \\
\mathrm{e} 2600 \\
\mathrm{e} 1100 \\
\mathrm{e} 600 \\
\cdots\end{array}$ & $\begin{array}{r}e 35 \\
e 33 \\
e 35 \\
1390 \\
e 1500 \\
e 600\end{array}$ & $\begin{array}{l}\text { e35 } \\
\text { e } 32 \\
\text { e } 31 \\
\text { e } 30 \\
\text { e28 } \\
\text { e26 }\end{array}$ & $\begin{array}{r}50 \\
47 \\
48 \\
\cdots- \\
\cdots \\
\cdots\end{array}$ & $\begin{array}{r}227 \\
\text { e860 } \\
\text { e640 } \\
306 \\
155 \\
114\end{array}$ & $\begin{array}{l}57 \\
55 \\
54 \\
70 \\
62 \\
\cdots\end{array}$ & $\begin{array}{l}481 \\
213 \\
111 \\
142 \\
628 \\
168\end{array}$ & $\begin{array}{l}19 \\
20 \\
16 \\
16 \\
16 \\
\cdots-\end{array}$ & $\begin{array}{r}8.6 \\
7.5 \\
7.6 \\
11.7 \\
7.7 \\
6.8\end{array}$ & $\begin{array}{l}11 \\
9.1 \\
6.5 \\
8.5 \\
17 \\
18\end{array}$ & $\begin{array}{l}7.1 \\
6.4 \\
6.7 \\
7.0 \\
7.4 \\
. . .\end{array}$ \\
\hline $\begin{array}{l}\text { TOTAL } \\
\text { MEAN } \\
\text { MAX } \\
\text { MIN } \\
\text { CF SM } \\
\text { IN. }\end{array}$ & $\begin{array}{r}4066 \\
131 \\
900 \\
13 \\
1.86 \\
2.14\end{array}$ & $\begin{array}{r}8232 \\
274 \\
2600 \\
22 \\
3.88 \\
4.33\end{array}$ & $\begin{array}{r}6719 \\
217 \\
1500 \\
33 \\
3.07 \\
3.54\end{array}$ & $\begin{array}{r}2794 \\
90.1 \\
370 \\
26 \\
1.27 \\
1.47\end{array}$ & $\begin{array}{r}3793 \\
135 \\
570 \\
25 \\
1.92 \\
2.00\end{array}$ & $\begin{array}{r}11073 \\
357 \\
1600 \\
76 \\
5.05 \\
5.83\end{array}$ & $\begin{array}{r}5501 \\
183 \\
1400 \\
49 \\
2.59 \\
2.89\end{array}$ & $\begin{array}{c}5208 \\
168 \\
648 \\
41 \\
2.38 \\
2.74\end{array}$ & $\begin{array}{c}903 \\
30.1 \\
102 \\
14 \\
.43 \\
.48\end{array}$ & $\begin{array}{r}340.0 \\
11.0 \\
30 \\
6.6 \\
.16 \\
.18\end{array}$ & $\begin{array}{c}651.3 \\
21.0 \\
153 \\
6.1 \\
.30 \\
.34\end{array}$ & $\begin{array}{c}465.0 \\
15.5 \\
54 \\
6.4 \\
.22 \\
.24\end{array}$ \\
\hline
\end{tabular}

STATISTICS OF MONTHLY MEAN DATA FOR WATER YEARS 1943 - 1991, BY WATER YEAR (WY)

$\begin{array}{lrrrrrrrrrrrr}\text { MEAN } & 27.5 & 46.8 & 62.9 & 56.1 & 79.4 & 136 & 130 & 98.5 & 59.0 & 29.1 & 25.9 & 25.0 \\ \text { MAX } & 282 & 287 & 279 & 172 & 236 & 429 & 363 & 367 & 249 & 161 & 155 & 201 \\ \text { (WY) } & 1955 & 1986 & 1983 & 1975 & 1985 & 1979 & 1947 & 1943 & 1981 & 1957 & 1990 & 1965 \\ \text { MIN } & 3.95 & 3.54 & 3.07 & 3.77 & 6.32 & 19.1 & 19.2 & 11.9 & 8.78 & 6.11 & 4.73 & 3.91 \\ \text { (WY) } & 1965 & 1972 & 1964 & 1977 & 1963 & 1957 & 1946 & 1958 & 1965 & 1965 & 1964 & 1956\end{array}$

SUMMARY STATISTICS

ANNUAL TOTAL

AMNUAL MEAH

HIGHEST ANNUAL MEAM

LOWE ST AMNUAL MEAN

HIGHEST DAILY MEAN

LOWEST DAILY MEAM

ANNUAL SEVEN-DAY MINIMUM

INSTANTANEOUS PEAK FLOW

INSTANTANEOUS PEAK STAGE

ANMUAL RUNOFF (CFSM)

ANNUAL RUNOFF (INCHES)

10 PERCENT EXCEEDS

50 PERCEMT EXCEEDS

90 PERCENT EXCEEDS
FOR 1990 CALENDAR YEAR
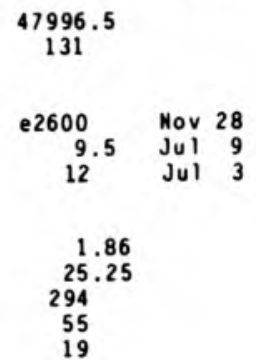

FOR 1991 WATER YEAR

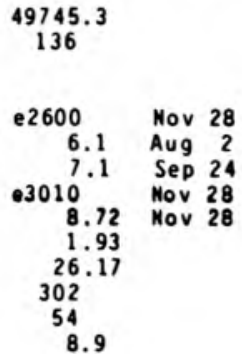

WATER YEARS 1943 - 1991

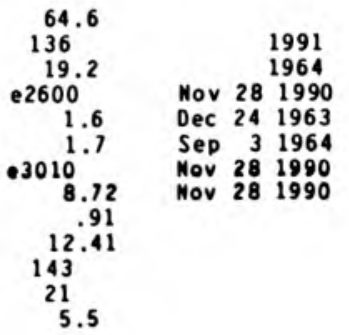

e Estinated 
LOCATION.- -Lat $41^{\circ} 34^{\prime} 07^{\prime \prime}$. Iong $87^{\circ} 31^{\prime} 18^{\circ}$, in SE 4 HWL sec.13, T.36 N., R.10 W. Lake County, Hydrologic Unit 07120003 , on left bank $200 \mathrm{ft}$ upstreas fro Hohan Street bridge at north city 1 iaits of Munster, 0.4 at upstrea from Indiang-I 11 inois State line, and 4.6 upstrean from Thorn Creek.

DRAINAGE AREA. - -90.0 i During times of fioods on Deep River, flow way enter basin from eastern portion of Little Caluet River basin; or, during tiaes of floods on Hart ditch, flow ay leave the basin and enter eastern portion of the Little Caluet River basin. PERIOD OF RECORD...-June 1958 to current year.

GAGE.-Water-stage recorder. Datue of gage is $580.72 \mathrm{ft}$ above National Geodetic Vertical Datue of 1929 .

REMARKS.--Records fair except for estiaated daily discharges, which are poor. Flow froe eastern portion of Little Caluet River basin is diverted to Lake Michigan by Burns ditch. Periods of high flow frequently are in backwater frod downstrean storage.

DISCHARGE, CUBIC FEET PER SECOND, WATER YEAR OCTOBER 1990 TO SEPTEMBER 1991 DAI IY MEAM VALUES

\begin{tabular}{|c|c|c|c|c|c|c|c|c|c|c|c|c|}
\hline DAY & OCT & NOV & DEC & JAN & FEB & MAR & APR & MAY & JUN & JUL & AUG & SEP \\
\hline $\begin{array}{l}1 \\
2 \\
3 \\
4 \\
5\end{array}$ & $\begin{array}{r}e 20 \\
e 25 \\
64 \\
103 \\
47\end{array}$ & $\begin{array}{r}21 \\
22 \\
21 \\
33 \\
369\end{array}$ & $\begin{array}{l}\text { e615 } \\
e 450 \\
e 360 \\
e 270 \\
e 230\end{array}$ & $\begin{array}{r}\text { e } 140 \\
\text { e } 112 \\
\text { e94 } \\
\text { e } 82 \\
\text { e } 74\end{array}$ & $\begin{array}{r}e 15 \\
e 17 \\
e 25 \\
74 \\
204\end{array}$ & $\begin{array}{r}66 \\
555 \\
706 \\
423 \\
+260\end{array}$ & $\begin{array}{r}122 \\
100 \\
84 \\
81 \\
96\end{array}$ & $\begin{array}{r}62 \\
58 \\
44 \\
35 \\
282\end{array}$ & $\begin{array}{r}106 \\
80 \\
60 \\
44 \\
33\end{array}$ & $\begin{array}{l}14 \\
12 \\
15 \\
20 \\
12\end{array}$ & $\begin{array}{r}7.2 \\
5.9 \\
16 \\
11 \\
9.3\end{array}$ & $\begin{array}{l}12 \\
10 \\
58 \\
34 \\
19\end{array}$ \\
\hline $\begin{array}{r}6 \\
7 \\
8 \\
9 \\
10\end{array}$ & $\begin{array}{r}27 \\
35 \\
65 \\
308 \\
493\end{array}$ & $\begin{array}{r}470 \\
295 \\
\text { e167 } \\
\text { el } 20 \\
\text { e94 }\end{array}$ & $\begin{array}{l}e 200 \\
e 170 \\
e 145 \\
e 123 \\
e 110\end{array}$ & $\begin{array}{r}e 66 \\
e 59 \\
47 \\
37 \\
33\end{array}$ & $\begin{array}{l}207 \\
167 \\
135 \\
114 \\
106\end{array}$ & $\begin{array}{l}\text { e2 } 00 \\
\text { e160 } \\
\text { e130 } \\
\text { e1 } 15 \\
\text { e103 }\end{array}$ & $\begin{array}{l}82 \\
71 \\
64 \\
65 \\
64\end{array}$ & $\begin{array}{r}300 \\
148 \\
111 \\
88 \\
69\end{array}$ & $\begin{array}{l}26 \\
23 \\
20 \\
18 \\
17\end{array}$ & $\begin{array}{l}9.9 \\
16 \\
28 \\
11 \\
8.8\end{array}$ & $\begin{array}{r}8.8 \\
7.8 \\
157 \\
43 \\
17\end{array}$ & $\begin{array}{l}13 \\
11 \\
10 \\
9.7 \\
30\end{array}$ \\
\hline $\begin{array}{l}11 \\
12 \\
13 \\
14 \\
15\end{array}$ & $\begin{array}{r}409 \\
e 240 \\
e 160 \\
e 120 \\
\text { e100 }\end{array}$ & $\begin{array}{r}\text { e78 } \\
\text { e62 } \\
\text { e } 52 \\
\text { e46 } \\
39\end{array}$ & $\begin{array}{r}e 95 \\
\text { e } 84 \\
\text { e75 } \\
68 \\
75\end{array}$ & $\begin{array}{l}35 \\
38 \\
37 \\
37 \\
36\end{array}$ & $\begin{array}{r}87 \\
e 56 \\
e 92 \\
e 100 \\
e 80\end{array}$ & $\begin{array}{r}92 \\
90 \\
88 \\
91 \\
115\end{array}$ & $\begin{array}{r}53 \\
44 \\
40 \\
102 \\
e 510\end{array}$ & $\begin{array}{l}53 \\
44 \\
37 \\
33 \\
30\end{array}$ & $\begin{array}{l}36 \\
20 \\
17 \\
15 \\
14\end{array}$ & $\begin{array}{l}7.8 \\
8.4 \\
8.3 \\
9.2 \\
8.9\end{array}$ & $\begin{array}{c}12 \\
10 \\
9.0 \\
8.0 \\
8.4\end{array}$ & $\begin{array}{l}12 \\
45 \\
59 \\
27 \\
18\end{array}$ \\
\hline $\begin{array}{l}16 \\
17 \\
18 \\
19 \\
20\end{array}$ & $\begin{array}{r}\text { e82 } \\
\text { e70 } \\
\text { e115 } \\
\text { e86 } \\
\text { e70 }\end{array}$ & $\begin{array}{l}35 \\
31 \\
29 \\
28 \\
29\end{array}$ & $\begin{array}{l}71 \\
68 \\
70 \\
65 \\
54\end{array}$ & $\begin{array}{l}108 \\
150 \\
127 \\
e 90 \\
e 86\end{array}$ & $\begin{array}{l}\text { e50 } \\
\text { e40 } \\
e 46 \\
130 \\
132\end{array}$ & $\begin{array}{l}150 \\
254 \\
487 \\
417 \\
262\end{array}$ & $\begin{array}{r}657 \\
559 \\
435 \\
e 250 \\
e 180\end{array}$ & $\begin{array}{r}34 \\
35 \\
158 \\
172 \\
100\end{array}$ & $\begin{array}{l}15 \\
14 \\
13 \\
13 \\
11\end{array}$ & $\begin{array}{l}7.2 \\
6.1 \\
7.2 \\
5.8 \\
5.7\end{array}$ & $\begin{array}{r}8.0 \\
7.3 \\
7.9 \\
73 \\
114\end{array}$ & $\begin{array}{l}15 \\
13 \\
12 \\
11 \\
10\end{array}$ \\
\hline $\begin{array}{l}21 \\
22 \\
23 \\
24 \\
25\end{array}$ & $\begin{array}{r}\text { e } 56 \\
\text { e } 46 \\
38 \\
32 \\
29\end{array}$ & $\begin{array}{l}58 \\
72 \\
62 \\
49 \\
42\end{array}$ & $\begin{array}{r}86 \\
143 \\
e 92 \\
e 59 \\
e 48\end{array}$ & $\begin{array}{l}e 76 \\
e 66 \\
e 60 \\
e 50 \\
e 40\end{array}$ & $\begin{array}{r}111 \\
107 \\
94 \\
73 \\
56\end{array}$ & $\begin{array}{l}197 \\
163 \\
173 \\
142 \\
118\end{array}$ & $\begin{array}{l}\text { e142 } \\
\text { e118 } \\
\text { e104 } \\
e 92 \\
\text { e } 81\end{array}$ & $\begin{array}{r}76 \\
64 \\
63 \\
72 \\
140\end{array}$ & $\begin{array}{l}12 \\
33 \\
17 \\
14 \\
13\end{array}$ & $\begin{array}{l}7.2 \\
7.2 \\
6.6 \\
6.0 \\
5.9\end{array}$ & $\begin{array}{l}27 \\
17 \\
12 \\
9.3 \\
9.0\end{array}$ & $\begin{array}{l}10 \\
25 \\
14 \\
11 \\
11\end{array}$ \\
\hline $\begin{array}{l}26 \\
27 \\
28 \\
29 \\
30 \\
31\end{array}$ & $\begin{array}{l}28 \\
25 \\
24 \\
24 \\
24 \\
21\end{array}$ & $\begin{array}{r}35 \\
487 \\
e 1100 \\
e 700 \\
e 650 \\
---\end{array}$ & $\begin{array}{r}e 34 \\
e 33 \\
e 32 \\
e 400 \\
e 500 \\
e 250\end{array}$ & $\begin{array}{l}\text { e32 } \\
\text { e27 } \\
\text { e24 } \\
\text { e22 } \\
\text { e19 } \\
\text { e16 }\end{array}$ & $\begin{array}{r}44 \\
36 \\
34 \\
\cdots- \\
\cdots-. \\
-\end{array}$ & $\begin{array}{l}158 \\
333 \\
408 \\
252 \\
188 \\
149\end{array}$ & $\begin{array}{r}67 \\
55 \\
47 \\
55 \\
50 \\
\cdots--\end{array}$ & $\begin{array}{r}508 \\
413 \\
130 \\
91 \\
250 \\
141\end{array}$ & $\begin{array}{r}12 \\
10 \\
12 \\
12 \\
12 \\
--\end{array}$ & $\begin{array}{l}6.6 \\
6.8 \\
6.1 \\
8.8 \\
7.4 \\
6.5\end{array}$ & $\begin{array}{l}9.1 \\
7.8 \\
7.4 \\
6.9 \\
16 \\
17\end{array}$ & $\begin{array}{l}11 \\
9.8 \\
9.5 \\
9.7 \\
9.4 \\
\ldots . .\end{array}$ \\
\hline $\begin{array}{l}\text { TOTAL } \\
\text { MEAN } \\
\text { MAX } \\
\text { MIN } \\
\text { CFSM } \\
\text { IN. }\end{array}$ & $\begin{array}{r}2986 \\
96.3 \\
493 \\
20 \\
1.07 \\
1.23\end{array}$ & $\begin{array}{r}5296 \\
177 \\
1100 \\
21 \\
1.96 \\
2.19\end{array}$ & $\begin{array}{r}5075 \\
164 \\
615 \\
32 \\
1.82 \\
2.10\end{array}$ & $\begin{array}{r}1920 \\
61.9 \\
150 \\
16 \\
.69 \\
.79\end{array}$ & $\begin{array}{r}2432 \\
86.9 \\
207 \\
15 \\
.97 \\
1.01\end{array}$ & $\begin{array}{r}7045 \\
227 \\
706 \\
66 \\
2.53 \\
2.91\end{array}$ & $\begin{array}{r}4470 \\
149 \\
657 \\
40 \\
1.66 \\
1.85\end{array}$ & $\begin{array}{c}3841 \\
124 \\
508 \\
30 \\
1.38 \\
1.59\end{array}$ & $\begin{array}{c}742 \\
24.7 \\
106 \\
10 \\
.27 \\
.31\end{array}$ & $\begin{array}{r}296.4 \\
9.56 \\
28 \\
5.7 \\
.11 \\
.12\end{array}$ & $\begin{array}{r}679.1 \\
21.9 \\
157 \\
5.9 \\
.24 \\
.28\end{array}$ & $\begin{array}{r}549.1 \\
18.3 \\
59 \\
9.4 \\
.20 \\
.23\end{array}$ \\
\hline
\end{tabular}

STATISTICS OF MONTHLY MEAN DATA FOR WATER YEARS 1959 - 1991, BY WATER YEAR (WN)

\begin{tabular}{|c|c|c|c|c|c|c|c|c|c|c|c|c|}
\hline $\begin{array}{l}\text { MEAN } \\
\text { MAX } \\
\text { (WY) } \\
\text { MI } \\
\text { (WY) }\end{array}$ & $\begin{array}{l}33.7 \\
96.3 \\
1991 \\
6.47 \\
1969\end{array}$ & $\begin{array}{r}58.7 \\
212 \\
1973 \\
5.29 \\
1972\end{array}$ & $\begin{array}{r}81.0 \\
301 \\
1983 \\
7.12 \\
1961\end{array}$ & $\begin{array}{r}61.6 \\
186 \\
1973 \\
7.32 \\
1961\end{array}$ & $\begin{array}{r}88.5 \\
252 \\
1959 \\
8.49 \\
1963\end{array}$ & $\begin{array}{r}142 \\
386 \\
1979 \\
32.4 \\
1964\end{array}$ & $\begin{array}{r}142 \\
268 \\
1973 \\
21.3 \\
1963\end{array}$ & $\begin{array}{r}102 \\
266 \\
1959 \\
21.8 \\
1968\end{array}$ & $\begin{array}{r}67.9 \\
218 \\
1981 \\
11.2 \\
1965\end{array}$ & $\begin{array}{r}37.4 \\
172 \\
1983 \\
9.56 \\
1965\end{array}$ & $\begin{array}{r}37.1 \\
141 \\
1990 \\
7.28 \\
1964\end{array}$ & $\begin{array}{r}41.0 \\
217 \\
1965 \\
5.54 \\
1966\end{array}$ \\
\hline
\end{tabular}

\section{SUMMARY STATISTICS}

ANNUAL TOTAL

ANNUAL MEAM

HIGHEST ANMUAL MEAN

LOWEST ANNUAL MEAN

HIGHEST DAILY MEAN

LOWEST DAILY MEAM

ANNUAL SEVEN-DAY MIMIMUM

INSTANTANEOUS PEAK FLOW

INSTANTANEOUS PEAK STAGE

AN NUAL RUNOFF (CFSM)

ANNUAL RUNOFF (INCHES)

10 PERCENT EXCEEDS

50 PERCENT EXCEEDS

90 PERCENT EXCEEDS
FOR 1990 CALENDAR YEAR

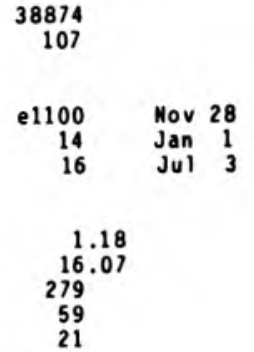

FOR 1991 WATER YEAR

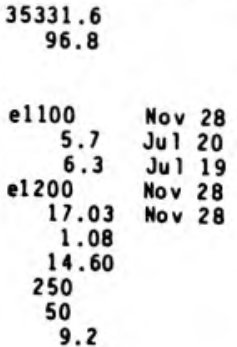

WATER YEARS 1959 - 1991

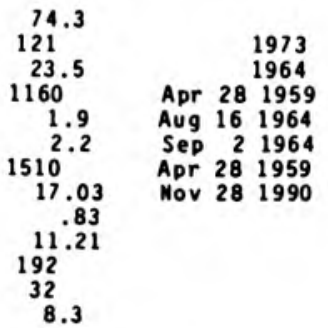


LAKE MICHIGAN?

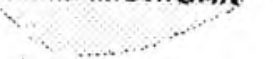

2
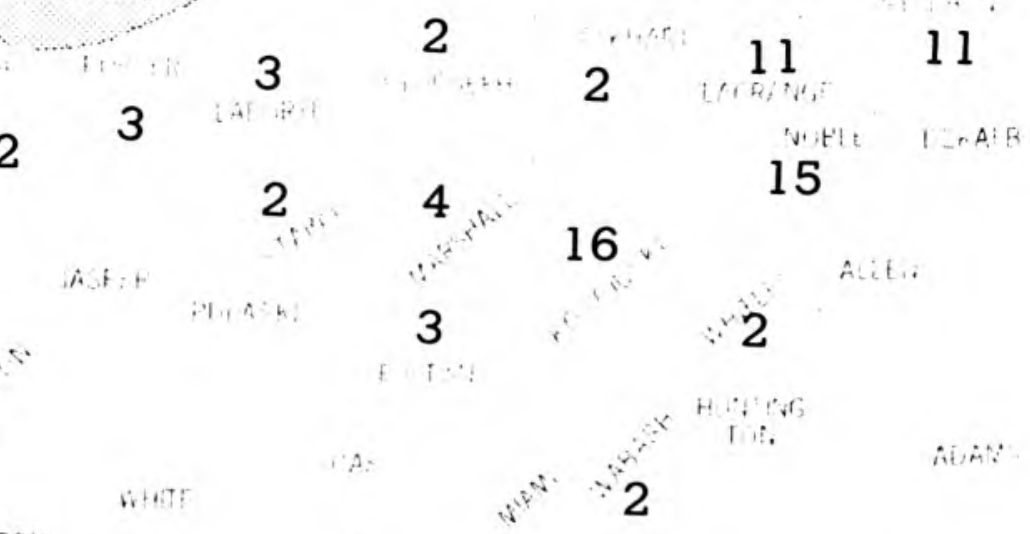

BENTON

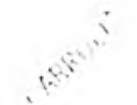

WARPEN

initivi. is.

$$
\text { GI: } 2 \text { VT }
$$

Nit.

if lin

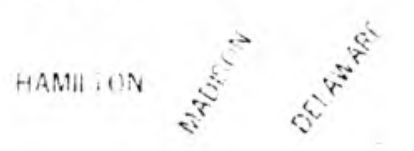

$$
\text { HENF. }
$$

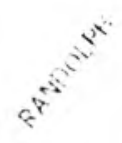

4.

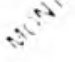

$F^{\circ}, N F$

(1)

$\therefore \therefore+v$

Atin: he vilull h:

HARECLC

Rish

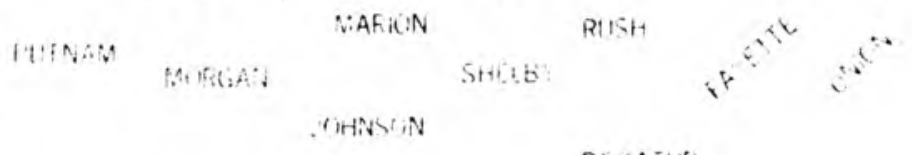

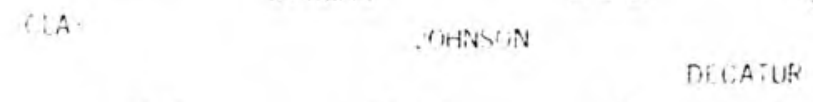

Wit? $\quad \therefore \therefore$ Eritin<smiles>C#CC#CC#CC#N</smiles>

1

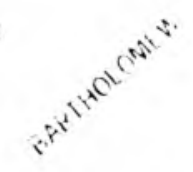

IACh $>0 \mathrm{~N}$

IF NRINGS

RIPLE:

fiss: is

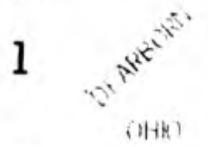

IEFFiRSOR.

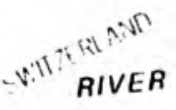

SCOTI

CLARh

Fik:

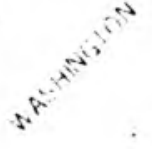

FICI)

$0^{11^{0}}$

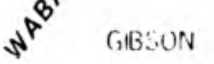

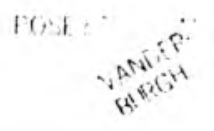

W. AFifill h

DIPuis

$\mathrm{OHIO}$

$$
\begin{aligned}
& \text { PIVER } \\
& \text { SHEVITR }
\end{aligned}
$$

EXPLANATION

11 Number of lakes in designated county

Figure 6.- Number of lakes by county having 1991 water-level records. 


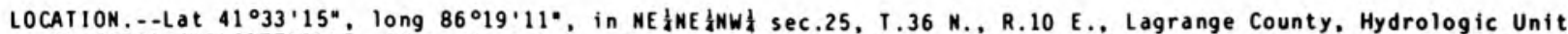
04050001 (WOLCOTTVILLE, IN quadrangle). The gage is on the east side of the lake on a dredged inlet. at the public access site, and 3.1 a northeast of Wolcottville.

SURFACE AREA.--308 acres.

DRAINAGE AREA. $--5.62=i^{2}$.

PERIOD OF RECORD.-1946 to current year.

DATUM OF GAGE.--949.90 ft above National Geodetic Vertical Datun of 1929, as corrected on the basis of levels of the Indiana Departaent of Matural Resources, 1976.

GAGE.--A water-stage recorder is installed in an alueinum shelter over a 15 -inch dianeter stilling well. An auxiliary staff gage is attached to the southwest wall of the dan on the outlet channel about 500 ft downstrean frow the lake.

ESTABLISHED LEGAL LEVEL. $-3.59 \mathrm{ft}$ gage datun or $953.59 \mathrm{ft}$ above National Geodetic Vertical Datum of 1929 as decreed on Decenber 17,1949 , by the Lagrange County Circuit Court. Minor errors were subsequent ly discovered in the establishment of the datud of the gage (see "DATUM OF GAGE") and the correct elevation of the legal level should be $3.59 \mathrm{ft}$ gage datu or $953.49 \mathrm{ft}$ above National Geodetic Vertical Datua of 1929.

LAKE-LEVEL CONTROL.- The level of the lake is controlled by a concrete dan with a fixed crest "V" notch weir.

INLET AND OUTLET.--One inlet enters on the east side from Blackman Lake 2.3 mi upstream. The other inlet enters on the northeastern shore fron Eve Lake. The outlet flows from the lake on the southern shore and into Little Elkhart Creek 1.7 i downstrean.

EXTREMES FOR PERIOD OF RECORD.--Maximum stage, $5.32 \mathrm{ft}$ June 15, 1981; ninimun stage, $2.12 \mathrm{ft}$ Jan. 8 , 1954. LAKE LEVEL, IN FEET ABOVE GAGE DATUM, WATER YEAR OCTOBER 1990 TO SEPTEMBER 1991 24:00 VALUES

\begin{tabular}{|c|c|c|c|c|c|c|c|c|c|c|c|c|}
\hline DAY & $\mathrm{OCT}$ & NOV & DEC & JAN & FEB & MAR & APR & MAY & JUN & JUL & AUG & SEP \\
\hline $\begin{array}{r}5 \\
10 \\
15 \\
20 \\
25 \\
\text { EOM }\end{array}$ & $\begin{array}{l}3.94 \\
4.42 \\
4.53 \\
4.45 \\
4.35 \\
4.21\end{array}$ & $\begin{array}{l}4.35 \\
4.35 \\
4.25 \\
4.19 \\
4.16 \\
4.21\end{array}$ & $\begin{array}{l}4.23 \\
4.18 \\
4.17 \\
4.16 \\
4.22 \\
4.81\end{array}$ & $\begin{array}{l}4.85 \\
4.84 \\
4.42 \\
4.41 \\
4.41 \\
4.41\end{array}$ & $\begin{array}{l}4.23 \\
4.12 \\
4.12 \\
4.18 \\
4.18 \\
4.17\end{array}$ & $\begin{array}{l}4.21 \\
4.17 \\
4.10 \\
4.08 \\
4.11 \\
4.19\end{array}$ & $\begin{array}{l}4.17 \\
4.21 \\
4.22 \\
4.41 \\
4.49 \\
4.47\end{array}$ & $\begin{array}{l}4.41 \\
4.34 \\
4.25 \\
4.16 \\
4.20 \\
4.40\end{array}$ & $\begin{array}{l}4.27 \\
4.14 \\
4.04 \\
3.93 \\
3.82 \\
3.98\end{array}$ & $\begin{array}{l}4.31 \\
4.17 \\
4.05 \\
3.92 \\
3.82 \\
3.69\end{array}$ & $\begin{array}{l}3.69 \\
3.69 \\
3.64 \\
3.67 \\
3.63 \\
3.83\end{array}$ & $\begin{array}{l}3.79 \\
3.74 \\
3.80 \\
3.68 \\
3.63 \\
3.57\end{array}$ \\
\hline
\end{tabular}

WTR YR 1991 MEAN 4.14 MAX 4.85 MIN 3.57

STREAMS TRIBUTARY TO LAKE ERIE

04177680 BALL LAKE NEAR HAMILTON, IN

LOCATION. - - Lat $41^{\circ} 32^{\prime} 12^{\prime \prime}$, long $84^{\circ} 56^{\prime} 18^{\circ}$, in SE 4 SW 3 HE $\frac{1}{2}$ sec.32. T.36 N., R.14 E., Steuben County, Hydrologic Unit 04100003 (HAMILION, IN quadrangle). The gage is on the northeastern shore of the lake, south of the bridge over the outlet, and 1.3 a west of Hanilton.

SURFACE AREA. --87 acres.

DRAINAGE AREA, $=-11.6 \mathrm{i}^{2}$.

PERIOD OF RECORD,--1961 to current year.

DATUM OF GAGE.--889.81 ft above National Geodetic Vertical Datun of 1929, as corrected on the basis of levels of the Indiana Department of Natural Resources in February 1972.

GAGE.--A water-stage recorder is installed in an aluminu shelter over a 15-inch dianeter stilling well. An auxiliary staff gage is driven into the lake bed near the recording gage and a high-water staff gage is attached to the control da.

ESTABLISHED LEGAL LEVEL. $-4.95 \mathrm{ft}$ gage datum or $894.76 \mathrm{ft}$ above National Geodetic Vertical Datun of 1929 as decreed on Septenber 20, 1974, by the Steuben County Circuit Court.

LAKE-LEVEL CONTROL.-.The level of the lake is controlled by a concrete sill with movable boards.

INLET AND OUTLET.--Fish Creek flows through the lake, entering at the western end and leaving at the northeastern end. Fish Creek eapties into the St. Joseph River.

EXTREMES FOR PERIOD OF RECORD.--Maximu stage, $10.02 \mathrm{ft}$ Dec. 26, 1965; inimun stage, $3.96 \mathrm{ft} 0 \mathrm{ct}$. $19-31$, Nov. $1-12,1978$.

LAKE LEVEL, IN FEET ABOVE GAGE DATUM, WATER YEAR OCTOBER 1990 TO SEPTEMBER 1991

\begin{tabular}{|c|c|c|c|c|c|c|c|c|c|c|c|c|}
\hline DAY & OCT & NOV & DEC & JAN & FEB & MAR & $A P R$ & MAY & JUN & JUL & AUG & SEP \\
\hline $\begin{array}{r}5 \\
10 \\
15 \\
20 \\
25 \\
\text { EOM }\end{array}$ & $\begin{array}{l}4.88 \\
5.68 \\
4.96 \\
4.91 \\
4.86 \\
4.83\end{array}$ & $\begin{array}{l}5.45 \\
4.94 \\
4.88 \\
4.85 \\
4.85 \\
4.91\end{array}$ & $\begin{array}{l}4.98 \\
4.89 \\
4.93 \\
4.93 \\
4.97 \\
6.53\end{array}$ & $\begin{array}{l}5.00 \\
5.00 \\
5.02 \\
4.99 \\
4.99 \\
4.99\end{array}$ & $\begin{array}{r}4.99 \\
4.99 \\
4.99 \\
4.99 \\
4.99 \\
4.99\end{array}$ & $\begin{array}{l}5.02 \\
4.96 \\
4.92 \\
4.90 \\
4.93 \\
4.88\end{array}$ & $\begin{array}{l}4.93 \\
4.96 \\
5.22 \\
5.48 \\
5.03 \\
4.95\end{array}$ & $\begin{array}{l}4.95 \\
4.89 \\
4.84 \\
4.83 \\
4.92 \\
5.16\end{array}$ & $\begin{array}{l}4.86 \\
4.82 \\
4.81 \\
4.80 \\
4.78 \\
4.85\end{array}$ & $\begin{array}{l}4.81 \\
4.78 \\
4.78 \\
4.77 \\
4.75 \\
4.76\end{array}$ & $\begin{array}{l}4.77 \\
4.77 \\
4.76 \\
4.83 \\
4.76 \\
4.76\end{array}$ & $\begin{array}{l}4.76 \\
4.77 \\
4.77 \\
4.75 \\
4.75 \\
4.76\end{array}$ \\
\hline
\end{tabular}

WTR YR 1991 MEAN 4.92 MAX 6.56 MIM 4.74 
05517200 BaSS LAKE AT BASS LAKE, IN

LOCATION.--Lat $41^{\circ} 12^{\prime} 28^{\prime \prime}$, long $86^{\circ} 36^{\prime} 07^{\prime \prime}$, in NWhHWSWl sec.24, T.32 N., R.2 W.. Starke County, Hydrologic Unit 07120001 (BASS LAKE, IN quadrangle). The gage is on the southern shore of the lake, just north of the junction of U.S. Highway 35 and State Highway 10, at the town of Bass Lake.

SURFACE AREA. $--1,400$ acres.

DRAINAGE AREA, $--5.18: i^{2}$.

PERIOD OF RECORD.--1943 to current year.

DATUM OF GAGE.--699.83 ft above National Geodetic Vertical Datue of 1929, as corrected from the unadjusted elevations.

GAGE.--A water-stage recorder is installed in an aluainum shelter over a 15-inch diaeter stilling well. An auxiliary staff gage in two sections is at the site.

ESTABLISHED LEGAL LEVEL. - - $13.65 \mathrm{ft}$ gage datun or $113.65 \mathrm{ft}$ above National Geodetic Vertical Datue of 1929 as decreed on August 10, 1948, by the Starke County Circuit Court. Minor errors were subsequent ly discovered in the establishment of the datum of the gage (see "DATUM OF GAGE") and the correct elevation of the legal level should be $13.65 \mathrm{ft}$ gage datue or $713.48 \mathrm{ft}$ above National Geodetic Vertical Datun of 1929.

LAKE-LEVEL CONTROL..-The level of the lake is controlled by a steel sheet piling dae.

INLET AND OUTLET.---Several sall unnaned ditches enter the lake at various locations. The outlet flows fron the western shore. into Cedar Lake ditch, and eventually into the Kankakee River.

EXTREMES FOR PERIOD OF RECORD..--Maximun stage, $15.03 \mathrm{ft}$ June 18, 1981; a inimun stage, 10.52 $\mathrm{ft}$ Nov. 12, $13,1964$.

LAKE LEVEL, In FEEt ABOVE GAGE DATUM, WATER YEAR OCTOBER 1990 TO SEPTEMBER 1991 24:00 VALUES

\begin{tabular}{|c|c|c|c|c|c|c|c|c|c|c|c|c|}
\hline DAY & OCT & NOV & DEC & JAN & FE B & MAR & APR & MAY & JUN & JUL & AUG & SEP \\
\hline $\begin{array}{r}5 \\
10 \\
15 \\
20 \\
25 \\
\text { EOM }\end{array}$ & $\begin{array}{l}13.93 \\
14.21 \\
14.22 \\
14.21 \\
14.17 \\
14.12\end{array}$ & $\begin{array}{l}14.26 \\
14.22 \\
14.19 \\
14.16 \\
14.17 \\
14.28\end{array}$ & $\begin{array}{l}14.26 \\
14.26 \\
14.28 \\
14.28 \\
14.32 \\
14.60\end{array}$ & $\begin{array}{l}14.51 \\
14.44 \\
14.42 \\
14.43 \\
14.39 \\
14.39\end{array}$ & $\begin{array}{l}14.35 \\
14.33 \\
14.32 \\
14.32 \\
14.26 \\
14.26\end{array}$ & $\begin{array}{l}14.30 \\
14.25 \\
14.29 \\
14.29 \\
14.36 \\
14.33\end{array}$ & $\begin{array}{l}14.28 \\
14.27 \\
14.42 \\
14.39 \\
14.34 \\
14.35\end{array}$ & $\begin{array}{l}14.30 \\
14.26 \\
14.24 \\
14.31 \\
14.38 \\
14.49\end{array}$ & $\begin{array}{l}14.32 \\
14.19 \\
14.21 \\
14.12 \\
14.02 \\
13.93\end{array}$ & $\begin{array}{l}13.83 \\
13.85 \\
13.75 \\
13.64 \\
13.53 \\
13.42\end{array}$ & $\begin{array}{l}13.33 \\
13.38 \\
13.30 \\
13.38 \\
13.31 \\
13.25\end{array}$ & $\begin{array}{l}13.17 \\
13.08 \\
13.09 \\
13.00 \\
12.96 \\
12.90\end{array}$ \\
\hline
\end{tabular}

WTR YR 1991 MEAN 14.05 MAX 14.64 MIM 12.90

\section{STREAMS TRIBUTARY TO LAKE MICHIGAN}

04100260 BEAR LAKE MEAR WOLFLAKE, IN

LOCATION.--Lat $41^{\circ} 19^{\prime} 07^{\prime \prime}$, long $85^{\circ} 30^{\prime} 49^{\circ}$, in SWHWl sec.17, T.33 N., R.9 E., Noble County, Hydrologic Unit 04050001 (ORMAS. IN quadrangle). The gage is on the southern shore of the lake on a dredged channel, at the end of the gravel lane to the Merry Lea Mature Center, 1.1 ai southwest of the town of Wolflake.

SURFACE AREA. -136 acres.

DRAI NAGE AREA. $--6.98 \cdot 1^{2}$.

PERIOD OF RECORD. - -1943 to current year.

DATUM OF GAGE. - $889.90 \mathrm{ft}$ above National Geodetic Vertical Datun of 1929, as corrected on the basis of levels of the Indiana Department of Matural Resources, 1974-75.

GAGE..-A water-stage recorder is installed in an aluninum shelter over a 15 -inch dianeter stilling well on the west side of the dredged channel.

ESTABLISHED LEGAL LEVEL. $-4.60 \mathrm{ft}$ gage datun or $894.60 \mathrm{ft}$ above National Geodetic Vertical Datun of 1929 as decreed on Septenber 23, 1959 , by the Noble County Circuit Court. Minor errors were subsequent ly discovered in the establishment of the datum of the gage (see "DATUM OF GAGE") and the correct elevation of the legal level should be $4.60 \mathrm{ft}$ gage datun or $894.50 \mathrm{ft}$ above National Geodetic Vertical Datun of 1929.

LAKE-LEVEL CONTROL...-The level of the lake is controlled by a steel sheet piling dae.

INLET AMD OUTLET. - There are two inlets to the lake, one enters on the southwest shore from High Lake. 0.6 a upstrean, and the other enters from the northeast. The outlet, Carrol Creek, leaves the lake on the southeast tip. flows into Muncie Lake, 3.1 a downstrean, and eventually into the Elkhart River.

EXTREMES FOR PERIOD OF RECORD..-Maximus stage, $8.25 \mathrm{ft} \mathrm{Dec.} 30,1942$ (before dredging of the outlet channel). Maxinum stage, $6.61 \mathrm{ft}$ Apr. 12, 1944 (after dredging): inimu stage, $2.90 \mathrm{ft}$ Oct. 31, Nov, 1-3, 7-17, 1952 , October $22-24,29-31$, Nov. $1-3,6,7,1966$.

LAKE LEVEL, In FEet abOVE GAGE DATUM, HATER YEAR OCTOBER 1990 TO SEPTEMBER 1991 24:00 VALUES

\begin{tabular}{|c|c|c|c|c|c|c|c|c|c|c|c|c|}
\hline DAY & $\mathrm{OCT}$ & NOV & DEC & JAN & FEB & MAR & APR & MAY & JUN & JUL & AUG & SEP \\
\hline $\begin{array}{r}5 \\
10 \\
15 \\
20 \\
25 \\
\text { EOM }\end{array}$ & $\begin{array}{l}4.68 \\
5.38 \\
5.26 \\
4.85 \\
4.65 \\
4.50\end{array}$ & $\begin{array}{l}4.76 \\
4.68 \\
4.56 \\
4.49 \\
4.45 \\
4.55\end{array}$ & $\begin{array}{l}4.63 \\
4.55 \\
4.55 \\
4.55 \\
4.59 \\
5.32\end{array}$ & $\begin{array}{l}4.81 \\
4.63 \\
4.61 \\
4.64 \\
4.51 \\
4.45\end{array}$ & $\begin{array}{l}4.49 \\
4.50 \\
4.45 \\
4.53 \\
4.49 \\
4.48\end{array}$ & $\begin{array}{l}4.58 \\
4.49 \\
4.47 \\
4.54 \\
4.52 \\
4.49\end{array}$ & $\begin{array}{l}4.49 \\
4.50 \\
4.57 \\
4.78 \\
4.72 \\
4.61\end{array}$ & $\begin{array}{l}4.55 \\
4.48 \\
4.46 \\
4.38 \\
4.61 \\
4.92\end{array}$ & $\begin{array}{l}4.77 \\
4.53 \\
4.46 \\
4.37 \\
4.31 \\
4.42\end{array}$ & $\begin{array}{l}4.40 \\
4.32 \\
4.26 \\
4.19 \\
4.38 \\
4.29\end{array}$ & $\begin{array}{l}4.28 \\
4.30 \\
4.24 \\
4.24 \\
4.20 \\
4.16\end{array}$ & $\begin{array}{l}4.08 \\
4.03 \\
4.25 \\
4.18 \\
4.13 \\
4.09\end{array}$ \\
\hline
\end{tabular}

WTR YR 1991 MEAN 4.50 MAX 5.47 MIN 4.02 
LOCATION.--Lat $41^{\circ} 16^{\prime} 53^{\circ}$, long $85^{\circ} 46^{\prime} 47^{\circ}$, in NWASE tSWl sec.25, T.33 N., R.6 E., Kosciusko County, Hydrologic Unit 05120106 (LEESBURG, IN quadrangle). The gage is on the southeastern shore of the lake. at the public fishing site, 4.9 if northeast of Warsaw.

SURFACE AREA. --581 acres.

DRAIMAGE AREA. $--4.17: 1^{2}$.

PERIOD OF RECORD.--1945-68, 1971, 1976 to current year.

DATUM OF GAGE. - $820.00 \mathrm{ft}$ above National Geodetic Vertical Datum of 1929.

GAGE.--A water-stage recorder and an electric tape gage (ETG) are installed in an aluainue shelter over a 15-inch dianeter stilling well.

ESTABLISHED LEGAL LEVEL.--7.75 ft gage datum or $827.75 \mathrm{ft}$ above National Geodetic Vertical Datum of 1929 as established on October 18, 1949, by the Kosciusko County Circuit Court. Little Chapan Lake has the sane control structure and established level and hence the same lake levels for the period of record.

LAKE-LEVEL CONTROL.- The level of the lake is controlled by a concrete dan with a fixed crest at the outlet channel downstrean from Little Chapan Lake.

INLET AND OUTLET.--Several small ditches enter the lake at various points. The outlet flows into Little Chapman Lake to the south, then into Deeds Creek, and eventually into the Tippecanoe River.

EXTREMES FOR PERIOD OF RECORD..--Maximun stage, $9.37 \mathrm{ft} 0 \mathrm{ct} .11,1954$; winimun stage, $6.75 \mathrm{ft} 0 \mathrm{ct} .20,1953$.

LAKE LEVEL, IN FEEt ABOVE GAgE DATUM, WATER YEAR OCTOBER 1990 TO SEPTEMBER 1991 24:00 VALUES

$\begin{array}{rrrrrrrrrrrrr}\text { DAY } & \text { OCT } & \text { NOV } & \text { DEC } & \text { JAN } & \text { FEB } & \text { MAR } & \text { APR } & \text { MAY } & \text { JUN } & \text { JUL } & \text { AUG } & \text { SEP } \\ 5 & 7.59 & 7.86 & 7.90 & 7.96 & 7.62 & 7.73 & 7.65 & 7.64 & 7.61 & 7.38 & 7.10 & 7.11 \\ 10 & 8.19 & 7.80 & 7.84 & 7.78 & 7.65 & 7.69 & 7.61 & 7.55 & 7.50 & 7.33 & 7.17 & 7.07 \\ 15 & 7.96 & 7.75 & 7.85 & 7.79 & 7.65 & 7.68 & 7.67 & 7.52 & 7.53 & 7.28 & 7.13 & 7.13 \\ 20 & 7.74 & 7.71 & 7.85 & 7.82 & 7.67 & 7.71 & 7.81 & 7.46 & 7.44 & 7.23 & 7.25 & 7.05 \\ 25 & 7.61 & 7.71 & 7.89 & 7.68 & 7.66 & 7.69 & 7.77 & 7.61 & 7.37 & 7.18 & 7.21 & 7.04 \\ \text { EOM } & 7.55 & 7.82 & 8.32 & 7.59 & 7.65 & 7.67 & 7.65 & 7.80 & 7.43 & 7.11 & 7.17 & 6.98\end{array}$

WTR YR 1991 MEAN 7.57 MAX 8.45 MIN 6.98

WABASH RIVER BASIN

03330040 BIG LAKE MEAR WOLFLAKE, IN

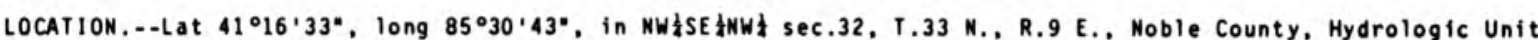
05120106 (ORMAS. IN quadrangle). The gage is at the head of the outlet channel, approxiately 20 feet north of the control structure and 4 a southwest of the town of Wolflake.

SURFACE AREA. -228 acres.

DRAINAGE AREA. $--8.89 \cdot i^{2}$.

PERIOD OF RECORD.--1943-74, 1978 to current year.

DATUM OF GAGE. - - $890.00 \mathrm{ft}$ above National Geodetic Vertical Datue of 1929.

GAGE.--A water-stage recorder is installed in an aluainus shelter over a 15-inch dianeter stilling well.

ESTABLISHED LEGAL LEVEL. $-8.40 \mathrm{ft}$ gage datum or $898.40 \mathrm{ft}$ above National Geodetic Vertical Datue of 1929 as decreed on July 18, 1956, by the Noble County Circuit Court.

LAKE-LEVEL CONTROL.-.The level of the lake is controlled by a steel sheet piling dan with a fixed crest.

IMLET AND OUTLET...-The ain inlet enters fron Crooked lake to the east. Three other inlets flow from Crane Lake to the east, Green Lake to the north, and Sell Brook to the south. The out let leaves the lake at the extreae west end and forms the headwaters of the Tippecanoe River.

EXTREMES FOR PERIOD OF RECORD. -- Maxinun stage, $12.76 \mathrm{ft}$ Apr. 4, 1950; - ininun stage, 7.12 ft Aug. $24,1987$.

LaKe LEVEL, IN FEet above gage DATUM, WATER YEAR OCTOBER 1990 TO SEPTEMBER 1991 24:00 VALUES

\begin{tabular}{|c|c|c|c|c|c|c|c|c|c|c|c|c|}
\hline DAY & OCT & NOV & DEC & JAN & FEB & MAR & APR & MAY & JUN & JUL & AUG & SEP \\
\hline $\begin{array}{r}5 \\
10 \\
15 \\
20 \\
25 \\
\text { EOM }\end{array}$ & $\begin{array}{l}8.43 \\
9.91 \\
9.67 \\
8.93 \\
8.34 \\
8.22\end{array}$ & $\begin{array}{l}8.61 \\
8.49 \\
8.27 \\
8.24 \\
8.22 \\
8.36\end{array}$ & $\begin{array}{r}8.48 \\
8.31 \\
8.35 \\
8.36 \\
\ldots . .\end{array}$ & $\begin{array}{r}\ldots . \\
\ldots . \\
8.44 \\
8.37 \\
8.37\end{array}$ & $\begin{array}{l}8.43 \\
8.31 \\
8.29 \\
8.46 \\
8.32 \\
8.29\end{array}$ & $\begin{array}{l}8.37 \\
8.27 \\
8.26 \\
8.41 \\
8.32 \\
8.35\end{array}$ & $\begin{array}{l}8.32 \\
8.47 \\
8.45 \\
8.93 \\
8.73 \\
8.49\end{array}$ & $\begin{array}{l}8.33 \\
8.27 \\
8.24 \\
8.18 \\
8.37 \\
9.50\end{array}$ & $\begin{array}{l}9.32 \\
8.43 \\
8.23 \\
8.16 \\
8.12 \\
8.34\end{array}$ & $\begin{array}{l}8.24 \\
8.16 \\
8.11 \\
8.04 \\
8.12 \\
8.06\end{array}$ & $\begin{array}{l}8.08 \\
8.09 \\
8.04 \\
8.09 \\
8.02 \\
7.97\end{array}$ & $\begin{array}{l}7.90 \\
7.83 \\
7.92 \\
7.82 \\
7.78 \\
7.71\end{array}$ \\
\hline
\end{tabular}

WTR YR 1991 MEAN 8.34 MAX 10.18 MIN 7.71 


\section{BIG LONG LAKE MEAR STROH. IN}

LOCATION.--Lat $41^{\circ} 33^{\prime} 17^{\circ}$, long $85^{\circ} 13^{\prime} 47^{\circ}$. in ME $\frac{1}{4}$ MHANH sec.26, T.36 N., R.11 E., Lagrange County, Hydrologic Unit 04050001 (STROH. IN quadrangle). The gage is on the northeast shore near the east end of the Shady Mook Addition in the vicinity of the Shady Nook Tavern, 2.4 a i southwest of Stroh.

SURFACE AREA. --388 acres.

DRAIMAGE AREA. $-4.77 \mathrm{i}^{2}$.

PERIOD OF RECORD.--1954 to current year.

DATUM OF GAGE.--950.00 ft above Mational Geodetic Vertical Datun of 1929.

GAGE.--A water-stage recorder is installed in an aluainua shelter over a 15-inch dianeter stilling well.

ESTABLISHED LEGAL LEVEL. - -6.21 ft gage datun or $956.21 \mathrm{ft}$ above National Geodetic Vertical Datue of 1929 as decreed on July 22, 1965, by the Lagrange County Circuit Court.

LAKE-LEVEL CONTROL..- The level of the lake is controlled by a concrete dan with a fixed sill and rewovable boards.

INLET AMD OUTLET..-The one inlet is a sall ditch that enters at the extrene western tip. The outlet flows froe the extrewe northern tip. northeastward to Mud and Little Turkey Lakes, thence to Turkey Creek.

EXTREMES FOR PERIOD OF RECORD. --Maximun stage, $7.49 \mathrm{ft}$ Mar. 31, 1978; - ininue stage, 4.58 ft Nov. $27,1964$.

LAKE LEVEL, IN FEET ABOVE GAGE DATUM, WATER YEAR OCTOBER 1990 TO SEPTEMBER 1991 24:00 VALUES

\begin{tabular}{|c|c|c|c|c|c|c|c|c|c|c|c|c|}
\hline DAY & OCT & NOV & DEC & JAM & FEB & MAR & APR & MAY & JUN & JUL & AUG & SEP \\
\hline $\begin{array}{r}5 \\
10 \\
15 \\
20 \\
25 \\
\text { EOM }\end{array}$ & $\begin{array}{l}6.22 \\
6.57 \\
6.40 \\
6.29 \\
6.19 \\
6.14\end{array}$ & $\begin{array}{l}6.50 \\
6.29 \\
6.21 \\
6.19 \\
6.19 \\
6.28\end{array}$ & $\begin{array}{l}6.30 \\
6.21 \\
6.28 \\
6.26 \\
6.30 \\
6.64\end{array}$ & $\begin{array}{l}6.41 \\
6.30 \\
6.30 \\
6.32 \\
6.25 \\
6.23\end{array}$ & $\begin{array}{l}6.25 \\
6.24 \\
6.26 \\
6.34 \\
6.27 \\
6.28\end{array}$ & $\begin{array}{l}6.37 \\
6.28 \\
6.22 \\
6.28 \\
6.28 \\
6.34\end{array}$ & $\begin{array}{l}6.30 \\
6.34 \\
6.39 \\
6.52 \\
6.49 \\
6.41\end{array}$ & $\begin{array}{l}6.41 \\
6.27 \\
6.21 \\
6.16 \\
6.28 \\
6.47\end{array}$ & $\begin{array}{l}6.27 \\
6.17 \\
6.14 \\
6.08 \\
5.99 \\
6.24\end{array}$ & $\begin{array}{l}6.27 \\
6.15 \\
6.12 \\
6.04 \\
5.96 \\
5.88\end{array}$ & $\begin{array}{l}5.88 \\
5.69 \\
5.65 \\
5.77 \\
5.72 \\
5.75\end{array}$ & $\begin{array}{l}5.73 \\
5.73 \\
5.78 \\
5.69 \\
5.67 \\
5.60\end{array}$ \\
\hline
\end{tabular}

WTR YR 1991 MEAN 6.18 MAX 6.72 MIN 5.60

STREAMS TRIBUTARY TO LAKE MICHIGAN

04100140 BIXLER LAKE AT KENDALLVILLE, IM

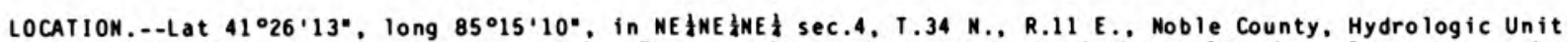
04050001 (KENDALLVILLE, IN quadrangle). The gage is on the south bank of the out let channel on the southwest shore of the lake and 0.7 a southeast of City Hall in Kendallville.

SURFACE AREA. -120 acres.

DRAI NAGE AREA. $--5.28 \cdot i^{2}$.

PERIOD OF RECORD.- 1946 to current year.

DATUM OF GAGE.--960.10 ft above National Geodetic Vertical Datue of 1929, as corrected on the basis of levels of the Indiana Departaent of Natural Resources, 1974-75.

GAGE.--A water-stage recorder is installed in an aluainue shelter over a 15-inch dianeter stilling well. An auxiliary staff gage is bolted to ancrete pier $20 \mathrm{ft}$ upstrean from from the control dae.

ESTABLISHED LEGAL LEVEL. $-3.65 \mathrm{ft}$ gage datun or $963.65 \mathrm{ft}$ above National Geodetic Vertical Datua of 1929 as decreed on Apri1 25, 1952, by the Noble County Circuit Court. Minor errors were subsequently discovered in the establishment of the datur of the gage (see. DATUM Of GAGE") and the correct elevation of the legal level should be $3.65 \mathrm{ft}$ gage datun or $963.75 \mathrm{ft}$ above National Geodetic Vertical Datua of 1929.

LAKE-LEVEL CONTROL.-.The level of the lake is controlled by a fixed deep-notch concrete dae with two flood gates.

INLET AND OUTLET,--Riddle ditch enters the lake from the north. Sheran ditch from the east, Shaffer ditch from the southeast, and an unnaed ditch from the southwest. The outlet leaves at the southwest corner and flows into Henderson Lake 1.9 a downstreas.

EXTREMES FOR PERIOD OF RECORD.--Maximum stage, $6.26 \mathrm{ft}$ Feb. 24, 1985; winimul stage, $1.24 \mathrm{ft}$ Jan. $13-15,18$, 1954 .

LAKE LEVEL, IN FEET ABOVE GAGE DATUM, WATER YEAR OCTOBER 1990 TO SEPTEMBER 1991

\begin{tabular}{|c|c|c|c|c|c|c|c|c|c|c|c|c|}
\hline DAY & $O C T$ & MOV & DEC & JAN & FE B & MAR & APR & MAY & JUN & JUL & AUG & SEP \\
\hline $\begin{array}{r}5 \\
10 \\
15 \\
20 \\
25 \\
\text { EOM }\end{array}$ & $\begin{array}{l}4.40 \\
5.48 \\
4.52 \\
4.03 \\
3.59 \\
3.57\end{array}$ & $\begin{array}{l}4.32 \\
4.05 \\
3.52 \\
3.35 \\
3.53 \\
3.73\end{array}$ & $\begin{array}{r}4.37 \\
4.38 \\
4.12 \\
4.02 \\
4.13 \\
\ldots . .\end{array}$ & $\begin{array}{r}\ldots . . \\
3.56 \\
4.07 \\
3.92 \\
3.61\end{array}$ & $\begin{array}{l}3.68 \\
3.74 \\
3.62 \\
3.94 \\
3.92 \\
3.80\end{array}$ & $\begin{array}{l}3.90 \\
3.65 \\
3.49 \\
3.67 \\
3.96 \\
3.55\end{array}$ & $\begin{array}{l}3.59 \\
3.81 \\
4.09 \\
4.84 \\
4.52 \\
4.15\end{array}$ & $\begin{array}{r}3.62 \\
3.49 \\
3.74 \\
4.08 \\
4.28 \\
. . .\end{array}$ & $\begin{array}{l}\cdots \\
\cdots \\
\cdots \\
\cdots \\
\cdots \\
\cdots\end{array}$ & $\begin{array}{l}\ldots \\
\ldots . .2 \\
3.42 \\
3.29 \\
3.19\end{array}$ & $\begin{array}{l}3.23 \\
3.28 \\
3.20 \\
3.18 \\
3.10 \\
3.02\end{array}$ & $\begin{array}{r}2.92 \\
\ldots \\
\ldots \\
\ldots \\
\ldots\end{array}$ \\
\hline
\end{tabular}

WTR YR 1991 MEAN 3.78 MAX 5.48 MIN 2.64 
LOCATION.--Lat $41^{\circ} 14^{\prime} 30^{\circ}$, long $85^{\circ} 21^{\prime} 04^{*}$, in SWHE $\frac{1}{4}$ SEl sec.10, T.32 N., R.10 E.. Whit ley County, Hydrologic Unit 05120104 (CHURUBUSCO, IN quadrangle). Gage is located on a dredged channel at the extreae east end of the

lake, approxinately $2.0 \mathrm{~m}$ west of Churubusco.

SURFACE AREA.--239 acres.

DRAI NAGE AREA. $--3.58 \cdot i^{2}$.

PERIOD OF RECORD, - $1946-68,1976$ to current year.

DATUM OF GAGE. - -840.00 ft above National Geodetic Vertical Datur of 1929.

GAGE.--A water-stage recorder installed in an aluainun shelter over a 15 -inch dianeter stilling well.

ESTABLISHED LEGAL LEVEL. $-10.28 \mathrm{ft}$ gage datue or $850.28 \mathrm{ft}$ above National Geodetic Vertical Datum of 1929 as decreed on July 23, 1948 , by the Whit ley County Circuit Court.

LAKE-LEVEL CONTROL.--A concrete dan with a fixed crest is located in the out let channel about $300 \mathrm{ft}$ downstrean fron the lake.

INLET AND OUTLET.--Maloney ditch enters at the eastern tip of the lake. The outlet flows from the lake at the northwest end and joins Carter Creek (Blue River) 0.2 a downstrea. Carter Creek eventually flows into Eel River.

EXTREMES FOR PERIOD OF RECORD.--Maximun stage, 15.80 ft Dec. 10, 1966: aninum stage, 7.64 ft Mov. 19, $20,1952$.

LAKE LEVEL, IN FEET ABOVE GAGE DATUM, HATER YEAR OCTOBER 1990 TO SEPTEMBER 1991 24:00 VALUES

\begin{tabular}{|c|c|c|c|c|c|c|c|c|c|c|c|c|}
\hline DAY & $\mathrm{OCT}$ & NOV & DEC & JAN & FE B & MAR & APR & MAY & JUN & JUL & AUG & SEP \\
\hline $\begin{array}{r}5 \\
10 \\
15 \\
20 \\
25 \\
\text { EOM }\end{array}$ & $\begin{array}{l}10.15 \\
11.24 \\
10.82 \\
10.50 \\
10.30 \\
10.22\end{array}$ & $\begin{array}{l}10.48 \\
10.45 \\
10.29 \\
10.26 \\
10.25 \\
10.37\end{array}$ & $\begin{array}{l}10.56 \\
10.45 \\
10.42 \\
10.42 \\
10.50 \\
12.69\end{array}$ & $\begin{array}{l}11.64 \\
10.73 \\
10.47 \\
10.41 \\
10.22 \\
10.12\end{array}$ & $\begin{array}{l}10.10 \\
10.12 \\
10.13 \\
10.23 \\
10.22 \\
10.19\end{array}$ & $\begin{array}{l}10.24 \\
10.19 \\
10.17 \\
10.24 \\
10.25 \\
10.26\end{array}$ & $\begin{array}{l}10.21 \\
10.29 \\
10.32 \\
10.62 \\
10.56 \\
10.34\end{array}$ & $\begin{array}{l}10.13 \\
10.02 \\
10.05 \\
10.09 \\
10.28 \\
11.18\end{array}$ & $\begin{array}{l}10.94 \\
10.43 \\
10.15 \\
9.98 \\
9.83 \\
9.78\end{array}$ & $\begin{array}{l}9.77 \\
9.71 \\
9.61 \\
9.50 \\
9.47 \\
9.32\end{array}$ & $\begin{array}{l}9.34 \\
9.36 \\
9.27 \\
9.36 \\
9.26 \\
9.17\end{array}$ & $\begin{array}{l}9.13 \\
9.05 \\
9.31 \\
9.20 \\
9.16 \\
9.05\end{array}$ \\
\hline
\end{tabular}

WTR YR 1991 MEAN 10.12 MAX 12.69 MIN 9.03

\section{STREAMS TRIBUTARY TO LAKE MICHIGAM}

04099250 BOWER LAKE NEAR PLEASANT LAKE, IN

LOCATION. - -Lat $41^{\circ} 36^{\prime} 03^{\prime \prime}$, long $85^{\circ} 03^{\prime} 24^{\prime \prime}$. In SWłSWłSE sec.5. T.36 N.. R.13 E.. Steuben County, Hydrologic Unit 04050001 (ASHLEY. IN quadrangle). The gage is located at the pubilic fishing site on the northwestern edge of the lake, $3.9 \backsim i$ southwest of Angola.

SURFACE AREA. --25 acres.

DRAINAGE AREA. $--84.6 \bullet i^{2}$.

PERIOD OF RECORD. $-1946-1970,1977$ to current year.

DATUM OF GAGE.--940.00 ft above National Geodetic Vertical Datun of 1929.

GAGE.--A water-stage recorder is installed in an aluminum shelter over a 15-inch dianeter stilling well. An auxiliary wire-weight gage is attached to the bridge over the outlet.

ESTABL ISHED LEGAL LEVEL. $-8.50 \mathrm{ft}$ gage datun or $948.50 \mathrm{ft}$ above Mational Geodetic Vertical Datul of 1929 , as decreed on October 28, 1959, by Steuben County Circuit Court. Golden Lake near Pleasant Lake has the saee established level and hence the same lake levels for the period of record.

LAKE-LEVEL CONTROL..-The lake level is controlled by the out let channel or the outlet of Golden Lake.

INLET AND OUTLET...Pigeon Creek flows through the lake, entering at the southern shore and leaving at the western end to flow into Golden Lake and eventualiy into the St. Joseph River.

EXTREMES FOR PERIOD OF RECORD.--Maximue stage, $17.13 \mathrm{ft}$ Mar. 22, 1982; ainiaun stage, $7.88 \mathrm{ft}$ Sept, $14,15,1964$.

LAKE LEVEL, IN FEET ABOVE GAGE DATUM, WATER YEAR OCTOBER 1990 TO SEPTEMBER 1991

\begin{tabular}{|c|c|c|c|c|c|c|c|c|c|c|c|c|}
\hline DAY & $O C T$ & NOV & DEC & JAN & FE B & MAR & APR & MAY & JUN & JUL & AUG & SEP \\
\hline $\begin{array}{r}5 \\
10 \\
15 \\
20 \\
25 \\
\text { EOM }\end{array}$ & $\begin{array}{r}8.83 \\
11.10 \\
11.39 \\
10.22 \\
9.62 \\
9.16\end{array}$ & $\begin{array}{r}9.79 \\
10.52 \\
9.72 \\
9.30 \\
9.18 \\
9.64\end{array}$ & $\begin{array}{r}10.26 \\
9.89 \\
9.63 \\
9.82 \\
10.18 \\
13.65\end{array}$ & $\begin{array}{l}\ldots \\
\ldots \\
\ldots \\
\ldots \\
\ldots\end{array}$ & $\begin{array}{l}\ldots \\
\ldots \\
\ldots \\
\ldots \\
\ldots\end{array}$ & $\begin{array}{l}\ldots \\
\ldots \\
\ldots \\
\ldots \\
\ldots \\
\ldots\end{array}$ & $\begin{array}{r}\ldots . \\
\ldots . \\
11.73 \\
11.83 \\
10.74\end{array}$ & $\begin{array}{r}10.01 \\
9.62 \\
9.34 \\
9.10 \\
9.10 \\
9.79\end{array}$ & $\begin{array}{r}10.09 \\
9.27 \\
8.96 \\
8.72 \\
8.54 \\
8.50\end{array}$ & $\begin{array}{l}9.00 \\
8.61 \\
8.46 \\
8.37 \\
8.32 \\
8.28\end{array}$ & $\begin{array}{l}8.27 \\
8.32 \\
8.27 \\
8.64 \\
8.58 \\
8.44\end{array}$ & $\begin{array}{l}8.38 \\
8.27 \\
8.31 \\
8.16 \\
8.16 \\
8.10\end{array}$ \\
\hline
\end{tabular}

WTR YR 1991 MEAN 9.34 MAX 13.71 MIN 8.10 
LOCATION.- Lat $41^{\circ} 41^{\prime} 42^{\circ}$, long $85^{\circ} 38^{\prime} 18^{\circ}$, in SWHWW $\frac{1}{2} N W$ sec.5. T.37 N, R.8 E., Lagrange County, Hydrologic Unit 04050001 (MIDDLEBURY, IN quadrangle). The gage is on the northeast shore of the lake, at the beach area in the Foxwood Hills Addition, and 3.3 i northwest of Shipshewana.

SURFACE AREA. --89 acres.

DRAI NAGE AREA, $--0.68 \cdot i^{2}$.

PERIOD OF RECORD.--1971 to current year.

DATUM OF GAGE. --840.95 ft above National Geodetic Vertical Datue of 1929.

GAGE.--A water-stage recorder is installed in an aluainua shelter over a 15-inch diaeter stilling well.

ESTABLISHEO LEGAL LEVEL. - - Not established.

LAKE-LEVEL CONTROL..-The level of the lake is controlled by the outlet channel.

INLET AMD OUTLET.--A sall unnaned ditch enters on the northwestern shore. The outlet leaves the lake at the southwest and flows into Mather ditch 1.0 i downstrea.. Mather ditch eventually eapties into the Little Elkhart River.

EXTREMES FOR PERIOD OF RECORD.--Maximun stage, $3.81 \mathrm{ft} J u l y ~ 28,1981$; minimum stage, $1.80 \mathrm{ft}$ May $15,1971$.

LAKE LEVEL, IN FEET ABOVE GAGE DATUM, HATER YEAR OCTOBER 1990 TO SEPTEMBER 1991

\begin{tabular}{|c|c|c|c|c|c|c|c|c|c|c|c|c|}
\hline DAY & OCT & NOV & DEC & JAN & FE B & MAR & APR & MAY & JUN & JUL & AUG & SEP \\
\hline $\begin{array}{r}5 \\
10 \\
15 \\
20 \\
25 \\
\text { EOM }\end{array}$ & $\begin{array}{l}3.13 \\
3.49 \\
3.42 \\
3.36 \\
3.05 \\
2.99\end{array}$ & $\begin{array}{l}3.20 \\
3.18 \\
3.15 \\
3.13 \\
3.14 \\
2.65\end{array}$ & $\begin{array}{l}2.51 \\
2.44 \\
2.43 \\
2.42 \\
2.43 \\
2.87\end{array}$ & $\begin{array}{l}2.54 \\
2.48 \\
2.48 \\
2.51 \\
2.59 \\
2.59\end{array}$ & $\begin{array}{l}2.66 \\
2.97 \\
2.97 \\
2.99 \\
2.99 \\
2.99\end{array}$ & $\begin{array}{l}3.03 \\
2.69 \\
2.46 \\
2.45 \\
2.57 \\
2.77\end{array}$ & $\begin{array}{l}2.88 \\
2.97 \\
3.07 \\
3.12 \\
2.83 \\
2.95\end{array}$ & $\begin{array}{l}2.95 \\
2.94 \\
2.94 \\
2.92 \\
2.58 \\
2.72\end{array}$ & $\begin{array}{l}2.71 \\
2.71 \\
2.73 \\
2.70 \\
2.66 \\
2.66\end{array}$ & $\begin{array}{l}2.77 \\
2.75 \\
2.74 \\
2.66 \\
2.63 \\
2.63\end{array}$ & $\begin{array}{l}2.63 \\
2.73 \\
2.71 \\
2.81 \\
2.77 \\
2.81\end{array}$ & $\begin{array}{l}2.81 \\
2.78 \\
2.91 \\
2.83 \\
2.81 \\
2.78\end{array}$ \\
\hline
\end{tabular}

WTR YR 1991 MEAN 2.81 MAX 3.49 MIN 2.41

ILLINOIS RIVER BASIN

05518700 CEDAR LAKE AT CEDAR LAKE, IN

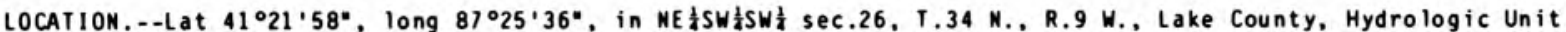
07120001 (LOWELL. IN quadrangle). The gage is on the south bank of the out let channel on the east shore of the lake, upstrean from the first bridge over the outlet, and 0.5 i east of the town of Cedar lake.

SURFACE AREA. --781 acres.

DRAI NAGE AREA. $--8.14 \cdot i^{2}$.

PERIOD OF RECORD.- 1943 to current year.

DATUM OF GAGE.--690.00 ft above Mational Geodetic Vertical Datun of 1929.

GAGE.--A water-stage recorder is installed in an alueinus shelter over a 24-inch dianeter stilling well. An auxiliary staff gage is driven into the channel bed.

ESTABLISHED LEGAL LEVEL. - - Not established.

LAKE-LEVEL CONTROL.--The level of the lake is controlled by a fixed-crest concrete da.

INLET AND OUTLET..--Several saall ditches enter the lake at various points. The outlet, Cedar Creek, flows from the lake on the eastern shore of the center lobe, into Dalecarlia Lake, 1.5 a downstrean, and eventually into the Kankakee River.

EXTREMES FOR PERIOD OF RECORD. -- Maximu stage, 4.30 ft May 15, 1970; ainiaue stage not deterained, below $1.22 \mathrm{ft}$ during July. August, Septemer, October 1988, and Septeaber 1991.

LAKE LEVEL, IN FEET ABOVE GAGE DATUM, WATER YEAR OCTOBER 1990 TO SEPTEMBER 1991

\begin{tabular}{|c|c|c|c|c|c|c|c|c|c|c|c|}
\hline DAY & OCT & NOV & DEC & JAM & FEB & MAR & APR & MAY & JUN & JUL & AUG \\
\hline $\begin{array}{r}5 \\
10 \\
15 \\
20 \\
25 \\
\text { EOM }\end{array}$ & $\begin{array}{l}2.82 \\
3.26 \\
3.22 \\
3.13 \\
3.06 \\
2.98\end{array}$ & $\begin{array}{l}3.21 \\
3.17 \\
3.11 \\
3.03 \\
3.00 \\
3.99\end{array}$ & $\begin{array}{l}3.62 \\
3.35 \\
3.18 \\
3.08 \\
3.06 \\
3.58\end{array}$ & $\begin{array}{l}3.53 \\
3.13 \\
3.06 \\
3.07 \\
2.99 \\
2.88\end{array}$ & $\begin{array}{l}2.94 \\
2.98 \\
2.93 \\
3.02 \\
2.99 \\
2.97\end{array}$ & $\begin{array}{l}3.14 \\
3.05 \\
3.09 \\
3.37 \\
3.29 \\
3.12\end{array}$ & $\begin{array}{l}3.04 \\
2.96 \\
3.24 \\
3.25 \\
3.11 \\
3.05\end{array}$ & $\begin{array}{l}3.12 \\
3.03 \\
3.01 \\
2.95 \\
3.08 \\
3.03\end{array}$ & $\begin{array}{l}2.84 \\
2.72 \\
2.67 \\
2.56 \\
2.45 \\
2.37\end{array}$ & $\begin{array}{l}2.32 \\
2.24 \\
2.15 \\
2.07 \\
2.00 \\
1.86\end{array}$ & $\begin{array}{l}1.82 \\
1.91 \\
1.85 \\
1.85 \\
1.79 \\
1.58\end{array}$ \\
\hline
\end{tabular}

WTR YR 1991 MEAM 2.79 MAX 4.13 MIN 1.23 


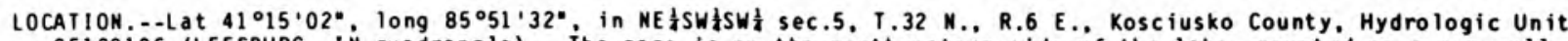
05120106 (LEESBURG, I ${ }^{2}$ quadrangle). The gage is on the northwestern side of the lake, counted on a sea wall behind the house at 300 Gillian Orive, 0.8 i north of the court house. Warsaw.

SURFACE AREA, -120 acres.

DRAINAGE AREA, $--0.73 \mathrm{mi}^{2}$.

PERIOD OF RECORD,--1943-1968, 1971 to current year.

DATUM OF GAGE.--800.00 ft above National Geodetic Vertical Datue of 1929.

GAGE.--A water-stage recorder is installed in an alueinus shelter over a 15-inch dianeter stilling well. An auxiliary staff gage is attached to the control das at the outlet.

ESTABLISHED LEGAL LEVEL. - -3.86 ft gage datun or $803.86 \mathrm{ft}$ above National Geodetic Vertical Datue of 1929 as decreed on December 3, 1963, by the Kosciusko County Circuit Court.

LAKE-LEVEL CONTROL... The level of the lake is controlled by a concrete das at the western end of the lake.

INLET AND OUTLET. .-The one inlet flows through a 24 -inch dianeter tile from Pike Lake and enters the lake on the southeastern side. The outlet flows from the western shore and joins Walnut Creek 0.65 i downstreae. which in turn flows into the Tippecanoe River.

EXTREMES FOR PERIOD OF RECORD. --Maximus stage, $7.24 \mathrm{ft}$ Oct. 15, 1954 ; minimus stage, $0.17 \mathrm{ft} 0 \mathrm{ct} .4,1955$.

LAKE LEVEL, IN FEET ABOVE GAGE DATUM, WATER YEAR OCTOBER 1990 TO SEPTEMBER 1991 24:00 VALUES

\begin{tabular}{|c|c|c|c|c|c|c|c|c|c|c|c|c|}
\hline DAY & $O C T$ & NOV & $\mathrm{DEC}$ & JAM & FE B & MAR & APR & MAY & JUN & JUL & AUG & SEP \\
\hline $\begin{array}{r}5 \\
10 \\
15 \\
20 \\
25 \\
\text { EOM }\end{array}$ & $\begin{array}{l}4.31 \\
4.78 \\
5.72 \\
5.81 \\
5.48 \\
5.02\end{array}$ & $\begin{array}{l}5.11 \\
5.12 \\
4.90 \\
4.74 \\
4.65 \\
4.63\end{array}$ & $\begin{array}{l}4.75 \\
4.75 \\
4.64 \\
4.55 \\
4.60 \\
5.16\end{array}$ & $\begin{array}{l}5.19 \\
5.35 \\
5.11 \\
5.27 \\
5.27 \\
5.27\end{array}$ & $\begin{array}{l}4.46 \\
4.27 \\
4.23 \\
4.75 \\
4.74 \\
4.73\end{array}$ & $\begin{array}{l}4.76 \\
4.58 \\
4.50 \\
4.52 \\
4.55 \\
4.60\end{array}$ & $\begin{array}{l}4.58 \\
4.51 \\
4.58 \\
4.73 \\
4.87 \\
4.70\end{array}$ & $\begin{array}{l}4.59 \\
4.41 \\
4.33 \\
4.28 \\
4.43 \\
4.83\end{array}$ & $\begin{array}{l}5.29 \\
4.85 \\
4.70 \\
4.49 \\
4.25 \\
4.40\end{array}$ & $\begin{array}{l}4.30 \\
4.24 \\
4.15 \\
4.06 \\
3.98 \\
3.92\end{array}$ & $\begin{array}{l}3.97 \\
4.13 \\
4.15 \\
4.24 \\
4.24 \\
4.28\end{array}$ & $\begin{array}{l}4.27 \\
4.22 \\
4.22 \\
4.08 \\
4.05 \\
4.03\end{array}$ \\
\hline
\end{tabular}

WTR YR 1991 MEAN 4.61 MAX 5.84 MIN 3.92

STREAMS TRIBUTARY TO LAKE ERIE

04177200 CLEAR LAKE AT CLEAR LAKE, IN

LOCATION.--Lat $41^{\circ} 44^{\prime} 52^{\prime \prime}$. long $84^{\circ} 50^{\prime} 2^{\circ}$, in SWa sWl sec.17, T.38 N., R.15 E., Steuben County. Hydrologic Unit 04100003 (CLEAR LAKE, IN-OH-MI quadrangle). The gage is on the northern shore of the lake, at the channel between clear and Round Lakes, and 4.75 inortheast of Fremont.

SURFACE AREA.-- 800 acres.

DRAINAGE AREA, $--6.86 \cdot i^{2}$.

PERIOD OF RECORD. -1943 to current year.

DATUM OF GAGE. - $1030.00 \mathrm{ft}$ above National Geodetic Vertical Datun of 1929.

GAGE.--A water-stage recorder is installed in a woden shelter over a 24 -inch stilling well. An auxiliary staff gage is attached to the north end of the upstrean culvert.

ESTABLISHED LEGAL LEVEL. - -7.38 ft gage datum or $1037.38 \mathrm{ft}$ above National Geodetic Vertical Datun of 1929 as decreed on June 1, 1950, by the Steuben County Circuit Court. Round Lake at Clear Lake has the sane established level and hence the same lake levels for the period of record.

LAKE-LEVEL CONTROL...The level of the lake is controlled by a fixed-crest concrete dan with an auxiliary slide gate at the out let of Round lake.

INLET ANO OUTLET.--Two unnamed ditches enter the lake on the southern shore. The outlet is a short channel connecting Clear and Round Lakes. The out let of Round Lake flows from the northeast end and eventually into the West Branch of the St. Joseph River.

EXTREMES FOR PERIOD OF RECORD. - - Maximum stage, $9.24 \mathrm{ft}$ May 20, 1943 (from high-water mark); maximun recorded stage, $8.49 \mathrm{ft}$ Mar. 20, 21, 1982; inimum stage, 6.24 ft Sept. 30, 1962.

LAKE LEVEL, IN FEET ABOVE GAGE DATUM. WATER YEAR OCTOBER 1990 TO SEPTEMBER 1991

\begin{tabular}{|c|c|c|c|c|c|c|c|c|c|c|c|c|}
\hline DAY & OCT & NOV & DEC & JAN & FEB & MAR & APR & MAY & JUN & JUL & AUG & SEP \\
\hline $\begin{array}{r}5 \\
10 \\
15 \\
20 \\
25 \\
\text { EOM }\end{array}$ & $\begin{array}{l}7.79 \\
8.10 \\
8.04 \\
7.97 \\
7.89 \\
7.83\end{array}$ & $\begin{array}{l}7.99 \\
7.96 \\
7.91 \\
7.87 \\
7.86 \\
7.92\end{array}$ & $\begin{array}{l}7.99 \\
7.95 \\
7.95 \\
7.97 \\
8.01 \\
8.40\end{array}$ & $\begin{array}{l}8.37 \\
8.33 \\
8.13 \\
8.12 \\
8.14 \\
8.14\end{array}$ & $\begin{array}{r}8.03 \\
8.01 \\
8.07 \\
7.92 \\
\ldots . .\end{array}$ & $\begin{array}{l}\ldots \\
\cdots \\
\cdots \\
\cdots \\
\cdots\end{array}$ & $\begin{array}{c}\ldots . \\
\ldots .2 \\
8.22 \\
8.21 \\
8.09\end{array}$ & $\begin{array}{l}8.03 \\
7.97 \\
7.97 \\
7.87 \\
7.97 \\
7.97\end{array}$ & $\begin{array}{l}7.89 \\
7.81 \\
7.77 \\
7.72 \\
7.68 \\
7.67\end{array}$ & \begin{tabular}{c}
7.71 \\
7.68 \\
$\cdots \ldots$ \\
\hdashline. \\
$\cdots$
\end{tabular} & $\begin{array}{l}\cdots \\
\cdots \\
\cdots \\
\cdots \\
\cdots\end{array}$ & $\begin{array}{l}\cdots \\
\cdots \\
\cdots \\
\cdots \\
\cdots\end{array}$ \\
\hline
\end{tabular}

WTR YR 1991 MEAN 7.96 MAX 8.40 MIM 7.57 


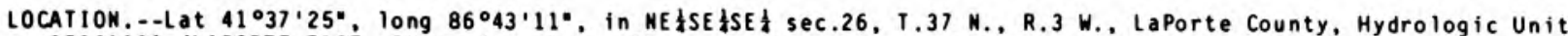
07120001 (LAPORTE EAST. IN quadrangle). The gage is on the northeast shore of the lake, $100 \mathrm{ft}$ south of the entrance to Fox Memorial Park, in Laporte.

SURFACE AREA. -106 acres.

DRAI NAGE AREA, $--0.65 \backsim i^{2}$.

PERIOD OF RECORD.--1942-49, 1952-75, 1979 to current year.

DATUM OF GAGE.--790.00 ft above National Geodetic Vertical Datun of 1929.

GAGE.--A water-stage recorder is installed in an aluainum shelter over a 15-inch dianeter stilling well. An auxiliary staff gage is attached to the north wingwall of the inlet culvert on the west side of the lake.

ESTABLISHED LEGAL LEVEL. $-8.20 \mathrm{ft}$ gage datun or $798.20 \mathrm{ft}$ above National Geodetic Vertical Datu of 1929 as decreed on August 31,1949 , by the LaPorte County Circuit Court.

LAKE-LEVEL CONTROL.--During periods of high water, water wa be released through the ain sewer systea of the city of LaPorte and diverted into the Kankakee River.

INLET AND OUTLET.--A sall ditch enters on the west shore. There is no outlet during periods of low and aediua water levels. When water levels are high, water ay flow fro the lake into the city sewer systea.

EXTREMES FOR PERIOD OF RECORD..-Maximu stage, 11.20 ft Apr. 23, 1973; inimun stage, 3.98 ft Nov. 27.1964.

LAKE LEVEL, IN FEET ABOVE GAGE DATUM, WATER YEAR OCTOBER 1990 TO SEPTEMBER 1991

\begin{tabular}{|c|c|c|c|c|c|c|c|c|c|c|c|c|}
\hline DAY & OCT & NOV & DEC & JAHA & FEB & MAR & APR & MAY & JUN & JUL & AUG & SEP \\
\hline $\begin{array}{r}5 \\
10 \\
15 \\
20 \\
25 \\
\text { EOM }\end{array}$ & $\begin{array}{l}8.61 \\
8.59 \\
8.63 \\
8.58 \\
8.52\end{array}$ & $\begin{array}{l}8.85 \\
8.76 \\
8.74 \\
8.69 \\
8.68 \\
9.33\end{array}$ & $\begin{array}{l}9.34 \\
9.32 \\
9.34 \\
9.34 \\
9.41 \\
9.75\end{array}$ & $\begin{array}{l}9.77 \\
9.77 \\
9.84 \\
9.91 \\
9.92 \\
9.91\end{array}$ & $\begin{array}{r}9.91 \\
9.90 \\
10.00 \\
10.03 \\
10.02 \\
10.03\end{array}$ & $\begin{array}{l}10.16 \\
10.14 \\
10.15 \\
10.21 \\
10.20 \\
10.22\end{array}$ & $\begin{array}{l}10.22 \\
10.28 \\
10.42 \\
10.42 \\
10.42 \\
10.43\end{array}$ & $\begin{array}{l}10.44 \\
10.39 \\
10.32 \\
10.39 \\
10.51 \\
10.65\end{array}$ & $\begin{array}{l}10.55 \\
10.43 \\
10.39 \\
10.30 \\
10.21 \\
10.09\end{array}$ & $\begin{array}{l}9.97 \\
9.91 \\
9.80 \\
9.68 \\
9.54 \\
9.37\end{array}$ & $\begin{array}{l}9.26 \\
9.31 \\
9.23 \\
9.28 \\
9.18 \\
9.28\end{array}$ & $\begin{array}{l}9.37 \\
9.29 \\
9.38 \\
9.26 \\
9.21 \\
9.12\end{array}$ \\
\hline
\end{tabular}

WTR YR 1991 MEAN 9.69 MAX 10.66 MIN 8.26

STREAMS TRIBUTARY TO LAKE MICHIGAN

04097850 CROOKED LAKE AT CROOKED LAKE, IN

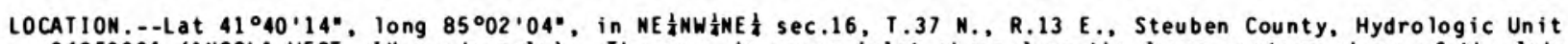
04050001 (ANGOLA WEST, IN quadrangle). The gage is on an inlet channel on the lower eastern shore of the lake, 3.1 i northwest of Angola.

SURFACE AREA.-- -828 acres.

DRAI NAGE AREA, $--10.4 \cdot i^{2}$.

PERIOD OF RECORD.--1946-70, 1972 to current year.

DATUM OF GAGE. - -980.26 ft above National Geodetic Vertical Datun of 1929, as corrected on the basis of levels of Indiana Department of Matural Resources, 1977-78.

GAGE.--A water-stage recorder is installed in an aluainum shelter over a 15-inch dianeter stilling well. An auxiliary staff gage is driven into the channel bed between the Second and Third Basins under County Road 400 West.

ESTABLISHED LEGAL LEVEL. - -8.17 ft gage datue or $988.17 \mathrm{ft}$ above National Geodetic Vertical Datun of 1929 as decreed on June 17, 1948, by the Steuben County Circuit Court. Minor errors were subsequently discovered in the establishment of the datur of the gage (see "DATUM OF GAGE") and the correct elevation of the legal level should be $8.17 \mathrm{ft}$ gage datun or $988.43 \mathrm{ft}$ above National Geodetic Vertical Datue of 1929.

LAKE-LEVEL CONTROL.--The level of the lake is controlled by a fixed-crest dan with an adjustable gate at the western end of the Third Basin.

INLET AND OUTLET.--The principal inlets enter the lake frow the south, froe loon and Buck Lakes, and the southeast, fro Center lake. Another ditch enters from the east. The outlet flows froe the western end of the Third Basin into Lake Gage 1.4 i downstrea and eventually into the St. Joseph River.

EXTREMES FOR PERIOD OF RECORD..-Maximum stage, 10.07 ft Apr. 6, 1985; wininun stage, $7.05 \mathrm{ft}$ Mov. $13-15,1964$.

LAKE LEVEL, IN FEET ABOVE GAGE DATUM, WATER YEAR OCTOBER 1990 TO SEPTEMBER 1991 24:00 VALUES

\begin{tabular}{|c|c|c|c|c|c|c|c|c|c|c|c|}
\hline DAY & OCT & NOV & DEC & JAN & FEB & MAR & APR & MAY & JUN & JUL & AUG \\
\hline $\begin{array}{r}5 \\
10 \\
15 \\
20 \\
25 \\
\text { EOM }\end{array}$ & $\begin{array}{l}9.04 \\
9.34 \\
9.33 \\
9.30 \\
9.23 \\
9.12\end{array}$ & $\begin{array}{l}9.27 \\
9.24 \\
9.19 \\
9.12 \\
9.10 \\
9.14\end{array}$ & $\begin{array}{l}9.22 \\
9.18 \\
9.19 \\
9.18 \\
9.24 \\
9.65\end{array}$ & $\begin{array}{l}9.63 \\
9.52 \\
9.47 \\
9.46 \\
9.36 \\
9.28\end{array}$ & $\begin{array}{l}9.24 \\
9.21 \\
9.22 \\
9.22 \\
9.19 \\
9.18\end{array}$ & $\begin{array}{l}9.22 \\
9.20 \\
9.13 \\
9.10 \\
9.10 \\
9.15\end{array}$ & $\begin{array}{l}9.13 \\
9.13 \\
9.17 \\
9.31 \\
9.37 \\
9.35\end{array}$ & $\begin{array}{l}9.29 \\
9.19 \\
9.16 \\
9.09 \\
9.14 \\
9.25\end{array}$ & $\begin{array}{l}9.19 \\
9.17 \\
9.14 \\
9.04 \\
8.96 \\
8.93\end{array}$ & $\begin{array}{l}8.99 \\
8.92 \\
8.89 \\
8.80 \\
8.18 \\
8.69\end{array}$ & $\begin{array}{l}8.65 \\
8.67 \\
8.59 \\
8.91 \\
8.74 \\
8.80\end{array}$ \\
\hline
\end{tabular}

WTR YR 1991 MEAN 9.10 MAX 9.66 MIN 8.55 


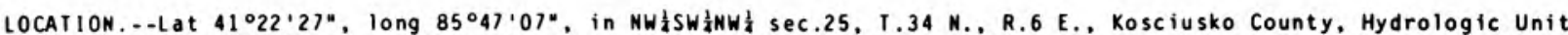
04050001 (LEESBURG, IN quadrangle). The gage is on the west shore of the lake, 0.1 a east of County Road 300 East at the Dewart Lake Marina, and $4.5 \mathrm{mi}$ northeast of Leesburg.

SURFACE AREA. - - 551 acres.

DRAINAGE AREA. $-8.05 \cdot i^{2}$.

PERIOD OF RECORD.--1945 to current year.

DATUM OF GAGE, - $-859.87 \mathrm{ft}$ above National Geodetic Vertical Datun of 1929, as corrected on the basis of levels of Indiana Departaent of Natural Resources, 1973-74.

GAGE.--A water-stage recorder is installed in an aluminum shelter over a 24 -inch dianeter stilling well.

ESTABLISHED LEGAL LEVEL. $-7.70 \mathrm{ft}$ gage datum or $867.70 \mathrm{ft}$ above Mational Geodetic Vertical Datu of 1929 as decreed on October 18, 1949, by the Kosciusko County Circuit Court. Minor errors were subsequent ly discovered in the establishment of the datum of the gage (see "DATUM OF GAGE") and the correct elevation of the legal level should be $7.70 \mathrm{ft}$ gage datu or $867.57 \mathrm{ft}$ above National Geodetic Vertical Datua of 1929 .

LAKE-LEVEL CONTROL..-The level of the lake is controlled by a steel sheet piling da..

INLET AND OUTLET.-.-Cable Run enters the lake on the southeastern $t$ ip, and an unnaned ditch enters on the eastern shore. The outlet, Hanond ditch, flows from the lake on the northwestern shore and into Wabee Lake 2.3 ai downstrean.

EXTREMES FOR PERIOD OF RECORD.--Maximum stage, $9.57 \mathrm{ft}$ June 14, 1981; ainimum stage, $3.95 \mathrm{ft}$ Dec. $21-24$, 1964.

LAKE LEVEL, IN FEET ABOVE GAGE DATUM, WATER YEAR OCTOBER 1990 TO SEPTEMBER 1991

\begin{tabular}{|c|c|c|c|c|c|c|c|c|c|c|c|c|}
\hline DAY & $O C T$ & NOV & DEC & JAN & FEB & MAR & APR & MAY & JUN & JUL & AUG & SEP \\
\hline $\begin{array}{r}5 \\
10 \\
15 \\
20 \\
25 \\
\text { EOM }\end{array}$ & $\begin{array}{l}8.63 \\
9.08 \\
9.03 \\
8.96 \\
8.85 \\
8.76\end{array}$ & $\begin{array}{l}8.96 \\
8.90 \\
8.83 \\
8.78 \\
8.76 \\
8.84\end{array}$ & $\begin{array}{l}8.89 \\
8.85 \\
8.87 \\
8.87 \\
8.95 \\
9.50\end{array}$ & $\begin{array}{l}9.32 \\
9.19 \\
9.13 \\
9.14 \\
9.13 \\
9.13\end{array}$ & $\begin{array}{l}9.08 \\
8.92 \\
8.92 \\
8.92 \\
8.89 \\
8.88\end{array}$ & $\begin{array}{l}8.96 \\
8.90 \\
8.91 \\
8.96 \\
8.97 \\
8.97\end{array}$ & $\begin{array}{l}8.94 \\
8.96 \\
9.00 \\
9.14 \\
9.16 \\
9.08\end{array}$ & $\begin{array}{l}9.01 \\
8.92 \\
8.86 \\
8.80 \\
8.91 \\
9.33\end{array}$ & $\begin{array}{l}9.14 \\
8.97 \\
8.89 \\
8.78 \\
8.66 \\
8.69\end{array}$ & $\begin{array}{l}8.60 \\
8.53 \\
8.46 \\
8.39 \\
8.36 \\
8.30\end{array}$ & $\begin{array}{l}8.28 \\
8.32 \\
8.26 \\
8.27 \\
8.20 \\
8.26\end{array}$ & $\begin{array}{l}8.28 \\
8.21 \\
8.25 \\
8.13 \\
8.08 \\
8.00\end{array}$ \\
\hline
\end{tabular}

WTR YR 1991 MEAN 8.79 MAX 9.53 MIN 8.00

WABASH RIVER BASIN

03331320 DIAMOND LAKE NEAR SILVER LAKE, IN

LOCATION..-Lat $41^{\circ} 06^{\prime} 23^{\prime \prime}$, long $85^{\circ} 56^{\prime} 05^{\prime \prime}$, in SW $\frac{1}{4}$ HW $\frac{1}{4} S E \frac{1}{4}$ sec.26, T.31 N., R.5 E., Kosciusko County, Hydrologic Unit 05120106 (SILVER LAKE, IN quadrangle). The gage is on the inlet channel on the northern shore of the lake, 2.2 morthwest of the town of Silver lake.

SURFACE AREA...79 acres.

DRAINAGE AREA. $--3.92 \mathrm{i}^{2}$.

PERIOD OF RECORD. $-1954-72,1975$ to current year.

DATUM OF GAGE, $-849.90 \mathrm{ft}$ above National Geodetic Vertical Datum of 1929 , as corrected on the basis of levels of Indiana Department of Natural Resources, 1976.

GAGE.--A water-stage recorder is installed in an aluminu shelter over a 15-inch dianeter stilling well.

ESTABLISHED LEGAL LEVEL.... Not established.

LAKE-LEVEL CONTROL..-The lake level is controlled by Yellow Creek Lake, 0.3 mi downstrean.

INLET AND OUTLET. - -There are two inlets. One enters from the north and east from Hill Lake, one enters froe the southeast. The one outlet flows from the western shore and into Yellow Creek Lake, 0.3 .1 downstreas. Yellow Creek Lake flows into Yellow Creek, which eventually discharges into the Tippecanoe River.

EXTREMES FOR PERIOD OF RECORD.--Maximum stage, 13.47 July 9, 1964; minim stage, 9.78 ft Sept. 18-19, 23, 27-30, OCt. $10-12,1988$.

LAKE LEVEL, IN FEET ABOVE GAGE DATUM, WATER YEAR OCTOBER 1990 TO SEPTEMBER 1991 $24: 00$ VALUES

$\begin{array}{rrrrrrrrrrrrr}\text { DAY } & \text { OCT } & \text { NOV } & \text { DEC } & \text { JAN } & \text { FEB } & \text { MAR } & \text { APR } & \text { MAY } & \text { JUN } & \text { JUL } & \text { AUG } & \text { SEP } \\ & & & & & & & & & & & \\ 10 & 10.70 & 11.12 & 10.86 & 11.50 & 10.73 & 10.72 & 10.66 & 10.85 & 10.65 & 10.39 & 10.17 & 10.14 \\ 10 & 11.78 & 10.86 & 10.70 & 10.79 & 10.68 & 10.63 & 10.66 & 10.67 & 10.50 & 10.48 & 10.21 & 10.07 \\ 15 & 11.26 & 10.69 & 10.75 & 10.87 & 10.64 & 10.62 & 10.93 & 10.68 & 10.56 & 10.40 & 10.15 & 10.08 \\ 20 & 10.87 & 10.61 & 10.70 & 10.95 & 10.78 & 10.81 & 10.98 & 10.59 & 10.46 & 10.36 & 10.23 & 10.03 \\ 25 & 10.67 & 10.65 & 10.77 & 10.79 & 10.66 & 10.71 & 10.84 & 10.63 & 10.39 & 10.30 & 10.16 & 10.03 \\ \text { EOM } & 10.64 & 10.78 & 12.17 & 10.80 & 10.64 & 10.72 & 10.73 & 11.27 & 10.42 & 10.22 & 10.16 & 9.96\end{array}$

WTR YR 1991 MEAN 10.63 MAX 12.20 MIN 9.96 
04100350 DIAMOND LAKE MEAR WAMAKA, IN

LOCATION.--Lat $41^{\circ} 26^{\prime} 15^{\circ}$, long $85^{\circ} 31^{\prime} 05^{\circ}$, in ME $\frac{1}{2}$ NWH 04050001 (LIGOMIER, IN quadrangle). The gage is located on the southeastern edge of the lake at a public fishing site, 2.5 i southwest of the town of Wawaka.

SURFACE AREA, --105 acres.

DRAINAGE AREA. $--4.80 \cdot i^{2}$.

PERIOD OF RECORD. - -1946 to current year.

DATUM OF GAGE. - $-870.00 \mathrm{ft}$ above National Geodetic Vertical Datun of 1929.

GAGE.--A water-stage recorder is installed in an alueinu shelter over a 15-inch dianeter stilling well. An auxiliary staff gage is ounted on a piling driven into the lake bed on the northern edge of the lake.

ESTABLISHEO LEGAL LEVEL. - - Not established.

LAKE-LEVEL CONTROL..-The lake level is controlled by a riffle at the head of the outlet channel.

INLET AND OUTLET.--Willets Ditch enters at the southwestern tip of the lake fron Eagle Lake, 0.6 a upstrean. One unnaned ditch enters the lake froe the south. The outlet flows froe the lake at the southeastern edge and joins the South Branch of the Elkhart River 0.8 a downstrean.

EXTREMES FOR PERIOD OF RECORD..--Maximun stage, $7.83 \mathrm{ft}$ Mar. 20, 1982: winimu stage, $2.29 \mathrm{ft} 0 \mathrm{ct} .17,1946$.

LAKE LEVEL, IN FEET ABOVE GAGE DATUM, WATER YEAR OCTOBER 1990 TO SEPTEMBER 1991 24:00 VALUES

\begin{tabular}{|c|c|c|c|c|c|c|c|c|c|c|c|}
\hline DAY & $\mathrm{OCT}$ & NOV & DEC & JAN & FE B & MAR & APR & MAY & JUN & JUL & AUG \\
\hline $\begin{array}{r}5 \\
10 \\
15 \\
20 \\
25 \\
\text { EOM }\end{array}$ & $\begin{array}{c}4.86 \\
5.66 \\
6.23 \\
5.90 \\
\ldots . . \\
\ldots . .\end{array}$ & $\begin{array}{l}5.29 \\
5.40 \\
5.25 \\
5.07 \\
4.98 \\
5.11\end{array}$ & $\begin{array}{l}5.20 \\
5.13 \\
5.08 \\
5.11 \\
5.14 \\
6.06\end{array}$ & $\begin{array}{l}6.41 \\
6.34 \\
5.61 \\
5.54 \\
5.54 \\
5.54\end{array}$ & $\begin{array}{l}5.00 \\
5.03 \\
4.97 \\
5.03 \\
5.04 \\
5.00\end{array}$ & $\begin{array}{l}5.11 \\
5.03 \\
4.96 \\
5.06 \\
5.04 \\
5.07\end{array}$ & $\begin{array}{l}4.99 \\
4.97 \\
5.03 \\
5.41 \\
5.51 \\
5.35\end{array}$ & $\begin{array}{l}5.23 \\
5.06 \\
4.93 \\
4.82 \\
4.92 \\
5.85\end{array}$ & $\begin{array}{l}6.47 \\
5.91 \\
5.47 \\
5.08 \\
4.83 \\
4.77\end{array}$ & $\begin{array}{l}4.74 \\
4.67 \\
4.61 \\
4.57 \\
4.56 \\
4.54\end{array}$ & $\begin{array}{l}4.63 \\
4.66 \\
4.60 \\
4.64 \\
4.58 \\
4.66\end{array}$ \\
\hline
\end{tabular}

WTR YR 1991 MEAN 5.12 MAX 6.57 MIN 4.51

\section{STREAMS TRIBUTARY TO LAKE MICHIGAN}

04100370 ENGLE LAKE MEAR LIGONIER, IN

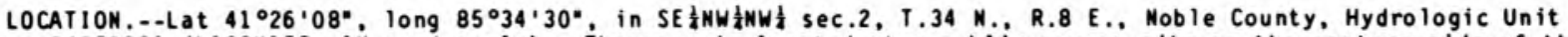
04050001 (LIGOMIER, I i quadrangle). The gage is located at a public access site on the eastern side of the lake, 2.2 i south of the town of Ligonier.

SURFACE AREA. --48 acres.

DRAI NAGE AREA. $--4.19 \cdot i^{2}$.

PERIOD OF RECORD.--1956-67, 1977 to current year.

DATUM OF GAGE. - $870.00 \mathrm{ft}$ above National Geodetic Vertical Datun of 1929.

GAGE.--A water-stage recorder is installed in an alueinua shelter over a 15-inch dianeter stilling well.

ESTABLISHED LEGAL LEVEL. - $-8.90 \mathrm{ft}$ gage datue or $878.90 \mathrm{ft}$ above National Geodetic Vertical Datul of 1929 as decreed on October 23,1984 , by the Noble County Circuit Court.

LAKE-LEVEL CONTROL..- The lake level is controlled by the outlet channel at low water and the first culvert downstrean at higher stages.

INLET AND OUILET.--Sparta Lake ditch feeds the lake fron the south, flowing from Sparta Lake. The outlet flows frow the northern shore through Indian Lake and into the Elkhart River 1.7 a downstreas.

EXTREMES FOR PERIOD OF RECORD. -- Maxinue stage $10.53 \mathrm{ft}$ Mar. 29, 1985; - ininum stage, $7.48 \mathrm{ft}$ Nov. $17,1964$.

LAKE LEVEL, IN FEET ABOVE GAGE DATUM. WATER YEAR OCTOBER 1990 TO SEPTEMBER 1991

\begin{tabular}{|c|c|c|c|c|c|c|c|c|c|c|c|c|}
\hline DAY & OCT & MOV & DEC & JAN & FEB & MAR & APR & MAY & JUN & JUL & AUG & SEP \\
\hline $\begin{array}{r}5 \\
10 \\
15 \\
20 \\
25 \\
\text { EOM }\end{array}$ & $\begin{array}{l}9.28 \\
9.74 \\
9.51 \\
9.48 \\
9.39 \\
9.34\end{array}$ & $\begin{array}{l}9.62 \\
9.44 \\
9.36 \\
9.32 \\
9.31 \\
9.39\end{array}$ & $\begin{array}{r}9.42 \\
9.36 \\
9.39 \\
9.40 \\
9.45 \\
10.05\end{array}$ & $\begin{array}{r}10.05 \\
9.72 \\
9.60 \\
9.60 \\
9.60 \\
9.60\end{array}$ & $\begin{array}{l}9.59 \\
9.56 \\
9.56 \\
9.63 \\
9.52 \\
9.51\end{array}$ & $\begin{array}{l}9.45 \\
9.36 \\
9.37 \\
9.42 \\
9.40 \\
9.39\end{array}$ & $\begin{array}{l}9.39 \\
9.39 \\
9.46 \\
9.57 \\
9.51 \\
9.45\end{array}$ & $\begin{array}{r}9.44 \\
9.35 \\
9.28 \\
9.23 \\
9.36 \\
10.07\end{array}$ & $\begin{array}{l}9.52 \\
9.36 \\
9.32 \\
9.21 \\
9.14 \\
9.08\end{array}$ & $\begin{array}{l}9.07 \\
9.01 \\
8.97 \\
8.91 \\
8.98 \\
8.94\end{array}$ & $\begin{array}{l}9.02 \\
9.07 \\
8.96 \\
9.00 \\
8.93 \\
8.99\end{array}$ & $\begin{array}{l}8.98 \\
8.92 \\
9.16 \\
9.01 \\
8.96 \\
8.91\end{array}$ \\
\hline
\end{tabular}

WTR YR 1991 MEAN 9.34 MAX 10.07 MIN 8.89 


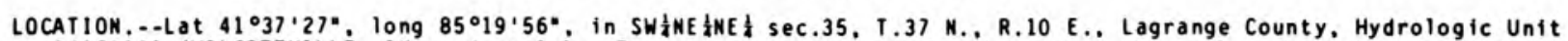
04050001 (WOLCOTIVILLE, IN quadrangle). The gage is on the northeast bank of the out let channel. approxieately $15 \mathrm{ft}$ downstrean of the lake on the northwest side, and $1.2 \mathrm{i}$ south of Plato.

SURFACE AREA.--100 acres.

DRAINAGE AREA. $-10.6 \cdots \mathrm{i}^{2}$.

PERIOD OF RECORD. - 1945 to current year.

DATUM OF GAGE.--930.75 ft above National Geodetic Vertical Datun of 1929, as corrected on the basis of levels of the U.S. Geological Survey, 1966.

GAGE.--A water-stage recorder is installed in an aluminun shelter over a 15-inch diameter stilling well. An auxiliary staff gage is mounted on a tree stump on the northern bank of the outlet channel at the sane site.

ESTABLISHED LEGAL LEVEL. - -6.50 ft gage datum or $936.50 \mathrm{ft}$ above National Geodetic Vertical Datun of 1929 as decreed on May 7. 1959. by the Lagrange County Circuit Court. Minor errors were subsequently discovered in the establishment of the datum of the gage (see "DATUM OF GAGE") and the correct elevation of the legal level should be $6.50 \mathrm{ft}$ gage datun or $937.25 \mathrm{ft}$ above National Geodetic Vertical Datum of 1929.

LAKE-LEVEL CONTROL... The level of the lake is controlled by the outlet channel.

INLET AND OUTLET.- - One inlet enters at the extreme southern tip from Royer Lake $700 \mathrm{ft}$ upstrean. The other enters on the north shore of the east lobe from Grass Lake, approximately 1.4 i upstream. The outlet, East Fly Creek. flows from the lake on the northwest shore and joins Fly Creek, which empties into Pigeon River.

EXTREMES FOR PERIOD OF RECORD.--Maximum stage, $9.23 \mathrm{ft}$ June 14, 15, 1981; minimun stage, 5.32 ft Mov. $17-20$, 1953 .

LAKE LEVEL, IN FEet ABOVE GAGE dATUM, WATER YEAR OCTOBER 1990 TO SEPTEMBER 1991 $24: 00$ VALUES

\begin{tabular}{|c|c|c|c|c|c|c|c|c|c|c|c|c|}
\hline DAY & OCT & MOV & DEC & JAN & FE B & MAR & APR & MAY & JUN & JUL & AUG & SEP \\
\hline $\begin{array}{r}5 \\
10 \\
15 \\
20 \\
25 \\
\text { EOM }\end{array}$ & $\begin{array}{l}6.67 \\
7.63 \\
7.48 \\
7.25 \\
7.04 \\
6.91\end{array}$ & $\begin{array}{l}7.37 \\
7.26 \\
7.07 \\
6.96 \\
6.91 \\
7.12\end{array}$ & $\begin{array}{l}7.19 \\
7.07 \\
7.03 \\
7.04 \\
7.09 \\
8.60\end{array}$ & $\begin{array}{l}7.71 \\
7.30 \\
7.27 \\
7.36 \\
7.22 \\
7.22\end{array}$ & $\begin{array}{l}7.04 \\
7.11 \\
7.09 \\
7.30 \\
7.23 \\
7.11\end{array}$ & $\begin{array}{l}7.26 \\
7.13 \\
7.02 \\
7.04 \\
7.04 \\
7.18\end{array}$ & $\begin{array}{l}7.12 \\
7.10 \\
7.12 \\
7.44 \\
7.52 \\
7.36\end{array}$ & $\begin{array}{l}7.27 \\
7.20 \\
7.06 \\
6.91 \\
6.95 \\
7.19\end{array}$ & $\begin{array}{l}7.22 \\
6.92 \\
6.80 \\
6.70 \\
6.61 \\
6.80\end{array}$ & $\begin{array}{l}7.37 \\
7.11 \\
7.03 \\
6.92 \\
6.85 \\
6.80\end{array}$ & $\begin{array}{l}6.84 \\
6.91 \\
6.86 \\
6.93 \\
6.88 \\
6.98\end{array}$ & $\begin{array}{l}6.94 \\
6.91 \\
6.98 \\
6.90 \\
6.88 \\
6.85\end{array}$ \\
\hline
\end{tabular}

WTR YR 1991 MEAN 7.10 MAX 8.60 MIN 6.59

\section{STREAMS TRIBUTARY TO LAKE MICHIGAN \\ 04099760 FISH LAKE NEAR SCOTT, IN}

LOCATION.--Lat $41^{\circ} 45^{\prime} 25^{\prime \prime}$, long $85^{\circ} 38^{\prime} 5^{\prime \prime}$, in NHA 04050001 (MIDDLEBURY. IN quadrangle). The gage is on the northwest shore of the lake, on the north side of the out let channel, 4.8 i northwest of $5 \cot t$.

SURFACE AREA. . 139 acres.

DRAINAGE AREA. $--6.21 \mathrm{~m}^{2}$.

PERIOD OF RECORD.--1954-69, 1978 to current year.

DATUM OF GAGE. - -809.84 ft above National Geodetic Vertical Datun of 1929, as corrected on the basis of levels of Indiana Departaent of Natural Resources, 1975.

GAGE.--A water-stage recorder is installed in an aluminum shelter over a 15-inch dianeter stilling well. An auxiliary staff gage is attached to the dan at the saue site.

ESTABLISHED LEGAL LEVEL. $-4.42 \mathrm{ft}$ gage datun or $814.42 \mathrm{ft}$ above National Geodetic Vertical Datue of 1929 as decreed on Septenber 11,1959 . by the Lagrange County Circuit Court. Minor errors were subsequently discovered in the establishment of the datum of the gage (see "DATUM OF GAGE") and the correct elevation of the legal level should be $4.42 \mathrm{ft}$ gage datun or $814.26 \mathrm{ft}$ above Mational Geodetic Vertical Datue of 1929.

LAKE-LEVEL CONTROL..-The level of the lake is controlled by a fixed concrete sill with rewovable boards.

INLET AND OUILET.--The inlet, fetch ditch, enters on the southeastern shore. The outlet flows from the lake at the lower west shore and empties into Pigeon River.

EXTREMES FOR PERIOD OF RECORD.,--Maxinun stage, $5.61 \mathrm{ft}$ Feb. 26, 1985; winimun stage, $1.54 \mathrm{ft}$ Nov. $26,1964$.

LAKE LEVEL, IN FEET ABOVE GAGE DATUM, WATER YEAR OCTOBER 1990 TO SEPTEMBER 1991

\begin{tabular}{|c|c|c|c|c|c|c|c|c|c|c|c|c|}
\hline DAY & OCT & NOV & DEC & JAN & FEB & MAR & APR & MAY & JUN & JUL & AUG & SEP \\
\hline $\begin{array}{r}5 \\
10 \\
15 \\
20 \\
25 \\
\text { EOM }\end{array}$ & $\begin{array}{l}4.23 \\
4.63 \\
4.79 \\
4.64 \\
4.50 \\
4.38\end{array}$ & $\begin{array}{l}4.55 \\
4.58 \\
4.51 \\
4.46 \\
4.44 \\
4.82\end{array}$ & $\begin{array}{l}4.84 \\
4.76 \\
4.71 \\
4.68 \\
4.67 \\
5.22\end{array}$ & $\begin{array}{l}5.16 \\
4.87 \\
4.80 \\
4.86 \\
4.85 \\
4.85\end{array}$ & $\begin{array}{l}4.67 \\
4.66 \\
4.68 \\
4.73 \\
4.64 \\
4.59\end{array}$ & $\begin{array}{l}4.63 \\
4.57 \\
4.49 \\
4.50 \\
4.53 \\
4.54\end{array}$ & $\begin{array}{l}4.54 \\
4.51 \\
4.63 \\
4.75 \\
4.81 \\
4.80\end{array}$ & $\begin{array}{r}4.73 \\
4.60 \\
4.52 \\
4.64 \\
\ldots . \\
\ldots .\end{array}$ & $\begin{array}{c}\cdots \\
\cdots \\
\cdots \\
\cdots \\
\cdots\end{array}$ & $\begin{array}{l}4.47 \\
4.40 \\
4.29 \\
4.21 \\
4.09\end{array}$ & $\begin{array}{l}4.00 \\
4.06 \\
3.96 \\
4.11 \\
4.04 \\
3.97\end{array}$ & \\
\hline
\end{tabular}

WTR YR 1991 MEAN 4.49 MAX 5.22 MIN 3.72 
LOCATION.--Lat $41^{\circ} 30^{\prime} 41^{\circ}$, long $87^{\circ} 02^{\prime} 23^{\circ}$, in NE $\frac{1}{4}$ SW $\frac{1}{4}$ sec.6, T.35 N., R.5 W., Porter County, Hydrologic Unit 07120001 (CHESTERTON. IN quadrangle). The gage is on the southeast shore of the lake, at the out let and the Valparaiso Water Works, 3.2 i northeast of Valparaiso.

SURFACE AREA, --86 acres.

DRAINAGE AREA. $--3.80 . i^{2}$, revised.

PERIOD OF RECORD, - -1946 to current year. From Jan. 1, 1911, to Aug. 14, 1946, readings of the lake level were taken approxiately once per week by Water Works personnel. These data are available upon request.

DATUM OF GAGE.--780.00 ft above National Geodetic Vertical Datun of 1929.

GAGE.--A water-stage recorder is installed inside the Valparaiso Water Works. An auxiliary staff gage is located lakeward of the concrete block punping station.

ESTABLISHED LEGAL LEVEL. - -17.66 ft gage datun or $797.66 \mathrm{ft}$ above National Geodetic Vertical Datue of 1929 as decreed on August 19, 1963, by the Porter County Circuit Court.

LAKE-LEVEL CONTROL..-The level of the lake is controlled by the outlet channel and two 30-inch corrugated aetal pipes under the road, $600 \mathrm{ft}$ downstrean.

INLET AND OUTLET.-.There are three inlets. One drains long lake to the northwest and another drains loouis Lake to the west and Listenberger drain enters from the south. The outlet flows from the lake at the southeast corner and into the West Branch of Crooked Creek approxinately 5.0 a d downstrean.

EXTREMES FOR PERIOD OF RECORD.--Maxinun stage, $21.18 \mathrm{ft}$ July 2,1983 as recorded by the Valparaiso Water Conpany; -ininue stage, $12.59 \mathrm{ft}$ Dec. $29,1948$.

LAKE LEVEL, IN FEET ABOVE GAGE DATUM. WATER YEAR OCTOBER 1990 TO SEPTEMBER 1991 24:00 VALUES

\begin{tabular}{|c|c|c|c|c|c|c|c|c|c|c|c|c|}
\hline DAY & OCT & NOV & DEC & JAN & FEB & MAR & APR & MAY & JUN & JUL & AUG & SEP \\
\hline $\begin{array}{r}5 \\
10 \\
15 \\
20 \\
25 \\
\text { EOM }\end{array}$ & $\begin{array}{l}19.28 \\
19.94 \\
19.79 \\
19.68 \\
19.56 \\
19.41\end{array}$ & $\begin{array}{l}19.84 \\
19.67 \\
19.57 \\
19.50 \\
19.44 \\
20.56\end{array}$ & $\begin{array}{l}20.23 \\
20.05 \\
19.92 \\
19.78 \\
19.75 \\
20.27\end{array}$ & $\begin{array}{l}20.03 \\
19.84 \\
19.77 \\
19.81 \\
19.71 \\
19.26\end{array}$ & $\begin{array}{l}19.62 \\
19.60 \\
19.57 \\
19.57 \\
19.55 \\
19.51\end{array}$ & $\begin{array}{l}19.75 \\
19.64 \\
19.63 \\
19.70 \\
19.59 \\
19.55\end{array}$ & $\begin{array}{l}19.53 \\
19.52 \\
19.77 \\
19.93 \\
19.78 \\
19.72\end{array}$ & $\begin{array}{l}19.86 \\
19.68 \\
19.54 \\
19.61 \\
20.14 \\
20.18\end{array}$ & $\begin{array}{l}20.00 \\
19.72 \\
19.58 \\
19.45 \\
19.29 \\
19.13\end{array}$ & $\begin{array}{l}18.94 \\
19.16 \\
19.00 \\
18.79 \\
18.57 \\
18.23\end{array}$ & $\begin{array}{l}18.03 \\
18.08 \\
17.82 \\
17.75 \\
17.51 \\
17.25\end{array}$ & $\begin{array}{l}17.25 \\
17.03 \\
16.90 \\
16.62 \\
16.40 \\
16.13\end{array}$ \\
\hline
\end{tabular}

WTR YR 1991 MEAN 19.23 MAX 20.82 MIN 16.13

WABASH RIVER BASIN

03330160 6ILBERT LAKE MEAR WASHINGTON CENTER, IN

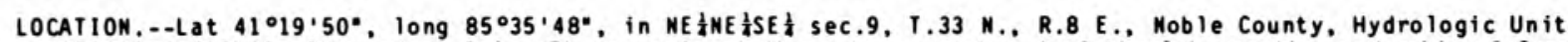
05120106 (ORMAS, IN quadrangle). The gage is at the extreae west end of the lake on the east side of County Road 925 West, approxinately $400 \mathrm{ft}$ south of Gilbert Lake Road, and 0.4 a north of Washington Center.

SURFACE AREA, --28 acres.

DRAIMAGE AREA. $--0.37 \cdot i^{2}$.

PERIOD OF RECORD, - -1954-59, 1961 to current year.

DATUM OF GAGE. - -884.85 ft above National Geodetic Vertical Datun of 1929, as corrected on the basis of levels of the Indiana Department of Matural Resources, 1974-75.

GAGE. - -A water-stage recorder is installed in an aluainum shelter over a 15 -inch dianeter stilling well. An auxiliary staff gage in one section is driven into the lake bed approxiately $100 \mathrm{ft}$ south of the prinary gage.

ESTABLISHED LEGAL LEVEL. - - Not established.

LAKE-LEVEL CONTROL... The level is controlled by the out let through the swapp. east of the lake.

INLET AND OUTLET.--The lake has no inlet. The outlet leaves fros the southeastern side and flows into Stump Lake.

EXIREMES FOR PERIOD OF RECORD.--Maxinun stage, 6.81 ft Dec. 4-5, 1987; wininue stage, 3.53 ft Nov. $1,1963$.

LAKE LEVEL, IN FEEt ABOVE GAGE DATUM. WATER YEAR OCTOBER 1990 TO SEPTEMBER 1991 24:00 VALUES

\begin{tabular}{|c|c|c|c|c|c|c|c|c|c|c|c|c|}
\hline DAY & $O C T$ & NOV & DEC & JAN & FE B & MAR & APR & MAY & JUN & JUL & AUG & SEP \\
\hline $\begin{array}{r}5 \\
10 \\
15 \\
20 \\
25 \\
\text { EOM }\end{array}$ & $\begin{array}{l}5.31 \\
5.42 \\
4.86 \\
4.90 \\
4.87 \\
4.95\end{array}$ & $\begin{array}{l}5.41 \\
5.20 \\
5.15 \\
5.20 \\
5.23 \\
5.23\end{array}$ & $\begin{array}{l}5.20 \\
5.20 \\
5.24 \\
5.25 \\
5.30 \\
5.54\end{array}$ & $\begin{array}{l}5.54 \\
5.53 \\
5.32 \\
5.47 \\
5.47 \\
5.47\end{array}$ & $\begin{array}{l}5.53 \\
5.71 \\
5.72 \\
5.86 \\
5.70 \\
5.71\end{array}$ & $\begin{array}{l}5.69 \\
5.60 \\
5.69 \\
5.76 \\
4.61 \\
4.58\end{array}$ & $\begin{array}{l}4.90 \\
5.13 \\
5.30 \\
5.54 \\
5.49 \\
5.44\end{array}$ & $\begin{array}{l}5.47 \\
5.45 \\
5.53 \\
5.56 \\
5.73 \\
5.72\end{array}$ & $\begin{array}{l}4.54 \\
4.47 \\
4.58 \\
4.65 \\
4.74 \\
4.96\end{array}$ & $\begin{array}{l}5.07 \\
5.14 \\
5.21 \\
5.26 \\
5.49 \\
5.41\end{array}$ & $\begin{array}{l}4.48 \\
4.62 \\
4.72 \\
4.89 \\
4.95 \\
5.08\end{array}$ & $\begin{array}{l}5.12 \\
5.16 \\
5.36 \\
5.39 \\
5.45 \\
5.50\end{array}$ \\
\hline
\end{tabular}

WTR YR 1991 MEAN 5.24 MAX 5.86 MIN 4.44 


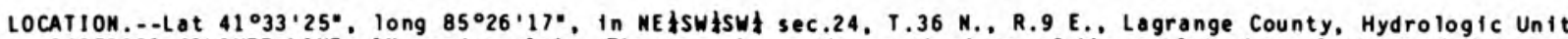
04050001 (OLIVER LAKE. IN quadrangle). The gage is on the north shore of the outlet channel at the bridge on County Road 75 West, and 4.2 i northwest of Wolcottville.

SURFACE AREA. --42 acres.

DRAIMAGE AREA, $--55.4 \cdot i^{2}$.

PERIOD OF RECORD.--1945 to current year.

DATUM OF GAGE.- $-890.00 \mathrm{ft}$ above National Geodetic Vertical Datun of 1929.

GAGE.--A water-stage recorder is installed in a woden shelter over a $24-i n c h$ dianeter stilling well. An auxiliary staff gage is bolted to the downstreas side of the bridge at the sane site.

ESTABLISHED LEGAL LEVEL. - -7.36 ft gage datue or $897.36 \mathrm{ft}$ above National Geodetic Vertical Datue of 1929 as decreed on February 2, 1954, by the Lagrange County Circuit Court. Witmer. Westler. Dallas, and Messick Lakes. all near Wolcottville, have the same established level and hence the same lake levels for the period of record.

LAKE-LEVEL CONTROL.--The level of the lake is controlled by a concrete sill with reavable stop logs located at the outlet of Messick Lake.

INLET AND OUTLET.--One inlet enters on the north shore from 01 iver Lake 1.6 apstream. The other inlet enters on the east shore from Dallas Lake 0.5 i upstrean, which is part of a chain of lakes including Westler and Witaer Lakes. The outlet flows from the lake on the southwest shore and into Messick Lake about 0.5 a

downstrean. Messick Lake expties into the North Branch of the Elkhart River.

EXTREMES FOR PERIOD OF RECORD.--Maxiaun stage, $11.17 \mathrm{ft} \mathrm{Apr.} \mathrm{7,1978;} \mathrm{minimu} \mathrm{stage,} \mathrm{6.34} \mathrm{ft} \mathrm{0ct.} 10,1953$. LAKE LEVEL, IN FEET ABOVE GAGE DATUM, WATER YEAR OCTOBER 1990 TO SEPTEMBER 1991 24:00 VALUES

\begin{tabular}{|c|c|c|c|c|c|c|c|c|c|c|c|}
\hline DAY & $\mathrm{OCT}$ & NOV & DEC & JAN & FE B & MAR & APR & MAY & JUN & JUL & AUG \\
\hline $\begin{array}{r}5 \\
10 \\
15 \\
20 \\
25 \\
\text { EOM }\end{array}$ & $\begin{array}{l}7.76 \\
8.47 \\
8.95 \\
8.98 \\
8.72 \\
8.39\end{array}$ & $\begin{array}{l}8.41 \\
8.51 \\
8.43 \\
8.27 \\
8.12 \\
8.19\end{array}$ & $\begin{array}{l}8.24 \\
8.21 \\
8.15 \\
8.15 \\
8.21 \\
9.29\end{array}$ & $\begin{array}{l}9.53 \\
9.11 \\
8.86 \\
8.80 \\
8.58 \\
8.24\end{array}$ & $\begin{array}{l}8.12 \\
8.15 \\
8.09 \\
8.16 \\
8.23 \\
8.18\end{array}$ & $\begin{array}{l}8.30 \\
8.21 \\
8.02 \\
7.97 \\
7.95 \\
8.10\end{array}$ & $\begin{array}{l}8.05 \\
8.00 \\
8.03 \\
8.50 \\
8.86 \\
8.85\end{array}$ & $\begin{array}{l}8.71 \\
8.52 \\
8.26 \\
7.99 \\
8.03 \\
8.34\end{array}$ & $\begin{array}{l}8.57 \\
8.43 \\
8.14 \\
7.88 \\
7.67 \\
7.82\end{array}$ & $\begin{array}{l}8.38 \\
8.35 \\
8.19 \\
7.97 \\
7.80 \\
7.62\end{array}$ & $\begin{array}{l}7.64 \\
7.67 \\
7.59 \\
7.65 \\
7.58 \\
7.67\end{array}$ \\
\hline
\end{tabular}

WTR YR 1991 MEAN 8.19 MAX 9.55 MIN 7.50

STREAMS TRIBUTARY TO LAKE ERIE

04177700 HAMILTON LAKE AT HAMILTON, IN

LOCATION.--Lat $41^{\circ} 32^{\prime} 10^{\prime \prime}$, long $84^{\circ} 54^{\prime} 45^{\prime \prime}$, in SW $\frac{1}{4}$ SW $\frac{1}{4} N W \frac{1}{2}$ sec.34, T.36 N., R.14 E.. Steuben County, Hydrologic Unit 04100003 (HANILTON, IN quadrangle). The gage is on the eastern shore of the southern lobe at the outlet. in the town of Hanilton.

SURFACE AREA.--802 acres.

DRAINAGE AREA. $--16.5 \bullet i^{2}$.

PERIOD OF RECORD.--1943 to current year.

DATUM OF GAGE.--890,12 ft above National Geodetic Vertical Datul of 1929, as corrected on the basis of levels of Indiana Departaent of Natural Resources, 1978.

GAGE.- - A water-stage recorder is installed in an aluinua shelter over a 15 -inch dianeter stilling well.

ESTABLISHED LEGAL LEVEL. - $-8.83 \mathrm{ft}$ gage datue or $898.83 \mathrm{ft}$ above National Geodetic Vertical Datue of 1929 as decreed on July 3,1947, by the Steuben County Circuit Court. Minor errors were subsequently discovered in the establisheent of the datum of the gage (see "DATUN OF GAGE") and the correct elevation of the legal level should be $8.83 \mathrm{ft}$ gage datua or $898.95 \mathrm{ft}$ above National Geodetic Vertical Datue of 1929

LAKE-LEVEL CONTROL.-. The level of the lake is controlled by two das. The northernaost dan is concrete and steel sheet piling with a fixed crest. The southern dae has a fixed concrete sill.

INLET AND OUTLET.--Black Creek enters the lake on the northeast shore. Two seall ditches enter from the east and the north. There are two outlets, both on the southern lobe, that flow into fish Creek thence into the St. Joseph River.

EXTREMES FOR PERIOD OF RECORD.--Maximu stage, $10.14 \mathrm{ft}$ Dec. 30,1965 ; inimun stage, 7.27 ft Jan. 4-9, 1953. LAKE LEVEL, IM FEET ABOVE GAGE DATUM. WATER YEAR OCTOBER 1990 TO SEPTEMBER 1991

\begin{tabular}{|c|c|c|c|c|c|c|c|c|c|c|c|c|}
\hline DAY & $\mathrm{OCT}$ & NOV & DEC & JAN & FEB & MAR & APR & MAY & JUN & JUL & AUG & SEP \\
\hline $\begin{array}{r}5 \\
10 \\
15 \\
20 \\
25 \\
\text { EOM }\end{array}$ & $\begin{array}{l}8.70 \\
9.30 \\
8.83 \\
8.73 \\
8.67 \\
8.63\end{array}$ & $\begin{array}{l}8.96 \\
8.79 \\
8.70 \\
8.66 \\
8.65 \\
8.74\end{array}$ & $\begin{array}{c}8.85 \\
8.73 \\
8.72 \\
8.76 \\
\ldots \ldots \\
\ldots .\end{array}$ & $\begin{array}{l}\ldots \\
\ldots \\
\ldots \\
\ldots \\
\ldots \\
\ldots\end{array}$ & $\begin{array}{r}\ldots . \\
\ldots .62 \\
8.62 \\
8.52 \\
8.50\end{array}$ & $\begin{array}{l}8.63 \\
8.53 \\
8.48 \\
8.53 \\
8.55 \\
8.59\end{array}$ & $\begin{array}{l}8.62 \\
8.63 \\
8.82 \\
9.11 \\
8.80 \\
8.66\end{array}$ & $\begin{array}{l}8.59 \\
8.53 \\
8.49 \\
8.46 \\
8.54 \\
8.68\end{array}$ & $\begin{array}{l}8.63 \\
8.49 \\
8.45 \\
8.43 \\
8.38 \\
8.45\end{array}$ & $\begin{array}{l}8.51 \\
8.44 \\
8.47 \\
8.41 \\
8.34 \\
8.26\end{array}$ & $\begin{array}{l}8.25 \\
8.27 \\
8.26 \\
8.47 \\
8.44 \\
8.41\end{array}$ & $\begin{array}{l}8.38 \\
8.40 \\
8.44 \\
8.36 \\
8.33 \\
8.28\end{array}$ \\
\hline
\end{tabular}

WTR YR 1991 MEAN 8.57 MAX 9.30 MIN 8.23 


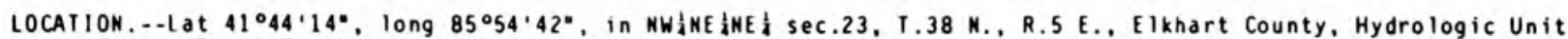
04050001 (ELKHART. IN quadrangle). The gage is on the east bank of the inlet on the north shore of the lake, 4.7 i northeast of the nain Post Office in Elkhart.

SURFACE AREA.--87 acres.

DRAI NAGE AREA. $-9.33 \cdot i^{2}$.

PERIOD OF RECORD.-1946-53,1970-75, 1977 to current year.

DATUM OF GAGE.--760.00 ft above National Geodetic Vertical Datun of 1929.

GAGE.--A water-stage recorder is installed in an aluanu shelter over a 15-inch dianeter stilling well.

ESTABLISHED LEGAL LEVEL. $-7.30 \mathrm{ft}$ gage datun or $767.30 \mathrm{ft}$ above National Geodetic Vertical Datua of 1929 as decreed on Septeaber 25, 1950, by the Elkhart County Circuit Court.

LAKE-LEVEL CONTROL.-. The level of the lake is controlled by a fixed-crest concrete das.

INLET AND OUTLET.-. The one inlet enters the lake at the extreme northern point of the lake. The out let. Puterbaugh Creek, flows from the west end of the lake and enters the St. Joseph River approxiately 4.0 ai downstrean.

EXIREMES FOR PERIOD OF RECORD.--Maximun stage, $9.73 \mathrm{ft}$ Feb. 26, 1985; minimustage, $4.55 \mathrm{ft}$ Nov. $12-18,1971$.

LAKE LEVEL. IN FEET ABOVE GAGE DATUM, WATER YEAR OCTOBER 1990 TO SEPTEMBER 1991 $24: 00$ VALUES

\begin{tabular}{|c|c|c|c|c|c|c|c|c|c|c|c|c|}
\hline DAY & $\mathrm{OCT}$ & NOV & DEC & JAN & FE B & MAR & APR & MAY & JUN & JUL & AUG & SEP \\
\hline $\begin{array}{r}5 \\
10 \\
15 \\
20 \\
25 \\
\text { EOM }\end{array}$ & $\begin{array}{l}7.39 \\
8.23 \\
8.28 \\
8.21 \\
8.12 \\
8.07\end{array}$ & $\begin{array}{l}8.32 \\
8.29 \\
8.18 \\
8.13 \\
8.12 \\
8.60\end{array}$ & $\begin{array}{l}8.44 \\
8.35 \\
8.30 \\
8.29 \\
8.31 \\
8.80\end{array}$ & $\begin{array}{l}8.77 \\
8.76 \\
8.38 \\
8.40 \\
8.40 \\
8.40\end{array}$ & $\begin{array}{l}8.38 \\
8.33 \\
8.33 \\
8.42 \\
8.37 \\
8.33\end{array}$ & $\begin{array}{l}8.37 \\
8.29 \\
8.24 \\
8.27 \\
8.26 \\
8.26\end{array}$ & $\begin{array}{l}8.24 \\
8.22 \\
8.42 \\
8.38 \\
8.41 \\
8.39\end{array}$ & $\begin{array}{l}8.31 \\
8.26 \\
8.20 \\
8.13 \\
8.22 \\
8.19\end{array}$ & $\begin{array}{l}8.13 \\
8.02 \\
8.02 \\
7.96 \\
7.77 \\
7.58\end{array}$ & $\begin{array}{l}7.57 \\
7.50 \\
7.37 \\
7.10 \\
6.89 \\
6.60\end{array}$ & $\begin{array}{l}6.41 \\
6.47 \\
6.30 \\
6.99 \\
7.06 \\
6.98\end{array}$ & $\begin{array}{l}6.87 \\
6.77 \\
7.01 \\
6.93 \\
6.83 \\
6.80\end{array}$ \\
\hline
\end{tabular}

WTR YR 1991 MEAN 7.92 MAX 8.80 MIN 6.26

\section{STREAMS TRIBUTARY TO LAKE MICHIGAN}

04100258 HIGH LAKE NEAR WOLFLAKE, IN

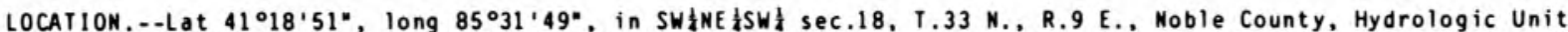
04050001 (ORMAS, IN quadrangle). The gage is on a dredged channel on the west shore of the east lobe, 2.1 i southwest of Wo if lake.

SURFACE AREA. --123 acres.

DRAINAGE AREA. $--4.43 \cdot i^{2}$.

PERIOD OF RECORD. $-1961-68,1970$ to current year.

DATUM OF GAGE. - $-890.00 \mathrm{ft}$ above National Geodetic Vertical Datun of 1929.

GAGE.--A water-stage recorder is installed in an aluainu shelter over a 15-inch dianeter stilling well. An auxiliary staff gage is driven into the lake bed at the sane site.

ESTABLISHED LEGAL LEVEL. - -6.35 ft gage datum or $896.35 \mathrm{ft}$ above National Geodetic Vertical Datum of 1929 as decreed on February 25, 1963 , by the Noble County Circuit Court.

LAKE-LEVEL CONTROL..-The level of the lake is controlled by a concrete, fixed-crest dan with a rectangular notch.

IMLET AND OUTLET.--The one inlet, Beal Branch, enters the lake on the southeast shore. The outlet flows from the east side of the north lobe, through Bear Lake, 0.6 i downstrean, into Carrol Creek, and eventually into the Elkhart River.

EXTREMES FOR PERIOD OF RECORD. - Maximu stage, $7.70 \mathrm{ft}$ June 28, 1968; inimum stage, 5.30 ft Nov. 15, 25-28, 1964, Oct. 13, 26-31, Nov. 1-3, 1966

LAKE LEVEL, IN FEET ABOVE GAGE DATUM, WATER YEAR OCTOBER 1990 TO SEPTEMBER 1991 24:00 VALUES

\begin{tabular}{|c|c|c|c|c|c|c|c|c|c|c|c|c|}
\hline OAY & $\mathrm{OCT}$ & NOV & DEC & JAM & FEB & MAR & $A P R$ & MAY & JUN & JUL & AUG & SEP \\
\hline $\begin{array}{r}5 \\
10 \\
15 \\
20 \\
25 \\
\text { EOM }\end{array}$ & $\begin{array}{l}\ldots \\
\ldots \\
\ldots \\
\ldots \\
\ldots \\
\ldots\end{array}$ & $\begin{array}{l}7.04 \\
6.98 \\
6.80 \\
6.71 \\
6.68 \\
6.82\end{array}$ & $\begin{array}{l}6.93 \\
6.81 \\
6.79 \\
6.82 \\
6.90 \\
7.26\end{array}$ & $\begin{array}{l}6.93 \\
6.57 \\
6.64 \\
7.00 \\
6.91 \\
6.90\end{array}$ & $\begin{array}{l}6.93 \\
6.83 \\
6.79 \\
7.04 \\
6.99 \\
6.97\end{array}$ & $\begin{array}{l}6.96 \\
6.84 \\
6.80 \\
6.92 \\
6.83 \\
6.76\end{array}$ & $\begin{array}{l}6.74 \\
6.77 \\
6.94 \\
7.22 \\
7.16 \\
6.99\end{array}$ & $\begin{array}{l}6.86 \\
6.78 \\
6.74 \\
6.66 \\
6.91 \\
7.27\end{array}$ & $\begin{array}{l}7.21 \\
6.93 \\
6.83 \\
6.69 \\
6.59 \\
6.74\end{array}$ & $\begin{array}{l}6.68 \\
6.58 \\
6.52 \\
6.46 \\
6.66 \\
6.54\end{array}$ & $\begin{array}{l}6.53 \\
6.57 \\
6.51 \\
6.55 \\
6.50 \\
6.46\end{array}$ & $\begin{array}{l}6.43 \\
6.41 \\
6.54 \\
6.46 \\
6.45 \\
6.44\end{array}$ \\
\hline
\end{tabular}

WTR YR 1991 MEAN 6.78 MAX 7.44 MIN 6.40 
LOCATION.--Lat $41^{\circ} 06^{\prime} 16^{\circ}$, long $85^{\circ} 5^{\prime} 4^{\prime} 5^{\circ}$, in SE $\frac{1}{2}$ NE 4 SE 05120106 (SILVER LAKE. IN quadrangle). The gage is located on the northern shore of the southwestern lobe of the lake, 2.5 i northwest of the town of Silver lake.

SURFACE AREA, - -67 acres.

DRAI NAGE AREA, $--0.85: i^{2}$.

PERIOD OF RECORD.--1952 to current year.

DATUM OF GAGE. --860.00 ft above National Geodetic Vertical Datun of 1929.

GAGE.--A water-stage recorder is installed in an aluainue shelter over a 15-inch dianeter stilling well. An auxiliary staff gage is located on the southernmost tip of the lake. The staff is nounted on a board driven into the lake bed.

ESTABLISHED LEGAL LEVEL. - $11.50 \mathrm{ft}$ gage datu or $871.50 \mathrm{ft}$ above National Geodetic Vertical Datua of 1929 as decreed on Septeaber 10, 1959, by the Koscuisko County Circuit Court.

LAKE-LEVEL CONTROL.--The level of the lake is controlled by a concrete fixed sill with reaovable boards.

INLET AND OUTLET.--There are no surface inlets. The one outlet flows from the western edge of the lake and eapties into Dianond Lake 1.5 i downstrean.

EXTREMES FOR PERIOD OF RECORD.--Maxinum stage, 12.54 ft July 21, 1963; wininun stage, 9.86 ft Jan. $18,19,1954$.

LAKE LEVEL, IN FEET ABOVE GAGE DATUM, WATER YEAR OCTOBER 1990 TO SEPTEMBER 1991 $24: 00$ VALUES

\begin{tabular}{|c|c|c|c|c|c|c|c|c|c|c|c|c|}
\hline DAY & OCT & NOV & DEC & JAN & FE B & MAR & APR & MAY & JUN & JUL & AUG & SEP \\
\hline $\begin{array}{r}5 \\
10 \\
15 \\
20 \\
25 \\
\text { EOM }\end{array}$ & $\begin{array}{l}11.41 \\
11.97 \\
11.62 \\
11.52 \\
11.48 \\
11.44\end{array}$ & $\begin{array}{l}11.69 \\
11.53 \\
11.45 \\
11.40 \\
11.38 \\
11.47\end{array}$ & $\begin{array}{l}11.51 \\
11.44 \\
11.45 \\
11.44 \\
11.49 \\
12.09\end{array}$ & $\begin{array}{l}12.27 \\
12.33 \\
11.55 \\
11.58 \\
11.58 \\
11.58\end{array}$ & $\begin{array}{l}11.47 \\
11.45 \\
11.45 \\
11.49 \\
11.47 \\
11.47\end{array}$ & $\begin{array}{l}11.46 \\
11.40 \\
11.40 \\
11.50 \\
11.50 \\
11.45\end{array}$ & $\begin{array}{l}11.44 \\
11.47 \\
11.58 \\
11.63 \\
11.56 \\
11.48\end{array}$ & $\begin{array}{l}11.52 \\
11.48 \\
11.47 \\
11.40 \\
11.43 \\
11.57\end{array}$ & $\begin{array}{l}11.42 \\
11.35 \\
11.40 \\
11.36 \\
11.29 \\
11.26\end{array}$ & $\begin{array}{l}11.22 \\
11.24 \\
11.19 \\
11.13 \\
11.05 \\
10.96\end{array}$ & $\begin{array}{l}10.90 \\
10.92 \\
10.88 \\
10.92 \\
10.87 \\
10.85\end{array}$ & $\begin{array}{l}10.85 \\
10.80 \\
10.80 \\
10.72 \\
10.68 \\
10.64\end{array}$ \\
\hline
\end{tabular}

WTR YR 1991 MEAN 11.37 MAX 12.33 MIN 10.64

STREAMS TRIBUTARY TO LAKE MICHIGAN

04099500 HOGBACK LAKE MEAR AMGOLA, IN

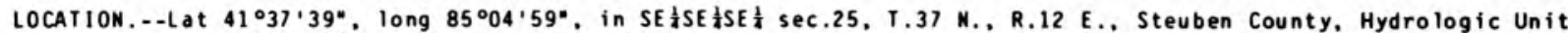
04050001 (ANGOLA WEST, IN quadrangle). The gage is on the northeast shore, 0.5 a south of the Tri-State A irport, on County Road 500 West, and 4.4 i southwest of Angola.

SURFACE AREA. -146 acres.

DRAI NAGE AREA. $--103: i^{2}$.

PERIOD OF RECORD. $-1946-73,1977$ to current year.

DATUM OF GAGE. - $-940.00 \mathrm{ft}$ above National Geodetic Vertical Datu of 1929.

GAGE.--A water-stage recorder is installed in an alueinua shelter over a 15-inch dianeter stilling well. An auxiliary staff gage in one section is attached to a tree at the sane site.

ESTABLISHED LEGAL LEVEL. $-\mathbf{- 8 . 5 0} \mathrm{ft}$ gage datue or $948.50 \mathrm{ft}$ above National Geodetic Vertical Datun of 1929 as decreed on October 28, 1959, by the Steuben County Circuit Court.

LAKE-LEVEL CONTROL..-The level of the lake is controlled by the outlet channel (Pigeon Creek).

INLET AND OUTLET.-.There are three inlets to the lake. One unnaned ditch enters froe the north. A seall tributary enters on the eastern tip from Silver Lake, 0.7 apstrean. Pigeon Creek flows through the lake, entering at the southeastern shore from Golden Lake, 1.2 i upstrea and leaving at the north end of the western lobe. Pigeon Creek joins Turkey Creek to becowe Pigeon River and eventually empties into the St. Joseph River.

EXTREMES FOR PERIOD OF RECORD.,-Maximu stage, $17.07 \mathrm{ft}$ Mar. 22, 1982; aininun stage, $7.24 \mathrm{ft}$ Sept. 9, $10,1953$. LAKE LEVEL, IN FEET ABOVE GAGE DATUM, WATER YEAR OCTOBER 1990 TO SEPTEMBER 1991

\begin{tabular}{|c|c|c|c|c|c|c|c|c|c|c|c|c|}
\hline DAY & OCT & NOV & DEC & JAN & FE B & MAR & APR & MAY & JUN & JUL & AUG & SEP \\
\hline $\begin{array}{r}5 \\
10 \\
15 \\
20 \\
25 \\
\text { EOM }\end{array}$ & $\begin{array}{r}8.39 \\
9.88 \\
10.95 \\
9.82 \\
9.24 \\
8.78\end{array}$ & $\begin{array}{r}8.93 \\
10.08 \\
9.31 \\
8.91 \\
8.79 \\
9.12\end{array}$ & $\begin{array}{r}9.64 \\
9.47 \\
9.16 \\
9.30 \\
9.64 \\
\ldots . .\end{array}$ & $\begin{array}{l}\ldots \\
\ldots \\
\ldots \\
\cdots \\
\cdots\end{array}$ & $\begin{array}{l}\ldots \\
\ldots \\
\ldots \\
\ldots \\
\ldots\end{array}$ & $\begin{array}{l}\cdots \\
\ldots \\
\cdots \\
\cdots \\
\cdots\end{array}$ & $\begin{array}{r}\ldots . \\
\ldots . .5 \\
11.13 \\
11.63 \\
10.59\end{array}$ & $\begin{array}{l}9.88 \\
9.53 \\
9.24 \\
9.03 \\
8.98 \\
9.44\end{array}$ & $\begin{array}{l}9.93 \\
9.17 \\
8.89 \\
8.66 \\
8.53 \\
8.45\end{array}$ & $\begin{array}{l}8.91 \\
8.59 \\
8.47 \\
8.35 \\
8.28 \\
8.26\end{array}$ & $\begin{array}{l}8.26 \\
8.28 \\
8.25 \\
8.50 \\
8.60 \\
8.42\end{array}$ & $\begin{array}{l}8.41 \\
8.29 \\
8.33 \\
8.20 \\
8.18 \\
8.15\end{array}$ \\
\hline
\end{tabular}

WTR YR 1991 MEAN 9.07 MAX 11.87 MIN 8.15 


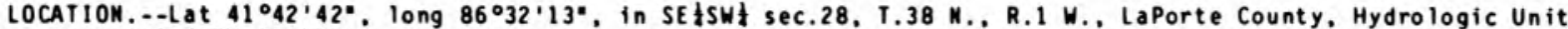
07120001 (NEW CARLISLE, IN quadrangle). The gage is on the southeast shore of the lake, and 0.1 a west of the town line of New Carlisle.

SURFACE AREA. --432 acres.

DRAI MAGE AREA. $\cdots 7.92 \backsim i^{2}$.

PERIOD OF RECORD.--1946-76, 1978 to current year.

DATUM OF GAGE. - -750.00 ft above Mational Geodetic Vertical Datue of 1929. Prior to 0ct. 1, 1965. the datue of the gage was $760.00 \mathrm{ft}$ above National Geodetic Vertical Datue of 1929 . All levels listed below are at the present datun.

GAGE.--A water-stage recorder is installed in a wooden shelter over a $24-i n c h$ diaseter stilling well. An auxiliary staff gage is driven into the lake bed.

ESTABLISHED LEGAL LEVEL. $-13.09 \mathrm{ft}$ gage datun or $763.09 \mathrm{ft}$ above National Geodetic Vertical Datua of 1929 as decreed on August 31,1949 , by the St. Joseph County Circuit Court.

LAKE-LEVEL CONTROL..-The level of the lake is controlled by a 24 -inch reinforced concrete pipe with a gate chaber and slide gate.

INLET AND OUTLET.--The one inlet flows into the lake at the extreae northeast tip from Saugany Lake, approxinately 1.7 i upstreas. The outlet flows from the lake on the east shore to Geyer ditch and eventually into the Kankakee River.

EXTREMES FOR PERIOD OF RECORD.--Maxiaue stage, 16.90 ft May 3, 1983; winimus stage, $7.60 \mathrm{ft}$ Mov. 15.1964. LAKE LEVEL. IN FEET ABOVE GAGE DATUM, WATER YEAR OCTOBER 1990 TO SEPTEMBER 1991 24:00 VALUES

\begin{tabular}{|c|c|c|c|c|c|c|c|c|c|c|c|c|}
\hline DAY & $O C T$ & NOV & DEC & JAM & FE B & MAR & $A P R$ & MAY & JUN & JUL & AUG & SEP \\
\hline $\begin{array}{r}5 \\
10 \\
15 \\
20 \\
25 \\
\text { EOM }\end{array}$ & $\begin{array}{l}13.62 \\
13.97 \\
13.99 \\
13.99 \\
13.92 \\
13.87\end{array}$ & $\begin{array}{l}14.09 \\
13.98 \\
13.93 \\
13.86 \\
13.80 \\
14.39\end{array}$ & $\begin{array}{l}14.36 \\
14.34 \\
14.32 \\
14.35 \\
14.36\end{array}$ & $\begin{array}{l}14.35 \\
14.35 \\
14.35 \\
14.35 \\
14.34 \\
14.34\end{array}$ & $\begin{array}{l}14.34 \\
14.36 \\
14.37 \\
14.36 \\
14.36 \\
14.36\end{array}$ & $\begin{array}{l}14.36 \\
14.53 \\
14.45 \\
14.42 \\
14.37 \\
14.39\end{array}$ & $\begin{array}{l}14.38 \\
14.33 \\
14.43 \\
14.40 \\
14.42 \\
14.41\end{array}$ & $\begin{array}{l}14.43 \\
14.36 \\
14.30 \\
14.29 \\
14.36 \\
14.39\end{array}$ & $\begin{array}{l}14.21 \\
14.06 \\
13.96 \\
13.81 \\
13.65 \\
13.52\end{array}$ & $\begin{array}{l}13.39 \\
13.39 \\
13.38 \\
13.36 \\
13.38 \\
13.32\end{array}$ & $\begin{array}{l}13.29 \\
13.42 \\
13.41 \\
13.48 \\
13.45 \\
13.54\end{array}$ & $\begin{array}{l}13.59 \\
13.57 \\
13.63 \\
13.54 \\
13.55 \\
13.52\end{array}$ \\
\hline
\end{tabular}

WTR YR 1991 MEAN 14.03 MAX 14.53 MIN 13.28

STREAMS TRIBUTARY TO LAKE MICHIGAN

04097680 JIMMERSON LAKE AT MEVADA MILLS, IN

LOCATION.--Lat $41^{\circ} 43^{\prime} 31^{\circ}$, Iong $85^{\circ} 04^{\prime} 55^{\circ}$, in SWłWH sec.30, T.38 N.. R.13 E.. Steuben County, Hydrologic Unit 04050001 (ANGOLA WEST: IN quadrangle). The gage is at the extreas west end of the lake on the abutaent of the concrete spillway structure and dae in the town of Mevada Mills, 4.6 east of Orland.

SURFACE AREA. --434 acres.

DRAI NAGE AREA. $--51.6 \bullet i^{2}$.

PERIOD OF RECORD,--1937-44, 1946 to current year. (Lake level readings were ade once a week by enployees of Northern Indiana Public Service Company frov ig37 to 1944.)

DATUM OF GAGE.--960.27 ft above National Geodetic Vertical Datua of 1929, as corrected on the basis of levels of Indiana Departaent of Natural Resources in June 1972.

GAGE.--A water-stage recorder is installed in an aluanu shelter over a 24-inch dianeter stilling well attached to the control structure. An auxiliary staff gage is bolted to the sase wall.

ESTABLISHED LEGAL LEVEL. $-4.66 \mathrm{ft}$ gage datue or $964.66 \mathrm{ft}$ above National Geodetic Vertical Datue of 1929 as decreed on July 3,1947, by the Steuben County Circuit Court. Minor errors were subsequently discovered in the establishment of the datur of the gage (see. DATUM OF GAGE") and the correct elevation of the legal level should be $4.66 \mathrm{ft}$ gage datur or $964.93 \mathrm{ft}$ above National Geodetic Vertical Datua of 1929.

LAKE-LEVEL CONTROL...The level of the lake is controlled by a concrete fixed-crest dae.

INLET AND OUTLET.--Crooked Creek flows through the lake, entering from Lake Janes at the extrene southeast end. and leaving frow the northwest. Crooked Creek flows through Taarack Lake and becoses fawn River, which eventually eapties into the St. Joseph River.

EXTREMES FOR PERIOD OF RECORD.--Maxinue stage, $6.22 \mathrm{ft}$ May 27,1943 ; ininu stage, $3.71 \mathrm{ft}$ Feb. 16,17 , 1948.

LAKE LEVEL, IN FEET ABOVE GAGE DATUM, WATER YEAR OCTOBER 1990 TO SEPTEMBER 1991 24:00 VALUES

\begin{tabular}{|c|c|c|c|c|c|c|c|c|c|c|c|}
\hline DAY & ОСТ & NOV & DEC & JAN & FE $B$ & MAR & APR & MAY & JUN & JUL & AUG \\
\hline $\begin{array}{r}5 \\
10 \\
15 \\
20 \\
25 \\
\text { EOM }\end{array}$ & $\begin{array}{l}5.00 \\
5.35 \\
5.43 \\
5.33 \\
5.20 \\
5.09\end{array}$ & $\begin{array}{l}5.18 \\
5.26 \\
5.20 \\
5.16 \\
5.12 \\
5.19\end{array}$ & $\begin{array}{l}5.26 \\
5.22 \\
5.15 \\
5.23 \\
5.27 \\
5.70\end{array}$ & $\begin{array}{l}5.71 \\
5.55 \\
5.46 \\
5.48 \\
5.38 \\
5.27\end{array}$ & $\begin{array}{l}5.23 \\
5.22 \\
5.19 \\
5.28 \\
5.26 \\
5.25\end{array}$ & $\begin{array}{l}5.36 \\
5.28 \\
5.21 \\
5.23 \\
5.24 \\
5.30\end{array}$ & $\begin{array}{l}5.27 \\
5.26 \\
5.25 \\
5.42 \\
5.52 \\
5.42\end{array}$ & $\begin{array}{l}5.36 \\
5.27 \\
5.17 \\
5.09 \\
5.12 \\
5.15\end{array}$ & $\begin{array}{l}5.12 \\
5.01 \\
4.94 \\
4.88 \\
4.79 \\
4.80\end{array}$ & $\begin{array}{l}4.95 \\
4.87 \\
4.83 \\
4.76 \\
4.81 \\
4.75\end{array}$ & $\begin{array}{r}4.75 \\
4.78 \\
4.75 \\
4.99 \\
4.98 \\
4.95\end{array}$ \\
\hline
\end{tabular}

WTR YR 1991 MEAN 5.14 MAX 5.77 MIN 4.72 
LOCATION.--Lat $41^{\circ} 07^{\prime} 48^{\prime \prime}$, long $86^{\circ} 25^{\prime} 23^{\circ}$, in NWt $\frac{1}{2}$ SWt 05120106 (CULVER. IN quadrangle). The gage is located on the northern shore of the lake, on the lake access road, $0.6 \mathrm{i}$ southwest of Delong.

SURFACE AREA. - -18 acres.

DRAI NAGE AREA. $-1.98 \mathrm{mi}^{2}$.

PERIOD OF RECORD, - -1970-72, 1975 to current year.

DATUM OF GAGE. $--730.00 \mathrm{ft}$ above National Geodetic Vertical Datun of 1929.

GAGE. - - A water-stage recorder is installed in an aluninu shelter over a 15-inch dianeter stilling well.

ESTABLISHEd LEGAL LEVEL. - - Not established.

LAKE-LEVEL CONTROL. - The lake level is normally controlled by the outlet channel bed. At high stages the control changes to the outlet culvert under old State Highway 17. The culvert is located about $700 \mathrm{ft}$ north of the lake.

INLET ANO OUTLET.--The inlet is an unnaned ditch which enters the lake from the southeastern side. The outlet exits the lake on the northern side and flows north approxinately 1.5 i to the Tippecanoe River.

EXTREMES FOR PERIOD OF RECORD. --Maximum stage, 8.69 ft June 14, 1981; ninimum stage, 3.60 ft 0ct. 23-26, 28-31, Novenber 1, 2, 1974 .

LAKE LEVEL, IN FEET ABOVE GAGE DATUM, WATER YEAR OCTOBER 1990 TO SEPIEMBER 1991 24:00 VALUES

\begin{tabular}{|c|c|c|c|c|c|c|c|c|c|c|c|c|}
\hline DAY & $O C T$ & NOV & DEC & JAN & FE B & MAR & APR & MAY & JUN & JUL & AUG & SEP \\
\hline $\begin{array}{r}5 \\
10 \\
15 \\
20 \\
25 \\
\text { EOM }\end{array}$ & $\begin{array}{l}5.56 \\
6.52 \\
5.47 \\
5.73 \\
5.50 \\
5.53\end{array}$ & $\begin{array}{l}5.91 \\
5.51 \\
5.87 \\
5.94 \\
5.63 \\
5.86\end{array}$ & $\begin{array}{l}\ldots \\
\ldots \\
\ldots \\
\ldots- \\
\cdots \\
\cdots\end{array}$ & $\begin{array}{l}\ldots \\
\ldots \\
\cdots \\
\cdots \\
\cdots \\
\cdots\end{array}$ & $\begin{array}{l}\ldots \\
\ldots- \\
\cdots \\
\cdots \\
\cdots \\
\cdots\end{array}$ & $\begin{array}{l}-\ldots \\
\ldots \\
\ldots \\
-\ldots \\
\cdots \\
\cdots\end{array}$ & $\begin{array}{l}5.50 \\
5.56 \\
6.31 \\
6.02 \\
5.90 \\
6.13\end{array}$ & $\begin{array}{l}6.19 \\
6.15 \\
6.23 \\
6.44 \\
6.49 \\
6.55\end{array}$ & $\begin{array}{l}6.56 \\
6.48 \\
6.46 \\
6.35 \\
6.22 \\
6.25\end{array}$ & $\begin{array}{l}6.14 \\
6.15 \\
6.04 \\
5.90 \\
5.74 \\
5.56\end{array}$ & $\begin{array}{l}5.46 \\
5.57 \\
5.48 \\
5.64 \\
5.53 \\
5.45\end{array}$ & $\begin{array}{l}5.35 \\
5.24 \\
5.20 \\
5.09 \\
5.06 \\
4.99\end{array}$ \\
\hline
\end{tabular}

WTR YR 1991 MEAN 5.84 MAX 6.85 MIN 4.99

\section{SIREAMS TRIBUTARY TO LAKE MICHIGAN}

04100390 KMAPP LAKE MEAR WASHINGTON CENTER, IH

LOCATION..-Lat. $41^{\circ} 20^{\prime} 36^{\circ}$, long $85^{\circ} 36^{\prime} 17^{\circ}$, in SWHEtSW 04050001 (ORMAS, IN quadrangle). The gage is at a public fishing site on the east side of the lake. and $5.8 . i$ west of the town of Wolflake.

SURFACE AREA. --88 acres.

DRAINAGE AREA, $--6.02 \mathrm{~m}^{2}$.

PERIOD OF RECORD,--1946-74, 1976 to current year.

DATUM OF GAGE. - $-870.00 \mathrm{ft}$ above National Geodetic Vertical Datum of 1929.

GAGE.--A water-stage recorder is installed in an aluminum shelter over a 15-inch diameter stilling well.

ESTABLISHED LEGAL LEVEL. - - $8.25 \mathrm{ft}$ gage datum or $878.25 \mathrm{ft}$ above National Geodetic Vertical Datum of 1929 as decreed on October 7, 1954, by the Noble County Circuit Court. Harper Lake, Moss Lake, and Hindman Lake, all near Washington Center. have the sane established level as knapp Lake and hence the same lake levels for the period of record.

LAKE-LEVEL CONTROL...The lake level is controlled by the out let channel.

INLET AND OUTLET.-. There are three inlets. The outlet of Little Knapp Lake enters at the southeastern corner, the out let of Harper lake enters at the southernmost $t$ ip. and Galloway ditch enters on the eastern shore. The outlet flows from the lake on the western shore, through a series of lakes, into Turkey Creek and eventually into the Elkhart River.

EXTREMES FOR PERIOD OF RECORD.--Maximum stage, $11.10 \mathrm{ft}$ June 27, 1968; minimum stage, 6.87 ft Sept. 14, $15,1983$.

LAKE LEVEL, IN FEET ABOVE GAGE DATUM, WATER YEAR OCTOBER 1990 TO SEPTEMBER 1991

\begin{tabular}{|c|c|c|c|c|c|c|c|c|c|c|c|c|}
\hline DAY & $O C T$ & NOV & $D E C$ & JAN & FEB & MAR & APR & MAY & JUN & JUL & AUG & SEP \\
\hline $\begin{array}{r}5 \\
10 \\
15 \\
20 \\
25 \\
\text { EOM }\end{array}$ & $\begin{array}{l}7.69 \\
9.42 \\
8.86 \\
8.32 \\
7.90 \\
7.60\end{array}$ & $\begin{array}{l}8.17 \\
8.11 \\
7.77 \\
7.58 \\
7.52 \\
7.76\end{array}$ & $\begin{array}{r}7.88 \\
7.70 \\
7.68 \\
7.76 \\
7.87 \\
10.00\end{array}$ & $\begin{array}{r}9.95 \\
\ldots . . \\
0.19 \\
7.93 \\
7.93\end{array}$ & $\begin{array}{l}7.69 \\
7.66 \\
7.56 \\
7.82 \\
7.69 \\
7.59\end{array}$ & $\begin{array}{l}7.77 \\
7.59 \\
7.53 \\
7.76 \\
7.66 \\
7.61\end{array}$ & $\begin{array}{l}7.54 \\
7.58 \\
7.72 \\
8.42 \\
8.24 \\
7.92\end{array}$ & $\begin{array}{l}7.72 \\
7.59 \\
7.52 \\
7.41 \\
7.53 \\
8.39\end{array}$ & $\begin{array}{l}8.13 \\
7.66 \\
7.47 \\
7.31 \\
7.21 \\
7.25\end{array}$ & $\begin{array}{l}7.18 \\
7.13 \\
7.09 \\
7.03 \\
7.23 \\
7.11\end{array}$ & $\begin{array}{l}7.10 \\
7.25 \\
7.14 \\
7.13 \\
7.07 \\
7.24\end{array}$ & $\begin{array}{l}7.14 \\
7.09 \\
7.30 \\
7.15 \\
7.08 \\
7.02\end{array}$ \\
\hline
\end{tabular}

WTR YR 1991 MEAN 7.67 MAX 10.02 MIN 7.02 
05515600 KOONTZ LAKE AT KOONTZ LAKE, IN

LOCATION.--Lat $41^{\circ} 24^{\prime} 42^{\circ}$, long $86^{\circ} 29^{\prime} 18^{\circ}$, in SWSE $\frac{1}{4} M E \frac{1}{4}$ sec.11. T.34 N., R.1 W. Starke County, Hydrologic Unit 07120001 (WALKERTON, IN quadrangle). The gage is on the western tip of the lake, at the control dae on State Highway 23, at the town of koontz Lake.

SURFACE AREA. --346 acres.

DRAI MAGE AREA. $--6.25 \cdot 1^{2}$.

PERIOD OF RECORD.--1943 to current year.

DATUM OF GAGE.--710.12 ft above National Geodetic Vertical Datue of 1929, as corrected on the basis of levels of Indiana Departent of Matural Resources, 1978.

GAGE.--A water-stage recorder is installed in an aluainus shelter over a 15-inch dianeter stilling well.

ESTABLISHED LEGAL LEVEL. $--4.56 \mathrm{ft}$ gage datue or $114.56 \mathrm{ft}$ above National Geodetic Vertical Datun of 1929 as decreed on Septenber 15, 1948, by the Strke County Circuit Court. Minor errors were subsequently discovered in the establishaent of the datue of the gage (see "OATUM OF GAGE") and the correct elevation of the legal level should be $4.56 \mathrm{ft}$ gage datue or $714.68 \mathrm{ft}$ above Mational Geodetic Vertical Datue of 1929 .

LAKE-LEVEL CONTROL.--The level of the lake is controlled by a steel sheet piling dan with a fixed crest.

INLET AND OUTLET.--Lawrence Pontius ditch and an unnased ditch enter the lake on the south shore of the east lobe. The out let flows froo the lake at the western tip and into Robbins ditch $1400 \mathrm{ft}$ downstrean. Robbins ditch enpties into the Kankakee River.

EXTREMES FOR PERIOD OF RECORD..--Maxinue stage, $6.10 \mathrm{ft} 0 \mathrm{ct}, 11.1954$; eininue stage, $3.10 \mathrm{ft} 0 \mathrm{ct}, 12,1970$.

LAKE LEVEL, IN FEET ABOVE GAGE DATUM, WATER YEAR OCTOBER 1990 TO SEPTEMBER 1991 24:00 VALUES

\begin{tabular}{|c|c|c|c|c|c|c|c|c|c|c|c|c|}
\hline DAY & $\mathrm{OCT}$ & NOV & DEC & JAN & FE B & MAR & APR & MAY & JUN & JUL & AUG & SEP \\
\hline $\begin{array}{r}5 \\
10 \\
15 \\
20 \\
25 \\
\text { EOM }\end{array}$ & $\begin{array}{l}4.57 \\
5.08 \\
4.76 \\
4.63 \\
4.58 \\
4.55\end{array}$ & $\begin{array}{l}4.79 \\
4.65 \\
4.59 \\
4.56 \\
4.56 \\
4.75\end{array}$ & $\begin{array}{l}4.67 \\
4.61 \\
4.64 \\
4.61 \\
4.64 \\
5.25\end{array}$ & $\begin{array}{l}5.25 \\
5.25 \\
5.17 \\
4.72 \\
4.72 \\
4.72\end{array}$ & $\begin{array}{l}4.73 \\
4.72 \\
4.71 \\
4.70 \\
4.62 \\
4.60\end{array}$ & $\begin{array}{l}4.61 \\
4.59 \\
4.61 \\
4.64 \\
4.71 \\
4.60\end{array}$ & $\begin{array}{l}4.62 \\
4.59 \\
4.97 \\
4.75 \\
4.66 \\
4.64\end{array}$ & $\begin{array}{l}4.61 \\
4.58 \\
4.57 \\
4.59 \\
4.87 \\
4.86\end{array}$ & $\begin{array}{r}4.62 \\
4.54 \\
4.59 \\
4.53 \\
4.49 \\
4.47\end{array}$ & $\begin{array}{l}4.44 \\
4.56 \\
4.49 \\
4.45 \\
4.40 \\
4.35\end{array}$ & $\begin{array}{r}4.36 \\
4.45 \\
4.42 \\
4.47 \\
4.44 \\
4.48\end{array}$ & $\begin{array}{r}4.45 \\
4.40 \\
4.45 \\
4.38 \\
4.38 \\
4.36\end{array}$ \\
\hline
\end{tabular}

WTR YR 1991 MEAN 4.62 MAX 5.29 MIN 4.33

ILLINOIS RIVER BASIN

05517800 LAKE ELIZA NEAR BEATRICE. IN

LOCATION.--Lat $41^{\circ} 25^{\prime} 55^{\circ}$, Iong $87^{\circ} 10^{\prime} 33^{\circ}$, In SWłNE tWW sec.1. T.34 N., R.7 W., Porter County, Hydrologic Unit 07120001 (PALMER, IN quadrangle). The gage is on the east bank of a boat channel off the northerneost end of the lake, south of the bridge over the channel, and at the town of Lake Eliza.

SURFACE AREA. --45 acres.

DRAI MAGE AREA. $--1.70 \cdot 1^{2}$.

PERIOD OF RECORD, - -1954-74, 1976 to current year.

DATUM OF GAGE.--735.00 ft above Mational Geodetic Vertical Datue of 1929.

GAGE.--A water-stage recorder is installed in an aluainum shelter over a 15-inch dianeter stilling well. An auxiliary staff gage is attached to the bridge piling.

ESTABLISHED LEGAL LEVEL. $-3.70 \mathrm{ft}$ gage datue or $738.70 \mathrm{ft}$ above National Geodetic Vertical Datue of 1929 as decreed on February 7 , 1982, by the Porter County Circuit Court.

LAKE-LEVEL CONTROL.--The level of the lake is controlled by a reinforced concrete dae with fixed crest.

INLET AND OUTLET.- -Two soall inlets enter the lake fron the northwest and the northeast. The outlet flows froe the lake on the south side through a dredged channel, foras the head waters of Wolf Creek, and eventually joins the Kankakee River.

EXTREMES FOR PERIOD OF RECORD. - -Maximu stage, $7.24 \mathrm{ft}$ June 14, 1981; ainimua stage, $2.45 \mathrm{ft} 0 \mathrm{ct}$. $13-15,1988$.

LAKE LEVEL, IN FEET ABOVE GAGE DATUM, WATER YEAR OCTOBER 1990 TO SEPTEMBER 1991 24:00 VALUES

\begin{tabular}{|c|c|c|c|c|c|c|c|c|c|c|c|c|}
\hline DAY & OCT & NOV & DEC & JAN & FE B & MAR & APR & MAY & JUN & JUL & AOG & SEP \\
\hline $\begin{array}{r}5 \\
10 \\
15 \\
20 \\
25 \\
\text { EON }\end{array}$ & $\begin{array}{l}4.01 \\
4.89 \\
4.07 \\
4.05 \\
4.04 \\
4.03\end{array}$ & $\begin{array}{l}4.52 \\
4.04 \\
4.02 \\
4.01 \\
4.00 \\
4.70\end{array}$ & $\begin{array}{l}4.08 \\
4.02 \\
4.03 \\
4.00 \\
4.01 \\
4.44\end{array}$ & $\begin{array}{l}4.02 \\
3.98 \\
3.99 \\
4.07 \\
3.99 \\
3.97\end{array}$ & $\begin{array}{l}4.14 \\
4.04 \\
4.01 \\
4.05 \\
4.00 \\
4.01\end{array}$ & $\begin{array}{l}4.05 \\
4.02 \\
4.05 \\
4.08 \\
4.04 \\
4.01\end{array}$ & $\begin{array}{l}4.05 \\
4.03 \\
4.56 \\
4.07 \\
4.02 \\
4.02\end{array}$ & $\begin{array}{l}4.29 \\
4.02 \\
3.97 \\
4.05 \\
4.30 \\
4.19\end{array}$ & $\begin{array}{l}3.97 \\
3.90 \\
3.98 \\
3.93 \\
3.86 \\
3.79\end{array}$ & $\begin{array}{l}3.72 \\
3.64 \\
3.54 \\
3.45 \\
3.33 \\
3.20\end{array}$ & $\begin{array}{l}3.17 \\
3.27 \\
3.20 \\
3.31 \\
3.24 \\
3.26\end{array}$ & $\begin{array}{l}3.38 \\
3.31 \\
3.35 \\
3.24 \\
3.21 \\
3.15\end{array}$ \\
\hline
\end{tabular}

WTR YR 1991 MEAN 3.89 MAX 6.56 MIN 3.14 
LOCATION. - Lat $41^{\circ} 42^{\prime} 32^{\circ}$. Iong $85^{\circ} 06^{\prime} 53^{\circ}$, in SE tSE thH sec.35, T.38 N., R.12 E... Steuben County, Hydrologic Unit 04050001 (ANGOLA WEST, IN quadrangle). The gage is at the bridge over the outlet on the northern tip of the lake, 0.4 i northwest of Panaa, and 3.3 i southeast of Orland.

SURFACE AREA. - - 332 acres.

DRAI NAGE AREA. $\cdots 17.3 \cdot i^{2}$.

PERIOD OF RECORD.- 1946 to current year.

DATUM OF GAGE. - -950.00 ft above National Geodetic Vertical Datua of 1929.

GAGE.--A water-stage recorder is installed in a wooden shelter over a $24-i n c h$ dianeter stilling well at the downstrean side of the bridge. An auxiliary staff gage is at the sane site.

ESTABLISHED LEGAL LEVEL. $-4.25 \mathrm{ft}$ gage datun or $954.25 \mathrm{ft}$ above Mational Geodetic Vertical Datue of 1929 as decreed on July 3,1947, by the Steuben County Circuit Court. Liae Lake at Panama has the saee established level and hence the same lake levels for the period of record.

LAKE-LEVEL CONTROL.--The level of the lake is controlled by a concrete dan with a fixed crest and one adjustable gate at the outlet of Liae Lake.

INLET AND OUTLET.--The one inlet flows into the lake on the extreane eastern shore from the Third Basin of Crooked Lake, 1.4 i upstrean. The outlet flows from the northern tip into line lake approxiadely 600 ft downstrean. then eventually into the St. Joseph River.

EXTREMES FOR PERIOD OF RECORD.--Maximun stage, $5.55 \mathrm{ft}$ Apr. 25, 1950; ainiaun stage, $3.41 \mathrm{ft}$ Nov. 13 , $15-20$. 1953.

LAKE LEVEL, IN FEET ABOVE GAGE DATUM, WATER YEAR OCTOBER 1990 TO SEPTEMBER 1991

\begin{tabular}{|c|c|c|c|c|c|c|c|c|c|c|c|c|}
\hline DAY & ОСТ & NOV & DEC & JAM & FE B & MAR & APR & MAY & JUN & JUL & $A \cup G$ & SEP \\
\hline $\begin{array}{r}5 \\
10 \\
15 \\
20 \\
25 \\
\text { EOM }\end{array}$ & $\begin{array}{l}4.72 \\
4.85 \\
4.61 \\
4.49 \\
4.34 \\
4.24\end{array}$ & $\begin{array}{l}4.32 \\
4.31 \\
4.28 \\
4.21 \\
4.20 \\
4.26\end{array}$ & $\begin{array}{l}4.31 \\
4.29 \\
4.29 \\
4.28 \\
4.31 \\
4.63\end{array}$ & $\begin{array}{l}4.74 \\
4.72 \\
4.70 \\
4.68 \\
4.58 \\
4.50\end{array}$ & $\begin{array}{l}4.44 \\
4.38 \\
4.37 \\
4.37 \\
4.34 \\
4.36\end{array}$ & $\begin{array}{l}4.40 \\
4.34 \\
4.30 \\
4.31 \\
4.33 \\
4.38\end{array}$ & $\begin{array}{l}4.36 \\
4.36 \\
4.40 \\
4.51 \\
4.55 \\
4.58\end{array}$ & $\begin{array}{l}4.56 \\
4.45 \\
4.57 \\
4.58 \\
4.68 \\
4.78\end{array}$ & $\begin{array}{l}4.76 \\
4.70 \\
4.65 \\
4.59 \\
4.50 \\
4.47\end{array}$ & $\begin{array}{l}4.57 \\
4.49 \\
4.48 \\
4.45 \\
4.47 \\
4.42\end{array}$ & $\begin{array}{l}4.41 \\
4.45 \\
4.41 \\
4.60 \\
4.53 \\
4.55\end{array}$ & $\begin{array}{l}4.53 \\
4.53 \\
4.53 \\
4.42 \\
4.39 \\
4.35\end{array}$ \\
\hline
\end{tabular}

WTR YR 1991 MEAN 4.47 MAX 4.85 MIN 4.20

\section{STREAMS TRIBUTARY TO LAKE MICHIGAN}

04092990 LAKE GEORGE AT HOBART, IN

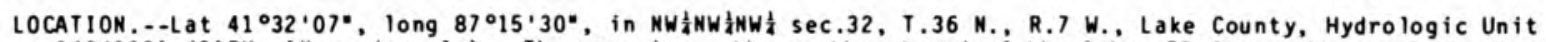
04040001 (GARY, IN quadrangle). The gage is on the northeast end of the lake, $70 \mathrm{ft}$ northwest of the dae and $400 \mathrm{ft}$ upstrea of the Ridge Road bridge, in Hobart.

SURFACE AREA.--282 acres.

DRAINAGE AREA. $--124: i^{2}$.

PERIOD OF RECORD.--1947 to current year.

DATUM OF GAGE.--600.00 ft above National Geodetic Vertical Datun of 1929.

GAGE.--A water-stage recorder is installed in a steel shelter over an 18-inch dianeter clay stilling well.

ESTABLISHED LEGAL LEVEL. $-2.23 \mathrm{ft}$ gage datun or $602.23 \mathrm{ft}$ above National Geodetic Vertical Datue of 1929 as decreed on Septeaber 18, 1959, by the Lake County Circuit Court.

LAKE-LEVEL CONTROL..-The level of the lake is controlled by a concrete dan with renovable boards.

INLET AND OUTLET...The two principal inlets are Turkey Creek, entering from the extrene southwestern tip. and Deep River, entering on the northeastern shore of the southern lobe. Three unnaed tributaries enter from the northwest, south, and southeast. The outlet, Deep River, flows from the lake at the northeast end and eventually joins the Calunet River.

EXTREMES FOR PERIOD OF RECORD..-Maximu stage, $7.14 \mathrm{ft} 0 \mathrm{ct}, 11,1954$; winimu stage, $0.27 \mathrm{ft}$ Nov. 6 , 1978 (while the lake was being drained).

LAKE LEVEL, IN FEET ABOVE GAGE DATUM, WATER YEAR OCTOBER 1990 TO SEPTEMBER 1991

\begin{tabular}{|c|c|c|c|c|c|c|c|c|c|c|c|}
\hline DAY & $\mathrm{OCT}$ & NOV & DEC & JAN & FE B & MAR & APR & MAY & JUN & JUL & AUG \\
\hline $\begin{array}{r}5 \\
10 \\
15 \\
20 \\
25 \\
\text { EOM }\end{array}$ & $\begin{array}{l}2.35 \\
4.30 \\
2.44 \\
2.40 \\
2.30 \\
2.18\end{array}$ & $\begin{array}{r}3.53 \\
2.41 \\
2.35 \\
2.24 \\
2.24 \\
\ldots . .\end{array}$ & $\begin{array}{l}\ldots \\
\cdots \\
\cdots \\
\cdots \\
\cdots \\
\cdots\end{array}$ & $\begin{array}{l}2.34 \\
2.27 \\
2.49 \\
2.36 \\
2.23\end{array}$ & $\begin{array}{l}3.17 \\
2.44 \\
2.37 \\
2.68 \\
2.29 \\
2.20\end{array}$ & $\begin{array}{l}2.83 \\
2.08 \\
2.60 \\
2.85 \\
2.15 \\
2.10\end{array}$ & $\begin{array}{l}2.42 \\
2.31 \\
4.00 \\
2.32 \\
2.28 \\
1.98\end{array}$ & $\begin{array}{l}2.74 \\
2.39 \\
2.03 \\
2.28 \\
2.51 \\
2.34\end{array}$ & $\begin{array}{l}1.95 \\
2.07 \\
2.08 \\
2.05 \\
2.04 \\
2.00\end{array}$ & $\begin{array}{l}1.99 \\
2.02 \\
1.99 \\
1.96 \\
1.50 \\
1.91\end{array}$ & $\begin{array}{l}1.98 \\
2.08 \\
1.97 \\
2.20 \\
1.98 \\
2.00\end{array}$ \\
\hline
\end{tabular}

WTR YR 1991 MEAN 2.30 MAX 5.14 MIN 1.40 
LOCATION.--Lat $41^{\circ} 44^{\prime} 58^{\circ}$, long $85^{\circ} 01^{\prime} 01^{\prime \prime}$, in SE 04050001 (ANGOLA WEST: IN quadrangle). The gage is $25 \mathrm{ft}$ east of the out let dae on the southwest end of the lake at Janestown, 8.0 i north of Angola.

SURFACE AREA. --488 acres.

DRAI NAGE AREA. $-14.7 \cdot i^{2}$.

PERIOD OF RECORD.-1946 to current year.

DATUM OF GAGE. - $-980.00 \mathrm{ft}$ above National Geodetic Vertical Datun of 1929.

GAGE.--A water-stage recorder is installed in an aluinua shelter over a $15-i n c h$ dianeter stilling well.

ESTABLISHED LEGAL LEVEL. $-5.28 \mathrm{ft}$ gage datun or $985.28 \mathrm{ft}$ above National Geodetic Vertical Datue of 1929 as decreed on October 12, 1945, by the Steuben County Circuit Court.

LAKE-LEVEL CONTROL.--The level of the lake is controlled by a concrete dan with removable boards.

INLET AND OUTLET.-.The inlet flows from Silver Lake, 0.8 i upstrean, and enters on the north shore. The outlet flows frov the southwest end of the lake and forms Crooked Creek. Crooked Creek flows into Mud Lake 0.8 a downstrean, then enters Snow Lake.

EXTREMES FOR PERIOD OF RECORD.--Maxinum stage, 6.20 ft Apr. 4, 25, 1950; ininum stage, 4.20 ft Dec. 6, 7. 1946: $0 \mathrm{ct} .23-31,1948$.

LAKE LEVEL, IN FEET ABOVE GAGE DATUM, WATER YEAR OCTOBER 1990 TO SEPTEMBER 1991 $24: 00$ VALUES

\begin{tabular}{|c|c|c|c|c|c|c|c|c|c|c|c|c|}
\hline DAY & $\mathrm{OCT}$ & MOV & DEC & JAN & FE B & MAR & $A P R$ & MAY & JUN & JUL & AUG & SEP \\
\hline $\begin{array}{r}5 \\
10 \\
15 \\
20 \\
25 \\
\text { EOM }\end{array}$ & $\begin{array}{l}5.35 \\
5.60 \\
5.48 \\
5.44 \\
5.39 \\
5.33\end{array}$ & $\begin{array}{l}5.51 \\
5.43 \\
5.39 \\
5.36 \\
5.35 \\
5.40\end{array}$ & $\begin{array}{r}5.43 \\
5.41 \\
5.40 \\
5.40 \\
5.41 \\
\ldots . .\end{array}$ & $\begin{array}{l}\ldots \\
\ldots .52 \\
\ldots \\
\ldots\end{array}$ & $\begin{array}{l}\ldots \\
\ldots \\
\ldots \\
\ldots \\
\ldots \\
\ldots\end{array}$ & $\begin{array}{l}5.83 \\
5.72 \\
5.72 \\
5.74 \\
5.75\end{array}$ & $\begin{array}{l}5.75 \\
5.76 \\
5.78 \\
5.85 \\
5.84 \\
5.82\end{array}$ & $\begin{array}{l}5.81 \\
5.76 \\
5.71 \\
5.70 \\
5.72 \\
5.76\end{array}$ & $\begin{array}{l}5.67 \\
5.63 \\
5.61 \\
5.58 \\
5.52 \\
5.63\end{array}$ & $\begin{array}{l}5.62 \\
5.54 \\
5.55 \\
5.51 \\
5.56 \\
5.52\end{array}$ & $\begin{array}{l}5.53 \\
5.55 \\
5.50 \\
5.65 \\
5.60 \\
5.59\end{array}$ & $\begin{array}{l}5.58 \\
5.59 \\
5.57 \\
5.49 \\
5.43 \\
5.41\end{array}$ \\
\hline
\end{tabular}

WTR YR 1991 MEAN 5.57 MAX 5.86 MIN 5.25

WABASH RIVER BASIN

03331380 LAKE MANITOU AT ROCHESTER, IN

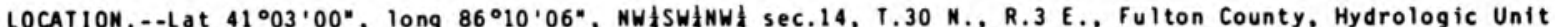
05120106 (ROCHESTER, in quadrangle). The gage is located at the Public fishing site on the eastern side of the lake, and 2.6 i southeast of the courthouse in Rochester.

SURFACE AREA. $-1,158$ acres.

DRAI NAGE AREA. $--44.2 \bullet i^{2}$.

PERIOD OF RECORD.--1943 to current year.

DATUM OF GAGE. $--770.00 \mathrm{ft}$ above National Geodetic Vertical Datun of 1929.

GAGE.--A water-stage recorder is installed in a aluminu shelter over a $15-i n c h$ dianeter stilling well. An auxiliary staff gage is located at the northwest end of the lake at the fish hatchery.

ESTABLISHED LEGAL LEVEL. $--8.41 \mathrm{ft}$ gage datu or $778.41 \mathrm{ft}$ above National Geodetic Vertical Datue of 1929 as decreed on Septenber 27.1948 , by the Fulton County Circuit Court.

LAKE-LEVEL CONTROL..-The lake level is controlled by a concrete dan and the gate of a feeder canal at the lake out let.

INLET AND OUTLET..-Rain Creek is the ain inlet and enters at the southeastern edge of the lake. The other inlet is located on the eastern shore of the lake at the site of the gage. The outlet is Will Creek. which exits at the northwestern tip of the lake and flows 3.5 .

EXTREMES FOR PERIOD OF RECORD.--Maximu stage, 10.87 ft Aug. 19, 1990: winimun stage, 6.48 ft Mov. 14, $25-27$. 1964 .

LAKE LEVEL, IN FEET ABOVE GAGE DATUM, WATER YEAR OCTOBER 1990 TO SEPTEMBER 1991 24:00 VALUES

\begin{tabular}{|c|c|c|c|c|c|c|c|c|c|c|c|c|}
\hline DAY & $\mathrm{OCT}$ & NOV & DEC & JAN & FE B & MAR & APR & MAY & JUN & JUL & AUG & SEP \\
\hline $\begin{array}{r}5 \\
10 \\
15 \\
20 \\
25 \\
\text { EOM }\end{array}$ & $\begin{array}{l}8.71 \\
9.37 \\
9.01 \\
8.82 \\
8.71 \\
8.65\end{array}$ & $\begin{array}{l}8.87 \\
8.80 \\
8.68 \\
8.65 \\
8.62 \\
8.82\end{array}$ & $\begin{array}{l}8.86 \\
8.71 \\
8.73 \\
8.72 \\
8.80 \\
9.90\end{array}$ & $\begin{array}{l}9.09 \\
8.88 \\
8.87 \\
8.96 \\
8.76 \\
8.69\end{array}$ & $\begin{array}{l}8.78 \\
8.77 \\
8.71 \\
8.80 \\
8.72 \\
8.68\end{array}$ & $\begin{array}{l}8.74 \\
8.66 \\
8.67 \\
8.91 \\
8.79 \\
8.76\end{array}$ & $\begin{array}{l}8.73 \\
8.75 \\
8.96 \\
8.89 \\
8.80 \\
8.72\end{array}$ & $\begin{array}{l}8.73 \\
8.66 \\
8.67 \\
8.66 \\
8.67 \\
8.72\end{array}$ & $\begin{array}{l}8.61 \\
8.56 \\
8.56 \\
8.55 \\
8.48 \\
8.45\end{array}$ & $\begin{array}{l}8.47 \\
8.62 \\
8.45 \\
8.39 \\
8.34 \\
8.31\end{array}$ & $\begin{array}{l}8.32 \\
8.42 \\
8.35 \\
8.44 \\
8.35 \\
8.36\end{array}$ & $\begin{array}{l}8.40 \\
8.33 \\
8.36 \\
8.28 \\
8.29 \\
8.26\end{array}$ \\
\hline
\end{tabular}

WTR YR 1991 MEAN 8.67 MAX 10.04 MIN 8.26 


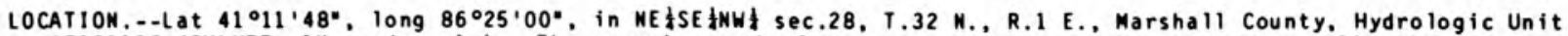
05120106 (CULVER, IN quadrangle). The gage is on the lower west side of the lake, at the public fishing site. 1.4 i south of the center of Culver.

SURFACE AREA. $-1,864$ acres.

DR.AI NAGE AREA. $--13.7 \cdot i^{2}$.

PERIOD OF RECORD, - 1943 to current year.

DATUM OF GAGE. $--730.00 \mathrm{ft}$ above National Geodetic Vertical Datun of 1929.

GAGE.--A water-stage recorder is installed in an aluainu shelter over a 15-inch dianeter stilling well. An auxiliary staff gage is attached to the upstrean side of the north abutaent of the outlet dae.

ESTABLISHED LEGAL LEVEL.--3.12 ft gage datue or $733.12 \mathrm{ft}$ above National Geodetic Vertical Datun of 1929 as decreed on August 9,1948 , by the Marshall County Circuit Court.

LAKE-LEVEL CONTROL.--The level of the lake is controlled by a concrete dan with a fixed crest at the out let channel.

INLET AND OUTLET.--Wilson ditch enters the lake at the northeast corner, Curtiss ditch enters at the east center. and Norris inlet enters at the southeast corner. The outlet leaves the lake at the western shore, north of the point, and flows into lost lake $1,600 \mathrm{ft}$ downstrean, thence into the Tippecanoe River.

EXTREMES FOR PERIOD OF RECORD.--Maximum stage, 5.48 ft June 14, 15, 1981; inimum stage, $2.12 \mathrm{ft}$ Mov. 19, 1953 and Nov. 19,1956 .

LAKE LEVEL, IN FEET ABOVE GAGE DATUM, WATER YEAR OCTOBER 1990 TO SEPTEMBER 1991 24:00 VALUES

\begin{tabular}{|c|c|c|c|c|c|c|c|c|c|c|c|c|}
\hline DAY & OCT & NOV & DEC & JAN & FE B & MAR & $A P R$ & MAY & JUN & JUL & AUG & SEP \\
\hline $\begin{array}{r}5 \\
10 \\
15 \\
20 \\
25 \\
\text { EOM }\end{array}$ & $\begin{array}{r}3.46 \\
3.82 \\
\ldots . \\
\ldots . \\
\ldots . \\
\ldots\end{array}$ & 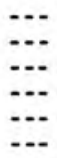 & $\begin{array}{l}\cdots .78 \\
3.78 \\
3.77 \\
3.83 \\
4.53\end{array}$ & $\begin{array}{l}4.46 \\
4.32 \\
4.35 \\
4.36 \\
4.24 \\
4.22\end{array}$ & $\begin{array}{l}4.05 \\
4.00 \\
3.96 \\
3.98 \\
3.93 \\
3.91\end{array}$ & $\begin{array}{l}3.94 \\
3.87 \\
3.88 \\
3.95 \\
3.99 \\
3.95\end{array}$ & $\begin{array}{l}3.94 \\
3.91 \\
4.12 \\
4.20 \\
4.10 \\
4.01\end{array}$ & $\begin{array}{r}3.97 \\
\ldots- \\
\ldots-. \\
\ldots- \\
-2 \\
4.01\end{array}$ & $\begin{array}{l}3.92 \\
3.77 \\
3.76 \\
3.67 \\
3.55 \\
3.46\end{array}$ & $\begin{array}{l}3.36 \\
3.49 \\
3.41 \\
3.42 \\
3.29 \\
3.15\end{array}$ & $\begin{array}{l}3.07 \\
3.13 \\
3.08 \\
3.19 \\
3.13 \\
3.10\end{array}$ & $\begin{array}{l}3.04 \\
2.98 \\
2.98 \\
2.86 \\
2.80 \\
2.75\end{array}$ \\
\hline
\end{tabular}

WTR YR 1991 MEAM 3.70 MAX 4.53 MIN 2.75

\section{ILLIMOIS RIVER BASIN}

05516200 LAKE OF THE WOODS NEAR BREMEM, IN

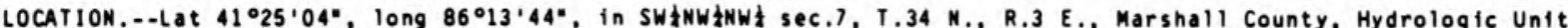
07120001 (BREMEN. IN quadrangle). The gage is on the southwest shore of the lake, at the pubific fishing site. and 4.7 i southwest of Breaen.

SURFACE AREA. --416 acres.

DRAINAGE AREA. $-9.45 \cdot i^{2}$.

PERIOD OF RECORD.- 1945 to current year.

DATUM OF GAGE.- $-800.00 \mathrm{ft}$ above National Geodetic Vertical Datum of 1929.

GAGE.--A water-stage recorder is installed in an aluminu shelter over a 15-inch diameter stilling well. An auxiliary staff gage is driven into the outlet channel.

ESTABLISHED LEGAL LEVEL. $-3.85 \mathrm{ft}$ gage datun or $803.85 \mathrm{ft}$ above National Geodetic Vertical Datun of 1929 as decreed on August 9.1948 , by the Marshall County Circuit Court.

LAKE-LEVEL CONTROL...The level of the lake is controlled by a concrete dan with a $13 \mathrm{ft}$ by $1 \mathrm{ft}$ notch. The das is equipped with a lift gate.

INLET AND OUTLET.-.Three ditches, Kimble, Martin, and Seltenright, enter the lake on the northwest shore. Scofield ditchenters at the west lobe. The outlet. Clark ditch, flows from the lake at the southern end and eventually into Yellow River.

EXTREMES FOR PERIOD OF RECORD.--Maximul stage, $7.68 \mathrm{ft} 0 \mathrm{ct}, 12,1954$; minimun stage, $2.75 \mathrm{ft}$ Nov. $18-20,1953$.

LAKE LEVEL, IN FEET ABOVE GAGE DATUM, WATER YEAR OCTOBER 1990 TO SEPTEMBER 1991

\begin{tabular}{|c|c|c|c|c|c|c|c|c|c|c|c|c|}
\hline DAY & $O C T$ & NOV & DEC & JAN & FEB & MAR & APR & MAY & JUN & JUL & AUG & SEP \\
\hline $\begin{array}{r}5 \\
10 \\
15 \\
20 \\
25 \\
\text { EOM }\end{array}$ & $\begin{array}{l}3.54 \\
4.43 \\
4.14 \\
3.92 \\
3.68 \\
3.49\end{array}$ & $\begin{array}{l}3.96 \\
3.91 \\
3.70 \\
3.55 \\
3.53 \\
4.00\end{array}$ & $\begin{array}{l}3.97 \\
3.84 \\
3.90 \\
3.79 \\
3.85 \\
4.80\end{array}$ & $\begin{array}{l}4.19 \\
3.92 \\
3.99 \\
4.10 \\
3.87 \\
3.64\end{array}$ & $\begin{array}{l}3.83 \\
3.81 \\
3.74 \\
3.99 \\
3.89 \\
3.79\end{array}$ & $\begin{array}{l}3.96 \\
3.82 \\
3.71 \\
3.88 \\
3.86 \\
3.76\end{array}$ & $\begin{array}{l}3.77 \\
3.64 \\
4.21 \\
4.25 \\
4.04 \\
3.87\end{array}$ & $\begin{array}{l}3.88 \\
3.66 \\
3.46 \\
3.66 \\
3.82 \\
4.35\end{array}$ & $\begin{array}{l}3.97 \\
3.84 \\
3.94 \\
3.90 \\
3.83 \\
3.82\end{array}$ & $\begin{array}{l}3.77 \\
3.87 \\
3.75 \\
3.68 \\
3.62 \\
3.49\end{array}$ & $\begin{array}{l}3.54 \\
3.63 \\
3.59 \\
3.71 \\
3.64 \\
3.63\end{array}$ & $\begin{array}{l}3.60 \\
3.56 \\
3.62 \\
3.28 \\
3.12 \\
3.00\end{array}$ \\
\hline
\end{tabular}

WTR YR 1991 MEAN 3.79 MAX 4.88 MIN 3.00 


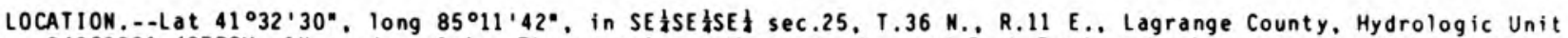
04050001 (STROH, IM quadrangle). The gage is on the west shore of Ouck Pond, a basin connecting Lake of the Woods and $\mathrm{McCl}$ ish Lake, approximately $100 \mathrm{ft}$ south of the bridge over the channel, and 1.5 oi northwest of Helner.

SURFACE AREA. -136 acres.

DRAI NAGE AREA, $--5.25 \cdot \mathrm{i}^{2}$.

PERIOD OF RECORD.-1951-74, 1977 to current year.

DATUM OF GAGE.--940.00 ft above National Geodetic Vertical Datun of 1929.

GAGE.--A water-stage recorder is installed in an aluminum shelter over a 15-inch dianeter stilling well.

ESTABLISHED LEGAL LEVEL. - - $11.09 \mathrm{ft}$ gage datue or $951.09 \mathrm{ft}$ above National Geodetic Vertical Datun of 1929 as decreed on July 21,1960 , by the Lagrange County Circuit Court. McClish Lake near Helaer has the sane established level and hence the same lake levels for the period of record.

LAKE-LEVEL CONTROL..-The level of the lake is controlled by a concrete dan with a fixed sill.

INLET ANO OUTLET.--There are four inlets to the lake. Spectacle Lakes drain into the west shore, Maunee ditch enters fron the south, Goose Pond flows through a short channel to the southwest shore, and McClish Lake drains into the lake on the southeast shore. The outlet flows to the north from the east end of the lake and through Taylor, Mud, and Little Turkey Lakes to Turkey Creek, thence into Pigeon River.

EXTREMES FOR PERIOD OF RECORD.--Maximu stage, 13.00 ft Dec. 24, 25, 1967; aninun stage, 9.81 ft Mov. 17-20, 1953.

LAKE LEVEL, IN FEET ABOVE GAGE DATUM, WATER YEAR OCTOBER 1990 TO SEPTEMBER 1991 24:00 VALUES

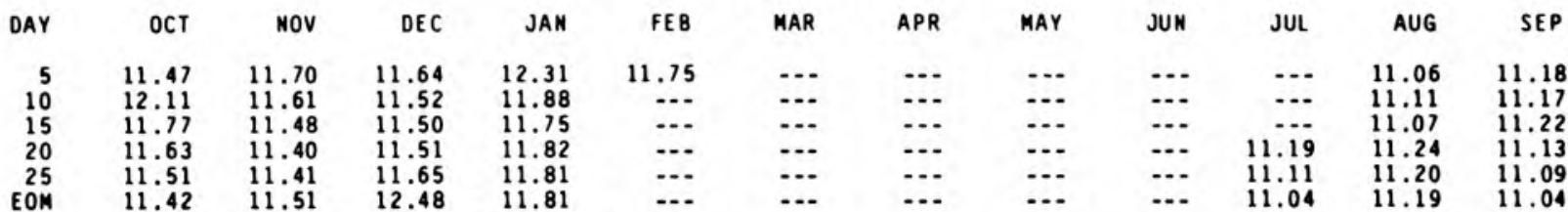

WTR YR 1991 MEAN 11.48 MAX 12.48 MIN 11.02

STREAMS TRIBUTARY TO LAKE MICHIGAN

04097520 LAKE PLEASANT NEAR MEVADA MILLS, IN

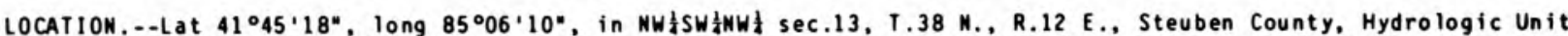
04050001 (KINDERHOOK, MI-IN quadrangle). The gage is at a bridge over a boat channel on the south shore of the lake, $2.3 \cdot i$ northwest of Nevada Mills.

SURFACE AREA. --424 acres.

DRAI MAGE AREA, $--3.18 \mathrm{mi}^{2}$.

PERIOD OF RECORD.--1954-69, 1971,1976 to current year.

DATUM OF GAGE. - $-960.40 \mathrm{ft}$ above Mational Geodetic Vertical Datue of 1929 as corrected on the basis of levels of Indiana Departaent of Natural Resources, 1977-78.

GAGE.--A water-stage recorder is installed in an alueinum shelter over a 15-inch dianeter stilling well. An auxiliary staff gage is attached to the southwest bridge abutaent at the site.

ESTABLISHED LEGAL LEVEL. - $1.10 \mathrm{ft}$ gage datua or $961.50 \mathrm{ft}$ above National Geodetic Vertical Datua of 1929 as decreed on April 11, 1986, by the Steuben County Circuit Court.

LAKE-LEVEL CONTROL.- The level of the lake is controlled by a metal plate welded across the botton of a corrugated netal pipe.

INLET AND OUTLET.--The one inlet enters the lake on the west side. The outlet flows from the northern shore, enters Michigan, and eventually eapties into Prairie River.

EXTREMES FOR PERIOD OF RECORD.--Maximu stage, $2.04 \mathrm{ft}$ Mar. 17, 1980: ainimu stage, -0.14 ft Nov. 6-14, 1964.

LAKE LEVEL, IN FEET ABOVE GAGE DATUM, WATER YEAR OCTOBER 1990 TO SEPTEMBER 1991 24:00 VALUES

\begin{tabular}{|c|c|c|c|c|c|c|c|c|c|c|c|}
\hline DAY & $O C T$ & NOV & DEC & JAN & FE B & MAR & APR & MAY & JUN & JUL & AUG \\
\hline $\begin{array}{r}5 \\
10 \\
15 \\
20 \\
25 \\
\text { EOM }\end{array}$ & $\begin{array}{l}1.47 \\
1.80 \\
1.74 \\
1.68 \\
1.61 \\
1.54\end{array}$ & $\begin{array}{l}1.68 \\
1.62 \\
1.57 \\
1.54 \\
1.53 \\
1.60\end{array}$ & $\begin{array}{l}1.63 \\
1.60 \\
1.59 \\
1.59 \\
1.62 \\
1.93\end{array}$ & $\begin{array}{r}1.93 \\
1.87 \\
1.74 \\
1.70 \\
1.70 \\
\ldots\end{array}$ & $\begin{array}{l}\ldots \\
\ldots \\
\ldots \\
\ldots \\
\ldots\end{array}$ & $\begin{array}{l}\ldots \\
\ldots \\
\ldots \\
\ldots \\
\ldots \\
\ldots\end{array}$ & $\begin{array}{l}\ldots \\
\ldots \\
1.70 \\
1.72 \\
1.69\end{array}$ & $\begin{array}{l}1.69 \\
1.64 \\
1.60 \\
1.52 \\
1.52 \\
1.57\end{array}$ & $\begin{array}{l}1.48 \\
1.41 \\
1.37 \\
1.31 \\
1.22 \\
1.30\end{array}$ & $\begin{array}{l}1.45 \\
1.38 \\
1.33 \\
1.24 \\
1.34 \\
1.27\end{array}$ & $\begin{array}{l}1.26 \\
1.30 \\
1.24 \\
1.45 \\
1.39 \\
1.41\end{array}$ \\
\hline
\end{tabular}

WTR YR 1991 MEAN 1.52 MAX 1.93 MIM 1.16 
LOCATION. - Lat $41^{\circ} 27^{\prime} 49^{\circ}$, long $85^{\circ} 15^{\prime} 27^{\circ}$, in SE $\frac{1}{2}$ NWW 04050001 (KENDALLVILLE, IN quadrangle). The gage is on the south side of the lake at the bridge over the dredged channel in Wakeville Village, 1.6 a northeast of City Hall in Kendallville.

SURFACE AREA...71 acres.

DRAINAGE AREA. $--4.55 \mathrm{i}^{2}$.

PERIOD OF RECORD.--1954 to current year.

DATUM OF GAGE. - $-950.00 \mathrm{ft}$ above National Geodetic Vertical Datun of 1929.

GAGE.--A water-stage recorder is installed in an aluminu shelter over a 15-inch dianeter stilling well. An auxiliary staff gage in one section is attached to the west wingwall on the south side of the bridge.

ESTABLISHED LEGAL LEVEL. $-4.50 \mathrm{ft}$ gage datua or $954.50 \mathrm{ft}$ above National Geodetic Vertical Datue of 1929 as decreed on March 26, 1970. Round Lake at Kendaliville has the save established level and hence the saee lake levels for the period of record.

LAKE-LEVEL CONTROL..-The level of the lake is controlled by a fixed-crest concrete dan.

INLET AND OUTLET...The one inlet enters on the east side from Round Lake. The outlet, Waterhouse ditch, flows frow the lake at the southwest end and into Henderson Lake ditch, thence into Sylvan Lake 4.8 a downstreas.

EXTREMES FOR PERIOD OF RECORO. - Maximue stage, $6.75 \mathrm{ft}$ Jan. 31, 1969; winimu stage, $3.33 \mathrm{ft}$ Mov. $17.18,1964$.

LAKE LEVEL, IN FEET ABOVE GAGE DATUM, WATER YEAR OCTOBER 1990 TO SEPTEMBER 1991 24:00 VALUES

\begin{tabular}{|c|c|c|c|c|c|c|c|c|c|c|c|}
\hline DAY & OCT & NOV & DEC & JAN & FEB & MAR & $A P R$ & MAY & JUN & JUL & AUG \\
\hline $\begin{array}{r}5 \\
10 \\
15 \\
20 \\
25 \\
\text { EOM }\end{array}$ & $\begin{array}{l}4.78 \\
5.49 \\
4.94 \\
4.81 \\
4.74 \\
4.73\end{array}$ & $\begin{array}{l}5.07 \\
4.85 \\
4.75 \\
4.71 \\
4.72 \\
4.80\end{array}$ & $\begin{array}{r}4.89 \\
4.78 \\
4.80 \\
4.82 \\
4.88 \\
\ldots . .\end{array}$ & $\begin{array}{l}\ldots \\
\ldots .90 \\
\ldots\end{array}$ & $\begin{array}{r}4.88 \\
4.84 \\
. .2 \\
4.91 \\
4.80 \\
4.77\end{array}$ & $\begin{array}{l}4.88 \\
4.77 \\
4.75 \\
4.81 \\
4.79 \\
4.79\end{array}$ & $\begin{array}{l}4.80 \\
4.88 \\
4.98 \\
5.28 \\
5.01 \\
4.89\end{array}$ & $\begin{array}{l}4.84 \\
4.76 \\
4.72 \\
4.69 \\
4.75 \\
5.99\end{array}$ & $\begin{array}{l}4.98 \\
4.75 \\
4.70 \\
4.64 \\
4.58 \\
4.65\end{array}$ & $\begin{array}{l}4.74 \\
4.65 \\
4.61 \\
4.53 \\
4.44 \\
4.36\end{array}$ & $\begin{array}{l}4.41 \\
4.45 \\
4.40 \\
4.39 \\
4.33 \\
4.28\end{array}$ \\
\hline
\end{tabular}

WTR YR 1991 MEAN 4.71 MAX 6.21 MIN 4.03

\section{WABASH RIVER BASIN \\ 03328100 LONG LAKE AT LAKETON, IN}

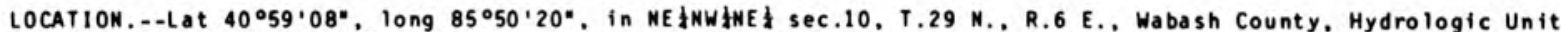
05120104 (NORTH MANCHESTER SOUTH. IN quadrangle). The gage is located on the north shore of the lake. 0.3 ai west of Crill Road, and $0.8 \mathrm{~m}$ north of Laketon.

SURFACE AREA. --48 acres.

DRAI MAGE AREA. $--0.55: i^{2}$.

PERIOD OF RECORD.--1946-51, 1959 to current year.

DATUM OF GAGE.--740.00 ft above National Geodetic Vertical Datun of 1929.

GAGE.--A water-stage recorder is installed in an aluainus shelter over a 15-inch dianeter stilling well. An auxiliary staff gage, driven into the lake bed, is located $50 \mathrm{ft}$ lakeward of the priaary gage.

ESTABLISHED LEGAL LEVEL.--11.19 ft gage datun or $751.19 \mathrm{ft}$ above National Geodetic Vertical Datua of 1929 as decreed on July 26, 1951, by the Wabash County Circuit Court.

LAKE-LEVEL CONTROL..-The level of the lake is controlled by an 18 -inch corrugated aetal pipe draining into a clay tile.

INLET AND OUTLET.--Two tile ditches flow into the lake. The outlet flows from the west end of the lake, joins the out let of Mud Lake, continues through Round Lake, then into Eel River.

EXTREMES FOR PERIOD OF RECORD..-Maxinum stage, $13.66 \mathrm{ft}$ Mar. 22, 1982; inimus stage, 8.68 ft Dec. $1-3.1964$.

LAKE LEVEL, IN FEET ABOVE GAGE DATUM, WATER YEAR OCTOBER 1990 TO SEPTEMBER 1991

\begin{tabular}{|c|c|c|c|c|c|c|c|c|c|c|c|c|}
\hline DAY & $\mathrm{OCT}$ & NOV & DEC & JAN & FEB & MAR & APR & MAY & JUN & JUL & AUG & SEP \\
\hline $\begin{array}{r}5 \\
10 \\
15 \\
20 \\
25 \\
\text { EOM }\end{array}$ & $\begin{array}{r}\ldots . \\
12.32 \\
12.20 \\
12.03\end{array}$ & $\begin{array}{l}12.18 \\
12.09 \\
12.01 \\
11.94 \\
11.89 \\
11.96\end{array}$ & $\begin{array}{r}12.09 \\
12.09 \\
12.12 \\
12.20 \\
\ldots . \\
\ldots\end{array}$ & $\begin{array}{l}\ldots \\
\ldots \\
\ldots \\
\cdots \\
\cdots\end{array}$ & $\begin{array}{l}\ldots \\
\ldots \\
\ldots \\
\ldots \\
\ldots\end{array}$ & $\begin{array}{r}\ldots \\
\ldots \\
\ldots \\
\ldots \\
12.07\end{array}$ & $\begin{array}{l}\ldots \\
\ldots \\
\cdots \\
\cdots \\
\cdots \\
\cdots\end{array}$ & $\begin{array}{l}12.03 \\
11.97 \\
11.93 \\
11.85 \\
12.13 \\
12.45\end{array}$ & $\begin{array}{l}12.40 \\
12.32 \\
12.26 \\
12.14 \\
11.99 \\
11.87\end{array}$ & $\begin{array}{l}11.84 \\
12.02 \\
11.88 \\
11.74 \\
11.64 \\
11.56\end{array}$ & $\begin{array}{l}11.47 \\
11.49 \\
11.40 \\
11.37 \\
11.28 \\
11.24\end{array}$ & $\begin{array}{l}11.21 \\
11.11 \\
11.05 \\
10.91 \\
10.83 \\
10.73\end{array}$ \\
\hline
\end{tabular}

WTR YR 1991 MEAN 11.81 MAX 12.47 MIN 10.73 


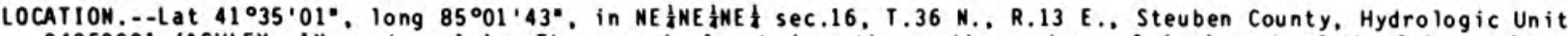
04050001 (ASHLEY, IN quadrangle). The gage is located on the northern shore, 0.4 e i east of the lake out let and 2.5 i north of Steubenville.

SURFACE AREA. - -92 acres.

DRAI NAGE AREA. $--67.9 \cdot i^{2}$.

PERIOD OF RECORD.--1946 to current year.

DATUM OF GAGE.--940.10 ft above Mational Geodetic Vertical Datue of 1929 as corrected on the basis of levels of Indiana Departaent of Natural Resources, 1977.

GAGE.--A water-stage recorder is installed in an alueinue shelter over a 15-inch dianeter stilling well. An auxiliary staff gage is located near the gage in two sections. One section is oouted on a post which is driven into the lake bed. The other section is mounted to a tree near the gage.

ESTABLISHED LEGAL LEVEL. - - Hot established.

LAKE-LEVEL CONTROL..-The lake level is controlled by the downstrean channel.

INLET AND OUTLET.--Pigeon Creek flows into Long Lake at the eastern end of the lake and exits at the western end. EXTREMES FOR PERIOD OF RECORD.--Maximun stage, $17.42 \mathrm{ft}$ Mar. 22, 1982; ainimun stage, 8.78 ft Sept. $30,1991$.

LAKE LEVEL, IN FEET ABOVE GAGE DATUM, WATER YEAR OCTOBER 1990 TO SEPTEMBER 1991 24:00 VALUES

\begin{tabular}{|c|c|c|c|c|c|c|c|c|c|c|c|}
\hline DAY & OCT & NOV & DEC & JAN & FE B & MAR & APR & MAY & JUN & JUL & AUG \\
\hline $\begin{array}{r}5 \\
10 \\
15 \\
20 \\
25 \\
\text { EOM }\end{array}$ & $\begin{array}{r}9.36 \\
12.11 \\
11.67 \\
10.55 \\
9.89 \\
9.54\end{array}$ & $\begin{array}{r}10.59 \\
10.84 \\
9.99 \\
9.61 \\
9.55 \\
10.11\end{array}$ & $\begin{array}{l}10.85 \\
10.26 \\
10.00 \\
10.24 \\
10.56 \\
14.35\end{array}$ & $\begin{array}{l}\ldots \\
\ldots \\
\ldots \\
\cdots \\
\cdots\end{array}$ & $\begin{array}{l}\ldots \\
\ldots \\
\ldots- \\
\cdots \\
\cdots \\
\cdots\end{array}$ & $\begin{array}{l}\ldots \\
\ldots \\
\ldots \\
\ldots \\
\ldots \\
\ldots\end{array}$ & $\begin{array}{r}\ldots \\
\ldots \\
12.60 \\
\ldots \\
\ldots\end{array}$ & $\begin{array}{l}\ldots \\
\ldots \\
\ldots \\
\ldots \\
\ldots \\
\ldots\end{array}$ & $\begin{array}{l}\ldots \\
\ldots \\
\ldots \\
\ldots \\
\ldots \\
\ldots\end{array}$ & $\begin{array}{r}\ldots . . \\
\ldots . \\
8.90 \\
8.95 \\
8.90\end{array}$ & $\begin{array}{l}8.89 \\
8.95 \\
8.89 \\
9.49 \\
9.01 \\
9.14\end{array}$ \\
\hline
\end{tabular}

WTR YR 1991 MEAN 9.79 MAX 14.35 MIN 8.79

WABASH RIVER BASIN

03331460 LOST LAKE NEAR CULVER, IN

LOCATION.--Lat $41^{\circ} 12^{\prime} 02^{\circ}$, long $86^{\circ} 25^{\prime} 17^{\circ}$, in NE $\frac{1}{4}$. I $\frac{1}{4} N W \frac{1}{4}$ sec.28, T.32 N.. R.1 E.. Marshall County. Hydrologic Unit 05120106 (CULVER. IN quadrangle). The gage is on the northern shore of the lake at the east end of West $19 t h$ Road (lake access road), 1.1 i south of the center of Culver.

SURFACE AREA. -40 acres.

DRAI MAGE AREA, $\cdots 14.2 \backsim i^{2}$.

PERIOD OF RECORD.--1954-61, 1963-74, 1976 to current year. (Foreerly published as Hawks Lake near Culver.) DATUM OF GAGE. $-720.00 \mathrm{ft}$ above National Geodetic Vertical Datun of 1929.

GAGE.--A water-stage recorder is installed in an alueinua shelter over a 15-inch diaeter stilling well.

ESTABLISHED LEGAL LEVEL. $-12.00 \mathrm{ft}$ gage datun or $732.00 \mathrm{ft}$ above National Geodetic Vertical Datum of 1929 as decreed on February 17,1960 , by the Marshall County Circuit Court.

LAKE-LEVEL CONTROL.--The level of the lake is controlled by a concrete dan and sill with reaovable boards in the outlet channel approxinately $850 \mathrm{ft}$ downstrea from the ain body of the lake.

INLET AND OUTLET.-.The one inlet flows into the lake from Maxinkuckee Lake and enters on the north shore. The outlet flows from the south end of the lake to the Tippecanoe River 3.7 a dowstrean.

EXTREMES FOR PERIOD OF RECORD. -.Maxinum stage, 13.05 ft June 15, 1981; inimu stage, $10.12 \mathrm{ft}$ July 9 , 1959.

LAKE LEVEL, IN FEET ABOVE GAGE DATUM, WATER YEAR OCTOBER 1990 TO SEPTEMBER 1991 24:00 VALUES

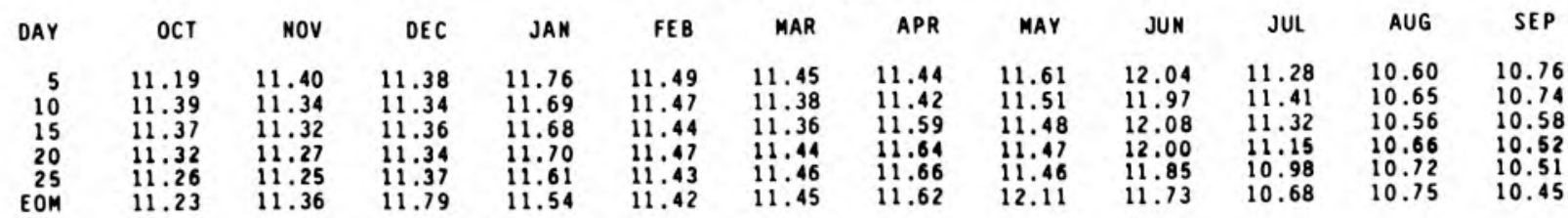

WTR YR 1991 MEAN 11.34 MAX 12.11 MIN 10.45 


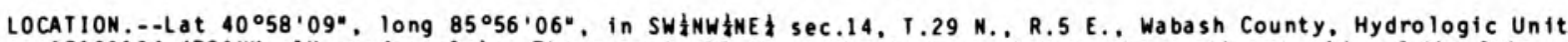
05120104 (ROANN. IN quadrangle). The gage is $25 \mathrm{ft}$ north of the outlet on the southwest side of the lake.

4.1 i north of Roann.

SURFACE AREA. -46 acres.

DRAINAGE AREA. $--1.76 \mathrm{~m}^{2}$.

PERIOD OF RECORD..-1948-49, 1959 to current year.

DATUM OF GAGE. - -760.00 ft above National Geodetic Vertical Datur of 1929.

GAGE.--A water-stage recorder is installed in an aluainum shelter over a 15-inch dianeter stilling well. An auxiliary staff gage in one section is driven into the lake bed about 5 ft upstrean from the outlet culvert.

ESTABLISHED LEGAL LEVEL. $-3.60 \mathrm{ft}$ gage datun or $763.60 \mathrm{ft}$ above the National Geodetic Vertical Datun of 1929 as decreed on March 29, 1978, by the Wabash County Circuit Court.

LAKE-LEVEL CONTROL.- - The level of the lake is controlled by two 18-inch corrugated aetal culverts at the out let.

INLET AND OUTLET.--The principal inlet is a tile drain from Mccolley Lake, 0.5 i to the north. The outlet flows from the southwestern shore, into Bolley Ditch 0.7 i downstrean, thence into Squirrel Creek, and eventually into Eel River.

EXTREMES FOR PERIOD OF RECORO.--Maximum stage, $5.10 \mathrm{ft}$ May 16, 1968; inimum stage, $2.32 \mathrm{ft} 0 \mathrm{ct}$. 12 , 1983.

LAKE LEVEL, IN FEET ABOVE GAGE DATUM, WATER YEAR OCTOBER 1990 TO SEPTEMBER 1991

\begin{tabular}{|c|c|c|c|c|c|c|c|c|c|c|c|c|}
\hline DAY & $O C T$ & NOV & DEC & JAN & FEB & MAR & $A P R$ & MAY & JUN & JUL & AUG & SEP \\
\hline $\begin{array}{r}5 \\
10 \\
15 \\
20 \\
25 \\
\text { EOM }\end{array}$ & $\begin{array}{l}3.81 \\
4.21 \\
4.02 \\
3.99 \\
3.99 \\
3.88\end{array}$ & $\begin{array}{l}3.97 \\
3.89 \\
3.83 \\
3.77 \\
3.70 \\
3.82\end{array}$ & $\begin{array}{l}3.88 \\
3.84 \\
3.83 \\
3.81 \\
3.88 \\
4.27\end{array}$ & $\begin{array}{l}4.06 \\
4.00 \\
4.03 \\
4.06 \\
3.95 \\
3.90\end{array}$ & $\begin{array}{l}3.90 \\
3.88 \\
3.83 \\
3.89 \\
3.83 \\
3.80\end{array}$ & $\begin{array}{r}3.81 \\
3.73 \\
3.75 \\
\ldots . . \\
3.84\end{array}$ & $\begin{array}{l}3.83 \\
3.79 \\
3.91 \\
3.93 \\
3.89 \\
3.84\end{array}$ & $\begin{array}{l}3.80 \\
3.72 \\
3.68 \\
3.65 \\
3.66 \\
3.82\end{array}$ & $\begin{array}{l}3.72 \\
3.64 \\
3.59 \\
3.51 \\
3.44 \\
3.38\end{array}$ & $\begin{array}{l}3.35 \\
3.56 \\
3.53 \\
3.48 \\
3.39 \\
3.28\end{array}$ & $\begin{array}{l}3.23 \\
3.29 \\
3.23 \\
3.27 \\
3.21 \\
3.18\end{array}$ & $\begin{array}{l}3.17 \\
3.11 \\
3.10 \\
2.99 \\
2.95 \\
2.88\end{array}$ \\
\hline
\end{tabular}

WTR YR 1991 MEAN 3.68 MAX 4.41 MIN 2.88

STREAMS TRIBUTARY TO LAKE MICHIGAN

04100280 MUNCIE LAKE MEAR BURR OAK, IN

LOCATION.--Lat $41^{\circ} 19^{\prime} 37^{\circ}$, Iong $85^{\circ} 27^{\prime} 28^{\prime \prime}$, in NE $\frac{1}{4}$ SW $\frac{1}{4} S W^{\frac{1}{4}}$ sec.11, T.33 N., R.9 E., Noble County, Hydrologic Unit 04050001 (MERRIAM, IN quadrangle). The gage is on the southwest shore of the lak?. just north of the gravel road on the Addis farm, and 1.3 i northwest of Burr Oak.

SURFACE AREA. --47 acres.

DRAI NAGE AREA. $--42.8 \cdot i^{2}$.

PERIOD OF RECORD.--1954 to current year.

DATUM OF GAGE. - $-880.00 \mathrm{ft}$ above National Geodetic Vertical Datun of 1929.

GAGE.--A water-stage recorder is installed in an aluminu shelter over a $15-i n c h$ diameter stilling well.

ESTABLISHED LEGAL LEVEL. - - Not established.

LAKE-LEVEL CONTROL.- The level of the lake is controlled by the out let channel.

INLET AND OUTLET.--There are three inlets to the lake. Forker Creek flows into the lake from the east, Brown Ditch froe the southeast. and Carrol Creek from the west. The outlet flows from the northwest shore into Willias Lake, then into the South Branch of the Elkhart River.

EXTREMES FOR PERIOD OF RECORD.--Maximu stage, 9.47 ft Mar. 24, 25, 1978, Feb. 25, 26, 1985; ainiaun stage, $1.88 \mathrm{ft} \mathrm{Aug.} \mathrm{8,1988.}$

LAKE LEVEL, IN FEET ABOVE GAGE DATUM, WATER YEAR OCTOBER 1990 TO SEPTEMBER 1991

\begin{tabular}{|c|c|c|c|c|c|c|c|c|c|c|c|c|}
\hline DAY & $O C T$ & NOV & DEC & JAN & FEB & MAR & $A P R$ & MAY & JUN & JUL & AUG & SEP \\
\hline $\begin{array}{r}5 \\
10 \\
15 \\
20 \\
25 \\
\text { EOM }\end{array}$ & $\begin{array}{l}3.69 \\
6.81 \\
5.95 \\
4.70 \\
3.68 \\
3.06\end{array}$ & $\begin{array}{l}4.20 \\
4.26 \\
3.35 \\
3.02 \\
2.94 \\
3.55\end{array}$ & $\begin{array}{r}4.27 \\
3.56 \\
3.44 \\
3.72 \\
\ldots . .\end{array}$ & $\begin{array}{l}\ldots \\
\ldots \\
\cdots \\
\cdots \\
\cdots\end{array}$ & $\begin{array}{l}3.62 \\
3.32 \\
3.07 \\
3.83 \\
3.24 \\
3.95\end{array}$ & $\begin{array}{l}3.61 \\
3.19 \\
3.79 \\
3.53 \\
3.64 \\
3.11\end{array}$ & $\begin{array}{l}3.22 \\
3.58 \\
3.60 \\
5.28 \\
4.92 \\
4.31\end{array}$ & $\begin{array}{l}3.56 \\
3.20 \\
3.01 \\
2.89 \\
3.52 \\
6.19\end{array}$ & $\begin{array}{l}5.96 \\
3.92 \\
3.13 \\
2.90 \\
2.65 \\
3.24\end{array}$ & $\begin{array}{l}2.90 \\
2.58 \\
2.43 \\
2.32 \\
2.52 \\
2.34\end{array}$ & $\begin{array}{l}2.39 \\
2.44 \\
2.35 \\
2.30 \\
2.32 \\
2.23\end{array}$ & $\begin{array}{l}2.22 \\
2.10 \\
2.64 \\
2.35 \\
2.29 \\
2.23\end{array}$ \\
\hline
\end{tabular}

WTR YR 1991 MEAN 3.37 MAX 7.22 MIN 2.10 
LOCATION.--Lat $41^{\circ} 43^{\prime} 45^{\circ}$, long $85^{\circ} 27^{\prime} 4^{\circ}$, in SE $\frac{1}{4} S W \frac{1}{4} S W^{\frac{1}{2}} \mathrm{sec} .23$, T.38 N., R.9 E., Lagrange County, Hydrologic Unit 04050001 (LAGRANGE. IN quadrangle). The gage is in the channel between North and South Twin Lakes. $100 \mathrm{ft}$ upstrean frow the county road bridge, and 2.2 i northwest of Howe.

SURFACE AREA. -135 acres.

DRAIMAGE AREA. $-1.54 \mathrm{mi}^{2}$.

PERIOD OF RECORD.--1953 to current year.

DATUM OF GAGE. - $-840.00 \mathrm{ft}$ above National Geodetic Vertical Datue of 1929.

GAGE.--A staff gage is attached to the east concrete retaining wall of the control dan.

ESTABLISHED LEGAL LEVEL. - - -3.56 ft gage datum or $843.56 \mathrm{ft}$ above National Geodetic Vertical Datun of 1929 as decreed on Septeaber 11, 1959, by the Lagrange County Circuit Court. South Twin Lake near Howe has the sane established level and hence the sane lake levels for the period of record.

LAKE-LEVEL CONTROL.--Prior to October 1, 1982, the low water control was a fixed-crest dan with removable boards at the upstrean end of the channel between the two lakes. At high stages the outlet channel of South Twin Lake was the control. After October 1, 1982, a concrete das with a fixed crest was installed in the outlet of South Twin Lake. This is now the control structure for both North and South Twin Lakes, although the original structure is still in place.

INLET AND OUTLET. - -There are two inlets to the lake. One enters at the southeast shore fron Still Lake 0.9 a upstrean, and the other, which drains the adjacent arsh land, enters on the northwest shore. The outlet flows frov the southwest shore and into South Twin Lake approxiateiy $200 \mathrm{ft}$ downstrea.

EXTREMES FOR PERIOD OF RECORD.--Maximus stage, $5.20 \mathrm{ft}$ feb. 26, 1985; winimus stage, 2.97 ft Aug. 20.1964. LAKE LEVEL, IN FEET ABOVE GAGE DATUM, WATER YEAR OCTOBER 1990 TO SEPTEMBER 1991

\begin{tabular}{|c|c|c|c|c|c|c|c|c|c|c|c|c|}
\hline DAY & OCT & Nov & DEC & JAN & FEB & MAR & APR & MAY & JUN & JUL & AUG & SEP \\
\hline $\begin{array}{r}5 \\
10 \\
15 \\
20 \\
25 \\
\text { EON }\end{array}$ & $\begin{array}{l}3.58 \\
3.92 \\
3.78 \\
3.71 \\
3.63 \\
3.60\end{array}$ & $\begin{array}{l}3.80 \\
3.70 \\
3.67 \\
3.64 \\
3.67 \\
3.74\end{array}$ & $\begin{array}{l}3.74 \\
3.70 \\
3.68 \\
3.69 \\
3.70 \\
4.00\end{array}$ & $\begin{array}{l}3.78 \\
3.78 \\
3.74 \\
3.72 \\
3.70 \\
3.67\end{array}$ & $\begin{array}{l}3.65 \\
3.64 \\
3.67 \\
3.66 \\
3.64 \\
3.63\end{array}$ & $\begin{array}{l}3.66 \\
3.63 \\
3.62 \\
3.64 \\
3.67 \\
3.70\end{array}$ & $\begin{array}{l}3.67 \\
. . \\
3.64 \\
3.70 \\
3.74 \\
3.72\end{array}$ & $\begin{array}{l}3.64 \\
3.60 \\
3.58 \\
3.55 \\
3.80 \\
3.96\end{array}$ & $\begin{array}{r}3.86 \\
3.78 \\
3.74 \\
\ldots . \\
\ldots . \\
\ldots\end{array}$ & $\begin{array}{l}\ldots . \\
\cdots \\
\cdots \\
-\ldots \\
\cdots\end{array}$ & $\begin{array}{r}3.5 \\
3.50 \\
3.48 \\
3.58 \\
3.52 \\
3.46\end{array}$ & $\begin{array}{l}3.48 \\
3.50 \\
3.50 \\
3.46 \\
3.44 \\
3.42\end{array}$ \\
\hline
\end{tabular}

WTR YR 1991 MEAN 3.66 MAX 4.10 MIN 3.36

\section{WABASH RIVER BASIN}

03331400 NYONA LAKE NEAR GREENOAK, IN

LOCATION..-Lat $40^{\circ} 57^{\prime} 40^{\circ}$, long $86^{\circ} 11^{\prime} 20^{\circ}$, in SE dSE tNE sec.16, T.29 N., R.3 E., Fulton County, Hydrologic Unit 05120106 (MACY, IN quadrangle). The gage is on the northwest shore of the southern lobe of the lake, at the public fishing site, and $2.4 \mathrm{hi}$ south of Greenoak.

SURFACE AREA, --104 acres.

DRAI NAGE AREA. $--7.59=i^{2}$.

PERIOD OF RECORD.--1946 to current year.

DATUM OF GAGE.--790.00 ft above National Geodetic Vertical Datue of 1929.

GAGE.--A water-stage recorder is installed in an aluninue shelter over a 15-inch dianeter stilling well.

ESTABLISHED LEGAL LEVEL. --3.91 ft gage datun or $793.91 \mathrm{ft}$ above National Geodetic Vertical Datul of 1929 as decreed on September 27,1948 , by the Fulton County Circuit Court.

LAKE-LEVEL CONTROL.- -The level of the lake is controlled by a concrete dan with a fixed crest.

INLET AND OUTLET. - - The lake is fed by two snall ditches entering from the east and northeast.. The outlet flows frow the lake at the southwest corner and into Mud Creek, which eventually joins the Tippecanoe River.

EXTREMES FOR PERIOD OF RECORD..--Maxinun stage, $6.13 \mathrm{ft}$ Aug. 18, 1990; wininue stage, 2.98 ft 0ct, 12-19, 25, 26, 1953.

LAKE LEVEL, IN FEET ABOVE GAGE OATUM, WATER YEAR OCTOBER 1990 TO SEPTEMBER 1991 24:00 VALUES

\begin{tabular}{|c|c|c|c|c|c|c|c|c|c|c|c|}
\hline DAY & $O C T$ & NOV & DEC & JAN & FE B & MAR & APR & MAY & JUN & JUL & AUG \\
\hline $\begin{array}{r}5 \\
10 \\
15 \\
20 \\
25 \\
\text { EOM }\end{array}$ & $\begin{array}{l}4.20 \\
5.07 \\
4.42 \\
4.29 \\
4.19 \\
4.15\end{array}$ & $\begin{array}{r}4.57 \\
4.25 \\
4.18 \\
4.14 \\
4.12 \\
. \ldots\end{array}$ & $\begin{array}{l}\cdots . . \\
4.24 \\
4.21 \\
4.27 \\
5.57\end{array}$ & $\begin{array}{l}4.45 \\
4.25 \\
4.35 \\
4.38 \\
4.21 \\
4.15\end{array}$ & $\begin{array}{r}4.31 \\
4.25 \\
4.18 \\
4.33 \\
4.19 \\
4.16\end{array}$ & $\begin{array}{l}4.22 \\
4.14 \\
4.18 \\
4.46 \\
4.28 \\
4.26\end{array}$ & $\begin{array}{l}4.24 \\
4.24 \\
4.66 \\
4.33 \\
4.25 \\
4.20\end{array}$ & $\begin{array}{l}4.21 \\
4.15 \\
4.14 \\
4.19 \\
4.34 \\
4.26\end{array}$ & $\begin{array}{l}4.09 \\
4.05 \\
3.98 \\
4.02 \\
3.98 \\
3.97\end{array}$ & $\begin{array}{l}3.96 \\
4.07 \\
3.97 \\
3.94 \\
3.91 \\
3.90\end{array}$ & $\begin{array}{l}3.92 \\
3.98 \\
3.91 \\
3.96 \\
3.91 \\
4.05\end{array}$ \\
\hline
\end{tabular}




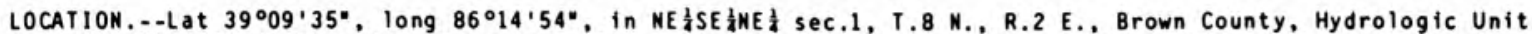
05120208 (NASHVILLE, IN quadrangle). The gage is on the dan, near the concrete intake structure on the west side of the lake, 3.3 a south of Nashville.

SURFACE AREA. --20 acres.

DRAI NAGE AREA. $--1.03 \mathrm{ai}^{2}$.

PERIOD OF RECORD.--1954 to current year.

DATUM OF GAGE.--710.00 ft above National Geodetic Vertical Datun of 1929.

GAGE.--A water-stage recorder is installed in an aluainu shelter over a 15-inch diameter stilling well.

ESTABLISHED LEGAL LEVEL. - - Not established.

LAKE-LEVEL CONTROL... The level of the lake is controlled by a concrete flood spillway with a fixed crest.

INLET AND OUTLET.-.Two ditches enter the lake, one from the east and one from the southeast. The outlet flows

into Upper Schooner Creek, which joins Lower Schooner Creek, then flows into the North Fork of Salt Creek. The

North Fork of Salt Creek enties into Monroe Reservoir.

EXTREMES FOR PERIOD OF RECORD.--Maximun stage, $6.80 \mathrm{ft}$ June 23, 1960; ainimum stage, -2.70 ft Feb. 12, 13 , 1977.

LAKE LEVEL, IN FEET ABOVE GAGE DATUM, WATER YEAR OCTOBER 1990 TO SEPTEMBER 1991 24:00 VALUES

\begin{tabular}{|c|c|c|c|c|c|c|c|c|c|c|c|c|}
\hline DAY & $\mathrm{OCT}$ & NOV & DEC & JAN & FEB & MAR & $A P R$ & MAY & JUN & JUL & AUG & SEP \\
\hline $\begin{array}{r}5 \\
10 \\
15 \\
20 \\
25 \\
\text { EOM }\end{array}$ & $\begin{array}{l}2.78 \\
2.93 \\
2.94 \\
2.93 \\
2.92 \\
2.84\end{array}$ & $\begin{array}{l}2.82 \\
2.79 \\
2.72 \\
2.71 \\
2.76 \\
3.20\end{array}$ & $\begin{array}{l}3.52 \\
3.58 \\
3.70 \\
4.65 \\
4.63 \\
4.70\end{array}$ & $\begin{array}{l}4.63 \\
4.64 \\
4.66 \\
4.63 \\
4.62 \\
4.62\end{array}$ & $\begin{array}{l}4.68 \\
4.67 \\
4.70 \\
4.70 \\
4.65 \\
4.62\end{array}$ & $\begin{array}{l}4.64 \\
4.64 \\
4.69 \\
4.69 \\
4.69 \\
4.70\end{array}$ & $\begin{array}{l}4.69 \\
4.68 \\
4.73 \\
4.72 \\
4.63 \\
4.59\end{array}$ & $\begin{array}{l}4.58 \\
4.58 \\
4.55 \\
4.46 \\
4.54 \\
4.57\end{array}$ & $\begin{array}{l}4.47 \\
4.31 \\
4.39 \\
4.36 \\
4.22 \\
4.03\end{array}$ & $\begin{array}{l}3.92 \\
3.79 \\
3.90 \\
3.75 \\
3.54 \\
3.30\end{array}$ & $\begin{array}{l}3.13 \\
3.13 \\
3.01 \\
2.94 \\
2.83 \\
2.68\end{array}$ & $\begin{array}{l}2.50 \\
2.34 \\
2.20 \\
2.04 \\
1.90 \\
1.76\end{array}$ \\
\hline
\end{tabular}

WTR YR 1991 MEAN 3.85 MAX 5.13 MIN 1.76

STREAMS TRIBUTARY TO LAKE MICHIGAM

04100100 OLIVER LAKE NEAR VALENTINE, IN

LOCATIOM.--Lat $41^{\circ} 34^{\prime} 37^{\circ}$, long $85^{\circ} 24^{\prime} 44^{\circ}$, in SE $\frac{1}{4}$ SW $\frac{1}{4}$, I $\frac{1}{4}$ sec.18, T.36 N., R.10 E., Lagrange County, Hydrologic Unit 04050001 (OLIVER LAKE, IN quadrangle). The gage is at the public fishing site on the northwest side of the lake, and 1.6 i southwest of Valentine.

SURFACE AREA. --362 acres.

DRAINAGE AREA. $\cdots 11.1 \backsim i^{2}$.

PERIOD OF RECORD. -1945 to current year.

DATUM OF GAGE.--889.78 ft above National Geodetic Vertical Datun of 1929 as corrected on the basis of levels of Indiana Departeent of Natural Resources, 1975-76.

GAGE.--A water-stage recorder is installed in an alueinue shelter over a 15-inch dianeter stilling well. An auxillary staff gage is attached to the dan in the outlet.

ESTABLISHEO LEGAL LEVEL. - $-9.45 \mathrm{ft}$ gage datue or $899.45 \mathrm{ft}$ above National Geodetic Vertical Datul of 1929 as decreed on Septeaber 29, 1952, by the Lagrange County Circuit Court. Minor errors were subsequently discovered in the estab-1 ishment of the datue of the gage (see "DATUM OF GAGE") and the correct elevation of the legal level should be 9.45 $\mathrm{ft}$ gage datue or $899.23 \mathrm{ft}$ above National Geodetic Vertical Datum of 1929 . Martin and 01 in Lakes near Valentine have have the same established level as 01 iver Lake and hence the same lake levels for the period of record.

LAKE-LEVEL CONTROL...The level of the lake is controlled by a fixed sill and dan with movable boards.

INLET AND OUTLET.--The lake has several inlets. Dove Creek enters on the northwest, the out let of Holsinger Hole on the north, Hart ditch on the east, and the channel between 01 iver and 01 in Lakes on the southeast shore.

The 01 iver Lake outlet flows fro the southwest lobe of the lake, through a wetland, into Hackenburg Lake

$1.6 \mathrm{i}$ downstrean, and eventually into the North Branch of the Elkhart River.

EXTREMES FOR PERIOD OF RECORD.--Maximun stage, $11.77 \mathrm{ft}$ June 14, 1981; ninimun stage, 8.42 ft Jan. 18 , 19, and Feb. 3-5, 1961 .

LAKE LEVEL, IN FEET ABOVE GAGE DATUM, WATER YEAR OCTOBER 1990 TO SEPTEMBER 1991

\begin{tabular}{|c|c|c|c|c|c|c|c|c|c|c|c|c|}
\hline DAY & OCT & NOV & DEC & JAN & FEB & MAR & APR & MAY & JUN & JUL & AUG & SEP \\
\hline $\begin{array}{r}5 \\
10 \\
15 \\
20 \\
25 \\
\text { EOM }\end{array}$ & $\begin{array}{r}9.81 \\
10.58 \\
10.42 \\
10.22 \\
10.00 \\
9.82\end{array}$ & $\begin{array}{r}10.04 \\
10.03 \\
9.87 \\
9.73 \\
9.68 \\
9.81\end{array}$ & $\begin{array}{r}9.81 \\
9.70 \\
9.66 \\
9.66 \\
9.69 \\
10.77\end{array}$ & $\begin{array}{r}10.37 \\
10.00 \\
9.91 \\
9.94 \\
9.85 \\
9.83\end{array}$ & $\begin{array}{l}9.62 \\
9.63 \\
9.63 \\
9.71 \\
9.66 \\
9.62\end{array}$ & $\begin{array}{l}9.70 \\
9.62 \\
9.55 \\
9.59 \\
9.67 \\
9.11\end{array}$ & $\begin{array}{r}9.69 \\
9.80 \\
9.87 \\
10.09 \\
10.08 \\
10.00\end{array}$ & $\begin{array}{r}9.91 \\
9.84 \\
9.75 \\
9.69 \\
9.91 \\
10.23\end{array}$ & $\begin{array}{r}10.17 \\
9.96 \\
9.82 \\
9.74 \\
9.68 \\
9.84\end{array}$ & $\begin{array}{r}10.15 \\
9.92 \\
9.83 \\
9.75 \\
9.70 \\
9.66\end{array}$ & $\begin{array}{l}9.70 \\
9.76 \\
9.73 \\
9.82 \\
9.76 \\
9.90\end{array}$ & $\begin{array}{l}9.83 \\
9.79 \\
9.86 \\
9.76 \\
9.72 \\
9.70\end{array}$ \\
\hline
\end{tabular}

WTR YR 1991 MEAN 9.85 MAX 10.77 MIN 9.54 
LOCATION.--Lat $41^{\circ} 10^{\prime} 48^{\prime \prime}$, long $85^{\circ} 56^{\prime} 54^{\circ}$, in NE $\frac{1}{4}$ NE $\frac{1}{4} S W^{\prime}$ sec.33, T.32 N., R.5 E., Kosciusko County, Hydrologic Unit 05120106 (BURKET, IN quadrangle). The gage is near the extrese northwestern corner of the lake, at the public access site, in the town of Palestine.

SURFACE AREA. --290 acres.

DRAINAGE AREA, $--32.4 \cdot i^{2}$

PERIOD OF RECORO, - 1954 to current year.

DATUM OF GAGE. - $815.00 \mathrm{ft}$ above National Geodetic Vertical Datue of 1929.

GAGE.--A water-stage recorder is installed in an aluainum shelter over a 15-inch dianeter stilling well. An auxiliary staff gage in one section is driven into the lake bed just north of the public access site.

ESTABLISHED LEGAL LEVEL. - - $1.62 \mathrm{ft}$ gage datu or $816.62 \mathrm{ft}$ above National Geodetic Vertical Datun of 1929 as decreed on August 5, 1965, by the Kosciusko County Circuit Court.

LAKE-LEVEL CONTROL.--The level of the lake is controlled by an old aill dae of stone and concrete (fixed crest) at the west lobe of the far northern shore.

INLET AND OUTLET.-.There are four inlets to the lake. Magee ditch enters from the north, Williason ditch from the west and the confluence of Adas and Sloan ditches from the southeast. Triable Creek flows through the lake, entering on the extrese southeastern end, leaving at the northwestern lobe and flowing into the Tippecanoe River 7.5 .i downstrea.

EXTREMES FOR PERIOD OF RECORD.--Maximum stage, $4.35 \mathrm{ft}$ June 13, 1981; winimu stage, below -0.90 ft, lake drained, 1988.

LAKE LEVEL, IN FEET ABOVE GAGE DATUM, WATER YEAR OCTOBER 1990 TO SEPTEMBER 1991 24:00 VALUES

\begin{tabular}{|c|c|c|c|c|c|c|c|c|c|c|c|c|}
\hline DAY & $O C T$ & NOV & DEC & JAN & FE B & MAR & $A P R$ & MAY & JUN & JUL & AUG & SEP \\
\hline $\begin{array}{r}5 \\
10 \\
15 \\
20 \\
25 \\
\text { EOM }\end{array}$ & $\begin{array}{l}2.01 \\
2.84 \\
2.23 \\
2.16 \\
2.06 \\
2.03\end{array}$ & $\begin{array}{l}2.35 \\
2.09 \\
2.02 \\
2.00 \\
1.98 \\
2.10\end{array}$ & $\begin{array}{l}2.16 \\
2.05 \\
2.08 \\
2.07 \\
2.17 \\
3.28\end{array}$ & $\begin{array}{l}2.13 \\
2.16 \\
2.06 \\
2.06\end{array}$ & $\begin{array}{l}2.21 \\
2.02 \\
1.96 \\
2.11 \\
1.98 \\
1.96\end{array}$ & $\begin{array}{l}2.05 \\
1.96 \\
1.96 \\
2.07 \\
2.02 \\
2.01\end{array}$ & $\begin{array}{l}2.00 \\
2.00 \\
2.28 \\
2.25 \\
2.10 \\
2.01\end{array}$ & $\begin{array}{l}2.04 \\
2.01 \\
1.95 \\
1.92 \\
1.99 \\
2.05\end{array}$ & $\begin{array}{l}1.96 \\
1.90 \\
1.89 \\
1.82 \\
1.81 \\
1.86\end{array}$ & $\begin{array}{l}1.78 \\
1.86 \\
1.82 \\
1.79 \\
1.73 \\
1.70\end{array}$ & $\begin{array}{l}1.68 \\
1.77 \\
1.71 \\
1.78 \\
1.71 \\
1.71\end{array}$ & $\begin{array}{l}1.71 \\
1.68 \\
1.72 \\
1.68 \\
1.71 \\
1.69\end{array}$ \\
\hline
\end{tabular}

WTR YR 1991 MEAN 1.98 MAX 3.34 MIN 1.67

WABASH RIVER BASIN

03331040 PIKE LAKE AT WARSAW, IN

LOCATION.--Lat $41^{\circ} 15^{\prime} 4^{\circ}$, long $85^{\circ} 51^{\prime} 00^{*}$, in NE $\frac{1}{2} N W \frac{1}{2} M E \frac{1}{2}$ sec.5. T.32 N., R.6 E.. Kosciusko County, Hydrologic Unit 05120106 (LEESBURG, IN quadrangle). The gage is on the extrene northwestern point of the lake at the bridge over the outlet, 1.6 a north of Warsaw.

SURFACE AREA, --203 acres.

DRAINAGE AREA. $--41.5 \bullet i^{2}$.

PERIOD OF RECORD..-1954 to current year.

DATUM OF GAGE. $-800.00 \mathrm{ft}$ above National Geodetic Vertical Datun of 1929.

GAGE.--A water-stage recorder is installed in an aluainua shelter over a 15-inch dianeter stilling well attached to the upstrean abutaent of the control structure.

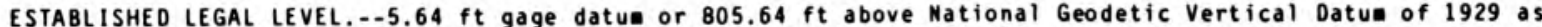
decreed on Deceaber 12, 1963, by the Kosciusko County Circuit Court.

LAKE-LEVEL CONTROL.- The level of the lake is controlled by a concrete dan with a fixed crest and reavable boards.

INLET AND OUTLET --The one inlet, Deeds Creek, flows fron Little Chapan Lake 3.4 a i ustrean, and enters the lake on the lower northern shore. The out let fiows to the west fro the extreae northern end of the lake through Lones ditch and enters the $T$ ippecanoe River 0.9 a downstrean.

EXTREMES FOR PERIOD OF RECORD.--Maximue stage, 10.79 ft Oct. 15, 1954; inimun stage, 3.71 ft Sept. 21.22 , 1955.

LAKE LEVEL, IN FEET ABOVE GAGE DATUM, WATER YEAR OCTOBER 1990 TO SEPTEMBER 1991 24:00 VALUES

\begin{tabular}{|c|c|c|c|c|c|c|c|c|c|c|c|}
\hline DAY & $\mathrm{OCT}$ & NOV & DEC & JAN & FE B & MAR & $A P R$ & MAY & JUN & JUL & AUG \\
\hline $\begin{array}{r}5 \\
10 \\
15 \\
20 \\
25 \\
\text { EOM }\end{array}$ & $\begin{array}{l}6.28 \\
7.50 \\
7.17 \\
6.63 \\
6.05 \\
5.79\end{array}$ & $\begin{array}{l}5.78 \\
5.64 \\
5.38 \\
5.14 \\
5.07 \\
5.32\end{array}$ & $\begin{array}{l}5.49 \\
5.25 \\
5.28 \\
5.26 \\
5.48 \\
8.71\end{array}$ & $\begin{array}{l}7.76 \\
7.01 \\
6.47 \\
6.23 \\
5.93 \\
5.48\end{array}$ & $\begin{array}{l}5.40 \\
5.27 \\
5.14 \\
5.37 \\
5.18 \\
5.14\end{array}$ & $\begin{array}{l}5.31 \\
5.15 \\
5.16 \\
5.39 \\
5.27 \\
5.28\end{array}$ & $\begin{array}{l}5.23 \\
5.25 \\
5.57 \\
6.07 \\
5.98 \\
5.77\end{array}$ & $\begin{array}{l}5.51 \\
5.25 \\
5.98 \\
5.94 \\
6.28 \\
6.39\end{array}$ & $\begin{array}{l}6.06 \\
5.95 \\
5.97 \\
5.88 \\
5.82 \\
6.09\end{array}$ & $\begin{array}{l}5.85 \\
5.79 \\
5.76 \\
5.72 \\
5.70 \\
5.70\end{array}$ & $\begin{array}{l}5.70 \\
5.76 \\
5.70 \\
5.79 \\
5.70 \\
5.73\end{array}$ \\
\hline
\end{tabular}

WTR YR 1991 MEAN 5.78 MAX 8.71 MIN 5.07 
LOCATION.--Lat $41^{\circ} 37^{\prime} 01^{\prime \prime}$, long $86^{\circ} 44^{\prime} 58^{\circ}$, in ME 07120001 (LAPORTE EAST, IN quadrangle). The gage is at the highway bridge over the channel connecting Pine and Stone Lakes, on Waverly Beach Road, in LaPorte.

SURFACE AREA.,--564 acres.

DRAI MAGE AREA, $--10.7 \mathrm{mi}^{2}$.

PERIOD OF RECORD.--1946-75, 1980 to current year.

DATUM OF GAGE. - -780.00 ft above National Geodetic Vertical Datun of 1929. Prior to 0ct. 1, 1964, the datun of the gage was $790.00 \mathrm{ft}$. All levels given below are at the present datue.

GAGE.--A water-stage recorder is installed in an aluainum shelter over a 15-inch dianeter stilling well. An auxiliary staff gage is driven into the channel bed at the sane site.

ESTABLISHED LEGAL LEVEL. - $16.20 \mathrm{ft}$ gage datun or $796.20 \mathrm{ft}$ above National Geodetic Vertical Datue of 1929 , as decreed on August 31, 1949, by the LaPorte County Circuit Court. Stone Lake at LaPorte has the same established level and hence the saue lake levels during the periods of record when the channel between the two lakes is open and flowing, water years 1946-63 and 1968-85.

LAKE-LEVEL CONTROL..-Pine and Stone Lakes form a closed basin; however, there is a capability of punping water fro the lakes into the Little Kankakee River during tiaes of high water.

INLET AND OUTLET,--Kabelin ditch enters Pine Lake fro the northwest through a large drain tile. Pine Lake is connected to Stone Lake by a channel on the southern $t$ ip.

EXTREMES FOR PERIOD OF RECORD.--Maximum stage, 20.81 ft May 7, 22, 1983; inimum stage, 9.00 ft Mov. 14, 1964.

LAKE LEVEL, IN FEET ABOVE GAGE DATUM, WATER YEAR OCTOBER 1990 TO SEPTEMBER 1991 24:00 VALUES

\begin{tabular}{|c|c|c|c|c|c|c|c|c|c|c|c|c|}
\hline DAY & $\mathrm{OCT}$ & MOV & DEC & JAN & FE B & MAR & APR & MAY & JUN & JUL & AUG & SEP \\
\hline $\begin{array}{r}5 \\
10 \\
15 \\
20 \\
25 \\
\text { EOM }\end{array}$ & $\begin{array}{l}17.23 \\
17.52 \\
17.52 \\
17.57 \\
17.52 \\
17.45\end{array}$ & $\begin{array}{l}17.69 \\
17.67 \\
17.63 \\
17.60 \\
17.59 \\
18.20\end{array}$ & $\begin{array}{l}18.23 \\
18.22 \\
18.24 \\
18.24 \\
18.29 \\
18.60\end{array}$ & $\begin{array}{l}18.61 \\
18.63 \\
18.71 \\
18.80 \\
18.81 \\
18.81\end{array}$ & $\begin{array}{l}18.82 \\
18.82 \\
18.93 \\
18.97 \\
18.97 \\
18.98\end{array}$ & $\begin{array}{l}19.13 \\
19.13 \\
19.15 \\
19.22 \\
19.19 \\
19.15\end{array}$ & $\begin{array}{l}19.11 \\
19.12 \\
19.19 \\
19.16 \\
19.12 \\
19.12\end{array}$ & $\begin{array}{l}19.11 \\
19.01 \\
18.94 \\
18.97 \\
19.12 \\
19.18\end{array}$ & $\begin{array}{l}19.05 \\
18.93 \\
18.88 \\
18.74 \\
18.68 \\
18.55\end{array}$ & $\begin{array}{r}18.44 \\
18.33 \\
18.24 \\
\ldots . \\
\ldots . \\
\ldots .\end{array}$ & $\begin{array}{r}\ldots . \\
\ldots \\
\cdots \\
17.88 \\
17.86\end{array}$ & $\begin{array}{l}17.90 \\
17.87 \\
17.90 \\
17.83 \\
17.79 \\
17.72\end{array}$ \\
\hline
\end{tabular}

WTR YR 1991 MEAN 18.48 MAX 19.24 MIN 17.12

\section{ILLINOIS RIVER BASIN}

\section{PRETTY LAKE NEAR PLYMOUTH}

LOCATION.--Lat $41^{\circ} 19^{\prime \prime} 39^{\prime \prime}$. Iong $86^{\circ} 22^{\prime} 15^{\circ}$, in NW/ $\frac{1}{4}$ SE $\frac{1}{4}$ NE $\frac{1}{4}$ sec. 11, T. 33 N., R. 1 E., Marshall County, Hydrologic Unit 07120001 , the gage is on the north shore of the lake, 3.3 ai southwest of Plyaouth.

SURFACE AREA. --97 acres.

DRAI NAGE AREA. $=-0.85 \mathrm{i}^{2}$.

PERIOD OF RECORD.-1954-66. 1989 to current year.

DATUM OF GAGE. $-780.00 \mathrm{ft}$ above National Geodetic Vertical Datun of 1929.

GAGE, - A staff gage in one section is driven into the lake bed near house at 10099 Pretty Lake Trail.

ESTABLISHED LEGAL LEVEL. - -7.36 ft gage datun or $787.36 \mathrm{ft}$ above National Geodetic Vertical Datua of 1929

as decreed on July 16, 1965, by the Marshall County Circuit Court.

LAKE-LEVEL CONTROL.--The level of the lake is controlled by the banks. At times of very high water levels, water overflows the southeastern shore.

INLET AND OUTLET.--There are no inlets. There is no well-defined outlet.

EXTREMES FOR PERIOD OF RECORD.--Maximun stage, 10.10 ft June 1, 1991; minimun stage, 4.90 ft Nov. 26 , 27.1964.

LAKE LEVEL. IN FEET ABOVE GAGE DATUM, WATER YEAR OCTOBER 1990 TO SEPTEMBER 1991 24:00 VALUES

\begin{tabular}{|c|c|c|c|c|c|c|c|c|c|c|c|c|}
\hline DAY & $\mathrm{OCT}$ & NOV & DEC & JAN & FEB & MAR & APR & MAY & JUN & JUL & AUG & SEP \\
\hline $\begin{array}{r}5 \\
10 \\
15 \\
20 \\
25 \\
\text { EOM }\end{array}$ & $\begin{array}{l}8.91 \\
9.18 \\
9.22 \\
9.24 \\
9.19 \\
9.14\end{array}$ & $\begin{array}{r}9.22 \\
9.28 \\
9.23 \\
\ldots . \\
\ldots \ldots\end{array}$ & $\begin{array}{l}\ldots \\
\cdots \\
\cdots \\
\cdots \\
\cdots \\
\cdots\end{array}$ & $\begin{array}{l}\ldots \\
\ldots \\
\ldots \\
\ldots \\
\ldots \\
\ldots\end{array}$ & $\begin{array}{l}\ldots \\
\ldots \\
\ldots \\
\ldots \\
\cdots\end{array}$ & $\begin{array}{l}\ldots \\
\ldots \\
\ldots \\
\ldots \\
\ldots \\
\ldots\end{array}$ & $\begin{array}{l}\ldots \\
\cdots \\
\cdots \\
\cdots \\
\cdots\end{array}$ & $\begin{array}{l}\ldots \\
\ldots \\
\cdots \\
\cdots \\
\cdots \\
\cdots\end{array}$ & $\begin{array}{r}10.07 \\
10.02 \\
9.78 \\
9.56 \\
9.32 \\
9.24\end{array}$ & $\begin{array}{l}9.20 \\
9.38 \\
9.27 \\
9.12 \\
8.96 \\
8.82\end{array}$ & $\begin{array}{l}8.80 \\
8.82 \\
8.76 \\
8.87 \\
8.79 \\
8.74\end{array}$ & $\begin{array}{l}8.68 \\
8.61 \\
8.64 \\
8.53 \\
8.46 \\
8.41\end{array}$ \\
\hline
\end{tabular}

WTR YR 1991 MEAN 9.09 MAX 10.10 MIN 8.08 
LOCATION.--Lat $41^{\circ} 30^{\prime} 19^{\circ}$, long $86^{\circ} 15^{\prime} 31^{\circ}$, in NW/ $\frac{1}{2}$ NE 07120001 (LAKEVILLE, in quadrangle). The gage is on the east side of the lake. about 1.4 a $i$ southeast of Lakeville.

SURFACE AREA. --71 acres.

ORAI NAGE AREA. $--11.7 \cdot i^{2}$.

PERIOD OF RECORD.--1946-71, 1976 to current year.

DATUM OF GAGE. - $810.00 \mathrm{ft}$ above Mational Geodetic Vertical Datun of 1929.

GAGE.--A water-stage recorder is installed in an alueinum shelter over a 15-inch diaeter stilling well. An auxiliary staff gage is attached to a wingwall of the control dae.

ESTABLISHED LEGAL LEVEL. $-7.50 \mathrm{ft}$ gage datue or $817.50 \mathrm{ft}$ above National Geodetic Vertical Datua of 1929 as decreed on July 3, 1953, by the St. Joseph County Circuit Court.

LAKE-LEVEL CONTROL.-.The level of the lake is controlled by a steel and concrete dan with a fixed crest. Boards ay be added to raise the water level.

IMLET AND OUTLET.--Heston ditch flows through the lake, entering on the northern shore and leaving on the southern. The outflow eventually enters Yellow River.

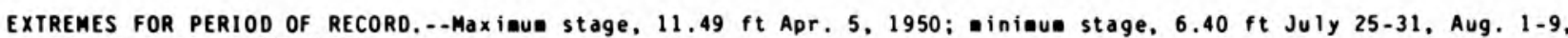
22-31. Sept. 1-30,1971.

LAKE LEVEL. IN FEET ABOVE GAGE DATUM, WAIER YEAR OCTOBER 1990 TO SEPTEMBER 1991 24:00 VALUES

\begin{tabular}{|c|c|c|c|c|c|c|c|c|c|c|c|c|}
\hline DAY & OCT & NOV & DEC & JAN & FEB & MAR & APR & MAY & JUN & JUL & AUG & SEP \\
\hline $\begin{array}{r}5 \\
10 \\
15 \\
20 \\
25 \\
\text { EOM }\end{array}$ & $\begin{array}{l}7.37 \\
8.47 \\
7.48 \\
7.39 \\
7.30 \\
7.29\end{array}$ & $\begin{array}{l}7.69 \\
7.38 \\
7.32 \\
7.30 \\
7.29 \\
7.54\end{array}$ & $\begin{array}{l}7.43 \\
7.37 \\
7.40 \\
7.34 \\
7.34 \\
8.35\end{array}$ & $\begin{array}{l}7.54 \\
7.42 \\
7.41 \\
7.48 \\
7.35 \\
7.31\end{array}$ & $\begin{array}{l}7.43 \\
7.37 \\
7.35 \\
7.55 \\
7.38 \\
7.35\end{array}$ & $\begin{array}{l}7.38 \\
7.33 \\
7.36 \\
7.38 \\
7.45 \\
7.39\end{array}$ & $\begin{array}{l}7.38 \\
7.35 \\
8.12 \\
7.62 \\
7.56 \\
7.52\end{array}$ & $\begin{array}{l}7.47 \\
7.44 \\
7.36 \\
7.39 \\
7.45 \\
7.59\end{array}$ & $\begin{array}{l}7.36 \\
7.29 \\
7.27 \\
7.23 \\
7.21 \\
7.23\end{array}$ & $\begin{array}{l}7.19 \\
7.20 \\
7.16 \\
7.12 \\
7.07 \\
7.01\end{array}$ & $\begin{array}{l}7.01 \\
7.12 \\
7.08 \\
7.39 \\
7.24 \\
7.30\end{array}$ & $\begin{array}{l}7.27 \\
7.21 \\
7.23 \\
7.16 \\
7.17 \\
7.17\end{array}$ \\
\hline
\end{tabular}

WTR YR 1991 MEAN 7.37 MAX 9.02 MIN 6.99

WABASH RIVER BASIN

03330300 RIDINGER LAKE MEAR PIERCETON, IN

LOCATION. - Lat $41^{\circ} 15^{\prime} 07^{\circ}$. Iong $85^{\circ} 39^{\prime} 34^{\circ}$, in SWłSWłSE sec.1, T.32 M., R.7 E.. Kosciusko County, Hydrologic Unit 05120106 (NORTH WEBSTER, IN quadrangle). The gage is on the inlet channel, attached to the Adaes Road bridge. 0.4 . 1 upstreas frov the lake and 4.4 i northeast of Pierceton.

SURFACE AREA. --136 acres.

DRAINAGE AREA,$--34.6 \cdot i^{2}$.

PERIOD OF RECORD..-1943 to current year.

DATUM OF GAGE. $-840.00 \mathrm{ft}$ above National Geodetic Vertical Datun of 1929.

GAGE, - -A water-stage recorder is installed in an alueinum shelter over a 15-inch dianeter stilling well attached to the right downstrea wingwall of the bridge. An auxiliary staff gage in two sections is at the control dan.

ESTABLISHED LEGAL LEVEL. - -3.12 ft gage datue or $843.12 \mathrm{ft}$ above National Geodetic Vertical Datua of 1929 , as decreed on April 11, 1949, by the Kosciusko County Circuit Court.

LAKE-LEVEL CONTROL.- - The level of the lake is controlled by a concrete dan with a fixed crest and a sluice-way with a steel gate for controlling high water. The dae is located in the outlet, $300 \mathrm{ft}$ downstreas froe the lake.

INLET AND OUTLET. - Grassy Creek flows through the lake, entering at the southwestern end. Grassy Creek is foraed $1.5 . i$ upstrea by the outlet of Robinson Lake and Cedar Lake Branch. Grassy Creek leaves the lake at the northwestern end and flows into Big Barbee Lake, 3.5 ai downstrean.

EXTREMES FOR PERIOD OF RECORD.--Maximum stage, 9.01 ft Feb. 24, 1985; wininue stage, $1.35 \mathrm{ft}$ Jan. $17-19$, 1944. LAKE LEVEL, IN FEET ABOVE GAGE DATUM. WATER YEAR OCTOBER 1990 TO SEPTEMBER 1991

\begin{tabular}{|c|c|c|c|c|c|c|c|c|c|c|c|c|}
\hline DAY & OCT & NOV & DEC & JAN & FE B & MAR & APR & MAY & JUN & JUL & AUG & SEP \\
\hline $\begin{array}{r}5 \\
10 \\
15 \\
20 \\
25 \\
\text { EOM }\end{array}$ & $\begin{array}{l}3.51 \\
6.34 \\
3.56 \\
3.22 \\
2.89 \\
2.80\end{array}$ & $\begin{array}{l}4.22 \\
3.07 \\
2.86 \\
2.78 \\
2.77 \\
3.06\end{array}$ & $\begin{array}{l}3.18 \\
2.90 \\
3.09 \\
2.96 \\
3.23 \\
6.65\end{array}$ & $\begin{array}{l}3.42 \\
2.99 \\
3.28 \\
3.16 \\
2.97 \\
2.82\end{array}$ & $\begin{array}{l}3.04 \\
2.89 \\
2.82 \\
3.09 \\
2.84 \\
2.81\end{array}$ & $\begin{array}{l}2.91 \\
2.78 \\
2.87 \\
3.05 \\
2.89 \\
2.86\end{array}$ & $\begin{array}{l}2.90 \\
2.96 \\
3.39 \\
3.69 \\
3.19 \\
2.97\end{array}$ & $\begin{array}{l}2.92 \\
2.77 \\
2.76 \\
2.70 \\
3.03 \\
4.00\end{array}$ & $\begin{array}{l}2.94 \\
2.72 \\
2.66 \\
2.59 \\
2.55 \\
2.68\end{array}$ & $\begin{array}{l}2.54 \\
2.52 \\
2.51 \\
2.49 \\
2.48 \\
2.48\end{array}$ & $\begin{array}{l}2.50 \\
2.51 \\
2.49 \\
2.52 \\
2.48 \\
2.56\end{array}$ & $\begin{array}{l}2.49 \\
2.50 \\
2.52 \\
2.48 \\
2.52 \\
2.52\end{array}$ \\
\hline
\end{tabular}

WTR YR 1991 MEAN 2.95 MAX 7.45 MIN 2.48 
LOCATION.--Lat $41^{\circ} 17^{\prime} 22^{\circ}$, long $85^{\circ} 42^{\prime} 52^{\circ}$, in NE $\frac{1}{4}$ SW $\frac{1}{2} M E$ t sec.28, T.33 M., R.7 E., Kosciusko County, Hydrologic Unit 05120106 (NORTH WEBSTER, IN quadrangle). The gage is near the southeastern corner of the county road bridge over the channel between Big Barbee Lake and Little Barbee Lake, 2.6 if southwest of North Webster.

SURFACE AREA. --36 acres.

DRAI NAGE AREA. $--51.8: i^{2}$.

PERIOD OF RECORD,--1945-1970, 1972 to current year.

DATUM OF GAGE. - - $830.00 \mathrm{ft}$ above National Geodetic Vertical Datun of 1929.

GAGE. - A water-stage recorder is installed in an aluainua shelter over a 15-inch dianeter stilling well. An auxiliary staff gage is attached to the stilling well.

ESTABLISHEO LEGAL LEVEL. . -7.50 ft gage datue or $837.50 \mathrm{ft}$ above National Geodetic Vertical Datue of 1929 as decreed on October 18, 1949, by the Kosciusko County Circuit Court. All lakes in the Barbee Chain have the sase established level and hence the sane lake levels for the period of record. The lakes are as follows: Kuhn, Big Barbee. Little Barbee, Irish. Banning, Sechrist and Sawaill.

LAKE-LEVEL CONTROL..-The level of the lakes is controlled by a concrete dan with a fixed crest, located 600 ft upstrean of the County Road 500 North bridge over the outlet of Sawnill Lake.

INLET AND OUTLET.-.There are four inlets to the Barbee Chain. Grassy Creek flows into Big Barbee Lake at the south. -eastern side. The outlet of Heron Lake flows into Kuhn Lake from the north. Punt ney ditch enters Little Barbee Lake from the south. The outlet from Shoe Lake flows into Banning Lake on the northeastern shore. The outlet. Grassy Creek, leaves Samill Lake at the northwestern tip and flows into Tippecanoe Lake 1.7 a downstrea.

EXTREMES FOR PERIOD OF RECORO.--Maxinum stage, 10.53 ft Mar. 20, 1982; winimu stage, 5.45 ft Jan. $29-31$, Feb. 1-28, Mar. 1, 2, 1978 .

LAKE LEVEL, IN FEET ABOVE GAGE DATUM, WATER YEAR OCTOBER 1990 TO SEPTEMBER 1991

\begin{tabular}{|c|c|c|c|c|c|c|c|c|c|c|c|}
\hline DAY & OCT & NOV & DEC & JAN & FE B & MAR & APR & MAY & JUN & JUL & AUG \\
\hline $\begin{array}{r}5 \\
10 \\
15 \\
20 \\
25 \\
\text { EOM }\end{array}$ & $\begin{array}{l}7.93 \\
8.91 \\
9.34 \\
8.86 \\
8.28 \\
7.73\end{array}$ & $\begin{array}{l}7.92 \\
8.07 \\
7.78 \\
7.56 \\
7.49 \\
7.77\end{array}$ & $\begin{array}{l}7.89 \\
7.69 \\
7.66 \\
7.76 \\
7.92 \\
9.70\end{array}$ & $\begin{array}{l}9.56 \\
8.86 \\
8.46 \\
8.32 \\
7.97 \\
7.68\end{array}$ & $\begin{array}{l}7.73 \\
7.76 \\
7.69 \\
7.79 \\
7.72 \\
7.66\end{array}$ & $\begin{array}{l}7.78 \\
7.57 \\
7.52 \\
7.83 \\
7.76 \\
7.68\end{array}$ & $\begin{array}{l}7.62 \\
7.70 \\
7.78 \\
8.29 \\
8.22 \\
8.02\end{array}$ & $\begin{array}{l}7.87 \\
7.67 \\
7.61 \\
7.51 \\
7.78 \\
8.00\end{array}$ & $\begin{array}{l}8.07 \\
7.72 \\
7.58 \\
7.44 \\
7.36 \\
7.36\end{array}$ & $\begin{array}{l}7.33 \\
7.28 \\
7.24 \\
7.20 \\
7.17 \\
7.14\end{array}$ & $\begin{array}{l}7.13 \\
7.21 \\
7.19 \\
7.26 \\
7.20 \\
7.31\end{array}$ \\
\hline
\end{tabular}

WTR YR 1991 MEAN 7.76 MAX 9.95 MIN 7.13

\section{WABASH RIVER BASIN}

03331120 SHERBURN LAKE NEAR PIERCETON, IN

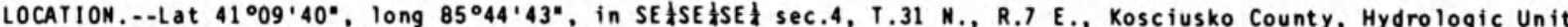
05120106 (PIERCETON, IN quadrangle). The gage is at the extreas northern end of the lake on the outlet channel just south of County Road 500 South, 3.4 ai southwest of Pierceton.

SURFACE AREA. --15 acres.

DRAINAGE AREA. $--5.51 \mathrm{i}^{2}$.

PERIOD OF RECORD.--1954 to current year. (Foreerly published as Johnson Lake near Pierceton.)

DATUM OF GAGE. - $-870.00 \mathrm{ft}$ above Mational Geodetic Vertical Datua of 1929. Prior to Oct. 1. 1980, the datua of the gage was $880.00 \mathrm{ft}$. All levels 1 isted below are at the present datum.

GAGE.--A water-stage recorder is installed in an aluainum shelter over a 15-inch dianeter stilling well. An auxiliary staff gage is driven into the lake bed just south of the western lobe of the lake, $400 \mathrm{ft}$ south of County Road 500 South on the first drive west of the outlet.

ESTABLISHED LEGAL LEVEL. - $-11.00 \mathrm{ft}$ gage datue or $881.00 \mathrm{ft}$ above National Geodetic Vertical Datue of 1929 as decreed on Decenber 19, 1974 , by the Kosciusko County Circuit Court.

LAKE-LEVEL CONTROL.-. The level of the lake is controlled by the invert of the culvert under the first east-west road north of the lake.

INLET AND OUTLET.-.The one inlet flows from Sellers Lake 0.35 apstreas. The outlet flows froe the northern shore through Wyland ditch and into Winona Lake 6.7 i downstrea.

EXTREMES FOR PERIOD OF RECORD.--Maxinue stage, 15.34 ft Dec, 30, 1990; wininue stage, 9.20 ft Sept. 14-18, 1983.

LAKE LEVEL, IN FEET ABOVE GAGE DATUM. WATER YEAR OCTOBER 1990 TO SEPTEMBER 1991

\begin{tabular}{|c|c|c|c|c|c|c|c|c|c|c|c|c|}
\hline DAY & $\mathrm{OCT}$ & NOV & DEC & JAN & FEB & MAR & APR & MAY & JUN & JUL & AUG & SEP \\
\hline $\begin{array}{r}5 \\
10 \\
15 \\
20 \\
25 \\
\text { EOM }\end{array}$ & $\begin{array}{l}11.55 \\
13.95 \\
11.88 \\
11.41 \\
11.01 \\
10.93\end{array}$ & $\begin{array}{l}12.08 \\
11.97 \\
11.35 \\
11.03 \\
10.89 \\
11.74\end{array}$ & $\begin{array}{r}12.15 \\
11.49 \\
11.33 \\
11.43 \\
11.75 \\
\ldots . .5\end{array}$ & $\begin{array}{r}\ldots . . \\
11.81 \\
12.03 \\
11.47 \\
11.05\end{array}$ & $\begin{array}{l}11.32 \\
11.41 \\
11.14 \\
11.64 \\
11.38 \\
11.20\end{array}$ & $\begin{array}{l}11.50 \\
10.96 \\
10.75 \\
11.48 \\
10.93 \\
10.91\end{array}$ & $\begin{array}{l}10.83 \\
10.94 \\
11.16 \\
11.91 \\
11.32 \\
10.86\end{array}$ & $\begin{array}{l}10.80 \\
10.50 \\
10.26 \\
10.15 \\
10.55 \\
10.88\end{array}$ & $\begin{array}{r}10.42 \\
10.00 \\
9.97 \\
9.93 \\
9.82 \\
9.91\end{array}$ & $\begin{array}{r}10.14 \\
10.12 \\
9.95 \\
9.85 \\
9.82 \\
9.85\end{array}$ & $\begin{array}{l}9.87 \\
9.95 \\
9.93 \\
9.89 \\
9.78 \\
9.79\end{array}$ & $\begin{array}{l}9.72 \\
9.66 \\
9.69 \\
9.62 \\
9.61 \\
9.59\end{array}$ \\
\hline
\end{tabular}

WTR YR 1991 MEAM 10.80 MAX 15.34 MIN 9.59 
LOCATION.--Lat $41^{\circ} 40^{\prime} 53^{\circ}$. long $85^{\circ} 36^{\prime} 03^{\circ}$. In SE tNE twe sec.9. T.37 N., R.8 E., Lagrange County, Hydrologic Unit 04050001 (SHIPSHEWAMA: IN quadrangle). The gage is on the south shore of the lake at the public fishing site, $1.1 . i$ northwest of Shipshewana.

SURFACE AREA.--202 acres.

DRAI NAGE AREA. $--6.74 \cdot i^{2}$.

PERIOD OF RECORD.--1951 to current year.

DATUM OF GAGE. - $-850.00 \mathrm{ft}$ above Mational Geodetic Vertical Datun of 1929.

GAGE.--A water-stage recorder is installed in an aluainu shelter over a 15-inch dianeter stilling well. An auxiliary staff gage is attached to a wingwall of the control dae at the extree eastern end of the lake.

ESTABLISHED LEGAL LEVEL. $-2.04 \mathrm{ft}$ gage datue or $852.04 \mathrm{ft}$ above Mational Geodetic Vertical Datue of 1929 as decreed on March 8, 1956, by the Lagrange County Circuit Court.

LAKE-LEVEL CONTROL.--The level of the lake is controlled by a sheet piling dae with a fixed crest at three elevations.

IMLET AND OUTLET.--The principal inlet enters on the southern shore fro Cotton Lake 2.0 i upstrea. Another suall ditch enters on the western shore. The outlet is on the extreae eastern tip of the lake and flows to the northeast through Page ditch, which eapties into Pigeon River, 6.1 ai downstrean.

EXTREMES FOR PERIOD OF RECORD.--Maxinue stage, $3.33 \mathrm{ft}$ Mar. 20, 1982; nininue stage, $1.39 \mathrm{ft}$ Sept. $19-22$, 1955.

LAKE LEVEL, IN FEET ABOVE GAGE DATUM, WATER YEAR OCTOBER 1990 TO SEPTEMBER 1991 24:00 VALUES

\begin{tabular}{|c|c|c|c|c|c|c|c|c|c|c|c|c|}
\hline DAY & OCT & NOV & DEC & JAN & FE B & MAR & APR & MAY & JUN & JUL & AUG & SEP \\
\hline $\begin{array}{r}5 \\
10 \\
15 \\
20 \\
25 \\
\text { EOM }\end{array}$ & $\begin{array}{l}2.39 \\
2.77 \\
2.70 \\
2.61 \\
2.50 \\
2.44\end{array}$ & $\begin{array}{l}2.63 \\
2.55 \\
2.48 \\
2.44 \\
2.45 \\
2.54\end{array}$ & $\begin{array}{l}2.56 \\
2.50 \\
2.52 \\
2.48 \\
2.50 \\
2.97\end{array}$ & $\begin{array}{l}2.86 \\
2.67 \\
2.58 \\
2.64 \\
2.63 \\
2.63\end{array}$ & $\begin{array}{l}2.63 \\
2.62 \\
2.62 \\
2.62 \\
2.62 \\
2.62\end{array}$ & $\begin{array}{l}2.63 \\
2.58 \\
2.49 \\
2.49 \\
2.45 \\
2.47\end{array}$ & $\begin{array}{l}2.48 \\
2.45 \\
2.52 \\
2.59 \\
2.62 \\
2.58\end{array}$ & $\begin{array}{l}2.51 \\
2.45 \\
2.39 \\
2.36 \\
2.42 \\
2.46\end{array}$ & $\begin{array}{l}2.37 \\
2.31 \\
2.28 \\
2.21 \\
2.15 \\
2.17\end{array}$ & $\begin{array}{l}2.30 \\
2.26 \\
2.26 \\
2.19 \\
2.13 \\
2.11\end{array}$ & $\begin{array}{l}2.11 \\
2.19 \\
2.14 \\
2.27 \\
2.19 \\
2.17\end{array}$ & $\begin{array}{l}2.19 \\
2.17 \\
2.32 \\
2.21 \\
2.19 \\
2.16\end{array}$ \\
\hline
\end{tabular}

WTR YR 1991 MEAN 2.44 MAX 2.97 MIN 2.09

WABASH RIVER BASIN

03330380 SHOE LAKE MEAR OSWEGO, IN

LOCATION, - -Lat $41^{\circ} 18 \cdot 32^{\prime \prime}$, long $85^{\circ} 45^{\prime} 10^{\circ}$, In SEłSWłSEł sec.18. T.33 N.. R.7 E.. Kosciusko County. Hydrologic Unit 05120106 (LEESBURG, I quadrangle). The gage is on the extreae western end of the lake on County Road 475 East, $2.0-i$ southeast of 0 swego.

SURFACE AREA. --40 acres.

DRAI NAGE AREA. $--0.34 \cdot i^{2}$.

PERIOD OF RECORD..-1946-52, 1972-74, 1977 to current year.

DATUM OF GAGE, $-830.00 \mathrm{ft}$ above Mational Geodetic Vertical Datue of 1929. Prior to 1972 , the datur of the gage was $840.00 \mathrm{ft}$ above National Geodetic Vertical Datur of 1929 . All levels listed below are at the present datun.

GAGE.--A water-stage recorder is installed in an aluainum shelter over a 15-inch dianeter stilling well.

ESTABLISHED LEGAL LEVEL. - -11.57 ft gage datue or $841.57 \mathrm{ft}$ above National Geodetic Vertical Datue of 1929 as decreed on October 18, 1948, by the Kosciusko County Circuit Court.

LAKE-LEVEL CONTROL...-The level of the lake is controlled by removable boards placed in wooden support posts in the out let channel, upstrean of the culvert under County Road 450 North.

INLET AND OUTLET.--There is no inlet except for sall drainage ditches. The outlet leaves the lake at the southeastern end and flows into Banning Lake 0.3 a downstrea.

EXTREMES FOR PERIOD OF RECORD.--Maximu stage, 12.95 ft Dec. 13-15, 1972; ininun stage. $10.50 \mathrm{ft} 0 \mathrm{ct}$. 15 , 16, 1988.

LAKE LEVEL, IN FEET ABOVE GAGE DATUM, WATER YEAR OCTOBER 1990 TO SEPTEMBER 1991

24:00 VALUES

$\begin{array}{rrrrrrrrrrrrr}\text { DAY } & \text { OCT } & \text { NOV } & \text { DEC } & \text { JAN } & \text { FEB } & \text { MAR } & \text { APR } & \text { MAY } & \text { JUM } & \text { JUL } & \text { AUG } & \text { SEP } \\ & & & & & & & & & & & \\ 5 & 12.09 & 12.32 & 12.27 & 12.49 & 12.43 & 12.34 & 12.21 & 12.25 & 12.26 & 11.92 & 11.43 & 11.23 \\ 10 & 12.34 & 12.27 & 12.24 & 12.45 & 12.40 & 12.27 & 12.21 & 12.20 & 12.19 & 11.84 & 11.45 & 11.15 \\ 15 & 12.26 & 12.25 & 12.26 & 12.45 & 12.40 & 12.27 & 12.24 & 12.17 & 12.21 & 11.77 & 11.38 & 11.16 \\ 20 & 12.24 & 12.21 & 12.24 & 12.43 & 12.39 & 12.28 & 12.29 & 12.12 & 12.15 & 11.68 & 11.47 & 11.05 \\ 25 & 12.20 & 12.20 & 12.27 & 12.40 & 12.34 & 12.26 & 12.29 & 12.23 & 12.06 & 11.57 & 11.39 & 10.99 \\ \text { EOM } & 12.17 & 12.24 & 12.53 & 12.42 & 12.34 & 12.23 & 12.25 & 12.43 & 12.00 & 11.47 & 11.31 & 10.90\end{array}$

WTR YR 1991 MEAN 12.06 MAX 12.56 MIN 10.90 
LOCATION.--Lat $41^{\circ} 14^{\prime} 37^{\circ}$, long $85^{\circ} 26^{\prime} 24^{\circ}$, in SE $\frac{1}{4}$ SW $\frac{1}{2}$ HWl sec.12, T.32 N., R.9 E., Whit ley County, Hydrologic Unit 05120104 (COLUMBIA CITY, IN quadrangle). The gage is at the head of the outlet channel at the east end of the lake, 6.2 i northeast of Coluabia City.

SURFACE AREA. --111 acres.

DRAI MAGE AREA, $--0.94 \cdot i^{2}$.

PERIOD OF RECORD.--1943-74, 1976-78, 1980 to current year.

DATUM OF GAGE.--900.19 ft above National Geodetic Vertical Datun of 1929.

GAGE.--A water-stage recorder is installed in an alueinum shelter over a 15-inch dianeter stilling well. An auxiliary staff gage in one section is attached to the concrete head wall at the outlet.

ESTABLISHED LEGAL LEVEL, $=-7.04 \mathrm{ft}$ gage datun or $907.04 \mathrm{ft}$ above National Geodetic Vertical Datum of 1929 as decreed on May 22, 1949, by the Whitley County Circuit Court. Minor errors were subsequently discovered in the establishment of the datun of the gage (see "DATUM OF GAGE") and the correct elevation of the legal level should be $7.04 \mathrm{ft}$ gage datua or $907.23 \mathrm{ft}$ above National Geodetic Vertical Datu of 1929.

LAKE-LEVEL CONTROL.--The level of the lake is controlled by a concrete dan in the outlet channel 300 ft downstrean of the lake.

INLET AND OUTLET.--A ditch from Catfish Lake, $650 \mathrm{ft}$ upstrean, enters at the extrene western end of the lake. Two sall ditches enter on the southern shore. The outlet is a dredged channel at the eastern edge of the lake that eapties into Round Lake $930 \mathrm{ft}$ downstrean.

EXTREMES FOR PERIOD OF RECORD.--Maximu stage, 8.26 ft Dec, 31, 1990; winimun stage, 5.44 ft Dec. 9-11, $23-30$, 1944 .

LAKE LEVEL, IN FEET ABOVE GAGE DATUM, WATER YEAR OCTOBER 1990 TO SEPTEMBER 1991 24:00 VALUES

\begin{tabular}{|c|c|c|c|c|c|c|c|c|c|c|c|}
\hline DAY & $\mathrm{OCT}$ & NoV & DEC & JAN & FEB & MAR & APR & MAY & JUN & JUL & AUG \\
\hline $\begin{array}{r}5 \\
10 \\
15 \\
20 \\
25 \\
\text { EOM }\end{array}$ & $\begin{array}{l}7.01 \\
7.85 \\
7.42 \\
7.23 \\
7.07 \\
6.95\end{array}$ & $\begin{array}{l}7.23 \\
7.17 \\
7.06 \\
6.96 \\
6.93 \\
7.09\end{array}$ & $\begin{array}{l}7.24 \\
7.18 \\
7.23 \\
7.22 \\
7.36 \\
8.26\end{array}$ & $\begin{array}{l}7.53 \\
7.43 \\
7.22 \\
7.19 \\
7.18 \\
7.18\end{array}$ & $\begin{array}{l}7.18 \\
7.10 \\
7.10 \\
7.10 \\
7.15 \\
7.15\end{array}$ & $\begin{array}{l}7.05 \\
6.97 \\
6.96 \\
7.07 \\
7.06 \\
7.08\end{array}$ & $\begin{array}{l}7.05 \\
7.13 \\
7.15 \\
7.38 \\
7.36 \\
7.29\end{array}$ & $\begin{array}{l}7.20 \\
7.11 \\
7.07 \\
6.96 \\
7.14 \\
7.70\end{array}$ & $\begin{array}{l}7.44 \\
7.20 \\
7.11 \\
7.04 \\
6.94 \\
7.07\end{array}$ & $\begin{array}{l}7.03 \\
6.95 \\
6.86 \\
6.77 \\
6.78 \\
6.66\end{array}$ & $\begin{array}{l}6.66 \\
6.67 \\
6.61 \\
6.65 \\
6.59 \\
6.54\end{array}$ \\
\hline
\end{tabular}

WTR YR 1991 MEAN 7.04 MAX 8.26 MIN 6.28

WABASH RIVER BASIN

03328350 SILVER LAKE AT SILVER LAKE, IN

LOCATION.--Lat $41^{\circ} 04^{\prime} 49^{\circ}$, Iong $85^{\circ} 54^{\prime} 29^{\prime}$, in SE $\frac{1}{4}$ SE $\frac{1}{4} N E \frac{1}{4}$ sec.1, T.30 N., R.5 E., Kosciusko County, Hydrologic Unit 05120104 (SILVER LAKE, IN quadrangle). The gage is located at the outlet channel on the west side of the lake, approxiately 30 feet above the control structure and 1.1 i northwest of the town of Silver Lake.

SURFACE AREA.--102 acres.

DRAINAGE AREA, $--6.31 \bullet i^{2}$.

PERIOD OF RECORD.--1947 to current year.

DATUM OF GAGE.--859.85 ft above National Geodetic Vertical Datun of 1929, as corrected on the basis of levels of Indiana Departaent of Natural Resources, 1974.

GAGE.--A water-stage recorder is installed in an alueinu shelter over a 15-inch dianeter stilling well. An auxiliary staff gage in one section is attached to the das.

ESTABLISHED LEGAL LEVEL. - $-1.73 \mathrm{ft}$ gage datue or $861.73 \mathrm{ft}$ above National Geodetic Vertical Datue of 1929 as decreed on Septeaber 20,1948, by the Kosciusko County Circuit Court. Minor errors were subsequently discovered in the estabiishment of the datum of the gage (see "DATUM OF GAGE") and the correct elevation of the legal level should be $1.73 \mathrm{ft}$ gage datua or $861.58 \mathrm{ft}$ above National Geodet ic Vertical Datua of 1929 . North Little Lake at Silver Lake has the same established level and hence the sane lake levels for the period of record.

LAKE-LEVEL CONTROL..-The level of the lake is controlled by a steel sheet piling dan with a fixed crest.

INLET AND OUTLET.-. The out let from North Little Lake enters from the north and two ditches enter from the east and southeast. The outlet leaves from the western side and flows into South Little Lake, then into Silver Creek. which joins Eel River 12 a downstrea.

EXTREMES FOR PERIOD OF RECORD.--Maximu stage, $3.80 \mathrm{ft}$ Dec. 10, 1966; ainimun stage, $-0.20 \mathrm{ft}$ Sept. 21.1959.

LAKE LEVEL. IN FEET ABOVE GAGE DATUM, WATER YEAR OCTOBER 1990 TO SEPTEMBER 1991 24:00 VALUES

\begin{tabular}{|c|c|c|c|c|c|c|c|c|c|c|c|c|}
\hline DAY & $\mathrm{OCT}$ & NOV & DEC & JAN & FEB & MAR & APR & MAY & JUN & JUL & AUG & SEP \\
\hline $\begin{array}{r}5 \\
10 \\
15 \\
20 \\
25 \\
\text { EOM }\end{array}$ & $\begin{array}{l}\ldots \\
\ldots \\
\ldots \\
\ldots \\
1.54\end{array}$ & $\begin{array}{l}1.88 \\
1.64 \\
1.57 \\
1.56 \\
1.54 \\
1.68\end{array}$ & $\begin{array}{r}1.71 \\
1.61 \\
1.66 \\
1.62 \\
\ldots . . \\
\ldots\end{array}$ & $\begin{array}{l}\cdots \\
1.71 \\
1.74 \\
1.74 \\
1.74\end{array}$ & $\begin{array}{l}1.75 \\
1.63 \\
1.60 \\
1.70 \\
1.60 \\
1.57\end{array}$ & $\begin{array}{l}1.61 \\
1.55 \\
1.56 \\
1.69 \\
1.62 \\
1.60\end{array}$ & $\begin{array}{l}1.62 \\
1.59 \\
1.74 \\
1.78 \\
1.67 \\
1.59\end{array}$ & $\begin{array}{l}1.66 \\
1.56 \\
1.52 \\
1.50 \\
1.52 \\
1.88\end{array}$ & $\begin{array}{l}1.57 \\
1.49 \\
1.57 \\
1.50 \\
1.46 \\
1.41\end{array}$ & $\begin{array}{l}1.40 \\
1.50 \\
1.44 \\
1.38 \\
1.28 \\
1.22\end{array}$ & $\begin{array}{l}1.19 \\
1.25 \\
1.21 \\
1.38 \\
1.36 \\
1.33\end{array}$ & $\begin{array}{l}1.37 \\
1.31 \\
1.32 \\
1.24 \\
1.20 \\
1.14\end{array}$ \\
\hline
\end{tabular}

WTR YR 1991 MEAN 1.53 MAX 1.91 MIN 1.14 
04099880 SIMONTON LAKE NEAR ELKHART, IN

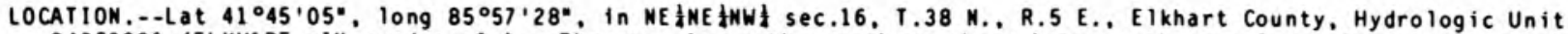
04050001 (ELKHART, IN quadrangle). The gage is on the southern shore between the two large lobes of the lake, at the public fishing site, 4.5 i north of the ain Post office in Elkhart.

SURFACE AREA.--303 acres.

DRAI NAGE AREA. $-7.44 \cdot i^{2}$.

PERIOD OF RECORD.--1946 to current year.

DATUM OF GAGE. - $770.00 \mathrm{ft}$ above National Geodetic Vertical Datue of 1929.

GAGE,--A water-stage recorder is installed in an aluainua shelter over a 15-inch diaeter stilling well.

ESTABLISHED LEGAL LEVEL. - $2.19 \mathrm{ft}$ gage datum or $772.19 \mathrm{ft}$ above National Geodetic Vertical Datue of 1929 as decreed on Septeaber 25, 1950, by the Elkhart County Circuit Court.

LAKE-LEVEL CONTROL..-The level of the lake is controlled by the outlet channel.

IMLET AND OUTLET.-. Two saall drainage ditches enter the lake on the eastern shore. The outlet. Osolo Township ditch, flows fro the lake at the southeastern tip and into the St. Joseph River. 4.0 a downstrean.

EXTREMES FOR PERIOD OF RECORD...Maximu stage, $3.42 \mathrm{ft}$ Feb. 24,1985 ; ainimun stage, $1.36 \mathrm{ft}$ Sept. 7.1946.

LAKE LEVEL, IN FEET ABOVE GAGE DATUM, WATER YEAR OCTOBER 1990 TO SEPTEMBER 1991 24:00 VALUES

\begin{tabular}{|c|c|c|c|c|c|c|c|c|c|c|c|c|}
\hline DAY & $\mathrm{OCT}$ & NOV & DEC & JAN & FE B & MAR & $A P R$ & MAY & JUN & JUL & AUG & SEP \\
\hline $\begin{array}{r}5 \\
10 \\
15 \\
20 \\
25 \\
\text { EOM }\end{array}$ & $\begin{array}{c}2.74 \\
2.97 \\
2.87 \\
2.85 \\
\ldots \ldots \\
\ldots . .\end{array}$ & $\begin{array}{l}2.97 \\
2.87 \\
2.85 \\
2.84 \\
2.83 \\
2.96\end{array}$ & $\begin{array}{l}2.93 \\
2.90 \\
2.90 \\
2.89 \\
2.91 \\
3.04\end{array}$ & $\begin{array}{l}2.97 \\
2.93 \\
2.94 \\
2.95 \\
2.93 \\
2.94\end{array}$ & $\begin{array}{l}2.94 \\
2.92 \\
2.97 \\
2.95 \\
2.92 \\
2.92\end{array}$ & $\begin{array}{l}2.92 \\
2.88 \\
2.87 \\
2.90 \\
2.89 \\
2.89\end{array}$ & $\begin{array}{l}2.91 \\
2.87 \\
2.97 \\
2.94 \\
2.96 \\
2.95\end{array}$ & $\begin{array}{l}2.97 \\
2.94 \\
2.90 \\
2.83 \\
2.94 \\
3.03\end{array}$ & $\begin{array}{l}2.85 \\
2.81 \\
2.81 \\
2.75 \\
2.68 \\
2.63\end{array}$ & $\begin{array}{c}2.65 \\
\ldots \\
\ldots \\
\ldots \\
\ldots\end{array}$ & $\begin{array}{l}\ldots \\
\ldots \\
\ldots \\
\ldots \\
\ldots \\
\ldots\end{array}$ & $\begin{array}{l}\ldots \\
\cdots \\
\cdots \\
\cdots\end{array}$ \\
\hline
\end{tabular}

WTR YR 1991 MEAN 2.89 MAX 3.16 MIN 2.63

STREAMS TRIBUTARY TO LAKE MICHIGAN

04100300 SKINMER LAKE NEAR ALBION, IN

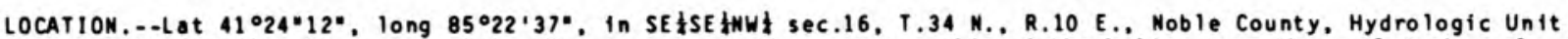
04050001 (ALBION, IN quadrangle). The gage is on the upstreas side of the bridge over the outlet channel on the northwest lobe of the lake, and 2.5 i northeast of Albion.

SURFACE AREA. --125 acres.

DRAINAGE AREA. $-14.0 \cdot 1^{2}$.

PERIOD OF RECORD,--1945-72, 1976 to current year.

DATUM OF GAGE.--920.00 ft above National Geodetic Vertical Datun of 1929.

GAGE.--A water-stage recorder is installed in an aluainu shelter over a 15-inch dianeter stilling well. An auxiliary staff gage is driven into the channel bed at the sane site.

ESTABLISHED LEGAL LEVEL. $-7.74 \mathrm{ft}$ gage datua or $927.74 \mathrm{ft}$ above National Geodetic Vertical Datue of 1929 . as decreed on August 31,1955 , by the Noble County Circuit Court.

LAKE-LEVEL CONTROL... The level of the lake is controlled by a steel sheet piling dan with a fixed crest.

INLET AND OUTLET.--Rineell Branch enters the lake on the southern shore, a seall ditch enters on the southeast tip. and the outlet channel of Sweet Lake flows into the lake fro the northeast. The outlet. Croft ditch. flows from the lake on the south shore of the northwest lobe. and into the South Branch of the Elkhart River 5.6 i downstrean.

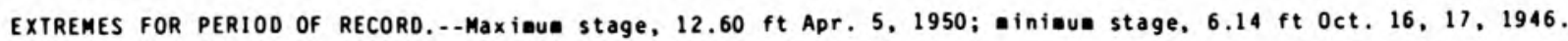

LAKE LEVEL, IN FEET ABOVE GAGE DATUM, WAIER YEAR OCTOBER 1990 TO SEPTEMBER 1991

\begin{tabular}{|c|c|c|c|c|c|c|c|c|c|c|c|c|}
\hline DAY & ОСТ & MOV & DEC & JAN & FE B & MAR & APR & MAY & JUN & JUL & AUG & SEP \\
\hline $\begin{array}{r}5 \\
10 \\
15 \\
20 \\
25 \\
\text { EOM }\end{array}$ & $\begin{array}{r}8.11 \\
10.28 \\
8.20 \\
8.03 \\
7.93 \\
7.88\end{array}$ & $\begin{array}{l}8.54 \\
8.01 \\
7.92 \\
7.88 \\
7.88 \\
8.03\end{array}$ & $\begin{array}{r}8.14 \\
7.96 \\
8.03 \\
8.02 \\
8.14 \\
11.44\end{array}$ & $\begin{array}{l}8.25 \\
7.98 \\
8.17 \\
8.11 \\
8.00 \\
8.00\end{array}$ & $\begin{array}{l}8.12 \\
7.99 \\
7.91 \\
8.16 \\
7.95 \\
7.92\end{array}$ & $\begin{array}{l}8.02 \\
7.93 \\
7.94 \\
8.01 \\
8.00 \\
7.93\end{array}$ & $\begin{array}{l}7.96 \\
8.02 \\
8.12 \\
8.58 \\
8.18 \\
8.06\end{array}$ & $\begin{array}{l}7.97 \\
7.90 \\
7.85 \\
7.83 \\
7.90 \\
9.28\end{array}$ & $\begin{array}{l}8.13 \\
7.87 \\
7.82 \\
7.79 \\
7.76 \\
7.89\end{array}$ & $\begin{array}{l}7.84 \\
7.76 \\
7.74 \\
7.73 \\
7.71 \\
7.74\end{array}$ & $\begin{array}{l}7.75 \\
7.76 \\
7.73 \\
7.78 \\
7.74 \\
7.73\end{array}$ & $\begin{array}{l}7.67 \\
7.66 \\
7.76 \\
7.70 \\
7.71 \\
7.67\end{array}$ \\
\hline
\end{tabular}

WTR YR 1991 MEAN 8.03 MAX 11.57 MIN 7.65 
LOCATION.--Lat $41^{\circ} 18^{\prime} 52^{\prime \prime}$, long $85^{\circ} 35^{\prime} 04^{\prime \prime}$, in SW'sWW 05120106 (ORMAS. IN quadrangle). The gage is located on the north side of the outlet channel, 300 ft upstreas frow the first bridge over the outlet, and 0.9 a southeast of Washington Center.

SURFACE AREA. - 69 acres.

DRAINAGE AREA. $--27.1 \div i^{2}$.

PERIOD OF RECORD. -1943 to current year.

DATUM OF GAGE. $-880.00 \mathrm{ft}$ above National Geodetic Vertical Datun of 1929.

GAGE.--A water-stage recorder is installed in an aluanus shelter over a $24-i n c h$ dianeter stilling well. An auxiliary staff gage is driven into the channel bed.

ESTABLISHED LEGAL LEVEL..-Not established.

LAKE-LEVEL CONTROL.-. The level of the lake is controlled by a riffle in the outlet channel 500 ft below the lake.

INLET AND OUTLET.- - The Tippecanoe River flows through the lake, entering at the south end from Big Lake, 4.2 a upstrean, and flowing from the lake at the northwestern end into Baugher Lake, 1.2 ai downstrean. Another

inlet enters on the north shore from Gilbert Lake 0.9 i upstrea.

EXTREMES FOR PERIOD OF RECORD.--Maximu stage, $7.00 \mathrm{ft}$ Mar. 24, 1978; winimu stage, $1.10 \mathrm{ft}$ Aug. 7 , 1963.

LAKE LEVEL, IN FEET ABOVE GAGE DATUM, WATER YEAR OCTOBER 1990 TO SEPTEMBER 1991 24:00 VALUES

\begin{tabular}{|c|c|c|c|c|c|c|c|c|c|c|c|c|}
\hline DAY & OCT & NOV & DEC & JAN & FE B & MAR & APR & MAY & JUN & JUL & AUG & SEP \\
\hline $\begin{array}{r}5 \\
10 \\
15 \\
20 \\
25 \\
\text { EOM }\end{array}$ & $\begin{array}{l}2.60 \\
4.68 \\
3.90 \\
3.18 \\
2.54 \\
2.08\end{array}$ & $\begin{array}{l}2.72 \\
2.88 \\
2.27 \\
2.06 \\
2.00 \\
2.51\end{array}$ & $\begin{array}{l}2.81 \\
2.35 \\
2.32 \\
2.47 \\
2.72 \\
5.51\end{array}$ & $\begin{array}{l}3.97 \\
2.94 \\
2.67 \\
2.81 \\
2.32 \\
2.11\end{array}$ & $\begin{array}{l}2.28 \\
2.28 \\
2.16 \\
2.56 \\
2.28 \\
2.13\end{array}$ & $\begin{array}{l}2.46 \\
2.10 \\
2.08 \\
2.54 \\
2.31 \\
2.30\end{array}$ & $\begin{array}{l}2.16 \\
2.50 \\
2.61 \\
3.42 \\
3.10 \\
2.77\end{array}$ & $\begin{array}{l}2.28 \\
2.11 \\
1.98 \\
1.79 \\
2.21 \\
3.32\end{array}$ & $\begin{array}{l}3.34 \\
2.44 \\
1.96 \\
1.69 \\
1.52 \\
1.72\end{array}$ & $\begin{array}{l}1.89 \\
1.60 \\
1.43 \\
1.35 \\
1.65 \\
1.44\end{array}$ & $\begin{array}{l}1.58 \\
1.49 \\
1.39 \\
1.41 \\
1.36 \\
1.33\end{array}$ & $\begin{array}{l}1.35 \\
1.42 \\
1.56 \\
1.57 \\
1.65 \\
1.71\end{array}$ \\
\hline
\end{tabular}

WTR YR 1991 MEAN 2.28 MAX 5.51 MIN 1.33

\section{STREAMS TRIBUTARY TO LAKE MICHIGAM \\ 04099780 STOME LAKE NEAR SCOTT, IN}

LOCATION.--Lat $41^{\circ} 44^{\prime} 32^{\prime \prime}$, long $85^{\circ} 39^{\prime} 03^{\prime \prime}$, in SE $\frac{1}{4}$ SE $\frac{1}{4} S W^{\frac{1}{4}}$ sec.18, T.38 N., R. 8 E., Lagrange County, Hydrologic Unit 04050001 (MIDDLEBURY, IN quadrangle). The gage is on the southeast shore of the lake approxiately 200 ft west of the intersection of County Road 1150 West and the lake access road, and 5.4 a northeast of Middlebury.

SURFACE AREA. --152 acres.

DRAI MAGE AREA. $\cdots 1.51 \mathrm{i}^{2}$.

PERIOD OF RECORD,--1954-71, 1975-76, 1978 to current year.

DATUM OF GAGE. - $-810.00 \mathrm{ft}$ above National Geodetic Vertical Datun of 1929.

GAGE.--A water-stage recorder is installed in an aluainu shelter over a 15-inch dianeter stilling well.

ESTABLISHED LEGAL LEVEL. - $8.76 \mathrm{ft}$ gage datun or $818.76 \mathrm{ft}$ above National Geodetic Vertical Datue of 1929 as decreed on July 28 , 1966 , by the Lagrange County Circuit Court.

LAKE-LEVEL CONTROL..-The level of the lake is controlled by a fixed-crest concrete sill.

INLET AND OUTLET.--The inlet enters on the eastern end of the south shore from Brokesha Lake 0.2 i upstrea. The outlet flows from the lake at the northern shore.

EXTREMES FOR PERIOD OF RECORD.--Maximu stage, 9.60 ft Apr. 16-30, 1969; ininue stage, 5.34 ft Mov. 26, 1964.

LAKE LEVEL. IN FEET ABOVE GAGE DATUM, WATER YEAR OCTOBER 1990 TO SEPTEMBER 1991

\begin{tabular}{|c|c|c|c|c|c|c|c|c|c|c|c|c|}
\hline DAY & ОСТ & MOV & DEC & JAN & FE B & MAR & APR & MAY & JUN & JUL & AUG & SEP \\
\hline $\begin{array}{r}5 \\
10 \\
15 \\
20 \\
25 \\
\text { EOM }\end{array}$ & $\begin{array}{l}8.09 \\
8.34 \\
8.34 \\
8.34 \\
8.30 \\
8.25\end{array}$ & $\begin{array}{l}8.40 \\
8.37 \\
8.35 \\
8.34 \\
8.33 \\
8.58\end{array}$ & $\begin{array}{l}8.63 \\
8.62 \\
8.64 \\
8.67 \\
8.69 \\
8.90\end{array}$ & $\begin{array}{l}8.83 \\
8.78 \\
8.78 \\
8.76 \\
8.71 \\
8.69\end{array}$ & $\begin{array}{l}8.68 \\
8.71 \\
8.83 \\
8.88 \\
8.87 \\
8.88\end{array}$ & $\begin{array}{l}8.92 \\
8.89 \\
8.85 \\
8.86 \\
8.88 \\
8.89\end{array}$ & $\begin{array}{l}8.89 \\
8.88 \\
8.95 \\
9.00 \\
9.01 \\
9.00\end{array}$ & $\begin{array}{l}8.99 \\
8.95 \\
8.92 \\
8.92 \\
8.95 \\
9.09\end{array}$ & $\begin{array}{l}8.94 \\
8.89 \\
8.86 \\
8.81 \\
8.72 \\
8.70\end{array}$ & $\begin{array}{l}8.74 \\
8.70 \\
8.63 \\
8.56 \\
8.50 \\
8.42\end{array}$ & $\begin{array}{l}8.34 \\
8.42 \\
8.30 \\
8.50 \\
8.45 \\
8.39\end{array}$ & $\begin{array}{l}8.40 \\
8.33 \\
8.28 \\
8.32 \\
8.31 \\
8.28\end{array}$ \\
\hline
\end{tabular}

WTR YR 1991 MEAM 8.65 MAX 9.09 MIN 8.02 
LOCATION.--Lat $41^{\circ} 29^{\prime} 53^{\circ}$. Iong $85^{\circ} 22^{\prime} 38^{\circ}$, in SE $\frac{1}{4}$ SE $\frac{1}{4} S W^{\frac{1}{4}} \sec .9$, T. 35 N., R.10 E., Noble County, Hydrologic Unit 04050001 (ALBION, IN quadrangle). The gage is at the south, upstrean side of the bridge over the outlet on the extreae western end of the lake, and et the northern edge of Rone City.

SURFACE AREA.--669 acres.

DRAI NAGE AREA. $--33.8 \cdot i^{2}$.

PERIOD OF RECORD. --1943 to current year.

DATUM OF GAGE. - $-907.00 \mathrm{ft}$ above National Geodetic Vertical Datua of 1929. Prior to 0ct. 1. 1978, the datua of the gage was $910.00 \mathrm{ft}$. All levels listed below are at the present datua.

GAGE.--A water-stage recorder is installed in an alueinum shelter over a 15-inch diaeeter stilling well. An auxiliary staff gage is attached to the north downstrean wall of the footbridge.

ESTABLISHED LEGAL LEVEL. - -9.20 ft present gage datu or $916.20 \mathrm{ft}$ above National Geodetic Vertical Datue of 1929 as decreed on June 14, 1951, by the Noble County Circuit Court.

LAKE-LEVEL CONTROL..-The level of the lake is controlled by a concrete dan with movable gates.

INLET AND OUTLET.--Barr Lake, 0.2 i upstrean, eopties into Sylvan Lake on the southeast shore of the northwest lobe. Oviatt ditch and Henderson Lake ditch both enter the lake on the extreme eastern end. The outlet flows fros the lake at the western tip. into Jones Lake 2.8 i downstrea and eventually into the North Branch of the Elkhart River.

EXTREMES FOR PERIOD OF RECORD.--Maximua stage, $10.76 \mathrm{ft}$ Feb. 251985 ; wininu stage, $2.72 \mathrm{ft}$ Nov. 8 , 1979.

LAKE LEVEL, IN FEET ABOVE GAGE DATUM, WATER YEAR OCTOBER 1990 TO SEPTEMBER 1991 24:00 VALUES

\begin{tabular}{|c|c|c|c|c|c|c|c|c|c|c|c|c|}
\hline DAY & $O C T$ & NOV & DEC & JAN & FE B & MAR & APR & MAY & JUN & JUL & AUG & SEP \\
\hline $\begin{array}{r}5 \\
10 \\
15 \\
20 \\
25 \\
\text { EOM }\end{array}$ & $\begin{array}{l}6.48 \\
7.07 \\
6.94 \\
6.68 \\
6.53 \\
6.42\end{array}$ & $\begin{array}{l}6.66 \\
6.72 \\
6.56 \\
6.46 \\
6.43 \\
6.57\end{array}$ & $\begin{array}{l}6.64 \\
6.55 \\
6.57 \\
6.62 \\
6.74 \\
7.58\end{array}$ & $\begin{array}{l}7.09 \\
6.76 \\
6.76 \\
6.77 \\
6.68 \\
6.52\end{array}$ & $\begin{array}{l}6.55 \\
6.55 \\
6.53 \\
6.63 \\
6.57 \\
6.54\end{array}$ & $\begin{array}{l}6.66 \\
6.54 \\
6.49 \\
6.50 \\
6.53 \\
6.58\end{array}$ & $\begin{array}{l}6.52 \\
6.57 \\
6.63 \\
7.02 \\
6.95 \\
6.80\end{array}$ & $\begin{array}{l}6.66 \\
6.54 \\
6.43 \\
6.41 \\
6.46 \\
7.24\end{array}$ & $\begin{array}{l}7.06 \\
6.61 \\
6.50 \\
6.38 \\
6.29 \\
6.52\end{array}$ & $\begin{array}{l}6.52 \\
6.37 \\
6.30 \\
6.26 \\
6.21 \\
6.22\end{array}$ & $\begin{array}{l}6.29 \\
6.33 \\
6.25 \\
6.29 \\
6.24 \\
6.25\end{array}$ & $\begin{array}{l}6.22 \\
6.22 \\
6.30 \\
6.21 \\
6.21 \\
6.20\end{array}$ \\
\hline
\end{tabular}

WTR YR 1991 MEAN 6.55 MAX 7.61 MIN 6.19

\section{STREAMS TRIBUTARY TO LAKE MICHIGAN}

04100460 SYRACUSE LAKE AT SYRACUSE, IN

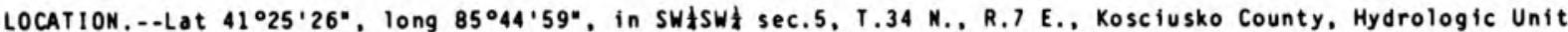
04050001 (LAKE WAWASEE. IN quadrangle). The gage is at the southwestern end of the lake, on the south abuteent of the das, and just west of the State Road 13 bridge in the town of Syracuse.

SURFACE AREA. -214 acres.

DRAI NAGE AREA. $--38.2 \backsim i^{2}$.

PERIOD OF RECORD. - - 1943 to current year.

DATUM OF GAGE. - $-849.85 \mathrm{ft}$ above National Geodetic Vertical Datun of 1929 as corrected on the basis of levels of Indiana Department of Natural Resources, 1973-14.

GAGE.--A water-stage recorder is installed in a concrete shelter over a stilling well in the south abutaent of the control structure. Two auxiliary staff gages are at the site. One is attached to the upstrean side of the south abutaent and the other is bolted to the seawall just west of the bridge over the outlet.

ESTABLISHED LEGAL LEVEL. - $-8.87 \mathrm{ft}$ gage datua or $858.87 \mathrm{ft}$ above National Geodetic Vertical Datue of 1929 as decreed on Septenber 20,1948, by the Kosciusko County Circuit Court. Minor errors were subsequent ly discovered in the estabiishnent of the datu of the gage (see "DATUM OF GAGE") and the correct elevation of the legal level should be $8.87 \mathrm{ft}$ gage datu or $858.72 \mathrm{ft}$ above National Geodetic Vertical Datua of 1929.

LAKE-LEVEL CONTROL.--The level of the lake is controlled by a concrete dan with two steel lift gates.

INLET AND OUTLET...The one inlet is the outlet channel from Lake Wawasee on the southern shore of the lake. The outlet. Turkey Creek, flows fro the lake at the southwest end and eventually into the Elkhart River.

EXTREMES FOR PERIOD OF RECORO..-Maximun stage, 10.15 ft Jan. 27, 28, 1950; ainimun stage, $7.00 \mathrm{ft}$ Nov. 19-21. 1953.

LAKE LEVEL, IN FEET ABOVE GAGE DATUM, WATER YEAR OCTOBER 1990 TO SEPIEMBER 1991 24:00 VALUES

\begin{tabular}{|c|c|c|c|c|c|c|c|c|c|c|c|c|}
\hline DAY & $\mathrm{OCT}$ & NOV & DEC & JAN & FE B & MAR & APR & MAY & JUN & JUL & AUG & SEP \\
\hline $\begin{array}{r}5 \\
10 \\
15 \\
20 \\
25 \\
\text { EOM }\end{array}$ & $\begin{array}{l}\ldots \\
\ldots \\
\ldots \\
\ldots \\
\ldots \\
\ldots\end{array}$ & $\begin{array}{l}8.84 \\
8.85 \\
8.78 \\
8.69 \\
8.60 \\
8.64\end{array}$ & $\begin{array}{l}8.68 \\
8.62 \\
8.57 \\
8.57 \\
8.58 \\
8.57\end{array}$ & $\begin{array}{l}8.57 \\
8.88 \\
9.20 \\
9.18 \\
9.11 \\
9.11\end{array}$ & $\begin{array}{l}8.83 \\
8.71 \\
8.62 \\
8.53 \\
8.43 \\
8.39\end{array}$ & $\begin{array}{l}8.40 \\
8.25 \\
8.37 \\
8.46 \\
8.49 \\
8.52\end{array}$ & $\begin{array}{l}8.51 \\
8.52 \\
8.54 \\
8.73 \\
8.84 \\
8.79\end{array}$ & $\begin{array}{l}8.70 \\
8.69 \\
8.68 \\
8.73 \\
8.88 \\
9.21\end{array}$ & $\begin{array}{l}9.03 \\
8.94 \\
8.87 \\
8.89 \\
8.82 \\
8.79\end{array}$ & $\begin{array}{l}8.74 \\
8.69 \\
8.62 \\
8.55 \\
8.56 \\
8.52\end{array}$ & $\begin{array}{l}8.53 \\
8.57 \\
8.53 \\
8.59 \\
8.56 \\
8.55\end{array}$ & $\begin{array}{l}8.57 \\
8.52 \\
8.65 \\
8.56 \\
8.53 \\
8.47\end{array}$ \\
\hline
\end{tabular}

WTR YR 1991 MEAN 8.68 MAX 9.21 MIN 8.25 


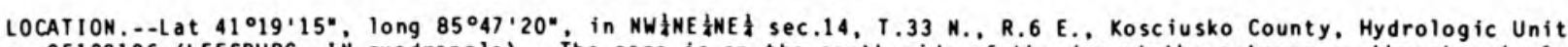
05120106 (LEESBURG. IN quadrangle). The gage is on the south side of the dan at the extreane southwest end of the lake, in the outlet channel, at 0 swego.

SURFACE AREA. -768 acres.

DRAINAGE AREA, $--113: \mathbf{i}^{2}$.

PERIOD OF RECORD. - 1943 to current year.

DATUM OF GAGE. $-830.00 \mathrm{ft}$ above National Geodetic Vertical Datun of 1929.

GAGE.--A water-stage recorder is installed in an aluninum shelter over a 15-inch diameter stilling well. An auxiliary staff gage is attached to the upstrean side of the south abutment of the dan.

ESTABLISHED LEGAL LEVEL. - -6.40 ft gage datum or $836.40 \mathrm{ft}$ above National Geodetic Vertical Datue of 1929 as decreed on October 18, 1949, by the Kosciusko County Circuit Court. Jaes Lake at 0 swego and 0 swego Lake at 0 swego have the sane established level and hence the sane lake levels for the period of record.

LAKE-LEVEL CONTROL.- The level of the lake is controlled by a concrete dan with multiple slide gates on the outlet channel of the lake.

INLET AND OUTLET.-.The lake has two principal inlets. The Tippecanoe River flows from Webster Lake, enters Janes Lake, and flows into Tippecanoe Lake on the eastern side. The outlet fro the Barbee Cha in of Lakes enters frow the southeast. The outlet, the Tippecanoe River, leaves the lake on the southwestern side.

EXTREMES FOR PERIOD OF RECORD.--Maximum stage, $9.43 \mathrm{ft}$ May 21, 1943; inimum stage, 4.90 ft Feb. 13-17, 1963.

LAKE LEVEL, IN FEET ABOVE GAGE DATUM, WATER YEAR OCTOBER 1990 TO SEPIEMBER 1991 $24: 00$ VALUES

\begin{tabular}{|c|c|c|c|c|c|c|c|c|c|c|c|c|}
\hline DAY & OCT & NOV & DEC & JAM & FEB & MAR & APR & MAY & JUN & JUL & AUG & SEP \\
\hline $\begin{array}{r}5 \\
10 \\
15 \\
20 \\
25 \\
\text { EOM }\end{array}$ & $\begin{array}{r}6.73 \\
6.77 \\
7.93 \\
\ldots \ldots \\
\ldots . .\end{array}$ & $\begin{array}{c}\ldots . \\
\cdots \\
\cdots \\
6.64 \\
6.62\end{array}$ & $\begin{array}{l}6.81 \\
6.84 \\
6.73 \\
6.73 \\
6.99 \\
8.18\end{array}$ & $\begin{array}{l}8.80 \\
8.28 \\
7.79 \\
7.65 \\
7.54 \\
7.02\end{array}$ & $\begin{array}{l}6.66 \\
6.57 \\
6.58 \\
6.58 \\
6.64 \\
6.60\end{array}$ & $\begin{array}{l}6.72 \\
6.66 \\
6.56 \\
6.54 \\
6.78 \\
6.84\end{array}$ & $\begin{array}{l}6.58 \\
6.74 \\
6.81 \\
7.27 \\
7.58 \\
7.50\end{array}$ & $\begin{array}{l}7.20 \\
6.85 \\
6.60 \\
6.56 \\
6.66 \\
7.13\end{array}$ & $\begin{array}{l}7.37 \\
7.12 \\
6.67 \\
6.67 \\
6.61 \\
6.58\end{array}$ & $\begin{array}{l}6.51 \\
6.45 \\
6.43 \\
6.34 \\
6.16 \\
6.02\end{array}$ & $\begin{array}{l}6.07 \\
6.30 \\
6.35 \\
6.47 \\
6.47 \\
6.49\end{array}$ & $\begin{array}{l}6.52 \\
6.51 \\
6.55 \\
6.40 \\
6.33 \\
6.24\end{array}$ \\
\hline
\end{tabular}

WTR YR 1991 MEAN 6.82 MAX 8.87 MIN 6.01

STREAMS TRIBUTARY TO LAKE MICHIGAN

04100320 UPPER LONG LAKE NEAR WOLFLAKE, IN

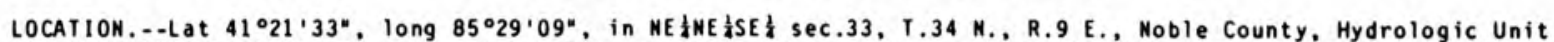
04050001 (MERRIAM, IN quadrangle). The gage is on the northeast shore of the lake, at the northernmost boat slip. and $1.8 \mathrm{i}$ north-northeast of the town of Wolflake.

SURFACE AREA. --86 acres.

DRAI NAGE AREA. $-2.08 \cdots i^{2}$.

PERIOD OF RECORD.- -1956 to current year.

DATUM OF GAGE. - -880.00 ft above National Geodetic Vertical Datun of 1929.

GAGE.--A water-stage recorder is installed in an aluminum shelter over a 15-inch dianeter stilling well. An auxillary staff gage is also located in the boat slip.

ESTABLISHED LEGAL LEVEL. - -11.19 ft gage datun or $891.19 \mathrm{ft}$ above National Geodetic Vertical Datum of 1929 as decreed on February 20,1968, by Noble County Circuit Court.

LAKE-LEVEL CONTROL..-The lake level is controlled by a fixed-sill concrete das.

INLET AND OUTLET.--There is one inlet that enters the lake from the eastern side. The outlet flows to the north through Dollar Lake, and eventually into the South Branch Elkhart River.

EXTREMES FOR PERIOD OF RECORD. --Maximum stage, 13.40 ft June 27, 1968; - inimua stage, 9.95 ft May $11,1970$.

LAKE LEVEL. IN FEET ABOVE GAGE DATUM, WATER YEAR OCTOBER 1990 TO SEPTEMBER 1991 24:00 VALUES

\begin{tabular}{|c|c|c|c|c|c|c|c|c|c|c|c|c|}
\hline DAY & OCT & NOV & DEC & JAN & FE B & MAR & APR & MAY & JUN & JUL & AUG & SEP \\
\hline $\begin{array}{r}5 \\
10 \\
15 \\
20 \\
25 \\
\text { EOM }\end{array}$ & $\begin{array}{l}11.70 \\
12.68 \\
12.13 \\
11.87 \\
11.58 \\
11.47\end{array}$ & $\begin{array}{l}11.80 \\
11.59 \\
11.49 \\
11.46 \\
11.45 \\
11.53\end{array}$ & $\begin{array}{l}11.61 \\
11.51 \\
11.53 \\
11.54 \\
11.59 \\
12.70\end{array}$ & $\begin{array}{l}11.70 \\
11.58 \\
11.63 \\
11.62 \\
11.53 \\
11.51\end{array}$ & $\begin{array}{l}11.53 \\
11.52 \\
11.52 \\
11.63 \\
11.56 \\
11.56\end{array}$ & $\begin{array}{l}11.65 \\
11.54 \\
11.53 \\
11.60 \\
11.61 \\
11.57\end{array}$ & $\begin{array}{l}11.57 \\
11.60 \\
11.75 \\
12.10 \\
11.83 \\
11.75\end{array}$ & $\begin{array}{l}11.74 \\
11.70 \\
11.71 \\
11.64 \\
11.83 \\
12.10\end{array}$ & $\begin{array}{l}11.71 \\
11.54 \\
11.50 \\
11.45 \\
11.41 \\
11.53\end{array}$ & $\begin{array}{l}11.51 \\
11.45 \\
11.43 \\
11.41 \\
11.44 \\
11.42\end{array}$ & $\begin{array}{r}11.43 \\
11.47 \\
\ldots . . \\
\ldots . . \\
\ldots . \\
\ldots .\end{array}$ & $\begin{array}{l}\ldots \\
\ldots \\
\ldots \\
\ldots \\
\ldots\end{array}$ \\
\hline
\end{tabular}

WTR YR 1991 MEAN 11.62 MAX 12.70 MIN 11.40 


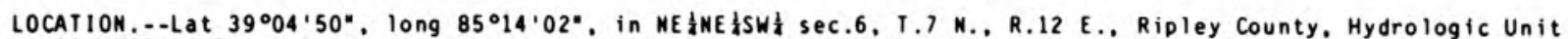
05090203 (MILAN. IN quadrangle). The gage is on the eastern side of the lake, on the downstrea side of the bridge over Falling Timber Creek in Versailles State Park.

SURFACE AREA. -232 acres.

DRAI NAGE AREA. $--168 \backsim i^{2}$.

PERIOD OF RECORD.--1958 to current year.

DATUM OF GAGE.--760.74 ft above National Geodetic Vertical Datum of 1929.

GAGE.--A water-stage recorder installed in an aluanua shelter over a 12 -inch dianeter stilling well.

ESTABLISHED LEGAL LEVEL. - - Not established.

LAKE-LEVEL CONTROL.--The level of the lake is controlled by a concrete spillway dan with a movable gate.

INLET AND OUTLET.--The inlets are Laughery Creek, Falling Timber Creek, and Cedar Creek. The outlet is Laughery Creek, which flows southeasterly and eapties into the Ohio River.

EXTREMES FOR PERIOD OF RECORD.--Maximua stage, $36.43 \mathrm{ft}$ Jan. 21, 1959, as deterained by the U.S. Geological Survey fro high-water arks during an indirect aeasurement of discharge: iniaum stage, 18.05 ft Apr. 12 . 1970 .

LAKE LEVEL, IN FEET ABOVE GAGE DATUM, WATER YEAR OCTOBER 1990 TO SEPTEMBER 1991 24:00 VALUES

\begin{tabular}{|c|c|c|c|c|c|c|c|c|c|c|c|c|}
\hline DAY & $O C T$ & NOV & DEC & JAN & FE B & MAR & APR & MAY & JUN & JUL & AUG & SEP \\
\hline $\begin{array}{r}5 \\
10 \\
15 \\
20 \\
25 \\
\text { EOM }\end{array}$ & $\begin{array}{l}29.41 \\
30.10 \\
29.28 \\
29.41 \\
29.33 \\
29.26\end{array}$ & $\begin{array}{l}29.25 \\
29.55 \\
29.29 \\
29.26 \\
29.38 \\
29.41\end{array}$ & $\begin{array}{l}29.52 \\
29.32 \\
30.22 \\
29.70 \\
29.60 \\
30.10\end{array}$ & $\begin{array}{l}29.39 \\
29.50 \\
29.51 \\
29.43 \\
29.32 \\
29.64\end{array}$ & $\begin{array}{l}29.74 \\
29.55 \\
29.60 \\
29.75 \\
29.38 \\
29.34\end{array}$ & $\begin{array}{l}29.32 \\
29.30 \\
29.64 \\
29.61 \\
29.58 \\
29.43\end{array}$ & $\begin{array}{l}29.42 \\
29.82 \\
30.30 \\
29.53 \\
29.36 \\
29.34\end{array}$ & $\begin{array}{l}29.33 \\
29.32 \\
29.27 \\
29.26 \\
29.24 \\
29.22\end{array}$ & $\begin{array}{l}29.19 \\
29.16 \\
29.15 \\
29.14 \\
29.07 \\
29.08\end{array}$ & $\begin{array}{l}28.99 \\
29.04 \\
29.13 \\
29.08 \\
28.95 \\
28.76\end{array}$ & $\begin{array}{l}28.73 \\
29.14 \\
29.05 \\
29.35 \\
29.12 \\
29.08\end{array}$ & $\begin{array}{l}29.54 \\
29.16 \\
29.23 \\
29.13 \\
29.12 \\
29.10\end{array}$ \\
\hline
\end{tabular}

WTR YR 1991 MEAN 29.45 MAX 32.90 MIN 28.73

STREAMS TRIBUTARY TO LAKE MICHIGAN

04100220 WALDRON LAKE NEAR COSPERVILLE, IN

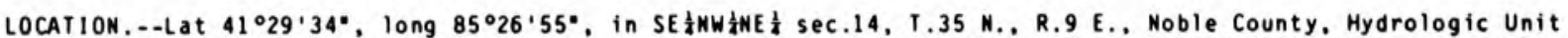
04050001 (ALBION. IN quadrangle). The gage is on a dredged channel at the public fishing site west of County Road 125 West at Dukes Bridge, and $6.8 \mathrm{i}$ northwest of Albion.

SURFACE AREA.--216 acres.

DRAI NAGE AREA. $--134 \mathbf{m}^{2}$.

PERIOD OF RECORD. - 1948 to current year.

DATUM OF GAGE, - $-880.00 \mathrm{ft}$ above National Geodetic Vertical Datun of 1929.

GAGE.--A water-stage recorder is installed in an aluainue shelter over a 15-inch dianeter stilling well. An auxiliary wire-weight gage is attached to the upstrea side of Dukes Bridge.

ESTABLISHED LEGAL LEVEL. $-5.55 \mathrm{ft}$ gage datue or $885.55 \mathrm{ft}$ above National Geodetic Vertical Datue of 1929 as decreed on May 6, 1968 , by the Moble County Circuit Court. Jones. Steinbarger and Tanarack Lakes, all near Cosperville, have the same established level as Waldron Lake and hence the same lake levels for the period of record.

LAKE-LEVEL CONTROL.--The level of the lake is controlled by a fixed-crest concrete dae with removable boards.

INLET AND OUTLET. - The North Branch of the Elkhart River flows through the lake, entering through Jones Lake at the north and leaving at the west end of Waldron Lake. Another inlet enters at the southeast from Steinbarger Lake, 0.1 i upstrean.

EXTREMES FOR PERIOD OF RECORD.--Maximue stage, 10.16 ft Mar. 22, 1982; ininua stage, 4.44 ft Aug. 9-11, Sept. 14-17, 1964 .

LAKE LEVEL, IN FEET ABOVE GAGE DATUM, WATER YEAR OCTOBER 1990 TO SEPTEMBER 1991 $24: 00$ VALUES

\begin{tabular}{|c|c|c|c|c|c|c|c|c|c|c|c|c|}
\hline DAY & OCT & MOV & DEC & JAN & FE B & MAR & $A P R$ & MAY & JUN & JUL & AUG & SEP \\
\hline $\begin{array}{r}5 \\
10 \\
15 \\
20 \\
25 \\
\text { EOM }\end{array}$ & $\begin{array}{l}6.59 \\
7.77 \\
8.35 \\
8.14 \\
7.66 \\
7.08\end{array}$ & $\begin{array}{l}7.12 \\
7.41 \\
7.14 \\
6.84 \\
6.62 \\
6.79\end{array}$ & $\begin{array}{l}6.95 \\
6.83 \\
6.69 \\
6.80 \\
6.94 \\
8.74\end{array}$ & $\begin{array}{l}8.75 \\
8.32 \\
8.10 \\
7.54 \\
7.09 \\
6.51\end{array}$ & $\begin{array}{l}6.62 \\
6.71 \\
6.54 \\
6.74 \\
6.70 \\
6.57\end{array}$ & $\begin{array}{l}6.83 \\
6.64 \\
6.40 \\
6.39 \\
6.35 \\
6.47\end{array}$ & $\begin{array}{l}6.37 \\
6.38 \\
6.49 \\
7.35 \\
7.70 \\
7.71\end{array}$ & $\begin{array}{l}7.43 \\
7.16 \\
6.90 \\
6.77 \\
6.92 \\
7.79\end{array}$ & $\begin{array}{l}8.50 \\
7.80 \\
7.21 \\
6.67 \\
6.13 \\
6.00\end{array}$ & $\begin{array}{l}6.80 \\
6.48 \\
6.17 \\
5.81 \\
5.67 \\
5.75\end{array}$ & $\begin{array}{l}5.85 \\
5.93 \\
5.80 \\
5.88 \\
5.79 \\
6.02\end{array}$ & $\begin{array}{l}5.88 \\
5.82 \\
6.12 \\
5.85 \\
5.77 \\
5.51\end{array}$ \\
\hline
\end{tabular}

WTR YR 1991 MEAN 6.80 MAX 8.86 MIN 5.51 
LOCATION.--Lat $41^{\circ} 32^{\prime} 02^{\prime \prime}$. long $87^{\circ} 02^{\prime} 42^{\circ}$, in NHW 07120001 (CHESTERTON, IN quadrangle). The gage is on the northwest shore of the lake, 4.7 i north of

Valparaiso.

SURFACE AREA, - -21 acres.

DRAINAGE AREA. $--0.40=i^{2}$.

PERIOD OF RECORD, - 1946 to current year.

DATUM OF GAGE. - $790.00 \mathrm{ft}$ above Mational Geodetic Vertical Datun of 1929.

GAGE.--A staff gage in one section is driven into the lake bed, $15 \mathrm{ft}$ fron Arthur J. Knoblich's cottage. An auxiliary staff gage is $20 \mathrm{ft}$ lakeward of the 1 in gage.

ESTABLISHED LEGAL LEVEL. - - Not established.

LAKE-LEVEL CONTROL.--The level of the lake is controlled by the out let channel.

INLET AND OUILET.--The lake has one inlet entering on the northeast side from Mink Lake 0.3 a upstrean. The outlet flows fro the southeast shore, southwesterly through a swap to Canada Lake 0.3 a downstrean.

EXTREMES FOR PERIOD OF RECORD. --Maxinum stage, $11.05 \mathrm{ft}$ Apr. 23, 1973; wininun stage, 6.58 ft Sept. 17.1964.

LAKE LEVEL. IN FEEt ABOVE GAGE DATUM. WATER YEAR OCTOBER 1990 TO SEPTEMBER 1991 24:00 VALUES

\begin{tabular}{|c|c|c|c|c|c|c|c|c|c|c|c|c|}
\hline DAY & $O C T$ & NOV & DEC & JAN & FEB & MAR & APR & MAY & JUN & JUL & AUG & SEP \\
\hline $\begin{array}{r}5 \\
10 \\
15 \\
20 \\
25 \\
\text { EOM }\end{array}$ & $\begin{array}{l}9.34 \\
9.88 \\
9.86 \\
9.76 \\
9.62 \\
9.46\end{array}$ & $\begin{array}{r}9.66 \\
9.70 \\
9.60 \\
9.48 \\
9.42 \\
10.60\end{array}$ & $\begin{array}{r}10.32 \\
10.08 \\
9.82 \\
9.78 \\
9.74 \\
10.24\end{array}$ & $\begin{array}{l}\ldots \\
\ldots \\
\cdots \\
\cdots \\
\cdots\end{array}$ & $\begin{array}{l}\ldots \\
\ldots \\
\ldots \\
\ldots \\
\ldots\end{array}$ & $\begin{array}{l}10.18 \\
10.06 \\
10.02 \\
10.11 \\
10.04 \\
10.00\end{array}$ & $\begin{array}{r}9.95 \\
9.95 \\
10.15 \\
10.35 \\
10.30 \\
10.18\end{array}$ & $\begin{array}{l}10.14 \\
10.20 \\
10.04 \\
10.08 \\
10.50 \\
10.70\end{array}$ & $\begin{array}{r}10.50 \\
10.40 \\
10.00 \\
9.90 \\
9.84 \\
9.72\end{array}$ & $\begin{array}{l}9.56 \\
9.68 \\
9.58 \\
9.46 \\
9.36 \\
9.14\end{array}$ & $\begin{array}{l}9.08 \\
9.18 \\
9.10 \\
9.10 \\
9.40 \\
8.60\end{array}$ & $\begin{array}{l}9.00 \\
8.98 \\
8.94 \\
8.85 \\
8.80 \\
8.90\end{array}$ \\
\hline
\end{tabular}

WTR YR 1991 MEAN 9.73 MAX 10.70 MIN 8.60

WABASH RIVER BASIN

03330240 WEBSTER LAKE AT NORTH WEBSTER, IN

LOCATION.--Lat $41^{\circ} 19^{\circ} 09^{*}$, long $85^{\circ} 41^{\prime} 20^{\circ}$, in NE $\frac{1}{4} S H^{\frac{1}{3}} \mathrm{HW} \frac{1}{4} \mathrm{sec} .14$, T.33 N., R.7 E., Kosciusko County, Hydrologic Unit 05120106 (NORTH WEBSTER, IN quadrangle). The gage is on the southwest side of the lake at the outlet. $0.3-i$ northeast of the intersection of State Road 13 and County Road 550 North and approxinately 0.6 southeast of the center of North Webster.

SURFACE AREA. --774 acres.

DRAI NAGE AREA. $--49.2 \cdot i^{2}$.

PERIOD OF RECORD..-1943 to current year.

DATUM OF GAGE. - $839.93 \mathrm{ft}$ above National Geodetic Vertical Datun of 1929, as corrected on the basis of levels of Indiana Department of Natural Resources, 1973-74.

GAGE.--A water-stage recorder is installed in an aluninum shelter over a 15-inch dianeter stilling well. An auxillary staff gage in one section is bolted to the southeast face of the concrete wall of the approach channel to the control dam.

ESTABLISHED LEGAL LEVEL, $-12.75 \mathrm{ft}$ gage datum or $852.75 \mathrm{ft}$ above National Geodetic Vertical Datue of 1929 as decreed July 2, 1945, by the Kosciusko County Circuit Court. Minor errors were subsequently discovered in the establishaent of the datum of the gage (see "DATUM OF GAGE") and the correct elevation of the legal level should be $12.75 \mathrm{ft}$. gage datun or $852.68 \mathrm{ft}$ above National Geodetic Vertical Datun of 1929 .

LAKE-LEVEL CONTROL..-The level of the lake is controlled by a concrete notch da with seven adjustable gates at the head of the outlet channel. North of this dan is another which used to serve as a ill race. This dan has one aetal gate.

INLET AND OUTLET. - The Tippecanoe River flows through Webster Lake, entering at the southeast end and leaving at the southwest side. The Tippecanoe River enters Janes Lake, 2.1 i downstrean.

EXTREMES FOR PERIOD OF RECORD,.--Maximu stage, $15.15 \mathrm{ft}$ Feb. 11, 1984; a iniau stage, $9.79 \mathrm{ft}$ (during repair of the dan) Oct. 5, 1962.

LAKE LEVEL, IN FEET ABOVE GAGE DATUM, WATER YEAR OCTOBER 1990 TO SEPTEMBER 1991 24:00 VALUES

\begin{tabular}{|c|c|c|c|c|c|c|c|c|c|c|c|c|}
\hline DAY & OCT & NOV & DEC & JAN & FEB & MAR & APR & MAY & JUN & JUL & AUG & SEP \\
\hline $\begin{array}{r}5 \\
10 \\
15 \\
20 \\
25 \\
\text { EOM }\end{array}$ & $\begin{array}{l}13.31 \\
13.59 \\
13.79 \\
13.36 \\
13.10 \\
12.99\end{array}$ & $\begin{array}{l}13.07 \\
12.95 \\
12.91 \\
12.81 \\
12.50 \\
12.68\end{array}$ & $\begin{array}{l}12.94 \\
13.15 \\
13.12 \\
13.22 \\
13.25 \\
14.04\end{array}$ & $\begin{array}{l}13.94 \\
13.18 \\
12.94 \\
13.32 \\
13.08 \\
12.57\end{array}$ & $\begin{array}{l}12.52 \\
12.81 \\
12.65 \\
12.60 \\
12.70 \\
12.63\end{array}$ & $\begin{array}{l}12.78 \\
12.70 \\
12.54 \\
12.91 \\
12.89 \\
12.77\end{array}$ & $\begin{array}{l}12.93 \\
12.97 \\
12.95 \\
13.41 \\
13.48 \\
13.11\end{array}$ & $\begin{array}{l}12.99 \\
13.01 \\
13.19 \\
13.10 \\
13.35 \\
13.45\end{array}$ & $\begin{array}{l}13.55 \\
13.14 \\
13.17 \\
13.20 \\
13.07 \\
13.14\end{array}$ & $\begin{array}{l}13.25 \\
13.25 \\
13.20 \\
13.10 \\
13.22 \\
13.20\end{array}$ & $\begin{array}{l}13.21 \\
13.14 \\
13.04 \\
13.09 \\
13.02 \\
13.07\end{array}$ & $\begin{array}{l}12.92 \\
12.78 \\
12.78 \\
12.75 \\
12.78 \\
12.77\end{array}$ \\
\hline
\end{tabular}

WTR YR 1991 MEAN 13.06 MAX 14.19 MIN 12.40 
05514770 WHARTON LAKE NEAR SOUTH BEND. IN

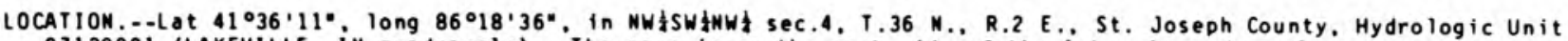
07120001 (LAKEVILLE, IN quadrangle). The gage is on the east side of the lake, in a channel west of a storage shed at the Calvert Rod and Gun Club property, and 5.7 i northwest of Lakeville.

SURFACE AREA.--18 acres (measured on U.S. Geological Survey topographic map. Scale $1: 24000$ ).

DRAI NAGE AREA. $-1.85 \cdot i^{2}$.

PERIOD OF RECORD.--1960-76, 1982 to current year.

DATUM OF GAGE. $--770.00 \mathrm{ft}$ above National Geodetic Vertical Datue of 1929.

GAGE.--A water-stage recorder is installed in an aluanu shelter over a 15-inch dianeter stilling well.

ESTABLISHED LEGAL LEVEL..--Not established.

LAKE-LEVEL CONTROL.--The level of the lake is controlled by a 48 -inch round concrete tile in the outlet channel.

INLET AND OUTLET.--The one inlet enters the lake on the southeastern shore and drains the inediately surrounding area. The outlet flows from the lake on the western shore, and eventually into the kankakee River.

EXTREMES FOR PERIOD OF RECORD.--Maximun stage. 8.51 ft Jan. 8, 9, 10, 1989; aininua stage, 4.94 ft Sept. $30,1991$.

LAKE LEVEL, IN FEET ABOVE GAGE DATUM, WATER YEAR OCTOBER 1990 TO SEPIEMBER 1991 24:00 VALUES

\begin{tabular}{|c|c|c|c|c|c|c|c|c|c|c|c|c|}
\hline DAY & $\mathrm{OCT}$ & MOV & DEC & JAK & FE B & MAR & APR & MAY & JUN & JUL & AUG & SEP \\
\hline $\begin{array}{r}5 \\
10 \\
15 \\
20 \\
25 \\
\text { EOM }\end{array}$ & $\begin{array}{l}6.88 \\
7.44 \\
7.05 \\
7.01 \\
6.93 \\
6.85\end{array}$ & $\begin{array}{l}7.30 \\
7.00 \\
6.91 \\
6.87 \\
6.89 \\
7.13\end{array}$ & $\begin{array}{l}7.07 \\
6.99 \\
7.00 \\
6.95 \\
7.01 \\
7.78\end{array}$ & $\begin{array}{l}7.77 \\
7.77 \\
6.98 \\
7.04 \\
7.04 \\
7.03\end{array}$ & $\begin{array}{l}7.06 \\
6.96 \\
6.97 \\
7.16 \\
6.97 \\
6.95\end{array}$ & $\begin{array}{l}6.99 \\
6.91 \\
6.91 \\
6.94 \\
6.99 \\
6.97\end{array}$ & $\begin{array}{c}6.98 \\
6.96 \\
7.33 \\
\ldots . \\
\ldots .\end{array}$ & $\begin{array}{l}\ldots \\
\cdots \\
\cdots \\
\cdots \\
\cdots\end{array}$ & $\begin{array}{l}6.76 \\
6.57 \\
6.49 \\
6.32 \\
6.19 \\
6.05\end{array}$ & $\begin{array}{l}5.92 \\
5.82 \\
5.68 \\
5.50 \\
5.37 \\
5.22\end{array}$ & $\begin{array}{l}5.12 \\
5.30 \\
5.19 \\
5.35 \\
5.16 \\
5.01\end{array}$ & $\begin{array}{l}5.08 \\
4.99 \\
5.14 \\
5.05 \\
5.05 \\
4.94\end{array}$ \\
\hline
\end{tabular}

WTR YR 1991 MEAN 6.50 MAX 7.93 MIN 4.94

\author{
WABASH RIVER BASIN \\ 03331140 WINONA LAKE AT WARSAW, IN
}

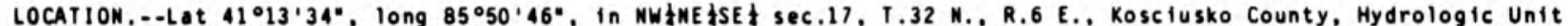
05120106 (WARSAW, IN quadrangle). The gage is on the western side of the lake, $20 \mathrm{ft}$ east of the dan on the northern side of the outlet channel. 1.0 ai south of Warsaw.

SURFACE AREA.- -562 acres.

DRAI MAGE AREA. $--32.1 \oplus i^{2}$.

PERIOD OF RECORD, $-1943-78,1980$ to current year.

DATUM OF GAGE. - $-800.10 \mathrm{ft}$ above National Geodetic Vertical Datu of 1929. Prior to Nov. 17. 1971, the datue of the gage was $810.10 \mathrm{ft}$ above National Geodetic Vertical Datu of 1929 as corrected on the basis of levels of Indiana Departaent of Natural Resources, 1973-74. All levels 1 isted below are at the present datue.

GAGE.--A water-stage recorder is installed in an alueinu shelter over a 15-inch dianeter stilling well. An auxiliary staff gage is attached to the stilling well.

ESTABLISHED LEGAL LEVEL. $-11.06 \mathrm{ft}$ gage datue or $811.06 \mathrm{ft}$ above National Geodetic Vertical Oatue of 1929 as decreed on June 17, 1949. by the Kosciusko County Circuit Court. Minor errors were subsequently discovered in the establisheent of the datue of the gage (see. DATUM OF GAGE") and the correct elevation of the legal level should be $11.06 \mathrm{ft}$ gage datun or $811.16 \mathrm{ft}$ above National Geodetic Vertical Datun of 1929.

LAKE-LEVEL CONTROL.-.The level of the lake is controlled by a concrete fixed-crest dan with steel lift gates.

INLET AND OUTLET.-.There are three inlets to the lake. Wyland ditch enters on the eastern shore froe Sherburn Lake 6,7 i upstrea. Keefer-Evans ditch enters on the southeastern shore and Paterson ditch on the southwestern shore. The outlet, Eagle Creek. flows fro the western lobe of the lake into Walnut Creek 1.4 i downstrean, thence into the Tippecanoe River.

EXTREMES FOR PERIOD OF RECORO. - Maxinua stage, 13.31 ft June 14, 1981; wininu stage. 9.40 ft Feb. 15 , 1982. LAKE LEVEL, IN FEET ABOVE GAGE DATUM, WATER YEAR OCTOBER 1990 TO SEPIEMBER 1991

\begin{tabular}{|c|c|c|c|c|c|c|c|c|c|c|c|c|}
\hline DAY & OCT & NOV & DEC & JAM & FEB & MAR & $A P R$ & MAY & JUN & JUL & AUG & SEP \\
\hline $\begin{array}{r}5 \\
10 \\
15 \\
20 \\
25 \\
\text { EOM }\end{array}$ & $\begin{array}{r}11.40 \\
12.20 \\
\ldots . . \\
10.29\end{array}$ & $\begin{array}{r}10.29 \\
10.16 \\
10.01 \\
9.95 \\
9.93 \\
10.11\end{array}$ & $\begin{array}{r}10.20 \\
10.04 \\
\ldots . . \\
\ldots . \\
\ldots\end{array}$ & $\begin{array}{r}\ldots . .2 \\
10.19 \\
10.25 \\
10.10 \\
10.02\end{array}$ & $\begin{array}{l}10.07 \\
10.06 \\
10.01 \\
10.11 \\
10.03 \\
10.00\end{array}$ & $\begin{array}{r}10.09 \\
10.00 \\
9.98 \\
10.19 \\
10.07 \\
10.04\end{array}$ & $\begin{array}{l}10.03 \\
10.03 \\
10.16 \\
10.33 \\
10.19 \\
10.07\end{array}$ & $\begin{array}{l}10.44 \\
11.01 \\
11.10 \\
11.07 \\
11.34 \\
11.26\end{array}$ & $\begin{array}{l}11.00 \\
11.03 \\
11.05 \\
10.97 \\
10.89 \\
11.26\end{array}$ & $\begin{array}{l}10.99 \\
10.97 \\
10.94 \\
10.88 \\
10.82 \\
10.80\end{array}$ & $\begin{array}{l}10.81 \\
10.90 \\
10.85 \\
10.93 \\
10.86 \\
10.85\end{array}$ & $\begin{array}{l}10.79 \\
10.77 \\
10.83 \\
10.76 \\
10.78 \\
10.79\end{array}$ \\
\hline
\end{tabular}

WTR YR 1991 MEAN 10.53 MAX 12.20 MIN 9.93 
Fur naany years, records of the water-surface elevations of many of the lakes in Indiana have been collected by the Geological Survey under cuoperative agreement with the Indiana Department of Natural Resources. Basic data for a few selected lakes have been published in WSP 1363 entitled "Hydrulogy of Indiana Lakes." Records which have not been published are available in the files of the District Office of the Geological Survey in Indiana polis, Indiana. In general, the records before 1976 were based on once-daily readings of a staff gage by a local observer and consist of daily, monthly, and yearly mean water-surface elevations. Starting in 1976, water-stage recorders were installed at many stations which had prevously bien nonrecurding gages. Discharge measurements, made at the outflow, are also available in some instances.

The lakes for which records have been collected are listed by duwnstrean order number in the following table. The established level, sometinies referred to as the legal level, is that elevation set by the courts to which the average level of the lake is to be held; it is normally set at about the average level that has prevailed for a number of years prior tw the establishment of the level. Surface area and capacity of the lake is that surface area and capacity at the established level. Depth contour maps are only those surveyed by the Water Resources Division of the Geologcal Survey. The inclusive years that records of stage have been collected at a iake are shown in the last column. If records are still being willected on a current basis, there is no closing date shown.

Lakes in the Ohio River basin for which records are available

siation
culisber Lake

03276800 Versailles Lake near Versailles

03322300 Hovey Lake near Mount Vernon

1)3327550 Everett Lake at Levert

0.3327600 Blue Lake near Churubusco

03327650 Shriner Lake at Th-Lakes

03327700 Cedar Lake at Tri-Lakes

03327750 Round Lake at Tri-Lakes

03327800 Wilson Lake near Larwill

03327850 little Wilson Lake near Larwill

03328100 Long Lake at Laketon

03328.250 North Little Lake at Silver Lake 03328350 Silver Lake at Silver Lake 0:3328400 Lukens Lake near Disko

U:33300.20 Crooked Lake near Wolflake 03330040 Big Lake near Wolflake

0.3:330060 Gouse Lake near Lorane 03330080 Loon Lake at Ormas

03330100 New Lake near Etna

03330120 Old Lake near Etna

03330140 Smalley lake near Washington Center

03330160 Gilbert Lake near Washington Center

03330180 Horseshoe l.ake $\mathrm{nr}$ Washington Center 03330200 Baugher Lake near Washington Center 03330220 Wilmot Pond at Wilmot

03330240 Webster Lake at North Webster

03330243 James Lake at Oswego

03330260 Robinson Lake near Pierceton

03330280 Troy Cedar Lake near Lorane

03330300 Ridinger Lake near Pierceton

03330320 Kuhn Lake near North Webster

03330340 Big Barbee Lake near North Webster

03330360 Little Barbee Lake nr North Webster

03330380 Shoe Lake near Oswego

U3330400 Banning Lake near North Webster 03330420 Irish Lake near North Webster

03330440 Sechrist Lake near North Webster

03330460 Sawmill Lake near North Webster

03330480 Tippecance Lake at Oswego

03330495 Oswego Lake at Oswego

03331010 Big Chapman Lake near Warsa w ${ }^{2}$

03331020 Little Chapman Lake near Warsaw

03331040 Pke Lake at Warsaw

03331060 rish Lake near Warsaw

03331080 Muskellunge Lake near Warsaw

03331100 Carr Lake near Claypool

03331120 Sherburn Lake near Piercewn ${ }^{3}$

03331140 Winona lake at Warsaw

$\begin{array}{cccc} & \begin{array}{c}\text { Drain- } \\ \text { age } \\ \text { (square } \\ \text { miles) }\end{array} & \begin{array}{c}\text { Surface } \\ \text { area } \\ \text { (acres) }\end{array} & \begin{array}{c}\text { Estab- } \\ \text { lished } \\ \text { level* }\end{array}\end{array}$

\begin{tabular}{|c|c|}
\hline $\begin{array}{c}\text { Capac- } \\
\text { ity } \\
\text { (acre- } \\
\text { feet) }\end{array}$ & $\begin{array}{c}\text { Contour } \\
\text { map } \\
\text { avail- } \\
\text { able }\end{array}$ \\
\hline
\end{tabular}

\section{LAUGHERY CREEK BASIN}

$\begin{array}{lcl}\text { Ripley } & 168.0 & 232 \\ \text { BAYOU DRAIN BASIN } & \end{array}$

\section{$\begin{array}{lll}\text { Posey } & 6.36 & 253\end{array}$ \\ WABASH RIVER BASIN}

\begin{tabular}{|c|c|c|c|c|c|c|}
\hline $\begin{array}{l}\text { Allen } \\
\text { Whitley }\end{array}$ & $\begin{array}{l}1.07 \\
3.58\end{array}$ & $\begin{array}{r}43 \\
239\end{array}$ & $\begin{array}{l}835.13 \\
850.28\end{array}$ & $\begin{array}{r}650 \\
5,010\end{array}$ & + & $\begin{array}{l}1946-66 \\
1946-69, \\
1976-\end{array}$ \\
\hline Whitley & .94 & 111 & 907.04 & ........ & - & 1943. \\
\hline Whitley & .79 & 131 & 901.90 & $\ldots$ & $\cdot$ & $1943-49$ \\
\hline Whitley & 3.36 & 125 & 901.90 & ...... & - & $1943-53$ \\
\hline Whitley & .46 & 29 & 865.39 & 390 & + & 1946-52 \\
\hline Whitley & .52 & 8 & 865.39 & 130 & + & $1946-52$ \\
\hline Wabash & .55 & 48 & 751.19 & 760 & + & $\begin{array}{l}1946-51, \\
1959 .\end{array}$ \\
\hline Kosciusko & 2.89 & 12 & 861.73 & 170 & + & 1947. \\
\hline Kusciusko & 6.31 & 102 & 861.73 & 1,520 & $\begin{array}{l}+ \\
+\end{array}$ & 1947- \\
\hline Wabash & 1.76 & 46 & 763.60 & 1,010 & + & $\begin{array}{l}1948-49 \\
1959-\end{array}$ \\
\hline Noble & 1.51 & 206 & 905.69 & 9,040 & + & $1943-53$ \\
\hline Noble & 8.89 & 228 & 898.18 & 5,630 & + & $\begin{array}{l}1943-75 \\
1976 .\end{array}$ \\
\hline Whitley & 1.51 & 84 & 910.96 & 2,180 & + & $1945-53$ \\
\hline Whitley & 11.1 & 222 & 895.14 & 5,730 & + & $1943-66$ \\
\hline Whitley & .29 & 50 & 903.91 & 880 & + & $1945-53$ \\
\hline Whitley & 2.81 & 32 & 898.07 & 620 & + & $1949-66$ \\
\hline Noble & 27.1 & 69 & ............. & 1,520 & + & 1943- \\
\hline Noble & .37 & 28 & ….... & 490 & $\begin{array}{lll}+ & & -1\end{array}$ & 1954 \\
\hline Noble & 1.62 & 18 & 901.80 & 250 & + & $1945-66$ \\
\hline Noble & $\begin{array}{l}31.0 \\
35\end{array}$ & 32 & 878.52 & 390 & + & $\begin{array}{l}1945-51 \\
1945-51\end{array}$ \\
\hline $\begin{array}{l}\text { Noble } \\
\text { Kosciusko }\end{array}$ & $\begin{array}{l}35.2 \\
49.2\end{array}$ & $\begin{array}{r}10 \\
774\end{array}$ & 85275 & $7 \longdiv { 1 7 0 }$ & i & $\begin{array}{l}1945-51 \\
1943-\end{array}$ \\
\hline Kosciusko & 55.9 & 282 & $\begin{array}{l}852.15 \\
836.40\end{array}$ & 7,580 & $\begin{array}{l}+ \\
+\end{array}$ & $\begin{array}{l}1943- \\
1943-\end{array}$ \\
\hline Kosciusko & 7.15 & 59 & 851.09 & 1,170 & + & $1946-51$ \\
\hline Whitley & 5.33 & 93 & 905.41 & 2,540 & + & $1945-52$ \\
\hline Kosciusko & 34.6 & 136 & 843.12 & 2,900 & + & 1943- \\
\hline Kosciusko & 3.85 & 137 & 837.50 & 1,290 & + & 1945. \\
\hline Kosciusko & 44.7 & 304 & 837.50 & 5,640 & + & 1945. \\
\hline Kosciusko & 49.0 & 74 & 837.50 & 960 & + & 1945. \\
\hline Kosciusko & & 40 & 841.57 & ........ & - & $\begin{array}{l}1946-53, \\
1972,74, \\
1976-\end{array}$ \\
\hline Kosciusko & .48 & 12 & 837.50 & 110 & + & 1945. \\
\hline Kosciusko & 50.9 & 182 & 837.50 & 2,330 & + & $1945-$ \\
\hline Kosciusko & .58 & $\begin{array}{r}105 \\
36\end{array}$ & 837.50 & $\begin{array}{r}2,490 \\
370\end{array}$ & + & 1945. \\
\hline $\begin{array}{l}\text { Kosciusko } \\
\text { Kosciusk ko }\end{array}$ & $\begin{array}{l}51.8 \\
113\end{array}$ & $\begin{array}{r}36 \\
768\end{array}$ & $\begin{array}{l}837.50 \\
836.40\end{array}$ & $\begin{array}{r}370 \\
28,380\end{array}$ & + & $\begin{array}{l}1945 . \\
1943 .\end{array}$ \\
\hline Kosciusko & 113 & 83 & $\begin{array}{l}836.40 \\
836.40\end{array}$ & $\begin{array}{r}20,300 \\
780\end{array}$ & + & 1943- \\
\hline Kosciusko & 4.17 & 581 & 827.75 & 6,080 & + & $\begin{array}{l}1945-72, \\
1976-\end{array}$ \\
\hline Kosciusko & 7.13 & 77 & 827.75 & 1,990 & + & 1945-72, \\
\hline Kosciusko & 41.5 & 203 & 805.64 & 2,830 & + & 1954 \\
\hline Kosciusko & 4.93 & 15 & 845.52 & ........ & - & $1951-66$ \\
\hline Kosciusko & 11.8 & 32 & 842.67 & 300 & + & $\begin{array}{l}1943-53, \\
1959 \cdot 71\end{array}$ \\
\hline Kosciusko & 2.27 & $\begin{array}{l}79 \\
15\end{array}$ & 848.88 & 1,340 & + & $1947-53$ \\
\hline $\begin{array}{l}\text { Kosclusko } \\
\text { Kosciusk ko }\end{array}$ & $\begin{array}{c}5.51 \\
32.1\end{array}$ & $\begin{array}{r}15 \\
562\end{array}$ & $\begin{array}{l}881.00 \\
811.06\end{array}$ & $\begin{array}{r}230 \\
16.680\end{array}$ & $\begin{array}{l}+ \\
+\end{array}$ & $\begin{array}{l}1954- \\
1943 .\end{array}$ \\
\hline & & & & 10,000 & 4 & \\
\hline
\end{tabular}

$1957-$

1950-69

$946-66$

976-

943-53

946-52

946-52

959.

1948-49,

959 -

943-75

976.

943-66

945-53

943 .

45. 6

945-51

(945-5

943.

$946-51$
$945-52$

.

945.

945.

1946-53,

976-

(945-

$1945-$

945.

943.

945-72,

1976

945-72,

954

$951-66$
$943-53$.

959.71

1943. 
Lakes in the Ohio River basin for which records are available--Continued

Station

number
Lake

$\begin{array}{cc}\begin{array}{c}\text { Drain- } \\ \text { age }\end{array} & \begin{array}{c}\text { Surface } \\ \text { area } \\ \text { (square } \\ \text { miles) }\end{array} \\ \text { (acres) }\end{array}$

County

area
(acres)
Estab-

lished

WABASH RIVER BASIN-.-Continued
03331160 Center Lake at Warsaw

03331180 Palestine Lake at Palestine

03331200 Crystal Lake near Atwood

03331220 Hoffman lake at Atwood

0333 240 Beaver Dam Lake near Silver Lake

03331260 Loon Lake near Silver lake

03331280 McClures Lake near Silver Lake

03331300 Hill Lake near Silver Lake

03331320 Diamond Lake near Silver Lake

03331340 Yellow Creek Lake near Silver Lake

03331360 Ruck Lake near Akron

03331370 Town Lake near Akron

03331380 Lake Manitou at Rochester

03331390 Zink Lake near Rochester

03331400 Nyona lake near Greenoak

03331420 South Mud Lake near Fulion

03331438 King Lake near Delong

03331440 Maxinkuckee Lake at Culver

03331460 Lost Lake near Culver

03331480 Langenbaum Lake near Monterey

03331700 Bruce Lake at Bruce Lake

03332200 Fletcher Lake at Fletcher

03370900 Starve Hollow Lake near Vallonia

03371700 Ogle Lake near Nashville

$\begin{array}{lc}\text { Kosciusko } & 0.73 \\ \text { Kosciusko } & 32.4 \\ \text { Kosciusko } & .45 \\ \text { Kosciusko } & 8.07 \\ \text { Kosciusko } & 2.83 \\ \text { Kosciusko } & 3.59 \\ \text { Kosciusko } & 1.29 \\ \text { Kosciusko } & .85 \\ \text { Kosciusko } & 3.92 \\ \text { Kosciusko } & 11.1 \\ \text { Kosciusko } & 2.74 \\ \text { Fulton } & 2.77 \\ \text { Fulton } & 44.2 \\ \text { Fulton } & 1.11 \\ \text { Fulton } & 7.59 \\ \text { Fulton } & 4.53 \\ \text { Fulton } & 1.98 \\ \text { Marshall } & 13.7 \\ \text { Marshall } & 14.2 \\ \text { Starke } & .72 \\ \text { Pulaski } & 6.38 \\ \text { Fulton } & .67 \\ \text { Jackson } & 6.67 \\ \text { Brown } & 1.03\end{array}$

\begin{tabular}{|c|c|}
\hline $\begin{array}{c}\text { Capac- } \\
\text { ity } \\
\text { (acre- } \\
\text { feet) }\end{array}$ & $\begin{array}{c}\text { Contour } \\
\text { map } \\
\text { avail- } \\
\text { able }\end{array}$ \\
\hline
\end{tabular}

Lakes in the St. Lawrence River basin for which records are available

STREAMS TRIBUTARY TO LAKE MICHIGAN

04092500 Wolf Lake at Hammond ${ }^{5}$

04092990 Lake George at Hobart

04097520 Lake Pleasant near Nevada Mills

04097550 Lake George at Jamestown

04097596 Marsh Lake near Fremont

04097600 Little Otter Lake near Fremont

04097640 Big Otter Lake near Fremont

04097650 Snow Lake at Lake James

04097660 Lake James at Lake James

04097680 Jimmerson Lake at Nevada Mills ${ }^{6}$

04097780 Loon Lake near Angola

04097850 Crooked Lake at Crooked Lake

04097950 Lake Gage at Panama

04097960 Lime Lake at Panama

04098100 Wall Lake near Orland

04098110 Mud Lake near Orland

04098300 Cedar Lake near Ontario

04099050 Pigeon Lake near Angola

04099100 Fox Lake near Angola

04099190 Pleasant Lake at Pleasant Lake

04099200 Long Lake at Moonlight

04099250 Bower Lake near Pleasant Lake

04099260 Golden Lake near Pleasant Lake

04099400 Silver Lake near Angola

04099430 Bass Lake near Angola

04099440 Howard Lake near Angola

04099500 Hogback Lake near Angola

04099520 Otter Lake near Flint

04099540 Story Lake near Hudson

04099560 Big Turkey Lake at Stroh

04099575 McClish Lake near Helmer

04099580 Lake of the Woods near Helmer

04099600 Big Long Lake near Stroh

04099620 Pretty Lake near Stroh

04099640 Little Turkey Lake at Elmira

04099660 Royer Lake near Plato

04099670 Fish Lake near Plato

04099700 North Twin Lake near Howe

04099710 South Twin Lake near Howe

04099740 Shipshewana Lake near Shipshewana

\begin{tabular}{|c|c|}
\hline $\begin{array}{l}\text { Lake } \\
\text { Lake } \\
\text { Steuben }\end{array}$ & $\begin{array}{c}5.72 \\
124 \\
3.18\end{array}$ \\
\hline $\begin{array}{l}\text { Steuben } \\
\text { Steuben } \\
\text { Steuben } \\
\text { Steuben } \\
\text { Steuben } \\
\text { Steuben } \\
\text { Steuben } \\
\text { Steuben } \\
\text { Steuben } \\
\text { Steuben } \\
\text { Steuben } \\
\text { Lagrange } \\
\text { Steuben } \\
\text { Lagrange } \\
\text { Steuben } \\
\text { Steuben } \\
\text { Steuben } \\
\text { Steuben } \\
\text { Steuben }\end{array}$ & $\begin{array}{c}\mathrm{a}_{14.7} \\
14.9 \\
15.7 \\
21.3 \\
\mathrm{a}_{40.2} \\
\mathrm{a}_{47.8} \\
\mathrm{a}_{51.6} \\
2.13 \\
10.4 \\
\mathrm{a}_{17.3} \\
\mathrm{a}_{17.5} \\
1.61 \\
1.85 \\
1.60 \\
\mathrm{a}_{35.2} \\
\mathrm{a}_{1} .25 \\
\mathrm{a}_{1} .12 \\
\mathrm{a}_{67.9} \\
\mathrm{a}_{84.6}\end{array}$ \\
\hline Steuben & ${ }^{\mathrm{a}} 88.8$ \\
\hline $\begin{array}{l}\text { Steuben } \\
\text { Steuben } \\
\text { Steuben } \\
\text { Steuben } \\
\text { Steuben } \\
\text { DeKalb }\end{array}$ & $\begin{array}{r}\mathrm{a}_{3.79} \\
\mathrm{a} .39 \\
\mathrm{a}_{3.90} \\
\mathrm{a}_{103} \\
\mathrm{a}^{2} 6.91 \\
3.16\end{array}$ \\
\hline $\begin{array}{l}\text { Lagrange } \\
\text { Lagrange }\end{array}$ & $\begin{array}{c}35.8 \\
1.28\end{array}$ \\
\hline Lagrange & 5.25 \\
\hline $\begin{array}{l}\text { Lagrange } \\
\text { Lagrange }\end{array}$ & $\begin{array}{l}4.77 \\
2.89\end{array}$ \\
\hline $\begin{array}{l}\text { Lagrange } \\
\text { Lagrange } \\
\text { Lagrange } \\
\text { Lagrange } \\
\text { Lagrange } \\
\text { Lagrange }\end{array}$ & $\begin{array}{c}56.5 \\
4.69 \\
\mathrm{a} 10.6 \\
1.54 \\
2.22 \\
\mathrm{a} 6.74\end{array}$ \\
\hline
\end{tabular}

……..

961.50

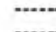

3,490

985.28

965.18

965.18

964.96

964.96

964.66

$1,011.98$

988.17

954.25

954.25

942.25

939.01

871.90

988.24

$1,018.83$

963.52

948.50

948.50

959.40

979.68

$\mathbf{9 7 7 . 3 4}$

948.50

934.15

942.20

926.61

951.09

951.09

956.2

965.50

925.72

936.50

936.50

843.56

843.56

$\begin{array}{rll}2,060 & + & 1945- \\ 1,170 & + & 1954- \\ 930 & + & 1945-51 \\ 3,160 & + & 1945-53 \\ 3,280 & + & 1947-53 \\ 670 & + & 1947-53 \\ 410 & + & 1945-52 \\ 1,300 & + & 1952- \\ 1,280 & + & 1954 \\ 4,730 & + & 1945-53 \\ 360 & + & 1946-66 \\ 220 & + & 1949-50 \\ 10,165 & + & 1943- \\ 17 . & + & 1952-55 \\ 1,340 & + & 1946- \\ 1,020 & + & 1946-66 \\ 180 & + & 1971- \\ 45,600 & + & 1943- \\ 17 . & + & 1954- \\ 260 & + & 1954-66 \\ 1,790 & + & 1943-53 \\ 880 & + & 1946-53 \\ 980 & + & 1946-61 \\ & + & 1963-71\end{array}$

1954
1946-49

1946 -

1954-69,

1971 ,

1976-

1967-69

1946-53

1946-5

1946-53

1943-49

1943-49

1946 .

1954-66

1946.

$1946-$

1946

$1946-$

1953-54

1956-67

1948-51

1954-63

1946- 53

1946-53

1946-66-

1946-

1976-

1946-71

1976-

1945-53

$1945-53$
$1954-66$

1954-66

1954-63

1946-

1946 ,

1954-66

1945-66

1951-66

1976-

1951-74,

$1976-$
1954.

1949-53,

1963-65

1945-66

1952 .

1945.

1953.

1953.70

1951 . 
Lakes in the St. Lawrence River basin for which records are available

Station
Number

Lake
Drain-

age

(square

Surface
area
(acres)

Estab-

lished
level*

\begin{tabular}{|c|c|}
\hline $\begin{array}{c}\text { Capac- } \\
\text { ity } \\
\text { (acre- } \\
\text { feet) }\end{array}$ & $\begin{array}{c}\text { Contour } \\
\text { map } \\
\text { avail- } \\
\text { able }\end{array}$ \\
\hline
\end{tabular}

\section{STREAMS TRIBUTARY TO LAKE MICHIGAN-.Continued}

\begin{abstract}
04099760 Fish Lake near Scott
04099780 Stone Lake near Scott
\end{abstract}

04099800 Emma Lake near Emma 04099810 Cass Lake near Shipshewana 04099820 Hunter Lake near Middlebury 04099840 Wolf Lake near Goshen 04099860 Heaton Lake near Elkhart

04099880 Simonton Lake near Elkhart 04099950 Indiana Lake near Bristol 04100010 Cree Lake near Kendallville 04100020 Blackman Lake near Wolcottville 04100030 Adams Lake near Wolcottville 04100040 Atwood Lake near Wolcottville 04100050 Witmer Laker near Wolcottville 04100060 Westler Lake near Wolcottville 04100070 Dallas Lake near Wolcottville 04100080 Martin Lake near Valentine 04100090 Olin Lake neaqr Valentine 04100100 Oliver Lake near Valentine 04100110 Hackenburg Lake near Wolcottville 04100120 Messick Lake near Wolcottvijle 04100130 Jones Lake near Cosperville 04100140 Bixler Lake at Kendallville 04100150 Round Lake at Kendallville 04100160 Little Long Lake at Kendallville 04100170 Latta Lake near Rome City 04100180 Sylvan Lake at Rome City 04100190 Sacarider Lake near Kendallville 04100200 Tamarack Lake near Cosperville 04100210 Steinbarger Lake near Cosperville 04100220 Waldron Lake near Cosperville 04100230 Long Lake near Burr Oak 04100240 Sand Lake near Burr Oak 04100250 Rivir Lake near Burr Oak 04100258 High Lake near Wolflake 04100260 Bear Lake near Wolflake 04100280 Muncie Lake near Burr Oak 04100290 Silver Lake near Wolflake 04100300 Skinner Lake near Albion

04100310 Pleasant Lake near Wolflake 04100320 Upper Long Lake near Wolflake 04100330 Lower Long Lake near Albion 04100340 Eagle Lake near Kimmel 04100350 Diamond Lake near Wawaka 04100360 Sparta Lake at Kimmel 04100370 Engle Lake near Ligonier

04100380 Harper Lake near Washington Center 04100390 Knapp Lake near Washington Center 04100400 Moss Lake near Washington Center 04100410 Hindman Lake near Washington Center 04100420 Gordy Lake near Cromwell 04100425 Rider Lake near Cromwell 04100430 Duely Lake near Cromwell ${ }^{8}$ 04100440 Village Lake near Cromwell 04100446 Flatbelly Lake near Syracuse 04100448 Papakeechie Lake near Syracuse 04100450 Wawasee Lake at Wawasee 04100460 Syracuse Lake at Syracuse 04100470 Dewart Lake near Leesburg 04100480 Wabee Lake near Milford

La

Lag

Elkh
Elkh
Noblert
Lagrang

Lagrange

Lagrange

Lagrange

Lagrange

Lagrange

Lagrange

lagrange

Lagrange

Lagrange

Lagrange

Noble

Noble

Noble

Noble

Noble

Noble

Noble

Noble

Noble

Noble

Noble

Noble

Noble

Noble

Nuble

Noble

Noble

Noble

Noble

Noble

Noble

Noble

Noble

Noble

Noble

Noble

Noble

Noble

Noble

Noble

Kosciusko

Kosciusko

Kosciusko

Kosciusko

Kosciusko

${ }^{\mathrm{a}} 6.21$
1.51
13.6
.68
.51
$a_{1.29}$
9.33

139

814.42

152

818.76

880.87

89

99

100

856.90

813.00
767.30

7.44

.62
4.85

.98
5.62

5.62

1.23

36.1

37.8
39.8

4.93

5.81

11.1

55.4
56.4

56.4
70.3

5.28
3.47

4.55

2.52

33.8

1.43
15.9

24.3

134

120

14.9

18.6
4.43

4.43
6.98

42.8

.28

14.0

.29

2.08
4.35

4.35
3.22

4.80

.69
.4 .19

4.19

2.76

6.02
6.12

8.66

9.40

10.9

11.2

12.0

4.66
5.52

36.9

38.2

8.05

${ }^{a} 14.6$
772.19

759.73

945.23

974.20

953.59

899.99

897.36

897.36

897.36

899.45

899.45

899.45

897.36

897.36

885.55

963.65

954.50

954.50

918.71

916.20

885.55

885.55

885.55

895.82

893.56

896.35

894.60

….....

.........

891.19

889.81

……

888.50

878.90

878.25

878.25
878.25

878.25

876.25

876.68

876.68

858.89

858.87

867.70
829.79

187

2,560

2,060

700

873
1,120

640

1,560

3,400

910
1210

7.690

1,560

7,040

1,770

9,970

15,358

510

1,450

960
2.090

2,140

1,750

900

5,986

740
880

1,590

3,120

630

1,270
380

380
1,240

3,030

580

220
1,750

540

1,900

1,560

1,050

2,580

170
670

160

3,040
80

140

140
680
30

180

160

….

5,360

9,000

4,750

\section{STREAMS TRIBUTARY TO LAKE ERIE}

04177200 Clear Lake at Clear Lake 04177210 Round Lake at Clear Lake 04177300 Long Lake near Ray 04177680 Ball Lake near Hamilton 04177700 Hamilton Lake at Hamilton 04179200 Indian Lake near Corunna 04179300 Cedar lake near Waterloo 
Lakes in the Upper Mississippi River basin for which records are available--Continued

\begin{tabular}{|c|c|c|c|c|c|c|c|}
\hline $\begin{array}{l}\text { Station } \\
\text { Number }\end{array}$ & County & $\begin{array}{l}\text { Drain- } \\
\text { age } \\
\text { (square } \\
\text { miles) }\end{array}$ & $\begin{array}{l}\text { Surface } \\
\text { area } \\
\text { (acres) }\end{array}$ & $\begin{array}{l}\text { Estab- } \\
\text { lished } \\
\text { level* }\end{array}$ & $\begin{array}{l}\text { Capac- } \\
\text { ity } \\
\text { (acre- } \\
\text { feet) }\end{array}$ & $\begin{array}{l}\text { Contour } \\
\text { map } \\
\text { avail- } \\
\text { able }\end{array}$ & $\begin{array}{l}\text { Records } \\
\text { avail- } \\
\text { able }\end{array}$ \\
\hline \multicolumn{8}{|c|}{ ILLINOIS RIVER BASIN } \\
\hline $\begin{array}{l}\text { 05514740 Saugany Lake near Rolling Prairie } \\
05514741 \text { Hudson lake at Hudson Lake } \\
05514750 \text { North Chain Lake at Lydick } \\
\text { 05514760 South Chain Lake at Westfield } \\
\text { 05514770 Wharton Lake near South Bend } \\
\text { 05514900 Silver Lake near Rolling Prairie } \\
\text { 05515200 Upper Fish Lake near Stillwell } \\
\text { 05515210 Lower Fish Lake near Stillwell } \\
\text { 05515220 Pine Lake at LaPorte }\end{array}$ & $\begin{array}{l}\text { LaPorte } \\
\text { LaPorte } \\
\text { St. Joseph } \\
\text { St. Joseph } \\
\text { St. Joseph } \\
\text { LaPorte } \\
\text { LaPorte } \\
\text { LaPorte } \\
\text { LaPorte }\end{array}$ & $\begin{array}{r}\mathrm{a}_{2.34} \\
7.92 \\
\mathrm{a}_{3.89} \\
\mathrm{a}_{6.32} \\
\mathrm{a}_{1.85} \\
1.72 \\
\mathrm{a}_{9.65} \\
\mathrm{a}_{10.4} \\
\mathrm{a}_{10.7}\end{array}$ & \begin{tabular}{r}
74 \\
432 \\
88 \\
90 \\
\hdashline.- \\
54 \\
139 \\
134 \\
564
\end{tabular} & $\begin{array}{l}781.21 \\
763.09 \\
721.17 \\
717.04 \\
795.20 \\
688.22 \\
688.22 \\
796.20\end{array}$ & $\begin{array}{r}2,190 \\
5,060 \\
1,400 \\
270 \\
1,040 \\
870 \\
\cdots\end{array}$ & $\begin{array}{l}+ \\
+ \\
+ \\
+ \\
- \\
+ \\
+ \\
+\end{array}$ & $\begin{array}{l}1946-50 \\
1946- \\
1946-53 \\
1946-53 \\
1960- \\
1946-66 \\
1946-53 \\
1946-53 \\
1946-75 \\
1980-\end{array}$ \\
\hline 05515230 Stone Lake at LaPorte & LaPorte & ${ }^{\mathrm{a}} 10.7$ & 140 & 796.20 & ....... & - & $\begin{array}{l}1946-75 \\
1980-\end{array}$ \\
\hline 05515240 Clear Lake at LaPorte & LaPorte & .65 & 106 & 798.20 & 760 & + & $\begin{array}{l}1942-49 \\
1952-75 \\
1980\end{array}$ \\
\hline $\begin{array}{l}\text { 05516200 Lake of the Woods near Bremen } \\
05516600 \text { Pretty Lake near Plymouth } \\
05516700 \text { Myers Lake near Twin Lakes } \\
\text { 05516800 Mill Pond and Kreighbaum Lake }\end{array}$ & $\begin{array}{l}\text { Marshall } \\
\text { Marshall } \\
\text { Marshall }\end{array}$ & $\begin{array}{r}\mathrm{a}_{9.45} \\
.85 \\
1.41\end{array}$ & $\begin{array}{r}416 \\
97 \\
96\end{array}$ & $\begin{array}{l}803.85 \\
787.36 \\
768.69\end{array}$ & $\begin{array}{l}6,810 \\
2,140 \\
2,000\end{array}$ & $\begin{array}{l}+ \\
+\end{array}$ & $\begin{array}{l}1945- \\
1954-66 \\
1945-53\end{array}$ \\
\hline $\begin{array}{l}\text { near Twin Lakes } \\
\text { 05516900 Eagle Lake near Ober } \\
05517100 \text { Skitz Lake near Knox } \\
05517200 \text { Bass Lake at Bass Lake } \\
05517600 \text { Wauhob Lake near Valparaiso } \\
05517650 \text { Long Lake near Valparaiso } \\
\text { 05517670 Spectacle Lake near Valparaiso } \\
\text { 05517700 Flint Lake near Valparaiso } \\
\text { 05517800 Lake Eliza near Beatrice }\end{array}$ & $\begin{array}{l}\text { Marshall } \\
\text { Starke } \\
\text { Starke } \\
\text { Starke } \\
\text { Porter } \\
\text { Porter } \\
\text { Porter } \\
\text { Porter } \\
\text { Porter }\end{array}$ & $\begin{array}{r}{ }^{a} 5.34 \\
25.5 \\
5.18 \\
.40 \\
1.31 \\
.53 \\
2.62 \\
1.70\end{array}$ & $\begin{array}{r}168 \\
24 \\
1,000 \\
1,400 \\
21 \\
65 \\
62 \\
86 \\
45\end{array}$ & $\begin{array}{c}767.75 \\
713.25 \\
\ldots \ldots \ldots \\
713.65 \\
\ldots \ldots 7.66 \\
797.66 \\
812.82 \\
797.66 \\
738.70\end{array}$ & $\begin{array}{r}1,020 \\
160 \\
\ldots \ldots \\
\ldots \ldots . . \\
520 \\
540 \\
\ldots . . . \\
\end{array}$ & $\begin{array}{l}+ \\
+ \\
\dot{5} \\
\dot{+} \\
+ \\
+ \\
\dot{-}\end{array}$ & $\begin{array}{l}1945-53 \\
1946-53 \\
1949-50^{2} \\
1943- \\
1946- \\
1947-52 \\
1946-53 \\
1946- \\
1954-74, \\
1976-\end{array}$ \\
\hline $\begin{array}{l}05518700 \text { Cedar Lake at Cedar Lake } \\
05518800 \text { Dalecarlia Lake near Creston } \\
05521300 \text { Ringneck Lake near Medaryville } \\
\text { 05525700 J.C. Murphy Lake near Morocco }\end{array}$ & $\begin{array}{l}\text { Lake } \\
\text { Lake } \\
\text { Jasper } \\
\text { Newton }\end{array}$ & $\begin{array}{l}8.14 \\
20.1 \\
1.94 \\
13.0\end{array}$ & $\begin{array}{r}781 \\
193 \\
1,400 \\
1,515\end{array}$ & 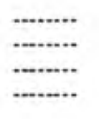 & 6,750 & $\dot{+}$ & $\begin{array}{l}1943- \\
1947-52 \\
1949-55 \\
1952-61\end{array}$ \\
\hline
\end{tabular}

+ Depth contour maps available for sale by Indiana Department of Natural Resources, State Office Building, Indianapolis, Indiana. - Elevation, in feet, above mean sea level.

${ }_{1}^{1}$ Formerly published as Rider Lake at Wilmot.

2 Formerly published as Rider Lake at Wilmot.

3 Formerly published as Johnson Lake near Pierceton.

4 Formerly published as Hawks Lake near Culver.

5 Same as Wolf Lake at Chicago, Illinois WRD District.

6 Formerly published as Jimerson Lake at Nevada Mills.

7 Formerly published as Sanford Lake near Cos perville.

8 Formerly published as Duley Lake near Cromwell, and Druely lake near Cromwell, and Druley Lake near Cromwell.

a Contains drainage area ( 5 percent or greater) that does not contribute directly to surface-water runofr. 
The lakes in Indiana which are not included in the cooperative stabilization program but which have been mapped for recreational purposes are shown in the following table. Surface area and capacities are related to reference mean sea level elevation at time of mapping. Additional data is shown on map, which are available for sale by the Indiana Department of Natural Resources, State Office Building, Indianapolis, Indiana.

Lake

County

area

(acres)
Capacity

(acre-
Lake

County $\begin{gathered}\text { Surface } \\ \text { area } \\ \text { (acres) }\end{gathered} \quad \begin{gathered}\text { Capacity } \\ \text { (acre- } \\ \text { feet) }\end{gathered}$

\section{OHIO RIVER BASIN}

Barr Lake

Bischoff Reservoir

Black Lake

Bowen Lake

Brown Lake

Caldwell Lake

Crane Lake

Crosley Lake

Ferdinand Lake

Franke Lake

Hartz Lake

Kunkel Lake

Lake Freeman

Lake Shafer

Fulton
Ripley
Whitley
Scutt
Whitley
Kosciusko
Noble
Jennings
Dubois
Clark
Starke
Wells
Carroll
White

$\begin{array}{rr}22 & 470 \\ 200 & 1,920 \\ 24 & 400 \\ 7 & 60 \\ 23 & 580 \\ 45 & 800 \\ 28 & 360 \\ 14 & 130 \\ 42 & 440 \\ 9 & 70 \\ 28 & 370 \\ 25 & 150 \\ 1,547 & 26,000 \\ 1,291 & 13,120\end{array}$
(eet)

\section{STREAMS TRIBUTARY TO LAKE MICHIGAN}

Appleman Lake

Bartley Lake

Barton Lak

Bell Lake

Boner Lake

Bowen Lake

Bristol Lake

Buck Lake

Center Lake

Cline Lake

Deer Lake

Dock Lake

Eve Lake

Fish Lake

Hog Lake

Hog Lake

Lime Lake

Little Turkey Lake

Marl Lake

Dunton Lake

Handy Lake

Lake Anne

Cook Lake

Dixon Lake

Flat Lake

Lagrange
Nuble
Steuben
Steuben
Kosciusko
Noble
Noble
Lagrange
Steuben
Lagrange
Noble
Noble
Lagrange
Steuben
LaPorte
Steuben
Steuben
Steuben
Noble

DeKalb

Steuben

Steuben

Marshall

Marshall

Marshall

Lake 16
Larwill Lake
Lenape Lake
Lincoln Park Lake
Little Pike Iake
McColley Lake
Round Lake
Scales Lake
Schlamm Lake
Sellers Lake
Shakamak Lake
Twin Lakes
Whitewater Lake
Yellowwood Lake

Fulton

Whitley

Greene

Spencer

Wabash

Wabash

Warrick

Warrick

Clark

Sullivan

Wabash

Brown

Mateer Lake
Miller Lake
Millers Lake
Mud Lake
Norman Lake
Pigeon Lake
Purt Mitchell Lake
Rainbow Lake
Schockopee Lake
Shock Lake
Smith Hole
Still Lake
Sweet Lake
Tamarack Lake
Walters Lake
Weir Lake
Wible Lake
Williams Lake
Wyland Lake

Lagrange

Noble

Noble

Noble

Lagrange

Noble

Lagrange

Noble

Kosciusko

Lagrange

Lagrange

Noble

Noble

Steuben

Lagrange

Noble

Kosciusko

$\begin{array}{rr}27 & 220 \\ 9 & 170 \\ 36 & 330 \\ 58 & 520 \\ 25 & 140 \\ 28 & 410 \\ 48 & 540 \\ 66 & 520 \\ 19 & 170 \\ 32 & 340 \\ 56 & 610 \\ 18 & 190 \\ 199 & 3,650 \\ 133 & 1,890\end{array}$

$\begin{array}{rr}18 & 150 \\ 11 & 160 \\ 28 & 410 \\ 8 & 70 \\ 14 & 280 \\ 61 & 1,160 \\ 15 & 180 \\ 16 & 250 \\ 21 & 280 \\ 37 & 1,210 \\ 2 & 10 \\ 30 & 620 \\ 16 & 210 \\ 84 & 1,340 \\ 53 & 550 \\ 6 & 70 \\ 49 & 650 \\ 46 & 1,070 \\ 6 & 100\end{array}$

STREAMS TRIBUTARY TO LAKE ERIE

$\begin{array}{ll}21 & 340 \\ 16 & 290 \\ 17 & 280\end{array}$

Mirror Lake

Terry Lake

Steuben

DeKalb

\section{UPPER MISSISSIPPI RIVER BASIN}

$\begin{array}{lr}93 & 1,650 \\ 33 & 480 \\ 26 & 210\end{array}$

Gilbert Lake

Lawrence Lake

Marshal
Marshall

Marshall

37
40
69

490

390
1,580 


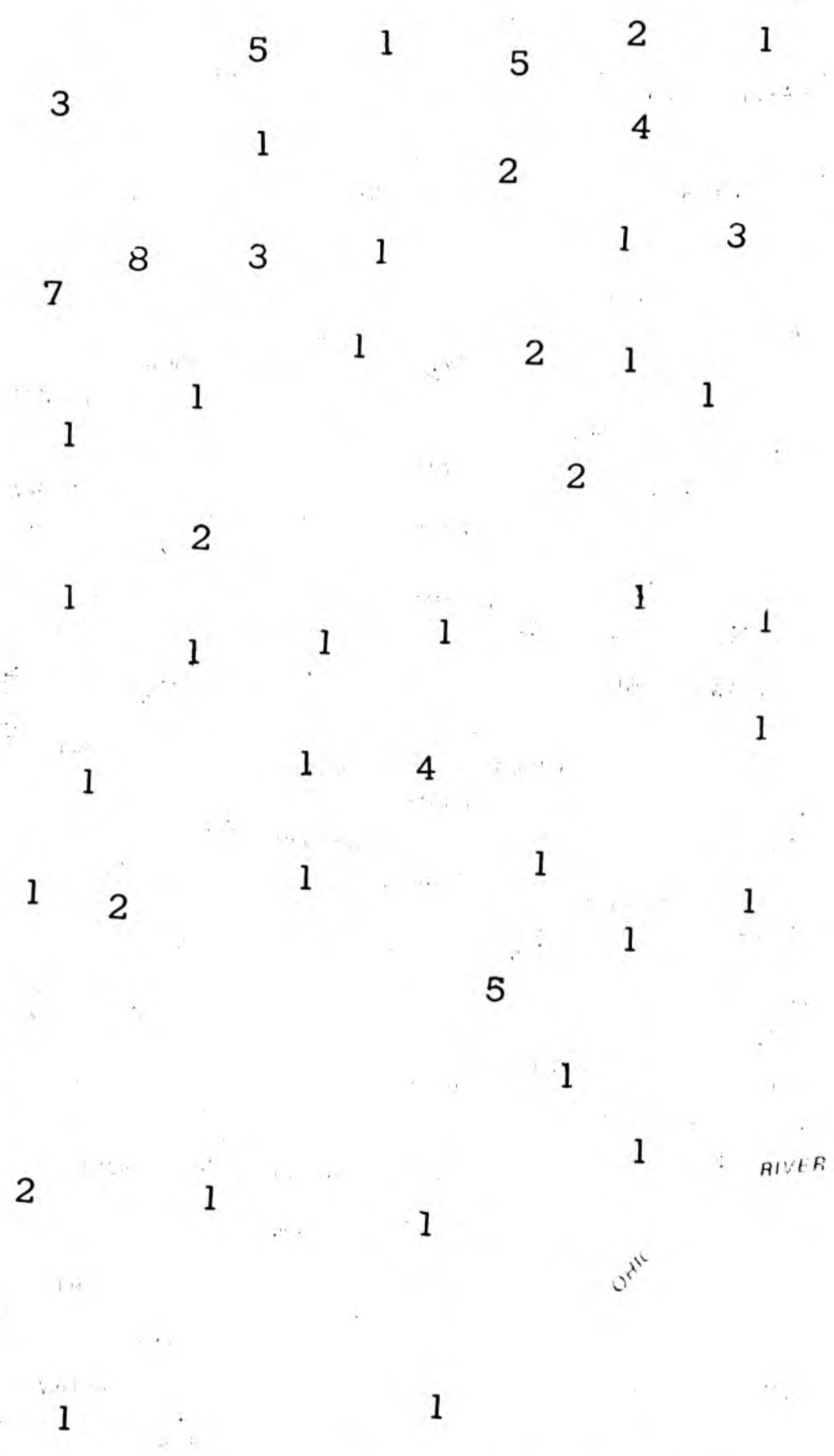

$\begin{array}{llll}2 & 2 & 1\end{array}$

EXPLANATION

3 Number of ground.water wells in designated county

Figure 7.- Number of ground-water wells by county having

1991 water-level records. 
410426084495201 . Local number, AL 5.

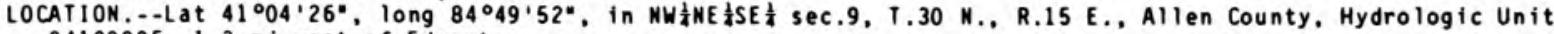
$04100005,1.3 \oplus i$ west of Edgerton.

Owner: Noei Gerig.

AQUIFER. - - Limestone of Salina Formation of Silurian age.

WELL CHARACTERISTICS.-.-Drilled artesian well, dianeter $4 \mathrm{in.}$ depth $97 \mathrm{ft}$, cased to $40 \mathrm{ft}$, open end.

INSTRUMENTATION.--Water-level recorder.

DATUM.--Elevation of land-surface datue is $760 \mathrm{ft}$ above National Geodetic Vertical Datue of 1929 , froe topographic

ap. Measuring point: Top of floor of shelter, $0.10 \mathrm{ft}$ above land-surface datua.

REMARKS.-- Nearby quarry operations were shut down in 1980 , and since that tiae water levels have been rising.

PERIOD OF RECORD.-.July 1962 to Decenber 1971. January 1973 to current year.

EXTREMES FOR PERIOD OF RECORD.--Highest water level, $10.04 \mathrm{ft}$ below land-surface datum, July 8 , 9 , 1962 ; 10west,

38.41 ft below land-surface datum. May 4, 1967.

\begin{tabular}{|c|c|c|c|c|c|c|c|c|c|c|c|c|}
\hline DAY & $\begin{array}{l}\text { HIGHEST } \\
\text { OCT }\end{array}$ & $\begin{array}{c}\text { WATER } \\
\text { MOV }\end{array}$ & LEVEL, IN & $\underset{\text { FAN }}{\text { FEET }}$ & $\begin{array}{l}\text { LAND- } \\
\text { FEB }\end{array}$ & $\begin{array}{l}\text { FACE } 0 \\
\text { MAR }\end{array}$ & DATUM, WATER & $\begin{array}{l}\text { YEAR } \\
\text { MAY }\end{array}$ & OCTOBER $\underset{\text { JUN }}{1990}$ & TO JUL & $\begin{array}{l}\text { BER } 1991 \\
\text { AUG }\end{array}$ & SEP \\
\hline $\begin{array}{r}5 \\
10 \\
15 \\
20 \\
25 \\
\text { EOM }\end{array}$ & $\begin{array}{l}15.11 \\
15.31 \\
15.18 \\
15.16 \\
15.16 \\
15.07\end{array}$ & $\begin{array}{l}14.49 \\
14.86 \\
15.11 \\
15.05 \\
14.64 \\
15.06\end{array}$ & $\begin{array}{l}14.93 \\
14.99 \\
14.64 \\
14.88 \\
15.14 \\
15.06\end{array}$ & $\begin{array}{l}14.96 \\
15.10 \\
14.48 \\
14.36 \\
14.99 \\
14.75\end{array}$ & $\begin{array}{l}14.68 \\
14.51 \\
14.33 \\
14.70 \\
14.79 \\
14.30\end{array}$ & $\begin{array}{l}13.95 \\
14.46 \\
14.78 \\
14.39 \\
14.62 \\
14.73\end{array}$ & $\begin{array}{l}14.51 \\
14.40 \\
14.18 \\
14.45 \\
14.44 \\
14.10\end{array}$ & $\begin{array}{l}14.10 \\
14.37 \\
14.26 \\
14.39 \\
14.14 \\
14.17\end{array}$ & $\begin{array}{l}14.22 \\
14.25 \\
14.13 \\
14.18 \\
14.12 \\
14.27\end{array}$ & $\begin{array}{l}14.02 \\
14.04 \\
14.17 \\
14.50 \\
14.13 \\
14.19\end{array}$ & $\begin{array}{l}14.37 \\
14.11 \\
14.13 \\
14.06 \\
14.48 \\
14.40\end{array}$ & $\begin{array}{l}14.37 \\
14.72 \\
14.58 \\
14.90 \\
14.37 \\
14.66\end{array}$ \\
\hline
\end{tabular}

WTR YR 1991 HIGH 13.75 MAR 6

LOWEST WATER LEVEL, IN FEET BELOW LAND-SURFACE DATUM, WATER YEAR OCTOBER 1990 TO SEPTEMBER 1991

\begin{tabular}{|c|c|c|c|c|c|c|c|c|c|c|c|c|}
\hline DAY & $O C T$ & NOV & DEC & JAN & FEB & MAR & $A P R$ & MAY & JUN & JUL & AUG & SEP \\
\hline $\begin{array}{r}5 \\
10 \\
15 \\
20 \\
25 \\
\text { EOM }\end{array}$ & $\begin{array}{l}15.72 \\
15.95 \\
15.87 \\
15.60 \\
15.58 \\
15.48\end{array}$ & $\begin{array}{l}15.17 \\
15.34 \\
15.41 \\
15.16 \\
15.21 \\
15.63\end{array}$ & $\begin{array}{l}15.59 \\
15.36 \\
15.21 \\
15.46 \\
15.54 \\
15.64\end{array}$ & $\begin{array}{l}15.52 \\
15.55 \\
15.02 \\
14.76 \\
15.38 \\
15.39\end{array}$ & $\begin{array}{l}15.09 \\
14.96 \\
15.16 \\
15.00 \\
15.20 \\
15.07\end{array}$ & $\begin{array}{l}14.52 \\
14.85 \\
15.15 \\
14.89 \\
15.03 \\
15.19\end{array}$ & $\begin{array}{l}14.94 \\
15.18 \\
14.65 \\
14.95 \\
15.01 \\
14.57\end{array}$ & $\begin{array}{l}14.74 \\
14.51 \\
14.79 \\
14.89 \\
14.28 \\
14.77\end{array}$ & $\begin{array}{l}14.69 \\
14.76 \\
14.88 \\
14.86 \\
14.80 \\
14.81\end{array}$ & $\begin{array}{l}14.67 \\
14.55 \\
14.95 \\
14.90 \\
14.51 \\
14.82\end{array}$ & $\begin{array}{l}14.75 \\
14.53 \\
14.20 \\
14.28 \\
15.04 \\
14.87\end{array}$ & $\begin{array}{l}14.83 \\
15.21 \\
15.16 \\
15.39 \\
15.10 \\
15.27\end{array}$ \\
\hline
\end{tabular}

WTR YR 1991 LOW 16.23 OCT 1

410932084561101 . Local number, AL 6 .

ALLEN COUNTY

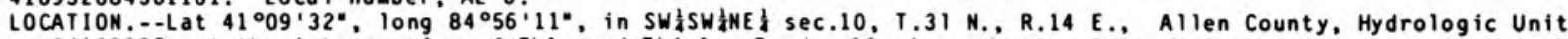
04100005 , at the intersection of Ehle and Thieler Roads, 10 northeast of New Haven.

Owner: U.S. Geological Survey.

AQUIFER. - - Sand and gravel of Pleistocene age.

WELL CHARACTERISTICS.--Drilled artesian well, dianeter $6 \mathrm{in.}$, depth $84 \mathrm{ft}$, cased to $81.5 \mathrm{ft}$, screened to $83.5 \mathrm{ft}$. INSTRUMENTATION. - Wa ter-level recorder.

DATUM.--Elevation of land-surface datun is $760 \mathrm{ft}$ above National Geodetic Vertical Datun of 1929 , froe topographic ap. Measuring point: Top of floor of shelter, $2.50 \mathrm{ft}$ above land-surface datua.

REMARKS. - - Water level affected by pumpage.

PERIOD OF RECORD..-Decenber 1966 to current year.

EXTREMES FOR PERIOD OF RECORD.--Highest water leve1, $7.90 \mathrm{ft}$ below land-surface datua. Feb. 24 , 1990: 10west, $14.77 \mathrm{ft}$ below land-surface datum. Oct. 29, 1978 .

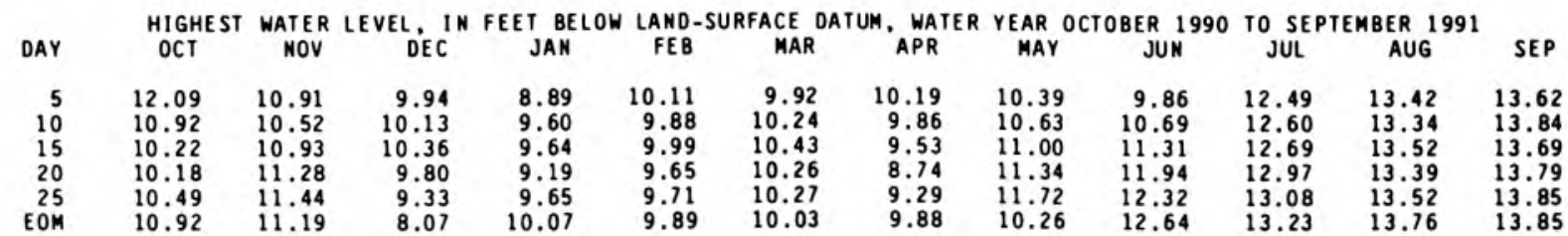

WTR YR 1991 HIGH 8.07 DEC 31

LOWEST WATER LEVEL, IN FEET BELOW LAND-SURFACE DATUM, WATER YEAR OCTOBER 1990 TO SEPTEMBER 1991

\begin{tabular}{|c|c|c|c|c|c|c|c|c|c|c|c|c|}
\hline DAY & OCT & NOV & DEC & JAN & FEB & MAR & APR & MAY & JUN & JUL & AUG & SEP \\
\hline $\begin{array}{r}5 \\
10 \\
15 \\
20 \\
25 \\
\text { EOM }\end{array}$ & $\begin{array}{l}12.25 \\
11.81 \\
10.47 \\
10.41 \\
10.76 \\
11.13\end{array}$ & $\begin{array}{l}11.15 \\
10.71 \\
11.08 \\
11.49 \\
11.67 \\
11.33\end{array}$ & $\begin{array}{r}10.15 \\
10.38 \\
10.51 \\
9.95 \\
9.53 \\
8.34\end{array}$ & $\begin{array}{r}9.09 \\
9.81 \\
9.88 \\
9.35 \\
9.87 \\
10.24\end{array}$ & $\begin{array}{r}10.28 \\
10.09 \\
10.28 \\
9.86 \\
9.94 \\
10.10\end{array}$ & $\begin{array}{l}10.11 \\
10.44 \\
10.66 \\
10.47 \\
10.50 \\
10.22\end{array}$ & $\begin{array}{r}10.38 \\
10.11 \\
10.00 \\
8.96 \\
9.54 \\
10.14\end{array}$ & $\begin{array}{l}10.59 \\
10.80 \\
11.26 \\
11.61 \\
11.88 \\
11.49\end{array}$ & $\begin{array}{l}10.18 \\
10.93 \\
11.53 \\
12.15 \\
12.53 \\
12.85\end{array}$ & $\begin{array}{l}12.71 \\
12.84 \\
12.95 \\
13.22 \\
13.27 \\
13.41\end{array}$ & $\begin{array}{l}13.64 \\
13.56 \\
13.77 \\
13.57 \\
13.72 \\
13.93\end{array}$ & $\begin{array}{l}13.83 \\
14.08 \\
13.91 \\
13.95 \\
14.04 \\
14.04\end{array}$ \\
\hline
\end{tabular}

WTR YR 1991 LOW 14.14 SEP 23 
410335085190701 . Local number. AL 8. (Formerly published as AL 7)

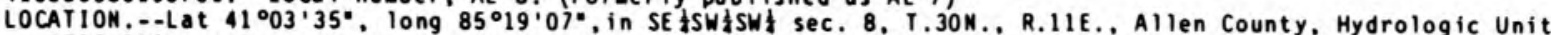
05120101 , on Covington Road about 5ai. West of Interstate Highway 69 on the northeast corner of the United Telephone Cospany property.

Owner: U.S. Geological Survey.

AQUIFER. - - Limestone.

WELL CHARACTERISTICS.--Drilled artesian well, dianeter $6 \mathrm{in.}$ depth $193 \mathrm{ft}$. , cased to $173 \mathrm{ft} .$. open end. INSTRUMENTATION, - - Water-level recorder.

DATUM.--Elevation of land-surface datue is $850.60 \mathrm{ft}$ (revised) above Mational Geodetic Vertical Datun of 1929.

Measuring point: Top of casing, $3.50 \mathrm{ft}$. above land-surface datua.

PERIOD OF RECORD.--July 1988 to current year. Records for WY1988, WY1989, WY1990 published as AL 7.

EXTREMES FOR PERIOD OF RECORD.--Highest water leve1, $55.70 \mathrm{ft}$ below land-surface datue, April 26 , 1989; lowest, $68.47 \mathrm{ft}$. below land-surface datun, June $19,1991$.

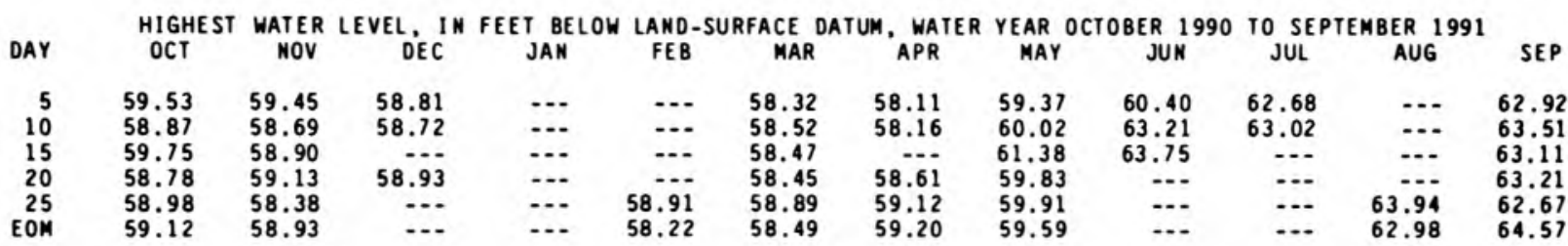

WTR YR 1991 HIGH 57.41 MAR 2

LOWEST WATER LEVEL, IN FEET BELOW LAND-SURFACE DATUM, WATER YEAR OCTOBER 1990 TO SEPTEMBER 1991

\begin{tabular}{|c|c|c|c|c|c|c|c|c|c|c|c|c|}
\hline DAY & OCT & NOV & DEC & JAN & FE B & MAR & $A P R$ & MAY & JUM & JUL & AUG & SEP \\
\hline $\begin{array}{r}5 \\
10 \\
15 \\
20 \\
25 \\
\text { EOM }\end{array}$ & $\begin{array}{l}60.63 \\
59.46 \\
61.50 \\
60.33 \\
60.10 \\
60.06\end{array}$ & $\begin{array}{l}60.56 \\
60.08 \\
59.75 \\
60.12 \\
60.22 \\
59.94\end{array}$ & $\begin{array}{r}59.87 \\
60.26 \\
60.02 \\
\ldots . .\end{array}$ & $\begin{array}{l}\ldots \\
\ldots \\
\ldots \\
\ldots \\
\ldots\end{array}$ & $\begin{array}{c}\ldots . \\
\ldots \\
\ldots \\
60 . \\
59.04 \\
59.12\end{array}$ & $\begin{array}{l}59.47 \\
60.07 \\
59.50 \\
59.46 \\
60.02 \\
59.16\end{array}$ & $\begin{array}{r}59.10 \\
59.21 \\
60.51 \\
60.36 \\
60.79\end{array}$ & $\begin{array}{l}61.03 \\
61.36 \\
63.15 \\
61.71 \\
62.08 \\
61.55\end{array}$ & $\begin{array}{r}62.21 \\
65.24 \\
61.53 \\
\ldots . . \\
\ldots\end{array}$ & $\begin{array}{r}66.04 \\
66.15 \\
\ldots . . \\
\ldots \\
\ldots . \\
\ldots\end{array}$ & $\begin{array}{r}\ldots \\
\cdots \\
66.93 \\
66.04\end{array}$ & $\begin{array}{l}64.60 \\
65.66 \\
66.20 \\
65.07 \\
64.49 \\
66.74\end{array}$ \\
\hline
\end{tabular}

WTR YR 1991 LOW 68.47 JUN 19

391627085534401. Local number, BA 4.

BARTHOLONEW COUNTY

LOCATION, - - at $39^{\circ} 16^{\prime} 27^{\circ}$, long $85^{\circ} 53^{\prime} 4^{\circ}$, in NE $\frac{1}{2}$ NE Unit 05120205 , by a cenetery on the north side of Bakalar AFB at the northern city liaits of Colunbus.

Owner: Bartholowew County.

AQUIFER.--Sand and gravel of Pleistocene age.

WELL CHARACTERISTICS.--Orilled water-table well, dianeter $6 \mathrm{in..,} \mathrm{depth} 93 \mathrm{ft}$, cased to $85 \mathrm{ft}$, screened to $90 \mathrm{ft}$. INST RUME NTATION. - - Ha ter-level recorder.

DATUM.--Elevation of land-surface datun is $654.04 \mathrm{ft}$ above Mational Geodetic Vertical Datun of 1929 . Measuring point: Top of floor of shelter, $2.60 \mathrm{ft}$ above land-surface datue.

PERIOD OF RECORD.--January 1965 to current year.

REVISED RECORDS, .-WDR IN-80-1: 1979.

EXTREMES FOR PERIOD OF RECORD.--Highest water level, $14.11 \mathrm{ft}$ below land-surface datue, April $8{ }^{2} 9,1991$; lowest, $21.15 \mathrm{ft}$ below land-surface datue. Feb. 11, 12, 1977 .

\begin{tabular}{|c|c|c|c|c|c|c|c|c|c|c|c|c|}
\hline DAY & $\begin{array}{l}\text { HIGHE ST } \\
\text { OCT }\end{array}$ & $\begin{array}{c}\text { WATER } \\
\text { NOV }\end{array}$ & LEVEL, IN & FEET BELOW & $\begin{array}{l}\text { LAND - } \\
\text { FEB }\end{array}$ & $\begin{array}{l}\text { FACE } 0 \\
\text { MAR }\end{array}$ & $\begin{array}{c}\text { DATUM, WATER } \\
\text { APR }\end{array}$ & $\begin{array}{l}\text { YEAR } \\
\text { MAY }\end{array}$ & OCTOBER $\underset{\text { JUN }}{ } 1990$ & TO JUL & $\begin{array}{l}\text { BER } 1991 \\
\text { AUG }\end{array}$ & SEP \\
\hline $\begin{array}{r}5 \\
10 \\
15 \\
20 \\
25 \\
\text { EOM }\end{array}$ & $\begin{array}{l}17.95 \\
18.03 \\
18.05 \\
18.07 \\
18.09 \\
18.15\end{array}$ & $\begin{array}{l}18.20 \\
18.28 \\
18.36 \\
18.42 \\
18.49 \\
18.57\end{array}$ & $\begin{array}{l}18.59 \\
18.58 \\
18.57 \\
18.55 \\
18.28 \\
17.48\end{array}$ & $\begin{array}{l}16.06 \\
15.66 \\
15.51 \\
15.48 \\
15.55 \\
15.59\end{array}$ & $\begin{array}{l}15.63 \\
15.60 \\
15.39 \\
15.22 \\
15.15 \\
15.12\end{array}$ & $\begin{array}{l}15.18 \\
15.33 \\
15.40 \\
15.38 \\
15.19 \\
14.52\end{array}$ & $\begin{array}{l}14.16 \\
14.16 \\
14.25 \\
14.37 \\
14.35 \\
14.34\end{array}$ & $\begin{array}{r}14.40 \\
14.54 \\
14.56 \\
14.67 \\
\ldots . . \\
\ldots .\end{array}$ & $\begin{array}{r}\ldots . \\
\ldots \\
\ldots \\
\ldots .9\end{array}$ & $\begin{array}{l}16.17 \\
16.32 \\
16.12 \\
16.18 \\
16.57 \\
16.92\end{array}$ & $\begin{array}{l}17.11 \\
17.11 \\
17.17 \\
17.26 \\
17.37 \\
17.49\end{array}$ & $\begin{array}{l}17.59 \\
17.67 \\
17.76 \\
17.86 \\
17.94 \\
18.06\end{array}$ \\
\hline
\end{tabular}

WTR YR 1991 HIGH 14.11 APR 8

LOWEST WATER LEVEL, IN FEET BELOW LAND-SURFACE DATUM, WATER YEAR OCTOBER 1990 TO SEPTEMBER 1991

\begin{tabular}{|c|c|c|c|c|c|c|c|c|c|c|c|c|}
\hline DAY & OCT & NOV & DEC & JAN & FEB & MAR & APR & MAY & JUN & JUL & AUG & SEP \\
\hline $\begin{array}{r}5 \\
10 \\
15 \\
20 \\
25 \\
\text { EOM }\end{array}$ & $\begin{array}{l}17.96 \\
18.04 \\
18.06 \\
18.07 \\
18.10 \\
18.16\end{array}$ & $\begin{array}{l}18.22 \\
18.29 \\
18.37 \\
18.43 \\
18.51 \\
18.58\end{array}$ & $\begin{array}{l}18.61 \\
18.58 \\
18.59 \\
18.59 \\
18.35 \\
17.87\end{array}$ & $\begin{array}{l}16.21 \\
15.72 \\
15.54 \\
15.51 \\
15.57 \\
15.63\end{array}$ & $\begin{array}{l}15.65 \\
15.62 \\
15.40 \\
15.25 \\
15.17 \\
15.13\end{array}$ & $\begin{array}{l}15.22 \\
15.35 \\
15.43 \\
15.41 \\
15.28 \\
14.63\end{array}$ & $\begin{array}{l}14.27 \\
14.22 \\
14.32 \\
14.38 \\
14.39 \\
14.38\end{array}$ & $\begin{array}{r}14.43 \\
14.57 \\
14.57 \\
14.69 \\
\ldots . . \\
. . .\end{array}$ & $\begin{array}{r}\ldots \\
\ldots \\
\ldots \\
\ldots .98\end{array}$ & $\begin{array}{l}16.18 \\
16.39 \\
16.12 \\
16.24 \\
16.63 \\
16.98\end{array}$ & $\begin{array}{l}17.11 \\
17.13 \\
17.19 \\
17.29 \\
17.39 \\
17.52\end{array}$ & $\begin{array}{l}17.61 \\
17.69 \\
17.78 \\
17.88 \\
17.96 \\
18.07\end{array}$ \\
\hline
\end{tabular}

WTR YR 1991 LOW 18.61 DEC 4 
390950085553501 . Local number, BA 8 .

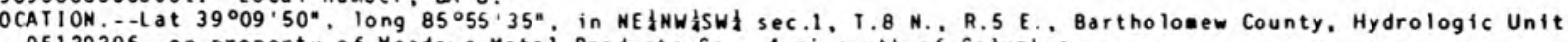
05120206 , on property of Keadows Metai Products Co.. 4 a south of Coluabus.

Owner: Meadows Metal Products Co.. Inc.

AQUIFER. - Sand and gravel of Pleistocene age.

WELL CHARACTERISTICS.-.-Drilled water-table well, diaeter 6 in., depth 49 ft, casing length unknown.

INST RUME NTATION. - - Wat er-level recorder.

DATUM.--Elevation of land-surface datum is $615.48 \mathrm{ft}$ above National Geodetic Vertical Datua of 1929 .

Measuring point: Top of floor of shelter, $3.00 \mathrm{ft}$ above land-surface datua.

PERIOD OF RECORD.--February 1967 to current year.

EXTREMES FOR PERIOD OF RECORD.--Highest water level, $8.06 \mathrm{ft}$ below land-surface datum, June 3 , 1968 ; lowest,

$24.13 \mathrm{ft}$ below land-surface datum, Dec. 27,1988 .

\begin{tabular}{|c|c|c|c|c|c|c|c|c|c|c|c|c|}
\hline DAY & $\begin{array}{l}\text { HIGHEST } \\
\text { OCT }\end{array}$ & $\begin{array}{l}\text { WATER } \\
\text { NOV }\end{array}$ & $\underset{\text { DEC }}{\text { LEVEL, }}$ & $\underset{\text { FAN }}{\text { FEET }}$ & $\begin{array}{r}\text { LAND } \\
\text { FEB }\end{array}$ & $\begin{array}{l}\text { ACE D } \\
\text { MAR }\end{array}$ & $\begin{array}{c}\text { DATUM, WAIER } \\
\text { APR }\end{array}$ & $\begin{array}{c}\text { YEAR } 0 \\
\text { MAY }\end{array}$ & $\underset{\text { OCTOBER }}{\text { OUN }} 1990$ & $\begin{array}{l}\text { TO SE } \\
\text { JUL }\end{array}$ & $\begin{array}{l}\text { EER } 1991 \\
\text { AUG }\end{array}$ & SEP \\
\hline $\begin{array}{r}5 \\
10 \\
15 \\
20 \\
25 \\
501\end{array}$ & $\begin{array}{l}18.79 \\
18.88 \\
18.98 \\
19.04 \\
19.10 \\
19.18\end{array}$ & $\begin{array}{l}19.19 \\
19.29 \\
19.40 \\
19.49 \\
19.58 \\
19.68\end{array}$ & $\begin{array}{l}19.64 \\
19.52 \\
19.36 \\
19.13 \\
18.52 \\
17.24\end{array}$ & $\begin{array}{l}14.16 \\
13.22 \\
13.05 \\
13.09 \\
13.31 \\
13.53\end{array}$ & $\begin{array}{l}13.80 \\
13.75 \\
13.49 \\
13.39 \\
13.34 \\
13.31\end{array}$ & $\begin{array}{l}13.34 \\
13.61 \\
13.78 \\
13.64 \\
12.96 \\
11.82\end{array}$ & $\begin{array}{l}11.61 \\
11.78 \\
11.74 \\
11.59 \\
11.66 \\
11.80\end{array}$ & $\begin{array}{l}12.06 \\
12.44 \\
12.76 \\
13.15 \\
13.42 \\
13.75\end{array}$ & $\begin{array}{l}14.05 \\
14.30 \\
14.52 \\
14.80 \\
15.06 \\
15.33\end{array}$ & $\begin{array}{l}93 \\
21 \\
47 \\
75 \\
06\end{array}$ & $\begin{array}{l}17.31 \\
17.51 \\
17.75 \\
17.97 \\
18.21 \\
18.42\end{array}$ & $\begin{array}{l}18.57 \\
18.78 \\
18.97 \\
19.17 \\
19.34 \\
19.53\end{array}$ \\
\hline
\end{tabular}

WTR YR 1991 HIGH 11.54 APR 22

LOWEST WATER LEVEL, IN FEET BELOW LAND-SURFACE DATUM, WATER YEAR OCTOBER 1990 TO SEPTEMBER 1991

\begin{tabular}{|c|c|c|c|c|c|c|c|c|c|c|c|c|}
\hline DAY & $\mathrm{OCT}$ & NOV & DEC & JAN & FEB & MAR & $A P R$ & MAY & JUN & JUL & AUG & SEP \\
\hline $\begin{array}{r}5 \\
10 \\
15 \\
20 \\
25 \\
\text { EOM }\end{array}$ & $\begin{array}{l}18.82 \\
18.91 \\
19.01 \\
19.06 \\
19.11 \\
19.18\end{array}$ & $\begin{array}{l}19.24 \\
19.32 \\
19.42 \\
19.51 \\
19.61 \\
19.71\end{array}$ & $\begin{array}{l}19.69 \\
19.55 \\
19.41 \\
19.18 \\
18.72 \\
17.49\end{array}$ & $\begin{array}{l}14.61 \\
13.31 \\
13.09 \\
13.15 \\
13.36 \\
13.63\end{array}$ & $\begin{array}{l}13.85 \\
13.76 \\
13.56 \\
13.44 \\
13.36 \\
13.32\end{array}$ & $\begin{array}{l}13.41 \\
13.65 \\
13.83 \\
13.70 \\
13.16 \\
11.93\end{array}$ & $\begin{array}{l}11.63 \\
11.87 \\
11.80 \\
11.61 \\
11.68 \\
11.84\end{array}$ & $\begin{array}{l}12.10 \\
12.51 \\
12.84 \\
13.21 \\
13.47 \\
13.81\end{array}$ & $\begin{array}{l}14.12 \\
14.34 \\
14.56 \\
14.83 \\
15.10 \\
15.38\end{array}$ & $\begin{array}{l}15.69 \\
15.99 \\
16.27 \\
16.52 \\
16.80 \\
17.11\end{array}$ & $\begin{array}{l}17.35 \\
17.57 \\
17.80 \\
18.02 \\
18.25 \\
18.48\end{array}$ & $\begin{array}{l}18.60 \\
18.81 \\
19.00 \\
19.20 \\
19.37 \\
19.56\end{array}$ \\
\hline
\end{tabular}

WP YR 1991 LOW 19.72 DEC 2

391035085560401. Local number, BA 9.

BARTHOLOMEW COUNTY

IOCATION.-.Lat $39^{\circ} 10^{\prime} 35^{\circ}$, long $85^{\circ} 56^{\prime} 04^{\circ}$, in SW $\frac{1}{4} N E \frac{1}{4} S W^{\frac{1}{4}}$ sec.35, T.9 N., R.5 E., Bartholoeew County, Hydrologic Unit 05120206, at the Bartholomew County Hone on the $4-\mathrm{H} \mathrm{Fairgrounds,} 3.0$ a south of Coluabus.

Owner: City of Colubus.

AQUIFER...-Sand and gravel of Pleistocene age.

WELL CHARACTERISTICS.--Drilled water-table well, diameter 6 in., depth $115 \mathrm{ft}$, cased to $106 \mathrm{ft}$, screened to $111 \mathrm{ft}$. INSTRUMENTATION. - - Water-level recorder.

DATUM..-Elevation of land-surface datum is $621.58 \mathrm{ft}$ above National Geodetic Vertical Datum of 1929 .

Measuring point: Top of floor of shelter, $1.65 \mathrm{ft}$ above land-surface datum.

REMARKS. - Water level affected by pumpage from nuicipal supply well field.

PERIOD OF RECORD..-April 1970 to current year.

REVISED RECORDS. - -WOR IN-80-1: 1979.

EXIREMES FOR PERIOD OF RECORD.--Highest water level, $12.75 \mathrm{ft}$ below land-surface datum, Apr. $27-30$, 1973; lowest,

$38.75 \mathrm{ft}$ below land-surface datur, Sept. $15,1977$.

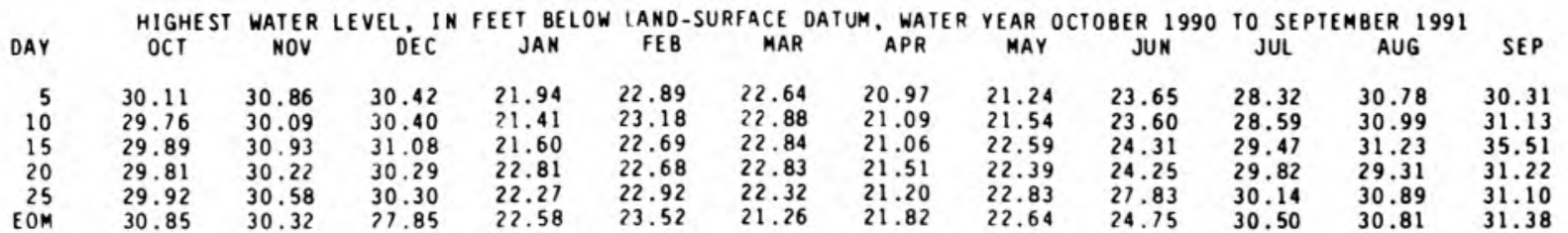

WTR YR 1991 HIGH 20.89 APR 3

LOWEST WATER LEVEL, IN FEET BELOW LAND-SURFACE DATUM, WATER YEAR OCTOBER 1990 TO SEPTEMBER 1991

\begin{tabular}{|c|c|c|c|c|c|c|c|c|c|c|c|c|}
\hline DAY & $O C T$ & NOV & DEC & JAM & FEB & MAR & $A P R$ & MAY & JUN & JUL & AUG & SEP \\
\hline $\begin{array}{r}5 \\
10 \\
15 \\
20 \\
25 \\
\text { EOM }\end{array}$ & $\begin{array}{l}30.55 \\
30.68 \\
30.75 \\
30.67 \\
30.80 \\
30.87\end{array}$ & $\begin{array}{l}30.92 \\
30.89 \\
31.03 \\
31.11 \\
31.20 \\
31.25\end{array}$ & $\begin{array}{l}31.27 \\
31.32 \\
31.20 \\
31.00 \\
30.75 \\
29.92\end{array}$ & $\begin{array}{l}22.52 \\
22.37 \\
22.59 \\
22.97 \\
23.22 \\
23.51\end{array}$ & $\begin{array}{l}23.82 \\
23.78 \\
23.65 \\
23.66 \\
23.68 \\
23.68\end{array}$ & $\begin{array}{l}23.61 \\
23.72 \\
23.76 \\
23.77 \\
23.27 \\
22.10\end{array}$ & $\begin{array}{l}21.82 \\
21.96 \\
21.99 \\
21.91 \\
21.89 \\
21.92\end{array}$ & $\begin{array}{l}22.14 \\
22.87 \\
23.61 \\
26.68 \\
22.90 \\
24.46\end{array}$ & $\begin{array}{l}23.77 \\
24.22 \\
24.47 \\
24.31 \\
28.11 \\
25.34\end{array}$ & $\begin{array}{l}28.85 \\
29.21 \\
29.55 \\
29.87 \\
30.20 \\
30.55\end{array}$ & $\begin{array}{l}30.83 \\
31.07 \\
33.74 \\
31.30 \\
34.52 \\
34.80\end{array}$ & $\begin{array}{l}34.74 \\
35.21 \\
35.58 \\
35.80 \\
35.76 \\
36.09\end{array}$ \\
\hline
\end{tabular}

WTR YR 1991 LOW 36.09 SEP 30 
390317085523701. Local number, BA 10.

LOCATION.-Lat $39^{\circ} 03^{\prime} 17^{\circ}$. Iong $85^{\circ} 52^{\prime} 37^{\circ}$. in NE $05120206,0.8$ ast of State Highway 11 and 1.0 a southeast of jonesvilie.

Owner: U.S. Geological Survey.

AQUIFER. - - Sand and gravel of Pleistocene age.

WELL CHARACTERISIICS.--Orilled water-table well, dianeter $6 \mathrm{in.}$. depth $85 \mathrm{ft}$, cased to $80 \mathrm{ft}$, screened to $85 \mathrm{ft}$. INSTRUMENTATION. - - Water-level recorder.

DATUM.--Elevation of land-surface datue is $580 \mathrm{ft}$ above Mational Geodetic Vertical Datue of 1929 , froe topographic ap. Measuring point: Top of floor of shelter, $3.50 \mathrm{ft}$ above land-surface datue.

PERIOD OF RECORD.--October 1978 to current year.

EXTREMES FOR PERIOD OF RECORD,--Highest water level, $0.67 \mathrm{ft}$ below land-surface datue, Apr. 14, 1979; lowest. $12.65 \mathrm{ft}$ below land-surface datue, Oct. 29, Nov. 2, 1988 .

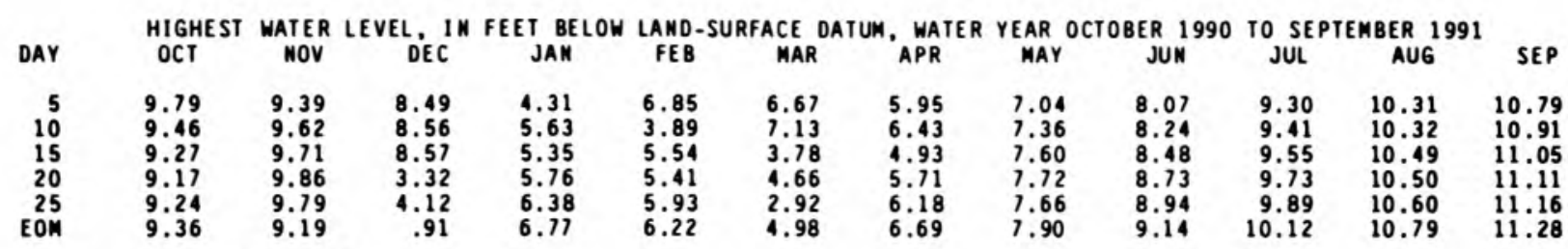

WTR YR 1991 HIGH .90 JAN 1

LOWEST WATER LEVEL, IN FEET BELOW LANO-SURFACE DATUM, WATER YEAR OCTOBER 1990 TO SEPTEMBER 1991

\begin{tabular}{|c|c|c|c|c|c|c|c|c|c|c|c|c|}
\hline DAY & $\mathrm{OCT}$ & NOV & DEC & JAN & FE B & MAR & $A P R$ & MAY & JUN & JUL & AUG & SEP \\
\hline $\begin{array}{r}5 \\
10 \\
15 \\
20 \\
25 \\
\text { EOM }\end{array}$ & $\begin{array}{l}9.98 \\
9.66 \\
9.41 \\
9.31 \\
9.28 \\
9.51\end{array}$ & $\begin{array}{l}9.71 \\
9.73 \\
9.83 \\
9.95 \\
9.86 \\
9.48\end{array}$ & $\begin{array}{l}8.80 \\
8.67 \\
8.86 \\
3.52 \\
4.81 \\
1.95\end{array}$ & $\begin{array}{l}4.79 \\
5.71 \\
5.51 \\
5.98 \\
6.50 \\
6.91\end{array}$ & $\begin{array}{l}6.99 \\
4.68 \\
5.88 \\
5.61 \\
6.13 \\
6.44\end{array}$ & $\begin{array}{l}6.76 \\
7.24 \\
5.28 \\
4.88 \\
3.20 \\
5.30\end{array}$ & $\begin{array}{l}6.04 \\
6.59 \\
5.14 \\
5.80 \\
6.31 \\
6.82\end{array}$ & $\begin{array}{l}7.13 \\
7.50 \\
7.76 \\
7.78 \\
7.80 \\
8.02\end{array}$ & $\begin{array}{l}8.11 \\
8.41 \\
8.59 \\
8.81 \\
9.07 \\
9.21\end{array}$ & $\begin{array}{r}9.37 \\
9.57 \\
9.64 \\
9.82 \\
10.02 \\
10.18\end{array}$ & $\begin{array}{l}10.41 \\
10.47 \\
10.55 \\
10.59 \\
10.73 \\
10.84\end{array}$ & $\begin{array}{l}10.95 \\
11.05 \\
11.13 \\
11.25 \\
11.30 \\
11.40\end{array}$ \\
\hline
\end{tabular}

WTR YR 1991 LOW 11.40 SEP 28

390658085572201 . Local nuaber, BA 13.

BARTHOLOMEW COUNTY

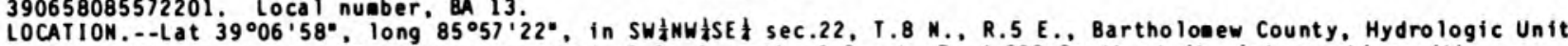
05120206 , at the end of fare access road, 0.3 a north of County Road 600 South at its intersection with Interstate Highway 65 .

Owner: U.S. Geological Survey.

AQUIFER.--Sand and gravel of Pleistocene age.

WELL CHARACTERISTICS.--Drilled water-table well, dianeter 6 in., depth $55.6 \mathrm{ft}$, cased to $50.6 \mathrm{ft}$, screened to $55.6 \mathrm{ft}$.

INSTRUMENTATION. - - Wa ter-level recorder.

DATUM.-.Elevation of land-surface datue is $633.91 \mathrm{ft}$ above Mational Geodetic Vertical Datue of 1929 .

Measuring point: Top of floor of shelter, $3.40 \mathrm{ft}$ above land-surface datua.

PERIOD OF RECORD.--July 1986 to current year.

EXTREMES FOR PERIOD OF RECORD.--Highest water leve1, $19.91 \mathrm{ft}$ below land-surface datue, March 27 , 1991; lowest. $24.17 \mathrm{ft}$ below land-surface datun. Feb. i6. 1989.

\begin{tabular}{|c|c|c|c|c|c|c|c|c|c|c|c|c|}
\hline DAY & $\begin{array}{l}\text { HIGHEST } \\
\text { OCT }\end{array}$ & $\begin{array}{l}\text { WATER } \\
\text { NOV }\end{array}$ & LEVEL, IN & FEET BELOW & $\begin{array}{c}\text { LAND -S } \\
\text { FE B }\end{array}$ & $\begin{array}{l}\text { FACE D } \\
\text { MAR }\end{array}$ & $\begin{array}{c}\text { DATUM, WATER } \\
\text { APR }\end{array}$ & $\begin{array}{c}\text { YEAR } 0 \\
\text { MAY }\end{array}$ & OCTOBER $\underset{\text { JUN }}{ } 1990$ & TO SUE & $\begin{array}{l}\text { BER 1991 } \\
\text { AUG }\end{array}$ & SEP \\
\hline $\begin{array}{r}5 \\
10 \\
15 \\
20 \\
25 \\
\text { EOM }\end{array}$ & $\begin{array}{l}21.22 \\
20.96 \\
21.13 \\
21.28 \\
21.29 \\
21.40\end{array}$ & $\begin{array}{l}20.75 \\
21.20 \\
21.53 \\
21.46 \\
21.01 \\
21.51\end{array}$ & $\begin{array}{l}21.29 \\
21.35 \\
20.95 \\
21.19 \\
21.39 \\
21.40\end{array}$ & $\begin{array}{l}21.18 \\
21.07 \\
20.59 \\
20.62 \\
21.19 \\
21.00\end{array}$ & $\begin{array}{l}20.93 \\
20.72 \\
20.34 \\
20.85 \\
20.84 \\
20.60\end{array}$ & $\begin{array}{l}20.12 \\
20.84 \\
20.72 \\
20.43 \\
20.64 \\
20.67\end{array}$ & $\begin{array}{l}20.69 \\
20.48 \\
20.20 \\
20.42 \\
20.50 \\
20.38\end{array}$ & $\begin{array}{l}20.27 \\
20.70 \\
20.43 \\
20.64 \\
20.40 \\
20.32\end{array}$ & $\begin{array}{l}20.58 \\
20.59 \\
20.32 \\
20.52 \\
20.64 \\
20.46\end{array}$ & $\begin{array}{l}20.49 \\
20.54 \\
20.83 \\
20.76 \\
20.70 \\
20.81\end{array}$ & $\begin{array}{l}20.87 \\
20.77 \\
20.84 \\
20.77 \\
21.10 \\
20.92\end{array}$ & $\begin{array}{l}\ldots \\
\ldots \\
\cdots \\
\cdots\end{array}$ \\
\hline
\end{tabular}

WTR YR 1991 HIGH 19.91 MAR 27

LOWEST WATER LEVEL, IN FEET BELOW LAND-SURFACE DATUM, WATER YEAR OCTOBER 1990 TO SEPTEMBER 1991

\begin{tabular}{|c|c|c|c|c|c|c|c|c|c|c|c|c|}
\hline DAY & $O C T$ & NOV & DEC & JAN & FE B & MAR & APR & MAY & JUN & JUL & AUG & SEP \\
\hline $\begin{array}{r}5 \\
10 \\
15 \\
20 \\
25 \\
\text { EOM }\end{array}$ & $\begin{array}{l}21.33 \\
21.29 \\
21.40 \\
21.40 \\
21.42 \\
21.49\end{array}$ & $\begin{array}{l}21.22 \\
21.40 \\
21.67 \\
21.55 \\
21.23 \\
21.79\end{array}$ & $\begin{array}{l}21.60 \\
21.43 \\
21.26 \\
21.35 \\
21.50 \\
21.60\end{array}$ & $\begin{array}{l}21.37 \\
21.52 \\
20.97 \\
20.84 \\
21.35 \\
21.35\end{array}$ & $\begin{array}{l}21.00 \\
20.88 \\
20.95 \\
21.00 \\
20.91 \\
20.75\end{array}$ & $\begin{array}{l}20.49 \\
20.97 \\
20.93 \\
20.67 \\
20.75 \\
20.83\end{array}$ & $\begin{array}{l}20.77 \\
20.83 \\
20.54 \\
20.52 \\
20.66 \\
20.52\end{array}$ & $\begin{array}{l}20.49 \\
20.79 \\
20.51 \\
20.71 \\
20.51 \\
20.39\end{array}$ & $\begin{array}{l}20.69 \\
20.72 \\
20.47 \\
20.63 \\
20.71 \\
20.59\end{array}$ & $\begin{array}{l}20.55 \\
20.59 \\
20.91 \\
20.83 \\
20.80 \\
20.90\end{array}$ & $\begin{array}{l}20.94 \\
20.94 \\
20.94 \\
20.92 \\
21.20 \\
21.05\end{array}$ & $\begin{array}{l}\ldots . \\
\ldots \\
\cdots \\
\ldots \\
\ldots\end{array}$ \\
\hline
\end{tabular}

WTR YR 1991 LOW 21.81 NOV 29 
402851087213501. Local number, BE 4.

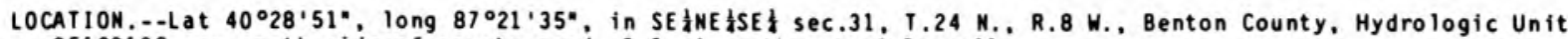

05120108 , On north side of county road, 3.6 i southeast of Boswell.

Owner: U.S. Geological Survey.

AQUIFER.-.-Sand and gravel of Pleistocene age.

WELL CHARACTERISTICS.--Orilled artesian well, dianeter $6 \mathrm{in}$., depth $310 \mathrm{ft}$, cased to $300 \mathrm{ft}$, screened to $305 \mathrm{ft}$. INSTRUMENTATION. - - Wat er-level recorder.

DATUM.--Elevation of land-surface datum is $710 \mathrm{ft}$ above National Geodetic Vertical Datum of 1929, from topographic ap. Measuring point: TOP of floor of shelter, $2.19 \mathrm{ft}$ above land-surface datua.

PERIOD OF RECORD.-- Novenber 1978 to current year.

EXTREMES FOR PERIOD OF RECORD.--Highest water level, $10.65 \mathrm{ft}$ below land-surface datum, May 7,1982 ; lowest,

$16.55 \mathrm{ft}$ below land-surface datun, Dec. $4,1988$.

\begin{tabular}{|c|c|c|c|c|c|c|c|c|c|c|c|c|}
\hline AY & $\begin{array}{l}\text { HIGHEST } \\
\text { OCT }\end{array}$ & $\begin{array}{c}\text { WATER } \\
\text { NOV }\end{array}$ & LEVEL, IN $^{\text {IN }}$ & $\begin{array}{c}\text { FEET BELOW } \\
\text { JAN }\end{array}$ & $\begin{array}{l}\text { LAND- } \\
\text { FEB }\end{array}$ & MAR & $\begin{array}{l}\text { WATER } \\
\text { APR }\end{array}$ & $\begin{array}{l}\text { YEAR } \\
\text { MAY }\end{array}$ & $\underset{\text { JUN }}{3 E R} 1990$ & $\begin{array}{l}\text { TO SEE } \\
\text { JUL }\end{array}$ & $\begin{array}{l}\text { BER } 1991 \\
\text { AUG }\end{array}$ & SEP \\
\hline $\begin{array}{r}5 \\
10 \\
15 \\
20 \\
25 \\
\text { EOM }\end{array}$ & $\begin{array}{l}13.94 \\
13.99 \\
13.96 \\
13.94 \\
13.86\end{array}$ & $\begin{array}{l}13.62 \\
13.65 \\
13.57 \\
13.35 \\
13.45\end{array}$ & $\begin{array}{l}13.28 \\
13.10 \\
13.09 \\
13.03 \\
12.87\end{array}$ & $\begin{array}{l}12.36 \\
11.97 \\
11.85 \\
11.94 \\
11.77\end{array}$ & $\begin{array}{l}11.80 \\
11.72 \\
11.51 \\
11.69 \\
11.78 \\
11.65\end{array}$ & $\begin{array}{l}11.78 \\
11.65 \\
11.44 \\
11.37 \\
11.28\end{array}$ & $\begin{array}{l}11.09 \\
10.97 \\
11.07 \\
11.10 \\
11.01\end{array}$ & $\begin{array}{l}11.30 \\
11.28 \\
11.41 \\
11.29 \\
11.26\end{array}$ & $\begin{array}{l}11.43 \\
11.56 \\
11.57 \\
11.74 \\
11.88 \\
12.02\end{array}$ & $\begin{array}{l}12.39 \\
12.64 \\
12.86 \\
13.12 \\
13.46\end{array}$ & $\begin{array}{l}13.70 \\
13.78 \\
13.99 \\
14.09 \\
14.42 \\
14.58\end{array}$ & $\begin{array}{l}14.95 \\
15.02 \\
15.32 \\
15.21 \\
15.46\end{array}$ \\
\hline
\end{tabular}

WTR YR 1991 HIGH 10.96 APR 23

LOWEST WATER LEVEL, IN FEET BELOW LAND-SURFACE DATUM, WATER YEAR OCTOBER 1990 TO SEPTEMBER 1991

\begin{tabular}{|c|c|c|c|c|c|c|c|c|c|c|c|c|}
\hline DAY & OCT & NOV & DEC & JAN & FE B & MAR & APR & MAY & JUN & JUL & AUG & SEP \\
\hline $\begin{array}{r}5 \\
10 \\
15 \\
20 \\
25 \\
\text { EOM }\end{array}$ & $\begin{array}{l}14.12 \\
14.01 \\
14.07 \\
14.02 \\
13.96 \\
13.90\end{array}$ & $\begin{array}{l}13.73 \\
13.67 \\
13.70 \\
13.59 \\
13.40 \\
13.54\end{array}$ & $\begin{array}{l}13.42 \\
13.30 \\
13.21 \\
13.13 \\
13.09 \\
12.89\end{array}$ & $\begin{array}{l}12.69 \\
12.49 \\
12.08 \\
11.88 \\
11.96 \\
11.86\end{array}$ & $\begin{array}{l}11.81 \\
11.76 \\
11.67 \\
11.71 \\
11.80 \\
11.73\end{array}$ & $\begin{array}{l}11.59 \\
11.82 \\
11.71 \\
11.54 \\
11.39 \\
11.32\end{array}$ & $\begin{array}{l}11.25 \\
11.23 \\
11.07 \\
11.11 \\
11.13 \\
11.08\end{array}$ & $\begin{array}{l}11.15 \\
11.34 \\
11.32 \\
11.42 \\
11.36 \\
11.31\end{array}$ & $\begin{array}{l}11.49 \\
11.60 \\
11.60 \\
11.76 \\
11.92 \\
12.03\end{array}$ & $\begin{array}{l}12.16 \\
12.43 \\
12.71 \\
12.92 \\
13.21 \\
13.49\end{array}$ & $\begin{array}{l}13.76 \\
13.87 \\
14.03 \\
14.17 \\
14.45 \\
14.65\end{array}$ & $\begin{array}{l}14.85 \\
14.99 \\
15.06 \\
15.37 \\
15.31 \\
15.49\end{array}$ \\
\hline
\end{tabular}

WTR YR 1991 LOW 15.49 SEP 30

400532086183901. Local number, BO 17.

BOONE COUNTY

LOCATION.--Lat $40^{\circ} 05^{\prime} 32^{\circ}$. long $86^{\circ} 18^{\prime} 39^{\circ}$, in SW $\frac{1}{2}$ SE $\frac{1}{2}$ WW $\frac{1}{4}$ sec.16, T.19 N., R.2 E., Boone County, Hydrologic Unit $05120201,0.6$ i north along U.S. Highway 421 from the intersection of U.S. Highway 421 and County Road 300 North at Waugh on the west side of the highway at the residence of John Sheets.

Owner: U.S. Geological Survey.

AQUIFER. - - Sand and gravel of Pleistocene age.

WELL CHARACTERISTICS.--Drilled artesian well, dianeter $6 \mathrm{in}$, depth $171.8 \mathrm{ft}$, cased to $166.8 \mathrm{ft}$, screened to $171.8 \mathrm{ft}$.

INSTRUMENTATION. - - Water-level recorder.

DATUM.--Elevation of land-surface datum is $956.50 \mathrm{ft}$ above Mational Geodetic Vertical Datua of 1929.

Measuring point: Mark on top of casing, $3.50 \mathrm{ft}$ above land-surface datua.

PERIOD OF RECORD.--July 1986 to current year.

EXTREMES FOR PERIOD OF RECORD..-Highest water leve1, $45.87 \mathrm{ft}$ below land-surface datun, July 11-13, 1986; lowest. $51.98 \mathrm{ft}$ below land-surface datun, $0 \mathrm{ct}$. 13, 14, i 988 .

\begin{tabular}{|c|c|c|c|c|c|c|c|c|c|c|c|c|}
\hline ay & $\begin{array}{l}\text { HIGHEST } \\
\text { OCT }\end{array}$ & $\begin{array}{l}\text { WATER } \\
\text { NOV }\end{array}$ & LEVEL, IN & $\begin{array}{c}\text { FEET BELOW } \\
\text { JAN }\end{array}$ & $\begin{array}{l}\text { LAND-S } \\
\text { FEB }\end{array}$ & $\begin{array}{l}\text { ACE } D \\
\text { MAR }\end{array}$ & $\begin{array}{l}\text { DATUM, WATER } \\
\text { APR }\end{array}$ & $\begin{array}{l}\text { YEAR } \\
\text { MAY }\end{array}$ & OCTOBER 1990 & $\begin{array}{c}\text { To SE } \\
\text { JUL }\end{array}$ & $\begin{array}{l}\text { BER } 1991 \\
\text { AUG }\end{array}$ & \\
\hline 5 & $\begin{array}{l}48.58 \\
48.32 \\
48.27 \\
48.22 \\
48.17 \\
48.14\end{array}$ & $\begin{array}{l}47.84 \\
48.06 \\
47.98 \\
47.95 \\
47.74 \\
47.76\end{array}$ & $\begin{array}{l}47.64 \\
47.66 \\
47.48 \\
47.55 \\
47.52 \\
47.51\end{array}$ & $\begin{array}{l}47.51 \\
47.54 \\
47.39 \\
47.37 \\
47.55 \\
47.49\end{array}$ & $\begin{array}{l}47.52 \\
47.50 \\
47.38 \\
47.52 \\
47.57 \\
47.48\end{array}$ & $\begin{array}{l}47.33 \\
47.54 \\
47.35 \\
47.21 \\
47.22 \\
47.15\end{array}$ & $\begin{array}{l}47.08 \\
46.95 \\
46.75 \\
46.77 \\
46.78 \\
46.69\end{array}$ & $\begin{array}{l}46.62 \\
46.71 \\
46.66 \\
46.91 \\
46.99 \\
47.02\end{array}$ & $\begin{array}{l}47.20 \\
47.39 \\
47.65 \\
48.04 \\
48.31 \\
48.63\end{array}$ & $\begin{array}{r}48.95 \\
49.25 \\
49.40 \\
\ldots . . \\
\ldots .\end{array}$ & $\begin{array}{l}50.76 \\
50.80 \\
50.74 \\
50.79 \\
50.92 \\
51.05\end{array}$ & \\
\hline
\end{tabular}

WTR YR 1991 HIGH 46.62 MAY 5

LOWEST WATER LEVEL, IN FEET BELOW LAND-SURFACE DATUM. WATER YEAR OCTOBER 1990 TO SEPTEMBER 1991

\begin{tabular}{|c|c|c|c|c|c|c|c|c|c|c|c|}
\hline DAY & OCT & NOV & DEC & JAN & FEB & MAR & APR & MAY & JUN & JUL & AUG \\
\hline $\begin{array}{r}5 \\
10 \\
15 \\
20 \\
25 \\
\text { EOM }\end{array}$ & $\begin{array}{l}48.58 \\
48.39 \\
48.34 \\
48.25 \\
48.18 \\
48.15\end{array}$ & $\begin{array}{l}48.03 \\
48.14 \\
48.03 \\
47.96 \\
47.80 \\
47.87\end{array}$ & $\begin{array}{l}47.75 \\
47.71 \\
47.64 \\
47.61 \\
47.58 \\
47.58\end{array}$ & $\begin{array}{l}47.59 \\
47.64 \\
47.46 \\
47.40 \\
47.57 \\
47.57\end{array}$ & $\begin{array}{l}47.53 \\
47.55 \\
47.53 \\
47.56 \\
47.61 \\
47.55\end{array}$ & $\begin{array}{l}47.43 \\
47.59 \\
47.41 \\
47.30 \\
47.25 \\
47.21\end{array}$ & $\begin{array}{l}47.10 \\
47.07 \\
46.86 \\
46.81 \\
46.82 \\
46.75\end{array}$ & $\begin{array}{l}46.69 \\
46.76 \\
46.72 \\
46.94 \\
47.05 \\
47.09\end{array}$ & $\begin{array}{l}47.23 \\
47.44 \\
47.74 \\
48.08 \\
48.38 \\
48.67\end{array}$ & $\begin{array}{r}49.00 \\
49.28 \\
49.43 \\
\ldots . . \\
\ldots . .\end{array}$ & $\begin{array}{l}50.81 \\
50.84 \\
50.74 \\
50.84 \\
50.93 \\
51.11\end{array}$ \\
\hline
\end{tabular}

WIR YR 1991 LOW 51.62 SEP 20 
403407086175701 . Local number. CS 3.

CASS COUNTY

LOCATION.--Lat $40^{\circ} 34^{\prime} 07^{\circ}$, long $86^{\circ} 17^{\prime} 57^{\circ}$, in NE 05120105, at intersection of State Highway 18 and County Road 400 East, 2.5 east of Young Anerica.

Owner: U.S. Geological Survey.

AQUIFER. - Dolonitic limestone of Devonian-Silurian age.

WELL CHARACTERISTICS.--Orilled artesian well, dianeter $6 \mathrm{in.}$, depth $130 \mathrm{ft}$, cased to $78 \mathrm{ft}$, open end.

INST RUME NTATION. - - Wa ter- level recorder.

DATUM.--Elevation of land-surface datue is $781.74 \mathrm{ft}$ above National Geodetic Vertical Datua of 1929 . Measuring point: Top of floor of shelter, $2.65 \mathrm{ft}$ above land-surface datue.

PERIOD OF RECORD.--August 1967 to current year.

EXTREMES FOR PERIOD OF RECORD.--Highest water leve1, $3.85 \mathrm{ft}$ below land-surface datua, Feb. 2 , 1968 ; 1owest, $9.55 \mathrm{ft}$ below land-surface datue, Nov. 11, 1988 .

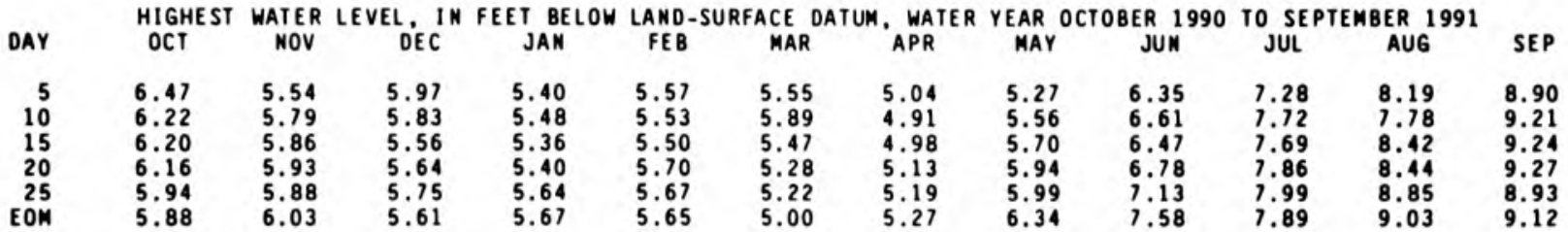

WTR YR 1991 HIGH 4.74 MAR 27

\section{LOWEST WATER LEVEL, IN FEET BELOW LAND-SURFACE DATUM, WATER YEAR OCTOBER 1990 TO SEPTEMBER 1991}

\begin{tabular}{|c|c|c|c|c|c|c|c|c|c|c|c|c|}
\hline DAY & OCT & NOV & DEC & JAN & FEB & MAR & $A P R$ & MAY & JUN & JUL & AUG & SEP \\
\hline $\begin{array}{r}5 \\
10 \\
15 \\
20 \\
25 \\
\text { EON }\end{array}$ & $\begin{array}{l}6.63 \\
6.38 \\
6.33 \\
6.23 \\
6.06 \\
6.00\end{array}$ & $\begin{array}{l}5.89 \\
5.93 \\
5.98 \\
6.01 \\
6.02 \\
6.19\end{array}$ & $\begin{array}{l}6.19 \\
5.91 \\
5.76 \\
5.79 \\
5.87 \\
5.72\end{array}$ & $\begin{array}{l}5.57 \\
5.60 \\
5.48 \\
5.52 \\
5.76 \\
5.81\end{array}$ & $\begin{array}{l}5.70 \\
5.64 \\
5.85 \\
5.75 \\
5.81 \\
5.81\end{array}$ & $\begin{array}{l}5.69 \\
5.97 \\
5.64 \\
5.41 \\
5.29 \\
5.13\end{array}$ & $\begin{array}{l}5.10 \\
5.21 \\
5.17 \\
5.24 \\
5.29 \\
5.38\end{array}$ & $\begin{array}{l}5.40 \\
5.64 \\
5.83 \\
6.01 \\
6.07 \\
6.41\end{array}$ & $\begin{array}{l}6.50 \\
6.76 \\
6.65 \\
6.91 \\
7.29 \\
7.80\end{array}$ & $\begin{array}{l}7.36 \\
7.87 \\
7.78 \\
8.00 \\
8.14 \\
8.02\end{array}$ & $\begin{array}{l}8.33 \\
7.93 \\
8.48 \\
8.51 \\
9.00 \\
9.11\end{array}$ & $\begin{array}{l}9.01 \\
9.36 \\
9.37 \\
9.39 \\
9.18 \\
9.26\end{array}$ \\
\hline
\end{tabular}

WTR YR 1991 LOW 9.45 SEP 16

392653087120501. Local number, CY 6.

CLAY COUNTY

LOCATION. - Lat $39^{\circ} 26^{\prime} 53^{\circ}$, long $87^{\circ} 12^{\circ} 05^{\prime \prime}$, in SE $\frac{1}{4} S E \frac{1}{4} S E \frac{1}{2}$ sec.29, T.12 N., R.7 W., Clay County, Hydrologic Unit $05120111,2.8 .1$ southwest of Staunton and 4.0 . 1 west of State Highway 59 just north of State Highway 42 . Owner: U.S. Geological Survey.

AQUIFER.--Sandstone of the Mansfield Foration. Pennsyluanian Period.

WELL CHARACTERISTICS.--Drilled artesian well, dianeter $6 \mathrm{in.,}$ depth $400 \mathrm{ft}$, cased to $347 \mathrm{ft}$, open end.

INST RUMENTATION. - - Wa ter-level recorder.

DATUM.--Elevation of land-surface datue is $653.16 \mathrm{ft}$ above Mational Geodetic Vertical Datue of 1929 . Measuring point: Top of casing, $3.40 \mathrm{ft}$ above land-surface datue.

PERIOD OF RECORD..-September 1987 to current year.

EXTREMES FOR PERIOD OF RECORD.--Highest water leve1, $151.36 \mathrm{ft}$ below land-surface datua, Jan. 19, 1988 ; lowest. $155.66 \mathrm{ft}$ below land-surface datum, Sept. 20, 1991.

\begin{tabular}{|c|c|c|c|c|c|c|c|c|c|c|c|c|}
\hline$A Y$ & $\begin{array}{l}\text { HIGHEST } \\
\text { OCT }\end{array}$ & $\begin{array}{c}\text { WATER } \\
\text { NOV }\end{array}$ & LEVEL, IN & $\underset{\text { JAN }}{\text { FEET BELOW }}$ & $\begin{array}{c}\text { WAND-S } \\
\text { FEB }\end{array}$ & $\begin{array}{l}\text { ACE D } \\
\text { MAR }\end{array}$ & $\begin{array}{c}\text { DATUM, WATER } \\
\text { APR }\end{array}$ & $\begin{array}{l}\text { YEAR } 0 \\
\text { MAY }\end{array}$ & JUN & JUL & $A U$ & SEP \\
\hline $\begin{array}{r}5 \\
10 \\
15 \\
20 \\
25\end{array}$ & $\begin{array}{l}153.42 \\
153.35 \\
153.46 \\
153.48 \\
153.62 \\
153.62\end{array}$ & $\begin{array}{l}153.22 \\
153.61 \\
153.77 \\
153.78 \\
153.53 \\
153.79\end{array}$ & $\begin{array}{l}153.72 \\
153.86 \\
153.65 \\
153.80 \\
153.94 \\
154.07\end{array}$ & $\begin{array}{l}.00 \\
.71 \\
.79 \\
.23 \\
.24\end{array}$ & $\begin{array}{l}.10 \\
.99 \\
.23 \\
.23 \\
.07\end{array}$ & $\begin{array}{l}15 \\
1 \\
1 \\
1 \\
1\end{array}$ & $\begin{array}{l}154.44 \\
154.36 \\
154.10 \\
154.36 \\
154.40 \\
154.40\end{array}$ & $\begin{array}{l}15 \\
15 \\
15 \\
15\end{array}$ & $\begin{array}{l}15 \\
15 \\
15 \\
15 \\
15\end{array}$ & & $\begin{array}{l}155 \\
155 \\
155 \\
155 \\
155 \\
155\end{array}$ & $\begin{array}{l}.26 \\
.28 \\
.46 \\
.04 \\
.35\end{array}$ \\
\hline
\end{tabular}

WTR YR 1991 HIGH 153.22 NOV 5

LOWEST WATER LEVEL, IN FEET BELOW LAND-SURFACE DATUM, WATER YEAR OCTOBER 1990 TO SEPTEMBER 1991

\begin{tabular}{|c|c|c|c|c|c|c|c|c|c|c|c|c|}
\hline DAY & OCT & NOV & DEC & JAN & FE B & MAR & APR & MAY & JUN & JUL & AUG & SEP \\
\hline $\begin{array}{r}5 \\
10 \\
15 \\
20 \\
25 \\
\text { EOM }\end{array}$ & $\begin{array}{l}153.65 \\
153.48 \\
153.68 \\
153.69 \\
153.69 \\
153.81\end{array}$ & $\begin{array}{l}153.60 \\
153.77 \\
153.97 \\
153.94 \\
153.70 \\
154.14\end{array}$ & $\begin{array}{l}154.09 \\
153.98 \\
153.99 \\
154.01 \\
154.11 \\
154.24\end{array}$ & $\begin{array}{l}154.10 \\
154.28 \\
154.04 \\
153.97 \\
154.34 \\
154.42\end{array}$ & $\begin{array}{l}154.25 \\
154.31 \\
154.32 \\
154.32 \\
154.43 \\
154.32\end{array}$ & $\begin{array}{l}154.14 \\
154.51 \\
154.54 \\
154.32 \\
154.41 \\
154.55\end{array}$ & $\begin{array}{l}154.52 \\
154.63 \\
154.46 \\
154.50 \\
154.60 \\
154.60\end{array}$ & $\begin{array}{l}154.48 \\
154.81 \\
154.73 \\
154.79 \\
154.79 \\
154.79\end{array}$ & $\begin{array}{l}154.99 \\
155.16 \\
154.99 \\
155.14 \\
155.27 \\
155.17\end{array}$ & $\begin{array}{l}155.23 \\
155.43 \\
155.55 \\
155.53 \\
155.53 \\
155.54\end{array}$ & $\begin{array}{l}155.65 \\
155.51 \\
155.45 \\
155.46 \\
155.61 \\
155.43\end{array}$ & $\begin{array}{l}155.46 \\
155.45 \\
155.38 \\
155.66 \\
155.35 \\
155.55\end{array}$ \\
\hline
\end{tabular}

WTR YR 1991 LOW 155.66 SEP 20 
391124087134701 . Local nubber, CY 7

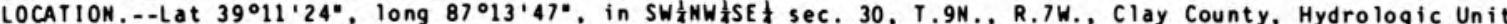

05120111 . $300 \mathrm{ft}$ east of State Highway 159 just south of Coaluont and about 3.6 a northwest of Jasonville.

Owner: U.S. Geological Survey

AQUIFER. -. Sandstone of Pennsylvanian age.

WELL CHARACTERISTICS.-.-Drilled artesian well, dianeter $6 \mathrm{in.}$, depth $121 \mathrm{ft}$, cased to $80 \mathrm{ft}$, open end.

I NST RUMENTATION. - - Water-level recorder.

DATUM.--Elevation of land-surface datua is $616.80 \mathrm{ft}$ (revised) above National Geodetic Vertical Datua of 1929. Measuring point: Top of casing, $3.50 \mathrm{ft}$ above land-surface datum.

PERIOD OF RECORD.--Septeaber 1988 to current year.

EXTREMES FOR PERIOD OF RECORD.--Highest water leve1, $25.59 \mathrm{ft}$ below land-surface datun, Sept. 4 , 5, 1988 ; lowest, $33.05 \mathrm{ft}$ below land-surface datun. Dec. 26, 1988 .

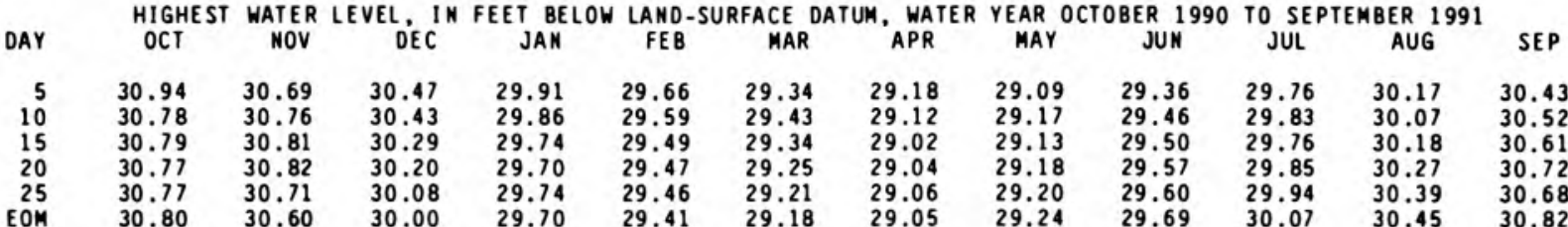

WTR YR 1991 HIGH 29.01 APR 29

LOWEST WATER LEVEL, IN FEET BELOW LAND-SURFACE DATUM, WATER YEAR OCTOBER 1990 TO SEPTEMBER 1991

\begin{tabular}{|c|c|c|c|c|c|c|c|c|c|c|c|c|}
\hline DAY & OCT & NOV & DEC & JAN & FE B & MAR & APR & MAY & JUN & JUL & AUG & SEP \\
\hline $\begin{array}{r}5 \\
10 \\
15 \\
20 \\
25 \\
\text { EOM }\end{array}$ & $\begin{array}{l}30.97 \\
30.81 \\
30.82 \\
30.79 \\
30.78 \\
30.82\end{array}$ & $\begin{array}{l}30.79 \\
30.78 \\
30.84 \\
30.84 \\
30.73 \\
30.66\end{array}$ & $\begin{array}{l}30.53 \\
30.44 \\
30.38 \\
30.24 \\
30.10 \\
30.02\end{array}$ & $\begin{array}{l}29.97 \\
29.92 \\
29.80 \\
29.72 \\
29.75 \\
29.72\end{array}$ & $\begin{array}{l}29.68 \\
29.62 \\
29.53 \\
29.49 \\
29.48 \\
29.45\end{array}$ & $\begin{array}{l}29.38 \\
29.44 \\
29.37 \\
29.28 \\
29.23 \\
29.20\end{array}$ & $\begin{array}{l}29.20 \\
29.17 \\
29.08 \\
29.06 \\
29.08 \\
29.09\end{array}$ & $\begin{array}{l}29.11 \\
29.19 \\
29.17 \\
29.20 \\
29.23 \\
29.27\end{array}$ & $\begin{array}{l}29.39 \\
29.49 \\
29.54 \\
29.59 \\
29.63 \\
29.71\end{array}$ & $\begin{array}{l}29.78 \\
29.87 \\
29.79 \\
29.88 \\
29.98 \\
30.09\end{array}$ & $\begin{array}{l}30.19 \\
30.11 \\
30.20 \\
30.30 \\
30.41 \\
30.46\end{array}$ & $\begin{array}{l}30.46 \\
30.55 \\
30.63 \\
30.74 \\
30.71 \\
30.84\end{array}$ \\
\hline
\end{tabular}

WTR YR $1991 \quad$ LOW 31.06 OCT 2

392022085371801. Local number, DC 2

DECATUR COUNTY

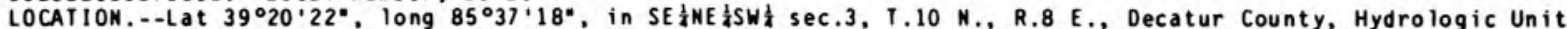
05120206, at the intersection of County Roads 50 North and 750 West and 7.5 a west of Greensburg.

Owner: U.S. Geological Survey.

AQUIFER, - - Limestone of Devonian age.

WELL CHARACTERISIICS.--Drilled artesian well, diameter $6 \mathrm{in}$., depth $49 \mathrm{ft}$, cased to $12.5 \mathrm{ft}$, open end.

INST RUMENTATION. - - Wa ter-level recorder.

DATUM.--Elevation of land-surface datue is $840.8 \mathrm{ft}$ above National Geodetic Vertical Datun of 1929 . Measuring

point: Top of floor of shelter, $3.02 \mathrm{ft}$ above land-surface datue.

PERIOD OF RECORD.--Septeaber 1966 to October 1971 , Septeaber 1974 to current year.

EXTREMES FOR PERIOD OF RECORD.--Highest water level, $0.12 \mathrm{ft}$ below land-surface datun, Dec. 30 , 1991 ; lowest,

$9.25 \mathrm{ft}$ below land-surface datus, Feb. 9-11, 1977.

\begin{tabular}{|c|c|c|c|c|c|c|c|c|c|c|c|c|}
\hline DAY & $\begin{array}{l}\text { HIGHEST } \\
\text { OCT }\end{array}$ & $\begin{array}{c}\text { WAIER } \\
\text { NOV }\end{array}$ & LEVEL, IN & FEET BELOW & $\begin{array}{l}\text { LAND -S } \\
\text { FEB }\end{array}$ & $\begin{array}{l}\text { FACE D } \\
\text { MAR }\end{array}$ & $\begin{array}{c}\text { DATUM, WATER } \\
\text { APR }\end{array}$ & $\begin{array}{l}\text { YEAR } 0 \\
\text { MAYY }\end{array}$ & $\underset{\text { OCTOB }}{\text { OCTOR }} 1990$ & $\begin{array}{l}\text { TO SEPTE } \\
\text { JUL }\end{array}$ & $\begin{array}{l}\text { MBER } 1991 \\
\text { AUG }\end{array}$ & SEP \\
\hline $\begin{array}{r}5 \\
10 \\
15 \\
20 \\
25 \\
\text { EOM }\end{array}$ & $\begin{array}{l}5.09 \\
1.88 \\
4.08 \\
3.10 \\
4.06 \\
4.70\end{array}$ & $\begin{array}{l}5.09 \\
5.36 \\
5.63 \\
5.99 \\
5.83 \\
4.72\end{array}$ & $\begin{array}{r}2.97 \\
3.99 \\
4.31 \\
.76 \\
1.30 \\
.76\end{array}$ & $\begin{array}{l}2.22 \\
2.64 \\
1.04 \\
1.85 \\
3.64 \\
3.93\end{array}$ & $\begin{array}{r}.92 \\
1.24 \\
2.34 \\
1.63 \\
3.17 \\
3.79\end{array}$ & $\begin{array}{l}4.14 \\
4.43 \\
1.77 \\
1.70 \\
1.30 \\
2.49\end{array}$ & $\begin{array}{r}3.88 \\
4.24 \\
.99 \\
1.69 \\
3.63 \\
4.15\end{array}$ & $\begin{array}{l}4.44 \\
4.70 \\
4.91 \\
4.09 \\
4.66 \\
5.16\end{array}$ & $\begin{array}{l}5.53 \\
5.88 \\
5.64 \\
6.07 \\
6.39 \\
6.64\end{array}$ & $\begin{array}{l}6.81 \\
6.97 \\
7.02 \\
7.18 \\
7.34 \\
7.53\end{array}$ & $\begin{array}{l}7.68 \\
7.63 \\
7.83 \\
7.68 \\
7.81 \\
8.01\end{array}$ & $\begin{array}{l}7.53 \\
7.62 \\
7.84 \\
8.01 \\
8.08 \\
8.16\end{array}$ \\
\hline
\end{tabular}

WTR YR 1991 HIGH .12 DEC 30

LOWEST WATER LEVEL, IN FEET BELOW LAND-SURFACE DATUM, WATER YEAR OCTOBER 1990 TO SEPTEMBER 1991

\begin{tabular}{|c|c|c|c|c|c|c|c|c|c|c|c|c|}
\hline DAY & $\mathrm{OCT}$ & MOV & DEC & JAN & FEB & MAR & APR & MAY & JUN & JUL & AUG & SEP \\
\hline $\begin{array}{r}5 \\
10 \\
15 \\
20 \\
25 \\
\text { EOM }\end{array}$ & $\begin{array}{l}5.13 \\
2.26 \\
4.28 \\
3.48 \\
4.19 \\
4.79\end{array}$ & $\begin{array}{l}5.13 \\
5.37 \\
5.70 \\
6.04 \\
5.86 \\
4.85\end{array}$ & $\begin{array}{r}3.14 \\
4.12 \\
4.48 \\
.87 \\
1.55 \\
1.05\end{array}$ & $\begin{array}{l}2.50 \\
2.96 \\
1.24 \\
2.27 \\
3.75 \\
4.05\end{array}$ & $\begin{array}{l}3.83 \\
1.61 \\
2.92 \\
1.74 \\
3.41 \\
3.88\end{array}$ & $\begin{array}{l}4.17 \\
4.49 \\
2.04 \\
1.95 \\
1.56 \\
2.96\end{array}$ & $\begin{array}{l}3.97 \\
4.34 \\
1.39 \\
2.03 \\
3.78 \\
4.21\end{array}$ & $\begin{array}{l}4.48 \\
4.75 \\
4.95 \\
4.25 \\
4.75 \\
5.24\end{array}$ & $\begin{array}{l}5.60 \\
5.94 \\
5.73 \\
6.14 \\
6.46 \\
6.69\end{array}$ & $\begin{array}{l}6.85 \\
6.99 \\
7.06 \\
7.21 \\
7.38 \\
7.56\end{array}$ & $\begin{array}{l}7.72 \\
7.68 \\
7.86 \\
7.70 \\
7.86 \\
8.04\end{array}$ & $\begin{array}{l}7.57 \\
7.66 \\
7.88 \\
8.02 \\
8.10 \\
8.16\end{array}$ \\
\hline
\end{tabular}

WTR YR 1991 LOW 8.16 SEP 29 
400541085213701. Local nueber. OW 4.

LOCATION.--Lat $40^{\circ} 05^{\prime} 41^{\circ}$, long $85^{\circ} 21^{\prime} 37^{\circ}$, in SE ANW 4 SWl sec.9, T.19 N., R.10 E., Delaware County, Hydrologic Unit 05120201 , on property owned by Monroe Township Conservation Club, and 8.0 a south of Muncie.

Owner: U.S. Geological Survey.

AQUIFER,--Sand and gravel of Pleistocene age.

WELL CHARACTERISTICS.--Drilled artesian well, dianeter $6 \mathrm{in}$., depth $91 \mathrm{ft}$, cased to $89 \mathrm{ft}$, screened to $91 \mathrm{ft}$. INST RUMENTATION. - - Hater-level recorder.

DATUM.--Elevation of land-surface datua is $1,005 \mathrm{ft}$ above National Geodetic Vertical Datue of 1929 . froa topographic ap. Measuring point: Top of floor of shelter, $2.88 \mathrm{ft}$ above land-surface datur.

PERIOD OF RECORO.---October 1966 to October 1971, October 1974 to current year.

EXTREMES FOR PERIOD OF RECORD.--Highest water level, 42.21 ft below land-surface datua, Dec. 30 , 1990 ; lowest, $49.50 \mathrm{ft}$ below land-surface datum, Oct.13, 14, i 966.

\begin{tabular}{|c|c|c|c|c|c|c|c|c|c|c|c|c|}
\hline DAY & $\begin{array}{l}\text { HIGHEST } \\
\text { OCT }\end{array}$ & $\begin{array}{c}\text { WATER } \\
\text { NOV }\end{array}$ & LEVEL, IN & $\underset{\text { JAN }}{\text { FEET BELOW }}$ & $\begin{array}{l}\text { LAND - } \\
\text { FEB }\end{array}$ & $\begin{array}{l}\text { FACE D } \\
\text { MAR }\end{array}$ & $\begin{array}{l}\text { DATUM, WATER } \\
\text { APR }\end{array}$ & $\begin{array}{l}\text { YEAR } \\
\text { MAY }\end{array}$ & OCTOBER $\underset{\text { JUN }}{1990}$ & $\begin{array}{c}\text { TO SEP } \\
\text { JUL }\end{array}$ & $\begin{array}{l}\text { BER } 1991 \\
\text { AUG }\end{array}$ & SEP \\
\hline $\begin{array}{r}5 \\
10 \\
15 \\
20 \\
25 \\
\text { EOM }\end{array}$ & $\begin{array}{l}47.50 \\
47.16 \\
47.28 \\
47.22 \\
47.44 \\
47.65\end{array}$ & $\begin{array}{l}47.77 \\
47.84 \\
47.93 \\
48.00 \\
48.01 \\
47.64\end{array}$ & $\begin{array}{l}47.40 \\
47.59 \\
47.42 \\
46.79 \\
46.44 \\
42.91\end{array}$ & $\begin{array}{l}46.27 \\
46.98 \\
46.90 \\
46.94 \\
47.27 \\
47.50\end{array}$ & $\begin{array}{l}47.13 \\
46.93 \\
47.25 \\
46.93 \\
47.27 \\
47.43\end{array}$ & $\begin{array}{l}47.59 \\
47.74 \\
46.69 \\
46.35 \\
45.95 \\
46.64\end{array}$ & $\begin{array}{l}47.06 \\
47.31 \\
47.05 \\
46.95 \\
47.27 \\
47.46\end{array}$ & $\begin{array}{l}47.61 \\
47.73 \\
47.83 \\
47.03 \\
47.31 \\
47.14\end{array}$ & $\begin{array}{l}47.36 \\
47.65 \\
47.83 \\
47.97 \\
48.05 \\
48.15\end{array}$ & $\begin{array}{l}48.23 \\
48.26 \\
48.34 \\
48.41 \\
48.49 \\
48.57\end{array}$ & $\begin{array}{l}48.64 \\
48.66 \\
48.70 \\
48.58 \\
48.69 \\
48.74\end{array}$ & $\begin{array}{l}48.76 \\
48.80 \\
48.83 \\
48.84 \\
48.81 \\
48.85\end{array}$ \\
\hline
\end{tabular}

WTR YR 1991 HIGH 42.21 DEC 30

LOWEST WATER LEVEL, IN FEET BELOW LAND-SURFACE DATUM, WATER YEAR OCTOBER 1990 TO SEPTEMBER 1991

DAY

$\begin{array}{rrrrr}\text { OCT } & \text { NOV } & \text { DEC } & \text { JAN } & \text { FEB } \\ 47.54 & 47.79 & 47.40 & 46.46 & 47.31 \\ 47.47 & 47.86 & 47.65 & 47.03 & 47.04 \\ 47.36 & 47.94 & 47.78 & 47.01 & 47.35 \\ 47.26 & 48.01 & 46.81 & 47.00 & 46.97 \\ 47.48 & 48.03 & 46.59 & 47.31 & 47.32 \\ 47.69 & 47.66 & 44.58 & 47.56 & 47.47\end{array}$

MAR
47.60
47.77
47.07
46.48
46.18
46.73

APR
47.11
47.37
47.09
47.01
47.31
47.50

MAY
47.62
47.75
47.85
47.10
47.38
47.30

JUN
47.43
47.69
47.86
47.99
48.08
48.17

JUL
48.25
48.27
48.35
48.43
48.50
48.58

$\begin{array}{cc}\text { AUG } & \text { SEP } \\ 48.64 & 48.77 \\ 48.68 & 48.81 \\ 48.71 & 48.83 \\ 48.60 & 48.84 \\ 48.71 & 48.82 \\ 48.75 & 48.85\end{array}$

WTR YR 1991 LOW 48.85 SEP 29

413121085481301 . Local number, EH 4.

\section{ELKHART COUNTY}

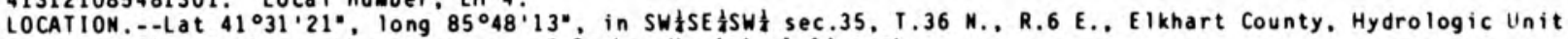
04050001 , at the southwest corner of Goshen Municipal Airport.

Owner: U.S. Geological Survey.

AQUIFER.-.-Sand and gravel of Pleistocene age.

WELL CHARACTERISTICS..-Drilled water-table well, dianeter $6 \mathrm{in}$., depth $62 \mathrm{ft}$, cased to $58 \mathrm{ft}$, screened to $60 \mathrm{ft}$. INSTRUME NTATION. - Water-level recorder.

DATUM.--Elevation of land-surface datum is $818 \mathrm{ft}$ above National Geodetic Vertical Datue of 1929 . from topographic

ap. Measuring point: Top of floor of shelter, $2.60 \mathrm{ft}$ above land-surface datua.

PERIOD OF RECORD..-Noveaber 1966 to current year.

EXTREMES FOR PERIOD OF RECORD.--Highest water level, $10.60 \mathrm{ft}$ below land-surface datue, Apr. 14, 1985 ; lowest,

$16.18 \mathrm{ft}$ below land-surface datue, Dec. 1-5, 1971

\begin{tabular}{|c|c|c|c|c|c|c|c|c|c|c|c|c|}
\hline DAY & $\begin{array}{l}\text { HIGHE ST } \\
\text { OCT }\end{array}$ & $\begin{array}{l}\text { WATER } \\
\text { NOV }\end{array}$ & LEVEL, IN & FEET JAN BELOW & $\begin{array}{l}\text { LAND-S } \\
\text { FEB }\end{array}$ & $\begin{array}{l}\text { ACE D } \\
\text { MAR }\end{array}$ & $\begin{array}{c}\text { DATUM, WATER } \\
\text { APR }\end{array}$ & $\begin{array}{l}\text { YEAR } 0 \\
\text { MAY }\end{array}$ & $\underset{\text { JUN }}{\text { OCTOBER }} 1990$ & TO SEL & $\begin{array}{l}\text { BER } 1991 \\
\text { AUG }\end{array}$ & SEP \\
\hline $\begin{array}{r}5 \\
10 \\
15 \\
20 \\
25 \\
\text { EOM }\end{array}$ & $\begin{array}{l}13.53 \\
13.29 \\
12.28 \\
12.19 \\
12.26 \\
12.39\end{array}$ & $\begin{array}{l}12.43 \\
12.49 \\
12.51 \\
12.54 \\
12.56 \\
12.61\end{array}$ & $\begin{array}{l}12.65 \\
12.71 \\
12.70 \\
12.77 \\
12.79 \\
11.73\end{array}$ & $\begin{array}{l}11.28 \\
11.37 \\
11.49 \\
11.43 \\
11.60 \\
11.73\end{array}$ & $\begin{array}{l}11.85 \\
11.94 \\
12.01 \\
12.07 \\
12.14 \\
12.18\end{array}$ & $\begin{array}{l}12.22 \\
12.31 \\
12.38 \\
12.41 \\
12.48 \\
12.52\end{array}$ & $\begin{array}{l}12.53 \\
12.54 \\
12.51 \\
12.21 \\
11.87 \\
11.72\end{array}$ & $\begin{array}{l}11.67 \\
11.71 \\
11.78 \\
11.90 \\
11.93 \\
11.56\end{array}$ & $\begin{array}{l}11.09 \\
11.11 \\
11.29 \\
11.68 \\
11.90 \\
12.22\end{array}$ & $\begin{array}{l}12.27 \\
12.52 \\
12.74 \\
13.06 \\
13.29 \\
13.49\end{array}$ & $\begin{array}{l}13.74 \\
13.76 \\
13.82 \\
13.89 \\
13.95 \\
14.03\end{array}$ & $\begin{array}{l}14.10 \\
14.17 \\
14.17 \\
14.22 \\
14.27 \\
14.34\end{array}$ \\
\hline
\end{tabular}

WTR YR 1991 HIGH 11.07 JUN 7

LOWEST WATER LEVEL, IN FEET BELOW LAND-SURFACE DATUM, WATER YEAR OCTOBER 1990 TO SEPTEMBER 1991

$\begin{array}{rrrrrrrrrrrrr}\text { DAY } & \text { OCT } & \text { NOV } & \text { DEC } & \text { JAN } & \text { FEB } & \text { MAR } & \text { APR } & \text { MAY } & \text { JUN } & \text { JUL } & \text { AUG } & \text { SEP } \\ & & & & & & & & & & & \\ 5 & 13.54 & 12.49 & 12.68 & 11.31 & 11.87 & 12.24 & 12.54 & 11.69 & 11.12 & 12.29 & 13.74 & 14.11 \\ 10 & 13.48 & 12.51 & 12.72 & 11.39 & 11.96 & 12.33 & 12.57 & 11.72 & 11.14 & 12.61 & 13.77 & 14.18 \\ 15 & 12.32 & 12.52 & 12.74 & 11.52 & 12.06 & 12.39 & 12.55 & 11.81 & 11.32 & 12.82 & 13.84 & 14.17 \\ 20 & 12.21 & 12.55 & 12.78 & 11.48 & 12.09 & 12.43 & 12.30 & 11.92 & 11.70 & 13.09 & 13.89 & 14.23 \\ 25 & 12.29 & 12.59 & 12.80 & 11.62 & 12.15 & 12.49 & 11.93 & 11.96 & 11.99 & 13.38 & 13.96 & 14.28 \\ \text { EOM } & 12.41 & 12.64 & 12.11 & 11.77 & 12.18 & 12.53 & 11.73 & 11.77 & 12.23 & 13.58 & 14.05 & 14.35\end{array}$

WTR YR 1991 LOW 14.35 SEP 30 
414419085544601 . Local number, EH 5

LOCATION, - - Lat $41^{\circ} 44^{\prime} 19^{\circ}$, Iong $85^{\circ} 54^{\prime} 46^{\circ}$, in NWtake $\frac{1}{4}$ NEE $\frac{1}{4}$ sec.23, T. 38 N., R.5 E., Elkhart County, Hydrologic Unit 04050001 , on the inlet to Heaton Lake, and 3.5 . i east of Elkhart.

Owner: State of Indiana.

AQUIFER.--Sand and gravel of Pleistocene age.

WELL CHARACTERISTICS.--Orilled water-table well, diameter $1.5 \mathrm{in}$., depth $13 \mathrm{ft}$, cased to $11 \mathrm{ft}$, screened to $13 \mathrm{ft}$ INSTRUMENTATION. - - Water-level recorder.

DATUM.--Elevation of land-surface datue is $770 \mathrm{ft}$ above National Geodetic Vertical Datue of 1929, froe topographic ap. Measuring point: Top of floor of shelter, $2.10 \mathrm{ft}$ above land-surface datua.

PERIOD OF RECORD.--May 1976 to current year.

EXTREMES FOR PERIOD OF RECORD.--Highest water level, $1.37 \mathrm{ft}$ below land-surface datue, June 16, 1981; lowest, $5.65 \mathrm{ft}$ below land-surface datum. Sept. 17-19, 1988 .

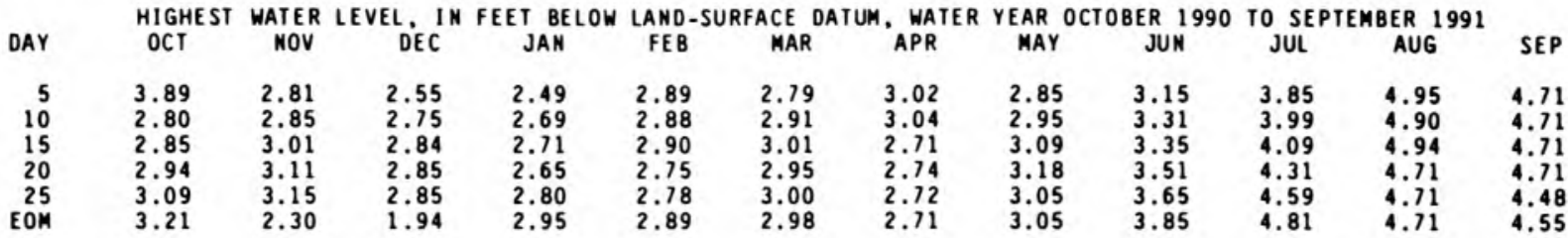

WTR YR 1991 HIGH 1.94 DEC 30

LOWEST WATER LEVEL, IN FEET BELOW LAND-SURFACE DATUM, WATER YEAR OCTOBER 1990 TO SEPTEMBER 1991

\begin{tabular}{|c|c|c|c|c|c|c|c|c|c|c|c|c|}
\hline DAY & OCT & NOV & DEC & JAN & FE B & MAR & APR & MAY & JUN & JUL & AUG & SEP \\
\hline $\begin{array}{r}5 \\
10 \\
15 \\
20 \\
25 \\
\text { EON }\end{array}$ & $\begin{array}{l}3.91 \\
3.30 \\
2.88 \\
2.96 \\
3.11 \\
3.22\end{array}$ & $\begin{array}{l}3.16 \\
2.90 \\
3.05 \\
3.16 \\
3.21 \\
2.39\end{array}$ & $\begin{array}{l}2.56 \\
2.78 \\
2.85 \\
2.88 \\
2.88 \\
1.98\end{array}$ & $\begin{array}{l}2.51 \\
2.69 \\
2.75 \\
2.65 \\
2.86 \\
2.96\end{array}$ & $\begin{array}{l}2.92 \\
2.88 \\
2.91 \\
2.78 \\
2.84 \\
2.89\end{array}$ & $\begin{array}{l}2.82 \\
2.94 \\
3.05 \\
2.98 \\
3.02 \\
2.99\end{array}$ & $\begin{array}{l}3.02 \\
3.08 \\
3.02 \\
2.74 \\
2.72 \\
2.76\end{array}$ & $\begin{array}{l}2.85 \\
2.99 \\
3.11 \\
3.20 \\
3.12 \\
3.21\end{array}$ & $\begin{array}{l}3.22 \\
3.35 \\
3.38 \\
3.54 \\
3.74 \\
3.86\end{array}$ & $\begin{array}{l}3.88 \\
4.05 \\
4.11 \\
4.44 \\
4.64 \\
4.84\end{array}$ & $\begin{array}{l}4.96 \\
4.91 \\
5.00 \\
4.72 \\
4.72 \\
4.72\end{array}$ & $\begin{array}{l}4.72 \\
4.72 \\
4.72 \\
4.71 \\
4.48 \\
4.61\end{array}$ \\
\hline
\end{tabular}

WTR YR 1991 LOW 5.09 AUG ?

414351085540401. Local number, EH 6.

EL KHART COUNTY

LOCATION.--Lat $41^{\circ} 43^{\prime} 51^{\prime \prime}$, long $85^{\circ} 54^{\prime} 04^{\prime \prime}$, in NW $\frac{1}{4} N E \frac{1}{4} S W \frac{1}{4}$ sec.24, T.38 M., R.5 E., Elkhart County, Hydrologic Unit 04050001 , on the southeast shore of Heaton Lake, and 4.0 ai east of Elkhart.

Owner: State of Indiana.

AQUIFER.--Sand and gravel of Pleistocene age.

WELL CHARACTERISTICS.--Drilled water-table well, dianeter $1.5 \mathrm{in}$., depth $22 \mathrm{ft}$, cased to $20 \mathrm{ft}$, screened to 22 ft. INSTRUMENTATION. - - Water-leve 1 recorder.

DATUM.--Elevation of land-surface datue is $770 \mathrm{ft}$ above Mational Geodetic Vertical Datun of 1929 . from topographic

ap. Measuring point: Top of floor of shelter, $2.50 \mathrm{ft}$ above land-surface datua.

PERIOD OF RECORD...-May 1976 to current year.

EXTREMES FOR PERIOD OF RECORD.--Highest water leve1, $5.10 \mathrm{ft}$ below land-surface datum, June 16-19, 1981 ; 10west,

$10.68 \mathrm{ft}$ below land-surface datur, Oct. 16, 17, 1988 .

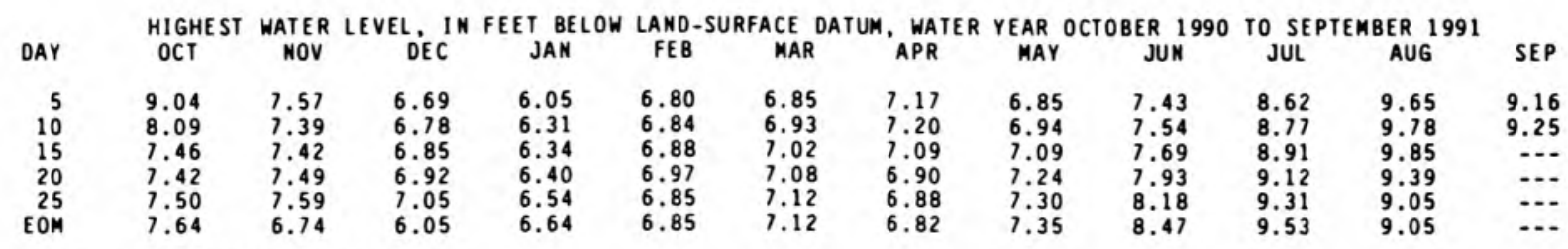

WTR YR 1991 HIGH 6.02 JAN 1

LOWEST WATER LEVEL. IN FEET BELOW LAND-SURFACE DATUM, WATER YEAR OCTOBER 1990 TO SEPTEMBER 1991

\begin{tabular}{|c|c|c|c|c|c|c|c|c|c|c|c|c|}
\hline DAY & $O C T$ & NOV & $D E C$ & JAN & FEB & MAR & APR & MAY & JUN & JUL & AUG & SEP \\
\hline $\begin{array}{r}5 \\
10 \\
15 \\
20 \\
25 \\
\text { EOM }\end{array}$ & $\begin{array}{l}9.08 \\
8.71 \\
7.47 \\
7.44 \\
7.54 \\
7.69\end{array}$ & $\begin{array}{l}7.73 \\
7.40 \\
7.44 \\
7.53 \\
7.65 \\
6.80\end{array}$ & $\begin{array}{l}6.70 \\
6.80 \\
6.85 \\
6.95 \\
7.06 \\
6.12\end{array}$ & $\begin{array}{l}6.05 \\
6.31 \\
6.41 \\
6.40 \\
6.56 \\
6.72\end{array}$ & $\begin{array}{l}6.80 \\
6.86 \\
6.92 \\
6.98 \\
6.86 \\
6.86\end{array}$ & $\begin{array}{l}6.87 \\
6.97 \\
7.06 \\
7.10 \\
7.15 \\
7.13\end{array}$ & $\begin{array}{l}7.18 \\
7.20 \\
7.22 \\
6.90 \\
6.88 \\
6.82\end{array}$ & $\begin{array}{l}6.85 \\
6.99 \\
7.13 \\
7.26 \\
7.30 \\
7.36\end{array}$ & $\begin{array}{l}7.44 \\
7.56 \\
7.71 \\
7.96 \\
8.23 \\
8.50\end{array}$ & $\begin{array}{l}8.64 \\
8.80 \\
8.95 \\
9.16 \\
9.32 \\
9.57\end{array}$ & $\begin{array}{l}9.69 \\
9.79 \\
9.87 \\
9.53 \\
9.08 \\
9.08\end{array}$ & $\begin{array}{r}9.18 \\
9.27 \\
\ldots \ldots \\
\ldots \\
\ldots\end{array}$ \\
\hline
\end{tabular}

WTR YR 1991 LOW 9.90 AUG 18 
414514085505001 . Local nuaber. EH 7.

ELKHART COUNTY

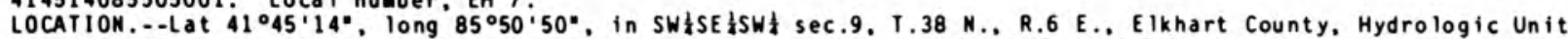
04050001 , on north side of County Road 2, $200 \mathrm{ft}$ east of County Road 21 , and 2.7 a northwest of Bristol.

Owner: U.S. Geological Survey.

AQUIFER.--Fine to aediun sand of Pleistocene age.

WELL CHARACTERISTICS.--Drilled water-table well, dianeter 6 in., depth $61 \mathrm{ft}$, cased to $56 \mathrm{ft}$, screened to 61 ft. INST RUMENTATION. - - Water-level recorder.

DATUM.--Elevation of land-surface datum is $781 \mathrm{ft}$ above National Geodetic Vertical Datun of 1929 , fron topographic

ap. Measuring point: Top of floor of shelter, $3.10 \mathrm{ft}$ above land-surface datue.

PERIOD OF RECORD.-.June 1981 to current year.

EXTREMES FOR PERIOD OF RECORD..--Highest water level, $5.50 \mathrm{ft}$ below land-surface datum, Feb. 24 , 1985; lowest,

$12.73 \mathrm{ft}$ below land-surface datur. Aug. 5, 6, 1988 .

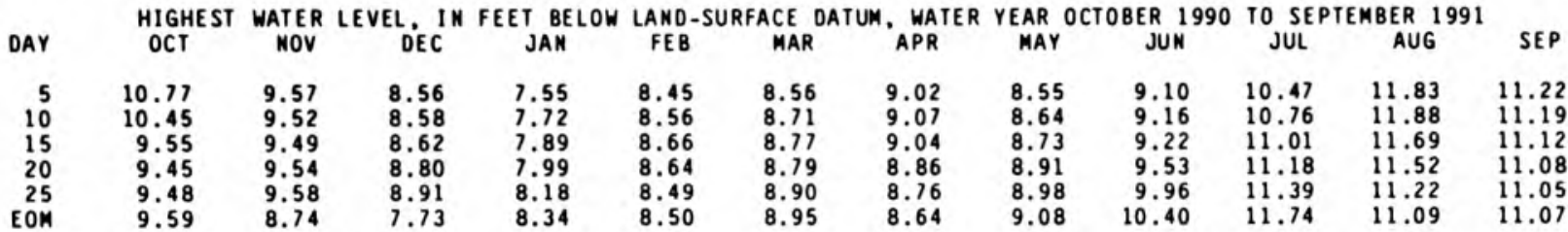

WTR YR 1991 HIGH 7.55 JAN 5

LOWEST WATER LEVEL. IN FEET BELOW LAND-SURFACE DATUM, WATER YEAR OCTOBER 1990 TO SEPTEMBER 1991

\begin{tabular}{|c|c|c|c|c|c|c|c|c|c|c|c|c|}
\hline DAY & OCT & NOV & DEC & JAN & FEB & MAR & $A P R$ & MAY & JUN & JUL & AUG & SEP \\
\hline $\begin{array}{r}5 \\
10 \\
15 \\
20 \\
25 \\
\text { EOM }\end{array}$ & $\begin{array}{r}10.78 \\
10.63 \\
9.59 \\
9.47 \\
9.51 \\
9.62\end{array}$ & $\begin{array}{l}9.66 \\
9.54 \\
9.51 \\
9.56 \\
9.64 \\
8.88\end{array}$ & $\begin{array}{l}8.62 \\
8.62 \\
8.71 \\
8.83 \\
8.95 \\
7.99\end{array}$ & $\begin{array}{l}7.59 \\
7.77 \\
7.92 \\
8.04 \\
8.19 \\
8.40\end{array}$ & $\begin{array}{l}8.48 \\
8.58 \\
8.72 \\
8.71 \\
8.51 \\
8.51\end{array}$ & $\begin{array}{l}8.60 \\
8.73 \\
8.79 \\
8.83 \\
8.92 \\
8.99\end{array}$ & $\begin{array}{l}9.04 \\
9.12 \\
9.11 \\
8.89 \\
8.80 \\
8.66\end{array}$ & $\begin{array}{l}8.58 \\
8.65 \\
8.75 \\
8.92 \\
9.00 \\
9.11\end{array}$ & $\begin{array}{r}9.12 \\
9.17 \\
9.24 \\
9.64 \\
10.06 \\
10.42\end{array}$ & $\begin{array}{l}10.51 \\
10.77 \\
11.02 \\
11.26 \\
11.44 \\
11.79\end{array}$ & $\begin{array}{l}11.89 \\
11.93 \\
11.71 \\
11.62 \\
11.26 \\
11.10\end{array}$ & $\begin{array}{l}11.23 \\
11.19 \\
11.13 \\
11.09 \\
11.06 \\
11.08\end{array}$ \\
\hline
\end{tabular}

WTR YR 1991 LOW 12.00 AUG 7 
414419085595801 . Local number, EH 9

LOCATION.--Lat $41^{\circ} 44^{\prime} 19^{\circ}$, Iong $85^{\circ} 59^{\prime} 58^{\prime \prime}$, in NF $\frac{1}{8} N{ }^{\frac{1}{2} N W} \frac{1}{2}$ sec.19, T. 38 N., R.5 E., Elkhart County, Hydrologic Unit 04050001 , on the west side of Iris Avenue, about 6 i northwest of Elkhart.

Owner: U.S. Geological Survey.

AQUIFER.--Sand and gravel of Pleistocene age.

WELL CHARACTERISTICS.--Orilled water-table well, dianeter 6 in, depth $33.8 \mathrm{ft}$, cased to $28.8 \mathrm{ft}$ with 5 ft stainless steel screen.

INST RUMENTATION, - - Wa ter-level recorder.

DATUM.--Elevation of land-surface datue is $785.27 \mathrm{ft}$ above National Geodetic Vertical Datua of 1929 . from topographic ap. Measuring point: Top of casing. $2.80 \mathrm{ft}$ above land-surface datun.

PERIOD OF RECORD..-July 1990 to current year.

EXIREMES FOR PERIOD OF RECORO.--Highest water level, $16.09 \mathrm{ft}$ below land-surface datua, Jan. 16, 1991; lowest.

$18.75 \mathrm{ft}$ below land-surface datum, 0ct. 3, 1990.

\begin{tabular}{|c|c|c|c|c|c|c|c|c|c|c|c|c|}
\hline AY & $\begin{array}{l}\text { HIGHEST } \\
\text { OCT }\end{array}$ & $\begin{array}{c}\text { WATER } \\
\text { NOV }\end{array}$ & LEVEL, IN & $\underset{\text { JAN }}{\text { FEET }}$ & $\begin{array}{l}\text { LAND - } \\
\text { FEB }\end{array}$ & MAR & $\begin{array}{c}\text { DATUM, WATER } \\
\text { APR }\end{array}$ & MAY & JUN & JUL & AUG & SEP \\
\hline $\begin{array}{r}5 \\
10 \\
15 \\
20 \\
25 \\
\text { EOM }\end{array}$ & $\begin{array}{l}18.51 \\
18.49 \\
18.05 \\
17.91 \\
17.87 \\
17.71\end{array}$ & $\begin{array}{l}17.65 \\
17.56 \\
17.52 \\
17.51 \\
17.51 \\
17.32\end{array}$ & $\begin{array}{l}17.11 \\
16.95 \\
16.86 \\
16.86 \\
16.88 \\
16.68\end{array}$ & $\begin{array}{l}34 \\
15 \\
10 \\
.09 \\
.23 \\
.39\end{array}$ & $\begin{array}{l}16.48 \\
16.55 \\
16.61 \\
16.67 \\
16.72 \\
16.74\end{array}$ & $\begin{array}{l}16.76 \\
16.82 \\
16.85 \\
16.88 \\
16.92 \\
16.92\end{array}$ & $\begin{array}{l}16.93 \\
16.94 \\
16.91 \\
16.82 \\
16.74 \\
16.65\end{array}$ & $\begin{array}{l}16.58 \\
16.56 \\
16.56 \\
16.63 \\
16.67 \\
16.68\end{array}$ & $\begin{array}{l}16.45 \\
16.48 \\
16.54 \\
16.70 \\
16.82 \\
16.93\end{array}$ & $\begin{array}{l}.02 \\
.11 \\
.19 \\
.29 \\
.37 \\
.50\end{array}$ & $\begin{array}{l}17.61 \\
17.71 \\
17.77 \\
17.66 \\
17.65 \\
17.73\end{array}$ & $\begin{array}{l}17.81 \\
17.90 \\
17.77 \\
17.75 \\
17.83 \\
17.94\end{array}$ \\
\hline
\end{tabular}

WTR YR 1991 HIGH 16.09 JAN 16

LOWEST WATER LEVEL, IN FEET BELOW LAND-SURFACE DATUM, WATER YEAR OCTOBER 1990 TO SEPTEMBER 1991

$\begin{array}{rrrrrrrrrrrrr}\text { DAY } & \text { OCT } & \text { NOV } & \text { DEC } & \text { JAN } & \text { FEB } & \text { MAR } & \text { APR } & \text { MAY } & \text { JUN } & \text { IUL } & \text { AUG } & \text { SEP } \\ & & & & & & & & & & & \\ \mathbf{5} & 18.58 & 17.67 & 17.16 & 16.39 & 16.49 & 16.78 & 16.94 & 16.60 & 16.46 & 17.64 & 17.64 & 17.86 \\ 10 & 18.62 & 17.58 & 16.97 & 16.19 & 16.57 & 16.83 & 16.96 & 16.56 & 16.49 & 17.12 & 17.72 & 17.92 \\ 15 & 18.10 & 17.53 & 16.88 & 16.11 & 16.64 & 16.86 & 16.94 & 16.57 & 16.57 & 17.21 & 17.79 & 17.77 \\ 20 & 17.96 & 17.52 & 16.88 & 16.11 & 16.68 & 16.89 & 16.83 & 16.64 & 16.72 & 17.31 & 17.75 & 17.77 \\ 25 & 17.90 & 17.54 & 16.90 & 16.26 & 16.73 & 16.93 & 16.76 & 16.67 & 16.84 & 17.39 & 17.67 & 17.84 \\ \text { EOM } & 17.73 & 17.37 & 16.75 & 16.43 & 16.75 & 16.94 & 16.66 & 16.72 & 16.95 & 17.52 & 17.79 & 17.95\end{array}$

WTR YR 1991 LOW 18.75 OCT 3

WATER-QUALITY RECOROS

414419085595801. Local number, EH 9.

WATER QUALITY DATA, WATER YEAR OCTOBER 1989 TO SEPTEMBER 1990

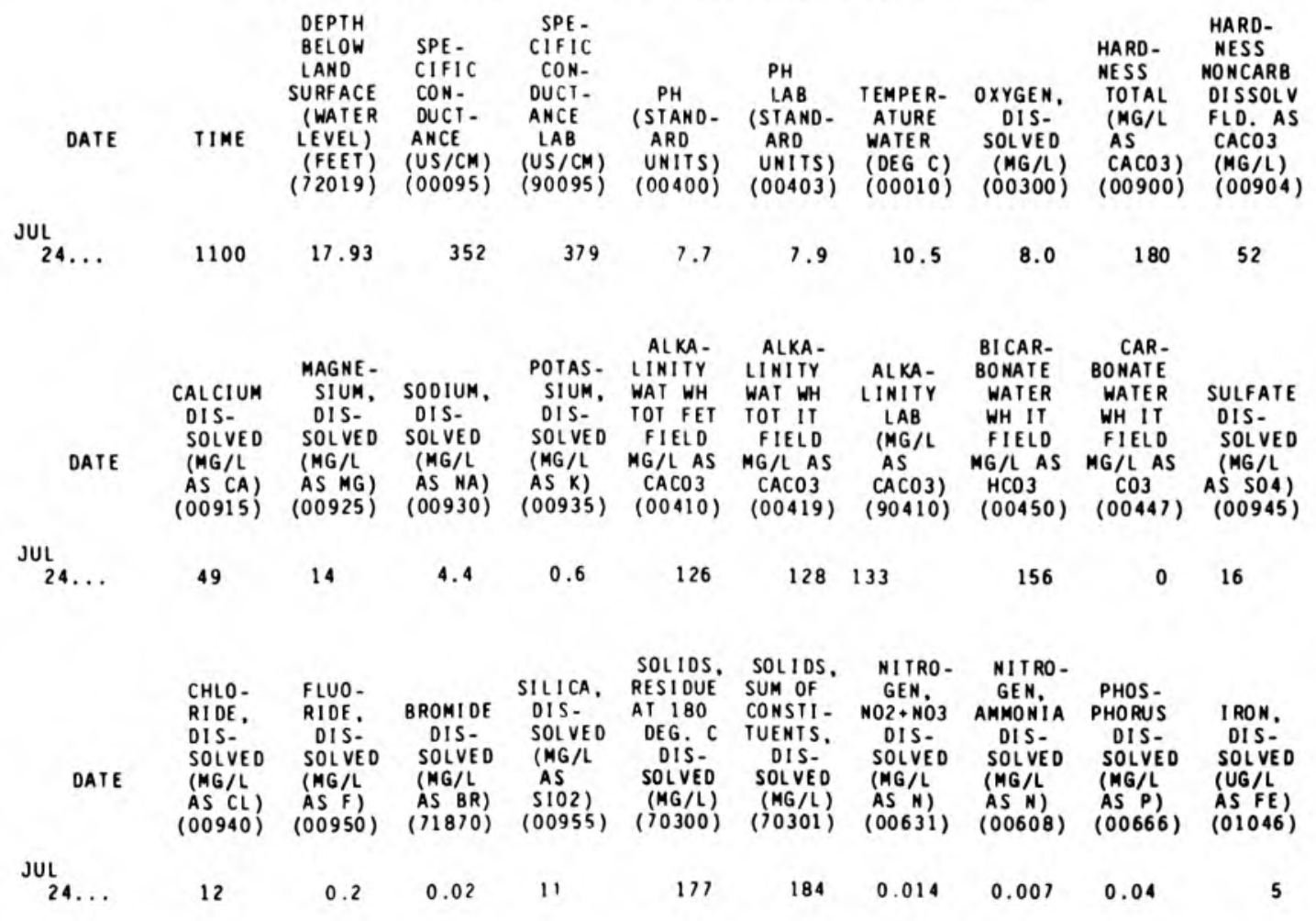


401200087121701. Local number, F0 3.

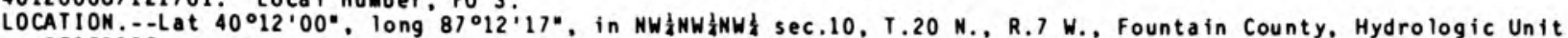
05120108 , on the southwest corner of the Union Church property on County Road 520 North, about 6.5 a $i$ southeast of Attica.

Owner: U.S. Geological Survey.

AQUIFER. - Shale and sandstone of the Mississippian Period.

WELL CHARACTERISTICS.--Drilled water-table well, dianeter $6 \mathrm{in}$, depth $102 \mathrm{ft}$, cased to 22 ft, open end. INSTRUMENTATION. - Wa ter-level recorder.

DATUM.--Elevation of land-surface datue is $670.99 \mathrm{ft}$ above National Geodetic Vertical Datua of 1929 . Measuring point: Top of casing. $3.60 \mathrm{ft}$ above land-surface datua.

PERIOD OF RECORD.-.July 1986 to current year.

EXTREMES FOR PERIOD OF RECORD.--Highest water level, $3.02 \mathrm{ft}$ below land-surface datun, Mar. 11, 1990; lowest, $13.53 \mathrm{ft}$ below land-surface datun, Dec. $21,22,25-27,1988$.

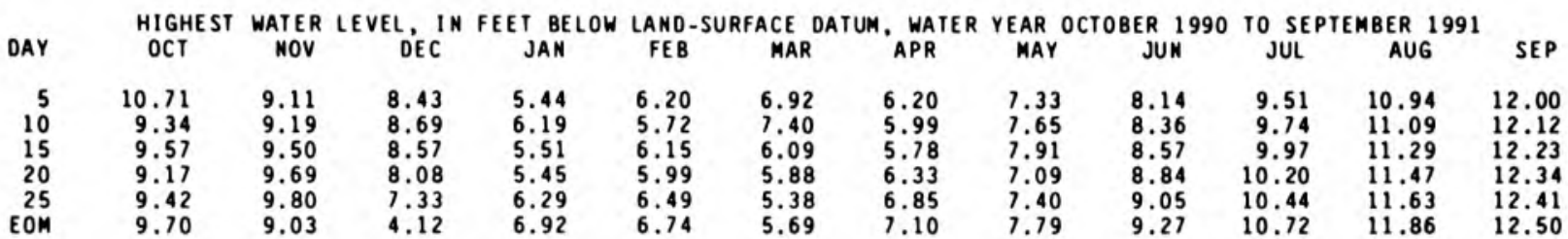

WTR YR 1991 HIGH 3.85 DEC 30

LOWEST WATER LEVEL, IN FEET BELOW LAND-SURFACE DATUM, WATER YEAR OCTOBER 1990 TO SEPTEMBER 1991

DAY

$\begin{array}{rrrr}\text { OCT } & \text { NOV } & \text { DEC } & \text { JAN } \\ 10.71 & 9.80 & 8.49 & 5.63 \\ 9.73 & 9.29 & 8.76 & 6.28 \\ 9.66 & 9.52 & 8.83 & 5.78 \\ 9.19 & 9.72 & 8.13 & 5.61 \\ 9.48 & 9.86 & 7.47 & 6.39 \\ 9.74 & 9.08 & 4.38 & 7.05\end{array}$

FEB
6.41
5.84
6.43
6.05
6.59
6.81

MAR
7.00
7.46
6.20
5.95
5.45
5.78

$\begin{array}{ll}\text { APR } & \text { MAY } \\ 6.25 & 7.39 \\ 6.22 & 7.71 \\ 5.96 & 7.95 \\ 6.43 & 7.16 \\ 6.89 & 7.44 \\ 7.17 & 7.88\end{array}$

JUN
8.19
8.39
8.63
8.87
9.11
9.32

JUL
9.57
9.78
10.02
10.25
10.49
10.76

$\begin{array}{rr}\text { AUG } & \text { SEP } \\ & \\ 10.98 & 12.03 \\ 11.14 & 12.15 \\ 11.33 & 12.25 \\ 11.51 & 12.35 \\ 11.66 & 12.41 \\ 11.89 & 12.51\end{array}$

WTR YR 1991 LOW 12.51 SEP 30

392416085004301. Local nuaber, FR 5 .

FRANKLIN COUNTY

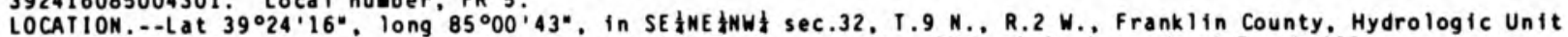
05080003 , adjacent to property of Franklin County Conservation Club, 1.0 i south of Brookville.

Owner: U.S. Geological Survey.

AQUIFER.--Sand and gravel of Pleistocene age.

WELL CHARACTERISTICS.--Drilled water-table well, dianeter 6 in., depth 61 ft, cased to 57 ft, screened to 59 ft. INST RUMENTATION, - - Water-level recorder.

DATUM.--Elevation of land-surface datue is $621.79 \mathrm{ft}$ above Mational Geodetic Vertical Datua of 1929 . Measuring point: Top of floor of shelter, $2.70 \mathrm{ft}$ above land-surface datur.

PERIOD OF RECORD..-March 1968 to October 1971, Septeaber 1974 to current year.

EXTREMES FOR PERIOD OF RECORD.--Highest water leve1, $11.95 \mathrm{ft}$ below land-surface datun, May 24, 1968; 10west, $27.32 \mathrm{ft}$ below land-surface datua, Feb. 1, 1977.

\begin{tabular}{|c|c|c|c|c|c|c|c|c|c|c|c|c|}
\hline DAY & $\begin{array}{l}\text { HIGHE ST } \\
\text { OCT }\end{array}$ & $\begin{array}{c}\text { WATER } \\
\text { MOV }\end{array}$ & LEVEL IN & $\underset{\text { JAN }}{\text { FEET BELOW }}$ & $\begin{array}{c}\text { LAND- } \\
\text { FEB }\end{array}$ & $\begin{array}{l}\text { RFACE D } \\
\text { MAR }\end{array}$ & DATUM, WATER & $\begin{array}{l}\text { YEAR } \\
\text { MAY }\end{array}$ & OCTOBER $\underset{\text { JUN }}{ } 1990$ & JUL & AUG & SEP \\
\hline $\begin{array}{r}5 \\
10 \\
15 \\
20 \\
25 \\
\text { EOM }\end{array}$ & $\begin{array}{l}25.50 \\
24.73 \\
24.59 \\
24.27 \\
24.52 \\
24.80\end{array}$ & $\begin{array}{l}24.85 \\
25.04 \\
24.97 \\
24.96 \\
25.04 \\
24.58\end{array}$ & $\begin{array}{l}24.16 \\
24.31 \\
24.66 \\
22.17 \\
21.58 \\
17.49\end{array}$ & $\begin{array}{l}20.20 \\
21.06 \\
21.13 \\
21.82 \\
23.38 \\
23.81\end{array}$ & $\begin{array}{l}23.93 \\
22.39 \\
23.16 \\
22.75 \\
23.31 \\
23.76\end{array}$ & $\begin{array}{l}24.16 \\
24.46 \\
22.96 \\
22.74 \\
21.82 \\
22.23\end{array}$ & $\begin{array}{l}23.25 \\
23.59 \\
22.18 \\
22.27 \\
23.25 \\
23.88\end{array}$ & $\begin{array}{l}24.50 \\
24.70 \\
24.78 \\
24.06 \\
24.17 \\
24.62\end{array}$ & $\begin{array}{l}24.92 \\
25.32 \\
25.58 \\
25.76 \\
25.90 \\
26.03\end{array}$ & $\begin{array}{l}26.13 \\
26.13 \\
25.94 \\
26.20 \\
26.31 \\
26.43\end{array}$ & $\begin{array}{l}26.50 \\
26.51 \\
26.57 \\
26.54 \\
26.60 \\
26.62\end{array}$ & $\begin{array}{l}26.46 \\
26.58 \\
26.63 \\
26.46 \\
26.43 \\
26.46\end{array}$ \\
\hline
\end{tabular}

WTR YR 1991 HIGH 17.40 JAN 1

LOWEST WATER LEVEL, IN FEET BELOW LAND-SURFACE DATUM, WATER YEAR OCTOBER 1990 TO SEPTEMBER 1991

$\begin{array}{rrrrrrrrrrrrr}\text { DAY } & \text { OCT } & \text { NOV } & \text { DEC } & \text { JAN } & \text { FEB } & \text { MAR } & \text { APR } & \text { MAY } & \text { JUN } & \text { JUL } & \text { AUG } & \text { SEP } \\ & & & & & & & & & & & & 24.12 \\ 10 & 25.05 & 25.07 & 24.41 & 21.17 & 22.47 & 24.52 & 23.62 & 24.75 & 25.38 & 26.15 & 26.53 & 26.60 \\ 15 & 24.62 & 24.99 & 24.83 & 21.25 & 23.31 & 23.03 & 22.32 & 24.87 & 25.62 & 26.01 & 26.58 & 26.65 \\ 20 & 24.40 & 25.04 & 22.32 & 22.27 & 22.91 & 22.94 & 22.39 & 24.21 & 25.79 & 26.23 & 26.54 & 26.47 \\ 25 & 24.62 & 25.09 & 21.70 & 23.56 & 23.47 & 22.12 & 23.38 & 24.32 & 25.92 & 26.33 & 26.61 & 26.44 \\ \text { EOM } & 24.81 & 24.71 & 17.49 & 23.83 & 23.88 & 22.46 & 24.02 & 24.69 & 26.07 & 26.44 & 26.63 & 26.46\end{array}$

WTR YR 1991 LOW 26.65 SEP 3 
405829086175801 . Local number, FU 7.

LOCATION.--Lat $40^{\circ} 58^{\prime} 29^{\prime \prime}$. Iong $86^{\circ} 17^{\prime} 58^{\prime \prime}$, in NW $\frac{1}{4} N W \frac{1}{4} S W \frac{1}{4}$ sec.10, T.29 N., R.2 E., Fulton County, Hydrologic Unit $05120106,2.5$ i northwest of Fulton.

Owner: U.S. Geological Survey.

AQUIFER. - Sand and gravel of Pleistocene age.

WELL CHARACTERISTICS.--Drilled artesian well, diameter $6 \mathrm{in.,}$ depth $102 \mathrm{ft}$, cased to $96 \mathrm{ft}$, screened to 102 ft. INST RUMENTATION. - - Wa ter-level recorder.

DATUM.--Elevation of land-surface datum is $776.45 \mathrm{ft}$ above National Geodetic Vertical Datun of 1929 . Measuring point: Top of floor of shelter, $2.50 \mathrm{ft}$ above land-surface datue.

PERIOD OF RECORD.--August 1967 to current year.

EXTREMES FOR PERIOD OF RECORD,--Highest water level, $6.35 \mathrm{ft}$ below land-surface datum, Apr. $23-27$, 1973 ; lowest.

$13.21 \mathrm{ft}$ below land-surface datun, $0 \mathrm{ct}, 13,1988$.

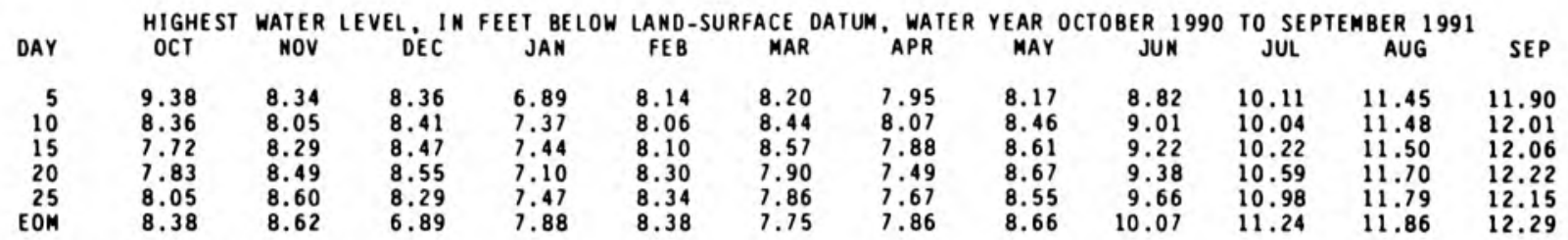

WTR YR 1991 HIGH 6.75 JAN 2

LOWEST WATER LEVEL. IN FEET BELOW LAND-SURFACE DATUM, WATER YEAR OCTOBER 1990 TO SEPTEMBER 1991

\begin{tabular}{|c|c|c|c|c|c|c|c|c|c|c|c|c|}
\hline DAY & $\mathrm{OCT}$ & NOV & DEC & JAN & FE B & MAR & APR & MAY & JUN & JUL & AUG & SEP \\
\hline $\begin{array}{r}5 \\
10 \\
15 \\
20 \\
25 \\
\text { EOM }\end{array}$ & $\begin{array}{l}9.39 \\
8.96 \\
7.78 \\
7.84 \\
8.13 \\
8.44\end{array}$ & $\begin{array}{l}8.57 \\
8.09 \\
8.30 \\
8.53 \\
8.70 \\
8.71\end{array}$ & $\begin{array}{l}8.46 \\
8.47 \\
8.58 \\
8.58 \\
8.32 \\
7.07\end{array}$ & $\begin{array}{l}6.94 \\
7.40 \\
7.49 \\
7.11 \\
7.55 \\
8.01\end{array}$ & $\begin{array}{l}8.14 \\
8.10 \\
8.26 \\
8.33 \\
8.36 \\
8.40\end{array}$ & $\begin{array}{l}8.27 \\
8.51 \\
8.64 \\
8.05 \\
7.88 \\
7.76\end{array}$ & $\begin{array}{l}7.99 \\
8.19 \\
8.13 \\
7.52 \\
7.71 \\
7.95\end{array}$ & $\begin{array}{l}8.21 \\
8.51 \\
8.67 \\
8.69 \\
8.59 \\
8.70\end{array}$ & $\begin{array}{r}8.87 \\
9.03 \\
9.29 \\
9.45 \\
9.72 \\
10.17\end{array}$ & $\begin{array}{l}10.13 \\
10.07 \\
10.34 \\
10.71 \\
11.12 \\
11.24\end{array}$ & $\begin{array}{l}11.47 \\
11.50 \\
11.53 \\
11.71 \\
11.81 \\
11.90\end{array}$ & $\begin{array}{l}11.93 \\
12.04 \\
12.09 \\
12.25 \\
12.20 \\
12.32\end{array}$ \\
\hline
\end{tabular}

WTR YR 1991 LOW 12.32 SEP 29

402322085481901 . Local number, GT 8 .

GRANT COUNTY

LOCATION. - Lat $40^{\circ} 23^{\prime} 22^{\circ}$, long $85^{\circ} 48^{\prime} 19^{\prime \prime}$, in NW/ $\frac{1}{4}$ SW $\frac{1}{4} N W \frac{1}{4}$ sec.1, T.22 N., R.6 E.. Grant County, Hydrologic Unit 05120107 , located on County Road 700 West right-of-way, and 1.0 i northwest of Rigdon.

Owner: U.S. Geological Survey.

AQUIFER.--Linestone of Silurian age.

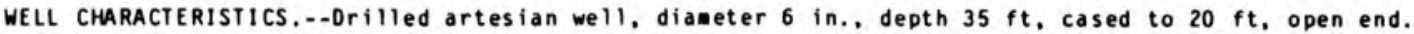

INSTRUMENTATION. - - Water-level recorder.

DATUM.--Elevation of land-surface datu is $880 \mathrm{ft}$ above National Geodetic Vertical Datum of 1929 , froe topographic ap. Measuring point: Top of floor of shelter, $3.10 \mathrm{ft}$ above land-surface datua.

PERIOD OF RECORO.--0ctober 1966 to October 1971, July 1974 to current year.

EXTREMES FOR PERIOD OF RECORD.--Highest water level, $1.16 \mathrm{ft}$ below land-surface datue, Mar. 21 , 1984 ; lowest.

$10.66 \mathrm{ft}$ below land-surface datua, Oct. 29, 1966.

\begin{tabular}{|c|c|c|c|c|c|c|c|c|c|c|c|c|}
\hline DAY & $\begin{array}{l}\text { HIGHEST } \\
\text { OCT }\end{array}$ & $\begin{array}{c}\text { WATER } \\
\text { NOV }\end{array}$ & ${ }_{\text {DEC }}$ & $\underset{\text { JAN }}{\text { FEET BELOW }}$ & $\begin{array}{l}\text { LAND - } \\
\text { FEB }\end{array}$ & $\begin{array}{l}\text { ACE D } \\
\text { MAR }\end{array}$ & $\begin{array}{c}\text { DATUM, WATER } \\
\text { APR }\end{array}$ & $\begin{array}{c}\text { YEAR } 0 \\
\text { MAYY }\end{array}$ & $\underset{\text { JUN }}{\text { OCTOBER }} 1990$ & $\begin{array}{l}\text { TO SE } \\
\text { JUL }\end{array}$ & AUG & SEP \\
\hline $\begin{array}{r}5 \\
10 \\
15 \\
20 \\
25 \\
\text { EOM }\end{array}$ & $\begin{array}{l}4.31 \\
2.43 \\
2.77 \\
3.43 \\
3.73 \\
4.05\end{array}$ & $\begin{array}{l}3.80 \\
3.74 \\
4.05 \\
4.21 \\
4.16 \\
2.87\end{array}$ & $\begin{array}{l}2.19 \\
2.90 \\
2.66 \\
2.09 \\
2.50 \\
1.55\end{array}$ & $\begin{array}{l}2.97 \\
3.58 \\
2.62 \\
2.43 \\
3.22 \\
3.89\end{array}$ & $\begin{array}{l}2.94 \\
2.48 \\
2.85 \\
2.29 \\
2.80 \\
3.08\end{array}$ & $\begin{array}{l}3.08 \\
3.62 \\
2.98 \\
1.52 \\
2.18 \\
2.91\end{array}$ & $\begin{array}{l}3.26 \\
2.28 \\
1.70 \\
1.91 \\
2.77 \\
3.04\end{array}$ & $\begin{array}{l}3.49 \\
3.78 \\
3.86 \\
4.04 \\
3.12 \\
2.92\end{array}$ & $\begin{array}{l}3.49 \\
3.82 \\
4.00 \\
4.37 \\
4.65 \\
4.85\end{array}$ & $\begin{array}{l}4.69 \\
4.72 \\
5.12 \\
5.38 \\
5.73 \\
6.14\end{array}$ & $\begin{array}{l}6.47 \\
6.63 \\
6.91 \\
7.18 \\
7.56 \\
7.65\end{array}$ & $\begin{array}{l}8 \\
8 \\
8\end{array}$ \\
\hline
\end{tabular}

WTR YR 1991 HIGH 1.34 MAR 18

LOWEST WATER LEVEL, IN FEET BELOW LAND-SURFACE DATUM, WATER YEAR OCTOBER 1990 TO SEPTEMBER 1991

\begin{tabular}{|c|c|c|c|c|c|c|c|c|c|c|c|}
\hline DAY & OCT & NOV & DEC & JAN & FE B & MAR & APR & MAY & JUN & JUL & AUG \\
\hline $\begin{array}{r}5 \\
10 \\
15 \\
20 \\
25 \\
\text { EOM }\end{array}$ & $\begin{array}{l}4.49 \\
3.32 \\
3.05 \\
3.45 \\
3.93 \\
4.08\end{array}$ & $\begin{array}{l}4.14 \\
3.82 \\
4.07 \\
4.27 \\
4.33 \\
2.98\end{array}$ & $\begin{array}{l}2.27 \\
3.02 \\
3.30 \\
2.16 \\
2.71 \\
2.07\end{array}$ & $\begin{array}{l}3.08 \\
3.66 \\
3.04 \\
2.45 \\
3.34 \\
4.09\end{array}$ & $\begin{array}{l}3.19 \\
2.55 \\
3.22 \\
2.34 \\
2.86 \\
3.11\end{array}$ & $\begin{array}{l}3.17 \\
3.70 \\
3.29 \\
1.76 \\
2.35 \\
3.01\end{array}$ & $\begin{array}{l}3.32 \\
2.67 \\
1.92 \\
1.96 \\
2.83 \\
3.69\end{array}$ & $\begin{array}{l}3.58 \\
3.89 \\
4.16 \\
4.35 \\
3.27 \\
3.41\end{array}$ & $\begin{array}{l}3.78 \\
4.01 \\
4.30 \\
4.70 \\
4.92 \\
5.26\end{array}$ & $\begin{array}{l}4.99 \\
5.14 \\
5.37 \\
5.76 \\
6.11 \\
6.49\end{array}$ & $\begin{array}{l}6.70 \\
7.02 \\
7.31 \\
7.10 \\
7.76 \\
7.90\end{array}$ \\
\hline
\end{tabular}

WTR YR 1991 LOW 9.06 SEP 27 
403836085374401 . Local number, GT 10.

GRANT COUNTY

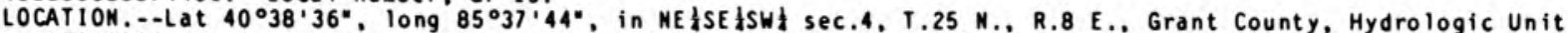

$05120103,0.20 \mathrm{mi}$ north of intersection of State Highway 9 and County Road 600 North on west side of road.

Owner: U.S. Geological Survey.

AQUIFER.-.-Sand and gravel of Pleistocene age.

WELL CHARACTERISTICS.--Drilled artesian well, dianeter $6 \mathrm{in.}$, depth $198 \mathrm{ft}$, cased to $193 \mathrm{ft}$, screened to $198 \mathrm{ft}$ INST RUMENTATION. - - Wa ter-level recorder.

DATUM.--Elevation of land-surface datue is $912.16 \mathrm{ft}$ above National Geodetic Vertical Datua of 1929 . Measuring point: Top of casing, $3.16 \mathrm{ft}$ above land-surface datue.

PERIOD OF RECORD.--August 1987 to current year.

EXTREMES FOR PERIOD OF RECORD.-. Highest water leve1, $107.39 \mathrm{ft}$ below land-surface datue, Apr. 6, 1988; 10west, $120.87 \mathrm{ft}$ below land-surface datun, June $29,1989$.

\begin{tabular}{|c|c|c|c|c|c|c|c|c|c|c|c|c|}
\hline DAY & $\begin{array}{l}\text { HIGHE ST } \\
\text { OCT }\end{array}$ & $\begin{array}{l}\text { WATER } \\
\text { NOV }\end{array}$ & ${ }_{\text {DEC }}^{\text {LEVEL, IN }}$ & $\begin{array}{c}\text { FEET BELOW } \\
\text { JAN }\end{array}$ & $\begin{array}{c}\text { LAND -S } \\
\text { FEB }\end{array}$ & $\begin{array}{c}\text { FACE } D \\
\text { MAR }\end{array}$ & $\begin{array}{c}\text { DATUM, WATER } \\
\text { APR }\end{array}$ & $\begin{array}{c}\text { YEAR } 0 \\
\text { MAY }\end{array}$ & OCTOBER $\underset{\text { JUN }}{1990}$ & TO JUL & $\underset{\text { AUG }}{\text { BER } 1991}$ & SEP \\
\hline $\begin{array}{r}5 \\
10 \\
15 \\
20 \\
25 \\
\text { EOM }\end{array}$ & $\begin{array}{l}120.13 \\
119.25 \\
118.99 \\
119.87 \\
119.82 \\
119.95\end{array}$ & $\begin{array}{l}119.26 \\
119.70 \\
119.93 \\
118.17 \\
116.99 \\
117.31\end{array}$ & $\begin{array}{l}118.70 \\
120.05 \\
119.55 \\
119.51 \\
119.49 \\
119.14\end{array}$ & $\begin{array}{l}118.14 \\
111.18 \\
110.20 \\
116.75 \\
110.27 \\
116.31\end{array}$ & $\begin{array}{l}118.85 \\
116.25 \\
117.53 \\
118.13 \\
118.21 \\
117.04\end{array}$ & $\begin{array}{r}117.12 \\
117.27 \\
\ldots . .2 \\
116.28 \\
118.36\end{array}$ & $\begin{array}{l}118.41 \\
118.22 \\
115.93 \\
118.69 \\
119.15 \\
118.49\end{array}$ & $\begin{array}{l}116.77 \\
116.81 \\
116.12 \\
117.99 \\
118.82 \\
118.65\end{array}$ & $\begin{array}{l}118.11 \\
118.88 \\
118.72 \\
118.97 \\
118.88 \\
119.37\end{array}$ & $\begin{array}{l}116.99 \\
118.65 \\
118.42 \\
118.99 \\
119.11 \\
118.91\end{array}$ & $\begin{array}{l}117.03 \\
117.19 \\
119.07 \\
119.20 \\
119.37 \\
119.67\end{array}$ & $\begin{array}{l}119.37 \\
119.37 \\
119.18 \\
119.07 \\
117.39 \\
119.08\end{array}$ \\
\hline
\end{tabular}

WTR YR 1991 HIGH 110.20 JAN 14

LOWEST WATER LEVEL, IN FEET BELOW LAND-SURFACE DATUM, WATER YEAR OCTOBER 1990 TO SEPTEMBER 1991

\begin{tabular}{|c|c|c|c|c|c|c|c|c|c|c|c|c|}
\hline DAY & OCT & NOV & DEC & JAN & FE B & MAR & $A P R$ & MAY & JUN & JUL & AUG & SEP \\
\hline $\begin{array}{r}5 \\
10 \\
15 \\
20 \\
25 \\
\text { EOM }\end{array}$ & $\begin{array}{l}120.24 \\
119.44 \\
120.07 \\
119.95 \\
119.98 \\
120.02\end{array}$ & $\begin{array}{l}119.70 \\
119.87 \\
120.05 \\
118.70 \\
117.21 \\
117.59\end{array}$ & $\begin{array}{l}119.12 \\
120.23 \\
119.81 \\
119.73 \\
119.63 \\
119.35\end{array}$ & $\begin{array}{l}119.17 \\
119.77 \\
118.70 \\
118.34 \\
118.87 \\
117.24\end{array}$ & $\begin{array}{l}119.02 \\
117.90 \\
118.65 \\
118.62 \\
118.74 \\
117.33\end{array}$ & $\begin{array}{r}118.73 \\
119.13 \\
\ldots . .5 \\
116.55 \\
118.52\end{array}$ & $\begin{array}{l}118.49 \\
118.96 \\
116.83 \\
118.82 \\
119.20 \\
118.77\end{array}$ & $\begin{array}{l}118.71 \\
117.34 \\
116.23 \\
118.56 \\
119.00 \\
118.95\end{array}$ & $\begin{array}{l}118.63 \\
118.97 \\
118.84 \\
119.03 \\
119.19 \\
119.46\end{array}$ & $\begin{array}{l}117.94 \\
118.75 \\
118.83 \\
119.07 \\
119.21 \\
119.28\end{array}$ & $\begin{array}{l}117.13 \\
117.59 \\
119.44 \\
119.27 \\
119.52 \\
119.83\end{array}$ & $\begin{array}{l}119.45 \\
119.50 \\
119.25 \\
119.75 \\
119.23 \\
119.29\end{array}$ \\
\hline
\end{tabular}

WTR YR 1991 LOW 120.41 DEC 14

400000086023001 . Local number, HA 5.

HAMILTON COUNTY

LOCATION - Lat $40000^{\circ} 00^{\circ}$, long $86^{\circ} 02^{\prime} 30^{\circ}$, in NE 05120201 , on south side of $146 \mathrm{th}$ Street, 1.0 - west of White River, 1.2 if west of Allisonville Road, and 3.5 .1 southwest of Noblesville.

Owner: Earlhan College.

AQUIFER.--Sand and gravel of Pleistocene age.

WELL CHARACTERISTICS.--Drilled water-table well, dianeter 6 in., depth $86 \mathrm{ft}$, cased to $82 \mathrm{ft}$, screened to $86 \mathrm{ft}$. INST RUME NTATION, - - Wa ter-level recorder.

DATUM.--Elevation of land-surface datum is $755.47 \mathrm{ft}$ above Mational Geodetic Vertical Datua of 1929 . Measuring point: Top of floor of shelter, $2.76 \mathrm{ft}$ above land-surface datua.

PERIOD OF RECORD..-July 1965 to Septeber 1971, July 1974 to current year.

EXTREMES FOR PERIOD OF RECORD.--Highest water leve 1, $7.39 \mathrm{ft}$ below land-surface datun, Dec. 31 , 1991; lowest,

$11.99 \mathrm{ft}$ below land-surface datun. Oct. 30-Nov. 4, 1988 .

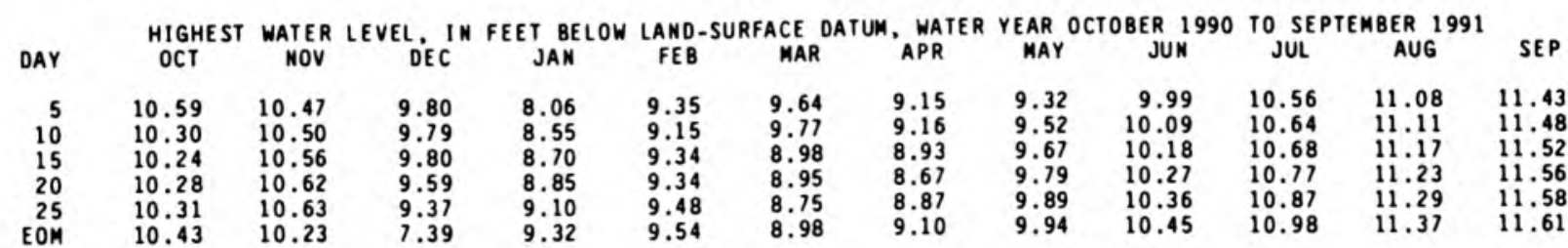

WTR YR 1991 HIGH 7.39 DEC 31

LOWEST WATER LEVEL, IN FEET BELOW LAND-SURFACE DATUM, WATER YEAR OCTOBER 1990 TO SEPTEMBER 1991

\begin{tabular}{|c|c|c|c|c|c|c|c|c|c|c|c|c|}
\hline DAY & $\mathrm{OCT}$ & NOV & DEC & JAN & FEB & MAR & APR & MAY & JUN & JUL & AUG & SEP \\
\hline $\begin{array}{r}5 \\
10 \\
15 \\
20 \\
25 \\
\text { EOM }\end{array}$ & $\begin{array}{l}10.60 \\
10.48 \\
10.27 \\
10.29 \\
10.34 \\
10.45\end{array}$ & $\begin{array}{l}10.50 \\
10.51 \\
10.57 \\
10.63 \\
10.65 \\
10.26\end{array}$ & $\begin{array}{l}9.87 \\
9.82 \\
9.93 \\
9.62 \\
9.39 \\
7.47\end{array}$ & $\begin{array}{l}8.17 \\
8.60 \\
8.74 \\
8.90 \\
9.14 \\
9.37\end{array}$ & $\begin{array}{l}9.41 \\
9.20 \\
9.42 \\
9.35 \\
9.50 \\
9.55\end{array}$ & $\begin{array}{l}9.65 \\
9.80 \\
9.03 \\
8.97 \\
8.78 \\
9.01\end{array}$ & $\begin{array}{l}9.18 \\
9.24 \\
9.09 \\
8.72 \\
8.92 \\
9.16\end{array}$ & $\begin{array}{l}9.34 \\
9.55 \\
9.70 \\
9.82 \\
9.90 \\
9.97\end{array}$ & $\begin{array}{l}10.01 \\
10.11 \\
10.20 \\
10.29 \\
10.38 \\
10.47\end{array}$ & $\begin{array}{l}10.58 \\
10.64 \\
10.70 \\
10.79 \\
10.89 \\
11.00\end{array}$ & $\begin{array}{l}11.09 \\
11.12 \\
11.18 \\
11.24 \\
11.30 \\
11.38\end{array}$ & $\begin{array}{l}11.44 \\
11.49 \\
11.53 \\
11.57 \\
11.58 \\
11.61\end{array}$ \\
\hline
\end{tabular}

WTR YR 1991 LOW 11.61 SEP 29 
382323086044501 . Local number, HR 8.

LOCATION..-Lat $38^{\circ} 23^{\prime} 23^{\circ}$, Iong $86^{\circ} 04^{\prime} 45^{\prime \prime}$, in NW $\frac{1}{4} N W \frac{1}{2} N E$ sec.33, T.1 S., R.4 E., Harrison County, Hydrologic Unit

05140104 , on Harrison County right-of-way, 2.0 1 i southeast of Paleyra.

Owner: U.S. Geological Survey.

AQUIFER.--Limestone of Mississippian age.

WELL CHARACTERISTICS...-Drilled artesian well, diameter $6 \mathrm{in.}$ depth $93 \mathrm{ft}$, cased to $54 \mathrm{ft}$, open end.

INSTRUMENTATION. - - Water-level recorder.

DATUM.-.Elevation of land-surface datun is $827 \mathrm{ft}$ above National Geodet1c Vertical Datue of 1929 , from topographic

ap. Measuring point: Top of floor of shelter, $3.10 \mathrm{ft}$ above land-surface datun.

PERIOD OF RECORD.--Novenber 1965 to current year.

EXTREMES FOR PERIOD OF RECORD.--Highest water leve1, $0.56 \mathrm{ft}$ below land-surface datun, June 7 , 1990 ; lowest,

$19.90 \mathrm{ft}$ below land-surface datum, Nov. 2-4, 1988.

\begin{tabular}{|c|c|c|c|c|c|c|c|c|c|c|c|c|}
\hline DAY & $\begin{array}{l}\text { HIGHEST } \\
\text { OCT }\end{array}$ & $\begin{array}{l}\text { WATER } \\
\text { NOV }\end{array}$ & LEVEL, IN $_{\text {DEC }}$ & $\underset{\text { JAN }}{\text { FEET BELOW }}$ & $\begin{array}{l}\text { LAND- } \\
\text { FEB }\end{array}$ & $\begin{array}{l}\text { ACE D } \\
\text { MAR }\end{array}$ & $\begin{array}{l}\text { DATUM, WATER } \\
\text { APR }\end{array}$ & $\begin{array}{l}\text { YEAR } 0 \\
\text { MAY }\end{array}$ & $\underset{\text { JUN }}{\text { OCTOBER }} 1990$ & TO SUE & $\begin{array}{l}\text { IBER } 1 \\
\text { AUG }\end{array}$ & SEP \\
\hline $\begin{array}{r}5 \\
10 \\
15 \\
20 \\
25 \\
\text { EOM }\end{array}$ & $\begin{array}{r}13.02 \\
12.78 \\
12.71 \\
10.72 \\
8.72 \\
8.79\end{array}$ & $\begin{array}{l}9.42 \\
9.07 \\
8.75 \\
9.25 \\
6.44 \\
6.02\end{array}$ & $\begin{array}{l}3.88 \\
5.22 \\
5.31 \\
2.36 \\
2.47 \\
1.90\end{array}$ & $\begin{array}{l}3.58 \\
2.62 \\
2.88 \\
3.45 \\
4.69 \\
4.79\end{array}$ & $\begin{array}{l}4.30 \\
2.79 \\
2.18 \\
2.50 \\
3.75 \\
4.25\end{array}$ & $\begin{array}{l}4.40 \\
4.93 \\
2.73 \\
2.77 \\
2.31 \\
3.68\end{array}$ & $\begin{array}{l}4.47 \\
2.76 \\
2.42 \\
3.85 \\
4.67 \\
5.18\end{array}$ & $\begin{array}{l}5.71 \\
6.01 \\
3.94 \\
5.07 \\
6.21 \\
5.90\end{array}$ & $\begin{array}{r}7.22 \\
8.46 \\
9.44 \\
10.27 \\
10.91 \\
11.50\end{array}$ & $\begin{array}{l}12.06 \\
12.55 \\
13.05 \\
13.54 \\
13.96 \\
14.43\end{array}$ & $\begin{array}{l}14.81 \\
15.19 \\
15.56 \\
15.90 \\
16.25 \\
16.59\end{array}$ & $\begin{array}{l}16.91 \\
17.18 \\
17.44 \\
17.74 \\
18.02 \\
18.29\end{array}$ \\
\hline
\end{tabular}

WTR YR 1991 HIGH .81 MAR 22

LOWEST WATER LEVEL, IN FEET BELOW LAND-SURFACE DATUM, WATER YEAR OCTOBER 1990 TO SEPTEMBER 1991

\begin{tabular}{|c|c|c|c|c|c|c|c|c|c|c|c|c|}
\hline DAY & OCT & NOV & DEC & JAN & FE B & MAR & APR & MAY & JUM & JUL & AUG & SEP \\
\hline $\begin{array}{r}5 \\
10 \\
15 \\
20 \\
25 \\
\text { EOM }\end{array}$ & $\begin{array}{r}13.12 \\
13.02 \\
12.79 \\
10.87 \\
8.90 \\
8.91\end{array}$ & $\begin{array}{l}9.59 \\
9.52 \\
8.79 \\
9.40 \\
6.48 \\
6.15\end{array}$ & $\begin{array}{l}3.98 \\
5.49 \\
6.42 \\
2.60 \\
2.89 \\
2.42\end{array}$ & $\begin{array}{l}3.70 \\
2.79 \\
3.07 \\
3.77 \\
4.85 \\
4.95\end{array}$ & $\begin{array}{l}4.88 \\
3.22 \\
2.79 \\
2.70 \\
3.94 \\
4.40\end{array}$ & $\begin{array}{l}4.54 \\
5.05 \\
3.03 \\
2.94 \\
2.65 \\
3.83\end{array}$ & $\begin{array}{l}4.60 \\
2.95 \\
2.52 \\
4.05 \\
4.72 \\
5.37\end{array}$ & $\begin{array}{l}6.16 \\
6.15 \\
4.09 \\
5.33 \\
6.37 \\
6.17\end{array}$ & $\begin{array}{r}7.50 \\
8.65 \\
9.60 \\
10.41 \\
11.05 \\
11.60\end{array}$ & $\begin{array}{l}12.17 \\
12.66 \\
13.18 \\
13.63 \\
14.03 \\
14.50\end{array}$ & $\begin{array}{l}14.88 \\
15.26 \\
15.63 \\
15.98 \\
16.32 \\
16.65\end{array}$ & $\begin{array}{l}16.97 \\
17.22 \\
17.50 \\
17.79 \\
18.07 \\
18.33\end{array}$ \\
\hline
\end{tabular}

WTR YR 1991 LOW 18.33 SEP 30

394025086400801 . Local number, HO 4.

\section{HENDRICKS COUNTY}

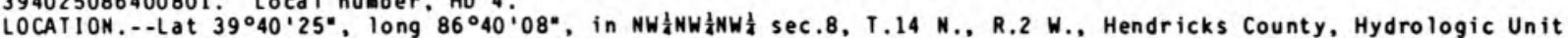
05120203, at the intersection of State Highway 75 and County Road 600 South on county right-of-way, and 1.0 a south of Coatesville.

Owner: U.S. Geological Survey.

AQUIFER. - - Sandstone of Mississippian age.

WELL CHARACTERISTICS.--Drilled artesian well, dianeter $6 \mathrm{in}$, depth $85 \mathrm{ft}$, cased to $70 \mathrm{ft}$, open end.

INSTRUMENTATION. - - Water-level recorder.

DATUM.--Elevation of land-surface datun is $860 \mathrm{ft}$ above National Geodetic Vertical Datun of 1929 , from topographic wap. Measuring point: Top of floor of shelter, $1.92 \mathrm{ft}$ above land-surface datue.

REMARKS. - - Water level affected by pumpage.

PERIOD OF RECORD.--October 1966 to September 1971, Novenber 1974 to current year.

EXTREMES FOR PERIOD OF RECORD.--Highest water leve1, $18.65 \mathrm{ft}$ below land-surface datun, Jan. 30 , 1976 ; lowest, $29.02 \mathrm{ft}$ below land-surface datun. Nov. 30, 1988 .

\begin{tabular}{|c|c|c|c|c|c|c|c|c|c|c|c|c|}
\hline DAY & $\begin{array}{l}\text { HIGHEST } \\
\text { OCT }\end{array}$ & $\begin{array}{l}\text { WATER } \\
\text { NOV }\end{array}$ & LEVEL, IN & $\underset{\text { JAN }}{\text { FEET BELOH }}$ & $\begin{array}{l}\text { LAND- } \\
\text { FEB }\end{array}$ & $\begin{array}{l}\text { ACE D } \\
\text { MAR }\end{array}$ & $\begin{array}{c}\text { DATUM, WATER } \\
\text { APR }\end{array}$ & $\begin{array}{l}\text { YEAR } 0 \\
\text { MAY }\end{array}$ & OCTOBER $\underset{\text { JUN }}{1990}$ & $\begin{array}{l}\text { TO SE } \\
\text { JUL }\end{array}$ & $\begin{array}{l}\text { BER } 1991 \\
\text { AUG }\end{array}$ & SEP \\
\hline $\begin{array}{r}5 \\
10 \\
15 \\
20 \\
25 \\
\text { EOM }\end{array}$ & $\begin{array}{l}22.93 \\
21.74 \\
21.30 \\
21.44 \\
21.40 \\
21.85\end{array}$ & $\begin{array}{l}22.12 \\
21.83 \\
22.04 \\
22.42 \\
22.28 \\
21.54\end{array}$ & $\begin{array}{l}21.09 \\
21.02 \\
21.46 \\
20.99 \\
20.82 \\
20.63\end{array}$ & $\begin{array}{l}20.96 \\
21.43 \\
21.33 \\
20.98 \\
20.92 \\
21.40\end{array}$ & $\begin{array}{l}21.65 \\
20.96 \\
20.87 \\
21.13 \\
20.91 \\
21.08\end{array}$ & $\begin{array}{l}21.27 \\
21.54 \\
21.29 \\
20.95 \\
20.56 \\
20.85\end{array}$ & $\begin{array}{l}21.19 \\
21.13 \\
20.74 \\
20.59 \\
20.77 \\
21.06\end{array}$ & $\begin{array}{l}21.32 \\
21.40 \\
21.69 \\
22.12 \\
22.47 \\
22.63\end{array}$ & $\begin{array}{l}22.96 \\
23.11 \\
23.28 \\
23.40 \\
23.53 \\
23.63\end{array}$ & $\begin{array}{l}23.81 \\
23.81 \\
23.02 \\
23.15 \\
23.52 \\
23.96\end{array}$ & $\begin{array}{l}24.34 \\
24.26 \\
24.60 \\
24.67 \\
24.99 \\
25.20\end{array}$ & $\begin{array}{l}25.31 \\
25.59 \\
25.63 \\
26.10 \\
26.02 \\
26.31\end{array}$ \\
\hline
\end{tabular}

WTR YR 1991 HIGH 20.47 MAR 26

LOWEST WATER LEVEL, IN FEET BELOW LAND-SURFACE DATUM. WATER YEAR OCTOBER 1990 TO SEPTEMBER 1991

\begin{tabular}{|c|c|c|c|c|c|c|c|c|c|c|c|c|}
\hline DAY & $\mathrm{OCT}$ & NOV & DEC & JAN & FE B & MAR & APR & MAY & JUN & JUL & AUG & SEP \\
\hline $\begin{array}{r}5 \\
10 \\
15 \\
20 \\
25 \\
\text { EOM }\end{array}$ & $\begin{array}{l}23.14 \\
21.96 \\
21.39 \\
21.59 \\
21.62 \\
22.11\end{array}$ & $\begin{array}{l}22.28 \\
21.93 \\
22.22 \\
22.81 \\
22.57 \\
21.80\end{array}$ & $\begin{array}{l}21.24 \\
21.26 \\
21.71 \\
21.23 \\
20.98 \\
20.80\end{array}$ & $\begin{array}{l}21.13 \\
21.53 \\
21.53 \\
21.11 \\
21.11 \\
21.70\end{array}$ & $\begin{array}{l}21.92 \\
21.05 \\
21.07 \\
21.32 \\
21.19 \\
21.29\end{array}$ & $\begin{array}{l}21.45 \\
21.62 \\
21.48 \\
21.14 \\
20.62 \\
20.94\end{array}$ & $\begin{array}{l}21.25 \\
21.24 \\
21.00 \\
20.69 \\
20.87 \\
21.24\end{array}$ & $\begin{array}{l}21.39 \\
21.60 \\
21.99 \\
22.37 \\
22.70 \\
22.83\end{array}$ & $\begin{array}{l}23.01 \\
23.29 \\
23.57 \\
23.48 \\
23.79 \\
23.98\end{array}$ & $\begin{array}{l}23.87 \\
24.15 \\
23.10 \\
23.27 \\
23.92 \\
24.09\end{array}$ & $\begin{array}{l}24.48 \\
24.44 \\
24.80 \\
24.93 \\
25.11 \\
25.47\end{array}$ & $\begin{array}{l}25.41 \\
25.72 \\
25.73 \\
26.24 \\
26.13 \\
26.42\end{array}$ \\
\hline
\end{tabular}

WTR YR 1991 LOW 26.67 SEP 26 
404858085284301 . Local number. HU 2.

LOCATION.--Lat $40^{\circ} 48^{\prime} 58^{\circ}$, long $85^{\circ} 28^{\circ} 43^{\circ}$, in SW $\frac{1}{4} S W \frac{1}{4} S E$ sec. $2, T .2 \mathrm{~N}$. R. RE. Hunt ington County, Hydrologic Unit 05120101. On the property of Luther Fusselaan, 3.0 . i south of Huntington and 0.5 . $i$ west of State Highway 5 .

AQUIFER. .- Sand and gravel of the Pleistocene Epoch.

WELL CHARACTERISIICS.--Orilled artesian well, dianeter $6 \mathrm{in}$., depth $148 \mathrm{ft}$, cased to $143 \mathrm{ft}$, screened to $148 \mathrm{ft}$. INSTRUMENTATION. - - Water-level recorder.

DATUM.--Elevation of land-surface datue is $819.70 \mathrm{ft}$ (revised) above National Geodetic Vertical Datun of 1929.

Measuring point: Top of casing, $3.30 \mathrm{ft}$ above land-surface datua.

PERIOD OF RECORD.--August 1988 to current year.

EXIREMES FOR PERIOD OF RECORD.--Highest water leve1, $65.46 \mathrm{ft}$ below land-surface datue, Dec. 24,1988 ; 10west,

$71.50 \mathrm{ft}$ below land-surface datue, Dec. 23, 1989 .

\begin{tabular}{|c|c|c|c|c|c|c|c|c|c|c|c|c|}
\hline AY & $\begin{array}{l}\text { HIGHEST } \\
\text { OCT }\end{array}$ & $\begin{array}{l}\text { WATER } \\
\text { MOV }\end{array}$ & LEVEL, IN & $\underset{\text { JAM }}{\text { FEET BELOW }}$ & $\begin{array}{l}\text { LAND }-S \\
\text { FEB }\end{array}$ & $\begin{array}{l}\text { FACE D } \\
\text { MAR }\end{array}$ & DATUM, WATER & $\begin{array}{l}\text { YEAR } 0 \\
\text { MAY }\end{array}$ & $\underset{\text { OCTOBER }}{1990}$ & TO JUL & $\underset{A \cup G}{B E R} 1991$ & SEP \\
\hline $\begin{array}{r}5 \\
10 \\
15 \\
20 \\
25 \\
\text { EOM }\end{array}$ & $\begin{array}{l}69.75 \\
69.71 \\
69.74 \\
69.98 \\
69.83 \\
69.78\end{array}$ & $\begin{array}{l}68.92 \\
69.33 \\
69.74 \\
70.05 \\
69.41 \\
69.86\end{array}$ & $\begin{array}{l}69.49 \\
69.39 \\
68.72 \\
69.30 \\
69.38 \\
69.67\end{array}$ & $\begin{array}{l}69.29 \\
69.19 \\
68.40 \\
68.50 \\
69.21 \\
68.49\end{array}$ & $\begin{array}{l}68.69 \\
68.43 \\
68.03 \\
68.68 \\
68.79 \\
68.49\end{array}$ & $\begin{array}{l}68.02 \\
68.61 \\
68.60 \\
68.72 \\
68.62 \\
68.87\end{array}$ & $\begin{array}{l}69.05 \\
68.79 \\
68.48 \\
68.68 \\
69.18 \\
68.98\end{array}$ & $\begin{array}{l}68.97 \\
69.51 \\
69.14 \\
69.70 \\
69.57 \\
69.74\end{array}$ & $\begin{array}{l}69.86 \\
69.50 \\
69.16 \\
69.38 \\
69.77 \\
69.52\end{array}$ & $\begin{array}{l}.49 \\
.88 \\
.56 \\
.93 \\
.15\end{array}$ & $\begin{array}{l}70.35 \\
70.24 \\
70.25 \\
70.12 \\
70.48 \\
70.33\end{array}$ & $\begin{array}{l}70.26 \\
70.21 \\
69.99 \\
70.54 \\
69.70 \\
70.25\end{array}$ \\
\hline
\end{tabular}

WTR YR 1991 HIGH 67.72 FEB 14

LOWEST WATER LEVEL, IN FEET BELOW LAND-SURFACE DATUM, WATER YEAR OCTOBER 1990 TO SEPTEMBER 1991

\begin{tabular}{|c|c|c|c|c|c|c|c|c|c|c|c|c|}
\hline DAY & $\mathrm{OCT}$ & NOV & DEC & JAN & FE B & MAR & APR & MAY & JUN & JUL & AUG & SEP \\
\hline $\begin{array}{r}5 \\
10 \\
15 \\
20 \\
25 \\
\text { EOM }\end{array}$ & $\begin{array}{l}69.99 \\
70.08 \\
70.12 \\
70.14 \\
70.13 \\
69.93\end{array}$ & $\begin{array}{l}69.48 \\
69.56 \\
69.87 \\
70.20 \\
69.75 \\
70.16\end{array}$ & $\begin{array}{l}69.98 \\
69.55 \\
69.07 \\
69.57 \\
69.61 \\
69.94\end{array}$ & $\begin{array}{l}69.62 \\
69.60 \\
68.89 \\
68.72 \\
69.35 \\
69.02\end{array}$ & $\begin{array}{l}68.84 \\
68.54 \\
68.69 \\
68.84 \\
68.91 \\
68.72\end{array}$ & $\begin{array}{l}68.40 \\
68.83 \\
68.91 \\
68.97 \\
68.81 \\
69.06\end{array}$ & $\begin{array}{l}69.15 \\
69.30 \\
68.87 \\
69.09 \\
69.35 \\
69.17\end{array}$ & $\begin{array}{l}69.38 \\
69.72 \\
69.29 \\
69.78 \\
69.72 \\
69.94\end{array}$ & $\begin{array}{l}69.95 \\
69.69 \\
69.29 \\
69.67 \\
69.88 \\
69.71\end{array}$ & $\begin{array}{l}69.59 \\
69.60 \\
70.03 \\
69.65 \\
70.13 \\
70.25\end{array}$ & $\begin{array}{l}70.45 \\
70.42 \\
70.30 \\
70.29 \\
70.64 \\
70.55\end{array}$ & $\begin{array}{l}70.40 \\
70.33 \\
70.20 \\
70.68 \\
70.19 \\
70.50\end{array}$ \\
\hline
\end{tabular}

WTR YR 1991 LOW 70.68 SEP 20

410249087011201. Local number, JP 4 .

JASPER COUNTY

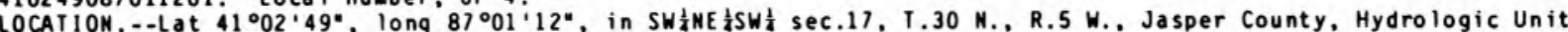
07120002 , on property of Willian Gehring, Inc., 0.9 a east of Newland.

Owner: Willian Gehring, Inc.

AQUIFER, - - Liaestone of Devonian age.

WELL CHARACTERISTICS.--Drilled artesian well, dianeter $16 \mathrm{in.}$, depth $300 \mathrm{ft}$.

INSTRUMENTATION. - - Water-level recorder.

DATUM.--Elevation of land-surface datun is $676.93 \mathrm{ft}$ above National Geodetic Vertical Datum of 1929 . Measuring point: Top of floor of shelter, $0.00 \mathrm{ft}$ above land-surface datur.

REMARKS. - - Water level ay be affected by irrigation punpage.

PERIOD OF RECORD.--July 1956 to current year.

EXTREMES FOR PERIOD OF RECORD.--Highest water level, $0.95 \mathrm{ft}$ below land-surface datua, Apr. 9 , 1962 ; $10 w e s t$, $40.17 \mathrm{ft}$ below land-surface datum, July 25,1980 .

\begin{tabular}{|c|c|c|c|c|c|c|c|c|c|c|c|c|}
\hline AY & $\begin{array}{l}\text { HIGHEST } \\
\text { OCT }\end{array}$ & $\begin{array}{c}\text { WATER } \\
\text { NOV }\end{array}$ & LEVEL, IN & $\underset{\text { JAN }}{\text { FEET BELOW }}$ & $\begin{array}{l}\text { LAND - } \\
\text { FE B }\end{array}$ & MAR & $\begin{array}{c}\text { DATUM, WATER } \\
\text { APR }\end{array}$ & MEAR & JUN & JUL & AUG & SEP \\
\hline $\begin{array}{r}5 \\
10 \\
15 \\
20 \\
25 \\
50 M\end{array}$ & $\begin{array}{l}3.66 \\
3.32 \\
3.02 \\
2.78 \\
2.80 \\
2.70\end{array}$ & $\begin{array}{l}2.32 \\
2.46 \\
2.52 \\
2.56 \\
2.40 \\
2.41\end{array}$ & $\begin{array}{l}2.26 \\
2.33 \\
2.14 \\
2.34 \\
2.34 \\
1.83\end{array}$ & $\begin{array}{l}1.44 \\
1.54 \\
1.42 \\
1.41 \\
1.49 \\
1.75\end{array}$ & $\begin{array}{l}2.08 \\
2.10 \\
2.08 \\
2.33 \\
2.40 \\
2.23\end{array}$ & $\begin{array}{l}2.14 \\
2.60 \\
2.50 \\
2.09 \\
2.12 \\
2.03\end{array}$ & $\begin{array}{l}2.06 \\
2.11 \\
1.95 \\
2.18 \\
2.20 \\
2.25\end{array}$ & $\begin{array}{l}2.25 \\
2.54 \\
2.56 \\
2.64 \\
2.45 \\
2.45\end{array}$ & $\begin{array}{r}2.71 \\
2.67 \\
5.85 \\
6.38 \\
6.55 \\
10.60\end{array}$ & $\begin{array}{r}8.49 \\
7.80 \\
8.00 \\
10.45 \\
12.97 \\
13.32\end{array}$ & $\begin{array}{r}12.01 \\
10.30 \\
8.80 \\
8.04 \\
7.59 \\
7.27\end{array}$ & $\begin{array}{l}7.05 \\
6.91 \\
6.79 \\
6.89 \\
6.46 \\
6.62\end{array}$ \\
\hline
\end{tabular}

WTR YR 1991 HIGH 1.27 JAN 11

LOWEST WATER LEVEL, IN FEET BELOW LAND-SURFACE DATUM, WATER YEAR OCTOBER 1990 TO SEPTEMBER 1991

$\begin{array}{rrrrrrrrrrrrr}\text { DAY } & \text { OCT } & \text { NOV } & \text { DEC } & \text { JAN } & \text { FEB } & \text { MAR } & \text { APR } & \text { MAY } & \text { JUN } & \text { JUL } & \text { AUG } & \text { SEP } \\ & & & & & & & & & & & & \\ 5 & 3.86 & 2.71 & 2.61 & 1.63 & 2.17 & 2.36 & 2.11 & 2.37 & 2.78 & 8.77 & 12.45 & 7.22 \\ 10 & 3.50 & 2.62 & 2.46 & 1.71 & 2.25 & 2.68 & 2.42 & 2.68 & 2.88 & 8.30 & 10.64 & 7.02 \\ 15 & 3.18 & 2.65 & 2.44 & 1.59 & 2.08 & 2.64 & 2.26 & 2.74 & 6.14 & 8.39 & 9.02 & 6.88 \\ 20 & 2.98 & 2.67 & 2.55 & 1.50 & 2.39 & 2.32 & 2.29 & 2.72 & 6.77 & 10.63 & 8.18 & 7.04 \\ 25 & 2.85 & 2.60 & 2.34 & 1.50 & 2.53 & 2.21 & 2.36 & 2.64 & 7.56 & 13.57 & 7.78 & 6.75 \\ \text { EOM } & 2.84 & 2.77 & 1.83 & 1.75 & 2.46 & 2.19 & 2.40 & 2.56 & 10.71 & 13.76 & 7.33 & 6.80\end{array}$

WTR YR 1991 LOW 13.98 JUL 28 
410809087580801 . Local nuaber, JP 7

LOCATION . - Lat $41^{\circ} 08^{\prime} 09^{\prime \prime}$, long $86^{\circ} 58^{\circ} 08^{\circ}$

07120002 in northwest corner of intersec

Owner: U.S. Geological Survey.

AQUIFER. - Doloaite of Middle Devonian age.

WELL CHARACTERISTICS.--Drilled artesian well, dianeter $6 \mathrm{in.}$, depth $130 \mathrm{ft}$, cased to $94 \mathrm{ft}$, open end.

INSTRUMENTATION. - - Wa ter-level recorder.

DATUM.--Elevation of land-surface datue is $699.38 \mathrm{ft}$ above National Geodetic Vertical Datue of 1929 . Measuring point: Top of floor of shelter, $2.75 \mathrm{ft}$ above land-surface datun.

REMARKS. - Water level affected by pumpage.

PERIOD OF RECORD.--May 1967 to current year. (Seai-annual tape-down readings only Septeaber 1971 to May 1978.)

EXTREMES FOR PERIOD OF RECORD.--Highest water leve1, $6.04 \mathrm{ft}$ below land-surface datun, Apr. 5, 1985; lowest.

$18.15 \mathrm{ft}$ below land-surface datue, Aug. 30, 1988 .

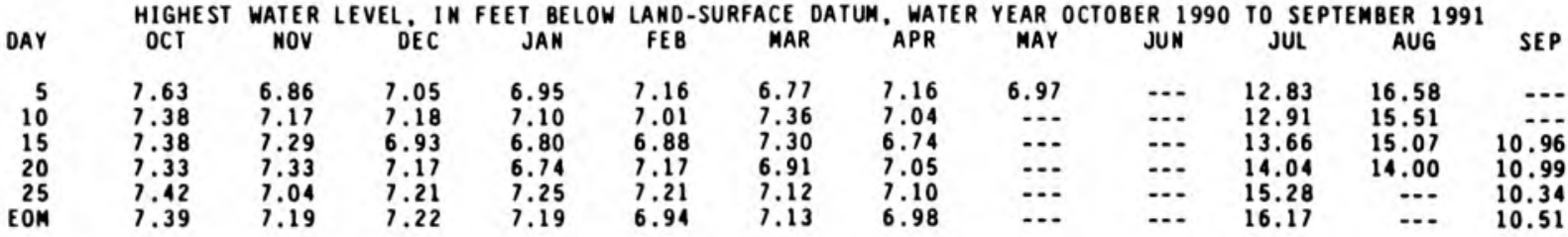

WTR YR 1991 HIGH 6.46 MAR 27

LOWEST WATER LEVEL, IN FEET BELOW LAND-SURFACE DATUM, WATER YEAR OCTOBER 1990 TO SEPTEMBER 1991

\begin{tabular}{|c|c|c|c|c|c|c|c|c|c|c|c|c|}
\hline DAY & OCT & NOV & DEC & JAN & FEB & MAR & APR & MAY & JUN & JUL & AUG & SEP \\
\hline $\begin{array}{r}5 \\
10 \\
15 \\
20 \\
25 \\
\text { EOM }\end{array}$ & $\begin{array}{l}7.86 \\
7.57 \\
7.60 \\
7.55 \\
7.53 \\
7.55\end{array}$ & $\begin{array}{l}7.33 \\
7.37 \\
7.47 \\
7.45 \\
7.29 \\
7.58\end{array}$ & $\begin{array}{l}7.45 \\
7.34 \\
7.27 \\
7.41 \\
7.41 \\
7.31\end{array}$ & $\begin{array}{l}7.18 \\
7.31 \\
7.00 \\
6.85 \\
7.28 \\
7.39\end{array}$ & $\begin{array}{l}7.22 \\
7.16 \\
7.24 \\
7.20 \\
7.38 \\
7.22\end{array}$ & $\begin{array}{l}7.03 \\
7.43 \\
7.46 \\
7.13 \\
7.20 \\
7.30\end{array}$ & $\begin{array}{l}7.20 \\
7.42 \\
7.10 \\
7.17 \\
7.26 \\
7.15\end{array}$ & $\begin{array}{c}1.15 \\
\ldots \\
\ldots \\
\ldots \\
\ldots \\
\ldots\end{array}$ & $\begin{array}{l}\ldots \\
\ldots \\
\cdots \\
\cdots \\
\cdots\end{array}$ & $\begin{array}{l}13.17 \\
13.22 \\
13.90 \\
14.34 \\
15.57 \\
16.22\end{array}$ & $\begin{array}{r}16.74 \\
15.94 \\
15.28 \\
14.51 \\
\ldots . \\
\ldots .\end{array}$ & $\begin{array}{l}\ldots . \\
11.06 \\
11.16 \\
10.71 \\
10.73\end{array}$ \\
\hline
\end{tabular}

WTR YR 1991 LOW 16.93 AUG 7

410535087035801 . Local nuaber, JP 8.

JASPER COUNTY

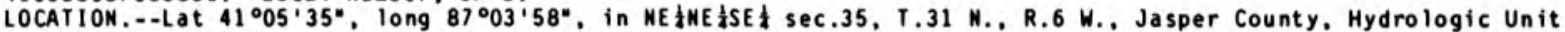
$07120002,1.7 \backsim i$ north of Gifford.

Owner: Wiliaa Gehring, Inc.

AQUIFER.-.-Limestone of Silurian age.

WELL CHARACTERISTICS.--Drilled artesian well, dianeter $12 \mathrm{in.,} \mathrm{depth} 310 \mathrm{ft}$.

INSTRUMENTATION. - -Water-level recorder.

DATUM.--Elevation of land-surface datue is $686 \mathrm{ft}$ above Mational Geodetic Vertical Datue of 1929, fros topographic

ap. Measuring point: Lower 1 ip of $2 \mathrm{in}$. tapedown pipe, $2.10 \mathrm{ft}$ above land-surface datue.

REMARKS. - Water level may be affected by irrigation punage.

PERIOD OF RECORD.--May 1978 to current year. Record prior to October 1, 1978 available in District files.

EXTREMES FOR PERIOD OF RECORD. --Highest water leve1, $8.52 \mathrm{ft}$ below land-surface datue, Jan. 1, 1991: lowest, $25.11 \mathrm{ft}$ below land-surface datue, July 26, 1980 .

\begin{tabular}{|c|c|c|c|c|c|c|c|c|c|c|c|c|c|}
\hline DAY & $\begin{array}{l}\text { HIGHEST } \\
\text { OCT }\end{array}$ & $\begin{array}{l}\text { WATER } \\
\text { MOV }\end{array}$ & $\underset{\text { LEC }}{\text { LEVEL, IN }}$ & $\underset{\text { JAN }}{\text { FEET }}$ & $\begin{array}{l}\text { LAND - } \\
\text { FEB }\end{array}$ & $\begin{array}{l}\text { ACE D } \\
\text { MAR }\end{array}$ & $\begin{array}{l}\text { DATUM, WATER } \\
\text { APR }\end{array}$ & $\begin{array}{l}\text { YEAR } \\
\text { MAY }\end{array}$ & $\underset{\text { JUN }}{\text { OCTOBER }} 1990$ & $\underset{\text { JUL }}{\text { SE }}$ & AUG & 1991 & SEP \\
\hline $\begin{array}{r}5 \\
10 \\
15 \\
20 \\
25 \\
\text { EOM }\end{array}$ & $\begin{array}{r}10.82 \\
10.24 \\
10.00 \\
9.88 \\
9.96 \\
10.05\end{array}$ & $\begin{array}{r}9.79 \\
9.75 \\
9.89 \\
10.00 \\
9.96 \\
9.67\end{array}$ & $\begin{array}{l}9.56 \\
9.65 \\
9.62 \\
9.72 \\
9.67 \\
8.61\end{array}$ & $\begin{array}{l}8.73 \\
9.07 \\
9.10 \\
8.98 \\
9.31 \\
9.51\end{array}$ & $\begin{array}{l}9.60 \\
9.58 \\
9.58 \\
9.71 \\
9.80 \\
9.74\end{array}$ & $\begin{array}{l}9.60 \\
9.88 \\
9.83 \\
9.20 \\
9.18 \\
9.28\end{array}$ & $\begin{array}{l}9.42 \\
9.51 \\
9.43 \\
9.28 \\
9.46 \\
9.47\end{array}$ & $\begin{array}{l}9.64 \\
9.84 \\
9.78 \\
9.65 \\
9.51 \\
9.59\end{array}$ & $\begin{array}{r}9.75 \\
9.93 \\
10.11 \\
10.41 \\
10.99 \\
11.91\end{array}$ & $\begin{array}{l}12.67 \\
12.76 \\
13.08 \\
13.61 \\
14.08 \\
14.61\end{array}$ & $\begin{array}{l}14.86 \\
14.73 \\
14.55 \\
14.70 \\
14.37 \\
14.33\end{array}$ & & $\begin{array}{l}13.95 \\
13.71 \\
13.66 \\
13.31 \\
13.30\end{array}$ \\
\hline
\end{tabular}

WTR YR 1991 HIGH 8.52 JAN 1

LOWEST WATER LEVEL, IN FEET BELOW LAND-SURFACE DATUM, WATER YEAR OCTOBER 1990 TO SEPTEMBER 1991

\begin{tabular}{|c|c|c|c|c|c|c|c|c|c|c|c|c|}
\hline DAY & OCT & NOV & DEC & JAN & FE B & MAR & APR & MAY & JUN & JUL & AUG & SEP \\
\hline $\begin{array}{r}5 \\
10 \\
15 \\
20 \\
25 \\
\text { EOM }\end{array}$ & $\begin{array}{r}10.87 \\
10.49 \\
10.07 \\
9.94 \\
9.99 \\
10.10\end{array}$ & $\begin{array}{r}10.05 \\
9.81 \\
9.93 \\
10.02 \\
10.05 \\
9.80\end{array}$ & $\begin{array}{l}9.67 \\
9.72 \\
9.75 \\
9.77 \\
9.74 \\
8.68\end{array}$ & $\begin{array}{l}8.84 \\
9.12 \\
9.14 \\
9.02 \\
9.38 \\
9.61\end{array}$ & $\begin{array}{l}9.63 \\
9.65 \\
9.72 \\
9.73 \\
9.84 \\
9.83\end{array}$ & $\begin{array}{l}9.69 \\
9.94 \\
9.89 \\
9.40 \\
9.21 \\
9.32\end{array}$ & $\begin{array}{l}9.45 \\
9.66 \\
9.57 \\
9.34 \\
9.50 \\
9.53\end{array}$ & $\begin{array}{l}9.69 \\
9.90 \\
9.83 \\
9.66 \\
9.63 \\
9.66\end{array}$ & $\begin{array}{r}9.82 \\
9.99 \\
10.15 \\
10.50 \\
11.18 \\
12.07\end{array}$ & $\begin{array}{l}12.76 \\
12.82 \\
13.21 \\
13.12 \\
14.21 \\
14.65\end{array}$ & $\begin{array}{l}14.93 \\
14.79 \\
14.60 \\
14.74 \\
14.45 \\
14.45\end{array}$ & $\begin{array}{l}14.28 \\
14.03 \\
13.75 \\
13.71 \\
13.45 \\
13.38\end{array}$ \\
\hline
\end{tabular}

WTR YR 1991 LOW 14.99 AUG 7 
410713087063201 . Local nuaber, JP 9.

JASPER COUNTY

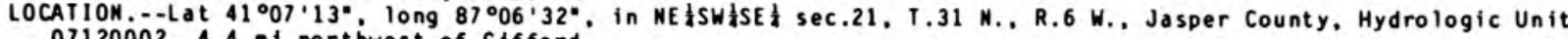
$07120002,4.4=1$ northwest of Gifford.

Owner: Wilian Gehring. Inc.

AQUIFER.--Silurian limestone.

WELL CHARACTERISTICS.--Drilled artesian well, dianeter $18 \mathrm{in.}$, depth $260 \mathrm{ft}$.

INSTRUMENTATION. - - Water-level recorder.

OATUM.--Elevation of land-surface datue is $685 \mathrm{ft}$ above Mational Geodetic Vertical Datue of 1929 , froe topographic ap. Measuring point: Lower 1 ip of $2 \mathrm{in.}$ tapedown pipe. $2.10 \mathrm{ft}$ above land-surface datua.

REMARKS. - - Water level ay be affected by irrigation punpage.

PERIOD OF RECORD.--July 1978 to current year. Record prior to October 1, 1978 available in District files.

EXTREMES FOR PERIOD OF RECORD.--Highest water leve1, $4.03 \mathrm{ft}$ below land-surface datun, Mar. 27 , 1991 ; lowest, $32.05 \mathrm{ft}$ below land-surface datue. Aug. 5,1988 .

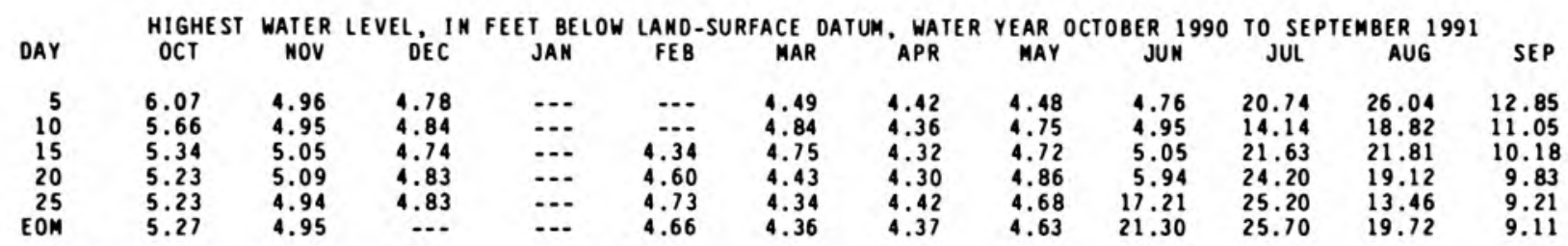

WTR YR 1991 HIGH 4.03 MAR 27

LOWEST WATER LEVEL, IN FEET BELOW LAND-SURFACE DATUM, WATER YEAR OCTOBER 1990 TO SEPTEMBER 1991

\begin{tabular}{|c|c|c|c|c|c|c|c|c|c|c|c|c|}
\hline DAY & $\mathrm{OCT}$ & NOV & DEC & JAN & FE B & MAR & $A P R$ & MAY & JUN & JUL & AUG & SEP \\
\hline $\begin{array}{r}5 \\
10 \\
15 \\
20 \\
25 \\
\text { EOM }\end{array}$ & $\begin{array}{l}6.10 \\
5.82 \\
5.43 \\
5.30 \\
5.27 \\
5.30\end{array}$ & $\begin{array}{l}5.20 \\
5.00 \\
5.09 \\
5.11 \\
5.06 \\
5.07\end{array}$ & $\begin{array}{r}4.88 \\
4.89 \\
4.89 \\
4.87 \\
4.89 \\
\ldots\end{array}$ & $\begin{array}{l}\ldots \\
\ldots \\
\ldots \\
\ldots \\
\ldots \\
\ldots\end{array}$ & $\begin{array}{r}\ldots . . \\
4.54 \\
4.65 \\
4.75 \\
4.72\end{array}$ & $\begin{array}{l}4.59 \\
4.90 \\
4.87 \\
4.53 \\
4.38 \\
4.39\end{array}$ & $\begin{array}{l}4.44 \\
4.53 \\
4.43 \\
4.35 \\
4.45 \\
4.44\end{array}$ & $\begin{array}{l}4.61 \\
4.78 \\
4.77 \\
4.87 \\
4.78 \\
4.71\end{array}$ & $\begin{array}{r}4.84 \\
4.98 \\
5.11 \\
8.18 \\
18.37 \\
21.71\end{array}$ & $\begin{array}{l}22.59 \\
15.69 \\
22.49 \\
24.56 \\
25.54 \\
26.19\end{array}$ & $\begin{array}{l}26.33 \\
20.58 \\
22.74 \\
21.67 \\
14.10 \\
20.54\end{array}$ & $\begin{array}{r}13.48 \\
11.26 \\
10.31 \\
9.91 \\
9.39 \\
9.23\end{array}$ \\
\hline
\end{tabular}

WTR YR 1991 LOW 26.42 AUG 6

410322087163101 . Local number, JP 11.

JASPER COUNTY

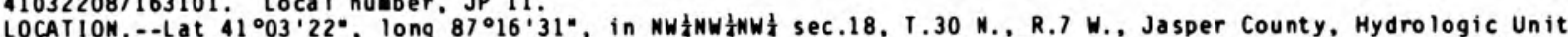
07120002 , on Prudential Life Insurance Company of Anerica property. 3.2 a north of State Highway 14 . and 1.5 i southwest of Fair Oaks.

Owner: Prudential Insurance Company of America.

AQUIFER.-- Liaestone of Devonian age.

WELL CHARACTERISTICS..--Drilled artesian we11, diameter $16 \mathrm{in.}$, depth $630 \mathrm{ft}$, cased to $63 \mathrm{ft}$, open end.

INST RUME NTATION. - - Wa ter-level recorder.

DATUM. - Elevation of land-surface datue is $680 \mathrm{ft}$ above National Geodetic Vertical Datue of 1929 . froe topographic ap Measuring point: Top of floor of shelter, $3.50 \mathrm{ft}$ above land-surface datua.

REMARKS. - - Water level wa be affected by irrigation puapage.

PERIOD OF RECORD.--March 1981 to current year.

EXTREMES FOR PERIOD OF RECORD.--Highest water leve1, $0.04 \mathrm{ft}$ above land-surface datue, Apr. 3, 1982: 10west.

$52.19 \mathrm{ft}$ below land-surface datur. July 9.1988.

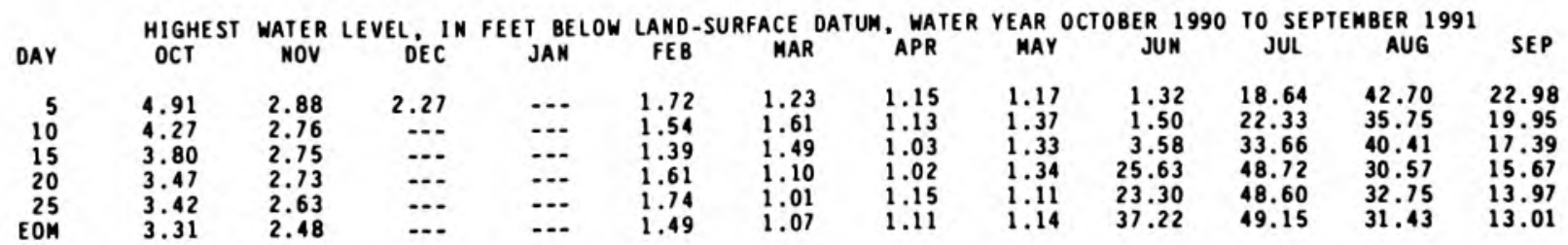

WTR YR 1991 HIGH .62 MAR 27

LOWEST WATER LEVEL, IN FEET BELOW LAMD-SURFACE DATUM, WATER YEAR OCTOBER 1990 TO SEPTEMBER 1991

\begin{tabular}{|c|c|c|c|c|c|c|c|c|c|c|c|c|}
\hline DAY & $\mathrm{OCT}$ & NOV & DEC & JAN & FEB & MAR & $A P R$ & MAY & JUN & JUL & AUG & SEP \\
\hline $\begin{array}{r}5 \\
10 \\
15 \\
20 \\
25 \\
\text { EOM }\end{array}$ & $\begin{array}{l}5.02 \\
4.43 \\
3.87 \\
3.59 \\
3.45 \\
3.35\end{array}$ & $\begin{array}{l}3.14 \\
2.85 \\
2.81 \\
2.81 \\
2.68 \\
2.62\end{array}$ & $\begin{array}{c}2.43 \\
\ldots . \\
\ldots \\
\ldots \\
\ldots\end{array}$ & $\begin{array}{l}\ldots \\
\ldots \\
\ldots \\
\ldots \\
\ldots \\
\ldots\end{array}$ & $\begin{array}{l}1.74 \\
1.59 \\
1.61 \\
1.63 \\
1.84 \\
1.63\end{array}$ & $\begin{array}{l}1.39 \\
1.67 \\
1.58 \\
1.28 \\
1.06 \\
1.11\end{array}$ & $\begin{array}{l}1.17 \\
1.35 \\
1.17 \\
1.08 \\
1.19 \\
1.19\end{array}$ & $\begin{array}{l}1.30 \\
1.43 \\
1.41 \\
1.37 \\
1.23 \\
1.21\end{array}$ & $\begin{array}{r}1.40 \\
1.58 \\
6.46 \\
28.29 \\
26.09 \\
43.16\end{array}$ & $\begin{array}{l}20.68 \\
23.31 \\
39.07 \\
49.97 \\
50.11 \\
50.46\end{array}$ & $\begin{array}{l}45.74 \\
39.25 \\
42.96 \\
32.67 \\
36.14 \\
34.50\end{array}$ & $\begin{array}{l}24.04 \\
20.18 \\
17.82 \\
16.02 \\
14.34 \\
13.28\end{array}$ \\
\hline
\end{tabular}

WTR YR 1991 LOW 52.04 AUG 3 
410145087130401 . Local number, JP 12.

\section{JASPER COUNTY}

LOCATION..-Lat $41^{\circ} 01^{\prime} 45^{\circ}$, long $87^{\circ} 13^{\prime} 04^{\circ}$, in MW $\frac{1}{4} S W 4 S W l$ sec.22, T.30 N., R.7 W. J Jasper County, Hydrologic Unit 07120002 , in $01 d$ Union Township school yard, $200 \mathrm{ft}$ east of County Road 900 West, $750 \mathrm{ft}$ north of State Highway 14, and in Parr.

Owner: Prudential Insurance Company of America.

AQUIFER. - - Liaestone/dolonite of Silurian/Devonian age.

WELL CHARACTERISTCS.-.-Drilled artesian well, diameter $5 \mathrm{in}$., depth $150 \mathrm{ft}$, cased to $103 \mathrm{ft}$, open end.

INST RUMENTATION.-- Water-level recorder, data-collection platfora, and increantal encoder.

DATUM.--Elevation of land-surface datua is $695 \mathrm{ft}$ above Mational Geodetic Vertical Datua of 1929 , from topographic

ap. Measuring point: Top of well casing, $2.6 \mathrm{ft}$ above land-surface datul.

REMARKS. - - Water level may be affected by irrigation punpage.

PERIOD OF RECORD.--May 1982 to current year.

EXTREMES FOR PERIOD OF RECORD.--Highest water leve1, $14.08 \mathrm{ft}$ below land-surface datun, May 22, 1983 ; 10 west, $53.41 \mathrm{ft}$ below land-surface datum, Aug. 18, 1988 .

\begin{tabular}{|c|c|c|c|c|c|c|c|c|c|c|c|c|}
\hline$A Y$ & $\begin{array}{l}\text { HIGHEST } \\
\text { OCT }\end{array}$ & $\begin{array}{l}\text { WATER } \\
\text { MOV }\end{array}$ & LEVEL, IN & $\underset{\text { JAN }}{\text { FEET BELOW }}$ & $\begin{array}{l}\text { LAND - } \\
\text { FEB }\end{array}$ & MAR & $\begin{array}{c}\text { DATUM, WATER } \\
\text { APR }\end{array}$ & $\begin{array}{l}\text { YEAR } \\
\text { MAY }\end{array}$ & OCTOBER $\underset{\text { JUN }}{ } 1990$ & $\begin{array}{c}\text { TO SEI } \\
\text { JUL }\end{array}$ & $\begin{array}{l}\text { BER } 1991 \\
\text { AUG }\end{array}$ & SEP \\
\hline $\begin{array}{r}5 \\
10 \\
15 \\
20 \\
25 \\
E O M\end{array}$ & $\begin{array}{l}20.75 \\
19.82 \\
19.18 \\
18.51 \\
18.30 \\
17.95\end{array}$ & $\begin{array}{l}17.36 \\
17.45 \\
17.35 \\
17.21 \\
16.96 \\
16.91\end{array}$ & $\begin{array}{l}16.68 \\
16.66 \\
16.36 \\
16.40 \\
16.38 \\
16.02\end{array}$ & $\begin{array}{l}15.97 \\
15.99 \\
15.69 \\
15.54 \\
15.80 \\
15.71\end{array}$ & $\begin{array}{l}15.70 \\
15.63 \\
15.50 \\
15.66 \\
15.95 \\
15.63\end{array}$ & $\begin{array}{l}15.42 \\
15.72 \\
15.53 \\
15.27 \\
15.32 \\
15.26\end{array}$ & $\begin{array}{l}15.20 \\
15.14 \\
14.91 \\
15.12 \\
15.15 \\
15.04\end{array}$ & $\begin{array}{l}15.09 \\
15.31 \\
15.25 \\
15.35 \\
15.20 \\
15.33\end{array}$ & $\begin{array}{l}15.50 \\
15.56 \\
15.71 \\
24.14 \\
27.23 \\
37.10\end{array}$ & $\begin{array}{l}31.66 \\
30.61 \\
36.07 \\
44.77 \\
43.53 \\
47.14\end{array}$ & $\begin{array}{l}39.99 \\
44.96 \\
46.60 \\
42.67 \\
44.05 \\
45.03\end{array}$ & $\begin{array}{l}35.35 \\
33.23 \\
31.67 \\
29.97 \\
28.96\end{array}$ \\
\hline
\end{tabular}

WTR YR 1991 HIGH 14.84 MAR 27

LOWEST WATER LEVEL, IN FEET BELOW LAND-SURFACE DATUM, WATER YEAR OCTOBER 1990 TO SEPTEMBER 1991

\begin{tabular}{|c|c|c|c|c|c|c|c|c|c|c|c|c|}
\hline DAY & $\mathrm{OCT}$ & NOV & DEC & JAM & FEB & MAR & APR & MAY & JUN & JUL & AUG & SEP \\
\hline $\begin{array}{r}5 \\
10 \\
15 \\
20 \\
25 \\
\text { EOM }\end{array}$ & $\begin{array}{l}20.97 \\
20.11 \\
19.59 \\
18.85 \\
18.36 \\
18.07\end{array}$ & $\begin{array}{l}17.71 \\
17.60 \\
17.67 \\
17.45 \\
17.16 \\
17.24\end{array}$ & $\begin{array}{l}16.96 \\
16.79 \\
16.61 \\
16.58 \\
16.58 \\
16.37\end{array}$ & $\begin{array}{l}16.17 \\
16.19 \\
15.86 \\
15.65 \\
15.93 \\
15.92\end{array}$ & $\begin{array}{l}15.82 \\
15.83 \\
15.83 \\
15.77 \\
16.13 \\
15.87\end{array}$ & $\begin{array}{l}15.61 \\
15.87 \\
15.75 \\
15.47 \\
15.60 \\
15.40\end{array}$ & $\begin{array}{l}15.34 \\
15.41 \\
15.28 \\
15.35 \\
15.27 \\
15.25\end{array}$ & $\begin{array}{l}15.22 \\
15.49 \\
15.48 \\
15.48 \\
15.46 \\
15.60\end{array}$ & $\begin{array}{l}15.62 \\
15.76 \\
16.46 \\
27.14 \\
27.23 \\
38.42\end{array}$ & $\begin{array}{l}32.45 \\
31.23 \\
37.55 \\
45.84 \\
44.01 \\
48.43\end{array}$ & $\begin{array}{l}48.29 \\
45.42 \\
47.37 \\
43.36 \\
46.40 \\
47.69\end{array}$ & $\begin{array}{l}40.03 \\
35.87 \\
33.57 \\
31.99 \\
30.38 \\
29.25\end{array}$ \\
\hline
\end{tabular}

WTR YR 1991 LOW 51.48 AUG 3

405902087141501. Local number, JP 13.

JASPER COUNTY

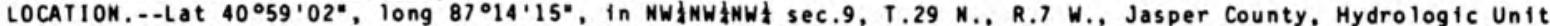

07120002 , at southwest corner of North Newton school, and 4.6 a northwest of Rensselaer.

Owner: Prudential Insurance Company of Aaerica.

AQUIFER. - Doloaite of Silurian/Devonian age.

WELL CHARACTERISTICS.--Drilled artesian well, dianeter $5 \mathrm{in.}$ depth $150 \mathrm{ft}$, cased to $106 \mathrm{ft}$, open end.

INST RUMENTATION. - -Water-level recorder.

DATUM.--Elevation of land-surface datua is $700 \mathrm{ft}$ above National Geodetic Vertical Datue of 1929 , froe topographic

ap. Measuring point: Top of well casing, $3.4 \mathrm{ft}$ above land-surface datum.

REMARKS. - - Water level wa be affected by irrigation punpage.

PERIOD OF RECORD.--March 1982 to current year.

EXTREMES FOR PERIOD OF RECORD.--Highest water level, $20.98 \mathrm{ft}$ below land-surface datum, Apr. 3 , 1982 ; 10west,

$55.85 \mathrm{ft}$ below land-surface datum, Aug. 19. 1988 .

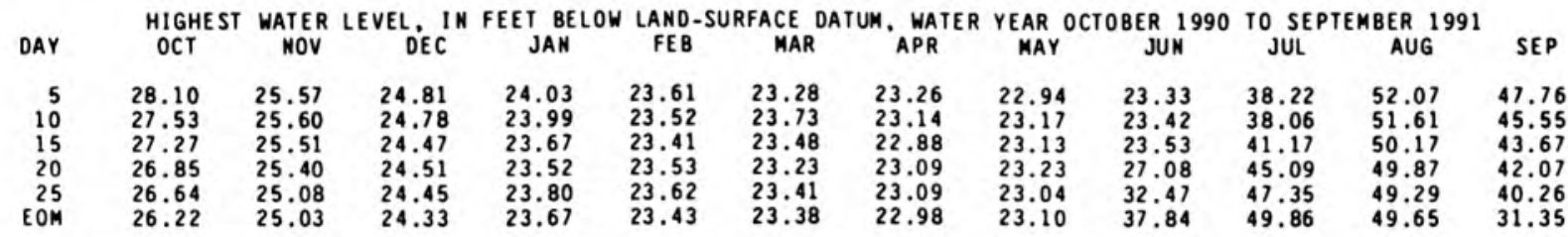

WTR YR 1991 HIGH 22.88 APR 15

LOWEST WATER LEVEL, IN FEET BELOW LAND-SURFACE DATUM, WATER YEAR OCTOBER 1990 TO SEPTEMBER 1991

\begin{tabular}{|c|c|c|c|c|c|c|c|c|c|c|c|c|}
\hline DAY & $\mathrm{OCT}$ & NOV & DEC & JAM & FE B & MAR & APR & MAY & JUN & JUL & AUG & SEP \\
\hline $\begin{array}{r}5 \\
10 \\
15 \\
20 \\
25 \\
\text { EOM }\end{array}$ & $\begin{array}{l}28.31 \\
27.67 \\
27.40 \\
27.02 \\
26.67 \\
26.33\end{array}$ & $\begin{array}{l}25.93 \\
25.73 \\
25.63 \\
25.50 \\
25.22 \\
25.33\end{array}$ & $\begin{array}{l}25.13 \\
24.87 \\
24.71 \\
24.70 \\
24.60 \\
24.41\end{array}$ & $\begin{array}{l}24.18 \\
24.17 \\
23.83 \\
23.61 \\
23.85 \\
23.82\end{array}$ & $\begin{array}{l}23.68 \\
23.64 \\
23.66 \\
23.59 \\
23.73 \\
23.63\end{array}$ & $\begin{array}{l}23.51 \\
23.79 \\
23.59 \\
23.39 \\
23.50 \\
23.53\end{array}$ & $\begin{array}{l}23.32 \\
23.40 \\
23.13 \\
23.19 \\
23.23 \\
23.11\end{array}$ & $\begin{array}{l}23.08 \\
23.28 \\
23.26 \\
23.27 \\
23.18 \\
23.21\end{array}$ & $\begin{array}{l}23.42 \\
23.57 \\
24.03 \\
28.38 \\
33.28 \\
38.70\end{array}$ & $\begin{array}{l}38.51 \\
38.70 \\
41.52 \\
45.71 \\
48.07 \\
50.52\end{array}$ & $\begin{array}{l}52.36 \\
51.98 \\
50.25 \\
50.17 \\
49.38 \\
49.78\end{array}$ & $\begin{array}{l}48.17 \\
45.87 \\
43.98 \\
42.42 \\
40.70 \\
39.46\end{array}$ \\
\hline
\end{tabular}

ITR YR 1991 LOW 52.48 AUG 4 
410839087130301 . Local number, JP 14

LOCATION.--Lat $41^{\circ} 08^{\prime} 39^{\circ}$, long $87^{\circ} 13^{\prime} 03^{\circ}$, in NW 07120001 . at the southeast corner of the intersection of State Highway 10 and County Road 900 West. about 3.5 if southwest of Denot te.

Owner: U.S. Geological Survey

AQUIFER.--Linestone of Silurian age.

WELL CHARACTERISTICS.--Orilled artesian well, dianeter $6 \mathrm{in.}$. depth $97.4 \mathrm{ft}$, cased to $56 \mathrm{ft}$, open end.

INSTRUMENTATION. - - Water-level recorder.

DATUM.--Elevation of land-surface datum is $690 \mathrm{ft}$ above National Geodetic Vertical Datum of 1929, fron topographic

ap. Measuring point: TOp of casing, $3.40 \mathrm{ft}$ above land-surface datue.

PERIOD OF RECORD.--July 1989 to current year.

EXTREMES FOR PERIOD OF RECORD. --Highest water leve1, $3.93 \mathrm{ft}$ below land-surface datum, Dec. 29, 1990; lowest, $8.80 \mathrm{ft}$ below land-surface datun, July $13,1989$.

\begin{tabular}{|c|c|c|c|c|c|c|c|c|c|c|c|c|}
\hline DAY & $\begin{array}{l}\text { HIGHEST } \\
\text { OCT }\end{array}$ & $\begin{array}{l}\text { WATER } \\
\text { NOV }\end{array}$ & LEVEL, IN & $\begin{array}{l}\text { FEET BELOW } \\
\text { JAM }\end{array}$ & $\begin{array}{l}\text { LAND- } \\
\text { FEB }\end{array}$ & $\begin{array}{l}\text { ACE } D \\
\text { MAR }\end{array}$ & $\begin{array}{c}\text { DATUM, WATER } \\
\text { APR }\end{array}$ & $\begin{array}{l}\text { YEAR } 0 \\
\text { MAY }\end{array}$ & $\begin{array}{c}\text { OCTOBER } \\
\text { JUN }\end{array}$ & $\begin{array}{l}\text { TO SE } \\
\text { JUL }\end{array}$ & $\begin{array}{l}\text { BER } 1991 \\
\text { AUG }\end{array}$ & SEP \\
\hline $\begin{array}{r}5 \\
10 \\
15 \\
20 \\
25 \\
\text { EOM }\end{array}$ & $\begin{array}{l}6.89 \\
4.95 \\
5.82 \\
5.96 \\
6.23 \\
6.36\end{array}$ & $\begin{array}{l}5.08 \\
5.88 \\
6.10 \\
6.25 \\
6.29 \\
5.60\end{array}$ & $\begin{array}{l}5.79 \\
6.01 \\
5.84 \\
5.92 \\
5.89 \\
4.52\end{array}$ & $\begin{array}{l}5.52 \\
5.71 \\
5.66 \\
5.38 \\
5.87 \\
6.07\end{array}$ & $\begin{array}{l}5.65 \\
5.56 \\
5.82 \\
5.61 \\
5.82 \\
5.89\end{array}$ & $\begin{array}{l}5.61 \\
5.93 \\
5.84 \\
4.65 \\
4.95 \\
5.59\end{array}$ & $\begin{array}{l}5.52 \\
5.82 \\
4.58 \\
5.31 \\
5.61 \\
5.62\end{array}$ & $\begin{array}{l}5.37 \\
5.74 \\
5.73 \\
5.38 \\
4.07 \\
4.32\end{array}$ & $\begin{array}{l}5.37 \\
5.67 \\
5.69 \\
5.58 \\
5.87 \\
6.14\end{array}$ & $\begin{array}{l}6.32 \\
6.41 \\
6.61 \\
6.81 \\
7.02 \\
7.28\end{array}$ & $\begin{array}{l}7.44 \\
7.49 \\
7.56 \\
7.54 \\
7.60 \\
7.56\end{array}$ & $\begin{array}{l}7.65 \\
7.67 \\
7.69 \\
7.76 \\
7.68 \\
7.76\end{array}$ \\
\hline
\end{tabular}

WTR YR 1991 HIGH 3.93 DEC 29

LOWEST WATER LEVEL, IN FEET BELOW LAND-SURFACE DATUM, WATER YEAR OCTOBER 1990 TO SEPTEMBER 1991

\begin{tabular}{|c|c|c|c|c|c|c|c|c|c|c|c|c|}
\hline DAY & $O C T$ & NOV & DEC & JAN & FEB & MAR & APR & MAY & JUN & JUL & AUG & SEP \\
\hline $\begin{array}{r}5 \\
10 \\
15 \\
20 \\
25 \\
\text { EOM }\end{array}$ & $\begin{array}{l}6.92 \\
5.28 \\
5.94 \\
6.03 \\
6.26 \\
6.40\end{array}$ & $\begin{array}{l}5.98 \\
6.00 \\
6.14 \\
6.29 \\
6.35 \\
5.71\end{array}$ & $\begin{array}{l}5.86 \\
6.07 \\
6.05 \\
5.98 \\
6.01 \\
4.87\end{array}$ & $\begin{array}{l}5.65 \\
5.81 \\
5.80 \\
5.42 \\
5.90 \\
6.14\end{array}$ & $\begin{array}{l}5.74 \\
5.61 \\
5.90 \\
5.68 \\
5.87 \\
5.96\end{array}$ & $\begin{array}{l}5.67 \\
5.98 \\
5.93 \\
4.81 \\
5.26 \\
5.63\end{array}$ & $\begin{array}{l}5.59 \\
5.85 \\
4.91 \\
5.36 \\
5.64 \\
5.69\end{array}$ & $\begin{array}{l}5.76 \\
5.78 \\
5.77 \\
5.48 \\
5.37 \\
5.33\end{array}$ & $\begin{array}{l}5.46 \\
5.72 \\
5.84 \\
5.61 \\
5.95 \\
6.22\end{array}$ & $\begin{array}{l}6.37 \\
6.46 \\
6.63 \\
6.85 \\
7.10 \\
7.31\end{array}$ & $\begin{array}{l}7.46 \\
7.52 \\
7.59 \\
7.59 \\
7.62 \\
7.63\end{array}$ & $\begin{array}{l}7.66 \\
7.70 \\
7.71 \\
7.78 \\
7.73 \\
7.79\end{array}$ \\
\hline
\end{tabular}

WTR YR 1991 LOW 7.79 SEP 28

384949085251901 . Local number, JF 5 .

JEFFERSON COUNTY

LOCATION. - Lat $38^{\circ} 49^{\prime} 49^{\circ}$, long $85^{\circ} 25^{\prime} 19^{\prime \prime}$, in SE $\frac{1}{4} N W \frac{1}{4} S W \frac{1}{4}$ sec.33, T.5 N., R.10 E.. Jefferson County, Hydrologic Unit 05120207 , on Jefferson Proving Ground, $500 \mathrm{ft}$ north of Airfield Road, 1,000 ft southwest of the water tower. and 2.2 i west of ain gate.

Owner: U.S. Aray

AQUIFER.--Lieestone, doloeite, and shale of Silurian and Ordovician age.

WELL CHARACTERISTICS.--Drilled artesian well, dianeter $5 \mathrm{in.}$ depth $200 \mathrm{ft}$, cased to $33 \mathrm{ft}$, open end.

INSTRUMENTATION. - - Wa ter-leve 1 recorder.

DATUM.--Elevation of land-surface datue is $855 \mathrm{ft}$ above National Geodetic Vertical Datua of 1929 , froe topographic ap. Measuring point: Top of floor of shelter, $3.00 \mathrm{ft}$ above land-surface datue.

REMARKS. - This well was drilled on a mapped fracture trace.

PERIOD OF RECORD.--March 1980 to current year.

EXTREMES FOR PERIOD OF RECORO..-Highest water leve1, $2.97 \mathrm{ft}$ below land-surface datua, Jan. 21 . 1991: lowest, 9.22 be low land-surface datue, Sept. $7,16,1988$.

\begin{tabular}{|c|c|c|c|c|c|c|c|c|c|c|c|c|}
\hline DAY & $\begin{array}{l}\text { HIGHEST } \\
\text { OCT }\end{array}$ & $\begin{array}{l}\text { WATER } \\
\text { NOV }\end{array}$ & LEVEL, IN & FEET BELOW & $\begin{array}{l}\text { LAND- } \\
\text { FEB }\end{array}$ & $\begin{array}{l}\text { ACE D } \\
\text { MAR }\end{array}$ & $\begin{array}{c}\text { DATUM, WATER } \\
\text { APR }\end{array}$ & MAY & $\underset{\text { JUN }}{\text { OCTOBER }} 1990$ & JUL & $\begin{array}{l}\text { BER } 1991 \\
\text { AUG }\end{array}$ & SEP \\
\hline $\begin{array}{r}5 \\
10 \\
15 \\
20 \\
25 \\
204\end{array}$ & $\begin{array}{l}\ldots \\
\ldots \\
\cdots \\
\cdots \\
\cdots \\
\cdots\end{array}$ & $\begin{array}{l}4.18 \\
4.29 \\
4.25 \\
4.12 \\
3.86 \\
3.97\end{array}$ & $\begin{array}{l}\ldots \\
\ldots \\
\ldots \\
\ldots \\
\ldots \\
\ldots\end{array}$ & $\begin{array}{l}\ldots . \\
\ldots \\
2 . \\
2.98 \\
3.22 \\
3.34\end{array}$ & $\begin{array}{l}3.05 \\
3.25 \\
3.47 \\
3.37 \\
3.43 \\
3.29\end{array}$ & $\begin{array}{r}3.37 \\
3.06 \\
. .99 \\
3.99 \\
3.99 \\
3.92\end{array}$ & $\begin{array}{r}4.20 \\
4.14 \\
4.02 \\
4.17 \\
\ldots . .\end{array}$ & $\begin{array}{l}\ldots \\
\ldots \\
\cdots \\
\cdots \\
\cdots \\
\cdots\end{array}$ & $\begin{array}{l}5.27 \\
5.48 \\
5.75 \\
5.96 \\
6.10\end{array}$ & $\begin{array}{l}6.34 \\
6.52 \\
6.86 \\
6.99 \\
7.15 \\
7.46\end{array}$ & $\begin{array}{l}7.63 \\
7.62 \\
7.74 \\
7.74 \\
7.90 \\
7.98\end{array}$ & $\begin{array}{l}7.92 \\
7.85 \\
7.90 \\
8.00 \\
7.77 \\
8.06\end{array}$ \\
\hline
\end{tabular}

WTR YR 1991 HIGH 2.97 JAN 21

LOWEST WATER LEVEL. IN FEET BELOW LAND-SURFACE OATUM, WATER YEAR OCTOBER 1990 TO SEPTEMBER 1991

\begin{tabular}{|c|c|c|c|c|c|c|c|c|c|c|c|c|}
\hline DAY & ОСТ & NOV & DEC & JAN & FEB & MAR & APR & MAY & JUM & JUL & AUG & SEP \\
\hline $\begin{array}{r}5 \\
10 \\
15 \\
20 \\
25 \\
\text { EOM }\end{array}$ & $\begin{array}{l}\ldots \\
\ldots \\
\ldots \\
\ldots \\
\ldots\end{array}$ & $\begin{array}{l}4.47 \\
4.41 \\
4.41 \\
4.25 \\
4.00 \\
4.22\end{array}$ & $\begin{array}{l}\ldots \\
\ldots \\
\ldots \\
\ldots \\
\ldots \\
\ldots\end{array}$ & $\begin{array}{c}\ldots . \\
\ldots . \\
3.09 \\
3.23 \\
3.35\end{array}$ & $\begin{array}{l}3.25 \\
3.51 \\
3.51 \\
3.40 \\
3.50 \\
3.34\end{array}$ & $\begin{array}{r}3.53 \\
3.14 \\
1.25 \\
4.14 \\
4.20 \\
4.14\end{array}$ & $\begin{array}{r}4.27 \\
4.29 \\
4.26 \\
4.29 \\
\ldots . .2\end{array}$ & $\begin{array}{l}\ldots \\
\ldots \\
\cdots \\
\cdots \\
\cdots\end{array}$ & $\begin{array}{l}5.46 \\
5.59 \\
5.84 \\
6.09 \\
6.18\end{array}$ & $\begin{array}{l}6.45 \\
6.68 \\
6.95 \\
7.12 \\
7.31 \\
7.52\end{array}$ & $\begin{array}{l}7.77 \\
7.79 \\
7.81 \\
7.86 \\
8.02 \\
8.04\end{array}$ & $\begin{array}{l}8.07 \\
7.99 \\
7.97 \\
8.14 \\
7.93 \\
8.22\end{array}$ \\
\hline
\end{tabular}

WTR YR 1991 LOW 8.22 SEP 30 
385601085365701. Local number, JN 3.

LOCATION, - - Lat $38^{\circ} 56^{\prime} 01^{\circ}$, long $85^{\circ} 36^{\prime} 57^{\circ}$, in SEASWANE sec.27, T.6 N., R.8 E., Jennings County, Hydrologic Unit $05120207,200 \mathrm{ft}$ west of State Highway 3, 1.6 i south of Crosley Fish and Gane Office and 3.0 ai south of Vernon.

Owner: U.S. Geological Survey.

AQUIFER.--Limestones and dolomites of Devonian age.

WELL CHARACTERISTICS.--Drilled artesian well, dianeter $6 \mathrm{in.}$ depth $180 \mathrm{ft}$, cased to $45 \mathrm{ft}$, open end.

INST RUMENTATION. - - Water-level recorder.

DATUM.--Elevation of land-surface datu is $718 \mathrm{ft}$ above National Geodetic Vertical Datun of 1929 . from topographic ap. Measuring point: Top of floor of shelter, $3.50 \mathrm{ft}$ above land-surface datua.

PERIOD OF RECORD.--0ctober 1978 to current year.

EXTREMES FOR PERIOD OF RECORD.--Highest water level, $36.64 \mathrm{ft}$ below land-surface datun, Jan. 21 . 1979; 10west. $40.87 \mathrm{ft}$ below land-surface datum, July $6,1988$.

\begin{tabular}{|c|c|c|c|c|c|c|c|c|c|c|c|c|}
\hline AY & $\begin{array}{l}\text { HIGHE ST } \\
\text { OCT }\end{array}$ & $\begin{array}{c}\text { WATER } \\
\text { NOV }\end{array}$ & ${ }_{\text {DEC }}^{\text {LEVEL IN }}$ & FEET BELOW & $\begin{array}{l}\text { LAND } \\
\text { FEB }\end{array}$ & MAR & $\begin{array}{l}\text { DATUM, WATER } \\
\text { APR }\end{array}$ & $\begin{array}{l}\text { YEAR } \\
\text { MAY }\end{array}$ & $\underset{\text { JUN }}{\text { OCTOBER }} 1990$ & JUL & $\begin{array}{l}\text { BER } 1991 \\
\text { AUG }\end{array}$ & SEP \\
\hline $\begin{array}{r}5 \\
10 \\
15 \\
20 \\
25\end{array}$ & $\begin{array}{l}39.42 \\
39.24 \\
39.31 \\
39.29 \\
39.22 \\
39.37\end{array}$ & $\begin{array}{l}39.07 \\
39.26 \\
39.37 \\
39.35 \\
38.97 \\
39.18\end{array}$ & $\begin{array}{l}38.90 \\
39.00 \\
38.85 \\
38.63 \\
38.64 \\
38.53\end{array}$ & $\begin{array}{l}38.58 \\
38.46 \\
38.32 \\
38.45 \\
38.88 \\
38.73\end{array}$ & $\begin{array}{l}38.66 \\
38.35 \\
38.40 \\
38.67 \\
38.75 \\
38.73\end{array}$ & $\begin{array}{l}38.68 \\
39.09 \\
38.85 \\
38.57 \\
38.58 \\
38.70\end{array}$ & $\begin{array}{l}38.80 \\
38.71 \\
38.28 \\
38.50 \\
38.75 \\
38.77\end{array}$ & $\begin{array}{l}38.86 \\
39.08 \\
38.92 \\
39.09 \\
39.05 \\
39.12\end{array}$ & $\begin{array}{l}39.51 \\
39.66 \\
39.66 \\
39.79 \\
39.91 \\
39.84\end{array}$ & $\begin{array}{l}39.93 \\
39.95 \\
40.06 \\
40.03 \\
40.02 \\
40.09\end{array}$ & $\begin{array}{l}40.11 \\
40.05 \\
40.09 \\
40.03 \\
40.23 \\
40.13\end{array}$ & $\begin{array}{l}40.12 \\
40.14 \\
40.16 \\
40.37 \\
40.05 \\
40.37\end{array}$ \\
\hline
\end{tabular}

WTR YR 1991 HIGH 38.10 FEB 13

LOWEST WATER LEVEL, IN FEET BELOW LAND-SURFACE DATUM, WATER YEAR OCTOBER 1990 TO SEPTEMBER 1991

\begin{tabular}{|c|c|c|c|c|c|c|c|c|c|c|c|c|}
\hline DAY & ОСТ & NOV & DEC & JAN & FEB & MAR & $A P R$ & MAY & JUN & JUL & AUG & SEP \\
\hline $\begin{array}{r}5 \\
10 \\
15 \\
20 \\
25\end{array}$ & $\begin{array}{l}39.48 \\
39.40 \\
39.43 \\
39.35 \\
39.30 \\
39.41\end{array}$ & $\begin{array}{l}39.29 \\
39.31 \\
39.42 \\
39.40 \\
39.10 \\
39.35\end{array}$ & $\begin{array}{l}39.06 \\
39.04 \\
39.04 \\
38.72 \\
38.69 \\
38.63\end{array}$ & $\begin{array}{l}38.66 \\
38.64 \\
38.48 \\
38.54 \\
38.95\end{array}$ & $\begin{array}{l}38.71 \\
38.46 \\
38.75 \\
38.75 \\
38.79\end{array}$ & $\begin{array}{l}38.81 \\
39.16 \\
38.96 \\
38.67 \\
38.63\end{array}$ & $\begin{array}{l}38.83 \\
38.82 \\
38.45 \\
38.62 \\
38.81\end{array}$ & $\begin{array}{l}38.96 \\
39.14 \\
38.99 \\
39.12 \\
39.11\end{array}$ & $\begin{array}{l}39.64 \\
39.73 \\
39.69 \\
39.83 \\
39.95\end{array}$ & $\begin{array}{l}39.98 \\
39.99 \\
40.11 \\
40.08 \\
40.08\end{array}$ & $\begin{array}{l}40.17 \\
40.14 \\
40.13 \\
40.12 \\
40.28\end{array}$ & $\begin{array}{l}40.18 \\
40.19 \\
40.20 \\
40.43 \\
40.18 \\
40.47\end{array}$ \\
\hline
\end{tabular}

WTR YR 1991 LOW 40.47 SEP 30

383247087361001 . Local number, KN 7

KNOX COUNTY

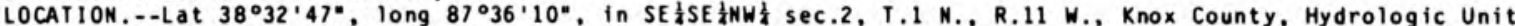
05120113 , in the right-of-way of $S i x t h$ Street Road, 9.8 a south of $V$ incennes.

Owner: Michael J. Kelley.

AQUIFER. - - Sand and gravel Quaternary age.

WELL CHARACTERISTICS,--Drilled artesian well, dianeter 6 in., depth $43 \mathrm{ft}$, cased to $16 \mathrm{ft}$, slotted to $19 \mathrm{ft}$, open end.

INSTRUMENTATION.--Water-level recorder. Prior to April 1968, hand-taped monthly.

DATUM.--Elevation of land-surface datun is $405 \mathrm{ft}$ above National Geodetic Vertical Datua of 1929 , from topographic ap. Measuring point: Top of floor of shelter, $2.42 \mathrm{ft}$ above land-surface datus.

PERIOD OF RECORD..-Novenber 1956 to December 1972, January 1974 to current year.

EXTREMES FOR PERIOD OF RECORD.--Highest water level, $2.57 \mathrm{ft}$ below land-surface datua, May 3 , 1983 ; lowest. $11.35 \mathrm{ft}$ be low land-surface datum. Feb. 1-13,1977.

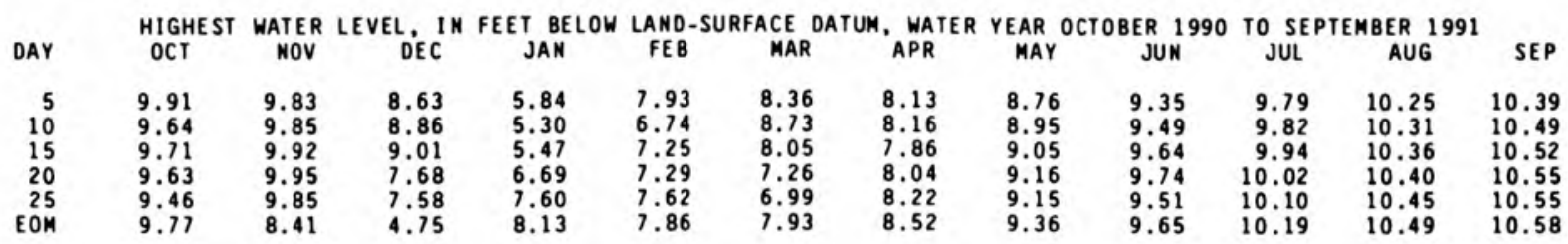

WTR YR 1991 HIGH 4.75 OEC 31

LOWEST WATER LEVEL, IN FEET BELOW LAND-SURFACE DATUM. WATER YEAR OCTOBER 1990 TO SEPTEMBER 1991

\begin{tabular}{|c|c|c|c|c|c|c|c|c|c|c|c|c|}
\hline DAY & $\mathrm{OCT}$ & NOV & DEC & JAN & FEB & MAR & APR & MAY & JUN & JUL & AUG & SEP \\
\hline $\begin{array}{r}5 \\
10 \\
15 \\
20 \\
25 \\
\text { EOM }\end{array}$ & $\begin{array}{l}9.92 \\
9.88 \\
9.76 \\
9.66 \\
9.48 \\
9.80\end{array}$ & $\begin{array}{l}9.89 \\
9.87 \\
9.93 \\
9.97 \\
9.86 \\
8.49\end{array}$ & $\begin{array}{l}8.72 \\
8.93 \\
9.11 \\
7.84 \\
7.66 \\
4.89\end{array}$ & $\begin{array}{l}5.93 \\
5.54 \\
5.55 \\
7.02 \\
7.64 \\
8.24\end{array}$ & $\begin{array}{l}8.23 \\
7.08 \\
7.53 \\
7.33 \\
7.74 \\
7.92\end{array}$ & $\begin{array}{l}8.40 \\
8.76 \\
8.11 \\
7.40 \\
7.22 \\
7.97\end{array}$ & $\begin{array}{l}8.16 \\
8.25 \\
7.98 \\
8.07 \\
8.24 \\
8.58\end{array}$ & $\begin{array}{l}8.82 \\
8.98 \\
9.07 \\
9.19 \\
9.20 \\
9.39\end{array}$ & $\begin{array}{l}9.38 \\
9.53 \\
9.66 \\
9.76 \\
9.56 \\
9.67\end{array}$ & $\begin{array}{r}9.81 \\
9.87 \\
9.95 \\
10.03 \\
10.12 \\
10.20\end{array}$ & $\begin{array}{l}10.27 \\
10.32 \\
10.37 \\
10.41 \\
10.46 \\
10.50\end{array}$ & $\begin{array}{l}10.41 \\
10.50 \\
10.53 \\
10.55 \\
10.55 \\
10.58\end{array}$ \\
\hline
\end{tabular}

WTR YR 1991 LOW 10.58 SEP 29 
384951087202501 . Local number, KN 8.

KNOX COUNTY

LOCATION - Lat $380^{\circ} 49$ '51." Nunger, $87^{\circ} 20^{\circ}$

on the northwest side of road at the southwest boundary of Chabers Cenetery about 2.5 i southwest of
Freelandville.

Owner: U.S. Geological Survey

AQUIFER.--Interbedded sandstone, shale, and coal of Pennsylvanian age.

WELL CHARACTERISTICS,--Drilled artesian well, diameter 6 in., depth $137 \mathrm{ft}$, cased to $41 \mathrm{ft}$, open hole.

INST RUMENTATION. - - Wa t er-level recorder.

DATUM.--Elevation of land-surface datua is $460 \mathrm{ft}$ above National Geodetic Vertical Datue of 1929 , froe topographic

ap. Measuring point: Top of casing. $3.50 \mathrm{ft}$ above land-surface datur.

PERIOD OF RECORD.--August 1989 to current year.

EXTREMES FOR PERIOD OF RECORD.--Highest water leve1, $12.00 \mathrm{ft}$ below land-surface datum, Feb. 22 , 1990; lowest,

$15.15 \mathrm{ft}$ below land-surface datun, Sept. 30, $199 \mathrm{i}$.

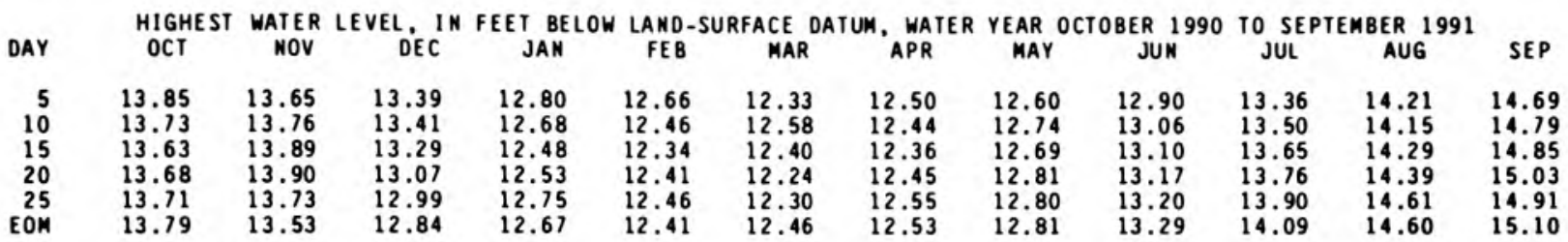

WTR YR 1991 HIGH 12.16 MAR 27

LOWEST WATER LEVEL, IN FEET BELOW LAND-SURFACE DATUM, WATER YEAR OCTOBER 1990 TO SEPTEMBER 1991

DAY

OCT

5
10
15
20
25
EOM

$\begin{array}{lll}13.90 & 13.74 & 13.50 \\ 13.75 & 13.80 & 13.43 \\ 13.71 & 13.92 & 13.39 \\ 13.72 & 13.92 & 13.15 \\ 13.75 & 13.79 & 13.04 \\ 13.81 & 13.66 & 12.85\end{array}$

12.85
12.80
12.57
12.57
12.76
12.78

FEB
12.70
12.51
12.48
12.44
12.49
12.46

MAR
12.41
12.60
12.46
12.28
12.31
12.48

APR
12.52
12.54
12.43
12.51
12.59
12.62

MAY
12.64
12.78
12.74
12.82
12.82
12.85

JUN
12.95
13.08
13.11
13.20
13.23
13.30

JUL
13.40
13.55
13.70
13.81
13.95
14.13

AUG
14.27
14.21
14.32
14.45
14.63
14.63

SEP

WTR YR 1991 LOW 15.15 SEP 30

412554085450001 . Local number, KO 6.

KOSCIUSKO COUNTY

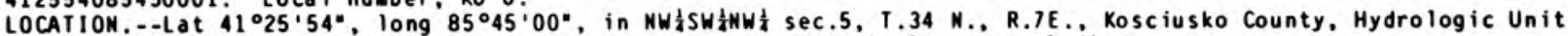
04050001 , west end of North Shore Drive and Lakeview Park in Syracuse. Indiana.

Owner: U.S. Geological Survey.

AQUIFER. - - Sand of Pleistocene age.

WELL CHARACTERISIICS.--Drilled water-table well, diaseter 2 in., depth $23 \mathrm{ft}$, cased to $20 \mathrm{ft}$, screened to 23 ft.

INSTRUMENTATION. - - Water-level recorder.

DATUM.--Elevation of land-surface datu is $870 \mathrm{ft}$ above National Geodetic Vertical Datue of 1929 , froa topographic ap. Measuring point: Top of floor of shelter, $3.00 \mathrm{ft}$ above land-surface datua.

PERIOD OF RECORD.--Noveaber 1978 to current year.

EXTREMES FOR PERIOD OF RECORD.--Highest water level, $6.94 \mathrm{ft}$ below land-surface datun, Apr. 15 , 16 , 1985 ; 10west, $10.64 \mathrm{ft}$ below land-surface datur, Feb. 9, 1979, Oct. 7, 13, 14, 1988 .

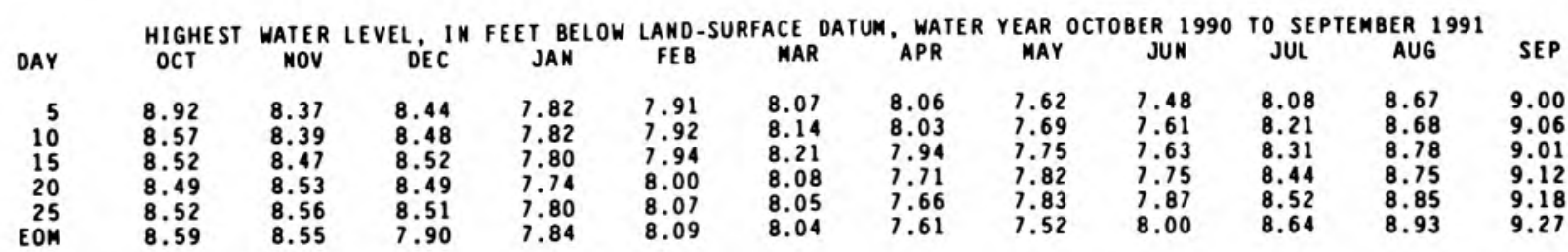

WTR YR 1991 HIGH 7.45 JUN 2

LOWEST WATER LEVEL. IN FEET BELOW LAND-SURFACE DATUM. WATER YEAR OCTOBER 1990 TO SEPTEMBER 1991

$\begin{array}{rrrrrrrrrrrrr}\text { DAY } & \text { OCT } & \text { NOV } & \text { DEC } & \text { JAN } & \text { FEB } & \text { MAR } & \text { APR } & \text { MAY } & \text { JUN } & \text { JUL } & \text { AUG } & \text { SEP } \\ & & & & & & & & & & & \\ 15 & 8.94 & 8.60 & 8.45 & 7.85 & 7.91 & 8.08 & 8.07 & 7.63 & 7.51 & 8.10 & 8.68 & 9.02 \\ 10 & 8.86 & 8.41 & 8.51 & 7.82 & 7.93 & 8.14 & 8.06 & 7.71 & 7.61 & 8.24 & 8.70 & 9.06 \\ 15 & 8.52 & 8.48 & 8.55 & 7.80 & 7.99 & 8.22 & 8.06 & 7.79 & 7.64 & 8.35 & 8.80 & 9.03 \\ 20 & 8.50 & 8.56 & 8.51 & 7.74 & 8.02 & 8.09 & 7.73 & 7.84 & 7.78 & 8.47 & 8.78 & 9.13 \\ 25 & 8.54 & 8.58 & 8.51 & 7.81 & 8.08 & 8.09 & 7.67 & 7.87 & 7.90 & 8.54 & 8.87 & 9.19 \\ \text { EOM } & 8.60 & 8.57 & 7.90 & 7.88 & 8.11 & 8.05 & 7.61 & 7.79 & 8.02 & 8.66 & 8.95 & 9.28\end{array}$

WTR YR 1991 LOW 9.28 SEP 30 
412556085513401 Local number. KO 9.

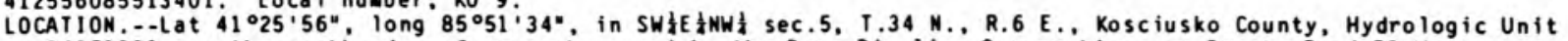
04050001. On the north edge of property owned by the Done Pipeline Corporation, on County Road 50 West.

$1.5 \backsim i$ northwest of Milford.

Owner: U.S. Geological Survey.

AQUIFER.-.-Sand and gravel of Pleistocene age.

WELL CHARACTERISTICS.--Drilled water-table well, dianeter 4 in., depth $102 \mathrm{ft}$, cased to $99 \mathrm{ft}$, screened to $102 \mathrm{ft}$. INSTRUMENTATION. - -Water-stage recorder.

DATUM.--Elevation of land-surface datue is $830.90 \mathrm{ft}$ above National Geodetic Vertical Datue of 1929 . Measuring point: Top of floor of shelter, $3.2 \mathrm{ft}$ above land-surface datue.

PERIOD OF RECORD.--October 1982 to current year.

EXTREMES FOR PERIOD OF RECORD.--Highest water level, $7.24 \mathrm{ft}$ below land-surface datum, Apr. 8, 9, 1985; 10west, $14.33 \mathrm{ft}$ below land-surface datun, Aug. 10, 1988 .

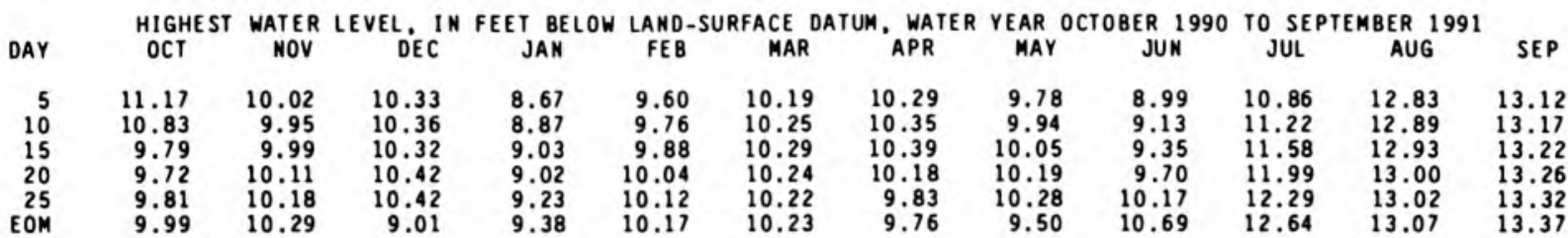

WTR YR 1991 HIGH 8.67 JAN 5

LOWEST WATER LEVEL, IN FEET BELOW LANO-SURFACE DATUM. WATER YEAR OCTOBER 1990 TO SEPTEMBER 1991

\begin{tabular}{|c|c|c|c|c|c|c|c|c|c|c|c|c|}
\hline DAY & OCT & NOV & DEC & JAN & FE B & MAR & $A P R$ & MAY & JUN & JUL & AUG & SEP \\
\hline $\begin{array}{r}5 \\
10 \\
15 \\
20 \\
25 \\
\text { EOM }\end{array}$ & $\begin{array}{r}11.18 \\
11.10 \\
9.82 \\
9.73 \\
9.85 \\
10.02\end{array}$ & $\begin{array}{r}10.10 \\
9.97 \\
10.00 \\
10.13 \\
10.22 \\
10.31\end{array}$ & $\begin{array}{r}10.37 \\
10.38 \\
10.37 \\
10.44 \\
10.44 \\
9.40\end{array}$ & $\begin{array}{l}8.68 \\
8.88 \\
9.06 \\
9.07 \\
9.25 \\
9.39\end{array}$ & $\begin{array}{r}9.64 \\
9.79 \\
9.94 \\
10.06 \\
10.14 \\
10.18\end{array}$ & $\begin{array}{l}10.23 \\
10.27 \\
10.31 \\
10.28 \\
10.24 \\
10.26\end{array}$ & $\begin{array}{r}10.32 \\
10.39 \\
10.49 \\
10.25 \\
9.88 \\
9.78\end{array}$ & $\begin{array}{r}9.81 \\
9.97 \\
10.08 \\
10.20 \\
10.30 \\
10.03\end{array}$ & $\begin{array}{r}9.00 \\
9.17 \\
9.39 \\
9.79 \\
10.27 \\
10.75\end{array}$ & $\begin{array}{l}10.94 \\
11.29 \\
11.65 \\
12.07 \\
12.35 \\
12.70\end{array}$ & $\begin{array}{l}12.84 \\
12.90 \\
12.94 \\
13.00 \\
13.02 \\
13.09\end{array}$ & $\begin{array}{l}13.14 \\
13.18 \\
13.23 \\
13.27 \\
13.32 \\
13.38\end{array}$ \\
\hline
\end{tabular}

WTR YR 1991 LOW 13.38 SEP 30

\section{LAGRANGE COUNTY}

414318085200601 . Local number. 162.

LOCATION.--Lat $41^{\circ} 43^{\prime} 18^{\circ}$, long $85^{\circ} 20^{\circ} 06^{\prime \prime}$, in SW $\frac{1}{4}$ SE $\frac{1}{4} N E \frac{1}{4}$ sec.26, T.38 N., R.10 E., Lagrange County, Hydrologic Unit 04050001 , on northeast corner of intersection of State Highway 120 and County Road 475 East, and 1.2 i

west of Brighton.

Owner: U.S. Geological Survey.

AQUIFER.-.-Sand and gravel of Pleistocene age.

WELL CHARACTERISTICS.--Drilled water-table well, dianeter 5 in., depth $86 \mathrm{ft}$, cased to $80 \mathrm{ft}$, screened to $86 \mathrm{ft}$. INSTRUMENTATION. - -Water-level recorder.

DATUM.--Elevation of land-surface datu is $911.02 \mathrm{ft}$ above National Geodetic Vertical Datun of 1929 . Measuring point: Top of floor of shelter, $3.0 \mathrm{ft}$ above land-surface datun.

PERIOD OF RECORO..-May 1980 to current year.

EXTREMES FOR PERIOD OF RECORD..-Highest water level, $10.99 \mathrm{ft}$ below land-surface datun, Apr. 3 , 1982; lowest, $16.93 \mathrm{ft}$ below land-surface datue, Aug. 14, 15, 1988 .

\begin{tabular}{|c|c|c|c|c|c|c|c|c|c|c|c|c|}
\hline AY & $\begin{array}{l}\text { HIGHEST } \\
\text { OCT }\end{array}$ & $\begin{array}{c}\text { WATER } \\
\text { NOV }\end{array}$ & LEVEL, IN & $\begin{array}{c}\text { FEET BELOW } \\
\text { JAN }\end{array}$ & $\begin{array}{l}\text { LAND- } \\
\text { FEB }\end{array}$ & $\begin{array}{l}\text { FACE D } \\
\text { MAR }\end{array}$ & DATUM, $\underset{\text { APR }}{\text { WATER }}$ & $\begin{array}{l}\text { YEAR } 0 \\
\text { MAY }\end{array}$ & OCTOBER $\underset{\text { JUN }}{ } 1990$ & TO SEF & $\begin{array}{l}\text { IBER } 1991 \\
\text { AUG }\end{array}$ & SEP \\
\hline $\begin{array}{r}5 \\
10 \\
15 \\
20 \\
25 \\
E O M\end{array}$ & $\begin{array}{l}14.61 \\
14.54 \\
14.31 \\
14.16 \\
14.11 \\
14.07\end{array}$ & $\begin{array}{l}14.03 \\
14.04 \\
14.02 \\
13.99 \\
13.95 \\
13.96\end{array}$ & $\begin{array}{l}13.95 \\
13.96 \\
13.93 \\
13.96 \\
13.94 \\
13.63\end{array}$ & $\begin{array}{l}13.22 \\
13.06 \\
12.95 \\
12.85 \\
12.86 \\
12.85\end{array}$ & $\begin{array}{l}12.86 \\
12.87 \\
12.89 \\
12.84 \\
12.92 \\
12.94\end{array}$ & $\begin{array}{l}12.97 \\
13.07 \\
13.11 \\
13.12 \\
13.18 \\
13.21\end{array}$ & $\begin{array}{l}13.24 \\
13.27 \\
13.23 \\
13.32 \\
13.30 \\
13.21\end{array}$ & $\begin{array}{l}13.13 \\
13.11 \\
13.07 \\
13.07 \\
13.07 \\
13.09\end{array}$ & $\begin{array}{l}13.14 \\
13.18 \\
13.36 \\
13.66 \\
13.92 \\
14.23\end{array}$ & $\begin{array}{l}.92 \\
.98 \\
.29 \\
.63 \\
.53 \\
.71\end{array}$ & $\begin{array}{l}14.92 \\
14.94 \\
15.06 \\
15.09 \\
15.04 \\
15.09\end{array}$ & $\begin{array}{l}15.11 \\
15.14 \\
15.17 \\
15.19 \\
15.24\end{array}$ \\
\hline
\end{tabular}

WTR YR 1991 HIGH 12.82 JAM 27

LOWEST WATER LEVEL, IN FEET BELOW LAND-SURFACE DATUM, WATER YEAR OCTOBER 1990 TO SEPTEMBER 1991

\begin{tabular}{|c|c|c|c|c|c|c|c|c|c|c|c|c|}
\hline DAY & OCT & NOV & DEC & JAN & FE B & MAR & APR & MAY & JUN & JUL & AUG & SEP \\
\hline $\begin{array}{r}5 \\
10 \\
15 \\
20 \\
25 \\
\text { EOM }\end{array}$ & $\begin{array}{l}14.62 \\
14.61 \\
14.35 \\
14.19 \\
14.11 \\
14.08\end{array}$ & $\begin{array}{l}14.06 \\
14.05 \\
14.03 \\
14.00 \\
13.98 \\
13.98\end{array}$ & $\begin{array}{l}13.99 \\
13.98 \\
13.95 \\
13.98 \\
13.96 \\
13.76\end{array}$ & $\begin{array}{l}13.27 \\
13.10 \\
12.98 \\
12.87 \\
12.88 \\
12.90\end{array}$ & $\begin{array}{l}12.87 \\
12.89 \\
12.96 \\
12.86 \\
12.93 \\
12.96\end{array}$ & $\begin{array}{l}13.01 \\
13.09 \\
13.13 \\
13.15 \\
13.19 \\
13.23\end{array}$ & $\begin{array}{l}13.26 \\
13.31 \\
13.31 \\
13.33 \\
13.33 \\
13.23\end{array}$ & $\begin{array}{l}13.17 \\
13.12 \\
13.07 \\
13.08 \\
13.07 \\
13.11\end{array}$ & $\begin{array}{l}13.16 \\
13.19 \\
13.39 \\
13.12 \\
13.94 \\
14.29\end{array}$ & $\begin{array}{l}13.94 \\
14.12 \\
14.35 \\
14.65 \\
14.63 \\
14.72\end{array}$ & $\begin{array}{l}14.95 \\
14.95 \\
15.11 \\
15.10 \\
15.05 \\
15.11\end{array}$ & $\begin{array}{l}15.11 \\
15.13 \\
15.15 \\
15.18 \\
15.20 \\
15.24\end{array}$ \\
\hline
\end{tabular}

WTR YR 1991 LOW 15.24 SEP 29 
414158085253401 . Local number, LG 3.

LAGRANGE COUNTY

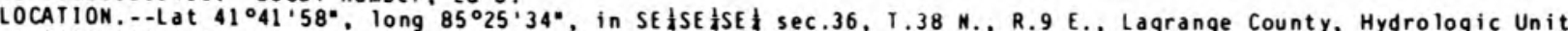
04050001 , at northwest corner of intersection of State Highway 9 and County Road 400 North, at edge of woods. and $1.4 \mathrm{i}$ south of Howe.

Owner: U.S. Geological Survey.

AQUIFER.-.Fine to mediun sand and gravel of Pleistocene age.

WELL CHARACTERISTICS..-Drilled water-table well, diameter $6 \mathrm{in.}$, depth $40 \mathrm{ft}$, cased to $35 \mathrm{ft}$, screened to $40 \mathrm{ft}$. INSTRUMENTATION.-- Water-level recorder.

DATUM.--Elevation of land-surface datue is $870 \mathrm{ft}$ above Mational Geodetic Vertical Datum of 1929 , froe topographic ap. Measuring point: Top of floor of shelter, $3.7 \mathrm{ft}$ above land-surface datue.

PERIOD OF RECORD...June 1981 to current year.

EXIREMES FOR PERIOD OF RECORD..-Highest water level. $3.48 \mathrm{ft}$ below land-surface datuan, Mar. 21. 1982; lowest, $8.82 \mathrm{ft}$ below land-surface datun, Sept. 2, 1988 .

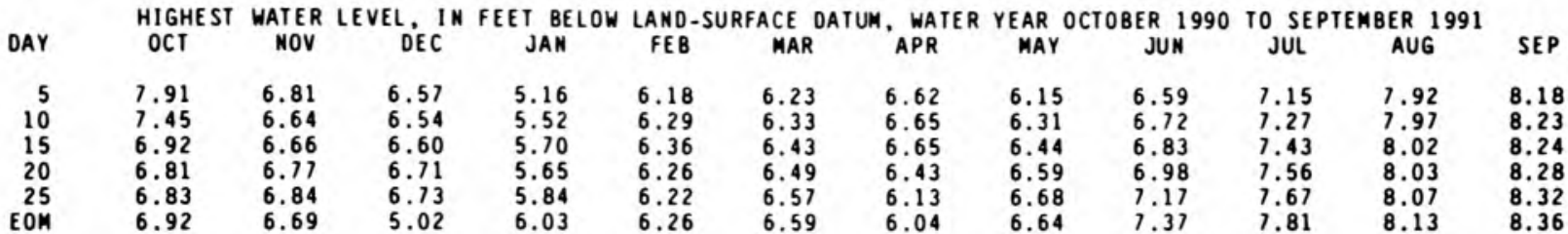

WTR YR 1991 HIGH 4.94 JAN 1

LOWEST WATER LEVEL, IN FEET BELOW LAND-SURFACE DATUM, WATER YEAR OCTOBER 1990 TO SEPTEMBER 1991

\begin{tabular}{|c|c|c|c|c|c|c|c|c|c|c|c|c|}
\hline DAY & OCT & NOV & DEC & JAK & FEB & MAR & APR & MAY & JUN & JUL & AUG & SEP \\
\hline $\begin{array}{r}5 \\
10 \\
15 \\
20 \\
25 \\
\text { EON }\end{array}$ & $\begin{array}{l}7.92 \\
7.66 \\
6.92 \\
6.81 \\
6.84 \\
6.96\end{array}$ & $\begin{array}{l}7.00 \\
6.66 \\
6.67 \\
6.79 \\
6.88 \\
6.12\end{array}$ & $\begin{array}{l}6.60 \\
6.56 \\
6.63 \\
6.72 \\
6.75 \\
5.35\end{array}$ & $\begin{array}{l}5.22 \\
5.56 \\
5.73 \\
5.71 \\
5.87 \\
6.09\end{array}$ & $\begin{array}{l}6.21 \\
6.31 \\
6.40 \\
6.31 \\
6.22 \\
6.28\end{array}$ & $\begin{array}{l}6.25 \\
6.35 \\
6.45 \\
6.50 \\
6.58 \\
6.59\end{array}$ & $\begin{array}{l}6.63 \\
6.68 \\
6.70 \\
6.51 \\
6.17 \\
6.05\end{array}$ & $\begin{array}{l}6.16 \\
6.34 \\
6.47 \\
6.61 \\
6.70 \\
6.76\end{array}$ & $\begin{array}{l}6.60 \\
6.75 \\
6.85 \\
7.03 \\
7.20 \\
7.38\end{array}$ & $\begin{array}{l}7.17 \\
7.31 \\
7.45 \\
7.59 \\
7.69 \\
7.83\end{array}$ & $\begin{array}{l}7.94 \\
7.98 \\
8.03 \\
8.05 \\
8.08 \\
8.14\end{array}$ & $\begin{array}{l}8.19 \\
8.26 \\
8.25 \\
8.29 \\
8.32 \\
8.37\end{array}$ \\
\hline
\end{tabular}

WTR YR 1991 LOW 8.37 SEP 30

411038087284701. Local nuaber, LK 12

LAKE COUNTY

LCATION 07120001 , on the northern edge of Kankakee River State Park, 2.0 - southwest of Schneider.

Owner: U.S. Geological Survey.

AQUIFER. - Dolonite of Silurian age.

WELL CHARACTERISTICS.---Drilled artesian well, dianeter 6 in., depth $82 \mathrm{ft}$, cased to $52 \mathrm{ft}$, open end.

INST RUMENTATION, - - Water-level recorder.

DATUM.--Elevation of land-surface datua is $630.59 \mathrm{ft}$ above National Geodetic Vertical Datum of 1929 . Measuring point: Top of floor of shelter, $2.55 \mathrm{ft}$ above land-surface datue.

REMARKS. - Water level way be affected by punping.

PERIOD OF RECORD..--March 1967 to current year.

EXTREMES FOR PERIOD OF RECORD.--Highest water leve1, $0.15 \mathrm{ft}$ below land-surface datue. Jan. 12 . 1973: lowest,

$17.92 \mathrm{ft}$ below land-surface datun. Aug. 27, 1988.

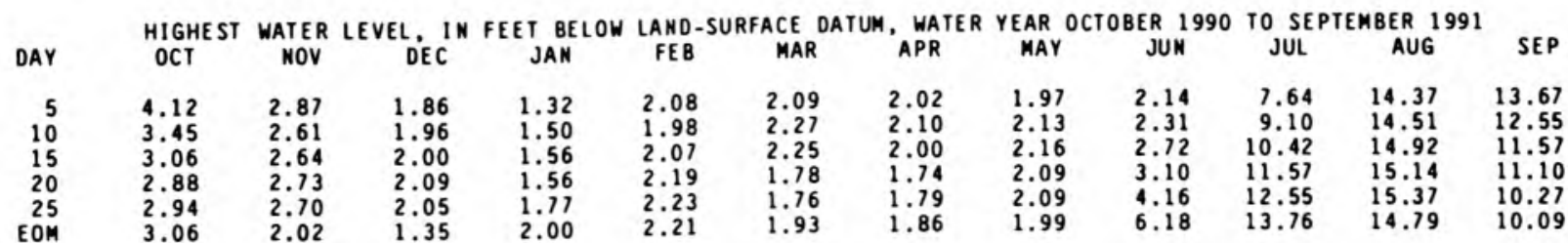

WTR YR 1991 HIGH 1.27 JAN 1

LOWEST WATER LEVEL, IN FEET BELOW LAND-SURFACE OATUM, WATER YEAR OCTOBER 1990 TO SEPTEMBER 1991

\begin{tabular}{|c|c|c|c|c|c|c|c|c|c|c|c|c|}
\hline DAY & OCT & MOV & DEC & JAM & FE B & MAR & $A P R$ & MAY & JUN & JUL & AUG & SEP \\
\hline $\begin{array}{r}5 \\
10 \\
15 \\
20 \\
25 \\
\text { EOM }\end{array}$ & $\begin{array}{l}4.22 \\
3.64 \\
3.15 \\
3.29 \\
3.06 \\
3.18\end{array}$ & $\begin{array}{l}3.04 \\
2.85 \\
2.75 \\
2.80 \\
2.82 \\
2.21\end{array}$ & $\begin{array}{l}2.00 \\
2.08 \\
2.09 \\
2.25 \\
2.17 \\
1.47\end{array}$ & $\begin{array}{l}1.45 \\
1.64 \\
1.70 \\
1.66 \\
1.92 \\
2.18\end{array}$ & $\begin{array}{l}2.22 \\
2.11 \\
2.19 \\
2.30 \\
2.35 \\
2.31\end{array}$ & $\begin{array}{l}2.22 \\
2.59 \\
2.34 \\
2.02 \\
2.00 \\
2.05\end{array}$ & $\begin{array}{l}2.10 \\
2.26 \\
2.14 \\
1.91 \\
1.91 \\
2.01\end{array}$ & $\begin{array}{l}2.08 \\
2.25 \\
2.38 \\
2.21 \\
2.28 \\
2.14\end{array}$ & $\begin{array}{l}2.26 \\
2.47 \\
2.86 \\
3.28 \\
4.53 \\
6.84\end{array}$ & $\begin{array}{r}7.96 \\
9.35 \\
10.65 \\
11.80 \\
12.81 \\
13.93\end{array}$ & $\begin{array}{l}14.53 \\
14.61 \\
15.04 \\
15.24 \\
15.52 \\
14.98\end{array}$ & $\begin{array}{l}13.94 \\
12.89 \\
11.97 \\
11.38 \\
10.61 \\
10.97\end{array}$ \\
\hline
\end{tabular}

WTR YR 1991 LOW 15.52 AUG 25 
41355908727031 Local number, LK 13

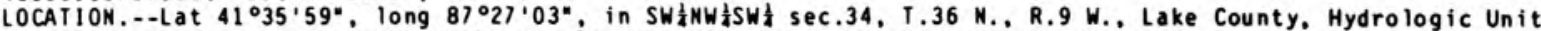
04040001 , at the Gibson Woods Nature Preserve on the north side of Hamand.

Owner: U.S. Geological Survey.

AQUIFER.--Sand and gravel of Pleistocene age.

WELL CHARACTERISTICS.--Drilled water-table well, dianeter $6.0 \mathrm{in} .$. depth $23 \mathrm{ft}$, cased to 18 ft, screened to $23 \mathrm{ft}$.

INST RUME NTATION, - -Water-level recorder.

DATUM.--Elevation of land-surface datua is $591.91 \mathrm{ft}$ above National Geodetic Vertical Datue of 1929 . Measuring point: Top of casing, $3.50 \mathrm{ft}$ above land-surface datur.

PERIOD OF RECORD.-.July 1986 to current year.

EXTREMES FOR PERIOD OF RECORD.--Highest water level, $0.01 \mathrm{ft}$ below land-surface datue, Apr. 15, 1991; lowest,

$5.15 \mathrm{ft}$ below land-surface datum. Sept. 10,1986.

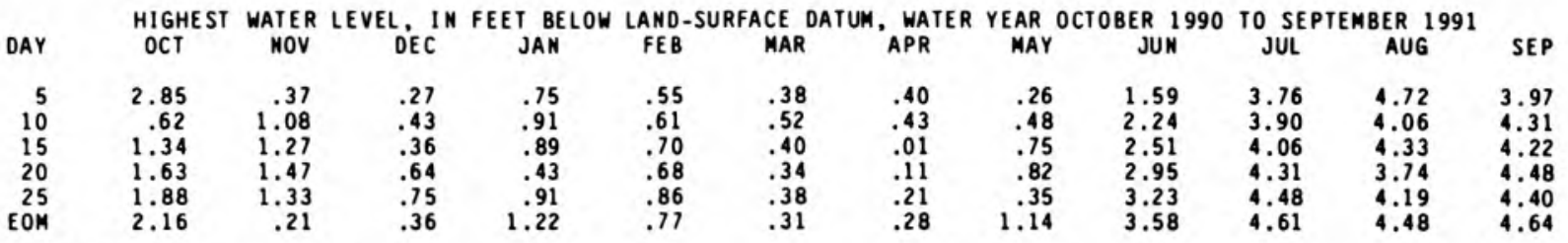

WTR YR 1991 HIGH .01 APR 15

LOWEST WATER LEVEL, IN FEET BELOW LAND-SURFACE DATUM, WATER YEAR OCTOBER 1990 TO SEPTEMBER 1991

\begin{tabular}{|c|c|c|c|c|c|c|c|c|c|c|c|c|}
\hline DAY & $\mathrm{OCT}$ & NOV & DEC & JAN & FE B & MAR & APR & MAY & JUN & JUL & AUG & SEP \\
\hline $\begin{array}{r}5 \\
10 \\
15 \\
20 \\
25 \\
\text { EOM }\end{array}$ & $\begin{array}{l}3.14 \\
1.10 \\
1.53 \\
1.72 \\
1.95 \\
2.19\end{array}$ & $\begin{array}{r}.76 \\
1.15 \\
1.29 \\
1.50 \\
1.40 \\
.23\end{array}$ & $\begin{array}{l}.34 \\
.46 \\
.56 \\
.66 \\
.85 \\
.39\end{array}$ & $\begin{array}{r}.81 \\
.96 \\
.93 \\
.48 \\
.99 \\
1.31\end{array}$ & $\begin{array}{r}.59 \\
.68 \\
.88 \\
.73 \\
.92 \\
1.02\end{array}$ & $\begin{array}{l}.41 \\
.54 \\
.48 \\
.36 \\
.39 \\
.36\end{array}$ & $\begin{array}{l}.45 \\
.53 \\
.15 \\
.14 \\
.24 \\
.35\end{array}$ & $\begin{array}{r}.31 \\
.55 \\
.91 \\
.93 \\
1.06 \\
1.43\end{array}$ & $\begin{array}{l}1.78 \\
2.52 \\
2.83 \\
3.25 \\
3.46 \\
3.71\end{array}$ & $\begin{array}{l}4.00 \\
4.12 \\
4.26 \\
4.53 \\
4.64 \\
4.79\end{array}$ & $\begin{array}{l}4.85 \\
4.21 \\
4.53 \\
3.96 \\
4.39 \\
4.64\end{array}$ & $\begin{array}{l}4.13 \\
4.42 \\
4.43 \\
4.56 \\
4.50 \\
4.78\end{array}$ \\
\hline
\end{tabular}

WTR YR 1991 LOW 4.88 AUG 6

411146087204101 . Local number. LK 14.

LAKE COUNTY

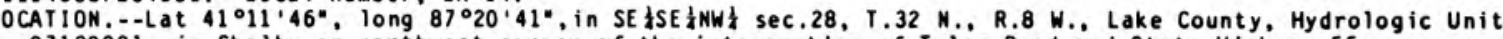

07120001 , in Shelby on northwest corner of the intersection of Tyler Road and State Highway 55 .

Owner: U.S. Geological Survey.

AQUIFER. - - Linestone of Silurian age.

WELL CHARACTERISTICS.--Drilled artesian well, dianeter 6 in., depth 96.2 ft, cased to 50 ft, open end.

I NST RUME NTAT ION. - - Wa ter-level recorder.

DATUM. --Elevation of land-surface datun is $641 \mathrm{ft}$ above National Geodetic Vertical Datua of 1929 . froe topographic

ap. Measuring point: Top of casing. $3.50 \mathrm{ft}$ above land-surface datue.

PERIOD OF RECORD.--July 1989 to current year.

EXTREMES FOR PERIOD OF RECORD.--Highest water leve1, $6.19 \mathrm{ft}$ below land-surface datue, Mar. 27 , 1991 ; lowest,

$22.86 \mathrm{ft}$ below land-surface datun, July 28, 1991 .

\begin{tabular}{|c|c|c|c|c|c|c|c|c|c|c|c|c|}
\hline AY & $\begin{array}{l}\text { HIGHEST } \\
\text { OCT }\end{array}$ & $\begin{array}{c}\text { WATER } \\
\text { MOV }\end{array}$ & LEVEL, IN $_{\text {IN }}$ & $\underset{\text { JAN }}{\text { FEET BELOW }}$ & $\begin{array}{l}\text { LAND - } \\
\text { FEB }\end{array}$ & $\begin{array}{l}\text { ACE } \\
\text { MAR }\end{array}$ & DATUM, WATER & $\begin{array}{l}\text { YEAR } \\
\text { MAY }\end{array}$ & OCTOBER ${ }_{\text {JUN }} 1990$ & TO SUL & $\begin{array}{l}\text { ABER } 1 \\
\text { AUG }\end{array}$ & SEP \\
\hline $\begin{array}{r}5 \\
10 \\
15 \\
20 \\
25 \\
\text { EOM }\end{array}$ & $\begin{array}{l}9.68 \\
9.41 \\
8.98 \\
8.68 \\
8.68 \\
8.71\end{array}$ & $\begin{array}{l}8.49 \\
8.18 \\
8.16 \\
8.28 \\
8.29 \\
7.81\end{array}$ & $\begin{array}{l}7.45 \\
7.51 \\
7.52 \\
7.71 \\
7.73 \\
6.83\end{array}$ & $\begin{array}{l}6.46 \\
6.71 \\
6.77 \\
6.69 \\
7.03 \\
7.37\end{array}$ & $\begin{array}{l}7.53 \\
7.39 \\
7.39 \\
7.57 \\
7.60 \\
7.56\end{array}$ & $\begin{array}{l}7.39 \\
7.64 \\
7.61 \\
6.86 \\
6.53 \\
6.54\end{array}$ & $\begin{array}{l}6.83 \\
7.04 \\
7.07 \\
6.76 \\
7.02 \\
7.16\end{array}$ & $\begin{array}{l}7.35 \\
7.61 \\
7.75 \\
7.88 \\
7.82 \\
7.48\end{array}$ & $\begin{array}{r}7.67 \\
7.93 \\
8.62 \\
14.65 \\
13.97 \\
16.95\end{array}$ & $\begin{array}{l}16.12 \\
14.64 \\
16.52 \\
17.34 \\
20.87 \\
21.07\end{array}$ & $\begin{array}{l}17.34 \\
15.39 \\
16.82 \\
16.04 \\
13.14 \\
14.39\end{array}$ & $\begin{array}{l}13.16 \\
12.01 \\
11.63 \\
11.50 \\
11.26 \\
11.34\end{array}$ \\
\hline
\end{tabular}

WTR YR 1991 HIGH 6.19 MAR 27

LOWEST WATER LEVEL, IN FEET BELOW LAND-SURFACE DATUM, WATER YEAR OCTOBER 1990 TO SEPTEMBER 1991

\begin{tabular}{|c|c|c|c|c|c|c|c|c|c|c|c|c|}
\hline DAY & $O C T$ & NOV & DEC & JAN & FEB & MAR & $A P R$ & MAY & JUN & JUL & AUG & SEP \\
\hline $\begin{array}{r}5 \\
10 \\
15 \\
20 \\
25 \\
\text { EOM }\end{array}$ & $\begin{array}{l}9.77 \\
9.54 \\
9.05 \\
8.78 \\
8.70 \\
8.79\end{array}$ & $\begin{array}{l}8.74 \\
8.25 \\
8.22 \\
8.32 \\
8.40 \\
8.06\end{array}$ & $\begin{array}{l}7.63 \\
7.61 \\
7.67 \\
7.79 \\
7.83 \\
7.07\end{array}$ & $\begin{array}{l}6.54 \\
6.76 \\
6.83 \\
6.75 \\
7.10 \\
7.47\end{array}$ & $\begin{array}{l}7.56 \\
7.47 \\
7.54 \\
7.61 \\
7.66 \\
7.66\end{array}$ & $\begin{array}{l}7.52 \\
7.69 \\
7.69 \\
7.11 \\
6.58 \\
6.61\end{array}$ & $\begin{array}{l}6.88 \\
7.22 \\
7.20 \\
6.81 \\
7.10 \\
7.27\end{array}$ & $\begin{array}{l}7.47 \\
7.70 \\
7.86 \\
7.92 \\
8.01 \\
7.53\end{array}$ & $\begin{array}{r}7.76 \\
8.03 \\
8.67 \\
15.82 \\
15.47 \\
18.73\end{array}$ & $\begin{array}{l}18.04 \\
17.12 \\
17.69 \\
19.65 \\
21.47 \\
22.05\end{array}$ & $\begin{array}{l}19.63 \\
16.36 \\
18.67 \\
16.10 \\
13.54 \\
14.49\end{array}$ & $\begin{array}{l}13.59 \\
12.17 \\
11.67 \\
11.59 \\
11.40 \\
11.42\end{array}$ \\
\hline
\end{tabular}

WTR YR 1991 LOW 22.86 JUL 28 
413700086445401 . Local number, LP 8.

LA PORTE COUNTY

LOCATION.--Lat $41^{\circ} 37^{\circ} 00^{\circ}$. Iong $86^{\circ} 44^{\circ} 54^{\circ}$, in ME 4 SE tNW sec.34, T.37 N., R.3 W., La Porte County, Hydrologic Unit 07120001 , at the west end of Soldiers Menorial Park in La Porte.

Owner: State of Indiana.

AQUIFER. - - Sand and gravel of Quaternary age.

WELL CHARACTERISIICS.--Drilled water-table well, dianeter $3.0 \mathrm{in.}$, depth 22 ft, cased to 20 ft, screened to $22 \mathrm{ft}$.

INSTRUMENTATION. - - Wa ter- level recorder.

DATUM.-Elevation of land-surface datue is $802.79 \mathrm{ft}$ above National Geodetic Vertical Datua of 1929 . Measuring point: Top of floor of shelter, $3.70 \mathrm{ft}$ above land-surface datur.

PERIOD OF RECORD.-- May 1976 to current year.

EXTREMES FOR PERIOD OF RECORD.--Highest water leve1, $1.84 \mathrm{ft}$ below land-surface datum, May $24,25,1983$; 10west, $7.04 \mathrm{ft}$ below land-surface datua, Mar. 8-11, 1978 .

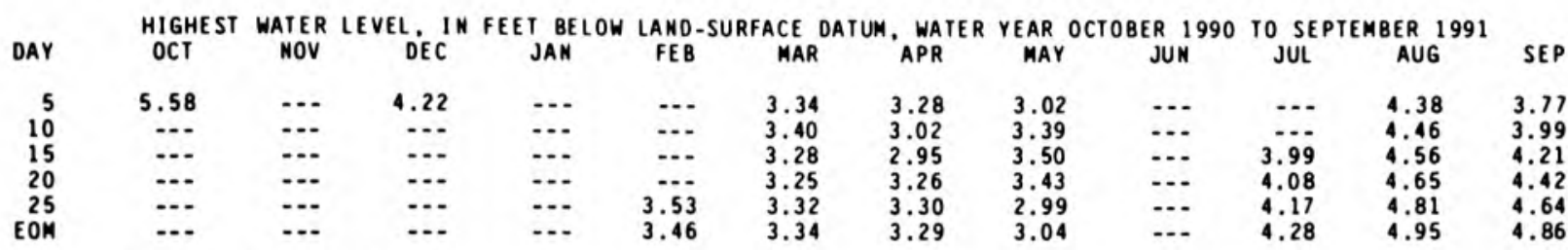

WTR YR 1991 HIGH 2.92 MAR 17

LOWEST WATER LEVEL, IN FEET BELOW LAND-SURFACE DATUM, WATER YEAR OCTOBER 1990 TO SEPTEMBER 1991

\begin{tabular}{|c|c|c|c|c|c|c|c|c|c|c|c|c|}
\hline DAY & OCT & NOV & DEC & JAN & FE B & MAR & $A P R$ & MAY & JUN & JUL & AUG & SEP \\
\hline $\begin{array}{r}5 \\
10 \\
15 \\
20 \\
25 \\
\text { EOM }\end{array}$ & 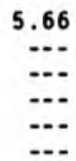 & 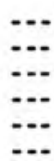 & $\begin{array}{r}4.24 \\
\ldots \\
\ldots \\
\ldots \\
\ldots\end{array}$ & $\begin{array}{l}\ldots \\
\ldots \\
\ldots \\
\ldots \\
\ldots\end{array}$ & $\begin{array}{l}\ldots . \\
\ldots \\
\ldots \\
3.5 \\
3.54 \\
3.54\end{array}$ & $\begin{array}{l}3.34 \\
3.40 \\
3.34 \\
3.25 \\
3.32 \\
3.35\end{array}$ & $\begin{array}{l}3.34 \\
3.37 \\
3.23 \\
3.28 \\
3.30 \\
3.32\end{array}$ & $\begin{array}{l}3.37 \\
3.41 \\
3.50 \\
3.44 \\
3.42 \\
3.35\end{array}$ & $\begin{array}{l}\ldots \\
\ldots \\
\ldots \\
\ldots \\
\ldots\end{array}$ & $\begin{array}{l}\ldots . .2 \\
4.01 \\
4.10 \\
4.19 \\
4.30\end{array}$ & $\begin{array}{r}4.39 \\
4.48 \\
4.58 \\
4.67 \\
4.87 \\
5.14\end{array}$ & $\begin{array}{l}3.81 \\
4.03 \\
4.25 \\
4.47 \\
4.68 \\
4.90\end{array}$ \\
\hline
\end{tabular}

WTR YR 1991 LOW 6.48 OCT 3

412350086512801. Local number, LP 9 .

LA PORTE COUNTY

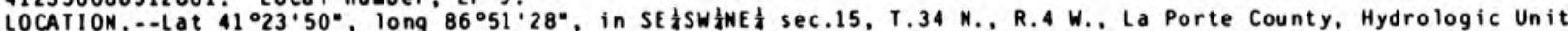
07120001 , at the intersection of County Roads 1450 South and 825 West, 3.0 i southeast of Wanatah.

Owner: U.S. Geological Survey.

AQUIFER. -. Sand of Pleistocene age.

WELL CHARACTERISTICS.--Orilled artesian well, dianeter $6 \mathrm{in.}$, depth $32 \mathrm{ft}$, cased to $27 \mathrm{ft}$, screened to $32 \mathrm{ft}$.

INST RUME NTATION. - - Water-level recorder.

DATUM.--Elevation of land-surface datue is $706.81 \mathrm{ft}$ above National Geodetic Vertical Datue of 1929 . Measuring point: Top of floor of shelter, $1.60 \mathrm{ft}$ above land-surface datue.

PERIOD OF RECORD..-June 1976 to current year.

EXTREMES FOR PERIOD OF RECORD..-Highest water leve1, $1.56 \mathrm{ft}$ below land-surface datua, Apr. 5 . 1985 ; lowest.

$8,28 \mathrm{ft}$ below land-surface datua, $0 \mathrm{ct} .16,17,1988$.

\begin{tabular}{|c|c|c|c|c|c|c|c|c|c|c|c|c|}
\hline DAY & $\begin{array}{l}\text { HIGHE ST } \\
\text { OCT }\end{array}$ & $\begin{array}{l}\text { WATER } \\
\text { NOV }\end{array}$ & LEVEL, IN & $\begin{array}{c}\text { FEET BELOW } \\
\text { JAN }\end{array}$ & $\begin{array}{l}\text { LAND-SU } \\
\text { FEB }\end{array}$ & $\begin{array}{l}\text { ACE } 0 \\
\text { MAR }\end{array}$ & $\begin{array}{c}\text { DATUM, WATER } \\
\text { APR }\end{array}$ & $\begin{array}{l}\text { YEAR } \\
\text { MAY }\end{array}$ & $\underset{\text { JUN }}{\text { OCTOBER } 1990}$ & $\begin{array}{c}\text { TO SEF } \\
\text { JUL }\end{array}$ & $\begin{array}{l}\text { IBER } 1991 \\
\text { AUG }\end{array}$ & SEP \\
\hline $\begin{array}{r}5 \\
10 \\
15 \\
20 \\
25 \\
\text { EOM }\end{array}$ & $\begin{array}{l}5.82 \\
4.31 \\
4.18 \\
4.23 \\
4.54 \\
4.83\end{array}$ & $\begin{array}{l}3.53 \\
3.99 \\
4.36 \\
4.66 \\
4.82 \\
2.99\end{array}$ & $\begin{array}{r}3.46 \\
3.88 \\
3.86 \\
4.24 \\
4.32 \\
\ldots . .\end{array}$ & $\begin{array}{l}\ldots \\
\ldots \\
\ldots \\
\ldots \\
\cdots \\
\ldots\end{array}$ & $\begin{array}{l}\ldots \\
\ldots . \\
\ldots \\
\ldots .06 \\
4.13\end{array}$ & $\begin{array}{l}3.81 \\
4.29 \\
4.33 \\
3.74 \\
4.10 \\
4.26\end{array}$ & $\begin{array}{l}4.47 \\
4.63 \\
3.94 \\
3.93 \\
4.21 \\
4.41\end{array}$ & $\begin{array}{l}4.49 \\
4.79 \\
4.91 \\
5.03 \\
3.94 \\
3.32\end{array}$ & $\begin{array}{l}4.08 \\
4.40 \\
4.67 \\
5.01 \\
5.33 \\
5.63\end{array}$ & $\begin{array}{c}5.91 \\
\ldots \\
\ldots \\
\ldots \\
\ldots \\
\ldots\end{array}$ & $\begin{array}{l}\ldots \\
\cdots \\
\cdots \\
\cdots \\
7.51 \\
7.60\end{array}$ & $\begin{array}{l}7.66 \\
7.72 \\
7.77 \\
7.82 \\
7.86 \\
7.91\end{array}$ \\
\hline
\end{tabular}

WTR YR 1991 HIGH 2.38 NOV 28

LOWEST WATER LEVEL. IN FEET BELOW LAND-SURFACE DATUM. WATER YEAR OCTOBER 1990 TO SEPTEMBER 1991

\begin{tabular}{|c|c|c|c|c|c|c|c|c|c|c|c|c|}
\hline DAY & OCT & NOV & DEC & JAN & FE B & MAR & APR & MAY & JUN & JUL & AUG & SEP \\
\hline $\begin{array}{r}5 \\
10 \\
15 \\
20 \\
25 \\
\text { EOM }\end{array}$ & $\begin{array}{l}5.84 \\
5.30 \\
4.28 \\
4.28 \\
4.61 \\
4.88\end{array}$ & $\begin{array}{r}4.86 \\
4.13 \\
4.41 \\
4.70 \\
4.93 \\
3.12\end{array}$ & $\begin{array}{r}3.65 \\
3.99 \\
4.14 \\
4.34 \\
4.47 \\
. . .2\end{array}$ & $\begin{array}{l}\ldots \\
\ldots \\
\ldots \\
\ldots \\
\ldots\end{array}$ & $\begin{array}{l}\ldots . \\
\ldots \\
\ldots \\
\ldots \\
4.09 \\
4.19\end{array}$ & $\begin{array}{r}3.95 \\
4.33 \\
4.52 \\
3.86 \\
4.16 \\
4.37\end{array}$ & $\begin{array}{l}4.53 \\
4.76 \\
4.65 \\
3.98 \\
4.26 \\
4.47\end{array}$ & $\begin{array}{l}4.61 \\
4.83 \\
4.94 \\
5.06 \\
5.13 \\
4.15\end{array}$ & $\begin{array}{l}4.15 \\
4.45 \\
4.75 \\
5.05 \\
5.39 \\
5.69\end{array}$ & $\begin{array}{r}5.95 \\
\ldots \\
\ldots \\
\ldots \\
\ldots\end{array}$ & $\begin{array}{l}\ldots . \\
\ldots \\
\ldots \\
\cdots .5 \\
7.53 \\
7.62\end{array}$ & $\begin{array}{l}7.67 \\
7.73 \\
7.78 \\
7.83 \\
7.87 \\
7.91\end{array}$ \\
\hline
\end{tabular}

WTR YR 1991 LOW 7.91 SEP 29 
413139086341401 . Local nuaber. LP 10.

LOCATION.--Lat $41^{\circ} 31^{\prime} 40^{\circ}$, Iong $86^{\circ} 34^{\prime} 10^{\circ}$, in SE $\frac{1}{4}$ SW $\frac{1}{4} N E \frac{1}{4}$ sec.31. T.36 N., R.1 W., La Porte County, Hydrologic Unit $07120001,200 \mathrm{ft}$ north of the wanagr's residence at the Mixsawbah Fish Hatchery and 2.6 a southeast of Stillwell.

Owner: State of Indiana.

AQUIFER. - Sand and gravel of Pleistocene age.

WELL CHARACTERISTICS.--Drilled water-table well, diameter 6 in.. depth 104 ft, cased to 102 ft, screened to $104 \mathrm{ft}$.

INSTRUMENTATION. - -Water-level recorder.

DATUM.--Elevation of land-surface datun is $695 \mathrm{ft}$ above National Geodetic Vertical Datue of 1929 , froe topographic ap. Measuring point: Top of floor of shelter, $3.60 \mathrm{ft}$ above land-surface datua.

PERIOD OF RECORD..-August 1980 to current year.

EXTREMES FOR PERIOD OF RECORD.--Highest water leve1, $2.65 \mathrm{ft}$ below land-surface datum, Dec. 29 , 1990 ; lowest, $9.61 \mathrm{ft}$ below land-surface datua, Sept. $17,18,1988$.

\begin{tabular}{|c|c|c|c|c|c|c|c|c|c|c|c|c|c|}
\hline AY & $\begin{array}{l}\text { HIGHEST } \\
\text { OCT }\end{array}$ & $\begin{array}{l}\text { WATER } \\
\text { NOV }\end{array}$ & ${ }_{\text {DEC }}$ & $\underset{\text { JAN }}{\text { FEET BELOW }}$ & $\begin{array}{l}\text { LAND } \\
\text { FEB }\end{array}$ & MAR & DATUM. & $\begin{array}{l}\text { WATER } \\
\text { APR }\end{array}$ & $\begin{array}{l}\text { YEAR } \\
\text { MAY }\end{array}$ & OCTOBER 1990 & TO SUL & $\begin{array}{l}\text { AER } 1991 \\
\text { AUG }\end{array}$ & SEP \\
\hline $\begin{array}{r}5 \\
10 \\
15 \\
20 \\
25 \\
E O M\end{array}$ & $\begin{array}{l}6.24 \\
3.30 \\
4.45 \\
5.08 \\
5.79 \\
6.27\end{array}$ & $\begin{array}{l}4.39 \\
4.93 \\
5.80 \\
6.30 \\
6.36 \\
3.47\end{array}$ & $\begin{array}{l}4.50 \\
5.14 \\
5.41 \\
5.78 \\
5.75 \\
3.07\end{array}$ & $\begin{array}{l}4.29 \\
5.21 \\
5.55 \\
5.03 \\
5.75 \\
6.11\end{array}$ & $\begin{array}{l}6.02 \\
6.05 \\
6.27 \\
5.12 \\
5.69 \\
5.85\end{array}$ & $\begin{array}{l}5.49 \\
6.22 \\
6.30 \\
5.47 \\
6.05 \\
5.67\end{array}$ & 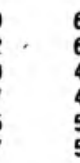 & $\begin{array}{l}6.03 \\
6.28 \\
4.65 \\
4.36 \\
5.57 \\
5.80\end{array}$ & $\begin{array}{l}6.14 \\
6.62 \\
6.85 \\
7.00 \\
6.59 \\
6.69\end{array}$ & $\begin{array}{l}7.06 \\
7.24 \\
7.43 \\
7.66 \\
7.82 \\
8.00\end{array}$ & $\begin{array}{l}8.16 \\
8.24 \\
8.39 \\
8.51 \\
8.64 \\
8.79\end{array}$ & $\begin{array}{l}8.89 \\
8.92 \\
8.99 \\
9.02 \\
9.09 \\
9.13\end{array}$ & $\begin{array}{l}9.14 \\
9.22 \\
9.21 \\
9.26 \\
9.26 \\
9.28\end{array}$ \\
\hline
\end{tabular}

WTR YR 1991 HIGH 2.65 DEC 29

\section{LOWEST WATER LEVEL, IN FEET BELOW LAND-SURFACE DATUM, WATER YEAR OCTOBER 1990 TO SEPTEMBER 1991}

\begin{tabular}{|c|c|c|c|c|c|c|c|c|c|c|c|c|}
\hline DAY & $\mathrm{OCT}$ & NOV & DEC & JAN & FEB & MAR & APR & MAY & JUN & JUL & AUG & SEP \\
\hline $\begin{array}{r}5 \\
10 \\
15 \\
20 \\
25 \\
\text { EOM }\end{array}$ & $\begin{array}{l}6.32 \\
4.43 \\
4.63 \\
5.17 \\
5.90 \\
6.36\end{array}$ & $\begin{array}{l}6.39 \\
5.23 \\
5.87 \\
6.36 \\
6.59 \\
3.69\end{array}$ & $\begin{array}{l}4.71 \\
5.34 \\
5.67 \\
5.95 \\
5.96 \\
3.24\end{array}$ & $\begin{array}{l}4.56 \\
5.34 \\
5.66 \\
5.14 \\
5.82 \\
6.33\end{array}$ & $\begin{array}{l}6.07 \\
6.17 \\
6.50 \\
5.32 \\
5.76 \\
5.91\end{array}$ & $\begin{array}{l}5.62 \\
6.31 \\
6.40 \\
5.60 \\
6.14 \\
5.83\end{array}$ & $\begin{array}{l}6.10 \\
6.51 \\
6.30 \\
4.58 \\
5.63 \\
5.91\end{array}$ & $\begin{array}{l}6.29 \\
6.68 \\
6.95 \\
7.05 \\
6.84 \\
6.79\end{array}$ & $\begin{array}{l}7.11 \\
7.28 \\
7.49 \\
7.69 \\
7.86 \\
8.04\end{array}$ & $\begin{array}{l}8.18 \\
8.27 \\
8.42 \\
8.53 \\
8.67 \\
8.81\end{array}$ & $\begin{array}{l}8.91 \\
8.94 \\
9.00 \\
9.03 \\
9.11 \\
9.14\end{array}$ & $\begin{array}{l}9.16 \\
9.23 \\
9.22 \\
9.27 \\
9.27 \\
9.30\end{array}$ \\
\hline
\end{tabular}

WTR YR 1991 LOW 9.30 SEP 30

412839086533101. Local number, LP 11.

LA PORTE COUNTY

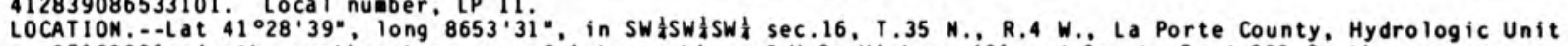
07120001 , in the northeast corner of intersection of U.S. Highway 421 and County Road 900 South.

Owner: U.S. Geological Survey.

AQUIFER, -. Sand and gravel of Pleistocene age.

WELL CHARACTERISTICS, --Drilled artesian well, diameter $6 \mathrm{in.}$, depth $100 \mathrm{ft}$, cased to $95 \mathrm{ft}$, screened to $100 \mathrm{ft}$. INSTRUMENTATION. - -Water-level recorder.

DATUM.--Elevation of land-surface datum is $760 \mathrm{ft}$ above National Geodetic Vertical Datue of 1929 , from topographic ap. Measuring point: Top of floor of shelter, $4.1 \mathrm{ft}$ above land-surface datue.

REMARKS. - Water level ay be affected by pumpage.

PERIOD OF RECORD.--June 1981 to current year.

EXTREMES FOR PERIOD OF RECORD.--Highest water level, $0.82 \mathrm{ft}$ below land-surface datun, Dec. 30 , 1990 ; lowest. $10.18 \mathrm{ft}$ below land-surface datum, $0 \mathrm{ct}$. 17, 1988 .

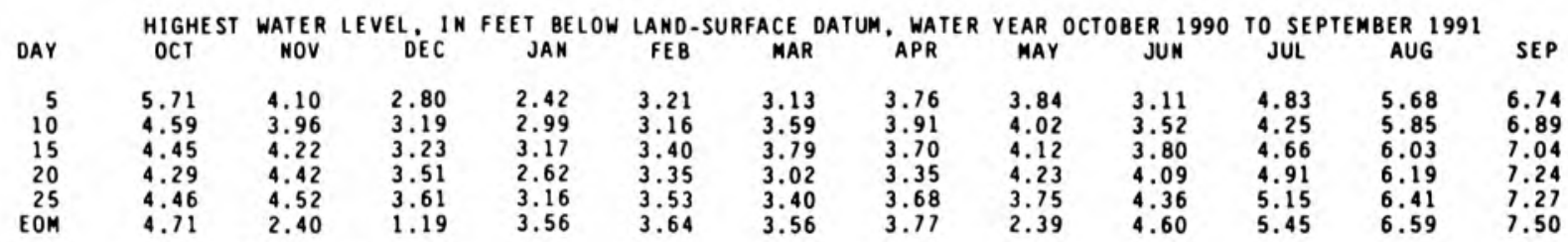

WTR YR 1991 HIGH .82 DEC 30

LOWEST WATER LEVEL, IN FEET BELOW LAND-SURFACE DATUM, WATER YEAR OCTOBER 1990 TO SEPTEMBER 1991

\begin{tabular}{|c|c|c|c|c|c|c|c|c|c|c|c|c|}
\hline DAY & $\mathrm{OCT}$ & NOV & DEC & JAN & FE B & MAR & APR & MAY & JUN & JUL & AUG & SEP \\
\hline $\begin{array}{r}5 \\
10 \\
15 \\
20 \\
25 \\
\text { EOM }\end{array}$ & $\begin{array}{l}5.78 \\
5.32 \\
4.51 \\
4.32 \\
4.52 \\
4.74\end{array}$ & $\begin{array}{l}4.74 \\
4.04 \\
4.24 \\
4.44 \\
4.60 \\
2.46\end{array}$ & $\begin{array}{l}2.91 \\
3.28 \\
3.38 \\
3.58 \\
3.70 \\
1.54\end{array}$ & $\begin{array}{l}2.60 \\
3.08 \\
3.23 \\
2.64 \\
3.22 \\
3.68\end{array}$ & $\begin{array}{l}3.31 \\
3.20 \\
3.59 \\
3.41 \\
3.57 \\
3.67\end{array}$ & $\begin{array}{l}3.20 \\
3.65 \\
3.85 \\
3.07 \\
3.45 \\
3.63\end{array}$ & $\begin{array}{l}3.80 \\
4.01 \\
3.97 \\
3.43 \\
3.71 \\
3.85\end{array}$ & $\begin{array}{l}3.98 \\
4.06 \\
4.15 \\
4.25 \\
4.35 \\
3.58\end{array}$ & $\begin{array}{l}3.22 \\
3.57 \\
3.86 \\
4.13 \\
4.41 \\
4.65\end{array}$ & $\begin{array}{l}4.89 \\
4.34 \\
4.71 \\
4.97 \\
5.22 \\
5.49\end{array}$ & $\begin{array}{l}5.73 \\
5.90 \\
6.07 \\
6.23 \\
6.43 \\
6.66\end{array}$ & $\begin{array}{l}6.78 \\
6.95 \\
7.07 \\
7.26 \\
7.35 \\
7.55\end{array}$ \\
\hline
\end{tabular}

WTR YR 1991 LOW 7.55 SEP 30 
413434086434701 . Local nuaber. LP 12

LA PORTE COUNTY

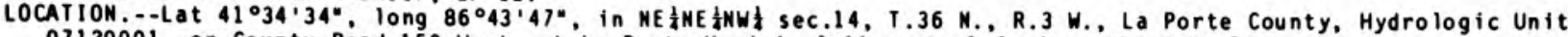
07120001 , on County Road 150 West, at La Porte Municipal Airport, 1.6 i south of La Porte.

Owner: U.S. Geological Survey.

AQUIFER. - - Sand and gravel of Pleistocene age.

WELL CHARACTERISIICS.--Orilled water-table well, dianeter $6 \mathrm{in.}$. depth $77 \mathrm{ft}$, cased to $71 \mathrm{ft}$, screened to $77 \mathrm{ft}$. INSTRUMENTATION. - - Water-level recorder.

DATUM.--Elevation of land-surface datun is $805 \mathrm{ft}$ above National Geodetic Vertical Datue of 1929, froe topographic ap. Measuring point: Top of floor of shelter, $3.70 \mathrm{ft}$ above land-surface datur.

REMARKS. - - Water level way be affected by punpage.

PERIOD OF RECORD.--July 1981 to current year.

EXTREMES FOR PERIOD OF RECORD.--Highest water level, $14.96 \mathrm{ft}$ below land-surface datun, Jan. 16, 1991; lowest, $22.82 \mathrm{ft}$ below land-surface datun, Jan. $27,28,31,1990 .$.

\begin{tabular}{|c|c|c|c|c|c|c|c|c|c|c|c|c|}
\hline AY & $\begin{array}{l}\text { HIGHEST } \\
\text { OCT }\end{array}$ & $\begin{array}{l}\text { WAT ER } \\
\text { NOV }\end{array}$ & LEVEL, IN & FEET BELOW & $\begin{array}{l}\text { LAND- } \\
\text { FEB }\end{array}$ & $\begin{array}{l}\text { ACE } \\
\text { MAR }\end{array}$ & $\begin{array}{l}\text { DATUM, WATER } \\
\text { APR }\end{array}$ & $\begin{array}{l}\text { YEAR } \\
\text { MAY }\end{array}$ & OCTOBER $\underset{\text { JUN }}{1990}$ & $\begin{array}{l}\text { TO SE } \\
\text { JUL }\end{array}$ & $\begin{array}{l}\text { IBER } 1991 \\
\text { AUG }\end{array}$ & SEP \\
\hline $\begin{array}{r}5 \\
10 \\
15 \\
20 \\
25 \\
\text { EOM }\end{array}$ & $\begin{array}{l}18.53 \\
18.52 \\
18.31 \\
18.06 \\
17.91 \\
17.81\end{array}$ & $\begin{array}{l}17.71 \\
17.70 \\
17.62 \\
17.52 \\
17.44 \\
17.02\end{array}$ & $\begin{array}{l}16.33 \\
16.12 \\
15.98 \\
16.08 \\
16.14 \\
15.93\end{array}$ & $\begin{array}{l}15.29 \\
15.06 \\
15.00 \\
15.00 \\
15.23 \\
15.26\end{array}$ & $\begin{array}{l}15.36 \\
15.36 \\
15.31 \\
15.42 \\
15.39 \\
15.28\end{array}$ & $\begin{array}{l}15.16 \\
15.33 \\
15.31 \\
15.23 \\
15.34 \\
15.38\end{array}$ & $\begin{array}{l}15.42 \\
15.46 \\
15.43 \\
15.51 \\
15.31 \\
15.20\end{array}$ & $\begin{array}{l}15.16 \\
15.34 \\
15.37 \\
15.52 \\
15.55 \\
15.59\end{array}$ & $\begin{array}{l}15.46 \\
15.30 \\
15.20 \\
15.33 \\
15.52 \\
15.68\end{array}$ & $\begin{array}{l}15.83 \\
16.01 \\
16.17 \\
16.36 \\
16.54 \\
16.80\end{array}$ & $\begin{array}{l}17.01 \\
17.15 \\
17.24 \\
17.39 \\
17.51 \\
17.62\end{array}$ & $\begin{array}{l}17.74 \\
17.78 \\
17.83 \\
17.93 \\
17.97 \\
18.09\end{array}$ \\
\hline
\end{tabular}

WTR YR 1991 HIGH 14.96 JAN 16

LOWEST WATER LEVEL, IN FEET BELOW LAND-SURFACE DATUM, WATER YEAR OCTOBER 1990 TO SEPTEMBER 1991

\begin{tabular}{|c|c|c|c|c|c|c|c|c|c|c|c|c|}
\hline DAY & OCT & NOV & DEC & JAN & FE B & MAR & APR & MAY & JUN & JUL & AUG & SEP \\
\hline $\begin{array}{r}5 \\
10 \\
15 \\
20 \\
25 \\
\text { EOM }\end{array}$ & $\begin{array}{l}18.54 \\
18.55 \\
18.33 \\
18.12 \\
17.92 \\
17.82\end{array}$ & $\begin{array}{l}17.82 \\
17.73 \\
17.66 \\
17.55 \\
17.49 \\
17.24\end{array}$ & $\begin{array}{l}16.42 \\
16.13 \\
16.06 \\
16.13 \\
16.18 \\
16.04\end{array}$ & $\begin{array}{l}15.38 \\
15.13 \\
15.02 \\
15.05 \\
15.25 \\
15.36\end{array}$ & $\begin{array}{l}15.39 \\
15.40 \\
15.44 \\
15.47 \\
15.40 \\
15.32\end{array}$ & $\begin{array}{l}15.25 \\
15.36 \\
15.36 \\
15.31 \\
15.37 \\
15.43\end{array}$ & $\begin{array}{l}15.45 \\
15.54 \\
15.56 \\
15.53 \\
15.38 \\
15.22\end{array}$ & $\begin{array}{l}15.23 \\
15.37 \\
15.40 \\
15.53 \\
15.57 \\
15.64\end{array}$ & $\begin{array}{l}15.48 \\
15.34 \\
15.22 \\
15.35 \\
15.56 \\
15.70\end{array}$ & $\begin{array}{l}15.86 \\
16.03 \\
16.22 \\
16.42 \\
16.57 \\
16.84\end{array}$ & $\begin{array}{l}17.05 \\
17.18 \\
17.27 \\
17.41 \\
17.52 \\
17.68\end{array}$ & $\begin{array}{l}17.74 \\
17.86 \\
17.85 \\
17.94 \\
17.99 \\
18.09\end{array}$ \\
\hline
\end{tabular}

WTR YR 1991 LOW 18.56 OCT 7

\section{MARION COUNTY}

393855086120701 . Local number, MA 34.

LOCATION.--Lat $39^{\circ} 38^{\prime} 55^{\circ}$, long $86^{\circ} 12^{\circ} 07^{\circ}$, in NE $\frac{1}{4}$ NWW $\frac{1}{2}$ I $\frac{1}{4} \mathrm{sec} .21$, T.14 N., R.3 E., Marion County, Hydrologic Unit 05120201 , about 0.5 i northwest of Gienns Valley.

Owner: U.S. Geological Survey.

AQUIFER.-.-Coarse sand and gravel of Pleistocene age.

WELL CHARACTERISTICS..-Drilled water-table well, dianeter $6 \mathrm{in.}$. depth $66 \mathrm{ft}$, cased to $61 \mathrm{ft}$, screened to $66 \mathrm{ft}$. INSTRUMENTATION. - - Water-level recorder.

DATUM.--Elevation of land-surface datue is $670.73 \mathrm{ft}$ above National Geodetic Vertical Datue of 1929 . Measuring point: Top of casing, $3.70 \mathrm{ft}$ above land-surface datum.

PERIOD OF RECORD..-July 1986 to current year.

EXTREMES FOR PERIOD OF RECORD..--Highest water level, $2.72 \mathrm{ft}$ below land-surface datue, Dec. 30, 1990; lowest,

$8.84 \mathrm{ft}$ below land-surface datua, Nov. 23-25, 1987.

\begin{tabular}{|c|c|c|c|c|c|c|c|c|c|c|c|c|}
\hline DAY & $\begin{array}{l}\text { HIGHEST } \\
\text { OCT }\end{array}$ & $\begin{array}{l}\text { WATER } \\
\text { MOV }\end{array}$ & LEVEL, IN & FEET BELOW & $\begin{array}{l}\text { LAND-SU } \\
\text { FEB }\end{array}$ & $\begin{array}{l}\text { RFACE DATUM } \\
\text { MAR }\end{array}$ & 1, WATER & $\begin{array}{l}\text { YEAR OCT } \\
\text { MAY }\end{array}$ & $\begin{array}{l}\text { OBER } 1990 \\
\text { JUN }\end{array}$ & $\begin{array}{l}\text { TO SEPTE } \\
\text { JUL }\end{array}$ & $\begin{array}{l}\text { BER } 1991 \\
\text { AUG }\end{array}$ & SEP \\
\hline $\begin{array}{r}5 \\
10 \\
15 \\
20 \\
25 \\
\text { EOM }\end{array}$ & $\begin{array}{l}6.05 \\
5.56 \\
5.99 \\
5.98 \\
6.02 \\
6.17\end{array}$ & $\begin{array}{l}6.13 \\
6.21 \\
6.35 \\
6.42 \\
6.26 \\
5.76\end{array}$ & $\begin{array}{l}5.64 \\
5.74 \\
5.60 \\
5.28 \\
5.25 \\
3.55\end{array}$ & $\begin{array}{l}4.31 \\
4.46 \\
4.41 \\
4.54 \\
4.77 \\
4.85\end{array}$ & $\begin{array}{l}4.77 \\
4.52 \\
4.66 \\
4.57 \\
4.82 \\
4.89\end{array}$ & $\begin{array}{l}4.99 \\
5.13 \\
4.66 \\
4.63 \\
4.21 \\
4.26\end{array}$ & $\begin{array}{l}4.39 \\
4.55 \\
4.37 \\
4.33 \\
4.67 \\
4.82\end{array}$ & $\begin{array}{l}4.80 \\
5.05 \\
4.88 \\
5.19 \\
5.01 \\
5.29\end{array}$ & $\begin{array}{r}5.48 \\
5.66 \\
5.64 \\
5.81 \\
6.03\end{array}$ & $\begin{array}{l}6.21 \\
5.98 \\
6.27 \\
6.46 \\
6.63 \\
6.85\end{array}$ & $\begin{array}{l}7.02 \\
7.02 \\
6.96 \\
7.06 \\
7.18 \\
7.28\end{array}$ & $\begin{array}{l}7.35 \\
7.43 \\
7.52 \\
7.59 \\
7.62 \\
7.69\end{array}$ \\
\hline
\end{tabular}

WTR YR 1991 HIGH 2.72 DEC 30

LOWEST WATER LEVEL. IN FEET BELOW LANO-SURFACE DATUM, WATER YEAR OCTOBER 1990 TO SEPTEMBER 1991

\begin{tabular}{|c|c|c|c|c|c|c|c|c|c|c|c|c|}
\hline DAY & OCT & NOV & DEC & JAN & FEB & MAR & APR & MAY & JUN & JUL & AUG & SEP \\
\hline $\begin{array}{r}5 \\
10 \\
15 \\
20 \\
25 \\
\text { EOW }\end{array}$ & $\begin{array}{l}6.13 \\
5.96 \\
6.02 \\
6.00 \\
6.05 \\
6.19\end{array}$ & $\begin{array}{l}6.24 \\
6.25 \\
6.36 \\
6.43 \\
6.28 \\
5.80\end{array}$ & $\begin{array}{l}5.66 \\
5.77 \\
5.79 \\
5.34 \\
5.29 \\
3.93\end{array}$ & $\begin{array}{l}4.34 \\
4.52 \\
4.49 \\
4.59 \\
4.79 \\
4.89\end{array}$ & $\begin{array}{l}4.85 \\
4.57 \\
4.75 \\
4.63 \\
4.85 \\
4.92\end{array}$ & $\begin{array}{l}5.01 \\
5.15 \\
4.74 \\
4.65 \\
4.26 \\
4.29\end{array}$ & $\begin{array}{l}4.42 \\
4.61 \\
4.52 \\
4.45 \\
4.70 \\
4.85\end{array}$ & $\begin{array}{l}4.96 \\
5.08 \\
5.05 \\
5.23 \\
5.08 \\
5.34\end{array}$ & $\begin{array}{l}5.53 \\
5.73 \\
5.69 \\
5.87 \\
6.10\end{array}$ & $\begin{array}{l}6.28 \\
6.39 \\
6.34 \\
6.50 \\
6.69 \\
6.89\end{array}$ & $\begin{array}{l}7.04 \\
7.06 \\
7.04 \\
7.11 \\
7.21 \\
7.30\end{array}$ & $\begin{array}{l}7.38 \\
7.46 \\
7.54 \\
7.60 \\
7.63 \\
7.70\end{array}$ \\
\hline
\end{tabular}

WTR YR 1991 LOW 7.70 SEP 30 
394632086092701. Local number, MA 35.

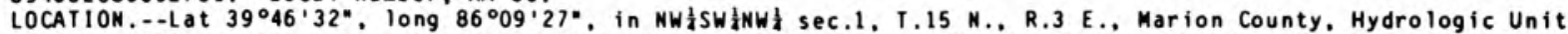
05120201 . In the northeast corner of the intersection of Meridian and Morth Streets in Indianapolis.

Owner: U.S. Geological Survey.

AQUIFER. - - Sand and gravel of Pleistocene age.

WELL CHARACTERISTICS.-.-Drilled artesian well, diameter $6 \mathrm{in}$., depth $83 \mathrm{ft}$, cased to $77.5 \mathrm{ft}$, screened to 83 ft. INSTRUMENTATION. - -Water-level recorder.

DATUM.--Elevation of land-surface datun is $716.40 \mathrm{ft}$ above Mational Geodetic Vertical Datua of 1929 . Measuring point: Top of casing, $2.50 \mathrm{ft}$ above land-surface datun.

PERIOD OF RECORD...-September 1987 to current year.

EXTREMES FOR PERIOD OF RECORD.--Highest water level, $30.30 \mathrm{ft}$ below land-surface datum, Mar. 27 , 1991 ; lowest, $36.95 \mathrm{ft}$ below land-surface datun, Sept. 25, 1987.

\begin{tabular}{|c|c|c|c|c|c|c|c|c|c|c|c|c|}
\hline AY & $\begin{array}{l}\text { HIGHEST } \\
\text { OCT }\end{array}$ & $\begin{array}{l}\text { WATER } \\
\text { NOV }\end{array}$ & LEVEL, IN & $\underset{\text { JAN }}{\text { FEET BELOW }}$ & $\begin{array}{l}\text { LAND- } \\
\text { FEB }\end{array}$ & $\begin{array}{l}\text { FACE D } \\
\text { MAR }\end{array}$ & DATUM, WATER & $\begin{array}{l}\text { YEAR } \\
\text { MAY }\end{array}$ & OCTOBER $\underset{\text { JUN }}{ } 1990$ & $\begin{array}{l}\text { TO SE } \\
\text { JUL }\end{array}$ & $\begin{array}{l}\text { BER } 1991 \\
\text { AUG }\end{array}$ & SEP \\
\hline $\begin{array}{r}5 \\
10 \\
15 \\
20 \\
25 \\
\text { EOM }\end{array}$ & $\begin{array}{l}32.50 \\
32.42 \\
32.24 \\
32.14 \\
32.05 \\
31.94\end{array}$ & $\begin{array}{l}31.91 \\
31.83 \\
31.81 \\
31.79 \\
31.70 \\
31.79\end{array}$ & $\begin{array}{r}31.70 \\
31.56 \\
31.52 \\
31.46 \\
31.52\end{array}$ & $\begin{array}{l}31.89 \\
32.01 \\
32.16 \\
32.27 \\
31.90 \\
32.04\end{array}$ & $\begin{array}{l}32.25 \\
32.23 \\
31.80 \\
31.77 \\
31.57 \\
31.39\end{array}$ & $\begin{array}{l}31.32 \\
31.13 \\
30.89 \\
30.78 \\
30.60 \\
30.44\end{array}$ & $\begin{array}{l}32.58 \\
32.43 \\
32.32 \\
32.09 \\
31.95 \\
31.43\end{array}$ & $\begin{array}{l}31.43 \\
30.80 \\
30.46 \\
30.60 \\
30.85 \\
30.88\end{array}$ & $\begin{array}{l}31.09 \\
31.32 \\
31.33 \\
31.49 \\
31.61 \\
31.79\end{array}$ & $\begin{array}{l}31.84 \\
31.86 \\
32.00 \\
32.13 \\
32.35 \\
32.64\end{array}$ & $\begin{array}{l}32.85 \\
32.98 \\
32.92 \\
32.95 \\
33.03 \\
32.75\end{array}$ & $\begin{array}{l}32.60 \\
33.36 \\
33.12 \\
33.35 \\
33.54 \\
33.25\end{array}$ \\
\hline
\end{tabular}

WTR YR 1991 HIGH 30.30 MAR 27

LOWEST WATER LEVEL, IN FEET BELOW LAND-SURFACE DATUM, WATER YEAR OCTOBER 1990 TO SEPTEMBER 1991

\begin{tabular}{|c|c|c|c|c|c|c|c|c|c|c|c|c|}
\hline DAY & OCT & NOV & DEC & JAN & FE B & MAR & APR & MAY & JUN & JUL & AUG & SEP \\
\hline $\begin{array}{r}5 \\
10 \\
15 \\
20 \\
25 \\
\text { EOM }\end{array}$ & $\begin{array}{l}32.79 \\
32.49 \\
32.44 \\
32.21 \\
32.09 \\
32.14\end{array}$ & $\begin{array}{l}31.97 \\
31.89 \\
32.07 \\
31.84 \\
31.76 \\
31.87\end{array}$ & $\begin{array}{r}31.77 \\
-.7 \\
31.58 \\
31.73 \\
31.50 \\
31.75\end{array}$ & $\begin{array}{l}31.95 \\
32.12 \\
32.27 \\
32.34 \\
32.09 \\
32.07\end{array}$ & $\begin{array}{l}32.31 \\
32.27 \\
31.97 \\
31.84 \\
31.69 \\
31.47\end{array}$ & $\begin{array}{l}31.38 \\
31.15 \\
30.99 \\
30.87 \\
30.69 \\
30.46\end{array}$ & $\begin{array}{l}32.77 \\
32.50 \\
32.46 \\
32.20 \\
32.08 \\
31.69\end{array}$ & $\begin{array}{l}31.56 \\
31.11 \\
30.75 \\
31.00 \\
30.96 \\
31.16\end{array}$ & $\begin{array}{l}31.32 \\
31.62 \\
31.56 \\
31.76 \\
31.88 \\
31.94\end{array}$ & $\begin{array}{l}32.10 \\
32.13 \\
32.36 \\
32.27 \\
32.40 \\
32.70\end{array}$ & $\begin{array}{l}33.06 \\
33.17 \\
33.20 \\
33.31 \\
33.18 \\
32.96\end{array}$ & $\begin{array}{l}32.87 \\
33.70 \\
33.37 \\
33.44 \\
33.61 \\
33.60\end{array}$ \\
\hline
\end{tabular}

WTR YR 1991 LOW 33.70 SEP 10

394626086100201 . Local number, MA 36.

MARION COUNTY

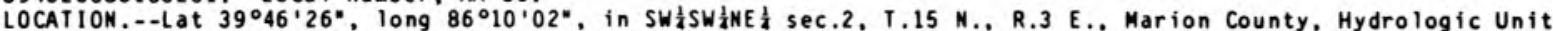
05120201 . in the southwest corner of the intersection of West and Michigan Streets in Indianapolis.

Owner: U.S. Geological Survey.

AQUIFER.-.-Sand and gravel of Pleistocene age.

WELL CHARACTERISTICS.--Drilled artesian well, diameter $6 \mathrm{in}$, depth $70.6 \mathrm{ft}$, cased to $65.1 \mathrm{ft}$, screened to $70.6 \mathrm{ft}$.

INST RUMENTATION. --Wat er-level recorder.

DATUM.--Elevation of land-surface datu is $710.06 \mathrm{ft}$ above National Geodetic Vertical Datun of 1929 . Measuring point: Top of casing, $3.00 \mathrm{ft}$ above land-surface datur.

PERIOD OF RECORD..-Septeaber 1987 to current year.

EXTREMES FOR PERIOD OF RECORD.--Highest water level, 26.86 ft below land-surface datun, May 14, 1991 ; lowest. $33.12 \mathrm{ft}$ below land-surface datun, Sept. $24,25,1987$.

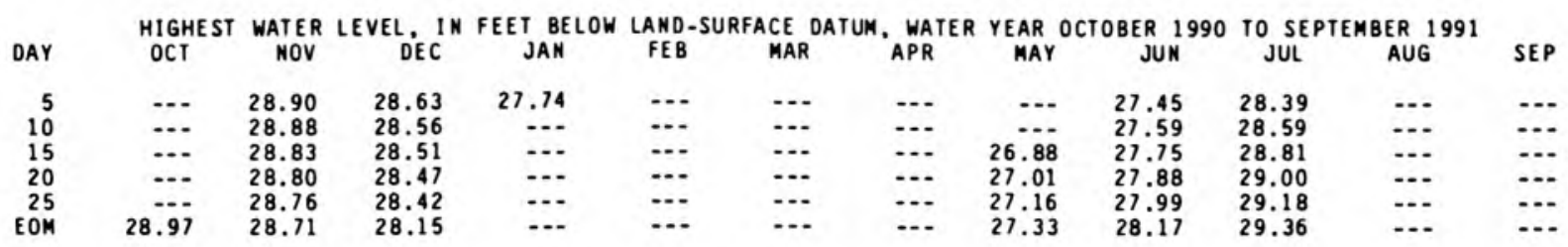

WTR YR 1991 HIGH 26.86 MAY 14

LOWEST WATER LEVEL, IN FEET BELOW LAND-SURFACE DATUM, WATER YEAR OCTOBER 1990 TO SEPTEMBER 1991

\begin{tabular}{|c|c|c|c|c|c|c|c|c|c|c|c|c|}
\hline DAY & OCT & NOV & DEC & JAM & FE B & MAR & APR & MAY & JUN & JUL & AUG & SEP \\
\hline $\begin{array}{r}5 \\
10 \\
15 \\
20 \\
25 \\
\text { EOM }\end{array}$ & $\begin{array}{r}\ldots \\
\ldots \\
\ldots \\
\ldots \\
\ldots .\end{array}$ & $\begin{array}{l}28.93 \\
28.88 \\
28.84 \\
28.80 \\
28.77 \\
28.73\end{array}$ & $\begin{array}{l}28.66 \\
28.58 \\
28.53 \\
28.49 \\
28.43 \\
28.28\end{array}$ & $\begin{array}{r}27.81 \\
\ldots . \\
\ldots- \\
\ldots \\
\ldots \\
\ldots\end{array}$ & $\begin{array}{l}\ldots \\
\ldots \\
\ldots \\
\ldots \\
\ldots\end{array}$ & $\begin{array}{l}\ldots \\
\cdots \\
\cdots \\
\cdots \\
\cdots\end{array}$ & $\begin{array}{l}\ldots \\
\ldots \\
\ldots \\
\ldots \\
\ldots\end{array}$ & $\begin{array}{r}. . . \\
26.91 \\
27.04 \\
27.19 \\
27.36\end{array}$ & $\begin{array}{l}27.47 \\
27.63 \\
27.78 \\
27.92 \\
28.03 \\
28.21\end{array}$ & $\begin{array}{l}28.43 \\
28.63 \\
28.85 \\
29.04 \\
29.21 \\
29.38\end{array}$ & $\begin{array}{l}\ldots \\
\ldots \\
\ldots \\
\ldots \\
\ldots\end{array}$ & $\begin{array}{l}\ldots \\
\ldots \\
\ldots \\
\ldots \\
\ldots\end{array}$ \\
\hline
\end{tabular}

WTR YR 1991 LOW 29.39 AUG 1 
394732086115501 . Local number, MA 37.

MARION COUNTY

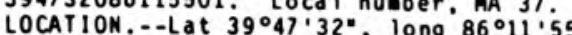

05120201 , on the South Grove Municipal Golf Course property, west of the lith fairway and east of

White River Parkway in Indianapolis.

Owner: U.S. Geological Survey.

AQUIFER. - Sand and gravel of Pleistocene Epoch.

WELL CHARACTERISITICS.--Drilled water-table well, dianeter $6 \mathrm{in}$., depth $74 \mathrm{ft}$, cased to $69 \mathrm{ft}$, screened to 74 ft. INST RUMENTATION. - - Wa ter-level recorder.

DATUM.--Elevation of land-surface datua is $690 \mathrm{ft}$ above National Geodetic Vertical Datua of 1929 . from

topographic ap. Measuring point: Top of casing, $3.35 \mathrm{ft}$ above land-surface datue.

PERIOD OF RECORD.--July 1988 to current year.

EXTREMES FOR PERIOD OF RECORD.--Highest water leve1, $3.22 \mathrm{ft}$ below land-surface datue, Mar. 20 , 1991 ; lowest,

$10.54 \mathrm{ft}$ below land-surface datuv. Aug. 18, 1988 .

\begin{tabular}{|c|c|c|c|c|c|c|c|c|c|c|c|c|c|}
\hline DAY & $\begin{array}{l}\text { HIGHEST } \\
\text { OCT }\end{array}$ & $\begin{array}{l}\text { WATER } \\
\text { MOV }\end{array}$ & LEVEL, IN & FEET BELOW & $\begin{array}{l}\text { LAND- } \\
\text { FEB }\end{array}$ & $\begin{array}{l}\text { FACE } \\
\text { MAR }\end{array}$ & $\begin{array}{l}\text { DATUM, WATER } \\
\text { APR }\end{array}$ & $\begin{array}{l}\text { YEAR } \\
\text { MAY }\end{array}$ & $\underset{\text { JUN }}{\text { OCTOBER }} 1990$ & TO SUL & $\begin{array}{c}\text { BER 1 } \\
\text { AUG }\end{array}$ & 1991 & SEP \\
\hline $\begin{array}{r}5 \\
10 \\
15 \\
20 \\
25 \\
\text { EOM }\end{array}$ & $\begin{array}{l}5.62 \\
6.59 \\
6.87 \\
5.40 \\
5.37 \\
5.54\end{array}$ & $\begin{array}{l}5.28 \\
5.37 \\
5.57 \\
5.51 \\
5.42 \\
4.85\end{array}$ & $\begin{array}{l}\ldots \\
\ldots \\
\cdots \\
\cdots \\
\cdots\end{array}$ & $\begin{array}{l}4.66 \\
4.01 \\
3.76 \\
3.65 \\
3.96 \\
5.58\end{array}$ & $\begin{array}{l}4.14 \\
3.77 \\
4.08 \\
3.88 \\
4.04 \\
4.16\end{array}$ & $\begin{array}{l}4.25 \\
4.40 \\
3.53 \\
3.22 \\
4.30 \\
3.61\end{array}$ & $\begin{array}{l}3.81 \\
3.77 \\
3.44 \\
4.94 \\
3.88 \\
4.13\end{array}$ & $\begin{array}{l}4.08 \\
4.27 \\
4.58 \\
4.24 \\
4.62 \\
4.71\end{array}$ & $\begin{array}{l}6.09 \\
4.97 \\
5.36 \\
5.43 \\
5.61 \\
5.95\end{array}$ & $\begin{array}{l}6.29 \\
6.43 \\
6.48 \\
6.71 \\
7.03 \\
6.27\end{array}$ & $\begin{array}{l}6.48 \\
6.29 \\
6.29 \\
6.25 \\
6.32 \\
6.56\end{array}$ & & $\begin{array}{l}6.49 \\
6.77 \\
6.90 \\
6.38 \\
6.18 \\
6.33\end{array}$ \\
\hline
\end{tabular}

WTR YR 1991 HIGH 3.22 MAR 20

LOWEST WATER LEVEL, IN FEET BELOW LAMD-SURFACE DATUM, WATER YEAR OCTOBER 1990 TO SEPTEMBER 1991

\begin{tabular}{|c|c|c|c|c|c|c|c|c|c|c|c|c|}
\hline DAY & $\mathrm{OCT}$ & NOV & DEC & JAN & FE B & MAR & APR & MAY & JUN & JUL & AUG & SEP \\
\hline $\begin{array}{r}5 \\
10 \\
15 \\
20 \\
25 \\
\text { EON }\end{array}$ & $\begin{array}{l}5.80 \\
6.87 \\
7.00 \\
5.54 \\
5.43 \\
5.72\end{array}$ & $\begin{array}{l}5.69 \\
5.41 \\
5.75 \\
5.63 \\
5.55 \\
4.93\end{array}$ & $\begin{array}{l}\ldots- \\
\ldots \\
\cdots \\
\cdots \\
\cdots \\
\ldots\end{array}$ & $\begin{array}{l}4.79 \\
4.16 \\
3.81 \\
3.73 \\
3.99 \\
5.63\end{array}$ & $\begin{array}{l}4.34 \\
3.89 \\
4.19 \\
3.98 \\
4.19 \\
4.30\end{array}$ & $\begin{array}{l}4.33 \\
4.47 \\
3.61 \\
3.39 \\
4.68 \\
3.71\end{array}$ & $\begin{array}{l}3.91 \\
3.87 \\
3.71 \\
5.10 \\
4.01 \\
4.19\end{array}$ & $\begin{array}{l}4.17 \\
4.40 \\
4.66 \\
5.85 \\
4.73 \\
4.98\end{array}$ & $\begin{array}{l}6.33 \\
5.22 \\
5.46 \\
5.75 \\
5.78 \\
6.05\end{array}$ & $\begin{array}{l}6.34 \\
6.52 \\
6.58 \\
6.76 \\
7.28 \\
6.45\end{array}$ & $\begin{array}{l}6.62 \\
6.44 \\
6.38 \\
6.32 \\
6.38 \\
6.68\end{array}$ & $\begin{array}{l}6.59 \\
6.88 \\
6.99 \\
6.48 \\
6.50 \\
6.57\end{array}$ \\
\hline
\end{tabular}

WTR YR $1991 \quad$ LOW 8.38 JUL 24

383659086545901 . Loca I number, MT 5.

MARTIN COUNTY

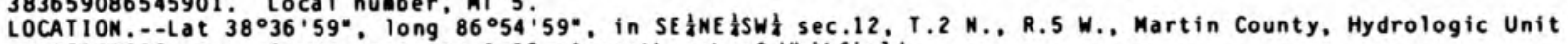
05120208 , on private property 0.25 i southwest of whitfield.

Owner: Marjorie A. Arvin.

AQUIFER. - - Sandstone of Pennsylvanian age.

WELL CHARACTERISIICS.-.-Drilled artesian well, dianeter $6 \mathrm{in.}$, depth $143 \mathrm{ft}$, cased to $53 \mathrm{ft}$, open end.

INST RUNENTATION. - - Water-level recorder.

DATUM.--Elevation of land-surface datu is $565 \mathrm{ft}$ above National Geodetic Vertical Datue of 1929 . from topographic ap. Measuring point: Top of floor of shelter. $2.80 \mathrm{ft}$ above land-surface datua.

PERIOD OF RECORD.--May 1958 to current year.

EXTREMES FOR PERIOD OF RECORD.--Highest water leve1, $23.91 \mathrm{ft}$ below land-surface datue, Apr. 14, 1980; 10west,

$34.10 \mathrm{ft}$ below land-surface datue, Jan. 1, 5, 22, 23, 1960, and Dec. 18, $19,1964$.

\begin{tabular}{|c|c|c|c|c|c|c|c|c|c|c|c|c|}
\hline AY & $\begin{array}{l}\text { HIGHE ST } \\
\text { OCT }\end{array}$ & $\begin{array}{c}\text { WATER } \\
\text { NOV }\end{array}$ & LEVEL, I N & $\underset{\text { JAN }}{\text { FEET BELOW }}$ & $\begin{array}{l}\text { LAND- } \\
\text { FEB }\end{array}$ & MAR & $\begin{array}{c}\text { DATUM, WATER } \\
\text { APR }\end{array}$ & MAY & JUN & JUL & AUG & SEP \\
\hline $\begin{array}{l}5 \\
10 \\
15 \\
20 \\
25 \\
201\end{array}$ & $\begin{array}{l}25.96 \\
26.08 \\
26.29 \\
26.38 \\
26.55\end{array}$ & $\begin{array}{l}25.92 \\
26.39 \\
26.79 \\
26.73 \\
26.36 \\
26.95\end{array}$ & $\begin{array}{l}26.78 \\
26.89 \\
26.55 \\
26.79 \\
27.06 \\
27.10\end{array}$ & $\begin{array}{l}26.85 \\
26.65 \\
26.13 \\
26.17 \\
26.67 \\
26.44\end{array}$ & $\begin{array}{l}26.29 \\
26.09 \\
25.68 \\
26.12 \\
26.05 \\
25.74\end{array}$ & $\begin{array}{l}25.20 \\
25.95 \\
25.71 \\
25.39 \\
25.55 \\
25.60\end{array}$ & $\begin{array}{l}25.57 \\
25.31 \\
25.04 \\
25.24 \\
25.25 \\
25.11\end{array}$ & $\begin{array}{l}25.00 \\
25.38 \\
25.14 \\
25.36 \\
25.14 \\
25.08\end{array}$ & $\begin{array}{l}25.31 \\
25.42 \\
25.17 \\
25.38 \\
25.53 \\
25.39\end{array}$ & $\begin{array}{l}25.45 \\
25.53 \\
25.89 \\
25.87 \\
25.88 \\
26.06\end{array}$ & $\begin{array}{l}26.14 \\
26.13 \\
26.28 \\
26.25 \\
26.61 \\
26.50\end{array}$ & $\begin{array}{l}26.65 \\
26.74 \\
26.80 \\
27.23 \\
26.73 \\
27.25\end{array}$ \\
\hline
\end{tabular}

WTR YR 1991 HIGH 24.88 MAR 27

LOWEST WATER LEVEL, IN FEET BELOW LAMD-SURFACE DATUM, WATER YEAR OCTOBER 1990 TO SEPTEMBER 1991

\begin{tabular}{|c|c|c|c|c|c|c|c|c|c|c|c|c|}
\hline DAY & OCT & MOV & DEC & JAN & FE B & MAR & $A P R$ & MAY & JUN & JUL & AUG & SEP \\
\hline $\begin{array}{r}5 \\
10 \\
15 \\
20 \\
25 \\
\text { EOM }\end{array}$ & $\begin{array}{l}26.19 \\
26.35 \\
26.38 \\
26.51 \\
26.63\end{array}$ & $\begin{array}{l}26.38 \\
26.59 \\
26.83 \\
26.81 \\
26.53 \\
27.21\end{array}$ & $\begin{array}{l}27.09 \\
26.93 \\
26.82 \\
26.92 \\
27.13 \\
27.30\end{array}$ & $\begin{array}{l}27.04 \\
27.12 \\
26.51 \\
26.40 \\
26.82 \\
26.78\end{array}$ & $\begin{array}{l}26.39 \\
26.24 \\
26.25 \\
26.26 \\
26.10 \\
25.89\end{array}$ & $\begin{array}{l}25.56 \\
26.06 \\
25.91 \\
25.63 \\
25.67 \\
25.75\end{array}$ & $\begin{array}{l}25.65 \\
25.63 \\
25.36 \\
25.35 \\
25.41 \\
25.29\end{array}$ & $\begin{array}{l}25.16 \\
25.47 \\
25.22 \\
25.42 \\
25.25 \\
25.16\end{array}$ & $\begin{array}{l}25.46 \\
25.54 \\
25.29 \\
25.46 \\
25.59 \\
25.52\end{array}$ & $\begin{array}{l}25.52 \\
25.60 \\
25.98 \\
25.96 \\
25.98 \\
26.13\end{array}$ & $\begin{array}{l}26.22 \\
26.29 \\
26.34 \\
26.38 \\
26.72 \\
26.60\end{array}$ & $\begin{array}{l}26.74 \\
26.83 \\
26.89 \\
27.35 \\
26.95 \\
27.41\end{array}$ \\
\hline
\end{tabular}

WTR YR 1991 LOW 27.41 SEP 30 
400247086482101 . Local nunber, MY 7

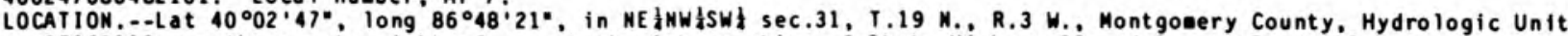
05120110 , on the county right-of-way at the intersection of State Highway 32 and County Road 525 East. and 4.5-1 east of Crawfordsuilie.

Owner: U.S. Geological Survey.

AQUIFER.--Sand and gravel of Pleistocene age.

WELL CHARACTERISTICS.--Drilled artesian well, dianeter 6 in., depth $111 \mathrm{ft}$, cased to $107 \mathrm{ft}$, screened to $109 \mathrm{ft}$, open end.

INST RUMENTATION. - - Wa ter-level recorder.

DATUM.--Elevation of land-surface datue is $801 \mathrm{ft}$ above National Geodetic Vertical Datua of 1929, froa topographic

ap. Measuring point: Top of floor of shelter, $2.38 \mathrm{ft}$ above land-surface datua.

PERIOD OF RECORD.--July 1967 to current year.

EXTREMES FOR PERIOD OF RECORD.--Highest water level, $26.10 \mathrm{ft}$ below land-surface datue, Apr. 13, 1974; lowest,

$33.97 \mathrm{ft}$ below land-surface datue, Sept. 20,1991 .

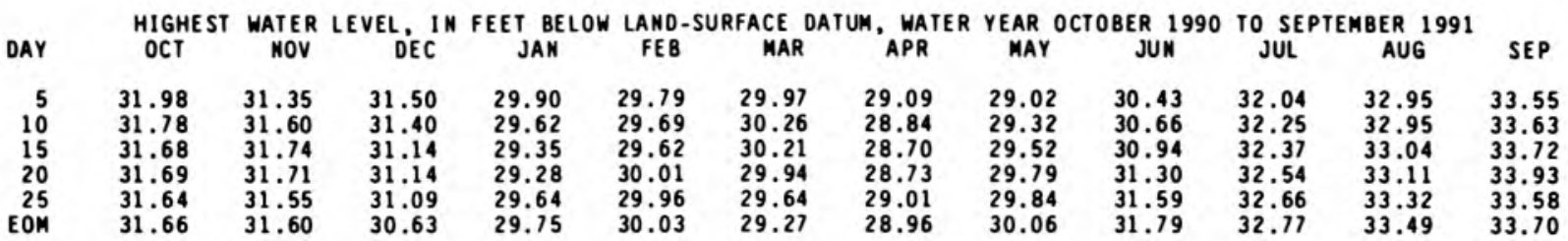

WTR YR 1991 HIGH 28.69 APR 19

LOWEST WATER LEVEL, IN FEET BELOW LAND-SURFACE DATUM, WATER YEAR OCTOBER 1990 TO SEPTEMBER 1991

\begin{tabular}{|c|c|c|c|c|c|c|c|c|c|c|c|c|}
\hline DAY & OCT & NOV & DEC & JAN & FEB & MAR & APR & MAY & JUN & JUL & AUG & SEP \\
\hline $\begin{array}{r}5 \\
10 \\
15 \\
20 \\
25 \\
\text { EOM }\end{array}$ & $\begin{array}{l}32.01 \\
31.84 \\
31.76 \\
31.74 \\
31.67 \\
31.70\end{array}$ & $\begin{array}{l}31.54 \\
31.65 \\
31.78 \\
31.72 \\
31.61 \\
31.67\end{array}$ & $\begin{array}{l}31.58 \\
31.42 \\
31.27 \\
31.17 \\
31.15 \\
30.64\end{array}$ & $\begin{array}{l}30.09 \\
29.73 \\
29.46 \\
29.32 \\
29.70 \\
29.89\end{array}$ & $\begin{array}{l}29.84 \\
29.74 \\
29.84 \\
30.04 \\
30.01 \\
30.07\end{array}$ & $\begin{array}{l}30.06 \\
30.32 \\
30.27 \\
30.02 \\
29.68 \\
29.35\end{array}$ & $\begin{array}{l}29.13 \\
28.96 \\
28.79 \\
28.81 \\
29.05 \\
29.02\end{array}$ & $\begin{array}{l}29.10 \\
29.41 \\
29.59 \\
29.81 \\
29.90 \\
30.13\end{array}$ & $\begin{array}{l}30.52 \\
30.69 \\
30.99 \\
31.35 \\
31.64 \\
31.82\end{array}$ & $\begin{array}{l}32.09 \\
32.46 \\
32.48 \\
32.57 \\
32.73 \\
32.79\end{array}$ & $\begin{array}{l}32.99 \\
33.02 \\
33.07 \\
33.14 \\
33.35 \\
33.54\end{array}$ & $\begin{array}{l}33.58 \\
33.68 \\
33.76 \\
33.97 \\
33.71 \\
33.75\end{array}$ \\
\hline
\end{tabular}

WTR YR 1991 LOW 33.97 SEP 20

393423086161001. Local number, MG 4.

MORGAM COUNTY

LOCATION. - Lat $39^{\circ} 34^{\prime} 23^{\circ}$, Iong $86^{\circ} 16^{\circ} 10^{\circ}$, in NW $\frac{1}{4} N W \frac{1}{4} N W \frac{1}{4}$ sec.13. T.13 N., R.2 E.., Morgan County, Hydrologic Unit 05120201 , on east side of County Road 850 East, 0.4 a north of County Road 950 North, and 1.1 i north of

Waverly.

Owner: U.S. Geological Survey.

AQUIFER. -. Sand and gravel of Pleistocene age.

WELL CHARACTERISTICS.--Drilled water-table well, dianeter $6 \mathrm{in.}$. depth $60 \mathrm{ft}$, cased to $56 \mathrm{ft}$, screened to $60 \mathrm{ft}$. INST RUME NTATION. - - Wa ter-level recorder.

DATUM.--Elevation of land-surface datum is $645 \mathrm{ft}$ above Mational Geodetic Vertical Datua of 1929, from topographic ap. Measuring point: Top of floor of shelter, $2.90 \mathrm{ft}$ above land-surface datur.

PERIOD OF RECORD.--May 1978 to current year.

EXTREMES FOR PERIOD OF RECORD.--Highest water leve1, $2.93 \mathrm{ft}$ below land-surface datue, Jan. 1, 1991: lowest,

$16.09 \mathrm{ft}$ below land-surface datun. Nov. 2-4, 1988 .

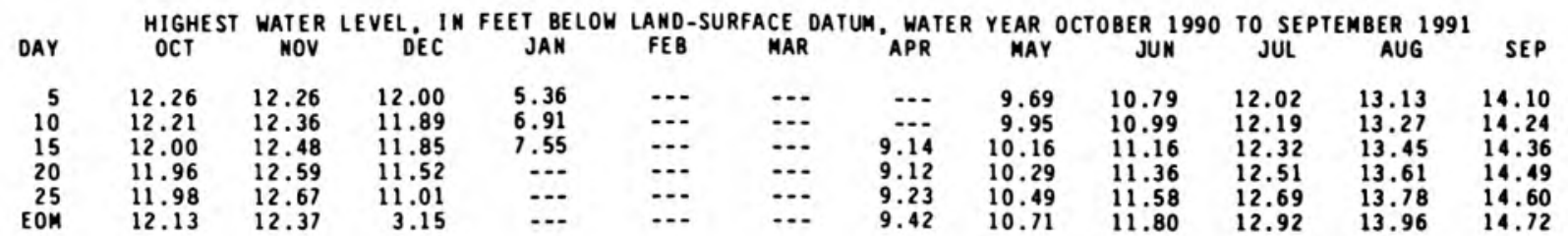

WTR YR 1991 HIGH 2.93 JAN 1

LOWEST WATER LEVEL, IN FEET BELOW LAND-SURFACE DATUM, WATER YEAR OCTOBER 1990 TO SEPTEMBER 1991

\begin{tabular}{|c|c|c|c|c|c|c|c|c|c|c|c|c|}
\hline DAY & OCT & NOV & DEC & JAN & FEB & MAR & APR & MAY & JUN & JUL & AUG & SEP \\
\hline $\begin{array}{r}5 \\
10 \\
15 \\
20 \\
25 \\
\text { EOM }\end{array}$ & $\begin{array}{l}12.29 \\
12.29 \\
12.02 \\
11.97 \\
12.01 \\
12.16\end{array}$ & $\begin{array}{l}12.27 \\
12.39 \\
12.50 \\
12.61 \\
12.69 \\
12.45\end{array}$ & $\begin{array}{r}12.07 \\
11.91 \\
11.88 \\
11.61 \\
11.06 \\
6.31\end{array}$ & $\begin{array}{r}5.73 \\
7.07 \\
7.65 \\
\ldots . . \\
\ldots .2 \\
\ldots .\end{array}$ & $\begin{array}{l}\ldots \\
\ldots \\
\ldots \\
\ldots \\
\ldots\end{array}$ & $\begin{array}{l}\ldots \\
\ldots \\
\ldots \\
\ldots \\
\ldots \\
\ldots\end{array}$ & $\begin{array}{r}\ldots . . \\
9.18 \\
9.15 \\
9.26 \\
9.47\end{array}$ & $\begin{array}{r}9.72 \\
9.99 \\
10.21 \\
10.33 \\
10.52 \\
10.74\end{array}$ & $\begin{array}{l}10.84 \\
11.03 \\
11.20 \\
11.40 \\
11.62 \\
11.84\end{array}$ & $\begin{array}{l}12.06 \\
12.21 \\
12.36 \\
12.54 \\
12.73 \\
12.96\end{array}$ & $\begin{array}{l}13.17 \\
13.31 \\
13.48 \\
13.64 \\
13.81 \\
13.99\end{array}$ & $\begin{array}{l}14.13 \\
14.27 \\
14.38 \\
14.52 \\
14.62 \\
14.74\end{array}$ \\
\hline
\end{tabular}

WTR YR 1991 LOW 14.74 SEP 30 
405105087173301. Local number, NE 6.

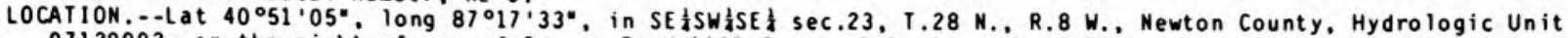
07120002 , on the right-of-way of County Road 1000 South, 1.0 i south of foresuan.

Owner: U.S. Geological Survey.

AQUIFER. - - Sand and gravel of Pleistocene age.

WELL CHARACTERISIICS.--Orilled artesian well, dianeter $6 \mathrm{in.}$, depth $80 \mathrm{ft}$, cased to $76 \mathrm{ft}$, screened to $78 \mathrm{ft}$. INST RUMENTATION. - - Water-level recorder.

DATUM.--Elevation of land-surface datue is $654.10 \mathrm{ft}$ above National Geodetic Vertical Datue of 1929 . Measuring point: TOD of floor of shelter, $2.15 \mathrm{ft}$ above land-surface datun.

PERIOD OF RECORD.--May 1967 to current year.

EXIREMES FOR PERIOD OF RECORD.--Highest water level, $7.94 \mathrm{ft}$ below land-surface datur. Mar. 20, 21, 1982; lowest. $18.82 \mathrm{ft}$ below land-surface datum, $0 \mathrm{ct} .29,1988$.

\begin{tabular}{|c|c|c|c|c|c|c|c|c|c|c|c|c|}
\hline DAY & $\begin{array}{l}\text { HIGHEST } \\
\text { OCT }\end{array}$ & $\begin{array}{l}\text { WATER } \\
\text { NOV }\end{array}$ & ${ }_{\text {DEC }}$ & $\underset{\text { JAN }}{\text { FEET BELOW }}$ & $\begin{array}{l}\text { LAND - } \\
\text { FEB }\end{array}$ & $\begin{array}{l}\text { FACE D } \\
\text { MAR }\end{array}$ & DATUM, WATER & $\begin{array}{l}\text { YEAR } 0 \\
\text { MAY }\end{array}$ & OCTOBER $\underset{\text { JUN }}{1990}$ & $\begin{array}{c}\text { TO SEP } \\
\text { JUL }\end{array}$ & $\begin{array}{l}\text { BER } 1991 \\
\text { AUG }\end{array}$ & SEP \\
\hline $\begin{array}{r}5 \\
10 \\
15 \\
20 \\
25 \\
\text { EOM }\end{array}$ & $\begin{array}{l}13.88 \\
12.43 \\
10.98 \\
10.69 \\
11.00 \\
11.40\end{array}$ & $\begin{array}{l}11.28 \\
10.63 \\
10.95 \\
11.27 \\
11.33 \\
10.64\end{array}$ & $\begin{array}{r}10.35 \\
10.73 \\
10.84 \\
10.94 \\
10.54 \\
8.12\end{array}$ & $\begin{array}{r}8.62 \\
9.72 \\
10.15 \\
9.82 \\
10.39 \\
10.92\end{array}$ & $\begin{array}{l}11.05 \\
10.89 \\
11.04 \\
11.17 \\
11.16 \\
11.14\end{array}$ & $\begin{array}{r}10.94 \\
11.27 \\
10.98 \\
9.07 \\
8.98 \\
9.49\end{array}$ & $\begin{array}{l}10.04 \\
10.47 \\
10.49 \\
10.07 \\
10.45 \\
10.74\end{array}$ & $\begin{array}{l}10.97 \\
11.29 \\
11.45 \\
11.04 \\
10.91 \\
11.07\end{array}$ & $\begin{array}{l}11.51 \\
11.95 \\
12.56 \\
12.94 \\
13.59 \\
14.08\end{array}$ & $\begin{array}{l}13.87 \\
14.18 \\
14.24 \\
14.52 \\
14.87 \\
15.29\end{array}$ & $\begin{array}{l}15.77 \\
15.79 \\
15.95 \\
16.05 \\
16.25 \\
16.65\end{array}$ & $\begin{array}{l}16.75 \\
16.93 \\
17.15 \\
17.30 \\
17.31 \\
17.46\end{array}$ \\
\hline
\end{tabular}

WTR YR 1991 HIGH 8.40 JAN 2

LOWEST WATER LEVEL, IN FEET BELOW LAND-SURFACE DATUM. WATER YEAR OCTOBER 1990 TO SEPTEMBER 1991

\begin{tabular}{|c|c|c|c|c|c|c|c|c|c|c|c|c|}
\hline DAY & OCT & NOV & DEC & JAN & FEB & MAR & APR & MAY & JUN & JUL & AUG & SEP \\
\hline $\begin{array}{r}5 \\
10 \\
15 \\
20 \\
25 \\
\text { EOM }\end{array}$ & $\begin{array}{l}13.93 \\
13.16 \\
11.04 \\
10.74 \\
11.10 \\
11.49\end{array}$ & $\begin{array}{l}11.58 \\
10.73 \\
11.00 \\
11.31 \\
11.48 \\
10.88\end{array}$ & $\begin{array}{r}10.54 \\
10.83 \\
10.99 \\
11.03 \\
10.66 \\
9.12\end{array}$ & $\begin{array}{r}8.80 \\
9.77 \\
10.17 \\
9.89 \\
10.47 \\
11.09\end{array}$ & $\begin{array}{l}11.11 \\
10.96 \\
11.23 \\
11.26 \\
11.19 \\
11.20\end{array}$ & $\begin{array}{r}11.09 \\
11.32 \\
11.03 \\
9.38 \\
9.02 \\
9.60\end{array}$ & $\begin{array}{l}10.16 \\
10.70 \\
10.75 \\
10.14 \\
10.50 \\
10.82\end{array}$ & $\begin{array}{l}11.05 \\
11.34 \\
11.50 \\
11.15 \\
10.95 \\
11.17\end{array}$ & $\begin{array}{l}11.61 \\
12.02 \\
12.65 \\
13.02 \\
13.74 \\
14.27\end{array}$ & $\begin{array}{l}13.97 \\
14.22 \\
14.26 \\
14.56 \\
14.93 \\
15.37\end{array}$ & $\begin{array}{l}15.81 \\
15.84 \\
15.99 \\
16.10 \\
16.32 \\
16.74\end{array}$ & $\begin{array}{l}16.79 \\
16.99 \\
17.17 \\
17.37 \\
17.37 \\
17.50\end{array}$ \\
\hline
\end{tabular}

WTR YR 1991 LOW 17.50 SEP 30

405959087282901. Local number. NE 7.

NEWTON COUNTY

405959087282901 . 07120002 , in the Willow Slough Gane Preserve, 2.0 i southwest of Enos.

Owner: State of Indiana.

AQUIFER.--Linestone of Silurian age.

WELL CHARACTERISTICS.--Orilled artesian well, dianeter $6 \mathrm{in}$, depth $150 \mathrm{ft}$, cased to $136 \mathrm{ft}$, open end.

INST RUMENTATION. - - Water-level recorder.

DATUM.--Elevation of land-surface datue is $680.83 \mathrm{ft}$ above National Geodetic Vertical Datue of 1929 . Measuring point: Top of floor of shelter, $2.03 \mathrm{ft}$ above land-surface datua.

PERIOD OF RECORD.-.-February 1976 to current year.

EXTREMES FOR PERIOD OF RECORD, -- Highest water level, $34.65 \mathrm{ft}$ below land-surface datum, Apr 14, 1980; lowest, $97.33 \mathrm{ft}$ below land-surface datun. Aug. 29, 30, 1988.

\begin{tabular}{|c|c|c|c|c|c|c|c|c|c|c|c|c|}
\hline AY & $\begin{array}{l}\text { HIGHEST } \\
\text { OCT }\end{array}$ & $\begin{array}{l}\text { WATER } \\
\text { NOV }\end{array}$ & $\underset{\text { LEC IN }}{\text { IN }}$ & $\begin{array}{c}\text { FEET BELOW } \\
\text { JAN }\end{array}$ & $\begin{array}{l}\text { LAND- } \\
\text { FEB }\end{array}$ & $\begin{array}{l}A C E \\
\text { MAR }\end{array}$ & $\begin{array}{c}\text { OATUM, WATER } \\
\text { APR }\end{array}$ & $\begin{array}{l}\text { EAR } 0 \\
\text { MAY }\end{array}$ & OCTOBER $\underset{\text { JUN }}{1990}$ & JUL & AUG & SEP \\
\hline $\begin{array}{r}5 \\
10 \\
15 \\
20\end{array}$ & $\begin{array}{l}50.91 \\
49.38 \\
49.19 \\
48.50\end{array}$ & $\begin{array}{l}47.64 \\
47.33 \\
46.92 \\
46.46 \\
45.91 \\
45.48\end{array}$ & $\begin{array}{l}44.13 \\
44.21 \\
43.94 \\
43.62 \\
43.15\end{array}$ & $\begin{array}{l}42.53 \\
42.12 \\
41.86 \\
41.88 \\
41.59\end{array}$ & $\begin{array}{l}41.13 \\
40.86 \\
40.77 \\
40.74 \\
40.73\end{array}$ & $\begin{array}{l}40.70 \\
40.68 \\
40.65 \\
39.80 \\
39.78 \\
39.68\end{array}$ & $\begin{array}{l}39.16 \\
39.23 \\
39.14 \\
38.99\end{array}$ & $\begin{array}{l}38.84 \\
38.92 \\
38.72 \\
38.70 \\
38.54 \\
38.53\end{array}$ & $\begin{array}{r}38.66 \\
38.64 \\
38.72 \\
40.28 \\
. . . \\
53.61\end{array}$ & $\begin{array}{l}\cdots \\
\cdots \\
\cdots \\
\cdots \\
\cdots\end{array}$ & $\begin{array}{l}\cdots \\
\cdots \\
\cdots \\
\cdots \\
\cdots\end{array}$ & $\begin{array}{r}91.22 \\
90.09 \\
88.54 \\
87.39\end{array}$ \\
\hline
\end{tabular}

WTR YR 1991 HIGH 38.53 MAY 31 LOWEST WATER LEVEL, IN FEET BELOW LAND-SURFACE DATUM, WATER YEAR OCTOBER 1990 TO SEPTEMBER 1991

\begin{tabular}{|c|c|c|c|c|c|c|c|c|c|c|c|c|}
\hline DAY & $\mathrm{OCT}$ & NOV & DEC & JAN & FE B & MAR & APR & MAY & JUN & JUL & AUG & SEP \\
\hline $\begin{array}{r}5 \\
10 \\
15 \\
20 \\
25 \\
\text { EOM }\end{array}$ & $\begin{array}{l}51.96 \\
51.05 \\
50.44 \\
49.85 \\
49.27 \\
48.63\end{array}$ & $\begin{array}{l}47.94 \\
47.42 \\
47.06 \\
46.59 \\
45.97 \\
45.72\end{array}$ & $\begin{array}{l}45.28 \\
44.79 \\
44.38 \\
44.10 \\
43.70 \\
43.23\end{array}$ & $\begin{array}{l}42.90 \\
42.70 \\
42.26 \\
41.90 \\
41.92 \\
41.67\end{array}$ & $\begin{array}{l}41.39 \\
41.18 \\
40.99 \\
40.82 \\
40.75 \\
40.73\end{array}$ & $\begin{array}{l}40.71 \\
40.68 \\
40.66 \\
39.93 \\
39.84 \\
39.77\end{array}$ & $\begin{array}{l}39.63 \\
39.61 \\
39.31 \\
39.28 \\
39.21 \\
39.06\end{array}$ & $\begin{array}{l}38.96 \\
38.99 \\
38.80 \\
38.74 \\
38.64 \\
38.62\end{array}$ & $\begin{array}{r}38.71 \\
38.74 \\
38.82 \\
40.98 \\
54.96\end{array}$ & $\begin{array}{l}\ldots \\
\cdots \\
\cdots \\
\cdots \\
\cdots\end{array}$ & $\begin{array}{l}\ldots- \\
\ldots \\
\ldots \\
\ldots- \\
\ldots \\
\ldots\end{array}$ & $\begin{array}{r}. . . \\
91.47 \\
90.35 \\
88.93 \\
87.72\end{array}$ \\
\hline
\end{tabular}

WTR YR 1991 LOW 92.04 SEP 13 
410428087231501 . Local nuaber, NE 8.

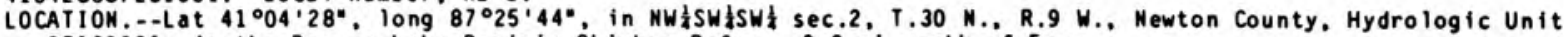
07120001 , in the Beaver Lake Prairie Chicken Refuge, 3.0 e1 north of Enos.

Owner: State of Indiana.

AQUIFER. - - Liestone of Silurian age.

WELL CHARACTERISTICS.--Drilled artesian well, dianeter 6 in., depth $150 \mathrm{ft}$, cased to $97 \mathrm{ft}$, open end.

INSTRUNENTATION, - - Wa ter-level recorder.

DATUM.--Elevation of land-surface datue is $663.34 \mathrm{ft}$ above National Geodetic Vertical Datua of 1929 . Measuring point: Top of floor of shelter, $2.83 \mathrm{ft}$ above land-surface datur.

REMARKS. - - Water level ady be affected by irrigation punage.

PERIOD OF RECORD.-.-February 1976 to current year.

EXTREMES FOR PERIOD OF RECORD.--Highest water leve1, $4.04 \mathrm{ft}$ below land-surface datum, May 31 , 1976 ; lowest, $98.40 \mathrm{ft}$ below land-surface datue, July 29,1988 .

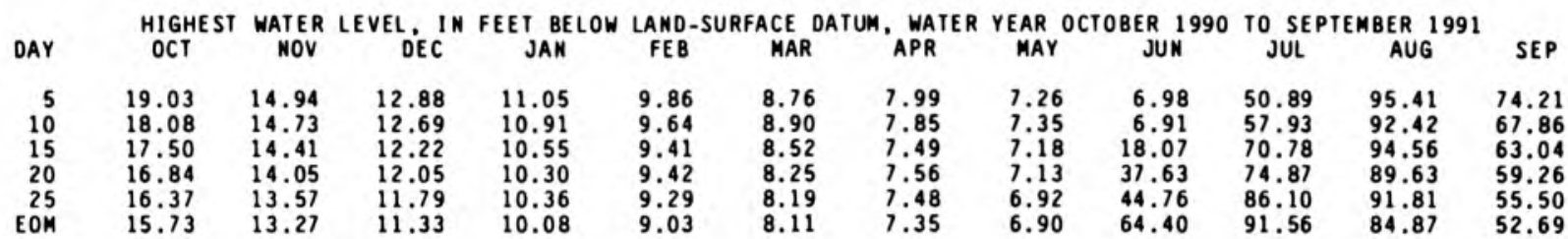

WTR YR 1991 HIGH 6.87 JUN 11

LOWEST WATER LEVEL, IN FEET BELOW LAND-SURFACE DATUM, WATER YEAR OCTOBER 1990 TO SEPTEMBER 1991

\begin{tabular}{|c|c|c|c|c|c|c|c|c|c|c|c|c|}
\hline DAY & OCT & NOV & DEC & JAN & FE B & MAR & APR & MAY & JUN & JUL & AUG & SEP \\
\hline $\begin{array}{r}5 \\
10 \\
15 \\
20 \\
25 \\
\text { EOM }\end{array}$ & $\begin{array}{l}19.25 \\
18.25 \\
17.57 \\
17.02 \\
16.45 \\
15.85\end{array}$ & $\begin{array}{l}15.25 \\
14.83 \\
14.53 \\
14.15 \\
13.64 \\
13.50\end{array}$ & $\begin{array}{l}13.14 \\
12.73 \\
12.40 \\
12.21 \\
11.87 \\
11.40\end{array}$ & $\begin{array}{l}11.19 \\
11.05 \\
10.65 \\
10.34 \\
10.41 \\
10.17\end{array}$ & $\begin{array}{l}9.88 \\
9.69 \\
9.58 \\
9.46 \\
9.39 \\
9.21\end{array}$ & $\begin{array}{l}8.89 \\
8.94 \\
8.65 \\
8.32 \\
8.23 \\
8.19\end{array}$ & $\begin{array}{l}8.03 \\
8.01 \\
7.63 \\
7.60 \\
7.56 \\
7.43\end{array}$ & $\begin{array}{l}7.37 \\
7.42 \\
7.29 \\
7.15 \\
7.04 \\
6.98\end{array}$ & $\begin{array}{r}7.07 \\
7.01 \\
22.02 \\
42.71 \\
47.19 \\
69.40\end{array}$ & $\begin{array}{l}55.22 \\
60.71 \\
71.71 \\
78.49 \\
87.04 \\
92.27\end{array}$ & $\begin{array}{l}95.83 \\
92.78 \\
95.71 \\
94.26 \\
92.62 \\
89.98\end{array}$ & $\begin{array}{l}75.70 \\
68.86 \\
63.87 \\
60.02 \\
56.27 \\
53.32\end{array}$ \\
\hline
\end{tabular}

WTR YR 1991 LOW 96.20 AUG 7

\section{NEWTON COUNTY}

405959087282902. Local number, NE 9.

LOCATION. - L a t $40^{\circ} 59^{\prime} 59^{\circ}$. long $87^{\circ} 28^{\prime} 29^{\circ}$, in SE $\frac{1}{4} S W \frac{1}{4} S E \frac{1}{4}$ sec.32, T.30 N., R.9 W., Newton County, Hydrologic Unit 07120002 , in the Willow Slough Gane Preserve, 2.0 i southwest of Enos.

Owner: U.S. Geological Survey.

AQUIFER. - - Sand of Pleistocene age.

WELL CHARACTERISTICS.--Drilled water-table well, dianeter 2 in., depth $45 \mathrm{ft}$, cased to $42 \mathrm{ft}$, screened to $45 \mathrm{ft}$. INSTRUMENTATION. - - Water-level recorder.

DATUM.--Elevation of land-surface datun is $681 \mathrm{ft}$ above National Geodetic Vertical Datun of 1929 , froe topographic

ap. Measuring point: Top of " $y$ " in well casing, $3.10 \mathrm{ft}$ above land-surface datum.

PERIOD OF RECORD.--May 1978 to current year. Frageentary record prior to March 1981.

EXTREMES FOR PERIOD OF RECORD.-.-Highest water leve1, $1.07 \mathrm{ft}$ below land-surface datua, May 3, 1978 ; lowest,

$15.44 \mathrm{ft}$ below land-surface datur, Oct. 19-21, 26-31, 1988.

\begin{tabular}{|c|c|c|c|c|c|c|c|c|c|c|c|c|}
\hline DAY & $\begin{array}{l}\text { HIGHEST } \\
\text { OCT }\end{array}$ & $\begin{array}{c}\text { WATER } \\
\text { NOV }\end{array}$ & LEVEL $_{\text {DEC }}$ IN & FEET BELOW & $\begin{array}{l}\text { LAND }-S \\
\text { FEB }\end{array}$ & $\begin{array}{l}\text { PFACE D } \\
\text { MAR }\end{array}$ & $\begin{array}{c}\text { DATUM, WATER } \\
\text { APR }\end{array}$ & $\begin{array}{c}\text { YEAR } \\
\text { MAY }\end{array}$ & OCTOBER $\underset{\text { JUN }}{1990}$ & TO JUL & $\underset{A U G}{A B E R} 1991$ & SEP \\
\hline $\begin{array}{r}5 \\
10 \\
15 \\
20 \\
25 \\
\text { EOM }\end{array}$ & $\begin{array}{l}12.23 \\
11.61 \\
11.23 \\
11.09 \\
11.07 \\
11.13\end{array}$ & $\begin{array}{l}10.93 \\
10.70 \\
10.68 \\
10.67 \\
10.66 \\
10.26\end{array}$ & $\begin{array}{r}10.09 \\
10.08 \\
9.95 \\
9.88 \\
9.81 \\
8.29\end{array}$ & $\begin{array}{l}8.26 \\
8.39 \\
8.37 \\
8.29 \\
8.51 \\
8.76\end{array}$ & $\begin{array}{l}8.65 \\
8.52 \\
8.55 \\
8.58 \\
8.64 \\
8.76\end{array}$ & $\begin{array}{l}8.51 \\
8.67 \\
8.54 \\
7.77 \\
7.60 \\
7.70\end{array}$ & $\begin{array}{l}7.84 \\
7.99 \\
7.92 \\
7.87 \\
8.03 \\
8.13\end{array}$ & $\begin{array}{l}8.17 \\
8.44 \\
8.38 \\
8.24 \\
8.41 \\
8.73\end{array}$ & $\begin{array}{r}9.05 \\
9.48 \\
9.94 \\
10.40 \\
10.80 \\
11.26\end{array}$ & $\begin{array}{l}11.23 \\
11.49 \\
11.78 \\
12.07 \\
12.33 \\
12.65\end{array}$ & $\begin{array}{l}12.85 \\
12.94 \\
13.09 \\
13.19 \\
13.36 \\
13.53\end{array}$ & $\begin{array}{l}13.71 \\
13.86 \\
14.01 \\
14.09 \\
14.19 \\
14.32\end{array}$ \\
\hline
\end{tabular}

WTR YR 1991 HIGH 7.58 MAR 27

$$
\text { LOWEST WATER LEVEL, IN FEET BELOW LAND-SURFACE DATUM, WATER YEAR OCTOBER } 1990 \text { TO SEPTEMBER } 1991
$$

\begin{tabular}{|c|c|c|c|c|c|c|c|c|c|c|c|c|}
\hline DAY & $\mathrm{OCT}$ & NOV & DEC & JAN & FE B & MAR & APR & MAY & JUN & JUL & AUG & SEP \\
\hline $\begin{array}{r}5 \\
10 \\
15 \\
20 \\
25 \\
\text { EOM }\end{array}$ & $\begin{array}{l}12.23 \\
11.91 \\
11.25 \\
11.09 \\
11.07 \\
11.15\end{array}$ & $\begin{array}{l}11.18 \\
10.71 \\
10.70 \\
10.68 \\
10.70 \\
10.31\end{array}$ & $\begin{array}{r}10.10 \\
10.10 \\
10.07 \\
9.88 \\
9.82 \\
8.38\end{array}$ & $\begin{array}{l}8.28 \\
8.41 \\
8.41 \\
8.29 \\
8.59 \\
8.95\end{array}$ & $\begin{array}{l}8.73 \\
8.53 \\
8.68 \\
8.59 \\
8.66 \\
8.77\end{array}$ & $\begin{array}{l}8.52 \\
8.72 \\
8.58 \\
7.78 \\
7.67 \\
7.73\end{array}$ & $\begin{array}{l}7.85 \\
8.07 \\
8.07 \\
7.88 \\
8.07 \\
8.21\end{array}$ & $\begin{array}{l}8.33 \\
8.48 \\
8.39 \\
8.25 \\
8.46 \\
8.98\end{array}$ & $\begin{array}{r}9.15 \\
9.54 \\
10.00 \\
10.48 \\
10.93 \\
11.33\end{array}$ & $\begin{array}{l}11.27 \\
11.56 \\
11.87 \\
12.13 \\
12.41 \\
12.73\end{array}$ & $\begin{array}{l}12.88 \\
12.98 \\
13.12 \\
13.21 \\
13.38 \\
13.57\end{array}$ & $\begin{array}{l}13.75 \\
13.86 \\
14.03 \\
14.12 \\
14.20 \\
14.34\end{array}$ \\
\hline
\end{tabular}

WTR YR 1991 LOW 14.34 SEP 30 
410428087231502 . Local number, NE 10.

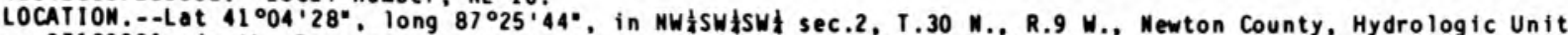
07120001 . In the Beaver Lake Prairie Chicken Refuge, 3.0 ei north of Enos.

Owner: U.S. Geological Survey.

AQUIFER.--Sand of Pleistocene age.

WELL CHARACTERISIICS.--Drilled water-table well, dianeter 2 in., depth $45 \mathrm{ft}$, cased to $41 \mathrm{ft}$, screened to 44 ft. INST RUME NTATION. - - Wa ter-1 evel recorder.

DATUM.--Elevation of land-surface datua is $663 \mathrm{ft}$ above Mational Geodetic Vertical Datua of 1929. froa topographic ap. Measuring point: Top of "y" in well casing, $2.65 \mathrm{ft}$ above land-surface datua.

PERIOD OF RECORD.--May 1978 to current year. Fragaentary record prior to March 1981.

EXTREMES FOR PERIOD OF RECORD.--Highest water level, $0.03 \mathrm{ft}$ below land-surface datua, Mar. 16, 1982; lowest, $6.48 \mathrm{ft}$ below land-surface datua. Sept. 30, 0ct. 1, 1988 .

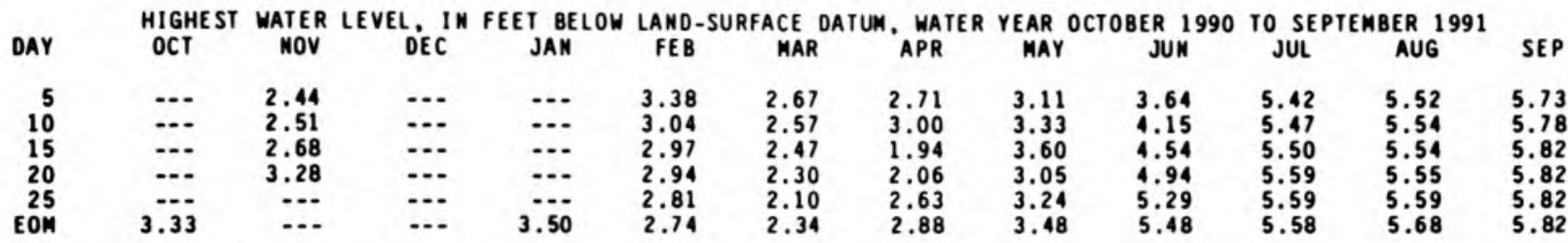

WTR YR 1991 HIGH 1.74 APR 17

LOWEST WATER LEVEL, IN FEET BELOW LAND-SURFACE DATUM, WATER YEAR OCTOBER 1990 TO SEPTEMBER 1991

\begin{tabular}{|c|c|c|c|c|c|c|c|c|c|c|c|c|}
\hline DAY & ОСТ & NOV & DEC & JAN & FEB & MAR & APR & MAY & JUN & JUL & AUG & SEP \\
\hline $\begin{array}{r}5 \\
10 \\
15 \\
20 \\
25 \\
\text { EOM }\end{array}$ & ב. & $\begin{array}{r}3.50 \\
2.59 \\
2.68 \\
3.36 \\
\ldots \ldots \\
\ldots .\end{array}$ & $\begin{array}{l}\ldots \\
\ldots- \\
\ldots \\
\ldots \\
\ldots \\
\ldots\end{array}$ & $\begin{array}{l}\ldots \\
\ldots \\
\ldots \\
\ldots \\
\ldots .5 \\
3.53\end{array}$ & $\begin{array}{l}3.40 \\
3.07 \\
2.99 \\
2.96 \\
2.83 \\
2.77\end{array}$ & $\begin{array}{l}2.70 \\
2.60 \\
2.50 \\
2.34 \\
2.12 \\
2.47\end{array}$ & $\begin{array}{l}2.72 \\
3.08 \\
3.03 \\
2.21 \\
2.68 \\
3.02\end{array}$ & $\begin{array}{l}3.19 \\
3.38 \\
3.62 \\
3.07 \\
3.28 \\
3.64\end{array}$ & $\begin{array}{l}3.80 \\
4.21 \\
4.65 \\
5.02 \\
5.35 \\
5.49\end{array}$ & $\begin{array}{l}5.45 \\
5.50 \\
5.55 \\
5.62 \\
5.61 \\
5.60\end{array}$ & $\begin{array}{l}5.54 \\
5.54 \\
5.55 \\
5.55 \\
5.61 \\
5.68\end{array}$ & $\begin{array}{l}5.74 \\
5.78 \\
5.82 \\
5.82 \\
5.82 \\
5.82\end{array}$ \\
\hline
\end{tabular}

WTR YR 1991 LOW 5.82 SEP 12

410235087305901 . Local nuaber, NE 11

NEWTON COUNTY

LOCATION 07120001 . On right-of-way of County Road 300 Morth, 0.5 ai west of County Road 600 West, and 4.0 ai northwest of Enos.

Owner: U.S. Geological Survey.

AQUIFER.--Liestone of Silurian age.

WELL CHARACTERISTICS.--Drilled artesian we11, dianeter $5 \mathrm{in.}$ depth of $150 \mathrm{ft}$, cased to $90 \mathrm{ft}$, open end.

INSTRUMENTATION. - - Wa ter-level recorder.

DATUM,--Elevation of land-surface datus is $670 \mathrm{ft}$ above National Geodetic Vertical Datue of 1929 , froe topographic ap. Measuring point: Top of casing. $3.30 \mathrm{ft}$ above land-surface datua.

PERIOD OF RECORD.--0ctober 1981 to current year.

EXTREMES FOR PERIOD OF RECORD.--Highest water leve1, $22.78 \mathrm{ft}$ below land-surface datum, May 6, 1982 ; lowest recorded, $98.83 \mathrm{ft}$ below land-surface datur. Aug. 5, 6. 1988.

\begin{tabular}{|c|c|c|c|c|c|c|c|c|c|c|c|c|}
\hline AY & $\begin{array}{l}\text { HIGHE ST } \\
\text { OCT }\end{array}$ & $\begin{array}{c}\text { WATER } \\
\text { MOV }\end{array}$ & LEVEL, IN & FEET $\underset{\text { JAN }}{B E L O W}$ & $\begin{array}{l}\text { LAND- } \\
\text { FEB }\end{array}$ & $\begin{array}{l}\text { FACE } \\
\text { MAR }\end{array}$ & $\begin{array}{c}\text { DATUM, WATER } \\
\text { APR }\end{array}$ & MAY & OCTOBER $\underset{\text { JUN }}{\text { 1990 }}$ & JUL & AUG & SEP \\
\hline $\begin{array}{r}5 \\
10 \\
15 \\
20 \\
25\end{array}$ & $\begin{array}{l}40.27 \\
39.26 \\
38.64 \\
37.80 \\
37.34 \\
36.48\end{array}$ & $\begin{array}{l}35.32 \\
35.15 \\
34.76 \\
34.23 \\
33.56 \\
33.26\end{array}$ & $\begin{array}{l}32.69 \\
32.46 \\
31.72 \\
31.57 \\
31.30 \\
30.96\end{array}$ & $\begin{array}{l}30.33 \\
30.05 \\
29.50 \\
29.23 \\
29.42 \\
29.06\end{array}$ & $\begin{array}{l}28.77 \\
28.45 \\
28.12 \\
28.13 \\
28.03 \\
27.61\end{array}$ & $\begin{array}{l}27.19 \\
27.72 \\
27.48 \\
26.88 \\
27.00 \\
26.92\end{array}$ & $\begin{array}{l}26.78 \\
26.59 \\
26.15 \\
26.41 \\
26.29 \\
26.08\end{array}$ & $\begin{array}{l}25.88 \\
26.11 \\
25.87 \\
25.90 \\
25.54 \\
25.48\end{array}$ & $\begin{array}{l}25.68 \\
25.51 \\
33.95 \\
34.19 \\
38.50 \\
45.84\end{array}$ & $\begin{array}{r}45.75 \\
54.28 \\
54.72 \\
\ldots . \\
\ldots\end{array}$ & $\begin{array}{l}\ldots \\
\ldots \\
\cdots \\
\cdots \\
\cdots\end{array}$ & $\begin{array}{l}\cdots \\
\cdots \\
\cdots \\
\cdots\end{array}$ \\
\hline
\end{tabular}

WTR YR 1991 HIGH 25.43 MAY 30 LOWEST WATER LEVEL, IN FEET BELOW LAND-SURFACE DATUM, WATER YEAR OCTOBER 1990 TO SEPTEMBER 1991

\begin{tabular}{|c|c|c|c|c|c|c|c|c|c|c|c|c|}
\hline DAY & OCT & NOV & DEC & JAK & FE B & MAR & APR & MAY & JUN & JUL & AUG & SEP \\
\hline $\begin{array}{r}5 \\
10 \\
15 \\
20 \\
25 \\
\text { EOM }\end{array}$ & $\begin{array}{l}40.53 \\
39.49 \\
38.79 \\
38.05 \\
37.42 \\
36.64\end{array}$ & $\begin{array}{l}35.76 \\
35.33 \\
34.95 \\
34.43 \\
33.73 \\
33.67\end{array}$ & $\begin{array}{l}33.16 \\
32.57 \\
32.03 \\
31.84 \\
31.51 \\
31.10\end{array}$ & $\begin{array}{l}30.57 \\
30.42 \\
29.74 \\
29.36 \\
29.54 \\
29.27\end{array}$ & $\begin{array}{l}28.81 \\
28.55 \\
28.45 \\
28.25 \\
28.18 \\
27.87\end{array}$ & $\begin{array}{l}27.56 \\
27.81 \\
27.81 \\
27.16 \\
27.12 \\
27.10\end{array}$ & $\begin{array}{l}26.85 \\
26.92 \\
26.49 \\
26.47 \\
26.42 \\
26.19\end{array}$ & $\begin{array}{l}26.10 \\
26.22 \\
25.98 \\
25.96 \\
25.71 \\
25.55\end{array}$ & $\begin{array}{l}25.75 \\
25.66 \\
36.97 \\
39.50 \\
38.67 \\
46.12\end{array}$ & $\begin{array}{r}45.92 \\
54.57 \\
56.84 \\
\ldots . \\
\ldots . \\
\ldots\end{array}$ & $\begin{array}{l}\ldots \\
\ldots \\
\cdots \\
\cdots \\
\cdots\end{array}$ & $\begin{array}{l}\ldots \\
\ldots \\
\ldots \\
\cdots \\
\cdots\end{array}$ \\
\hline
\end{tabular}

WTR YR 1991 LOW 86.19 SEP 14 
410917087285801 . Local number. NE 14.

LOCATION, - - Lat $41^{\circ} 09^{\prime} 17^{\circ}$, long $87^{\circ} 28^{\prime} 58^{\circ}$, in NE $\frac{1}{5}$ SW 3 NWt sec.8, T.31 N., R.9 W. Newton County, Hydrologic Unit $07120001,100 \mathrm{ft}$ south of wildlife area parking lot in La Salle State Fish and Wildlife Area.

Owner: U.S. Geological Survey.

AQUIFER.--Dolomitic linestone of Silurian/Devonian age.

WCLL CHARACTERISTICS.--Drilled artesian well, diameter $6 \mathrm{in.}$, depth $150 \mathrm{ft}$, cased to $82 \mathrm{ft}$, open end.

INSTRUMENTATION. - - Water-level recorder, data-collection platform, and incremental encoder.

DATUM,--Elevation of land-surface datum is $636.62 \mathrm{ft}$ (revised) above National Geodetic Vertical Datum of 1929. Measuring point: TOp of casing, $3.30 \mathrm{ft}$ above land-surface datua.

REMARKS. - - Water level ma be affected by punpage.

PERIOD OF RECORD.--August 1985 to current year.

EXTREMES FOR PERIOD OF RECORD.--Highest water level, $6.18 \mathrm{ft}$ below land-surface datum, Mar. 27, 1991; lowest,

$31.19 \mathrm{ft}$ below land-surface datum, Aug. $26,1988$.

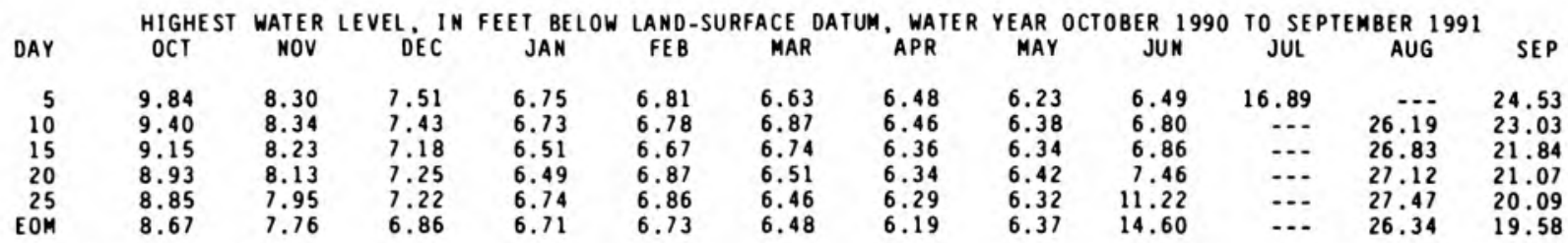

WTR YR 1991 HIGH 6.18 MAR 27

LOWEST WATER LEVEL, IN FEET BELOW LAND-SURFACE DATUM. WATER YEAR OCTOBER 1990 TO SEPTEMBER 1991

\begin{tabular}{|c|c|c|c|c|c|c|c|c|c|c|c|c|}
\hline DAY & $\mathrm{OCT}$ & NOV & DEC & JAN & FE B & MAR & APR & MAY & JUN & JUL & AUG & SEP \\
\hline $\begin{array}{r}5 \\
10 \\
15 \\
20 \\
25 \\
\text { EOM }\end{array}$ & $\begin{array}{l}9.91 \\
9.51 \\
9.19 \\
9.02 \\
8.89 \\
8.71\end{array}$ & $\begin{array}{l}8.52 \\
8.38 \\
8.28 \\
8.17 \\
8.08 \\
7.91\end{array}$ & $\begin{array}{l}7.64 \\
7.47 \\
7.31 \\
7.30 \\
7.30 \\
6.93\end{array}$ & $\begin{array}{l}6.83 \\
6.83 \\
6.58 \\
6.55 \\
6.77 \\
6.86\end{array}$ & $\begin{array}{l}6.85 \\
6.84 \\
6.84 \\
7.01 \\
6.88 \\
6.82\end{array}$ & $\begin{array}{l}6.75 \\
6.92 \\
6.82 \\
6.62 \\
6.50 \\
6.52\end{array}$ & $\begin{array}{l}6.50 \\
6.58 \\
6.47 \\
6.38 \\
6.34 \\
6.25\end{array}$ & $\begin{array}{l}6.33 \\
6.43 \\
6.39 \\
6.50 \\
6.44 \\
6.40\end{array}$ & $\begin{array}{r}6.53 \\
6.97 \\
7.28 \\
7.59 \\
11.98 \\
15.24\end{array}$ & $\begin{array}{r}17.37 \\
\ldots . \\
\ldots \\
\ldots \\
\ldots \\
\ldots\end{array}$ & $\begin{array}{l}26.39 \\
26.97 \\
27.15 \\
27.57 \\
26.52\end{array}$ & $\begin{array}{l}24.83 \\
23.28 \\
22.04 \\
21.23 \\
20.36 \\
19.77\end{array}$ \\
\hline
\end{tabular}

WTR YR 1991 LOW 27.57 AUG 25

411922085221801 . Local nuaber, NO 8.

NOBLE COUNTY

LOCATION.--Lat $41^{\circ} 19^{\prime} 22^{*}$, long $85^{\circ} 22^{\prime} 18^{\prime \prime}$, in SE $\frac{1}{4}$ SW $\frac{1}{4}$ SE $\frac{1}{4} \mathrm{sec} .9$, T.33 N.. R.10 E., Noble County, Hydrologic Unit 04050001 , near the east edge of Cha in 0 'Lakes Stae Park, and 5.0 if south of Albion.

Owner: U.S. Geological Survey.

AQUIFER. --Sand and gravel of Pleistocene age.

WELL CHARACTERISTICS.--Orilled artesian (revised) well, diameter $6 \mathrm{in}$., depth $149 \mathrm{ft}$, cased to $146 \mathrm{ft}$, screened to $148 \mathrm{ft}$.

INSTRUMENTATION. - - Wa ter-level recorder.

DATUM.--Elevation of land-surface datum is $928 \mathrm{ft}$ above National Geodetic Vertical Datun of 1929 . fron topographic

ap. Measuring point: Top of floor of shelter, $2.65 \mathrm{ft}$ above land-surface datun.

PERIOD OF RECORD.--Decenber 1966 to Septenber 1971. August 1974 to current year.

EXTREMES FOR PERIOD OF RECORD..-Highest water leve1, $27.68 \mathrm{ft}$ below land-surface datun, Feb. 14, 1991; lowest,

$32.49 \mathrm{ft}$ below land-surface datum, Jan. 18, 1967.

\begin{tabular}{|c|c|c|c|c|c|c|c|c|c|c|c|c|}
\hline DAY & $\begin{array}{l}\text { HIGHEST } \\
\text { OCT }\end{array}$ & $\begin{array}{l}\text { WATER } \\
\text { NOV }\end{array}$ & $\underset{\text { LEC }}{\text { LEVEL, IN }}$ & $\underset{\text { JAN }}{\text { FEET BELOW }}$ & $\begin{array}{l}\text { LAND-S } \\
\text { FEB }\end{array}$ & $\begin{array}{l}\text { FACE D } \\
\text { MAR }\end{array}$ & $\begin{array}{c}\text { DATUM, WATER } \\
\text { APR }\end{array}$ & $\begin{array}{l}\text { YEAR } 0 \\
\text { MAY }\end{array}$ & $\underset{\text { OCTN }}{\text { OCTOBER }} 1990$ & $\begin{array}{l}\text { TO SEP } \\
\text { JUL }\end{array}$ & $\begin{array}{l}\text { ABER } 1991 \\
\text { AUG }\end{array}$ & SEP \\
\hline $\begin{array}{r}5 \\
10 \\
15 \\
20 \\
25 \\
\text { EOM }\end{array}$ & $\begin{array}{l}29.36 \\
29.18 \\
29.18 \\
29.26 \\
29.23 \\
29.19\end{array}$ & $\begin{array}{l}28.64 \\
28.98 \\
29.10 \\
29.10 \\
28.77 \\
29.14\end{array}$ & $\begin{array}{l}28.95 \\
29.01 \\
28.75 \\
29.05 \\
29.05 \\
28.92\end{array}$ & $\begin{array}{l}28.63 \\
28.64 \\
28.32 \\
28.22 \\
28.66 \\
28.40\end{array}$ & $\begin{array}{l}28.48 \\
28.35 \\
28.07 \\
28.55 \\
28.57 \\
28.38\end{array}$ & $\begin{array}{l}28.21 \\
28.61 \\
28.61 \\
28.38 \\
28.57 \\
28.58\end{array}$ & $\begin{array}{l}28.52 \\
28.33 \\
28.14 \\
28.37 \\
28.44 \\
28.19\end{array}$ & $\begin{array}{l}28.14 \\
28.47 \\
28.27 \\
28.43 \\
28.23 \\
28.04\end{array}$ & $\begin{array}{l}28.36 \\
28.22 \\
28.09 \\
28.28 \\
28.37 \\
28.25\end{array}$ & $\begin{array}{l}28.37 \\
28.47 \\
28.68 \\
28.59 \\
28.61 \\
28.70\end{array}$ & $\begin{array}{l}28.83 \\
28.74 \\
28.81 \\
28.86 \\
29.10 \\
28.97\end{array}$ & $\begin{array}{l}29.07 \\
29.07 \\
29.09 \\
29.39 \\
28.96 \\
29.30\end{array}$ \\
\hline
\end{tabular}

WTR YR 1991 HIGH 27.88 FEB 14

LOWEST WATER LEVEL, IN FEET BELOW LAND-SURFACE DATUM, WATER YEAR OCTOBER 1990 TO SEPTEMBER 1991

\begin{tabular}{|c|c|c|c|c|c|c|c|c|c|c|c|c|}
\hline DAY & OCT & NOV & DEC & JAN & FEB & MAR & APR & MAY & JUN & JUL & AUG & SEP \\
\hline $\begin{array}{r}5 \\
10 \\
15 \\
20 \\
25 \\
\text { EOM }\end{array}$ & $\begin{array}{l}29.42 \\
29.35 \\
29.41 \\
29.38 \\
29.31 \\
29.22\end{array}$ & $\begin{array}{l}29.00 \\
29.10 \\
29.19 \\
29.17 \\
29.04 \\
29.38\end{array}$ & $\begin{array}{l}29.19 \\
29.14 \\
29.03 \\
29.21 \\
29.15 \\
29.10\end{array}$ & $\begin{array}{l}28.88 \\
28.83 \\
28.45 \\
28.30 \\
28.72 \\
28.73\end{array}$ & $\begin{array}{l}28.53 \\
28.41 \\
28.52 \\
28.62 \\
28.62 \\
28.51\end{array}$ & $\begin{array}{l}28.40 \\
28.75 \\
28.77 \\
28.54 \\
28.65 \\
28.74\end{array}$ & $\begin{array}{l}28.57 \\
28.70 \\
28.40 \\
28.47 \\
28.54 \\
28.30\end{array}$ & $\begin{array}{l}28.40 \\
28.52 \\
28.33 \\
28.49 \\
28.31 \\
28.20\end{array}$ & $\begin{array}{l}28.41 \\
28.31 \\
28.14 \\
28.35 \\
28.41 \\
28.33\end{array}$ & $\begin{array}{l}28.42 \\
28.50 \\
28.74 \\
28.66 \\
28.73 \\
28.75\end{array}$ & $\begin{array}{l}28.89 \\
28.88 \\
28.86 \\
28.97 \\
29.18 \\
29.15\end{array}$ & $\begin{array}{l}29.12 \\
29.15 \\
29.15 \\
29.44 \\
29.18 \\
29.47\end{array}$ \\
\hline
\end{tabular}

WTR YR 1991 LOW 29.55 OCT 1 
413106085232701 . Local nubber, No 9.

LOCATION .-Lat $41^{\circ} 31^{\prime} 06^{\circ}$ long $85^{\circ} 23^{\circ}$

04050001 , at the intersection of County Roads 175 East and 1150 North, and 2.0 ar west of Wolcottuille.

Owner: U.S. Geological Survey.

AQUIFER.--Sand of Pleistocene age.

WELL CHARACTERISTICS.--Drilled water-table well, dianeter $6 \mathrm{in},$. depth $44 \mathrm{ft}$, cased to $39 \mathrm{ft}$, screened to 42 ft.

INST RUNENTATION. - - Wa ter-level recorder.

DATUM.--Elevation of land-surface datue is $930 \mathrm{ft}$ above Mational Geodetic Vertical Datue of 1929 , froe topographic ap. Measuring point: Top of floor of shelter, $2.60 \mathrm{ft}$ above land-surface datue.

PERIOD OF RECORD.-.June 1976 to current year.

EXTREMES FOR PERIOD OF RECORO.--Highest water level, $8.45 \mathrm{ft}$ below land-surface datue, Mar. 31 , Apr. 1. 1985;

lowest. $17.55 \mathrm{ft}$ below land-surface datun. Dec. $27,28,1978$.

\begin{tabular}{|c|c|c|c|c|c|c|c|c|c|c|c|c|}
\hline$A Y$ & $\begin{array}{l}\text { HIGHEST } \\
\text { OCT }\end{array}$ & $\begin{array}{c}\text { WAT ER } \\
\text { MOV }\end{array}$ & LEVEL, IN & FEET & $\begin{array}{l}\text { LAND- } \\
\text { FEB }\end{array}$ & $\begin{array}{l}\text { ACE D } \\
\text { MAR }\end{array}$ & DATUM, WATER & MAY & JUN & JUL & AUG & SEP \\
\hline $\begin{array}{r}5 \\
10 \\
15 \\
20 \\
25 \\
\text { EOM }\end{array}$ & $\begin{array}{l}13.73 \\
10.95 \\
10.44 \\
10.78 \\
11.18 \\
11.72\end{array}$ & $\begin{array}{l}11.47 \\
10.68 \\
11.26 \\
11.66 \\
11.81 \\
11.50\end{array}$ & $\begin{array}{r}11.17 \\
11.45 \\
11.63 \\
11.67 \\
11.29 \\
8.77\end{array}$ & $\begin{array}{r}9.84 \\
10.66 \\
10.64 \\
10.34 \\
10.87 \\
11.40\end{array}$ & $\begin{array}{l}11.37 \\
11.11 \\
11.31 \\
11.07 \\
11.06 \\
11.32\end{array}$ & $\begin{array}{l}10.98 \\
11.33 \\
11.68 \\
11.62 \\
11.84 \\
11.56\end{array}$ & $\begin{array}{l}11.68 \\
11.79 \\
11.71 \\
10.24 \\
10.08 \\
10.27\end{array}$ & $\begin{array}{l}10.87 \\
11.10 \\
11.54 \\
11.99 \\
11.63 \\
10.58\end{array}$ & $\begin{array}{l}10.60 \\
11.33 \\
11.81 \\
12.34 \\
12.73 \\
12.98\end{array}$ & $\begin{array}{l}53 \\
37 \\
92 \\
26 \\
64 \\
07\end{array}$ & $\begin{array}{l}14 . \\
14 . \\
14 . \\
14 . \\
15 . \\
15 .\end{array}$ & $\begin{array}{l}15.53 \\
15.47 \\
15.72 \\
15.64 \\
15.87\end{array}$ \\
\hline
\end{tabular}

WTR YR 1991 HIGH 8.77 DEC 31

LOWEST WATER LEVEL, IN FEET BELOW LAND-SURFACE DATUM, WATER YEAR OCTOBER 1990 TO SEPTEMBER 1991

\begin{tabular}{|c|c|c|c|c|c|c|c|c|c|c|c|c|}
\hline DAY & OCT & MOV & DEC & JAM & FE B & MAR & APR & MAY & JUN & JUL & AUG & SEP \\
\hline $\begin{array}{r}5 \\
10 \\
15 \\
20 \\
25 \\
\text { EOM }\end{array}$ & $\begin{array}{l}13.93 \\
12.58 \\
10.68 \\
10.81 \\
11.32 \\
11.82\end{array}$ & $\begin{array}{l}12.07 \\
10.81 \\
11.30 \\
11.77 \\
12.02 \\
11.72\end{array}$ & $\begin{array}{r}11.33 \\
11.57 \\
11.81 \\
11.82 \\
11.34 \\
8.86\end{array}$ & $\begin{array}{r}9.95 \\
10.74 \\
10.70 \\
10.40 \\
10.94 \\
11.65\end{array}$ & $\begin{array}{l}11.50 \\
11.15 \\
11.64 \\
11.34 \\
11.14 \\
11.37\end{array}$ & $\begin{array}{l}11.05 \\
11.45 \\
11.78 \\
11.67 \\
11.86 \\
11.62\end{array}$ & $\begin{array}{l}11.71 \\
11.96 \\
11.82 \\
10.83 \\
10.18 \\
10.43\end{array}$ & $\begin{array}{l}10.91 \\
11.21 \\
11.64 \\
12.02 \\
11.94 \\
11.35\end{array}$ & $\begin{array}{l}10.80 \\
11.41 \\
11.89 \\
12.38 \\
12.78 \\
13.06\end{array}$ & $\begin{array}{l}11.79 \\
12.45 \\
12.99 \\
13.37 \\
13.75 \\
14.12\end{array}$ & $\begin{array}{l}14.39 \\
14.54 \\
14.75 \\
14.98 \\
15.16 \\
15.31\end{array}$ & $\begin{array}{l}15.45 \\
15.59 \\
15.51 \\
15.73 \\
15.74 \\
15.93\end{array}$ \\
\hline
\end{tabular}

WTR YR 1991 LOW 15.93 SEP 28

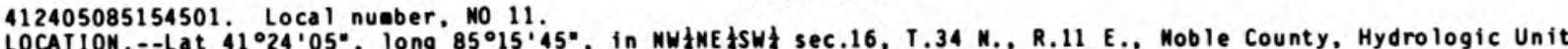

NOBLE COUNTY 04100003 , on the property of Ron Karst on the south side of County Road 350 North, 0.6 - west of State Highway 3 and about 22.1 north of Fort Wayne.

Owner: U.S. Geological Survey.

AQUIFER.--Sand and gravel of Pleistocene age.

WELL CHARACTERISTICS.--Drilled artsian well, dianeter 6 in.. depth $216 \mathrm{ft}$, cased to $211 \mathrm{ft}$, screened to 216 ft. INSTRUME NTATION. - - Water-leve 1 recorder.

DATUM.--Elevation of land-surface datue is $1.036 .94 \mathrm{ft}$ above Mational Geodetic Vertical Datue of 1929 . Measuring point: Top of casing, $3.45 \mathrm{ft}$ above land-surface datua.

PERIOD OF RECORD.--Noveaber 1987 to current year.

EXTREMES FOR PERIOD OF RECORD..-Highest water leve1, $113.24 \mathrm{ft}$ below land-surface datua, Mov. 6, 1988; lowest, $115.00 \mathrm{ft}$ below land-surface datur, Feb. 17.1989.

\begin{tabular}{|c|c|c|c|c|c|c|c|c|c|c|c|c|}
\hline DAY & $\begin{array}{l}\text { HIGHE ST } \\
\text { OCT }\end{array}$ & $\begin{array}{c}\text { WATER } \\
\text { NOV }\end{array}$ & LEVEL, IN & FEET BAELOW & $\begin{array}{c}\text { LAND } \\
\text { FEB }\end{array}$ & $\begin{array}{c}\text { FACE } 0 \\
\text { MAR }\end{array}$ & $\begin{array}{l}\text { TUM, WATER } \\
\text { APR }\end{array}$ & $\begin{array}{c}\text { YEAR } 0 \\
\text { MAY }\end{array}$ & $\underset{\text { OCTOBER }}{ } 1990$ & JUL & $\begin{array}{l}\text { BER } 199 \\
\text { AUG }\end{array}$ & SEP \\
\hline $\begin{array}{r}5 \\
10 \\
15 \\
20 \\
25 \\
\text { EOM }\end{array}$ & $\begin{array}{l}114.10 \\
114.00 \\
113.97 \\
114.25 \\
114.19 \\
114.31\end{array}$ & $\begin{array}{l}113.67 \\
114.06 \\
114.36 \\
114.30 \\
113.74 \\
114.34\end{array}$ & $\begin{array}{l}114.11 \\
114.19 \\
113.93 \\
114.20 \\
114.23 \\
114.14\end{array}$ & $\begin{array}{l}114.28 \\
114.44 \\
113.94 \\
113.76 \\
114.26 \\
114.01\end{array}$ & $\begin{array}{l}114.22 \\
114.02 \\
113.37 \\
114.01 \\
114.20 \\
113.96\end{array}$ & $\begin{array}{l}113.63 \\
114.04 \\
114.04 \\
113.90 \\
113.90 \\
114.06\end{array}$ & $\begin{array}{l}114.14 \\
113.75 \\
113.71 \\
113.88 \\
114.01 \\
113.77\end{array}$ & $\begin{array}{l}113.81 \\
114.25 \\
113.94 \\
114.25 \\
113.93 \\
113.75\end{array}$ & $\begin{array}{l}114.08 \\
114.11 \\
113.85 \\
114.09 \\
114.14 \\
113.94\end{array}$ & $\begin{array}{l}113.89 \\
113.99 \\
114.14 \\
114.03 \\
113.99 \\
114.07\end{array}$ & $\begin{array}{l}114.08 \\
113.98 \\
114.02 \\
113.87 \\
114.29 \\
114.05\end{array}$ & $\begin{array}{l}114.11 \\
114.08 \\
114.00 \\
114.32 \\
113.80 \\
114.20\end{array}$ \\
\hline
\end{tabular}

WTR YR 1991 HIGH 113.27 FEB 14

LOWEST WATER LEVEL, IN FEET BELOW LAND-SURFACE DATUM, WATER YEAR OCTOBER 1990 TO SEPIEMBER 1991

\begin{tabular}{|c|c|c|c|c|c|c|c|c|c|c|c|c|}
\hline DAY & $\mathrm{OCT}$ & MOV & DEC & JAN & FE B & MAR & $A P R$ & MAY & JUN & JUL & AUG & SEP \\
\hline $\begin{array}{r}5 \\
10 \\
15 \\
20 \\
25 \\
\text { EOM }\end{array}$ & $\begin{array}{l}114.15 \\
114.14 \\
114.27 \\
114.30 \\
114.30 \\
114.35\end{array}$ & $\begin{array}{l}114.13 \\
114.13 \\
114.46 \\
114.38 \\
114.00 \\
114.50\end{array}$ & $\begin{array}{l}114.27 \\
114.31 \\
114.28 \\
114.28 \\
114.28 \\
114.49\end{array}$ & $\begin{array}{l}114.51 \\
114.56 \\
114.02 \\
113.85 \\
114.38 \\
114.36\end{array}$ & $\begin{array}{l}114.26 \\
114.07 \\
113.81 \\
114.12 \\
114.22 \\
114.08\end{array}$ & $\begin{array}{l}113.77 \\
114.24 \\
114.28 \\
114.02 \\
114.07 \\
114.15\end{array}$ & $\begin{array}{l}114.18 \\
114.14 \\
113.91 \\
114.03 \\
114.10 \\
113.87\end{array}$ & $\begin{array}{l}114.08 \\
114.32 \\
114.02 \\
114.30 \\
114.03 \\
113.85\end{array}$ & $\begin{array}{l}114.19 \\
114.20 \\
113.95 \\
114.13 \\
114.18 \\
114.03\end{array}$ & $\begin{array}{l}113.90 \\
114.02 \\
114.24 \\
114.08 \\
114.09 \\
114.10\end{array}$ & $\begin{array}{l}114.20 \\
114.10 \\
114.03 \\
114.01 \\
114.34 \\
114.16\end{array}$ & $\begin{array}{l}114.15 \\
114.13 \\
114.02 \\
114.40 \\
114.13 \\
114.38\end{array}$ \\
\hline
\end{tabular}

WTR YR 1991 LOW 114.66 DEC 27 
412405085154504 . Local number, NO 14

LOCATION.--Lat $41^{\circ} 24^{\prime} 05^{\circ}$. Iong $85^{\circ} 15^{\circ} 45^{\prime \prime}$, in MHE 04100003 , on the property of Ron Karst on the south side of County Road 350 North, 0.6 a west of State Highway 3 and about $22 \mathrm{mi}$ north of Fort Wayne.

Owner: U.S. Geological Survey.

AQUIFER, - - Sand and gravel of Pleistocene age.

WELL CHARACTERISTICS.--Drilled artesian well, diameter $6 \mathrm{in.}$, depth $145 \mathrm{ft}$, cased to $140 \mathrm{ft}$, screened to $145 \mathrm{ft}$. INSTRUMENTATION. - - Water-level recorder.

DATUM.--Elevation of land-surface datum is 1,037.24 ft above National Geodetic Vertical Datua of 1929 . Measuring point: Top of casing, $3.50 \mathrm{ft}$ above land-surface datum.

PERIOD OF RECORD. - - Novenber 1987 to current year.

EXTREMES FOR PERIOD OF RECORD.--Highest water leve1, $112.21 \mathrm{ft}$ below land-surface datun, Dec. 15, 1987: 1owest, $114.29 \mathrm{ft}$ below land-surface datun. Feb. 17, 1989.

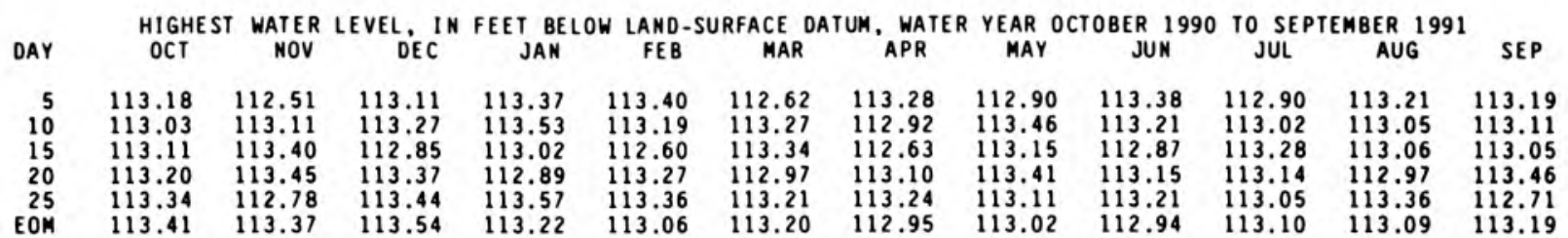

WTR YR 1991 HIGH 112.24 MAR 27

LOWEST WATER LEVEL, IN FEET BELOW LAND-SURFACE DATUM, WATER YEAR OCTOBER 1990 TO SEPTEMBER 1991

\begin{tabular}{|c|c|c|c|c|c|c|c|c|c|c|c|}
\hline $\mathrm{OCT}$ & MOV & DEC & JAN & FE B & MAR & APR & MAY & JUN & JUL & AUG & SEP \\
\hline $\begin{array}{l}113.32 \\
113.32 \\
113.46 \\
113.48 \\
113.49 \\
113.48\end{array}$ & $\begin{array}{l}113.08 \\
113.37 \\
113.56 \\
113.57 \\
113.21 \\
113.71\end{array}$ & $\begin{array}{l}113.54 \\
113.50 \\
113.24 \\
113.57 \\
113.64 \\
113.82\end{array}$ & $\begin{array}{l}113.72 \\
113.90 \\
113.28 \\
113.06 \\
113.71 \\
113.75\end{array}$ & $\begin{array}{l}113.50 \\
113.27 \\
113.24 \\
113.40 \\
113.44 \\
113.25\end{array}$ & $\begin{array}{l}112.95 \\
113.50 \\
113.57 \\
113.24 \\
113.33 \\
113.44\end{array}$ & $\begin{array}{l}113.38 \\
113.51 \\
113.10 \\
113.23 \\
113.39 \\
113.09\end{array}$ & $\begin{array}{l}113.27 \\
113.55 \\
113.23 \\
113.51 \\
113.23 \\
113.13\end{array}$ & $\begin{array}{l}113.47 \\
113.35 \\
113.04 \\
113.28 \\
113.29 \\
113.05\end{array}$ & $\begin{array}{l}112.94 \\
113.07 \\
113.39 \\
113.21 \\
113.23 \\
113.21\end{array}$ & $\begin{array}{l}113.30 \\
113.23 \\
113.10 \\
113.14 \\
113.47 \\
113.36\end{array}$ & $\begin{array}{l}113.26 \\
113.23 \\
113.11 \\
113.56 \\
113.08 \\
113.47\end{array}$ \\
\hline
\end{tabular}

WTR YR 1991 LOW 114.00 DEC 26

393619087043001 . Local number, PA 6.

PARKE COUNTY

LOCATION.--Lat $39^{\circ} 36^{\prime} 19^{\prime \prime}$, long $87^{\circ} 04^{\prime} 30^{\prime \prime}$, in SE $\frac{1}{4}$ SW 4 SE $\frac{1}{4} \mathrm{sec} .33$, T.14 N., R.6 W., Parke County, Hydrologic Unit 05120111 , on county right-of-way on north side of road at the Parke-Clay county line, 1.7 i east of Carbon. 2.6 i east of State Highway 59 , and 6.2 i north of Brazil.

Owner: U.S. Geological Survey.

AQUIFER. --Sandstone of Pennsylvanian age.

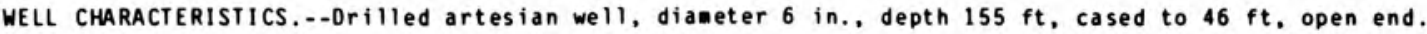

INST RUMENTATION. - - Water-level recorder.

DATUM.--Elevation of land-surface datu is $703 \mathrm{ft}$ above National Geodetic Vertical Datun of 1929, from topographic ap. Measuring point: Top of casing, $2.40 \mathrm{ft}$ above land-surface datun.

PERIOD OF RECORD.--July 1967 to August 1971, October 1981 to current year.

EXTREMES FOR PERIOD OF RECORD.--Highest water level, $11.53 \mathrm{ft}$ below land-surface datum, Apr. 19, 1970; lowest, $16.87 \mathrm{ft}$ below land-surface datun, $0 \mathrm{ct}$. 30,1988 .

\begin{tabular}{|c|c|c|c|c|c|c|c|c|c|c|c|c|}
\hline DAY & $\begin{array}{l}\text { HIGHEST } \\
\text { OCT }\end{array}$ & $\begin{array}{l}\text { WATER } \\
\text { NOV }\end{array}$ & ${ }_{\text {DEC }}^{\text {LEVEL, IN }}$ & $\underset{\text { JAN }}{\text { FEET BELOW }}$ & $\begin{array}{l}\text { LAND - } \\
\text { FEB }\end{array}$ & $\begin{array}{l}\text { ACE D } \\
\text { MAR }\end{array}$ & $\begin{array}{c}\text { DATUM, WATER } \\
\text { APR }\end{array}$ & $\begin{array}{l}\text { YEAR } 0 \\
\text { MAY }\end{array}$ & $\underset{\text { JUN }}{\text { OCTOBER }} 1990$ & TO JUL & $\begin{array}{l}\text { IBER } 1991 \\
\text { AUG }\end{array}$ & SEP \\
\hline $\begin{array}{r}5 \\
10 \\
15 \\
20 \\
25 \\
\text { EOM }\end{array}$ & $\begin{array}{l}15.34 \\
15.13 \\
15.07 \\
14.89 \\
14.81 \\
14.73\end{array}$ & $\begin{array}{l}14.09 \\
14.28 \\
14.28 \\
14.20 \\
14.04 \\
13.99\end{array}$ & $\begin{array}{l}13.78 \\
13.70 \\
13.44 \\
13.41 \\
13.33 \\
13.26\end{array}$ & $\begin{array}{l}13.00 \\
12.96 \\
12.76 \\
12.69 \\
12.81 \\
12.72\end{array}$ & $\begin{array}{l}12.71 \\
12.61 \\
12.51 \\
12.53 \\
12.50 \\
12.35\end{array}$ & $\begin{array}{l}12.19 \\
12.41 \\
12.32 \\
12.18 \\
12.20 \\
12.16\end{array}$ & $\begin{array}{l}12.12 \\
12.05 \\
11.95 \\
11.99 \\
11.96 \\
12.00\end{array}$ & $\begin{array}{l}11.98 \\
12.13 \\
12.15 \\
12.29 \\
12.28 \\
12.33\end{array}$ & $\begin{array}{l}12.58 \\
12.59 \\
12.65 \\
12.81 \\
12.93 \\
13.02\end{array}$ & $\begin{array}{l}13.09 \\
13.31 \\
13.50 \\
13.61 \\
13.80 \\
14.00\end{array}$ & $\begin{array}{l}14.13 \\
14.16 \\
14.33 \\
14.46 \\
14.71 \\
14.77\end{array}$ & $\begin{array}{l}14.80 \\
14.94 \\
14.99 \\
15.17 \\
15.05 \\
15.29\end{array}$ \\
\hline
\end{tabular}

WTR YR 1991 HIGH 11.88 APR 23

LOWEST WATER LEVEL, IN FEET BELOW LAND-SURFACE DATUM, WATER YEAR OCTOBER 1990 TO SEPTEMBER 1991

\begin{tabular}{|c|c|c|c|c|c|c|c|c|c|c|c|c|}
\hline DAY & OCT & NOV & DEC & JAN & FE B & MAR & APR & MAY & JUN & JUL & AUG & SEP \\
\hline $\begin{array}{r}5 \\
10 \\
15 \\
20 \\
25 \\
\text { EOM }\end{array}$ & $\begin{array}{l}15.43 \\
15.17 \\
15.15 \\
14.99 \\
14.83 \\
14.81\end{array}$ & $\begin{array}{l}14.29 \\
14.34 \\
14.36 \\
14.25 \\
14.12 \\
14.16\end{array}$ & $\begin{array}{l}13.96 \\
13.74 \\
13.58 \\
13.49 \\
13.39 \\
13.33\end{array}$ & $\begin{array}{l}13.09 \\
13.12 \\
12.90 \\
12.77 \\
12.85 \\
12.82\end{array}$ & $\begin{array}{l}12.73 \\
12.70 \\
12.63 \\
12.56 \\
12.56 \\
12.46\end{array}$ & $\begin{array}{l}12.31 \\
12.44 \\
12.39 \\
12.26 \\
12.24 \\
12.24\end{array}$ & $\begin{array}{l}12.16 \\
12.16 \\
12.05 \\
12.04 \\
12.05 \\
12.08\end{array}$ & $\begin{array}{l}12.08 \\
12.23 \\
12.20 \\
12.32 \\
12.36 \\
12.40\end{array}$ & $\begin{array}{l}12.64 \\
12.67 \\
12.69 \\
12.86 \\
12.99 \\
13.05\end{array}$ & $\begin{array}{l}13.13 \\
13.39 \\
13.55 \\
13.67 \\
13.87 \\
14.03\end{array}$ & $\begin{array}{l}14.20 \\
14.26 \\
14.36 \\
14.53 \\
14.76 \\
14.81\end{array}$ & $\begin{array}{l}14.86 \\
15.00 \\
15.05 \\
15.25 \\
15.16 \\
15.37\end{array}$ \\
\hline
\end{tabular}

WTR YR 1991 LOW 15.57 OCT 1 
380758087551001 . Local nuaber, PY 3.

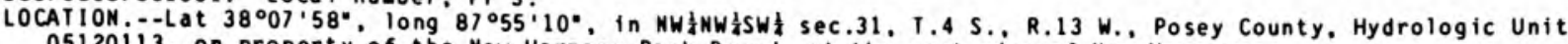
05120113 , on property of the New Harmony Park Board, at the east edge of New Harmony.

Owner: U.S. Geological Survey.

AQUIFER.--Sand and gravel of Pleistocene age.

WELL CHARACTERISTICS.--Drilled artesian well, dianeter 6 in., depth $58 \mathrm{ft}$, cased to $54 \mathrm{ft}$, screened to $56 \mathrm{ft}$. INST RUMENTATION. - -Wa ter-level recorder.

DATUM.--Elevation of land-surface datun is $380 \mathrm{ft}$ above National Geodetic Vertical Datun of 1929 , froe topographic ap. Measuring point: Top of floor of shelter, $3.00 \mathrm{ft}$ above land-surface datum.

REMARKS. - - Water level affected by Wabash River floods.

PERIOD OF RECORD.--April 1967 to Septeaber 1971, September 1974 to current year.

EXTREMES FOR PERIOD OF RECORD.--Highest water level, $4.95 \mathrm{ft}$ below land-surface datun, May 14, 1983 ; lowest, $21.40 \mathrm{ft}$ below land-surface datua, Nov, 4, 8-15, 1988 .

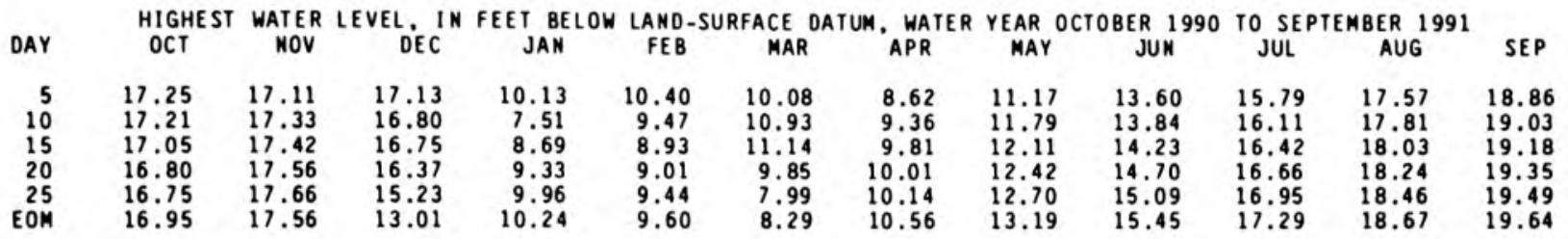

WTR YR 1991 HIGH 7.34 MAR 23

LOWEST WATER LEVEL. IN FEET BELOW LAND-SURFACE DATUM, WATER YEAR OCTOBER 1990 TO SEPTEMBER 1991

\begin{tabular}{|c|c|c|c|c|c|c|c|c|c|c|c|c|}
\hline DAY & $\mathrm{OCT}$ & NOV & DEC & JAN & FE B & MAR & APR & MAY & JUN & JUL & AUG & SEP \\
\hline $\begin{array}{r}5 \\
10 \\
15 \\
20 \\
25 \\
\text { EOM }\end{array}$ & $\begin{array}{l}17.27 \\
17.23 \\
17.10 \\
16.84 \\
16.77 \\
16.99\end{array}$ & $\begin{array}{l}17.21 \\
17.36 \\
17.44 \\
17.59 \\
17.70 \\
17.68\end{array}$ & $\begin{array}{l}17.22 \\
16.85 \\
16.84 \\
16.50 \\
15.39 \\
13.36\end{array}$ & $\begin{array}{r}11.10 \\
7.69 \\
8.80 \\
9.63 \\
10.08 \\
10.38\end{array}$ & $\begin{array}{r}10.52 \\
9.62 \\
9.18 \\
9.12 \\
9.51 \\
9.70\end{array}$ & $\begin{array}{r}10.21 \\
11.01 \\
11.23 \\
10.07 \\
8.06 \\
8.42\end{array}$ & $\begin{array}{r}8.73 \\
9.61 \\
10.04 \\
10.07 \\
10.23 \\
10.65\end{array}$ & $\begin{array}{l}11.36 \\
11.88 \\
12.22 \\
12.50 \\
12.78 \\
13.29\end{array}$ & $\begin{array}{l}13.66 \\
13.90 \\
14.32 \\
14.77 \\
15.17 \\
15.51\end{array}$ & $\begin{array}{l}15.85 \\
16.18 \\
16.47 \\
16.72 \\
17.01 \\
17.35\end{array}$ & $\begin{array}{l}17.62 \\
17.86 \\
18.08 \\
18.29 \\
18.49 \\
18.71\end{array}$ & $\begin{array}{l}18.89 \\
19.06 \\
19.21 \\
19.37 \\
19.52 \\
19.67\end{array}$ \\
\hline
\end{tabular}

WTR YR 1991 LOW 19.67 SEP 30

POSEY COUNTY

380546087474301 . Local nuaber, PY 5 .

LOCATION.--Lat $38^{\circ} 05^{\prime} 46^{\circ}$, Iong $87^{\circ} 47^{\prime} 43^{\circ}$, in NE $\frac{1}{4}$, I

05120113 , about $0.5 \bullet i$ southwest of Wadesville along the west edge of Laurel Hill Ceaetary.

Owner: U.S. Geological Survey

AQUIFER. --Sandstone of Pennsylvanian age.

WELL CHARACTERISTICS.--Drilled artesian well, dianeter $6 \mathrm{in.}$, depth $221 \mathrm{ft}$, cased to $160 \mathrm{ft}$, open end.

INST RUMENTATION. - - Water-level recorder.

DATUM, --Elevation of land-surface datum is $460.60 \mathrm{ft}$ (revised) above National Geodetic Vertical Datue of 1929 .

Measuring point: Top of casing, $3.60 \mathrm{ft}$ above land-surface datue.

PERIOD OF RECORD.--Septeaber 1988 to current year.

EXTREMES FOR PERIOD OF RECORD.--Highest water level, $132.83 \mathrm{ft}$ below land-surface datua, Mar. 27 , 1991; 10west, $142.09 \mathrm{ft}$ below land-surface datum, Sept. 19, 1991.

\begin{tabular}{|c|c|c|c|c|c|c|c|c|c|c|c|c|}
\hline DAY & $\begin{array}{l}\text { HIGHEST } \\
\text { OCT }\end{array}$ & $\begin{array}{l}\text { WATER } \\
\text { NOV }\end{array}$ & LEVEL, IN & $\underset{\text { JAN }}{\text { FEET BELOW }}$ & $\begin{array}{c}\text { WAND - } \\
\text { FEB }\end{array}$ & $\begin{array}{c}\text { FACE D } \\
\text { MAR }\end{array}$ & DATUM, WATER & $\begin{array}{c}\text { YEAR } 0 \\
\text { MAY }\end{array}$ & OСTOBER ${ }_{\text {JUN }} 1990$ & JUL & $\begin{array}{l}\text { BER 1991 } \\
\text { AUG }\end{array}$ & SEP \\
\hline $\begin{array}{r}5 \\
10 \\
15 \\
20 \\
25 \\
\text { EOM }\end{array}$ & $\begin{array}{l}137.46 \\
137.38 \\
137.18 \\
137.15 \\
137.21 \\
137.12\end{array}$ & $\begin{array}{l}136.88 \\
136.84 \\
136.82 \\
136.73 \\
136.49 \\
136.47\end{array}$ & $\begin{array}{l}136.23 \\
136.11 \\
135.70 \\
135.62 \\
135.67 \\
135.78\end{array}$ & $\begin{array}{l}135.73 \\
135.47 \\
135.12 \\
135.16 \\
135.25 \\
135.01\end{array}$ & $\begin{array}{l}134.78 \\
134.68 \\
134.44 \\
134.55 \\
134.31 \\
134.07\end{array}$ & $\begin{array}{l}133.69 \\
133.97 \\
133.87 \\
133.48 \\
133.28 \\
133.24\end{array}$ & $\begin{array}{l}133.27 \\
133.31 \\
133.26 \\
133.35 \\
133.38 \\
133.39\end{array}$ & $\begin{array}{l}133.46 \\
133.98 \\
133.87 \\
134.24 \\
134.58 \\
134.76\end{array}$ & $\begin{array}{l}135.29 \\
136.05 \\
136.50 \\
137.95 \\
138.31 \\
138.19\end{array}$ & $\begin{array}{l}138.30 \\
138.66 \\
139.02 \\
139.22 \\
140.14 \\
140.58\end{array}$ & $\begin{array}{l}140.98 \\
141.12 \\
141.30 \\
141.31 \\
141.34 \\
141.52\end{array}$ & $\begin{array}{l}141.43 \\
141.30 \\
141.43 \\
141.87 \\
141.55 \\
141.85\end{array}$ \\
\hline
\end{tabular}

WTR YR 1991 HIGH 132.83 MAR 27

LOWEST WATER LEVEL, IN FEET BELOW LAND-SURFACE DATUM, WATER YEAR OCTOBER 1990 TO SEPTEMBER 1991

$\begin{array}{rrrrrrrrrrrrr}\text { DAY } & \text { OCT } & \text { NOV } & \text { DEC } & \text { JAN } & \text { FEB } & \text { MAR } & \text { APR } & \text { MAY } & \text { JUN } & \text { JUL } & \text { AUG } & \text { SEP } \\ & & & & & & & & & & & \\ 5 & 137.60 & 137.12 & 136.51 & 135.84 & 134.85 & 133.94 & 133.40 & 133.71 & 135.61 & 138.36 & 141.19 & 141.55 \\ 10 & 137.43 & 136.97 & 136.19 & 135.74 & 134.92 & 134.05 & 133.45 & 134.11 & 136.18 & 138.81 & 141.30 & 141.44 \\ 15 & 137.32 & 136.96 & 135.88 & 135.38 & 134.65 & 134.00 & 133.44 & 134.10 & 136.69 & 139.08 & 141.40 & 141.87 \\ 20 & 137.24 & 136.83 & 135.78 & 135.34 & 134.67 & 133.68 & 133.43 & 134.40 & 138.14 & 139.39 & 141.40 & 142.01 \\ 25 & 137.34 & 136.57 & 135.75 & 135.34 & 134.46 & 133.38 & 133.52 & 134.68 & 138.42 & 140.35 & 141.47 & 141.74 \\ \text { EOM } & 137.25 & 136.73 & 135.90 & 135.12 & 134.20 & 133.38 & 133.51 & 134.85 & 138.39 & 140.68 & 141.62 & 141.97\end{array}$

WTR YR 1991 LOW 142.09 SEP 19 
405916086530701. Local number. PU 6.

LOCATION..-Lat $40^{\circ} 59^{\prime} 16^{\circ}$, Iong $86^{\circ} 53^{\prime} 07^{\circ}$, in WWtsE 05120106 , on private property at the north edge of Francesville.

Owner: Earl Overaeyer.

AQUIFER.--Liaestone of Devonian age.

WELL CHARACTERISIICS.-.-Drilled artesian well, dianeter $8 \mathrm{in.}$ depth $663 \mathrm{ft}$, cased to $11 \mathrm{ft}$, open end.

INST RUMENTATION. - - Wa ter-leve 1 recorder.

DATUM.--Elevation of land-surface datue is $678.60 \mathrm{ft}$ above National Geodetic Vertical Datue of 1929 . Measuring point: Top of floor of shelter, $3.00 \mathrm{ft}$ above land-surface datun.

REMARKS. - -Water level affected by punpage and earthquakes.

PERIOD OF RECORD.--July 1956 to February 1971, January 1974 to current year.

EXTREMES FOR PERIOD OF RECORD.--Highest water level, $4.03 \mathrm{ft}$ below land-surface datun, June 15. 1958; lowest. $25.33 \mathrm{ft}$ below land-surface datue. Mov. 22, 1988.

\begin{tabular}{|c|c|c|c|c|c|c|c|c|c|c|c|c|}
\hline DAY & $\begin{array}{l}\text { HIGHEST } \\
\text { OCT }\end{array}$ & $\begin{array}{l}\text { WATER } \\
\text { NOV }\end{array}$ & LEVEL, IN & FEET BELOW & $\begin{array}{l}\text { LAND - } \\
\text { FEB }\end{array}$ & $\begin{array}{l}\text { ACE D } \\
\text { MAR }\end{array}$ & DATUM, WATER & $\begin{array}{l}\text { YEAR } \\
\text { MAY }\end{array}$ & OCTOBER $\underset{\text { JUN }}{1990}$ & TO SUE & $\begin{array}{l}\text { BER } 1991 \\
\text { AUG }\end{array}$ & SEP \\
\hline $\begin{array}{r}5 \\
10 \\
15 \\
20 \\
25 \\
\text { EOM }\end{array}$ & $\begin{array}{l}18.33 \\
16.78 \\
14.38 \\
14.42 \\
14.76 \\
15.21\end{array}$ & $\begin{array}{l}15.20 \\
14.45 \\
14.86 \\
15.30 \\
15.46 \\
15.25\end{array}$ & $\begin{array}{l}14.74 \\
14.95 \\
15.05 \\
15.57 \\
15.27 \\
13.38\end{array}$ & $\begin{array}{l}12.97 \\
13.99 \\
14.01 \\
13.14 \\
14.17 \\
14.74\end{array}$ & $\begin{array}{l}14.93 \\
14.64 \\
14.74 \\
15.23 \\
15.06 \\
14.90\end{array}$ & $\begin{array}{l}14.95 \\
15.52 \\
15.73 \\
13.39 \\
12.66 \\
13.09\end{array}$ & $\begin{array}{l}13.59 \\
14.05 \\
14.25 \\
13.91 \\
14.50 \\
14.70\end{array}$ & $\begin{array}{l}15.06 \\
15.70 \\
15.83 \\
15.13 \\
14.67 \\
14.91\end{array}$ & $\begin{array}{l}15.70 \\
15.98 \\
16.38 \\
17.16 \\
17.86 \\
18.17\end{array}$ & $\begin{array}{r}18.26 \\
18.87 \\
\ldots . \\
\ldots . \\
\ldots .\end{array}$ & $\begin{array}{r}21.79 \\
22.29 \\
22.63 \\
23.12 \\
23.42\end{array}$ & $\begin{array}{l}23.61 \\
23.97 \\
24.27 \\
24.58 \\
24.64 \\
25.07\end{array}$ \\
\hline
\end{tabular}

WTR YR 1991 HIGH 11.95 MAR 27

LOWEST WATER LEVEL, IN FEET BELOW LAND-SURFACE DATUM, WATER YEAR OCTOBER 1990 TO SEPTEMBER 1991

\begin{tabular}{|c|c|c|c|c|c|c|c|c|c|c|c|c|}
\hline DAY & OCT & MOV & DEC & JAK & FE B & MAR & APR & MAY & JUN & JUL & AUG & SEP \\
\hline $\begin{array}{r}5 \\
10 \\
15 \\
20 \\
25 \\
\text { EOM }\end{array}$ & $\begin{array}{l}18.53 \\
17.89 \\
14.82 \\
14.73 \\
15.05 \\
15.58\end{array}$ & $\begin{array}{l}15.66 \\
14.84 \\
15.08 \\
15.54 \\
15.85 \\
15.88\end{array}$ & $\begin{array}{l}15.27 \\
15.29 \\
15.54 \\
15.82 \\
15.54 \\
13.75\end{array}$ & $\begin{array}{l}13.25 \\
14.17 \\
14.25 \\
13.44 \\
14.37 \\
15.22\end{array}$ & $\begin{array}{l}15.13 \\
14.95 \\
15.44 \\
15.46 \\
15.33 \\
15.12\end{array}$ & $\begin{array}{l}15.20 \\
15.76 \\
16.03 \\
14.31 \\
12.94 \\
13.33\end{array}$ & $\begin{array}{l}13.84 \\
14.68 \\
14.68 \\
14.17 \\
14.72 \\
14.99\end{array}$ & $\begin{array}{l}15.35 \\
15.98 \\
16.07 \\
15.30 \\
14.80 \\
15.25\end{array}$ & $\begin{array}{l}15.98 \\
16.20 \\
16.63 \\
17.49 \\
18.03 \\
18.32\end{array}$ & $\begin{array}{r}18.61 \\
19.15 \\
\ldots . \\
\ldots \\
\ldots . \\
\ldots\end{array}$ & $\begin{array}{l}22.15 \\
22.60 \\
22.88 \\
23.51 \\
23.68\end{array}$ & $\begin{array}{l}23.93 \\
24.38 \\
24.47 \\
24.79 \\
24.94 \\
25.25\end{array}$ \\
\hline
\end{tabular}

WTR YR 1991 LOW 25.29 SEP 29

410739086365201. Local number. PU 7.

PULASKI COUNTY

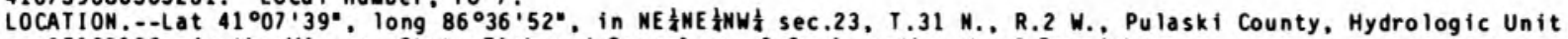
05120106 , in the Winaiac State Fish and Gane Area, 0.8 i southwest of Beardstown.

Owner: U.S. Geological Survey.

AQUIFER, --Sand and gravel of Pleistocene age.

WELL CHARACTERISTICS.-.-Drilled artesian well, dianeter $6 \mathrm{in.}$ depth $105 \mathrm{ft}$, cased to $98 \mathrm{ft}$, screened to $100 \mathrm{ft}$, open end.

INST RUMENTATION.-- Water-level recorder.

DATUM.--Elevation of land-surface datue is $715.26 \mathrm{ft}$ above Mational Geodetic Vertical Datua of 1929 . Measuring point: Top of floor of shelter, $2.50 \mathrm{ft}$ above land-surface datue.

PERIOD OF RECORO.--August 1967 to Septeaber 1971, Septeaber 1974 to current year.

EXTREMES FOR PERIOD OF RECORD.--Highest water level, $4.69 \mathrm{ft}$ below land-surface datum, June 15, 1981 ; lowest, $11.86 \mathrm{ft}$ below land-surface dature, Nov. 6-9, 1988 .

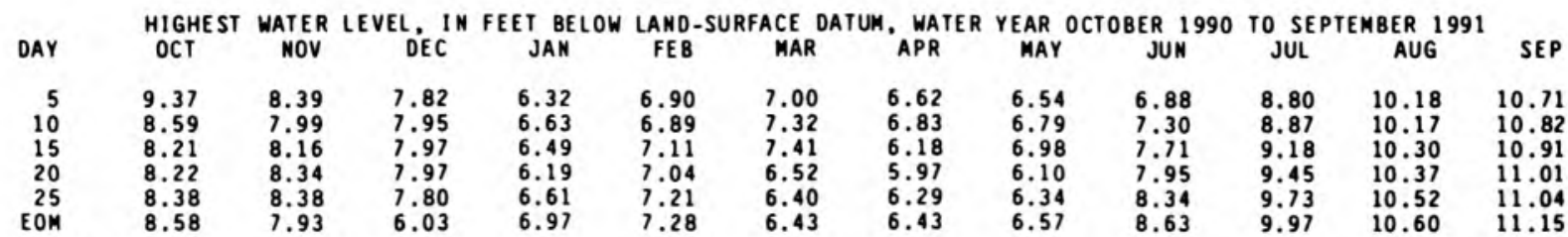

WTR YR 1991 HIGH 5.84 APR 17

LOWEST WATER LEVEL, IN FEET BELOW LAND-SURFACE DATUM, WATER YEAR OCTOBER 1990 TO SEPTEMBER 1991

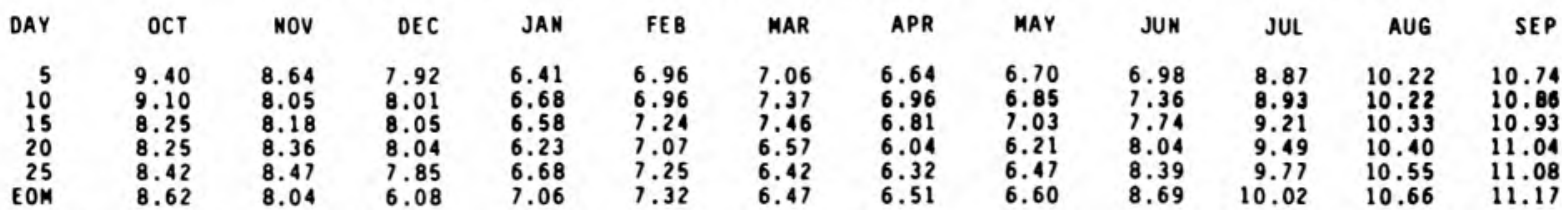

WTR YR 1991 LOW 11.17 SEP 29 
405605086551701 . Local number. PU 8.

LOCATION.--Lat $40^{\circ} 56^{\circ} 05^{\circ}$. IOng $86^{\circ} 55^{\prime} 17^{\circ}$, in SE 4 SE twWt sec.30, T.29 N., R.4 W. Pulaski County, Hydrologic Unit 05120106, at the Arrowhead Country Resource Conservation and Developaent Office property. $1 \mathrm{i}$ a $i$ east of Rensselaer on State Highway 114.

Owner: U.S. Geological Survey.

AQUIFER.--Limestone of Middle Silurian Period, Wabash Foreation.

WELL CHARACTERISTICS.--Drilled water-table well, dianeter 6 in.. depth $102 \mathrm{ft}$, cased to 12 ft, open end. INSTRUMENTATION.-- Water-level recorder.

DATUM.--Elevation of land-surface datue is $683.76 \mathrm{ft}$ above National Geodetic Vertical Datue of 1929 . Measuring point: Top of casing. $3.50 \mathrm{ft}$ above land-surface datur.

PERIOD OF RECORD.--August 1986 to current year.

EXTREMES FOR PERIOD OF RECORD.--Highest water level, $0.68 \mathrm{ft}$ below land-surface datua, Dec. 29 , 1991 ; lowest, $11.74 \mathrm{ft}$ below land-surface datue. Aug. 25, 1988.

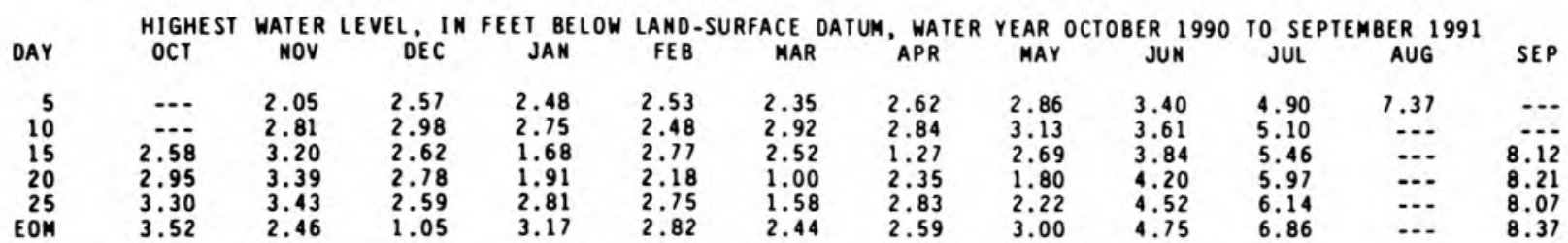

WTR YR 1991 HIGH .68 DEC 29

LOWESt WATER LEVEL, IN FEEt BELOW LAND-SURFACE DATUM, WATER YEAR OCTOBER 1990 TO SEPTEMBER 1991

\begin{tabular}{|c|c|c|c|c|c|c|c|c|c|c|c|c|}
\hline DAY & OCT & NOV & DEC & JAM & FE B & MAR & APR & MAY & JUN & JUL & AUG & SEP \\
\hline $\begin{array}{r}5 \\
10 \\
15 \\
20 \\
25 \\
\text { EOM }\end{array}$ & $\begin{array}{r}\ldots . \\
2.74 \\
3.00 \\
3.37 \\
3.56\end{array}$ & $\begin{array}{l}3.43 \\
3.01 \\
3.26 \\
3.46 \\
3.55 \\
2.58\end{array}$ & $\begin{array}{l}2.69 \\
3.08 \\
3.02 \\
2.86 \\
2.80 \\
1.49\end{array}$ & $\begin{array}{l}2.66 \\
2.94 \\
2.20 \\
2.00 \\
2.89 \\
3.33\end{array}$ & $\begin{array}{l}2.70 \\
2.58 \\
2.96 \\
2.29 \\
2.79 \\
2.90\end{array}$ & $\begin{array}{l}2.47 \\
2.99 \\
2.78 \\
1.15 \\
1.79 \\
2.54\end{array}$ & $\begin{array}{l}2.68 \\
3.00 \\
1.96 \\
2.47 \\
2.88 \\
2.75\end{array}$ & $\begin{array}{l}2.96 \\
3.18 \\
2.83 \\
2.11 \\
2.46 \\
3.10\end{array}$ & $\begin{array}{l}3.46 \\
3.67 \\
3.90 \\
4.38 \\
4.58 \\
4.83\end{array}$ & $\begin{array}{l}4.99 \\
5.22 \\
5.51 \\
6.01 \\
6.30 \\
6.96\end{array}$ & $\begin{array}{c}7.49 \\
\ldots \\
\ldots \\
\ldots \\
\ldots \\
\ldots\end{array}$ & $\begin{array}{l}\ldots \\
8.37 \\
8.27 \\
8.18 \\
8.42\end{array}$ \\
\hline
\end{tabular}

WTR YR 1991 LOW 8.78 SEP 14

RANDOLPH COUNTY

401532085085301 . Local number, RA 3.

LOCATION. - Lat $40^{\circ} 15^{\prime} 32^{\circ}$, long $85^{\circ} 08^{\prime} 53^{\circ}$, in ME 05120103 , at the east edge of Purdue University Agriculture Experiaent Station, about 5.5 a north of

Fareland.

Owner: U.S. Geological Survey.

AQUIFER. - - Liaestone of Silurian age.

WELL CHARACTERISTICS,--Drilled artesian well, dianeter 6 in., depth $54 \mathrm{ft}$, cased to $33 \mathrm{ft}$, open end.

INST RUMENTATION. - - Water-level recorder.

DATUM.--Elevation of land-surface datue is $970 \mathrm{ft}$ above Mational Geodetic Vertical Datua of 1929 . from topographic

ap. Measuring point: Top of floor of shelter, $3.85 \mathrm{ft}$ above land-surface datua.

PERIOD OF RECORD.--October 1966 to current year.

EXTREMES FOR PERIOD OF RECORD.--Highest water level, $7.68 \mathrm{ft}$ below land-surface datum, Dec. 30 , 1990 ; lowest,

$15.18 \mathrm{ft}$ below land-surface datun, Oct. 12, 13, 1988 .

\begin{tabular}{|c|c|c|c|c|c|c|c|c|c|c|c|c|}
\hline DAY & $\begin{array}{l}\text { HIGHEST } \\
\text { OCT }\end{array}$ & $\begin{array}{c}\text { WATER } \\
\text { NOV }\end{array}$ & LEVEL, IN & $\underset{\text { JAN }}{\text { FEET }}$ & $\begin{array}{l}\text { LAND - } \\
\text { FE B }\end{array}$ & $\begin{array}{l}\text { RFACE } \\
\text { MAR }\end{array}$ & $\begin{array}{c}\text { DATUM, WATER } \\
\text { APR }\end{array}$ & $\begin{array}{l}\text { YEAR } \\
\text { MAY }\end{array}$ & JUN & JUL & AUG & SEP \\
\hline $\begin{array}{r}5 \\
10 \\
15 \\
20 \\
25 \\
E O M\end{array}$ & $\begin{array}{r}10.39 \\
9.66 \\
9.85 \\
9.92 \\
9.95 \\
10.34\end{array}$ & $\begin{array}{r}10.22 \\
10.44 \\
10.70 \\
10.83 \\
10.49 \\
9.86\end{array}$ & $\begin{array}{l}9.41 \\
9.88 \\
9.26 \\
9.10 \\
9.16 \\
8.24\end{array}$ & $\begin{array}{r}9.39 \\
9.90 \\
9.39 \\
9.22 \\
9.84 \\
10.17\end{array}$ & $\begin{array}{l}9.36 \\
9.07 \\
9.27 \\
9.17 \\
9.46 \\
9.61\end{array}$ & $\begin{array}{r}9.74 \\
10.24 \\
9.82 \\
9.00 \\
9.06 \\
9.46\end{array}$ & $\begin{array}{r}9.80 \\
10.02 \\
9.36 \\
9.24 \\
9.59 \\
9.79\end{array}$ & $\begin{array}{l}10.11 \\
10.52 \\
10.68 \\
10.00 \\
10.99 \\
10.85\end{array}$ & $\begin{array}{l}10.74 \\
11.07 \\
11.26 \\
11.59 \\
11.65 \\
11.79\end{array}$ & $\begin{array}{l}11.89 \\
11.71 \\
11.91 \\
12.16 \\
12.41 \\
12.72\end{array}$ & $\begin{array}{l}12.90 \\
12.88 \\
13.10 \\
13.21 \\
13.51 \\
13.65\end{array}$ & $\begin{array}{l}13.83 \\
14.00 \\
14.15 \\
14.32 \\
14.11 \\
14.34\end{array}$ \\
\hline
\end{tabular}

WTR YR 1991 HIGH 7.68 DEC 30

LOWEST WATER LEVEL, IN FEET BELOW LAND-SURFACE DATUM, WATER YEAR OCTOBER 1990 TO SEPTEMBER 1991

$\begin{array}{rrrrrrrrrrrrr}\text { DAY } & \text { OCT } & \text { NOV } & \text { DEC } & \text { JAN } & \text { FEB } & \text { MAR } & \text { APR } & \text { MAY } & \text { JUN } & \text { JUL } & \text { AUG } & \text { SEP } \\ & & & & & & & & & & & \\ 10 & 10.47 & 10.45 & 9.55 & 9.56 & 9.68 & 9.86 & 9.88 & 10.22 & 10.86 & 11.93 & 12.96 & 13.91 \\ 10 & 10.05 & 10.55 & 9.97 & 10.04 & 9.22 & 10.35 & 10.30 & 10.60 & 11.11 & 11.77 & 13.00 & 14.11 \\ 15 & 10.09 & 10.75 & 10.12 & 9.63 & 9.81 & 10.03 & 9.56 & 10.77 & 11.33 & 11.99 & 13.18 & 14.19 \\ 20 & 9.97 & 10.89 & 9.16 & 9.30 & 9.28 & 9.09 & 9.30 & 10.99 & 11.62 & 12.21 & 13.33 & 14.41 \\ 25 & 10.07 & 10.69 & 9.30 & 9.91 & 9.53 & 9.17 & 9.63 & 11.03 & 11.69 & 12.54 & 13.57 & 14.23 \\ \text { EOM } & 10.41 & 10.03 & 8.90 & 10.39 & 9.68 & 9.52 & 9.97 & 11.18 & 11.83 & 12.74 & 13.78 & 14.46\end{array}$

WTR YR 1991 LOW 14.48 SEP 28 
413120086055601 . Local nuaber, SJ 31.

LOCATION, - Lat $41^{\circ} 31^{\prime} 20^{\circ}$, long $86^{\circ} 05^{\prime} 56^{\prime \prime}$, in SWtsWtsWt sec.31, T.36 N., R.4 E., St. Joseph County, Hydrologic Unit 07120001.4 west of Wakarusa.

Owner: U.S. Geological Survey.

AQUIFER.-.-Sand and gravel of Pleistocene age.

WELL CHARACTERISTICS.--Drilled water-table well, diameter $6 \mathrm{in.}$, depth $109 \mathrm{ft}$, cased to $104 \mathrm{ft}$, screened to $109 \mathrm{ft}$.

INSTRUME NTATION. - - Wa ter-level recorder.

DATUM.--Elevation of land-surface datua is $830.50 \mathrm{ft}$ above National Geodetic Vertical Datue of 1929 . Measuring point: Top of casing, $3.40 \mathrm{ft}$ above land-surface datua.

PERIOD OF RECORD..-August 1986 to current year.

EXTREMES FOR PERIOD OF RECORD.--Highest water leve1, $7.71 \mathrm{ft}$ below land-surface datua, Jan. 23, 1991; lowest,

$12.64 \mathrm{ft}$ below land-surface datur. 0ct. $6,7,1988$.

\begin{tabular}{|c|c|c|c|c|c|c|c|c|c|c|c|c|}
\hline AY & $\begin{array}{l}\text { HIGHEST } \\
\text { OCT }\end{array}$ & $\begin{array}{l}\text { WATER } \\
\text { NOV }\end{array}$ & LEVEL, IN & $\underset{\text { JAN }}{\text { FEET BELOW }}$ & $\begin{array}{l}\text { LAND- } \\
\text { FEB }\end{array}$ & $\begin{array}{l}\text { ACE D } \\
\text { MAR }\end{array}$ & $\begin{array}{c}\text { DATUM, WATER } \\
\text { APR }\end{array}$ & $\begin{array}{l}\text { YEAR } \\
\text { MAY }\end{array}$ & $\underset{\text { JUN }}{\text { OCTOBER }} 1990$ & $\begin{array}{l}\text { TO SE } \\
\text { JUL }\end{array}$ & $\begin{array}{c}\text { MBER 1 } \\
\text { AUG }\end{array}$ & 1991 \\
\hline $\begin{array}{r}5 \\
10 \\
15 \\
20 \\
25 \\
\text { EOM }\end{array}$ & $\begin{array}{l}9.14 \\
8.76 \\
8.60 \\
8.49 \\
8.47 \\
8.52\end{array}$ & $\begin{array}{l}8.31 \\
8.29 \\
8.37 \\
8.42 \\
8.30 \\
8.27\end{array}$ & $\begin{array}{l}8.11 \\
8.10 \\
8.02 \\
8.05 \\
8.00 \\
7.85\end{array}$ & $\begin{array}{l}7.88 \\
8.00 \\
7.84 \\
7.73 \\
7.87 \\
7.96\end{array}$ & $\begin{array}{l}8.14 \\
8.05 \\
7.89 \\
8.08 \\
8.08 \\
8.04\end{array}$ & $\begin{array}{l}7.87 \\
8.05 \\
8.10 \\
8.01 \\
8.01 \\
8.01\end{array}$ & $\begin{array}{l}8.07 \\
8.03 \\
7.98 \\
7.88 \\
7.83 \\
7.77\end{array}$ & $\begin{array}{l}7.85 \\
8.01 \\
8.19 \\
8.25 \\
8.29 \\
8.40\end{array}$ & $\begin{array}{l}8.44 \\
8.59 \\
8.66 \\
9.08 \\
9.40 \\
9.71\end{array}$ & $\begin{array}{r}9.73 \\
9.98 \\
10.27 \\
10.60 \\
11.08 \\
11.22\end{array}$ & $\begin{array}{l}11.68 \\
11.85 \\
12.05 \\
11.95 \\
11.87 \\
12.06\end{array}$ & $\begin{array}{l}12.24 \\
12.41 \\
12.37 \\
12.47 \\
12.32 \\
12.44\end{array}$ \\
\hline
\end{tabular}

WTR YR 1991 HIGH 7.71 JAN 23

LOWEST WATER LEVEL, IN FEET BELOW LAND-SURFACE DATUM, WATER YEAR OCTOBER 1990 TO SEPTEMBER 1991

\begin{tabular}{|c|c|c|c|c|c|c|c|c|c|c|c|c|}
\hline DAY & $O C T$ & MOV & DEC & JAN & FEB & MAR & APR & MAY & JUN & JUL & AUG & SEP \\
\hline $\begin{array}{r}5 \\
10 \\
15 \\
20 \\
25 \\
\text { EOM }\end{array}$ & $\begin{array}{l}9.20 \\
8.89 \\
8.66 \\
8.53 \\
8.49 \\
8.56\end{array}$ & $\begin{array}{l}8.50 \\
8.33 \\
8.40 \\
8.43 \\
8.37 \\
8.34\end{array}$ & $\begin{array}{l}8.19 \\
8.15 \\
8.12 \\
8.09 \\
8.05 \\
7.91\end{array}$ & $\begin{array}{l}7.96 \\
8.04 \\
7.88 \\
7.76 \\
7.93 \\
8.07\end{array}$ & $\begin{array}{l}8.16 \\
8.08 \\
8.01 \\
8.09 \\
8.12 \\
8.09\end{array}$ & $\begin{array}{l}7.93 \\
8.11 \\
8.16 \\
8.06 \\
8.05 \\
8.04\end{array}$ & $\begin{array}{l}8.11 \\
8.15 \\
8.09 \\
7.91 \\
7.86 \\
7.81\end{array}$ & $\begin{array}{l}7.95 \\
8.08 \\
8.25 \\
8.30 \\
8.33 \\
8.44\end{array}$ & $\begin{array}{l}8.48 \\
8.65 \\
8.74 \\
9.17 \\
9.54 \\
9.85\end{array}$ & $\begin{array}{r}9.84 \\
10.05 \\
10.35 \\
10.73 \\
11.15 \\
11.27\end{array}$ & $\begin{array}{l}11.75 \\
11.93 \\
12.08 \\
11.99 \\
11.91 \\
12.16\end{array}$ & $\begin{array}{l}12.32 \\
12.46 \\
12.39 \\
12.51 \\
12.41 \\
12.48\end{array}$ \\
\hline
\end{tabular}

WTR YR 1991 LOW 12.51 SEP 20

393943085490901 . Local number, SH 2.

SHELBY COUNTY

LOCATION - - at $39^{\circ} 39^{\prime} 43^{\circ}$, long $85^{\circ} 49^{\prime} 09^{\prime \prime}$, in SW $\frac{1}{4}$ SW $\frac{1}{4} N W \frac{1}{4}$ sec.13, T.14 N., R.6 E., Shelby County, Hydrologic Unit 05120204 , on the county right-of-way at the intersection of County Roads 950 North and 200 West, 3.0 . $i$ south of Carroliton.

Owner: U.S. Geological Survey.

AQUIFER.--Limestone of Devonian age.

WELL CHARACTERISTICS.--Drilled artesian well, diameter $6 \mathrm{in}$, depth $150 \mathrm{ft}$, cased to $128 \mathrm{ft}$, open end.

INST RUMENTATION. - - Wa ter-level recorder.

DATUM.--Elevation of land-surface datum is $816.10 \mathrm{ft}$ above Mational Geodetic Vertical Datum of 1929 . Measuring point: TOD of floor of shelter, $3.00 \mathrm{ft}$ above land-surface datua.

PERIOD OF RECORD..--Septeaber 1966 to current year.

EXTREMES FOR PERIOD OF RECORD.--Highest water level, $15.90 \mathrm{ft}$ below land-surface datua, May 27 , 1968; lowest,

$22.65 \mathrm{ft}$ below land-surface datun, Feb. $7,1977$.

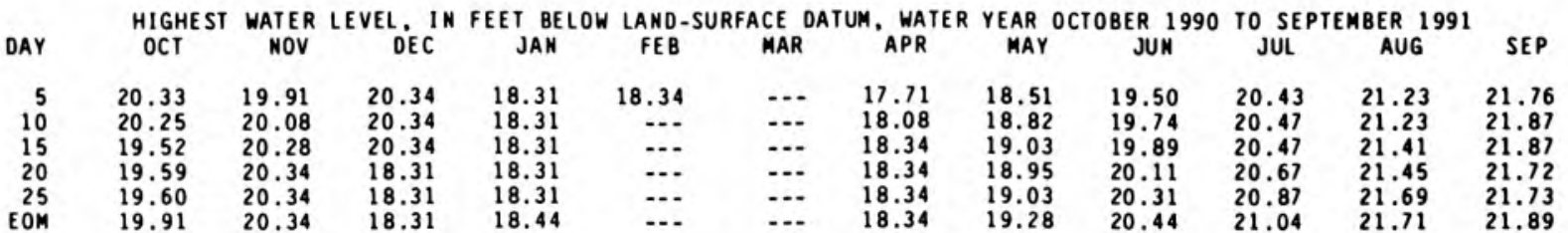

WTR YR 1991 HIGH 17.17 FEB 8

LOWEST WATER LEVEL, IN FEET BELOW LAND-SURFACE DATUM, WATER YEAR OCTOBER 1990 TO SEPTEMBER 1991

\begin{tabular}{|c|c|c|c|c|c|c|c|c|c|c|c|c|}
\hline DAY & $\mathrm{OCT}$ & NOV & DEC & JAN & FE B & MAR & APR & MAY & JUN & JUL & AUG & SEP \\
\hline $\begin{array}{r}5 \\
10 \\
15 \\
20 \\
25 \\
\text { EOM }\end{array}$ & $\begin{array}{l}20.47 \\
20.26 \\
19.68 \\
19.59 \\
19.67 \\
19.91\end{array}$ & $\begin{array}{l}19.99 \\
20.13 \\
20.28 \\
20.34 \\
20.34 \\
20.34\end{array}$ & $\begin{array}{l}20.34 \\
20.34 \\
20.34 \\
18.31 \\
18.31 \\
18.31\end{array}$ & $\begin{array}{l}18.31 \\
18.31 \\
18.31 \\
18.31 \\
18.31 \\
18.56\end{array}$ & $\begin{array}{r}18.34 \\
\ldots . \\
\ldots \\
\ldots \\
\ldots\end{array}$ & $\begin{array}{l}\ldots \\
\ldots \\
\ldots \\
\cdots \\
\cdots \\
\ldots\end{array}$ & $\begin{array}{l}17.75 \\
18.29 \\
18.34 \\
18.34 \\
18.34 \\
18.35\end{array}$ & $\begin{array}{l}18.51 \\
18.86 \\
19.07 \\
18.95 \\
19.07 \\
19.40\end{array}$ & $\begin{array}{l}19.58 \\
19.18 \\
19.92 \\
20.17 \\
20.37 \\
20.44\end{array}$ & $\begin{array}{l}20.44 \\
20.47 \\
20.55 \\
20.77 \\
20.93 \\
21.09\end{array}$ & $\begin{array}{l}21.23 \\
21.29 \\
21.42 \\
21.52 \\
21.69 \\
21.71\end{array}$ & $\begin{array}{l}21.78 \\
21.87 \\
21.89 \\
21.72 \\
21.73 \\
21.89\end{array}$ \\
\hline
\end{tabular}

WTR YR 1991 LOW 21.92 SEP 12 
411342086365601 L Local number. SK 2.

STARKE COUNTY

LOCATION. - - Lat $41^{\circ} 13^{\prime} 42^{\prime \prime}$. Iong $86^{\circ} 36^{\prime} 56^{\circ}$, in WW 07120001 , on private property in the southeast angle of intersection of U.S. Highway 35 and County Road 500 South, and 5.0 i south of Knox.

Owner: Sanuel A. Craigaile.

AQUIFER.--Gravel of Pleistocene age.

WELL CHARACTERISTICS.--Drilled artesian well, dianeter 6 in., depth $85 \mathrm{ft}$, cased to $71 \mathrm{ft}$, screened to 85 ft. INSTRUMENTATION. - - Wa ter-level recorder.

DATUM.--Elevation of land-surface datun is $712.97 \mathrm{ft}$ above Mational Geodetic Vertical Datue of 1929 . Measuring point: Top of floor of shelter, $3.00 \mathrm{ft}$ above land-surface datue.

PERIOD OF RECORD.--October 1935 to Decenber 1952 (randon instantaneous weasureaents only). August 1963 to October 1966, June 1976 to current year.

EXTREMES FOR PERIOD OF RECORD..-Highest water level, $0.83 \mathrm{ft}$ below land-surface datum, June 17 , 1949 ; lowest, $6.99 \mathrm{ft}$ below land-surface datua. Aug. 2, 1939, Sept. 17, 18, 1988.

\begin{tabular}{|c|c|c|c|c|c|c|c|c|c|c|c|c|}
\hline AY & $\begin{array}{l}\text { HIGHEST } \\
\text { OCT }\end{array}$ & $\begin{array}{l}\text { WATER } \\
\text { NOV }\end{array}$ & LEVEL, IN & $\begin{array}{c}\text { FEET BELOW } \\
\text { JAN }\end{array}$ & $\begin{array}{l}\text { LAND- } \\
\text { FEB }\end{array}$ & $\begin{array}{l}\text { ACE D } \\
\text { MAR }\end{array}$ & DATUM, WATER & $\begin{array}{l}\text { YEAR } 0 \\
\text { MAY }\end{array}$ & OCTOBER $\underset{\text { JUN }}{1990}$ & TO JUL & $\begin{array}{l}\text { BER } 1991 \\
\text { AUG }\end{array}$ & SEP \\
\hline $\begin{array}{r}5 \\
10 \\
15 \\
20 \\
25\end{array}$ & $\begin{array}{l}5.32 \\
3.83 \\
4.04 \\
4.24 \\
4.50 \\
4.73\end{array}$ & $\begin{array}{l}4.00 \\
4.19 \\
4.49 \\
4.69 \\
4.73 \\
4.03\end{array}$ & $\begin{array}{r}4.17 \\
4.39 \\
4.33 \\
4.42 \\
4.31 \\
2.55\end{array}$ & $\begin{array}{l}3.55 \\
3.87 \\
3.66 \\
3.48 \\
3.95 \\
4.28\end{array}$ & $\begin{array}{l}4.00 \\
4.05 \\
4.31 \\
4.19 \\
4.40 \\
4.47\end{array}$ & $\begin{array}{l}4.16 \\
4.45 \\
4.40 \\
3.90 \\
3.82 \\
4.05\end{array}$ & $\begin{array}{l}4.23 \\
4.44 \\
3.57 \\
3.59 \\
3.97 \\
3.94\end{array}$ & $\begin{array}{l}4.04 \\
4.32 \\
4.45 \\
3.84 \\
3.81 \\
3.34\end{array}$ & $\begin{array}{l}3.80 \\
4.32 \\
4.42 \\
4.68 \\
4.97 \\
5.16\end{array}$ & $\begin{array}{l}5.33 \\
5.36 \\
5.65 \\
5.83 \\
6.04 \\
6.15\end{array}$ & $\begin{array}{l}6.26 \\
6.17 \\
6.33 \\
6.24 \\
6.40 \\
6.45\end{array}$ & $\begin{array}{l}6.52 \\
6.61 \\
6.58 \\
6.63 \\
6.60 \\
6.65\end{array}$ \\
\hline
\end{tabular}

WTR YR 1991 HIGH 2.40 DEC 30

LOWEST WATER LEVEL, IN FEET BELOW LAND-SURFACE DATUM, WATER YEAR OCTOBER 1990 TO SEPTEMBER 1991

\begin{tabular}{|c|c|c|c|c|c|c|c|c|c|c|c|c|}
\hline DAY & OCT & NOV & DEC & JAN & FEB & MAR & APR & MAY & JUN & JUL & AUG & SEP \\
\hline $\begin{array}{r}5 \\
10 \\
15 \\
20 \\
25 \\
\text { EOM }\end{array}$ & $\begin{array}{l}5.36 \\
4.38 \\
4.13 \\
4.29 \\
4.55 \\
4.76\end{array}$ & $\begin{array}{l}4.72 \\
4.29 \\
4.52 \\
4.71 \\
4.80 \\
4.07\end{array}$ & $\begin{array}{r}4.19 \\
4.45 \\
4.55 \\
4.44 \\
4.37 \\
2.87\end{array}$ & $\begin{array}{l}3.63 \\
3.89 \\
3.80 \\
3.50 \\
4.03 \\
4.34\end{array}$ & $\begin{array}{l}4.08 \\
4.12 \\
4.39 \\
4.21 \\
4.44 \\
4.53\end{array}$ & $\begin{array}{r}4.20 \\
4.49 \\
4.52 \\
3.93 \\
3.89 \\
4.09\end{array}$ & $\begin{array}{l}4.27 \\
4.53 \\
4.39 \\
3.70 \\
4.02 \\
4.07\end{array}$ & $\begin{array}{l}4.29 \\
4.36 \\
4.50 \\
3.94 \\
4.17 \\
3.74\end{array}$ & $\begin{array}{l}3.94 \\
4.37 \\
4.59 \\
4.77 \\
5.01 \\
5.18\end{array}$ & $\begin{array}{l}5.37 \\
5.42 \\
5.70 \\
5.91 \\
6.09 \\
6.19\end{array}$ & $\begin{array}{l}6.28 \\
6.24 \\
6.38 \\
6.27 \\
6.42 \\
6.50\end{array}$ & $\begin{array}{l}6.55 \\
6.63 \\
6.61 \\
6.65 \\
6.62 \\
6.66\end{array}$ \\
\hline
\end{tabular}

WTR YR 1991 LOW 6.66 SEP 27 
414204085054002 . Local number, SB 6.

LOCATION.--Lat $41^{\circ} 42^{\prime} 04^{\circ}$. Iong $85^{\circ} 05^{\prime} 40^{\prime \prime}$, in SE $\frac{1}{4}$ SE 04050001 . 0.5 east of Panas on the north side of the Lake Gage Congregational Church.

Owner: U.S. Geological Survey.

AQUIFER. - - Sand and gravel of Pleistocene age.

WELL CHARACTERISTICS..-Drilled water-table well, dianeter 6 in., depth $76 \mathrm{ft}$, cased to 71 ft, screened to 76 ft. INSTRUMENTATION. - -Water-level recorder.

DATUM.--Elevation of land-surface datum is $987.89 \mathrm{ft}$ above National Geodetic Vertical Datun of 1929 . Measuring point: Top of casing. $3.60 \mathrm{ft}$ above land-surface datur.

PERIOD OF RECORD.--August 1986 to current year.

REVISED RECORDS. --WDR IN-91-1: 1989.

EXTREMES FOR PERIOD OF RECORD.--Highest water level, $14.79 \mathrm{ft}$ below land-surface datua, May 5, 1991 ; lowest, $19.12 \mathrm{ft}$ below land-surface datue, 0ct. 17, 1988.

HIGHEST WATER LEVEL, IN FEET BELOW LAND-SURFACE DATUM, WATER YEAR OCTOBER 1988 TO SEPTEMBER 1989

$\begin{array}{rrrrrrrrrrrrr}\text { DAY } & \text { OCT } & \text { NOV } & \text { DEC } & \text { JAN } & \text { FEB } & \text { MAR } & \text { APR } & \text { MAY } & \text { JUN } & \text { JUL } & \text { AUG } & \text { SEP } \\ & & & & & & & & & & \\ 5 & 19.00 & 18.95 & 18.36 & 18.21 & 17.83 & 17.85 & 17.62 & 17.33 & 17.00 & 16.75 & 16.83 & 16.98 \\ 10 & 18.98 & 18.88 & 18.33 & 18.10 & 17.82 & 17.81 & 17.54 & 17.39 & 16.88 & 16.78 & 16.92 & 16.95 \\ 15 & 19.08 & 18.88 & 18.39 & 18.01 & 17.85 & 17.75 & 17.45 & 17.39 & 16.76 & 16.77 & 16.90 & 16.95 \\ 20 & 18.99 & 18.63 & 18.32 & 17.96 & 17.79 & 17.72 & 17.40 & 17.36 & -36 & 16.76 & 16.91 & 16.98 \\ 25 & 18.98 & 18.53 & 18.35 & 17.90 & 17.81 & 17.72 & 17.36 & 17.34 & 16.69 & 16.80 & 16.97 & 16.98 \\ \text { EOM } & 18.95 & 18.43 & 18.25 & 17.84 & 17.85 & 17.67 & 17.39 & 17.30 & 16.69 & 16.83 & 16.98 & 17.05\end{array}$

WTR YR 1989 HIGH 16.68 JUN 26

LOWEST WATER LEVEL, IN FEET BELOW LAND-SURFACE DATUM, WATER YEAR OCTOBER 1988 TO SEPTEMBER 1989

\begin{tabular}{|c|c|c|c|c|c|c|c|c|c|c|c|c|}
\hline DAY & OCT & NOV & DEC & JAN & FE B & MAR & APR & MAY & JUN & JUL & AUG & SEP \\
\hline $\begin{array}{r}5 \\
10 \\
15 \\
20 \\
25 \\
\text { EOM }\end{array}$ & $\begin{array}{l}19.03 \\
19.06 \\
19.10 \\
19.05 \\
19.02 \\
19.00\end{array}$ & $\begin{array}{l}19.00 \\
19.05 \\
18.96 \\
18.75 \\
18.57 \\
18.47\end{array}$ & $\begin{array}{l}18.40 \\
18.42 \\
18.42 \\
18.40 \\
18.37 \\
18.29\end{array}$ & $\begin{array}{l}18.25 \\
18.14 \\
18.05 \\
18.07 \\
17.98 \\
17.88\end{array}$ & $\begin{array}{l}17.89 \\
17.89 \\
17.92 \\
17.85 \\
17.85 \\
17.89\end{array}$ & $\begin{array}{l}17.89 \\
17.86 \\
17.90 \\
17.79 \\
17.77 \\
17.71\end{array}$ & $\begin{array}{l}17.65 \\
17.58 \\
17.48 \\
17.45 \\
17.40 \\
17.43\end{array}$ & $\begin{array}{l}17.39 \\
17.42 \\
17.42 \\
17.42 \\
17.41 \\
17.36\end{array}$ & $\begin{array}{r}17.06 \\
16.91 \\
16.78 \\
16.71 \\
16.73\end{array}$ & $\begin{array}{l}16.79 \\
16.81 \\
16.81 \\
16.80 \\
16.84 \\
16.86\end{array}$ & $\begin{array}{l}16.89 \\
16.97 \\
16.95 \\
16.96 \\
17.01 \\
17.02\end{array}$ & $\begin{array}{l}17.00 \\
16.98 \\
16.98 \\
16.99 \\
17.03 \\
17.08\end{array}$ \\
\hline
\end{tabular}

WTR YR 1989 LOW 19.12 OCT 17

HIGHEST WATER LEVEL, IN FEET BELOW LAND-SURFACE DATUM, WATER YEAR OCTOBER 1990 TO SEPTEMBER 1991

\begin{tabular}{|c|c|c|c|c|c|c|c|c|c|c|c|c|}
\hline DAY & OCT & NOV & DEC & JAN & FEB & MAR & APR & MAY & JUN & JUL & AUG & SEP \\
\hline $\begin{array}{r}5 \\
10 \\
15 \\
20 \\
25 \\
\text { EOM }\end{array}$ & $\begin{array}{l}16.01 \\
15.92 \\
15.85 \\
15.84 \\
15.88 \\
15.91\end{array}$ & $\begin{array}{l}15.79 \\
15.88 \\
15.92 \\
15.98 \\
15.95 \\
15.98\end{array}$ & $\begin{array}{l}15.96 \\
15.99 \\
15.92 \\
16.01 \\
16.01 \\
15.70\end{array}$ & $\begin{array}{l}15.38 \\
15.28 \\
15.19 \\
15.09 \\
15.09 \\
15.06\end{array}$ & $\begin{array}{l}15.04 \\
15.02 \\
15.03 \\
15.02 \\
15.02 \\
14.99\end{array}$ & $\begin{array}{l}14.95 \\
15.07 \\
15.10 \\
15.05 \\
15.14 \\
15.09\end{array}$ & $\begin{array}{l}15.08 \\
15.10 \\
15.02 \\
15.04 \\
14.93 \\
14.86\end{array}$ & $\begin{array}{l}14.79 \\
14.84 \\
14.84 \\
14.89 \\
14.88 \\
14.91\end{array}$ & $\begin{array}{l}14.98 \\
14.99 \\
15.04 \\
15.13 \\
15.22 \\
15.29\end{array}$ & $\begin{array}{l}15.31 \\
15.38 \\
15.47 \\
15.55 \\
15.57 \\
15.66\end{array}$ & $\begin{array}{l}15.76 \\
15.79 \\
15.87 \\
15.88 \\
16.00 \\
16.07\end{array}$ & $\begin{array}{l}16.13 \\
16.20 \\
16.27 \\
16.36 \\
16.37 \\
16.47\end{array}$ \\
\hline
\end{tabular}

WTR YR 1991 HIGH 14.79 MAY 5

LOWEST WATER LEVEL, IN FEET BELOW LAND-SURFACE DATUM. WATER YEAR OCTOBER 1990 TO SEPTEMBER 1991

\begin{tabular}{|c|c|c|c|c|c|c|c|c|c|c|c|c|}
\hline DAY & $O C T$ & MOV & DEC & JAN & FEB & MAR & APR & MAY & JUN & JUL & AUG & SEP \\
\hline $\begin{array}{r}5 \\
10 \\
15 \\
20 \\
25 \\
\text { EOM }\end{array}$ & $\begin{array}{l}16.05 \\
15.98 \\
15.90 \\
15.88 \\
15.90 \\
15.94\end{array}$ & $\begin{array}{l}15.95 \\
15.94 \\
15.95 \\
16.00 \\
16.03 \\
16.05\end{array}$ & $\begin{array}{l}16.06 \\
16.05 \\
16.02 \\
16.08 \\
16.04 \\
15.80\end{array}$ & $\begin{array}{l}15.45 \\
15.36 \\
15.24 \\
15.13 \\
15.13 \\
15.13\end{array}$ & $\begin{array}{l}15.06 \\
15.06 \\
15.12 \\
15.06 \\
15.05 \\
15.05\end{array}$ & $\begin{array}{l}15.02 \\
15.11 \\
15.14 \\
15.11 \\
15.17 \\
15.15\end{array}$ & $\begin{array}{l}15.13 \\
15.20 \\
15.13 \\
15.07 \\
14.98 \\
14.91\end{array}$ & $\begin{array}{l}14.84 \\
14.88 \\
14.88 \\
14.93 \\
14.93 \\
14.98\end{array}$ & $\begin{array}{l}15.00 \\
15.03 \\
15.06 \\
15.16 \\
15.26 \\
15.32\end{array}$ & $\begin{array}{l}15.35 \\
15.44 \\
15.49 \\
15.59 \\
15.63 \\
15.68\end{array}$ & $\begin{array}{l}15.78 \\
15.84 \\
15.90 \\
15.94 \\
16.03 \\
16.12\end{array}$ & $\begin{array}{l}16.18 \\
16.24 \\
16.29 \\
16.39 \\
16.40 \\
16.51\end{array}$ \\
\hline
\end{tabular}

WTR YR 1991 LOW 16.51 SEP 29 
402734087033401 . Local nusber. IC 17.

TIPPECANOE COUNTY

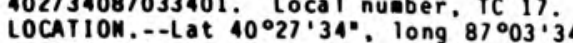

300 . On the property of Purdue University and at the southeast corner of the intersection of County Roads

3orth and 825 West, about 3.0 - i southeast of Otterbein.

Owner: U.S. Geological Survey.

AQUIFER.--Sand and gravel of Pleistocene age (Teays Valley aquifer).

WELL CHARACTERISTICS.--Orilled artesian well, dianeter $6 \mathrm{in.}$. depth $212.5 \mathrm{ft}$, cased to $207.5 \mathrm{ft}$, $5 \mathrm{creened} \mathrm{to} 212.5 \mathrm{ft}$. INSTRUMENTATION. - - Water-level recorder.

DATUM.--Elevation of land-surface datue is $681 \mathrm{ft}$ above National Geodetic Vertical Datue of 1929, froe topographic

a. Measuring point: TOP of casing, $3.60 \mathrm{ft}$ above land-surface datue.

PERIOD OF RECORD.--August 1989 to current year.

EXTREMES FOR PERIOD OF RECORD..--Highest water level, $110.98 \mathrm{ft}$ below land-surface datua, October 2, 1989; lowest,

$121.28 \mathrm{ft}$ below land-surface datun, August $18,1989$.

\begin{tabular}{|c|c|c|c|c|c|c|c|c|c|c|c|c|}
\hline DAY & $\begin{array}{l}\text { HIGHE ST } \\
\text { OCT }\end{array}$ & $\begin{array}{c}\text { T WATER } \\
\text { MOV }\end{array}$ & LEVEL, IN & 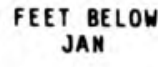 & $\begin{array}{l}\text { W LAMD-S } \\
\text { FEB }\end{array}$ & ${ }_{\text {MAR }}^{\text {FACE }}$ & $\begin{array}{c}\text { DATUM, WATER } \\
\text { APR }\end{array}$ & $\begin{array}{l}\text { YEAR } \\
\text { MAY }\end{array}$ & OCTOBER 1990 & TO SUL & $\begin{array}{l}\text { ABER } 1991 \\
\text { AUG }\end{array}$ & SEP \\
\hline $\begin{array}{r}5 \\
10 \\
15 \\
20 \\
25 \\
\text { EOM }\end{array}$ & $\begin{array}{l}119.10 \\
118.91 \\
118.90 \\
119.08 \\
119.10 \\
119.08\end{array}$ & $\begin{array}{l}118.33 \\
118.77 \\
118.95 \\
118.84 \\
118.32 \\
118.86\end{array}$ & $\begin{array}{l}118.60 \\
118.66 \\
118.26 \\
118.49 \\
118.62 \\
118.63\end{array}$ & $\begin{array}{l}118.34 \\
118.27 \\
117.85 \\
117.72 \\
118.21 \\
117.87\end{array}$ & $\begin{array}{l}117.88 \\
117.69 \\
117.08 \\
117.59 \\
117.65 \\
117.22\end{array}$ & $\begin{array}{l}116.81 \\
117.48 \\
117.43 \\
117.01 \\
117.15 \\
117.15\end{array}$ & $\begin{array}{l}117.05 \\
116.75 \\
116.50 \\
116.68 \\
116.69 \\
116.37\end{array}$ & $\begin{array}{l}116.34 \\
116.69 \\
116.31 \\
116.44 \\
116.06 \\
115.88\end{array}$ & $\begin{array}{l}116.14 \\
116.13 \\
115.83 \\
116.00 \\
116.02 \\
115.80\end{array}$ & $\begin{array}{l}115.74 \\
115.77 \\
115.93 \\
115.76 \\
115.74 \\
115.69\end{array}$ & $\begin{array}{l}115.69 \\
115.54 \\
115.71 \\
115.54 \\
115.90 \\
115.66\end{array}$ & $\begin{array}{l}115.73 \\
115.68 \\
115.52 \\
115.91 \\
115.29 \\
115.79\end{array}$ \\
\hline
\end{tabular}

WTR YR 1991 HIGH 115.29 SEP 25

LOMEST MATER LEVEL, IN FEET BELOW LAND-SURFACE DATUM, WATER YEAR OCTOBER 1990 TO SEPTEMBER 1991

\begin{tabular}{|c|c|c|c|c|c|c|c|c|c|c|c|c|}
\hline DAY & OCT & nov & DEC & JAM & FE B & MAR & APR & MAY & JUN & JUL & AU6 & SEP \\
\hline $\begin{array}{r}5 \\
10 \\
15 \\
20 \\
25 \\
\text { EOM }\end{array}$ & $\begin{array}{l}119.15 \\
119.07 \\
119.19 \\
119.21 \\
119.19 \\
119.11\end{array}$ & $\begin{array}{l}118.68 \\
118.87 \\
119.05 \\
118.88 \\
118.52 \\
119.13\end{array}$ & $\begin{array}{l}118.89 \\
118.71 \\
118.54 \\
118.61 \\
118.74 \\
118.82\end{array}$ & $\begin{array}{l}118.62 \\
118.56 \\
117.98 \\
117.79 \\
118.31 \\
118.22\end{array}$ & $\begin{array}{l}117.91 \\
117.74 \\
117.64 \\
117.67 \\
117.69 \\
117.42\end{array}$ & $\begin{array}{l}117.10 \\
117.61 \\
117.64 \\
117.25 \\
117.23 \\
117.30\end{array}$ & $\begin{array}{l}117.13 \\
117.12 \\
116.72 \\
116.78 \\
116.79 \\
116.52\end{array}$ & $\begin{array}{l}116.56 \\
116.75 \\
116.36 \\
116.51 \\
116.17 \\
115.96\end{array}$ & $\begin{array}{l}116.30 \\
116.26 \\
115.89 \\
116.08 \\
116.06 \\
115.88\end{array}$ & $\begin{array}{l}115.77 \\
115.83 \\
116.03 \\
115.81 \\
115.81 \\
115.74\end{array}$ & $\begin{array}{l}115.74 \\
115.68 \\
115.71 \\
115.65 \\
115.93 \\
115.74\end{array}$ & $\begin{array}{l}115.74 \\
115.68 \\
115.55 \\
115.97 \\
115.62 \\
115.85\end{array}$ \\
\hline
\end{tabular}

WTR YR 1991 LOW 119.35 OCT 29

402734087033402. Local number. TC 18.

TIPPECAMOE COUNTY

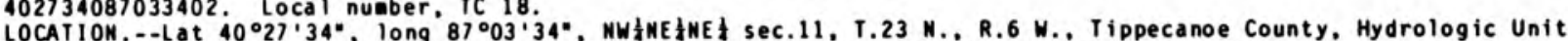
05120108 , on the property of Purdue University and at the southeast corner of the intersection of County Roads 300 North and 825 West, about 3.0 i southeast of Otterbein.

Owner: U.S. Geologicai Survey

AQUIFER. --Sand and gravel of Pleistocene age.

WELL CHARACTERISTICS.--Orilled water-table well, dianeter $6 \mathrm{in.}$, depth $64 \mathrm{ft}$, cased to $59 \mathrm{ft}$, screened to $64 \mathrm{ft}$. INSTRUMENTATION. - - Water-level recorder.

DATUM, --Elevation of land-surface datue is $681 \mathrm{ft}$ above National Geodetic Vertical Datun of 1929, froe topographic ap. Measuring point: TOp of casing, $3.50 \mathrm{ft}$ above land-surface datua.

PERIOD OF RECORD.--August 1989 to current year.

EXTREMES FOR PERIOD OF RECORD.--Highest water level, $16.67 \mathrm{ft}$ below land-surface datue, Mar. 27, 1991; lowest, $21.46 \mathrm{ft}$ below land-surface datur, Sept. 30, $199 \mathrm{i}$.

\begin{tabular}{|c|c|c|c|c|c|c|c|c|c|c|c|c|}
\hline$\gamma$ & $\begin{array}{l}\text { HIGHEST } \\
\text { OCT }\end{array}$ & $\begin{array}{l}\text { WATER } \\
\text { NOV }\end{array}$ & LEVEL, IN & $\begin{array}{c}\text { FEET BELOW } \\
\text { JAN }\end{array}$ & $\begin{array}{l}\text { LAND-S } \\
\text { FEB }\end{array}$ & $\begin{array}{l}\text { ACE } D \\
\text { MAR }\end{array}$ & $\begin{array}{l}\text { DATUM. WATER } \\
\text { APR }\end{array}$ & YEAR 0 & $\begin{array}{c}\text { OBER } 1990 \\
\text { JUN }\end{array}$ & $\begin{array}{l}\text { TO SEF } \\
\text { JUL }\end{array}$ & $\begin{array}{l}\text { EER } 199 \\
\text { AU6 }\end{array}$ & SEP \\
\hline $\begin{array}{r}5 \\
10 \\
15 \\
20 \\
25\end{array}$ & $\begin{array}{r}.58 \\
.45 \\
.45 \\
51\end{array}$ & $\begin{array}{l}20.50 \\
20.45 \\
20.53 \\
20.59 \\
20.59 \\
20.43\end{array}$ & $\begin{array}{l}20.21 \\
20.14 \\
20.05\end{array}$ & $\begin{array}{l}18.14 \\
18.49 \\
18.38 \\
17.98 \\
18.35 \\
18.63\end{array}$ & $\begin{array}{l}18.77 \\
18.77 \\
18.77 \\
18.95 \\
19.03 \\
19.02\end{array}$ & $\begin{array}{l}19.03 \\
19.26 \\
17.97 \\
17.07 \\
17.06 \\
17.21\end{array}$ & $\begin{array}{l}17.66 \\
18.00 \\
18.11 \\
18.18 \\
18.46 \\
18.63\end{array}$ & $\begin{array}{l}18.82 \\
19.06 \\
19.08 \\
18.94 \\
18.88 \\
18.93\end{array}$ & $\begin{array}{l}19.11 \\
19.31 \\
19.44 \\
19.64 \\
19.79 \\
19.92\end{array}$ & $\begin{array}{l}20.04 \\
20.20 \\
20.32 \\
20.41 \\
20.52 \\
20.66\end{array}$ & $\begin{array}{l}20.76 \\
20.77 \\
20.88 \\
20.92 \\
21.04 \\
21.09\end{array}$ & $\begin{array}{l}21.15 \\
21.21 \\
21.27 \\
21.36 \\
21.35 \\
21.43\end{array}$ \\
\hline
\end{tabular}

WTR YR 1991 HIGH 16.67 MAR 27 LOWEST WATER LEVEL, IN FEET BELOW LAND-SURFACE DATUM, WATER YEAR OCTOBER 1990 TO SEPTEMBER 1991

\begin{tabular}{|c|c|c|c|c|c|c|c|c|c|c|c|c|}
\hline DAY & OCT & NOV & DEC & JAN & FE B & MAR & APR & MAY & JUN & JUL & AU6 & SEP \\
\hline $\begin{array}{r}5 \\
10 \\
15 \\
20 \\
25 \\
\text { EOM }\end{array}$ & $\begin{array}{l}20.99 \\
20.76 \\
20.51 \\
20.46 \\
20.54 \\
20.64\end{array}$ & $\begin{array}{l}20.64 \\
20.48 \\
20.55 \\
20.60 \\
20.64 \\
20.51\end{array}$ & $\begin{array}{l}20.29 \\
20.24 \\
20.22 \\
20.10 \\
19.74 \\
17.92\end{array}$ & $\begin{array}{l}18.20 \\
18.54 \\
18.51 \\
18.03 \\
18.40 \\
18.73\end{array}$ & $\begin{array}{l}18.78 \\
18.82 \\
18.91 \\
18.97 \\
19.05 \\
19.05\end{array}$ & $\begin{array}{l}19.09 \\
19.29 \\
18.21 \\
17.15 \\
17.08 \\
17.28\end{array}$ & $\begin{array}{l}17.75 \\
18.14 \\
18.17 \\
18.25 \\
18.49 \\
18.69\end{array}$ & $\begin{array}{l}18.86 \\
19.10 \\
19.11 \\
18.94 \\
18.90 \\
19.03\end{array}$ & $\begin{array}{l}19.18 \\
19.33 \\
19.47 \\
19.66 \\
19.82 \\
19.94\end{array}$ & $\begin{array}{l}20.08 \\
20.23 \\
20.34 \\
20.44 \\
20.56 \\
20.68\end{array}$ & $\begin{array}{l}20.78 \\
20.82 \\
20.90 \\
20.96 \\
21.05 \\
21.12\end{array}$ & $\begin{array}{l}21.18 \\
21.24 \\
21.28 \\
21.38 \\
21.38 \\
21.46\end{array}$ \\
\hline
\end{tabular}

WTR YR 1991 LOW 21.46 SEP 30 
380608087395901 . Local nuaber, VA 6.

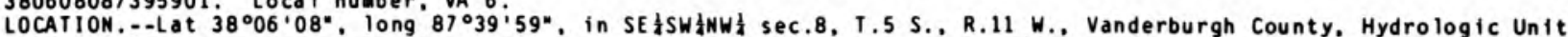
05120113 , on county right-of-way at the intersection of Buente and New Harmony Roads, 1.0 al southwest of Arnstrong.

Owner: U.S. Geological Survey.

AQUIFER. - - Sandstone of Pennsylvanian age.

WELL CHARACTERISTICS.--Drilled artesian well, diameter $6 \mathrm{in}$, depth $125 \mathrm{ft}$, cased to $80 \mathrm{ft}$, open end.

INST RUME NTATION. - - Wa ter-level recorder.

DATUM.--Elevation of land-surface datun is $446.57 \mathrm{ft}$ above National Geodetic Vertical Datue of 1929 . Measuring point: Top of floor of shelter, $3.40 \mathrm{ft}$ above land-surface datur.

PERIOD OF RECORD.--May 1965 to current year.

EXTREMES FOR PERIOD OF RECORD.--Highest water level, $24.88 \mathrm{ft}$ below land-surface datun, Apr. 3, 4, 1968; 10west, $35.43 \mathrm{ft}$ below land-surface datum, Sept. $2,3,1988$.

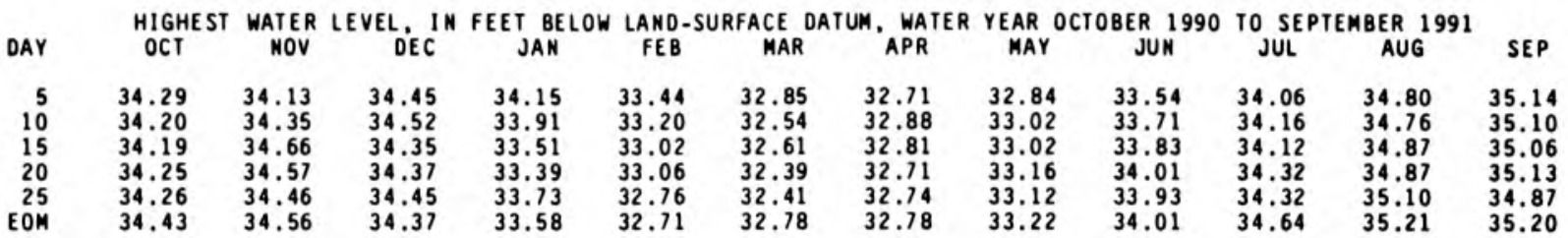

WTR YR 1991 HIGH 32.39 MAR 20

LOWEST WATER LEVEL, IM FEET BELOW LAND-SURFACE DATUM, WATER YEAR OCTOBER 1990 TO SEPTEMBER 1991

\begin{tabular}{|c|c|c|c|c|c|c|c|c|c|c|c|c|}
\hline DAY & OCT & NOV & DEC & JAN & FE B & MAR & $A P R$ & MAY & JUN & JUL & AUG & SEP \\
\hline $\begin{array}{r}5 \\
10 \\
15 \\
20 \\
25 \\
\text { EOM }\end{array}$ & $\begin{array}{l}34.42 \\
34.29 \\
34.37 \\
34.34 \\
34.32 \\
34.54\end{array}$ & $\begin{array}{l}34.42 \\
34.52 \\
34.74 \\
34.65 \\
34.49 \\
34.72\end{array}$ & $\begin{array}{l}34.67 \\
34.64 \\
34.56 \\
34.47 \\
34.55 \\
34.50\end{array}$ & $\begin{array}{l}34.30 \\
34.17 \\
33.80 \\
33.60 \\
33.81 \\
33.71\end{array}$ & $\begin{array}{l}33.56 \\
33.36 \\
33.28 \\
33.11 \\
32.93 \\
32.75\end{array}$ & $\begin{array}{l}32.93 \\
32.66 \\
32.75 \\
32.47 \\
32.65 \\
32.84\end{array}$ & $\begin{array}{l}32.77 \\
32.97 \\
32.93 \\
32.81 \\
32.81 \\
32.90\end{array}$ & $\begin{array}{l}33.01 \\
33.14 \\
33.13 \\
33.19 \\
33.22 \\
33.30\end{array}$ & $\begin{array}{l}33.64 \\
33.84 \\
33.95 \\
34.04 \\
34.02 \\
34.08\end{array}$ & $\begin{array}{l}34.09 \\
34.26 \\
34.21 \\
34.45 \\
34.43 \\
34.76\end{array}$ & $\begin{array}{l}34.86 \\
34.94 \\
34.92 \\
34.98 \\
35.21 \\
35.24\end{array}$ & $\begin{array}{l}35.23 \\
35.22 \\
35.11 \\
35.23 \\
35.03 \\
35.26\end{array}$ \\
\hline
\end{tabular}

WTR YR 1991 LOW 35.35 SEP 3

\section{VANDERBURGH COUNTY}

380626087344401 . Local number, VA 7

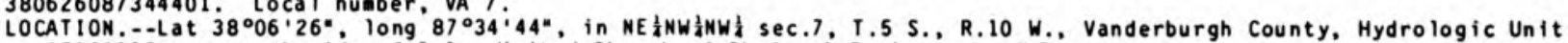
05120113 , on north side of Salen United Church of Christ 0.5 ai north of Darnstadt.

Owner: U.S. Geological Survey.

AQUIfER.--Inglefield Sandstone Member. Patoka Formation of Pennsylvanian Period.

WELL CHARACTERISTICS.--Drilled water-table well, diameter $6 \mathrm{in.}$, depth $70 \mathrm{ft}$, cased to $39.3 \mathrm{ft}$, open end.

INST RUMENTATION. - - Water-level recorder.

DATUM.--Elevation of land-surface datum is $475.35 \mathrm{ft}$ above National Geodetic Vertical Datua of 1929 . Measuring point: Top of floor of shelter, $4.04 \mathrm{ft}$ above land-surface datue.

PERIOD OF RECORD.--June 1986 to current year.

EXTREMES FOR PERIOD OF RECORD.--Highest water level, $19.93 \mathrm{ft}$ below land-surface datum, Mar. 27 , 1991 :

lowest, $25.06 \mathrm{ft}$ below land-surface datum, Oct. $29,1988$.

\begin{tabular}{|c|c|c|c|c|c|c|c|c|c|c|c|c|}
\hline DAY & $\begin{array}{l}\text { HIGHEST } \\
\text { OCT }\end{array}$ & $\begin{array}{l}\text { WATER } \\
\text { NOV }\end{array}$ & LEVEL, IN & $\underset{\text { JAN }}{\text { FEET BELOW }}$ & $\begin{array}{l}\text { LAND } \\
\text { FEB }\end{array}$ & $\begin{array}{l}\text { FCE D } \\
\text { MAR }\end{array}$ & $\begin{array}{c}\text { DATUM, WATER } \\
\text { APR }\end{array}$ & $\begin{array}{l}\text { YEAR } 0 \\
\text { MAY }\end{array}$ & OCTOBER $\underset{\text { JUN }}{ } 1990$ & TO SUL & $\begin{array}{l}\text { IBER } 1991 \\
\text { AUG }\end{array}$ & SEP \\
\hline $\begin{array}{r}5 \\
10 \\
15 \\
20 \\
25 \\
E O M\end{array}$ & $\begin{array}{l}23.07 \\
22.87 \\
22.86 \\
22.95 \\
23.01 \\
23.02\end{array}$ & $\begin{array}{l}22.45 \\
22.88 \\
23.12 \\
23.05 \\
22.82 \\
23.07\end{array}$ & $\begin{array}{l}22.81 \\
22.85 \\
22.58 \\
22.60 \\
22.60 \\
22.59\end{array}$ & $\begin{array}{l}21.99 \\
21.47 \\
20.95 \\
21.06 \\
21.67 \\
21.65\end{array}$ & $\begin{array}{l}21.28 \\
20.98 \\
20.68 \\
21.05 \\
20.93 \\
20.71\end{array}$ & $\begin{array}{l}20.32 \\
21.24 \\
21.08 \\
20.53 \\
20.56 \\
20.79\end{array}$ & $\begin{array}{l}20.86 \\
20.79 \\
20.62 \\
20.92 \\
21.04 \\
21.09\end{array}$ & $\begin{array}{l}21.11 \\
21.47 \\
21.28 \\
21.59 \\
21.38 \\
21.36\end{array}$ & $\begin{array}{l}21.70 \\
21.82 \\
21.74 \\
21.99 \\
22.15 \\
22.06\end{array}$ & $\begin{array}{l}22.20 \\
22.34 \\
22.67 \\
22.66 \\
22.74 \\
22.94\end{array}$ & $\begin{array}{l}23.03 \\
23.06 \\
23.20 \\
23.28 \\
23.51 \\
23.47\end{array}$ & $\begin{array}{l}23.67 \\
23.74 \\
24.05 \\
23.58 \\
24.04\end{array}$ \\
\hline
\end{tabular}

WTR YR 1991 HIGH 19.93 MAR 27

LOWEST WATER LEVEL, IN FEET BELOW LAND-SURFACE DATUM, WATER YEAR OCTOBER 1990 TO SEPTEMBER 1991

$\begin{array}{rrrrrrrrrrrrr}\text { DAY } & \text { OCT } & \text { NOV } & \text { DEC } & \text { JAN } & \text { FEB } & \text { MAR } & \text { APR } & \text { MAY } & \text { JUN } & \text { JUL } & \text { AUG } & \text { SEP } \\ & & & & & & & & & & & & \\ 10 & 23.16 & 22.92 & 23.16 & 22.16 & 21.43 & 20.72 & 20.94 & 21.28 & 21.87 & 22.29 & 23.12 & 23.77 \\ 15 & 23.10 & 23.09 & 22.92 & 22.00 & 21.13 & 21.36 & 21.09 & 21.57 & 21.94 & 22.44 & 23.23 & 23.84 \\ 20 & 23.13 & 23.27 & 22.87 & 21.35 & 21.20 & 21.27 & 20.93 & 21.36 & 21.85 & 22.76 & 23.26 & 23.85 \\ 25 & 23.11 & 23.14 & 22.80 & 21.34 & 21.17 & 20.84 & 21.04 & 21.66 & 22.08 & 22.85 & 23.41 & 24.25 \\ \text { EOM } & 23.11 & 23.02 & 22.74 & 21.83 & 20.98 & 20.69 & 21.19 & 21.51 & 22.20 & 22.85 & 23.64 & 23.77 \\ & & 23.46 & 22.76 & 21.93 & 20.83 & 20.91 & 21.26 & 21.48 & 22.18 & 23.01 & 23.62 & 24.21\end{array}$

WTR YR 1991 LOW 24.30 SEP 19 
392820087242601. Local number, VI 7.

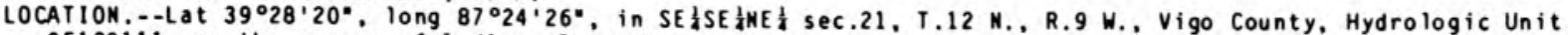
05120111 , on the campus of Indiana State University, in Terre Haute.

Owner: U.S. Geological Survey.

AQUIFER. - - Sand and gravel of Pleistocene age.

WELL CHARACTERISTICS.--Orilled water-table well, diameter $6 \mathrm{in.}$. depth $70 \mathrm{ft}$, cased to $67 \mathrm{ft}$, screened to $70 \mathrm{ft}$. INSTRUMENTATION. - - Water-level recorder.

DATUM.--Elevation of land-surface datum is $502 \mathrm{ft}$ above National Geodetic Vertical Datun of 1929, fron topographic ap. Measuring point: TOp of floor of shelter, $3.00 \mathrm{ft}$ above land-surface datur.

PERIOD OF RECORD.--January 1970 to current year.

EXTREMES FOR PERIOD OF RECORD.--Highest water level, $41.13 \mathrm{ft}$ below land-surface datun, Jan. 27, 1991; lowest. $51.90 \mathrm{ft}$ below land-surface datum, Sept. 29 to $0 \mathrm{ct} .1,1972$.

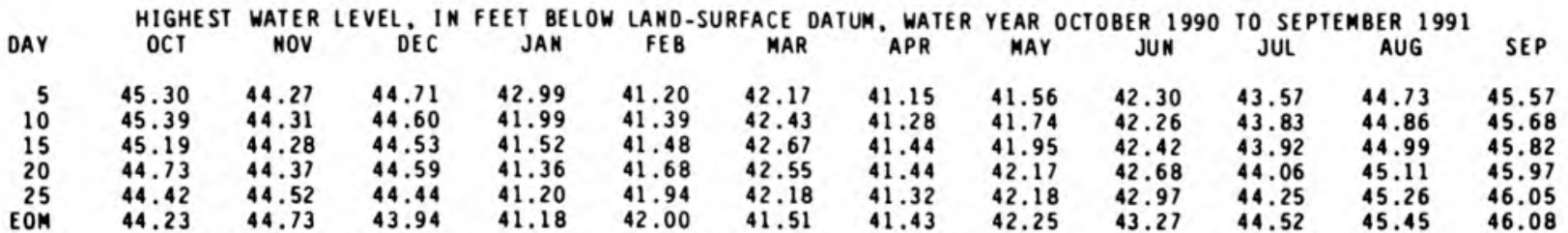

WTR YR 1991 HIGH 41.13 JAN 27

LOWEST WATER LEVEL, IN FEET BELOW LAND-SURFACE DATUM, WATER YEAR OCTOBER 1990 TO SEPTEMBER 1991

\begin{tabular}{|c|c|c|c|c|c|c|c|c|c|c|c|c|}
\hline DAY & OCT & NOV & DEC & JAN & FEB & MAR & APR & MAY & JUN & JUL & AUG & SEP \\
\hline $\begin{array}{r}5 \\
10 \\
15 \\
20 \\
25\end{array}$ & $\begin{array}{l}45.34 \\
45.40 \\
45.24 \\
44.83 \\
44.47 \\
44.25\end{array}$ & $\begin{array}{l}44.31 \\
44.33 \\
44.29 \\
44.40 \\
44.57 \\
44.74\end{array}$ & $\begin{array}{l}44.75 \\
44.62 \\
44.56 \\
44.61 \\
44.47 \\
44.05\end{array}$ & $\begin{array}{l}43.23 \\
42.15 \\
41.60 \\
41.38 \\
41.23 \\
41.22\end{array}$ & $\begin{array}{l}41.23 \\
41.43 \\
41.53 \\
41.73 \\
41.97 \\
42.01\end{array}$ & $\begin{array}{l}42.19 \\
42.48 \\
42.71 \\
42.61 \\
42.29 \\
41.62\end{array}$ & $\begin{array}{l}41.17 \\
41.32 \\
41.48 \\
41.48 \\
41.33 \\
41.46\end{array}$ & $\begin{array}{l}41.61 \\
41.79 \\
41.99 \\
42.19 \\
42.20 \\
42.28\end{array}$ & $\begin{array}{l}42.33 \\
42.28 \\
42.46 \\
42.73 \\
43.03 \\
43.32\end{array}$ & $\begin{array}{l}43.62 \\
43.87 \\
43.94 \\
44.10 \\
44.30 \\
44.56\end{array}$ & $\begin{array}{l}44.77 \\
44.89 \\
45.01 \\
45.14 \\
45.29 \\
45.48\end{array}$ & $\begin{array}{l}45.59 \\
45.69 \\
45.85 \\
45.98 \\
46.06 \\
46.09\end{array}$ \\
\hline
\end{tabular}

WTR YR 1991 LOW 46.09 SEP 29

404424085422801 . Local number, WB 3.

WABASH COUNTY

$4044240854228010^{\circ} 0^{\prime} 4^{\circ}$ U. 05120101 , on State Highway $124,3.5$. $i$ west of the county $i$ ine and in the southwest corner of United Telephone Company property.

Owner: U.S. Geological Survey.

AQUIFER. -. Sand and gravel of Pleistocene age.

WELL CHARACTERISIICS.--Orilled artesian well, dianeter $6 \mathrm{in.}$. depth $105 \mathrm{ft}$. cased to $100 \mathrm{ft}$, screened to $105 \mathrm{ft}$.

INST RUMENTATION. - - Wa ter-level recorder.

DATUM.--Elevation of land-surface datue is $850.45 \mathrm{ft}$ above National Geodetic Vertical Datue of 1929 . Measuring point: Top of casing, $3.50 \mathrm{ft}$ above land-surface datuan.

PERIOD OF RECORD.--August 1986 to current year.

EXTREMES FOR PERIOD OF RECORD.--Highest water level, $43.85 \mathrm{ft}$ below land-surface datua, Mar. 27, 1991; lowest, $48.20 \mathrm{ft}$ below land-surface datun, $0 \mathrm{ct}$. 30,1988 .

\begin{tabular}{|c|c|c|c|c|c|c|c|c|c|c|c|c|}
\hline DAY & $\begin{array}{l}\text { HIGHEST } \\
\text { OCT }\end{array}$ & $\begin{array}{l}\text { WATER } \\
\text { NOV }\end{array}$ & LEVEL, IN & FEET BELOW & $\begin{array}{l}\text { LAND- } \\
\text { FEB }\end{array}$ & $\begin{array}{l}\text { FACE } D \\
\text { MAR }\end{array}$ & $\begin{array}{l}\text { DATUM, WATER } \\
\text { APR }\end{array}$ & $\begin{array}{l}\text { YEAR } \\
\text { MAY }\end{array}$ & JUN & JuL & $A \cup G$ & SEP \\
\hline $\begin{array}{r}5 \\
10 \\
15 \\
20 \\
25 \\
\text { EOM }\end{array}$ & $\begin{array}{l}45.49 \\
45.24 \\
45.22 \\
45.19 \\
45.28\end{array}$ & $\begin{array}{l}44.90 \\
45.11 \\
45.36 \\
45.35 \\
45.02 \\
45.24\end{array}$ & $\begin{array}{l}44.88 \\
44.72 \\
44.78 \\
44.67 \\
44.63\end{array}$ & $\begin{array}{l}44.50 \\
44.63 \\
44.39 \\
44.26 \\
44.61 \\
44.58\end{array}$ & $\begin{array}{l}44.19 \\
44.63 \\
44.62 \\
44.46\end{array}$ & $\begin{array}{l}44.28 \\
44.66 \\
44.69 \\
44.44 \\
44.31 \\
44.26\end{array}$ & $\begin{array}{l}44.28 \\
44.13 \\
44.12 \\
44.04\end{array}$ & $\begin{array}{l}44.21 \\
44.57 \\
44.52 \\
44.82 \\
44.69 \\
44.48\end{array}$ & $\begin{array}{l}44.59 \\
44.78 \\
44.77 \\
45.00 \\
45.18 \\
45.28\end{array}$ & $\begin{array}{l}45.25 \\
45.32 \\
45.51 \\
45.55 \\
45.66 \\
45.82\end{array}$ & $\begin{array}{l}45.98 \\
45.85 \\
46.03 \\
45.96 \\
46.33 \\
46.31\end{array}$ & $\begin{array}{l}46.43 \\
46.48 \\
46.50 \\
46.79 \\
46.53 \\
46.86\end{array}$ \\
\hline
\end{tabular}

WTR YR 1991 HIGH 43.85 MAR 27

LOWEST WATER LEVEL, IN FEET BELOW LAND-SURFACE DATUM. WATER YEAR OCTOBER 1990 TO SEPTEMBER 1991

\begin{tabular}{|c|c|c|c|c|c|c|c|c|c|c|c|c|}
\hline DAY & OCT & NOV & DEC & JAN & FEB & MAR & $A P R$ & MAY & JUN & JUL & AUG & SEP \\
\hline $\begin{array}{r}5 \\
10 \\
15 \\
20 \\
25 \\
\text { EOM }\end{array}$ & $\begin{array}{l}45.74 \\
45.62 \\
45.39 \\
45.31 \\
45.26 \\
45.35\end{array}$ & $\begin{array}{l}45.23 \\
45.21 \\
45.44 \\
45.38 \\
45.21 \\
45.41\end{array}$ & $\begin{array}{l}45.05 \\
44.98 \\
44.95 \\
44.87 \\
44.81 \\
44.71\end{array}$ & $\begin{array}{l}44.61 \\
44.78 \\
44.50 \\
44.32 \\
44.69 \\
44.81\end{array}$ & $\begin{array}{l}44.80 \\
44.64 \\
44.53 \\
44.68 \\
44.68 \\
44.59\end{array}$ & $\begin{array}{l}44.39 \\
44.84 \\
44.86 \\
44.58 \\
44.37 \\
44.31\end{array}$ & $\begin{array}{l}44.43 \\
44.45 \\
44.47 \\
44.21 \\
44.19 \\
44.13\end{array}$ & $\begin{array}{l}44.33 \\
44.63 \\
44.60 \\
44.84 \\
44.74 \\
44.51\end{array}$ & $\begin{array}{l}44.67 \\
44.86 \\
44.82 \\
45.06 \\
45.35 \\
45.47\end{array}$ & $\begin{array}{l}45.36 \\
45.37 \\
45.59 \\
45.70 \\
45.76 \\
45.92\end{array}$ & $\begin{array}{l}46.02 \\
45.98 \\
46.06 \\
46.06 \\
46.38 \\
46.39\end{array}$ & $\begin{array}{l}46.49 \\
46.55 \\
46.54 \\
46.86 \\
46.72 \\
46.96\end{array}$ \\
\hline
\end{tabular}

WTR YR 1991 LOW 46.96 SEP 30 
403948085414601 . Local number. WB 4.

LOCATION, - - Lat $40^{\circ} 39^{\prime} 48^{\prime \prime}$, long $85^{\circ} 41^{\prime} 46^{\circ}$, in NE \&SE tNE sec. 35, T.26N., R.7E.. Wabash County, Hydrologic Unit 05120103 , on America Road, 1.3 i southeast of La Fountaine.

Owner: U.S. Geological Survey

AQUIFER.-. Sand and gravel of the Pleistocene age.

WELL CHARACTERISTICS.--Drilled artesian well, dianeter 6 in., depth $118 \mathrm{ft}$, cased to $113 \mathrm{ft}$, screened to 118 ft. INST RUMENTATION. - - Wa ter-level recorder.

DATUM.--Elevation of land-surface datun is $837.40 \mathrm{ft}$ (revised) above Mational Geodetic Vertical Datun of 1929. Measuring point: Top of casing, $3.30 \mathrm{ft}$ above land-surface datua.

PERIOD OF RECORD..-August 1988 to current year.

EXTREMES FOR PERIOD OF RECORD.--Highest water level, $38.19 \mathrm{ft}$ below land-surface datue, Mov. 5, 1988; lowest, $44.58 \mathrm{ft}$ below land-surface datun, Dec. 23, 1989.

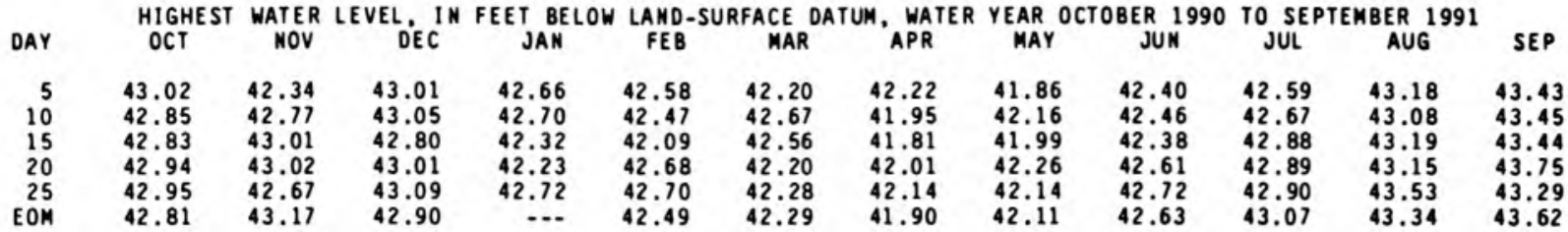

WTR YR 1991 HIGH 41.70 MAR 27

LOWEST WATER LEVEL, IN FEET BELOW LAND-SURFACE DATUM, WATER YEAR OCTOBER 1990 TO SEPTEMBER 1991

\begin{tabular}{|c|c|c|c|c|c|c|c|c|c|c|c|c|}
\hline DAY & $O C T$ & NOV & DEC & JAN & FEB & MAR & $A P R$ & MAY & JUN & JUL & AUG & SEP \\
\hline $\begin{array}{r}5 \\
10 \\
15 \\
20 \\
25 \\
\text { EOM }\end{array}$ & $\begin{array}{l}43.08 \\
43.00 \\
43.05 \\
43.04 \\
43.01 \\
42.87\end{array}$ & $\begin{array}{l}42.68 \\
42.87 \\
43.09 \\
43.07 \\
42.89 \\
43.36\end{array}$ & $\begin{array}{l}43.23 \\
43.13 \\
43.05 \\
43.14 \\
43.17 \\
43.06\end{array}$ & $\begin{array}{r}42.88 \\
42.88 \\
42.48 \\
42.29 \\
42.79 \\
\ldots . .\end{array}$ & $\begin{array}{l}42.60 \\
42.53 \\
42.57 \\
42.77 \\
42.76 \\
42.63\end{array}$ & $\begin{array}{l}42.42 \\
42.79 \\
42.73 \\
42.38 \\
42.35 \\
42.41\end{array}$ & $\begin{array}{l}42.28 \\
42.27 \\
42.01 \\
42.12 \\
42.22 \\
42.02\end{array}$ & $\begin{array}{l}42.08 \\
42.22 \\
42.06 \\
42.29 \\
42.21 \\
42.22\end{array}$ & $\begin{array}{l}42.50 \\
42.53 \\
42.43 \\
42.65 \\
42.75 \\
42.69\end{array}$ & $\begin{array}{l}42.64 \\
42.70 \\
42.98 \\
42.96 \\
43.01 \\
43.11\end{array}$ & $\begin{array}{l}43.24 \\
43.21 \\
43.24 \\
43.28 \\
43.56 \\
43.47\end{array}$ & $\begin{array}{l}43.48 \\
43.49 \\
43.50 \\
43.82 \\
43.53 \\
43.77\end{array}$ \\
\hline
\end{tabular}

WTR YR 1991 LOW 43.82 SEP 20

380624087164801 . Local nuaber, WK 4 .

WARRICK COUNTY

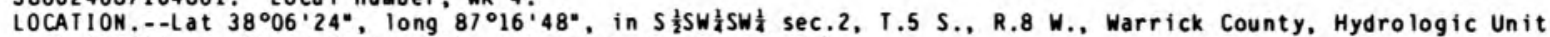

05140201 , on State Highway $61,4.2 \backsim i$ north of Boonville.

Owner: U.S. Geological Survey.

AQUIFER.--Sandstone from lower Dugger Foration of Pennsylvanian age.

WELL CHARACTERISIICS.--Drilled water-table well, dianeter $6 \mathrm{in.}$, depth $105 \mathrm{ft}$, cased to $30 \mathrm{ft}$, open end.

INST RUMENTATION. - - Wa ter-level recorder.

DATUM.--Elevation of land-surface datum is $446.18 \mathrm{ft}$ above National Geodetic Vertical Datum of 1929 . Measuring point: Top of floor of shelter, $4.09 \mathrm{ft}$ above land-surface datu.

PERIOD OF RECORD..-June 1986 to current year.

EXTREMES FOR PERIOD OF RECORD.--Highest water level, $8.01 \mathrm{ft}$ below land-surface datua, Mar. 22 , 1991; lowest,

$18.20 \mathrm{ft}$ below land-surface datur. Oct. 30, 1988.

\begin{tabular}{|c|c|c|c|c|c|c|c|c|c|c|c|c|c|}
\hline AY & $\begin{array}{l}\text { HIGHEST } \\
\text { OCT }\end{array}$ & $\begin{array}{l}\text { WATER } \\
\text { MOV }\end{array}$ & ${ }_{\text {DEC }}$ & FEET BELOW & $\begin{array}{l}\text { LAND- } \\
\text { FEB }\end{array}$ & $\begin{array}{l}\text { ACE D } \\
\text { MAR }\end{array}$ & $\begin{array}{c}\text { DATUM, WATER } \\
\text { APR }\end{array}$ & $\begin{array}{l}\text { YEAR } \\
\text { MAY }\end{array}$ & $\underset{\text { OCTOM }}{\text { OCTOBER }} 1990$ & TO JUL & $\begin{array}{l}\text { ABER } 1 \\
\text { AUG }\end{array}$ & 1991 & SEP \\
\hline $\begin{array}{r}5 \\
10 \\
15 \\
20 \\
25 \\
\text { EOM }\end{array}$ & $\begin{array}{r}10.27 \\
9.90 \\
9.66 \\
9.69 \\
9.55 \\
9.65\end{array}$ & $\begin{array}{l}9.61 \\
9.61 \\
9.70 \\
9.73 \\
9.44 \\
9.30\end{array}$ & $\begin{array}{l}9.03 \\
9.07 \\
9.09 \\
8.65 \\
8.42 \\
8.33\end{array}$ & $\begin{array}{l}8.44 \\
8.18 \\
8.07 \\
8.18 \\
8.53 \\
8.53\end{array}$ & $\begin{array}{l}8.54 \\
8.35 \\
8.20 \\
8.21 \\
8.37 \\
8.50\end{array}$ & $\begin{array}{l}8.46 \\
8.73 \\
8.53 \\
8.27 \\
8.12 \\
8.47\end{array}$ & $\begin{array}{l}8.75 \\
8.87 \\
8.89 \\
8.76 \\
8.75 \\
8.82\end{array}$ & $\begin{array}{l}9.04 \\
9.25 \\
9.34 \\
9.53 \\
9.62 \\
9.53\end{array}$ & $\begin{array}{r}9.73 \\
10.02 \\
10.26 \\
10.50 \\
10.11 \\
10.17\end{array}$ & $\begin{array}{l}10.11 \\
10.25 \\
10.52 \\
10.82 \\
11.11 \\
11.40\end{array}$ & $\begin{array}{l}11.62 \\
11.78 \\
11.94 \\
12.04 \\
12.27 \\
12.20\end{array}$ & & $\begin{array}{l}12.05 \\
11.98 \\
11.93 \\
11.96 \\
11.85 \\
12.02\end{array}$ \\
\hline
\end{tabular}

WTR YR 1991 HIGH 8.01 MAR 22

LOWEST WATER LEVEL, IN FEET BELOW LAND-SURFACE DATUM, WATER YEAR OCTOBER 1990 TO SEPIEMBER 1991

\begin{tabular}{|c|c|c|c|c|c|c|c|c|c|c|c|c|}
\hline DAY & OCT & NOV & DEC & JAN & FEB & MAR & APR & MAY & JUN & JUL & AUG & SEP \\
\hline $\begin{array}{r}5 \\
10 \\
15 \\
20 \\
25 \\
\text { EOM }\end{array}$ & $\begin{array}{r}10.33 \\
10.00 \\
9.70 \\
9.71 \\
9.56 \\
9.68\end{array}$ & $\begin{array}{l}9.69 \\
9.63 \\
9.72 \\
9.74 \\
9.46 \\
9.37\end{array}$ & $\begin{array}{l}9.08 \\
9.09 \\
9.14 \\
8.72 \\
8.46 \\
8.35\end{array}$ & $\begin{array}{l}8.48 \\
8.27 \\
8.12 \\
8.23 \\
8.60 \\
8.58\end{array}$ & $\begin{array}{l}8.62 \\
8.40 \\
8.29 \\
8.24 \\
8.42 \\
8.53\end{array}$ & $\begin{array}{l}8.49 \\
8.79 \\
8.56 \\
8.31 \\
8.17 \\
8.53\end{array}$ & $\begin{array}{l}8.78 \\
8.96 \\
8.93 \\
8.77 \\
8.77 \\
8.87\end{array}$ & $\begin{array}{l}9.07 \\
9.29 \\
9.38 \\
9.57 \\
9.67 \\
9.56\end{array}$ & $\begin{array}{r}9.80 \\
10.06 \\
10.29 \\
10.54 \\
10.13 \\
10.20\end{array}$ & $\begin{array}{l}10.12 \\
10.30 \\
10.60 \\
10.88 \\
11.17 \\
11.45\end{array}$ & $\begin{array}{l}11.65 \\
11.84 \\
11.97 \\
12.09 \\
12.30 \\
12.32\end{array}$ & $\begin{array}{l}12.07 \\
12.04 \\
11.95 \\
11.98 \\
11.89 \\
12.04\end{array}$ \\
\hline
\end{tabular}

WTR YR 1991 LOW 12.39 AUG 28 
383012086124501 . Local number, WA 2.

WASHINGTON COUNTY

LOCATION

05140104 , on West Washington School Road, 5.1 i north of Fredericksburg.
Owner: U.S. Geological Survey.

AQUIFER. --Limestone of Mississippian age.

WELL CHARACTERISTICS.--Drilled artesian well, diameter 6 in., depty $142.5 \mathrm{ft}$, cased to $101 \mathrm{ft}$, open end.

INST RUMENTAT ION. - - Wa ter-level recorder.

DATUM.--Elevation of land-surface datun is $780 \mathrm{ft}$ above National Geodetic Vertical Datue of 1929 , from topographic ap. Measuring point: Top of casing, $3.50 \mathrm{ft}$ above land-surface datue.

PERIOD OF RECORD.--August 1989 to current year.

EXTREMES FOR PERIOD OF RECORD.--Highest water level, $65.57 \mathrm{ft}$ below land-surface datue, June 8 , 1990 ; lowest,

$14.07 \mathrm{ft}$ below land-surface datum, Sept. 19, 1991 .

\begin{tabular}{|c|c|c|c|c|c|c|c|c|c|c|c|c|}
\hline DAY & $\begin{array}{l}\text { HIGHE ST } \\
\text { OCT }\end{array}$ & $\begin{array}{c}\text { WATER } \\
\text { NOV }\end{array}$ & LEVEL, IN & $\underset{\text { JAN }}{B E L O W}$ & $\begin{array}{l}\text { LAND-S } \\
\text { FEB }\end{array}$ & $\begin{array}{l}\text { FACE D } \\
\text { MAR }\end{array}$ & DATUM, WATER & $\begin{array}{c}\text { YEAR } 0 \\
\text { MAY }\end{array}$ & OCTOBER $\underset{\text { JUN }}{1990}$ & $\begin{array}{c}\text { TO SE } \\
\text { JUL }\end{array}$ & $\begin{array}{l}\text { BER } 1991 \\
\text { AUG }\end{array}$ & SEP \\
\hline $\begin{array}{r}5 \\
10 \\
15 \\
20 \\
25 \\
\text { EOM }\end{array}$ & $\begin{array}{l}73.10 \\
73.09 \\
73.09 \\
72.80 \\
72.75 \\
73.08\end{array}$ & $\begin{array}{l}72.76 \\
72.91 \\
73.05 \\
73.12 \\
72.86 \\
72.85\end{array}$ & $\begin{array}{l}72.67 \\
72.76 \\
72.54 \\
71.32 \\
71.35 \\
69.66\end{array}$ & $\begin{array}{l}70.66 \\
70.19 \\
70.10 \\
70.08 \\
70.62 \\
70.89\end{array}$ & $\begin{array}{l}70.85 \\
70.28 \\
70.10 \\
70.37 \\
70.62 \\
70.75\end{array}$ & $\begin{array}{l}70.69 \\
70.94 \\
70.85 \\
70.72 \\
69.40 \\
70.20\end{array}$ & $\begin{array}{l}70.30 \\
70.45 \\
70.46 \\
70.63 \\
70.81 \\
71.03\end{array}$ & $\begin{array}{l}71.15 \\
71.44 \\
71.75 \\
71.96 \\
72.04 \\
72.03\end{array}$ & $\begin{array}{l}72.19 \\
72.33 \\
72.58 \\
72.69 \\
72.77 \\
72.89\end{array}$ & $\begin{array}{l}73.31 \\
73.47 \\
73.51 \\
73.60 \\
73.72 \\
73.86\end{array}$ & $\begin{array}{l}73.84 \\
73.83 \\
73.85 \\
73.72 \\
73.87 \\
73.87\end{array}$ & $\begin{array}{l}73.71 \\
73.87 \\
74.01 \\
74.07 \\
73.87 \\
73.93\end{array}$ \\
\hline
\end{tabular}

WTR YR 1991 HIGH 67.44 MAR 23

LOWEST WATER LEVEL, IN FEET BELOW LAND-SURFACE DATUM, WATER YEAR OCTOBER 1990 TO SEPTEMBER 1991

\begin{tabular}{|c|c|c|c|c|c|c|c|c|c|c|c|c|}
\hline DAY & OCT & NOV & DEC & JAN & FEB & MAR & $A P R$ & MAY & JUN & JUL & AUG & SEP \\
\hline $\begin{array}{r}5 \\
10 \\
15 \\
20 \\
25 \\
\text { EOM }\end{array}$ & $\begin{array}{l}73.22 \\
73.18 \\
73.18 \\
72.82 \\
72.76 \\
73.21\end{array}$ & $\begin{array}{l}72.90 \\
72.98 \\
73.13 \\
73.15 \\
72.95 \\
72.97\end{array}$ & $\begin{array}{l}72.75 \\
72.80 \\
72.70 \\
71.50 \\
71.50 \\
70.31\end{array}$ & $\begin{array}{l}70.72 \\
70.29 \\
70.18 \\
70.18 \\
70.71 \\
70.98\end{array}$ & $\begin{array}{l}70.89 \\
70.43 \\
70.48 \\
70.44 \\
70.70 \\
70.87\end{array}$ & $\begin{array}{l}70.77 \\
70.99 \\
70.96 \\
70.79 \\
69.81 \\
70.21\end{array}$ & $\begin{array}{l}70.37 \\
70.61 \\
70.64 \\
70.73 \\
70.87 \\
71.10\end{array}$ & $\begin{array}{l}71.19 \\
71.58 \\
71.85 \\
71.97 \\
72.11 \\
72.11\end{array}$ & $\begin{array}{l}72.24 \\
72.39 \\
72.64 \\
72.73 \\
72.80 \\
72.89\end{array}$ & $\begin{array}{l}73.38 \\
73.49 \\
73.52 \\
73.66 \\
73.75 \\
73.87\end{array}$ & $\begin{array}{l}73.85 \\
73.84 \\
73.88 \\
73.80 \\
73.89 \\
73.88\end{array}$ & $\begin{array}{l}73.77 \\
73.90 \\
74.05 \\
74.07 \\
74.04 \\
73.95\end{array}$ \\
\hline
\end{tabular}

WTR YR 1991 LOW 74.07 SEP 19

394426085080601 . Local number. WE 6.

WAYNE COUNTY

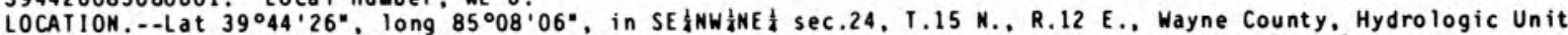
05080003 , on county right-of-way. $750 \mathrm{ft}$ east of State Highway 1, and 4.0 mi south of East Geraantown.

Owner: U.S. Geological Survey.

AQUIFER.-.-Sand and gravel of Pleistocene age.

WELL CHARACTERISTICS.--Drilled water-table well, dianeter $6 \mathrm{in.}$. depth $49 \mathrm{ft}$, cased to $47 \mathrm{ft}$, screened to $49 \mathrm{ft}$. INST RUMENTATION. - - Wa ter-level recorder.

DATUM.--Elevation of land-surface datum is $888 \mathrm{ft}$ above National Geodetic Vertical Datun of 1929 , froe topographic

ap. Measuring point: Top of collar in shelter, $3.60 \mathrm{ft}$ above land-surface datua.

PERIOD OF RECORD.-.Septenber 1966 to current year.

REVISED RECORDS.--WDR IN-81-1: 1980 .

EXTREMES FOR PERIOD OF RECORD...-Highest water leve1, $9.03 \mathrm{ft}$ below land-surface datum, Jan, 1, 1991: lowest,

$21.68 \mathrm{ft}$ below land-surface datum, Feb. $1,1971$.

\begin{tabular}{|c|c|c|c|c|c|c|c|c|c|c|c|c|}
\hline DAY & $\begin{array}{l}\text { HIGHEST } \\
\text { OCT }\end{array}$ & $\begin{array}{l}\text { WATER } \\
\text { NOV }\end{array}$ & LEVC $^{\text {IN }}$ & $\underset{\text { JAN }}{\text { FEET }}$ & $\begin{array}{l}\text { LAND-S } \\
\text { FEB }\end{array}$ & $\begin{array}{c}\text { FACE D D } \\
\text { MAR }\end{array}$ & DATUM, WATER & $\begin{array}{c}\text { YEAR } 0 \\
\text { MAY }\end{array}$ & OCTOBER $\underset{\text { JUN }}{\text { ONO }}$ & TO SULP & AUG & SEP \\
\hline $\begin{array}{r}5 \\
10 \\
15 \\
20 \\
25 \\
\text { EOM }\end{array}$ & $\begin{array}{l}13.81 \\
13.76 \\
13.26 \\
13.17 \\
13.28 \\
13.46\end{array}$ & $\begin{array}{l}13.63 \\
13.81 \\
14.00 \\
14.19 \\
14.36 \\
14.49\end{array}$ & $\begin{array}{r}14.18 \\
14.00 \\
13.94 \\
12.65 \\
11.61 \\
9.06\end{array}$ & $\begin{array}{r}9.65 \\
10.58 \\
10.86 \\
11.28 \\
11.71 \\
12.08\end{array}$ & $\begin{array}{l}12.27 \\
11.98 \\
12.08 \\
12.11 \\
12.17 \\
12.26\end{array}$ & $\begin{array}{l}12.38 \\
12.54 \\
11.65 \\
11.24 \\
10.13 \\
10.37\end{array}$ & $\begin{array}{l}10.98 \\
11.46 \\
11.30 \\
11.44 \\
11.66 \\
11.93\end{array}$ & $\begin{array}{l}12.19 \\
12.40 \\
12.60 \\
11.50 \\
10.71 \\
10.86\end{array}$ & $\begin{array}{l}11.36 \\
11.88 \\
12.21 \\
12.51 \\
12.78 \\
13.02\end{array}$ & $\begin{array}{l}13.27 \\
13.51 \\
13.71 \\
13.93 \\
14.19 \\
14.55\end{array}$ & $\begin{array}{l}14.85 \\
15.10 \\
15.37 \\
15.59 \\
15.79 \\
16.04\end{array}$ & $\begin{array}{l}16.24 \\
16.46 \\
16.67 \\
16.88 \\
17.07 \\
17.27\end{array}$ \\
\hline
\end{tabular}

WTR YR 1991 HIGH 9.03 JAN 1

LOWEST WATER LEVEL, IN FEET BELOW LAND-SURFACE DATUM, WATER YEAR OCTOBER 1990 TO SEPTEMBER 1991

$\begin{array}{rrrrrrrrrrrrr}\text { DAY } & \text { OCT } & \text { NOV } & \text { DEC } & \text { JAN } & \text { FEB } & \text { MAR } & \text { APR } & \text { MAY } & \text { JUN } & \text { JUL } & \text { AUG } & \text { SEP } \\ & & & & & & & & & & & \\ 5 & 13.83 & 13.67 & 14.26 & 9.85 & 12.29 & 12.40 & 11.06 & 12.22 & 11.47 & 13.32 & 14.91 & 16.28 \\ 10 & 13.84 & 13.85 & 14.02 & 10.71 & 11.99 & 12.57 & 11.55 & 12.43 & 11.96 & 13.55 & 15.15 & 16.50 \\ 15 & 13.31 & 14.03 & 14.00 & 10.94 & 12.13 & 11.85 & 11.37 & 12.64 & 12.27 & 13.76 & 15.41 & 16.71 \\ 20 & 13.17 & 14.23 & 12.87 & 11.36 & 12.17 & 11.25 & 11.45 & 11.62 & 12.57 & 13.98 & 15.63 & 16.91 \\ 25 & 13.31 & 14.39 & 11.68 & 11.79 & 12.20 & 10.18 & 11.71 & 10.74 & 12.82 & 14.25 & 15.83 & 17.11 \\ \text { EOM } & 13.49 & 14.49 & 9.73 & 12.13 & 12.28 & 10.49 & 11.98 & 10.96 & 13.07 & 14.61 & 16.08 & 17.31\end{array}$

WTR YR 1991 LOW 17.31 SEP 30 
404331085064701 LOCal number, WL 4

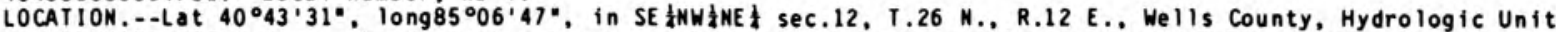
$05120101,1000 \mathrm{ft}$ south of north entrance to Ouabache State Recreation Area, and 3.5 al southeast of Bluffon. Owner: U.S. Geological Survey.

AQUIFER.--Silty doloaite of Silurian age.

WELL CHARACTERISTICS.--Drilled artesian we 11 , dianeter $6 \mathrm{in.}$, depth $79 \mathrm{ft}$, cased to $46 \mathrm{ft}$, open end.

INST RUMENTATION. - - Water-level recorder.

DATUM.--Elevation of land-surface datun is $826.04 \mathrm{ft}$ above National Geodetic Vertical Datun of 1929 . Measuring point: Top of floor of shelter, $2.35 \mathrm{ft}$ above land-surface datur.

PERIOD OF RECORD.--January 1967 to current year. (Seai-annual tape-down readings only Septeaber 1971 to Deceaber 1981.)

EXTREMES FOR PERIOD OF RECORD.--Highest water level, $17.70 \mathrm{ft}$ below land-surface datum, Apr. 4, 1973; lowest, $25.21 \mathrm{ft}$ below land-surface datun, Sept. 24, 1988.

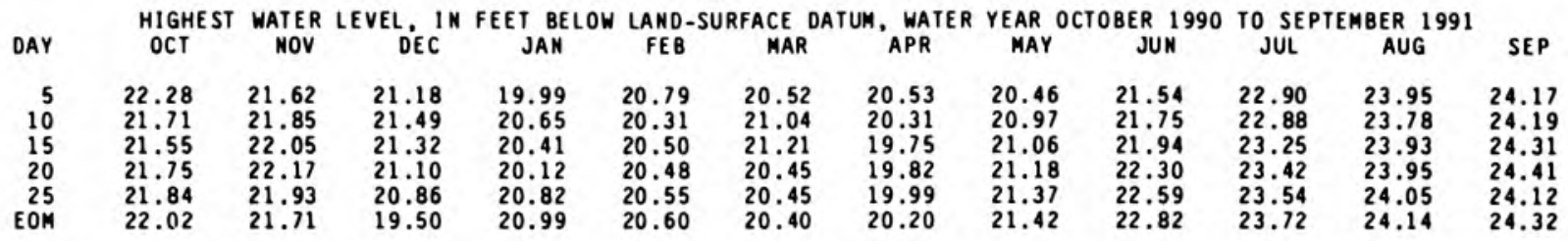

WTR YR 1991 HIGH 19.16 JAN 1

LOWEST WATER LEVEL, IN FEET BELOW LAND-SURFACE DATUM, WATER YEAR OCTOBER 1990 TO SEPTEMBER 1991

\begin{tabular}{|c|c|c|c|c|c|c|c|c|c|c|c|c|}
\hline DAY & ОСТ & NOV & DEC & JAN & FE B & MAR & APR & MAY & JUN & JUL & AUG & SEP \\
\hline $\begin{array}{r}5 \\
10 \\
15 \\
20 \\
25 \\
\text { EOM }\end{array}$ & $\begin{array}{l}22.45 \\
21.95 \\
21.84 \\
21.90 \\
22.20 \\
22.09\end{array}$ & $\begin{array}{l}21.95 \\
22.02 \\
22.13 \\
22.23 \\
22.15 \\
21.97\end{array}$ & $\begin{array}{l}21.55 \\
21.69 \\
21.61 \\
21.39 \\
21.05 \\
20.07\end{array}$ & $\begin{array}{l}20.20 \\
20.86 \\
20.63 \\
20.27 \\
20.90 \\
21.25\end{array}$ & $\begin{array}{l}20.91 \\
20.47 \\
21.00 \\
20.68 \\
20.65 \\
20.74\end{array}$ & $\begin{array}{l}20.74 \\
21.17 \\
21.31 \\
20.67 \\
20.52 \\
20.53\end{array}$ & $\begin{array}{l}20.67 \\
20.70 \\
19.97 \\
19.88 \\
20.10 \\
20.33\end{array}$ & $\begin{array}{l}20.66 \\
21.19 \\
21.16 \\
21.24 \\
21.63 \\
21.60\end{array}$ & $\begin{array}{l}21.66 \\
21.82 \\
22.07 \\
22.34 \\
22.66 \\
22.92\end{array}$ & $\begin{array}{l}22.98 \\
23.03 \\
23.32 \\
23.56 \\
23.69 \\
23.77\end{array}$ & $\begin{array}{l}24.00 \\
23.93 \\
24.01 \\
24.00 \\
24.14 \\
24.33\end{array}$ & $\begin{array}{l}24.25 \\
24.30 \\
24.36 \\
24.51 \\
24.30 \\
24.44\end{array}$ \\
\hline
\end{tabular}

WTR YR 1991 LOW 24.51 SEP 20

404914086403001. Local number, WT 4

WHITE COUNTY

LOCATION, - L at $40^{\circ} 49^{\prime} 14^{\circ}$, Iong $86^{\circ} 40^{\circ} 30^{\circ}$, in NWtSW 05120106 , in the southwest corner of the Pious Chapel property, 4.25 ai north of Idaville.

Owner: U.S. Geological Survey.

AQUIFER.-.-Sand and gravel of Pleistocene age.

WELL CHARACTERISTICS.--Drilled water-table well, dianeter 6 in., depth 134 ft, cased to 129 ft, screened to $134 \mathrm{ft}$.

INSTRUMENTATION. - - Wa ter-level recorder.

DATUM.--Elevation of land-surface datun is $683.06 \mathrm{ft}$ above Mational Geodetic Vertical Datun of 1929 . Measuring point: Top of casing, $3.20 \mathrm{ft}$ above land-surface datun.

PERIOD OF RECORD..-July 1986 to current year.

EXTREMES FOR PERIOD OF RECORD.--Highest water level, $1.94 \mathrm{ft}$ below land-surface datum, Mar. 27 . 1991 ; lowest, $13.66 \mathrm{ft}$ below land-surface datun. Aug. 3, 1991.

\begin{tabular}{|c|c|c|c|c|c|c|c|c|c|c|c|c|}
\hline DAY & $\begin{array}{l}\text { HIGHEST } \\
\text { OCT }\end{array}$ & $\begin{array}{c}\text { WATER } \\
\text { NOV }\end{array}$ & ${ }_{\text {DEC }}$ & $\underset{\text { JAN }}{\text { FEET BELOW }}$ & FEB & $\begin{array}{l}\text { ACE D } \\
\text { MAR }\end{array}$ & $\begin{array}{c}\text { DATUM, WATER } \\
\text { APR }\end{array}$ & $\begin{array}{l}\text { YEAR } \\
\text { MAY }\end{array}$ & $\underset{\text { JUN }}{\text { OCTOBER } 1990}$ & $\begin{array}{l}\text { TO SE } \\
\text { JUL }\end{array}$ & $\begin{array}{l}\text { ABER } 1991 \\
\text { AUG }\end{array}$ & SEP \\
\hline $\begin{array}{r}5 \\
10 \\
15 \\
20 \\
25 \\
\text { EON }\end{array}$ & $\begin{array}{l}4.95 \\
3.72 \\
3.13 \\
3.29 \\
3.56 \\
3.84\end{array}$ & $\begin{array}{l}3.75 \\
3.44 \\
3.72 \\
3.93 \\
3.99 \\
3.87\end{array}$ & $\begin{array}{l}3.62 \\
3.74 \\
3.76 \\
3.82 \\
3.60 \\
2.12\end{array}$ & $\begin{array}{l}2.36 \\
2.92 \\
2.83 \\
2.38 \\
2.91 \\
3.30\end{array}$ & $\begin{array}{l}3.35 \\
3.13 \\
3.26 \\
3.41 \\
3.47 \\
3.50\end{array}$ & $\begin{array}{l}3.30 \\
3.61 \\
3.68 \\
2.23 \\
2.23 \\
2.44\end{array}$ & $\begin{array}{l}2.79 \\
3.01 \\
2.82 \\
2.63 \\
2.94 \\
3.07\end{array}$ & $\begin{array}{l}3.19 \\
3.34 \\
3.47 \\
2.92 \\
2.94 \\
3.09\end{array}$ & $\begin{array}{r}3.39 \\
3.62 \\
.0 .14 \\
. .63\end{array}$ & $\begin{array}{r}8.31 \\
8.39 \\
8.34 \\
12.25 \\
12.66 \\
11.10\end{array}$ & $\begin{array}{r}12.73 \\
7.35 \\
6.67 \\
6.37 \\
6.42 \\
6.50\end{array}$ & $\begin{array}{l}6.47 \\
6.59 \\
6.56 \\
6.62 \\
6.50 \\
6.60\end{array}$ \\
\hline
\end{tabular}

WTR YR 1991 HIGH 1.94 MAR 27

LOWEST WATER LEVEL. IN FEET BELOW LAND-SURFACE DATUM, WATER YEAR OCTUBER 1990 TO SEPTEMBER 1991

\begin{tabular}{|c|c|c|c|c|c|c|c|c|c|c|c|}
\hline DAY & $\mathrm{OCT}$ & MOV & DEC & JAN & FEB & MAR & APR & MAY & JUN & JUL & AUG \\
\hline $\begin{array}{r}5 \\
10 \\
15 \\
20 \\
25 \\
\text { EOM }\end{array}$ & $\begin{array}{l}5.01 \\
4.32 \\
3.24 \\
3.31 \\
3.63 \\
3.92\end{array}$ & $\begin{array}{l}3.99 \\
3.51 \\
3.76 \\
3.96 \\
4.10 \\
4.02\end{array}$ & $\begin{array}{l}3.76 \\
3.80 \\
3.87 \\
3.89 \\
3.67 \\
2.36\end{array}$ & $\begin{array}{l}2.46 \\
2.94 \\
2.95 \\
2.44 \\
2.99 \\
3.43\end{array}$ & $\begin{array}{l}3.40 \\
3.19 \\
3.45 \\
3.46 \\
3.52 \\
3.55\end{array}$ & $\begin{array}{l}3.40 \\
3.66 \\
3.74 \\
2.54 \\
2.27 \\
2.51\end{array}$ & $\begin{array}{l}2.85 \\
3.18 \\
3.01 \\
2.69 \\
2.97 \\
3.14\end{array}$ & $\begin{array}{l}3.29 \\
3.40 \\
3.53 \\
2.98 \\
3.00 \\
3.16\end{array}$ & $\begin{array}{r}3.46 \\
3.66 \\
5.39 \\
10.52\end{array}$ & $\begin{array}{r}8.77 \\
8.67 \\
9.02 \\
12.79 \\
13.01 \\
12.70\end{array}$ & $\begin{array}{r}13.10 \\
8.90 \\
6.76 \\
6.39 \\
6.45 \\
6.54\end{array}$ \\
\hline
\end{tabular}

WTR YR 1991 LOW 13.66 AUG 3 
410337085264201 . Local number, WY 3.

WHITLEY COUNTY

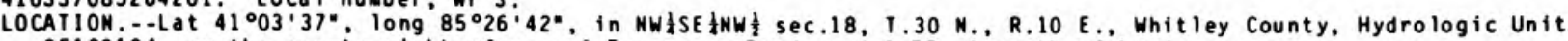
05120104 , on the county right-of-way of Evergreen Road, and 0.75 a north of Laud.

Owner: U.S. Geological Survey.

AQUIFER. - - Sand and gravel of Pleistocene age.

WELL CHARACTERISTICS.--Orilled artesian well, dianeter $6 \mathrm{in}$., depth $191 \mathrm{ft}$, cased to $187 \mathrm{ft}$, screened to 191 ft. INSTRUMENTATION. - - Wa ter-level recorder.

DATUM.--Elevation of land-surface datun is $870 \mathrm{ft}$ above National Geodetic Vertical Datun of 1929 . from topographic ap. Measuring point: Top of floor of shelter, $2.68 \mathrm{ft}$ above land-surface datua.

PERIOD OF RECORO.--Deceaber 1966 to Septeaber 1971, August 1974 to current year.

EXTREMES FOR PERIOD OF RECORD.--Highest water level, 49.30 ft below land-surface datun, Mar. 27 , 1976 ; lowest. $52.96 \mathrm{ft}$ below land-surface datum, Dec. 7, 1989.

\begin{tabular}{|c|c|c|c|c|c|c|c|c|c|c|c|c|}
\hline AY & $\begin{array}{l}\text { HIGHEST } \\
\text { OCT }\end{array}$ & $\begin{array}{c}\text { WATER } \\
\text { NOV }\end{array}$ & ${ }_{\text {DEC }}$ & FEET BELOW & $\begin{array}{l}\text { LAND- } \\
\text { FEB }\end{array}$ & MAR & $\begin{array}{c}\text { DATUM, WATER } \\
\text { APR }\end{array}$ & $\begin{array}{l}\text { YEAR } \\
\text { MAY }\end{array}$ & OCTOBER 1990 & JUL & $A \cup G$ & SEP \\
\hline $\begin{array}{l}5 \\
10 \\
15 \\
20 \\
25\end{array}$ & $\begin{array}{l}51.64 \\
51.53 \\
51.55 \\
51.58 \\
51.54 \\
51.50\end{array}$ & $\begin{array}{l}51.08 \\
51.40 \\
51.49 \\
51.51 \\
51.18 \\
51.46\end{array}$ & $\begin{array}{l}51.32 \\
51.40 \\
51.17 \\
51.34 \\
51.24 \\
51.14\end{array}$ & $\begin{array}{l}50.86 \\
50.85 \\
50.60 \\
50.53 \\
50.85 \\
50.76\end{array}$ & $\begin{array}{l}50.83 \\
50.70 \\
50.44 \\
50.73 \\
50.77 \\
50.61\end{array}$ & $\begin{array}{l}50.41 \\
50.74 \\
50.77 \\
50.59 \\
50.68 \\
50.68\end{array}$ & $\begin{array}{l}50.73 \\
50.56 \\
50.43 \\
50.57 \\
50.58 \\
50.47\end{array}$ & $\begin{array}{l}50.47 \\
50.71 \\
50.63 \\
50.79 \\
50.64 \\
50.58\end{array}$ & $\begin{array}{l}50.74 \\
50.71 \\
50.65 \\
50.85 \\
50.96 \\
51.05\end{array}$ & $\begin{array}{l}50.99 \\
51.09 \\
51.39 \\
51.50 \\
51.50 \\
51.65\end{array}$ & $\begin{array}{l}51.70 \\
51.56 \\
51.67 \\
51.58 \\
51.82 \\
51.84\end{array}$ & $\begin{array}{r}51.87 \\
52.01 \\
\ldots . . \\
\ldots \\
\ldots . . \\
\ldots\end{array}$ \\
\hline
\end{tabular}

WTR YR 1991 HIGH 50.26 MAR 27

LOWEST WATER LEVEL, IN FEET BELOW LAND-SURFACE DATUM, WATER YEAR OCTOBER 1990 TO SEPTEMBER 1991

\begin{tabular}{|c|c|c|c|c|c|c|c|c|c|c|c|c|}
\hline DAY & OCT & NOV & DEC & JAN & FEB & MAR & APR & MAY & JUN & JUL & AUG & SEP \\
\hline $\begin{array}{r}5 \\
10 \\
15 \\
20 \\
25 \\
\text { EOM }\end{array}$ & $\begin{array}{l}51.74 \\
51.65 \\
51.71 \\
51.71 \\
51.59 \\
51.60\end{array}$ & $\begin{array}{l}51.44 \\
51.53 \\
51.61 \\
51.56 \\
51.33 \\
51.63\end{array}$ & $\begin{array}{l}51.55 \\
51.52 \\
51.40 \\
51.47 \\
51.35 \\
51.26\end{array}$ & $\begin{array}{l}51.04 \\
51.00 \\
50.73 \\
50.62 \\
50.92 \\
50.92\end{array}$ & $\begin{array}{l}50.89 \\
50.80 \\
50.71 \\
50.79 \\
50.87 \\
50.80\end{array}$ & $\begin{array}{l}50.60 \\
50.86 \\
50.89 \\
50.75 \\
50.77 \\
50.81\end{array}$ & $\begin{array}{l}50.79 \\
50.83 \\
50.66 \\
50.67 \\
50.71 \\
50.56\end{array}$ & $\begin{array}{l}50.61 \\
50.81 \\
50.74 \\
50.84 \\
50.77 \\
50.65\end{array}$ & $\begin{array}{l}50.81 \\
50.86 \\
50.72 \\
50.93 \\
51.06 \\
51.11\end{array}$ & $\begin{array}{l}51.06 \\
51.22 \\
51.56 \\
51.61 \\
51.62 \\
51.71\end{array}$ & $\begin{array}{l}51.80 \\
51.69 \\
51.70 \\
51.67 \\
51.93 \\
51.94\end{array}$ & $\begin{array}{r}51.97 \\
52.09 \\
\ldots \\
\ldots \\
\ldots \\
\ldots\end{array}$ \\
\hline
\end{tabular}

WTR YR 1991 LOW 52.12 SEP 8 
Page

Access to WATSTORE Data

Accuracy of the records

Adams Lake near Wolcottville

Allen 5

Allen 6

Anderson River (tributary to Ohio River) basin, gaging-station records in

Annual mean, definition of

Annual precipitation in Indiana, average 1951-80

Annual runoff (AC-FT), definition of

Annual runofr (INCHIES), definition of

Annual runoff in Indiana, average 1951-80

Annual 7-day minimum, definition of...

Annual totals, definition of

Aquifer, definition of

Arrangement of records

Artesian, definition of ......

Back Creek at Lesville

Bacteria, definition of .........

Ball Lake near $\mathrm{H}$

Bartholomew 4

Bartholomew 8

Bartholomew 9

Bartholomew 10

Bartholomew 13...

Bass lake at Bass Lake........................

Bean Creek at Indianapol is

Bear Lake near Wolfa

Bed load, definition of.

Bed load discharge, definition of

Bed material, definition of

Benton 4

Bice ditch near South Marion

Big Blue Ruver (head of East Fork White River) at Carthage. at Shelbyville.

Big Chapman Lake near Warsaw

Big Creek near Wadesville

Big Lake near Wolflake

Big Lick Creek near Hartford City

Big Long Lake near Stroh

Big Raccoon Creek at Coxville.

at Ferndale

near Fincastle.

near Mecca.

Big Wulnut Creek (head of Eel River) near Reelsville

Bixler Lake at Kendallville

Blue Lake near Churubusco

Blue River (tributary to Ohi River) basin, gaging-station records in

Blue River at Federicksburg

$$
\text { near White Cloud }
$$

Boone 17

Bower Lake near Pleasant lake

Brush Creek near Nebranka

Buck (reek (tributary to Ohio River) basin, gaging-station records in.

Buck Creek near New Middletown

Buck Creek (tributary to Sugar Creek) at Acton

Buck Creek (tributaiy to White River) near Muncie

Burns Waterway, gaging station records in

Burns ditch at Gary.

Busseron Creek near Carlisle

near Hymera

Cass Lake near Shipahewana

Cass 3.

Cedar Creek near Cedarville.

Cedar Lake at Cedar lake.

Center Lake at Warsaw.

Cicero Creek at Noblesville...

Classification of Records.

Clay 6 .

Clay 6

Clay 7 ..................................

Clear Lake at LaPorte

Clifty Creek at Hartsvill

Cobb ditch near Kouts

Collection and computation of data, surface water

Collection and examination of data, surface-water quality

Collection and examination of data, lake levels...

Collection and examination of data, ground-water quality

Collection and examination of data, ground water

Color unit, definition of.

Contents, definition of

Control definition of

Control structure, definition of

Conversion of chemical constituents, factors of

Conversion of sediment concentrations, fucturs of

Cooperation

Cooperation, definition of
Page

Crooked Creek (tributary to Ohio River) basin, gaging-station

records in

Crooked Creeh (tributary to White River) at Indiana polis..................... 134

Crooked Lake at Crooked Lake ............................................................. 257

Cubic foot per second, definition of

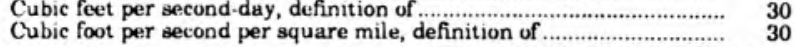

Data collection and computation ................................................11,23,25

Data presentation.

Data table of dauly mean values. $12,21,23,25,27$

atum, definition of

Datum of gage, defintion of

Decatur $2 \ldots$

Delaware 4

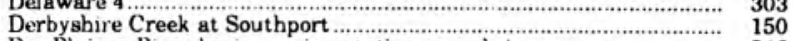

Des Plaines River basin, gaging-station records in................................. 246

Dewart leake near Leesburg............................................................... 258

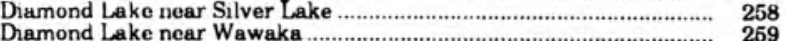

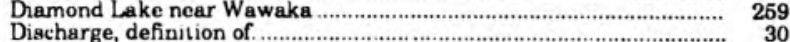

Discharge, definition of.
Dissolved, definition of...

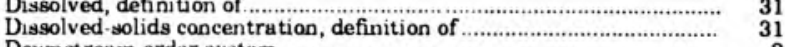

Downstream order system $\ldots$..............................................................

Druinage basin, definition of .................................................... 131

Driftwood River (continuation of Big Blue River) near Edinburgh...... 172

Eagle Creek (tributary to White River) at Indianapolis.

Eagle Creek Reservoir near Indianapolis

East Fork Coul Creek near Hillsboro

East Fork Whute River at Columbus.

at Sey mour

at Shoals B......

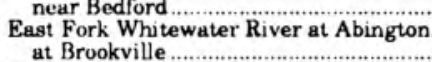

Eel River (tributary to Wabash River) at North Manchester

Eel River (tributary to White River) at Bowling Green

Elkhart River at Goshen.

Elkhart 4

Elkhart 5

Elkhurt 6

Elkhart 7

Elkhart 9

Engle Lake near Ligonier

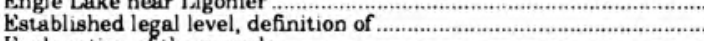

Explanation of the records.

Extremes for period of record, definition of

Extremes outside penod of record, definition of

Factors for conversion of chemical constituents.

Factors for conversin of sediment.

Falcon Creek at 30rb St. at Indianapolis.

Fall Creek at Millersville.

at 16th Street at Indianapolis near Fortville

Fecal coliform basteria, definition of.

Fecal streptococcal bacteria, definition of

Fish Creek at Hamilion

Fish Lake near Plato.

Flatrock River at Columbus at St. Paul

Flint Lake near Valparaiso..

Forker Creek near Burr Oak

Fountain 3

Franklin 5

Fulion 7 .

Gage, definition of

Gage height, definition of

Gaping station, definition of

Galena Kiver near laPorte.

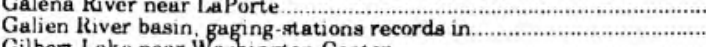

Gilbert Lake near Washington Center..

Grant 8 .......

Graph showing mean discharges at index stations............................

Great Miami River basin, gaging-station records in................................

Ground-water data, collection and computation of .................................24-26

Ground-water levels, records of.

Ground-water quality, records of ......................................................

Guion Creek above 52nd St. at Indiang ..................................... 295

Hackenburg Lake ncar Wolcottville................................................ 262

Hall Creek aear St. Anthony ......................................................... 196

$\begin{array}{lll}\text { Hamilton } 5 & \\ \text { Hamilton Lake at Hamilton }\end{array}$ 


\section{INDEX}

Page

Harber ditch at Fort Wayne

Harberts Creek near Madison....

Hardness, definition of

Harrison 8.

Hart ditch at Dyer

at Munster.

Haw Creek near Clifford.

Heat on Lake near Elkhart

Hendricks 4

High Lake near Wolflake.

Highest annual mean, definition of

Highest daily mean, definition of

Hill Lake near Silver Lake

Hogan Creek basin, gaging-station records in

Hogback Lake near Ångola.

Hudson Lake at Hudson Lake.

Huntington 2

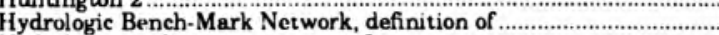

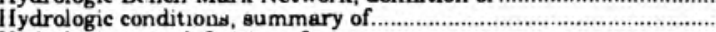

Hydrologic unit, definition of...............

Identifying estimated dauly diacharge

Illinois River basin, gaging-station records in

Indian Creek neur Corydon.........

Indian Creek near Montmorenci.

Indian Creek (tributary to Ohio River) basin gaging-station

records in

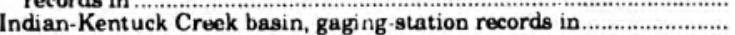

Indian-Kentuck Creek near Canaan

Inlet and outlet, definition of

Instantaneous discharge, definition of

Instantaneous low flow, definition of

Instantaneous peak flow, definition of.

Instantaneous peak stage, definition of

Instrumentation, definition of.

Introduction

Iroquois River at Renswelar

at Rosebud

near Foresman

near North Marion

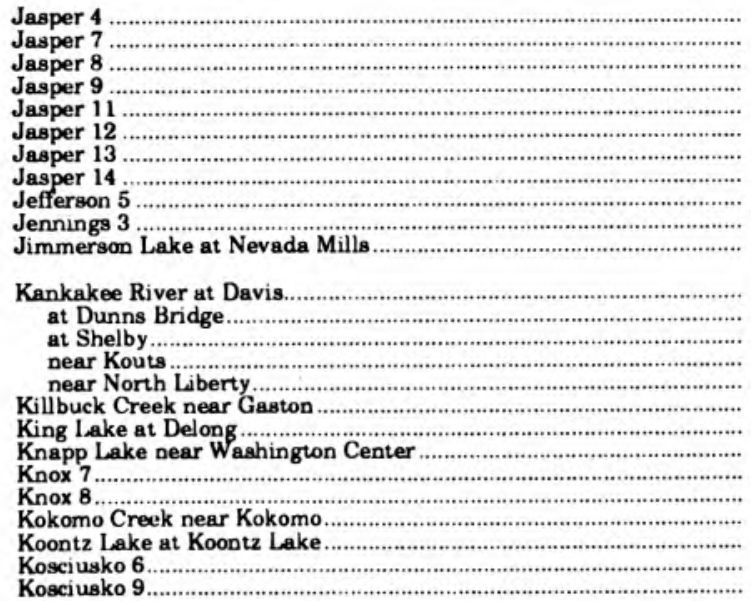

Kosciusko

Lagrange 2 ..

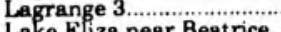

Lake Eliza near Beatrice

Lake Gage at Panama.

Lake George at Hobart ............

Lake George at Jamestown .......

Lake levels, records of

Lake Munitou at Rochester.

Lake Maxinkuckee at Culver...

Lake of the Woods near Bremen

Lake of the Woods near Helmer...

Lake 12

Lake 13

Lakes by county, number of

land-surface datum, definition of.

LaPorte 8

LaPorte 9

LaPorte 10

LaPorte 12

Laboratory measurement.

Latitude-Longitude System
229

179

31

216

216
247

247
176

263

310
263

16
16
264

264
56

26

265

311

$\begin{array}{r}8 \\ 3 \\ \hline\end{array}$

31

17
232

232
63

106

62

59

59

24
31

31
16

16

16
26

1

243

241

242

311

312

312

313

313
314

314

315

315
316

265

233

236

239

237

232
127

127
266

266

316
317

99

267
317

317
318

20

318

319

267

268

269

24

22
269

270

270

271
271

319

320

320
249

32

321

32

322
322

323

20

Lick Creek at Indianspolis

List of discontinued surface-water discharge or stage-only stations

List of discontinued surface-water-quality stations.

List of ground-water stations

List of lake-level station.

Lust of streamflow gaging otations

attle Buck Creek at Southport.

near Indianapolis

near Southport ................
ittle Calumet River at Gary

at Munster

at Porter.

Little Eagle Creek at Speedway

at 52 nd $\mathrm{St}$. at Indianapolis

Little Elkhart River at Middlebury

Little Indian Creek (tributary to lndian Cre

Little Long Lake at Kendallville.

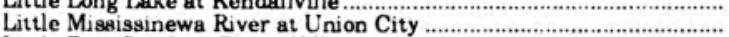

Litt'c Pune Creek at Green Hill

Little River near Iluntington

Little Willams Creek at Connersville

Location, definition of .

tocation of streamflow and water-quality gaging stations in Indians County, IN

Long Lake ut Laketon.

Long Lake at Moonlight

Lost Lake near Culver

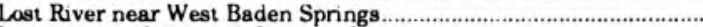

(owe

Lowest daily mean, definition of

Lukens Lake near Disko.

Map showing average annual precipitation

Map showing average annual runoff.......................................

Mup showing locations of streamflow gaging stations and water-

quality stations in Indians

in Marion County

Map showing number of lake gages by county

Marion 34.

Marion 35

Marion 36.

Marshall Ditch near Moutmorenc

Martin 5

Maumee River at New Hlaven

Maumee River basin, gagng-station records in ..........................

Mean concentration, definition of

Mean discharge, definition of

Mean discharges at Indiana index station

Measuring point, definition of.

Microgram per gram, definition of

Middle Fork Anderson River at Bristow

Mill Creek (tributary to Eel Kiver) near Cataract

near Manhat tan

Milligrams per liter, definition of

Missisans per River, at Manon.

at Peoria.

near Ridgeville.

Montgomery

Murgan Creek (tributary to Busseron Creek) near Cass

Mud Pine Creek near Oxford

Muncie Lake near Burr Oak.........

National Geodetic Vertical Datum of 1929, definition of

National Stream Quality Accounting Network definition of

Newton 6

Newton 7

Newton

Newton 9

Newton 10.

Newton 11

Noble 8 .

Noble 9

Noble 11

Noble 14 .....

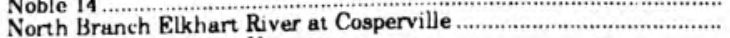

North Twin Lake near Howe.

Nyona Lake at Greenoak

Ogle Lake near Nashville

Ohio Kiver basin, gagng-station records in

On-site measurements and sample collection

Oliver Lake near Valentine

Organism count/volume and total, definition o

Other records available.

Other lake maps available. 
Page

Parameter code, definition of

Parke 6

Purtial-record station, definition of

Particle size, definition of

Particle size classification, definition of

Patoka Kiver at Jasper

at Winsl ow.

near Hardinsburg

near Princeton

Percent exceeds, definition of

Period of record, definition of

Picocurie, definition of

Pigeon Creek (tributary to Ohio River) basin, gaging-station

Pigeon Creek near For Branch.

Pigeon Creek (tributary to Lake Michigan) near Angol

Pigeon River near Scott

Pike Lake at Warsaw.......

Pine Creek near Elkhs

Pine Lake at LaPorte ... Wabash River) near Bunker Hil

Pike Creek (tributary to White River) at Frankton

Pleasant Run at Arlington Avenue at Indianapolis.

Plum Creek near Bainbridge.

Posey 3 .

Posey 5

Praine Creek near Lebanon

Pretty Lake near Plymouth

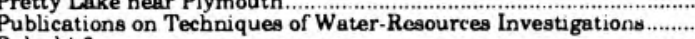

Pulaski 6

Pulaski 7

Pulaski 8.

Rattlounake Creck near Patton

Records available on lakes.

References, selected

Remarks codes

Remarks, definition of

Return period, definition of

Revised records, definition of ....

Revisions, definition of .

Riddles Lake near Lakeville.

Ridinger Lake near Pierceton

Rimmell Branch near Albion.
Runoff in inches, definition of

St. Joseph 31

St. Joseph River (atreams tributary to Lake Erie) near For Wayne

near Newville

St. Joseph River (streams tributary to Lake Michigan) basin,

gaging-station records in

St. Joseph River at Elkhart

St. Marys River at Decatur

near Fort Wayne

Salamanie River at Dora

at Portland.

near Warren

Salt Creek (tributary to White River) near Harrodsburg

Salt Creek (tnbutary to Little Calumet Kiver) near McCoo.

Sample collection and and ysis..

Sawmill lake near North Webster.

Sediment, definition of

Shel by 2

Sherburn Lake near Pierceton

Shipshewana Lake near Shipshewang

Shoe Lake near Oswego

Shriner Lake at Tri-Lakes.

Silver Creek basin, gaging-station records in

Silver Creek near Sellersburg

Silver Lake at Silver Lake.

Simonton Lake near Elkhart.

Singleton ditch at Schneider

Skinner Lake near Albion ......................

Sodium-adsorption ratio, definition of

Solomon Creek near Syracuse

Solute, definition of

South Fork Wildcat Creek near Lafayette

South Hogan Creek near Dillsboro

Special networks and programs..

Spy Run Creek at Fort Wayne

Stage-discharge relation, definition of

Stauon Identification Numbers

Station manuscript

Statistics of monthly mean data

Stephens Creek near Bloumington

Steuben 6

Stone Lake near Scott

Stony Creek near Noblesville

Streamflow, definition of ....
32

332

3

$\begin{array}{r}33 \\ 33 \\ 195 \\ \hline\end{array}$

197

197

194

198

17

$13,21,23,26$

33

70

70

213

214
277
216

278

85

139

160

(6)

333

278

40

334
334

334
335

335
90

90

290
43

22

$13,21,26$

33

$14,21,24$

279

279
219
33

336

336
226
224

213

213
222
227

228

77
75

76

188

206

27

280
33

33

280

280
281
281

281
281
282

60

60
282
283
240

240

283

284

34

220

102

56

$\begin{array}{r}34 \\ \hline\end{array}$

230

35
35

337

9
12

14

187

338

284
131

131
35
Streams tributary to Lake Erie, gaging-station records in...

Page

Sugar Creek (rributery to Dnftwood jever) at New Palesta in ............

near tidinburgh

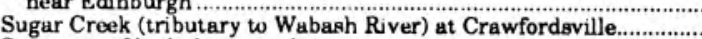

Summary of hydrolugic conditions ........................................................

Summary statistics

Surface area, definition of.

Surface-water-quality, records of

Surficial bed material, definition of

Suspended, definition of

Suspended recoverable, definition of

Suspended sediment, definition of

Suspended sediment concentration, definition of

Suspended sediment discharge, definition of

Suspended sediment load, definition of

Suspended total, definition of

Sylvan Lake at Rome City

Syracuse Lake at Syracuse.

Techniques of Water-Resources Invesitgations, Publications

Time-weighted averagc, definition of.

Tippecanoe Lake at Oswego

at North Webster

at Oswego.

near Deph

Tippecanoe 17

Tippecanoe 18

Tons per acre-foot, definition of

Tons per day, definition

Total discharge, definition of

Total recoverable, definition of

Total-sediment discharge, definition of

Total-sediment-loud, definition of

Trail Creek basin, gaging-station records in

Trail Creek at Michigan City.

Upper Long Lake near Wolflake

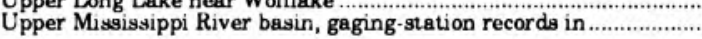

Vanderburgh 6.

Vanderburgh ?

Vernon Fork Muscatatuck River at Vernon

near Butlerville.

Versailles Lake ne.......................

Vigo 7

Wabash River basin, gaging-station records in

Wabash River at Blufton

at Covington

at Huntington

at Lafayette

at Linn Grove

at Logansport.

at Mount Carmel, IL

at New Harmony

at Peru

at Riverton.

at Terre Haute.

at Vincennes

at Wabash 3

Wabash

Waldron Lake near Cosperville.

Warrick 4

Washington 2

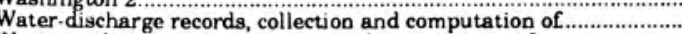

Water-quality records, collection and examination of

Water-resources data, records of

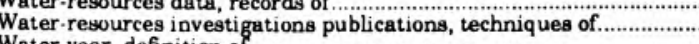

Water year, definition of

Wauhob Lake near Valparaiso

Wayne 6

WDR, definition of

Webster Lake at North Webster

Weesuu Creck near Deedsville.

Well characteristics, definition of

Weighted average, definition of.

Wells 4

West Fork Blue River at Salem

West Fork White lack Creek at Denvili.................

Wharton Lake near South Bend

Whiskey Run at Marengo

White 4

White Lick Creek at Mooresville

White River above Petersburg

at Anderson

at Broad Ripple

340

340

183 


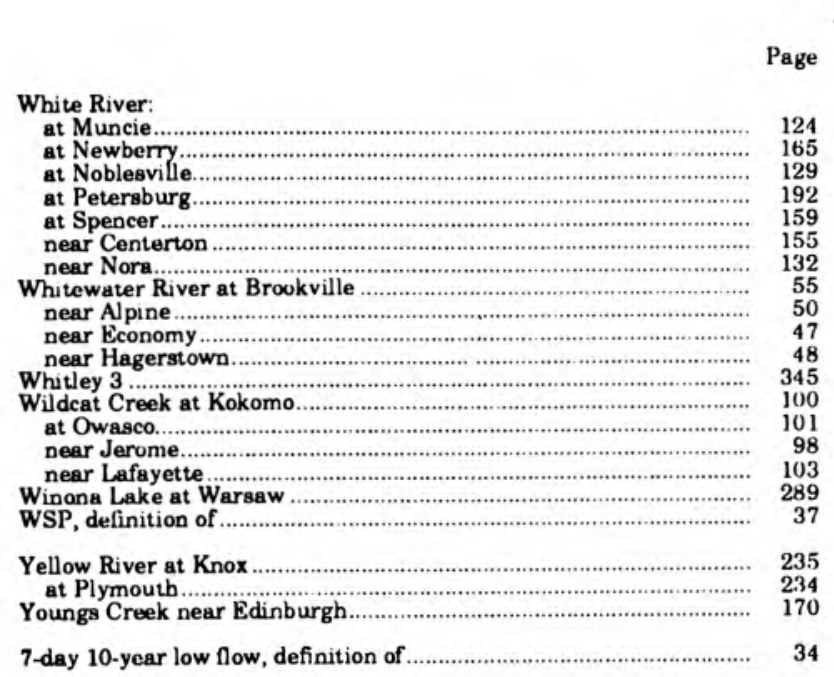

-U.S COVERNMENT PRINTINC OFFCE 1992.644 .56 ł 



\section{FACTORS FOR CONVERTING INCH-POUND UNITS TO INTERNATIONAL SYSTEM UNITS (SI)}

The following factors may be used to convert the inch-pound units published herein to the International System of Units (SI).

$$
\begin{aligned}
& \text { inches (in) } \\
& \text { feet (ft) } \\
& \text { miles (mi) }
\end{aligned}
$$

acres

square miles $\left(\mathrm{mi}^{2}\right)$

gallons (gal)

million gallons

cubic feet $\left(\mathrm{ft}^{3}\right)$

cfs-days
Multiply inch-pound units

acre-feet (acre-ft)

By

\section{Length}

$$
\begin{aligned}
& 2.54 \times 10^{1} \\
& 2.54 \times 10^{-2} \\
& 3.048 \times 10^{-1} \\
& 1.609 \times 10^{\circ}
\end{aligned}
$$

Area

$4.047 \times 10^{3}$

$4.047 \times 10^{-1}$

$4.047 \times 10^{-3}$

$2.590 \times 10^{\circ}$

Volume

$3.785 \times 10^{\circ}$

$3.785 \times 10^{\circ}$

$3.785 \times 10^{-3}$

$3.785 \times 10^{3}$

$3.785 \times 10^{-3}$

$2.832 \times 10^{1}$

$2.832 \times 10^{2}$

$2.447 \times 10^{3}$

$2.447 \times 10^{-3}$

$1.233 \times 10^{3}$

$1.233 \times 10^{-3}$

$1.233 \times 10^{6}$

Flow

cubic feet per second $\left(\mathrm{ft}^{3} / \mathrm{s}\right)$

gallons per minute (gal/min)

million gallons per day

tons (short)
$2.832 \times 10^{1}$

$2.832 \times 10^{1}$

$2.832 \times 10^{2}$

$6.309 \times 10^{-2}$

$6.309 \times 10^{2}$

$6.309 \times 10^{5}$

$4.381 \times 10^{1}$

$4.381 \times 10^{-2}$

Mass

$9.072 \times 10^{-1}$
To obtain SI units

\author{
millimeters (mm) \\ meters (m) \\ meters (m) \\ kilometers $(\mathrm{km})$
}

liters (L)

cubic decimeters $\left(\mathrm{dm}^{3}\right)$

cubic meters $\left(\mathrm{m}^{3}\right)$

cubic meters $\left(\mathrm{m}^{3}\right)$

cubic hectometers $\left(\mathrm{hm}^{3}\right)$

cubic decimeters $\left(\mathrm{dm}^{3}\right)$

cubic meters $\left(\mathrm{m}^{3}\right)$

cubic meters $\left(\mathrm{m}^{3}\right)$

cubic hectometers $\left(\mathrm{hm}^{3}\right)$

cubic meters $\left(\mathrm{m}^{3}\right)$

cubic hectometers $\left(\mathrm{hm}^{3}\right)$

cubic kilometers $\left(\mathrm{km}^{3}\right)$

\section{liters per second $(\mathrm{L} / \mathrm{s})$}

cubic decimeters per second $\left(\mathrm{dm}^{3} / \mathrm{s}\right)$

cubic meters per second $\left(\mathrm{m}^{3} / \mathrm{s}\right)$

liters per second $(\mathrm{L} / \mathrm{s})$

cubic decimeters per second $\left(\mathrm{dm}^{3} / \mathrm{s}\right)$

cubic meters per second $\left(\mathrm{m}^{3} / \mathrm{s}\right)$

cubic decimeters per second $\left(\mathrm{dm}^{3} / \mathrm{s}\right)$

cubic meters per second $\left(\mathrm{m}^{3} / \mathrm{s}\right)$

megagrams $(\mathrm{Mg})$ or metric tons 
